\title{
Supporting Information: How Accurately Do Approximate Density Functionals Predict Trends in Acidic Zeolite Catalysis?
}

\author{
Philipp N. Plessow, ${ }^{* \dagger}$ and Felix Studt ${ }^{\dagger}$, \\ ${ }^{\dagger}$ Institute of Catalysis Research and Technology, Karlsruhe Institute of Technology, Hermann-von-Helmholtz \\ Platz 1, 76344 Eggenstein-Leopoldshafen, Germany \\ Institute for Chemical Technology and Polymer Chemistry, Karlsruhe Institute of Technology, Engesserstrasse \\ 18, 76131 Karlsruhe, Germany \\ *plessow@kit.edu
}

\section{Table of contents}

S1 List of reactions and additional computational details

S2 Additional analysis of the data

S2 Tabulated reaction energies and barriers

S3 Total energies

S4 Cartesian coordinates of non-periodic structures in xyz-format for all structures

S5 Cartesian coordinates of periodic structures in cif-format for all structures

\section{S1 List of reactions and additional computational details}

Periodic DFT calculations. As in previous work, ${ }^{1}$ we use a periodic structure of chabazite with $36 \mathrm{~T}$ atoms per unit cell, out of which one is substituted with a heteroatom. Structures were fully optimized at the PBE-D3 ${ }^{2-3}$ (zero damping) level of theory with VASP, k-point sampling restricted to the $\Gamma$-point, Gaussian smearing with $\sigma=0.1$ $\mathrm{eV}$ and a plane wave cutoff of $400 \mathrm{eV} .^{4-5}$ Standard PAW potentials were used except for Ga, where the Ga_d potentials, in which the $3 \mathrm{~d}$ states are treated as valence states, lead to better SCF and geometry convergence. Transition state search was carried out with Automated Relaxed Potential Energy Surface Scans (ARPESS). ${ }^{6}$ Structures for the other zeotypes were generated from H-SSZ-13 and then fully reoptimized. The SCF convergence criterion was $10^{-8} \mathrm{eV}$ and the geometry convergence criterion was $0.005 \mathrm{eV} / \AA$ for the maximum norm of the force on an individual ion.

Calculations on cluster models. As described previously, ${ }^{1} 46 \mathrm{~T}$ cluster models, consisting of $46 \mathrm{Si}$ (or equivalently $46 \mathrm{Al}$ and $\mathrm{P}$ ) atoms were constructed from the periodic structures and dangling bonds were terminated by hydrogen with the predefined bond length $1.489 \AA$ along the original Si-O, Al-O or P-O vector. All energies discussed in this work were then computed as single point energies on these structures. Reference energies were obtained with the ORCA program package ${ }^{7}$ at the DLNPO-CCSD(T)/cc-pVDZ level of theory, ${ }^{8}$ together with CBS-extrapolation based on DLPNO-MP2 calculations with cc-pVXZ and X =2, 3 for extrapolation of correlation with the $l^{-3}$ formula and $\mathrm{X}=2,3,4$ for extrapolation of the Hartree-Fock energy with the exponential formula. Restricted Hartree-Fock energies for $\mathrm{X}=3,4$ were computed within the RIJCOSX ${ }^{9}$ approximation with grid X6. For subsequent correlation treatment $(\mathrm{X}=2,3)$, an SCF-convergence criterion of $10^{-9}$ Hartree was employed and $10^{-7}$ Hartree to obtain only the Hartree Fock energy $(X=4)$. DLPNO-calculations were run using the 'TightPNO' setting. For Ti and $\mathrm{Zn}$ and the cc-pVDZ basis set, an auxiliary basis set for correlation (AuxC) was generated using the AutoAux keyword. DFT energies (PBE-D3 and BEEF-vdW) were computed as single point energies using VASP as described above also for the cluster models, which were separated by $16 \AA$ from periodic images. The periodic structure and the corresponding cluster models are illustrated in Fig. S1.

List of reactions. All investigated reactions are listed and numbered in Fig. S2. 
a

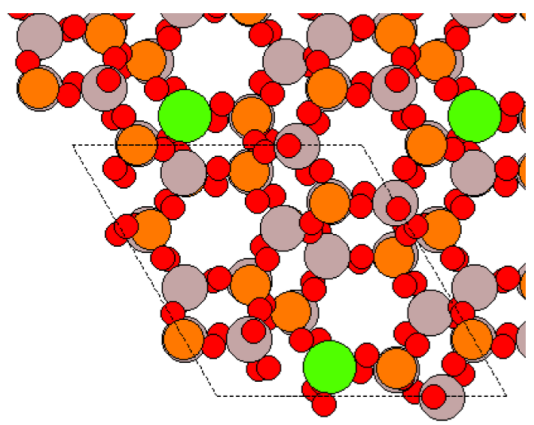

b

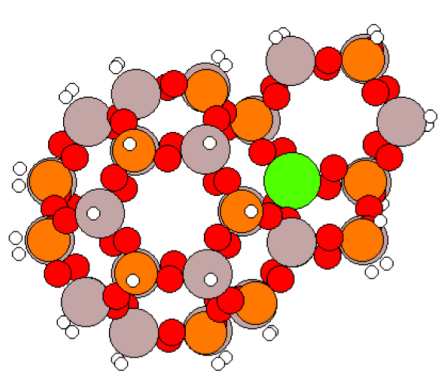

c

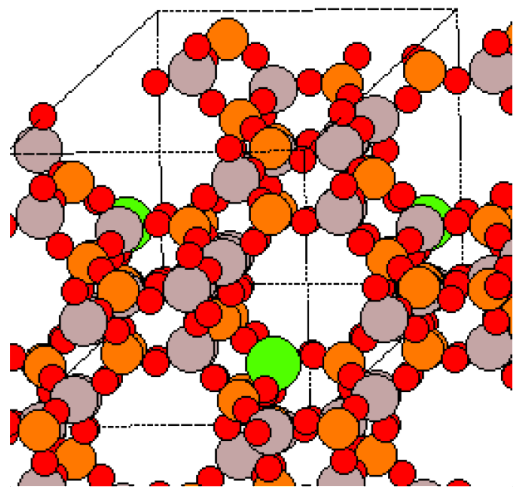

d

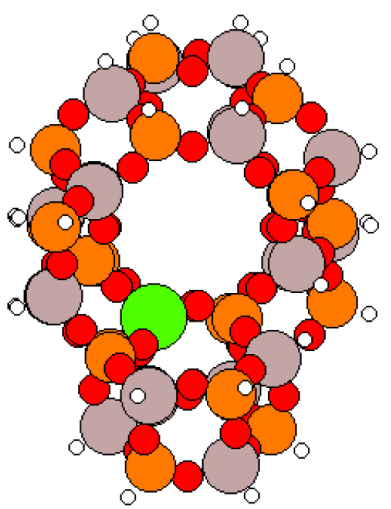

Fig. S1 | Illustration of periodic structure and cluster model for Mg-SAPO-34. a, b, view along the c-axis, c, d, view along a channel of the CHA-framework. 


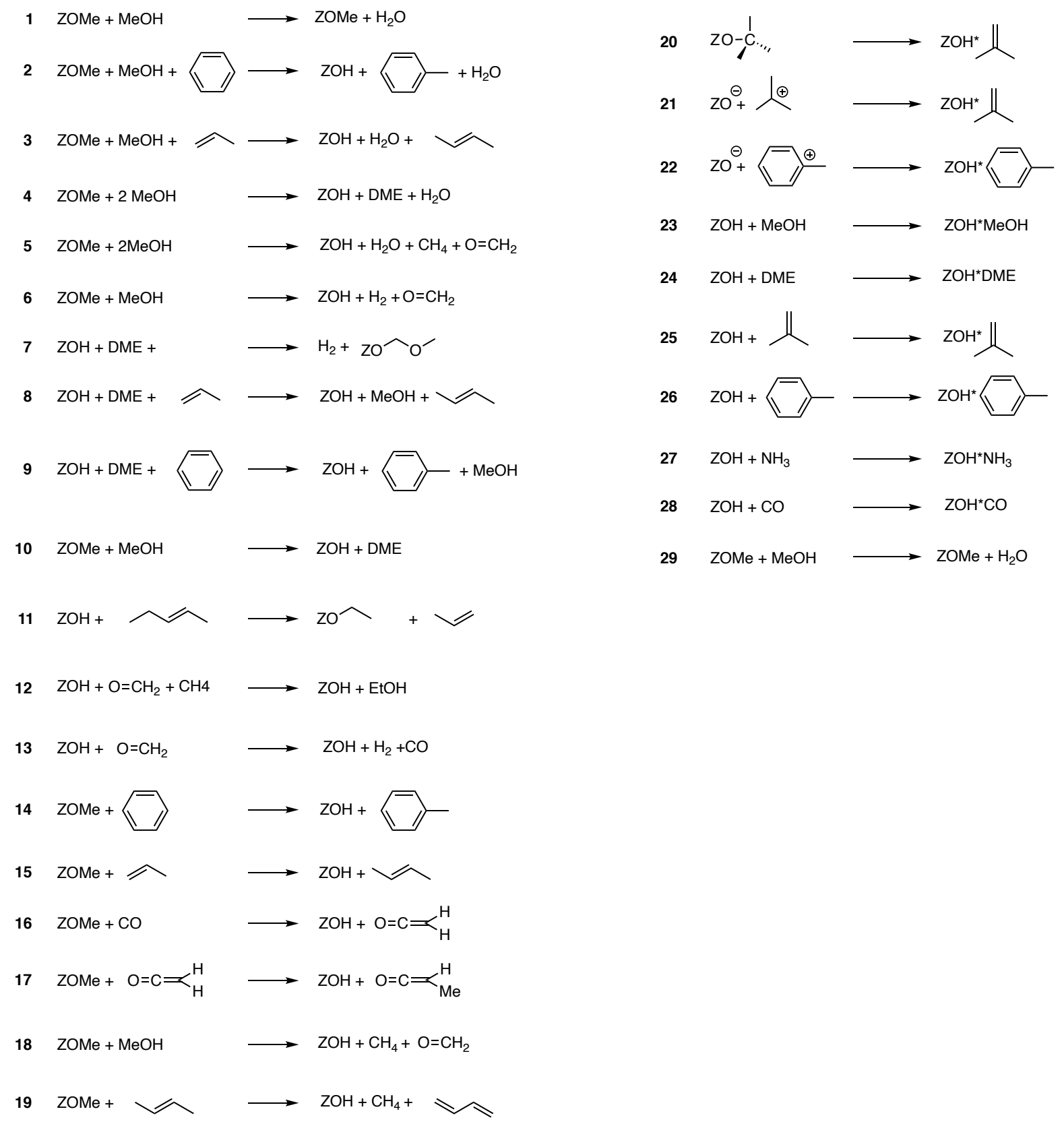

Fig. S2 | Numbered list of all investigated reactions. For barriers, the barrier for the displayed reaction is investigated, for reaction energies, the reaction energy of the displayed reaction. 


\section{S2 Additional analysis of the data}

Figure S3 shows the data from the main text (Figure 4) also for BEEF-vdW. To better illustrate the error, the difference with respect to DLPNO-CCSD(T) is shown in Figure S4.

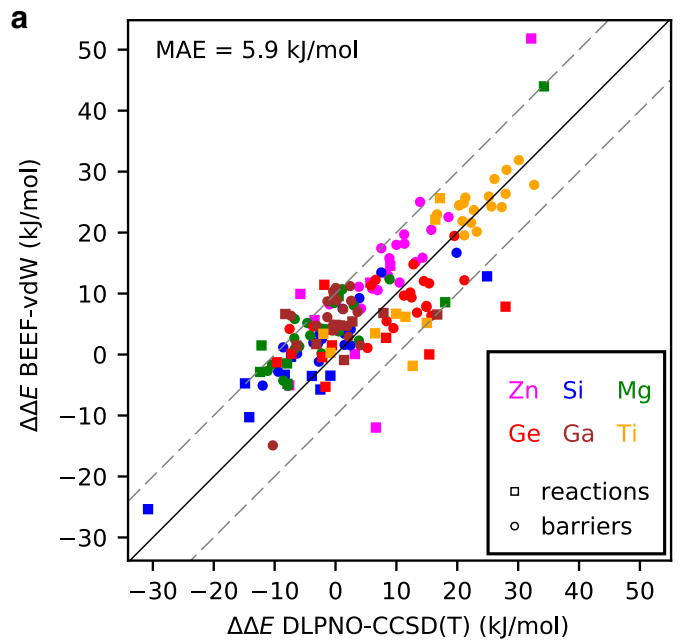

b

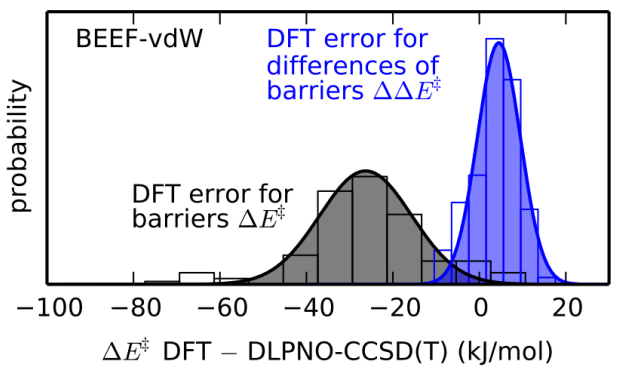

Fig. S3 | Prediction of DFT for differences of reaction energies and barriers relative to H-SSZ-13. a, Parity plot for differences of reaction energies and barriers with respect to H-SSZ-13 computed using DFT (BEEF$\mathrm{vdW}$ ) and DLPNO-CCSD(T). Gray dashed lines indicate a range of $10 \mathrm{~kJ} / \mathrm{mol}$. Barriers are indicated with circles and reaction energies with squares. b, Probability distribution for errors are shown as bars as well as Gaussian curves fit to the distributions. (Same as Figure $4 \mathrm{a}$ and $4 \mathrm{~b}$ but for BEEF-vdW instead of PBE-d3)
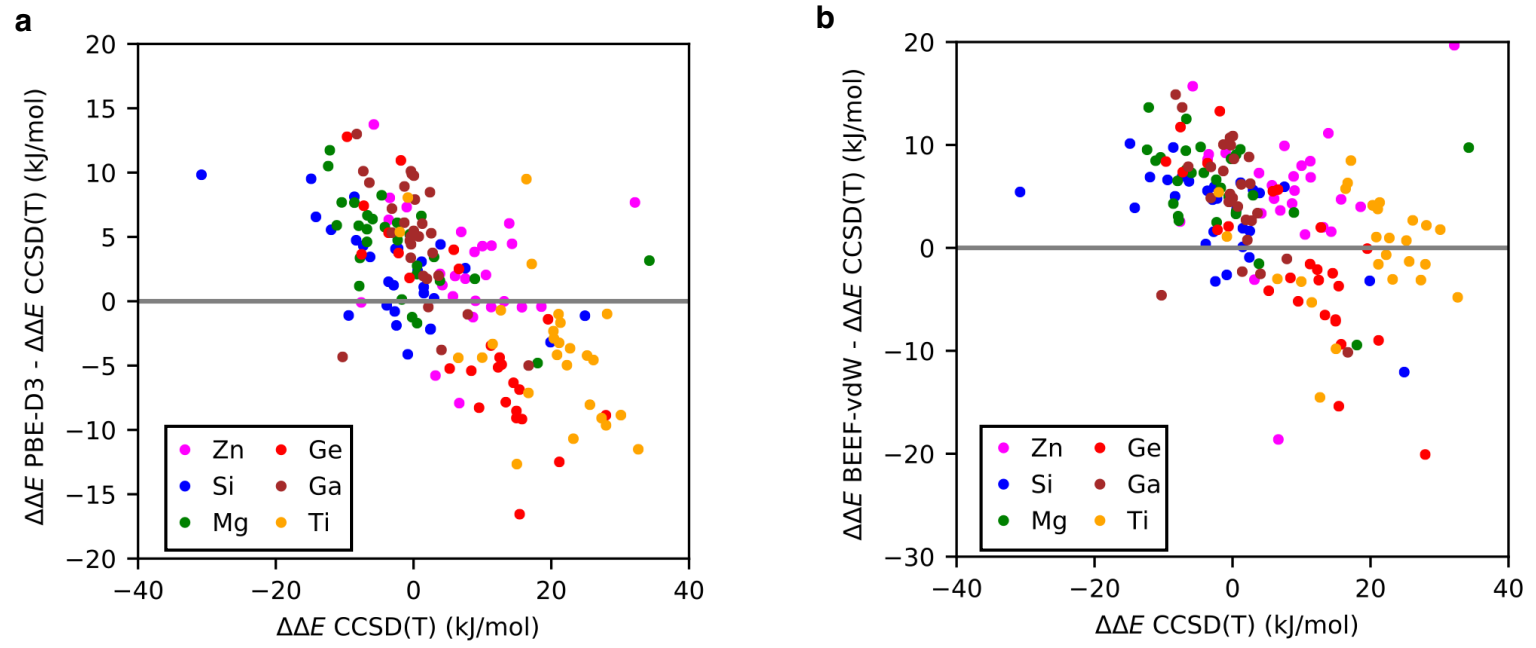

Fig. S4 | Error for the prediction of DFT for differences of reaction energies and barriers relative to $H$ SSZ-13. a, PBE-D3, b, BEEF-vdW. The same data as in Fig. 4a and Fig. S3a, but $\Delta \Delta E$ is given relative to DLPNO-CCSD(T), which is only denoted $\operatorname{CCSD}(\mathrm{T})$ for brevity. 


\section{S2 Tabulated reaction energies and barriers}

All computed reaction energies and barriers used in the main text are listed in Table S1. Additionally, the predictions relative to H-SSZ-13 as well as the errors relative to DLPNO-CCSD(T) that are derived from these values are listed in Table S1. Reaction energies for reaction 21 were obtained only for H-SSZ-13 and Ga-SSZ13 , because the carbocation was for the other catalysts not stable but was during the geometry optimization spontaneously deprotonated to give adsorbed isobutene.

Table S1, Computed reaction energies and barriers. Reaction are labeled according to Fig. S2 and catalysts are labeled according to the substituting element. Columns labeled ' $\mathrm{E}$ ' give the reaction energy for the respective method, columns labeled ' $\Delta \mathrm{E}$ ' give the difference with respect to H-SSZ-13 ( $\mathrm{Al})$. Columns labeled 'E-err' and ' $\triangle \mathrm{E}$-err' give the difference of these values with respect to $\operatorname{CCSD}(\mathrm{T}) / \mathrm{CBS}$, which refers to DLNPO$\mathrm{CCSD}(\mathrm{T}) / \mathrm{cc}-\mathrm{pVDZ}$ with a CBS-correction from MP2. All energies are given in $\mathrm{kJ} / \mathrm{mol}$.

\begin{tabular}{|c|c|c|c|c|c|c|c|c|c|c|c|}
\hline \multirow[b]{2}{*}{ No. } & \multicolumn{3}{|c|}{$\operatorname{CCSD}(\mathrm{T}) / \mathrm{CBS}$} & \multicolumn{4}{|c|}{ PBE-D3/400eV } & \multicolumn{4}{|c|}{ BEEF-vdW/400eV } \\
\hline & cat & $\mathrm{E}$ & $\Delta \mathrm{E}$ & E & E-err & $\Delta \mathrm{E}$ & $\Delta$ E-err & E & E-err & $\Delta \mathrm{E}$ & $\Delta$ E-err \\
\hline 1 & $\mathrm{Zn}$ & 67.0 & -1.0 & 50.0 & -17.0 & 6.3 & 7.3 & 72.5 & 5.5 & 8.2 & 9.2 \\
\hline 1 & $\mathrm{Si}$ & 70.4 & 2.4 & 43.9 & -26.5 & 0.3 & -2.2 & 65.8 & -4.6 & 1.5 & -0.9 \\
\hline 1 & $\mathrm{Mg}$ & 60.2 & -7.8 & 39.2 & -21.0 & -4.4 & 3.4 & 59.2 & -1.0 & -5.1 & 2.7 \\
\hline 1 & $\mathrm{Al}$ & 68.0 & - & 43.6 & -24.4 & - & - & 64.3 & -3.7 & - & - \\
\hline 1 & $\mathrm{Ge}$ & 73.8 & 5.8 & 53.5 & -20.4 & 9.8 & 4.0 & 75.7 & 1.8 & 11.3 & 5.5 \\
\hline 1 & $\mathrm{Ga}$ & 68.2 & 0.2 & 51.7 & -16.4 & 8.1 & 7.9 & 73.2 & 5.0 & 8.8 & 8.6 \\
\hline 1 & $\mathrm{Ti}$ & 93.2 & 25.2 & 64.6 & -28.6 & 21.0 & -4.2 & 90.2 & -3.0 & 25.9 & 0.7 \\
\hline 2 & $\mathrm{Zn}$ & 22.7 & 18.6 & -30.2 & -52.9 & 18.1 & -0.4 & -2.2 & -24.8 & 22.6 & 4.0 \\
\hline 2 & $\mathrm{Si}$ & 0.5 & -3.6 & -50.5 & -50.9 & -2.1 & 1.5 & -22.8 & -23.2 & 1.9 & 5.6 \\
\hline 2 & $\mathrm{Mg}$ & 7.1 & 3.0 & -41.9 & -49.0 & 6.4 & 3.4 & -16.6 & -23.7 & 8.1 & 5.1 \\
\hline 2 & $\mathrm{Al}$ & 4.1 & - & -48.4 & -52.4 & - & - & -24.7 & -28.8 & - & - \\
\hline 2 & $\mathrm{Ge}$ & 16.4 & 12.3 & -41.2 & -57.6 & 7.1 & -5.1 & -14.5 & -30.9 & 10.2 & -2.1 \\
\hline 2 & $\mathrm{Ga}$ & 3.8 & -0.3 & -38.7 & -42.6 & 9.6 & 9.9 & -15.0 & -18.8 & 9.7 & 10.0 \\
\hline 2 & $\mathrm{Ti}$ & 31.4 & 27.3 & -30.1 & -61.5 & 18.2 & -9.1 & -0.5 & -31.9 & 24.2 & -3.1 \\
\hline 3 & $\mathrm{Zn}$ & 11.0 & 10.0 & -44.8 & -55.8 & 14.3 & 4.3 & -15.6 & -26.6 & 18.0 & 8.0 \\
\hline 3 & $\mathrm{Si}$ & 3.4 & 2.5 & -58.8 & -62.2 & 0.4 & -2.1 & -29.5 & -32.9 & 4.1 & 1.6 \\
\hline 3 & $\mathrm{Mg}$ & 1.4 & 0.5 & -56.5 & -58.0 & 2.6 & 2.1 & -29.8 & -31.2 & 3.8 & 3.3 \\
\hline 3 & $\mathrm{Al}$ & 1.0 & - & -59.1 & -60.1 & - & - & -33.6 & -34.5 & - & - \\
\hline 3 & $\mathrm{Ge}$ & 7.5 & 6.6 & -50.0 & -57.6 & 9.1 & 2.5 & -21.3 & -28.9 & 12.3 & 5.7 \\
\hline 3 & $\mathrm{Ga}$ & 3.3 & 2.4 & -48.3 & -51.6 & 10.9 & 8.5 & -22.4 & -25.7 & 11.2 & 8.8 \\
\hline 3 & $\mathrm{Ti}$ & 27.1 & 26.1 & -37.6 & -64.6 & 21.6 & -4.6 & -4.8 & -31.9 & 28.8 & 2.7 \\
\hline 4 & $\mathrm{Zn}$ & 11.6 & 13.9 & -19.0 & -30.5 & 19.9 & 6.1 & 8.5 & -3.0 & 25.0 & 11.1 \\
\hline 4 & $\mathrm{Si}$ & -5.1 & -2.7 & -42.4 & -37.4 & -3.5 & -0.8 & -17.7 & -12.6 & -1.2 & 1.6 \\
\hline 4 & $\mathrm{Mg}$ & -2.5 & -0.2 & -40.3 & -37.8 & -1.4 & -1.2 & -8.1 & -5.5 & 8.4 & 8.7 \\
\hline 4 & $\mathrm{Al}$ & -2.3 & - & -38.9 & -36.6 & - & - & -16.5 & -14.2 & - & - \\
\hline 4 & $\mathrm{Ge}$ & -6.0 & -3.6 & -37.2 & -31.2 & 1.7 & 5.3 & -11.9 & -5.9 & 4.6 & 8.2 \\
\hline 4 & $\mathrm{Ga}$ & 0.2 & 2.6 & -31.0 & -31.3 & 7.9 & 5.3 & -7.7 & -7.9 & 8.8 & 6.2 \\
\hline 4 & $\mathrm{Ti}$ & 18.0 & 20.4 & -21.4 & -39.4 & 17.5 & -2.9 & 8.0 & -10.0 & 24.5 & 4.1 \\
\hline 5 & $\mathrm{Zn}$ & 66.6 & 15.7 & -3.3 & -69.9 & 15.3 & -0.5 & 41.2 & -25.4 & 20.4 & 4.7 \\
\hline 5 & $\mathrm{Si}$ & 48.6 & -2.2 & -16.7 & -65.3 & 1.9 & 4.1 & 23.3 & -25.3 & 2.6 & 4.8 \\
\hline 5 & $\mathrm{Mg}$ & 52.0 & 1.1 & -10.8 & -62.8 & 7.8 & 6.6 & 31.4 & -20.5 & 10.7 & 9.6 \\
\hline 5 & $\mathrm{Al}$ & 50.8 & - & -18.6 & -69.4 & - & - & 20.7 & -30.1 & - & - \\
\hline 5 & $\mathrm{Ge}$ & 65.8 & 14.9 & -12.2 & -77.9 & 6.4 & -8.5 & 28.5 & -37.2 & 7.8 & -7.1 \\
\hline 5 & $\mathrm{Ga}$ & 52.1 & 1.3 & -11.3 & -63.4 & 7.3 & 6.0 & 28.2 & -23.9 & 7.4 & 6.2 \\
\hline 5 & $\mathrm{Ti}$ & 83.5 & 32.6 & 2.5 & -80.9 & 21.1 & -11.5 & 48.5 & -34.9 & 27.8 & -4.8 \\
\hline 6 & $\mathrm{Zn}$ & 156.7 & 13.2 & 98.7 & -58.0 & 13.2 & 0.0 & 130.4 & -26.2 & 15.2 & 2.0 \\
\hline 6 & $\mathrm{Si}$ & 137.2 & -6.3 & 82.7 & -54.6 & -2.9 & 3.4 & 115.4 & -21.8 & 0.2 & 6.5 \\
\hline 6 & $\mathrm{Mg}$ & 143.0 & -0.6 & 90.2 & -52.8 & 4.6 & 5.2 & 119.7 & -23.3 & 4.4 & 5.0 \\
\hline 6 & $\mathrm{Al}$ & 143.5 & - & 85.5 & -58.0 & - & - & 115.3 & -28.2 & - & - \\
\hline 6 & $\mathrm{Ge}$ & 153.0 & 9.5 & 86.8 & -66.3 & 1.2 & -8.3 & 119.6 & -33.4 & 4.3 & -5.2 \\
\hline 6 & $\mathrm{Ga}$ & 143.2 & -0.4 & 89.6 & -53.6 & 4.1 & 4.4 & 120.2 & -23.0 & 4.9 & 5.2 \\
\hline 6 & $\mathrm{Ti}$ & 166.7 & 23.2 & 98.0 & -68.7 & 12.5 & -10.7 & 135.4 & -31.3 & 20.1 & -3.1 \\
\hline 7 & $\mathrm{Zn}$ & 155.4 & 8.6 & 118.8 & -36.6 & 7.4 & -1.2 & 136.0 & -19.4 & 12.9 & 4.3 \\
\hline 7 & $\mathrm{Si}$ & 138.2 & -8.6 & 110.9 & -27.2 & -0.5 & 8.1 & 124.2 & -13.9 & 1.2 & 9.8 \\
\hline
\end{tabular}




\begin{tabular}{|c|c|c|c|c|c|c|c|c|c|c|c|}
\hline 7 & $\mathrm{Mg}$ & 140.0 & -6.8 & 109.3 & -30.7 & -2.1 & 4.6 & 123.8 & -16.1 & 0.8 & 7.6 \\
\hline 7 & $\mathrm{Al}$ & 146.7 & - & 111.4 & -35.3 & - & - & 123.0 & -23.7 & - & - \\
\hline 7 & $\mathrm{Ge}$ & 159.2 & 12.5 & 119.5 & -39.7 & 8.1 & -4.4 & 132.4 & -26.8 & 9.4 & -3.1 \\
\hline 7 & $\mathrm{Ga}$ & 145.4 & -1.3 & 119.0 & -26.4 & 7.6 & 8.9 & 131.8 & -13.7 & 8.7 & 10.0 \\
\hline 7 & $\mathrm{Ti}$ & 167.8 & 21.1 & 131.4 & -36.4 & 20.1 & -1.0 & 147.9 & -19.9 & 24.8 & 3.8 \\
\hline 8 & $\mathrm{Zn}$ & 28.7 & 11.3 & -28.7 & -57.4 & 10.8 & -0.5 & 8.7 & -20.1 & 19.7 & 8.4 \\
\hline 8 & $\mathrm{Si}$ & 8.0 & -9.4 & -50.0 & -58.1 & -10.5 & -1.1 & -13.8 & -21.9 & -2.8 & 6.6 \\
\hline 8 & $\mathrm{Mg}$ & 10.8 & -6.7 & -39.5 & -50.3 & 0.0 & 6.7 & -5.2 & -16.0 & 5.8 & 12.5 \\
\hline 8 & $\mathrm{Al}$ & 17.5 & - & -39.5 & -57.0 & - & - & -11.0 & -28.5 & - & - \\
\hline 8 & $\mathrm{Ge}$ & 9.9 & -7.5 & -43.4 & -53.3 & -3.9 & 3.7 & -6.8 & -16.7 & 4.2 & 11.7 \\
\hline 8 & $\mathrm{Ga}$ & 10.2 & -7.3 & -36.7 & -46.9 & 2.8 & 10.1 & -4.7 & -14.8 & 6.4 & 13.6 \\
\hline 8 & $\mathrm{Ti}$ & 34.2 & 16.7 & -29.9 & -64.1 & 9.6 & -7.1 & 12.0 & -22.2 & 23.0 & 6.3 \\
\hline 9 & $\mathrm{Zn}$ & 32.1 & 7.5 & -20.6 & -52.7 & 9.3 & 1.8 & 9.5 & -22.5 & 17.4 & 9.9 \\
\hline 9 & $\mathrm{Si}$ & 27.5 & 3.0 & -26.7 & -54.2 & 3.2 & 0.2 & 0.7 & -26.8 & 8.6 & 5.6 \\
\hline 9 & $\mathrm{Mg}$ & 17.8 & -6.8 & -31.1 & -48.9 & -1.2 & 5.6 & -5.2 & -23.0 & 2.7 & 9.4 \\
\hline 9 & $\mathrm{Al}$ & 24.6 & - & -29.9 & -54.5 & - & - & -7.9 & -32.5 & - & - \\
\hline 9 & $\mathrm{Ge}$ & 37.3 & 12.8 & -22.0 & -59.4 & 7.9 & -4.9 & 6.9 & -30.5 & 14.8 & 2.0 \\
\hline 9 & $\mathrm{Ga}$ & 24.6 & 0.0 & -20.1 & -44.7 & 9.8 & 9.8 & 3.0 & -21.6 & 10.9 & 10.9 \\
\hline 9 & $\mathrm{Ti}$ & 54.7 & 30.1 & -8.7 & -63.3 & 21.3 & -8.9 & 24.0 & -30.7 & 31.9 & 1.8 \\
\hline 10 & $\mathrm{Zn}$ & 82.2 & 14.3 & 59.9 & -22.4 & 18.8 & 4.5 & 68.4 & -13.8 & 15.9 & 1.6 \\
\hline 10 & $\mathrm{Si}$ & 87.8 & 19.9 & 57.8 & -30.0 & 16.7 & -3.2 & 69.3 & -18.6 & 16.7 & -3.2 \\
\hline 10 & $\mathrm{Mg}$ & 71.8 & 3.8 & 46.5 & -25.2 & 5.4 & 1.6 & 54.9 & -16.9 & 2.3 & -1.5 \\
\hline 10 & $\mathrm{Al}$ & 67.9 & - & 41.1 & -26.8 & - & - & 52.6 & -15.4 & - & - \\
\hline 10 & $\mathrm{Ge}$ & 87.5 & 19.5 & 59.3 & -28.2 & 18.1 & -1.4 & 72.0 & -15.5 & 19.5 & -0.1 \\
\hline 10 & $\mathrm{Ga}$ & 71.6 & 3.6 & 46.7 & -24.8 & 5.6 & 2.0 & 59.6 & -12.0 & 7.0 & 3.4 \\
\hline 10 & $\mathrm{Ti}$ & 96.0 & 28.1 & 68.2 & -27.8 & 27.1 & -1.0 & 82.9 & -13.2 & 30.3 & 2.2 \\
\hline 11 & $\mathrm{Zn}$ & 115.5 & 3.8 & 69.5 & -46.0 & 6.0 & 2.1 & 84.9 & -30.6 & 11.1 & 7.3 \\
\hline 11 & $\mathrm{Si}$ & 108.8 & -2.9 & 61.9 & -46.9 & -1.6 & 1.2 & 75.6 & -33.2 & 1.8 & 4.7 \\
\hline 11 & $\mathrm{Mg}$ & 100.5 & -11.1 & 58.3 & -42.2 & -5.3 & 5.9 & 71.1 & -29.4 & -2.7 & 8.5 \\
\hline 11 & $\mathrm{Al}$ & 111.7 & - & 63.6 & -48.1 & - & - & 73.8 & -37.9 & - & - \\
\hline 11 & $\mathrm{Ge}$ & 127.1 & 15.4 & 72.1 & -55.0 & 8.5 & -6.9 & 85.5 & -41.6 & 11.7 & -3.7 \\
\hline 11 & $\mathrm{Ga}$ & 111.3 & -0.4 & 73.3 & -38.0 & 9.7 & 10.1 & 84.1 & -27.2 & 10.3 & 10.7 \\
\hline 11 & $\mathrm{Ti}$ & 139.6 & 28.0 & 81.9 & -57.8 & 18.3 & -9.6 & 100.1 & -39.5 & 26.4 & -1.6 \\
\hline 12 & $\mathrm{Zn}$ & - & - & - & - & - & - & - & - & - & - \\
\hline 12 & $\mathrm{Si}$ & 62.2 & -12.0 & 4.8 & -57.4 & -6.4 & 5.6 & 67.6 & 5.4 & -5.1 & 6.9 \\
\hline 12 & $\mathrm{Mg}$ & 83.1 & 8.9 & 21.9 & -61.2 & 10.6 & 1.7 & 85.0 & 2.0 & 12.3 & 3.4 \\
\hline 12 & $\mathrm{Al}$ & 74.2 & - & 11.2 & -63.0 & - & - & 72.7 & -1.5 & - & - \\
\hline 12 & $\mathrm{Ge}$ & 79.4 & 5.2 & 11.2 & -68.2 & 0.0 & -5.2 & 73.8 & -5.6 & 1.1 & -4.2 \\
\hline 12 & $\mathrm{Ga}$ & 73.6 & -0.5 & 15.4 & -58.3 & 4.2 & 4.7 & 76.7 & 3.0 & 3.9 & 4.5 \\
\hline 12 & $\mathrm{Ti}$ & - & - & - & - & - & - & - & - & - & - \\
\hline 13 & $\mathrm{Zn}$ & 183.0 & 6.0 & 125.1 & -57.9 & 8.0 & 2.0 & 160.4 & -22.6 & 10.8 & 4.8 \\
\hline 13 & $\mathrm{Si}$ & 174.3 & -2.6 & 118.5 & -55.8 & 1.4 & 4.1 & 152.9 & -21.5 & 3.3 & 6.0 \\
\hline 13 & $\mathrm{Mg}$ & 174.6 & -2.4 & 120.8 & -53.8 & 3.7 & 6.1 & 153.8 & -20.8 & 4.3 & 6.6 \\
\hline 13 & $\mathrm{Al}$ & 177.0 & - & 117.1 & -59.9 & - & - & 149.6 & -27.4 & - & - \\
\hline 13 & $\mathrm{Ge}$ & 185.4 & 8.4 & 120.1 & -65.3 & 3.0 & -5.4 & 155.0 & -30.3 & 5.5 & -2.9 \\
\hline 13 & $\mathrm{Ga}$ & 173.8 & -3.1 & 121.1 & -52.7 & 4.1 & 7.2 & 154.3 & -19.5 & 4.7 & 7.9 \\
\hline 13 & $\mathrm{Ti}$ & 202.6 & 25.6 & 134.6 & -67.9 & 17.6 & -8.0 & 173.8 & -28.7 & 24.3 & -1.3 \\
\hline 14 & $\mathrm{Zn}$ & 80.2 & 8.9 & 36.8 & -43.4 & 12.7 & 3.8 & 49.8 & -30.4 & 15.8 & 6.9 \\
\hline 14 & $\mathrm{Si}$ & 72.0 & 0.6 & 27.1 & -44.9 & 3.0 & 2.4 & 38.4 & -33.5 & 4.4 & 3.8 \\
\hline 14 & $\mathrm{Mg}$ & 67.2 & -4.2 & 25.7 & -41.5 & 1.6 & 5.8 & 37.1 & -30.1 & 3.1 & 7.3 \\
\hline 14 & $\mathrm{Al}$ & 71.4 & - & 24.1 & -47.2 & - & - & 34.0 & -37.4 & - & - \\
\hline 14 & $\mathrm{Ge}$ & 82.6 & 11.2 & 31.9 & -50.7 & 7.8 & -3.4 & 43.7 & -38.9 & 9.7 & -1.6 \\
\hline 14 & $\mathrm{Ga}$ & 70.0 & -1.3 & 28.9 & -41.1 & 4.8 & 6.1 & 40.1 & -29.9 & 6.1 & 7.5 \\
\hline 14 & $\mathrm{Ti}$ & 94.1 & 22.7 & 43.2 & -50.9 & 19.1 & -3.7 & 57.7 & -36.4 & 23.7 & 1.0 \\
\hline 15 & $\mathrm{Zn}$ & - & - & - & - & - & - & - & - & - & - \\
\hline 15 & $\mathrm{Si}$ & 70.1 & 1.2 & 25.2 & -44.9 & 4.2 & 3.1 & 38.0 & -32.1 & 7.5 & 6.3 \\
\hline 15 & $\mathrm{Mg}$ & 63.0 & -6.0 & 21.4 & -41.6 & 0.4 & 6.4 & 31.9 & -31.1 & 1.3 & 7.3 \\
\hline 15 & $\mathrm{Al}$ & 68.9 & - & 21.0 & -48.0 & - & - & 30.5 & -38.4 & - & - \\
\hline 15 & $\mathrm{Ge}$ & 83.4 & 14.5 & 29.1 & -54.3 & 8.2 & -6.3 & 42.6 & -40.9 & 12.0 & -2.5 \\
\hline 15 & $\mathrm{Ga}$ & 73.0 & 4.1 & 21.2 & -51.8 & 0.3 & -3.8 & 32.1 & -40.9 & 1.5 & -2.5 \\
\hline 15 & $\mathrm{Ti}$ & 90.3 & 21.3 & 40.6 & -49.6 & 19.7 & -1.7 & 56.3 & -34.0 & 25.7 & 4.4 \\
\hline 16 & $\mathrm{Zn}$ & 133.3 & 6.9 & 103.2 & -30.2 & 12.3 & 5.4 & 114.6 & -18.7 & 10.6 & 3.6 \\
\hline
\end{tabular}




\begin{tabular}{|c|c|c|c|c|c|c|c|c|c|c|c|}
\hline 16 & $\mathrm{Si}$ & 133.9 & 7.5 & 100.9 & -33.0 & 10.1 & 2.6 & 117.5 & -16.4 & 13.4 & 5.9 \\
\hline 16 & $\mathrm{Mg}$ & 117.8 & -8.6 & 89.9 & -27.9 & -0.9 & 7.7 & 99.8 & -18.1 & -4.3 & 4.3 \\
\hline 16 & $\mathrm{Al}$ & 126.4 & - & 90.9 & -35.6 & - & - & 104.1 & -22.4 & - & - \\
\hline 16 & $\mathrm{Ge}$ & 147.6 & 21.2 & 99.5 & -48.1 & 8.7 & -12.5 & 116.3 & -31.3 & 12.2 & -9.0 \\
\hline 16 & $\mathrm{Ga}$ & 128.6 & 2.1 & 92.6 & -36.0 & 1.7 & -0.5 & 107.0 & -21.6 & 2.9 & 0.8 \\
\hline 16 & $\mathrm{Ti}$ & 147.3 & 20.8 & 107.5 & -39.7 & 16.7 & -4.2 & 126.0 & -21.3 & 21.9 & 1.1 \\
\hline 17 & $\mathrm{Zn}$ & 76.0 & 10.5 & 42.1 & -34.0 & 12.6 & 2.0 & 53.4 & -22.7 & 11.8 & 1.3 \\
\hline 17 & $\mathrm{Si}$ & 67.0 & 1.5 & 32.1 & -34.9 & 2.6 & 1.1 & 43.1 & -23.9 & 1.6 & 0.1 \\
\hline 17 & $\mathrm{Mg}$ & 63.2 & -2.3 & 32.0 & -31.2 & 2.4 & 4.8 & 41.7 & -21.5 & 0.2 & 2.5 \\
\hline 17 & $\mathrm{Al}$ & 65.5 & - & 29.5 & -36.0 & - & - & 41.5 & -24.0 & - & - \\
\hline 17 & $\mathrm{Ge}$ & 81.3 & 15.7 & 36.1 & -45.2 & 6.6 & -9.2 & 47.9 & -33.4 & 6.4 & -9.4 \\
\hline 17 & $\mathrm{Ga}$ & 65.1 & -0.4 & 32.5 & -32.6 & 3.0 & 3.4 & 45.7 & -19.4 & 4.1 & 4.6 \\
\hline 17 & $\mathrm{Ti}$ & 86.7 & 21.1 & 47.4 & -39.2 & 17.9 & -3.2 & 61.1 & -25.6 & 19.5 & -1.6 \\
\hline 18 & $\mathrm{Zn}$ & 148.7 & 4.2 & 90.6 & -58.1 & 5.4 & 1.3 & 114.5 & -34.2 & 7.5 & 3.4 \\
\hline 18 & $\mathrm{Si}$ & 148.4 & 3.9 & 93.5 & -54.9 & 8.3 & 4.4 & 116.2 & -32.2 & 9.2 & 5.3 \\
\hline 18 & $\mathrm{Mg}$ & 134.1 & -10.4 & 82.4 & -51.6 & -2.7 & 7.7 & 105.3 & -28.8 & -1.6 & 8.8 \\
\hline 18 & $\mathrm{Al}$ & 144.5 & - & 85.2 & -59.3 & - & - & 106.9 & -37.6 & - & - \\
\hline 18 & $\mathrm{Ge}$ & 157.9 & 13.4 & 90.7 & -67.2 & 5.6 & -7.8 & 113.8 & -44.1 & 6.9 & -6.5 \\
\hline 18 & $\mathrm{Ga}$ & 134.2 & -10.3 & 70.6 & -63.6 & -14.6 & -4.3 & 92.0 & -42.2 & -14.9 & -4.6 \\
\hline 18 & $\mathrm{Ti}$ & 164.8 & 20.3 & 103.2 & -61.6 & 18.0 & -2.3 & 131.4 & -33.4 & 24.5 & 4.1 \\
\hline 19 & $\mathrm{Zn}$ & 141.3 & 11.3 & 70.3 & -71.0 & 15.6 & 4.3 & 80.8 & -60.5 & 18.2 & 6.9 \\
\hline 19 & $\mathrm{Si}$ & 131.5 & 1.5 & 56.8 & -74.7 & 2.1 & 0.6 & 66.0 & -65.4 & 3.4 & 1.9 \\
\hline 19 & $\mathrm{Mg}$ & 125.3 & -4.6 & 58.3 & -67.1 & 3.6 & 8.2 & 67.8 & -57.5 & 5.2 & 9.8 \\
\hline 19 & $\mathrm{Al}$ & 130.0 & - & 54.6 & -75.3 & - & - & 62.6 & -67.3 & - & - \\
\hline 19 & $\mathrm{Ge}$ & 144.9 & 14.9 & 60.5 & -84.4 & 5.9 & -9.1 & 70.6 & -74.3 & 8.0 & -7.0 \\
\hline 19 & $\mathrm{Ga}$ & 131.9 & 1.9 & 58.3 & -73.6 & 3.7 & 1.7 & 67.3 & -64.6 & 4.7 & 2.7 \\
\hline 19 & $\mathrm{Ti}$ & 152.2 & 22.3 & 72.0 & -80.3 & 17.3 & -5.0 & 84.2 & -68.0 & 21.6 & -0.7 \\
\hline 20 & $\mathrm{Zn}$ & -14.3 & 32.1 & -31.6 & -17.4 & 39.8 & 7.7 & -34.7 & -20.5 & 51.8 & 19.7 \\
\hline 20 & $\mathrm{Si}$ & -77.2 & -30.8 & -92.4 & -15.2 & -21.0 & 9.8 & -111.9 & -34.7 & -25.4 & 5.4 \\
\hline 20 & $\mathrm{Mg}$ & -12.2 & 34.2 & -34.1 & -21.9 & 37.4 & 3.2 & -42.6 & -30.4 & 44.0 & 9.7 \\
\hline 20 & $\mathrm{Al}$ & -46.4 & - & -71.5 & -25.1 & - & - & -86.5 & -40.1 & - & - \\
\hline 20 & $\mathrm{Ge}$ & -48.1 & -1.7 & -72.7 & -24.7 & -1.2 & 0.4 & -91.8 & -43.8 & -5.3 & -3.6 \\
\hline 20 & $\mathrm{Ga}$ & -38.5 & 7.9 & -64.6 & -26.1 & 6.9 & -1.0 & -79.7 & -41.2 & 6.8 & -1.1 \\
\hline 20 & $\mathrm{Ti}$ & -30.0 & 16.4 & -45.6 & -15.6 & 25.9 & 9.5 & -64.4 & -34.4 & 22.1 & 5.7 \\
\hline 21 & $\mathrm{Zn}$ & - & - & - & - & - & - & - & - & - & - \\
\hline 21 & $\mathrm{Si}$ & - & - & - & - & - & - & - & - & - & - \\
\hline 21 & $\mathrm{Mg}$ & - & - & - & - & - & - & - & - & - & - \\
\hline 21 & Al & -61.6 & - & -35.1 & 26.5 & - & - & -34.7 & 26.9 & - & - \\
\hline 21 & $\mathrm{Ge}$ & - & - & - & - & - & - & - & - & - & - \\
\hline 21 & $\mathrm{Ga}$ & -60.2 & 1.4 & -31.7 & 28.5 & 3.4 & 2.0 & -35.6 & 24.6 & -0.9 & -2.3 \\
\hline 21 & $\mathrm{Ti}$ & - & - & - & - & - & - & - & - & - & - \\
\hline 22 & $\mathrm{Zn}$ & -146.9 & 6.6 & -121.4 & 25.5 & -1.3 & -7.9 & -112.2 & 34.7 & -12.0 & -18.6 \\
\hline 22 & $\mathrm{Si}$ & -128.6 & 24.9 & -96.4 & 32.3 & 23.8 & -1.1 & -87.4 & 41.2 & 12.8 & -12.1 \\
\hline 22 & $\mathrm{Mg}$ & -135.5 & 18.0 & -106.9 & 28.6 & 13.2 & -4.8 & -91.7 & 43.8 & 8.6 & -9.4 \\
\hline 22 & $\mathrm{Al}$ & -153.5 & - & -120.1 & 33.4 & - & - & -100.3 & 53.3 & - & - \\
\hline 22 & $\mathrm{Ge}$ & -125.6 & 27.9 & -101.1 & 24.5 & 19.1 & -8.9 & -92.4 & 33.2 & 7.9 & -20.1 \\
\hline 22 & $\mathrm{Ga}$ & -136.8 & 16.7 & -108.4 & 28.4 & 11.7 & -5.0 & -93.7 & 43.1 & 6.6 & -10.1 \\
\hline 22 & $\mathrm{Ti}$ & -140.9 & 12.7 & -108.1 & 32.7 & 12.0 & -0.7 & -102.1 & 38.7 & -1.9 & -14.5 \\
\hline 23 & $\mathrm{Zn}$ & -79.9 & -3.4 & -94.8 & -14.9 & 4.6 & 8.0 & -66.4 & 13.5 & 5.6 & 9.1 \\
\hline 23 & $\mathrm{Si}$ & -90.6 & -14.2 & -107.0 & -16.4 & -7.6 & 6.6 & -82.3 & 8.3 & -10.3 & 3.9 \\
\hline 23 & $\mathrm{Mg}$ & -84.4 & -8.0 & -101.5 & -17.1 & -2.1 & 5.9 & -73.5 & 10.9 & -1.5 & 6.5 \\
\hline 23 & $\mathrm{Al}$ & -76.4 & - & -99.4 & -22.9 & - & - & -72.0 & 4.4 & - & - \\
\hline 23 & $\mathrm{Ge}$ & -86.1 & -9.7 & -96.2 & -10.2 & 3.1 & 12.8 & -73.3 & 12.8 & -1.3 & 8.4 \\
\hline 23 & $\mathrm{Ga}$ & -82.8 & -6.4 & -96.6 & -13.7 & 2.8 & 9.2 & -70.5 & 12.3 & 1.5 & 7.9 \\
\hline 23 & $\mathrm{Ti}$ & -77.2 & -0.8 & -92.1 & -14.9 & 7.2 & 8.1 & -71.7 & 5.5 & 0.3 & 1.1 \\
\hline 24 & $\mathrm{Zn}$ & -90.0 & 5.7 & -104.2 & -14.2 & 6.1 & 0.4 & -80.1 & 10.0 & 11.8 & 6.1 \\
\hline 24 & $\mathrm{Si}$ & -98.2 & -2.5 & -114.7 & -16.5 & -4.4 & -1.9 & -97.6 & 0.6 & -5.7 & -3.3 \\
\hline 24 & $\mathrm{Mg}$ & -95.2 & 0.5 & -111.5 & -16.3 & -1.2 & -1.7 & -87.8 & 7.4 & 4.0 & 3.5 \\
\hline 24 & $\mathrm{Al}$ & -95.7 & - & -110.3 & -14.6 & - & - & -91.8 & 3.9 & - & . \\
\hline 24 & $\mathrm{Ge}$ & -97.9 & -2.2 & -108.8 & -10.8 & 1.6 & 3.7 & -92.3 & 5.6 & -0.4 & 1.7 \\
\hline 24 & $\mathrm{Ga}$ & -96.2 & -0.4 & -105.7 & -9.6 & 4.6 & 5.0 & -87.8 & 8.4 & 4.0 & 4.5 \\
\hline 24 & $\mathrm{Ti}$ & -84.3 & 11.5 & -102.2 & -17.9 & 8.2 & -3.3 & -85.7 & -1.4 & 6.2 & -5.3 \\
\hline
\end{tabular}




\begin{tabular}{|c|c|c|c|c|c|c|c|c|c|c|c|}
\hline 25 & $\mathrm{Zn}$ & -54.4 & 9.0 & -80.6 & -26.2 & 9.0 & 0.0 & -55.8 & -1.4 & 14.6 & 5.6 \\
\hline 25 & $\mathrm{Si}$ & -71.7 & -8.3 & -93.3 & -21.5 & -3.6 & 4.7 & -73.6 & -1.9 & -3.3 & 5.0 \\
\hline 25 & $\mathrm{Mg}$ & -62.9 & 0.5 & -86.4 & -23.5 & 3.3 & 2.8 & -60.8 & 2.1 & 9.6 & 9.1 \\
\hline 25 & $\mathrm{Al}$ & -63.4 & - & -89.7 & -26.3 & - & - & -70.3 & -6.9 & - & - \\
\hline 25 & Ge & -55.1 & 8.3 & -86.4 & -31.3 & 3.3 & -5.0 & -67.6 & -12.5 & 2.7 & -5.6 \\
\hline 25 & $\mathrm{Ga}$ & -62.6 & 0.8 & -83.9 & -21.2 & 5.8 & 5.0 & -65.5 & -2.9 & 4.8 & 4.0 \\
\hline 25 & $\mathrm{Ti}$ & -53.4 & 10.0 & -84.1 & -30.7 & 5.6 & -4.4 & -63.6 & -10.2 & 6.7 & -3.3 \\
\hline 26 & $\mathrm{Zn}$ & -58.4 & 3.2 & -74.6 & -16.1 & -2.6 & -5.8 & -48.8 & 9.7 & 0.1 & -3.1 \\
\hline 26 & $\mathrm{Si}$ & -62.5 & -0.8 & -76.9 & -14.5 & -5.0 & -4.1 & -52.3 & 10.1 & -3.5 & -2.6 \\
\hline 26 & $\mathrm{Mg}$ & -63.3 & -1.7 & -73.5 & -10.2 & -1.6 & 0.1 & -44.7 & 18.6 & 4.1 & 5.8 \\
\hline 26 & $\mathrm{Al}$ & -61.6 & - & -72.0 & -10.3 & - & - & -48.9 & 12.8 & - & - \\
\hline 26 & $\mathrm{Ge}$ & -46.2 & 15.4 & -73.1 & -26.9 & -1.1 & -16.6 & -48.8 & -2.6 & 0.0 & -15.4 \\
\hline 26 & $\mathrm{Ga}$ & -58.9 & 2.8 & -65.4 & -6.6 & 6.5 & 3.8 & -43.4 & 15.4 & 5.4 & 2.6 \\
\hline 26 & $\mathrm{Ti}$ & -46.6 & 15.0 & -69.6 & -23.0 & 2.3 & -12.7 & -43.7 & 3.0 & 5.2 & -9.8 \\
\hline 27 & $\mathrm{Zn}$ & -125.8 & -5.8 & -137.3 & -11.5 & 8.0 & 13.7 & -111.2 & 14.6 & 9.9 & 15.7 \\
\hline 27 & $\mathrm{Si}$ & -127.3 & -7.3 & -148.3 & -21.0 & -3.0 & 4.3 & -121.5 & 5.8 & -0.4 & 6.9 \\
\hline 27 & $\mathrm{Mg}$ & -132.4 & -12.4 & -147.2 & -14.8 & -1.9 & 10.5 & -124.0 & 8.4 & -2.9 & 9.5 \\
\hline 27 & $\mathrm{Al}$ & -120.0 & - & -145.3 & -25.3 & - & - & -121.2 & -1.1 & - & - \\
\hline 27 & $\mathrm{Ge}$ & -121.9 & -1.8 & -136.2 & -14.3 & 9.1 & 10.9 & -109.7 & 12.1 & 11.4 & 13.3 \\
\hline 27 & $\mathrm{Ga}$ & -128.3 & -8.2 & -140.6 & -12.3 & 4.7 & 13.0 & -114.5 & 13.8 & 6.6 & 14.9 \\
\hline 27 & $\mathrm{Ti}$ & -102.9 & 17.2 & -125.3 & -22.4 & 20.1 & 2.9 & -95.5 & 7.3 & 25.6 & 8.5 \\
\hline 28 & $\mathrm{Zn}$ & -30.2 & -3.6 & -39.4 & -9.1 & 2.7 & 6.3 & -28.6 & 1.6 & 5.0 & 8.6 \\
\hline 28 & $\mathrm{Si}$ & -41.5 & -14.9 & -47.4 & -5.9 & -5.4 & 9.5 & -38.3 & 3.2 & -4.7 & 10.1 \\
\hline 28 & $\mathrm{Mg}$ & -38.8 & -12.2 & -42.5 & -3.7 & -0.4 & 11.7 & -32.1 & 6.7 & 1.5 & 13.6 \\
\hline 28 & $\mathrm{Al}$ & -26.6 & - & -42.1 & -15.5 & - & - & -33.6 & -7.0 & - & - \\
\hline 28 & $\mathrm{Ge}$ & -33.9 & -7.2 & -41.9 & -8.0 & 0.2 & 7.4 & -33.5 & 0.4 & 0.1 & 7.4 \\
\hline 28 & $\mathrm{Ga}$ & -29.8 & -3.2 & -39.9 & -10.1 & 2.2 & 5.3 & -31.9 & -2.1 & 1.7 & 4.9 \\
\hline 28 & $\mathrm{Ti}$ & -28.6 & -2.0 & -38.7 & -10.1 & 3.4 & 5.4 & -30.2 & -1.6 & 3.4 & 5.4 \\
\hline 29 & $\mathrm{Zn}$ & -21.6 & -7.6 & -14.3 & 7.3 & -7.7 & -0.1 & -8.9 & 12.7 & -5.0 & 2.6 \\
\hline 29 & $\mathrm{Si}$ & -17.9 & -3.9 & -10.8 & 7.1 & -4.2 & -0.3 & -7.4 & 10.5 & -3.5 & 0.4 \\
\hline 29 & $\mathrm{Mg}$ & -21.9 & -7.9 & -13.3 & 8.6 & -6.7 & 1.2 & -8.7 & 13.2 & -4.8 & 3.1 \\
\hline 29 & $\mathrm{Al}$ & -14.0 & - & -6.6 & 7.4 & - & - & -3.9 & 10.1 & - & - \\
\hline 29 & $\mathrm{Ge}$ & -14.6 & -0.6 & -5.4 & 9.2 & 1.2 & 1.8 & -2.4 & 12.2 & 1.5 & 2.1 \\
\hline 29 & $\mathrm{Ga}$ & -14.0 & 0.0 & -1.1 & 12.9 & 5.5 & 5.5 & 1.0 & 15.0 & 4.9 & 4.8 \\
\hline 29 & $\mathrm{Ti}$ & -7.5 & 6.5 & -4.5 & 3.0 & 2.1 & -4.4 & -0.4 & 7.1 & 3.5 & -3.0 \\
\hline
\end{tabular}

\section{S3 Total energies}

All total energies required are given in Tables S2-S4. The zeolite species are labeled according to the reaction in which they occur in Figure S2. ZOH is given additionally and the SMS is given in reaction 29.

Table S2, Computed and extrapolated total energies. Except for molecules and the clean acid site $(\mathrm{ZOH})$, species are labeled according to Fig. S2 and catalysts are labeled according to the substituting element. $\operatorname{CCSD}(\mathrm{T}) / \mathrm{CBS}$ refers to DLNPO-CCSD(T)/cc-pVDZ with a CBS-correction from MP2. All energies are given in $\mathrm{eV}$.

\begin{tabular}{|c|c|c|c|c|}
\hline No. & $\mathrm{El}$ & $\operatorname{CCSD}(\mathrm{T}) / \mathrm{CBS}$ & BEEF-vdW/400 & PBE-D3/400 \\
\hline 2-pentene & & -5340.113 & -76.566 & -81.962 \\
\hline $\mathrm{CH} 4$ & & -1100.915 & -23.264 & -24.034 \\
\hline $\mathrm{CO}$ & & -3080.143 & -12.095 & -14.800 \\
\hline DME & & -4213.442 & -42.878 & -46.440 \\
\hline FA & & -3112.361 & -19.557 & -22.153 \\
\hline $\mathrm{H} 2 \mathrm{O}$ & & -2078.038 & -12.812 & -14.224 \\
\hline $\mathrm{MeOH}$ & & -3145.633 & -27.749 & -30.236 \\
\hline NH3 & & -1537.454 & -18.408 & -19.520 \\
\hline benzene & & -6310.127 & -68.969 & -76.115 \\
\hline i-butene & & -4271.973 & -61.153 & -65.439 \\
\hline ketene & & -4147.357 & -26.995 & -30.971 \\
\hline n-butene & & -4271.918 & -61.118 & -65.409 \\
\hline propene & & -3203.618 & -45.550 & -48.710 \\
\hline
\end{tabular}




\begin{tabular}{|c|c|c|c|c|}
\hline toluene & & -7378.396 & -84.516 & -92.790 \\
\hline 1 & $\mathrm{Zn}$ & -557917.577 & -830.567 & -1008.366 \\
\hline 1 & $\mathrm{Si}$ & -514694.581 & -840.731 & -1016.097 \\
\hline 1 & $\mathrm{Mg}$ & -514951.138 & -835.884 & -1011.691 \\
\hline 1 & $\mathrm{Al}$ & -511850.192 & -907.476 & -1078.519 \\
\hline 1 & $\mathrm{Ge}$ & -563306.345 & -835.440 & -1011.148 \\
\hline 1 & $\mathrm{Ga}$ & -557602.424 & -902.939 & -1074.354 \\
\hline 1 & $\mathrm{Ti}$ & -529928.029 & -842.055 & -1018.271 \\
\hline 2 & $\mathrm{Zn}$ & -564228.164 & -900.310 & -1085.312 \\
\hline 2 & $\mathrm{Si}$ & -521005.433 & -910.618 & -1093.190 \\
\hline 2 & $\mathrm{Mg}$ & -521261.816 & -905.639 & -1088.647 \\
\hline 2 & $\mathrm{Al}$ & -518160.981 & -977.367 & -1155.587 \\
\hline 2 & $\mathrm{Ge}$ & -569617.068 & -905.343 & -1088.245 \\
\hline 2 & $\mathrm{Ga}$ & -563913.218 & -972.821 & -1151.406 \\
\hline 2 & $\mathrm{Ti}$ & -536238.797 & -911.964 & -1095.368 \\
\hline 3 & $\mathrm{Zn}$ & -561121.775 & -877.031 & -1058.059 \\
\hline 3 & $\mathrm{Si}$ & -517898.893 & -887.269 & -1065.872 \\
\hline 3 & $\mathrm{Mg}$ & -518155.365 & -882.356 & -1061.394 \\
\hline 3 & $\mathrm{Al}$ & -515054.504 & -954.041 & -1128.294 \\
\hline 3 & $\mathrm{Ge}$ & -566510.651 & -881.995 & -1060.932 \\
\hline 3 & $\mathrm{Ga}$ & -560806.714 & -949.479 & -1124.101 \\
\hline 3 & $\mathrm{Ti}$ & -533132.333 & -888.590 & -1068.040 \\
\hline 4 & $\mathrm{Zn}$ & -561063.784 & -858.980 & -1039.316 \\
\hline 4 & $\mathrm{Si}$ & -517840.996 & -869.345 & -1047.228 \\
\hline 4 & $\mathrm{Mg}$ & -518097.422 & -864.330 & -1042.752 \\
\hline 4 & $\mathrm{Al}$ & -514996.554 & -936.062 & -1109.610 \\
\hline 4 & $\mathrm{Ge}$ & -566452.806 & -864.096 & -1042.325 \\
\hline 4 & $\mathrm{Ga}$ & -560748.762 & -931.525 & -1105.448 \\
\hline 4 & $\mathrm{Ti}$ & -533074.441 & -870.656 & -1049.399 \\
\hline 5 & $\mathrm{Zn}$ & -561063.214 & -858.641 & -1039.154 \\
\hline 5 & $\mathrm{Si}$ & -517840.440 & -868.921 & -1046.961 \\
\hline 5 & $\mathrm{Mg}$ & -518096.857 & -863.921 & -1042.446 \\
\hline 5 & $\mathrm{Al}$ & -514996.003 & -935.676 & -1109.400 \\
\hline 5 & $\mathrm{Ge}$ & -566452.062 & -863.677 & -1042.065 \\
\hline 5 & $\mathrm{Ga}$ & -560748.224 & -931.154 & -1105.244 \\
\hline 5 & $\mathrm{Ti}$ & -533073.763 & -870.236 & -1049.150 \\
\hline 6 & $\mathrm{Zn}$ & -557916.647 & -829.967 & -1007.861 \\
\hline 6 & $\mathrm{Si}$ & -514693.889 & -840.217 & -1015.695 \\
\hline 6 & $\mathrm{Mg}$ & -514950.281 & -835.257 & -1011.163 \\
\hline 6 & $\mathrm{Al}$ & -511849.409 & -906.948 & -1078.084 \\
\hline 6 & $\mathrm{Ge}$ & -563305.525 & -834.985 & -1010.803 \\
\hline 6 & $\mathrm{Ga}$ & -557601.647 & -902.452 & -1073.962 \\
\hline 6 & $\mathrm{Ti}$ & -529927.267 & -841.586 & -1017.924 \\
\hline 7 & $\mathrm{Zn}$ & -558984.470 & -845.039 & -1023.856 \\
\hline 7 & $\mathrm{Si}$ & -515761.688 & -855.255 & -1031.606 \\
\hline 7 & $\mathrm{Mg}$ & -516018.120 & -850.343 & -1027.169 \\
\hline 7 & $\mathrm{Al}$ & -512917.184 & -921.996 & -1094.020 \\
\hline 7 & $\mathrm{Ge}$ & -564373.269 & -849.981 & -1026.668 \\
\hline 7 & $\mathrm{Ga}$ & -558669.433 & -917.461 & -1089.861 \\
\hline 7 & $\mathrm{Ti}$ & -530995.065 & -856.587 & -1033.782 \\
\hline 8 & $\mathrm{Zn}$ & -562189.400 & -891.909 & -1074.095 \\
\hline 8 & $\mathrm{Si}$ & -518966.654 & -902.236 & -1081.985 \\
\hline 8 & $\mathrm{Mg}$ & -519223.078 & -897.231 & -1077.422 \\
\hline 8 & $\mathrm{Al}$ & -516122.142 & -968.936 & -1144.294 \\
\hline 8 & $\mathrm{Ge}$ & -567578.435 & -896.974 & -1077.067 \\
\hline 8 & $\mathrm{Ga}$ & -561874.452 & -964.425 & -1140.185 \\
\hline 8 & $\mathrm{Ti}$ & -534200.068 & -903.545 & -1084.165 \\
\hline 9 & $\mathrm{Zn}$ & -565295.875 & -915.319 & -1101.416 \\
\hline 9 & $\mathrm{Si}$ & -522072.962 & -925.504 & -1109.147 \\
\hline 9 & $\mathrm{Mg}$ & -522329.514 & -920.650 & -1104.739 \\
\hline 9 & $\mathrm{Al}$ & -519228.578 & -992.322 & -1171.599 \\
\hline 9 & $\mathrm{Ge}$ & -570684.660 & -920.251 & -1104.250 \\
\hline 9 & $\mathrm{Ga}$ & -564980.812 & -987.764 & -1167.417 \\
\hline
\end{tabular}




\begin{tabular}{|c|c|c|c|c|}
\hline 9 & $\mathrm{Ti}$ & -537306.365 & -926.840 & -1111.349 \\
\hline 10 & $\mathrm{Zn}$ & -558985.237 & -845.639 & -1024.424 \\
\hline 10 & $\mathrm{Si}$ & -515762.181 & -855.709 & -1032.077 \\
\hline 10 & $\mathrm{Mg}$ & -516018.840 & -850.956 & -1027.766 \\
\hline 10 & $\mathrm{Al}$ & -512917.932 & -922.575 & -1094.626 \\
\hline 10 & $\mathrm{Ge}$ & -564373.950 & -850.439 & -1027.157 \\
\hline 10 & $\mathrm{Ga}$ & -558670.129 & -918.006 & -1090.430 \\
\hline 10 & $\mathrm{Ti}$ & -530995.672 & -857.072 & -1034.293 \\
\hline 11 & $\mathrm{Zn}$ & -560111.554 & -879.257 & -1059.889 \\
\hline 11 & $\mathrm{Si}$ & -516888.664 & -889.448 & -1067.636 \\
\hline 11 & $\mathrm{Mg}$ & -517145.201 & -884.578 & -1063.219 \\
\hline 11 & $\mathrm{Al}$ & -514044.219 & -956.195 & -1130.038 \\
\hline 11 & $\mathrm{Ge}$ & -565500.274 & -884.156 & -1062.682 \\
\hline 11 & $\mathrm{Ga}$ & -559796.458 & -951.643 & -1125.857 \\
\hline 11 & $\mathrm{Ti}$ & -532122.028 & -890.770 & -1069.818 \\
\hline 12 & $\mathrm{Zn}$ & - & - & - \\
\hline 12 & $\mathrm{Si}$ & -515762.308 & -855.784 & -1032.452 \\
\hline 12 & $\mathrm{Mg}$ & -516018.544 & -850.688 & -1027.822 \\
\hline 12 & $\mathrm{Al}$ & -512917.770 & -922.461 & -1094.805 \\
\hline 12 & $\mathrm{Ge}$ & -564373.930 & -850.531 & -1027.537 \\
\hline 12 & $\mathrm{Ga}$ & -558670.010 & -917.974 & -1090.681 \\
\hline 12 & $\mathrm{Ti}$ & - & - & - \\
\hline 13 & $\mathrm{Zn}$ & -557883.102 & -821.465 & -999.504 \\
\hline 13 & $\mathrm{Si}$ & -514660.232 & -831.637 & -1007.240 \\
\hline 13 & $\mathrm{Mg}$ & -514916.680 & -826.711 & -1002.762 \\
\hline 13 & $\mathrm{Al}$ & -511815.790 & -898.400 & -1069.674 \\
\hline 13 & $\mathrm{Ge}$ & -563271.917 & -826.425 & -1002.375 \\
\hline 13 & $\mathrm{Ga}$ & -557568.057 & -893.906 & -1065.551 \\
\hline 13 & $\mathrm{Ti}$ & -529893.623 & -832.996 & -1009.461 \\
\hline 14 & $\mathrm{Zn}$ & -562149.753 & -887.053 & -1070.541 \\
\hline 14 & $\mathrm{Si}$ & -518926.840 & -897.249 & -1078.274 \\
\hline 14 & $\mathrm{Mg}$ & -519183.382 & -892.360 & -1073.860 \\
\hline 14 & $\mathrm{Al}$ & -516082.391 & -963.987 & -1140.680 \\
\hline 14 & $\mathrm{Ge}$ & -567538.495 & -891.953 & -1073.319 \\
\hline 14 & $\mathrm{Ga}$ & -561834.639 & -959.428 & -1136.493 \\
\hline 14 & $\mathrm{Ti}$ & -534160.187 & -898.553 & -1080.430 \\
\hline 15 & $\mathrm{Zn}$ & - & -858.129 & -1037.205 \\
\hline 15 & $\mathrm{Si}$ & -515820.350 & -873.834 & -1050.889 \\
\hline 15 & $\mathrm{Mg}$ & -516076.916 & -868.996 & -1046.501 \\
\hline 15 & $\mathrm{Al}$ & -512975.907 & -940.604 & -1113.309 \\
\hline 15 & $\mathrm{Ge}$ & -564431.977 & -868.546 & -1045.943 \\
\hline 15 & $\mathrm{Ga}$ & -558728.099 & -936.093 & -1109.169 \\
\hline 15 & $\mathrm{Ti}$ & -531053.717 & -875.149 & -1053.053 \\
\hline 16 & $\mathrm{Zn}$ & -558919.218 & -829.507 & -1008.539 \\
\hline 16 & $\mathrm{Si}$ & -515696.213 & -839.555 & -1016.194 \\
\hline 16 & $\mathrm{Mg}$ & -515952.873 & -834.836 & -1011.880 \\
\hline 16 & $\mathrm{Al}$ & -512851.836 & -906.387 & -1078.674 \\
\hline 16 & $\mathrm{Ge}$ & -564307.837 & -834.327 & -1011.303 \\
\hline 16 & $\mathrm{Ga}$ & -558604.048 & -901.861 & -1074.519 \\
\hline 16 & $\mathrm{Ti}$ & -530929.652 & -840.971 & -1018.449 \\
\hline 17 & $\mathrm{Zn}$ & -559987.026 & -845.042 & -1025.343 \\
\hline 17 & $\mathrm{Si}$ & -516764.121 & -855.227 & -1033.079 \\
\hline 17 & $\mathrm{Mg}$ & -517020.653 & -850.339 & -1028.652 \\
\hline 17 & $\mathrm{Al}$ & -513919.682 & -921.936 & -1095.481 \\
\hline 17 & $\mathrm{Ge}$ & -565375.739 & -849.936 & -1028.132 \\
\hline 17 & $\mathrm{Ga}$ & -559671.920 & -917.397 & -1091.313 \\
\hline 17 & $\mathrm{Ti}$ & -531997.494 & -856.545 & -1035.243 \\
\hline 18 & $\mathrm{Zn}$ & -558984.549 & -845.162 & -1024.105 \\
\hline 18 & $\mathrm{Si}$ & -515761.553 & -855.223 & -1031.707 \\
\hline 18 & $\mathrm{Mg}$ & -516018.195 & -850.433 & -1027.394 \\
\hline 18 & $\mathrm{Al}$ & -512917.139 & -922.011 & -1094.169 \\
\hline 18 & $\mathrm{Ge}$ & -564373.220 & -850.006 & -1026.831 \\
\hline 18 & $\mathrm{Ga}$ & -558669.480 & -917.670 & -1090.183 \\
\hline
\end{tabular}




\begin{tabular}{|c|c|c|c|c|}
\hline 18 & $\mathrm{Ti}$ & -530994.960 & -856.569 & -1033.930 \\
\hline 19 & $\mathrm{Zn}$ & -560110.911 & -878.881 & -1059.488 \\
\hline 19 & $\mathrm{Si}$ & -516888.014 & -889.112 & -1067.260 \\
\hline 19 & $\mathrm{Mg}$ & -517144.570 & -884.191 & -1062.817 \\
\hline 19 & $\mathrm{Al}$ & -514043.574 & -955.840 & -1129.658 \\
\hline 19 & $\mathrm{Ge}$ & -565499.640 & -883.824 & -1062.316 \\
\hline 19 & $\mathrm{Ga}$ & -559795.789 & -951.296 & -1125.482 \\
\hline 19 & $\mathrm{Ti}$ & -532121.375 & -890.428 & -1069.426 \\
\hline 20 & $\mathrm{Zn}$ & -559045.027 & -864.942 & -1044.594 \\
\hline 20 & $\mathrm{Si}$ & -515821.594 & -874.421 & -1051.763 \\
\hline 20 & $\mathrm{Mg}$ & -516078.628 & -870.090 & -1047.842 \\
\hline 20 & $\mathrm{Al}$ & -512977.412 & -941.379 & -1114.362 \\
\hline 20 & $\mathrm{Ge}$ & -564433.524 & -869.377 & -1047.047 \\
\hline 20 & $\mathrm{Ga}$ & -558729.721 & -936.954 & -1110.292 \\
\hline 20 & $\mathrm{Ti}$ & -531055.578 & -876.386 & -1054.542 \\
\hline 21 & $\mathrm{Zn}$ & - & - & - \\
\hline 21 & $\mathrm{Si}$ & - & - & - \\
\hline 21 & $\mathrm{Mg}$ & - & - & - \\
\hline 21 & $\mathrm{Al}$ & -512977.255 & -941.916 & -1114.739 \\
\hline 21 & $\mathrm{Ge}$ & - & - & - \\
\hline 21 & $\mathrm{Ga}$ & -558729.496 & -937.412 & -1110.633 \\
\hline 21 & $\mathrm{Ti}$ & - & - & - \\
\hline 22 & $\mathrm{Zn}$ & -562150.118 & -887.429 & -1070.952 \\
\hline 22 & $\mathrm{Si}$ & -518927.389 & -897.817 & -1078.904 \\
\hline 22 & $\mathrm{Mg}$ & -519183.778 & -892.779 & -1074.305 \\
\hline 22 & $\mathrm{Al}$ & -516082.707 & -964.377 & -1141.025 \\
\hline 22 & $\mathrm{Ge}$ & -567539.052 & -892.540 & -1073.967 \\
\hline 22 & $\mathrm{Ga}$ & -561835.086 & -959.944 & -1136.999 \\
\hline 22 & $\mathrm{Ti}$ & -534160.782 & -899.152 & -1081.095 \\
\hline 23 & $\mathrm{Zn}$ & -557919.099 & -832.007 & -1009.866 \\
\hline 23 & $\mathrm{Si}$ & -514696.250 & -842.266 & -1017.661 \\
\hline 23 & $\mathrm{Mg}$ & -514952.637 & -837.259 & -1013.149 \\
\hline 23 & $\mathrm{Al}$ & -511851.688 & -908.889 & -1080.001 \\
\hline 23 & $\mathrm{Ge}$ & -563308.003 & -836.983 & -1012.700 \\
\hline 23 & $\mathrm{Ga}$ & -557603.990 & -904.428 & -1075.891 \\
\hline 23 & $\mathrm{Ti}$ & -529929.796 & -843.733 & -1019.895 \\
\hline 24 & $\mathrm{Zn}$ & -558987.013 & -847.278 & -1026.168 \\
\hline 24 & $\mathrm{Si}$ & -515764.138 & -857.554 & -1033.944 \\
\hline 24 & $\mathrm{Mg}$ & -516020.558 & -852.537 & -1029.457 \\
\hline 24 & $\mathrm{Al}$ & -512919.697 & -924.224 & -1096.318 \\
\hline 24 & $\mathrm{Ge}$ & -564375.934 & -852.310 & -1029.034 \\
\hline 24 & $\mathrm{Ga}$ & -558671.936 & -919.736 & -1092.190 \\
\hline 24 & $\mathrm{Ti}$ & -530997.677 & -859.007 & -1036.203 \\
\hline 25 & $\mathrm{Zn}$ & -559045.175 & -865.302 & -1044.922 \\
\hline 25 & $\mathrm{Si}$ & -515822.394 & -875.581 & -1052.721 \\
\hline 25 & $\mathrm{Mg}$ & -516078.754 & -870.532 & -1048.195 \\
\hline 25 & $\mathrm{Al}$ & -512977.893 & -942.276 & -1115.102 \\
\hline 25 & $\mathrm{Ge}$ & -564434.022 & -870.329 & -1047.800 \\
\hline 25 & $\mathrm{Ga}$ & -558730.120 & -937.781 & -1110.962 \\
\hline 25 & $\mathrm{Ti}$ & -531055.889 & -877.054 & -1055.014 \\
\hline 26 & $\mathrm{Zn}$ & -562151.640 & -888.592 & -1072.210 \\
\hline 26 & $\mathrm{Si}$ & -518928.722 & -898.723 & -1079.903 \\
\hline 26 & $\mathrm{Mg}$ & -519185.182 & -893.729 & -1075.414 \\
\hline 26 & $\mathrm{Al}$ & -516084.298 & -965.416 & -1142.270 \\
\hline 26 & $\mathrm{Ge}$ & -567540.353 & -893.498 & -1075.014 \\
\hline 26 & $\mathrm{Ga}$ & -561836.504 & -960.915 & -1138.122 \\
\hline 26 & $\mathrm{Ti}$ & -534162.242 & -900.210 & -1082.216 \\
\hline 27 & $\mathrm{Zn}$ & -556311.396 & -823.131 & -999.591 \\
\hline 27 & $\mathrm{Si}$ & -513088.451 & -833.332 & -1007.373 \\
\hline 27 & $\mathrm{Mg}$ & -513344.956 & -828.442 & -1002.907 \\
\hline 27 & $\mathrm{Al}$ & -510243.961 & -900.057 & -1069.761 \\
\hline 27 & $\mathrm{Ge}$ & -561700.195 & -828.021 & -1002.398 \\
\hline 27 & $\mathrm{Ga}$ & -555996.281 & -895.543 & -1065.631 \\
\hline
\end{tabular}




\begin{tabular}{rrrrr}
\hline \hline 27 & $\mathrm{Ti}$ & -528321.882 & -834.639 & -1009.523 \\
28 & $\mathrm{Zn}$ & -557853.094 & -815.962 & -993.855 \\
28 & $\mathrm{Si}$ & -514630.251 & -826.156 & -1001.607 \\
28 & $\mathrm{Mg}$ & -514886.674 & -821.176 & -997.102 \\
28 & $\mathrm{Al}$ & -511785.682 & -892.836 & -1063.971 \\
28 & $\mathrm{Ge}$ & -563241.972 & -820.917 & -996.701 \\
28 & $\mathrm{Ga}$ & -557537.950 & -888.373 & -1059.868 \\
28 & $\mathrm{Ti}$ & -529863.802 & -827.649 & -1003.905 \\
29 & $\mathrm{Zn}$ & -555840.457 & -818.600 & -994.808 \\
29 & $\mathrm{Si}$ & -512617.458 & -828.678 & -1002.440 \\
29 & $\mathrm{Mg}$ & -512873.951 & -823.776 & -998.012 \\
29 & $\mathrm{Al}$ & -509773.003 & -895.371 & -1064.816 \\
29 & $\mathrm{Ge}$ & -561229.224 & -823.437 & -997.535 \\
29 & $\mathrm{Ga}$ & -555525.238 & -890.875 & -1060.678 \\
29 & $\mathrm{Ti}$ & -527851.035 & -830.182 & -1004.763 \\
$\mathrm{ZOH}$ & $\mathrm{Zn}$ & -554772.638 & -803.570 & -978.647 \\
$\mathrm{ZOH}$ & $\mathrm{Si}$ & -511549.678 & -813.664 & -986.316 \\
$\mathrm{ZOH}$ & $\mathrm{Mg}$ & -511806.129 & -808.749 & -981.862 \\
$\mathrm{ZOH}$ & $\mathrm{Al}$ & -508705.263 & -880.394 & -1048.735 \\
$\mathrm{ZOH}$ & $\mathrm{Ge}$ & -560161.478 & -808.475 & -981.466 \\
$\mathrm{ZOH}$ & $\mathrm{Ga}$ & -554457.498 & -875.948 & -1044.654 \\
$\mathrm{ZOH}$ & $\mathrm{Ti}$ & -526783.362 & -815.241 & -988.704 \\
\hline \hline
\end{tabular}

Table S3, Computed and extrapolated total energies. Except for molecules and the clean acid site (ZOH), species are labeled according to Fig. S2 and catalysts are labeled according to the substituting element. All energies are given in $\mathrm{eV}$.

\begin{tabular}{|c|c|c|c|c|c|}
\hline No. & $\mathrm{El}$ & $\mathrm{HF} / \mathrm{cc}-\mathrm{pVDZ}$ & HF/cc-pTDZ & $\mathrm{HF} / \mathrm{cc}-\mathrm{pVQZ}$ & $\mathrm{HF} / \mathrm{CBS}$ \\
\hline 2-pentene & & -5310.576 & -5312.030 & -5312.372 & -5312.477 \\
\hline $\mathrm{CH} 4$ & & -1093.860 & -1094.250 & -1094.328 & -1094.347 \\
\hline $\mathrm{CO}$ & & -3068.010 & -3068.846 & -3069.073 & -3069.157 \\
\hline DME & & -4192.587 & -4193.940 & -4194.253 & -4194.347 \\
\hline FA & & -3098.692 & -3099.647 & -3099.889 & -3099.971 \\
\hline $\mathrm{H} 2 \mathrm{O}$ & & -2068.762 & -2069.584 & -2069.792 & -2069.862 \\
\hline $\mathrm{MeOH}$ & & -3130.617 & -3131.699 & -3131.956 & -3132.037 \\
\hline NH3 & & -1529.144 & -1529.740 & -1529.882 & -1529.926 \\
\hline benzene & & -6278.250 & -6279.790 & -6280.176 & -6280.306 \\
\hline i-butene & & -4248.335 & -4249.520 & -4249.798 & -4249.883 \\
\hline ketene & & -4129.006 & -4130.197 & -4130.493 & -4130.591 \\
\hline n-butene & & -4248.323 & -4249.501 & -4249.775 & -4249.858 \\
\hline propene & & -3185.959 & -3186.873 & -3187.078 & -3187.137 \\
\hline toluene & & -7340.561 & -7342.371 & -7342.825 & -7342.977 \\
\hline 1 & $\mathrm{Zn}$ & -557080.973 & -557181.647 & -557205.777 & -557213.383 \\
\hline 1 & $\mathrm{Si}$ & -513881.928 & -513983.249 & -514007.378 & -514014.921 \\
\hline 1 & $\mathrm{Mg}$ & -514137.499 & -514238.432 & -514262.470 & -514269.985 \\
\hline 1 & $\mathrm{Al}$ & -511040.084 & -511147.091 & -511170.858 & -511177.643 \\
\hline 1 & $\mathrm{Ge}$ & -562489.828 & -562591.958 & -562616.022 & -562623.439 \\
\hline 1 & $\mathrm{Ga}$ & -556788.083 & -556896.185 & -556919.844 & -556926.472 \\
\hline 1 & $\mathrm{Ti}$ & -529106.792 & -529206.392 & -529230.233 & -529237.736 \\
\hline 2 & $\mathrm{Zn}$ & -563358.946 & -563461.157 & -563485.619 & -563493.315 \\
\hline 2 & $\mathrm{Si}$ & -520160.097 & -520262.979 & -520287.478 & -520295.136 \\
\hline 2 & $\mathrm{Mg}$ & -520415.482 & -520517.965 & -520542.366 & -520549.991 \\
\hline 2 & $\mathrm{Al}$ & -517318.226 & -517426.712 & -517450.792 & -517457.662 \\
\hline 2 & $\mathrm{Ge}$ & -568767.976 & -568871.692 & -568896.059 & -568903.541 \\
\hline 2 & $\mathrm{Ga}$ & -563066.177 & -563175.819 & -563199.806 & -563206.523 \\
\hline 2 & $\mathrm{Ti}$ & -535385.004 & -535486.161 & -535510.326 & -535517.910 \\
\hline 3 & $\mathrm{Zn}$ & -560266.979 & -560368.580 & -560392.882 & -560400.522 \\
\hline 3 & $\mathrm{Si}$ & -517068.080 & -517170.333 & -517194.623 & -517202.190 \\
\hline 3 & $\mathrm{Mg}$ & -517323.517 & -517425.388 & -517449.592 & -517457.135 \\
\hline 3 & $\mathrm{Al}$ & -514226.225 & -514334.102 & -514358.020 & -514364.834 \\
\hline 3 & $\mathrm{Ge}$ & -565675.959 & -565779.065 & -565803.290 & -565810.729 \\
\hline 3 & $\mathrm{Ga}$ & -559974.172 & -560083.190 & -560106.999 & -560113.651 \\
\hline
\end{tabular}




\begin{tabular}{|c|c|c|c|c|c|}
\hline 3 & $\mathrm{Ti}$ & -532292.948 & -532393.500 & -532417.504 & -532425.031 \\
\hline 4 & $\mathrm{Zn}$ & -560211.911 & -560313.752 & -560338.121 & -560345.786 \\
\hline 4 & $\mathrm{Si}$ & -517013.162 & -517115.604 & -517139.970 & -517147.574 \\
\hline 4 & $\mathrm{Mg}$ & -517268.396 & -517370.514 & -517394.795 & -517402.369 \\
\hline 4 & $\mathrm{Al}$ & -514171.281 & -514279.339 & -514303.318 & -514310.156 \\
\hline 4 & $\mathrm{Ge}$ & -565621.067 & -565724.315 & -565748.614 & -565756.092 \\
\hline 4 & $\mathrm{Ga}$ & -559919.182 & -560028.450 & -560052.329 & -560059.007 \\
\hline 4 & $\mathrm{Ti}$ & -532237.987 & -532338.733 & -532362.810 & -532370.371 \\
\hline 5 & $\mathrm{Zn}$ & -560211.009 & -560312.774 & -560337.131 & -560344.795 \\
\hline 5 & $\mathrm{Si}$ & -517012.194 & -517114.577 & -517138.972 & -517146.603 \\
\hline 5 & $\mathrm{Mg}$ & -517267.550 & -517369.573 & -517393.882 & -517401.485 \\
\hline 5 & $\mathrm{Al}$ & -514170.376 & -514278.384 & -514302.359 & -514309.199 \\
\hline 5 & $\mathrm{Ge}$ & -565620.028 & -565723.263 & -565747.509 & -565754.952 \\
\hline 5 & $\mathrm{Ga}$ & -559918.229 & -560027.476 & -560051.370 & -560058.060 \\
\hline 5 & $\mathrm{Ti}$ & -532236.925 & -532337.679 & -532361.748 & -532369.303 \\
\hline 6 & $\mathrm{Zn}$ & -557079.657 & -557180.718 & -557204.895 & -557212.498 \\
\hline 6 & $\mathrm{Si}$ & -513880.791 & -513982.415 & -514006.637 & -514014.217 \\
\hline 6 & $\mathrm{Mg}$ & -514136.249 & -514237.490 & -514261.606 & -514269.147 \\
\hline 6 & $\mathrm{Al}$ & -511038.988 & -511146.232 & -511170.026 & -511176.811 \\
\hline 6 & $\mathrm{Ge}$ & -562488.667 & -562591.157 & -562615.224 & -562622.610 \\
\hline 6 & $\mathrm{Ga}$ & -556786.880 & -556895.355 & -556919.050 & -556925.673 \\
\hline 6 & $\mathrm{Ti}$ & -529105.566 & -529205.573 & -529229.470 & -529236.973 \\
\hline 7 & $\mathrm{Zn}$ & -558141.860 & -558243.076 & -558267.283 & -558274.893 \\
\hline 7 & $\mathrm{Si}$ & -514943.001 & -515044.859 & -515069.123 & -515076.710 \\
\hline 7 & $\mathrm{Mg}$ & -515198.417 & -515299.871 & -515324.027 & -515331.575 \\
\hline 7 & $\mathrm{Al}$ & -512101.124 & -512208.632 & -512232.474 & -512239.268 \\
\hline 7 & $\mathrm{Ge}$ & -563550.890 & -563653.585 & -563677.673 & -563685.055 \\
\hline 7 & $\mathrm{Ga}$ & -557849.090 & -557957.741 & -557981.480 & -557988.117 \\
\hline 7 & $\mathrm{Ti}$ & -530167.870 & -530268.051 & -530291.979 & -530299.487 \\
\hline 8 & $\mathrm{Zn}$ & -561328.609 & -561430.596 & -561454.951 & -561462.592 \\
\hline 8 & $\mathrm{Si}$ & -518129.817 & -518232.454 & -518256.820 & -518264.405 \\
\hline 8 & $\mathrm{Mg}$ & -518385.153 & -518487.379 & -518511.690 & -518519.275 \\
\hline 8 & $\mathrm{Al}$ & -515287.916 & -515396.201 & -515420.185 & -515427.009 \\
\hline 8 & $\mathrm{Ge}$ & -566737.729 & -566841.162 & -566865.457 & -566872.915 \\
\hline 8 & $\mathrm{Ga}$ & -561035.884 & -561145.267 & -561169.147 & -561175.816 \\
\hline 8 & $\mathrm{Ti}$ & -533354.655 & -533455.572 & -533479.648 & -533487.191 \\
\hline 9 & $\mathrm{Zn}$ & -564420.754 & -564523.353 & -564547.858 & -564555.547 \\
\hline 9 & $\mathrm{Si}$ & -521221.743 & -521324.955 & -521349.504 & -521357.166 \\
\hline 9 & $\mathrm{Mg}$ & -521477.299 & -521580.131 & -521604.576 & -521612.200 \\
\hline 9 & $\mathrm{Al}$ & -518379.936 & -518488.796 & -518512.928 & -518519.801 \\
\hline 9 & $\mathrm{Ge}$ & -569829.672 & -569933.665 & -569958.079 & -569965.569 \\
\hline 9 & $\mathrm{Ga}$ & -564127.878 & -564237.874 & -564261.912 & -564268.633 \\
\hline 9 & $\mathrm{Ti}$ & -536446.643 & -536548.096 & -536572.312 & -536579.904 \\
\hline 10 & $\mathrm{Zn}$ & -558142.679 & -558243.862 & -558268.078 & -558275.697 \\
\hline 10 & $\mathrm{Si}$ & -514943.519 & -515045.367 & -515069.603 & -515077.172 \\
\hline 10 & $\mathrm{Mg}$ & -515199.205 & -515300.631 & -515324.755 & -515332.283 \\
\hline 10 & $\mathrm{Al}$ & -512101.879 & -512209.316 & -512233.155 & -512239.953 \\
\hline 10 & $\mathrm{Ge}$ & -563551.451 & -563654.070 & -563678.232 & -563685.674 \\
\hline 10 & $\mathrm{Ga}$ & -557849.799 & -557958.422 & -557982.156 & -557988.792 \\
\hline 10 & $\mathrm{Ti}$ & -530168.406 & -530268.577 & -530292.528 & -530300.054 \\
\hline 11 & $\mathrm{Zn}$ & -559260.085 & -559361.380 & -559385.586 & -559393.186 \\
\hline 11 & $\mathrm{Si}$ & -516061.125 & -516163.016 & -516187.260 & -516194.831 \\
\hline 11 & $\mathrm{Mg}$ & -516316.627 & -516418.154 & -516442.300 & -516449.835 \\
\hline 11 & $\mathrm{Al}$ & -513219.285 & -513326.799 & -513350.629 & -513357.414 \\
\hline 11 & $\mathrm{Ge}$ & -564669.010 & -564771.701 & -564795.792 & -564803.176 \\
\hline 11 & $\mathrm{Ga}$ & -558967.221 & -559075.882 & -559099.614 & -559106.245 \\
\hline 11 & $\mathrm{Ti}$ & -531285.950 & -531386.106 & -531410.022 & -531417.525 \\
\hline 12 & $\mathrm{Zn}$ & - & - & - & - \\
\hline 12 & $\mathrm{Si}$ & -514943.013 & -515044.927 & -515069.205 & -515076.797 \\
\hline 12 & $\mathrm{Mg}$ & -515198.262 & -515299.838 & -515323.990 & -515331.524 \\
\hline 12 & $\mathrm{Al}$ & -512101.108 & -512208.629 & -512232.473 & -512239.268 \\
\hline 12 & $\mathrm{Ge}$ & -563550.880 & -563653.661 & -563677.782 & -563685.179 \\
\hline 12 & $\mathrm{Ga}$ & -557849.010 & -557957.794 & -557981.543 & -557988.175 \\
\hline
\end{tabular}




\begin{tabular}{|c|c|c|c|c|c|}
\hline 12 & $\mathrm{Ti}$ & - & - & - & - \\
\hline 13 & $\mathrm{Zn}$ & -557047.193 & -557148.157 & -557172.351 & -557179.976 \\
\hline 13 & $\mathrm{Si}$ & -513848.239 & -513949.832 & -513974.071 & -513981.667 \\
\hline 13 & $\mathrm{Mg}$ & -514103.703 & -514204.906 & -514229.042 & -514236.600 \\
\hline 13 & $\mathrm{Al}$ & -511006.413 & -511113.661 & -511137.475 & -511144.271 \\
\hline 13 & $\mathrm{Ge}$ & -562456.110 & -562558.542 & -562582.654 & -562590.078 \\
\hline 13 & $\mathrm{Ga}$ & -556754.307 & -556862.783 & -556886.517 & -556893.165 \\
\hline 13 & $\mathrm{Ti}$ & -529072.996 & -529172.950 & -529196.874 & -529204.401 \\
\hline 14 & $\mathrm{Zn}$ & -561289.865 & -561391.428 & -561415.730 & -561423.375 \\
\hline 14 & $\mathrm{Si}$ & -518090.905 & -518193.105 & -518217.450 & -518225.062 \\
\hline 14 & $\mathrm{Mg}$ & -518346.392 & -518448.234 & -518472.489 & -518480.071 \\
\hline 14 & $\mathrm{~A} 1$ & -515249.047 & -515356.871 & -515380.805 & -515387.634 \\
\hline 14 & $\mathrm{Ge}$ & -566698.793 & -566801.815 & -566826.031 & -566833.471 \\
\hline 14 & $\mathrm{Ga}$ & -560996.992 & -561105.954 & -561129.798 & -561136.478 \\
\hline 14 & $\mathrm{Ti}$ & -533315.746 & -533416.220 & -533440.238 & -533447.783 \\
\hline 15 & $\mathrm{Zn}$ & -555499.449 & -555599.025 & None & None \\
\hline 15 & $\mathrm{Si}$ & -514998.771 & -515100.434 & -515124.638 & -515132.202 \\
\hline 15 & $\mathrm{Mg}$ & -515254.312 & -515355.594 & -515379.697 & -515387.225 \\
\hline 15 & $\mathrm{Al}$ & -512156.976 & -512264.192 & -512287.961 & -512294.731 \\
\hline 15 & $\mathrm{Ge}$ & -563606.668 & -563709.134 & -563733.178 & -563740.551 \\
\hline 15 & $\mathrm{Ga}$ & -557904.866 & -558013.233 & -558036.920 & -558043.547 \\
\hline 15 & $\mathrm{Ti}$ & -530223.599 & -530323.563 & -530347.437 & -530354.929 \\
\hline 16 & $\mathrm{Zn}$ & -558079.399 & -558180.488 & -558204.710 & -558212.343 \\
\hline 16 & $\mathrm{Si}$ & -514880.186 & -514981.900 & -515006.179 & -515013.792 \\
\hline 16 & $\mathrm{Mg}$ & -515135.950 & -515237.271 & -515261.440 & -515269.011 \\
\hline 16 & $\mathrm{Al}$ & -512038.487 & -512145.866 & -512169.718 & -512176.529 \\
\hline 16 & $\mathrm{Ge}$ & -563488.117 & -563590.653 & -563614.775 & -563622.195 \\
\hline 16 & $\mathrm{Ga}$ & -557786.433 & -557894.999 & -557918.743 & -557925.389 \\
\hline 16 & $\mathrm{Ti}$ & -530105.065 & -530205.135 & -530229.096 & -530236.640 \\
\hline 17 & $\mathrm{Zn}$ & -559140.841 & -559242.152 & -559266.416 & -559274.057 \\
\hline 17 & $\mathrm{Si}$ & -515941.828 & -516043.790 & -516068.097 & -516075.705 \\
\hline 17 & $\mathrm{Mg}$ & -516197.373 & -516298.936 & -516323.147 & -516330.725 \\
\hline 17 & $\mathrm{Al}$ & -513100.023 & -513207.599 & -513231.490 & -513238.311 \\
\hline 17 & $\mathrm{Ge}$ & -564549.727 & -564652.488 & -564676.640 & -564684.060 \\
\hline 17 & $\mathrm{Ga}$ & -558847.974 & -558956.696 & -558980.485 & -558987.148 \\
\hline 17 & $\mathrm{Ti}$ & -531166.649 & -531266.910 & -531290.892 & -531298.431 \\
\hline 18 & $\mathrm{Zn}$ & -558141.675 & -558242.959 & -558267.186 & -558274.803 \\
\hline 18 & $\mathrm{Si}$ & -514942.601 & -515044.457 & -515068.730 & -515076.324 \\
\hline 18 & $\mathrm{Mg}$ & -515198.188 & -515299.718 & -515323.896 & -515331.453 \\
\hline 18 & $\mathrm{Al}$ & -512100.807 & -512208.334 & -512232.185 & -512238.983 \\
\hline 18 & $\mathrm{Ge}$ & -563550.488 & -563653.184 & -563677.298 & -563684.699 \\
\hline 18 & $\mathrm{Ga}$ & -557848.854 & -557957.373 & -557981.109 & -557987.753 \\
\hline 18 & $\mathrm{Ti}$ & -530167.338 & -530267.561 & -530291.512 & -530299.034 \\
\hline 19 & $\mathrm{Zn}$ & -559259.363 & -559360.601 & -559384.815 & -559392.427 \\
\hline 19 & $\mathrm{Si}$ & -516060.343 & -516162.221 & -516186.477 & -516194.057 \\
\hline 19 & $\mathrm{Mg}$ & -516315.917 & -516417.395 & -516441.558 & -516449.109 \\
\hline 19 & $\mathrm{Al}$ & -513218.545 & -513326.016 & -513349.846 & -513356.635 \\
\hline 19 & $\mathrm{Ge}$ & -564668.242 & -564770.922 & -564795.024 & -564802.417 \\
\hline 19 & $\mathrm{Ga}$ & -558966.483 & -559075.104 & -559098.830 & -559105.461 \\
\hline 19 & $\mathrm{Ti}$ & -531285.171 & -531385.338 & -531409.268 & -531416.780 \\
\hline 20 & $\mathrm{Zn}$ & -558199.497 & -558300.472 & -558324.575 & -558332.132 \\
\hline 20 & $\mathrm{Si}$ & -514999.848 & -515101.285 & -515125.400 & -515132.920 \\
\hline 20 & $\mathrm{Mg}$ & -515255.914 & -515357.047 & -515381.080 & -515388.571 \\
\hline 20 & $\mathrm{Al}$ & -512158.248 & -512265.361 & -512289.111 & -512295.878 \\
\hline 20 & Ge & -563607.870 & -563710.254 & -563734.315 & -563741.705 \\
\hline 20 & $\mathrm{Ga}$ & -557906.276 & -558014.655 & -558038.314 & -558044.921 \\
\hline 20 & $\mathrm{Ti}$ & -530225.199 & -530325.144 & -530348.977 & -530356.439 \\
\hline 21 & $\mathrm{Zn}$ & - & - & - & - \\
\hline 21 & $\mathrm{Si}$ & - & - & - & - \\
\hline 21 & $\mathrm{Mg}$ & - & - & - & - \\
\hline 21 & $\mathrm{Al}$ & -512158.646 & -512265.915 & -512289.701 & -512296.478 \\
\hline 21 & $\mathrm{Ge}$ & - & - & - & - \\
\hline 21 & $\mathrm{Ga}$ & -557906.493 & -558014.919 & -558038.605 & -558045.226 \\
\hline
\end{tabular}




\begin{tabular}{|c|c|c|c|c|c|}
\hline 21 & $\mathrm{Ti}$ & - & - & - & - \\
\hline 22 & $\mathrm{Zn}$ & -561290.560 & -561392.139 & -561416.430 & -561424.065 \\
\hline 22 & $\mathrm{Si}$ & -518091.758 & -518193.951 & -518218.288 & -518225.895 \\
\hline 22 & $\mathrm{Mg}$ & -518347.134 & -518448.961 & -518473.200 & -518480.773 \\
\hline 22 & $\mathrm{Al}$ & -515249.810 & -515357.519 & -515381.444 & -515388.276 \\
\hline 22 & $\mathrm{Ge}$ & -566699.665 & -566802.685 & -566826.888 & -566834.319 \\
\hline 22 & $\mathrm{Ga}$ & -560997.829 & -561106.671 & -561130.483 & -561137.151 \\
\hline 22 & $\mathrm{Ti}$ & -533316.666 & -533417.134 & -533441.142 & -533448.681 \\
\hline 23 & $\mathrm{Zn}$ & -557082.321 & -557183.362 & -557207.537 & -557215.140 \\
\hline 23 & $\mathrm{Si}$ & -513883.453 & -513985.207 & -514009.408 & -514016.961 \\
\hline 23 & $\mathrm{Mg}$ & -514138.805 & -514240.054 & -514264.146 & -514271.669 \\
\hline 23 & $\mathrm{Al}$ & -511041.461 & -511148.836 & -511172.602 & -511179.357 \\
\hline 23 & $\mathrm{Ge}$ & -562491.345 & -562593.976 & -562618.122 & -562625.551 \\
\hline 23 & $\mathrm{Ga}$ & -556789.449 & -556898.015 & -556921.711 & -556928.328 \\
\hline 23 & $\mathrm{Ti}$ & -529108.455 & -529208.594 & -529232.523 & -529240.036 \\
\hline 24 & $\mathrm{Zn}$ & -558144.296 & -558245.622 & -558269.832 & -558277.433 \\
\hline 24 & $\mathrm{Si}$ & -514945.494 & -515047.500 & -515071.722 & -515079.265 \\
\hline 24 & $\mathrm{Mg}$ & -515200.802 & -515302.352 & -515326.464 & -515333.972 \\
\hline 24 & $\mathrm{Al}$ & -512103.542 & -512211.180 & -512235.007 & -512241.781 \\
\hline 24 & $\mathrm{Ge}$ & -563553.421 & -563656.256 & -563680.415 & -563687.833 \\
\hline 24 & $\mathrm{Ga}$ & -557851.538 & -557960.337 & -557984.059 & -557990.674 \\
\hline 24 & $\mathrm{Ti}$ & -530170.456 & -530270.815 & -530294.762 & -530302.267 \\
\hline 25 & $\mathrm{Zn}$ & -558199.588 & -558300.779 & -558324.951 & -558332.537 \\
\hline 25 & $\mathrm{Si}$ & -515000.747 & -515102.681 & -515126.917 & -515134.476 \\
\hline 25 & $\mathrm{Mg}$ & -515256.045 & -515357.475 & -515381.597 & -515389.123 \\
\hline 25 & $\mathrm{Al}$ & -512158.815 & -512266.389 & -512290.193 & -512296.957 \\
\hline 25 & $\mathrm{Ge}$ & -563608.667 & -563711.427 & -563735.505 & -563742.873 \\
\hline 25 & $\mathrm{Ga}$ & -557906.820 & -558015.530 & -558039.222 & -558045.825 \\
\hline 25 & $\mathrm{Ti}$ & -530225.710 & -530325.986 & -530349.896 & -530357.382 \\
\hline 26 & $\mathrm{Zn}$ & -561291.621 & -561393.347 & -561417.657 & -561425.290 \\
\hline 26 & $\mathrm{Si}$ & -518092.673 & -518195.068 & -518219.428 & -518227.033 \\
\hline 26 & $\mathrm{Mg}$ & -518348.023 & -518450.003 & -518474.266 & -518481.841 \\
\hline 26 & $\mathrm{Al}$ & -515250.731 & -515358.797 & -515382.743 & -515389.559 \\
\hline 26 & $\mathrm{Ge}$ & -566700.572 & -566803.821 & -566828.027 & -566835.440 \\
\hline 26 & $\mathrm{Ga}$ & -560998.690 & -561107.951 & -561131.780 & -561138.427 \\
\hline 26 & $\mathrm{Ti}$ & -533317.568 & -533418.410 & -533442.461 & -533449.994 \\
\hline 27 & $\mathrm{Zn}$ & -555481.615 & -555581.985 & -555606.038 & -555613.619 \\
\hline 27 & $\mathrm{Si}$ & -512282.611 & -512383.658 & -512407.723 & -512415.245 \\
\hline 27 & $\mathrm{Mg}$ & -512538.146 & -512638.771 & -512662.735 & -512670.226 \\
\hline 27 & $\mathrm{Al}$ & -509440.778 & -509547.498 & -509571.132 & -509577.855 \\
\hline 27 & $\mathrm{Ge}$ & -560890.460 & -560992.367 & -561016.366 & -561023.758 \\
\hline 27 & $\mathrm{Ga}$ & -555188.749 & -555296.617 & -555320.190 & -555326.783 \\
\hline 27 & $\mathrm{Ti}$ & -527507.421 & -527606.819 & -527630.604 & -527638.086 \\
\hline 28 & $\mathrm{Zn}$ & -557019.288 & -557120.297 & -557144.487 & -557152.104 \\
\hline 28 & $\mathrm{Si}$ & -513820.381 & -513922.089 & -513946.343 & -513953.938 \\
\hline 28 & $\mathrm{Mg}$ & -514075.788 & -514177.036 & -514201.181 & -514208.743 \\
\hline 28 & $\mathrm{Al}$ & -510978.453 & -511085.866 & -511109.649 & -511116.412 \\
\hline 28 & $\mathrm{Ge}$ & -562428.293 & -562530.827 & -562554.978 & -562562.420 \\
\hline 28 & $\mathrm{Ga}$ & -556726.469 & -556834.983 & -556858.686 & -556865.310 \\
\hline 28 & $\mathrm{Ti}$ & -529045.355 & -529145.407 & -529169.343 & -529176.869 \\
\hline 29 & $\mathrm{Zn}$ & -555013.004 & -555113.429 & -555137.445 & -555144.994 \\
\hline 29 & $\mathrm{Si}$ & -511814.063 & -511915.081 & -511939.121 & -511946.628 \\
\hline 29 & $\mathrm{Mg}$ & -512069.481 & -512170.143 & -512194.086 & -512201.557 \\
\hline 29 & $\mathrm{Al}$ & -508972.144 & -509078.864 & -509102.510 & -509109.241 \\
\hline 29 & $\mathrm{Ge}$ & -560421.942 & -560523.828 & -560547.804 & -560555.183 \\
\hline 29 & $\mathrm{Ga}$ & -554720.116 & -554828.034 & -554851.580 & -554858.151 \\
\hline 29 & $\mathrm{Ti}$ & -527038.989 & -527138.423 & -527162.187 & -527169.650 \\
\hline $\mathrm{ZOH}$ & $\mathrm{Zn}$ & -553951.210 & -554051.451 & -554075.424 & -554082.959 \\
\hline $\mathrm{ZOH}$ & $\mathrm{Si}$ & -510752.186 & -510853.216 & -510877.237 & -510884.730 \\
\hline $\mathrm{ZOH}$ & $\mathrm{Mg}$ & -511007.701 & -511108.179 & -511132.068 & -511139.520 \\
\hline $\mathrm{ZOH}$ & $\mathrm{Al}$ & -507910.357 & -508017.025 & -508040.639 & -508047.353 \\
\hline $\mathrm{ZOH}$ & $\mathrm{Ge}$ & -559360.144 & -559461.967 & -559485.914 & -559493.278 \\
\hline $\mathrm{ZOH}$ & $\mathrm{Ga}$ & -553658.383 & -553766.186 & -553789.690 & -553796.243 \\
\hline
\end{tabular}




\begin{tabular}{llllll}
\hline ZOH & Ti & -525977.272 & -526076.584 & -526100.315 & -526107.767 \\
\hline
\end{tabular}

Table S4. Computed and extrapolated total energies. Except for molecules and the clean acid site (ZOH), species are labeled according to Fig. S2 and catalysts are labeled according to the substituting element. All energies are given in $\mathrm{eV}$.

\begin{tabular}{|c|c|c|c|c|c|}
\hline No. & $\mathrm{El}$ & MP2/cc-pVDZ & MP2/cc-pVTZ & MP2/CBS & $\operatorname{CCSD}(T) / c c-p V D Z$ \\
\hline 2-pentene & & -5329.769 & -5335.412 & -5337.623 & -5332.260 \\
\hline $\mathrm{CH} 4$ & & -1098.254 & -1099.649 & -1100.168 & -1099.001 \\
\hline $\mathrm{CO}$ & & -3075.890 & -3078.577 & -3079.668 & -3076.365 \\
\hline DME & & -4205.643 & -4210.247 & -4212.023 & -4207.062 \\
\hline FA & & -3107.355 & -3110.448 & -3111.672 & -3108.044 \\
\hline $\mathrm{H} 2 \mathrm{O}$ & & -2074.278 & -2076.729 & -2077.692 & -2074.624 \\
\hline $\mathrm{MeOH}$ & & -3139.856 & -3143.376 & -3144.741 & -3140.748 \\
\hline $\mathrm{NH3}$ & & -1534.233 & -1536.155 & -1536.900 & -1534.787 \\
\hline benzene & & -6299.593 & -6305.667 & -6308.092 & -6301.628 \\
\hline i-butene & & -4263.654 & -4268.191 & -4269.965 & -4265.663 \\
\hline ketene & & -4140.950 & -4144.932 & -4146.501 & -4141.806 \\
\hline n-butene & & -4263.606 & -4268.134 & -4269.901 & -4265.622 \\
\hline propene & & -3197.339 & -3200.751 & -3202.068 & -3198.889 \\
\hline toluene & & -7365.870 & -7373.066 & -7375.939 & -7368.327 \\
\hline 1 & $\mathrm{Zn}$ & -557566.367 & -557806.106 & -557896.397 & -557587.547 \\
\hline 1 & $\mathrm{Si}$ & -514350.657 & -514584.236 & -514671.596 & -514373.642 \\
\hline 1 & $\mathrm{Mg}$ & -514606.536 & -514840.541 & -514928.125 & -514629.549 \\
\hline 1 & Al & -511506.060 & -511742.392 & -511827.397 & -511528.854 \\
\hline 1 & $\mathrm{Ge}$ & -562959.619 & -563195.578 & -563283.407 & -562982.557 \\
\hline 1 & $\mathrm{Ga}$ & -557254.997 & -557494.157 & -557579.628 & -557277.793 \\
\hline 1 & $\mathrm{Ti}$ & -529583.952 & -529817.245 & -529904.880 & -529607.102 \\
\hline 2 & $\mathrm{Zn}$ & -563866.535 & -564112.441 & -564205.102 & -563889.596 \\
\hline 2 & $\mathrm{Si}$ & -520650.977 & -520890.761 & -520980.562 & -520675.848 \\
\hline 2 & $\mathrm{Mg}$ & -520906.705 & -521146.905 & -521236.917 & -520931.605 \\
\hline 2 & $\mathrm{Al}$ & -517806.467 & -518048.933 & -518136.296 & -517831.152 \\
\hline 2 & $\mathrm{Ge}$ & -569259.924 & -569502.099 & -569592.247 & -569284.745 \\
\hline 2 & $\mathrm{Ga}$ & -563555.338 & -563800.691 & -563888.536 & -563580.020 \\
\hline 2 & $\mathrm{Ti}$ & -535884.337 & -536123.781 & -536213.756 & -535909.378 \\
\hline 3 & $\mathrm{Zn}$ & -560764.374 & -561007.609 & -561099.186 & -560786.964 \\
\hline 3 & $\mathrm{Si}$ & -517548.777 & -517785.870 & -517874.501 & -517573.169 \\
\hline 3 & $\mathrm{Mg}$ & -517804.542 & -518042.068 & -518130.932 & -517828.975 \\
\hline 3 & $\mathrm{Al}$ & -514704.239 & -514944.023 & -515030.296 & -514728.447 \\
\hline 3 & $\mathrm{Ge}$ & -566157.702 & -566397.208 & -566486.304 & -566182.049 \\
\hline 3 & $\mathrm{Ga}$ & -560453.123 & -560695.779 & -560782.509 & -560477.328 \\
\hline 3 & $\mathrm{Ti}$ & -532782.087 & -533018.878 & -533107.774 & -532806.646 \\
\hline 4 & $\mathrm{Zn}$ & -560706.758 & -560950.135 & -561041.764 & -560728.779 \\
\hline 4 & $\mathrm{Si}$ & -517491.305 & -517728.474 & -517817.170 & -517515.131 \\
\hline 4 & $\mathrm{Mg}$ & -517746.973 & -517984.638 & -518073.564 & -517770.831 \\
\hline 4 & $\mathrm{Al}$ & -514646.724 & -514886.592 & -514972.909 & -514670.369 \\
\hline 4 & $\mathrm{Ge}$ & -566100.327 & -566339.863 & -566429.024 & -566124.108 \\
\hline 4 & $\mathrm{Ga}$ & -560395.542 & -560638.342 & -560725.123 & -560419.181 \\
\hline 4 & $\mathrm{Ti}$ & -532724.605 & -532961.483 & -533050.440 & -532748.606 \\
\hline 5 & $\mathrm{Zn}$ & -560706.339 & -560949.593 & -561041.187 & -560728.367 \\
\hline 5 & $\mathrm{Si}$ & -517490.747 & -517727.849 & -517816.599 & -517514.588 \\
\hline 5 & $\mathrm{Mg}$ & -517746.456 & -517984.012 & -518072.990 & -517770.324 \\
\hline 5 & $\mathrm{Al}$ & -514646.223 & -514886.029 & -514972.339 & -514669.886 \\
\hline 5 & $\mathrm{Ge}$ & -566099.675 & -566339.193 & -566428.265 & -566123.472 \\
\hline 5 & $\mathrm{Ga}$ & -560394.994 & -560637.761 & -560724.564 & -560418.654 \\
\hline 5 & $\mathrm{Ti}$ & -532723.994 & -532960.836 & -533049.759 & -532747.999 \\
\hline 6 & $\mathrm{Zn}$ & -557565.237 & -557805.227 & -557895.503 & -557586.381 \\
\hline 6 & $\mathrm{Si}$ & -514349.758 & -514583.509 & -514670.944 & -514372.703 \\
\hline 6 & $\mathrm{Mg}$ & -514605.509 & -514839.680 & -514927.309 & -514628.481 \\
\hline 6 & $\mathrm{Al}$ & -511505.233 & -511741.671 & -511826.647 & -511527.995 \\
\hline 6 & $\mathrm{Ge}$ & -562958.724 & -563194.891 & -563282.629 & -562981.619 \\
\hline 6 & $\mathrm{Ga}$ & -557254.051 & -557493.445 & -557578.886 & -557276.812 \\
\hline
\end{tabular}




\begin{tabular}{|c|c|c|c|c|c|}
\hline 6 & $\mathrm{Ti}$ & -529583.005 & -529816.544 & -529904.168 & -529606.103 \\
\hline 7 & $\mathrm{Zn}$ & -558631.073 & -558872.071 & -558962.744 & -558652.799 \\
\hline 7 & $\mathrm{Si}$ & -515415.444 & -515650.299 & -515738.149 & -515438.983 \\
\hline 7 & $\mathrm{Mg}$ & -515671.243 & -515906.509 & -515994.555 & -515694.809 \\
\hline 7 & $\mathrm{Al}$ & -512570.864 & -512808.438 & -512893.837 & -512594.211 \\
\hline 7 & $\mathrm{Ge}$ & -564024.411 & -564261.658 & -564349.781 & -564047.899 \\
\hline 7 & $\mathrm{Ga}$ & -558319.780 & -558560.223 & -558646.092 & -558343.121 \\
\hline 7 & $\mathrm{Ti}$ & -530648.751 & -530883.329 & -530971.354 & -530672.462 \\
\hline 8 & $\mathrm{Zn}$ & -561829.910 & -562074.322 & -562166.286 & -561853.024 \\
\hline 8 & $\mathrm{Si}$ & -518614.344 & -518852.650 & -518941.725 & -518639.272 \\
\hline 8 & $\mathrm{Mg}$ & -518870.043 & -519108.750 & -519198.111 & -518895.010 \\
\hline 8 & $\mathrm{Al}$ & -515769.652 & -516010.694 & -516097.399 & -515794.395 \\
\hline 8 & $\mathrm{Ge}$ & -567223.346 & -567464.016 & -567553.553 & -567248.228 \\
\hline 8 & $\mathrm{Ga}$ & -561518.668 & -561762.535 & -561849.710 & -561543.411 \\
\hline 8 & $\mathrm{Ti}$ & -533847.690 & -534085.647 & -534174.967 & -533872.791 \\
\hline 9 & $\mathrm{Zn}$ & -564932.155 & -565179.242 & -565272.274 & -564955.756 \\
\hline 9 & $\mathrm{Si}$ & -521716.403 & -521957.344 & -522047.547 & -521741.818 \\
\hline 9 & $\mathrm{Mg}$ & -521972.292 & -522213.664 & -522304.065 & -521997.741 \\
\hline 9 & $\mathrm{Al}$ & -518871.917 & -519115.581 & -519203.345 & -518897.150 \\
\hline 9 & $\mathrm{Ge}$ & -570325.481 & -570568.754 & -570659.302 & -570350.838 \\
\hline 9 & $\mathrm{Ga}$ & -564620.825 & -564867.349 & -564955.593 & -564646.044 \\
\hline 9 & $\mathrm{Ti}$ & -536949.899 & -537190.418 & -537280.780 & -536975.484 \\
\hline 10 & $\mathrm{Zn}$ & -558631.743 & -558872.803 & -558963.533 & -558653.447 \\
\hline 10 & $\mathrm{Si}$ & -515415.884 & -515650.826 & -515738.670 & -515439.395 \\
\hline 10 & $\mathrm{Mg}$ & -515671.970 & -515907.275 & -515995.298 & -515695.512 \\
\hline 10 & $\mathrm{Al}$ & -512571.556 & -512809.151 & -512894.592 & -512594.895 \\
\hline 10 & $\mathrm{Ge}$ & -564024.928 & -564262.198 & -564350.497 & -564048.381 \\
\hline 10 & $\mathrm{Ga}$ & -558320.385 & -558560.895 & -558646.795 & -558343.719 \\
\hline 10 & $\mathrm{Ti}$ & -530649.190 & -530883.885 & -530972.004 & -530672.858 \\
\hline 11 & $\mathrm{Zn}$ & -559755.532 & -559997.649 & -560088.748 & -559778.338 \\
\hline 11 & $\mathrm{Si}$ & -516539.894 & -516775.816 & -516864.065 & -516564.493 \\
\hline 11 & $\mathrm{Mg}$ & -516795.692 & -517032.079 & -517120.544 & -516820.348 \\
\hline 11 & $\mathrm{Al}$ & -513695.367 & -513933.981 & -514019.797 & -513719.789 \\
\hline 11 & $\mathrm{Ge}$ & -565148.874 & -565387.157 & -565475.722 & -565173.426 \\
\hline 11 & $\mathrm{Ga}$ & -559444.254 & -559685.746 & -559772.037 & -559468.674 \\
\hline 11 & $\mathrm{Ti}$ & -531773.264 & -532008.838 & -532097.274 & -531798.018 \\
\hline 12 & $\mathrm{Zn}$ & - & - & - & - \\
\hline 12 & $\mathrm{Si}$ & -515416.070 & -515651.050 & -515738.949 & -515439.429 \\
\hline 12 & $\mathrm{Mg}$ & -515671.637 & -515907.097 & -515995.155 & -515695.026 \\
\hline 12 & $\mathrm{Al}$ & -512571.501 & -512809.164 & -512894.599 & -512594.672 \\
\hline 12 & $\mathrm{Ge}$ & -564025.005 & -564262.410 & -564350.610 & -564048.324 \\
\hline 12 & $\mathrm{Ga}$ & -558320.292 & -558560.936 & -558646.838 & -558343.464 \\
\hline 12 & $\mathrm{Ti}$ & - & - & - & - \\
\hline 13 & $\mathrm{Zn}$ & -557532.505 & -557772.100 & -557862.291 & -557553.317 \\
\hline 13 & $\mathrm{Si}$ & -514316.863 & -514550.281 & -514637.620 & -514339.475 \\
\hline 13 & $\mathrm{Mg}$ & -514572.649 & -514806.490 & -514894.032 & -514595.298 \\
\hline 13 & $\mathrm{Al}$ & -511472.321 & -511708.471 & -511793.355 & -511494.756 \\
\hline 13 & $\mathrm{Ge}$ & -562925.846 & -563161.651 & -563249.344 & -562948.420 \\
\hline 13 & $\mathrm{Ga}$ & -557221.143 & -557460.240 & -557545.620 & -557243.580 \\
\hline 13 & $\mathrm{Ti}$ & -529550.101 & -529783.284 & -529870.831 & -529572.893 \\
\hline 14 & $\mathrm{Zn}$ & -561791.683 & -562035.257 & -562126.999 & -561814.437 \\
\hline 14 & $\mathrm{Si}$ & -518575.938 & -518813.370 & -518902.267 & -518600.511 \\
\hline 14 & $\mathrm{Mg}$ & -518831.789 & -519069.671 & -519158.789 & -518856.382 \\
\hline 14 & $\mathrm{Al}$ & -515731.439 & -515971.556 & -516058.022 & -515755.808 \\
\hline 14 & $\mathrm{Ge}$ & -567184.907 & -567424.722 & -567513.975 & -567209.427 \\
\hline 14 & $\mathrm{Ga}$ & -561480.329 & -561723.314 & -561810.270 & -561504.698 \\
\hline 14 & $\mathrm{Ti}$ & -533809.301 & -534046.387 & -534135.471 & -533834.017 \\
\hline 15 & $\mathrm{Zn}$ & -555996.358 & -556235.324 & None & -556016.669 \\
\hline 15 & $\mathrm{Si}$ & -515473.608 & -515708.432 & -515796.268 & -515497.690 \\
\hline 15 & $\mathrm{Mg}$ & -515729.493 & -515964.743 & -516052.781 & -515753.628 \\
\hline 15 & $\mathrm{Al}$ & -512629.162 & -512866.622 & -512951.999 & -512653.069 \\
\hline 15 & $\mathrm{Ge}$ & -564082.595 & -564319.792 & -564407.938 & -564106.633 \\
\hline 15 & $\mathrm{Ga}$ & -558378.006 & -558618.321 & -558704.192 & -558401.913 \\
\hline
\end{tabular}




\begin{tabular}{|c|c|c|c|c|c|}
\hline 15 & $\mathrm{Ti}$ & -530706.921 & -530941.455 & -531029.482 & -530731.157 \\
\hline 16 & $\mathrm{Zn}$ & -558567.066 & -558807.459 & -558897.970 & -558588.315 \\
\hline 16 & $\mathrm{Si}$ & -515351.238 & -515585.465 & -515673.152 & -515374.299 \\
\hline 16 & $\mathrm{Mg}$ & -515607.282 & -515841.918 & -515929.790 & -515630.365 \\
\hline 16 & $\mathrm{Al}$ & -512506.773 & -512743.734 & -512828.959 & -512529.650 \\
\hline 16 & $\mathrm{Ge}$ & -563960.221 & -564196.835 & -564284.831 & -563983.227 \\
\hline 16 & $\mathrm{Ga}$ & -558255.619 & -558495.496 & -558581.175 & -558278.492 \\
\hline 16 & $\mathrm{Ti}$ & -530584.506 & -530818.526 & -530906.431 & -530607.727 \\
\hline 17 & $\mathrm{Zn}$ & -559632.937 & -559874.471 & -559965.418 & -559654.545 \\
\hline 17 & $\mathrm{Si}$ & -516417.212 & -516652.610 & -516740.709 & -516440.624 \\
\hline 17 & $\mathrm{Mg}$ & -516673.105 & -516908.898 & -516997.206 & -516696.552 \\
\hline 17 & Al & -513572.686 & -513810.785 & -513896.454 & -513595.913 \\
\hline 17 & $\mathrm{Ge}$ & -565026.201 & -565263.963 & -565352.378 & -565049.562 \\
\hline 17 & $\mathrm{Ga}$ & -559321.580 & -559562.556 & -559648.694 & -559344.806 \\
\hline 17 & $\mathrm{Ti}$ & -531650.521 & -531885.634 & -531973.936 & -531674.079 \\
\hline 18 & $\mathrm{Zn}$ & -558630.954 & -558872.083 & -558962.810 & -558652.693 \\
\hline 18 & $\mathrm{Si}$ & -515415.178 & -515650.107 & -515738.005 & -515438.726 \\
\hline 18 & $\mathrm{Mg}$ & -515671.080 & -515906.501 & -515994.610 & -515694.665 \\
\hline 18 & $\mathrm{Al}$ & -512570.644 & -512808.322 & -512893.771 & -512594.012 \\
\hline 18 & $\mathrm{Ge}$ & -564024.154 & -564261.502 & -564349.714 & -564047.661 \\
\hline 18 & $\mathrm{Ga}$ & -558319.799 & -558560.205 & -558646.116 & -558343.164 \\
\hline 18 & $\mathrm{Ti}$ & -530648.481 & -530883.163 & -530971.250 & -530672.191 \\
\hline 19 & $\mathrm{Zn}$ & -559754.895 & -559996.959 & -560088.080 & -559777.725 \\
\hline 19 & $\mathrm{Si}$ & -516539.201 & -516775.117 & -516863.391 & -516563.824 \\
\hline 19 & $\mathrm{Mg}$ & -516795.096 & -517031.411 & -517119.897 & -516819.769 \\
\hline 19 & $\mathrm{Al}$ & -513694.707 & -513933.296 & -514019.123 & -513719.158 \\
\hline 19 & $\mathrm{Ge}$ & -565148.190 & -565386.477 & -565475.070 & -565172.760 \\
\hline 19 & $\mathrm{Ga}$ & -559443.592 & -559685.056 & -559771.348 & -559468.034 \\
\hline 19 & $\mathrm{Ti}$ & -531772.506 & -532008.129 & -532096.604 & -531797.277 \\
\hline 20 & $\mathrm{Zn}$ & -558691.339 & -558932.240 & -559022.817 & -558713.549 \\
\hline 20 & $\mathrm{Si}$ & -515475.221 & -515709.845 & -515797.559 & -515499.256 \\
\hline 20 & $\mathrm{Mg}$ & -515731.562 & -515966.641 & -516054.564 & -515755.626 \\
\hline 20 & $\mathrm{Al}$ & -512630.857 & -512868.204 & -512953.556 & -512654.713 \\
\hline 20 & $\mathrm{Ge}$ & -564084.282 & -564321.369 & -564409.537 & -564108.268 \\
\hline 20 & $\mathrm{Ga}$ & -558379.765 & -558620.058 & -558705.866 & -558403.620 \\
\hline 20 & $\mathrm{Ti}$ & -530709.058 & -530943.497 & -531031.421 & -530733.215 \\
\hline 21 & $\mathrm{Zn}$ & - & - & - & - \\
\hline 21 & $\mathrm{Si}$ & - & - & - & - \\
\hline 21 & $\mathrm{Mg}$ & - & - & - & - \\
\hline 21 & $\mathrm{Al}$ & -512630.440 & -512867.965 & -512953.373 & -512654.322 \\
\hline 21 & $\mathrm{Ge}$ & - & - & - & - \\
\hline 21 & $\mathrm{Ga}$ & -558379.320 & -558619.738 & -558705.621 & -558403.195 \\
\hline 21 & $\mathrm{Ti}$ & - & - & - & - \\
\hline 22 & $\mathrm{Zn}$ & -561791.998 & -562035.552 & -562127.258 & -561814.858 \\
\hline 22 & $\mathrm{Si}$ & -518576.478 & -518813.856 & -518902.719 & -518601.147 \\
\hline 22 & $\mathrm{Mg}$ & -518832.191 & -519070.010 & -519159.081 & -518856.887 \\
\hline 22 & $\mathrm{Al}$ & -515731.810 & -515971.777 & -516058.222 & -515756.295 \\
\hline 22 & $\mathrm{Ge}$ & -567185.466 & -567425.225 & -567514.433 & -567210.085 \\
\hline 22 & $\mathrm{Ga}$ & -561480.920 & -561723.732 & -561810.621 & -561505.385 \\
\hline 22 & $\mathrm{Ti}$ & -533809.859 & -534046.896 & -534135.946 & -533834.695 \\
\hline 23 & $\mathrm{Zn}$ & -557567.712 & -557807.727 & -557898.020 & -557588.791 \\
\hline 23 & $\mathrm{Si}$ & -514352.072 & -514585.959 & -514673.348 & -514374.974 \\
\hline 23 & $\mathrm{Mg}$ & -514607.891 & -514842.123 & -514929.731 & -514630.797 \\
\hline 23 & $\mathrm{Al}$ & -511507.424 & -511744.038 & -511828.976 & -511530.137 \\
\hline 23 & $\mathrm{Ge}$ & -562960.960 & -563197.276 & -563285.140 & -562983.823 \\
\hline 23 & $\mathrm{Ga}$ & -557256.306 & -557495.822 & -557581.273 & -557279.023 \\
\hline 23 & $\mathrm{Ti}$ & -529585.352 & -529819.050 & -529906.728 & -529608.419 \\
\hline 24 & $\mathrm{Zn}$ & -558633.612 & -558874.727 & -558965.397 & -558655.228 \\
\hline 24 & $\mathrm{Si}$ & -515417.957 & -515652.938 & -515740.693 & -515441.402 \\
\hline 24 & $\mathrm{Mg}$ & -515673.776 & -515909.139 & -515997.101 & -515697.233 \\
\hline 24 & $\mathrm{Al}$ & -512573.379 & -512811.082 & -512896.448 & -512596.629 \\
\hline 24 & $\mathrm{Ge}$ & -564026.937 & -564264.304 & -564352.527 & -564050.344 \\
\hline 24 & $\mathrm{Ga}$ & -558322.274 & -558562.857 & -558648.682 & -558345.529 \\
\hline
\end{tabular}




\begin{tabular}{|c|c|c|c|c|c|}
\hline 24 & $\mathrm{Ti}$ & -530651.313 & -530886.053 & -530974.087 & -530674.904 \\
\hline 25 & $\mathrm{Zn}$ & -558691.259 & -558932.323 & -559022.976 & -558713.457 \\
\hline 25 & $\mathrm{Si}$ & -515475.557 & -515710.554 & -515798.377 & -515499.575 \\
\hline 25 & $\mathrm{Mg}$ & -515731.382 & -515966.698 & -516054.719 & -515755.417 \\
\hline 25 & $\mathrm{Al}$ & -512630.971 & -512868.699 & -512954.069 & -512654.795 \\
\hline 25 & $\mathrm{Ge}$ & -564084.526 & -564321.911 & -564410.040 & -564108.508 \\
\hline 25 & $\mathrm{Ga}$ & -558379.897 & -558620.474 & -558706.292 & -558403.726 \\
\hline 25 & $\mathrm{Ti}$ & -530708.986 & -530943.714 & -531031.723 & -530733.152 \\
\hline 26 & $\mathrm{Zn}$ & -561793.608 & -562037.268 & -562128.974 & -561816.273 \\
\hline 26 & $\mathrm{Si}$ & -518577.880 & -518815.404 & -518904.265 & -518602.336 \\
\hline 26 & $\mathrm{Mg}$ & -518833.683 & -519071.606 & -519160.684 & -518858.181 \\
\hline 26 & $\mathrm{Al}$ & -515733.274 & -515973.579 & -516060.021 & -515757.551 \\
\hline 26 & $\mathrm{Ge}$ & -567186.838 & -567426.766 & -567515.934 & -567211.257 \\
\hline 26 & $\mathrm{Ga}$ & -561482.136 & -561725.345 & -561812.221 & -561506.420 \\
\hline 26 & $\mathrm{Ti}$ & -533811.238 & -534048.591 & -534137.654 & -533835.826 \\
\hline 27 & $\mathrm{Zn}$ & -555962.677 & -556200.947 & -556290.645 & -555983.428 \\
\hline 27 & $\mathrm{Si}$ & -512746.990 & -512979.117 & -513065.897 & -512769.544 \\
\hline 27 & $\mathrm{Mg}$ & -513002.851 & -513235.375 & -513322.367 & -513025.440 \\
\hline 27 & $\mathrm{Al}$ & -509902.390 & -510137.266 & -510221.583 & -509924.769 \\
\hline 27 & $\mathrm{Ge}$ & -561355.888 & -561590.438 & -561677.680 & -561378.402 \\
\hline 27 & $\mathrm{Ga}$ & -555651.296 & -555889.052 & -555973.908 & -555673.670 \\
\hline 27 & $\mathrm{Ti}$ & -527980.190 & -528212.100 & -528299.161 & -528002.911 \\
\hline 28 & $\mathrm{Zn}$ & -557502.948 & -557742.323 & -557832.388 & -557523.655 \\
\hline 28 & $\mathrm{Si}$ & -514287.297 & -514520.525 & -514607.751 & -514309.797 \\
\hline 28 & $\mathrm{Mg}$ & -514543.119 & -514776.712 & -514864.143 & -514565.651 \\
\hline 28 & $\mathrm{Al}$ & -511442.628 & -511678.661 & -511763.364 & -511464.947 \\
\hline 28 & $\mathrm{Ge}$ & -562896.280 & -563131.882 & -563219.503 & -562918.749 \\
\hline 28 & $\mathrm{Ga}$ & -557191.599 & -557430.432 & -557515.629 & -557213.919 \\
\hline 28 & $\mathrm{Ti}$ & -529520.671 & -529753.700 & -529841.152 & -529543.321 \\
\hline 29 & $\mathrm{Zn}$ & -555492.505 & -555730.262 & -555819.651 & -555513.311 \\
\hline 29 & $\mathrm{Si}$ & -512276.795 & -512508.338 & -512594.842 & -512299.412 \\
\hline 29 & $\mathrm{Mg}$ & -512532.606 & -512764.598 & -512851.308 & -512555.249 \\
\hline 29 & $\mathrm{Al}$ & -509432.137 & -509666.464 & -509750.570 & -509454.570 \\
\hline 29 & $\mathrm{Ge}$ & -560885.700 & -561119.673 & -561206.644 & -560908.280 \\
\hline 29 & $\mathrm{Ga}$ & -555180.997 & -555418.235 & -555502.802 & -555203.433 \\
\hline 29 & $\mathrm{Ti}$ & -527510.103 & -527741.489 & -527828.275 & -527532.863 \\
\hline $\mathrm{ZOH}$ & $\mathrm{Zn}$ & -554426.681 & -554663.399 & -554752.372 & -554446.947 \\
\hline $\mathrm{ZOH}$ & $\mathrm{Si}$ & -511210.835 & -511441.503 & -511527.601 & -511232.912 \\
\hline $\mathrm{ZOH}$ & $\mathrm{Mg}$ & -511466.833 & -511697.760 & -511784.026 & -511488.936 \\
\hline $\mathrm{ZOH}$ & $\mathrm{Al}$ & -508366.308 & -508599.699 & -508683.383 & -508388.189 \\
\hline $\mathrm{ZOH}$ & $\mathrm{Ge}$ & -559819.908 & -560052.904 & -560139.446 & -559841.940 \\
\hline $\mathrm{ZOH}$ & $\mathrm{Ga}$ & -554115.256 & -554351.483 & -554435.614 & -554137.139 \\
\hline $\mathrm{ZOH}$ & $\mathrm{Ti}$ & -526444.333 & -526674.762 & -526761.152 & -526466.543 \\
\hline
\end{tabular}

S4 Cartesian coordinates of non-periodic structures in xyz-format for all structures Structures are labeled according to Fig. S2 and corresponding to Tables S2-S4.

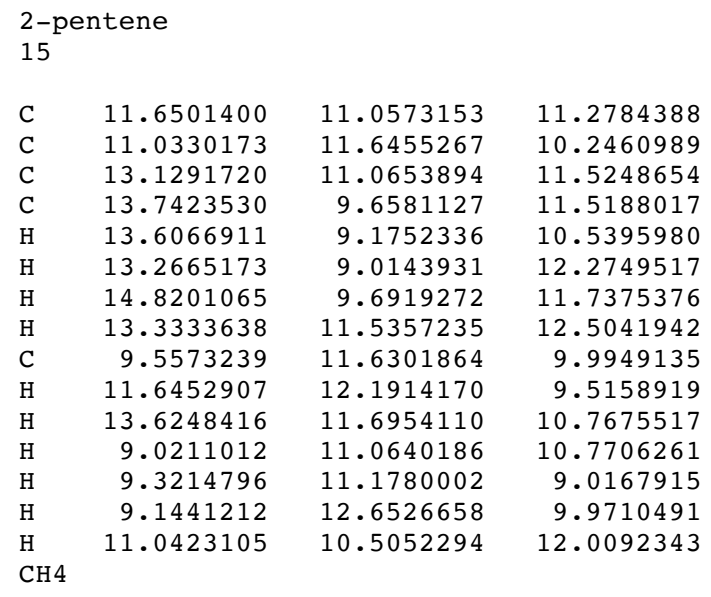


10.7214622

10.6934255

9.0124940 FA

10.2115216 10.6987785

10.0136863

9.0047574

9.0069161

10.8950881 H2O

10.1424549

9.2826312

9.3882938

9.3013765

9.8466289

10.2515332

8.9792202 $\mathrm{MeOH}$

9.0009119

6

9.4906687

10.8711370

10.8779160

$\begin{array}{ll}9.1602599 & 11.3303940\end{array}$

9.1131490

11.3303940
11.4831784

9.5597834

8.9510299

8.9944228 NH3

$\begin{array}{lr}\mathrm{N} & 9.3421047 \\ \mathrm{H} & 10.3611144 \\ \mathrm{H} & 9.0060705 \\ \mathrm{H} & 9.0002624\end{array}$

benzene

12

9.5634119

9.4653122

9.1021834

9.0043727

9.8459841

9.0102821

9.9336760

9.9700584

8.9845750

10.7636128

10.1169611

9.3919256

9.8523976

9.8502358

9.0024930

10.6389529

$\begin{array}{lrrr}\text { C } & 9.9458480 & 12.1887491 & 8.9999991 \\ \mathrm{C} & 9.9458480 & 10.7913678 & 8.9999993 \\ \mathrm{C} & 11.1562369 & 10.0925274 & 8.9999994 \\ \mathrm{C} & 12.3666259 & 10.7913678 & 8.9999996 \\ \mathrm{C} & 12.3666259 & 12.1887491 & 8.9999993 \\ \mathrm{C} & 11.1562369 & 12.8875896 & 8.9999992 \\ \mathrm{H} & 9.0000470 & 12.7347321 & 8.9999993 \\ \mathrm{H} & 11.1562370 & 13.9795510 & 8.9999994 \\ \mathrm{H} & 9.0000470 & 10.2453849 & 8.9999993 \\ \mathrm{H} & 11.1562370 & 9.0005659 & 8.9999994 \\ \mathrm{H} & 13.3124269 & 10.2453848 & 8.9999994 \\ \mathrm{H} & 13.3124269 & 12.7347321 & 8.9999994 \\ \mathrm{i}-\mathrm{butene} & & & \\ \mathrm{I} & & & \\ & & & \\ \mathrm{C} & 10.0095870 & 11.1237002 & 11.1197858 \\ \mathrm{H} & 10.8920657 & 12.9413560 & 11.8780130 \\ \mathrm{C} & 10.0353734 & 12.2771798 & 12.0840664 \\ \mathrm{C} & 9.9196333 & 11.4924904 & 9.6645883 \\ \mathrm{H} & 10.7726854 & 12.1259068 & 9.3669491 \\ \mathrm{H} & 9.9044181 & 10.6061380 & 9.0155568 \\ \mathrm{H} & 9.0099548 & 12.0842364 & 9.4652253 \\ \mathrm{H} & 10.1023839 & 11.9404502 & 13.1276339 \\ \mathrm{C} & 10.0636367 & 9.8490366 & 11.5308432\end{array}$




\begin{tabular}{|c|c|c|c|}
\hline H & 10.1288506 & 9.5937077 & 12.5907411 \\
\hline $\mathrm{H}$ & 10.0436810 & 9.0193573 & 10.8207884 \\
\hline $\mathrm{H}$ & 9.1296438 & 12.8982570 & 11.9770894 \\
\hline \multicolumn{4}{|c|}{ ketene } \\
\hline \multicolumn{4}{|c|}{5} \\
\hline $\mathrm{C}$ & 9.9924189 & 9.6722806 & 9.8817427 \\
\hline $\mathrm{H}$ & 8.9999992 & 9.3461940 & 10.1846865 \\
\hline $\mathrm{H}$ & 10.8438606 & 8.9999992 & 9.9591937 \\
\hline C & 10.1656063 & 10.8889996 & 9.4163255 \\
\hline 0 & 10.3215922 & 11.9787145 & 8.9999992 \\
\hline \multicolumn{4}{|c|}{ n-butene } \\
\hline \multicolumn{4}{|c|}{12} \\
\hline C & 9.7600482 & 9.6453660 & 12.1312736 \\
\hline $\mathrm{H}$ & 9.0803084 & 9.1298220 & 11.4371216 \\
\hline $\mathrm{H}$ & 10.6575141 & 9.0169489 & 12.2599744 \\
\hline $\mathrm{H}$ & 9.2687763 & 9.6928813 & 13.1177725 \\
\hline $\mathrm{C}$ & 9.6854343 & 11.5644097 & 10.4980769 \\
\hline $\mathrm{C}$ & 10.1202688 & 11.0119066 & 11.6373781 \\
\hline $\mathrm{H}$ & 9.0075830 & 10.9814280 & 9.8606452 \\
\hline $\mathrm{C}$ & 10.0455702 & 12.9309993 & 10.0042491 \\
\hline $\mathrm{H}$ & 10.7981194 & 11.5948776 & 12.2748238 \\
\hline $\mathrm{H}$ & 10.5360541 & 12.8836857 & 9.0173529 \\
\hline $\mathrm{H}$ & 10.7259233 & 13.4461907 & 10.6980564 \\
\hline $\mathrm{H}$ & 9.1481136 & 13.5596153 & 9.8764798 \\
\hline \multicolumn{4}{|c|}{ propene } \\
\hline 9 & & & \\
\hline C & 9.6141499 & 9.7024292 & 10.7820235 \\
\hline $\mathrm{C}$ & 10.9466097 & 9.6019356 & 10.7636266 \\
\hline $\mathrm{H}$ & 11.4411301 & 9.0058466 & 11.5401380 \\
\hline $\mathrm{C}$ & 11.8470561 & 10.2449411 & 9.7561212 \\
\hline $\mathrm{H}$ & 9.0115207 & 9.2081778 & 11.5464390 \\
\hline $\mathrm{H}$ & 9.0767239 & 10.2858749 & 10.0285965 \\
\hline $\mathrm{H}$ & 11.2784095 & 10.8232297 & 9.0134923 \\
\hline $\mathrm{H}$ & 12.4458906 & 9.4896023 & 9.2204964 \\
\hline $\mathrm{H}$ & 12.5671199 & 10.9230543 & 10.2437339 \\
\hline \multicolumn{4}{|c|}{$\begin{array}{l}\text { toluene } \\
15\end{array}$} \\
\hline $\mathrm{C}$ & 9.9878179 & 12.1540563 & 9.9517734 \\
\hline $\mathrm{C}$ & 10.0496819 & 10.7610200 & 9.9996837 \\
\hline $\mathrm{C}$ & 11.2880952 & 10.1126024 & 10.0252000 \\
\hline $\mathrm{C}$ & 12.4596640 & 10.8709327 & 10.0013409 \\
\hline C & 12.3918382 & 12.2663140 & 9.9530849 \\
\hline C & 11.1577339 & 12.9302642 & 9.9285817 \\
\hline $\mathrm{H}$ & 9.0142391 & 12.6518054 & 9.9312151 \\
\hline $\mathrm{H}$ & 9.1265079 & 10.1774519 & 10.0164896 \\
\hline $\mathrm{H}$ & 11.3378117 & 9.0227179 & 10.0624969 \\
\hline $\mathrm{H}$ & 13.4330892 & 10.3759394 & 10.0192773 \\
\hline $\mathrm{H}$ & 13.3145238 & 12.8526431 & 9.9337227 \\
\hline C & 11.0797349 & 14.4341176 & 9.8816932 \\
\hline $\mathrm{H}$ & 12.0789486 & 14.8875024 & 9.8228714 \\
\hline $\mathrm{H}$ & 10.5802446 & 14.8352290 & 10.7779503 \\
\hline $\mathrm{H}$ & 10.5004997 & 14.7770589 & 9.0100491 \\
\hline \multicolumn{4}{|c|}{$\mathrm{Zn} 1$} \\
\hline \multicolumn{4}{|c|}{165} \\
\hline $\mathrm{H}$ & 8.5647003 & 9.0706448 & 15.2390868 \\
\hline Al & 5.3742690 & 9.3828010 & 16.6592650 \\
\hline $\mathrm{P}$ & 5.3725116 & 9.3608804 & 28.4573264 \\
\hline Al & 5.2471221 & 6.7727780 & 21.5770438 \\
\hline $\mathrm{P}$ & 5.3056137 & 6.7983449 & 18.4362144 \\
\hline Al & 3.1387288 & 8.1425681 & 26.6109900 \\
\hline $\mathrm{P}$ & 3.2280714 & 8.2480615 & 23.4978619 \\
\hline Al & 8.4679349 & 9.3419962 & 28.4850939 \\
\hline $\mathrm{P}$ & 8.4971373 & 9.4157431 & 16.6859673 \\
\hline Al & 8.4852043 & 6.8672125 & 18.5172193 \\
\hline $\mathrm{P}$ & 8.4520999 & 6.8516492 & 21.6360598 \\
\hline Al & 1.4965406 & 10.8735641 & 23.5146545 \\
\hline $\mathrm{P}$ & 1.4824423 & 10.8442573 & 26.6759751 \\
\hline 0 & 7.0498714 & 9.7788042 & 17.1074192 \\
\hline 0 & 4.9566812 & 10.8160896 & 28.1667406 \\
\hline $\mathrm{H}$ & 4.7651912 & 5.3818447 & 21.8010253 \\
\hline $\mathrm{H}$ & 9.0148239 & 5.4770794 & 21.7410369 \\
\hline 0 & 6.8070339 & 6.4883987 & 18.2431880 \\
\hline 0 & 1.9224505 & 9.3769345 & 26.8527903 \\
\hline $\mathrm{H}$ & 2.1506106 & 7.2344093 & 23.3284275 \\
\hline $\mathrm{H}$ & 0.1291940 & 10.3340367 & 23.2771802 \\
\hline
\end{tabular}




\begin{tabular}{|c|c|c|}
\hline 4.8836039 & 7.9483935 & 17.5129783 \\
\hline 4.4676394 & 8.3747446 & 27.7169262 \\
\hline 4.4173671 & 7.9394898 & 22.5764844 \\
\hline 2.3095166 & 11.7652522 & 27.5807873 \\
\hline 8.9886808 & 8.2296447 & 17.5317209 \\
\hline 1.7728277 & 12.3056158 & 22.5814571 \\
\hline 4.3518177 & 10.7176931 & 17.1083016 \\
\hline 6.8140364 & 9.1512651 & 27.9742619 \\
\hline 6.9582776 & 6.8210799 & 21.9344289 \\
\hline 9.3329996 & 5.6845711 & 18.2014295 \\
\hline 4.5247050 & 5.5865152 & 18.0636949 \\
\hline 0.0588222 & 10.9589228 & 27.0970194 \\
\hline 2.5334404 & 6.8195863 & 26.9279535 \\
\hline 2.6772547 & 9.6317321 & 23.1279588 \\
\hline 5.2953458 & 9.1189160 & 15.1959617 \\
\hline 5.0354580 & 7.2220190 & 19.8897157 \\
\hline 3.7271782 & 8.2314352 & 24.9598277 \\
\hline 8.5513698 & 9.1045791 & 29.9526743 \\
\hline 8.6974688 & 7.4249472 & 20.1958704 \\
\hline 1.6638358 & 11.2895178 & 25.2170455 \\
\hline 5.2849374 & 9.0835993 & 29.9176573 \\
\hline 3.3963953 & 12.0419282 & 15.2338369 \\
\hline 3.2384760 & 16.1184079 & 21.5622532 \\
\hline 3.1375384 & 16.1233175 & 18.4256386 \\
\hline 3.7565297 & 12.0572878 & 28.4942123 \\
\hline 3.7564427 & 12.0689269 & 16.6783982 \\
\hline 1.6008897 & 13.3852715 & 18.5609377 \\
\hline 1.6312414 & 13.4943855 & 21.6202224 \\
\hline 4.8133362 & 13.1616839 & 16.9491954 \\
\hline 0.2683109 & 14.0933340 & 21.5919112 \\
\hline 2.2742164 & 17.2426221 & 21.7154403 \\
\hline 2.0527272 & 15.0533596 & 18.1898368 \\
\hline 4.3192548 & 15.9357413 & 17.4664644 \\
\hline 4.6766421 & 16.4096599 & 22.4926665 \\
\hline 2.4848373 & 12.3185368 & 17.4907220 \\
\hline 4.4015804 & 13.6074352 & 28.0316627 \\
\hline 2.6290311 & 14.5805065 & 22.0845668 \\
\hline 2.5515941 & 17.4659534 & 18.1589580 \\
\hline 0.1465411 & 13.1846280 & 18.3124769 \\
\hline 3.6697169 & 16.0538935 & 19.8645980 \\
\hline 3.4402565 & 12.0434798 & 29.9491698 \\
\hline 2.0430791 & 12.9973994 & 20.2045553 \\
\hline 10.0897614 & 12.1473465 & 16.4806452 \\
\hline 10.0027799 & 12.1052033 & 28.3219190 \\
\hline 12.2358093 & 10.7329044 & 26.6175842 \\
\hline 12.2808382 & 10.6670438 & 23.4241512 \\
\hline 15.3715393 & 10.8735641 & 23.5146545 \\
\hline 10.5392311 & 8.0901303 & 23.6063104 \\
\hline 10.6431923 & 8.0517635 & 26.7112357 \\
\hline 15.3574410 & 10.8442573 & 26.6759751 \\
\hline 8.9795929 & 10.9721986 & 28.1011984 \\
\hline 11.7196150 & 9.1042127 & 27.0422761 \\
\hline 15.7823129 & 9.4274105 & 26.8467078 \\
\hline 11.4262327 & 6.9009465 & 23.4790681 \\
\hline 13.7598021 & 10.2376052 & 23.2347356 \\
\hline 11.2463352 & 11.8980077 & 27.4614006 \\
\hline 9.4772931 & 8.1574249 & 27.7065751 \\
\hline 16.1606264 & 11.7386504 & 27.5546529 \\
\hline 9.1216950 & 7.8287166 & 22.6082466 \\
\hline 15.6478264 & 12.3056158 & 22.5814571 \\
\hline 9.4018182 & 10.6164730 & 17.0116234 \\
\hline 13.8909773 & 10.9623736 & 27.1096906 \\
\hline 11.2371985 & 6.6927313 & 26.8427977 \\
\hline 16.3723638 & 9.8209334 & 23.1868745 \\
\hline 11.3869290 & 9.4747740 & 23.0031401 \\
\hline 10.3839400 & 12.1259500 & 15.0211515 \\
\hline 12.0385411 & 10.9773466 & 24.9170093 \\
\hline 15.5388345 & 11.2895178 & 25.2170455 \\
\hline 10.0855369 & 8.2767084 & 25.2897232 \\
\hline 10.4174293 & 12.1219007 & 29.7519217 \\
\hline 8.6335567 & 15.1323630 & 15.1555860 \\
\hline 5.3167089 & 14.8051344 & 16.5933851 \\
\hline 5.2767739 & 14.8038584 & 28.4170765 \\
\hline 12.1846215 & 18.7888793 & 21.5770438 \\
\hline 12.3184724 & 13.4719461 & 21.6602554 \\
\hline 17.1134747 & 16.1184079 & 21.5622532 \\
\hline 17.0125372 & 16.1233175 & 18.4256386 \\
\hline 12.2533331 & 13.2765293 & 18.4103153 \\
\hline 12.2431131 & 18.8144463 & 18.4362144 \\
\hline 5.3526330 & 17.3076173 & 26.5664490 \\
\hline
\end{tabular}




\begin{tabular}{|c|c|c|c|}
\hline $\mathrm{P}$ & 5.3301135 & 17.3635299 & 23.4933927 \\
\hline Al & 8.4280155 & 14.8309086 & 28.4140286 \\
\hline $\mathrm{P}$ & 8.4679208 & 14.8347612 & 16.6051096 \\
\hline Al & 15.4758885 & 13.3852715 & 18.5609377 \\
\hline Al & 15.4227037 & 18.8833138 & 18.5172193 \\
\hline Al & 10.6987972 & 16.0426510 & 18.4662894 \\
\hline $\mathrm{P}$ & 10.5260530 & 16.0878171 & 21.6232883 \\
\hline $\mathrm{P}$ & 15.3895993 & 18.8677506 & 21.6360598 \\
\hline$P$ & 15.5062402 & 13.4943855 & 21.6202224 \\
\hline Al & 8.4767456 & 17.5676714 & 23.4883670 \\
\hline $\mathrm{P}$ & 8.5020215 & 17.4012741 & 26.6198269 \\
\hline $\mathrm{O}$ & 8.9135270 & 13.3796509 & 16.9007806 \\
\hline $\mathrm{O}$ & 6.7454492 & 14.4656096 & 28.0969683 \\
\hline 0 & 11.6229275 & 17.1677363 & 21.8380959 \\
\hline 0 & 14.1111896 & 14.1074493 & 21.5912440 \\
\hline $\mathrm{O}$ & 15.9687747 & 17.4529945 & 21.7441059 \\
\hline $\mathrm{O}$ & 15.9277259 & 15.0533596 & 18.1898368 \\
\hline $\mathrm{O}$ & 11.8623310 & 14.7528612 & 18.1965064 \\
\hline 0 & 13.7445332 & 18.5045000 & 18.2431880 \\
\hline 0 & 7.0214878 & 17.7481668 & 26.8937066 \\
\hline $\mathrm{H}$ & 8.9645346 & 18.9674413 & 23.3475593 \\
\hline $\mathrm{H}$ & 4.6509106 & 18.6881624 & 23.4594394 \\
\hline $\mathrm{H}$ & 18.1599541 & 15.9411857 & 17.4943046 \\
\hline $\mathrm{H}$ & 11.8334754 & 19.9307786 & 17.5400450 \\
\hline 0 & 11.5910841 & 12.3926101 & 17.3311427 \\
\hline $\mathrm{O}$ & 4.8175508 & 16.0217320 & 27.6112507 \\
\hline $\mathrm{H}$ & 11.4770099 & 19.7838463 & 22.4293625 \\
\hline $\mathrm{O}$ & 11.8914290 & 11.8508242 & 22.5768999 \\
\hline $\mathrm{H}$ & 18.3459699 & 16.3680082 & 22.3596088 \\
\hline 0 & 8.9403635 & 16.2218279 & 27.4997498 \\
\hline $\mathrm{H}$ & 16.2277379 & 12.4779509 & 17.6506562 \\
\hline 0 & 9.3186335 & 15.8187200 & 17.4106313 \\
\hline $\mathrm{H}$ & 15.8498078 & 20.0390789 & 17.6812110 \\
\hline $\mathrm{O}$ & 9.2481002 & 16.5125793 & 22.3651516 \\
\hline 0 & 7.0009607 & 14.9846063 & 17.0310179 \\
\hline $\mathrm{O}$ & 9.3662741 & 13.4418692 & 27.9371649 \\
\hline 0 & 13.8957770 & 18.8371813 & 21.9344289 \\
\hline $\mathrm{O}$ & 10.9800846 & 14.7443723 & 22.1446493 \\
\hline 0 & 16.5040298 & 14.5805065 & 22.0845668 \\
\hline $\mathrm{O}$ & 16.4076578 & 17.5093411 & 18.1503401 \\
\hline $\mathrm{O}$ & 13.7707813 & 13.1500331 & 18.2696374 \\
\hline 0 & 11.4412919 & 17.5701642 & 18.0537189 \\
\hline $\mathrm{H}$ & 4.4637561 & 18.4779080 & 26.8061117 \\
\hline $\mathrm{H}$ & 9.3442227 & 18.5777347 & 26.9716197 \\
\hline 0 & 6.7877173 & 17.5648992 & 23.0920251 \\
\hline $\mathrm{H}$ & 5.1470986 & 15.0825841 & 15.1403281 \\
\hline 0 & 11.9729574 & 19.2381204 & 19.8897157 \\
\hline $\mathrm{O}$ & 17.5447157 & 16.0538935 & 19.8645980 \\
\hline $\mathrm{O}$ & 5.2232341 & 16.7584064 & 24.9071011 \\
\hline $\mathrm{H}$ & 8.6071603 & 15.0951431 & 29.8684040 \\
\hline $\mathrm{O}$ & 15.9180778 & 12.9973994 & 20.2045553 \\
\hline $\mathrm{O}$ & 15.6349682 & 19.4410486 & 20.1958704 \\
\hline $\mathrm{O}$ & 10.1650305 & 16.0403959 & 20.1155907 \\
\hline 0 & 8.7049388 & 17.0205282 & 25.1428113 \\
\hline 0 & 11.7800043 & 12.7670756 & 19.7997793 \\
\hline $\mathrm{H}$ & 8.0720487 & 10.4445032 & 19.3973843 \\
\hline C & 10.1975135 & 11.5105349 & 19.9922252 \\
\hline $\mathrm{H}$ & 9.5365711 & 12.3317876 & 19.7341524 \\
\hline $\mathrm{H}$ & 10.6126268 & 10.8789788 & 19.2157499 \\
\hline $\mathrm{H}$ & 10.4841644 & 11.3644134 & 21.0308855 \\
\hline 0 & 8.6037033 & 10.3508406 & 20.2149294 \\
\hline $\mathrm{H}$ & 8.8251888 & 9.3865836 & 20.2741076 \\
\hline $\mathrm{H}$ & 5.1230873 & 15.1198159 & 29.8640292 \\
\hline $\mathrm{H}$ & 16.0402420 & 19.8171629 & 22.5807296 \\
\hline \multicolumn{4}{|c|}{ Si 1} \\
\hline \multicolumn{4}{|c|}{165} \\
\hline $\mathrm{H}$ & 8.5960900 & 9.0983211 & 15.1064857 \\
\hline $\mathrm{P}$ & 5.3622266 & 9.4374178 & 16.7141483 \\
\hline Al & 5.3066994 & 9.3977819 & 28.5054583 \\
\hline $\mathrm{P}$ & 5.3397902 & 6.8247289 & 21.6350409 \\
\hline Al & 5.3847588 & 6.8411647 & 18.4887976 \\
\hline $\mathrm{P}$ & 3.1412749 & 8.0586893 & 26.6672959 \\
\hline Al & 3.1834359 & 8.1227715 & 23.5403382 \\
\hline $\mathrm{P}$ & 8.4257434 & 9.3333130 & 28.3819328 \\
\hline Al & 8.4913760 & 9.3711448 & 16.5665278 \\
\hline $\mathrm{P}$ & 8.5728776 & 6.8826576 & 18.4776690 \\
\hline Al & 8.5164510 & 6.8391192 & 21.5993495 \\
\hline $\mathrm{P}$ & 1.5862972 & 10.8414555 & 23.4677824 \\
\hline & & & \\
\hline
\end{tabular}




\begin{tabular}{|c|c|c|c|}
\hline $\mathrm{O}$ & 6.8442285 & 9.7721303 & 17.0511864 \\
\hline 0 & 4.8259085 & 11.0442995 & 28.1520379 \\
\hline $\mathrm{H}$ & 4.8977005 & 5.4189993 & 21.8485861 \\
\hline $\mathrm{H}$ & 9.0258081 & 5.4453099 & 21.7217089 \\
\hline 0 & 7.1016642 & 6.5124395 & 18.2503300 \\
\hline 0 & 2.0822019 & 9.1611979 & 26.8488493 \\
\hline $\mathrm{H}$ & 2.1205581 & 7.1008990 & 23.3325207 \\
\hline $\mathrm{H}$ & 0.1930008 & 10.3552586 & 23.2691415 \\
\hline 0 & 4.9153291 & 8.2151888 & 17.5189621 \\
\hline 0 & 4.3021585 & 8.2657467 & 27.6505123 \\
\hline 0 & 4.5721294 & 7.7984299 & 22.5353840 \\
\hline 0 & 2.5053478 & 11.8938051 & 27.6212161 \\
\hline 0 & 9.0177186 & 7.9958473 & 17.5163220 \\
\hline 0 & 1.8999578 & 12.0266812 & 22.5554088 \\
\hline 0 & 4.4941411 & 10.6339795 & 17.1136104 \\
\hline 0 & 6.9557250 & 9.1701296 & 27.9923573 \\
\hline 0 & 6.8313895 & 6.9313427 & 21.9853855 \\
\hline $\mathrm{H}$ & 9.4303334 & 5.6843029 & 18.2635753 \\
\hline $\mathrm{H}$ & 4.6131729 & 5.6445831 & 18.0529442 \\
\hline $\mathrm{H}$ & 0.1528768 & 10.9174181 & 27.0358739 \\
\hline $\mathrm{H}$ & 2.5214114 & 6.7416664 & 26.9808885 \\
\hline 0 & 2.5581984 & 9.6984667 & 23.1314217 \\
\hline $\mathrm{H}$ & 5.2246635 & 9.1343335 & 15.2628258 \\
\hline $\mathrm{O}$ & 5.1208853 & 7.2495595 & 20.1659895 \\
\hline 0 & 3.6891303 & 8.0805583 & 25.2271847 \\
\hline $\mathrm{H}$ & 8.6063950 & 9.0641378 & 29.8352154 \\
\hline 0 & 8.7599035 & 7.4460663 & 19.9268998 \\
\hline 0 & 1.7837590 & 11.2834711 & 24.9355792 \\
\hline $\mathrm{H}$ & 5.2334498 & 9.1661613 & 29.9745080 \\
\hline $\mathrm{H}$ & 3.4546233 & 12.1164690 & 15.1700953 \\
\hline $\mathrm{P}$ & 3.1411377 & 16.0303310 & 21.6358140 \\
\hline Al & 3.1522383 & 16.0576531 & 18.5152096 \\
\hline $\mathrm{P}$ & 3.7706536 & 12.1313763 & 28.4452105 \\
\hline Al & 3.7743052 & 12.1552574 & 16.6238558 \\
\hline $\mathrm{P}$ & 1.5489456 & 13.3806595 & 18.4499976 \\
\hline Al & 1.4482728 & 13.3860890 & 21.5428001 \\
\hline 0 & 4.9542818 & 13.4152308 & 16.9554431 \\
\hline $\mathrm{H}$ & -0.0011833 & 13.7269394 & 21.5384656 \\
\hline $\mathrm{H}$ & 2.2084483 & 17.1865197 & 21.7379834 \\
\hline 0 & 1.9300104 & 14.8540741 & 18.1468723 \\
\hline 0 & 4.5611856 & 15.8532812 & 17.5020153 \\
\hline 0 & 4.3549353 & 16.2377809 & 22.5473788 \\
\hline 0 & 2.2922727 & 12.4422199 & 17.4841965 \\
\hline 0 & 4.3470371 & 13.4948492 & 28.0539751 \\
\hline 0 & 2.4175397 & 14.7604480 & 22.0713799 \\
\hline $\mathrm{H}$ & 2.6100001 & 17.4272142 & 18.2974919 \\
\hline $\mathrm{H}$ & 0.0880716 & 13.2092603 & 18.2185023 \\
\hline 0 & 3.6475597 & 15.9172563 & 20.1843757 \\
\hline $\mathrm{H}$ & 3.4113611 & 12.1104804 & 29.8900610 \\
\hline 0 & 1.9520266 & 13.0091548 & 19.8842971 \\
\hline $\mathrm{P}$ & 10.0661843 & 12.0816489 & 16.5896158 \\
\hline Al & 10.0214800 & 12.0523580 & 28.3906169 \\
\hline $\mathrm{P}$ & 12.3140601 & 10.7794704 & 26.7224691 \\
\hline Al & 12.3322370 & 10.7906797 & 23.5189432 \\
\hline $\mathrm{P}$ & 15.4612959 & 10.8414555 & 23.4677824 \\
\hline $\mathrm{P}$ & 10.6312580 & 8.1551702 & 23.4725329 \\
\hline $\mathrm{Al}$ & 10.6761427 & 8.1269561 & 26.6225074 \\
\hline Al & 15.4511475 & 10.8223229 & 26.6088208 \\
\hline 0 & 8.8751808 & 10.7679871 & 28.0480293 \\
\hline 0 & 11.8532264 & 9.3454441 & 27.0678419 \\
\hline $\mathrm{H}$ & 15.8809874 & 9.4113688 & 26.8127002 \\
\hline $\mathrm{H}$ & 11.5420820 & 6.9908111 & 23.2942415 \\
\hline 0 & 14.0186807 & 10.3380486 & 23.2621101 \\
\hline 0 & 11.5118732 & 11.8020856 & 27.5401387 \\
\hline 0 & 9.2453422 & 8.3034338 & 27.6046257 \\
\hline $\mathrm{H}$ & 16.2451499 & 11.7379066 & 27.4739146 \\
\hline 0 & 9.3717479 & 7.9734373 & 22.6057260 \\
\hline 0 & 15.7749565 & 12.0266812 & 22.5554088 \\
\hline 0 & 9.4903770 & 10.7234005 & 17.0563924 \\
\hline 0 & 13.7873271 & 10.9334902 & 27.1080505 \\
\hline $\mathrm{H}$ & 11.2547294 & 6.7824567 & 26.8957826 \\
\hline $\mathrm{H}$ & 16.4024894 & 9.7345800 & 23.1420492 \\
\hline 0 & 11.3432073 & 9.4241860 & 23.0050289 \\
\hline $\mathrm{H}$ & 10.3410871 & 12.0441046 & 15.1266942 \\
\hline 0 & 12.0951835 & 11.0542038 & 25.2352872 \\
\hline 0 & 15.6587577 & 11.2834711 & 24.9355792 \\
\hline 0 & 10.1999125 & 8.2778038 & 24.9443697 \\
\hline $\mathrm{H}$ & 10.3000088 & 12.0444986 & 29.8533133 \\
\hline $\mathrm{H}$ & 8.6990099 & 15.0648251 & 15.099307 \\
\hline $\mathrm{P}$ & 5.3883585 & 14.8679134 & 16.6658765 \\
\hline
\end{tabular}




\begin{tabular}{|c|c|c|c|}
\hline Al & 5.3515325 & 14.8446322 & 28.4946233 \\
\hline $\mathrm{P}$ & 12.2772895 & 18.8408303 & 21.6350409 \\
\hline $\mathrm{Si}$ & 12.1032054 & 13.3393989 & 21.6016572 \\
\hline $\mathrm{P}$ & 17.0161365 & 16.0303310 & 21.6358140 \\
\hline Al & 17.0272370 & 16.0576531 & 18.5152096 \\
\hline Al & 12.2104680 & 13.3327151 & 18.5207480 \\
\hline Al & 12.3222581 & 18.8572661 & 18.4887976 \\
\hline $\mathrm{P}$ & 5.2939509 & 17.3646703 & 26.6486729 \\
\hline Al & 5.2580918 & 17.3598146 & 23.5213074 \\
\hline $\mathrm{P}$ & 8.4997759 & 14.7898053 & 28.3741063 \\
\hline Al & 8.5362832 & 14.8251143 & 16.5598485 \\
\hline $\mathrm{P}$ & 15.4239443 & 13.3806595 & 18.4499976 \\
\hline$P$ & 15.5103769 & 18.8987590 & 18.4776690 \\
\hline $\mathrm{P}$ & 10.7142310 & 16.1620777 & 18.3996753 \\
\hline Al & 10.6023487 & 16.1549868 & 21.5346669 \\
\hline Al & 15.4539504 & 18.8552205 & 21.5993495 \\
\hline Al & 15.3232715 & 13.3860890 & 21.5428001 \\
\hline $\mathrm{P}$ & 8.4131567 & 17.4664773 & 23.4211411 \\
\hline Al & 8.4467953 & 17.3586758 & 26.5612137 \\
\hline 0 & 9.0248911 & 13.1691696 & 16.9358023 \\
\hline 0 & 7.0174654 & 14.4487052 & 28.1296270 \\
\hline 0 & 11.8226904 & 17.3953239 & 21.8546286 \\
\hline 0 & 13.6590421 & 13.7774450 & 21.5378234 \\
\hline 0 & 16.0474636 & 17.2311257 & 21.7419251 \\
\hline 0 & 15.8050091 & 14.8540741 & 18.1468723 \\
\hline 0 & 11.7262763 & 15.0063457 & 18.2919429 \\
\hline 0 & 14.0391636 & 18.5285409 & 18.2503300 \\
\hline 0 & 6.7663906 & 17.7478733 & 26.8952956 \\
\hline $\mathrm{H}$ & 8.8531458 & 18.8838176 & 23.2999933 \\
\hline $\mathrm{H}$ & 4.7239025 & 18.7354580 & 23.3228951 \\
\hline $\mathrm{H}$ & 18.2278225 & 15.8835047 & 17.6518513 \\
\hline $\mathrm{H}$ & 11.9219499 & 20.0289712 & 17.6617661 \\
\hline 0 & 11.3800349 & 12.3259685 & 17.3323242 \\
\hline 0 & 4.8547016 & 16.2416024 & 27.5920827 \\
\hline $\mathrm{H}$ & 11.5313328 & 19.7870018 & 22.5099287 \\
\hline 0 & 11.8149061 & 12.1492021 & 22.6459035 \\
\hline $\mathrm{H}$ & 18.1957982 & 16.2319468 & 22.5217428 \\
\hline $\mathrm{O}$ & 8.9295439 & 16.0003920 & 27.5427987 \\
\hline $\mathrm{H}$ & 16.1435084 & 12.4722204 & 17.5150717 \\
\hline 0 & 9.5421870 & 15.9420980 & 17.4303222 \\
\hline $\mathrm{H}$ & 15.9414266 & 19.9774366 & 17.5461265 \\
\hline 0 & 9.1764059 & 16.5668039 & 22.4584322 \\
\hline 0 & 6.8683576 & 15.0215729 & 17.0462062 \\
\hline 0 & 9.3485442 & 13.5901188 & 27.9399318 \\
\hline 0 & 13.7688888 & 18.9474440 & 21.9853855 \\
\hline 0 & 11.1489042 & 14.5953013 & 21.9132984 \\
\hline 0 & 16.2925384 & 14.7604480 & 22.0713799 \\
\hline 0 & 16.3879917 & 17.6722307 & 18.2585419 \\
\hline $\mathrm{O}$ & 13.9218573 & 13.2044249 & 18.2119716 \\
\hline $\mathrm{O}$ & 11.4227540 & 17.4623078 & 17.9806857 \\
\hline $\mathrm{H}$ & 4.4347733 & 18.5470991 & 26.9329203 \\
\hline $\mathrm{H}$ & 9.2979179 & 18.5241155 & 26.9279030 \\
\hline 0 & 6.9274106 & 17.3858470 & 23.0530034 \\
\hline $\mathrm{H}$ & 5.1872428 & 15.1906603 & 15.2262559 \\
\hline 0 & 12.0583846 & 19.2656609 & 20.1659895 \\
\hline 0 & 17.5225584 & 15.9172563 & 20.1843757 \\
\hline 0 & 5.1006254 & 16.8868038 & 25.1989878 \\
\hline $\mathrm{H}$ & 8.7197342 & 15.0959591 & 29.8145954 \\
\hline 0 & 15.8270253 & 13.0091548 & 19.8842971 \\
\hline 0 & 15.6974029 & 19.4621677 & 19.9268998 \\
\hline 0 & 10.1599204 & 16.2916125 & 19.8236175 \\
\hline 0 & 8.6354362 & 16.9714650 & 24.8663338 \\
\hline 0 & 11.6987092 & 12.7260204 & 20.0838081 \\
\hline $\mathrm{H}$ & 7.9854273 & 10.4869982 & 19.3397206 \\
\hline C & 10.0589594 & 11.4194723 & 20.1306981 \\
\hline $\mathrm{H}$ & 9.4525285 & 12.2681333 & 19.8332361 \\
\hline $\mathrm{H}$ & 10.5827253 & 10.8430416 & 19.3782694 \\
\hline $\mathrm{H}$ & 10.2548665 & 11.2516788 & 21.1859998 \\
\hline 0 & 8.5096932 & 10.2733431 & 20.1394536 \\
\hline $\mathrm{H}$ & 8.7470778 & 9.3097226 & 20.0595185 \\
\hline $\mathrm{H}$ & 5.2061559 & 15.1480975 & 29.9451043 \\
\hline $\mathrm{H}$ & 16.1854571 & 19.8253647 & 22.4600695 \\
\hline \multicolumn{4}{|c|}{ Mg 1} \\
\hline \multicolumn{4}{|c|}{$165^{1}$} \\
\hline $\mathrm{H}$ & 8.5647760 & 9.0665585 & 15.2414185 \\
\hline Al & 5.3812558 & 9.4009368 & 16.6678783 \\
\hline $\mathrm{P}$ & 5.3691567 & 9.3629682 & 28.4635958 \\
\hline Al & 5.2431743 & 6.7857279 & 21.5759126 \\
\hline $\mathrm{P}$ & 5.3203303 & 6.7992669 & 18.4220758 \\
\hline
\end{tabular}




\begin{tabular}{|c|c|c|c|}
\hline Al & 3.1462654 & 8.1236568 & 26.6140543 \\
\hline $\mathrm{P}$ & 3.2556817 & 8.2350424 & 23.5070277 \\
\hline Al & 8.4632457 & 9.3310760 & 28.4868150 \\
\hline $\mathrm{P}$ & 8.5053880 & 9.4281544 & 16.6846240 \\
\hline Al & 8.5024508 & 6.8864077 & 18.5220632 \\
\hline $\mathrm{P}$ & 8.4555999 & 6.8632659 & 21.6370580 \\
\hline Al & 1.5172632 & 10.8840114 & 23.5296978 \\
\hline $\mathrm{P}$ & 1.4761919 & 10.8438614 & 26.6789403 \\
\hline $\mathrm{O}$ & 7.0600696 & 9.7965527 & 17.1090990 \\
\hline 0 & 4.9580605 & 10.8167342 & 28.1603991 \\
\hline $\mathrm{H}$ & 4.7166962 & 5.4185417 & 21.8418886 \\
\hline $\mathrm{H}$ & 9.0351354 & 5.4952214 & 21.7356159 \\
\hline $\mathrm{O}$ & 6.8265953 & 6.5078243 & 18.2422651 \\
\hline $\mathrm{O}$ & 1.9437069 & 9.3797812 & 26.7936650 \\
\hline $\mathrm{H}$ & 2.1813440 & 7.2301954 & 23.2763728 \\
\hline $\mathrm{H}$ & 0.1574604 & 10.3375002 & 23.2662926 \\
\hline $\mathrm{O}$ & 4.8973364 & 7.9635972 & 17.5177422 \\
\hline 0 & 4.4592971 & 8.3728421 & 27.7348095 \\
\hline $\mathrm{O}$ & 4.4474185 & 7.9817541 & 22.5703156 \\
\hline $\mathrm{O}$ & 2.3065443 & 11.7496516 & 27.5948955 \\
\hline $\mathrm{O}$ & 9.0030801 & 8.2511273 & 17.5394604 \\
\hline 0 & 1.8863394 & 12.2748167 & 22.5643581 \\
\hline $\mathrm{O}$ & 4.3562393 & 10.7321545 & 17.1259333 \\
\hline $\mathrm{O}$ & 6.8085209 & 9.1452741 & 27.9788969 \\
\hline 0 & 6.9591641 & 6.8079103 & 21.9185391 \\
\hline $\mathrm{H}$ & 9.3526573 & 5.7043490 & 18.2106044 \\
\hline $\mathrm{H}$ & 4.5619309 & 5.5857311 & 18.0106370 \\
\hline $\mathrm{H}$ & 0.0630442 & 10.9196961 & 27.1419559 \\
\hline $\mathrm{H}$ & 2.5191049 & 6.8190204 & 26.9629302 \\
\hline $\mathrm{O}$ & 2.7056261 & 9.6341004 & 23.2135193 \\
\hline $\mathrm{H}$ & 5.2956658 & 9.1371216 & 15.2049373 \\
\hline $\mathrm{O}$ & 5.0281363 & 7.1930543 & 19.8791785 \\
\hline $\mathrm{O}$ & 3.7530759 & 8.1387572 & 24.9672839 \\
\hline $\mathrm{H}$ & 8.5505253 & 9.0991214 & 29.9550452 \\
\hline $\mathrm{O}$ & 8.7066604 & 7.4481341 & 20.2011545 \\
\hline $\mathrm{O}$ & 1.6112618 & 11.3396126 & 25.2310959 \\
\hline $\mathrm{H}$ & 5.2840385 & 9.1012609 & 29.9269429 \\
\hline $\mathrm{H}$ & 3.4101529 & 12.0434318 & 15.2391188 \\
\hline Al & 3.2401464 & 16.1202968 & 21.5619240 \\
\hline $\mathrm{P}$ & 3.1506643 & 16.1382192 & 18.4234086 \\
\hline Al & 3.7559011 & 12.0523277 & 28.4977766 \\
\hline $\mathrm{P}$ & 3.7575401 & 12.0796124 & 16.6865765 \\
\hline Al & 1.6039904 & 13.4098624 & 18.5546316 \\
\hline$P$ & 1.6401033 & 13.4706282 & 21.6269694 \\
\hline $\mathrm{O}$ & 4.8081067 & 13.1774046 & 16.9618946 \\
\hline $\mathrm{H}$ & 0.2294795 & 13.9472693 & 21.6356011 \\
\hline $\mathrm{H}$ & 2.2920160 & 17.2587519 & 21.7105480 \\
\hline $\mathrm{O}$ & 2.0632015 & 15.0742827 & 18.1715380 \\
\hline $\mathrm{O}$ & 4.3346704 & 15.9570918 & 17.4654870 \\
\hline $\mathrm{O}$ & 4.6852760 & 16.3960531 & 22.4919296 \\
\hline 0 & 2.4766358 & 12.3303380 & 17.4850382 \\
\hline $\mathrm{O}$ & 4.3866975 & 13.6041805 & 28.0252672 \\
\hline $\mathrm{O}$ & 2.5818691 & 14.6081883 & 22.0900033 \\
\hline $\mathrm{H}$ & 2.5711705 & 17.4859526 & 18.1686097 \\
\hline $\mathrm{H}$ & 0.1464649 & 13.2356089 & 18.3048800 \\
\hline 0 & 3.6757803 & 16.0510046 & 19.8642406 \\
\hline $\mathrm{H}$ & 3.4520862 & 12.0437696 & 29.9554268 \\
\hline $\mathrm{O}$ & 2.0600640 & 13.0279832 & 20.1933925 \\
\hline Al & 10.0925162 & 12.1653778 & 16.4692886 \\
\hline $\mathrm{P}$ & 10.0027724 & 12.0997137 & 28.3128562 \\
\hline Al & 12.2430125 & 10.6897000 & 26.6550625 \\
\hline$P$ & 12.3033367 & 10.6350666 & 23.4443276 \\
\hline Al & 15.3922619 & 10.8840114 & 23.5296978 \\
\hline Al & 10.5318761 & 8.0940997 & 23.6131774 \\
\hline $\mathrm{P}$ & 10.6300398 & 8.0414892 & 26.7186576 \\
\hline$P$ & 15.3511906 & 10.8438614 & 26.6789403 \\
\hline $\mathrm{O}$ & 8.9837836 & 10.9599572 & 28.1087663 \\
\hline 0 & 11.7108462 & 9.0722680 & 27.1028956 \\
\hline $\mathrm{H}$ & 15.8028742 & 9.4293590 & 26.7897801 \\
\hline $\mathrm{H}$ & 11.3775049 & 6.8732287 & 23.5059086 \\
\hline $\mathrm{O}$ & 13.7872940 & 10.2389672 & 23.2188020 \\
\hline $\mathrm{O}$ & 11.2451607 & 11.8832501 & 27.4519324 \\
\hline 0 & 9.4527088 & 8.1328431 & 27.7026855 \\
\hline $\mathrm{H}$ & 16.1579118 & 11.7238735 & 27.5688281 \\
\hline $\mathrm{O}$ & 9.1053464 & 7.8439931 & 22.6204897 \\
\hline 0 & 15.7613381 & 12.2748167 & 22.5643581 \\
\hline $\mathrm{O}$ & 9.4139652 & 10.6300494 & 16.9948496 \\
\hline $\mathrm{O}$ & 13.8945571 & 10.9220297 & 27.1562040 \\
\hline $\mathrm{H}$ & 11.2061645 & 6.6716918 & 26.8127632 \\
\hline $\mathrm{H}$ & 16.4014214 & 9.8225851 & 23.2611985 \\
\hline
\end{tabular}




\begin{tabular}{|c|c|c|}
\hline 11.4216786 & 9.4445589 & 22.9855829 \\
\hline 10.3889110 & 12.1437657 & 15.0102465 \\
\hline 12.0710666 & 10.8765444 & 24.9489701 \\
\hline 15.4862605 & 11.3396126 & 25.2310959 \\
\hline 10.0944236 & 8.3185446 & 25.2974203 \\
\hline 10.4224165 & 12.1388988 & 29.7409612 \\
\hline 8.6294229 & 15.1257104 & 15.1297124 \\
\hline 5.3177653 & 14.8153928 & 16.5901087 \\
\hline 5.2657592 & 14.7970336 & 28.4110359 \\
\hline 12.1806737 & 18.8018293 & 21.5759126 \\
\hline 12.2603070 & 13.4129041 & 21.6469018 \\
\hline 17.1151451 & 16.1202968 & 21.5619240 \\
\hline 17.0256630 & 16.1382192 & 18.4234086 \\
\hline 12.2481125 & 13.2806092 & 18.4308679 \\
\hline 12.2578296 & 18.8153683 & 18.4220758 \\
\hline 5.3440122 & 17.2987849 & 26.5624375 \\
\hline 5.3235919 & 17.3590331 & 23.4953652 \\
\hline 8.4175247 & 14.8183944 & 28.3904104 \\
\hline 8.4683355 & 14.8434154 & 16.5828060 \\
\hline 15.4789891 & 13.4098624 & 18.5546316 \\
\hline 15.4399501 & 18.9025091 & 18.5220632 \\
\hline 10.6725289 & 16.0864576 & 18.4630184 \\
\hline 10.4791260 & 16.1394966 & 21.5869119 \\
\hline 15.3930993 & 18.8793672 & 21.6370580 \\
\hline 15.5151020 & 13.4706282 & 21.6269694 \\
\hline 8.4611976 & 17.5865736 & 23.4771794 \\
\hline 8.4816081 & 17.4137008 & 26.6285198 \\
\hline 8.9103074 & 13.3898532 & 16.8908691 \\
\hline 6.7326175 & 14.4542022 & 28.0864590 \\
\hline 11.5674364 & 17.2093423 & 21.8857192 \\
\hline 14.0801000 & 13.9555065 & 21.6357503 \\
\hline 15.9891641 & 17.4723036 & 21.7384269 \\
\hline 15.9382002 & 15.0742827 & 18.1715380 \\
\hline 11.8070241 & 14.7515455 & 18.3083319 \\
\hline 13.7640947 & 18.5239256 & 18.2422651 \\
\hline 7.0027453 & 17.7552070 & 26.9191149 \\
\hline 8.9886339 & 18.9676800 & 23.2997624 \\
\hline 4.5956300 & 18.6579362 & 23.4888442 \\
\hline 18.1751473 & 15.9623729 & 17.4934169 \\
\hline 11.8471791 & 19.9457224 & 17.5441315 \\
\hline 11.5877106 & 12.4300677 & 17.3262507 \\
\hline 4.8055834 & 16.0161490 & 27.6083277 \\
\hline 11.5024959 & 19.8211349 & 22.4233862 \\
\hline 11.9059816 & 11.8568243 & 22.6605776 \\
\hline 18.3514529 & 16.3562062 & 22.3575435 \\
\hline 8.9224995 & 16.2081552 & 27.4716888 \\
\hline 16.2204678 & 12.4926005 & 17.6458080 \\
\hline 9.3266677 & 15.8329145 & 17.3728458 \\
\hline 15.8647990 & 20.0606506 & 17.6881974 \\
\hline 9.2139034 & 16.4726434 & 22.3965948 \\
\hline 7.0043876 & 14.9996043 & 17.0153987 \\
\hline 9.3588089 & 13.4292482 & 27.9134677 \\
\hline 13.8966635 & 18.8240117 & 21.9185391 \\
\hline 10.9777029 & 14.7670164 & 21.9440311 \\
\hline 16.4568678 & 14.6081883 & 22.0900033 \\
\hline 16.4273637 & 17.5296889 & 18.1603410 \\
\hline 13.7660278 & 13.2050705 & 18.2611103 \\
\hline 11.4786848 & 17.5686371 & 17.9993824 \\
\hline 4.4355206 & 18.4584766 & 26.7789527 \\
\hline 9.3254353 & 18.5792614 & 27.0113314 \\
\hline 6.7697607 & 17.6176722 & 23.0805407 \\
\hline 5.1413777 & 15.0772356 & 15.1349640 \\
\hline 11.9656357 & 19.2091556 & 19.8791785 \\
\hline 17.5507790 & 16.0510046 & 19.8642406 \\
\hline 5.2562448 & 16.7357342 & 24.9041580 \\
\hline 8.6019015 & 15.0871103 & 29.8433101 \\
\hline 15.9350628 & 13.0279832 & 20.1933925 \\
\hline 15.6441597 & 19.4642354 & 20.2011545 \\
\hline 10.0815740 & 16.2361904 & 20.0875794 \\
\hline 8.6767618 & 17.0732809 & 25.1423784 \\
\hline 11.8287081 & 12.6980747 & 19.8097292 \\
\hline 8.0647247 & 10.4486745 & 19.4006693 \\
\hline 10.2312607 & 11.4769056 & 19.9868693 \\
\hline 9.5739678 & 12.3110950 & 19.7644544 \\
\hline 10.6148985 & 10.8529343 & 19.1886064 \\
\hline 10.5164267 & 11.2840833 & 21.0181796 \\
\hline 8.6040798 & 10.3391334 & 20.2109645 \\
\hline 8.8069423 & 9.3691299 & 20.2619867 \\
\hline 5.1161217 & 15.1117943 & 29.8586736 \\
\hline 16.0240565 & 19.8317339 & 22.5920509 \\
\hline
\end{tabular}




\begin{tabular}{|c|c|c|}
\hline 9.2390379 & 8.1622734 & 27.7126150 \\
\hline 15.9786942 & 11.6468055 & 27.5775041 \\
\hline 9.1396493 & 7.8614743 & 22.6569330 \\
\hline 15.5597244 & 12.0075252 & 22.5898547 \\
\hline 9.3610721 & 10.5815746 & 17.0043862 \\
\hline 13.6559608 & 10.8369565 & 27.1235359 \\
\hline 11.0830471 & 6.6799378 & 26.8672130 \\
\hline 16.1864897 & 9.6816914 & 23.3049261 \\
\hline 11.2179789 & 9.3801928 & 23.1117265 \\
\hline 10.3518145 & 11.9919474 & 15.0949131 \\
\hline 11.8693351 & 10.9791334 & 25.1400801 \\
\hline 15.4016245 & 11.2860973 & 25.1328383 \\
\hline 9.9351494 & 8.2371811 & 25.1684886 \\
\hline 10.3432449 & 11.9877698 & 29.9078726 \\
\hline 8.6400630 & 15.0142316 & 15.1306947 \\
\hline 5.2978154 & 14.7126586 & 16.6143645 \\
\hline 5.2575895 & 14.6873139 & 28.5679338 \\
\hline 12.0642356 & 18.6084315 & 21.6280602 \\
\hline 12.0360586 & 13.2154836 & 21.6316386 \\
\hline 16.8536007 & 15.8796691 & 21.6183822 \\
\hline 16.8201524 & 15.9146723 & 18.5421470 \\
\hline 12.0698524 & 13.1726386 & 18.5281518 \\
\hline 12.1129134 & 18.6329423 & 18.5383749 \\
\hline 5.2679323 & 17.0889253 & 26.6261334 \\
\hline 5.2514725 & 17.1147698 & 23.5933640 \\
\hline 8.3873211 & 14.6650531 & 28.5027753 \\
\hline 8.4294052 & 14.6998763 & 16.5708074 \\
\hline 15.2546304 & 13.2350230 & 18.5655327 \\
\hline 15.2599030 & 18.6710811 & 18.5686070 \\
\hline 10.5257603 & 15.9400120 & 18.5087484 \\
\hline 10.4012061 & 15.9446614 & 21.5828322 \\
\hline 15.2213076 & 18.6292469 & 21.6470131 \\
\hline 15.2207816 & 13.2541875 & 21.6000865 \\
\hline 8.3760069 & 17.2634263 & 23.5398662 \\
\hline 8.3877815 & 17.1430866 & 26.6218845 \\
\hline 8.8833155 & 13.1554842 & 16.8773182 \\
\hline 6.8148406 & 14.3067917 & 28.2899301 \\
\hline 11.5386196 & 17.0979475 & 21.8435742 \\
\hline 13.6909598 & 13.7058983 & 21.6067568 \\
\hline 15.7966630 & 17.1226052 & 21.7584998 \\
\hline 15.6797623 & 14.7880668 & 18.2568505 \\
\hline 11.6056437 & 14.7269053 & 18.3691699 \\
\hline 13.7009882 & 18.2970609 & 18.3337546 \\
\hline 6.8199828 & 17.5144170 & 26.8879611 \\
\hline 8.8577767 & 18.6663854 & 23.4105442 \\
\hline 4.6500060 & 18.4742663 & 23.5089367 \\
\hline 17.9793799 & 15.7569568 & 17.6210400 \\
\hline 11.7089458 & 19.7603584 & 17.6535791 \\
\hline 11.3521785 & 12.2515671 & 17.3879798 \\
\hline 4.7941725 & 15.9331756 & 27.6522085 \\
\hline 11.3733995 & 19.5736697 & 22.5270492 \\
\hline 11.7124140 & 11.8961663 & 22.6817817 \\
\hline 18.0452142 & 16.0945218 & 22.4849941 \\
\hline 8.8374952 & 15.9089865 & 27.5731918 \\
\hline 15.9591125 & 12.3267068 & 17.6190723 \\
\hline 9.3027813 & 15.7268889 & 17.4608077 \\
\hline 15.6842708 & 19.7838296 & 17.6748378 \\
\hline 9.0990292 & 16.2856268 & 22.4906293 \\
\hline 6.8701592 & 14.8467994 & 16.9869198 \\
\hline 9.2553994 & 13.3704623 & 28.0657712 \\
\hline 13.6477892 & 18.6484955 & 21.9755560 \\
\hline 10.9556080 & 14.5097423 & 21.9512451 \\
\hline 16.1655655 & 14.4995869 & 22.0768268 \\
\hline 16.1830362 & 17.3870731 & 18.2779643 \\
\hline 13.6658889 & 13.0824668 & 18.2986697 \\
\hline 11.2692300 & 17.3268469 & 18.1084722 \\
\hline 4.3921439 & 18.2697856 & 26.8621082 \\
\hline 9.2225988 & 18.3227466 & 26.9804971 \\
\hline 6.8014103 & 17.2456486 & 23.1826930 \\
\hline 5.0677927 & 15.0737582 & 15.1882448 \\
\hline 11.8384212 & 19.0796031 & 20.0782166 \\
\hline 17.3619074 & 15.8128895 & 20.0700298 \\
\hline 5.0901165 & 16.5296713 & 25.1061563 \\
\hline 8.6358618 & 15.0103877 & 29.9296923 \\
\hline 15.6745890 & 12.8151405 & 20.0767289 \\
\hline 15.4725220 & 19.2290196 & 20.1142144 \\
\hline 9.9231579 & 16.0334183 & 20.0094990 \\
\hline 8.6200034 & 16.7288653 & 25.0651025 \\
\hline 11.6256039 & 12.5744940 & 19.9847329 \\
\hline 7.8462064 & 10.4225817 & 19.3760066 \\
\hline
\end{tabular}




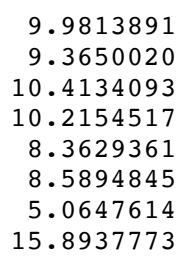

11.3653566

12.2238451

10.7613373

11.1595521

10.2585585

9.2898065

15.0710153

19.5786589

9.1000591

9.4590794

9.4012523

6.8123728

6.8497327

8.0503625

8.1802239

9.2963947

9.3876660

6.8910731

6.8215706

10.8641296

10.8068413

9.7987772

11.0523094

5.4197493

5.4492533

6.5203705

9.1442863

7.2151381

10.3003000

8.2317079

8.2726033

7.8054878

11.8578934

8.0221257

12.0648783

10.6484743

9.1393893

6.8582479

5.6988460

5.6605886

10.8617372

6.7301680

9.7876127

9.1612781

7.2565750

8.0726444

9.0622685

7.4324241

11.3188048

9.1897457

12.1376132

16.0342851

16.0741744

12.1302223

12.1704766

13.3957995

13.4266108

13.4220765

13.8953931

17.1923466

14.8642988

15.8698557

16.2166793

12.4505290

13.4960993

14.7591654

17.4414117

13.2364280

15.9391092

12.1318793

13.0171113

12.0887753

12.0240903

10.6978602

10.6636805

10.8641296

8.1391210
20.0869542

19.8419957

19.2985646

21.1280760

20.1916073

20.1788273

29.9936656

22.5762719

15.1196176

16.7397894

28.5254536

21.6372712

18.4925833

26.6750421

23.5803619

28.3869087

16.5793202

18.4860387

21.6190501

23.4885424

26.6355373

17.0968050

28.1686281

21.8353927

21.7502309

18.2491648

26.7917432

23.3763174

23.1965935

17.5342108

27.7170469

22.5449021

27.6481684

17.5440133

22.5874979

17.1335807

27.9796963

21.9879682

18.2534273

18.0482328

27.1360044

26.9657594

23.2208258

15.2855850

20.1718340

25.2629687

29.8493254

19.9445662

24.9654827

29.9988404

15.1857948

21.6248860

18.5002630

28.4537724

16.6409463

18.4560689

21.5676599

16.9873566

21.6050229

21.7664911

18.1566422

17.4885728

22.5037655

17.5066436

28.0310667

22.0659846

18.2862844

18.1937687

20.1626772

29.9033369

19.8995579

16.5252047

28.3313533

26.7574023

23.5169190

23.4885424

23.5313899 


\begin{tabular}{|c|c|c|c|}
\hline Al & 10.6427127 & 8.1136772 & 26.6310330 \\
\hline Al & 15.4237361 & 10.8068413 & 26.6355373 \\
\hline 0 & 8.8755577 & 10.7179991 & 28.0215393 \\
\hline 0 & 11.8268559 & 9.2939066 & 27.1673732 \\
\hline $\mathrm{H}$ & 15.8742392 & 9.3938506 & 26.7682953 \\
\hline $\mathrm{H}$ & 11.3618264 & 6.8767943 & 23.4870467 \\
\hline 0 & 14.0870680 & 10.2796519 & 23.1859020 \\
\hline $\mathrm{O}$ & 11.4800550 & 11.7806613 & 27.4428289 \\
\hline $\mathrm{O}$ & 9.2301152 & 8.2349376 & 27.6521592 \\
\hline $\mathrm{H}$ & 16.2377891 & 11.7046994 & 27.5005744 \\
\hline 0 & 9.3275147 & 7.9970493 & 22.6349629 \\
\hline $\mathrm{O}$ & 15.7715406 & 12.0648783 & 22.5874979 \\
\hline 0 & 9.5220043 & 10.7357422 & 17.0203982 \\
\hline 0 & 13.7803847 & 10.8712196 & 27.2224520 \\
\hline $\mathrm{H}$ & 11.2250044 & 6.7496690 & 26.7634658 \\
\hline $\mathrm{H}$ & 16.5149461 & 9.8222317 & 23.2294351 \\
\hline 0 & 11.4253842 & 9.2880670 & 22.9900499 \\
\hline $\mathrm{H}$ & 10.3575413 & 12.0235799 & 15.0624057 \\
\hline 0 & 12.2246583 & 10.8578036 & 25.2452495 \\
\hline 0 & 15.5546166 & 11.3188048 & 24.9654827 \\
\hline 0 & 10.1255345 & 8.4202164 & 24.9791182 \\
\hline $\mathrm{H}$ & 10.3117596 & 12.0222335 & 29.7890441 \\
\hline $\mathrm{H}$ & 8.7051227 & 15.0831515 & 15.0436386 \\
\hline $\mathrm{P}$ & 5.4043668 & 14.8684594 & 16.6621376 \\
\hline Al & 5.3371085 & 14.8377940 & 28.4862927 \\
\hline $\mathrm{P}$ & 12.2841916 & 18.8284742 & 21.6372712 \\
\hline $\mathrm{Ge}$ & 12.0600347 & 13.3691438 & 21.6582985 \\
\hline $\mathrm{P}$ & 17.0864282 & 16.0342851 & 21.6248860 \\
\hline Al & 17.0506560 & 16.0741744 & 18.5002630 \\
\hline Al & 12.2134808 & 13.3408465 & 18.4715259 \\
\hline Al & 12.3350285 & 18.8658340 & 18.4925833 \\
\hline $\mathrm{P}$ & 5.3026046 & 17.3316418 & 26.6287863 \\
\hline Al & 5.2513881 & 17.3296538 & 23.5664476 \\
\hline $\mathrm{P}$ & 8.4857646 & 14.7786610 & 28.3247163 \\
\hline Al & 8.5538466 & 14.8366127 & 16.5042736 \\
\hline $\mathrm{P}$ & 15.4272455 & 13.3957995 & 18.4560689 \\
\hline$P$ & 15.5209359 & 18.9071744 & 18.4860387 \\
\hline $\mathrm{P}$ & 10.7201891 & 16.1717778 & 18.3724105 \\
\hline Al & 10.5113719 & 16.2095747 & 21.5160630 \\
\hline Al & 15.4690183 & 18.8376720 & 21.6190501 \\
\hline Al & 15.3447682 & 13.4266108 & 21.5676599 \\
\hline $\mathrm{P}$ & 8.3821240 & 17.6050304 & 23.4039185 \\
\hline Al & 8.4364064 & 17.3653737 & 26.5254276 \\
\hline 0 & 9.0403169 & 13.1754441 & 16.8561572 \\
\hline 0 & 6.9985802 & 14.4411735 & 28.1051210 \\
\hline 0 & 11.7820748 & 17.3965391 & 21.8409853 \\
\hline 0 & 13.7138862 & 13.9677599 & 21.6107907 \\
\hline 0 & 16.1251753 & 17.2374967 & 21.7720120 \\
\hline 0 & 15.8278749 & 14.8642988 & 18.1566422 \\
\hline 0 & 11.7422988 & 15.0235901 & 18.2835242 \\
\hline $\mathrm{O}$ & 14.0512379 & 18.5364718 & 18.2491648 \\
\hline 0 & 6.7604355 & 17.7634358 & 26.8938040 \\
\hline $\mathrm{H}$ & 8.8648665 & 19.0122679 & 23.3425774 \\
\hline $\mathrm{H}$ & 4.5578903 & 18.6454763 & 23.4972203 \\
\hline $\mathrm{H}$ & 18.2522379 & 15.9000901 & 17.6382791 \\
\hline $\mathrm{H}$ & 11.9367313 & 20.0448191 & 17.6749805 \\
\hline 0 & 11.4046115 & 12.3571911 & 17.2525200 \\
\hline $\mathrm{O}$ & 4.8495482 & 16.2747674 & 27.6403751 \\
\hline $\mathrm{H}$ & 11.5692251 & 19.7926007 & 22.5184089 \\
\hline 0 & 11.7554230 & 12.0372011 & 22.7466168 \\
\hline $\mathrm{H}$ & 18.2929734 & 16.2115909 & 22.4792466 \\
\hline 0 & 8.9103737 & 15.9697335 & 27.4618423 \\
\hline $\mathrm{H}$ & 16.1590065 & 12.4808483 & 17.5370962 \\
\hline 0 & 9.5706009 & 15.9443603 & 17.3778219 \\
\hline $\mathrm{H}$ & 15.9505079 & 20.0026658 & 17.5736314 \\
\hline 0 & 9.0806443 & 16.7396571 & 22.3650856 \\
\hline $\mathrm{O}$ & 6.8906328 & 15.0316010 & 17.0134317 \\
\hline 0 & 9.3199703 & 13.5633159 & 27.9046773 \\
\hline 0 & 13.7780032 & 18.8743493 & 21.9879682 \\
\hline 0 & 10.9077660 & 14.6324442 & 22.0263934 \\
\hline 0 & 16.3789787 & 14.7591654 & 22.0659846 \\
\hline 0 & 16.4025474 & 17.6866420 & 18.2479048 \\
\hline 0 & 13.9295933 & 13.2319841 & 18.1864547 \\
\hline 0 & 11.4276063 & 17.4792459 & 17.9744534 \\
\hline $\mathrm{H}$ & 4.4066314 & 18.5111119 & 26.7811106 \\
\hline $\mathrm{H}$ & 9.3033568 & 18.5136184 & 26.9089008 \\
\hline 0 & 6.8872084 & 17.6033676 & 23.0743181 \\
\hline $\mathrm{H}$ & 5.1787173 & 15.1595429 & 15.2194065 \\
\hline 0 & 12.0788322 & 19.2726763 & 20.1718340 \\
\hline 0 & 17.5583153 & 15.9391092 & 20.1626772 \\
\hline
\end{tabular}




\begin{tabular}{|c|c|c|}
\hline 5.1819978 & 16.7333180 & 25.2132553 \\
\hline 8.7232627 & 15.1144987 & 29.7557748 \\
\hline 15.7898725 & 13.0171113 & 19.8995579 \\
\hline 15.7037712 & 19.4485255 & 19.9445662 \\
\hline 10.1391811 & 16.2910293 & 19.7861897 \\
\hline 8.6214696 & 17.0267936 & 24.8167529 \\
\hline 11.6745229 & 12.6866116 & 20.0064225 \\
\hline 7.9349542 & 10.4559488 & 19.3524715 \\
\hline 10.0305874 & 11.3833771 & 20.0946557 \\
\hline 9.4215494 & 12.2458053 & 19.8460826 \\
\hline 10.5237623 & 10.8287198 & 19.3060125 \\
\hline 10.2712330 & 11.1872688 & 21.1368129 \\
\hline 8.4843185 & 10.2505901 & 20.1378335 \\
\hline 8.7227053 & 9.2865217 & 20.0619151 \\
\hline 5.1960756 & 15.1198998 & 29.9415063 \\
\hline 16.1479685 & 19.8403049 & 22.4855801 \\
\hline 8.5474095 & 8.9169373 & 15.2135586 \\
\hline 5.3237771 & 9.3325490 & 16.6970672 \\
\hline 5.2911901 & 9.2752488 & 28.6131825 \\
\hline 5.2642213 & 6.7883066 & 21.6464150 \\
\hline 5.3062007 & 6.8426504 & 18.5588249 \\
\hline 3.1853815 & 8.0402529 & 26.6726579 \\
\hline 3.3107803 & 8.1585855 & 23.6267335 \\
\hline 8.3762139 & 9.2089656 & 28.5668430 \\
\hline 8.4290863 & 9.3113482 & 16.6444884 \\
\hline 8.4421022 & 6.8698636 & 18.5765805 \\
\hline 8.4197976 & 6.8128801 & 21.6616918 \\
\hline 1.6221062 & 10.7900833 & 23.5897251 \\
\hline 1.5717898 & 10.7437090 & 26.6783256 \\
\hline 6.8900998 & 9.7179175 & 17.0316587 \\
\hline 4.8736561 & 10.8268580 & 28.3449706 \\
\hline 4.7076721 & 5.4180112 & 21.8186476 \\
\hline 9.0296711 & 5.4586289 & 21.7674206 \\
\hline 6.8866727 & 6.4859126 & 18.3231466 \\
\hline 2.0437934 & 9.1903462 & 26.8060194 \\
\hline 2.2378720 & 7.1455014 & 23.4276130 \\
\hline 0.2571562 & 10.2432664 & 23.3551545 \\
\hline 4.8683672 & 8.0750984 & 17.6034695 \\
\hline 4.3529679 & 8.2612588 & 27.7758811 \\
\hline 4.5642985 & 7.8661915 & 22.6364733 \\
\hline 2.4319510 & 11.6881787 & 27.6734828 \\
\hline 8.9095693 & 8.0941500 & 17.6115746 \\
\hline 1.9183168 & 12.0476306 & 22.6237175 \\
\hline 4.4040743 & 10.6011517 & 17.0892224 \\
\hline 6.8240937 & 9.0514855 & 28.1390590 \\
\hline 6.8479571 & 6.7306060 & 21.9943621 \\
\hline 9.3063035 & 5.6868567 & 18.3105516 \\
\hline 4.4938424 & 5.6528798 & 18.1824734 \\
\hline 0.1507027 & 10.8227652 & 27.1157979 \\
\hline 2.5589865 & 6.7205197 & 26.9608489 \\
\hline 2.7214238 & 9.6292951 & 23.2833039 \\
\hline 5.1705665 & 8.9663421 & 15.2619576 \\
\hline 5.0696038 & 7.2958182 & 20.1035463 \\
\hline 3.8365771 & 8.0862271 & 25.1758409 \\
\hline 8.5412996 & 8.9124312 & 30.0166480 \\
\hline 8.6345477 & 7.4209991 & 20.1267097 \\
\hline 1.7590724 & 11.2710147 & 25.1497109 \\
\hline 5.1684834 & 8.9631393 & 30.0639242 \\
\hline 3.3217943 & 11.9724201 & 15.2214872 \\
\hline 3.3024310 & 15.8830987 & 21.6112315 \\
\hline 3.2074075 & 15.9204241 & 18.5407693 \\
\hline 3.7302624 & 11.9665165 & 28.5898290 \\
\hline 3.7307906 & 12.0127342 & 16.6526467 \\
\hline 1.6282433 & 13.2398414 & 18.5821921 \\
\hline 1.6074194 & 13.2938146 & 21.6260246 \\
\hline 4.8452212 & 13.1789097 & 16.9013479 \\
\hline 0.2110664 & 13.8095757 & 21.6622117 \\
\hline 2.3628223 & 17.0283787 & 21.7615307 \\
\hline 2.0599894 & 14.7933291 & 18.2844284 \\
\hline 4.4517930 & 15.7504366 & 17.5160239 \\
\hline 4.6199739 & 16.0807975 & 22.5315212 \\
\hline 2.4147218 & 12.2538368 & 17.5571012 \\
\hline 4.3366702 & 13.4067214 & 28.1713710 \\
\hline 2.6069238 & 14.5064414 & 22.0695574 \\
\hline 2.6172022 & 17.2679153 & 18.3104523 \\
\hline 0.1705425 & 13.0914853 & 18.3172025 \\
\hline 3.7840889 & 15.8189326 & 20.0552643 \\
\hline
\end{tabular}




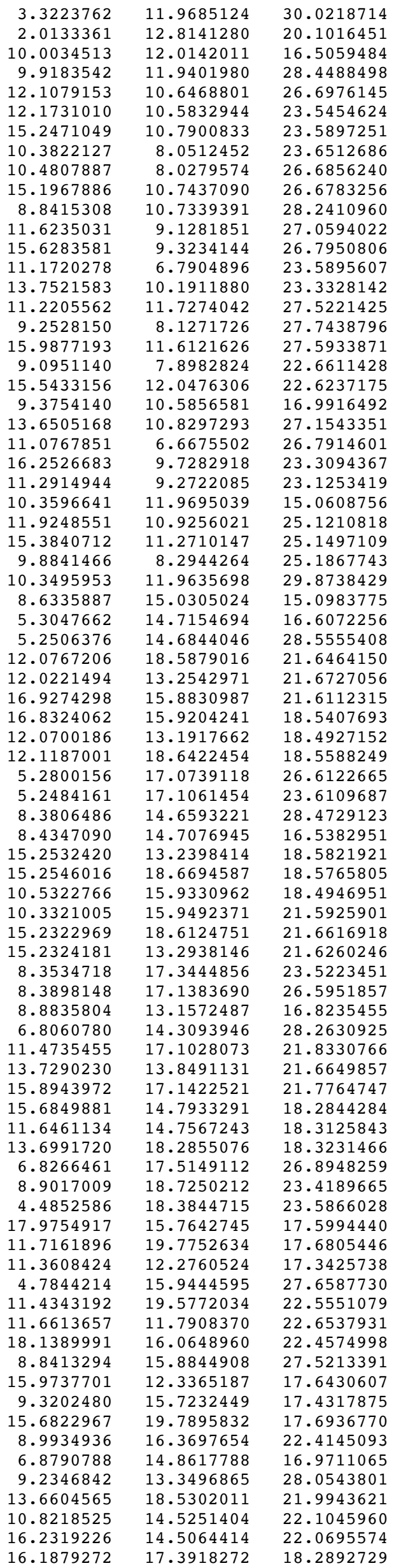




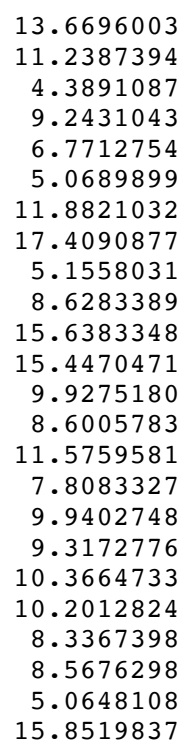

13.0786678

17.3534652

18.2543173

18.3044887

17.4410113

15.0594825

19.0954133

15.8189326

16.4593523

15.0254295

12.8141280

19.2205941

15.9430118

16.7506790

12.6036255

10.4018591

11.3726025

12.2297184

10.7771954

11.1699842

10.2563735

9.2888130

15.0563456

19.6084666

9.1066835

9.4771536

9.4028421

6.8337046

6.8591187

8.0431267

8.2062381

9.2771305

9.4012036

6.8963376

6.8225112

10.8847262

10.7931499

9.8263088

11.0542193

5.4810512

5.4706980

6.5107933

9.1310098

7.2442274

10.3291229

8.2456650

8.2738001

7.8690220

11.8355225

8.0318824

12.0868332

10.6596030

9.1212784

6.7744347

5.7120814

5.6788400

10.8324490

6.7199543

9.8113992

9.1801219

7.2918972

8.0650529

9.0668626

7.4427468

11.3282688

9.2060605

12.1477890

16.0446021

16.0826118

12.1272921

12.1797779

13.4102716

13.4284380

13.4290549

13.8015694

17.2159030

14.8779888
18.2943082

18.1511543

26.7856107

26.9546052

23.2114721

15.1778254

20.1035463

20.0552643

25.1055345

29.8947897

20.1016451

20.1267097

19.9976128

25.0264093

19.9361454

19.3782144

20.0603802

19.8277692

19.2622934

21.0962255

20.1901809

20.1924370

29.9853131

22.5788122

15.1220188

16.7567555

28.5392377

21.6498698

18.5056560

26.6883337

23.6073502

28.3849634

16.5811159

18.4907977

21.6272886

23.5106683

26.6582604

17.1183006

28.1775264

21.8466130

21.7414930

18.2456231

26.7739535

23.3733436

23.1543019

17.5470588

27.7585331

22.5638319

27.6742541

17.5513723

22.6305206

17.1495095

27.9756915

21.9967352

18.2665996

18.0762024

27.1870857

26.9653143

23.2841489

15. 3017185

20.1842103

25.2920787

29.8517728

19.9508093

24.9933023

30.0150795

15. 1991834

21.6138257

18.4932574

28.4628505

16.6569778

18.4738913

21.5925740

17.0135000

21.6514868

21.7550869

18.1601229 


\begin{tabular}{|c|c|c|c|}
\hline 0 & 4.5975912 & 15.8843712 & 17.4733791 \\
\hline 0 & 4.5244527 & 16.2108930 & 22.4724427 \\
\hline 0 & 2.3047626 & 12.4623102 & 17.5144953 \\
\hline $\mathrm{O}$ & 4.3105168 & 13.4935065 & 28.0200570 \\
\hline $\mathrm{O}$ & 2.5425987 & 14.7846915 & 22.0763887 \\
\hline $\mathrm{H}$ & 2.6417105 & 17.4527571 & 18.2966946 \\
\hline $\mathrm{H}$ & 0.0991858 & 13.2484061 & 18.2410132 \\
\hline $\mathrm{O}$ & 3.7169418 & 15.9306919 & 20.1479606 \\
\hline $\mathrm{H}$ & 3.4482446 & 12.1417775 & 29.9159714 \\
\hline $\mathrm{O}$ & 1.9544740 & 13.0395343 & 19.9123177 \\
\hline $\mathrm{P}$ & 10.1075549 & 12.0973432 & 16.4813316 \\
\hline Al & 9.9997321 & 12.0100553 & 28.2855572 \\
\hline $\mathrm{P}$ & 12.3397669 & 10.6579935 & 26.7719544 \\
\hline Al & 12.4237935 & 10.5753760 & 23.5221598 \\
\hline $\mathrm{P}$ & 15.5144065 & 10.8847262 & 23.5106683 \\
\hline$P$ & 10.5439322 & 8.1050503 & 23.5639330 \\
\hline Al & 10.6282378 & 8.1022824 & 26.6373994 \\
\hline Al & 15.4124324 & 10.7931499 & 26.6582604 \\
\hline $\mathrm{O}$ & 8.8777885 & 10.6896848 & 27.9945699 \\
\hline $\mathrm{O}$ & 11.8100214 & 9.2717381 & 27.2088698 \\
\hline $\mathrm{H}$ & 15.8738152 & 9.3808528 & 26.7565632 \\
\hline $\mathrm{H}$ & 11.2012319 & 6.7691348 & 23.5841204 \\
\hline 0 & 14.1301144 & 10.3084796 & 23.1410612 \\
\hline $\mathrm{O}$ & 11.4676258 & 11.7677767 & 27.3845166 \\
\hline $\mathrm{O}$ & 9.2218180 & 8.1978510 & 27.6710940 \\
\hline $\mathrm{H}$ & 16.2317452 & 11.6835043 & 27.5260830 \\
\hline $\mathrm{O}$ & 9.3082637 & 8.0308753 & 22.6399531 \\
\hline 0 & 15.8591790 & 12.0868332 & 22.6305206 \\
\hline $\mathrm{O}$ & 9.5586198 & 10.7413575 & 16.9908474 \\
\hline O & 13.7769725 & 10.8393432 & 27.2798567 \\
\hline $\mathrm{H}$ & 11.2190062 & 6.7379836 & 26.7198745 \\
\hline $\mathrm{H}$ & 16.5580186 & 9.8455456 & 23.2913553 \\
\hline 0 & 11.5176325 & 9.1496199 & 23.0122160 \\
\hline $\mathrm{H}$ & 10.3491808 & 12.0238706 & 15.0139056 \\
\hline 0 & 12.3021095 & 10.7595950 & 25.2527786 \\
\hline $\mathrm{O}$ & 15.5181911 & 11.3282688 & 24.9933023 \\
\hline $\mathrm{O}$ & 10.0987917 & 8.4689028 & 24.9959027 \\
\hline $\mathrm{H}$ & 10.3030981 & 12.0202651 & 29.7432902 \\
\hline $\mathrm{H}$ & 8.7076597 & 15.0712343 & 15.0148275 \\
\hline $\mathrm{P}$ & 5.4122143 & 14.8677810 & 16.6602619 \\
\hline Al & 5.3290835 & 14.8315586 & 28.4789167 \\
\hline $\mathrm{P}$ & 12.2891861 & 18.8498060 & 21.6498698 \\
\hline $\mathrm{Ti}$ & 12.0109158 & 13.3428385 & 21.6844195 \\
\hline $\mathrm{P}$ & 17.1391742 & 16.0446021 & 21.6138257 \\
\hline Al & 17.0655129 & 16.0826118 & 18.4932574 \\
\hline Al & 12.2019978 & 13.3444239 & 18.4457270 \\
\hline$A 1$ & 12.3457282 & 18.8752201 & 18.5056560 \\
\hline $\mathrm{P}$ & 5.3090808 & 17.3198209 & 26.6269992 \\
\hline Al & 5.2452854 & 17.3205256 & 23.5938876 \\
\hline $\mathrm{P}$ & 8.4776715 & 14.7667104 & 28.2936440 \\
\hline Al & 8.5650467 & 14.8381718 & 16.4785433 \\
\hline $\mathrm{P}$ & 15.4359260 & 13.4102716 & 18.4738913 \\
\hline$P$ & 15.5225355 & 18.9124390 & 18.4907977 \\
\hline $\mathrm{P}$ & 10.7121536 & 16.1762329 & 18.3660843 \\
\hline Al & 10.4265515 & 16.2618830 & 21.5159876 \\
\hline Al & 15.4794567 & 18.8386126 & 21.6272886 \\
\hline Al & 15.4096289 & 13.4284380 & 21.5925740 \\
\hline $\mathrm{P}$ & 8.3562374 & 17.6737338 & 23.3982914 \\
\hline Al & 8.4338967 & 17.3676990 & 26.5126514 \\
\hline $\mathrm{O}$ & 9.0582777 & 13.1778706 & 16.8292901 \\
\hline 0 & 6.9874483 & 14.4373085 & 28.0830238 \\
\hline $\mathrm{O}$ & 11.6826398 & 17.4604975 & 21.8519445 \\
\hline $\mathrm{O}$ & 13.7441747 & 13.8599033 & 21.6606970 \\
\hline 0 & 16.1956185 & 17.2612115 & 21.7605512 \\
\hline $\mathrm{O}$ & 15.8330376 & 14.8779888 & 18.1601229 \\
\hline 0 & 11.7445745 & 15.0383950 & 18.2685133 \\
\hline 0 & 14.0574139 & 18.5268947 & 18.2456231 \\
\hline $\mathrm{O}$ & 6.7611113 & 17.7685434 & 26.9012183 \\
\hline $\mathrm{H}$ & 8.9283092 & 19.0469783 & 23.3346202 \\
\hline $\mathrm{H}$ & 4.4130135 & 18.5551835 & 23.5858861 \\
\hline $\mathrm{H}$ & 18.2633570 & 15.9138497 & 17.6250354 \\
\hline $\mathrm{H}$ & 11.9593808 & 20.0580625 & 17.6878907 \\
\hline 0 & 11.4395477 & 12.3845583 & 17.1738920 \\
\hline $\mathrm{O}$ & 4.8458862 & 16.2872185 & 27.6596287 \\
\hline $\mathrm{H}$ & 11.6373698 & 19.8534378 & 22.5358604 \\
\hline 0 & 11.7027498 & 11.9331402 & 22.7697641 \\
\hline $\mathrm{H}$ & 18.3624762 & 16.2060142 & 22.4472517 \\
\hline $\mathrm{O}$ & 8.9035043 & 15.9558388 & 27.4275693 \\
\hline $\mathrm{H}$ & 16.1550121 & 12.4938511 & 17.5464167 \\
\hline & & & \\
\hline
\end{tabular}




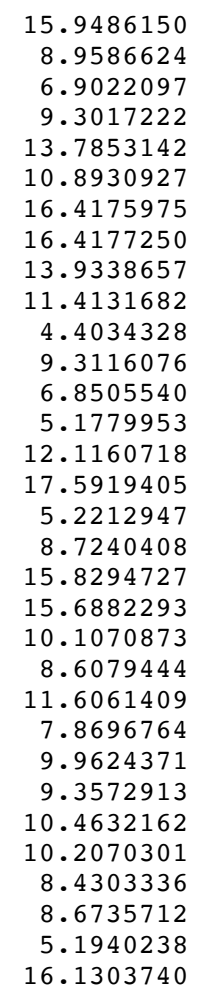

20.0117483

16.7845831

15.0315423

13.5472560

18.7905360

14.7119226

14.7846915

17.6998816

13.2439414

17.4989739

18.4971786

18.5042971

17.7817853

15.1342153

19.3079986

15.9306919

16.6775898

15.1004413

13.0395343

19.4588481

16.2707472

17.0580461

12.6973851

10.4366433

11.3789548

12.2418860

10.8248456

11.1922662

10.2496749

9.2846055

15.0968759

19.8650233

9.0455737

9.3337520

9.3063729

6.7230151

6.7644448

8.0868277

8.1935718

9.2921000

9.3899841

6.8123746

6.7491550

10.8309872

10.7940941

9.7500869

10.7658815

5.3574275

5.3867914

6.4292286

.3237364

7.1624059

10.3070773

7.9319115

8.3297599

7.9375290

11.7040044

8.2061318

12.2313869

10.6917514

9.0926961

6.7634194

5.6575744

5.5748567

10.9085313

6.7680902

9.5750564

9.0558355

7.1903619

8.1486905

9.0736502

7.1748594

11.2507077

9.0180563

11.9873123

16.0771877

16.1241326
17.5813496

22.3154199

16.9969735

27.8637916

21.9967352

22.0646695

22.0763887

18.2612418

18.2345898

18.0048980

26.7306870

26.9062105

23.1318185

15.2141379

20.1842103

20.1479606

25.2260069

29.7236952

19.9123177

19.9508093

19.7731829

24.7941448

19.9548344

19.3172548

20.0406420

19.7849173

19.2566748

21.0835237

20.1003188

20.0423118

29.9378500

22.4874679

15.3503175

16.7316415

28.5512074

21.6844773

18.5303369

26.6922318

23.5632906

28.5996899

16.7896520

18.5990934

21.7749097

23.6154628

26.7681924

17.0946372

28.2428804

21.9099036

22.0197568

18.2769056

26.9363003

23. 3420021

23.4047203

17.6362310

27.7522825

22.6541067

27.6926381

17.6555218

22.6594065

17.2225001

28.1451243

22.1229007

18.2060330

18.1853212

27.1645700

27.0311054

23. 2194687

15.2781578

19.9973149

25.0318113

30.0633807

20.3083671

25.3149586

30.0008826

15.3317657

21.6785941

18.5196628 


\begin{tabular}{|c|c|c|c|}
\hline Al & 3.8326963 & 12.0026387 & 28.5911405 \\
\hline $\mathrm{P}$ & 3.8658823 & 12.0349973 & 16.7731686 \\
\hline Al & 1.6743234 & 13.3604099 & 18.6255564 \\
\hline $\mathrm{P}$ & 1.7025424 & 13.4267243 & 21.7107586 \\
\hline 0 & 4.9333707 & 13.1276295 & 17.0163542 \\
\hline $\mathrm{H}$ & 0.3454630 & 14.0356780 & 21.7788128 \\
\hline $\mathrm{H}$ & 2.3116391 & 17.1613261 & 21.9737733 \\
\hline $\mathrm{O}$ & 2.1654100 & 15.0256291 & 18.3139467 \\
\hline 0 & 4.4408210 & 15.8925489 & 17.6157791 \\
\hline 0 & 4.7525373 & 16.3415938 & 22.5914920 \\
\hline 0 & 2.6075283 & 12.3028258 & 17.5912510 \\
\hline 0 & 4.4685139 & 13.5596755 & 28.1327114 \\
\hline 0 & 2.7491983 & 14.4913084 & 22.1202847 \\
\hline $\mathrm{H}$ & 2.6298117 & 17.4396058 & 18.1513360 \\
\hline $\mathrm{H}$ & 0.2373722 & 13.1996598 & 18.2699565 \\
\hline 0 & 3.7073974 & 16.1471973 & 19.9788346 \\
\hline $\mathrm{H}$ & 3.5351481 & 11.9882745 & 30.0500371 \\
\hline 0 & 2.0359497 & 12.9260474 & 20.2774443 \\
\hline Al & 10.1552296 & 12.1088802 & 16.5991602 \\
\hline$P$ & 10.0604844 & 12.0488550 & 28.4201280 \\
\hline Al & 12.2928125 & 10.6890246 & 26.7216618 \\
\hline $\mathrm{P}$ & 12.3391811 & 10.6464613 & 23.5281075 \\
\hline Al & 15.4442386 & 10.8309872 & 23.6154628 \\
\hline Al & 10.6147159 & 8.0429803 & 23.6691657 \\
\hline$P$ & 10.7086428 & 8.0086326 & 26.7908714 \\
\hline$P$ & 15.4322739 & 10.7940941 & 26.7681924 \\
\hline 0 & 9.0489824 & 10.9148989 & 28.1485628 \\
\hline 0 & 11.7777946 & 9.0600582 & 27.1482466 \\
\hline $\mathrm{H}$ & 15.8523365 & 9.3748206 & 26.9304598 \\
\hline $\mathrm{H}$ & 11.5121605 & 6.8624314 & 23.5349346 \\
\hline 0 & 13.8204135 & 10.2135087 & 23.3670824 \\
\hline 0 & 11.3242698 & 11.8601790 & 27.5796112 \\
\hline 0 & 9.5224146 & 8.1050066 & 27.7600592 \\
\hline $\mathrm{H}$ & 16.2265150 & 11.6775995 & 27.6658115 \\
\hline 0 & 9.1978362 & 7.7962016 & 22.6697928 \\
\hline 0 & 15.7731418 & 12.2313869 & 22.6594065 \\
\hline 0 & 9.4567703 & 10.6001737 & 17.1593259 \\
\hline $\mathrm{O}$ & 13.9595451 & 10.9118929 & 27.1762134 \\
\hline $\mathrm{H}$ & 11.3026261 & 6.6499321 & 26.9259181 \\
\hline $\mathrm{H}$ & 16.4295650 & 9.7662989 & 23.2797674 \\
\hline 0 & 11.4582151 & 9.4431761 & 23.0571108 \\
\hline $\mathrm{H}$ & 10.4084617 & 12.0540062 & 15.1328782 \\
\hline 0 & 12.0517520 & 10.9108945 & 25.0193011 \\
\hline 0 & 15.6396678 & 11.2507077 & 25.3149586 \\
\hline 0 & 10.1839793 & 8.2369728 & 25.3561293 \\
\hline $\mathrm{H}$ & 10.4391178 & 12.0449497 & 29.8601774 \\
\hline $\mathrm{H}$ & 8.7128107 & 15.1205440 & 15.2360596 \\
\hline Al & 5.3962272 & 14.7873809 & 16.6761908 \\
\hline $\mathrm{P}$ & 5.3369276 & 14.7638700 & 28.5113152 \\
\hline Al & 12.2624225 & 18.7391164 & 21.6844773 \\
\hline $\mathrm{Zn}$ & 12.3855103 & 13.3978257 & 21.6544417 \\
\hline Al & 17.1636914 & 16.0771877 & 21.6785941 \\
\hline $\mathrm{P}$ & 17.0972514 & 16.1241326 & 18.5196628 \\
\hline $\mathrm{P}$ & 12.3655695 & 13.2651541 & 18.4738898 \\
\hline $\mathrm{P}$ & 12.3275100 & 18.7805461 & 18.5303369 \\
\hline Al & 5.4212647 & 17.2687941 & 26.6580201 \\
\hline$P$ & 5.4056076 & 17.3194111 & 23.5707143 \\
\hline Al & 8.4974635 & 14.7837170 & 28.5050364 \\
\hline$P$ & 8.5473219 & 14.8079229 & 16.6824350 \\
\hline Al & 15.5493221 & 13.3604099 & 18.6255564 \\
\hline Al & 15.4895257 & 18.8284759 & 18.5990934 \\
\hline Al & 10.7706789 & 16.0104142 & 18.5698277 \\
\hline$P$ & 10.5701850 & 16.0309116 & 21.7061128 \\
\hline$P$ & 15.4419942 & 18.7652564 & 21.7749097 \\
\hline$P$ & 15.5775412 & 13.4267243 & 21.7107586 \\
\hline Al & 8.5535186 & 17.5135332 & 23.5616332 \\
\hline$P$ & 8.5664055 & 17.3585275 & 26.7116976 \\
\hline 0 & 8.9539373 & 13.3436445 & 16.9658400 \\
\hline 0 & 6.8085549 & 14.4225584 & 28.2073723 \\
\hline 0 & 11.6232365 & 17.1493924 & 21.9469032 \\
\hline 0 & 14.1917272 & 14.0485718 & 21.7802538 \\
\hline 0 & 16.0083871 & 17.3591131 & 22.0276250 \\
\hline 0 & 16.0404088 & 15.0256291 & 18.3139467 \\
\hline 0 & 11.9602384 & 14.7537957 & 18.3380536 \\
\hline 0 & 13.8109965 & 18.4453300 & 18.2769056 \\
\hline 0 & 7.0882363 & 17.7051280 & 26.9965166 \\
\hline $\mathrm{H}$ & 9.0607393 & 18.9000603 & 23.3682670 \\
\hline $\mathrm{H}$ & 4.7392718 & 18.6498084 & 23.5144991 \\
\hline $\mathrm{H}$ & 18.2794727 & 15.8994565 & 17.6427398 \\
\hline $\mathrm{H}$ & 11.9016177 & 19.9133034 & 17.6628132 \\
\hline
\end{tabular}




\begin{tabular}{|c|c|c|}
\hline 11.6665210 & 12.4370806 & 17.3727373 \\
\hline 4.8824471 & 15.9663877 & 27.6795985 \\
\hline 11.5723638 & 19.7702514 & 22.5077028 \\
\hline 11.9560968 & 11.8285514 & 22.6855181 \\
\hline 18.4125553 & 16.3027630 & 22.4574235 \\
\hline 9.0035954 & 16.1597555 & 27.5633309 \\
\hline 16.3437816 & 12.4600634 & 17.7450277 \\
\hline 9.4043911 & 15.7755364 & 17.4971564 \\
\hline 15.8917241 & 20.0156549 & 17.7953750 \\
\hline 9.2843922 & 16.3849284 & 22.4822434 \\
\hline 7.0797011 & 14.9789887 & 17.1116295 \\
\hline 9.4244033 & 13.3875583 & 28.0326272 \\
\hline 13.9528456 & 18.7795208 & 22.1229007 \\
\hline 11.0715641 & 14.6915379 & 22.1821961 \\
\hline 16.6241970 & 14.4913084 & 22.1202847 \\
\hline 16.4866805 & 17.4798621 & 18.1400645 \\
\hline 13.8763867 & 13.1732606 & 18.2115578 \\
\hline 11.4795477 & 17.5599446 & 18.1763264 \\
\hline 4.5282623 & 18.4372967 & 26.8909777 \\
\hline 9.4137415 & 18.5267639 & 27.0782572 \\
\hline 6.8643109 & 17.4953422 & 23.1550858 \\
\hline 5.1978535 & 15.0689377 & 15.2275728 \\
\hline 12.1204146 & 19.2064633 & 19.9973149 \\
\hline 11.9725464 & 12.6939285 & 19.8386194 \\
\hline 17.5823961 & 16.1471973 & 19.9788346 \\
\hline 5.3068473 & 16.7326012 & 24.9920163 \\
\hline 8.6851717 & 15.0787849 & 29.9523861 \\
\hline 15.9109484 & 12.9260474 & 20.2774443 \\
\hline 15.6624000 & 19.1909608 & 20.3083671 \\
\hline 10.1793937 & 16.0282842 & 20.2055704 \\
\hline 8.7612555 & 17.0049275 & 25.2269850 \\
\hline 11.3338728 & 11.0344051 & 20.0907969 \\
\hline 8.7418281 & 10.8132656 & 20.5113306 \\
\hline 8.6433746 & 9.8669660 & 21.0365940 \\
\hline 9.1321165 & 11.6730320 & 21.0512452 \\
\hline 8.8309847 & 10.7832103 & 19.4314217 \\
\hline 10.8884687 & 10.1615637 & 20.2633551 \\
\hline 11.1352060 & 9.9347194 & 21.1881431 \\
\hline 6.6300495 & 12.6101109 & 22.5746250 \\
\hline 6.8404284 & 13.7702603 & 21.8127012 \\
\hline 6.9565924 & 13.7116233 & 20.4168598 \\
\hline 6.8852521 & 12.4839619 & 19.7751160 \\
\hline 6.7642788 & 11.2843830 & 20.5367128 \\
\hline 6.5636702 & 11.3763060 & 21.9455392 \\
\hline 6.5117247 & 12.6849956 & 23.6564579 \\
\hline 6.3889132 & 10.4633479 & 22.5197753 \\
\hline 6.9061455 & 14.7389009 & 22.3084025 \\
\hline 7.1004191 & 14.6277679 & 19.8424380 \\
\hline 6.9711842 & 12.4165960 & 18.6895738 \\
\hline 6.4652516 & 10.3666407 & 20.0223906 \\
\hline 5.1693754 & 15.1059944 & 29.9507587 \\
\hline 16.1114934 & 19.7762978 & 22.6390201 \\
\hline 8.7154611 & 9.0357701 & 15.2476815 \\
\hline 5.4107678 & 9.3980705 & 16.7941533 \\
\hline 5.3633852 & 9.3402619 & 28.6111248 \\
\hline 5.4245270 & 6.8034564 & 21.7380359 \\
\hline 5.4664926 & 6.7995302 & 18.5785351 \\
\hline 3.2131998 & 7.9985349 & 26.7481616 \\
\hline 3.2672765 & 8.0558833 & 23.6234922 \\
\hline 8.5078545 & 9.2706828 & 28.5214532 \\
\hline 8.5685512 & 9.3308435 & 16.6997386 \\
\hline 8.6247653 & 6.7820081 & 18.5482956 \\
\hline 8.5888537 & 6.7254329 & 21.7103112 \\
\hline 1.6550604 & 10.7847312 & 23.5532554 \\
\hline 1.6414499 & 10.7742522 & 26.6849808 \\
\hline 6.8945310 & 9.7520696 & 17.0528623 \\
\hline 4.8970316 & 10.9887209 & 28.2283638 \\
\hline 4.9078906 & 5.4236390 & 21.9532368 \\
\hline 9.0893868 & 5.3459645 & 21.9626091 \\
\hline 7.1527434 & 6.4133321 & 18.2823293 \\
\hline 2.1629297 & 9.1135269 & 26.8998319 \\
\hline 2.2313774 & 7.0169654 & 23.3691634 \\
\hline 0.2559087 & 10.3161235 & 23.3535004 \\
\hline 4.9966368 & 8.1938132 & 17.6407626 \\
\hline 4.3775481 & 8.2153075 & 27.7222270 \\
\hline 4.6751126 & 7.8211166 & 22.6144650 \\
\hline 2.5783806 & 11.8421748 & 27.6942063 \\
\hline
\end{tabular}




\begin{tabular}{|c|c|c|c|}
\hline 0 & 9.0440444 & 7.9684258 & 17.6719309 \\
\hline 0 & 2.0149125 & 11.9369739 & 22.6180409 \\
\hline 0 & 4.5567327 & 10.5995826 & 17.2174542 \\
\hline 0 & 7.0282660 & 9.1061920 & 28.1625088 \\
\hline 0 & 6.9075176 & 6.8605395 & 22.1352710 \\
\hline $\mathrm{H}$ & 9.4863204 & 5.6191646 & 18.1980983 \\
\hline $\mathrm{H}$ & 4.6325769 & 5.6349174 & 18.1718631 \\
\hline $\mathrm{H}$ & 0.2174441 & 10.8613832 & 27.1112864 \\
\hline $\mathrm{H}$ & 2.5785391 & 6.6942190 & 27.0844449 \\
\hline 0 & 2.6135117 & 9.6220164 & 23.2500627 \\
\hline $\mathrm{H}$ & 5.1926212 & 9.0722197 & 15.3577154 \\
\hline 0 & 5.2624324 & 7.2320898 & 20.2645304 \\
\hline 0 & 3.7652251 & 7.9803253 & 25.3084566 \\
\hline $\mathrm{H}$ & 8.7329354 & 8.9946886 & 29.9672355 \\
\hline $\mathrm{O}$ & 8.8115474 & 7.1751812 & 20.0286155 \\
\hline 0 & 1.8452903 & 11.2527011 & 25.0148606 \\
\hline $\mathrm{H}$ & 5.2121975 & 9.1033933 & 30.0733684 \\
\hline $\mathrm{H}$ & 3.5185438 & 12.0588155 & 15.2473453 \\
\hline$P$ & 3.2394301 & 15.9775524 & 21.7467529 \\
\hline Al & 3.2301852 & 16.0359541 & 18.5831925 \\
\hline $\mathrm{P}$ & 3.8410444 & 12.0754784 & 28.5245314 \\
\hline Al & 3.8347306 & 12.1066737 & 16.7015998 \\
\hline $\mathrm{P}$ & 1.6100845 & 13.3384649 & 18.5190348 \\
\hline Al & 1.5405550 & 13.3232424 & 21.6458245 \\
\hline 0 & 5.0278575 & 13.3624653 & 17.0169536 \\
\hline $\mathrm{H}$ & 0.1066180 & 13.7023272 & 21.7771256 \\
\hline $\mathrm{H}$ & 2.2742312 & 17.0835067 & 21.9965064 \\
\hline 0 & 2.0482931 & 14.7970051 & 18.2406898 \\
\hline 0 & 4.6717834 & 15.7914731 & 17.6243600 \\
\hline 0 & 4.4959182 & 16.1753539 & 22.6108711 \\
\hline 0 & 2.3650010 & 12.3862297 & 17.5749376 \\
\hline 0 & 4.4206383 & 13.4413733 & 28.1398202 \\
\hline 0 & 2.6086740 & 14.6443781 & 22.1275736 \\
\hline $\mathrm{H}$ & 2.6690652 & 17.3733844 & 18.2462279 \\
\hline $\mathrm{H}$ & 0.1554517 & 13.2209786 & 18.2234656 \\
\hline $\mathrm{O}$ & 3.6832380 & 15.9903325 & 20.2716795 \\
\hline $\mathrm{H}$ & 3.4757750 & 12.0513465 & 29.9678320 \\
\hline 0 & 1.9509453 & 12.9440178 & 19.9636615 \\
\hline $\mathrm{P}$ & 10.1358793 & 12.0436469 & 16.6965244 \\
\hline Al & 10.0926152 & 11.9933022 & 28.5064310 \\
\hline$P$ & 12.3736910 & 10.7210816 & 26.8115542 \\
\hline Al & 12.3947278 & 10.7602983 & 23.6056903 \\
\hline $\mathrm{P}$ & 15.5300591 & 10.7847312 & 23.5532554 \\
\hline$P$ & 10.6906720 & 8.1074452 & 23.5626318 \\
\hline Al & 10.7287762 & 8.0815981 & 26.7129478 \\
\hline Al & 15.5164486 & 10.7742522 & 26.6849808 \\
\hline 0 & 8.9431203 & 10.7079806 & 28.1712780 \\
\hline 0 & 11.9191292 & 9.2855589 & 27.1609501 \\
\hline $\mathrm{H}$ & 15.9591707 & 9.3643419 & 26.8673835 \\
\hline $\mathrm{H}$ & 11.6125440 & 6.9476490 & 23.4138193 \\
\hline 0 & 14.0814237 & 10.2995503 & 23.3464357 \\
\hline 0 & 11.5715931 & 11.7433331 & 27.6281850 \\
\hline 0 & 9.3053339 & 8.2492365 & 27.7042046 \\
\hline $\mathrm{H}$ & 16.3170044 & 11.6867334 & 27.5473085 \\
\hline $\mathrm{O}$ & 9.4419879 & 7.9097031 & 22.6854957 \\
\hline $\mathrm{O}$ & 15.8899113 & 11.9369739 & 22.6180409 \\
\hline 0 & 9.5467284 & 10.7001728 & 17.1652657 \\
\hline $\mathrm{O}$ & 13.8510917 & 10.8761508 & 27.1835398 \\
\hline $\mathrm{H}$ & 11.3042617 & 6.7284686 & 26.9474211 \\
\hline $\mathrm{H}$ & 16.4585602 & 9.6583495 & 23.2595370 \\
\hline 0 & 11.4081183 & 9.3749346 & 23.0707322 \\
\hline $\mathrm{H}$ & 10.4287324 & 11.9952083 & 15.2374112 \\
\hline $\mathrm{O}$ & 12.1442476 & 10.9879583 & 25.3230534 \\
\hline 0 & 15.7202890 & 11.2527011 & 25.0148606 \\
\hline 0 & 10.2579619 & 8.2663972 & 25.0292987 \\
\hline $\mathrm{H}$ & 10.3875166 & 11.9937292 & 29.9659356 \\
\hline $\mathrm{H}$ & 8.7855462 & 15.0500004 & 15.1696074 \\
\hline $\mathrm{P}$ & 5.4625687 & 14.8190759 & 16.7454192 \\
\hline Al & 5.4122475 & 14.8000499 & 28.5870402 \\
\hline $\mathrm{P}$ & 12.3620264 & 18.8195577 & 21.7380359 \\
\hline $\mathrm{Si}$ & 12.2171445 & 13.3097634 & 21.7038140 \\
\hline $\mathrm{P}$ & 17.1144288 & 15.9775524 & 21.7467529 \\
\hline Al & 17.1051839 & 16.0359541 & 18.5831925 \\
\hline Al & 12.2895514 & 13.3228413 & 18.6043472 \\
\hline Al & 12.4039920 & 18.8156316 & 18.5785351 \\
\hline $\mathrm{P}$ & 5.3569669 & 17.3115705 & 26.7283379 \\
\hline Al & 5.3362431 & 17.3201921 & 23.6127760 \\
\hline $\mathrm{P}$ & 8.5693262 & 14.7395900 & 28.4568536 \\
\hline Al & 8.6220975 & 14.7901515 & 16.6266193 \\
\hline $\mathrm{P}$ & 15.4850832 & 13.3384649 & 18.5190348 \\
\hline
\end{tabular}




\begin{tabular}{|c|c|c|c|}
\hline $\mathrm{P}$ & 15.5622647 & 18.7981095 & 18.5482956 \\
\hline $\mathrm{P}$ & 10.7595442 & 16.1336804 & 18.4985596 \\
\hline Al & 10.6741340 & 16.1025522 & 21.6290030 \\
\hline Al & 15.5263531 & 18.7415343 & 21.7103112 \\
\hline Al & 15.4155537 & 13.3232424 & 21.6458245 \\
\hline $\mathrm{P}$ & 8.4929489 & 17.4001637 & 23.4962709 \\
\hline Al & 8.5052893 & 17.3135729 & 26.6513241 \\
\hline $\mathrm{O}$ & 9.0822627 & 13.1358160 & 16.9994141 \\
\hline 0 & 7.0810140 & 14.4036126 & 28.2338957 \\
\hline 0 & 11.8312767 & 17.4020471 & 21.9591156 \\
\hline 0 & 13.7760663 & 13.7566678 & 21.7959472 \\
\hline $\mathrm{O}$ & 16.1128239 & 17.1252218 & 22.0059267 \\
\hline 0 & 15.9232918 & 14.7970051 & 18.2406898 \\
\hline 0 & 11.7886551 & 15.0001423 & 18.3652521 \\
\hline 0 & 14.0902427 & 18.4294335 & 18.2823293 \\
\hline 0 & 6.8250276 & 17.7051779 & 26.9871736 \\
\hline $\mathrm{H}$ & 8.9693890 & 18.8010477 & 23.3299904 \\
\hline $\mathrm{H}$ & 4.7943750 & 18.6961398 & 23.4388002 \\
\hline $\mathrm{H}$ & 18.3328134 & 15.8277601 & 17.7666745 \\
\hline $\mathrm{H}$ & 12.0030125 & 20.0055262 & 17.7782309 \\
\hline 0 & 11.4369013 & 12.3132703 & 17.4407323 \\
\hline 0 & 4.9149293 & 16.1938069 & 27.6761833 \\
\hline $\mathrm{H}$ & 11.6364786 & 19.8048085 & 22.5865533 \\
\hline 0 & 11.8654937 & 12.0948147 & 22.7133061 \\
\hline $\mathrm{H}$ & 18.3311058 & 16.1690867 & 22.5834920 \\
\hline 0 & 8.9913397 & 15.9300297 & 27.5921997 \\
\hline $\mathrm{H}$ & 16.2155583 & 12.4170594 & 17.6055039 \\
\hline 0 & 9.5835041 & 15.9148606 & 17.5314032 \\
\hline $\mathrm{H}$ & 15.9693963 & 19.9501541 & 17.6973211 \\
\hline 0 & 9.2230093 & 16.4482607 & 22.5571952 \\
\hline 0 & 6.9480710 & 14.9553325 & 17.1090615 \\
\hline 0 & 9.4059865 & 13.5258937 & 28.0407081 \\
\hline 0 & 13.8450169 & 18.8766409 & 22.1352710 \\
\hline 0 & 11.2601207 & 14.5679074 & 22.0242728 \\
\hline 0 & 16.4836727 & 14.6443781 & 22.1275736 \\
\hline $\mathrm{O}$ & 16.4477321 & 17.6029915 & 18.1883786 \\
\hline 0 & 13.9932697 & 13.2179756 & 18.2159108 \\
\hline 0 & 11.4325664 & 17.4589781 & 18.1048042 \\
\hline $\mathrm{H}$ & 4.4840286 & 18.4914059 & 26.9795106 \\
\hline $\mathrm{H}$ & 9.3544741 & 18.4765240 & 27.0302043 \\
\hline 0 & 7.0032940 & 17.3419074 & 23.1296162 \\
\hline $\mathrm{H}$ & 5.2374872 & 15.1642734 & 15.3145812 \\
\hline 0 & 12.1999317 & 19.2481911 & 20.2645304 \\
\hline 0 & 11.9015477 & 12.7386313 & 20.1796209 \\
\hline 0 & 17.5582368 & 15.9903325 & 20.2716795 \\
\hline 0 & 5.1896768 & 16.8125614 & 25.2801966 \\
\hline $\mathrm{H}$ & 8.8058838 & 15.0834188 & 29.8861691 \\
\hline 0 & 15.8259440 & 12.9440178 & 19.9636615 \\
\hline 0 & 15.7490467 & 19.1912826 & 20.0286155 \\
\hline 0 & 10.2014783 & 16.2300490 & 19.9266897 \\
\hline 0 & 8.6975237 & 16.9393780 & 24.9531800 \\
\hline $\mathrm{H}$ & 11.2860678 & 11.1145086 & 20.2508259 \\
\hline C & 8.6945898 & 10.8345326 & 20.5085842 \\
\hline $\mathrm{H}$ & 8.6066281 & 9.8873191 & 21.0328585 \\
\hline $\mathrm{H}$ & 9.0864176 & 11.6912296 & 21.0520845 \\
\hline $\mathrm{H}$ & 8.8082715 & 10.8047211 & 19.4305159 \\
\hline 0 & 10.8633726 & 10.2066899 & 20.2935823 \\
\hline $\mathrm{H}$ & 11.0638643 & 9.8832000 & 21.1984848 \\
\hline C & 6.6118291 & 12.6205282 & 22.5665880 \\
\hline C & 6.8196640 & 13.7800160 & 21.8025045 \\
\hline C & 6.9238131 & 13.7211258 & 20.4057278 \\
\hline C & 6.8494880 & 12.4932977 & 19.7653429 \\
\hline C & 6.7375141 & 11.2929635 & 20.5284625 \\
\hline $\mathrm{C}$ & 6.5390535 & 11.3870029 & 21.9384360 \\
\hline $\mathrm{H}$ & 6.5020787 & 12.6952237 & 23.6493179 \\
\hline $\mathrm{H}$ & 6.3702042 & 10.4733206 & 22.5132601 \\
\hline $\mathrm{H}$ & 6.8958892 & 14.7484503 & 22.2977925 \\
\hline $\mathrm{H}$ & 7.0566307 & 14.6373286 & 19.8288889 \\
\hline $\mathrm{H}$ & 6.9303698 & 12.4255522 & 18.6795302 \\
\hline $\mathrm{H}$ & 6.4306727 & 10.3764439 & 20.0162206 \\
\hline $\mathrm{H}$ & 5.2574070 & 15.1194020 & 30.0331243 \\
\hline $\mathrm{H}$ & 16.2500283 & 19.7460972 & 22.5375162 \\
\hline \multicolumn{4}{|c|}{ Mg 2} \\
\hline \multicolumn{4}{|c|}{177} \\
\hline $\mathrm{H}$ & 8.7493456 & 9.0401449 & 15.3542133 \\
\hline Al & 5.4458862 & 9.3484967 & 16.7352726 \\
\hline $\mathrm{P}$ & 5.4302853 & 9.3118507 & 28.5504944 \\
\hline Al & 5.3199389 & 6.7404055 & 21.6777311 \\
\hline $\mathrm{P}$ & 5.4053574 & 6.7657169 & 18.5185579 \\
\hline
\end{tabular}




\begin{tabular}{|c|c|c|c|}
\hline Al & 3.2123490 & 8.0726375 & 26.6952692 \\
\hline $\mathrm{P}$ & 3.3158036 & 8.1807684 & 23.5747500 \\
\hline Al & 8.5595703 & 9.2837808 & 28.6038321 \\
\hline $\mathrm{P}$ & 8.5931898 & 9.3974064 & 16.7912590 \\
\hline Al & 8.5683307 & 6.8232671 & 18.6054951 \\
\hline $\mathrm{P}$ & 8.5041867 & 6.7544796 & 21.7769896 \\
\hline Al & 1.5791463 & 10.8351427 & 23.6260102 \\
\hline $\mathrm{P}$ & 1.5551057 & 10.8006786 & 26.7652099 \\
\hline $\mathrm{O}$ & 7.1212673 & 9.7651973 & 17.0981066 \\
\hline 0 & 5.0369917 & 10.7683027 & 28.2256955 \\
\hline $\mathrm{H}$ & 4.7419708 & 5.3902171 & 21.9228122 \\
\hline $\mathrm{H}$ & 9.0543856 & 5.3919910 & 22.0178770 \\
\hline 0 & 6.8922610 & 6.4366021 & 18.2804725 \\
\hline $\mathrm{O}$ & 2.0154600 & 9.3336184 & 26.8820083 \\
\hline $\mathrm{H}$ & 2.2621438 & 7.1625734 & 23.3097962 \\
\hline $\mathrm{H}$ & 0.2111597 & 10.2883421 & 23.4098099 \\
\hline $\mathrm{O}$ & 4.9705416 & 7.9361786 & 17.6267518 \\
\hline 0 & 4.5608781 & 8.3277567 & 27.7657640 \\
\hline 0 & 4.5249625 & 7.9655133 & 22.6490146 \\
\hline $\mathrm{O}$ & 2.3751552 & 11.6982295 & 27.6987899 \\
\hline 0 & 9.0340267 & 8.2194995 & 17.6636813 \\
\hline 0 & 1.9639990 & 12.1942414 & 22.6297292 \\
\hline $\mathrm{O}$ & 4.4648070 & 10.6992278 & 17.2381773 \\
\hline $\mathrm{O}$ & 6.8909011 & 9.0912683 & 28.1437917 \\
\hline 0 & 7.0121976 & 6.7621673 & 22.1122301 \\
\hline $\mathrm{H}$ & 9.4266258 & 5.6705936 & 18.2158878 \\
\hline $\mathrm{H}$ & 4.5906453 & 5.5737385 & 18.1544806 \\
\hline $\mathrm{H}$ & 0.1318139 & 10.8810042 & 27.1952203 \\
\hline $\mathrm{H}$ & 2.5905787 & 6.7707540 & 27.0635376 \\
\hline $\mathrm{O}$ & 2.7531152 & 9.5758591 & 23.2937979 \\
\hline $\mathrm{H}$ & 5.2765371 & 9.0785997 & 15.2807633 \\
\hline $\mathrm{O}$ & 5.1811248 & 7.1854064 & 19.9849186 \\
\hline $\mathrm{O}$ & 3.7939676 & 8.0680967 & 25.0384550 \\
\hline $\mathrm{H}$ & 8.7249111 & 9.0673965 & 30.0677176 \\
\hline $\mathrm{O}$ & 8.7356627 & 7.1899011 & 20.3148019 \\
\hline $\mathrm{O}$ & 1.7230349 & 11.3019527 & 25.3210513 \\
\hline $\mathrm{H}$ & 5.2535356 & 9.0415722 & 30.0040520 \\
\hline $\mathrm{H}$ & 3.5106596 & 11.9762169 & 15.3306367 \\
\hline Al & 3.2814571 & 16.0721269 & 21.6836067 \\
\hline$P$ & 3.2314956 & 16.1290425 & 18.5183345 \\
\hline Al & 3.8355958 & 11.9997921 & 28.5893522 \\
\hline $\mathrm{P}$ & 3.8650661 & 12.0369479 & 16.7755686 \\
\hline Al & 1.6806892 & 13.3755240 & 18.6168425 \\
\hline$P$ & 1.7151240 & 13.4021348 & 21.7039752 \\
\hline $\mathrm{O}$ & 4.9253370 & 13.1358529 & 17.0221218 \\
\hline $\mathrm{H}$ & 0.3188135 & 13.9151703 & 21.7690315 \\
\hline $\mathrm{H}$ & 2.3119336 & 17.1646523 & 21.9726279 \\
\hline $\mathrm{O}$ & 2.1730736 & 15.0378083 & 18.2833838 \\
\hline $\mathrm{O}$ & 4.4587621 & 15.9044510 & 17.6236011 \\
\hline $\mathrm{O}$ & 4.7531404 & 16.3398340 & 22.5862750 \\
\hline 0 & 2.5958195 & 12.3049379 & 17.5766851 \\
\hline $\mathrm{O}$ & 4.4619498 & 13.5597602 & 28.1326407 \\
\hline $\mathrm{O}$ & 2.7141777 & 14.5025969 & 22.1433557 \\
\hline $\mathrm{H}$ & 2.6507570 & 17.4529009 & 18.1615961 \\
\hline $\mathrm{H}$ & 0.2389221 & 13.2303793 & 18.2742625 \\
\hline 0 & 3.6991043 & 16.1290275 & 19.9832447 \\
\hline $\mathrm{H}$ & 3.5488014 & 11.9780373 & 30.0503095 \\
\hline $\mathrm{O}$ & 2.0861239 & 12.9524171 & 20.2611559 \\
\hline Al & 10.1659717 & 12.1192556 & 16.5973450 \\
\hline $\mathrm{P}$ & 10.0637589 & 12.0452000 & 28.4190744 \\
\hline Al & 12.2993078 & 10.6587081 & 26.7501858 \\
\hline$P$ & 12.3575028 & 10.6182408 & 23.5483861 \\
\hline Al & 15.4541450 & 10.8351427 & 23.6260102 \\
\hline Al & 10.6099433 & 8.0425080 & 23.6771288 \\
\hline $\mathrm{P}$ & 10.6994865 & 7.9987724 & 26.7985807 \\
\hline$P$ & 15.4301044 & 10.8006786 & 26.7652099 \\
\hline $\mathrm{O}$ & 9.0545885 & 10.9064373 & 28.1601314 \\
\hline 0 & 11.7711202 & 9.0369663 & 27.1877904 \\
\hline $\mathrm{H}$ & 15.8746294 & 9.3840635 & 26.8779922 \\
\hline $\mathrm{H}$ & 11.4941537 & 6.8510985 & 23.5512881 \\
\hline $\mathrm{O}$ & 13.8386731 & 10.1894193 & 23.3706967 \\
\hline $\mathrm{O}$ & 11.3259083 & 11.8490280 & 27.5769203 \\
\hline 0 & 9.5076416 & 8.0870449 & 27.7617673 \\
\hline $\mathrm{H}$ & 16.2266912 & 11.6725493 & 27.6720789 \\
\hline $\mathrm{O}$ & 9.1880093 & 7.7990539 & 22.6832396 \\
\hline $\mathrm{O}$ & 15.8389977 & 12.1942414 & 22.6297292 \\
\hline 0 & 9.4693993 & 10.6070469 & 17.1505526 \\
\hline $\mathrm{O}$ & 13.9642574 & 10.8834059 & 27.2080773 \\
\hline $\mathrm{H}$ & 11.2839899 & 6.6337579 & 26.9090875 \\
\hline $\mathrm{H}$ & 16.4510957 & 9.7657416 & 23.3438910 \\
\hline
\end{tabular}




\begin{tabular}{|c|c|c|}
\hline 11.4689230 & 9.4305432 & 23.0500533 \\
\hline 10.4176975 & 12.0670197 & 15.1307073 \\
\hline 12.0720874 & 10.8454138 & 25.0440325 \\
\hline 15.5980336 & 11.3019527 & 25.3210513 \\
\hline 10.1872885 & 8.2578324 & 25.3641330 \\
\hline 10.4479487 & 12.0578811 & 29.8576007 \\
\hline 8.7120124 & 15.1136750 & 15.2219056 \\
\hline 5.3991079 & 14.7913399 & 16.6772686 \\
\hline 5.3337906 & 14.7612259 & 28.5106387 \\
\hline 12.2574382 & 18.7565069 & 21.6777311 \\
\hline 12.3441505 & 13.3584404 & 21.6694183 \\
\hline 17.1564558 & 16.0721269 & 21.6836067 \\
\hline 17.1064943 & 16.1290425 & 18.5183345 \\
\hline 12.3645613 & 13.2685370 & 18.4924706 \\
\hline 12.3428567 & 18.7818183 & 18.5185579 \\
\hline 5.4155626 & 17.2606182 & 26.6524133 \\
\hline 5.4013580 & 17.3150315 & 23.5717068 \\
\hline 8.4937109 & 14.7753378 & 28.4923151 \\
\hline 8.5510099 & 14.8111532 & 16.6709327 \\
\hline 15.5556879 & 13.3755240 & 18.6168425 \\
\hline 15.5058300 & 18.8393684 & 18.6054951 \\
\hline 10.7582588 & 16.0347165 & 18.5635937 \\
\hline 10.5407956 & 16.0706532 & 21.6766013 \\
\hline 15.4416860 & 18.7705809 & 21.7769896 \\
\hline 15.5901227 & 13.4021348 & 21.7039752 \\
\hline 8.5489081 & 17.5247912 & 23.5567973 \\
\hline 8.5586941 & 17.3663527 & 26.7185243 \\
\hline 8.9611468 & 13.3499031 & 16.9644773 \\
\hline 6.8036012 & 14.4154026 & 28.2023742 \\
\hline 11.5853688 & 17.1864887 & 21.9627149 \\
\hline 14.1715653 & 13.9233443 & 21.7700680 \\
\hline 16.0094081 & 17.3646988 & 22.0255490 \\
\hline 16.0480723 & 15.0378083 & 18.2833838 \\
\hline 11.9294957 & 14.7523438 & 18.3872501 \\
\hline 13.8297603 & 18.4527034 & 18.2804725 \\
\hline 7.0780247 & 17.7036363 & 27.0009754 \\
\hline 9.0714784 & 18.9019348 & 23.3388151 \\
\hline 4.7188854 & 18.6378181 & 23.5318639 \\
\hline 18.2967435 & 15.9112253 & 17.6505885 \\
\hline 11.9209046 & 19.9176529 & 17.6531351 \\
\hline 11.6719163 & 12.4497377 & 17.3796386 \\
\hline 4.8783490 & 15.9637894 & 27.6803238 \\
\hline 11.5825423 & 19.7965632 & 22.5023031 \\
\hline 11.9962665 & 11.8306642 & 22.7428214 \\
\hline 18.4107325 & 16.3002865 & 22.4529270 \\
\hline 8.9947380 & 16.1513033 & 27.5477788 \\
\hline 16.3339462 & 12.4650608 & 17.7322570 \\
\hline 9.4091827 & 15.7878873 & 17.4729303 \\
\hline 15.9026639 & 20.0291412 & 17.8029465 \\
\hline 9.2659250 & 16.3682144 & 22.4950173 \\
\hline 7.0847021 & 14.9797085 & 17.1046789 \\
\hline 9.4233651 & 13.3790901 & 28.0201268 \\
\hline 13.9496970 & 18.7782686 & 22.1122301 \\
\hline 11.0836208 & 14.7223494 & 22.0519827 \\
\hline 16.5891764 & 14.5025969 & 22.1433557 \\
\hline 16.5078964 & 17.4936131 & 18.1506254 \\
\hline 13.8757819 & 13.2064056 & 18.2176780 \\
\hline 11.5070736 & 17.5590114 & 18.1450644 \\
\hline 4.5111762 & 18.4223392 & 26.8751467 \\
\hline 9.3976600 & 18.5308369 & 27.1150509 \\
\hline 6.8572214 & 17.5134573 & 23.1558814 \\
\hline 5.1994079 & 15.0672838 & 15.2277530 \\
\hline 12.1186242 & 19.2015078 & 19.9849186 \\
\hline 12.0021002 & 12.6830753 & 19.8548502 \\
\hline 17.5741030 & 16.1290275 & 19.9832447 \\
\hline 5.3143242 & 16.7147747 & 24.9886170 \\
\hline 8.6838617 & 15.0714886 & 29.9391247 \\
\hline 15.9611226 & 12.9524171 & 20.2611559 \\
\hline 15.6731620 & 19.2060025 & 20.3148019 \\
\hline 10.1243470 & 16.1430170 & 20.1826570 \\
\hline 8.7635792 & 17.0426022 & 25.2287510 \\
\hline 11.3301255 & 11.0242547 & 20.0898708 \\
\hline 8.7327262 & 10.8114425 & 20.5101963 \\
\hline 8.6274606 & 9.8638902 & 21.0311811 \\
\hline 9.1120012 & 11.6714685 & 21.0564738 \\
\hline 8.8233245 & 10.7886760 & 19.4304717 \\
\hline 10.8715397 & 10.1613201 & 20.2761322 \\
\hline 11.1268834 & 9.9300979 & 21.1981679 \\
\hline 6.6179539 & 12.6119891 & 22.5686078 \\
\hline 6.8389553 & 13.7699825 & 21.8062118 \\
\hline
\end{tabular}




\begin{tabular}{|c|c|c|c|}
\hline $\mathrm{C}$ & 6.9573131 & 13.7092709 & 20.4107784 \\
\hline C & 6.8771675 & 12.4815094 & 19.7697432 \\
\hline $\mathrm{C}$ & 6.7446295 & 11.2844759 & 20.5322917 \\
\hline $\mathrm{C}$ & 6.5433375 & 11.3780130 & 21.9404731 \\
\hline $\mathrm{H}$ & 6.4983239 & 12.6881804 & 23.6502631 \\
\hline $\mathrm{H}$ & 6.3607160 & 10.4669023 & 22.5152428 \\
\hline $\mathrm{H}$ & 6.9140985 & 14.7379875 & 22.3014946 \\
\hline $\mathrm{H}$ & 7.1100818 & 14.6237172 & 19.8359250 \\
\hline $\mathrm{H}$ & 6.9655361 & 12.4126792 & 18.6845090 \\
\hline $\mathrm{H}$ & 6.4474404 & 10.3661950 & 20.0183483 \\
\hline $\mathrm{H}$ & 5.1705099 & 15.1034632 & 29.9505462 \\
\hline $\mathrm{H}$ & 16.1016894 & 19.7787702 & 22.6516727 \\
\hline \multicolumn{4}{|c|}{$\begin{array}{l}\text { Al } 2 \\
177\end{array}$} \\
\hline $\mathrm{H}$ & 8.6839515 & 8.8785445 & 15.3247197 \\
\hline $\mathrm{Si}$ & 5.3594393 & 9.2757221 & 16.7547210 \\
\hline $\mathrm{Si}$ & 5.3393417 & 9.2297182 & 28.6930196 \\
\hline $\mathrm{Si}$ & 5.3245736 & 6.7743114 & 21.7296099 \\
\hline $\mathrm{Si}$ & 5.3767523 & 6.7948695 & 18.6432580 \\
\hline $\mathrm{Si}$ & 3.2410660 & 7.9935057 & 26.7500987 \\
\hline $\mathrm{Si}$ & 3.3229141 & 8.0670661 & 23.6889009 \\
\hline $\mathrm{Si}$ & 8.4553696 & 9.1846314 & 28.6859652 \\
\hline $\mathrm{Si}$ & 8.4873046 & 9.2715713 & 16.7473864 \\
\hline $\mathrm{Si}$ & 8.4951095 & 6.7986445 & 18.6577072 \\
\hline $\mathrm{Si}$ & 8.4616238 & 6.7203355 & 21.7697481 \\
\hline $\mathrm{Si}$ & 1.6617721 & 10.7334008 & 23.6760809 \\
\hline $\mathrm{Si}$ & 1.6449543 & 10.7180908 & 26.7457359 \\
\hline 0 & 6.9248252 & 9.6774274 & 17.0092298 \\
\hline 0 & 4.9258701 & 10.7784941 & 28.3930136 \\
\hline $\mathrm{H}$ & 4.7565042 & 5.4078421 & 21.8944712 \\
\hline $\mathrm{H}$ & 8.9902685 & 5.3446270 & 21.9820719 \\
\hline 0 & 6.9388181 & 6.4001457 & 18.3892852 \\
\hline 0 & 2.1242394 & 9.1670928 & 26.8865571 \\
\hline $\mathrm{H}$ & 2.2829792 & 7.0274799 & 23.4545583 \\
\hline $\mathrm{H}$ & 0.2736701 & 10.2221414 & 23.5060595 \\
\hline 0 & 4.9382097 & 8.0233382 & 17.6822089 \\
\hline 0 & 4.4533856 & 8.2155865 & 27.7996718 \\
\hline $\mathrm{O}$ & 4.5925924 & 7.8564854 & 22.6976661 \\
\hline $\mathrm{O}$ & 2.4851070 & 11.6674345 & 27.7531522 \\
\hline $\mathrm{O}$ & 8.9179928 & 8.0595307 & 17.7292438 \\
\hline 0 & 2.0191952 & 11.9379131 & 22.6690965 \\
\hline 0 & 4.4558536 & 10.5474722 & 17.1883850 \\
\hline 0 & 6.8935039 & 9.0195730 & 28.2984752 \\
\hline 0 & 6.8918245 & 6.7549957 & 22.1449902 \\
\hline $\mathrm{H}$ & 9.3625406 & 5.6435478 & 18.2965488 \\
\hline $\mathrm{H}$ & 4.5274138 & 5.6186587 & 18.3081865 \\
\hline $\mathrm{H}$ & 0.2130937 & 10.7966877 & 27.1466330 \\
\hline $\mathrm{H}$ & 2.6009978 & 6.6915819 & 27.0854013 \\
\hline 0 & 2.7028136 & 9.5237297 & 23.3696723 \\
\hline $\mathrm{H}$ & 5.1301239 & 8.9138365 & 15.3286867 \\
\hline $\mathrm{O}$ & 5.1751350 & 7.2905068 & 20.1857605 \\
\hline $\mathrm{O}$ & 3.8477827 & 7.9807857 & 25.2344750 \\
\hline $\mathrm{H}$ & 8.6803912 & 8.8725071 & 30.1243894 \\
\hline 0 & 8.6922298 & 7.2074048 & 20.2273485 \\
\hline 0 & 1.8639042 & 11.2435802 & 25.2201985 \\
\hline $\mathrm{H}$ & 5.1289330 & 8.9107388 & 30.1321515 \\
\hline $\mathrm{H}$ & 3.3936295 & 11.9084496 & 15.2973832 \\
\hline $\mathrm{Si}$ & 3.3068595 & 15.8289433 & 21.7244388 \\
\hline $\mathrm{Si}$ & 3.2661228 & 15.9010977 & 18.6290560 \\
\hline $\mathrm{Si}$ & 3.7923889 & 11.9210781 & 28.6662381 \\
\hline $\mathrm{Si}$ & 3.7952462 & 11.9576244 & 16.7303544 \\
\hline $\mathrm{Si}$ & 1.6770830 & 13.2002081 & 18.6405365 \\
\hline $\mathrm{Si}$ & 1.6597762 & 13.1952285 & 21.6944652 \\
\hline 0 & 4.9228767 & 13.1173278 & 16.9688378 \\
\hline $\mathrm{H}$ & 0.2507638 & 13.6635336 & 21.8062454 \\
\hline $\mathrm{H}$ & 2.3208331 & 16.9158433 & 21.9764723 \\
\hline 0 & 2.1463654 & 14.7491826 & 18.3983748 \\
\hline 0 & 4.5429780 & 15.6777993 & 17.6536805 \\
\hline 0 & 4.6172511 & 16.0469063 & 22.6571487 \\
\hline 0 & 2.4820571 & 12.2217227 & 17.6227552 \\
\hline 0 & 4.4070998 & 13.3634722 & 28.2655829 \\
\hline 0 & 2.6950051 & 14.3931378 & 22.1074965 \\
\hline $\mathrm{H}$ & 2.6763096 & 17.2269727 & 18.2954447 \\
\hline $\mathrm{H}$ & 0.2297945 & 13.1027731 & 18.3044070 \\
\hline 0 & 3.7952578 & 15.8851150 & 20.1692198 \\
\hline $\mathrm{H}$ & 3.3934298 & 11.9053753 & 30.1007086 \\
\hline $\mathrm{O}$ & 2.0221091 & 12.7286025 & 20.1564337 \\
\hline $\mathrm{Si}$ & 10.0587004 & 11.9676146 & 16.6529927 \\
\hline & & & \\
\hline
\end{tabular}




\begin{tabular}{|c|c|c|c|}
\hline $\mathrm{Si}$ & 12.1539900 & 10.6287764 & 26.7912725 \\
\hline $\mathrm{Si}$ & 12.1943698 & 10.6196807 & 23.6531801 \\
\hline $\mathrm{Si}$ & 15.2867708 & 10.7334008 & 23.6760809 \\
\hline $\mathrm{Si}$ & 10.4828157 & 8.0224071 & 23.7079148 \\
\hline $\mathrm{Si}$ & 10.5498292 & 7.9986559 & 26.7772796 \\
\hline $\mathrm{Si}$ & 15.2699530 & 10.7180908 & 26.7457359 \\
\hline 0 & 8.9020599 & 10.7149504 & 28.3505913 \\
\hline 0 & 11.6906858 & 9.1014012 & 27.1435377 \\
\hline $\mathrm{H}$ & 15.7079236 & 9.3007894 & 26.8744183 \\
\hline $\mathrm{H}$ & 11.3865022 & 6.8432920 & 23.6071244 \\
\hline 0 & 13.7659362 & 10.1732539 & 23.4898018 \\
\hline 0 & 11.3002275 & 11.6913548 & 27.6692671 \\
\hline 0 & 9.2972584 & 8.1243232 & 27.7980501 \\
\hline $\mathrm{H}$ & 16.0425211 & 11.5910661 & 27.6721123 \\
\hline 0 & 9.1944006 & 7.8092537 & 22.7377614 \\
\hline 0 & 15.6441940 & 11.9379131 & 22.6690965 \\
\hline 0 & 9.3981795 & 10.5579663 & 17.1301042 \\
\hline 0 & 13.7137013 & 10.8035158 & 27.1814605 \\
\hline $\mathrm{H}$ & 11.1343639 & 6.6385277 & 26.9369387 \\
\hline $\mathrm{H}$ & 16.2406250 & 9.6250398 & 23.3953340 \\
\hline 0 & 11.2786182 & 9.3316598 & 23.1718582 \\
\hline $\mathrm{H}$ & 10.4157146 & 11.9190594 & 15.2082422 \\
\hline 0 & 11.8897016 & 10.9254491 & 25.2251011 \\
\hline 0 & 15.4889029 & 11.2435802 & 25.2201985 \\
\hline 0 & 9.9999324 & 8.2186528 & 25.2517008 \\
\hline $\mathrm{H}$ & 10.4095786 & 11.9140523 & 30.0189113 \\
\hline $\mathrm{H}$ & 8.6904703 & 15.0084389 & 15.2113444 \\
\hline $\mathrm{Si}$ & 5.3686854 & 14.6642078 & 16.7030934 \\
\hline $\mathrm{Si}$ & 5.3171778 & 14.6413509 & 28.6565432 \\
\hline $\mathrm{Si}$ & 12.1370729 & 18.5739065 & 21.7296099 \\
\hline Al & 12.1199380 & 13.1832190 & 21.7126026 \\
\hline $\mathrm{Si}$ & 16.9318583 & 15.8289433 & 21.7244388 \\
\hline $\mathrm{Si}$ & 16.8911216 & 15.9010977 & 18.6290560 \\
\hline $\mathrm{Si}$ & 12.1491281 & 13.1599579 & 18.6129480 \\
\hline $\mathrm{Si}$ & 12.1892517 & 18.5944646 & 18.6432580 \\
\hline $\mathrm{Si}$ & 5.3300510 & 17.0490333 & 26.7223676 \\
\hline $\mathrm{Si}$ & 5.3162991 & 17.0752106 & 23.6882913 \\
\hline $\mathrm{Si}$ & 8.4479548 & 14.6225734 & 28.5924853 \\
\hline $\mathrm{Si}$ & 8.4987513 & 14.6702827 & 16.6487083 \\
\hline $\mathrm{Si}$ & 15.3020818 & 13.2002081 & 18.6405365 \\
\hline $\mathrm{Si}$ & 15.3076089 & 18.5982395 & 18.6577072 \\
\hline $\mathrm{Si}$ & 10.5705155 & 15.8959303 & 18.6148978 \\
\hline $\mathrm{Si}$ & 10.4416613 & 15.8832922 & 21.6764043 \\
\hline $\mathrm{Si}$ & 15.2741231 & 18.5199306 & 21.7697481 \\
\hline $\mathrm{Si}$ & 15.2847750 & 13.1952285 & 21.6944652 \\
\hline $\mathrm{Si}$ & 8.4403463 & 17.2161901 & 23.6204276 \\
\hline $\mathrm{Si}$ & 8.4453959 & 17.1037887 & 26.7174330 \\
\hline $\mathrm{O}$ & 8.9371197 & 13.1235829 & 16.9316579 \\
\hline 0 & 6.8745967 & 14.2640310 & 28.3720858 \\
\hline 0 & 11.5225954 & 17.0958038 & 21.9079395 \\
\hline 0 & 13.7782862 & 13.6959312 & 21.8139784 \\
\hline 0 & 15.8498864 & 17.0216042 & 22.0009964 \\
\hline 0 & 15.7713642 & 14.7491826 & 18.3983748 \\
\hline 0 & 11.6766740 & 14.7200558 & 18.4442295 \\
\hline $\mathrm{O}$ & 13.7513174 & 18.1997408 & 18.3892852 \\
\hline $\mathrm{O}$ & 6.8796492 & 17.4775482 & 26.9953784 \\
\hline $\mathrm{H}$ & 8.9526198 & 18.6037180 & 23.4487801 \\
\hline $\mathrm{H}$ & 4.7020537 & 18.4290902 & 23.6056272 \\
\hline $\mathrm{H}$ & 18.0631230 & 15.6961363 & 17.7337771 \\
\hline $\mathrm{H}$ & 11.7862230 & 19.7234499 & 17.7600363 \\
\hline 0 & 11.4041336 & 12.2398100 & 17.4886844 \\
\hline 0 & 4.8515046 & 15.8911399 & 27.7438348 \\
\hline $\mathrm{H}$ & 11.4667850 & 19.5648721 & 22.6160758 \\
\hline 0 & 11.7747593 & 11.8422683 & 22.7469305 \\
\hline $\mathrm{H}$ & 18.1339563 & 16.0288934 & 22.5800676 \\
\hline 0 & 8.8983294 & 15.8502296 & 27.6391528 \\
\hline $\mathrm{H}$ & 16.0395920 & 12.3037283 & 17.7080541 \\
\hline 0 & 9.3592577 & 15.6977397 & 17.5478555 \\
\hline $\mathrm{H}$ & 15.6958297 & 19.7557747 & 17.8053472 \\
\hline 0 & 9.1272256 & 16.1887015 & 22.5918091 \\
\hline 0 & 6.9391026 & 14.8075346 & 17.0802804 \\
\hline 0 & 9.3177615 & 13.3210757 & 28.1849476 \\
\hline 0 & 13.7043239 & 18.5545908 & 22.1449902 \\
\hline 0 & 11.0477300 & 14.4815328 & 22.0792039 \\
\hline 0 & 16.3200038 & 14.3931378 & 22.1074965 \\
\hline 0 & 16.2488954 & 17.3447948 & 18.2657988 \\
\hline 0 & 13.7357567 & 13.0947593 & 18.2767610 \\
\hline 0 & 11.2702927 & 17.3218395 & 18.2807206 \\
\hline $\mathrm{H}$ & 4.4440892 & 18.2271423 & 26.9327283 \\
\hline $\mathrm{H}$ & 9.2857377 & 18.2773564 & 27.0830631 \\
\hline
\end{tabular}




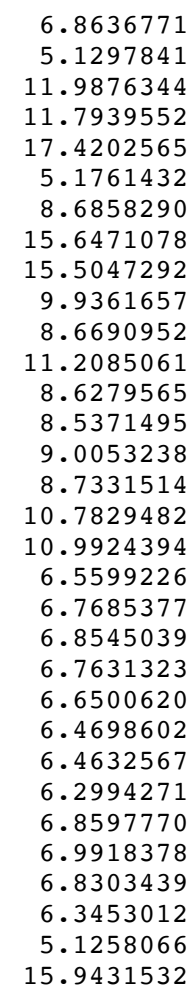

17.2162146

15.0252336

19.0901018

12.5809724

15.8851150

16.4824252

15.0038517

12.7286025

19.0069999

15.9270035

16.7079289

10.9183771

10.6668674

9.7165316

11.5267327

10.6460286

10.0235201

9.7743842

12.4262074

13.5880621

13.5371258

12.3138160

11.1114200

11.1971014

12.4957370

10.2816445

14.5524917

14.4562620

12.2516627

10.1943469

15.0226837

19.5141200

23.2636856

15.2784156

20.1857605

20.0717608

20.1692198

25.1997271

30.0120497

20.1564337

20.2273485

20.1106899

25.1539625

20.1979898

20.5186208

21.0345510

21.0668935

19.4397633

20.3186773

21.2455606

22.5950515

21.8354423

20.4371923

19.7898568

20.5479740

21.9602621

23.6793362

22.5315332

22.3348336

19.8660494

18.7024489

20.0360069

30.0831065

22.6535506

$9.0761468 \quad 15.2642733$

$9.4092969 \quad 16.8084898$

$9.3395234 \quad 28.6200079$

$6.7882285 \quad 21.7276170$

$6.8034301 \quad 18.5728131$

$\begin{array}{ll}7.9936700 & 26.7415538\end{array}$

$8.1160723 \quad 23.6380472$

$9.2430172 \quad 28.5247889$

$9.3535510 \quad 16.7220306$

$\begin{array}{ll}6.7922459 & 18.5564211\end{array}$

$6.7080416 \quad 21.7236487$

$10.8024544 \quad 23.5731936$

$10.7556984 \quad 26.7126006$

$9.7693311 \quad 17.0862782$

$10.9917500 \quad 28.2382039$

$\begin{array}{ll}5.4228564 & 21.9277495\end{array}$

$\begin{array}{ll}5.3438714 & 21.9719017\end{array}$

$6.4243018 \quad 18.2824992$

$9.0964225 \quad 26.8686056$

$7.1223451 \quad 23.4012088$

$10.2466880 \quad 23.3251854$

$8.1992409 \quad 17.6438667$

$8.2147247 \quad 27.7528950$

$\begin{array}{ll}7.8239012 & 22.6087678\end{array}$

$\begin{array}{ll}11.8122777 & 27.7202447\end{array}$

$7.9896429 \quad 17.6925011$

$11.9846424 \quad 22.6534983$

$10.6035116 \quad 17.2289651$

$9.0785537 \quad 28.1587811$

$6.7882018 \quad 22.1268643$

$5.6344550 \quad 18.1923581$

$5.6402082 \quad 18.1533237$

$10.8045108 \quad 27.1991107$

$6.6806639 \quad 27.0510584$

$9.7117978 \quad 23.2939941$

$9.0883944 \quad 15.3688318$

$\begin{array}{ll}7.2342985 & 20.2580380\end{array}$

$\begin{array}{ll}7.9979374 & 25.3178087\end{array}$

$9.0358156 \quad 29.9842772$

$\begin{array}{ll}7.1657487 & 20.0430596\end{array}$

$11.2701839 \quad 25.0436651$

$9.1171706 \quad 30.0862903$

$12.0845852 \quad 15.2586114$

$15.9843334 \quad 21.7321041$

$16.0544643 \quad 18.5796423$ 


\begin{tabular}{|c|c|c|c|}
\hline $\mathrm{P}$ & 3.8512633 & 12.0750159 & 28.5285263 \\
\hline Al & 3.8547792 & 12.1184984 & 16.7157260 \\
\hline $\mathrm{P}$ & 1.6126310 & 13.3484532 & 18.5248825 \\
\hline Al & 1.5342138 & 13.3683812 & 21.6525494 \\
\hline 0 & 5.0575456 & 13.3613592 & 17.0517146 \\
\hline $\mathrm{H}$ & 0.1474341 & 13.8896133 & 21.8018136 \\
\hline $\mathrm{H}$ & 2.3272408 & 17.0824255 & 22.0044840 \\
\hline $\mathrm{O}$ & 2.0745703 & 14.8055141 & 18.2849037 \\
\hline 0 & 4.6860156 & 15.8010802 & 17.6021705 \\
\hline 0 & 4.5519656 & 16.1601663 & 22.6000625 \\
\hline 0 & 2.3871470 & 12.4033162 & 17.5902551 \\
\hline 0 & 4.4120601 & 13.4397087 & 28.1089608 \\
\hline 0 & 2.6768451 & 14.6383993 & 22.0853546 \\
\hline $\mathrm{H}$ & 2.6894192 & 17.3880253 & 18.2404972 \\
\hline $\mathrm{H}$ & 0.1673264 & 13.2526007 & 18.1798792 \\
\hline 0 & 3.7420442 & 16.0315917 & 20.2593267 \\
\hline $\mathrm{H}$ & 3.5086231 & 12.0786171 & 29.9775623 \\
\hline 0 & 1.8928736 & 12.9221270 & 19.9741107 \\
\hline$P$ & 10.1396854 & 12.0499542 & 16.6507588 \\
\hline Al & 10.0751294 & 11.9663007 & 28.4502498 \\
\hline $\mathrm{P}$ & 12.3897027 & 10.6606887 & 26.8583193 \\
\hline Al & 12.4322933 & 10.6549009 & 23.6285677 \\
\hline $\mathrm{P}$ & 15.5290893 & 10.8024544 & 23.5731936 \\
\hline $\mathrm{P}$ & 10.6176944 & 8.0946413 & 23.6284693 \\
\hline Al & 10.7028097 & 8.0665226 & 26.7358424 \\
\hline Al & 15.5026369 & 10.7556984 & 26.7126006 \\
\hline 0 & 8.9571724 & 10.6561040 & 28.1024188 \\
\hline 0 & 11.8916514 & 9.2500113 & 27.2493073 \\
\hline $\mathrm{H}$ & 15.9629618 & 9.34 & 26.8451537 \\
\hline $\mathrm{H}$ & 11.4565567 & 6.8657322 & 23.5717838 \\
\hline 0 & 14.1203324 & 10.2263172 & 23.3160950 \\
\hline 0 & 11.5686746 & 11.7334551 & 27.5892430 \\
\hline 0 & 9.3012194 & 8.1715530 & 27.7695628 \\
\hline $\mathrm{H}$ & 16.3161718 & 11.6581895 & 27.5732930 \\
\hline $\mathrm{O}$ & 9.3805040 & 7.9193909 & 22.7282024 \\
\hline 0 & 15.8246893 & 11.9846424 & 22.6534983 \\
\hline 0 & 9.5714952 & 10.7178121 & 17.1787658 \\
\hline $\mathrm{O}$ & 13.8548823 & 10.8128863 & 27.2825893 \\
\hline $\mathrm{H}$ & 11.3006260 & 6.7083189 & 26.8583945 \\
\hline $\mathrm{H}$ & 16.5445362 & 9.74 & 23.3031191 \\
\hline 0 & 11.4324187 & 9.2822187 & 23.0890589 \\
\hline $\mathrm{H}$ & 10.3781214 & 11.9588126 & 15.1838021 \\
\hline 0 & 12.2362598 & 10.8532751 & 25.3517407 \\
\hline 0 & 15.6417022 & 11.2701839 & 25.0436651 \\
\hline 0 & 10.1749187 & 8.3597325 & 25.0789227 \\
\hline $\mathrm{H}$ & 10.3403539 & 11.9577325 & 29.9154130 \\
\hline $\mathrm{H}$ & 8.7855793 & 15.0425093 & 15.1182350 \\
\hline$P$ & 5.4811915 & 14.8143241 & 16.7433002 \\
\hline Al & 5.4088240 & 14.7906570 & 28.5744488 \\
\hline $\mathrm{P}$ & 12.3564393 & 18.8043299 & 21.7276170 \\
\hline $\mathrm{Ge}$ & 12.1633851 & 13.3375910 & 21.7244535 \\
\hline $\mathrm{P}$ & 17.1702909 & 15.9843334 & 21.7321041 \\
\hline Al & 17.1333786 & 16.0544643 & 18.5796423 \\
\hline Al & 12.2966891 & 13.3233759 & 18.5419051 \\
\hline Al & 12.4207686 & 18.8195314 & 18.5728131 \\
\hline $\mathrm{P}$ & 5.3727687 & 17.2861234 & 26.7210329 \\
\hline Al & 5.3136205 & 17.3032099 & 23.6599510 \\
\hline$P$ & 8.5623496 & 14.7248517 & 28.4047007 \\
\hline Al & 8.6354791 & 14.7975958 & 16.5792648 \\
\hline $\mathrm{P}$ & 15.4876298 & 13.3484532 & 18.5248825 \\
\hline $\mathrm{P}$ & 15.5793705 & 18.8083473 & 18.5564211 \\
\hline $\mathrm{P}$ & 10.7663065 & 16.1432855 & 18.4613470 \\
\hline Al & 10.5698455 & 16.1578758 & 21.5922310 \\
\hline Al & 15.5289508 & 18.7241429 & 21.7236487 \\
\hline Al & 15.4092125 & 13.3683812 & 21.6525494 \\
\hline $\mathrm{P}$ & 8.4512390 & 17.5249173 & 23.4773425 \\
\hline Al & 8.5115744 & 17.3131733 & 26.6147459 \\
\hline 0 & 9.0925335 & 13.1455332 & 16.9616480 \\
\hline 0 & 7.0706921 & 14.4003556 & 28.1887517 \\
\hline 0 & 11.7817593 & 17.4014348 & 21.9332495 \\
\hline 0 & 13.8120478 & 13.9686882 & 21.8244581 \\
\hline 0 & 16.1654906 & 17.1241111 & 22.0148241 \\
\hline 0 & 15.9495690 & 14.8055141 & 18.2849037 \\
\hline 0 & 11.7969525 & 15.0077568 & 18.3688936 \\
\hline 0 & 14.1085274 & 18.4404031 & 18.2824992 \\
\hline 0 & 6.8343823 & 17.7053361 & 26.9851245 \\
\hline $\mathrm{H}$ & 8.9633643 & 18.9184498 & 23.3636970 \\
\hline $\mathrm{H}$ & 4.6490506 & 18.6334428 & 23.5828287 \\
\hline $\mathrm{H}$ & 18.3490261 & 15.8387050 & 17.7473143 \\
\hline $\mathrm{H}$ & 12.0131885 & 20.0117645 & 17.7793527 \\
\hline
\end{tabular}




\begin{tabular}{|c|c|c|}
\hline 11.4694990 & 12.3500185 & 17.3311058 \\
\hline 4.9145349 & 16.2237592 & 27.7237160 \\
\hline 11.6587901 & 19.8062264 & 22.5800310 \\
\hline 11.8204271 & 12.0001008 & 22.8049190 \\
\hline 18.3874282 & 16.1546345 & 22.5727557 \\
\hline 8.9916190 & 15.9064928 & 27.5296215 \\
\hline 16.2372729 & 12.4336683 & 17.6202697 \\
\hline 9.6210719 & 15.9224504 & 17.4589758 \\
\hline 15.9836242 & 19.9705093 & 17.7179230 \\
\hline 9.1118594 & 16.6072241 & 22.4571977 \\
\hline 6.9691571 & 14.9725861 & 17.0895466 \\
\hline 9.3845807 & 13.4996478 & 27.9919679 \\
\hline 13.8386843 & 18.8043032 & 22.1268643 \\
\hline 10.9971102 & 14.5926441 & 22.0946783 \\
\hline 16.5518438 & 14.6383993 & 22.0853546 \\
\hline 16.4663821 & 17.6178071 & 18.1820602 \\
\hline 14.0050599 & 13.2501293 & 18.1709838 \\
\hline 11.4546140 & 17.4646706 & 18.0842135 \\
\hline 4.4840853 & 18.4709344 & 26.8746082 \\
\hline 9.3771180 & 18.4633966 & 26.9954575 \\
\hline 6.9529553 & 17.5384876 & 23.1590508 \\
\hline 5.2434755 & 15.1208223 & 15.3057082 \\
\hline 12.2087128 & 19.2503999 & 20.2580380 \\
\hline 11.8692168 & 12.6628481 & 20.0814159 \\
\hline 17.6170429 & 16.0315917 & 20.2593267 \\
\hline 5.2469400 & 16.6955909 & 25.3008014 \\
\hline 8.8034934 & 15.0732751 & 29.8321359 \\
\hline 15.7678723 & 12.9221270 & 19.9741107 \\
\hline 15.7618158 & 19.1818501 & 20.0430596 \\
\hline 10.1672717 & 16.2462732 & 19.8719063 \\
\hline 8.6888988 & 16.9822683 & 24.9028207 \\
\hline 11.2722998 & 11.0466254 & 20.2169976 \\
\hline 8.6872212 & 10.8103805 & 20.5189662 \\
\hline 8.5832946 & 9.8587553 & 21.0318872 \\
\hline 9.0878670 & 11.6555145 & 21.0739800 \\
\hline 8.8064900 & 10.7930982 & 19.4412899 \\
\hline 10.8443265 & 10.1437008 & 20.3049345 \\
\hline 11.0573766 & 9.8507879 & 21.2171719 \\
\hline 6.6265275 & 12.6249533 & 22.5732185 \\
\hline 6.8506510 & 13.7808394 & 21.8085064 \\
\hline 6.9542563 & 13.7204526 & 20.4118465 \\
\hline 6.8652297 & 12.4934001 & 19.7721512 \\
\hline 6.7365978 & 11.2950480 & 20.5357761 \\
\hline 6.5379074 & 11.3923536 & 21.9455670 \\
\hline 6.5181505 & 12.7019236 & 23.6558864 \\
\hline 6.3577218 & 10.4812361 & 22.5209002 \\
\hline 6.9414732 & 14.7478708 & 22.3035388 \\
\hline 7.0997848 & 14.6346716 & 19.8348786 \\
\hline 6.9466194 & 12.4237079 & 18.6865344 \\
\hline 6.4184645 & 10.3824918 & 20.0233921 \\
\hline 5.2616137 & 15.0802056 & 30.0275873 \\
\hline 16.1963457 & 19.7487240 & 22.5733183 \\
\hline 8.6852653 & 8.8860572 & 15.3350050 \\
\hline 5.3696770 & 9.2878372 & 16.7703982 \\
\hline 5.3365008 & 9.2227940 & 28.7120981 \\
\hline 5.3221062 & 6.7566108 & 21.7437228 \\
\hline 5.3807435 & 6.8031527 & 18.6560477 \\
\hline 3.2425871 & 7.9955267 & 26.7566879 \\
\hline 3.3585625 & 8.1080635 & 23.7017341 \\
\hline 8.4511098 & 9.1638994 & 28.6914322 \\
\hline 8.4951064 & 9.2829816 & 16.7574716 \\
\hline 8.4940824 & 6.8044168 & 18.6657089 \\
\hline 8.4610071 & 6.7071031 & 21.7815512 \\
\hline 1.6647946 & 10.7453990 & 23.6845310 \\
\hline 1.6325330 & 10.7070525 & 26.7659749 \\
\hline 6.9343585 & 9.6956751 & 17.0191576 \\
\hline 4.9300163 & 10.7751119 & 28.4161924 \\
\hline 4.7074033 & 5.4095647 & 21.9009738 \\
\hline 9.0435321 & 5.3535625 & 21.9953572 \\
\hline 6.9393554 & 6.4019663 & 18.3900435 \\
\hline 2.1117279 & 9.1551841 & 26.8936664 \\
\hline 2.3079601 & 7.0786028 & 23.4702911 \\
\hline 0.2926465 & 10.2034739 & 23.4829190 \\
\hline 4.9484675 & 8.0452511 & 17.7107287 \\
\hline 4.4352315 & 8.2127265 & 27.8295066 \\
\hline 4.6289060 & 7.8642510 & 22.7161246 \\
\hline 2.4851629 & 11.6497325 & 27.7699089 \\
\hline
\end{tabular}




\begin{tabular}{|c|c|c|}
\hline 8.9170991 & 8.0726967 & 17.7461790 \\
\hline 1.9817857 & 11.9791875 & 22.6986358 \\
\hline 4.4665002 & 10.5613611 & 17.1962127 \\
\hline 6.8871667 & 8.9962751 & 28.3100419 \\
\hline 6.8891788 & 6.6706701 & 22.1503486 \\
\hline 9.3651036 & 5.6539377 & 18.2985026 \\
\hline 4.5193914 & 5.6374810 & 18.3148694 \\
\hline 0.2054999 & 10.7806396 & 27.1846418 \\
\hline 2.6085248 & 6.6831118 & 27.0610771 \\
\hline 2.7522338 & 9.5731330 & 23.3752719 \\
\hline 5.1366273 & 8.9115282 & 15.3487091 \\
\hline 5.1863327 & 7.2857767 & 20.2032264 \\
\hline 3.8748848 & 8.0211907 & 25.2506860 \\
\hline 8.6806525 & 8.8772837 & 30.1344437 \\
\hline 8.6807989 & 7.2024855 & 20.2395892 \\
\hline 1.8325389 & 11.2377117 & 25.2387867 \\
\hline 5.1343854 & 8.9069310 & 30.1531048 \\
\hline 3.4005976 & 11.9274272 & 15.3120962 \\
\hline 3.3584671 & 15.8386671 & 21.7158318 \\
\hline 3.2807716 & 15.9163269 & 18.6276673 \\
\hline 3.7935659 & 11.9190498 & 28.6777113 \\
\hline 3.8092933 & 11.9735095 & 16.7431674 \\
\hline 1.6774516 & 13.2118735 & 18.6505634 \\
\hline 1.6599382 & 13.2371021 & 21.7128010 \\
\hline 4.9418984 & 13.1294606 & 16.9773708 \\
\hline 0.2897447 & 13.8025833 & 21.8539441 \\
\hline 2.3785151 & 16.9262026 & 21.9880103 \\
\hline 2.1611398 & 14.7584842 & 18.4269859 \\
\hline 4.5444137 & 15.6928149 & 17.6360156 \\
\hline 4.6826935 & 16.0360563 & 22.6364797 \\
\hline 2.5054716 & 12.2355876 & 17.6501879 \\
\hline 4.4031171 & 13.3588033 & 28.2560295 \\
\hline 2.7526737 & 14.3954748 & 22.0858632 \\
\hline 2.6802156 & 17.2380163 & 18.2966230 \\
\hline 0.2391189 & 13.1197647 & 18.2766174 \\
\hline 3.8348215 & 15.9114404 & 20.1584458 \\
\hline 3.3993554 & 11.9228158 & 30.1135750 \\
\hline 1.9655350 & 12.7298781 & 20.1756966 \\
\hline 10.0556945 & 11.9769963 & 16.6262763 \\
\hline 9.9709526 & 11.8907151 & 28.5602597 \\
\hline 12.1537860 & 10.6060397 & 26.7992656 \\
\hline 12.2086997 & 10.5711547 & 23.6497904 \\
\hline 15.2897933 & 10.7453990 & 23.6845310 \\
\hline 10.4300651 & 8.0166220 & 23.7335931 \\
\hline 10.5322073 & 7.9907711 & 26.7803427 \\
\hline 15.2575318 & 10.7070525 & 26.7659749 \\
\hline 8.8947932 & 10.6878112 & 28.3224673 \\
\hline 11.6769791 & 9.0852658 & 27.1628053 \\
\hline 15.6954950 & 9.2887124 & 26.8826794 \\
\hline 11.2562685 & 6.7795045 & 23.6699629 \\
\hline 13.7859477 & 10.1514605 & 23.4635684 \\
\hline 11.2830138 & 11.6842337 & 27.6412925 \\
\hline 9.2962084 & 8.0852419 & 27.8264171 \\
\hline 16.0413478 & 11.5736509 & 27.6888836 \\
\hline 9.1446189 & 7.8324167 & 22.7495186 \\
\hline 15.6067844 & 11.9791875 & 22.6986358 \\
\hline 9.4154397 & 10.5666556 & 17.1324929 \\
\hline 13.7058620 & 10.7870667 & 27.2212080 \\
\hline 11.1265422 & 6.6293013 & 26.8817658 \\
\hline 16.2840130 & 9.6736242 & 23.4017828 \\
\hline 11.3086595 & 9.2658595 & 23.1866629 \\
\hline 10.3939232 & 11.9094130 & 15.1777756 \\
\hline 11.9297116 & 10.8805387 & 25.2246116 \\
\hline 15.4575376 & 11.2377117 & 25.2387867 \\
\hline 9.9515345 & 8.2635956 & 25.2728835 \\
\hline 10.3863910 & 11.9024462 & 29.9900827 \\
\hline 8.6982690 & 15.0075549 & 15.1795381 \\
\hline 5.3764148 & 14.6768194 & 16.6937267 \\
\hline 5.3076582 & 14.6419721 & 28.6462142 \\
\hline 12.1346056 & 18.5562058 & 21.7437228 \\
\hline 12.1059976 & 13.2210711 & 21.7278365 \\
\hline 16.9834658 & 15.8386671 & 21.7158318 \\
\hline 16.9057703 & 15.9163269 & 18.6276673 \\
\hline 12.1573464 & 13.1765759 & 18.5747696 \\
\hline 12.1932429 & 18.6027477 & 18.6560477 \\
\hline 5.3316313 & 17.0366384 & 26.7088887 \\
\hline 5.3029607 & 17.0794560 & 23.7038261 \\
\hline 8.4422438 & 14.6175332 & 28.5615718 \\
\hline 8.5058738 & 14.6778088 & 16.6187643 \\
\hline 15.3024504 & 13.2118735 & 18.6505634 \\
\hline
\end{tabular}

17.7461790

17.1962127

28.3100419

2.1503486

18.3148694

27.1846418

.0610771

15.3487091

20.2032264

30.1344437

20.2395892

5.2387867

15.3120962

21.7158318

18.6276673

77113

18.6505634

1.7128010

21.8539441

.9880103

17.6360156

2.6364797

28.2560295

22.0858632

18.2966230
18.2766174

20.1584458

30.1135750
20.1756966

16.6262763

28.5602597

23.6497904

23.6845310

26.7803427

26.7659749

28.3224673

1628053

23.6699629

23.4635684

27.6412925

22.7495186

86358

27.2212080

6.8817658

23.1866629

.1777756

25.2387867

2728835

15.1795381

6.6937267

28.6462142
21.7437228

21.7278365

21.7158318

18.5747696

18.6560477

23.7038261

16.6187643

18.6505634 


\begin{tabular}{|c|c|c|c|}
\hline $\mathrm{Si}$ & 15.3065818 & 18.6040118 & 18.6657089 \\
\hline & 10.5770955 & 15.9028893 & 18.5990941 \\
\hline $\mathrm{Si}$ & 10.3710007 & 15.9023977 & 21.6737487 \\
\hline $\mathrm{Si}$ & 15.2735065 & 18.5066982 & 21.7815512 \\
\hline $\mathrm{Si}$ & 15.2849369 & 13.2371021 & 21.7128010 \\
\hline $\mathrm{Si}$ & 8.4121524 & 17.2893703 & 23.6065284 \\
\hline $\mathrm{Si}$ & 8.4427376 & 17.1007658 & 26.6912965 \\
\hline 0 & 8.9259791 & 13.1258360 & 16.9047826 \\
\hline $\mathrm{O}$ & 6.8647325 & 14.2735771 & 28.3536596 \\
\hline 0 & 11.4692456 & 17.0981509 & 21.9139327 \\
\hline 0 & 13.8120782 & 13.8449535 & 21.8645196 \\
\hline 0 & 15.9081668 & 17.0320173 & 22.0144926 \\
\hline 0 & 15.7861386 & 14.7584842 & 18.4269859 \\
\hline O & 11.7023910 & 14.7444016 & 18.4367271 \\
\hline 0 & 13.7518548 & 18.2015614 & 18.3900435 \\
\hline O & 6.8790453 & 17.4729057 & 26.9928316 \\
\hline $\mathrm{H}$ & 8.9743291 & 18.6606124 & 23.4624003 \\
\hline $\mathrm{H}$ & 4.5695802 & 18.3748212 & 23.6677338 \\
\hline $\mathrm{H}$ & 18.0659648 & 15.7111127 & 17.7171968 \\
\hline $\mathrm{H}$ & 11.7958392 & 19.7446443 & 17.7869890 \\
\hline O & 11.4139013 & 12.2815997 & 17.4299109 \\
\hline 0 & 4.8363102 & 15.8984319 & 27.7450473 \\
\hline $\mathrm{H}$ & 11.5008992 & 19.5687830 & 22.6326684 \\
\hline O & 11.7256465 & 11.7752998 & 22.7471781 \\
\hline $\mathrm{H}$ & 18.1969781 & 16.0195532 & 22.5595074 \\
\hline 0 & 8.8991859 & 15.8354142 & 27.5972013 \\
\hline $\mathrm{H}$ & 16.0613327 & 12.3171051 & 17.7337168 \\
\hline 0 & 9.3837350 & 15.6956657 & 17.5135084 \\
\hline $\mathrm{H}$ & 15.6947551 & 19.7678252 & 17.8219195 \\
\hline 0 & 9.0260402 & 16.2714231 & 22.5214831 \\
\hline 0 & 6.9492270 & 14.8362219 & 17.0562859 \\
\hline 0 & 9.2907051 & 13.3018657 & 28.1540632 \\
\hline 0 & 13.7016782 & 18.4702651 & 22.1503486 \\
\hline $\mathrm{O}$ & 10.9009514 & 14.4920378 & 22.1708077 \\
\hline 0 & 16.3776724 & 14.3954748 & 22.0858632 \\
\hline 0 & 16.2518443 & 17.3554718 & 18.2672038 \\
\hline 0 & 13.7454617 & 13.1121662 & 18.2457685 \\
\hline 0 & 11.2609999 & 17.3411392 & 18.2867898 \\
\hline $\mathrm{H}$ & 4.4385294 & 18.2162499 & 26.8762400 \\
\hline $\mathrm{H}$ & 9.2924973 & 18.2678202 & 27.0560060 \\
\hline 0 & 6.8300574 & 17.3834518 & 23.2949946 \\
\hline $\mathrm{H}$ & 5.1234216 & 15.0221003 & 15.2675794 \\
\hline 0 & 11.9988321 & 19.0853717 & 20.2032264 \\
\hline O & 11.7762885 & 12.5593970 & 20.0143291 \\
\hline 0 & 17.4598202 & 15.9114404 & 20.1584458 \\
\hline O & 5.2094317 & 16.4311840 & 25.1968565 \\
\hline $\mathrm{H}$ & 8.6924325 & 15.0017788 & 29.9782163 \\
\hline 0 & 15.5905337 & 12.7298781 & 20.1756966 \\
\hline $\mathrm{O}$ & 15.4932983 & 19.0020805 & 20.2395892 \\
\hline 0 & 9.9303191 & 15.9059804 & 20.0894121 \\
\hline 0 & 8.6537020 & 16.7234902 & 25.1195699 \\
\hline $\mathrm{H}$ & 11.2191999 & 10.8978122 & 20.1749124 \\
\hline C & 8.6445780 & 10.6484436 & 20.5074421 \\
\hline $\mathrm{H}$ & 8.5467305 & 9.6830805 & 20.9933041 \\
\hline $\mathrm{H}$ & 9.0196469 & 11.4899885 & 21.0853114 \\
\hline $\mathrm{H}$ & 8.7637057 & 10.6591386 & 19.4299442 \\
\hline 0 & 10.8017434 & 10.0001389 & 20.3065530 \\
\hline $\mathrm{H}$ & 11.0154299 & 9.7640081 & 21.2350629 \\
\hline $\mathrm{C}$ & 6.5599320 & 12.3637664 & 22.5981943 \\
\hline C & 6.7826112 & 13.5410527 & 21.8671350 \\
\hline $\mathrm{C}$ & 6.8833522 & 13.5219381 & 20.4691040 \\
\hline C & 6.7947079 & 12.3136823 & 19.7938573 \\
\hline C & 6.6695922 & 11.0949691 & 20.5238731 \\
\hline C & 6.4723888 & 11.1494236 & 21.9353245 \\
\hline $\mathrm{H}$ & 6.4513291 & 12.4095891 & 23.6826087 \\
\hline $\mathrm{H}$ & 6.2917345 & 10.2222008 & 22.4840565 \\
\hline $\mathrm{H}$ & 6.8732366 & 14.4930140 & 22.3894934 \\
\hline $\mathrm{H}$ & 7.0309098 & 14.4534580 & 19.9208837 \\
\hline $\mathrm{H}$ & 6.8742830 & 12.2747312 & 18.7061751 \\
\hline $\mathrm{H}$ & 6.3683502 & 10.1906864 & 19.9878960 \\
\hline $\mathrm{H}$ & 5.1180597 & 15.0185606 & 30.0742738 \\
\hline $\mathrm{H}$ & 15.8963780 & 19.5320253 & 22.6635127 \\
\hline \multicolumn{4}{|c|}{ Ti 2} \\
\hline \multicolumn{4}{|c|}{177} \\
\hline $\mathrm{H}$ & 8.6695051 & 9.0877860 & 15.2617666 \\
\hline $\mathrm{P}$ & 5.4168416 & 9.4315907 & 16.8194533 \\
\hline Al & 5.3464901 & 9.3372628 & 28.6266535 \\
\hline $\mathrm{P}$ & 5.3945329 & 6.8066811 & 21.7254412 \\
\hline & & & \\
\hline
\end{tabular}




\begin{tabular}{|c|c|c|c|}
\hline $\mathrm{P}$ & 3.2240250 & 7.9868700 & 26.7422875 \\
\hline Al & 3.3639674 & 8.1553199 & 23.6572867 \\
\hline$P$ & 8.4739896 & 9.2217924 & 28.5168147 \\
\hline Al & 8.5655865 & 9.3792825 & 16.7182526 \\
\hline $\mathrm{P}$ & 8.6350479 & 6.8226447 & 18.5672027 \\
\hline Al & 8.5734263 & 6.7065307 & 21.7245150 \\
\hline $\mathrm{P}$ & 1.6536067 & 10.8258975 & 23.5862065 \\
\hline Al & 1.5921205 & 10.7434737 & 26.7279190 \\
\hline 0 & 6.8948824 & 9.8015730 & 17.0956538 \\
\hline $\mathrm{O}$ & 4.8970205 & 10.9884636 & 28.2282075 \\
\hline $\mathrm{H}$ & 4.7229499 & 5.4919582 & 21.9193499 \\
\hline $\mathrm{H}$ & 9.1767490 & 5.3622849 & 21.9392835 \\
\hline $\mathrm{O}$ & 7.1707143 & 6.4322861 & 18.2855567 \\
\hline $\mathrm{O}$ & 2.1501453 & 9.0852032 & 26.8349390 \\
\hline $\mathrm{H}$ & 2.2896122 & 7.1590411 & 23.3921262 \\
\hline $\mathrm{H}$ & 0.3111852 & 10.2626093 & 23.2735863 \\
\hline 0 & 5.0095398 & 8.2133180 & 17.6476771 \\
\hline $\mathrm{O}$ & 4.3171128 & 8.2075241 & 27.7946154 \\
\hline $\mathrm{O}$ & 4.7524421 & 7.8868132 & 22.6202139 \\
\hline $\mathrm{O}$ & 2.5502607 & 11.7871885 & 27.7439495 \\
\hline $\mathrm{O}$ & 9.0434699 & 8.0190380 & 17.6979599 \\
\hline $\mathrm{O}$ & 1.9905004 & 12.0087550 & 22.6802722 \\
\hline $\mathrm{O}$ & 4.5422442 & 10.6165740 & 17.2468070 \\
\hline $\mathrm{O}$ & 6.9959600 & 9.0505871 & 28.1510637 \\
\hline $\mathrm{O}$ & 6.8753337 & 6.6819848 & 22.1143596 \\
\hline $\mathrm{H}$ & 9.5155899 & 5.6727673 & 18.2214451 \\
\hline $\mathrm{H}$ & 4.6533302 & 5.6524031 & 18.1621863 \\
\hline $\mathrm{H}$ & 0.1976723 & 10.7694802 & 27.2494154 \\
\hline $\mathrm{H}$ & 2.5889640 & 6.6697665 & 27.0234577 \\
\hline $\mathrm{O}$ & 2.7265741 & 9.7466637 & 23.3521909 \\
\hline $\mathrm{H}$ & 5.2132216 & 9.1152077 & 15.3787724 \\
\hline 0 & 5.2760722 & 7.2703375 & 20.2586906 \\
\hline $\mathrm{O}$ & 3.8677033 & 8.0011299 & 25.3386890 \\
\hline $\mathrm{H}$ & 8.6803796 & 9.0438726 & 29.9806686 \\
\hline 0 & 8.7968985 & 7.2121330 & 20.0537019 \\
\hline $\mathrm{O}$ & 1.6927032 & 11.2872615 & 25.0634546 \\
\hline $\mathrm{H}$ & 5.2275625 & 9.1396980 & 30.0976888 \\
\hline $\mathrm{H}$ & 3.5580138 & 12.0924557 & 15.2661019 \\
\hline$P$ & 3.3369329 & 15.9925566 & 21.7055905 \\
\hline Al & 3.2571450 & 16.0744633 & 18.5588372 \\
\hline $\mathrm{P}$ & 3.8328998 & 12.0676640 & 28.5282029 \\
\hline $\mathrm{Al}$ & 3.8519148 & 12.1360743 & 16.7251564 \\
\hline$P$ & 1.6048408 & 13.3832593 & 18.5252081 \\
\hline Al & 1.5712325 & 13.3847480 & 21.6665597 \\
\hline 0 & 5.0627900 & 13.3726367 & 17.0646806 \\
\hline $\mathrm{H}$ & 0.1608393 & 13.8356999 & 21.8232572 \\
\hline $\mathrm{H}$ & 2.3801991 & 17.1032758 & 21.9665193 \\
\hline $\mathrm{O}$ & 2.0514924 & 14.8436351 & 18.2691083 \\
\hline 0 & 4.6717734 & 15.8213586 & 17.5603481 \\
\hline $\mathrm{O}$ & 4.6113879 & 16.1703256 & 22.5502623 \\
\hline $\mathrm{O}$ & 2.3803861 & 12.4392611 & 17.5884254 \\
\hline $\mathrm{O}$ & 4.3771655 & 13.4326677 & 28.0858851 \\
\hline 0 & 2.7078393 & 14.6611737 & 22.0960474 \\
\hline $\mathrm{H}$ & 2.6995315 & 17.4230026 & 18.2628144 \\
\hline $\mathrm{H}$ & 0.1574308 & 13.2734931 & 18.1934304 \\
\hline $\mathrm{O}$ & 3.7675540 & 16.0045083 & 20.2287984 \\
\hline $\mathrm{H}$ & 3.5171473 & 12.0843516 & 29.9832432 \\
\hline 0 & 1.9062385 & 12.9684558 & 19.9741415 \\
\hline$P$ & 10.1345297 & 12.0689823 & 16.5990612 \\
\hline Al & 10.0402863 & 11.9470913 & 28.3968149 \\
\hline $\mathrm{P}$ & 12.3786927 & 10.6074469 & 26.8717244 \\
\hline Al & 12.4333596 & 10.5724876 & 23.6272186 \\
\hline$P$ & 15.5286055 & 10.8258975 & 23.5862065 \\
\hline $\mathrm{P}$ & 10.5508181 & 8.0778625 & 23.6481702 \\
\hline Al & 10.6675576 & 8.0488263 & 26.7367562 \\
\hline Al & 15.4671192 & 10.7434737 & 26.7279190 \\
\hline $\mathrm{O}$ & 8.9272657 & 10.6269104 & 28.0669208 \\
\hline 0 & 11.8594298 & 9.2132351 & 27.2931396 \\
\hline $\mathrm{H}$ & 15.9411294 & 9.3348677 & 26.8188263 \\
\hline $\mathrm{H}$ & 11.2891144 & 6.7848285 & 23.6380465 \\
\hline $\mathrm{O}$ & 14.1352414 & 10.2412335 & 23.2617229 \\
\hline $\mathrm{O}$ & 11.5306100 & 11.7081458 & 27.5284885 \\
\hline $\mathrm{O}$ & 9.2725297 & 8.1350449 & 27.7837283 \\
\hline $\mathrm{H}$ & 16.2854125 & 11.6348514 & 27.5956531 \\
\hline $\mathrm{O}$ & 9.3054975 & 7.9474856 & 22.7469567 \\
\hline 0 & 15.8654991 & 12.0087550 & 22.6802722 \\
\hline $\mathrm{O}$ & 9.5773656 & 10.7403182 & 17.1511235 \\
\hline $\mathrm{O}$ & 13.8300497 & 10.7740051 & 27.3401510 \\
\hline $\mathrm{H}$ & 11.2698209 & 6.6885919 & 26.8012693 \\
\hline $\mathrm{H}$ & 16.5662215 & 9.7822215 & 23.3599011 \\
\hline
\end{tabular}




\begin{tabular}{|c|c|c|}
\hline 11.4554531 & 9.1863124 & 23.0784807 \\
\hline 10.3437605 & 11.9586379 & 15.1289703 \\
\hline 12.2899547 & 10.7365513 & 25.3547777 \\
\hline 15.5677020 & 11.2872615 & 25.0634546 \\
\hline 10.1290977 & 8.4136435 & 25.0920913 \\
\hline 10.3053717 & 11.9544056 & 29.8620101 \\
\hline 8.7591867 & 15.0363570 & 15.0632032 \\
\hline 5.4792785 & 14.8218976 & 16.7267904 \\
\hline 5.3830888 & 14.7789202 & 28.5480099 \\
\hline 12.3320323 & 18.8227824 & 21.7254412 \\
\hline 12.0971603 & 13.3305891 & 21.7450942 \\
\hline 17.2119317 & 15.9925566 & 21.7055905 \\
\hline 17.1321437 & 16.0744633 & 18.5588372 \\
\hline 12.2743346 & 13.3246976 & 18.5060757 \\
\hline 12.4207272 & 18.8331816 & 18.5768161 \\
\hline 5.3567337 & 17.2682975 & 26.6968810 \\
\hline 5.2910049 & 17.3119998 & 23.6650509 \\
\hline 8.5313050 & 14.7094099 & 28.3475948 \\
\hline 8.6282180 & 14.8166282 & 16.5300662 \\
\hline 15.4798395 & 13.3832593 & 18.5252081 \\
\hline 15.5725473 & 18.8387461 & 18.5672027 \\
\hline 10.7412746 & 16.1567898 & 18.4321773 \\
\hline 10.4431392 & 16.2264459 & 21.5555360 \\
\hline 15.5109257 & 18.7226321 & 21.7245150 \\
\hline 15.4462312 & 13.3847480 & 21.6665597 \\
\hline 8.4067254 & 17.6092778 & 23.4548018 \\
\hline 8.4866167 & 17.3116491 & 26.5766168 \\
\hline 9.0911793 & 13.1661078 & 16.9204019 \\
\hline 7.0387405 & 14.3886698 & 28.1338618 \\
\hline 11.6424681 & 17.4728587 & 21.9245417 \\
\hline 13.8196911 & 13.9048096 & 21.8472716 \\
\hline 16.2187119 & 17.1456340 & 21.9764701 \\
\hline 15.9264911 & 14.8436351 & 18.2691083 \\
\hline 11.7632878 & 15.0127677 & 18.3688438 \\
\hline 14.1082136 & 18.4483874 & 18.2855567 \\
\hline 6.8128076 & 17.7036691 & 26.9709854 \\
\hline 9.0223437 & 18.9609673 & 23.3495869 \\
\hline 4.4954534 & 18.5704377 & 23.6415412 \\
\hline 18.3358461 & 15.8590974 & 17.7092263 \\
\hline 12.0160085 & 20.0261261 & 17.7829605 \\
\hline 11.4789756 & 12.3842722 & 17.2441593 \\
\hline 4.8903369 & 16.2252878 & 27.7163538 \\
\hline 11.7122480 & 19.8653903 & 22.5891291 \\
\hline 11.7641747 & 11.9295162 & 22.8440115 \\
\hline 18.4447765 & 16.1645216 & 22.5226843 \\
\hline 8.9634650 & 15.8862737 & 27.4658139 \\
\hline 16.2299281 & 12.4702471 & 17.6191746 \\
\hline 9.6317719 & 15.9496316 & 17.3851994 \\
\hline 15.9689382 & 19.9998968 & 17.7235655 \\
\hline 8.9540089 & 16.6724438 & 22.3798354 \\
\hline 6.9678802 & 14.9962669 & 17.0664781 \\
\hline 9.3486861 & 13.4800966 & 27.9352154 \\
\hline 13.8128331 & 18.6980861 & 22.1143596 \\
\hline 10.9297516 & 14.6783820 & 22.0725279 \\
\hline 16.5828380 & 14.6611737 & 22.0960474 \\
\hline 16.4781024 & 17.6562047 & 18.2116234 \\
\hline 13.9952976 & 13.2706772 & 18.1849189 \\
\hline 11.4539091 & 17.4763505 & 18.0937787 \\
\hline 4.4557626 & 18.4484690 & 26.8089827 \\
\hline 9.3596099 & 18.4534573 & 26.9655607 \\
\hline 6.9015576 & 17.7566201 & 23.2094154 \\
\hline 5.2409008 & 15.0961770 & 15.2828141 \\
\hline 12.2135716 & 19.2864388 & 20.2586906 \\
\hline 11.8311577 & 12.6520572 & 20.0338228 \\
\hline 17.6425528 & 16.0045083 & 20.2287984 \\
\hline 5.2616827 & 16.6452048 & 25.2864174 \\
\hline 8.7737655 & 15.0626681 & 29.7736180 \\
\hline 15.7812372 & 12.9684558 & 19.9741415 \\
\hline 15.7343978 & 19.2282344 & 20.0537019 \\
\hline 10.0900118 & 16.2611148 & 19.8218531 \\
\hline 8.6580418 & 17.0068212 & 24.8554529 \\
\hline 11.3170685 & 11.0111404 & 20.1567221 \\
\hline 8.7590947 & 10.7989003 & 20.4789415 \\
\hline 8.6248356 & 9.8001647 & 20.8830689 \\
\hline 9.1712850 & 11.5706689 & 21.1247459 \\
\hline 8.8876033 & 10.8944808 & 19.4060654 \\
\hline 10.9030481 & 10.0999323 & 20.2404984 \\
\hline 11.1152464 & 9.8013339 & 21.1500818 \\
\hline 6.7539882 & 12.4539568 & 22.6923361 \\
\hline 7.0041045 & 13.6735350 & 22.0441775 \\
\hline
\end{tabular}




\begin{tabular}{|c|c|c|c|}
\hline $\mathrm{C}$ & 7.0970205 & 13.7508259 & 20.6469769 \\
\hline C & 6.9728605 & 12.5957373 & 19.8897197 \\
\hline $\mathrm{C}$ & 6.8164817 & 11.3312368 & 20.5321461 \\
\hline $\mathrm{C}$ & 6.6278660 & 11.2922352 & 21.9458202 \\
\hline $\mathrm{H}$ & 6.6574608 & 12.4246072 & 23.7785042 \\
\hline $\mathrm{H}$ & 6.4281275 & 10.3334738 & 22.4301924 \\
\hline $\mathrm{H}$ & 7.1307882 & 14.5823237 & 22.6334476 \\
\hline $\mathrm{H}$ & 7.2644514 & 14.7146568 & 20.1637314 \\
\hline $\mathrm{H}$ & 7.0454643 & 12.6308304 & 18.8014472 \\
\hline $\mathrm{H}$ & 6.4794731 & 10.4811644 & 19.9321708 \\
\hline $\mathrm{H}$ & 5.2554869 & 15.0568786 & 30.0052599 \\
\hline $\mathrm{H}$ & 16.1279202 & 19.7685172 & 22.5862357 \\
\hline \multicolumn{4}{|c|}{$\begin{array}{l}\mathrm{Zn} 3 \\
174\end{array}$} \\
\hline $\mathrm{H}$ & 8.7065498 & 8.9926741 & 15.3236124 \\
\hline Al & 5.4136830 & 9.2723535 & 16.7082407 \\
\hline $\mathrm{P}$ & 5.4033170 & 9.2447100 & 28.5235785 \\
\hline Al & 5.3000479 & 6.6707743 & 21.6520112 \\
\hline $\mathrm{P}$ & 5.3637811 & 6.7040123 & 18.5089077 \\
\hline Al & 3.1802687 & 8.0260978 & 26.6691451 \\
\hline $\mathrm{P}$ & 3.2611116 & 8.1299587 & 23.5474148 \\
\hline Al & 8.5290140 & 9.2338570 & 28.5709754 \\
\hline $\mathrm{P}$ & 8.5545904 & 9.3277618 & 16.7664378 \\
\hline Al & 8.5200889 & 6.7505077 & 18.5785230 \\
\hline $\mathrm{P}$ & 8.4756775 & 6.7000573 & 21.7450239 \\
\hline Al & 1.5346435 & 10.7663829 & 23.5935172 \\
\hline $\mathrm{P}$ & 1.5289945 & 10.7312041 & 26.7469290 \\
\hline 0 & 7.0846797 & 9.6946936 & 17.0838041 \\
\hline 0 & 5.0003893 & 10.7016184 & 28.2137619 \\
\hline $\mathrm{H}$ & 4.7691987 & 5.2925483 & 21.8412544 \\
\hline $\mathrm{H}$ & 9.0264595 & 5.3349949 & 21.9694442 \\
\hline 0 & 6.8440524 & 6.3511802 & 18.2585012 \\
\hline 0 & 1.9675091 & 9.2628300 & 26.9188536 \\
\hline $\mathrm{H}$ & 2.2009747 & 7.1025338 & 23.3534338 \\
\hline $\mathrm{H}$ & 0.1571260 & 10.2409660 & 23.3849428 \\
\hline $\mathrm{O}$ & 4.9312107 & 7.8580572 & 17.5951811 \\
\hline 0 & 4.5343786 & 8.2612993 & 27.7378431 \\
\hline $\mathrm{O}$ & 4.4595640 & 7.8552084 & 22.6275386 \\
\hline $\mathrm{O}$ & 2.3425231 & 11.6444433 & 27.6726372 \\
\hline $\mathrm{O}$ & 8.9926627 & 8.1326436 & 17.6177380 \\
\hline 0 & 1.8472669 & 12.1707885 & 22.6348611 \\
\hline 0 & 4.4239460 & 10.6213830 & 17.2018721 \\
\hline 0 & 6.8625398 & 9.0329636 & 28.1075667 \\
\hline $\mathrm{O}$ & 6.9878098 & 6.7058393 & 22.0984193 \\
\hline $\mathrm{H}$ & 9.3785128 & 5.5922140 & 18.2062534 \\
\hline $\mathrm{H}$ & 4.5260460 & 5.5159890 & 18.1865399 \\
\hline $\mathrm{H}$ & 0.0974998 & 10.8434161 & 27.1410762 \\
\hline $\mathrm{H}$ & 2.5757142 & 6.7062855 & 27.0004000 \\
\hline 0 & 2.6944682 & 9.5104269 & 23.1927785 \\
\hline $\mathrm{H}$ & 5.2572839 & 9.0000507 & 15.2527302 \\
\hline $\mathrm{O}$ & 5.1625841 & 7.1564360 & 19.9683470 \\
\hline $\mathrm{O}$ & 3.7500975 & 8.1003446 & 25.0111178 \\
\hline $\mathrm{H}$ & 8.6838253 & 9.0201658 & 30.0364071 \\
\hline 0 & 8.6897760 & 7.1413570 & 20.2814121 \\
\hline 0 & 1.7348884 & 11.1861573 & 25.2925804 \\
\hline $\mathrm{H}$ & 5.2362856 & 8.9631878 & 29.9761508 \\
\hline $\mathrm{H}$ & 3.4828445 & 11.9345792 & 15.3083020 \\
\hline Al & 3.2571633 & 16.0147502 & 21.6571893 \\
\hline $\mathrm{P}$ & 3.1924786 & 16.0494118 & 18.4954046 \\
\hline Al & 3.8051882 & 11.9421067 & 28.5633803 \\
\hline $\mathrm{P}$ & 3.8302999 & 11.9668825 & 16.7558350 \\
\hline Al & 1.6492659 & 13.2917947 & 18.6080115 \\
\hline $\mathrm{P}$ & 1.6772419 & 13.3669147 & 21.6832032 \\
\hline $\mathrm{O}$ & 4.8913892 & 13.0611440 & 17.0294350 \\
\hline $\mathrm{H}$ & 0.3176415 & 13.9733923 & 21.7113504 \\
\hline $\mathrm{H}$ & 2.2834005 & 17.1082170 & 21.9278127 \\
\hline 0 & 2.1337609 & 14.9550800 & 18.2703959 \\
\hline 0 & 4.4105649 & 15.8307463 & 17.5866002 \\
\hline 0 & 4.7277721 & 16.2811918 & 22.5556290 \\
\hline 0 & 2.5596784 & 12.2251264 & 17.5599479 \\
\hline 0 & 4.4373802 & 13.4983311 & 28.0971147 \\
\hline 0 & 2.7091130 & 14.4352128 & 22.1193471 \\
\hline $\mathrm{H}$ & 2.6032632 & 17.3735169 & 18.1538035 \\
\hline $\mathrm{H}$ & 0.2045842 & 13.1196303 & 18.2911918 \\
\hline 0 & 3.6821834 & 16.0388155 & 19.9544979 \\
\hline $\mathrm{H}$ & 3.5213856 & 11.9348319 & 30.0250655 \\
\hline 0 & 2.0496006 & 12.8712181 & 20.2561734 \\
\hline Al & 10.1349032 & 12.0402102 & 16.5781366 \\
\hline & & & \\
\hline
\end{tabular}




\begin{tabular}{|c|c|c|c|}
\hline Al & 12.2640090 & 10.6256384 & 26.6975617 \\
\hline $\mathrm{P}$ & 12.3051825 & 10.5861167 & 23.5055595 \\
\hline Al & 15.4096422 & 10.7663829 & 23.5935172 \\
\hline Al & 10.5894936 & 7.9768596 & 23.6459329 \\
\hline $\mathrm{P}$ & 10.6810505 & 7.9438645 & 26.7686231 \\
\hline $\mathrm{P}$ & 15.4039932 & 10.7312041 & 26.7469290 \\
\hline 0 & 9.0209485 & 10.8570144 & 28.1235562 \\
\hline 0 & 11.7507671 & 8.9966052 & 27.1208062 \\
\hline $\mathrm{H}$ & 15.8274168 & 9.3133626 & 26.9129370 \\
\hline $\mathrm{H}$ & 11.4899986 & 6.7995082 & 23.5043170 \\
\hline 0 & 13.7841562 & 10.1463852 & 23.3473970 \\
\hline 0 & 11.3016310 & 11.7950572 & 27.5643777 \\
\hline 0 & 9.4958905 & 8.0462725 & 27.7386289 \\
\hline $\mathrm{H}$ & 16.1937215 & 11.6177259 & 27.6455550 \\
\hline 0 & 9.1718999 & 7.7349958 & 22.6483389 \\
\hline 0 & 15.7222656 & 12.1707885 & 22.6348611 \\
\hline 0 & 9.4367968 & 10.5305204 & 17.1367593 \\
\hline 0 & 13.9303703 & 10.8467184 & 27.1526758 \\
\hline $\mathrm{H}$ & 11.2748965 & 6.5857076 & 26.9096105 \\
\hline $\mathrm{H}$ & 16.3931673 & 9.7013390 & 23.2536930 \\
\hline 0 & 11.4113351 & 9.3928783 & 23.0330233 \\
\hline $\mathrm{H}$ & 10.3732640 & 12.0020240 & 15.1088352 \\
\hline 0 & 12.0185759 & 10.8569898 & 24.9958623 \\
\hline 0 & 15.6098871 & 11.1861573 & 25.2925804 \\
\hline 0 & 10.1570178 & 8.1665311 & 25.3330649 \\
\hline $\mathrm{H}$ & 10.4011325 & 11.9955394 & 29.8367746 \\
\hline $\mathrm{H}$ & 8.6826069 & 15.0234641 & 15.2251706 \\
\hline Al & 5.3646118 & 14.7132414 & 16.6564580 \\
\hline $\mathrm{P}$ & 5.3105099 & 14.6955062 & 28.4862438 \\
\hline Al & 12.2375473 & 18.6868756 & 21.6520112 \\
\hline $\mathrm{Zn}$ & 12.3536707 & 13.3491752 & 21.6411668 \\
\hline Al & 17.1321620 & 16.0147502 & 21.6571893 \\
\hline $\mathrm{P}$ & 17.0674774 & 16.0494118 & 18.4954046 \\
\hline$P$ & 12.3266883 & 13.2028032 & 18.4502166 \\
\hline $\mathrm{P}$ & 12.3012805 & 18.7201137 & 18.5089077 \\
\hline Al & 5.3917082 & 17.2041869 & 26.6293303 \\
\hline $\mathrm{P}$ & 5.3771607 & 17.2513891 & 23.5449362 \\
\hline Al & 8.4689108 & 14.7166997 & 28.4861722 \\
\hline $\mathrm{P}$ & 8.5178406 & 14.7298306 & 16.6756023 \\
\hline Al & 15.5242646 & 13.2917947 & 18.6080115 \\
\hline Al & 15.4575883 & 18.7666091 & 18.5785230 \\
\hline Al & 10.7461857 & 15.9401651 & 18.5388523 \\
\hline $\mathrm{P}$ & 10.5562972 & 15.9655073 & 21.6816074 \\
\hline $\mathrm{P}$ & 15.4131768 & 18.7161586 & 21.7450239 \\
\hline $\mathrm{P}$ & 15.5522407 & 13.3669147 & 21.6832032 \\
\hline Al & 8.5258279 & 17.4426248 & 23.5483630 \\
\hline $\mathrm{P}$ & 8.5425420 & 17.2920937 & 26.6863818 \\
\hline 0 & 8.9439629 & 13.2750083 & 16.9848173 \\
\hline 0 & 6.7818888 & 14.3516524 & 28.1872995 \\
\hline 0 & 11.6190418 & 17.0810707 & 21.8725031 \\
\hline 0 & 14.1636905 & 13.9863060 & 21.7119497 \\
\hline 0 & 15.9820606 & 17.3062328 & 21.9768198 \\
\hline 0 & 16.0087597 & 14.9550800 & 18.2703959 \\
\hline 0 & 11.9354411 & 14.6897644 & 18.2612418 \\
\hline 0 & 13.7815518 & 18.3672815 & 18.2585012 \\
\hline 0 & 7.0615520 & 17.6434316 & 26.9505552 \\
\hline $\mathrm{H}$ & 9.0160305 & 18.8381307 & 23.3769416 \\
\hline $\mathrm{H}$ & 4.7183337 & 18.5852664 & 23.4829768 \\
\hline $\mathrm{H}$ & 18.2487475 & 15.8373554 & 17.6140684 \\
\hline $\mathrm{H}$ & 11.8814600 & 19.8401433 & 17.6221129 \\
\hline 0 & 11.6529317 & 12.3488810 & 17.3524687 \\
\hline 0 & 4.8643229 & 15.9085235 & 27.6664837 \\
\hline $\mathrm{H}$ & 11.5222347 & 19.6949147 & 22.4822556 \\
\hline 0 & 11.9300589 & 11.7690039 & 22.6578836 \\
\hline $\mathrm{H}$ & 18.3878811 & 16.2422586 & 22.4243463 \\
\hline 0 & 8.9694499 & 16.1064819 & 27.5622944 \\
\hline $\mathrm{H}$ & 16.2985707 & 12.3845930 & 17.7166330 \\
\hline 0 & 9.3647598 & 15.7165811 & 17.4803459 \\
\hline $\mathrm{H}$ & 15.8600601 & 19.9437179 & 17.7602616 \\
\hline 0 & 9.2726943 & 16.3542074 & 22.4390518 \\
\hline 0 & 7.0478625 & 14.8881497 & 17.1006564 \\
\hline 0 & 9.4025039 & 13.3296888 & 27.9980198 \\
\hline 0 & 13.9253092 & 18.7219407 & 22.0984193 \\
\hline 0 & 11.0497575 & 14.6386456 & 22.2054248 \\
\hline 0 & 16.5841118 & 14.4352128 & 22.1193471 \\
\hline 0 & 16.4605868 & 17.4132371 & 18.1435562 \\
\hline 0 & 13.8427371 & 13.0914051 & 18.2392514 \\
\hline 0 & 11.4413989 & 17.5006835 & 18.1780177 \\
\hline $\mathrm{H}$ & 4.5009034 & 18.3722089 & 26.8728709 \\
\hline $\mathrm{H}$ & 9.3864959 & 18.4647891 & 27.0464485 \\
\hline
\end{tabular}




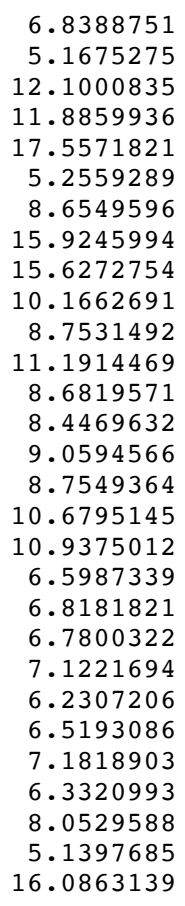

17.4272451

14.9857430

19.1725374

12.6739163

16.0388155

16.6675538

14.9853257

12.8712181

19.1574584

15.8952804

16.9170670

11.0790822

11.0019299

10.0440547

11.8118682

11.0468501

10.2438911

9.9945686

11.3654351

12.5364303

12.5104923

13.8432791

10.4861137

11.3535304

13.8007416

14.5630278

14.2756503

15.0211549

19.7167807

8.9874167

9.3370908

9.2848529

6.7338208

6.7435503

7.9401778

7.9995377

9.2146411

9.2747692

6.7342364

6.6756081

10.7260062

10.7135170

9.6936201

10.9336925

5.3523026

5.2958444

6.3491855

9.0512835

6.9621094

10.2468073

8.1266637

8.1604144

7.7381183

11.7719052

7.8942280

11.8836529

10.5344197

9.0467077

6.7637037

5.5650772

5.5791989

10.8049224

6.6339358

9.5704307

9.0197529

7.1915418

7.9250117

8.9473096

7.1752032

11.1946469

9.0509145

12.0165265

15.9075737

15.9706565

12.0193954

12.0457893

13.2810554
23.1477791

15.2059336

19.9683470

19.8198493

19.9544979

24.9660192

29.9388753

20.2561734

20.2814121

20.1800218

25.2082979

20.1078523

20.4464012

20.9048693

21.0635093

19.3664553

20.3005785

21.2183361

20.6762378

20.0053833

18.9096594

20.6263705

20.1439871

21.7662640

21.7215282

20.3452814

20.2222142

29.9291301

22.6183867

15.2268908

16.7774344

28.5880305

21.7159718

18.5656905

26.7308557

23.6048937

28.4960105

16.6819222

18.5333527

21.6786506

23.5346815

26.6653639

17.0547322

28.2147535

21.8968199

21.8773414

18.2572447

26.8802660

23.3482083

23.3389069

17.6124176

27.7103416

22.6040369

27.6940658

17.6269546

22.5980643

17.2009911

28.1258574

22.1223599

18.2334782

18.1839917

27.0837216

27.0664883

23.2268269

15.3369834

20.2488611

25.2928430

29.9454185

20.0039273

24.9960039

30.0522999

15.2347357

21.7104343

18.5637641

28.5079523

16.6916969

18.4993412 


\begin{tabular}{|c|c|c|c|}
\hline Al & 1.5028581 & 13.2716672 & 21.6257206 \\
\hline 0 & 4.9951242 & 13.2998556 & 17.0452684 \\
\hline $\mathrm{H}$ & 0.0672574 & 13.6505757 & 21.7379688 \\
\hline $\mathrm{H}$ & 2.2699215 & 17.0342924 & 21.9042871 \\
\hline 0 & 2.0159507 & 14.7386836 & 18.2079944 \\
\hline 0 & 4.6370361 & 15.7433495 & 17.5870816 \\
\hline 0 & 4.4686691 & 16.1099973 & 22.5866457 \\
\hline 0 & 2.3315597 & 12.3216951 & 17.5589472 \\
\hline 0 & 4.3786695 & 13.3834612 & 28.1038388 \\
\hline 0 & 2.5626558 & 14.5956525 & 22.1159420 \\
\hline $\mathrm{H}$ & 2.6421748 & 17.3192871 & 18.2743390 \\
\hline $\mathrm{H}$ & 0.1253495 & 13.1581005 & 18.2128604 \\
\hline 0 & 3.6953231 & 15.8631836 & 20.2415029 \\
\hline $\mathrm{H}$ & 3.4598349 & 12.0117664 & 29.9555159 \\
\hline 0 & 1.9296511 & 12.8974716 & 19.9455863 \\
\hline $\mathrm{P}$ & 10.1128641 & 11.9838883 & 16.6692900 \\
\hline Al & 10.0598030 & 11.9351933 & 28.4754055 \\
\hline $\mathrm{P}$ & 12.3417351 & 10.6602055 & 26.7822251 \\
\hline Al & 12.3704521 & 10.6872018 & 23.5776948 \\
\hline $\mathrm{P}$ & 15.5054658 & 10.7260062 & 23.5346815 \\
\hline $\mathrm{P}$ & 10.6579028 & 8.0422517 & 23.5454217 \\
\hline Al & 10.6975598 & 8.0211588 & 26.6929840 \\
\hline Al & 15.4855507 & 10.7135170 & 26.6653639 \\
\hline 0 & 8.9091237 & 10.6509682 & 28.1443109 \\
\hline 0 & 11.8908850 & 9.2247408 & 27.1358540 \\
\hline $\mathrm{H}$ & 15.9222764 & 9.3017529 & 26.8478840 \\
\hline $\mathrm{H}$ & 11.5748182 & 6.8774220 & 23.4055693 \\
\hline 0 & 14.0591721 & 10.2295872 & 23.3318717 \\
\hline 0 & 11.5376260 & 11.682 & 27.5971378 \\
\hline 0 & 9.2786363 & 8.1904586 & 27.6913997 \\
\hline $\mathrm{H}$ & 16.2777649 & 11.6175983 & 27.5440870 \\
\hline 0 & 9.4088243 & 7.8446960 & 22.6702249 \\
\hline 0 & 15.8467527 & 11.8836529 & 22.5980643 \\
\hline 0 & 9.5265305 & 10.6395382 & 17.1390947 \\
\hline $\mathrm{O}$ & 13.8180898 & 10.8203929 & 27.1545289 \\
\hline $\mathrm{H}$ & 11.2693821 & 6.6660150 & 26.9247707 \\
\hline $\mathrm{H}$ & 16.4411178 & 9.6067371 & 23.2364992 \\
\hline $\mathrm{O}$ & 11.3749576 & 9.3080910 & 23.0419440 \\
\hline $\mathrm{H}$ & 10.3953935 & 11.9433813 & 15.2079013 \\
\hline 0 & 12.1110729 & 10.92 & 25.2930392 \\
\hline 0 & 15.6968069 & 11.1946469 & 24.9960039 \\
\hline 0 & 10.2259326 & 8.2135799 & 25.0108973 \\
\hline $\mathrm{H}$ & 10.3533982 & 11.9412128 & 29.9351611 \\
\hline $\mathrm{H}$ & 8.7424912 & 14.9792660 & 15.1471102 \\
\hline $\mathrm{P}$ & 5.4335633 & 14.7499315 & 16.7358710 \\
\hline Al & 5.3823687 & 14.7297897 & 28.5609796 \\
\hline $\mathrm{P}$ & 12.3372639 & 18.7499222 & 21.7159718 \\
\hline $\mathrm{Si}$ & 12.1791348 & 13.2500122 & 21.6792519 \\
\hline $\mathrm{P}$ & 17.0988839 & 15.9075737 & 21.7104343 \\
\hline Al & 17.0780203 & 15.9706565 & 18.5637641 \\
\hline Al & 12.2588985 & 13.2649276 & 18.5784291 \\
\hline Al & 12.3749377 & 18.7596516 & 18.5656905 \\
\hline $\mathrm{P}$ & 5.3249931 & 17.2492740 & 26.7099275 \\
\hline Al & 5.3077136 & 17.2492260 & 23.5970999 \\
\hline $\mathrm{P}$ & 8.5337711 & 14.6771400 & 28.4310608 \\
\hline Al & 8.5882083 & 14.7261966 & 16.6063131 \\
\hline $\mathrm{P}$ & 15.4563466 & 13.2810554 & 18.4993412 \\
\hline$P$ & 15.5255872 & 18.7503378 & 18.5333527 \\
\hline $\mathrm{P}$ & 10.7238454 & 16.0655814 & 18.4795904 \\
\hline Al & 10.6334305 & 16.0340398 & 21.6098040 \\
\hline Al & 15.4969766 & 18.6917094 & 21.6786506 \\
\hline Al & 15.3778568 & 13.2716672 & 21.6257206 \\
\hline $\mathrm{P}$ & 8.4603437 & 17.3483843 & 23.4743329 \\
\hline Al & 8.4731955 & 17.2563248 & 26.6274320 \\
\hline 0 & 9.0619602 & 13.0757702 & 16.9917253 \\
\hline 0 & 7.0489042 & 14.3327970 & 28.2016612 \\
\hline 0 & 11.7975364 & 17.3301570 & 21.9018266 \\
\hline 0 & 13.7354508 & 13.7051593 & 21.7541387 \\
\hline 0 & 16.1099947 & 17.0755426 & 21.9113842 \\
\hline 0 & 15.8909494 & 14.7386836 & 18.2079944 \\
\hline 0 & 11.7635162 & 14.9422937 & 18.3327444 \\
\hline 0 & 14.0589459 & 18.3652869 & 18.2572447 \\
\hline 0 & 6.7926184 & 17.6496462 & 26.9616837 \\
\hline $\mathrm{H}$ & 8.9450257 & 18.7465266 & 23.3087969 \\
\hline $\mathrm{H}$ & 4.7586770 & 18.6231962 & 23.4301110 \\
\hline $\mathrm{H}$ & 18.2982663 & 15.7772342 & 17.7326756 \\
\hline $\mathrm{H}$ & 11.9714244 & 19.9397864 & 17.7523151 \\
\hline 0 & 11.4176489 & 12.2504741 & 17.4099297 \\
\hline $\mathrm{O}$ & 4.8900779 & 16.1385582 & 27.6703731 \\
\hline $\mathrm{H}$ & 11.6109540 & 19.7236702 & 22.5770231 \\
\hline
\end{tabular}




\begin{tabular}{|c|c|c|c|}
\hline 0 & 11.8452935 & 12.0200737 & 22.6766512 \\
\hline $\mathrm{H}$ & 18.3058567 & 16.1038486 & 22.5600302 \\
\hline $\mathrm{O}$ & 8.9536843 & 15.8750891 & 27.5765893 \\
\hline $\mathrm{H}$ & 16.1823367 & 12.3526695 & 17.5893091 \\
\hline $\mathrm{O}$ & 9.5581004 & 15.8553430 & 17.4982836 \\
\hline $\mathrm{H}$ & 15.9423294 & 19.8767392 & 17.6532014 \\
\hline $\mathrm{O}$ & 9.1857488 & 16.3948869 & 22.5321006 \\
\hline $\mathrm{O}$ & 6.9179018 & 14.8879778 & 17.1047172 \\
\hline 0 & 9.3798612 & 13.4708427 & 28.0128595 \\
\hline 0 & 13.8181085 & 18.7798051 & 22.1223599 \\
\hline 0 & 11.2119080 & 14.4962129 & 22.0172044 \\
\hline $\mathrm{O}$ & 16.4376546 & 14.5956525 & 22.1159420 \\
\hline 0 & 16.4218064 & 17.5486102 & 18.2251248 \\
\hline $\mathrm{O}$ & 13.9635326 & 13.1549915 & 18.2056166 \\
\hline 0 & 11.3892017 & 17.4029780 & 18.1209445 \\
\hline $\mathrm{H}$ & 4.4490974 & 18.4278900 & 26.9564867 \\
\hline $\mathrm{H}$ & 9.3242567 & 18.4162629 & 27.0113056 \\
\hline $\mathrm{O}$ & 6.9712034 & 17.3062558 & 23.1149512 \\
\hline $\mathrm{H}$ & 5.2148262 & 15.0610034 & 15.2962499 \\
\hline $\mathrm{O}$ & 12.1872255 & 19.2076432 & 20.2488611 \\
\hline $\mathrm{O}$ & 11.8476599 & 12.6862233 & 20.1523975 \\
\hline $\mathrm{O}$ & 17.5703218 & 15.8631836 & 20.2415029 \\
\hline 0 & 5.1546657 & 16.7409044 & 25.2653628 \\
\hline $\mathrm{H}$ & 8.7612827 & 15.0114169 & 29.8641058 \\
\hline $\mathrm{O}$ & 15.8046498 & 12.8974716 & 19.9455863 \\
\hline 0 & 15.6887130 & 19.1913046 & 20.0039273 \\
\hline $\mathrm{O}$ & 10.1496143 & 16.1199797 & 19.9045601 \\
\hline $\mathrm{O}$ & 8.6718404 & 16.8849191 & 24.9302786 \\
\hline $\mathrm{H}$ & 11.1568240 & 11.1233912 & 20.2572197 \\
\hline $\mathrm{C}$ & 8.6321580 & 11.0088418 & 20.4249093 \\
\hline $\mathrm{H}$ & 8.3850037 & 10.0029661 & 20.7553781 \\
\hline $\mathrm{H}$ & 8.9904374 & 11.7394354 & 21.1441339 \\
\hline $\mathrm{H}$ & 8.7775094 & 11.1664572 & 19.3622124 \\
\hline $\mathrm{O}$ & 10.6556411 & 10.2529433 & 20.3176972 \\
\hline $\mathrm{H}$ & 10.8593102 & 9.9066994 & 21.2149993 \\
\hline C & 6.5655728 & 11.3613049 & 20.6380835 \\
\hline C & 6.8076898 & 12.5388072 & 19.9843278 \\
\hline $\mathrm{H}$ & 6.7702245 & 12.5298345 & 18.8885278 \\
\hline C & 7.1286075 & 13.8330316 & 20.6239566 \\
\hline $\mathrm{H}$ & 6.1815290 & 10.4979313 & 20.0912313 \\
\hline $\mathrm{H}$ & 6.4799682 & 11.3343048 & 21.7273368 \\
\hline $\mathrm{H}$ & 7.2277777 & 13.7661596 & 21.7151619 \\
\hline $\mathrm{H}$ & 6.3194501 & 14.5489631 & 20.3894636 \\
\hline $\mathrm{H}$ & 8.0397552 & 14.2807492 & 20.1939651 \\
\hline $\mathrm{H}$ & 5.2340792 & 15.0197530 & 30.0139257 \\
\hline & 16.2186045 & 19.6849977 & 22.5211186 \\
\hline \multirow{2}{*}{\multicolumn{4}{|c|}{$\begin{array}{l}\text { Mg } 3 \\
174\end{array}$}} \\
\hline & & & \\
\hline $\mathrm{H}$ & 8.7126550 & 9.0022522 & 15.3287207 \\
\hline Al & 5.4190689 & 9.2887236 & 16.7126905 \\
\hline $\mathrm{P}$ & 5.4027713 & 9.2519749 & 28.5254082 \\
\hline Al & 5.2944911 & 6.6758509 & 21.6490860 \\
\hline $\mathrm{P}$ & 5.3820734 & 6.7047236 & 18.4924655 \\
\hline Al & 3.1882592 & 8.0177703 & 26.6661861 \\
\hline $\mathrm{P}$ & 3.2785404 & 8.1204920 & 23.5485425 \\
\hline Al & 8.5285977 & 9.2319317 & 28.5756481 \\
\hline $\mathrm{P}$ & 8.5627842 & 9.3411554 & 16.7708732 \\
\hline Al & 8.5366007 & 6.7717426 & 18.5889228 \\
\hline $\mathrm{P}$ & 8.4730527 & 6.7074241 & 21.7481186 \\
\hline Al & 1.5453838 & 10.7696684 & 23.6007373 \\
\hline $\mathrm{P}$ & 1.5296939 & 10.7358087 & 26.7436832 \\
\hline $\mathrm{O}$ & 7.0922494 & 9.7056619 & 17.0881909 \\
\hline $\mathrm{O}$ & 5.0049643 & 10.7077047 & 28.2039290 \\
\hline $\mathrm{H}$ & 4.7231370 & 5.3185465 & 21.8690856 \\
\hline $\mathrm{H}$ & 9.0416198 & 5.3465376 & 21.9526666 \\
\hline 0 & 6.8669786 & 6.3689551 & 18.2486297 \\
\hline $\mathrm{O}$ & 1.9831932 & 9.2683585 & 26.8773873 \\
\hline $\mathrm{H}$ & 2.2246260 & 7.0938065 & 23.3198468 \\
\hline $\mathrm{H}$ & 0.1727798 & 10.2302011 & 23.3956673 \\
\hline $\mathrm{O}$ & 4.9448054 & 7.8711006 & 17.5967880 \\
\hline $\mathrm{O}$ & 4.5318148 & 8.2655638 & 27.7456422 \\
\hline $\mathrm{O}$ & 4.4777511 & 7.8844653 & 22.6173301 \\
\hline $\mathrm{O}$ & 2.3426859 & 11.6372253 & 27.6807863 \\
\hline $\mathrm{O}$ & 9.0088147 & 8.1512229 & 17.6250116 \\
\hline 0 & 1.9129148 & 12.1389488 & 22.6096216 \\
\hline $\mathrm{O}$ & 4.4285391 & 10.6354130 & 17.2139129 \\
\hline 0 & 6.8619460 & 9.0328521 & 28.1134461 \\
\hline $\mathrm{O}$ & 6.9837365 & 6.6841814 & 22.0951370 \\
\hline $\mathrm{H}$ & 9.4046189 & 5.6140404 & 18.2376530 \\
\hline
\end{tabular}

22.6766512

22.5600302

17.5893091

17.4982836

22.5321006

17.1047172

22.1223599

22.0172044

18.2056166

9445

27.0113056

20.2488611

.1523975

25.2653628

.8641058

20.0039273

.9045601

2786

20.4249093

20.7553781

21.1441339

21.2149993

6380835

18.8885278

20.6239566

20.0912313
21.7273368

21.7151619

20.3894636

30.0139257

22.5211186 Mg 3 


\begin{tabular}{|c|c|c|c|}
\hline $\mathrm{H}$ & 4.5620576 & 5.5135424 & 18.1378075 \\
\hline $\mathrm{H}$ & 0.1024762 & 10.8252414 & 27.1586193 \\
\hline $\mathrm{H}$ & 2.5714277 & 6.7086360 & 27.0166240 \\
\hline 0 & 2.7066965 & 9.5072031 & 23.2396415 \\
\hline $\mathrm{H}$ & 5.2559171 & 9.0204581 & 15.2571714 \\
\hline 0 & 5.1657113 & 7.1307199 & 19.9573850 \\
\hline 0 & 3.7697166 & 8.0454161 & 25.0106120 \\
\hline $\mathrm{H}$ & 8.6889026 & 9.0279191 & 30.0418683 \\
\hline 0 & 8.6846034 & 7.1757370 & 20.2918895 \\
\hline 0 & 1.7128206 & 11.2245630 & 25.2968487 \\
\hline $\mathrm{H}$ & 5.2338157 & 8.9838029 & 29.9802822 \\
\hline $\mathrm{H}$ & 3.5020245 & 11.9406079 & 15.3094578 \\
\hline Al & 3.2595949 & 16.0101215 & 21.6610882 \\
\hline $\mathrm{P}$ & 3.2060595 & 16.0597039 & 18.5040659 \\
\hline Al & 3.8080870 & 11.9440485 & 28.5626045 \\
\hline $\mathrm{P}$ & 3.8374195 & 11.9800728 & 16.7596555 \\
\hline Al & 1.6514778 & 13.3148880 & 18.5991152 \\
\hline $\mathrm{P}$ & 1.6813353 & 13.3473446 & 21.6811616 \\
\hline 0 & 4.8976532 & 13.0738816 & 17.0386293 \\
\hline $\mathrm{H}$ & 0.2845609 & 13.8615225 & 21.7231496 \\
\hline $\mathrm{H}$ & 2.2970654 & 17.1178014 & 21.9134820 \\
\hline 0 & 2.1366272 & 14.9796695 & 18.2615790 \\
\hline $\mathrm{O}$ & 4.4189067 & 15.8466430 & 17.5864766 \\
\hline 0 & 4.7294505 & 16.2724218 & 22.5648261 \\
\hline 0 & 2.5593032 & 12.2447643 & 17.5497933 \\
\hline 0 & 4.4276836 & 13.5032317 & 28.0919820 \\
\hline 0 & 2.6720728 & 14.4495357 & 22.1332595 \\
\hline $\mathrm{H}$ & 2.6299900 & 17.3959210 & 18.1881730 \\
\hline $\mathrm{H}$ & 0.2069752 & 13.1597138 & 18.2728427 \\
\hline 0 & 3.7003682 & 16.0168711 & 19.9613449 \\
\hline $\mathrm{H}$ & 3.5383661 & 11.9400663 & 30.0269662 \\
\hline 0 & 2.0725618 & 12.8977568 & 20.2422181 \\
\hline Al & 10.1343243 & 12.0579133 & 16.5759374 \\
\hline$P$ & 10.0330566 & 11.9895567 & 28.3903603 \\
\hline Al & 12.2686822 & 10.6027626 & 26.7224756 \\
\hline $\mathrm{P}$ & 12.3167643 & 10.5625467 & 23.5250654 \\
\hline Al & 15.4203825 & 10.7696684 & 23.6007373 \\
\hline Al & 10.5772496 & 7.9795239 & 23.6584516 \\
\hline $\mathrm{P}$ & 10.6734506 & 7.9410969 & 26.7797460 \\
\hline$P$ & 15.4046927 & 10.7358087 & 26.7436832 \\
\hline $\mathrm{O}$ & 9.0262155 & 10.8515590 & 28.1223245 \\
\hline 0 & 11.7465009 & 8.9808257 & 27.1614005 \\
\hline $\mathrm{H}$ & 15.8426798 & 9.3185532 & 26.8728139 \\
\hline $\mathrm{H}$ & 11.4544567 & 6.7834913 & 23.5275531 \\
\hline 0 & 13.7979594 & 10.1320160 & 23.3583438 \\
\hline 0 & 11.3068854 & 11.7900060 & 27.5672219 \\
\hline 0 & 9.4842567 & 8.0327569 & 27.7460378 \\
\hline $\mathrm{H}$ & 16.1940846 & 11.6110585 & 27.6535836 \\
\hline 0 & 9.1525783 & 7.7399559 & 22.6683812 \\
\hline 0 & 15.7879135 & 12.1389488 & 22.6096216 \\
\hline 0 & 9.4430358 & 10.5466564 & 17.1379275 \\
\hline 0 & 13.9351203 & 10.8278955 & 27.1709331 \\
\hline $\mathrm{H}$ & 11.2585266 & 6.5767634 & 26.8955077 \\
\hline $\mathrm{H}$ & 16.4068272 & 9.6973025 & 23.2940146 \\
\hline 0 & 11.4231234 & 9.3773002 & 23.0273944 \\
\hline $\mathrm{H}$ & 10.3688383 & 12.0143685 & 15.1061661 \\
\hline 0 & 12.0237996 & 10.8014102 & 25.0180165 \\
\hline 0 & 15.5878193 & 11.2245630 & 25.2968487 \\
\hline 0 & 10.1585741 & 8.1955550 & 25.3459246 \\
\hline $\mathrm{H}$ & 10.3962803 & 12.0066177 & 29.8342779 \\
\hline $\mathrm{H}$ & 8.6750014 & 15.0169712 & 15.2036117 \\
\hline Al & 5.3690887 & 14.7246089 & 16.6578468 \\
\hline $\mathrm{P}$ & 5.3066586 & 14.6951208 & 28.4833972 \\
\hline Al & 12.2319905 & 18.6919522 & 21.6490860 \\
\hline $\mathrm{Mg}$ & 12.3127355 & 13.3039463 & 21.6438895 \\
\hline $\mathrm{Al}$ & 17.1345936 & 16.0101215 & 21.6610882 \\
\hline$P$ & 17.0810582 & 16.0597039 & 18.5040659 \\
\hline$P$ & 12.3282712 & 13.2043063 & 18.4658049 \\
\hline $\mathrm{P}$ & 12.3195727 & 18.7208249 & 18.4924655 \\
\hline Al & 5.3893057 & 17.2035120 & 26.6324465 \\
\hline $\mathrm{P}$ & 5.3692969 & 17.2504807 & 23.5533192 \\
\hline Al & 8.4630760 & 14.7098038 & 28.4669720 \\
\hline $\mathrm{P}$ & 8.5181272 & 14.7409693 & 16.6583743 \\
\hline Al & 15.5264765 & 13.3148880 & 18.5991152 \\
\hline Al & 15.4741000 & 18.7878440 & 18.5889228 \\
\hline Al & 10.7292823 & 15.9726547 & 18.5305856 \\
\hline $\mathrm{P}$ & 10.5097205 & 16.0040323 & 21.6451557 \\
\hline $\mathrm{P}$ & 15.4105521 & 18.7235255 & 21.7481186 \\
\hline$P$ & 15.5563340 & 13.3473446 & 21.6811616 \\
\hline Al & 8.5134126 & 17.4513485 & 23.5414333 \\
\hline
\end{tabular}




\begin{tabular}{|c|c|c|c|}
\hline$P$ & 8.5327734 & 17.3019785 & 26.6910505 \\
\hline 0 & 8.9387783 & 13.2874659 & 16.9819312 \\
\hline $\mathrm{O}$ & 6.7748542 & 14.3465400 & 28.1729092 \\
\hline $\mathrm{O}$ & 11.5667685 & 17.1116561 & 21.9052293 \\
\hline 0 & 14.1369686 & 13.8698387 & 21.7238287 \\
\hline 0 & 15.9974627 & 17.3187328 & 21.9592659 \\
\hline $\mathrm{O}$ & 16.0116259 & 14.9796695 & 18.2615790 \\
\hline $\mathrm{O}$ & 11.8992403 & 14.6883048 & 18.3453628 \\
\hline $\mathrm{O}$ & 13.8044779 & 18.3850565 & 18.2486297 \\
\hline 0 & 7.0537182 & 17.6522102 & 26.9680426 \\
\hline $\mathrm{H}$ & 9.0346085 & 18.8324302 & 23.3462697 \\
\hline $\mathrm{H}$ & 4.6784921 & 18.5687457 & 23.5076387 \\
\hline $\mathrm{H}$ & 18.2570259 & 15.8531216 & 17.6143781 \\
\hline $\mathrm{H}$ & 11.8951971 & 19.8528128 & 17.6231960 \\
\hline $\mathrm{O}$ & 11.6496484 & 12.3791036 & 17.3492499 \\
\hline $\mathrm{O}$ & 4.8587988 & 15.9131558 & 27.6726937 \\
\hline $\mathrm{H}$ & 11.5373801 & 19.7198390 & 22.4725456 \\
\hline $\mathrm{O}$ & 11.9606053 & 11.7696302 & 22.7070048 \\
\hline $\mathrm{H}$ & 18.3886094 & 16.2339045 & 22.4321175 \\
\hline $\mathrm{O}$ & 8.9621103 & 16.1020256 & 27.5465116 \\
\hline $\mathrm{H}$ & 16.2979133 & 12.4055361 & 17.7074399 \\
\hline $\mathrm{O}$ & 9.3776226 & 15.7336849 & 17.4405821 \\
\hline $\mathrm{H}$ & 15.8763745 & 19.9630096 & 17.7677764 \\
\hline 0 & 9.2395074 & 16.3206321 & 22.4589992 \\
\hline $\mathrm{O}$ & 7.0528079 & 14.9105055 & 17.0936256 \\
\hline $\mathrm{O}$ & 9.4010269 & 13.3239982 & 27.9812171 \\
\hline 0 & 13.9212359 & 18.7002828 & 22.0951370 \\
\hline $\mathrm{O}$ & 11.0395408 & 14.6531136 & 22.0351656 \\
\hline 0 & 16.5470715 & 14.4495357 & 22.1332595 \\
\hline $\mathrm{O}$ & 16.4877487 & 17.4359100 & 18.1787193 \\
\hline $\mathrm{O}$ & 13.8429806 & 13.1340402 & 18.2188608 \\
\hline $\mathrm{O}$ & 11.4781477 & 17.4985440 & 18.1285480 \\
\hline $\mathrm{H}$ & 4.4859453 & 18.3649649 & 26.8606738 \\
\hline $\mathrm{H}$ & 9.3794991 & 18.4680979 & 27.0656728 \\
\hline $\mathrm{O}$ & 6.8235365 & 17.4666197 & 23.1465594 \\
\hline $\mathrm{H}$ & 5.1719356 & 14.9825483 & 15.2046715 \\
\hline $\mathrm{O}$ & 12.1032107 & 19.1468212 & 19.9573850 \\
\hline 0 & 11.9418716 & 12.6304772 & 19.8290931 \\
\hline $\mathrm{O}$ & 17.5753669 & 16.0168711 & 19.9613449 \\
\hline 0 & 5.2742949 & 16.6548222 & 24.9715009 \\
\hline $\mathrm{H}$ & 8.6475000 & 14.9784024 & 29.9198874 \\
\hline $\mathrm{O}$ & 15.9475605 & 12.8977568 & 20.2422181 \\
\hline $\mathrm{O}$ & 15.6221028 & 19.1918383 & 20.2918895 \\
\hline $\mathrm{O}$ & 10.0877936 & 16.0495049 & 20.1493304 \\
\hline $\mathrm{O}$ & 8.7355872 & 16.9472549 & 25.2078279 \\
\hline $\mathrm{H}$ & 11.2038275 & 11.0474737 & 20.1004581 \\
\hline C & 8.6873898 & 10.9797306 & 20.4476407 \\
\hline $\mathrm{H}$ & 8.4444370 & 10.0149247 & 20.8870782 \\
\hline $\mathrm{H}$ & 9.0509674 & 11.7821970 & 21.0824991 \\
\hline $\mathrm{H}$ & 8.7669197 & 11.0453843 & 19.3691197 \\
\hline $\mathrm{O}$ & 10.6784944 & 10.2242681 & 20.3086712 \\
\hline $\mathrm{H}$ & 10.9423624 & 9.9724946 & 21.2249151 \\
\hline C & 6.5921140 & 11.3406603 & 20.6704336 \\
\hline C & 6.8156075 & 12.5118678 & 20.0019175 \\
\hline $\mathrm{H}$ & 6.7818171 & 12.4872074 & 18.9060499 \\
\hline C & 7.1145008 & 13.8189837 & 20.6258617 \\
\hline $\mathrm{H}$ & 6.2279444 & 10.4613437 & 20.1357075 \\
\hline $\mathrm{H}$ & 6.5084843 & 11.3266172 & 21.7601349 \\
\hline $\mathrm{H}$ & 7.1761986 & 13.7745460 & 21.7208708 \\
\hline $\mathrm{H}$ & 6.3199495 & 14.5353558 & 20.3486420 \\
\hline $\mathrm{H}$ & 8.0416217 & 14.2579071 & 20.2208178 \\
\hline $\mathrm{H}$ & 5.1439136 & 15.0156780 & 29.9283463 \\
\hline & 16.0671365 & 19.7211985 & 22.6373127 \\
\hline \multicolumn{4}{|c|}{ Al 3} \\
\hline \multicolumn{4}{|c|}{174} \\
\hline $\mathrm{H}$ & 8.6579037 & 8.8311447 & 15.2918446 \\
\hline $\mathrm{Si}$ & 5.3418387 & 9.2163515 & 16.7337854 \\
\hline $\mathrm{Si}$ & 5.3133577 & 9.1755883 & 28.6702907 \\
\hline $\mathrm{Si}$ & 5.3031783 & 6.7059213 & 21.7060034 \\
\hline $\mathrm{Si}$ & 5.3565272 & 6.7342580 & 18.6149554 \\
\hline $\mathrm{Si}$ & 3.2151084 & 7.9405363 & 26.7261671 \\
\hline $\mathrm{Si}$ & 3.2959863 & 8.0093575 & 23.6636690 \\
\hline $\mathrm{Si}$ & 8.4280035 & 9.1331322 & 28.6527770 \\
\hline $\mathrm{Si}$ & 8.4691344 & 9.2122050 & 16.7188274 \\
\hline $\mathrm{Si}$ & 8.4734429 & 6.7555597 & 18.6384732 \\
\hline $\mathrm{Si}$ & 8.4390478 & 6.6883813 & 21.7356331 \\
\hline $\mathrm{Si}$ & 1.6399666 & 10.6784975 & 23.6534977 \\
\hline $\mathrm{Si}$ & 1.6213630 & 10.6647207 & 26.7257897 \\
\hline 0 & 6.9077031 & 9.6113196 & 16.9962933 \\
\hline
\end{tabular}

26.6910505

16.9819312

21. 9052293

21.7238287

21.9592659

18.3453628

18.2486297

80426

23.3462697

(2)

17.6231960

22.4725456

7070048

27.5465116

.7074399

17.7677764

. 4589992

27.9812171

2.0951370

22.1332595

.1787193

18.1285480

6.8606738

0656728

19.9573850

19.8290931

3449

29.9198874

20.2422181

20.2918895

25.2078279

20.1004581

0.4476407

21.0824991

21.2249151

18.9060499

20.6258617

21.7601349

21.7208708

0.3486420

29.9283463

2.6373127

Al 3 28.6702907

21.7060034

23.6636690

6527770

18.6384732

16.9962933 


\begin{tabular}{|c|c|c|}
\hline 4.8970053 & 10.7245944 & 28.3790726 \\
\hline 4.7509428 & 5.3328739 & 21.8700079 \\
\hline 8.9888422 & 5.3156685 & 21.9102935 \\
\hline 6.9212026 & 6.3495882 & 18.3592250 \\
\hline 2.0990317 & 9.1142617 & 26.8689674 \\
\hline 2.2518877 & 6.9714739 & 23.4405631 \\
\hline 0.2510034 & 10.1703564 & 23.4811770 \\
\hline 4.9114084 & 7.9654316 & 17.6600612 \\
\hline 4.4253726 & 8.1608423 & 27.7796355 \\
\hline 4.5588158 & 7.7810615 & 22.6693025 \\
\hline 2.4558401 & 11.6134202 & 27.7395578 \\
\hline 8.9124524 & 7.9888521 & 17.6814192 \\
\hline 1.9899132 & 11.8881654 & 22.6478751 \\
\hline 4.4414860 & 10.4917943 & 17.1664947 \\
\hline 6.8658835 & 8.9688137 & 28.2686730 \\
\hline 6.8710303 & 6.6899349 & 22.1183953 \\
\hline 9.3463354 & 5.5910013 & 18.3238575 \\
\hline 4.5174800 & 5.5537303 & 18.2693043 \\
\hline 0.1880998 & 10.7434933 & 27.1216080 \\
\hline 2.5724449 & 6.6390681 & 27.0582588 \\
\hline 2.6769149 & 9.4672946 & 23.3379734 \\
\hline 5.1137774 & 8.8560381 & 15.3071520 \\
\hline 5.1470037 & 7.2152369 & 20.1598749 \\
\hline 3.8210494 & 7.9329856 & 25.2104563 \\
\hline 8.6535641 & 8.8258080 & 30.0921501 \\
\hline 8.6492329 & 7.2104848 & 20.1994081 \\
\hline 1.8427493 & 11.1861026 & 25.1985883 \\
\hline 5.1120230 & 8.8536294 & 30.1100572 \\
\hline 3.3763746 & 11.8665436 & 15.2814508 \\
\hline 3.2835581 & 15.7710236 & 21.6999935 \\
\hline 3.2423690 & 15.8344146 & 18.6089779 \\
\hline 3.7666482 & 11.8702893 & 28.6473733 \\
\hline 3.7757076 & 11.9016088 & 16.7154746 \\
\hline 1.6576170 & 13.1439980 & 18.6195610 \\
\hline 1.6270792 & 13.1479597 & 21.6780776 \\
\hline 4.8982546 & 13.0638383 & 16.9752780 \\
\hline 0.2103689 & 13.5973131 & 21.7682675 \\
\hline 2.3180411 & 16.8856489 & 21.9061678 \\
\hline 2.1167731 & 14.6925649 & 18.3483178 \\
\hline 4.5166437 & 15.6308491 & 17.6247449 \\
\hline 4.5979523 & 15.9796697 & 22.6262852 \\
\hline 2.4607343 & 12.1538996 & 17.6109324 \\
\hline 4.3806061 & 13.3094790 & 28.2367158 \\
\hline 2.6348431 & 14.3596939 & 22.1153680 \\
\hline 2.6592205 & 17.1741205 & 18.3221913 \\
\hline 0.2079342 & 13.0305830 & 18.2991276 \\
\hline 3.7844541 & 15.7605741 & 20.1447594 \\
\hline 3.3761379 & 11.8639318 & 30.0842387 \\
\hline 2.0185995 & 12.7001513 & 20.1405848 \\
\hline 10.0352158 & 11.9092053 & 16.6229000 \\
\hline 9.9622798 & 11.8554299 & 28.5530600 \\
\hline 12.1294209 & 10.5709292 & 26.7670436 \\
\hline 12.1693367 & 10.5561809 & 23.6276878 \\
\hline 15.2649653 & 10.6784975 & 23.6534977 \\
\hline 10.4618731 & 7.9593274 & 23.6830378 \\
\hline 10.5273596 & 7.9409678 & 26.7561135 \\
\hline 15.2463617 & 10.6647207 & 26.7257897 \\
\hline 8.8774621 & 10.6616609 & 28.3133907 \\
\hline 11.6655784 & 9.0457139 & 27.1261469 \\
\hline 15.6830649 & 9.2472312 & 26.8566883 \\
\hline 11.3555103 & 6.7732863 & 23.5742282 \\
\hline 13.7428284 & 10.1216359 & 23.4646549 \\
\hline 11.2782979 & 11.6376678 & 27.6428129 \\
\hline 9.2689708 & 8.0686809 & 27.7693466 \\
\hline 16.0134020 & 11.5367527 & 27.6576319 \\
\hline 9.1669433 & 7.7623076 & 22.7193090 \\
\hline 15.6149119 & 11.8881654 & 22.6478751 \\
\hline 9.3833921 & 10.4968776 & 17.1016120 \\
\hline 13.6885219 & 10.7503400 & 27.1560118 \\
\hline 11.1105598 & 6.5807852 & 26.9201302 \\
\hline 16.2149123 & 9.5689161 & 23.3644463 \\
\hline 11.2565619 & 9.2685876 & 23.1408063 \\
\hline 10.3775430 & 11.8762477 & 15.1741604 \\
\hline 11.8633126 & 10.8610173 & 25.1993413 \\
\hline 15.4677480 & 11.1861026 & 25.1985883 \\
\hline 9.9869583 & 8.1595801 & 25.2279260 \\
\hline 10.3703861 & 11.8718813 & 29.9849466 \\
\hline 8.6710055 & 14.9285473 & 15.1896014 \\
\hline 5.3454392 & 14.6076143 & 16.6851824 \\
\hline 5.2930150 & 14.5836456 & 28.6331864 \\
\hline
\end{tabular}

28.3790726

21.8700079

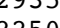

26.8689674

.4405631

17.6600612

0355
3025

27.7395578

17.1664947

18.3238575

27.0582588

.3379734

20.1598749

2104563

20.1994081

.1985883

15.2814508

1.6999935

28.6473733

6.7154746

95610

6. 9752780

21.7682675

18.3483178

17.6247449

17.6109324

28.2367158

18.2991276

. 0.1447594

20.1405848

26.7670436

276878

23.6830378

28.3133907

.1261469

23.5742282

.4646549

27.7693466

.6576319

22.6478751

.1016120

26.9201302

23.3644463

23.1408063

25.1993413

25.1985883

29.9849466

16.6851824

28.6331864 


\begin{tabular}{|c|c|c|c|}
\hline $\mathrm{Si}$ & 12.1156777 & 18.5055164 & 21.7060034 \\
\hline Al & 12.0815481 & 13.1151419 & 21.6827073 \\
\hline $\mathrm{Si}$ & 16.9085569 & 15.7710236 & 21.6999935 \\
\hline $\mathrm{Si}$ & 16.8673678 & 15.8344146 & 18.6089779 \\
\hline $\mathrm{Si}$ & 12.1234917 & 13.0915173 & 18.5860332 \\
\hline $\mathrm{Si}$ & 12.1690265 & 18.5338530 & 18.6149554 \\
\hline $\mathrm{Si}$ & 5.3019143 & 16.9903357 & 26.6960776 \\
\hline $\mathrm{Si}$ & 5.2916501 & 17.0067628 & 23.6630172 \\
\hline $\mathrm{Si}$ & 8.4233083 & 14.5648224 & 28.5656248 \\
\hline $\mathrm{Si}$ & 8.4750030 & 14.6043349 & 16.6295979 \\
\hline $\mathrm{Si}$ & 15.2826158 & 13.1439980 & 18.6195610 \\
\hline $\mathrm{Si}$ & 15.2859422 & 18.5551547 & 18.6384732 \\
\hline $\mathrm{Si}$ & 10.5563184 & 15.8354475 & 18.5829149 \\
\hline $\mathrm{Si}$ & 10.4199978 & 15.8245425 & 21.6496163 \\
\hline $\mathrm{Si}$ & 15.2515472 & 18.4879763 & 21.7356331 \\
\hline $\mathrm{Si}$ & 15.2520779 & 13.1479597 & 21.6780776 \\
\hline $\mathrm{Si}$ & 8.4157824 & 17.1555851 & 23.5987131 \\
\hline $\mathrm{Si}$ & 8.4207272 & 17.0481785 & 26.6905887 \\
\hline 0 & 8.9144146 & 13.0599872 & 16.9332464 \\
\hline $\mathrm{O}$ & 6.8499289 & 14.2068766 & 28.3498682 \\
\hline 0 & 11.5176962 & 17.0187289 & 21.8835936 \\
\hline $\mathrm{O}$ & 13.7374316 & 13.6283766 & 21.7745023 \\
\hline $\mathrm{O}$ & 15.8505343 & 16.9924403 & 21.9259212 \\
\hline 0 & 15.7417719 & 14.6925649 & 18.3483178 \\
\hline $\mathrm{O}$ & 11.6575726 & 14.6531856 & 18.4192842 \\
\hline $\mathrm{O}$ & 13.7337019 & 18.1491833 & 18.3592250 \\
\hline 0 & 6.8530410 & 17.4198034 & 26.9586896 \\
\hline $\mathrm{H}$ & 8.9214332 & 18.5465227 & 23.4352185 \\
\hline $\mathrm{H}$ & 4.6711734 & 18.3573220 & 23.5729116 \\
\hline $\mathrm{H}$ & 18.0364785 & 15.6476491 & 17.7059721 \\
\hline $\mathrm{H}$ & 11.7600065 & 19.6651794 & 17.7375024 \\
\hline $\mathrm{O}$ & 11.3882361 & 12.1768427 & 17.4512130 \\
\hline 0 & 4.8294752 & 15.8391153 & 27.7285443 \\
\hline $\mathrm{H}$ & 11.4332665 & 19.4911754 & 22.5891296 \\
\hline $\mathrm{O}$ & 11.7381060 & 11.7758724 & 22.7195218 \\
\hline $\mathrm{H}$ & 18.1155644 & 15.9626232 & 22.5506067 \\
\hline $\mathrm{O}$ & 8.8707891 & 15.8047921 & 27.6283470 \\
\hline $\mathrm{H}$ & 16.0182399 & 12.2371065 & 17.6956965 \\
\hline $\mathrm{O}$ & 9.3415632 & 15.6348114 & 17.5206123 \\
\hline $\mathrm{H}$ & 15.6890453 & 19.6875766 & 17.7596962 \\
\hline 0 & 9.1072758 & 16.1411279 & 22.5599036 \\
\hline $\mathrm{O}$ & 6.9162248 & 14.7483326 & 17.0613502 \\
\hline $\mathrm{O}$ & 9.2934610 & 13.2693365 & 28.1388661 \\
\hline 0 & 13.6835297 & 18.4895299 & 22.1183953 \\
\hline $\mathrm{O}$ & 11.0008699 & 14.4079892 & 22.0434361 \\
\hline $\mathrm{O}$ & 16.2598419 & 14.3596939 & 22.1153680 \\
\hline 0 & 16.2331455 & 17.2914558 & 18.2970738 \\
\hline $\mathrm{O}$ & 13.7136973 & 13.0212547 & 18.2727722 \\
\hline $\mathrm{O}$ & 11.2606811 & 17.2558237 & 18.2407565 \\
\hline $\mathrm{H}$ & 4.4197625 & 18.1696634 & 26.9154293 \\
\hline $\mathrm{H}$ & 9.2572635 & 18.2246534 & 27.0556020 \\
\hline 0 & 6.8388718 & 17.1634255 & 23.2519597 \\
\hline $\mathrm{H}$ & 5.1047617 & 14.9556742 & 15.2575798 \\
\hline $\mathrm{O}$ & 11.9595030 & 19.0148320 & 20.1598749 \\
\hline $\mathrm{O}$ & 11.7461439 & 12.5093581 & 20.0407918 \\
\hline $\mathrm{O}$ & 17.4094529 & 15.7605741 & 20.1447594 \\
\hline 0 & 5.1354971 & 16.4218536 & 25.1764619 \\
\hline $\mathrm{H}$ & 8.6660484 & 14.9243172 & 29.9900409 \\
\hline $\mathrm{O}$ & 15.6435983 & 12.7001513 & 20.1405848 \\
\hline $\mathrm{O}$ & 15.4617323 & 19.0100798 & 20.1994081 \\
\hline 0 & 9.9215578 & 15.8702011 & 20.0794641 \\
\hline $\mathrm{O}$ & 8.6554996 & 16.6432360 & 25.1306999 \\
\hline $\mathrm{H}$ & 11.0630561 & 10.9257906 & 20.1999042 \\
\hline C & 8.5491622 & 10.8190216 & 20.4443665 \\
\hline $\mathrm{H}$ & 8.3023381 & 9.8041227 & 20.7448060 \\
\hline $\mathrm{H}$ & 8.8864068 & 11.5399680 & 21.1830041 \\
\hline $\mathrm{H}$ & 8.6861448 & 11.0109678 & 19.3858950 \\
\hline 0 & 10.5582857 & 10.0719018 & 20.3435381 \\
\hline $\mathrm{H}$ & 10.7800265 & 9.8036903 & 21.2640429 \\
\hline C & 6.4612492 & 11.1491096 & 20.6761814 \\
\hline C & 6.6881963 & 12.3354957 & 20.0355098 \\
\hline $\mathrm{H}$ & 6.6396171 & 12.3404546 & 18.9395906 \\
\hline C & 7.0046806 & 13.6226322 & 20.6913512 \\
\hline $\mathrm{H}$ & 6.0845331 & 10.2859072 & 20.1243992 \\
\hline $\mathrm{H}$ & 6.3907502 & 11.1071897 & 21.7661549 \\
\hline $\mathrm{H}$ & 7.0948529 & 13.5421555 & 21.7824713 \\
\hline $\mathrm{H}$ & 6.2003195 & 14.3444921 & 20.4602944 \\
\hline $\mathrm{H}$ & 7.9196449 & 14.0766093 & 20.2759264 \\
\hline $\mathrm{H}$ & 5.1009801 & 14.9526415 & 30.0629014 \\
\hline $\mathrm{H}$ & 15.9172460 & 19.4701387 & 22.6352567 \\
\hline
\end{tabular}




\begin{tabular}{|c|c|c|}
\hline 9.2730027 & 8.1260014 & 27.7421107 \\
\hline 16.2767375 & 11.5968743 & 27.5722513 \\
\hline 9.3620838 & 7.8600040 & 22.6981561 \\
\hline 15.8083037 & 11.9253404 & 22.6321300 \\
\hline 9.5509478 & 10.6606760 & 17.1502859 \\
\hline 13.8200764 & 10.7623975 & 27.2442781 \\
\hline 11.2610608 & 6.6429444 & 26.8406235 \\
\hline 16.5267447 & 9.6862497 & 23.2840699 \\
\hline 11.4248576 & 9.2002921 & 23.0563872 \\
\hline 10.3272722 & 11.9220442 & 15.1528762 \\
\hline 12.1971625 & 10.8018806 & 25.3159251 \\
\hline 15.6320441 & 11.2155845 & 25.0258288 \\
\hline 10.1573329 & 8.2907730 & 25.0464462 \\
\hline 10.2903893 & 11.9191760 & 29.8836225 \\
\hline 8.7522515 & 14.9685432 & 15.1014208 \\
\hline 5.4542639 & 14.7527940 & 16.7328153 \\
\hline 5.3810261 & 14.7238895 & 28.5516844 \\
\hline 12.3388212 & 18.7307333 & 21.7081804 \\
\hline 12.1212423 & 13.2655098 & 21.6983324 \\
\hline 17.1510998 & 15.9130668 & 21.6980385 \\
\hline 17.1043608 & 15.9899344 & 18.5585521 \\
\hline 12.2657267 & 13.2639996 & 18.5085770 \\
\hline 12.3959603 & 18.7650576 & 18.5609955 \\
\hline 5.3397584 & 17.2265611 & 26.7011599 \\
\hline 5.2930870 & 17.2211797 & 23.6377113 \\
\hline 8.5305714 & 14.6663532 & 28.3843077 \\
\hline 8.6047887 & 14.7392016 & 16.5652438 \\
\hline 15.4607183 & 13.2918008 & 18.5056077 \\
\hline 15.5482301 & 18.7628485 & 18.5364637 \\
\hline 10.7383872 & 16.0792003 & 18.4401295 \\
\hline 10.5467956 & 16.0888899 & 21.5744044 \\
\hline 15.5064554 & 18.6792669 & 21.6868840 \\
\hline 15.3768106 & 13.3072008 & 21.6359122 \\
\hline 8.4276781 & 17.4648985 & 23.4655581 \\
\hline 8.4777148 & 17.2584554 & 26.5936723 \\
\hline 9.0717218 & 13.0916682 & 16.9697831 \\
\hline 7.0420208 & 14.3313740 & 28.1673549 \\
\hline 11.7789907 & 17.3163241 & 21.8808925 \\
\hline 13.7709471 & 13.8876483 & 21.7988612 \\
\hline 16.1659126 & 17.0797842 & 21.9260168 \\
\hline 15.9130820 & 14.7498236 & 18.2506249 \\
\hline 11.7742045 & 14.9494260 & 18.3273720 \\
\hline 14.0815925 & 18.3809086 & 18.2560647 \\
\hline 6.8000038 & 17.6577949 & 26.9537900 \\
\hline 8.9325093 & 18.8625685 & 23.3718321 \\
\hline 4.6207027 & 18.5470561 & 23.5536176 \\
\hline 18.3151665 & 15.7898213 & 17.7153293 \\
\hline 11.9874353 & 19.9531587 & 17.7618436 \\
\hline 11.4513431 & 12.2882041 & 17.2906854 \\
\hline 4.8957462 & 16.1675828 & 27.7148601 \\
\hline 11.6271890 & 19.7094286 & 22.5758530 \\
\hline 11.7772496 & 11.9065772 & 22.7514007 \\
\hline 18.3639704 & 16.0792142 & 22.5456590 \\
\hline 8.9516495 & 15.8632964 & 27.5280930 \\
\hline 16.2093522 & 12.3733078 & 17.6039212 \\
\hline 9.5952551 & 15.8710088 & 17.4324409 \\
\hline 15.9620385 & 19.8997031 & 17.6684517 \\
\hline 9.0996865 & 16.5660973 & 22.4363967 \\
\hline 6.9405414 & 14.9166321 & 17.0824758 \\
\hline 9.3634157 & 13.4538597 & 27.9550937 \\
\hline 13.8200892 & 18.7270923 & 22.1106074 \\
\hline 10.9531625 & 14.5161719 & 22.0825204 \\
\hline 16.4962794 & 14.5922746 & 22.0806580 \\
\hline 16.4435127 & 17.5644851 & 18.2100507 \\
\hline 13.9768527 & 13.1816204 & 18.1628905 \\
\hline 11.4207552 & 17.4098996 & 18.0905462 \\
\hline 4.4433818 & 18.4050603 & 26.8585416 \\
\hline 9.3429694 & 18.4090876 & 26.9738045 \\
\hline 6.9306973 & 17.4797220 & 23.1466374 \\
\hline 5.2191896 & 15.0280681 & 15.2884867 \\
\hline 12.1928390 & 19.2024626 & 20.2452593 \\
\hline 11.8110757 & 12.6120288 & 20.0462195 \\
\hline 17.6202606 & 15.9001940 & 20.2287144 \\
\hline 5.2086000 & 16.6291717 & 25.2847482 \\
\hline 8.7694730 & 14.9967451 & 29.8163999 \\
\hline 15.7519385 & 12.8776237 & 19.9564548 \\
\hline 15.7107696 & 19.1813592 & 20.0135451 \\
\hline 10.1345289 & 16.1456709 & 19.8518652 \\
\hline 8.6674208 & 16.9089762 & 24.8865140 \\
\hline 11.1235713 & 11.0653518 & 20.2097506 \\
\hline
\end{tabular}




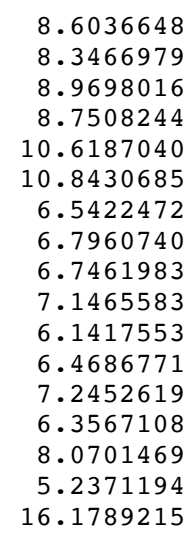

10.9804646

9.9758286

11.7041592

11.1429863

10.2013055

9.8963199

11.3601151

12.5277261

12.5098200

13.8217086

10.4968510

11.3438860

13.7648515

14.5554455

14.2385964

14.9901299

19.6940256

8.8457090

.2253143

9.1647641

6.6916711

6.7431037

7.9375854

8.0460959

9.1156684

9.2246793

6.7556301

6.6655171

10.6811872

10.6482462

9.6277097

10.7155260

5.3408875

5.3141994

6.3468202

9.0977163

7.0156352

10.1398239

7.9790811

8.1513060

7.7915857

11.5929501

8.0001037

11.9170949

10.4992405

8.9417557

6.5963587

5.5970175

5.5730103

10.7221653

6.6245824

9.5091001

8.8564691

7.2270257

7.9700077

8.8378039

7.1942169

11.1748991

8.8524392

11.8791372

15.7735923

15.8429674

11.8630527

11.9124100

13.1496565

13.1805892

13.0659823

13.7330545

16.8855713

14.7002869

15.6327773

15.9716499

12.1718498

13.2994214

14.3506195

17.1803810

13.0296833
20.4393386

20.7657036

21.1616332

19.3774754

20.3237868

21.2304648

20.6634915

19.9967655

18.9015990

20.6212405

20.1284016

21.7539035

21.7130337

20.3771798

20.1866194

30.0096033

22.5443073

15.3131441

16.7543711

28.6898448

21.7201985

18.6344043

26.7341338

23.6787907

28.6669827

16.7413223

18.6501704

21.7516439

23.6616688

26.7433233

17.0196960

28.3952956

21.8659072

21.9281443

18.3625528

26.8770445

23.4568797

23.4655375

17.6854324

27.8119137

22.6916152

27.7517293

17.7063696

22.6727024

17.1787210

28.2826065

22.1268028

18.3242719

18.3003460

27.1566287

27.0334905

23.3438884

15.3292480

20.1807108

25.2280321

30.1127005

20.2160977

25.2144849

30.1326783

15.2903023

21.6943122

18.6070895

28.6526967

16.7245658

18.6310575

21.6916678

16.9833578

21.7969926

21.9222017

18.3780623

17.6067972

22.6054814

17.6258040

28.2217629

22.1014086

18.3214386

18.2917110 


\begin{tabular}{|c|c|c|}
\hline 3.8238189 & 15.7786903 & 20.1334945 \\
\hline 3.3956945 & 11.8749707 & 30.0910678 \\
\hline 1.9924815 & 12.6923641 & 20.1565422 \\
\hline 10.0369165 & 11.9156623 & 16.6066924 \\
\hline 9.9575462 & 11.8373333 & 28.5341376 \\
\hline 12.1403439 & 10.5443568 & 26.7770891 \\
\hline 12.1886185 & 10.5039967 & 23.6291404 \\
\hline 15.2719199 & 10.6811872 & 23.6616688 \\
\hline 10.4127709 & 7.9491938 & 23.7156097 \\
\hline 10.5198457 & 7.9286469 & 26.7645787 \\
\hline 15.2461527 & 10.6482462 & 26.7433233 \\
\hline 8.8781210 & 10.6384818 & 28.2923000 \\
\hline 11.6680711 & 9.0224676 & 27.1404350 \\
\hline 15.6846446 & 9.2305380 & 26.8655897 \\
\hline 11.2367431 & 6.7111554 & 23.6417769 \\
\hline 13.7662876 & 10.0875988 & 23.4466168 \\
\hline 11.2754799 & 11.6215098 & 27.6266619 \\
\hline 9.2862003 & 8.0332645 & 27.8124845 \\
\hline 16.0237616 & 11.5163979 & 27.6700151 \\
\hline 9.1230569 & 7.7745816 & 22.7366638 \\
\hline 15.5767635 & 11.9170949 & 22.6727024 \\
\hline 9.3987851 & 10.5080281 & 17.1207361 \\
\hline 13.6931157 & 10.7286052 & 27.1926362 \\
\hline 11.1094405 & 6.5655380 & 26.8715025 \\
\hline 16.2637822 & 9.6093298 & 23.3710631 \\
\hline 11.2819347 & 9.2049315 & 23.1653020 \\
\hline 10.3656298 & 11.8555585 & 15.1556735 \\
\hline 11.9081789 & 10.8207835 & 25.2028127 \\
\hline 15.4474378 & 11.1748991 & 25.2144849 \\
\hline 9.9401557 & 8.1953050 & 25.2565096 \\
\hline 10.3580612 & 11.8492842 & 29.9682106 \\
\hline 8.6859452 & 14.9357579 & 15.1626918 \\
\hline 5.3586783 & 14.6122236 & 16.6761452 \\
\hline 5.2985823 & 14.5758833 & 28.6226111 \\
\hline 12.1209619 & 18.4912661 & 21.7201985 \\
\hline 12.0769149 & 13.1571999 & 21.7075439 \\
\hline 16.9664203 & 15.7735923 & 21.6943122 \\
\hline 16.8807597 & 15.8429674 & 18.6070895 \\
\hline 12.1333519 & 13.1081907 & 18.5548838 \\
\hline 12.1778924 & 18.5426987 & 18.6344043 \\
\hline 5.3172027 & 16.9766266 & 26.6851927 \\
\hline 5.2882337 & 17.0115245 & 23.6790986 \\
\hline 8.4315659 & 14.5583750 & 28.5406451 \\
\hline 8.4882050 & 14.6147390 & 16.6031661 \\
\hline 15.2892045 & 13.1496565 & 18.6310575 \\
\hline 15.2886161 & 18.5552251 & 18.6501704 \\
\hline 10.5696419 & 15.8347255 & 18.5736313 \\
\hline 10.3572969 & 15.8370751 & 21.6548824 \\
\hline 15.2564553 & 18.4651122 & 21.7516439 \\
\hline 15.2668559 & 13.1805892 & 21.6916678 \\
\hline 8.3954511 & 17.2249390 & 23.5846212 \\
\hline 8.4283702 & 17.0429756 & 26.6644269 \\
\hline 8.9110523 & 13.0650161 & 16.9061966 \\
\hline 6.8558068 & 14.2041186 & 28.3381525 \\
\hline 11.4609811 & 17.0281786 & 21.8780214 \\
\hline 13.7850829 & 13.7743581 & 21.8048669 \\
\hline 15.9103986 & 16.9921165 & 21.9440371 \\
\hline 15.7491031 & 14.7002869 & 18.3780623 \\
\hline 11.6980993 & 14.6798037 & 18.3962344 \\
\hline 13.7374714 & 18.1464153 & 18.3625528 \\
\hline 6.8645481 & 17.4203376 & 26.9574240 \\
\hline 8.9573990 & 18.5971599 & 23.4491770 \\
\hline 4.5511971 & 18.3046990 & 23.6391330 \\
\hline 18.0373496 & 15.6501256 & 17.6893574 \\
\hline 11.7708626 & 19.6787543 & 17.7621515 \\
\hline 11.4031649 & 12.2130899 & 17.4022338 \\
\hline 4.8355272 & 15.8405057 & 27.7303833 \\
\hline 11.4793456 & 19.4983901 & 22.6096649 \\
\hline 11.7048705 & 11.7051410 & 22.7197059 \\
\hline 18.1853471 & 15.9552387 & 22.5299812 \\
\hline 8.8783341 & 15.7857537 & 27.5853763 \\
\hline 16.0414864 & 12.2536950 & 17.7099465 \\
\hline 9.3695949 & 15.6342301 & 17.4939364 \\
\hline 15.6914281 & 19.6973905 & 17.7839595 \\
\hline 9.0103285 & 16.2188332 & 22.4890391 \\
\hline 6.9309794 & 14.7771865 & 17.0384987 \\
\hline 9.2906218 & 13.2527790 & 28.1223215 \\
\hline 13.6874244 & 18.3959538 & 22.1268028 \\
\hline 10.8770417 & 14.4266268 & 22.1682981 \\
\hline 16.3337514 & 14.3506195 & 22.1014086 \\
\hline
\end{tabular}

20.1334945

0910678

28.5341376

23.6616688

23.7156097

7645787

28.2923000

27.1404350

26.8655897

27.6266619

124845

22.7366638

.6727024

7.1926362

.8715025

3. 1653020

.1556735

5.2144849

5.2565096

9682106

6.6761452

28.6226111

21.7201985

18.6070895

18.5548838

18.6344043

23.6790986

28.5406451

18.6310575

18.6501704

21.7516439

26.6644269

9061966

21.8780214

21.8048669

9440371

8. 3962344

8.3625528

26.9574240

.4491770

17.6893574

.7621515

27.7303833

.6096649

197059

27.5853763

17.7099465

17.4939364

22.4890391

17.0384987

22.1268028

22.1014086 


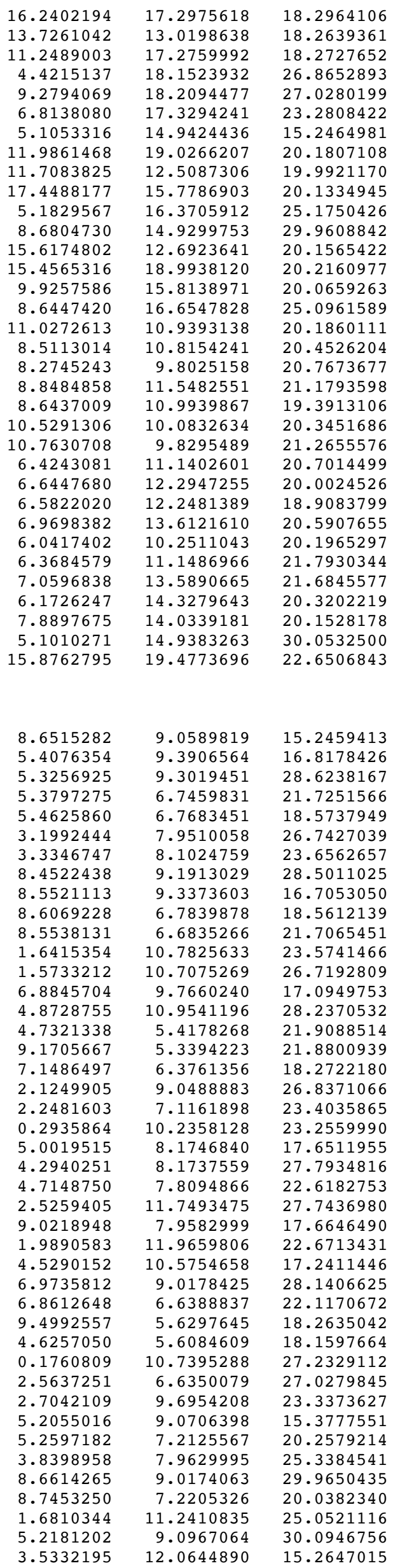

18.2964106

18.2639361

18.2727652

26.8652893

27.0280199

23.2808422

15.2464981

20.1807108

19.9921170

20.1334945

25.1750426

29.9608842

20.1565422

20.2160977

20.0659263

25.0961589

20.1860111

20.4526204

20.7673677

21.1793598

19.3913106

20.3451686

21.2655576

20.7014499

20.0024526

18.9083799

20.5907655

20.1965297

21.7930344

21.6845577

20.3202219

20.1528178

30.0532500

22.6506843

15.2459413

16.8178426

28.6238167

21.7251566

18.5737949

26.7427039

23.6562657

28.5011025

16.7053050

18.5612139

21.7065451

23.5741466

26.7192809

17.0949753

28.2370532

21.9088514

21.8800939

18.2722180

26.8371066

23.4035865

23.2559990

17.6511955

27.7934816

22.6182753

27.7436980

17.6646490

22.6713431

17.2411446

28.1406625

22.1170672

18.2635042

18.1597664

27.2329112

27.0279845

23.3373627

15.3777551

20.2579214

25.3384541

29.9650435

20.0382340

25.0521116

30.0946756

15.2647015 


\begin{tabular}{|c|c|c|c|}
\hline $\mathrm{P}$ & 3.3102578 & 15.9419840 & 21.6947036 \\
\hline Al & 3.2370381 & 16.0221049 & 18.5600932 \\
\hline $\mathrm{P}$ & 3.8082699 & 12.0348622 & 28.5266328 \\
\hline Al & 3.8246564 & 12.0913524 & 16.7246547 \\
\hline $\mathrm{P}$ & 1.5849108 & 13.3370818 & 18.5222433 \\
\hline Al & 1.5420086 & 13.3350771 & 21.6618320 \\
\hline 0 & 5.0269366 & 13.3302239 & 17.0958930 \\
\hline $\mathrm{H}$ & 0.1187243 & 13.7490427 & 21.8033052 \\
\hline $\mathrm{H}$ & 2.3742379 & 17.0812207 & 21.9023738 \\
\hline 0 & 2.0305292 & 14.7951485 & 18.2475096 \\
\hline 0 & 4.6516586 & 15.7877477 & 17.5554090 \\
\hline 0 & 4.5752532 & 16.1092786 & 22.5525590 \\
\hline 0 & 2.3483203 & 12.3826349 & 17.5857369 \\
\hline 0 & 4.3514111 & 13.3976219 & 28.0775269 \\
\hline 0 & 2.6381843 & 14.6386305 & 22.1078999 \\
\hline $\mathrm{H}$ & 2.6825866 & 17.3793073 & 18.2998897 \\
\hline $\mathrm{H}$ & 0.1330846 & 13.2235994 & 18.2116905 \\
\hline 0 & 3.7656393 & 15.8974402 & 20.2233051 \\
\hline $\mathrm{H}$ & 3.4932552 & 12.0590544 & 29.9817277 \\
\hline 0 & 1.9045917 & 12.9358930 & 19.9711340 \\
\hline $\mathrm{P}$ & 10.1195955 & 12.0271851 & 16.5834298 \\
\hline Al & 10.0143393 & 11.9167829 & 28.3746414 \\
\hline $\mathrm{P}$ & 12.3574127 & 10.5749959 & 26.8536964 \\
\hline Al & 12.4131985 & 10.5194417 & 23.6104610 \\
\hline$P$ & 15.5165342 & 10.7825633 & 23.5741466 \\
\hline$P$ & 10.5433970 & 8.0189989 & 23.6405414 \\
\hline Al & 10.6482366 & 8.0116931 & 26.7268357 \\
\hline Al & 15.4483199 & 10.7075269 & 26.7192809 \\
\hline $\mathrm{O}$ & 8.9037415 & 10.5953275 & 28.0474007 \\
\hline 0 & 11.8416168 & 9.1794386 & 27.2740162 \\
\hline $\mathrm{H}$ & 15.9171911 & 9.2978276 & 26.8194226 \\
\hline $\mathrm{H}$ & 11.2635338 & 6.7157247 & 23.6405286 \\
\hline 0 & 14.1176477 & 10.2151517 & 23.2439766 \\
\hline 0 & 11.5075728 & 11.6731495 & 27.5130709 \\
\hline $\mathrm{O}$ & 9.2510744 & 8.1039680 & 27.7699609 \\
\hline $\mathrm{H}$ & 16.2615487 & 11.5969047 & 27.5938018 \\
\hline 0 & 9.3010934 & 7.9052965 & 22.7341215 \\
\hline $\mathrm{O}$ & 15.8640570 & 11.9659806 & 22.6713431 \\
\hline 0 & 9.5760593 & 10.6921512 & 17.1351826 \\
\hline 0 & 13.8079877 & 10.7450965 & 27.3222726 \\
\hline $\mathrm{H}$ & 11.2447350 & 6.6495639 & 26.8037398 \\
\hline $\mathrm{H}$ & 16.5449662 & 9.7304527 & 23.3449928 \\
\hline 0 & 11.4631788 & 9.1138232 & 23.0679487 \\
\hline $\mathrm{H}$ & 10.3031720 & 11.9340700 & 15.1087265 \\
\hline 0 & 12.2681938 & 10.7086046 & 25.3361506 \\
\hline 0 & 15.5560331 & 11.2410835 & 25.0521116 \\
\hline 0 & 10.1182545 & 8.3695698 & 25.0796438 \\
\hline $\mathrm{H}$ & 10.2659157 & 11.9295199 & 29.8421794 \\
\hline $\mathrm{H}$ & 8.7395746 & 14.9778967 & 15.0704428 \\
\hline $\mathrm{P}$ & 5.4534673 & 14.7726357 & 16.7337708 \\
\hline Al & 5.3620302 & 14.7377363 & 28.5473792 \\
\hline $\mathrm{P}$ & 12.3172269 & 18.7620844 & 21.7251566 \\
\hline $\mathrm{Ti}$ & 12.0479676 & 13.2589794 & 21.7246335 \\
\hline $\mathrm{P}$ & 17.1852566 & 15.9419840 & 21.6947036 \\
\hline Al & 17.1120368 & 16.0221049 & 18.5600932 \\
\hline Al & 12.2461961 & 13.2774609 & 18.4902426 \\
\hline Al & 12.4000854 & 18.7844464 & 18.5737949 \\
\hline$P$ & 5.3312479 & 17.2304949 & 26.7029058 \\
\hline Al & 5.2682701 & 17.2417349 & 23.6705017 \\
\hline $\mathrm{P}$ & 8.5104070 & 14.6733795 & 28.3507516 \\
\hline Al & 8.6033936 & 14.7641285 & 16.5377119 \\
\hline $\mathrm{P}$ & 15.4599095 & 13.3370818 & 18.5222433 \\
\hline$P$ & 15.5444222 & 18.8000892 & 18.5612139 \\
\hline $\mathrm{P}$ & 10.7188917 & 16.1094775 & 18.4287191 \\
\hline Al & 10.4279289 & 16.1733826 & 21.5597648 \\
\hline Al & 15.4913124 & 18.6996280 & 21.7065451 \\
\hline Al & 15.4170074 & 13.3350771 & 21.6618320 \\
\hline $\mathrm{P}$ & 8.3826384 & 17.5571380 & 23.4610808 \\
\hline Al & 8.4625491 & 17.2769162 & 26.5795203 \\
\hline 0 & 9.0791443 & 13.1179208 & 16.9415994 \\
\hline 0 & 7.0184491 & 14.3511319 & 28.1380069 \\
\hline 0 & 11.6518727 & 17.3975029 & 21.9138893 \\
\hline 0 & 13.7752855 & 13.8125758 & 21.8250177 \\
\hline 0 & 16.2145740 & 17.1234088 & 21.9100642 \\
\hline 0 & 15.9055280 & 14.7951485 & 18.2475096 \\
\hline 0 & 11.7438107 & 14.9678063 & 18.3515461 \\
\hline 0 & 14.0861490 & 18.3922369 & 18.2722180 \\
\hline 0 & 6.7875161 & 17.6721866 & 26.9646304 \\
\hline $\mathrm{H}$ & 8.9787732 & 18.9180727 & 23.3630979 \\
\hline $\mathrm{H}$ & 4.4711028 & 18.4991046 & 23.6446827 \\
\hline
\end{tabular}




\begin{tabular}{|c|c|c|}
\hline 18.3150945 & 15.8227969 & 17.7056640 \\
\hline 12.0067787 & 19.9852302 & 17.7860457 \\
\hline 11.4743696 & 12.3410758 & 17.2102503 \\
\hline 4.8736994 & 16.1965627 & 27.7364963 \\
\hline 11.6742743 & 19.7905567 & 22.5888564 \\
\hline 11.7035868 & 11.8479844 & 22.8075275 \\
\hline 18.4102934 & 16.1039941 & 22.5254611 \\
\hline 8.9387591 & 15.8646542 & 27.4886324 \\
\hline 16.1981606 & 12.4140890 & 17.6165997 \\
\hline 9.6018793 & 15.9036339 & 17.3900153 \\
\hline 15.9470598 & 19.9394968 & 17.6912979 \\
\hline 8.9494073 & 16.6363791 & 22.3842648 \\
\hline 6.9425792 & 14.9389052 & 17.0718658 \\
\hline 9.3306332 & 13.4532896 & 27.9172027 \\
\hline 13.7987641 & 18.6549850 & 22.1170672 \\
\hline 10.8913570 & 14.6115629 & 22.0643320 \\
\hline 16.5131830 & 14.6386305 & 22.1078999 \\
\hline 16.4620624 & 17.6131311 & 18.2550609 \\
\hline 13.9714194 & 13.2207335 & 18.2038479 \\
\hline 11.4248702 & 17.4328366 & 18.0913287 \\
\hline 4.4293111 & 18.4100704 & 26.8135052 \\
\hline 9.3346215 & 18.4189427 & 26.9698864 \\
\hline 6.8767662 & 17.6887089 & 23.2137976 \\
\hline 5.2140589 & 15.0278090 & 15.2864661 \\
\hline 12.1972175 & 19.2286581 & 20.2579214 \\
\hline 11.7599923 & 12.5991807 & 20.0049308 \\
\hline 17.6406380 & 15.8974402 & 20.2233051 \\
\hline 5.2274198 & 16.5939534 & 25.2995909 \\
\hline 8.7547817 & 15.0036273 & 29.7819532 \\
\hline 15.7795904 & 12.9358930 & 19.9711340 \\
\hline 15.6828244 & 19.2366340 & 20.0382340 \\
\hline 10.0771098 & 16.2009408 & 19.8234289 \\
\hline 8.6419015 & 16.9591545 & 24.8624542 \\
\hline 11.1802729 & 11.0116259 & 20.1589830 \\
\hline 8.6841511 & 10.8516198 & 20.3927709 \\
\hline 8.4318669 & 9.8055677 & 20.5458411 \\
\hline 9.0015749 & 11.4709666 & 21.2262382 \\
\hline 8.8708003 & 11.1742002 & 19.3742125 \\
\hline 10.7126661 & 10.1247930 & 20.2693984 \\
\hline 10.9370608 & 9.8236270 & 21.1762896 \\
\hline 6.6053313 & 11.1921699 & 20.6525975 \\
\hline 6.8589497 & 12.3473512 & 19.9656211 \\
\hline 6.7810284 & 12.3180183 & 18.8722638 \\
\hline 7.2392012 & 13.6456657 & 20.5663409 \\
\hline 6.1938031 & 10.3223766 & 20.1372846 \\
\hline 6.5604065 & 11.1857676 & 21.7445423 \\
\hline 7.3496247 & 13.6031670 & 21.6577247 \\
\hline 6.4635237 & 14.3921868 & 20.3182382 \\
\hline 8.1689974 & 14.0334002 & 20.1179584 \\
\hline 5.2297502 & 14.9916238 & 30.0085992 \\
\hline 16.1225651 & 19.7316977 & 22.5745732 \\
\hline 8.8056531 & 9.0024940 & 15.1849701 \\
\hline 5.4675690 & 9.2735120 & 16.5481012 \\
\hline 5.4709314 & 9.2171498 & 28.3790682 \\
\hline 5.3710421 & 6.6778319 & 21.5126121 \\
\hline 5.3982498 & 6.7085499 & 18.3566025 \\
\hline 3.2544999 & 7.9956865 & 26.5107994 \\
\hline 3.3276735 & 8.1035756 & 23.3884989 \\
\hline 8.6083086 & 9.2131920 & 28.4306840 \\
\hline 8.6195624 & 9.3361834 & 16.6241164 \\
\hline 8.5663342 & 6.7487217 & 18.4239653 \\
\hline 8.5545451 & 6.7136255 & 21.5925131 \\
\hline 1.6081627 & 10.7801481 & 23.4144059 \\
\hline 1.5875563 & 10.7029516 & 26.5951456 \\
\hline 7.1394310 & 9.6963467 & 16.8965458 \\
\hline 5.0820393 & 10.6783280 & 28.0718260 \\
\hline 4.8467192 & 5.3088240 & 21.7734252 \\
\hline 9.0830610 & 5.3440789 & 21.8417789 \\
\hline 6.8830848 & 6.3656940 & 18.1263611 \\
\hline 2.0473852 & 9.2392075 & 26.7439889 \\
\hline 2.3006645 & 7.0497019 & 23.1610711 \\
\hline 0.2147609 & 10.3872407 & 23.0663027 \\
\hline 4.9775074 & 7.8933270 & 17.4791127 \\
\hline 4.6132672 & 8.2429408 & 27.5688154 \\
\hline 4.5379314 & 7.8913911 & 22.4638186 \\
\hline 2.4453948 & 11.6282511 & 27.4652624 \\
\hline 9.0394264 & 8.1351263 & 17.4764106 \\
\hline
\end{tabular}

17.7056640

860457

22.5888564

8075275

27.4886324

17.6165997

22.3842648

17.0718658

27.9172027

0672

22.1078999

2550609

18.0913287

.8135052

3. 2137976

2864661

0.0049308

.2233051

9. 7819532

9.9711340

(2)

4.8624542

20.1589830

20.3927709

19.3742125

20.2693984

21.1762896

18.8722638

20.5663409

21.6577247

20.3182382

20.1179584

30.0085992

15.1849701

16.5481012

3790682

18.3566025

26.5107994

23.3884989

8.4306840

18.4239653

1.5925131

26.5951456

16.8965458

8.0718260

21.8417789

18.1263611

26.7439889

1610711

17.4791127

.5688154

27.4652624

17.4764106 


\begin{tabular}{|c|c|c|c|}
\hline 0 & 2.1231683 & 12.1408989 & 22.4743876 \\
\hline 0 & 4.4894772 & 10.6376706 & 17.0355759 \\
\hline $\mathrm{O}$ & 6.9357519 & 8.9984965 & 27.9916606 \\
\hline $\mathrm{O}$ & 7.0610303 & 6.7414604 & 21.9272847 \\
\hline $\mathrm{H}$ & 9.4024392 & 5.5859884 & 18.0164111 \\
\hline $\mathrm{H}$ & 4.5655757 & 5.5337047 & 17.9777710 \\
\hline $\mathrm{H}$ & 0.1809268 & 10.8027716 & 27.0732148 \\
\hline $\mathrm{H}$ & 2.6470207 & 6.6764665 & 26.8390495 \\
\hline $\mathrm{O}$ & 2.7200616 & 9.4707852 & 23.0632074 \\
\hline $\mathrm{H}$ & 5.2900669 & 8.9699797 & 15.1012143 \\
\hline $\mathrm{O}$ & 5.1688121 & 7.1085027 & 19.8266281 \\
\hline O & 3.8184604 & 8.0539970 & 24.8494375 \\
\hline $\mathrm{H}$ & 8.7812357 & 9.0248626 & 29.8975681 \\
\hline $\mathrm{O}$ & 8.7886229 & 7.1203496 & 20.1241977 \\
\hline 0 & 1.7029912 & 11.1531755 & 25.1293534 \\
\hline $\mathrm{H}$ & 5.2667789 & 8.9281665 & 29.8254191 \\
\hline $\mathrm{H}$ & 3.5158258 & 11.9156695 & 15.1334311 \\
\hline Al & 3.3151932 & 16.0360850 & 21.4882536 \\
\hline $\mathrm{P}$ & 3.2346898 & 16.0567525 & 18.3203116 \\
\hline Al & 3.8820935 & 11.9205694 & 28.3962592 \\
\hline $\mathrm{P}$ & 3.8653002 & 11.9689667 & 16.5798570 \\
\hline Al & 1.7031584 & 13.2841743 & 18.4511491 \\
\hline $\mathrm{P}$ & 1.7921433 & 13.3233229 & 21.5414404 \\
\hline 0 & 4.9083017 & 13.0791423 & 16.8487533 \\
\hline $\mathrm{H}$ & 0.3862799 & 13.8009691 & 21.6533446 \\
\hline $\mathrm{H}$ & 2.3396175 & 17.1183833 & 21.7948526 \\
\hline $\mathrm{O}$ & 2.1957956 & 14.9419390 & 18.1028455 \\
\hline 0 & 4.4616623 & 15.8453763 & 17.4206305 \\
\hline 0 & 4.7962008 & 16.2764423 & 22.3792996 \\
\hline O & 2.5937705 & 12.2088729 & 17.3889804 \\
\hline 0 & 4.5246810 & 13.4733420 & 27.9436621 \\
\hline 0 & 2.7517847 & 14.4649535 & 21.9454292 \\
\hline $\mathrm{H}$ & 2.6247681 & 17.3659768 & 17.9583061 \\
\hline $\mathrm{H}$ & 0.2486302 & 13.1139989 & 18.1818747 \\
\hline $\mathrm{O}$ & 3.7117730 & 16.0754717 & 19.7824212 \\
\hline $\mathrm{H}$ & 3.5612783 & 11.9149925 & 29.8502768 \\
\hline 0 & 2.1429767 & 12.8715469 & 20.0945614 \\
\hline Al & 10.2002343 & 12.0286301 & 16.4423892 \\
\hline $\mathrm{P}$ & 10.0992212 & 11.9596175 & 28.2509304 \\
\hline Al & 12.3567807 & 10.5952753 & 26.5862156 \\
\hline $\mathrm{P}$ & 12.3627330 & 10.5967892 & 23.3560237 \\
\hline Al & 15.4831614 & 10.7801481 & 23.4144059 \\
\hline Al & 10.6693161 & 7.9663120 & 23.4971639 \\
\hline $\mathrm{P}$ & 10.7490061 & 7.9172610 & 26.6205812 \\
\hline $\mathrm{P}$ & 15.4625550 & 10.7029516 & 26.5951456 \\
\hline 0 & 9.0874101 & 10.8324638 & 27.9522691 \\
\hline $\mathrm{O}$ & 11.8189665 & 8.9682022 & 26.9783604 \\
\hline $\mathrm{H}$ & 15.9067305 & 9.2890361 & 26.7389220 \\
\hline $\mathrm{H}$ & 11.5662402 & 6.7871614 & 23.3479940 \\
\hline 0 & 13.8416493 & 10.3172792 & 23.0043191 \\
\hline O & 11.3719991 & 11.7691482 & 27.4208738 \\
\hline $\mathrm{O}$ & 9.5663588 & 8.0168856 & 27.5949923 \\
\hline $\mathrm{H}$ & 16.2959349 & 11.6018691 & 27.4404537 \\
\hline 0 & 9.2483207 & 7.7432433 & 22.5005035 \\
\hline $\mathrm{O}$ & 15.9981670 & 12.1408989 & 22.4743876 \\
\hline $\mathrm{O}$ & 9.4931307 & 10.5325099 & 17.0221729 \\
\hline 0 & 14.0140947 & 10.8057400 & 27.0874318 \\
\hline $\mathrm{H}$ & 11.3464915 & 6.5598154 & 26.7527678 \\
\hline $\mathrm{H}$ & 16.4274432 & 9.6681698 & 23.1161501 \\
\hline 0 & 11.5271265 & 9.3686573 & 22.9449327 \\
\hline $\mathrm{H}$ & 10.4275076 & 11.9520122 & 14.9728324 \\
\hline 0 & 12.2235157 & 10.8232774 & 24.8742572 \\
\hline 0 & 15.5779899 & 11.1531755 & 25.1293534 \\
\hline $\mathrm{O}$ & 10.2224660 & 8.1430506 & 25.1866806 \\
\hline $\mathrm{H}$ & 10.4550432 & 11.9396566 & 29.6966526 \\
\hline $\mathrm{H}$ & 8.7652043 & 15.0402328 & 15.0801407 \\
\hline Al & 5.4115737 & 14.7253931 & 16.4883865 \\
\hline $\mathrm{P}$ & 5.3856287 & 14.6809646 & 28.3261997 \\
\hline Al & 12.3085415 & 18.6939332 & 21.5126121 \\
\hline $\mathrm{Zn}$ & 12.4136002 & 13.2490085 & 21.4390641 \\
\hline Al & 17.1901920 & 16.0360850 & 21.4882536 \\
\hline $\mathrm{P}$ & 17.1096885 & 16.0567525 & 18.3203116 \\
\hline $\mathrm{P}$ & 12.3673476 & 13.2284037 & 18.2911457 \\
\hline $\mathrm{P}$ & 12.3357492 & 18.7246513 & 18.3566025 \\
\hline Al & 5.4635719 & 17.1804762 & 26.4572040 \\
\hline $\mathrm{P}$ & 5.4497917 & 17.2366676 & 23.3752972 \\
\hline Al & 8.5501192 & 14.7011214 & 28.3446964 \\
\hline $\mathrm{P}$ & 8.5762709 & 14.7294276 & 16.5240329 \\
\hline Al & 15.5781571 & 13.2841743 & 18.4511491 \\
\hline$A 1$ & 15.5038336 & 18.7648230 & 18.4239653 \\
\hline
\end{tabular}




\begin{tabular}{|c|c|c|c|}
\hline Al & 10.8216680 & 15.9475232 & 18.3580415 \\
\hline $\mathrm{P}$ & 10.6670491 & 15.9720969 & 21.5406684 \\
\hline $\mathrm{P}$ & 15.4920445 & 18.7297269 & 21.5925131 \\
\hline $\mathrm{P}$ & 15.6671420 & 13.3233229 & 21.5414404 \\
\hline Al & 8.6005051 & 17.4041687 & 23.3784763 \\
\hline $\mathrm{P}$ & 8.6161774 & 17.2617341 & 26.5206348 \\
\hline 0 & 9.0090221 & 13.2750030 & 16.8208247 \\
\hline 0 & 6.8614719 & 14.3388734 & 28.0533827 \\
\hline 0 & 11.6963500 & 17.0955006 & 21.8171335 \\
\hline 0 & 14.2336018 & 13.8103724 & 21.6555477 \\
\hline 0 & 16.0384512 & 17.3138197 & 21.8502168 \\
\hline 0 & 16.0707943 & 14.9419390 & 18.1028455 \\
\hline 0 & 12.0156726 & 14.7203761 & 18.0256676 \\
\hline 0 & 13.8205842 & 18.3817953 & 18.1263611 \\
\hline 0 & 7.1352380 & 17.6141780 & 26.7795341 \\
\hline $\mathrm{H}$ & 9.1140740 & 18.7886117 & 23.1869427 \\
\hline $\mathrm{H}$ & 4.7942006 & 18.5726241 & 23.3248869 \\
\hline $\mathrm{H}$ & 18.2990484 & 15.8518560 & 17.4482100 \\
\hline $\mathrm{H}$ & 11.9271368 & 19.8752711 & 17.5044108 \\
\hline 0 & 11.7289943 & 12.3634334 & 17.1788143 \\
\hline 0 & 4.9399196 & 15.8755751 & 27.4809632 \\
\hline $\mathrm{H}$ & 11.6007334 & 19.7249691 & 22.3207540 \\
\hline 0 & 11.8100345 & 11.8168278 & 22.6313677 \\
\hline $\mathrm{H}$ & 18.4539091 & 16.2411775 & 22.2485671 \\
\hline 0 & 9.0447689 & 16.0764857 & 27.3942207 \\
\hline $\mathrm{H}$ & 16.3340714 & 12.3715034 & 17.5496247 \\
\hline 0 & 9.3964683 & 15.7135146 & 17.3604290 \\
\hline $\mathrm{H}$ & 15.9076024 & 19.9480745 & 17.6152581 \\
\hline 0 & 9.3494725 & 16.2892710 & 22.2838688 \\
\hline 0 & 7.0977236 & 14.8711018 & 16.9239878 \\
\hline O & 9.4802529 & 13.3081276 & 27.8702830 \\
\hline 0 & 13.9985296 & 18.7575618 & 21.9272847 \\
\hline 0 & 11.1688134 & 14.6372674 & 22.0619060 \\
\hline 0 & 16.6267834 & 14.4649535 & 21.9454292 \\
\hline 0 & 16.4814478 & 17.4052992 & 17.9474333 \\
\hline 0 & 13.8913630 & 13.0868244 & 18.1388757 \\
\hline 0 & 11.4812578 & 17.5190234 & 17.9678451 \\
\hline $\mathrm{H}$ & 4.5729778 & 18.3458819 & 26.7137043 \\
\hline $\mathrm{H}$ & 9.4573924 & 18.4353337 & 26.8841479 \\
\hline 0 & 6.9145151 & 17.4079993 & 22.9794624 \\
\hline $\mathrm{H}$ & 5.2186451 & 14.9971717 & 15.0371678 \\
\hline 0 & 12.1063114 & 19.1246040 & 19.8266281 \\
\hline 0 & 11.8576540 & 12.7579284 & 19.6465130 \\
\hline 0 & 17.5867717 & 16.0754717 & 19.7824212 \\
\hline 0 & 5.3312582 & 16.6447383 & 24.7932145 \\
\hline $\mathrm{H}$ & 8.7380251 & 14.9977449 & 29.7917024 \\
\hline 0 & 16.0179754 & 12.8715469 & 20.0945614 \\
\hline $\mathrm{O}$ & 15.7261223 & 19.1364510 & 20.1241977 \\
\hline 0 & 10.3366675 & 15.9319075 & 20.0339120 \\
\hline 0 & 8.8316707 & 16.8899426 & 25.0408584 \\
\hline $\mathrm{H}$ & 9.7503605 & 13.7588726 & 23.0076364 \\
\hline C & 8.2431246 & 12.0358211 & 21.7681539 \\
\hline $\mathrm{H}$ & 9.0801412 & 12.2157112 & 21.0973829 \\
\hline $\mathrm{H}$ & 8.2737843 & 11.1573496 & 22.4060880 \\
\hline $\mathrm{H}$ & 7.5736377 & 12.8530986 & 22.0215290 \\
\hline $\mathrm{O}$ & 9.4250531 & 12.8830049 & 23.3334280 \\
\hline $\mathrm{H}$ & 10.2696873 & 12.3573614 & 23.2475273 \\
\hline $\mathrm{H}$ & 6.4029379 & 10.9273169 & 20.9480168 \\
\hline 0 & 7.2072299 & 11.2661762 & 20.5027583 \\
\hline $\mathrm{C}$ & 6.8140574 & 12.1860656 & 19.4310582 \\
\hline $\mathrm{H}$ & 6.1401990 & 11.6511378 & 18.7542001 \\
\hline $\mathrm{H}$ & 6.3274830 & 13.0788134 & 19.8496113 \\
\hline $\mathrm{H}$ & 7.7341830 & 12.4528760 & 18.9013096 \\
\hline $\mathrm{H}$ & 5.1922406 & 15.0317830 & 29.7603016 \\
\hline & 16.1636542 & 19.7264487 & 22.4714935 \\
\hline \multicolumn{4}{|c|}{$\mathrm{Si} 4$} \\
\hline \multicolumn{4}{|c|}{171} \\
\hline $\mathrm{H}$ & 8.7244909 & 8.9727931 & 15.0737898 \\
\hline $\mathrm{P}$ & 5.4087242 & 9.3130943 & 16.5825193 \\
\hline Al & 5.3983793 & 9.2769436 & 28.4049363 \\
\hline $\mathrm{P}$ & 5.4596974 & 6.7971439 & 21.5396140 \\
\hline Al & 5.4856507 & 6.7384128 & 18.3861667 \\
\hline $\mathrm{P}$ & 3.2465616 & 7.9251577 & 26.5483416 \\
\hline Al & 3.2999626 & 7.9746908 & 23.4203730 \\
\hline$P$ & 8.5398947 & 9.2128454 & 28.3443084 \\
\hline Al & 8.5714186 & 9.2722780 & 16.5243064 \\
\hline $\mathrm{P}$ & 8.6473504 & 6.7056550 & 18.3448868 \\
\hline Al & 8.6329952 & 6.6847244 & 21.5152031 \\
\hline $\mathrm{P}$ & 1.6886199 & 10.7339839 & 23.3386558 \\
\hline
\end{tabular}




\begin{tabular}{|c|c|c|c|}
\hline Al & 1.6644810 & 10.6961935 & 26.4918163 \\
\hline 0 & 6.8874093 & 9.6718088 & 16.8542002 \\
\hline 0 & 4.9310144 & 10.9286540 & 28.0452967 \\
\hline $\mathrm{H}$ & 4.9107796 & 5.4330773 & 21.7744159 \\
\hline $\mathrm{H}$ & 9.1147451 & 5.3019146 & 21.7851561 \\
\hline 0 & 7.1693096 & 6.3465085 & 18.0939542 \\
\hline 0 & 2.1930059 & 9.0368127 & 26.6998324 \\
\hline $\mathrm{H}$ & 2.3252418 & 6.8847954 & 23.1390051 \\
\hline $\mathrm{H}$ & 0.2698677 & 10.3909526 & 23.0443904 \\
\hline 0 & 4.9906597 & 8.1044913 & 17.4206718 \\
\hline $\mathrm{O}$ & 4.4195785 & 8.1544695 & 27.5069995 \\
\hline $\mathrm{O}$ & 4.7244927 & 7.8325792 & 22.4104672 \\
\hline 0 & 2.6181001 & 11.7705300 & 27.4775337 \\
\hline $\mathrm{O}$ & 9.0606389 & 7.8977099 & 17.4739790 \\
\hline 0 & 2.1942594 & 11.8650797 & 22.4392048 \\
\hline $\mathrm{O}$ & 4.5482964 & 10.5129898 & 17.0091026 \\
\hline $\mathrm{O}$ & 7.0646462 & 9.0453388 & 27.9652532 \\
\hline 0 & 6.9437227 & 6.8257470 & 21.9266609 \\
\hline $\mathrm{H}$ & 9.4960584 & 5.5408675 & 17.9706070 \\
\hline $\mathrm{H}$ & 4.6441100 & 5.5663707 & 18.0184070 \\
\hline $\mathrm{H}$ & 0.2490654 & 10.7873947 & 26.9450287 \\
\hline $\mathrm{H}$ & 2.6213947 & 6.6201984 & 26.8995797 \\
\hline $\mathrm{O}$ & 2.5610001 & 9.5016835 & 23.0612141 \\
\hline $\mathrm{H}$ & 5.1977931 & 8.9934501 & 15.1436113 \\
\hline 0 & 5.2908672 & 7.2129342 & 20.0639800 \\
\hline $\mathrm{O}$ & 3.7872917 & 7.8977601 & 25.1045767 \\
\hline $\mathrm{H}$ & 8.7439914 & 8.9306914 & 29.7920149 \\
\hline 0 & 8.8606759 & 7.0823948 & 19.8232009 \\
\hline $\mathrm{O}$ & 1.8342423 & 11.1626942 & 24.8146319 \\
\hline $\mathrm{H}$ & 5.2221956 & 9.0273833 & 29.8622624 \\
\hline $\mathrm{H}$ & 3.5205242 & 11.9948725 & 15.0435897 \\
\hline $\mathrm{P}$ & 3.2635262 & 15.9327387 & 21.5594670 \\
\hline Al & 3.2438899 & 15.9661255 & 18.3862470 \\
\hline $\mathrm{P}$ & 3.8677204 & 12.0114152 & 28.3247204 \\
\hline Al & 3.8275141 & 12.0276625 & 16.5002306 \\
\hline $\mathrm{P}$ & 1.6272495 & 13.2630908 & 18.3477230 \\
\hline Al & 1.6167162 & 13.2330794 & 21.4879239 \\
\hline $\mathrm{O}$ & 5.0257721 & 13.2708744 & 16.8490297 \\
\hline $\mathrm{H}$ & 0.1709171 & 13.5103446 & 21.7113284 \\
\hline $\mathrm{H}$ & 2.2975573 & 17.0349108 & 21.8226048 \\
\hline $\mathrm{O}$ & 2.0640843 & 14.7188979 & 18.0560310 \\
\hline $\mathrm{O}$ & 4.6927769 & 15.7044628 & 17.4432944 \\
\hline $\mathrm{O}$ & 4.5320484 & 16.1216930 & 22.4067164 \\
\hline $\mathrm{O}$ & 2.3698009 & 12.3036578 & 17.3986049 \\
\hline 0 & 4.4472705 & 13.3779014 & 27.9461568 \\
\hline $\mathrm{O}$ & 2.6341134 & 14.5979458 & 21.9427315 \\
\hline $\mathrm{H}$ & 2.6797708 & 17.2952372 & 18.0224444 \\
\hline $\mathrm{H}$ & 0.1673718 & 13.1401099 & 18.0817279 \\
\hline $\mathrm{O}$ & 3.6852988 & 15.9438210 & 20.0776206 \\
\hline $\mathrm{H}$ & 3.4808409 & 11.9899668 & 29.7624217 \\
\hline 0 & 1.9904741 & 12.8794612 & 19.7923345 \\
\hline $\mathrm{P}$ & 10.1777734 & 11.9655544 & 16.5410465 \\
\hline Al & 10.1358946 & 11.9273442 & 28.3473248 \\
\hline $\mathrm{P}$ & 12.4130444 & 10.6594515 & 26.6154750 \\
\hline Al & 12.4073717 & 10.7202024 & 23.3976782 \\
\hline$P$ & 15.5636187 & 10.7339839 & 23.3386558 \\
\hline $\mathrm{P}$ & 10.7347254 & 8.0399143 & 23.3773903 \\
\hline Al & 10.7571436 & 8.0032199 & 26.5206502 \\
\hline Al & 15.5394797 & 10.6961935 & 26.4918163 \\
\hline 0 & 8.9732724 & 10.6543455 & 28.0111076 \\
\hline $\mathrm{O}$ & 11.9547968 & 9.2168641 & 26.9218985 \\
\hline $\mathrm{H}$ & 15.9881798 & 9.2874345 & 26.6684150 \\
\hline $\mathrm{H}$ & 11.6626607 & 6.8869878 & 23.2136311 \\
\hline $\mathrm{O}$ & 14.0957537 & 10.3790780 & 23.0342039 \\
\hline $\mathrm{O}$ & 11.5969863 & 11.6632500 & 27.4411340 \\
\hline $\mathrm{O}$ & 9.3517036 & 8.1980610 & 27.5336892 \\
\hline $\mathrm{H}$ & 16.3545105 & 11.6143979 & 27.3342805 \\
\hline 0 & 9.4931766 & 7.8555832 & 22.4877633 \\
\hline $\mathrm{O}$ & 16.0692581 & 11.8650797 & 22.4392048 \\
\hline 0 & 9.5487458 & 10.6365977 & 16.9946129 \\
\hline $\mathrm{O}$ & 13.8845208 & 10.8028295 & 27.0217299 \\
\hline $\mathrm{H}$ & 11.3355855 & 6.6558722 & 26.7798404 \\
\hline $\mathrm{H}$ & 16.4097911 & 9.5387038 & 23.0695489 \\
\hline 0 & 11.4518884 & 9.3164045 & 22.9441486 \\
\hline $\mathrm{H}$ & 10.4779331 & 11.9250016 & 15.0831781 \\
\hline 0 & 12.2268774 & 10.9661370 & 25.1275522 \\
\hline $\mathrm{O}$ & 15.7092410 & 11.1626942 & 24.8146319 \\
\hline $\mathrm{O}$ & 10.2683629 & 8.1463258 & 24.8428161 \\
\hline $\mathrm{H}$ & 10.4357575 & 11.9242853 & 29.8058149 \\
\hline $\mathrm{H}$ & 8.8159491 & 14.9947514 & 15.0169200 \\
\hline
\end{tabular}




\begin{tabular}{|c|c|c|c|}
\hline $\mathrm{P}$ & 5.4795048 & 14.7225178 & 16.5706043 \\
\hline Al & 5.4531288 & 14.7219284 & 28.4077157 \\
\hline $\mathrm{P}$ & 12.3971968 & 18.8132453 & 21.5396140 \\
\hline $\mathrm{Si}$ & 12.2566089 & 13.2735702 & 21.5702267 \\
\hline $\mathrm{P}$ & 17.1385249 & 15.9327387 & 21.5594670 \\
\hline Al & 17.1188886 & 15.9661255 & 18.3862470 \\
\hline Al & 12.2969604 & 13.2540914 & 18.4464223 \\
\hline Al & 12.4231500 & 18.7545142 & 18.3861667 \\
\hline $\mathrm{P}$ & 5.3945518 & 17.2453042 & 26.5415685 \\
\hline Al & 5.3803078 & 17.2537385 & 23.4193310 \\
\hline $\mathrm{P}$ & 8.6077186 & 14.6727719 & 28.3059608 \\
\hline Al & 8.6460828 & 14.7250202 & 16.4713997 \\
\hline $\mathrm{P}$ & 15.5022482 & 13.2630908 & 18.3477230 \\
\hline$P$ & 15.5848497 & 18.7217563 & 18.3448868 \\
\hline$P$ & 10.7865715 & 16.0482802 & 18.3145868 \\
\hline Al & 10.7446188 & 16.0616437 & 21.4720880 \\
\hline Al & 15.5704945 & 18.7008257 & 21.5152031 \\
\hline Al & 15.4917149 & 13.2330794 & 21.4879239 \\
\hline $\mathrm{P}$ & 8.5457520 & 17.2878614 & 23.3158184 \\
\hline Al & 8.5416056 & 17.2411407 & 26.4771496 \\
\hline 0 & 9.1541634 & 13.0863686 & 16.8495321 \\
\hline $\mathrm{O}$ & 7.1248366 & 14.3127341 & 28.0846968 \\
\hline $\mathrm{O}$ & 11.8329446 & 17.4110728 & 21.7809752 \\
\hline $\mathrm{O}$ & 13.8408747 & 13.5496659 & 21.7430113 \\
\hline $\mathrm{O}$ & 16.1365689 & 17.0759722 & 21.8324080 \\
\hline $\mathrm{O}$ & 15.9390830 & 14.7188979 & 18.0560310 \\
\hline 0 & 11.8021049 & 14.9199456 & 18.0827616 \\
\hline $\mathrm{O}$ & 14.1068090 & 18.3626098 & 18.0939542 \\
\hline $\mathrm{O}$ & 6.8629244 & 17.6508108 & 26.7858087 \\
\hline $\mathrm{H}$ & 9.0734425 & 18.6628899 & 23.0968210 \\
\hline $\mathrm{H}$ & 4.8458920 & 18.6317791 & 23.2389854 \\
\hline $\mathrm{H}$ & 18.3528129 & 15.7432842 & 17.5831946 \\
\hline $\mathrm{H}$ & 12.0006616 & 19.9204997 & 17.5620903 \\
\hline $\mathrm{O}$ & 11.4780409 & 12.1920699 & 17.3023129 \\
\hline 0 & 4.9773447 & 16.1179747 & 27.4896490 \\
\hline $\mathrm{H}$ & 11.6862555 & 19.8145089 & 22.3817270 \\
\hline 0 & 11.7499993 & 12.0923720 & 22.6001523 \\
\hline $\mathrm{H}$ & 18.3673496 & 16.1157798 & 22.3802023 \\
\hline 0 & 9.0120199 & 15.8658892 & 27.4352718 \\
\hline $\mathrm{H}$ & 16.2200392 & 12.3356502 & 17.4302533 \\
\hline 0 & 9.5651374 & 15.8750687 & 17.3947157 \\
\hline $\mathrm{H}$ & 15.9862595 & 19.8795492 & 17.4990107 \\
\hline 0 & 9.2605551 & 16.2809811 & 22.4071087 \\
\hline 0 & 6.9640462 & 14.8386508 & 16.9373501 \\
\hline 0 & 9.4659288 & 13.4723590 & 27.8981450 \\
\hline $\mathrm{O}$ & 13.8812220 & 18.8418483 & 21.9266609 \\
\hline $\mathrm{O}$ & 11.3980321 & 14.5847223 & 21.9902381 \\
\hline $\mathrm{O}$ & 16.5091121 & 14.5979458 & 21.9427315 \\
\hline $\mathrm{O}$ & 16.4578072 & 17.5236885 & 17.9599130 \\
\hline $\mathrm{O}$ & 14.0075105 & 13.1371733 & 18.0753762 \\
\hline $\mathrm{O}$ & 11.4438134 & 17.3905591 & 17.9581891 \\
\hline $\mathrm{H}$ & 4.5174116 & 18.4168513 & 26.8158368 \\
\hline $\mathrm{H}$ & 9.3965729 & 18.4027140 & 26.8471480 \\
\hline $\mathrm{O}$ & 7.0572958 & 17.2684576 & 22.9578261 \\
\hline $\mathrm{H}$ & 5.2589052 & 15.0661258 & 15.1386860 \\
\hline $\mathrm{O}$ & 12.2283665 & 19.2290355 & 20.0639800 \\
\hline $\mathrm{O}$ & 11.8905275 & 12.8215147 & 20.0503912 \\
\hline $\mathrm{O}$ & 17.5602975 & 15.9438210 & 20.0776206 \\
\hline $\mathrm{O}$ & 5.2163901 & 16.7558467 & 25.0914254 \\
\hline $\mathrm{H}$ & 8.8375812 & 15.0293861 & 29.7332344 \\
\hline $\mathrm{O}$ & 15.8654729 & 12.8794612 & 19.7923345 \\
\hline $\mathrm{O}$ & 15.7981753 & 19.0984962 & 19.8232009 \\
\hline 0 & 10.2907256 & 16.0783331 & 19.7704875 \\
\hline $\mathrm{O}$ & 8.7524411 & 16.8552790 & 24.7809480 \\
\hline $\mathrm{H}$ & 9.4029362 & 13.9002307 & 23.2451230 \\
\hline C & 8.2756399 & 12.0190521 & 21.8248767 \\
\hline $\mathrm{H}$ & 9.1036513 & 12.2851206 & 21.1716206 \\
\hline $\mathrm{H}$ & 8.3739115 & 11.1348448 & 22.4480395 \\
\hline $\mathrm{H}$ & 7.5120682 & 12.7555979 & 22.0589377 \\
\hline 0 & 9.3377515 & 12.9373023 & 23.4174117 \\
\hline $\mathrm{H}$ & 10.2738067 & 12.6172671 & 23.2134962 \\
\hline $\mathrm{H}$ & 6.5723589 & 10.7291517 & 20.9203960 \\
\hline 0 & 7.3478607 & 11.1612587 & 20.5061091 \\
\hline C & 6.8919982 & 12.0569116 & 19.4396010 \\
\hline $\mathrm{H}$ & 6.2916522 & 11.4713653 & 18.7350710 \\
\hline $\mathrm{H}$ & 6.3107235 & 12.8919602 & 19.8565032 \\
\hline $\mathrm{H}$ & 7.7947536 & 12.4197650 & 18.9375381 \\
\hline $\mathrm{H}$ & 5.2818937 & 15.0240960 & 29.8556431 \\
\hline $\mathrm{H}$ & 16.3030805 & 19.6980046 & 22.3434980 \\
\hline
\end{tabular}


8.8561259

6.6515628

16.9410628

7.0925595

5.4344873

27.8980562

9.4661683

5.3826498

21.8524921

17.9315657

4.5911329

10.6337318

17.8879182

2. 6688142

6.5228235

9.3203199

26.9922166

2.7039763

8.8100521

26.7526122

5.3231516

6.9574048

.2135646

7. 8511439

23.0337860

15.0150929

19.7247429

24.7576815

8.8398871

8.8316747

29.7889600

8.8225115

1.7275595

5.2949848

6.9527090

11.0501937

8.7653204

20.0314814

25.0664505 29.7374066 15.0730896

15.8948824

21.4232934

18.2558901

28.3364247

11.7633051

11.8020781

16.5155039

18.3690294

21.4906504

16.7780168

21.6567488

21.7555278

18.0294582

17.3982186

22.3177063

17.3387290

27.8758050

21.8906922

17.8744287

18.0339029

19.7347565

29.7913262

20.0277488

16.3616015

28.1758300

26.5034097

23. 2740611

23.3491477

23.3738452

26.5213255

26.5186536

27.8839678

26.8873128

26.6266014

23.1629890

22.9057486

27.3284682

27.4493849 


\begin{tabular}{|c|c|c|c|}
\hline $\mathrm{H}$ & 16.3104267 & 11.4429640 & 27.3904372 \\
\hline $\mathrm{O}$ & 9.3055442 & 7.6327305 & 22.3896033 \\
\hline 0 & 16.1447394 & 11.9893267 & 22.3994615 \\
\hline $\mathrm{O}$ & 9.5660384 & 10.3431143 & 16.8987508 \\
\hline $\mathrm{O}$ & 14.0365566 & 10.6359742 & 27.0064082 \\
\hline $\mathrm{H}$ & 11.3742674 & 6.3966597 & 26.7047955 \\
\hline $\mathrm{H}$ & 16.4223436 & 9.5220796 & 23.0806173 \\
\hline 0 & 11.6835561 & 9.1374665 & 22.8671299 \\
\hline $\mathrm{H}$ & 10.4834585 & 11.8025646 & 14.8933349 \\
\hline 0 & 12.2292590 & 10.6646652 & 24.7938720 \\
\hline 0 & 15.6025582 & 11.0501937 & 25.0664505 \\
\hline 0 & 10.3065615 & 7.9261665 & 25.0640938 \\
\hline $\mathrm{H}$ & 10.5136938 & 11.7923683 & 29.6160206 \\
\hline $\mathrm{H}$ & 8.8152562 & 14.9155748 & 15.0130181 \\
\hline Al & 5.4523057 & 14.5493822 & 16.4240747 \\
\hline $\mathrm{P}$ & 5.4137812 & 14.5183019 & 28.2713565 \\
\hline Al & 12.3419692 & 18.5917913 & 21.4180269 \\
\hline Mg & 12.3488045 & 13.0432309 & 21.4090890 \\
\hline$A l$ & 17.1492294 & 15.8948824 & 21.4232934 \\
\hline $\mathrm{P}$ & 17.1583372 & 15.9024302 & 18.2558901 \\
\hline$P$ & 12.4275078 & 13.0961151 & 18.1786304 \\
\hline $\mathrm{P}$ & 12.3860270 & 18.5575105 & 18.2611095 \\
\hline Al & 5.4830198 & 17.0187273 & 26.3918036 \\
\hline $\mathrm{P}$ & 5.4620362 & 17.0137024 & 23.2836687 \\
\hline Al & 8.5847704 & 14.5498745 & 28.2848562 \\
\hline $\mathrm{P}$ & 8.6177116 & 14.5703017 & 16.4478990 \\
\hline Al & 15.6185481 & 13.1317170 & 18.3690294 \\
\hline Al & 15.5418667 & 18.5978945 & 18.3291950 \\
\hline Al & 10.8733226 & 15.7869011 & 18.2616709 \\
\hline $\mathrm{P}$ & 10.7428993 & 15.8510333 & 21.4610977 \\
\hline $\mathrm{P}$ & 15.5205168 & 18.6172553 & 21.5100387 \\
\hline $\mathrm{P}$ & 15.6648830 & 13.1409706 & 21.4906504 \\
\hline Al & 8.6242518 & 17.2581742 & 23.2965599 \\
\hline $\mathrm{P}$ & 8.6437786 & 17.1023382 & 26.4304223 \\
\hline O & 9.0524705 & 13.1156229 & 16.7130248 \\
\hline 0 & 6.8930996 & 14.1777060 & 28.0128757 \\
\hline 0 & 11.7652254 & 16.9743482 & 21.7290261 \\
\hline 0 & 14.1959179 & 13.4478522 & 21.6591028 \\
\hline 0 & 16.0594160 & 17.2019081 & 21.8128217 \\
\hline 0 & 16.1212001 & 14.7927368 & 18.0294582 \\
\hline 0 & 12.0631064 & 14.5786942 & 17.8661240 \\
\hline 0 & 13.8657051 & 18.1741272 & 18.0506996 \\
\hline 0 & 7.1588723 & 17.4558277 & 26.6632435 \\
\hline $\mathrm{H}$ & 9.0744560 & 18.6657511 & 23.1144500 \\
\hline $\mathrm{H}$ & 4.8014238 & 18.3392132 & 23.1296139 \\
\hline $\mathrm{H}$ & 18.3726387 & 15.6765855 & 17.4242732 \\
\hline $\mathrm{H}$ & 12.0095880 & 19.7057375 & 17.3910583 \\
\hline 0 & 11.7647777 & 12.1911652 & 17.1141202 \\
\hline 0 & 4.9806001 & 15.7098841 & 27.4126764 \\
\hline $\mathrm{H}$ & 11.5621561 & 19.5757820 & 22.2185108 \\
\hline 0 & 11.7022668 & 11.6167668 & 22.5551079 \\
\hline $\mathrm{H}$ & 18.4347572 & 15.9722485 & 22.1706576 \\
\hline 0 & 9.0581592 & 15.9156346 & 27.3050696 \\
\hline $\mathrm{H}$ & 16.3912356 & 12.2092988 & 17.4919779 \\
\hline 0 & 9.4197245 & 15.5471441 & 17.3121723 \\
\hline $\mathrm{H}$ & 15.9351919 & 19.7788668 & 17.5120534 \\
\hline 0 & 9.4072088 & 16.1895769 & 22.1747598 \\
\hline 0 & 7.1378905 & 14.7143519 & 16.8385469 \\
\hline $\mathrm{O}$ & 9.5123680 & 13.1595912 & 27.8000552 \\
\hline 0 & 14.0300588 & 18.6676642 & 21.8524921 \\
\hline 0 & 11.2427728 & 14.5306849 & 22.0222266 \\
\hline 0 & 16.5213457 & 14.3663546 & 21.8906922 \\
\hline O & 16.5515793 & 17.2536756 & 17.8633202 \\
\hline 0 & 13.9473069 & 12.9517946 & 17.9807506 \\
\hline 0 & 11.5059978 & 17.3681609 & 17.8780663 \\
\hline $\mathrm{H}$ & 4.5979392 & 18.1844733 & 26.6652797 \\
\hline $\mathrm{H}$ & 9.4775918 & 18.2795239 & 26.7993534 \\
\hline 0 & 6.9342365 & 17.1171965 & 22.8869470 \\
\hline $\mathrm{H}$ & 5.2335838 & 14.8392505 & 14.9800325 \\
\hline 0 & 12.1510640 & 18.9735062 & 19.7247429 \\
\hline 0 & 11.9740241 & 12.7011958 & 19.5664721 \\
\hline 0 & 17.6034691 & 15.9352404 & 19.7347565 \\
\hline 0 & 5.3173609 & 16.4853925 & 24.7196506 \\
\hline $\mathrm{H}$ & 8.7865719 & 14.8710199 & 29.7247390 \\
\hline 0 & 16.0185121 & 12.7579956 & 20.0277488 \\
\hline 0 & 15.7600108 & 18.9688104 & 20.0314814 \\
\hline 0 & 10.4269065 & 15.7582609 & 19.9560803 \\
\hline 0 & 8.8691495 & 16.7238953 & 24.9493153 \\
\hline $\mathrm{H}$ & 10.1629771 & 13.7971929 & 23.2711388 \\
\hline C & 7.8814981 & 13.3146711 & 22.6089307 \\
\hline
\end{tabular}




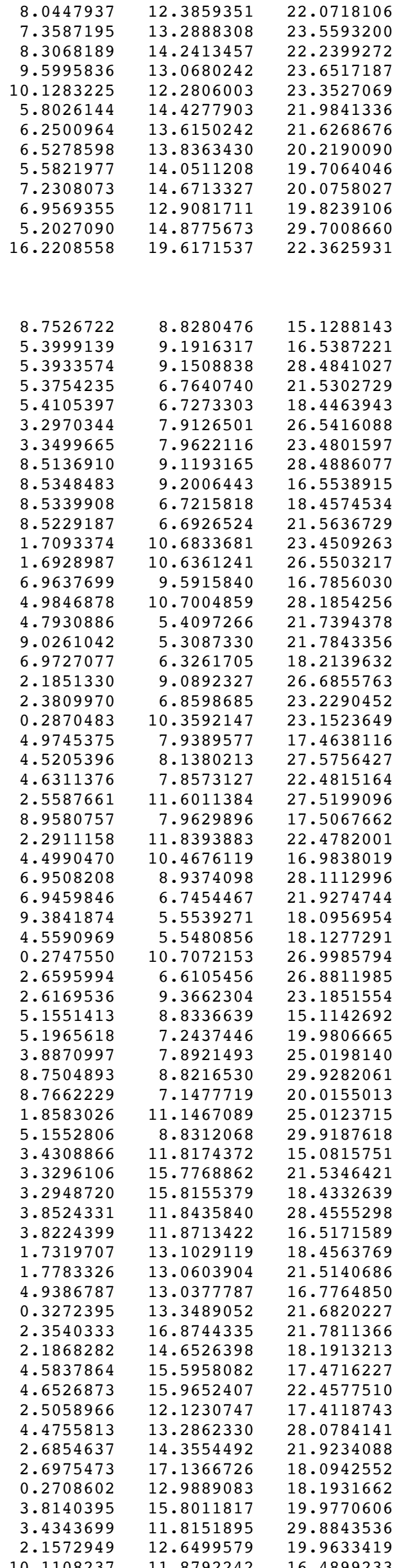




\begin{tabular}{|c|c|c|c|}
\hline $\mathrm{Si}$ & 10.0400989 & 11.8300161 & 28.4096287 \\
\hline $\mathrm{Si}$ & 12.2209955 & 10.5570457 & 26.6153395 \\
\hline $\mathrm{Si}$ & 12.2012246 & 10.5991953 & 23.4573735 \\
\hline $\mathrm{Si}$ & 15.3343361 & 10.6833681 & 23.4509263 \\
\hline $\mathrm{Si}$ & 10.5674204 & 7.9371201 & 23.5101091 \\
\hline $\mathrm{Si}$ & 10.6069917 & 7.9089828 & 26.5811494 \\
\hline $\mathrm{Si}$ & 15.3178975 & 10.6361241 & 26.5503217 \\
\hline 0 & 8.9450603 & 10.6512907 & 28.1383338 \\
\hline 0 & 11.7465307 & 9.0242600 & 26.9140005 \\
\hline $\mathrm{H}$ & 15.7678432 & 9.2221284 & 26.6739564 \\
\hline $\mathrm{H}$ & 11.4831626 & 6.7704879 & 23.3777980 \\
\hline 0 & 13.7792772 & 10.3289552 & 23.1244944 \\
\hline 0 & 11.3603804 & 11.6035875 & 27.5043895 \\
\hline 0 & 9.3582552 & 8.0591711 & 27.6029285 \\
\hline $\mathrm{H}$ & 16.1142510 & 11.5236648 & 27.4420688 \\
\hline 0 & 9.2757261 & 7.7513986 & 22.5405623 \\
\hline 0 & 15.9161146 & 11.8393883 & 22.4782001 \\
\hline 0 & 9.4450587 & 10.4743081 & 16.9698598 \\
\hline 0 & 13.7765633 & 10.7133908 & 27.0375184 \\
\hline $\mathrm{H}$ & 11.1992637 & 6.5569454 & 26.7769284 \\
\hline $\mathrm{H}$ & 16.1677883 & 9.4738576 & 23.2068723 \\
\hline 0 & 11.3689755 & 9.2588526 & 23.0540934 \\
\hline $\mathrm{H}$ & 10.4365778 & 11.8315344 & 15.0377765 \\
\hline 0 & 12.0128670 & 10.8995530 & 25.0496639 \\
\hline 0 & 15.4833013 & 11.1467089 & 25.0123715 \\
\hline 0 & 10.0545945 & 8.0764340 & 25.0537614 \\
\hline $\mathrm{H}$ & 10.4308918 & 11.8274869 & 29.8464290 \\
\hline $\mathrm{H}$ & 8.7660653 & 14.9167373 & 15.0619644 \\
\hline $\mathrm{Si}$ & 5.4043092 & 14.5819805 & 16.5160946 \\
\hline $\mathrm{Si}$ & 5.3823893 & 14.5638093 & 28.4774429 \\
\hline $\mathrm{Si}$ & 12.1879229 & 18.5636690 & 21.5302729 \\
\hline $\mathrm{Al}$ & 12.1635396 & 13.0644340 & 21.5222188 \\
\hline $\mathrm{Si}$ & 16.9546094 & 15.7768862 & 21.5346421 \\
\hline $\mathrm{Si}$ & 16.9198707 & 15.8155379 & 18.4332639 \\
\hline $\mathrm{Si}$ & 12.1780576 & 13.0801051 & 18.4388105 \\
\hline $\mathrm{Si}$ & 12.2230391 & 18.5269253 & 18.4463943 \\
\hline $\mathrm{Si}$ & 5.3895518 & 16.9701314 & 26.5275737 \\
\hline $\mathrm{Si}$ & 5.3807744 & 16.9831192 & 23.4813961 \\
\hline $\mathrm{Si}$ & 8.5171493 & 14.5463761 & 28.4384717 \\
\hline $\mathrm{Si}$ & 8.5459142 & 14.5818647 & 16.4960197 \\
\hline $\mathrm{Si}$ & 15.3569694 & 13.1029119 & 18.4563769 \\
\hline $\mathrm{Si}$ & 15.3464902 & 18.5211769 & 18.4574534 \\
\hline $\mathrm{Si}$ & 10.6364086 & 15.8066235 & 18.4276705 \\
\hline $\mathrm{Si}$ & 10.5662336 & 15.8204845 & 21.5172293 \\
\hline $\mathrm{Si}$ & 15.3354181 & 18.4922475 & 21.5636729 \\
\hline $\mathrm{Si}$ & 15.4033314 & 13.0603904 & 21.5140686 \\
\hline $\mathrm{Si}$ & 8.5136872 & 17.0636197 & 23.4384292 \\
\hline $\mathrm{Si}$ & 8.5072297 & 17.0147112 & 26.5374953 \\
\hline 0 & 9.0010682 & 13.0432988 & 16.7957430 \\
\hline 0 & 6.9438958 & 14.1824054 & 28.2276301 \\
\hline 0 & 11.5570036 & 17.0963279 & 21.7568885 \\
\hline 0 & 13.8567668 & 13.3678874 & 21.6930729 \\
\hline 0 & 15.8853086 & 16.9798746 & 21.8048172 \\
\hline 0 & 15.8118269 & 14.6526398 & 18.1913213 \\
\hline $\mathrm{O}$ & 11.7442545 & 14.6480772 & 18.1771414 \\
\hline $\mathrm{O}$ & 13.7852071 & 18.1257655 & 18.2139632 \\
\hline 0 & 6.9416126 & 17.3994605 & 26.7860624 \\
\hline $\mathrm{H}$ & 9.0554379 & 18.4340933 & 23.2252888 \\
\hline $\mathrm{H}$ & 4.8007063 & 18.3503768 & 23.3753386 \\
\hline $\mathrm{H}$ & 18.1023219 & 15.6139577 & 17.5510535 \\
\hline $\mathrm{H}$ & 11.8222333 & 19.6407435 & 17.5431311 \\
\hline 0 & 11.4767139 & 12.1461527 & 17.2944375 \\
\hline 0 & 4.9304517 & 15.8029265 & 27.5460732 \\
\hline $\mathrm{H}$ & 11.5076483 & 19.5628852 & 22.3997061 \\
\hline 0 & 11.5875946 & 11.8387923 & 22.6460752 \\
\hline $\mathrm{H}$ & 18.1675256 & 15.9495582 & 22.3808922 \\
\hline 0 & 8.9528786 & 15.7874564 & 27.4943434 \\
\hline $\mathrm{H}$ & 16.0648644 & 12.2066739 & 17.5009907 \\
\hline 0 & 9.3738448 & 15.6203844 & 17.4171514 \\
\hline $\mathrm{H}$ & 15.7362559 & 19.6621236 & 17.5837006 \\
\hline 0 & 9.2240037 & 15.9946297 & 22.4503807 \\
\hline 0 & 6.9755504 & 14.7009387 & 16.8911637 \\
\hline 0 & 9.3932069 & 13.2578116 & 28.0048538 \\
\hline 0 & 13.7584840 & 18.5450417 & 21.9274744 \\
\hline 0 & 11.2547149 & 14.4702860 & 21.9729933 \\
\hline 0 & 16.3104624 & 14.3554492 & 21.9234088 \\
\hline 0 & 16.2700682 & 17.2527406 & 18.0644717 \\
\hline 0 & 13.7804417 & 12.9799029 & 18.1723744 \\
\hline 0 & 11.3016876 & 17.2508575 & 18.1015647 \\
\hline $\mathrm{H}$ & 4.5093586 & 18.1457796 & 26.7729956 \\
\hline
\end{tabular}




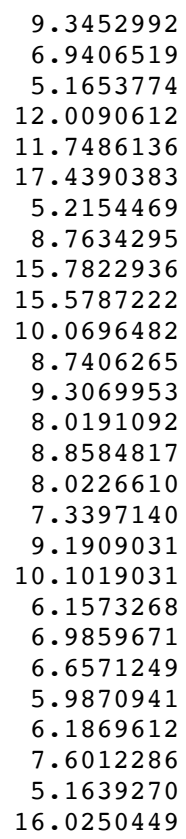

$\begin{array}{lrrr}\mathrm{H} & 8.7151752 & 9.0262233 & 15.0933502 \\ \mathrm{P} & 5.4306677 & 9.3414332 & 16.6133347 \\ \mathrm{Al} & 5.4032141 & 9.2769840 & 28.4268766 \\ \mathrm{P} & 5.4576333 & 6.7603734 & 21.5407528 \\ \mathrm{Al} & 5.5012383 & 6.7509670 & 18.3954844 \\ \mathrm{P} & 3.2672136 & 7.9250431 & 26.5582685 \\ \mathrm{Al} & 3.3591748 & 8.0407064 & 23.4575109 \\ \mathrm{P} & 8.5360012 & 9.1881785 & 28.3506060 \\ \mathrm{Al} & 8.5873719 & 9.3048496 & 16.5504550 \\ \mathrm{P} & 8.6614770 & 6.7262632 & 18.3640811 \\ \mathrm{Al} & 8.6385349 & 6.6763824 & 21.5322096 \\ \mathrm{P} & 1.7039373 & 10.7570138 & 23.3667223 \\ \mathrm{Al} & 1.6532807 & 10.6865667 & 26.5222840 \\ \mathrm{O} & 6.9057294 & 9.7084568 & 16.8960434 \\ \mathrm{O} & 4.9434377 & 10.9280988 & 28.0469174 \\ \mathrm{H} & 4.8713497 & 5.4066500 & 21.7428049 \\ \mathrm{H} & 9.1807641 & 5.3126058 & 21.7836484 \\ \mathrm{O} & 7.1858179 & 6.3585082 & 18.1104560 \\ \mathrm{O} & 2.2022591 & 9.0296363 & 26.6787162 \\ \mathrm{H} & 2.3101132 & 7.0169794 & 23.1956458 \\ \mathrm{H} & 0.3286434 & 10.2945912 & 23.0322787 \\ \mathrm{O} & 5.0140389 & 8.1279237 & 17.4438525 \\ \mathrm{O} & 4.3967249 & 8.1471506 & 27.5695348 \\ \mathrm{O} & 4.7574709 & 7.8036114 & 22.4311281 \\ \mathrm{O} & 2.6154298 & 11.7498964 & 27.5117409 \\ \mathrm{O} & 9.0692168 & 7.9225829 & 17.4951659 \\ \mathrm{O} & 2.1176207 & 11.9304842 & 22.4777898 \\ \mathrm{O} & 4.5589890 & 10.5330808 & 17.0399750 \\ \mathrm{O} & 7.0608476 & 9.0125743 & 27.9726482 \\ \mathrm{O} & 6.9409977 & 6.7264080 & 21.9246496 \\ \mathrm{H} & 9.5153217 & 5.5664657 & 17.9860075 \\ \mathrm{H} & 4.6516835 & 5.5905461 & 18.0097377 \\ \mathrm{H} & 0.2516977 & 10.7412662 & 27.0219777 \\ \mathrm{H} & 2.6347993 & 6.6127469 & 26.8665729 \\ \mathrm{O} & 2.7009048 & 9.6147250 & 23.1133186 \\ \mathrm{H} & 5.2280443 & 9.0271608 & 15.1720515 \\ \mathrm{O} & 5.2976875 & 7.2138750 & 20.0750692 \\ \mathrm{O} & 3.8663335 & 7.9263785 & 25.1360873 \\ \mathrm{H} & 8.7306713 & 8.9851712 & 29.8128003 \\ \mathrm{O} & 8.8706017 & 7.1011153 & 19.8445797 \\ \mathrm{O} & 1.7677233 & 11.1907044 & 24.8476186 \\ \mathrm{H} & 5.2488989 & 9.0562639 & 29.8913185 \\ \mathrm{H} & 3.5630072 & 12.0181364 & 15.0573004 \\ \mathrm{P} & 3.3276979 & 15.9403045 & 21.5404114 \\ \mathrm{Al} & 3.2700968 & 15.9879681 & 18.3799930 \\ \mathrm{P} & 3.8806496 & 12.0111641 & 28.3294003 \\ \mathrm{Al} & 3.8538326 & 12.0492942 & 16.5172903 \\ \mathrm{P} & 1.6366191 & 13.2813646 & 18.3550440 \\ \mathrm{Al} & 1.6074167 & 13.2922095 & 21.4863629 \\ \mathrm{O} & 5.0608942 & 13.2795328 & 16.8880614\end{array}$

26.8810650

23.0730437

15.0940437

19.9806665

19.8962846

19.9770606

25.0021510

29.8603472

19.9633419

20.0155013

19.9554200

24.9815026

23.2412347

21.9197768

21.2421010

22.5895202

22.1081256

23.4409658

23.2547944

20.6532424

19.5099323

18.8476414

19.8466688

18.9929684

29.8985275

22.4585753
21.0867668

5. 0933502 28.4268766 1.5407528

23.4575109

. 3640811

26.5222840

16.8960434

21.7836484

. 1104560

23.1956458

23.0322787

27.5695348

22.4311281

27.5117409

(

17.0399750

26482

17.9860075

.0097377

26.8665729

133186

20.0750692

1360873

19.8445797

8476186

15.0573004

21.5404114

28.3294003

16.8880614 


\begin{tabular}{|c|c|c|c|}
\hline $\mathrm{H}$ & 0.1987055 & 13.7285085 & 21.6920241 \\
\hline $\mathrm{H}$ & 2.3733322 & 17.0491586 & 21.8174477 \\
\hline 0 & 2.0796473 & 14.7395989 & 18.0879266 \\
\hline $\mathrm{O}$ & 4.7034482 & 15.7242361 & 17.4126248 \\
\hline $\mathrm{O}$ & 4.6017973 & 16.1001761 & 22.3852972 \\
\hline $\mathrm{O}$ & 2.3908919 & 12.3337635 & 17.4042762 \\
\hline $\mathrm{O}$ & 4.4430093 & 13.3759930 & 27.9168564 \\
\hline $\mathrm{O}$ & 2.6938843 & 14.6057436 & 21.9131880 \\
\hline $\mathrm{H}$ & 2.7006099 & 17.3196820 & 18.0345317 \\
\hline $\mathrm{H}$ & 0.1803055 & 13.1606346 & 18.0692200 \\
\hline $\mathrm{O}$ & 3.7496613 & 15.9634058 & 20.0597743 \\
\hline $\mathrm{H}$ & 3.5251364 & 12.0127427 & 29.7753355 \\
\hline $\mathrm{O}$ & 1.9689675 & 12.8735876 & 19.8016141 \\
\hline$P$ & 10.1851442 & 11.9773643 & 16.4817967 \\
\hline Al & 10.1152067 & 11.9024616 & 28.2757203 \\
\hline $\mathrm{P}$ & 12.4288119 & 10.5960190 & 26.6544324 \\
\hline Al & 12.4623066 & 10.5854011 & 23.4135317 \\
\hline $\mathrm{P}$ & 15.5789360 & 10.7570138 & 23.3667223 \\
\hline $\mathrm{P}$ & 10.6530131 & 8.0243466 & 23.4492860 \\
\hline Al & 10.7313286 & 7.9948994 & 26.5494051 \\
\hline Al & 15.5282794 & 10.6865667 & 26.5222840 \\
\hline $\mathrm{O}$ & 8.9818893 & 10.6040558 & 27.9318146 \\
\hline $\mathrm{O}$ & 11.9347615 & 9.1800631 & 27.0252575 \\
\hline $\mathrm{H}$ & 15.9947145 & 9.2787693 & 26.6551954 \\
\hline $\mathrm{H}$ & 11.4620105 & 6.7757036 & 23.3898356 \\
\hline $\mathrm{O}$ & 14.1531033 & 10.2775982 & 23.0199887 \\
\hline 0 & 11.5894006 & 11.6574351 & 27.3814571 \\
\hline $\mathrm{O}$ & 9.3477069 & 8.1210035 & 27.6059195 \\
\hline $\mathrm{H}$ & 16.3505736 & 11.5953342 & 27.3679166 \\
\hline $\mathrm{O}$ & 9.4145699 & 7.8819815 & 22.5440912 \\
\hline $\mathrm{O}$ & 15.9926194 & 11.9304842 & 22.4777898 \\
\hline $\mathrm{O}$ & 9.5917805 & 10.6568835 & 17.0076918 \\
\hline 0 & 13.8866417 & 10.7506348 & 27.1075622 \\
\hline $\mathrm{H}$ & 11.3270334 & 6.6367303 & 26.6821948 \\
\hline $\mathrm{H}$ & 16.5446433 & 9.6505418 & 23.1212641 \\
\hline $\mathrm{O}$ & 11.5019305 & 9.1912146 & 22.9444359 \\
\hline $\mathrm{H}$ & 10.4222270 & 11.8886534 & 15.0144717 \\
\hline $\mathrm{O}$ & 12.3141322 & 10.8057811 & 25.1450675 \\
\hline $\mathrm{O}$ & 15.6427220 & 11.1907044 & 24.8476186 \\
\hline $\mathrm{O}$ & 10.1880597 & 8.2767117 & 24.8990127 \\
\hline $\mathrm{H}$ & 10.3836069 & 11.8884454 & 29.7402630 \\
\hline $\mathrm{H}$ & 8.8119247 & 14.9861016 & 14.9553674 \\
\hline $\mathrm{P}$ & 5.5020738 & 14.7271173 & 16.5677778 \\
\hline Al & 5.4510551 & 14.7154237 & 28.3922326 \\
\hline $\mathrm{P}$ & 12.3951326 & 18.7764748 & 21.5407528 \\
\hline $\mathrm{Ge}$ & 12.1857737 & 13.2795456 & 21.5657050 \\
\hline $\mathrm{P}$ & 17.2026967 & 15.9403045 & 21.5404114 \\
\hline Al & 17.1450955 & 15.9879681 & 18.3799930 \\
\hline Al & 12.3006968 & 13.2682737 & 18.3719956 \\
\hline Al & 12.4387377 & 18.7670683 & 18.3954844 \\
\hline $\mathrm{P}$ & 5.4048643 & 17.2183194 & 26.5325021 \\
\hline Al & 5.3492118 & 17.2281922 & 23.4738015 \\
\hline$P$ & 8.6001036 & 14.6606358 & 28.2402916 \\
\hline Al & 8.6608312 & 14.7352231 & 16.4152822 \\
\hline $\mathrm{P}$ & 15.5116179 & 13.2813646 & 18.3550440 \\
\hline$P$ & 15.5989763 & 18.7423645 & 18.3640811 \\
\hline$P$ & 10.8037927 & 16.0614285 & 18.2693256 \\
\hline Al & 10.6234989 & 16.1029232 & 21.4358783 \\
\hline Al & 15.5760342 & 18.6924837 & 21.5322096 \\
\hline Al & 15.4824155 & 13.2922095 & 21.4863629 \\
\hline $\mathrm{P}$ & 8.4955199 & 17.4358670 & 23.2961511 \\
\hline Al & 8.5450620 & 17.2425222 & 26.4300372 \\
\hline 0 & 9.1606037 & 13.0951387 & 16.7982759 \\
\hline $\mathrm{O}$ & 7.1136735 & 14.3143714 & 28.0223766 \\
\hline 0 & 11.7921346 & 17.3841580 & 21.7485652 \\
\hline 0 & 13.8620088 & 13.7940737 & 21.7229300 \\
\hline 0 & 16.2131654 & 17.0900166 & 21.8276557 \\
\hline $\mathrm{O}$ & 15.9546461 & 14.7395989 & 18.0879266 \\
\hline $\mathrm{O}$ & 11.8448038 & 14.9526469 & 18.0567510 \\
\hline 0 & 14.1233173 & 18.3746096 & 18.1104560 \\
\hline 0 & 6.8675650 & 17.6500342 & 26.7732399 \\
\hline $\mathrm{H}$ & 9.0485558 & 18.8111505 & 23.1551999 \\
\hline $\mathrm{H}$ & 4.6581357 & 18.5450489 & 23.4001620 \\
\hline $\mathrm{H}$ & 18.3652003 & 15.7634728 & 17.5565449 \\
\hline $\mathrm{H}$ & 12.0225993 & 19.9431874 & 17.5826539 \\
\hline 0 & 11.5199346 & 12.2499683 & 17.1654792 \\
\hline 0 & 4.9725553 & 16.1568358 & 27.5478842 \\
\hline $\mathrm{H}$ & 11.7181205 & 19.7852189 & 22.4016886 \\
\hline 0 & 11.7469703 & 11.9628338 & 22.679768 \\
\hline $\mathrm{H}$ & 18.4369145 & 16.0951719 & 22.358850 \\
\hline
\end{tabular}




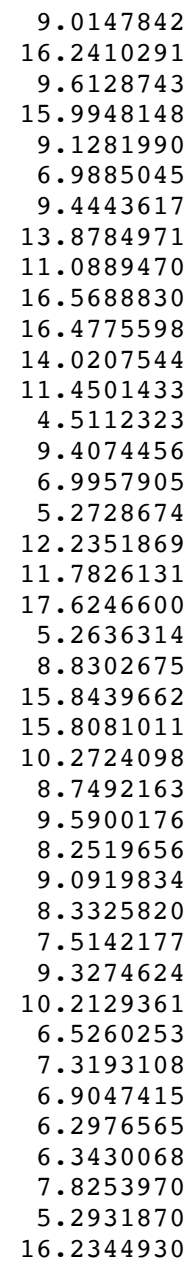

$\begin{array}{ll}\mathrm{H} & 8.7404901 \\ \mathrm{Si} & 5.4138277 \\ \mathrm{Si} & 5.3927648 \\ \mathrm{Si} & 5.3816829 \\ \mathrm{Si} & 5.4154645 \\ \mathrm{Si} & 3.3012847 \\ \mathrm{Si} & 3.3942306 \\ \mathrm{Si} & 8.5069509 \\ \mathrm{Si} & 8.5421092 \\ \mathrm{Si} & 8.5399451 \\ \mathrm{Si} & 8.5323629 \\ \mathrm{Si} & 1.7315796 \\ \mathrm{Si} & 1.6847991 \\ \mathrm{O} & 6.9755881 \\ \mathrm{O} & 4.9896006 \\ \mathrm{H} & 4.8045875 \\ \mathrm{H} & 9.0961581 \\ \mathrm{O} & 6.9790839 \\ \mathrm{O} & 2.1746948 \\ \mathrm{H} & 2.3625482 \\ \mathrm{H} & 0.3344200 \\ \mathrm{O} & 4.9837507 \\ \mathrm{O} & 4.4937557 \\ \mathrm{O} & 4.6605815 \\ \mathrm{O} & 2.5608268 \\ \mathrm{O} & 8.9679966 \\ \mathrm{O} & 2.2261827 \\ \mathrm{O} & 4.5072177 \\ \mathrm{O} & 6.9431257 \\ \mathrm{O} & 6.9544830 \\ \mathrm{H} & 9.3898692 \\ \mathrm{H} & 4.5639552 \\ \mathrm{H} & 0.2716615 \\ \mathrm{H} & 2.6651466 \\ \mathrm{O} & 2.7424174 \\ \mathrm{H} & 5.1787286 \\ & \end{array}$

15.8475182

12.3649973

15.8804671

19.9037652

16.4919798

14.8698936

13.4494201

18.7425093

14.5810570

14.6057436

17.5489639

13.1577704

17.4167311

18.3975287

18.3951625

17.4970140

15.0240336

19.2299764

12.7472120

15.9634058

16.6215245

15.0174451

12.8735876

19.1172167

16.0625895

16.8968930

13.7550514

11.9532238

12.2148303

11.0610245

12.7085522

12.8553189

12.3940861

10.7386761

11.1529550

12.0830764

11.5278911

12.9262217

12.4282658

14.9862359

19.7154236

8.8444262

9.2050188

9.1405101

6.7075228

6.7272412

7.9107295

8.0078581

9.0977927

9.2139880

6.7315151

6.6923733

10.6959064

10.6230574

9.6115508

10.6934115

5.3493379

5.3315222

6.3349853

9.0747094

6.9582845

10.2960634

7.9643484

8.1292424

7.8065401

11.5793337

7.9724476

11.9027207

10.4807057

8.9113101

6.6667140

5.5634913

5.5581887

10.6900448

6.5983289

9.4529948

8.8317410
27.3647033

17.4356144

17.3124344

17.5205285

22.2738528

16.9202529

27.8346104

21.9246496

22.0724714

21.9131880

17.9750535

18.0624390

17.9466058

26.6998574

26.8106100

23.0060107

15.1267969

20.0750692

19.9276717

20.0597743

25.1164765

29.6674679

19.8016141

19.8445797

19.7124656

24.7208351

23.1341964

21.8259043

21.1863726

22.4407307

22.0814435

23.4476068

23.3386248

20.8995761

20.5006698

19.4455145

18.7231291

19.8725584

18.9634528

29.8478627

22.3907820

15.1365151

16.5665038

28.5095799

21.5444866

18.4556767

26.5538553

23.5060298

28.4884161

16.5652172

18.4629390

21.5678499

23.4640312

26.5697351

16.8169997

28.2145009

21.7430194

21.7854270

18.2170780

26.6877192

23.2798720

23.1396996

17.5043727

27.6251442

22.5062068

27.5390363

17.5124923

22.5100581

16.9957100

28.1113125

21.9241594

18.1017329

18.1016023

27.0341438

26.8539445

23.1899395

15.1443531 


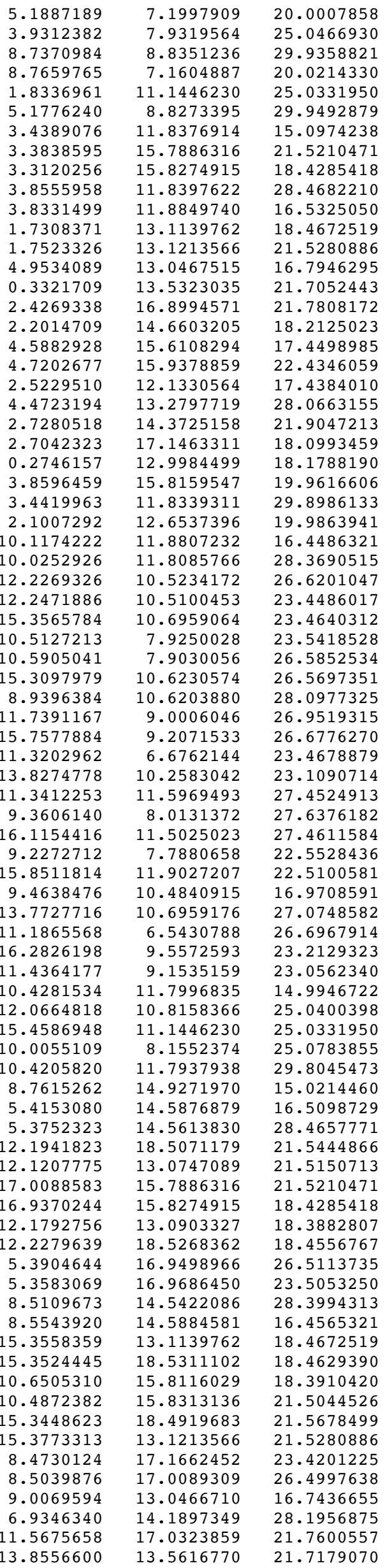

21.7179070 


\begin{tabular}{|c|c|c|}
\hline 15.9608102 & 17.0052344 & 21.8055536 \\
\hline 15.8264697 & 14.6603205 & 18.2125023 \\
\hline 11.7699567 & 14.6646859 & 18.1414894 \\
\hline 13.7915833 & 18.1345803 & 18.2170780 \\
\hline 6.9398835 & 17.3913561 & 26.7778394 \\
\hline 9.0313934 & 18.5387050 & 23.2728634 \\
\hline 4.6327219 & 18.2682707 & 23.4650741 \\
\hline 18.1080491 & 15.6286956 & 17.5305986 \\
\hline 11.8309629 & 19.6644714 & 17.5808642 \\
\hline 11.4979011 & 12.1745812 & 17.2192837 \\
\hline 4.9122617 & 15.8165264 & 27.5602633 \\
\hline 11.5349411 & 19.5118551 & 22.4237049 \\
\hline 11.5813272 & 11.7289805 & 22.6469539 \\
\hline 18.2329029 & 15.9253368 & 22.3577950 \\
\hline 8.9562112 & 15.7665559 & 27.4368693 \\
\hline 16.0806194 & 12.2164353 & 17.5258541 \\
\hline 9.3949100 & 15.6200298 & 17.3741977 \\
\hline 15.7457253 & 19.6712415 & 17.5896972 \\
\hline 9.1177812 & 16.1552510 & 22.3385251 \\
\hline 6.9890015 & 14.7146224 & 16.8731553 \\
\hline 9.3710319 & 13.2374420 & 27.9828683 \\
\hline 13.7669824 & 18.4663090 & 21.9241594 \\
\hline 11.0134943 & 14.4310527 & 22.0645763 \\
\hline 16.3530505 & 14.3725158 & 21.9047213 \\
\hline 16.2759234 & 17.2620023 & 18.0704731 \\
\hline 13.7847550 & 12.9893377 & 18.1560689 \\
\hline 11.3060667 & 17.2611469 & 18.0723337 \\
\hline 4.4991129 & 18.1290061 & 26.6911344 \\
\hline 9.3497771 & 18.1834085 & 26.8495682 \\
\hline 6.8937547 & 17.2489291 & 23.1022965 \\
\hline 5.1680990 & 14.9389675 & 15.0841762 \\
\hline 12.0012182 & 18.9993859 & 20.0007858 \\
\hline 11.6865213 & 12.5588642 & 19.8185998 \\
\hline 17.4846446 & 15.8159547 & 19.9616606 \\
\hline 5.2548030 & 16.3348134 & 25.0045757 \\
\hline 8.7574563 & 14.9227026 & 29.8177359 \\
\hline 15.7257279 & 12.6537396 & 19.9863941 \\
\hline 15.5784758 & 18.9600837 & 20.0214330 \\
\hline 10.0887098 & 15.7839104 & 19.9182292 \\
\hline 8.7252424 & 16.6029422 & 24.9334206 \\
\hline 9.5132225 & 13.6567536 & 23.1674828 \\
\hline 7.9802334 & 11.9485534 & 21.9477648 \\
\hline 8.8533628 & 11.9762828 & 21.3004305 \\
\hline 7.8846186 & 11.1303452 & 22.6553198 \\
\hline 7.3973062 & 12.8532707 & 22.0990113 \\
\hline 9.2174982 & 12.7687521 & 23.4819817 \\
\hline 10.0659948 & 12.2564117 & 23.3411463 \\
\hline 6.0481779 & 10.9923928 & 21.1076521 \\
\hline 6.9145639 & 11.1877860 & 20.6931744 \\
\hline 6.7096925 & 12.0293286 & 19.5111983 \\
\hline 6.0214232 & 11.5079886 & 18.8374881 \\
\hline 6.3119909 & 13.0127559 & 19.8004076 \\
\hline 7.6891501 & 12.1310707 & 19.0319365 \\
\hline 5.1652448 & 14.9359928 & 29.8915026 \\
\hline 15.9800471 & 19.4934923 & 22.4681889 \\
\hline 8.7106445 & 9.0381953 & 15.1001620 \\
\hline 5.4389470 & 9.3551479 & 16.6304272 \\
\hline 5.3990794 & 9.2599040 & 28.4418473 \\
\hline 5.4537786 & 6.7552778 & 21.5531799 \\
\hline 5.5036037 & 6.7581923 & 18.4093864 \\
\hline 3.2723894 & 7.9166408 & 26.5641674 \\
\hline 3.3975447 & 8.0700379 & 23.4835331 \\
\hline 8.5289828 & 9.1646640 & 28.3526856 \\
\hline 8.5917471 & 9.3197928 & 16.5574495 \\
\hline 8.6590362 & 6.7370210 & 18.3743475 \\
\hline 8.6383785 & 6.6755716 & 21.5407645 \\
\hline 1.7148884 & 10.7660229 & 23.3848609 \\
\hline 1.6430924 & 10.6690923 & 26.5409078 \\
\hline 6.9127325 & 9.7323615 & 16.9085015 \\
\hline 4.9450350 & 10.9106246 & 28.0484544 \\
\hline 4.8143997 & 5.4249882 & 21.7497625 \\
\hline 9.2178393 & 5.3234861 & 21.7714386 \\
\hline 7.1863192 & 6.3571613 & 18.1186444 \\
\hline 2.1956033 & 9.0108158 & 26.6746152 \\
\hline 2.3301348 & 7.0615967 & 23.2369503 \\
\hline 0.3517414 & 10.2868024 & 23.0252796 \\
\hline 5.0286501 & 8.1438275 & 17.4662344 \\
\hline
\end{tabular}

21.8055536

8.2125023

18.2170780

26.7778394

.2728634

17.5305986

17.5808642

2192837

22.4237049

22.6469539

22.3577950

(1)

17.3741977

(

16.8731553

.9828683

22.0645763

1.9047213

18.1560689

.0723337

911344

23.1022965

15.0841762

20.0007858

25.0045757

29.8177359

19.9863941

19.9182292

24.9334206

23.1674828

9477648

21.3004305

2.0990113

23.4819817

20.6931744

19.8004076

19365

29.8915026

15.1001620

16.6304272

21.5531799

18.4093864

26.5641674

.4835331

16.5574495

8.3743475

21.5407645
23.3848609

26.5409078

16.9085015

21. 7497625

21.7714386

26.6746152

23.0252796

17.4662344 


\begin{tabular}{|c|c|c|c|}
\hline 0 & 4.3705806 & 8.1273228 & 27.6126927 \\
\hline 0 & 4.7894407 & 7.8173071 & 22.4505163 \\
\hline 0 & 2.6111698 & 11.7269659 & 27.5304600 \\
\hline $\mathrm{O}$ & 9.0623689 & 7.9338706 & 17.5033715 \\
\hline 0 & 2.1336758 & 11.9475566 & 22.5077150 \\
\hline 0 & 4.5610695 & 10.5428107 & 17.0541075 \\
\hline $\mathrm{O}$ & 7.0529487 & 8.9800594 & 27.9799236 \\
\hline 0 & 6.9371791 & 6.6619277 & 21.9307314 \\
\hline $\mathrm{H}$ & 9.5215787 & 5.5821541 & 18.0009528 \\
\hline $\mathrm{H}$ & 4.6372730 & 5.6112365 & 18.0206910 \\
\hline $\mathrm{H}$ & 0.2495296 & 10.7093680 & 27.0638622 \\
\hline $\mathrm{H}$ & 2.6423179 & 6.5934348 & 26.8273339 \\
\hline 0 & 2.7384289 & 9.6439417 & 23.1435098 \\
\hline $\mathrm{H}$ & 5.2368122 & 9.0332363 & 15.1907623 \\
\hline $\mathrm{O}$ & 5.3076753 & 7.2208767 & 20.0899151 \\
\hline $\mathrm{O}$ & 3.9129924 & 7.9524557 & 25.1600889 \\
\hline $\mathrm{H}$ & 8.7246094 & 8.9954580 & 29.8190485 \\
\hline 0 & 8.8603841 & 7.1184839 & 19.8548638 \\
\hline 0 & 1.7441161 & 11.1921086 & 24.8700245 \\
\hline $\mathrm{H}$ & 5.2557480 & 9.0586930 & 29.9102107 \\
\hline $\mathrm{H}$ & 3.5811760 & 12.0215310 & 15.0619867 \\
\hline$P$ & 3.3629814 & 15.9445435 & 21.5262541 \\
\hline Al & 3.2763527 & 15.9965243 & 18.3682027 \\
\hline $\mathrm{P}$ & 3.8853724 & 11.9971797 & 28.3308946 \\
\hline Al & 3.8555415 & 12.0555909 & 16.5250944 \\
\hline $\mathrm{P}$ & 1.6429263 & 13.2918780 & 18.3574617 \\
\hline Al & 1.6486402 & 13.2971144 & 21.4885270 \\
\hline 0 & 5.0573003 & 13.2881043 & 16.9063610 \\
\hline $\mathrm{H}$ & 0.2202583 & 13.6782602 & 21.6662166 \\
\hline $\mathrm{H}$ & 2.4168775 & 17.0607706 & 21.8020166 \\
\hline $\mathrm{O}$ & 2.0809349 & 14.7504667 & 18.0791980 \\
\hline 0 & 4.7076033 & 15.7407168 & 17.3928084 \\
\hline 0 & 4.6509615 & 16.0956744 & 22.3543737 \\
\hline 0 & 2.3820614 & 12.3429966 & 17.3951306 \\
\hline 0 & 4.4437448 & 13.3581201 & 27.8980043 \\
\hline 0 & 2.7225161 & 14.6179548 & 21.9185971 \\
\hline $\mathrm{H}$ & 2.7072786 & 17.3341402 & 18.0456209 \\
\hline $\mathrm{H}$ & 0.1821639 & 13.1695344 & 18.0960693 \\
\hline 0 & 3.7715294 & 15.9508233 & 20.0427242 \\
\hline $\mathrm{H}$ & 3.5455978 & 12.0151098 & 29.7804988 \\
\hline 0 & 2.0046863 & 12.8874127 & 19.7988418 \\
\hline $\mathrm{P}$ & 10.1922344 & 11.9826953 & 16.4504010 \\
\hline Al & 10.0989303 & 11.8794994 & 28.2428955 \\
\hline $\mathrm{P}$ & 12.4333621 & 10.5493641 & 26.6778293 \\
\hline Al & 12.4745198 & 10.4996528 & 23.4289637 \\
\hline $\mathrm{P}$ & 15.5898871 & 10.7660229 & 23.3848609 \\
\hline $\mathrm{P}$ & 10.6172405 & 7.9895955 & 23.4856193 \\
\hline Al & 10.7187055 & 7.9740623 & 26.5613313 \\
\hline Al & 15.5180911 & 10.6690923 & 26.5409078 \\
\hline 0 & 8.9740812 & 10.5715812 & 27.9011056 \\
\hline 0 & 11.9249636 & 9.1448414 & 27.0735233 \\
\hline $\mathrm{H}$ & 15.9873930 & 9.2605548 & 26.6544787 \\
\hline $\mathrm{H}$ & 11.3172710 & 6.6754147 & 23.4830559 \\
\hline 0 & 14.1763553 & 10.2690894 & 23.0119887 \\
\hline 0 & 11.5777885 & 11.6324828 & 27.3546103 \\
\hline 0 & 9.3415251 & 8.0805142 & 27.6312972 \\
\hline $\mathrm{H}$ & 16.3454440 & 11.5731881 & 27.3866138 \\
\hline $\mathrm{O}$ & 9.3834566 & 7.8996550 & 22.5633935 \\
\hline 0 & 16.0086745 & 11.9475566 & 22.5077150 \\
\hline 0 & 9.6049103 & 10.6708507 & 17.0077036 \\
\hline $\mathrm{O}$ & 13.8831963 & 10.7163428 & 27.1544254 \\
\hline $\mathrm{H}$ & 11.3194082 & 6.6137331 & 26.6373665 \\
\hline $\mathrm{H}$ & 16.5809210 & 9.6795778 & 23.1511749 \\
\hline 0 & 11.5686398 & 9.0666789 & 22.9612967 \\
\hline $\mathrm{H}$ & 10.3977623 & 11.8667978 & 14.9802150 \\
\hline 0 & 12.3565255 & 10.7149274 & 25.1616096 \\
\hline 0 & 15.6191148 & 11.1921086 & 24.8700245 \\
\hline $\mathrm{O}$ & 10.1591403 & 8.3196275 & 24.9234105 \\
\hline $\mathrm{H}$ & 10.3596454 & 11.8658311 & 29.7088292 \\
\hline $\mathrm{H}$ & 8.8182799 & 14.9890494 & 14.9268388 \\
\hline $\mathrm{P}$ & 5.5000920 & 14.7287891 & 16.5585356 \\
\hline Al & 5.4437466 & 14.7015703 & 28.3811820 \\
\hline $\mathrm{P}$ & 12.3912779 & 18.7713792 & 21.5531799 \\
\hline $\mathrm{Ti}$ & 12.1288172 & 13.2698729 & 21.5968625 \\
\hline$P$ & 17.2379801 & 15.9445435 & 21.5262541 \\
\hline Al & 17.1513514 & 15.9965243 & 18.3682027 \\
\hline Al & 12.2905899 & 13.2906695 & 18.3222363 \\
\hline Al & 12.4411031 & 18.7742937 & 18.4093864 \\
\hline $\mathrm{P}$ & 5.4083236 & 17.1939098 & 26.5229489 \\
\hline & & & \\
\hline
\end{tabular}




\begin{tabular}{|c|c|c|c|}
\hline $\mathrm{P}$ & 8.5967985 & 14.6507576 & 28.2138040 \\
\hline Al & 8.6647643 & 14.7464288 & 16.3878963 \\
\hline $\mathrm{P}$ & 15.5179250 & 13.2918780 & 18.3574617 \\
\hline $\mathrm{P}$ & 15.5965356 & 18.7531224 & 18.3743475 \\
\hline$P$ & 10.7932723 & 16.0735190 & 18.2509953 \\
\hline Al & 10.5428316 & 16.1436266 & 21.4321437 \\
\hline Al & 15.5758779 & 18.6916730 & 21.5407645 \\
\hline Al & 15.5236389 & 13.2971144 & 21.4885270 \\
\hline $\mathrm{P}$ & 8.4578908 & 17.5055861 & 23.2874373 \\
\hline Al & 8.5399322 & 17.2290961 & 26.3988481 \\
\hline 0 & 9.1792041 & 13.1098483 & 16.7716901 \\
\hline 0 & 7.1075377 & 14.3105142 & 28.0086513 \\
\hline 0 & 11.7337937 & 17.4034197 & 21.7553291 \\
\hline 0 & 13.8755313 & 13.7368913 & 21.6935504 \\
\hline $\mathrm{O}$ & 16.2573969 & 17.1014497 & 21.8120664 \\
\hline $\mathrm{O}$ & 15.9559336 & 14.7504667 & 18.0791980 \\
\hline $\mathrm{O}$ & 11.8395928 & 14.9760233 & 18.0031416 \\
\hline 0 & 14.1238185 & 18.3732627 & 18.1186444 \\
\hline $\mathrm{O}$ & 6.8667714 & 17.6379881 & 26.7727997 \\
\hline $\mathrm{H}$ & 9.0655565 & 18.8619736 & 23.1975706 \\
\hline $\mathrm{H}$ & 4.5251680 & 18.4619384 & 23.4843450 \\
\hline $\mathrm{H}$ & 18.3685828 & 15.7789685 & 17.5386620 \\
\hline $\mathrm{H}$ & 12.0351655 & 19.9585807 & 17.6032849 \\
\hline 0 & 11.5447823 & 12.2654148 & 17.0971465 \\
\hline 0 & 4.9641343 & 16.1547889 & 27.5564111 \\
\hline $\mathrm{H}$ & 11.7493283 & 19.7976179 & 22.4202759 \\
\hline 0 & 11.7079172 & 11.8564464 & 22.7011399 \\
\hline $\mathrm{H}$ & 18.4843800 & 16.0907954 & 22.3276393 \\
\hline 0 & 9.0131612 & 15.8265788 & 27.3232801 \\
\hline $\mathrm{H}$ & 16.2324048 & 12.3746484 & 17.4272310 \\
\hline $\mathrm{O}$ & 9.6005291 & 15.9026377 & 17.2922029 \\
\hline $\mathrm{H}$ & 15.9879890 & 19.9147217 & 17.5290240 \\
\hline 0 & 9.0242448 & 16.5917895 & 22.1993685 \\
\hline 0 & 6.9906986 & 14.8719692 & 16.8937251 \\
\hline $\mathrm{O}$ & 9.4304485 & 13.4304378 & 27.8111980 \\
\hline 0 & 13.8746785 & 18.6780290 & 21.9307314 \\
\hline $\mathrm{O}$ & 11.0043227 & 14.6323311 & 22.1082732 \\
\hline 0 & 16.5975149 & 14.6179548 & 21.9185971 \\
\hline $\mathrm{O}$ & 16.4842521 & 17.5645496 & 17.9900549 \\
\hline 0 & 14.0222343 & 13.1666090 & 18.0898191 \\
\hline $\mathrm{O}$ & 11.4326324 & 17.4391553 & 17.9569172 \\
\hline $\mathrm{H}$ & 4.5059548 & 18.3718403 & 26.6467657 \\
\hline $\mathrm{H}$ & 9.4130520 & 18.3762645 & 26.7713894 \\
\hline 0 & 6.9538306 & 17.6480498 & 23.0437799 \\
\hline $\mathrm{H}$ & 5.2586223 & 15.0017570 & 15.1148246 \\
\hline $\mathrm{O}$ & 12.2451746 & 19.2369781 & 20.0899151 \\
\hline 0 & 11.7325410 & 12.8180305 & 19.8819856 \\
\hline 0 & 17.6465281 & 15.9508233 & 20.0427242 \\
\hline 0 & 5.2968792 & 16.5579245 & 25.1197319 \\
\hline $\mathrm{H}$ & 8.8367375 & 15.0186231 & 29.6365566 \\
\hline 0 & 15.8796850 & 12.8874127 & 19.7988418 \\
\hline $\mathrm{O}$ & 15.7978834 & 19.1345852 & 19.8548638 \\
\hline $\mathrm{O}$ & 10.2659899 & 16.0435201 & 19.6956381 \\
\hline 0 & 8.7207058 & 16.8903493 & 24.6815060 \\
\hline $\mathrm{H}$ & 9.6073391 & 13.7201639 & 23.1638367 \\
\hline $\mathrm{C}$ & 8.2497394 & 11.9665232 & 21.8426096 \\
\hline $\mathrm{H}$ & 9.1119721 & 12.2054593 & 21.2242895 \\
\hline $\mathrm{H}$ & 8.2847447 & 11.0675258 & 22.4518074 \\
\hline $\mathrm{H}$ & 7.5216992 & 12.7388064 & 22.0740933 \\
\hline 0 & 9.3014665 & 12.8347206 & 23.4868073 \\
\hline $\mathrm{H}$ & 10.1632799 & 12.3302887 & 23.4047087 \\
\hline $\mathrm{H}$ & 6.5141183 & 10.8058008 & 20.8408239 \\
\hline $\mathrm{O}$ & 7.3361366 & 11.1943301 & 20.4759229 \\
\hline $\mathrm{C}$ & 6.9955001 & 12.1439072 & 19.4122135 \\
\hline $\mathrm{H}$ & 6.4136760 & 11.6108475 & 18.6533439 \\
\hline $\mathrm{H}$ & 6.4323532 & 12.9958112 & 19.8192785 \\
\hline $\mathrm{H}$ & 7.9468533 & 12.4724295 & 18.9813148 \\
\hline $\mathrm{H}$ & 5.2796322 & 14.9646469 & 29.8375397 \\
\hline & 16.2060588 & 19.7269926 & 22.4056956 \\
\hline \multicolumn{4}{|c|}{$\mathrm{Zn} 5$} \\
\hline \multicolumn{4}{|c|}{171} \\
\hline $\mathrm{H}$ & 8.7478825 & 8.9649974 & 15.1452258 \\
\hline Al & 5.4417906 & 9.2559025 & 16.5265262 \\
\hline$P$ & 5.4420507 & 9.2177881 & 28.3511272 \\
\hline Al & 5.3310104 & 6.6949470 & 21.4836262 \\
\hline $\mathrm{P}$ & 5.3624058 & 6.6713441 & 18.3263874 \\
\hline Al & 3.2183214 & 8.0047423 & 26.4917980 \\
\hline $\mathrm{P}$ & 3.2863827 & 8.1207030 & 23.361335 \\
\hline & & & \\
\hline
\end{tabular}




\begin{tabular}{|c|c|c|c|}
\hline $\mathrm{P}$ & 8.5851668 & 9.3111799 & 16.5842539 \\
\hline Al & 8.5469680 & 6.7312425 & 18.3996146 \\
\hline $\mathrm{P}$ & 8.5295315 & 6.7273527 & 21.5564452 \\
\hline Al & 1.5459169 & 10.7722941 & 23.3862792 \\
\hline $\mathrm{P}$ & 1.5459208 & 10.7062232 & 26.5859042 \\
\hline 0 & 7.1143533 & 9.6822533 & 16.8832129 \\
\hline 0 & 5.0370729 & 10.6766101 & 28.0605348 \\
\hline $\mathrm{H}$ & 4.8373629 & 5.3253008 & 21.7958793 \\
\hline $\mathrm{H}$ & 9.0145882 & 5.3430797 & 21.8126268 \\
\hline 0 & 6.8588286 & 6.3458757 & 18.1528767 \\
\hline 0 & 2.0115704 & 9.2458885 & 26.7461960 \\
\hline $\mathrm{H}$ & 2.2545538 & 7.0718439 & 23.1325466 \\
\hline $\mathrm{H}$ & 0.1668675 & 10.3596150 & 23.0054388 \\
\hline 0 & 4.9639173 & 7.8515507 & 17.4340866 \\
\hline 0 & 4.5805262 & 8.2423869 & 27.5450357 \\
\hline 0 & 4.4956000 & 7.8966144 & 22.4435869 \\
\hline 0 & 2.4359554 & 11.6539652 & 27.3951869 \\
\hline 0 & 9.0114778 & 8.1145199 & 17.4424219 \\
\hline 0 & 2.0091181 & 12.1786413 & 22.4925406 \\
\hline 0 & 4.4249833 & 10.5973647 & 16.9748491 \\
\hline 0 & 6.9016080 & 9.0215865 & 27.9308363 \\
\hline 0 & 7.0308787 & 6.7977344 & 21.8534515 \\
\hline $\mathrm{H}$ & 9.3645895 & 5.5627539 & 17.9715375 \\
\hline $\mathrm{H}$ & 4.5631291 & 5.4845658 & 17.9142774 \\
\hline $\mathrm{H}$ & 0.1600679 & 10.8159889 & 27.1192744 \\
\hline $\mathrm{H}$ & 2.6164920 & 6.6818727 & 26.8157395 \\
\hline O & 2.6786791 & 9.4875745 & 23.0332614 \\
\hline $\mathrm{H}$ & 5.2911797 & 8.9523880 & 15.0765897 \\
\hline 0 & 5.0706959 & 7.0543490 & 19.7892103 \\
\hline 0 & 3.7659465 & 8.0719136 & 24.8259225 \\
\hline H & 8.7250888 & 8.9951279 & 29.8589640 \\
\hline 0 & 8.8130933 & 7.1342714 & 20.0930300 \\
\hline 0 & 1.5923153 & 11.1222992 & 25.1066476 \\
\hline $\mathrm{H}$ & 5.2707873 & 8.9100907 & 29.7978863 \\
\hline $\mathrm{H}$ & 3.4405175 & 11.9047387 & 15.1040638 \\
\hline Al & 3.2701460 & 16.0508283 & 21.4644241 \\
\hline $\mathrm{P}$ & 3.1810702 & 16.0318110 & 18.2962921 \\
\hline Al & 3.8463511 & 11.9266343 & 28.3755378 \\
\hline $\mathrm{P}$ & 3.8287372 & 11.9445177 & 16.5410133 \\
\hline Al & 1.6881442 & 13.2535228 & 18.4516563 \\
\hline $\mathrm{P}$ & 1.7743442 & 13.3457743 & 21.5184991 \\
\hline 0 & 4.8908504 & 13.0384735 & 16.7807576 \\
\hline $\mathrm{H}$ & 0.3872434 & 13.8858951 & 21.5551260 \\
\hline $\mathrm{H}$ & 2.2756405 & 17.1171938 & 21.7659934 \\
\hline $\mathrm{O}$ & 2.1233663 & 14.9266043 & 18.1052780 \\
\hline 0 & 4.4022228 & 15.7868805 & 17.4012237 \\
\hline 0 & 4.7294647 & 16.3640721 & 22.3575400 \\
\hline 0 & 2.5712587 & 12.2032039 & 17.3703517 \\
\hline 0 & 4.5107400 & 13.4746360 & 27.9394183 \\
\hline O & 2.7517014 & 14.4655278 & 21.9363386 \\
\hline $\mathrm{H}$ & 2.5840544 & 17.3403603 & 17.9110759 \\
\hline $\mathrm{H}$ & 0.2353730 & 13.0354108 & 18.2087498 \\
\hline $\mathrm{O}$ & 3.6536158 & 16.0822114 & 19.7582155 \\
\hline $\mathrm{H}$ & 3.4895589 & 11.9068444 & 29.8210233 \\
\hline 0 & 2.1439267 & 12.8493109 & 20.0930481 \\
\hline Al & 10.1655451 & 12.0055433 & 16.3833923 \\
\hline $\mathrm{P}$ & 10.1070146 & 11.9570919 & 28.2605904 \\
\hline Al & 12.3433649 & 10.5786511 & 26.6191940 \\
\hline $\mathrm{P}$ & 12.3415317 & 10.6197127 & 23.3661841 \\
\hline Al & 15.4209156 & 10.7722941 & 23.3862792 \\
\hline Al & 10.6581590 & 8.0223712 & 23.4570414 \\
\hline $\mathrm{P}$ & 10.7294913 & 7.9306730 & 26.6175919 \\
\hline$P$ & 15.4209196 & 10.7062232 & 26.5859042 \\
\hline 0 & 9.0545729 & 10.8630227 & 27.9730435 \\
\hline 0 & 11.7890247 & 8.9680125 & 27.0446872 \\
\hline $\mathrm{H}$ & 15.8708163 & 9.2952912 & 26.7407734 \\
\hline $\mathrm{H}$ & 11.6101917 & 6.8896478 & 23.2906324 \\
\hline 0 & 13.7860719 & 10.2830688 & 22.9347982 \\
\hline 0 & 11.3123187 & 11.7962936 & 27.3255238 \\
\hline 0 & 9.5045375 & 8.0365510 & 27.5349765 \\
\hline H & 16.2862878 & 11.6276996 & 27.3727586 \\
\hline 0 & 9.2326827 & 7.7375943 & 22.4818599 \\
\hline $\mathrm{O}$ & 15.8841168 & 12.1786413 & 22.4925406 \\
\hline 0 & 9.4816397 & 10.4980335 & 16.9622893 \\
\hline 0 & 13.9910258 & 10.8194771 & 27.1362243 \\
\hline $\mathrm{H}$ & 11.3083630 & 6.5670187 & 26.7675091 \\
\hline $\mathrm{H}$ & 16.3853997 & 9.6784268 & 23.0857042 \\
\hline $\mathrm{O}$ & 11.3943839 & 9.4996102 & 22.8705131 \\
\hline $\mathrm{H}$ & 10.5320799 & 11.8574154 & 14.9478329 \\
\hline 0 & 12.2605636 & 10.7007621 & 24.8961817 \\
\hline
\end{tabular}




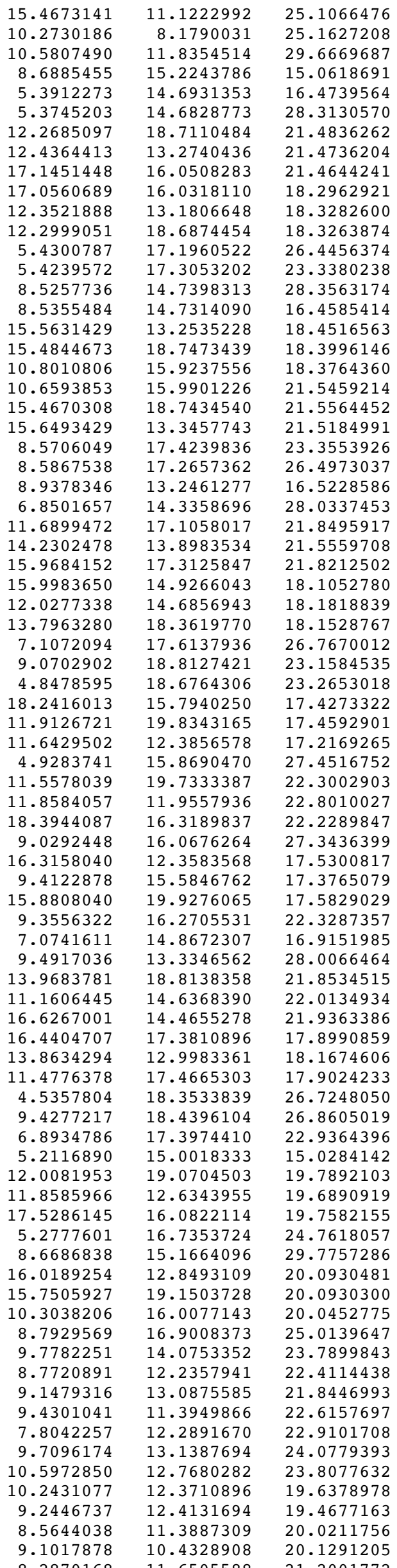




\begin{tabular}{|c|c|c|c|}
\hline $\mathrm{H}$ & 7.5535816 & 11.2928817 & 19.5986190 \\
\hline $\mathrm{H}$ & 5.1863513 & 15.0441673 & 29.7452520 \\
\hline $\mathrm{H}$ & 16.1469242 & 19.7202802 & 22.4512503 \\
\hline \multirow{2}{*}{\multicolumn{4}{|c|}{ Si 5}} \\
\hline & & & \\
\hline $\mathrm{H}$ & 8.7020155 & 8.9742915 & 15.0365267 \\
\hline P & 5.4095320 & 9.2933295 & 16.5612582 \\
\hline Al & 5.3922102 & 9.2600951 & 28.3836280 \\
\hline $\mathrm{P}$ & 5.4291781 & 6.7603869 & 21.5194967 \\
\hline Al & 5.4614576 & 6.7045816 & 18.3571508 \\
\hline $\mathrm{P}$ & 3.2349749 & 7.9108294 & 26.5317470 \\
\hline $\mathrm{Al}$ & 3.2803716 & 7.9649915 & 23.4052617 \\
\hline $\mathrm{P}$ & 8.5269930 & 9.2119314 & 28.3035836 \\
\hline Al & 8.5573959 & 9.2590813 & 16.4908652 \\
\hline $\mathrm{P}$ & 8.6381605 & 6.6942569 & 18.3290986 \\
\hline Al & 8.6094193 & 6.6926025 & 21.4799535 \\
\hline $\mathrm{P}$ & 1.6668104 & 10.7100499 & 23.3134276 \\
\hline $\mathrm{Al}$ & 1.6481827 & 10.6766040 & 26.4831759 \\
\hline 0 & 6.8824659 & 9.6681519 & 16.8423817 \\
\hline $\mathrm{O}$ & 4.9170838 & 10.9106221 & 28.0289600 \\
\hline $\mathrm{H}$ & 4.9385656 & 5.3857024 & 21.8138814 \\
\hline $\mathrm{H}$ & 9.0758580 & 5.3034408 & 21.7441225 \\
\hline $\mathrm{O}$ & 7.1573373 & 6.3257655 & 18.1198491 \\
\hline 0 & 2.1755208 & 9.0167268 & 26.6950029 \\
\hline $\mathrm{H}$ & 2.2833848 & 6.8869731 & 23.1582508 \\
\hline $\mathrm{H}$ & 0.2665765 & 10.3300636 & 22.9786499 \\
\hline $\mathrm{O}$ & 4.9977402 & 8.0802798 & 17.3972308 \\
\hline $\mathrm{O}$ & 4.4056547 & 8.1349548 & 27.4933399 \\
\hline $\mathrm{O}$ & 4.6848039 & 7.7862748 & 22.3868279 \\
\hline 0 & 2.6183550 & 11.7652931 & 27.4342498 \\
\hline $\mathrm{O}$ & 9.0362592 & 7.8663086 & 17.4241399 \\
\hline $\mathrm{O}$ & 2.1423496 & 11.8753082 & 22.4452601 \\
\hline $\mathrm{O}$ & 4.5184211 & 10.4744810 & 16.9614914 \\
\hline $\mathrm{O}$ & 7.0542334 & 9.0514321 & 27.9129307 \\
\hline 0 & 6.9202992 & 6.8449818 & 21.8641630 \\
\hline $\mathrm{H}$ & 9.4800818 & 5.5205183 & 17.9676752 \\
\hline $\mathrm{H}$ & 4.6400768 & 5.5361746 & 17.9361052 \\
\hline $\mathrm{H}$ & 0.2403182 & 10.7799085 & 26.9568490 \\
\hline $\mathrm{H}$ & 2.6147981 & 6.5989103 & 26.8654677 \\
\hline 0 & 2.5730244 & 9.5057600 & 23.0362448 \\
\hline $\mathrm{H}$ & 5.2241148 & 8.9583096 & 15.1223340 \\
\hline $\mathrm{O}$ & 5.1993883 & 7.1154341 & 20.0394318 \\
\hline $\mathrm{O}$ & 3.7747874 & 7.9005529 & 25.0880945 \\
\hline $\mathrm{H}$ & 8.7205788 & 8.9342833 & 29.7536031 \\
\hline $\mathrm{O}$ & 8.8804743 & 7.1128482 & 19.7955998 \\
\hline 0 & 1.7655183 & 11.1229080 & 24.7961824 \\
\hline $\mathrm{H}$ & 5.2437725 & 8.9935428 & 29.8410355 \\
\hline $\mathrm{H}$ & 3.4943512 & 11.9715427 & 15.0197105 \\
\hline $\mathrm{P}$ & 3.2164067 & 15.9269118 & 21.5390869 \\
\hline Al & 3.2088356 & 15.9305498 & 18.3647369 \\
\hline $\mathrm{P}$ & 3.8565017 & 11.9970614 & 28.3037935 \\
\hline Al & 3.8237609 & 12.0004136 & 16.4715288 \\
\hline $\mathrm{P}$ & 1.6341068 & 13.2248079 & 18.3427877 \\
\hline $\mathrm{Al}$ & 1.6146610 & 13.2184429 & 21.4414276 \\
\hline 0 & 5.0240723 & 13.2411147 & 16.7931190 \\
\hline $\mathrm{H}$ & 0.1523028 & 13.4842127 & 21.5308446 \\
\hline $\mathrm{H}$ & 2.2547748 & 17.0377175 & 21.7809451 \\
\hline 0 & 2.0021341 & 14.6977951 & 18.0386532 \\
\hline $\mathrm{O}$ & 4.6532711 & 15.6594367 & 17.4207814 \\
\hline $\mathrm{O}$ & 4.4797381 & 16.1288239 & 22.3910668 \\
\hline 0 & 2.3552530 & 12.2935107 & 17.3556061 \\
\hline $\mathrm{O}$ & 4.4450266 & 13.3633136 & 27.9376689 \\
\hline 0 & 2.5690819 & 14.6065771 & 21.9487926 \\
\hline $\mathrm{H}$ & 2.6614029 & 17.2710170 & 18.0174823 \\
\hline $\mathrm{H}$ & 0.1679954 & 13.0410886 & 18.1587090 \\
\hline 0 & 3.6398754 & 15.9050374 & 20.0599372 \\
\hline $\mathrm{H}$ & 3.4500389 & 11.9674619 & 29.7359361 \\
\hline 0 & 2.0715926 & 12.8544780 & 19.7705962 \\
\hline $\mathrm{P}$ & 10.1870581 & 11.9118937 & 16.4505261 \\
\hline Al & 10.1558049 & 11.8974598 & 28.3317076 \\
\hline$P$ & 12.4127025 & 10.6471750 & 26.5999792 \\
\hline Al & 12.4214003 & 10.6777681 & 23.3667532 \\
\hline $\mathrm{P}$ & 15.5418091 & 10.7100499 & 23.3134276 \\
\hline $\mathrm{P}$ & 10.7246631 & 8.0374625 & 23.3465496 \\
\hline Al & 10.7589000 & 7.9969216 & 26.5138574 \\
\hline Al & 15.5231814 & 10.6766040 & 26.4831759 \\
\hline 0 & 8.9734247 & 10.6493620 & 27.9645567 \\
\hline 0 & 11.9338576 & 9.2223251 & 26.9500673 \\
\hline $\mathrm{H}$ & 15.9707288 & 9.2678803 & 26.6629517 \\
\hline
\end{tabular}




\begin{tabular}{|c|c|c|}
\hline 11.6696127 & 6.9014035 & 23.1633532 \\
\hline 14.0901017 & 10.3160950 & 22.9663433 \\
\hline 11.5751952 & 11.6957256 & 27.3427571 \\
\hline 9.3350790 & 8.1870181 & 27.4994374 \\
\hline 16.3529350 & 11.6077208 & 27.2965953 \\
\hline 9.4652845 & 7.8367646 & 22.4895082 \\
\hline 16.0173484 & 11.8753082 & 22.4452601 \\
\hline 9.5694172 & 10.5994150 & 16.9717925 \\
\hline 13.8741636 & 10.7976035 & 27.0379845 \\
\hline 11.3436766 & 6.6544951 & 26.7841316 \\
\hline 16.4223354 & 9.5398970 & 23.0441019 \\
\hline 11.4022373 & 9.3310064 & 22.8802510 \\
\hline 10.6178944 & 11.7423274 & 15.0353413 \\
\hline 12.2707713 & 10.8893377 & 25.0952040 \\
\hline 15.6405170 & 11.1229080 & 24.7961824 \\
\hline 10.3064885 & 8.1493851 & 24.8245756 \\
\hline 10.5615973 & 11.7605264 & 29.7577869 \\
\hline 8.7369562 & 15.0983637 & 15.0054175 \\
\hline 5.4714944 & 14.6979462 & 16.5516682 \\
\hline 5.4516841 & 14.7100780 & 28.3916564 \\
\hline 12.3666774 & 18.7764883 & 21.5194967 \\
\hline 12.2255347 & 13.2450506 & 21.5385923 \\
\hline 17.0914055 & 15.9269118 & 21.5390869 \\
\hline 17.0838343 & 15.9305498 & 18.3647369 \\
\hline 12.2943451 & 13.2230119 & 18.4451383 \\
\hline 12.3989570 & 18.7206829 & 18.3571508 \\
\hline 5.3857272 & 17.2354998 & 26.5244625 \\
\hline 5.3518598 & 17.2520682 & 23.3905906 \\
\hline 8.5925496 & 14.6865999 & 28.3139189 \\
\hline 8.6181693 & 14.6894219 & 16.4322241 \\
\hline 15.5091056 & 13.2248079 & 18.3427877 \\
\hline 15.5756598 & 18.7103582 & 18.3290986 \\
\hline 10.8144280 & 16.0212327 & 18.3039602 \\
\hline 10.7361397 & 16.0593683 & 21.4531206 \\
\hline 15.5469186 & 18.7087039 & 21.4799535 \\
\hline 15.4896597 & 13.2184429 & 21.4414276 \\
\hline 8.5213753 & 17.2742924 & 23.3012160 \\
\hline 8.5396210 & 17.2130531 & 26.4521935 \\
\hline 9.1183381 & 13.0165539 & 16.5451943 \\
\hline 7.1224188 & 14.2992554 & 28.0464998 \\
\hline 11.8608808 & 17.3592582 & 21.8229925 \\
\hline 13.8109597 & 13.5235307 & 21.5440730 \\
\hline 16.0941806 & 17.0788319 & 21.7898970 \\
\hline 15.8771328 & 14.6977951 & 18.0386532 \\
\hline 11.8787710 & 14.9166631 & 18.1725730 \\
\hline 14.0948367 & 18.3418669 & 18.1198491 \\
\hline 6.8615002 & 17.6200396 & 26.7600875 \\
\hline 9.0254550 & 18.6636083 & 23.1200379 \\
\hline 4.8499376 & 18.6397668 & 23.1918760 \\
\hline 18.3151670 & 15.6994350 & 17.5600466 \\
\hline 12.0022256 & 19.8976555 & 17.5358954 \\
\hline 11.4207733 & 12.2390935 & 17.2878415 \\
\hline 4.9670594 & 16.0983949 & 27.4593607 \\
\hline 11.6450049 & 19.7710890 & 22.3603764 \\
\hline 11.7926028 & 12.1116736 & 22.6437365 \\
\hline 18.3152120 & 16.1225069 & 22.3644116 \\
\hline 9.0270878 & 15.8168281 & 27.3715478 \\
\hline 16.2078008 & 12.3225041 & 17.3863394 \\
\hline 9.6157722 & 15.7374274 & 17.3910525 \\
\hline 15.9622460 & 19.8485158 & 17.4503102 \\
\hline 9.2539615 & 16.2923344 & 22.3808193 \\
\hline 6.9497427 & 14.8270409 & 16.9406199 \\
\hline 9.4773587 & 13.4707420 & 28.0308307 \\
\hline 13.8577985 & 18.8610832 & 21.8641630 \\
\hline 11.3621207 & 14.5521076 & 21.9413757 \\
\hline 16.4440807 & 14.6065771 & 21.9487926 \\
\hline 16.4416168 & 17.5031112 & 17.9573571 \\
\hline 14.0028036 & 13.0360523 & 18.1536629 \\
\hline 11.4390359 & 17.3552035 & 17.8650885 \\
\hline 4.5267843 & 18.4150193 & 26.8212308 \\
\hline 9.3907401 & 18.3799162 & 26.8143364 \\
\hline 7.0342102 & 17.2362738 & 22.9437548 \\
\hline 5.2708736 & 15.0650940 & 15.1226566 \\
\hline 12.1368877 & 19.1315355 & 20.0394318 \\
\hline 11.7532723 & 12.7311196 & 20.0344126 \\
\hline 17.5148741 & 15.9050374 & 20.0599372 \\
\hline 5.1845638 & 16.7740403 & 25.0680079 \\
\hline 8.7530494 & 15.1565304 & 29.7176731 \\
\hline 15.9465913 & 12.8544780 & 19.7705962 \\
\hline 15.8179737 & 19.1289496 & 19.7955998 \\
\hline
\end{tabular}




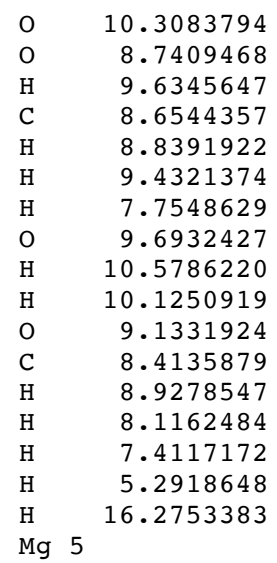

\section{$\mathrm{H} \quad 8.7549576$}

$\mathrm{Al} \quad 5.4469675$

$\mathrm{P} \quad 5.4426237$

$\mathrm{Al} \quad 5.3348104$

P $\quad 5.3744074$

Al $\quad 3.2221956$

$\mathrm{P} \quad 3.2928881$

Al $\quad 8.5677045$

$\mathrm{P} \quad 8.5914286$

Al $\quad 8.5516296$

P $\quad 8.5327745$

Al 1.5670964

P $\quad 1.5497554$

7. 1213308

5.0454525

4.8018664

9.0148103

6.8681721

2.0277159

2. 2921906

0.1757625

4.9807550

4.5795082

4.5101315

2.4353930

9.0097646

2.1663406

4.4270251

6.9026982

7. 0354501

9.3824701

4.5667701

0.1667805

2.6068270

2. 6464534

5.2870200

5.0940963

3.7720629

8.7313411

8.8052338

1.5846838

5.2651739

3.4553113

Al $\quad 3.2659311$

$\mathrm{P} \quad 3.1925480$

Al $\quad 3.8520431$

$\mathrm{P} \quad 3.8276813$

Al $\quad 1.6956219$

1.8164345

4.8830235

0.3810706

2. 2753163

2. 1328278

4.4175494

4.7259973

2.5592106

4.5093766

2.7156010

2. 6034968

0.2383850
16.1312675

16.8017955

14.1308962

12.3223609

13.2549933

11.5641267

12.1948113

13.1599080

12.9152956

12.5627789

12.6457853

11.6000304

10.6255657

11.7708355

11.5618600

15.0230987

19.6824905

8.9567476

9. 2679738

9. 2216453

6.7227583

6.6764386

7.9928486

8.0889057

9.2239184

9.3174607

6.7373791

6.7293489

10.7860646

10.7140855

9.6989851

10.6801816

5.3712069

5. 3420595

6.3399068

9.2540176

7.0236622

10.4290747

7.8580338

8.2459602

7.9395601

11.6480366

8.1271292

12.1192334

10.6039992

9.0161927

6.8010049

5.5751186

5.4939974

10.8001139

6.6852620

9. 4470364

8.9670504

7.0662845

7.9861225

8.9869721

7.1446289

11.1694761

8.9247623

11.8989281

16.0421796

16.0385039

11.9248598

11.9471529

13.2673413

13.2934444

13.0461618

13.6816914

17.1148430

14.9392097

15.8011417

16.3489748

12.2060405

13.4741547

14.4738792

17.3540972

13.0735045
19.7518791

24.7557972

24.0147496

22.5231793

21.9910114

22.5579757

23.1254885

24.1370694

23.7354320

19.8511382

19.6402787

20.0966903

20.1369311

21.2860616

19.6437718

29.8385830

22.3391770

15.1512339

16.5312557

28.3543907

21.4907562

18.3274941

26.4950926

23.3671527

28.4036951

16.5865962

18.4079638

21.5650757

23.3964644

26.5811668

16.8783200

28.0523114

21.8169461

21.8104130

18.1489687

26.6996844

23.0825808

23.0042033

17.4350983

27.5506106

22.4426385

27.4099184

17.4571135

22.4638110

16.9917759

27.9404940

21.8726732

17.9884700

17.9192350

27.1262356

26.8537839

23.1010273

15.0817791

19.7907644

24.8291543

29.8645853

20.1020193

25.1125817

29.8026630

15.1064832

21.4731299

18.3026898

28.3777557

16.5473633

18.4483507

21.5255238

16.7945156

21.6037236

21.7650138

18.0911623

17.4106284

22.3702294

17.3596013

27.9402673

21.9548645

17.9293890

18.2116895 


\begin{tabular}{|c|c|c|c|}
\hline 0 & 3.6568844 & 16.0692985 & 19.7681127 \\
\hline $\mathrm{H}$ & 3.5032870 & 11.9013874 & 29.8251461 \\
\hline 0 & 2.1955380 & 12.8702989 & 20.0776337 \\
\hline Al & 10.1720252 & 12.0173529 & 16.3896744 \\
\hline $\mathrm{P}$ & 10.1078644 & 11.9561122 & 28.2663461 \\
\hline Al & 12.3474827 & 10.5703970 & 26.6309852 \\
\hline $\mathrm{P}$ & 12.3357999 & 10.6308982 & 23.3793762 \\
\hline Al & 15.4420952 & 10.7860646 & 23.3964644 \\
\hline Al & 10.6780732 & 8.0106901 & 23.4615318 \\
\hline$P$ & 10.7293162 & 7.9262436 & 26.6201318 \\
\hline $\mathrm{P}$ & 15.4247541 & 10.7140855 & 26.5811668 \\
\hline 0 & 9.0567077 & 10.8590341 & 27.9857475 \\
\hline 0 & 11.7895565 & 8.9601740 & 27.0541960 \\
\hline $\mathrm{H}$ & 15.8866240 & 9.3031708 & 26.6956945 \\
\hline $\mathrm{H}$ & 11.6283009 & 6.8759514 & 23.2985713 \\
\hline 0 & 13.7918628 & 10.3626463 & 22.9312117 \\
\hline 0 & 11.3132855 & 11.7899780 & 27.3314656 \\
\hline 0 & 9.5011221 & 8.0337696 & 27.5328794 \\
\hline $\mathrm{H}$ & 16.2861901 & 11.6225149 & 27.3872714 \\
\hline 0 & 9.2486360 & 7.7321350 & 22.4888535 \\
\hline 0 & 16.0413393 & 12.1192334 & 22.4638110 \\
\hline 0 & 9.4939096 & 10.5021433 & 16.9571737 \\
\hline 0 & 13.9973706 & 10.8028763 & 27.1437382 \\
\hline $\mathrm{H}$ & 11.3029676 & 6.5601132 & 26.7675505 \\
\hline $\mathrm{H}$ & 16.3630649 & 9.6435284 & 23.1443804 \\
\hline $\mathrm{O}$ & 11.4355322 & 9.4758308 & 22.8780669 \\
\hline $\mathrm{H}$ & 10.5354184 & 11.8690858 & 14.9533308 \\
\hline 0 & 12.2665952 & 10.6957864 & 24.9091811 \\
\hline 0 & 15.4596825 & 11.1694761 & 25.1125817 \\
\hline 0 & 10.2807160 & 8.1773429 & 25.1635339 \\
\hline $\mathrm{H}$ & 10.5837470 & 11.8466291 & 29.6729980 \\
\hline $\mathrm{H}$ & 8.6898926 & 15.2214186 & 15.0636789 \\
\hline Al & 5.3910907 & 14.6965501 & 16.4799483 \\
\hline$P$ & 5.3715174 & 14.6820057 & 28.3175844 \\
\hline Al & 12.2723098 & 18.7388597 & 21.4907562 \\
\hline Mg & 12.4067239 & 13.2232432 & 21.4898917 \\
\hline Al & 17.1409298 & 16.0421796 & 21.4731299 \\
\hline $\mathrm{P}$ & 17.0675467 & 16.0385039 & 18.3026898 \\
\hline$P$ & 12.3497998 & 13.1908920 & 18.3456319 \\
\hline$P$ & 12.3119067 & 18.6925399 & 18.3274941 \\
\hline Al & 5.4295798 & 17.1919998 & 26.4535569 \\
\hline $\mathrm{P}$ & 5.4357922 & 17.2872404 & 23.3429125 \\
\hline Al & 8.5242511 & 14.7359187 & 28.3591080 \\
\hline $\mathrm{P}$ & 8.5358101 & 14.7363972 & 16.4630121 \\
\hline Al & 15.5706207 & 13.2673413 & 18.4483507 \\
\hline Al & 15.4891289 & 18.7534805 & 18.4079638 \\
\hline Al & 10.7793722 & 15.9484523 & 18.3973889 \\
\hline $\mathrm{P}$ & 10.6580221 & 16.0135876 & 21.5394099 \\
\hline P & 15.4702739 & 18.7454502 & 21.5650757 \\
\hline$P$ & 15.6914332 & 13.2934444 & 21.5255238 \\
\hline Al & 8.5803671 & 17.3961770 & 23.3605666 \\
\hline$P$ & 8.5818328 & 17.2731897 & 26.5209091 \\
\hline 0 & 8.9394832 & 13.2520221 & 16.5357673 \\
\hline 0 & 6.8474740 & 14.3371155 & 28.0376671 \\
\hline 0 & 11.6482148 & 17.1561486 & 21.8727353 \\
\hline $\mathrm{O}$ & 14.2322682 & 13.6881293 & 21.6050203 \\
\hline 0 & 15.9684157 & 17.3118083 & 21.8186103 \\
\hline $\mathrm{O}$ & 16.0078265 & 14.9392097 & 18.0911623 \\
\hline 0 & 11.9971860 & 14.6954305 & 18.2463069 \\
\hline 0 & 13.8056715 & 18.3560082 & 18.1489687 \\
\hline 0 & 7.1011718 & 17.6122795 & 26.7942056 \\
\hline $\mathrm{H}$ & 9.1048764 & 18.7678635 & 23.1146262 \\
\hline $\mathrm{H}$ & 4.8662263 & 18.6612539 & 23.2736151 \\
\hline $\mathrm{H}$ & 18.2567169 & 15.8080845 & 17.4367211 \\
\hline $\mathrm{H}$ & 11.9293422 & 19.8408538 & 17.4602339 \\
\hline 0 & 11.6501318 & 12.4173953 & 17.2122138 \\
\hline 0 & 4.9211662 & 15.8680552 & 27.4589282 \\
\hline $\mathrm{H}$ & 11.5711159 & 19.7734611 & 22.3001064 \\
\hline 0 & 11.8054186 & 11.9456158 & 22.8126887 \\
\hline $\mathrm{H}$ & 18.3897371 & 16.3045842 & 22.2404269 \\
\hline 0 & 9.0290005 & 16.0648700 & 27.3500053 \\
\hline $\mathrm{H}$ & 16.3060093 & 12.3635909 & 17.5212264 \\
\hline 0 & 9.4086371 & 15.5974734 & 17.3772055 \\
\hline $\mathrm{H}$ & 15.8800286 & 19.9392725 & 17.5966591 \\
\hline 0 & 9.3747609 & 16.1888856 & 22.3944938 \\
\hline 0 & 7.0741395 & 14.8699675 & 16.9179587 \\
\hline 0 & 9.4885994 & 13.3304534 & 28.0023981 \\
\hline 0 & 13.9729494 & 18.8171063 & 21.8726732 \\
\hline 0 & 11.2420621 & 14.6699159 & 21.8959532 \\
\hline 0 & 16.5905997 & 14.4738792 & 21.9548645 \\
\hline
\end{tabular}




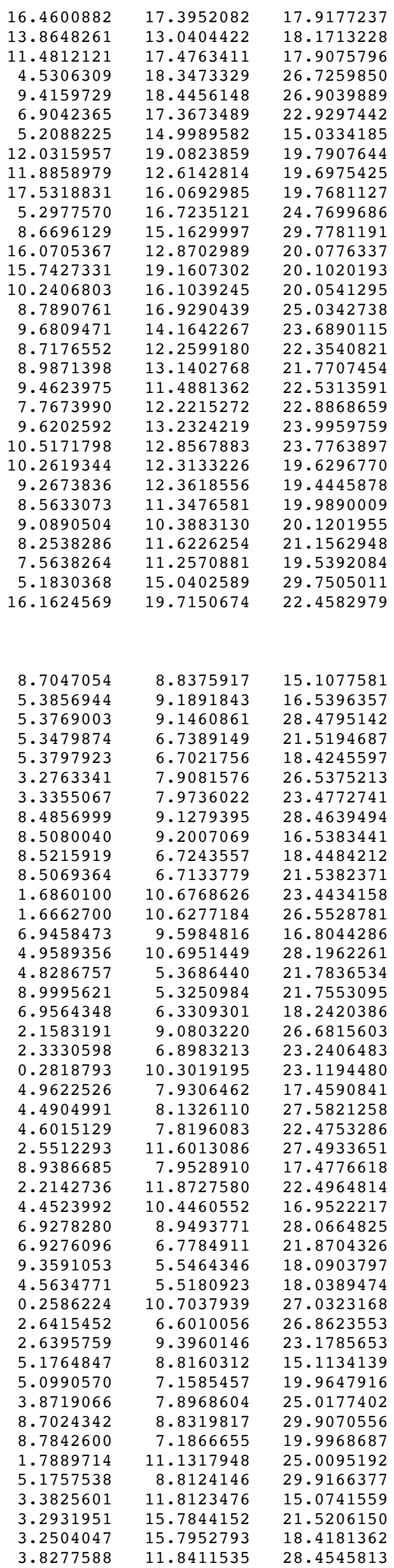




\begin{tabular}{|c|c|c|c|}
\hline $\mathrm{Si}$ & 3.7968664 & 11.8607233 & 16.5035371 \\
\hline $\mathrm{Si}$ & 1.7186502 & 13.0869433 & 18.4646740 \\
\hline $\mathrm{Si}$ & 1.7540524 & 13.0779884 & 21.4963296 \\
\hline 0 & 4.9216596 & 13.0188516 & 16.7364168 \\
\hline $\mathrm{H}$ & 0.2965449 & 13.3728837 & 21.5726802 \\
\hline $\mathrm{H}$ & 2.3252834 & 16.8918817 & 21.7525319 \\
\hline 0 & 2.1148518 & 14.6508235 & 18.1815230 \\
\hline $\mathrm{O}$ & 4.5311667 & 15.5623186 & 17.4517972 \\
\hline 0 & 4.6125563 & 15.9911140 & 22.4430179 \\
\hline 0 & 2.4803588 & 12.1263060 & 17.3998757 \\
\hline $\mathrm{O}$ & 4.4590305 & 13.2821843 & 28.0840766 \\
\hline $\mathrm{O}$ & 2.6269094 & 14.3819420 & 21.9418867 \\
\hline $\mathrm{H}$ & 2.6701242 & 17.1264587 & 18.0889609 \\
\hline $\mathrm{H}$ & 0.2538876 & 12.9150167 & 18.2596563 \\
\hline 0 & 3.7669822 & 15.7779884 & 19.9622215 \\
\hline $\mathrm{H}$ & 3.3847427 & 11.8106400 & 29.8758224 \\
\hline $\mathrm{O}$ & 2.1851175 & 12.6569877 & 19.9644961 \\
\hline $\mathrm{Si}$ & 10.0928624 & 11.8551334 & 16.4285257 \\
\hline $\mathrm{Si}$ & 10.0456675 & 11.8159303 & 28.4081536 \\
\hline $\mathrm{Si}$ & 12.2123672 & 10.5475944 & 26.6252682 \\
\hline $\mathrm{Si}$ & 12.2108275 & 10.5791842 & 23.4498907 \\
\hline $\mathrm{Si}$ & 15.3110087 & 10.6768626 & 23.4434158 \\
\hline $\mathrm{Si}$ & 10.5464329 & 7.9558747 & 23.4953369 \\
\hline $\mathrm{Si}$ & 10.5937470 & 7.9134138 & 26.5844254 \\
\hline $\mathrm{Si}$ & 15.2912687 & 10.6277184 & 26.5528781 \\
\hline 0 & 8.9317706 & 10.6578807 & 28.1151320 \\
\hline $\mathrm{O}$ & 11.7240258 & 9.0270573 & 26.9558294 \\
\hline $\mathrm{H}$ & 15.7410752 & 9.2131666 & 26.6705129 \\
\hline $\mathrm{H}$ & 11.4739680 & 6.7991488 & 23.3582809 \\
\hline $\mathrm{O}$ & 13.7708880 & 10.2656062 & 23.0880718 \\
\hline 0 & 11.3250486 & 11.6355947 & 27.4336075 \\
\hline 0 & 9.3306188 & 8.0573338 & 27.5881328 \\
\hline $\mathrm{H}$ & 16.1060419 & 11.5240932 & 27.4187750 \\
\hline $\mathrm{O}$ & 9.2470568 & 7.7609934 & 22.5389100 \\
\hline $\mathrm{O}$ & 15.8392723 & 11.8727580 & 22.4964814 \\
\hline $\mathrm{O}$ & 9.4405816 & 10.4598058 & 16.9556936 \\
\hline $\mathrm{O}$ & 13.7589895 & 10.7105295 & 27.0747657 \\
\hline $\mathrm{H}$ & 11.1844826 & 6.5597392 & 26.7734153 \\
\hline $\mathrm{H}$ & 16.1881999 & 9.4986025 & 23.1997781 \\
\hline 0 & 11.3099842 & 9.2950922 & 23.0046990 \\
\hline $\mathrm{H}$ & 10.5188354 & 11.7102557 & 15.0091321 \\
\hline $\mathrm{O}$ & 12.0418852 & 10.8381616 & 25.0455945 \\
\hline 0 & 15.4139701 & 11.1317948 & 25.0095192 \\
\hline $\mathrm{O}$ & 10.0685457 & 8.1046284 & 25.0482906 \\
\hline $\mathrm{H}$ & 10.5152835 & 11.7068483 & 29.8169412 \\
\hline $\mathrm{H}$ & 8.6795626 & 15.0379554 & 15.0472466 \\
\hline $\mathrm{Si}$ & 5.3889124 & 14.5643073 & 16.5096363 \\
\hline $\mathrm{Si}$ & 5.3720297 & 14.5599652 & 28.4679112 \\
\hline $\mathrm{Si}$ & 12.1604868 & 18.5385100 & 21.5194687 \\
\hline Al & 12.1347866 & 13.0589787 & 21.5154708 \\
\hline $\mathrm{Si}$ & 16.9181938 & 15.7844152 & 21.5206150 \\
\hline $\mathrm{Si}$ & 16.8754035 & 15.7952793 & 18.4181362 \\
\hline $\mathrm{Si}$ & 12.1560971 & 13.0542151 & 18.4515859 \\
\hline $\mathrm{Si}$ & 12.1922916 & 18.5017707 & 18.4245597 \\
\hline $\mathrm{Si}$ & 5.3681973 & 16.9674868 & 26.5176371 \\
\hline $\mathrm{Si}$ & 5.3518969 & 17.0019766 & 23.4618388 \\
\hline $\mathrm{Si}$ & 8.4925059 & 14.5696331 & 28.4443237 \\
\hline $\mathrm{Si}$ & 8.5098432 & 14.5759307 & 16.4525399 \\
\hline $\mathrm{Si}$ & 15.3436490 & 13.0869433 & 18.4646740 \\
\hline $\mathrm{Si}$ & 15.3340913 & 18.5239508 & 18.4484212 \\
\hline $\mathrm{Si}$ & 10.6374160 & 15.7973658 & 18.4231205 \\
\hline $\mathrm{Si}$ & 10.5460231 & 15.8343083 & 21.5080698 \\
\hline $\mathrm{Si}$ & 15.3194357 & 18.5129730 & 21.5382371 \\
\hline $\mathrm{Si}$ & 15.3790511 & 13.0779884 & 21.4963296 \\
\hline $\mathrm{Si}$ & 8.4798288 & 17.0922258 & 23.4209588 \\
\hline $\mathrm{Si}$ & 8.4881918 & 17.0044874 & 26.5171460 \\
\hline $\mathrm{O}$ & 8.9591050 & 13.0156520 & 16.5489028 \\
\hline 0 & 6.9309616 & 14.1762649 & 28.1914940 \\
\hline $\mathrm{O}$ & 11.5959171 & 17.0488201 & 21.8066770 \\
\hline $\mathrm{O}$ & 13.8198690 & 13.3934553 & 21.5780064 \\
\hline $\mathrm{O}$ & 15.8566640 & 16.9989979 & 21.7749633 \\
\hline $\mathrm{O}$ & 15.7398505 & 14.6508235 & 18.1815230 \\
\hline $\mathrm{O}$ & 11.7720791 & 14.6384232 & 18.2839092 \\
\hline 0 & 13.7689341 & 18.1305251 & 18.2420386 \\
\hline 0 & 6.9241306 & 17.3852670 & 26.7788760 \\
\hline $\mathrm{H}$ & 9.0044037 & 18.4733029 & 23.2350348 \\
\hline $\mathrm{H}$ & 4.7913206 & 18.3773353 & 23.3557107 \\
\hline $\mathrm{H}$ & 18.0516941 & 15.5813211 & 17.5306212 \\
\hline $\mathrm{H}$ & 11.8078726 & 19.6327949 & 17.5356689 \\
\hline $\mathrm{O}$ & 11.4133975 & 12.1877416 & 17.2921497 \\
\hline
\end{tabular}




\begin{tabular}{|c|c|c|}
\hline 4.9090445 & 15.7935041 & 27.5285034 \\
\hline 11.4762488 & 19.5291017 & 22.3956348 \\
\hline 11.6263241 & 11.8785020 & 22.7076132 \\
\hline 18.1285930 & 15.9740434 & 22.3668394 \\
\hline 8.9493699 & 15.7577449 & 27.4403278 \\
\hline 16.0421118 & 12.2060691 & 17.4882874 \\
\hline 9.3966542 & 15.5189307 & 17.4181096 \\
\hline 15.7173518 & 19.6528778 & 17.5563698 \\
\hline 9.2130390 & 16.0305938 & 22.4437691 \\
\hline 6.9552903 & 14.6952241 & 16.9053789 \\
\hline 9.3990120 & 13.2699168 & 28.1229826 \\
\hline 13.7401090 & 18.5780862 & 21.8704326 \\
\hline 11.1689213 & 14.4339189 & 21.9195232 \\
\hline 16.2519082 & 14.3819420 & 21.9418867 \\
\hline 16.2434670 & 17.2449588 & 18.0596581 \\
\hline 13.7540852 & 12.9003681 & 18.2421883 \\
\hline 11.3064868 & 17.2168910 & 18.0061218 \\
\hline 4.4947056 & 18.1470339 & 26.7682394 \\
\hline 9.3269823 & 18.1856502 & 26.8612472 \\
\hline 6.9106817 & 17.0819039 & 23.0473420 \\
\hline 5.1759043 & 14.9540046 & 15.0884100 \\
\hline 11.9115563 & 18.9581407 & 19.9647916 \\
\hline 11.6543084 & 12.5014113 & 19.8967649 \\
\hline 17.3919809 & 15.7779884 & 19.9622215 \\
\hline 5.1895404 & 16.4405516 & 24.9840311 \\
\hline 8.6785250 & 15.0386580 & 29.8452281 \\
\hline 15.8101162 & 12.6569877 & 19.9644961 \\
\hline 15.5967593 & 18.9862606 & 19.9968687 \\
\hline 10.0665268 & 15.8918799 & 19.9450426 \\
\hline 8.7100845 & 16.5783824 & 24.9552620 \\
\hline 9.4749403 & 14.0271506 & 23.8976999 \\
\hline 8.5009267 & 12.1700632 & 22.4793064 \\
\hline 8.7017510 & 13.0832340 & 21.9196825 \\
\hline 9.2763920 & 11.4130343 & 22.5615783 \\
\hline 7.5868496 & 12.0684783 & 23.0643428 \\
\hline 9.4867369 & 13.0666505 & 24.1005488 \\
\hline 10.3816917 & 12.7650992 & 23.7777979 \\
\hline 10.0004686 & 12.2624677 & 19.7655884 \\
\hline 9.0099108 & 12.3520362 & 19.5758586 \\
\hline 8.2740345 & 11.3411907 & 20.0840065 \\
\hline 8.7671028 & 10.3588648 & 20.1658460 \\
\hline 7.9847343 & 11.5731049 & 21.2641399 \\
\hline 7.2688045 & 11.3047740 & 19.6386291 \\
\hline 5.1741641 & 14.9542049 & 29.8900733 \\
\hline 15.9968448 & 19.4718227 & 22.4541218 \\
\hline 8.6748857 & 9.0053948 & 15.0530986 \\
\hline 5.4242988 & 9.3129182 & 16.5891168 \\
\hline 5.3917923 & 9.2533432 & 28.4053156 \\
\hline 5.4241380 & 6.7387255 & 21.5172595 \\
\hline 5.4717290 & 6.7142960 & 18.3635871 \\
\hline 3.2505562 & 7.9172182 & 26.5353269 \\
\hline 3.3412949 & 8.0419782 & 23.4383096 \\
\hline 8.5135654 & 9.1873657 & 28.3096592 \\
\hline 8.5609027 & 9.2835613 & 16.5114373 \\
\hline 8.6586497 & 6.7100350 & 18.3423994 \\
\hline 8.6217003 & 6.6816862 & 21.4935176 \\
\hline 1.6642355 & 10.7290290 & 23.3351646 \\
\hline 1.6306045 & 10.6628463 & 26.5143505 \\
\hline 6.8919465 & 9.6949931 & 16.8885645 \\
\hline 4.9239415 & 10.9055988 & 28.0426279 \\
\hline 4.9109653 & 5.3714227 & 21.8075309 \\
\hline 9.1319171 & 5.3099575 & 21.7676707 \\
\hline 7.1734152 & 6.3511896 & 18.1510309 \\
\hline 2.1676681 & 9.0022801 & 26.6884194 \\
\hline 2.2888378 & 7.0082485 & 23.2361767 \\
\hline 0.3047378 & 10.2504444 & 22.9612084 \\
\hline 5.0073656 & 8.0992374 & 17.4200557 \\
\hline 4.3718988 & 8.1235444 & 27.5584563 \\
\hline 4.7179680 & 7.7788325 & 22.4009785 \\
\hline 2.6195241 & 11.7465302 & 27.4526532 \\
\hline 9.0471811 & 7.8948806 & 17.4491714 \\
\hline 2.0529594 & 11.9399141 & 22.4887958 \\
\hline 4.5227089 & 10.4889473 & 16.9776643 \\
\hline 7.0435940 & 9.0194511 & 27.9089759 \\
\hline 6.9212748 & 6.7817788 & 21.8343759 \\
\hline 9.4876757 & 5.5377713 & 17.9478943 \\
\hline 4.6668400 & 5.5479379 & 17.9065499 \\
\hline
\end{tabular}

27.5285034

2.3956348

27.4403278

17.5563698

22.4437691

.9053789

28.1229826

8704326

1.9418867

0596581

18.0061218

682394

23.0473420

.0884100

9.8967649

9622215

9. 8452281

9.9644961

968687

4.9552620

23.8976999

22.4793064

23.0643428

.1005488

23.7777979
19.7655884

19.5758586

20.0840065

1.2641399

19.6386291

9.8900733 


\begin{tabular}{|c|c|c|c|}
\hline $\mathrm{H}$ & 0.2388123 & 10.7442057 & 27.0372421 \\
\hline $\mathrm{H}$ & 2.6359563 & 6.5862041 & 26.7956902 \\
\hline 0 & 2.6771363 & 9.6085996 & 23.0654707 \\
\hline $\mathrm{H}$ & 5.2570924 & 8.9753782 & 15.1485511 \\
\hline 0 & 5.1735291 & 7.1077128 & 20.0436387 \\
\hline 0 & 3.8565140 & 7.9742974 & 25.1176105 \\
\hline $\mathrm{H}$ & 8.6887465 & 8.9648549 & 29.7714803 \\
\hline 0 & 8.9259218 & 7.1027580 & 19.8127509 \\
\hline 0 & 1.6941250 & 11.1273050 & 24.8254987 \\
\hline $\mathrm{H}$ & 5.2723065 & 9.0069763 & 29.8689232 \\
\hline $\mathrm{H}$ & 3.5176390 & 11.9961722 & 15.0295829 \\
\hline $\mathrm{P}$ & 3.2832057 & 15.9451419 & 21.5241097 \\
\hline Al & 3.2274184 & 15.9512441 & 18.3489609 \\
\hline $\mathrm{P}$ & 3.8644581 & 11.9957256 & 28.3079008 \\
\hline Al & 3.8455260 & 12.0189694 & 16.4818539 \\
\hline $\mathrm{P}$ & 1.6456253 & 13.2354679 & 18.3525052 \\
\hline Al & 1.6257993 & 13.2840451 & 21.4458529 \\
\hline 0 & 5.0556319 & 13.2478431 & 16.8163395 \\
\hline $\mathrm{H}$ & 0.2077531 & 13.7330696 & 21.5139896 \\
\hline $\mathrm{H}$ & 2.3197608 & 17.0451466 & 21.8049728 \\
\hline $\mathrm{O}$ & 2.0182448 & 14.7099317 & 18.0627633 \\
\hline 0 & 4.6702844 & 15.6729724 & 17.4018588 \\
\hline 0 & 4.5647904 & 16.1387581 & 22.3484936 \\
\hline 0 & 2.3795987 & 12.3124181 & 17.3683965 \\
\hline $\mathrm{O}$ & 4.4464515 & 13.3579594 & 27.9132096 \\
\hline 0 & 2.6673888 & 14.6101323 & 21.9318035 \\
\hline $\mathrm{H}$ & 2.6712610 & 17.2870220 & 17.9975254 \\
\hline $\mathrm{H}$ & 0.1826611 & 13.0492536 & 18.1471266 \\
\hline 0 & 3.6747436 & 15.9492915 & 20.0377662 \\
\hline $\mathrm{H}$ & 3.4730724 & 11.9922887 & 29.7445378 \\
\hline 0 & 2.0578279 & 12.8489323 & 19.7846521 \\
\hline $\mathrm{P}$ & 10.1954511 & 11.9186196 & 16.3931737 \\
\hline Al & 10.1381845 & 11.8740677 & 28.2714062 \\
\hline $\mathrm{P}$ & 12.4260129 & 10.5858718 & 26.6434375 \\
\hline Al & 12.4629491 & 10.5793988 & 23.3911574 \\
\hline $\mathrm{P}$ & 15.5392342 & 10.7290290 & 23.3351646 \\
\hline $\mathrm{P}$ & 10.6508292 & 8.0470262 & 23.4044942 \\
\hline Al & 10.7385297 & 7.9896321 & 26.5430273 \\
\hline Al & 15.5056032 & 10.6628463 & 26.5143505 \\
\hline 0 & 8.9692183 & 10.6087548 & 27.9155791 \\
\hline 0 & 11.9149944 & 9.1885056 & 27.0557105 \\
\hline $\mathrm{H}$ & 15.9615476 & 9.2530955 & 26.6621276 \\
\hline $\mathrm{H}$ & 11.5370984 & 6.8560657 & 23.2893390 \\
\hline 0 & 14.1263785 & 10.2316608 & 22.9465313 \\
\hline 0 & 11.5607255 & 11.6830751 & 27.2799492 \\
\hline $\mathrm{O}$ & 9.3279144 & 8.1254206 & 27.5589461 \\
\hline $\mathrm{H}$ & 16.3511501 & 11.5894187 & 27.3166189 \\
\hline 0 & 9.3913650 & 7.8589517 & 22.5426843 \\
\hline $\mathrm{O}$ & 15.9279581 & 11.9399141 & 22.4887958 \\
\hline 0 & 9.5898478 & 10.6215496 & 16.9654332 \\
\hline 0 & 13.8718404 & 10.7583505 & 27.1281496 \\
\hline $\mathrm{H}$ & 11.3434666 & 6.6395555 & 26.7117438 \\
\hline $\mathrm{H}$ & 16.5222316 & 9.6416775 & 23.0734327 \\
\hline 0 & 11.3968801 & 9.2810422 & 22.8780096 \\
\hline $\mathrm{H}$ & 10.5954909 & 11.7102618 & 14.9741333 \\
\hline 0 & 12.3600028 & 10.7211900 & 25.1234399 \\
\hline 0 & 15.5691238 & 11.1273050 & 24.8254987 \\
\hline 0 & 10.2386603 & 8.2535849 & 24.8752720 \\
\hline $\mathrm{H}$ & 10.5388087 & 11.7287879 & 29.6981208 \\
\hline $\mathrm{H}$ & 8.7469516 & 15.1047199 & 14.9492519 \\
\hline $\mathrm{P}$ & 5.4926520 & 14.7031609 & 16.5448754 \\
\hline Al & 5.4539463 & 14.7018407 & 28.3790515 \\
\hline $\mathrm{P}$ & 12.3616374 & 18.7548269 & 21.5172595 \\
\hline $\mathrm{Ge}$ & 12.1868214 & 13.2932353 & 21.5542919 \\
\hline $\mathrm{P}$ & 17.1582044 & 15.9451419 & 21.5241097 \\
\hline Al & 17.1024171 & 15.9512441 & 18.3489609 \\
\hline Al & 12.3024488 & 13.2279266 & 18.3797201 \\
\hline Al & 12.4092284 & 18.7303974 & 18.3635871 \\
\hline $\mathrm{P}$ & 5.3949317 & 17.2110140 & 26.5047527 \\
\hline Al & 5.3313558 & 17.2588468 & 23.4276667 \\
\hline $\mathrm{P}$ & 8.5921154 & 14.6788785 & 28.2598548 \\
\hline $\mathrm{Al}$ & 8.6378176 & 14.7029166 & 16.3788548 \\
\hline $\mathrm{P}$ & 15.5206241 & 13.2354679 & 18.3525052 \\
\hline$P$ & 15.5961491 & 18.7261363 & 18.3423994 \\
\hline $\mathrm{P}$ & 10.8426073 & 16.0291372 & 18.2538971 \\
\hline Al & 10.6395002 & 16.1123717 & 21.4211695 \\
\hline Al & 15.5591996 & 18.6977875 & 21.4935176 \\
\hline Al & 15.5007980 & 13.2840451 & 21.4458529 \\
\hline $\mathrm{P}$ & 8.4922638 & 17.4097551 & 23.2806342 \\
\hline Al & 8.5500645 & 17.2042808 & 26.3882646 \\
\hline
\end{tabular}




\begin{tabular}{|c|c|c|c|}
\hline 0 & 9.1301430 & 13.0269297 & 16.4840554 \\
\hline $\mathrm{O}$ & 7.1188467 & 14.2949517 & 28.0068930 \\
\hline $\mathrm{O}$ & 11.8325086 & 17.3450108 & 21.8165563 \\
\hline $\mathrm{O}$ & 13.8622441 & 13.8028934 & 21.5245849 \\
\hline 0 & 16.1585066 & 17.0865380 & 21.8155412 \\
\hline 0 & 15.8932435 & 14.7099317 & 18.0627633 \\
\hline $\mathrm{O}$ & 11.9123082 & 14.9290471 & 18.1313379 \\
\hline 0 & 14.1109145 & 18.3672909 & 18.1510309 \\
\hline $\mathrm{O}$ & 6.8713646 & 17.6106332 & 26.7171187 \\
\hline $\mathrm{H}$ & 9.0247102 & 18.7981500 & 23.2032967 \\
\hline $\mathrm{H}$ & 4.7252035 & 18.6134605 & 23.3063337 \\
\hline $\mathrm{H}$ & 18.3313344 & 15.7142346 & 17.5422954 \\
\hline $\mathrm{H}$ & 12.0116109 & 19.9162724 & 17.5556754 \\
\hline 0 & 11.4519701 & 12.2700608 & 17.1865651 \\
\hline $\mathrm{O}$ & 4.9746671 & 16.1228435 & 27.4948952 \\
\hline $\mathrm{H}$ & 11.6773889 & 19.7626460 & 22.3735453 \\
\hline 0 & 11.8137653 & 12.0552647 & 22.7758896 \\
\hline $\mathrm{H}$ & 18.4005056 & 16.1328234 & 22.3232243 \\
\hline 0 & 9.0266994 & 15.7965214 & 27.3011399 \\
\hline $\mathrm{H}$ & 16.2321519 & 12.3406458 & 17.3984915 \\
\hline 0 & 9.6562076 & 15.7442668 & 17.3249394 \\
\hline $\mathrm{H}$ & 15.9733216 & 19.8763426 & 17.4752852 \\
\hline $\mathrm{O}$ & 9.1356584 & 16.5091686 & 22.2297349 \\
\hline 0 & 6.9753327 & 14.8508532 & 16.9122173 \\
\hline $\mathrm{O}$ & 9.4665770 & 13.4534684 & 27.9831302 \\
\hline $\mathrm{O}$ & 13.8587742 & 18.7978801 & 21.8343759 \\
\hline 0 & 11.0818930 & 14.5761180 & 22.0436646 \\
\hline 0 & 16.5423875 & 14.6101323 & 21.9318035 \\
\hline $\mathrm{O}$ & 16.4494421 & 17.5195585 & 17.9363464 \\
\hline $\mathrm{O}$ & 14.0175761 & 13.0441515 & 18.1414994 \\
\hline 0 & 11.4681880 & 17.3667433 & 17.8292396 \\
\hline $\mathrm{H}$ & 4.5290876 & 18.4005763 & 26.7336110 \\
\hline $\mathrm{H}$ & 9.4100689 & 18.3668110 & 26.7432811 \\
\hline 0 & 6.9945254 & 17.4539245 & 22.9915201 \\
\hline $\mathrm{H}$ & 5.2765287 & 15.0399924 & 15.1106662 \\
\hline 0 & 12.1110284 & 19.1238141 & 20.0436387 \\
\hline $\mathrm{O}$ & 11.6910854 & 12.6843470 & 19.9338667 \\
\hline 0 & 17.5497423 & 15.9492915 & 20.0377662 \\
\hline $\mathrm{O}$ & 5.1974341 & 16.6715831 & 25.0732473 \\
\hline $\mathrm{H}$ & 8.7610720 & 15.1614561 & 29.6583158 \\
\hline 0 & 15.9328266 & 12.8489323 & 19.7846521 \\
\hline 0 & 15.8634211 & 19.1188593 & 19.8127509 \\
\hline $\mathrm{O}$ & 10.3255271 & 16.1275482 & 19.6967649 \\
\hline 0 & 8.7547846 & 16.8092652 & 24.6840148 \\
\hline $\mathrm{H}$ & 9.6652149 & 13.9309620 & 24.1168667 \\
\hline C & 8.6698703 & 12.2279637 & 22.5442210 \\
\hline $\mathrm{H}$ & 8.9905555 & 13.1391746 & 22.0384752 \\
\hline $\mathrm{H}$ & 9.3491725 & 11.3816819 & 22.6137477 \\
\hline $\mathrm{H}$ & 7.7277112 & 12.1972511 & 23.0916167 \\
\hline 0 & 9.6891556 & 12.9563091 & 24.2201567 \\
\hline $\mathrm{H}$ & 10.5791311 & 12.7027442 & 23.8195589 \\
\hline $\mathrm{H}$ & 10.0700561 & 12.5746716 & 19.7756297 \\
\hline 0 & 9.0691650 & 12.6683794 & 19.6084754 \\
\hline C & 8.3677949 & 11.6144794 & 20.0749691 \\
\hline $\mathrm{H}$ & 8.8802689 & 10.6383080 & 20.0670451 \\
\hline $\mathrm{H}$ & 8.1286863 & 11.7571575 & 21.2791626 \\
\hline $\mathrm{H}$ & 7.3462988 & 11.5870263 & 19.6675920 \\
\hline $\mathrm{H}$ & 5.2964913 & 14.9998059 & 29.8294119 \\
\hline $\mathrm{H}$ & 16.2123079 & 19.6967703 & 22.3838006 \\
\hline \multicolumn{4}{|c|}{$\mathrm{Ga} 5$} \\
\hline \multicolumn{4}{|c|}{171} \\
\hline $\mathrm{H}$ & 8.6835529 & 8.8342178 & 15.1116791 \\
\hline $\mathrm{Si}$ & 5.3888402 & 9.2078419 & 16.5514635 \\
\hline $\mathrm{Si}$ & 5.3659477 & 9.1457982 & 28.4923523 \\
\hline $\mathrm{Si}$ & 5.3373947 & 6.7087260 & 21.5178829 \\
\hline $\mathrm{Si}$ & 5.3741603 & 6.7156006 & 18.4262660 \\
\hline $\mathrm{Si}$ & 3.2767244 & 7.9202216 & 26.5359390 \\
\hline $\mathrm{Si}$ & 3.3728495 & 8.0341413 & 23.4911209 \\
\hline $\mathrm{Si}$ & 8.4694035 & 9.1131839 & 28.4651078 \\
\hline $\mathrm{Si}$ & 8.5059116 & 9.2139148 & 16.5404528 \\
\hline $\mathrm{Si}$ & 8.5223486 & 6.7395540 & 18.4508771 \\
\hline $\mathrm{Si}$ & 8.5044820 & 6.7027697 & 21.5435970 \\
\hline $\mathrm{Si}$ & 1.6704835 & 10.6824996 & 23.4414777 \\
\hline $\mathrm{Si}$ & 1.6463746 & 10.6219505 & 26.5636921 \\
\hline $\mathrm{O}$ & 6.9478181 & 9.6181683 & 16.8190705 \\
\hline $\mathrm{O}$ & 4.9507700 & 10.6958922 & 28.2073601 \\
\hline $\mathrm{H}$ & 4.8110751 & 5.3390174 & 21.7708782 \\
\hline $\mathrm{H}$ & 9.0330483 & 5.3295790 & 21.7718196 \\
\hline 0 & 6.9541209 & 6.3578097 & 18.2518859 \\
\hline
\end{tabular}

16.4840554

28.0068930

21. 5245849

21.8155412

18.0627633

8.1313379

8.1510309

23.2032967

23.3063337

17.5422954

17.1865651

48952

22.7758896

2243

17.3984915

3249394

22.2297349

(22173

21.8343759

2.0436646

17.9363464

8.1414994

26.7336110

26.7432811

15.1106662

436387

20.0377662

25.0732473

29.6583158
19.7846521

19.8127509

19.6967649

. 1168667

22.5442210

22.6137477

23.0916167

195589

19.7756297

20.0670451

21.2791626

675920

29.8294119
22.3838006

Ga 5

171 


$$
\begin{aligned}
& \text { 2. } 1418266 \\
& 9.0755857 \\
& 6.9868418 \\
& \text { 2. } 3327549 \\
& 0.2963237 \\
& 4.9579254 \\
& 4.4614810 \\
& 4.6233227 \\
& \text { 2. } 5489180 \\
& 8.9410425 \\
& 2.0897484 \\
& 4.4555417 \\
& 6.9115397 \\
& 6.9202447 \\
& \text { 9. } 3484735 \\
& 4.5702838 \\
& 0.2508752 \\
& \text { 2. } 6456577 \\
& 2.7235464 \\
& 5.1838672 \\
& 5.0731205 \\
& 3.9128658 \\
& 8.6801194 \\
& 8.7993706 \\
& 1.7312879 \\
& 5.1819527 \\
& 3.3753305 \\
& \text { 3. } 3440409 \\
& \text { 3. } 2537050 \\
& \text { 3. } 8203012 \\
& 3.8000066 \\
& 1.7160099 \\
& \text { 1. } 7463190 \\
& \text { 4. } 9268424 \\
& 0.3390961 \\
& \text { 2. } 3644700 \\
& \text { 2. } 1233597 \\
& 4.5277319 \\
& 4.6796625 \\
& 2.4930804 \\
& 4.4493910 \\
& \text { 2. } 7353175 \\
& 2.6598733 \\
& 0.2550837 \\
& \text { 3. } 7843268 \\
& 3.3766003 \\
& \text { 2. } 1387755 \\
& 10.0905018 \\
& 10.0266554 \\
& 12.2132842 \\
& 12.2378633 \\
& 15.2954822 \\
& 10.4886170 \\
& 10.5729706 \\
& 15.2713734 \\
& 8.9224069 \\
& 11.7078624 \\
& 15.7244485 \\
& 11.3782106 \\
& 13.7844729 \\
& 11.3031497 \\
& \text { 9.3118500 } \\
& 16.1021844 \\
& \text { 9. } 1859285 \\
& 15.7147471 \\
& 9.4512918 \\
& 13.7507698 \\
& 11.1650366 \\
& 16.2617859 \\
& 11.2756184 \\
& 10.5061143 \\
& 12.0918959 \\
& 15.3562867 \\
& 10.0393306 \\
& 10.5011464 \\
& 8.6789827 \\
& \text { 5. } 3912801 \\
& 5.3621813 \\
& 12.1498941 \\
& 12.1411816 \\
& 16.9690397
\end{aligned}
$$




\begin{tabular}{|c|c|c|c|}
\hline $\mathrm{Si}$ & 12.1578245 & 13.0655506 & 18.4101402 \\
\hline $\mathrm{Si}$ & 12.1866597 & 18.5151956 & 18.4262660 \\
\hline $\mathrm{Si}$ & 5.3599867 & 16.9647629 & 26.4861952 \\
\hline $\mathrm{Si}$ & 5.3346522 & 17.0429990 & 23.4625099 \\
\hline $\mathrm{Si}$ & 8.4819562 & 14.5673516 & 28.3983750 \\
\hline $\mathrm{Si}$ & 8.5114671 & 14.5869602 & 16.4147210 \\
\hline $\mathrm{Si}$ & 15.3410087 & 13.1037127 & 18.4618105 \\
\hline $\mathrm{Si}$ & 15.3348479 & 18.5391490 & 18.4508771 \\
\hline $\mathrm{Si}$ & 10.6431288 & 15.8082778 & 18.3822213 \\
\hline $\mathrm{Si}$ & 10.4671600 & 15.8569147 & 21.4829075 \\
\hline $\mathrm{Si}$ & 15.3169813 & 18.5023647 & 21.5435970 \\
\hline $\mathrm{Si}$ & 15.3713178 & 13.1555742 & 21.4939418 \\
\hline $\mathrm{Si}$ & 8.4557456 & 17.1870689 & 23.4040901 \\
\hline $\mathrm{Si}$ & 8.4834221 & 17.0054594 & 26.4700993 \\
\hline 0 & 8.9539190 & 13.0257615 & 16.5335255 \\
\hline $\mathrm{O}$ & 6.9178549 & 14.1835612 & 28.1524740 \\
\hline 0 & 11.5773065 & 17.0182034 & 21.7931186 \\
\hline 0 & 13.8565018 & 13.6752004 & 21.5605344 \\
\hline $\mathrm{O}$ & 15.8938476 & 17.0036932 & 21.7926744 \\
\hline $\mathrm{O}$ & 15.7483584 & 14.6649216 & 18.1865339 \\
\hline $\mathrm{O}$ & 11.7799881 & 14.6504945 & 18.2533822 \\
\hline 0 & 13.7666202 & 18.1574047 & 18.2518859 \\
\hline 0 & 6.9182306 & 17.3878406 & 26.7389904 \\
\hline $\mathrm{H}$ & 9.0013554 & 18.5675764 & 23.2873440 \\
\hline $\mathrm{H}$ & 4.6934970 & 18.3854113 & 23.3995045 \\
\hline $\mathrm{H}$ & 18.0487861 & 15.6040779 & 17.4991049 \\
\hline $\mathrm{H}$ & 11.8033400 & 19.6598741 & 17.5545449 \\
\hline 0 & 11.4212749 & 12.2070174 & 17.2424418 \\
\hline 0 & 4.8967484 & 15.8045159 & 27.5107756 \\
\hline $\mathrm{H}$ & 11.4958149 & 19.5100699 & 22.4043365 \\
\hline $\mathrm{O}$ & 11.6825894 & 11.8869862 & 22.7908690 \\
\hline $\mathrm{H}$ & 18.1952338 & 16.0118871 & 22.3183586 \\
\hline 0 & 8.9408063 & 15.7547786 & 27.3923575 \\
\hline $\mathrm{H}$ & 16.0540253 & 12.2224943 & 17.4963147 \\
\hline $\mathrm{O}$ & 9.4123544 & 15.5345847 & 17.3636882 \\
\hline $\mathrm{H}$ & 15.7195977 & 19.6783327 & 17.5726125 \\
\hline 0 & 9.1102515 & 16.1789081 & 22.3306129 \\
\hline 0 & 6.9595403 & 14.7225539 & 16.8741193 \\
\hline 0 & 9.3730536 & 13.2585702 & 28.0707823 \\
\hline 0 & 13.7327441 & 18.5183838 & 21.8478982 \\
\hline 0 & 10.9616710 & 14.4266469 & 21.9917652 \\
\hline 0 & 16.3603163 & 14.3791300 & 21.9214505 \\
\hline 0 & 16.2320841 & 17.2612486 & 18.0299534 \\
\hline 0 & 13.7561351 & 12.9173334 & 18.2113585 \\
\hline $\mathrm{O}$ & 11.3139323 & 17.2304620 & 17.9779609 \\
\hline $\mathrm{H}$ & 4.4767175 & 18.1426434 & 26.7088019 \\
\hline $\mathrm{H}$ & 9.3303133 & 18.1831199 & 26.8062714 \\
\hline $\mathrm{O}$ & 6.8822958 & 17.2580458 & 23.0784305 \\
\hline $\mathrm{H}$ & 5.1757365 & 14.9636659 & 15.0624949 \\
\hline 0 & 11.8856198 & 18.9444255 & 19.9699722 \\
\hline 0 & 11.6401662 & 12.4788565 & 19.8417956 \\
\hline 0 & 17.4093256 & 15.8257142 & 19.9321964 \\
\hline O & 5.1864483 & 16.4132094 & 24.9597162 \\
\hline $\mathrm{H}$ & 8.6769095 & 15.0304582 & 29.8000333 \\
\hline 0 & 15.7637742 & 12.6642320 & 19.9727691 \\
\hline 0 & 15.6118699 & 18.9761562 & 20.0048729 \\
\hline 0 & 10.0665145 & 15.8843753 & 19.8997031 \\
\hline 0 & 8.7069053 & 16.5820533 & 24.9052263 \\
\hline $\mathrm{H}$ & 9.5171805 & 13.8972156 & 24.0146058 \\
\hline C & 8.5733081 & 12.0551406 & 22.5686066 \\
\hline $\mathrm{H}$ & 8.9305112 & 12.9070352 & 21.9898751 \\
\hline $\mathrm{H}$ & 9.2320982 & 11.2102134 & 22.7509896 \\
\hline $\mathrm{H}$ & 7.6089780 & 12.0958339 & 23.0754446 \\
\hline 0 & 9.5429548 & 12.9350486 & 24.2036841 \\
\hline $\mathrm{H}$ & 10.4382447 & 12.6546270 & 23.8523526 \\
\hline $\mathrm{H}$ & 10.0034325 & 12.2076144 & 19.7537941 \\
\hline 0 & 9.0024325 & 12.2534826 & 19.6034682 \\
\hline $\mathrm{C}$ & 8.3350774 & 11.2202343 & 20.1592531 \\
\hline $\mathrm{H}$ & 8.8783802 & 10.2649474 & 20.2441769 \\
\hline $\mathrm{H}$ & 8.0756524 & 11.4644455 & 21.3412192 \\
\hline $\mathrm{H}$ & 7.3184566 & 11.1237981 & 19.7502494 \\
\hline $\mathrm{H}$ & 5.1729455 & 14.9628157 & 29.8654091 \\
\hline $\mathrm{H}$ & 15.9392635 & 19.4892643 & 22.4687536 \\
\hline \multicolumn{4}{|c|}{ Ti 5} \\
\hline \multicolumn{4}{|c|}{171} \\
\hline $\mathrm{H}$ & 8.6701502 & 9.0260102 & 15.0646791 \\
\hline$P$ & 5.4392594 & 9.3378417 & 16.6130936 \\
\hline Al & 5.3939188 & 9.2530086 & 28.4232892 \\
\hline & & & \\
\hline
\end{tabular}




\begin{tabular}{|c|c|c|c|}
\hline Al & 5.4835130 & 6.7306308 & 18.3815440 \\
\hline $\mathrm{P}$ & 3.2630184 & 7.9092878 & 26.5494455 \\
\hline Al & 3.3917666 & 8.0616642 & 23.4703065 \\
\hline $\mathrm{P}$ & 8.5096070 & 9.1689236 & 28.3150067 \\
\hline Al & 8.5720289 & 9.3059346 & 16.5238347 \\
\hline $\mathrm{P}$ & 8.6576738 & 6.7243334 & 18.3553756 \\
\hline Al & 8.6304673 & 6.6843447 & 21.5118216 \\
\hline $\mathrm{P}$ & 1.6944308 & 10.7515932 & 23.3640625 \\
\hline Al & 1.6270637 & 10.6543416 & 26.5350468 \\
\hline 0 & 6.9057339 & 9.7278488 & 16.9112538 \\
\hline $\mathrm{O}$ & 4.9332821 & 10.9037820 & 28.0423873 \\
\hline $\mathrm{H}$ & 4.8449134 & 5.4134922 & 21.8090103 \\
\hline $\mathrm{H}$ & 9.1881962 & 5.3277924 & 21.7683851 \\
\hline $\mathrm{O}$ & 7.1789465 & 6.3464379 & 18.1450861 \\
\hline $\mathrm{O}$ & 2.1748989 & 8.9932578 & 26.6655819 \\
\hline $\mathrm{H}$ & 2.3357033 & 7.0359956 & 23.2470244 \\
\hline $\mathrm{H}$ & 0.3414827 & 10.2875201 & 22.9501926 \\
\hline 0 & 5.0292601 & 8.1179351 & 17.4378104 \\
\hline $\mathrm{O}$ & 4.3529600 & 8.1202139 & 27.6053110 \\
\hline 0 & 4.7685224 & 7.8185237 & 22.4234948 \\
\hline 0 & 2.6150836 & 11.7282811 & 27.4849723 \\
\hline $\mathrm{O}$ & 9.0447522 & 7.9146231 & 17.4673722 \\
\hline $\mathrm{O}$ & 2.1320106 & 11.9506490 & 22.5216557 \\
\hline 0 & 4.5291087 & 10.5053226 & 17.0090885 \\
\hline $\mathrm{O}$ & 7.0393439 & 8.9931995 & 27.9169998 \\
\hline $\mathrm{O}$ & 6.9289711 & 6.7096827 & 21.8692017 \\
\hline $\mathrm{H}$ & 9.5046964 & 5.5616431 & 17.9708961 \\
\hline $\mathrm{H}$ & 4.6478174 & 5.5775168 & 17.9467320 \\
\hline $\mathrm{H}$ & 0.2451078 & 10.7075656 & 27.0868488 \\
\hline $\mathrm{H}$ & 2.6435706 & 6.5778014 & 26.7955128 \\
\hline $\mathrm{O}$ & 2.7098712 & 9.6255631 & 23.1324207 \\
\hline $\mathrm{H}$ & 5.2725984 & 9.0060499 & 15.1711301 \\
\hline 0 & 5.2215969 & 7.1465580 & 20.0630829 \\
\hline 0 & 3.9089822 & 7.9619603 & 25.1484001 \\
\hline $\mathrm{H}$ & 8.6814030 & 8.9839036 & 29.7824447 \\
\hline $\mathrm{O}$ & 8.9005116 & 7.1211943 & 19.8290511 \\
\hline 0 & 1.6789207 & 11.1554731 & 24.8544053 \\
\hline $\mathrm{H}$ & 5.2858628 & 9.0332500 & 29.8920133 \\
\hline $\mathrm{H}$ & 3.5466177 & 12.0051622 & 15.0438766 \\
\hline $\mathrm{P}$ & 3.3310144 & 15.9524663 & 21.5174808 \\
\hline Al & 3.2450444 & 15.9681102 & 18.3460546 \\
\hline $\mathrm{P}$ & 3.8731448 & 11.9915585 & 28.3159583 \\
\hline Al & 3.8504745 & 12.0314025 & 16.5013069 \\
\hline $\mathrm{P}$ & 1.6536249 & 13.2563264 & 18.3618344 \\
\hline Al & 1.6878643 & 13.2780517 & 21.4629280 \\
\hline 0 & 5.0570399 & 13.2587638 & 16.8559948 \\
\hline $\mathrm{H}$ & 0.2447480 & 13.6338018 & 21.5522471 \\
\hline $\mathrm{H}$ & 2.3834597 & 17.0650574 & 21.8027909 \\
\hline $\mathrm{O}$ & 2.0293891 & 14.7298655 & 18.0672404 \\
\hline $\mathrm{O}$ & 4.6850462 & 15.6962298 & 17.3903628 \\
\hline 0 & 4.6270138 & 16.1221112 & 22.3274428 \\
\hline 0 & 2.3713239 & 12.3312441 & 17.3659434 \\
\hline 0 & 4.4425566 & 13.3532835 & 27.8989508 \\
\hline $\mathrm{O}$ & 2.6973412 & 14.6291477 & 21.9370638 \\
\hline $\mathrm{H}$ & 2.6890773 & 17.3096369 & 18.0169235 \\
\hline $\mathrm{H}$ & 0.1867194 & 13.0763473 & 18.1804062 \\
\hline 0 & 3.7103515 & 15.9461531 & 20.0294178 \\
\hline $\mathrm{H}$ & 3.5055533 & 12.0002896 & 29.7588446 \\
\hline $\mathrm{O}$ & 2.0888658 & 12.8676859 & 19.7878268 \\
\hline $\mathrm{P}$ & 10.2191568 & 11.9273583 & 16.3601984 \\
\hline Al & 10.1301825 & 11.8538050 & 28.2314234 \\
\hline $\mathrm{P}$ & 12.4405799 & 10.5268078 & 26.6737023 \\
\hline Al & 12.4860863 & 10.4981353 & 23.4161342 \\
\hline $\mathrm{P}$ & 15.5694295 & 10.7515932 & 23.3640625 \\
\hline $\mathrm{P}$ & 10.6249779 & 8.0152927 & 23.4484716 \\
\hline Al & 10.7252431 & 7.9711855 & 26.5569096 \\
\hline Al & 15.5020624 & 10.6543416 & 26.5350468 \\
\hline 0 & 8.9669826 & 10.5796077 & 27.8841172 \\
\hline $\mathrm{O}$ & 11.9103957 & 9.1455515 & 27.1169200 \\
\hline $\mathrm{H}$ & 15.9671405 & 9.2441846 & 26.6458630 \\
\hline $\mathrm{H}$ & 11.4001188 & 6.7445809 & 23.4088662 \\
\hline 0 & 14.1634761 & 10.2693388 & 22.9339782 \\
\hline 0 & 11.5572002 & 11.6480567 & 27.2448595 \\
\hline $\mathrm{O}$ & 9.3249992 & 8.0858570 & 27.5930292 \\
\hline $\mathrm{H}$ & 16.3469594 & 11.5727121 & 27.3473677 \\
\hline $\mathrm{O}$ & 9.3710219 & 7.8841093 & 22.5640999 \\
\hline $\mathrm{O}$ & 16.0070093 & 11.9506490 & 22.5216557 \\
\hline 0 & 9.6159906 & 10.6403664 & 16.9629831 \\
\hline $\mathrm{O}$ & 13.8763626 & 10.7169531 & 27.184173 \\
\hline $\mathrm{H}$ & 11.3280662 & 6.6127398 & 26.6482888 \\
\hline
\end{tabular}




\begin{tabular}{|c|c|c|}
\hline 16.5551729 & 9.6584943 & 23.1391951 \\
\hline 11.4909608 & 9.1513372 & 22.8879651 \\
\hline 10.5790654 & 11.6960553 & 14.9339848 \\
\hline 12.4247068 & 10.6015386 & 25.1495258 \\
\hline 15.5539194 & 11.1554731 & 24.8544053 \\
\hline 10.2081820 & 8.3172912 & 24.9036240 \\
\hline 10.5227624 & 11.7130586 & 29.6608261 \\
\hline 8.7631796 & 15.0963709 & 14.9273338 \\
\hline 5.4987704 & 14.7053372 & 16.5478905 \\
\hline 5.4536513 & 14.6912997 & 28.3771806 \\
\hline 12.3721306 & 18.7693140 & 21.5360588 \\
\hline 12.1410611 & 13.2616422 & 21.5919484 \\
\hline 17.2060131 & 15.9524663 & 21.5174808 \\
\hline 17.1200431 & 15.9681102 & 18.3460546 \\
\hline 12.2948391 & 13.2515569 & 18.3369053 \\
\hline 12.4210123 & 18.7467322 & 18.3815440 \\
\hline 5.4069938 & 17.1883202 & 26.5014912 \\
\hline 5.3360519 & 17.2287253 & 23.4587605 \\
\hline 8.5943994 & 14.6661476 & 28.2362515 \\
\hline 8.6507382 & 14.7144361 & 16.3621172 \\
\hline 15.5286236 & 13.2563264 & 18.3618344 \\
\hline 15.5951732 & 18.7404348 & 18.3553756 \\
\hline 10.8349481 & 16.0392956 & 18.2477530 \\
\hline 10.5807215 & 16.1480441 & 21.4311891 \\
\hline 15.5679667 & 18.7004461 & 21.5118216 \\
\hline 15.5628630 & 13.2780517 & 21.4629280 \\
\hline 8.4743314 & 17.4692070 & 23.2768011 \\
\hline 8.5474585 & 17.2053534 & 26.3777060 \\
\hline 9.1650449 & 13.0446805 & 16.4714024 \\
\hline 7.1175556 & 14.2846455 & 28.0004321 \\
\hline 11.7645716 & 17.3890620 & 21.8172681 \\
\hline 13.8885143 & 13.6908042 & 21.5665588 \\
\hline 16.2234217 & 17.1061965 & 21.8133405 \\
\hline 15.9043878 & 14.7298655 & 18.0672404 \\
\hline 11.9119317 & 14.9546311 & 18.0663791 \\
\hline 14.1164458 & 18.3625393 & 18.1450861 \\
\hline 6.8729179 & 17.6199594 & 26.7310810 \\
\hline 9.0712941 & 18.8316815 & 23.2103221 \\
\hline 4.5996820 & 18.5221543 & 23.4149275 \\
\hline 18.3456048 & 15.7367173 & 17.5326811 \\
\hline 12.0319005 & 19.9350935 & 17.5731443 \\
\hline 11.5024419 & 12.2821017 & 17.1088473 \\
\hline 4.9793976 & 16.1335823 & 27.5244621 \\
\hline 11.7273374 & 19.8005348 & 22.3950966 \\
\hline 11.7436987 & 11.9397085 & 22.8135730 \\
\hline 18.4609909 & 16.1167415 & 22.3018054 \\
\hline 9.0205029 & 15.7818076 & 27.2703786 \\
\hline 16.2238651 & 12.3601909 & 17.3971059 \\
\hline 9.6447508 & 15.7784759 & 17.3136103 \\
\hline 15.9707359 & 19.8953132 & 17.4937904 \\
\hline 9.0524826 & 16.5643530 & 22.1884449 \\
\hline 6.9862051 & 14.8528388 & 16.8944112 \\
\hline 9.4627056 & 13.4376907 & 27.9467150 \\
\hline 13.8664704 & 18.7257841 & 21.8692017 \\
\hline 11.0701361 & 14.6360286 & 22.0966798 \\
\hline 16.5723399 & 14.6291477 & 21.9370638 \\
\hline 16.4671743 & 17.5434570 & 17.9595579 \\
\hline 14.0221507 & 13.0714927 & 18.1755125 \\
\hline 11.4445615 & 17.3994006 & 17.8734971 \\
\hline 4.5152385 & 18.3702675 & 26.6592684 \\
\hline 9.4156830 & 18.3591255 & 26.7411848 \\
\hline 6.9727047 & 17.5978352 & 23.0267547 \\
\hline 5.2695706 & 15.0115714 & 15.1088601 \\
\hline 12.1590963 & 19.1626594 & 20.0630829 \\
\hline 11.6288495 & 12.7566348 & 19.8772790 \\
\hline 17.5853502 & 15.9461531 & 20.0294178 \\
\hline 5.2612275 & 16.5827462 & 25.0881132 \\
\hline 8.7775305 & 15.1498850 & 29.6325258 \\
\hline 15.9638645 & 12.8676859 & 19.7878268 \\
\hline 15.8380110 & 19.1372957 & 19.8290511 \\
\hline 10.3269081 & 16.0770968 & 19.6975838 \\
\hline 8.7378191 & 16.8319171 & 24.6644703 \\
\hline 9.6455458 & 13.8153492 & 24.1140176 \\
\hline 8.6238957 & 12.1946896 & 22.4830262 \\
\hline 8.9367474 & 13.1306486 & 22.0193020 \\
\hline 9.3096331 & 11.3509214 & 22.5092685 \\
\hline 7.6775708 & 12.1293503 & 23.0196023 \\
\hline 9.6151002 & 12.8391235 & 24.1994239 \\
\hline 10.5080435 & 12.5429666 & 23.8277522 \\
\hline 10.0137199 & 12.6930054 & 19.7080215 \\
\hline
\end{tabular}

23.1391951

2.8879651

25.1495258

24.8544053

.9036240

14.9273338

16.5478905

771806

21.5360588

18.3460546

3369053

26.5014912

587605

16.3621172

.3618344

18.2477530

4311891

21.4629280

3.2768011

77060

28.0004321

21.8172681

21.5665588

133405

72404

26.7310810

23.4149275

17.5326811

17.1088473

27.5244621

22.3018054

17.3136103

17.4937904

16.8944112

27.9467150

21.8692017

22.0966798

17.9595579

18.1755125

26.7411848

. 0267547

20.0630829

(272790

25.0881132

29.6325258

878268

19.6975838

24.6644703

22.4830262

22.0193020

23.0196023

24.1994239

19.7080215 


\begin{tabular}{|c|c|c|c|}
\hline $\mathrm{O}$ & 9.0086491 & 12.7950582 & 19.5647547 \\
\hline C & 8.3220447 & 11.7088441 & 19.9780887 \\
\hline $\mathrm{H}$ & 8.8468800 & 10.7414612 & 19.9131108 \\
\hline $\mathrm{H}$ & 8.0899206 & 11.7830359 & 21.1873141 \\
\hline $\mathrm{H}$ & 7.2989942 & 11.6894359 & 19.5741264 \\
\hline $\mathrm{H}$ & 5.2901066 & 14.9732649 & 29.8300638 \\
\hline $\mathrm{H}$ & 16.1947410 & 19.7158765 & 22.4024258 \\
\hline \multicolumn{4}{|c|}{$\begin{array}{l}\mathrm{Zn} \quad 6 \\
165\end{array}$} \\
\hline $\mathrm{H}$ & 8.7007699 & 9.0444534 & 15.2902848 \\
\hline Al & 5.3862663 & 9.3112935 & 16.6785169 \\
\hline $\mathrm{P}$ & 5.3883316 & 9.2529096 & 28.5033112 \\
\hline Al & 5.2903513 & 6.6869115 & 21.6311922 \\
\hline $\mathrm{P}$ & 5.3125411 & 6.7325164 & 18.4698499 \\
\hline Al & 3.1600779 & 8.0480427 & 26.6344778 \\
\hline $\mathrm{P}$ & 3.2166757 & 8.1307439 & 23.5240606 \\
\hline Al & 8.5110615 & 9.2632731 & 28.5369229 \\
\hline $\mathrm{P}$ & 8.5303902 & 9.3700996 & 16.7332144 \\
\hline Al & 8.4779213 & 6.7765721 & 18.5175901 \\
\hline $\mathrm{P}$ & 8.4750277 & 6.7696311 & 21.6825376 \\
\hline Al & 1.5588814 & 10.8236105 & 23.5201037 \\
\hline $\mathrm{P}$ & 1.5000251 & 10.7402865 & 26.7118584 \\
\hline $\mathrm{O}$ & 7.0605474 & 9.7334885 & 17.0338808 \\
\hline $\mathrm{O}$ & 4.9940312 & 10.7166125 & 28.2152076 \\
\hline $\mathrm{H}$ & 4.8328620 & 5.2905811 & 21.8722013 \\
\hline $\mathrm{H}$ & 9.0009686 & 5.3985502 & 21.9287973 \\
\hline $\mathrm{O}$ & 6.7982497 & 6.3886142 & 18.2344273 \\
\hline $\mathrm{O}$ & 1.9347825 & 9.2736068 & 26.8945277 \\
\hline $\mathrm{H}$ & 2.1531782 & 7.0989084 & 23.3777418 \\
\hline $\mathrm{H}$ & 0.1523238 & 10.5037776 & 23.1507483 \\
\hline $\mathrm{O}$ & 4.8978484 & 7.9225435 & 17.5993413 \\
\hline $\mathrm{O}$ & 4.5096675 & 8.2859511 & 27.7074416 \\
\hline 0 & 4.4021933 & 7.8413114 & 22.5962177 \\
\hline 0 & 2.3610582 & 11.6704318 & 27.5714345 \\
\hline $\mathrm{O}$ & 8.9645565 & 8.1684379 & 17.5806332 \\
\hline $\mathrm{O}$ & 2.0886248 & 12.1983389 & 22.6164818 \\
\hline $\mathrm{O}$ & 4.3619532 & 10.6462300 & 17.1197865 \\
\hline 0 & 6.8463448 & 9.0363114 & 28.0778685 \\
\hline 0 & 6.9876479 & 6.8131820 & 22.0318416 \\
\hline $\mathrm{H}$ & 9.3166054 & 5.6160752 & 18.1089626 \\
\hline $\mathrm{H}$ & 4.4851377 & 5.5593938 & 18.0744923 \\
\hline $\mathrm{H}$ & 0.0880495 & 10.8714172 & 27.1660062 \\
\hline $\mathrm{H}$ & 2.5606232 & 6.7191553 & 26.9375173 \\
\hline 0 & 2.6208449 & 9.4905528 & 23.1418188 \\
\hline $\mathrm{H}$ & 5.2457197 & 8.9953875 & 15.2302176 \\
\hline 0 & 5.0806008 & 7.1099911 & 19.9423247 \\
\hline 0 & 3.7298268 & 8.1515234 & 24.9791802 \\
\hline $\mathrm{H}$ & 8.6768478 & 9.0686306 & 30.0038073 \\
\hline 0 & 8.7060351 & 7.1844519 & 20.2124923 \\
\hline $\mathrm{O}$ & 1.6289790 & 11.1590591 & 25.2386842 \\
\hline $\mathrm{H}$ & 5.2268121 & 8.9509280 & 29.9523933 \\
\hline $\mathrm{H}$ & 3.4011450 & 11.9685895 & 15.2495174 \\
\hline Al & 3.2387254 & 16.0876893 & 21.5881600 \\
\hline $\mathrm{P}$ & 3.1553946 & 16.0970413 & 18.4349756 \\
\hline Al & 3.7921435 & 11.9634982 & 28.5166552 \\
\hline $\mathrm{P}$ & 3.7701410 & 11.9950686 & 16.6918285 \\
\hline Al & 1.6287854 & 13.3177004 & 18.5745414 \\
\hline $\mathrm{P}$ & 1.7048878 & 13.3592107 & 21.6815146 \\
\hline 0 & 4.8252644 & 13.0882715 & 16.9599575 \\
\hline $\mathrm{H}$ & 0.2994364 & 13.8143586 & 21.8677059 \\
\hline $\mathrm{H}$ & 2.2603328 & 17.1707590 & 21.8828269 \\
\hline 0 & 2.1066887 & 14.9817712 & 18.2616887 \\
\hline $\mathrm{O}$ & 4.3634374 & 15.8630803 & 17.5215249 \\
\hline 0 & 4.6941840 & 16.3070301 & 22.5150456 \\
\hline $\mathrm{O}$ & 2.5038310 & 12.2468889 & 17.5103467 \\
\hline $\mathrm{O}$ & 4.4392470 & 13.5135876 & 28.0539201 \\
\hline $\mathrm{O}$ & 2.6501917 & 14.5241967 & 22.0221073 \\
\hline $\mathrm{H}$ & 2.5388812 & 17.3972559 & 18.0522568 \\
\hline $\mathrm{H}$ & 0.1791389 & 13.1531324 & 18.2769462 \\
\hline $\mathrm{O}$ & 3.6496639 & 16.1559247 & 19.8887636 \\
\hline $\mathrm{H}$ & 3.4488625 & 11.9670841 & 29.9655395 \\
\hline 0 & 1.9744951 & 12.8876272 & 20.2282641 \\
\hline Al & 10.1035934 & 12.0623986 & 16.5316234 \\
\hline $\mathrm{P}$ & 10.0078638 & 12.0075031 & 28.3607384 \\
\hline Al & 12.2687123 & 10.6741583 & 26.6612603 \\
\hline $\mathrm{P}$ & 12.2875327 & 10.6332483 & 23.4576010 \\
\hline Al & 15.4338801 & 10.8236105 & 23.5201037 \\
\hline Al & 10.5812877 & 7.9699911 & 23.6250703 \\
\hline & & & \\
\hline
\end{tabular}




\begin{tabular}{|c|c|c|c|}
\hline $\mathrm{P}$ & 15.3750238 & 10.7402865 & 26.7118584 \\
\hline 0 & 8.9825790 & 10.8906125 & 28.0769738 \\
\hline 0 & 11.7431604 & 9.0332918 & 26.9931614 \\
\hline $\mathrm{H}$ & 15.7952123 & 9.3227559 & 26.8884064 \\
\hline $\mathrm{H}$ & 11.4966482 & 6.8046049 & 23.4797748 \\
\hline 0 & 13.7633119 & 10.4437450 & 23.0814204 \\
\hline 0 & 11.2604888 & 11.8191733 & 27.4997817 \\
\hline 0 & 9.5162377 & 8.0896292 & 27.7265363 \\
\hline $\mathrm{H}$ & 16.2121757 & 11.6446337 & 27.5475937 \\
\hline 0 & 9.1993987 & 7.8022136 & 22.5689009 \\
\hline 0 & 15.9636235 & 12.1983389 & 22.6164818 \\
\hline 0 & 9.4242383 & 10.5581030 & 17.1276611 \\
\hline 0 & 13.9189624 & 10.8755114 & 27.1801860 \\
\hline $\mathrm{H}$ & 11.2783935 & 6.6154587 & 26.8753209 \\
\hline $\mathrm{H}$ & 16.3396195 & 9.6866572 & 23.1974678 \\
\hline 0 & 11.4930303 & 9.3647560 & 23.1123302 \\
\hline $\mathrm{H}$ & 10.3725602 & 11.9801799 & 15.0694272 \\
\hline 0 & 12.1471767 & 10.9781474 & 24.9451167 \\
\hline 0 & 15.5039777 & 11.1590591 & 25.2386842 \\
\hline 0 & 10.0893663 & 8.1442698 & 25.2969672 \\
\hline $\mathrm{H}$ & 10.4048910 & 11.9676783 & 29.7952780 \\
\hline $\mathrm{H}$ & 8.6684273 & 15.1048512 & 15.2028243 \\
\hline Al & 5.3284979 & 14.7315482 & 16.6178997 \\
\hline $\mathrm{P}$ & 5.2965794 & 14.7203204 & 28.4497069 \\
\hline Al & 12.2278507 & 18.7030129 & 21.6311922 \\
\hline $\mathrm{Zn}$ & 12.3340423 & 13.3615996 & 21.6022078 \\
\hline Al & 17.1137241 & 16.0876893 & 21.5881600 \\
\hline $\mathrm{P}$ & 17.0303934 & 16.0970413 & 18.4349756 \\
\hline $\mathrm{P}$ & 12.2982696 & 13.2685049 & 18.3737893 \\
\hline $\mathrm{P}$ & 12.2500405 & 18.7486178 & 18.4698499 \\
\hline Al & 5.3788879 & 17.2186704 & 26.5891750 \\
\hline $\mathrm{P}$ & 5.3634493 & 17.2507272 & 23.5113962 \\
\hline Al & 8.4553797 & 14.7561910 & 28.4734279 \\
\hline $\mathrm{P}$ & 8.4833620 & 14.7695624 & 16.6417311 \\
\hline Al & 15.5037841 & 13.3177004 & 18.5745414 \\
\hline Al & 15.4154206 & 18.7926734 & 18.5175901 \\
\hline Al & 10.7260587 & 15.9891856 & 18.4800125 \\
\hline $\mathrm{P}$ & 10.6030426 & 15.9910644 & 21.6664416 \\
\hline$P$ & 15.4125271 & 18.7857325 & 21.6825376 \\
\hline $\mathrm{P}$ & 15.5798865 & 13.3592107 & 21.6815146 \\
\hline Al & 8.5136537 & 17.4240364 & 23.5205529 \\
\hline $\mathrm{P}$ & 8.5344967 & 17.2954336 & 26.6432055 \\
\hline 0 & 8.9313567 & 13.3132236 & 16.9023095 \\
\hline 0 & 6.7729417 & 14.3895281 & 28.1589776 \\
\hline 0 & 11.6931617 & 17.0710568 & 21.9128707 \\
\hline 0 & 14.1438601 & 13.8242601 & 21.8717564 \\
\hline 0 & 15.9557801 & 17.3695205 & 21.9369033 \\
\hline 0 & 15.9816875 & 14.9817712 & 18.2616887 \\
\hline 0 & 11.9183081 & 14.7458994 & 18.1377287 \\
\hline 0 & 13.7357491 & 18.4047156 & 18.2344273 \\
\hline 0 & 7.0526028 & 17.6493165 & 26.9014245 \\
\hline $\mathrm{H}$ & 8.9749463 & 18.8341950 & 23.3949251 \\
\hline $\mathrm{H}$ & 4.7243297 & 18.5945335 & 23.4581866 \\
\hline $\mathrm{H}$ & 18.2041605 & 15.8697184 & 17.5474421 \\
\hline $\mathrm{H}$ & 11.8468925 & 19.9055154 & 17.6235756 \\
\hline 0 & 11.6265700 & 12.3759402 & 17.3121163 \\
\hline 0 & 4.8431030 & 15.9294077 & 27.6270775 \\
\hline $\mathrm{H}$ & 11.4709479 & 19.6868114 & 22.4536028 \\
\hline 0 & 11.6497570 & 11.7650444 & 22.6124554 \\
\hline $\mathrm{H}$ & 18.3596427 & 16.2754520 & 22.3816035 \\
\hline 0 & 8.9711220 & 16.1327433 & 27.5420048 \\
\hline $\mathrm{H}$ & 16.2504774 & 12.4039563 & 17.6664436 \\
\hline 0 & 9.3080090 & 15.7419016 & 17.4865067 \\
\hline $\mathrm{H}$ & 15.8301898 & 19.9789892 & 17.7190025 \\
\hline 0 & 9.3083799 & 16.4006612 & 22.3873309 \\
\hline 0 & 7.0106068 & 14.9059560 & 17.0465370 \\
\hline 0 & 9.3911794 & 13.3619998 & 28.0088126 \\
\hline 0 & 13.9251472 & 18.8292834 & 22.0318416 \\
\hline 0 & 11.0495386 & 14.6442367 & 22.1946326 \\
\hline 0 & 16.5251905 & 14.5241967 & 22.0221073 \\
\hline 0 & 16.3948000 & 17.4374949 & 18.0404124 \\
\hline 0 & 13.8111734 & 13.1255504 & 18.2270685 \\
\hline 0 & 11.4001740 & 17.5436463 & 18.0637588 \\
\hline $\mathrm{H}$ & 4.5042462 & 18.3978581 & 26.8374466 \\
\hline $\mathrm{H}$ & 9.3737560 & 18.4786690 & 26.9789411 \\
\hline 0 & 6.8278106 & 17.4059533 & 23.1184534 \\
\hline $\mathrm{H}$ & 5.1392151 & 15.0108167 & 15.1676233 \\
\hline 0 & 12.0181002 & 19.1260924 & 19.9423247 \\
\hline 0 & 11.8176067 & 12.7838107 & 19.765053 \\
\hline 0 & 17.5246626 & 16.1559247 & 19.8887636 \\
\hline
\end{tabular}




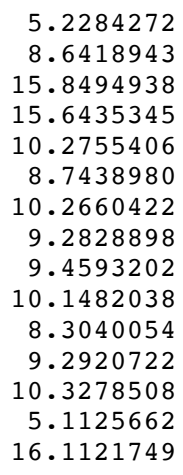

16.6699128

15.0623470

12.8876272

19.2005532

15.9464113

16.8839986

12.2824374

10.9016018

12.0247072

10.3098291

10.6972106

11.4973898

11.6106473

15.0483492

19.7830724

9.0274344

9.3500172

9.3117962

6.7806170

6.7658430

7.9642678

8.0066227

9.2543557

9.3083577

6.7505124

6.7663770

10.7884351

10.7351673

9.7242583

10.9688800

5.3752340

5.3854796

6.3653347

9.0714843

6.9797540

10.4516531

8.1418196

8.1939594

7.7511509

11.8108153

7.9177637

11.9394751

10.5350825

9.0792327

6.9098511

5.5834060

5.6047828

10.8389721

6.6551183

9.5640619

9.0091272

7.1862257

7.9519488

8.9881079

7.1899252

11.1983874

9.0445661

12.0367758

15.9799493

15.9958368

12.0533449

12.0628624

13.2958235

13.2529498

13.3149837

13.4052355

17.1256085

14.7606949

15.7386682

16.1196275

12.3451524

13.4198241

14.6921201

17.3354381

13.1383009

15.9530545

12.0329068
24.9316962

29.9186273

20.2282641

20.2124923

20.1545511

25.1750617

19.6687054

20.8615903

19.6317891

20.5316193

20.4065747

21.9875234

22.3551883

29.8904209

22.5386489

15.1591005

16.6960352

28.5232010

21.6572272

18.5025643

26.6689986

23.5490037

28.4292720

16.6123661

18.4577387

21.6117581

23.4593694

26.6187824

16.9532360

28.1780428

21.8816358

21.8830675

18.2305544

26.8285274

23.3242656

23.1398002

17.5423974

27.6316583

22.5369262

27.5995974

17.5487389

22.5823964

17.1040504

28.0616115

22.0362497

18.1222926

18.1045989

27.0527235

27.0111226

23.1701853

15.2610512

20.1848115

25.2269757

29.8780015

19.9228170

24.9401812

29.9795070

15.1694851

21.6865273

18.5151079

28.4525711

16.6212701

18.4665895

21.5853157

16.9510888

21.7300647

21.9206624

18.1618426

17.5792843

22.5577947

17.5037128

28.0740023

22.0759877

18.1722108

18.2481672

20.2131926

29.8876282 


\begin{tabular}{|c|c|c|c|}
\hline 0 & 1.9695433 & 12.9250507 & 19.9053715 \\
\hline $\mathrm{P}$ & 10.1061389 & 11.9792085 & 16.6145316 \\
\hline Al & 10.0476649 & 11.9632412 & 28.4292986 \\
\hline $\mathrm{P}$ & 12.3409505 & 10.7268703 & 26.7017855 \\
\hline Al & 12.3759058 & 10.7194482 & 23.5128067 \\
\hline $\mathrm{P}$ & 15.5222803 & 10.7884351 & 23.4593694 \\
\hline $\mathrm{P}$ & 10.6713093 & 8.0482157 & 23.4766977 \\
\hline Al & 10.6810943 & 8.0445044 & 26.6164395 \\
\hline Al & 15.4711326 & 10.7351673 & 26.6187824 \\
\hline 0 & 8.8909197 & 10.6924311 & 28.0764539 \\
\hline 0 & 11.8695493 & 9.2833812 & 26.9700792 \\
\hline $\mathrm{H}$ & 15.9013827 & 9.3208783 & 26.7970856 \\
\hline $\mathrm{H}$ & 11.5708067 & 6.8748633 & 23.2998667 \\
\hline 0 & 14.0529183 & 10.4386576 & 23.1274689 \\
\hline 0 & 11.5129436 & 11.7242162 & 27.5193890 \\
\hline $\mathrm{O}$ & 9.2744624 & 8.2370401 & 27.6239335 \\
\hline $\mathrm{H}$ & 16.2862268 & 11.6559404 & 27.4583768 \\
\hline $\mathrm{O}$ & 9.4417211 & 7.9351739 & 22.5589475 \\
\hline $\mathrm{O}$ & 16.0141948 & 11.9394751 & 22.5823964 \\
\hline $\mathrm{O}$ & 9.5183062 & 10.6410674 & 17.0993944 \\
\hline 0 & 13.8062691 & 10.8568226 & 27.1273451 \\
\hline $\mathrm{H}$ & 11.2761100 & 6.7096225 & 26.9013384 \\
\hline $\mathrm{H}$ & 16.3701331 & 9.5971748 & 23.1780063 \\
\hline $\mathrm{O}$ & 11.4355408 & 9.3120587 & 23.0642719 \\
\hline $\mathrm{H}$ & 10.4104512 & 11.9167450 & 15.1582992 \\
\hline 0 & 12.1794731 & 11.0657102 & 25.2110227 \\
\hline $\mathrm{O}$ & 15.6373458 & 11.1983874 & 24.9401812 \\
\hline 0 & 10.1924079 & 8.1569714 & 24.9343374 \\
\hline $\mathrm{H}$ & 10.3650547 & 11.9219742 & 29.8834930 \\
\hline $\mathrm{H}$ & 8.7505886 & 15.0255487 & 15.1357750 \\
\hline $\mathrm{P}$ & 5.4014265 & 14.7692187 & 16.6911651 \\
\hline Al & 5.3653182 & 14.7756158 & 28.5376770 \\
\hline $\mathrm{P}$ & 12.3176853 & 18.7967184 & 21.6572272 \\
\hline $\mathrm{Si}$ & 12.1296833 & 13.2628502 & 21.6269595 \\
\hline $\mathrm{P}$ & 17.0043086 & 15.9799493 & 21.6865273 \\
\hline Al & 17.0376780 & 15.9958368 & 18.5151079 \\
\hline Al & 12.2374166 & 13.3027367 & 18.4896282 \\
\hline Al & 12.3415403 & 18.7819444 & 18.5025643 \\
\hline$P$ & 5.3156811 & 17.2880407 & 26.6650980 \\
\hline Al & 5.2846042 & 17.2415093 & 23.5354175 \\
\hline $\mathrm{P}$ & 8.5269536 & 14.7171866 & 28.4247642 \\
\hline Al & 8.5646013 & 14.7373543 & 16.5847310 \\
\hline$P$ & 15.4519113 & 13.2958235 & 18.4665895 \\
\hline$P$ & 15.5042668 & 18.7666138 & 18.4577387 \\
\hline$P$ & 10.7311197 & 16.0795866 & 18.4220201 \\
\hline Al & 10.6800384 & 16.0742201 & 21.5968116 \\
\hline Al & 15.4800501 & 18.7824784 & 21.6117581 \\
\hline Al & 15.4127319 & 13.2529498 & 21.5853157 \\
\hline $\mathrm{P}$ & 8.4435120 & 17.3451298 & 23.4392341 \\
\hline Al & 8.4678082 & 17.2714657 & 26.5846044 \\
\hline 0 & 9.0743860 & 13.0872558 & 16.9128991 \\
\hline $\mathrm{O}$ & 7.0396103 & 14.3746600 & 28.2130849 \\
\hline $\mathrm{O}$ & 11.8666593 & 17.3488451 & 21.8884205 \\
\hline $\mathrm{O}$ & 13.7172451 & 13.4281061 & 21.7518035 \\
\hline 0 & 16.0491060 & 17.1670872 & 21.9291393 \\
\hline $\mathrm{O}$ & 15.8430863 & 14.7606949 & 18.1618426 \\
\hline $\mathrm{O}$ & 11.7803759 & 14.9729124 & 18.1895689 \\
\hline 0 & 14.0306030 & 18.3814360 & 18.2305544 \\
\hline $\mathrm{O}$ & 6.7887271 & 17.6760680 & 26.9004258 \\
\hline $\mathrm{H}$ & 8.8718022 & 18.7633815 & 23.2900692 \\
\hline $\mathrm{H}$ & 4.7522784 & 18.6169219 & 23.3305031 \\
\hline $\mathrm{H}$ & 18.2753171 & 15.7764666 & 17.7168305 \\
\hline $\mathrm{H}$ & 11.9478312 & 19.9595781 & 17.6808025 \\
\hline 0 & 11.4137812 & 12.2378747 & 17.3655149 \\
\hline $\mathrm{O}$ & 4.8854424 & 16.1716154 & 27.6199839 \\
\hline $\mathrm{H}$ & 11.5439770 & 19.7393291 & 22.5116165 \\
\hline $\mathrm{O}$ & 11.6110905 & 11.9962385 & 22.5868735 \\
\hline $\mathrm{H}$ & 18.2226368 & 16.1154553 & 22.5317699 \\
\hline $\mathrm{O}$ & 8.9432261 & 15.9049237 & 27.5536729 \\
\hline $\mathrm{H}$ & 16.1550837 & 12.3736809 & 17.5326076 \\
\hline $\mathrm{O}$ & 9.5114936 & 15.8575582 & 17.5165659 \\
\hline $\mathrm{H}$ & 15.8962621 & 19.8999629 & 17.5751403 \\
\hline $\mathrm{O}$ & 9.2218394 & 16.4404911 & 22.4903557 \\
\hline 0 & 6.8885440 & 14.8985946 & 17.0383714 \\
\hline 0 & 9.3685801 & 13.5067733 & 28.0064709 \\
\hline 0 & 13.8004610 & 18.9259525 & 22.0362497 \\
\hline 0 & 11.3052023 & 14.5599779 & 22.0735101 \\
\hline $\mathrm{O}$ & 16.2846069 & 14.6921201 & 22.0759877 \\
\hline $\mathrm{O}$ & 16.3899429 & 17.5669790 & 18.1129434 \\
\hline $\mathrm{O}$ & 13.9477737 & 13.1340314 & 18.2422470 \\
\hline
\end{tabular}




\begin{tabular}{|c|c|c|c|}
\hline 0 & 11.3578935 & 17.4272048 & 18.0382133 \\
\hline $\mathrm{H}$ & 4.4593814 & 18.4746055 & 26.9406615 \\
\hline $\mathrm{H}$ & 9.3168822 & 18.4363859 & 26.9576391 \\
\hline 0 & 6.9582809 & 17.2469277 & 23.0725545 \\
\hline $\mathrm{H}$ & 5.1643598 & 15.1298484 & 15.2660804 \\
\hline 0 & 12.1138501 & 19.2023271 & 20.1848115 \\
\hline 0 & 11.7050122 & 12.8152725 & 20.0852017 \\
\hline 0 & 17.4470670 & 15.9530545 & 20.2131926 \\
\hline 0 & 5.1179044 & 16.7963643 & 25.2197766 \\
\hline $\mathrm{H}$ & 8.7748716 & 15.0644110 & 29.8513309 \\
\hline 0 & 15.8445420 & 12.9250507 & 19.9053715 \\
\hline 0 & 15.7202441 & 19.2060266 & 19.9228170 \\
\hline 0 & 10.2608938 & 16.1001491 & 19.8826102 \\
\hline 0 & 8.6713187 & 16.8777960 & 24.8914048 \\
\hline $\mathrm{H}$ & 10.2399736 & 12.1777210 & 19.8575237 \\
\hline C & 9.1728678 & 10.9316699 & 21.0979579 \\
\hline $\mathrm{H}$ & 9.4537802 & 11.8557436 & 19.7567263 \\
\hline $\mathrm{H}$ & 9.9915864 & 10.2416469 & 20.8499236 \\
\hline $\mathrm{H}$ & 8.1779085 & 10.7314909 & 20.6750104 \\
\hline 0 & 9.2260671 & 11.6530670 & 22.1497389 \\
\hline $\mathrm{H}$ & 10.2978272 & 11.8011029 & 22.4519840 \\
\hline $\mathrm{H}$ & 5.1875062 & 15.0874166 & 29.9827666 \\
\hline $\mathrm{H}$ & 16.2439614 & 19.7754572 & 22.4164651 \\
\hline \multicolumn{4}{|c|}{$\begin{array}{l}\mathrm{Mg} 6 \\
165\end{array}$} \\
\hline $\mathrm{H}$ & 8.7031854 & 9.0531476 & 15.2867735 \\
\hline Al & 5.3987150 & 9.3377011 & 16.6772476 \\
\hline $\mathrm{P}$ & 5.3874958 & 9.2795132 & 28.4975152 \\
\hline Al & 5.2858120 & 6.7321431 & 21.6234870 \\
\hline $\mathrm{P}$ & 5.3349306 & 6.7432867 & 18.4584067 \\
\hline Al & 3.1638058 & 8.0464896 & 26.6283587 \\
\hline $\mathrm{P}$ & 3.2260330 & 8.1267444 & 23.5235420 \\
\hline Al & 8.5086036 & 9.2707343 & 28.5341613 \\
\hline $\mathrm{P}$ & 8.5404626 & 9.3913256 & 16.7277029 \\
\hline Al & 8.4940180 & 6.7981148 & 18.5251811 \\
\hline $\mathrm{P}$ & 8.4758140 & 6.8053162 & 21.6833080 \\
\hline Al & 1.5794682 & 10.8597344 & 23.5340876 \\
\hline $\mathrm{P}$ & 1.5004208 & 10.7632993 & 26.7023816 \\
\hline $\mathrm{O}$ & 7.0736611 & 9.7689709 & 17.0286924 \\
\hline 0 & 5.0009813 & 10.7430416 & 28.1992473 \\
\hline $\mathrm{H}$ & 4.7799743 & 5.3568763 & 21.8878543 \\
\hline $\mathrm{H}$ & 9.0154978 & 5.4382599 & 21.9220948 \\
\hline 0 & 6.8208857 & 6.3893544 & 18.2354861 \\
\hline 0 & 1.9492702 & 9.2947870 & 26.8210303 \\
\hline $\mathrm{H}$ & 2.1735900 & 7.0936098 & 23.3183170 \\
\hline $\mathrm{H}$ & 0.1733067 & 10.5457820 & 23.1582365 \\
\hline 0 & 4.9325049 & 7.9304388 & 17.5790117 \\
\hline 0 & 4.5008266 & 8.3116338 & 27.7110044 \\
\hline 0 & 4.4128830 & 7.9088909 & 22.5764739 \\
\hline 0 & 2.3530064 & 11.6674468 & 27.5963543 \\
\hline $\mathrm{O}$ & 8.9675733 & 8.1914247 & 17.5823988 \\
\hline 0 & 2.1801042 & 12.1771758 & 22.5853146 \\
\hline 0 & 4.3632408 & 10.6582413 & 17.1386551 \\
\hline 0 & 6.8437577 & 9.0518926 & 28.0714574 \\
\hline $\mathrm{O}$ & 6.9867736 & 6.8317454 & 22.0284197 \\
\hline $\mathrm{H}$ & 9.3511594 & 5.6406103 & 18.1475404 \\
\hline $\mathrm{H}$ & 4.5050716 & 5.5721623 & 18.0622724 \\
\hline $\mathrm{H}$ & 0.0894365 & 10.8625441 & 27.1675636 \\
\hline $\mathrm{H}$ & 2.5483236 & 6.7330462 & 26.9647643 \\
\hline 0 & 2.6144938 & 9.4959539 & 23.2211697 \\
\hline $\mathrm{H}$ & 5.2489094 & 9.0333522 & 15.2274025 \\
\hline 0 & 5.0977597 & 7.1325993 & 19.9269899 \\
\hline 0 & 3.7475467 & 8.0701806 & 24.9752500 \\
\hline $\mathrm{H}$ & 8.6783244 & 9.0768306 & 30.0006936 \\
\hline 0 & 8.7060348 & 7.2360787 & 20.2167309 \\
\hline 0 & 1.6169783 & 11.2448796 & 25.2462655 \\
\hline $\mathrm{H}$ & 5.2283092 & 8.9904052 & 29.9494782 \\
\hline $\mathrm{H}$ & 3.4206414 & 11.9759897 & 15.2576837 \\
\hline Al & 3.2076442 & 16.0812400 & 21.6161550 \\
\hline $\mathrm{P}$ & 3.1589783 & 16.0981859 & 18.4492578 \\
\hline $\mathrm{Al}$ & 3.7917725 & 11.9777114 & 28.5228330 \\
\hline $\mathrm{P}$ & 3.7704156 & 12.0059687 & 16.7047082 \\
\hline Al & 1.6384127 & 13.3425175 & 18.5752286 \\
\hline $\mathrm{P}$ & 1.7079695 & 13.3324132 & 21.6771699 \\
\hline 0 & 4.8189366 & 13.1022142 & 16.9867394 \\
\hline $\mathrm{H}$ & 0.2474905 & 13.5885440 & 21.8132536 \\
\hline $\mathrm{H}$ & 2.2675111 & 17.2051329 & 21.8809850 \\
\hline $\mathrm{O}$ & 2.0981921 & 15.0057615 & 18.2094434 \\
\hline 0 & 4.3875253 & 15.8771325 & 17.5583343 \\
\hline
\end{tabular}




\begin{tabular}{|c|c|c|}
\hline 4.6774819 & 16.2673919 & 22.5367254 \\
\hline 2.4906792 & 12.2555549 & 17.5038565 \\
\hline 4.4209165 & 13.5350229 & 28.0616889 \\
\hline 2.5092373 & 14.5794955 & 22.0978122 \\
\hline 2.5753326 & 17.4215673 & 18.0955065 \\
\hline 0.1805998 & 13.1675625 & 18.3276543 \\
\hline 3.6178189 & 16.0965245 & 19.9158704 \\
\hline 3.4656459 & 11.9754061 & 29.9756774 \\
\hline 2.0845941 & 12.9597306 & 20.2172276 \\
\hline 10.1232567 & 12.0823083 & 16.5225458 \\
\hline 10.0100735 & 12.0192305 & 28.3504421 \\
\hline 12.2680508 & 10.6605405 & 26.6729689 \\
\hline 12.2997592 & 10.6028654 & 23.4636212 \\
\hline 15.4544670 & 10.8597344 & 23.5340876 \\
\hline 10.5801374 & 7.9645715 & 23.6355277 \\
\hline 10.6567914 & 7.9722791 & 26.7221273 \\
\hline 15.3754195 & 10.7632993 & 26.7023816 \\
\hline 8.9887780 & 10.8960270 & 28.0770142 \\
\hline 11.7412853 & 9.0248836 & 27.0333363 \\
\hline 15.8093612 & 9.3435609 & 26.8170896 \\
\hline 11.4401224 & 6.7547165 & 23.5180659 \\
\hline 13.7821613 & 10.4863602 & 23.0870992 \\
\hline 11.2605948 & 11.8267504 & 27.4857856 \\
\hline 9.5021520 & 8.0850494 & 27.7252283 \\
\hline 16.2046848 & 11.6427162 & 27.5719020 \\
\hline 9.1940472 & 7.8386774 & 22.5764036 \\
\hline 16.0551030 & 12.1771758 & 22.5853146 \\
\hline 9.4466299 & 10.5728824 & 17.1125147 \\
\hline 13.9198993 & 10.8656767 & 27.1822465 \\
\hline 11.2525734 & 6.6127948 & 26.8403089 \\
\hline 16.3399687 & 9.6929709 & 23.2663751 \\
\hline 11.5693889 & 9.3002023 & 23.1026131 \\
\hline 10.3825970 & 12.0041656 & 15.0583884 \\
\hline 12.1382634 & 10.9289063 & 24.9519774 \\
\hline 15.4919770 & 11.2448796 & 25.2462655 \\
\hline 10.0916452 & 8.1991478 & 25.3007522 \\
\hline 10.4131480 & 11.9919311 & 29.7835877 \\
\hline 8.6751501 & 15.1084634 & 15.1927401 \\
\hline 5.3340151 & 14.7408555 & 16.6390086 \\
\hline 5.2861496 & 14.7322745 & 28.4694228 \\
\hline 12.2233114 & 18.7482445 & 21.6234870 \\
\hline 12.2549968 & 13.2891443 & 21.6208579 \\
\hline 17.0826429 & 16.0812400 & 21.6161550 \\
\hline 17.0339770 & 16.0981859 & 18.4492578 \\
\hline 12.2903139 & 13.2792423 & 18.3942518 \\
\hline 12.2724300 & 18.7593880 & 18.4584067 \\
\hline 5.3702966 & 17.2203567 & 26.5948605 \\
\hline 5.3449085 & 17.2209234 & 23.5278576 \\
\hline 8.4472569 & 14.7607357 & 28.4651306 \\
\hline 8.4944213 & 14.7812127 & 16.6340467 \\
\hline 15.5134114 & 13.3425175 & 18.5752286 \\
\hline 15.4315173 & 18.8142162 & 18.5251811 \\
\hline 10.7239714 & 16.0139568 & 18.4799671 \\
\hline 10.5834014 & 16.0316971 & 21.6583417 \\
\hline 15.4133134 & 18.8214176 & 21.6833080 \\
\hline 15.5829682 & 13.3324132 & 21.6771699 \\
\hline 8.4926265 & 17.4363878 & 23.5051410 \\
\hline 8.5138823 & 17.3200779 & 26.6494755 \\
\hline 8.9495219 & 13.3282843 & 16.9024250 \\
\hline 6.7602324 & 14.3930774 & 28.1759595 \\
\hline 11.6334369 & 17.1444992 & 21.9317746 \\
\hline 14.0996207 & 13.5925546 & 21.8153844 \\
\hline 15.9699477 & 17.4114242 & 21.9295947 \\
\hline 15.9731908 & 15.0057615 & 18.2094434 \\
\hline 11.9135070 & 14.7594578 & 18.1639701 \\
\hline 13.7583850 & 18.4054558 & 18.2354861 \\
\hline 7.0345614 & 17.6766872 & 26.9180245 \\
\hline 8.9889537 & 18.8305360 & 23.3404265 \\
\hline 4.6580712 & 18.5417640 & 23.5003791 \\
\hline 18.2267934 & 15.8835616 & 17.5842456 \\
\hline 11.8810984 & 19.9138125 & 17.6032550 \\
\hline 11.6468451 & 12.3987286 & 17.3029637 \\
\hline 4.8390115 & 15.9506077 & 27.6569445 \\
\hline 11.4796532 & 19.7507293 & 22.4353474 \\
\hline 11.6173939 & 11.7168482 & 22.6295525 \\
\hline 18.3373633 & 16.2401477 & 22.4019958 \\
\hline 8.9460018 & 16.1360808 & 27.5230178 \\
\hline 16.2393767 & 12.4166368 & 17.6626279 \\
\hline 9.3180308 & 15.7625417 & 17.4691862 \\
\hline 15.8349787 & 20.0012936 & 17.7219459 \\
\hline
\end{tabular}

22.5367254

7.5038565

2.0978122

18.0955065

18.3276543

20.2172276

16.5225458

28.3504421

23.5340876

23.6355277

21273

8.0770142

27.0333363

26.8170896

3.5180659

27.4857856

.7252283

22.5764036

.5853146

27.1822465

.8403089

23.1026131

5.0583884

25.2462655

25.3007522

29.7835877

16.6390086

28.4694228

21.6161550

18.4492578

8.3942518

18.4584067

28.4651306

18.5251811

21.6833080

1.6771699

26.6494755

6.9024250

21.9317746

21.8153844

(

18.1639701

18.2354861

. 3404265

23.5003791

17.5842456

27.6569445

.4353474

22.4019958

17.7219459 


\begin{tabular}{|c|c|c|}
\hline 9.2785847 & 16.3694249 & 22.4033549 \\
\hline 7.0223253 & 14.9110230 & 17.0427590 \\
\hline 9.3859709 & 13.3690879 & 27.9912572 \\
\hline 13.9242730 & 18.8478468 & 22.0284197 \\
\hline 11.1063039 & 14.6982449 & 22.1242991 \\
\hline 16.3842360 & 14.5794955 & 22.0978122 \\
\hline 16.4319916 & 17.4631516 & 18.0843907 \\
\hline 13.8091664 & 13.1379877 & 18.2858038 \\
\hline 11.4203609 & 17.5569201 & 18.0516704 \\
\hline 4.4807579 & 18.3953760 & 26.8073954 \\
\hline 9.3571576 & 18.4927328 & 27.0112600 \\
\hline 6.7989320 & 17.4277824 & 23.1119515 \\
\hline 5.1313137 & 15.0141832 & 15.1894140 \\
\hline 12.0352591 & 19.1487006 & 19.9269899 \\
\hline 11.7868435 & 12.7948835 & 19.7715320 \\
\hline 17.4928176 & 16.0965245 & 19.9158704 \\
\hline 5.2545646 & 16.6285849 & 24.9475643 \\
\hline 8.6462960 & 15.0658946 & 29.9088695 \\
\hline 15.9595928 & 12.9597306 & 20.2172276 \\
\hline 15.6435341 & 19.2521800 & 20.2167309 \\
\hline 10.2410208 & 16.0253479 & 20.1468528 \\
\hline 8.7184703 & 16.9380506 & 25.1736012 \\
\hline 10.2547368 & 12.1936711 & 19.6442206 \\
\hline 9.3130464 & 10.7471976 & 20.8236502 \\
\hline 9.4699583 & 11.8915192 & 19.5994973 \\
\hline 10.2052009 & 10.1930554 & 20.5010303 \\
\hline 8.3501612 & 10.5147821 & 20.3492262 \\
\hline 9.2825684 & 11.3338411 & 21.9540100 \\
\hline 10.3013833 & 11.4814117 & 22.3441551 \\
\hline 5.1022667 & 15.0511277 & 29.9122119 \\
\hline 16.1063430 & 19.8185170 & 22.5450639 \\
\hline 8.6450744 & 8.8936758 & 15.2263211 \\
\hline 5.3197849 & 9.2474033 & 16.6676158 \\
\hline 5.3048258 & 9.2009664 & 28.6074622 \\
\hline 5.2912844 & 6.7732753 & 21.6510928 \\
\hline 5.3228049 & 6.7679287 & 18.5578021 \\
\hline 3.1999702 & 7.9675033 & 26.6692952 \\
\hline 3.2355276 & 8.0155061 & 23.6155941 \\
\hline 8.4149504 & 9.1805650 & 28.5853778 \\
\hline 8.4430318 & 9.2559643 & 16.6563723 \\
\hline 8.4519772 & 6.7833399 & 18.5634064 \\
\hline 8.4376032 & 6.7913310 & 21.6593556 \\
\hline 1.6606931 & 10.7578262 & 23.5774553 \\
\hline 1.6041450 & 10.6924340 & 26.6810277 \\
\hline 6.8836168 & 9.6534826 & 16.9220912 \\
\hline 4.8865925 & 10.7513202 & 28.3270595 \\
\hline 4.8245725 & 5.3744304 & 21.8573296 \\
\hline 8.9467597 & 5.4097764 & 21.8811371 \\
\hline 6.8930989 & 6.3817363 & 18.3383843 \\
\hline 2.0859614 & 9.1446497 & 26.8171770 \\
\hline 2.1839720 & 6.9799999 & 23.4179118 \\
\hline 0.2439768 & 10.4359730 & 23.2511946 \\
\hline 4.8978737 & 7.9934105 & 17.5923740 \\
\hline 4.4167046 & 8.1895021 & 27.7125388 \\
\hline 4.4869098 & 7.8073903 & 22.6070727 \\
\hline 2.4645626 & 11.6565905 & 27.6529836 \\
\hline 8.8815916 & 8.0121186 & 17.5974497 \\
\hline 2.2092366 & 11.9423327 & 22.6286756 \\
\hline 4.3912657 & 10.5049418 & 17.0825416 \\
\hline 6.8567483 & 8.9964067 & 28.1962893 \\
\hline 6.8678182 & 6.8656385 & 22.0314274 \\
\hline 9.3044209 & 5.6098384 & 18.2267249 \\
\hline 4.4930853 & 5.5875306 & 18.1899078 \\
\hline 0.1819036 & 10.7709249 & 27.1148356 \\
\hline 2.5577204 & 6.6659165 & 27.0017220 \\
\hline 2.5737886 & 9.4539608 & 23.3012139 \\
\hline 5.1066158 & 8.8727833 & 15.2423652 \\
\hline 5.0756987 & 7.2313347 & 20.0995998 \\
\hline 3.7937268 & 7.9557535 & 25.1500855 \\
\hline 8.6421552 & 8.8881171 & 30.0275888 \\
\hline 8.6875392 & 7.2629003 & 20.1117839 \\
\hline 1.7667559 & 11.2037967 & 25.1437360 \\
\hline 5.1054595 & 8.8690446 & 30.0452388 \\
\hline 3.3351337 & 11.8906851 & 15.2140019 \\
\hline 3.2058048 & 15.8409621 & 21.6556247 \\
\hline 3.1985561 & 15.8602438 & 18.5555660 \\
\hline 3.7602371 & 11.9021208 & 28.5881121 \\
\hline
\end{tabular}




\begin{tabular}{|c|c|c|c|}
\hline $\mathrm{Si}$ & 3.7389803 & 11.9231789 & 16.6468217 \\
\hline $\mathrm{Si}$ & 1.6597691 & 13.1538426 & 18.5904514 \\
\hline $\mathrm{Si}$ & 1.6700228 & 13.1199752 & 21.6360958 \\
\hline 0 & 4.8561537 & 13.0828794 & 16.9054536 \\
\hline $\mathrm{H}$ & 0.1994768 & 13.3186681 & 21.7591254 \\
\hline $\mathrm{H}$ & 2.2699099 & 16.9773177 & 21.8790461 \\
\hline 0 & 2.0711263 & 14.7114875 & 18.3018787 \\
\hline $\mathrm{O}$ & 4.4892620 & 15.6382984 & 17.6009127 \\
\hline 0 & 4.5196165 & 15.9830953 & 22.5943677 \\
\hline $\mathrm{O}$ & 2.4157774 & 12.1765086 & 17.5385962 \\
\hline $\mathrm{O}$ & 4.3883928 & 13.3395982 & 28.1963511 \\
\hline 0 & 2.4628797 & 14.4752247 & 22.0590529 \\
\hline $\mathrm{H}$ & 2.6163799 & 17.1908462 & 18.2274066 \\
\hline $\mathrm{H}$ & 0.1948480 & 13.0024701 & 18.3708767 \\
\hline $\mathrm{O}$ & 3.6978785 & 15.8340087 & 20.1035053 \\
\hline $\mathrm{H}$ & 3.3367076 & 11.8888840 & 30.0155462 \\
\hline 0 & 2.0918262 & 12.7235110 & 20.0978484 \\
\hline $\mathrm{Si}$ & 10.0238121 & 11.9241709 & 16.5690530 \\
\hline $\mathrm{Si}$ & 9.9455486 & 11.8889498 & 28.5030584 \\
\hline $\mathrm{Si}$ & 12.1327761 & 10.6333644 & 26.7073775 \\
\hline $\mathrm{Si}$ & 12.1590557 & 10.6089468 & 23.5717943 \\
\hline $\mathrm{Si}$ & 15.2856918 & 10.7578262 & 23.5774553 \\
\hline $\mathrm{Si}$ & 10.4824994 & 7.9579748 & 23.6330324 \\
\hline $\mathrm{Si}$ & 10.5140695 & 7.9653074 & 26.6864243 \\
\hline $\mathrm{Si}$ & 15.2291437 & 10.6924340 & 26.6810277 \\
\hline 0 & 8.8535204 & 10.7096461 & 28.2318306 \\
\hline $\mathrm{O}$ & 11.6463730 & 9.1009184 & 26.9746323 \\
\hline $\mathrm{H}$ & 15.6701605 & 9.2757144 & 26.8056481 \\
\hline $\mathrm{H}$ & 11.3714687 & 6.7709874 & 23.4991852 \\
\hline 0 & 13.7276637 & 10.4038694 & 23.2186514 \\
\hline $\mathrm{O}$ & 11.2544688 & 11.6794454 & 27.5751093 \\
\hline $\mathrm{O}$ & 9.2762963 & 8.1193420 & 27.7171835 \\
\hline $\mathrm{H}$ & 16.0214628 & 11.5802815 & 27.5760573 \\
\hline 0 & 9.2175040 & 7.8575856 & 22.6149562 \\
\hline $\mathrm{O}$ & 15.8342354 & 11.9423327 & 22.6286756 \\
\hline $\mathrm{O}$ & 9.3832100 & 10.5138894 & 17.0690763 \\
\hline 0 & 13.6803745 & 10.7779078 & 27.1534288 \\
\hline $\mathrm{H}$ & 11.1208446 & 6.6208953 & 26.8901414 \\
\hline $\mathrm{H}$ & 16.1272436 & 9.5561226 & 23.3228582 \\
\hline 0 & 11.3431932 & 9.2570431 & 23.1972274 \\
\hline $\mathrm{H}$ & 10.3713816 & 11.8634800 & 15.1224595 \\
\hline $\mathrm{O}$ & 11.9555983 & 10.9992888 & 25.1335117 \\
\hline $\mathrm{O}$ & 15.3917547 & 11.2037967 & 25.1437360 \\
\hline $\mathrm{O}$ & 9.9424467 & 8.1118115 & 25.1614068 \\
\hline $\mathrm{H}$ & 10.3642249 & 11.8606655 & 29.9317049 \\
\hline $\mathrm{H}$ & 8.6845503 & 14.9871452 & 15.1771909 \\
\hline $\mathrm{Si}$ & 5.3163172 & 14.6247145 & 16.6475812 \\
\hline $\mathrm{Si}$ & 5.2827066 & 14.6222895 & 28.6092522 \\
\hline $\mathrm{Si}$ & 12.1037838 & 18.5728703 & 21.6510928 \\
\hline Al & 12.0318207 & 13.1095002 & 21.6290938 \\
\hline $\mathrm{Si}$ & 16.8308036 & 15.8409621 & 21.6556247 \\
\hline $\mathrm{Si}$ & 16.8235548 & 15.8602438 & 18.5555660 \\
\hline $\mathrm{Si}$ & 12.0956386 & 13.1304585 & 18.5204591 \\
\hline $\mathrm{Si}$ & 12.1353043 & 18.5675237 & 18.5578021 \\
\hline $\mathrm{Si}$ & 5.2922007 & 17.0178594 & 26.6531467 \\
\hline $\mathrm{Si}$ & 5.2704115 & 16.9881633 & 23.6106771 \\
\hline $\mathrm{Si}$ & 8.4216733 & 14.6140182 & 28.5575670 \\
\hline $\mathrm{Si}$ & 8.4574519 & 14.6295366 & 16.6046582 \\
\hline $\mathrm{Si}$ & 15.2847678 & 13.1538426 & 18.5904514 \\
\hline $\mathrm{Si}$ & 15.2644765 & 18.5829349 & 18.5634064 \\
\hline $\mathrm{Si}$ & 10.5676246 & 15.8597826 & 18.5352815 \\
\hline $\mathrm{Si}$ & 10.4923011 & 15.8648173 & 21.6432705 \\
\hline $\mathrm{Si}$ & 15.2501025 & 18.5909260 & 21.6593556 \\
\hline $\mathrm{Si}$ & 15.2950215 & 13.1199752 & 21.6360958 \\
\hline $\mathrm{Si}$ & 8.4002043 & 17.1421581 & 23.5590553 \\
\hline $\mathrm{Si}$ & 8.4143197 & 17.0668999 & 26.6446358 \\
\hline 0 & 8.9178863 & 13.0845020 & 16.8634693 \\
\hline 0 & 6.8474487 & 14.2543264 & 28.3567226 \\
\hline $\mathrm{O}$ & 11.5971926 & 17.0544982 & 21.8749520 \\
\hline 0 & 13.7213672 & 13.3325996 & 21.7677517 \\
\hline $\mathrm{O}$ & 15.8041818 & 17.0874774 & 21.9007048 \\
\hline 0 & 15.6961250 & 14.7114875 & 18.3018787 \\
\hline 0 & 11.6853979 & 14.6958270 & 18.2969083 \\
\hline 0 & 13.7055983 & 18.1813313 & 18.3383843 \\
\hline 0 & 6.8463614 & 17.4422911 & 26.8966409 \\
\hline $\mathrm{H}$ & 8.8568514 & 18.5519036 & 23.4134137 \\
\hline $\mathrm{H}$ & 4.6839326 & 18.3521684 & 23.4981909 \\
\hline $\mathrm{H}$ & 18.0094043 & 15.6563292 & 17.6784683 \\
\hline $\mathrm{H}$ & 11.7439903 & 19.6960548 & 17.6687513 \\
\hline 0 & 11.3909063 & 12.1971848 & 17.3865277 \\
\hline
\end{tabular}


4.8257325
11.3652854
11.4617841
18.0376527
8.8652333
15.9784893
9.3026473
15.6591146
9.1625525
6.8913819
9.2898985
13.6803176
11.0981425
16.0878784
16.1893905
13.6954094
11.2360360
4.4307936
9.2435627
6.8251096
5.0614474
11.8881981
11.5836994
17.3228772
5.0994025
8.6815525
15.7168249
15.5000386
10.0345672
8.6515139
10.0978207
9.0488850
9.3169339
9.8811119
8.0618790
9.0817046
10.1266231
5.0584993
15.9623496 6
15.8712788

19.5222939

11.7628301

15.9715237

15.8423025

12.2570304

15.6400822

19.7116747

16.1805239

14.7626251

13.3168263

18.6652336

14.4677165

14.4752247

17.3096686

12.9896118

17.2881824

18.2096452

18.2515515

17.0835916

14.9973785

19.0309298

12.6078613

15.8340087

16.4475676

14.9859368

12.7235110

19.0624954

15.8683475

16.6365038

11.9424003

10.7066492

11.6263814

10.0304949

10.4957763

11.4432361

11.5742609

14.9973318

19.5646866

165

$\begin{array}{lrrr}\mathrm{H} & 8.6355205 & 9.0608956 & 15.1726912 \\ \mathrm{P} & 5.3699126 & 9.3824304 & 16.7261030 \\ \mathrm{Al} & 5.3247176 & 9.3222022 & 28.5452748 \\ \mathrm{P} & 5.3876123 & 6.7624714 & 21.6623566 \\ \mathrm{Al} & 5.4129155 & 6.7933382 & 18.5195480 \\ \mathrm{P} & 3.1696338 & 7.9726613 & 26.6854105 \\ \mathrm{Al} & 3.2329378 & 8.0566938 & 23.5954763 \\ \mathrm{P} & 8.4503331 & 9.2360755 & 28.4323212 \\ \mathrm{Al} & 8.5065467 & 9.3364651 & 16.6302740 \\ \mathrm{P} & 8.5736676 & 6.7723259 & 18.4712711 \\ \mathrm{Al} & 8.5548957 & 6.7618102 & 21.6305445 \\ \mathrm{P} & 1.6689990 & 10.8194373 & 23.4801172 \\ \mathrm{Al} & 1.5815264 & 10.7347805 & 26.6430243 \\ \mathrm{O} & 6.8431299 & 9.7599872 & 17.0039087 \\ \mathrm{O} & 4.8707457 & 10.9820505 & 28.1957379 \\ \mathrm{H} & 4.9351110 & 5.3540363 & 21.8316902 \\ \mathrm{H} & 9.0859806 & 5.3951980 & 21.8902372 \\ \mathrm{O} & 7.0999414 & 6.3904702 & 18.2377789 \\ \mathrm{O} & 2.0917950 & 9.0674173 & 26.8069182 \\ \mathrm{H} & 2.1105925 & 7.0963433 & 23.4078903 \\ \mathrm{H} & 0.2784860 & 10.4431020 & 23.1033335 \\ \mathrm{O} & 4.9569896 & 8.1728166 & 17.5653909 \\ \mathrm{O} & 4.2927924 & 8.2058401 & 27.7006293 \\ \mathrm{O} & 4.5932622 & 7.7117959 & 22.5668530 \\ \mathrm{O} & 2.5438960 & 11.7908700 & 27.6363043 \\ \mathrm{O} & 8.9816990 & 7.9480405 & 17.5734980 \\ \mathrm{O} & 2.1506440 & 11.9847362 & 22.6178008 \\ \mathrm{O} & 4.4779350 & 10.5615687 & 17.1240890 \\ \mathrm{O} & 6.9762833 & 9.0557524 & 28.0553613 \\ \mathrm{O} & 6.8696655 & 6.8571649 & 22.0527253 \\ \mathrm{H} & 9.4321568 & 5.6056442 & 18.1263495 \\ \mathrm{H} & 4.5570716 & 5.6404392 & 18.1252438 \\ \mathrm{H} & 0.1715266 & 10.8186979 & 27.1141710 \\ \mathrm{H} & 2.5481816 & 6.6538075 & 26.9879702 \\ \mathrm{O} & 2.6047153 & 9.6350115 & 23.2244530 \\ \mathrm{H} & 5.1857671 & 9.0415424 & 15.2883943 \\ \mathrm{O} & 5.1967184 & 7.2193502 & 20.2028099 \\ \mathrm{O} & 3.7732607 & 7.9823800 & 25.2665954\end{array}$

27.6913158

22.5287804

22.6537720

22.5179410

27.6038229

17.5404521

17.6760914

22.5224174

16.9966876

28.1276826

22.0314274

22.0909937

22.0590529

18.1981021

18.3522250

18.1590702

26.8871234

26.9997092

23.1988958

15.2286789

20.0995998

19.9777335

20.1035053

25.1381877

29.9757559

20.0978484

20.1117839

20.0667099

25.0919081

19.7894588

21.0874051

19.7185923

20.8512037

20.6536084

22.1280493

22.4685219

22.5320611
17.6252577

30.0326970 


\begin{tabular}{|c|c|c|c|}
\hline $\mathrm{H}$ & 8.6508763 & 9.0209756 & 29.8919907 \\
\hline 0 & 8.7863367 & 7.1996523 & 19.9414145 \\
\hline 0 & 1.7087027 & 11.2278087 & 24.9667150 \\
\hline $\mathrm{H}$ & 5.2012695 & 9.0736857 & 30.0081899 \\
\hline $\mathrm{H}$ & 3.4764298 & 12.0785099 & 15.1890803 \\
\hline $\mathrm{P}$ & 3.1882958 & 15.9911293 & 21.6707325 \\
\hline Al & 3.1837896 & 16.0224239 & 18.5110031 \\
\hline $\mathrm{P}$ & 3.8025830 & 12.0641974 & 28.4630499 \\
\hline Al & 3.7925161 & 12.0908333 & 16.6440917 \\
\hline $\mathrm{P}$ & 1.5761660 & 13.3112165 & 18.4778424 \\
\hline Al & 1.5513586 & 13.2854724 & 21.6064710 \\
\hline $\mathrm{O}$ & 4.9784886 & 13.3337028 & 17.0077918 \\
\hline $\mathrm{H}$ & 0.1053628 & 13.5566655 & 21.8359725 \\
\hline $\mathrm{H}$ & 2.2721778 & 17.1370350 & 21.9251900 \\
\hline $\mathrm{O}$ & 1.9894089 & 14.7751949 & 18.2024449 \\
\hline $\mathrm{O}$ & 4.6251681 & 15.7739226 & 17.5582641 \\
\hline $\mathrm{O}$ & 4.4494146 & 16.0981557 & 22.5374937 \\
\hline $\mathrm{O}$ & 2.3160560 & 12.3665993 & 17.5207639 \\
\hline $\mathrm{O}$ & 4.3630676 & 13.4287102 & 28.0443241 \\
\hline $\mathrm{O}$ & 2.4734248 & 14.7007778 & 22.0442214 \\
\hline $\mathrm{H}$ & 2.6169439 & 17.3576618 & 18.1749282 \\
\hline $\mathrm{H}$ & 0.1162384 & 13.1702253 & 18.2212231 \\
\hline $\mathrm{O}$ & 3.6293653 & 15.9902561 & 20.1977903 \\
\hline $\mathrm{H}$ & 3.4334774 & 12.0759786 & 29.9055279 \\
\hline $\mathrm{O}$ & 1.9174510 & 12.9109506 & 19.9217665 \\
\hline $\mathrm{P}$ & 10.1125476 & 11.9986222 & 16.5636576 \\
\hline Al & 10.0260567 & 11.9509108 & 28.3724696 \\
\hline $\mathrm{P}$ & 12.3495426 & 10.6772452 & 26.7318651 \\
\hline Al & 12.4143370 & 10.6080832 & 23.5179852 \\
\hline $\mathrm{P}$ & 15.5439977 & 10.8194373 & 23.4801172 \\
\hline $\mathrm{P}$ & 10.6259574 & 8.0311393 & 23.5410574 \\
\hline $\mathrm{Al}$ & 10.6608784 & 8.0462393 & 26.6324341 \\
\hline Al & 15.4565251 & 10.7347805 & 26.6430243 \\
\hline 0 & 8.8906547 & 10.6579390 & 28.0275465 \\
\hline $\mathrm{O}$ & 11.8623198 & 9.2515606 & 27.0658986 \\
\hline $\mathrm{H}$ & 15.8903484 & 9.3172114 & 26.7823646 \\
\hline $\mathrm{H}$ & 11.4011206 & 6.7605015 & 23.4995565 \\
\hline $\mathrm{O}$ & 14.0976008 & 10.4279773 & 23.0881908 \\
\hline 0 & 11.4929409 & 11.7208278 & 27.4600048 \\
\hline 0 & 9.2718482 & 8.1835243 & 27.6772055 \\
\hline $\mathrm{H}$ & 16.2800040 & 11.6384535 & 27.4929526 \\
\hline $\mathrm{O}$ & 9.4142617 & 7.9511780 & 22.5946382 \\
\hline $\mathrm{O}$ & 16.0256427 & 11.9847362 & 22.6178008 \\
\hline $\mathrm{O}$ & 9.5516551 & 10.6634810 & 17.0904408 \\
\hline 0 & 13.8016689 & 10.8332708 & 27.1959889 \\
\hline $\mathrm{H}$ & 11.2552818 & 6.6896353 & 26.7855054 \\
\hline $\mathrm{H}$ & 16.4540769 & 9.6674629 & 23.2314578 \\
\hline $\mathrm{O}$ & 11.5341069 & 9.1683865 & 23.0555126 \\
\hline $\mathrm{H}$ & 10.3761009 & 11.9075454 & 15.1010007 \\
\hline $\mathrm{O}$ & 12.2473749 & 10.9257680 & 25.2204534 \\
\hline $\mathrm{O}$ & 15.5837014 & 11.2278087 & 24.9667150 \\
\hline $\mathrm{O}$ & 10.1331157 & 8.3089525 & 24.9735128 \\
\hline $\mathrm{H}$ & 10.3316369 & 11.9116435 & 29.8292466 \\
\hline $\mathrm{H}$ & 8.7475647 & 15.0288419 & 15.0934962 \\
\hline $\mathrm{P}$ & 5.4154711 & 14.7805163 & 16.6987692 \\
\hline Al & 5.3569004 & 14.7756360 & 28.5334956 \\
\hline $\mathrm{P}$ & 12.3251117 & 18.7785728 & 21.6623566 \\
\hline $\mathrm{Ge}$ & 12.0601173 & 13.2937712 & 21.6664482 \\
\hline $\mathrm{P}$ & 17.0632945 & 15.9911293 & 21.6707325 \\
\hline Al & 17.0587883 & 16.0224239 & 18.5110031 \\
\hline Al & 12.2376856 & 13.3299501 & 18.4262322 \\
\hline Al & 12.3504149 & 18.8094395 & 18.5195480 \\
\hline $\mathrm{P}$ & 5.3231988 & 17.2624897 & 26.6596768 \\
\hline Al & 5.2650358 & 17.2003346 & 23.5969114 \\
\hline$P$ & 8.5153179 & 14.7153582 & 28.3812541 \\
\hline Al & 8.5747962 & 14.7558019 & 16.5470163 \\
\hline $\mathrm{P}$ & 15.4511648 & 13.3112165 & 18.4778424 \\
\hline$P$ & 15.5111670 & 18.7884272 & 18.4712711 \\
\hline $\mathrm{P}$ & 10.7394743 & 16.0978143 & 18.3958674 \\
\hline Al & 10.5913795 & 16.1242573 & 21.5766505 \\
\hline Al & 15.4923950 & 18.7779116 & 21.6305445 \\
\hline $\mathrm{Al}$ & 15.4263573 & 13.2854724 & 21.6064710 \\
\hline $\mathrm{P}$ & 8.4016523 & 17.4713984 & 23.4365295 \\
\hline Al & 8.4626771 & 17.2801062 & 26.5536367 \\
\hline 0 & 9.0791996 & 13.1029135 & 16.8714764 \\
\hline $\mathrm{O}$ & 7.0250535 & 14.3819164 & 28.1773979 \\
\hline 0 & 11.8587091 & 17.3268692 & 21.8368922 \\
\hline 0 & 13.7598567 & 13.5980207 & 21.8709700 \\
\hline $\mathrm{O}$ & 16.1138759 & 17.1786884 & 21.9344394 \\
\hline $\mathrm{O}$ & 15.8644076 & 14.7751949 & 18.202444 \\
\hline
\end{tabular}




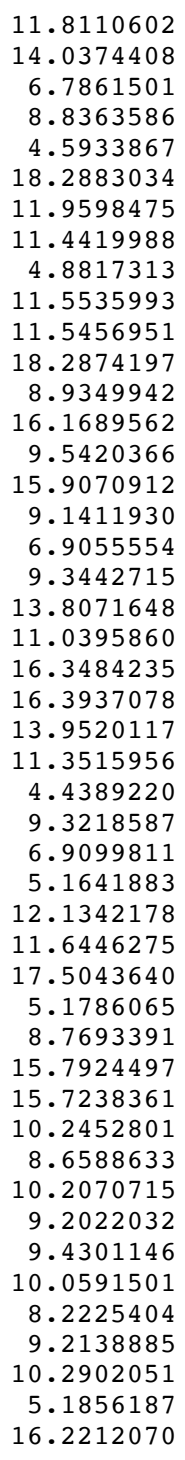

$\begin{array}{lrrr}\mathrm{H} & 8.6796428 & 8.8670861 & 15.2141814 \\ \mathrm{Si} & 5.3842561 & 9.2322273 & 16.6631187 \\ \mathrm{Si} & 5.3564966 & 9.1698695 & 28.5990390 \\ \mathrm{Si} & 5.3455779 & 6.7179656 & 21.6333304 \\ \mathrm{Si} & 5.3746242 & 6.7565997 & 18.5503976 \\ \mathrm{Si} & 3.2530791 & 7.9422636 & 26.6563077 \\ \mathrm{Si} & 3.3367407 & 8.0242506 & 23.6142114 \\ \mathrm{Si} & 8.4589691 & 9.1320740 & 28.5668680 \\ \mathrm{Si} & 8.5004769 & 9.2372041 & 16.6452764 \\ \mathrm{Si} & 8.4981572 & 6.7580329 & 18.5441593 \\ \mathrm{Si} & 8.4928015 & 6.7327835 & 21.6463510 \\ \mathrm{Si} & 1.7222113 & 10.7312211 & 23.5614815 \\ \mathrm{Si} & 1.6440508 & 10.6544782 & 26.6709583 \\ \mathrm{O} & 6.9452271 & 9.6400715 & 16.9300907 \\ \mathrm{O} & 4.9420838 & 10.7220027 & 28.3167758 \\ \mathrm{H} & 4.8245852 & 5.3322794 & 21.7932081 \\ \mathrm{H} & 9.0550390 & 5.3711909 & 21.8633195 \\ \mathrm{O} & 6.9393191 & 6.3601660 & 18.3050550 \\ \mathrm{O} & 2.1225730 & 9.1045787 & 26.7997019 \\ \mathrm{H} & 2.2641128 & 7.0081904 & 23.4292474 \\ \mathrm{H} & 0.3200821 & 10.3698280 & 23.2143195 \\ \mathrm{O} & 4.9481518 & 7.9826081 & 17.5873492 \\ \mathrm{O} & 4.4429903 & 8.1574243 & 27.7314070 \\ \mathrm{O} & 4.5833016 & 7.7636343 & 22.6123745 \\ \mathrm{O} & 2.5113558 & 11.6109830 & 27.6446798 \\ \mathrm{O} & 8.9391104 & 7.9997212 & 17.5966717 \\ \mathrm{O} & 2.2251137 & 11.9427694 & 22.6251166 \\ \mathrm{O} & 4.4525481 & 10.4895752 & 17.0674887 \\ \mathrm{O} & 6.9018471 & 8.9473673 & 28.1681407 \\ \mathrm{O} & 6.9220091 & 6.7287699 & 22.0194383\end{array}$

18.1592369

18.2377789

26.8956497

23.3771479

23.5125462

17.6983040

17.7021726

17.2634037

27.6915671

22.5408485

22.6330054

22.5120682

27.5040739

17.5493492

17.4606924

17.6001369

22.3960087

17.0272494

27.9601189

22.0527253

22.2134208

22.0442214

18.1166861

18.2143282

18.0593722

26.9322077

23.0999232

15.2646356

20.2028099

19.9866256

20.1977903

25.2550959

29.8061519

19.9217665

19.9414145

19.8488736

24.8502659

19.7873582

20.9894886

19.7042364

20.6991942

20.5447146

22.0807285

22.4215525

$\begin{array}{ll}15.0543733 & 29.9861101 \\ 19.7865918 & 22.4481740\end{array}$

$\begin{array}{ll}15.0543733 & 29.9861101 \\ 19.7865918 & 22.4481740\end{array}$

15.2141814

16.6631187

8.5990390

18.5503976

26.6563077

-

16.6452764

18.5441593

6.6709583

21.8633195

.3050550

23.4292474

2143195

27.7314070

22.6123745

.6446798

22.6251166
26.8066861 


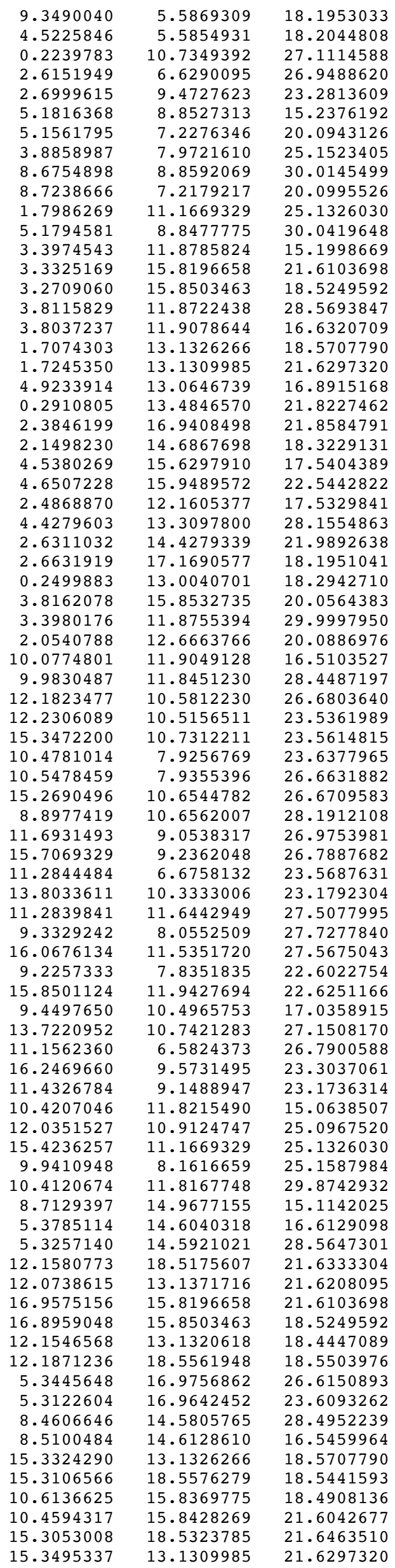




\begin{tabular}{|c|c|c|c|}
\hline $\mathrm{Si}$ & 8.4255552 & 17.1921776 & 23.5238136 \\
\hline $\mathrm{Si}$ & 8.4606714 & 17.0352895 & 26.5937264 \\
\hline 0 & 8.9679992 & 13.0648856 & 16.7947884 \\
\hline 0 & 6.8862862 & 14.2305479 & 28.2814209 \\
\hline $\mathrm{O}$ & 11.5921284 & 17.0123043 & 21.8070038 \\
\hline $\mathrm{O}$ & 13.8094769 & 13.5109577 & 21.8371002 \\
\hline $\mathrm{O}$ & 15.9174864 & 17.0498250 & 21.8825945 \\
\hline 0 & 15.7748217 & 14.6867698 & 18.3229131 \\
\hline 0 & 11.7553501 & 14.7009585 & 18.2333977 \\
\hline 0 & 13.7518185 & 18.1597610 & 18.3050550 \\
\hline 0 & 6.8954006 & 17.4109816 & 26.8770902 \\
\hline $\mathrm{H}$ & 8.9334323 & 18.5881735 & 23.4219474 \\
\hline $\mathrm{H}$ & 4.5950490 & 18.2684429 & 23.5669357 \\
\hline $\mathrm{H}$ & 18.0607561 & 15.6475921 & 17.6198997 \\
\hline $\mathrm{H}$ & 11.7942411 & 19.6856399 & 17.6632011 \\
\hline $\mathrm{O}$ & 11.4500903 & 12.2028978 & 17.3086729 \\
\hline $\mathrm{O}$ & 4.8551914 & 15.8575558 & 27.6748709 \\
\hline $\mathrm{H}$ & 11.4585891 & 19.4770983 & 22.5317313 \\
\hline $\mathrm{O}$ & 11.5043140 & 11.6493445 & 22.6124604 \\
\hline $\mathrm{H}$ & 18.1686239 & 15.9384529 & 22.4684065 \\
\hline $\mathrm{O}$ & 8.9208619 & 15.7987986 & 27.5347656 \\
\hline $\mathrm{H}$ & 16.0481567 & 12.2400166 & 17.6178352 \\
\hline 0 & 9.3730970 & 15.6247752 & 17.4648713 \\
\hline $\mathrm{H}$ & 15.7152161 & 19.6968345 & 17.6748719 \\
\hline 0 & 9.1141067 & 16.2487332 & 22.4196804 \\
\hline 0 & 6.9516464 & 14.7532395 & 16.9675228 \\
\hline 0 & 9.3193065 & 13.2715487 & 28.0839188 \\
\hline 0 & 13.7345085 & 18.5283649 & 22.0194383 \\
\hline 0 & 10.9755255 & 14.4439382 & 22.1737581 \\
\hline 0 & 16.2561020 & 14.4279339 & 21.9892638 \\
\hline $\mathrm{O}$ & 16.2338828 & 17.2869032 & 18.1656269 \\
\hline 0 & 13.7519332 & 12.9932159 & 18.2709251 \\
\hline 0 & 11.2637497 & 17.2870410 & 18.1755201 \\
\hline $\mathrm{H}$ & 4.4690100 & 18.1678740 & 26.7860067 \\
\hline $\mathrm{H}$ & 9.3003968 & 18.2140509 & 26.9437313 \\
\hline 0 & 6.8448340 & 17.2346494 & 23.1986883 \\
\hline $\mathrm{H}$ & 5.1277823 & 14.9552693 & 15.1878176 \\
\hline 0 & 11.9686789 & 19.0272296 & 20.0943126 \\
\hline 0 & 11.6279749 & 12.5849207 & 19.8909189 \\
\hline 0 & 17.4412066 & 15.8532735 & 20.0564383 \\
\hline 0 & 5.1996030 & 16.3495176 & 25.1148095 \\
\hline $\mathrm{H}$ & 8.7086389 & 14.9648638 & 29.9122464 \\
\hline 0 & 15.6790776 & 12.6663766 & 20.0886976 \\
\hline 0 & 15.5363660 & 19.0175167 & 20.0995526 \\
\hline $\mathrm{O}$ & 10.0608026 & 15.7718983 & 20.0142710 \\
\hline $\mathrm{O}$ & 8.6802696 & 16.6179823 & 25.0327482 \\
\hline $\mathrm{H}$ & 10.1468961 & 11.9491795 & 19.7018491 \\
\hline C & 9.1532852 & 10.6147940 & 20.9293469 \\
\hline $\mathrm{H}$ & 9.3636119 & 11.6295687 & 19.6266869 \\
\hline $\mathrm{H}$ & 10.0124863 & 9.9907720 & 20.6470117 \\
\hline $\mathrm{H}$ & 8.1752698 & 10.3838671 & 20.4843746 \\
\hline 0 & 9.1603094 & 11.2841822 & 22.0136454 \\
\hline $\mathrm{H}$ & 10.2084782 & 11.4339091 & 22.3726081 \\
\hline $\mathrm{H}$ & 5.1233248 & 14.9543514 & 29.9947422 \\
\hline & 15.9736547 & 19.5376471 & 22.5180497 \\
\hline \\
\hline \\
\hline $\mathrm{H}$ & 8.6319934 & 9.0782111 & 15.1859633 \\
\hline $\mathrm{P}$ & 5.3763052 & 9.4058076 & 16.7372912 \\
\hline Al & 5.3252944 & 9.3178293 & 28.5515805 \\
\hline $\mathrm{P}$ & 5.3812396 & 6.8125098 & 21.6722120 \\
\hline Al & 5.4228953 & 6.8137090 & 18.5261501 \\
\hline $\mathrm{P}$ & 3.1801031 & 7.9633251 & 26.6883122 \\
\hline Al & 3.2918334 & 8.0929256 & 23.6073671 \\
\hline $\mathrm{P}$ & 8.4476160 & 9.2099475 & 28.4398187 \\
\hline Al & 8.5141818 & 9.3624971 & 16.6428169 \\
\hline $\mathrm{P}$ & 8.5812053 & 6.7934403 & 18.4845859 \\
\hline Al & 8.5602543 & 6.7548956 & 21.6395643 \\
\hline $\mathrm{P}$ & 1.6550417 & 10.8322890 & 23.5077040 \\
\hline Al & 1.5695767 & 10.7252794 & 26.6617429 \\
\hline 0 & 6.8492408 & 9.7866091 & 17.0139621 \\
\hline 0 & 4.8765414 & 10.9743340 & 28.1783405 \\
\hline $\mathrm{H}$ & 4.8074086 & 5.4529773 & 21.8709830 \\
\hline $\mathrm{H}$ & 9.1257034 & 5.3976734 & 21.8747999 \\
\hline 0 & 7.1094391 & 6.4043759 & 18.2472384 \\
\hline 0 & 2.1035162 & 9.0616793 & 26.7789343 \\
\hline $\mathrm{H}$ & 2.2047824 & 7.1056589 & 23.3609020 \\
\hline $\mathrm{H}$ & 0.2798205 & 10.4334005 & 23.099323 \\
\hline & & & \\
\hline
\end{tabular}




\begin{tabular}{|c|c|c|c|}
\hline 0 & 4.2812981 & 8.1968867 & 27.7270770 \\
\hline 0 & 4.6718841 & 7.8358225 & 22.5710751 \\
\hline 0 & 2.5389290 & 11.7747200 & 27.6547292 \\
\hline 0 & 8.9854220 & 7.9738887 & 17.5907405 \\
\hline 0 & 2.1476556 & 11.9937703 & 22.6438180 \\
\hline 0 & 4.4803620 & 10.5792910 & 17.1439590 \\
\hline 0 & 6.9732185 & 9.0254723 & 28.0649842 \\
\hline 0 & 6.8691570 & 6.7833562 & 22.0488837 \\
\hline $\mathrm{H}$ & 9.4448871 & 5.6303470 & 18.1405099 \\
\hline $\mathrm{H}$ & 4.5594734 & 5.6666019 & 18.1314747 \\
\hline $\mathrm{H}$ & 0.1708324 & 10.7769468 & 27.1696459 \\
\hline $\mathrm{H}$ & 2.5490828 & 6.6474918 & 26.9841443 \\
\hline 0 & 2.6171370 & 9.6619995 & 23.2911318 \\
\hline $\mathrm{H}$ & 5.1886709 & 9.0711375 & 15.2985730 \\
\hline 0 & 5.2149842 & 7.2574879 & 20.2066642 \\
\hline 0 & 3.8123931 & 7.9647579 & 25.2813420 \\
\hline $\mathrm{H}$ & 8.6456190 & 9.0353209 & 29.9052268 \\
\hline 0 & 8.7889056 & 7.2194898 & 19.9563751 \\
\hline $\mathrm{O}$ & 1.6514835 & 11.2552277 & 24.9915627 \\
\hline $\mathrm{H}$ & 5.2037000 & 9.0983838 & 30.0192927 \\
\hline $\mathrm{H}$ & 3.5064162 & 12.0831034 & 15.1900977 \\
\hline$P$ & 3.2342019 & 15.9940217 & 21.6540703 \\
\hline Al & 3.1949610 & 16.0380448 & 18.4949910 \\
\hline$P$ & 3.8110981 & 12.0562052 & 28.4578647 \\
\hline Al & 3.7973694 & 12.1054724 & 16.6502232 \\
\hline $\mathrm{P}$ & 1.5853950 & 13.3321347 & 18.4751501 \\
\hline Al & 1.6078086 & 13.2943814 & 21.6015061 \\
\hline 0 & 4.9791989 & 13.3491733 & 17.0295729 \\
\hline $\mathrm{H}$ & 0.1475096 & 13.5272413 & 21.7759308 \\
\hline $\mathrm{H}$ & 2.3178558 & 17.1402894 & 21.9060637 \\
\hline 0 & 1.9934058 & 14.7959268 & 18.1853649 \\
\hline 0 & 4.6344182 & 15.7991928 & 17.5342563 \\
\hline 0 & 4.5124134 & 16.1027650 & 22.4980092 \\
\hline 0 & 2.3040712 & 12.3868800 & 17.5006677 \\
\hline 0 & 4.3624523 & 13.4189906 & 28.0206480 \\
\hline $\mathrm{O}$ & 2.5233210 & 14.7069340 & 22.0551179 \\
\hline $\mathrm{H}$ & 2.6300308 & 17.3803021 & 18.1846366 \\
\hline $\mathrm{H}$ & 0.1189208 & 13.1919973 & 18.2585035 \\
\hline 0 & 3.6551360 & 15.9738299 & 20.1767279 \\
\hline $\mathrm{H}$ & 3.4669923 & 12.0784934 & 29.9063863 \\
\hline 0 & 1.9702270 & 12.9352953 & 19.9113054 \\
\hline$P$ & 10.1213808 & 12.0178692 & 16.5334563 \\
\hline Al & 10.0110228 & 11.9289542 & 28.3370102 \\
\hline $\mathrm{P}$ & 12.3563756 & 10.6209698 & 26.7708404 \\
\hline Al & 12.4122412 & 10.5123593 & 23.5448405 \\
\hline$P$ & 15.5300405 & 10.8322890 & 23.5077040 \\
\hline $\mathrm{P}$ & 10.5842453 & 7.9947291 & 23.5889962 \\
\hline Al & 10.6480308 & 8.0229953 & 26.6544301 \\
\hline Al & 15.4445754 & 10.7252794 & 26.6617429 \\
\hline 0 & 8.8929883 & 10.6192070 & 27.9951278 \\
\hline 0 & 11.8510274 & 9.2096762 & 27.1401587 \\
\hline $\mathrm{H}$ & 15.8985933 & 9.3106917 & 26.7613928 \\
\hline $\mathrm{H}$ & 11.2497766 & 6.6629009 & 23.6095442 \\
\hline 0 & 14.0996703 & 10.4174044 & 23.0829461 \\
\hline 0 & 11.4897261 & 11.6949480 & 27.4432529 \\
\hline $\mathrm{O}$ & 9.2667202 & 8.1326056 & 27.7152853 \\
\hline $\mathrm{H}$ & 16.2741792 & 11.6234254 & 27.5115734 \\
\hline $\mathrm{O}$ & 9.3786432 & 7.9566524 & 22.6301216 \\
\hline $\mathrm{O}$ & 16.0226543 & 11.9937703 & 22.6438180 \\
\hline 0 & 9.5681897 & 10.6895666 & 17.0891227 \\
\hline 0 & 13.8009313 & 10.7859930 & 27.2585723 \\
\hline $\mathrm{H}$ & 11.2465793 & 6.6620984 & 26.7370131 \\
\hline $\mathrm{H}$ & 16.4661125 & 9.6936542 & 23.2969898 \\
\hline 0 & 11.5901839 & 9.0370699 & 23.0789680 \\
\hline $\mathrm{H}$ & 10.3420230 & 11.9039149 & 15.0653105 \\
\hline 0 & 12.2910062 & 10.8134240 & 25.2518374 \\
\hline 0 & 15.5264822 & 11.2552277 & 24.9915627 \\
\hline $\mathrm{O}$ & 10.1050605 & 8.3586727 & 25.0085796 \\
\hline $\mathrm{H}$ & 10.2995604 & 11.9048790 & 29.7975879 \\
\hline $\mathrm{H}$ & 8.7612129 & 15.0268316 & 15.0607226 \\
\hline $\mathrm{P}$ & 5.4189612 & 14.7882038 & 16.6887766 \\
\hline Al & 5.3532918 & 14.7640171 & 28.5217540 \\
\hline $\mathrm{P}$ & 12.3187390 & 18.8286112 & 21.6722120 \\
\hline $\mathrm{Ti}$ & 12.0285461 & 13.2567895 & 21.6898078 \\
\hline $\mathrm{P}$ & 17.1092006 & 15.9940217 & 21.6540703 \\
\hline Al & 17.0699598 & 16.0380448 & 18.4949910 \\
\hline Al & 12.2280076 & 13.3497238 & 18.3882393 \\
\hline Al & 12.3603947 & 18.8298103 & 18.5261501 \\
\hline $\mathrm{P}$ & 5.3310754 & 17.2384626 & 26.6497498 \\
\hline Al & 5.2630020 & 17.1945958 & 23.6164679 \\
\hline
\end{tabular}




\begin{tabular}{|c|c|c|c|}
\hline $\mathrm{P}$ & 8.5156613 & 14.7030900 & 28.3486938 \\
\hline Al & 8.5854443 & 14.7763940 & 16.5179484 \\
\hline$P$ & 15.4603937 & 13.3321347 & 18.4751501 \\
\hline$P$ & 15.5187047 & 18.8095417 & 18.4845859 \\
\hline $\mathrm{P}$ & 10.7305273 & 16.1235816 & 18.3797525 \\
\hline Al & 10.5147921 & 16.1918793 & 21.5621798 \\
\hline Al & 15.4977536 & 18.7709969 & 21.6395643 \\
\hline Al & 15.4828073 & 13.2943814 & 21.6015061 \\
\hline$P$ & 8.3860401 & 17.5236789 & 23.4157302 \\
\hline Al & 8.4596733 & 17.2801071 & 26.5373984 \\
\hline 0 & 9.1012100 & 13.1298146 & 16.8584040 \\
\hline 0 & 7.0215814 & 14.3784297 & 28.1612115 \\
\hline 0 & 11.7279046 & 17.4287941 & 21.8768728 \\
\hline 0 & 13.7856646 & 13.5650085 & 21.8042205 \\
\hline 0 & 16.1600429 & 17.1813338 & 21.9150868 \\
\hline 0 & 15.8684045 & 14.7959268 & 18.1853649 \\
\hline 0 & 11.7999709 & 15.0385486 & 18.1404786 \\
\hline 0 & 14.0469384 & 18.4204773 & 18.2472384 \\
\hline 0 & 6.7859333 & 17.6879882 & 26.9042787 \\
\hline $\mathrm{H}$ & 8.9351496 & 18.9044972 & 23.3211766 \\
\hline $\mathrm{H}$ & 4.4574232 & 18.4468467 & 23.6108980 \\
\hline $\mathrm{H}$ & 18.2968173 & 15.8344699 & 17.6761513 \\
\hline $\mathrm{H}$ & 11.9709556 & 20.0102827 & 17.7064290 \\
\hline 0 & 11.4743530 & 12.3180646 & 17.1851413 \\
\hline 0 & 4.8761433 & 16.2191588 & 27.6970707 \\
\hline $\mathrm{H}$ & 11.6309452 & 19.8208190 & 22.5437531 \\
\hline 0 & 11.4985339 & 11.7507142 & 22.7103064 \\
\hline $\mathrm{H}$ & 18.3486714 & 16.0994692 & 22.4724306 \\
\hline 0 & 8.9344130 & 15.8780777 & 27.4592401 \\
\hline $\mathrm{H}$ & 16.1570316 & 12.4158664 & 17.5305504 \\
\hline 0 & 9.5421376 & 15.9133103 & 17.4282938 \\
\hline $\mathrm{H}$ & 15.9108426 & 19.9547160 & 17.6174503 \\
\hline 0 & 9.0169968 & 16.6255791 & 22.3537453 \\
\hline 0 & 6.9131784 & 14.9419645 & 16.9968643 \\
\hline 0 & 9.3302651 & 13.4761632 & 27.9219824 \\
\hline 0 & 13.8066564 & 18.7994575 & 22.0488837 \\
\hline 0 & 11.0752473 & 14.6862978 & 22.1829680 \\
\hline 0 & 16.3983197 & 14.7069340 & 22.0551179 \\
\hline 0 & 16.4069177 & 17.6134129 & 18.1307371 \\
\hline 0 & 13.9541962 & 13.1882013 & 18.2526350 \\
\hline 0 & 11.3527427 & 17.4910852 & 18.0655463 \\
\hline $\mathrm{H}$ & 4.4322331 & 18.4214893 & 26.7479882 \\
\hline $\mathrm{H}$ & 9.3217602 & 18.4301606 & 26.9263762 \\
\hline 0 & 6.8810660 & 17.5950817 & 23.1374227 \\
\hline $\mathrm{H}$ & 5.1539826 & 15.0714330 & 15.2511786 \\
\hline 0 & 12.1524836 & 19.2735893 & 20.2066642 \\
\hline 0 & 11.5909129 & 12.8317459 & 19.9366430 \\
\hline 0 & 17.5301347 & 15.9738299 & 20.1767279 \\
\hline 0 & 5.2299653 & 16.5781725 & 25.2575262 \\
\hline $\mathrm{H}$ & 8.7831980 & 15.0590299 & 29.7695567 \\
\hline 0 & 15.8452258 & 12.9352953 & 19.9113054 \\
\hline 0 & 15.7264050 & 19.2355912 & 19.9563751 \\
\hline 0 & 10.2188042 & 16.0942745 & 19.8280217 \\
\hline $\mathrm{O}$ & 8.6459007 & 16.9434517 & 24.8235438 \\
\hline $\mathrm{H}$ & 10.1978868 & 12.1418141 & 19.7641867 \\
\hline C & 9.1836951 & 10.7161207 & 20.9822430 \\
\hline $\mathrm{H}$ & 9.4219593 & 11.7556089 & 19.7249114 \\
\hline $\mathrm{H}$ & 10.0400806 & 10.0953902 & 20.6794808 \\
\hline $\mathrm{H}$ & 8.2075402 & 10.4973871 & 20.5225775 \\
\hline 0 & 9.1903796 & 11.3407944 & 22.0908156 \\
\hline $\mathrm{H}$ & 10.2908874 & 11.5025931 & 22.4743409 \\
\hline $\mathrm{H}$ & 5.1758902 & 15.0342724 & 29.9752365 \\
\hline & 16.1903994 & 19.7881072 & 22.4779253 \\
\hline \multicolumn{4}{|c|}{$\mathrm{Zn} 7$} \\
\hline \multicolumn{4}{|c|}{168} \\
\hline $\mathrm{H}$ & 8.6558186 & 9.0147481 & 15.3323770 \\
\hline Al & 5.3167711 & 9.3112600 & 16.6983528 \\
\hline $\mathrm{P}$ & 5.3139828 & 9.2458366 & 28.5258151 \\
\hline Al & 5.2076114 & 6.6442525 & 21.6454218 \\
\hline$P$ & 5.2577809 & 6.7297006 & 18.4906998 \\
\hline Al & 3.0898006 & 8.0386065 & 26.6567742 \\
\hline $\mathrm{P}$ & 3.1498239 & 8.1147074 & 23.5377085 \\
\hline Al & 8.4492102 & 9.2400423 & 28.5786183 \\
\hline $\mathrm{P}$ & 8.4668995 & 9.3736462 & 16.7650746 \\
\hline Al & 8.4193682 & 6.7784828 & 18.5592349 \\
\hline$P$ & 8.3932809 & 6.7095378 & 21.7231872 \\
\hline Al & 1.4559139 & 10.7690993 & 23.5463078 \\
\hline $\mathrm{P}$ & 1.4372450 & 10.7294328 & 26.7212903 \\
\hline 0 & 6.9929826 & 9.7364026 & 17.0354944 \\
\hline
\end{tabular}




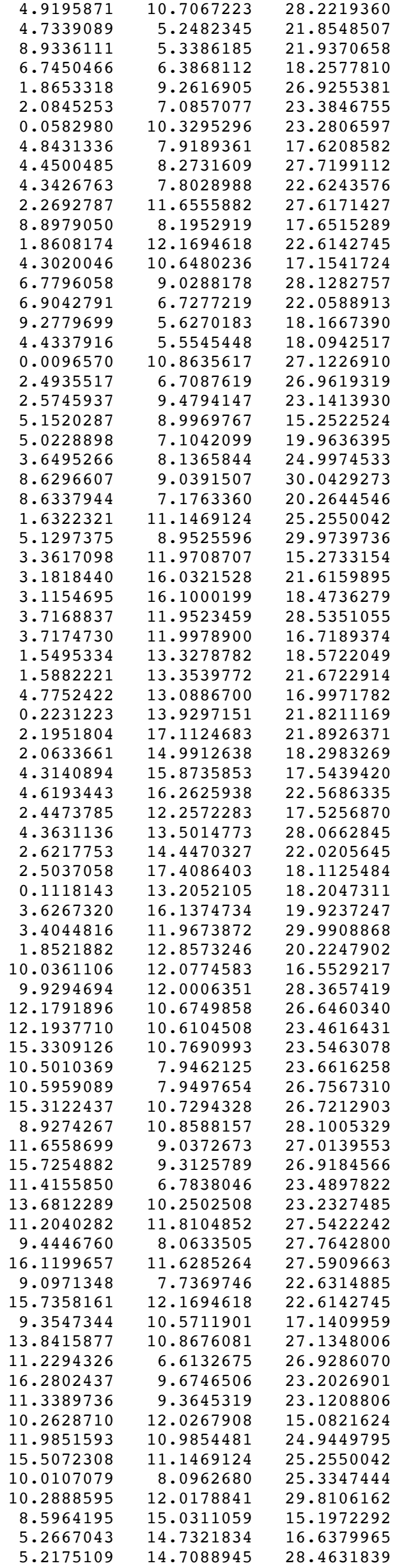

Al 12.1791896 


\begin{tabular}{|c|c|c|c|}
\hline Al & 12.1451107 & 18.6603538 & 21.6454218 \\
\hline $\mathrm{Zn}$ & 12.2793267 & 13.3212314 & 21.6111032 \\
\hline $\mathrm{Al}$ & 17.0568428 & 16.0321528 & 21.6159895 \\
\hline $\mathrm{P}$ & 16.9904682 & 16.1000199 & 18.4736279 \\
\hline $\mathrm{P}$ & 12.2399690 & 13.2604624 & 18.3837460 \\
\hline$P$ & 12.1952802 & 18.7458020 & 18.4906998 \\
\hline Al & 5.3111772 & 17.2112474 & 26.6301416 \\
\hline $\mathrm{P}$ & 5.2885009 & 17.2327596 & 23.5414313 \\
\hline $\mathrm{Al}$ & 8.3803018 & 14.7276315 & 28.4612636 \\
\hline $\mathrm{P}$ & 8.4201894 & 14.7678165 & 16.6521321 \\
\hline Al & 15.4245321 & 13.3278782 & 18.5722049 \\
\hline Al & 15.3568676 & 18.7945842 & 18.5592349 \\
\hline Al & 10.6390080 & 15.9985651 & 18.4865038 \\
\hline $\mathrm{P}$ & 10.4838495 & 15.9670077 & 21.6440826 \\
\hline $\mathrm{P}$ & 15.3307803 & 18.7256392 & 21.7231872 \\
\hline $\mathrm{P}$ & 15.4632209 & 13.3539772 & 21.6722914 \\
\hline Al & 8.4359467 & 17.4148630 & 23.5419736 \\
\hline $\mathrm{P}$ & 8.4681790 & 17.2825953 & 26.6707870 \\
\hline 0 & 8.8739813 & 13.3261745 & 16.9902616 \\
\hline 0 & 6.6919774 & 14.3912215 & 28.1505414 \\
\hline 0 & 11.5910573 & 17.0275387 & 21.8903747 \\
\hline 0 & 14.0676132 & 13.9425820 & 21.8244429 \\
\hline 0 & 15.8879505 & 17.3119935 & 21.9437316 \\
\hline 0 & 15.9383649 & 14.9912638 & 18.2983269 \\
\hline 0 & 11.8069810 & 14.7328021 & 18.1953697 \\
\hline 0 & 13.6825459 & 18.4029126 & 18.2577810 \\
\hline 0 & 6.9877815 & 17.6242790 & 26.9481522 \\
\hline $\mathrm{H}$ & 8.9042112 & 18.8215284 & 23.4036205 \\
\hline $\mathrm{H}$ & 4.6445226 & 18.5730823 & 23.4643099 \\
\hline $\mathrm{H}$ & 18.1541435 & 15.8801868 & 17.5710461 \\
\hline $\mathrm{H}$ & 11.7919114 & 19.9026902 & 17.6445179 \\
\hline 0 & 11.5674573 & 12.3778901 & 17.3077117 \\
\hline 0 & 4.7498536 & 15.9219004 & 27.6545893 \\
\hline $\mathrm{H}$ & 11.4075338 & 19.6483943 & 22.4802133 \\
\hline 0 & 11.7020717 & 11.7236569 & 22.5557212 \\
\hline $\mathrm{H}$ & 18.2870930 & 16.2293702 & 22.4312871 \\
\hline 0 & 8.9179755 & 16.1156149 & 27.5589400 \\
\hline $\mathrm{H}$ & 16.1903331 & 12.4146865 & 17.6795962 \\
\hline 0 & 9.2451910 & 15.7808147 & 17.4471676 \\
\hline $\mathrm{H}$ & 15.7641819 & 20.0005242 & 17.7866262 \\
\hline 0 & 9.2148896 & 16.3635039 & 22.4195357 \\
\hline 0 & 6.9500662 & 14.9137713 & 17.0662389 \\
\hline 0 & 9.2924510 & 13.3319755 & 27.9592182 \\
\hline 0 & 13.8417785 & 18.7438233 & 22.0588913 \\
\hline 0 & 10.9169980 & 14.5924454 & 22.1039631 \\
\hline $\mathrm{O}$ & 16.4967741 & 14.4470327 & 22.0205645 \\
\hline 0 & 16.3591986 & 17.4503652 & 18.1010355 \\
\hline 0 & 13.7510741 & 13.1850971 & 18.1444774 \\
\hline 0 & 11.3493138 & 17.5393027 & 18.0836778 \\
\hline $\mathrm{H}$ & 4.4507519 & 18.3983777 & 26.8899693 \\
\hline $\mathrm{H}$ & 9.3068089 & 18.4669305 & 27.0042094 \\
\hline 0 & 6.7506003 & 17.3836844 & 23.1360629 \\
\hline $\mathrm{H}$ & 5.0762530 & 14.9923296 & 15.1843209 \\
\hline 0 & 11.9603891 & 19.1203113 & 19.9636395 \\
\hline 0 & 11.8312785 & 12.7244328 & 19.7625016 \\
\hline $\mathrm{O}$ & 17.5017307 & 16.1374734 & 19.9237247 \\
\hline 0 & 5.1635495 & 16.6727064 & 24.9701495 \\
\hline $\mathrm{H}$ & 8.5688230 & 14.9927722 & 29.9142882 \\
\hline 0 & 15.7271869 & 12.8573246 & 20.2247902 \\
\hline 0 & 15.5712937 & 19.1924373 & 20.2644546 \\
\hline 0 & 10.0989634 & 15.9783150 & 20.1411148 \\
\hline 0 & 8.6643184 & 16.8801362 & 25.1977691 \\
\hline $\mathrm{H}$ & 11.1310297 & 11.0203336 & 19.7096609 \\
\hline C & 9.4072758 & 10.5842467 & 20.8449236 \\
\hline $\mathrm{H}$ & 10.7483489 & 10.3261652 & 19.6155335 \\
\hline $\mathrm{H}$ & 9.3122694 & 9.4986489 & 20.7220189 \\
\hline 0 & 8.4608350 & 11.2604725 & 20.3213513 \\
\hline $\mathrm{H}$ & 10.1129234 & 11.0363690 & 21.5645390 \\
\hline $\mathrm{C}$ & 8.4237362 & 12.7214191 & 20.4948485 \\
\hline $\mathrm{H}$ & 9.2075373 & 13.0500291 & 21.1899544 \\
\hline $\mathrm{H}$ & 8.5647051 & 13.1421889 & 19.4925795 \\
\hline $\mathrm{H}$ & 7.4180413 & 12.9481452 & 20.8657960 \\
\hline $\mathrm{H}$ & 5.0491837 & 15.0265236 & 29.9081401 \\
\hline & 16.0106874 & 19.7181201 & 22.6005859 \\
\hline \multicolumn{4}{|c|}{$\mathrm{Si} 7$} \\
\hline \multicolumn{4}{|c|}{168} \\
\hline $\mathrm{H}$ & 8.6228684 & 9.0300483 & 15.2205353 \\
\hline $\mathrm{P}$ & 5.2750450 & 9.3504933 & 16.7366354 \\
\hline Al & 5.2447746 & 9.2771324 & 28.5732924 \\
\hline
\end{tabular}




\begin{tabular}{|c|c|c|c|}
\hline $\mathrm{P}$ & 5.3047635 & 6.7206313 & 21.7089293 \\
\hline Al & 5.3479425 & 6.7674431 & 18.5480154 \\
\hline $\mathrm{P}$ & 3.0930076 & 7.9516244 & 26.7003947 \\
\hline Al & 3.1243340 & 7.9949628 & 23.5699110 \\
\hline $\mathrm{P}$ & 8.3994000 & 9.2305681 & 28.4911654 \\
\hline Al & 8.4350742 & 9.3253399 & 16.6678282 \\
\hline $\mathrm{P}$ & 8.5087681 & 6.7708430 & 18.5251590 \\
\hline Al & 8.4644859 & 6.6852785 & 21.6754182 \\
\hline $\mathrm{P}$ & 1.5486664 & 10.7394684 & 23.4901181 \\
\hline Al & 1.5325511 & 10.7154847 & 26.6359768 \\
\hline 0 & 6.7558245 & 9.7292903 & 16.9638308 \\
\hline 0 & 4.7789708 & 10.9310687 & 28.2171670 \\
\hline $\mathrm{H}$ & 4.8257776 & 5.3266859 & 21.9201382 \\
\hline $\mathrm{H}$ & 8.9784095 & 5.3062139 & 21.9016568 \\
\hline 0 & 7.0424651 & 6.3808675 & 18.2689210 \\
\hline 0 & 2.0335677 & 9.0536225 & 26.8904208 \\
\hline $\mathrm{H}$ & 2.0888556 & 6.9511469 & 23.3346375 \\
\hline $\mathrm{H}$ & 0.1292069 & 10.3431324 & 23.2775783 \\
\hline 0 & 4.8872513 & 8.1615015 & 17.6161083 \\
\hline 0 & 4.2722421 & 8.1628539 & 27.6572795 \\
\hline 0 & 4.5361381 & 7.7138620 & 22.5876511 \\
\hline 0 & 2.4661643 & 11.7824810 & 27.6503940 \\
\hline 0 & 8.9186652 & 7.9604923 & 17.6457871 \\
\hline 0 & 1.9519449 & 11.8943325 & 22.5738926 \\
\hline 0 & 4.4027801 & 10.5439056 & 17.1363492 \\
\hline 0 & 6.9188864 & 9.0415913 & 28.1512166 \\
\hline O & 6.7875108 & 6.7970493 & 22.1020001 \\
\hline $\mathrm{H}$ & 9.3856627 & 5.6133094 & 18.1960808 \\
\hline $\mathrm{H}$ & 4.5049475 & 5.6146645 & 18.1266113 \\
\hline $\mathrm{H}$ & 0.1013101 & 10.8239905 & 27.0320778 \\
\hline H & 2.4758054 & 6.6355114 & 27.0229294 \\
\hline 0 & 2.4492328 & 9.5418446 & 23.1565963 \\
\hline $\mathrm{H}$ & 5.0461484 & 8.9811401 & 15.3124496 \\
\hline 0 & 5.1270960 & 7.1447541 & 20.2388707 \\
\hline 0 & 3.6212988 & 7.9661212 & 25.2539238 \\
\hline $\mathrm{H}$ & 8.6465722 & 8.9877494 & 29.9392903 \\
\hline 0 & 8.7006515 & 7.1961419 & 20.0024584 \\
\hline O & 1.7595447 & 11.1646643 & 24.9602715 \\
\hline $\mathrm{H}$ & 5.0693855 & 9.0149854 & 30.0285032 \\
\hline $\mathrm{H}$ & 3.4002331 & 12.0571131 & 15.2032178 \\
\hline $\mathrm{P}$ & 3.1111195 & 15.9251645 & 21.7007133 \\
\hline Al & 3.1267832 & 16.0130980 & 18.5440647 \\
\hline $\mathrm{P}$ & 3.7278718 & 12.0308360 & 28.4795683 \\
\hline Al & 3.7163718 & 12.0747091 & 16.6581636 \\
\hline $\mathrm{P}$ & 1.4877103 & 13.3219498 & 18.4626384 \\
\hline Al & 1.4035842 & 13.2612056 & 21.6136927 \\
\hline 0 & 4.9014064 & 13.3240740 & 17.0184582 \\
\hline H & -0.0403244 & 13.5646126 & 21.8141737 \\
\hline $\mathrm{H}$ & 2.1625367 & 17.0496205 & 21.9307353 \\
\hline O & 1.9400208 & 14.7780752 & 18.1989118 \\
\hline 0 & 4.5560730 & 15.7712326 & 17.5683089 \\
\hline 0 & 4.3525654 & 16.0892247 & 22.5878277 \\
\hline $\mathrm{O}$ & 2.2510266 & 12.3592761 & 17.5402185 \\
\hline O & 4.3183794 & 13.3828279 & 28.0617275 \\
\hline 0 & 2.4308610 & 14.6144789 & 22.0703578 \\
\hline $\mathrm{H}$ & 2.5703696 & 17.3604086 & 18.2402907 \\
\hline $\mathrm{H}$ & 0.0407623 & 13.2195736 & 18.1265117 \\
\hline 0 & 3.5766968 & 15.9322656 & 20.2321922 \\
\hline $\mathrm{H}$ & 3.3574445 & 12.0533377 & 29.9215800 \\
\hline 0 & 1.7719271 & 12.9208934 & 19.9167966 \\
\hline $\mathrm{P}$ & 10.0217713 & 12.0104568 & 16.6587739 \\
\hline Al & 9.9646203 & 11.9464018 & 28.4497588 \\
\hline $\mathrm{P}$ & 12.2546568 & 10.7084246 & 26.7221425 \\
\hline Al & 12.2583937 & 10.7187986 & 23.5401519 \\
\hline $\mathrm{P}$ & 15.4236651 & 10.7394684 & 23.4901181 \\
\hline $\mathrm{P}$ & 10.5689380 & 8.0203827 & 23.5366085 \\
\hline Al & 10.6087320 & 8.0194159 & 26.6684127 \\
\hline Al & 15.4075498 & 10.7154847 & 26.6359768 \\
\hline $\mathrm{O}$ & 8.8152052 & 10.6650792 & 28.1061594 \\
\hline 0 & 11.8008727 & 9.2582233 & 26.9979401 \\
\hline H & 15.8328000 & 9.3049381 & 26.8519424 \\
\hline H & 11.4769411 & 6.8557570 & 23.3460886 \\
\hline $\mathrm{O}$ & 13.9529686 & 10.3288262 & 23.2699064 \\
\hline 0 & 11.4555875 & 11.6858630 & 27.5950091 \\
\hline 0 & 9.2095320 & 8.2061530 & 27.6901177 \\
\hline $\mathrm{H}$ & 16.2049661 & 11.6268259 & 27.5024092 \\
\hline 0 & 9.3313418 & 7.8778992 & 22.6253328 \\
\hline $\mathrm{O}$ & 15.8269436 & 11.8943325 & 22.5738926 \\
\hline 0 & 9.4331583 & 10.6768105 & 17.1604401 \\
\hline 0 & 13.7326279 & 10.8424645 & 27.0995174 \\
\hline
\end{tabular}




\begin{tabular}{|c|c|c|}
\hline 11.2114725 & 6.6862867 & 26.9451633 \\
\hline 16.2971818 & 9.5778168 & 23.1666141 \\
\hline 11.3013125 & 9.2949688 & 23.1188511 \\
\hline 10.2553859 & 11.9554884 & 15.1892423 \\
\hline 12.0283554 & 11.0633639 & 25.2472475 \\
\hline 15.6345434 & 11.1646643 & 24.9602715 \\
\hline 10.0886889 & 8.1117827 & 24.9944403 \\
\hline 10.2185936 & 11.9528891 & 29.9169248 \\
\hline 8.6961633 & 14.9876362 & 15.1258385 \\
\hline 5.3375909 & 14.7708395 & 16.7082474 \\
\hline 5.2978756 & 14.7388606 & 28.5442217 \\
\hline 12.2422628 & 18.7367327 & 21.7089293 \\
\hline 12.0647775 & 13.2306847 & 21.6364357 \\
\hline 16.9861182 & 15.9251645 & 21.7007133 \\
\hline 17.0017819 & 16.0130980 & 18.5440647 \\
\hline 12.1804699 & 13.3190691 & 18.4945172 \\
\hline 12.2854418 & 18.7835445 & 18.5480154 \\
\hline 5.2480618 & 17.2650769 & 26.6990937 \\
\hline 5.2106994 & 17.2327292 & 23.5758117 \\
\hline 8.4625021 & 14.6890008 & 28.4146196 \\
\hline 8.5020146 & 14.7626965 & 16.5848892 \\
\hline 15.3627090 & 13.3219498 & 18.4626384 \\
\hline 15.4462674 & 18.7869443 & 18.5251590 \\
\hline 10.6379336 & 16.1058918 & 18.4263037 \\
\hline 10.5667026 & 16.0357833 & 21.5914449 \\
\hline 15.4019853 & 18.7013799 & 21.6754182 \\
\hline 15.2785829 & 13.2612056 & 21.6136927 \\
\hline 8.3689488 & 17.3264713 & 23.4517404 \\
\hline 8.4020168 & 17.2540540 & 26.5943655 \\
\hline 9.0102613 & 13.1290502 & 17.0105155 \\
\hline 6.9731756 & 14.3540143 & 28.2115917 \\
\hline 11.7491351 & 17.3016317 & 21.9263740 \\
\hline 13.6233518 & 13.6090175 & 21.8435150 \\
\hline 16.0017020 & 17.0920977 & 21.9394245 \\
\hline 15.8150195 & 14.7780752 & 18.1989118 \\
\hline 11.6592011 & 14.9767734 & 18.2096167 \\
\hline 13.9799645 & 18.3969689 & 18.2689210 \\
\hline 6.7234588 & 17.6494595 & 26.9248209 \\
\hline 8.8282178 & 18.7345689 & 23.2985945 \\
\hline 4.6607625 & 18.6018219 & 23.3751246 \\
\hline 18.2197006 & 15.8070010 & 17.7126089 \\
\hline 11.8909778 & 19.9771988 & 17.7500755 \\
\hline 11.3560389 & 12.2539278 & 17.3575896 \\
\hline 4.8167576 & 16.1481258 & 27.6516747 \\
\hline 11.4955961 & 19.7015881 & 22.5625472 \\
\hline 11.6136014 & 11.9513941 & 22.5453989 \\
\hline 18.1906549 & 16.0843471 & 22.5614530 \\
\hline 8.8800365 & 15.8865684 & 27.5602116 \\
\hline 16.1025188 & 12.3889218 & 17.5686246 \\
\hline 9.4277510 & 15.9178666 & 17.4956618 \\
\hline 15.8438513 & 19.9408568 & 17.6722032 \\
\hline 9.1050941 & 16.3984356 & 22.4910440 \\
\hline 6.8268567 & 14.9145196 & 17.0461879 \\
\hline 9.2948753 & 13.4804694 & 27.9740812 \\
\hline 13.7250101 & 18.8131507 & 22.1020001 \\
\hline 11.1002554 & 14.4756199 & 22.0031709 \\
\hline 16.3058597 & 14.6144789 & 22.0703578 \\
\hline 16.3475954 & 17.5971578 & 18.1869116 \\
\hline 13.8785832 & 13.2169431 & 18.1178753 \\
\hline 11.3026977 & 17.4396618 & 18.0567522 \\
\hline 4.3953800 & 18.4522482 & 26.9831334 \\
\hline 9.2522291 & 18.4176169 & 26.9690400 \\
\hline 6.8781231 & 17.2628922 & 23.1039373 \\
\hline 5.0943688 & 15.0826491 & 15.2727202 \\
\hline 12.0645954 & 19.1608554 & 20.2388707 \\
\hline 11.7732059 & 12.7739329 & 20.0769110 \\
\hline 17.4516955 & 15.9322656 & 20.2321922 \\
\hline 5.0430855 & 16.7735943 & 25.2544683 \\
\hline 8.7206420 & 15.0150797 & 29.8443597 \\
\hline 15.6469258 & 12.9208934 & 19.9167966 \\
\hline 15.6381509 & 19.2122432 & 20.0024584 \\
\hline 10.1333584 & 16.1372046 & 19.8768873 \\
\hline 8.6009793 & 16.8534404 & 24.9021415 \\
\hline 11.1328998 & 10.9666587 & 19.8596887 \\
\hline 9.3419986 & 10.6100998 & 20.9190904 \\
\hline 10.8036773 & 10.2697529 & 19.6927145 \\
\hline 9.2802892 & 9.5218487 & 20.8159738 \\
\hline 8.4180805 & 11.2534122 & 20.3272377 \\
\hline 10.0290487 & 11.1032381 & 21.6335235 \\
\hline 8.3414206 & 12.7183978 & 20.4519331 \\
\hline
\end{tabular}




\begin{tabular}{|c|c|c|c|}
\hline $\mathrm{H}$ & 9.0768705 & 13.0811608 & 21.1816890 \\
\hline $\mathrm{H}$ & 8.5382899 & 13.1068253 & 19.4463082 \\
\hline $\mathrm{H}$ & 7.3096414 & 12.9318245 & 20.7519422 \\
\hline $\mathrm{H}$ & 5.1179133 & 15.0401601 & 29.9912714 \\
\hline $\mathrm{H}$ & 16.1379210 & 19.7138805 & 22.4818683 \\
\hline \multicolumn{4}{|c|}{$\begin{array}{l}\mathrm{Mg} 7 \\
168\end{array}$} \\
\hline $\mathrm{H}$ & 8.6618339 & 9.0145895 & 15.3391820 \\
\hline Al & 5.3249972 & 9.3246698 & 16.7016120 \\
\hline $\mathrm{P}$ & 5.3179679 & 9.2539141 & 28.5268468 \\
\hline Al & 5.2025128 & 6.6629967 & 21.6425661 \\
\hline $\mathrm{P}$ & 5.2804083 & 6.7287951 & 18.4797806 \\
\hline Al & 3.1007152 & 8.0283647 & 26.6542892 \\
\hline$P$ & 3.1758068 & 8.1103772 & 23.5360583 \\
\hline Al & 8.4526608 & 9.2345408 & 28.5851351 \\
\hline $\mathrm{P}$ & 8.4751564 & 9.3851483 & 16.7692024 \\
\hline Al & 8.4381797 & 6.7952041 & 18.5721696 \\
\hline $\mathrm{P}$ & 8.3943247 & 6.7183314 & 21.7282903 \\
\hline Al & 1.4655724 & 10.7791862 & 23.5519814 \\
\hline$P$ & 1.4384983 & 10.7321025 & 26.7171500 \\
\hline 0 & 7.0016955 & 9.7520240 & 17.0372651 \\
\hline 0 & 4.9278987 & 10.7140362 & 28.2139822 \\
\hline $\mathrm{H}$ & 4.6685841 & 5.2938259 & 21.8821748 \\
\hline $\mathrm{H}$ & 8.9623949 & 5.3561158 & 21.9252301 \\
\hline 0 & 6.7703080 & 6.3922203 & 18.2561909 \\
\hline 0 & 1.8814436 & 9.2640854 & 26.8784016 \\
\hline $\mathrm{H}$ & 2.1271606 & 7.0733210 & 23.3311774 \\
\hline $\mathrm{H}$ & 0.0698820 & 10.3372806 & 23.2801574 \\
\hline 0 & 4.8666820 & 7.9226588 & 17.6158003 \\
\hline 0 & 4.4513161 & 8.2788914 & 27.7261802 \\
\hline 0 & 4.3768650 & 7.8581767 & 22.6130493 \\
\hline 0 & 2.2708043 & 11.6441454 & 27.6262761 \\
\hline 0 & 8.9092552 & 8.2141185 & 17.6639547 \\
\hline 0 & 1.9338504 & 12.1376346 & 22.5850494 \\
\hline 0 & 4.3048553 & 10.6558122 & 17.1661214 \\
\hline 0 & 6.7831639 & 9.0307560 & 28.1318600 \\
\hline $\mathrm{O}$ & 6.9028215 & 6.6957567 & 22.0514325 \\
\hline $\mathrm{H}$ & 9.3094976 & 5.6468128 & 18.1991776 \\
\hline $\mathrm{H}$ & 4.4669219 & 5.5520974 & 18.0665698 \\
\hline $\mathrm{H}$ & 0.0152964 & 10.8429460 & 27.1406244 \\
\hline $\mathrm{H}$ & 2.4907653 & 6.7105733 & 26.9836938 \\
\hline 0 & 2.5838039 & 9.4796818 & 23.1952525 \\
\hline $\mathrm{H}$ & 5.1554386 & 9.0146853 & 15.2551404 \\
\hline 0 & 5.0342176 & 7.0948010 & 19.9527810 \\
\hline 0 & 3.6722168 & 8.0750025 & 24.9970929 \\
\hline $\mathrm{H}$ & 8.6352034 & 9.0379072 & 30.0497627 \\
\hline $\mathrm{O}$ & 8.6352561 & 7.2101772 & 20.2768691 \\
\hline 0 & 1.6083796 & 11.1884869 & 25.2590220 \\
\hline $\mathrm{H}$ & 5.1323273 & 8.9706185 & 29.9768129 \\
\hline $\mathrm{H}$ & 3.3781553 & 11.9737023 & 15.2762584 \\
\hline Al & 3.1863564 & 16.0245645 & 21.6231677 \\
\hline $\mathrm{P}$ & 3.1258909 & 16.1014827 & 18.4736115 \\
\hline Al & 3.7201858 & 11.9528846 & 28.5356461 \\
\hline $\mathrm{P}$ & 3.7199205 & 12.0047985 & 16.7251718 \\
\hline Al & 1.5554137 & 13.3502297 & 18.5658145 \\
\hline $\mathrm{P}$ & 1.5970638 & 13.3377411 & 21.6784232 \\
\hline 0 & 4.7745223 & 13.0973732 & 17.0112263 \\
\hline $\mathrm{H}$ & 0.1879882 & 13.7952507 & 21.8277942 \\
\hline $\mathrm{H}$ & 2.2203876 & 17.1274815 & 21.8831659 \\
\hline 0 & 2.0617212 & 15.0120384 & 18.2561204 \\
\hline 0 & 4.3275328 & 15.8874516 & 17.5439029 \\
\hline 0 & 4.6368539 & 16.2523749 & 22.5628531 \\
\hline 0 & 2.4419171 & 12.2653019 & 17.5194899 \\
\hline 0 & 4.3512009 & 13.5059881 & 28.0598870 \\
\hline 0 & 2.5697902 & 14.4738262 & 22.0692043 \\
\hline $\mathrm{H}$ & 2.5360147 & 17.4291786 & 18.1474365 \\
\hline $\mathrm{H}$ & 0.1145480 & 13.2367432 & 18.2078375 \\
\hline 0 & 3.6274022 & 16.0868257 & 19.9276721 \\
\hline $\mathrm{H}$ & 3.4192897 & 11.9697730 & 29.9938288 \\
\hline 0 & 1.9045784 & 12.9082494 & 20.2157988 \\
\hline Al & 10.0455479 & 12.0919210 & 16.5525638 \\
\hline $\mathrm{P}$ & 9.9373872 & 11.9987494 & 28.3656784 \\
\hline Al & 12.1849654 & 10.6438411 & 26.6720087 \\
\hline $\mathrm{P}$ & 12.1971177 & 10.5830334 & 23.4721868 \\
\hline Al & 15.3405711 & 10.7791862 & 23.5519814 \\
\hline Al & 10.4857119 & 7.9515737 & 23.6741371 \\
\hline $\mathrm{P}$ & 10.5903906 & 7.9486544 & 26.7672777 \\
\hline $\mathrm{P}$ & 15.3134971 & 10.7321025 & 26.7171500 \\
\hline $\mathrm{O}$ & 8.9390222 & 10.8515082 & 28.1096557 \\
\hline
\end{tabular}




\begin{tabular}{|c|c|c|}
\hline 11.6608045 & 9.0135534 & 27.0749577 \\
\hline 15.7412617 & 9.3143974 & 26.8728751 \\
\hline 11.3574645 & 6.7532193 & 23.5288274 \\
\hline 13.6914057 & 10.2570249 & 23.2307907 \\
\hline 11.2115585 & 11.8033721 & 27.5418654 \\
\hline 9.4345145 & 8.0439424 & 27.7722213 \\
\hline 16.1217462 & 11.6177839 & 27.5999989 \\
\hline 9.0707827 & 7.7493335 & 22.6547537 \\
\hline 15.8088491 & 12.1376346 & 22.5850494 \\
\hline 9.3630868 & 10.5850671 & 17.1372399 \\
\hline 13.8471111 & 10.8463093 & 27.1534739 \\
\hline 11.2041838 & 6.5976218 & 26.8901165 \\
\hline 16.2914197 & 9.6741987 & 23.2486496 \\
\hline 11.3640330 & 9.3316706 & 23.0917774 \\
\hline 10.2722981 & 12.0402163 & 15.0818390 \\
\hline 11.9814058 & 10.9051750 & 24.9659597 \\
\hline 15.4833783 & 11.1884869 & 25.2590220 \\
\hline 10.0169029 & 8.1577805 & 25.3478085 \\
\hline 10.2982442 & 12.0306609 & 29.8099376 \\
\hline 8.5872842 & 15.0266217 & 15.1802576 \\
\hline 5.2720596 & 14.7367855 & 16.6403813 \\
\hline 5.2157895 & 14.7050128 & 28.4600130 \\
\hline 12.1400121 & 18.6790980 & 21.6425661 \\
\hline 12.2235241 & 13.2863484 & 21.6246431 \\
\hline 17.0613551 & 16.0245645 & 21.6231677 \\
\hline 17.0008896 & 16.1014827 & 18.4736115 \\
\hline 12.2407463 & 13.2623305 & 18.4050639 \\
\hline 12.2179077 & 18.7448965 & 18.4797806 \\
\hline 5.3089485 & 17.2050756 & 26.6249230 \\
\hline 5.2789419 & 17.2277686 & 23.5504649 \\
\hline 8.3750571 & 14.7196360 & 28.4447118 \\
\hline 8.4234798 & 14.7782684 & 16.6392330 \\
\hline 15.4304124 & 13.3502297 & 18.5658145 \\
\hline 15.3756790 & 18.8113055 & 18.5721696 \\
\hline 10.6250894 & 16.0246211 & 18.4819047 \\
\hline 10.4351136 & 16.0069040 & 21.6189723 \\
\hline 15.3318241 & 18.7344328 & 21.7282903 \\
\hline 15.4720625 & 13.3377411 & 21.6784232 \\
\hline 8.4231846 & 17.4286823 & 23.5297737 \\
\hline 8.4587198 & 17.2940334 & 26.6726355 \\
\hline 8.8834438 & 13.3409967 & 16.9888713 \\
\hline 6.6865569 & 14.3790908 & 28.1364693 \\
\hline 11.5163252 & 17.0797571 & 21.9224552 \\
\hline 14.0397161 & 13.8028065 & 21.8302610 \\
\hline 15.9170319 & 17.3311217 & 21.9311714 \\
\hline 15.9367199 & 15.0120384 & 18.2561204 \\
\hline 11.7755676 & 14.7299374 & 18.2559761 \\
\hline 13.7078074 & 18.4083217 & 18.2561909 \\
\hline 6.9790587 & 17.6364297 & 26.9561733 \\
\hline 8.9397851 & 18.8141732 & 23.3546747 \\
\hline 4.5787485 & 18.5411424 & 23.5068863 \\
\hline 18.1670446 & 15.8937724 & 17.5713591 \\
\hline 11.8154436 & 19.9062612 & 17.6393193 \\
\hline 11.5718951 & 12.3927746 & 17.3158685 \\
\hline 4.7504025 & 15.9264181 & 27.6630513 \\
\hline 11.4362950 & 19.6977754 & 22.4697295 \\
\hline 11.7028533 & 11.7249447 & 22.6094308 \\
\hline 18.3003145 & 16.2191514 & 22.4258110 \\
\hline 8.9045431 & 16.1083330 & 27.5383828 \\
\hline 16.1852855 & 12.4263947 & 17.6748509 \\
\hline 9.2540947 & 15.8017648 & 17.4143674 \\
\hline 15.7766551 & 20.0190752 & 17.7991036 \\
\hline 9.1621109 & 16.3241285 & 22.4272580 \\
\hline 6.9564346 & 14.9218844 & 17.0646844 \\
\hline 9.2954827 & 13.3253886 & 27.9488175 \\
\hline 13.8403209 & 18.7118581 & 22.0514325 \\
\hline 10.9250147 & 14.6288877 & 21.9810421 \\
\hline 16.4447889 & 14.4738262 & 22.0692043 \\
\hline 16.3921855 & 17.4715565 & 18.1370255 \\
\hline 13.7515279 & 13.2179961 & 18.1487028 \\
\hline 11.3828625 & 17.5370142 & 18.0556190 \\
\hline 4.4284835 & 18.3836062 & 26.8550699 \\
\hline 9.3006206 & 18.4691403 & 27.0296333 \\
\hline 6.7317003 & 17.4503842 & 23.1408830 \\
\hline 5.0842188 & 14.9830236 & 15.1839462 \\
\hline 11.9717169 & 19.1109024 & 19.9527810 \\
\hline 11.8714368 & 12.7054399 & 19.7816183 \\
\hline 17.5024009 & 16.0868257 & 19.9276721 \\
\hline 5.1886377 & 16.6379745 & 24.9703977 \\
\hline 8.5599239 & 14.9873437 & 29.8977353 \\
\hline
\end{tabular}




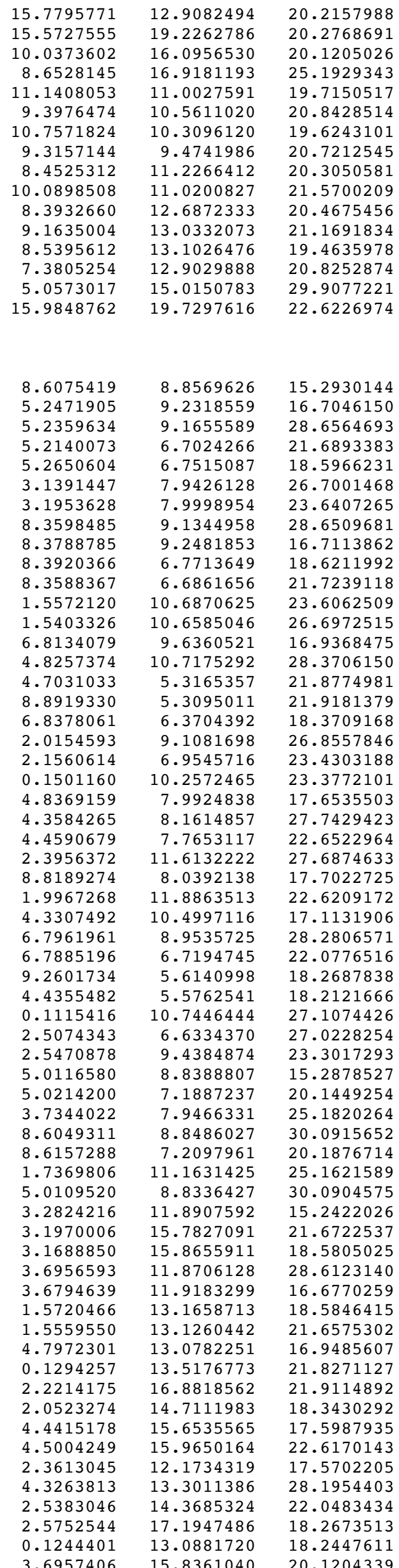




\begin{tabular}{|c|c|c|c|}
\hline $\mathrm{H}$ & 3.2837671 & 11.8867046 & 30.0431203 \\
\hline 0 & 1.8907232 & 12.6923514 & 20.1053067 \\
\hline $\mathrm{Si}$ & 9.9501948 & 11.9291551 & 16.6102443 \\
\hline $\mathrm{Si}$ & 9.8748750 & 11.8557820 & 28.5297491 \\
\hline $\mathrm{Si}$ & 12.0555625 & 10.6028188 & 26.7224183 \\
\hline $\mathrm{Si}$ & 12.0616290 & 10.5822670 & 23.5890432 \\
\hline $\mathrm{Si}$ & 15.1822107 & 10.6870625 & 23.6062509 \\
\hline $\mathrm{Si}$ & 10.3789599 & 7.9361759 & 23.6849991 \\
\hline $\mathrm{Si}$ & 10.4465680 & 7.9331445 & 26.7377108 \\
\hline $\mathrm{Si}$ & 15.1653314 & 10.6585046 & 26.6972515 \\
\hline 0 & 8.7939112 & 10.6609942 & 28.2822132 \\
\hline 0 & 11.5767205 & 9.0699472 & 27.0180573 \\
\hline $\mathrm{H}$ & 15.5995611 & 9.2416161 & 26.8421387 \\
\hline $\mathrm{H}$ & 11.2802207 & 6.7602247 & 23.5367143 \\
\hline 0 & 13.6401691 & 10.2160256 & 23.3552443 \\
\hline 0 & 11.1991139 & 11.6380696 & 27.6303871 \\
\hline 0 & 9.2152092 & 8.0702146 & 27.7815239 \\
\hline $\mathrm{H}$ & 15.9515995 & 11.5361616 & 27.6075377 \\
\hline 0 & 9.0953032 & 7.7704930 & 22.6923220 \\
\hline 0 & 15.6217256 & 11.8863513 & 22.6209172 \\
\hline 0 & 9.2962514 & 10.5257767 & 17.1138398 \\
\hline 0 & 13.6109246 & 10.7522176 & 27.1435056 \\
\hline $\mathrm{H}$ & 11.0624522 & 6.5915212 & 26.9322726 \\
\hline $\mathrm{H}$ & 16.0908079 & 9.5410077 & 23.3267335 \\
\hline 0 & 11.1777958 & 9.2559194 & 23.2165894 \\
\hline $\mathrm{H}$ & 10.2688545 & 11.8803619 & 15.1565608 \\
\hline O & 11.8277572 & 10.9646156 & 25.1600941 \\
\hline 0 & 15.3619793 & 11.1631425 & 25.1621589 \\
\hline 0 & 9.8548001 & 8.0753004 & 25.2202559 \\
\hline $\mathrm{H}$ & 10.2614655 & 11.8744475 & 29.9675669 \\
\hline H & 8.6276700 & 14.9372682 & 15.1667906 \\
\hline $\mathrm{Si}$ & 5.2521724 & 14.6153318 & 16.6571496 \\
\hline $\mathrm{Si}$ & 5.2155606 & 14.5849266 & 28.6129524 \\
\hline $\mathrm{Si}$ & 12.0265067 & 18.5020216 & 21.6893383 \\
\hline Al & 11.9955658 & 13.0960184 & 21.6519795 \\
\hline $\mathrm{Si}$ & 16.8219994 & 15.7827091 & 21.6722537 \\
\hline $\mathrm{Si}$ & 16.7938837 & 15.8655911 & 18.5805025 \\
\hline $\mathrm{Si}$ & 12.0427476 & 13.1305873 & 18.5312511 \\
\hline $\mathrm{Si}$ & 12.0775597 & 18.5511038 & 18.5966231 \\
\hline $\mathrm{Si}$ & 5.2352575 & 16.9934737 & 26.6818389 \\
\hline $\mathrm{Si}$ & 5.2094411 & 16.9926757 & 23.6411615 \\
\hline $\mathrm{Si}$ & 8.3581119 & 14.5712613 & 28.5481017 \\
\hline $\mathrm{Si}$ & 8.3938402 & 14.6332845 & 16.6055533 \\
\hline $\mathrm{Si}$ & 15.1970454 & 13.1658713 & 18.5846415 \\
\hline $\mathrm{Si}$ & 15.2045359 & 18.5709599 & 18.6211992 \\
\hline $\mathrm{Si}$ & 10.4628093 & 15.8705392 & 18.5420107 \\
\hline $\mathrm{Si}$ & 10.3574463 & 15.8282311 & 21.6279246 \\
\hline $\mathrm{Si}$ & 15.1713360 & 18.4857606 & 21.7239118 \\
\hline $\mathrm{Si}$ & 15.1809538 & 13.1260442 & 21.6575302 \\
\hline $\mathrm{Si}$ & 8.3345992 & 17.1337424 & 23.5777538 \\
\hline $\mathrm{Si}$ & 8.3569550 & 17.0398838 & 26.6631073 \\
\hline 0 & 8.8596618 & 13.1017042 & 16.9425125 \\
\hline $\mathrm{O}$ & 6.7809052 & 14.2260246 & 28.3557375 \\
\hline 0 & 11.4720553 & 16.9980031 & 21.8935360 \\
\hline 0 & 13.6540825 & 13.5452247 & 21.8390411 \\
\hline 0 & 15.7506445 & 16.9897580 & 21.9349747 \\
\hline 0 & 15.6773261 & 14.7111983 & 18.3430292 \\
\hline 0 & 11.5448151 & 14.6769044 & 18.3392086 \\
\hline 0 & 13.6503055 & 18.1700343 & 18.3709168 \\
\hline 0 & 6.7906361 & 17.4108451 & 26.9330504 \\
\hline $\mathrm{H}$ & 8.8280211 & 18.5302843 & 23.4250247 \\
\hline $\mathrm{H}$ & 4.5956775 & 18.3450345 & 23.5337354 \\
\hline $\mathrm{H}$ & 17.9627366 & 15.6708474 & 17.6788494 \\
\hline $\mathrm{H}$ & 11.6831577 & 19.6942765 & 17.7278747 \\
\hline 0 & 11.3234714 & 12.1800423 & 17.4134207 \\
\hline 0 & 4.7570808 & 15.8370254 & 27.7029075 \\
\hline $\mathrm{H}$ & 11.3329513 & 19.4784836 & 22.5739984 \\
\hline 0 & 11.5191452 & 11.7391388 & 22.6355495 \\
\hline $\mathrm{H}$ & 18.0199494 & 15.9502639 & 22.5405635 \\
\hline 0 & 8.8116940 & 15.8038179 & 27.6062268 \\
\hline H & 15.9207571 & 12.2558518 & 17.6544659 \\
\hline 0 & 9.2181572 & 15.6866351 & 17.5119605 \\
\hline $\mathrm{H}$ & 15.5961832 & 19.7341369 & 17.7781380 \\
\hline 0 & 9.0398804 & 16.1340641 & 22.5332036 \\
\hline 0 & 6.8283038 & 14.7582477 & 17.0007342 \\
\hline 0 & 9.2106741 & 13.2685088 & 28.1084110 \\
\hline 0 & 13.6010190 & 18.5190695 & 22.0776516 \\
\hline $\mathrm{O}$ & 10.9106402 & 14.3920655 & 22.0055045 \\
\hline 0 & 16.1633033 & 14.3685324 & 22.0483434 \\
\hline 0 & 16.1463056 & 17.3155389 & 18.2388929 \\
\hline
\end{tabular}




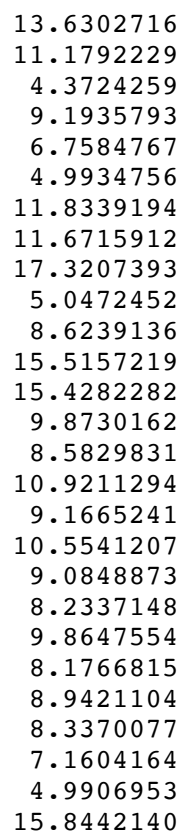

$\begin{array}{lrrr}\mathrm{H} & 8.5969707 & 9.0609125 & 15.2483975 \\ \mathrm{P} & 5.2900923 & 9.3836750 & 16.7752087 \\ \mathrm{Al} & 5.2424754 & 9.2934404 & 28.6044526 \\ \mathrm{P} & 5.2961826 & 6.6991178 & 21.7153873 \\ \mathrm{Al} & 5.3615646 & 6.7853977 & 18.5562740 \\ \mathrm{P} & 3.1015314 & 7.9639719 & 26.7112423 \\ \mathrm{Al} & 3.1728315 & 8.0505948 & 23.6085367 \\ \mathrm{P} & 8.3856267 & 9.2098760 & 28.5084777 \\ \mathrm{Al} & 8.4410894 & 9.3595314 & 16.6987934 \\ \mathrm{P} & 8.5245681 & 6.7890862 & 18.5399834 \\ \mathrm{Al} & 8.4658219 & 6.6583424 & 21.7048822 \\ \mathrm{P} & 1.5573607 & 10.7773143 & 23.5169202 \\ \mathrm{Al} & 1.5109549 & 10.7242621 & 26.6611928 \\ \mathrm{O} & 6.7669445 & 9.7698110 & 17.0183348 \\ \mathrm{O} & 4.7880828 & 10.9524783 & 28.2485429 \\ \mathrm{H} & 4.7774626 & 5.3169144 & 21.9092012 \\ \mathrm{H} & 9.0122577 & 5.2933272 & 21.9399613 \\ \mathrm{O} & 7.0575468 & 6.4098772 & 18.2759401 \\ \mathrm{O} & 2.0269172 & 9.0587159 & 26.8463713 \\ \mathrm{H} & 2.0891359 & 7.0544160 & 23.3841432 \\ \mathrm{H} & 0.1651280 & 10.3200757 & 23.2528338 \\ \mathrm{O} & 4.8984164 & 8.1937337 & 17.6501760 \\ \mathrm{O} & 4.2337995 & 8.1864194 & 27.7203822 \\ \mathrm{O} & 4.5550675 & 7.7084483 & 22.6016531 \\ \mathrm{O} & 2.4554946 & 11.7617370 & 27.6967252 \\ \mathrm{O} & 8.9319942 & 8.0081651 & 17.6976327 \\ \mathrm{O} & 1.9348562 & 11.9391340 & 22.5982921 \\ \mathrm{O} & 4.4071313 & 10.5705019 & 17.1686070 \\ \mathrm{O} & 6.9060980 & 9.0216174 & 28.1596611 \\ \mathrm{O} & 6.7806487 & 6.7240882 & 22.1073661 \\ \mathrm{H} & 9.3971815 & 5.6408055 & 18.1696894 \\ \mathrm{H} & 4.5252858 & 5.6395441 & 18.1037501 \\ \mathrm{H} & 0.0889186 & 10.8000377 & 27.0961541 \\ \mathrm{H} & 2.4799777 & 6.6449705 & 27.0129489 \\ \mathrm{O} & 2.5321663 & 9.6245469 & 23.2318988 \\ \mathrm{H} & 5.0757812 & 9.0145494 & 15.3486963 \\ \mathrm{O} & 5.1314328 & 7.1424783 & 20.2495728 \\ \mathrm{O} & 3.6928399 & 7.9777233 & 25.2876184 \\ \mathrm{H} & 8.6157905 & 9.0163725 & 29.9667992 \\ \mathrm{O} & 8.7212916 & 7.1655970 & 20.0307379 \\ \mathrm{O} & 1.6901061 & 11.2251735 & 24.9909726 \\ \mathrm{H} & 5.0946777 & 9.0458760 & 30.0652703 \\ \mathrm{H} & 3.4197218 & 12.0939471 & 15.2329735 \\ \mathrm{P} & 3.1779908 & 15.9460005 & 21.6831821 \\ \mathrm{Al} & 3.1678185 & 16.0595065 & 18.5525928 \\ \mathrm{P} & 3.7250233 & 12.0434836 & 28.5030260 \\ \mathrm{Al} & 3.7362387 & 12.1054572 & 16.6878979 \\ \mathrm{P} & 1.4704103 & 13.3518266 & 18.4687961 \\ \mathrm{Al} & 1.3935702 & 13.3023607 & 21.6287671 \\ \mathrm{O} & 4.9328737 & 13.3401498 & 17.0621918\end{array}$

18.2167821

18.1802682 26.9278421 27.0201298 23.2298526 15.2317392 20.1449254 19.9914627 25.1623687 29.9683231 20.1053067 20.1876714 20.0563045 25.1064748 19.8260646 20.9313418 19.6844859 20.8301264 20.3659087 21.6436764 20.4888590 21.1890363 19.4755813 20.8292135 30.0372206

22.6087068 20.1204339

14.9564319

19.4764642

5. 2483975 3. 6085367 21.7048822 17.0183348 .2485429 21.9399613 .2759401 23.3841432 .2528338 27.7203822 17.6976327 17.1686070 .1596611 8.1696894

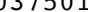
7.0129489 3.2318988 20.2495728 .2876184 20.0307379 .9909726 15.2329735 6831821 28.5030260

17.0621918 


\begin{tabular}{|c|c|c|c|}
\hline $\mathrm{H}$ & 0.0105022 & 13.7468239 & 21.9554107 \\
\hline $\mathrm{H}$ & 2.2048294 & 17.0361915 & 21.9687713 \\
\hline 0 & 1.9885608 & 14.7983850 & 18.3069620 \\
\hline 0 & 4.5707631 & 15.7985216 & 17.5480648 \\
\hline $\mathrm{O}$ & 4.4039320 & 16.0618994 & 22.5983589 \\
\hline $\mathrm{O}$ & 2.2797389 & 12.3973394 & 17.5796905 \\
\hline 0 & 4.2901734 & 13.3969328 & 28.0511147 \\
\hline $\mathrm{O}$ & 2.5285011 & 14.5983507 & 21.9514157 \\
\hline $\mathrm{H}$ & 2.5870295 & 17.3892232 & 18.2184395 \\
\hline $\mathrm{H}$ & 0.0560938 & 13.3181630 & 18.0043649 \\
\hline 0 & 3.6685403 & 16.0625186 & 20.2274320 \\
\hline $\mathrm{H}$ & 3.3761127 & 12.0904128 & 29.9498085 \\
\hline 0 & 1.5981217 & 12.8808549 & 19.9239278 \\
\hline$P$ & 10.0253996 & 12.0370010 & 16.6144739 \\
\hline Al & 9.9341082 & 11.9364625 & 28.4005750 \\
\hline $\mathrm{P}$ & 12.2520044 & 10.6656801 & 26.7558148 \\
\hline Al & 12.2822080 & 10.6179786 & 23.5499828 \\
\hline $\mathrm{P}$ & 15.4323594 & 10.7773143 & 23.5169202 \\
\hline $\mathrm{P}$ & 10.5062282 & 8.0026591 & 23.6056927 \\
\hline Al & 10.5745994 & 8.0225291 & 26.6896352 \\
\hline Al & 15.3859536 & 10.7242621 & 26.6611928 \\
\hline 0 & 8.8139183 & 10.6259314 & 28.0710469 \\
\hline $\mathrm{O}$ & 11.7784194 & 9.2329969 & 27.0888659 \\
\hline $\mathrm{H}$ & 15.8241025 & 9.3099007 & 26.8184441 \\
\hline $\mathrm{H}$ & 11.3028423 & 6.7461779 & 23.5441972 \\
\hline $\mathrm{O}$ & 13.9883206 & 10.3030615 & 23.2430069 \\
\hline $\mathrm{O}$ & 11.4311568 & 11.6907866 & 27.5513864 \\
\hline 0 & 9.1995432 & 8.1492872 & 27.7565607 \\
\hline $\mathrm{H}$ & 16.1924795 & 11.6101438 & 27.5454158 \\
\hline 0 & 9.2861992 & 7.8832030 & 22.6647570 \\
\hline $\mathrm{O}$ & 15.8098549 & 11.9391340 & 22.5982921 \\
\hline $\mathrm{O}$ & 9.4611259 & 10.7082317 & 17.1575329 \\
\hline $\mathrm{O}$ & 13.7198159 & 10.8130451 & 27.1708179 \\
\hline $\mathrm{H}$ & 11.1842207 & 6.6719793 & 26.8362559 \\
\hline $\mathrm{H}$ & 16.3771247 & 9.6600714 & 23.2406822 \\
\hline $\mathrm{O}$ & 11.3704250 & 9.1668483 & 23.1185790 \\
\hline $\mathrm{H}$ & 10.2078926 & 11.9572108 & 15.1388552 \\
\hline $\mathrm{O}$ & 12.0762918 & 10.9435182 & 25.2598778 \\
\hline 0 & 15.5651048 & 11.2251735 & 24.9909726 \\
\hline 0 & 10.0052538 & 8.2526119 & 25.0396821 \\
\hline $\mathrm{H}$ & 10.1725202 & 11.9524495 & 29.8702773 \\
\hline $\mathrm{H}$ & 8.6780312 & 14.9837101 & 15.0775418 \\
\hline $\mathrm{P}$ & 5.3592545 & 14.7816431 & 16.7147325 \\
\hline Al & 5.2829958 & 14.7436679 & 28.5398836 \\
\hline $\mathrm{P}$ & 12.2336819 & 18.7152192 & 21.7153873 \\
\hline $\mathrm{Ge}$ & 12.0361093 & 13.2576894 & 21.6650359 \\
\hline $\mathrm{P}$ & 17.0529895 & 15.9460005 & 21.6831821 \\
\hline Al & 17.0428172 & 16.0595065 & 18.5525928 \\
\hline Al & 12.2021284 & 13.3462889 & 18.4187591 \\
\hline Al & 12.2990639 & 18.8014991 & 18.5562740 \\
\hline $\mathrm{P}$ & 5.2543586 & 17.2483924 & 26.7058116 \\
\hline Al & 5.1936477 & 17.2002884 & 23.6418862 \\
\hline $\mathrm{P}$ & 8.4400782 & 14.6848976 & 28.3633821 \\
\hline Al & 8.5125845 & 14.7854835 & 16.5439845 \\
\hline $\mathrm{P}$ & 15.3454090 & 13.3518266 & 18.4687961 \\
\hline$P$ & 15.4620674 & 18.8051876 & 18.5399834 \\
\hline$P$ & 10.6315309 & 16.1455432 & 18.3927973 \\
\hline Al & 10.4520635 & 16.0933376 & 21.5515473 \\
\hline Al & 15.4033213 & 18.6744438 & 21.7048822 \\
\hline Al & 15.2685689 & 13.3023607 & 21.6287671 \\
\hline $\mathrm{P}$ & 8.3246841 & 17.4499634 & 23.4500488 \\
\hline Al & 8.3901454 & 17.2747141 & 26.5799397 \\
\hline 0 & 9.0184843 & 13.1545257 & 16.9826300 \\
\hline $\mathrm{O}$ & 6.9479642 & 14.3639844 & 28.1578475 \\
\hline 0 & 11.6993459 & 17.2914046 & 21.9150360 \\
\hline 0 & 13.6708374 & 13.8158083 & 22.0061085 \\
\hline 0 & 16.0423149 & 17.0782160 & 21.9797801 \\
\hline 0 & 15.8635595 & 14.7983850 & 18.3069620 \\
\hline 0 & 11.6476447 & 15.0042789 & 18.2352644 \\
\hline 0 & 13.9950461 & 18.4259785 & 18.2759401 \\
\hline 0 & 6.7166635 & 17.6732069 & 26.9552796 \\
\hline $\mathrm{H}$ & 8.8212400 & 18.8500473 & 23.3484716 \\
\hline $\mathrm{H}$ & 4.4993536 & 18.5147552 & 23.5567198 \\
\hline $\mathrm{H}$ & 18.2398607 & 15.8368247 & 17.6954929 \\
\hline $\mathrm{H}$ & 11.9021575 & 20.0084077 & 17.7797707 \\
\hline $\mathrm{O}$ & 11.3832076 & 12.3062780 & 17.2557624 \\
\hline 0 & 4.7994715 & 16.2001879 & 27.7245216 \\
\hline $\mathrm{H}$ & 11.5143551 & 19.6948761 & 22.5755976 \\
\hline $\mathrm{O}$ & 11.5385944 & 11.8297352 & 22.5910476 \\
\hline $\mathrm{H}$ & 18.2427762 & 16.0584814 & 22.571369 \\
\hline
\end{tabular}




\begin{tabular}{|c|c|c|}
\hline 8.8695896 & 15.8798087 & 27.5095451 \\
\hline 16.1304270 & 12.4260103 & 17.6063974 \\
\hline 9.4591927 & 15.9543146 & 17.4159710 \\
\hline 15.8568253 & 19.9863612 & 17.7238242 \\
\hline 9.0052623 & 16.5497984 & 22.4258734 \\
\hline 6.8481836 & 14.9471113 & 17.0424031 \\
\hline 9.2587593 & 13.4673117 & 27.9211354 \\
\hline 13.7181481 & 18.7401896 & 22.1073661 \\
\hline 10.8314245 & 14.4914363 & 22.0090083 \\
\hline 16.4034998 & 14.5983507 & 21.9514157 \\
\hline 16.3592068 & 17.6246329 & 18.1592818 \\
\hline 13.8933918 & 13.3172656 & 17.9919848 \\
\hline 11.3245468 & 17.4662337 & 18.0289470 \\
\hline 4.3693456 & 18.4363320 & 26.8563832 \\
\hline 9.2533456 & 18.4276407 & 26.9577840 \\
\hline 6.8268776 & 17.4561033 & 23.1327620 \\
\hline 5.1077186 & 15.0517440 & 15.2722015 \\
\hline 12.0689322 & 19.1585797 & 20.2495728 \\
\hline 11.8364148 & 12.6986741 & 19.9744593 \\
\hline 17.5435390 & 16.0625186 & 20.2274320 \\
\hline 5.1227191 & 16.6361701 & 25.2966065 \\
\hline 8.6975834 & 15.0066825 & 29.7942091 \\
\hline 15.4731204 & 12.8808549 & 19.9239278 \\
\hline 15.6587910 & 19.1816984 & 20.0307379 \\
\hline 10.0771030 & 16.2071648 & 19.8244871 \\
\hline 8.5695730 & 16.9069634 & 24.8749722 \\
\hline 11.2265448 & 10.8810506 & 19.7579406 \\
\hline 9.4245372 & 10.4641327 & 20.8348541 \\
\hline 10.9114853 & 10.1806500 & 19.5854373 \\
\hline 9.3984636 & 9.3776387 & 20.7042840 \\
\hline 8.4785637 & 11.0843159 & 20.2546611 \\
\hline 10.0997138 & 10.9683838 & 21.5565597 \\
\hline 8.3469631 & 12.5438082 & 20.3970976 \\
\hline 9.0513762 & 12.9281908 & 21.1466423 \\
\hline 8.5452188 & 12.9533025 & 19.3996793 \\
\hline 7.3022769 & 12.7131613 & 20.6798672 \\
\hline 5.1268432 & 15.0136702 & 29.9958492 \\
\hline 16.0977084 & 19.7111954 & 22.5173434 \\
\hline 8.5894432 & 8.8574103 & 15.3153984 \\
\hline 5.2521399 & 9.2494983 & 16.7317887 \\
\hline 5.2298987 & 9.1648724 & 28.6826037 \\
\hline 5.2106171 & 6.6751772 & 21.7109778 \\
\hline 5.2643854 & 6.7653715 & 18.6193274 \\
\hline 3.1308474 & 7.9493909 & 26.7149772 \\
\hline 3.2278738 & 8.0382262 & 23.6604154 \\
\hline 8.3483348 & 9.1168043 & 28.6678911 \\
\hline 8.3770773 & 9.2644297 & 16.7318576 \\
\hline 8.3866131 & 6.7748341 & 18.6315901 \\
\hline 8.3583657 & 6.6616009 & 21.7451611 \\
\hline 1.5670849 & 10.6996852 & 23.6204811 \\
\hline 1.5270828 & 10.6543389 & 26.7158764 \\
\hline 6.8155311 & 9.6655901 & 16.9638673 \\
\hline 4.8296263 & 10.7212350 & 28.4001331 \\
\hline 4.6561470 & 5.3038474 & 21.8816770 \\
\hline 8.9371005 & 5.3051834 & 21.9508751 \\
\hline 6.8325709 & 6.3766695 & 18.3756294 \\
\hline 1.9892335 & 9.0989510 & 26.8648089 \\
\hline 2.1693211 & 7.0116776 & 23.4535701 \\
\hline 0.1738086 & 10.2325872 & 23.3802288 \\
\hline 4.8416532 & 8.0190911 & 17.6916959 \\
\hline 4.3274841 & 8.1689692 & 27.7841285 \\
\hline 4.4926969 & 7.7570723 & 22.6841485 \\
\hline 2.3899255 & 11.5940268 & 27.7144880 \\
\hline 8.8116660 & 8.0634240 & 17.7375494 \\
\hline 1.9503739 & 11.9266987 & 22.6462433 \\
\hline 4.3280555 & 10.5140078 & 17.1292332 \\
\hline 6.7849045 & 8.9308468 & 28.2911261 \\
\hline 6.7864387 & 6.6303634 & 22.0920259 \\
\hline 9.2544822 & 5.6247941 & 18.2556486 \\
\hline 4.4198843 & 5.6019427 & 18.2315490 \\
\hline 0.0982467 & 10.7486700 & 27.1241039 \\
\hline 2.5079090 & 6.6296845 & 27.0106853 \\
\hline 2.6074055 & 9.4902856 & 23.3067260 \\
\hline 5.0216761 & 8.8444450 & 15.3175967 \\
\hline 5.0333307 & 7.1879559 & 20.1731309 \\
\hline 3.7533693 & 7.9867786 & 25.2072197 \\
\hline 8.5860174 & 8.8461258 & 30.1126612 \\
\hline
\end{tabular}




\begin{tabular}{|c|c|c|c|}
\hline 0 & 8.6099223 & 7.1819806 & 20.2063291 \\
\hline 0 & 1.7293045 & 11.1647572 & 25.1820921 \\
\hline $\mathrm{H}$ & 5.0200619 & 8.8377155 & 30.1199824 \\
\hline $\mathrm{H}$ & 3.2902725 & 11.9167298 & 15.2610345 \\
\hline $\mathrm{Si}$ & 3.2543603 & 15.7950062 & 21.6643153 \\
\hline $\mathrm{Si}$ & 3.1889002 & 15.8924466 & 18.5881012 \\
\hline $\mathrm{Si}$ & 3.6940338 & 11.8731777 & 28.6277717 \\
\hline $\mathrm{Si}$ & 3.6889982 & 11.9372826 & 16.6955086 \\
\hline $\mathrm{Si}$ & 1.5615984 & 13.1817728 & 18.5954487 \\
\hline $\mathrm{Si}$ & 1.5482003 & 13.1677316 & 21.6698478 \\
\hline 0 & 4.8157432 & 13.0877292 & 16.9709487 \\
\hline $\mathrm{H}$ & 0.1722172 & 13.6887957 & 21.8985036 \\
\hline $\mathrm{H}$ & 2.2720803 & 16.8791539 & 21.9415699 \\
\hline $\mathrm{O}$ & 2.0793192 & 14.7213968 & 18.4139605 \\
\hline $\mathrm{O}$ & 4.4417145 & 15.6695244 & 17.5853360 \\
\hline 0 & 4.5583560 & 15.9449076 & 22.6159225 \\
\hline 0 & 2.3777450 & 12.1969560 & 17.5968978 \\
\hline 0 & 4.3139722 & 13.3020912 & 28.1841844 \\
\hline $\mathrm{O}$ & 2.6199931 & 14.3550486 & 21.9805389 \\
\hline $\mathrm{H}$ & 2.5724162 & 17.2060565 & 18.2541891 \\
\hline $\mathrm{H}$ & 0.1294866 & 13.1354462 & 18.1904421 \\
\hline $\mathrm{O}$ & 3.7514508 & 15.9132910 & 20.1155077 \\
\hline $\mathrm{H}$ & 3.2907830 & 11.9112595 & 30.0606217 \\
\hline 0 & 1.7837174 & 12.6672855 & 20.1205036 \\
\hline $\mathrm{Si}$ & 9.9506715 & 11.9429370 & 16.5860344 \\
\hline $\mathrm{Si}$ & 9.8521823 & 11.8452835 & 28.5095392 \\
\hline $\mathrm{Si}$ & 12.0467058 & 10.5887956 & 26.7226856 \\
\hline $\mathrm{Si}$ & 12.0782192 & 10.5270759 & 23.5846673 \\
\hline $\mathrm{Si}$ & 15.1920836 & 10.6996852 & 23.6204811 \\
\hline $\mathrm{Si}$ & 10.3263131 & 7.9293405 & 23.7172378 \\
\hline $\mathrm{Si}$ & 10.4268415 & 7.9377834 & 26.7418697 \\
\hline $\mathrm{Si}$ & 15.1520815 & 10.6543389 & 26.7158764 \\
\hline 0 & 8.7781134 & 10.6404859 & 28.2806845 \\
\hline 0 & 11.5707374 & 9.0582319 & 27.0398159 \\
\hline $\mathrm{H}$ & 15.5744061 & 9.2329875 & 26.8519745 \\
\hline $\mathrm{H}$ & 11.1405293 & 6.6857005 & 23.6304517 \\
\hline 0 & 13.6641882 & 10.1874560 & 23.3570155 \\
\hline $\mathrm{O}$ & 11.1695046 & 11.6346637 & 27.5982190 \\
\hline $\mathrm{O}$ & 9.2188901 & 8.0454722 & 27.8187515 \\
\hline $\mathrm{H}$ & 15.9451003 & 11.5179843 & 27.6336772 \\
\hline 0 & 9.0522406 & 7.7861786 & 22.7054994 \\
\hline $\mathrm{O}$ & 15.5753726 & 11.9266987 & 22.6462433 \\
\hline $\mathrm{O}$ & 9.3082856 & 10.5404376 & 17.1105493 \\
\hline $\mathrm{O}$ & 13.5969139 & 10.7570103 & 27.1601977 \\
\hline $\mathrm{H}$ & 11.0432122 & 6.5878195 & 26.8635458 \\
\hline $\mathrm{H}$ & 16.1448447 & 9.5920759 & 23.3331335 \\
\hline 0 & 11.2218379 & 9.1776919 & 23.2237521 \\
\hline $\mathrm{H}$ & 10.2607134 & 11.8788539 & 15.1310815 \\
\hline $\mathrm{O}$ & 11.8407440 & 10.9222168 & 25.1515335 \\
\hline $\mathrm{O}$ & 15.3543033 & 11.1647572 & 25.1820921 \\
\hline 0 & 9.7998265 & 8.1499225 & 25.2442179 \\
\hline $\mathrm{H}$ & 10.2514347 & 11.8710238 & 29.9437831 \\
\hline $\mathrm{H}$ & 8.6227154 & 14.9474483 & 15.1396579 \\
\hline $\mathrm{Si}$ & 5.2575504 & 14.6243371 & 16.6564434 \\
\hline $\mathrm{Si}$ & 5.1978800 & 14.5892117 & 28.6079505 \\
\hline $\mathrm{Si}$ & 12.0231164 & 18.4747722 & 21.7109778 \\
\hline $\mathrm{Ga}$ & 11.9955835 & 13.1410045 & 21.6739497 \\
\hline $\mathrm{Si}$ & 16.8793591 & 15.7950062 & 21.6643153 \\
\hline $\mathrm{Si}$ & 16.8138989 & 15.8924466 & 18.5881012 \\
\hline $\mathrm{Si}$ & 12.0516426 & 13.1588328 & 18.4894492 \\
\hline $\mathrm{Si}$ & 12.0768848 & 18.5649665 & 18.6193274 \\
\hline $\mathrm{Si}$ & 5.2327753 & 16.9852015 & 26.6813107 \\
\hline $\mathrm{Si}$ & 5.1939583 & 16.9880663 & 23.6729877 \\
\hline $\mathrm{Si}$ & 8.3443698 & 14.5717367 & 28.5234170 \\
\hline $\mathrm{Si}$ & 8.3969280 & 14.6481882 & 16.5806937 \\
\hline $\mathrm{Si}$ & 15.1865971 & 13.1817728 & 18.5954487 \\
\hline $\mathrm{Si}$ & 15.1991125 & 18.5744291 & 18.6315901 \\
\hline $\mathrm{Si}$ & 10.4569814 & 15.8846714 & 18.5303068 \\
\hline $\mathrm{Si}$ & 10.2782849 & 15.8404116 & 21.6279691 \\
\hline $\mathrm{Si}$ & 15.1708651 & 18.4611960 & 21.7451611 \\
\hline $\mathrm{Si}$ & 15.1731990 & 13.1677316 & 21.6698478 \\
\hline $\mathrm{Si}$ & 8.2978080 & 17.2115293 & 23.5705934 \\
\hline $\mathrm{Si}$ & 8.3451475 & 17.0433267 & 26.6496921 \\
\hline 0 & 8.8566979 & 13.1137142 & 16.9150667 \\
\hline 0 & 6.7630264 & 14.2435833 & 28.3362740 \\
\hline $\mathrm{O}$ & 11.4207964 & 16.9850988 & 21.8964080 \\
\hline $\mathrm{O}$ & 13.6914636 & 13.7288425 & 21.9160771 \\
\hline 0 & 15.8002838 & 16.9859874 & 21.9688909 \\
\hline $\mathrm{O}$ & 15.7043180 & 14.7213968 & 18.413960 \\
\hline 0 & 11.5530465 & 14.7064636 & 18.3223729 \\
\hline
\end{tabular}




\begin{tabular}{|c|c|c|c|}
\hline 0 & 13.6450702 & 18.1762646 & 18.3756294 \\
\hline 0 & 6.7831081 & 17.4139018 & 26.9571474 \\
\hline $\mathrm{H}$ & 8.8374955 & 18.5936911 & 23.4461477 \\
\hline $\mathrm{H}$ & 4.4540607 & 18.2794180 & 23.6273485 \\
\hline $\mathrm{H}$ & 17.9653228 & 15.6875656 & 17.6664899 \\
\hline $\mathrm{H}$ & 11.6873419 & 19.7202548 & 17.7645257 \\
\hline $\mathrm{O}$ & 11.3322207 & 12.2153199 & 17.3665185 \\
\hline 0 & 4.7286814 & 15.8573294 & 27.7235715 \\
\hline $\mathrm{H}$ & 11.3643248 & 19.4675614 & 22.6039972 \\
\hline 0 & 11.4941767 & 11.6591965 & 22.6204258 \\
\hline $\mathrm{H}$ & 18.0769885 & 15.9326803 & 22.5383004 \\
\hline 0 & 8.8095943 & 15.7905805 & 27.5675409 \\
\hline $\mathrm{H}$ & 15.9355115 & 12.2780828 & 17.6791560 \\
\hline 0 & 9.2305323 & 15.7012337 & 17.4789335 \\
\hline $\mathrm{H}$ & 15.5886051 & 19.7552146 & 17.8123455 \\
\hline 0 & 8.9419663 & 16.2219409 & 22.4765220 \\
\hline $\mathrm{O}$ & 6.8346653 & 14.7833591 & 16.9862751 \\
\hline 0 & 9.1759885 & 13.2530312 & 28.0915101 \\
\hline 0 & 13.5989380 & 18.4299585 & 22.0920259 \\
\hline 0 & 10.7454116 & 14.3879626 & 22.0859736 \\
\hline 0 & 16.2449918 & 14.3550486 & 21.9805389 \\
\hline 0 & 16.1409517 & 17.3263689 & 18.2236064 \\
\hline 0 & 13.6363477 & 13.1316246 & 18.1570323 \\
\hline 0 & 11.1624255 & 17.3051597 & 18.1994256 \\
\hline $\mathrm{H}$ & 4.3555976 & 18.1752369 & 26.8587811 \\
\hline $\mathrm{H}$ & 9.1934196 & 18.2141534 & 27.0056694 \\
\hline 0 & 6.7170889 & 17.2934553 & 23.2552191 \\
\hline $\mathrm{H}$ & 4.9823078 & 14.9476749 & 15.2292732 \\
\hline 0 & 11.8458300 & 18.9875510 & 20.1731309 \\
\hline 0 & 11.6763268 & 12.5548646 & 19.9363171 \\
\hline 0 & 17.3764495 & 15.9132910 & 20.1155077 \\
\hline 0 & 5.0992495 & 16.3684220 & 25.1764063 \\
\hline $\mathrm{H}$ & 8.6174820 & 14.9399231 & 29.9400924 \\
\hline 0 & 15.4087161 & 12.6672855 & 20.1205036 \\
\hline 0 & 15.4224217 & 18.9815756 & 20.2063291 \\
\hline 0 & 9.8539241 & 15.8799965 & 20.0389831 \\
\hline 0 & 8.5482938 & 16.6444992 & 25.0822451 \\
\hline $\mathrm{H}$ & 11.0127760 & 10.7815166 & 19.7652212 \\
\hline $\mathrm{C}$ & 9.2521081 & 10.4190110 & 20.8683398 \\
\hline $\mathrm{H}$ & 10.6647882 & 10.0871479 & 19.6201768 \\
\hline $\mathrm{H}$ & 9.1899324 & 9.3311583 & 20.7595243 \\
\hline 0 & 8.3099392 & 11.0580106 & 20.2990374 \\
\hline $\mathrm{H}$ & 9.9427741 & 10.9071647 & 21.5820220 \\
\hline C & 8.2166549 & 12.5202102 & 20.4309290 \\
\hline $\mathrm{H}$ & 8.9498052 & 12.8919008 & 21.1585910 \\
\hline $\mathrm{H}$ & 8.3985491 & 12.9194458 & 19.4263998 \\
\hline $\mathrm{H}$ & 7.1847503 & 12.7196010 & 20.7401645 \\
\hline $\mathrm{H}$ & 4.9777021 & 14.9442640 & 30.0371392 \\
\hline & 15.8033518 & 19.4862806 & 22.6205368 \\
\hline \multirow{2}{*}{\multicolumn{4}{|c|}{ Ti 7}} \\
\hline & & & \\
\hline $\mathrm{H}$ & 8.5898364 & 9.0822571 & 15.2537691 \\
\hline $\mathrm{P}$ & 5.3012161 & 9.4122280 & 16.7951858 \\
\hline Al & 5.2370314 & 9.2948665 & 28.6160409 \\
\hline $\mathrm{P}$ & 5.2883696 & 6.7257799 & 21.7253211 \\
\hline Al & 5.3662283 & 6.8044704 & 18.5702763 \\
\hline $\mathrm{P}$ & 3.1075624 & 7.9594772 & 26.7236583 \\
\hline Al & 3.2299948 & 8.0883120 & 23.6383228 \\
\hline $\mathrm{P}$ & 8.3758644 & 9.1965268 & 28.5086749 \\
\hline Al & 8.4501420 & 9.3827132 & 16.7054344 \\
\hline $\mathrm{P}$ & 8.5243949 & 6.8072705 & 18.5502335 \\
\hline Al & 8.4646639 & 6.6571114 & 21.7118038 \\
\hline $\mathrm{P}$ & 1.5644801 & 10.7913474 & 23.5412389 \\
\hline Al & 1.4967002 & 10.7233190 & 26.6805453 \\
\hline $\mathrm{O}$ & 6.7782316 & 9.8001708 & 17.0361395 \\
\hline 0 & 4.7881650 & 10.9478650 & 28.2232905 \\
\hline $\mathrm{H}$ & 4.6688432 & 5.3853460 & 21.9164878 \\
\hline $\mathrm{H}$ & 9.0606049 & 5.3085357 & 21.9199347 \\
\hline 0 & 7.0604087 & 6.4175916 & 18.2836177 \\
\hline 0 & 2.0374865 & 9.0618976 & 26.8207951 \\
\hline $\mathrm{H}$ & 2.1418098 & 7.1041488 & 23.3845573 \\
\hline $\mathrm{H}$ & 0.1954618 & 10.2932340 & 23.2333549 \\
\hline 0 & 4.9144072 & 8.2128133 & 17.6591473 \\
\hline 0 & 4.2104353 & 8.1760127 & 27.7664763 \\
\hline $\mathrm{O}$ & 4.6174038 & 7.7768745 & 22.6225394 \\
\hline 0 & 2.4449351 & 11.7553303 & 27.7181508 \\
\hline 0 & 8.9295701 & 8.0271255 & 17.7071686 \\
\hline 0 & 1.9483793 & 11.9517351 & 22.6239348 \\
\hline 0 & 4.4146700 & 10.5928980 & 17.2012274 \\
\hline
\end{tabular}




\begin{tabular}{|c|c|c|c|}
\hline 0 & 6.8955345 & 9.0025891 & 28.1653131 \\
\hline 0 & 6.7746816 & 6.6414821 & 22.1066942 \\
\hline $\mathrm{H}$ & 9.4070464 & 5.6635793 & 18.1896542 \\
\hline $\mathrm{H}$ & 4.5165955 & 5.6636182 & 18.1301617 \\
\hline $\mathrm{H}$ & 0.0837651 & 10.7661743 & 27.1484112 \\
\hline $\mathrm{H}$ & 2.4680000 & 6.6458163 & 27.0106696 \\
\hline 0 & 2.5852005 & 9.6681103 & 23.3043978 \\
\hline $\mathrm{H}$ & 5.0825584 & 9.0555149 & 15.3661773 \\
\hline 0 & 5.1498304 & 7.1858281 & 20.2615701 \\
\hline 0 & 3.7410082 & 7.9652521 & 25.3173738 \\
\hline $\mathrm{H}$ & 8.6059185 & 9.0361564 & 29.9710281 \\
\hline $\mathrm{O}$ & 8.7116000 & 7.1906531 & 20.0420579 \\
\hline 0 & 1.6308853 & 11.2563407 & 25.0150603 \\
\hline $\mathrm{H}$ & 5.0994786 & 9.0812475 & 30.0832037 \\
\hline $\mathrm{H}$ & 3.4526892 & 12.0951399 & 15.2343663 \\
\hline $\mathrm{P}$ & 3.2178886 & 15.9464426 & 21.6725429 \\
\hline Al & 3.1622415 & 16.0652668 & 18.5314384 \\
\hline $\mathrm{P}$ & 3.7308028 & 12.0399282 & 28.4976439 \\
\hline Al & 3.7423703 & 12.1204904 & 16.6946960 \\
\hline $\mathrm{P}$ & 1.4879121 & 13.3690292 & 18.4737754 \\
\hline Al & 1.4536766 & 13.3128399 & 21.6302817 \\
\hline 0 & 4.9342374 & 13.3573063 & 17.0821096 \\
\hline $\mathrm{H}$ & 0.0371700 & 13.7015755 & 21.8742370 \\
\hline $\mathrm{H}$ & 2.2605923 & 17.0539582 & 21.9447810 \\
\hline 0 & 1.9643881 & 14.8248090 & 18.2555246 \\
\hline 0 & 4.5694936 & 15.8212035 & 17.5246134 \\
\hline 0 & 4.4757086 & 16.0773847 & 22.5447898 \\
\hline 0 & 2.2625910 & 12.4197842 & 17.5468326 \\
\hline 0 & 4.2857903 & 13.3931608 & 28.0319927 \\
\hline 0 & 2.5625862 & 14.6164956 & 22.0114365 \\
\hline $\mathrm{H}$ & 2.5949639 & 17.4091402 & 18.2325722 \\
\hline $\mathrm{H}$ & 0.0487790 & 13.2951660 & 18.0988612 \\
\hline 0 & 3.6692842 & 16.0068444 & 20.2024052 \\
\hline $\mathrm{H}$ & 3.4127478 & 12.0891598 & 29.9514450 \\
\hline 0 & 1.7265771 & 12.9249680 & 19.9243869 \\
\hline$P$ & 10.0309259 & 12.0526574 & 16.5780656 \\
\hline Al & 9.9153300 & 11.9247515 & 28.3599034 \\
\hline $\mathrm{P}$ & 12.2561708 & 10.6132573 & 26.7816063 \\
\hline $\mathrm{Al}$ & 12.3034318 & 10.5181796 & 23.5593310 \\
\hline$P$ & 15.4394788 & 10.7913474 & 23.5412389 \\
\hline$P$ & 10.4608193 & 7.9770252 & 23.6395748 \\
\hline $\mathrm{Al}$ & 10.5544087 & 8.0090267 & 26.6998613 \\
\hline $\mathrm{Al}$ & 15.3716989 & 10.7233190 & 26.6805453 \\
\hline 0 & 8.8058182 & 10.6015795 & 28.0365573 \\
\hline 0 & 11.7664602 & 9.1949448 & 27.1530141 \\
\hline $\mathrm{H}$ & 15.8310858 & 9.3119756 & 26.7996846 \\
\hline $\mathrm{H}$ & 11.1352613 & 6.6495461 & 23.6464802 \\
\hline $\mathrm{O}$ & 14.0187769 & 10.2744291 & 23.2217316 \\
\hline 0 & 11.4150024 & 11.6705763 & 27.5143422 \\
\hline 0 & 9.1872294 & 8.1155205 & 27.7810776 \\
\hline $\mathrm{H}$ & 16.1813821 & 11.6045375 & 27.5665406 \\
\hline 0 & 9.2436839 & 7.9077947 & 22.6852999 \\
\hline 0 & 15.8233780 & 11.9517351 & 22.6239348 \\
\hline 0 & 9.4879339 & 10.7253216 & 17.1499626 \\
\hline 0 & 13.7139054 & 10.7736011 & 27.2294913 \\
\hline $\mathrm{H}$ & 11.1597071 & 6.6510025 & 26.7805138 \\
\hline $\mathrm{H}$ & 16.4288970 & 9.7025563 & 23.3116609 \\
\hline 0 & 11.4333080 & 9.0405133 & 23.1209994 \\
\hline $\mathrm{H}$ & 10.1696964 & 11.9543427 & 15.0988099 \\
\hline 0 & 12.1256124 & 10.8299902 & 25.2726870 \\
\hline 0 & 15.5058840 & 11.2563407 & 25.0150603 \\
\hline 0 & 9.9753740 & 8.3228509 & 25.0609271 \\
\hline $\mathrm{H}$ & 10.1362729 & 11.9479725 & 29.8322368 \\
\hline $\mathrm{H}$ & 8.6761404 & 14.9801535 & 15.0500091 \\
\hline $\mathrm{P}$ & 5.3617560 & 14.7922715 & 16.7083098 \\
\hline Al & 5.2761084 & 14.7399854 & 28.5273266 \\
\hline $\mathrm{P}$ & 12.2258690 & 18.7418812 & 21.7253211 \\
\hline $\mathrm{Ti}$ & 11.9693465 & 13.2483561 & 21.6888513 \\
\hline $\mathrm{P}$ & 17.0928874 & 15.9464426 & 21.6725429 \\
\hline $\mathrm{Al}$ & 17.0372402 & 16.0652668 & 18.5314384 \\
\hline $\mathrm{Al}$ & 12.1729476 & 13.3540119 & 18.3980461 \\
\hline $\mathrm{Al}$ & 12.3037276 & 18.8205718 & 18.5702763 \\
\hline $\mathrm{P}$ & 5.2473843 & 17.2308296 & 26.6928121 \\
\hline Al & 5.1796395 & 17.2024400 & 23.6610990 \\
\hline $\mathrm{P}$ & 8.4327435 & 14.6816199 & 28.3312229 \\
\hline Al & 8.5168667 & 14.7975086 & 16.5191563 \\
\hline $\mathrm{P}$ & 15.3629108 & 13.3690292 & 18.4737754 \\
\hline$P$ & 15.4618943 & 18.8233718 & 18.5502335 \\
\hline$P$ & 10.6251845 & 16.1572799 & 18.3816828 \\
\hline Al & 10.3533058 & 16.1572821 & 21.5471340 \\
\hline
\end{tabular}




\begin{tabular}{|c|c|c|c|}
\hline Al & 15.4021632 & 18.6732128 & 21.7118038 \\
\hline Al & 15.3286754 & 13.3128399 & 21.6302817 \\
\hline $\mathrm{P}$ & 8.2882500 & 17.5404457 & 23.4413676 \\
\hline Al & 8.3740988 & 17.2828787 & 26.5631044 \\
\hline 0 & 9.0274966 & 13.1685565 & 16.9637371 \\
\hline $\mathrm{O}$ & 6.9385768 & 14.3678462 & 28.1302616 \\
\hline $\mathrm{O}$ & 11.5885415 & 17.3629321 & 21.9219807 \\
\hline $\mathrm{O}$ & 13.6918135 & 13.7620482 & 21.9121872 \\
\hline $\mathrm{O}$ & 16.0990230 & 17.0962645 & 21.9551803 \\
\hline 0 & 15.8393869 & 14.8248090 & 18.2555246 \\
\hline $\mathrm{O}$ & 11.6536956 & 15.0276612 & 18.2170738 \\
\hline $\mathrm{O}$ & 13.9979080 & 18.4336929 & 18.2836177 \\
\hline 0 & 6.7017301 & 17.6767706 & 26.9575612 \\
\hline $\mathrm{H}$ & 8.8725248 & 18.9065428 & 23.3437855 \\
\hline $\mathrm{H}$ & 4.3471195 & 18.4368937 & 23.6486438 \\
\hline $\mathrm{H}$ & 18.2363499 & 15.8573022 & 17.6735298 \\
\hline $\mathrm{H}$ & 11.9164511 & 20.0277267 & 17.7893061 \\
\hline 0 & 11.4077403 & 12.3447865 & 17.1697136 \\
\hline O & 4.7836285 & 16.2055523 & 27.7310840 \\
\hline $\mathrm{H}$ & 11.5755305 & 19.7606623 & 22.5949564 \\
\hline $\mathrm{O}$ & 11.5255263 & 11.7470553 & 22.6427594 \\
\hline $\mathrm{H}$ & 18.3120189 & 16.0733572 & 22.5179609 \\
\hline 0 & 8.8609589 & 15.8751810 & 27.4729288 \\
\hline $\mathrm{H}$ & 16.1137071 & 12.4490487 & 17.5754095 \\
\hline 0 & 9.4712996 & 15.9718324 & 17.3799803 \\
\hline $\mathrm{H}$ & 15.8543659 & 20.0049804 & 17.7336014 \\
\hline $\mathrm{O}$ & 8.8738821 & 16.6235888 & 22.3697989 \\
\hline $\mathrm{O}$ & 6.8527809 & 14.9646354 & 17.0261437 \\
\hline 0 & 9.2440971 & 13.4601409 & 27.8829720 \\
\hline 0 & 13.7121809 & 18.6575835 & 22.1066942 \\
\hline $\mathrm{O}$ & 10.7913172 & 14.5806660 & 22.0515826 \\
\hline $\mathrm{O}$ & 16.4375849 & 14.6164956 & 22.0114365 \\
\hline 0 & 16.3693030 & 17.6476016 & 18.1795404 \\
\hline O & 13.8872714 & 13.2932924 & 18.0893508 \\
\hline O & 11.3137122 & 17.4912195 & 18.0574427 \\
\hline $\mathrm{H}$ & 4.3458959 & 18.4118269 & 26.7912233 \\
\hline $\mathrm{H}$ & 9.2402420 & 18.4295790 & 26.9529696 \\
\hline 0 & 6.7816199 & 17.6585834 & 23.1857204 \\
\hline $\mathrm{H}$ & 5.1072010 & 15.0350215 & 15.2614529 \\
\hline 0 & 12.0873298 & 19.2019295 & 20.2615701 \\
\hline 0 & 11.7049689 & 12.7284831 & 19.9382761 \\
\hline 0 & 17.5442830 & 16.0068444 & 20.2024052 \\
\hline 0 & 5.1555433 & 16.5762604 & 25.2970102 \\
\hline $\mathrm{H}$ & 8.6946742 & 15.0007520 & 29.7618408 \\
\hline 0 & 15.6015758 & 12.9249680 & 19.9243869 \\
\hline $\mathrm{O}$ & 15.6490993 & 19.2067545 & 20.0420579 \\
\hline 0 & 10.0420751 & 16.1935371 & 19.8039590 \\
\hline 0 & 8.5457847 & 16.9508995 & 24.8468094 \\
\hline $\mathrm{H}$ & 11.2875193 & 10.8633619 & 19.7560033 \\
\hline $\mathrm{C}$ & 9.4472301 & 10.3961450 & 20.8124374 \\
\hline $\mathrm{H}$ & 11.0538949 & 10.1260887 & 19.6219567 \\
\hline $\mathrm{H}$ & 9.4438460 & 9.3173556 & 20.6282147 \\
\hline 0 & 8.5309371 & 11.0327769 & 20.2067462 \\
\hline $\mathrm{H}$ & 10.0894757 & 10.8796800 & 21.5762809 \\
\hline C & 8.3705358 & 12.4830560 & 20.3992541 \\
\hline $\mathrm{H}$ & 8.9921124 & 12.8354059 & 21.2320908 \\
\hline $\mathrm{H}$ & 8.6680597 & 12.9406728 & 19.4487927 \\
\hline $\mathrm{H}$ & 7.3005816 & 12.6311937 & 20.5808066 \\
\hline $\mathrm{H}$ & 5.1252338 & 14.9983085 & 29.9859652 \\
\hline $\mathrm{H}$ & 16.0589906 & 19.7277209 & 22.5326028 \\
\hline \multicolumn{4}{|c|}{$\mathrm{Zn} 8$} \\
\hline \multicolumn{4}{|c|}{177} \\
\hline $\mathrm{H}$ & 8.5660383 & 8.8151260 & 14.9835733 \\
\hline Al & 5.3185619 & 9.2522958 & 16.3583139 \\
\hline $\mathrm{P}$ & 5.3122275 & 9.2047246 & 28.1771648 \\
\hline Al & 5.2209949 & 6.6344296 & 21.3218022 \\
\hline $\mathrm{P}$ & 5.2335468 & 6.6768221 & 18.1634087 \\
\hline Al & 3.0857769 & 7.9855198 & 26.3282392 \\
\hline $\mathrm{P}$ & 3.1843818 & 8.0922569 & 23.2033903 \\
\hline$A 1$ & 8.4311353 & 9.1699428 & 28.2494174 \\
\hline $\mathrm{P}$ & 8.4445654 & 9.2647197 & 16.3978683 \\
\hline Al & 8.3839409 & 6.6823301 & 18.2024625 \\
\hline $\mathrm{P}$ & 8.3971509 & 6.6264324 & 21.3986844 \\
\hline Al & 1.4567777 & 10.7265847 & 23.2391992 \\
\hline $\mathrm{P}$ & 1.4320020 & 10.6812232 & 26.4029271 \\
\hline 0 & 6.9897973 & 9.6838200 & 16.6985777 \\
\hline O & 4.8971333 & 10.6608625 & 27.8791261 \\
\hline $\mathrm{H}$ & 4.6939664 & 5.2626205 & 21.5615962 \\
\hline $\mathrm{H}$ & 8.9419326 & 5.2719454 & 21.6914277 \\
\hline
\end{tabular}




\begin{tabular}{|c|c|c|}
\hline 6.7056216 & 6.2937836 & 17.9021389 \\
\hline 1.8652590 & 9.2127379 & 26.5939796 \\
\hline 2.1430486 & 7.0465125 & 23.0054902 \\
\hline 0.0721379 & 10.2268293 & 23.0152849 \\
\hline 4.8298312 & 7.8620725 & 17.2810684 \\
\hline 4.4449133 & 8.2207411 & 27.3878750 \\
\hline 4.3997081 & 7.8304224 & 22.3019628 \\
\hline 2.2495586 & 11.6076916 & 27.3087269 \\
\hline 8.8636080 & 8.1117860 & 17.3205054 \\
\hline 1.8091516 & 12.1382023 & 22.3049850 \\
\hline 4.2920022 & 10.5836370 & 16.8034066 \\
\hline 6.7704378 & 9.0121378 & 27.7391123 \\
\hline 6.9123312 & 6.6693845 & 21.7586563 \\
\hline 9.2365761 & 5.5402273 & 17.7714926 \\
\hline 4.3643671 & 5.5197086 & 17.8130723 \\
\hline 0.0019398 & 10.8009589 & 26.8000495 \\
\hline 2.4940088 & 6.6529592 & 26.6302547 \\
\hline 2.5997045 & 9.4595729 & 22.8304006 \\
\hline 5.1760399 & 8.9489483 & 14.9075250 \\
\hline 5.0473900 & 7.0843954 & 19.6373265 \\
\hline 3.6566138 & 8.0842698 & 24.6718653 \\
\hline 8.5495611 & 8.8546860 & 29.6998343 \\
\hline 8.6104100 & 6.9943770 & 19.9169022 \\
\hline 1.6391987 & 11.1165507 & 24.9436260 \\
\hline 5.1562798 & 8.9058475 & 29.6275004 \\
\hline 3.3426485 & 11.9248339 & 14.9403683 \\
\hline 3.1890073 & 15.9836042 & 21.2904452 \\
\hline 3.0814951 & 16.0339814 & 18.1244334 \\
\hline 3.7062790 & 11.9115505 & 28.2069830 \\
\hline 3.7043689 & 11.9365023 & 16.3847168 \\
\hline 1.5460996 & 13.2472089 & 18.2568199 \\
\hline 1.6148639 & 13.3209224 & 21.3404962 \\
\hline 4.7587017 & 13.0288489 & 16.6614005 \\
\hline 0.2727740 & 13.9577494 & 21.4423134 \\
\hline 2.2050885 & 17.0462078 & 21.6367079 \\
\hline 2.0464685 & 14.9082406 & 17.9594544 \\
\hline 4.3023834 & 15.7991946 & 17.2275300 \\
\hline 4.6600495 & 16.2375559 & 22.1940136 \\
\hline 2.4348758 & 12.1802236 & 17.1986082 \\
\hline 4.3597493 & 13.4561409 & 27.7229638 \\
\hline 2.6867980 & 14.3753278 & 21.7020424 \\
\hline 2.4620802 & 17.3236167 & 17.7117752 \\
\hline 0.1004930 & 13.1080745 & 17.9282109 \\
\hline 3.5582135 & 16.1185042 & 19.5846189 \\
\hline 3.3857637 & 11.9225654 & 29.6610357 \\
\hline 1.8941109 & 12.7914073 & 19.9076685 \\
\hline 10.0315011 & 12.0111682 & 16.2411170 \\
\hline 9.9455100 & 11.9640256 & 28.0848114 \\
\hline 12.1729087 & 10.6237726 & 26.3200686 \\
\hline 12.2242195 & 10.5758948 & 23.1543727 \\
\hline 15.3317765 & 10.7265847 & 23.2391992 \\
\hline 10.5015661 & 7.9177939 & 23.2911051 \\
\hline 10.5739863 & 7.9027891 & 26.3819489 \\
\hline 15.3070007 & 10.6812232 & 26.4029271 \\
\hline 8.9351494 & 10.8130576 & 27.8925915 \\
\hline 11.6447495 & 8.9790875 & 26.6448525 \\
\hline 15.7251115 & 9.2640746 & 26.5873006 \\
\hline 11.4140840 & 6.7506098 & 23.1423999 \\
\hline 13.6995278 & 10.1374604 & 22.9752433 \\
\hline 11.1741730 & 11.7529018 & 27.1967803 \\
\hline 9.4256645 & 8.0258296 & 27.3888999 \\
\hline 16.1015777 & 11.5816507 & 27.2832670 \\
\hline 9.1096362 & 7.7016395 & 22.2480278 \\
\hline 15.6841504 & 12.1382023 & 22.3049850 \\
\hline 9.3780337 & 10.4477402 & 16.6548502 \\
\hline 13.8337361 & 10.8045762 & 26.8120467 \\
\hline 11.1977823 & 6.5604746 & 26.5437852 \\
\hline 16.3016792 & 9.6513818 & 22.8922873 \\
\hline 11.3289176 & 9.3613771 & 22.8181213 \\
\hline 10.3424734 & 12.0323726 & 14.7851063 \\
\hline 11.9819896 & 10.9803773 & 24.6288196 \\
\hline 15.5141974 & 11.1165507 & 24.9436260 \\
\hline 9.9832410 & 8.0642154 & 24.9624556 \\
\hline 10.3838075 & 12.0340084 & 29.5061200 \\
\hline 8.6111573 & 15.0259443 & 14.8924103 \\
\hline 5.2514601 & 14.6717197 & 16.3033739 \\
\hline 5.2124764 & 14.6627442 & 28.1325154 \\
\hline 12.1584943 & 18.6505310 & 21.3218022 \\
\hline 12.3162001 & 13.3453240 & 21.3315548 \\
\hline 17.0640060 & 15.9836042 & 21.2904452 \\
\hline
\end{tabular}




\begin{tabular}{|c|c|c|c|}
\hline $\mathrm{P}$ & 16.9564938 & 16.0339814 & 18.1244334 \\
\hline$P$ & 12.2276857 & 13.2408996 & 18.0769221 \\
\hline$P$ & 12.1710462 & 18.6929235 & 18.1634087 \\
\hline Al & 5.3047850 & 17.1669132 & 26.2709566 \\
\hline $\mathrm{P}$ & 5.3021130 & 17.2083735 & 23.1851014 \\
\hline Al & 8.3793918 & 14.6886564 & 28.1637196 \\
\hline $\mathrm{P}$ & 8.4095368 & 14.7020666 & 16.3317063 \\
\hline Al & 15.4210983 & 13.2472089 & 18.2568199 \\
\hline Al & 15.3214403 & 18.6984315 & 18.2024625 \\
\hline Al & 10.6457305 & 15.9202084 & 18.1736915 \\
\hline $\mathrm{P}$ & 10.5053612 & 15.9237681 & 21.3640966 \\
\hline$P$ & 15.3346503 & 18.6425337 & 21.3986844 \\
\hline $\mathrm{P}$ & 15.4898626 & 13.3209224 & 21.3404962 \\
\hline Al & 8.4521333 & 17.3932407 & 23.1879607 \\
\hline $\mathrm{P}$ & 8.4603365 & 17.2346242 & 26.3230167 \\
\hline 0 & 8.8369551 & 13.2448369 & 16.6107653 \\
\hline 0 & 6.6919889 & 14.3356461 & 27.8484109 \\
\hline 0 & 11.5440265 & 17.0511252 & 21.6013804 \\
\hline 0 & 14.1173403 & 13.9721897 & 21.4446222 \\
\hline 0 & 15.8973063 & 17.2436060 & 21.7010326 \\
\hline 0 & 15.9214673 & 14.9082406 & 17.9594544 \\
\hline 0 & 11.8518565 & 14.7123804 & 17.7770545 \\
\hline 0 & 13.6431209 & 18.3098850 & 17.9021389 \\
\hline 0 & 6.9809882 & 17.5900510 & 26.5887232 \\
\hline $\mathrm{H}$ & 8.9571279 & 18.7846897 & 23.0268068 \\
\hline H & 4.6418326 & 18.5414011 & 23.1203898 \\
\hline $\mathrm{H}$ & 18.1423302 & 15.8059354 & 17.2532803 \\
\hline $\mathrm{H}$ & 11.7786039 & 19.8450768 & 17.3057069 \\
\hline 0 & 11.5311984 & 12.3037479 & 17.0655977 \\
\hline 0 & 4.7684986 & 15.8735733 & 27.3051530 \\
\hline $\mathrm{H}$ & 11.4600529 & 19.6676310 & 22.1553536 \\
\hline 0 & 11.8263772 & 11.7087024 & 22.2389739 \\
\hline $\mathrm{H}$ & 18.3192663 & 16.2003046 & 22.0614724 \\
\hline 0 & 8.8897925 & 16.0497622 & 27.1981737 \\
\hline $\mathrm{H}$ & 16.1790925 & 12.3372288 & 17.3543224 \\
\hline 0 & 9.2286498 & 15.6807345 & 17.1748109 \\
\hline H & 15.7303185 & 19.9169296 & 17.4506638 \\
\hline 0 & 9.1860827 & 16.2985369 & 22.0716587 \\
\hline 0 & 6.9335166 & 14.8600607 & 16.7149552 \\
\hline 0 & 9.2798575 & 13.2803564 & 27.6608958 \\
\hline 0 & 13.8498305 & 18.6854859 & 21.7586563 \\
\hline 0 & 10.9907609 & 14.6085445 & 21.9396659 \\
\hline 0 & 16.5617968 & 14.3753278 & 21.7020424 \\
\hline 0 & 16.3177272 & 17.3639074 & 17.6988829 \\
\hline 0 & 13.7378366 & 13.0852011 & 17.8741882 \\
\hline 0 & 11.2788908 & 17.5052231 & 17.8038116 \\
\hline $\mathrm{H}$ & 4.4241984 & 18.3439043 & 26.5084012 \\
\hline $\mathrm{H}$ & 9.3068132 & 18.4088800 & 26.6719022 \\
\hline 0 & 6.7648477 & 17.3929155 & 22.7968971 \\
\hline H & 5.0470469 & 14.9460227 & 14.8542039 \\
\hline 0 & 11.9848894 & 19.1004968 & 19.6373265 \\
\hline 0 & 11.7850572 & 12.8307269 & 19.4873382 \\
\hline 0 & 17.4332123 & 16.1185042 & 19.5846189 \\
\hline 0 & 5.1762045 & 16.6257019 & 24.6070661 \\
\hline $\mathrm{H}$ & 8.5830891 & 14.9860190 & 29.6084353 \\
\hline 0 & 15.7691096 & 12.7914073 & 19.9076685 \\
\hline 0 & 15.5479094 & 19.0104784 & 19.9169022 \\
\hline 0 & 10.1966125 & 15.8297899 & 19.8529698 \\
\hline 0 & 8.6675756 & 16.8445788 & 24.8453789 \\
\hline $\mathrm{H}$ & 10.5949214 & 11.6839902 & 19.5996011 \\
\hline C & 8.8140436 & 11.1384061 & 21.3860092 \\
\hline $\mathrm{H}$ & 8.6382106 & 10.0659807 & 21.3280428 \\
\hline $\mathrm{H}$ & 9.7254675 & 11.4979182 & 21.8553487 \\
\hline $\mathrm{H}$ & 8.2023414 & 11.7958663 & 20.7763107 \\
\hline 0 & 9.9783927 & 10.8904685 & 19.6102144 \\
\hline C & 7.5951140 & 10.9883949 & 23.1200074 \\
\hline $\mathrm{C}$ & 7.7723259 & 12.3370899 & 23.2624298 \\
\hline $\mathrm{C}$ & 8.8464298 & 12.9886514 & 24.0374532 \\
\hline $\mathrm{H}$ & 9.4924903 & 12.2738826 & 24.5623051 \\
\hline $\mathrm{H}$ & 8.3955747 & 13.6783303 & 24.7715093 \\
\hline $\mathrm{H}$ & 9.4689247 & 13.6269263 & 23.3835766 \\
\hline $\mathrm{C}$ & 10.8320504 & 9.7309879 & 19.5406389 \\
\hline $\mathrm{H}$ & 10.2319662 & 8.8546761 & 19.8070623 \\
\hline $\mathrm{H}$ & 11.6811206 & 9.8219231 & 20.2313853 \\
\hline $\mathrm{H}$ & 11.1961005 & 9.6158623 & 18.5088573 \\
\hline $\mathrm{H}$ & 8.1941783 & 10.2883988 & 23.7080728 \\
\hline $\mathrm{H}$ & 7.0767268 & 13.0029662 & 22.7355817 \\
\hline $\mathrm{H}$ & 6.6978014 & 10.5857961 & 22.6460023 \\
\hline $\mathrm{H}$ & 5.0175809 & 14.9836917 & 29.5733932 \\
\hline H & 16.0215893 & 19.6791891 & 22.2175745 \\
\hline
\end{tabular}


8.8767872

9.3119147

9.2541084

6.7129006

6.7225997

7.9165022

7.9720719

9.1762779

9.2478089

6.6681505

6.6144516

10.6913340

10.6815118

9.6954609

10.8982156

5.3328148

5.2440155

6.2981995

9.0236396

6.9224643

10.2190657

8.1124022

8.1199351

7.7286300

11.7638168

7.8944906

11.8581076

10.4936326

9.0590954

6.7726208

5.5253114

5.5866625

10.7759226

6.6037278

9.5348569

8.9564961

7.1292991

7.9284619

8.8226772

7.0044892

11.1408389

8.9901911

12.0122055

15.8964114

15.9562364

12.0005734

12.0224152

13.2449894

13.2376959

13.2703158

13.6293271

16.9840599

14.7042439

15.7073758

16.0773576

12.2936109

13.3526308

14.5493372

17.2787731

13.1283423

15.9602555

12.0101320

12.8395090

11.9639317

11.9260592

10.6607043

10.6619804

10.6913340

7.9971595

7.9865825

10.6815118

10.6214226

9.2164544

9.2743729

6.8353345

10.2018686

11.6604828
14.8893616

16.4031008

28.2293819

21.3718762

18.2036636

26.3720822

23.2496528

28.1698361

16.3270266

18.1525596

21.3424214

23.1677246

26.3099260

16.6635285

27.8609335

21.5931196

21.6400698

17.8886474

26.5427901

23.0248951

22.9521701

17.2607709

27.3483539

22.2428162

27.3092297

17.3263734

22.2488840

16.7914435

27.7454397

21.7817510

17.7584454

17.8126743

26.7194426

26.6833528

22.8518903

14.9703680

19.8979573

24.9344628

29.6067828

19.6460075

24.6347426

29.6878974

14.8617929

21.3730789

18.1933626

28.1384980

16.3171193

18.1468684

21.2677500

16.6686035

21.4100023

21.6792516

17.8780843

17.2465526

22.2177346

17.1928580

27.7270524

21.7329761

17.8134870

17.8644845

19.8891904

29.5807368

19.5894351

16.3066380

28.1562811

26.3891124

23.2027876

23.1677246

23.2005525

26.3178416

26.3099260

27.9003875

26.6784682

26.5075722

23.0634212

22.9443209

27.2177193 


\begin{tabular}{|c|c|c|c|}
\hline 0 & 9.1901230 & 8.1814219 & 27.3348459 \\
\hline $\mathrm{H}$ & 16.1850751 & 11.6067877 & 27.1642430 \\
\hline 0 & 9.3439463 & 7.8219306 & 22.2700577 \\
\hline 0 & 15.7740432 & 11.8581076 & 22.2488840 \\
\hline 0 & 9.4806211 & 10.5818764 & 16.6485009 \\
\hline 0 & 13.7177688 & 10.7920763 & 26.7895106 \\
\hline $\mathrm{H}$ & 11.1937790 & 6.6478994 & 26.5596816 \\
\hline $\mathrm{H}$ & 16.3527149 & 9.5699334 & 22.8614697 \\
\hline 0 & 11.2918731 & 9.2725341 & 22.7898193 \\
\hline $\mathrm{H}$ & 10.4149790 & 12.0200236 & 14.8643003 \\
\hline 0 & 12.0417879 & 10.9953226 & 24.9079627 \\
\hline 0 & 15.6007134 & 11.1408389 & 24.6347426 \\
\hline 0 & 10.0451804 & 8.1191355 & 24.6492913 \\
\hline $\mathrm{H}$ & 10.3647717 & 12.0081881 & 29.5953982 \\
\hline $\mathrm{H}$ & 8.6689519 & 14.9416632 & 14.8168995 \\
\hline $\mathrm{P}$ & 5.3243832 & 14.7171037 & 16.3764896 \\
\hline Al & 5.2792642 & 14.7125559 & 28.2159624 \\
\hline $\mathrm{P}$ & 12.2522397 & 18.7290020 & 21.3718762 \\
\hline $\mathrm{Si}$ & 12.1041531 & 13.2724459 & 21.3563428 \\
\hline $\mathrm{P}$ & 16.9976027 & 15.8964114 & 21.3730789 \\
\hline Al & 16.9735383 & 15.9562364 & 18.1933626 \\
\hline Al & 12.1664174 & 13.2988245 & 18.1987597 \\
\hline $\mathrm{Al}$ & 12.2638382 & 18.7387010 & 18.2036636 \\
\hline $\mathrm{P}$ & 5.2396933 & 17.2212366 & 26.3534690 \\
\hline Al & 5.2211203 & 17.2104761 & 23.2423387 \\
\hline $\mathrm{P}$ & 8.4449510 & 14.6518165 & 28.0959337 \\
\hline Al & 8.4887747 & 14.6806696 & 16.2717325 \\
\hline $\mathrm{P}$ & 15.3605975 & 13.2449894 & 18.1468684 \\
\hline $\mathrm{P}$ & 15.4116123 & 18.6842518 & 18.1525596 \\
\hline$P$ & 10.6380349 & 16.0464020 & 18.1046847 \\
\hline Al & 10.5745414 & 16.0069667 & 21.2856571 \\
\hline $\mathrm{Al}$ & 15.4046930 & 18.6305530 & 21.3424214 \\
\hline Al & 15.3052312 & 13.2376959 & 21.2677500 \\
\hline $\mathrm{P}$ & 8.3777032 & 17.3061575 & 23.1311302 \\
\hline Al & 8.3922691 & 17.2174625 & 26.2744411 \\
\hline 0 & 8.9829077 & 13.0337562 & 16.6276339 \\
\hline 0 & 6.9541908 & 14.3329605 & 27.8668246 \\
\hline 0 & 11.7243930 & 17.3099614 & 21.5993645 \\
\hline 0 & 13.6669179 & 13.6865301 & 21.4307802 \\
\hline $\mathrm{O}$ & 15.9907166 & 17.0257202 & 21.6909790 \\
\hline 0 & 15.7965066 & 14.7042439 & 17.8780843 \\
\hline 0 & 11.7018386 & 14.9624465 & 17.8479046 \\
\hline 0 & 13.9409600 & 18.3143009 & 17.8886474 \\
\hline 0 & 6.7112508 & 17.6100075 & 26.6024493 \\
\hline $\mathrm{H}$ & 8.8649246 & 18.7061231 & 22.9903027 \\
\hline $\mathrm{H}$ & 4.6658857 & 18.5832288 & 23.0861820 \\
\hline $\mathrm{H}$ & 18.2061609 & 15.7438920 & 17.3854814 \\
\hline $\mathrm{H}$ & 11.8763503 & 19.9284354 & 17.3965045 \\
\hline 0 & 11.3216079 & 12.1965166 & 17.1189784 \\
\hline 0 & 4.7923396 & 16.1206813 & 27.3181017 \\
\hline $\mathrm{H}$ & 11.5207204 & 19.7135458 & 22.2160761 \\
\hline 0 & 11.7577694 & 11.9796662 & 22.2753075 \\
\hline $\mathrm{H}$ & 18.2291795 & 16.0717108 & 22.1913756 \\
\hline $\mathrm{O}$ & 8.8760165 & 15.8429050 & 27.2325176 \\
\hline $\mathrm{H}$ & 16.0762390 & 12.3229624 & 17.2222906 \\
\hline 0 & 9.4212632 & 15.8241053 & 17.1922484 \\
\hline $\mathrm{H}$ & 15.8093656 & 19.8742760 & 17.3508394 \\
\hline 0 & 9.1012520 & 16.3679476 & 22.1716440 \\
\hline 0 & 6.8114912 & 14.8567789 & 16.7125408 \\
\hline 0 & 9.2630189 & 13.4311684 & 27.6528008 \\
\hline 0 & 13.7316746 & 18.7887222 & 21.7817510 \\
\hline 0 & 11.1488593 & 14.4949651 & 21.8187325 \\
\hline 0 & 16.3834961 & 14.5493372 & 21.7329761 \\
\hline 0 & 16.3054762 & 17.5091435 & 17.7473172 \\
\hline 0 & 13.8661253 & 13.1253683 & 17.8572850 \\
\hline 0 & 11.2383123 & 17.4144813 & 17.7478675 \\
\hline $\mathrm{H}$ & 4.3787130 & 18.4122072 & 26.5930991 \\
\hline $\mathrm{H}$ & 9.2434011 & 18.3856499 & 26.6322583 \\
\hline 0 & 6.8887670 & 17.2746649 & 22.7754736 \\
\hline $\mathrm{H}$ & 5.0797388 & 15.0465372 & 14.9451465 \\
\hline 0 & 12.0939532 & 19.1454004 & 19.8979573 \\
\hline 0 & 11.7136169 & 12.8469635 & 19.8048982 \\
\hline 0 & 17.4005924 & 15.9602555 & 19.8891904 \\
\hline 0 & 5.0672002 & 16.7032037 & 24.9117370 \\
\hline $\mathrm{H}$ & 8.6932058 & 14.9778761 & 29.5274278 \\
\hline 0 & 15.6985012 & 12.8395090 & 19.5894351 \\
\hline 0 & 15.6163853 & 19.0205906 & 19.6460075 \\
\hline 0 & 10.1701260 & 16.0367980 & 19.5677043 \\
\hline 0 & 8.5889653 & 16.8107806 & 24.5797193 \\
\hline $\mathrm{H}$ & 10.5809183 & 11.6533970 & 19.7368955 \\
\hline
\end{tabular}




\begin{tabular}{|c|c|c|c|}
\hline $\mathrm{C}$ & 8.7808402 & 11.0601911 & 21.4364129 \\
\hline $\mathrm{H}$ & 8.6819227 & 9.9771259 & 21.4215337 \\
\hline $\mathrm{H}$ & 9.6709629 & 11.4936461 & 21.8848082 \\
\hline $\mathrm{H}$ & 8.1406816 & 11.6490488 & 20.7872106 \\
\hline 0 & 9.9840328 & 10.8425599 & 19.6649245 \\
\hline $\mathrm{C}$ & 7.5611826 & 10.9050630 & 23.1490556 \\
\hline $\mathrm{C}$ & 7.7162818 & 12.2594823 & 23.2660311 \\
\hline $\mathrm{C}$ & 8.7761765 & 12.9451265 & 24.0341431 \\
\hline $\mathrm{H}$ & 9.4315459 & 12.2498959 & 24.5741351 \\
\hline $\mathrm{H}$ & 8.3096066 & 13.6368742 & 24.7562453 \\
\hline $\mathrm{H}$ & 9.3949153 & 13.5816524 & 23.3749632 \\
\hline C & 10.8675568 & 9.7154037 & 19.5300637 \\
\hline $\mathrm{H}$ & 10.2781477 & 8.8039948 & 19.6678787 \\
\hline $\mathrm{H}$ & 11.6771339 & 9.7453223 & 20.2732818 \\
\hline $\mathrm{H}$ & 11.2958869 & 9.7137963 & 18.5158461 \\
\hline $\mathrm{H}$ & 8.1690215 & 10.2237287 & 23.7504141 \\
\hline $\mathrm{H}$ & 7.0136906 & 12.9029090 & 22.7209858 \\
\hline $\mathrm{H}$ & 6.6739586 & 10.4798012 & 22.6749612 \\
\hline $\mathrm{H}$ & 5.1019667 & 15.0070247 & 29.6647461 \\
\hline & 16.1476928 & 19.6538251 & 22.1285423 \\
\hline \multicolumn{4}{|c|}{$\begin{array}{l}\mathrm{Mg} 8 \\
177\end{array}$} \\
\hline $\mathrm{H}$ & 8.5614666 & 8.8061941 & 14.9913041 \\
\hline Al & 5.3243547 & 9.2724529 & 16.3645172 \\
\hline $\mathrm{P}$ & 5.3113101 & 9.2122500 & 28.1769114 \\
\hline Al & 5.2120066 & 6.6517603 & 21.3173190 \\
\hline $\mathrm{P}$ & 5.2425137 & 6.6861944 & 18.1591037 \\
\hline Al & 3.0901476 & 7.9802059 & 26.3311653 \\
\hline $\mathrm{P}$ & 3.2053913 & 8.0900662 & 23.2127575 \\
\hline Al & 8.4298024 & 9.1585148 & 28.2563212 \\
\hline $\mathrm{P}$ & 8.4486006 & 9.2730545 & 16.4007094 \\
\hline Al & 8.3944700 & 6.6976773 & 18.2145747 \\
\hline $\mathrm{P}$ & 8.3952165 & 6.6308856 & 21.4038757 \\
\hline Al & 1.4699319 & 10.7345228 & 23.2513332 \\
\hline $\mathrm{P}$ & 1.4312560 & 10.6925482 & 26.4026805 \\
\hline 0 & 6.9969173 & 9.7015979 & 16.7026588 \\
\hline 0 & 4.9011423 & 10.6647404 & 27.8541216 \\
\hline $\mathrm{H}$ & 4.6440066 & 5.2989765 & 21.5712336 \\
\hline $\mathrm{H}$ & 8.9508986 & 5.2787267 & 21.6867260 \\
\hline 0 & 6.7178018 & 6.3040725 & 17.9146917 \\
\hline 0 & 1.8796576 & 9.2245069 & 26.5553592 \\
\hline $\mathrm{H}$ & 2.1686207 & 7.0469124 & 22.9802553 \\
\hline $\mathrm{H}$ & 0.0909628 & 10.2166263 & 23.0337373 \\
\hline 0 & 4.8458726 & 7.8709019 & 17.2734474 \\
\hline $\mathrm{O}$ & 4.4383644 & 8.2190020 & 27.4049521 \\
\hline 0 & 4.4224211 & 7.8644112 & 22.3027350 \\
\hline 0 & 2.2457921 & 11.6065179 & 27.3231141 \\
\hline $\mathrm{O}$ & 8.8689293 & 8.1291846 & 17.3337075 \\
\hline 0 & 1.8720067 & 12.1074217 & 22.2803474 \\
\hline 0 & 4.2954958 & 10.5963379 & 16.8281022 \\
\hline 0 & 6.7691087 & 9.0079829 & 27.7422683 \\
\hline 0 & 6.9060342 & 6.6508081 & 21.7465271 \\
\hline $\mathrm{H}$ & 9.2512081 & 5.5568796 & 17.7883106 \\
\hline $\mathrm{H}$ & 4.3797621 & 5.5280903 & 17.7963709 \\
\hline $\mathrm{H}$ & 0.0041659 & 10.7892917 & 26.8164137 \\
\hline $\mathrm{H}$ & 2.4796499 & 6.6591117 & 26.6460037 \\
\hline 0 & 2.6175795 & 9.4641768 & 22.8824766 \\
\hline $\mathrm{H}$ & 5.1756157 & 8.9809971 & 14.9119158 \\
\hline 0 & 5.0412948 & 7.0944269 & 19.6309295 \\
\hline $\mathrm{O}$ & 3.6797203 & 8.0376173 & 24.6799502 \\
\hline $\mathrm{H}$ & 8.5451974 & 8.8449463 & 29.7073482 \\
\hline 0 & 8.6208113 & 7.0189723 & 19.9284282 \\
\hline 0 & 1.6192209 & 11.1641886 & 24.9517416 \\
\hline $\mathrm{H}$ & 5.1547957 & 8.9391495 & 29.6322601 \\
\hline $\mathrm{H}$ & 3.3657891 & 11.9155247 & 14.9408743 \\
\hline Al & 3.1896484 & 15.9804411 & 21.2944989 \\
\hline $\mathrm{P}$ & 3.0868824 & 16.0405092 & 18.1228807 \\
\hline Al & 3.7116972 & 11.9110642 & 28.2050072 \\
\hline $\mathrm{P}$ & 3.7054676 & 11.9429461 & 16.3903525 \\
\hline Al & 1.5505563 & 13.2628909 & 18.2498790 \\
\hline $\mathrm{P}$ & 1.6234671 & 13.3020721 & 21.3385775 \\
\hline 0 & 4.7511185 & 13.0421248 & 16.6725873 \\
\hline $\mathrm{H}$ & 0.2392275 & 13.8412868 & 21.4398147 \\
\hline $\mathrm{H}$ & 2.2128614 & 17.0521164 & 21.6329066 \\
\hline 0 & 2.0473937 & 14.9229907 & 17.9313861 \\
\hline 0 & 4.3112923 & 15.8160605 & 17.2269546 \\
\hline 0 & 4.6712931 & 16.2341915 & 22.1864645 \\
\hline 0 & 2.4225858 & 12.1886022 & 17.1822317 \\
\hline & & & \\
\hline
\end{tabular}




\begin{tabular}{|c|c|c|c|}
\hline 0 & 2.6507802 & 14.3925206 & 21.7286547 \\
\hline $\mathrm{H}$ & 2.4768444 & 17.3404533 & 17.7290283 \\
\hline $\mathrm{H}$ & 0.1020576 & 13.1284294 & 17.9322436 \\
\hline 0 & 3.5563333 & 16.0969838 & 19.5866938 \\
\hline $\mathrm{H}$ & 3.4067808 & 11.9141165 & 29.6624492 \\
\hline 0 & 1.9400261 & 12.8202025 & 19.8942438 \\
\hline Al & 10.0385760 & 12.0222509 & 16.2389731 \\
\hline $\mathrm{P}$ & 9.9457126 & 11.9613596 & 28.0843364 \\
\hline $\mathrm{Al}$ & 12.1742578 & 10.5940580 & 26.3494452 \\
\hline $\mathrm{P}$ & 12.2360078 & 10.5435437 & 23.1707079 \\
\hline Al & 15.3449306 & 10.7345228 & 23.2513332 \\
\hline Al & 10.4893095 & 7.9230899 & 23.3041977 \\
\hline $\mathrm{P}$ & 10.5695351 & 7.9026488 & 26.3939223 \\
\hline$P$ & 15.3062547 & 10.6925482 & 26.4026805 \\
\hline 0 & 8.9437991 & 10.8004723 & 27.9080551 \\
\hline 0 & 11.6491638 & 8.9554905 & 26.7132539 \\
\hline $\mathrm{H}$ & 15.7390845 & 9.2754882 & 26.5500571 \\
\hline $\mathrm{H}$ & 11.3632218 & 6.7234465 & 23.1848098 \\
\hline 0 & 13.7172845 & 10.1232312 & 22.9944970 \\
\hline 0 & 11.1738419 & 11.7462690 & 27.1959549 \\
\hline 0 & 9.4136499 & 8.0022946 & 27.3961830 \\
\hline $\mathrm{H}$ & 16.0980999 & 11.5810570 & 27.2974732 \\
\hline 0 & 9.0871700 & 7.7050099 & 22.2729869 \\
\hline 0 & 15.7470054 & 12.1074217 & 22.2803474 \\
\hline 0 & 9.3875891 & 10.4551219 & 16.6417606 \\
\hline 0 & 13.8356610 & 10.7922408 & 26.8290260 \\
\hline $\mathrm{H}$ & 11.1762976 & 6.5472445 & 26.5027299 \\
\hline $\mathrm{H}$ & 16.3207093 & 9.6544207 & 22.9377156 \\
\hline 0 & 11.3536616 & 9.3321300 & 22.7842587 \\
\hline $\mathrm{H}$ & 10.3470711 & 12.0512099 & 14.7825690 \\
\hline 0 & 11.9683366 & 10.8980468 & 24.6520611 \\
\hline 0 & 15.4942196 & 11.1641886 & 24.9517416 \\
\hline 0 & 9.9926959 & 8.1304812 & 24.9766435 \\
\hline $\mathrm{H}$ & 10.3877830 & 12.0535263 & 29.5032090 \\
\hline $\mathrm{H}$ & 8.6027034 & 15.0157424 & 14.8763897 \\
\hline $\mathrm{Al}$ & 5.2528806 & 14.6795418 & 16.3049828 \\
\hline $\mathrm{P}$ & 5.2073927 & 14.6660695 & 28.1292135 \\
\hline $\mathrm{Al}$ & 12.1495059 & 18.6678617 & 21.3173190 \\
\hline $\mathrm{Mg}$ & 12.2638289 & 13.3179237 & 21.3462630 \\
\hline Al & 17.0646471 & 15.9804411 & 21.2944989 \\
\hline $\mathrm{P}$ & 16.9618811 & 16.0405092 & 18.1228807 \\
\hline $\mathrm{P}$ & 12.2256124 & 13.2495210 & 18.0872795 \\
\hline $\mathrm{P}$ & 12.1800131 & 18.7022958 & 18.1591037 \\
\hline $\mathrm{Al}$ & 5.2970265 & 17.1565490 & 26.2637839 \\
\hline $\mathrm{P}$ & 5.2934876 & 17.2034175 & 23.1931363 \\
\hline Al & 8.3749168 & 14.6838604 & 28.1461280 \\
\hline $\mathrm{P}$ & 8.4107080 & 14.7084273 & 16.3206250 \\
\hline Al & 15.4255550 & 13.2628909 & 18.2498790 \\
\hline Al & 15.3319694 & 18.7137787 & 18.2145747 \\
\hline $\mathrm{Al}$ & 10.6347200 & 15.9411383 & 18.1641582 \\
\hline$P$ & 10.4676082 & 15.9538017 & 21.3493124 \\
\hline$P$ & 15.3327158 & 18.6469869 & 21.4038757 \\
\hline $\mathrm{P}$ & 15.4984658 & 13.3020721 & 21.3385775 \\
\hline Al & 8.4378156 & 17.4118692 & 23.1808265 \\
\hline $\mathrm{P}$ & 8.4497555 & 17.2414746 & 26.3245466 \\
\hline $\mathrm{O}$ & 8.8466033 & 13.2564411 & 16.6151059 \\
\hline 0 & 6.6850694 & 14.3451093 & 27.8288400 \\
\hline 0 & 11.4879676 & 17.0923012 & 21.6130483 \\
\hline 0 & 14.0907644 & 13.8504261 & 21.4415305 \\
\hline 0 & 15.9062646 & 17.2513528 & 21.6958203 \\
\hline 0 & 15.9223924 & 14.9229907 & 17.9313861 \\
\hline 0 & 11.8339703 & 14.7181079 & 17.7928204 \\
\hline 0 & 13.6553011 & 18.3201739 & 17.9146917 \\
\hline 0 & 6.9688699 & 17.5856565 & 26.5990636 \\
\hline $\mathrm{H}$ & 8.9771841 & 18.7883377 & 23.0032401 \\
\hline $\mathrm{H}$ & 4.5843638 & 18.5124470 & 23.1665690 \\
\hline $\mathrm{H}$ & 18.1506041 & 15.8226023 & 17.2530675 \\
\hline $\mathrm{H}$ & 11.7943585 & 19.8541881 & 17.2979792 \\
\hline 0 & 11.5333497 & 12.3087592 & 17.0754255 \\
\hline 0 & 4.7499148 & 15.8786643 & 27.3113960 \\
\hline $\mathrm{H}$ & 11.4779569 & 19.6992314 & 22.1554235 \\
\hline 0 & 11.8598874 & 11.7120282 & 22.2954703 \\
\hline $\mathrm{H}$ & 18.3268072 & 16.1966020 & 22.0543324 \\
\hline 0 & 8.8881774 & 16.0456539 & 27.1817433 \\
\hline $\mathrm{H}$ & 16.1685104 & 12.3476139 & 17.3402604 \\
\hline 0 & 9.2312865 & 15.7010235 & 17.1459058 \\
\hline $\mathrm{H}$ & 15.7364761 & 19.9342298 & 17.4635794 \\
\hline 0 & 9.1439287 & 16.2904750 & 22.0710940 \\
\hline 0 & 6.9366324 & 14.8635282 & 16.7119187 \\
\hline $\mathrm{O}$ & 9.2692783 & 13.2685407 & 27.6466239 \\
\hline
\end{tabular}




\begin{tabular}{|c|c|c|}
\hline 13.8435335 & 18.6669095 & 21.7465271 \\
\hline 10.9932530 & 14.6396812 & 21.8732383 \\
\hline 16.5257789 & 14.3925206 & 21.7286547 \\
\hline 16.3326992 & 17.3812475 & 17.7166686 \\
\hline 13.7371894 & 13.1061630 & 17.8796442 \\
\hline 11.2946630 & 17.5138569 & 17.7868697 \\
\hline 4.4046427 & 18.3303818 & 26.4708782 \\
\hline 9.2889852 & 18.4160513 & 26.6894899 \\
\hline 6.7465002 & 17.4510132 & 22.8000690 \\
\hline 5.0525443 & 14.9443686 & 14.8534826 \\
\hline 11.9787941 & 19.1105282 & 19.6309295 \\
\hline 11.8033802 & 12.8455643 & 19.5024154 \\
\hline 17.4313320 & 16.0969838 & 19.5866938 \\
\hline 5.2005635 & 16.5880214 & 24.6048346 \\
\hline 8.5749325 & 14.9761123 & 29.5924001 \\
\hline 15.8150248 & 12.8202025 & 19.8942438 \\
\hline 15.5583107 & 19.0350737 & 19.9284282 \\
\hline 10.1517543 & 15.8959292 & 19.8360218 \\
\hline 8.6547476 & 16.8733788 & 24.8414521 \\
\hline 10.6057978 & 11.6831872 & 19.5887887 \\
\hline 8.8312942 & 11.1148037 & 21.3759526 \\
\hline 8.6429163 & 10.0455426 & 21.3048641 \\
\hline 9.7386975 & 11.4591280 & 21.8634594 \\
\hline 8.2263863 & 11.7879117 & 20.7768726 \\
\hline 9.9962508 & 10.8852387 & 19.6062022 \\
\hline 7.6079358 & 10.9480988 & 23.1174024 \\
\hline 7.7551263 & 12.3011399 & 23.2465097 \\
\hline 8.8148269 & 12.9843153 & 24.0159453 \\
\hline 9.4899731 & 12.2888289 & 24.5303254 \\
\hline 8.3446333 & 13.6490920 & 24.7611239 \\
\hline 9.4064753 & 13.6516742 & 23.3634843 \\
\hline 10.8588653 & 9.7314169 & 19.5312581 \\
\hline 10.2626612 & 8.8506057 & 19.7908613 \\
\hline 11.7050799 & 9.8229636 & 20.2253305 \\
\hline 11.2257212 & 9.6262367 & 18.4995128 \\
\hline 8.2251764 & 10.2673435 & 23.7091349 \\
\hline 7.0423780 & 12.9469522 & 22.7176852 \\
\hline 6.7199235 & 10.5208001 & 22.6476222 \\
\hline 5.0234384 & 14.9806163 & 29.5729384 \\
\hline 15.9994670 & 19.6819895 & 22.2413321 \\
\hline 8.5192534 & 8.7637609 & 15.0537310 \\
\hline 5.2344106 & 9.2343904 & 16.4678515 \\
\hline 5.2159780 & 9.1676374 & 28.4065141 \\
\hline 5.1908474 & 6.6956735 & 21.4468989 \\
\hline 5.2312129 & 6.7533673 & 18.3467274 \\
\hline 3.1154551 & 7.9396397 & 26.4589461 \\
\hline 3.1914963 & 8.0048236 & 23.4003496 \\
\hline 8.3253898 & 9.1044504 & 28.4194090 \\
\hline 8.3529956 & 9.2211479 & 16.4609539 \\
\hline 8.3498060 & 6.7497186 & 18.3604749 \\
\hline 8.3264174 & 6.6512068 & 21.4863970 \\
\hline 1.5277848 & 10.6702641 & 23.3716688 \\
\hline 1.5113933 & 10.6532067 & 26.4573047 \\
\hline 6.7965144 & 9.6325947 & 16.7255045 \\
\hline 4.7959232 & 10.7152416 & 28.1101179 \\
\hline 4.6448645 & 5.3226263 & 21.6306505 \\
\hline 8.8605683 & 5.2793894 & 21.7098258 \\
\hline 6.7948525 & 6.3618059 & 18.0854064 \\
\hline 1.9879511 & 9.1021661 & 26.6104951 \\
\hline 2.1604811 & 6.9517451 & 23.1878553 \\
\hline 0.1351140 & 10.1823158 & 23.1729350 \\
\hline 4.7951091 & 7.9975553 & 17.4097564 \\
\hline 4.3222336 & 8.1539824 & 27.5165673 \\
\hline 4.4552305 & 7.7789298 & 22.4081061 \\
\hline 2.3626510 & 11.6093578 & 27.4486575 \\
\hline 8.7962241 & 8.0306929 & 17.4712930 \\
\hline 1.9071802 & 11.8798128 & 22.3749464 \\
\hline 4.3155222 & 10.5029953 & 16.8675449 \\
\hline 6.7687424 & 8.9632619 & 27.9939462 \\
\hline 6.7587093 & 6.6884604 & 21.8609425 \\
\hline 9.2174367 & 5.5981655 & 17.9886375 \\
\hline 4.3785331 & 5.5878655 & 17.9838730 \\
\hline 0.0817371 & 10.7356195 & 26.8652407 \\
\hline 2.4834847 & 6.6262492 & 26.7634774 \\
\hline 2.5509247 & 9.4482078 & 23.0588032 \\
\hline 5.0194952 & 8.8502134 & 15.0454100 \\
\hline 5.0263311 & 7.1948764 & 19.9026676 \\
\hline
\end{tabular}




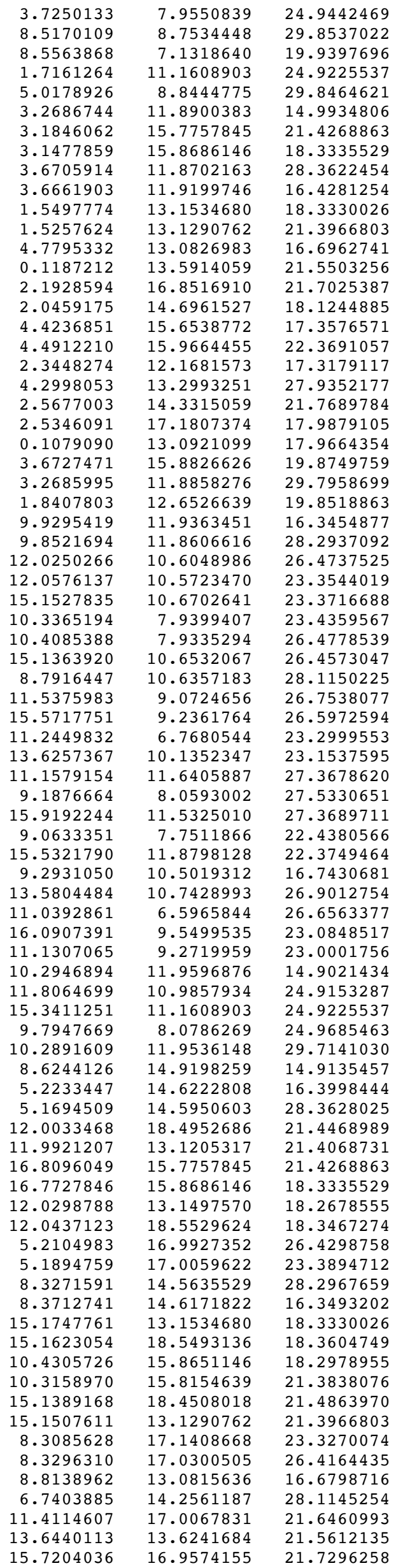

21.7296258 


\begin{tabular}{|c|c|c|c|}
\hline 0 & 15.6709162 & 14.6961527 & 18.1244885 \\
\hline 0 & 11.5428659 & 14.6983226 & 18.0922176 \\
\hline 0 & 13.6073519 & 18.1614010 & 18.0854064 \\
\hline $\mathrm{O}$ & 6.7656538 & 17.3972166 & 26.7070127 \\
\hline $\mathrm{H}$ & 8.8305946 & 18.5277620 & 23.1816626 \\
\hline $\mathrm{H}$ & 4.5625920 & 18.3533700 & 23.2965761 \\
\hline $\mathrm{H}$ & 17.9450617 & 15.6713171 & 17.4369144 \\
\hline $\mathrm{H}$ & 11.6422387 & 19.6983515 & 17.4841596 \\
\hline $\mathrm{O}$ & 11.2865759 & 12.1914242 & 17.1782383 \\
\hline 0 & 4.7056402 & 15.8405521 & 27.4439070 \\
\hline $\mathrm{H}$ & 11.3290235 & 19.4882650 & 22.3280157 \\
\hline $\mathrm{O}$ & 11.5997852 & 11.7495911 & 22.3936678 \\
\hline $\mathrm{H}$ & 18.0089694 & 15.9507956 & 22.2917658 \\
\hline $\mathrm{O}$ & 8.7955394 & 15.7876595 & 27.3460811 \\
\hline $\mathrm{H}$ & 15.9042919 & 12.2493742 & 17.4015834 \\
\hline $\mathrm{O}$ & 9.2001246 & 15.6673355 & 17.2566296 \\
\hline $\mathrm{H}$ & 15.5721225 & 19.7252635 & 17.5441952 \\
\hline 0 & 8.9956509 & 16.1196375 & 22.2902331 \\
\hline 0 & 6.8020225 & 14.7782309 & 16.7105205 \\
\hline $\mathrm{O}$ & 9.1354305 & 13.2384108 & 27.8308603 \\
\hline $\mathrm{O}$ & 13.5712086 & 18.4880555 & 21.8609425 \\
\hline $\mathrm{O}$ & 10.8873124 & 14.3928047 & 21.7925177 \\
\hline 0 & 16.1926990 & 14.3315059 & 21.7689784 \\
\hline 0 & 16.1043339 & 17.2990168 & 17.9567531 \\
\hline $\mathrm{O}$ & 13.6133883 & 13.0870238 & 17.9360499 \\
\hline 0 & 11.1208195 & 17.2914885 & 17.9539941 \\
\hline $\mathrm{H}$ & 4.3498913 & 18.1872396 & 26.6526658 \\
\hline $\mathrm{H}$ & 9.1692122 & 18.2106625 & 26.7605062 \\
\hline 0 & 6.7346281 & 17.1701362 & 22.9693250 \\
\hline $\mathrm{H}$ & 4.9306400 & 14.9643969 & 14.9805485 \\
\hline $\mathrm{O}$ & 11.8388305 & 18.9944714 & 19.9026676 \\
\hline $\mathrm{O}$ & 11.6884413 & 12.5807312 & 19.7402633 \\
\hline $\mathrm{O}$ & 17.2977459 & 15.8826626 & 19.8749759 \\
\hline $\mathrm{O}$ & 5.0504483 & 16.4305664 & 24.9071922 \\
\hline $\mathrm{H}$ & 8.6210661 & 14.9157496 & 29.7133451 \\
\hline $\mathrm{O}$ & 15.4657790 & 12.6526639 & 19.8518863 \\
\hline $\mathrm{O}$ & 15.3688862 & 18.9314590 & 19.9397696 \\
\hline 0 & 9.8428028 & 15.8753186 & 19.8124258 \\
\hline $\mathrm{O}$ & 8.5349759 & 16.6084581 & 24.8549348 \\
\hline $\mathrm{H}$ & 10.9368123 & 11.1319263 & 19.6156014 \\
\hline C & 8.8519055 & 10.6982111 & 20.8976481 \\
\hline $\mathrm{H}$ & 8.5483979 & 9.6648334 & 20.7559527 \\
\hline $\mathrm{H}$ & 9.6152159 & 10.9361134 & 21.6316390 \\
\hline $\mathrm{H}$ & 8.5613235 & 11.4294928 & 20.1497574 \\
\hline 0 & 10.4261501 & 10.2673235 & 19.5382163 \\
\hline C & 7.1449531 & 10.7890145 & 22.1543279 \\
\hline C & 7.4820482 & 12.0860995 & 22.4265797 \\
\hline C & 8.3438620 & 12.5427931 & 23.5370176 \\
\hline $\mathrm{H}$ & 8.7022888 & 11.7189782 & 24.1680588 \\
\hline $\mathrm{H}$ & 7.7744831 & 13.2538577 & 24.1617395 \\
\hline $\mathrm{H}$ & 9.2039314 & 13.1199703 & 23.1537274 \\
\hline C & 11.3548279 & 9.1823875 & 19.6790791 \\
\hline $\mathrm{H}$ & 10.7841583 & 8.2716030 & 19.8926283 \\
\hline $\mathrm{H}$ & 12.0749709 & 9.3591568 & 20.4913484 \\
\hline $\mathrm{H}$ & 11.8939232 & 9.0497748 & 18.7268265 \\
\hline $\mathrm{H}$ & 7.4072955 & 9.9871962 & 22.8491203 \\
\hline $\mathrm{H}$ & 7.1071290 & 12.8671968 & 21.7526301 \\
\hline $\mathrm{H}$ & 6.3873879 & 10.5574176 & 21.4028795 \\
\hline $\mathrm{H}$ & 4.9258787 & 14.9623654 & 29.7850824 \\
\hline & 15.8118660 & 19.4552974 & 22.3554474 \\
\hline \multicolumn{4}{|c|}{$\mathrm{Ge} 8$} \\
\hline \multicolumn{4}{|c|}{177} \\
\hline $\mathrm{H}$ & 8.5230163 & 8.8906827 & 14.9043311 \\
\hline $\mathrm{P}$ & 5.2913304 & 9.3307376 & 16.4278695 \\
\hline Al & 5.2443279 & 9.2552407 & 28.2483707 \\
\hline$P$ & 5.3178337 & 6.7022604 & 21.3746941 \\
\hline Al & 5.3361636 & 6.7362785 & 18.2193974 \\
\hline $\mathrm{P}$ & 3.1050693 & 7.9079262 & 26.3808392 \\
\hline Al & 3.2286021 & 8.0238729 & 23.2811522 \\
\hline $\mathrm{P}$ & 8.3699346 & 9.1363442 & 28.1721714 \\
\hline Al & 8.4240548 & 9.2616106 & 16.3429901 \\
\hline $\mathrm{P}$ & 8.4821996 & 6.6732190 & 18.1636228 \\
\hline Al & 8.4801697 & 6.5799501 & 21.3551368 \\
\hline $\mathrm{P}$ & 1.5680568 & 10.7066633 & 23.1894059 \\
\hline Al & 1.4973626 & 10.6641250 & 26.3334340 \\
\hline 0 & 6.7638379 & 9.7141771 & 16.6890392 \\
\hline 0 & 4.7793203 & 10.9053070 & 27.8629883 \\
\hline $\mathrm{H}$ & 4.7276101 & 5.3482880 & 21.5631499 \\
\hline $\mathrm{H}$ & 9.0319325 & 5.2278141 & 21.6456647 \\
\hline
\end{tabular}

18.1244885

8.0922176

(7)

23.1816626

2965761

17.4841596

(1)

22.3280157

(2)

27.3460811

15834

17.5441952

(1)

27.8308603

21.8609425

17.9567531

26.6526658

26.7605062

22.9693250

19.7402633

.8749759

29.7133451

. 8518863

19.8124258

24.8549348

19.6156014

20.7559527

21.6316390

20.1497574

22.1543279

22.4265797

24.1617395

23.1537274

19.6790791

18.7268265

22.8491203

29.7850824

4.9258787

10.557417

14.962365

Ge 8

177

8.8906827

16.4278695

28.2483707

8. 2193974

26.3808392

8.1721714

16.3429901

18.1636228

26.3334340

21.6456647 


$$
\begin{aligned}
& \text { 7. } 0105541 \\
& 6.3050434 \\
& \text { 9. } 0014535 \\
& 7.0099364 \\
& \text { 2. } 1649187 \\
& 0.2114653 \\
& 4.8865726 \\
& 4.2230036 \\
& 10.1572590 \\
& 8.1244989 \\
& \text { 8. } 1265303 \\
& 7.7407140 \\
& 4.6228535 \\
& 2.4460030 \\
& 8.8881221 \\
& 1.8785490 \\
& 4.3982521 \\
& 6.8991250 \\
& 6.7980808 \\
& 9.3489913 \\
& 4.4421448 \\
& 0.0818889 \\
& 2.4795781 \\
& 2.6123844 \\
& 5.0939817 \\
& 5.1771568 \\
& \text { 3. } 7200574 \\
& 8.5352339 \\
& 8.6923612 \\
& 1.6579951 \\
& 5.1104835 \\
& 3.4174752 \\
& 3.2034276 \\
& 11.7227769 \\
& 7.9099491 \\
& 11.8912380 \\
& 10.5083475 \\
& 9.0119893 \\
& 6.6603293 \\
& 5.5351650 \\
& 5.6087035 \\
& 10.7307245 \\
& 6.5876290 \\
& \text { 9. } 6124319 \\
& 8.9869635 \\
& 7.1601947 \\
& 7.9294427 \\
& 8.8347502 \\
& 6.9892053 \\
& 11.1670213 \\
& 9.0166423 \\
& 12.0184392 \\
& 15.8944948 \\
& 15.9755218 \\
& 11.9931782 \\
& 12.0349611 \\
& 13.2547276 \\
& 13.2684974 \\
& 13.2800845 \\
& 13.7974509 \\
& 16.9683051 \\
& 14.7107574 \\
& 15.7281421 \\
& 16.0577538 \\
& 12.3106835 \\
& 13.3521418 \\
& 14.5302225 \\
& 17.2892822 \\
& 13.1650623 \\
& 15.9981903 \\
& 12.0148772 \\
& 12.8126091 \\
& 11.9681128 \\
& 11.8927721 \\
& 10.5872916 \\
& 10.5380791 \\
& 10.7066633 \\
& 7.9767545 \\
& 7.9704151 \\
& 10.6641250 \\
& 10.5690168 \\
& 9.1660788 \\
& \text { 9. } 2522266 \\
& 6.7255818 \\
& 10.1367021 \\
& 11.6420549 \\
& 8.1054571 \\
& 11.5692212 \\
& 7.8231592 \\
& 11.8912380 \\
& 10.5975972 \\
& 10.7422480
\end{aligned}
$$




\begin{tabular}{|c|c|c|c|}
\hline Al & 17.0046452 & 15.9755218 & 18.1824844 \\
\hline Al & 12.1716166 & 13.3172670 & 18.1326477 \\
\hline Al & 12.2736630 & 18.7523799 & 18.2193974 \\
\hline $\mathrm{P}$ & 5.2499290 & 17.1895962 & 26.3321724 \\
\hline Al & 5.2151593 & 17.1881143 & 23.2789222 \\
\hline $\mathrm{P}$ & 8.4316624 & 14.6377680 & 28.0432358 \\
\hline Al & 8.5047901 & 14.6969194 & 16.2180241 \\
\hline $\mathrm{P}$ & 15.3649842 & 13.2547276 & 18.1495120 \\
\hline P & 15.4196989 & 18.6893204 & 18.1636228 \\
\hline $\mathrm{P}$ & 10.6384660 & 16.0542638 & 18.0759415 \\
\hline Al & 10.4706694 & 16.0494962 & 21.2633256 \\
\hline Al & 15.4176691 & 18.5960515 & 21.3551368 \\
\hline Al & 15.3341883 & 13.2684974 & 21.2746395 \\
\hline $\mathrm{P}$ & 8.3456668 & 17.4277641 & 23.1073712 \\
\hline Al & 8.3872422 & 17.2185297 & 26.2388187 \\
\hline 0 & 9.0033873 & 13.0496372 & 16.5657953 \\
\hline 0 & 6.9371415 & 14.3265698 & 27.8286641 \\
\hline 0 & 11.6487124 & 17.3267744 & 21.5683855 \\
\hline $\mathrm{O}$ & 13.7424171 & 13.8786795 & 21.4850916 \\
\hline 0 & 16.0649611 & 17.0098139 & 21.6959652 \\
\hline 0 & 15.8291326 & 14.7107574 & 17.9195919 \\
\hline $\mathrm{O}$ & 11.7176001 & 14.9888420 & 17.8069214 \\
\hline $\mathrm{O}$ & 13.9480535 & 18.3211448 & 17.9005796 \\
\hline 0 & 6.7095796 & 17.6148933 & 26.6026324 \\
\hline $\mathrm{H}$ & 8.9003926 & 18.8056283 & 23.0030162 \\
\hline $\mathrm{H}$ & 4.5083162 & 18.4977618 & 23.2307897 \\
\hline $\mathrm{H}$ & 18.2278970 & 15.7644216 & 17.3601631 \\
\hline $\mathrm{H}$ & 11.8884815 & 19.9417201 & 17.4105552 \\
\hline 0 & 11.3506047 & 12.2217202 & 17.0296238 \\
\hline 0 & 4.7835638 & 16.1437380 & 27.3478978 \\
\hline $\mathrm{H}$ & 11.5823791 & 19.7239034 & 22.2425303 \\
\hline $\mathrm{O}$ & 11.7242292 & 11.8694670 & 22.3436849 \\
\hline $\mathrm{H}$ & 18.3165525 & 16.0526123 & 22.1603005 \\
\hline $\mathrm{O}$ & 8.8653418 & 15.8098864 & 27.1539192 \\
\hline $\mathrm{H}$ & 16.0930061 & 12.3394871 & 17.2278615 \\
\hline $\mathrm{O}$ & 9.4425564 & 15.8436480 & 17.1328763 \\
\hline $\mathrm{H}$ & 15.8134093 & 19.8888436 & 17.3741566 \\
\hline 0 & 8.9815735 & 16.4987449 & 22.0780113 \\
\hline $\mathrm{O}$ & 6.8326530 & 14.8725122 & 16.6816374 \\
\hline 0 & 9.2346707 & 13.4014923 & 27.6158121 \\
\hline 0 & 13.7355802 & 18.6764307 & 21.7789077 \\
\hline $\mathrm{O}$ & 10.9444981 & 14.5425542 & 21.9279201 \\
\hline $\mathrm{O}$ & 16.4879900 & 14.5302225 & 21.6808660 \\
\hline 0 & 16.3113993 & 17.5185626 & 17.7386840 \\
\hline $\mathrm{O}$ & 13.8773308 & 13.1627747 & 17.8176608 \\
\hline $\mathrm{O}$ & 11.2313861 & 17.4378154 & 17.7732843 \\
\hline $\mathrm{H}$ & 4.3604713 & 18.3769456 & 26.4594004 \\
\hline $\mathrm{H}$ & 9.2527523 & 18.3707355 & 26.6135650 \\
\hline 0 & 6.8483999 & 17.5016981 & 22.8026033 \\
\hline $\mathrm{H}$ & 5.0810128 & 15.0176692 & 14.9303694 \\
\hline $\mathrm{O}$ & 12.1146562 & 19.1762961 & 19.9110916 \\
\hline 0 & 11.6635212 & 12.8252413 & 19.7132813 \\
\hline 0 & 17.4728078 & 15.9981903 & 19.8656797 \\
\hline $\mathrm{O}$ & 5.1430106 & 16.5741750 & 24.9198902 \\
\hline $\mathrm{H}$ & 8.6900870 & 14.9869079 & 29.4674684 \\
\hline $\mathrm{O}$ & 15.6480766 & 12.8126091 & 19.5940800 \\
\hline 0 & 15.6298606 & 19.0053067 & 19.6613439 \\
\hline $\mathrm{O}$ & 10.1458367 & 15.9941241 & 19.5303232 \\
\hline $\mathrm{O}$ & 8.5734801 & 16.8626480 & 24.5289953 \\
\hline $\mathrm{H}$ & 10.5295383 & 11.6537511 & 19.6891110 \\
\hline $\mathrm{C}$ & 8.7699216 & 11.0538364 & 21.4439830 \\
\hline $\mathrm{H}$ & 8.6048487 & 9.9805467 & 21.3854742 \\
\hline $\mathrm{H}$ & 9.6814063 & 11.4196206 & 21.9116624 \\
\hline $\mathrm{H}$ & 8.1614221 & 11.7042254 & 20.8237572 \\
\hline $\mathrm{O}$ & 9.9409817 & 10.8315109 & 19.6568269 \\
\hline C & 7.5581497 & 10.9108929 & 23.1678774 \\
\hline $\mathrm{C}$ & 7.7109138 & 12.2646440 & 23.2955117 \\
\hline C & 8.7745201 & 12.9468645 & 24.0585548 \\
\hline $\mathrm{H}$ & 9.4364412 & 12.2493254 & 24.5874712 \\
\hline $\mathrm{H}$ & 8.3132461 & 13.6345038 & 24.7880042 \\
\hline $\mathrm{H}$ & 9.3855025 & 13.5889934 & 23.3960445 \\
\hline $\mathrm{C}$ & 10.8438503 & 9.7183571 & 19.5344023 \\
\hline $\mathrm{H}$ & 10.2803525 & 8.7995042 & 19.7219132 \\
\hline $\mathrm{H}$ & 11.6738593 & 9.7925428 & 20.2511869 \\
\hline $\mathrm{H}$ & 11.2422308 & 9.6919742 & 18.5083614 \\
\hline $\mathrm{H}$ & 8.1681686 & 10.2256287 & 23.7624552 \\
\hline $\mathrm{H}$ & 7.0026330 & 12.9111989 & 22.7613849 \\
\hline $\mathrm{H}$ & 6.6656233 & 10.4903678 & 22.6998475 \\
\hline $\mathrm{H}$ & 5.1007862 & 14.9805168 & 29.6535333 \\
\hline $\mathrm{H}$ & 16.1023757 & 19.6464978 & 22.1581686 \\
\hline
\end{tabular}




\begin{tabular}{|c|c|c|}
\hline 9.2029671 & 7.9908883 & 27.4648947 \\
\hline 15.9296828 & 11.4770324 & 27.3100000 \\
\hline 9.0630520 & 7.7212564 & 22.3478428 \\
\hline 15.5229431 & 11.8733001 & 22.3412982 \\
\hline 9.3429695 & 10.4291586 & 16.6501698 \\
\hline 13.5907663 & 10.6799953 & 26.8543201 \\
\hline 11.0335171 & 6.5349483 & 26.5056048 \\
\hline 16.1701976 & 9.5513113 & 23.0201229 \\
\hline 11.1935111 & 9.1727658 & 22.9130440 \\
\hline 10.3369469 & 11.8962915 & 14.8200676 \\
\hline 11.8523963 & 10.8857562 & 24.8356984 \\
\hline 15.3451782 & 11.1085560 & 24.8698033 \\
\hline 9.7753828 & 8.1004445 & 24.8940773 \\
\hline 10.3313457 & 11.8901885 & 29.6300071 \\
\hline 8.6413049 & 14.8896893 & 14.8315329 \\
\hline 5.2436099 & 14.5693424 & 16.3212409 \\
\hline 5.1843897 & 14.5473751 & 28.2859362 \\
\hline 12.0361056 & 18.4629593 & 21.3773194 \\
\hline 12.0343495 & 13.1631556 & 21.3895003 \\
\hline 16.8857651 & 15.7398154 & 21.3465007 \\
\hline 16.7879509 & 15.8217460 & 18.2499516 \\
\hline 12.0391525 & 13.1373436 & 18.1741442 \\
\hline 12.0571539 & 18.5157611 & 18.2893059 \\
\hline 5.2316120 & 16.9353401 & 26.3323133 \\
\hline 5.2107295 & 16.9663914 & 23.3265567 \\
\hline 8.3403335 & 14.5147245 & 28.2165740 \\
\hline 8.3932353 & 14.5657831 & 16.2635478 \\
\hline 15.1967687 & 13.0919713 & 18.2860635 \\
\hline 15.1624476 & 18.4736523 & 18.2777427 \\
\hline 10.4654697 & 15.8014419 & 18.2117889 \\
\hline 10.3006320 & 15.7852194 & 21.3335566 \\
\hline 15.1681245 & 18.3750598 & 21.4187689 \\
\hline 15.2118747 & 13.1180748 & 21.3376690 \\
\hline 8.3165540 & 17.1657441 & 23.2382942 \\
\hline 8.3448500 & 16.9813487 & 26.3145518 \\
\hline 8.8341570 & 13.0229909 & 16.5647015 \\
\hline 6.7541627 & 14.1983360 & 28.0378425 \\
\hline 11.3762290 & 17.0007334 & 21.5457788 \\
\hline 13.7465754 & 13.7466118 & 21.5034141 \\
\hline 15.7916997 & 16.9027885 & 21.7036426 \\
\hline 15.6925824 & 14.6351021 & 18.0837778 \\
\hline 11.6146137 & 14.6931869 & 17.8944361 \\
\hline 13.6061811 & 18.0799442 & 18.0100668 \\
\hline 6.7830043 & 17.3638721 & 26.6103307 \\
\hline 8.8895971 & 18.5350757 & 23.1213610 \\
\hline 4.4796499 & 18.2630552 & 23.2904158 \\
\hline 17.9598242 & 15.6156505 & 17.3547654 \\
\hline 11.6746697 & 19.6563173 & 17.4118335 \\
\hline 11.3053165 & 12.1437246 & 17.1064808 \\
\hline 4.7325500 & 15.8032537 & 27.3725948 \\
\hline 11.4013868 & 19.4663515 & 22.2759054 \\
\hline 11.6246704 & 11.6616702 & 22.3275081 \\
\hline 18.1079770 & 15.9102713 & 22.1797255 \\
\hline 8.7947262 & 15.7224720 & 27.2340638 \\
\hline 15.9234612 & 12.1989622 & 17.3418319 \\
\hline 9.2169230 & 15.6058639 & 17.1890959 \\
\hline 15.5581051 & 19.6664140 & 17.4790594 \\
\hline 8.9302395 & 16.1639182 & 22.1357696 \\
\hline 6.8234297 & 14.7240975 & 16.6246748 \\
\hline 9.1485690 & 13.1822122 & 27.7675831 \\
\hline 13.5998176 & 18.3706459 & 21.7952213 \\
\hline 10.8376864 & 14.4110249 & 21.9438693 \\
\hline 16.3164644 & 14.2716159 & 21.6792010 \\
\hline 16.1028014 & 17.2338313 & 17.8360352 \\
\hline 13.6307111 & 13.0103992 & 17.9126607 \\
\hline 11.0852064 & 17.2757065 & 17.9443708 \\
\hline 4.3477215 & 18.1216677 & 26.5010880 \\
\hline 9.1983935 & 18.1512158 & 26.6609546 \\
\hline 6.7377978 & 17.2832219 & 22.9307241 \\
\hline 4.9470456 & 14.9134539 & 14.9032291 \\
\hline 11.8937226 & 18.9915588 & 19.8410670 \\
\hline 11.5890420 & 12.6633143 & 19.6515560 \\
\hline 17.3249373 & 15.8825371 & 19.7850029 \\
\hline 5.1067926 & 16.3240416 & 24.8224605 \\
\hline 8.6376367 & 14.8864396 & 29.6274458 \\
\hline 15.4862481 & 12.5853645 & 19.8049163 \\
\hline 15.3852921 & 18.8147689 & 19.8615439 \\
\hline 9.9260293 & 15.6841173 & 19.7406217 \\
\hline 8.5526800 & 16.5726655 & 24.7462523 \\
\hline 10.4468694 & 11.4883401 & 19.6519415 \\
\hline
\end{tabular}




\begin{tabular}{|c|c|c|c|}
\hline $\mathrm{C}$ & 8.6431657 & 10.9522895 & 21.3701401 \\
\hline $\mathrm{H}$ & 8.4351123 & 9.8867210 & 21.3122798 \\
\hline $\mathrm{H}$ & 9.5411036 & 11.2839270 & 21.8851743 \\
\hline $\mathrm{H}$ & 8.0945222 & 11.6248374 & 20.7185256 \\
\hline 0 & 9.8807228 & 10.6546013 & 19.6484602 \\
\hline $\mathrm{C}$ & 7.3081064 & 10.8792173 & 23.0145512 \\
\hline C & 7.5620214 & 12.2119058 & 23.1907200 \\
\hline C & 8.6181040 & 12.7836809 & 24.0498364 \\
\hline $\mathrm{H}$ & 9.1855727 & 12.0213742 & 24.5984718 \\
\hline $\mathrm{H}$ & 8.1590991 & 13.4825370 & 24.7703959 \\
\hline $\mathrm{H}$ & 9.3158698 & 13.4005962 & 23.4539168 \\
\hline C & 10.8212330 & 9.5647014 & 19.6083998 \\
\hline $\mathrm{H}$ & 10.2935160 & 8.6490200 & 19.8888883 \\
\hline $\mathrm{H}$ & 11.6586399 & 9.7355828 & 20.2990902 \\
\hline $\mathrm{H}$ & 11.2012974 & 9.4611917 & 18.5801388 \\
\hline $\mathrm{H}$ & 7.8157967 & 10.1329179 & 23.6312628 \\
\hline $\mathrm{H}$ & 6.9518247 & 12.9290081 & 22.6263848 \\
\hline $\mathrm{H}$ & 6.4202151 & 10.5443912 & 22.4742664 \\
\hline $\mathrm{H}$ & 4.9415787 & 14.9122345 & 29.7089755 \\
\hline $\mathrm{H}$ & 15.8119898 & 19.4179033 & 22.2643665 \\
\hline \multirow{2}{*}{\multicolumn{4}{|c|}{$\begin{array}{l}\text { Ti } 8 \\
177\end{array}$}} \\
\hline & & & \\
\hline $\mathrm{H}$ & 8.5121200 & 8.9096589 & 14.9139463 \\
\hline $\mathrm{P}$ & 5.2996422 & 9.3469578 & 16.4422247 \\
\hline Al & 5.2401695 & 9.2533920 & 28.2562073 \\
\hline $\mathrm{P}$ & 5.3089607 & 6.7225166 & 21.3735596 \\
\hline Al & 5.3466470 & 6.7475998 & 18.2273581 \\
\hline $\mathrm{P}$ & 3.1116742 & 7.8979390 & 26.3868512 \\
\hline Al & 3.2772260 & 8.0491216 & 23.3023846 \\
\hline $\mathrm{P}$ & 8.3601394 & 9.1183373 & 28.1735635 \\
\hline Al & 8.4293936 & 9.2787560 & 16.3541005 \\
\hline $\mathrm{P}$ & 8.4936367 & 6.6887303 & 18.1791355 \\
\hline Al & 8.4773173 & 6.5674245 & 21.3648801 \\
\hline $\mathrm{P}$ & 1.5723747 & 10.7115171 & 23.2029608 \\
\hline Al & 1.4786962 & 10.6503128 & 26.3498334 \\
\hline 0 & 6.7705721 & 9.7332937 & 16.7109049 \\
\hline $\mathrm{O}$ & 4.7802521 & 10.9010487 & 27.8524285 \\
\hline $\mathrm{H}$ & 4.6326187 & 5.4083113 & 21.5539667 \\
\hline $\mathrm{H}$ & 9.0670118 & 5.2273666 & 21.6362212 \\
\hline $\mathrm{O}$ & 7.0228243 & 6.3142619 & 17.9164791 \\
\hline 0 & 2.0304090 & 8.9905826 & 26.4787521 \\
\hline $\mathrm{H}$ & 2.2075651 & 7.0471723 & 23.0396228 \\
\hline $\mathrm{H}$ & 0.2386590 & 10.1387191 & 22.8709589 \\
\hline 0 & 4.8971928 & 8.1312765 & 17.2770866 \\
\hline 0 & 4.2016061 & 8.1190716 & 27.4402252 \\
\hline 0 & 4.6753472 & 7.7902800 & 22.2848554 \\
\hline $\mathrm{O}$ & 2.4392795 & 11.7059681 & 27.3486377 \\
\hline 0 & 8.8941411 & 7.9267462 & 17.3632825 \\
\hline $\mathrm{O}$ & 1.9087835 & 11.8992878 & 22.3045014 \\
\hline 0 & 4.3995675 & 10.5179442 & 16.8463757 \\
\hline 0 & 6.8896326 & 8.9899821 & 27.7552652 \\
\hline 0 & 6.7867454 & 6.5828082 & 21.7670760 \\
\hline $\mathrm{H}$ & 9.3645162 & 5.5533077 & 17.7674255 \\
\hline $\mathrm{H}$ & 4.4517292 & 5.6177686 & 17.8535610 \\
\hline $\mathrm{H}$ & 0.0772801 & 10.6945109 & 26.8510321 \\
\hline $\mathrm{H}$ & 2.4815318 & 6.5767132 & 26.6596209 \\
\hline 0 & 2.6514462 & 9.6405650 & 22.9771890 \\
\hline $\mathrm{H}$ & 5.1068059 & 9.0125540 & 15.0041325 \\
\hline 0 & 5.1898724 & 7.1996776 & 19.9140822 \\
\hline 0 & 3.7630302 & 7.9176515 & 24.9879326 \\
\hline $\mathrm{H}$ & 8.5216465 & 8.8527256 & 29.6297525 \\
\hline 0 & 8.7014465 & 7.0061964 & 19.6778306 \\
\hline 0 & 1.5871027 & 11.1723412 & 24.6790629 \\
\hline $\mathrm{H}$ & 5.1209007 & 9.0383883 & 29.7247675 \\
\hline $\mathrm{H}$ & 3.4295557 & 12.0136110 & 14.8771839 \\
\hline $\mathrm{P}$ & 3.2471206 & 15.8959895 & 21.3381262 \\
\hline Al & 3.1407976 & 15.9819538 & 18.1709982 \\
\hline $\mathrm{P}$ & 3.7182581 & 11.9849328 & 28.1417962 \\
\hline Al & 3.7210330 & 12.0406726 & 16.3371254 \\
\hline $\mathrm{P}$ & 1.5045856 & 13.2667128 & 18.1575065 \\
\hline Al & 1.5195191 & 13.2705221 & 21.2799539 \\
\hline 0 & 4.9077723 & 13.2846651 & 16.6996402 \\
\hline $\mathrm{H}$ & 0.1176727 & 13.7477759 & 21.4354402 \\
\hline $\mathrm{H}$ & 2.2697940 & 16.9690471 & 21.6705426 \\
\hline 0 & 1.9545570 & 14.7253000 & 17.9061961 \\
\hline 0 & 4.5744278 & 15.7367757 & 17.2031909 \\
\hline 0 & 4.5400920 & 16.0705819 & 22.1542823 \\
\hline 0 & 2.2336278 & 12.3249138 & 17.1860141 \\
\hline $\mathrm{O}$ & 4.2714905 & 13.3460633 & 27.6961140 \\
\hline
\end{tabular}




\begin{tabular}{|c|c|c|c|}
\hline 0 & 2.6669264 & 14.5338472 & 21.6999296 \\
\hline $\mathrm{H}$ & 2.5550941 & 17.3044642 & 17.8173906 \\
\hline $\mathrm{H}$ & 0.0449380 & 13.1662447 & 17.8810003 \\
\hline 0 & 3.6221008 & 15.9810154 & 19.8504541 \\
\hline $\mathrm{H}$ & 3.3889579 & 12.0081575 & 29.5937406 \\
\hline 0 & 1.8417458 & 12.8331525 & 19.5941911 \\
\hline $\mathrm{P}$ & 10.0791504 & 11.9710156 & 16.2132734 \\
\hline Al & 9.9608234 & 11.8710308 & 28.0551366 \\
\hline $\mathrm{P}$ & 12.2616555 & 10.5300066 & 26.4505147 \\
\hline Al & 12.3632261 & 10.4435146 & 23.2133813 \\
\hline $\mathrm{P}$ & 15.4473734 & 10.7115171 & 23.2029608 \\
\hline$P$ & 10.4619677 & 7.9493267 & 23.2801356 \\
\hline Al & 10.5506980 & 7.9515443 & 26.3485931 \\
\hline Al & 15.3536949 & 10.6503128 & 26.3498334 \\
\hline 0 & 8.8397916 & 10.5408648 & 27.8105697 \\
\hline $\mathrm{O}$ & 11.7485614 & 9.1307908 & 26.8596812 \\
\hline $\mathrm{H}$ & 15.8221144 & 9.2411558 & 26.4592889 \\
\hline $\mathrm{H}$ & 11.1869181 & 6.6489118 & 23.3022415 \\
\hline $\mathrm{O}$ & 14.0625185 & 10.1167561 & 22.8582288 \\
\hline 0 & 11.3899634 & 11.6231902 & 27.0891987 \\
\hline 0 & 9.1665610 & 8.0626583 & 27.4034030 \\
\hline $\mathrm{H}$ & 16.1747439 & 11.5526236 & 27.2035514 \\
\hline 0 & 9.2392991 & 7.8254118 & 22.3447017 \\
\hline 0 & 15.7837822 & 11.8992878 & 22.3045014 \\
\hline 0 & 9.5117092 & 10.6108133 & 16.6412141 \\
\hline 0 & 13.7062337 & 10.7022707 & 26.9390270 \\
\hline $\mathrm{H}$ & 11.1636589 & 6.5960916 & 26.4129932 \\
\hline $\mathrm{H}$ & 16.4927596 & 9.6739969 & 22.9842369 \\
\hline 0 & 11.3863362 & 9.0480535 & 22.7518404 \\
\hline $\mathrm{H}$ & 10.3929434 & 11.9540332 & 14.7578126 \\
\hline $\mathrm{O}$ & 12.1898312 & 10.6790022 & 24.9335970 \\
\hline 0 & 15.4621014 & 11.1723412 & 24.6790629 \\
\hline 0 & 9.9787302 & 8.2948997 & 24.7079398 \\
\hline $\mathrm{H}$ & 10.3402289 & 11.9418570 & 29.4932450 \\
\hline $\mathrm{H}$ & 8.6702121 & 14.9561498 & 14.7246497 \\
\hline$P$ & 5.3513531 & 14.7210538 & 16.3571375 \\
\hline Al & 5.2639999 & 14.6931101 & 28.1895701 \\
\hline $\mathrm{P}$ & 12.2464601 & 18.7386179 & 21.3735596 \\
\hline $\mathrm{Ti}$ & 12.0396574 & 13.3007932 & 21.4219173 \\
\hline$P$ & 17.1221193 & 15.8959895 & 21.3381262 \\
\hline Al & 17.0157963 & 15.9819538 & 18.1709982 \\
\hline Al & 12.1629020 & 13.3157539 & 18.1119589 \\
\hline Al & 12.2841464 & 18.7637012 & 18.2273581 \\
\hline $\mathrm{P}$ & 5.2542082 & 17.1741729 & 26.3239739 \\
\hline Al & 5.2110925 & 17.1909536 & 23.2953415 \\
\hline $\mathrm{P}$ & 8.4253118 & 14.6255577 & 28.0090284 \\
\hline Al & 8.5180886 & 14.7070991 & 16.1847706 \\
\hline $\mathrm{P}$ & 15.3795843 & 13.2667128 & 18.1575065 \\
\hline $\mathrm{P}$ & 15.4311361 & 18.7048317 & 18.1791355 \\
\hline $\mathrm{P}$ & 10.6356681 & 16.0604835 & 18.0632299 \\
\hline Al & 10.3847146 & 16.1062070 & 21.2461223 \\
\hline Al & 15.4148167 & 18.5835258 & 21.3648801 \\
\hline Al & 15.3945179 & 13.2705221 & 21.2799539 \\
\hline $\mathrm{P}$ & 8.3194806 & 17.4987421 & 23.0926915 \\
\hline Al & 8.3826951 & 17.2167183 & 26.2131995 \\
\hline 0 & 9.0321625 & 13.0628299 & 16.5269322 \\
\hline $\mathrm{O}$ & 6.9299937 & 14.3102075 & 27.8061766 \\
\hline $\mathrm{O}$ & 11.5520823 & 17.3893672 & 21.5587775 \\
\hline 0 & 13.7739986 & 13.8222223 & 21.4596943 \\
\hline 0 & 16.1070208 & 17.0105188 & 21.6833899 \\
\hline 0 & 15.8295557 & 14.7253000 & 17.9061961 \\
\hline 0 & 11.7160750 & 14.9950034 & 17.8015047 \\
\hline 0 & 13.9603237 & 18.3303632 & 17.9164791 \\
\hline 0 & 6.7088444 & 17.6159697 & 26.5986673 \\
\hline $\mathrm{H}$ & 8.9413487 & 18.8483043 & 22.9973898 \\
\hline $\mathrm{H}$ & 4.3958548 & 18.4369341 & 23.3017135 \\
\hline $\mathrm{H}$ & 18.2376954 & 15.7729857 & 17.3461252 \\
\hline $\mathrm{H}$ & 11.8990172 & 19.9493486 & 17.4130877 \\
\hline $\mathrm{O}$ & 11.3865696 & 12.2361874 & 16.9581351 \\
\hline 0 & 4.7850433 & 16.1421718 & 27.3521738 \\
\hline $\mathrm{H}$ & 11.6338874 & 19.7709235 & 22.2545934 \\
\hline 0 & 11.7163366 & 11.8114090 & 22.4138142 \\
\hline $\mathrm{H}$ & 18.3731241 & 16.0649150 & 22.1277919 \\
\hline 0 & 8.8532576 & 15.7880632 & 27.1032978 \\
\hline $\mathrm{H}$ & 16.0858712 & 12.3543098 & 17.2163369 \\
\hline 0 & 9.4584029 & 15.8617401 & 17.0916305 \\
\hline $\mathrm{H}$ & 15.8194342 & 19.9051163 & 17.3881474 \\
\hline 0 & 8.8703070 & 16.5666815 & 22.0149109 \\
\hline 0 & 6.8453159 & 14.8703202 & 16.662321 \\
\hline & & & \\
\hline
\end{tabular}




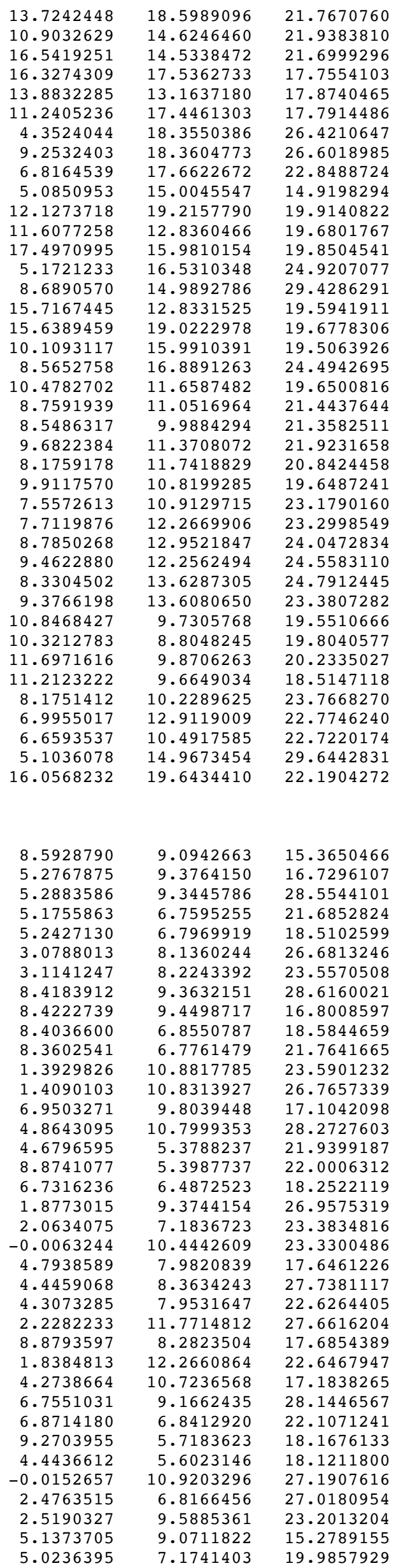




\begin{tabular}{|c|c|c|c|}
\hline 0 & 3.6234717 & 8.2082353 & 25.0150855 \\
\hline $\mathrm{H}$ & 8.5706172 & 9.1262772 & 30.0781267 \\
\hline 0 & 8.5962751 & 7.2020702 & 20.2955473 \\
\hline 0 & 1.5801151 & 11.2630442 & 25.3016266 \\
\hline $\mathrm{H}$ & 5.1191931 & 9.0295401 & 29.9998354 \\
\hline $\mathrm{H}$ & 3.3185061 & 12.0718504 & 15.3281743 \\
\hline Al & 3.1541724 & 16.1252525 & 21.6505490 \\
\hline $\mathrm{P}$ & 3.1105565 & 16.2088502 & 18.5253251 \\
\hline Al & 3.6722707 & 12.0532553 & 28.5866320 \\
\hline$P$ & 3.7060421 & 12.0874181 & 16.7657744 \\
\hline Al & 1.5007497 & 13.4369301 & 18.5987390 \\
\hline $\mathrm{P}$ & 1.5259213 & 13.4522578 & 21.7166854 \\
\hline 0 & 4.7946220 & 13.1553708 & 17.0208974 \\
\hline $\mathrm{H}$ & 0.1970045 & 14.0714507 & 21.9768792 \\
\hline $\mathrm{H}$ & 2.1419738 & 17.1748882 & 21.9519445 \\
\hline 0 & 2.0584039 & 15.0954367 & 18.4069685 \\
\hline 0 & 4.2982331 & 15.9414042 & 17.5944241 \\
\hline 0 & 4.5673101 & 16.3493295 & 22.6431249 \\
\hline $\mathrm{O}$ & 2.4641556 & 12.3684108 & 17.6064950 \\
\hline 0 & 4.3419500 & 13.5934532 & 28.1204818 \\
\hline $\mathrm{O}$ & 2.6261540 & 14.5098466 & 21.9576112 \\
\hline $\mathrm{H}$ & 2.4983218 & 17.5014630 & 18.1112701 \\
\hline $\mathrm{H}$ & 0.1020040 & 13.3705572 & 18.0925515 \\
\hline 0 & 3.6312259 & 16.3156757 & 19.9691564 \\
\hline $\mathrm{H}$ & 3.3605210 & 12.0686402 & 30.0425496 \\
\hline $\mathrm{O}$ & 1.6494783 & 12.9290019 & 20.2579266 \\
\hline Al & 10.0004432 & 12.1788122 & 16.6198904 \\
\hline$P$ & 9.9291395 & 12.1137753 & 28.4420764 \\
\hline Al & 12.1579346 & 10.7821402 & 26.6823673 \\
\hline $\mathrm{P}$ & 12.1372349 & 10.7582323 & 23.5297825 \\
\hline Al & 15.2679813 & 10.8817785 & 23.5901232 \\
\hline Al & 10.4752751 & 8.0379231 & 23.6973712 \\
\hline $\mathrm{P}$ & 10.5544342 & 8.0286678 & 26.7915944 \\
\hline$P$ & 15.2840091 & 10.8313927 & 26.7657339 \\
\hline 0 & 8.9010626 & 10.9917824 & 28.1845886 \\
\hline $\mathrm{O}$ & 11.6044841 & 9.1388964 & 26.9709155 \\
\hline $\mathrm{H}$ & 15.7360998 & 9.4248191 & 26.9508967 \\
\hline $\mathrm{H}$ & 11.4189537 & 6.9085683 & 23.4712096 \\
\hline 0 & 13.6213457 & 10.3669293 & 23.2840802 \\
\hline 0 & 11.1987667 & 11.8942142 & 27.6248713 \\
\hline 0 & 9.4130676 & 8.1931079 & 27.8032775 \\
\hline $\mathrm{H}$ & 16.0784592 & 11.7430646 & 27.6345399 \\
\hline 0 & 9.0808086 & 7.8054275 & 22.6555573 \\
\hline 0 & 15.7134800 & 12.2660864 & 22.6467947 \\
\hline 0 & 9.3019495 & 10.6599343 & 17.1626315 \\
\hline 0 & 13.8174091 & 10.9229725 & 27.2033918 \\
\hline $\mathrm{H}$ & 11.2026199 & 6.7136795 & 27.0519438 \\
\hline $\mathrm{H}$ & 16.2215642 & 9.7866107 & 23.2608699 \\
\hline $\mathrm{O}$ & 11.2672301 & 9.5074992 & 23.2934907 \\
\hline $\mathrm{H}$ & 10.2622918 & 12.1371821 & 15.1546863 \\
\hline 0 & 11.9874623 & 11.1939265 & 25.0101266 \\
\hline 0 & 15.4551138 & 11.2630442 & 25.3016266 \\
\hline 0 & 9.9504106 & 8.0670665 & 25.3725591 \\
\hline $\mathrm{H}$ & 10.2937976 & 12.1298409 & 29.8856438 \\
\hline $\mathrm{H}$ & 8.5601879 & 15.1488662 & 15.2518551 \\
\hline Al & 5.2545807 & 14.8141866 & 16.6798871 \\
\hline $\mathrm{P}$ & 5.2103929 & 14.7937531 & 28.5073330 \\
\hline Al & 12.1130857 & 18.7756269 & 21.6852824 \\
\hline $\mathrm{Zn}$ & 12.2678786 & 13.4176018 & 21.6854702 \\
\hline Al & 17.0291711 & 16.1252525 & 21.6505490 \\
\hline $\mathrm{P}$ & 16.9855552 & 16.2088502 & 18.5253251 \\
\hline$P$ & 12.2660853 & 13.3223409 & 18.4495144 \\
\hline$P$ & 12.1802123 & 18.8130933 & 18.5102599 \\
\hline Al & 5.2885350 & 17.3285544 & 26.6941346 \\
\hline $\mathrm{P}$ & 5.2598418 & 17.3456605 & 23.5736511 \\
\hline Al & 8.3638093 & 14.8310020 & 28.5166978 \\
\hline $\mathrm{P}$ & 8.3920886 & 14.8636885 & 16.7035910 \\
\hline Al & 15.3757484 & 13.4369301 & 18.5987390 \\
\hline Al & 15.3411594 & 18.8711801 & 18.5844659 \\
\hline Al & 10.5979310 & 16.0847713 & 18.5751420 \\
\hline $\mathrm{P}$ & 10.4426554 & 16.0976067 & 21.6898013 \\
\hline$P$ & 15.2977535 & 18.7922492 & 21.7641665 \\
\hline $\mathrm{P}$ & 15.4009201 & 13.4522578 & 21.7166854 \\
\hline Al & 8.4053452 & 17.5229099 & 23.5921601 \\
\hline $\mathrm{P}$ & 8.4375463 & 17.4002302 & 26.7323134 \\
\hline 0 & 8.8166707 & 13.4103670 & 17.0154244 \\
\hline 0 & 6.6827004 & 14.4566265 & 28.1985029 \\
\hline 0 & 11.5342366 & 17.1640625 & 21.9824957 \\
\hline 0 & 14.0429327 & 14.0849958 & 21.9825710 \\
\hline 0 & 15.8280512 & 17.3707971 & 22.0081984 \\
\hline
\end{tabular}


15.9334026

11.7261976

13.6691230

6.9616824

8.8818961

4.6546660

18.1394892

11.7444783

11.5096507

4.7556076

11.3745544

11.6453848

18.2375069

8.8821932

16.1965509

9.2370386

15.7453089

9.1899129

6.9270504

9.3127613

13.8089173

10.9030425

16.5011527

16.3532578

13.7395868

11.3604043

4.4252622

9.2879346

6.7267652

5.0719913

11.9611388

12.0986588

17.5062246

5.1261076

8.5354421

15.5244770

15.5337744

10.0086654

8.6196594

11.9464711

9.5129035

9.4863215

9.9280004

9.4721607

11.6869351

7.6802548

7.6770288

7.5422510

7.4325401

7.5166869

7.5685526

7.7754277

7.5736466

7.7898043

7.5242696

7.3224877

7.2034471

12.0593999

11.7197697

13.1563188

11.6012680

5.0462200

15.9942115 Si 9

180

$\begin{array}{ll}\mathrm{H} & 8.5828359 \\ \mathrm{P} & 5.2812111 \\ \mathrm{Al} & 5.2534903 \\ \mathrm{P} & 5.3005994 \\ \mathrm{Al} & 5.3565184 \\ \mathrm{P} & 3.1182413 \\ \mathrm{Al} & 3.1340730 \\ \mathrm{P} & 8.3943125 \\ \mathrm{Al} & 8.4297867 \\ \mathrm{P} & 8.5175681 \\ \mathrm{Al} & 8.4645895 \\ \mathrm{P} & 1.4942857 \\ \mathrm{Al} & 1.5232970 \\ \mathrm{O} & 6.7605079\end{array}$

15.0954367

14.7676265

18.5033536

17.7497630

18.9216608

18.6993277

15.9490026

19.9635450

12.4508771

16.0033107

19.7909242

11.8556785

16.3168546

16.2225569

12.5265731

15.8555127

20.0837753

16.4176863

15.0252785

13.4539787

18.8573934

14.7089677

14.5098466

17.5438214

13.3592914

17.5873829

18.5006895

18.5760814

17.4388012

15.0864020

19.1902416

12.6892262

16.3156757

16.8408862

15.1091608

12.9290019

19.2181715

16.2235402

17.0093552

10.9685141

10.5098121

9.5269574

11.3329013

10.5732131

10.0212059

12.1907337

13.3705874

13.3358005

12.1163482

10.9027981

10.9632673

12.2397384

10.0323330

14.3345931

14.2680519

12.0725612

9.9709172

9.2017253

8.1798410

9.1941558

9.5428160

15.1221155

19.7871082

18.4069685

18.4101242

18.2522119

27.0197903

23.4090875

23.4377539

17.6208716

17.6713814

17.4193944

27.6883519

22.4858219

22.6196349

22.4992738

27.6086624

17.7533670

17.5007444

17.8206619

22.5291646

17.1321040

28.0290948

22.1071241

22.0400036

21.9576112

18.0977017

18.0066338

18.1110732

27.0071523

27.0659813

23.1633835

15.2274132

19.9857929

19.8305192

19.9691564

25.0221549

29.9693817

20.2579266

20.2955473

20.2047185

25.2552848

19.9939220

20.4933384

20.9508524

21.0696777

19.4116013

20.1680142

22.8272038

22.0707526

20.6739784

20.0240784

20.7671766

22.1896569

23.9127660

22.7599756

22.5684939

20.1070039

18.9388333

20.2884791

19.0543762

19.2702996

18.9426221

18.1127502

29.9503667

22.6257478

9.0682175

9.4250838

9.3592290

6.8243098

6.8301609

8.0246206

8.0833409

9.3087911

9.3756044

6.8256492

6.7394778

10.8034815

10.7832199

9.7936405
15.2575665

16.7847836

28.6066133

21.7319225

18.5602486

26.7262406

23.6024078

28.5336118

16.7064315

18.5470612

21.7197540

23.5230291

26.6719064

17.0590102 


\begin{tabular}{|c|c|c|}
\hline 4.7772854 & 11.0096130 & 28.2586249 \\
\hline 4.7951673 & 5.4432902 & 21.9652543 \\
\hline 8.9584594 & 5.3554574 & 21.9599637 \\
\hline 7.0496563 & 6.4643516 & 18.2582648 \\
\hline 2.0624732 & 9.1291798 & 26.9044342 \\
\hline 2.1144907 & 7.0223228 & 23.3747830 \\
\hline 0.0836539 & 10.3848988 & 23.2949348 \\
\hline 4.8677247 & 8.2311812 & 17.6454186 \\
\hline 4.2892381 & 8.2370405 & 27.6942225 \\
\hline 4.5352291 & 7.8469045 & 22.5847247 \\
\hline 2.4733333 & 11.8611964 & 27.6644506 \\
\hline 8.9424809 & 8.0386143 & 17.7032181 \\
\hline 1.9043271 & 11.9574583 & 22.6064808 \\
\hline 4.4106833 & 10.6233206 & 17.1744578 \\
\hline 6.9210519 & 9.1412816 & 28.1549610 \\
\hline 6.7820637 & 6.8954745 & 22.1337684 \\
\hline 9.3898330 & 5.6751914 & 18.1827518 \\
\hline 4.5415162 & 5.6638985 & 18.1212451 \\
\hline 0.1073115 & 10.8484350 & 27.1278149 \\
\hline 2.4997168 & 6.7103321 & 27.0536455 \\
\hline 2.4206794 & 9.6163221 & 23.2134289 \\
\hline 5.0901585 & 9.0695715 & 15.3515249 \\
\hline 5.1463092 & 7.2242446 & 20.2500640 \\
\hline 3.6569186 & 8.0317845 & 25.2818697 \\
\hline 8.6012452 & 9.0265689 & 29.9809024 \\
\hline 8.6970608 & 7.1962944 & 20.0343213 \\
\hline 1.6889896 & 11.2416641 & 24.9938170 \\
\hline 5.1094136 & 9.1032679 & 30.0663552 \\
\hline 3.3719168 & 12.1096012 & 15.2387487 \\
\hline 3.1425691 & 16.0160556 & 21.7369862 \\
\hline 3.1478722 & 16.0974304 & 18.5916915 \\
\hline 3.7184098 & 12.1022136 & 28.5184800 \\
\hline 3.7096467 & 12.1485618 & 16.6884180 \\
\hline 1.4682068 & 13.4001631 & 18.5025469 \\
\hline 1.3977784 & 13.3551738 & 21.6660695 \\
\hline 4.9125723 & 13.3922792 & 17.0089026 \\
\hline-0.0098698 & 13.7598825 & 21.9341330 \\
\hline 2.1449764 & 17.0918557 & 21.9911193 \\
\hline 1.9643412 & 14.8507386 & 18.3057091 \\
\hline 4.5544428 & 15.8318004 & 17.5918081 \\
\hline 4.3619030 & 16.2023065 & 22.6523222 \\
\hline 2.2655185 & 12.4450123 & 17.5984187 \\
\hline 4.3147618 & 13.4596778 & 28.1303171 \\
\hline 2.5275645 & 14.6569701 & 22.0386536 \\
\hline 2.5770467 & 17.4256679 & 18.2352313 \\
\hline 0.0433478 & 13.3451653 & 18.0737431 \\
\hline 3.6297889 & 16.1012371 & 20.2741792 \\
\hline 3.3262485 & 12.1027935 & 29.9549095 \\
\hline 1.6571584 & 12.9539916 & 19.9570109 \\
\hline 10.0245929 & 12.0833799 & 16.7113169 \\
\hline 9.9959288 & 12.0192371 & 28.5226076 \\
\hline 12.2738861 & 10.7943306 & 26.7628550 \\
\hline 12.2249748 & 10.8356823 & 23.5936147 \\
\hline 15.3692844 & 10.8034815 & 23.5230291 \\
\hline 10.5444767 & 8.0866193 & 23.5992855 \\
\hline 10.6086636 & 8.0645551 & 26.7177325 \\
\hline 15.3982958 & 10.7832199 & 26.6719064 \\
\hline 8.8261588 & 10.7505903 & 28.2012247 \\
\hline 11.7689455 & 9.3469453 & 26.9460672 \\
\hline 15.8557057 & 9.3800153 & 26.8691713 \\
\hline 11.5271964 & 7.0135127 & 23.2833349 \\
\hline 13.9091243 & 10.3702020 & 23.2869263 \\
\hline 11.4753596 & 11.7458027 & 27.6651336 \\
\hline 9.2119006 & 8.2962371 & 27.7320732 \\
\hline 16.2083293 & 11.7023397 & 27.5181836 \\
\hline 9.3164333 & 7.9379294 & 22.6741307 \\
\hline 15.7793258 & 11.9574583 & 22.6064808 \\
\hline 9.4281134 & 10.7360195 & 17.1726208 \\
\hline 13.7414048 & 10.8595302 & 27.2053798 \\
\hline 11.2521863 & 6.7813059 & 27.1130433 \\
\hline 16.2665503 & 9.6536489 & 23.2231634 \\
\hline 11.1771914 & 9.4439766 & 23.3572986 \\
\hline 10.3332922 & 12.0344487 & 15.2554903 \\
\hline 12.1169788 & 11.2386449 & 25.3105342 \\
\hline 15.5639883 & 11.2416641 & 24.9938170 \\
\hline 10.0586867 & 7.9622498 & 25.0570629 \\
\hline 10.2911317 & 12.0310715 & 29.9820033 \\
\hline 8.6656472 & 15.0689947 & 15.1690137 \\
\hline 5.3537112 & 14.8452615 & 16.7352924 \\
\hline 5.3181462 & 14.8119120 & 28.5690567 \\
\hline
\end{tabular}




\begin{tabular}{|c|c|c|c|}
\hline $\mathrm{P}$ & 12.2380987 & 18.8404112 & 21.7319225 \\
\hline $\mathrm{Si}$ & 12.1265822 & 13.3528630 & 21.7080067 \\
\hline$P$ & 17.0175678 & 16.0160556 & 21.7369862 \\
\hline Al & 17.0228709 & 16.0974304 & 18.5916915 \\
\hline Al & 12.2053467 & 13.3862353 & 18.5751717 \\
\hline Al & 12.2940178 & 18.8462623 & 18.5602486 \\
\hline $\mathrm{P}$ & 5.2630748 & 17.3732265 & 26.7704711 \\
\hline Al & 5.2161654 & 17.3852843 & 23.6029377 \\
\hline $\mathrm{P}$ & 8.4715505 & 14.7591629 & 28.4545828 \\
\hline Al & 8.5005590 & 14.8276165 & 16.6290147 \\
\hline$P$ & 15.3432055 & 13.4001631 & 18.5025469 \\
\hline$P$ & 15.4550675 & 18.8417506 & 18.5470612 \\
\hline $\mathrm{P}$ & 10.6221033 & 16.2006949 & 18.4817863 \\
\hline Al & 10.5431258 & 16.1547137 & 21.5914571 \\
\hline Al & 15.4020889 & 18.7555792 & 21.7197540 \\
\hline Al & 15.2727771 & 13.3551738 & 21.6660695 \\
\hline$P$ & 8.3798022 & 17.4028539 & 23.5030165 \\
\hline Al & 8.4231236 & 17.3248780 & 26.6482777 \\
\hline 0 & 8.9831332 & 13.1812457 & 17.0154180 \\
\hline $\mathrm{O}$ & 6.9883092 & 14.4176497 & 28.2111159 \\
\hline $\mathrm{O}$ & 11.7184217 & 17.4204693 & 21.9718305 \\
\hline $\mathrm{O}$ & 13.6593107 & 13.8190567 & 21.9733277 \\
\hline $\mathrm{O}$ & 15.9806246 & 17.1342912 & 22.0011437 \\
\hline $\mathrm{O}$ & 15.8393399 & 14.8507386 & 18.3057091 \\
\hline $\mathrm{O}$ & 11.6140801 & 15.0306983 & 18.3983011 \\
\hline $\mathrm{O}$ & 13.9871556 & 18.4804530 & 18.2582648 \\
\hline $\mathrm{O}$ & 6.7491682 & 17.7067254 & 27.0015140 \\
\hline $\mathrm{H}$ & 8.8559802 & 18.8042122 & 23.3400128 \\
\hline $\mathrm{H}$ & 4.7100754 & 18.7570092 & 23.3212214 \\
\hline $\mathrm{H}$ & 18.2223539 & 15.8709088 & 17.7390197 \\
\hline $\mathrm{H}$ & 11.8764981 & 20.0429913 & 17.7788155 \\
\hline 0 & 11.3183012 & 12.3249266 & 17.4813182 \\
\hline $\mathrm{O}$ & 4.8250580 & 16.1909402 & 27.6391624 \\
\hline $\mathrm{H}$ & 11.4960642 & 19.8318274 & 22.5587231 \\
\hline 0 & 11.6569372 & 12.1465197 & 22.6769555 \\
\hline $\mathrm{H}$ & 18.1995891 & 16.1966070 & 22.6243122 \\
\hline $\mathrm{O}$ & 8.9110424 & 15.9511264 & 27.6019164 \\
\hline $\mathrm{H}$ & 16.1151115 & 12.4754475 & 17.6272282 \\
\hline $\mathrm{O}$ & 9.4510710 & 15.9796389 & 17.5111835 \\
\hline $\mathrm{H}$ & 15.8665765 & 20.0164529 & 17.7298370 \\
\hline 0 & 9.1059031 & 16.4547979 & 22.5536500 \\
\hline $\mathrm{O}$ & 6.8329718 & 14.9815501 & 17.1225919 \\
\hline $\mathrm{O}$ & 9.3188423 & 13.5500896 & 28.0472517 \\
\hline $\mathrm{O}$ & 13.7195630 & 18.9115759 & 22.1337684 \\
\hline $\mathrm{O}$ & 11.1140784 & 14.5933438 & 21.8750989 \\
\hline $\mathrm{O}$ & 16.4025632 & 14.6569701 & 22.0386536 \\
\hline $\mathrm{O}$ & 16.3517051 & 17.6591469 & 18.1725724 \\
\hline $\mathrm{O}$ & 13.8781274 & 13.3436129 & 18.0616394 \\
\hline 0 & 11.3441181 & 17.4869626 & 18.0485822 \\
\hline $\mathrm{H}$ & 4.4441522 & 18.5513737 & 27.1685360 \\
\hline $\mathrm{H}$ & 9.2761541 & 18.4924856 & 27.0034565 \\
\hline $\mathrm{O}$ & 6.8899584 & 17.3408179 & 23.1487115 \\
\hline $\mathrm{H}$ & 5.1538935 & 15.1817881 & 15.2986493 \\
\hline $\mathrm{O}$ & 12.0838086 & 19.2403460 & 20.2500640 \\
\hline 0 & 12.0083014 & 12.7503159 & 20.1630482 \\
\hline $\mathrm{O}$ & 17.5047876 & 16.1012371 & 20.2741792 \\
\hline $\mathrm{O}$ & 5.0224998 & 17.0032763 & 25.2967301 \\
\hline $\mathrm{H}$ & 8.6866995 & 15.0989329 & 29.8882452 \\
\hline $\mathrm{O}$ & 15.5321571 & 12.9539916 & 19.9570109 \\
\hline $\mathrm{O}$ & 15.6345602 & 19.2123958 & 20.0343213 \\
\hline $\mathrm{O}$ & 10.0576681 & 16.3677325 & 19.9000404 \\
\hline $\mathrm{O}$ & 8.5990305 & 16.9287535 & 24.9536475 \\
\hline $\mathrm{H}$ & 11.8238851 & 11.0866763 & 20.2450839 \\
\hline $\mathrm{C}$ & 9.3609025 & 10.6035427 & 20.5665382 \\
\hline $\mathrm{H}$ & 9.3628858 & 9.6668931 & 21.1127450 \\
\hline $\mathrm{H}$ & 9.7319003 & 11.4907508 & 21.0746571 \\
\hline $\mathrm{H}$ & 9.3774394 & 10.5727393 & 19.4816217 \\
\hline 0 & 11.5687936 & 10.1259302 & 20.3979975 \\
\hline C & 7.3569527 & 12.3402478 & 22.7247052 \\
\hline C & 7.3344159 & 13.4783340 & 21.9054726 \\
\hline C & 7.2754773 & 13.3639795 & 20.5080417 \\
\hline C & 7.2589357 & 12.1079682 & 19.9207261 \\
\hline C & 7.3613297 & 10.9392901 & 20.7314476 \\
\hline $\mathrm{C}$ & 7.3362503 & 11.0774481 & 22.1504714 \\
\hline $\mathrm{H}$ & 7.3906200 & 12.4507568 & 23.8093454 \\
\hline $\mathrm{H}$ & 7.3548014 & 10.1790595 & 22.7712302 \\
\hline $\mathrm{H}$ & 7.3664054 & 14.4714761 & 22.3568004 \\
\hline $\mathrm{H}$ & 7.2346384 & 14.2620098 & 19.8893062 \\
\hline $\mathrm{H}$ & 7.2062481 & 12.0031666 & 18.8356080 \\
\hline $\mathrm{H}$ & 7.0964963 & 9.9731848 & 20.2921455 \\
\hline
\end{tabular}




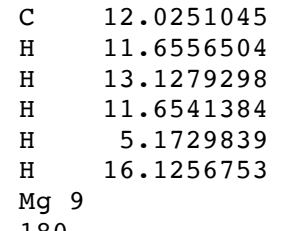

9.3090057

8.2898749

9.2894721

9.6639331

15.1356937

19.7735865

180

$\mathrm{H} \quad 8.6205442$

$\mathrm{Al} \quad 5.3069284$

$\mathrm{P} \quad 5.3119264$

Al $\quad 5.1937771$

P $\quad 5.2833969$

Al $\quad 3.1060060$

P $\quad 3.1735395$

Al 8.4431987

$\mathrm{P} \quad 8.4515023$

Al $\quad 8.4392315$

$\mathrm{P} \quad 8.3836599$

Al 1.4315981

P $\quad 1.4322368$

O $\quad 6.9812107$

4.9065971

4.6263911

8.9309380

6.7725320

1.9077986

2. 1350205

0.0417090

4.8455519

4.4569695

4.3773006

2. 2558021

8.8970018

1.9008875

4.2963291

6.7777055

6.8906780

9.3224506

4.4814247

0.0138995

2.4890339

2.5739272

5.1559659

5.0582975

3.6726900

8.5977279

8.6204357

1.5827920

5.1360507

3. 3653940

3.1865985

3. 1443155

Al $\quad 3.7033143$

P $\quad 3.7244676$

Al $\quad 1.5290950$

P $\quad 1.5575312$

4.8009701

0.1860081

2. 1950761

2.0839215

4.3429002

4.6261795

2.4626269

4.3487832

2. 6140093

2. 5524679

0.1181518

3. 6463846

3.4056981

1.7473621

Al $\quad 10.0352504$

P 9.9542536

Al 12.1840415

$\mathrm{P} \quad 12.1797505$

Al $\quad 15.3065968$

Al $\quad 10.4774994$

P $\quad 10.5687466$

15.3072355
9.0784557

9.3928803

9. 3447966

.7652027

6.7982705

8.1130922

8.2083263

9.3347747

9.4581409

.8641563

6.7672482

10.8757277

10.8285611

9.8301545

10.8023075

5.4146194

5.4014670

6.4803047

9. 3675956

7. 1685152

10.4068929

7.9902868

8.3652395

7.9946978

11.7418747

8.3000775

12.2215188

10.7311607

9.1451637

6.7837796

5.7370014

5.6098661

10.8986654

6.8069579

9. 5834480

9.0908956

7.1731002

8.1216945

9.1080815

7.2125376

11.3118849

9.0491891

12.0622610

16.1054890

16.2086540

12.0435786

12.0891166

13.4543291

13.4286987

13.1658502

13.9571630

17.1757519

15.1098935

15.9603764

16.3294444

12.3675382

13.5908295

17.5209343

13.3980038

16.2604424

12.0587468

12.9644818

12.1862715

12.0958978

10.7338612

10.7011756

10.8757277

8.0417026

8.0247600

10.8285611
14.5176836
19.3156939

19.4916866

19.2986620

18.3412269

30.0151597

22.5304355

15.3811553

16.7413018

28.5637414

21.6895564

18.5135236

26.6854389

23.5657879

28.6300675

16.8109750

18.6085507

21.7844280

23.6037579

26.7591968

17.1052571

28.2646017

21.9562367

22.0130081

18.2654281

26.8935834

23.3262219

23.3477834

17.6538641

27.7579547

22.6321765

27.6771396

17.7135716

22.6163536

17.2097743

28.1605865

22.1129397

18.2004251

18.1114588

27.2069972

27.0466579

23.2736572

15.2910824

19.9883804

25.0251655

30.0935741

20.3207419

25.3084943

30.0124665

15.3301018

21.6671859

18.5250744

28.5870336

16.7749082

18.5918696

21.7200487

17.0462904

21.9583146

21.9647445

18.3532037

17.6013122

22.6273057

17.5865770

28.1118064

22.0235098

18.1446045

18.1194426

19.9779813

30.0459082

20.2464556

16.6154607

28.4400420

26.7191523

23.5386115

23.6037579

23.7149640

26.8105942

26.7591968 


\subsection{0}

11.6349256

15.7663672

11.3655538

13.6702744

11.2207048

9. 4210602

16.1063249

9.0693362

15.7758862

9. 3383581

13.8462779

11.1901071

16.2751823

11.3238615

10.2983248

11.9963714

15.4577907

9.9784456

10.3296325

8.5686227

5.2775375

5. 2212843

12.1312764

12.2321675

17.0615973

17.0193143

12.2766330

12.2208962

5.3049739

5.2770331

8.3749197

8.4159867

15.4040937

15.3767309

10.6015234

10.4089550

15.3211593

15.4325299

Al 8.4207252

8.4487696

8.8526344

6.6905996

11.4701798

14.0388835

15.8855018

15.9589202

11.7187712

13.7100314

6.9717644

8.9457073

4.5919456

18.1831272

11.7957572

11.5378795

4. 7629452

11.4370617

11.7226905

18.2901148

8.8904526

16.1983040

9.2613082

15.7655992

9.1512691

6.9536095

9. 3170950

13.8281773

10.9328010

16.4890080

16.4079298

13.7536233

11.3981342

4.4154435

9.2968224

6.7322723

5.0914539

11.9957969

12.1084315

17.5213833

5.1900817
10.9586821

9. 1017173

9.4180700

6.8586779

10.3237665

11.8851033

8.1436632

11.7147315

7.8086327

12.2215188

10.6664817

10.9007720

6.6819912

9.7799985

9.4558724

12.1374452

11.0589862

11.3118849

8.1763188

12.1283712

15.1428008

14.8156457

14.7858271

18.7813041

13.3901190

16.1054890

16.2086540

13.3373237

18.8143719

17.3048258

17.3252726

14.8136254

14.8681373

13.4543291

18.8802577

16.1087172

16.1246138

18.7833496

13.4286987

17.5344392

17.3993969

13.4204518

14.4479073

17.2076558

13.9656874

17.3749826

15.1098935

14.7770870

18.4964060

17.7433569

18.9106966

18.6453860

15.9675791

19.9717967

12.4617355

16.0050515

19.8266908

11.8521972

16.2966093

16.1974542

12.5297325

15.8745620

20.1000492

16.3782599

15.0208966

13.4257983

18.7998809

14.7454441

14.5176836

17.5642524

13.3884418

17.5951599

18.4707153

18.5663386

17.5183913

15.0685542

19.1892015

12.7132508

16.2604424

16.7605336
28.1966156

27.0826038

26.8889405

23.5448680

23.3023980

27.6141309

27.8233118

27.6498588

22.6899782

22.6163536

17.1597364

27.2204534

26.9779373

23.3238642

23.2234885

15.1506985

25.0344511

25.3084943

25.3930847

29.8805824

15.2296932

16.6844909

28.5058628

21.6895564

21.6935187

21.6671859

18.5250744

18.4665079

18.5135236

26.6818995

23.5902226

28.4967585

16.6851597

18.5918696

18.6085507

18.5634413

21.6578255

21.7844280

21.7200487

23.5732979

26.7289568

17.0056742

28.1839940

22.0002821

21.9621580

22.0201353

18.3532037

18.4279770

18.2654281

27.0220727

23.3555134

23.5189748

17.6281112

17.6788108

17.4265325

27.7035180

22.4910257

22.6849870

22.4865382

27.5745256

17.7366084

17.4636951

17.8482806

22.5170712

17.1266327

28.0234438

22.1129397

21.9276127

22.0235098

18.1320452

18.0392416

18.1010359

26.9398878

27.0979748

23.1699496

15.2289736

19.9883804

19.8482019

19.9779813

25.0208747 


\subsection{3 \\ 15.6223608 \\ 15.5579351 \\ 9.9725728 \\ 8.6371064 \\ 11.8937725 \\ 9.4386704 \\ 9.4167787 \\ 9.8362888 \\ 9.4112011 \\ 11.6124487 \\ 7.4856491 \\ 7.4614817 \\ 7.3767012 \\ 7.3307329 \\ 7.4306296 \\ 7.4400998 \\ 7.5393712 \\ 7.4571643 \\ 7.5172055 \\ 7.3427087 \\ 7.2538047 \\ 7.1516710 \\ 12.0038367 \\ 11.6462009 \\ 13.1034291 \\ 11.5761346 \\ 5.0649195 \\ 15.9837015} 9

180

$\begin{array}{ll}\mathrm{H} & 8.5741773 \\ \mathrm{Si} & 5.2515959 \\ \mathrm{Si} & 5.2492429 \\ \mathrm{Si} & 5.2200809 \\ \mathrm{Si} & 5.2736861 \\ \mathrm{Si} & 3.1613105 \\ \mathrm{Si} & 3.2167370 \\ \mathrm{Si} & 8.3647294 \\ \mathrm{Si} & 8.3722066 \\ \mathrm{Si} & 8.3927007 \\ \mathrm{Si} & 8.3634085 \\ \mathrm{Si} & 1.5364031 \\ \mathrm{Si} & 1.5437771 \\ \mathrm{O} & 6.8146505 \\ \mathrm{O} & 4.8189519 \\ \mathrm{H} & 4.6580922 \\ \mathrm{H} & 8.8831372 \\ \mathrm{O} & 6.8384658 \\ \mathrm{O} & 2.0505475 \\ \mathrm{H} & 2.1895024 \\ \mathrm{H} & 0.1393987 \\ \mathrm{O} & 4.8299948 \\ \mathrm{O} & 4.3806648 \\ \mathrm{O} & 4.4830670 \\ \mathrm{O} & 2.3919667 \\ \mathrm{O} & 8.8182569 \\ \mathrm{O} & 1.9586638 \\ \mathrm{O} & 4.3359989 \\ \mathrm{O} & 6.8071329 \\ \mathrm{O} & 6.7908859 \\ \mathrm{H} & 9.2633889 \\ \mathrm{H} & 4.4395080 \\ \mathrm{H} & 0.1209949 \\ \mathrm{H} & 2.5232362 \\ \mathrm{O} & 2.5603510 \\ \mathrm{H} & 5.0432671 \\ \mathrm{O} & 5.0679422 \\ \mathrm{O} & 3.7562320 \\ \mathrm{H} & 8.5720541 \\ \mathrm{O} & 8.6101902 \\ \mathrm{O} & 1.7216942 \\ \mathrm{H} & 5.0436661 \\ \mathrm{H} & 3.2804208 \\ \mathrm{Si} & 3.2271423 \\ \mathrm{Si} & 3.1837098 \\ \mathrm{Si} & 3.6906928 \\ \mathrm{Si} & 3.6938412 \\ \mathrm{Si} & 1.5580570 \\ \mathrm{~S} & \end{array}$
15.1011351

12.9644818

19.2286389

16.3000007

17.0464403

10.9983108

10.5484767

9.5767257

11.3893453

10.5905065

10.0640954

12.2756264

13.4327347

13.3519590

12.1106573

10.9224056

11.0265809

12.3596416

10.1136363

14.4148050

14.2655002

12.0315509

9.9691779

9.1873904

8.1811998

9.1620456

9.4861003

15.1013089

19.7895987

8.8909027

9.3009928

9.2463290

6.7978873

6.8184874

8.0118668

8.0890854

9.2113554

9.3020967

6.8152890

6.7214607

10.7565526

10.7284419

9.7112644

10.7923136

5.4312889

5.3445111

6.4323223

9.1866534

7.0352690

10.2891506

8.0536529

8.2279238

7.8865307

11.6942613

8.1102733

11.9594460

10.5673467

9.0564599

6.7798918

5.6739798

5.6391009

10.7786219

6.7091452

9.5283711

8.9201726

7.2887162

8.0055829

8.8858685

7.1893422

11.2450749

8.9165818

11.9522041

15.8580271

15.9479273

11.9441114

11.9899897

13.2381710
29.9479359

20.2464556

20.3207419

20.1767057

25.2436302

19.9879519

20.5062572

20.9878369

21.0689329

19.4233388

20.1944427

22.7597483

21.9685082

20.5697646

19.9539687

20.7352963

22.1562541

23.8460176

22.7551600

22.4404632

19.9738322

18.8680363

20.2776063

19.1328649

19.3895075

19.0545801

18.1630236

29.9526322

22.6594257

15.3447218

16.7551806

28.6964306

21.7326953

18.6349656

26.7470426

23.6855348

28.7083441

16.7614956

18.6540718

21.7799145

23.6667914

26.7538229

17.0224867

28.4138504

21.9162658

22.0057741

18.3768745

26.8998047

23.4588618

23.4499160

17.6878709

27.7918870

22.6869135

27.7420479

17.7671669

22.6755087

17.1688282

28.3037588

22.1383033

18.2585519

18.2739739

27.1900491

27.0830459

23.3728766

15.3308577

20.1813211

25.2272595

30.1464663

20.2291331

25.2212833

30.1338329

15.2982558

21.7155163

18.6342086

28.6677469

16.7282126

18.6329746 


\begin{tabular}{|c|c|c|c|}
\hline $\mathrm{Si}$ & 1.5482277 & 13.2115911 & 21.7134516 \\
\hline 0 & 4.8323218 & 13.1364819 & 16.9712047 \\
\hline $\mathrm{H}$ & 0.1622480 & 13.7028365 & 21.9476709 \\
\hline $\mathrm{H}$ & 2.2176635 & 16.9155425 & 21.9978888 \\
\hline 0 & 2.0719206 & 14.7806939 & 18.4669057 \\
\hline 0 & 4.4412237 & 15.7031483 & 17.6425302 \\
\hline 0 & 4.5215880 & 16.0510699 & 22.6734320 \\
\hline $\mathrm{O}$ & 2.3955166 & 12.2620472 & 17.6410187 \\
\hline 0 & 4.3247621 & 13.3761913 & 28.2629434 \\
\hline 0 & 2.6349770 & 14.3958308 & 22.0116194 \\
\hline $\mathrm{H}$ & 2.5803508 & 17.2565129 & 18.2591323 \\
\hline $\mathrm{H}$ & 0.1372469 & 13.1954655 & 18.1895838 \\
\hline 0 & 3.7303198 & 16.0032692 & 20.1669924 \\
\hline $\mathrm{H}$ & 3.2805353 & 11.9483159 & 30.0991356 \\
\hline 0 & 1.7699904 & 12.7179061 & 20.1548129 \\
\hline $\mathrm{Si}$ & 9.9542609 & 12.0046200 & 16.6727682 \\
\hline $\mathrm{Si}$ & 9.9117354 & 11.9316315 & 28.6149380 \\
\hline $\mathrm{Si}$ & 12.0697409 & 10.6764987 & 26.7753888 \\
\hline $\mathrm{Si}$ & 12.0612948 & 10.6820209 & 23.6570847 \\
\hline $\mathrm{Si}$ & 15.1614018 & 10.7565526 & 23.6667914 \\
\hline $\mathrm{Si}$ & 10.3664176 & 8.0194901 & 23.7371113 \\
\hline $\mathrm{Si}$ & 10.4381450 & 7.9954722 & 26.7798749 \\
\hline $\mathrm{Si}$ & 15.1687759 & 10.7284419 & 26.7538229 \\
\hline 0 & 8.8159891 & 10.7439510 & 28.3951126 \\
\hline 0 & 11.5619315 & 9.1442912 & 27.0205760 \\
\hline $\mathrm{H}$ & 15.6318538 & 9.3195824 & 26.8872185 \\
\hline $\mathrm{H}$ & 11.2973188 & 6.8703163 & 23.5640705 \\
\hline 0 & 13.6329566 & 10.2451739 & 23.4295108 \\
\hline 0 & 11.2220995 & 11.69 & 27.7073792 \\
\hline 0 & 9.2217254 & 8.1541478 & 27.8387971 \\
\hline $\mathrm{H}$ & 15.9477214 & 11.6154142 & 27.6613717 \\
\hline 0 & 9.0993108 & 7.8231245 & 22.7274171 \\
\hline 0 & 15.5836625 & 11.9594460 & 22.6755087 \\
\hline 0 & 9.2973799 & 10.5845921 & 17.1349910 \\
\hline $\mathrm{O}$ & 13.6218606 & 10.7829999 & 27.2281084 \\
\hline $\mathrm{H}$ & 11.0706613 & 6.6684163 & 27.0164475 \\
\hline $\mathrm{H}$ & 16.0991808 & 9.6317270 & 23.3976106 \\
\hline $\mathrm{O}$ & 11.1293163 & 9.3767231 & 23.3630079 \\
\hline $\mathrm{H}$ & 10.3332983 & 11.9641784 & 15.2333879 \\
\hline 0 & 11.8723763 & 11.0978396 & 25.2322576 \\
\hline 0 & 15.3466929 & 11.2450749 & 25.2212833 \\
\hline 0 & 9.8139981 & 8.0726233 & 25.2733179 \\
\hline $\mathrm{H}$ & 10.3279977 & 11.9582285 & 30.0443221 \\
\hline $\mathrm{H}$ & 8.5927613 & 15.0279163 & 15.2165570 \\
\hline $\mathrm{Si}$ & 5.2723387 & 14.6832594 & 16.7031151 \\
\hline $\mathrm{Si}$ & 5.2359594 & 14.6519792 & 28.6544739 \\
\hline $\mathrm{Si}$ & 12.0325802 & 18.5974824 & 21.7326953 \\
\hline Al & 12.0455753 & 13.2164480 & 21.7424232 \\
\hline $\mathrm{Si}$ & 16.8521411 & 15.8580271 & 21.7155163 \\
\hline $\mathrm{Si}$ & 16.8087086 & 15.9479273 & 18.6342086 \\
\hline $\mathrm{Si}$ & 12.0796454 & 13.2054681 & 18.6041811 \\
\hline $\mathrm{Si}$ & 12.0861855 & 18.6180824 & 18.6349656 \\
\hline $\mathrm{Si}$ & 5.2459639 & 17.0779375 & 26.7401826 \\
\hline $\mathrm{Si}$ & 5.2175766 & 17.1000988 & 23.6884394 \\
\hline $\mathrm{Si}$ & 8.3638223 & 14.6407153 & 28.5970089 \\
\hline $\mathrm{Si}$ & 8.3931388 & 14.7014797 & 16.6555534 \\
\hline $\mathrm{Si}$ & 15.1830557 & 13.2381710 & 18.6329746 \\
\hline $\mathrm{Si}$ & 15.2052000 & 18.6148840 & 18.6540718 \\
\hline $\mathrm{Si}$ & 10.4550946 & 15.9412632 & 18.6149090 \\
\hline $\mathrm{Si}$ & 10.3346253 & 15.9230463 & 21.6632619 \\
\hline $\mathrm{Si}$ & 15.1759079 & 18.5210557 & 21.7799145 \\
\hline $\mathrm{Si}$ & 15.1732265 & 13.2115911 & 21.7134516 \\
\hline $\mathrm{Si}$ & 8.3469300 & 17.2253550 & 23.6306292 \\
\hline $\mathrm{Si}$ & 8.3678454 & 17.1186402 & 26.7215035 \\
\hline 0 & 8.8355081 & 13.1572337 & 16.9523815 \\
\hline 0 & 6.7937969 & 14.2725381 & 28.3720753 \\
\hline 0 & 11.4243552 & 17.1184500 & 21.9313686 \\
\hline 0 & 13.6898566 & 13.7373553 & 21.9641290 \\
\hline 0 & 15.7421734 & 17.0208132 & 22.0259977 \\
\hline 0 & 15.6969194 & 14.7806939 & 18.4669057 \\
\hline 0 & 11.5378978 & 14.7405092 & 18.4802925 \\
\hline 0 & 13.6509651 & 18.2319173 & 18.3768745 \\
\hline 0 & 6.8026846 & 17.4882573 & 26.9982006 \\
\hline $\mathrm{H}$ & 8.8605150 & 18.6117650 & 23.4539424 \\
\hline $\mathrm{H}$ & 4.6160231 & 18.4561055 & 23.5599869 \\
\hline $\mathrm{H}$ & 17.9644720 & 15.7229543 & 17.7227709 \\
\hline $\mathrm{H}$ & 11.6779904 & 19.7544319 & 17.7636406 \\
\hline 0 & 11.2852149 & 12.2473762 & 17.5435129 \\
\hline $\mathrm{O}$ & 4.7742734 & 15.8997268 & 27.7410169 \\
\hline $\mathrm{H}$ & 11.3570238 & 19.5953470 & 22.6073440 \\
\hline
\end{tabular}




\begin{tabular}{|c|c|c|c|}
\hline 0 & 11.5907471 & 11.8797832 & 22.7357464 \\
\hline $\mathrm{H}$ & 18.0405416 & 16.0352552 & 22.5949565 \\
\hline 0 & 8.8202630 & 15.8692709 & 27.6496456 \\
\hline $\mathrm{H}$ & 15.9507887 & 12.3433190 & 17.7236086 \\
\hline 0 & 9.2499874 & 15.7381920 & 17.5454275 \\
\hline $\mathrm{H}$ & 15.5948412 & 19.8005773 & 17.8420178 \\
\hline 0 & 9.0304273 & 16.1946560 & 22.6013067 \\
\hline 0 & 6.8377508 & 14.8385439 & 17.0901031 \\
\hline $\mathrm{O}$ & 9.2427047 & 13.3434894 & 28.1949615 \\
\hline $\mathrm{O}$ & 13.6033853 & 18.5794869 & 22.1383033 \\
\hline $\mathrm{O}$ & 10.9334883 & 14.5027782 & 21.9949205 \\
\hline $\mathrm{O}$ & 16.2599757 & 14.3958308 & 22.0116194 \\
\hline $\mathrm{O}$ & 16.1501499 & 17.3762317 & 18.2248177 \\
\hline $\mathrm{O}$ & 13.6400995 & 13.1917941 & 18.1514657 \\
\hline $\mathrm{O}$ & 11.1838686 & 17.3423594 & 18.2444868 \\
\hline $\mathrm{H}$ & 4.3822615 & 18.2596008 & 27.0136976 \\
\hline $\mathrm{H}$ & 9.2079294 & 18.2941493 & 27.0814450 \\
\hline $\mathrm{O}$ & 6.7707834 & 17.2215788 & 23.2825965 \\
\hline $\mathrm{H}$ & 5.0435681 & 15.0384874 & 15.2753204 \\
\hline 0 & 11.8804416 & 19.0883112 & 20.1813211 \\
\hline 0 & 11.8723579 & 12.6000010 & 20.0789140 \\
\hline 0 & 17.3553185 & 16.0032692 & 20.1669924 \\
\hline $\mathrm{O}$ & 5.0543596 & 16.5463349 & 25.2115178 \\
\hline $\mathrm{H}$ & 8.5897446 & 15.0218812 & 30.0185547 \\
\hline 0 & 15.3949891 & 12.7179061 & 20.1548129 \\
\hline $\mathrm{O}$ & 15.4226896 & 18.9889373 & 20.2291331 \\
\hline $\mathrm{O}$ & 9.8155136 & 16.0269517 & 20.1042724 \\
\hline $\mathrm{O}$ & 8.5899681 & 16.7138389 & 25.1608920 \\
\hline $\mathrm{H}$ & 11.6774896 & 10.9066900 & 20.1812756 \\
\hline C & 9.2168995 & 10.4788162 & 20.5417790 \\
\hline $\mathrm{H}$ & 9.1938251 & 9.5313057 & 21.0666675 \\
\hline $\mathrm{H}$ & 9.5861867 & 11.3519284 & 21.0743353 \\
\hline $\mathrm{H}$ & 9.2330580 & 10.4736787 & 19.4572814 \\
\hline $\mathrm{O}$ & 11.3987426 & 9.9603866 & 20.3480976 \\
\hline C & 7.1410778 & 12.1741805 & 22.7194724 \\
\hline C & 7.1425540 & 13.3347154 & 21.9322072 \\
\hline C & 7.1300805 & 13.2598543 & 20.5310970 \\
\hline C & 7.1295595 & 12.0203847 & 19.9089449 \\
\hline C & 7.2020702 & 10.8298805 & 20.6894473 \\
\hline C & 7.1395365 & 10.9278754 & 22.1096975 \\
\hline $\mathrm{H}$ & 7.1369252 & 12.2539081 & 23.8073567 \\
\hline $\mathrm{H}$ & 7.1344179 & 10.0133680 & 22.7065806 \\
\hline $\mathrm{H}$ & 7.1560994 & 14.3149488 & 22.4108085 \\
\hline $\mathrm{H}$ & 7.1148148 & 14.1757279 & 19.9380533 \\
\hline $\mathrm{H}$ & 7.1096727 & 11.9455868 & 18.8200813 \\
\hline $\mathrm{H}$ & 6.9489582 & 9.8766205 & 20.2169107 \\
\hline $\mathrm{C}$ & 11.8540465 & 9.1168548 & 19.2850135 \\
\hline $\mathrm{H}$ & 11.4896368 & 8.1016414 & 19.4903012 \\
\hline $\mathrm{H}$ & 12.9567085 & 9.1011891 & 19.2674374 \\
\hline $\mathrm{H}$ & 11.4801709 & 9.4439591 & 18.3023073 \\
\hline $\mathrm{H}$ & 5.0409985 & 15.0349973 & 30.0800994 \\
\hline & 15.8486492 & 19.5281660 & 22.6460949 \\
\hline \multirow{2}{*}{\multicolumn{4}{|c|}{$\begin{array}{l}\text { Ge } 9 \\
180\end{array}$}} \\
\hline & & & \\
\hline $\mathrm{H}$ & 8.5444646 & 9.0985414 & 15.2827812 \\
\hline $\mathrm{P}$ & 5.2827447 & 9.4589581 & 16.8072668 \\
\hline Al & 5.2446826 & 9.3757816 & 28.6208369 \\
\hline $\mathrm{P}$ & 5.2845759 & 6.8141151 & 21.7334162 \\
\hline Al & 5.3553159 & 6.8523197 & 18.5717205 \\
\hline $\mathrm{P}$ & 3.1040459 & 8.0333304 & 26.7339029 \\
\hline Al & 3.1825904 & 8.1395197 & 23.6270648 \\
\hline $\mathrm{P}$ & 8.3762767 & 9.2777394 & 28.5473936 \\
\hline Al & 8.4204612 & 9.4109254 & 16.7333535 \\
\hline $\mathrm{P}$ & 8.5150010 & 6.8451782 & 18.5660372 \\
\hline Al & 8.4599585 & 6.7073036 & 21.7426134 \\
\hline $\mathrm{P}$ & 1.5194783 & 10.8475683 & 23.5320404 \\
\hline Al & 1.4954742 & 10.7939222 & 26.6804194 \\
\hline 0 & 6.7555590 & 9.8432425 & 17.0979357 \\
\hline $\mathrm{O}$ & 4.7838065 & 11.0323746 & 28.2686597 \\
\hline $\mathrm{H}$ & 4.7039528 & 5.4580203 & 21.9359111 \\
\hline $\mathrm{H}$ & 9.0055558 & 5.3424541 & 21.9805841 \\
\hline $\mathrm{O}$ & 7.0478341 & 6.4800083 & 18.2781118 \\
\hline $\mathrm{O}$ & 2.0352679 & 9.1333402 & 26.8566322 \\
\hline $\mathrm{H}$ & 2.1307842 & 7.1165058 & 23.3735557 \\
\hline $\mathrm{H}$ & 0.1378958 & 10.3744158 & 23.2413910 \\
\hline $\mathrm{O}$ & 4.8757347 & 8.2544320 & 17.6563547 \\
\hline $\mathrm{O}$ & 4.2371450 & 8.2626357 & 27.7423982 \\
\hline $\mathrm{O}$ & 4.5782324 & 7.8602822 & 22.6100548 \\
\hline 0 & 2.4552485 & 11.8370506 & 27.7005305 \\
\hline
\end{tabular}

22.7357464

2.5949565

17.7236086

17.5454275

22.6013067

17.0901031

22.1383033

21.9949205

16194

18.1514657

18.2444868

23.2825965

5. 2753204

20.1813211

0789140

25.2115178

.0185547

20.2291331

.1042724

1608920

20.5417790

21.0666675

21.0743353

22.7194724

.9322072

20.5310970
19.9089449

20.6894473

22.1096975

22.7065806

22.4108085

19.9380533

200813

19.2850135

19.4903012

19.2674374
18.3023073

30.0800994

$\mathrm{H}$

180

9. 4589581

16.8072668

28.6208369

7334162

26.7339029

3.6270648

16.7333535

8.5660372

23.5320404

26.6804194

17.0979357
28.2686597

21.9359111

1.9805841

26.8566322

23.3735557

17.6563547

22.6100548

27.7005305 


\begin{tabular}{|c|c|c|c|}
\hline 0 & 8.9254801 & 8.0808533 & 17.7468489 \\
\hline $\mathrm{O}$ & 1.9085275 & 12.0111641 & 22.6190251 \\
\hline 0 & 4.3909560 & 10.6412976 & 17.1960716 \\
\hline 0 & 6.9041611 & 9.1153068 & 28.1548856 \\
\hline 0 & 6.7671614 & 6.7864272 & 22.1308332 \\
\hline $\mathrm{H}$ & 9.3884623 & 5.7067903 & 18.1682196 \\
\hline $\mathrm{H}$ & 4.5354979 & 5.6914623 & 18.1273907 \\
\hline $\mathrm{H}$ & 0.0880107 & 10.8467811 & 27.1635065 \\
\hline $\mathrm{H}$ & 2.4801331 & 6.7190802 & 27.0510777 \\
\hline 0 & 2.5151943 & 9.7039790 & 23.2722360 \\
\hline $\mathrm{H}$ & 5.1067531 & 9.1090844 & 15.3706959 \\
\hline $\mathrm{O}$ & 5.1462406 & 7.2526921 & 20.2607681 \\
\hline 0 & 3.6945102 & 8.0310211 & 25.3086493 \\
\hline $\mathrm{H}$ & 8.5588789 & 9.0541437 & 30.0081406 \\
\hline 0 & 8.7022164 & 7.1813579 & 20.0610077 \\
\hline $\mathrm{O}$ & 1.6289238 & 11.2985132 & 25.0089160 \\
\hline $\mathrm{H}$ & 5.1226275 & 9.1395232 & 30.0858984 \\
\hline $\mathrm{H}$ & 3.3957468 & 12.1514033 & 15.2542833 \\
\hline $\mathrm{P}$ & 3.1997211 & 16.0213508 & 21.7034124 \\
\hline Al & 3.1675852 & 16.1355545 & 18.5783261 \\
\hline $\mathrm{P}$ & 3.7129783 & 12.1159991 & 28.5237543 \\
\hline Al & 3.7087713 & 12.1741898 & 16.7098303 \\
\hline $\mathrm{P}$ & 1.4482869 & 13.4304576 & 18.4947418 \\
\hline Al & 1.3980814 & 13.3924647 & 21.6566957 \\
\hline 0 & 4.9151695 & 13.4039178 & 17.0773776 \\
\hline $\mathrm{H}$ & 0.0421302 & 13.9010291 & 22.0029315 \\
\hline $\mathrm{H}$ & 2.2009414 & 17.0824210 & 22.0095002 \\
\hline 0 & 1.9932005 & 14.8687710 & 18.3509626 \\
\hline $\mathrm{O}$ & 4.5621670 & 15.8648537 & 17.5639699 \\
\hline $\mathrm{O}$ & 4.4249891 & 16.1561771 & 22.6192583 \\
\hline $\mathrm{O}$ & 2.2527842 & 12.4708717 & 17.6019930 \\
\hline $\mathrm{O}$ & 4.2785757 & 13.4749757 & 28.0921012 \\
\hline $\mathrm{O}$ & 2.5929213 & 14.6482106 & 21.9420265 \\
\hline $\mathrm{H}$ & 2.5801867 & 17.4561082 & 18.2202458 \\
\hline $\mathrm{H}$ & 0.0400925 & 13.4275095 & 18.0109026 \\
\hline $\mathrm{O}$ & 3.6849936 & 16.1776068 & 20.2475635 \\
\hline $\mathrm{H}$ & 3.3531651 & 12.1463982 & 29.9683064 \\
\hline $\mathrm{O}$ & 1.5571079 & 12.9465426 & 19.9465779 \\
\hline $\mathrm{P}$ & 10.0272523 & 12.1022319 & 16.6465156 \\
\hline Al & 9.9669539 & 12.0021310 & 28.4570672 \\
\hline $\mathrm{P}$ & 12.2610249 & 10.7156849 & 26.7951944 \\
\hline Al & 12.2565673 & 10.6995888 & 23.5620245 \\
\hline $\mathrm{P}$ & 15.3944771 & 10.8475683 & 23.5320404 \\
\hline$P$ & 10.4659621 & 8.0877157 & 23.6595664 \\
\hline Al & 10.5639481 & 8.0889495 & 26.7310002 \\
\hline Al & 15.3704729 & 10.7939222 & 26.6804194 \\
\hline 0 & 8.8294758 & 10.6983322 & 28.1535232 \\
\hline 0 & 11.7644091 & 9.2943492 & 27.1496341 \\
\hline $\mathrm{H}$ & 15.8284565 & 9.3850150 & 26.8299257 \\
\hline $\mathrm{H}$ & 11.2816754 & 6.8435924 & 23.5971981 \\
\hline 0 & 13.9637898 & 10.3575989 & 23.2310606 \\
\hline $\mathrm{O}$ & 11.4322296 & 11.7621703 & 27.5592882 \\
\hline $\mathrm{O}$ & 9.1964259 & 8.2164277 & 27.8085645 \\
\hline $\mathrm{H}$ & 16.1887874 & 11.6833053 & 27.5501777 \\
\hline $\mathrm{O}$ & 9.2461999 & 7.9331436 & 22.7233732 \\
\hline 0 & 15.7835262 & 12.0111641 & 22.6190251 \\
\hline 0 & 9.4484019 & 10.7646329 & 17.1589944 \\
\hline $\mathrm{O}$ & 13.7213630 & 10.8558564 & 27.2464473 \\
\hline $\mathrm{H}$ & 11.1809195 & 6.7412921 & 26.8734315 \\
\hline $\mathrm{H}$ & 16.3582049 & 9.7407177 & 23.2805824 \\
\hline $\mathrm{O}$ & 11.3075420 & 9.2650063 & 23.1967293 \\
\hline $\mathrm{H}$ & 10.3133657 & 12.0109168 & 15.1881188 \\
\hline $\mathrm{O}$ & 12.1253002 & 10.9646509 & 25.2982366 \\
\hline $\mathrm{O}$ & 15.5039225 & 11.2985132 & 25.0089160 \\
\hline $\mathrm{O}$ & 9.9535993 & 8.3104634 & 25.0978368 \\
\hline $\mathrm{H}$ & 10.2692483 & 12.0075072 & 29.9150486 \\
\hline $\mathrm{H}$ & 8.6217759 & 15.0880233 & 15.1068125 \\
\hline $\mathrm{P}$ & 5.3622256 & 14.8440035 & 16.7484586 \\
\hline Al & 5.2892476 & 14.8127471 & 28.5628278 \\
\hline $\mathrm{P}$ & 12.2220753 & 18.8302165 & 21.7334162 \\
\hline $\mathrm{Ge}$ & 12.0764781 & 13.3731270 & 21.7460169 \\
\hline $\mathrm{P}$ & 17.0747198 & 16.0213508 & 21.7034124 \\
\hline Al & 17.0425839 & 16.1355545 & 18.5783261 \\
\hline Al & 12.2021904 & 13.4134257 & 18.5154922 \\
\hline Al & 12.2928153 & 18.8684211 & 18.5717205 \\
\hline$P$ & 5.2528438 & 17.3179700 & 26.7410692 \\
\hline Al & 5.1856244 & 17.3060403 & 23.6750331 \\
\hline $\mathrm{P}$ & 8.4308573 & 14.7583480 & 28.3916799 \\
\hline Al & 8.4960514 & 14.8480986 & 16.5709676 \\
\hline $\mathrm{P}$ & 15.3232857 & 13.4304576 & 18.4947418 \\
\hline
\end{tabular}




\begin{tabular}{|c|c|c|c|}
\hline $\mathrm{P}$ & 15.4525003 & 18.8612796 & 18.5660372 \\
\hline $\mathrm{P}$ & 10.6005054 & 16.2260788 & 18.4529779 \\
\hline Al & 10.4125739 & 16.2102152 & 21.5551689 \\
\hline Al & 15.3974578 & 18.7234050 & 21.7426134 \\
\hline Al & 15.2730801 & 13.3924647 & 21.6566957 \\
\hline $\mathrm{P}$ & 8.3177971 & 17.5331026 & 23.4760693 \\
\hline Al & 8.3865559 & 17.3488327 & 26.6200476 \\
\hline 0 & 8.9813098 & 13.1988774 & 16.9375378 \\
\hline 0 & 6.9460139 & 14.4277845 & 28.1419529 \\
\hline 0 & 11.6249597 & 17.4356022 & 21.9416630 \\
\hline 0 & 13.7068694 & 13.9798892 & 22.0566204 \\
\hline 0 & 16.0368307 & 17.1239695 & 22.0214858 \\
\hline 0 & 15.8681992 & 14.8687710 & 18.3509626 \\
\hline 0 & 11.5992545 & 15.0597084 & 18.4251998 \\
\hline 0 & 13.9853335 & 18.4961097 & 18.2781118 \\
\hline 0 & 6.7144556 & 17.7349291 & 27.0126386 \\
\hline $\mathrm{H}$ & 8.8670275 & 18.9097823 & 23.3338734 \\
\hline $\mathrm{H}$ & 4.4798150 & 18.6153389 & 23.6065417 \\
\hline $\mathrm{H}$ & 18.2321770 & 15.9046439 & 17.7130694 \\
\hline $\mathrm{H}$ & 11.8828354 & 20.0670456 & 17.7892013 \\
\hline 0 & 11.3339418 & 12.3831174 & 17.3801500 \\
\hline $\mathrm{O}$ & 4.7864332 & 16.2622144 & 27.7476850 \\
\hline $\mathrm{H}$ & 11.5377201 & 19.8438165 & 22.5827652 \\
\hline 0 & 11.5627671 & 12.0352180 & 22.7616031 \\
\hline $\mathrm{H}$ & 18.2627633 & 16.1520810 & 22.5914343 \\
\hline 0 & 8.8799573 & 15.9359937 & 27.5214387 \\
\hline $\mathrm{H}$ & 16.1022215 & 12.5013608 & 17.6303585 \\
\hline $\mathrm{O}$ & 9.4799519 & 15.9952528 & 17.4268663 \\
\hline $\mathrm{H}$ & 15.8498168 & 20.0573308 & 17.7731175 \\
\hline $\mathrm{O}$ & 8.9623853 & 16.5774564 & 22.4752741 \\
\hline 0 & 6.8439178 & 14.9960460 & 17.1211533 \\
\hline 0 & 9.2667415 & 13.5330916 & 28.0085080 \\
\hline 0 & 13.7046608 & 18.8025286 & 22.1308332 \\
\hline 0 & 10.8641092 & 14.6210912 & 21.9339282 \\
\hline 0 & 16.4679200 & 14.6482106 & 21.9420265 \\
\hline 0 & 16.3510768 & 17.6901588 & 18.1567809 \\
\hline 0 & 13.8747073 & 13.4274250 & 17.9970272 \\
\hline 0 & 11.3368052 & 17.5147165 & 18.0535765 \\
\hline $\mathrm{H}$ & 4.3673912 & 18.5053989 & 26.8930783 \\
\hline $\mathrm{H}$ & 9.2520439 & 18.5005027 & 26.9964879 \\
\hline 0 & 6.8193855 & 17.5800947 & 23.1648166 \\
\hline $\mathrm{H}$ & 5.1574176 & 15.1208583 & 15.2998297 \\
\hline 0 & 12.0837399 & 19.2687934 & 20.2607681 \\
\hline 0 & 12.0079573 & 12.6965325 & 20.0728662 \\
\hline 0 & 17.5599923 & 16.1776068 & 20.2475635 \\
\hline 0 & 5.1380163 & 16.7178216 & 25.3245628 \\
\hline $\mathrm{H}$ & 8.6363907 & 15.1170654 & 29.8221338 \\
\hline 0 & 15.4321066 & 12.9465426 & 19.9465779 \\
\hline 0 & 15.6397157 & 19.1974593 & 20.0610077 \\
\hline 0 & 9.9747664 & 16.3917691 & 19.8466228 \\
\hline 0 & 8.5493748 & 17.0077569 & 24.9090629 \\
\hline $\mathrm{H}$ & 11.8440391 & 11.0556614 & 20.1484003 \\
\hline C & 9.3969223 & 10.5560676 & 20.5332609 \\
\hline $\mathrm{H}$ & 9.3709920 & 9.5619536 & 20.9657640 \\
\hline $\mathrm{H}$ & 9.7891561 & 11.3650767 & 21.1447737 \\
\hline $\mathrm{H}$ & 9.4227905 & 10.6474103 & 19.4522804 \\
\hline 0 & 11.6065969 & 10.0899779 & 20.3119857 \\
\hline $\mathrm{C}$ & 7.4872736 & 12.2029096 & 22.8105920 \\
\hline $\mathrm{C}$ & 7.5145023 & 13.3910867 & 22.0668994 \\
\hline $\mathrm{C}$ & 7.4291851 & 13.3720626 & 20.6658560 \\
\hline $\mathrm{C}$ & 7.3464234 & 12.1597302 & 19.9992793 \\
\hline $\mathrm{C}$ & 7.4090902 & 10.9365200 & 20.7311072 \\
\hline $\mathrm{C}$ & 7.4005977 & 10.9823167 & 22.1564731 \\
\hline $\mathrm{H}$ & 7.5403718 & 12.2405466 & 23.8993581 \\
\hline $\mathrm{H}$ & 7.3863205 & 10.0463768 & 22.7188035 \\
\hline $\mathrm{H}$ & 7.6106897 & 14.3493557 & 22.5799858 \\
\hline $\mathrm{H}$ & 7.4257442 & 14.3103244 & 20.1083162 \\
\hline $\mathrm{H}$ & 7.2761122 & 12.1274541 & 18.9102875 \\
\hline $\mathrm{H}$ & 7.1030681 & 10.0130301 & 20.2312947 \\
\hline $\mathrm{C}$ & 12.0521874 & 9.2740196 & 19.2256222 \\
\hline $\mathrm{H}$ & 11.7051163 & 8.2493427 & 19.4158020 \\
\hline $\mathrm{H}$ & 13.1544532 & 9.2732497 & 19.1819856 \\
\hline $\mathrm{H}$ & 11.6521658 & 9.6144135 & 18.2570145 \\
\hline $\mathrm{H}$ & 5.1714516 & 15.0828490 & 30.0223789 \\
\hline $\mathrm{H}$ & 16.0642362 & 19.7629884 & 22.5743546 \\
\hline \multicolumn{4}{|c|}{$\mathrm{Ga} 9$} \\
\hline \multicolumn{4}{|c|}{180} \\
\hline $\mathrm{H}$ & 8.5663586 & 8.8999974 & 15.3544463 \\
\hline $\mathrm{Si}$ & 5.2605294 & 9.3115682 & 16.7750252 \\
\hline
\end{tabular}




\begin{tabular}{|c|c|c|c|}
\hline $\mathrm{Si}$ & 5.2458872 & 9.2429037 & 28.7185044 \\
\hline $\mathrm{Si}$ & 5.2177923 & 6.7682931 & 21.7503192 \\
\hline $\mathrm{Si}$ & 5.2752483 & 6.8213069 & 18.6493163 \\
\hline $\mathrm{Si}$ & 3.1560609 & 8.0147916 & 26.7534438 \\
\hline $\mathrm{Si}$ & 3.2474245 & 8.1216074 & 23.7006581 \\
\hline $\mathrm{Si}$ & 8.3575349 & 9.1912958 & 28.7115342 \\
\hline $\mathrm{Si}$ & 8.3762116 & 9.3137853 & 16.7721008 \\
\hline $\mathrm{Si}$ & 8.3923243 & 6.8219287 & 18.6643706 \\
\hline $\mathrm{Si}$ & 8.3656875 & 6.7133858 & 21.7924705 \\
\hline $\mathrm{Si}$ & 1.5576540 & 10.7760034 & 23.6692453 \\
\hline $\mathrm{Si}$ & 1.5331630 & 10.7189693 & 26.7659846 \\
\hline 0 & 6.8217217 & 9.7328647 & 17.0391915 \\
\hline 0 & 4.8299745 & 10.7965617 & 28.4496934 \\
\hline $\mathrm{H}$ & 4.6274934 & 5.4133640 & 21.9315234 \\
\hline $\mathrm{H}$ & 8.9332497 & 5.3556530 & 22.0195288 \\
\hline $\mathrm{O}$ & 6.8390516 & 6.4340462 & 18.3867230 \\
\hline $\mathrm{O}$ & 2.0229811 & 9.1701806 & 26.8974234 \\
\hline $\mathrm{H}$ & 2.2017975 & 7.0841292 & 23.4828880 \\
\hline $\mathrm{H}$ & 0.1695279 & 10.3021537 & 23.4129393 \\
\hline $\mathrm{O}$ & 4.8407943 & 8.0746103 & 17.7222411 \\
\hline 0 & 4.3507127 & 8.2374329 & 27.8250307 \\
\hline 0 & 4.5115540 & 7.8762122 & 22.7081289 \\
\hline $\mathrm{O}$ & 2.3959660 & 11.6670331 & 27.7589547 \\
\hline $\mathrm{O}$ & 8.8145333 & 8.1211502 & 17.7811599 \\
\hline 0 & 1.9607055 & 12.0020378 & 22.6978857 \\
\hline $\mathrm{O}$ & 4.3383912 & 10.5766804 & 17.1748606 \\
\hline $\mathrm{O}$ & 6.7981708 & 9.0307008 & 28.3089821 \\
\hline 0 & 6.7903103 & 6.7078941 & 22.1432637 \\
\hline $\mathrm{H}$ & 9.2647874 & 5.6840679 & 18.2628713 \\
\hline $\mathrm{H}$ & 4.4356199 & 5.6518739 & 18.2690913 \\
\hline $\mathrm{H}$ & 0.1128302 & 10.7811807 & 27.2085960 \\
\hline $\mathrm{H}$ & 2.5296480 & 6.6988727 & 27.0585418 \\
\hline $\mathrm{O}$ & 2.6130533 & 9.5714333 & 23.3748308 \\
\hline $\mathrm{H}$ & 5.0548644 & 8.9152936 & 15.3545362 \\
\hline $\mathrm{O}$ & 5.0661732 & 7.2669422 & 20.2017020 \\
\hline $\mathrm{O}$ & 3.7812355 & 8.0428316 & 25.2452245 \\
\hline $\mathrm{H}$ & 8.5633216 & 8.8922001 & 30.1555959 \\
\hline $\mathrm{O}$ & 8.6053372 & 7.1888615 & 20.2422164 \\
\hline $\mathrm{O}$ & 1.7083863 & 11.2424280 & 25.2343614 \\
\hline $\mathrm{H}$ & 5.0542058 & 8.9105479 & 30.1572255 \\
\hline $\mathrm{H}$ & 3.2826345 & 11.9752457 & 15.3150182 \\
\hline $\mathrm{Si}$ & 3.2715128 & 15.8684913 & 21.7063044 \\
\hline $\mathrm{Si}$ & 3.2011836 & 15.9648713 & 18.6382299 \\
\hline $\mathrm{Si}$ & 3.6911230 & 11.9442277 & 28.6821264 \\
\hline $\mathrm{Si}$ & 3.7011122 & 12.0033254 & 16.7437269 \\
\hline $\mathrm{Si}$ & 1.5564941 & 13.2522936 & 18.6438117 \\
\hline $\mathrm{Si}$ & 1.5488883 & 13.2460177 & 21.7267282 \\
\hline 0 & 4.8447340 & 13.1443882 & 16.9904837 \\
\hline $\mathrm{H}$ & 0.1978288 & 13.8066164 & 22.0050946 \\
\hline $\mathrm{H}$ & 2.2707930 & 16.9284715 & 22.0098215 \\
\hline 0 & 2.0941822 & 14.7886723 & 18.5044689 \\
\hline $\mathrm{O}$ & 4.4457026 & 15.7176142 & 17.6312882 \\
\hline $\mathrm{O}$ & 4.5754902 & 16.0218524 & 22.6616266 \\
\hline 0 & 2.4109363 & 12.2731382 & 17.6696467 \\
\hline $\mathrm{O}$ & 4.3107066 & 13.3775250 & 28.2536144 \\
\hline 0 & 2.6721187 & 14.4042024 & 21.9733905 \\
\hline $\mathrm{H}$ & 2.5836869 & 17.2667646 & 18.2628736 \\
\hline $\mathrm{H}$ & 0.1477932 & 13.2250732 & 18.1622089 \\
\hline $\mathrm{O}$ & 3.7728130 & 16.0392058 & 20.1605739 \\
\hline $\mathrm{H}$ & 3.2822238 & 11.9701775 & 30.1136461 \\
\hline $\mathrm{O}$ & 1.7053878 & 12.7217738 & 20.1709180 \\
\hline $\mathrm{Si}$ & 9.9573129 & 12.0082314 & 16.6415382 \\
\hline $\mathrm{Si}$ & 9.8918398 & 11.9157793 & 28.5821975 \\
\hline $\mathrm{Si}$ & 12.0673454 & 10.6466415 & 26.7792260 \\
\hline $\mathrm{Si}$ & 12.0784934 & 10.6204187 & 23.6386014 \\
\hline $\mathrm{Si}$ & 15.1826528 & 10.7760034 & 23.6692453 \\
\hline $\mathrm{Si}$ & 10.3239401 & 8.0109929 & 23.7623364 \\
\hline $\mathrm{Si}$ & 10.4234477 & 7.9983981 & 26.7807427 \\
\hline $\mathrm{Si}$ & 15.1581618 & 10.7189693 & 26.7659846 \\
\hline 0 & 8.8046349 & 10.7190248 & 28.3666035 \\
\hline $\mathrm{O}$ & 11.5664814 & 9.1190056 & 27.0735448 \\
\hline $\mathrm{H}$ & 15.6056896 & 9.3039012 & 26.8860751 \\
\hline $\mathrm{H}$ & 11.1481816 & 6.7746384 & 23.6665553 \\
\hline $\mathrm{O}$ & 13.6641244 & 10.2576397 & 23.3888616 \\
\hline $\mathrm{O}$ & 11.1956134 & 11.6948291 & 27.6606194 \\
\hline 0 & 9.2244702 & 8.1174259 & 27.8678692 \\
\hline $\mathrm{H}$ & 15.9504640 & 11.5895656 & 27.6778179 \\
\hline $\mathrm{O}$ & 9.0571859 & 7.8453770 & 22.7433004 \\
\hline $\mathrm{O}$ & 15.5857042 & 12.0020378 & 22.6978857 \\
\hline $\mathrm{O}$ & 9.3159867 & 10.5902888 & 17.1351957 \\
\hline
\end{tabular}




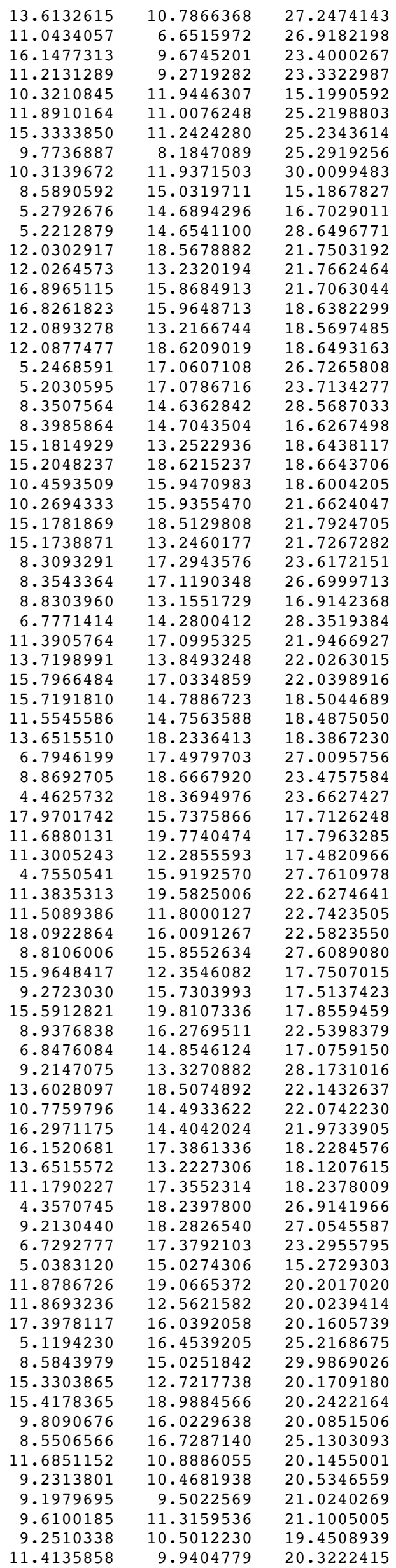




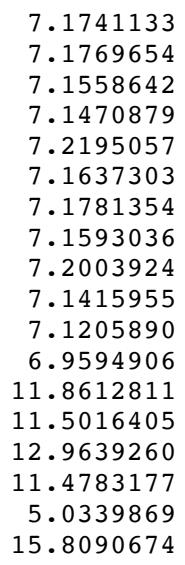

12.1683445

13.3303102

13.2591502

12.0214667

10.8287489

10.9235190

12.2458559

10.0077939

14.3091148

14.1767381

11.9489421

9.8782660

9.0936987

8.0780969

9.0799984

9.4148180

15.0236491

19.5457398

9.1003661

9.4698904

9.3694501

6.8203723

6.8583701

8.0212997

8.1779316

9.2485618

9.4190631

6.8544769

6.6918401

10.8538182

10.7736373

9.8560542

11.0273535

5.5088855

5.3457831

6.4792349

9.1125546

7.1726528

10.3305939

8.2646428

8.2537201

7.9011848

11.8053621

8.0949430

12.0301180

10.6519277

9.0891530

6.6833903

5.7236879

5.7020431

10.8044001

6.7012515

9.7504328

9.1198113

7.2795790

8.0315889

9.0538839

7.1894127

11.3052674

9.1476618

12.1618637

16.0243925

16.1443063

12.1065947

12.1866476

13.4445889

13.4141551

13.4126533

13.8988949

17.0872469

14.8878877

15.8790716

16.1685980

12.4874674

13.4643097

14.6528470

17.4719592
22.7267249

21.9422387

20.5410703

19.9162002

20.6934897

22.1141975

23.8147135

22.7090942

22.4229707

19.9506008

18.8272630

20.2193059

19.2596574

19.4718106

19.2319358

18.2782403

30.0798798

22.6599491

15.2919638

16.8276341

28.6417272

21.7429735

18.5866921

26.7472231

23.6566557

28.5526976

16.7418182

18.5837891

21.7596936

23.5634679

26.7118028

17.1090892

28.2807404

21.9345729

21.9765823

18.2877599

26.8429977

23.3882010

23.2382495

17.6765637

27.7886928

22.6338702

27.7404769

17.7692715

22.6619378

17.2228674

28.1704979

22.1335191

18.1870903

18.1489167

27.2247473

27.0418673

23.3301296

15.3921221

20.2741318

25.3391944

30.0168449

20.0815567

25.0446989

30.1093854

15.2758561

21.6933554

18.5688761

28.5396648

16.7326950

18.5127374

21.6822853

17.1026599

22.0004971

22.0020371

18.3489398

17.5394721

22.5816221

17.6189963

28.0797949

21.9630004

18.2348650 


\begin{tabular}{|c|c|c|c|}
\hline $\mathrm{H}$ & 0.0512151 & 13.4216875 & 18.0400248 \\
\hline 0 & 3.7207148 & 16.1628626 & 20.2298113 \\
\hline $\mathrm{H}$ & 3.3797909 & 12.1558788 & 29.9893976 \\
\hline 0 & 1.5940580 & 12.9743679 & 19.9672751 \\
\hline $\mathrm{P}$ & 10.0296124 & 12.1079616 & 16.6146138 \\
\hline Al & 9.9557593 & 11.9762289 & 28.4218947 \\
\hline $\mathrm{P}$ & 12.2690957 & 10.6507864 & 26.8338872 \\
\hline Al & 12.2883553 & 10.5955491 & 23.5825596 \\
\hline $\mathrm{P}$ & 15.4092434 & 10.8538182 & 23.5634679 \\
\hline$P$ & 10.4217849 & 8.0641270 & 23.6955872 \\
\hline Al & 10.5507319 & 8.0679963 & 26.7517333 \\
\hline Al & 15.3589620 & 10.7736373 & 26.7118028 \\
\hline 0 & 8.8318233 & 10.6576544 & 28.1261342 \\
\hline 0 & 11.7518536 & 9.2503535 & 27.2408551 \\
\hline $\mathrm{H}$ & 15.8254561 & 9.3639891 & 26.8231390 \\
\hline $\mathrm{H}$ & 11.1337735 & 6.7563853 & 23.6934299 \\
\hline 0 & 14.0042156 & 10.3115070 & 23.2263857 \\
\hline 0 & 11.4217098 & 11.7371646 & 27.5205580 \\
\hline $\mathrm{O}$ & 9.1799335 & 8.1648565 & 27.8312376 \\
\hline $\mathrm{H}$ & 16.1803089 & 11.6531479 & 27.5887127 \\
\hline 0 & 9.1936570 & 7.9442641 & 22.7602894 \\
\hline 0 & 15.7861120 & 12.0301180 & 22.6619378 \\
\hline 0 & 9.4667121 & 10.7726152 & 17.1547453 \\
\hline 0 & 13.7189653 & 10.8097376 & 27.3137458 \\
\hline $\mathrm{H}$ & 11.1697298 & 6.7160292 & 26.8301367 \\
\hline $\mathrm{H}$ & 16.4225677 & 9.7864189 & 23.3377398 \\
\hline 0 & 11.3509192 & 9.1571350 & 23.1835071 \\
\hline $\mathrm{H}$ & 10.2928197 & 11.9941802 & 15.1534854 \\
\hline 0 & 12.1803189 & 10.8167915 & 25.3230237 \\
\hline 0 & 15.4612665 & 11.3052674 & 25.0446989 \\
\hline 0 & 9.9385012 & 8.3798231 & 25.1276112 \\
\hline $\mathrm{H}$ & 10.2496989 & 11.9889337 & 29.8815380 \\
\hline $\mathrm{H}$ & 8.6251552 & 15.0805593 & 15.0693529 \\
\hline $\mathrm{P}$ & 5.3738445 & 14.8497342 & 16.7414781 \\
\hline Al & 5.2847778 & 14.7959931 & 28.5512046 \\
\hline $\mathrm{P}$ & 12.2165180 & 18.8364737 & 21.7429735 \\
\hline $\mathrm{Ti}$ & 12.0312294 & 13.3848264 & 21.7872974 \\
\hline $\mathrm{P}$ & 17.1330111 & 16.0243925 & 21.6933554 \\
\hline Al & 17.0543070 & 16.144 & 18.5688761 \\
\hline Al & 12.1987849 & 13.4123217 & 18.4955002 \\
\hline Al & 12.3013910 & 18.8744715 & 18.5866921 \\
\hline $\mathrm{P}$ & 5.2588263 & 17.2962860 & 26.7320201 \\
\hline Al & 5.1788611 & 17.3123223 & 23.7002709 \\
\hline $\mathrm{P}$ & 8.4238805 & 14.7375856 & 28.3552058 \\
\hline Al & 8.5063303 & 14.8540859 & 16.5362241 \\
\hline$P$ & 15.3379996 & 13.4445889 & 18.5127374 \\
\hline P & 15.4557437 & 18.8705782 & 18.5837891 \\
\hline $\mathrm{P}$ & 10.5992506 & 16.2252730 & 18.4373848 \\
\hline Al & 10.3055883 & 16.2687510 & 21.5453583 \\
\hline Al & 15.3958065 & 18.7079415 & 21.7596936 \\
\hline Al & 15.3171868 & 13.4141551 & 21.6822853 \\
\hline$P$ & 8.2849747 & 17.6298517 & 23.4719319 \\
\hline Al & 8.3838388 & 17.3438351 & 26.5977376 \\
\hline 0 & 8.9783080 & 13.2006272 & 16.9048774 \\
\hline 0 & 6.9369862 & 14.4063019 & 28.1185464 \\
\hline $\mathrm{O}$ & 11.5194290 & 17.4891296 & 21.9398114 \\
\hline 0 & 13.7326905 & 13.9741941 & 22.0499279 \\
\hline $\mathrm{O}$ & 16.0979181 & 17.1288746 & 22.0141269 \\
\hline 0 & 15.8670042 & 14.8878877 & 18.3489398 \\
\hline 0 & 11.6071840 & 15.0678020 & 18.4162997 \\
\hline 0 & 13.9923711 & 18.4953363 & 18.2877599 \\
\hline 0 & 6.7144256 & 17.7334723 & 27.0093834 \\
\hline $\mathrm{H}$ & 8.9130612 & 18.9739656 & 23.3454972 \\
\hline $\mathrm{H}$ & 4.3451189 & 18.5459994 & 23.6943152 \\
\hline $\mathrm{H}$ & 18.2360426 & 15.9182803 & 17.6916452 \\
\hline $\mathrm{H}$ & 11.8958646 & 20.0772622 & 17.8082556 \\
\hline $\mathrm{O}$ & 11.3475246 & 12.4137019 & 17.3170450 \\
\hline 0 & 4.7890359 & 16.2602954 & 27.7571549 \\
\hline $\mathrm{H}$ & 11.5989657 & 19.8819733 & 22.6047624 \\
\hline 0 & 11.5964694 & 11.9687009 & 22.8293455 \\
\hline $\mathrm{H}$ & 18.3404102 & 16.1640289 & 22.5534773 \\
\hline 0 & 8.8666726 & 15.9080563 & 27.4705279 \\
\hline $\mathrm{H}$ & 16.1196980 & 12.5183236 & 17.6478092 \\
\hline 0 & 9.5063309 & 15.9986229 & 17.3793500 \\
\hline $\mathrm{H}$ & 15.8500461 & 20.0708071 & 17.7956922 \\
\hline 0 & 8.8263474 & 16.6745772 & 22.4069811 \\
\hline $\mathrm{O}$ & 6.8577977 & 15.0221114 & 17.0989752 \\
\hline 0 & 9.2547660 & 13.5079646 & 27.9728348 \\
\hline 0 & 13.6957915 & 18.6994917 & 22.1335191 \\
\hline 0 & 10.7983450 & 14.6983530 & 21.9831152 \\
\hline
\end{tabular}




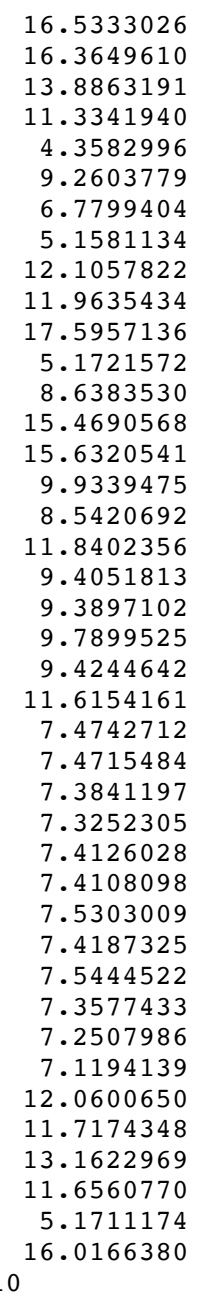

$\begin{array}{lrrr}\mathrm{H} & 8.5602428 & 9.1080043 & 15.3660902 \\ \mathrm{Al} & 5.1705304 & 9.4730438 & 16.7171021 \\ \mathrm{P} & 5.1658014 & 9.4061045 & 28.5517077 \\ \mathrm{Al} & 5.0505088 & 6.8081040 & 21.6529743 \\ \mathrm{P} & 5.0890293 & 6.9034410 & 18.4424225 \\ \mathrm{Al} & 2.9571185 & 8.1898836 & 26.6385702 \\ \mathrm{P} & 3.0062214 & 8.3020098 & 23.5109038 \\ \mathrm{Al} & 8.3137191 & 9.3800289 & 28.6110807 \\ \mathrm{P} & 8.3638018 & 9.5105378 & 16.7861248 \\ \mathrm{Al} & 8.2337478 & 6.9343337 & 18.5390566 \\ \mathrm{P} & 8.2141447 & 6.8489859 & 21.7377955 \\ \mathrm{Al} & 1.3096870 & 10.9770395 & 23.5560101 \\ \mathrm{P} & 1.2866361 & 10.8962551 & 26.7198617 \\ \mathrm{O} & 6.8774669 & 9.7939577 & 17.0602134 \\ \mathrm{O} & 4.7927335 & 10.8743267 & 28.2580497 \\ \mathrm{H} & 4.5441156 & 5.4327505 & 21.9158223 \\ \mathrm{H} & 8.7590551 & 5.4867979 & 21.9920339 \\ \mathrm{O} & 6.5768159 & 6.6576695 & 18.1006734 \\ \mathrm{O} & 1.7381109 & 9.4283064 & 26.8546208 \\ \mathrm{H} & 1.9213780 & 7.3059069 & 23.2917818 \\ \mathrm{H} & -0.0688058 & 10.5017419 & 23.2543972 \\ \mathrm{O} & 4.5915371 & 8.1282594 & 17.6620515 \\ \mathrm{O} & 4.3061380 & 8.4543565 & 27.7159840 \\ \mathrm{O} & 4.1858443 & 8.0218405 & 22.5699031 \\ \mathrm{O} & 2.1302992 & 11.7950838 & 27.6328026 \\ \mathrm{O} & 8.8729509 & 8.3832537 & 17.7285986 \\ \mathrm{O} & 1.6949015 & 12.3767548 & 22.6063597 \\ \mathrm{O} & 4.2364500 & 10.8732968 & 17.1541017 \\ \mathrm{O} & 6.6375066 & 9.1766029 & 28.1877434 \\ \mathrm{O} & 6.7319523 & 6.8719344 & 22.1041397 \\ \mathrm{H} & 9.0793344 & 5.7921831 & 18.0945390 \\ \mathrm{H} & 4.3151603 & 5.7075883 & 18.0086212 \\ \mathrm{H} & -0.1310639 & 10.9955128 & 27.1641533 \\ \mathrm{H} & 2.3451533 & 6.8799010 & 26.9943295 \\ \mathrm{O} & 2.4608721 & 9.7009143 & 23.2008271 \\ \mathrm{H} & 4.9820888 & 9.1486865 & 15.2761292\end{array}$

21.9630004 18.1756724 18.0266668 18.0763612 26.8403417 26.9846921 23.2329854 15.2885456 20.2741318 20.0507806 20.2298113 25.3275524 29.7815983 19.9672751 20.0815567 19.8158056 24.8762919 20.1369073 20.5315098 21.0025884 21.1078687 19.4479993 20.3152173 22.7533686 21.9634661 20.5644671 19.9463810 20.7257063 22.1481445 23.8395960 22.7469977 22.4389132 19.9696188 18.8600066 20.2649280 $\begin{array}{rr}9.2788044 & 19.2316040 \\ 8.2536575 & 19.4271316 \\ 9.2818780 & 19.1848264 \\ 9.6141269 & 18.2628458 \\ 15.0565518 & 30.0128171 \\ 19.7653216 & 22.6044635\end{array}$ $\begin{array}{ll}9.2788044 & 19.2316040 \\ 8.2536575 & 19.4271316 \\ 9.2818780 & 19.1848264 \\ 9.6141269 & 18.2628458 \\ 15.0565518 & 30.0128171 \\ 19.7653216 & 22.6044635\end{array}$ $\begin{array}{ll}9.2788044 & 19.2316040 \\ 8.2536575 & 19.4271316 \\ 9.2818780 & 19.1848264 \\ 9.6141269 & 18.2628458 \\ 15.0565518 & 30.0128171 \\ 19.7653216 & 22.6044635\end{array}$ $\begin{array}{ll}9.2788044 & 19.2316040 \\ 8.2536575 & 19.4271316 \\ 9.2818780 & 19.1848264 \\ 9.6141269 & 18.2628458 \\ 15.0565518 & 30.0128171 \\ 19.7653216 & 22.6044635\end{array}$ $\begin{array}{rr}9.2788044 & 19.2316040 \\ 8.2536575 & 19.4271316 \\ 9.2818780 & 19.1848264 \\ 9.6141269 & 18.2628458 \\ 15.0565518 & 30.0128171 \\ 19.7653216 & 22.6044635\end{array}$ $\begin{array}{rr}9.2788044 & 19.2316040 \\ 8.2536575 & 19.4271316 \\ 9.2818780 & 19.1848264 \\ 9.6141269 & 18.2628458 \\ 15.0565518 & 30.0128171 \\ 19.7653216 & 22.6044635\end{array}$ 15.3660902 16.7171021 1. 6529743 8.4424225 8.6110807 ( 21.7377955 .2580497 21.9920339 .1006734 3. 2917818 .2543972 27.7159840 .5699031 17.7285986 6063597 28.1877434 (1) 18.0086212 15.2761292 17.0602134 


\begin{tabular}{|c|c|c|c|}
\hline $\mathrm{O}$ & 4.9151286 & 7.1782954 & 19.9409565 \\
\hline 0 & 3.5059718 & 8.2194566 & 24.9710738 \\
\hline $\mathrm{H}$ & 8.5264959 & 9.1402996 & 30.0651703 \\
\hline 0 & 8.4076565 & 7.2187984 & 20.2490465 \\
\hline 0 & 1.4374803 & 11.3763637 & 25.2671945 \\
\hline $\mathrm{H}$ & 4.9566743 & 9.1029914 & 29.9944512 \\
\hline $\mathrm{H}$ & 3.2118203 & 12.1462521 & 15.2821658 \\
\hline Al & 3.0255421 & 16.2221756 & 21.5938351 \\
\hline $\mathrm{P}$ & 2.9707613 & 16.3095639 & 18.4592783 \\
\hline Al & 3.5755409 & 12.1125353 & 28.5439578 \\
\hline$P$ & 3.5980196 & 12.1982461 & 16.7192696 \\
\hline Al & 1.3881046 & 13.5042794 & 18.5437813 \\
\hline $\mathrm{P}$ & 1.3861455 & 13.5379407 & 21.6450680 \\
\hline $\mathrm{O}$ & 4.6224736 & 13.3231393 & 16.9714729 \\
\hline $\mathrm{H}$ & 0.0513954 & 14.1580479 & 21.8709658 \\
\hline $\mathrm{H}$ & 2.0221026 & 17.2669760 & 21.9382504 \\
\hline 0 & 1.9657904 & 15.1525659 & 18.3459547 \\
\hline $\mathrm{O}$ & 4.1737736 & 16.0948641 & 17.5340638 \\
\hline $\mathrm{O}$ & 4.4587690 & 16.4324798 & 22.5590893 \\
\hline 0 & 2.3300523 & 12.4230454 & 17.5473624 \\
\hline 0 & 4.2087106 & 13.6624279 & 28.0651887 \\
\hline 0 & 2.4795901 & 14.6044045 & 21.8602036 \\
\hline $\mathrm{H}$ & 2.3070689 & 17.5727326 & 18.0337929 \\
\hline $\mathrm{H}$ & -0.0221238 & 13.4587049 & 18.0680719 \\
\hline 0 & 3.4780497 & 16.4545122 & 19.9046664 \\
\hline $\mathrm{H}$ & 3.2555402 & 12.1397981 & 29.9979099 \\
\hline $\mathrm{O}$ & 1.5143579 & 12.9766870 & 20.1989257 \\
\hline Al & 9.8364363 & 12.2856771 & 16.5393007 \\
\hline $\mathrm{P}$ & 9.7946045 & 12.1555176 & 28.3900496 \\
\hline Al & 12.0423658 & 10.8068746 & 26.6592377 \\
\hline$P$ & 12.0676066 & 10.7806460 & 23.4627039 \\
\hline Al & 15.1846857 & 10.9770395 & 23.5560101 \\
\hline Al & 10.3197210 & 8.1572967 & 23.6203471 \\
\hline$P$ & 10.4303163 & 8.1153909 & 26.7261032 \\
\hline$P$ & 15.1616349 & 10.8962551 & 26.7198617 \\
\hline 0 & 8.7733747 & 11.0176442 & 28.1874785 \\
\hline 0 & 11.5125045 & 9.1706307 & 27.0291609 \\
\hline $\mathrm{H}$ & 15.5976746 & 9.4784927 & 26.8500137 \\
\hline $\mathrm{H}$ & 11.1990795 & 6.9645567 & 23.4746740 \\
\hline 0 & 13.5583329 & 10.4162810 & 23.2001657 \\
\hline $\mathrm{O}$ & 11.0388722 & 11.9422964 & 27.5292973 \\
\hline 0 & 9.2818291 & 8.2257624 & 27.7408788 \\
\hline $\mathrm{H}$ & 15.9805549 & 11.7687229 & 27.6060279 \\
\hline 0 & 8.9287462 & 7.9042840 & 22.5928875 \\
\hline 0 & 15.5699003 & 12.3767548 & 22.6063597 \\
\hline 0 & 9.2183686 & 10.7450175 & 17.1251747 \\
\hline 0 & 13.6996827 & 10.9986110 & 27.1780214 \\
\hline $\mathrm{H}$ & 11.0298413 & 6.7598007 & 26.8677562 \\
\hline $\mathrm{H}$ & 16.1614125 & 9.8943068 & 23.2546539 \\
\hline 0 & 11.2342551 & 9.5316243 & 23.0991738 \\
\hline $\mathrm{H}$ & 10.1702894 & 12.2022428 & 15.0906111 \\
\hline 0 & 11.8881062 & 11.1070477 & 24.9611035 \\
\hline 0 & 15.3124790 & 11.3763637 & 25.2671945 \\
\hline 0 & 9.8550013 & 8.3172978 & 25.3092423 \\
\hline $\mathrm{H}$ & 10.2112914 & 12.1873552 & 29.8192028 \\
\hline $\mathrm{H}$ & 8.4684205 & 15.2829033 & 15.1481915 \\
\hline Al & 5.1149172 & 14.9623620 & 16.6008138 \\
\hline$P$ & 5.0593468 & 14.8800353 & 28.4385316 \\
\hline Al & 11.9880082 & 18.8242054 & 21.6529743 \\
\hline $\mathrm{Zn}$ & 12.1047317 & 13.5220862 & 21.6816722 \\
\hline Al & 16.9005408 & 16.2221756 & 21.5938351 \\
\hline$P$ & 16.8457600 & 16.3095639 & 18.4592783 \\
\hline$P$ & 12.1266029 & 13.4532683 & 18.4038907 \\
\hline $\mathrm{P}$ & 12.0265287 & 18.9195424 & 18.4424225 \\
\hline Al & 5.1640569 & 17.3888034 & 26.6003024 \\
\hline $\mathrm{P}$ & 5.1297024 & 17.4359167 & 23.4997095 \\
\hline Al & 8.2314990 & 14.9005559 & 28.4281374 \\
\hline $\mathrm{P}$ & 8.2594221 & 14.9669287 & 16.5881917 \\
\hline Al & 15.2631033 & 13.5042794 & 18.5437813 \\
\hline Al & 15.1712472 & 18.9504351 & 18.5390566 \\
\hline Al & 10.4584574 & 16.2103786 & 18.5274025 \\
\hline $\mathrm{P}$ & 10.2681880 & 16.2031720 & 21.6114463 \\
\hline$P$ & 15.1516441 & 18.8650873 & 21.7377955 \\
\hline $\mathrm{P}$ & 15.2611442 & 13.5379407 & 21.6450680 \\
\hline Al & 8.2411202 & 17.6476382 & 23.4981173 \\
\hline $\mathrm{P}$ & 8.2855505 & 17.4858426 & 26.6678311 \\
\hline 0 & 8.6056767 & 13.4838454 & 16.8586826 \\
\hline 0 & 6.5381203 & 14.5462829 & 28.1664820 \\
\hline 0 & 11.3958522 & 17.2159221 & 21.9603383 \\
\hline 0 & 13.8956734 & 14.1723204 & 21.8761651 \\
\hline
\end{tabular}




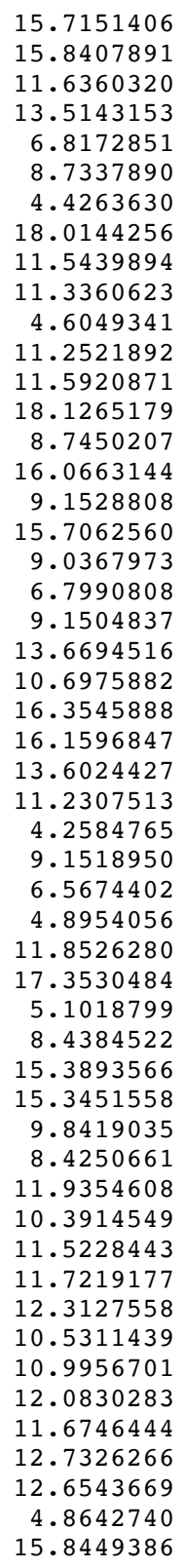

17.4564370

15.1525659

14.9036322

18.6737709

17.8275088

19.0409480

18.7474586

16.1009939

20.1075470

12.6727018

16.0658812

19.8570802

11.9299861

16.4020691

16.2581740

2.5822970

15.8869877

20.1631717

16.5119788

15.1991465

13.4854270

18.8880358

14.7801070

14.6044045

17.6153328

13.4506116

17.6898349

18.5476489

18.6368193

17.6560146

15.2117095

19.1943967

16.4545122

16.8699388

15.2339596

12.9766870

19.2348998

16.4352334

17.1715690

12.7282436

8.7732897

10.8083776

10.7509646

10.6087799

11.0368907

8.8945542

7.9428446

6.9225440

8.1207706

8.0662184

15.2423675

19.8889200

9.1537882

9.5170508

9.4424783

6.8930390

6.9503936

8.1171023

8.1861381

9.3757579

9.4770138

6.9323405

6.8554952

10.9174093

10.8817534

9.7894618

11.1020228

5.5093851

5.4751716

6.6985089

9.2207898

7.1434886

10.4694574

8.3591738

8.3444189

7.9264576

11.9391195
22.0007056

18.3459547

18.5063249

18.1006734

27.0116485

23. 3162223

23.4518325

17.5604792

17.6855067

17.3359172

27.5849350

22.4332695

22.6095248

22.4195100

27.4671316

17.6941219

17.4184877

17.8607085

22.4772879

16.9952110

27.9905514

22.1041397

21.8583111

21.8602036

18.0194435

17.9835941

17.9963402

26.8329435

27.0444215

23.0290722

15.1493452

19.9409565

19.9046664

24.9308325

29.8644984

20.1989257

20.2490465

20.1338441

25.1718439

19.7669186

18.9787460

19.7312291

18.6678018

20.4464186

20.1014058

19.7492778

19.6929798

19.6533731

18.8217559

20.6213887

29.8695391

22.5673916

15.2456950

16.7341095

28.5676050

21.6853619

18.4789966

26.6608531

23.5343104

28.5176078

16.6863444

18.4784072

21.7055255

23.4784835

26.6284248

16.9785201

28.2060179

21.9392798

21.9698351

18.0608251

26.8288697

23.2946198

23.2291854

17.6146169

27.6225910

22.4786685

27.6151370 


\begin{tabular}{|c|c|c|c|}
\hline 0 & 8.9033752 & 8.2002388 & 17.7678134 \\
\hline 0 & 1.7214541 & 12.0873241 & 22.5700822 \\
\hline $\mathrm{O}$ & 4.3184692 & 10.7674433 & 17.1248359 \\
\hline 0 & 6.7729548 & 9.1856586 & 28.1964094 \\
\hline 0 & 6.5994722 & 6.9950130 & 22.1393295 \\
\hline $\mathrm{H}$ & 9.1744632 & 5.7727283 & 18.0623519 \\
\hline $\mathrm{H}$ & 4.4117216 & 5.7594774 & 18.0309113 \\
\hline $\mathrm{H}$ & -0.0447803 & 10.9710275 & 27.0943174 \\
\hline $\mathrm{H}$ & 2.3346846 & 6.8066302 & 27.0032343 \\
\hline 0 & 2.2895204 & 9.7486273 & 23.1720147 \\
\hline $\mathrm{H}$ & 4.8686186 & 9.1604279 & 15.3087408 \\
\hline 0 & 5.0296688 & 7.2414369 & 20.1873456 \\
\hline 0 & 3.4855817 & 8.1089824 & 25.2143437 \\
\hline $\mathrm{H}$ & 8.5220548 & 9.1081164 & 29.9580233 \\
\hline 0 & 8.4605475 & 7.1870402 & 19.9858693 \\
\hline 0 & 1.5012982 & 11.3572851 & 24.9504505 \\
\hline $\mathrm{H}$ & 4.8955004 & 9.1929357 & 30.0223327 \\
\hline $\mathrm{H}$ & 3.2436432 & 12.2084252 & 15.1803759 \\
\hline $\mathrm{P}$ & 2.9417950 & 16.1505688 & 21.6799662 \\
\hline Al & 2.9477372 & 16.2053425 & 18.5143846 \\
\hline $\mathrm{P}$ & 3.5879323 & 12.1912586 & 28.4621951 \\
\hline Al & 3.5829713 & 12.2688515 & 16.6289358 \\
\hline $\mathrm{P}$ & 1.3301872 & 13.4688764 & 18.4434009 \\
\hline Al & 1.2537805 & 13.4530153 & 21.5690920 \\
\hline 0 & 4.7450968 & 13.5451065 & 16.9572864 \\
\hline $\mathrm{H}$ & -0.1748618 & 13.8465919 & 21.7146924 \\
\hline $\mathrm{H}$ & 1.9490802 & 17.2120324 & 22.0038992 \\
\hline 0 & 1.7906233 & 14.9310174 & 18.2389215 \\
\hline 0 & 4.3843228 & 15.9771480 & 17.5477685 \\
\hline 0 & 4.1890899 & 16.3110097 & 22.5573455 \\
\hline 0 & 2.1008286 & 12.5371367 & 17.4962999 \\
\hline 0 & 4.1704600 & 13.5515102 & 28.0664376 \\
\hline $\mathrm{O}$ & 2.3384073 & 14.7799751 & 21.9542366 \\
\hline $\mathrm{H}$ & 2.3659127 & 17.5184668 & 18.1215674 \\
\hline $\mathrm{H}$ & -0.1130965 & 13.3902236 & 18.0858168 \\
\hline 0 & 3.3825186 & 16.2885072 & 20.2044401 \\
\hline $\mathrm{H}$ & 3.1977510 & 12.1977475 & 29.8991492 \\
\hline $\mathrm{O}$ & 1.5897420 & 13.0089196 & 19.8836317 \\
\hline $\mathrm{P}$ & 9.8433660 & 12.2002225 & 16.6342661 \\
\hline Al & 9.8085783 & 12.1134157 & 28.4475113 \\
\hline $\mathrm{P}$ & 12.1155142 & 10.8551237 & 26.7647697 \\
\hline $\mathrm{Al}$ & 12.0875657 & 10.9092525 & 23.5629415 \\
\hline $\mathrm{P}$ & 15.2168071 & 10.9174093 & 23.4784835 \\
\hline $\mathrm{P}$ & 10.4095284 & 8.2264216 & 23.5069482 \\
\hline Al & 10.4560268 & 8.1888068 & 26.6628988 \\
\hline $\mathrm{Al}$ & 15.2416343 & 10.8817534 & 26.6284248 \\
\hline 0 & 8.6594577 & 10.8191557 & 28.1546232 \\
\hline 0 & 11.6456130 & 9.4134662 & 27.0554517 \\
\hline $\mathrm{H}$ & 15.6877593 & 9.4713903 & 26.7986273 \\
\hline $\mathrm{H}$ & 11.3524030 & 7.0949225 & 23.2882753 \\
\hline 0 & 13.7666357 & 10.4527294 & 23.2198758 \\
\hline 0 & 11.3008229 & 11.8530627 & 27.5991586 \\
\hline 0 & 9.0550328 & 8.3678551 & 27.6877643 \\
\hline $\mathrm{H}$ & 16.0725864 & 11.7850945 & 27.4714041 \\
\hline 0 & 9.1630525 & 8.0393081 & 22.6282672 \\
\hline $\mathrm{O}$ & 15.5964529 & 12.0873241 & 22.5700822 \\
\hline 0 & 9.3072525 & 10.8431422 & 17.1436499 \\
\hline 0 & 13.5871177 & 10.9864039 & 27.1745622 \\
\hline $\mathrm{H}$ & 11.0502555 & 6.8544534 & 26.9518866 \\
\hline $\mathrm{H}$ & 16.1357466 & 9.7841115 & 23.1813191 \\
\hline 0 & 11.1060491 & 9.5229050 & 23.0965386 \\
\hline $\mathrm{H}$ & 10.1428091 & 12.1220451 & 15.1777831 \\
\hline 0 & 11.9240939 & 11.1842645 & 25.2835637 \\
\hline 0 & 15.3762969 & 11.3572851 & 24.9504505 \\
\hline 0 & 9.9710022 & 8.2887135 & 24.9828994 \\
\hline $\mathrm{H}$ & 10.1006644 & 12.1190554 & 29.9075711 \\
\hline $\mathrm{H}$ & 8.5469266 & 15.1872352 & 15.1108967 \\
\hline $\mathrm{P}$ & 5.1745816 & 14.9970887 & 16.6684234 \\
\hline Al & 5.1389841 & 14.9242203 & 28.5195023 \\
\hline $\mathrm{P}$ & 12.0749290 & 18.9091403 & 21.6853619 \\
\hline $\mathrm{Si}$ & 11.9467355 & 13.4209432 & 21.6221588 \\
\hline $\mathrm{P}$ & 16.8167937 & 16.1505688 & 21.6799662 \\
\hline Al & 16.8227359 & 16.2053425 & 18.5143846 \\
\hline Al & 12.0349535 & 13.4848100 & 18.5244543 \\
\hline Al & 12.1225636 & 18.9664950 & 18.4789966 \\
\hline$P$ & 5.0952645 & 17.4479013 & 26.6769967 \\
\hline Al & 5.0617202 & 17.4571658 & 23.5313034 \\
\hline $\mathrm{P}$ & 8.3088713 & 14.8683465 & 28.4031088 \\
\hline $\mathrm{Al}$ & 8.3369827 & 14.9391137 & 16.5639900 \\
\hline $\mathrm{P}$ & 15.2051860 & 13.4688764 & 18.4434009 \\
\hline
\end{tabular}




\begin{tabular}{|c|c|c|c|}
\hline $\mathrm{P}$ & 15.2757100 & 18.9484418 & 18.4784072 \\
\hline $\mathrm{P}$ & 10.4901371 & 16.3095992 & 18.4376677 \\
\hline Al & 10.3780820 & 16.2473785 & 21.5328498 \\
\hline Al & 15.2100466 & 18.8715966 & 21.7055255 \\
\hline Al & 15.1287792 & 13.4530153 & 21.5690920 \\
\hline $\mathrm{P}$ & 8.2033195 & 17.5204425 & 23.4224749 \\
\hline Al & 8.2390432 & 17.4343127 & 26.5841874 \\
\hline $\mathrm{O}$ & 8.7818843 & 13.2756697 & 16.9283547 \\
\hline 0 & 6.8172136 & 14.5356133 & 28.2146657 \\
\hline 0 & 11.5726865 & 17.4851168 & 21.9466882 \\
\hline 0 & 13.4890234 & 13.9047516 & 21.7362081 \\
\hline $\mathrm{O}$ & 15.7875368 & 17.2511052 & 22.0158233 \\
\hline 0 & 15.6656220 & 14.9310174 & 18.2389215 \\
\hline 0 & 11.4973950 & 15.1440020 & 18.4282812 \\
\hline 0 & 13.8199643 & 18.7146102 & 18.0608251 \\
\hline 0 & 6.5654257 & 17.8238796 & 26.9521704 \\
\hline $\mathrm{H}$ & 8.6680561 & 18.9254916 & 23.2582273 \\
\hline $\mathrm{H}$ & 4.5374777 & 18.8343850 & 23.3178616 \\
\hline $\mathrm{H}$ & 18.0475275 & 16.0107904 & 17.6902755 \\
\hline $\mathrm{H}$ & 11.6480485 & 20.1694726 & 17.7408904 \\
\hline 0 & 11.1547521 & 12.4989904 & 17.3646027 \\
\hline 0 & 4.6474712 & 16.2931010 & 27.5756136 \\
\hline $\mathrm{H}$ & 11.2886445 & 19.9121518 & 22.4553263 \\
\hline 0 & 11.5699582 & 12.2524756 & 22.6627725 \\
\hline $\mathrm{H}$ & 18.0279818 & 16.3063652 & 22.5319470 \\
\hline 0 & 8.7269227 & 16.0485280 & 27.5233566 \\
\hline $\mathrm{H}$ & 15.9522889 & 12.5655956 & 17.5252280 \\
\hline 0 & 9.3368917 & 16.0394883 & 17.4614610 \\
\hline $\mathrm{H}$ & 15.8153385 & 20.1590522 & 17.7999205 \\
\hline 0 & 8.9596608 & 16.5682944 & 22.5050951 \\
\hline 0 & 6.6623892 & 15.1601897 & 17.0028958 \\
\hline 0 & 9.1322284 & 13.6461465 & 27.9807428 \\
\hline 0 & 13.5369715 & 19.0111144 & 22.1393295 \\
\hline 0 & 10.9433990 & 14.6660347 & 21.7505021 \\
\hline 0 & 16.2134060 & 14.7799751 & 21.9542366 \\
\hline $\mathrm{O}$ & 16.1357067 & 17.7559043 & 18.0505387 \\
\hline 0 & 13.7195525 & 13.3879157 & 18.0753243 \\
\hline 0 & 11.2194403 & 17.5757219 & 17.9557147 \\
\hline $\mathrm{H}$ & 4.2329779 & 18.6204143 & 26.9913144 \\
\hline $\mathrm{H}$ & 9.1063216 & 18.5877797 & 26.9508789 \\
\hline 0 & 6.7220584 & 17.4679050 & 23.0311647 \\
\hline $\mathrm{H}$ & 4.9218723 & 15.3258971 & 15.2383382 \\
\hline 0 & 11.9671682 & 19.2575383 & 20.1873456 \\
\hline 0 & 17.2575173 & 16.2885072 & 20.2044401 \\
\hline 0 & 4.9181305 & 17.0116404 & 25.2131232 \\
\hline $\mathrm{H}$ & 8.5744556 & 15.2185280 & 29.8257678 \\
\hline 0 & 15.4647407 & 13.0089196 & 19.8836317 \\
\hline 0 & 15.3980469 & 19.2031416 & 19.9858693 \\
\hline 0 & 9.9154025 & 16.5312461 & 19.8424750 \\
\hline 0 & 8.3938666 & 17.0684759 & 24.8835914 \\
\hline 0 & 11.7466701 & 12.7425970 & 20.0847312 \\
\hline $\mathrm{H}$ & 10.3592476 & 8.7240388 & 19.1033662 \\
\hline C & 11.3839963 & 10.7401898 & 19.9748121 \\
\hline $\mathrm{H}$ & 11.2370827 & 10.8663607 & 18.9094641 \\
\hline $\mathrm{H}$ & 12.3776400 & 10.5454554 & 20.3656751 \\
\hline $\mathrm{H}$ & 10.5633617 & 10.8757711 & 20.6690149 \\
\hline 0 & 10.9890761 & 8.8467466 & 19.8541073 \\
\hline C & 12.1347216 & 7.9784224 & 19.6858706 \\
\hline $\mathrm{H}$ & 11.7856699 & 6.9401431 & 19.5930901 \\
\hline $\mathrm{H}$ & 12.7270875 & 8.2582813 & 18.8014350 \\
\hline $\mathrm{H}$ & 12.7373427 & 8.0758247 & 20.5971630 \\
\hline $\mathrm{H}$ & 4.9474382 & 15.2746981 & 29.9539347 \\
\hline $\mathrm{H}$ & 15.9698055 & 19.8815990 & 22.4927879 \\
\hline \multicolumn{4}{|c|}{ Mg 10} \\
\hline \multicolumn{4}{|c|}{168} \\
\hline $\mathrm{H}$ & 8.5624902 & 9.1290973 & 15.3614454 \\
\hline Al & 5.1672506 & 9.4787651 & 16.7232621 \\
\hline $\mathrm{P}$ & 5.1653547 & 9.4071812 & 28.5523241 \\
\hline Al & 5.0493960 & 6.8276379 & 21.6581974 \\
\hline $\mathrm{P}$ & 5.0986652 & 6.9079652 & 18.4455401 \\
\hline Al & 2.9610372 & 8.1803893 & 26.6436463 \\
\hline $\mathrm{P}$ & 3.0322161 & 8.3050971 & 23.5191178 \\
\hline Al & 8.3132694 & 9.3765526 & 28.6051706 \\
\hline $\mathrm{P}$ & 8.3612747 & 9.5161257 & 16.7851174 \\
\hline Al & 8.2405325 & 6.9471677 & 18.5547479 \\
\hline $\mathrm{P}$ & 8.2125847 & 6.8536575 & 21.7474599 \\
\hline Al & 1.3220905 & 10.9689422 & 23.5942384 \\
\hline $\mathrm{P}$ & 1.2975056 & 10.9067539 & 26.7280382 \\
\hline $\mathrm{O}$ & 6.8757680 & 9.7911679 & 17.0650136 \\
\hline
\end{tabular}




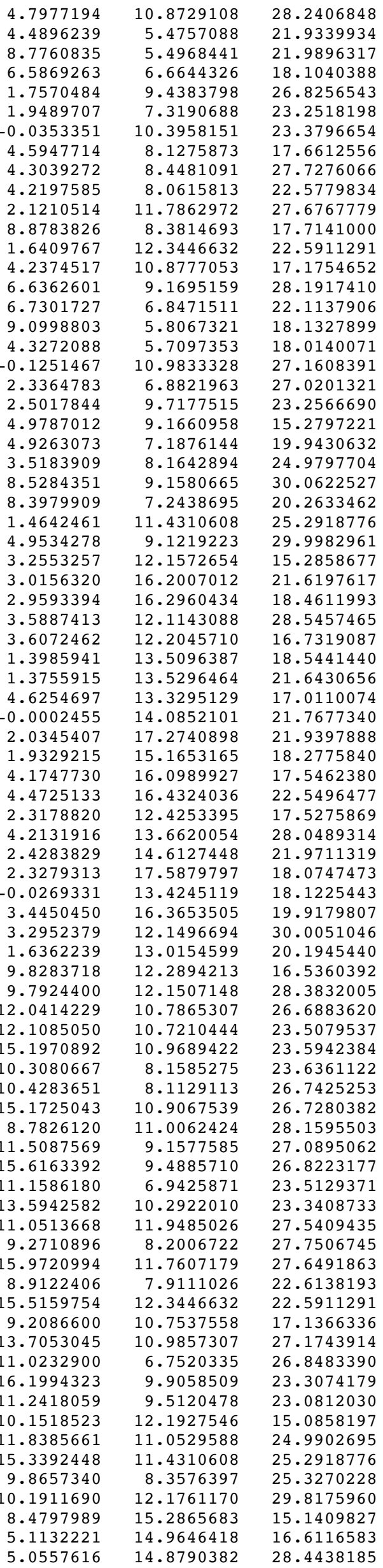




\begin{tabular}{|c|c|c|c|}
\hline Al & 11.9868953 & 18.8437393 & 21.6581974 \\
\hline $\mathrm{Mg}$ & 12.0385665 & 13.4903738 & 21.6502679 \\
\hline $\mathrm{Al}$ & 16.8906307 & 16.2007012 & 21.6197617 \\
\hline $\mathrm{P}$ & 16.8343381 & 16.2960434 & 18.4611993 \\
\hline $\mathrm{P}$ & 12.1041231 & 13.4536260 & 18.4112864 \\
\hline$P$ & 12.0361645 & 18.9240665 & 18.4455401 \\
\hline Al & 5.1606580 & 17.3797896 & 26.5967717 \\
\hline $\mathrm{P}$ & 5.1207099 & 17.4331693 & 23.5099031 \\
\hline $\mathrm{Al}$ & 8.2335613 & 14.9013980 & 28.4214849 \\
\hline $\mathrm{P}$ & 8.2620527 & 14.9756237 & 16.5807816 \\
\hline Al & 15.2735928 & 13.5096387 & 18.5441440 \\
\hline Al & 15.1780318 & 18.9632691 & 18.5547479 \\
\hline Al & 10.4562384 & 16.2204874 & 18.5290002 \\
\hline $\mathrm{P}$ & 10.2360540 & 16.2292042 & 21.6110907 \\
\hline$P$ & 15.1500840 & 18.8697588 & 21.7474599 \\
\hline $\mathrm{P}$ & 15.2505902 & 13.5296464 & 21.6430656 \\
\hline Al & 8.2335007 & 17.6763428 & 23.4869929 \\
\hline $\mathrm{P}$ & 8.2832385 & 17.4924259 & 26.6660145 \\
\hline 0 & 8.6003956 & 13.4910173 & 16.8564814 \\
\hline 0 & 6.5370371 & 14.5538870 & 28.1765693 \\
\hline 0 & 11.3338047 & 17.2664326 & 21.9799708 \\
\hline 0 & 13.8510523 & 14.0947805 & 21.7698816 \\
\hline 0 & 15.7322045 & 17.4681078 & 21.9976346 \\
\hline 0 & 15.8079202 & 15.1653165 & 18.2775840 \\
\hline 0 & 11.6409565 & 14.9140885 & 18.5045106 \\
\hline 0 & 13.5244257 & 18.6805340 & 18.1040388 \\
\hline 0 & 6.8122460 & 17.8218065 & 27.0091972 \\
\hline $\mathrm{H}$ & 8.7552169 & 19.0553722 & 23.2791209 \\
\hline $\mathrm{H}$ & 4.3803223 & 18.7249379 & 23.4931517 \\
\hline $\mathrm{H}$ & 18.0140902 & 16.1047776 & 17.5730985 \\
\hline $\mathrm{H}$ & 11.5473986 & 20.1070733 & 17.6848014 \\
\hline 0 & 11.3299865 & 12.6857377 & 17.3255464 \\
\hline 0 & 4.6011724 & 16.0729019 & 27.6019551 \\
\hline $\mathrm{H}$ & 11.2803485 & 19.8946064 & 22.4415177 \\
\hline 0 & 11.7632167 & 11.8990945 & 22.6375251 \\
\hline $\mathrm{H}$ & 18.1346279 & 16.3985465 & 22.4137698 \\
\hline 0 & 8.7423602 & 16.2495155 & 27.4435331 \\
\hline $\mathrm{H}$ & 16.0568397 & 12.5857998 & 17.6780224 \\
\hline 0 & 9.1584670 & 15.8923238 & 17.4119754 \\
\hline $\mathrm{H}$ & 15.7114053 & 20.1626393 & 17.8517939 \\
\hline $\mathrm{O}$ & 8.9882340 & 16.5073988 & 22.4664189 \\
\hline 0 & 6.8015925 & 15.2155581 & 16.9821588 \\
\hline 0 & 9.1446785 & 13.4792585 & 27.9846311 \\
\hline 0 & 13.6676720 & 18.8632524 & 22.1137906 \\
\hline 0 & 10.7231306 & 14.8262189 & 21.8422209 \\
\hline $\mathrm{O}$ & 16.3033816 & 14.6127448 & 21.9711319 \\
\hline 0 & 16.1818560 & 17.6310997 & 18.0618489 \\
\hline $\mathrm{O}$ & 13.5920809 & 13.4092255 & 18.0468368 \\
\hline 0 & 11.2429357 & 17.6920195 & 18.0018281 \\
\hline $\mathrm{H}$ & 4.2524685 & 18.5394188 & 26.8148830 \\
\hline $\mathrm{H}$ & 9.1405216 & 18.6398277 & 27.0730223 \\
\hline 0 & 6.5518243 & 17.7050066 & 23.0442872 \\
\hline $\mathrm{H}$ & 4.8819257 & 15.1933542 & 15.1586224 \\
\hline 0 & 11.8638067 & 19.2037157 & 19.9430632 \\
\hline 0 & 17.3200437 & 16.3653505 & 19.9179807 \\
\hline $\mathrm{O}$ & 5.1103899 & 16.8398659 & 24.9316765 \\
\hline $\mathrm{H}$ & 8.4485936 & 15.2369413 & 29.8561599 \\
\hline 0 & 15.5112226 & 13.0154599 & 20.1945440 \\
\hline 0 & 15.3354902 & 19.2599709 & 20.2633462 \\
\hline 0 & 9.8224441 & 16.4558632 & 20.1274785 \\
\hline 0 & 8.4339637 & 17.2128194 & 25.1642777 \\
\hline 0 & 11.8515199 & 12.7415006 & 19.7732046 \\
\hline $\mathrm{H}$ & 10.4477764 & 8.7409545 & 18.8219478 \\
\hline C & 11.4838746 & 10.8263002 & 19.6627241 \\
\hline $\mathrm{H}$ & 12.2285305 & 10.6733172 & 18.8883883 \\
\hline $\mathrm{H}$ & 11.7396458 & 10.7157125 & 20.7098580 \\
\hline $\mathrm{H}$ & 10.4554053 & 11.0317539 & 19.3920205 \\
\hline 0 & 11.0062906 & 8.8875118 & 19.6222990 \\
\hline $\mathrm{C}$ & 12.1142766 & 7.9614621 & 19.6572083 \\
\hline $\mathrm{H}$ & 11.7330752 & 6.9308333 & 19.6127523 \\
\hline $\mathrm{H}$ & 12.8154957 & 8.1355948 & 18.8257609 \\
\hline $\mathrm{H}$ & 12.6236702 & 8.1170982 & 20.6164206 \\
\hline $\mathrm{H}$ & 4.8490843 & 15.2212312 & 29.8781508 \\
\hline $\mathrm{H}$ & 15.8284762 & 19.8950663 & 22.5874892 \\
\hline \multicolumn{4}{|c|}{ Al 10} \\
\hline \multicolumn{4}{|c|}{168} \\
\hline $\mathrm{H}$ & 8.4573301 & 9.0620315 & 15.2755170 \\
\hline $\mathrm{Si}$ & 5.0854757 & 9.4037959 & 16.6995296 \\
\hline $\mathrm{Si}$ & 5.0745940 & 9.3582073 & 28.6429383 \\
\hline
\end{tabular}




\begin{tabular}{|c|c|c|c|}
\hline $\mathrm{Si}$ & 5.0183139 & 6.9114375 & 21.6486151 \\
\hline $\mathrm{Si}$ & 5.0628931 & 6.9271180 & 18.5830241 \\
\hline $\mathrm{Si}$ & 2.9813326 & 8.1285134 & 26.6951560 \\
\hline $\mathrm{Si}$ & 3.0296120 & 8.2103161 & 23.6291845 \\
\hline $\mathrm{Si}$ & 8.1968576 & 9.3297821 & 28.6340737 \\
\hline $\mathrm{Si}$ & 8.2284239 & 9.4190148 & 16.7028521 \\
\hline $\mathrm{Si}$ & 8.2478032 & 6.9541025 & 18.6021311 \\
\hline $\mathrm{Si}$ & 8.2118670 & 6.9083073 & 21.6847180 \\
\hline $\mathrm{Si}$ & 1.3675249 & 10.8750379 & 23.6254490 \\
\hline $\mathrm{Si}$ & 1.3745264 & 10.8428346 & 26.7168612 \\
\hline 0 & 6.6595597 & 9.7630556 & 16.9523692 \\
\hline $\mathrm{O}$ & 4.6680742 & 10.9080420 & 28.3456844 \\
\hline $\mathrm{H}$ & 4.5798101 & 5.5141733 & 21.9178506 \\
\hline $\mathrm{H}$ & 8.6570765 & 5.5055584 & 21.9110025 \\
\hline $\mathrm{O}$ & 6.6688481 & 6.6516489 & 18.4841970 \\
\hline $\mathrm{O}$ & 1.8639681 & 9.2968786 & 26.8643873 \\
\hline $\mathrm{H}$ & 1.9770940 & 7.1796929 & 23.4120623 \\
\hline $\mathrm{H}$ & -0.0206950 & 10.3800555 & 23.4134153 \\
\hline $\mathrm{O}$ & 4.6366322 & 8.1490676 & 17.6139922 \\
\hline $\mathrm{O}$ & 4.2053366 & 8.3447108 & 27.7335628 \\
\hline $\mathrm{O}$ & 4.2958428 & 7.9682730 & 22.6431523 \\
\hline 0 & 2.2336453 & 11.8074331 & 27.6937282 \\
\hline $\mathrm{O}$ & 8.7075930 & 8.1888099 & 17.6548438 \\
\hline 0 & 1.7230291 & 12.1098922 & 22.6483311 \\
\hline 0 & 4.2000863 & 10.6887815 & 17.1248904 \\
\hline $\mathrm{O}$ & 6.6337675 & 9.1419252 & 28.2770626 \\
\hline 0 & 6.6211010 & 7.0200305 & 21.8745333 \\
\hline $\mathrm{H}$ & 9.0290602 & 5.7542655 & 18.1932919 \\
\hline $\mathrm{H}$ & 4.3677165 & 5.6933292 & 18.1230074 \\
\hline $\mathrm{H}$ & -0.0451907 & 10.9104780 & 27.1606499 \\
\hline $\mathrm{H}$ & 2.3505637 & 6.8219242 & 27.0299334 \\
\hline $\mathrm{O}$ & 2.4053086 & 9.6667859 & 23.3010432 \\
\hline $\mathrm{H}$ & 4.8459641 & 9.0407978 & 15.2754555 \\
\hline 0 & 4.6694512 & 7.3294630 & 20.1075630 \\
\hline $\mathrm{O}$ & 3.5626201 & 8.1338827 & 25.1723028 \\
\hline $\mathrm{H}$ & 8.4530732 & 9.0564600 & 30.0751736 \\
\hline $\mathrm{O}$ & 8.6464117 & 7.3800655 & 20.1495034 \\
\hline $\mathrm{O}$ & 1.5471502 & 11.3526236 & 25.1808991 \\
\hline $\mathrm{H}$ & 4.8455612 & 9.0377029 & 30.0788845 \\
\hline $\mathrm{H}$ & 3.1360523 & 12.0530818 & 15.2411497 \\
\hline $\mathrm{Si}$ & 2.9935966 & 16.0021244 & 21.6628687 \\
\hline $\mathrm{Si}$ & 2.9731248 & 16.0377576 & 18.5699477 \\
\hline $\mathrm{Si}$ & 3.5399461 & 12.0568476 & 28.6095250 \\
\hline $\mathrm{Si}$ & 3.5379850 & 12.0984680 & 16.6741573 \\
\hline $\mathrm{Si}$ & 1.4082856 & 13.3047423 & 18.5879307 \\
\hline $\mathrm{Si}$ & 1.3639704 & 13.3272795 & 21.6276013 \\
\hline 0 & 4.6403331 & 13.2755565 & 16.9298455 \\
\hline $\mathrm{H}$ & -0.0518028 & 13.7828715 & 21.6993157 \\
\hline $\mathrm{H}$ & 1.9860655 & 17.0709737 & 21.9069235 \\
\hline $\mathrm{O}$ & 1.8815766 & 14.8544805 & 18.3759280 \\
\hline 0 & 4.2592115 & 15.8353891 & 17.6042688 \\
\hline $\mathrm{O}$ & 4.2853341 & 16.2144491 & 22.6137656 \\
\hline $\mathrm{O}$ & 2.2060020 & 12.3375670 & 17.5579777 \\
\hline $\mathrm{O}$ & 4.1622834 & 13.4937509 & 28.2083521 \\
\hline $\mathrm{O}$ & 2.3769248 & 14.5553859 & 21.9893848 \\
\hline $\mathrm{H}$ & 2.3412122 & 17.3324077 & 18.1935328 \\
\hline $\mathrm{H}$ & -0.0382938 & 13.2245567 & 18.2442754 \\
\hline $\mathrm{O}$ & 3.4949570 & 16.1102610 & 20.1094693 \\
\hline $\mathrm{H}$ & 3.1366833 & 12.0495864 & 30.0428593 \\
\hline 0 & 1.7176313 & 12.8041117 & 20.1014246 \\
\hline $\mathrm{Si}$ & 9.7454351 & 12.1107632 & 16.6026056 \\
\hline $\mathrm{Si}$ & 9.7082603 & 12.0434987 & 28.5296831 \\
\hline $\mathrm{Si}$ & 11.9018507 & 10.7822614 & 26.7641878 \\
\hline $\mathrm{Si}$ & 11.9074268 & 10.7869409 & 23.6338720 \\
\hline $\mathrm{Si}$ & 14.9925237 & 10.8750379 & 23.6254490 \\
\hline $\mathrm{Si}$ & 10.2142002 & 8.1616949 & 23.6760289 \\
\hline $\mathrm{Si}$ & 10.2794223 & 8.1201402 & 26.7390877 \\
\hline $\mathrm{Si}$ & 14.9995251 & 10.8428346 & 26.7168612 \\
\hline 0 & 8.6281919 & 10.8538436 & 28.2543166 \\
\hline $\mathrm{O}$ & 11.4035190 & 9.2548371 & 27.0537847 \\
\hline $\mathrm{H}$ & 15.4471008 & 9.4291173 & 26.8517681 \\
\hline $\mathrm{H}$ & 11.1499738 & 7.0140814 & 23.5197234 \\
\hline 0 & 13.4707364 & 10.3324309 & 23.3930145 \\
\hline $\mathrm{O}$ & 11.0497486 & 11.8324941 & 27.6588033 \\
\hline $\mathrm{O}$ & 9.0388776 & 8.2517302 & 27.7732428 \\
\hline $\mathrm{H}$ & 15.7894122 & 11.7297012 & 27.6150075 \\
\hline $\mathrm{O}$ & 8.9306463 & 7.9497518 & 22.6954085 \\
\hline $\mathrm{O}$ & 15.3480279 & 12.1098922 & 22.6483311 \\
\hline $\mathrm{O}$ & 9.1465440 & 10.6902671 & 17.1320500 \\
\hline $\mathrm{O}$ & 13.4552255 & 10.9164138 & 27.1995930 \\
\hline
\end{tabular}




\begin{tabular}{|c|c|c|}
\hline 10.8917111 & 6.7788715 & 26.9469844 \\
\hline 15.9431860 & 9.7682179 & 23.3282769 \\
\hline 10.9701601 & 9.5113430 & 23.2335633 \\
\hline 10.0914273 & 12.0368934 & 15.1562470 \\
\hline 11.6933676 & 11.1500095 & 25.2079393 \\
\hline 15.1721490 & 11.3526236 & 25.1808991 \\
\hline 9.7008203 & 8.2624587 & 25.2201611 \\
\hline 10.0863050 & 12.0317155 & 29.9698442 \\
\hline 8.4751515 & 15.1506771 & 15.1696840 \\
\hline 5.0853094 & 14.8179832 & 16.6487134 \\
\hline 5.0491328 & 14.7824567 & 28.6142682 \\
\hline 11.8308133 & 18.7110326 & 21.6486151 \\
\hline 11.8195585 & 13.2950382 & 21.6467683 \\
\hline 16.6185953 & 16.0021244 & 21.6628687 \\
\hline 16.5981235 & 16.0377576 & 18.5699477 \\
\hline 11.8763717 & 13.2613511 & 18.5541955 \\
\hline 11.8753925 & 18.7267131 & 18.5830241 \\
\hline 5.0751154 & 17.1944445 & 26.6752823 \\
\hline 5.0451455 & 17.2267987 & 23.6192397 \\
\hline 8.1956436 & 14.7692216 & 28.5545988 \\
\hline 8.2245279 & 14.8153916 & 16.5986319 \\
\hline 15.0332843 & 13.3047423 & 18.5879307 \\
\hline 15.0603026 & 18.7536975 & 18.6021311 \\
\hline 10.3192768 & 16.0549979 & 18.5651504 \\
\hline 10.1983415 & 16.0704286 & 21.6029544 \\
\hline 15.0243664 & 18.7079023 & 21.6847180 \\
\hline 14.9889691 & 13.3272795 & 21.6276013 \\
\hline 8.1638870 & 17.3506240 & 23.5636016 \\
\hline 8.1860515 & 17.2400382 & 26.6631374 \\
\hline 8.6312675 & 13.2601727 & 16.8873709 \\
\hline 6.6171067 & 14.4159290 & 28.3864822 \\
\hline 11.3542033 & 17.1923454 & 21.9412473 \\
\hline 13.4725595 & 13.8152561 & 21.7044133 \\
\hline 15.5098077 & 17.1783927 & 21.9314509 \\
\hline 15.5065754 & 14.8544805 & 18.3759280 \\
\hline 11.3637340 & 14.8022371 & 18.5473933 \\
\hline 13.4813474 & 18.4512440 & 18.4841970 \\
\hline 6.6246320 & 17.6164162 & 26.9542330 \\
\hline 8.6457626 & 18.7507218 & 23.4066223 \\
\hline 4.4683693 & 18.5956095 & 23.5152832 \\
\hline 17.7795125 & 15.8518635 & 17.6828828 \\
\hline 11.4828134 & 19.8521080 & 17.6905621 \\
\hline 11.1218363 & 12.3931875 & 17.4037112 \\
\hline 4.6007933 & 16.0145788 & 27.6734622 \\
\hline 11.1672155 & 19.6817478 & 22.5621087 \\
\hline 11.4709545 & 12.0123033 & 22.7316572 \\
\hline 17.8073567 & 16.1975228 & 22.5379610 \\
\hline 8.6370248 & 15.9878995 & 27.5884693 \\
\hline 15.7653536 & 12.4171595 & 17.6427364 \\
\hline 9.1062761 & 15.8107587 & 17.5158555 \\
\hline 15.4822001 & 19.8866499 & 17.7329119 \\
\hline 8.9113839 & 16.3513387 & 22.5523782 \\
\hline 6.6605354 & 14.9990213 & 16.9819190 \\
\hline 9.0504851 & 13.4633775 & 28.1270336 \\
\hline 13.4336004 & 18.8196255 & 21.8745333 \\
\hline 10.7328397 & 14.6017590 & 21.8345867 \\
\hline 16.0019236 & 14.5553859 & 21.9893848 \\
\hline 15.9077006 & 17.4522825 & 18.1586796 \\
\hline 13.4588684 & 13.2174706 & 18.2139060 \\
\hline 11.1202129 & 17.3864317 & 18.0833018 \\
\hline 4.2018886 & 18.3706326 & 26.9420729 \\
\hline 9.0352202 & 18.4075824 & 27.0276555 \\
\hline 6.5929965 & 17.3214150 & 23.1814692 \\
\hline 4.8096939 & 15.1738274 & 15.2293715 \\
\hline 11.4819506 & 19.1290580 & 20.1075630 \\
\hline 17.1199558 & 16.1102610 & 20.1094693 \\
\hline 4.8988993 & 16.6701624 & 25.1432598 \\
\hline 8.4721567 & 15.1460147 & 29.9683484 \\
\hline 15.3426300 & 12.8041117 & 20.1014246 \\
\hline 15.4589110 & 19.1796606 & 20.1495034 \\
\hline 9.7049756 & 16.2907403 & 20.0463004 \\
\hline 8.3906403 & 16.8461688 & 25.0989411 \\
\hline 11.5615330 & 12.5497363 & 19.9974011 \\
\hline 10.2720437 & 8.3018893 & 20.1252301 \\
\hline 11.3692597 & 10.5642722 & 20.0091837 \\
\hline 10.6659545 & 10.6568236 & 20.8283307 \\
\hline 11.0237440 & 10.5527039 & 18.9804754 \\
\hline 12.4246483 & 10.4558161 & 20.2342191 \\
\hline 11.2220893 & 8.5811308 & 20.1662414 \\
\hline 11.9817828 & 7.8249955 & 19.1974294 \\
\hline
\end{tabular}




\begin{tabular}{|c|c|c|c|}
\hline $\mathrm{H}$ & 11.9575207 & 6.7598192 & 19.4703427 \\
\hline $\mathrm{H}$ & 11.5882707 & 7.9630455 & 18.1788364 \\
\hline $\mathrm{H}$ & 13.0166195 & 8.1839707 & 19.2528324 \\
\hline $\mathrm{H}$ & 4.8070227 & 15.1701885 & 30.0313664 \\
\hline $\mathrm{H}$ & 15.6852304 & 19.6654330 & 22.6139727 \\
\hline \multicolumn{4}{|c|}{ Ge 10} \\
\hline $\mathrm{H}$ & 8.4774743 & 9.1638651 & 15.2590917 \\
\hline $\mathrm{P}$ & 5.1184281 & 9.5275712 & 16.7523928 \\
\hline Al & 5.0961634 & 9.4482877 & 28.5812090 \\
\hline$P$ & 5.1397674 & 6.8766051 & 21.6827485 \\
\hline Al & 5.1957533 & 6.9546437 & 18.4791167 \\
\hline $\mathrm{P}$ & 2.9663262 & 8.1207277 & 26.6599745 \\
\hline Al & 3.0107345 & 8.2470021 & 23.5549016 \\
\hline $\mathrm{P}$ & 8.2516371 & 9.3464777 & 28.5221955 \\
\hline Al & 8.3081235 & 9.4906501 & 16.7018850 \\
\hline$P$ & 8.3478123 & 6.9384305 & 18.4845313 \\
\hline Al & 8.2833601 & 6.8426421 & 21.7162023 \\
\hline $\mathrm{P}$ & 1.3674805 & 10.9609081 & 23.4912886 \\
\hline Al & 1.3504693 & 10.8763062 & 26.6501661 \\
\hline $\mathrm{O}$ & 6.6174920 & 9.8063829 & 17.0149903 \\
\hline 0 & 4.6600724 & 11.1124501 & 28.2283081 \\
\hline $\mathrm{H}$ & 4.6209357 & 5.5004272 & 21.9152754 \\
\hline $\mathrm{H}$ & 8.8177118 & 5.4772438 & 21.9755792 \\
\hline 0 & 6.8935549 & 6.7118223 & 18.0598914 \\
\hline 0 & 1.8919244 & 9.2155638 & 26.7957875 \\
\hline $\mathrm{H}$ & 1.9161891 & 7.2619010 & 23.3342960 \\
\hline $\mathrm{H}$ & -0.0002638 & 10.4699538 & 23.1666962 \\
\hline $\mathrm{O}$ & 4.6327847 & 8.3668461 & 17.6262550 \\
\hline 0 & 4.1074250 & 8.3539723 & 27.6583137 \\
\hline 0 & 4.3477967 & 7.9190626 & 22.4848209 \\
\hline 0 & 2.3332161 & 11.9155848 & 27.6483817 \\
\hline 0 & 8.9146492 & 8.2137553 & 17.7839143 \\
\hline 0 & 1.7342788 & 12.1555671 & 22.6094988 \\
\hline $\mathrm{O}$ & 4.3145557 & 10.7722540 & 17.1354799 \\
\hline 0 & 6.7689190 & 9.1677222 & 28.1885416 \\
\hline 0 & 6.6028232 & 6.9354425 & 22.1401087 \\
\hline $\mathrm{H}$ & 9.1812616 & 5.7807564 & 18.0575963 \\
\hline $\mathrm{H}$ & 4.4347943 & 5.7618024 & 18.0152292 \\
\hline $\mathrm{H}$ & -0.0466451 & 10.9337383 & 27.1619213 \\
\hline $\mathrm{H}$ & 2.3482211 & 6.8049285 & 26.9820601 \\
\hline 0 & 2.3818979 & 9.8385079 & 23.2202373 \\
\hline $\mathrm{H}$ & 4.8944878 & 9.1709615 & 15.3241768 \\
\hline 0 & 5.0411744 & 7.2439474 & 20.1883037 \\
\hline 0 & 3.5439050 & 8.1249757 & 25.2299065 \\
\hline $\mathrm{H}$ & 8.4973444 & 9.1162871 & 29.9726302 \\
\hline $\mathrm{O}$ & 8.4667451 & 7.1781665 & 19.9948810 \\
\hline 0 & 1.4369967 & 11.3865760 & 24.9758472 \\
\hline $\mathrm{H}$ & 4.9185708 & 9.2027550 & 30.0390482 \\
\hline $\mathrm{H}$ & 3.2667847 & 12.2454025 & 15.2004415 \\
\hline$P$ & 3.0062692 & 16.1649768 & 21.6517081 \\
\hline Al & 2.9884230 & 16.2306491 & 18.5242623 \\
\hline$P$ & 3.5901775 & 12.1984396 & 28.4734540 \\
\hline Al & 3.5945426 & 12.2844778 & 16.6523948 \\
\hline $\mathrm{P}$ & 1.3164231 & 13.4844874 & 18.4567708 \\
\hline Al & 1.2409657 & 13.4933332 & 21.5812169 \\
\hline 0 & 4.7664983 & 13.5457821 & 17.0104488 \\
\hline $\mathrm{H}$ & -0.1363673 & 13.9998072 & 21.8333253 \\
\hline $\mathrm{H}$ & 2.0113705 & 17.2139897 & 22.0078949 \\
\hline 0 & 1.8412940 & 14.9333775 & 18.3400861 \\
\hline 0 & 4.4026470 & 15.9929505 & 17.5296496 \\
\hline 0 & 4.2358107 & 16.2614279 & 22.5629686 \\
\hline 0 & 2.1180988 & 12.5574809 & 17.5306803 \\
\hline 0 & 4.1554971 & 13.5558545 & 28.0385191 \\
\hline 0 & 2.3999181 & 14.7825236 & 21.8314808 \\
\hline $\mathrm{H}$ & 2.3788288 & 17.5273111 & 18.1190668 \\
\hline $\mathrm{H}$ & -0.1012738 & 13.4739806 & 18.0016382 \\
\hline 0 & 3.4806654 & 16.3820648 & 20.1954035 \\
\hline $\mathrm{H}$ & 3.2220750 & 12.2372815 & 29.9157135 \\
\hline 0 & 1.4455326 & 12.9664702 & 19.8962233 \\
\hline $\mathrm{P}$ & 9.8537602 & 12.2043201 & 16.5833959 \\
\hline Al & 9.8002233 & 12.0916497 & 28.3984279 \\
\hline $\mathrm{P}$ & 12.1269548 & 10.7907079 & 26.7930370 \\
\hline Al & 12.1297570 & 10.7942313 & 23.5588423 \\
\hline $\mathrm{P}$ & 15.2424792 & 10.9609081 & 23.4912886 \\
\hline$P$ & 10.3576021 & 8.2042507 & 23.5663801 \\
\hline Al & 10.4298944 & 8.1870427 & 26.6681453 \\
\hline Al & 15.2254680 & 10.8763062 & 26.6501661 \\
\hline 0 & 8.6744184 & 10.7736308 & 28.1182777 \\
\hline
\end{tabular}




\begin{tabular}{|c|c|c|}
\hline 11.6284449 & 9.3738953 & 27.1564716 \\
\hline 15.6854228 & 9.4655404 & 26.7738684 \\
\hline 11.1704607 & 6.9582460 & 23.5043010 \\
\hline 13.8221557 & 10.4510804 & 23.1542182 \\
\hline 11.2819265 & 11.8479124 & 27.5214386 \\
\hline 9.0508650 & 8.3015995 & 27.7359884 \\
\hline 16.0644129 & 11.7635108 & 27.5023163 \\
\hline 9.1289583 & 8.0553666 & 22.6528257 \\
\hline 15.6092775 & 12.1555671 & 22.6094988 \\
\hline 9.3224595 & 10.8580951 & 17.1276944 \\
\hline 13.5841629 & 10.9437764 & 27.2513670 \\
\hline 11.0310199 & 6.8313893 & 26.8022075 \\
\hline 16.2252322 & 9.8735428 & 23.2286980 \\
\hline 11.2151921 & 9.3695784 & 23.0692765 \\
\hline 10.1439004 & 12.0935274 & 15.1271459 \\
\hline 12.0120842 & 11.0100352 & 25.2871376 \\
\hline 15.3119954 & 11.3865760 & 24.9758472 \\
\hline 9.8912935 & 8.4545697 & 25.0160749 \\
\hline 10.1000922 & 12.0908066 & 29.8569198 \\
\hline 8.5345563 & 15.2050123 & 15.0597144 \\
\hline 5.1928730 & 14.9893649 & 16.6769411 \\
\hline 5.1292527 & 14.9196888 & 28.5151326 \\
\hline 12.0772668 & 18.8927064 & 21.6827485 \\
\hline 11.8908653 & 13.4405945 & 21.6744667 \\
\hline 16.8812679 & 16.1649768 & 21.6517081 \\
\hline 16.8634217 & 16.2306491 & 18.5242623 \\
\hline 12.0482279 & 13.4952407 & 18.4663296 \\
\hline 12.1332526 & 18.9707450 & 18.4791167 \\
\hline 5.1108603 & 17.4149412 & 26.6729356 \\
\hline 5.0433039 & 17.3996644 & 23.5962498 \\
\hline 8.2955165 & 14.8640254 & 28.3541678 \\
\hline 8.3492919 & 14.9514439 & 16.5152214 \\
\hline 15.1914219 & 13.4844874 & 18.4567708 \\
\hline 15.2853116 & 18.9545319 & 18.4845313 \\
\hline 10.4863561 & 16.3247443 & 18.4114918 \\
\hline 10.2814169 & 16.3095783 & 21.5003921 \\
\hline 15.2208595 & 18.8587434 & 21.7162023 \\
\hline 15.1159644 & 13.4933332 & 21.5812169 \\
\hline 8.1529620 & 17.6550551 & 23.4088065 \\
\hline 8.2321770 & 17.4461929 & 26.5604258 \\
\hline 8.7923891 & 13.2840973 & 16.8604117 \\
\hline 6.8011092 & 14.5415473 & 28.1675066 \\
\hline 11.5431034 & 17.4758620 & 21.9221467 \\
\hline 13.5242797 & 14.0786288 & 21.8725605 \\
\hline 15.8492001 & 17.2531805 & 22.0212019 \\
\hline 15.7162927 & 14.9333775 & 18.3400861 \\
\hline 11.4784419 & 15.1474130 & 18.4566770 \\
\hline 13.8310543 & 18.7279236 & 18.0598914 \\
\hline 6.5647201 & 17.8372300 & 26.9776701 \\
\hline 8.6444203 & 19.0563441 & 23.2993613 \\
\hline 4.3662221 & 18.7233704 & 23.5157305 \\
\hline 18.0700216 & 16.0278474 & 17.6756700 \\
\hline 11.6523685 & 20.1770392 & 17.7506077 \\
\hline 11.1709359 & 12.5241484 & 17.2941223 \\
\hline 4.6316907 & 16.3448206 & 27.6572335 \\
\hline 11.3091974 & 19.9037031 & 22.4606147 \\
\hline 11.4551893 & 12.1305891 & 22.7477071 \\
\hline 18.0751682 & 16.2586321 & 22.5365535 \\
\hline 8.7227048 & 16.0266067 & 27.4530635 \\
\hline 15.9685057 & 12.5859173 & 17.5590887 \\
\hline 9.3646471 & 16.0488708 & 17.4006314 \\
\hline 15.8257928 & 20.1705590 & 17.8164903 \\
\hline 8.8648760 & 16.7380622 & 22.4258712 \\
\hline 6.6831390 & 15.1678211 & 16.9929877 \\
\hline 9.1072020 & 13.6259228 & 27.9548406 \\
\hline 13.5403226 & 18.9515438 & 22.1401087 \\
\hline 10.6782758 & 14.6854857 & 21.8021221 \\
\hline 16.2749168 & 14.7825236 & 21.8314808 \\
\hline 16.1428130 & 17.7634492 & 18.0452757 \\
\hline 13.7305266 & 13.4736604 & 17.9877700 \\
\hline 11.2442193 & 17.5771409 & 17.9371540 \\
\hline 4.2149282 & 18.5950531 & 26.8204557 \\
\hline 9.1159901 & 18.5865404 & 26.9286684 \\
\hline 6.6649038 & 17.6579655 & 23.0420901 \\
\hline 4.9275275 & 15.2746568 & 15.2398187 \\
\hline 11.9786737 & 19.2600487 & 20.1883037 \\
\hline 17.3556641 & 16.3820648 & 20.1954035 \\
\hline 5.0216000 & 16.8308319 & 25.2495442 \\
\hline 8.5578916 & 15.2364843 & 29.7717552 \\
\hline 15.3205313 & 12.9664702 & 19.8962233 \\
\hline
\end{tabular}




\begin{tabular}{|c|c|c|c|}
\hline 0 & 15.4042444 & 19.1942679 & 19.9948810 \\
\hline 0 & 9.8722569 & 16.5767181 & 19.7941562 \\
\hline 0 & 8.3574146 & 17.1306517 & 24.8446438 \\
\hline $\mathrm{O}$ & 11.7953341 & 12.6937040 & 20.0021352 \\
\hline $\mathrm{H}$ & 10.3838416 & 8.6808170 & 19.0679640 \\
\hline $\mathrm{C}$ & 11.4063213 & 10.6917675 & 19.9225071 \\
\hline $\mathrm{H}$ & 11.2345579 & 10.8230630 & 18.8611285 \\
\hline $\mathrm{H}$ & 12.4100237 & 10.5011778 & 20.2887428 \\
\hline $\mathrm{H}$ & 10.6049649 & 10.8406936 & 20.6367199 \\
\hline 0 & 11.0010083 & 8.8133295 & 19.8286280 \\
\hline $\mathrm{C}$ & 12.1400731 & 7.9272323 & 19.7132917 \\
\hline $\mathrm{H}$ & 11.7810611 & 6.8896459 & 19.6575351 \\
\hline $\mathrm{H}$ & 12.7488949 & 8.1662261 & 18.8281664 \\
\hline $\mathrm{H}$ & 12.7296851 & 8.0556691 & 20.6294121 \\
\hline $\mathrm{H}$ & 4.9503414 & 15.2296712 & 29.9604776 \\
\hline $\mathrm{H}$ & 15.9402839 & 19.8905143 & 22.5130698 \\
\hline \multicolumn{4}{|c|}{$\mathrm{Ga} 10$} \\
\hline \multicolumn{4}{|c|}{168} \\
\hline $\mathrm{H}$ & 8.4368490 & 9.0695938 & 15.2884786 \\
\hline $\mathrm{Si}$ & 5.0931594 & 9.4077868 & 16.7166515 \\
\hline $\mathrm{Si}$ & 5.0788284 & 9.3577541 & 28.6552905 \\
\hline $\mathrm{Si}$ & 5.0146023 & 6.8890267 & 21.6543902 \\
\hline $\mathrm{Si}$ & 5.0671393 & 6.9289340 & 18.5881467 \\
\hline $\mathrm{Si}$ & 2.9831982 & 8.1290676 & 26.6995176 \\
\hline $\mathrm{Si}$ & 3.0540254 & 8.2442819 & 23.6424891 \\
\hline $\mathrm{Si}$ & 8.1923432 & 9.3145571 & 28.6405432 \\
\hline $\mathrm{Si}$ & 8.2303245 & 9.4278965 & 16.7188937 \\
\hline $\mathrm{Si}$ & 8.2540097 & 6.9611315 & 18.6101343 \\
\hline $\mathrm{Si}$ & 8.2154429 & 6.9010605 & 21.6981167 \\
\hline $\mathrm{Si}$ & 1.3851446 & 10.8982882 & 23.6309925 \\
\hline $\mathrm{Si}$ & 1.3673426 & 10.8354017 & 26.7309041 \\
\hline 0 & 6.6638738 & 9.7682258 & 16.9893280 \\
\hline 0 & 4.6792459 & 10.9126467 & 28.3699898 \\
\hline $\mathrm{H}$ & 4.5552834 & 5.4964398 & 21.9129410 \\
\hline $\mathrm{H}$ & 8.7021649 & 5.5134606 & 21.9321865 \\
\hline 0 & 6.6745259 & 6.6664162 & 18.4852652 \\
\hline 0 & 1.8527138 & 9.2866008 & 26.8545107 \\
\hline $\mathrm{H}$ & 1.9704582 & 7.2439917 & 23.4365226 \\
\hline $\mathrm{H}$ & 0.0085268 & 10.3918538 & 23.3749300 \\
\hline $\mathrm{O}$ & 4.6317490 & 8.1549192 & 17.6279739 \\
\hline 0 & 4.1870547 & 8.3519889 & 27.7594839 \\
\hline 0 & 4.3080509 & 7.9564442 & 22.6516732 \\
\hline 0 & 2.2379016 & 11.7862469 & 27.7110908 \\
\hline $\mathrm{O}$ & 8.7210830 & 8.2004779 & 17.6704020 \\
\hline $\mathrm{O}$ & 1.7239356 & 12.1528665 & 22.6720044 \\
\hline $\mathrm{O}$ & 4.2029584 & 10.6921917 & 17.1316240 \\
\hline 0 & 6.6315793 & 9.1257287 & 28.2678658 \\
\hline 0 & 6.6201258 & 6.9628806 & 21.8766306 \\
\hline $\mathrm{H}$ & 9.0291314 & 5.7607202 & 18.1914222 \\
\hline $\mathrm{H}$ & 4.3813419 & 5.6928902 & 18.1201742 \\
\hline $\mathrm{H}$ & -0.0465972 & 10.9006555 & 27.1931128 \\
\hline $\mathrm{H}$ & 2.3565401 & 6.8168334 & 27.0196137 \\
\hline 0 & 2.4604802 & 9.7171562 & 23.3160045 \\
\hline $\mathrm{H}$ & 4.8700926 & 9.0413685 & 15.2907835 \\
\hline 0 & 4.6714244 & 7.3194231 & 20.1153480 \\
\hline $\mathrm{O}$ & 3.5895030 & 8.1541939 & 25.1852596 \\
\hline $\mathrm{H}$ & 8.4322043 & 9.0619061 & 30.0882153 \\
\hline 0 & 8.6481371 & 7.3750611 & 20.1621958 \\
\hline 0 & 1.5223668 & 11.3588546 & 25.1964243 \\
\hline $\mathrm{H}$ & 4.8693926 & 9.0379599 & 30.0943836 \\
\hline $\mathrm{H}$ & 3.1462144 & 12.0726730 & 15.2573298 \\
\hline $\mathrm{Si}$ & 3.0399076 & 16.0143927 & 21.6517610 \\
\hline $\mathrm{Si}$ & 2.9967617 & 16.0573427 & 18.5764528 \\
\hline $\mathrm{Si}$ & 3.5431429 & 12.0575634 & 28.6218567 \\
\hline $\mathrm{Si}$ & 3.5500338 & 12.1081031 & 16.6900877 \\
\hline $\mathrm{Si}$ & 1.4019010 & 13.3166333 & 18.5938551 \\
\hline $\mathrm{Si}$ & 1.3591593 & 13.3594396 & 21.6410589 \\
\hline 0 & 4.6585810 & 13.2780621 & 16.9529240 \\
\hline $\mathrm{H}$ & -0.0162590 & 13.9112240 & 21.7855542 \\
\hline $\mathrm{H}$ & 2.0354832 & 17.0788609 & 21.9259139 \\
\hline $\mathrm{O}$ & 1.9166514 & 14.8577736 & 18.4323269 \\
\hline 0 & 4.2662350 & 15.8470598 & 17.5915684 \\
\hline 0 & 4.3319947 & 16.1791595 & 22.6123137 \\
\hline 0 & 2.2258150 & 12.3492877 & 17.5853394 \\
\hline 0 & 4.1499159 & 13.4964858 & 28.2006782 \\
\hline 0 & 2.4320086 & 14.5536674 & 21.9217277 \\
\hline $\mathrm{H}$ & 2.3434802 & 17.3388009 & 18.1914738 \\
\hline $\mathrm{H}$ & -0.0291704 & 13.2716826 & 18.1850342 \\
\hline & & & \\
\hline
\end{tabular}




\begin{tabular}{|c|c|c|c|}
\hline $\mathrm{H}$ & 3.1461449 & 12.0683783 & 30.0569164 \\
\hline 0 & 1.6137767 & 12.7842336 & 20.1142795 \\
\hline $\mathrm{Si}$ & 9.7524696 & 12.1138198 & 16.5787304 \\
\hline $\mathrm{Si}$ & 9.7005349 & 12.0283204 & 28.5082531 \\
\hline $\mathrm{Si}$ & 11.9077996 & 10.7514843 & 26.7751177 \\
\hline $\mathrm{Si}$ & 11.9263066 & 10.7324101 & 23.6269247 \\
\hline $\mathrm{Si}$ & 15.0101434 & 10.8982882 & 23.6309925 \\
\hline $\mathrm{Si}$ & 10.1712517 & 8.1514487 & 23.7086388 \\
\hline $\mathrm{Si}$ & 10.2667044 & 8.1183672 & 26.7445509 \\
\hline $\mathrm{Si}$ & 14.9923413 & 10.8354017 & 26.7309041 \\
\hline $\mathrm{O}$ & 8.6248758 & 10.8331118 & 28.2386244 \\
\hline 0 & 11.4074927 & 9.2291751 & 27.0910413 \\
\hline $\mathrm{H}$ & 15.4363328 & 9.4186421 & 26.8439728 \\
\hline $\mathrm{H}$ & 11.0177703 & 6.9300911 & 23.6147643 \\
\hline 0 & 13.5006854 & 10.3429841 & 23.3502206 \\
\hline 0 & 11.0349877 & 11.8225420 & 27.6249462 \\
\hline 0 & 9.0482874 & 8.2208272 & 27.8102087 \\
\hline $\mathrm{H}$ & 15.7927555 & 11.7096330 & 27.6321128 \\
\hline 0 & 8.8942246 & 7.9730508 & 22.7095447 \\
\hline 0 & 15.3489343 & 12.1528665 & 22.6720044 \\
\hline 0 & 9.1555361 & 10.7000992 & 17.1303494 \\
\hline 0 & 13.4535333 & 10.9064182 & 27.2339315 \\
\hline $\mathrm{H}$ & 10.8725913 & 6.7640945 & 26.8709124 \\
\hline $\mathrm{H}$ & 15.9936189 & 9.8180539 & 23.3429122 \\
\hline $\mathrm{O}$ & 11.0383260 & 9.4201898 & 23.2327700 \\
\hline $\mathrm{H}$ & 10.0927955 & 12.0179546 & 15.1323180 \\
\hline 0 & 11.7336803 & 11.0761377 & 25.2066816 \\
\hline 0 & 15.1473655 & 11.3588546 & 25.1964243 \\
\hline $\mathrm{O}$ & 9.6563703 & 8.3433214 & 25.2453627 \\
\hline $\mathrm{H}$ & 10.0865178 & 12.0113821 & 29.9462555 \\
\hline $\mathrm{H}$ & 8.4548148 & 15.1573763 & 15.1412104 \\
\hline $\mathrm{Si}$ & 5.1005331 & 14.8183474 & 16.6549488 \\
\hline $\mathrm{Si}$ & 5.0456251 & 14.7788945 & 28.6099464 \\
\hline $\mathrm{Si}$ & 11.8271017 & 18.6886217 & 21.6543902 \\
\hline $\mathrm{Ga}$ & 11.8064447 & 13.3198057 & 21.6798476 \\
\hline $\mathrm{Si}$ & 16.6649063 & 16.0143927 & 21.6517610 \\
\hline $\mathrm{Si}$ & 16.6217605 & 16.0573427 & 18.5764528 \\
\hline $\mathrm{Si}$ & 11.8919892 & 13.2669346 & 18.5217427 \\
\hline $\mathrm{Si}$ & 11.8796386 & 18.7285290 & 18.5881467 \\
\hline $\mathrm{Si}$ & 5.0764980 & 17.1779477 & 26.6706932 \\
\hline $\mathrm{Si}$ & 5.0274375 & 17.2037154 & 23.6510820 \\
\hline $\mathrm{Si}$ & 8.1855078 & 14.7621304 & 28.5259559 \\
\hline $\mathrm{Si}$ & 8.2307781 & 14.8212997 & 16.5743819 \\
\hline $\mathrm{Si}$ & 15.0268997 & 13.3166333 & 18.5938551 \\
\hline $\mathrm{Si}$ & 15.0665091 & 18.7607266 & 18.6101343 \\
\hline $\mathrm{Si}$ & 10.3233944 & 16.0568316 & 18.5503617 \\
\hline $\mathrm{Si}$ & 10.1355272 & 16.0878487 & 21.5927269 \\
\hline $\mathrm{Si}$ & 15.0279422 & 18.7006555 & 21.6981167 \\
\hline $\mathrm{Si}$ & 14.9841581 & 13.3594396 & 21.6410589 \\
\hline $\mathrm{Si}$ & 8.1320484 & 17.4249437 & 23.5572297 \\
\hline $\mathrm{Si}$ & 8.1793616 & 17.2430386 & 26.6478424 \\
\hline 0 & 8.6365028 & 13.2641602 & 16.8510962 \\
\hline 0 & 6.6076447 & 14.4099715 & 28.3489777 \\
\hline $\mathrm{O}$ & 11.3271969 & 17.1729845 & 21.9357868 \\
\hline 0 & 13.5035232 & 13.9534343 & 21.7966078 \\
\hline 0 & 15.5591392 & 17.1862619 & 21.9535749 \\
\hline 0 & 15.5416502 & 14.8577736 & 18.4323269 \\
\hline $\mathrm{O}$ & 11.3618417 & 14.8012990 & 18.5627243 \\
\hline 0 & 13.4870252 & 18.4660113 & 18.4852652 \\
\hline 0 & 6.6202879 & 17.6216907 & 26.9606358 \\
\hline $\mathrm{H}$ & 8.6355615 & 18.8203873 & 23.4294314 \\
\hline $\mathrm{H}$ & 4.3325997 & 18.5200226 & 23.6103833 \\
\hline $\mathrm{H}$ & 17.7882724 & 15.8641149 & 17.6714481 \\
\hline $\mathrm{H}$ & 11.4787018 & 19.8574994 & 17.7039544 \\
\hline 0 & 11.1336678 & 12.4132115 & 17.3633841 \\
\hline 0 & 4.5883085 & 16.0341543 & 27.7037315 \\
\hline $\mathrm{H}$ & 11.1787672 & 19.6680884 & 22.5695012 \\
\hline 0 & 11.3887246 & 11.9395364 & 22.7493667 \\
\hline $\mathrm{H}$ & 17.8536657 & 16.1659832 & 22.5354986 \\
\hline 0 & 8.6318027 & 15.9738862 & 27.5511853 \\
\hline $\mathrm{H}$ & 15.7831381 & 12.4287447 & 17.6681780 \\
\hline 0 & 9.1322845 & 15.8135438 & 17.4760819 \\
\hline $\mathrm{H}$ & 15.4947670 & 19.8970790 & 17.7484969 \\
\hline $\mathrm{O}$ & 8.8353424 & 16.4475238 & 22.4957760 \\
\hline 0 & 6.6745882 & 15.0090076 & 16.9896591 \\
\hline 0 & 9.0392236 & 13.4498233 & 28.1159081 \\
\hline 0 & 13.4326252 & 18.7624757 & 21.8766306 \\
\hline 0 & 10.5687435 & 14.5936199 & 21.8966448 \\
\hline $\mathrm{O}$ & 16.0570073 & 14.5536674 & 21.9217277 \\
\hline $\mathrm{O}$ & 15.9077669 & 17.4578919 & 18.1556962 \\
\hline
\end{tabular}




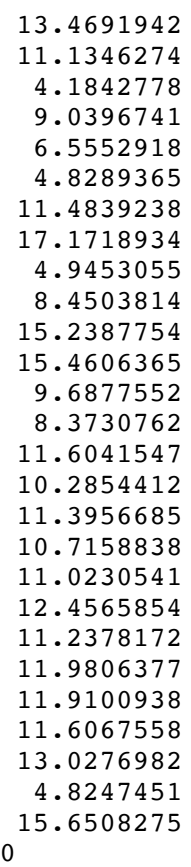

13.2677049

17.3857613

18.3540549

18.4013648

17.4495500

15.1548214

19.1190181

16.1711682

16.5857916

15.1514909

12.7842336

19.1746561

16.2941300

16.8727419

12.5150780

8.2881564

10.5301325

10.6386799

10.5235278

10.4214978

8.5608100

7.8027178

6.7325076

7.9851168

8.1191427

15.1508641

19.6843694

9.1752556

9.5456668

9.4448039

6.8937547

6.9685360

8.1102120

8.2784019

9.3200708

9.5068810

6.9541194

6.8231807

10.9643314

10.8640765

9.8198113

11.1069492

5.5638015

5.4706756

6.7302739

9.2039023

7.2985105

10.4348672

8.3824017

8.3439088

7.9858359

11.8946380

8.2326122

12.1594928

10.7911956

9.1386080

6.8355695

5.7997646

5.7719196

10.9020389

6.7931710

9.8699290

9.1950630

7.2717113

8.1166442

9.1254207

7.1869681

11.3990580

9.2228517

12.2503252

16.1636776

16.2449892

12.1906796

12.2987932

13.5010916

13.4990765

13.5628901
18.1488581

18.0797680

26.8652064

27.0156242

23.2040248

15.2301186

20.1153480

20.1038287

25.1570810

29.9385283

20.1142795

20.1621958

20.0213458

25.0751253

19.9478063

20.1196687

19.9804413

20.8177516

18.9609997

20.1778813

20.1471657

19.1664649

19.4089659

18.1472146

19.2463859

30.0347170

22.6262555

15.2739910

16.7776575

28.6019387

21.6963892

18.4969502

26.6809434

23.5851613

28.5322311

16.7168364

18.5036708

21.7313603

23.5222882

26.6752054

17.0390468

28.2287518

21.9335072

21.9755421

18.0808899

26.7911997

23.3279135

23.1789662

17.6460006

27.7061369

22.5163466

27.6821230

17.8065760

22.6390251

17.1667269

28.2064191

22.1327368

18.0678844

18.0318396

27.2022225

26.9871673

23.2783443

15.3484614

20.2038762

25.2635621

29.9873111

20.0152425

25.0065590

30.0645213

15.2156931

21.6396871

18.5120415

28.4833292

16.6695122

18.4617638

21.5961835

17.0291939 


\begin{tabular}{|c|c|c|c|}
\hline $\mathrm{H}$ & -0.1069421 & 13.9708808 & 21.8392381 \\
\hline $\mathrm{H}$ & 2.0566645 & 17.2077671 & 22.0050608 \\
\hline $\mathrm{O}$ & 1.8525843 & 14.9498334 & 18.3351786 \\
\hline $\mathrm{O}$ & 4.4128789 & 16.0171120 & 17.5079653 \\
\hline $\mathrm{O}$ & 4.3008796 & 16.2664017 & 22.5285223 \\
\hline $\mathrm{O}$ & 2.1279504 & 12.5716929 & 17.5358653 \\
\hline 0 & 4.1432924 & 13.5478771 & 28.0278087 \\
\hline 0 & 2.4596931 & 14.7772915 & 21.8343144 \\
\hline $\mathrm{H}$ & 2.3881895 & 17.5453310 & 18.1257194 \\
\hline $\mathrm{H}$ & -0.0905627 & 13.4905580 & 18.0077492 \\
\hline $\mathrm{O}$ & 3.5092710 & 16.3820128 & 20.1787900 \\
\hline $\mathrm{H}$ & 3.2486202 & 12.2402353 & 29.9313216 \\
\hline 0 & 1.4661243 & 12.9881912 & 19.9021829 \\
\hline $\mathrm{P}$ & 9.8556156 & 12.2163180 & 16.5560360 \\
\hline Al & 9.7785370 & 12.0702270 & 28.3621693 \\
\hline $\mathrm{P}$ & 12.1261339 & 10.7488491 & 26.8181011 \\
\hline Al & 12.1491908 & 10.7042454 & 23.5794914 \\
\hline $\mathrm{P}$ & 15.2534207 & 10.9643314 & 23.5222882 \\
\hline$P$ & 10.3049642 & 8.1811367 & 23.6074444 \\
\hline Al & 10.4112888 & 8.1704943 & 26.6842924 \\
\hline Al & 15.2142737 & 10.8640765 & 26.6752054 \\
\hline 0 & 8.6715680 & 10.7348366 & 28.0870881 \\
\hline 0 & 11.6113970 & 9.3443244 & 27.2078430 \\
\hline $\mathrm{H}$ & 15.6828713 & 9.4541712 & 26.7737137 \\
\hline $\mathrm{H}$ & 11.0242303 & 6.8773958 & 23.6014082 \\
\hline $\mathrm{O}$ & 13.8517900 & 10.4140769 & 23.1654851 \\
\hline $\mathrm{O}$ & 11.2715526 & 11.8296273 & 27.5007574 \\
\hline $\mathrm{O}$ & 9.0424262 & 8.2526233 & 27.7705700 \\
\hline $\mathrm{H}$ & 16.0536940 & 11.7437335 & 27.5346807 \\
\hline $\mathrm{O}$ & 9.0783836 & 8.0668365 & 22.6822759 \\
\hline 0 & 15.6152015 & 12.1594928 & 22.6390251 \\
\hline $\mathrm{O}$ & 9.3368895 & 10.8760927 & 17.1301261 \\
\hline 0 & 13.5770722 & 10.9087229 & 27.2950139 \\
\hline $\mathrm{H}$ & 11.0222688 & 6.8145984 & 26.7575754 \\
\hline $\mathrm{H}$ & 16.2715875 & 9.9038683 & 23.2859094 \\
\hline $\mathrm{O}$ & 11.2458866 & 9.2718007 & 23.0841980 \\
\hline $\mathrm{H}$ & 10.0941700 & 12.0861749 & 15.0920431 \\
\hline 0 & 12.0423897 & 10.9235859 & 25.3052232 \\
\hline $\mathrm{O}$ & 15.2839803 & 11.3990580 & 25.0065590 \\
\hline $\mathrm{O}$ & 9.8497776 & 8.5061334 & 25.0473195 \\
\hline $\mathrm{H}$ & 10.0536699 & 12.0810947 & 29.8254889 \\
\hline $\mathrm{H}$ & 8.5364294 & 15.1865799 & 15.0215823 \\
\hline$P$ & 5.2029472 & 15.0013120 & 16.6684454 \\
\hline Al & 5.1200749 & 14.9108989 & 28.5026464 \\
\hline $\mathrm{P}$ & 12.0601809 & 18.9098561 & 21.6963892 \\
\hline $\mathrm{Ti}$ & 11.8511856 & 13.4369883 & 21.6807483 \\
\hline $\mathrm{P}$ & 16.9284078 & 16.1636776 & 21.6396871 \\
\hline Al & 16.8771809 & 16.2449892 & 18.5120415 \\
\hline Al & 12.0460834 & 13.4931028 & 18.4271262 \\
\hline Al & 12.1384896 & 18.9846374 & 18.4969502 \\
\hline $\mathrm{P}$ & 5.1091438 & 17.3958430 & 26.6616996 \\
\hline Al & 5.0281907 & 17.4022591 & 23.6206908 \\
\hline $\mathrm{P}$ & 8.2850347 & 14.8450738 & 28.3137698 \\
\hline$A 1$ & 8.3590811 & 14.9628827 & 16.4829610 \\
\hline $\mathrm{P}$ & 15.2024911 & 13.5010916 & 18.4617638 \\
\hline$P$ & 15.2936281 & 18.9702208 & 18.5036708 \\
\hline $\mathrm{P}$ & 10.4808433 & 16.3306126 & 18.3881201 \\
\hline$A 1$ & 10.1742177 & 16.3683395 & 21.4863665 \\
\hline Al & 15.2196904 & 18.8392820 & 21.7313603 \\
\hline Al & 15.1592596 & 13.4990765 & 21.5961835 \\
\hline $\mathrm{P}$ & 8.1223325 & 17.7334953 & 23.4002546 \\
\hline Al & 8.2271502 & 17.4434373 & 26.5408813 \\
\hline 0 & 8.8051423 & 13.3015590 & 16.8565931 \\
\hline 0 & 6.7874366 & 14.5332858 & 28.1362489 \\
\hline 0 & 11.4161816 & 17.5420888 & 21.9402491 \\
\hline O & 13.5503751 & 14.0447040 & 21.8772689 \\
\hline $\mathrm{O}$ & 15.8941350 & 17.2470780 & 22.0188174 \\
\hline $\mathrm{O}$ & 15.7275830 & 14.9498334 & 18.3351786 \\
\hline 0 & 11.4623325 & 15.1459185 & 18.4382313 \\
\hline 0 & 13.8384256 & 18.7463752 & 18.0808899 \\
\hline 0 & 6.5598328 & 17.8296356 & 26.9687237 \\
\hline $\mathrm{H}$ & 8.7035168 & 19.0996893 & 23.2868556 \\
\hline $\mathrm{H}$ & 4.2317407 & 18.6602364 & 23.6039273 \\
\hline $\mathrm{H}$ & 18.0799072 & 16.0507065 & 17.6559900 \\
\hline $\mathrm{H}$ & 11.6597842 & 20.1926678 & 17.7698847 \\
\hline 0 & 11.1985481 & 12.5450592 & 17.2113861 \\
\hline 0 & 4.6210691 & 16.3500715 & 27.6676269 \\
\hline $\mathrm{H}$ & 11.3764029 & 19.9676091 & 22.4905723 \\
\hline 0 & 11.4729206 & 12.0536883 & 22.7744561 \\
\hline $\mathrm{H}$ & 18.1383566 & 16.2633120 & 22.5017877 \\
\hline
\end{tabular}


8.7131484
15.9780439
9.3819064
15.8347794
8.7197782
6.6953689
9.0842557
13.5302275
10.6434633
16.3346918
16.1512234
13.7420037
11.2573076
4.2086002
9.1128760
6.6218480
4.9286292
11.9724901
17.3842698
5.0410597
8.5580485
15.3411230
15.4146494
9.8313558
8.3569403
11.7685826
10.3978242
11.4132016
11.2806000
12.4059312
10.5876335
11.0221496
12.1639858
11.8062976
12.7701696
12.7542948
4.9496513
15.8946787 11

Zn 174

$\begin{array}{lrrr}\mathrm{H} & 8.7595478 & 8.8835927 & 15.3174874 \\ \mathrm{Al} & 5.4830531 & 9.2511829 & 16.6884399 \\ \mathrm{P} & 5.5015315 & 9.2199070 & 28.5024514 \\ \mathrm{Al} & 5.4090662 & 6.6333322 & 21.6337256 \\ \mathrm{P} & 5.4415793 & 6.6778759 & 18.4835735 \\ \mathrm{Al} & 3.2786789 & 8.0010911 & 26.6505927 \\ \mathrm{P} & 3.3487551 & 8.0936645 & 23.5287324 \\ \mathrm{Al} & 8.6247223 & 9.2019177 & 28.5734476 \\ \mathrm{P} & 8.6169830 & 9.2934482 & 16.7418519 \\ \mathrm{Al} & 8.5997557 & 6.7110193 & 18.5511585 \\ \mathrm{P} & 8.5841801 & 6.6548741 & 21.7281336 \\ \mathrm{Al} & 1.6364484 & 10.7247390 & 23.5640544 \\ \mathrm{P} & 1.6256917 & 10.7020883 & 26.7236723 \\ \mathrm{O} & 7.1551731 & 9.6795817 & 17.0566939 \\ \mathrm{O} & 5.0890599 & 10.6751028 & 28.1999055 \\ \mathrm{H} & 4.9269967 & 5.2382932 & 21.8301839 \\ \mathrm{H} & 9.1033726 & 5.2836289 & 21.9874523 \\ \mathrm{O} & 6.9228931 & 6.3300834 & 18.2286702 \\ \mathrm{O} & 2.0686797 & 9.2374211 & 26.9175503 \\ \mathrm{H} & 2.2745270 & 7.0769180 & 23.3573232 \\ \mathrm{H} & 0.2590995 & 10.2014613 & 23.3490866 \\ \mathrm{O} & 5.0066082 & 7.8395455 & 17.5831266 \\ \mathrm{O} & 4.6403123 & 8.2335052 & 27.7118187 \\ \mathrm{O} & 4.5398991 & 7.7868942 & 22.6128787 \\ \mathrm{O} & 2.4380564 & 11.6317288 & 27.6336908 \\ \mathrm{O} & 9.0686781 & 8.1424965 & 17.6527170 \\ \mathrm{O} & 1.9349444 & 12.1433147 & 22.6181873 \\ \mathrm{O} & 4.4583487 & 10.5816954 & 17.154426 \\ \mathrm{O} & 6.9633041 & 9.0230498 & 28.0824779 \\ \mathrm{O} & 7.0953086 & 6.6996673 & 22.0691924 \\ \mathrm{H} & 9.4472278 & 5.5578896 & 18.1398151 \\ \mathrm{H} & 4.6083428 & 5.4926553 & 18.1399316 \\ \mathrm{H} & 0.1955173 & 10.8159742 & 27.1221092 \\ \mathrm{H} & 2.6794891 & 6.6772728 & 26.9755500 \\ \mathrm{O} & 2.7962311 & 9.4738437 & 23.1523112 \\ \mathrm{H} & 5.3526664 & 8.9685008 & 15.2323456 \\ \mathrm{O} & 5.2355302 & 7.0985205 & 19.9487384 \\ \mathrm{O} & 3.8407113 & 8.0835191 & 24.9916402 \\ \mathrm{H} & 8.7427964 & 8.9212550 & 30.0309823\end{array}$

27.4095810

17.5646734

17.3447142

17.8396099

22.3599646

16.9704409

27.9059031

22.1327368

21.8356366

21.8343144

18.0552715

17.9941638

17.9535708

26.7669284

26.9296506

23.1086925

15.2279756

20.2038762

20.1787900

25.2526471

29.7305282

19.9021829

20.0152425

19.7580480

24.8157531

19.9452821

19.0498551

19.8561857

18.7869502

20.2647210

20.5366532

19.8042067

19.6944839

19.6484561

18.8060539

20.6086460

29.9501985

$\begin{array}{ll}15.2153150 & 29.9501985 \\ 19.8936163 & 22.5375182\end{array}$

7.9259857

6.8877135

8.1589687

19.8936163

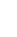
.

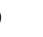




\begin{tabular}{|c|c|c|c|}
\hline 0 & 8.8176448 & 7.0538994 & 20.2548423 \\
\hline 0 & 1.8325725 & 11.1373548 & 25.2642847 \\
\hline $\mathrm{H}$ & 5.3358534 & 8.9297880 & 29.9534863 \\
\hline $\mathrm{H}$ & 3.5440400 & 11.9230413 & 15.2706381 \\
\hline Al & 3.3524210 & 15.9870644 & 21.6425685 \\
\hline $\mathrm{P}$ & 3.2640402 & 16.0256338 & 18.4679043 \\
\hline Al & 3.8954573 & 11.9203678 & 28.5325017 \\
\hline $\mathrm{P}$ & 3.8775461 & 11.9352675 & 16.7217565 \\
\hline $\mathrm{Al}$ & 1.7324200 & 13.2570900 & 18.5981797 \\
\hline $\mathrm{P}$ & 1.8091176 & 13.3310989 & 21.6550986 \\
\hline 0 & 4.9359255 & 13.0229521 & 17.0209718 \\
\hline $\mathrm{H}$ & 0.4660825 & 13.9739789 & 21.6641814 \\
\hline $\mathrm{H}$ & 2.3629167 & 17.0586534 & 21.9420659 \\
\hline 0 & 2.2100012 & 14.9209102 & 18.2587825 \\
\hline 0 & 4.4939532 & 15.7901806 & 17.5796551 \\
\hline 0 & 4.8231196 & 16.2515311 & 22.5360236 \\
\hline 0 & 2.5924398 & 12.1913830 & 17.5098540 \\
\hline 0 & 4.5450497 & 13.4704362 & 28.0686754 \\
\hline 0 & 2.8546045 & 14.3840706 & 22.0861613 \\
\hline $\mathrm{H}$ & 2.6725747 & 17.3364852 & 18.0819537 \\
\hline $\mathrm{H}$ & 0.2722999 & 13.0916337 & 18.3577755 \\
\hline 0 & 3.7336505 & 16.0557879 & 19.9314027 \\
\hline $\mathrm{H}$ & 3.5872146 & 11.9223208 & 29.9892458 \\
\hline 0 & 2.1704682 & 12.8188926 & 20.2319271 \\
\hline $\mathrm{Al}$ & 10.2441730 & 12.0111569 & 16.5411150 \\
\hline $\mathrm{P}$ & 10.1516440 & 11.9763332 & 28.3980069 \\
\hline Al & 12.3690751 & 10.6267602 & 26.6345936 \\
\hline $\mathrm{P}$ & 12.4150417 & 10.5639907 & 23.4744176 \\
\hline $\mathrm{Al}$ & 15.5114471 & 10.7247390 & 23.5640544 \\
\hline Al & 10.6925483 & 7.9229082 & 23.6389995 \\
\hline $\mathrm{P}$ & 10.7798612 & 7.9081474 & 26.7384565 \\
\hline $\mathrm{P}$ & 15.5006904 & 10.7020883 & 26.7236723 \\
\hline 0 & 9.1216111 & 10.8442214 & 28.2112468 \\
\hline 0 & 11.8526261 & 8.9846119 & 26.9917386 \\
\hline $\mathrm{H}$ & 15.9283344 & 9.2881536 & 26.9108348 \\
\hline $\mathrm{H}$ & 11.6227193 & 6.7718333 & 23.4748989 \\
\hline 0 & 13.8906650 & 10.1089770 & 23.3110931 \\
\hline $\mathrm{O}$ & 11.3783496 & 11.7596408 & 27.5169712 \\
\hline 0 & 9.6290202 & 8.0499205 & 27.7432283 \\
\hline $\mathrm{H}$ & 16.2893675 & 11.6046215 & 27.6071557 \\
\hline $\mathrm{O}$ & 9.2985044 & 7.6900091 & 22.6109298 \\
\hline 0 & 15.8099431 & 12.1433147 & 22.6181873 \\
\hline 0 & 9.5139707 & 10.5032350 & 17.0432881 \\
\hline 0 & 14.0280129 & 10.8193587 & 27.1339503 \\
\hline $\mathrm{H}$ & 11.3938494 & 6.5654639 & 26.9316926 \\
\hline $\mathrm{H}$ & 16.4955500 & 9.6633249 & 23.2146806 \\
\hline 0 & 11.5167326 & 9.3553664 & 23.1325284 \\
\hline $\mathrm{H}$ & 10.5607160 & 12.0162941 & 15.0861598 \\
\hline 0 & 12.1773705 & 10.9705066 & 24.9473189 \\
\hline 0 & 15.7075712 & 11.1373548 & 25.2642847 \\
\hline 0 & 10.1980491 & 8.0447302 & 25.3169692 \\
\hline $\mathrm{H}$ & 10.5972906 & 12.0158018 & 29.8182048 \\
\hline $\mathrm{H}$ & 8.7956029 & 15.0304060 & 15.2213113 \\
\hline Al & 5.4355061 & 14.6639176 & 16.6460891 \\
\hline $\mathrm{P}$ & 5.4096221 & 14.6662002 & 28.4794414 \\
\hline Al & 12.3465656 & 18.6494335 & 21.6337256 \\
\hline $\mathrm{Zn}$ & 12.5198700 & 13.3499278 & 21.7198100 \\
\hline $\mathrm{Al}$ & 17.2274197 & 15.9870644 & 21.6425685 \\
\hline $\mathrm{P}$ & 17.1390390 & 16.0256338 & 18.4679043 \\
\hline$P$ & 12.3813182 & 13.2013489 & 18.4403502 \\
\hline $\mathrm{P}$ & 12.3790786 & 18.6939772 & 18.4835735 \\
\hline Al & 5.4930771 & 17.1776426 & 26.6143615 \\
\hline $\mathrm{P}$ & 5.4823502 & 17.2115224 & 23.5276905 \\
\hline $\mathrm{Al}$ & 8.5726548 & 14.7000073 & 28.4867044 \\
\hline $\mathrm{P}$ & 8.6057773 & 14.7114624 & 16.6633105 \\
\hline Al & 15.6074187 & 13.2570900 & 18.5981797 \\
\hline Al & 15.5372551 & 18.7271207 & 18.5511585 \\
\hline Al & 10.8322787 & 15.9213275 & 18.5013772 \\
\hline $\mathrm{P}$ & 10.6994350 & 15.9273371 & 21.6764990 \\
\hline $\mathrm{P}$ & 15.5216795 & 18.6709755 & 21.7281336 \\
\hline $\mathrm{P}$ & 15.6841163 & 13.3310989 & 21.6550986 \\
\hline $\mathrm{Al}$ & 8.6368933 & 17.4021414 & 23.5331281 \\
\hline $\mathrm{P}$ & 8.6514210 & 17.2586665 & 26.6618145 \\
\hline 0 & 9.0823677 & 13.2671760 & 16.9581481 \\
\hline 0 & 6.8865843 & 14.3239675 & 28.2061680 \\
\hline 0 & 11.7834035 & 17.0197246 & 21.8632317 \\
\hline 0 & 14.3081203 & 13.9897565 & 21.6644044 \\
\hline 0 & 16.0586415 & 17.2527991 & 21.9963275 \\
\hline 0 & 16.0849999 & 14.9209102 & 18.2587825 \\
\hline $\mathrm{O}$ & 11.9888472 & 14.6601557 & 18.1103063 \\
\hline
\end{tabular}




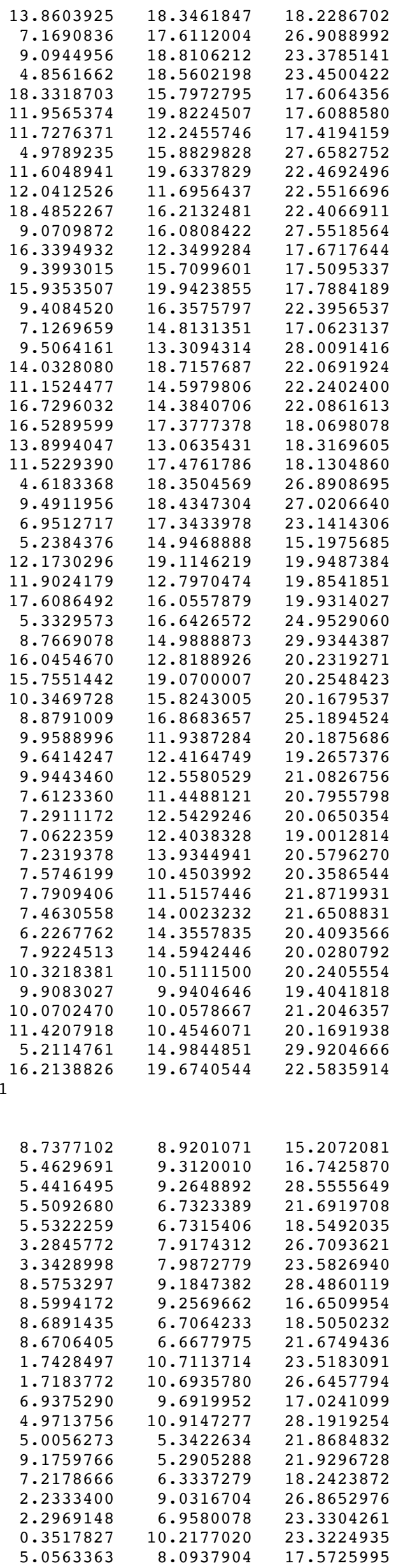

15.2072081

16.7425870

28.5555649

21.6919708

18.5492035 26.7093621 23.5826940

28.4860119

16.6509954

18.5050232

21.6749436

23.5183091

26.6457794

17.0241099

28.1919254

21.8684832

21.9296728

18.2423872

26.8652976

23.3304261

23.3224935

17.5725995 


\begin{tabular}{|c|c|c|c|}
\hline 0 & 4.4521005 & 8.1358750 & 27.6791098 \\
\hline $\mathrm{O}$ & 4.7457343 & 7.7171288 & 22.5846242 \\
\hline 0 & 2.6497704 & 11.7613644 & 27.6594752 \\
\hline 0 & 9.1004760 & 7.9125014 & 17.6445527 \\
\hline $\mathrm{O}$ & 2.0653512 & 11.8769541 & 22.5845523 \\
\hline $\mathrm{O}$ & 4.5752749 & 10.4918916 & 17.1546274 \\
\hline 0 & 7.1041489 & 9.0393366 & 28.0872867 \\
\hline $\mathrm{O}$ & 6.9891145 & 6.7821469 & 22.0952703 \\
\hline $\mathrm{H}$ & 9.5551600 & 5.5523046 & 18.1374010 \\
\hline $\mathrm{H}$ & 4.6774804 & 5.5668128 & 18.1887316 \\
\hline $\mathrm{H}$ & 0.2935760 & 10.7824245 & 27.0690623 \\
\hline $\mathrm{H}$ & 2.6541901 & 6.6125699 & 27.0515164 \\
\hline 0 & 2.7188463 & 9.5669830 & 23.2056091 \\
\hline $\mathrm{H}$ & 5.2789324 & 8.9875397 & 15.3010684 \\
\hline 0 & 5.3474784 & 7.1875465 & 20.2265897 \\
\hline $\mathrm{O}$ & 3.8307288 & 7.9001398 & 25.2692872 \\
\hline $\mathrm{H}$ & 8.7548262 & 8.8740545 & 29.9311338 \\
\hline 0 & 8.8927101 & 7.0915254 & 19.9831463 \\
\hline 0 & 1.9318556 & 11.1802633 & 24.9789804 \\
\hline $\mathrm{H}$ & 5.2982207 & 9.0201283 & 30.0172902 \\
\hline $\mathrm{H}$ & 3.5981072 & 12.0069439 & 15.2007058 \\
\hline $\mathrm{P}$ & 3.3095455 & 15.9093650 & 21.7076604 \\
\hline Al & 3.2846459 & 15.9610859 & 18.5345418 \\
\hline$P$ & 3.9178213 & 12.0051620 & 28.4773269 \\
\hline Al & 3.8931938 & 12.0217836 & 16.6600976 \\
\hline $\mathrm{P}$ & 1.6896098 & 13.2627428 & 18.4901004 \\
\hline Al & 1.6319330 & 13.2501479 & 21.5854943 \\
\hline 0 & 5.0966208 & 13.2566324 & 17.0261247 \\
\hline $\mathrm{H}$ & 0.1922986 & 13.6288868 & 21.6191159 \\
\hline $\mathrm{H}$ & 2.3604466 & 17.0275768 & 21.9644367 \\
\hline $\mathrm{O}$ & 2.0838048 & 14.7311598 & 18.1962258 \\
\hline $\mathrm{O}$ & 4.7377931 & 15.6913656 & 17.5976234 \\
\hline $\mathrm{O}$ & 4.5807500 & 16.0841448 & 22.5516921 \\
\hline $\mathrm{O}$ & 2.4080283 & 12.3242261 & 17.5068810 \\
\hline $\mathrm{O}$ & 4.4973148 & 13.3651361 & 28.0730733 \\
\hline $\mathrm{O}$ & 2.6597611 & 14.5858686 & 22.0970568 \\
\hline $\mathrm{H}$ & 2.7378889 & 17.3017828 & 18.1871094 \\
\hline $\mathrm{H}$ & 0.2244426 & 13.1094770 & 18.2735012 \\
\hline $\mathrm{O}$ & 3.7318184 & 15.9091798 & 20.2239612 \\
\hline $\mathrm{H}$ & 3.5593129 & 12.0044374 & 29.9225230 \\
\hline $\mathrm{O}$ & 2.1026820 & 12.8713345 & 19.9174081 \\
\hline $\mathrm{P}$ & 10.2328943 & 11.9664001 & 16.6428563 \\
\hline Al & 10.1790616 & 11.9210340 & 28.4668127 \\
\hline$P$ & 12.4527503 & 10.6590370 & 26.7468904 \\
\hline Al & 12.4905035 & 10.6636627 & 23.5555269 \\
\hline$P$ & 15.6178484 & 10.7113714 & 23.5183091 \\
\hline$P$ & 10.7673231 & 8.0108894 & 23.5401379 \\
\hline Al & 10.8006760 & 7.9955650 & 26.6648456 \\
\hline Al & 15.5933759 & 10.6935780 & 26.6457794 \\
\hline 0 & 9.0278509 & 10.6279250 & 28.1869176 \\
\hline 0 & 11.9899448 & 9.2187111 & 27.0604380 \\
\hline $\mathrm{H}$ & 16.0306221 & 9.2824807 & 26.8321686 \\
\hline $\mathrm{H}$ & 11.6695943 & 6.8358789 & 23.3905471 \\
\hline 0 & 14.1783154 & 10.2005021 & 23.3156712 \\
\hline $\mathrm{O}$ & 11.6470840 & 11.6651308 & 27.5803706 \\
\hline 0 & 9.3935275 & 8.1756409 & 27.6778984 \\
\hline $\mathrm{H}$ & 16.3894091 & 11.6061823 & 27.5121541 \\
\hline $\mathrm{O}$ & 9.5361909 & 7.8489844 & 22.6303950 \\
\hline $\mathrm{O}$ & 15.9403499 & 11.8769541 & 22.5845523 \\
\hline $\mathrm{O}$ & 9.6120690 & 10.6216413 & 17.0592314 \\
\hline $\mathrm{O}$ & 13.9267821 & 10.7975020 & 27.1408946 \\
\hline $\mathrm{H}$ & 11.3932461 & 6.6522920 & 26.9130372 \\
\hline $\mathrm{H}$ & 16.5638442 & 9.6021599 & 23.2152211 \\
\hline $\mathrm{O}$ & 11.5157475 & 9.2687149 & 23.1062968 \\
\hline $\mathrm{H}$ & 10.5593567 & 11.9683789 & 15.1900869 \\
\hline $\mathrm{O}$ & 12.2436582 & 10.9748351 & 25.2656104 \\
\hline $\mathrm{O}$ & 15.8068543 & 11.1802633 & 24.9789804 \\
\hline 0 & 10.2845829 & 8.1370849 & 24.9966809 \\
\hline $\mathrm{H}$ & 10.5107621 & 11.9614516 & 29.9178337 \\
\hline $\mathrm{H}$ & 8.8761336 & 14.9718075 & 15.1335740 \\
\hline$P$ & 5.5250116 & 14.7096122 & 16.7227956 \\
\hline Al & 5.4827704 & 14.7157448 & 28.5553081 \\
\hline$P$ & 12.4467673 & 18.7484403 & 21.6919708 \\
\hline $\mathrm{Si}$ & 12.2940365 & 13.2668881 & 21.6844194 \\
\hline $\mathrm{P}$ & 17.1845442 & 15.9093650 & 21.7076604 \\
\hline Al & 17.1596446 & 15.9610859 & 18.5345418 \\
\hline Al & 12.3499407 & 13.2671475 & 18.5505810 \\
\hline Al & 12.4697253 & 18.7476419 & 18.5492035 \\
\hline$P$ & 5.4342985 & 17.2267373 & 26.6904367 \\
\hline Al & 5.4098957 & 17.2141836 & 23.5824936 \\
\hline
\end{tabular}




\begin{tabular}{|c|c|c|c|}
\hline $\mathrm{P}$ & 8.6463495 & 14.6612891 & 28.4231406 \\
\hline Al & 8.6931238 & 14.7171245 & 16.5891716 \\
\hline $\mathrm{P}$ & 15.5646085 & 13.2627428 & 18.4901004 \\
\hline $\mathrm{P}$ & 15.6266428 & 18.7225247 & 18.5050232 \\
\hline$P$ & 10.8333796 & 16.0330262 & 18.4514806 \\
\hline Al & 10.7716921 & 16.0139321 & 21.6218441 \\
\hline Al & 15.6081399 & 18.6838989 & 21.6749436 \\
\hline Al & 15.5069317 & 13.2501479 & 21.5854943 \\
\hline $\mathrm{P}$ & 8.5723897 & 17.3348087 & 23.4545671 \\
\hline Al & 8.5921829 & 17.2292511 & 26.5999760 \\
\hline 0 & 9.2038151 & 13.0747402 & 16.9788165 \\
\hline 0 & 7.1565179 & 14.3265015 & 28.2227167 \\
\hline 0 & 11.9287527 & 17.3186920 & 21.8735209 \\
\hline 0 & 13.8550666 & 13.6847204 & 21.6240724 \\
\hline $\mathrm{O}$ & 16.2009536 & 17.0682143 & 21.9737684 \\
\hline $\mathrm{O}$ & 15.9588036 & 14.7311598 & 18.1962258 \\
\hline $\mathrm{O}$ & 11.8704966 & 14.9243888 & 18.1868484 \\
\hline 0 & 14.1553660 & 18.3498293 & 18.2423872 \\
\hline $\mathrm{O}$ & 6.9087606 & 17.6145969 & 26.9182429 \\
\hline $\mathrm{H}$ & 9.0323912 & 18.7415416 & 23.2914055 \\
\hline $\mathrm{H}$ & 4.8533497 & 18.5849947 & 23.4144040 \\
\hline $\mathrm{H}$ & 18.3961253 & 15.7315813 & 17.7373194 \\
\hline $\mathrm{H}$ & 12.0630446 & 19.9117788 & 17.7146277 \\
\hline 0 & 11.5203351 & 12.1767127 & 17.4389735 \\
\hline 0 & 5.0025917 & 16.1272739 & 27.6653465 \\
\hline $\mathrm{H}$ & 11.7050753 & 19.7050592 & 22.5590889 \\
\hline 0 & 11.9998982 & 11.9967293 & 22.6309633 \\
\hline $\mathrm{H}$ & 18.4169550 & 16.0788110 & 22.5259344 \\
\hline 0 & 9.0651157 & 15.8485357 & 27.5542235 \\
\hline $\mathrm{H}$ & 16.2604010 & 12.3537839 & 17.5378467 \\
\hline $\mathrm{O}$ & 9.6206475 & 15.8561674 & 17.5196929 \\
\hline $\mathrm{H}$ & 16.0249729 & 19.8904777 & 17.6717528 \\
\hline 0 & 9.2995850 & 16.4042604 & 22.4889753 \\
\hline 0 & 7.0155245 & 14.8520089 & 17.0621429 \\
\hline $\mathrm{O}$ & 9.4757492 & 13.4444714 & 28.0013981 \\
\hline 0 & 13.9266138 & 18.7982483 & 22.0952703 \\
\hline $\mathrm{O}$ & 11.3602815 & 14.5039466 & 22.1347609 \\
\hline 0 & 16.5347598 & 14.5858686 & 22.0970568 \\
\hline $\mathrm{O}$ & 16.5178397 & 17.5348487 & 18.1267120 \\
\hline $\mathrm{O}$ & 14.0597817 & 13.1053283 & 18.2676382 \\
\hline $\mathrm{O}$ & 11.4730107 & 17.3894585 & 18.1288589 \\
\hline $\mathrm{H}$ & 4.5758142 & 18.4159206 & 26.9472798 \\
\hline $\mathrm{H}$ & 9.4315771 & 18.3940323 & 26.9947199 \\
\hline 0 & 7.0797841 & 17.2672304 & 23.1178551 \\
\hline $\mathrm{H}$ & 5.2809069 & 15.0353346 & 15.2905113 \\
\hline $\mathrm{O}$ & 12.2849778 & 19.2036478 & 20.2265897 \\
\hline 0 & 11.8262363 & 12.8057317 & 20.1447260 \\
\hline 0 & 17.6068171 & 15.9091798 & 20.2239612 \\
\hline 0 & 5.2403913 & 16.7090108 & 25.2521727 \\
\hline $\mathrm{H}$ & 8.8987638 & 15.0036143 & 29.8501028 \\
\hline 0 & 15.9776807 & 12.8713345 & 19.9174081 \\
\hline $\mathrm{O}$ & 15.8302095 & 19.1076268 & 19.9831463 \\
\hline $\mathrm{O}$ & 10.3331591 & 15.9974078 & 19.9030254 \\
\hline 0 & 8.8158904 & 16.8624041 & 24.9035814 \\
\hline $\mathrm{C}$ & 9.8061071 & 11.8735177 & 20.3158207 \\
\hline $\mathrm{H}$ & 9.6079544 & 12.4125622 & 19.3952630 \\
\hline $\mathrm{H}$ & 9.7460870 & 12.4430370 & 21.2405605 \\
\hline $\mathrm{C}$ & 7.5229522 & 11.3457657 & 20.7484421 \\
\hline $\mathrm{C}$ & 7.2572895 & 12.4445198 & 19.9975433 \\
\hline $\mathrm{H}$ & 7.0972562 & 12.3070690 & 18.9212378 \\
\hline $\mathrm{C}$ & 7.1753240 & 13.8354667 & 20.5086607 \\
\hline $\mathrm{H}$ & 7.4965868 & 10.3480201 & 20.3093693 \\
\hline $\mathrm{H}$ & 7.6194489 & 11.4081805 & 21.8354551 \\
\hline $\mathrm{H}$ & 7.3538942 & 13.9042301 & 21.5900981 \\
\hline $\mathrm{H}$ & 6.1784392 & 14.2549259 & 20.2900422 \\
\hline $\mathrm{H}$ & 7.8871257 & 14.4959451 & 19.9847760 \\
\hline C & 10.2142446 & 10.4550431 & 20.3017425 \\
\hline $\mathrm{H}$ & 9.8346983 & 9.9202995 & 19.4257061 \\
\hline $\mathrm{H}$ & 9.9583204 & 9.9340535 & 21.2285015 \\
\hline $\mathrm{H}$ & 11.3143269 & 10.4392490 & 20.2288299 \\
\hline $\mathrm{H}$ & 5.3045499 & 14.9962688 & 30.0067433 \\
\hline $\mathrm{H}$ & 16.3452295 & 19.6897798 & 22.4885916 \\
\hline \multicolumn{4}{|c|}{ Mg 11} \\
\hline $\mathrm{H}$ & 8.7585121 & 8.8789027 & 15.3258018 \\
\hline Al & 5.4955983 & 9.2750840 & 16.7014390 \\
\hline $\mathrm{P}$ & 5.5023885 & 9.2304761 & 28.5114150 \\
\hline Al & 5.4059970 & 6.6534069 & 21.6330801 \\
\hline & & & \\
\hline
\end{tabular}




\begin{tabular}{|c|c|c|c|}
\hline Al & 3.2825223 & 7.9895600 & 26.6621067 \\
\hline $\mathrm{P}$ & 3.3880990 & 8.0913989 & 23.5490343 \\
\hline Al & 8.6229685 & 9.1849318 & 28.5791383 \\
\hline $\mathrm{P}$ & 8.6276992 & 9.3043061 & 16.7467313 \\
\hline Al & 8.6157033 & 6.7277655 & 18.5674181 \\
\hline $\mathrm{P}$ & 8.5907910 & 6.6638326 & 21.7361743 \\
\hline Al & 1.6643857 & 10.7324727 & 23.5872667 \\
\hline $\mathrm{P}$ & 1.6236948 & 10.7078237 & 26.7286876 \\
\hline 0 & 7.1697137 & 9.7020532 & 17.0669978 \\
\hline 0 & 5.1006508 & 10.6855275 & 28.1931954 \\
\hline $\mathrm{H}$ & 4.8679944 & 5.2808436 & 21.8422307 \\
\hline $\mathrm{H}$ & 9.1307623 & 5.2995116 & 21.9895119 \\
\hline 0 & 6.9390720 & 6.3434127 & 18.2460044 \\
\hline 0 & 2.0764457 & 9.2402451 & 26.8688455 \\
\hline $\mathrm{H}$ & 2.3158820 & 7.0832676 & 23.3228873 \\
\hline $\mathrm{H}$ & 0.3015655 & 10.1716326 & 23.3744286 \\
\hline 0 & 5.0277962 & 7.8525994 & 17.5807588 \\
\hline 0 & 4.6269005 & 8.2410447 & 27.7406680 \\
\hline 0 & 4.5847741 & 7.8291700 & 22.6258177 \\
\hline 0 & 2.4362917 & 11.6130720 & 27.6619063 \\
\hline 0 & 9.0795822 & 8.1597554 & 17.6657575 \\
\hline 0 & 2.0060724 & 12.1130341 & 22.6012213 \\
\hline 0 & 4.4647040 & 10.5959062 & 17.1826747 \\
\hline 0 & 6.9604898 & 9.0163968 & 28.0872348 \\
\hline 0 & 7.0967472 & 6.6722682 & 22.0542804 \\
\hline $\mathrm{H}$ & 9.4644390 & 5.5735537 & 18.1617537 \\
\hline $\mathrm{H}$ & 4.6269331 & 5.5056350 & 18.1276072 \\
\hline $\mathrm{H}$ & 0.1973970 & 10.8003688 & 27.1460971 \\
\hline $\mathrm{H}$ & 2.6677192 & 6.6778437 & 27.0064003 \\
\hline 0 & 2.8428064 & 9.4864335 & 23.2325186 \\
\hline $\mathrm{H}$ & 5.3605582 & 8.9996730 & 15.2443757 \\
\hline 0 & 5.2329764 & 7.1114905 & 19.9465441 \\
\hline $\mathrm{O}$ & 3.8737741 & 8.0128373 & 25.0120982 \\
\hline $\mathrm{H}$ & 8.7413051 & 8.9144070 & 30.0385674 \\
\hline 0 & 8.8367319 & 7.0817314 & 20.2693061 \\
\hline 0 & 1.8125257 & 11.1935269 & 25.2825975 \\
\hline $\mathrm{H}$ & 5.3428022 & 8.9616320 & 29.9672226 \\
\hline $\mathrm{H}$ & 3.5679349 & 11.9229444 & 15.2809220 \\
\hline Al & 3.3607627 & 15.9842969 & 21.6523994 \\
\hline $\mathrm{P}$ & 3.2711488 & 16.0319443 & 18.4739438 \\
\hline Al & 3.9006259 & 11.9213671 & 28.5402439 \\
\hline $\mathrm{P}$ & 3.8830943 & 11.9453251 & 16.7360146 \\
\hline Al & 1.7385679 & 13.2733247 & 18.6019570 \\
\hline $\mathrm{P}$ & 1.8161259 & 13.3135602 & 21.6593758 \\
\hline 0 & 4.9360241 & 13.0365146 & 17.0410621 \\
\hline $\mathrm{H}$ & 0.4293746 & 13.8557027 & 21.6704571 \\
\hline $\mathrm{H}$ & 2.3876745 & 17.0726978 & 21.9449798 \\
\hline $\mathrm{O}$ & 2.2105406 & 14.9369157 & 18.2451345 \\
\hline 0 & 4.5026114 & 15.8036093 & 17.5850872 \\
\hline 0 & 4.8446895 & 16.2382915 & 22.5344643 \\
\hline 0 & 2.5868769 & 12.2033132 & 17.5058333 \\
\hline 0 & 4.5297133 & 13.4772606 & 28.0685233 \\
\hline 0 & 2.8141634 & 14.4048495 & 22.1134487 \\
\hline $\mathrm{H}$ & 2.6894737 & 17.3519084 & 18.1045263 \\
\hline $\mathrm{H}$ & 0.2758357 & 13.1147765 & 18.3730520 \\
\hline 0 & 3.7368021 & 16.0368118 & 19.9388675 \\
\hline $\mathrm{H}$ & 3.6087575 & 11.9221243 & 30.0003579 \\
\hline 0 & 2.2130714 & 12.8476425 & 20.2268828 \\
\hline Al & 10.2538610 & 12.0257130 & 16.5309511 \\
\hline $\mathrm{P}$ & 10.1494158 & 11.9700474 & 28.3890027 \\
\hline Al & 12.3709233 & 10.5937296 & 26.6661311 \\
\hline $\mathrm{P}$ & 12.4520413 & 10.5133775 & 23.4877017 \\
\hline Al & 15.5393845 & 10.7324727 & 23.5872667 \\
\hline Al & 10.6820574 & 7.9328701 & 23.6520879 \\
\hline $\mathrm{P}$ & 10.7729420 & 7.9115199 & 26.7523950 \\
\hline$P$ & 15.4986935 & 10.7078237 & 26.7286876 \\
\hline O & 9.1339267 & 10.8229547 & 28.2168746 \\
\hline 0 & 11.8484653 & 8.9656194 & 27.0824111 \\
\hline $\mathrm{H}$ & 15.9358231 & 9.2908811 & 26.8640096 \\
\hline $\mathrm{H}$ & 11.5551329 & 6.7329045 & 23.5298490 \\
\hline 0 & 13.9334500 & 10.0715840 & 23.3364603 \\
\hline 0 & 11.3743561 & 11.7600288 & 27.5024256 \\
\hline 0 & 9.6089112 & 8.0146420 & 27.7486765 \\
\hline H & 16.2878672 & 11.5869780 & 27.6350060 \\
\hline 0 & 9.2737945 & 7.7053352 & 22.6385290 \\
\hline 0 & 15.8810711 & 12.1130341 & 22.6012213 \\
\hline 0 & 9.5327327 & 10.5126253 & 17.0327682 \\
\hline 0 & 14.0294119 & 10.8031578 & 27.1586764 \\
\hline $\mathrm{H}$ & 11.3723191 & 6.5543953 & 26.8792039 \\
\hline $\mathrm{H}$ & 16.5412941 & 9.6730729 & 23.2856549 \\
\hline
\end{tabular}




\begin{tabular}{|c|c|c|c|}
\hline 0 & 11.5654777 & 9.3111678 & 23.0860389 \\
\hline $\mathrm{H}$ & 10.5667039 & 12.0301501 & 15.0751935 \\
\hline 0 & 12.1782567 & 10.8614694 & 24.9684272 \\
\hline $\mathrm{O}$ & 15.6875244 & 11.1935269 & 25.2825975 \\
\hline 0 & 10.2140214 & 8.1325020 & 25.3315657 \\
\hline $\mathrm{H}$ & 10.6021116 & 12.0288516 & 29.8062991 \\
\hline $\mathrm{H}$ & 8.7902577 & 15.0247975 & 15.2001599 \\
\hline Al & 5.4390800 & 14.6727374 & 16.6516368 \\
\hline $\mathrm{P}$ & 5.3964684 & 14.6712741 & 28.4806160 \\
\hline$A 1$ & 12.3434964 & 18.6695083 & 21.6330801 \\
\hline $\mathrm{Mg}$ & 12.4607546 & 13.3168862 & 21.7127980 \\
\hline Al & 17.2357614 & 15.9842969 & 21.6523994 \\
\hline $\mathrm{P}$ & 17.1461475 & 16.0319443 & 18.4739438 \\
\hline $\mathrm{P}$ & 12.3788045 & 13.2168387 & 18.4500618 \\
\hline$P$ & 12.3921884 & 18.7070790 & 18.4838426 \\
\hline Al & 5.4875397 & 17.1674911 & 26.6100470 \\
\hline $\mathrm{P}$ & 5.4747709 & 17.2036441 & 23.5419318 \\
\hline$A 1$ & 8.5620554 & 14.6925540 & 28.4668882 \\
\hline $\mathrm{P}$ & 8.6098444 & 14.7205601 & 16.6465386 \\
\hline Al & 15.6135667 & 13.2733247 & 18.6019570 \\
\hline Al & 15.5532027 & 18.7438669 & 18.5674181 \\
\hline Al & 10.8182595 & 15.9510065 & 18.4951677 \\
\hline $\mathrm{P}$ & 10.6542491 & 15.9604153 & 21.6607198 \\
\hline$P$ & 15.5282904 & 18.6799340 & 21.7361743 \\
\hline $\mathrm{P}$ & 15.6911246 & 13.3135602 & 21.6593758 \\
\hline Al & 8.6231314 & 17.4309701 & 23.5242495 \\
\hline $\mathrm{P}$ & 8.6397377 & 17.2661453 & 26.6671121 \\
\hline $\mathrm{O}$ & 9.0912095 & 13.2795013 & 16.9523013 \\
\hline $\mathrm{O}$ & 6.8715457 & 14.3319617 & 28.1933726 \\
\hline 0 & 11.7160803 & 17.0688313 & 21.8769906 \\
\hline $\mathrm{O}$ & 14.2790102 & 13.8656182 & 21.6706597 \\
\hline 0 & 16.0863460 & 17.2699201 & 21.9979965 \\
\hline $\mathrm{O}$ & 16.0855393 & 14.9369157 & 18.2451345 \\
\hline $\mathrm{O}$ & 11.9749958 & 14.6759778 & 18.1435112 \\
\hline $\mathrm{O}$ & 13.8765714 & 18.3595140 & 18.2460044 \\
\hline 0 & 7.1573625 & 17.6087795 & 26.9302466 \\
\hline $\mathrm{H}$ & 9.1275551 & 18.8205681 & 23.3462197 \\
\hline $\mathrm{H}$ & 4.7779296 & 18.5191538 & 23.5108365 \\
\hline $\mathrm{H}$ & 18.3400785 & 15.8105683 & 17.6121771 \\
\hline $\mathrm{H}$ & 11.9772898 & 19.8360629 & 17.6061325 \\
\hline 0 & 11.7323198 & 12.2684864 & 17.4187141 \\
\hline $\mathrm{O}$ & 4.9573316 & 15.8931369 & 27.6713654 \\
\hline $\mathrm{H}$ & 11.6424433 & 19.6732214 & 22.4805500 \\
\hline 0 & 12.1147293 & 11.6881130 & 22.6106904 \\
\hline $\mathrm{H}$ & 18.5020792 & 16.2010447 & 22.4051147 \\
\hline 0 & 9.0667208 & 16.0668996 & 27.5258979 \\
\hline $\mathrm{H}$ & 16.3349396 & 12.3634236 & 17.6698510 \\
\hline $\mathrm{O}$ & 9.4080085 & 15.7297539 & 17.4750681 \\
\hline $\mathrm{H}$ & 15.9468530 & 19.9590618 & 17.8022637 \\
\hline $\mathrm{O}$ & 9.3588884 & 16.3409548 & 22.4026788 \\
\hline 0 & 7.1337811 & 14.8222770 & 17.0551543 \\
\hline 0 & 9.4842981 & 13.2916155 & 27.9931150 \\
\hline 0 & 14.0342466 & 18.6883696 & 22.0542804 \\
\hline 0 & 11.1594623 & 14.6317618 & 22.1615311 \\
\hline 0 & 16.6891622 & 14.4048495 & 22.1134487 \\
\hline 0 & 16.5460925 & 17.3936172 & 18.0928533 \\
\hline O & 13.8985508 & 13.0874310 & 18.3335717 \\
\hline $\mathrm{O}$ & 11.5416429 & 17.4891018 & 18.1177994 \\
\hline $\mathrm{H}$ & 4.5988451 & 18.3391422 & 26.8436623 \\
\hline $\mathrm{H}$ & 9.4759304 & 18.4358006 & 27.0541637 \\
\hline 0 & 6.9313209 & 17.4244382 & 23.1452691 \\
\hline $\mathrm{H}$ & 5.2368242 & 14.9440870 & 15.2016083 \\
\hline 0 & 12.1704757 & 19.1275919 & 19.9465441 \\
\hline 0 & 11.9072533 & 12.8020847 & 19.8640422 \\
\hline 0 & 17.6118008 & 16.0368118 & 19.9388675 \\
\hline 0 & 5.3717159 & 16.5950268 & 24.9557060 \\
\hline $\mathrm{H}$ & 8.7604631 & 14.9825177 & 29.9138422 \\
\hline 0 & 16.0880701 & 12.8476425 & 20.2268828 \\
\hline 0 & 15.7742312 & 19.0978328 & 20.2693061 \\
\hline 0 & 10.2896313 & 15.8988010 & 20.1505000 \\
\hline 0 & 8.8627028 & 16.9120374 & 25.1857429 \\
\hline $\mathrm{C}$ & 9.9741512 & 11.9332390 & 20.1712433 \\
\hline $\mathrm{H}$ & 9.6592421 & 12.4010952 & 19.2436458 \\
\hline $\mathrm{H}$ & 9.9124699 & 12.5559549 & 21.0626606 \\
\hline $\mathrm{C}$ & 7.5931098 & 11.4171347 & 20.7258882 \\
\hline C & 7.2722220 & 12.5146153 & 20.0013362 \\
\hline $\mathrm{H}$ & 7.0711999 & 12.3853664 & 18.9310380 \\
\hline $\mathrm{C}$ & 7.1766097 & 13.8982744 & 20.5322745 \\
\hline $\mathrm{H}$ & 7.5840205 & 10.4236776 & 20.2762427 \\
\hline $\mathrm{H}$ & 7.7448838 & 11.4736075 & 21.8070838 \\
\hline
\end{tabular}




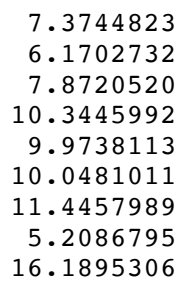

8.7193064 5.4356800

5.4281710

5.4149018

5.4513997

3. 3278506

3. 4058675

8.5326807

8.5463581

8.5713006

8.5537858

1. 7442617

1.7242396

6.9957409

5.0048340

4.8744021

9.0761109

7.0140489

2.2083305

2. 3564844

0.3586450

5.0116244

4.5363531

4.6633924

2.5659115

8.9985094

2.0968448

4.5037688

6.9786670

6.9822262

9.4325931

4.5987488

0.2963374

2. 6940321

2.7892637

5.2395498

5.2461479

3.9364237

8.7171003

8.7984605

1.9306360

5.2393725

3.4733716

3. 3779682

3. 3269005

3.8755122

3.8567647

1.7698674

1.7675094

4.9836505

0.3464676

2. 4039658

2.2016498

4.6244887

4.7103928

2.5262238

4.4967847

2.7495858

2. 7468827

0.3053664

3. 8363348

3. 4755904

2. 1977662

10.1565173

10.0789179

12.2435509

12.2836294
13.9553653

14.3061409

14.5765953

10.5086987

9.9343341

10.0545171

10.4539049

14.9799807

19.6882501

8.7625854

9.1922740

9.1466640

6.7020013

6.7157756

7.9050402

7.9861690

9.0916648

9.1838619

6.7067301

6.6592321

10.6444512

10.6236110

9.6048452

10.6937727

5. 3227160

5. 2833530

6.3142491

9.0747335

6.9516919

10.1343327

7.9254799

8.1242755

7.7526495

11.5832848

7.9823033

11.8647211

10.4462746

8.9448929

6.6912385

5.5501383

5.5385193

10.6971469

6.5972411

9.4427158

8.8320696

7.2145998

7.9089944

8.7569649

7.1181633

11.1443134

8.8290351

11.8395929

15.7549264

15.8031761

11.8405830

11.8649479

13.1000543

13.1078104

13.0178833

13.5515876

16.8531871

14.6538514

15.5751114

15.9551120

12.1253906

13.2780221

14.3309286

17.1301481

12.9652359

15.7804854

11.8375670

12.6527555

11.8773306

11.8266834

10.5571351

10.5320647

10.6444512
21.6108364

20.3376790

20.0098393

20.2444474

19.3906910

21.1957546

20.2303807

29.9251077

22.6097763

15.2848228

16.7128159

28.6422574

21.6783932

18.5997471

26.7097614

23.6521817

28.6474922

16.7024743

18.6112748

21.7252330

23.6391118

26.7155898

16.9917363

28.3535458

21.8285684

21.9516260

18.3477346

26.8608841

23.4382357

23.4468462

17.6193506

27.7652823

22.6566676

27.7126417

17.6958515

22.6463537

17.1350376

28.2242953

22.0837351

18.2403419

18.2769860

27.1312918

27.0338852

23.3247734

15.2814158

20.1361526

25.1964959

30.0866190

20.1738773

25.1875006

30.0846816

15.2509118

21.6988720

18.5855604

28.6198245

16.6894831

18.6232964

21.6518403

16.9643653

21.6805194

21.9483983

18.3378967

17.6370071

22.6006438

17.5661933

28.2116093

22.1046669

18.2393737

18.3905276

20.1311112

30.0541097

20.1255505

16.5994187

28.5479112

26.7360053

23.6118434

23.6391118 


\begin{tabular}{|c|c|c|c|}
\hline $\mathrm{Si}$ & 10.5617707 & 7.9204192 & 23.6851371 \\
\hline $\mathrm{Si}$ & 10.6276924 & 7.8993828 & 26.7346968 \\
\hline $\mathrm{Si}$ & 15.3492384 & 10.6236110 & 26.7155898 \\
\hline 0 & 8.9971636 & 10.6245597 & 28.3528911 \\
\hline $\mathrm{O}$ & 11.7607613 & 9.0273061 & 27.0406493 \\
\hline $\mathrm{H}$ & 15.7916557 & 9.2080704 & 26.8483763 \\
\hline $\mathrm{H}$ & 11.4605585 & 6.7395819 & 23.5629726 \\
\hline $\mathrm{O}$ & 13.8535154 & 10.0864256 & 23.4287898 \\
\hline 0 & 11.3825667 & 11.6044667 & 27.6263861 \\
\hline 0 & 9.3972850 & 8.0361967 & 27.7807715 \\
\hline $\mathrm{H}$ & 16.1229820 & 11.5058331 & 27.6321734 \\
\hline $\mathrm{O}$ & 9.2901565 & 7.7435113 & 22.6862305 \\
\hline 0 & 15.7218436 & 11.8647211 & 22.6463537 \\
\hline $\mathrm{O}$ & 9.4876717 & 10.4625190 & 17.0407304 \\
\hline 0 & 13.7966254 & 10.7035694 & 27.1675985 \\
\hline $\mathrm{H}$ & 11.2384482 & 6.5542403 & 26.9209479 \\
\hline $\mathrm{H}$ & 16.3278242 & 9.5421184 & 23.3507742 \\
\hline 0 & 11.3701702 & 9.2351326 & 23.2267072 \\
\hline $\mathrm{H}$ & 10.5274568 & 11.8764458 & 15.1573633 \\
\hline $\mathrm{O}$ & 12.0234093 & 10.9191183 & 25.1782614 \\
\hline 0 & 15.5556348 & 11.1443134 & 25.1875006 \\
\hline 0 & 10.0343026 & 8.0620351 & 25.2223422 \\
\hline $\mathrm{H}$ & 10.5181271 & 11.8721475 & 29.9699340 \\
\hline $\mathrm{H}$ & 8.8180517 & 14.9088025 & 15.1823076 \\
\hline $\mathrm{Si}$ & 5.4341740 & 14.5589017 & 16.6724012 \\
\hline $\mathrm{Si}$ & 5.3951528 & 14.5549623 & 28.6318283 \\
\hline $\mathrm{Si}$ & 12.2274012 & 18.5015963 & 21.6783932 \\
\hline Al & 12.2060199 & 13.1202125 & 21.7100315 \\
\hline $\mathrm{Si}$ & 17.0029669 & 15.7549264 & 21.6988720 \\
\hline $\mathrm{Si}$ & 16.9518992 & 15.8031761 & 18.5855604 \\
\hline $\mathrm{Si}$ & 12.2061331 & 13.0900886 & 18.5627909 \\
\hline $\mathrm{Si}$ & 12.2638991 & 18.5153707 & 18.5997471 \\
\hline $\mathrm{Si}$ & 5.4198802 & 16.9591812 & 26.6793930 \\
\hline $\mathrm{Si}$ & 5.3989107 & 16.9750728 & 23.6491239 \\
\hline $\mathrm{Si}$ & 8.5386442 & 14.5367695 & 28.5648741 \\
\hline $\mathrm{Si}$ & 8.5843720 & 14.5800304 & 16.6156336 \\
\hline $\mathrm{Si}$ & 15.3948661 & 13.1000543 & 18.6232964 \\
\hline $\mathrm{Si}$ & 15.3838000 & 18.5063251 & 18.6112748 \\
\hline $\mathrm{Si}$ & 10.6650616 & 15.8003883 & 18.5548346 \\
\hline $\mathrm{Si}$ & 10.5589385 & 15.7950061 & 21.6592117 \\
\hline $\mathrm{Si}$ & 15.3662852 & 18.4588271 & 21.7252330 \\
\hline $\mathrm{Si}$ & 15.3925081 & 13.1078104 & 21.6518403 \\
\hline $\mathrm{Si}$ & 8.5278429 & 17.1309642 & 23.5802863 \\
\hline $\mathrm{Si}$ & 8.5425767 & 17.0060140 & 26.6625315 \\
\hline 0 & 9.0581972 & 13.0443866 & 16.9306310 \\
\hline $\mathrm{O}$ & 6.9605048 & 14.1836976 & 28.3909403 \\
\hline 0 & 11.6414948 & 17.0064389 & 21.8411845 \\
\hline $\mathrm{O}$ & 13.8699636 & 13.5832859 & 21.6825679 \\
\hline $\mathrm{O}$ & 15.9360699 & 16.9579327 & 21.9721966 \\
\hline $\mathrm{O}$ & 15.8266485 & 14.6538514 & 18.3378967 \\
\hline 0 & 11.7711007 & 14.6381402 & 18.2660791 \\
\hline $\mathrm{O}$ & 13.8265483 & 18.1138441 & 18.3477346 \\
\hline $\mathrm{O}$ & 6.9756244 & 17.3820793 & 26.9226072 \\
\hline $\mathrm{H}$ & 9.0256834 & 18.5264261 & 23.4320922 \\
\hline $\mathrm{H}$ & 4.7768012 & 18.3249565 & 23.5601614 \\
\hline $\mathrm{H}$ & 18.1420442 & 15.5939956 & 17.7155495 \\
\hline $\mathrm{H}$ & 11.8591893 & 19.6286190 & 17.6975227 \\
\hline $\mathrm{O}$ & 11.4958418 & 12.1004089 & 17.4752916 \\
\hline $\mathrm{O}$ & 4.9544478 & 15.8106511 & 27.7183415 \\
\hline $\mathrm{H}$ & 11.5368263 & 19.4670549 & 22.5773463 \\
\hline $\mathrm{O}$ & 11.8632872 & 11.7373078 & 22.6747531 \\
\hline $\mathrm{H}$ & 18.2266621 & 15.9387763 & 22.5270568 \\
\hline $\mathrm{O}$ & 8.9794531 & 15.7628273 & 27.6077625 \\
\hline $\mathrm{H}$ & 16.0880675 & 12.2067741 & 17.6544605 \\
\hline 0 & 9.4026274 & 15.6219965 & 17.5427631 \\
\hline $\mathrm{H}$ & 15.7747391 & 19.6736032 & 17.7735702 \\
\hline $\mathrm{O}$ & 9.2184348 & 16.1422701 & 22.5138141 \\
\hline $\mathrm{O}$ & 7.0149355 & 14.6904755 & 17.0075094 \\
\hline $\mathrm{O}$ & 9.3904574 & 13.2302584 & 28.1330759 \\
\hline 0 & 13.7947255 & 18.4908336 & 22.0837351 \\
\hline $\mathrm{O}$ & 11.1522224 & 14.4110604 & 22.1569289 \\
\hline $\mathrm{O}$ & 16.3745845 & 14.3309286 & 22.1046669 \\
\hline 0 & 16.3196822 & 17.2495701 & 18.2082184 \\
\hline 0 & 13.8045682 & 12.9536553 & 18.3705334 \\
\hline $\mathrm{O}$ & 11.3397543 & 17.2394026 & 18.2499228 \\
\hline $\mathrm{H}$ & 4.5491315 & 18.1434927 & 26.9167191 \\
\hline $\mathrm{H}$ & 9.3791834 & 18.1815452 & 27.0304121 \\
\hline $\mathrm{O}$ & 6.9494614 & 17.1281362 & 23.2469129 \\
\hline $\mathrm{H}$ & 5.1650892 & 14.9194378 & 15.2529901 \\
\hline $\mathrm{O}$ & 12.0586472 & 19.0141948 & 20.1361526 \\
\hline
\end{tabular}




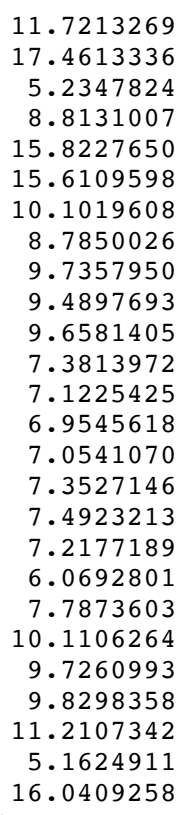

8.9425420

9.3035824

9.2351563

6.6843113

6.7062790

7.8874747

8.0168255

9.1313627

9.2513664

6.6812896

6.6268700

10.6995416

10.6506999

9.6858561

10.8891476

5.3018694

5.2609526

6.3074476

8.9872706

7.0411627

10.1274010

8.0827444

8.1119546

7.6834246

11.7012466

7.8935516

11.8912218

10.4790685

8.9663285

6.7023335

5.5298763

5.5551872

10.7115057

6.5721316

9.6238152

8.9834076

7.1402324

7.8923152

8.8984175

7.0520954

11.1676441

9.0122695

11.9877419

15.8836554

15.9399439

11.9714259

12.0033518

13.2338815

13.2555549

13.2375669

13.7589227
20.0463884

20.1311112

25.1624578

29.9816194

20.1255505

20.1738773

20.0764993

25.1037886

20.2701460

19.3340182

21.1709514

20.7424698

20.0058400

18.9290881

20.5317387

20.2937531

21.8288041

21.6163687

20.3032978

20.0309868

20.3215059

19.4659101

21.2685307

20.2711075

30.0570048

22.6056699

15.2182156

16.7644995

28.5727435

21.6952045

18.5492357

26.7100583

23.6091340

28.4822821

16.6697312

18.5085543

21.6817279

23.5341850

26.6714964

17.0480317

28.1973306

21.8749777

21.9337546

18.2518397

26.8311091

23.3758944

23.2709097

17.5907185

27.7275391

22.5909093

27.6823212

17.6533530

22.6196077

17.1805544

28.0954856

22.0869744

18.1258129

18.1594568

27.1508661

27.0185886

23.2565090

15.3222335

20.2308307

25.2908974

29.9409851

19.9898940

25.0046998

30.0394337

15.2117318

21.6942772

18.5239600

28.4818483

16.6728206

18.4982268

21.5930781

17.0437120

21.6306145 


\begin{tabular}{|c|c|c|c|}
\hline $\mathrm{H}$ & 2.4259505 & 16.9980885 & 21.9679175 \\
\hline 0 & 2.1194044 & 14.7007911 & 18.2125572 \\
\hline 0 & 4.7739547 & 15.6765386 & 17.5866211 \\
\hline 0 & 4.6584061 & 16.0456369 & 22.5226413 \\
\hline 0 & 2.4377157 & 12.2996784 & 17.5153774 \\
\hline 0 & 4.4994761 & 13.3350887 & 28.0539379 \\
\hline 0 & 2.7415907 & 14.5535832 & 22.0835894 \\
\hline $\mathrm{H}$ & 2.7676207 & 17.2787465 & 18.1751827 \\
\hline $\mathrm{H}$ & 0.2485342 & 13.0884662 & 18.2741125 \\
\hline 0 & 3.7837990 & 15.8961043 & 20.2076320 \\
\hline $\mathrm{H}$ & 3.6027780 & 11.9846413 & 29.9316031 \\
\hline $\mathrm{O}$ & 2.1078816 & 12.8300661 & 19.9282918 \\
\hline $\mathrm{P}$ & 10.2570308 & 11.9371868 & 16.5903613 \\
\hline Al & 10.1675288 & 11.8631389 & 28.3997754 \\
\hline $\mathrm{P}$ & 12.4806244 & 10.5607162 & 26.7818913 \\
\hline Al & 12.5523131 & 10.5147716 & 23.5560634 \\
\hline $\mathrm{P}$ & 15.6444435 & 10.6995416 & 23.5341850 \\
\hline $\mathrm{P}$ & 10.7300086 & 7.9657891 & 23.5893091 \\
\hline Al & 10.7927751 & 7.9542022 & 26.6782415 \\
\hline Al & 15.5883996 & 10.6506999 & 26.6714964 \\
\hline 0 & 9.0350411 & 10.5566082 & 28.0999223 \\
\hline 0 & 11.9902413 & 9.1439092 & 27.1595705 \\
\hline $\mathrm{H}$ & 16.0376931 & 9.237 & 26.8070896 \\
\hline $\mathrm{H}$ & 11.5243192 & 6.7069516 & 23.5503282 \\
\hline 0 & 14.2471656 & 10.1070329 & 23.2615371 \\
\hline 0 & 11.6395469 & 11.6208123 & 27.5106259 \\
\hline 0 & 9.4021147 & 8.0787903 & 27.7259615 \\
\hline $\mathrm{H}$ & 16.4039116 & 11.5484343 & 27.5352868 \\
\hline 0 & 9.5040314 & 7.8297801 & 22.6677900 \\
\hline 0 & 15.9225964 & 11.8912218 & 22.6196077 \\
\hline 0 & 9.6646067 & 10.6051335 & 17.0881133 \\
\hline 0 & 13.9378499 & 10.7219595 & 27.2332800 \\
\hline $\mathrm{H}$ & 11.3849884 & 6.5942671 & 26.8085501 \\
\hline $\mathrm{H}$ & 16.6741239 & 9.6580951 & 23.2653577 \\
\hline 0 & 11.5947165 & 9.1178553 & 23.0804470 \\
\hline $\mathrm{H}$ & 10.5236639 & 11.8799396 & 15.1265478 \\
\hline 0 & 12.3517104 & 10.7746291 & 25.2765597 \\
\hline $\mathrm{O}$ & 15.7402804 & 11.1676441 & 25.0046998 \\
\hline 0 & 10.2503255 & 8.2353364 & 25.0297519 \\
\hline $\mathrm{H}$ & 10.4774075 & 11.8762209 & 29.8561149 \\
\hline $\mathrm{H}$ & 8.9094598 & 14.9524906 & 15.0851615 \\
\hline$P$ & 5.5525880 & 14.6870953 & 16.7126010 \\
\hline Al & 5.4881948 & 14.6821047 & 28.5472307 \\
\hline $\mathrm{P}$ & 12.4673051 & 18.7004127 & 21.6952045 \\
\hline $\mathrm{Ge}$ & 12.2595657 & 13.2612807 & 21.7132541 \\
\hline $\mathrm{P}$ & 17.2497803 & 15.8836554 & 21.6942772 \\
\hline Al & 17.1931487 & 15.9399439 & 18.5239600 \\
\hline Al & 12.3636225 & 13.2453470 & 18.4929477 \\
\hline Al & 12.5001680 & 18.7223803 & 18.5492357 \\
\hline $\mathrm{P}$ & 5.4615803 & 17.1729858 & 26.6739395 \\
\hline Al & 5.4129895 & 17.1618093 & 23.6185308 \\
\hline $\mathrm{P}$ & 8.6544799 & 14.6240980 & 28.3802836 \\
\hline $\mathrm{Al}$ & 8.7259230 & 14.6965563 & 16.5404734 \\
\hline $\mathrm{P}$ & 15.5883701 & 13.2338815 & 18.4982268 \\
\hline $\mathrm{P}$ & 15.6581142 & 18.6973910 & 18.5085543 \\
\hline $\mathrm{P}$ & 10.8638997 & 16.0191106 & 18.4176699 \\
\hline Al & 10.7058234 & 16.0431822 & 21.6022349 \\
\hline $\mathrm{Al}$ & 15.6363747 & 18.6429714 & 21.6817279 \\
\hline Al & 15.5380995 & 13.2555549 & 21.5930781 \\
\hline $\mathrm{P}$ & 8.5494515 & 17.4340589 & 23.4341044 \\
\hline Al & 8.6001946 & 17.2060721 & 26.5622902 \\
\hline 0 & 9.2302862 & 13.0505651 & 16.9216696 \\
\hline 0 & 7.1602304 & 14.2917384 & 28.2102318 \\
\hline 0 & 11.9290514 & 17.2779824 & 21.8801778 \\
\hline 0 & 13.9205002 & 13.8368144 & 21.6364230 \\
\hline 0 & 16.2666810 & 17.0383377 & 21.9778004 \\
\hline 0 & 15.9944031 & 14.7007911 & 18.2125572 \\
\hline 0 & 11.9120846 & 14.9189198 & 18.1684888 \\
\hline 0 & 14.1859457 & 18.3235490 & 18.2518397 \\
\hline 0 & 6.9228175 & 17.6056497 & 26.9175484 \\
\hline $\mathrm{H}$ & 9.0381879 & 18.8372806 & 23.3380509 \\
\hline $\mathrm{H}$ & 4.7193660 & 18.4780360 & 23.5589131 \\
\hline $\mathrm{H}$ & 18.4308500 & 15.7160010 & 17.7270499 \\
\hline $\mathrm{H}$ & 12.1013781 & 19.8996623 & 17.7294221 \\
\hline 0 & 11.5760783 & 12.1956187 & 17.3168494 \\
\hline $\mathrm{O}$ & 5.0208624 & 16.1236996 & 27.6990455 \\
\hline $\mathrm{H}$ & 11.7458535 & 19.6702743 & 22.5646851 \\
\hline 0 & 11.9578684 & 11.8585218 & 22.7078166 \\
\hline $\mathrm{H}$ & 18.4939107 & 16.0406531 & 22.4971545 \\
\hline $\mathrm{O}$ & 9.0605509 & 15.7985602 & 27.4869550 \\
\hline
\end{tabular}




\begin{tabular}{|c|c|c|}
\hline 16.2899398 & 12.3290514 & 17.5462798 \\
\hline 9.6578794 & 15.8262644 & 17.4799383 \\
\hline 16.0498887 & 19.8712281 & 17.6804602 \\
\hline 9.2283019 & 16.5483249 & 22.3941001 \\
\hline 7.0492210 & 14.8383928 & 17.0225729 \\
\hline 9.4707608 & 13.3979317 & 27.9590958 \\
\hline 13.9490694 & 18.7184349 & 22.0869744 \\
\hline 11.1327433 & 14.5089671 & 22.2239274 \\
\hline 16.6165895 & 14.5535832 & 22.0835894 \\
\hline 16.5467737 & 17.5118287 & 18.1144614 \\
\hline 14.0836368 & 13.0845057 & 18.2680085 \\
\hline 11.4960238 & 17.3788820 & 18.0943047 \\
\hline 4.5685867 & 18.3547230 & 26.8261902 \\
\hline 9.4599151 & 18.3548673 & 26.9601227 \\
\hline 7.0509547 & 17.4278194 & 23.1253050 \\
\hline 5.2811733 & 14.9905868 & 15.2803484 \\
\hline 12.3007958 & 19.1563337 & 20.2308307 \\
\hline 11.7561375 & 12.7342954 & 20.0473007 \\
\hline 17.6587977 & 15.8961043 & 20.2076320 \\
\hline 5.3294745 & 16.5592107 & 25.2638544 \\
\hline 8.9312837 & 14.9838717 & 29.7984032 \\
\hline 15.9828803 & 12.8300661 & 19.9282918 \\
\hline 15.8700012 & 19.0681967 & 19.9898940 \\
\hline 10.3542751 & 15.9890955 & 19.8665797 \\
\hline 8.8058065 & 16.8757626 & 24.8517346 \\
\hline 9.6813364 & 11.9516604 & 20.2810860 \\
\hline 9.5157896 & 12.4033355 & 19.3081344 \\
\hline 9.6543508 & 12.6163555 & 21.1423326 \\
\hline 7.3620831 & 11.6080311 & 20.7414477 \\
\hline 7.1744160 & 12.7246169 & 19.9937782 \\
\hline 6.9868557 & 12.6009715 & 18.9205590 \\
\hline 7.2122380 & 14.1161949 & 20.5056480 \\
\hline 7.2474028 & 10.6161956 & 20.3031258 \\
\hline 7.4779586 & 11.6639526 & 21.8268987 \\
\hline 7.4180043 & 14.1683139 & 21.5830502 \\
\hline 6.2470349 & 14.6131148 & 20.3084849 \\
\hline 7.9631646 & 14.7194748 & 19.9680464 \\
\hline 9.9929552 & 10.5138067 & 20.4080557 \\
\hline 9.5297824 & 9.9150007 & 19.6164153 \\
\hline 9.7559996 & 10.1123622 & 21.3979280 \\
\hline 11.0832415 & 10.4115348 & 20.2775605 \\
\hline 5.3049015 & 14.9526071 & 29.9999359 \\
\hline 16.3208791 & 19.6656269 & 22.5200298 \\
\hline \\
\hline 8.7255316 & 8.7735501 & 15.2983431 \\
\hline 5.4431096 & 9.1979320 & 16.7304185 \\
\hline 5.4326034 & 9.1332059 & 28.6629491 \\
\hline 5.4221614 & 6.6718101 & 21.6977134 \\
\hline 5.4525511 & 6.7189792 & 18.6197404 \\
\hline 3.3313696 & 7.9044669 & 26.7172396 \\
\hline 3.4444743 & 8.0158127 & 23.6658756 \\
\hline 8.5353535 & 9.0697984 & 28.6541147 \\
\hline 8.5518105 & 9.1921480 & 16.7166933 \\
\hline 8.5686426 & 6.7054784 & 18.6211362 \\
\hline 8.5629386 & 6.6365580 & 21.7367093 \\
\hline 1.7601922 & 10.6449727 & 23.6422748 \\
\hline 1.7230756 & 10.6105854 & 26.7260670 \\
\hline 7.0020058 & 9.6188239 & 17.0031248 \\
\hline 5.0244335 & 10.6858985 & 28.3774493 \\
\hline 4.8503424 & 5.3042149 & 21.8385224 \\
\hline 9.1301698 & 5.2779184 & 21.9591227 \\
\hline 7.0117470 & 6.3095974 & 18.3566486 \\
\hline 2.1931282 & 9.0567251 & 26.8663957 \\
\hline 2.3815309 & 6.9938313 & 23.4589313 \\
\hline 0.3898433 & 10.1002140 & 23.4361138 \\
\hline 5.0203781 & 7.9425186 & 17.6532658 \\
\hline 4.5200401 & 8.1213894 & 27.7952427 \\
\hline 4.7036894 & 7.7412767 & 22.6824674 \\
\hline 2.5804019 & 11.5581137 & 27.7214830 \\
\hline 8.9925407 & 7.9875330 & 17.7122920 \\
\hline 2.0577108 & 11.8917460 & 22.6641877 \\
\hline 4.5080577 & 10.4533206 & 17.1398738 \\
\hline 6.9793926 & 8.9081784 & 28.2381898 \\
\hline 6.9904159 & 6.6076927 & 22.0923902 \\
\hline 9.4319763 & 5.5532474 & 18.2414797 \\
\hline 4.5856428 & 5.5535651 & 18.2920200 \\
\hline 0.2975142 & 10.6943106 & 27.1478316 \\
\hline 2.7086142 & 6.5843296 & 27.0114063 \\
\hline
\end{tabular}




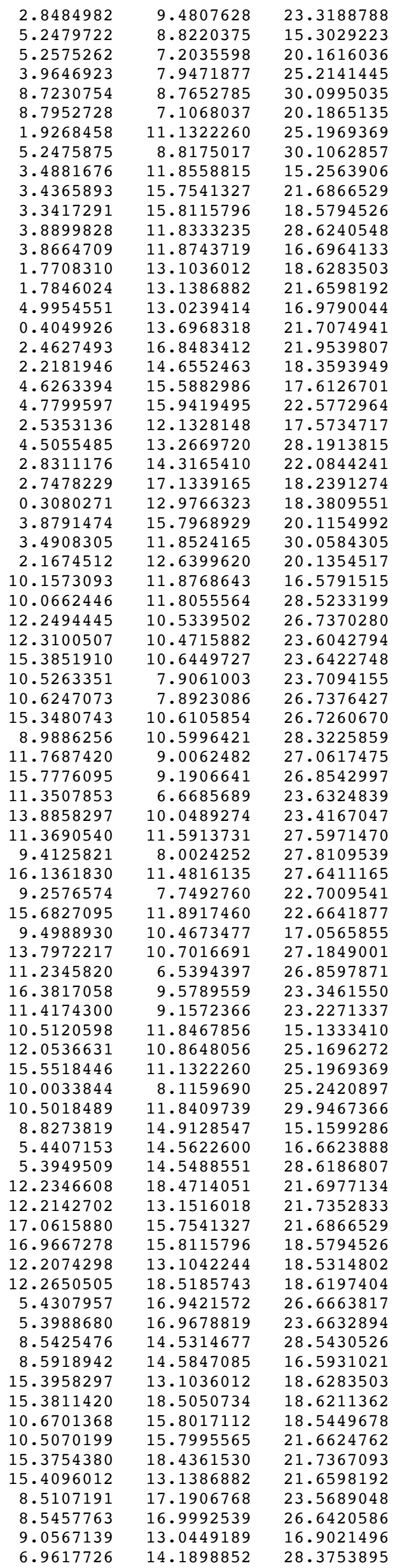

14.1898852

15.3029223

20.1616036

25.2141445

30.0995035

20.1865135

25.1969369

30.1062857

15.2563906

21.6866529

18.5794526

28.6240548

16.6964133

18.6283503

21.6598192

16.9790044

21.7074941

21.9539807

18.3593949

17.6126701

22.5772964

17.5734717

28.1913815

22.0844241

18.2391274

18.3809551

20.1154992

30.0584305

20.1354517

16.5791515

28.5233199

26.7370280

23.6042794

23.6422748

23.7094155

26.7376427

26.7260670

28.3225859

27.0617475

26.8542997

23.6324839

23.4167047

27.5971470

27.8109539

27.6411165

22.7009541

22.6641877

17.0565855

27.1849001

26.8597871

23.3461550

23. 2271337

15.1333410

25.1696272

25.1969369

25.2420897

29.9467366

15.1599286

16.6623888

28.6186807

21.6977134

21.7352833

21.6866529

18.5794526

18.5314802

18.6197404

26.6663817

23.6632894

28.5430526

16.5931021

18.6283503

18.6211362

18.5449678

21.6624762

21.7367093

21.6598192

23.5689048

26.6420586

16.9021496

28.3753895 


\begin{tabular}{|c|c|c|}
\hline 11.6144182 & 16.9879974 & 21.8504466 \\
\hline 13.9234440 & 13.7399373 & 21.7111760 \\
\hline 15.9946987 & 16.9528917 & 21.9795236 \\
\hline 15.8431934 & 14.6552463 & 18.3593949 \\
\hline 11.7917421 & 14.6595310 & 18.2402449 \\
\hline 13.8242463 & 18.1091924 & 18.3566486 \\
\hline 6.9819880 & 17.3770132 & 26.9288092 \\
\hline 9.0482023 & 18.5742557 & 23.4508288 \\
\hline 4.6646801 & 18.2628388 & 23.6290036 \\
\hline 18.1451384 & 15.6067574 & 17.6925947 \\
\hline 11.8673316 & 19.6445693 & 17.7303162 \\
\hline 11.5104600 & 12.1273746 & 17.4241603 \\
\hline 4.9479811 & 15.8138291 & 27.7202577 \\
\hline 11.5749535 & 19.4533988 & 22.6019232 \\
\hline 11.8377539 & 11.6549313 & 22.6612843 \\
\hline 18.2942710 & 15.9264742 & 22.5039115 \\
\hline 8.9897296 & 15.7453289 & 27.5715974 \\
\hline 16.0964631 & 12.2138944 & 17.6615747 \\
\hline 9.4127238 & 15.6203134 & 17.5262660 \\
\hline 15.7689228 & 19.6778935 & 17.7897280 \\
\hline 9.1461100 & 16.2148982 & 22.4551771 \\
\hline 7.0228042 & 14.7043962 & 16.9860684 \\
\hline 9.3785789 & 13.2123960 & 28.1188969 \\
\hline 13.8029153 & 18.4072878 & 22.0923902 \\
\hline 11.0167667 & 14.4082548 & 22.2488130 \\
\hline 16.4561163 & 14.3165410 & 22.0844241 \\
\hline 16.3194158 & 17.2528251 & 18.2085243 \\
\hline 13.8083900 & 12.9658141 & 18.3598762 \\
\hline 11.3251429 & 17.2550247 & 18.2644238 \\
\hline 4.5474445 & 18.1260068 & 26.8542943 \\
\hline 9.3936544 & 18.1680393 & 27.0056020 \\
\hline 6.9286850 & 17.2678409 & 23.2652451 \\
\hline 5.1609744 & 14.9025949 & 15.2400534 \\
\hline 12.0700256 & 19.0031549 & 20.1616036 \\
\hline 11.6874542 & 12.6219945 & 19.9964090 \\
\hline 17.5041461 & 15.7968929 & 20.1154992 \\
\hline 5.2880133 & 16.3272785 & 25.1602367 \\
\hline 8.8220440 & 14.9067918 & 29.9566063 \\
\hline 15.7924500 & 12.6399620 & 20.1354517 \\
\hline 15.6077721 & 18.9063987 & 20.1865135 \\
\hline 10.1112842 & 15.6990147 & 20.0666716 \\
\hline 8.7699176 & 16.6061611 & 25.0747391 \\
\hline 9.6962921 & 11.7577925 & 20.2505881 \\
\hline 9.4545621 & 12.2214832 & 19.2995674 \\
\hline 9.6341457 & 12.3932603 & 21.1318713 \\
\hline 7.3584178 & 11.2617492 & 20.7502307 \\
\hline 7.1039998 & 12.3623860 & 20.0015777 \\
\hline 6.9278038 & 12.2265759 & 18.9274806 \\
\hline 7.0512603 & 13.7548877 & 20.5123266 \\
\hline 7.3171251 & 10.2631488 & 20.3142137 \\
\hline 7.4773820 & 11.3261895 & 21.8349402 \\
\hline 7.2186369 & 13.8180556 & 21.5957572 \\
\hline 6.0705612 & 14.2033318 & 20.2817645 \\
\hline 7.7897011 & 14.3962147 & 20.0021534 \\
\hline 10.0703002 & 10.3346834 & 20.3392720 \\
\hline 9.6626522 & 9.7443144 & 19.5134436 \\
\hline 9.8163216 & 9.8949918 & 21.3081865 \\
\hline 11.1686221 & 10.2831258 & 20.2581276 \\
\hline 5.1579067 & 14.9004361 & 30.0460284 \\
\hline 16.0108219 & 19.4538355 & 22.6185995 \\
\hline & & \\
\hline 8.7555151 & 8.9800966 & 15.2318335 \\
\hline 5.5123691 & 9.3346090 & 16.7906275 \\
\hline 5.4586009 & 9.2430782 & 28.5940718 \\
\hline 5.5276530 & 6.7102542 & 21.7067920 \\
\hline 5.5720414 & 6.7327069 & 18.5714863 \\
\hline 3.3204036 & 7.8886835 & 26.7296330 \\
\hline 3.4782413 & 8.0523674 & 23.6459056 \\
\hline 8.5791344 & 9.1251023 & 28.4885125 \\
\hline 8.6461770 & 9.2837889 & 16.6854279 \\
\hline 8.7230306 & 6.7099700 & 18.5279053 \\
\hline 8.7007668 & 6.6236441 & 21.6941126 \\
\hline 1.7899497 & 10.7139487 & 23.5550698 \\
\hline 1.7016385 & 10.6466235 & 26.6911825 \\
\hline 6.9853881 & 9.7204439 & 17.0757464 \\
\hline 5.0144365 & 10.8952455 & 28.1970614 \\
\hline 4.8916549 & 5.3733079 & 21.8655416 \\
\hline 9.2882650 & 5.2728065 & 21.9113781 \\
\hline
\end{tabular}

21.8504466

1.7111760

18.3593949

18.2402449

18.3566486

.9288092

23.4508288

17.6925947

17.7303162

22.6019232

.6612843

27.5715974

. 6615747

17.7897280

2.4551771

28.1188969

22.0923902

88130

18.2085243

18.3598762

18.2644238

.8542943

23.2652451

5.2400534

19.9964090

0.1154992

5.1602367

20.1354517

20.1865135

20.0666716

0747391

0.2505881

8713

20.7502307

20.0015777

274806

20.3142137

21.8349402

21.5957572

7645

20.3392720

19.5134436

30.0460284

22.6185995

15.2318335 275

21.7067920

18.5714863

26.7296330
23.6459056

28.4885125

16.6854279

21. 6941126

23.5550698

17.0757464

21.8655416

21.9113781 


\begin{tabular}{|c|c|c|}
\hline 7.2549271 & 6.3243681 & 18.2615098 \\
\hline 2.2415169 & 8.9833415 & 26.8131748 \\
\hline 2.3824718 & 7.0782181 & 23.3862082 \\
\hline 0.4604461 & 10.1186993 & 23.2464940 \\
\hline 5.1106099 & 8.1075489 & 17.6082002 \\
\hline 4.4104720 & 8.1181894 & 27.7829520 \\
\hline 4.8604908 & 7.7472611 & 22.6228879 \\
\hline 2.6640989 & 11.6859260 & 27.7061121 \\
\hline 9.1269420 & 7.9212348 & 17.6694704 \\
\hline 2.0926541 & 11.9040289 & 22.6450893 \\
\hline 4.6158680 & 10.5054740 & 17.2109660 \\
\hline 7.1053312 & 8.9486834 & 28.1080834 \\
\hline 7.0083993 & 6.6021233 & 22.0931539 \\
\hline 9.5968466 & 5.5624183 & 18.1581876 \\
\hline 4.6957159 & 5.5858009 & 18.2057258 \\
\hline 0.3033690 & 10.6884042 & 27.2012973 \\
\hline 2.6910487 & 6.5707012 & 27.0193840 \\
\hline 2.8832619 & 9.6576844 & 23.3229666 \\
\hline 5.3286486 & 9.0209805 & 15.3466731 \\
\hline 5.3973268 & 7.1996927 & 20.2491437 \\
\hline 3.9681681 & 7.8961761 & 25.3296071 \\
\hline 8.7675782 & 8.9352340 & 29.9532853 \\
\hline 8.9196480 & 7.0912775 & 20.0096839 \\
\hline 1.8207829 & 11.1874077 & 25.0278094 \\
\hline 5.3430379 & 9.0455822 & 30.0653845 \\
\hline 3.6629591 & 11.9991632 & 15.2227885 \\
\hline 3.4374783 & 15.8948491 & 21.6777639 \\
\hline 3.3340749 & 15.9633381 & 18.5172389 \\
\hline 3.9464592 & 11.9718469 & 28.4873610 \\
\hline 3.9326560 & 12.0253080 & 16.6869267 \\
\hline 1.7167984 & 13.2658572 & 18.5068825 \\
\hline 1.7224018 & 13.2702914 & 21.6117453 \\
\hline 5.1390892 & 13.2578004 & 17.0598828 \\
\hline 0.3047888 & 13.7219907 & 21.6705836 \\
\hline 2.4880959 & 17.0115336 & 21.9400791 \\
\hline 2.1205826 & 14.7341506 & 18.2200236 \\
\hline 4.7757467 & 15.7056754 & 17.5548987 \\
\hline 4.7307046 & 16.0643474 & 22.4929435 \\
\hline 2.4367205 & 12.3352537 & 17.5147861 \\
\hline 4.4876994 & 13.3361985 & 28.0403111 \\
\hline 2.8087348 & 14.5679225 & 22.0890159 \\
\hline 2.7816408 & 17.3096818 & 18.2021265 \\
\hline 0.2503157 & 13.1205508 & 18.2937280 \\
\hline 3.8378363 & 15.8874971 & 20.1893582 \\
\hline 3.6270595 & 11.9939622 & 29.9415327 \\
\hline 2.1280412 & 12.8590967 & 19.9321496 \\
\hline 10.2669047 & 11.9591704 & 16.5600023 \\
\hline 10.1536092 & 11.8530813 & 28.3621555 \\
\hline 12.4885950 & 10.5195915 & 26.8081061 \\
\hline 12.5805057 & 10.4266264 & 23.5717172 \\
\hline 15.6649484 & 10.7139487 & 23.5550698 \\
\hline 10.6871284 & 7.9460285 & 23.6296167 \\
\hline 10.7789157 & 7.9457920 & 26.6975844 \\
\hline 15.5766373 & 10.6466235 & 26.6911825 \\
\hline 9.0283370 & 10.5385791 & 28.0625411 \\
\hline 11.9810240 & 9.1176427 & 27.2180042 \\
\hline 16.0352217 & 9.2337954 & 26.7948054 \\
\hline 11.3799856 & 6.6281280 & 23.6440357 \\
\hline 14.2866629 & 10.0968585 & 23.2351718 \\
\hline 11.6273428 & 11.6066322 & 27.4729465 \\
\hline 9.3959958 & 8.0505036 & 27.7606077 \\
\hline 16.3990436 & 11.5346901 & 27.5584229 \\
\hline 9.4602858 & 7.8500329 & 22.6998160 \\
\hline 15.9676528 & 11.9040289 & 22.6450893 \\
\hline 9.6888808 & 10.6327903 & 17.0960131 \\
\hline 13.9352289 & 10.6956693 & 27.2899989 \\
\hline 11.3739740 & 6.5829549 & 26.7730904 \\
\hline 16.7235503 & 9.6912185 & 23.3303354 \\
\hline 11.6410825 & 9.0157592 & 23.0929747 \\
\hline 10.4909437 & 11.8720555 & 15.0905337 \\
\hline 12.4092462 & 10.6741074 & 25.2932402 \\
\hline 15.6957816 & 11.1874077 & 25.0278094 \\
\hline 10.2247264 & 8.2933099 & 25.0603951 \\
\hline 10.4466595 & 11.8674235 & 29.8219625 \\
\hline 8.9018962 & 14.9518522 & 15.0555759 \\
\hline 5.5614433 & 14.7011623 & 16.7037147 \\
\hline 5.4847535 & 14.6775259 & 28.5321659 \\
\hline 12.4651524 & 18.7263556 & 21.7067920 \\
\hline 12.2274559 & 13.2600803 & 21.7403667 \\
\hline 17.3124770 & 15.8948491 & 21.6777639 \\
\hline
\end{tabular}




\begin{tabular}{|c|c|c|c|}
\hline Al & 17.2090736 & 15.9633381 & 18.5172389 \\
\hline Al & 12.3555596 & 13.2642970 & 18.4660662 \\
\hline Al & 12.5095408 & 18.7488083 & 18.5714863 \\
\hline$P$ & 5.4665602 & 17.1659305 & 26.6720223 \\
\hline Al & 5.4116122 & 17.1749233 & 23.6420820 \\
\hline$P$ & 8.6467421 & 14.6187161 & 28.3480069 \\
\hline Al & 8.7340680 & 14.7183243 & 16.5165409 \\
\hline $\mathrm{P}$ & 15.5917972 & 13.2658572 & 18.5068825 \\
\hline$P$ & 15.6605299 & 18.7260714 & 18.5279053 \\
\hline$P$ & 10.8484082 & 16.0412732 & 18.4190187 \\
\hline Al & 10.6052267 & 16.1012936 & 21.5931189 \\
\hline Al & 15.6382662 & 18.6397455 & 21.6941126 \\
\hline Al & 15.5974005 & 13.2702914 & 21.6117453 \\
\hline $\mathrm{P}$ & 8.5256472 & 17.5139895 & 23.4365604 \\
\hline Al & 8.5936073 & 17.2157796 & 26.5540515 \\
\hline 0 & 9.2438773 & 13.0736981 & 16.9018308 \\
\hline O & 7.1525420 & 14.2870172 & 28.1760268 \\
\hline 0 & 11.8114987 & 17.3522950 & 21.8699486 \\
\hline 0 & 13.9575570 & 13.7928009 & 21.6798073 \\
\hline 0 & 16.3289122 & 17.0517396 & 21.9495237 \\
\hline 0 & 15.9955813 & 14.7341506 & 18.2200236 \\
\hline 0 & 11.9073230 & 14.9494438 & 18.1800074 \\
\hline 0 & 14.1924265 & 18.3404695 & 18.2615098 \\
\hline 0 & 6.9201063 & 17.6157802 & 26.9351459 \\
\hline $\mathrm{H}$ & 9.1100434 & 18.8803780 & 23.3439106 \\
\hline $\mathrm{H}$ & 4.5892282 & 18.4162135 & 23.6440674 \\
\hline $\mathrm{H}$ & 18.4340502 & 15.7444043 & 17.6995464 \\
\hline $\mathrm{H}$ & 12.1148956 & 19.9246595 & 17.7476236 \\
\hline 0 & 11.6073614 & 12.2414085 & 17.2369986 \\
\hline 0 & 5.0136777 & 16.1320877 & 27.7073937 \\
\hline $\mathrm{H}$ & 11.8184628 & 19.7315406 & 22.5947763 \\
\hline O & 11.9588548 & 11.7896732 & 22.7496778 \\
\hline $\mathrm{H}$ & 18.5644387 & 16.0589390 & 22.4669325 \\
\hline O & 9.0551367 & 15.7921604 & 27.4537232 \\
\hline $\mathrm{H}$ & 16.2883233 & 12.3654964 & 17.5470271 \\
\hline 0 & 9.6753575 & 15.8601855 & 17.4354413 \\
\hline $\mathrm{H}$ & 16.0514264 & 19.8983064 & 17.6971312 \\
\hline 0 & 9.1049576 & 16.6031896 & 22.3546400 \\
\hline 0 & 7.0584788 & 14.8591734 & 17.0118913 \\
\hline O & 9.4617445 & 13.3916355 & 27.9252491 \\
\hline O & 13.9458986 & 18.6182246 & 22.0931539 \\
\hline 0 & 11.0908232 & 14.5880676 & 22.2307687 \\
\hline 0 & 16.6837335 & 14.5679225 & 22.0890159 \\
\hline O & 16.5603327 & 17.5443922 & 18.1471924 \\
\hline 0 & 14.0858252 & 13.1166380 & 18.2879882 \\
\hline O & 11.4867217 & 17.4101762 & 18.1445823 \\
\hline $\mathrm{H}$ & 4.5593455 & 18.3414417 & 26.7827266 \\
\hline $\mathrm{H}$ & 9.4626744 & 18.3549840 & 26.9590901 \\
\hline O & 7.0192591 & 17.6306349 & 23.1850145 \\
\hline $\mathrm{H}$ & 5.2923148 & 14.9773832 & 15.2655240 \\
\hline 0 & 12.3348262 & 19.2157940 & 20.2491437 \\
\hline O & 11.7274858 & 12.7464684 & 20.0055334 \\
\hline 0 & 17.7128350 & 15.8874971 & 20.1893582 \\
\hline 0 & 5.3735569 & 16.5213207 & 25.2709224 \\
\hline $\mathrm{H}$ & 8.9211941 & 14.9794721 & 29.7663340 \\
\hline 0 & 16.0030399 & 12.8590967 & 19.9321496 \\
\hline 0 & 15.8571473 & 19.1073789 & 20.0096839 \\
\hline 0 & 10.2894275 & 15.9880887 & 19.8507009 \\
\hline O & 8.7870858 & 16.9108437 & 24.8354686 \\
\hline C & 9.6622573 & 11.9143429 & 20.2487907 \\
\hline $\mathrm{H}$ & 9.5163826 & 12.3308782 & 19.2582252 \\
\hline $\mathrm{H}$ & 9.5967534 & 12.6074559 & 21.0852960 \\
\hline C & 7.3545215 & 11.4948753 & 20.6273703 \\
\hline C & 7.1574823 & 12.6285271 & 19.9080191 \\
\hline $\mathrm{H}$ & 7.0064084 & 12.5317909 & 18.8267258 \\
\hline $\mathrm{C}$ & 7.1452573 & 14.0051082 & 20.4592856 \\
\hline $\mathrm{H}$ & 7.2800688 & 10.5144395 & 20.1556388 \\
\hline $\mathrm{H}$ & 7.4349821 & 11.5202777 & 21.7170423 \\
\hline $\mathrm{H}$ & 7.3113373 & 14.0323551 & 21.5444779 \\
\hline $\mathrm{H}$ & 6.1777430 & 14.4879494 & 20.2403451 \\
\hline $\mathrm{H}$ & 7.9012826 & 14.6380130 & 19.9638450 \\
\hline C & 10.0260444 & 10.4968281 & 20.4412739 \\
\hline $\mathrm{H}$ & 9.7075605 & 9.8630771 & 19.6074010 \\
\hline $\mathrm{H}$ & 9.6800455 & 10.0932445 & 21.3982852 \\
\hline $\mathrm{H}$ & 11.1283458 & 10.4592147 & 20.4760101 \\
\hline $\mathrm{H}$ & 5.3138933 & 14.9401346 & 29.9878321 \\
\hline $\mathrm{H}$ & 16.2813830 & 19.6781805 & 22.5456841 \\
\hline
\end{tabular}




\begin{tabular}{|c|c|c|c|}
\hline $\mathrm{H}$ & 8.6744164 & 8.9056479 & 15.1221505 \\
\hline $\mathrm{P}$ & 5.3790201 & 9.2350210 & 16.6536530 \\
\hline Al & 5.3498144 & 9.1946681 & 28.4887628 \\
\hline $\mathrm{P}$ & 5.4107255 & 6.6469934 & 21.6320691 \\
\hline Al & 5.4177032 & 6.6561878 & 18.4703688 \\
\hline $\mathrm{P}$ & 3.1774460 & 7.8673139 & 26.6416730 \\
\hline Al & 3.2142136 & 7.8939323 & 23.5047406 \\
\hline $\mathrm{P}$ & 8.4869479 & 9.1478825 & 28.3919453 \\
\hline Al & 8.5243324 & 9.1956661 & 16.5749013 \\
\hline $\mathrm{P}$ & 8.5806057 & 6.6297853 & 18.4147284 \\
\hline Al & 8.5748622 & 6.6478167 & 21.5706794 \\
\hline $\mathrm{P}$ & 1.6873049 & 10.6641300 & 23.4044518 \\
\hline Al & 1.6251101 & 10.6282456 & 26.5789822 \\
\hline $\mathrm{O}$ & 6.8532247 & 9.6153898 & 16.9071621 \\
\hline $\mathrm{O}$ & 4.8731383 & 10.8505526 & 28.1554952 \\
\hline $\mathrm{H}$ & 4.9744918 & 5.2426806 & 21.8660056 \\
\hline $\mathrm{H}$ & 9.0715669 & 5.2736922 & 21.8573621 \\
\hline $\mathrm{O}$ & 7.1042994 & 6.2493258 & 18.1937030 \\
\hline $\mathrm{O}$ & 2.1156615 & 8.9664681 & 26.8435756 \\
\hline $\mathrm{H}$ & 2.1652366 & 6.8602708 & 23.2849415 \\
\hline $\mathrm{H}$ & 0.2681730 & 10.3374070 & 23.0939081 \\
\hline $\mathrm{O}$ & 4.9709502 & 8.0432471 & 17.5208984 \\
\hline $\mathrm{O}$ & 4.3631135 & 8.0803438 & 27.5872896 \\
\hline $\mathrm{O}$ & 4.6221960 & 7.6189568 & 22.5189861 \\
\hline $\mathrm{O}$ & 2.5754491 & 11.7130183 & 27.5525860 \\
\hline 0 & 8.9847184 & 7.7975350 & 17.5079625 \\
\hline 0 & 2.1759214 & 11.8312806 & 22.5473015 \\
\hline $\mathrm{O}$ & 4.4930189 & 10.4234144 & 17.0358992 \\
\hline $\mathrm{O}$ & 7.0127634 & 8.9813299 & 28.0091975 \\
\hline $\mathrm{O}$ & 6.8954374 & 6.7805497 & 22.0026963 \\
\hline $\mathrm{H}$ & 9.4362998 & 5.4606492 & 18.0711747 \\
\hline $\mathrm{H}$ & 4.5591367 & 5.5095278 & 18.0639760 \\
\hline $\mathrm{H}$ & 0.1960034 & 10.7589850 & 26.9760740 \\
\hline $\mathrm{H}$ & 2.5652920 & 6.5485370 & 26.9629445 \\
\hline $\mathrm{O}$ & 2.5500351 & 9.4423138 & 23.0774408 \\
\hline $\mathrm{H}$ & 5.1802868 & 8.8693070 & 15.2240101 \\
\hline 0 & 5.1940077 & 7.0490710 & 20.1612833 \\
\hline $\mathrm{O}$ & 3.6962482 & 7.8887053 & 25.1913424 \\
\hline $\mathrm{H}$ & 8.6940006 & 8.8640746 & 29.8389086 \\
\hline $\mathrm{O}$ & 8.8051828 & 7.0576906 & 19.8811856 \\
\hline $\mathrm{O}$ & 1.8244990 & 11.0409893 & 24.8919497 \\
\hline $\mathrm{H}$ & 5.1996294 & 8.9068766 & 29.9419459 \\
\hline $\mathrm{H}$ & 3.4617739 & 11.9499427 & 15.1298123 \\
\hline $\mathrm{P}$ & 3.1704612 & 15.8690124 & 21.6463868 \\
\hline Al & 3.1951527 & 15.8880999 & 18.4764432 \\
\hline $\mathrm{P}$ & 3.8202158 & 11.9490807 & 28.4132581 \\
\hline $\mathrm{Al}$ & 3.8011325 & 11.9555703 & 16.5796139 \\
\hline $\mathrm{P}$ & 1.5985557 & 13.1773901 & 18.4267163 \\
\hline Al & 1.5530424 & 13.1462024 & 21.5625203 \\
\hline 0 & 4.9798066 & 13.2090798 & 16.9191115 \\
\hline $\mathrm{H}$ & 0.0888428 & 13.3187990 & 21.7709681 \\
\hline $\mathrm{H}$ & 2.2520510 & 17.0138832 & 21.8972137 \\
\hline 0 & 2.0154738 & 14.6376880 & 18.1406507 \\
\hline $\mathrm{O}$ & 4.6411004 & 15.6379999 & 17.5335500 \\
\hline 0 & 4.4263543 & 15.9929969 & 22.5217860 \\
\hline 0 & 2.3431920 & 12.2191566 & 17.4873999 \\
\hline 0 & 4.4184003 & 13.3048942 & 28.0220960 \\
\hline 0 & 2.4525800 & 14.5773667 & 22.0207566 \\
\hline $\mathrm{H}$ & 2.6214300 & 17.2157337 & 18.1223934 \\
\hline $\mathrm{H}$ & 0.1411093 & 13.0381142 & 18.1554734 \\
\hline 0 & 3.6144969 & 15.8626946 & 20.1735244 \\
\hline $\mathrm{H}$ & 3.4152885 & 11.9489590 & 29.8461414 \\
\hline 0 & 1.9347741 & 12.7980903 & 19.8770203 \\
\hline $\mathrm{P}$ & 10.1383732 & 11.8689182 & 16.5628579 \\
\hline $\mathrm{Al}$ & 10.0839597 & 11.8587555 & 28.3971649 \\
\hline $\mathrm{P}$ & 12.3589365 & 10.6360076 & 26.6278356 \\
\hline Al & 12.4066956 & 10.6041772 & 23.4406824 \\
\hline $\mathrm{P}$ & 15.5623036 & 10.6641300 & 23.4044518 \\
\hline $\mathrm{P}$ & 10.6951649 & 7.9289672 & 23.4430167 \\
\hline $\mathrm{Al}$ & 10.7124022 & 7.9452688 & 26.5722747 \\
\hline $\mathrm{Al}$ & 15.5001088 & 10.6282456 & 26.5789822 \\
\hline 0 & 8.9222781 & 10.5887517 & 28.0513301 \\
\hline 0 & 11.9031307 & 9.1885195 & 26.9048044 \\
\hline $\mathrm{H}$ & 15.9168416 & 9.2165341 & 26.8037593 \\
\hline $\mathrm{H}$ & 11.5808431 & 6.7419140 & 23.2893946 \\
\hline 0 & 14.0887096 & 10.3248684 & 23.0819904 \\
\hline 0 & 11.5235177 & 11.6296690 & 27.4419335 \\
\hline $\mathrm{O}$ & 9.3069845 & 8.1384379 & 27.5798700 \\
\hline $\mathrm{H}$ & 16.3133344 & 11.5565090 & 27.412116 \\
\hline 0 & 9.4665307 & 7.8222648 & 22.522824 \\
\hline
\end{tabular}




\begin{tabular}{|c|c|c|c|}
\hline $\mathrm{O}$ & 16.0509202 & 11.8312806 & 22.5473015 \\
\hline $\mathrm{O}$ & 9.5649951 & 10.5205675 & 17.0249973 \\
\hline 0 & 13.8251607 & 10.7814754 & 27.0443835 \\
\hline $\mathrm{H}$ & 11.3124294 & 6.6095360 & 26.8422852 \\
\hline $\mathrm{H}$ & 16.4013461 & 9.4758608 & 23.0864194 \\
\hline $\mathrm{O}$ & 11.4798205 & 9.1771312 & 23.0238728 \\
\hline $\mathrm{H}$ & 10.4871151 & 11.8114761 & 15.1164139 \\
\hline 0 & 12.1826870 & 10.9699737 & 25.1360879 \\
\hline 0 & 15.6994977 & 11.0409893 & 24.8919497 \\
\hline 0 & 10.2035786 & 8.0674814 & 24.8949678 \\
\hline $\mathrm{H}$ & 10.4385441 & 11.8167148 & 29.8427177 \\
\hline $\mathrm{H}$ & 8.7661388 & 14.9340978 & 15.0996509 \\
\hline$P$ & 5.4265229 & 14.6600710 & 16.6528121 \\
\hline Al & 5.3916546 & 14.6700488 & 28.4976306 \\
\hline $\mathrm{P}$ & 12.3482248 & 18.6630947 & 21.6320691 \\
\hline $\mathrm{Si}$ & 12.1654101 & 13.1564313 & 21.6030738 \\
\hline$P$ & 17.0454599 & 15.8690124 & 21.6463868 \\
\hline Al & 17.0701515 & 15.8880999 & 18.4764432 \\
\hline Al & 12.2743223 & 13.2131788 & 18.4401976 \\
\hline Al & 12.3552025 & 18.6722891 & 18.4703688 \\
\hline $\mathrm{P}$ & 5.3435819 & 17.1738818 & 26.6334662 \\
\hline Al & 5.3112471 & 17.1163622 & 23.5092754 \\
\hline $\mathrm{P}$ & 8.5565014 & 14.6206026 & 28.3864434 \\
\hline Al & 8.5859775 & 14.6212654 & 16.5442264 \\
\hline$P$ & 15.4735544 & 13.1773901 & 18.4267163 \\
\hline$P$ & 15.5181051 & 18.6458866 & 18.4147284 \\
\hline$P$ & 10.7595221 & 15.9711883 & 18.3828811 \\
\hline Al & 10.7080072 & 15.9464914 & 21.5677535 \\
\hline Al & 15.5123616 & 18.6639180 & 21.5706794 \\
\hline Al & 15.4280412 & 13.1462024 & 21.5625203 \\
\hline$P$ & 8.4679810 & 17.2273373 & 23.3993538 \\
\hline Al & 8.4978545 & 17.1595454 & 26.5460080 \\
\hline 0 & 9.0834533 & 12.9627491 & 16.8195716 \\
\hline 0 & 7.0681848 & 14.2928652 & 28.1547927 \\
\hline $\mathrm{O}$ & 11.8985692 & 17.2155745 & 21.8732033 \\
\hline 0 & 13.7441343 & 13.3446976 & 21.8022463 \\
\hline 0 & 16.0938314 & 17.0552923 & 21.9062859 \\
\hline $\mathrm{O}$ & 15.8904726 & 14.6376880 & 18.1406507 \\
\hline 0 & 11.8273232 & 14.8873167 & 18.1326535 \\
\hline 0 & 14.04 & 18.2654272 & 18.1937030 \\
\hline 0 & 6.8182874 & 17.5511605 & 26.8764789 \\
\hline $\mathrm{H}$ & 8.9024473 & 18.6438439 & 23.2514736 \\
\hline $\mathrm{H}$ & 4.7629267 & 18.4874827 & 23.3182417 \\
\hline $\mathrm{H}$ & 18.3045113 & 15.6745975 & 17.6715251 \\
\hline $\mathrm{H}$ & 11.9727317 & 19.8597679 & 17.6575153 \\
\hline 0 & 11.4209895 & 12.1483463 & 17.3448958 \\
\hline 0 & 4.8932850 & 16.0739368 & 27.5975684 \\
\hline $\mathrm{H}$ & 11.5828201 & 19.6065540 & 22.4929760 \\
\hline $\mathrm{H}$ & 18.2630097 & 15.9892116 & 22.4950594 \\
\hline 0 & 8.9952362 & 15.7961317 & 27.5079043 \\
\hline $\mathrm{H}$ & 16.1960621 & 12.2476328 & 17.5153138 \\
\hline 0 & 9.5320513 & 15.7270375 & 17.4945583 \\
\hline $\mathrm{H}$ & 15.9106956 & 19.7803412 & 17.5338164 \\
\hline 0 & 9.2407359 & 16.3169230 & 22.4507090 \\
\hline 0 & 6.9123255 & 14.7909240 & 16.9988084 \\
\hline 0 & 9.3887774 & 13.3986035 & 27.9811938 \\
\hline 0 & 13.8329367 & 18.7966510 & 22.0026963 \\
\hline $\mathrm{O}$ & 11.2960387 & 14.4230006 & 22.0734803 \\
\hline 0 & 16.3275788 & 14.5773667 & 22.0207566 \\
\hline 0 & 16.3978096 & 17.4439450 & 18.0615347 \\
\hline $\mathrm{O}$ & 13.9775227 & 13.0344269 & 18.1482923 \\
\hline 0 & 11.3529144 & 17.3336815 & 17.9959470 \\
\hline $\mathrm{H}$ & 4.4965934 & 18.3734521 & 26.8799662 \\
\hline $\mathrm{H}$ & 9.3429827 & 18.3300141 & 26.9105379 \\
\hline 0 & 6.9819836 & 17.1344663 & 23.0353135 \\
\hline $\mathrm{H}$ & 5.1899385 & 15.0125294 & 15.2256045 \\
\hline 0 & 12.1315070 & 19.0651724 & 20.1612833 \\
\hline 0 & 17.4894956 & 15.8626946 & 20.1735244 \\
\hline 0 & 5.1575433 & 16.6621277 & 25.1922524 \\
\hline $\mathrm{H}$ & 8.7905509 & 14.9780878 & 29.8128184 \\
\hline 0 & 15.8097728 & 12.7980903 & 19.8770203 \\
\hline 0 & 15.7426822 & 19.0737920 & 19.8811856 \\
\hline 0 & 10.3110026 & 15.9781637 & 19.8512704 \\
\hline 0 & 8.6932247 & 16.7569784 & 24.8519936 \\
\hline 0 & 11.6260159 & 11.8538211 & 22.4960359 \\
\hline C & 8.9579220 & 11.6453318 & 22.8956561 \\
\hline $\mathrm{H}$ & 8.6765258 & 10.7380260 & 23.4387764 \\
\hline $\mathrm{H}$ & 8.0968833 & 12.2125262 & 22.5310942 \\
\hline $\mathrm{H}$ & 9.4326571 & 12.3514334 & 23.6164125 \\
\hline 0 & 11.7866889 & 12.7570853 & 20.0475134 \\
\hline
\end{tabular}




\begin{tabular}{|c|c|c|c|}
\hline C & 9.2626367 & 10.9585668 & 21.1321873 \\
\hline $\mathrm{H}$ & 10.1756284 & 11.6937116 & 22.5235549 \\
\hline $\mathrm{H}$ & 8.3055386 & 10.4271468 & 21.1436006 \\
\hline $\mathrm{H}$ & 10.1355055 & 10.3018267 & 21.2274770 \\
\hline 0 & 9.3110384 & 11.9208110 & 20.2190925 \\
\hline $\mathrm{H}$ & 10.2755235 & 12.2262212 & 20.0764630 \\
\hline $\mathrm{H}$ & 5.2128549 & 14.9722082 & 29.9446451 \\
\hline $\mathrm{H}$ & 16.2687650 & 19.6602038 & 22.3783854 \\
\hline \multicolumn{4}{|c|}{$\begin{array}{l}\operatorname{Mg} 12 \\
168\end{array}$} \\
\hline $\mathrm{H}$ & 8.7256392 & 8.8568701 & 15.2497336 \\
\hline Al & 5.4227098 & 9.2025265 & 16.6317744 \\
\hline$P$ & 5.4101809 & 9.1496620 & 28.4548967 \\
\hline Al & 5.3098081 & 6.5880375 & 21.5947531 \\
\hline $\mathrm{P}$ & 5.3513465 & 6.6103741 & 18.4264672 \\
\hline Al & 3.1827724 & 7.9335301 & 26.5901256 \\
\hline$P$ & 3.2618649 & 7.9989709 & 23.4749258 \\
\hline Al & 8.5363310 & 9.1340183 & 28.5064676 \\
\hline $\mathrm{P}$ & 8.5633145 & 9.2425704 & 16.6787215 \\
\hline Al & 8.5096447 & 6.6569413 & 18.4856458 \\
\hline$P$ & 8.4979764 & 6.6323433 & 21.6603546 \\
\hline Al & 1.5940158 & 10.7118304 & 23.4753701 \\
\hline $\mathrm{P}$ & 1.5262150 & 10.6435220 & 26.6525344 \\
\hline $\mathrm{O}$ & 7.0969550 & 9.6367594 & 16.9558755 \\
\hline 0 & 5.0143366 & 10.6113561 & 28.1558637 \\
\hline $\mathrm{H}$ & 4.7843758 & 5.2239412 & 21.8780955 \\
\hline $\mathrm{H}$ & 9.0396277 & 5.2723096 & 21.9324625 \\
\hline 0 & 6.8335187 & 6.2473384 & 18.1996553 \\
\hline 0 & 1.9649108 & 9.1750417 & 26.8122499 \\
\hline $\mathrm{H}$ & 2.2434289 & 6.9315669 & 23.2735372 \\
\hline $\mathrm{H}$ & 0.1797421 & 10.4078089 & 23.1224942 \\
\hline 0 & 4.9561501 & 7.8074742 & 17.5565204 \\
\hline 0 & 4.5345584 & 8.1802116 & 27.6563433 \\
\hline 0 & 4.4684690 & 7.7895810 & 22.5506409 \\
\hline $\mathrm{O}$ & 2.3759951 & 11.5624853 & 27.5339874 \\
\hline 0 & 8.9754308 & 8.0608909 & 17.5636910 \\
\hline 0 & 2.2023801 & 12.0291423 & 22.5334369 \\
\hline 0 & 4.3872809 & 10.5286009 & 17.0764631 \\
\hline 0 & 6.8699456 & 8.9369661 & 28.0317562 \\
\hline 0 & 7.0087108 & 6.6608771 & 22.0061195 \\
\hline $\mathrm{H}$ & 9.3610828 & 5.5081656 & 18.0703288 \\
\hline $\mathrm{H}$ & 4.5094682 & 5.4485074 & 18.0284381 \\
\hline $\mathrm{H}$ & 0.1092808 & 10.7628462 & 27.0943259 \\
\hline $\mathrm{H}$ & 2.5703067 & 6.6149329 & 26.9115409 \\
\hline 0 & 2.6158348 & 9.3434744 & 23.1338577 \\
\hline $\mathrm{H}$ & 5.2629855 & 8.8937769 & 15.1839199 \\
\hline 0 & 5.1177718 & 6.9867547 & 19.9004161 \\
\hline 0 & 3.7591562 & 7.9882134 & 24.9350255 \\
\hline $\mathrm{H}$ & 8.7023138 & 8.8867627 & 29.9653833 \\
\hline $\mathrm{O}$ & 8.7301849 & 7.0299235 & 20.1895630 \\
\hline 0 & 1.6640199 & 11.0886945 & 25.1868637 \\
\hline $\mathrm{H}$ & 5.2405645 & 8.8495603 & 29.9034442 \\
\hline $\mathrm{H}$ & 3.4300597 & 11.8495072 & 15.2041708 \\
\hline Al & 3.2668734 & 15.9571460 & 21.5675574 \\
\hline $\mathrm{P}$ & 3.1852693 & 15.9829588 & 18.3969536 \\
\hline Al & 3.8130945 & 11.8553101 & 28.4730474 \\
\hline $\mathrm{P}$ & 3.7926297 & 11.8759334 & 16.6481117 \\
\hline Al & 1.6629795 & 13.2099603 & 18.5209939 \\
\hline $\mathrm{P}$ & 1.7779708 & 13.2086399 & 21.6336744 \\
\hline 0 & 4.8401399 & 12.9741327 & 16.9218754 \\
\hline $\mathrm{H}$ & 0.3441758 & 13.5637954 & 21.8213364 \\
\hline $\mathrm{H}$ & 2.2984694 & 17.0432413 & 21.8833280 \\
\hline 0 & 2.1374263 & 14.8731982 & 18.1881087 \\
\hline $\mathrm{O}$ & 4.4134930 & 15.7503626 & 17.5098477 \\
\hline 0 & 4.7397668 & 16.1750011 & 22.4743439 \\
\hline 0 & 2.5190379 & 12.1226544 & 17.4564779 \\
\hline 0 & 4.4578425 & 13.4082406 & 28.0152886 \\
\hline 0 & 2.6746525 & 14.3999286 & 22.0208231 \\
\hline $\mathrm{H}$ & 2.5855509 & 17.2903997 & 18.0121721 \\
\hline $\mathrm{H}$ & 0.2094047 & 13.0537002 & 18.2384630 \\
\hline 0 & 3.6454630 & 16.0261058 & 19.8631134 \\
\hline $\mathrm{H}$ & 3.4759905 & 11.8496074 & 29.9233746 \\
\hline 0 & 2.0764478 & 12.8026633 & 20.1665195 \\
\hline Al & 10.1423773 & 11.9506108 & 16.4981140 \\
\hline $\mathrm{P}$ & 10.0386132 & 11.9032486 & 28.3310522 \\
\hline Al & 12.2830768 & 10.5567679 & 26.6177402 \\
\hline $\mathrm{P}$ & 12.3007261 & 10.5106888 & 23.4067049 \\
\hline Al & 15.4690145 & 10.7118304 & 23.4753701 \\
\hline Al & 10.6103598 & 7.8483527 & 23.5717427 \\
\hline
\end{tabular}




\begin{tabular}{|c|c|c|}
\hline 10.6870455 & 7.8601324 & 26.6647818 \\
\hline 15.4012137 & 10.6435220 & 26.6525344 \\
\hline 9.0224829 & 10.7683299 & 28.0838861 \\
\hline 11.7666713 & 8.9177963 & 26.9746328 \\
\hline 15.8251313 & 9.2245100 & 26.8068696 \\
\hline 11.5065184 & 6.6654052 & 23.4506819 \\
\hline 13.7865497 & 10.3501568 & 23.0555778 \\
\hline 11.2742780 & 11.7124806 & 27.4423059 \\
\hline 9.5251375 & 7.9716010 & 27.6573824 \\
\hline 16.2277490 & 11.5373481 & 27.5098762 \\
\hline 9.2070315 & 7.6835615 & 22.5430869 \\
\hline 16.0773788 & 12.0291423 & 22.5334369 \\
\hline 9.4790482 & 10.4218716 & 17.0209732 \\
\hline 13.9396961 & 10.7666007 & 27.1082267 \\
\hline 11.2908795 & 6.5050783 & 26.7925848 \\
\hline 16.3426338 & 9.5419342 & 23.1833890 \\
\hline 11.5314081 & 9.2325033 & 23.0330715 \\
\hline 10.4302087 & 11.9095083 & 15.0377769 \\
\hline 12.1196176 & 10.8325940 & 24.8970079 \\
\hline 15.5390186 & 11.0886945 & 25.1868637 \\
\hline 10.1273924 & 8.0788308 & 25.2394288 \\
\hline 10.4670519 & 11.9023908 & 29.7570816 \\
\hline 8.6922361 & 14.9939915 & 15.1645651 \\
\hline 5.3574396 & 14.6142189 & 16.5890888 \\
\hline 5.3102705 & 14.6164166 & 28.4192289 \\
\hline 12.2473075 & 18.6041388 & 21.5947531 \\
\hline 12.3678881 & 13.2091604 & 21.5841212 \\
\hline 17.1418721 & 15.9571460 & 21.5675574 \\
\hline 17.0602680 & 15.9829588 & 18.3969536 \\
\hline 12.3270363 & 13.1597349 & 18.3590523 \\
\hline 12.2888458 & 18.6264755 & 18.4264672 \\
\hline 5.3940539 & 17.1013724 & 26.5502205 \\
\hline 5.3927593 & 17.1238807 & 23.4775115 \\
\hline 8.4734185 & 14.6439602 & 28.4380371 \\
\hline 8.5126100 & 14.6491550 & 16.6019039 \\
\hline 15.5379782 & 13.2099603 & 18.5209939 \\
\hline 15.4471441 & 18.6730427 & 18.4856458 \\
\hline 10.7437315 & 15.8818313 & 18.4459285 \\
\hline 10.6051218 & 15.8840032 & 21.6328881 \\
\hline 15.4354757 & 18.6484447 & 21.6603546 \\
\hline 15.6529695 & 13.2086399 & 21.6336744 \\
\hline 8.5437411 & 17.2892925 & 23.4771278 \\
\hline 8.5505800 & 17.1864753 & 26.6139177 \\
\hline 8.9624653 & 13.1958635 & 16.8503665 \\
\hline 6.7870682 & 14.2950937 & 28.1173883 \\
\hline 11.6336308 & 17.0109479 & 21.9256817 \\
\hline 14.1946614 & 13.5698674 & 21.8245447 \\
\hline 15.9950970 & 17.2432901 & 21.9414901 \\
\hline 16.0124250 & 14.8731982 & 18.1881087 \\
\hline 11.9380939 & 14.6376272 & 18.1236132 \\
\hline 13.7710181 & 18.2634398 & 18.1996553 \\
\hline 7.0665830 & 17.5305789 & 26.8721105 \\
\hline 9.0592892 & 18.6746484 & 23.2979074 \\
\hline 4.7294179 & 18.4562160 & 23.4329964 \\
\hline 18.2533655 & 15.7570147 & 17.5352182 \\
\hline 11.9046610 & 19.7902203 & 17.5807600 \\
\hline 11.6514830 & 12.2650173 & 17.3021207 \\
\hline 4.8482090 & 15.8279212 & 27.6019168 \\
\hline 11.5317729 & 19.6260170 & 22.4077081 \\
\hline 18.3999015 & 16.1432207 & 22.3420630 \\
\hline 8.9941986 & 16.0187589 & 27.5025021 \\
\hline 16.2680603 & 12.2826607 & 17.6131304 \\
\hline 9.3335489 & 15.6255074 & 17.4459221 \\
\hline 15.8450543 & 19.8724039 & 17.6980414 \\
\hline 9.2896205 & 16.1890815 & 22.3768486 \\
\hline 7.0398651 & 14.7831975 & 17.0064049 \\
\hline 9.3940736 & 13.2414382 & 27.9564275 \\
\hline 13.9462101 & 18.6769785 & 22.0061195 \\
\hline 11.1366454 & 14.5514189 & 22.1036011 \\
\hline 16.5496512 & 14.3999286 & 22.0208231 \\
\hline 16.4420898 & 17.3306438 & 18.0003282 \\
\hline 13.8422540 & 13.0276690 & 18.1913965 \\
\hline 11.4240668 & 17.4330037 & 18.0176110 \\
\hline 4.5170357 & 18.2861882 & 26.7603897 \\
\hline 9.3806595 & 18.3743050 & 26.9561879 \\
\hline 6.8541706 & 17.3131201 & 23.0875162 \\
\hline 5.1585251 & 14.8971568 & 15.1408140 \\
\hline 12.0552711 & 19.0028561 & 19.9004161 \\
\hline 17.5204617 & 16.0261058 & 19.8631134 \\
\hline 5.2687524 & 16.5319971 & 24.8949642 \\
\hline
\end{tabular}

26.6647818

6.6525344

26.8068696

506819

27.4423059

27.6573824

.5098762

2.5430869

5334369

27.1082267

925848

23.0330715

(7)

25.1868637

25.2394288

15.1645651

16.5890888

21.5841212

21.5675574

18.3969536

26.5502205

.4775115

16.6019039

18.5209939

18.4856458

21.6328881

21.6603546

26.6139177

16.8503665

21.9256817

21.8245447

9414901

8.1881087

26.8721105

9074

17.5352182

(1)

27.6019168

.4077081

27.5025021

6131304

17.6980414

2.3768486

17.0064049
27.9564275

22.0061195

22.1036011

18.0003282

18.1913965

18.0176110

26.9561879

23.0875162

19.9004161

24.8949642 


\begin{tabular}{|c|c|c|c|}
\hline $\mathrm{H}$ & 8.6652930 & 14.9525932 & 29.8820074 \\
\hline $\mathrm{O}$ & 15.9514465 & 12.8026633 & 20.1665195 \\
\hline 0 & 15.6676842 & 19.0460249 & 20.1895630 \\
\hline $\mathrm{O}$ & 10.2781933 & 15.8817265 & 20.1213211 \\
\hline 0 & 8.7643037 & 16.7828694 & 25.1430816 \\
\hline 0 & 11.6732685 & 11.6522274 & 22.5717542 \\
\hline $\mathrm{C}$ & 8.9788482 & 11.7755600 & 22.7206959 \\
\hline $\mathrm{H}$ & 8.6280076 & 10.9816796 & 23.3869603 \\
\hline $\mathrm{H}$ & 8.1557473 & 12.3248274 & 22.2540103 \\
\hline $\mathrm{H}$ & 9.4712851 & 12.5837982 & 23.3123175 \\
\hline 0 & 11.8846767 & 12.6962102 & 19.7580484 \\
\hline $\mathrm{C}$ & 9.3269815 & 10.9704076 & 21.0559850 \\
\hline $\mathrm{H}$ & 10.2117190 & 11.6359176 & 22.4719432 \\
\hline $\mathrm{H}$ & 8.3749569 & 10.4293030 & 21.0585181 \\
\hline H & 10.1920600 & 10.3074671 & 21.1822510 \\
\hline $\mathrm{O}$ & 9.4009548 & 11.8867884 & 20.0886102 \\
\hline $\mathrm{H}$ & 10.3613269 & 12.1660477 & 19.9178219 \\
\hline $\mathrm{H}$ & 5.1295777 & 14.9363947 & 29.8621720 \\
\hline $\mathrm{H}$ & 16.1188290 & 19.6615582 & 22.5110896 \\
\hline \multicolumn{4}{|c|}{ Al 12} \\
\hline \multicolumn{4}{|c|}{168} \\
\hline $\mathrm{H}$ & 8.6573284 & 8.7494839 & 15.1970710 \\
\hline $\mathrm{Si}$ & 5.3571003 & 9.1362749 & 16.6334265 \\
\hline $\mathrm{Si}$ & 5.3339640 & 9.0877039 & 28.5761085 \\
\hline $\mathrm{Si}$ & 5.3182662 & 6.6411142 & 21.6217477 \\
\hline $\mathrm{Si}$ & 5.3472800 & 6.6519150 & 18.5300601 \\
\hline $\mathrm{Si}$ & 3.2212879 & 7.8547664 & 26.6375553 \\
\hline $\mathrm{Si}$ & 3.2782762 & 7.8990206 & 23.5805792 \\
\hline $\mathrm{Si}$ & 8.4410050 & 9.0527000 & 28.5569660 \\
\hline $\mathrm{Si}$ & 8.4702406 & 9.1379618 & 16.6222740 \\
\hline $\mathrm{Si}$ & 8.4748297 & 6.6597803 & 18.5335381 \\
\hline $\mathrm{Si}$ & 8.4683806 & 6.6543440 & 21.6308734 \\
\hline $\mathrm{Si}$ & 1.6933687 & 10.6313535 & 23.5321434 \\
\hline $\mathrm{Si}$ & 1.6287978 & 10.5704437 & 26.6381227 \\
\hline 0 & 6.9152371 & 9.5572293 & 16.8786274 \\
\hline $\mathrm{O}$ & 4.9168629 & 10.6402037 & 28.2987491 \\
\hline $\mathrm{H}$ & 4.8310394 & 5.2502979 & 21.8347280 \\
\hline $\mathrm{H}$ & 8.9895604 & 5.2802477 & 21.8703553 \\
\hline 0 & 6.9147047 & 6.2490743 & 18.3217665 \\
\hline $\mathrm{O}$ & 2.0896757 & 9.0164036 & 26.7910650 \\
\hline $\mathrm{H}$ & 2.2431497 & 6.8470827 & 23.3829422 \\
\hline H & 0.2730552 & 10.3147115 & 23.2165996 \\
\hline 0 & 4.9425059 & 7.8858318 & 17.5672626 \\
\hline 0 & 4.4336031 & 8.0836176 & 27.6833320 \\
\hline 0 & 4.5410122 & 7.6897015 & 22.5870927 \\
\hline $\mathrm{O}$ & 2.4907618 & 11.5294475 & 27.6139927 \\
\hline 0 & 8.8897153 & 7.8954054 & 17.5729166 \\
\hline 0 & 2.2433209 & 11.8157649 & 22.5847472 \\
\hline 0 & 4.4149446 & 10.3871217 & 17.0353671 \\
\hline 0 & 6.8834477 & 8.8831682 & 28.1491982 \\
\hline $\mathrm{O}$ & 6.8961678 & 6.7096658 & 21.9972632 \\
\hline $\mathrm{H}$ & 9.3288071 & 5.4927949 & 18.1785898 \\
\hline $\mathrm{H}$ & 4.5010521 & 5.4847163 & 18.1576813 \\
\hline $\mathrm{H}$ & 0.2005136 & 10.6725035 & 27.0464221 \\
\hline $\mathrm{H}$ & 2.5950982 & 6.5408741 & 26.9517110 \\
\hline 0 & 2.5997972 & 9.3246516 & 23.2423071 \\
\hline $\mathrm{H}$ & 5.1442385 & 8.7522110 & 15.2106456 \\
\hline 0 & 5.0944398 & 7.1057159 & 20.0750025 \\
\hline 0 & 3.8214934 & 7.8667138 & 25.1204962 \\
\hline $\mathrm{H}$ & 8.6551163 & 8.7417379 & 29.9973061 \\
\hline 0 & 8.7228922 & 7.1149544 & 20.0855523 \\
\hline 0 & 1.8166661 & 11.0696590 & 25.0991272 \\
\hline $\mathrm{H}$ & 5.1420016 & 8.7476011 & 30.0129805 \\
\hline $\mathrm{H}$ & 3.3573174 & 11.7834463 & 15.1760685 \\
\hline $\mathrm{Si}$ & 3.2572826 & 15.7231259 & 21.6181805 \\
\hline $\mathrm{Si}$ & 3.2359161 & 15.7517771 & 18.5171229 \\
\hline $\mathrm{Si}$ & 3.7844158 & 11.7882144 & 28.5505801 \\
\hline $\mathrm{Si}$ & 3.7683690 & 11.8084282 & 16.6069888 \\
\hline $\mathrm{Si}$ & 1.6849797 & 13.0407901 & 18.5462455 \\
\hline $\mathrm{Si}$ & 1.7030141 & 13.0058064 & 21.6064997 \\
\hline 0 & 4.8857114 & 12.9670895 & 16.8631650 \\
\hline $\mathrm{H}$ & 0.2421038 & 13.2361577 & 21.7791265 \\
\hline $\mathrm{H}$ & 2.3146815 & 16.8484759 & 21.8676018 \\
\hline 0 & 2.1158093 & 14.5950445 & 18.2779521 \\
\hline 0 & 4.5225925 & 15.5258675 & 17.5592501 \\
\hline 0 & 4.5739420 & 15.8613184 & 22.5558637 \\
\hline 0 & 2.4514066 & 12.0596250 & 17.5069120 \\
\hline $\mathrm{O}$ & 4.4076781 & 13.2272928 & 28.1497326 \\
\hline 0 & 2.5369369 & 14.3418008 & 22.0086706 \\
\hline
\end{tabular}

29.8820074

1665195

20.1213211

25.1430816

(7)

23.3869603

22.2540103

3123175

19.7580484

(2)

21.0585181

822510

19.9178219

29.8621720

5.1295777

14.9363947

22.5110896 


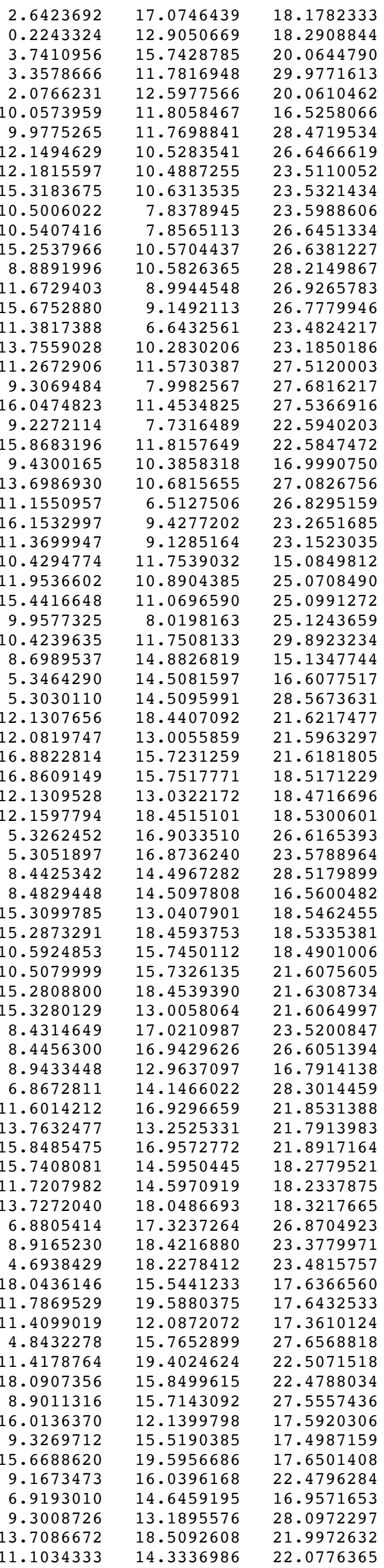

18.1782333

18.2908844

20.0644790

29.9771613

20.0610462

16.5258066

28.4719534

26.6466619

23. 5110052

23.5321434

23.5988606

26.6451334

26.6381227

28.2149867

26.9265783

26.7779946

23.4824217

23.1850186

27.5120003

27.6816217

27.5366916

22.5940203

22.5847472

16.9990750

27.0826756

26.8295159

23.2651685

23.1523035

15.0849812

25.0708490

25.0991272

25.1243659

29.8923234

15.1347744

16.6077517

28.5673631

21.6217477

21.5963297

21.6181805

18.5171229

18.4716696

18.5300601

26.6165393

23.5788964

28.5179899

16.5600482

18.5462455

18.5335381

18.4901006

21.6075605

21.6308734

21.6064997

23.5200847

26.6051394

16.7914138

28.3014459

21.8531388

21.7913983

21.8917164

18.2779521

18.2337875

18.3217665

26.8704923

23.3779971

23.4815757

17.6366560

17.6432533

17.3610124

27.6568818

22.5071518

22.4788034

27.5557436

17.5920306

17.4987159

17.6501408

22.4796284

16.9571653

28.0972297

21.9972632

22.0776365 


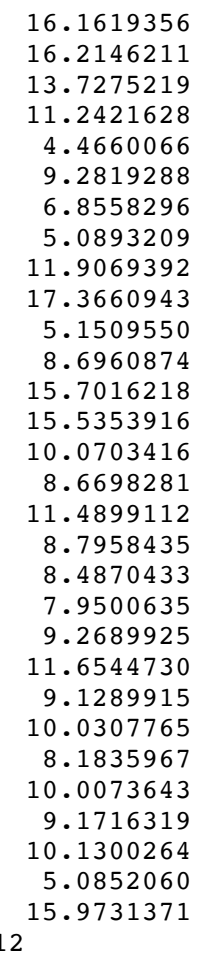

14.3418008 17.1922032 12.8937484 17.1858452 18.1003745 18.1259176 17.0004619 14.8791811 18.9053110 15.7428785 16.3189481 14.8825564 12.5977566 18.9145494 15.7305810 16.5035352 11.6306938 11.5267051 10.6670424 12.0854726 12.2828715 12.5359452 10.7796156 11.5116431 10.2272961 10.1322563 11.7113344 12.0052717 14.8799941 19.4367299

8.9401359 9.2573086

9.1963402

6.6483942

6.6718520

7.8579627

7.9465164

9.1199281

9.2208391

6.6421947

6.6241684

10.6970767

10.6174384

9.6350932

10.8544412

5.2609633

5.2636990

6.2685997

8.9521493

6.9534208

10.3170779

8.0539323

8.0782682

7.6427309

11.6771269

7.8253635

11.8643260

10.4387616

8.9410784

6.7028893

5.4762119

5.5240837

10.7082151

6.5377218

9.5131798

8.9085325

7.0836452

7.8812631

8.8981775

7.0423583

11.1022009

8.9409590 11.9629423 15.8819904 15.9107534 11.9435542 11.9716970
22.0086706 18.1481171 18.2695888 18.1262670 26.8268846 26.9491489 23.1615105 15.1888228 20.0750025 20.0644790 25.1034816 29.9336057 20.0610462 20.0855523 20.0274698 25.0512857 22.5734322 22.8549607 23.4569774 22.4438375 23.5257942 19.9422441 21.1518522 22.5450331 21.1641634 21.2603148 20.2005965 20.0291655 29.9930170 22.5095216

15.1405266 16.6790395 28.5037120 21.6241153 18.4734975 26.6377703 23.5414817 28.3977096 16.5971755 18.4184212 21.5806750 23.4305804 26.5950843 16.9501057 28.1456513 21.8322266 21.8617140 18.1955209 26.7719631 23.3311888 23.0581681 17.5254496 27.6514182 22.5250338 27.5824785 17.5308897 22.5700355 17.0687122 28.0105213 21.9950077 18.0472953 18.0714108 27.0510389 26.9277762 23.1687683 15.2436370 20.1607524 25.2189196 29.8572855 19.8923824 24.9172503 29.9643772 15.1367188 21.6123335 18.4539263 28.4108161 16.5919516 


\begin{tabular}{|c|c|c|c|}
\hline $\mathrm{P}$ & 1.6021168 & 13.1881845 & 18.4286720 \\
\hline Al & 1.5986563 & 13.1768104 & 21.5608947 \\
\hline 0 & 5.0050718 & 13.2159240 & 16.9486835 \\
\hline $\mathrm{H}$ & 0.1698420 & 13.4997471 & 21.8279568 \\
\hline $\mathrm{H}$ & 2.3151663 & 17.0045081 & 21.8994399 \\
\hline O & 2.0333824 & 14.6502066 & 18.1769549 \\
\hline $\mathrm{O}$ & 4.6536051 & 15.6569382 & 17.4974069 \\
\hline 0 & 4.5161286 & 15.9996278 & 22.4724343 \\
\hline 0 & 2.3484813 & 12.2460893 & 17.4750417 \\
\hline 0 & 4.4048568 & 13.3025263 & 27.9865605 \\
\hline 0 & 2.5735992 & 14.5661537 & 21.9672711 \\
\hline $\mathrm{H}$ & 2.6300252 & 17.2318467 & 18.0980336 \\
\hline $\mathrm{H}$ & 0.1455204 & 13.0662483 & 18.1448074 \\
\hline 0 & 3.6789798 & 15.9192645 & 20.1372957 \\
\hline $\mathrm{H}$ & 3.4617826 & 11.9608525 & 29.8524245 \\
\hline 0 & 1.9149415 & 12.7704942 & 19.8747586 \\
\hline $\mathrm{P}$ & 10.1446323 & 11.8795411 & 16.5195057 \\
\hline Al & 10.0614372 & 11.8333918 & 28.3402326 \\
\hline $\mathrm{P}$ & 12.3729943 & 10.5651252 & 26.6692270 \\
\hline Al & 12.4407557 & 10.5044205 & 23.4535852 \\
\hline $\mathrm{P}$ & 15.5740353 & 10.6970767 & 23.4305804 \\
\hline$P$ & 10.6364072 & 7.9238707 & 23.4998446 \\
\hline Al & 10.6853543 & 7.9313622 & 26.5858924 \\
\hline Al & 15.4858902 & 10.6174384 & 26.5950843 \\
\hline 0 & 8.9194097 & 10.5438138 & 27.9950946 \\
\hline 0 & 11.8937853 & 9.1358313 & 26.9991687 \\
\hline $\mathrm{H}$ & 15.9222129 & 9.2017643 & 26.7454502 \\
\hline $\mathrm{H}$ & 11.4230310 & 6.6600942 & 23.4650192 \\
\hline 0 & 14.1272253 & 10.3017446 & 23.0431410 \\
\hline 0 & 11.5128812 & 11.6033016 & 27.4008637 \\
\hline $\mathrm{O}$ & 9.3043187 & 8.0715973 & 27.6389737 \\
\hline $\mathrm{H}$ & 16.3105063 & 11.5245115 & 27.4402749 \\
\hline 0 & 9.4219652 & 7.8286853 & 22.5580102 \\
\hline 0 & 16.0537638 & 11.8643260 & 22.5700355 \\
\hline 0 & 9.5782085 & 10.5451156 & 17.0302054 \\
\hline 0 & 13.8257182 & 10.7239766 & 27.1302062 \\
\hline H & 11.2855021 & 6.5761161 & 26.7281985 \\
\hline H & 16.4830622 & 9.5455796 & 23.1759334 \\
\hline 0 & 11.5309099 & 9.0714377 & 23.0128606 \\
\hline $\mathrm{H}$ & 10.4382595 & 11.7902154 & 15.0624797 \\
\hline 0 & 12.2604189 & 10.8212280 & 25.1590525 \\
\hline O & 15.6200169 & 11.1022009 & 24.9172503 \\
\hline 0 & 10.1373036 & 8.2045510 & 24.9313665 \\
\hline $\mathrm{H}$ & 10.3919850 & 11.7940454 & 29.7915460 \\
\hline $\mathrm{H}$ & 8.7745164 & 14.9235530 & 15.0451037 \\
\hline $\mathrm{P}$ & 5.4423174 & 14.6617339 & 16.6392956 \\
\hline Al & 5.3859716 & 14.6588411 & 28.4765558 \\
\hline $\mathrm{P}$ & 12.3517456 & 18.6644955 & 21.6241153 \\
\hline $\mathrm{Ge}$ & 12.1354872 & 13.2027676 & 21.6340541 \\
\hline $\mathrm{P}$ & 17.1253894 & 15.8819904 & 21.6123335 \\
\hline Al & 17.0925386 & 15.9107534 & 18.4539263 \\
\hline Al & 12.2698778 & 13.2193920 & 18.3820148 \\
\hline Al & 12.3674093 & 18.6879533 & 18.4734975 \\
\hline $\mathrm{P}$ & 5.3507774 & 17.1432335 & 26.6074662 \\
\hline Al & 5.3021660 & 17.1079282 & 23.5462718 \\
\hline $\mathrm{P}$ & 8.5486885 & 14.6041197 & 28.3317596 \\
\hline Al & 8.6022816 & 14.6380961 & 16.4962998 \\
\hline $\mathrm{P}$ & 15.4771155 & 13.1881845 & 18.4286720 \\
\hline$P$ & 15.5313833 & 18.6582960 & 18.4184212 \\
\hline $\mathrm{P}$ & 10.7624288 & 15.9799936 & 18.3476171 \\
\hline Al & 10.6103796 & 16.0009110 & 21.5395373 \\
\hline Al & 15.5275603 & 18.6402698 & 21.5806750 \\
\hline Al & 15.4736551 & 13.1768104 & 21.5608947 \\
\hline $\mathrm{P}$ & 8.4389433 & 17.3475936 & 23.3811964 \\
\hline Al & 8.4913792 & 17.1615530 & 26.5048505 \\
\hline 0 & 9.1080480 & 12.9862767 & 16.7975556 \\
\hline O & 7.0573483 & 14.2799061 & 28.1161575 \\
\hline 0 & 11.8377349 & 17.2348828 & 21.8385538 \\
\hline 0 & 13.8251364 & 13.5494041 & 21.8690221 \\
\hline 0 & 16.1556699 & 17.0459114 & 21.9100296 \\
\hline 0 & 15.9083812 & 14.6502066 & 18.1769549 \\
\hline 0 & 11.8325618 & 14.8995814 & 18.0953883 \\
\hline O & 14.0536372 & 18.2847011 & 18.1955209 \\
\hline 0 & 6.8143121 & 17.5646940 & 26.8585781 \\
\hline $\mathrm{H}$ & 8.9310672 & 18.7504294 & 23.2976127 \\
\hline $\mathrm{H}$ & 4.6172530 & 18.4281771 & 23.4758620 \\
\hline $\mathrm{H}$ & 18.3186087 & 15.6940534 & 17.6372783 \\
\hline $\mathrm{H}$ & 11.9743579 & 19.8722835 & 17.6610978 \\
\hline 0 & 11.4613947 & 12.1684109 & 17.2407013 \\
\hline 0 & 4.8955031 & 16.0987683 & 27.6295109 \\
\hline
\end{tabular}




\begin{tabular}{|c|c|c|}
\hline 11.6283366 & 19.6289571 & 22.4979654 \\
\hline 18.3533319 & 15.9961151 & 22.4467514 \\
\hline 8.9797960 & 15.7771922 & 27.4453793 \\
\hline 16.2014532 & 12.2738925 & 17.5031853 \\
\hline 9.5531870 & 15.7583507 & 17.4280308 \\
\hline 15.9230323 & 19.8074793 & 17.5563833 \\
\hline 9.1330426 & 16.4669298 & 22.3491940 \\
\hline 6.9311703 & 14.8125130 & 16.9643202 \\
\hline 9.3705978 & 13.3759970 & 27.9203510 \\
\hline 13.8403589 & 18.7189907 & 21.9950077 \\
\hline 11.0740659 & 14.4777868 & 22.1860211 \\
\hline 16.4485979 & 14.5661537 & 21.9672711 \\
\hline 16.4038924 & 17.4592524 & 18.0367722 \\
\hline 13.9824526 & 13.0630616 & 18.1373889 \\
\hline 11.3651091 & 17.3488878 & 18.0043954 \\
\hline 4.4709417 & 18.3362584 & 26.7478270 \\
\hline 9.3509584 & 18.3201378 & 26.8735311 \\
\hline 6.9438179 & 17.3532464 & 23.0567664 \\
\hline 5.1884252 & 14.9739304 & 15.2057013 \\
\hline 12.1514862 & 19.0997466 & 20.1607524 \\
\hline 17.5539785 & 15.9192645 & 20.1372957 \\
\hline 5.2183023 & 16.5302351 & 25.1978715 \\
\hline 8.7970389 & 14.9626456 & 29.7554527 \\
\hline 15.7899402 & 12.7704942 & 19.8747586 \\
\hline 15.7626521 & 19.0584597 & 19.8923824 \\
\hline 10.2904668 & 15.9521868 & 19.8087341 \\
\hline 8.6796916 & 16.7858211 & 24.8002148 \\
\hline 11.5950906 & 11.7545077 & 22.5698785 \\
\hline 8.9291519 & 11.6057119 & 22.9362023 \\
\hline 8.6440980 & 10.7109937 & 23.4982605 \\
\hline 8.0678188 & 12.1569749 & 22.5484310 \\
\hline 9.3950495 & 12.3371220 & 23.6361189 \\
\hline 11.7201354 & 12.7102944 & 19.9586121 \\
\hline 9.2393748 & 10.8980976 & 21.1639495 \\
\hline 10.1531640 & 11.6203764 & 22.5743171 \\
\hline 8.2854459 & 10.3616668 & 21.1926422 \\
\hline 10.1189543 & 10.2513165 & 21.2639580 \\
\hline 9.2752337 & 11.8509195 & 20.2432112 \\
\hline 10.2373927 & 12.1576938 & 20.0658678 \\
\hline 5.2101638 & 14.9366905 & 29.9287996 \\
\hline 16.2313123 & 19.6592345 & 22.4074547 \\
\hline & & \\
\hline 8.6514062 & 8.7446550 & 15.2173392 \\
\hline 5.3595360 & 9.1357504 & 16.6513278 \\
\hline 5.3351605 & 9.0633863 & 28.5960417 \\
\hline 5.3164250 & 6.6100246 & 21.6346905 \\
\hline 5.3443215 & 6.6543876 & 18.5446894 \\
\hline 3.2267784 & 7.8456689 & 26.6449373 \\
\hline 3.3242726 & 7.9256239 & 23.5976419 \\
\hline 8.4383145 & 9.0234624 & 28.5712596 \\
\hline 8.4704488 & 9.1402674 & 16.6413707 \\
\hline 8.4716013 & 6.6514814 & 18.5384554 \\
\hline 8.4714601 & 6.6051728 & 21.6453457 \\
\hline 1.6921403 & 10.6203238 & 23.5386335 \\
\hline 1.6217088 & 10.5474156 & 26.6521575 \\
\hline 6.9159503 & 9.5594142 & 16.8995383 \\
\hline 4.9248264 & 10.6182668 & 28.3189227 \\
\hline 4.7788039 & 5.2360222 & 21.8351932 \\
\hline 9.0254119 & 5.2446448 & 21.8887002 \\
\hline 6.9090620 & 6.2521079 & 18.3211328 \\
\hline 2.0795725 & 8.9916996 & 26.7988417 \\
\hline 2.2834437 & 6.8777927 & 23.4083127 \\
\hline 0.2837847 & 10.2682575 & 23.2074170 \\
\hline 4.9358398 & 7.8971535 & 17.5961716 \\
\hline 4.4174331 & 8.0620564 & 27.7179646 \\
\hline 4.5877605 & 7.6843097 & 22.6116913 \\
\hline 2.4970173 & 11.4992534 & 27.6234240 \\
\hline 8.8903799 & 7.9068103 & 17.6040726 \\
\hline 2.2002422 & 11.8326490 & 22.6055232 \\
\hline 4.4163897 & 10.3893066 & 17.0376872 \\
\hline 6.8811804 & 8.8433348 & 28.1618112 \\
\hline 6.8964459 & 6.6061175 & 21.9993165 \\
\hline 9.3139306 & 5.4866693 & 18.1501067 \\
\hline 4.4905191 & 5.4931841 & 18.1708598 \\
\hline 0.1976876 & 10.6519330 & 27.0744846 \\
\hline 2.6052004 & 6.5210622 & 26.9209420 \\
\hline 2.6545746 & 9.3534974 & 23.2412169 \\
\hline 5.1530615 & 8.7358174 & 15.2319820 \\
\hline
\end{tabular}

22.4979654

2.4467514

7.5031853

17.4280308

17.5563833

27.9203510

21.9950077

22.1860211

18.1373889

43954

26.8735311

.0567664

20.1607524

1372957

9. 7554527

.8747586

9.8087341

4.8002148

698785

23.4982605

22.5484310

23.6361189

22.5743171

.1926422

1.2639580

0.0658678

29.9287996

22.4074547

15.2173392

16.6513278

1. 5960417

18.5446894

26.6449373

16.6413707

18.5384554

21.6453457

. 5386335

16.8995383

.3189227

21.8887002

(11328

23.4083127

23. 2074170

27.7179646

22.6116913

17.6040726

22.6055232

28.1618112

21.9993165

8.1501067

27.0744846

23.2412169

15.2319820 


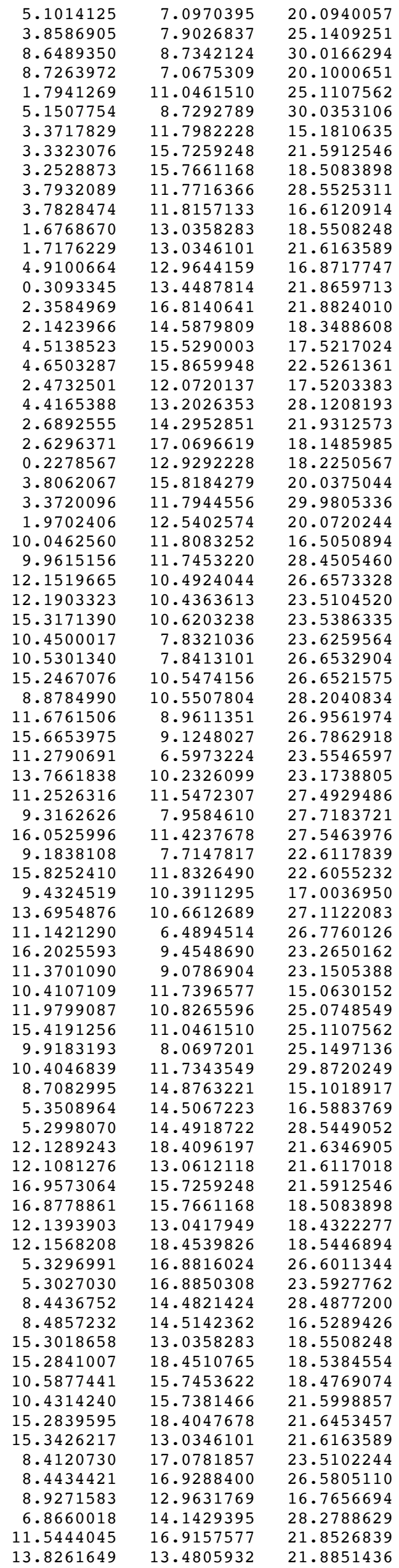

7.0970395

7.9026837

8.7342124

7.0675309

11.0461510

8.7292789

11.7982228

15.7259248

15.7661168

11.7716366

11.8157133

13.0358283

13.0346101

12.9644159

13.4487814

16.8140641

14.5879809

15.5290003

15.8659948

12.0720137

13.2026353

14.2952851

17.0696619

12.9292228

15.8184279

11.7944556

12.5402574

11.8083252

11.7453220

10.4924044

10.4363613

10.6203238

7.8321036

7.8413101

10.5474156

10.5507804

8.9611351

9. 1248027

6.5973224

10.2326099

11.5472307

7.9584610

11.4237678

7.7147817

11.8326490

10.3911295

10.6612689

6.4894514

9. 4548690

9.0786904

11.7396577

10.8265596

11.0461510

8.0697201

11.7343549

14.8763221

14.5067223

14.4918722

18.4096197

13.0612118

15.7259248

15.7661168

13.0417949

18.4539826

16.8816024

16.8850308

14.4821424

14.5142362

13.0358283

18.4510765

15.7453622

15.7381466

18.4047678

13.0346101

17.0781857

16.9288400

12.9631769

14.1429395

16.9157577

13.4805932

20.0940057

25.1409251

30.0166294

20.1000651

25.1107562

30.0353106

15.1810635

21.5912546

18.5083898

28.5525311

16.6120914

18.5508248

21.6163589

16.8717747

21.8659713

21.8824010

18.3488608

17.5217024

22.5261361

17.5203383

28.1208193

21.9312573

18.1485985

18.2250567

20.0375044

29.9805336

20.0720244

16.5050894

28.4505460

26.6573328

23.5104520

23.5386335

23.6259564

26.6532904

26.6521575

28.2040834

26.9561974

26.7862918

23.5546597

23.1738805

27.4929486

27.7183721

27.5463976

22.6117839

22.6055232

17.0036950

27.1122083

26.7760126

23. 2650162

23. 1505388

15.0630152

25.0748549

25.1107562

25.1497136

29.8720249

15.1018917

16.5883769

28.5449052

21.6346905

21.6117018

21.5912546

18.5083898

18.4322277

18.5446894

26.6011344

23.5927762

28.4877200

16.5289426

18.5508248

18.5384554

18.4769074

21.5998857

21.6453457

21.6163589

23.5102244

26.5805110

16.7656694

28.2788629

21.8526839

21.8851436 


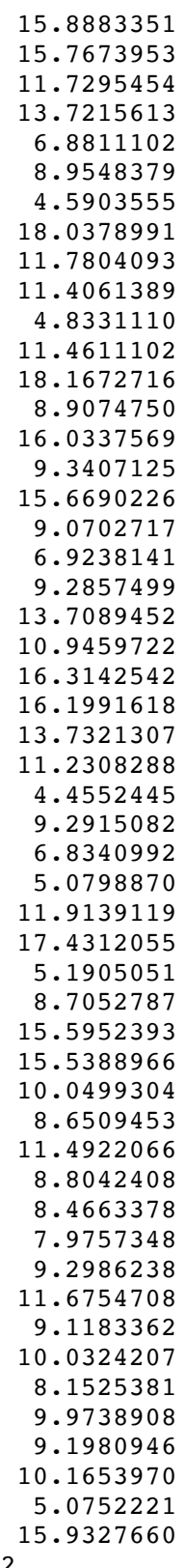

16.9203969

14.5879809

14.6104462

18.0517029

17.3113770

18.4604492

18.1919588

15.5479837

19.5991782

2.1126063

15.7553477

19.3941918

15.8545113

15.6918432

12.1500644

15.5182238

19.6049167

16.1013088

14.6723484

13.1637449

18.4057125

14.3290604

14.2952851

17.1856874

12.9203409

17.1945986

18.0746534

18.1059112

17.1610640

14.8518618

18.8966345

15.8184279

16.2646403

14.8745058

12.5402574

18.8671260

15.7014695

16.4993965

11.5834436

11.6435196

10.8323936

12.1949062

12.4338533

12.4977044

10.8027874

11.5397184

10.2885036

10.1325444

11.6921237

11.9613149

14.8511765

19.4153957

20.9872298

21.3077046

21.2182579

18.7115855

18.7064597

19.8720951

19.9964005

21.1172518

21.2699323

18.6806722

18.6354319

22.7289630

22.6329715

21.6994794

22.8711908

17.3636482

17.2827903

18.2874226

20.9703506

18.9898763

22.3299310

20.0869169

20.0952110

19.7547399

23.6813597
21.9108517

18.3488608

18.2307653

18.3211328

26.8714758

23.4012534

23.5525151

17.6006959

17.6706403

17.3187008

27.6484056

22.5301025

22.4494914

27.5170553

17.6037882

17.4636370

17.6796140

22.4147984

16.9256281

28.0694390

21.9993165

22.1527527

21.9312573

18.1165743

18.1979152

18.1392522

26.7716598

26.9157835

23.1847032

15.1655090

20.0940057

20.0375044

25.0958043

29.9000709

20.0720244

20.1000651

20.0079076

25.0200692

22.5881238

22.8533715

23.5055116

22.3993136

23.4657123

19.8936747

21.1714747

22.5511207

21.2066864

21.3157541

20.1856646

20.0127216

29.9723444

22.5255741

30.1689368

31.7065332

43.5223877

36.6389909

33.4915136

41.6512902

38.5720309

43. 4190571

31.6260112

33.4504901

36.6087233

38.4692808

41.6210083

31.9728964

43.1308347

36.8578872

36.8682142

33.2263140

41.7441101

38.3299064

38.0717701

32.5367219

42.6959456

37.5369124

42.6172954 


\begin{tabular}{|c|c|c|c|}
\hline 0 & 15.9373317 & 19.8716992 & 32.5657029 \\
\hline $\mathrm{O}$ & 9.1156352 & 23.8839425 & 37.5990316 \\
\hline 0 & 11.4374065 & 22.4720940 & 32.1178721 \\
\hline 0 & 13.9448102 & 20.9336447 & 43.0377464 \\
\hline 0 & 13.8363258 & 18.6669307 & 37.0070218 \\
\hline $\mathrm{H}$ & 16.4129771 & 17.5256347 & 33.0803027 \\
\hline $\mathrm{H}$ & 11.5277697 & 17.5622376 & 33.0897940 \\
\hline $\mathrm{H}$ & 7.1346633 & 22.6896622 & 42.1120935 \\
\hline $\mathrm{H}$ & 9.5185303 & 18.5551719 & 41.9327623 \\
\hline $\mathrm{O}$ & 9.5777485 & 21.5539055 & 38.2522225 \\
\hline $\mathrm{H}$ & 12.1491845 & 20.9751500 & 30.2682418 \\
\hline 0 & 12.1732775 & 19.1467527 & 35.1724672 \\
\hline 0 & 10.7946834 & 19.8845344 & 40.2476043 \\
\hline $\mathrm{H}$ & 15.6149211 & 20.9432778 & 44.8847797 \\
\hline 0 & 15.7725820 & 19.0819966 & 34.9265735 \\
\hline $\mathrm{O}$ & 8.6289706 & 23.1595623 & 39.9506617 \\
\hline $\mathrm{H}$ & 12.1649159 & 21.0014302 & 44.9898616 \\
\hline $\mathrm{H}$ & 10.4797543 & 23.9741485 & 30.1533542 \\
\hline $\mathrm{P}$ & 10.2257521 & 27.8993840 & 36.6206954 \\
\hline Al & 10.1630820 & 27.9391426 & 33.4560633 \\
\hline $\mathrm{P}$ & 10.7816641 & 23.9545673 & 43.4197752 \\
\hline Al & 10.7643661 & 23.9994829 & 31.6146806 \\
\hline$P$ & 8.5553106 & 25.2289371 & 33.4431968 \\
\hline Al & 8.6012762 & 25.2000971 & 36.5622764 \\
\hline 0 & 11.9510562 & 25.2400647 & 31.9841273 \\
\hline $\mathrm{H}$ & 7.1499605 & 25.4793210 & 36.7434867 \\
\hline $\mathrm{H}$ & 9.2911290 & 29.0237070 & 36.9026491 \\
\hline 0 & 8.9606601 & 26.6957072 & 33.1642546 \\
\hline $\mathrm{O}$ & 11.6020837 & 27.6868721 & 32.4998027 \\
\hline $\mathrm{O}$ & 11.5120037 & 28.0293746 & 37.4508216 \\
\hline 0 & 9.2699140 & 24.2928078 & 32.4567859 \\
\hline 0 & 11.3365167 & 25.3170832 & 42.9847645 \\
\hline $\mathrm{O}$ & 9.5574460 & 26.5883731 & 37.0164069 \\
\hline $\mathrm{H}$ & 9.5981322 & 29.2768599 & 33.1267234 \\
\hline $\mathrm{H}$ & 7.0877513 & 25.0881365 & 33.2344733 \\
\hline $\mathrm{O}$ & 10.6259995 & 27.9078082 & 35.1386460 \\
\hline $\mathrm{H}$ & 10.4408078 & 23.9692571 & 44.8691619 \\
\hline $\mathrm{O}$ & 8.9534195 & 24.8231799 & 34.8740255 \\
\hline$P$ & 17.0988574 & 23.9152249 & 31.5128459 \\
\hline Al & 16.9836011 & 23.8356373 & 43.3183016 \\
\hline $\mathrm{P}$ & 19.3161683 & 22.5362969 & 41.7223061 \\
\hline Al & 19.3703477 & 22.4459125 & 38.4940250 \\
\hline $\mathrm{P}$ & 22.4962793 & 22.7289630 & 38.4692808 \\
\hline $\mathrm{P}$ & 17.5407227 & 19.9123347 & 38.5577443 \\
\hline Al & 17.6143122 & 19.9300905 & 41.6259734 \\
\hline Al & 22.4142054 & 22.6329715 & 41.6210083 \\
\hline 0 & 15.8654402 & 22.5255418 & 42.9677391 \\
\hline $\mathrm{O}$ & 18.8182320 & 21.1223425 & 42.0912870 \\
\hline $\mathrm{H}$ & 22.8714074 & 21.2197699 & 41.7256429 \\
\hline $\mathrm{H}$ & 18.2374105 & 18.5964642 & 38.5729677 \\
\hline $\mathrm{O}$ & 21.0626437 & 22.3139292 & 38.0558293 \\
\hline $\mathrm{O}$ & 18.4533818 & 23.6063130 & 42.4061079 \\
\hline 0 & 16.2383271 & 20.0401880 & 42.6921572 \\
\hline $\mathrm{H}$ & 23.2419488 & 23.5301849 & 42.4736335 \\
\hline 0 & 16.3245563 & 19.8498716 & 37.6118901 \\
\hline $\mathrm{O}$ & 22.9906339 & 23.8839425 & 37.5990316 \\
\hline $\mathrm{O}$ & 16.5485253 & 22.5851855 & 32.0578687 \\
\hline $\mathrm{O}$ & 20.7644372 & 22.6995601 & 42.1978340 \\
\hline $\mathrm{H}$ & 18.2178825 & 18.5713366 & 41.7072843 \\
\hline $\mathrm{H}$ & 23.4267576 & 21.5858348 & 38.2581205 \\
\hline $\mathrm{O}$ & 18.5115899 & 20.9829369 & 38.0402141 \\
\hline $\mathrm{H}$ & 17.3219195 & 23.8102885 & 30.0443936 \\
\hline $\mathrm{O}$ & 19.2298697 & 22.7372844 & 40.2049594 \\
\hline 0 & 22.5039694 & 23.1595623 & 39.9506617 \\
\hline 0 & 17.0592281 & 20.2664031 & 39.9806993 \\
\hline $\mathrm{H}$ & 17.2795602 & 23.8112460 & 44.7773883 \\
\hline $\mathrm{H}$ & 15.7251271 & 26.9188773 & 30.0346585 \\
\hline $\mathrm{P}$ & 12.3888515 & 26.6806230 & 31.6513155 \\
\hline Al & 12.3208045 & 26.6676141 & 43.4846029 \\
\hline $\mathrm{P}$ & 19.2836800 & 30.7276869 & 36.6389909 \\
\hline $\mathrm{Ti}$ & 19.0361996 & 25.1875762 & 36.6624352 \\
\hline$P$ & 24.1007508 & 27.8993840 & 36.6206954 \\
\hline Al & 24.0380807 & 27.9391426 & 33.4560633 \\
\hline Al & 19.1962328 & 25.2441263 & 33.3720815 \\
\hline Al & 19.3292699 & 30.7225611 & 33.4915136 \\
\hline$P$ & 12.2971239 & 29.1427181 & 41.6148864 \\
\hline Al & 12.2403294 & 29.1224160 & 38.5803371 \\
\hline $\mathrm{P}$ & 15.4838593 & 26.6070782 & 43.3171621 \\
\hline Al & 15.5555094 & 26.6681839 & 31.4925691 \\
\hline $\mathrm{P}$ & 22.4303093 & 25.2289371 & 33.4431968 \\
\hline
\end{tabular}




\begin{tabular}{|c|c|c|c|}
\hline $\mathrm{P}$ & 22.4867807 & 30.6967736 & 33.4504901 \\
\hline $\mathrm{P}$ & 17.7025088 & 28.0195017 & 33.3434562 \\
\hline Al & 17.4785636 & 28.0867436 & 36.5327270 \\
\hline Al & 22.4680758 & 30.6515333 & 36.6087233 \\
\hline Al & 22.4762750 & 25.2000971 & 36.5622764 \\
\hline $\mathrm{P}$ & 15.3629488 & 29.4193037 & 38.3850626 \\
\hline Al & 15.4299918 & 29.1812218 & 41.5045841 \\
\hline 0 & 16.0791777 & 25.0278566 & 31.8321389 \\
\hline 0 & 13.9895556 & 26.2905942 & 43.1151260 \\
\hline 0 & 18.6727276 & 29.3401671 & 36.8643152 \\
\hline 0 & 20.7928436 & 25.5239785 & 36.7724685 \\
\hline $\mathrm{O}$ & 23.1316524 & 29.0651798 & 36.9130495 \\
\hline 0 & 22.8356588 & 26.6957072 & 33.1642546 \\
\hline 0 & 18.7679285 & 26.9330469 & 33.0994072 \\
\hline 0 & 21.0140757 & 30.3035240 & 33.2263140 \\
\hline 0 & 13.7544453 & 29.5825582 & 41.8741879 \\
\hline $\mathrm{H}$ & 15.9396345 & 30.7888833 & 38.2912224 \\
\hline $\mathrm{H}$ & 11.4439133 & 30.3805119 & 38.5742746 \\
\hline $\mathrm{H}$ & 25.2652132 & 27.7240148 & 32.6405963 \\
\hline $\mathrm{H}$ & 18.9489129 & 31.9065542 & 32.6726061 \\
\hline 0 & 18.4514116 & 24.2123143 & 32.1643860 \\
\hline 0 & 11.8349588 & 28.1179253 & 42.6534162 \\
\hline $\mathrm{H}$ & 18.6195236 & 31.7377125 & 37.5083960 \\
\hline $\mathrm{H}$ & 25.3473394 & 28.0253662 & 37.4252238 \\
\hline 0 & 15.9120289 & 27.7849245 & 42.4338756 \\
\hline $\mathrm{H}$ & 23.1229428 & 24.3215883 & 32.4871123 \\
\hline $\mathrm{O}$ & 16.5059188 & 27.8116841 & 32.4014243 \\
\hline $\mathrm{H}$ & 22.8635419 & 31.8531513 & 32.5914430 \\
\hline 0 & 15.9704272 & 28.5081241 & 37.3200309 \\
\hline 0 & 13.8813657 & 26.8368543 & 31.9610165 \\
\hline 0 & 16.2937003 & 25.3767910 & 42.8853751 \\
\hline 0 & 20.7738252 & 30.6830320 & 37.0070218 \\
\hline 0 & 18.0320701 & 26.5865588 & 37.1711408 \\
\hline 0 & 23.4324448 & 26.5883731 & 37.0164069 \\
\hline 0 & 23.3752711 & 29.5085777 & 33.0696755 \\
\hline $\mathrm{O}$ & 20.9245080 & 25.0844675 & 33.2290343 \\
\hline 0 & 18.3211724 & 29.3875076 & 33.0227959 \\
\hline $\mathrm{H}$ & 11.4046871 & 30.3301801 & 41.7178962 \\
\hline $\mathrm{H}$ & 16.2914227 & 30.3370821 & 41.8774708 \\
\hline 0 & 13.8594146 & 29.5252511 & 38.1131513 \\
\hline $\mathrm{H}$ & 12.1250167 & 26.9709432 & 30.2149221 \\
\hline $\mathrm{O}$ & 19.1107769 & 31.1628541 & 35.1724672 \\
\hline 0 & 24.5009982 & 27.9078082 & 35.1386460 \\
\hline 0 & 12.1942839 & 28.4945297 & 40.2166966 \\
\hline $\mathrm{H}$ & 15.7467921 & 26.9523556 & 44.7415113 \\
\hline 0 & 22.8284182 & 24.8231799 & 34.8740255 \\
\hline 0 & 22.7100814 & 31.0980979 & 34.9265735 \\
\hline 0 & 17.2018095 & 27.9943499 & 34.7965883 \\
\hline 0 & 15.6120215 & 28.8292262 & 39.7919020 \\
\hline 0 & 18.4830579 & 23.6992943 & 37.6624007 \\
\hline $\mathrm{C}$ & 15.8217722 & 23.5278307 & 37.9902142 \\
\hline $\mathrm{H}$ & 15.5340984 & 22.6164806 & 38.5233342 \\
\hline $\mathrm{H}$ & 14.9598056 & 24.0722105 & 37.5935982 \\
\hline $\mathrm{H}$ & 16.2651796 & 24.2484020 & 38.7139892 \\
\hline $\mathrm{O}$ & 18.5719324 & 24.7498661 & 34.9246938 \\
\hline C & 16.1558791 & 22.8727825 & 36.1747739 \\
\hline $\mathrm{H}$ & 17.0509235 & 23.5387900 & 37.6418349 \\
\hline $\mathrm{H}$ & 15.2206863 & 22.3050791 & 36.2066059 \\
\hline $\mathrm{H}$ & 17.0612167 & 22.2594083 & 36.2525047 \\
\hline 0 & 16.1472677 & 23.8546981 & 35.2883406 \\
\hline $\mathrm{H}$ & 17.0963035 & 24.1843049 & 35.0779708 \\
\hline $\mathrm{H}$ & 12.1461584 & 26.9349312 & 44.9389621 \\
\hline $\mathrm{H}$ & 23.1382867 & 31.6766609 & 37.4555122 \\
\hline \multicolumn{4}{|c|}{$\mathrm{Zn} 13$} \\
\hline \multicolumn{4}{|c|}{163} \\
\hline $\mathrm{H}$ & 8.7108828 & 8.9280265 & 15.2526864 \\
\hline Al & 5.4121200 & 9.2710405 & 16.6281615 \\
\hline $\mathrm{P}$ & 5.4142054 & 9.2328738 & 28.4443823 \\
\hline Al & 5.3057381 & 6.6658504 & 21.5664160 \\
\hline$P$ & 5.3361326 & 6.6911232 & 18.4265148 \\
\hline Al & 3.1888561 & 8.0184000 & 26.5978120 \\
\hline $\mathrm{P}$ & 3.2582337 & 8.1110280 & 23.4798560 \\
\hline Al & 8.5368022 & 9.2159767 & 28.5087116 \\
\hline $\mathrm{P}$ & 8.5518158 & 9.3072021 & 16.6837853 \\
\hline Al & 8.5183975 & 6.7282016 & 18.4929623 \\
\hline $\mathrm{P}$ & 8.5018844 & 6.6787350 & 21.6552831 \\
\hline Al & 1.5566643 & 10.7607053 & 23.4824192 \\
\hline $\mathrm{P}$ & 1.5225478 & 10.7093462 & 26.6762250 \\
\hline $\mathrm{O}$ & 7.0865385 & 9.6929326 & 16.9751894 \\
\hline
\end{tabular}




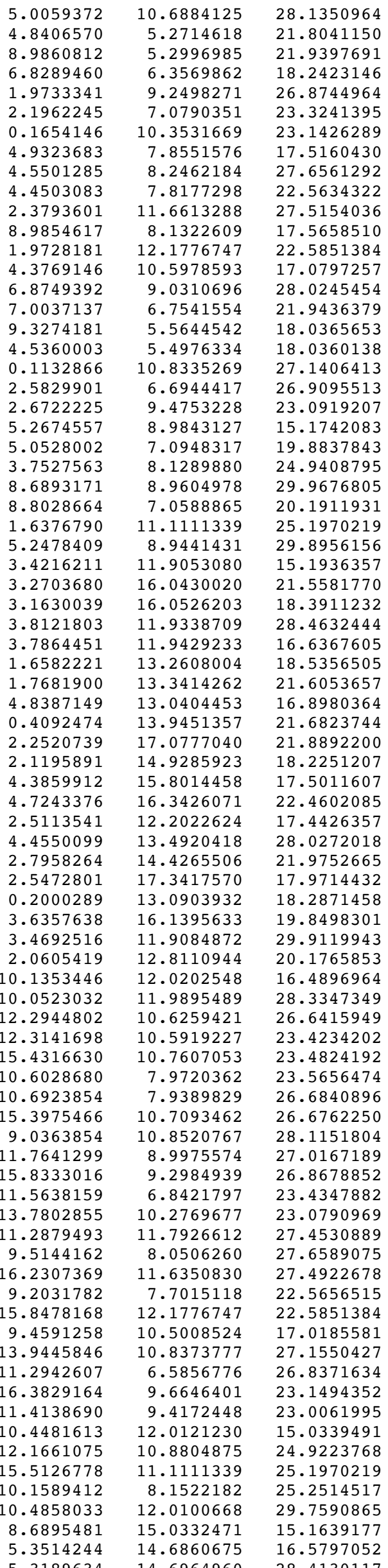




\begin{tabular}{|c|c|c|c|}
\hline Al & 12.2432374 & 18.6819517 & 21.5664160 \\
\hline $\mathrm{Zn}$ & 12.4554334 & 13.4124702 & 21.6382915 \\
\hline Al & 17.1453667 & 16.0430020 & 21.5581770 \\
\hline $\mathrm{P}$ & 17.0380027 & 16.0526203 & 18.3911232 \\
\hline P & 12.3112312 & 13.1964172 & 18.3865378 \\
\hline$P$ & 12.2736319 & 18.7072245 & 18.4265148 \\
\hline Al & 5.3984079 & 17.1956400 & 26.5476752 \\
\hline $\mathrm{P}$ & 5.3995056 & 17.2710679 & 23.4660912 \\
\hline Al & 8.4757228 & 14.7169066 & 28.4290334 \\
\hline $\mathrm{P}$ & 8.5089627 & 14.7156568 & 16.6074016 \\
\hline Al & 15.5332208 & 13.2608004 & 18.5356505 \\
\hline Al & 15.4558968 & 18.7443030 & 18.4929623 \\
\hline Al & 10.7394377 & 15.9448569 & 18.4470940 \\
\hline $\mathrm{P}$ & 10.6122577 & 15.9668808 & 21.6179985 \\
\hline$P$ & 15.4393838 & 18.6948364 & 21.6552831 \\
\hline$P$ & 15.6431887 & 13.3414262 & 21.6053657 \\
\hline Al & 8.5497661 & 17.4081385 & 23.4883555 \\
\hline $\mathrm{P}$ & 8.5578301 & 17.2696495 & 26.6114277 \\
\hline $\mathrm{O}$ & 8.9703737 & 13.2674979 & 16.8922211 \\
\hline 0 & 6.7922326 & 14.3581686 & 28.1145971 \\
\hline 0 & 11.6990457 & 17.0503767 & 21.8445478 \\
\hline $\mathrm{O}$ & 14.2489331 & 13.9608235 & 21.6843755 \\
\hline 0 & 15.9406796 & 17.2671004 & 21.9498155 \\
\hline 0 & 15.9945878 & 14.9285923 & 18.2251207 \\
\hline $\mathrm{O}$ & 11.9147906 & 14.6653718 & 18.1554169 \\
\hline $\mathrm{O}$ & 13.7664453 & 18.3730876 & 18.2423146 \\
\hline $\mathrm{O}$ & 7.0742836 & 17.6191013 & 26.8621190 \\
\hline $\mathrm{H}$ & 9.0166712 & 18.8146713 & 23.3441823 \\
\hline $\mathrm{H}$ & 4.8006610 & 18.6333826 & 23.4150567 \\
\hline $\mathrm{H}$ & 18.2257031 & 15.8086930 & 17.5268388 \\
\hline $\mathrm{H}$ & 11.8811952 & 19.8386021 & 17.5415861 \\
\hline $\mathrm{O}$ & 11.6275947 & 12.2802059 & 17.3580287 \\
\hline 0 & 4.8669109 & 15.9009485 & 27.5823618 \\
\hline $\mathrm{H}$ & 11.5142130 & 19.6636200 & 22.4161049 \\
\hline $\mathrm{O}$ & 11.8170158 & 11.8210229 & 22.6279722 \\
\hline $\mathrm{H}$ & 18.3916874 & 16.2998190 & 22.3313848 \\
\hline $\mathrm{O}$ & 8.9901060 & 16.1043275 & 27.5105110 \\
\hline $\mathrm{H}$ & 16.2614341 & 12.3572574 & 17.6026789 \\
\hline $\mathrm{O}$ & 9.3350764 & 15.7039766 & 17.4339158 \\
\hline $\mathrm{H}$ & 15.8541762 & 19.9415855 & 17.7023873 \\
\hline 0 & 9.3290378 & 16.3612782 & 22.3641086 \\
\hline $\mathrm{O}$ & 7.0362008 & 14.8471893 & 17.0138775 \\
\hline $\mathrm{O}$ & 9.4070756 & 13.3230768 & 27.9516910 \\
\hline 0 & 13.9412131 & 18.7702567 & 21.9436379 \\
\hline $\mathrm{O}$ & 11.0752149 & 14.6206304 & 22.1389446 \\
\hline $\mathrm{O}$ & 16.6708251 & 14.4265506 & 21.9752665 \\
\hline 0 & 16.4032933 & 17.3815068 & 17.9585026 \\
\hline $\mathrm{O}$ & 13.8231482 & 13.0609581 & 18.2442206 \\
\hline $\mathrm{O}$ & 11.4503379 & 17.4791862 & 18.0247098 \\
\hline $\mathrm{H}$ & 4.5191503 & 18.3707316 & 26.7990437 \\
\hline $\mathrm{H}$ & 9.3943729 & 18.4532849 & 26.9524908 \\
\hline 0 & 6.8686308 & 17.3937152 & 23.0827563 \\
\hline $\mathrm{H}$ & 5.1709572 & 14.9896963 & 15.1332054 \\
\hline $\mathrm{O}$ & 11.9902996 & 19.1109331 & 19.8837843 \\
\hline $\mathrm{O}$ & 11.8558084 & 12.7219639 & 19.8026318 \\
\hline $\mathrm{O}$ & 17.5107625 & 16.1395633 & 19.8498301 \\
\hline 0 & 5.2422102 & 16.6792505 & 24.8806100 \\
\hline $\mathrm{H}$ & 8.6627240 & 14.9949652 & 29.8798382 \\
\hline $\mathrm{O}$ & 15.9355406 & 12.8110944 & 20.1765853 \\
\hline 0 & 15.7403658 & 19.0749878 & 20.1911931 \\
\hline 0 & 10.2559918 & 15.9137851 & 20.1129723 \\
\hline $\mathrm{O}$ & 8.7780380 & 16.8655033 & 25.1423663 \\
\hline $\mathrm{H}$ & 10.3889987 & 11.7823987 & 22.2830670 \\
\hline C & 9.7295783 & 11.2820492 & 20.3340342 \\
\hline $\mathrm{H}$ & 9.6017697 & 11.7725855 & 21.8665794 \\
\hline 0 & 8.8909179 & 10.5252951 & 20.0895132 \\
\hline $\mathrm{H}$ & 10.7237540 & 11.9372581 & 19.9843433 \\
\hline $\mathrm{H}$ & 5.1452673 & 15.0315446 & 29.8533911 \\
\hline $\mathrm{H}$ & 16.1181608 & 19.6847743 & 22.5364218 \\
\hline \multicolumn{4}{|c|}{ Si 13} \\
\hline \multicolumn{4}{|c|}{163} \\
\hline $\mathrm{H}$ & 8.6675951 & 8.9570102 & 15.1340628 \\
\hline $\mathrm{P}$ & 5.3619157 & 9.3183287 & 16.6647460 \\
\hline Al & 5.3378425 & 9.2872408 & 28.4921491 \\
\hline $\mathrm{P}$ & 5.3992810 & 6.7644012 & 21.6261272 \\
\hline Al & 5.4236471 & 6.7412702 & 18.4644511 \\
\hline$P$ & 3.1846934 & 7.9333705 & 26.6442552 \\
\hline Al & 3.2276336 & 7.9775368 & 23.5196504 \\
\hline $\mathrm{P}$ & 8.4778467 & 9.2224023 & 28.4105572 \\
\hline
\end{tabular}




\begin{tabular}{|c|c|c|c|}
\hline Al & 8.5138631 & 9.2636982 & 16.5830037 \\
\hline $\mathrm{P}$ & 8.5966501 & 6.7093150 & 18.4114850 \\
\hline Al & 8.5682543 & 6.7245184 & 21.5812690 \\
\hline $\mathrm{P}$ & 1.6614189 & 10.7548622 & 23.4365340 \\
\hline Al & 1.6140374 & 10.7128732 & 26.5940063 \\
\hline 0 & 6.8426755 & 9.6741225 & 16.9203586 \\
\hline 0 & 4.8678812 & 10.9394874 & 28.1367356 \\
\hline $\mathrm{H}$ & 4.9455122 & 5.3700404 & 21.8849174 \\
\hline $\mathrm{H}$ & 9.0355739 & 5.3437369 & 21.8848731 \\
\hline 0 & 7.1132700 & 6.3652038 & 18.1847784 \\
\hline 0 & 2.1388994 & 9.0550252 & 26.7930723 \\
\hline $\mathrm{H}$ & 2.1879453 & 6.9418449 & 23.2676362 \\
\hline $\mathrm{H}$ & 0.2518142 & 10.4075130 & 23.1056507 \\
\hline 0 & 4.9423373 & 8.1113562 & 17.5059678 \\
\hline 0 & 4.3587022 & 8.1597973 & 27.6010162 \\
\hline 0 & 4.6217131 & 7.7574410 & 22.4992977 \\
\hline 0 & 2.5611883 & 11.7973810 & 27.5692964 \\
\hline 0 & 9.0164005 & 7.8970242 & 17.5369452 \\
\hline 0 & 2.1550165 & 11.9018245 & 22.5544408 \\
\hline 0 & 4.4927838 & 10.5110469 & 17.0755141 \\
\hline 0 & 7.0025453 & 9.0707983 & 28.0317370 \\
\hline 0 & 6.8853501 & 6.8801185 & 21.9856008 \\
\hline $\mathrm{H}$ & 9.4256544 & 5.5358428 & 18.0205434 \\
\hline $\mathrm{H}$ & 4.6103688 & 5.5629530 & 18.0554676 \\
\hline $\mathrm{H}$ & 0.1975788 & 10.8035253 & 27.0440594 \\
\hline $\mathrm{H}$ & 2.5456949 & 6.6371775 & 27.0029821 \\
\hline 0 & 2.5428914 & 9.5345674 & 23.1679903 \\
\hline $\mathrm{H}$ & 5.1520628 & 8.9854304 & 15.2286885 \\
\hline 0 & 5.1780416 & 7.1383911 & 20.1485283 \\
\hline 0 & 3.7235594 & 7.8959489 & 25.2015853 \\
\hline $\mathrm{H}$ & 8.6873044 & 8.9140630 & 29.8521448 \\
\hline 0 & 8.8403217 & 7.0801320 & 19.8865217 \\
\hline $\mathrm{O}$ & 1.7582748 & 11.1810408 & 24.9144348 \\
\hline $\mathrm{H}$ & 5.1736253 & 9.0206813 & 29.9478618 \\
\hline $\mathrm{H}$ & 3.4654289 & 12.0078747 & 15.1377613 \\
\hline $\mathrm{P}$ & 3.1616981 & 15.9642742 & 21.6521594 \\
\hline Al & 3.1741947 & 15.9714703 & 18.4693209 \\
\hline $\mathrm{P}$ & 3.8124992 & 12.0283118 & 28.4203328 \\
\hline Al & 3.7997579 & 12.0343042 & 16.5885011 \\
\hline $\mathrm{P}$ & 1.6022650 & 13.2549018 & 18.4373797 \\
\hline Al & 1.5922759 & 13.2258650 & 21.5528673 \\
\hline 0 & 4.9848749 & 13.2874357 & 16.9125559 \\
\hline H & 0.1238723 & 13.4306850 & 21.6905636 \\
\hline $\mathrm{H}$ & 2.2136949 & 17.0788920 & 21.9279084 \\
\hline 0 & 1.9888483 & 14.7204198 & 18.1392440 \\
\hline 0 & 4.6330485 & 15.7056722 & 17.5501605 \\
\hline 0 & 4.4326928 & 16.1229484 & 22.4977292 \\
\hline 0 & 2.3214902 & 12.3107743 & 17.4652411 \\
\hline 0 & 4.3974364 & 13.3928322 & 28.0448864 \\
\hline 0 & 2.4943332 & 14.6457195 & 22.0347085 \\
\hline $\mathrm{H}$ & 2.6089090 & 17.2918343 & 18.0766229 \\
\hline $\mathrm{H}$ & 0.1364797 & 13.0986521 & 18.2271889 \\
\hline 0 & 3.5720509 & 15.9724307 & 20.1691378 \\
\hline $\mathrm{H}$ & 3.4200552 & 12.0040688 & 29.8564807 \\
\hline $\mathrm{O}$ & 1.9997200 & 12.8742865 & 19.8721216 \\
\hline $\mathrm{P}$ & 10.1249592 & 11.9620288 & 16.5776931 \\
\hline Al & 10.0788538 & 11.9461199 & 28.4086144 \\
\hline $\mathrm{P}$ & 12.3649605 & 10.6781852 & 26.6933477 \\
\hline Al & 12.3971966 & 10.6802807 & 23.4929905 \\
\hline $\mathrm{P}$ & 15.5364176 & 10.7548622 & 23.4365340 \\
\hline $\mathrm{P}$ & 10.6934209 & 8.0383954 & 23.4398107 \\
\hline Al & 10.6995612 & 8.0195023 & 26.5869572 \\
\hline Al & 15.4890361 & 10.7128732 & 26.5940063 \\
\hline 0 & 8.9208578 & 10.6671005 & 28.1001331 \\
\hline 0 & 11.8936676 & 9.2401903 & 26.9897140 \\
\hline $\mathrm{H}$ & 15.9355409 & 9.3025272 & 26.7633535 \\
\hline $\mathrm{H}$ & 11.6111461 & 6.8759507 & 23.2861124 \\
\hline 0 & 14.0725072 & 10.3941312 & 23.0929032 \\
\hline 0 & 11.5315962 & 11.6927817 & 27.4845437 \\
\hline 0 & 9.2834762 & 8.2194780 & 27.5788851 \\
\hline $\mathrm{H}$ & 16.2999806 & 11.6414218 & 27.4290434 \\
\hline 0 & 9.4592151 & 7.8840638 & 22.5418961 \\
\hline 0 & 16.0300152 & 11.9018245 & 22.5544408 \\
\hline 0 & 9.5411155 & 10.6107853 & 17.0122227 \\
\hline 0 & 13.8284329 & 10.8191503 & 27.1216317 \\
\hline $\mathrm{H}$ & 11.2767336 & 6.6733996 & 26.8552855 \\
\hline $\mathrm{H}$ & 16.3947587 & 9.5665901 & 23.1750374 \\
\hline 0 & 11.4355597 & 9.3066039 & 22.9949172 \\
\hline $\mathrm{H}$ & 10.4796661 & 11.9474699 & 15.1316324 \\
\hline 0 & 12.2085358 & 10.9844186 & 25.1966294 \\
\hline
\end{tabular}




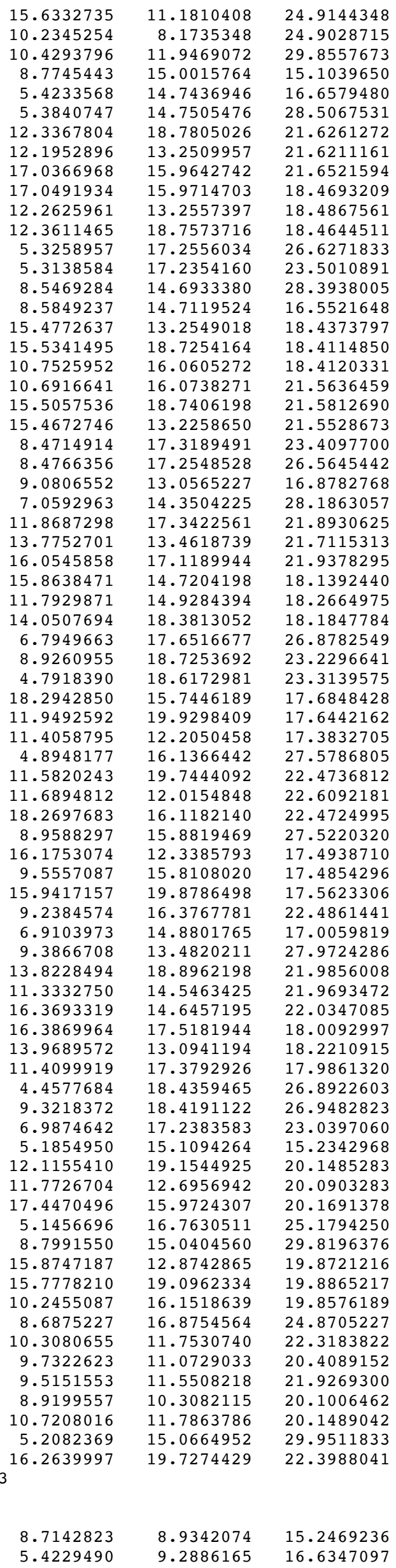




\begin{tabular}{|c|c|c|c|}
\hline $\mathrm{P}$ & 5.4106227 & 9.2473723 & 28.4486731 \\
\hline Al & 5.3022808 & 6.7008792 & 21.5668818 \\
\hline $\mathrm{P}$ & 5.3607654 & 6.6861197 & 18.4109594 \\
\hline Al & 3.1917441 & 8.0125363 & 26.5921641 \\
\hline $\mathrm{P}$ & 3.2788662 & 8.0884119 & 23.4846806 \\
\hline Al & 8.5310797 & 9.2167287 & 28.5034339 \\
\hline $\mathrm{P}$ & 8.5634072 & 9.3227460 & 16.6763973 \\
\hline Al & 8.5415595 & 6.7501680 & 18.4982978 \\
\hline $\mathrm{P}$ & 8.5079568 & 6.7104067 & 21.6553727 \\
\hline Al & 1.5845833 & 10.7917988 & 23.4962192 \\
\hline $\mathrm{P}$ & 1.5192015 & 10.7387943 & 26.6597413 \\
\hline 0 & 7.1005011 & 9.7166652 & 16.9710498 \\
\hline 0 & 5.0142156 & 10.7048746 & 28.1334546 \\
\hline $\mathrm{H}$ & 4.7845176 & 5.3372416 & 21.8661047 \\
\hline $\mathrm{H}$ & 9.0047600 & 5.3356013 & 21.9385994 \\
\hline 0 & 6.8578782 & 6.3644821 & 18.2426569 \\
\hline 0 & 1.9935611 & 9.2777958 & 26.7700085 \\
\hline $\mathrm{H}$ & 2.2335639 & 7.0543269 & 23.2498787 \\
\hline $\mathrm{H}$ & 0.1930878 & 10.4117917 & 23.1268203 \\
\hline 0 & 4.9617659 & 7.8625497 & 17.5140825 \\
\hline 0 & 4.5337713 & 8.2662618 & 27.6682316 \\
\hline 0 & 4.4722691 & 7.8924957 & 22.5416976 \\
\hline 0 & 2.3764200 & 11.6584535 & 27.5326120 \\
\hline 0 & 8.9985971 & 8.1524046 & 17.5636390 \\
\hline 0 & 2.1386881 & 12.1199264 & 22.5376279 \\
\hline 0 & 4.3779068 & 10.6055158 & 17.0990530 \\
\hline $\mathrm{O}$ & 6.8680968 & 9.0315763 & 28.0245204 \\
\hline 0 & 7.0064086 & 6.7677003 & 21.9303742 \\
\hline $\mathrm{H}$ & 9.3614625 & 5.5884532 & 18.0563721 \\
\hline $\mathrm{H}$ & 4.5793367 & 5.4919017 & 17.9863030 \\
\hline $\mathrm{H}$ & 0.1178620 & 10.8191488 & 27.1566431 \\
\hline $\mathrm{H}$ & 2.5560775 & 6.7167477 & 26.9581974 \\
\hline 0 & 2.6693410 & 9.4636056 & 23.2065862 \\
\hline $\mathrm{H}$ & 5.2691704 & 9.0073108 & 15.1806327 \\
\hline 0 & 5.0554693 & 7.0667801 & 19.8692671 \\
\hline O & 3.7824682 & 8.0026352 & 24.9413257 \\
\hline $\mathrm{H}$ & 8.6910979 & 8.9656971 & 29.9623711 \\
\hline 0 & 8.8167417 & 7.1007619 & 20.1949932 \\
\hline 0 & 1.5981081 & 11.2174667 & 25.1999800 \\
\hline $\mathrm{H}$ & 5.2478221 & 8.9676910 & 29.9020811 \\
\hline $\mathrm{H}$ & 3.4346647 & 11.9061847 & 15.2027495 \\
\hline Al & 3.2579181 & 16.0441901 & 21.5743043 \\
\hline $\mathrm{P}$ & 3.1695742 & 16.0577496 & 18.3929599 \\
\hline Al & 3.8129098 & 11.9405526 & 28.4705360 \\
\hline $\mathrm{P}$ & 3.7846726 & 11.9484220 & 16.6494115 \\
\hline Al & 1.6660620 & 13.2868466 & 18.5324024 \\
\hline $\mathrm{P}$ & 1.7934123 & 13.3025913 & 21.6142416 \\
\hline 0 & 4.8318794 & 13.0490693 & 16.9195353 \\
\hline $\mathrm{H}$ & 0.3638628 & 13.7064204 & 21.7163736 \\
\hline H & 2.2662542 & 17.1089905 & 21.8904106 \\
\hline $\mathrm{O}$ & 2.1149910 & 14.9520958 & 18.1744314 \\
\hline 0 & 4.4070038 & 15.8137138 & 17.5201988 \\
\hline 0 & 4.7291591 & 16.3128698 & 22.4663297 \\
\hline 0 & 2.4987305 & 12.2076954 & 17.4391970 \\
\hline 0 & 4.4444845 & 13.5020725 & 28.0330779 \\
\hline 0 & 2.7062301 & 14.4701841 & 22.0347589 \\
\hline $\mathrm{H}$ & 2.5818197 & 17.3661953 & 17.9934161 \\
\hline $\mathrm{H}$ & 0.2016560 & 13.1191067 & 18.3214547 \\
\hline 0 & 3.6142993 & 16.1000070 & 19.8623659 \\
\hline $\mathrm{H}$ & 3.4807288 & 11.9100807 & 29.9216899 \\
\hline 0 & 2.1423869 & 12.8789974 & 20.1605411 \\
\hline Al & 10.1502686 & 12.0358887 & 16.4696302 \\
\hline $\mathrm{P}$ & 10.0483106 & 11.9930607 & 28.3161167 \\
\hline Al & 12.2986362 & 10.6030002 & 26.6594178 \\
\hline $\mathrm{P}$ & 12.3303780 & 10.5687115 & 23.4301555 \\
\hline Al & 15.4595820 & 10.7917988 & 23.4962192 \\
\hline Al & 10.6049409 & 7.9684757 & 23.5744220 \\
\hline $\mathrm{P}$ & 10.6835314 & 7.9425862 & 26.6878248 \\
\hline$P$ & 15.3942002 & 10.7387943 & 26.6597413 \\
\hline 0 & 9.0338515 & 10.8519760 & 28.1083782 \\
\hline 0 & 11.7594783 & 8.9833864 & 27.0645412 \\
\hline $\mathrm{H}$ & 15.8528415 & 9.3262072 & 26.7663547 \\
\hline $\mathrm{H}$ & 11.5199574 & 6.7986826 & 23.4674202 \\
\hline 0 & 13.8056692 & 10.3401275 & 23.0571567 \\
\hline 0 & 11.2800725 & 11.7909649 & 27.4287605 \\
\hline 0 & 9.4966040 & 8.0406815 & 27.6534359 \\
\hline $\mathrm{H}$ & 16.2281625 & 11.6335032 & 27.5089311 \\
\hline 0 & 9.1954786 & 7.7364805 & 22.5748818 \\
\hline 0 & 16.0136868 & 12.1199264 & 22.5376279 \\
\hline 0 & 9.4803214 & 10.5134074 & 17.0007783 \\
\hline
\end{tabular}




\begin{tabular}{|c|c|c|}
\hline 13.9482207 & 10.8217085 & 27.1724721 \\
\hline 11.2699899 & 6.5789079 & 26.8043088 \\
\hline 16.3883076 & 9.6546536 & 23.2482472 \\
\hline 11.4843888 & 9.3632087 & 22.9881863 \\
\hline 10.4551411 & 12.0253488 & 15.0122140 \\
\hline 12.1868176 & 10.8079408 & 24.9355151 \\
\hline 15.4731068 & 11.2174667 & 25.1999800 \\
\hline 10.1679968 & 8.2026865 & 25.2556701 \\
\hline 10.4908237 & 12.0225807 & 29.7375355 \\
\hline 8.6899161 & 15.0298927 & 15.1549158 \\
\hline 5.3570740 & 14.6893430 & 16.5935283 \\
\hline 5.3103897 & 14.7036485 & 28.4231946 \\
\hline 12.2397801 & 18.7169806 & 21.5668818 \\
\hline 12.3836843 & 13.3185721 & 21.6186856 \\
\hline 17.1329169 & 16.0441901 & 21.5743043 \\
\hline 17.0445729 & 16.0577496 & 18.3929599 \\
\hline 12.3019099 & 13.1878973 & 18.4139033 \\
\hline 12.2982648 & 18.7022211 & 18.4109594 \\
\hline 5.3859518 & 17.1900260 & 26.5514796 \\
\hline 5.3897754 & 17.2442129 & 23.4811286 \\
\hline 8.4686251 & 14.7191219 & 28.4198190 \\
\hline 8.5160408 & 14.7185310 & 16.6005790 \\
\hline 15.5410608 & 13.2868466 & 18.5324024 \\
\hline 15.4790588 & 18.7662693 & 18.4982978 \\
\hline 10.7254373 & 15.9821411 & 18.4589305 \\
\hline 10.5847214 & 16.0244864 & 21.6043329 \\
\hline 15.4454561 & 18.7265080 & 21.6553727 \\
\hline 15.6684110 & 13.3025913 & 21.6142416 \\
\hline 8.5423900 & 17.4088597 & 23.4873673 \\
\hline 8.5403864 & 17.2950351 & 26.6342031 \\
\hline 8.9789990 & 13.2711450 & 16.8868698 \\
\hline 6.7820315 & 14.3680708 & 28.1121265 \\
\hline 11.6348730 & 17.1238311 & 21.9164665 \\
\hline 14.2127925 & 13.7137846 & 21.7182361 \\
\hline 15.9594083 & 17.3042464 & 21.9483760 \\
\hline 15.9899897 & 14.9520958 & 18.1744314 \\
\hline 11.8769424 & 14.6597965 & 18.2730228 \\
\hline 13.7953775 & 18.3805835 & 18.2426569 \\
\hline 7.0532200 & 17.6273587 & 26.8860169 \\
\hline 9.0478413 & 18.7937933 & 23.2785645 \\
\hline 4.7481433 & 18.5875407 & 23.4511420 \\
\hline 18.2458704 & 15.8208395 & 17.5456828 \\
\hline 11.9105100 & 19.8454965 & 17.5393586 \\
\hline 11.6457311 & 12.3208701 & 17.3269251 \\
\hline 4.8499534 & 15.9140381 & 27.6062058 \\
\hline 11.5331706 & 19.7314333 & 22.3967668 \\
\hline 11.7773126 & 11.7984831 & 22.6768818 \\
\hline 18.3909201 & 16.2739281 & 22.3370420 \\
\hline 8.9790051 & 16.1116206 & 27.5073247 \\
\hline 16.2506438 & 12.3672160 & 17.6007951 \\
\hline 9.3475119 & 15.7092970 & 17.4182534 \\
\hline 15.8688092 & 19.9620620 & 17.7012439 \\
\hline 9.3053297 & 16.2949147 & 22.4146324 \\
\hline 7.0456653 & 14.8480049 & 17.0155123 \\
\hline 9.3975840 & 13.3243055 & 27.9321606 \\
\hline 13.9439080 & 18.7838017 & 21.9303742 \\
\hline 11.1268875 & 14.6665521 & 21.9644812 \\
\hline 16.5812288 & 14.4701841 & 22.0347589 \\
\hline 16.4386622 & 17.4066141 & 17.9810739 \\
\hline 13.8193656 & 13.0896356 & 18.2843921 \\
\hline 11.4938797 & 17.4729201 & 17.9738277 \\
\hline 4.4963898 & 18.3638281 & 26.7705429 \\
\hline 9.3620062 & 18.4787159 & 27.0096516 \\
\hline 6.8546625 & 17.4152444 & 23.0951420 \\
\hline 5.1724931 & 14.9866360 & 15.1462317 \\
\hline 11.9929687 & 19.0828815 & 19.8692671 \\
\hline 11.8508608 & 12.6337757 & 19.8017705 \\
\hline 17.4892981 & 16.1000070 & 19.8623659 \\
\hline 5.2578307 & 16.6367157 & 24.8922298 \\
\hline 8.6617520 & 14.9922006 & 29.8707672 \\
\hline 16.0173856 & 12.8789974 & 20.1605411 \\
\hline 15.7542411 & 19.1168633 & 20.1949932 \\
\hline 10.1916130 & 16.1089048 & 20.1062146 \\
\hline 8.7697008 & 16.9258960 & 25.1588511 \\
\hline 10.3663917 & 11.6747354 & 22.2715300 \\
\hline 9.6964232 & 11.2005583 & 20.2737271 \\
\hline 9.5973985 & 11.6311174 & 21.8250182 \\
\hline 8.8295325 & 10.4839306 & 20.0112259 \\
\hline 10.7023407 & 11.8471498 & 19.9419525 \\
\hline 5.1458125 & 15.0277339 & 29.8671488 \\
\hline
\end{tabular}

27.1724721

23.2482472

2.9881863

24.9355151

5. 1999800

25.2556701

5.1549158

16.5935283

1946

21.6186856

5743043

18.4139033

109594

23.4811286

.4198190

18.5324024

. 4982978

21.6043329

.6553727

6142416

26.6342031

16.8868698

28.1121265

21.9483760

.1744314

18.2730228
18.2426569

26.8860169

23.2785645

7.5456828

17.5393586

17.3269251

062058

22.6768818

22.3370420

27.5073247

17.7012439

146324

27.9321606

1.9303742

22.0347589

.9810739

17.9738277

.7705429

23.0951420

1462317

92671

19.8623659

24.8922298

29.8707672

20.1062146

.1588511

20.2737271

8250182

19.9419525

29.8671488 
$\mathrm{H}$

Al 13

163

H

Si $\quad 5.3459797$

Si $\quad 5.3302835$

Si $\quad 5.3068927$

$\mathrm{Si} \quad 5.3419645$

$\mathrm{Si} \quad 3.2287149$

$\mathrm{Si} \quad 3.2870113$

$\mathrm{Si} \quad 8.4390493$

$\mathrm{Si} \quad 8.4645307$

$\mathrm{Si} \quad 8.4913679$

$\mathrm{Si} \quad 8.4713027$

$\mathrm{Si} \quad 1.6806819$

Si $\quad 1.6274457$

o 6.9094192

4.9052374

4.8243402

8. 9473579

6.9198170

2. 1257412

2. 2486638

0.2707275

4.9205252

4.4461286

4.5445388

2. 4844996

8.9121248

2.2090017

4. 4142829

6.8821876

6.8908378

9. 3060428

4.5491438

0.2082809

2.5709531

2.6186829

5.1305954

5.0371504

3.8280984

8.6524381

8.7927709

1.7760363

5.1292327

3.3555226

3.2440980

3.2151519

3. 7823359

3.7587133

1.6859832

1.7264830

4.8712675

0.2661888

2. 2724597

2.1005773

4. 5164504

4.5701742

2.4258860

4.4104067

2.5765431

2.6172876

0.2174757

3.7011184

3. 3573493

2. 1233120

10.0524012

9.9820095

12.1612758

12.1874661

15.3056806

10.4975940

10.5374299

15.2524444

8.8921219

11.6770649

15.7086652

11.4061561

13.7556396
8.8103781

9. 2119053

9.1736912

6.7510932

6.7317909

7.9353342

7. 9840390

9.1371517

9.2048180

6.7375194

6.7304333

10.7107830

10.6662653

9.6153578

10.7196750

5.3631848

5.3452861

6. 3690912

9.1236624

6.9404221

10.3568445

7.9484100

8.1515968

7.8008113

11.6392473

7.9816575

11.8940534

10.4668859

8.9784896

6.8217847

5.5578093

5.5337036

10.7329602

6.6442202

9.4229351

8.8500100

7. 1830695

7.9061985

8.8051480

7. 1491034

11.1806398

8.8467261

11.8406958

15.8162119

15.8294642

11.8696596

11.8795413

13.1063307

13.0851304

3. 0448873

13.3559550

16.9115689

14.6623619

15.5924087

15.9865468

12.1342117

13.3099206

14.4049710

17.1388687

12.9672409

15.8563468

11.8398464

12.6578013

11.8897380

11.8627890

10.5846124

10.5655455

10.7107830

7.9436822

7.9357783

10.6662653

10.6727411

9.0561782

9.2539156

6.7693421

10.3216787
15.2020226

16.6393525

28.5763329

21.6124801

18.5280085

26.6474839

23.5923931

28.5678295

16.6251532

18.5359261

21.6313643

23.5568024

26.6547370

16.8897716

28.2826554

21.8532583

21.8994298

18.3492866

26.7851265

23.3691919

23.2345034

17.5502579

27.6898712

22.5870629

27.6200239

17.5855450

22.5959309

17.0596613

28.1632618

21.9412866

18.1337948

18.1366738

27.1004317

26.9902591

23.2968737

15.2111502

20.0621828

25.1313423

30.0035730

20.0861116

25.1168480

30.0150104

15.1794971

21.6274127

18.5136419

28.5556858

16.6123436

18.5592014

21.5960597

16.8633081

21.7024336

21.8980277

18.2830031

17.5770826

22.5438996

17.4928088

28.1776268

22.0129129

18.1326711

18.3560744

20.0647535

29.9824367

20.0593858

16.5293940

28.4814584

26.6904834

23.5470446

23.5568024

23.5969625

26.6579040

26.6547370

28.2607861

26.9806758

26.7741167

23. 4848865

23.2024812 


\begin{tabular}{|c|c|c|}
\hline 11.2765805 & 11.6432204 & 27.5383473 \\
\hline 9.2922345 & 8.0880171 & 27.6794094 \\
\hline 16.0419077 & 11.5625141 & 27.5438975 \\
\hline 9.2229716 & 7.7945520 & 22.6057992 \\
\hline 15.8340004 & 11.8940534 & 22.5959309 \\
\hline 9.4152585 & 10.4703128 & 16.9873320 \\
\hline 13.7069792 & 10.7388958 & 27.1400969 \\
\hline 11.1321038 & 6.5843806 & 26.8507975 \\
\hline 16.1708756 & 9.5228956 & 23.3170489 \\
\hline 11.3322072 & 9.2521229 & 23.1332976 \\
\hline 10.4386136 & 11.8759574 & 15.0914195 \\
\hline 11.9862359 & 10.9289312 & 25.1141477 \\
\hline 15.4010351 & 11.1806398 & 25.1168480 \\
\hline 9.9807238 & 8.1147155 & 25.1330432 \\
\hline 10.4309272 & 11.8737374 & 29.9011321 \\
\hline 8.7038280 & 14.9447879 & 15.1460336 \\
\hline 5.3411367 & 14.5852452 & 16.6171453 \\
\hline 5.3066749 & 14.5938848 & 28.5786081 \\
\hline 12.1193921 & 18.5506882 & 21.6124801 \\
\hline 12.1040643 & 13.1060567 & 21.6251606 \\
\hline 16.8690968 & 15.8162119 & 21.6274127 \\
\hline 16.8401506 & 15.8294642 & 18.5136419 \\
\hline 12.1156995 & 13.0743169 & 18.5105362 \\
\hline 12.1544639 & 18.5313859 & 18.5280085 \\
\hline 5.3105925 & 16.9844869 & 26.6187095 \\
\hline 5.3041731 & 16.9839678 & 23.5795151 \\
\hline 8.4443658 & 14.5800032 & 28.5238851 \\
\hline 8.4806735 & 14.5899496 & 16.5748136 \\
\hline 15.3109819 & 13.1063307 & 18.5592014 \\
\hline 15.3038673 & 18.5371144 & 18.5359261 \\
\hline 10.5815465 & 15.8339972 & 18.5137506 \\
\hline 10.4989411 & 15.8560830 & 21.6077216 \\
\hline 15.2838020 & 18.5300283 & 21.6313643 \\
\hline 15.3514817 & 13.0851304 & 21.5960597 \\
\hline 8.4346993 & 17.1167309 & 23.5352571 \\
\hline 8.4339198 & 17.0433518 & 26.6262281 \\
\hline 8.9492695 & 13.0473463 & 16.8407038 \\
\hline 6.8701646 & 14.2255732 & 28.3163279 \\
\hline 11.5948210 & 17.0419270 & 21.8742242 \\
\hline 13.7852038 & 13.3756106 & 21.7101539 \\
\hline 15.8037276 & 17.0172345 & 21.9241331 \\
\hline 15.7255761 & 14.6623619 & 18.2830031 \\
\hline 11.6756081 & 14.6317327 & 18.3436233 \\
\hline 13.7323164 & 18.1686862 & 18.3492866 \\
\hline 6.8633978 & 17.4086625 & 26.8771694 \\
\hline 8.9204297 & 18.5138895 & 23.3645687 \\
\hline 4.7208758 & 18.3506234 & 23.4839260 \\
\hline 18.0356931 & 15.6116741 & 17.6531964 \\
\hline 11.7663170 & 19.6518957 & 17.6274973 \\
\hline 11.3985076 & 12.1357764 & 17.3967239 \\
\hline 4.8416776 & 15.8360715 & 27.6550221 \\
\hline 11.4198178 & 19.5139623 & 22.5068062 \\
\hline 11.5580067 & 11.7738411 & 22.6559277 \\
\hline 18.0872354 & 15.9726822 & 22.4693010 \\
\hline 8.8906615 & 15.8140609 & 27.5785575 \\
\hline 15.9903719 & 12.2137162 & 17.5800235 \\
\hline 9.3321380 & 15.6023350 & 17.5039108 \\
\hline 15.6903247 & 19.6798322 & 17.6630187 \\
\hline 9.1756493 & 16.1192000 & 22.5130863 \\
\hline 6.9165541 & 14.7146743 & 16.9740890 \\
\hline 9.3101099 & 13.2807396 & 28.0927342 \\
\hline 13.7033372 & 18.6213797 & 21.9412866 \\
\hline 11.1197097 & 14.4472745 & 21.9945642 \\
\hline 16.2015418 & 14.4049710 & 22.0129129 \\
\hline 16.1892654 & 17.2549918 & 18.0988852 \\
\hline 13.7129563 & 12.9549735 & 18.3381592 \\
\hline 11.2931838 & 17.2298450 & 18.1028824 \\
\hline 4.4420435 & 18.1721044 & 26.8474190 \\
\hline 9.2561812 & 18.2306353 & 26.9886710 \\
\hline 6.8605441 & 17.0873545 & 23.1768777 \\
\hline 5.0972851 & 14.9711107 & 15.1998363 \\
\hline 11.8496497 & 18.9826645 & 20.0621828 \\
\hline 11.6316432 & 12.5076630 & 19.9804546 \\
\hline 17.3261171 & 15.8563468 & 20.0647535 \\
\hline 5.1303667 & 16.4192826 & 25.0997935 \\
\hline 8.7004998 & 14.9436241 & 29.9449044 \\
\hline 15.7483107 & 12.6578013 & 20.0593858 \\
\hline 15.6052703 & 18.9486984 & 20.0861116 \\
\hline 10.0243308 & 15.9029866 & 20.0353645 \\
\hline 8.6784898 & 16.6225517 & 25.0724531 \\
\hline
\end{tabular}




\begin{tabular}{|c|c|c|c|}
\hline $\mathrm{H}$ & 10.1706059 & 11.5300769 & 22.3056039 \\
\hline C & 9.4698679 & 11.0560658 & 20.3235611 \\
\hline $\mathrm{H}$ & 9.3867119 & 11.3836241 & 21.8918093 \\
\hline 0 & 8.5701783 & 10.4016673 & 20.0078613 \\
\hline $\mathrm{H}$ & 10.5039729 & 11.7012772 & 20.0492934 \\
\hline $\mathrm{H}$ & 5.0942798 & 14.9719755 & 30.0030576 \\
\hline $\mathrm{H}$ & 15.9717479 & 19.5039359 & 22.5231911 \\
\hline \multicolumn{4}{|c|}{$\begin{array}{l}\mathrm{Ge} 13 \\
163\end{array}$} \\
\hline $\mathrm{H}$ & 8.6451770 & 9.0060170 & 15.1489746 \\
\hline $\mathrm{P}$ & 5.3826481 & 9.3381478 & 16.6892325 \\
\hline Al & 5.3461784 & 9.2892614 & 28.5059309 \\
\hline$P$ & 5.4039406 & 6.7470525 & 21.6177430 \\
\hline Al & 5.4374816 & 6.7518151 & 18.4791786 \\
\hline $\mathrm{P}$ & 3.2007831 & 7.9306561 & 26.6554079 \\
\hline Al & 3.2839098 & 8.0367671 & 23.5608517 \\
\hline$P$ & 8.4711931 & 9.1998278 & 28.4099206 \\
\hline Al & 8.5212819 & 9.2922183 & 16.6049483 \\
\hline $\mathrm{P}$ & 8.6124873 & 6.7210082 & 18.4267730 \\
\hline Al & 8.5885560 & 6.7232414 & 21.5886851 \\
\hline$P$ & 1.6844795 & 10.7840050 & 23.4684682 \\
\hline Al & 1.6008598 & 10.6985505 & 26.6262954 \\
\hline 0 & 6.8555824 & 9.7122434 & 16.9640525 \\
\hline 0 & 4.8849866 & 10.9416440 & 28.1320786 \\
\hline $\mathrm{H}$ & 4.9309517 & 5.3513253 & 21.8306927 \\
\hline $\mathrm{H}$ & 9.0999423 & 5.3563614 & 21.8840551 \\
\hline $\mathrm{O}$ & 7.1278374 & 6.3649913 & 18.2250991 \\
\hline 0 & 2.1371736 & 9.0393959 & 26.7705011 \\
\hline $\mathrm{H}$ & 2.1751919 & 7.0671814 & 23.3422907 \\
\hline $\mathrm{H}$ & 0.3092481 & 10.3626237 & 23.0833747 \\
\hline $\mathrm{O}$ & 4.9707762 & 8.1141943 & 17.5076821 \\
\hline 0 & 4.3287004 & 8.1565294 & 27.6658963 \\
\hline 0 & 4.6496483 & 7.7251318 & 22.5278222 \\
\hline 0 & 2.5563606 & 11.7672822 & 27.6096401 \\
\hline $\mathrm{O}$ & 9.0125043 & 7.9078136 & 17.5412722 \\
\hline 0 & 2.1295126 & 11.9611758 & 22.6027697 \\
\hline 0 & 4.4899810 & 10.5110252 & 17.1071586 \\
\hline 0 & 6.9989785 & 9.0379792 & 28.0193207 \\
\hline 0 & 6.8943589 & 6.8184319 & 21.9657058 \\
\hline $\mathrm{H}$ & 9.4393207 & 5.5494967 & 18.0254900 \\
\hline $\mathrm{H}$ & 4.6147220 & 5.5793229 & 18.0724241 \\
\hline $\mathrm{H}$ & 0.1981322 & 10.7595983 & 27.1220262 \\
\hline $\mathrm{H}$ & 2.5619518 & 6.6234931 & 26.9721726 \\
\hline 0 & 2.6579038 & 9.6271622 & 23.2280679 \\
\hline $\mathrm{H}$ & 5.1907911 & 9.0204044 & 15.2472371 \\
\hline 0 & 5.1725117 & 7.1730931 & 20.1556062 \\
\hline $\mathrm{O}$ & 3.8019689 & 7.9218991 & 25.2358541 \\
\hline $\mathrm{H}$ & 8.6604658 & 8.9642180 & 29.8679276 \\
\hline 0 & 8.8758980 & 7.0984966 & 19.8979665 \\
\hline $\mathrm{O}$ & 1.7002569 & 11.2060665 & 24.9512941 \\
\hline $\mathrm{H}$ & 5.2083022 & 9.0510837 & 29.9692771 \\
\hline $\mathrm{H}$ & 3.5124939 & 12.0234799 & 15.1534869 \\
\hline $\mathrm{P}$ & 3.2236532 & 15.9742381 & 21.6333417 \\
\hline Al & 3.1948481 & 15.9818378 & 18.4600409 \\
\hline $\mathrm{P}$ & 3.8256091 & 12.0247093 & 28.4250514 \\
\hline Al & 3.8168680 & 12.0397587 & 16.6109546 \\
\hline $\mathrm{P}$ & 1.6124504 & 13.2561327 & 18.4541441 \\
\hline Al & 1.6129310 & 13.2637562 & 21.5552034 \\
\hline 0 & 5.0072900 & 13.2808211 & 16.9662366 \\
\hline $\mathrm{H}$ & 0.1711675 & 13.6119989 & 21.6862206 \\
\hline $\mathrm{H}$ & 2.2855930 & 17.0931447 & 21.9252520 \\
\hline 0 & 2.0017340 & 14.7245386 & 18.1723824 \\
\hline 0 & 4.6435557 & 15.7148950 & 17.5224843 \\
\hline $\mathrm{O}$ & 4.5031141 & 16.1043378 & 22.4707112 \\
\hline 0 & 2.3265941 & 12.3241346 & 17.4664054 \\
\hline 0 & 4.3854681 & 13.3910392 & 28.0135870 \\
\hline 0 & 2.5580943 & 14.6562413 & 22.0112045 \\
\hline $\mathrm{H}$ & 2.6244143 & 17.3034763 & 18.0792554 \\
\hline $\mathrm{H}$ & 0.1453421 & 13.1001892 & 18.2531572 \\
\hline 0 & 3.6270269 & 15.9940087 & 20.1498135 \\
\hline $\mathrm{H}$ & 3.4710978 & 12.0207828 & 29.8712280 \\
\hline 0 & 2.0081948 & 12.8518924 & 19.8844416 \\
\hline$P$ & 10.1463736 & 11.9631533 & 16.5275696 \\
\hline Al & 10.0627290 & 11.9205856 & 28.3467655 \\
\hline $\mathrm{P}$ & 12.3813825 & 10.6189272 & 26.7291767 \\
\hline Al & 12.4500002 & 10.5592125 & 23.5075283 \\
\hline $\mathrm{P}$ & 15.5594783 & 10.7840050 & 23.4684682 \\
\hline $\mathrm{P}$ & 10.6349166 & 8.0184807 & 23.5106896 \\
\hline Al & 10.6775945 & 8.0087853 & 26.6079325 \\
\hline
\end{tabular}




\begin{tabular}{|c|c|c|c|}
\hline Al & 15.4758586 & 10.6985505 & 26.6262954 \\
\hline 0 & 8.9258454 & 10.6242698 & 28.0276110 \\
\hline 0 & 11.8784258 & 9.2027461 & 27.0772252 \\
\hline $\mathrm{H}$ & 15.9322802 & 9.2865524 & 26.7490195 \\
\hline $\mathrm{H}$ & 11.4364810 & 6.7641753 & 23.4741778 \\
\hline 0 & 14.1291012 & 10.3457267 & 23.0679328 \\
\hline 0 & 11.5238313 & 11.6819932 & 27.4281467 \\
\hline $\mathrm{O}$ & 9.2846279 & 8.1485358 & 27.6452440 \\
\hline $\mathrm{H}$ & 16.2942643 & 11.6139409 & 27.4685501 \\
\hline 0 & 9.4155021 & 7.9065669 & 22.5841908 \\
\hline 0 & 16.0045114 & 11.9611758 & 22.6027697 \\
\hline $\mathrm{O}$ & 9.5782868 & 10.6232111 & 17.0186044 \\
\hline 0 & 13.8294522 & 10.7702033 & 27.2081434 \\
\hline $\mathrm{H}$ & 11.2654762 & 6.6486062 & 26.7543175 \\
\hline $\mathrm{H}$ & 16.5062648 & 9.6588191 & 23.2346464 \\
\hline 0 & 11.5158708 & 9.1712680 & 23.0080218 \\
\hline $\mathrm{H}$ & 10.4455688 & 11.9100530 & 15.0699060 \\
\hline $\mathrm{O}$ & 12.3018931 & 10.8425933 & 25.2144559 \\
\hline $\mathrm{O}$ & 15.5752556 & 11.2060665 & 24.9512941 \\
\hline $\mathrm{O}$ & 10.1608482 & 8.2971432 & 24.9506457 \\
\hline $\mathrm{H}$ & 10.3966737 & 11.9103335 & 29.7977984 \\
\hline $\mathrm{H}$ & 8.7601247 & 14.9912170 & 15.0571096 \\
\hline$P$ & 5.4434375 & 14.7290217 & 16.6644564 \\
\hline Al & 5.3835646 & 14.7358048 & 28.4948075 \\
\hline $\mathrm{P}$ & 12.3414399 & 18.7631539 & 21.6177430 \\
\hline $\mathrm{Ge}$ & 12.1280742 & 13.2882681 & 21.6618961 \\
\hline $\mathrm{P}$ & 17.0986520 & 15.9742381 & 21.6333417 \\
\hline Al & 17.0698468 & 15.9818378 & 18.4600409 \\
\hline Al & 12.2627024 & 13.2630329 & 18.4252819 \\
\hline $\mathrm{Al}$ & 12.3749809 & 18.7679165 & 18.4791786 \\
\hline $\mathrm{P}$ & 5.3381779 & 17.2248253 & 26.6197519 \\
\hline Al & 5.2931150 & 17.1995393 & 23.5572408 \\
\hline $\mathrm{P}$ & 8.5364367 & 14.6784189 & 28.3420997 \\
\hline Al & 8.5992980 & 14.7151266 & 16.5114237 \\
\hline$P$ & 15.4874491 & 13.2561327 & 18.4541441 \\
\hline$P$ & 15.5499866 & 18.7371095 & 18.4267730 \\
\hline $\mathrm{P}$ & 10.7694568 & 16.0555532 & 18.3715454 \\
\hline $\mathrm{Al}$ & 10.6050974 & 16.1168627 & 21.5415967 \\
\hline $\mathrm{Al}$ & 15.5260553 & 18.7393428 & 21.5886851 \\
\hline Al & 15.4879297 & 13.2637562 & 21.5552034 \\
\hline $\mathrm{P}$ & 8.4335135 & 17.4542893 & 23.3994426 \\
\hline $\mathrm{Al}$ & 8.4794440 & 17.2529555 & 26.5249589 \\
\hline 0 & 9.1142213 & 13.0660042 & 16.8417907 \\
\hline 0 & 7.0491950 & 14.3378752 & 28.1292339 \\
\hline 0 & 11.8534434 & 17.3231411 & 21.8374495 \\
\hline 0 & 13.8202465 & 13.6665675 & 21.7067506 \\
\hline 0 & 16.1269126 & 17.1333166 & 21.9357324 \\
\hline 0 & 15.8767327 & 14.7245386 & 18.1723824 \\
\hline 0 & 11.8282614 & 14.9443974 & 18.1990825 \\
\hline 0 & 14.0653367 & 18.3810927 & 18.2250991 \\
\hline $\mathrm{O}$ & 6.8000393 & 17.6568690 & 26.8623939 \\
\hline $\mathrm{H}$ & 8.9022597 & 18.8645697 & 23.3072108 \\
\hline $\mathrm{H}$ & 4.6283912 & 18.5299770 & 23.4851414 \\
\hline $\mathrm{H}$ & 18.3052108 & 15.7542063 & 17.6605534 \\
\hline $\mathrm{H}$ & 11.9749444 & 19.9356799 & 17.6464602 \\
\hline $\mathrm{O}$ & 11.4616962 & 12.2284642 & 17.2687412 \\
\hline 0 & 4.9007335 & 16.1744245 & 27.6443586 \\
\hline $\mathrm{H}$ & 11.6093814 & 19.7124031 & 22.5009965 \\
\hline 0 & 11.6579754 & 11.8812283 & 22.6753149 \\
\hline $\mathrm{H}$ & 18.3400581 & 16.1004683 & 22.4458055 \\
\hline 0 & 8.9533837 & 15.8634976 & 27.4665175 \\
\hline $\mathrm{H}$ & 16.1804823 & 12.3516850 & 17.4956036 \\
\hline 0 & 9.5874114 & 15.8223814 & 17.4210273 \\
\hline $\mathrm{H}$ & 15.9383123 & 19.8892280 & 17.5671529 \\
\hline 0 & 9.1446053 & 16.5818414 & 22.3716330 \\
\hline 0 & 6.9322939 & 14.8815426 & 17.0035828 \\
\hline 0 & 9.3736545 & 13.4630266 & 27.9266747 \\
\hline 0 & 13.8318582 & 18.8345333 & 21.9657058 \\
\hline 0 & 11.0701709 & 14.5773849 & 22.1451970 \\
\hline 0 & 16.4330930 & 14.6562413 & 22.0112045 \\
\hline 0 & 16.4011681 & 17.5311001 & 18.0136733 \\
\hline 0 & 13.9780995 & 13.0956992 & 18.2473703 \\
\hline 0 & 11.4129400 & 17.3969383 & 18.0035664 \\
\hline $\mathrm{H}$ & 4.4486720 & 18.4088940 & 26.7742869 \\
\hline $\mathrm{H}$ & 9.3360196 & 18.4067497 & 26.9150328 \\
\hline $\mathrm{O}$ & 6.9398754 & 17.4289447 & 23.0742610 \\
\hline $\mathrm{H}$ & 5.2050063 & 15.0468323 & 15.2294415 \\
\hline 0 & 12.1100111 & 19.1891945 & 20.1556062 \\
\hline $\mathrm{O}$ & 11.6569960 & 12.6942594 & 19.9932236 \\
\hline $\mathrm{O}$ & 17.5020257 & 15.9940087 & 20.1498135 \\
\hline
\end{tabular}




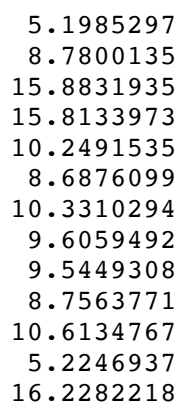

8.6457005

5.3557298

5.3359275

5.3122379

5.3442196

3.2363169

3. 3322264

8.4384321

8.4674230

8.4871668

8.4767552

1.6898214

1.6213102

6.9158789

4.9231133

4.8030867

9.0056708

6.9173385

2.1065751

2.2587779

0.2997791

4.9281242

4.4269613

4.5780559

2.4930889

8.9083916

2.1313571

4.4150951

6.8820103

6.8946536

9.3056803

4.5281417

0.2063019

2.5945320

2.7093558

5.1484747

5.0565604

3.8714652

8.6430161

8.7790090

1.7617314

5.1467677

3.3725740

3. 3117259

3.2292502

3.7924113

3.7722092

1.6857689

1.7270060

4.8936861

0.3089712

2.3364009

2.1129599

4.5133570

4.6475056

2.4435389

4.4067411

2.6796459

2.6186893

0.2212333

3.7511564

3.3742535

2. 0726076

10.0525108
16.6170497

15.0277373

12.8518924

19.1145980

16.0801046

16.9026130

11.5636259

11.1153479

11.3657661

10.3975689

11.8603678

15.0098628

19.7441137

8.8130747

9.2207387

9.1635379

6.7080156

6.7365654

7.9313480

8.0243149

9.1095355

9.2127659

6.7361699

6.7052958

10.7058640

10.6420222

9.6339484

10.7143905

5.3238732

5.3388979

6.3606613

9.0946143

7.0105342

10.2875446

7.9634689

8.1463670

7.7642896

11.6057122

7.9912485

11.9364170

10.4722078

8.9457433

6.7243647

5.5627857

5.5528290

10.7177870

6.6212360

9.4815715

8.8476447

7.1805968

7.9593060

8.8047507

7.1358480

11.1564971

8.8427675

11.8598183

15.8209933

15.8404191

11.8625982

11.8898878

13.1101591

13.1347837

13.0453098

13.5739173

16.9068833

14.6667357

15.5992626

15.9796296

12.1495168

13.3018782

14.3907853

17.1444251

12.9712842

15.8866637

11.8574986

12.6387358

11.8913842
25.2087200

29.7689030

19.8844416

19.8979665

19.8155970

24.8192102

22.3178622

20.3277776

21.8972894

20.0003181

20.0610222

29.9497208

22.4339769

15.2203212

16.6606721

28.5970424

21.6244307

18.5445309

26.6574408

23.6140620

28.5789967

16.6435516

18.5461774

21.6474954

23.5677160

26.6735832

16.9136142

28.3050180

21.8294566

21.9126853

18.3488105

26.7974545

23.4215063

23.2361863

17.5785434

27.7300949

22.6132715

27.6347142

17.6096467

22.6265324

17.0683516

28.1688610

21.9595674

18.1334719

18.1573548

27.1308923

26.9554997

23.2862037

15.2341495

20.0840861

25.1547447

30.0220394

20.1014116

25.1343920

30.0387239

15.1884760

21.6144094

18.5104972

28.5606103

16.6225290

18.5710886

21.6069835

16.8806617

21.7229981

21.9088657

18.3215649

17.5520644

22.5189941

17.5080729

28.1516490

21.9882837

18.1311499

18.3409369

20.0485631

29.9896794

20.0789411

16.5051175 


\begin{tabular}{|c|c|c|c|}
\hline $\mathrm{Si}$ & 9.9685547 & 11.8409108 & 28.4532675 \\
\hline $\mathrm{Si}$ & 12.1666048 & 10.5571669 & 26.6984727 \\
\hline $\mathrm{Si}$ & 12.2172093 & 10.4955053 & 23.5484486 \\
\hline $\mathrm{Si}$ & 15.3148202 & 10.7058640 & 23.5677160 \\
\hline $\mathrm{Si}$ & 10.4438929 & 7.9362560 & 23.6324946 \\
\hline $\mathrm{Si}$ & 10.5272448 & 7.9263882 & 26.6667112 \\
\hline $\mathrm{Si}$ & 15.2463090 & 10.6420222 & 26.6735832 \\
\hline 0 & 8.8910419 & 10.6386291 & 28.2376617 \\
\hline 0 & 11.6756643 & 9.0339411 & 27.0074326 \\
\hline $\mathrm{H}$ & 15.6905680 & 9.2253733 & 26.7869871 \\
\hline $\mathrm{H}$ & 11.2783048 & 6.7045999 & 23.5700402 \\
\hline 0 & 13.7857648 & 10.2457100 & 23.2030312 \\
\hline 0 & 11.2646158 & 11.6303632 & 27.5094941 \\
\hline $\mathrm{O}$ & 9.3051443 & 8.0419249 & 27.7229516 \\
\hline $\mathrm{H}$ & 16.0494195 & 11.5298043 & 27.5590079 \\
\hline 0 & 9.1790635 & 7.8044440 & 22.6243525 \\
\hline 0 & 15.7563558 & 11.9364170 & 22.6265324 \\
\hline 0 & 9.4306734 & 10.4736988 & 16.9900989 \\
\hline $\mathrm{O}$ & 13.7048876 & 10.7245556 & 27.1717470 \\
\hline $\mathrm{H}$ & 11.1288030 & 6.5697166 & 26.7879159 \\
\hline $\mathrm{H}$ & 16.2531286 & 9.5791106 & 23.3086317 \\
\hline $\mathrm{O}$ & 11.3602397 & 9.1801541 & 23.1461155 \\
\hline $\mathrm{H}$ & 10.4230995 & 11.8615215 & 15.0632808 \\
\hline 0 & 12.0260074 & 10.8710702 & 25.1135470 \\
\hline $\mathrm{O}$ & 15.3867301 & 11.1564971 & 25.1343920 \\
\hline $\mathrm{O}$ & 9.9317283 & 8.1736088 & 25.1632176 \\
\hline $\mathrm{H}$ & 10.4143599 & 11.8574013 & 29.8738682 \\
\hline $\mathrm{H}$ & 8.7095987 & 14.9369297 & 15.1119520 \\
\hline $\mathrm{Si}$ & 5.3475829 & 14.5859522 & 16.6071942 \\
\hline $\mathrm{Si}$ & 5.3006041 & 14.5854007 & 28.5639961 \\
\hline $\mathrm{Si}$ & 12.1247372 & 18.5076106 & 21.6244307 \\
\hline $\mathrm{Ga}$ & 12.0980000 & 13.1654623 & 21.6558442 \\
\hline $\mathrm{Si}$ & 16.9367247 & 15.8209933 & 21.6144094 \\
\hline $\mathrm{Si}$ & 16.8542490 & 15.8404191 & 18.5104972 \\
\hline $\mathrm{Si}$ & 12.1202912 & 13.0947363 & 18.4663656 \\
\hline $\mathrm{Si}$ & 12.1567190 & 18.5361605 & 18.5445309 \\
\hline $\mathrm{Si}$ & 5.3213143 & 16.9683138 & 26.6050751 \\
\hline $\mathrm{Si}$ & 5.2950509 & 16.9855852 & 23.6017569 \\
\hline $\mathrm{Si}$ & 8.4406426 & 14.5655229 & 28.4913425 \\
\hline $\mathrm{Si}$ & 8.4867559 & 14.5917271 & 16.5431392 \\
\hline $\mathrm{Si}$ & 15.3107677 & 13.1101591 & 18.5710886 \\
\hline $\mathrm{Si}$ & 15.2996662 & 18.5357650 & 18.5461774 \\
\hline $\mathrm{Si}$ & 10.5874132 & 15.8292602 & 18.4884683 \\
\hline $\mathrm{Si}$ & 10.4291751 & 15.8530555 & 21.6027476 \\
\hline $\mathrm{Si}$ & 15.2892546 & 18.5048908 & 21.6474954 \\
\hline $\mathrm{Si}$ & 15.3520048 & 13.1347837 & 21.6069835 \\
\hline $\mathrm{Si}$ & 8.4104269 & 17.1990603 & 23.5263252 \\
\hline $\mathrm{Si}$ & 8.4386885 & 17.0299311 & 26.5945019 \\
\hline 0 & 8.9453781 & 13.0467186 & 16.8144936 \\
\hline $\mathrm{O}$ & 6.8632106 & 14.2224062 & 28.2952403 \\
\hline $\mathrm{O}$ & 11.5706008 & 17.0011745 & 21.8475714 \\
\hline 0 & 13.8227633 & 13.6083554 & 21.7320963 \\
\hline 0 & 15.8672462 & 17.0117102 & 21.9372912 \\
\hline $\mathrm{O}$ & 15.7379586 & 14.6667357 & 18.3215649 \\
\hline $\mathrm{O}$ & 11.7089676 & 14.6580907 & 18.2852497 \\
\hline $\mathrm{O}$ & 13.7298379 & 18.1602564 & 18.3488105 \\
\hline 0 & 6.8720906 & 17.4049157 & 26.8685981 \\
\hline $\mathrm{H}$ & 8.9270137 & 18.5910820 & 23.4143678 \\
\hline $\mathrm{H}$ & 4.5907951 & 18.2970718 & 23.5678891 \\
\hline $\mathrm{H}$ & 18.0342297 & 15.6188176 & 17.6297822 \\
\hline $\mathrm{H}$ & 11.7733317 & 19.6666202 & 17.6544772 \\
\hline $\mathrm{O}$ & 11.4111393 & 12.1597671 & 17.3458288 \\
\hline $\mathrm{O}$ & 4.8381874 & 15.8448058 & 27.6624034 \\
\hline $\mathrm{H}$ & 11.4509690 & 19.4769669 & 22.5319026 \\
\hline $\mathrm{O}$ & 11.5710775 & 11.6962107 & 22.6567379 \\
\hline $\mathrm{H}$ & 18.1637055 & 15.9667087 & 22.4453160 \\
\hline $\mathrm{O}$ & 8.8929090 & 15.7897803 & 27.5349148 \\
\hline $\mathrm{H}$ & 16.0069096 & 12.2276442 & 17.5945261 \\
\hline $\mathrm{O}$ & 9.3473999 & 15.6028881 & 17.4663932 \\
\hline $\mathrm{H}$ & 15.6864355 & 19.6881801 & 17.6862533 \\
\hline $\mathrm{O}$ & 9.0834205 & 16.2406584 & 22.4238044 \\
\hline $\mathrm{O}$ & 6.9250548 & 14.7346145 & 16.9484918 \\
\hline 0 & 9.2889957 & 13.2543545 & 28.0622866 \\
\hline 0 & 13.7071530 & 18.5239597 & 21.9595674 \\
\hline 0 & 10.9267290 & 14.4305825 & 22.1327121 \\
\hline $\mathrm{O}$ & 16.3046446 & 14.3907853 & 21.9882837 \\
\hline $\mathrm{O}$ & 16.1895256 & 17.2601024 & 18.0974983 \\
\hline $\mathrm{O}$ & 13.7176406 & 12.9590904 & 18.3207287 \\
\hline $\mathrm{O}$ & 11.2703469 & 17.2504611 & 18.1240048 \\
\hline $\mathrm{H}$ & 4.4409375 & 18.1559333 & 26.7828872 \\
\hline
\end{tabular}


$\begin{array}{ll}9.2791642 & 18.2063805 \\ 6.8313079 & 17.2538536\end{array}$

$5.0892771 \quad 14.9484461$

$11.8690598 \quad 18.9801919$

$11.5936336 \quad 12.5341035$

$17.3761552 \quad 15.8866637$

$5.1731455 \quad 16.3527091$

$8.7053667 \quad 14.9343033$

$15.6976063 \quad 12.6387358$

$15.5915084 \quad 18.9354430$

$10.0310111 \quad 15.8228074$

$8.6689144 \quad 16.6204938$

$10.2054926 \quad 11.4499365$

$9.4198523 \quad 11.1309516$

$9.4162035 \quad 11.3222777$

$8.4949684 \quad 10.5146156$

$10.4718418 \quad 11.7814650$

$5.0852705 \quad 14.9484894$

15.9309664 13

163

$\mathrm{H} \quad 8.6566757$

5.3992547

Al 5.3479839

$\mathrm{P} \quad 5.3951542$

Al $\quad 5.4565345$

P 3.2144193

Al $\quad 3.3403726$

P $\quad 8.4717815$

Al 8.5385815

$\mathrm{P} \quad 8.6263832$

Al $\quad 8.5903003$

P $\quad 1.6808727$

Al 1.5943518

O 6.8710093

4.8947160

4.8187689

9.1439940

7.1482238

2. 1468852

2. 2577570

0.3184068

5. 0020422

4.3147504

4.7128439

2.5576513

9.0162684

2. 1281610

4.4978954

6.9965787

6.8896094

9.4714878

4.6449723

0.2010890

2.5683510

2. 6785239

5.1985968

5.1833036

3.8501441

8.6707670

8.8735742

1.6659366

5. 2149170

3. 5311616

3. 2776689

3. 2180228

3.8327381

Al $\quad 3.8245966$

$\mathrm{P} \quad 1.6178517$

Al $\quad 1.6619850$

5.0143406

0.2106549

2.3377642

2. 0141024

4.6613527

4.5681488

2. 3265812

4.3849373

2. 6171767
19.5092024

9.0482303

9.3636342

9.2809626

6.7637110

6.7571217

7.9246374

8.0620396

9.1765372

9.3256312

6.7470099

6.7142589

10.7858878

10.6892178

9.7519446

10.9332026

5.4135845

5.3575016

6.3700281

9. 0321000

7.0720348

10.3381981

8.1397582

8.1537217

7.8084998

11.7445087

7.9370642

11.9590138

8.9997455

6.7309842

5.5855523

5.5854069

10.7235750

6.6186630

9.6436133

9.0363839

7.1685052

7.9105947

9.0056409

7.1307042

11.2251117

9.0631377

12.0301269

15.9748986

16.0032268

12.0149497

12.0562957

13.2898566

13.2772177

13.2983938

13.5870336

17.0942815

14.7559968

15.7424299

16.1095471

12.3523621

13.3792012

14.6593476
10.5303824
26.9504344

23.2062955

15.1862802

20.0840861

19.9259310

20.0485631

25.1005493

29.9094550

20.0789411

20.1014116

20.0113332

25.0329678

22.2914593

20.2892163

21.8757060

19.9652993

20.0089632

29.9919031

22.5400674

15.1643955

16.7108342

28.5269717

21.6324260

18.4839686

26.6583619

23.5768800

28.4161549

16.6225530

18.4480975

21.6040407

23.4876469

26.6371125

16.9728385

28.1392278

21.8815426

21.8681492

18.2371335

26.7377229

23.3220185

23.0871707

17.5364222

27.6978657

22.5292675

27.6279687

17.5620907

22.6147303

17.1286371

28.0421364

21.9693288

18.0557520

18.0531881

27.1612870

26.9651961

23.2793686

15.2721666

20.1622606

25.2527949

29.8818697

19.9211504

24.9671443

29.9939298

15.1622338

21.6205240

18.4512086

28.4301611

16.6217993

18.4501858

21.5623223

16.9832315

21.6838781

21.9045694

18.1623558

17.5019885

22.4422822

17.4620076

28.0005281

22.0241323 


\begin{tabular}{|c|c|c|c|}
\hline $\mathrm{H}$ & 2.6558063 & 17.3375504 & 18.1039137 \\
\hline $\mathrm{H}$ & 0.1486685 & 13.1433213 & 18.2574456 \\
\hline 0 & 3.6693887 & 15.9751020 & 20.1356773 \\
\hline $\mathrm{H}$ & 3.4911506 & 12.0252534 & 29.8794134 \\
\hline 0 & 2.0240754 & 12.8872153 & 19.8795437 \\
\hline $\mathrm{P}$ & 10.1516516 & 11.9806297 & 16.4938140 \\
\hline Al & 10.0369372 & 11.8981356 & 28.2931626 \\
\hline $\mathrm{P}$ & 12.3876992 & 10.5656158 & 26.7630047 \\
\hline Al & 12.4531321 & 10.4670311 & 23.5318556 \\
\hline$P$ & 15.5558715 & 10.7858878 & 23.4876469 \\
\hline $\mathrm{P}$ & 10.5897784 & 7.9857001 & 23.5609416 \\
\hline Al & 10.6660916 & 7.9869034 & 26.6343360 \\
\hline Al & 15.4693505 & 10.6892178 & 26.6371125 \\
\hline 0 & 8.9243179 & 10.5819960 & 27.9636168 \\
\hline $\mathrm{O}$ & 11.8702001 & 9.1634492 & 27.1473259 \\
\hline $\mathrm{H}$ & 15.9395577 & 9.2790068 & 26.7227321 \\
\hline $\mathrm{H}$ & 11.2930259 & 6.6733573 & 23.5788273 \\
\hline 0 & 14.1389506 & 10.3203049 & 23.0711645 \\
\hline $\mathrm{O}$ & 11.5235264 & 11.6552395 & 27.4143404 \\
\hline 0 & 9.2822717 & 8.0924598 & 27.6916977 \\
\hline $\mathrm{H}$ & 16.2942662 & 11.5929098 & 27.4856262 \\
\hline $\mathrm{O}$ & 9.3700803 & 7.9116459 & 22.6278601 \\
\hline 0 & 16.0031597 & 11.9590138 & 22.6147303 \\
\hline 0 & 9.6172526 & 10.6440273 & 17.0367826 \\
\hline $\mathrm{O}$ & 13.8316376 & 10.7296030 & 27.2532542 \\
\hline $\mathrm{H}$ & 11.2594386 & 6.6235695 & 26.7142147 \\
\hline $\mathrm{H}$ & 16.5262537 & 9.6748352 & 23.2850615 \\
\hline 0 & 11.5582525 & 9.0528485 & 23.0293386 \\
\hline $\mathrm{H}$ & 10.3602777 & 11.9015540 & 15.0216242 \\
\hline 0 & 12.3335778 & 10.7354853 & 25.2418060 \\
\hline 0 & 15.5409353 & 11.2251117 & 24.9671443 \\
\hline 0 & 10.1324052 & 8.3419085 & 24.9907718 \\
\hline $\mathrm{H}$ & 10.3184615 & 11.8993106 & 29.7553060 \\
\hline $\mathrm{H}$ & 8.7812447 & 14.9560783 & 15.0243947 \\
\hline $\mathrm{P}$ & 5.4537487 & 14.7401979 & 16.6550433 \\
\hline Al & 5.3808110 & 14.7248848 & 28.4843205 \\
\hline $\mathrm{P}$ & 12.3326536 & 18.7798123 & 21.6324260 \\
\hline $\mathrm{Ti}$ & 12.1053946 & 13.2381642 & 21.6516532 \\
\hline $\mathrm{P}$ & 17.1526676 & 15.9748986 & 21.6205240 \\
\hline Al & 17.0930215 & 16.0032268 & 18.4512086 \\
\hline Al & 12.2536164 & 13.2540573 & 18.3855588 \\
\hline Al & 12.3940338 & 18.7732231 & 18.4839686 \\
\hline $\mathrm{P}$ & 5.3463343 & 17.2037147 & 26.6171860 \\
\hline Al & 5.2924565 & 17.1967926 & 23.5812327 \\
\hline$P$ & 8.5384965 & 14.6596430 & 28.3054262 \\
\hline Al & 8.6140043 & 14.7217610 & 16.4853008 \\
\hline $\mathrm{P}$ & 15.4928504 & 13.2898566 & 18.4501858 \\
\hline $\mathrm{P}$ & 15.5638826 & 18.7631112 & 18.4480975 \\
\hline $\mathrm{P}$ & 10.7570406 & 16.0829297 & 18.3558705 \\
\hline Al & 10.5121441 & 16.1839034 & 21.5112828 \\
\hline Al & 15.5277996 & 18.7303603 & 21.6040407 \\
\hline Al & 15.5369837 & 13.2772177 & 21.5623223 \\
\hline $\mathrm{P}$ & 8.4157298 & 17.5018765 & 23.3957561 \\
\hline Al & 8.4762694 & 17.2543129 & 26.5205288 \\
\hline 0 & 9.1302325 & 13.0809852 & 16.8538002 \\
\hline $\mathrm{O}$ & 7.0453990 & 14.3378467 & 28.1071396 \\
\hline 0 & 11.7379886 & 17.3868677 & 21.8894431 \\
\hline $\mathrm{O}$ & 13.8436312 & 13.6386982 & 21.7041486 \\
\hline $\mathrm{O}$ & 16.1791457 & 17.1343181 & 21.9147287 \\
\hline 0 & 15.8891011 & 14.7559968 & 18.1623558 \\
\hline 0 & 11.7910291 & 14.9430606 & 18.2507931 \\
\hline 0 & 14.0857232 & 18.3861294 & 18.2371335 \\
\hline 0 & 6.7998830 & 17.6521670 & 26.8847384 \\
\hline $\mathrm{H}$ & 8.9885028 & 18.8715431 & 23.2814533 \\
\hline $\mathrm{H}$ & 4.4991408 & 18.4568592 & 23.5795144 \\
\hline $\mathrm{H}$ & 18.3231523 & 15.7809531 & 17.6422010 \\
\hline $\mathrm{H}$ & 12.0043621 & 19.9586655 & 17.6715630 \\
\hline $\mathrm{O}$ & 11.5107138 & 12.2779438 & 17.1384974 \\
\hline 0 & 4.8905459 & 16.1709913 & 27.6513443 \\
\hline $\mathrm{H}$ & 11.6715238 & 19.7921684 & 22.5014273 \\
\hline 0 & 11.6336604 & 11.7864568 & 22.7264836 \\
\hline $\mathrm{H}$ & 18.4038035 & 16.1054419 & 22.4172285 \\
\hline $\mathrm{O}$ & 8.9580448 & 15.8529470 & 27.4411948 \\
\hline $\mathrm{H}$ & 16.1801274 & 12.3807390 & 17.4919186 \\
\hline 0 & 9.6020968 & 15.8517493 & 17.3705195 \\
\hline $\mathrm{H}$ & 15.9423231 & 19.9182326 & 17.5880986 \\
\hline 0 & 9.0290555 & 16.5750566 & 22.3467467 \\
\hline 0 & 6.9463439 & 14.8965104 & 16.9761177 \\
\hline 0 & 9.3556819 & 13.4411683 & 27.8569516 \\
\hline 0 & 13.8271088 & 18.7470856 & 21.9693288 \\
\hline
\end{tabular}




\begin{tabular}{|c|c|c|}
\hline 11.0583310 & 14.6314848 & 22.0282639 \\
\hline 16.4921754 & 14.6593476 & 22.0241323 \\
\hline 16.4340228 & 17.5672463 & 18.0441290 \\
\hline 13.9821322 & 13.1391787 & 18.2519966 \\
\hline 11.4443604 & 17.4021063 & 17.9798781 \\
\hline 4.4439365 & 18.3832388 & 26.7245254 \\
\hline 9.3409082 & 18.4028648 & 26.9082773 \\
\hline 6.9136931 & 17.5992358 & 23.1184155 \\
\hline 5.2033614 & 15.0338779 & 15.2169269 \\
\hline 12.1208029 & 19.1846066 & 20.1622606 \\
\hline 11.6449618 & 12.6146466 & 19.9169494 \\
\hline 17.5443875 & 15.9751020 & 20.1356773 \\
\hline 5.2516918 & 16.5612343 & 25.2160793 \\
\hline 8.8016870 & 14.9861770 & 29.7341413 \\
\hline 15.8990741 & 12.8872153 & 19.8795437 \\
\hline 15.8110735 & 19.1468056 & 19.9211504 \\
\hline 10.1854695 & 16.1720820 & 19.7802424 \\
\hline 8.6684147 & 16.9276217 & 24.8065700 \\
\hline 10.3317921 & 11.4973890 & 22.3386850 \\
\hline 9.5219306 & 11.1480197 & 20.3030125 \\
\hline 9.5490217 & 11.3280689 & 21.8678686 \\
\hline 8.6248912 & 10.4818512 & 19.9863852 \\
\hline 10.5572107 & 11.8587849 & 19.9947357 \\
\hline 5.2224968 & 14.9967127 & 29.9397128 \\
\hline 16.1883221 & 19.7446220 & 22.4712798 \\
\hline \\
\hline 8.7253713 & 9.1047707 & 15.2585351 \\
\hline 5.4051490 & 9.3757087 & 16.6265983 \\
\hline 5.4211331 & 9.3542551 & 28.4377340 \\
\hline 5.3208946 & 6.7878638 & 21.5624346 \\
\hline 5.3593298 & 6.8174735 & 18.4326041 \\
\hline 3.1947214 & 8.1455233 & 26.5903037 \\
\hline 3.2626986 & 8.2335321 & 23.4663302 \\
\hline 8.5495971 & 9.3584278 & 28.5050271 \\
\hline 8.5533683 & 9.4373103 & 16.6996988 \\
\hline 8.5159176 & 6.8437060 & 18.4927151 \\
\hline 8.4960355 & 6.7867564 & 21.6643778 \\
\hline 1.5448489 & 10.8592793 & 23.5035304 \\
\hline 1.5508429 & 10.8466664 & 26.6614092 \\
\hline 7.0795595 & 9.7933882 & 16.9994876 \\
\hline 5.0155619 & 10.8079641 & 28.1173035 \\
\hline 4.8106182 & 5.3985174 & 21.7250854 \\
\hline 9.0240733 & 5.4148196 & 21.9012031 \\
\hline 6.8380077 & 6.4591589 & 18.1742235 \\
\hline 1.9859170 & 9.3809719 & 26.8681330 \\
\hline 2.2013039 & 7.2030552 & 23.2969801 \\
\hline 0.1671249 & 10.3242451 & 23.3226009 \\
\hline 4.9201982 & 7.9524973 & 17.4988358 \\
\hline 4.5624917 & 8.3653697 & 27.6470660 \\
\hline 4.4616817 & 7.9340295 & 22.5588613 \\
\hline 2.3618744 & 11.7763776 & 27.5729986 \\
\hline 8.9958360 & 8.2493608 & 17.5622200 \\
\hline 1.8250688 & 12.2783897 & 22.5509367 \\
\hline 4.4054634 & 10.7204854 & 17.1062099 \\
\hline 6.8860945 & 9.1469602 & 28.0355752 \\
\hline 7.0072005 & 6.8151144 & 22.0075423 \\
\hline 9.3615926 & 5.6853170 & 18.0926034 \\
\hline 4.5184826 & 5.6239391 & 18.1400770 \\
\hline 0.1181398 & 10.9700180 & 27.0477600 \\
\hline 2.5948518 & 6.8199071 & 26.9065612 \\
\hline 2.6953487 & 9.6046158 & 23.0790958 \\
\hline 5.2624858 & 9.1128921 & 15.1679362 \\
\hline 5.1710530 & 7.2891899 & 19.8854275 \\
\hline 3.7494255 & 8.2379684 & 24.9303738 \\
\hline 8.7032195 & 9.1345232 & 29.9690584 \\
\hline 8.7262504 & 7.2108782 & 20.1960885 \\
\hline 1.7689736 & 11.2731543 & 25.2006769 \\
\hline 5.2439882 & 9.0772165 & 29.8899702 \\
\hline 3.4964949 & 12.0459915 & 15.2068455 \\
\hline 3.2736673 & 16.1149160 & 21.5683264 \\
\hline 3.1838115 & 16.1521846 & 18.4030527 \\
\hline 3.8270173 & 12.0553703 & 28.4647037 \\
\hline 3.8232189 & 12.0694432 & 16.6593681 \\
\hline 1.6592441 & 13.3800601 & 18.5256723 \\
\hline 1.7301320 & 13.4637294 & 21.5793620 \\
\hline 4.8775544 & 13.1621395 & 16.9539648 \\
\hline 0.3982417 & 14.1294463 & 21.5762234 \\
\hline 2.2839518 & 17.1892681 & 21.8570327 \\
\hline
\end{tabular}




\begin{tabular}{|c|c|c|c|}
\hline $\mathrm{O}$ & 2.1297122 & 15.0478076 & 18.1996392 \\
\hline 0 & 4.4012014 & 15.9259101 & 17.4964892 \\
\hline 0 & 4.7348780 & 16.4007928 & 22.4771635 \\
\hline 0 & 2.5345002 & 12.3259202 & 17.4396161 \\
\hline 0 & 4.4730929 & 13.6061939 & 27.9992301 \\
\hline 0 & 2.7898029 & 14.5048077 & 22.0123425 \\
\hline $\mathrm{H}$ & 2.5853635 & 17.4653643 & 18.0362562 \\
\hline $\mathrm{H}$ & 0.2046112 & 13.2144661 & 18.2541166 \\
\hline 0 & 3.6726291 & 16.1722366 & 19.8614940 \\
\hline $\mathrm{H}$ & 3.5366277 & 12.0467519 & 29.9250873 \\
\hline 0 & 2.0912910 & 12.9376067 & 20.1613678 \\
\hline Al & 10.1351965 & 12.1481117 & 16.5006152 \\
\hline $\mathrm{P}$ & 10.0566639 & 12.1102286 & 28.3302373 \\
\hline Al & 12.2864941 & 10.7701296 & 26.5873533 \\
\hline $\mathrm{P}$ & 12.3241119 & 10.7045865 & 23.4235997 \\
\hline Al & 15.4198476 & 10.8592793 & 23.5035304 \\
\hline Al & 10.6119431 & 8.0758484 & 23.5645182 \\
\hline $\mathrm{P}$ & 10.7055004 & 8.0560850 & 26.6836967 \\
\hline$P$ & 15.4258416 & 10.8466664 & 26.6614092 \\
\hline 0 & 9.0262429 & 10.9913855 & 28.0702365 \\
\hline 0 & 11.7769134 & 9.1285612 & 26.9587924 \\
\hline $\mathrm{H}$ & 15.8457393 & 9.4320989 & 26.8609220 \\
\hline $\mathrm{H}$ & 11.5526447 & 6.9341933 & 23.3947400 \\
\hline 0 & 13.7953951 & 10.2284290 & 23.2901993 \\
\hline $\mathrm{O}$ & 11.3148337 & 11.9058431 & 27.4889804 \\
\hline 0 & 9.5421910 & 8.1937853 & 27.6752671 \\
\hline $\mathrm{H}$ & 16.2130857 & 11.7491093 & 27.5462618 \\
\hline 0 & 9.2024357 & 7.8133553 & 22.5645871 \\
\hline 0 & 15.7000675 & 12.2783897 & 22.5509367 \\
\hline 0 & 9.4304467 & 10.6449915 & 17.0771066 \\
\hline 0 & 13.9510002 & 10.9736460 & 27.0591232 \\
\hline $\mathrm{H}$ & 11.3139646 & 6.7113654 & 26.8802192 \\
\hline $\mathrm{H}$ & 16.3962946 & 9.7944270 & 23.1433062 \\
\hline 0 & 11.3990541 & 9.5264039 & 23.0370049 \\
\hline $\mathrm{H}$ & 10.4106601 & 12.1066616 & 15.0379046 \\
\hline 0 & 12.0549682 & 11.0893062 & 24.8981455 \\
\hline 0 & 15.6439723 & 11.2731543 & 25.2006769 \\
\hline 0 & 10.1463570 & 8.2009007 & 25.2529599 \\
\hline $\mathrm{H}$ & 10.4430223 & 12.1002082 & 29.7682037 \\
\hline $\mathrm{H}$ & 8.6941041 & 15.1653360 & 15.1634353 \\
\hline Al & 5.3658544 & 14.8074807 & 16.5775839 \\
\hline $\mathrm{P}$ & 5.3379735 & 14.8036715 & 28.4043268 \\
\hline Al & 12.2583939 & 18.8039652 & 21.5624346 \\
\hline $\mathrm{Zn}$ & 12.4512369 & 13.5008961 & 21.6332646 \\
\hline Al & 17.1486660 & 16.1149160 & 21.5683264 \\
\hline $\mathrm{P}$ & 17.0588102 & 16.1521846 & 18.4030527 \\
\hline$P$ & 12.3187920 & 13.3267675 & 18.3670497 \\
\hline $\mathrm{P}$ & 12.2968292 & 18.8335748 & 18.4326041 \\
\hline Al & 5.4087166 & 17.3234338 & 26.5570953 \\
\hline $\mathrm{P}$ & 5.3973199 & 17.3670037 & 23.4636368 \\
\hline $\mathrm{Al}$ & 8.4942433 & 14.8428382 & 28.4270109 \\
\hline $\mathrm{P}$ & 8.5199203 & 14.8531028 & 16.6088733 \\
\hline $\mathrm{Al}$ & 15.5342428 & 13.3800601 & 18.5256723 \\
\hline Al & 15.4534170 & 18.8598073 & 18.4927151 \\
\hline Al & 10.7478916 & 16.0407245 & 18.4633318 \\
\hline $\mathrm{P}$ & 10.6104360 & 16.0539864 & 21.6166862 \\
\hline $\mathrm{P}$ & 15.4335348 & 18.8028577 & 21.6643778 \\
\hline $\mathrm{P}$ & 15.6051307 & 13.4637294 & 21.5793620 \\
\hline Al & 8.5578848 & 17.5311514 & 23.4746891 \\
\hline $\mathrm{P}$ & 8.5698442 & 17.3967990 & 26.6025465 \\
\hline 0 & 8.9727180 & 13.4029181 & 16.8975712 \\
\hline 0 & 6.8127770 & 14.4668583 & 28.1110559 \\
\hline 0 & 11.6632020 & 17.1834163 & 21.7521523 \\
\hline 0 & 14.2405787 & 14.1457715 & 21.5761464 \\
\hline 0 & 15.9796838 & 17.3838649 & 21.9093260 \\
\hline 0 & 16.0047109 & 15.0478076 & 18.1996392 \\
\hline 0 & 11.9300662 & 14.7974103 & 18.0900971 \\
\hline 0 & 13.7755071 & 18.4752603 & 18.1742235 \\
\hline 0 & 7.0868440 & 17.7467267 & 26.8508362 \\
\hline $\mathrm{H}$ & 9.0209152 & 18.9376658 & 23.3183538 \\
\hline $\mathrm{H}$ & 4.7886092 & 18.7226065 & 23.3691215 \\
\hline $\mathrm{H}$ & 18.2400011 & 15.9326383 & 17.5234459 \\
\hline $\mathrm{H}$ & 11.8705689 & 19.9353299 & 17.5262055 \\
\hline 0 & 11.6416160 & 12.4084611 & 17.3289291 \\
\hline 0 & 4.8934100 & 16.0210194 & 27.5903329 \\
\hline $\mathrm{H}$ & 11.5252058 & 19.7820175 & 22.4127108 \\
\hline 0 & 11.9933119 & 11.8608498 & 22.5155728 \\
\hline $\mathrm{H}$ & 18.3959560 & 16.3589406 & 22.3441101 \\
\hline 0 & 8.9970567 & 16.2269750 & 27.4985257 \\
\hline $\mathrm{H}$ & 16.2796544 & 12.4823022 & 17.6007329 \\
\hline
\end{tabular}


9. 3450804

15.8611265

9.3233795

7.0463505

9.4394142

13.9446999

11.1167874

16.6648016

16.4419889

13.8340428

11.4334957

4.5370078

9.4070884

6.8699993

5.1809283

12.1085523

17.5476278

5.2355317

8.6691183

15.9662898

15.6637497

10.2315537

8.7913620

11.8741235

9.9627879

10.4872662

9.9046418

9.6124679

7. 6487231

6.9003443

6.6853955

7.2309333

8.0302216

8.1893041

7.8127149

8.7792173

6.4780877

6.0905571

7.0724862

8.3337878

5.1553995

16.1177420 14

174

\begin{tabular}{|c|c|}
\hline $\mathrm{H}$ & 8.725253 \\
\hline $\mathrm{P}$ & 5.41226 \\
\hline Al & 5.38185 \\
\hline $\mathrm{P}$ & 5.44966 \\
\hline Al & 5.48062 \\
\hline $\mathrm{P}$ & 3.23829 \\
\hline Al & 3.29027 \\
\hline $\mathrm{P}$ & 8.52561 \\
\hline Al & 8.56551 \\
\hline $\mathrm{P}$ & 8.63867 \\
\hline Al & 8.61204 \\
\hline $\mathrm{P}$ & 1.68305 \\
\hline Al & 1.66222 \\
\hline 0 & 6.89277 \\
\hline 0 & 4.90765 \\
\hline $\mathrm{H}$ & 4.95515 \\
\hline $\mathrm{H}$ & 9.12658 \\
\hline 0 & 7.16991 \\
\hline 0 & 2.19158 \\
\hline $\mathrm{H}$ & 2.24042 \\
\hline $\mathrm{H}$ & 0.29698 \\
\hline 0 & 5.01144 \\
\hline 0 & 4.40737 \\
\hline 0 & 4.68968 \\
\hline O & 2.58760 \\
\hline 0 & 9.05250 \\
\hline 0 & 1.99647 \\
\hline 0 & 4.53839 \\
\hline 0 & 7.04799 \\
\hline 0 & 6.93287 \\
\hline $\mathrm{H}$ & 9.50660 \\
\hline $\mathrm{H}$ & 4.64211 \\
\hline $\mathrm{H}$ & 0.23868 \\
\hline $\mathrm{H}$ & 2.60230 \\
\hline 0 & 2.66864 \\
\hline
\end{tabular}

15.8442123

20.0539663

16.4654134

14.9863001

13.4589871

18.8312157

14.7554105

14.5048077

17.5056810

3.1865110

17.6081225

18.4972618

18.5779302

17.4728648

15.0805617

19.3052913

16.1722366

16.8068628

5. 1258871

12.9376067

19.2269796

15.8996382

16.9955425

12.8802714

12.0715376

11.5933569

11.5590243

13.0940609

12.9099719

13.6558863

13.1821796

11.9678671

11.2241618

11.6872983

13.2894293

11.0961439

14.6172711

13.7698059

11.5956857

10.2044016

15.1168434

19.7972038

9.1467740

9.4656427

9.4153916

6.8842208

6.8754568

8.0748607

8.1539021

9.3641272

9. 4226057

6.8718523

6.8439268

10.8714669

10.8485231

9.8382373

11.0615169

5.4961093

5.4653843

6.4882984

9. 1916930

7. 1259566

10.3652990

8.2508284

8.2813618

7.8845591

11.9207548

8.0461267

12.0476153

10.6522127

9.1952606

6.9480903

5.7071543

5.7090048

10.9293123

6.7705730

9.7365179
17.4311633

17.7022230

22.3550844

17.0198205

27.9498720

22.0075423

22.2041400

22.0123425

18.0249950

18.2082733

18.1322541

26.8388259

26.9505000

23.0825591

15.1255682

19.8854275

19.8614940

24.8903804

29.8783629

20.1613678

20.1960885

20.1194164

25.1318889

19.7792938

20.2166623

21.0392602

19.2610718

20.3192267

22.5327107

21.6135737

20.3116276

19.9127961

20.8190383

22.1505456

23. 5421874

22.8534088

21.9118021

19.6119732

18.8988976

20.5672826

29.8485258

22.5363051

15.1360639

16.6802316

28.4978043

21.6309636

18.4779168

26.6411811

23.5144254

28.4061320

16.5905467

18.4398331

21.5935648

23.4570021

26.5882614

16.9398471

28.1214052

21.8448056

21.8215850

18.1846664

26.8068268

23.2730364

23.2576815

17.5159410

27.6117319

22.5109224

27.6028688

17.5413800

22.5333559

17.1033812

28.0447989

22.0204329

18.1122633

18.0862418

27.0173777

26.9750507

23.1392146 


\begin{tabular}{|c|c|c|c|}
\hline $\mathrm{H}$ & 5.2061525 & 9.1422960 & 15.2414530 \\
\hline 0 & 5.2734249 & 7.3072130 & 20.1586451 \\
\hline 0 & 3.7836553 & 8.0676966 & 25.2005472 \\
\hline $\mathrm{H}$ & 8.7448299 & 9.1087460 & 29.8565963 \\
\hline 0 & 8.8335682 & 7.3049428 & 19.9092262 \\
\hline 0 & 1.8669743 & 11.3342492 & 24.9204830 \\
\hline $\mathrm{H}$ & 5.2266863 & 9.1741311 & 29.9589119 \\
\hline $\mathrm{H}$ & 3.5474674 & 12.1525379 & 15.1435481 \\
\hline $\mathrm{P}$ & 3.2527441 & 16.0688762 & 21.6334686 \\
\hline Al & 3.2235399 & 16.1049963 & 18.4722883 \\
\hline$P$ & 3.8596110 & 12.1548044 & 28.4175707 \\
\hline Al & 3.8471121 & 12.1764983 & 16.6018894 \\
\hline $\mathrm{P}$ & 1.6344249 & 13.4112804 & 18.4347900 \\
\hline Al & 1.5700214 & 13.4176869 & 21.5253359 \\
\hline 0 & 5.0520434 & 13.4147030 & 16.9463323 \\
\hline $\mathrm{H}$ & 0.1310908 & 13.8001522 & 21.5432135 \\
\hline $\mathrm{H}$ & 2.3120103 & 17.2019501 & 21.8532047 \\
\hline $\mathrm{O}$ & 2.0126216 & 14.8839723 & 18.1351049 \\
\hline 0 & 4.6608519 & 15.8442141 & 17.5112911 \\
\hline $\mathrm{O}$ & 4.5168333 & 16.2548707 & 22.4911825 \\
\hline 0 & 2.3659085 & 12.4796824 & 17.4542109 \\
\hline 0 & 4.4427902 & 13.5135322 & 28.0130297 \\
\hline 0 & 2.5921320 & 14.7579924 & 22.0487382 \\
\hline $\mathrm{H}$ & 2.6861683 & 17.4574410 & 18.1572557 \\
\hline $\mathrm{H}$ & 0.1708481 & 13.2382882 & 18.2223347 \\
\hline 0 & 3.6937311 & 16.0255001 & 20.1569096 \\
\hline $\mathrm{H}$ & 3.5073002 & 12.1486249 & 29.8642772 \\
\hline 0 & 2.0587317 & 13.0338446 & 19.8635655 \\
\hline $\mathrm{P}$ & 10.1607045 & 12.1112691 & 16.5822763 \\
\hline Al & 10.1203284 & 12.0714609 & 28.3963164 \\
\hline $\mathrm{P}$ & 12.3989741 & 10.7978247 & 26.7004923 \\
\hline Al & 12.4388983 & 10.8191487 & 23.4956840 \\
\hline $\mathrm{P}$ & 15.5580491 & 10.8714669 & 23.4570021 \\
\hline $\mathrm{P}$ & 10.7045249 & 8.1965483 & 23.4590813 \\
\hline Al & 10.7458175 & 8.1524069 & 26.6073210 \\
\hline Al & 15.5372235 & 10.8485231 & 26.5882614 \\
\hline 0 & 8.9616283 & 10.7989765 & 28.0431536 \\
\hline 0 & 11.9345241 & 9.3638613 & 27.0412720 \\
\hline $\mathrm{H}$ & 15.9868570 & 9.4412259 & 26.7739089 \\
\hline $\mathrm{H}$ & 11.6129589 & 7.0286394 & 23.2921767 \\
\hline $\mathrm{O}$ & 14.1229037 & 10.3473770 & 23.2506241 \\
\hline 0 & 11.5953824 & 11.8224271 & 27.5149763 \\
\hline 0 & 9.3289121 & 8.3330022 & 27.6083956 \\
\hline $\mathrm{H}$ & 16.3280898 & 11.7648978 & 27.4553879 \\
\hline 0 & 9.4506187 & 8.0186541 & 22.5836854 \\
\hline 0 & 15.8714757 & 12.0476153 & 22.5333559 \\
\hline 0 & 9.5622674 & 10.7777183 & 17.0799794 \\
\hline 0 & 13.8729774 & 10.9429732 & 27.0899385 \\
\hline $\mathrm{H}$ & 11.3237178 & 6.8027784 & 26.8556250 \\
\hline $\mathrm{H}$ & 16.5132402 & 9.7715236 & 23.1490162 \\
\hline 0 & 11.4199384 & 9.4663048 & 22.9971261 \\
\hline $\mathrm{H}$ & 10.4683568 & 12.0345662 & 15.1274267 \\
\hline 0 & 12.1870656 & 11.0785817 & 25.2128251 \\
\hline $\mathrm{O}$ & 15.7419730 & 11.3342492 & 24.9204830 \\
\hline 0 & 10.2619721 & 8.3223464 & 24.9293870 \\
\hline $\mathrm{H}$ & 10.4243829 & 12.0381994 & 29.8535621 \\
\hline $\mathrm{H}$ & 8.7943868 & 15.1488456 & 15.0787840 \\
\hline$P$ & 5.4718993 & 14.8715551 & 16.6485365 \\
\hline Al & 5.4339706 & 14.8656157 & 28.4797782 \\
\hline $\mathrm{P}$ & 12.3871595 & 18.9003222 & 21.6309636 \\
\hline $\mathrm{Si}$ & 12.2365754 & 13.4210312 & 21.6194064 \\
\hline $\mathrm{P}$ & 17.1277428 & 16.0688762 & 21.6334686 \\
\hline Al & 17.0985386 & 16.1049963 & 18.4722883 \\
\hline Al & 12.2941296 & 13.3995630 & 18.5080662 \\
\hline Al & 12.4181209 & 18.8915582 & 18.4779168 \\
\hline $\mathrm{P}$ & 5.3769634 & 17.3879134 & 26.6201702 \\
\hline Al & 5.3505426 & 17.4060689 & 23.5010619 \\
\hline $\mathrm{P}$ & 8.5894192 & 14.8255438 & 28.3661222 \\
\hline Al & 8.6294773 & 14.8707802 & 16.5322644 \\
\hline $\mathrm{P}$ & 15.5094237 & 13.4112804 & 18.4347900 \\
\hline $\mathrm{P}$ & 15.5761726 & 18.8879537 & 18.4398331 \\
\hline $\mathrm{P}$ & 10.7943284 & 16.1893716 & 18.3944511 \\
\hline Al & 10.7094950 & 16.1863964 & 21.5543616 \\
\hline Al & 15.5495460 & 18.8600281 & 21.5935648 \\
\hline Al & 15.4450202 & 13.4176869 & 21.5253359 \\
\hline$P$ & 8.5080957 & 17.5041427 & 23.3869444 \\
\hline Al & 8.5281295 & 17.3920984 & 26.5369386 \\
\hline 0 & 9.1166003 & 13.2135932 & 16.8681460 \\
\hline 0 & 7.1064856 & 14.4687691 & 28.1407569 \\
\hline 0 & 11.8786570 & 17.4729291 & 21.8508570 \\
\hline
\end{tabular}




\begin{tabular}{|c|c|c|}
\hline 13.7939570 & 13.8565367 & 21.5458491 \\
\hline 16.1532356 & 17.2426287 & 21.8610935 \\
\hline 15.8876204 & 14.8839723 & 18.1351049 \\
\hline 11.8368109 & 15.0731716 & 18.1965170 \\
\hline 14.1074174 & 18.5043998 & 18.1846664 \\
\hline 6.8463931 & 17.7844053 & 26.8654778 \\
\hline 8.9751050 & 18.9098834 & 23.2355638 \\
\hline 4.7973627 & 18.7763276 & 23.3180223 \\
\hline 18.3225075 & 15.8829225 & 17.6539339 \\
\hline 12.0172588 & 20.0666727 & 17.6560068 \\
\hline 11.4561674 & 12.3722153 & 17.3474462 \\
\hline 4.9500181 & 16.2649635 & 27.5699937 \\
\hline 11.6493841 & 19.8714363 & 22.4852150 \\
\hline 11.9641588 & 12.1881415 & 22.6202507 \\
\hline 18.3508492 & 16.2488406 & 22.4633747 \\
\hline 9.0026491 & 16.0096220 & 27.4887021 \\
\hline 16.2177470 & 12.5091786 & 17.4852580 \\
\hline 9.5975481 & 15.9785260 & 17.4519750 \\
\hline 15.9775060 & 20.0267546 & 17.5685211 \\
\hline 9.2428831 & 16.5706495 & 22.4327892 \\
\hline 6.9547338 & 15.0294225 & 17.0100855 \\
\hline 9.4435655 & 13.6172773 & 27.9679760 \\
\hline 13.8703757 & 18.9641917 & 22.0204329 \\
\hline 11.2900882 & 14.6618691 & 22.0251148 \\
\hline 16.4671307 & 14.7579924 & 22.0487382 \\
\hline 16.4686289 & 17.6903389 & 18.1030055 \\
\hline 14.0064519 & 13.2336318 & 18.2166161 \\
\hline 11.4406383 & 17.5317832 & 18.0213272 \\
\hline 4.5049343 & 18.5643912 & 26.8895878 \\
\hline 9.3780526 & 18.5531067 & 26.9200982 \\
\hline 7.0182281 & 17.4469307 & 23.0317003 \\
\hline 5.2420605 & 15.1962108 & 15.2136520 \\
\hline 12.2109242 & 19.3233144 & 20.1586451 \\
\hline 17.5687298 & 16.0255001 & 20.1569096 \\
\hline 5.1930557 & 16.8981871 & 25.1704405 \\
\hline 8.8154979 & 15.1851772 & 29.7932427 \\
\hline 15.9337304 & 13.0338446 & 19.8635655 \\
\hline 15.7710676 & 19.3210442 & 19.9092262 \\
\hline 10.2759452 & 16.2229013 & 19.8383690 \\
\hline 8.7277267 & 17.0253765 & 24.8378641 \\
\hline 11.7813945 & 12.8944324 & 20.0953526 \\
\hline 9.7819087 & 11.9862240 & 20.3776321 \\
\hline 10.2787305 & 11.3631886 & 21.1156168 \\
\hline 9.8245152 & 11.6945289 & 19.3341324 \\
\hline 9.4648472 & 12.9864324 & 20.6564992 \\
\hline 7.1856645 & 12.3466331 & 22.5908436 \\
\hline 6.5226270 & 13.2594919 & 21.7591328 \\
\hline 6.4957965 & 13.0784126 & 20.3682020 \\
\hline 7.1426333 & 11.9898098 & 19.7983314 \\
\hline 7.8709869 & 11.0879675 & 20.6225297 \\
\hline 7.8343545 & 11.2511758 & 22.0339352 \\
\hline 7.1876903 & 12.4934106 & 23.6718405 \\
\hline 8.3480737 & 10.5228342 & 22.6645388 \\
\hline 6.0122395 & 14.1213873 & 22.1950458 \\
\hline 5.9626690 & 13.7912558 & 19.7381645 \\
\hline 7.1226372 & 11.8365293 & 18.7179898 \\
\hline 8.2134824 & 10.1357303 & 20.2076230 \\
\hline 5.2644373 & 15.1557233 & 29.9303700 \\
\hline 16.2629314 & 19.8593858 & 22.4358748 \\
\hline & & \\
\hline 8.7294951 & 9.0964235 & 15.2720331 \\
\hline 5.4137507 & 9.4061006 & 16.6394415 \\
\hline 5.4210883 & 9.3626212 & 28.4518766 \\
\hline 5.3178495 & 6.8013418 & 21.5706206 \\
\hline 5.3789699 & 6.8246680 & 18.4267814 \\
\hline 3.2048841 & 8.1285371 & 26.5953708 \\
\hline 3.3070622 & 8.2300507 & 23.4793386 \\
\hline 8.5495555 & 9.3368100 & 28.5171020 \\
\hline 8.5599141 & 9.4589819 & 16.7062278 \\
\hline 8.5331303 & 6.8679702 & 18.5134342 \\
\hline 8.4999583 & 6.7969866 & 21.6778955 \\
\hline 1.5657004 & 10.8670253 & 23.5188905 \\
\hline 1.5442364 & 10.8460155 & 26.6625413 \\
\hline 7.0895727 & 9.8357587 & 16.9975422 \\
\hline 5.0282196 & 10.8175299 & 28.1206508 \\
\hline 4.7431947 & 5.4431451 & 21.7760326 \\
\hline 9.0586275 & 5.4356624 & 21.9055044 \\
\hline 6.8609796 & 6.4692720 & 18.1848277 \\
\hline
\end{tabular}

21.5458491

8610935

8.1965170

18.1846664

26.8654778

23.3180223

17.6539339

.6560068

17.3474462

.5699937

22.6202507

(2)

17.4852580

(

22.4327892

.0100855

22.0204329

0251148

18.1030055

8.2166161

213272

26. 9200982

23.0317003

15.2136520

25.1704405

.7932427

19.8635655

19.8383690

24.8378641

21.1156168

19.3341324

20.6564992

22.5908436

19.7983314

20.6225297

22.0339352

23.6718405

22.1950458

19.7381645

.7179898

29.9303700

22.4358748

15.2720331

16.6394415

28.4518766

18.4267814

26.5953708

3.4793386

16.7062278

18.5134342

21.6778955

88905

16.9975422

18.1848277 


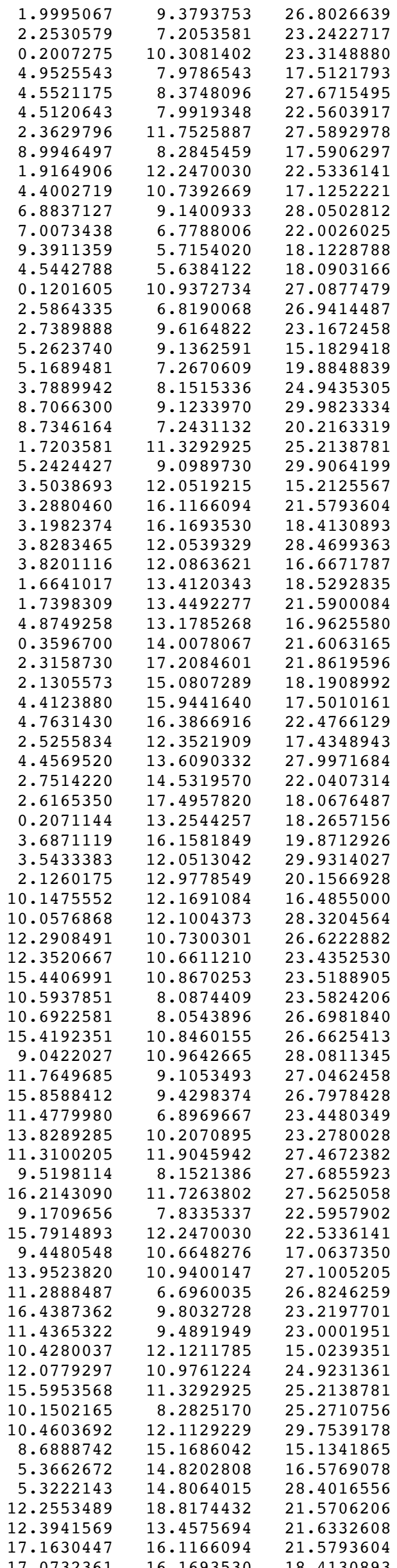




\begin{tabular}{|c|c|c|c|}
\hline $\mathrm{P}$ & 12.3157035 & 13.3454298 & 18.3817107 \\
\hline $\mathrm{P}$ & 12.3164693 & 18.8407693 & 18.4267814 \\
\hline Al & 5.4057802 & 17.3132629 & 26.5526765 \\
\hline $\mathrm{P}$ & 5.3930221 & 17.3644960 & 23.4748978 \\
\hline Al & 8.4824708 & 14.8329675 & 28.4016783 \\
\hline $\mathrm{P}$ & 8.5221646 & 14.8667335 & 16.5827039 \\
\hline Al & 15.5391004 & 13.4120343 & 18.5292835 \\
\hline Al & 15.4706296 & 18.8840716 & 18.5134342 \\
\hline Al & 10.7290411 & 16.0836518 & 18.4503072 \\
\hline $\mathrm{P}$ & 10.5549657 & 16.0977132 & 21.5972036 \\
\hline$P$ & 15.4374576 & 18.8130879 & 21.6778955 \\
\hline$P$ & 15.6148296 & 13.4492277 & 21.5900084 \\
\hline Al & 8.5437683 & 17.5633838 & 23.4605796 \\
\hline $\mathrm{P}$ & 8.5567174 & 17.4073656 & 26.6091661 \\
\hline O & 8.9791286 & 13.4189310 & 16.8783680 \\
\hline $\mathrm{O}$ & 6.7956100 & 14.4717516 & 28.0986560 \\
\hline 0 & 11.5860459 & 17.2355455 & 21.8098649 \\
\hline 0 & 14.2097217 & 14.0179033 & 21.6066113 \\
\hline $\mathrm{O}$ & 16.0148424 & 17.4061592 & 21.9131293 \\
\hline O & 16.0055560 & 15.0807289 & 18.1908992 \\
\hline 0 & 11.9045248 & 14.8151039 & 18.1450237 \\
\hline 0 & 13.7984790 & 18.4853733 & 18.1848277 \\
\hline 0 & 7.0750685 & 17.7471506 & 26.8828759 \\
\hline $\mathrm{H}$ & 9.0634334 & 18.9453471 & 23.2675866 \\
\hline $\mathrm{H}$ & 4.7034760 & 18.6833514 & 23.4272814 \\
\hline $\mathrm{H}$ & 18.2508706 & 15.9509366 & 17.5284471 \\
\hline $\mathrm{H}$ & 11.9022858 & 19.9616524 & 17.5384156 \\
\hline 0 & 11.6455140 & 12.4410328 & 17.3277200 \\
\hline 0 & 4.8703887 & 16.0250693 & 27.5935349 \\
\hline $\mathrm{H}$ & 11.5679370 & 19.8331329 & 22.4149901 \\
\hline 0 & 12.0307613 & 11.8625336 & 22.5885393 \\
\hline $\mathrm{H}$ & 18.4199037 & 16.3467334 & 22.3438660 \\
\hline 0 & 8.9921651 & 16.2072061 & 27.4615589 \\
\hline $\mathrm{H}$ & 16.2720256 & 12.5103483 & 17.5982069 \\
\hline $\mathrm{O}$ & 9.3508987 & 15.8653666 & 17.3914490 \\
\hline $\mathrm{H}$ & 15.8627566 & 20.0876559 & 17.7293794 \\
\hline O & 9.2639794 & 16.4343756 & 22.3696541 \\
\hline 0 & 7.0512574 & 14.9980276 & 17.0031493 \\
\hline 0 & 9.4145494 & 13.4357517 & 27.9342252 \\
\hline $\mathrm{O}$ & 13.9448431 & 18.7949019 & 22.0026025 \\
\hline 0 & 11.1066589 & 14.7807634 & 22.0740585 \\
\hline 0 & 16.6264207 & 14.5319570 & 22.0407314 \\
\hline 0 & 16.4734984 & 17.5369070 & 18.0569386 \\
\hline 0 & 13.8326833 & 13.2274439 & 18.2205940 \\
\hline O & 11.4593599 & 17.6226528 & 18.0812797 \\
\hline $\mathrm{H}$ & 4.5146920 & 18.4825829 & 26.7888397 \\
\hline $\mathrm{H}$ & 9.3944330 & 18.5780471 & 26.9897679 \\
\hline 0 & 6.8512091 & 17.5701691 & 23.0769987 \\
\hline $\mathrm{H}$ & 5.1733677 & 15.0823146 & 15.1238942 \\
\hline O & 12.1064474 & 19.2831623 & 19.8848839 \\
\hline 0 & 17.5621106 & 16.1581849 & 19.8712926 \\
\hline O & 5.2869104 & 16.7631043 & 24.8907791 \\
\hline $\mathrm{H}$ & 8.6626641 & 15.1268311 & 29.8502276 \\
\hline O & 16.0010162 & 12.9778549 & 20.1566928 \\
\hline $\mathrm{O}$ & 15.6721158 & 19.2592145 & 20.2163319 \\
\hline 0 & 10.1649683 & 16.0406361 & 20.0943991 \\
\hline O & 8.7666409 & 17.0541515 & 25.1262092 \\
\hline 0 & 11.8904514 & 12.8724484 & 19.7911292 \\
\hline C & 9.9825843 & 12.0548531 & 20.2015928 \\
\hline $\mathrm{H}$ & 10.4802728 & 11.5264677 & 21.0104491 \\
\hline $\mathrm{H}$ & 9.9272462 & 11.5824331 & 19.2260061 \\
\hline $\mathrm{H}$ & 9.6293643 & 13.0704383 & 20.3516807 \\
\hline $\mathrm{C}$ & 7.6209810 & 12.7794014 & 22.5320579 \\
\hline $\mathrm{C}$ & 6.9043648 & 13.5990352 & 21.6514040 \\
\hline C & 6.7073095 & 13.2166584 & 20.3167791 \\
\hline $\mathrm{C}$ & 7.2372599 & 12.0202539 & 19.8489922 \\
\hline $\mathrm{C}$ & 8.0041273 & 11.2024734 & 20.7182394 \\
\hline C & 8.1474776 & 11.5743509 & 22.0791346 \\
\hline $\mathrm{H}$ & 7.7679901 & 13.0860321 & 23.5684641 \\
\hline $\mathrm{H}$ & 8.7070903 & 10.9232679 & 22.7531432 \\
\hline $\mathrm{H}$ & 6.4905948 & 14.5455686 & 22.0043177 \\
\hline $\mathrm{H}$ & 6.1372692 & 13.8613231 & 19.6471493 \\
\hline $\mathrm{H}$ & 7.0899277 & 11.7172725 & 18.8109815 \\
\hline $\mathrm{H}$ & 8.2953994 & 10.1964306 & 20.4045049 \\
\hline $\mathrm{H}$ & 5.1462842 & 15.1167953 & 29.8472783 \\
\hline $\mathrm{H}$ & 16.0868443 & 19.8162363 & 22.5662146 \\
\hline \multicolumn{4}{|c|}{ Al } \\
\hline & & & \\
\hline
\end{tabular}




\begin{tabular}{|c|c|c|c|}
\hline $\mathrm{Si}$ & 5.3650616 & 9.3368880 & 16.6577260 \\
\hline $\mathrm{Si}$ & 5.3589242 & 9.2922275 & 28.5931142 \\
\hline $\mathrm{Si}$ & 5.3394101 & 6.8453744 & 21.6250094 \\
\hline $\mathrm{Si}$ & 5.3799646 & 6.8598825 & 18.5473582 \\
\hline $\mathrm{Si}$ & 3.2568670 & 8.0574707 & 26.6517294 \\
\hline $\mathrm{Si}$ & 3.3430695 & 8.1374069 & 23.5934122 \\
\hline $\mathrm{Si}$ & 8.4717007 & 9.2513547 & 28.5844043 \\
\hline $\mathrm{Si}$ & 8.4916702 & 9.3418609 & 16.6534100 \\
\hline $\mathrm{Si}$ & 8.5041923 & 6.8679422 & 18.5618566 \\
\hline $\mathrm{Si}$ & 8.4822843 & 6.8180317 & 21.6611135 \\
\hline $\mathrm{Si}$ & 1.6739552 & 10.7897472 & 23.5781573 \\
\hline $\mathrm{Si}$ & 1.6589373 & 10.7747259 & 26.6543754 \\
\hline 0 & 6.9306015 & 9.7419617 & 16.9174711 \\
\hline $\mathrm{O}$ & 4.9545328 & 10.8435221 & 28.2957838 \\
\hline $\mathrm{H}$ & 4.7914732 & 5.4709229 & 21.7916498 \\
\hline $\mathrm{H}$ & 9.0169856 & 5.4430515 & 21.8627188 \\
\hline $\mathrm{O}$ & 6.9474494 & 6.4702783 & 18.3072442 \\
\hline 0 & 2.1321179 & 9.2225205 & 26.7985622 \\
\hline $\mathrm{H}$ & 2.2996576 & 7.0977558 & 23.3753809 \\
\hline $\mathrm{H}$ & 0.2922506 & 10.2649649 & 23.3975569 \\
\hline $\mathrm{O}$ & 4.9435003 & 8.0743726 & 17.5697085 \\
\hline 0 & 4.4651934 & 8.2796975 & 27.7067312 \\
\hline $\mathrm{O}$ & 4.6066267 & 7.9078903 & 22.6055235 \\
\hline $\mathrm{O}$ & 2.5127039 & 11.7261104 & 27.6484986 \\
\hline 0 & 8.9342823 & 8.1199339 & 17.6206793 \\
\hline $\mathrm{O}$ & 2.0132285 & 12.0126820 & 22.5833030 \\
\hline $\mathrm{O}$ & 4.4484562 & 10.6017724 & 17.0833271 \\
\hline 0 & 6.9121601 & 9.0743198 & 28.1955425 \\
\hline $\mathrm{O}$ & 6.9107417 & 6.8262898 & 22.0160017 \\
\hline $\mathrm{H}$ & 9.3649877 & 5.7039756 & 18.2135268 \\
\hline $\mathrm{H}$ & 4.5395871 & 5.6772950 & 18.2121373 \\
\hline $\mathrm{H}$ & 0.2326288 & 10.8588340 & 27.0735300 \\
\hline $\mathrm{H}$ & 2.6247320 & 6.7486484 & 26.9750095 \\
\hline 0 & 2.7242438 & 9.5928855 & 23.2633058 \\
\hline $\mathrm{H}$ & 5.1505582 & 8.9781085 & 15.2286052 \\
\hline $\mathrm{O}$ & 5.1588829 & 7.3522011 & 20.0832379 \\
\hline $\mathrm{O}$ & 3.8680196 & 8.0632993 & 25.1398099 \\
\hline $\mathrm{H}$ & 8.6932318 & 8.9592787 & 30.0275731 \\
\hline $\mathrm{O}$ & 8.7272419 & 7.3129114 & 20.1192609 \\
\hline $\mathrm{O}$ & 1.8632116 & 11.2945663 & 25.1252954 \\
\hline $\mathrm{H}$ & 5.1504810 & 8.9750619 & 30.0329329 \\
\hline $\mathrm{H}$ & 3.4164747 & 11.9842816 & 15.1900862 \\
\hline $\mathrm{Si}$ & 3.3117361 & 15.9034185 & 21.6302097 \\
\hline $\mathrm{Si}$ & 3.2520186 & 15.9480163 & 18.5278899 \\
\hline $\mathrm{Si}$ & 3.8197882 & 11.9865447 & 28.5587840 \\
\hline $\mathrm{Si}$ & 3.8016938 & 12.0184414 & 16.6279874 \\
\hline $\mathrm{Si}$ & 1.7015638 & 13.2491049 & 18.5604466 \\
\hline $\mathrm{Si}$ & 1.7002676 & 13.2611338 & 21.5883615 \\
\hline 0 & 4.9313148 & 13.1714552 & 16.8905792 \\
\hline $\mathrm{H}$ & 0.2819578 & 13.7140517 & 21.6079432 \\
\hline $\mathrm{H}$ & 2.3448393 & 17.0123509 & 21.8593386 \\
\hline $\mathrm{O}$ & 2.1157382 & 14.8095243 & 18.2804726 \\
\hline $\mathrm{O}$ & 4.5334256 & 15.7237557 & 17.5576799 \\
\hline 0 & 4.6394247 & 16.1168658 & 22.5419748 \\
\hline $\mathrm{O}$ & 2.4728932 & 12.2860319 & 17.5035289 \\
\hline 0 & 4.4348061 & 13.4253811 & 28.1472691 \\
\hline 0 & 2.6841645 & 14.4825655 & 22.0538799 \\
\hline $\mathrm{H}$ & 2.6774572 & 17.2848191 & 18.2117284 \\
\hline $\mathrm{H}$ & 0.2399364 & 13.0969454 & 18.3204189 \\
\hline $\mathrm{O}$ & 3.7825288 & 15.8996950 & 20.0672400 \\
\hline $\mathrm{H}$ & 3.4184334 & 11.9816138 & 29.9926635 \\
\hline 0 & 2.1381499 & 12.8087212 & 20.0637299 \\
\hline $\mathrm{Si}$ & 10.0668287 & 12.0275155 & 16.5438354 \\
\hline $\mathrm{Si}$ & 10.0041905 & 11.9681232 & 28.4837539 \\
\hline $\mathrm{Si}$ & 12.1784931 & 10.7012338 & 26.6906044 \\
\hline $\mathrm{Si}$ & 12.2197213 & 10.6739145 & 23.5558985 \\
\hline $\mathrm{Si}$ & 15.2989539 & 10.7897472 & 23.5781573 \\
\hline $\mathrm{Si}$ & 10.4922823 & 8.0892905 & 23.6161081 \\
\hline $\mathrm{Si}$ & 10.5666982 & 8.0586361 & 26.6800277 \\
\hline $\mathrm{Si}$ & 15.2839360 & 10.7747259 & 26.6543754 \\
\hline 0 & 8.9137578 & 10.7810130 & 28.2351733 \\
\hline $\mathrm{O}$ & 11.7036351 & 9.1732643 & 27.0213160 \\
\hline $\mathrm{H}$ & 15.7164186 & 9.3560251 & 26.7861607 \\
\hline $\mathrm{H}$ & 11.3913691 & 6.9082950 & 23.4977311 \\
\hline $\mathrm{O}$ & 13.7860548 & 10.2151361 & 23.3804086 \\
\hline 0 & 11.3160614 & 11.7594472 & 27.5680987 \\
\hline $\mathrm{O}$ & 9.3268695 & 8.1858343 & 27.7176639 \\
\hline $\mathrm{H}$ & 16.0689729 & 11.6495223 & 27.5684700 \\
\hline $\mathrm{O}$ & 9.2000912 & 7.8931309 & 22.6478527 \\
\hline $\mathrm{O}$ & 15.6382272 & 12.0126820 & 22.5833030 \\
\hline
\end{tabular}




\begin{tabular}{|c|c|c|}
\hline 9.4116933 & 10.6225338 & 17.0505651 \\
\hline 13.7327756 & 10.8661964 & 27.1102207 \\
\hline 11.1639666 & 6.7053375 & 26.8502451 \\
\hline 16.2624200 & 9.6918245 & 23.2893331 \\
\hline 11.2783314 & 9.4077752 & 23.1220001 \\
\hline 10.4294040 & 11.9645502 & 15.1010273 \\
\hline 11.9444433 & 11.0252349 & 25.1272279 \\
\hline 15.4882104 & 11.2945663 & 25.1252954 \\
\hline 9.9939753 & 8.2522929 & 25.1621562 \\
\hline 10.4218965 & 11.9599233 & 29.9129408 \\
\hline 8.7236055 & 15.0827890 & 15.1232104 \\
\hline 5.3686068 & 14.7179522 & 16.6039578 \\
\hline 5.3312689 & 14.7061543 & 28.5595295 \\
\hline 12.1519094 & 18.6449694 & 21.6250094 \\
\hline 12.1466121 & 13.2620772 & 21.6405628 \\
\hline 16.9367349 & 15.9034185 & 21.6302097 \\
\hline 16.8770173 & 15.9480163 & 18.5278899 \\
\hline 12.1419326 & 13.2200732 & 18.5158097 \\
\hline 12.1924639 & 18.6594775 & 18.5473582 \\
\hline 5.3509555 & 17.1129646 & 26.6178671 \\
\hline 5.3324351 & 17.1450494 & 23.5833451 \\
\hline 8.4702316 & 14.6947809 & 28.5062360 \\
\hline 8.5064863 & 14.7358003 & 16.5548453 \\
\hline 15.3265626 & 13.2491049 & 18.5604466 \\
\hline 15.3166917 & 18.6675373 & 18.5618566 \\
\hline 10.5993364 & 15.9452457 & 18.5103446 \\
\hline 10.4794287 & 15.9435619 & 21.5986518 \\
\hline 15.2947837 & 18.6176267 & 21.6611135 \\
\hline 15.3252663 & 13.2611338 & 21.5883615 \\
\hline 8.4580925 & 17.2818206 & 23.5197245 \\
\hline 8.4693863 & 17.1597544 & 26.6085602 \\
\hline 8.9550475 & 13.1876415 & 16.8276208 \\
\hline 6.8952445 & 14.3369090 & 28.3035905 \\
\hline 11.5583087 & 17.1559741 & 21.8055372 \\
\hline 13.8057961 & 13.7463559 & 21.6093398 \\
\hline 15.8781478 & 17.1175103 & 21.8810668 \\
\hline 15.7407370 & 14.8095243 & 18.2804726 \\
\hline 11.7166079 & 14.7811890 & 18.2808143 \\
\hline 13.7599488 & 18.2698734 & 18.3072442 \\
\hline 6.9036216 & 17.5341505 & 26.8823979 \\
\hline 8.9681997 & 18.6725750 & 23.3690147 \\
\hline 4.7079100 & 18.4938646 & 23.4951035 \\
\hline 18.0527443 & 15.7422509 & 17.6376949 \\
\hline 11.7910559 & 19.7764215 & 17.6482319 \\
\hline 11.4128653 & 12.2841323 & 17.3964636 \\
\hline 4.8766923 & 15.9563815 & 27.6436832 \\
\hline 11.4787564 & 19.6210230 & 22.5257341 \\
\hline 11.8210616 & 11.9096379 & 22.6525170 \\
\hline 18.1535348 & 16.0990387 & 22.4658241 \\
\hline 8.9191964 & 15.9126487 & 27.5417606 \\
\hline 16.0334836 & 12.3664514 & 17.5917847 \\
\hline 9.3627233 & 15.7506338 & 17.4730721 \\
\hline 15.7109619 & 19.8152575 & 17.6990647 \\
\hline 9.1473989 & 16.2709732 & 22.4754413 \\
\hline 6.9419061 & 14.8718892 & 16.9613422 \\
\hline 9.3338886 & 13.3882742 & 28.0978133 \\
\hline 13.7232410 & 18.6258848 & 22.0160017 \\
\hline 11.0840579 & 14.5528074 & 22.0560914 \\
\hline 16.3091632 & 14.4825655 & 22.0538799 \\
\hline 16.2513823 & 17.4036496 & 18.1836243 \\
\hline 13.7395128 & 13.0838886 & 18.2998221 \\
\hline 11.2819960 & 17.3782580 & 18.1841787 \\
\hline 4.4738235 & 18.2944556 & 26.8455487 \\
\hline 9.3101344 & 18.3337363 & 26.9719189 \\
\hline 6.8807067 & 17.2929332 & 23.1717724 \\
\hline 5.1120524 & 15.0746074 & 15.1812500 \\
\hline 11.9713823 & 19.1517961 & 20.0832379 \\
\hline 17.4075275 & 15.8996950 & 20.0672400 \\
\hline 5.1807142 & 16.5515575 & 25.0947255 \\
\hline 8.7201935 & 15.0787975 & 29.9229826 \\
\hline 15.7631486 & 12.8087212 & 20.0637299 \\
\hline 15.5397413 & 19.1125064 & 20.1192609 \\
\hline 10.0085538 & 15.9166828 & 20.0213905 \\
\hline 8.6938669 & 16.7533716 & 25.0476924 \\
\hline 11.6829958 & 12.7047310 & 19.9901943 \\
\hline 9.7287620 & 11.8437974 & 20.3052793 \\
\hline 10.1990580 & 11.2701223 & 21.0987946 \\
\hline 9.7412775 & 11.4488027 & 19.2948028 \\
\hline 9.3864611 & 12.8549717 & 20.5023768 \\
\hline 7.2347752 & 12.4012070 & 22.5520228 \\
\hline
\end{tabular}




\begin{tabular}{|c|c|c|c|}
\hline $\mathrm{C}$ & 6.5897582 & 13.2997412 & 21.6930332 \\
\hline $\mathrm{C}$ & 6.4872250 & 13.0347333 & 20.3198324 \\
\hline $\mathrm{C}$ & 7.0450698 & 11.8773135 & 19.7921853 \\
\hline C & 7.7516862 & 10.9854894 & 20.6417043 \\
\hline C & 7.7915943 & 11.2356551 & 22.0380936 \\
\hline $\mathrm{H}$ & 7.2985245 & 12.6154230 & 23.6197606 \\
\hline $\mathrm{H}$ & 8.2919534 & 10.5184931 & 22.6913440 \\
\hline $\mathrm{H}$ & 6.1558200 & 14.2172137 & 22.0940708 \\
\hline $\mathrm{H}$ & 5.9692838 & 13.7408680 & 19.6702339 \\
\hline $\mathrm{H}$ & 6.9715913 & 11.6632530 & 18.7245341 \\
\hline $\mathrm{H}$ & 8.0540928 & 10.0036903 & 20.2678362 \\
\hline $\mathrm{H}$ & 5.1094033 & 15.0728495 & 29.9855137 \\
\hline $\mathrm{H}$ & 15.9520038 & 19.6019817 & 22.5645665 \\
\hline \multicolumn{4}{|c|}{ Ge 14} \\
\hline \multicolumn{4}{|c|}{174} \\
\hline $\mathrm{H}$ & 8.7123411 & 9.1600929 & 15.1542039 \\
\hline $\mathrm{P}$ & 5.4331417 & 9.4881404 & 16.7040340 \\
\hline Al & 5.3905301 & 9.4126337 & 28.5148943 \\
\hline $\mathrm{P}$ & 5.4541819 & 6.8768450 & 21.6315429 \\
\hline Al & 5.4946701 & 6.8933979 & 18.4880299 \\
\hline $\mathrm{P}$ & 3.2551168 & 8.0692132 & 26.6503403 \\
\hline Al & 3.3525924 & 8.2086210 & 23.5511314 \\
\hline $\mathrm{P}$ & 8.5233798 & 9.3270846 & 28.4154860 \\
\hline Al & 8.5791049 & 9.4404519 & 16.6104894 \\
\hline $\mathrm{P}$ & 8.6527836 & 6.8807950 & 18.4525875 \\
\hline Al & 8.6251196 & 6.8254434 & 21.6127589 \\
\hline $\mathrm{P}$ & 1.6972966 & 10.8883807 & 23.4767778 \\
\hline Al & 1.6476994 & 10.8313714 & 26.6177249 \\
\hline 0 & 6.9109850 & 9.8623808 & 16.9772971 \\
\hline $\mathrm{O}$ & 4.9303957 & 11.0616653 & 28.1251868 \\
\hline $\mathrm{H}$ & 4.9122017 & 5.5022064 & 21.8152453 \\
\hline $\mathrm{H}$ & 9.1808668 & 5.4633304 & 21.8427886 \\
\hline $\mathrm{O}$ & 7.1828728 & 6.5027102 & 18.1947295 \\
\hline $\mathrm{O}$ & 2.1903541 & 9.1732557 & 26.7821658 \\
\hline $\mathrm{H}$ & 2.2592674 & 7.2232411 & 23.3257707 \\
\hline $\mathrm{H}$ & 0.3477236 & 10.3201217 & 23.2068608 \\
\hline $\mathrm{O}$ & 5.0267491 & 8.2699356 & 17.5305851 \\
\hline 0 & 4.3796401 & 8.2773709 & 27.6717729 \\
\hline $\mathrm{O}$ & 4.7286915 & 7.8880506 & 22.5298368 \\
\hline $\mathrm{O}$ & 2.5954396 & 11.8898768 & 27.6265932 \\
\hline 0 & 9.0655093 & 8.0707329 & 17.5732418 \\
\hline $\mathrm{O}$ & 1.9824000 & 12.0848959 & 22.5694597 \\
\hline 0 & 4.5533490 & 10.6702869 & 17.1256642 \\
\hline 0 & 7.0472281 & 9.1542908 & 28.0458546 \\
\hline $\mathrm{O}$ & 6.9383056 & 6.8752964 & 22.0198760 \\
\hline $\mathrm{H}$ & 9.5169373 & 5.7203757 & 18.1007553 \\
\hline $\mathrm{H}$ & 4.6471621 & 5.7356509 & 18.0899436 \\
\hline $\mathrm{H}$ & 0.2406196 & 10.8851231 & 27.1018301 \\
\hline $\mathrm{H}$ & 2.6206823 & 6.7546244 & 26.9443978 \\
\hline $\mathrm{O}$ & 2.7595260 & 9.8114216 & 23.2004992 \\
\hline $\mathrm{H}$ & 5.2378375 & 9.1700015 & 15.2625887 \\
\hline $\mathrm{O}$ & 5.2907910 & 7.3334174 & 20.1674637 \\
\hline $\mathrm{O}$ & 3.8608963 & 8.0884088 & 25.2325979 \\
\hline $\mathrm{H}$ & 8.7279237 & 9.1197494 & 29.8757238 \\
\hline $\mathrm{O}$ & 8.8522610 & 7.2882726 & 19.9286497 \\
\hline $\mathrm{O}$ & 1.7889203 & 11.3492072 & 24.9501498 \\
\hline $\mathrm{H}$ & 5.2552556 & 9.1974765 & 29.9820442 \\
\hline $\mathrm{H}$ & 3.5837379 & 12.1682598 & 15.1527342 \\
\hline $\mathrm{P}$ & 3.3163944 & 16.0748565 & 21.6210352 \\
\hline Al & 3.2476583 & 16.1231042 & 18.4619022 \\
\hline $\mathrm{P}$ & 3.8759178 & 12.1500437 & 28.4199251 \\
\hline Al & 3.8671349 & 12.1924574 & 16.6143159 \\
\hline $\mathrm{P}$ & 1.6427197 & 13.4204631 & 18.4419148 \\
\hline Al & 1.5940459 & 13.4506385 & 21.5416879 \\
\hline 0 & 5.0723957 & 13.4270736 & 16.9758071 \\
\hline $\mathrm{H}$ & 0.1947753 & 13.9571841 & 21.5924234 \\
\hline $\mathrm{H}$ & 2.3747564 & 17.2002466 & 21.8738897 \\
\hline 0 & 2.0393156 & 14.8910958 & 18.1590875 \\
\hline 0 & 4.6815319 & 15.8659259 & 17.4934377 \\
\hline $\mathrm{O}$ & 4.5957891 & 16.2434160 & 22.4597562 \\
\hline 0 & 2.3836829 & 12.4921269 & 17.4650621 \\
\hline $\mathrm{O}$ & 4.4388638 & 13.5100657 & 27.9879987 \\
\hline $\mathrm{O}$ & 2.6785323 & 14.7510462 & 22.0271291 \\
\hline $\mathrm{H}$ & 2.6989164 & 17.4706157 & 18.1453338 \\
\hline $\mathrm{H}$ & 0.1813698 & 13.2621126 & 18.2042126 \\
\hline 0 & 3.7369916 & 16.0592355 & 20.1395221 \\
\hline $\mathrm{H}$ & 3.5456768 & 12.1636626 & 29.8717777 \\
\hline $\mathrm{O}$ & 2.0320007 & 13.0225159 & 19.8756810 \\
\hline & & & \\
\hline
\end{tabular}




\begin{tabular}{|c|c|c|c|}
\hline Al & 10.1040332 & 12.0431333 & 28.3439198 \\
\hline $\mathrm{P}$ & 12.4166545 & 10.7376004 & 26.7345902 \\
\hline Al & 12.4826001 & 10.7125435 & 23.5027859 \\
\hline $\mathrm{P}$ & 15.5722953 & 10.8883807 & 23.4767778 \\
\hline$P$ & 10.6477373 & 8.1776742 & 23.5173305 \\
\hline Al & 10.7258018 & 8.1390258 & 26.6205995 \\
\hline Al & 15.5226981 & 10.8313714 & 26.6177249 \\
\hline 0 & 8.9684760 & 10.7460818 & 28.0034876 \\
\hline 0 & 11.9200653 & 9.3244828 & 27.1174120 \\
\hline $\mathrm{H}$ & 15.9837905 & 9.4224742 & 26.7574500 \\
\hline $\mathrm{H}$ & 11.4531286 & 6.9269442 & 23.4529892 \\
\hline $\mathrm{O}$ & 14.1738043 & 10.2995240 & 23.1970771 \\
\hline 0 & 11.5801949 & 11.8049494 & 27.4585515 \\
\hline 0 & 9.3309491 & 8.2627966 & 27.6639770 \\
\hline $\mathrm{H}$ & 16.3325399 & 11.7358617 & 27.4798004 \\
\hline 0 & 9.4054012 & 8.0352931 & 22.6164673 \\
\hline 0 & 15.8573987 & 12.0848959 & 22.5694597 \\
\hline 0 & 9.5938001 & 10.7935917 & 17.0735816 \\
\hline 0 & 13.8741682 & 10.8943467 & 27.1849008 \\
\hline $\mathrm{H}$ & 11.3185618 & 6.7795768 & 26.7534699 \\
\hline $\mathrm{H}$ & 16.6008873 & 9.8455255 & 23.2092481 \\
\hline 0 & 11.4836632 & 9.3485814 & 23.0018847 \\
\hline $\mathrm{H}$ & 10.4364259 & 12.0187229 & 15.0755087 \\
\hline 0 & 12.2885231 & 10.9399320 & 25.2278736 \\
\hline 0 & 15.6639191 & 11.3492072 & 24.9501498 \\
\hline 0 & 10.1903971 & 8.4287646 & 24.9690771 \\
\hline $\mathrm{H}$ & 10.3938530 & 12.0199489 & 29.8042580 \\
\hline $\mathrm{H}$ & 8.8083244 & 15.1391127 & 15.0306723 \\
\hline $\mathrm{P}$ & 5.4884443 & 14.8780993 & 16.6435541 \\
\hline Al & 5.4289692 & 14.8601670 & 28.4699451 \\
\hline $\mathrm{P}$ & 12.3916813 & 18.8929464 & 21.6315429 \\
\hline $\mathrm{Ge}$ & 12.1933304 & 13.4546772 & 21.6595323 \\
\hline $\mathrm{P}$ & 17.1913931 & 16.0748565 & 21.6210352 \\
\hline Al & 17.1226570 & 16.1231042 & 18.4619022 \\
\hline $\mathrm{Al}$ & 12.2983974 & 13.4185063 & 18.4470525 \\
\hline $\mathrm{Al}$ & 12.4321694 & 18.9094993 & 18.4880299 \\
\hline $\mathrm{P}$ & 5.3915012 & 17.3574946 & 26.6041507 \\
\hline Al & 5.3413786 & 17.3815692 & 23.5436735 \\
\hline $\mathrm{P}$ & 8.5862174 & 14.8093120 & 28.3183487 \\
\hline Al & 8.6473806 & 14.8806637 & 16.4882119 \\
\hline $\mathrm{P}$ & 15.5177184 & 13.4204631 & 18.4419148 \\
\hline $\mathrm{P}$ & 15.5902830 & 18.8968964 & 18.4525875 \\
\hline $\mathrm{P}$ & 10.8048383 & 16.2045613 & 18.3576785 \\
\hline $\mathrm{Al}$ & 10.6169516 & 16.2391431 & 21.5253791 \\
\hline Al & 15.5626190 & 18.8415448 & 21.6127589 \\
\hline Al & 15.4690446 & 13.4506385 & 21.5416879 \\
\hline $\mathrm{P}$ & 8.4802849 & 17.6227145 & 23.3742897 \\
\hline Al & 8.5345882 & 17.3850532 & 26.4990336 \\
\hline 0 & 9.1309918 & 13.2245074 & 16.8360172 \\
\hline 0 & 7.0970998 & 14.4701186 & 28.1092063 \\
\hline 0 & 11.8344774 & 17.4796957 & 21.8204053 \\
\hline 0 & 13.8546317 & 14.0350671 & 21.6002242 \\
\hline 0 & 16.2156389 & 17.2410203 & 21.8830508 \\
\hline 0 & 15.9143143 & 14.8910958 & 18.1590875 \\
\hline 0 & 11.8627906 & 15.1027709 & 18.1602475 \\
\hline $\mathrm{O}$ & 14.1203721 & 18.5188116 & 18.1947295 \\
\hline 0 & 6.8545757 & 17.7793643 & 26.8543570 \\
\hline $\mathrm{H}$ & 8.9884044 & 19.0197482 & 23.2892493 \\
\hline $\mathrm{H}$ & 4.6488585 & 18.6973237 & 23.4641342 \\
\hline $\mathrm{H}$ & 18.3431653 & 15.9041949 & 17.6375485 \\
\hline $\mathrm{H}$ & 12.0319395 & 20.0869023 & 17.6690923 \\
\hline 0 & 11.4914826 & 12.4081949 & 17.2508615 \\
\hline 0 & 4.9474572 & 16.2939549 & 27.6130657 \\
\hline $\mathrm{H}$ & 11.6878692 & 19.8739361 & 22.5029948 \\
\hline 0 & 11.8888006 & 12.0796246 & 22.6945658 \\
\hline $\mathrm{H}$ & 18.4291710 & 16.2379330 & 22.4324738 \\
\hline 0 & 9.0052051 & 15.9843841 & 27.4299540 \\
\hline $\mathrm{H}$ & 16.2351306 & 12.5216334 & 17.4961107 \\
\hline 0 & 9.6280264 & 15.9962255 & 17.3891684 \\
\hline $\mathrm{H}$ & 15.9903586 & 20.0503628 & 17.6001937 \\
\hline 0 & 9.1430448 & 16.7329302 & 22.3303410 \\
\hline 0 & 6.9759941 & 15.0476778 & 16.9803019 \\
\hline 0 & 9.4177408 & 13.5861382 & 27.9159715 \\
\hline 0 & 13.8758050 & 18.8913978 & 22.0198760 \\
\hline 0 & 11.0621399 & 14.7079529 & 22.1336339 \\
\hline 0 & 16.5535310 & 14.7510462 & 22.0271291 \\
\hline 0 & 16.4791801 & 17.7032507 & 18.0906813 \\
\hline 0 & 14.0174588 & 13.2578964 & 18.1978836 \\
\hline 0 & 11.4441735 & 17.5598372 & 18.0239544 \\
\hline $\mathrm{H}$ & 4.5022684 & 18.5400865 & 26.7710703 \\
\hline
\end{tabular}




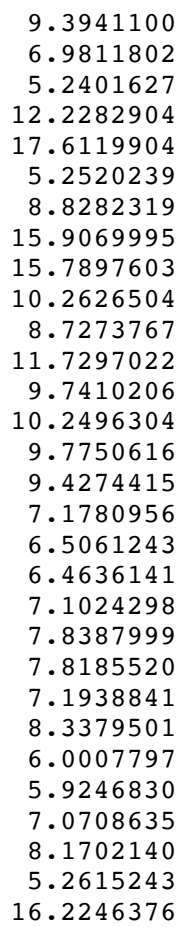

8. 6909791

5.3703736

5.3608785

5.3459659

5.3868031

3.2606739

3. 3814456

8.4710182

8.4941106

8.5030036

8.4860599

1.6853394

1. 6515518

6.9345278

4.9642645

4.7484122

9. 0718085

6.9484474

2.1195235

2.3271250

0.3176830

4. 9469798

4.4505402

4.6466359

2. 5145032

8.9338901

1.9812961

4.4513958

6.9106947

6.9147400

9.3695555

4.5262703

0.2273016

2. 6383505

2.7764359

5. 1593201

5.1930506

3.8962160

8.6879454

8.7134104

1.8492784

5.1589742

3.4308253

3. 3716810

3. 2712121

3. 8258625

3.8119717
18.5373172

17.6468505

15.1693559

19.3495188

16.0592355

16.7683757

15.1719807

13.0225159

19.3043740

16.2043813

17.0502744

12.8714998

11.9599572

11.3520762

11.6522063

12.9652149

12.3338937

13.2455277

13.0624065

11.9720797

11.0702514

11.2363974

12.4836738

10.5084606

14.1083400

13.7747325

11.8167849

10.1143497

15.1313247

19.8680243
8.9682974

9. 3482748

9.2884519

6.8353268

6.8733407

8.0610807

8.1760305

9. 2333497

9.3542926

6.8735192

6.8002867

10.8022059

10.7657220

9.7587136

10.8433660

5.4787153

5.4461113

6.4725483

9. 2106754

7.1468989

10.2506464

8.0906478

8.2814945

7. 9153214

11.7068044

8.1388812

12.0515564

10.6130487

9.0539874

6.7436466

5.7159150

5.7002896

10.8515144

6.7410522

9.6397390

8.9796860

7.3709432

8.1024215

8.9597150

7. 3029651

11.2916757

8.9754221

12.0077722

15.9118678

15.9652661

11.9864886

12.0340084
26.8871452

23.0671049

15.2045800

20.1674637

20.1395221

25.1842134

29.7420836

19.8756810

19.9286497

19.7934945

24.7885239

20.0027672

20.3357262

21.0795650

19.2962903

20.6005477

22.5931431

21.7672090

20.3769455

19.8019839

20.6197718

22.0314344

23.6735691

22.6577092

22.2069620

19.7512731

18.7223259

20.2041935

29.9244403

22.4643408

15.2403539

16.6720023

28.6083247

21.6350850

18.5617095

26.6567569

23.6044948

28.5928080

16.6649139

18.5681158

21.6736656

23.5866697

26.6706242

16.9318004

28.3141637

21.7752828

21.8742352

18.2987537

26.8029831

23.3890491

23.3807121

17.5896058

27.7327445

22.6243570

27.6670915

17.6431717

22.6103546

17.0906992

28.2025590

22.0297236

18.2129244

18.2446055

27.0963841

26.9523223

23.2664839

15.2448656

20.0999888

25.1547015

30.0402842

20.1314615

25.1417129

30.0499792

15.2013308

21.6199331

18.5241265

28.5663590

16.6404832 


\begin{tabular}{|c|c|c|c|}
\hline $\mathrm{Si}$ & 1.7026712 & 13.2622348 & 18.5707855 \\
\hline $\mathrm{Si}$ & 1.7146172 & 13.3013298 & 21.6057042 \\
\hline 0 & 4.9459558 & 13.1817481 & 16.9103956 \\
\hline $\mathrm{H}$ & 0.3371629 & 13.8646499 & 21.6548030 \\
\hline $\mathrm{H}$ & 2.4048832 & 17.0165904 & 21.8689524 \\
\hline 0 & 2.1357197 & 14.8198383 & 18.3078606 \\
\hline 0 & 4.5389759 & 15.7423297 & 17.5367843 \\
\hline 0 & 4.7109051 & 16.1086544 & 22.5207968 \\
\hline 0 & 2.4860185 & 12.3010550 & 17.5209146 \\
\hline 0 & 4.4327107 & 13.4226197 & 28.1285144 \\
\hline 0 & 2.7652057 & 14.4782754 & 22.0343266 \\
\hline $\mathrm{H}$ & 2.6839886 & 17.2971198 & 18.2103516 \\
\hline $\mathrm{H}$ & 0.2439955 & 13.1198455 & 18.3078957 \\
\hline 0 & 3.8281122 & 15.9282250 & 20.0538806 \\
\hline $\mathrm{H}$ & 3.4324694 & 12.0037538 & 30.0023479 \\
\hline 0 & 2.0976404 & 12.8046884 & 20.0811065 \\
\hline $\mathrm{Si}$ & 10.0718544 & 12.0380973 & 16.5215382 \\
\hline $\mathrm{Si}$ & 9.9920465 & 11.9560639 & 28.4603814 \\
\hline $\mathrm{Si}$ & 12.1794876 & 10.6850925 & 26.6893328 \\
\hline $\mathrm{Si}$ & 12.2382323 & 10.6254993 & 23.5468223 \\
\hline $\mathrm{Si}$ & 15.3103382 & 10.8022059 & 23.5866697 \\
\hline $\mathrm{Si}$ & 10.4498984 & 8.0775471 & 23.6430080 \\
\hline $\mathrm{Si}$ & 10.5552505 & 8.0541480 & 26.6814398 \\
\hline $\mathrm{Si}$ & 15.2765506 & 10.7657220 & 26.6706242 \\
\hline 0 & 8.9104706 & 10.7589102 & 28.2207746 \\
\hline $\mathrm{O}$ & 11.6990525 & 9.1604869 & 27.0307203 \\
\hline $\mathrm{H}$ & 15.7042194 & 9.3445997 & 26.7915840 \\
\hline $\mathrm{H}$ & 11.2754243 & 6.8406411 & 23.5675703 \\
\hline 0 & 13.8125330 & 10.1981590 & 23.3611128 \\
\hline 0 & 11.3005823 & 11.7530226 & 27.5384058 \\
\hline 0 & 9.3356061 & 8.1558099 & 27.7476026 \\
\hline H & 16.0698911 & 11.6308911 & 27.5867104 \\
\hline $\mathrm{O}$ & 9.1645566 & 7.9086201 & 22.6569959 \\
\hline O & 15.6062948 & 12.0515564 & 22.6103546 \\
\hline 0 & 9.4192475 & 10.6369135 & 17.0459745 \\
\hline 0 & 13.7271892 & 10.8590507 & 27.1337843 \\
\hline $\mathrm{H}$ & 11.1586892 & 6.6975302 & 26.7935583 \\
\hline $\mathrm{H}$ & 16.3094157 & 9.7377771 & 23.2934871 \\
\hline 0 & 11.3220324 & 9.3342065 & 23.1360775 \\
\hline $\mathrm{H}$ & 10.4217501 & 11.9596399 & 15.0763607 \\
\hline $\mathrm{O}$ & 11.9770614 & 10.9894790 & 25.1180245 \\
\hline 0 & 15.4742771 & 11.2916757 & 25.1417129 \\
\hline 0 & 9.9477382 & 8.2981624 & 25.1820831 \\
\hline $\mathrm{H}$ & 10.4129772 & 11.9531986 & 29.8886425 \\
\hline $\mathrm{H}$ & 8.7318868 & 15.0901265 & 15.0947238 \\
\hline $\mathrm{Si}$ & 5.3771834 & 14.7254102 & 16.5973949 \\
\hline $\mathrm{Si}$ & 5.3260054 & 14.7046176 & 28.5487470 \\
\hline $\mathrm{Si}$ & 12.1584653 & 18.6349218 & 21.6350850 \\
\hline $\mathrm{Ga}$ & 12.1483729 & 13.3116531 & 21.6723797 \\
\hline $\mathrm{Si}$ & 16.9966797 & 15.9118678 & 21.6199331 \\
\hline $\mathrm{Si}$ & 16.8962109 & 15.9652661 & 18.5241265 \\
\hline $\mathrm{Si}$ & 12.1446871 & 13.2448344 & 18.4801871 \\
\hline $\mathrm{Si}$ & 12.1993025 & 18.6729358 & 18.5617095 \\
\hline $\mathrm{Si}$ & 5.3591350 & 17.1029087 & 26.6061962 \\
\hline $\mathrm{Si}$ & 5.3293678 & 17.1446522 & 23.6009988 \\
\hline $\mathrm{Si}$ & 8.4681745 & 14.6916981 & 28.4792304 \\
\hline $\mathrm{Si}$ & 8.5169057 & 14.7510299 & 16.5285708 \\
\hline $\mathrm{Si}$ & 15.3276699 & 13.2622348 & 18.5707855 \\
\hline $\mathrm{Si}$ & 15.3155029 & 18.6731142 & 18.5681158 \\
\hline $\mathrm{Si}$ & 10.6036554 & 15.9503165 & 18.4954428 \\
\hline $\mathrm{Si}$ & 10.4211568 & 15.9585325 & 21.5977331 \\
\hline $\mathrm{Si}$ & 15.2985593 & 18.5998817 & 21.6736656 \\
\hline $\mathrm{Si}$ & 15.3396160 & 13.3013298 & 21.6057042 \\
\hline $\mathrm{Si}$ & 8.4389759 & 17.3512497 & 23.5053541 \\
\hline $\mathrm{Si}$ & 8.4711891 & 17.1593752 & 26.5830353 \\
\hline 0 & 8.9638440 & 13.2026382 & 16.8049909 \\
\hline O & 6.8901522 & 14.3429978 & 28.2879130 \\
\hline 0 & 11.5108885 & 17.1647441 & 21.7870192 \\
\hline 0 & 13.8564566 & 13.9078788 & 21.6585708 \\
\hline 0 & 15.9379972 & 17.1215835 & 21.8926193 \\
\hline 0 & 15.7607184 & 14.8198383 & 18.3078606 \\
\hline 0 & 11.7363230 & 14.8091651 & 18.2314318 \\
\hline 0 & 13.7609467 & 18.2721434 & 18.2987537 \\
\hline 0 & 6.9083838 & 17.5374646 & 26.8793061 \\
\hline $\mathrm{H}$ & 8.9931545 & 18.7276484 & 23.3807221 \\
\hline $\mathrm{H}$ & 4.5893128 & 18.4362012 & 23.5643875 \\
\hline $\mathrm{H}$ & 18.0598250 & 15.7606444 & 17.6178966 \\
\hline $\mathrm{H}$ & 11.7947264 & 19.7926883 & 17.6675098 \\
\hline 0 & 11.4289328 & 12.3063990 & 17.3530104 \\
\hline 0 & 4.8711179 & 15.9679724 & 27.6502882 \\
\hline
\end{tabular}




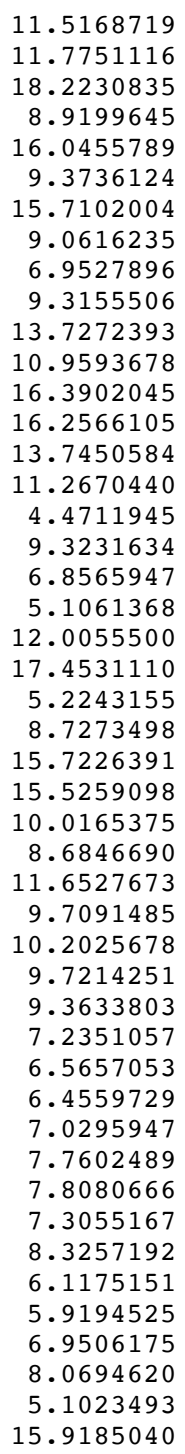

19.6257522

11.8338307

16.0920765

15.8988969

12.3813489

15.7685325

19.8322018

16.3552244

14.8912611

13.3733729

18.5432416

14.5760600

14.4782754

17.4159131

13.1077474

17.4021104

18.2843117

18.3251480

17.4487453

15.0600903

19.1705383

15.9282250

16.4964510

15.0844989

12.8046884

19.1025602

15.8583149

16.7703940

12.7260933

11.8371392

11.2730822

11.4483480

12.8461843

12.3250765

13.2271588

12.9860804

11.8491636

10.9543007

11.1798944

12.5205284

10.4588756

14.1283096

13.6945243

11.6534265

9.9816140

15.0576497

19.6125697

9.1802505

9.5086185

9.4112480

6.8870272

6.9046656

8.0615430

8.2408247

9.3129167

9.4618900

6.9013674

6.8199198

10.9055347

10.8196812

9.8897516

11.0603882

5.5563629

5.4732224

6.5095754

9.1633370

7.2655926

10.3210326

8.2902973

8.2758979

7.9427540

11.8654053

8.0886907

12.1011204

10.6875902

9.1338275

6.7788121
22.5426828

22.6329632

22.4449053

27.5006978

17.6086175

17.4461608

17.7208553

22.4041188

16.9378431

28.0751450

22.0297236

22.1750273

22.0343266

18.1823647

18.2855594

18.2181748

26.7877712

26.9466757

23.2001539

15.1720375

20.0999888

20.0538806

25.0947954

29.8919074

20.0811065

20.1314615

20.0061971

25.0141786

19.9421029

20.2772652

21.0641729

19.2645155

20.4788648

22.5618447

21.7256340

20.3482465

19.7943886

20.6208964

22.0214180

23.6327335

22.6560914

22.1478658

19.7162901

18.7237859

20.2289290

29.9778960

22.5721378

15.1572150

16.7225634

28.5320515

21.6432946

18.5002286

26.6584054

23.5778929

28.4136880

16.6145465

18.4648748

21.6168565

23.4994378

26.6379458

16.9929664

28.1343403

21.8316201

21.8130030

18.2004247

26.7485373

23.3209184

23.1714850

17.5518462

27.7156630

22.5512448

27.6548917

17.5791876

22.6012326

17.1422735

28.0495960

22.0170632 


\begin{tabular}{|c|c|c|c|}
\hline $\mathrm{H}$ & 9.5365741 & 5.7444683 & 18.1303265 \\
\hline $\mathrm{H}$ & 4.6513272 & 5.7519086 & 18.1059676 \\
\hline $\mathrm{H}$ & 0.2412657 & 10.8459620 & 27.1596530 \\
\hline $\mathrm{H}$ & 2.6260521 & 6.7470444 & 26.9388664 \\
\hline 0 & 2.8178955 & 9.8463945 & 23.2723047 \\
\hline $\mathrm{H}$ & 5.2524651 & 9.1857244 & 15.2821618 \\
\hline 0 & 5.3160109 & 7.3541989 & 20.1804738 \\
\hline $\mathrm{O}$ & 3.9183232 & 8.0758171 & 25.2603488 \\
\hline $\mathrm{H}$ & 8.7216439 & 9.1385120 & 29.8780960 \\
\hline 0 & 8.8457169 & 7.3223149 & 19.9400843 \\
\hline 0 & 1.7429244 & 11.3683763 & 24.9761483 \\
\hline $\mathrm{H}$ & 5.2674858 & 9.2105266 & 30.0024492 \\
\hline $\mathrm{H}$ & 3.6039359 & 12.1846978 & 15.1652992 \\
\hline$P$ & 3.3785457 & 16.0784034 & 21.6005857 \\
\hline Al & 3.2677369 & 16.1371069 & 18.4514205 \\
\hline $\mathrm{P}$ & 3.8777690 & 12.1460652 & 28.4276136 \\
\hline Al & 3.8739030 & 12.2092168 & 16.6294157 \\
\hline $\mathrm{P}$ & 1.6498190 & 13.4429045 & 18.4504319 \\
\hline Al & 1.6526534 & 13.4588145 & 21.5617592 \\
\hline 0 & 5.0784048 & 13.4427415 & 17.0030399 \\
\hline $\mathrm{H}$ & 0.2323499 & 13.8998926 & 21.6346188 \\
\hline $\mathrm{H}$ & 2.4425293 & 17.2116158 & 21.8389625 \\
\hline $\mathrm{O}$ & 2.0487282 & 14.9121738 & 18.1573679 \\
\hline $\mathrm{O}$ & 4.6921849 & 15.8924938 & 17.4638067 \\
\hline 0 & 4.6702436 & 16.2493680 & 22.4236093 \\
\hline 0 & 2.3832946 & 12.5103632 & 17.4695633 \\
\hline 0 & 4.4272806 & 13.5034192 & 27.9683665 \\
\hline $\mathrm{O}$ & 2.7373671 & 14.7642042 & 22.0348250 \\
\hline $\mathrm{H}$ & 2.7193351 & 17.4924287 & 18.1695006 \\
\hline $\mathrm{H}$ & 0.1858539 & 13.2877048 & 18.2271832 \\
\hline 0 & 3.7897987 & 16.0353949 & 20.1178958 \\
\hline $\mathrm{H}$ & 3.5674689 & 12.1794064 & 29.8835404 \\
\hline 0 & 2.0562878 & 13.0496702 & 19.8815001 \\
\hline $\mathrm{P}$ & 10.1872614 & 12.1357301 & 16.4967023 \\
\hline Al & 10.0929777 & 12.0269476 & 28.2990211 \\
\hline $\mathrm{P}$ & 12.4293191 & 10.6799458 & 26.7594243 \\
\hline Al & 12.5168700 & 10.6160810 & 23.5142892 \\
\hline $\mathrm{P}$ & 15.6010688 & 10.9055347 & 23.4994378 \\
\hline $\mathrm{P}$ & 10.6158620 & 8.1437622 & 23.5533890 \\
\hline Al & 10.7111352 & 8.1190923 & 26.6312192 \\
\hline Al & 15.5106286 & 10.8196812 & 26.6379458 \\
\hline 0 & 8.9620935 & 10.7219774 & 27.9678492 \\
\hline 0 & 11.9108279 & 9.2830336 & 27.1728188 \\
\hline $\mathrm{H}$ & 15.9868278 & 9.4120161 & 26.7319334 \\
\hline $\mathrm{H}$ & 11.3097182 & 6.8263091 & 23.5521572 \\
\hline 0 & 14.2220963 & 10.2993433 & 23.1593156 \\
\hline 0 & 11.5677517 & 11.7758792 & 27.4101820 \\
\hline $\mathrm{O}$ & 9.3218579 & 8.2291258 & 27.6858005 \\
\hline $\mathrm{H}$ & 16.3253052 & 11.7132025 & 27.5068775 \\
\hline 0 & 9.3775690 & 8.0506499 & 22.6359445 \\
\hline 0 & 15.9201641 & 12.1011204 & 22.6012326 \\
\hline 0 & 9.6176201 & 10.8131102 & 17.0619161 \\
\hline 0 & 13.8734649 & 10.8505383 & 27.2504975 \\
\hline $\mathrm{H}$ & 11.3011288 & 6.7538462 & 26.7028518 \\
\hline $\mathrm{H}$ & 16.6581077 & 9.8801396 & 23.2795414 \\
\hline $\mathrm{O}$ & 11.5564014 & 9.2230474 & 23.0132930 \\
\hline $\mathrm{H}$ & 10.4169844 & 12.0097134 & 15.0309370 \\
\hline 0 & 12.3647345 & 10.8191730 & 25.2429453 \\
\hline 0 & 15.6179231 & 11.3683763 & 24.9761483 \\
\hline 0 & 10.1650487 & 8.4794221 & 24.9915070 \\
\hline $\mathrm{H}$ & 10.3749661 & 12.0094182 & 29.7609705 \\
\hline $\mathrm{H}$ & 8.8167619 & 15.1397802 & 14.9939945 \\
\hline $\mathrm{P}$ & 5.4968423 & 14.8847705 & 16.6342157 \\
\hline Al & 5.4260602 & 14.8463276 & 28.4562701 \\
\hline$P$ & 12.3963966 & 18.9031285 & 21.6432946 \\
\hline $\mathrm{Ti}$ & 12.1545936 & 13.4343810 & 21.6885700 \\
\hline$P$ & 17.2535444 & 16.0784034 & 21.6005857 \\
\hline Al & 17.1427356 & 16.1371069 & 18.4514205 \\
\hline Al & 12.2903244 & 13.4237441 & 18.4150014 \\
\hline Al & 12.4448816 & 18.9207670 & 18.5002286 \\
\hline$P$ & 5.3976610 & 17.3394447 & 26.5927066 \\
\hline Al & 5.3468444 & 17.3770994 & 23.5624633 \\
\hline $\mathrm{P}$ & 8.5822982 & 14.7984929 & 28.2819699 \\
\hline Al & 8.6602879 & 14.8960862 & 16.4545593 \\
\hline $\mathrm{P}$ & 15.5248177 & 13.4429045 & 18.4504319 \\
\hline P & 15.5984123 & 18.9174688 & 18.4648748 \\
\hline $\mathrm{P}$ & 10.7948999 & 16.2192942 & 18.3476722 \\
\hline $\mathrm{Al}$ & 10.5287124 & 16.2931111 & 21.5161185 \\
\hline Al & 15.5733811 & 18.8360212 & 21.6168565 \\
\hline Al & 15.5276522 & 13.4588145 & 21.5617592 \\
\hline
\end{tabular}




\begin{tabular}{|c|c|c|c|}
\hline $\mathrm{P}$ & 8.4614735 & 17.7056919 & 23.3633507 \\
\hline Al & 8.5274072 & 17.3916342 & 26.4777716 \\
\hline 0 & 9.1525268 & 13.2420935 & 16.8062784 \\
\hline 0 & 7.0922054 & 14.4530213 & 28.0899747 \\
\hline $\mathrm{O}$ & 11.7377599 & 17.5360281 & 21.8367768 \\
\hline $\mathrm{O}$ & 13.8860227 & 13.9686258 & 21.6459725 \\
\hline $\mathrm{O}$ & 16.2839121 & 17.2523137 & 21.8475235 \\
\hline 0 & 15.9237270 & 14.9121738 & 18.1573679 \\
\hline 0 & 11.8507299 & 15.1151701 & 18.1571567 \\
\hline 0 & 14.1325715 & 18.5256768 & 18.2004247 \\
\hline 0 & 6.8509911 & 17.7903290 & 26.8558896 \\
\hline $\mathrm{H}$ & 9.0560018 & 19.0682347 & 23.2788892 \\
\hline $\mathrm{H}$ & 4.5196059 & 18.6151290 & 23.5535379 \\
\hline $\mathrm{H}$ & 18.3543874 & 15.9290362 & 17.6113449 \\
\hline $\mathrm{H}$ & 12.0510389 & 20.1057561 & 17.6891741 \\
\hline $\mathrm{O}$ & 11.5251285 & 12.4358005 & 17.1697640 \\
\hline 0 & 4.9506183 & 16.2950136 & 27.6200284 \\
\hline $\mathrm{H}$ & 11.7643685 & 19.9253068 & 22.5223923 \\
\hline $\mathrm{O}$ & 11.8679181 & 11.9933761 & 22.7399353 \\
\hline $\mathrm{H}$ & 18.5015498 & 16.2435850 & 22.3957700 \\
\hline $\mathrm{O}$ & 8.9890498 & 15.9686833 & 27.3807845 \\
\hline $\mathrm{H}$ & 16.2342836 & 12.5408891 & 17.5016711 \\
\hline 0 & 9.6361487 & 16.0219950 & 17.3527819 \\
\hline $\mathrm{H}$ & 15.9951215 & 20.0678439 & 17.6067492 \\
\hline 0 & 9.0284938 & 16.7944220 & 22.2778853 \\
\hline 0 & 6.9880802 & 15.0591678 & 16.9532364 \\
\hline 0 & 9.4127218 & 13.5748386 & 27.8756509 \\
\hline 0 & 13.8817842 & 18.7949135 & 22.0170632 \\
\hline 0 & 11.0159724 & 14.7731403 & 22.1328199 \\
\hline 0 & 16.6123658 & 14.7642042 & 22.0348250 \\
\hline $\mathrm{O}$ & 16.4993475 & 17.7271782 & 18.1206705 \\
\hline 0 & 14.0221117 & 13.2835978 & 18.2212753 \\
\hline 0 & 11.4465973 & 17.5764851 & 18.0404630 \\
\hline $\mathrm{H}$ & 4.4863933 & 18.5110148 & 26.7115984 \\
\hline $\mathrm{H}$ & 9.3973418 & 18.5315324 & 26.8789779 \\
\hline 0 & 6.9543023 & 17.8396362 & 23.1185394 \\
\hline $\mathrm{H}$ & 5.2381899 & 15.1423940 & 15.1906612 \\
\hline 0 & 12.2535102 & 19.3703003 & 20.1804738 \\
\hline 0 & 17.6647975 & 16.0353949 & 20.1178958 \\
\hline 0 & 5.3013795 & 16.7083683 & 25.1851537 \\
\hline $\mathrm{H}$ & 8.8356006 & 15.1699342 & 29.7014733 \\
\hline 0 & 15.9312865 & 13.0496702 & 19.8815001 \\
\hline 0 & 15.7832163 & 19.3384162 & 19.9400843 \\
\hline 0 & 10.2251236 & 16.2152318 & 19.7740936 \\
\hline $\mathrm{O}$ & 8.7177089 & 17.0904527 & 24.7587854 \\
\hline $\mathrm{O}$ & 11.6993172 & 12.8727871 & 19.9564962 \\
\hline $\mathrm{C}$ & 9.7045120 & 11.9668112 & 20.3029538 \\
\hline $\mathrm{H}$ & 10.2247270 & 11.3395616 & 21.0224556 \\
\hline $\mathrm{H}$ & 9.7232099 & 11.6861546 & 19.2557377 \\
\hline $\mathrm{H}$ & 9.3997866 & 12.9674152 & 20.5954407 \\
\hline C & 7.1511527 & 12.2927395 & 22.5989899 \\
\hline C & 6.4616616 & 13.2079444 & 21.7914742 \\
\hline C & 6.4140907 & 13.0477312 & 20.3986197 \\
\hline $\mathrm{C}$ & 7.0636601 & 11.9753369 & 19.8027597 \\
\hline C & 7.8161646 & 11.0696562 & 20.6017435 \\
\hline $\mathrm{C}$ & 7.8028470 & 11.2134490 & 22.0164153 \\
\hline $\mathrm{H}$ & 7.1699191 & 12.4246872 & 23.6817417 \\
\hline $\mathrm{H}$ & 8.3342875 & 10.4817044 & 22.6280659 \\
\hline $\mathrm{H}$ & 5.9470405 & 14.0561652 & 22.2481201 \\
\hline $\mathrm{H}$ & 5.8615703 & 13.7627074 & 19.7879629 \\
\hline $\mathrm{H}$ & 7.0283543 & 11.8369176 & 18.7209527 \\
\hline $\mathrm{H}$ & 8.1490783 & 10.1209924 & 20.1707585 \\
\hline $\mathrm{H}$ & 5.2590686 & 15.1055986 & 29.9129832 \\
\hline $\mathrm{H}$ & 16.2002851 & 19.8762839 & 22.4782308 \\
\hline \multicolumn{4}{|c|}{$\mathrm{Zn} 15$} \\
\hline \multicolumn{4}{|c|}{171} \\
\hline $\mathrm{H}$ & 8.7055262 & 9.0232274 & 15.2004371 \\
\hline $\mathrm{P}$ & 5.4378647 & 9.3815884 & 16.7446694 \\
\hline Al & 5.3752785 & 9.2565820 & 28.5566183 \\
\hline $\mathrm{P}$ & 5.4222766 & 6.6887969 & 21.6583102 \\
\hline Al & 5.4861025 & 6.7686074 & 18.5145849 \\
\hline $\mathrm{P}$ & 3.2455256 & 7.9044132 & 26.6792392 \\
\hline Al & 3.3862769 & 8.0856099 & 23.5929017 \\
\hline $\mathrm{P}$ & 8.5089420 & 9.1492340 & 28.4579137 \\
\hline Al & 8.5809319 & 9.3231860 & 16.6535791 \\
\hline $\mathrm{P}$ & 8.6280167 & 6.7500851 & 18.4928041 \\
\hline Al & 8.5939608 & 6.6478698 & 21.6501700 \\
\hline $\mathrm{P}$ & 1.7057313 & 10.7307006 & 23.5139548 \\
\hline & & & \\
\hline
\end{tabular}




\begin{tabular}{|c|c|c|c|}
\hline 0 & 6.9141526 & 9.7717460 & 17.0044599 \\
\hline 0 & 4.9252743 & 10.9077889 & 28.1579560 \\
\hline $\mathrm{H}$ & 4.7813358 & 5.3534702 & 21.8106849 \\
\hline $\mathrm{H}$ & 9.2000220 & 5.3008192 & 21.8379607 \\
\hline 0 & 7.1660181 & 6.3537414 & 18.2054263 \\
\hline 0 & 2.1630564 & 8.9941736 & 26.7845220 \\
\hline $\mathrm{H}$ & 2.2641209 & 7.1388213 & 23.3449545 \\
\hline $\mathrm{H}$ & 0.3908707 & 10.0947353 & 23.2244548 \\
\hline 0 & 5.0443402 & 8.1743001 & 17.5926692 \\
\hline 0 & 4.3414377 & 8.1260477 & 27.7294618 \\
\hline 0 & 4.7559889 & 7.7277004 & 22.5735839 \\
\hline 0 & 2.5762148 & 11.6997385 & 27.6722744 \\
\hline 0 & 9.0413987 & 7.9497772 & 17.6257328 \\
\hline 0 & 1.9506434 & 11.9351724 & 22.6047749 \\
\hline 0 & 4.5485129 & 10.5583661 & 17.1594594 \\
\hline 0 & 7.0306452 & 8.9701770 & 28.0961834 \\
\hline 0 & 6.9009599 & 6.5754204 & 22.0499230 \\
\hline $\mathrm{H}$ & 9.5115314 & 5.6006358 & 18.1532623 \\
\hline $\mathrm{H}$ & 4.5954681 & 5.6493320 & 18.1009261 \\
\hline $\mathrm{H}$ & 0.2200910 & 10.6984894 & 27.1553605 \\
\hline $\mathrm{H}$ & 2.6220343 & 6.5796893 & 26.9503216 \\
\hline O & 2.8267223 & 9.7060694 & 23.2579726 \\
\hline $\mathrm{H}$ & 5.2327660 & 9.0403685 & 15.3098788 \\
\hline 0 & 5.2937977 & 7.1831450 & 20.2032914 \\
\hline 0 & 3.8836588 & 7.9343068 & 25.2748044 \\
\hline $\mathrm{H}$ & 8.7194779 & 8.9782661 & 29.9220056 \\
\hline 0 & 8.7922487 & 7.1517558 & 19.9737190 \\
\hline 0 & 1.7506887 & 11.1960729 & 24.9885446 \\
\hline $\mathrm{H}$ & 5.2484423 & 9.0633628 & 30.0275702 \\
\hline $\mathrm{H}$ & 3.5899277 & 12.0445778 & 15.1802479 \\
\hline $\mathrm{P}$ & 3.3452208 & 15.9136221 & 21.6182008 \\
\hline Al & 3.2579975 & 15.9990345 & 18.4738925 \\
\hline $\mathrm{P}$ & 3.8638817 & 11.9928327 & 28.4426830 \\
\hline Al & 3.8531332 & 12.0739825 & 16.6455052 \\
\hline $\mathrm{P}$ & 1.6237066 & 13.2961613 & 18.4584943 \\
\hline Al & 1.5851012 & 13.2976030 & 21.5619881 \\
\hline 0 & 5.0480522 & 13.3105795 & 17.0393270 \\
\hline $\mathrm{H}$ & 0.2009602 & 13.8453665 & 21.5970527 \\
\hline $\mathrm{H}$ & 2.4023428 & 17.0398325 & 21.8626424 \\
\hline 0 & 2.0513078 & 14.7608548 & 18.1919092 \\
\hline 0 & 4.6698869 & 15.7693738 & 17.4604653 \\
\hline 0 & 4.6238561 & 16.0668116 & 22.4641775 \\
\hline 0 & 2.3534438 & 12.3650059 & 17.4737579 \\
\hline 0 & 4.4058590 & 13.3513016 & 27.9773074 \\
\hline O & 2.6990514 & 14.5883344 & 22.0194362 \\
\hline $\mathrm{H}$ & 2.6970175 & 17.3492396 & 18.1921691 \\
\hline $\mathrm{H}$ & 0.1600259 & 13.1718647 & 18.2149584 \\
\hline $\mathrm{O}$ & 3.7815856 & 15.8989645 & 20.1409872 \\
\hline $\mathrm{H}$ & 3.5546714 & 12.0380664 & 29.8985208 \\
\hline 0 & 1.9997529 & 12.8663928 & 19.8884836 \\
\hline $\mathrm{P}$ & 10.1675789 & 12.0000449 & 16.5258905 \\
\hline Al & 10.0817163 & 11.8674101 & 28.3297442 \\
\hline $\mathrm{P}$ & 12.4046676 & 10.5321053 & 26.7633131 \\
\hline Al & 12.5078929 & 10.4144677 & 23.5221357 \\
\hline $\mathrm{P}$ & 15.5807300 & 10.7307006 & 23.5139548 \\
\hline $\mathrm{P}$ & 10.5650704 & 7.9645824 & 23.5913950 \\
\hline Al & 10.6909108 & 7.9633182 & 26.6586301 \\
\hline Al & 15.4963060 & 10.6568688 & 26.6533830 \\
\hline 0 & 8.9542208 & 10.5581694 & 28.0115078 \\
\hline 0 & 11.8933008 & 9.1339077 & 27.1808542 \\
\hline $\mathrm{H}$ & 15.9563009 & 9.2450874 & 26.7647321 \\
\hline $\mathrm{H}$ & 11.2343256 & 6.6345250 & 23.6042614 \\
\hline 0 & 14.2173681 & 10.0712764 & 23.2137760 \\
\hline 0 & 11.5497831 & 11.6249709 & 27.4274657 \\
\hline 0 & 9.3150563 & 8.0647521 & 27.7318917 \\
\hline $\mathrm{H}$ & 16.3121237 & 11.5478363 & 27.5238649 \\
\hline O & 9.3325514 & 7.8785994 & 22.6684493 \\
\hline 0 & 15.8256421 & 11.9351724 & 22.6047749 \\
\hline 0 & 9.6145912 & 10.6740923 & 17.0988432 \\
\hline 0 & 13.8525714 & 10.7056930 & 27.2422413 \\
\hline $\mathrm{H}$ & 11.2975280 & 6.6051937 & 26.7267033 \\
\hline H & 16.6645019 & 9.7400891 & 23.2664717 \\
\hline 0 & 11.5378053 & 9.0182011 & 23.0555113 \\
\hline H & 10.4147684 & 11.8643471 & 15.0638358 \\
\hline 0 & 12.3232374 & 10.6737464 & 25.2463761 \\
\hline 0 & 15.6256874 & 11.1960729 & 24.9885446 \\
\hline 0 & 10.1180151 & 8.3144641 & 25.0273308 \\
\hline $\mathrm{H}$ & 10.3715012 & 11.8616972 & 29.7902621 \\
\hline $\mathrm{H}$ & 8.7585447 & 14.9920896 & 14.9816709 \\
\hline $\mathrm{P}$ & 5.4807166 & 14.7438199 & 16.6581108 \\
\hline
\end{tabular}




\begin{tabular}{|c|c|c|c|}
\hline Al & 5.4134398 & 14.6877391 & 28.4650934 \\
\hline $\mathrm{P}$ & 12.3597759 & 18.7048983 & 21.6583102 \\
\hline $\mathrm{Zn}$ & 12.0931028 & 13.3357460 & 21.7049556 \\
\hline $\mathrm{P}$ & 17.2202195 & 15.9136221 & 21.6182008 \\
\hline Al & 17.1329962 & 15.9990345 & 18.4738925 \\
\hline Al & 12.2753664 & 13.3386347 & 18.4381561 \\
\hline Al & 12.4236019 & 18.7847088 & 18.5145849 \\
\hline $\mathrm{P}$ & 5.3877103 & 17.1848300 & 26.6249878 \\
\hline Al & 5.2945856 & 17.2008961 & 23.6007180 \\
\hline $\mathrm{P}$ & 8.5551335 & 14.6357575 & 28.2706852 \\
\hline Al & 8.6259398 & 14.7489266 & 16.4446844 \\
\hline $\mathrm{P}$ & 15.4987053 & 13.2961613 & 18.4584943 \\
\hline $\mathrm{P}$ & 15.5655161 & 18.7661864 & 18.4928041 \\
\hline $\mathrm{P}$ & 10.7625726 & 16.1052424 & 18.3192264 \\
\hline Al & 10.4401634 & 16.1468793 & 21.4751685 \\
\hline Al & 15.5314602 & 18.6639711 & 21.6501700 \\
\hline Al & 15.4600999 & 13.2976030 & 21.5619881 \\
\hline $\mathrm{P}$ & 8.4017578 & 17.5776528 & 23.3715809 \\
\hline Al & 8.5167470 & 17.2294980 & 26.4804308 \\
\hline 0 & 9.1116797 & 13.0953971 & 16.8107592 \\
\hline 0 & 7.0687420 & 14.2921622 & 28.0525944 \\
\hline O & 11.7001811 & 17.3307082 & 21.8151197 \\
\hline O & 13.8540227 & 13.9331961 & 21.6026751 \\
\hline 0 & 16.2445845 & 17.0789587 & 21.8711347 \\
\hline 0 & 15.9263065 & 14.7608548 & 18.1919092 \\
\hline 0 & 11.8519875 & 15.0318257 & 18.1573960 \\
\hline O & 14.1035174 & 18.3698427 & 18.2054263 \\
\hline O & 6.8454372 & 17.6277012 & 26.8793988 \\
\hline $\mathrm{H}$ & 8.9863348 & 18.9454166 & 23.3036653 \\
\hline $\mathrm{H}$ & 4.4467801 & 18.4249612 & 23.6040606 \\
\hline $\mathrm{H}$ & 18.3322171 & 15.8039669 & 17.6131147 \\
\hline $\mathrm{H}$ & 12.0451558 & 19.9889286 & 17.7248041 \\
\hline O & 11.4936920 & 12.3339122 & 17.2073672 \\
\hline 0 & 4.9343329 & 16.1542200 & 27.6635445 \\
\hline $\mathrm{H}$ & 11.7141072 & 19.7116518 & 22.5452599 \\
\hline 0 & 11.9042304 & 11.7859254 & 22.7035021 \\
\hline $\mathrm{H}$ & 18.4558718 & 16.0616619 & 22.4357388 \\
\hline 0 & 8.9840899 & 15.7970110 & 27.3671603 \\
\hline $\mathrm{H}$ & 16.2046223 & 12.3954008 & 17.5059019 \\
\hline 0 & 9.6303124 & 15.8797632 & 17.3027943 \\
\hline $\mathrm{H}$ & 15.9660230 & 19.9285134 & 17.6527382 \\
\hline 0 & 8.9604558 & 16.6938471 & 22.2540370 \\
\hline 0 & 6.9702513 & 14.9157825 & 17.0015024 \\
\hline O & 9.3943498 & 13.4091951 & 27.8989184 \\
\hline 0 & 13.8384593 & 18.5915217 & 22.0499230 \\
\hline $\mathrm{O}$ & 10.7788317 & 14.5857539 & 22.1060449 \\
\hline 0 & 16.5740501 & 14.5883344 & 22.0194362 \\
\hline 0 & 16.4748133 & 17.5831942 & 18.1433539 \\
\hline O & 13.9969961 & 13.1686353 & 18.2086310 \\
\hline $\mathrm{O}$ & 11.3843203 & 17.4786259 & 18.0318863 \\
\hline $\mathrm{H}$ & 4.4849389 & 18.3638074 & 26.7351541 \\
\hline $\mathrm{H}$ & 9.3916923 & 18.3630636 & 26.8886225 \\
\hline 0 & 6.8918776 & 17.6970349 & 23.1442061 \\
\hline $\mathrm{H}$ & 5.2566740 & 14.9771346 & 15.2046701 \\
\hline $\mathrm{O}$ & 12.2312970 & 19.1992464 & 20.2032914 \\
\hline O & 17.6565843 & 15.8989645 & 20.1409872 \\
\hline O & 5.2856568 & 16.5380593 & 25.2249368 \\
\hline $\mathrm{H}$ & 8.7739043 & 15.0208296 & 29.6922968 \\
\hline 0 & 15.8747516 & 12.8663928 & 19.8884836 \\
\hline 0 & 15.7297481 & 19.1678572 & 19.9737190 \\
\hline 0 & 10.1500384 & 16.0817042 & 19.7317455 \\
\hline O & 8.6864421 & 16.9418769 & 24.7523024 \\
\hline 0 & 11.6072163 & 12.7653824 & 19.9401726 \\
\hline C & 9.5463052 & 12.1977740 & 20.2057384 \\
\hline $\mathrm{H}$ & 9.8415717 & 11.9276109 & 21.2172923 \\
\hline $\mathrm{H}$ & 9.7454006 & 11.4823479 & 19.4085871 \\
\hline $\mathrm{H}$ & 9.3493252 & 13.2332480 & 19.9571910 \\
\hline C & 7.6243792 & 11.4139737 & 20.0811118 \\
\hline $\mathrm{H}$ & 7.8420092 & 10.3759084 & 20.3413604 \\
\hline $\mathrm{H}$ & 7.3863551 & 11.6238329 & 19.0350957 \\
\hline C & 7.3422025 & 12.3318628 & 21.0587980 \\
\hline $\mathrm{C}$ & 6.8567936 & 13.7094114 & 20.8304184 \\
\hline $\mathrm{H}$ & 7.5066571 & 14.4456203 & 21.3340948 \\
\hline $\mathrm{H}$ & 6.7603098 & 13.9607855 & 19.7660939 \\
\hline $\mathrm{H}$ & 5.8709071 & 13.8249811 & 21.3146378 \\
\hline $\mathrm{H}$ & 7.5028246 & 12.0354000 & 22.1021657 \\
\hline $\mathrm{H}$ & 5.2740079 & 14.9405149 & 29.9258410 \\
\hline $\mathrm{H}$ & 16.1563745 & 19.7052796 & 22.5117263 \\
\hline
\end{tabular}




\begin{tabular}{|c|c|c|c|}
\hline $\mathrm{H}$ & 8.6940997 & 8.9959062 & 15.1661160 \\
\hline$P$ & 5.3830427 & 9.3152396 & 16.6904753 \\
\hline Al & 5.3626623 & 9.2677752 & 28.5044529 \\
\hline $\mathrm{P}$ & 5.4220104 & 6.7609551 & 21.6385603 \\
\hline Al & 5.4454513 & 6.7434484 & 18.5006584 \\
\hline $\mathrm{P}$ & 3.2083019 & 7.9220816 & 26.6609441 \\
\hline Al & 3.2580658 & 7.9911143 & 23.5296363 \\
\hline $\mathrm{P}$ & 8.5039692 & 9.2127503 & 28.4343745 \\
\hline $\mathrm{Al}$ & 8.5344237 & 9.2709436 & 16.6207564 \\
\hline $\mathrm{P}$ & 8.6018626 & 6.7070349 & 18.4484169 \\
\hline Al & 8.5853590 & 6.6784551 & 21.6115298 \\
\hline $\mathrm{P}$ & 1.6487940 & 10.7089405 & 23.4696918 \\
\hline Al & 1.6382122 & 10.6918963 & 26.6042188 \\
\hline 0 & 6.8605742 & 9.6807874 & 16.9678567 \\
\hline $\mathrm{O}$ & 4.8884781 & 10.9133501 & 28.1239779 \\
\hline $\mathrm{H}$ & 4.9029915 & 5.3772904 & 21.8208020 \\
\hline $\mathrm{H}$ & 9.0773333 & 5.2947581 & 21.8574252 \\
\hline $\mathrm{O}$ & 7.1271304 & 6.3392713 & 18.1962896 \\
\hline 0 & 2.1570707 & 9.0330388 & 26.8382271 \\
\hline $\mathrm{H}$ & 2.2283998 & 6.9456390 & 23.2768714 \\
\hline $\mathrm{H}$ & 0.2498206 & 10.2392135 & 23.2713217 \\
\hline 0 & 4.9678565 & 8.0931193 & 17.5103708 \\
\hline 0 & 4.3838248 & 8.1319173 & 27.6230698 \\
\hline $\mathrm{O}$ & 4.6709341 & 7.7498488 & 22.5376601 \\
\hline 0 & 2.5651355 & 11.7682446 & 27.6139766 \\
\hline 0 & 9.0206050 & 7.8909273 & 17.5653214 \\
\hline 0 & 1.9916882 & 11.8804237 & 22.5491893 \\
\hline 0 & 4.5069872 & 10.4990087 & 17.1164439 \\
\hline $\mathrm{O}$ & 7.0298564 & 9.0366075 & 28.0608999 \\
\hline 0 & 6.9031752 & 6.7925870 & 22.0326608 \\
\hline $\mathrm{H}$ & 9.4558983 & 5.5403238 & 18.0927080 \\
\hline $\mathrm{H}$ & 4.5911501 & 5.5734433 & 18.1565972 \\
\hline $\mathrm{H}$ & 0.2118822 & 10.7849887 & 27.0213963 \\
\hline $\mathrm{H}$ & 2.5812323 & 6.6129595 & 26.9927627 \\
\hline 0 & 2.6058778 & 9.5543694 & 23.1394824 \\
\hline $\mathrm{H}$ & 5.1866169 & 9.0030917 & 15.2478731 \\
\hline $\mathrm{O}$ & 5.2543295 & 7.2146143 & 20.1741125 \\
\hline $\mathrm{O}$ & 3.7429626 & 7.9207655 & 25.2164659 \\
\hline $\mathrm{H}$ & 8.7139857 & 8.9579768 & 29.8863056 \\
\hline 0 & 8.8098757 & 7.1095265 & 19.9219963 \\
\hline 0 & 1.8525274 & 11.1603572 & 24.9330555 \\
\hline $\mathrm{H}$ & 5.2074603 & 9.0339870 & 29.9667716 \\
\hline $\mathrm{H}$ & 3.5315104 & 12.0020507 & 15.1511876 \\
\hline $\mathrm{P}$ & 3.2203605 & 15.9173581 & 21.6492614 \\
\hline Al & 3.1920688 & 15.9534432 & 18.4813712 \\
\hline $\mathrm{P}$ & 3.8400867 & 12.0054101 & 28.4239027 \\
\hline Al & 3.8217346 & 12.0232929 & 16.6114750 \\
\hline $\mathrm{P}$ & 1.6152997 & 13.2463107 & 18.4474512 \\
\hline Al & 1.5670987 & 13.2428899 & 21.5341242 \\
\hline 0 & 5.0164876 & 13.2656861 & 16.9718060 \\
\hline $\mathrm{H}$ & 0.1239669 & 13.6091160 & 21.5533536 \\
\hline $\mathrm{H}$ & 2.2601492 & 17.0292574 & 21.8917380 \\
\hline 0 & 1.9916678 & 14.7189512 & 18.1528204 \\
\hline 0 & 4.6322672 & 15.7003392 & 17.5222194 \\
\hline 0 & 4.4865813 & 16.1087421 & 22.4995540 \\
\hline $\mathrm{O}$ & 2.3307366 & 12.3179909 & 17.4533034 \\
\hline 0 & 4.4191436 & 13.3661557 & 28.0204895 \\
\hline 0 & 2.5829091 & 14.5886857 & 22.0476064 \\
\hline $\mathrm{H}$ & 2.6379859 & 17.2929521 & 18.1410350 \\
\hline $\mathrm{H}$ & 0.1488481 & 13.0786356 & 18.2511722 \\
\hline 0 & 3.6504019 & 15.9032793 & 20.1687122 \\
\hline $\mathrm{H}$ & 3.4929572 & 11.9986320 & 29.8718585 \\
\hline $\mathrm{O}$ & 2.0492930 & 12.8577381 & 19.8703424 \\
\hline$P$ & 0.1284899 & 11.9618258 & 16.6217129 \\
\hline Al & 10.0950168 & 11.9198652 & 28.4278558 \\
\hline $\mathrm{P}$ & 12.3705433 & 10.6586028 & 26.7068612 \\
\hline Al & 12.3872403 & 10.6774897 & 23.5103896 \\
\hline $\mathrm{P}$ & 15.5237927 & 10.7089405 & 23.4696918 \\
\hline $\mathrm{P}$ & 10.6754229 & 8.0311579 & 23.4824558 \\
\hline Al & 10.7193046 & 7.9993948 & 26.6189805 \\
\hline Al & 15.5132109 & 10.6918963 & 26.6042188 \\
\hline 0 & 8.9339847 & 10.6508425 & 28.0782783 \\
\hline 0 & 11.9152663 & 9.2155877 & 27.0182499 \\
\hline $\mathrm{H}$ & 15.9537310 & 9.2834966 & 26.8028960 \\
\hline $\mathrm{H}$ & 11.5964627 & 6.8718407 & 23.3250077 \\
\hline 0 & 14.0769583 & 10.2231434 & 23.2645352 \\
\hline 0 & 11.5715734 & 11.6609806 & 27.5532142 \\
\hline $\mathrm{O}$ & 9.3203696 & 8.1873156 & 27.6436466 \\
\hline $\mathrm{H}$ & 16.3051522 & 11.6115027 & 27.4669319 \\
\hline
\end{tabular}




\subsection{6}

15.8666869

9.5295050

13.8464283

11.3036860

16.4518294

11.3962075

10.4264285

12.1495668

15.7275261

10.2115000

10.3843398

8.7671515

5.4431790

5.4152394

12.3595098

12.2211510

17.0953592

17.0670676

12.2750055

12.3829507

5.3536498

5. 3234779

8.5679886

8.5990669

15.4902984

15.5393619

10.7611581

10.6940418

15.5228583

15.4420974

8.4870660

8.5069968

9.0942725

7.0871629

11.8256600

13.7865138

16.1008251

15.8666666

11.8162926

14.0646298

6.8259293

8.9665358

4.7803051

18.2933306

11.9744377

11.4299793

4.9345137

11.6300402

11.8991995

18.3218879

8.9802753

16.1834528

9.5611423

15.9455058

9.2089942

6.9263995

9.4288460

13.8406746

11.3180899

16.4579078

16.4177757

13.9831546

11.3862887

4. 4859752

9. 3572781

6.9960342

5.2289495

12.1918289

17.5254006

5.1613211

8.7884107

15.9242917

15.7473750

10.2429868

8.7182417

11.7288402

9.7016259

9.8799450

9.8841583
7.8455423

11.8804237

10.6281725

10.8006823

6.6538220

9.5894102

9.3027123

11.8992659

10.9752741

11.1603572

8.1441570

11.9008637

14.9915374

14.7184902

14.7118481

18.7770565

13.2797593

15.9173581

15.9534432

13.2659383

18.7595498

17.2361444

17.2431416

14.6710628

14.7210231

13.2463107

18.7231363

16.0312526

16.0344696

18.6945565

13.2428899

17.3280847

17.2349145

13.0718879

14.3109401

17.3538537

13.6630303

17.0690024

14.7189512

14.9346353

18.3553727

17.6322050

18.7277339

18.6185474

15.7379367

19.9139972

12.2140797

16.1197253

19.7375020

12.0330802

16.1027428

15.8605925

12.3469038

15.8386156

19.8714092

16.3825876

14.8725448

13.4680791

18.8086883

14.5401977

14.5886857

17.5231220

13.0739829

17.3945750

18.4154529

18.3955896

17.2737505

15.0363657

19.2307157

15.9032793

16.7357388

15.0257537

12.8577381

19.1256278

15.9877702

16.8573743

12.8079544

12.2524442

12.0408078

11.4645878
22.5893037

22.5491893

17.1132304

27.0917247

26.8740346

23.1495041

23.0416760

15.1641672

25.2268494

24.9330555

24.9479995

29.8883529

15.0991838

16.6706821

28.4959298

21.6385603

21.6477979

21.6492614

18.4813712

18.5122289

18.5006584

26.6382731

23.5234944

28.3870319

16.5537250

18.4474512

18.4484169

18.4156940

21.5778739

21.6115298

21.5341242

23.4057776

26.5543309

16.9246137

28.1585156

21.8260095

21.5561845

21.9004054

18.1528204

18.1704855

18.1962896

26.8704188

23.2378148

23.3493033

17.6646972

17.6536112

17.3819855

27.5993799

22.5117951

22.6139193

22.4729000

27.5174524

17.4842665

17.4732782

17.5918908

22.4465627

17.0431330

27.9896792

22.0326608

22.0882380

22.0476064

18.0825545

18.2457257

18.0992628

26.9093686

26.9377049

23.0585353

15.2318696

20.1741125

20.1687122

25.1933484

29.8162726

19.8703424

19.9219963

19.8626354

24.8567837

20.1098347

20.2750291

21.3260669

19.5486293 


\begin{tabular}{|c|c|c|c|}
\hline $\mathrm{H}$ & 9.4514491 & 13.2531508 & 19.9440509 \\
\hline C & 7.6539869 & 11.4460091 & 20.0906333 \\
\hline $\mathrm{H}$ & 7.8721573 & 10.4161708 & 20.3809860 \\
\hline $\mathrm{H}$ & 7.4867757 & 11.6400568 & 19.0281271 \\
\hline $\mathrm{C}$ & 7.3627484 & 12.3896702 & 21.0298061 \\
\hline $\mathrm{C}$ & 6.9092917 & 13.7738138 & 20.7514227 \\
\hline $\mathrm{H}$ & 7.5551849 & 14.5149646 & 21.2524976 \\
\hline $\mathrm{H}$ & 6.8561950 & 13.9965513 & 19.6774659 \\
\hline $\mathrm{H}$ & 5.9084378 & 13.9228702 & 21.1923573 \\
\hline $\mathrm{H}$ & 7.4709110 & 12.1145616 & 22.0859239 \\
\hline $\mathrm{H}$ & 5.2510175 & 14.9964344 & 29.9482254 \\
\hline $\mathrm{H}$ & 16.2506582 & 19.6902980 & 22.4457520 \\
\hline \multicolumn{4}{|c|}{$\begin{array}{l}\operatorname{Mg} 15 \\
171\end{array}$} \\
\hline $\mathrm{H}$ & 8.7147087 & 8.9827125 & 15.2802638 \\
\hline Al & 5.4023991 & 9.3064210 & 16.6412183 \\
\hline $\mathrm{P}$ & 5.4118847 & 9.2519452 & 28.4505371 \\
\hline Al & 5.3059885 & 6.7207360 & 21.5675370 \\
\hline $\mathrm{P}$ & 5.3578678 & 6.7354512 & 18.4379633 \\
\hline Al & 3.1953863 & 8.0146733 & 26.6086002 \\
\hline $\mathrm{P}$ & 3.2957377 & 8.1146055 & 23.4892584 \\
\hline Al & 8.5401999 & 9.2274318 & 28.5255019 \\
\hline $\mathrm{P}$ & 8.5451312 & 9.3459947 & 16.7142757 \\
\hline Al & 8.5071061 & 6.7491024 & 18.5132660 \\
\hline $\mathrm{P}$ & 8.4852161 & 6.6696182 & 21.6819139 \\
\hline Al & 1.5517747 & 10.7597797 & 23.5212454 \\
\hline $\mathrm{P}$ & 1.5307402 & 10.7304835 & 26.6752120 \\
\hline 0 & 7.0771478 & 9.7335737 & 17.0031965 \\
\hline $\mathrm{O}$ & 5.0100779 & 10.7013395 & 28.1058975 \\
\hline $\mathrm{H}$ & 4.7015206 & 5.3704155 & 21.7359821 \\
\hline $\mathrm{H}$ & 9.0375743 & 5.3071308 & 21.9178144 \\
\hline 0 & 6.8316231 & 6.3528364 & 18.1904340 \\
\hline $\mathrm{O}$ & 1.9952531 & 9.2681013 & 26.8263859 \\
\hline $\mathrm{H}$ & 2.2649360 & 7.0681143 & 23.2454866 \\
\hline $\mathrm{H}$ & 0.1744837 & 10.2497115 & 23.2762546 \\
\hline 0 & 4.9358467 & 7.8708173 & 17.5003025 \\
\hline 0 & 4.5486127 & 8.2513548 & 27.6796774 \\
\hline $\mathrm{O}$ & 4.5110513 & 7.9013619 & 22.5763522 \\
\hline 0 & 2.3489569 & 11.6499418 & 27.5894819 \\
\hline 0 & 8.9699419 & 8.1677200 & 17.5970109 \\
\hline $\mathrm{O}$ & 1.9732418 & 12.1306983 & 22.5468157 \\
\hline 0 & 4.3747161 & 10.6261861 & 17.1343502 \\
\hline 0 & 6.8756913 & 9.0328252 & 28.0524475 \\
\hline 0 & 6.9912493 & 6.6551602 & 22.0064980 \\
\hline $\mathrm{H}$ & 9.3565593 & 5.5972856 & 18.1023306 \\
\hline $\mathrm{H}$ & 4.5038981 & 5.5526671 & 18.1398391 \\
\hline $\mathrm{H}$ & 0.1081192 & 10.8181668 & 27.1060041 \\
\hline $\mathrm{H}$ & 2.5760290 & 6.7046323 & 26.9511051 \\
\hline $\mathrm{O}$ & 2.7008867 & 9.4875071 & 23.1728709 \\
\hline $\mathrm{H}$ & 5.2525648 & 9.0405744 & 15.1838247 \\
\hline 0 & 5.1680289 & 7.2145034 & 19.8878770 \\
\hline 0 & 3.7726377 & 8.0461152 & 24.9548313 \\
\hline $\mathrm{H}$ & 8.6926713 & 9.0103221 & 29.9906765 \\
\hline 0 & 8.7188876 & 7.1036033 & 20.2174030 \\
\hline 0 & 1.6965650 & 11.2015473 & 25.2211383 \\
\hline $\mathrm{H}$ & 5.2329366 & 9.0035407 & 29.9077239 \\
\hline $\mathrm{H}$ & 3.4983397 & 11.9350240 & 15.2113701 \\
\hline Al & 3.2900299 & 16.0139914 & 21.5731634 \\
\hline $\mathrm{P}$ & 3.1791312 & 16.0638817 & 18.4068812 \\
\hline Al & 3.8178519 & 11.9411938 & 28.4678944 \\
\hline $\mathrm{P}$ & 3.7982885 & 11.9722404 & 16.6693708 \\
\hline Al & 1.6576934 & 13.2935368 & 18.5394949 \\
\hline $\mathrm{P}$ & 1.7683690 & 13.3211733 & 21.5942891 \\
\hline 0 & 4.8454009 & 13.0670181 & 16.9764527 \\
\hline $\mathrm{H}$ & 0.3813305 & 13.8616890 & 21.6272664 \\
\hline $\mathrm{H}$ & 2.2981872 & 17.0836684 & 21.8717598 \\
\hline 0 & 2.1201920 & 14.9617681 & 18.2054697 \\
\hline 0 & 4.3900026 & 15.8389124 & 17.4905812 \\
\hline 0 & 4.7615059 & 16.2872352 & 22.4706097 \\
\hline 0 & 2.4925028 & 12.2371753 & 17.4217540 \\
\hline 0 & 4.4462280 & 13.4964517 & 27.9977320 \\
\hline 0 & 2.7759408 & 14.4162630 & 22.0190982 \\
\hline $\mathrm{H}$ & 2.5809654 & 17.3783145 & 18.0441350 \\
\hline $\mathrm{H}$ & 0.1937432 & 13.1453108 & 18.3114611 \\
\hline 0 & 3.6729300 & 16.0794700 & 19.8626150 \\
\hline $\mathrm{H}$ & 3.5375420 & 11.9349515 & 29.9302582 \\
\hline 0 & 2.1363950 & 12.8429517 & 20.1580211 \\
\hline Al & 10.1366278 & 12.0527264 & 16.5050737 \\
\hline $\mathrm{P}$ & 10.0549850 & 11.9888916 & 28.3392667 \\
\hline
\end{tabular}




\begin{tabular}{|c|c|c|c|}
\hline Al & 12.2818131 & 10.6142507 & 26.6276698 \\
\hline $\mathrm{P}$ & 12.3188961 & 10.5709352 & 23.4320325 \\
\hline Al & 15.4267735 & 10.7597797 & 23.5212454 \\
\hline Al & 10.5785843 & 7.9766449 & 23.5830735 \\
\hline $\mathrm{P}$ & 10.6793713 & 7.9368470 & 26.7001052 \\
\hline $\mathrm{P}$ & 15.4057389 & 10.7304835 & 26.6752120 \\
\hline 0 & 9.0326875 & 10.8586938 & 28.1052534 \\
\hline $\mathrm{O}$ & 11.7564863 & 8.9870189 & 27.0372830 \\
\hline $\mathrm{H}$ & 15.8543404 & 9.3181936 & 26.8212076 \\
\hline $\mathrm{H}$ & 11.4723277 & 6.7930311 & 23.4511586 \\
\hline 0 & 13.8036644 & 10.1586749 & 23.2325288 \\
\hline $\mathrm{O}$ & 11.3068277 & 11.7816368 & 27.4891393 \\
\hline 0 & 9.5115017 & 8.0459321 & 27.6921333 \\
\hline $\mathrm{H}$ & 16.2003557 & 11.6234218 & 27.5631116 \\
\hline $\mathrm{O}$ & 9.1598225 & 7.7079749 & 22.5933071 \\
\hline $\mathrm{O}$ & 15.8482405 & 12.1306983 & 22.5468157 \\
\hline $\mathrm{O}$ & 9.4435900 & 10.5445305 & 17.0748421 \\
\hline 0 & 13.9408552 & 10.8207716 & 27.1188019 \\
\hline $\mathrm{H}$ & 11.2739547 & 6.5786253 & 26.8373094 \\
\hline $\mathrm{H}$ & 16.4048228 & 9.6769040 & 23.2247317 \\
\hline 0 & 11.4297413 & 9.3767785 & 23.0146619 \\
\hline $\mathrm{H}$ & 10.4224092 & 12.0153424 & 15.0442342 \\
\hline $\mathrm{O}$ & 12.0823339 & 10.8738235 & 24.9295251 \\
\hline $\mathrm{O}$ & 15.5715637 & 11.2015473 & 25.2211383 \\
\hline 0 & 10.1327507 & 8.1556209 & 25.2741952 \\
\hline $\mathrm{H}$ & 10.4553410 & 12.0085592 & 29.7732990 \\
\hline $\mathrm{H}$ & 8.6672425 & 15.0377886 & 15.1477805 \\
\hline Al & 5.3497051 & 14.7027793 & 16.5881730 \\
\hline$P$ & 5.3201619 & 14.6860963 & 28.4059203 \\
\hline Al & 12.2434879 & 18.7368373 & 21.5675370 \\
\hline Mg & 12.4063938 & 13.3541288 & 21.6663743 \\
\hline Al & 17.1650287 & 16.0139914 & 21.5731634 \\
\hline $\mathrm{P}$ & 17.0541299 & 16.0638817 & 18.4068812 \\
\hline $\mathrm{P}$ & 12.2987550 & 13.2522270 & 18.3986120 \\
\hline $\mathrm{P}$ & 12.2953672 & 18.7515526 & 18.4379633 \\
\hline Al & 5.3944304 & 17.1990763 & 26.5552750 \\
\hline $\mathrm{P}$ & 5.3844813 & 17.2567184 & 23.4797503 \\
\hline Al & 8.4731033 & 14.7133920 & 28.4110521 \\
\hline $\mathrm{P}$ & 8.5044594 & 14.7475209 & 16.5991133 \\
\hline Al & 15.5326921 & 13.2935368 & 18.5394949 \\
\hline Al & 15.4446055 & 18.7652037 & 18.5132660 \\
\hline Al & 10.7091000 & 15.9817916 & 18.4577732 \\
\hline $\mathrm{P}$ & 10.5472453 & 15.9911895 & 21.5982025 \\
\hline P & 15.4227155 & 18.6857196 & 21.6819139 \\
\hline $\mathrm{P}$ & 15.6433677 & 13.3211733 & 21.5942891 \\
\hline Al & 8.5391442 & 17.4347853 & 23.4752244 \\
\hline$P$ & 8.5490309 & 17.2912758 & 26.6189512 \\
\hline $\mathrm{O}$ & 8.9717509 & 13.3052391 & 16.9112723 \\
\hline $\mathrm{O}$ & 6.7908743 & 14.3425547 & 28.0997974 \\
\hline $\mathrm{O}$ & 11.5398546 & 17.1649915 & 21.7636161 \\
\hline 0 & 14.2306912 & 13.8716799 & 21.6278760 \\
\hline $\mathrm{O}$ & 15.9937344 & 17.2772022 & 21.9257840 \\
\hline $\mathrm{O}$ & 15.9951907 & 14.9617681 & 18.2054697 \\
\hline $\mathrm{O}$ & 11.8937898 & 14.7196230 & 18.1413241 \\
\hline $\mathrm{O}$ & 13.7691224 & 18.3689378 & 18.1904340 \\
\hline 0 & 7.0658050 & 17.6347808 & 26.8759017 \\
\hline $\mathrm{H}$ & 9.0741405 & 18.8094686 & 23.2723808 \\
\hline $\mathrm{H}$ & 4.7006143 & 18.5784747 & 23.4306910 \\
\hline $\mathrm{H}$ & 18.2286643 & 15.8456635 & 17.5180784 \\
\hline $\mathrm{H}$ & 11.8851338 & 19.8552060 & 17.5264929 \\
\hline $\mathrm{O}$ & 11.6321885 & 12.3342451 & 17.3562525 \\
\hline 0 & 4.8744781 & 15.9108965 & 27.6044861 \\
\hline $\mathrm{H}$ & 11.5650032 & 19.7445101 & 22.4285681 \\
\hline $\mathrm{O}$ & 11.9462390 & 11.7726146 & 22.6027493 \\
\hline $\mathrm{H}$ & 18.4205723 & 16.2471379 & 22.3389136 \\
\hline $\mathrm{O}$ & 8.9774962 & 16.0986806 & 27.4852864 \\
\hline $\mathrm{H}$ & 16.2430361 & 12.3946730 & 17.5884030 \\
\hline $\mathrm{O}$ & 9.3319098 & 15.7566926 & 17.3992550 \\
\hline $\mathrm{H}$ & 15.8381738 & 19.9715129 & 17.7341364 \\
\hline $\mathrm{O}$ & 9.2499556 & 16.3027803 & 22.3733091 \\
\hline $\mathrm{O}$ & 7.0350610 & 14.8735752 & 17.0267977 \\
\hline $\mathrm{O}$ & 9.4222242 & 13.3275256 & 27.9476446 \\
\hline 0 & 13.9287486 & 18.6712616 & 22.0064980 \\
\hline 0 & 11.1469006 & 14.7061110 & 22.1014039 \\
\hline $\mathrm{O}$ & 16.6509395 & 14.4162630 & 22.0190982 \\
\hline 0 & 16.4375009 & 17.4188863 & 18.0329383 \\
\hline $\mathrm{O}$ & 13.8146181 & 13.1195805 & 18.2718773 \\
\hline $\mathrm{O}$ & 11.4177713 & 17.5360452 & 18.1315912 \\
\hline $\mathrm{H}$ & 4.5008571 & 18.3646763 & 26.8002730 \\
\hline $\mathrm{H}$ & 9.3841926 & 18.4640650 & 26.9986761 \\
\hline
\end{tabular}




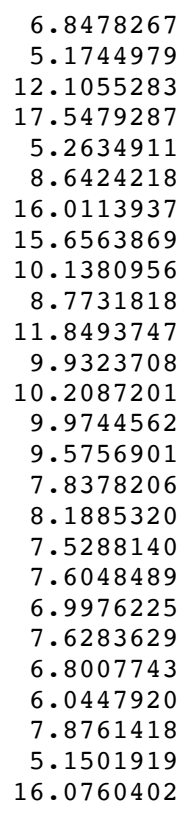

$\begin{array}{lrrr}\mathrm{H} & 8.7327961 & 8.8481203 & 15.2375599 \\ \mathrm{Si} & 5.4180122 & 9.2112645 & 16.6651154 \\ \mathrm{Si} & 5.4179140 & 9.1715137 & 28.5942060 \\ \mathrm{Si} & 5.3966394 & 6.7361240 & 21.6246586 \\ \mathrm{Si} & 5.4298811 & 6.7450529 & 18.5604268 \\ \mathrm{Si} & 3.3143121 & 7.9299312 & 26.6615541 \\ \mathrm{Si} & 3.3986694 & 8.0040426 & 23.6030893 \\ \mathrm{Si} & 8.5254608 & 9.1337187 & 28.5915882 \\ \mathrm{Si} & 8.5376864 & 9.2157905 & 16.6672002 \\ \mathrm{Si} & 8.5451214 & 6.7368732 & 18.5684528 \\ \mathrm{Si} & 8.5354539 & 6.6897266 & 21.6663152 \\ \mathrm{Si} & 1.7332444 & 10.6671192 & 23.5827661 \\ \mathrm{Si} & 1.7146787 & 10.6486938 & 26.6604188 \\ \mathrm{O} & 6.9792325 & 9.6201007 & 16.9460864 \\ \mathrm{O} & 5.0052490 & 10.7205934 & 28.2993988 \\ \mathrm{H} & 4.8165418 & 5.3703375 & 21.7480874 \\ \mathrm{H} & 9.0827757 & 5.3174179 & 21.8515944 \\ \mathrm{O} & 6.9895218 & 6.3348086 & 18.3032960 \\ \mathrm{O} & 2.1928128 & 9.0984032 & 26.8057876 \\ \mathrm{H} & 2.3647042 & 6.9572759 & 23.3743628 \\ \mathrm{H} & 0.3422008 & 10.1769204 & 23.3782581 \\ \mathrm{O} & 4.9875481 & 7.9391355 & 17.5613538 \\ \mathrm{O} & 4.5226695 & 8.153311 & 27.7159997 \\ \mathrm{O} & 4.6686725 & 7.7898104 & 22.6181453 \\ \mathrm{O} & 2.5628168 & 11.6030992 & 27.6560421 \\ \mathrm{O} & 8.9803235 & 7.9838271 & 17.6214366 \\ \mathrm{O} & 2.1146139 & 11.8807159 & 22.5899416 \\ \mathrm{O} & 4.4902373 & 10.4683527 & 17.0916863 \\ \mathrm{O} & 6.9693481 & 8.9573350 & 28.1884920 \\ \mathrm{O} & 6.9632203 & 6.6748759 & 22.0298958 \\ \mathrm{H} & 9.4080786 & 5.5708993 & 18.2324021 \\ \mathrm{H} & 4.5702831 & 5.5641819 & 18.2710214 \\ \mathrm{H} & 0.2878680 & 10.7297619 & 27.0784614 \\ \mathrm{H} & 2.6800398 & 6.6230803 & 26.9886014 \\ \mathrm{O} & 2.7647036 & 9.4527831 & 23.2763775 \\ \mathrm{H} & 5.2194508 & 8.8597825 & 15.2318832 \\ \mathrm{O} & 5.2402805 & 7.2734074 & 20.0892056 \\ \mathrm{O} & 3.9229736 & 7.9292651 & 25.1490170 \\ \mathrm{H} & 8.7306136 & 8.8430268 & 30.0374551 \\ \mathrm{O} & 8.7573399 & 7.1926005 & 20.1229325 \\ \mathrm{O} & 1.9171272 & 11.1676498 & 25.1310192 \\ \mathrm{H} & 5.2199533 & 8.8573118 & 30.0361524 \\ \mathrm{H} & 3.4702646 & 11.8591987 & 15.1963951 \\ \mathrm{Si} & 3.3773567 & 15.7734807 & 21.6324116 \\ \mathrm{Si} & 3.3045076 & 15.8156496 & 18.5332422 \\ \mathrm{Si} & 3.8708212 & 11.8629057 & 28.5642467 \\ \mathrm{Si} & 3.8452522 & 11.8859228 & 16.6371556 \\ \mathrm{Si} & 1.7581726 & 13.1160820 & 18.5720241 \\ \mathrm{Si} & 1.7738851 & 13.1212213 & 21.5955884 \\ \mathrm{O} & 4.9695854 & 13.0396408 & 16.9197242 \\ \mathrm{H} & 0.3440474 & 13.5364146 & 21.6128913 \\ & & & \end{array}$

23.0990823

15.1314905

19.8878770

19.8626150

24.8936552

29.8629929

20.1580211

20.2174030

20.1005534

25.1398848

19.8162959

20.1275205

21.1350891

19.3362317

19.9227312

20.2543865

20.5902687

19.2096096

21.1400333

20.8145662

21.1686166

19.7405086

21.3628911

22.1900563

$\begin{array}{ll}14.9901090 & 29.8536106 \\ 19.6913195 & 22.5645555\end{array}$

$\begin{array}{ll}14.9901090 & 29.8536106 \\ 19.6913195 & 22.5645555\end{array}$

5.2375599

6.6651154

11.6246586

18.5604268

6.6672002

.5684528

23.5827661

.6604188

28.2993988

21.7480874

11.8515944

8.3032960

23.3782581

5613538

22.6181453

27.6560421

17.6214366

5899416

8.1884920

2.0298958

8.2710214

7.0784614

23.2763775

2318832

25.1490170

0.0374551

25.1310192

.0361524

21.6324116

18.5332422

8.5642467

18.5720241 


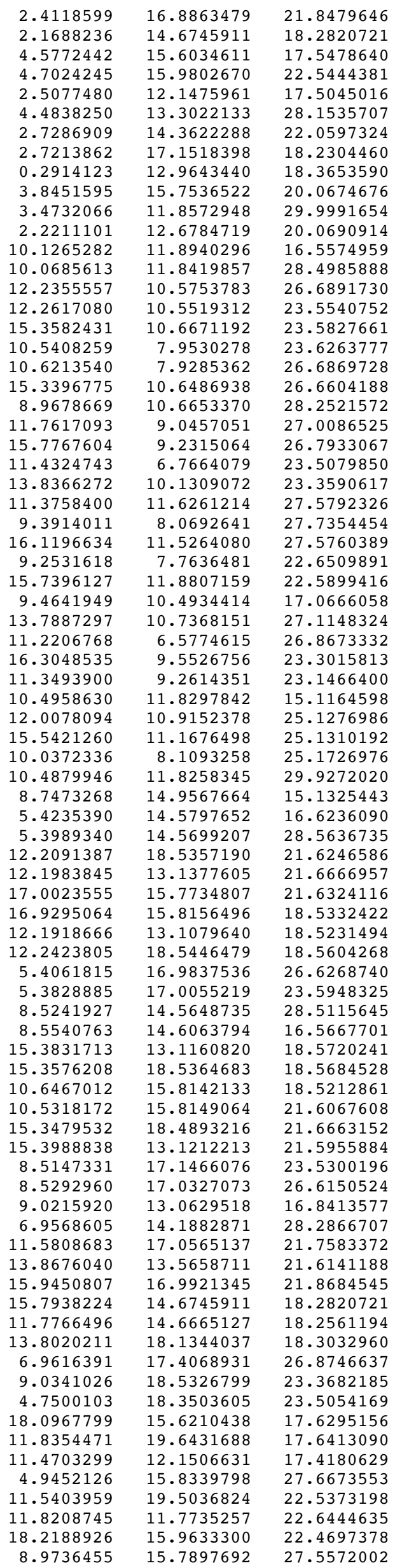

16.8863479

14.6745911

15.6034611

15.9802670

12.1475961

13.3022133

14.3622288

17.1518398

12.9643440

15.7536522

11.8572948

12.6784719

11.8940296

11.8419857

10.5753783

10.5519312

10.6671192

7.9530278

7.9285362

10.6486938

10.6653370

9. 0457051

9.2315064

6.7664079

10.1309072

11.6261214

8.0692641

11.5264080

7.7636481

11.8807159

10.4934414

10.7368151

6.5774615

9. 5526756

9. 2614351

11.8297842

10.9152378

11.1676498

8.1093258

11.8258345

14.9567664

14.5797652

14.5699207

18.5357190

13.1377605

15.7734807

15.8156496

13.1079640

18.5446479

16.9837536

17.0055219

14.5648735

14.6063794

13.1160820

18.5364683

15.8142133

15.8149064

18.4893216

13.1212213

17.1466076

17.0327073

13.0629518

14.1882871

17.0565137

13.5658711

16.9921345

14.6745911

14.6665127

18.1344037

17.4068931

18.5326799

18.3503605

15.6210438

19.6431688

12.1506631

15.8339798

19.5036824

11.7735257

15.9633300

15.7897692

21.8479646

18.2820721

17.5478640

22.5444381

17.5045016

28.1535707

22.0597324

18.2304460

18.3653590

20.0674676

29.9991654

20.0690914

16.5574959

28.4985888

26.6891730

23.5540752

23.5827661

23.6263777

26.6869728

26.6604188

28.2521572

27.0086525

26.7933067

23.5079850

23.3590617

27.5792326

27.7354454

27.5760389

22.6509891

22.5899416

17.0666058

27.1148324

26.8673332

23.3015813

23.1466400

15.1164598

25.1276986

25.1310192

25.1726976

29.9272020

15.1325443

16.6236090

28.5636735

21.6246586

21.6666957

21.6324116

18.5332422

18.5231494

18.5604268

26.6268740

23.5948325

28.5115645

16.5667701

18.5720241

18.5684528

18.5212861

21.6067608

21.6663152

21.5955884

23.5300196

26.6150524

16.8413577

28.2866707

21.7583372

21.6141188

21.8684545

18.2820721

18.2561194

18.3032960

26.8746637

23.3682185

23.5054169

17.6295156

17.6413090

17.4180629

27.6673553

22.5373198

22.6444635

22.4697378

27.5572002 


\begin{tabular}{|c|c|c|c|}
\hline $\mathrm{H}$ & 16.0701681 & 12.2284505 & 17.5936242 \\
\hline $\mathrm{O}$ & 9.4122831 & 15.6288743 & 17.4784855 \\
\hline $\mathrm{H}$ & 15.7563613 & 19.6789514 & 17.7007783 \\
\hline 0 & 9.1937397 & 16.1344331 & 22.4765141 \\
\hline $\mathrm{O}$ & 6.9952430 & 14.7232443 & 17.0062140 \\
\hline $\mathrm{O}$ & 9.4139608 & 13.2715932 & 28.1230290 \\
\hline $\mathrm{O}$ & 13.7757196 & 18.4744709 & 22.0298958 \\
\hline $\mathrm{O}$ & 11.1796799 & 14.4561216 & 22.1014910 \\
\hline 0 & 16.3536896 & 14.3622288 & 22.0597324 \\
\hline 0 & 16.2946230 & 17.2704493 & 18.2035677 \\
\hline 0 & 13.7893228 & 12.9511965 & 18.3474524 \\
\hline $\mathrm{O}$ & 11.3102912 & 17.2641922 & 18.2466153 \\
\hline $\mathrm{H}$ & 4.5313547 & 18.1653466 & 26.8627482 \\
\hline $\mathrm{H}$ & 9.3654036 & 18.2079104 & 26.9851100 \\
\hline 0 & 6.9352850 & 17.1702461 & 23.2005535 \\
\hline $\mathrm{H}$ & 5.2005806 & 14.9243158 & 15.1922827 \\
\hline $\mathrm{O}$ & 12.0527799 & 19.0730024 & 20.0892056 \\
\hline $\mathrm{O}$ & 11.6948719 & 12.6259053 & 20.0039480 \\
\hline 0 & 17.4701583 & 15.7536522 & 20.0674676 \\
\hline $\mathrm{O}$ & 5.2220576 & 16.4162372 & 25.1083256 \\
\hline $\mathrm{H}$ & 8.7439408 & 14.9517347 & 29.9325394 \\
\hline $\mathrm{O}$ & 15.8461088 & 12.6784719 & 20.0690914 \\
\hline 0 & 15.5698393 & 18.9921955 & 20.1229325 \\
\hline 0 & 10.0509310 & 15.7149715 & 20.0304760 \\
\hline 0 & 8.7698004 & 16.6237638 & 25.0569548 \\
\hline $\mathrm{C}$ & 9.7559404 & 11.9605489 & 20.2163172 \\
\hline $\mathrm{H}$ & 10.0230220 & 11.5691169 & 21.1972890 \\
\hline $\mathrm{H}$ & 9.4015255 & 12.9827079 & 20.1356865 \\
\hline $\mathrm{H}$ & 9.8641870 & 11.3326847 & 19.3398009 \\
\hline C & 7.8125439 & 10.9158303 & 20.7379348 \\
\hline C & 7.2626361 & 11.8753780 & 19.9449711 \\
\hline $\mathrm{H}$ & 7.2271876 & 11.6963303 & 18.8634270 \\
\hline C & 6.6753885 & 13.1540919 & 20.4216897 \\
\hline $\mathrm{H}$ & 8.1156891 & 9.9471985 & 20.3356367 \\
\hline $\mathrm{H}$ & 7.8048382 & 11.0150182 & 21.8264220 \\
\hline $\mathrm{H}$ & 6.8057582 & 13.3106944 & 21.5005903 \\
\hline $\mathrm{H}$ & 5.5944236 & 13.1534262 & 20.1963498 \\
\hline $\mathrm{H}$ & 7.0869571 & 14.0178232 & 19.8744158 \\
\hline $\mathrm{H}$ & 5.1991172 & 14.9224913 & 29.9964637 \\
\hline $\mathrm{H}$ & 16.0059222 & 19.4738545 & 22.5690291 \\
\hline \multicolumn{4}{|c|}{ Ge 15} \\
\hline \multicolumn{4}{|c|}{171} \\
\hline $\mathrm{H}$ & 8.6805187 & 9.0175180 & 15.1883252 \\
\hline$P$ & 5.3965916 & 9.3319116 & 16.7133466 \\
\hline Al & 5.3706309 & 9.2644505 & 28.5205533 \\
\hline $\mathrm{P}$ & 5.4257775 & 6.7618833 & 21.6347734 \\
\hline Al & 5.4614498 & 6.7582619 & 18.5126765 \\
\hline $\mathrm{P}$ & 3.2292829 & 7.9142509 & 26.6647178 \\
\hline Al & 3.3262414 & 8.0474385 & 23.5596754 \\
\hline $\mathrm{P}$ & 8.5030285 & 9.1744125 & 28.4459849 \\
\hline Al & 8.5427900 & 9.2908717 & 16.6455243 \\
\hline $\mathrm{P}$ & 8.6145091 & 6.7147641 & 18.4635929 \\
\hline Al & 8.5949074 & 6.6503299 & 21.6347885 \\
\hline $\mathrm{P}$ & 1.6572733 & 10.7308465 & 23.4937171 \\
\hline Al & 1.6261618 & 10.6769740 & 26.6313938 \\
\hline 0 & 6.8707760 & 9.7013510 & 17.0052222 \\
\hline $\mathrm{O}$ & 4.9101298 & 10.9123377 & 28.1262962 \\
\hline $\mathrm{H}$ & 4.8292026 & 5.4048516 & 21.7750728 \\
\hline $\mathrm{H}$ & 9.1375317 & 5.2852202 & 21.8780065 \\
\hline 0 & 7.1405745 & 6.3469634 & 18.2036107 \\
\hline 0 & 2.1650211 & 9.0179400 & 26.8000285 \\
\hline $\mathrm{H}$ & 2.2641821 & 7.0355614 & 23.3042236 \\
\hline $\mathrm{H}$ & 0.2925816 & 10.1946060 & 23.2345193 \\
\hline 0 & 4.9790189 & 8.1019142 & 17.5186326 \\
\hline 0 & 4.3621197 & 8.1273022 & 27.6756041 \\
\hline $\mathrm{O}$ & 4.7227667 & 7.7718863 & 22.5515193 \\
\hline 0 & 2.5703185 & 11.7360205 & 27.6434563 \\
\hline O & 9.0288437 & 7.9176887 & 17.6027772 \\
\hline $\mathrm{O}$ & 1.9661910 & 11.9170286 & 22.5800356 \\
\hline 0 & 4.5123100 & 10.5090317 & 17.1409570 \\
\hline $\mathrm{O}$ & 7.0299369 & 8.9967465 & 28.0658883 \\
\hline 0 & 6.9036805 & 6.6946767 & 22.0351085 \\
\hline $\mathrm{H}$ & 9.4698991 & 5.5567215 & 18.0836381 \\
\hline $\mathrm{H}$ & 4.5913647 & 5.5968839 & 18.1790995 \\
\hline $\mathrm{H}$ & 0.2149763 & 10.7314166 & 27.1033175 \\
\hline $\mathrm{H}$ & 2.5982084 & 6.5999911 & 26.9673509 \\
\hline $\mathrm{O}$ & 2.6930262 & 9.6317411 & 23.2087425 \\
\hline $\mathrm{H}$ & 5.2110401 & 9.0293235 & 15.2672720 \\
\hline 0 & 5.2918166 & 7.2587521 & 20.1805324 \\
\hline
\end{tabular}

17.5936242

7.4784855

2.4765141

17.0062140

.

22.1014910

22.0597324

2035677

18.2466153

26.8627482

26.9851100

5535

20.0892056

20.0039480

0674676

9.9325394

20.0690914

20.1229325

.0304760

20.2163172

1.1972890

56865

0.7379348

19.9449711

18.8634270

20.3356367

21.8264220

21.5005903

0.1963498

19.8744158

29.9964637 Ge 15

171 


\begin{tabular}{|c|c|c|c|}
\hline 0 & 3.8227918 & 7.9267713 & 25.2421191 \\
\hline $\mathrm{H}$ & 8.6971837 & 8.9780044 & 29.9091487 \\
\hline 0 & 8.8230789 & 7.0876783 & 19.9451828 \\
\hline 0 & 1.7747060 & 11.1927705 & 24.9640199 \\
\hline $\mathrm{H}$ & 5.2296940 & 9.0560549 & 29.9881461 \\
\hline $\mathrm{H}$ & 3.5720120 & 12.0163224 & 15.1631673 \\
\hline $\mathrm{P}$ & 3.2950902 & 15.9205223 & 21.6337671 \\
\hline Al & 3.2165198 & 15.9723318 & 18.4703702 \\
\hline $\mathrm{P}$ & 3.8559400 & 11.9990116 & 28.4282375 \\
\hline Al & 3.8425574 & 12.0369347 & 16.6272373 \\
\hline$P$ & 1.6213253 & 13.2591500 & 18.4535241 \\
\hline Al & 1.5955194 & 13.2802342 & 21.5473911 \\
\hline 0 & 5.0442493 & 13.2700613 & 17.0063606 \\
\hline $\mathrm{H}$ & 0.1966398 & 13.7876164 & 21.6004929 \\
\hline $\mathrm{H}$ & 2.3306388 & 17.0205754 & 21.9109623 \\
\hline $\mathrm{O}$ & 2.0135959 & 14.7311872 & 18.1805093 \\
\hline 0 & 4.6477867 & 15.7142656 & 17.4976704 \\
\hline 0 & 4.5759227 & 16.1002772 & 22.4650449 \\
\hline 0 & 2.3471593 & 12.3383589 & 17.4596398 \\
\hline $\mathrm{O}$ & 4.4129349 & 13.3606789 & 27.9946197 \\
\hline $\mathrm{O}$ & 2.6874887 & 14.5756124 & 22.0214277 \\
\hline $\mathrm{H}$ & 2.6542463 & 17.3086907 & 18.1310858 \\
\hline $\mathrm{H}$ & 0.1569212 & 13.1047352 & 18.2326231 \\
\hline $\mathrm{O}$ & 3.7029137 & 15.9373726 & 20.1484169 \\
\hline $\mathrm{H}$ & 3.5359288 & 12.0123592 & 29.8823817 \\
\hline $\mathrm{O}$ & 2.0217273 & 12.8453974 & 19.8799581 \\
\hline $\mathrm{P}$ & 10.1359242 & 11.9723585 & 16.5785602 \\
\hline Al & 10.0804082 & 11.8885009 & 28.3788066 \\
\hline $\mathrm{P}$ & 12.3864725 & 10.5951237 & 26.7491434 \\
\hline Al & 12.4219775 & 10.5742094 & 23.5248785 \\
\hline $\mathrm{P}$ & 15.5322720 & 10.7308465 & 23.4937171 \\
\hline $\mathrm{P}$ & 10.6098488 & 8.0133605 & 23.5466703 \\
\hline Al & 10.6981637 & 7.9808894 & 26.6417508 \\
\hline Al & 15.5011605 & 10.6769740 & 26.6313938 \\
\hline 0 & 8.9479095 & 10.5927344 & 28.0309851 \\
\hline $\mathrm{O}$ & 11.8965443 & 9.1743147 & 27.1085215 \\
\hline $\mathrm{H}$ & 15.9590028 & 9.2673742 & 26.7746744 \\
\hline $\mathrm{H}$ & 11.4353971 & 6.7756747 & 23.4856413 \\
\hline $\mathrm{O}$ & 14.1192669 & 10.1756218 & 23.2253430 \\
\hline $\mathrm{O}$ & 11.5660456 & 11.6471256 & 27.5126680 \\
\hline $\mathrm{O}$ & 9.3207322 & 8.1083057 & 27.7088098 \\
\hline $\mathrm{H}$ & 16.3078310 & 11.5818043 & 27.4960818 \\
\hline $\mathrm{O}$ & 9.3807853 & 7.8545585 & 22.6341998 \\
\hline $\mathrm{O}$ & 15.8411897 & 11.9170286 & 22.5800356 \\
\hline $\mathrm{O}$ & 9.5488896 & 10.6495540 & 17.1162820 \\
\hline 0 & 13.8496768 & 10.7406871 & 27.1836772 \\
\hline $\mathrm{H}$ & 11.3015911 & 6.6267958 & 26.7811301 \\
\hline $\mathrm{H}$ & 16.5357512 & 9.6659889 & 23.2176222 \\
\hline $\mathrm{O}$ & 11.4423004 & 9.1938023 & 23.0497882 \\
\hline $\mathrm{H}$ & 10.3937475 & 11.8728045 & 15.1154346 \\
\hline 0 & 12.2341275 & 10.8357994 & 25.2491642 \\
\hline $\mathrm{O}$ & 15.6497047 & 11.1927705 & 24.9640199 \\
\hline $\mathrm{O}$ & 10.1379094 & 8.2485151 & 24.9970251 \\
\hline $\mathrm{H}$ & 10.3534831 & 11.8728949 & 29.8424689 \\
\hline $\mathrm{H}$ & 8.7699047 & 14.9852772 & 15.0448485 \\
\hline$P$ & 5.4632573 & 14.7177883 & 16.6670912 \\
\hline Al & 5.4132018 & 14.7000673 & 28.4832733 \\
\hline$P$ & 12.3632769 & 18.7779846 & 21.6347734 \\
\hline $\mathrm{Ge}$ & 12.1884552 & 13.3216139 & 21.6956241 \\
\hline $\mathrm{P}$ & 17.1700889 & 15.9205223 & 21.6337671 \\
\hline Al & 17.0915186 & 15.9723318 & 18.4703702 \\
\hline Al & 12.2768757 & 13.2844887 & 18.4554063 \\
\hline Al & 12.3989491 & 18.7743632 & 18.5126765 \\
\hline $\mathrm{P}$ & 5.3699129 & 17.2020792 & 26.6246330 \\
\hline Al & 5.3125388 & 17.2235824 & 23.5690037 \\
\hline $\mathrm{P}$ & 8.5632283 & 14.6512449 & 28.3319819 \\
\hline Al & 8.6152881 & 14.7357724 & 16.5046299 \\
\hline $\mathrm{P}$ & 15.4963240 & 13.2591500 & 18.4535241 \\
\hline $\mathrm{P}$ & 15.5520084 & 18.7308655 & 18.4635929 \\
\hline $\mathrm{P}$ & 10.7648062 & 16.0420378 & 18.3814057 \\
\hline Al & 10.5896002 & 16.0873551 & 21.5442298 \\
\hline Al & 15.5324067 & 18.6664313 & 21.6347885 \\
\hline Al & 15.4705181 & 13.2802342 & 21.5473911 \\
\hline $\mathrm{P}$ & 8.4618949 & 17.4456620 & 23.3873931 \\
\hline Al & 8.5181789 & 17.2281846 & 26.5142934 \\
\hline 0 & 9.1091076 & 13.0884534 & 16.8840756 \\
\hline $\mathrm{O}$ & 7.0782060 & 14.3049535 & 28.1115729 \\
\hline $\mathrm{O}$ & 11.7499701 & 17.3828928 & 21.7790077 \\
\hline $\mathrm{O}$ & 13.8566909 & 13.8655793 & 21.6086524 \\
\hline $\mathrm{O}$ & 16.1708578 & 17.0602451 & 21.9209585 \\
\hline
\end{tabular}




\begin{tabular}{|c|c|c|c|}
\hline 0 & 15.8885946 & 14.7311872 & 18.1805093 \\
\hline $\mathrm{O}$ & 11.8361927 & 14.9624791 & 18.1337392 \\
\hline 0 & 14.0780738 & 18.3630647 & 18.2036107 \\
\hline $\mathrm{O}$ & 6.8370541 & 17.6211520 & 26.8565709 \\
\hline $\mathrm{H}$ & 8.9983575 & 18.8291430 & 23.2636645 \\
\hline $\mathrm{H}$ & 4.6303894 & 18.5451057 & 23.4957312 \\
\hline $\mathrm{H}$ & 18.3095671 & 15.7527102 & 17.6425752 \\
\hline $\mathrm{H}$ & 11.9860192 & 19.9244434 & 17.6618387 \\
\hline 0 & 11.4595141 & 12.2472464 & 17.2914589 \\
\hline 0 & 4.9354739 & 16.1443110 & 27.6438672 \\
\hline $\mathrm{H}$ & 11.6811205 & 19.7580265 & 22.5243246 \\
\hline $\mathrm{O}$ & 11.8291642 & 11.9317809 & 22.6909274 \\
\hline $\mathrm{H}$ & 18.4105282 & 16.0946083 & 22.4388292 \\
\hline 0 & 8.9852930 & 15.8291667 & 27.4494164 \\
\hline $\mathrm{H}$ & 16.1994713 & 12.3671392 & 17.4907047 \\
\hline 0 & 9.5915583 & 15.8626660 & 17.4025136 \\
\hline $\mathrm{H}$ & 15.9536300 & 19.8968808 & 17.6291895 \\
\hline $\mathrm{O}$ & 9.0891793 & 16.5250189 & 22.3410390 \\
\hline 0 & 6.9490473 & 14.8916434 & 17.0215458 \\
\hline 0 & 9.4067635 & 13.4339943 & 27.9406103 \\
\hline $\mathrm{O}$ & 13.8411798 & 18.7107781 & 22.0351085 \\
\hline $\mathrm{O}$ & 11.1009487 & 14.5990814 & 22.2045357 \\
\hline 0 & 16.5624874 & 14.5756124 & 22.0214277 \\
\hline 0 & 16.4322900 & 17.5391243 & 18.0725816 \\
\hline 0 & 13.9915846 & 13.1004820 & 18.2265386 \\
\hline 0 & 11.3840659 & 17.4197106 & 18.1235861 \\
\hline $\mathrm{H}$ & 4.4867903 & 18.3880663 & 26.7997033 \\
\hline $\mathrm{H}$ & 9.3724162 & 18.3820802 & 26.9091658 \\
\hline 0 & 6.9594073 & 17.4887768 & 23.1076788 \\
\hline $\mathrm{H}$ & 5.2376325 & 14.9961016 & 15.2218384 \\
\hline $\mathrm{O}$ & 12.2293159 & 19.2748535 & 20.1805324 \\
\hline 0 & 17.5779124 & 15.9373726 & 20.1484169 \\
\hline 0 & 5.2137873 & 16.6077028 & 25.2087292 \\
\hline $\mathrm{H}$ & 8.7886679 & 15.0155377 & 29.7580213 \\
\hline $\mathrm{O}$ & 15.8967260 & 12.8453974 & 19.8799581 \\
\hline 0 & 15.7605783 & 19.1037797 & 19.9451828 \\
\hline 0 & 10.2156162 & 15.9521447 & 19.8161498 \\
\hline 0 & 8.7299270 & 16.8925362 & 24.8046229 \\
\hline 0 & 11.6821216 & 12.7891193 & 20.0253566 \\
\hline C & 9.6582584 & 12.2304435 & 20.2260302 \\
\hline $\mathrm{H}$ & 9.8638216 & 11.9800463 & 21.2639029 \\
\hline $\mathrm{H}$ & 9.8222004 & 11.4689357 & 19.4676703 \\
\hline $\mathrm{H}$ & 9.4097406 & 13.2436314 & 19.9346630 \\
\hline $\mathrm{C}$ & 7.6171624 & 11.4299270 & 20.0787871 \\
\hline $\mathrm{H}$ & 7.8390810 & 10.3987057 & 20.3612041 \\
\hline $\mathrm{H}$ & 7.4244453 & 11.6269641 & 19.0211820 \\
\hline C & 7.3462022 & 12.3710256 & 21.0270075 \\
\hline $\mathrm{C}$ & 6.8876613 & 13.7555592 & 20.7605440 \\
\hline $\mathrm{H}$ & 7.5403403 & 14.4954603 & 21.2543646 \\
\hline $\mathrm{H}$ & 6.8182526 & 13.9816325 & 19.6882450 \\
\hline $\mathrm{H}$ & 5.8938610 & 13.9018093 & 21.2177983 \\
\hline $\mathrm{H}$ & 7.4782339 & 12.0942291 & 22.0799009 \\
\hline $\mathrm{H}$ & 5.2577214 & 14.9595597 & 29.9412205 \\
\hline $\mathrm{H}$ & 16.2006301 & 19.6903735 & 22.4845769 \\
\hline \multicolumn{4}{|c|}{$\mathrm{Ga} 15$} \\
\hline \multicolumn{4}{|c|}{171} \\
\hline $\mathrm{H}$ & 8.6628495 & 8.8546490 & 15.2471631 \\
\hline $\mathrm{Si}$ & 5.3491722 & 9.2299166 & 16.6743467 \\
\hline $\mathrm{Si}$ & 5.3411340 & 9.1686390 & 28.6063378 \\
\hline $\mathrm{Si}$ & 5.3265656 & 6.7310850 & 21.6350265 \\
\hline $\mathrm{Si}$ & 5.3627939 & 6.7640544 & 18.5707239 \\
\hline $\mathrm{Si}$ & 3.2466799 & 7.9378980 & 26.6627901 \\
\hline $\mathrm{Si}$ & 3.3662147 & 8.0577582 & 23.6113168 \\
\hline $\mathrm{Si}$ & 8.4501398 & 9.1186667 & 28.5979620 \\
\hline $\mathrm{Si}$ & 8.4691859 & 9.2343041 & 16.6738645 \\
\hline $\mathrm{Si}$ & 8.4749970 & 6.7469197 & 18.5686995 \\
\hline $\mathrm{Si}$ & 8.4660381 & 6.6689214 & 21.6778813 \\
\hline $\mathrm{Si}$ & 1.6641693 & 10.6882264 & 23.5892433 \\
\hline $\mathrm{Si}$ & 1.6283358 & 10.6433700 & 26.6793115 \\
\hline $\mathrm{O}$ & 6.9106080 & 9.6418626 & 16.9432382 \\
\hline $\mathrm{O}$ & 4.9296011 & 10.7181712 & 28.3057240 \\
\hline $\mathrm{H}$ & 4.7023754 & 5.3846482 & 21.7559197 \\
\hline $\mathrm{H}$ & 9.0532508 & 5.3161468 & 21.8835573 \\
\hline 0 & 6.9181441 & 6.3479078 & 18.3018523 \\
\hline 0 & 2.1142177 & 9.0945979 & 26.8148158 \\
\hline $\mathrm{H}$ & 2.3198574 & 7.0219411 & 23.3891911 \\
\hline $\mathrm{H}$ & 0.2902329 & 10.1666416 & 23.3497255 \\
\hline $\mathrm{O}$ & 4.9213140 & 7.9658599 & 17.5824559 \\
\hline 0 & 4.4384202 & 8.1470720 & 27.7388204 \\
\hline
\end{tabular}

18.1805093

1337392

26.8565709

23.2636645

17.6425752

17.6618387

27.6438672

22.5243246

6909274

27.4494164

17.6291895

410390

27.9406103

.0351085

22.0214277

0725816

18.1235861

6.7997033

23.1076788

5. 2218384

20.1484169

5.2087292

19.8799581

.9451828

9.8161498

20.0253566

20.2260302

19.4676703

19.9346630

20.0787871

19.0211820

21.0270075

605440

21.2543646

22.0799009

29.9412205 $\mathrm{Ga} 15$

171 


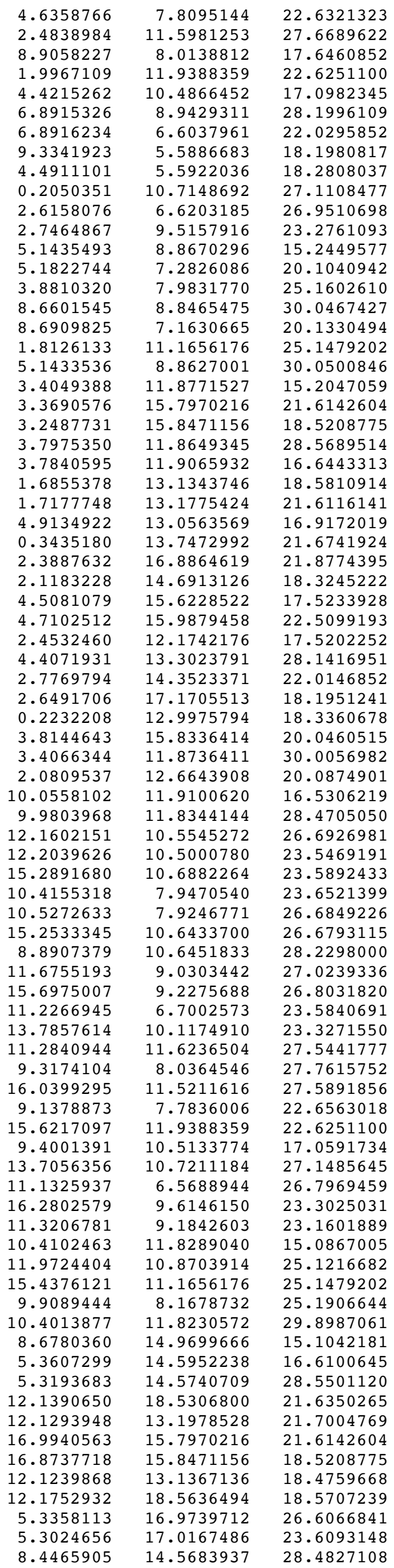

27.1485645 26.7969459 23.3025031

23.1601889 15.0867005 25.1216682

25.1479202

25.1906644

29.8987061

15.1042181 16.6100645 28.5501120

21.6350265

21.7004769

21.6142604

18.5208775

18.4759668

18.5707239

26.6066841

23.6093148

28.4827108 


\begin{tabular}{|c|c|c|c|}
\hline $\mathrm{Si}$ & 8.4899326 & 14.6274126 & 16.5410182 \\
\hline $\mathrm{Si}$ & 15.3105366 & 13.1343746 & 18.5810914 \\
\hline $\mathrm{Si}$ & 15.2874964 & 18.5465147 & 18.5686995 \\
\hline $\mathrm{Si}$ & 10.5818203 & 15.8312987 & 18.4995280 \\
\hline $\mathrm{Si}$ & 10.3913738 & 15.8495735 & 21.6040295 \\
\hline $\mathrm{Si}$ & 15.2785375 & 18.4685164 & 21.6778813 \\
\hline $\mathrm{Si}$ & 15.3427735 & 13.1775424 & 21.6116141 \\
\hline $\mathrm{Si}$ & 8.4145662 & 17.2347700 & 23.5100133 \\
\hline $\mathrm{Si}$ & 8.4526456 & 17.0351096 & 26.5806539 \\
\hline 0 & 8.9571701 & 13.0843692 & 16.8158519 \\
\hline $\mathrm{O}$ & 6.8767258 & 14.1994969 & 28.2644781 \\
\hline $\mathrm{O}$ & 11.4623154 & 17.0708676 & 21.7660994 \\
\hline $\mathrm{O}$ & 13.8619300 & 13.7914893 & 21.6790460 \\
\hline $\mathrm{O}$ & 15.9200856 & 16.9905682 & 21.9025887 \\
\hline $\mathrm{O}$ & 15.7433215 & 14.6913126 & 18.3245222 \\
\hline 0 & 11.7204345 & 14.6992333 & 18.2130939 \\
\hline $\mathrm{O}$ & 13.7306435 & 18.1475028 & 18.3018523 \\
\hline $\mathrm{O}$ & 6.8876913 & 17.4124042 & 26.8650630 \\
\hline $\mathrm{H}$ & 8.9857498 & 18.6037669 & 23.3807172 \\
\hline $\mathrm{H}$ & 4.5411238 & 18.2960706 & 23.5807762 \\
\hline $\mathrm{H}$ & 18.0297761 & 15.6412534 & 17.6052381 \\
\hline $\mathrm{H}$ & 11.7688557 & 19.6700620 & 17.6608994 \\
\hline $\mathrm{O}$ & 11.4144157 & 12.1820421 & 17.3619886 \\
\hline 0 & 4.8610300 & 15.8442385 & 27.6627929 \\
\hline $\mathrm{H}$ & 11.5054198 & 19.5200422 & 22.5497816 \\
\hline $\mathrm{O}$ & 11.6840030 & 11.6948402 & 22.6373845 \\
\hline $\mathrm{H}$ & 18.2237400 & 15.9720719 & 22.4354522 \\
\hline $\mathrm{O}$ & 8.8984069 & 15.7815547 & 27.5106568 \\
\hline $\mathrm{H}$ & 16.0145149 & 12.2539232 & 17.6082910 \\
\hline $\mathrm{O}$ & 9.3513608 & 15.6514363 & 17.4506118 \\
\hline $\mathrm{H}$ & 15.6821610 & 19.7071348 & 17.7235241 \\
\hline $\mathrm{O}$ & 9.0140964 & 16.2423956 & 22.3863414 \\
\hline 0 & 6.9326491 & 14.7507113 & 16.9837055 \\
\hline $\mathrm{O}$ & 9.3193363 & 13.2619372 & 28.0968491 \\
\hline 0 & 13.7041228 & 18.4033912 & 22.0295852 \\
\hline $\mathrm{O}$ & 10.9363807 & 14.4870916 & 22.2234650 \\
\hline $\mathrm{O}$ & 16.4019781 & 14.3523371 & 22.0146852 \\
\hline $\mathrm{O}$ & 16.2207849 & 17.2883809 & 18.1661213 \\
\hline 0 & 13.7224964 & 12.9858184 & 18.3150019 \\
\hline 0 & 11.2299944 & 17.2928339 & 18.2563195 \\
\hline $\mathrm{H}$ & 4.4465047 & 18.1539402 & 26.7908788 \\
\hline $\mathrm{H}$ & 9.3000580 & 18.2041036 & 26.9446127 \\
\hline 0 & 6.8305982 & 17.3522618 & 23.2289265 \\
\hline $\mathrm{H}$ & 5.1277622 & 14.9285364 & 15.1776716 \\
\hline $\mathrm{O}$ & 11.9947738 & 19.0822037 & 20.1040942 \\
\hline $\mathrm{O}$ & 17.4394631 & 15.8336414 & 20.0460515 \\
\hline 0 & 5.1944989 & 16.3586429 & 25.0994787 \\
\hline $\mathrm{H}$ & 8.6736257 & 14.9636903 & 29.9002143 \\
\hline $\mathrm{O}$ & 15.7059524 & 12.6643908 & 20.0874901 \\
\hline $\mathrm{O}$ & 15.5034818 & 18.9626615 & 20.1330494 \\
\hline 0 & 9.9967157 & 15.6932360 & 20.0110300 \\
\hline 0 & 8.6793437 & 16.6439447 & 25.0123705 \\
\hline 0 & 11.6030621 & 12.6375812 & 19.9428888 \\
\hline $\mathrm{C}$ & 9.6529134 & 12.0168109 & 20.1905870 \\
\hline $\mathrm{H}$ & 9.9190507 & 11.7033277 & 21.1971657 \\
\hline $\mathrm{H}$ & 9.7566427 & 11.3034883 & 19.3768008 \\
\hline $\mathrm{H}$ & 9.3190020 & 13.0284185 & 19.9894070 \\
\hline C & 7.6063303 & 11.0826364 & 20.1780690 \\
\hline $\mathrm{H}$ & 7.9341007 & 10.0787464 & 20.4566279 \\
\hline $\mathrm{H}$ & 7.3291806 & 11.2468553 & 19.1335026 \\
\hline C & 7.3447217 & 12.0236246 & 21.1254826 \\
\hline $\mathrm{C}$ & 6.7583430 & 13.3634298 & 20.8724652 \\
\hline $\mathrm{H}$ & 7.3844046 & 14.1644644 & 21.3001878 \\
\hline $\mathrm{H}$ & 6.5922804 & 13.5581303 & 19.8042451 \\
\hline $\mathrm{H}$ & 5.7919144 & 13.4384869 & 21.4003254 \\
\hline $\mathrm{H}$ & 7.5767239 & 11.7822426 & 22.1697269 \\
\hline $\mathrm{H}$ & 5.1247675 & 14.9260400 & 29.9837678 \\
\hline $\mathrm{H}$ & 15.8929292 & 19.4878669 & 22.5726260 \\
\hline \multicolumn{4}{|c|}{$\begin{array}{l}\text { Ti } 15 \\
171\end{array}$} \\
\hline $\mathrm{H}$ & 8.6806002 & 9.0281393 & 15.1941891 \\
\hline $\mathrm{P}$ & 5.4136104 & 9.3573860 & 16.7340189 \\
\hline Al & 5.3701556 & 9.2614175 & 28.5386533 \\
\hline $\mathrm{P}$ & 5.4242030 & 6.7669817 & 21.6469204 \\
\hline Al & 5.4748427 & 6.7700333 & 18.5239905 \\
\hline $\mathrm{P}$ & 3.2378640 & 7.9051716 & 26.6752493 \\
\hline Al & 3.3775522 & 8.0702935 & 23.5890057 \\
\hline $\mathrm{P}$ & 8.4981160 & 9.1541768 & 28.4484680 \\
\hline & & & \\
\hline
\end{tabular}




\begin{tabular}{|c|c|c|c|}
\hline $\mathrm{P}$ & 8.6245465 & 6.7366329 & 18.4788436 \\
\hline Al & 8.5972220 & 6.6497047 & 21.6475351 \\
\hline $\mathrm{P}$ & 1.6774447 & 10.7458711 & 23.5072041 \\
\hline Al & 1.6117651 & 10.6604362 & 26.6530554 \\
\hline 0 & 6.8883139 & 9.7349695 & 17.0174037 \\
\hline 0 & 4.9213180 & 10.9105394 & 28.1333958 \\
\hline $\mathrm{H}$ & 4.7538366 & 5.4451411 & 21.7899824 \\
\hline $\mathrm{H}$ & 9.1805471 & 5.2980256 & 21.8707301 \\
\hline 0 & 7.1541597 & 6.3567350 & 18.2133179 \\
\hline $\mathrm{O}$ & 2.1617438 & 9.0008424 & 26.7780090 \\
\hline $\mathrm{H}$ & 2.3099876 & 7.0680016 & 23.3191218 \\
\hline $\mathrm{H}$ & 0.3282304 & 10.2139503 & 23.1698589 \\
\hline 0 & 5.0049834 & 8.1272662 & 17.5431291 \\
\hline $\mathrm{O}$ & 4.3371761 & 8.1252746 & 27.7212165 \\
\hline $\mathrm{O}$ & 4.7730605 & 7.8084462 & 22.5702157 \\
\hline 0 & 2.5731979 & 11.7111115 & 27.6585368 \\
\hline $\mathrm{O}$ & 9.0337968 & 7.9437312 & 17.6206361 \\
\hline 0 & 2.0452007 & 11.9352700 & 22.6179277 \\
\hline $\mathrm{O}$ & 4.5245758 & 10.5302128 & 17.1640716 \\
\hline 0 & 7.0234168 & 8.9710957 & 28.0751730 \\
\hline 0 & 6.9003640 & 6.6192907 & 22.0366225 \\
\hline $\mathrm{H}$ & 9.4894042 & 5.5847724 & 18.1015383 \\
\hline $\mathrm{H}$ & 4.5984977 & 5.6152486 & 18.1839723 \\
\hline $\mathrm{H}$ & 0.2167804 & 10.6980312 & 27.1724058 \\
\hline $\mathrm{H}$ & 2.6077198 & 6.5856093 & 26.9559521 \\
\hline $\mathrm{O}$ & 2.7319693 & 9.6535315 & 23.2704456 \\
\hline $\mathrm{H}$ & 5.2234046 & 9.0506143 & 15.2894313 \\
\hline $\mathrm{O}$ & 5.3085356 & 7.2704783 & 20.1936038 \\
\hline 0 & 3.8741368 & 7.9230329 & 25.2704164 \\
\hline $\mathrm{H}$ & 8.6946564 & 8.9856782 & 29.9147901 \\
\hline $\mathrm{O}$ & 8.8219662 & 7.1115462 & 19.9622830 \\
\hline $\mathrm{O}$ & 1.7118570 & 11.1950319 & 24.9868099 \\
\hline $\mathrm{H}$ & 5.2400602 & 9.0736795 & 30.0100302 \\
\hline $\mathrm{H}$ & 3.5848207 & 12.0180603 & 15.1736709 \\
\hline $\mathrm{P}$ & 3.3433130 & 15.9334037 & 21.6215339 \\
\hline Al & 3.2380909 & 15.9937987 & 18.4653154 \\
\hline $\mathrm{P}$ & 3.8602123 & 11.9910048 & 28.4353337 \\
\hline Al & 3.8484558 & 12.0521040 & 16.6387505 \\
\hline $\mathrm{P}$ & 1.6295197 & 13.2819841 & 18.4642704 \\
\hline Al & 1.6490023 & 13.2829885 & 21.5693969 \\
\hline 0 & 5.0504889 & 13.2855012 & 17.0183288 \\
\hline $\mathrm{H}$ & 0.2269685 & 13.7156530 & 21.6573848 \\
\hline $\mathrm{H}$ & 2.3810126 & 17.0349448 & 21.9002911 \\
\hline $\mathrm{O}$ & 2.0299121 & 14.7530801 & 18.1924195 \\
\hline $\mathrm{O}$ & 4.6638810 & 15.7363661 & 17.4818754 \\
\hline $\mathrm{O}$ & 4.6327942 & 16.1054981 & 22.4438120 \\
\hline 0 & 2.3502817 & 12.3610228 & 17.4648395 \\
\hline $\mathrm{O}$ & 4.4037919 & 13.3550924 & 27.9905630 \\
\hline $\mathrm{O}$ & 2.7349766 & 14.5912859 & 22.0170115 \\
\hline $\mathrm{H}$ & 2.6749585 & 17.3346503 & 18.1457537 \\
\hline $\mathrm{H}$ & 0.1632882 & 13.1369637 & 18.2492010 \\
\hline 0 & 3.7468352 & 15.9470739 & 20.1360647 \\
\hline $\mathrm{H}$ & 3.5495407 & 12.0115380 & 29.8914183 \\
\hline 0 & 2.0362004 & 12.8631010 & 19.8879016 \\
\hline $\mathrm{P}$ & 10.1593393 & 11.9857188 & 16.5333774 \\
\hline Al & 10.0697655 & 11.8707768 & 28.3335734 \\
\hline $\mathrm{P}$ & 12.4029153 & 10.5393456 & 26.7781773 \\
\hline Al & 12.4482465 & 10.4897829 & 23.5330082 \\
\hline $\mathrm{P}$ & 15.5524434 & 10.7458711 & 23.5072041 \\
\hline $\mathrm{P}$ & 10.5767416 & 7.9913835 & 23.5801307 \\
\hline Al & 10.6882183 & 7.9667811 & 26.6561447 \\
\hline Al & 15.4867638 & 10.6604362 & 26.6530554 \\
\hline 0 & 8.9434344 & 10.5636595 & 28.0035187 \\
\hline 0 & 11.8895608 & 9.1375203 & 27.1782797 \\
\hline $\mathrm{H}$ & 15.9539670 & 9.2506226 & 26.7592027 \\
\hline $\mathrm{H}$ & 11.3002382 & 6.6899753 & 23.5769908 \\
\hline $\mathrm{O}$ & 14.1542911 & 10.1946567 & 23.1576229 \\
\hline $\mathrm{O}$ & 11.5487704 & 11.6267959 & 27.4522368 \\
\hline $\mathrm{O}$ & 9.3126719 & 8.0713535 & 27.7299634 \\
\hline $\mathrm{H}$ & 16.3079268 & 11.5578215 & 27.5118404 \\
\hline $\mathrm{O}$ & 9.3436179 & 7.8749172 & 22.6625474 \\
\hline 0 & 15.9201994 & 11.9352700 & 22.6179277 \\
\hline 0 & 9.5856820 & 10.6661299 & 17.0992170 \\
\hline $\mathrm{O}$ & 13.8499617 & 10.7045482 & 27.2624340 \\
\hline $\mathrm{H}$ & 11.2891345 & 6.6067855 & 26.7363478 \\
\hline $\mathrm{H}$ & 16.5742705 & 9.6874016 & 23.2777867 \\
\hline 0 & 11.5028936 & 9.0863579 & 23.0480344 \\
\hline $\mathrm{H}$ & 10.3855025 & 11.8626609 & 15.0668074 \\
\hline $\mathrm{O}$ & 12.3252423 & 10.7024731 & 25.2642871 \\
\hline 0 & 15.5868558 & 11.1950319 & 24.9868099 \\
\hline
\end{tabular}




\begin{tabular}{|c|c|c|c|}
\hline $\mathrm{O}$ & 10.1237976 & 8.3113620 & 25.0216590 \\
\hline $\mathrm{H}$ & 10.3443618 & 11.8611864 & 29.7970028 \\
\hline $\mathrm{H}$ & 8.7759133 & 14.9851748 & 15.0133710 \\
\hline$P$ & 5.4749185 & 14.7273071 & 16.6610606 \\
\hline Al & 5.4088177 & 14.6935227 & 28.4756155 \\
\hline $\mathrm{P}$ & 12.3617024 & 18.7830831 & 21.6469204 \\
\hline $\mathrm{Ti}$ & 12.1390575 & 13.2954507 & 21.7185393 \\
\hline $\mathrm{P}$ & 17.2183117 & 15.9334037 & 21.6215339 \\
\hline Al & 17.1130896 & 15.9937987 & 18.4653154 \\
\hline$A 1$ & 12.2717818 & 13.2905059 & 18.4261678 \\
\hline$A 1$ & 12.4123420 & 18.7861346 & 18.5239905 \\
\hline $\mathrm{P}$ & 5.3780926 & 17.1879328 & 26.6206979 \\
\hline Al & 5.3108371 & 17.2224942 & 23.5893071 \\
\hline $\mathrm{P}$ & 8.5585277 & 14.6419260 & 28.3014406 \\
\hline Al & 8.6294779 & 14.7467736 & 16.4758491 \\
\hline $\mathrm{P}$ & 15.5045184 & 13.2819841 & 18.4642704 \\
\hline$P$ & 15.5620458 & 18.7527342 & 18.4788436 \\
\hline $\mathrm{P}$ & 10.7572799 & 16.0625729 & 18.3718247 \\
\hline Al & 10.5029277 & 16.1439614 & 21.5295221 \\
\hline Al & 15.5347213 & 18.6658061 & 21.6475351 \\
\hline Al & 15.5240010 & 13.2829885 & 21.5693969 \\
\hline $\mathrm{P}$ & 8.4300870 & 17.5146905 & 23.3801740 \\
\hline$A 1$ & 8.5098461 & 17.2279107 & 26.4988725 \\
\hline 0 & 9.1331094 & 13.1004126 & 16.8484636 \\
\hline 0 & 7.0709059 & 14.3003125 & 28.0920828 \\
\hline $\mathrm{O}$ & 11.6728185 & 17.4247296 & 21.7939342 \\
\hline $\mathrm{O}$ & 13.8804331 & 13.7830564 & 21.6710922 \\
\hline $\mathrm{O}$ & 16.2214616 & 17.0744937 & 21.9102994 \\
\hline $\mathrm{O}$ & 15.9049108 & 14.7530801 & 18.1924195 \\
\hline 0 & 11.8292210 & 14.9791927 & 18.1500622 \\
\hline $\mathrm{O}$ & 14.0916590 & 18.3728363 & 18.2133179 \\
\hline 0 & 6.8357476 & 17.6281769 & 26.8784428 \\
\hline $\mathrm{H}$ & 9.0429581 & 18.8676747 & 23.2755622 \\
\hline $\mathrm{H}$ & 4.5073623 & 18.4760627 & 23.5785949 \\
\hline $\mathrm{H}$ & 18.3254806 & 15.7748962 & 17.6290676 \\
\hline $\mathrm{H}$ & 12.0100845 & 19.9480936 & 17.6842520 \\
\hline 0 & 11.4996851 & 12.2811342 & 17.2049353 \\
\hline $\mathrm{O}$ & 4.9291672 & 16.1460084 & 27.6500325 \\
\hline $\mathrm{H}$ & 11.7307266 & 19.7922920 & 22.5416200 \\
\hline 0 & 11.7840761 & 11.8641260 & 22.7587967 \\
\hline $\mathrm{H}$ & 18.4658998 & 16.0999070 & 22.4170975 \\
\hline $\mathrm{O}$ & 8.9803722 & 15.8123780 & 27.4079739 \\
\hline $\mathrm{H}$ & 16.2021571 & 12.3905688 & 17.4969030 \\
\hline 0 & 9.6068609 & 15.8825799 & 17.3644454 \\
\hline $\mathrm{H}$ & 15.9586225 & 19.9224513 & 17.6472130 \\
\hline 0 & 8.9851047 & 16.5871082 & 22.2966293 \\
\hline 0 & 6.9641608 & 14.8981783 & 17.0043959 \\
\hline 0 & 9.3926628 & 13.4184300 & 27.9075690 \\
\hline 0 & 13.8378634 & 18.6353921 & 22.0366225 \\
\hline $\mathrm{O}$ & 11.0380112 & 14.6556890 & 22.1802223 \\
\hline 0 & 16.6099753 & 14.5912859 & 22.0170115 \\
\hline 0 & 16.4524223 & 17.5668866 & 18.0904054 \\
\hline 0 & 13.9983516 & 13.1330139 & 18.2433432 \\
\hline 0 & 11.3895846 & 17.4384182 & 18.1271649 \\
\hline $\mathrm{H}$ & 4.4754323 & 18.3654399 & 26.7464044 \\
\hline $\mathrm{H}$ & 9.3792430 & 18.3694342 & 26.8966083 \\
\hline $\mathrm{O}$ & 6.9258360 & 17.6575954 & 23.1369712 \\
\hline $\mathrm{H}$ & 5.2431577 & 14.9888349 & 15.2136454 \\
\hline 0 & 12.2460349 & 19.2865797 & 20.1936038 \\
\hline 0 & 17.6218339 & 15.9470739 & 20.1360647 \\
\hline $\mathrm{O}$ & 5.2704973 & 16.5588231 & 25.2135406 \\
\hline $\mathrm{H}$ & 8.7930558 & 15.0134524 & 29.7241441 \\
\hline 0 & 15.9111991 & 12.8631010 & 19.8879016 \\
\hline 0 & 15.7594655 & 19.1276476 & 19.9622830 \\
\hline 0 & 10.1713772 & 15.9865788 & 19.7938938 \\
\hline 0 & 8.6920774 & 16.9126349 & 24.7795362 \\
\hline 0 & 11.6558857 & 12.7707887 & 19.9737202 \\
\hline $\mathrm{C}$ & 9.6218426 & 12.2107882 & 20.1854383 \\
\hline $\mathrm{H}$ & 9.8403904 & 11.9087355 & 21.2068036 \\
\hline $\mathrm{H}$ & 9.7777995 & 11.4869927 & 19.3893093 \\
\hline $\mathrm{H}$ & 9.3898529 & 13.2420490 & 19.9483270 \\
\hline C & 7.5910109 & 11.4248176 & 20.0371244 \\
\hline $\mathrm{H}$ & 7.8139393 & 10.3875707 & 20.2959027 \\
\hline $\mathrm{H}$ & 7.3857195 & 11.6427568 & 18.9860647 \\
\hline $\mathrm{C}$ & 7.3234092 & 12.3447114 & 21.0078548 \\
\hline C & 6.8585424 & 13.7319852 & 20.7723390 \\
\hline $\mathrm{H}$ & 7.5101747 & 14.4649416 & 21.2775848 \\
\hline $\mathrm{H}$ & 6.7819565 & 13.9795724 & 19.7053495 \\
\hline $\mathrm{H}$ & 5.8666744 & 13.8639161 & 21.2381336 \\
\hline $\mathrm{H}$ & 7.4647915 & 12.0463895 & 22.0536618 \\
\hline
\end{tabular}




\begin{tabular}{|c|c|c|c|}
\hline $\mathrm{H}$ & 5.2615835 & 14.9520702 & 29.9345863 \\
\hline $\mathrm{H}$ & 16.1671185 & 19.7038891 & 22.5075223 \\
\hline & & & \\
\hline & & & \\
\hline $\mathrm{H}$ & 8.7167388 & 9.0080031 & 15.2759523 \\
\hline Al & 5.3763237 & 9.3070397 & 16.6498852 \\
\hline$P$ & 5.3642315 & 9.2623800 & 28.4764041 \\
\hline Al & 5.2435999 & 6.6670972 & 21.5782444 \\
\hline $\mathrm{P}$ & 5.2981397 & 6.7215262 & 18.4151130 \\
\hline Al & 3.1390939 & 8.0473766 & 26.5957842 \\
\hline $\mathrm{P}$ & 3.1993814 & 8.1446332 & 23.4675284 \\
\hline Al & 8.4971388 & 9.2512185 & 28.5257557 \\
\hline $\mathrm{P}$ & 8.5394327 & 9.3635326 & 16.7109722 \\
\hline Al & 8.4875891 & 6.7974835 & 18.5073398 \\
\hline $\mathrm{P}$ & 8.4520417 & 6.7236024 & 21.6613254 \\
\hline $\mathrm{Al}$ & 1.5136980 & 10.8134213 & 23.4998064 \\
\hline$P$ & 1.4809138 & 10.7549285 & 26.6688882 \\
\hline $\mathrm{O}$ & 7.0620553 & 9.6951766 & 16.9969369 \\
\hline 0 & 4.9799196 & 10.7280168 & 28.1853656 \\
\hline $\mathrm{H}$ & 4.7763277 & 5.2807046 & 21.8551793 \\
\hline $\mathrm{H}$ & 8.9506649 & 5.3436319 & 21.9146569 \\
\hline 0 & 6.8050622 & 6.4596678 & 18.2243974 \\
\hline 0 & 1.9214704 & 9.2859529 & 26.8208930 \\
\hline $\mathrm{H}$ & 2.1060551 & 7.1561535 & 23.2561850 \\
\hline $\mathrm{H}$ & 0.1372156 & 10.3384725 & 23.1886147 \\
\hline 0 & 4.8594089 & 7.9113621 & 17.5522776 \\
\hline 0 & 4.4948310 & 8.3038752 & 27.6596580 \\
\hline 0 & 4.3891214 & 7.846 & 22.5463128 \\
\hline 0 & 2.3291635 & 11.6639020 & 27.5652362 \\
\hline $\mathrm{O}$ & 9.0128253 & 8.1960835 & 17.5912754 \\
\hline 0 & 1.8935894 & 12.2133736 & 22.5546128 \\
\hline 0 & 4.3853692 & 10.6677247 & 17.0994519 \\
\hline 0 & 6.8280437 & 9.0414758 & 28.0785338 \\
\hline $\mathrm{O}$ & 6.9495936 & 6.7736589 & 21.9241923 \\
\hline $\mathrm{H}$ & 9.3021370 & 5.6340855 & 18.0599726 \\
\hline $\mathrm{H}$ & 4.5603435 & 5.5095825 & 17.9634828 \\
\hline $\mathrm{H}$ & 0.0646168 & 10.8704247 & 27.1137297 \\
\hline $\mathrm{H}$ & 2.5284449 & 6.7363126 & 26.9498173 \\
\hline 0 & 2.6636449 & 9.5425635 & 23.1321512 \\
\hline $\mathrm{H}$ & 5.2032826 & 9.0017909 & 15.2028190 \\
\hline $\mathrm{O}$ & 4.9888752 & 7.0518329 & 19.8831852 \\
\hline 0 & 3.6877586 & 8.0829020 & 24.9306238 \\
\hline $\mathrm{H}$ & 8.6882001 & 9.0353448 & 29.9865825 \\
\hline 0 & 8.7727752 & 7.1413619 & 20.2049878 \\
\hline 0 & 1.6284902 & 11.2121520 & 25.2083240 \\
\hline $\mathrm{H}$ & 5.1794908 & 8.9590783 & 29.9224330 \\
\hline $\mathrm{H}$ & 3.4065586 & 11.9786481 & 15.2283491 \\
\hline Al & 3.2155155 & 16.0645138 & 21.5447137 \\
\hline $\mathrm{P}$ & 3.1618471 & 16.1313408 & 18.4102040 \\
\hline Al & 3.7707927 & 11.9665470 & 28.4891618 \\
\hline $\mathrm{P}$ & 3.7879041 & 12.0130183 & 16.6672775 \\
\hline Al & 1.5846550 & 13.3418928 & 18.4936000 \\
\hline $\mathrm{P}$ & 1.5847073 & 13.3773815 & 21.5974732 \\
\hline 0 & 4.8369963 & 13.1146893 & 16.9252975 \\
\hline $\mathrm{H}$ & 0.2404686 & 13.9808845 & 21.8117794 \\
\hline $\mathrm{H}$ & 2.2140574 & 17.1189687 & 21.8645999 \\
\hline 0 & 2.1286222 & 14.9966337 & 18.2825474 \\
\hline 0 & 4.3596056 & 15.8895259 & 17.4862113 \\
\hline 0 & 4.6382031 & 16.2855382 & 22.5234381 \\
\hline $\mathrm{O}$ & 2.5226753 & 12.2635661 & 17.4922460 \\
\hline 0 & 4.4050318 & 13.5176292 & 28.0175996 \\
\hline 0 & 2.6612204 & 14.4531998 & 21.8384089 \\
\hline $\mathrm{H}$ & 2.5235207 & 17.4115428 & 17.9969936 \\
\hline $\mathrm{H}$ & 0.1675926 & 13.2482775 & 18.0460611 \\
\hline 0 & 3.6709933 & 16.2418191 & 19.8567213 \\
\hline $\mathrm{H}$ & 3.4502499 & 11.9758838 & 29.9432201 \\
\hline 0 & 1.7335272 & 12.8210252 & 20.1512810 \\
\hline Al & 10.0434203 & 12.1020044 & 16.4773939 \\
\hline$P$ & 9.9935053 & 12.0124384 & 28.3183918 \\
\hline Al & 12.2400123 & 10.6442638 & 26.6292735 \\
\hline $\mathrm{P}$ & 12.2705857 & 10.5947433 & 23.4089239 \\
\hline Al & 15.3886968 & 10.8134213 & 23.4998064 \\
\hline Al & 10.5346251 & 7.9967312 & 23.6010581 \\
\hline $\mathrm{P}$ & 10.6408521 & 7.9745163 & 26.7061871 \\
\hline$P$ & 15.3559126 & 10.7549285 & 26.6688882 \\
\hline 0 & 8.9751598 & 10.8791460 & 28.0802212 \\
\hline 0 & 11.7199098 & 9.0188175 & 27.0592250 \\
\hline $\mathrm{H}$ & 15.7815666 & 9.3356433 & 26.8157512 \\
\hline $\mathrm{H}$ & 11.4154112 & 6.8033522 & 23.4699749 \\
\hline
\end{tabular}




\begin{tabular}{|c|c|c|}
\hline 13.7608105 & 10.2517268 & 23.1317779 \\
\hline 11.2402932 & 11.8153362 & 27.4537714 \\
\hline 9.4690466 & 8.0685384 & 27.6924831 \\
\hline 16.1799716 & 11.6379797 & 27.5396740 \\
\hline 9.1311010 & 7.7399005 & 22.5934550 \\
\hline 15.7685882 & 12.2133736 & 22.5546128 \\
\hline 9.4224593 & 10.5733491 & 17.0725484 \\
\hline 13.8956463 & 10.8740103 & 27.1275398 \\
\hline 11.2295851 & 6.6113672 & 26.8172662 \\
\hline 16.3655233 & 9.7338865 & 23.1875004 \\
\hline 11.4414263 & 9.3516602 & 22.9798471 \\
\hline 10.3638746 & 12.0280332 & 15.0251687 \\
\hline 12.0768171 & 10.8494423 & 24.9146010 \\
\hline 15.5034890 & 11.2121520 & 25.2083240 \\
\hline 10.0995586 & 8.2233290 & 25.2813948 \\
\hline 10.4033574 & 12.0155508 & 29.7498708 \\
\hline 8.6441458 & 15.1272981 & 15.1130925 \\
\hline 5.3211758 & 14.7629463 & 16.5718699 \\
\hline 5.2612551 & 14.7276274 & 28.4028615 \\
\hline 12.1810993 & 18.6831985 & 21.5782444 \\
\hline 12.2906371 & 13.3604550 & 21.6393060 \\
\hline 17.0905143 & 16.0645138 & 21.5447137 \\
\hline 17.0368458 & 16.1313408 & 18.4102040 \\
\hline 12.3108201 & 13.2411610 & 18.3602932 \\
\hline 12.2356391 & 18.7376275 & 18.4151130 \\
\hline 5.3541709 & 17.2299327 & 26.5663257 \\
\hline 5.3233708 & 17.2626831 & 23.4789002 \\
\hline 8.4253610 & 14.7559475 & 28.3894506 \\
\hline 8.4614187 & 14.8004714 & 16.5542434 \\
\hline 15.4596537 & 13.3418928 & 18.4936000 \\
\hline 15.4250885 & 18.8135849 & 18.5073398 \\
\hline 10.6713441 & 16.0271519 & 18.4738539 \\
\hline 10.4956002 & 16.0508356 & 21.5737773 \\
\hline 15.3895410 & 18.7397038 & 21.6613254 \\
\hline 15.4597060 & 13.3773815 & 21.5974732 \\
\hline 8.4449032 & 17.4900711 & 23.4618166 \\
\hline 8.4839699 & 17.3343375 & 26.6250309 \\
\hline 8.8437056 & 13.3256528 & 16.8119166 \\
\hline 6.7360132 & 14.4010535 & 28.1007636 \\
\hline 11.6338912 & 17.0596368 & 21.9025543 \\
\hline 14.0850232 & 13.9945525 & 21.8166330 \\
\hline 15.9052183 & 17.3125351 & 21.9233214 \\
\hline 16.0036210 & 14.9966337 & 18.2825474 \\
\hline 11.8140925 & 14.6901956 & 18.4232402 \\
\hline 13.7425615 & 18.4757692 & 18.2243974 \\
\hline 7.0111565 & 17.6712560 & 26.9515704 \\
\hline 8.9207679 & 18.8893322 & 23.2808696 \\
\hline 4.6416377 & 18.5861213 & 23.4493763 \\
\hline 18.2010257 & 15.8963050 & 17.5121150 \\
\hline 11.8097353 & 19.8926764 & 17.5775042 \\
\hline 11.5469388 & 12.4291570 & 17.2973608 \\
\hline 4.7941288 & 15.9308524 & 27.5796062 \\
\hline 11.4536296 & 19.6875106 & 22.4024201 \\
\hline 11.7816009 & 11.7702249 & 22.5957085 \\
\hline 18.3073334 & 16.2535551 & 22.3818129 \\
\hline 8.9450596 & 16.1199974 & 27.4416546 \\
\hline 16.2600151 & 12.4218157 & 17.6391994 \\
\hline 9.3462951 & 15.7358834 & 17.3778861 \\
\hline 15.8713611 & 20.0019206 & 17.7289957 \\
\hline 9.2609660 & 16.3900786 & 22.4225207 \\
\hline 7.0018223 & 15.0005434 & 16.9803017 \\
\hline 9.3547000 & 13.3511041 & 27.9424543 \\
\hline 13.8870930 & 18.7897603 & 21.9241923 \\
\hline 10.9090719 & 14.6309762 & 21.8686554 \\
\hline 16.5362191 & 14.4531998 & 21.8384089 \\
\hline 16.3782254 & 17.4522436 & 17.9838566 \\
\hline 13.7929128 & 13.2317830 & 17.9672073 \\
\hline 11.4761975 & 17.4901281 & 17.9502329 \\
\hline 4.4566560 & 18.3979434 & 26.7838998 \\
\hline 9.3373565 & 18.4957173 & 26.9992620 \\
\hline 6.7651606 & 17.4660851 & 23.0158335 \\
\hline 5.1151361 & 15.0261734 & 15.1208772 \\
\hline 11.9263746 & 19.0679343 & 19.8831852 \\
\hline 17.5459920 & 16.2418191 & 19.8567213 \\
\hline 5.2776140 & 16.6830133 & 24.9043885 \\
\hline 8.6164167 & 15.0806906 & 29.8299922 \\
\hline 15.6085259 & 12.8210252 & 20.1512810 \\
\hline 15.7102745 & 19.1574633 & 20.2049878 \\
\hline 10.0787606 & 16.2437073 & 20.0901103 \\
\hline 8.6425279 & 17.0075152 & 25.1328712 \\
\hline
\end{tabular}

23.1317779

27.6924831

27.5396740

22.5934550

27.1275398

23.1875004

22.9798471

(51687

25.2083240

15.1130925

18699

21.5782444

6393060

18.4102040

8.3602932

26.5663257

3. 4789002

3894506

18.4936000

18.5073398

18.4738539

21.5974732

4618166

26.6250309
16.8119166

28.1007636

21.9025543

18.2825474

18.4232402

2243974

23.2808696

23.4493763

17.5121150

27.5796062

24201

22.3818129

4

17.3778861

4957

16.9803017

. 9424543

21.8686554

21.8384089

17.9838566

17.9502329

26.7838998

26.9992620

158335

9.8831852

(567213

29.8299922

25.1328712 


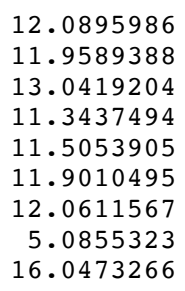

12.5473765

10.5517292

10.5105797

10.6776029

10.5109092

8.5703751

7.4576206

15.0605172

19.7241632

9.0431320

9.3557338

9.2984356

6.7376359

6.7699184

7.9612399

8.0254591

9.2371883

9.3270921

6.7755405

6.7241039

10.7580206

10.7297634

9.7006864

10.9548813

5.3435100

5.3388858

6.4445454

9.0701679

6.9972273

10.3081839

8.1641393

8.1867529

7.7461192

11.7967450

7.9738805

11.9270734

10.5613793

9.0552641

6.8559954

5.6041097

5.5884069

10.8181145

6.6543686

9.5929387

9.0058413

7.1093498

7.9473074

.0024299

7.1472126

11.2001173

9.0397296

12.0523950

15.9761135

16.0204442

12.0451733

12.0870331

13.3089969

13.2950721

13.3423905

13.6403925

17.0752113

14.7749772

15.7717510

16.1495958

12.3716724

13.4049001

14.6400395

17.3532146

13.1840500

16.0183600

12.0463386

12.8858111

12.0181593

11.9570285

10.6935820

10.7293365

10.7580206
19.7365330

19.7900219

19.8998189

20.6788972

18.8017217

19.9950241

20.1670374

29.8434955

22.5642531

15.1649738

16.6756396

28.5072018

21.6277141

18.4588040

26.6329092

23.5043643

28.4317367

16.6150220

18.4453989

21.6119645

23.4382959

26.5888889

16.9187957

28.1485309

21.8913857

21.8725014

18.1934414

26.7995010

23.2556947

23.1890598

17.5380815

27.5887066

22.4891547

27.5761074

17.5895288

22.5271286

17.0795236

28.0934529

21.9888368

18.0637294

17.9948959

27.0413801

26.9814240

23.1321969

15.2460361

20.1477698

25.1865419

29.8814983

19.9264136

24.9094254

29.9625740

15.1376991

21.6446352

18.4782508

28.4161463

16.5898378

18.4109476

21.5331971

16.9261014

21.6330677

21.9076646

18.1616435

17.5209640

22.5190452

17.4567252

28.0165978

21.9942568

18.1163148

18.1088904

20.1699952

29.8553872

19.8527522

16.5822150

28.3901534

26.7255457

23.5211292

23.4382959 


\begin{tabular}{|c|c|c|c|}
\hline $\mathrm{P}$ & 10.6303870 & 8.0654307 & 23.4766147 \\
\hline Al & 10.6659274 & 8.0421418 & 26.6201644 \\
\hline Al & 15.4543180 & 10.7297634 & 26.5888889 \\
\hline 0 & 8.8838920 & 10.6671342 & 28.0400978 \\
\hline 0 & 11.8517447 & 9.2592057 & 27.0503427 \\
\hline $\mathrm{H}$ & 15.8965691 & 9.3192692 & 26.7678886 \\
\hline $\mathrm{H}$ & 11.5501649 & 6.9051486 & 23.3188982 \\
\hline 0 & 13.9936700 & 10.2910776 & 23.1795818 \\
\hline 0 & 11.5168692 & 11.7151448 & 27.5391972 \\
\hline 0 & 9.2568456 & 8.2009022 & 27.6341202 \\
\hline $\mathrm{H}$ & 16.2741424 & 11.6421260 & 27.4330471 \\
\hline 0 & 9.3943724 & 7.8818930 & 22.5823647 \\
\hline 0 & 15.8156641 & 11.9270734 & 22.5271286 \\
\hline 0 & 9.5201925 & 10.6683558 & 17.1041211 \\
\hline 0 & 13.7956619 & 10.8332677 & 27.1189870 \\
\hline $\mathrm{H}$ & 11.2532550 & 6.6941499 & 26.8548654 \\
\hline $\mathrm{H}$ & 16.3668958 & 9.6277394 & 23.1413400 \\
\hline 0 & 11.3645154 & 9.3277780 & 23.0020768 \\
\hline $\mathrm{H}$ & 10.3460643 & 11.9318854 & 15.1239349 \\
\hline 0 & 12.1182064 & 10.9839930 & 25.2357313 \\
\hline 0 & 15.5989745 & 11.2001173 & 24.9094254 \\
\hline $\mathrm{O}$ & 10.1835906 & 8.2135264 & 24.9400423 \\
\hline $\mathrm{H}$ & 10.3050108 & 11.9335903 & 29.8514985 \\
\hline $\mathrm{H}$ & 8.7530665 & 15.03 & 15.0734308 \\
\hline $\mathrm{P}$ & 5.3860715 & 14.7987029 & 16.6400804 \\
\hline Al & 5.3457908 & 14.7695863 & 28.4884821 \\
\hline$P$ & 12.2765088 & 18.7537373 & 21.6277141 \\
\hline $\mathrm{Si}$ & 12.1316856 & 13.2449597 & 21.5799015 \\
\hline $\mathrm{P}$ & 17.0163536 & 15.97 & 21.6446352 \\
\hline Al & 17.0319175 & 16.0204442 & 18.4782508 \\
\hline Al & 12.2282090 & 13.3074924 & 18.4767902 \\
\hline Al & 12.3330099 & 18.7860198 & 18.4588040 \\
\hline $\mathrm{P}$ & 5.3055748 & 17.2795711 & 26.6321814 \\
\hline Al & 5.2748097 & 17.2674139 & 23.5087560 \\
\hline $\mathrm{P}$ & 8.5156380 & 14.7150302 & 28.3653747 \\
\hline Al & 8.5474579 & 14.7662359 & 16.5242730 \\
\hline $\mathrm{P}$ & 15.4216764 & 13.3089969 & 18.4109476 \\
\hline $\mathrm{P}$ & 15.5177094 & 18.7916418 & 18.4453989 \\
\hline $\mathrm{P}$ & 10.7011303 & 16.1345360 & 18.3957131 \\
\hline Al & 10.6001749 & 16.0872798 & 21.5029592 \\
\hline Al & 15.4480207 & 18.7402052 & 21.6119645 \\
\hline Al & 15.3431844 & 13.2950721 & 21.5331971 \\
\hline $\mathrm{P}$ & 8.4165879 & 17.3734217 & 23.3857036 \\
\hline Al & 8.4472270 & 17.2812009 & 26.5479136 \\
\hline 0 & 9.0091056 & 13.1051682 & 16.8755967 \\
\hline 0 & 7.0238091 & 14.3844277 & 28.1730402 \\
\hline 0 & 11.8111033 & 17.3172331 & 21.8994007 \\
\hline 0 & 13.6844747 & 13.6914759 & 21.6478416 \\
\hline 0 & 16.0108281 & 17.1160587 & 21.9174399 \\
\hline 0 & 15.8433407 & 14.7749772 & 18.1616435 \\
\hline 0 & 11.7108659 & 14.9688821 & 18.3656734 \\
\hline 0 & 14.0394487 & 18.4606467 & 18.1934414 \\
\hline 0 & 6.7712596 & 17.6732564 & 26.9047289 \\
\hline $\mathrm{H}$ & 8.8705930 & 18.7815440 & 23.2177999 \\
\hline $\mathrm{H}$ & 4.7352202 & 18.6452558 & 23.3428781 \\
\hline $\mathrm{H}$ & 18.2585094 & 15.8081879 & 17.6612196 \\
\hline $\mathrm{H}$ & 11.9149654 & 19.9785585 & 17.6712694 \\
\hline $\mathrm{O}$ & 11.3760893 & 12.3089267 & 17.3085508 \\
\hline 0 & 4.8549119 & 16.1610142 & 27.5740848 \\
\hline $\mathrm{H}$ & 11.5288008 & 19.7328223 & 22.4640429 \\
\hline $\mathrm{O}$ & 11.7712209 & 12.0597278 & 22.6109863 \\
\hline $\mathrm{H}$ & 18.2278452 & 16.1445809 & 22.4937686 \\
\hline 0 & 8.9343193 & 15.8944722 & 27.4847164 \\
\hline $\mathrm{H}$ & 16.1537253 & 12.4003745 & 17.4859447 \\
\hline 0 & 9.5390517 & 15.8666434 & 17.4305642 \\
\hline $\mathrm{H}$ & 15.9486287 & 19.9514815 & 17.6170263 \\
\hline 0 & 9.1809178 & 16.4281118 & 22.4672311 \\
\hline 0 & 6.8741044 & 14.9650113 & 16.9689172 \\
\hline 0 & 9.3408874 & 13.4939475 & 27.9444380 \\
\hline 0 & 13.7634232 & 18.8720968 & 21.9888368 \\
\hline 0 & 11.1541860 & 14.5023358 & 21.7508357 \\
\hline $\mathrm{O}$ & 16.3715015 & 14.6400395 & 21.9942568 \\
\hline 0 & 16.3776953 & 17.5868624 & 18.0528639 \\
\hline 0 & 13.9257745 & 13.1803322 & 18.0999025 \\
\hline 0 & 11.4227717 & 17.4044333 & 17.9163385 \\
\hline $\mathrm{H}$ & 4.4341607 & 18.4598648 & 26.8864745 \\
\hline $\mathrm{H}$ & 9.3066182 & 18.4365011 & 26.9271876 \\
\hline 0 & 6.9334373 & 17.3056812 & 23.0031980 \\
\hline $\mathrm{H}$ & 5.1278878 & 15.1322643 & 15.2120753 \\
\hline 0 & 12.0620205 & 19.1254512 & 20.1477698 \\
\hline
\end{tabular}




\begin{tabular}{|c|c|c|c|}
\hline 0 & 17.4618501 & 16.0183600 & 20.1699952 \\
\hline 0 & 5.1453073 & 16.7850846 & 25.1837943 \\
\hline $\mathrm{H}$ & 8.7800326 & 15.0649640 & 29.7883162 \\
\hline 0 & 15.7390873 & 12.8858111 & 19.8527522 \\
\hline 0 & 15.7521293 & 19.1633140 & 19.9264136 \\
\hline 0 & 10.1423126 & 16.3390532 & 19.8090492 \\
\hline $\mathrm{O}$ & 8.6179819 & 16.9245420 & 24.8466484 \\
\hline $\mathrm{O}$ & 11.8672746 & 12.5811706 & 20.0387483 \\
\hline C & 11.6545713 & 10.5725321 & 19.9774964 \\
\hline $\mathrm{H}$ & 12.7306135 & 10.5119351 & 20.1438284 \\
\hline $\mathrm{H}$ & 10.9865488 & 10.6362052 & 20.8319640 \\
\hline $\mathrm{H}$ & 11.2573806 & 10.6343760 & 18.9663320 \\
\hline C & 11.6435725 & 8.6217737 & 19.9718172 \\
\hline 0 & 12.0647836 & 7.5637809 & 19.9816144 \\
\hline $\mathrm{H}$ & 5.1530454 & 15.0876964 & 29.9302781 \\
\hline $\mathrm{H}$ & 16.1999479 & 19.7251825 & 22.4375225 \\
\hline \multicolumn{4}{|c|}{ Mg 16} \\
\hline $\mathrm{H}$ & 8.7185163 & 9.0214034 & 15.2806081 \\
\hline Al & 5.3843358 & 9.3231851 & 16.6573125 \\
\hline$P$ & 5.3681235 & 9.2699976 & 28.4749463 \\
\hline Al & 5.2371362 & 6.6975750 & 21.5727569 \\
\hline $\mathrm{P}$ & 5.3089231 & 6.7281499 & 18.4091396 \\
\hline Al & 3.1488677 & 8.0327613 & 26.5994611 \\
\hline $\mathrm{P}$ & 3.2344064 & 8.1443025 & 23.4790029 \\
\hline Al & 8.4980455 & 9.2456269 & 28.5278259 \\
\hline $\mathrm{P}$ & 8.5468735 & 9.3735867 & 16.7171408 \\
\hline Al & 8.4984726 & 6.8096729 & 18.5161790 \\
\hline $\mathrm{P}$ & 8.4516915 & 6.7365085 & 21.6628341 \\
\hline Al & 1.5217026 & 10.8117377 & 23.5228940 \\
\hline $\mathrm{P}$ & 1.4824896 & 10.7549612 & 26.6716254 \\
\hline 0 & 7.0709514 & 9.7062901 & 17.0090967 \\
\hline 0 & 4.9910767 & 10.7318364 & 28.1566597 \\
\hline $\mathrm{H}$ & 4.7106523 & 5.3370207 & 21.8707957 \\
\hline $\mathrm{H}$ & 8.9672699 & 5.3622261 & 21.9131285 \\
\hline 0 & 6.8176797 & 6.4676055 & 18.2300477 \\
\hline 0 & 1.9411002 & 9.2875870 & 26.7764586 \\
\hline $\mathrm{H}$ & 2.1531955 & 7.1551373 & 23.2150790 \\
\hline $\mathrm{H}$ & 0.1585411 & 10.2873701 & 23.2331529 \\
\hline 0 & 4.8726969 & 7.9121184 & 17.5374564 \\
\hline 0 & 4.4901588 & 8.3009582 & 27.6795535 \\
\hline 0 & 4.4302526 & 7.9039750 & 22.5481133 \\
\hline 0 & 2.3239797 & 11.6478198 & 27.5896386 \\
\hline 0 & 9.0237519 & 8.2041559 & 17.5929511 \\
\hline 0 & 1.9036612 & 12.1816224 & 22.5361625 \\
\hline 0 & 4.3909291 & 10.6764743 & 17.1259029 \\
\hline 0 & 6.8298975 & 9.0331774 & 28.0785479 \\
\hline 0 & 6.9464684 & 6.7582276 & 21.9097359 \\
\hline $\mathrm{H}$ & 9.3220471 & 5.6468235 & 18.0841755 \\
\hline $\mathrm{H}$ & 4.5783503 & 5.5122611 & 17.9563721 \\
\hline $\mathrm{H}$ & 0.0688706 & 10.8402799 & 27.1315412 \\
\hline $\mathrm{H}$ & 2.5244633 & 6.7328012 & 26.9700599 \\
\hline 0 & 2.6919820 & 9.5506238 & 23.2048443 \\
\hline $\mathrm{H}$ & 5.2099071 & 9.0364194 & 15.2066365 \\
\hline $\mathrm{O}$ & 4.9903316 & 7.0671377 & 19.8730711 \\
\hline 0 & 3.7170294 & 8.0184545 & 24.9402863 \\
\hline $\mathrm{H}$ & 8.6896426 & 9.0460394 & 29.9908966 \\
\hline 0 & 8.7805518 & 7.1685922 & 20.2118559 \\
\hline $\mathrm{O}$ & 1.6129431 & 11.2580699 & 25.2241322 \\
\hline $\mathrm{H}$ & 5.1858566 & 8.9960444 & 29.9271340 \\
\hline $\mathrm{H}$ & 3.4401654 & 11.9668266 & 15.2272167 \\
\hline Al & 3.2061859 & 16.0548134 & 21.5629468 \\
\hline $\mathrm{P}$ & 3.1579064 & 16.1239998 & 18.4072780 \\
\hline Al & 3.7794565 & 11.9621069 & 28.4853739 \\
\hline $\mathrm{P}$ & 3.7928946 & 12.0157420 & 16.6730071 \\
\hline Al & 1.5993511 & 13.3498470 & 18.4923154 \\
\hline $\mathrm{P}$ & 1.5883146 & 13.3619548 & 21.5971659 \\
\hline 0 & 4.8318660 & 13.1246776 & 16.9420773 \\
\hline $\mathrm{H}$ & 0.1932632 & 13.8630630 & 21.7380305 \\
\hline $\mathrm{H}$ & 2.2265979 & 17.1345062 & 21.8659178 \\
\hline 0 & 2.1127849 & 15.0078032 & 18.2194224 \\
\hline 0 & 4.3704157 & 15.8994303 & 17.4964037 \\
\hline 0 & 4.6554186 & 16.2887084 & 22.5053789 \\
\hline 0 & 2.5083672 & 12.2658793 & 17.4679679 \\
\hline 0 & 4.3966612 & 13.5188129 & 28.0106243 \\
\hline 0 & 2.6012646 & 14.4780344 & 21.9309896 \\
\hline $\mathrm{H}$ & 2.5434756 & 17.4247975 & 18.0231938 \\
\hline $\mathrm{H}$ & 0.1678195 & 13.2352868 & 18.0989785 \\
\hline $\mathrm{O}$ & 3.6412064 & 16.1763860 & 19.8650478 \\
\hline
\end{tabular}




\begin{tabular}{|c|c|c|c|}
\hline $\mathrm{H}$ & 3.4807863 & 11.9647899 & 29.9441095 \\
\hline 0 & 1.8551095 & 12.8625570 & 20.1445526 \\
\hline Al & 10.0459634 & 12.1095076 & 16.4734982 \\
\hline $\mathrm{P}$ & 9.9943724 & 12.0060512 & 28.3130990 \\
\hline Al & 12.2437483 & 10.6205193 & 26.6485553 \\
\hline $\mathrm{P}$ & 12.2936452 & 10.5593588 & 23.4312019 \\
\hline Al & 15.3967013 & 10.8117377 & 23.5228940 \\
\hline Al & 10.5161759 & 8.0007438 & 23.6131838 \\
\hline $\mathrm{P}$ & 10.6341005 & 7.9661289 & 26.7153083 \\
\hline$P$ & 15.3574883 & 10.7549612 & 26.6716254 \\
\hline $\mathrm{O}$ & 8.9799419 & 10.8698248 & 28.0715343 \\
\hline $\mathrm{O}$ & 11.7156988 & 9.0006791 & 27.0888613 \\
\hline $\mathrm{H}$ & 15.8006402 & 9.3370489 & 26.7729249 \\
\hline $\mathrm{H}$ & 11.3705923 & 6.7875102 & 23.4900678 \\
\hline $\mathrm{O}$ & 13.7828066 & 10.1909205 & 23.1798593 \\
\hline $\mathrm{O}$ & 11.2469088 & 11.8072507 & 27.4568219 \\
\hline $\mathrm{O}$ & 9.4635969 & 8.0493692 & 27.7050591 \\
\hline $\mathrm{H}$ & 16.1751807 & 11.6225694 & 27.5636768 \\
\hline $\mathrm{O}$ & 9.1074735 & 7.7573060 & 22.6077070 \\
\hline $\mathrm{O}$ & 15.7786599 & 12.1816224 & 22.5361625 \\
\hline $\mathrm{O}$ & 9.4330557 & 10.5816459 & 17.0802670 \\
\hline $\mathrm{O}$ & 13.8996084 & 10.8429513 & 27.1459413 \\
\hline $\mathrm{H}$ & 11.2175031 & 6.5988232 & 26.8003801 \\
\hline $\mathrm{H}$ & 16.3926666 & 9.7384678 & 23.2522181 \\
\hline $\mathrm{O}$ & 11.4479612 & 9.3343163 & 22.9795394 \\
\hline $\mathrm{H}$ & 10.3593425 & 12.0267803 & 15.0202018 \\
\hline 0 & 12.0742617 & 10.8082860 & 24.9339264 \\
\hline $\mathrm{O}$ & 15.4879419 & 11.2580699 & 25.2241322 \\
\hline $\mathrm{O}$ & 10.0930224 & 8.2433186 & 25.2951137 \\
\hline $\mathrm{H}$ & 10.3975652 & 12.0128013 & 29.7464554 \\
\hline $\mathrm{H}$ & 8.6497494 & 15.1272221 & 15.0979414 \\
\hline Al & 5.3210252 & 14.7687329 & 16.5743085 \\
\hline $\mathrm{P}$ & 5.2570838 & 14.7236915 & 28.4028682 \\
\hline Al & 12.1746355 & 18.7136764 & 21.5727569 \\
\hline $\mathrm{Mg}$ & 12.2203388 & 13.3240604 & 21.6112916 \\
\hline Al & 17.0811846 & 16.0548134 & 21.5629468 \\
\hline $\mathrm{P}$ & 17.0329051 & 16.1239998 & 18.4072780 \\
\hline $\mathrm{P}$ & 12.2959417 & 13.2416847 & 18.3737477 \\
\hline $\mathrm{P}$ & 12.2464224 & 18.7442513 & 18.4091396 \\
\hline Al & 5.3509258 & 17.2223084 & 26.5567386 \\
\hline $\mathrm{P}$ & 5.3141209 & 17.2683327 & 23.4786512 \\
\hline Al & 8.4232288 & 14.7497303 & 28.3758060 \\
\hline $\mathrm{P}$ & 8.4653196 & 14.8063427 & 16.5402114 \\
\hline Al & 15.4743498 & 13.3498470 & 18.4923154 \\
\hline Al & 15.4359720 & 18.8257743 & 18.5161790 \\
\hline Al & 10.6684740 & 16.0413136 & 18.4676040 \\
\hline $\mathrm{P}$ & 10.4586857 & 16.0868477 & 21.5566503 \\
\hline $\mathrm{P}$ & 15.3891909 & 18.7526099 & 21.6628341 \\
\hline $\mathrm{P}$ & 15.4633133 & 13.3619548 & 21.5971659 \\
\hline Al & 8.4394560 & 17.5108012 & 23.4448240 \\
\hline $\mathrm{P}$ & 8.4800374 & 17.3386803 & 26.6168749 \\
\hline $\mathrm{O}$ & 8.8442104 & 13.3314051 & 16.8052176 \\
\hline 0 & 6.7315960 & 14.3911921 & 28.1047738 \\
\hline $\mathrm{O}$ & 11.5595917 & 17.1242628 & 21.9209289 \\
\hline $\mathrm{O}$ & 14.0448539 & 13.8714712 & 21.7403942 \\
\hline 0 & 15.9219633 & 17.3324964 & 21.9214755 \\
\hline 0 & 15.9877837 & 15.0078032 & 18.2194224 \\
\hline $\mathrm{O}$ & 11.8067721 & 14.6943182 & 18.4389890 \\
\hline $\mathrm{O}$ & 13.7551790 & 18.4837069 & 18.2300477 \\
\hline 0 & 7.0057506 & 17.6711993 & 26.9412351 \\
\hline $\mathrm{H}$ & 8.9598475 & 18.8910432 & 23.2417350 \\
\hline $\mathrm{H}$ & 4.5918942 & 18.5704232 & 23.4703141 \\
\hline $\mathrm{H}$ & 18.2105596 & 15.9058858 & 17.5225877 \\
\hline $\mathrm{H}$ & 11.8228805 & 19.8937932 & 17.5628026 \\
\hline 0 & 11.5535077 & 12.4445996 & 17.2858996 \\
\hline $\mathrm{O}$ & 4.7967972 & 15.9302765 & 27.5812339 \\
\hline $\mathrm{H}$ & 11.4875635 & 19.7409419 & 22.4032857 \\
\hline $\mathrm{O}$ & 11.8603019 & 11.7543658 & 22.6219634 \\
\hline $\mathrm{H}$ & 18.3181865 & 16.2544559 & 22.3673658 \\
\hline 0 & 8.9335178 & 16.1062857 & 27.4117329 \\
\hline $\mathrm{H}$ & 16.2493017 & 12.4257459 & 17.6190415 \\
\hline 0 & 9.3549507 & 15.7419081 & 17.3590713 \\
\hline $\mathrm{H}$ & 15.8821562 & 20.0102800 & 17.7319682 \\
\hline $\mathrm{O}$ & 9.2054451 & 16.3715108 & 22.4023089 \\
\hline 0 & 7.0062158 & 15.0096499 & 16.9660007 \\
\hline 0 & 9.3543787 & 13.3432226 & 27.9323469 \\
\hline 0 & 13.8839677 & 18.7743290 & 21.9097359 \\
\hline $\mathrm{O}$ & 10.9421080 & 14.6864322 & 21.8086944 \\
\hline 0 & 16.4762634 & 14.4780344 & 21.930989 \\
\hline 0 & 16.3990046 & 17.4660164 & 18.011023 \\
\hline
\end{tabular}




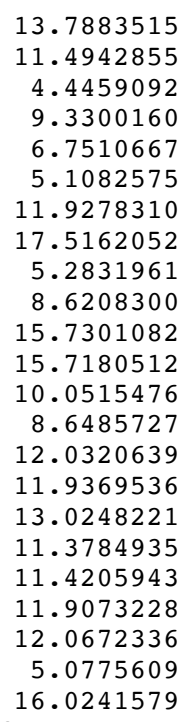

13.2149227

17.4924734

18.3857836

18.4922743

17.5260316

15.0201928

19.0832391

16.1763860

16.6658165

15.0794004

12.8625570

19.1846936

16.2956428

17.0423590

12.5483313

10.5461080

10.5125378

10.6448438

10.5072405

8.5525684

7.4408193

15.0527125

19.7410067

8.8901763

9.2435870

9.1951272

6.7287926

6.7598243

7.9655034

8.0341492

9.1622679

9.2567372

6.7938824

6.7352333

10.7104735

10.6861924

9.6161828

10.7470279

5.3363531

5.3442148

6.4583019

9.1372778

7.0130341

10.2204583

7.9966576

8.1906474

7.7914846

11.6417160

8.0431686

11.9298097

10.5223635

8.9764962

6.8166481

5.6134484

5.5464740

10.7669689

6.6639197

9.4954122

8.8723205

7.1525016

7.9529245

8.8835326

7.1951227

11.1999540

8.8686580

11.8953861

15.8293293

15.8837780

11.8952878

11.9360734

13.1643695

13.1619340

13.1037875

13.5902451

16.9104378

14.7133038

15.6621568
18.0290595

17.9430079

26.7674304

27.0216933

23.0247318

15.1222003

19.8730711

19.8650478

24.8962274

29.8143441

20.1445526

20.2118559

20.0704853

25.1196797

19.7434208

19.7770088

19.8148592

20.7059432

18.8197935

19.9709704

20.1483644

29.8439224

22.5777162

15.2274613

16.6488841

28.5921126

21.6113628

18.5209497

26.6413793

23.5771251

28.5836593

16.6537766

18.5563221

21.6468789

23.5601543

26.6482453

16.8988965

28.3006830

21.8671944

21.8843006

18.3574875

26.7891064

23.3579791

23.3333995

17.5756201

27.6826604

22.5819959

27.6295901

17.6211060

22.5703954

17.0622722

28.2154606

21.9114954

18.1502220

18.0753372

27.0821090

26.9846042

23.2535074

15.2258522

20.0609556

25.1207881

30.0249786

20.1111673

25.1127706

30.0279370

15.1825201

21.6182319

18.5185452

28.5528115

16.6145844

18.5243859

21.5764114

16.8709641

21.6723323

21.8803840

18.3020640

17.5568425 


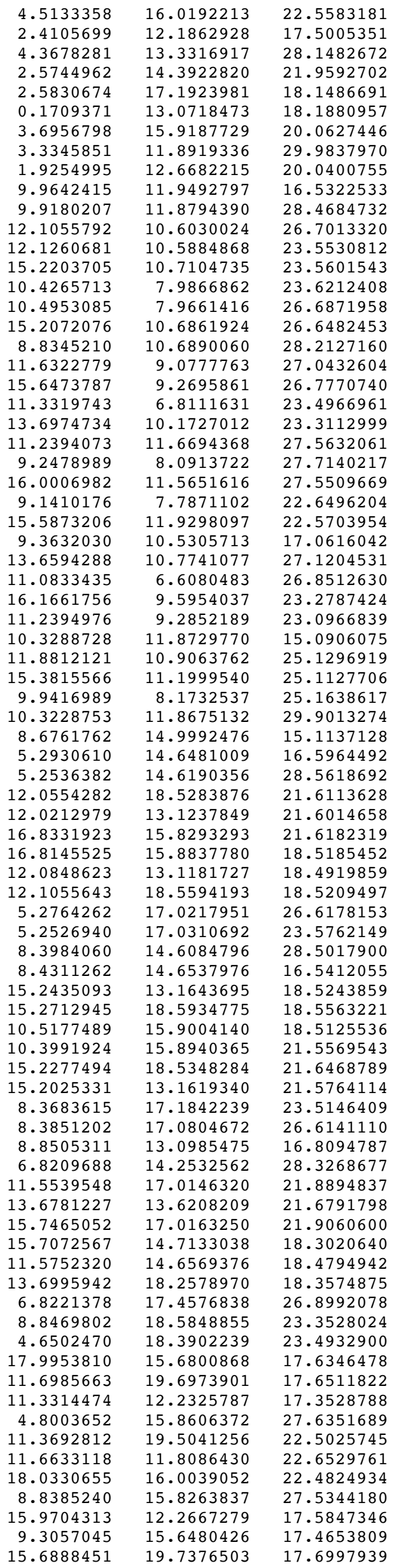




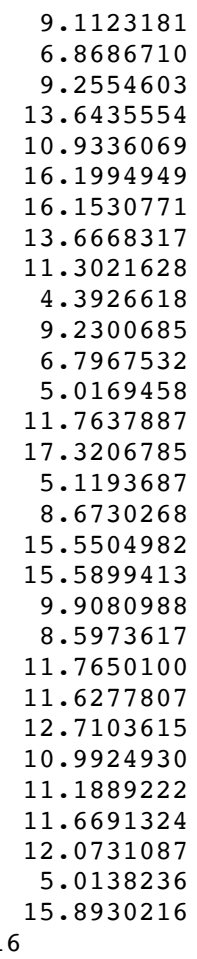

$\begin{array}{lrrr}\mathrm{H} & 8.6584058 & 9.0477650 & 15.1781024 \\ \mathrm{P} & 5.3395403 & 9.3715859 & 16.6991012 \\ \mathrm{Al} & 5.3029226 & 9.3034792 & 28.5269759 \\ \mathrm{P} & 5.3331602 & 6.7132155 & 21.6274455 \\ \mathrm{Al} & 5.4085877 & 6.7750460 & 18.4614516 \\ \mathrm{P} & 3.1610148 & 7.9631112 & 26.6362693 \\ \mathrm{Al} & 3.2165216 & 8.0701562 & 23.5288166 \\ \mathrm{P} & 8.4462896 & 9.2090257 & 28.4384411 \\ \mathrm{Al} & 8.5035507 & 9.3418349 & 16.6295373 \\ \mathrm{P} & 8.5937351 & 6.7862280 & 18.4555992 \\ \mathrm{Al} & 8.5147629 & 6.7049688 & 21.6289937 \\ \mathrm{P} & 1.5861965 & 10.7898858 & 23.4476372 \\ \mathrm{Al} & 1.5604605 & 10.7227676 & 26.6089929 \\ \mathrm{O} & 6.8239438 & 9.7204434 & 16.9517572 \\ \mathrm{O} & 4.8608088 & 10.9665305 & 28.1774931 \\ \mathrm{H} & 4.8495700 & 5.3258709 & 21.8693877 \\ \mathrm{H} & 9.0337215 & 5.3337425 & 21.8888800 \\ \mathrm{O} & 7.1159940 & 6.4605088 & 18.1952127 \\ \mathrm{O} & 2.0887941 & 9.0606971 & 26.7688139 \\ \mathrm{H} & 2.1173644 & 7.0924759 & 23.2983493 \\ \mathrm{H} & 0.2151764 & 10.3092764 & 23.1213871 \\ \mathrm{O} & 4.9152661 & 8.1790385 & 17.5586518 \\ \mathrm{O} & 4.3027146 & 8.1989816 & 27.6309661 \\ \mathrm{O} & 4.5796345 & 7.7280243 & 22.4981403 \\ \mathrm{O} & 2.5345658 & 11.7710637 & 27.6027827 \\ \mathrm{O} & 9.0395706 & 7.9988021 & 17.6180434 \\ \mathrm{O} & 1.9580796 & 11.9790420 & 22.5615658 \\ \mathrm{O} & 4.4780927 & 10.5741479 & 17.0968041 \\ \mathrm{O} & 6.9664264 & 9.0308136 & 28.0909080 \\ \mathrm{O} & 6.8218423 & 6.7874758 & 21.9909582 \\ \mathrm{H} & 9.4268239 & 5.6192648 & 18.0540020 \\ \mathrm{H} & 4.6463733 & 5.5900828 & 17.9797751 \\ \mathrm{H} & 0.1600605 & 10.7866543 & 27.1109081 \\ \mathrm{H} & 2.5413202 & 6.6493252 & 26.9634779 \\ \mathrm{O} & 2.5929103 & 9.6615451 & 23.1786157 \\ \mathrm{H} & 5.1225615 & 9.0196602 & 15.2686506 \\ \mathrm{O} & 5.1293034 & 7.1062094 & 20.1511708 \\ \mathrm{O} & 3.7365155 & 7.9606493 & 25.2061694 \\ \mathrm{H} & 8.6770114 & 9.0043335 & 29.8951460 \\ \mathrm{O} & 8.8243724 & 7.1334274 & 19.9434586 \\ \mathrm{O} & 1.6526453 & 11.2190509 & 24.9303405 \\ \mathrm{H} & 5.1433820 & 9.0521376 & 29.9859121 \\ \mathrm{H} & 3.4646770 & 12.0772723 & 15.1604957 \\ \mathrm{P} & 3.2043023 & 15.9908073 & 21.6192229 \\ \mathrm{Al} & 3.2113455 & 16.0579321 & 18.4903773 \\ \mathrm{P} & 3.7901051 & 12.0490357 & 28.4327504 \\ \mathrm{Al} & 3.7940651 & 12.1038416 & 16.6123629\end{array}$

22.5057507

16.9277867

28.0810037

21.9114954

21.8021045

21.9592702

18.1151331

18.1581032

18.0365968

26.8457447

26.9826462

23.1357569

15.1773374

20.0609556

20.0627446

25.0960660

29.9133142

20.0400755

20.1111673

19.9994203

25.0510007

19.9383217

19.9182532

20.0422619

20.7988728

18.9225764

20.0017853

20.1124915

$\begin{array}{ll}15.0016778 & 29.9807401 \\ 19.4990274 & 22.5660382\end{array}$

$\begin{array}{ll}15.0016778 & 29.9807401 \\ 19.4990274 & 22.5660382\end{array}$

15.1781024

8.5269759

21.6274455

8.4384411

21.6289937

(

6.9517572

1774931

1.8888800

18.1952127

26.7688139

2983493

7.5586518

7.6309661

7.6027827

.6180434

.0909080

18.0540020

6.9634779

.1786157

20.1511708

-

19.9434586

24.9303405

15.1604957

16.6123629
7.0968041 


\begin{tabular}{|c|c|c|c|}
\hline $\mathrm{P}$ & 1.5287152 & 13.3298880 & 18.4168016 \\
\hline Al & 1.4478983 & 13.3237135 & 21.5511867 \\
\hline 0 & 4.9819386 & 13.3508124 & 16.9616202 \\
\hline $\mathrm{H}$ & 0.0582109 & 13.7978018 & 21.7984311 \\
\hline $\mathrm{H}$ & 2.2238809 & 17.0695629 & 21.9228358 \\
\hline 0 & 2.0410226 & 14.7783690 & 18.2751416 \\
\hline 0 & 4.6231109 & 15.7955827 & 17.5021443 \\
\hline $\mathrm{O}$ & 4.4259451 & 16.0960555 & 22.5395122 \\
\hline 0 & 2.3241880 & 12.3921087 & 17.4971279 \\
\hline $\mathrm{O}$ & 4.3510021 & 13.4106511 & 28.0071950 \\
\hline $\mathrm{O}$ & 2.5667304 & 14.6305723 & 21.8553182 \\
\hline $\mathrm{H}$ & 2.6183978 & 17.3696033 & 18.1095203 \\
\hline $\mathrm{H}$ & 0.1059070 & 13.2989050 & 17.9788775 \\
\hline $\mathrm{O}$ & 3.6966401 & 16.1356816 & 20.1655112 \\
\hline $\mathrm{H}$ & 3.4193539 & 12.0718503 & 29.8746740 \\
\hline $\mathrm{O}$ & 1.6710449 & 12.8273426 & 19.8618776 \\
\hline $\mathrm{P}$ & 10.0793985 & 12.0237464 & 16.5291251 \\
\hline Al & 10.0062500 & 11.9351907 & 28.3395560 \\
\hline $\mathrm{P}$ & 12.3343715 & 10.6359959 & 26.7489263 \\
\hline Al & 12.3461273 & 10.6178397 & 23.5174458 \\
\hline $\mathrm{P}$ & 15.4611952 & 10.7898858 & 23.4476372 \\
\hline$P$ & 10.5760304 & 8.0351368 & 23.5306744 \\
\hline Al & 10.6430937 & 8.0348937 & 26.6305734 \\
\hline Al & 15.4354593 & 10.7227676 & 26.6089929 \\
\hline 0 & 8.8819806 & 10.6275985 & 28.0161467 \\
\hline $\mathrm{O}$ & 11.8383058 & 9.2223385 & 27.1270468 \\
\hline $\mathrm{H}$ & 15.8846542 & 9.3096573 & 26.7448744 \\
\hline $\mathrm{H}$ & 11.3801454 & 6.7827297 & 23.4859987 \\
\hline $\mathrm{O}$ & 14.0362702 & 10.2903801 & 23.1085598 \\
\hline $\mathrm{O}$ & 11.4913113 & 11.7027138 & 27.4628929 \\
\hline 0 & 9.2487776 & 8.1487567 & 27.6742324 \\
\hline $\mathrm{H}$ & 16.2679720 & 11.6186870 & 27.4583289 \\
\hline $\mathrm{O}$ & 9.3476734 & 7.8931771 & 22.6157870 \\
\hline 0 & 15.8330783 & 11.9790420 & 22.5615658 \\
\hline 0 & 9.5477458 & 10.6822287 & 17.0800326 \\
\hline $\mathrm{O}$ & 13.7913011 & 10.7977746 & 27.1982730 \\
\hline $\mathrm{H}$ & 11.2368824 & 6.6749924 & 26.7538791 \\
\hline $\mathrm{H}$ & 16.4371662 & 9.6960022 & 23.1868311 \\
\hline $\mathrm{O}$ & 11.4452188 & 9.1849499 & 22.9969349 \\
\hline $\mathrm{H}$ & 10.3498328 & 11.9137736 & 15.0690251 \\
\hline 0 & 12.2125841 & 10.8356617 & 25.2383641 \\
\hline $\mathrm{O}$ & 15.5276441 & 11.2190509 & 24.9303405 \\
\hline 0 & 10.1218538 & 8.3244492 & 24.9730672 \\
\hline $\mathrm{H}$ & 10.3056451 & 11.9144450 & 29.7979979 \\
\hline $\mathrm{H}$ & 8.7339247 & 15.0315824 & 15.0231112 \\
\hline$P$ & 5.4112752 & 14.7979867 & 16.6452600 \\
\hline Al & 5.3375505 & 14.7654029 & 28.4821895 \\
\hline $\mathrm{P}$ & 12.2706596 & 18.7293169 & 21.6274455 \\
\hline $\mathrm{Ge}$ & 12.0790484 & 13.2604975 & 21.6306226 \\
\hline $\mathrm{P}$ & 17.0793010 & 15.9908073 & 21.6192229 \\
\hline Al & 17.0863442 & 16.0579321 & 18.4903773 \\
\hline Al & 12.2498788 & 13.3216023 & 18.4083154 \\
\hline Al & 12.3460870 & 18.7911474 & 18.4614516 \\
\hline $\mathrm{P}$ & 5.3134445 & 17.2555069 & 26.6353196 \\
\hline Al & 5.2507574 & 17.2211342 & 23.5667693 \\
\hline $\mathrm{P}$ & 8.4982487 & 14.7037973 & 28.3144386 \\
\hline Al & 8.5636175 & 14.7736255 & 16.4796737 \\
\hline $\mathrm{P}$ & 15.4037139 & 13.3298880 & 18.4168016 \\
\hline$P$ & 15.5312344 & 18.8023294 & 18.4555992 \\
\hline $\mathrm{P}$ & 10.6929872 & 16.1542115 & 18.3697176 \\
\hline Al & 10.4963706 & 16.1426242 & 21.4619235 \\
\hline Al & 15.4522623 & 18.7210702 & 21.6289937 \\
\hline Al & 15.3228970 & 13.3237135 & 21.5511867 \\
\hline $\mathrm{P}$ & 8.3674451 & 17.4824402 & 23.3782406 \\
\hline Al & 8.4381350 & 17.2877937 & 26.5269707 \\
\hline 0 & 9.0334371 & 13.1139350 & 16.8206502 \\
\hline $\mathrm{O}$ & 7.0052122 & 14.3820170 & 28.1152109 \\
\hline 0 & 11.7720591 & 17.2989102 & 21.8768974 \\
\hline $\mathrm{O}$ & 13.7166383 & 13.8716846 & 21.8369621 \\
\hline $\mathrm{O}$ & 16.0618962 & 17.1102557 & 21.9342887 \\
\hline $\mathrm{O}$ & 15.9160213 & 14.7783690 & 18.2751416 \\
\hline $\mathrm{O}$ & 11.6788224 & 14.9693919 & 18.4083779 \\
\hline $\mathrm{O}$ & 14.0534933 & 18.4766102 & 18.1952127 \\
\hline 0 & 6.7681358 & 17.6827440 & 26.9257263 \\
\hline $\mathrm{H}$ & 8.8453459 & 18.8878655 & 23.2620022 \\
\hline $\mathrm{H}$ & 4.5755992 & 18.5464042 & 23.4964747 \\
\hline $\mathrm{H}$ & 18.2922868 & 15.8338309 & 17.6462198 \\
\hline $\mathrm{H}$ & 11.9240685 & 19.9922115 & 17.6891395 \\
\hline $\mathrm{O}$ & 11.4063653 & 12.3321296 & 17.2303394 \\
\hline $\mathrm{O}$ & 4.8398878 & 16.2002044 & 27.6380643 \\
\hline
\end{tabular}




\begin{tabular}{|c|c|c|}
\hline 11.5396410 & 19.7138142 & 22.4721333 \\
\hline 11.6396865 & 11.9216242 & 22.6721301 \\
\hline 18.2657965 & 16.0930275 & 22.5130350 \\
\hline 8.9284855 & 15.8745837 & 27.4262551 \\
\hline 16.1750568 & 12.4205553 & 17.5250254 \\
\hline 9.5685252 & 15.8831375 & 17.3616514 \\
\hline 15.9623957 & 19.9749927 & 17.6456107 \\
\hline 9.0841247 & 16.5715374 & 22.3932370 \\
\hline 6.9005186 & 14.9649944 & 16.9681507 \\
\hline 9.3155302 & 13.4722616 & 27.9083964 \\
\hline 13.7593417 & 18.8035772 & 21.9909582 \\
\hline 10.8790591 & 14.5123507 & 21.7718713 \\
\hline 16.4417291 & 14.6305723 & 21.8553182 \\
\hline 16.3886808 & 17.6012469 & 18.0422603 \\
\hline 13.9375858 & 13.2979617 & 17.9655441 \\
\hline 11.4540153 & 17.4043037 & 17.8977125 \\
\hline 4.4194443 & 18.4385600 & 26.7704855 \\
\hline 9.3116843 & 18.4318155 & 26.9080826 \\
\hline 6.8767500 & 17.4682768 & 23.0253171 \\
\hline 5.1526337 & 15.1001463 & 15.2103646 \\
\hline 12.0668027 & 19.1223108 & 20.1511708 \\
\hline 17.5716388 & 16.1356816 & 20.1655112 \\
\hline 5.2161541 & 16.6528096 & 25.2205306 \\
\hline 8.7548685 & 15.0642786 & 29.7361700 \\
\hline 15.5460436 & 12.8273426 & 19.8618776 \\
\hline 15.7618717 & 19.1495287 & 19.9434586 \\
\hline 10.0862205 & 16.3990318 & 19.7567385 \\
\hline 8.5885851 & 16.9648970 & 24.8145047 \\
\hline 11.9649205 & 12.5208002 & 19.9474932 \\
\hline 11.7190212 & 10.5203166 & 19.9204745 \\
\hline 12.8045932 & 10.4530944 & 20.0016655 \\
\hline 11.1185175 & 10.6002732 & 20.8246681 \\
\hline 11.2452740 & 10.5810388 & 18.9427980 \\
\hline 11.6866275 & 8.5761720 & 19.9613289 \\
\hline 12.0876328 & 7.5135082 & 20.0437067 \\
\hline 5.1728561 & 15.0590883 & 29.9326189 \\
\hline 16.1590096 & 19.7292974 & 22.4663148 \\
\hline \\
\hline 8.6446757 & 8.8877952 & 15.2376021 \\
\hline 5.3000867 & 9.2470243 & 16.6665350 \\
\hline 5.2792955 & 9.1903410 & 28.6111994 \\
\hline 5.2384388 & 6.6944971 & 21.6234669 \\
\hline 5.2931028 & 6.7611980 & 18.5287172 \\
\hline 3.1773865 & 7.9657870 & 26.6475077 \\
\hline 3.2566396 & 8.0667441 & 23.5887251 \\
\hline 8.3953106 & 9.1421595 & 28.5897304 \\
\hline 8.4378858 & 9.2600236 & 16.6644183 \\
\hline 8.4555361 & 6.7929770 & 18.5583952 \\
\hline 8.4132314 & 6.7180926 & 21.6572713 \\
\hline 1.6112244 & 10.7318888 & 23.5684091 \\
\hline 1.5718998 & 10.6763352 & 26.6634544 \\
\hline 6.8717154 & 9.6211954 & 16.9184958 \\
\hline 4.8819561 & 10.7484137 & 28.3372656 \\
\hline 4.7556408 & 5.3060881 & 21.8608424 \\
\hline 8.9298332 & 5.3427145 & 21.8993002 \\
\hline 6.8846132 & 6.4620579 & 18.3449114 \\
\hline 2.0421290 & 9.1226925 & 26.7890721 \\
\hline 2.1622740 & 7.0785560 & 23.3814354 \\
\hline 0.2339701 & 10.2276164 & 23.3115033 \\
\hline 4.8461325 & 8.0113722 & 17.6033050 \\
\hline 4.3793510 & 8.1979904 & 27.7073752 \\
\hline 4.5020434 & 7.7661547 & 22.5955594 \\
\hline 2.4423896 & 11.6157364 & 27.6539057 \\
\hline 8.9201512 & 8.0501675 & 17.6363317 \\
\hline 1.9526987 & 11.9758412 & 22.5993890 \\
\hline 4.4002638 & 10.5289750 & 17.0688427 \\
\hline 6.8321558 & 8.9573722 & 28.2194867 \\
\hline 6.8271155 & 6.7469589 & 21.9294860 \\
\hline 9.2624896 & 5.6126305 & 18.1427885 \\
\hline 4.5500999 & 5.5539126 & 18.0731634 \\
\hline 0.1510966 & 10.7602281 & 27.1009484 \\
\hline 2.5504407 & 6.6548580 & 26.9723530 \\
\hline 2.6781645 & 9.5448525 & 23.2581664 \\
\hline 5.0716246 & 8.8636632 & 15.2459858 \\
\hline 4.9606423 & 7.1350685 & 20.0753690 \\
\hline 3.7861040 & 7.9786036 & 25.1335462 \\
\hline 8.6400486 & 8.8790371 & 30.0347184 \\
\hline 8.7598525 & 7.1778523 & 20.1189295 \\
\hline
\end{tabular}




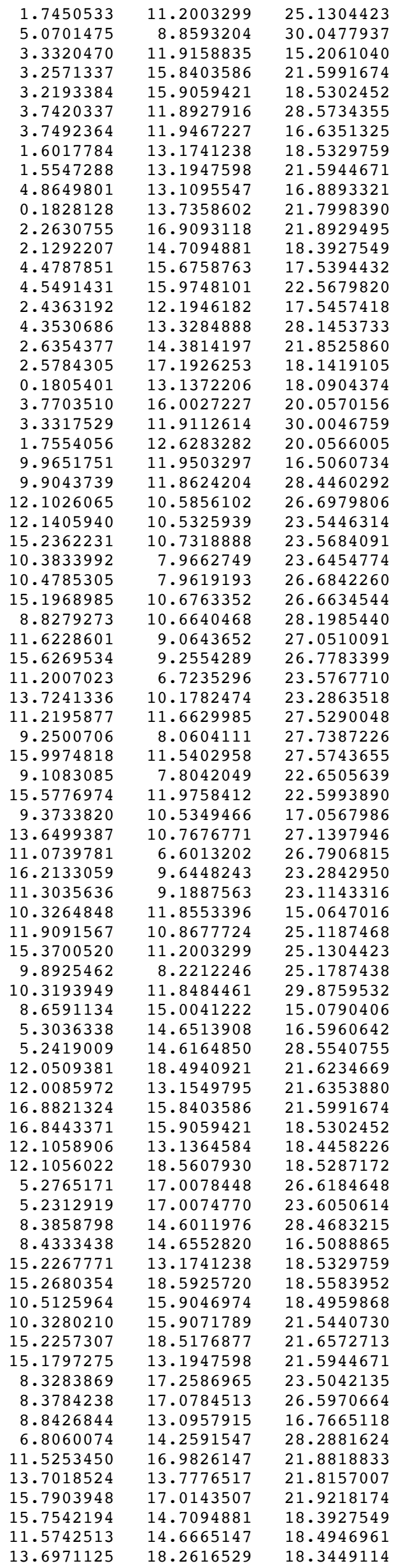

18.3449114 


$\begin{array}{rrr}6.8189510 & 17.4506204 & 26.9179962 \\ 8.8266822 & 18.6558224 & 23.3743614 \\ 4.5149169 & 18.3124474 & 23.5737581 \\ 18.0027288 & 15.6943362 & 17.6189428 \\ 11.6943608 & 19.7110336 & 17.6772786 \\ 11.3335140 & 12.2618888 & 17.3120070 \\ 4.7736580 & 15.8745950 & 27.6556407 \\ 11.3755423 & 19.4769787 & 22.5150358 \\ 11.5860678 & 11.7107726 & 22.6324590 \\ 18.0693100 & 15.9639009 & 22.4893737 \\ 8.8414614 & 15.8053889 & 27.4886239 \\ 15.9929405 & 12.2748732 & 17.6266301 \\ 9.3276320 & 15.6424120 & 17.4219437 \\ 15.6932853 & 19.7432450 & 17.7144551 \\ 9.0310518 & 16.2757996 & 22.4478293 \\ 6.8788281 & 14.8345935 & 16.9236976 \\ 9.2310125 & 13.2809430 & 28.0659325 \\ 13.6396149 & 18.5465540 & 21.9294860 \\ 10.7531094 & 14.4088256 & 21.8570319 \\ 16.2604364 & 14.3814197 & 21.8525860 \\ 16.1451990 & 17.3095280 & 18.1066281 \\ 13.6774009 & 13.1338934 & 18.0505385 \\ 11.2980182 & 17.2485715 & 18.0335671 \\ 4.3855487 & 18.1891153 & 26.7854856 \\ 9.2339021 & 18.2392162 & 26.9684184 \\ 6.7516136 & 17.2877125 & 23.1509316 \\ 5.0256442 & 14.9899721 & 15.1729672 \\ 11.7731417 & 18.9346635 & 20.0753690 \\ 17.3953498 & 16.0027227 & 20.0570156 \\ 5.1645215 & 16.3930144 & 25.1120394 \\ 8.6546359 & 14.9988793 & 29.8778391 \\ 15.3804044 & 12.6283282 & 20.0566005 \\ 15.5723519 & 18.9774473 & 20.1189295 \\ 9.8798615 & 16.1089029 & 19.9731326 \\ 8.5697537 & 16.7127692 & 25.0232544 \\ 11.8443189 & 12.3883128 & 19.8810081 \\ 11.7301147 & 10.3814199 & 19.8661507 \\ 12.8202422 & 10.3637242 & 19.8624573 \\ 11.1984497 & 10.4509007 & 20.8147771 \\ 11.1815317 & 10.3856717 & 18.9267869 \\ 11.7715480 & 8.4178075 & 19.9950636 \\ 12.1305979 & 7.3622220 & 20.2230140 \\ 5.0207713 & 14.9866149 & 29.9792864 \\ 15.8615793 & 19.5112507 & 22.5659240 \\ & & \end{array}$
16

$\begin{array}{lrrl}\mathrm{H} & 8.6499620 & 9.0788805 & 15.1789787 \\ \mathrm{P} & 5.3491883 & 9.3771403 & 16.7140727 \\ \mathrm{Al} & 5.3021456 & 9.3040209 & 28.5323218 \\ \mathrm{P} & 5.3228495 & 6.7458922 & 21.6256744 \\ \mathrm{Al} & 5.4213832 & 6.7760363 & 18.4675137 \\ \mathrm{P} & 3.1710055 & 7.9581914 & 26.6429129 \\ \mathrm{Al} & 3.2797413 & 8.1168741 & 23.5546514 \\ \mathrm{P} & 8.4378594 & 9.1936986 & 28.4324317 \\ \mathrm{Al} & 8.5108190 & 9.3571804 & 16.6351068 \\ \mathrm{P} & 8.6175416 & 6.8061602 & 18.4684668 \\ \mathrm{Al} & 8.5255798 & 6.7182083 & 21.6310065 \\ \mathrm{P} & 1.6026780 & 10.8064479 & 23.4882622 \\ \mathrm{Al} & 1.5503550 & 10.7155374 & 26.6383382 \\ \mathrm{O} & 6.8325097 & 9.7217370 & 16.9785035 \\ \mathrm{O} & 4.8683692 & 10.9640402 & 28.1557726 \\ \mathrm{H} & 4.7620516 & 5.3933115 & 21.8961404 \\ \mathrm{H} & 9.0768643 & 5.3584525 & 21.8845220 \\ \mathrm{O} & 7.1362899 & 6.4824669 & 18.2321848 \\ \mathrm{O} & 2.0946571 & 9.0545151 & 26.7448638 \\ \mathrm{H} & 2.1733281 & 7.1511613 & 23.3089495 \\ \mathrm{H} & 0.2551524 & 10.2748115 & 23.1437946 \\ \mathrm{O} & 4.9226692 & 8.1668971 & 17.5476468 \\ \mathrm{O} & 4.2799907 & 8.1895570 & 27.6746911 \\ \mathrm{O} & 4.6397079 & 7.8058336 & 22.5044063 \\ \mathrm{O} & 2.5236703 & 11.7544361 & 27.6426202 \\ \mathrm{O} & 9.0572374 & 8.0112406 & 17.6165432 \\ \mathrm{O} & 1.9583857 & 11.9979493 & 22.5996075 \\ \mathrm{O} & 4.4865727 & 10.5731314 & 17.1301982 \\ \mathrm{O} & 6.9584239 & 9.0061280 & 28.0876932 \\ \mathrm{O} & 6.8219773 & 6.7393214 & 21.9532712 \\ \mathrm{H} & 9.4437669 & 5.6351814 & 18.0643864 \\ \mathrm{H} & 4.6913097 & 5.5717205 & 17.9840504 \\ \mathrm{H} & 0.1586541 & 10.7505815 & 27.1666005\end{array}$




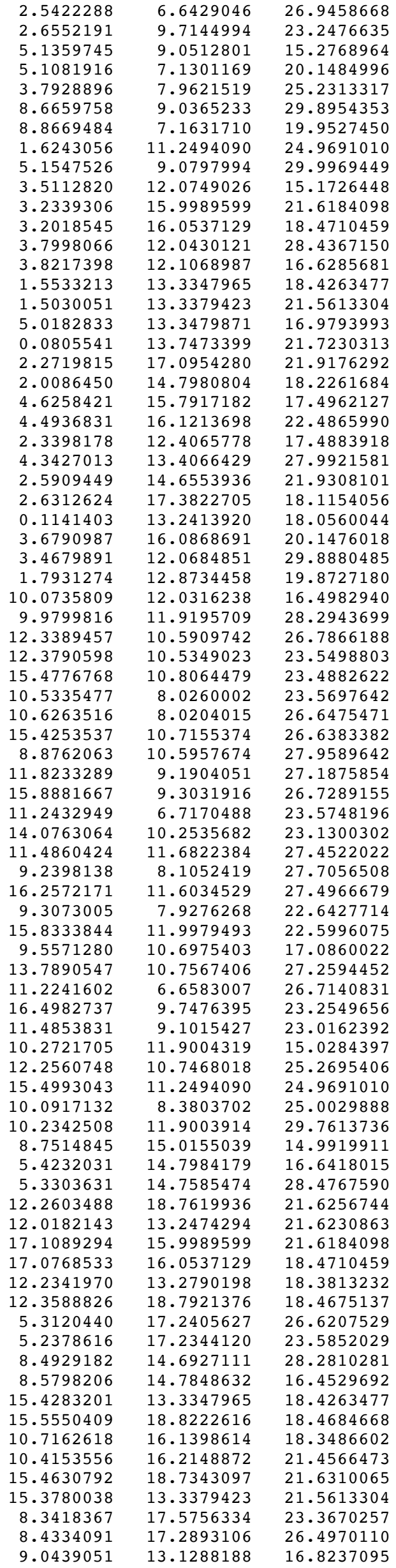

Al 12.3588826 


\begin{tabular}{|c|c|c|}
\hline 6.9964009 & 14.3746268 & 28.1060527 \\
\hline 11.6825129 & 17.3683190 & 21.9043577 \\
\hline 13.7314601 & 13.8118364 & 21.7485056 \\
\hline 16.1108178 & 17.1366474 & 21.9288778 \\
\hline 15.8836437 & 14.7980804 & 18.2261684 \\
\hline 11.6818093 & 14.9398464 & 18.3944537 \\
\hline 14.0737893 & 18.4985682 & 18.2321848 \\
\hline 6.7637707 & 17.6858271 & 26.9020888 \\
\hline 8.8991817 & 18.9529274 & 23.2693097 \\
\hline 4.4500034 & 18.4978684 & 23.5763683 \\
\hline 18.2916044 & 15.8302149 & 17.6394517 \\
\hline 11.9322338 & 19.9820160 & 17.6805696 \\
\hline 11.4357333 & 12.3454833 & 17.1255058 \\
\hline 4.8424793 & 16.2059741 & 27.6466527 \\
\hline 11.5985359 & 19.7888422 & 22.4769711 \\
\hline 11.6714123 & 11.8613909 & 22.7268949 \\
\hline 18.3310630 & 16.1177144 & 22.4606730 \\
\hline 8.9109558 & 15.8655070 & 27.3883944 \\
\hline 16.1906484 & 12.4351009 & 17.5172141 \\
\hline 9.6027457 & 15.8947512 & 17.3190668 \\
\hline 15.9802000 & 19.9875009 & 17.6447086 \\
\hline 8.9584426 & 16.6627627 & 22.3136456 \\
\hline 6.9151946 & 14.9933244 & 16.9410661 \\
\hline 9.2993650 & 13.4599656 & 27.8527369 \\
\hline 13.7594767 & 18.7554228 & 21.9532712 \\
\hline 10.8558880 & 14.6052566 & 21.8300434 \\
\hline 16.4659436 & 14.6553936 & 21.9308101 \\
\hline 16.4054384 & 17.6170245 & 18.0525646 \\
\hline 13.9469749 & 13.2386555 & 18.0451544 \\
\hline 11.5045330 & 17.3828182 & 17.9017534 \\
\hline 4.4085898 & 18.4197892 & 26.7223205 \\
\hline 9.3115149 & 18.4264712 & 26.8880566 \\
\hline 6.8385857 & 17.6663760 & 23.0836662 \\
\hline 5.1423704 & 15.0794788 & 15.2067899 \\
\hline 12.0456910 & 19.1462182 & 20.1484996 \\
\hline 17.5540974 & 16.0868691 & 20.1476018 \\
\hline 5.2284289 & 16.6022984 & 25.2182848 \\
\hline 8.7720949 & 15.0440268 & 29.7008022 \\
\hline 15.6681261 & 12.8734458 & 19.8727180 \\
\hline 15.8044478 & 19.1792723 & 19.9527450 \\
\hline 10.0857500 & 16.3901791 & 19.7255544 \\
\hline 8.5903720 & 16.9943281 & 24.7759111 \\
\hline 11.8473092 & 12.4702698 & 19.8887483 \\
\hline 11.6555784 & 10.4694201 & 19.8825924 \\
\hline 12.7450469 & 10.4393377 & 19.9281748 \\
\hline 11.0852535 & 10.5578023 & 20.8051773 \\
\hline 11.1448357 & 10.4941358 & 18.9214794 \\
\hline 11.6821471 & 8.5450479 & 19.9711932 \\
\hline 12.1392165 & 7.5037034 & 20.0404592 \\
\hline 5.1623574 & 15.0400214 & 29.9292283 \\
\hline 16.1244487 & 19.7575301 & 22.4870035 \\
\hline & & \\
\hline 8.6852207 & 8.9879371 & 15.2762154 \\
\hline 5.4141955 & 9.2909230 & 16.6527700 \\
\hline 5.4230799 & 9.2577037 & 28.4598225 \\
\hline 5.3111790 & 6.6923882 & 21.5855325 \\
\hline 5.3538039 & 6.7223963 & 18.4525386 \\
\hline 3.1919393 & 8.0405304 & 26.6169420 \\
\hline 3.2705863 & 8.1367654 & 23.4946278 \\
\hline 8.5395928 & 9.2479382 & 28.5219309 \\
\hline 8.5491635 & 9.3310370 & 16.7187449 \\
\hline 8.5090609 & 6.7346962 & 18.5128735 \\
\hline 8.4914931 & 6.6877253 & 21.6835810 \\
\hline 1.5367633 & 10.7615699 & 23.5173377 \\
\hline 1.5378176 & 10.7360507 & 26.6852254 \\
\hline 7.0865979 & 9.7192577 & 17.0505536 \\
\hline 5.0127138 & 10.7114262 & 28.1472491 \\
\hline 4.7880439 & 5.3081368 & 21.7507551 \\
\hline 9.0302085 & 5.3217936 & 21.9308396 \\
\hline 6.8296690 & 6.3497088 & 18.2029114 \\
\hline 1.9780686 & 9.2720517 & 26.8898044 \\
\hline 2.2227831 & 7.0931483 & 23.3211560 \\
\hline 0.1534003 & 10.2644358 & 23.2800925 \\
\hline 4.9321272 & 7.8647251 & 17.5209062 \\
\hline 4.5477855 & 8.2672874 & 27.6896161 \\
\hline 4.4745267 & 7.8549024 & 22.5847891 \\
\hline 2.3608872 & 11.6702096 & 27.5811640 \\
\hline 8.9843457 & 8.1425502 & 17.5821648 \\
\hline
\end{tabular}

28.1060527

1.9043577

1. 9288778

18.2261684

18.3944537

2321848

23.2693097

23.5763683

17.6394517

27.6466527

.4769711

22.4606730

27.3883944

17.3190668

17.6447086

2.3136456

27.8527369

21.9532712

21.8300434

1.9308101

525646

7. 9017534

26.7223205

26.8880566

20.1484996

20.1476018

5.2182848

19.8727180

19.9527450

19.7255544

7759111

19.8887483

19. 9281748

20.8051773

18.9214794

.9711932

29.9292283

22.4870035

15.2762154

6527700

1.5855325

.4525386

3. 4946278

8.5219309

8.5128735

1.6835810

23.5173377
26.6852254

17.0505536

28.1472491

21.9308396

18.2029114

26.8898044

211560

17.5209062

17.5821648 


\begin{tabular}{|c|c|c|c|}
\hline $\mathrm{O}$ & 1.8644038 & 12.1865042 & 22.5869744 \\
\hline $\mathrm{O}$ & 4.3877435 & 10.6174039 & 17.1246355 \\
\hline $\mathrm{O}$ & 6.8805065 & 9.0480094 & 28.0305262 \\
\hline $\mathrm{O}$ & 6.9999907 & 6.7063080 & 22.0183579 \\
\hline $\mathrm{H}$ & 9.3516213 & 5.5797141 & 18.0966656 \\
\hline $\mathrm{H}$ & 4.5051786 & 5.5381380 & 18.1451496 \\
\hline $\mathrm{H}$ & 0.1102938 & 10.8582053 & 27.0906572 \\
\hline $\mathrm{H}$ & 2.5943063 & 6.7131962 & 26.9302139 \\
\hline $\mathrm{O}$ & 2.6886653 & 9.5026016 & 23.1089875 \\
\hline $\mathrm{H}$ & 5.2934282 & 9.0210268 & 15.1934237 \\
\hline $\mathrm{O}$ & 5.1567252 & 7.1890570 & 19.9057722 \\
\hline $\mathrm{O}$ & 3.7569656 & 8.1447740 & 24.9595827 \\
\hline $\mathrm{H}$ & 8.6664091 & 9.0190438 & 29.9877568 \\
\hline $\mathrm{O}$ & 8.7231084 & 7.1058293 & 20.2131990 \\
\hline $\mathrm{O}$ & 1.7319668 & 11.1580218 & 25.2204371 \\
\hline $\mathrm{H}$ & 5.2777972 & 8.9844100 & 29.9162991 \\
\hline $\mathrm{H}$ & 3.4691559 & 11.9378013 & 15.2267451 \\
\hline Al & 3.2872745 & 16.0274294 & 21.5911931 \\
\hline $\mathrm{P}$ & 3.1787049 & 16.0552918 & 18.4207567 \\
\hline Al & 3.8162025 & 11.9540562 & 28.4861252 \\
\hline $\mathrm{P}$ & 3.8008598 & 11.9655428 & 16.6780630 \\
\hline Al & 1.6647640 & 13.2816077 & 18.5637696 \\
\hline $\mathrm{P}$ & 1.7426583 & 13.3653108 & 21.6118159 \\
\hline $\mathrm{O}$ & 4.8529646 & 13.0581402 & 16.9717621 \\
\hline $\mathrm{H}$ & 0.3959792 & 14.0005070 & 21.6017269 \\
\hline $\mathrm{H}$ & 2.2931313 & 17.0962703 & 21.8850964 \\
\hline 0 & 2.1273151 & 14.9453665 & 18.2212920 \\
\hline $\mathrm{O}$ & 4.3969057 & 15.8272037 & 17.5161776 \\
\hline 0 & 4.7480483 & 16.3117197 & 22.4914669 \\
\hline $\mathrm{O}$ & 2.5122128 & 12.2194996 & 17.4626088 \\
\hline $\mathrm{O}$ & 4.4570825 & 13.5090360 & 28.0303345 \\
\hline $\mathrm{O}$ & 2.7770444 & 14.4280110 & 22.0407224 \\
\hline $\mathrm{H}$ & 2.5742876 & 17.3613819 & 18.0387505 \\
\hline $\mathrm{H}$ & 0.2031126 & 13.1164271 & 18.3326612 \\
\hline $\mathrm{O}$ & 3.6569839 & 16.0924841 & 19.8791673 \\
\hline $\mathrm{H}$ & 3.5119134 & 11.9394782 & 29.9436286 \\
\hline 0 & 2.1127180 & 12.8412227 & 20.1943882 \\
\hline Al & 10.1452400 & 12.0387655 & 16.5187430 \\
\hline $\mathrm{P}$ & 10.0596622 & 12.0030431 & 28.3548442 \\
\hline Al & 12.2845549 & 10.6570368 & 26.6069791 \\
\hline $\mathrm{P}$ & 12.3040457 & 10.6093872 & 23.4281499 \\
\hline Al & 15.4117620 & 10.7615699 & 23.5173377 \\
\hline Al & 10.5872105 & 7.9818854 & 23.5927466 \\
\hline $\mathrm{P}$ & 10.6935483 & 7.9506043 & 26.7010932 \\
\hline$P$ & 15.4128163 & 10.7360507 & 26.6852254 \\
\hline 0 & 9.0271652 & 10.8829494 & 28.1165476 \\
\hline $\mathrm{O}$ & 11.7708825 & 9.0171003 & 26.9785884 \\
\hline $\mathrm{H}$ & 15.8378280 & 9.3227282 & 26.8827228 \\
\hline $\mathrm{H}$ & 11.5098001 & 6.8219651 & 23.4494505 \\
\hline $\mathrm{O}$ & 13.7829360 & 10.1762246 & 23.2379959 \\
\hline 0 & 11.3086101 & 11.7932997 & 27.5029872 \\
\hline 0 & 9.5424603 & 8.0815866 & 27.7096209 \\
\hline $\mathrm{H}$ & 16.2118011 & 11.6428740 & 27.5549469 \\
\hline $\mathrm{O}$ & 9.1827766 & 7.7305871 & 22.5780878 \\
\hline 0 & 15.7394025 & 12.1865042 & 22.5869744 \\
\hline $\mathrm{O}$ & 9.4543652 & 10.5239359 & 17.0798361 \\
\hline O & 13.9431790 & 10.8618090 & 27.1026179 \\
\hline $\mathrm{H}$ & 11.2996577 & 6.6017966 & 26.8756491 \\
\hline $\mathrm{H}$ & 16.3892951 & 9.6931776 & 23.1708014 \\
\hline 0 & 11.4043348 & 9.4110939 & 23.0564196 \\
\hline $\mathrm{H}$ & 10.4308495 & 12.0106968 & 15.0576613 \\
\hline $\mathrm{O}$ & 12.0817930 & 10.9725546 & 24.9154621 \\
\hline $\mathrm{O}$ & 15.6069655 & 11.1580218 & 25.2204371 \\
\hline 0 & 10.1164253 & 8.1193882 & 25.2804580 \\
\hline $\mathrm{H}$ & 10.4634334 & 12.0060320 & 29.7880506 \\
\hline $\mathrm{H}$ & 8.6864061 & 15.0338884 & 15.1790242 \\
\hline Al & 5.3605908 & 14.6992470 & 16.6089996 \\
\hline $\mathrm{P}$ & 5.3334658 & 14.7001855 & 28.4306748 \\
\hline Al & 12.2486784 & 18.7084895 & 21.5855325 \\
\hline $\mathrm{Zn}$ & 12.4493558 & 13.4002366 & 21.7072298 \\
\hline Al & 17.1622732 & 16.0274294 & 21.5911931 \\
\hline $\mathrm{P}$ & 17.0537036 & 16.0552918 & 18.4207567 \\
\hline$P$ & 12.3121885 & 13.2376170 & 18.4033923 \\
\hline$P$ & 12.2913033 & 18.7384977 & 18.4525386 \\
\hline Al & 5.4061583 & 17.2155338 & 26.5739089 \\
\hline $\mathrm{P}$ & 5.3909587 & 17.2711824 & 23.4929998 \\
\hline Al & 8.4847384 & 14.7290990 & 28.4390269 \\
\hline $\mathrm{P}$ & 8.5153789 & 14.7307822 & 16.6267801 \\
\hline Al & 15.5397628 & 13.2816077 & 18.5637696 \\
\hline & & 187507976 & \\
\hline
\end{tabular}




\begin{tabular}{|c|c|c|c|}
\hline Al & 10.7369381 & 15.9570820 & 18.4783493 \\
\hline $\mathrm{P}$ & 10.5874033 & 15.9650764 & 21.6311021 \\
\hline $\mathrm{P}$ & 15.4289925 & 18.7038267 & 21.6835810 \\
\hline$P$ & 15.6176570 & 13.3653108 & 21.6118159 \\
\hline Al & 8.5466616 & 17.4321552 & 23.4991100 \\
\hline $\mathrm{P}$ & 8.5633911 & 17.2931454 & 26.6264249 \\
\hline $\mathrm{O}$ & 8.9738510 & 13.2823902 & 16.9300205 \\
\hline $\mathrm{O}$ & 6.8038995 & 14.3524534 & 28.1273174 \\
\hline $\mathrm{O}$ & 11.6388889 & 17.0949449 & 21.7781233 \\
\hline $\mathrm{O}$ & 14.2369969 & 14.0165350 & 21.6014723 \\
\hline $\mathrm{O}$ & 15.9856092 & 17.2925053 & 21.9390559 \\
\hline $\mathrm{O}$ & 16.0023139 & 14.9453665 & 18.2212920 \\
\hline 0 & 11.9262722 & 14.7060589 & 18.1311223 \\
\hline $\mathrm{O}$ & 13.7671683 & 18.3658102 & 18.2029114 \\
\hline $\mathrm{O}$ & 7.0819812 & 17.6482103 & 26.8786525 \\
\hline $\mathrm{H}$ & 9.0387447 & 18.8287780 & 23.3428429 \\
\hline $\mathrm{H}$ & 4.7420990 & 18.6097816 & 23.4277789 \\
\hline $\mathrm{H}$ & 18.2358807 & 15.8339486 & 17.5429270 \\
\hline $\mathrm{H}$ & 11.8817797 & 19.8479034 & 17.5477568 \\
\hline $\mathrm{O}$ & 11.6453284 & 12.3162928 & 17.3633031 \\
\hline $\mathrm{O}$ & 4.8923518 & 15.9224385 & 27.6224058 \\
\hline $\mathrm{H}$ & 11.5353426 & 19.6996576 & 22.4375059 \\
\hline $\mathrm{O}$ & 11.9112647 & 11.7712076 & 22.5474198 \\
\hline $\mathrm{H}$ & 18.4128272 & 16.2708075 & 22.3619086 \\
\hline $\mathrm{O}$ & 8.9878164 & 16.1225243 & 27.5245928 \\
\hline $\mathrm{H}$ & 16.2612567 & 12.3773588 & 17.6262724 \\
\hline 0 & 9.3458690 & 15.7258828 & 17.4402123 \\
\hline $\mathrm{H}$ & 15.8501916 & 19.9464048 & 17.7224776 \\
\hline $\mathrm{O}$ & 9.2992537 & 16.3662556 & 22.3691003 \\
\hline 0 & 7.0456503 & 14.8598163 & 17.0480745 \\
\hline $\mathrm{O}$ & 9.4378785 & 13.3481397 & 27.9722507 \\
\hline $\mathrm{O}$ & 13.9374900 & 18.7224094 & 22.0183579 \\
\hline 0 & 11.1001511 & 14.6638164 & 22.2060855 \\
\hline $\mathrm{O}$ & 16.6520431 & 14.4280110 & 22.0407224 \\
\hline 0 & 16.4304556 & 17.4020735 & 18.0268490 \\
\hline $\mathrm{O}$ & 13.8258800 & 13.0879226 & 18.2927798 \\
\hline $\mathrm{O}$ & 11.4192721 & 17.5215764 & 18.1366715 \\
\hline $\mathrm{H}$ & 4.5251258 & 18.3868361 & 26.8364983 \\
\hline $\mathrm{H}$ & 9.4063249 & 18.4705162 & 26.9733848 \\
\hline 0 & 6.8589295 & 17.4386137 & 23.1174589 \\
\hline $\mathrm{H}$ & 5.1880099 & 14.9744069 & 15.1558570 \\
\hline $\mathrm{O}$ & 12.0942246 & 19.2051583 & 19.9057722 \\
\hline $\mathrm{O}$ & 17.5319826 & 16.0924841 & 19.8791673 \\
\hline $\mathrm{O}$ & 5.2475972 & 16.6840468 & 24.9121112 \\
\hline $\mathrm{H}$ & 8.6606022 & 14.9960733 & 29.8933024 \\
\hline $\mathrm{O}$ & 15.9877168 & 12.8412227 & 20.1943882 \\
\hline 0 & 15.6606078 & 19.1219306 & 20.2131990 \\
\hline $\mathrm{O}$ & 10.2134052 & 15.8228152 & 20.1302494 \\
\hline $\mathrm{O}$ & 8.7835292 & 16.8936393 & 25.1558186 \\
\hline 0 & 11.8371632 & 12.7878266 & 19.8200368 \\
\hline C & 10.0241515 & 12.0973691 & 20.0469077 \\
\hline $\mathrm{H}$ & 10.1965946 & 11.9821332 & 21.1132538 \\
\hline $\mathrm{H}$ & 10.2117360 & 11.2558117 & 19.3879893 \\
\hline $\mathrm{H}$ & 9.5638313 & 13.0019854 & 19.6639226 \\
\hline C & 7.9861655 & 11.1454366 & 20.2821533 \\
\hline $\mathrm{H}$ & 8.2260149 & 10.3493873 & 20.9921687 \\
\hline $\mathrm{H}$ & 7.7770904 & 10.8559757 & 19.2469501 \\
\hline $\mathrm{C}$ & 7.2581920 & 12.1737616 & 20.7381124 \\
\hline $\mathrm{O}$ & 6.7126241 & 13.1309228 & 21.1074666 \\
\hline $\mathrm{H}$ & 5.1640019 & 15.0113471 & 29.8769048 \\
\hline $\mathrm{H}$ & 16.0982332 & 19.7134351 & 22.5495650 \\
\hline \multicolumn{4}{|c|}{ Si 17} \\
\hline \multicolumn{4}{|c|}{167} \\
\hline $\mathrm{H}$ & 8.6800437 & 9.0015125 & 15.1544840 \\
\hline $\mathrm{P}$ & 5.3957388 & 9.3345203 & 16.7059404 \\
\hline Al & 5.3614159 & 9.2893418 & 28.5110489 \\
\hline $\mathrm{P}$ & 5.4203997 & 6.7738513 & 21.6422207 \\
\hline $\mathrm{Al}$ & 5.4470622 & 6.7545435 & 18.5000926 \\
\hline $\mathrm{P}$ & 3.2137119 & 7.9416004 & 26.6681652 \\
\hline Al & 3.2611821 & 8.0169468 & 23.5475757 \\
\hline $\mathrm{P}$ & 8.4961419 & 9.2303688 & 28.4256641 \\
\hline Al & 8.5417002 & 9.2737814 & 16.6118280 \\
\hline $\mathrm{P}$ & 8.6092793 & 6.7264143 & 18.4531329 \\
\hline Al & 8.5857805 & 6.7024675 & 21.6132803 \\
\hline $\mathrm{P}$ & 1.6475463 & 10.7354841 & 23.4862974 \\
\hline Al & 1.6351023 & 10.7163834 & 26.6136422 \\
\hline $\mathrm{O}$ & 6.8753371 & 9.6915026 & 17.0035812 \\
\hline $\mathrm{O}$ & 4.8778333 & 10.9307595 & 28.1302844 \\
\hline & & & \\
\hline
\end{tabular}




\begin{tabular}{|c|c|c|}
\hline 9.0718783 & 5.3173834 & 21.8630232 \\
\hline 7.1329579 & 6.3682762 & 18.1994371 \\
\hline 2.1690886 & 9.0610281 & 26.8290825 \\
\hline 2.2138760 & 6.9859043 & 23.3083647 \\
\hline 0.2568116 & 10.2428411 & 23.2855969 \\
\hline 4.9681475 & 8.1117983 & 17.5175767 \\
\hline 4.3775022 & 8.1461205 & 27.6464207 \\
\hline 4.6572924 & 7.7604671 & 22.5343702 \\
\hline 2.5556110 & 11.7931968 & 27.6284204 \\
\hline 9.0380440 & 7.9018669 & 17.5616684 \\
\hline 1.9722424 & 11.9035618 & 22.5560204 \\
\hline 4.5240062 & 10.5222941 & 17.1287561 \\
\hline 7.0231911 & 9.0645465 & 28.0453629 \\
\hline 6.9031764 & 6.8399681 & 22.0285567 \\
\hline 9.4561621 & 5.5517185 & 18.1067232 \\
\hline 4.6078689 & 5.5800643 & 18.1347519 \\
\hline 0.2097466 & 10.7920371 & 27.0376212 \\
\hline 2.5739245 & 6.6381361 & 26.9979735 \\
\hline 2.6251938 & 9.5929578 & 23.1727587 \\
\hline 5.2171833 & 9.0304222 & 15.2593019 \\
\hline 5.2407773 & 7.2147173 & 20.1742577 \\
\hline 3.7667377 & 7.9339653 & 25.2300406 \\
\hline 8.6961287 & 8.9653448 & 29.8771765 \\
\hline 8.8145953 & 7.1419134 & 19.9240783 \\
\hline 1.8352495 & 11.2046905 & 24.9462479 \\
\hline 5.2339877 & 9.0610129 & 29.9769099 \\
\hline 3.5278055 & 12.0146351 & 15.1622453 \\
\hline 3.2094562 & 15.9355128 & 21.6635837 \\
\hline 3.1899534 & 15.9633698 & 18.4949679 \\
\hline 3.8331494 & 12.0246959 & 28.4356340 \\
\hline 3.8242590 & 12.0418027 & 16.6211825 \\
\hline 1.6176767 & 13.2577659 & 18.4581616 \\
\hline 1.5586295 & 13.2674348 & 21.5394933 \\
\hline 5.0175999 & 13.2837367 & 16.9801807 \\
\hline 0.1142152 & 13.6288996 & 21.5280488 \\
\hline 2.2538656 & 17.0532716 & 21.8972128 \\
\hline 1.9880280 & 14.7298817 & 18.1541997 \\
\hline 4.6305228 & 15.7165127 & 17.5352263 \\
\hline 4.4707237 & 16.1282003 & 22.5152393 \\
\hline 2.3324492 & 12.3257226 & 17.4665034 \\
\hline 4.4148288 & 13.3848921 & 28.0369456 \\
\hline 2.5549007 & 14.6172313 & 22.0689829 \\
\hline 2.6375115 & 17.3038282 & 18.1557042 \\
\hline 0.1513406 & 13.0819530 & 18.2682436 \\
\hline 3.6335218 & 15.9135511 & 20.1826359 \\
\hline 3.4884331 & 12.0104673 & 29.8841121 \\
\hline 2.0560600 & 12.8767639 & 19.8812411 \\
\hline 10.1279633 & 11.9754638 & 16.6246382 \\
\hline 10.0937187 & 11.9414387 & 28.4291679 \\
\hline 12.3695204 & 10.6688197 & 26.7183761 \\
\hline 12.3957788 & 10.6878540 & 23.5212860 \\
\hline 15.5225450 & 10.7354841 & 23.4862974 \\
\hline 10.6747999 & 8.0511397 & 23.4812750 \\
\hline 10.7147945 & 8.0131388 & 26.6186506 \\
\hline 15.5101010 & 10.7163834 & 26.6136422 \\
\hline 8.9355423 & 10.6683876 & 28.0838868 \\
\hline 11.9065188 & 9.2289966 & 27.0313776 \\
\hline 15.9637619 & 9.3100366 & 26.7966747 \\
\hline 11.5873381 & 6.8853229 & 23.3223230 \\
\hline 14.0834353 & 10.2257051 & 23.2786158 \\
\hline 11.5715484 & 11.6773612 & 27.5586721 \\
\hline 9.3099882 & 8.2041070 & 27.6352436 \\
\hline 16.2966505 & 11.6364910 & 27.4807423 \\
\hline 9.4350426 & 7.8797181 & 22.5859139 \\
\hline 15.8472411 & 11.9035618 & 22.5560204 \\
\hline 9.5299644 & 10.6362022 & 17.1060570 \\
\hline 13.8442336 & 10.8048028 & 27.1091626 \\
\hline 11.2937466 & 6.6659833 & 26.8777010 \\
\hline 16.4702430 & 9.6279582 & 23.1823637 \\
\hline 11.4005545 & 9.3209413 & 23.0403237 \\
\hline 10.4258399 & 11.9220017 & 15.1667178 \\
\hline 12.1551125 & 10.9827488 & 25.2368012 \\
\hline 15.7102482 & 11.2046905 & 24.9462479 \\
\hline 10.2118362 & 8.1668421 & 24.9468711 \\
\hline 10.3832492 & 11.9236734 & 29.8896395 \\
\hline 8.7764304 & 15.0023836 & 15.1103641 \\
\hline 5.4427346 & 14.7385341 & 16.6811229 \\
\hline 5.4122891 & 14.7316766 & 28.5081122 \\
\hline 12.3578990 & 18.7899527 & 21.6422207 \\
\hline 12.2127439 & 13.2953601 & 21.6568709 \\
\hline
\end{tabular}




\begin{tabular}{|c|c|c|c|}
\hline $\mathrm{P}$ & 17.0844549 & 15.9355128 & 21.6635837 \\
\hline Al & 17.0649521 & 15.9633698 & 18.4949679 \\
\hline Al & 12.2764772 & 13.2735774 & 18.5185251 \\
\hline Al & 12.3845616 & 18.7706449 & 18.5000926 \\
\hline $\mathrm{P}$ & 5.3506712 & 17.2535201 & 26.6433823 \\
\hline Al & 5.3229711 & 17.2586989 & 23.5246275 \\
\hline $\mathrm{P}$ & 8.5674330 & 14.6903016 & 28.3968746 \\
\hline Al & 8.6000021 & 14.7347565 & 16.5644512 \\
\hline $\mathrm{P}$ & 15.4926754 & 13.2577659 & 18.4581616 \\
\hline$P$ & 15.5467786 & 18.7425157 & 18.4531329 \\
\hline $\mathrm{P}$ & 10.7705424 & 16.0490201 & 18.4201740 \\
\hline Al & 10.6918311 & 16.0586779 & 21.5858331 \\
\hline Al & 15.5232799 & 18.7185688 & 21.6132803 \\
\hline $\mathrm{Al}$ & 15.4336282 & 13.2674348 & 21.5394933 \\
\hline $\mathrm{P}$ & 8.4821738 & 17.3649412 & 23.4184775 \\
\hline $\mathrm{Al}$ & 8.4995434 & 17.2581805 & 26.5633888 \\
\hline 0 & 9.0937315 & 13.0822024 & 16.9378244 \\
\hline 0 & 7.0855551 & 14.3283301 & 28.1780181 \\
\hline 0 & 11.8531424 & 17.3581005 & 21.8413873 \\
\hline $\mathrm{O}$ & 13.7729962 & 13.6830081 & 21.5263356 \\
\hline 0 & 16.0929938 & 17.0952295 & 21.9059827 \\
\hline 0 & 15.8630267 & 14.7298817 & 18.1541997 \\
\hline 0 & 11.8201487 & 14.9415639 & 18.1926655 \\
\hline 0 & 14.0704572 & 18.3843775 & 18.1994371 \\
\hline 0 & 6.8194200 & 17.6577446 & 26.8847449 \\
\hline $\mathrm{H}$ & 8.9505283 & 18.7707031 & 23.2715151 \\
\hline $\mathrm{H}$ & 4.7722747 & 18.6307518 & 23.3476393 \\
\hline $\mathrm{H}$ & 18.2917162 & 15.7531506 & 17.6776685 \\
\hline $\mathrm{H}$ & 11.9753555 & 19.9303438 & 17.6605872 \\
\hline $\mathrm{O}$ & 11.4304412 & 12.2217427 & 17.3879506 \\
\hline $\mathrm{O}$ & 4.9332469 & 16.1340617 & 27.6021547 \\
\hline $\mathrm{H}$ & 11.6169443 & 19.7479276 & 22.5084717 \\
\hline 0 & 11.9149593 & 12.0504935 & 22.6292052 \\
\hline $\mathrm{H}$ & 18.3087007 & 16.1225444 & 22.4902408 \\
\hline 0 & 8.9723226 & 15.8846379 & 27.5305069 \\
\hline $\mathrm{H}$ & 16.1850347 & 12.3549489 & 17.4975990 \\
\hline 0 & 9.5704716 & 15.8463158 & 17.4811119 \\
\hline $\mathrm{H}$ & 15.9623407 & 19.8817734 & 17.5891187 \\
\hline 0 & 9.2245963 & 16.4398200 & 22.4595908 \\
\hline 0 & 6.9270725 & 14.8931013 & 17.0435308 \\
\hline $\mathrm{O}$ & 9.4271091 & 13.4886599 & 27.9892240 \\
\hline 0 & 13.8406757 & 18.8560695 & 22.0285567 \\
\hline 0 & 11.3031394 & 14.5521355 & 22.0829637 \\
\hline 0 & 16.4298994 & 14.6172313 & 22.0689829 \\
\hline 0 & 16.4171241 & 17.5352753 & 18.0971260 \\
\hline 0 & 13.9840499 & 13.0768825 & 18.2627664 \\
\hline 0 & 11.4060631 & 17.4012033 & 18.0741057 \\
\hline $\mathrm{H}$ & 4.4755462 & 18.4275643 & 26.9133771 \\
\hline $\mathrm{H}$ & 9.3493762 & 18.4203588 & 26.9431865 \\
\hline 0 & 6.9944091 & 17.3093714 & 23.0617423 \\
\hline $\mathrm{H}$ & 5.2206515 & 15.0577050 & 15.2437887 \\
\hline 0 & 12.1782767 & 19.2308187 & 20.1742577 \\
\hline 0 & 17.5085205 & 15.9135511 & 20.1826359 \\
\hline 0 & 5.1658027 & 16.7573266 & 25.1975257 \\
\hline $\mathrm{H}$ & 8.7988184 & 15.0365111 & 29.8264621 \\
\hline $\mathrm{O}$ & 15.9310587 & 12.8767639 & 19.8812411 \\
\hline 0 & 15.7520947 & 19.1580147 & 19.9240783 \\
\hline $\mathrm{O}$ & 10.2589962 & 16.0377866 & 19.8671903 \\
\hline 0 & 8.7064471 & 16.8816806 & 24.8672157 \\
\hline 0 & 11.7101448 & 12.8001374 & 20.1170164 \\
\hline $\mathrm{C}$ & 9.8356683 & 12.1014018 & 20.2116350 \\
\hline $\mathrm{H}$ & 9.9042863 & 12.0035836 & 21.2914328 \\
\hline $\mathrm{H}$ & 10.1197399 & 11.2669544 & 19.5799473 \\
\hline $\mathrm{H}$ & 9.4523788 & 13.0140859 & 19.7694972 \\
\hline C & 7.8302339 & 11.1905666 & 20.1883492 \\
\hline $\mathrm{H}$ & 7.9855131 & 10.3301800 & 20.8456585 \\
\hline $\mathrm{H}$ & 7.7061795 & 10.9847520 & 19.1191921 \\
\hline C & 7.0350983 & 12.1646542 & 20.6595107 \\
\hline 0 & 6.4414476 & 13.0788572 & 21.0590813 \\
\hline $\mathrm{H}$ & 5.2431896 & 15.0177533 & 29.9595549 \\
\hline $\mathrm{H}$ & 16.2469824 & 19.7217683 & 22.4421145 \\
\hline \multicolumn{4}{|c|}{ Mg 17} \\
\hline \multicolumn{4}{|c|}{167} \\
\hline $\mathrm{H}$ & 8.6772626 & 8.9742555 & 15.281086 \\
\hline Al & 5.4198560 & 9.3108373 & 16.660310 \\
\hline $\mathrm{P}$ & 5.4220366 & 9.2666228 & 28.4619004 \\
\hline Al & 5.3094811 & 6.7164123 & 21.5786362 \\
\hline $\mathrm{P}$ & 5.3661882 & 6.7345815 & 18.4475011 \\
\hline Al & 3.2008126 & 8.0211937 & 26.6249686 \\
\hline
\end{tabular}




\begin{tabular}{|c|c|c|c|}
\hline $\mathrm{P}$ & 3.3038251 & 8.1225784 & 23.5130638 \\
\hline Al & 8.5361069 & 9.2320433 & 28.5260064 \\
\hline $\mathrm{P}$ & 8.5528169 & 9.3404070 & 16.7189903 \\
\hline Al & 8.5216415 & 6.7503708 & 18.5229525 \\
\hline $\mathrm{P}$ & 8.4949808 & 6.6898974 & 21.6875909 \\
\hline Al & 1.5599102 & 10.7669906 & 23.5358627 \\
\hline $\mathrm{P}$ & 1.5312864 & 10.7373115 & 26.6882777 \\
\hline 0 & 7.0938215 & 9.7395266 & 17.0554336 \\
\hline 0 & 5.0124329 & 10.7158220 & 28.1286791 \\
\hline $\mathrm{H}$ & 4.7322076 & 5.3543327 & 21.7477955 \\
\hline $\mathrm{H}$ & 9.0469728 & 5.3277342 & 21.9262054 \\
\hline O & 6.8438891 & 6.3622686 & 18.2081704 \\
\hline 0 & 1.9995777 & 9.2754993 & 26.8300355 \\
\hline $\mathrm{H}$ & 2.2568186 & 7.0893610 & 23.2820667 \\
\hline $\mathrm{H}$ & 0.1874565 & 10.2496022 & 23.2793464 \\
\hline 0 & 4.9468404 & 7.8714376 & 17.5089821 \\
\hline 0 & 4.5402225 & 8.2650391 & 27.7139301 \\
\hline 0 & 4.5084927 & 7.8933818 & 22.5886242 \\
\hline 0 & 2.3512554 & 11.6547978 & 27.6034647 \\
\hline 0 & 8.9911786 & 8.1634437 & 17.5964395 \\
\hline 0 & 1.9713949 & 12.1422273 & 22.5648006 \\
\hline 0 & 4.3844941 & 10.6259328 & 17.1473621 \\
\hline 0 & 6.8769214 & 9.0495363 & 28.0287093 \\
\hline 0 & 6.9997883 & 6.6834849 & 22.0061071 \\
\hline $\mathrm{H}$ & 9.3667336 & 5.5952769 & 18.1122240 \\
\hline $\mathrm{H}$ & 4.5229325 & 5.5473136 & 18.1369604 \\
\hline $\mathrm{H}$ & 0.1109913 & 10.8187722 & 27.1278757 \\
\hline $\mathrm{H}$ & 2.5799699 & 6.7115939 & 26.9664703 \\
\hline 0 & 2.7246426 & 9.5041608 & 23.2006711 \\
\hline $\mathrm{H}$ & 5.2994845 & 9.0530165 & 15.1987502 \\
\hline $\mathrm{O}$ & 5.1621838 & 7.2092302 & 19.8970204 \\
\hline 0 & 3.7932880 & 8.0516046 & 24.9754414 \\
\hline $\mathrm{H}$ & 8.6588038 & 9.0045429 & 29.9923998 \\
\hline 0 & 8.7344920 & 7.1251688 & 20.2228447 \\
\hline 0 & 1.6872450 & 11.2152852 & 25.2358814 \\
\hline $\mathrm{H}$ & 5.2837332 & 9.0177551 & 29.9234262 \\
\hline $\mathrm{H}$ & 3.4924412 & 11.9357469 & 15.2310454 \\
\hline Al & 3.2939789 & 16.0218663 & 21.5944947 \\
\hline $\mathrm{P}$ & 3.1844968 & 16.0614472 & 18.4213393 \\
\hline Al & 3.8152316 & 11.9520348 & 28.4872395 \\
\hline $\mathrm{P}$ & 3.8008582 & 11.9718758 & 16.6873057 \\
\hline Al & 1.6710380 & 13.2962350 & 18.5633741 \\
\hline $\mathrm{P}$ & 1.7658916 & 13.3337579 & 21.6143296 \\
\hline 0 & 4.8484199 & 13.0661009 & 16.9923115 \\
\hline $\mathrm{H}$ & 0.3706926 & 13.8538109 & 21.6235606 \\
\hline $\mathrm{H}$ & 2.3087325 & 17.1008332 & 21.8812706 \\
\hline 0 & 2.1259595 & 14.9605813 & 18.2047078 \\
\hline 0 & 4.4025215 & 15.8382606 & 17.5143292 \\
\hline 0 & 4.7627877 & 16.3014580 & 22.4883620 \\
\hline 0 & 2.4985648 & 12.2296047 & 17.4487709 \\
\hline 0 & 4.4394430 & 13.5110458 & 28.0244754 \\
\hline 0 & 2.7477764 & 14.4415061 & 22.0582796 \\
\hline $\mathrm{H}$ & 2.5896725 & 17.3763469 & 18.0548104 \\
\hline $\mathrm{H}$ & 0.2056753 & 13.1405892 & 18.3498161 \\
\hline 0 & 3.6613027 & 16.0751978 & 19.8805810 \\
\hline $\mathrm{H}$ & 3.5321393 & 11.9372095 & 29.9490054 \\
\hline 0 & 2.1609341 & 12.8634228 & 20.1816746 \\
\hline Al & 10.1558157 & 12.0536979 & 16.5078099 \\
\hline $\mathrm{P}$ & 10.0655608 & 11.9975255 & 28.3468580 \\
\hline Al & 12.2883137 & 10.6150363 & 26.6372294 \\
\hline $\mathrm{P}$ & 12.3323585 & 10.5666214 & 23.4386854 \\
\hline Al & 15.4349090 & 10.7669906 & 23.5358627 \\
\hline Al & 10.5803309 & 7.9823582 & 23.6034647 \\
\hline $\mathrm{P}$ & 10.6780031 & 7.9425846 & 26.7115997 \\
\hline$P$ & 15.4062852 & 10.7373115 & 26.6882777 \\
\hline 0 & 9.0445212 & 10.8628831 & 28.1307495 \\
\hline 0 & 11.7562238 & 8.9908426 & 27.0517267 \\
\hline H & 15.8586212 & 9.3253047 & 26.8252056 \\
\hline $\mathrm{H}$ & 11.4650087 & 6.7896895 & 23.4938886 \\
\hline 0 & 13.8171367 & 10.1571219 & 23.2334955 \\
\hline 0 & 11.3101764 & 11.7880804 & 27.4878534 \\
\hline 0 & 9.5150004 & 8.0460002 & 27.7107421 \\
\hline $\mathrm{H}$ & 16.2024470 & 11.6281593 & 27.5768930 \\
\hline 0 & 9.1667036 & 7.7328305 & 22.5980704 \\
\hline 0 & 15.8463936 & 12.1422273 & 22.5648006 \\
\hline 0 & 9.4636630 & 10.5358664 & 17.0576632 \\
\hline 0 & 13.9434899 & 10.8212098 & 27.1410300 \\
\hline $\mathrm{H}$ & 11.2715279 & 6.5827153 & 26.8365168 \\
\hline $\mathrm{H}$ & 16.4257366 & 9.6927124 & 23.2507182 \\
\hline 0 & 11.4444705 & 9.3702410 & 23.0256358 \\
\hline
\end{tabular}




\begin{tabular}{|c|c|c|c|}
\hline $\mathrm{H}$ & 10.4463251 & 12.0318787 & 15.0475877 \\
\hline 0 & 12.1022646 & 10.8686008 & 24.9374221 \\
\hline 0 & 15.5622437 & 11.2152852 & 25.2358814 \\
\hline 0 & 10.1224324 & 8.1750097 & 25.2907428 \\
\hline $\mathrm{H}$ & 10.4790984 & 12.0272871 & 29.7769704 \\
\hline $\mathrm{H}$ & 8.6732113 & 15.0244002 & 15.1578449 \\
\hline Al & 5.3626669 & 14.7019650 & 16.6130737 \\
\hline $\mathrm{P}$ & 5.3225150 & 14.6958252 & 28.4287262 \\
\hline Al & 12.2469805 & 18.7325137 & 21.5786362 \\
\hline Mg & 12.3950959 & 13.3577734 & 21.6897223 \\
\hline Al & 17.1689777 & 16.0218663 & 21.5944947 \\
\hline $\mathrm{P}$ & 17.0594955 & 16.0614472 & 18.4213393 \\
\hline$P$ & 12.3076155 & 13.2473727 & 18.4128489 \\
\hline $\mathrm{P}$ & 12.3036875 & 18.7506829 & 18.4475011 \\
\hline Al & 5.3976065 & 17.2032154 & 26.5705803 \\
\hline $\mathrm{P}$ & 5.3864750 & 17.2597531 & 23.5044577 \\
\hline Al & 8.4728822 & 14.7151535 & 28.4191136 \\
\hline $\mathrm{P}$ & 8.5170164 & 14.7408982 & 16.6112377 \\
\hline Al & 15.5460367 & 13.2962350 & 18.5633741 \\
\hline Al & 15.4591409 & 18.7664722 & 18.5229525 \\
\hline Al & 10.7188289 & 15.9832636 & 18.4701489 \\
\hline $\mathrm{P}$ & 10.5512306 & 15.9976900 & 21.6093353 \\
\hline $\mathrm{P}$ & 15.4324801 & 18.7059988 & 21.6875909 \\
\hline$P$ & 15.6408903 & 13.3337579 & 21.6143296 \\
\hline Al & 8.5378495 & 17.4489821 & 23.4924580 \\
\hline $\mathrm{P}$ & 8.5497914 & 17.2995314 & 26.6344104 \\
\hline 0 & 8.9891408 & 13.2989585 & 16.9286443 \\
\hline 0 & 6.7896237 & 14.3453962 & 28.1114908 \\
\hline 0 & 11.5756112 & 17.1484146 & 21.7753685 \\
\hline 0 & 14.2195847 & 13.8635420 & 21.6237334 \\
\hline 0 & 16.0025321 & 17.2992687 & 21.9340123 \\
\hline 0 & 16.0009582 & 14.9605813 & 18.2047078 \\
\hline 0 & 11.9014451 & 14.7123826 & 18.1600898 \\
\hline 0 & 13.7813884 & 18.3783699 & 18.2081704 \\
\hline O & 7.0673446 & 17.6467604 & 26.8930643 \\
\hline $\mathrm{H}$ & 9.0663990 & 18.8285916 & 23.3068950 \\
\hline $\mathrm{H}$ & 4.6904673 & 18.5757811 & 23.4768153 \\
\hline $\mathrm{H}$ & 18.2410595 & 15.8449415 & 17.5414799 \\
\hline $\mathrm{H}$ & 11.8962912 & 19.8551385 & 17.5357300 \\
\hline 0 & 11.6511649 & 12.3266439 & 17.3673839 \\
\hline 0 & 4.8779995 & 15.9259829 & 27.6348544 \\
\hline $\mathrm{H}$ & 11.5637131 & 19.7365043 & 22.4401865 \\
\hline 0 & 11.9518036 & 11.7660367 & 22.6107138 \\
\hline $\mathrm{H}$ & 18.4244622 & 16.2608511 & 22.3585401 \\
\hline 0 & 8.9757337 & 16.1074207 & 27.5037813 \\
\hline $\mathrm{H}$ & 16.2498748 & 12.3890317 & 17.6153684 \\
\hline 0 & 9.3503994 & 15.7520651 & 17.4020358 \\
\hline $\mathrm{H}$ & 15.8577938 & 19.9662190 & 17.7363115 \\
\hline $\mathrm{O}$ & 9.2664136 & 16.3423179 & 22.3834014 \\
\hline 0 & 7.0503267 & 14.8636334 & 17.0455037 \\
\hline 0 & 9.4243803 & 13.3309896 & 27.9532244 \\
\hline $\mathrm{O}$ & 13.9372877 & 18.6995863 & 22.0061071 \\
\hline 0 & 11.1274877 & 14.7010640 & 22.1119919 \\
\hline 0 & 16.6227751 & 14.4415061 & 22.0582796 \\
\hline 0 & 16.4460160 & 17.4175856 & 18.0433152 \\
\hline 0 & 13.8231325 & 13.1132340 & 18.3122827 \\
\hline 0 & 11.4372921 & 17.5308351 & 18.1284388 \\
\hline $\mathrm{H}$ & 4.4996335 & 18.3683473 & 26.8013024 \\
\hline $\mathrm{H}$ & 9.3874522 & 18.4706891 & 27.0136659 \\
\hline 0 & 6.8457739 & 17.4882901 & 23.1224247 \\
\hline $\mathrm{H}$ & 5.1889800 & 14.9609158 & 15.1570868 \\
\hline 0 & 12.0996832 & 19.2253315 & 19.8970204 \\
\hline 0 & 17.5363015 & 16.0751978 & 19.8805810 \\
\hline 0 & 5.2757458 & 16.6414988 & 24.9140335 \\
\hline $\mathrm{H}$ & 8.6471820 & 14.9853263 & 29.8729867 \\
\hline 0 & 16.0359328 & 12.8634228 & 20.1816746 \\
\hline 0 & 15.6719914 & 19.1412702 & 20.2228447 \\
\hline $\mathrm{O}$ & 10.1496267 & 15.8940800 & 20.1097393 \\
\hline 0 & 8.7737415 & 16.9342247 & 25.1563841 \\
\hline 0 & 11.8389200 & 12.7887383 & 19.8303389 \\
\hline $\mathrm{C}$ & 10.0289511 & 12.1051058 & 20.0382041 \\
\hline $\mathrm{H}$ & 10.1800570 & 11.9521568 & 21.1037031 \\
\hline $\mathrm{H}$ & 10.2051871 & 11.2755549 & 19.3611609 \\
\hline $\mathrm{H}$ & 9.5685958 & 13.0199612 & 19.6804647 \\
\hline C & 7.9618947 & 11.1597661 & 20.2427692 \\
\hline $\mathrm{H}$ & 8.1885480 & 10.3549522 & 20.9470440 \\
\hline $\mathrm{H}$ & 7.7630047 & 10.8823061 & 19.2021786 \\
\hline $\mathrm{C}$ & 7.2353796 & 12.1879708 & 20.7001378 \\
\hline 0 & 6.6901637 & 13.1443124 & 21.0722221 \\
\hline $\mathrm{H}$ & 5.1644798 & 14.9953695 & 29.8786981 \\
\hline
\end{tabular}


Al 1

167

\begin{tabular}{|c|c|c|c|}
\hline $\mathrm{H}$ & 8.6315338 & 8.8606224 & 15.2227585 \\
\hline $\mathrm{Si}$ & 5.3229043 & 9.2698802 & 16.6521851 \\
\hline $\mathrm{Si}$ & 5.3126360 & 9.2241633 & 28.5824848 \\
\hline $\mathrm{Si}$ & 5.2970740 & 6.7875783 & 21.6153849 \\
\hline $\mathrm{Si}$ & 5.3360061 & 6.7945424 & 18.5417668 \\
\hline $\mathrm{Si}$ & 3.2127727 & 7.9890438 & 26.6506657 \\
\hline $\mathrm{Si}$ & 3.3030133 & 8.0707057 & 23.5919194 \\
\hline $\mathrm{Si}$ & 8.4222010 & 9.1788114 & 28.5836499 \\
\hline $\mathrm{Si}$ & 8.4434033 & 9.2627917 & 16.6440211 \\
\hline $\mathrm{Si}$ & 8.4649196 & 6.7843605 & 18.5487408 \\
\hline $\mathrm{Si}$ & 8.4458867 & 6.7302195 & 21.6617150 \\
\hline $\mathrm{Si}$ & 1.6276467 & 10.7180199 & 23.5763895 \\
\hline $\mathrm{Si}$ & 1.6127525 & 10.7138214 & 26.6487883 \\
\hline 0 & 6.8879212 & 9.6729124 & 16.9248825 \\
\hline $\mathrm{O}$ & 4.8946168 & 10.7694295 & 28.2788671 \\
\hline $\mathrm{H}$ & 4.7528254 & 5.4109170 & 21.7757523 \\
\hline $\mathrm{H}$ & 8.9620954 & 5.3517026 & 21.8860815 \\
\hline $\mathrm{O}$ & 6.9035209 & 6.4029751 & 18.3082480 \\
\hline $\mathrm{O}$ & 2.1014919 & 9.1670192 & 26.7925675 \\
\hline $\mathrm{H}$ & 2.2587382 & 7.0339328 & 23.3645160 \\
\hline $\mathrm{H}$ & 0.2514824 & 10.1773626 & 23.4003724 \\
\hline 0 & 4.8999231 & 8.0003688 & 17.5554635 \\
\hline 0 & 4.4225633 & 8.1997890 & 27.7065591 \\
\hline 0 & 4.5686586 & 7.8476323 & 22.6016022 \\
\hline $\mathrm{O}$ & 2.4572498 & 11.6743183 & 27.6404927 \\
\hline 0 & 8.8912849 & 8.0585254 & 17.6342613 \\
\hline 0 & 1.9448752 & 11.9392914 & 22.5719669 \\
\hline 0 & 4.4012963 & 10.5280683 & 17.0846643 \\
\hline $\mathrm{O}$ & 6.8655356 & 9.0152341 & 28.1808342 \\
\hline 0 & 6.8706976 & 6.7729708 & 21.9969840 \\
\hline $\mathrm{H}$ & 9.3150519 & 5.6220198 & 18.1701119 \\
\hline $\mathrm{H}$ & 4.5017448 & 5.6061639 & 18.2117893 \\
\hline $\mathrm{H}$ & 0.1865440 & 10.7847249 & 27.0707156 \\
\hline $\mathrm{H}$ & 2.5660488 & 6.6893039 & 26.9816415 \\
\hline 0 & 2.6910699 & 9.5314258 & 23.2668305 \\
\hline $\mathrm{H}$ & 5.1152534 & 8.9163625 & 15.2207429 \\
\hline 0 & 5.1123358 & 7.2982550 & 20.0741852 \\
\hline 0 & 3.8243669 & 7.9844689 & 25.1384223 \\
\hline $\mathrm{H}$ & 8.6283391 & 8.8559925 & 30.0225438 \\
\hline 0 & 8.7103635 & 7.2065700 & 20.1121964 \\
\hline 0 & 1.8101281 & 11.2353046 & 25.1190090 \\
\hline $\mathrm{H}$ & 5.1150195 & 8.9135618 & 30.0252582 \\
\hline $\mathrm{H}$ & 3.3595647 & 11.8921504 & 15.1823271 \\
\hline $\mathrm{Si}$ & 3.2717084 & 15.8298800 & 21.6289188 \\
\hline $\mathrm{Si}$ & 3.2052607 & 15.8753192 & 18.5128364 \\
\hline $\mathrm{Si}$ & 3.7660482 & 11.9150662 & 28.5533307 \\
\hline $\mathrm{Si}$ & 3.7505719 & 11.9400400 & 16.6182730 \\
\hline $\mathrm{Si}$ & 1.6646754 & 13.1725403 & 18.5547634 \\
\hline $\mathrm{Si}$ & 1.6650445 & 13.1907268 & 21.5726887 \\
\hline 0 & 4.8728875 & 13.0990063 & 16.8701075 \\
\hline $\mathrm{H}$ & 0.2512623 & 13.6578996 & 21.5631941 \\
\hline $\mathrm{H}$ & 2.2915634 & 16.9220417 & 21.8811475 \\
\hline 0 & 2.0720478 & 14.7310921 & 18.2662455 \\
\hline $\mathrm{O}$ & 4.4917579 & 15.6504143 & 17.5529840 \\
\hline $\mathrm{O}$ & 4.6005879 & 16.0584395 & 22.5256430 \\
\hline 0 & 2.4170704 & 12.2044710 & 17.4909877 \\
\hline $\mathrm{O}$ & 4.3858818 & 13.3552583 & 28.1605487 \\
\hline 0 & 2.6519720 & 14.4026341 & 22.0468785 \\
\hline $\mathrm{H}$ & 2.6264833 & 17.2035404 & 18.1693750 \\
\hline $\mathrm{H}$ & 0.1991029 & 13.0210992 & 18.3396277 \\
\hline 0 & 3.7078654 & 15.8563883 & 20.0581109 \\
\hline $\mathrm{H}$ & 3.3614905 & 11.8901087 & 29.9861010 \\
\hline 0 & 2.1121376 & 12.7289998 & 20.0535151 \\
\hline $\mathrm{Si}$ & 10.0264009 & 11.9583385 & 16.5428458 \\
\hline $\mathrm{Si}$ & 9.9624607 & 11.9060963 & 28.4864776 \\
\hline $\mathrm{Si}$ & 12.1328137 & 10.6284722 & 26.6863768 \\
\hline $\mathrm{Si}$ & 12.1836826 & 10.6038695 & 23.5555886 \\
\hline $\mathrm{Si}$ & 15.2526455 & 10.7180199 & 23.5763895 \\
\hline $\mathrm{Si}$ & 10.4509626 & 8.0252337 & 23.6028529 \\
\hline $\mathrm{Si}$ & 10.5191104 & 7.9855681 & 26.6708010 \\
\hline $\mathrm{Si}$ & 15.2377513 & 10.7138214 & 26.6487883 \\
\hline 0 & 8.8721334 & 10.7135428 & 28.2759062 \\
\hline 0 & 11.6586429 & 9.0992247 & 27.0069331 \\
\hline $\mathrm{H}$ & 15.6846140 & 9.2995539 & 26.7802480 \\
\hline $\mathrm{H}$ & 11.3570478 & 6.8506612 & 23.4743631 \\
\hline 0 & 13.7446395 & 10.1255656 & 23.3835093 \\
\hline
\end{tabular}

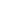




\begin{tabular}{|c|c|c|}
\hline 11.2695103 & 11.6801884 & 27.5693204 \\
\hline 9.2780803 & 8.1261406 & 27.7046506 \\
\hline 16.0147279 & 11.5975231 & 27.5612023 \\
\hline 9.1624320 & 7.8270517 & 22.6255488 \\
\hline 15.5698740 & 11.9392914 & 22.5719669 \\
\hline 9.3785652 & 10.5400202 & 17.0148365 \\
\hline 13.6867402 & 10.7909294 & 27.1076369 \\
\hline 11.1124790 & 6.6328105 & 26.8581002 \\
\hline 16.2281631 & 9.6295130 & 23.2924196 \\
\hline 11.2251733 & 9.3544906 & 23.1136008 \\
\hline 10.3986721 & 11.9345079 & 15.1013303 \\
\hline 11.9050077 & 10.9623731 & 25.1235616 \\
\hline 15.4351269 & 11.2353046 & 25.1190090 \\
\hline 9.9520696 & 8.1709014 & 25.1498286 \\
\hline 10.3902957 & 11.9302263 & 29.9124844 \\
\hline 8.6831144 & 14.9889746 & 15.1216598 \\
\hline 5.3256582 & 14.6427175 & 16.6006072 \\
\hline 5.2879869 & 14.6360150 & 28.5571693 \\
\hline 12.1095734 & 18.5871733 & 21.6153849 \\
\hline 12.1188647 & 13.2132904 & 21.6522967 \\
\hline 16.8967071 & 15.8298800 & 21.6289188 \\
\hline 16.8302594 & 15.8753192 & 18.5128364 \\
\hline 12.1004869 & 13.1504769 & 18.5071022 \\
\hline 12.1485054 & 18.5941374 & 18.5417668 \\
\hline 5.2968990 & 17.0414007 & 26.6089366 \\
\hline 5.2884762 & 17.0806328 & 23.5715115 \\
\hline 8.4240556 & 14.6201288 & 28.4993442 \\
\hline 8.4633430 & 14.6589963 & 16.5569073 \\
\hline 15.2896742 & 13.1725403 & 18.5547634 \\
\hline 15.2774190 & 18.5839555 & 18.5487408 \\
\hline 10.5531679 & 15.8782375 & 18.5056914 \\
\hline 10.4379052 & 15.8848478 & 21.5941578 \\
\hline 15.2583860 & 18.5298146 & 21.6617150 \\
\hline 15.2900432 & 13.1907268 & 21.5726887 \\
\hline 8.4184618 & 17.2188486 & 23.5210263 \\
\hline 8.4211947 & 17.0948222 & 26.6078202 \\
\hline 8.9245996 & 13.1179984 & 16.8587583 \\
\hline 6.8501509 & 14.2616746 & 28.2987887 \\
\hline 11.5202543 & 17.0965074 & 21.7890328 \\
\hline 13.7728842 & 13.6920597 & 21.5624999 \\
\hline 15.8202604 & 17.0293494 & 21.9059297 \\
\hline 15.6970465 & 14.7310921 & 18.2662455 \\
\hline 11.6678526 & 14.7057309 & 18.2793078 \\
\hline 13.7160203 & 18.2025702 & 18.3082480 \\
\hline 6.8514793 & 17.4616783 & 26.8660131 \\
\hline 8.9277721 & 18.6085949 & 23.3587651 \\
\hline 4.6745047 & 18.4335100 & 23.4720993 \\
\hline 18.0121455 & 15.6687023 & 17.6310341 \\
\hline 11.7471182 & 19.7040257 & 17.6339360 \\
\hline 11.3745787 & 12.1938034 & 17.4075318 \\
\hline 4.8316231 & 15.8797172 & 27.6334467 \\
\hline 11.4403830 & 19.5610379 & 22.5214162 \\
\hline 11.8138956 & 11.8504334 & 22.6510751 \\
\hline 18.1186226 & 16.0400423 & 22.4534640 \\
\hline 8.8679652 & 15.8516622 & 27.5491514 \\
\hline 15.9798513 & 12.2845237 & 17.5789546 \\
\hline 9.3206019 & 15.6860022 & 17.4646767 \\
\hline 15.6680318 & 19.7512767 & 17.7109440 \\
\hline 9.1119671 & 16.2130453 & 22.4738055 \\
\hline 6.8996435 & 14.7896862 & 16.9606199 \\
\hline 9.2910822 & 13.3192265 & 28.0788416 \\
\hline 13.6831969 & 18.5725659 & 21.9969840 \\
\hline 11.0542019 & 14.4987421 & 22.0546295 \\
\hline 16.2769708 & 14.4026341 & 22.0468785 \\
\hline 16.1990573 & 17.3238486 & 18.1382649 \\
\hline 13.6954420 & 13.0078045 & 18.3207413 \\
\hline 11.2446128 & 17.3065712 & 18.1842478 \\
\hline 4.4223500 & 18.2214938 & 26.8532011 \\
\hline 9.2508805 & 18.2744119 & 26.9783743 \\
\hline 6.8416993 & 17.2341547 & 23.1831438 \\
\hline 5.0782130 & 15.0123552 & 15.1796007 \\
\hline 11.9248352 & 19.0978500 & 20.0741852 \\
\hline 17.3328641 & 15.8563883 & 20.0581109 \\
\hline 5.1129092 & 16.4961151 & 25.0838447 \\
\hline 8.6791015 & 14.9847022 & 29.9203152 \\
\hline 15.7371363 & 12.7289998 & 20.0535151 \\
\hline 15.5228629 & 19.0061650 & 20.1121964 \\
\hline 9.9660250 & 15.8449288 & 20.0169970 \\
\hline 8.6679032 & 16.6961679 & 25.0485149 \\
\hline 11.6245275 & 12.6338574 & 19.9941307 \\
\hline
\end{tabular}


9.9255710

10.2173370

10.1081712

9.3400259

7.9982430

8.4077494

7.4261785

7.5687814

7.2843624

5.0753773

15.9143625 Ge 17

167

$\mathrm{H} \quad 8.6590734$

P 5.4182507

Al $\quad 5.3652797$

$\mathrm{P} \quad 5.4238027$

Al $\quad 5.4580635$

$\mathrm{P} \quad 3.2243453$

Al $\quad 3.3289812$

P $\quad 8.4877804$

Al 8.5541904

$\mathrm{P} \quad 8.6180880$

Al $\quad 8.5987067$

$\mathrm{P} \quad 1.6634434$

Al $\quad 1.6150437$

O 6.8944768

6.8944768
4.8941085

4.8679600

9.1384690

7. 1418988

2.1596535

2. 2444450

0.3099096

4.9920447

4.3410410

4.7084209

2.5572022

9.0402270

1.9602655

4.5344856

7. 0162547

6.9081318

9.4662969

4.6001150

0.2060748

2.5881573

2. 7198074

5.2543183

5.2615214

3. 8389218

8.6701633

8.8271488

1. 7544869

5.2666069

3.5586943

3. 2846029

3.2144566

3.8421887

$\mathrm{Al} \quad 3.8396764$

1.6233192

1.5859027

5.0334850

0.1796171

2. 3303743

2.0131934

4.6478000

4.5619435

2. 3432958

4.4022270

2.6491626

2.6503944

0.1577804

3. 6872004

3.5211296

2. 0320315

10.1444234

10.0767793

12.3830552
11.6925411

11.3485679

11.0580115

12.6002686

10.5176293

9.5087300

10.9297087

10.8179647

11.1356784

15.0111956

19.5339326

9.0230658

9.3636661

9.2925008

6.7653417

.7725877

7.9420860

8.0752348

. 2024611

9.2967513

6.7374638

6.6789428

10.7541955

10.7038704

9. 7288357

10.9360756

5.3937401

5.3126869

6.3763712

9.0467432

7.0818557

10.1978914

8.1352641

8.1498376

7.7710783

11.7661999

7.9274428

11.9440149

10.5424819

9.0334389

6.7459515

5.5698038

5.6120773

10.7530061

6.6272620

9. 6705918

9.0651349

7.2433352

7. 9620937

8.9851693

7.1333522

11.2201391

9.0912580

12.0339652

15.9381512

15.9838669

12.0244766

12.0601421

13.2718476

13.3032964

13.2970873

13.7922289

17.0504876

14.7411228

15.7427764

16.1144050

12.3407771

13.3863537

14.6108671

17.3213138

13.1116653

15.9393588

12.0293291

12.8705194

11.9887857

11.9208517

10.6112154
20.1881119

21.1760885

19.3276579

20.0804954

20.3346199

20.2168585

19.4991164

21.5669056

22.6476319

29.9823560

22.5440769

15.1683511

16.7338857

28.5306479

21.6486640

18.5163272

26.6818675

23.5860369

28.4307039

16.6282197

18.4675208

21.6314971

23.5025602

26.6415998

17.0446422

28.1366338

21.8125803

21.8746476

18.2142128

26.8065292

23.3534429

23.2276190

17.5365987

27.7131742

22.5613755

27.6525737

17.5903732

22.5904432

17.1547877

28.0413153

22.0311831

18.1011435

18.1499112

27.1206746

26.9710444

23.2313308

15.2843596

20.1897809

25.2674483

29.8924294

19.9438815

24.9735945

30.0026824

15.1743890

21.6435420

18.4803060

28.4398238

16.6364028

18.4645250

21.5542081

17.0158903

21.5748540

21.9067456

18.1737976

17.5074954

22.4755669

17.4751939

28.0127390

22.0451797

18.1483569

18.2555792

20.1581411

29.8937901

19.8915102

16.5658204

28.3700186

26.7483539 


\begin{tabular}{|c|c|c|c|}
\hline Al & 12.4403595 & 10.5743116 & 23.5202827 \\
\hline $\mathrm{P}$ & 15.5384421 & 10.7541955 & 23.5025602 \\
\hline $\mathrm{P}$ & 10.6141960 & 8.0296024 & 23.5401101 \\
\hline Al & 10.6898750 & 8.0054377 & 26.6330858 \\
\hline Al & 15.4900424 & 10.7038704 & 26.6415998 \\
\hline 0 & 8.9391017 & 10.6244720 & 28.0404498 \\
\hline 0 & 11.8861811 & 9.1950582 & 27.1165511 \\
\hline $\mathrm{H}$ & 15.9528708 & 9.2955861 & 26.7817626 \\
\hline $\mathrm{H}$ & 11.4140622 & 6.7746205 & 23.4915837 \\
\hline 0 & 14.1365169 & 10.1780025 & 23.2177893 \\
\hline 0 & 11.5498950 & 11.6731635 & 27.4842092 \\
\hline 0 & 9.3044152 & 8.1408116 & 27.6879629 \\
\hline $\mathrm{H}$ & 16.2948742 & 11.6113573 & 27.5052166 \\
\hline 0 & 9.3840524 & 7.8933693 & 22.6223890 \\
\hline 0 & 15.8352642 & 11.9440149 & 22.5904432 \\
\hline 0 & 9.5709048 & 10.6516538 & 17.0857111 \\
\hline 0 & 13.8400325 & 10.7614121 & 27.2026329 \\
\hline $\mathrm{H}$ & 11.2823413 & 6.6467619 & 26.7748757 \\
\hline $\mathrm{H}$ & 16.5615350 & 9.7047208 & 23.2398734 \\
\hline 0 & 11.4686032 & 9.1922213 & 23.0366815 \\
\hline $\mathrm{H}$ & 10.4140569 & 11.9055618 & 15.1038039 \\
\hline O & 12.2559004 & 10.8328897 & 25.2435221 \\
\hline 0 & 15.6294856 & 11.2201391 & 24.9735945 \\
\hline 0 & 10.1415248 & 8.2861366 & 24.9866076 \\
\hline $\mathrm{H}$ & 10.3701941 & 11.9059780 & 29.8297471 \\
\hline $\mathrm{H}$ & 8.7717926 & 15.0048839 & 15.0593449 \\
\hline $\mathrm{P}$ & 5.4595065 & 14.7433858 & 16.6772097 \\
\hline Al & 5.4032036 & 14.7287976 & 28.4950010 \\
\hline $\mathrm{P}$ & 12.3613020 & 18.7814431 & 21.6486640 \\
\hline $\mathrm{Ge}$ & 12.1696592 & 13.3298842 & 21.7035135 \\
\hline $\mathrm{P}$ & 17.1596016 & 15.9381512 & 21.6435420 \\
\hline Al & 17.0894553 & 15.9838669 & 18.4803060 \\
\hline Al & 12.2766948 & 13.2988300 & 18.4607527 \\
\hline Al & 12.3955628 & 18.7886891 & 18.5163272 \\
\hline $\mathrm{P}$ & 5.3608077 & 17.2278316 & 26.6306595 \\
\hline Al & 5.3129495 & 17.2325570 & 23.5698747 \\
\hline $\mathrm{P}$ & 8.5551948 & 14.6816774 & 28.3458366 \\
\hline Al & 8.6129456 & 14.7458573 & 16.5170120 \\
\hline $\mathrm{P}$ & 15.4983179 & 13.2718476 & 18.4645250 \\
\hline$P$ & 15.5555874 & 18.7535652 & 18.4675208 \\
\hline $\mathrm{P}$ & 10.7758438 & 16.0638885 & 18.3891389 \\
\hline Al & 10.5901113 & 16.1082559 & 21.5614897 \\
\hline Al & 15.5362060 & 18.6950441 & 21.6314971 \\
\hline Al & 15.4609014 & 13.3032964 & 21.5542081 \\
\hline $\mathrm{P}$ & 8.4532118 & 17.4863650 & 23.4054098 \\
\hline Al & 8.5002365 & 17.2584789 & 26.5270070 \\
\hline 0 & 9.1047802 & 13.0904263 & 16.8781660 \\
\hline $\mathrm{O}$ & 7.0698630 & 14.3334760 & 28.1314558 \\
\hline 0 & 11.7899642 & 17.3716056 & 21.8171497 \\
\hline 0 & 13.8356808 & 13.8683475 & 21.5780683 \\
\hline 0 & 16.1693059 & 17.0925308 & 21.9166940 \\
\hline 0 & 15.8881921 & 14.7411228 & 18.1737976 \\
\hline 0 & 11.8488091 & 14.9798889 & 18.1594975 \\
\hline 0 & 14.0793982 & 18.3924725 & 18.2142128 \\
\hline 0 & 6.8221799 & 17.6594066 & 26.8790004 \\
\hline $\mathrm{H}$ & 8.9756360 & 18.8778431 & 23.3160675 \\
\hline $\mathrm{H}$ & 4.6116782 & 18.5442955 & 23.5014554 \\
\hline $\mathrm{H}$ & 18.3097315 & 15.7786146 & 17.6521042 \\
\hline $\mathrm{H}$ & 11.9971848 & 19.9535786 & 17.6788023 \\
\hline 0 & 11.4618098 & 12.2675250 & 17.2907187 \\
\hline 0 & 4.9241425 & 16.1693282 & 27.6490726 \\
\hline $\mathrm{H}$ & 11.6673724 & 19.7570207 & 22.5340061 \\
\hline 0 & 11.8349474 & 11.9313870 & 22.6920101 \\
\hline H & 18.3990042 & 16.1091701 & 22.4508551 \\
\hline 0 & 8.9712337 & 15.8645097 & 27.4677397 \\
\hline $\mathrm{H}$ & 16.1955640 & 12.3701720 & 17.5064282 \\
\hline O & 9.5987094 & 15.8586932 & 17.4210048 \\
\hline $\mathrm{H}$ & 15.9644332 & 19.9060716 & 17.6179946 \\
\hline 0 & 9.1110637 & 16.5920279 & 22.3595230 \\
\hline O & 6.9467597 & 14.9090254 & 17.0235968 \\
\hline 0 & 9.3978327 & 13.4663651 & 27.9433972 \\
\hline 0 & 13.8456311 & 18.7620529 & 22.0311831 \\
\hline 0 & 11.0776704 & 14.6020260 & 22.2057875 \\
\hline 0 & 16.5241614 & 14.6108671 & 22.0451797 \\
\hline 0 & 16.4276546 & 17.5530614 & 18.0908381 \\
\hline 0 & 13.9911053 & 13.1071104 & 18.2496377 \\
\hline 0 & 11.3946532 & 17.4348013 & 18.0888548 \\
\hline $\mathrm{H}$ & 4.4664304 & 18.4070368 & 26.7940152 \\
\hline $\mathrm{H}$ & 9.3612155 & 18.4101611 & 26.9136127 \\
\hline 0 & 6.9544681 & 17.5243907 & 23.1043904 \\
\hline
\end{tabular}


5.2270331

12.1990208

17.5621991

5.2255323

8.7910429

15.9070302

15.7646481

10.2406648

8.7035923

11.6573007

9.7974231

9.9202140

10.0633393

9.3914935

7.8129934

7.9987158

7. 6413188

7.0237088

6.4356727

5. 2468926

16.2032298

167

\begin{tabular}{|c|c|c|c|}
\hline $\mathrm{H}$ & 8.6212361 & 8.8666596 & 15.2353380 \\
\hline $\mathrm{Si}$ & 5.3264104 & 9.2742188 & 16.6674833 \\
\hline $\mathrm{Si}$ & 5.3164795 & 9.2159080 & 28.5965620 \\
\hline $\mathrm{Si}$ & 5.3029815 & 6.7714424 & 21.6258149 \\
\hline $\mathrm{Si}$ & 5.3374485 & 6.8006765 & 18.5561609 \\
\hline $\mathrm{Si}$ & 3.2180473 & 7.9874620 & 26.6549344 \\
\hline $\mathrm{Si}$ & 3.3418823 & 8.1068136 & 23.6041322 \\
\hline $\mathrm{Si}$ & 8.4208363 & 9.1597793 & 28.5896917 \\
\hline $\mathrm{Si}$ & 8.4421759 & 9.2697572 & 16.6575090 \\
\hline $\mathrm{Si}$ & 8.4591714 & 6.7819869 & 18.5522357 \\
\hline $\mathrm{Si}$ & 8.4490050 & 6.7056550 & 21.6715278 \\
\hline $\mathrm{Si}$ & 1.6365719 & 10.7227972 & 23.5835010 \\
\hline $\mathrm{Si}$ & 1.6058269 & 10.6954559 & 26.6641405 \\
\hline 0 & 6.8886892 & 9.6823883 & 16.9479136 \\
\hline 0 & 4.9068905 & 10.7650630 & 28.2971000 \\
\hline $\mathrm{H}$ & 4.7144303 & 5.4104423 & 21.7614860 \\
\hline $\mathrm{H}$ & 9.0135115 & 5.3464605 & 21.8974553 \\
\hline 0 & 6.8991924 & 6.3982674 & 18.2994539 \\
\hline 0 & 2.0851881 & 9.1449188 & 26.7990649 \\
\hline $\mathrm{H}$ & 2.2870585 & 7.0783262 & 23.3880742 \\
\hline $\mathrm{H}$ & 0.2744077 & 10.1546653 & 23.3863834 \\
\hline $\mathrm{O}$ & 4.8978857 & 8.0085910 & 17.5740018 \\
\hline 0 & 4.4067005 & 8.1972190 & 27.7343677 \\
\hline 0 & 4.6065260 & 7.8484674 & 22.6197452 \\
\hline 0 & 2.4618244 & 11.6471368 & 27.6546695 \\
\hline 0 & 8.8883476 & 8.0657761 & 17.6505097 \\
\hline O & 1.9063942 & 11.9723958 & 22.5995351 \\
\hline 0 & 4.3992142 & 10.5311041 & 17.0892298 \\
\hline 0 & 6.8646738 & 8.9890859 & 28.1818306 \\
\hline 0 & 6.8736344 & 6.6873861 & 22.0106303 \\
\hline $\mathrm{H}$ & 9.3132060 & 5.6244285 & 18.1677830 \\
\hline $\mathrm{H}$ & 4.4827861 & 5.6216775 & 18.2453008 \\
\hline $\mathrm{H}$ & 0.1820007 & 10.7711582 & 27.0932194 \\
\hline $\mathrm{H}$ & 2.5859356 & 6.6722804 & 26.9513340 \\
\hline O & 2.7401915 & 9.5722763 & 23.2630577 \\
\hline $\mathrm{H}$ & 5.1293023 & 8.9131286 & 15.2364407 \\
\hline 0 & 5.1417894 & 7.3095826 & 20.0911574 \\
\hline 0 & 3.8569839 & 8.0294840 & 25.1535152 \\
\hline $\mathrm{H}$ & 8.6180871 & 8.8597562 & 30.0347518 \\
\hline 0 & 8.6947114 & 7.1893297 & 20.1211639 \\
\hline $\mathrm{O}$ & 1.7976220 & 11.2213598 & 25.1343385 \\
\hline $\mathrm{H}$ & 5.1290797 & 8.9093151 & 30.0415543 \\
\hline $\mathrm{H}$ & 3.3723561 & 11.9108442 & 15.1903861 \\
\hline $\mathrm{Si}$ & 3.3294619 & 15.8312495 & 21.6186215 \\
\hline $\mathrm{Si}$ & 3.2187439 & 15.8837453 & 18.5095579 \\
\hline $\mathrm{Si}$ & 3.7732330 & 11.9100191 & 28.5580680 \\
\hline $\mathrm{Si}$ & 3.7580376 & 11.9483840 & 16.6280791 \\
\hline $\mathrm{Si}$ & 1.6623326 & 13.1758356 & 18.5640568 \\
\hline $\mathrm{Si}$ & 1.6778314 & 13.2229465 & 21.5885642 \\
\hline 0 & 4.8859514 & 13.1002841 & 16.8892959 \\
\hline $\mathrm{H}$ & 0.3065118 & 13.8028816 & 21.6052523 \\
\hline $\mathrm{H}$ & 2.3481874 & 16.9175995 & 21.8907696 \\
\hline 0 & 2.0869176 & 14.7324204 & 18.2942568 \\
\hline O & 4.4933379 & 15.6588785 & 17.5342085 \\
\hline $\mathrm{O}$ & 4.6700658 & 16.0454033 & 22.5038246 \\
\hline 0 & 2.4266267 & 12.2124994 & 17.5044546 \\
\hline
\end{tabular}

15.2332994

20.1897809

20.1581411

25.2156391

19.8915102

19.9438815

19.8278386

24.8193615

20.0265620

20.1584575

21.2261650

19.4648427

19.7884364

20.2021871

20.8650387

19.1429689

20.6881270

21.0927553

29.9530902

22.4730990

14.9869902

19.7265024

15.2353380

28.5965620

21.6258149

28.5896917

21.6715278

16.9479136

.

21.8974553

994539

7.6546695

7.0892298

8.1818306

18.1677830

23.2630577

25.1535152

5.1343385

0415543
29.7723805

18.2453008 


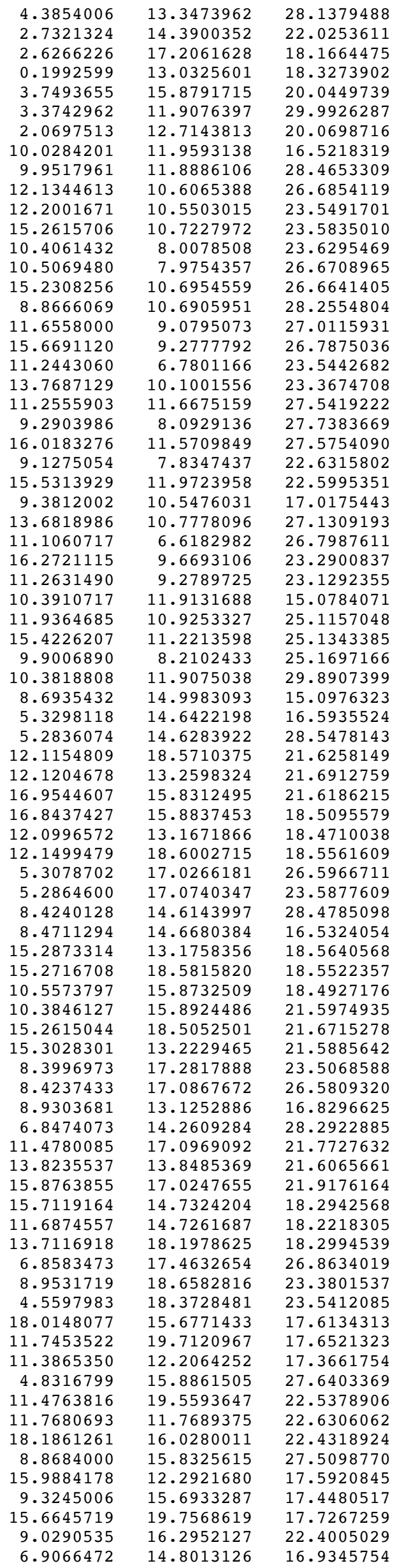

16.9345754 
9.2783202

13.6861338

10.9299955

16.3571311

16.1978666

13.6970635

11.2239690

4.4187884

9.2701636

6.8186864

5.0655591

11.9542888

17.3743642

5.1614556

8.6888085

15.6947500

15.5072108

9.9826618

8.6535706

11.5912713

9.9013080

10.2215361

10.0782480

9.3141214

8.0031477

8.4179241

7.4188855

7.5757782

7.2937863

5.0620391

15.8813118 17

167

$\mathrm{H} \quad 8.6574749$

$\mathrm{P} \quad 5.4257494$

Al $\quad 5.3660549$

$\mathrm{P} \quad 5.4206711$

Al $\quad 5.4685934$

P 3.2382754

Al $\quad 3.3831500$

$\mathrm{P} \quad 8.4850003$

Al 8.5618726

$\mathrm{P} \quad 8.6240569$

Al $\quad 8.6004461$

$\mathrm{P} \quad 1.6793500$

Al 1.6059897

O 6.9027890

4.9047567

4. 7718057

9.1808663

7.1510706

2.1650748

2. 2998548

0.3407108

5.0043252

4.3266331

4.7646224

2.5554103

9.0426605

2.0132746

4.5404299

7.0118801

6.9023644

9.4807640

4.6045458

0.2102193

2. 6023352

2. 7560571

5.2586498

5.2887070

3. 8891480

8.6670689

8.8230877

1.7080897

5.2703389

3.5811926

3. 3378028

3. 2294995

3. 8478268
13.3027572

18.4869811

14.5160895

14.3900352

17.3262161

13.0201042

17.3228922

18.2048157

18.2563142

17.3795703

14.9915284

19.1091776

15.8791715

16.4333615

14.9927139

12.7143813

18.9889247

15.7723242

16.6996439

12.6588229

11.7010415

1.3598115

11.0747546

12.6090323

10.5148063

9.5067070

10.9072550

10.8262970

11.1559610

14.9898185

19.5366682

9. 0292058

9.3776218

9. 2886737

6.7851775

6.7814593

7.9282948

8.0999491

9.1737985

9.3080505

6.7483514

6.6708662

10.7657454

10.6840309

9.7448838

10.9321905

5.4538130

5. 3178378

6.3776868

9.0275023

7. 1105394

10.2012972

8.1419213

8.1425106

7.8247427

11.7391128

7.9413443

11.9568531

10.5519707

9.0047112

6.6643540

5.5854589

5.6221457

10.7095350

6.6099131

9.6935020

9.0882679

7.2818486

7.9510444

8.9892330

7.1474720

11.2266211

9. 1106347

12.0310028

15.9460985

15.9933780

12.0137712
28.0654525

22.0106303

22.1865636

22.0253611

18.1352988

18.3068151

18.2193614

26.7928971

26.9454220

23.2056308

15.1704310

20.0911574

20.0449739

25.0832111

29.8940953

20.0698716

20.1211639

20.0065658

25.0137742

19.9476518

20.1665138

21.1469229

19.2989265

20.0712248

20.3409786

20.2352742

19.5043197

21.5718222

22.6493368

29.9751892

22.5485318

15.1762021

16.7475119

28.5410177

21.6492291

18.5244148

26.6879266

23.6086368

28.4335474

16.6357316

18.4815155

21.6434376

23.5244179

26.6639081

17.0557467

28.1334611

21.8027312

21.8660294

18.2211091

26.7834919

23.3543527

23.1979769

17.5409875

27.7476612

22.5722556

27.6762143

17.6057602

22.6260058

17.1796360

28.0493511

22.0281989

18.1197772

18.1686981

27.1818802

26.9610024

23.2917612

15.2964872

20.1932620

25.2891011

29.8998035

19.9593074

25.0005948

30.0162333

15.1852962

21.6327827

18.4758764

28.4456877 


\begin{tabular}{|c|c|c|c|}
\hline Al & 3.8464270 & 12.0679201 & 16.6500174 \\
\hline $\mathrm{P}$ & 1.6277815 & 13.2850583 & 18.4763693 \\
\hline Al & 1.6446074 & 13.3095484 & 21.5755424 \\
\hline 0 & 5.0432517 & 13.3039615 & 17.0293591 \\
\hline $\mathrm{H}$ & 0.2224282 & 13.7480177 & 21.6232021 \\
\hline $\mathrm{H}$ & 2.3807067 & 17.0562312 & 21.8948760 \\
\hline 0 & 2.0187391 & 14.7551931 & 18.1861600 \\
\hline $\mathrm{O}$ & 4.6548827 & 15.7546987 & 17.4880469 \\
\hline 0 & 4.6258283 & 16.1281643 & 22.4490488 \\
\hline $\mathrm{O}$ & 2.3454308 & 12.3573653 & 17.4798810 \\
\hline $\mathrm{O}$ & 4.3913988 & 13.3781243 & 28.0041914 \\
\hline 0 & 2.7125900 & 14.6184075 & 22.0503996 \\
\hline $\mathrm{H}$ & 2.6654328 & 17.3355916 & 18.1637677 \\
\hline $\mathrm{H}$ & 0.1607259 & 13.1279240 & 18.2759263 \\
\hline 0 & 3.7295079 & 15.9364740 & 20.1452206 \\
\hline $\mathrm{H}$ & 3.5456409 & 12.0243328 & 29.9036633 \\
\hline $\mathrm{O}$ & 2.0490679 & 12.8811737 & 19.8998399 \\
\hline $\mathrm{P}$ & 10.1522541 & 11.9952752 & 16.5356085 \\
\hline Al & 10.0659186 & 11.8951728 & 28.3343079 \\
\hline $\mathrm{P}$ & 12.3958751 & 10.5550571 & 26.7873520 \\
\hline Al & 12.4618644 & 10.4990560 & 23.5442475 \\
\hline$P$ & 15.5543488 & 10.7657454 & 23.5244179 \\
\hline $\mathrm{P}$ & 10.5789187 & 8.0132644 & 23.5726376 \\
\hline Al & 10.6805115 & 7.9852470 & 26.6512500 \\
\hline Al & 15.4809884 & 10.6840309 & 26.6639081 \\
\hline 0 & 8.9433360 & 10.5840871 & 28.0083789 \\
\hline $\mathrm{O}$ & 11.8742860 & 9.1569441 & 27.1893465 \\
\hline $\mathrm{H}$ & 15.9560339 & 9.2765053 & 26.7655165 \\
\hline $\mathrm{H}$ & 11.2986832 & 6.7097975 & 23.5668219 \\
\hline 0 & 14.1665340 & 10.1805620 & 23.1859849 \\
\hline $\mathrm{O}$ & 11.5471196 & 11.6487684 & 27.4579543 \\
\hline $\mathrm{O}$ & 9.2957694 & 8.0907073 & 27.7132729 \\
\hline $\mathrm{H}$ & 16.2918788 & 11.5851655 & 27.5285084 \\
\hline 0 & 9.3452515 & 7.9056568 & 22.6517972 \\
\hline 0 & 15.8882733 & 11.9568531 & 22.6260058 \\
\hline 0 & 9.5867272 & 10.6630249 & 17.0806772 \\
\hline $\mathrm{O}$ & 13.8432156 & 10.7139570 & 27.2716876 \\
\hline $\mathrm{H}$ & 11.2796099 & 6.6250260 & 26.7406969 \\
\hline $\mathrm{H}$ & 16.5972619 & 9.7271558 & 23.2990635 \\
\hline 0 & 11.5037407 & 9.1109629 & 23.0418694 \\
\hline $\mathrm{H}$ & 10.3830317 & 11.8929922 & 15.0681616 \\
\hline 0 & 12.3191359 & 10.7140955 & 25.2729025 \\
\hline $\mathrm{O}$ & 15.5830884 & 11.2266211 & 25.0005948 \\
\hline 0 & 10.1253781 & 8.3326065 & 25.0141866 \\
\hline $\mathrm{H}$ & 10.3415876 & 11.8911184 & 29.7975613 \\
\hline $\mathrm{H}$ & 8.7779107 & 14.9894292 & 15.0267086 \\
\hline $\mathrm{P}$ & 5.4679374 & 14.7461094 & 16.6692388 \\
\hline Al & 5.4020109 & 14.7148623 & 28.4842804 \\
\hline $\mathrm{P}$ & 12.3581704 & 18.8012788 & 21.6492291 \\
\hline $\mathrm{Ti}$ & 12.1378644 & 13.3217084 & 21.7242647 \\
\hline $\mathrm{P}$ & 17.2128015 & 15.9460985 & 21.6327827 \\
\hline $\mathrm{Al}$ & 17.1044982 & 15.9933780 & 18.4758764 \\
\hline Al & 12.2671698 & 13.2960360 & 18.4331837 \\
\hline Al & 12.4060928 & 18.7975607 & 18.5244148 \\
\hline $\mathrm{P}$ & 5.3721322 & 17.2103783 & 26.6235079 \\
\hline Al & 5.3125193 & 17.2410547 & 23.5883434 \\
\hline$P$ & 8.5527450 & 14.6603222 & 28.3122236 \\
\hline Al & 8.6239838 & 14.7531685 & 16.4887647 \\
\hline $\mathrm{P}$ & 15.5027802 & 13.2850583 & 18.4763693 \\
\hline$P$ & 15.5615563 & 18.7644528 & 18.4815155 \\
\hline$P$ & 10.7651156 & 16.0727531 & 18.3776225 \\
\hline Al & 10.5015612 & 16.1654909 & 21.5413675 \\
\hline Al & 15.5379455 & 18.6869675 & 21.6434376 \\
\hline Al & 15.5196061 & 13.3095484 & 21.5755424 \\
\hline $\mathrm{P}$ & 8.4308038 & 17.5523173 & 23.3957882 \\
\hline Al & 8.5022202 & 17.2517999 & 26.5079225 \\
\hline $\mathrm{O}$ & 9.1214168 & 13.1016683 & 16.8637658 \\
\hline 0 & 7.0648385 & 14.3162153 & 28.1086492 \\
\hline $\mathrm{O}$ & 11.6918269 & 17.4340521 & 21.8068660 \\
\hline 0 & 13.8727674 & 13.8172820 & 21.6307309 \\
\hline 0 & 16.2194635 & 17.0982681 & 21.9048006 \\
\hline $\mathrm{O}$ & 15.8937378 & 14.7551931 & 18.1861600 \\
\hline 0 & 11.8372592 & 14.9861127 & 18.1616752 \\
\hline 0 & 14.0885699 & 18.3937882 & 18.2211091 \\
\hline $\mathrm{O}$ & 6.8279034 & 17.6565594 & 26.8826625 \\
\hline $\mathrm{H}$ & 9.0313935 & 18.9123160 & 23.3132285 \\
\hline $\mathrm{H}$ & 4.5075870 & 18.4935944 & 23.5696677 \\
\hline $\mathrm{H}$ & 18.3169013 & 15.7903621 & 17.6356480 \\
\hline $\mathrm{H}$ & 12.0091852 & 19.9606334 & 17.6836729 \\
\hline $\mathrm{O}$ & 11.4906958 & 12.2850437 & 17.2161084 \\
\hline
\end{tabular}


4.9281372
11.7227048

11.8270103

18.4616391

8.9668244

16.1970989

9.6111553

15.9668264

9.0001000

6.9578422

9. 3875362

13.8398637

11.0381921

16.5875887

16.4424622

13.9940463

11.3980325

4.4655024

9.3731315

6.9267644

5.2298095

12.2262064

17.6045066

5.2644052

8.7960803

15.9240666

15.7605871

10.1914082

8.6910093

11.6276968

9.7526060

9.8711917

10.0252014

9.3650660

7.7783790

7.9573622

7.5937531

6.9898843

6.4055768

5.2489088

16.1682069 n 18

168

$\mathrm{H} \quad 8.7130625$

Al $\quad 5.3744529$

P $\quad 5.3818277$

Al $\quad 5.2810068$

$\mathrm{P} \quad 5.3239240$

Al $\quad 3.1658147$

P 3.2355971

Al 8.5130366

$\mathrm{P} \quad 8.5263612$

$\mathrm{Al} \quad 8.4978056$

$\mathrm{P} \quad 8.4708760$

Al 1.5238974

1.4915811

7.0517975

4.9891453

4.7772083

8.9739770

6.8151527

1. 9504578

2. 2016876

0.1277562

4.8988640

4.5197218

4.4331686

2. 3665572

8.9630304

2.0572591

4. 3452090

6.8443313

6.9746592

9.3210388

4.5269236

0.0943978

2. 5551261

2.6179727

5.2168703
16.1659174

19.8082285

11.8877538

16.1226250

15.8405154

12.3875243

15.8799552

19.9194461

16.6453894

14.9175507

13.4410868

18.6804554

14.6761869

14.6184075

17.5687128

13.1234599

17.4450218

18.3845202

18.3935212

17.6906240

15.0052952

19.2979500

15.9364740

16.5847321

15.0178891

12.8811737

19.1635734

16.0158350

16.9366753

12.7746300

12.0519992

11.9038943

11.2529983

12.9892515

11.1416446

10.2833653

10.9217239

12.1102075

13.0230975

14.9693541

19.7318591

8.9357823

9.2305534

9. 1852682

6.6295324

6.6460514

7.9719867

8.0641946

9. 1778604

9.2910276

6.7061294

6.6572772

10.7438691

10.6692702

9. 6546119

10.6480016

5.2548366

5.2795572

6.3264131

9. 2071448

7.0111869

10.4126877

7.8303874

8.2158949

7.8263447

11.6067575

8. 1126968

12.1262780

10.5654539

8.9762184

6.7034163

5.5457075

5.4566485

10.7798766

6.6543000

9.4245984

8.9226042
27.6529834

22.5432964

22.7696406

22.4242141

27.4282118

17.5122765

17.3774759

17.6336551

22.3061791

17.0040005

27.9039640

22.0281989

22.1944729

22.0503996

18.1095594

18.2702318

18.1094100

26.7520913

26.9017582

23. 1497013

15.2224360

20.1932620

20.1452206

25.2162054

29.7370234

19.8998399

19.9593074

19.8026800

24.7904773

19.9799620

20.1221686

21.1920312

19.4415263

19.7398739

20.1694440

20.8241955

19.1108108

20.6671061

21.0813947

29.9433603

22.4967211

15.2591098

16.6346993

28.4631070

21.5870505

18.4222389

26.5887568

23.4705159

28.5072506

16.6930079

18.4970977

21.6675825

23.4805028

26.6729907

16.9694931

28.1693048

21.8581951

21.9242877

18.2070016

26.8327074

23.2722065

23.0827223

17.5482813

27.6521091

22.5411404

27.5106222

17.5692174

22.5829894

17.0807964

28.0585510

21.9820923

18.0579751

18.0132990

27.1757488

26.9172105

23.1317652

15.1864398 


\begin{tabular}{|c|c|c|c|}
\hline 0 & 5.0578377 & 7.0126138 & 19.8914986 \\
\hline 0 & 3.7336846 & 8.0396254 & 24.9304091 \\
\hline $\mathrm{H}$ & 8.6880284 & 8.9625354 & 29.9701701 \\
\hline 0 & 8.7331337 & 7.0541695 & 20.1990252 \\
\hline 0 & 1.5728963 & 11.0966835 & 25.1990308 \\
\hline $\mathrm{H}$ & 5.1958104 & 8.8795897 & 29.9084716 \\
\hline $\mathrm{H}$ & 3.3857550 & 11.8803062 & 15.2012728 \\
\hline Al & 3.2491869 & 16.0151300 & 21.5571241 \\
\hline $\mathrm{P}$ & 3.1542694 & 16.0253842 & 18.3974660 \\
\hline Al & 3.7861826 & 11.8910062 & 28.4715444 \\
\hline $\mathrm{P}$ & 3.7542755 & 11.9129976 & 16.6435781 \\
\hline $\mathrm{Al}$ & 1.6293285 & 13.2416782 & 18.5430286 \\
\hline $\mathrm{P}$ & 1.7496247 & 13.2893736 & 21.6262957 \\
\hline 0 & 4.8115642 & 13.0068789 & 16.9053290 \\
\hline $\mathrm{H}$ & 0.3644561 & 13.8200860 & 21.7558064 \\
\hline $\mathrm{H}$ & 2.2366369 & 17.0593208 & 21.8757597 \\
\hline 0 & 2.1050658 & 14.9073958 & 18.2309220 \\
\hline 0 & 4.3693417 & 15.7746015 & 17.4953511 \\
\hline 0 & 4.7055343 & 16.2825451 & 22.4683032 \\
\hline 0 & 2.4841519 & 12.1757338 & 17.4554575 \\
\hline 0 & 4.4321802 & 13.4452785 & 28.0249921 \\
\hline 0 & 2.7396986 & 14.4148280 & 21.9770630 \\
\hline $\mathrm{H}$ & 2.5436529 & 17.3225007 & 17.9952761 \\
\hline $\mathrm{H}$ & 0.1705289 & 13.0930705 & 18.2843009 \\
\hline 0 & 3.6412937 & 16.0983726 & 19.8527077 \\
\hline $\mathrm{H}$ & 3.4349806 & 11.8809846 & 29.9184988 \\
\hline 0 & 2.0275707 & 12.7912897 & 20.1819375 \\
\hline Al & 10.1236766 & 11.9852729 & 16.4734213 \\
\hline $\mathrm{P}$ & 10.0223985 & 11.9375209 & 28.3122751 \\
\hline $\mathrm{Al}$ & 12.2791212 & 10.5525972 & 26.6653864 \\
\hline $\mathrm{P}$ & 12.2774169 & 10.5752910 & 23.4222471 \\
\hline $\mathrm{Al}$ & 15.3988961 & 10.7438691 & 23.4805028 \\
\hline Al & 10.5838098 & 7.9598638 & 23.5636053 \\
\hline $\mathrm{P}$ & 10.6615550 & 7.8980101 & 26.6940643 \\
\hline $\mathrm{P}$ & 15.3665798 & 10.6692702 & 26.6729907 \\
\hline 0 & 9.0011239 & 10.8084233 & 28.0741405 \\
\hline 0 & 11.7330297 & 8.9378141 & 27.0852496 \\
\hline $\mathrm{H}$ & 15.8100461 & 9.2562474 & 26.8273437 \\
\hline $\mathrm{H}$ & 11.4992258 & 6.7912819 & 23.4471993 \\
\hline 0 & 13.7495921 & 10.3526344 & 23.0105926 \\
\hline $\mathrm{O}$ & 11.2621978 & 11.7450768 & 27.4360310 \\
\hline 0 & 9.4670271 & 7.9945583 & 27.6537007 \\
\hline $\mathrm{H}$ & 16.2171660 & 11.5806251 & 27.4872732 \\
\hline 0 & 9.1733398 & 7.6770119 & 22.5753525 \\
\hline 0 & 15.9322578 & 12.1262780 & 22.5829894 \\
\hline 0 & 9.4088411 & 10.4979841 & 17.0590364 \\
\hline 0 & 13.9257842 & 10.7833291 & 27.1914421 \\
\hline $\mathrm{H}$ & 11.2474363 & 6.5352030 & 26.8229845 \\
\hline $\mathrm{H}$ & 16.3303159 & 9.6207335 & 23.1836118 \\
\hline 0 & 11.4526699 & 9.3516508 & 22.9785716 \\
\hline $\mathrm{H}$ & 10.4113712 & 11.9420413 & 15.0131188 \\
\hline 0 & 12.1854927 & 10.7374623 & 24.9475904 \\
\hline 0 & 15.4478950 & 11.0966835 & 25.1990308 \\
\hline $\mathrm{O}$ & 10.1601350 & 8.1524110 & 25.2576758 \\
\hline $\mathrm{H}$ & 10.4443224 & 11.9349986 & 29.7402437 \\
\hline $\mathrm{H}$ & 8.6708373 & 15.0066583 & 15.1540926 \\
\hline Al & 5.3255085 & 14.6501106 & 16.5743654 \\
\hline $\mathrm{P}$ & 5.2940858 & 14.6514092 & 28.4090464 \\
\hline Al & 12.2185061 & 18.6456337 & 21.5870505 \\
\hline $\mathrm{Zn}$ & 12.4156406 & 13.2509917 & 21.6622802 \\
\hline Al & 17.1241856 & 16.0151300 & 21.5571241 \\
\hline $\mathrm{P}$ & 17.0292681 & 16.0253842 & 18.3974660 \\
\hline$P$ & 12.2784156 & 13.1485590 & 18.3906753 \\
\hline $\mathrm{P}$ & 12.2614234 & 18.6621528 & 18.4222389 \\
\hline Al & 5.3696806 & 17.1557764 & 26.5489424 \\
\hline $\mathrm{P}$ & 5.3677559 & 17.2297220 & 23.4679773 \\
\hline Al & 8.4526933 & 14.6746086 & 28.4212635 \\
\hline $\mathrm{P}$ & 8.4888784 & 14.6866390 & 16.5968675 \\
\hline Al & 15.5043272 & 13.2416782 & 18.5430286 \\
\hline $\mathrm{Al}$ & 15.4353049 & 18.7222308 & 18.4970977 \\
\hline $\mathrm{Al}$ & 10.6977944 & 15.9282387 & 18.4511147 \\
\hline $\mathrm{P}$ & 10.5696574 & 15.9408454 & 21.6185073 \\
\hline$P$ & 15.4083754 & 18.6733785 & 21.6675825 \\
\hline $\mathrm{P}$ & 15.6246234 & 13.2893736 & 21.6262957 \\
\hline $\mathrm{Al}$ & 8.5122954 & 17.3637738 & 23.4798630 \\
\hline $\mathrm{P}$ & 8.5205439 & 17.2376747 & 26.6172501 \\
\hline 0 & 8.9661477 & 13.2431882 & 16.8811699 \\
\hline 0 & 6.7685004 & 14.3129095 & 28.1150047 \\
\hline $\mathrm{O}$ & 11.6278894 & 17.0340402 & 21.9049207 \\
\hline $\mathrm{O}$ & 14.2054793 & 13.8331034 & 21.758983 \\
\hline
\end{tabular}




\begin{tabular}{|c|c|c|}
\hline 15.9290043 & 17.2476591 & 21.9332313 \\
\hline 15.9800645 & 14.9073958 & 18.2309220 \\
\hline 11.8370023 & 14.6146621 & 18.2162530 \\
\hline 13.7526520 & 18.3425144 & 18.2070016 \\
\hline 7.0406598 & 17.5883493 & 26.8859304 \\
\hline 9.0175369 & 18.7524669 & 23.2971521 \\
\hline 4.7318284 & 18.5755258 & 23.4288742 \\
\hline 18.2087091 & 15.7819555 & 17.5218051 \\
\hline 11.8483032 & 19.8132209 & 17.5728306 \\
\hline 11.6264963 & 12.2714228 & 17.3078347 \\
\hline 4.8416485 & 15.8534234 & 27.5761734 \\
\hline 11.4969965 & 19.6641201 & 22.3989802 \\
\hline 18.3714591 & 16.2441549 & 22.3374939 \\
\hline 8.9601715 & 16.0595043 & 27.4962441 \\
\hline 16.2331760 & 12.3328212 & 17.6157320 \\
\hline 9.2979400 & 15.6830557 & 17.4313842 \\
\hline 15.8315767 & 19.9203244 & 17.7067427 \\
\hline 9.2793102 & 16.2488535 & 22.4016922 \\
\hline 7.0139942 & 14.7980457 & 17.0031075 \\
\hline 9.3867634 & 13.2814725 & 27.9465319 \\
\hline 13.9121586 & 18.7195177 & 21.9820923 \\
\hline 11.0581199 & 14.5701818 & 22.0388253 \\
\hline 16.6146973 & 14.4148280 & 21.9770630 \\
\hline 16.3996030 & 17.3629653 & 17.9827295 \\
\hline 13.7952711 & 13.0675769 & 18.2399162 \\
\hline 11.4412324 & 17.4381414 & 18.0013999 \\
\hline 4.4742907 & 18.3214511 & 26.7868499 \\
\hline 9.3653645 & 18.4140110 & 26.9631280 \\
\hline 6.8324215 & 17.3812163 & 23.0654560 \\
\hline 5.1439780 & 14.9491328 & 15.1270392 \\
\hline 11.9953370 & 19.0287152 & 19.8914986 \\
\hline 11.8617409 & 12.5954030 & 19.7865016 \\
\hline 17.5162924 & 16.0983726 & 19.8527077 \\
\hline 5.2476429 & 16.6280182 & 24.8823236 \\
\hline 8.6431234 & 14.9656557 & 29.8690717 \\
\hline 15.9025694 & 12.7912897 & 20.1819375 \\
\hline 15.6706331 & 19.0702709 & 20.1990252 \\
\hline 10.1887331 & 15.9675665 & 20.1153913 \\
\hline 8.7245093 & 16.8465835 & 25.1421719 \\
\hline 9.8645867 & 12.2222599 & 20.2635532 \\
\hline 9.4670929 & 11.9878954 & 19.2747863 \\
\hline 10.3021673 & 11.4270852 & 20.8626841 \\
\hline 9.8794423 & 13.2504832 & 20.6101348 \\
\hline 11.6769995 & 11.8191694 & 22.7596447 \\
\hline 8.1420750 & 12.1327269 & 22.1401227 \\
\hline 8.5544646 & 11.9844166 & 21.0061019 \\
\hline 7.1363931 & 11.6939517 & 22.0721689 \\
\hline 8.1385413 & 13.2293794 & 22.2507951 \\
\hline 8.9082862 & 11.4409892 & 23.0287023 \\
\hline 9.8196133 & 11.8327893 & 23.1028311 \\
\hline 5.1183822 & 14.9897192 & 29.8484196 \\
\hline 16.0896239 & 19.6623160 & 22.5479368 \\
\hline & & \\
\hline 8.6645130 & 8.9585601 & 15.1219051 \\
\hline 5.3379422 & 9.2657341 & 16.6546703 \\
\hline 5.3218998 & 9.2359256 & 28.4796091 \\
\hline 5.3844755 & 6.7330689 & 21.6146515 \\
\hline 5.4102757 & 6.6893617 & 18.4534213 \\
\hline 3.1722470 & 7.8945394 & 26.6304231 \\
\hline 3.2067716 & 7.9489946 & 23.5000509 \\
\hline 8.4655520 & 9.1856457 & 28.3914676 \\
\hline 8.4966017 & 9.2316144 & 16.5759916 \\
\hline 8.5815814 & 6.6775985 & 18.4065288 \\
\hline 8.5587682 & 6.6922893 & 21.5713416 \\
\hline 1.6307374 & 10.7177151 & 23.4286661 \\
\hline 1.5985477 & 10.6737123 & 26.5848401 \\
\hline 6.8188080 & 9.6223697 & 16.9153609 \\
\hline 4.8449033 & 10.8843798 & 28.1176572 \\
\hline 4.9203366 & 5.3429425 & 21.8777945 \\
\hline 9.0295234 & 5.3066239 & 21.8460073 \\
\hline 7.1013803 & 6.3223787 & 18.1756682 \\
\hline 2.1347100 & 9.0196859 & 26.7963147 \\
\hline 2.1814538 & 6.8999284 & 23.2445039 \\
\hline 0.2202591 & 10.3515485 & 23.1227352 \\
\hline 4.9202369 & 8.0551693 & 17.4918394 \\
\hline 4.3553851 & 8.1040762 & 27.5801355 \\
\hline 4.6102895 & 7.7331089 & 22.4846198 \\
\hline 2.5395666 & 11.7589751 & 27.5673049 \\
\hline
\end{tabular}

21.9332313

2309220

26.8859304

17.5218051

17.5728306

.3078347

22.3989802

22.3374939

27.4962441

17.7067427

.4016922

27.9465319

1.9820923

21.9770630

9827295

18.0013999

.7868499

631280

15.1270392

19.8914986

19.7865016

9.8527077

24.8823236
29.8690717

20.1819375

20.1990252

25.1421719

20.2635532

19.2747863

0.8626841

20.6101348

22.1401227

21.0061019

(2)

23.0287023

23.1028311

29.8484196

22.5479368

15.1219051

16.6546703

21. 6146515

18.4534213

26.6304231

3.5000509

16.5759916

8.4065288

21.5713416

26.5848401

16.9153609

21.8777945

21.8460073

18.1756682

963147

23.1227352

27.5673049 


\begin{tabular}{|c|c|c|c|}
\hline 0 & 8.9986397 & 7.8531294 & 17.5134660 \\
\hline 0 & 2.1016070 & 11.8739280 & 22.5441061 \\
\hline 0 & 4.4680077 & 10.4573231 & 17.0701153 \\
\hline 0 & 6.9878589 & 9.0194273 & 28.0296833 \\
\hline 0 & 6.8707675 & 6.8396750 & 21.9740120 \\
\hline $\mathrm{H}$ & 9.4188490 & 5.5021869 & 18.0397711 \\
\hline $\mathrm{H}$ & 4.6097684 & 5.5001273 & 18.0508913 \\
\hline $\mathrm{H}$ & 0.1809622 & 10.7531309 & 27.0334653 \\
\hline $\mathrm{H}$ & 2.5304855 & 6.5979516 & 26.9827337 \\
\hline 0 & 2.5283200 & 9.5081342 & 23.1423789 \\
\hline $\mathrm{H}$ & 5.1306199 & 8.9383689 & 15.2169742 \\
\hline 0 & 5.1646240 & 7.1027168 & 20.1355343 \\
\hline 0 & 3.6998314 & 7.8656214 & 25.1828796 \\
\hline $\mathrm{H}$ & 8.6858983 & 8.9206239 & 29.8400295 \\
\hline 0 & 8.8105439 & 7.0787477 & 19.8770054 \\
\hline 0 & 1.7587626 & 11.1401003 & 24.9069463 \\
\hline $\mathrm{H}$ & 5.1532040 & 8.9733682 & 29.9355369 \\
\hline $\mathrm{H}$ & 3.4633091 & 11.9661105 & 15.1279145 \\
\hline $\mathrm{P}$ & 3.1550939 & 15.9195078 & 21.6307994 \\
\hline Al & 3.1556164 & 15.9241332 & 18.4568152 \\
\hline $\mathrm{P}$ & 3.7991253 & 11.9810433 & 28.4072936 \\
\hline Al & 3.7817963 & 11.9862087 & 16.5823156 \\
\hline $\mathrm{P}$ & 1.5797245 & 13.2134196 & 18.4302888 \\
\hline Al & 1.5554281 & 13.2017082 & 21.5347915 \\
\hline 0 & 4.9750151 & 13.2328778 & 16.9158975 \\
\hline $\mathrm{H}$ & 0.0907198 & 13.4510749 & 21.6325997 \\
\hline $\mathrm{H}$ & 2.2083328 & 17.0403214 & 21.8848485 \\
\hline 0 & 1.9591928 & 14.6828459 & 18.1308230 \\
\hline 0 & 4.6059365 & 15.6572783 & 17.5208999 \\
\hline 0 & 4.4226399 & 16.0846211 & 22.4830690 \\
\hline 0 & 2.3035637 & 12.2758328 & 17.4523468 \\
\hline 0 & 4.3929522 & 13.3395568 & 28.0224989 \\
\hline 0 & 2.4861841 & 14.6054174 & 22.0247722 \\
\hline $\mathrm{H}$ & 2.6002582 & 17.2566250 & 18.0918991 \\
\hline $\mathrm{H}$ & 0.1139629 & 13.0488359 & 18.2263880 \\
\hline 0 & 3.5794810 & 15.9076151 & 20.1513312 \\
\hline $\mathrm{H}$ & 3.4203157 & 11.9632034 & 29.8471913 \\
\hline $\mathrm{O}$ & 1.9938295 & 12.8353323 & 19.8615808 \\
\hline $\mathrm{P}$ & 10.1022466 & 11.9178316 & 16.5770264 \\
\hline Al & 10.0564126 & 11.8955302 & 28.3872516 \\
\hline $\mathrm{P}$ & 12.3459847 & 10.6230345 & 26.6968374 \\
\hline $\mathrm{Al}$ & 12.3596218 & 10.6633072 & 23.4803799 \\
\hline $\mathrm{P}$ & 15.5057361 & 10.7177151 & 23.4286661 \\
\hline $\mathrm{P}$ & 10.6773471 & 8.0120684 & 23.4359885 \\
\hline Al & 10.6850119 & 7.9764800 & 26.5846997 \\
\hline Al & 15.4735464 & 10.6737123 & 26.5848401 \\
\hline 0 & 8.9010684 & 10.6230460 & 28.0388730 \\
\hline 0 & 11.8741149 & 9.1902301 & 27.0220242 \\
\hline $\mathrm{H}$ & 15.9293352 & 9.2676331 & 26.7646136 \\
\hline $\mathrm{H}$ & 11.5848616 & 6.8411531 & 23.2860035 \\
\hline 0 & 14.0455915 & 10.3386549 & 23.1119627 \\
\hline 0 & 11.5275708 & 11.6491995 & 27.4934892 \\
\hline 0 & 9.2676754 & 8.1614760 & 27.5829914 \\
\hline $\mathrm{H}$ & 16.2786944 & 11.6022772 & 27.4254497 \\
\hline 0 & 9.4357022 & 7.8432194 & 22.5483869 \\
\hline $\mathrm{O}$ & 15.9766058 & 11.8739280 & 22.5441061 \\
\hline 0 & 9.4960045 & 10.5869818 & 17.0571719 \\
\hline 0 & 13.8143667 & 10.7666660 & 27.1099230 \\
\hline $\mathrm{H}$ & 11.2603814 & 6.6275331 & 26.8424064 \\
\hline $\mathrm{H}$ & 16.3774429 & 9.5430045 & 23.1506321 \\
\hline 0 & 11.4263041 & 9.2660143 & 22.9804491 \\
\hline $\mathrm{H}$ & 10.4047015 & 11.8693781 & 15.1198737 \\
\hline 0 & 12.1699571 & 10.9087754 & 25.2026118 \\
\hline 0 & 15.6337613 & 11.1401003 & 24.9069463 \\
\hline 0 & 10.2264994 & 8.1465658 & 24.9026115 \\
\hline $\mathrm{H}$ & 10.3605539 & 11.8720839 & 29.8446702 \\
\hline $\mathrm{H}$ & 8.7483035 & 14.9545774 & 15.0887985 \\
\hline $\mathrm{P}$ & 5.4096125 & 14.6887765 & 16.6478403 \\
\hline Al & 5.3772727 & 14.6977882 & 28.4856105 \\
\hline $\mathrm{P}$ & 12.3219749 & 18.7491703 & 21.6146515 \\
\hline $\mathrm{Si}$ & 12.1684096 & 13.1968341 & 21.6300380 \\
\hline $\mathrm{P}$ & 17.0300927 & 15.9195078 & 21.6307994 \\
\hline Al & 17.0306151 & 15.9241332 & 18.4568152 \\
\hline Al & 12.2360517 & 13.1822047 & 18.4957877 \\
\hline Al & 12.3477750 & 18.7054630 & 18.4534213 \\
\hline $\mathrm{P}$ & 5.3104606 & 17.2085119 & 26.6141177 \\
\hline Al & 5.2916069 & 17.2039467 & 23.4922922 \\
\hline $\mathrm{P}$ & 8.5363296 & 14.6503706 & 28.3739117 \\
\hline $\mathrm{Al}$ & 8.5682999 & 14.6771203 & 16.5406032 \\
\hline $\mathrm{P}$ & 15.4547233 & 13.2134196 & 18.4302888 \\
\hline
\end{tabular}




\begin{tabular}{|c|c|c|c|}
\hline $\mathrm{P}$ & 15.5190808 & 18.6936999 & 18.4065288 \\
\hline $\mathrm{P}$ & 10.7337528 & 16.0046029 & 18.3970919 \\
\hline Al & 10.6781981 & 16.0430488 & 21.5488396 \\
\hline Al & 15.4962675 & 18.7083907 & 21.5713416 \\
\hline $\mathrm{Al}$ & 15.4304268 & 13.2017082 & 21.5347915 \\
\hline $\mathrm{P}$ & 8.4551983 & 17.2782443 & 23.3932650 \\
\hline Al & 8.4639872 & 17.2137319 & 26.5490653 \\
\hline 0 & 9.0775385 & 13.0307209 & 16.8932106 \\
\hline 0 & 7.0515795 & 14.3052443 & 28.1497638 \\
\hline 0 & 11.8430310 & 17.3147022 & 21.8861881 \\
\hline 0 & 13.7457516 & 13.4885243 & 21.6472883 \\
\hline $\mathrm{O}$ & 16.0492621 & 17.0806541 & 21.8939905 \\
\hline 0 & 15.8341916 & 14.6828459 & 18.1308230 \\
\hline 0 & 11.7474234 & 14.8543434 & 18.2463780 \\
\hline 0 & 14.0388796 & 18.3384801 & 18.1756682 \\
\hline 0 & 6.7810871 & 17.6040155 & 26.8607413 \\
\hline $\mathrm{H}$ & 8.9202898 & 18.6802465 & 23.2056474 \\
\hline $\mathrm{H}$ & 4.7658043 & 18.5852729 & 23.3117646 \\
\hline $\mathrm{H}$ & 18.2670393 & 15.6966345 & 17.6589304 \\
\hline $\mathrm{H}$ & 11.9286063 & 19.8737458 & 17.6309046 \\
\hline 0 & 11.4073485 & 12.1596152 & 17.3372737 \\
\hline 0 & 4.8836156 & 16.0899810 & 27.5690232 \\
\hline $\mathrm{H}$ & 11.5709994 & 19.7192284 & 22.4585376 \\
\hline $\mathrm{H}$ & 18.2585919 & 16.0795348 & 22.4568148 \\
\hline 0 & 8.9521346 & 15.8442476 & 27.5104424 \\
\hline $\mathrm{H}$ & 16.1564008 & 12.3045388 & 17.4822883 \\
\hline 0 & 9.5299746 & 15.7877921 & 17.4687029 \\
\hline $\mathrm{H}$ & 15.9238860 & 19.8346941 & 17.5397039 \\
\hline 0 & 9.2090218 & 16.3252866 & 22.4645736 \\
\hline 0 & 6.8942449 & 14.8326060 & 17.0088603 \\
\hline 0 & 9.3841702 & 13.4436813 & 27.9563277 \\
\hline 0 & 13.8082669 & 18.8557764 & 21.9740120 \\
\hline 0 & 11.2714271 & 14.4970260 & 21.9467880 \\
\hline 0 & 16.3611828 & 14.6054174 & 22.0247722 \\
\hline 0 & 16.3800943 & 17.4849522 & 18.0293695 \\
\hline $\mathrm{O}$ & 13.9478293 & 13.0442174 & 18.2206661 \\
\hline 0 & 11.4126973 & 17.3163106 & 17.9832234 \\
\hline $\mathrm{H}$ & 4.4414054 & 18.3883824 & 26.8782561 \\
\hline $\mathrm{H}$ & 9.3075618 & 18.3804537 & 26.9288846 \\
\hline 0 & 6.9689638 & 17.1998983 & 23.0316500 \\
\hline $\mathrm{H}$ & 5.1868796 & 15.0383005 & 15.2176852 \\
\hline 0 & 12.1021234 & 19.1188182 & 20.1355343 \\
\hline 0 & 11.7492629 & 12.6436845 & 20.0956109 \\
\hline 0 & 17.4544797 & 15.9076151 & 20.1513312 \\
\hline 0 & 5.1305009 & 16.7119711 & 25.1670405 \\
\hline $\mathrm{H}$ & 8.7716651 & 14.9913283 & 29.8041165 \\
\hline 0 & 15.8688282 & 12.8353323 & 19.8615808 \\
\hline 0 & 15.7480433 & 19.0948491 & 19.8770054 \\
\hline 0 & 10.2198576 & 16.1004416 & 19.8432740 \\
\hline 0 & 8.6774984 & 16.8325601 & 24.8528817 \\
\hline $\mathrm{C}$ & 9.6731600 & 12.1436078 & 20.4417847 \\
\hline $\mathrm{H}$ & 9.3357974 & 11.9336867 & 19.4239082 \\
\hline $\mathrm{H}$ & 10.1394246 & 11.3514550 & 21.0222256 \\
\hline $\mathrm{H}$ & 9.6754190 & 13.1724863 & 20.7866911 \\
\hline $\mathrm{O}$ & 11.6982549 & 12.0410481 & 22.6816560 \\
\hline C & 8.0419342 & 12.0529917 & 22.3468465 \\
\hline $\mathrm{H}$ & 8.4039052 & 11.8709134 & 21.1816467 \\
\hline $\mathrm{H}$ & 7.1073448 & 11.4754274 & 22.3795923 \\
\hline $\mathrm{H}$ & 7.8948693 & 13.1455087 & 22.3653999 \\
\hline $\mathrm{O}$ & 8.9504535 & 11.5464575 & 23.2189860 \\
\hline $\mathrm{H}$ & 9.8150519 & 12.0384524 & 23.1918845 \\
\hline $\mathrm{H}$ & 5.2088954 & 14.9975485 & 29.9343732 \\
\hline $\mathrm{H}$ & 16.2441525 & 19.6899506 & 22.4046055 \\
\hline \multicolumn{4}{|c|}{$\operatorname{Mg} 18$} \\
\hline \multicolumn{4}{|c|}{168} \\
\hline $\mathrm{H}$ & 8.7210490 & 8.9500809 & 15.2537047 \\
\hline Al & 5.3831729 & 9.2531967 & 16.6304400 \\
\hline $\mathrm{P}$ & 5.3837466 & 9.1990228 & 28.4543016 \\
\hline $\mathrm{Al}$ & 5.2750332 & 6.6725265 & 21.5755292 \\
\hline $\mathrm{P}$ & 5.3347453 & 6.6560763 & 18.4137402 \\
\hline Al & 3.1725888 & 7.9645162 & 26.5856586 \\
\hline $\mathrm{P}$ & 3.2335466 & 8.0436216 & 23.4742866 \\
\hline Al & 8.5162813 & 9.1833763 & 28.5019591 \\
\hline $\mathrm{P}$ & 8.5331426 & 9.3076634 & 16.6868643 \\
\hline Al & 8.5101388 & 6.7212354 & 18.5025267 \\
\hline $\mathrm{P}$ & 8.4739685 & 6.6784454 & 21.6623579 \\
\hline Al & 1.5384356 & 10.7623526 & 23.4882643 \\
\hline $\mathrm{P}$ & 1.4984057 & 10.6863259 & 26.6630490 \\
\hline $\mathrm{O}$ & 7.0609992 & 9.6862032 & 16.9577641 \\
\hline
\end{tabular}




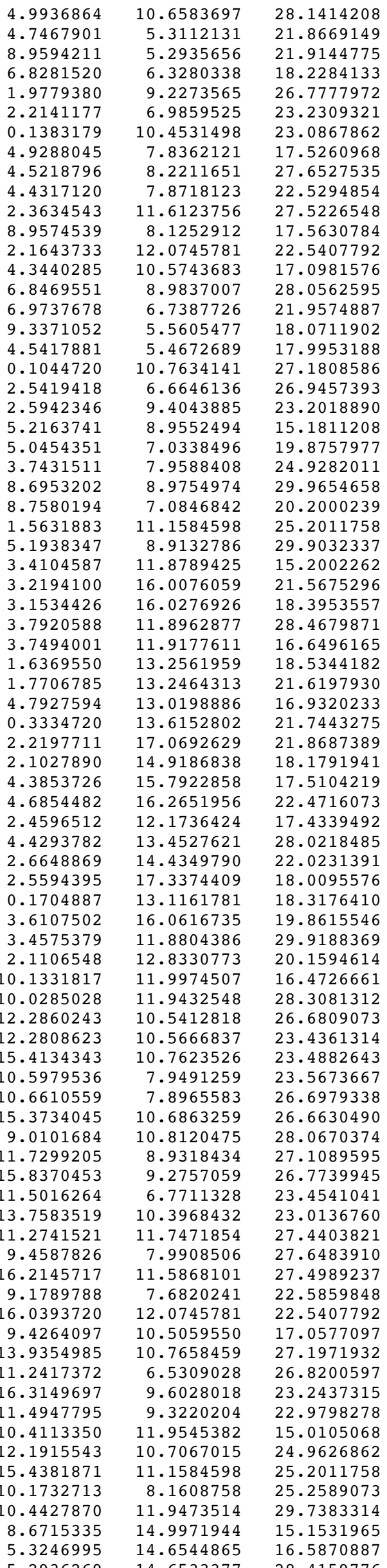




\begin{tabular}{|c|c|c|c|}
\hline Al & 12.2125326 & 18.6886279 & 21.5755292 \\
\hline Mg & 12.3535292 & 13.2027523 & 21.6524862 \\
\hline Al & 17.0944087 & 16.0076059 & 21.5675296 \\
\hline$P$ & 17.0284413 & 16.0276926 & 18.3953557 \\
\hline$P$ & 12.2697169 & 13.1624643 & 18.4033824 \\
\hline $\mathrm{P}$ & 12.2722447 & 18.6721777 & 18.4137402 \\
\hline Al & 5.3639140 & 17.1513320 & 26.5492630 \\
\hline $\mathrm{P}$ & 5.3604875 & 17.2036998 & 23.4711583 \\
\hline Al & 8.4523481 & 14.6737009 & 28.4194152 \\
\hline $\mathrm{P}$ & 8.4909493 & 14.6891569 & 16.5987493 \\
\hline Al & 15.5119537 & 13.2561959 & 18.5344182 \\
\hline Al & 15.4476381 & 18.7373367 & 18.5025267 \\
\hline Al & 10.6860049 & 15.9571590 & 18.4530247 \\
\hline $\mathrm{P}$ & 10.5658066 & 15.9813472 & 21.6018422 \\
\hline$P$ & 15.4114679 & 18.6945467 & 21.6623579 \\
\hline$P$ & 15.6456772 & 13.2464313 & 21.6197930 \\
\hline$A 1$ & 8.5110962 & 17.3489875 & 23.4785210 \\
\hline $\mathrm{P}$ & 8.5156399 & 17.2481417 & 26.6277817 \\
\hline $\mathrm{O}$ & 8.9757270 & 13.2502873 & 16.8952818 \\
\hline $\mathrm{O}$ & 6.7671307 & 14.3135469 & 28.1174416 \\
\hline $\mathrm{O}$ & 11.5940318 & 17.0947154 & 21.9167021 \\
\hline $\mathrm{O}$ & 14.1832849 & 13.6217440 & 21.7465098 \\
\hline 0 & 15.9138299 & 17.2614285 & 21.9232594 \\
\hline $\mathrm{O}$ & 15.9777877 & 14.9186838 & 18.1791941 \\
\hline 0 & 11.8161538 & 14.6271762 & 18.2518031 \\
\hline 0 & 13.7656514 & 18.3441351 & 18.2284133 \\
\hline $\mathrm{O}$ & 7.0322184 & 17.5898121 & 26.8852058 \\
\hline $\mathrm{H}$ & 9.0280763 & 18.7282256 & 23.2604514 \\
\hline $\mathrm{H}$ & 4.7322897 & 18.5532425 & 23.4361944 \\
\hline $\mathrm{H}$ & 18.2234660 & 15.7993380 & 17.5369322 \\
\hline $\mathrm{H}$ & 11.8775629 & 19.8195818 & 17.5507161 \\
\hline $\mathrm{O}$ & 11.6392553 & 12.2964331 & 17.2994615 \\
\hline 0 & 4.8407757 & 15.8622362 & 27.5942032 \\
\hline $\mathrm{H}$ & 11.4946362 & 19.7095472 & 22.3876062 \\
\hline $\mathrm{H}$ & 18.3478540 & 16.2278420 & 22.3405054 \\
\hline 0 & 8.9536731 & 16.0635327 & 27.4993196 \\
\hline $\mathrm{H}$ & 16.2122613 & 12.3346888 & 17.5976608 \\
\hline $\mathrm{O}$ & 9.2962139 & 15.6968443 & 17.4232716 \\
\hline $\mathrm{H}$ & 15.8287670 & 19.9336437 & 17.7020824 \\
\hline $\mathrm{O}$ & 9.2841642 & 16.2099002 & 22.4277688 \\
\hline 0 & 7.0164207 & 14.7941101 & 17.0061648 \\
\hline $\mathrm{O}$ & 9.3922683 & 13.2856622 & 27.9357042 \\
\hline 0 & 13.9112671 & 18.7548740 & 21.9574887 \\
\hline 0 & 11.1271750 & 14.6220350 & 21.9356641 \\
\hline 0 & 16.5398856 & 14.4349790 & 22.0231391 \\
\hline 0 & 16.4158786 & 17.3783641 & 17.9975033 \\
\hline $\mathrm{O}$ & 13.7902163 & 13.0918049 & 18.2799061 \\
\hline $\mathrm{O}$ & 11.4560212 & 17.4484893 & 17.9830419 \\
\hline $\mathrm{H}$ & 4.4682766 & 18.3174116 & 26.7842367 \\
\hline $\mathrm{H}$ & 9.3484802 & 18.4260669 & 26.9965499 \\
\hline 0 & 6.8273902 & 17.3444526 & 23.0691305 \\
\hline $\mathrm{H}$ & 5.1446039 & 14.9411272 & 15.1370806 \\
\hline $\mathrm{O}$ & 11.9829345 & 19.0499510 & 19.8757977 \\
\hline 0 & 11.8450612 & 12.5973177 & 19.7903899 \\
\hline 0 & 17.4857489 & 16.0616735 & 19.8615546 \\
\hline $\mathrm{O}$ & 5.2399335 & 16.6049750 & 24.8877090 \\
\hline $\mathrm{H}$ & 8.6436308 & 14.9571445 & 29.8686188 \\
\hline $\mathrm{O}$ & 15.9856535 & 12.8330773 & 20.1594614 \\
\hline 0 & 15.6955188 & 19.1007855 & 20.2000239 \\
\hline O & 10.1506177 & 16.0613602 & 20.1076155 \\
\hline $\mathrm{O}$ & 8.7338177 & 16.8724989 & 25.1514397 \\
\hline C & 9.8502724 & 12.2223944 & 20.2584995 \\
\hline $\mathrm{H}$ & 9.4531963 & 12.0037943 & 19.2661494 \\
\hline $\mathrm{H}$ & 10.2751480 & 11.4128363 & 20.8477176 \\
\hline $\mathrm{H}$ & 9.8519146 & 13.2459281 & 20.6214228 \\
\hline 0 & 11.6549784 & 11.8012783 & 22.7873326 \\
\hline C & 8.1278543 & 12.0791972 & 22.1470013 \\
\hline $\mathrm{H}$ & 8.5307920 & 11.9688886 & 21.0081590 \\
\hline $\mathrm{H}$ & 7.1172804 & 11.6528113 & 22.0730982 \\
\hline $\mathrm{H}$ & 8.1324553 & 13.1713317 & 22.2984285 \\
\hline 0 & 8.8944288 & 11.3497198 & 23.0062124 \\
\hline $\mathrm{H}$ & 9.8079419 & 11.7350780 & 23.0960461 \\
\hline $\mathrm{H}$ & 5.1192083 & 14.9799725 & 29.8582010 \\
\hline $\mathrm{H}$ & 16.0951953 & 19.6678294 & 22.5581023 \\
\hline \multicolumn{4}{|c|}{ Al 18} \\
\hline \multicolumn{4}{|c|}{168} \\
\hline $\mathrm{H}$ & 8.6671744 & 8.8264580 & 15.208437 \\
\hline $\mathrm{Si}$ & 5.3106716 & 9.1723413 & 16.638489 \\
\hline $\mathrm{Si}$ & 5.3070145 & 9.1289106 & 28.5823629 \\
\hline
\end{tabular}




\begin{tabular}{|c|c|c|c|}
\hline $\mathrm{Si}$ & 5.2902750 & 6.7008239 & 21.6155492 \\
\hline $\mathrm{Si}$ & 5.3310989 & 6.6879326 & 18.5229012 \\
\hline $\mathrm{Si}$ & 3.2143535 & 7.8913940 & 26.6349502 \\
\hline $\mathrm{Si}$ & 3.2691269 & 7.9545759 & 23.5758211 \\
\hline $\mathrm{Si}$ & 8.4260920 & 9.1009491 & 28.5652211 \\
\hline $\mathrm{Si}$ & 8.4424197 & 9.1874759 & 16.6354172 \\
\hline $\mathrm{Si}$ & 8.4713066 & 6.7141197 & 18.5421778 \\
\hline $\mathrm{Si}$ & 8.4503507 & 6.6973807 & 21.6389657 \\
\hline $\mathrm{Si}$ & 1.6455146 & 10.6716953 & 23.5478150 \\
\hline $\mathrm{Si}$ & 1.6094208 & 10.6141065 & 26.6493119 \\
\hline 0 & 6.8768214 & 9.5747328 & 16.8801212 \\
\hline $\mathrm{O}$ & 4.8962576 & 10.6794686 & 28.2919319 \\
\hline $\mathrm{H}$ & 4.7855830 & 5.3203520 & 21.8536749 \\
\hline $\mathrm{H}$ & 8.9425330 & 5.3112846 & 21.8705142 \\
\hline $\mathrm{O}$ & 6.9066778 & 6.3274725 & 18.3257621 \\
\hline 0 & 2.1021336 & 9.0684564 & 26.7790964 \\
\hline $\mathrm{H}$ & 2.2436979 & 6.8997491 & 23.3456990 \\
\hline $\mathrm{H}$ & 0.2344039 & 10.3122067 & 23.2369212 \\
\hline $\mathrm{O}$ & 4.8950210 & 7.9133372 & 17.5609560 \\
\hline 0 & 4.4323024 & 8.1158212 & 27.6758506 \\
\hline 0 & 4.5310450 & 7.7697405 & 22.5732920 \\
\hline $\mathrm{O}$ & 2.4741571 & 11.5821151 & 27.6143979 \\
\hline $\mathrm{O}$ & 8.8876829 & 7.9553166 & 17.5851393 \\
\hline 0 & 2.1687338 & 11.8640094 & 22.5908559 \\
\hline $\mathrm{O}$ & 4.3855666 & 10.4329257 & 17.0607004 \\
\hline $\mathrm{O}$ & 6.8631600 & 8.9230269 & 28.1957286 \\
\hline 0 & 6.8689314 & 6.7527058 & 21.9660099 \\
\hline $\mathrm{H}$ & 9.3051786 & 5.5402707 & 18.1628938 \\
\hline $\mathrm{H}$ & 4.5353802 & 5.4906669 & 18.1349486 \\
\hline $\mathrm{H}$ & 0.1943566 & 10.6818086 & 27.1077115 \\
\hline $\mathrm{H}$ & 2.5719076 & 6.5912242 & 26.9725037 \\
\hline $\mathrm{O}$ & 2.5990349 & 9.3914998 & 23.2754719 \\
\hline $\mathrm{H}$ & 5.0832820 & 8.8029135 & 15.2140819 \\
\hline $\mathrm{O}$ & 5.0427091 & 7.1328330 & 20.0623133 \\
\hline $\mathrm{O}$ & 3.8084442 & 7.8741719 & 25.1156300 \\
\hline $\mathrm{H}$ & 8.6650348 & 8.8201123 & 30.0078429 \\
\hline 0 & 8.7343487 & 7.1479690 & 20.0932852 \\
\hline 0 & 1.7615263 & 11.1295381 & 25.1125052 \\
\hline $\mathrm{H}$ & 5.0831366 & 8.7994962 & 30.0171052 \\
\hline $\mathrm{H}$ & 3.3378902 & 11.8109076 & 15.1768748 \\
\hline $\mathrm{Si}$ & 3.2370537 & 15.7761716 & 21.6191310 \\
\hline $\mathrm{Si}$ & 3.2046729 & 15.7990307 & 18.5140416 \\
\hline $\mathrm{Si}$ & 3.7660625 & 11.8268019 & 28.5519553 \\
\hline $\mathrm{Si}$ & 3.7346973 & 11.8492515 & 16.6115157 \\
\hline $\mathrm{Si}$ & 1.6572662 & 13.0873463 & 18.5553536 \\
\hline $\mathrm{Si}$ & 1.6910602 & 13.0636862 & 21.5955212 \\
\hline 0 & 4.8538078 & 13.0096277 & 16.8655096 \\
\hline $\mathrm{H}$ & 0.2356404 & 13.3610602 & 21.6977106 \\
\hline $\mathrm{H}$ & 2.2675889 & 16.8785746 & 21.8680611 \\
\hline $\mathrm{O}$ & 2.0804127 & 14.6427303 & 18.2797246 \\
\hline 0 & 4.4941301 & 15.5633356 & 17.5592473 \\
\hline 0 & 4.5585898 & 15.9507479 & 22.5424892 \\
\hline 0 & 2.4046526 & 12.1141988 & 17.4922181 \\
\hline $\mathrm{O}$ & 4.3901271 & 13.2667338 & 28.1622422 \\
\hline 0 & 2.5677065 & 14.3684666 & 22.0138341 \\
\hline $\mathrm{H}$ & 2.6170061 & 17.1209266 & 18.1613950 \\
\hline $\mathrm{H}$ & 0.1897750 & 12.9571613 & 18.3393858 \\
\hline $\mathrm{O}$ & 3.7104838 & 15.7976804 & 20.0597144 \\
\hline $\mathrm{H}$ & 3.3406055 & 11.8090078 & 29.9787665 \\
\hline 0 & 2.0886963 & 12.6357129 & 20.0568074 \\
\hline $\mathrm{Si}$ & 10.0278617 & 11.8556726 & 16.5334284 \\
\hline $\mathrm{Si}$ & 9.9585532 & 11.8092766 & 28.4678694 \\
\hline $\mathrm{Si}$ & 12.1463610 & 10.5246509 & 26.7081406 \\
\hline $\mathrm{Si}$ & 12.1517510 & 10.5500754 & 23.5448173 \\
\hline $\mathrm{Si}$ & 15.2705134 & 10.6716953 & 23.5478150 \\
\hline $\mathrm{Si}$ & 10.4767481 & 7.9314293 & 23.5990339 \\
\hline $\mathrm{Si}$ & 10.5193795 & 7.8949785 & 26.6692042 \\
\hline $\mathrm{Si}$ & 15.2344196 & 10.6141065 & 26.6493119 \\
\hline 0 & 8.8667032 & 10.6290532 & 28.2036027 \\
\hline 0 & 11.6582879 & 9.0032156 & 27.0355909 \\
\hline $\mathrm{H}$ & 15.6852120 & 9.1999612 & 26.7680542 \\
\hline $\mathrm{H}$ & 11.3675149 & 6.7431025 & 23.4916337 \\
\hline 0 & 13.7258734 & 10.2781894 & 23.2075022 \\
\hline $\mathrm{O}$ & 11.2731554 & 11.5994545 & 27.5532075 \\
\hline 0 & 9.2675996 & 8.0299676 & 27.6907087 \\
\hline $\mathrm{H}$ & 16.0304741 & 11.5052310 & 27.5377458 \\
\hline $\mathrm{O}$ & 9.1907508 & 7.7528824 & 22.6246694 \\
\hline $\mathrm{O}$ & 15.7937325 & 11.8640094 & 22.5908559 \\
\hline $\mathrm{O}$ & 9.3583606 & 10.4659743 & 17.0506472 \\
\hline $\mathrm{O}$ & 13.6948998 & 10.6877631 & 27.1480279 \\
\hline
\end{tabular}




\begin{tabular}{|c|c|c|}
\hline 11.1058152 & 6.5375119 & 26.8438414 \\
\hline 16.1472834 & 9.4945446 & 23.2973932 \\
\hline 11.3179701 & 9.2211991 & 23.1131955 \\
\hline 10.3782656 & 11.7932667 & 15.0875919 \\
\hline 11.9588613 & 10.8382863 & 25.1345776 \\
\hline 15.3865250 & 11.1295381 & 25.1125052 \\
\hline 9.9788660 & 8.1039375 & 25.1436601 \\
\hline 10.3701801 & 11.7897367 & 29.8987090 \\
\hline 8.6829182 & 14.9163763 & 15.1281425 \\
\hline 5.3182407 & 14.5502476 & 16.6051071 \\
\hline 5.2918509 & 14.5462867 & 28.5653407 \\
\hline 12.1027744 & 18.5004190 & 21.6155492 \\
\hline 12.0799172 & 13.0385796 & 21.6418959 \\
\hline 16.8620524 & 15.7761716 & 21.6191310 \\
\hline 16.8296717 & 15.7990307 & 18.5140416 \\
\hline 12.0870218 & 13.0278057 & 18.5131918 \\
\hline 12.1435983 & 18.4875277 & 18.5229012 \\
\hline 5.2996711 & 16.9489615 & 26.6111872 \\
\hline 5.2819802 & 16.9629069 & 23.5738314 \\
\hline 8.4270065 & 14.5338140 & 28.5097583 \\
\hline 8.4592387 & 14.5686477 & 16.5585875 \\
\hline 15.2822649 & 13.0873463 & 18.5553536 \\
\hline 15.2838059 & 18.5137148 & 18.5421778 \\
\hline 10.5457533 & 15.8012836 & 18.5020316 \\
\hline 10.4595385 & 15.8178782 & 21.5894087 \\
\hline 15.2628500 & 18.4969758 & 21.6389657 \\
\hline 15.3160589 & 13.0636862 & 21.5955212 \\
\hline 8.4084789 & 17.0856261 & 23.5178452 \\
\hline 8.4150320 & 17.0026755 & 26.6114905 \\
\hline 8.9410371 & 13.0331012 & 16.8397831 \\
\hline 6.8544452 & 14.1664924 & 28.3103272 \\
\hline 11.5535047 & 16.9980146 & 21.8747077 \\
\hline 13.7563043 & 13.3823781 & 21.7050363 \\
\hline 15.8002276 & 16.9835995 & 21.8917764 \\
\hline 15.7054114 & 14.6427303 & 18.2797246 \\
\hline 11.6128899 & 14.5799675 & 18.3443060 \\
\hline 13.7191771 & 18.1270676 & 18.3257621 \\
\hline 6.8501815 & 17.3842822 & 26.8737233 \\
\hline 8.9150529 & 18.4745547 & 23.3406993 \\
\hline 4.6833713 & 18.3236679 & 23.4894666 \\
\hline 18.0136214 & 15.5826209 & 17.6373716 \\
\hline 11.7422263 & 19.6154065 & 17.6375139 \\
\hline 11.3891485 & 12.1064710 & 17.3692856 \\
\hline 4.8402611 & 15.7914058 & 27.6414748 \\
\hline 11.4065136 & 19.4806814 & 22.4938584 \\
\hline 18.0755392 & 15.9364744 & 22.4669951 \\
\hline 8.8634592 & 15.7618421 & 27.5523678 \\
\hline 15.9677196 & 12.1948382 & 17.5803143 \\
\hline 9.2963691 & 15.5956860 & 17.4853604 \\
\hline 15.6661147 & 19.6533579 & 17.6634434 \\
\hline 9.1335682 & 16.0632819 & 22.5024114 \\
\hline 6.8943668 & 14.6805918 & 16.9607251 \\
\hline 9.3035248 & 13.2388930 & 28.0903238 \\
\hline 13.6814307 & 18.5523008 & 21.9660099 \\
\hline 11.0545194 & 14.3888339 & 21.9423072 \\
\hline 16.1927052 & 14.3684666 & 22.0138341 \\
\hline 16.1898203 & 17.2383103 & 18.1300801 \\
\hline 13.6871567 & 12.9458400 & 18.3206046 \\
\hline 11.2797664 & 17.1877765 & 18.1017400 \\
\hline 4.4160512 & 18.1255076 & 26.8393884 \\
\hline 9.2565217 & 18.1773319 & 26.9709319 \\
\hline 6.8358028 & 17.0741062 & 23.1548616 \\
\hline 5.0759402 & 14.9258334 & 15.1847739 \\
\hline 11.8552085 & 18.9324281 & 20.0623133 \\
\hline 11.6447025 & 12.4474752 & 19.9812739 \\
\hline 17.3354826 & 15.7976804 & 20.0597144 \\
\hline 5.1330900 & 16.3822064 & 25.0911426 \\
\hline 8.6797412 & 14.9127618 & 29.9273776 \\
\hline 15.7136950 & 12.6357129 & 20.0568074 \\
\hline 15.5468481 & 18.9475640 & 20.0932852 \\
\hline 9.9702517 & 15.8809688 & 20.0205040 \\
\hline 8.6453138 & 16.5847903 & 25.0536474 \\
\hline 9.6091449 & 11.9622314 & 20.3675731 \\
\hline 9.2761373 & 11.7034607 & 19.3601428 \\
\hline 10.0649402 & 11.1940320 & 20.9880575 \\
\hline 9.5692942 & 12.9984830 & 20.6895898 \\
\hline 11.5336790 & 11.7970224 & 22.7412977 \\
\hline 7.8901850 & 11.8446052 & 22.2284388 \\
\hline 8.3058691 & 11.6768397 & 21.0908911 \\
\hline 6.9395366 & 11.2932332 & 22.2038412 \\
\hline
\end{tabular}

26.8438414

3. 2973932

25.1345776

29.8987090

(281425

28.5653407

(5)

21.6191310

5140416

18.5229012

1872

28.5097583

6.5585875

18.5421778

5020316

21.6389657

.5955212

26.6114905

6.8397831

21.8747077

.7050363

917764

18.3443060

18.3257621

26.8737233

.3406993

3.4894666

17.6375139

17.3692856

27.6414748

22.4669951

27.5523678

5803143

17.6634434

22.5024114

16.9607251

(2)

21.9423072

18.3206046

18.1017400

26.9709319

23.1548616

5.1847739

19.9812739

20.0597144

25.0911426

20.0932852

.0205040

20.3675731

19.3601428

20.9880575

22.7412977

21.0908911

22.2038412 


\begin{tabular}{|c|c|c|c|}
\hline $\mathrm{H}$ & 7.7663574 & 12.9391783 & 22.2723167 \\
\hline 0 & 8.7373857 & 11.2947396 & 23.1402945 \\
\hline $\mathrm{H}$ & 9.6035660 & 11.7779578 & 23.1804145 \\
\hline $\mathrm{H}$ & 5.0738120 & 14.9253233 & 29.9886857 \\
\hline $\mathrm{H}$ & 15.9421514 & 19.4653761 & 22.5433279 \\
\hline \multicolumn{4}{|c|}{ Ge 18} \\
\hline \multicolumn{4}{|c|}{168} \\
\hline $\mathrm{H}$ & 8.6547470 & 9.0125363 & 15.1472287 \\
\hline $\mathrm{P}$ & 5.3526545 & 9.3155800 & 16.6952722 \\
\hline Al & 5.3186053 & 9.2595356 & 28.5163695 \\
\hline $\mathrm{P}$ & 5.3722587 & 6.7013694 & 21.6239343 \\
\hline Al & 5.4282655 & 6.7160049 & 18.4589287 \\
\hline$P$ & 3.1827746 & 7.9152767 & 26.6381171 \\
\hline Al & 3.2584855 & 8.0278928 & 23.5363256 \\
\hline $\mathrm{P}$ & 8.4535347 & 9.1787494 & 28.4082062 \\
\hline Al & 8.5076907 & 9.2831325 & 16.6040309 \\
\hline$P$ & 8.6040643 & 6.7306514 & 18.4359969 \\
\hline Al & 8.5604364 & 6.6974156 & 21.5994300 \\
\hline$P$ & 1.6310362 & 10.7626757 & 23.4591839 \\
\hline Al & 1.5750207 & 10.6788859 & 26.6201679 \\
\hline $\mathrm{O}$ & 6.8328270 & 9.6742158 & 16.9581052 \\
\hline 0 & 4.8680852 & 10.9160172 & 28.1487535 \\
\hline $\mathrm{H}$ & 4.8790139 & 5.3204280 & 21.8824512 \\
\hline $\mathrm{H}$ & 9.0803136 & 5.3268773 & 21.8611032 \\
\hline 0 & 7.1261308 & 6.3766236 & 18.1938590 \\
\hline 0 & 2.1186960 & 9.0208457 & 26.7615584 \\
\hline $\mathrm{H}$ & 2.1741265 & 7.0348054 & 23.3016695 \\
\hline $\mathrm{H}$ & 0.2562009 & 10.3219704 & 23.0948664 \\
\hline 0 & 4.9352274 & 8.1067216 & 17.5350830 \\
\hline $\mathrm{O}$ & 4.3158663 & 8.1385549 & 27.6439912 \\
\hline $\mathrm{O}$ & 4.6279892 & 7.7246550 & 22.4965016 \\
\hline 0 & 2.5421354 & 11.7390691 & 27.6056821 \\
\hline 0 & 9.0219572 & 7.9177753 & 17.5569104 \\
\hline 0 & 2.0521005 & 11.9475428 & 22.5886263 \\
\hline $\mathrm{O}$ & 4.4805945 & 10.5064792 & 17.1069743 \\
\hline 0 & 6.9751269 & 9.0036028 & 28.0521923 \\
\hline 0 & 6.8622002 & 6.7698203 & 21.9759400 \\
\hline $\mathrm{H}$ & 9.4427777 & 5.5596104 & 18.0587127 \\
\hline $\mathrm{H}$ & 4.6582969 & 5.5244967 & 18.0066265 \\
\hline $\mathrm{H}$ & 0.1773558 & 10.7319411 & 27.1308913 \\
\hline $\mathrm{H}$ & 2.5482998 & 6.6059993 & 26.9549056 \\
\hline 0 & 2.6208974 & 9.6166746 & 23.2069728 \\
\hline $\mathrm{H}$ & 5.1466129 & 8.9843525 & 15.2582769 \\
\hline 0 & 5.1531292 & 7.0811662 & 20.1469840 \\
\hline 0 & 3.7750652 & 7.9111198 & 25.2136648 \\
\hline $\mathrm{H}$ & 8.6724786 & 8.9732721 & 29.8666174 \\
\hline $\mathrm{O}$ & 8.8259656 & 7.1167556 & 19.9123625 \\
\hline 0 & 1.6712788 & 11.1837844 & 24.9438783 \\
\hline $\mathrm{H}$ & 5.1663728 & 9.0159255 & 29.9773965 \\
\hline $\mathrm{H}$ & 3.4906267 & 12.0147892 & 15.1546449 \\
\hline$P$ & 3.2218601 & 15.9519923 & 21.6232835 \\
\hline Al & 3.1917993 & 15.9807817 & 18.4615330 \\
\hline $\mathrm{P}$ & 3.8068448 & 12.0017665 & 28.4261384 \\
\hline Al & 3.8027519 & 12.0361546 & 16.6104066 \\
\hline $\mathrm{P}$ & 1.5755884 & 13.2647125 & 18.4382786 \\
\hline Al & 1.5491074 & 13.2770793 & 21.5608927 \\
\hline 0 & 4.9996492 & 13.2770327 & 16.9554135 \\
\hline $\mathrm{H}$ & 0.1313720 & 13.7041358 & 21.7182768 \\
\hline $\mathrm{H}$ & 2.2685923 & 17.0626437 & 21.8968792 \\
\hline 0 & 1.9980097 & 14.7283984 & 18.1767796 \\
\hline 0 & 4.6261165 & 15.7150592 & 17.5013547 \\
\hline 0 & 4.4888083 & 16.1008178 & 22.4758497 \\
\hline 0 & 2.3254820 & 12.3258578 & 17.4819462 \\
\hline $\mathrm{O}$ & 4.3707996 & 13.3638352 & 28.0057819 \\
\hline 0 & 2.5753965 & 14.6234365 & 21.9954568 \\
\hline $\mathrm{H}$ & 2.6267995 & 17.3124697 & 18.1086835 \\
\hline $\mathrm{H}$ & 0.1181490 & 13.1373465 & 18.1612067 \\
\hline 0 & 3.6480314 & 15.9731416 & 20.1454129 \\
\hline $\mathrm{H}$ & 3.4479905 & 12.0107773 & 29.8712207 \\
\hline 0 & 1.9031357 & 12.8502169 & 19.8822349 \\
\hline $\mathrm{P}$ & 10.1032095 & 11.9601556 & 16.5278676 \\
\hline Al & 10.0277993 & 11.8937823 & 28.3317324 \\
\hline $\mathrm{P}$ & 12.3577595 & 10.5815935 & 26.7506936 \\
\hline Al & 12.3954847 & 10.5801472 & 23.5087181 \\
\hline $\mathrm{P}$ & 15.5060349 & 10.7626757 & 23.4591839 \\
\hline $\mathrm{P}$ & 10.6013946 & 8.0327922 & 23.5043784 \\
\hline Al & 10.6553081 & 7.9937415 & 26.6128058 \\
\hline Al & 15.4500194 & 10.6788859 & 26.6201679 \\
\hline $\mathrm{O}$ & 8.8944744 & 10.5980453 & 27.9921321 \\
\hline
\end{tabular}




\begin{tabular}{|c|c|c|}
\hline 11.8502728 & 9.1741640 & 27.1307571 \\
\hline 15.9124455 & 9.2686306 & 26.7404283 \\
\hline 11.4139578 & 6.7861215 & 23.4526671 \\
\hline 14.0792400 & 10.3053147 & 23.0810976 \\
\hline 11.5072854 & 11.6581309 & 27.4437399 \\
\hline 9.2546211 & 8.1167544 & 27.6466684 \\
\hline 16.2772238 & 11.5856947 & 27.4631099 \\
\hline 9.3646047 & 7.8859130 & 22.6029228 \\
\hline 15.9270992 & 11.9475428 & 22.5886263 \\
\hline 9.5168144 & 10.6405241 & 17.0685259 \\
\hline 13.8096893 & 10.7411526 & 27.2195641 \\
\hline 11.2427802 & 6.6331497 & 26.7569825 \\
\hline 16.4661246 & 9.6511422 & 23.2145584 \\
\hline 11.4582387 & 9.1922787 & 22.9842842 \\
\hline 10.3603299 & 11.8651748 & 15.0643143 \\
\hline 12.2674997 & 10.7702763 & 25.2367671 \\
\hline 15.5462775 & 11.1837844 & 24.9438783 \\
\hline 10.1524891 & 8.2950527 & 24.9559345 \\
\hline 10.3173505 & 11.8672395 & 29.7920667 \\
\hline 8.7435970 & 14.9790520 & 15.0298886 \\
\hline 5.4265633 & 14.7275266 & 16.6464283 \\
\hline 5.3610492 & 14.7171908 & 28.4771222 \\
\hline 12.3097581 & 18.7174708 & 21.6239343 \\
\hline 12.1224478 & 13.2374136 & 21.6586732 \\
\hline 17.0968588 & 15.9519923 & 21.6232835 \\
\hline 17.0667980 & 15.9807817 & 18.4615330 \\
\hline 12.2396473 & 13.2065221 & 18.4419689 \\
\hline 12.3657648 & 18.7321063 & 18.4589287 \\
\hline 5.3160151 & 17.2122579 & 26.6124789 \\
\hline 5.2674008 & 17.2204810 & 23.5458911 \\
\hline 8.5167883 & 14.6601068 & 28.3174464 \\
\hline 8.5812737 & 14.7223771 & 16.4875887 \\
\hline 15.4505871 & 13.2647125 & 18.4382786 \\
\hline 15.5415636 & 18.7467528 & 18.4359969 \\
\hline 10.7351641 & 16.0589116 & 18.3589393 \\
\hline 10.5517370 & 16.1079960 & 21.4990624 \\
\hline 15.4979357 & 18.7135170 & 21.5994300 \\
\hline 15.4241061 & 13.2770793 & 21.5608927 \\
\hline 8.4058842 & 17.4333387 & 23.3805052 \\
\hline 8.4553005 & 17.2406830 & 26.5154378 \\
\hline 9.0845200 & 13.0759302 & 16.8443641 \\
\hline 7.0278186 & 14.3259192 & 28.1075315 \\
\hline 11.8004146 & 17.2914577 & 21.8908888 \\
\hline 13.7831973 & 13.7713611 & 21.7430515 \\
\hline 16.1087547 & 17.1032314 & 21.9068775 \\
\hline 15.8730084 & 14.7283984 & 18.1767796 \\
\hline 11.7235723 & 14.8797082 & 18.2988311 \\
\hline 14.0636301 & 18.3927250 & 18.1938590 \\
\hline 6.7779358 & 17.6368834 & 26.8721661 \\
\hline 8.9061664 & 18.8309958 & 23.2647766 \\
\hline 4.6060383 & 18.5520540 & 23.4644440 \\
\hline 18.2897319 & 15.7542202 & 17.6428615 \\
\hline 11.9440627 & 19.9216050 & 17.6687510 \\
\hline 11.4342902 & 12.2293764 & 17.2315897 \\
\hline 4.8701406 & 16.1467476 & 27.6181947 \\
\hline 11.5887404 & 19.7087879 & 22.4692416 \\
\hline 18.3263744 & 16.0964207 & 22.4506602 \\
\hline 8.9386817 & 15.8413817 & 27.4391782 \\
\hline 16.1776789 & 12.3544054 & 17.5110251 \\
\hline 9.5689098 & 15.8364282 & 17.3854053 \\
\hline 15.9468933 & 19.8981877 & 17.5833387 \\
\hline 9.0956640 & 16.5207037 & 22.3719075 \\
\hline 6.9151493 & 14.8888643 & 16.9834842 \\
\hline 9.3490336 & 13.4400376 & 27.9051026 \\
\hline 13.7996996 & 18.7859217 & 21.9759400 \\
\hline 10.9377519 & 14.4983966 & 21.9373414 \\
\hline 16.4503952 & 14.6234365 & 21.9954568 \\
\hline 16.4044040 & 17.5420250 & 18.0478596 \\
\hline 13.9525223 & 13.1337962 & 18.1534835 \\
\hline 11.4654975 & 17.3389638 & 17.9300852 \\
\hline 4.4252830 & 18.3941223 & 26.7765323 \\
\hline 9.3209633 & 18.3898509 & 26.8990546 \\
\hline 6.9130450 & 17.4368304 & 23.0538625 \\
\hline 5.1846827 & 15.0371241 & 15.2101958 \\
\hline 12.0906286 & 19.0972675 & 20.1469840 \\
\hline 11.7783107 & 12.5362995 & 20.0039480 \\
\hline 17.5230302 & 15.9731416 & 20.1454129 \\
\hline 5.1861062 & 16.6247730 & 25.1926645 \\
\hline 8.7634510 & 15.0117686 & 29.7431435 \\
\hline 15.7781344 & 12.8502169 & 19.8822349 \\
\hline
\end{tabular}




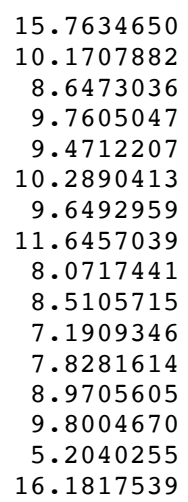

8.7017627

5.3873921

5.3807581

5.3680985

5.4010994

3.2873424

3. 4108617

8.4901001

8.5118320

8.5210658

8.5085175

1.6995503

1. 6726865

6.9521074

4.9713307

4.7545868

9.1061298

6.9602145

2. 1526301

2. 3628288

0.3327842

4.9437671

4.4785397

4.6813639

2. 5284596

8.9633950

1.9839556

4.4719226

6.9326690

6.9372077

9.3728722

4.5379767

0.2474607

2.6578339

2.7960391

5.1825717

5.2447787

3.9217979

8.6987766

8.7452840

1.8621990

5.1825254

3.4392618

3.4122029

3. 2864855

3. 8400044

3.8284699

1.7248883

1.7425752

4.9530859

0.3745228

2. 4431010

2.1608198

4.5615393

4.7607636

2.4994475

4.4557722

2.8106792

2.6867049

0.2641298

3. 8153771
19.1328569

16.2218491

16.8960298

11.8751736

11.5854460

11.1572192

12.9120746

11.9691727

11.6630465

11.4940229

11.0049687

12.7380061

11.2575113

11.8124119

14.9985200

19.7241463

8.8539723

9. 2587393

9. 1953722

6.7567364

6.7978578

7.9680453

8.0911836

9. 1417952

9.2593333

6.7695235

6.6634935

10.7041945

10.6731372

9.6490682

10.7433866

5.4039676

5.3238439

6.3971062

9. 1232097

7.0564649

10.1495689

7.9989598

8.1736778

7.8301517

11.6296977

8.0615264

11.9560345

10.5249678

8.9682128

6.6379373

5.6132662

5.6168796

10.7487372

6.6493510

9. 5482497

8.8947514

7.3238769

8.0212451

8.8458239

7.1458074

11.1909185

8.8903019

11.8960409

15.8098646

15.8779304

11.8913412

11.9400965

13.1654169

13.2068840

13.0964699

13.7926496

16.8982116

14.7208124

15.6542283

16.0113503

12.2035403

13.3276705

14.3697236

17.1957276

13.0327740

15.8884327
19.9123625

19.7786980

24.8076556

20.3843994

19.3714274

21.0067437

20.6902089

22.8015190

22.2392852

21.0976614

22.2347498

22.2243812

23.1691964

23.1663702

29.9308477

22.4527421

15.2397152

16.6610339

28.5930902

21.6162112

18.5524690

26.6468243

23.5936276

28.5927018

16.6598312

18.5408802

21.6646573

23.5677560

26.6545163

16.9380919

28.2870559

21.7198472

21.9202332

18.2722068

26.8004593

23.3742991

23.3641352

17.5707675

27.7246664

22.6177349

27.6414913

17.6593817

22.5909354

17.0795100

28.1914687

22.0193635

18.1476683

18.2742064

27.0789413

26.9329801

23.2433543

15.2318097

20.0883504

25.1441153

30.0369925

20.1198861

25.1220660

30.0369588

15.1797206

21.6054724

18.4935010

28.5470069

16.6162778

18.5498247

21.5824722

16.8701811

21.6317890

21.9111893

18.2903430

17.5191522

22.4825817

17.4963218

28.1273600

22.0001521

18.1459462

18.2934833

20.0305783 


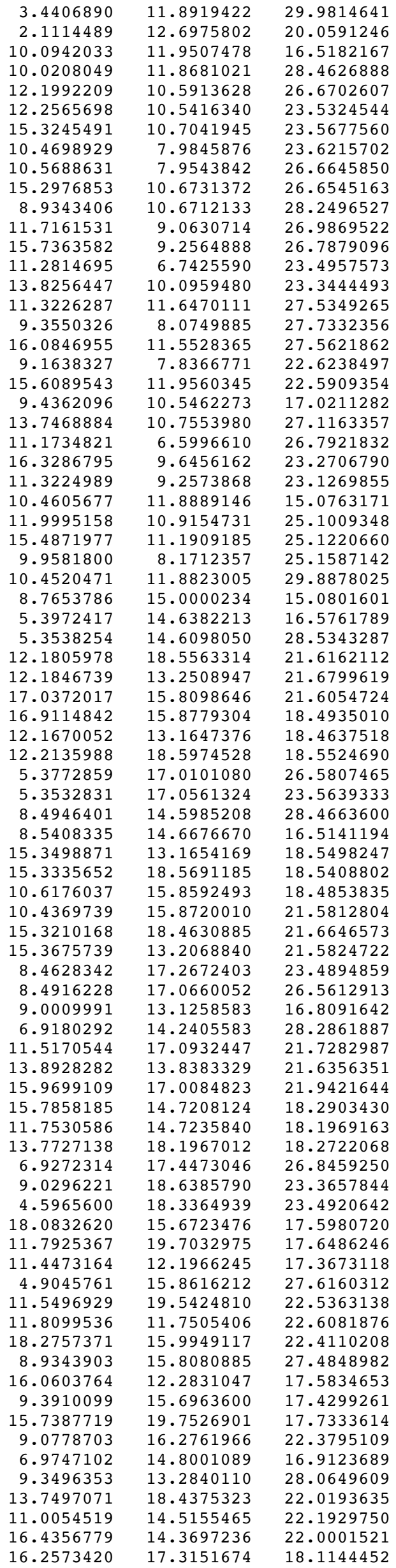

11.8919422

12.6975802

11.9507478

11.8681021

10.5913628

10.5416340

10.7041945

7.9845876

7.9543842

10.6731372

10.6712133

9.0630714

9.2564888

6.7425590

10.0959480

11.6470111

8.0749885

11.5528365

7.8366771

11.9560345

10.5462273

10.7553980

6.5996610

9. 6456162

9.2573868

11.8889146

10.9154731

11.1909185

8.1712357

11.8823005

15.0000234

14.6382213

14.6098050

18.5563314

13.2508947

15.8098646

15.8779304

13.1647376

18.5974528

17.0101080

17.0561324

14.5985208

14.6676670

13.1654169

18.5691185

15.8592493

15.8720010

18.4630885

13.2068840

17.2672403

17.0660052

13.1258583

14.2405583

17.0932447

13.8383329

17.0084823

14.7208124

14.7235840

18.1967012

17.4473046

18.6385790

18.3364939

15.6723476

19.7032975

12.1966245

15.8616212

19.5424810

11.7505406

15.9949117

15.8080885

12.2831047

15.6963600

19.7526901

16.2761966

14.8001089

13.2840110

18.4375323

14.5155465

14.3697236

17.3151674

29.9814641

20.0591246

16.5182167

28.4626888

26.6702607

23.5324544

23.5677560

23.6215702

26.6645850

26.6545163

28.2496527

26.9869522

26.7879096

23.4957573

23.3444493

27.5349265

27.7332356

27.5621862

22.6238497

22.5909354

17.0211282

27.1163357

26.7921832

23.2706790

23.1269855

15.0763171

25.1009348

25.1220660

25.1587142

29.8878025

15.0801601

16.5761789

28.5343287

21.6162112

21.6799619

21.6054724

18.4935010

18.4637518

18.5524690

26.5807465

23.5639333

28.4663600

16.5141194

18.5498247

18.5408802

18.4853835

21.5812804

21.6646573

21.5824722

23.4894859

26.5612913

16.8091642

28.2861887

21.7282987

21.6356351

21.9421644

18.2903430

18.1969163

18.2722068

26.8459250

23.3657844

23.4920642

17.5980720

17.6486246

17.3673118

27.6160312

22.5363138

22.6081876

22.4110208

27.4848982

17.5834653

17.4299261

17.7333614

22.3795109

16.9123689

28.0649609

22.0193635

22.1929750

22.0001521

18.1144452 


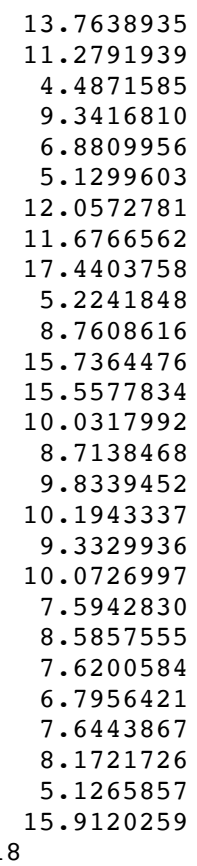

9.0289625 9.3299488

9.2466561

6.7527888

6.7386958

7.8900436

8.0342963

9.1475483

9.2945916

6.7202553

6.6785572

10.7612825

10.6480900

9.7018322

10.8996343

5.4062295

5.3184601

6.3475529

8.9901432

7.0248468

10.3546389

8.1069512

8.1146886

7.7951421

11.7037294

7.9108606

11.9302331

10.5043169

8.9648363

6.6971559

5.5572659

5.5684768

10.6809492

6.5751295

9.5977641

9.0106221

7.1859142

7.8972974

8.9886908

7.1085731

11.1805250

9.0366923

12.0083834

15.9382989

15.9717452

11.9820556

12.0318372

13.2588787

13.2425554

13.2671881
18.2715065

18.2512257

26.7854645

26.9261866

23. 1957180

15.1533191

20.0883504

19.9416134

20.0305783

25.0630753

29.8771824

20.0591246

20.1198861

19.9935007

24.9936512

20.2023944

21.2033216

20.0242392

19.3639749

20.8394142

20.4667602

20.1878702

20.5883481

22.1770128

22.3724451

29.9576575

22.5297240

15.1573522

16.7021173

28.5153172

21.6241130

18.4780111

26.6456943

23.5613539

28.4091227

16.6167270

18.4376972

21.6036073

23.4810615

26.6368745

16.9770295

28.1296650

21.8364373

21.8464006

18.1933255

26.7448510

23.3067714

23.0799929

17.5217625

27.6830292

22.5198523

27.6301101

17.5582244

22.6205280

17.1237227

28.0433335

21.9932356

18.0641397

18.0849907

27.1670409

26.9374276

23.2555508

15.2609175

20.1559223

25.2370203

29.8754209

19.9147624

24.9672438

29.9829981

15.1559955

21.6064993

18.4462894

28.4216213

16.6177642

18.4493099

21.5671519

16.9883266 


\begin{tabular}{|c|c|c|c|}
\hline $\mathrm{H}$ & 0.1902850 & 13.5509392 & 21.7136659 \\
\hline $\mathrm{H}$ & 2.3249344 & 17.0546437 & 21.8794237 \\
\hline 0 & 1.9924421 & 14.7270527 & 18.1680502 \\
\hline 0 & 4.6322592 & 15.7148889 & 17.4786394 \\
\hline 0 & 4.5570469 & 16.0843220 & 22.4357227 \\
\hline 0 & 2.3125623 & 12.3277352 & 17.4602166 \\
\hline 0 & 4.3657225 & 13.3441501 & 27.9792155 \\
\hline $\mathrm{O}$ & 2.6206074 & 14.6188453 & 22.0073617 \\
\hline $\mathrm{H}$ & 2.6357235 & 17.3087600 & 18.1110870 \\
\hline $\mathrm{H}$ & 0.1264433 & 13.1128943 & 18.2407029 \\
\hline 0 & 3.6769180 & 15.9384294 & 20.1240076 \\
\hline $\mathrm{H}$ & 3.4862372 & 12.0036306 & 29.8733453 \\
\hline 0 & 1.9953496 & 12.8518601 & 19.8784787 \\
\hline$P$ & 10.1213617 & 11.9549698 & 16.5097240 \\
\hline Al & 10.0206504 & 11.8604053 & 28.2990034 \\
\hline $\mathrm{P}$ & 12.3709219 & 10.5283677 & 26.7692286 \\
\hline Al & 12.3993459 & 10.5023339 & 23.5250681 \\
\hline$P$ & 15.5210408 & 10.7612825 & 23.4810615 \\
\hline $\mathrm{P}$ & 10.5795077 & 7.9776134 & 23.5490588 \\
\hline Al & 10.6488214 & 7.9539903 & 26.6251566 \\
\hline Al & 15.4491869 & 10.6480900 & 26.6368745 \\
\hline 0 & 8.9036804 & 10.5525529 & 27.9497263 \\
\hline 0 & 11.8514256 & 9.1256106 & 27.1508864 \\
\hline $\mathrm{H}$ & 15.9189929 & 9.2381358 & 26.7287001 \\
\hline $\mathrm{H}$ & 11.3027042 & 6.6760677 & 23.5583390 \\
\hline 0 & 14.0936502 & 10.3391762 & 23.0647421 \\
\hline $\mathrm{O}$ & 11.5150473 & 11.6154154 & 27.4395911 \\
\hline 0 & 9.2668742 & 8.0606733 & 27.6891605 \\
\hline $\mathrm{H}$ & 16.2733353 & 11.5512773 & 27.4866701 \\
\hline 0 & 9.3627819 & 7.8734429 & 22.6149512 \\
\hline 0 & 16.0076362 & 11.9302331 & 22.6205280 \\
\hline 0 & 9.5500507 & 10.6384443 & 17.0741875 \\
\hline 0 & 13.8161812 & 10.6866652 & 27.2592656 \\
\hline $\mathrm{H}$ & 11.2419066 & 6.5910872 & 26.7138439 \\
\hline $\mathrm{H}$ & 16.4660058 & 9.6315834 & 23.2621056 \\
\hline $\mathrm{O}$ & 11.5320519 & 9.0606231 & 23.0301710 \\
\hline $\mathrm{H}$ & 10.3066446 & 11.8547517 & 15.0356999 \\
\hline $\mathrm{O}$ & 12.3109151 & 10.7068164 & 25.2531146 \\
\hline 0 & 15.5293630 & 11.1805250 & 24.9672438 \\
\hline 0 & 10.1139165 & 8.3050988 & 24.9840779 \\
\hline $\mathrm{H}$ & 10.2692715 & 11.8534025 & 29.7670835 \\
\hline $\mathrm{H}$ & 8.7563364 & 14.9296008 & 15.0124424 \\
\hline $\mathrm{P}$ & 5.4341630 & 14.7088282 & 16.6457555 \\
\hline Al & 5.3674658 & 14.6836344 & 28.4692487 \\
\hline $\mathrm{P}$ & 12.3264413 & 18.7688902 & 21.6241130 \\
\hline $\mathrm{Ti}$ & 12.0848754 & 13.2046213 & 21.6894803 \\
\hline$P$ & 17.1467210 & 15.9382989 & 21.6064993 \\
\hline Al & 17.0738841 & 15.9717452 & 18.4462894 \\
\hline Al & 12.2298590 & 13.2345752 & 18.3816376 \\
\hline Al & 12.3772128 & 18.7547972 & 18.4780111 \\
\hline$P$ & 5.3301067 & 17.1717701 & 26.6030267 \\
\hline Al & 5.2728121 & 17.1827165 & 23.5711768 \\
\hline $\mathrm{P}$ & 8.5202883 & 14.6204487 & 28.2947734 \\
\hline Al & 8.5936331 & 14.7118773 & 16.4764249 \\
\hline $\mathrm{P}$ & 15.4685113 & 13.2588787 & 18.4493099 \\
\hline$P$ & 15.5372364 & 18.7363567 & 18.4376972 \\
\hline$P$ & 10.7350109 & 16.0464660 & 18.3362467 \\
\hline Al & 10.5079539 & 16.1458125 & 21.5030765 \\
\hline Al & 15.5127815 & 18.6946586 & 21.6036073 \\
\hline Al & 15.5146124 & 13.2425554 & 21.5671519 \\
\hline$P$ & 8.4040894 & 17.4561259 & 23.3762367 \\
\hline Al & 8.4643327 & 17.2136605 & 26.4962932 \\
\hline 0 & 9.1208271 & 13.0782921 & 16.8716960 \\
\hline 0 & 7.0304357 & 14.2848369 & 28.0936793 \\
\hline 0 & 11.7088923 & 17.3806632 & 21.8430074 \\
\hline 0 & 13.8335006 & 13.6002573 & 21.7370970 \\
\hline 0 & 16.1659566 & 17.0947050 & 21.8892178 \\
\hline 0 & 15.8674408 & 14.7270527 & 18.1680502 \\
\hline 0 & 11.7696450 & 14.9208919 & 18.1498944 \\
\hline 0 & 14.0622828 & 18.3636542 & 18.1933255 \\
\hline 0 & 6.7879097 & 17.6194932 & 26.8518035 \\
\hline $\mathrm{H}$ & 8.9842928 & 18.8230186 & 23.2662867 \\
\hline $\mathrm{H}$ & 4.5045889 & 18.4581910 & 23.5602897 \\
\hline $\mathrm{H}$ & 18.2946005 & 15.7529965 & 17.6222014 \\
\hline $\mathrm{H}$ & 11.9643222 & 19.9274134 & 17.6584911 \\
\hline 0 & 11.4867784 & 12.2322772 & 17.1438172 \\
\hline 0 & 4.8897329 & 16.1349493 & 27.6400780 \\
\hline $\mathrm{H}$ & 11.6576590 & 19.7778750 & 22.4911773 \\
\hline $\mathrm{H}$ & 18.3922679 & 16.0798030 & 22.4100602 \\
\hline 0 & 8.9322894 & 15.8125541 & 27.4255079 \\
\hline
\end{tabular}




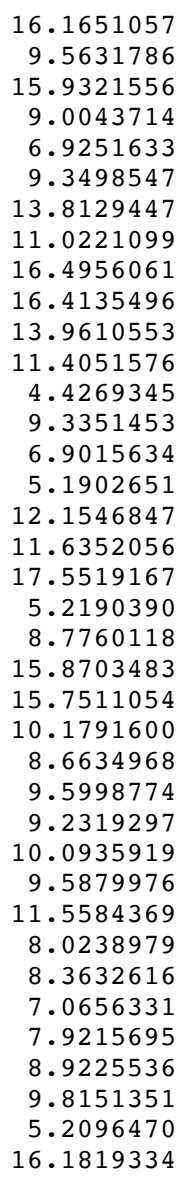

$\begin{array}{lrrl}\mathrm{H} & 8.7097713 & 9.2054017 & 15.3296762 \\ \mathrm{Al} & 5.3961149 & 9.5162456 & 16.6893802 \\ \mathrm{P} & 5.4148210 & 9.4836151 & 28.5040484 \\ \mathrm{Al} & 5.3148550 & 6.9333632 & 21.6260992 \\ \mathrm{P} & 5.3505006 & 6.9581474 & 18.4987087 \\ \mathrm{Al} & 3.1908748 & 8.2653812 & 26.6558103 \\ \mathrm{P} & 3.2794857 & 8.3706119 & 23.5358144 \\ \mathrm{Al} & 8.5436275 & 9.4707049 & 28.5775767 \\ \mathrm{P} & 8.5393418 & 9.5675428 & 16.7638757 \\ \mathrm{Al} & 8.5040794 & 6.9705267 & 18.5550241 \\ \mathrm{P} & 8.4922096 & 6.9146615 & 21.7316119 \\ \mathrm{Al} & 1.5409259 & 10.9929784 & 23.5642627 \\ \mathrm{P} & 1.5364380 & 10.9644899 & 26.7296023 \\ \mathrm{O} & 7.0689418 & 9.9384343 & 17.0568886 \\ \mathrm{O} & 5.0115655 & 10.9385676 & 28.1839709 \\ \mathrm{H} & 4.7808702 & 5.5529700 & 21.7888729 \\ \mathrm{H} & 9.0317253 & 5.5495480 & 21.9816289 \\ \mathrm{O} & 6.8255740 & 6.5863000 & 18.2405347 \\ \mathrm{O} & 1.9776327 & 9.4992096 & 26.9208610 \\ \mathrm{H} & 2.2293207 & 7.3311532 & 23.3519679 \\ \mathrm{H} & 0.1592002 & 10.4945311 & 23.3203265 \\ \mathrm{O} & 4.9168794 & 8.0908701 & 17.5612992 \\ \mathrm{O} & 4.5537651 & 8.4953891 & 27.7155298 \\ \mathrm{O} & 4.4852222 & 8.0975989 & 22.6279544 \\ \mathrm{O} & 2.3594200 & 11.8932214 & 27.6306132 \\ \mathrm{O} & 8.9747971 & 8.3915403 & 17.6466394 \\ \mathrm{O} & 1.9061321 & 12.4125915 & 22.6357256 \\ \mathrm{O} & 4.3793727 & 10.8490516 & 17.1669140 \\ \mathrm{O} & 6.8791478 & 9.2740953 & 28.1002428 \\ \mathrm{O} & 7.0018216 & 6.9351692 & 22.0694860 \\ \mathrm{H} & 9.3475741 & 5.8165201 & 18.1380038 \\ \mathrm{H} & 4.5008668 & 5.7691164 & 18.2133171 \\ \mathrm{H} & 0.1090299 & 11.0828046 & 27.1365766 \\ \mathrm{H} & 2.5904792 & 6.9399231 & 26.9717324 \\ \mathrm{O} & 2.7007808 & 9.7410440 & 23.1612103 \\ \mathrm{H} & 5.2537429 & 9.2444986 & 15.2323269 \\ \mathrm{O} & 5.1710285 & 7.4410350 & 19.9498297 \\ \mathrm{O} & 3.7629352 & 8.3670498 & 25.0011917 \\ \mathrm{H} & 8.6891320 & 9.2359723 & 30.0407409\end{array}$

17.4911052

17.3579381

17.5846841

22.3127512

16.9733311

27.8570218

21.9932356

22.0714418

22.0073617

18.0532484

18.2349602

18.0191689

26.7253969

26.8805967

23.1107567

15.2032335

20.1559223

19.9332921

20.1240076

25.2010851

29.7227185

19.8784787

19.9147624

19.7712291

24.7834186

20.3438411

19.3235372

20.8393116

20.7711209

22.8024959

22.2747680

21.0840778

22.2370457

22.4512193

23.0420000

23.0808793

$\begin{array}{ll}14.9491223 & 29.9258646 \\ 19.7099732 & 22.4629633\end{array}$

$\begin{array}{ll}14.9491223 & 29.9258646 \\ 19.7099732 & 22.4629633\end{array}$

15.3296762

16.6893802

28.5040484

40992

26.6558103

23.5358144

28.5775767

21.7316119

.5642627

7.0568886

1839709

1.9816289

.2405347

3.3519679

.3203265

27.7155298

2.6279544

17.6466394

.6357256

28.1002428

.0694860

18.2133171

27.1365766

23.1612103

30.0407409 


\begin{tabular}{|c|c|c|c|}
\hline 0 & 8.7199545 & 7.3283508 & 20.2597606 \\
\hline 0 & 1.7311651 & 11.3979336 & 25.2667855 \\
\hline $\mathrm{H}$ & 5.2353256 & 9.2072368 & 29.9561218 \\
\hline $\mathrm{H}$ & 3.4751234 & 12.1797678 & 15.2708299 \\
\hline Al & 3.2897164 & 16.2604534 & 21.6292369 \\
\hline $\mathrm{P}$ & 3.1754305 & 16.2917838 & 18.4629621 \\
\hline Al & 3.8179483 & 12.1824857 & 28.5299733 \\
\hline $\mathrm{P}$ & 3.8033221 & 12.2020449 & 16.7230385 \\
\hline Al & 1.6488548 & 13.5157544 & 18.5992495 \\
\hline $\mathrm{P}$ & 1.7421994 & 13.5931125 & 21.6636389 \\
\hline 0 & 4.8595625 & 13.2901888 & 17.0188987 \\
\hline $\mathrm{H}$ & 0.3962806 & 14.2283946 & 21.7088046 \\
\hline $\mathrm{H}$ & 2.2942965 & 17.3249431 & 21.9343954 \\
\hline 0 & 2.1220997 & 15.1823389 & 18.2795378 \\
\hline $\mathrm{O}$ & 4.3886598 & 16.0577267 & 17.5544609 \\
\hline 0 & 4.7547291 & 16.5277919 & 22.5337225 \\
\hline 0 & 2.5156905 & 12.4612078 & 17.5066631 \\
\hline 0 & 4.4608498 & 13.7323390 & 28.0558386 \\
\hline $\mathrm{O}$ & 2.7989650 & 14.6491113 & 22.0636361 \\
\hline $\mathrm{H}$ & 2.5710075 & 17.5975085 & 18.0797173 \\
\hline $\mathrm{H}$ & 0.1920432 & 13.3545859 & 18.3368659 \\
\hline $\mathrm{O}$ & 3.6639068 & 16.3365825 & 19.9197954 \\
\hline $\mathrm{H}$ & 3.5169524 & 12.1795652 & 29.9882303 \\
\hline 0 & 2.0716661 & 13.0691559 & 20.2372967 \\
\hline Al & 10.1313242 & 12.2806327 & 16.5661154 \\
\hline $\mathrm{P}$ & 10.0562657 & 12.2307724 & 28.4029453 \\
\hline Al & 12.2817513 & 10.8782717 & 26.6583044 \\
\hline $\mathrm{P}$ & 12.3116244 & 10.8331307 & 23.4727844 \\
\hline Al & 15.4159246 & 10.9929784 & 23.5642627 \\
\hline Al & 10.5912309 & 8.2122321 & 23.6328934 \\
\hline $\mathrm{P}$ & 10.6895118 & 8.1803412 & 26.7408151 \\
\hline$P$ & 15.4114368 & 10.9644899 & 26.7296023 \\
\hline 0 & 9.0263747 & 11.1067675 & 28.1665473 \\
\hline 0 & 11.7710176 & 9.2381550 & 27.0366163 \\
\hline $\mathrm{H}$ & 15.8374210 & 9.5497260 & 26.9142672 \\
\hline $\mathrm{H}$ & 11.4987327 & 7.0392977 & 23.4995293 \\
\hline 0 & 13.7920921 & 10.4071929 & 23.2775839 \\
\hline 0 & 11.3023231 & 12.020 & 27.5445913 \\
\hline $\mathrm{O}$ & 9.5340299 & 8.30 & 27.7443198 \\
\hline $\mathrm{H}$ & 16.2105301 & 11.8662632 & 27.6044596 \\
\hline 0 & 9.1845925 & 7.9581012 & 22.6239207 \\
\hline $\mathrm{O}$ & 15.7811308 & 12.4125915 & 22.6357256 \\
\hline $\mathrm{O}$ & 9.4289393 & 10.7709227 & 17.1226623 \\
\hline 0 & 13.9421319 & 11.0862773 & 27.1485220 \\
\hline $\mathrm{H}$ & 11.2883689 & 6.8259312 & 26.8959420 \\
\hline $\mathrm{H}$ & 16.4007788 & 9.9299378 & 23.2220235 \\
\hline 0 & 11.4193097 & 9.6323238 & 23.0867169 \\
\hline $\mathrm{H}$ & 10.4277865 & 12.2443045 & 15.1073794 \\
\hline $\mathrm{O}$ & 12.0858683 & 11.1777147 & 24.9627731 \\
\hline $\mathrm{O}$ & 15.6061638 & 11.3979336 & 25.2667855 \\
\hline 0 & 10.1209741 & 8.3702459 & 25.3186573 \\
\hline $\mathrm{H}$ & 10.4629684 & 12.2380639 & 29.8353071 \\
\hline $\mathrm{H}$ & 8.6974328 & 15.2957207 & 15.2190026 \\
\hline Al & 5.3557153 & 14.9330322 & 16.6457232 \\
\hline $\mathrm{P}$ & 5.3265151 & 14.9275495 & 28.4703552 \\
\hline Al & 12.2523544 & 18.9494646 & 21.6260992 \\
\hline $\mathrm{Zn}$ & 12.4370609 & 13.6338328 & 21.7325883 \\
\hline Al & 17.1647151 & 16.2604534 & 21.6292369 \\
\hline $\mathrm{P}$ & 17.0504292 & 16.2917838 & 18.4629621 \\
\hline$P$ & 12.3053828 & 13.4693101 & 18.4477699 \\
\hline $\mathrm{P}$ & 12.2879999 & 18.9742487 & 18.4987087 \\
\hline Al & 5.4040997 & 17.4422078 & 26.6113174 \\
\hline $\mathrm{P}$ & 5.3950211 & 17.4944639 & 23.5330704 \\
\hline Al & 8.4858056 & 14.9631698 & 28.4852901 \\
\hline $\mathrm{P}$ & 8.5143356 & 14.9861505 & 16.6639117 \\
\hline Al & 15.5238535 & 13.5157544 & 18.5992495 \\
\hline Al & 15.4415787 & 18.9866280 & 18.5550241 \\
\hline Al & 10.7329478 & 16.1832166 & 18.5272129 \\
\hline$P$ & 10.5930998 & 16.1987955 & 21.6806667 \\
\hline P & 15.4297089 & 18.9307629 & 21.7316119 \\
\hline P & 15.6171981 & 13.5931125 & 21.6636389 \\
\hline Al & 8.5480128 & 17.6719593 & 23.5325229 \\
\hline $\mathrm{P}$ & 8.5574235 & 17.5232948 & 26.6625416 \\
\hline $\mathrm{O}$ & 8.9694843 & 13.5370596 & 16.9595212 \\
\hline 0 & 6.8017468 & 14.5869511 & 28.1841884 \\
\hline $\mathrm{O}$ & 11.6308035 & 17.3427061 & 21.8155656 \\
\hline 0 & 14.2404643 & 14.2429395 & 21.7098387 \\
\hline $\mathrm{O}$ & 15.9875379 & 17.5193122 & 21.9901155 \\
\hline $\mathrm{O}$ & 15.9970985 & 15.1823389 & 18.2795378 \\
\hline 0 & 11.9163089 & 14.9366207 & 18.1590760 \\
\hline
\end{tabular}




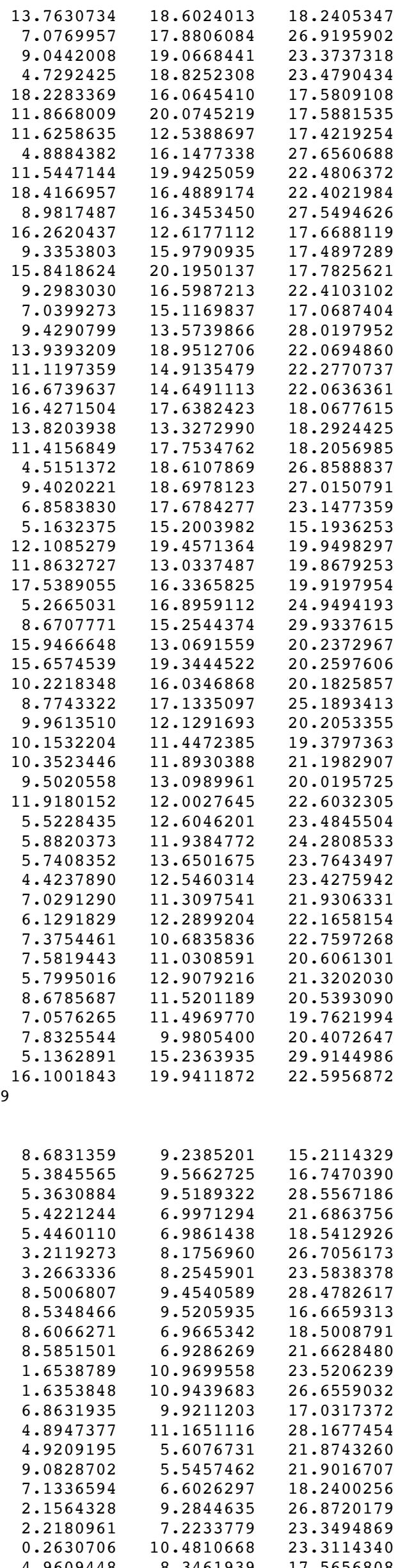




\begin{tabular}{|c|c|c|c|}
\hline 0 & 4.3738991 & 8.3851997 & 27.6840487 \\
\hline 0 & 4.6643704 & 7.9898825 & 22.5773734 \\
\hline 0 & 2.5689409 & 12.0149351 & 27.6641088 \\
\hline $\mathrm{O}$ & 9.0342999 & 8.1475525 & 17.6177167 \\
\hline 0 & 1.9885999 & 12.1482212 & 22.6026794 \\
\hline 0 & 4.5138178 & 10.7550764 & 17.1708891 \\
\hline 0 & 7.0264919 & 9.2828666 & 28.0994475 \\
\hline 0 & 6.9036295 & 7.0541773 & 22.0843225 \\
\hline $\mathrm{H}$ & 9.4620766 & 5.7963768 & 18.1602056 \\
\hline $\mathrm{H}$ & 4.6081236 & 5.8123822 & 18.1706859 \\
\hline $\mathrm{H}$ & 0.2117553 & 11.0305481 & 27.0835755 \\
\hline $\mathrm{H}$ & 2.5829985 & 6.8642451 & 27.0244681 \\
\hline 0 & 2.6357433 & 9.8326149 & 23.2006018 \\
\hline $\mathrm{H}$ & 5.1930331 & 9.2595885 & 15.3026068 \\
\hline $\mathrm{O}$ & 5.2557564 & 7.4455388 & 20.2193399 \\
\hline 0 & 3.7676951 & 8.1856603 & 25.2679911 \\
\hline $\mathrm{H}$ & 8.7014948 & 9.1992557 & 29.9314891 \\
\hline 0 & 8.8028410 & 7.3794893 & 19.9756841 \\
\hline $\mathrm{O}$ & 1.8423573 & 11.4273143 & 24.9852120 \\
\hline $\mathrm{H}$ & 5.2130636 & 9.2897459 & 30.0203056 \\
\hline $\mathrm{H}$ & 3.5419730 & 12.2530859 & 15.2006381 \\
\hline$P$ & 3.2252196 & 16.1654709 & 21.6982774 \\
\hline Al & 3.1982812 & 16.2051937 & 18.5318260 \\
\hline$P$ & 3.8452898 & 12.2561215 & 28.4713179 \\
\hline Al & 3.8298865 & 12.2801789 & 16.6612861 \\
\hline $\mathrm{P}$ & 1.6123177 & 13.5018325 & 18.4904370 \\
\hline Al & 1.5494040 & 13.5088458 & 21.5820893 \\
\hline 0 & 5.0210482 & 13.5250882 & 17.0175723 \\
\hline $\mathrm{H}$ & 0.1088277 & 13.8838784 & 21.6168891 \\
\hline $\mathrm{H}$ & 2.2671770 & 17.2806058 & 21.9343905 \\
\hline 0 & 1.9965677 & 14.9731314 & 18.1983229 \\
\hline 0 & 4.6355097 & 15.9600139 & 17.5685967 \\
\hline 0 & 4.4868974 & 16.3570297 & 22.5534077 \\
\hline 0 & 2.3408238 & 12.5703684 & 17.5082292 \\
\hline 0 & 4.4198341 & 13.6165275 & 28.0608508 \\
\hline $\mathrm{O}$ & 2.5829566 & 14.8395604 & 22.1026209 \\
\hline $\mathrm{H}$ & 2.6439046 & 17.5483821 & 18.2068150 \\
\hline $\mathrm{H}$ & 0.1481900 & 13.3365315 & 18.2756666 \\
\hline $\mathrm{O}$ & 3.6538299 & 16.1451567 & 20.2193846 \\
\hline $\mathrm{H}$ & 3.5033669 & 12.2486667 & 29.9205087 \\
\hline 0 & 2.0288508 & 13.1159656 & 19.9206766 \\
\hline $\mathrm{P}$ & 10.1292291 & 12.2142447 & 16.6577660 \\
\hline Al & 10.0900499 & 12.1692090 & 28.4647654 \\
\hline $\mathrm{P}$ & 12.3726145 & 10.8999600 & 26.7623358 \\
\hline Al & 12.4006390 & 10.9199826 & 23.5582820 \\
\hline $\mathrm{P}$ & 15.5288776 & 10.9699558 & 23.5206239 \\
\hline $\mathrm{P}$ & 10.6706438 & 8.2912907 & 23.5285759 \\
\hline Al & 10.7172296 & 8.2501401 & 26.6653173 \\
\hline Al & 15.5103835 & 10.9439683 & 26.6559032 \\
\hline 0 & 8.9378338 & 10.8893696 & 28.1206083 \\
\hline 0 & 11.9117002 & 9.4613739 & 27.0867656 \\
\hline $\mathrm{H}$ & 15.9530239 & 9.5341869 & 26.8394968 \\
\hline $\mathrm{H}$ & 11.5798513 & 7.1216893 & 23.3785929 \\
\hline 0 & 14.0908460 & 10.4644671 & 23.3043312 \\
\hline $\mathrm{O}$ & 11.5670256 & 11.9140925 & 27.5872527 \\
\hline $\mathrm{O}$ & 9.3157134 & 8.4243948 & 27.6901884 \\
\hline $\mathrm{H}$ & 16.3083001 & 11.8593308 & 27.5176232 \\
\hline $\mathrm{O}$ & 9.4272997 & 8.1079491 & 22.6409380 \\
\hline $\mathrm{O}$ & 15.8635986 & 12.1482212 & 22.6026794 \\
\hline 0 & 9.5386513 & 10.8736604 & 17.1409927 \\
\hline 0 & 13.8464663 & 11.0451615 & 27.1557603 \\
\hline $\mathrm{H}$ & 11.3005597 & 6.9001256 & 26.8983565 \\
\hline $\mathrm{H}$ & 16.4805527 & 9.8675846 & 23.2104415 \\
\hline 0 & 11.3986387 & 9.5551666 & 23.0715854 \\
\hline $\mathrm{H}$ & 10.4258026 & 12.1576641 & 15.1996976 \\
\hline 0 & 12.1663836 & 11.1955370 & 25.2761827 \\
\hline $\mathrm{O}$ & 15.7173560 & 11.4273143 & 24.9852120 \\
\hline $\mathrm{O}$ & 10.2126509 & 8.4235464 & 24.9943904 \\
\hline $\mathrm{H}$ & 10.3834670 & 12.1580200 & 29.9245263 \\
\hline $\mathrm{H}$ & 8.7795234 & 15.2311936 & 15.1405074 \\
\hline P & 5.4434937 & 14.9790259 & 16.7125601 \\
\hline Al & 5.4074814 & 14.9680962 & 28.5427219 \\
\hline $\mathrm{P}$ & 12.3596238 & 19.0132308 & 21.6863756 \\
\hline $\mathrm{Si}$ & 12.2113449 & 13.5226464 & 21.6867849 \\
\hline $\mathrm{P}$ & 17.1002183 & 16.1654709 & 21.6982774 \\
\hline Al & 17.0732799 & 16.2051937 & 18.5318260 \\
\hline Al & 12.2727600 & 13.5045487 & 18.5594872 \\
\hline Al & 12.3835103 & 19.0022451 & 18.5412926 \\
\hline $\mathrm{P}$ & 5.3548780 & 17.4821211 & 26.6755016 \\
\hline Al & 5.3271839 & 17.4994628 & 23.5632052 \\
\hline
\end{tabular}




\begin{tabular}{|c|c|c|c|}
\hline $\mathrm{P}$ & 8.5661014 & 14.9185672 & 28.4266739 \\
\hline Al & 8.6027089 & 14.9690322 & 16.5955430 \\
\hline $\mathrm{P}$ & 15.4873164 & 13.5018325 & 18.4904370 \\
\hline$P$ & 15.5441265 & 18.9826356 & 18.5008791 \\
\hline$P$ & 10.7644367 & 16.2849956 & 18.4544617 \\
\hline Al & 10.6827758 & 16.2843586 & 21.6117077 \\
\hline Al & 15.5226494 & 18.9447282 & 21.6628480 \\
\hline Al & 15.4244027 & 13.5088458 & 21.5820893 \\
\hline $\mathrm{P}$ & 8.4838737 & 17.6028609 & 23.4513903 \\
\hline Al & 8.5046193 & 17.4842689 & 26.5967290 \\
\hline 0 & 9.0933800 & 13.3186184 & 16.9654983 \\
\hline 0 & 7.0803620 & 14.5713272 & 28.2074791 \\
\hline 0 & 11.8445757 & 17.5853979 & 21.8795172 \\
\hline 0 & 13.7736520 & 13.9385942 & 21.6219663 \\
\hline $\mathrm{O}$ & 16.1067531 & 17.3218367 & 21.9431205 \\
\hline $\mathrm{O}$ & 15.8715664 & 14.9731314 & 18.1983229 \\
\hline $\mathrm{O}$ & 11.8127554 & 15.1756559 & 18.2418753 \\
\hline 0 & 14.0711587 & 18.6187311 & 18.2400256 \\
\hline $\mathrm{O}$ & 6.8238254 & 17.8805048 & 26.9237271 \\
\hline $\mathrm{H}$ & 8.9549531 & 19.0086100 & 23.3132803 \\
\hline $\mathrm{H}$ & 4.7659445 & 18.8691050 & 23.4013070 \\
\hline $\mathrm{H}$ & 18.2979468 & 15.9962752 & 17.7110553 \\
\hline $\mathrm{H}$ & 11.9690486 & 20.1643313 & 17.7076873 \\
\hline 0 & 11.4331066 & 12.4626784 & 17.4155495 \\
\hline 0 & 4.9240823 & 16.3686879 & 27.6348035 \\
\hline $\mathrm{H}$ & 11.6241722 & 19.9767649 & 22.5511493 \\
\hline $\mathrm{H}$ & 18.3231662 & 16.3511494 & 22.5271577 \\
\hline 0 & 8.9806762 & 16.1080772 & 27.5565839 \\
\hline $\mathrm{H}$ & 16.1929655 & 12.5995933 & 17.5390462 \\
\hline 0 & 9.5727550 & 16.0867979 & 17.5040254 \\
\hline $\mathrm{H}$ & 15.9588546 & 20.1279071 & 17.6444480 \\
\hline 0 & 9.2200250 & 16.6777782 & 22.4903276 \\
\hline 0 & 6.9282233 & 15.1409708 & 17.0619598 \\
\hline 0 & 9.4118870 & 13.7088309 & 28.0151110 \\
\hline $\mathrm{O}$ & 13.8411289 & 19.0702786 & 22.0843225 \\
\hline 0 & 11.2845896 & 14.7736902 & 22.0995270 \\
\hline $\mathrm{O}$ & 16.4579554 & 14.8395604 & 22.1026209 \\
\hline 0 & 16.4232914 & 17.7800382 & 18.1507612 \\
\hline $\mathrm{O}$ & 13.9835806 & 13.3320597 & 18.2698566 \\
\hline 0 & 11.4077107 & 17.6352880 & 18.1096858 \\
\hline $\mathrm{H}$ & 4.4825867 & 18.6616690 & 26.9302469 \\
\hline $\mathrm{H}$ & 9.3578881 & 18.6459644 & 26.9702478 \\
\hline 0 & 6.9950133 & 17.5565509 & 23.0931995 \\
\hline $\mathrm{H}$ & 5.2073338 & 15.2932462 & 15.2763795 \\
\hline 0 & 12.1932557 & 19.4616402 & 20.2193399 \\
\hline $\mathrm{O}$ & 11.7657286 & 13.0090922 & 20.1540641 \\
\hline 0 & 17.5288286 & 16.1451567 & 20.2193846 \\
\hline 0 & 5.1782264 & 16.9763136 & 25.2302254 \\
\hline $\mathrm{H}$ & 8.8023196 & 15.2651186 & 29.8553879 \\
\hline 0 & 15.9038495 & 13.1159656 & 19.9206766 \\
\hline 0 & 15.7403403 & 19.3955907 & 19.9756841 \\
\hline $\mathrm{O}$ & 10.2411735 & 16.2881803 & 19.8971968 \\
\hline $\mathrm{O}$ & 8.7016408 & 17.1118099 & 24.8985107 \\
\hline $\mathrm{C}$ & 9.7888461 & 12.0188722 & 20.3503202 \\
\hline $\mathrm{H}$ & 10.1125693 & 11.3623572 & 19.5447727 \\
\hline $\mathrm{H}$ & 10.1108369 & 11.8119547 & 21.3731256 \\
\hline $\mathrm{H}$ & 9.3731288 & 12.9954840 & 20.1089768 \\
\hline $\mathrm{O}$ & 11.9147239 & 12.2828334 & 22.6739568 \\
\hline $\mathrm{C}$ & 5.4747604 & 12.6781395 & 23.5083963 \\
\hline $\mathrm{H}$ & 5.7699886 & 11.9621168 & 24.2872334 \\
\hline $\mathrm{H}$ & 5.7856030 & 13.6918808 & 23.8164269 \\
\hline $\mathrm{H}$ & 4.3745476 & 12.7170735 & 23.4496267 \\
\hline C & 6.8596805 & 11.2909327 & 21.9211061 \\
\hline $\mathrm{C}$ & 6.0557575 & 12.3470799 & 22.1837752 \\
\hline $\mathrm{H}$ & 7.1408555 & 10.6091111 & 22.7303973 \\
\hline C & 7.3885141 & 11.0089227 & 20.5939710 \\
\hline $\mathrm{H}$ & 5.7942435 & 13.0194382 & 21.3558930 \\
\hline $\mathrm{H}$ & 8.5465066 & 11.4156005 & 20.5394732 \\
\hline $\mathrm{H}$ & 6.9227949 & 11.5474650 & 19.7592924 \\
\hline $\mathrm{H}$ & 7.5758938 & 9.9532055 & 20.3598140 \\
\hline $\mathrm{H}$ & 5.2304556 & 15.2537438 & 29.9933038 \\
\hline $\mathrm{H}$ & 16.2398806 & 19.9491182 & 22.4958551 \\
\hline \multicolumn{4}{|c|}{ Mg 19} \\
\hline $\mathrm{H}$ & 8.7145199 & 9.1960464 & 15.3413935 \\
\hline Al & 5.4042145 & 9.5426501 & 16.6974005 \\
\hline $\mathrm{P}$ & 5.4111464 & 9.4996045 & 28.5066128 \\
\hline Al & 5.3036130 & 6.9573120 & 21.619190 \\
\hline & & & \\
\hline
\end{tabular}




\begin{tabular}{|c|c|c|c|}
\hline Al & 3.1962345 & 8.2557828 & 26.6618592 \\
\hline $\mathrm{P}$ & 3.3012100 & 8.3651570 & 23.5458404 \\
\hline Al & 8.5407970 & 9.4605574 & 28.5891642 \\
\hline $\mathrm{P}$ & 8.5495153 & 9.5806074 & 16.7703816 \\
\hline Al & 8.5170279 & 6.9914064 & 18.5731266 \\
\hline $\mathrm{P}$ & 8.4834012 & 6.9147412 & 21.7447198 \\
\hline Al & 1.5484047 & 10.9989516 & 23.5834534 \\
\hline $\mathrm{P}$ & 1.5308977 & 10.9756398 & 26.7299731 \\
\hline 0 & 7.0802224 & 9.9593005 & 17.0599403 \\
\hline 0 & 5.0109251 & 10.9497363 & 28.1613416 \\
\hline $\mathrm{H}$ & 4.7083267 & 5.6024844 & 21.7841058 \\
\hline $\mathrm{H}$ & 9.0435260 & 5.5558660 & 21.9831289 \\
\hline $\mathrm{O}$ & 6.8433164 & 6.6023471 & 18.2405902 \\
\hline $\mathrm{O}$ & 1.9970982 & 9.5128513 & 26.8689401 \\
\hline $\mathrm{H}$ & 2.2530208 & 7.3356951 & 23.3037075 \\
\hline $\mathrm{H}$ & 0.1778717 & 10.4674492 & 23.3462508 \\
\hline 0 & 4.9346381 & 8.1029865 & 17.5497929 \\
\hline $\mathrm{O}$ & 4.5477587 & 8.5008078 & 27.7334971 \\
\hline $\mathrm{O}$ & 4.5099303 & 8.1420690 & 22.6268441 \\
\hline $\mathrm{O}$ & 2.3476442 & 11.8895419 & 27.6511498 \\
\hline $\mathrm{O}$ & 8.9865377 & 8.4184828 & 17.6710523 \\
\hline 0 & 1.9590981 & 12.3740263 & 22.6074153 \\
\hline $\mathrm{O}$ & 4.3870152 & 10.8686042 & 17.1970282 \\
\hline 0 & 6.8755353 & 9.2801445 & 28.1098631 \\
\hline $\mathrm{O}$ & 6.9894919 & 6.9007568 & 22.0664944 \\
\hline $\mathrm{H}$ & 9.3698512 & 5.8402029 & 18.1674872 \\
\hline $\mathrm{H}$ & 4.5216112 & 5.7816188 & 18.2030439 \\
\hline $\mathrm{H}$ & 0.1071981 & 11.0581438 & 27.1582171 \\
\hline $\mathrm{H}$ & 2.5747357 & 6.9480816 & 27.0093896 \\
\hline $\mathrm{O}$ & 2.7256814 & 9.7505911 & 23.2395132 \\
\hline $\mathrm{H}$ & 5.2502194 & 9.2857667 & 15.2388337 \\
\hline $\mathrm{O}$ & 5.1823270 & 7.4615768 & 19.9401786 \\
\hline $\mathrm{O}$ & 3.7828643 & 8.2853939 & 25.0100760 \\
\hline $\mathrm{H}$ & 8.6925367 & 9.2259681 & 30.0517179 \\
\hline $\mathrm{O}$ & 8.7176134 & 7.3510116 & 20.2796066 \\
\hline 0 & 1.6981241 & 11.4588007 & 25.2789315 \\
\hline $\mathrm{H}$ & 5.2298838 & 9.2501781 & 29.9633389 \\
\hline $\mathrm{H}$ & 3.4962681 & 12.1721826 & 15.2771058 \\
\hline Al & 3.2884151 & 16.2522546 & 21.6417460 \\
\hline $\mathrm{P}$ & 3.1860346 & 16.3034543 & 18.4715921 \\
\hline Al & 3.8153289 & 12.1850392 & 28.5325919 \\
\hline $\mathrm{P}$ & 3.8062070 & 12.2138721 & 16.7328944 \\
\hline $\mathrm{Al}$ & 1.6562983 & 13.5392107 & 18.5958190 \\
\hline $\mathrm{P}$ & 1.7436459 & 13.5717378 & 21.6616612 \\
\hline 0 & 4.8530948 & 13.3103011 & 17.0301360 \\
\hline $\mathrm{H}$ & 0.3552216 & 14.1080243 & 21.7040332 \\
\hline $\mathrm{H}$ & 2.3043810 & 17.3300217 & 21.9370688 \\
\hline $\mathrm{O}$ & 2.1250082 & 15.2053632 & 18.2594687 \\
\hline $\mathrm{O}$ & 4.4012281 & 16.0785724 & 17.5623025 \\
\hline $\mathrm{O}$ & 4.7608581 & 16.5130971 & 22.5413578 \\
\hline 0 & 2.5063533 & 12.4759385 & 17.4961459 \\
\hline 0 & 4.4425066 & 13.7406191 & 28.0607769 \\
\hline $\mathrm{O}$ & 2.7529555 & 14.6627237 & 22.0950627 \\
\hline $\mathrm{H}$ & 2.5943740 & 17.6213044 & 18.1105803 \\
\hline $\mathrm{H}$ & 0.1956822 & 13.3876067 & 18.3493693 \\
\hline $\mathrm{O}$ & 3.6668565 & 16.3135360 & 19.9315285 \\
\hline $\mathrm{H}$ & 3.5350274 & 12.1729589 & 29.9949208 \\
\hline $\mathrm{O}$ & 2.1156013 & 13.1007093 & 20.2247857 \\
\hline Al & 10.1391874 & 12.3014355 & 16.5591326 \\
\hline $\mathrm{P}$ & 10.0550440 & 12.2316641 & 28.3972501 \\
\hline Al & 12.2791379 & 10.8501487 & 26.6856213 \\
\hline $\mathrm{P}$ & 12.3256305 & 10.7948044 & 23.4909434 \\
\hline Al & 15.4234035 & 10.9989516 & 23.5834534 \\
\hline Al & 10.5717774 & 8.2147850 & 23.6457843 \\
\hline $\mathrm{P}$ & 10.6744871 & 8.1787474 & 26.7544421 \\
\hline $\mathrm{P}$ & 15.4058964 & 10.9756398 & 26.7299731 \\
\hline 0 & 9.0381346 & 11.0925306 & 28.1818145 \\
\hline 0 & 11.7557793 & 9.2223123 & 27.0993672 \\
\hline $\mathrm{H}$ & 15.8562018 & 9.5627250 & 26.8642020 \\
\hline $\mathrm{H}$ & 11.4425406 & 7.0125742 & 23.5292453 \\
\hline 0 & 13.8098921 & 10.3732205 & 23.3041978 \\
\hline 0 & 11.3020711 & 12.0202886 & 27.5399634 \\
\hline $\mathrm{O}$ & 9.5087188 & 8.2802769 & 27.7493182 \\
\hline $\mathrm{H}$ & 16.1990708 & 11.8631658 & 27.6245638 \\
\hline 0 & 9.1506804 & 7.9612536 & 22.6542299 \\
\hline $\mathrm{O}$ & 15.8340969 & 12.3740263 & 22.6074153 \\
\hline 0 & 9.4420147 & 10.7877887 & 17.1099173 \\
\hline 0 & 13.9398317 & 11.0605988 & 27.1709604 \\
\hline $\mathrm{H}$ & 11.2647443 & 6.8167693 & 26.8716282 \\
\hline $\mathrm{H}$ & 16.4250683 & 9.9368063 & 23.290818 \\
\hline
\end{tabular}




\begin{tabular}{|c|c|c|c|}
\hline 0 & 11.4346559 & 9.6040471 & 23.0632106 \\
\hline $\mathrm{H}$ & 10.4317249 & 12.2741937 & 15.0994065 \\
\hline 0 & 12.0774763 & 11.0984209 & 24.9852978 \\
\hline $\mathrm{O}$ & 15.5731228 & 11.4588007 & 25.2789315 \\
\hline $\mathrm{O}$ & 10.1228026 & 8.4172432 & 25.3327547 \\
\hline $\mathrm{H}$ & 10.4658398 & 12.2684682 & 29.8279887 \\
\hline $\mathrm{H}$ & 8.6836462 & 15.2828656 & 15.1919127 \\
\hline Al & 5.3595146 & 14.9481652 & 16.6498824 \\
\hline $\mathrm{P}$ & 5.3137638 & 14.9333745 & 28.4691037 \\
\hline Al & 12.2411124 & 18.9734134 & 21.6191905 \\
\hline Mg & 12.3772861 & 13.5993644 & 21.7243327 \\
\hline Al & 17.1634139 & 16.2522546 & 21.6417460 \\
\hline $\mathrm{P}$ & 17.0610333 & 16.3034543 & 18.4715921 \\
\hline$P$ & 12.3018489 & 13.4817761 & 18.4560493 \\
\hline$P$ & 12.3040129 & 18.9894193 & 18.4913385 \\
\hline Al & 5.3946726 & 17.4391471 & 26.6140499 \\
\hline $\mathrm{P}$ & 5.3822472 & 17.4915280 & 23.5426980 \\
\hline Al & 8.4724057 & 14.9558927 & 28.4584911 \\
\hline $\mathrm{P}$ & 8.5172410 & 15.0002712 & 16.6443486 \\
\hline Al & 15.5312970 & 13.5392107 & 18.5958190 \\
\hline Al & 15.4545272 & 19.0075078 & 18.5731266 \\
\hline Al & 10.7111870 & 16.2149571 & 18.5164096 \\
\hline $\mathrm{P}$ & 10.5376346 & 16.2359685 & 21.6521655 \\
\hline $\mathrm{P}$ & 15.4209006 & 18.9308426 & 21.7447198 \\
\hline$P$ & 15.6186446 & 13.5717378 & 21.6616612 \\
\hline Al & 8.5282047 & 17.6982095 & 23.5226781 \\
\hline $\mathrm{P}$ & 8.5423478 & 17.5388825 & 26.6732299 \\
\hline 0 & 8.9836249 & 13.5593005 & 16.9643554 \\
\hline 0 & 6.7848076 & 14.5930301 & 28.1609385 \\
\hline 0 & 11.5494283 & 17.3991917 & 21.8108114 \\
\hline $\mathrm{O}$ & 14.2064876 & 14.1171912 & 21.7047575 \\
\hline 0 & 15.9995840 & 17.5269436 & 21.9910281 \\
\hline 0 & 16.0000069 & 15.2053632 & 18.2594687 \\
\hline 0 & 11.8896387 & 14.9470246 & 18.1981673 \\
\hline $\mathrm{O}$ & 13.7808157 & 18.6184484 & 18.2405902 \\
\hline 0 & 7.0615040 & 17.8820812 & 26.9484128 \\
\hline $\mathrm{H}$ & 9.0613643 & 19.0749938 & 23.3294776 \\
\hline $\mathrm{H}$ & 4.6666858 & 18.7969363 & 23.5110495 \\
\hline $\mathrm{H}$ & 18.2403487 & 16.0852120 & 17.5891489 \\
\hline $\mathrm{H}$ & 11.8844516 & 20.0868774 & 17.5766394 \\
\hline $\mathrm{O}$ & 11.6344988 & 12.5572021 & 17.4183352 \\
\hline O & 4.8645402 & 16.1556064 & 27.6643363 \\
\hline $\mathrm{H}$ & 11.5643026 & 19.9837102 & 22.4784631 \\
\hline $\mathrm{H}$ & 18.4197589 & 16.4748155 & 22.4093295 \\
\hline 0 & 8.9756953 & 16.3365942 & 27.5238570 \\
\hline $\mathrm{H}$ & 16.2545815 & 12.6345065 & 17.6601425 \\
\hline $\mathrm{O}$ & 9.3455369 & 16.0136614 & 17.4376774 \\
\hline $\mathrm{H}$ & 15.8534777 & 20.2201187 & 17.8066189 \\
\hline 0 & 9.2498478 & 16.5775244 & 22.4251330 \\
\hline 0 & 7.0468671 & 15.1297312 & 17.0638911 \\
\hline 0 & 9.4103260 & 13.5612160 & 27.9941912 \\
\hline $\mathrm{O}$ & 13.9269913 & 18.9168582 & 22.0664944 \\
\hline $\mathrm{O}$ & 11.1243070 & 14.9496079 & 22.1678580 \\
\hline 0 & 16.6279542 & 14.6627237 & 22.0950627 \\
\hline 0 & 16.4508080 & 17.6626550 & 18.0992527 \\
\hline 0 & 13.8191276 & 13.3614969 & 18.3069247 \\
\hline $\mathrm{O}$ & 11.4366984 & 17.7661088 & 18.1953965 \\
\hline $\mathrm{H}$ & 4.4930485 & 18.6028655 & 26.8375540 \\
\hline $\mathrm{H}$ & 9.3817892 & 18.7071444 & 27.0574472 \\
\hline 0 & 6.8348470 & 17.7365935 & 23.1466904 \\
\hline $\mathrm{H}$ & 5.1687334 & 15.2045175 & 15.1955761 \\
\hline 0 & 12.1198263 & 19.4776781 & 19.9401786 \\
\hline 0 & 11.8707339 & 13.0275043 & 19.8745885 \\
\hline 0 & 17.5418552 & 16.3135360 & 19.9315285 \\
\hline 0 & 5.2905597 & 16.8762100 & 24.9549238 \\
\hline $\mathrm{H}$ & 8.6565841 & 15.2416530 & 29.9081600 \\
\hline 0 & 15.9906000 & 13.1007093 & 20.2247857 \\
\hline 0 & 15.6551128 & 19.3671130 & 20.2796066 \\
\hline $\mathrm{O}$ & 10.1358705 & 16.1204822 & 20.1547648 \\
\hline 0 & 8.7533284 & 17.1919677 & 25.1894083 \\
\hline $\mathrm{C}$ & 10.0007109 & 12.1000380 & 20.1913472 \\
\hline $\mathrm{H}$ & 10.1880647 & 11.4326661 & 19.3530353 \\
\hline $\mathrm{H}$ & 10.3732716 & 11.8302888 & 21.1822972 \\
\hline $\mathrm{H}$ & 9.5169977 & 13.0626698 & 20.0330388 \\
\hline 0 & 11.9684232 & 11.9969678 & 22.6563351 \\
\hline C & 5.5360739 & 12.5925331 & 23.4468661 \\
\hline $\mathrm{H}$ & 5.9209454 & 11.9641522 & 24.2616602 \\
\hline $\mathrm{H}$ & 5.7252011 & 13.6528122 & 23.6894174 \\
\hline $\mathrm{H}$ & 4.4389685 & 12.4986875 & 23.4010762 \\
\hline & & & \\
\hline
\end{tabular}




\begin{tabular}{|c|c|c|c|}
\hline C & 6.1406372 & 12.2501880 & 22.1340091 \\
\hline $\mathrm{H}$ & 7.4260477 & 10.6926362 & 22.7698127 \\
\hline $\mathrm{C}$ & 7.6111482 & 10.9725402 & 20.6035252 \\
\hline $\mathrm{H}$ & 5.7889905 & 12.8309378 & 21.2709587 \\
\hline $\mathrm{H}$ & 8.6975324 & 11.4652899 & 20.5106044 \\
\hline $\mathrm{H}$ & 7.0726436 & 11.4069288 & 19.7513431 \\
\hline $\mathrm{H}$ & 7.8657211 & 9.9176761 & 20.4345818 \\
\hline $\mathrm{H}$ & 5.1415026 & 15.2387316 & 29.9162401 \\
\hline $\mathrm{H}$ & 16.0666183 & 19.9435396 & 22.6248414 \\
\hline \multicolumn{4}{|c|}{ Al 19} \\
\hline \multicolumn{4}{|c|}{174} \\
\hline $\mathrm{H}$ & 8.6539549 & 9.0619386 & 15.2911611 \\
\hline $\mathrm{Si}$ & 5.3384843 & 9.4491763 & 16.7133657 \\
\hline $\mathrm{Si}$ & 5.3391883 & 9.4068481 & 28.6429332 \\
\hline $\mathrm{Si}$ & 5.3154857 & 6.9646928 & 21.6723713 \\
\hline $\mathrm{Si}$ & 5.3588821 & 6.9798285 & 18.6002301 \\
\hline $\mathrm{Si}$ & 3.2415694 & 8.1654072 & 26.7042730 \\
\hline $\mathrm{Si}$ & 3.3210563 & 8.2484138 & 23.6471087 \\
\hline $\mathrm{Si}$ & 8.4481544 & 9.3588637 & 28.6479796 \\
\hline $\mathrm{Si}$ & 8.4613446 & 9.4506981 & 16.7155514 \\
\hline $\mathrm{Si}$ & 8.4788705 & 6.9777899 & 18.6158838 \\
\hline $\mathrm{Si}$ & 8.4547233 & 6.9190605 & 21.7222153 \\
\hline $\mathrm{Si}$ & 1.6465712 & 10.9016081 & 23.6339673 \\
\hline $\mathrm{Si}$ & 1.6352077 & 10.8810734 & 26.7122534 \\
\hline 0 & 6.9017290 & 9.8446344 & 16.9908711 \\
\hline $\mathrm{O}$ & 4.9277779 & 10.9551298 & 28.3384315 \\
\hline $\mathrm{H}$ & 4.7458893 & 5.5960032 & 21.8115449 \\
\hline $\mathrm{H}$ & 8.9954943 & 5.5464143 & 21.9235352 \\
\hline O & 6.9225309 & 6.5876461 & 18.3426830 \\
\hline 0 & 2.1179958 & 9.3317476 & 26.8511455 \\
\hline $\mathrm{H}$ & 2.2788212 & 7.2075302 & 23.4293292 \\
\hline $\mathrm{H}$ & 0.2600552 & 10.3969244 & 23.4339967 \\
\hline $\mathrm{O}$ & 4.9050544 & 8.1797045 & 17.6128585 \\
\hline O & 4.4487007 & 8.3875001 & 27.7601823 \\
\hline $\mathrm{O}$ & 4.5839582 & 8.0278727 & 22.6549519 \\
\hline $\mathrm{O}$ & 2.4841025 & 11.8367804 & 27.7060990 \\
\hline $\mathrm{O}$ & 8.9186567 & 8.2374204 & 17.6887140 \\
\hline 0 & 2.0150941 & 12.1263687 & 22.6472596 \\
\hline 0 & 4.4167737 & 10.7093695 & 17.1428165 \\
\hline $\mathrm{O}$ & 6.8915073 & 9.1919996 & 28.2408272 \\
\hline $\mathrm{O}$ & 6.8822214 & 6.9236476 & 22.0830197 \\
\hline $\mathrm{H}$ & 9.3384897 & 5.8131810 & 18.2667969 \\
\hline $\mathrm{H}$ & 4.5136902 & 5.7918105 & 18.2979312 \\
\hline $\mathrm{H}$ & 0.2088152 & 10.9559410 & 27.1328719 \\
\hline $\mathrm{H}$ & 2.6091546 & 6.8560892 & 27.0249886 \\
\hline $\mathrm{O}$ & 2.6963656 & 9.7036607 & 23.3225761 \\
\hline $\mathrm{H}$ & 5.1333326 & 9.0998009 & 15.2805468 \\
\hline 0 & 5.1654550 & 7.4961912 & 20.1340778 \\
\hline O & 3.8530584 & 8.1761012 & 25.1915197 \\
\hline $\mathrm{H}$ & 8.6519402 & 9.0556849 & 30.0914735 \\
\hline 0 & 8.6863472 & 7.4122035 & 20.1779288 \\
\hline 0 & 1.8350604 & 11.4038983 & 25.1821100 \\
\hline $\mathrm{H}$ & 5.1337060 & 9.0967600 & 30.0847179 \\
\hline $\mathrm{H}$ & 3.4001030 & 12.0954763 & 15.2462199 \\
\hline $\mathrm{Si}$ & 3.2966276 & 16.0112744 & 21.6845506 \\
\hline $\mathrm{Si}$ & 3.2341240 & 16.0615361 & 18.5835188 \\
\hline $\mathrm{Si}$ & 3.7950735 & 12.0983180 & 28.6116583 \\
\hline $\mathrm{Si}$ & 3.7765140 & 12.1289507 & 16.6864681 \\
\hline $\mathrm{Si}$ & 1.6763571 & 13.3599819 & 18.6163362 \\
\hline $\mathrm{Si}$ & 1.6739981 & 13.3650430 & 21.6448884 \\
\hline $\mathrm{O}$ & 4.9020072 & 13.2812364 & 16.9592064 \\
\hline $\mathrm{H}$ & 0.2508629 & 13.8012822 & 21.6836484 \\
\hline $\mathrm{H}$ & 2.3254304 & 17.1152704 & 21.9192621 \\
\hline $\mathrm{O}$ & 2.0990904 & 14.9181106 & 18.3451323 \\
\hline 0 & 4.5071593 & 15.8420911 & 17.6033052 \\
\hline $\mathrm{O}$ & 4.6180312 & 16.2117876 & 22.6041357 \\
\hline 0 & 2.4412529 & 12.3951279 & 17.5561168 \\
\hline $\mathrm{O}$ & 4.4065848 & 13.5370352 & 28.1939472 \\
\hline O & 2.6598147 & 14.5886543 & 22.0968293 \\
\hline $\mathrm{H}$ & 2.6513658 & 17.3943396 & 18.2654806 \\
\hline $\mathrm{H}$ & 0.2129158 & 13.2187593 & 18.3807169 \\
\hline $\mathrm{O}$ & 3.7637453 & 16.0209543 & 20.1220357 \\
\hline $\mathrm{H}$ & 3.4018559 & 12.0928977 & 30.0477889 \\
\hline $\mathrm{O}$ & 2.1024464 & 12.9068059 & 20.1200951 \\
\hline $\mathrm{Si}$ & 10.0421861 & 12.1424942 & 16.6084555 \\
\hline $\mathrm{Si}$ & 9.9855183 & 12.0809342 & 28.5451181 \\
\hline $\mathrm{Si}$ & 12.1556908 & 10.8019986 & 26.7474563 \\
\hline $\mathrm{Si}$ & 12.1836247 & 10.7836857 & 23.6106107 \\
\hline & & & \\
\hline
\end{tabular}




\begin{tabular}{|c|c|c|c|}
\hline $\mathrm{Si}$ & 10.4564038 & 8.1933191 & 23.6770613 \\
\hline $\mathrm{Si}$ & 10.5367233 & 8.1625903 & 26.7338473 \\
\hline $\mathrm{Si}$ & 15.2602064 & 10.8810734 & 26.7122534 \\
\hline 0 & 8.8961757 & 10.8898658 & 28.3151093 \\
\hline $\mathrm{O}$ & 11.6809089 & 9.2725706 & 27.0673635 \\
\hline $\mathrm{H}$ & 15.7015737 & 9.4646721 & 26.8392292 \\
\hline $\mathrm{H}$ & 11.3414603 & 7.0009491 & 23.5672910 \\
\hline $\mathrm{O}$ & 13.7561492 & 10.3500039 & 23.4154054 \\
\hline $\mathrm{O}$ & 11.2981741 & 11.8552740 & 27.6348421 \\
\hline 0 & 9.3076758 & 8.2948252 & 27.7836630 \\
\hline $\mathrm{H}$ & 16.0408536 & 11.7599455 & 27.6261979 \\
\hline $\mathrm{O}$ & 9.1686371 & 8.0027619 & 22.7013983 \\
\hline 0 & 15.6400928 & 12.1263687 & 22.6472596 \\
\hline $\mathrm{O}$ & 9.3855806 & 10.7327542 & 17.0930726 \\
\hline $\mathrm{O}$ & 13.7100920 & 10.9624348 & 27.1693553 \\
\hline $\mathrm{H}$ & 11.1318403 & 6.8072230 & 26.8948925 \\
\hline $\mathrm{H}$ & 16.2346933 & 9.8025633 & 23.3482846 \\
\hline 0 & 11.2657731 & 9.4995680 & 23.1896936 \\
\hline $\mathrm{H}$ & 10.4058507 & 12.1032815 & 15.1650806 \\
\hline $\mathrm{O}$ & 11.9277124 & 11.1375404 & 25.1848907 \\
\hline 0 & 15.4600592 & 11.4038983 & 25.1821100 \\
\hline 0 & 9.9520953 & 8.3622599 & 25.2213772 \\
\hline $\mathrm{H}$ & 10.3988825 & 12.0982999 & 29.9754849 \\
\hline $\mathrm{H}$ & 8.7020653 & 15.1753993 & 15.1739274 \\
\hline $\mathrm{Si}$ & 5.3463225 & 14.8237175 & 16.6665894 \\
\hline $\mathrm{Si}$ & 5.3121038 & 14.8099656 & 28.6153660 \\
\hline $\mathrm{Si}$ & 12.1279850 & 18.7642878 & 21.6723713 \\
\hline Al & 12.1096101 & 13.3738961 & 21.7098974 \\
\hline $\mathrm{Si}$ & 16.9216263 & 16.0112744 & 21.6845506 \\
\hline $\mathrm{Si}$ & 16.8591228 & 16.0615361 & 18.5835188 \\
\hline $\mathrm{Si}$ & 12.1140915 & 13.3351577 & 18.5692579 \\
\hline $\mathrm{Si}$ & 12.1713814 & 18.7794235 & 18.6002301 \\
\hline $\mathrm{Si}$ & 5.3316800 & 17.2213472 & 26.6715557 \\
\hline $\mathrm{Si}$ & 5.3053062 & 17.2465804 & 23.6407480 \\
\hline $\mathrm{Si}$ & 8.4472238 & 14.7955673 & 28.5538216 \\
\hline $\mathrm{Si}$ & 8.4842093 & 14.8503360 & 16.6105878 \\
\hline $\mathrm{Si}$ & 15.3013558 & 13.3599819 & 18.6163362 \\
\hline $\mathrm{Si}$ & 15.2913699 & 18.7773849 & 18.6158838 \\
\hline $\mathrm{Si}$ & 10.5659730 & 16.0575564 & 18.5643682 \\
\hline $\mathrm{Si}$ & 10.4435926 & 16.0558249 & 21.6474218 \\
\hline $\mathrm{Si}$ & 15.2672227 & 18.7186555 & 21.7222153 \\
\hline $\mathrm{Si}$ & 15.2989968 & 13.3650430 & 21.6448884 \\
\hline $\mathrm{Si}$ & 8.4275003 & 17.3963095 & 23.5727789 \\
\hline $\mathrm{Si}$ & 8.4448738 & 17.2721411 & 26.6607481 \\
\hline 0 & 8.9456420 & 13.3110784 & 16.9146968 \\
\hline $\mathrm{O}$ & 6.8732864 & 14.4307095 & 28.3549625 \\
\hline 0 & 11.5116496 & 17.2832884 & 21.8229649 \\
\hline $\mathrm{O}$ & 13.7759523 & 13.8319078 & 21.6863695 \\
\hline $\mathrm{O}$ & 15.8571008 & 17.2213601 & 21.9418170 \\
\hline $\mathrm{O}$ & 15.7240891 & 14.9181106 & 18.3451323 \\
\hline 0 & 11.6796640 & 14.8907280 & 18.3218288 \\
\hline $\mathrm{O}$ & 13.7350303 & 18.3872411 & 18.3426830 \\
\hline $\mathrm{O}$ & 6.8811912 & 17.6581097 & 26.9341510 \\
\hline $\mathrm{H}$ & 8.9478118 & 18.7834089 & 23.4232740 \\
\hline $\mathrm{H}$ & 4.6589806 & 18.5858161 & 23.5643832 \\
\hline $\mathrm{H}$ & 18.0280589 & 15.8600356 & 17.6834596 \\
\hline $\mathrm{H}$ & 11.7539471 & 19.8830791 & 17.6920378 \\
\hline $\mathrm{O}$ & 11.3925327 & 12.3771124 & 17.4649177 \\
\hline $\mathrm{O}$ & 4.8667414 & 16.0688418 & 27.7065515 \\
\hline $\mathrm{H}$ & 11.4564493 & 19.7402775 & 22.5743716 \\
\hline $\mathrm{H}$ & 18.1344324 & 16.1953087 & 22.5285609 \\
\hline 0 & 8.8854513 & 16.0238306 & 27.5968938 \\
\hline $\mathrm{H}$ & 16.0023088 & 12.4757865 & 17.6447477 \\
\hline $\mathrm{O}$ & 9.3377959 & 15.8846913 & 17.5131263 \\
\hline $\mathrm{H}$ & 15.6944180 & 19.9317908 & 17.7661662 \\
\hline $\mathrm{O}$ & 9.1147638 & 16.3871211 & 22.5255723 \\
\hline $\mathrm{O}$ & 6.9205019 & 14.9835982 & 17.0167896 \\
\hline $\mathrm{O}$ & 9.3181798 & 13.4965305 & 28.1359632 \\
\hline $\mathrm{O}$ & 13.6947208 & 18.7232427 & 22.0830197 \\
\hline 0 & 11.0720361 & 14.6823065 & 22.1251208 \\
\hline $\mathrm{O}$ & 16.2848134 & 14.5886543 & 22.0968293 \\
\hline $\mathrm{O}$ & 16.2242570 & 17.5135129 & 18.2370431 \\
\hline 0 & 13.7120400 & 13.2066124 & 18.3604506 \\
\hline 0 & 11.2562103 & 17.4930412 & 18.2729018 \\
\hline $\mathrm{H}$ & 4.4429920 & 18.3958992 & 26.8901462 \\
\hline $\mathrm{H}$ & 9.2935279 & 18.4411825 & 27.0216482 \\
\hline $\mathrm{O}$ & 6.8505208 & 17.4273224 & 23.2283405 \\
\hline $\mathrm{H}$ & 5.0936277 & 15.1686504 & 15.2403050 \\
\hline $\mathrm{O}$ & 11.9779544 & 19.2957862 & 20.1340778 \\
\hline $\mathrm{O}$ & 11.6546232 & 12.8274594 & 20.0506932 \\
\hline
\end{tabular}




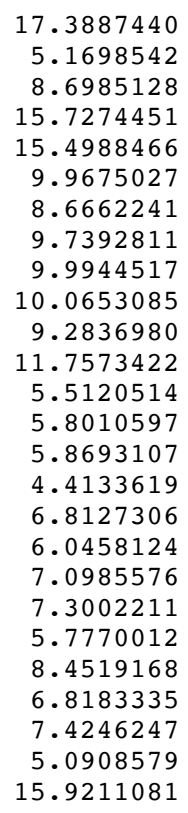

16.0209543

16.6456414

15.1701346

12.9068059

19.2117986

15.9968473

16.8653642

11.8682959

11.2109170

11.6149545

12.8375108

12.0139016

12.5588096

11.8133007

13.5519210

12.6398680

11.1659394

12.2366226

10.4635613

10.8893476

12.9294793

11.2416988

11.4541302

9.8284016

15.1673082

19.7112354

9.2449357

9.5971473

9.5281253

6.9967182

7.0089328

8.1799904

8.3156200

9.4234411

9.5420510

6.9798125

6.9062026

10.9914520

10.9363657

9.9578153

11.1785070

5.6254236

5.5425082

6.6152441

9.2760590

7.3259904

10.4376841

8.3734206

8.3952153

8.0043418

11.9945728

8.1845348

12.1878934

10.7802012

9.2581707

6.9759580

5.8206519

5.8438837

10.9927669

6.8594363

9.9129110

9.2911752

7.4820858

8.2107246

9.2020229

7.3584055

11.4516656

9.3180204

12.2765534

16.1715344

16.2323688

12.2622744

12.3045799

13.5245353

13.5483769

13.5420056

14.0523718
20.1220357

25.1526075

29.9728614

20.1200951

20.1779288

20.0719340

25.0995378

20.2769758

19.4481360

21.2881566

20.0832491

22.7071999

23.5904870

24.3437548

23.9141037

23.5614433

21.9397254

22.2429804

22.7299154

20.5907689

21.4346481

20.5124456

19.7824143

20.3365375

30.0438187

22. 6190651

15.2259186

16.7643348

28.5709326

21.6832655

18.5479919

26.7072300

23.6122755

28.4861532

16.6795883

18.5142151

21.6867725

23.5347790

26.6785937

17.0537405

28.1754207

21.8354241

21.9349932

18.2433629

26.8359981

23.3907230

23.2571420

17.5790884

27.7334483

22.5879862

27.6801290

17.6582240

22.6305962

17.1881082

28.1014876

22.0898741

18.1474674

18.1826665

27.1636241

26.9925403

23.2563857

15.3192311

20.2247435

25.2919791

29.9463890

19.9987780

25.0078578

30.0388279

15.2092989

21.6934878

18.5278751

28.4742177

16.6715245

18.4982546

21.5970228

17.0413352

21.6675301 


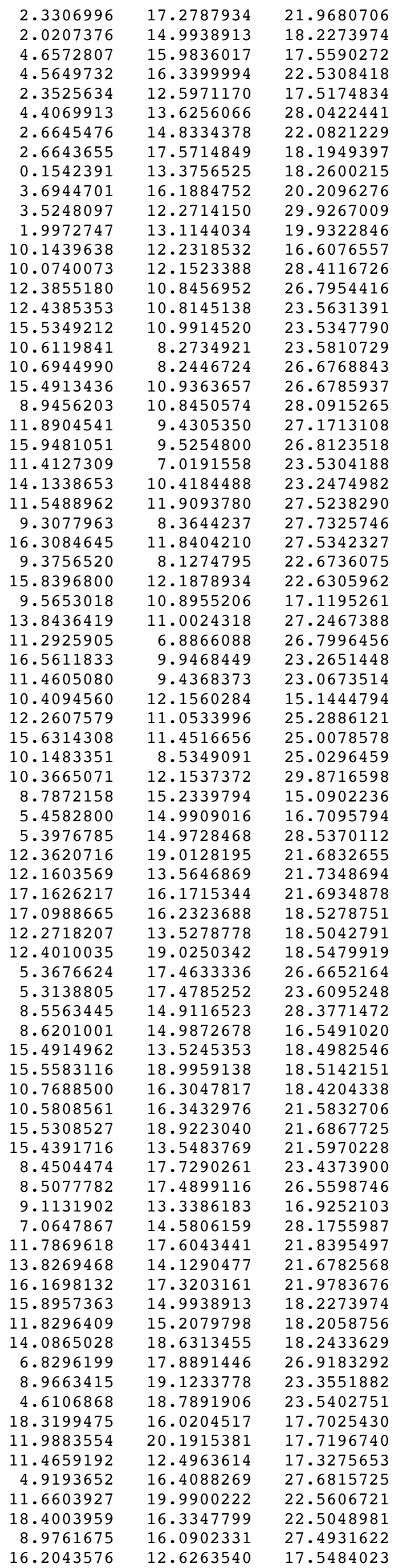

17.2787934

14.9938913

15.9836017

16.3399994

12.5971170

13.6256066

14.8334378

17.5714849

13.3756525

16.1884752

12.2714150

13.1144034

12.2318532

12.1523388

10.8456952

10.8145138

10.9914520

8.2734921

8.2446724

10.9363657

10.8450574

9. 4305350

9.5254800

7.0191558

10.4184488

11.9093780

8.3644237

11.8404210

8.1274795

12.1878934

10.8955206

11.0024318

6.8866088

9.9468449

9.4368373

12.1560284

11.0533996

11.4516656

8.5349091

12.1537372

15.2339794

14.9909016

14.9728468

19.0128195

13.5646869

16.1715344

16.2323688

13.5278778

19.0250342

17.4633336

17.4785252

14.9116523

14.9872678

13.5245353

18.9959138

16.3047817

16.3432976

18.9223040

13.5483769

17.7290261

17.4899116

13.3386183

14.5806159

17.6043441

14.1290477

17.3203161

14.9938913

15.2079798

18.6313455

17.8891446

19.1233778

18.7891906

16.0204517

20.1915381

12.4963614

16.4088269

19.9900222

16.3347799

16.0902331

12.6263540

21.9680706

8. 2273974

17.5590272

22.5308418

17.5174834

28.0422441

22.0821229

18.1949397

18.2600215

20.2096276

29.9267009

19.9322846

16.6076557

28.4116726

26.7954416

23.5631391

23.5347790

23.5810729

26.6768843

26.6785937

28.0915265

27.1713108

26.8123518

23.5304188

23.2474982

27.5238290

27.7325746

27.5342327

22.6736075

22.6305962

17.1195261

27.2467388

26.7996456

23.2651448

23.0673514

15.1444794

25.2886121

25.0078578

25.0296459

29.8716598

15.0902236

16.7095794

28.5370112

21.6832655

21.7348694

21.6934878

18.5278751

18.5042791

18.5479919

26.6652164

23.6095248

28.3771472

16.5491020

18.4982546

18.5142151

18.4204338

21.5832706

21.6867725

21.5970228

23.4373900

26.5598746

16.9252103

28.1755987

21.8395497

21.6782568

21.9783676

18.2273974

18.2058756

18.2433629

26.9183292

23.3551882

23.5402751

17.7025430

17.7196740

17.3275653

27.6815725

22.5606721

22.5048981

27.4931622

17.5484023 


\begin{tabular}{|c|c|c|c|}
\hline 0 & 9.5991293 & 16.1160852 & 17.4399174 \\
\hline $\mathrm{H}$ & 15.9660447 & 20.1633215 & 17.6847372 \\
\hline 0 & 9.1098248 & 16.8405179 & 22.3900652 \\
\hline $\mathrm{O}$ & 6.9484157 & 15.1606339 & 17.0336170 \\
\hline 0 & 9.3799907 & 13.6865718 & 27.9643541 \\
\hline $\mathrm{O}$ & 13.8414264 & 18.9920594 & 22.0898741 \\
\hline 0 & 11.0551146 & 14.8330818 & 22.2213447 \\
\hline 0 & 16.5395463 & 14.8334378 & 22.0821229 \\
\hline 0 & 16.4421963 & 17.8040469 & 18.1371194 \\
\hline 0 & 13.9900368 & 13.3716611 & 18.2536348 \\
\hline 0 & 11.4081902 & 17.6678202 & 18.1224092 \\
\hline $\mathrm{H}$ & 4.4772288 & 18.6471844 & 26.8160342 \\
\hline $\mathrm{H}$ & 9.3734864 & 18.6413509 & 26.9365144 \\
\hline 0 & 6.9514114 & 17.7658352 & 23.1331983 \\
\hline $\mathrm{H}$ & 5.2025346 & 15.2793437 & 15.2713458 \\
\hline $\mathrm{O}$ & 12.2245764 & 19.4981872 & 20.2247435 \\
\hline $\mathrm{O}$ & 11.7094540 & 12.9920992 & 20.0690319 \\
\hline 0 & 17.5694688 & 16.1884752 & 20.2096276 \\
\hline 0 & 5.2373501 & 16.8598473 & 25.2500404 \\
\hline $\mathrm{H}$ & 8.8078460 & 15.2650561 & 29.8015676 \\
\hline 0 & 15.8722735 & 13.1144034 & 19.9322846 \\
\hline 0 & 15.7522548 & 19.3745069 & 19.9987780 \\
\hline 0 & 10.2186891 & 16.2689311 & 19.8535342 \\
\hline 0 & 8.6979529 & 17.1525948 & 24.8494030 \\
\hline C & 9.7623168 & 11.9538306 & 20.3219713 \\
\hline $\mathrm{H}$ & 10.0579608 & 11.3418487 & 19.4719225 \\
\hline $\mathrm{H}$ & 10.1364412 & 11.7050090 & 21.3185661 \\
\hline $\mathrm{H}$ & 9.3278779 & 12.9362748 & 20.1454722 \\
\hline 0 & 11.8333295 & 12.1783774 & 22.7510831 \\
\hline $\mathrm{C}$ & 5.4830936 & 12.6402496 & 23.5001394 \\
\hline $\mathrm{H}$ & 5.7961551 & 11.9518137 & 24.2966385 \\
\hline $\mathrm{H}$ & 5.7829869 & 13.6666491 & 23.7744487 \\
\hline $\mathrm{H}$ & 4.3821255 & 12.6642404 & 23.4511994 \\
\hline $\mathrm{C}$ & 6.8682191 & 11.2244976 & 21.9383645 \\
\hline $\mathrm{C}$ & 6.0544438 & 12.2784526 & 22.1795857 \\
\hline $\mathrm{H}$ & 7.1661575 & 10.5681465 & 22.7625642 \\
\hline C & 7.3874760 & 10.9137418 & 20.6146868 \\
\hline $\mathrm{H}$ & 5.7762009 & 12.9237964 & 21.3357560 \\
\hline H & 8.5433259 & 11.3317718 & 20.5400760 \\
\hline $\mathrm{H}$ & 6.9103132 & 11.4265929 & 19.7704064 \\
\hline $\mathrm{H}$ & 7.5875740 & 9.8552559 & 20.4050524 \\
\hline $\mathrm{H}$ & 5.2242941 & 15.2420774 & 29.9911685 \\
\hline H & 16.1948689 & 19.9589255 & 22.5243994 \\
\hline \multicolumn{4}{|c|}{$\mathrm{Ga} 19$} \\
\hline \multicolumn{4}{|c|}{174} \\
\hline $\mathrm{H}$ & 8.6499776 & 9.0645668 & 15.2996910 \\
\hline $\mathrm{Si}$ & 5.3423882 & 9.4495817 & 16.7207883 \\
\hline $\mathrm{Si}$ & 5.3406152 & 9.3890838 & 28.6501371 \\
\hline $\mathrm{Si}$ & 5.3208448 & 6.9490370 & 21.6744960 \\
\hline $\mathrm{Si}$ & 5.3613841 & 6.9848642 & 18.6122509 \\
\hline $\mathrm{Si}$ & 3.2452168 & 8.1623105 & 26.7022492 \\
\hline $\mathrm{Si}$ & 3.3558638 & 8.2756406 & 23.6509189 \\
\hline $\mathrm{Si}$ & 8.4471704 & 9.3383936 & 28.6509454 \\
\hline $\mathrm{Si}$ & 8.4617556 & 9.4547083 & 16.7242902 \\
\hline $\mathrm{Si}$ & 8.4747484 & 6.9698918 & 18.6154235 \\
\hline $\mathrm{Si}$ & 8.4580822 & 6.8820628 & 21.7296320 \\
\hline $\mathrm{Si}$ & 1.6497896 & 10.8967776 & 23.6280815 \\
\hline $\mathrm{Si}$ & 1.6305310 & 10.8640963 & 26.7154978 \\
\hline 0 & 6.9030627 & 9.8524741 & 17.0003866 \\
\hline 0 & 4.9323861 & 10.9387083 & 28.3428375 \\
\hline $\mathrm{H}$ & 4.6997437 & 5.6001184 & 21.7829980 \\
\hline $\mathrm{H}$ & 9.0409801 & 5.5277260 & 21.9372916 \\
\hline 0 & 6.9186233 & 6.5786407 & 18.3353571 \\
\hline $\mathrm{O}$ & 2.1068964 & 9.3132536 & 26.8598762 \\
\hline $\mathrm{H}$ & 2.3107566 & 7.2346945 & 23.4476882 \\
\hline $\mathrm{H}$ & 0.2735415 & 10.3684432 & 23.4185001 \\
\hline 0 & 4.9068396 & 8.1841151 & 17.6249368 \\
\hline 0 & 4.4359818 & 8.3706165 & 27.7800248 \\
\hline 0 & 4.6238055 & 8.0255512 & 22.6702856 \\
\hline 0 & 2.4873275 & 11.8177893 & 27.7051244 \\
\hline 0 & 8.9120321 & 8.2436127 & 17.7047271 \\
\hline 0 & 1.9720985 & 12.1477880 & 22.6582497 \\
\hline 0 & 4.4162482 & 10.7090857 & 17.1409047 \\
\hline 0 & 6.8907288 & 9.1615713 & 28.2418335 \\
\hline 0 & 6.8840430 & 6.8314025 & 22.0844361 \\
\hline $\mathrm{H}$ & 9.3363191 & 5.8123369 & 18.2481592 \\
\hline $\mathrm{H}$ & 4.4952268 & 5.8062032 & 18.3335927 \\
\hline $\mathrm{H}$ & 0.2050832 & 10.9446436 & 27.1382639 \\
\hline $\mathrm{H}$ & 2.6197574 & 6.8405884 & 26.9832687 \\
\hline
\end{tabular}

17.4399174

7.6847372

17.0336170

27.9643541

22.0898741

22.0821229

18.2536348

18.1224092

8160342

23.1331983

13458

20.0690319

406276

29.8015676

.9322846

19.8535342

8494030

19.4719225

1.3185661

22.7510831

3.5001394

23.7744487

23.4511994

383645

22.7625642

20.6146868

21.3357560

20.4050524

29.9911685 $\mathrm{Ga} 19$

174 


$$
\begin{aligned}
& \text { 2. } 7331086 \\
& 9.7296753
\end{aligned}
$$




\begin{tabular}{|c|c|c|c|}
\hline 0 & 11.4611812 & 17.2888162 & 21.7919182 \\
\hline 0 & 13.8363605 & 13.9967070 & 21.7149049 \\
\hline $\mathrm{O}$ & 15.9068945 & 17.2032138 & 21.9563209 \\
\hline $\mathrm{O}$ & 15.7362865 & 14.9172499 & 18.3639981 \\
\hline 0 & 11.7041068 & 14.9114630 & 18.2680282 \\
\hline $\mathrm{O}$ & 13.7311227 & 18.3782357 & 18.3353571 \\
\hline $\mathrm{O}$ & 6.8865869 & 17.6418654 & 26.9184795 \\
\hline $\mathrm{H}$ & 8.9778526 & 18.8156412 & 23.4402017 \\
\hline $\mathrm{H}$ & 4.5600232 & 18.5340376 & 23.6096679 \\
\hline $\mathrm{H}$ & 18.0278511 & 15.8618423 & 17.6554879 \\
\hline $\mathrm{H}$ & 11.7557130 & 19.8877425 & 17.7039447 \\
\hline $\mathrm{O}$ & 11.4040086 & 12.3925897 & 17.4195680 \\
\hline $\mathrm{O}$ & 4.8602327 & 16.0637598 & 27.7002299 \\
\hline $\mathrm{H}$ & 11.4941234 & 19.7358508 & 22.5876862 \\
\hline $\mathrm{H}$ & 18.2041267 & 16.1870573 & 22.4947469 \\
\hline $\mathrm{O}$ & 8.8954156 & 16.0073840 & 27.5625872 \\
\hline $\mathrm{H}$ & 16.0133657 & 12.4820360 & 17.6460115 \\
\hline $\mathrm{O}$ & 9.3486729 & 15.8887929 & 17.4871778 \\
\hline $\mathrm{H}$ & 15.6877579 & 19.9360935 & 17.7813126 \\
\hline $\mathrm{O}$ & 9.0305940 & 16.4542542 & 22.4484562 \\
\hline $\mathrm{O}$ & 6.9279868 & 14.9920640 & 17.0002054 \\
\hline 0 & 9.3086862 & 13.4791693 & 28.1182578 \\
\hline $\mathrm{O}$ & 13.6965423 & 18.6309975 & 22.0844361 \\
\hline 0 & 10.9609509 & 14.7048494 & 22.2467099 \\
\hline 0 & 16.3806754 & 14.5632263 & 22.0673026 \\
\hline $\mathrm{O}$ & 16.2226288 & 17.5127648 & 18.2166958 \\
\hline 0 & 13.7167863 & 13.2134606 & 18.3368466 \\
\hline $\mathrm{O}$ & 11.2358636 & 17.5080082 & 18.3104733 \\
\hline $\mathrm{H}$ & 4.4446481 & 18.3786776 & 26.8439483 \\
\hline $\mathrm{H}$ & 9.3040864 & 18.4246272 & 26.9774085 \\
\hline $\mathrm{O}$ & 6.8308992 & 17.5577965 & 23.2580756 \\
\hline $\mathrm{H}$ & 5.0997218 & 15.1514005 & 15.2221356 \\
\hline $\mathrm{O}$ & 12.0076350 & 19.3131639 & 20.1455904 \\
\hline $\mathrm{O}$ & 11.6276586 & 12.8440930 & 19.9998932 \\
\hline $\mathrm{O}$ & 17.4238823 & 16.0462034 & 20.0988646 \\
\hline 0 & 5.1946982 & 16.5950670 & 25.1429265 \\
\hline $\mathrm{H}$ & 8.6979391 & 15.1691435 & 29.9459727 \\
\hline 0 & 15.6927336 & 12.8889713 & 20.1238425 \\
\hline $\mathrm{O}$ & 15.4931543 & 19.1778167 & 20.1845720 \\
\hline $\mathrm{O}$ & 9.9776553 & 15.9203148 & 20.0543115 \\
\hline $\mathrm{O}$ & 8.6610438 & 16.8531365 & 25.0630475 \\
\hline C & 9.7039296 & 11.8902981 & 20.2731192 \\
\hline $\mathrm{H}$ & 9.9238337 & 11.2606608 & 19.4131751 \\
\hline $\mathrm{H}$ & 10.0825009 & 11.6087445 & 21.2589689 \\
\hline $\mathrm{H}$ & 9.2638530 & 12.8751458 & 20.1262637 \\
\hline $\mathrm{O}$ & 11.7190078 & 11.9388079 & 22.6806802 \\
\hline C & 5.5273989 & 12.5887107 & 23.6549932 \\
\hline $\mathrm{H}$ & 5.8294639 & 11.8500041 & 24.4098702 \\
\hline $\mathrm{H}$ & 5.8822093 & 13.5860984 & 23.9678985 \\
\hline $\mathrm{H}$ & 4.4279257 & 12.6648422 & 23.6387551 \\
\hline C & 6.8166116 & 11.1939865 & 21.9960524 \\
\hline C & 6.0464352 & 12.2616570 & 22.3029224 \\
\hline $\mathrm{H}$ & 7.1173873 & 10.4979782 & 22.7861901 \\
\hline C & 7.2850747 & 10.9118588 & 20.6426747 \\
\hline $\mathrm{H}$ & 5.7625999 & 12.9485679 & 21.4946989 \\
\hline $\mathrm{H}$ & 8.4358269 & 11.2796788 & 20.5439173 \\
\hline $\mathrm{H}$ & 6.7884130 & 11.4664173 & 19.8366338 \\
\hline $\mathrm{H}$ & 7.4212408 & 9.8513160 & 20.3941679 \\
\hline $\mathrm{H}$ & 5.0963489 & 15.1493046 & 30.0272603 \\
\hline $\mathrm{H}$ & 15.8859332 & 19.7025858 & 22.6219151 \\
\hline \multicolumn{4}{|c|}{ Ti 19} \\
\hline \multicolumn{4}{|c|}{174} \\
\hline $\mathrm{H}$ & 8.6652858 & 9.2615436 & 15.2317865 \\
\hline $\mathrm{P}$ & 5.4081357 & 9.6131992 & 16.7777691 \\
\hline Al & 5.3600808 & 9.5187940 & 28.5819237 \\
\hline$P$ & 5.4159153 & 7.0139165 & 21.6872875 \\
\hline Al & 5.4706878 & 7.0180833 & 18.5565243 \\
\hline $\mathrm{P}$ & 3.2337028 & 8.1671201 & 26.7100895 \\
\hline Al & 3.3793648 & 8.3404278 & 23.6318018 \\
\hline $\mathrm{P}$ & 8.4863850 & 9.4023119 & 28.4867117 \\
\hline Al & 8.5506408 & 9.5598665 & 16.6860837 \\
\hline $\mathrm{P}$ & 8.6242370 & 6.9935784 & 18.5258588 \\
\hline Al & 8.5909929 & 6.8933036 & 21.6948303 \\
\hline $\mathrm{P}$ & 1.6722337 & 11.0027041 & 23.5503177 \\
\hline Al & 1.6017887 & 10.9228554 & 26.6923624 \\
\hline 0 & 6.8841658 & 9.9805331 & 17.0635692 \\
\hline $\mathrm{O}$ & 4.9126727 & 11.1671329 & 28.1695946 \\
\hline $\mathrm{H}$ & 4.7534654 & 5.6892051 & 21.8403255 \\
\hline $\mathrm{H}$ & 9.1769542 & 5.5430018 & 21.9194521 \\
\hline
\end{tabular}

21.7919182

1.7149049

18.3639981

18.2680282

18.3353571

4795

23.6096679

17.6554879

17.7039447

22.5876862

(5)

17.6460115

.4871778

22.4484562

17.0002054

22.0844361

. 2467099

18.2166958

18.3368466

26.8439483

.9774085

580756

20.1455904

19.9998932

20.0988646

429265

29.9459727
20.1238425

20.1845720

20.0543115

20.2731192

19.4131751

21.2589689

22.6806802

23.6549932

4098702

33.9678985

22.3029224

21.4946989

20.3941679

30.0272603 19

174 


$$
\begin{aligned}
& \text { 7. } 1553562 \\
& 6.6183154 \\
& \text { 9. } 2651785 \\
& 7.3546578 \\
& \text { 2. } 2926194 \\
& 0.3365715 \\
& 4.9946148 \\
& \text { 4. } 3238281 \\
& 4.7639982 \\
& \text { 2. } 5667339 \\
& 9.0380195 \\
& 2.0082575 \\
& \text { 4. } 5250264 \\
& 7.0109840 \\
& 6.8939939 \\
& 9.4924735 \\
& 4.6116538 \\
& 0.2089547 \\
& \text { 2. } 5979326 \\
& \text { 2. } 7585907 \\
& 5.2174929 \\
& 5.3038442 \\
& 3.8857472 \\
& 8.6782936 \\
& 8.8115975 \\
& 1.7015897 \\
& 5.2334362 \\
& 3.5780858 \\
& \text { 3. } 3406307 \\
& 0.4320710 \\
& 8.3857828 \\
& \text { 8. } 3838438 \\
& 8.0644399 \\
& 11.9735765 \\
& \text { 8. } 2041030 \\
& 12.1974847 \\
& 10.7917585 \\
& 9.2306526 \\
& 6.8830002 \\
& 5.8414276 \\
& 5.8569990 \\
& 10.9525153 \\
& 6.8486164 \\
& 9.9392131 \\
& .3079078 \\
& 7.5104482 \\
& 8.1912458 \\
& \text { 9. } 2170497 \\
& \text { 7. } 3718001 \\
& 11.4668986 \\
& 9.3308834 \\
& 12.2758304 \\
& 16.1787759 \\
& 16.2451722 \\
& 12.2501842 \\
& 12.3135012 \\
& 13.5401793 \\
& 13.5547004 \\
& 13.5490175 \\
& 14.0129302 \\
& 17.2805667 \\
& 15.0109862 \\
& 15.9972614 \\
& 16.3576871 \\
& 12.6161600 \\
& 13.6116435 \\
& 14.8372176 \\
& 17.5902621 \\
& 13.3917887 \\
& 16.1883208 \\
& 12.2687174 \\
& 13.1274263 \\
& 12.2396378 \\
& 12.1281480 \\
& 10.7878556 \\
& 10.7326230 \\
& 11.0027041 \\
& 8.2542900 \\
& 8.2236647 \\
& 10.9228554 \\
& 10.8126307 \\
& 9.3915099 \\
& \text { 9.5141951 } \\
& 6.9525971 \\
& 10.4116551 \\
& 11.8844042 \\
& 8.3212301 \\
& 11.8204385 \\
& 8.1360361 \\
& 12.1974847 \\
& 10.9115425 \\
& 10.9576754
\end{aligned}
$$




\begin{tabular}{|c|c|c|c|}
\hline Al & 17.1107857 & 16.2451722 & 18.5100929 \\
\hline Al & 12.2630973 & 13.5305155 & 18.4702013 \\
\hline Al & 12.4081872 & 19.0341847 & 18.5565243 \\
\hline $\mathrm{P}$ & 5.3667394 & 17.4426510 & 26.6521084 \\
\hline Al & 5.3069001 & 17.4875698 & 23.6221492 \\
\hline $\mathrm{P}$ & 8.5529248 & 14.8989018 & 28.3365773 \\
\hline Al & 8.6271980 & 14.9991912 & 16.5118935 \\
\hline $\mathrm{P}$ & 15.4954856 & 13.5401793 & 18.4996061 \\
\hline$P$ & 15.5617364 & 19.0096798 & 18.5258588 \\
\hline$P$ & 10.7575419 & 16.3157334 & 18.4045178 \\
\hline Al & 10.4848685 & 16.4010788 & 21.5630197 \\
\hline Al & 15.5284923 & 18.9094050 & 21.6948303 \\
\hline Al & 15.4977193 & 13.5547004 & 21.6058124 \\
\hline $\mathrm{P}$ & 8.4234999 & 17.7972381 & 23.4214845 \\
\hline Al & 8.5016764 & 17.4855617 & 26.5338193 \\
\hline 0 & 9.1272887 & 13.3508015 & 16.8807373 \\
\hline $\mathrm{O}$ & 7.0606463 & 14.5690127 & 28.1358797 \\
\hline $\mathrm{O}$ & 11.6737503 & 17.6708825 & 21.8443024 \\
\hline $\mathrm{O}$ & 13.8651770 & 14.0836717 & 21.7033576 \\
\hline 0 & 16.2174158 & 17.3218349 & 21.9589215 \\
\hline 0 & 15.8979071 & 15.0109862 & 18.2272362 \\
\hline 0 & 11.8195771 & 15.2189085 & 18.2031087 \\
\hline 0 & 14.0928555 & 18.6344167 & 18.2518507 \\
\hline 0 & 6.8249766 & 17.8788775 & 26.9132172 \\
\hline $\mathrm{H}$ & 9.0238841 & 19.1572243 & 23.3372418 \\
\hline $\mathrm{H}$ & 4.4980001 & 18.7375898 & 23.6062938 \\
\hline $\mathrm{H}$ & 18.3227917 & 16.0341545 & 17.6712642 \\
\hline $\mathrm{H}$ & 12.0010841 & 20.2037419 & 17.7297693 \\
\hline 0 & 11.4918620 & 12.5238393 & 17.2463939 \\
\hline 0 & 4.9113468 & 16.4009313 & 27.6780518 \\
\hline $\mathrm{H}$ & 11.7222419 & 20.0471130 & 22.5728715 \\
\hline $\mathrm{H}$ & 18.4638353 & 16.3519798 & 22.4634575 \\
\hline 0 & 8.9745282 & 16.0696010 & 27.4419432 \\
\hline $\mathrm{H}$ & 16.2027225 & 12.6459511 & 17.5418522 \\
\hline 0 & 9.6100859 & 16.1338799 & 17.3947540 \\
\hline $\mathrm{H}$ & 15.9625497 & 20.1822630 & 17.7003177 \\
\hline 0 & 8.9845307 & 16.8893435 & 22.3300038 \\
\hline 0 & 6.9576719 & 15.1689572 & 17.0131583 \\
\hline 0 & 9.3731373 & 13.6685731 & 27.9311682 \\
\hline 0 & 13.8314933 & 18.8991016 & 22.0814888 \\
\hline 0 & 11.0146575 & 14.9088289 & 22.2086933 \\
\hline 0 & 16.6083637 & 14.8372176 & 22.0751628 \\
\hline 0 & 16.4547159 & 17.8246948 & 18.1467982 \\
\hline 0 & 13.9923292 & 13.3878371 & 18.2670332 \\
\hline 0 & 11.4071081 & 17.6811099 & 18.1346334 \\
\hline $\mathrm{H}$ & 4.4672142 & 18.6229128 & 26.7744085 \\
\hline $\mathrm{H}$ & 9.3690462 & 18.6311591 & 26.9241999 \\
\hline 0 & 6.9179981 & 17.9405978 & 23.1822565 \\
\hline $\mathrm{H}$ & 5.2127621 & 15.2589373 & 15.2505253 \\
\hline 0 & 12.2413435 & 19.5265495 & 20.2301996 \\
\hline 0 & 11.6828748 & 12.9908514 & 20.0217753 \\
\hline 0 & 17.6078596 & 16.1883208 & 20.1835907 \\
\hline 0 & 5.2596145 & 16.8156108 & 25.2436104 \\
\hline $\mathrm{H}$ & 8.8025331 & 15.2637178 & 29.7584512 \\
\hline 0 & 15.8940974 & 13.1274263 & 19.9289154 \\
\hline 0 & 15.7490969 & 19.3879015 & 20.0122876 \\
\hline 0 & 10.1729563 & 16.2779107 & 19.8253808 \\
\hline 0 & 8.6858585 & 17.1798979 & 24.8145717 \\
\hline C & 9.7287476 & 11.9496534 & 20.2972415 \\
\hline $\mathrm{H}$ & 9.9903038 & 11.3839501 & 19.4050801 \\
\hline $\mathrm{H}$ & 10.1376465 & 11.6435766 & 21.2631406 \\
\hline $\mathrm{H}$ & 9.3100836 & 12.9493594 & 20.1923809 \\
\hline 0 & 11.8290918 & 12.1240250 & 22.8103689 \\
\hline C & 5.5276657 & 12.6443221 & 23.5599252 \\
\hline $\mathrm{H}$ & 5.8678718 & 11.9647010 & 24.3527552 \\
\hline $\mathrm{H}$ & 5.8231726 & 13.6758302 & 23.8193139 \\
\hline $\mathrm{H}$ & 4.4254501 & 12.6560358 & 23.5375629 \\
\hline C & 6.8799055 & 11.2274216 & 21.9701867 \\
\hline C & 6.0677421 & 12.2793166 & 22.2275162 \\
\hline $\mathrm{H}$ & 7.2023578 & 10.5764249 & 22.7892612 \\
\hline C & 7.3629954 & 10.9120061 & 20.6354144 \\
\hline $\mathrm{H}$ & 5.7647134 & 12.9190187 & 21.3879839 \\
\hline $\mathrm{H}$ & 8.5171660 & 11.3423747 & 20.5215444 \\
\hline $\mathrm{H}$ & 6.8623310 & 11.4173092 & 19.8002312 \\
\hline $\mathrm{H}$ & 7.5703891 & 9.8548533 & 20.4267107 \\
\hline $\mathrm{H}$ & 5.2328648 & 15.2219698 & 29.9726719 \\
\hline $\mathrm{H}$ & 16.1491190 & 19.9601500 & 22.5479879 \\
\hline \multicolumn{4}{|c|}{$\mathrm{Zn}$} \\
\hline
\end{tabular}




\begin{tabular}{|c|c|c|c|}
\hline $\mathrm{H}$ & 8.5930585 & 9.1748247 & 15.3184005 \\
\hline Al & 5.2661825 & 9.2992425 & 16.7230907 \\
\hline $\mathrm{P}$ & 5.2710394 & 9.3110855 & 28.5323921 \\
\hline Al & 5.1496063 & 6.7058245 & 21.6322160 \\
\hline $\mathrm{P}$ & 5.2776522 & 6.6801162 & 18.4591600 \\
\hline Al & 3.0510601 & 8.1290485 & 26.6285426 \\
\hline $\mathrm{P}$ & 3.0880229 & 8.2185863 & 23.5114519 \\
\hline Al & 8.3968698 & 9.3434985 & 28.5598994 \\
\hline $\mathrm{P}$ & 8.4223060 & 9.4513004 & 16.7715094 \\
\hline Al & 8.4617059 & 6.8918069 & 18.5755828 \\
\hline $\mathrm{P}$ & 8.3480745 & 6.8150059 & 21.7312159 \\
\hline Al & 1.4296939 & 10.8989885 & 23.6026909 \\
\hline $\mathrm{P}$ & 1.4293901 & 10.8736521 & 26.7120029 \\
\hline 0 & 6.9389402 & 9.7189813 & 17.0911165 \\
\hline $\mathrm{O}$ & 4.8968529 & 10.7789200 & 28.2378782 \\
\hline $\mathrm{H}$ & 4.7005155 & 5.3201963 & 21.9412020 \\
\hline $\mathrm{H}$ & 8.8535244 & 5.4351119 & 21.9710773 \\
\hline 0 & 6.7922942 & 6.4820217 & 18.2707855 \\
\hline $\mathrm{O}$ & 1.8576180 & 9.3968266 & 26.8187143 \\
\hline $\mathrm{H}$ & 1.9615619 & 7.2621432 & 23.3286333 \\
\hline $\mathrm{H}$ & 0.0509859 & 10.3465836 & 23.4971743 \\
\hline $\mathrm{O}$ & 4.7897144 & 7.8345636 & 17.5630119 \\
\hline 0 & 4.3929893 & 8.3612077 & 27.7144345 \\
\hline 0 & 4.2395825 & 7.8886749 & 22.5512053 \\
\hline $\mathrm{O}$ & 2.2334451 & 11.7372208 & 27.6922210 \\
\hline $\mathrm{O}$ & 8.9354693 & 8.2616210 & 17.5938166 \\
\hline 0 & 1.6131767 & 12.2506126 & 22.5236082 \\
\hline 0 & 4.2918517 & 10.6813061 & 17.1866774 \\
\hline 0 & 6.7313124 & 9.0764394 & 28.1277696 \\
\hline 0 & 6.8441317 & 6.8461851 & 22.0073323 \\
\hline $\mathrm{H}$ & 9.3356678 & 5.7546898 & 18.1752380 \\
\hline $\mathrm{H}$ & 4.6109806 & 5.4107731 & 18.0573669 \\
\hline $\mathrm{H}$ & -0.0074052 & 10.9727681 & 27.0900450 \\
\hline $\mathrm{H}$ & 2.4176545 & 6.8352541 & 27.0053901 \\
\hline 0 & 2.5853967 & 9.6380546 & 23.2021871 \\
\hline $\mathrm{H}$ & 5.1054542 & 9.0456308 & 15.2646778 \\
\hline 0 & 4.9412940 & 7.0347359 & 19.9175087 \\
\hline 0 & 3.6124868 & 8.1313269 & 24.9628459 \\
\hline $\mathrm{H}$ & 8.5680523 & 9.1929615 & 30.0313462 \\
\hline 0 & 8.6551474 & 7.2477160 & 20.2803307 \\
\hline 0 & 1.6643081 & 11.3966963 & 25.2799406 \\
\hline $\mathrm{H}$ & 5.0836265 & 9.0113239 & 29.9788153 \\
\hline $\mathrm{H}$ & 3.3940808 & 12.0463526 & 15.3136073 \\
\hline Al & 3.0834712 & 16.1126581 & 21.6565385 \\
\hline$P$ & 3.0962316 & 16.1936537 & 18.4812943 \\
\hline Al & 3.7107174 & 12.0321519 & 28.5666990 \\
\hline $\mathrm{P}$ & 3.7585638 & 12.0580461 & 16.7572610 \\
\hline Al & 1.5217234 & 13.4773583 & 18.4836507 \\
\hline $\mathrm{P}$ & 1.4386709 & 13.4809820 & 21.6175634 \\
\hline $\mathrm{O}$ & 4.8358600 & 13.1338532 & 17.0349654 \\
\hline $\mathrm{H}$ & 0.0776434 & 14.0806655 & 21.6890093 \\
\hline $\mathrm{H}$ & 2.1096973 & 17.2053933 & 21.9300615 \\
\hline 0 & 2.0044505 & 15.1375772 & 18.2057544 \\
\hline 0 & 4.3292874 & 15.9206732 & 17.6151681 \\
\hline 0 & 4.5204989 & 16.3183102 & 22.6193002 \\
\hline $\mathrm{O}$ & 2.4863318 & 12.3503627 & 17.5628551 \\
\hline 0 & 4.3580639 & 13.5743425 & 28.0804513 \\
\hline $\mathrm{O}$ & 2.4658369 & 14.5378038 & 22.0627602 \\
\hline $\mathrm{H}$ & 2.5638176 & 17.5358008 & 18.1175678 \\
\hline $\mathrm{H}$ & 0.1219459 & 13.3573482 & 17.9903547 \\
\hline 0 & 3.5172838 & 16.1647363 & 19.9581889 \\
\hline $\mathrm{H}$ & 3.4310737 & 12.0439238 & 30.0291563 \\
\hline 0 & 1.7444250 & 13.0461885 & 20.1599882 \\
\hline Al & 9.8842684 & 12.1753424 & 16.5019651 \\
\hline $\mathrm{P}$ & 9.8589234 & 12.0664194 & 28.3376244 \\
\hline Al & 12.1437971 & 10.7575125 & 26.6801124 \\
\hline $\mathrm{P}$ & 12.1838929 & 10.6539865 & 23.5631997 \\
\hline Al & 15.3046926 & 10.8989885 & 23.6026909 \\
\hline Al & 10.4135749 & 8.0403595 & 23.7005681 \\
\hline $\mathrm{P}$ & 10.5577516 & 8.0404816 & 26.7859760 \\
\hline P & 15.3043888 & 10.8736521 & 26.7120029 \\
\hline $\mathrm{O}$ & 8.8532490 & 10.9467708 & 27.9941146 \\
\hline 0 & 11.6400308 & 9.1115670 & 27.0439147 \\
\hline $\mathrm{H}$ & 15.7180707 & 9.4469913 & 26.8150895 \\
\hline $\mathrm{H}$ & 11.2833205 & 6.8406766 & 23.5541984 \\
\hline 0 & 13.6786862 & 10.2474989 & 23.4782479 \\
\hline 0 & 11.1641988 & 11.9018598 & 27.5588063 \\
\hline 0 & 9.4305398 & 8.1521089 & 27.8211364 \\
\hline $\mathrm{H}$ & 16.0848688 & 11.7119009 & 27.6634809 \\
\hline 0 & 9.0169211 & 7.8220951 & 22.6779329 \\
\hline
\end{tabular}




\begin{tabular}{|c|c|c|c|}
\hline $\mathrm{O}$ & 15.4881754 & 12.2506126 & 22.5236082 \\
\hline $\mathrm{O}$ & 9.2720821 & 10.6762421 & 17.1673065 \\
\hline 0 & 13.8233812 & 10.9758181 & 27.1016779 \\
\hline $\mathrm{H}$ & 11.1744959 & 6.6927982 & 26.9291418 \\
\hline $\mathrm{H}$ & 16.2842782 & 9.8302080 & 23.2632198 \\
\hline 0 & 11.3483715 & 9.4126415 & 23.2096719 \\
\hline $\mathrm{H}$ & 10.1504248 & 12.0124942 & 15.0460249 \\
\hline 0 & 11.8719635 & 11.1147772 & 25.0008079 \\
\hline 0 & 15.5393068 & 11.3966963 & 25.2799406 \\
\hline 0 & 9.9446771 & 8.2159097 & 25.3819083 \\
\hline $\mathrm{H}$ & 10.1829628 & 11.9889818 & 29.7888730 \\
\hline $\mathrm{H}$ & 8.6184872 & 15.2188591 & 15.1920879 \\
\hline Al & 5.2818875 & 14.8050556 & 16.6797553 \\
\hline $\mathrm{P}$ & 5.1853923 & 14.7933374 & 28.5040504 \\
\hline Al & 12.0871057 & 18.7219259 & 21.6322160 \\
\hline $\mathrm{Zn}$ & 12.1635545 & 13.4656438 & 21.9298312 \\
\hline Al & 16.9584699 & 16.1126581 & 21.6565385 \\
\hline $\mathrm{P}$ & 16.9712304 & 16.1936537 & 18.4812943 \\
\hline $\mathrm{P}$ & 12.2628103 & 13.2011713 & 18.2948983 \\
\hline $\mathrm{P}$ & 12.2151516 & 18.6962175 & 18.4591600 \\
\hline Al & 5.2575347 & 17.2866123 & 26.6630378 \\
\hline $\mathrm{P}$ & 5.1975659 & 17.3059544 & 23.5725483 \\
\hline Al & 8.3639441 & 14.8505926 & 28.4671560 \\
\hline$P$ & 8.4006053 & 14.8590122 & 16.6204290 \\
\hline Al & 15.3967222 & 13.4773583 & 18.4836507 \\
\hline Al & 15.3992053 & 18.9079082 & 18.5755828 \\
\hline Al & 10.6678684 & 15.9601699 & 18.6128044 \\
\hline $\mathrm{P}$ & 10.3882499 & 16.1173823 & 21.6708737 \\
\hline $\mathrm{P}$ & 15.2855738 & 18.8311073 & 21.7312159 \\
\hline$P$ & 15.3136696 & 13.4809820 & 21.6175634 \\
\hline Al & 8.3215647 & 17.5865287 & 23.5404238 \\
\hline $\mathrm{P}$ & 8.3990676 & 17.4118768 & 26.6939722 \\
\hline 0 & 8.6378288 & 13.3478682 & 16.8280081 \\
\hline 0 & 6.6686921 & 14.5097742 & 28.2040861 \\
\hline 0 & 11.5579757 & 17.0893442 & 21.9962710 \\
\hline 0 & 13.9158125 & 14.0968931 & 21.6909426 \\
\hline 0 & 15.8087414 & 17.4028435 & 21.9794853 \\
\hline $\mathrm{O}$ & 15.8794492 & 15.1375772 & 18.2057544 \\
\hline $\mathrm{O}$ & 11.7237818 & 14.5348667 & 18.8353659 \\
\hline 0 & 13.7297936 & 18.4981230 & 18.2707855 \\
\hline 0 & 6.9222394 & 17.7114700 & 27.0263863 \\
\hline $\mathrm{H}$ & 8.7768211 & 18.9920696 & 23.3551754 \\
\hline $\mathrm{H}$ & 4.5070574 & 18.6245208 & 23.5313026 \\
\hline $\mathrm{H}$ & 18.1701632 & 15.9282275 & 17.6391367 \\
\hline $\mathrm{H}$ & 11.7436028 & 19.8118891 & 17.5931119 \\
\hline $\mathrm{O}$ & 11.4352600 & 12.7467344 & 17.0890397 \\
\hline 0 & 4.6993123 & 16.0079899 & 27.7072437 \\
\hline $\mathrm{H}$ & 11.3139809 & 19.7268346 & 22.4129575 \\
\hline $\mathrm{O}$ & 11.8142298 & 11.7462664 & 22.5790600 \\
\hline $\mathrm{H}$ & 18.1868535 & 16.2884512 & 22.4795155 \\
\hline 0 & 8.8910877 & 16.2085569 & 27.5112200 \\
\hline $\mathrm{H}$ & 16.2193548 & 12.5162394 & 17.6983822 \\
\hline 0 & 9.3793548 & 15.6671508 & 17.4744412 \\
\hline $\mathrm{H}$ & 15.8021650 & 20.0730044 & 17.7405410 \\
\hline 0 & 9.1554765 & 16.5000213 & 22.4952359 \\
\hline 0 & 6.9583359 & 15.1631587 & 17.0485876 \\
\hline $\mathrm{O}$ & 9.2523732 & 13.4279432 & 27.9904786 \\
\hline 0 & 13.7816311 & 18.8622865 & 22.0073323 \\
\hline 0 & 10.7463124 & 14.6765081 & 21.9911637 \\
\hline 0 & 16.3408356 & 14.5378038 & 22.0627602 \\
\hline 0 & 16.4228598 & 17.5760252 & 18.1066668 \\
\hline 0 & 13.7369771 & 13.3350598 & 17.8987395 \\
\hline 0 & 11.5259745 & 17.3840241 & 18.0438032 \\
\hline $\mathrm{H}$ & 4.3949496 & 18.4780068 & 26.8946558 \\
\hline $\mathrm{H}$ & 9.2235194 & 18.5967993 & 27.0591548 \\
\hline 0 & 6.6416454 & 17.5090175 & 23.1146657 \\
\hline $\mathrm{H}$ & 5.0311951 & 15.0454474 & 15.2318307 \\
\hline 0 & 11.8787934 & 19.0508373 & 19.9175087 \\
\hline 0 & 17.3922825 & 16.1647363 & 19.9581889 \\
\hline 0 & 5.1504242 & 16.7341165 & 25.0032216 \\
\hline $\mathrm{H}$ & 8.5860053 & 15.1731347 & 29.9037409 \\
\hline 0 & 15.6194237 & 13.0461885 & 20.1599882 \\
\hline 0 & 15.5926468 & 19.2638174 & 20.2803307 \\
\hline 0 & 10.0000952 & 16.2909513 & 20.1807816 \\
\hline 0 & 8.5626894 & 17.0874267 & 25.2009992 \\
\hline 0 & 12.1226347 & 12.1340540 & 19.4487622 \\
\hline $\mathrm{C}$ & 12.4343214 & 10.6152473 & 19.2962092 \\
\hline C & 13.6882577 & 10.3738768 & 20.1165538 \\
\hline $\mathrm{H}$ & 14.5871661 & 10.7562754 & 19.6171177 \\
\hline $\mathrm{H}$ & 13.6028103 & 10.8366420 & 21.1012580 \\
\hline
\end{tabular}




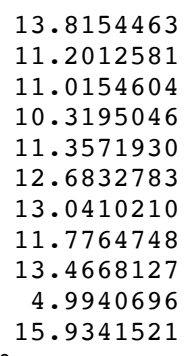

9.2916103

9.9430099

10.2721439

10.1541407

8.8542063

10.1862304

9.1469016

10.1847216

10.7773345

15.0778291

19.8076783

9.1252766

9.4011489

9.3159788

6.6849737

6.8152208

8.0027084

8.0107138

9.3066866

9.4005055

6.8616905

6.7636985

10.8004524

10.7821202

9.7140278

10.9655564

5.2771845

5.3735433

6.5186482

9.1149075

6.9518279

10.4367058

8.2342266

8.2183975

7.6733199

11.8399396

8.0706636

11.9363752

10.6369212

9.0856726

6.8299351

5.7003156

5.6445024

10.8943881

6.6946125

9.5695326

9.0416637

7.0719785

7.9889231

9.0849960

7.2085564

11.2392535

9.0728202

12.1699211

16.0083546

16.1234662

12.0901716

12.1954724

13.4088883

13.3098262

13.4457248

13.6692373

17.1041337

14.8841930

15.8770545

16.1535897

12.5146587

13.4178502

14.6591986

17.4565794

13.3039225

16.0770841

12.1633283

12.9083150

12.1651744

12.0016671

10.7757483
20.2636441

19.8719259

20.8976142

19.2575758

19.8787542

17.8517291

17.8976631

17.2387124

17.3588721

29.9530434

22.6492442

15.2154213

16.6994641

28.5486391

21.6722437

18.4775740

26.6544221

23.4822589

28.4906891

16.6527473

18.4794093

21.6595264

23.5621249

26.6234515

16.8683600

28.1634873

21.8965060

21.8840486

18.1471318

26.8974107

23.1906685

23.6265916

17.6021149

27.5398781

22.5162313

27.7047031

17.6505936

22.5658816

17.1282238

28.2258743

22.0881876

18.1205823

18.0022443

26.9139230

27.0289292

23. 1015910

15.2849773

20.1903346

25.1766586

29.9289478

19.9704099

24.9744608

29.9923496

15.1829536

21.6609271

18.5192306

28.4496065

16.6436677

18.3985754

21.5370021

17.0169687

21.6328272

21.9146220

18.2493050

17.4789478

22.5816609

17.4461714

27.9658958

21.9591768

18.1699137

18.0015406

20.1982539

29.9070563

19.8329839

16.6054270

28.4578877

26.7453702 


\begin{tabular}{|c|c|c|c|}
\hline Al & 12.1954145 & 10.8170808 & 23.6770280 \\
\hline $\mathrm{P}$ & 15.4174374 & 10.8004524 & 23.5621249 \\
\hline $\mathrm{P}$ & 10.6079105 & 8.0428843 & 23.5149802 \\
\hline Al & 10.6243588 & 8.0508368 & 26.6656155 \\
\hline Al & 15.4485989 & 10.7821202 & 26.6234515 \\
\hline 0 & 8.7905283 & 10.7468421 & 28.0759876 \\
\hline 0 & 11.8245955 & 9.3011441 & 26.9526207 \\
\hline $\mathrm{H}$ & 15.8508717 & 9.3674612 & 26.8559107 \\
\hline $\mathrm{H}$ & 11.5725302 & 6.9503410 & 23.2100562 \\
\hline 0 & 13.9215775 & 10.4232365 & 23.6289787 \\
\hline 0 & 11.5192248 & 11.6791053 & 27.7575719 \\
\hline 0 & 9.2090233 & 8.2964129 & 27.6568679 \\
\hline $\mathrm{H}$ & 16.1891485 & 11.6854895 & 27.5468316 \\
\hline 0 & 9.3715117 & 7.9081330 & 22.6092688 \\
\hline 0 & 15.6773265 & 11.9363752 & 22.5658816 \\
\hline 0 & 9.3431108 & 10.8051203 & 17.1730489 \\
\hline 0 & 13.7437555 & 10.9135693 & 26.9635506 \\
\hline $\mathrm{H}$ & 11.2251695 & 6.7377500 & 27.0288652 \\
\hline $\mathrm{H}$ & 16.1941882 & 9.6106536 & 23.1169759 \\
\hline 0 & 11.3031214 & 9.3743316 & 23.2332229 \\
\hline $\mathrm{H}$ & 10.2251403 & 11.9959241 & 15.1911884 \\
\hline $\mathrm{O}$ & 11.8310941 & 11.2391858 & 25.3368379 \\
\hline 0 & 15.8650824 & 11.2392535 & 24.9744608 \\
\hline 0 & 10.1447286 & 7.9880260 & 24.9823197 \\
\hline $\mathrm{H}$ & 10.1963789 & 11.9931270 & 29.9278141 \\
\hline $\mathrm{H}$ & 8.7112780 & 15.1651990 & 15.0737466 \\
\hline $\mathrm{P}$ & 5.3052503 & 14.9110790 & 16.6452995 \\
\hline Al & 5.3094754 & 14.7776914 & 28.4853711 \\
\hline $\mathrm{P}$ & 12.2224484 & 18.7010750 & 21.6722437 \\
\hline $\mathrm{Si}$ & 12.1039901 & 13.1817693 & 21.5328373 \\
\hline $\mathrm{P}$ & 16.9616067 & 16.0083546 & 21.6609271 \\
\hline Al & 16.9615512 & 16.1234662 & 18.5192306 \\
\hline Al & 12.1742670 & 13.3975850 & 18.4407957 \\
\hline Al & 12.2565275 & 18.8313222 & 18.4775740 \\
\hline $\mathrm{P}$ & 5.2579138 & 17.3459267 & 26.6782945 \\
\hline Al & 5.2319617 & 17.3005182 & 23.5056716 \\
\hline $\mathrm{P}$ & 8.4861175 & 14.7739887 & 28.3883916 \\
\hline Al & 8.4290712 & 14.8747779 & 16.5066233 \\
\hline $\mathrm{P}$ & 15.3407317 & 13.4088883 & 18.3985754 \\
\hline$P$ & 15.4174080 & 18.8777919 & 18.4794093 \\
\hline $\mathrm{P}$ & 10.6623525 & 16.1781462 & 18.4508000 \\
\hline Al & 10.5468147 & 16.0355731 & 21.4693780 \\
\hline Al & 15.3811375 & 18.7797998 & 21.6595264 \\
\hline Al & 15.2742790 & 13.3098262 & 21.5370021 \\
\hline$P$ & 8.3815479 & 17.3139477 & 23.3878659 \\
\hline Al & 8.4052768 & 17.3275864 & 26.5599650 \\
\hline 0 & 8.6103799 & 13.1403232 & 16.7341310 \\
\hline 0 & 7.0001264 & 14.3990282 & 28.2308774 \\
\hline $\mathrm{O}$ & 11.7772363 & 17.2437061 & 21.9044041 \\
\hline $\mathrm{O}$ & 13.6113631 & 13.7243594 & 21.6475237 \\
\hline 0 & 15.9506826 & 17.1436707 & 21.9237756 \\
\hline 0 & 15.7543712 & 14.8841930 & 18.2493050 \\
\hline 0 & 11.7510239 & 15.0834879 & 18.5811173 \\
\hline 0 & 13.9544463 & 18.5347496 & 18.1471318 \\
\hline $\mathrm{O}$ & 6.7346266 & 17.7203570 & 26.9099978 \\
\hline $\mathrm{H}$ & 8.7891884 & 18.7256782 & 23.1471028 \\
\hline $\mathrm{H}$ & 4.7523084 & 18.6858851 & 23.2452645 \\
\hline $\mathrm{H}$ & 18.1365064 & 15.9126447 & 17.6291996 \\
\hline $\mathrm{H}$ & 11.8122831 & 20.0408392 & 17.7313595 \\
\hline 0 & 10.9974964 & 12.7030413 & 17.3746286 \\
\hline 0 & 4.8471611 & 16.1586799 & 27.5493186 \\
\hline $\mathrm{H}$ & 11.4282991 & 19.6589056 & 22.4901728 \\
\hline 0 & 11.7179116 & 12.0779966 & 22.6218053 \\
\hline $\mathrm{H}$ & 18.1437640 & 16.1494160 & 22.5552014 \\
\hline 0 & 8.8795726 & 15.9198312 & 27.4591608 \\
\hline $\mathrm{H}$ & 16.1224785 & 12.5414479 & 17.4747033 \\
\hline $\mathrm{O}$ & 9.5747242 & 15.7626898 & 17.4567856 \\
\hline $\mathrm{H}$ & 15.8669383 & 20.0486006 & 17.6767574 \\
\hline 0 & 9.1814877 & 16.3342193 & 22.5281863 \\
\hline 0 & 6.7789042 & 15.2183090 & 16.9497076 \\
\hline 0 & 9.3376216 & 13.5590602 & 27.9999473 \\
\hline $\mathrm{O}$ & 13.6938505 & 18.8460364 & 22.0881876 \\
\hline 0 & 11.0537018 & 14.3884419 & 21.4462743 \\
\hline 0 & 16.3068563 & 14.6591986 & 21.9591768 \\
\hline 0 & 16.3017127 & 17.6835724 & 18.1104345 \\
\hline 0 & 13.8585670 & 13.3001883 & 17.9874156 \\
\hline 0 & 11.3312348 & 17.4562500 & 17.9192736 \\
\hline $\mathrm{H}$ & 4.4109547 & 18.5033450 & 27.0784991 \\
\hline $\mathrm{H}$ & 9.2575099 & 18.4775053 & 26.9704597 \\
\hline 0 & 6.8983250 & 17.1746655 & 23.0220679 \\
\hline
\end{tabular}


5.0197923

12.0447143

17.4503055

5.0325358

8.7515220

15.5843414

15.5757198

10.0226615

8.6049413

12.0492962

12.1870320

13.3984135

14.3297497

13.4442952

13.3581852

10.8475540

10.6052468

10.0547715

10.8712392

12.4780449

12.8175406

11.6032335

13.3040290

5.0551539

16.1693150 Mg 20

171

$\mathrm{H} \quad 8.6508923$

Al $\quad 5.2771678$

P $\quad 5.2868952$

Al 5.1555914

$\mathrm{P} \quad 5.2881496$

Al 3.0687306

$\mathrm{P} \quad 3.0729375$

Al 8.4255274

$\mathrm{P} \quad 8.4477855$

Al 8.4691161

P 8.3546623

Al $\quad 1.4295321$

$\mathrm{P} \quad 1.4563005$

O 6.9590045

4.9179217

4.6909599

8.8424984

6.8018566

1.8802297

1.9872619

0.0333921

4. 7972816

4.4291095

4.2445342

2. 2378390

8.9574342

1. 6790978

4.3116029

6.7567165

6.8504143

9.3305683

4.6198065

0.0123911

2. 4438378

2.5219421

5.0948350

4.9566953

3.5924718

8.6220040

8.6646609

1.7315843

5.0703912

3.4499648

3.0573678

3. 0949888

3. 7342443

3. 7694254

1. 5555159

1.4473181

4.8240450

0.0320157

2.0954043
15.1365127

19.0880799

16.0770841

16.9620445

15.2012039

12.9083150

19.2246578

16.4395755

16.9571721

12.3641428

10.7879208

10.3449032

10.5919852

10.7942251

9.2554282

10.2262565

10.4714406

10.6003514

9.1312293

10.4001800

9.3545393

10.4193841

10.9686079

15.0891410

19.7519341

9. 1648260

9.3175731

9.3109601

6.7180226

6.7135957

8.1122369

8. 1790592

9.3367797

9.4458382

6.9000967

6.8189444

10.8889996

10.8574795

9.7144185

10.7748925

5.3350187

5.4285063

6.5119468

9.3801881

7. 1806169

10.3729197

7.8675699

8.3516209

7.9028824

11.7211239

8. 2671261

12.2031801

10.6973061

9.0775050

6.8670038

5.7493441

5.4502241

10.9591544

6.8164841

9.5796739

9.0633238

7.0589028

8.0984593

9. 1836554

7.2718458

11.3785631

9. 0285734

12.0496474

16.0888914

16.1844850

12.0247792

12.0658237

13.4599239

13.4181091

13.1531162

13.8804020

17.1970622
15.2014110

20.1903346

20.1982539

25.2074547

29.7898794

19.8329839

19.9704099

19.8225825

24.8682257

19.9353908

19.7388692

20.5370498

20.0103763

21.5244543

20.6759752

20.1721598

21.2078722

19.5138588

20.0729433

18.2866146

18.3353954

17.6382412

17.8401345

29.9190518

22.4662803

15.3126818

16.6933592

28.5053334

21.6150906

18.4400650

26.6100473

23. 4815110

28.5567738

16.7607496

18.5813723

21.7289724

23.6060032

26.7014433

17.0479898

28.1878563

21.9126445

21.9430247

18.2506331

26.8244095

23.2776927

23.5663144

17.5477772

27.6767174

22.5283434

27.7005118

17.5998902

22.4963652

17.1788356

28.1392150

22.0019611

18.1930567

18.0225362

27.0505970

26.9943053

23.1813652

15.2376007

19.8994108

24.9352942

30.0247896

20.2821039

25.2768224

29.9511910

15.2810847

21.6523132

18.4796591

28.5337861

16.7353212

18.4817894

21.5751057

17.0506546

21.5570778

21.9047102 


\begin{tabular}{|c|c|c|c|}
\hline $\mathrm{O}$ & 2.0078084 & 15.1262437 & 18.1864842 \\
\hline $\mathrm{O}$ & 4.3264962 & 15.9363108 & 17.6017751 \\
\hline 0 & 4.4918269 & 16.3043029 & 22.6190536 \\
\hline 0 & 2.4646042 & 12.3424982 & 17.4952494 \\
\hline $\mathrm{O}$ & 4.3684027 & 13.5685176 & 28.0402865 \\
\hline 0 & 2.3879047 & 14.5406819 & 22.0609120 \\
\hline $\mathrm{H}$ & 2.5557192 & 17.5294982 & 18.1372434 \\
\hline $\mathrm{H}$ & 0.1380228 & 13.3478297 & 18.0398973 \\
\hline 0 & 3.5164601 & 16.1307772 & 19.9553219 \\
\hline $\mathrm{H}$ & 3.4835225 & 12.0455764 & 30.0013783 \\
\hline $\mathrm{O}$ & 1.8711594 & 12.9979219 & 20.1321250 \\
\hline Al & 9.8691590 & 12.1963472 & 16.5342106 \\
\hline $\mathrm{P}$ & 9.8829605 & 12.0761610 & 28.3494652 \\
\hline Al & 12.1529032 & 10.7388028 & 26.7062995 \\
\hline $\mathrm{P}$ & 12.1562561 & 10.6787877 & 23.6033155 \\
\hline Al & 15.3045308 & 10.8889996 & 23.6060032 \\
\hline Al & 10.4628133 & 8.0277516 & 23.6829723 \\
\hline$P$ & 10.5858427 & 8.0203547 & 26.7950919 \\
\hline $\mathrm{P}$ & 15.3312992 & 10.8574795 & 26.7014433 \\
\hline $\mathrm{O}$ & 8.8966281 & 10.9399054 & 28.0073623 \\
\hline $\mathrm{O}$ & 11.6563838 & 9.0937967 & 27.0868507 \\
\hline $\mathrm{H}$ & 15.7407038 & 9.4308029 & 26.8201964 \\
\hline $\mathrm{H}$ & 11.3596566 & 6.8543741 & 23.4932943 \\
\hline $\mathrm{O}$ & 13.6585007 & 10.2805484 & 23.5592107 \\
\hline $\mathrm{O}$ & 11.2250635 & 11.8822242 & 27.6453844 \\
\hline 0 & 9.4260290 & 8.1366154 & 27.7934794 \\
\hline $\mathrm{H}$ & 16.0896427 & 11.6954922 & 27.6708609 \\
\hline 0 & 9.0429645 & 7.7995202 & 22.6891202 \\
\hline $\mathrm{O}$ & 15.5540965 & 12.2031801 & 22.4963652 \\
\hline $\mathrm{O}$ & 9.2828651 & 10.6785040 & 17.1711852 \\
\hline 0 & 13.8442644 & 10.9621911 & 27.0610253 \\
\hline $\mathrm{H}$ & 11.1980447 & 6.6744010 & 26.9704142 \\
\hline $\mathrm{H}$ & 16.2301683 & 9.7795618 & 23.2461925 \\
\hline 0 & 11.3461883 & 9.4320156 & 23.1878552 \\
\hline $\mathrm{H}$ & 10.1100515 & 12.0837212 & 15.0691486 \\
\hline $\mathrm{O}$ & 11.7861221 & 11.0765228 & 25.0461335 \\
\hline 0 & 15.6065830 & 11.3785631 & 25.2768224 \\
\hline $\mathrm{O}$ & 10.0177956 & 8.1783011 & 25.3718950 \\
\hline $\mathrm{H}$ & 10.1394084 & 12.0666609 & 29.8161843 \\
\hline $\mathrm{H}$ & 8.6349326 & 15.1398930 & 15.1810090 \\
\hline Al & 5.2754383 & 14.8155534 & 16.6673928 \\
\hline$P$ & 5.2005311 & 14.7759416 & 28.4851491 \\
\hline Al & 12.0930907 & 18.7341240 & 21.6150906 \\
\hline Mg & 12.0816773 & 13.2775592 & 21.5152135 \\
\hline Al & 16.9323665 & 16.0888914 & 21.6523132 \\
\hline $\mathrm{P}$ & 16.9699875 & 16.1844850 & 18.4796591 \\
\hline $\mathrm{P}$ & 12.2561815 & 13.2547962 & 18.3098456 \\
\hline $\mathrm{P}$ & 12.2256490 & 18.7296971 & 18.4400650 \\
\hline Al & 5.2790934 & 17.2820254 & 26.6526525 \\
\hline $\mathrm{P}$ & 5.2140491 & 17.2854344 & 23.5461731 \\
\hline Al & 8.3803289 & 14.8216964 & 28.4468997 \\
\hline $\mathrm{P}$ & 8.3995119 & 14.8660083 & 16.6255452 \\
\hline Al & 15.4305147 & 13.4599239 & 18.4817894 \\
\hline Al & 15.4066155 & 18.9161981 & 18.5813723 \\
\hline Al & 10.6395295 & 16.0346896 & 18.5874222 \\
\hline $\mathrm{P}$ & 10.4087790 & 16.1080950 & 21.6111461 \\
\hline $\mathrm{P}$ & 15.2921617 & 18.8350458 & 21.7289724 \\
\hline $\mathrm{P}$ & 15.3223168 & 13.4181091 & 21.5751057 \\
\hline Al & 8.3529728 & 17.5049688 & 23.5190176 \\
\hline $\mathrm{P}$ & 8.4221531 & 17.3963038 & 26.6838576 \\
\hline $\mathrm{O}$ & 8.6501246 & 13.3723646 & 16.9334121 \\
\hline $\mathrm{O}$ & 6.6843385 & 14.4792256 & 28.1999181 \\
\hline $\mathrm{O}$ & 11.5474535 & 17.1100016 & 21.9645213 \\
\hline 0 & 13.8826973 & 13.8883449 & 21.5567680 \\
\hline 0 & 15.7966038 & 17.3972769 & 21.9503111 \\
\hline 0 & 15.8828071 & 15.1262437 & 18.1864842 \\
\hline $\mathrm{O}$ & 11.7180956 & 14.6061461 & 18.7933326 \\
\hline 0 & 13.7393560 & 18.5280481 & 18.2506331 \\
\hline $\mathrm{O}$ & 6.9446650 & 17.7084452 & 27.0010141 \\
\hline $\mathrm{H}$ & 8.8041161 & 18.9082223 & 23.3081391 \\
\hline $\mathrm{H}$ & 4.5903123 & 18.6349940 & 23.4639429 \\
\hline $\mathrm{H}$ & 18.1664557 & 15.9433720 & 17.6267530 \\
\hline $\mathrm{H}$ & 11.7507551 & 19.8461179 & 17.5768147 \\
\hline 0 & 11.4386226 & 12.7247818 & 17.1364266 \\
\hline 0 & 4.7328503 & 15.9976611 & 27.6926945 \\
\hline $\mathrm{H}$ & 11.3185999 & 19.7413747 & 22.3914479 \\
\hline $\mathrm{O}$ & 11.8335153 & 11.8092651 & 22.6625545 \\
\hline $\mathrm{H}$ & 18.1576643 & 16.2728933 & 22.478091 \\
\hline $\mathrm{O}$ & 8.8986746 & 16.2006820 & 27.5215508 \\
\hline $\mathrm{H}$ & 16.2058129 & 12.5069491 & 17.6404379 \\
\hline
\end{tabular}




\begin{tabular}{|c|c|c|c|}
\hline 0 & 9.3674971 & 15.7293733 & 17.4372435 \\
\hline $\mathrm{H}$ & 15.8215607 & 20.0778226 & 17.7473642 \\
\hline $\mathrm{O}$ & 9.1966521 & 16.3882417 & 22.5108889 \\
\hline 0 & 6.9529981 & 15.1826013 & 17.0242330 \\
\hline $\mathrm{O}$ & 9.2833606 & 13.4203167 & 27.9266626 \\
\hline 0 & 13.7879137 & 18.8831052 & 22.0019611 \\
\hline $\mathrm{O}$ & 10.8532156 & 14.6786669 & 21.7744120 \\
\hline $\mathrm{O}$ & 16.2629034 & 14.5406819 & 22.0609120 \\
\hline $\mathrm{O}$ & 16.4145957 & 17.5697091 & 18.1270064 \\
\hline 0 & 13.7381060 & 13.3260897 & 17.9541946 \\
\hline 0 & 11.5348018 & 17.4237860 & 18.0084775 \\
\hline $\mathrm{H}$ & 4.4166781 & 18.4638283 & 26.9296043 \\
\hline $\mathrm{H}$ & 9.2511457 & 18.5779360 & 27.0494217 \\
\hline 0 & 6.6698622 & 17.4022986 & 23.0935359 \\
\hline $\mathrm{H}$ & 5.0303609 & 15.0244887 & 15.2136378 \\
\hline 0 & 11.8941947 & 19.0750042 & 19.8994108 \\
\hline 0 & 17.3914588 & 16.1307772 & 19.9553219 \\
\hline 0 & 5.1342505 & 16.7536738 & 24.9906878 \\
\hline $\mathrm{H}$ & 8.6026803 & 15.0990317 & 29.8928477 \\
\hline 0 & 15.7461581 & 12.9979219 & 20.1321250 \\
\hline 0 & 15.6021603 & 19.2879471 & 20.2821039 \\
\hline 0 & 9.9607658 & 16.3867281 & 20.1438406 \\
\hline $\mathrm{O}$ & 8.5914593 & 17.0548121 & 25.1962397 \\
\hline $\mathrm{O}$ & 12.0818925 & 12.2465497 & 19.5437325 \\
\hline $\mathrm{C}$ & 12.3626160 & 10.6600607 & 19.4066583 \\
\hline C & 13.6029463 & 10.4116064 & 20.2370637 \\
\hline $\mathrm{H}$ & 14.5093609 & 10.7841402 & 19.7446207 \\
\hline $\mathrm{H}$ & 13.5239416 & 10.8585786 & 21.2286150 \\
\hline $\mathrm{H}$ & 13.7128457 & 9.3265988 & 20.3790723 \\
\hline $\mathrm{C}$ & 11.0930016 & 10.0541345 & 19.9630173 \\
\hline $\mathrm{H}$ & 10.9008388 & 10.3823556 & 20.9880058 \\
\hline $\mathrm{H}$ & 10.2338871 & 10.2934753 & 19.3273466 \\
\hline $\mathrm{H}$ & 11.2049303 & 8.9599235 & 19.9761690 \\
\hline C & 12.6230289 & 10.2211263 & 17.9719059 \\
\hline $\mathrm{H}$ & 12.9720263 & 9.1799742 & 18.0470654 \\
\hline $\mathrm{H}$ & 11.7263496 & 10.2118182 & 17.3469003 \\
\hline $\mathrm{H}$ & 13.4231821 & 10.7908501 & 17.4822393 \\
\hline $\mathrm{H}$ & 4.9948977 & 15.0514783 & 29.9339124 \\
\hline $\mathrm{H}$ & 15.9597030 & 19.7860449 & 22.6601597 \\
\hline \multicolumn{4}{|c|}{ Al 20} \\
\hline \multicolumn{4}{|c|}{171} \\
\hline $\mathrm{H}$ & 8.6709454 & 8.9983936 & 15.2613374 \\
\hline $\mathrm{Si}$ & 5.2076614 & 9.2577410 & 16.6682787 \\
\hline $\mathrm{Si}$ & 5.2152083 & 9.2191282 & 28.6238237 \\
\hline $\mathrm{Si}$ & 5.1839244 & 6.7111850 & 21.6467087 \\
\hline $\mathrm{Si}$ & 5.2562419 & 6.7722971 & 18.5261055 \\
\hline $\mathrm{Si}$ & 3.1335879 & 8.0092091 & 26.6466679 \\
\hline $\mathrm{Si}$ & 3.1074527 & 8.0498411 & 23.5623696 \\
\hline $\mathrm{Si}$ & 8.3616530 & 9.2243883 & 28.6196528 \\
\hline $\mathrm{Si}$ & 8.3781044 & 9.3151841 & 16.6864720 \\
\hline $\mathrm{Si}$ & 8.4020257 & 6.8684160 & 18.5875425 \\
\hline $\mathrm{Si}$ & 8.3330316 & 6.7872964 & 21.6953549 \\
\hline $\mathrm{Si}$ & 1.5328800 & 10.7623345 & 23.6452706 \\
\hline $\mathrm{Si}$ & 1.5721993 & 10.7281785 & 26.6786915 \\
\hline 0 & 6.7896988 & 9.6006029 & 16.8728376 \\
\hline 0 & 4.8166727 & 10.7706226 & 28.3221855 \\
\hline $\mathrm{H}$ & 4.7639245 & 5.3021232 & 21.8817944 \\
\hline $\mathrm{H}$ & 8.8036007 & 5.3886140 & 21.8937810 \\
\hline 0 & 6.8461560 & 6.5092290 & 18.2995933 \\
\hline $\mathrm{O}$ & 2.0137232 & 9.1704118 & 26.8680687 \\
\hline $\mathrm{H}$ & 2.0622670 & 7.0044203 & 23.3840356 \\
\hline $\mathrm{H}$ & 0.1060051 & 10.3371506 & 23.6644352 \\
\hline 0 & 4.7604785 & 8.0191547 & 17.6120457 \\
\hline $\mathrm{O}$ & 4.3871065 & 8.2232403 & 27.6539616 \\
\hline 0 & 4.3509484 & 7.7632866 & 22.5623580 \\
\hline 0 & 2.3631025 & 11.6719974 & 27.7329385 \\
\hline 0 & 8.8727799 & 8.1115484 & 17.6524086 \\
\hline 0 & 1.8045854 & 11.9572966 & 22.5870972 \\
\hline 0 & 4.3578498 & 10.5683207 & 17.1065171 \\
\hline 0 & 6.7894687 & 9.0074155 & 28.3233372 \\
\hline $\mathrm{O}$ & 6.7529453 & 6.8591702 & 22.0272130 \\
\hline $\mathrm{H}$ & 9.2460148 & 5.6977476 & 18.2210203 \\
\hline $\mathrm{H}$ & 4.5428448 & 5.5412312 & 18.0871729 \\
\hline $\mathrm{H}$ & 0.1185468 & 10.8269856 & 26.9856963 \\
\hline $\mathrm{H}$ & 2.5246839 & 6.6920631 & 26.9805584 \\
\hline 0 & 2.4565408 & 9.4942263 & 23.2051505 \\
\hline $\mathrm{H}$ & 4.9248160 & 8.8961880 & 15.2518047 \\
\hline O & 4.9487347 & 7.1209131 & 20.0825064 \\
\hline 0 & 3.6590240 & 8.0346066 & 25.1024596 \\
\hline
\end{tabular}

17.4372435

7.7473642

17.0242330

27.9266626

2.0019611

22.0609120

18.1270064

7.9541946

26.9296043

27.0494217

23.0935359

(1)

19.9553219

28878

20.1321250

821039

25.1962397

.5437325

20.2370637

. 7446207

20.3790723

19.9630173

19.3273466

9.9761690

17.9719059
18.0470654

17.3469003

17.4822393

29.9339124

Al 20

171 


\begin{tabular}{|c|c|c|c|}
\hline $\mathrm{H}$ & 8.6681544 & 8.9918225 & 30.0580862 \\
\hline 0 & 8.6202844 & 7.2632111 & 20.1544276 \\
\hline 0 & 1.9208247 & 11.2368881 & 25.1651091 \\
\hline $\mathrm{H}$ & 4.9258852 & 8.8933173 & 30.0476425 \\
\hline $\mathrm{H}$ & 3.3525590 & 11.9827030 & 15.2313650 \\
\hline $\mathrm{Si}$ & 3.1188722 & 15.8627494 & 21.6587863 \\
\hline $\mathrm{Si}$ & 3.1303758 & 15.9524722 & 18.5679355 \\
\hline $\mathrm{Si}$ & 3.7083813 & 11.9365348 & 28.5907611 \\
\hline $\mathrm{Si}$ & 3.7540379 & 12.0073943 & 16.6650058 \\
\hline $\mathrm{Si}$ & 1.5648345 & 13.2533447 & 18.5173828 \\
\hline $\mathrm{Si}$ & 1.4735763 & 13.2042092 & 21.5850558 \\
\hline 0 & 4.8862382 & 13.1575539 & 16.9365781 \\
\hline $\mathrm{H}$ & 0.0506964 & 13.6397361 & 21.6384379 \\
\hline $\mathrm{H}$ & 2.1304748 & 16.9521026 & 21.8900889 \\
\hline 0 & 1.9892888 & 14.8132932 & 18.3369305 \\
\hline 0 & 4.3894468 & 15.7072400 & 17.5825512 \\
\hline 0 & 4.3990674 & 16.0383437 & 22.6332266 \\
\hline 0 & 2.4159312 & 12.2885360 & 17.5326324 \\
\hline 0 & 4.3380887 & 13.3555851 & 28.1354646 \\
\hline 0 & 2.4664357 & 14.4263161 & 21.9928736 \\
\hline $\mathrm{H}$ & 2.5558438 & 17.2813506 & 18.2199184 \\
\hline $\mathrm{H}$ & 0.1427172 & 13.1541617 & 18.0874227 \\
\hline 0 & 3.6413435 & 15.9296440 & 20.1113639 \\
\hline $\mathrm{H}$ & 3.3490765 & 11.9767598 & 30.0351996 \\
\hline 0 & 1.8213426 & 12.7385508 & 20.0375455 \\
\hline $\mathrm{Si}$ & 9.7637068 & 12.0514584 & 16.5757964 \\
\hline $\mathrm{Si}$ & 9.8438550 & 11.9230933 & 28.5069279 \\
\hline $\mathrm{Si}$ & 12.0290782 & 10.6826865 & 26.7488889 \\
\hline $\mathrm{Si}$ & 12.0004866 & 10.6968187 & 23.7148022 \\
\hline $\mathrm{Si}$ & 15.1578788 & 10.7623345 & 23.6452706 \\
\hline $\mathrm{Si}$ & 10.3951011 & 7.9986881 & 23.6591531 \\
\hline $\mathrm{Si}$ & 10.4533917 & 7.9858906 & 26.7389928 \\
\hline $\mathrm{Si}$ & 15.1971981 & 10.7281785 & 26.6786915 \\
\hline 0 & 8.7687226 & 10.7424521 & 28.1766888 \\
\hline 0 & 11.5767571 & 9.1360876 & 27.0149428 \\
\hline $\mathrm{H}$ & 15.6004874 & 9.3053093 & 26.8516693 \\
\hline $\mathrm{H}$ & 11.3482244 & 6.8771299 & 23.4338009 \\
\hline 0 & 13.5944829 & 10.2964697 & 23.6662688 \\
\hline 0 & 11.2545248 & 11.6856633 & 27.7584904 \\
\hline 0 & 9.1969823 & 8.1477439 & 27.7498968 \\
\hline $\mathrm{H}$ & 15.9236807 & 11.5951216 & 27.6470681 \\
\hline 0 & 9.1059065 & 7.8166061 & 22.6863333 \\
\hline 0 & 15.4295841 & 11.9572966 & 22.5870972 \\
\hline 0 & 9.2322974 & 10.6267650 & 17.1474483 \\
\hline 0 & 13.6170188 & 10.8355859 & 27.0124182 \\
\hline $\mathrm{H}$ & 11.0688636 & 6.6576543 & 27.0112119 \\
\hline $\mathrm{H}$ & 16.0019492 & 9.6034971 & 23.2430749 \\
\hline 0 & 11.1650270 & 9.3648232 & 23.2878881 \\
\hline $\mathrm{H}$ & 10.1354378 & 11.9261280 & 15.1394020 \\
\hline 0 & 11.6278005 & 11.1211608 & 25.2422850 \\
\hline 0 & 15.5458235 & 11.2368881 & 25.1651091 \\
\hline 0 & 9.8939852 & 8.0456589 & 25.2094130 \\
\hline $\mathrm{H}$ & 10.1392940 & 11.9167529 & 29.9663100 \\
\hline $\mathrm{H}$ & 8.6718121 & 15.0382231 & 15.1424491 \\
\hline $\mathrm{Si}$ & 5.2419680 & 14.7240676 & 16.6248514 \\
\hline $\mathrm{Si}$ & 5.2133396 & 14.6380067 & 28.5909278 \\
\hline $\mathrm{Si}$ & 11.9964238 & 18.5107801 & 21.6467087 \\
\hline Al & 11.9511153 & 13.0914845 & 21.5731471 \\
\hline $\mathrm{Si}$ & 16.7438709 & 15.8627494 & 21.6587863 \\
\hline $\mathrm{Si}$ & 16.7553745 & 15.9524722 & 18.5679355 \\
\hline $\mathrm{Si}$ & 12.0618970 & 13.1734512 & 18.4496520 \\
\hline $\mathrm{Si}$ & 12.0687412 & 18.5718921 & 18.5261055 \\
\hline $\mathrm{Si}$ & 5.2410593 & 17.0840232 & 26.6719653 \\
\hline $\mathrm{Si}$ & 5.1928163 & 17.0686189 & 23.5921047 \\
\hline $\mathrm{Si}$ & 8.3669033 & 14.6448702 & 28.5365480 \\
\hline $\mathrm{Si}$ & 8.3516611 & 14.7182026 & 16.5609733 \\
\hline $\mathrm{Si}$ & 15.1898332 & 13.2533447 & 18.5173828 \\
\hline $\mathrm{Si}$ & 15.2145251 & 18.6680110 & 18.5875425 \\
\hline $\mathrm{Si}$ & 10.4933630 & 15.9202338 & 18.5821834 \\
\hline $\mathrm{Si}$ & 10.3451450 & 15.8895076 & 21.5493259 \\
\hline $\mathrm{Si}$ & 15.1455310 & 18.5868915 & 21.6953549 \\
\hline $\mathrm{Si}$ & 15.0985751 & 13.2042092 & 21.5850558 \\
\hline $\mathrm{Si}$ & 8.3112553 & 17.1531108 & 23.5429715 \\
\hline $\mathrm{Si}$ & 8.3498816 & 17.1127187 & 26.6341129 \\
\hline 0 & 8.5719669 & 13.1222796 & 16.8239279 \\
\hline 0 & 6.7888960 & 14.2707672 & 28.4151057 \\
\hline 0 & 11.5372688 & 16.9703565 & 21.9037106 \\
\hline 0 & 13.5714222 & 13.6716529 & 21.6423499 \\
\hline $\mathrm{O}$ & 15.6602120 & 17.0570943 & 21.9123818 \\
\hline 0 & 15.6142875 & 14.8132932 & 18.3369305 \\
\hline
\end{tabular}




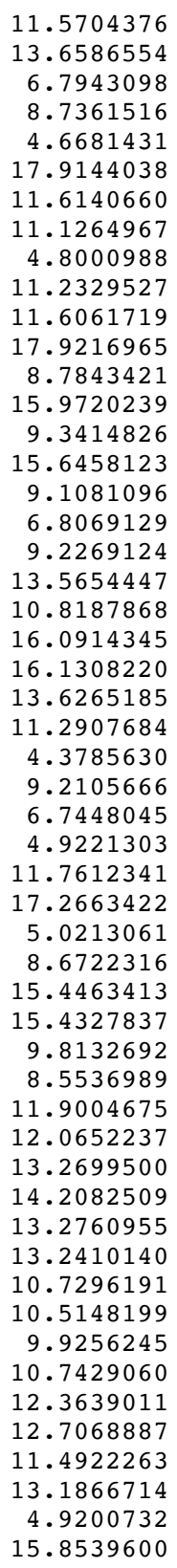

14.6841151

18.3088240

17.5125056

18.5711480

18.4524462

15.7267253

19.7154120

12.5283193

15.8787666

19.4750925

11.8698944

16.0243024

15.8720599

12.3666483

15.5783281

19.8069220

16.1531424

15.0390577

13.3525785

18.6587652

14.3714758

14.4263161

17.3970468

13.1443141

17.2293918

18.2508659

18.2775340

17.0648428

15.0190809

18.9205081

15.9296440

16.5892003

15.0308593

12.7385508

19.0628062

16.2196492

16.6755344

12.2084298

10.5985400

10.2223205

10.4614739

10.7074341

9.1385721

10.0724733

10.3588132

10.4240362

8.9744554

10.1512079

9.1099231

10.1400404

10.7061046

15.0112783

19.5303725

9.1789796

9.4088078

9.3132923

6.7083289

6.8187127

8.0034233

8.0730038

9.2719855

9.4224545

6.8883287

6.7589151

10.8301366

10.7750020

9.7074835

10.9565344

5.3033683

5.3708601

6.5695958

9.1076833

7.0471982

10.3902286

8.2202272

8.1970842

7.6963316
18.7497887

18.2995933

26.9120366

23.3824900

23.4282124

17.6608467

17.6878016

17.3106718

27.6507682

22.4859547

22.7175501

22.5553063

27.5765736

17.6123592

17.5007126

17.7308081

22.5654986

16.9216874

28.0708055

22.0272130

21.6266613

21.9928736

18.1896189

18.0447333

18.0474414

27.0061787

26.9798691

23.1527819

15.2008459

20.0825064

20.1113639

25.1383039

29.9418621

20.0375455

20.1544276

20.0228676

25.0826562

19.8292554

19.6737972

20.5104267

19.9943328

21.4827858

20.6944735

20.1489263

21.1812054

19.4920426

20.0947695

18.2442153

18.3419096

17.5905753

17.7763407

30.0022335

22.6037009

15.2198225

16.7232446

28.5576111

21.6468185

18.4673774

26.6507677

23.5093357

28.4844433

16.6695574

18.4842268

21.6617385

23.5930930

26.6569232

16.9130134

28.1396238

21.8609798

21.8909486

18.1608187

26.8724553

23.2781711

23.6377258

17.5898913

27.5953902

22.4977898 


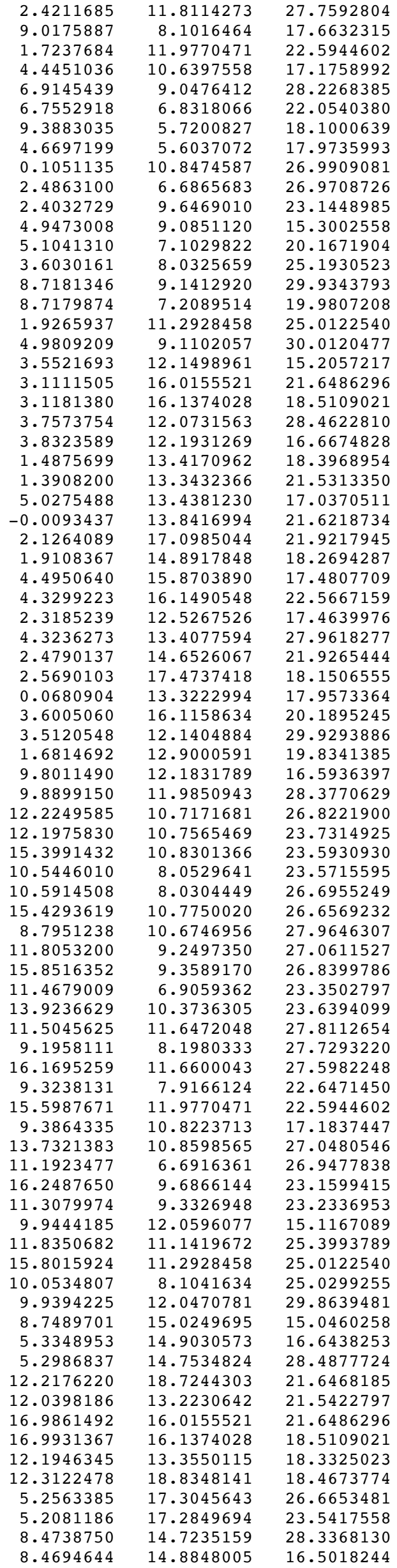

Ge $\quad 12.0398186$

P $\quad 16.9861492$

Al 12.1946345

Al 12.3122478

Al $\quad 5.2081186$

$\mathrm{P} \quad 8.4738750$ 


\begin{tabular}{|c|c|c|c|}
\hline $\mathrm{P}$ & 15.3625686 & 13.4170962 & 18.3968954 \\
\hline $\mathrm{P}$ & 15.4863145 & 18.9044301 & 18.4842268 \\
\hline $\mathrm{P}$ & 10.6866626 & 16.1955602 & 18.3872536 \\
\hline Al & 10.4751304 & 16.1288066 & 21.4096186 \\
\hline Al & 15.3898725 & 18.7750165 & 21.6617385 \\
\hline Al & 15.2658187 & 13.3432366 & 21.5313350 \\
\hline $\mathrm{P}$ & 8.3509328 & 17.4097334 & 23.3917774 \\
\hline Al & 8.3908528 & 17.3220795 & 26.5369680 \\
\hline 0 & 8.7193006 & 13.2081701 & 16.9673891 \\
\hline 0 & 6.9815021 & 14.3649663 & 28.2069506 \\
\hline 0 & 11.7576428 & 17.2696632 & 21.8685719 \\
\hline 0 & 13.6407529 & 13.9217653 & 21.6364162 \\
\hline 0 & 15.9648342 & 17.1387254 & 21.9319399 \\
\hline 0 & 15.7858354 & 14.8917848 & 18.2694287 \\
\hline 0 & 11.6601897 & 15.0007019 & 18.5473368 \\
\hline $\mathrm{O}$ & 14.0176878 & 18.5856972 & 18.1608187 \\
\hline $\mathrm{O}$ & 6.7215448 & 17.7279173 & 26.8918304 \\
\hline $\mathrm{H}$ & 8.7731555 & 18.8297866 & 23.2424540 \\
\hline $\mathrm{H}$ & 4.6523247 & 18.6558928 & 23.3721006 \\
\hline $\mathrm{H}$ & 18.1712830 & 15.9089364 & 17.6294856 \\
\hline $\mathrm{H}$ & 11.8350971 & 20.0303064 & 17.7188815 \\
\hline $\mathrm{O}$ & 11.1649884 & 12.6243946 & 17.1389611 \\
\hline $\mathrm{O}$ & 4.8514831 & 16.1653927 & 27.5982104 \\
\hline $\mathrm{H}$ & 11.4288479 & 19.6813368 & 22.4710065 \\
\hline 0 & 11.6400919 & 12.0483763 & 22.7543054 \\
\hline $\mathrm{H}$ & 18.1709432 & 16.1453329 & 22.5411209 \\
\hline 0 & 8.8434813 & 15.9337879 & 27.4807126 \\
\hline $\mathrm{H}$ & 16.1690885 & 12.5529331 & 17.4914295 \\
\hline $\mathrm{O}$ & 9.6005177 & 15.8945661 & 17.3489209 \\
\hline $\mathrm{H}$ & 15.9401073 & 20.0789733 & 17.6894684 \\
\hline O & 9.1186026 & 16.4910881 & 22.4471321 \\
\hline 0 & 6.8109101 & 15.2312050 & 16.9090809 \\
\hline 0 & 9.3018713 & 13.5320704 & 27.8296309 \\
\hline 0 & 13.6927911 & 18.8479080 & 22.0540380 \\
\hline 0 & 10.8060969 & 14.4398790 & 21.4407441 \\
\hline 0 & 16.3540124 & 14.6526067 & 21.9265444 \\
\hline 0 & 16.3500077 & 17.7025003 & 18.0889874 \\
\hline 0 & 13.8937231 & 13.3190026 & 17.9420496 \\
\hline $\mathrm{O}$ & 11.4852781 & 17.4096622 & 17.8881958 \\
\hline $\mathrm{H}$ & 4.3741822 & 18.4618660 & 26.9809010 \\
\hline $\mathrm{H}$ & 9.2593135 & 18.4706167 & 26.9161236 \\
\hline 0 & 6.8653932 & 17.3151591 & 23.0316585 \\
\hline $\mathrm{H}$ & 5.0158024 & 15.1040232 & 15.2033694 \\
\hline 0 & 12.0416303 & 19.1190835 & 20.1671904 \\
\hline 0 & 17.4755047 & 16.1158634 & 20.1895245 \\
\hline $\mathrm{O}$ & 5.0647099 & 16.8208454 & 25.2185060 \\
\hline $\mathrm{H}$ & 8.7872319 & 15.0386817 & 29.7579389 \\
\hline 0 & 15.5564679 & 12.9000591 & 19.8341385 \\
\hline 0 & 15.6554868 & 19.2250528 & 19.9807208 \\
\hline 0 & 10.0284586 & 16.5178418 & 19.7372509 \\
\hline 0 & 8.5853303 & 16.9417326 & 24.8419046 \\
\hline 0 & 12.0321624 & 12.3133199 & 19.8124367 \\
\hline C & 12.1812611 & 10.7571729 & 19.7069903 \\
\hline C & 13.3824300 & 10.3650641 & 20.5471627 \\
\hline $\mathrm{H}$ & 14.3218854 & 10.6142904 & 20.0366223 \\
\hline $\mathrm{H}$ & 13.3892830 & 10.8545055 & 21.5192713 \\
\hline $\mathrm{H}$ & 13.3623513 & 9.2820613 & 20.7324031 \\
\hline C & 10.8477605 & 10.1962935 & 20.1648618 \\
\hline $\mathrm{H}$ & 10.6103021 & 10.4794637 & 21.1936906 \\
\hline $\mathrm{H}$ & 10.0482193 & 10.5407884 & 19.4990844 \\
\hline $\mathrm{H}$ & 10.8774087 & 9.0987606 & 20.1106012 \\
\hline $\mathrm{C}$ & 12.4935959 & 10.3133644 & 18.2762889 \\
\hline $\mathrm{H}$ & 12.8273307 & 9.2680869 & 18.3578815 \\
\hline $\mathrm{H}$ & 11.6288102 & 10.3261448 & 17.6136298 \\
\hline $\mathrm{H}$ & 13.3271717 & 10.8718481 & 17.8289246 \\
\hline $\mathrm{H}$ & 5.0490959 & 15.0574647 & 29.9238857 \\
\hline $\mathrm{H}$ & 16.1303531 & 19.7587358 & 22.4990588 \\
\hline \multicolumn{4}{|c|}{$\mathrm{Ga} 20$} \\
\hline \multicolumn{4}{|c|}{171} \\
\hline $\mathrm{H}$ & 8.6483120 & 9.0106537 & 15.2810183 \\
\hline $\mathrm{Si}$ & 5.2089036 & 9.2599996 & 16.6899569 \\
\hline $\mathrm{Si}$ & 5.2160225 & 9.2185252 & 28.6375721 \\
\hline $\mathrm{Si}$ & 5.1768285 & 6.6920709 & 21.6491698 \\
\hline $\mathrm{Si}$ & 5.2690494 & 6.7589203 & 18.5305641 \\
\hline $\mathrm{Si}$ & 3.1344637 & 8.0144980 & 26.6501061 \\
\hline $\mathrm{Si}$ & 3.1310477 & 8.0806004 & 23.5786597 \\
\hline $\mathrm{Si}$ & 8.3548368 & 9.2056735 & 28.6325012 \\
\hline $\mathrm{Si}$ & 8.3728300 & 9.3298742 & 16.709068 \\
\hline & & & \\
\hline
\end{tabular}




\begin{tabular}{|c|c|c|c|}
\hline $\mathrm{Si}$ & 8.3311572 & 6.7738019 & 21.7121810 \\
\hline $\mathrm{Si}$ & 1.5369387 & 10.7816042 & 23.6521254 \\
\hline $\mathrm{Si}$ & 1.5633234 & 10.7436401 & 26.6874391 \\
\hline 0 & 6.7858430 & 9.6195841 & 16.9095349 \\
\hline $\mathrm{O}$ & 4.8284567 & 10.7727893 & 28.3308594 \\
\hline $\mathrm{H}$ & 4.7429142 & 5.2865278 & 21.8800109 \\
\hline $\mathrm{H}$ & 8.8251507 & 5.3845627 & 21.9197994 \\
\hline $\mathrm{O}$ & 6.8613584 & 6.5059601 & 18.3136675 \\
\hline $\mathrm{O}$ & 2.0205818 & 9.1870119 & 26.8292517 \\
\hline $\mathrm{H}$ & 2.0430712 & 7.0800132 & 23.3990686 \\
\hline $\mathrm{H}$ & 0.1280717 & 10.3000012 & 23.6356034 \\
\hline $\mathrm{O}$ & 4.7694010 & 8.0066351 & 17.6186909 \\
\hline 0 & 4.3670957 & 8.2265812 & 27.6820169 \\
\hline $\mathrm{O}$ & 4.3543078 & 7.7539073 & 22.5651048 \\
\hline 0 & 2.3687741 & 11.6670400 & 27.7488858 \\
\hline $\mathrm{O}$ & 8.8720617 & 8.1292255 & 17.6769463 \\
\hline $\mathrm{O}$ & 1.7605244 & 11.9777972 & 22.5834450 \\
\hline 0 & 4.3428839 & 10.5606855 & 17.1294199 \\
\hline 0 & 6.7847521 & 8.9850555 & 28.3225762 \\
\hline $\mathrm{O}$ & 6.7470357 & 6.8165119 & 22.0273124 \\
\hline $\mathrm{H}$ & 9.2672853 & 5.7140835 & 18.2174473 \\
\hline $\mathrm{H}$ & 4.5714420 & 5.5205390 & 18.0868568 \\
\hline $\mathrm{H}$ & 0.1158888 & 10.8193067 & 27.0285085 \\
\hline $\mathrm{H}$ & 2.5032501 & 6.7090865 & 26.9886188 \\
\hline 0 & 2.5308313 & 9.5548539 & 23.2469926 \\
\hline $\mathrm{H}$ & 4.9367753 & 8.9060073 & 15.2694794 \\
\hline $\mathrm{O}$ & 4.9460589 & 7.1043383 & 20.0851568 \\
\hline $\mathrm{O}$ & 3.6914829 & 8.0200099 & 25.1154740 \\
\hline $\mathrm{H}$ & 8.6455069 & 9.0011733 & 30.0784650 \\
\hline $\mathrm{O}$ & 8.6304393 & 7.2497178 & 20.1737533 \\
\hline $\mathrm{O}$ & 1.8684703 & 11.2891404 & 25.1756805 \\
\hline $\mathrm{H}$ & 4.9377198 & 8.9028070 & 30.0658544 \\
\hline $\mathrm{H}$ & 3.3754028 & 11.9895777 & 15.2451290 \\
\hline $\mathrm{Si}$ & 3.1439027 & 15.8645887 & 21.6611155 \\
\hline $\mathrm{Si}$ & 3.1464888 & 15.9679580 & 18.5734424 \\
\hline $\mathrm{Si}$ & 3.7182599 & 11.9378622 & 28.5997583 \\
\hline $\mathrm{Si}$ & 3.7662273 & 12.0098918 & 16.6817794 \\
\hline $\mathrm{Si}$ & 1.5571566 & 13.2748585 & 18.5094804 \\
\hline $\mathrm{Si}$ & 1.4650473 & 13.2320053 & 21.5825144 \\
\hline 0 & 4.9109554 & 13.1465476 & 16.9640416 \\
\hline $\mathrm{H}$ & 0.0791079 & 13.7697494 & 21.6669169 \\
\hline $\mathrm{H}$ & 2.1548181 & 16.9482973 & 21.9149027 \\
\hline $\mathrm{O}$ & 1.9985323 & 14.8327181 & 18.3585598 \\
\hline $\mathrm{O}$ & 4.4043916 & 15.7014129 & 17.5935569 \\
\hline $\mathrm{O}$ & 4.4244415 & 16.0135120 & 22.6387012 \\
\hline 0 & 2.4279573 & 12.3109301 & 17.5423272 \\
\hline $\mathrm{O}$ & 4.3398269 & 13.3575368 & 28.1340971 \\
\hline $\mathrm{O}$ & 2.5085456 & 14.4148519 & 21.9689470 \\
\hline $\mathrm{H}$ & 2.5782985 & 17.2969321 & 18.2155203 \\
\hline $\mathrm{H}$ & 0.1457746 & 13.1893105 & 18.0427868 \\
\hline 0 & 3.6620938 & 15.9615697 & 20.1151583 \\
\hline $\mathrm{H}$ & 3.3716983 & 11.9835054 & 30.0471464 \\
\hline 0 & 1.7616307 & 12.7447798 & 20.0334401 \\
\hline $\mathrm{Si}$ & 9.7689741 & 12.0518597 & 16.5490934 \\
\hline $\mathrm{Si}$ & 9.8230111 & 11.9096930 & 28.4813398 \\
\hline $\mathrm{Si}$ & 12.0309496 & 10.6565219 & 26.7681443 \\
\hline $\mathrm{Si}$ & 12.0204104 & 10.6267901 & 23.7094624 \\
\hline $\mathrm{Si}$ & 15.1619375 & 10.7816042 & 23.6521254 \\
\hline $\mathrm{Si}$ & 10.3436551 & 7.9947155 & 23.7036241 \\
\hline $\mathrm{Si}$ & 10.4337101 & 7.9934899 & 26.7520684 \\
\hline $\mathrm{Si}$ & 15.1883221 & 10.7436401 & 26.6874391 \\
\hline 0 & 8.7647513 & 10.7125839 & 28.1526483 \\
\hline 0 & 11.5719171 & 9.1187711 & 27.0768241 \\
\hline $\mathrm{H}$ & 15.6063893 & 9.3204292 & 26.8170970 \\
\hline $\mathrm{H}$ & 11.2307440 & 6.8064510 & 23.5686378 \\
\hline $\mathrm{O}$ & 13.6185987 & 10.2540338 & 23.6340265 \\
\hline $\mathrm{O}$ & 11.2315066 & 11.6964285 & 27.7205266 \\
\hline $\mathrm{O}$ & 9.2048174 & 8.1052004 & 27.8047742 \\
\hline $\mathrm{H}$ & 15.9281211 & 11.5917743 & 27.6623680 \\
\hline 0 & 9.0664704 & 7.8220555 & 22.7135284 \\
\hline $\mathrm{O}$ & 15.3855232 & 11.9777972 & 22.5834450 \\
\hline $\mathrm{O}$ & 9.2385075 & 10.6398886 & 17.1533943 \\
\hline 0 & 13.6137339 & 10.8259538 & 27.0584706 \\
\hline $\mathrm{H}$ & 11.0470670 & 6.6465071 & 26.9150141 \\
\hline $\mathrm{H}$ & 16.0698601 & 9.6609656 & 23.2820358 \\
\hline 0 & 11.2053017 & 9.2870038 & 23.2720212 \\
\hline $\mathrm{H}$ & 10.1237789 & 11.8990515 & 15.1110796 \\
\hline $\mathrm{O}$ & 11.6595335 & 11.0357186 & 25.2411551 \\
\hline $\mathrm{O}$ & 15.4934690 & 11.2891404 & 25.1756805 \\
\hline $\mathrm{O}$ & 9.8322827 & 8.1584894 & 25.2440971 \\
\hline
\end{tabular}




\begin{tabular}{|c|c|c|c|}
\hline $\mathrm{H}$ & 10.1256535 & 11.8888096 & 29.9391094 \\
\hline $\mathrm{H}$ & 8.6664560 & 15.0521816 & 15.1174135 \\
\hline $\mathrm{Si}$ & 5.2579197 & 14.7137783 & 16.6417090 \\
\hline $\mathrm{Si}$ & 5.1984805 & 14.6483715 & 28.6000530 \\
\hline $\mathrm{Si}$ & 11.9893279 & 18.4916660 & 21.6491698 \\
\hline $\mathrm{Ga}$ & 11.9328023 & 13.1232042 & 21.6116775 \\
\hline $\mathrm{Si}$ & 16.7689014 & 15.8645887 & 21.6611155 \\
\hline $\mathrm{Si}$ & 16.7714876 & 15.9679580 & 18.5734424 \\
\hline $\mathrm{Si}$ & 12.0691448 & 13.1648469 & 18.4135555 \\
\hline $\mathrm{Si}$ & 12.0815488 & 18.5585153 & 18.5305641 \\
\hline $\mathrm{Si}$ & 5.2321769 & 17.0591881 & 26.6759719 \\
\hline $\mathrm{Si}$ & 5.1710993 & 17.0410578 & 23.6356246 \\
\hline $\mathrm{Si}$ & 8.3592682 & 14.6545584 & 28.5117370 \\
\hline $\mathrm{Si}$ & 8.3627132 & 14.7235698 & 16.5375808 \\
\hline $\mathrm{Si}$ & 15.1821553 & 13.2748585 & 18.5094804 \\
\hline $\mathrm{Si}$ & 15.2278990 & 18.6728472 & 18.6018162 \\
\hline $\mathrm{Si}$ & 10.5009082 & 15.9088076 & 18.5749712 \\
\hline $\mathrm{Si}$ & 10.2870031 & 15.9143631 & 21.5455395 \\
\hline $\mathrm{Si}$ & 15.1436566 & 18.5733970 & 21.7121810 \\
\hline $\mathrm{Si}$ & 15.0900460 & 13.2320053 & 21.5825144 \\
\hline $\mathrm{Si}$ & 8.2742539 & 17.2355823 & 23.5386365 \\
\hline $\mathrm{Si}$ & 8.3364127 & 17.1250166 & 26.6331161 \\
\hline 0 & 8.5782665 & 13.1257917 & 16.7872285 \\
\hline 0 & 6.7750845 & 14.3145108 & 28.3848932 \\
\hline 0 & 11.5145128 & 16.9536364 & 21.9017700 \\
\hline 0 & 13.5937837 & 13.8125547 & 21.6736355 \\
\hline O & 15.6843080 & 17.0529433 & 21.9394091 \\
\hline 0 & 15.6235311 & 14.8327181 & 18.3585598 \\
\hline 0 & 11.5538098 & 14.6562239 & 18.7783480 \\
\hline 0 & 13.6738577 & 18.3055552 & 18.3136675 \\
\hline 0 & 6.7793597 & 17.4944719 & 26.9514975 \\
\hline $\mathrm{H}$ & 8.7119480 & 18.6516051 & 23.3957240 \\
\hline $\mathrm{H}$ & 4.5465526 & 18.3908080 & 23.5632607 \\
\hline $\mathrm{H}$ & 17.9300703 & 15.7224585 & 17.6709255 \\
\hline $\mathrm{H}$ & 11.6234854 & 19.7023847 & 17.6945848 \\
\hline 0 & 11.1429389 & 12.5468756 & 17.2514249 \\
\hline 0 & 4.7478505 & 15.9079757 & 27.7004467 \\
\hline $\mathrm{H}$ & 11.2359809 & 19.4642023 & 22.4880750 \\
\hline 0 & 11.5542649 & 11.8037386 & 22.7451164 \\
\hline $\mathrm{H}$ & 17.9474111 & 16.0016463 & 22.5608104 \\
\hline 0 & 8.8029218 & 15.8657737 & 27.5396207 \\
\hline $\mathrm{H}$ & 15.9827778 & 12.3886136 & 17.6202706 \\
\hline 0 & 9.3683588 & 15.5729413 & 17.4710712 \\
\hline $\mathrm{H}$ & 15.6462811 & 19.8235376 & 17.7544742 \\
\hline $\mathrm{O}$ & 9.0429560 & 16.2498246 & 22.5277973 \\
\hline 0 & 6.8228452 & 15.0442271 & 16.9222483 \\
\hline 0 & 9.1884373 & 13.3363863 & 28.0612225 \\
\hline 0 & 13.5595351 & 18.6161070 & 22.0273124 \\
\hline 0 & 10.6588500 & 14.3683773 & 21.6918395 \\
\hline 0 & 16.1335444 & 14.4148519 & 21.9689470 \\
\hline 0 & 16.1535331 & 17.4133284 & 18.1841722 \\
\hline 0 & 13.6316374 & 13.1808771 & 17.9967795 \\
\hline $\mathrm{O}$ & 11.3204795 & 17.2074775 & 18.0464924 \\
\hline $\mathrm{H}$ & 4.3558659 & 18.2401809 & 26.9093293 \\
\hline $\mathrm{H}$ & 9.1874731 & 18.2942806 & 26.9875713 \\
\hline 0 & 6.7056492 & 17.1757575 & 23.1608963 \\
\hline $\mathrm{H}$ & 4.9244702 & 14.9953989 & 15.2181143 \\
\hline 0 & 11.7585582 & 18.9039333 & 20.0851568 \\
\hline 0 & 17.2870925 & 15.9615697 & 20.1151583 \\
\hline 0 & 5.0754883 & 16.4799237 & 25.1618698 \\
\hline $\mathrm{H}$ & 8.6652543 & 15.0451197 & 29.9156440 \\
\hline 0 & 15.3866294 & 12.7447798 & 20.0334401 \\
\hline 0 & 15.4429387 & 19.0493128 & 20.1737533 \\
\hline 0 & 9.8005314 & 16.2271349 & 20.0017961 \\
\hline 0 & 8.5246911 & 16.7293030 & 25.0681174 \\
\hline 0 & 11.9228968 & 12.1642513 & 19.7592563 \\
\hline C & 12.0983240 & 10.5873599 & 19.6257312 \\
\hline $\mathrm{C}$ & 13.3051506 & 10.2211814 & 20.4657380 \\
\hline $\mathrm{H}$ & 14.2427475 & 10.4781917 & 19.9578385 \\
\hline $\mathrm{H}$ & 13.2947740 & 10.7063010 & 21.4391606 \\
\hline H & 13.2937765 & 9.1370508 & 20.6477501 \\
\hline C & 10.7763568 & 10.0318051 & 20.1129407 \\
\hline $\mathrm{H}$ & 10.5608517 & 10.3260136 & 21.1432041 \\
\hline $\mathrm{H}$ & 9.9602970 & 10.3585435 & 19.4588754 \\
\hline $\mathrm{H}$ & 10.8146836 & 8.9340227 & 20.0727763 \\
\hline C & 12.3967265 & 10.1367483 & 18.1953166 \\
\hline $\mathrm{H}$ & 12.7360093 & 9.0938390 & 18.2865300 \\
\hline $\mathrm{H}$ & 11.5236499 & 10.1336712 & 17.5419463 \\
\hline $\mathrm{H}$ & 13.2196969 & 10.6944537 & 17.7295509 \\
\hline $\mathrm{H}$ & 4.9197520 & 14.9895603 & 30.0223825 \\
\hline
\end{tabular}


$\mathrm{H}$ Ti 20

171

$\mathrm{H} \quad 8.6111334$

$\mathrm{P} \quad 5.2555521$

Al $\quad 5.2368748$

P $\quad 5.2602417$

Al $\quad 5.3945826$

$\mathrm{P} \quad 3.1020128$

Al 3.1286935

$\mathrm{P} \quad 8.3845357$

Al $\quad 8.4429575$

$\mathrm{P} \quad 8.5719156$

Al 8.4449402

$\mathrm{P} \quad 1.5294525$

Al 1.5367914

O 6.7434746

4.7999575

4.7694240

8.9555041

7.1061749

2. 0438002

2. 0343292

0.1307930

4.8134391

4.2517571

4.4737975

2. 4294191

9.0336983

1.7281273

4.4257437

6.9042589

6.7406883

9.4248006

4.7496970

0.0992097

2.4683263

2.4850078

5.0195786

5.0926256

3.6648758

8.6317940

8.7311747

1.8423889

5.0454391

3.5797726

3.1017125

Al 3.1328001

3. 7684871

3.8548730

1. 5022641

1.3834476

5.0617515

$-0.0477346$

2.1439480

1.9136513

4.5345664

4.3363080

2. 3468632

4.3036110

2.4364200

2.6034977

0.0877301

3.5796204

3. 5397355

1.6981865

9.8188544

Al $\quad 9.8411317$

P $\quad 12.2254661$

Al 12.2245947

P $\quad 15.4044513$

P $\quad 10.4728001$

Al 10.5634592

Al 15.4117901

15.4117901
8.7968209

11.7937940

15.8427043

11.2837832

13.9534057
9. 2247905

9.3944614

9.3304768

6.7511873

6.7921042

.0167772

8.1339097

9.2543776

9.4432972

6.9057142

6.7969605

0.8759594

10.7978183

9.7081580

0.9810865

5.3654045

5.4175910

6.5720613

9.1255524

7.1494256

0.3655144

8.1660981

8.2231019

7.7698326

11.7956181

8.1116908

12.0156843

10.6044930

9.0201497

6.8330046

5.7426010

5.5269118

10.8396189

6.7072237

9.7329773

9.1148350

7. 1284296

8.0205449

9.1893292

7. 2429424

11.3801472

9.1392425

12.1349025

16.0384703

16.1443836

12.0779459

12.1760838

13.4438466

13.3750227

13.4154265

13.7820957

17.1472207

14.9194661

15.8476807

16.1554519

12.5354526

13.4276789

14.6986349

17.4926139

13.3269035

16.0985829

12.1263906

12.9703933

12.1809713

11.9788042

10.6967322

10.6854867

10.8759594

8.0728428

8.0497883

10.7978183

10.6294498

9. 2380389

9.3765350

6.8265567

10.3463960
22.6294467

15.2326147

16.7566936

28.5628540

21.6480879

18.4756658

26.6560155

23.5449514

28.4812706

16.6958618

18.5011810

21.6768422

23.6178973

26.6832690

17.0176424

28.1484286

21.8843601

21.9087578

18.1811757

26.8088239

23.3207227

23.6000610

17.5620716

27.6496069

22.4900393

27.8003609

17.6643435

22.6130362

17.2141197

28.1697295

22.0459254

18.1312143

18.0278585

27.0689271

26.9732408

23.2302695

15.3133481

20.1625543

25.2198130

29.9481559

19.9964723

25.0468968

30.0270611

15.2383437

21.6750061

18.5248933

28.4900902

16.7011303

18.3975500

21.5505897

17.0625234

21.6065331

21.9404873

18.2345853

17.5344734

22.5762793

17.4945952

27.9934404

21.9855326

18.1795896

17.9475074

20.2117322

29.9606161

19.8486546

16.5448981

28.3258515

26.8672511

23.7493777

23.6178973

23.6497573

26.7178841

26.6832690

27.9051102

27.1417527

26.7899799

23.5710309

23.5993929 


\begin{tabular}{|c|c|c|}
\hline 11.4749461 & 11.6637183 & 27.7990088 \\
\hline 9.2081500 & 8.1448240 & 27.8150966 \\
\hline 16.1740587 & 11.6498997 & 27.6372211 \\
\hline 9.2749340 & 7.9651533 & 22.6905214 \\
\hline 15.6031260 & 12.0156843 & 22.6130362 \\
\hline 9.4111829 & 10.8349496 & 17.1763140 \\
\hline 13.7255361 & 10.8468496 & 27.1356381 \\
\hline 11.1596772 & 6.6894321 & 26.8231245 \\
\hline 16.3287221 & 9.7703979 & 23.2429602 \\
\hline 11.3656700 & 9.2461433 & 23.2386107 \\
\hline 9.8102948 & 12.0485674 & 15.0618214 \\
\hline 11.8831371 & 11.0707385 & 25.4187739 \\
\hline 15.7173876 & 11.3801472 & 25.0468968 \\
\hline 9.9555410 & 8.2886680 & 25.0862211 \\
\hline 9.8143888 & 12.0367929 & 29.8134814 \\
\hline 8.7564198 & 15.0103941 & 15.0287956 \\
\hline 5.3585046 & 14.8851951 & 16.6748864 \\
\hline 5.2711446 & 14.7815405 & 28.5182395 \\
\hline 12.1977410 & 18.7672887 & 21.6480879 \\
\hline 11.9371660 & 13.1801831 & 21.4694755 \\
\hline 16.9767112 & 16.0384703 & 21.6750061 \\
\hline 17.0077988 & 16.1443836 & 18.5248933 \\
\hline 12.1991577 & 13.2787490 & 18.2410629 \\
\hline 12.3320820 & 18.8082056 & 18.4756658 \\
\hline 5.2488437 & 17.2876300 & 26.6764598 \\
\hline 5.1664605 & 17.2728792 & 23.6115805 \\
\hline 8.4535608 & 14.7326890 & 28.3136326 \\
\hline 8.5010494 & 14.8926383 & 16.4909995 \\
\hline 15.3772628 & 13.4438466 & 18.3975500 \\
\hline 15.5094149 & 18.9218156 & 18.5011810 \\
\hline 10.6935585 & 16.1472643 & 18.4003319 \\
\hline 10.3931023 & 16.2084149 & 21.4454839 \\
\hline 15.3824396 & 18.8130619 & 21.6768422 \\
\hline 15.2584463 & 13.3750227 & 21.5505897 \\
\hline 8.2848132 & 17.5361139 & 23.4014425 \\
\hline 8.3641299 & 17.3472485 & 26.5449224 \\
\hline 8.8056497 & 13.2400053 & 17.0074939 \\
\hline 6.9512866 & 14.4148995 & 28.1979999 \\
\hline 11.6899558 & 17.3335995 & 21.8925280 \\
\hline 13.5937511 & 13.8485141 & 21.6156609 \\
\hline 15.9841129 & 17.1875458 & 21.9501428 \\
\hline 15.7886500 & 14.9194661 & 18.2345853 \\
\hline 11.5818390 & 14.8865033 & 18.5655113 \\
\hline 14.0436742 & 18.5881626 & 18.1811757 \\
\hline 6.6988503 & 17.7401654 & 26.9495836 \\
\hline 8.7612067 & 18.9420353 & 23.2850171 \\
\hline 4.4800476 & 18.5937168 & 23.5748956 \\
\hline 18.2061075 & 15.8907452 & 17.6782266 \\
\hline 11.8374294 & 19.9777093 & 17.6980409 \\
\hline 11.2439319 & 12.5871790 & 16.9554143 \\
\hline 4.8009507 & 16.2223401 & 27.6781742 \\
\hline 11.4362836 & 19.7535697 & 22.4632890 \\
\hline 11.6599010 & 11.9795862 & 22.7624901 \\
\hline 18.1758420 & 16.1520915 & 22.5503896 \\
\hline 8.8394554 & 15.9444200 & 27.4633138 \\
\hline 16.1969638 & 12.5622313 & 17.5212137 \\
\hline 9.6216864 & 15.9338045 & 17.3226765 \\
\hline 15.9562516 & 20.0887596 & 17.6914285 \\
\hline 9.0024188 & 16.6254309 & 22.4102688 \\
\hline 6.8395260 & 15.2128058 & 16.9104699 \\
\hline 9.2449821 & 13.5259811 & 27.7806171 \\
\hline 13.6781877 & 18.8491060 & 22.0459254 \\
\hline 10.7677216 & 14.5315578 & 21.6057961 \\
\hline 16.3114187 & 14.6986349 & 21.9855326 \\
\hline 16.3875526 & 17.7242643 & 18.1202601 \\
\hline 13.9143332 & 13.3229025 & 17.9321101 \\
\hline 11.5751465 & 17.3231840 & 17.9500512 \\
\hline 4.3407972 & 18.4568304 & 26.8362804 \\
\hline 9.2396215 & 18.4920172 & 26.9192749 \\
\hline 6.7927161 & 17.5140737 & 23.0570814 \\
\hline 5.0096218 & 15.0954597 & 15.2426888 \\
\hline 12.0301250 & 19.1445310 & 20.1625543 \\
\hline 17.4546191 & 16.0985829 & 20.2117322 \\
\hline 5.1474671 & 16.6866463 & 25.2609570 \\
\hline 8.7897613 & 15.0210032 & 29.7352390 \\
\hline 15.5731852 & 12.9703933 & 19.8486546 \\
\hline 15.6686740 & 19.2590438 & 19.9964723 \\
\hline 10.0127861 & 16.4843637 & 19.7351148 \\
\hline 8.5192024 & 17.0117153 & 24.8333401 \\
\hline 11.9826624 & 12.2096612 & 19.6722491 \\
\hline
\end{tabular}




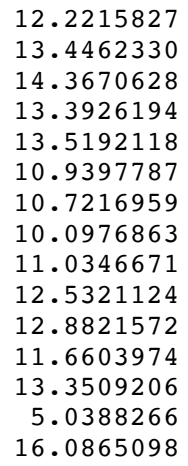

10.6932607

10.3737043

10.7203684

10.8257234

9. 2869551

10.0525264

10.3421945

10.3369307

8.9582975

10.2379704

9.1978532

10.2421771

10.8128404

15.0547506

19.8040207

8.7990796

9.1654252

9.1421992

6.6363603

6.5980772

7.7876149

7.8681162

9.0719048

9.1090415

6.5559404

6.5539392

10.5687058

10.5595666

9.5366586

10.7861167

5.2501538

5. 1635220

6.1984718

8.9041460

6.8245335

10.0503903

7.9427963

8.0000030

7.6343689

11.6523371

7.7425656

11.7563408

10.3436519

8.9398561

6.7041364

5.3849256

5.4223346

10.6495765

6.4833360

9.4466211

.8481433

7.0339547

7.7761912

8.7565808

6.9374674

11.0273376

8.8829600

11.8670381

15.8001313

15.8107724

11.8808972

11.8785628

13.0924852

13.1174598

13.1165313

13.5068727

16.8936424

14.5725363

15.5359901

16.0064146

12.1806679

13.2413851

14.4598965

17.1391594

12.8986809

15.7960709

11.8655509
19.5823307

20.4254824

19.9388181

21.4169860

20.5719201

20.0876061

21.1207448

19.4470049

20.0573897

18.1542102

18.2290899

17.4986223

17.6980493

29.9634056

22.5367297

15.0503268

16.5701313

28.3924033

21.5379773

18.3945786

26.5610957

23.4194359

28.3288154

16.4980603

18.3450623

21.5010823

23.3745471

26.5096042

16.8303955

28.0201620

21.7834171

21.7791459

18.1429768

26.7442154

23.1531248

23.1823339

17.3966742

27.5035799

22.4343607

27.5030903

17.4570209

22.4565253

16.9957714

27.9426935

21.8804819

17.9468436

18.0060317

26.9328787

26.9129418

23.0352422

15.1301764

20.0675874

25.1108038

29.7705850

19.8123518

24.8356312

29.8489209

15.0449667

21.5584393

18.3809866

28.3210827

16.5009997

18.3561441

21.4196075

16.8458524

21.3574637

21.8189645

18.0685880

17.4407119

22.3971382

17.3424949

27.9258086

21.9578417

18.0003618

18.1942620

20.0727164

29.7665082 


\begin{tabular}{|c|c|c|c|}
\hline 0 & 2.1159030 & 12.6982642 & 19.7698787 \\
\hline $\mathrm{P}$ & 10.1605808 & 11.8102481 & 16.5005171 \\
\hline Al & 10.1458544 & 11.7940777 & 28.3422583 \\
\hline $\mathrm{P}$ & 12.4011119 & 10.5220850 & 26.6215790 \\
\hline Al & 12.4462445 & 10.5200173 & 23.4243882 \\
\hline $\mathrm{P}$ & 15.5523425 & 10.5687058 & 23.3745471 \\
\hline$P$ & 10.7310414 & 7.9118687 & 23.3694221 \\
\hline Al & 10.7536563 & 7.8733244 & 26.5189756 \\
\hline Al & 15.5418946 & 10.5595666 & 26.5096042 \\
\hline 0 & 8.9905042 & 10.5137026 & 28.0295960 \\
\hline 0 & 11.9338173 & 9.0913630 & 26.9662345 \\
\hline $\mathrm{H}$ & 15.9871850 & 9.1527666 & 26.7089801 \\
\hline $\mathrm{H}$ & 11.6746277 & 6.7699116 & 23.2187591 \\
\hline 0 & 14.1210820 & 10.0321399 & 23.1755659 \\
\hline 0 & 11.6040482 & 11.5543663 & 27.4307888 \\
\hline 0 & 9.3269559 & 8.0597504 & 27.5015585 \\
\hline $\mathrm{H}$ & 16.3300816 & 11.4942949 & 27.3594071 \\
\hline 0 & 9.4886208 & 7.6990102 & 22.4962250 \\
\hline 0 & 15.8388125 & 11.7563408 & 22.4565253 \\
\hline 0 & 9.5670870 & 10.4632236 & 16.9330488 \\
\hline 0 & 13.8766315 & 10.6647725 & 27.0043387 \\
\hline $\mathrm{H}$ & 11.3315832 & 6.5254211 & 26.7764203 \\
\hline $\mathrm{H}$ & 16.5128032 & 9.4795897 & 23.0452115 \\
\hline 0 & 11.420 & 9.1966314 & 22.8993477 \\
\hline $\mathrm{H}$ & 10.5551189 & 11.7838501 & 15.0649811 \\
\hline 0 & 12.1861316 & 10.8012570 & 25.1323429 \\
\hline 0 & 15.7440197 & 11.0273376 & 24.8356312 \\
\hline 0 & 10.2901131 & 8.0440586 & 24.8388617 \\
\hline $\mathrm{H}$ & 10.503 & 47394 & 29.7876249 \\
\hline $\mathrm{H}$ & 8.8058018 & 14.8807868 & 15.0065896 \\
\hline $\mathrm{P}$ & 5.4704011 & 14.5770670 & 16.5683946 \\
\hline Al & 5.4372165 & 14.5878136 & 28.4041911 \\
\hline $\mathrm{P}$ & 12.3901827 & 18.6524617 & 21.5379773 \\
\hline $\mathrm{Si}$ & 12.3069650 & 13.1831801 & 21.6164987 \\
\hline $\mathrm{P}$ & 17.1137160 & 15.8001313 & 21.5584393 \\
\hline Al & 17.0853488 & 15.8107724 & 18.3809866 \\
\hline Al & 12.3182958 & 13.1211478 & 18.3878764 \\
\hline Al & 12.4094737 & 18.6141786 & 18.3945786 \\
\hline $\mathrm{P}$ & 5.3843112 & 17.1109363 & 26.5358821 \\
\hline Al & 5.3667755 & 17.1240573 & 23.4153804 \\
\hline $\mathrm{P}$ & 8.5941444 & 14.5426261 & 28.3000475 \\
\hline Al & 8.6261500 & 14.5728106 & 16.4522716 \\
\hline $\mathrm{P}$ & 15.5337191 & 13.0924852 & 18.3561441 \\
\hline $\mathrm{P}$ & 15.5823759 & 18.5720417 & 18.3450623 \\
\hline $\mathrm{P}$ & 10.8063668 & 15.8998390 & 18.3292040 \\
\hline Al & 10.7378417 & 15.9369074 & 21.4904439 \\
\hline Al & 15.5668667 & 18.5700406 & 21.5010823 \\
\hline Al & 15.4995277 & 13.1174598 & 21.4196075 \\
\hline $\mathrm{P}$ & 8.5261233 & 17.2085087 & 23.3058415 \\
\hline Al & 8.5350450 & 17.1088716 & 26.4631692 \\
\hline 0 & 9.1110369 & 12.9095397 & 16.7588648 \\
\hline 0 & 7.1120647 & 14.1794076 & 28.0885286 \\
\hline O & 11.8901200 & 17.2234661 & 21.7909933 \\
\hline 0 & 13.8378971 & 13.5681114 & 21.3476910 \\
\hline 0 & 16.1018515 & 16.9332870 & 21.8284097 \\
\hline 0 & 15.8742174 & 14.5725363 & 18.0685880 \\
\hline 0 & 11.8705332 & 14.7894709 & 18.1555873 \\
\hline 0 & 14.0974292 & 18.2145731 & 18.1429768 \\
\hline 0 & 6.8545317 & 17.5104628 & 26.7757496 \\
\hline $\mathrm{H}$ & 9.0038069 & 18.6054954 & 23.1125360 \\
\hline $\mathrm{H}$ & 4.8549378 & 18.5117102 & 23.2434441 \\
\hline $\mathrm{H}$ & 18.3177403 & 15.5763659 & 17.5788734 \\
\hline $\mathrm{H}$ & 12.0069970 & 19.7653928 & 17.5402725 \\
\hline 0 & 11.4208872 & 12.0607990 & 17.3406618 \\
\hline 0 & 4.9659350 & 15.9871991 & 27.4882727 \\
\hline $\mathrm{H}$ & 11.6703284 & 19.6221747 & 22.4089464 \\
\hline 0 & 12.0425306 & 11.9334260 & 22.5648905 \\
\hline $\mathrm{H}$ & 18.3444371 & 16.0003066 & 22.3723043 \\
\hline 0 & 8.9998213 & 15.7172777 & 27.4060691 \\
\hline $\mathrm{H}$ & 16.2155048 & 12.2072000 & 17.3719901 \\
\hline 0 & 9.6160908 & 15.6474201 & 17.3962264 \\
\hline $\mathrm{H}$ & 15.9655166 & 19.7240289 & 17.4829432 \\
\hline 0 & 9.2619159 & 16.2477620 & 22.3721559 \\
\hline 0 & 6.9545037 & 14.7446346 & 16.9236713 \\
\hline 0 & 9.4508452 & 13.3321050 & 27.9156933 \\
\hline 0 & 13.8800209 & 18.7202378 & 21.8804819 \\
\hline 0 & 11.3754025 & 14.4281413 & 21.9685346 \\
\hline 0 & 16.4934511 & 14.4598965 & 21.9578417 \\
\hline 0 & 16.4357000 & 17.3666904 & 17.9351670 \\
\hline 0 & 14.0181227 & 12.8923198 & 18.1889486 \\
\hline
\end{tabular}




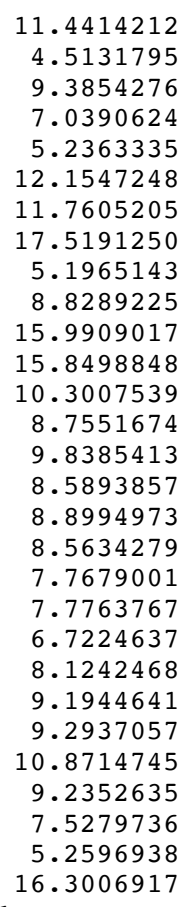

17.2377533

18.2865787

18.2660867

17.1448740

14.9183898

19.0500560

12.6188881

15.7960709

16.6224323

14.9212632

12.6982642

18.9535687

15.9328307

16.7592439

10.3319659

12.0581041

13.3415185

12.3172538

12.9910778

12.7141387

12.9965480

14.0301123

11.6130313

11.0362737

12.1374763

10.8097145

12.2359743

14.8787116

19.5479613

20.9221399

21.1999493

21.1210272

18.5391180

18.6091336

19.9023024

19.9963399

21.1245933

21.2583868

18.6445845

18.5795763

22.6430639

22.6021967

21.6391587

22.5817547

17.1729232

17.2236759

18.2428347

21.1301435

18.9472320

22.1573715

19.8154093

20.1461061

19.7371412

23.5165333

20.0609589

24.0194400

22.5248128

20.9003284

18.5721974

17.4987442

17.4592167

22.7303006

18.5674682

21.3572527

20.8820342

18.9680109

19.9880906

20.9435331

19.0076247

23.0447038

20.8364725

23.8500409

27.8982618

27.9607289

23.8264468

23.8739161

25.2013922
17.9397122

26.8117719

26.8566448

22.9524484

15.1380689

20.0675874

20.0397911

20.0727164

25.0868617

29.7208339

19.7698787

19.8123518

19.7774231

24.7628878

21.0464342

20.9500562

22.6543586

22.4276058

20.1079534

19.0464851

20.4584457

20.2103976

22.9834961

20.4127034

20.1252229

19.3456711

22.7988567

29.8536685

22.3509603

30.1916410

31.5523227

43.3762629

36.5107037

33.3448241

41.5046300

38.3817608

43.4346632

31.6286389

33.4158524

36.5883245

38.4095204

41.5684476

31.8904984

43.0642080

36.7682444

36.8383305

33.1053575

41.7564932

38.1836258

38.2029310

32.4925650

42.5735060

37.4752960

42.4849471

32.4956626

37.4423057

32.0109171

42.9812510

36.9306589

33.0157243

32.9375823

41.9572973

41.8016988

38.0109931

30.1063003

34.8236784

39.8467442

44.9021942

35.1224802

40.1121059

44.8257451

30.1197921

36.4868533

33.3156752

43.3848005

31.5726595

33.4324072 


\begin{tabular}{|c|c|c|c|}
\hline $\mathrm{P}$ & 8.6756691 & 25.2214099 & 36.5121251 \\
\hline 0 & 11.8094523 & 24.9665992 & 31.8711328 \\
\hline $\mathrm{H}$ & 7.2726632 & 25.7160837 & 36.5753139 \\
\hline $\mathrm{H}$ & 9.2765100 & 28.9960380 & 36.7907447 \\
\hline $\mathrm{O}$ & 9.1010198 & 26.8620299 & 33.0877076 \\
\hline 0 & 11.3801464 & 27.7447445 & 32.4173378 \\
\hline 0 & 11.7117668 & 28.1358476 & 37.3900335 \\
\hline $\mathrm{O}$ & 9.4709140 & 24.1245728 & 32.3541239 \\
\hline 0 & 11.4323655 & 25.3767103 & 42.9077801 \\
\hline $\mathrm{O}$ & 9.6539785 & 26.3360745 & 36.9540378 \\
\hline $\mathrm{H}$ & 9.5632825 & 29.2804971 & 32.9596409 \\
\hline $\mathrm{H}$ & 7.1519558 & 25.0549986 & 33.1621554 \\
\hline $\mathrm{O}$ & 10.6240712 & 27.9650916 & 34.7804149 \\
\hline $\mathrm{H}$ & 10.4765870 & 23.8459326 & 44.8404375 \\
\hline 0 & 9.0544822 & 24.7793256 & 35.0697937 \\
\hline Al & 17.1168201 & 23.9375308 & 31.4269351 \\
\hline $\mathrm{P}$ & 17.0089351 & 23.8657831 & 43.2410605 \\
\hline Al & 19.2472273 & 22.5438640 & 41.5014661 \\
\hline $\mathrm{P}$ & 19.2728379 & 22.4716728 & 38.3343194 \\
\hline Al & 22.4024622 & 22.6430639 & 38.4095204 \\
\hline Al & 17.5495122 & 19.8276994 & 38.5096516 \\
\hline$P$ & 17.6606256 & 19.8234371 & 41.6075166 \\
\hline $\mathrm{P}$ & 22.3889614 & 22.6021967 & 41.5684476 \\
\hline $\mathrm{O}$ & 15.9908678 & 22.7436479 & 42.9432374 \\
\hline $\mathrm{O}$ & 18.7311447 & 20.9017272 & 41.8623872 \\
\hline $\mathrm{H}$ & 22.7982004 & 21.1820791 & 41.7498588 \\
\hline $\mathrm{H}$ & 18.4469276 & 18.6519708 & 38.3381043 \\
\hline 0 & 20.7597327 & 22.0700179 & 38.1657751 \\
\hline $\mathrm{O}$ & 18.2782951 & 23.6794064 & 42.4074577 \\
\hline $\mathrm{O}$ & 16.5188617 & 19.9455647 & 42.6261651 \\
\hline $\mathrm{H}$ & 23.1865270 & 23.4902491 & 42.4586008 \\
\hline 0 & 16.1391376 & 19.6330918 & 37.4864915 \\
\hline $\mathrm{O}$ & 22.8048985 & 24.0194400 & 37.4423057 \\
\hline 0 & 16.4081186 & 22.4473697 & 32.0338240 \\
\hline 0 & 20.9146048 & 22.7341257 & 41.9689081 \\
\hline $\mathrm{H}$ & 18.2847617 & 18.4812324 & 41.7689522 \\
\hline $\mathrm{H}$ & 23.3556441 & 21.5504175 & 38.0708631 \\
\hline $\mathrm{O}$ & 18.4005737 & 21.2430039 & 37.9892231 \\
\hline $\mathrm{H}$ & 17.3445582 & 23.8512962 & 29.9579833 \\
\hline 0 & 19.0182615 & 22.8732047 & 39.8077596 \\
\hline $\mathrm{O}$ & 22.6036528 & 23.0447038 & 40.1121059 \\
\hline $\mathrm{O}$ & 17.0668981 & 19.9789420 & 40.1896579 \\
\hline $\mathrm{H}$ & 17.3716034 & 23.8377170 & 44.6849457 \\
\hline $\mathrm{H}$ & 15.6711412 & 26.9664374 & 30.0649943 \\
\hline Al & 12.3149296 & 26.6023915 & 31.4948378 \\
\hline$P$ & 12.2907322 & 26.5763334 & 43.3234311 \\
\hline Al & 19.2151761 & 30.5552194 & 36.5107037 \\
\hline Mg & 19.3009770 & 25.1937616 & 36.4542309 \\
\hline Al & 24.1104967 & 27.8982618 & 36.4868533 \\
\hline $\mathrm{P}$ & 24.0286812 & 27.9607289 & 33.3156752 \\
\hline$P$ & 19.2681875 & 25.1799312 & 33.2487445 \\
\hline $\mathrm{P}$ & 19.2575405 & 30.6252349 & 33.3448241 \\
\hline Al & 12.3791033 & 29.0859709 & 41.4632537 \\
\hline $\mathrm{P}$ & 12.3459566 & 29.1140731 & 38.3811221 \\
\hline Al & 15.4547746 & 26.6094375 & 43.3365446 \\
\hline $\mathrm{P}$ & 15.4818653 & 26.6456311 & 31.5066526 \\
\hline Al & 22.4838874 & 25.2013922 & 33.4324072 \\
\hline Al & 22.4119767 & 30.6606859 & 33.4158524 \\
\hline Al & 17.7285885 & 27.8754608 & 33.3097802 \\
\hline $\mathrm{P}$ & 17.5450007 & 27.8535719 & 36.5171023 \\
\hline $\mathrm{P}$ & 22.3960981 & 30.5956777 & 36.5883245 \\
\hline$P$ & 22.5506679 & 25.2214099 & 36.5121251 \\
\hline Al & 15.5027218 & 29.3001429 & 38.3614522 \\
\hline $\mathrm{P}$ & 15.5372895 & 29.1506539 & 41.4908319 \\
\hline $\mathrm{O}$ & 15.9458666 & 25.1999097 & 31.7964250 \\
\hline $\mathrm{O}$ & 13.7686863 & 26.2386877 & 43.0463338 \\
\hline $\mathrm{O}$ & 18.5912123 & 28.9564721 & 36.8120827 \\
\hline 0 & 21.1235319 & 25.7245915 & 36.5764006 \\
\hline $\mathrm{O}$ & 22.9762530 & 29.1966574 & 36.8462811 \\
\hline $\mathrm{O}$ & 22.9760185 & 26.8620299 & 33.0877076 \\
\hline $\mathrm{O}$ & 18.9022318 & 26.6503899 & 32.8941940 \\
\hline $\mathrm{O}$ & 20.7369263 & 30.2589361 & 33.1053575 \\
\hline $\mathrm{O}$ & 14.0588873 & 29.5116533 & 41.7503445 \\
\hline $\mathrm{H}$ & 16.0177339 & 30.6883315 & 38.2039224 \\
\hline $\mathrm{H}$ & 11.6734645 & 30.4407720 & 38.3122376 \\
\hline $\mathrm{H}$ & 25.2179752 & 27.7512903 & 32.4445634 \\
\hline $\mathrm{H}$ & 18.8681192 & 31.7990073 & 32.5155292 \\
\hline $\mathrm{O}$ & 18.6395563 & 24.2429874 & 32.1882023 \\
\hline $\mathrm{O}$ & 11.8561446 & 27.7924197 & 42.5016445 \\
\hline $\mathrm{H}$ & 18.5115346 & 31.5773428 & 37.3336697 \\
\hline
\end{tabular}




\begin{tabular}{|c|c|c|}
\hline 18.8672251 & 23.5979542 & 37.4127687 \\
\hline 25.3688418 & 28.1007757 & 37.2567080 \\
\hline 15.9608147 & 27.9699222 & 42.3733490 \\
\hline 23.2170099 & 24.2855947 & 32.5153648 \\
\hline 16.2770979 & 27.6427981 & 32.3520813 \\
\hline 22.7975006 & 31.8667331 & 32.6323079 \\
\hline 16.2106414 & 28.2138984 & 37.2081744 \\
\hline 14.0043996 & 26.7589723 & 31.9077750 \\
\hline 16.3875362 & 25.2152523 & 42.8660687 \\
\hline 20.9065839 & 30.5882987 & 36.9306589 \\
\hline 18.0121169 & 26.5082114 & 37.0307350 \\
\hline 23.5289772 & 26.3360745 & 36.9540378 \\
\hline 23.4196699 & 29.3221004 & 32.9484176 \\
\hline 20.7908675 & 25.0312764 & 33.1183627 \\
\hline 18.3809489 & 29.4446150 & 32.9267088 \\
\hline 11.5090713 & 30.2647627 & 41.7289880 \\
\hline 16.3855747 & 30.3228159 & 41.8423558 \\
\hline 13.8095875 & 29.3032355 & 37.9934547 \\
\hline 12.1188944 & 26.8625109 & 30.0418998 \\
\hline 19.0326143 & 30.9841123 & 34.8236784 \\
\hline 18.7541834 & 24.8143769 & 34.6312710 \\
\hline 24.4990700 & 27.9650916 & 34.7804149 \\
\hline 12.2221156 & 28.5367351 & 39.8048111 \\
\hline 15.6440263 & 26.9219367 & 44.7800295 \\
\hline 22.9294809 & 24.7793256 & 35.0697937 \\
\hline 22.6190911 & 31.0237260 & 35.1224802 \\
\hline 17.2625094 & 27.8109151 & 34.9933896 \\
\hline 15.7478096 & 28.7551359 & 40.0149878 \\
\hline 15.9008882 & 21.8911760 & 36.2980488 \\
\hline 15.6842865 & 24.0026791 & 36.1414927 \\
\hline 16.4386337 & 25.1007493 & 37.6825423 \\
\hline 15.6288407 & 24.3329184 & 37.5588812 \\
\hline 15.3235459 & 25.0154547 & 35.1591591 \\
\hline 16.3228801 & 25.3767111 & 34.8094648 \\
\hline 14.8628351 & 24.5903089 & 34.2551774 \\
\hline 14.7770086 & 25.8772999 & 35.5571274 \\
\hline 15.8352455 & 23.4968075 & 38.2342435 \\
\hline 16.2660841 & 22.7479423 & 35.7062253 \\
\hline 17.3340324 & 22.8216128 & 36.0421113 \\
\hline 16.2326125 & 22.5679411 & 34.6271872 \\
\hline 14.7080884 & 24.8780869 & 37.8185135 \\
\hline 12.0916185 & 26.8969071 & 44.7638153 \\
\hline 23.0529743 & 31.6125620 & 37.4552619 \\
\hline 8.7329648 & 8.7255507 & 15.1273735 \\
\hline 5.3830893 & 9.0726738 & 16.5451242 \\
\hline 5.3770551 & 9.0090863 & 28.4926746 \\
\hline 5.3686278 & 6.5524018 & 21.5285390 \\
\hline 5.3918628 & 6.6012997 & 18.4455378 \\
\hline 3.2752955 & 7.7899380 & 26.5436563 \\
\hline 3.3439510 & 7.8599468 & 23.4800584 \\
\hline 8.4957931 & 8.9915803 & 28.4817734 \\
\hline 8.5081515 & 9.0879418 & 16.5539961 \\
\hline 8.5117796 & 6.5940973 & 18.4462813 \\
\hline 8.5087647 & 6.5392768 & 21.5511874 \\
\hline 1.6993475 & 10.5262975 & 23.4576195 \\
\hline 1.6836143 & 10.5001260 & 26.5423407 \\
\hline 6.9442449 & 9.4856816 & 16.7910002 \\
\hline 4.9607912 & 10.5594664 & 28.2057668 \\
\hline 4.8481735 & 5.1671144 & 21.6935443 \\
\hline 9.0478185 & 5.1687802 & 21.7709161 \\
\hline 6.9526746 & 6.1923168 & 18.2025028 \\
\hline 2.1450548 & 8.9463859 & 26.7196539 \\
\hline 2.3042005 & 6.8131259 & 23.2795449 \\
\hline 0.2972707 & 10.0573143 & 23.2805433 \\
\hline 4.9657817 & 7.8321838 & 17.4888694 \\
\hline 4.4933889 & 7.9998256 & 27.5895157 \\
\hline 4.6129511 & 7.6012238 & 22.5059313 \\
\hline 2.5271516 & 11.4566668 & 27.5407405 \\
\hline 8.9317562 & 7.8505372 & 17.5100361 \\
\hline 2.0735057 & 11.7473368 & 22.4745189 \\
\hline 4.4601441 & 10.3355271 & 16.9513342 \\
\hline 6.9343860 & 8.8001876 & 28.1012079 \\
\hline 6.9380731 & 6.5540989 & 21.9222013 \\
\hline 9.3729993 & 5.4351937 & 18.0824634 \\
\hline 4.5249473 & 5.4414245 & 18.0987418 \\
\hline 0.2478736 & 10.5973055 & 26.9248659 \\
\hline 2.6532324 & 6.4700764 & 26.8405121 \\
\hline
\end{tabular}

37.4127687 2567080 32.3520813 32.6323079 42.8660687 36.9306589 37.0307350 33.1183627 9267088 41.8423558 9934547 34.8236784 6312710 39.8048111 .7800295 35.1224802 34.9933896 40.0149878 36.2980488 .1414927 37.5588812 35.1591591 094648 35.5571274 38.2342435 35.7062253 .0421113 37.8185135 44.7638153 37.4552619

15.1273735 21.5285390 18.4455378 26.5436563 ( 16.5539961 23.4576195 26.5423407 6.7910002 21.6935443 21.7709161 18.2025028 7196539 23.2805433 7.4888694 22.5059313 .5407405 22.4745189 .9513342 012079 18.0824634 26.9248659 26.8405121 


$$
\begin{aligned}
& \text { 2. } 7096958 \\
& 9.2999617 \\
& 8.6823587
\end{aligned}
$$




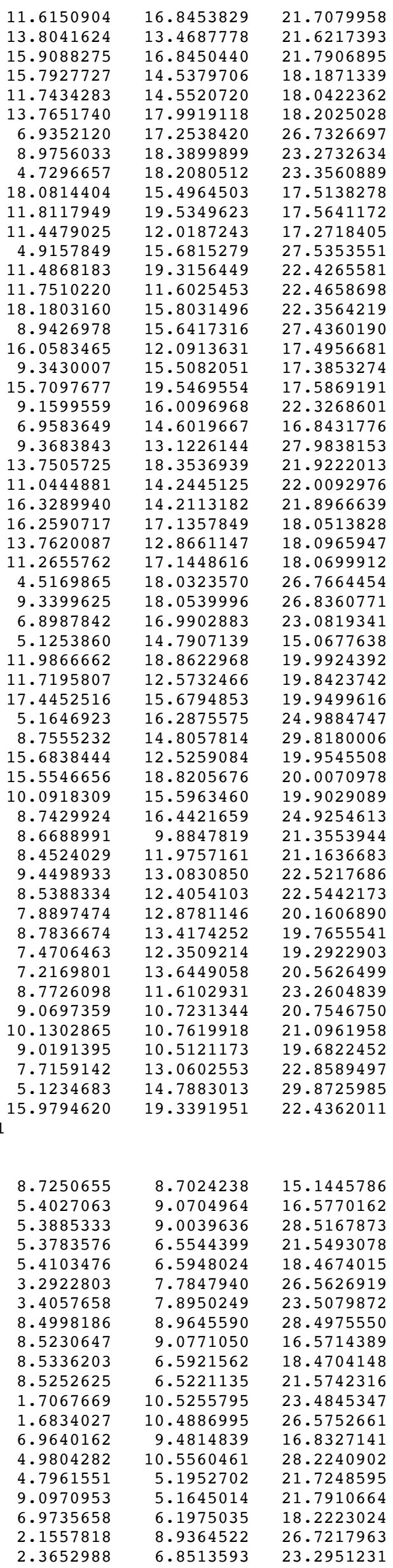
$21^{1}$

171

$\begin{array}{ll}\mathrm{H} & 8.7250655 \\ \mathrm{Si} & 5.4027063 \\ \mathrm{Si} & 5.3885333 \\ \mathrm{Si} & 5.3783576 \\ \mathrm{Si} & 5.4103476 \\ \mathrm{Si} & 3.2922803 \\ \mathrm{Si} & 3.4057658 \\ \mathrm{Si} & 8.4998186 \\ \mathrm{Si} & 8.5230647 \\ \mathrm{Si} & 8.5336203 \\ \mathrm{Si} & 8.5252625 \\ \mathrm{Si} & 1.7067669 \\ \mathrm{Si} & 1.6834027 \\ \mathrm{O} & 6.9640162 \\ \mathrm{O} & 4.9804282 \\ \mathrm{H} & 4.7961551 \\ \mathrm{H} & 9.0970953 \\ \mathrm{O} & 6.9735658 \\ \mathrm{O} & 2.1557818 \\ \mathrm{H} & 2.3652988\end{array}$




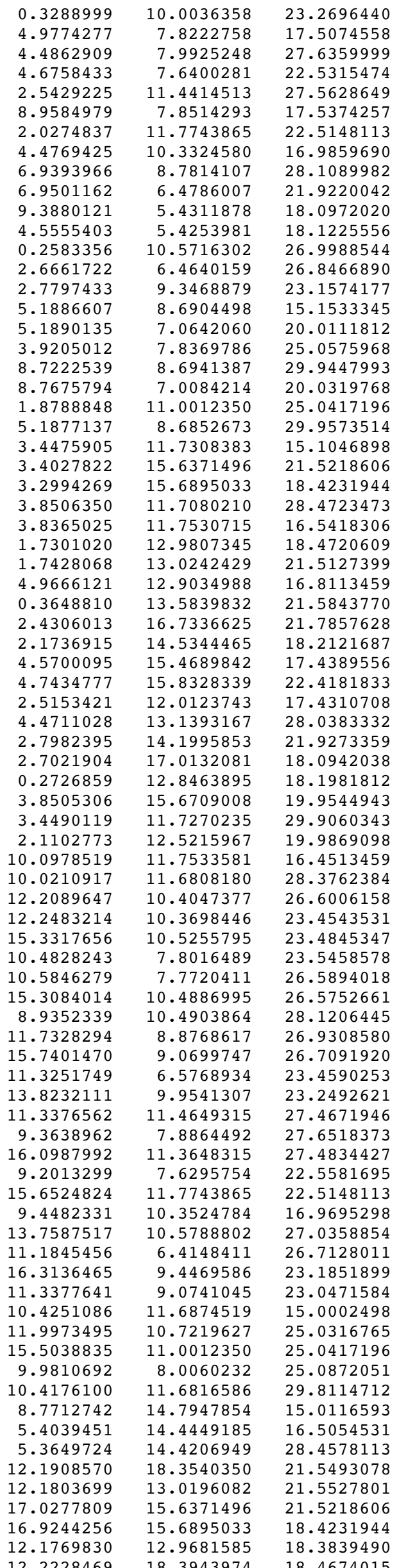




\begin{tabular}{|c|c|c|c|}
\hline $\mathrm{Si}$ & 5.3849280 & 16.8223376 & 26.5083591 \\
\hline $\mathrm{Si}$ & 5.3570868 & 16.8656203 & 23.5007612 \\
\hline $\mathrm{Si}$ & 8.5053306 & 14.4107005 & 28.3928554 \\
\hline $\mathrm{Si}$ & 8.5461308 & 14.4654676 & 16.4462258 \\
\hline $\mathrm{Si}$ & 15.3551008 & 12.9807345 & 18.4720609 \\
\hline $\mathrm{Si}$ & 15.3461197 & 18.3917512 & 18.4704148 \\
\hline $\mathrm{Si}$ & 10.6429581 & 15.6766229 & 18.3928353 \\
\hline $\mathrm{Si}$ & 10.4649733 & 15.6880642 & 21.5086265 \\
\hline $\mathrm{Si}$ & 15.3377619 & 18.3217085 & 21.5742316 \\
\hline $\mathrm{Si}$ & 15.3678056 & 13.0242429 & 21.5127399 \\
\hline $\mathrm{Si}$ & 8.4724596 & 17.0587954 & 23.4156241 \\
\hline $\mathrm{Si}$ & 8.5012786 & 16.8780824 & 26.4870189 \\
\hline 0 & 8.9917006 & 12.9212828 & 16.7503544 \\
\hline 0 & 6.9293684 & 14.0544641 & 28.2025927 \\
\hline 0 & 11.5583325 & 16.8773870 & 21.7400331 \\
\hline 0 & 13.8836501 & 13.6271358 & 21.5898998 \\
\hline 0 & 15.9623577 & 16.8388295 & 21.8110738 \\
\hline 0 & 15.7986903 & 14.5344465 & 18.2121687 \\
\hline 0 & 11.7694045 & 14.5349853 & 18.1242395 \\
\hline 0 & 13.7860652 & 17.9970985 & 18.2223024 \\
\hline 0 & 6.9370353 & 17.2596022 & 26.7650292 \\
\hline $\mathrm{H}$ & 9.0325617 & 18.4324459 & 23.2872087 \\
\hline $\mathrm{H}$ & 4.6401424 & 18.1698705 & 23.4555673 \\
\hline $\mathrm{H}$ & 18.0906349 & 15.4870990 & 17.5198069 \\
\hline $\mathrm{H}$ & 11.8242665 & 19.5245070 & 17.5835992 \\
\hline 0 & 11.4670451 & 12.0275398 & 17.2551801 \\
\hline 0 & 4.9149048 & 15.6809699 & 27.5527222 \\
\hline $\mathrm{H}$ & 11.5466739 & 19.3494846 & 22.4499901 \\
\hline 0 & 11.7591414 & 11.5850013 & 22.5606818 \\
\hline $\mathrm{H}$ & 18.2566134 & 15.8165066 & 22.3433972 \\
\hline 0 & 8.9455135 & 15.6299436 & 27.4230567 \\
\hline $\mathrm{H}$ & 16.0749823 & 12.0929746 & 17.5177164 \\
\hline 0 & 9.3909665 & 15.4884110 & 17.3701328 \\
\hline $\mathrm{H}$ & 15.7357236 & 19.5464785 & 17.6148832 \\
\hline 0 & 9.0903755 & 16.0590462 & 22.3078001 \\
\hline 0 & 6.9808097 & 14.6048870 & 16.8506629 \\
\hline 0 & 9.3618560 & 13.1030732 & 27.9732605 \\
\hline 0 & 13.7626156 & 18.2781958 & 21.9220042 \\
\hline 0 & 10.9717105 & 14.2833736 & 22.0777154 \\
\hline 0 & 16.4232383 & 14.1995853 & 21.9273359 \\
\hline 0 & 16.2741990 & 17.1306543 & 18.0650140 \\
\hline 0 & 13.7766288 & 12.8352306 & 18.1754322 \\
\hline 0 & 11.2965089 & 17.1271367 & 18.0936987 \\
\hline $\mathrm{H}$ & 4.4970743 & 18.0011236 & 26.7066012 \\
\hline $\mathrm{H}$ & 9.3512441 & 18.0482939 & 26.8409740 \\
\hline $\mathrm{O}$ & 6.8922688 & 17.1537825 & 23.1130233 \\
\hline $\mathrm{H}$ & 5.1429802 & 14.7830703 & 15.0790340 \\
\hline $\mathrm{O}$ & 12.0015129 & 18.8638011 & 20.0111812 \\
\hline 0 & 11.6743490 & 12.4682169 & 19.8387771 \\
\hline 0 & 17.4755293 & 15.6709008 & 19.9544943 \\
\hline 0 & 5.2352232 & 16.2235797 & 24.9960697 \\
\hline $\mathrm{H}$ & 8.7671971 & 14.7892515 & 29.8089224 \\
\hline 0 & 15.7352761 & 12.5215967 & 19.9869098 \\
\hline $\mathrm{O}$ & 15.5800788 & 18.8080165 & 20.0319768 \\
\hline 0 & 10.0736669 & 15.6067785 & 19.9154672 \\
\hline $\mathrm{O}$ & 8.7262644 & 16.4717757 & 24.9213143 \\
\hline $\mathrm{H}$ & 9.6200215 & 10.2085355 & 21.0941523 \\
\hline C & 8.4027897 & 11.9778321 & 21.0056375 \\
\hline $\mathrm{H}$ & 9.2977486 & 13.0145016 & 22.5293125 \\
\hline $\mathrm{C}$ & 8.4609699 & 12.2717999 & 22.4351921 \\
\hline C & 7.5365481 & 12.8098651 & 20.1520464 \\
\hline $\mathrm{H}$ & 7.7700317 & 12.7317086 & 19.0835196 \\
\hline $\mathrm{H}$ & 6.5036600 & 12.4304019 & 20.2974967 \\
\hline $\mathrm{H}$ & 7.5108869 & 13.8577470 & 20.4906471 \\
\hline $\mathrm{H}$ & 8.7510752 & 11.4124403 & 23.0506447 \\
\hline $\mathrm{C}$ & 9.2428149 & 10.9844180 & 20.4188878 \\
\hline $\mathrm{H}$ & 10.1897366 & 11.6166339 & 20.1508750 \\
\hline $\mathrm{H}$ & 8.9196471 & 10.6248512 & 19.4334782 \\
\hline $\mathrm{H}$ & 7.5628020 & 12.7837989 & 22.8058947 \\
\hline $\mathrm{H}$ & 5.1400000 & 14.7806300 & 29.8850306 \\
\hline $\mathrm{H}$ & 15.9559558 & 19.3343681 & 22.4739413 \\
\hline \multicolumn{4}{|c|}{$\mathrm{Zn} 22$} \\
\hline \multicolumn{4}{|c|}{174} \\
\hline $\mathrm{H}$ & 8.6987476 & 9.0844090 & 15.2605619 \\
\hline Al & 5.4196523 & 9.4073952 & 16.6395241 \\
\hline $\mathrm{P}$ & 5.4165441 & 9.3679708 & 28.4540700 \\
\hline Al & 5.3203420 & 6.8235105 & 21.5862191 \\
\hline $\mathrm{P}$ & 5.3473295 & 6.8552379 & 18.4429678 \\
\hline Al & 3.1905896 & 8.1533251 & 26.6066137 \\
\hline
\end{tabular}




\begin{tabular}{|c|c|c|c|}
\hline $\mathrm{P}$ & 3.2613105 & 8.2688697 & 23.4946822 \\
\hline Al & 8.5385906 & 9.3560727 & 28.5109157 \\
\hline$P$ & 8.5634126 & 9.4500792 & 16.6976041 \\
\hline Al & 8.5047081 & 6.8676544 & 18.4910697 \\
\hline $\mathrm{P}$ & 8.4934963 & 6.8404469 & 21.6730583 \\
\hline Al & 1.5560309 & 10.9243389 & 23.5274780 \\
\hline $\mathrm{P}$ & 1.5344298 & 10.8540613 & 26.6945805 \\
\hline $\mathrm{O}$ & 7.0934237 & 9.8109449 & 17.0258694 \\
\hline 0 & 5.0117085 & 10.8226827 & 28.1393042 \\
\hline $\mathrm{H}$ & 4.8285155 & 5.4307599 & 21.7745621 \\
\hline $\mathrm{H}$ & 9.0205096 & 5.4706725 & 21.9242467 \\
\hline $\mathrm{O}$ & 6.8250237 & 6.4996075 & 18.1713238 \\
\hline $\mathrm{O}$ & 1.9764229 & 9.3857221 & 26.8639652 \\
\hline $\mathrm{H}$ & 2.1904869 & 7.2484547 & 23.3237716 \\
\hline $\mathrm{H}$ & 0.1646517 & 10.4671897 & 23.2587789 \\
\hline $\mathrm{O}$ & 4.9085294 & 8.0104953 & 17.5341049 \\
\hline 0 & 4.5438567 & 8.3798815 & 27.6782681 \\
\hline $\mathrm{O}$ & 4.4477403 & 7.9792178 & 22.5650112 \\
\hline $\mathrm{O}$ & 2.3564692 & 11.7685340 & 27.6120742 \\
\hline $\mathrm{O}$ & 9.0095440 & 8.2692284 & 17.5711752 \\
\hline $\mathrm{O}$ & 1.9747927 & 12.3105119 & 22.5826383 \\
\hline $\mathrm{O}$ & 4.4537844 & 10.7716178 & 17.1296868 \\
\hline $\mathrm{O}$ & 6.8746201 & 9.1545117 & 28.0331297 \\
\hline $\mathrm{O}$ & 7.0084322 & 6.8903951 & 22.0341193 \\
\hline $\mathrm{H}$ & 9.3516709 & 5.7095295 & 18.0929224 \\
\hline $\mathrm{H}$ & 4.4954551 & 5.6742188 & 18.1321228 \\
\hline $\mathrm{H}$ & 0.1079822 & 10.9640310 & 27.1072240 \\
\hline $\mathrm{H}$ & 2.5896483 & 6.8261727 & 26.9142768 \\
\hline $\mathrm{O}$ & 2.6937342 & 9.6445996 & 23.1368408 \\
\hline $\mathrm{H}$ & 5.2730654 & 9.1322046 & 15.1835354 \\
\hline 0 & 5.1737937 & 7.3081699 & 19.9054140 \\
\hline 0 & 3.7683479 & 8.2439704 & 24.9520206 \\
\hline $\mathrm{H}$ & 8.6781007 & 9.1158990 & 29.9737807 \\
\hline $\mathrm{O}$ & 8.7075266 & 7.2367277 & 20.1964695 \\
\hline $\mathrm{O}$ & 1.7262151 & 11.3071131 & 25.2383373 \\
\hline $\mathrm{H}$ & 5.2537378 & 9.0948632 & 29.9087270 \\
\hline $\mathrm{H}$ & 3.5165239 & 12.0892037 & 15.2383030 \\
\hline Al & 3.2607684 & 16.1710183 & 21.5687347 \\
\hline$P$ & 3.2056068 & 16.1982344 & 18.4157036 \\
\hline Al & 3.8241377 & 12.0696288 & 28.4908840 \\
\hline $\mathrm{P}$ & 3.8444594 & 12.1111425 & 16.6905762 \\
\hline Al & 1.6486920 & 13.4125711 & 18.5303019 \\
\hline$P$ & 1.7053568 & 13.4833593 & 21.6236552 \\
\hline $\mathrm{O}$ & 4.8843499 & 13.2181642 & 16.9918471 \\
\hline $\mathrm{H}$ & 0.3382323 & 14.0609172 & 21.7441468 \\
\hline $\mathrm{H}$ & 2.2780475 & 17.2462866 & 21.8772444 \\
\hline $\mathrm{O}$ & 2.1809276 & 15.0686624 & 18.2338491 \\
\hline $\mathrm{O}$ & 4.4247794 & 15.9900004 & 17.5069748 \\
\hline 0 & 4.7391905 & 16.3994286 & 22.4762960 \\
\hline $\mathrm{O}$ & 2.5649846 & 12.3432009 & 17.4876754 \\
\hline $\mathrm{O}$ & 4.4680552 & 13.6147054 & 28.0037781 \\
\hline $\mathrm{O}$ & 2.7466352 & 14.5732249 & 21.9788015 \\
\hline $\mathrm{H}$ & 2.5747638 & 17.4929771 & 18.0378158 \\
\hline $\mathrm{H}$ & 0.2119688 & 13.2802540 & 18.1622810 \\
\hline 0 & 3.7034583 & 16.2530588 & 19.8726851 \\
\hline $\mathrm{H}$ & 3.5535185 & 12.0857180 & 29.9549970 \\
\hline 0 & 2.0022056 & 12.9729310 & 20.1843688 \\
\hline Al & 10.1372811 & 12.1825232 & 16.5300094 \\
\hline$P$ & 10.0389269 & 12.1199781 & 28.3472836 \\
\hline Al & 12.2812526 & 10.7697646 & 26.6269310 \\
\hline $\mathrm{P}$ & 12.3058269 & 10.7549145 & 23.4369577 \\
\hline Al & 15.4310296 & 10.9243389 & 23.5274780 \\
\hline Al & 10.6216061 & 8.0923826 & 23.5787529 \\
\hline $\mathrm{P}$ & 10.6919023 & 8.0603713 & 26.6915936 \\
\hline $\mathrm{P}$ & 15.4094285 & 10.8540613 & 26.6945805 \\
\hline 0 & 9.0202206 & 10.9883294 & 28.0906457 \\
\hline $\mathrm{O}$ & 11.7620005 & 9.1274925 & 26.9876554 \\
\hline $\mathrm{H}$ & 15.8360231 & 9.4368772 & 26.8580640 \\
\hline $\mathrm{H}$ & 11.5331647 & 6.9272834 & 23.4092676 \\
\hline $\mathrm{O}$ & 13.7949082 & 10.3867776 & 23.2115150 \\
\hline $\mathrm{O}$ & 11.3022164 & 11.9096769 & 27.5124292 \\
\hline $\mathrm{O}$ & 9.5238202 & 8.1854672 & 27.6785401 \\
\hline $\mathrm{H}$ & 16.2072435 & 11.7415856 & 27.5850368 \\
\hline 0 & 9.2173297 & 7.8761936 & 22.5522010 \\
\hline $\mathrm{O}$ & 15.8497914 & 12.3105119 & 22.5826383 \\
\hline 0 & 9.4458506 & 10.6535391 & 17.0426600 \\
\hline 0 & 13.9414436 & 10.9672333 & 27.1192399 \\
\hline $\mathrm{H}$ & 11.2987755 & 6.7118933 & 26.8660429 \\
\hline $\mathrm{H}$ & 16.3955630 & 9.8393888 & 23.1962997 \\
\hline $\mathrm{O}$ & 11.4601870 & 9.5123510 & 23.0642401 \\
\hline
\end{tabular}




\begin{tabular}{|c|c|c|}
\hline 10.3826406 & 12.1476539 & 15.0617780 \\
\hline 12.0869784 & 11.0733799 & 24.9340743 \\
\hline 15.6012138 & 11.3071131 & 25.2383373 \\
\hline 10.1377663 & 8.2236983 & 25.2598721 \\
\hline 10.4129058 & 12.1411455 & 29.7883986 \\
\hline 8.7128435 & 15.1701370 & 15.1730649 \\
\hline 5.3677330 & 14.8584628 & 16.5805938 \\
\hline 5.3243870 & 14.8175267 & 28.4117771 \\
\hline 12.2578414 & 18.8396119 & 21.5862191 \\
\hline 12.3674183 & 13.4591016 & 21.5733746 \\
\hline 17.1357671 & 16.1710183 & 21.5687347 \\
\hline 17.0806055 & 16.1982344 & 18.4157036 \\
\hline 12.3445524 & 13.3917076 & 18.3502990 \\
\hline 12.2848289 & 18.8713392 & 18.4429678 \\
\hline 5.4037888 & 17.3287116 & 26.5585395 \\
\hline 5.3972008 & 17.3677125 & 23.4667799 \\
\hline 8.4913300 & 14.8490025 & 28.4375940 \\
\hline 8.5231829 & 14.8725246 & 16.6196389 \\
\hline 15.5236907 & 13.4125711 & 18.5303019 \\
\hline 15.4422075 & 18.8837558 & 18.4910697 \\
\hline 10.7614645 & 16.0742988 & 18.4600911 \\
\hline 10.6240748 & 16.1006187 & 21.6248512 \\
\hline 15.4309957 & 18.8565483 & 21.6730583 \\
\hline 15.5803555 & 13.4833593 & 21.6236552 \\
\hline 8.5536185 & 17.5754480 & 23.4832714 \\
\hline 8.5599807 & 17.4057623 & 26.6096196 \\
\hline 8.9428869 & 13.4168401 & 16.9242569 \\
\hline 6.8028844 & 14.4878015 & 28.1368604 \\
\hline 11.6850235 & 17.2175104 & 21.8055774 \\
\hline 14.1866979 & 14.0721264 & 21.7464853 \\
\hline 15.9760045 & 17.4400011 & 21.9328239 \\
\hline 16.0559263 & 15.0686624 & 18.2338491 \\
\hline 11.9606934 & 14.8711276 & 18.0617773 \\
\hline 13.7625230 & 18.5157089 & 18.1713238 \\
\hline 7.0783993 & 17.7589034 & 26.8642785 \\
\hline 9.0111827 & 18.9853474 & 23.3420650 \\
\hline 4.7645323 & 18.7130318 & 23.3833102 \\
\hline 18.2634167 & 15.9962110 & 17.5340774 \\
\hline 11.8589047 & 19.9926972 & 17.5607743 \\
\hline 11.6515433 & 12.4823961 & 17.3049056 \\
\hline 4.8804421 & 16.0277650 & 27.5870573 \\
\hline 11.5144867 & 19.8241394 & 22.4200356 \\
\hline 11.8284491 & 11.9096213 & 22.5939264 \\
\hline 18.3938839 & 16.3653923 & 22.3410568 \\
\hline 8.9874481 & 16.2303869 & 27.4967606 \\
\hline 16.3023446 & 12.5038338 & 17.6442910 \\
\hline 9.3465176 & 15.8625223 & 17.4436247 \\
\hline 15.8715422 & 20.0757161 & 17.7087508 \\
\hline 9.3287639 & 16.5218506 & 22.3580499 \\
\hline 7.0466051 & 15.0362461 & 17.0139479 \\
\hline 9.4112804 & 13.4569287 & 27.9357636 \\
\hline 13.9459316 & 18.9064965 & 22.0341193 \\
\hline 11.0995966 & 14.7888295 & 22.2030243 \\
\hline 16.6216339 & 14.5732249 & 21.9788015 \\
\hline 16.4306943 & 17.5321128 & 18.0263936 \\
\hline 13.8576269 & 13.2591325 & 18.1035348 \\
\hline 11.4121153 & 17.6614292 & 18.1245186 \\
\hline 4.5228364 & 18.4988509 & 26.8265271 \\
\hline 9.4015890 & 18.5840184 & 26.9567919 \\
\hline 6.8672654 & 17.4919852 & 23.0732870 \\
\hline 5.1547657 & 15.1071328 & 15.1280344 \\
\hline 12.1112931 & 19.3242712 & 19.9054140 \\
\hline 17.5784570 & 16.2530588 & 19.8726851 \\
\hline 5.2547147 & 16.7992615 & 24.8913255 \\
\hline 8.6852643 & 15.1308089 & 29.8867645 \\
\hline 15.8772043 & 12.9729310 & 20.1843688 \\
\hline 15.6450259 & 19.2528290 & 20.1964695 \\
\hline 10.2540316 & 15.9900156 & 20.1253185 \\
\hline 8.7722716 & 17.0127957 & 25.1336463 \\
\hline 11.9211432 & 12.9553216 & 19.7404012 \\
\hline 9.5647738 & 10.7034419 & 20.3560257 \\
\hline 10.1914630 & 10.3122287 & 21.1634678 \\
\hline 9.2424843 & 9.8770820 & 19.7152302 \\
\hline 10.1602492 & 11.4202459 & 19.7799958 \\
\hline 7.9249907 & 13.5929728 & 22.0895773 \\
\hline 6.9037049 & 13.8641082 & 21.1609910 \\
\hline 6.5741085 & 12.9649857 & 20.1247133 \\
\hline 7.2722175 & 11.7868995 & 20.0063305 \\
\hline 8.3313907 & 11.4258922 & 20.9575796 \\
\hline 8.6432690 & 12.4231825 & 21.9869627 \\
\hline
\end{tabular}




\begin{tabular}{|c|c|c|c|}
\hline $\mathrm{H}$ & 8.1750340 & 14.3281692 & 22.8528284 \\
\hline $\mathrm{H}$ & 9.4760943 & 12.2100339 & 22.6637182 \\
\hline $\mathrm{H}$ & 6.3534385 & 14.8057951 & 21.2472121 \\
\hline $\mathrm{H}$ & 5.7835579 & 13.2103656 & 19.4147851 \\
\hline $\mathrm{H}$ & 7.0440657 & 11.0818823 & 19.2021108 \\
\hline $\mathrm{H}$ & 7.8346941 & 10.6141636 & 21.5689477 \\
\hline $\mathrm{H}$ & 5.1252465 & 15.1386970 & 29.8520247 \\
\hline $\mathrm{H}$ & 16.1311535 & 19.8584172 & 22.5234455 \\
\hline \multicolumn{4}{|c|}{$\begin{array}{l}\text { Si } 22 \\
174\end{array}$} \\
\hline $\mathrm{H}$ & 8.6471830 & 9.0778260 & 15.1517190 \\
\hline $\mathrm{P}$ & 5.3856262 & 9.4691720 & 16.7003466 \\
\hline Al & 5.3522224 & 9.4210747 & 28.5094011 \\
\hline $\mathrm{P}$ & 5.4300418 & 6.8840749 & 21.6401502 \\
\hline Al & 5.4268451 & 6.8839414 & 18.4906686 \\
\hline $\mathrm{P}$ & 3.1986188 & 8.0752861 & 26.6591928 \\
\hline Al & 3.2538197 & 8.1366746 & 23.5475136 \\
\hline $\mathrm{P}$ & 8.4831474 & 9.3471960 & 28.4282232 \\
\hline Al & 8.5302103 & 9.4018713 & 16.6003158 \\
\hline $\mathrm{P}$ & 8.5857264 & 6.8439855 & 18.4377804 \\
\hline Al & 8.5879499 & 6.8178668 & 21.6150037 \\
\hline $\mathrm{P}$ & 1.6732660 & 10.8834509 & 23.4572609 \\
\hline Al & 1.6232108 & 10.8497091 & 26.5919525 \\
\hline 0 & 6.8644650 & 9.8229940 & 16.9962773 \\
\hline $\mathrm{O}$ & 4.8715336 & 11.0681042 & 28.1472535 \\
\hline $\mathrm{H}$ & 4.9598831 & 5.4825165 & 21.8182102 \\
\hline $\mathrm{H}$ & 9.1025432 & 5.4444684 & 21.8720860 \\
\hline $\mathrm{O}$ & 7.1110976 & 6.4887905 & 18.1729937 \\
\hline $\mathrm{O}$ & 2.1446984 & 9.1876226 & 26.8023476 \\
\hline $\mathrm{H}$ & 2.1856370 & 7.1220362 & 23.3316078 \\
\hline $\mathrm{H}$ & 0.2692135 & 10.4486434 & 23.2191446 \\
\hline $\mathrm{O}$ & 4.9529335 & 8.2599926 & 17.5293034 \\
\hline $\mathrm{O}$ & 4.3514549 & 8.2901017 & 27.6472726 \\
\hline $\mathrm{O}$ & 4.6422878 & 7.8533807 & 22.5316262 \\
\hline $\mathrm{O}$ & 2.5473432 & 11.9104854 & 27.6216674 \\
\hline $\mathrm{O}$ & 9.0156312 & 8.0419228 & 17.5787501 \\
\hline $\mathrm{O}$ & 2.0791793 & 12.0317121 & 22.5336829 \\
\hline $\mathrm{O}$ & 4.5226612 & 10.6669082 & 17.1141721 \\
\hline $\mathrm{O}$ & 7.0112208 & 9.1995236 & 28.0270128 \\
\hline $\mathrm{O}$ & 6.9094135 & 6.9706079 & 22.0474524 \\
\hline $\mathrm{H}$ & 9.4402389 & 5.6805145 & 18.0727266 \\
\hline $\mathrm{H}$ & 4.5590935 & 5.7317697 & 18.1210360 \\
\hline $\mathrm{H}$ & 0.1978466 & 10.9345785 & 27.0141548 \\
\hline $\mathrm{H}$ & 2.5633900 & 6.7685929 & 26.9850114 \\
\hline $\mathrm{O}$ & 2.6150040 & 9.7043513 & 23.1663601 \\
\hline $\mathrm{H}$ & 5.2047370 & 9.1522457 & 15.2567548 \\
\hline 0 & 5.2634698 & 7.3383091 & 20.1748584 \\
\hline $\mathrm{O}$ & 3.7688661 & 8.0622754 & 25.2269722 \\
\hline $\mathrm{H}$ & 8.6609500 & 9.0335396 & 29.8729122 \\
\hline 0 & 8.7900813 & 7.2233510 & 19.9184922 \\
\hline $\mathrm{O}$ & 1.8409099 & 11.3365117 & 24.9261957 \\
\hline $\mathrm{H}$ & 5.2220023 & 9.1840477 & 29.9736352 \\
\hline $\mathrm{H}$ & 3.5054685 & 12.1675408 & 15.1597846 \\
\hline $\mathrm{P}$ & 3.2307598 & 16.0592512 & 21.6406696 \\
\hline Al & 3.1994383 & 16.1083081 & 18.4691140 \\
\hline $\mathrm{P}$ & 3.8185150 & 12.1590912 & 28.4329095 \\
\hline Al & 3.7959130 & 12.1775981 & 16.6201481 \\
\hline $\mathrm{P}$ & 1.5730922 & 13.4074734 & 18.4274592 \\
\hline Al & 1.5176546 & 13.4013515 & 21.5810867 \\
\hline $\mathrm{O}$ & 4.9718837 & 13.4344877 & 17.0013773 \\
\hline $\mathrm{H}$ & 0.0848541 & 13.7427895 & 21.7993146 \\
\hline $\mathrm{H}$ & 2.2886061 & 17.1810443 & 21.9072160 \\
\hline $\mathrm{O}$ & 2.0358667 & 14.8547044 & 18.1268391 \\
\hline $\mathrm{O}$ & 4.6541109 & 15.8817244 & 17.5259100 \\
\hline $\mathrm{O}$ & 4.5128896 & 16.2262704 & 22.4801258 \\
\hline $\mathrm{O}$ & 2.3305965 & 12.4285853 & 17.5109734 \\
\hline 0 & 4.3976138 & 13.5167141 & 28.0180548 \\
\hline $\mathrm{O}$ & 2.5850841 & 14.7369799 & 22.0263015 \\
\hline $\mathrm{H}$ & 2.6246163 & 17.4372898 & 18.1219716 \\
\hline $\mathrm{H}$ & 0.1212677 & 13.2984298 & 18.1153122 \\
\hline $\mathrm{O}$ & 3.6589603 & 16.0637832 & 20.1586265 \\
\hline $\mathrm{H}$ & 3.4674208 & 12.1656095 & 29.8799102 \\
\hline $\mathrm{O}$ & 1.8908996 & 13.0412833 & 19.8849956 \\
\hline $\mathrm{P}$ & 10.1384377 & 12.1121221 & 16.6103049 \\
\hline Al & 10.0958341 & 12.0740208 & 28.4316782 \\
\hline $\mathrm{P}$ & 12.3599569 & 10.7988942 & 26.6866122 \\
\hline Al & 12.3958987 & 10.8295964 & 23.4781007 \\
\hline$P$ & 15.5482648 & 10.8834509 & 23.4572609 \\
\hline $\mathrm{P}$ & 10.6897309 & 8.1602326 & 23.4761454 \\
\hline
\end{tabular}




\begin{tabular}{|c|c|c|c|}
\hline Al & 10.7092393 & 8.1453936 & 26.6069674 \\
\hline Al & 15.4982095 & 10.8497091 & 26.5919525 \\
\hline 0 & 8.9324001 & 10.7912167 & 28.1298743 \\
\hline $\mathrm{O}$ & 11.9074229 & 9.3563577 & 27.0093231 \\
\hline $\mathrm{H}$ & 15.9407486 & 9.4392474 & 26.7704957 \\
\hline $\mathrm{H}$ & 11.5819625 & 6.9769420 & 23.3316928 \\
\hline $\mathrm{O}$ & 14.0955803 & 10.4335830 & 23.2108970 \\
\hline $\mathrm{O}$ & 11.5437874 & 11.8049602 & 27.5107661 \\
\hline $\mathrm{O}$ & 9.3005964 & 8.3394535 & 27.6155185 \\
\hline $\mathrm{H}$ & 16.2874731 & 11.7556747 & 27.4713898 \\
\hline 0 & 9.4547422 & 8.0009417 & 22.5692874 \\
\hline 0 & 15.9541781 & 12.0317121 & 22.5336829 \\
\hline 0 & 9.5347600 & 10.7581744 & 17.0245839 \\
\hline $\mathrm{O}$ & 13.8318990 & 10.9489250 & 27.0855246 \\
\hline $\mathrm{H}$ & 11.2871081 & 6.7945364 & 26.8485726 \\
\hline $\mathrm{H}$ & 16.4607082 & 9.7410293 & 23.1754091 \\
\hline $\mathrm{O}$ & 11.4494169 & 9.4065421 & 23.0334193 \\
\hline $\mathrm{H}$ & 10.4698567 & 12.1006233 & 15.1587024 \\
\hline 0 & 12.1570103 & 11.0966096 & 25.2009390 \\
\hline $\mathrm{O}$ & 15.7159086 & 11.3365117 & 24.9261957 \\
\hline $\mathrm{O}$ & 10.2078065 & 8.2951028 & 24.9325839 \\
\hline $\mathrm{H}$ & 10.4241647 & 12.0964514 & 29.8838546 \\
\hline $\mathrm{H}$ & 8.7650148 & 15.1254635 & 15.1076353 \\
\hline $\mathrm{P}$ & 5.4309137 & 14.8740949 & 16.6713167 \\
\hline Al & 5.3976422 & 14.8584756 & 28.4989731 \\
\hline $\mathrm{P}$ & 12.3675412 & 18.9001763 & 21.6401502 \\
\hline $\mathrm{Si}$ & 12.1846659 & 13.4107651 & 21.6638588 \\
\hline $\mathrm{P}$ & 17.1057586 & 16.0592512 & 21.6406696 \\
\hline Al & 17.0744370 & 16.1083081 & 18.4691140 \\
\hline Al & 12.2603156 & 13.4377269 & 18.5061203 \\
\hline Al & 12.3643444 & 18.9000428 & 18.4906686 \\
\hline $\mathrm{P}$ & 5.3415498 & 17.3746445 & 26.6347151 \\
\hline Al & 5.3237544 & 17.3599239 & 23.5287604 \\
\hline $\mathrm{P}$ & 8.5559360 & 14.8149433 & 28.3919841 \\
\hline Al & 8.5960209 & 14.8540437 & 16.5619024 \\
\hline $\mathrm{P}$ & 15.4480909 & 13.4074734 & 18.4274592 \\
\hline$P$ & 15.5232258 & 18.8600868 & 18.4377804 \\
\hline $\mathrm{P}$ & 10.7356753 & 16.1926580 & 18.3987029 \\
\hline Al & 10.7096936 & 16.1673295 & 21.5714849 \\
\hline Al & 15.5254493 & 18.8339681 & 21.6150037 \\
\hline Al & 15.3926533 & 13.4013515 & 21.5810867 \\
\hline $\mathrm{P}$ & 8.4851231 & 17.4892106 & 23.4220352 \\
\hline Al & 8.4962452 & 17.3810769 & 26.5601876 \\
\hline 0 & 9.0877334 & 13.2057244 & 16.9166615 \\
\hline 0 & 7.0707450 & 14.4650011 & 28.1667278 \\
\hline $\mathrm{O}$ & 11.8844928 & 17.4601935 & 21.8230918 \\
\hline 0 & 13.7576696 & 13.7909699 & 21.8301089 \\
\hline 0 & 16.1296114 & 17.2215192 & 21.9168332 \\
\hline 0 & 15.9108654 & 14.8547044 & 18.1268391 \\
\hline $\mathrm{O}$ & 11.7765029 & 15.0980607 & 18.1145576 \\
\hline 0 & 14.0485970 & 18.5048918 & 18.1729937 \\
\hline 0 & 6.8118308 & 17.7788832 & 26.8638107 \\
\hline $\mathrm{H}$ & 8.9173813 & 18.9086074 & 23.2971907 \\
\hline $\mathrm{H}$ & 4.7648025 & 18.7291667 & 23.3559375 \\
\hline $\mathrm{H}$ & 18.3132590 & 15.9153459 & 17.6658667 \\
\hline $\mathrm{H}$ & 11.9597791 & 20.0747400 & 17.6699774 \\
\hline 0 & 11.4174201 & 12.3455416 & 17.4036121 \\
\hline $\mathrm{O}$ & 4.9198640 & 16.2721576 & 27.6093352 \\
\hline $\mathrm{H}$ & 11.6031695 & 19.8407110 & 22.5051652 \\
\hline 0 & 11.7793462 & 12.1361267 & 22.5896376 \\
\hline $\mathrm{H}$ & 18.3441653 & 16.2205747 & 22.4514988 \\
\hline 0 & 8.9669472 & 16.0093796 & 27.5259444 \\
\hline $\mathrm{H}$ & 16.1804501 & 12.4610791 & 17.5413958 \\
\hline $\mathrm{O}$ & 9.5066971 & 16.0062023 & 17.4899157 \\
\hline $\mathrm{H}$ & 15.9401077 & 20.0217355 & 17.6047724 \\
\hline $\mathrm{O}$ & 9.2428979 & 16.5935979 & 22.4482244 \\
\hline $\mathrm{O}$ & 6.9158780 & 14.9975901 & 17.0255537 \\
\hline 0 & 9.4027481 & 13.6082706 & 27.9737013 \\
\hline $\mathrm{O}$ & 13.8469128 & 18.9867092 & 22.0474524 \\
\hline 0 & 11.2531477 & 14.6599739 & 22.1238474 \\
\hline 0 & 16.4600829 & 14.7369799 & 22.0263015 \\
\hline 0 & 16.4013610 & 17.6644519 & 18.0626347 \\
\hline 0 & 13.9619389 & 13.2958516 & 18.1079317 \\
\hline $\mathrm{O}$ & 11.3545022 & 17.5592078 & 18.0605103 \\
\hline $\mathrm{H}$ & 4.4684807 & 18.5551329 & 26.8823400 \\
\hline $\mathrm{H}$ & 9.3403729 & 18.5499974 & 26.9319319 \\
\hline 0 & 6.9970783 & 17.3866726 & 23.0592582 \\
\hline $\mathrm{H}$ & 5.1971120 & 15.1761244 & 15.2321379 \\
\hline $\mathrm{O}$ & 12.2009692 & 19.3544105 & 20.1748584 \\
\hline 0 & 17.5339590 & 16.0637832 & 20.1586265 \\
\hline
\end{tabular}




\begin{tabular}{|c|c|c|c|}
\hline 0 & 5.1582117 & 16.8494211 & 25.1956809 \\
\hline $\mathrm{H}$ & 8.7869234 & 15.1614705 & 29.8215589 \\
\hline $\mathrm{O}$ & 15.7658983 & 13.0412833 & 19.8849956 \\
\hline $\mathrm{O}$ & 15.7275807 & 19.2394523 & 19.9184922 \\
\hline 0 & 10.2621656 & 16.1729312 & 19.8602447 \\
\hline $\mathrm{O}$ & 8.7108727 & 16.9850841 & 24.8638564 \\
\hline $\mathrm{O}$ & 11.8593619 & 13.0270517 & 20.1094755 \\
\hline C & 9.4965409 & 10.6633545 & 20.3540814 \\
\hline $\mathrm{H}$ & 10.1121807 & 10.2605384 & 21.1641214 \\
\hline $\mathrm{H}$ & 9.1565611 & 9.8391787 & 19.7183784 \\
\hline $\mathrm{H}$ & 10.1067894 & 11.3644593 & 19.7754503 \\
\hline C & 7.9245229 & 13.6006871 & 22.0708159 \\
\hline C & 6.9096995 & 13.8892190 & 21.1410641 \\
\hline C & 6.5618750 & 12.9933771 & 20.1075031 \\
\hline C & 7.2310771 & 11.7984166 & 19.9955563 \\
\hline C & 8.2800846 & 11.4175956 & 20.9506299 \\
\hline C & 8.6153566 & 12.4128214 & 21.9745917 \\
\hline $\mathrm{H}$ & 8.1913339 & 14.3331015 & 22.8317495 \\
\hline $\mathrm{H}$ & 9.4454436 & 12.1862595 & 22.6507448 \\
\hline $\mathrm{H}$ & 6.3753002 & 14.8405679 & 21.2203568 \\
\hline $\mathrm{H}$ & 5.7813115 & 13.2579268 & 19.3938765 \\
\hline $\mathrm{H}$ & 6.9835480 & 11.0944217 & 19.1959033 \\
\hline $\mathrm{H}$ & 7.7628742 & 10.6239103 & 21.5686433 \\
\hline $\mathrm{H}$ & 5.2208399 & 15.1367509 & 29.9510145 \\
\hline $\mathrm{H}$ & 16.2630677 & 19.8407351 & 22.4270751 \\
\hline \multicolumn{4}{|c|}{$\begin{array}{l}\text { Mg } 22 \\
174\end{array}$} \\
\hline $\mathrm{H}$ & 8.6946733 & 9.0810535 & 15.2643584 \\
\hline Al & 5.4299718 & 9.4272139 & 16.6382161 \\
\hline $\mathrm{P}$ & 5.4200104 & 9.3797750 & 28.4504384 \\
\hline Al & 5.3131380 & 6.8379405 & 21.5777457 \\
\hline $\mathrm{P}$ & 5.3667025 & 6.8597597 & 18.4268697 \\
\hline Al & 3.2068722 & 8.1371374 & 26.6004745 \\
\hline $\mathrm{P}$ & 3.2877196 & 8.2546175 & 23.4992362 \\
\hline Al & 8.5412284 & 9.3494916 & 28.5135228 \\
\hline $\mathrm{P}$ & 8.5686105 & 9.4658988 & 16.6972307 \\
\hline Al & 8.5212371 & 6.8857341 & 18.5010621 \\
\hline $\mathrm{P}$ & 8.4905475 & 6.8497199 & 21.6762016 \\
\hline Al & 1.5710580 & 10.9321341 & 23.5372623 \\
\hline $\mathrm{P}$ & 1.5356563 & 10.8579624 & 26.6869493 \\
\hline $\mathrm{O}$ & 7.1016447 & 9.8391348 & 17.0263316 \\
\hline $\mathrm{O}$ & 5.0137675 & 10.8317038 & 28.1256965 \\
\hline $\mathrm{H}$ & 4.7722083 & 5.4673180 & 21.7920113 \\
\hline $\mathrm{H}$ & 9.0358859 & 5.4844146 & 21.9121423 \\
\hline $\mathrm{O}$ & 6.8468756 & 6.5037443 & 18.1682381 \\
\hline 0 & 2.0081847 & 9.3941833 & 26.7943868 \\
\hline $\mathrm{H}$ & 2.2207898 & 7.2410499 & 23.2723841 \\
\hline $\mathrm{H}$ & 0.1854327 & 10.4660226 & 23.2545909 \\
\hline $\mathrm{O}$ & 4.9352140 & 8.0215872 & 17.5244742 \\
\hline 0 & 4.5461248 & 8.3846106 & 27.6847943 \\
\hline 0 & 4.4722651 & 8.0232161 & 22.5496889 \\
\hline 0 & 2.3535412 & 11.7579883 & 27.6216100 \\
\hline $\mathrm{O}$ & 9.0127277 & 8.2930312 & 17.5828122 \\
\hline 0 & 2.0605432 & 12.2665665 & 22.5476996 \\
\hline $\mathrm{O}$ & 4.4529761 & 10.7799126 & 17.1390505 \\
\hline $\mathrm{O}$ & 6.8774142 & 9.1663601 & 28.0281702 \\
\hline $\mathrm{O}$ & 7.0024623 & 6.8688275 & 22.0265564 \\
\hline $\mathrm{H}$ & 9.3840312 & 5.7325770 & 18.1229937 \\
\hline $\mathrm{H}$ & 4.5175214 & 5.6819086 & 18.0972047 \\
\hline $\mathrm{H}$ & 0.1159321 & 10.9246408 & 27.1308611 \\
\hline $\mathrm{H}$ & 2.5856463 & 6.8260827 & 26.9356380 \\
\hline 0 & 2.7149929 & 9.6430113 & 23.2200147 \\
\hline $\mathrm{H}$ & 5.2809462 & 9.1548344 & 15.1819464 \\
\hline 0 & 5.1803847 & 7.3020563 & 19.8910244 \\
\hline 0 & 3.8033729 & 8.1519253 & 24.9505169 \\
\hline $\mathrm{H}$ & 8.6748045 & 9.1115329 & 29.9773034 \\
\hline 0 & 8.7073780 & 7.2702789 & 20.2062693 \\
\hline 0 & 1.6885496 & 11.3655922 & 25.2434928 \\
\hline $\mathrm{H}$ & 5.2610989 & 9.1176421 & 29.9075430 \\
\hline $\mathrm{H}$ & 3.5306804 & 12.0936919 & 15.2398165 \\
\hline Al & 3.2577376 & 16.1631061 & 21.5780853 \\
\hline $\mathrm{P}$ & 3.2202907 & 16.2035943 & 18.4193902 \\
\hline Al & 3.8234999 & 12.0722993 & 28.4903622 \\
\hline $\mathrm{P}$ & 3.8448165 & 12.1189526 & 16.6950832 \\
\hline Al & 1.6554321 & 13.4369059 & 18.5210545 \\
\hline $\mathrm{P}$ & 1.7147286 & 13.4557616 & 21.6283089 \\
\hline $\mathrm{O}$ & 4.8810560 & 13.2270957 & 17.0059367 \\
\hline $\mathrm{H}$ & 0.3024799 & 13.9082965 & 21.7620487 \\
\hline $\mathrm{H}$ & 2.2907884 & 17.2577184 & 21.8678332 \\
\hline
\end{tabular}

25.1956809

29.8215589

19.9184922

19.8602447

.8638564

20.3540814

21.1641214

.7183784

19.7754503

(1)

20.1075031

(

21.9745917

8317495

21.2203568

9.3938765

21.5686433

29.9510145 Mg 22

174 


\begin{tabular}{|c|c|c|c|}
\hline 0 & 2.1847988 & 15.0910998 & 18.1965754 \\
\hline 0 & 4.4453530 & 16.0044545 & 17.5151971 \\
\hline 0 & 4.7451765 & 16.3801077 & 22.4793759 \\
\hline $\mathrm{O}$ & 2.5579782 & 12.3517729 & 17.4795050 \\
\hline 0 & 4.4541922 & 13.6213018 & 27.9993077 \\
\hline 0 & 2.6881051 & 14.5955415 & 22.0217610 \\
\hline $\mathrm{H}$ & 2.6093664 & 17.5159013 & 18.0704741 \\
\hline $\mathrm{H}$ & 0.2169063 & 13.3110035 & 18.1578567 \\
\hline 0 & 3.7054873 & 16.2125455 & 19.8818640 \\
\hline $\mathrm{H}$ & 3.5657340 & 12.0898564 & 29.9567759 \\
\hline $\mathrm{O}$ & 2.0484580 & 13.0196455 & 20.1710963 \\
\hline Al & 10.1575059 & 12.1960744 & 16.5197845 \\
\hline $\mathrm{P}$ & 10.0538819 & 12.1200668 & 28.3395658 \\
\hline Al & 12.2884230 & 10.7337724 & 26.6538603 \\
\hline$P$ & 12.3193663 & 10.7171301 & 23.4475440 \\
\hline Al & 15.4460567 & 10.9321341 & 23.5372623 \\
\hline Al & 10.6081324 & 8.0921294 & 23.5901981 \\
\hline$P$ & 10.6809596 & 8.0561434 & 26.7038494 \\
\hline P & 15.4106550 & 10.8579624 & 26.6869493 \\
\hline 0 & 9.0454734 & 10.9758097 & 28.0970894 \\
\hline 0 & 11.7506255 & 9.1071335 & 27.0571409 \\
\hline $\mathrm{H}$ & 15.8669698 & 9.4444090 & 26.7907003 \\
\hline $\mathrm{H}$ & 11.4778230 & 6.8921275 & 23.4461340 \\
\hline 0 & 13.8148072 & 10.3833969 & 23.2044829 \\
\hline $\mathrm{O}$ & 11.3140724 & 11.9119562 & 27.4980715 \\
\hline $\mathrm{O}$ & 9.5022314 & 8.1552773 & 27.6823075 \\
\hline $\mathrm{H}$ & 16.2046455 & 11.7316941 & 27.5943040 \\
\hline 0 & 9.1931915 & 7.8854941 & 22.5741298 \\
\hline 0 & 15.9355419 & 12.2665665 & 22.5476996 \\
\hline 0 & 9.4585675 & 10.6677565 & 17.0255845 \\
\hline 0 & 13.9489183 & 10.9266139 & 27.1439973 \\
\hline $\mathrm{H}$ & 11.2784035 & 6.6982592 & 26.8316450 \\
\hline $\mathrm{H}$ & 16.4180227 & 9.8368065 & 23.2677068 \\
\hline 0 & 11.4931793 & 9.4717567 & 23.0361541 \\
\hline $\mathrm{H}$ & 10.4061957 & 12.1648452 & 15.0520316 \\
\hline $\mathrm{O}$ & 12.0999965 & 10.9795640 & 24.9536444 \\
\hline 0 & 15.5635483 & 11.3655922 & 25.2434928 \\
\hline 0 & 10.1452242 & 8.2780908 & 25.2725526 \\
\hline $\mathrm{H}$ & 10.4367526 & 12.1584208 & 29.7779884 \\
\hline $\mathrm{H}$ & 8.7050698 & 15.1726874 & 15.1502687 \\
\hline Al & 5.3741353 & 14.8622234 & 16.5856097 \\
\hline $\mathrm{P}$ & 5.3203616 & 14.8154331 & 28.4123717 \\
\hline Al & 12.2506373 & 18.8540419 & 21.5777457 \\
\hline $\mathrm{Mg}$ & 12.3129780 & 13.4227065 & 21.5991091 \\
\hline Al & 17.1327363 & 16.1631061 & 21.5780853 \\
\hline $\mathrm{P}$ & 17.0952894 & 16.2035943 & 18.4193902 \\
\hline P & 12.3475855 & 13.4070301 & 18.3526240 \\
\hline $\mathrm{P}$ & 12.3042018 & 18.8758610 & 18.4268697 \\
\hline Al & 5.4018389 & 17.3216291 & 26.5555959 \\
\hline $\mathrm{P}$ & 5.3855108 & 17.3545905 & 23.4771091 \\
\hline Al & 8.4856518 & 14.8409357 & 28.4169268 \\
\hline$P$ & 8.5303938 & 14.8833217 & 16.6003984 \\
\hline Al & 15.5304308 & 13.4369059 & 18.5210545 \\
\hline Al & 15.4587365 & 18.9018355 & 18.5010621 \\
\hline Al & 10.7554824 & 16.0971762 & 18.4393034 \\
\hline $\mathrm{P}$ & 10.5856976 & 16.1260904 & 21.6044464 \\
\hline P & 15.4280469 & 18.8658213 & 21.6762016 \\
\hline $\mathrm{P}$ & 15.5897273 & 13.4557616 & 21.6283089 \\
\hline Al & 8.5394751 & 17.5883009 & 23.4649619 \\
\hline$P$ & 8.5526222 & 17.4146673 & 26.6064640 \\
\hline $\mathrm{O}$ & 8.9674884 & 13.4345189 & 16.9122985 \\
\hline $\mathrm{O}$ & 6.7953840 & 14.4781255 & 28.1258560 \\
\hline $\mathrm{O}$ & 11.6212840 & 17.2593692 & 21.8270364 \\
\hline 0 & 14.1575452 & 13.9146838 & 21.7639364 \\
\hline $\mathrm{O}$ & 15.9916078 & 17.4548941 & 21.9200263 \\
\hline 0 & 16.0597975 & 15.0910998 & 18.1965754 \\
\hline $\mathrm{O}$ & 11.9415273 & 14.8784620 & 18.0522632 \\
\hline $\mathrm{O}$ & 13.7843749 & 18.5198456 & 18.1682381 \\
\hline 0 & 7.0714483 & 17.7658107 & 26.8681594 \\
\hline $\mathrm{H}$ & 9.0353773 & 18.9818233 & 23.2937981 \\
\hline $\mathrm{H}$ & 4.7014436 & 18.6760780 & 23.4237856 \\
\hline $\mathrm{H}$ & 18.2831925 & 16.0104950 & 17.5426236 \\
\hline $\mathrm{H}$ & 11.8851206 & 20.0042808 & 17.5504222 \\
\hline $\mathrm{O}$ & 11.6635102 & 12.4815422 & 17.3143275 \\
\hline 0 & 4.8786317 & 16.0343321 & 27.5997062 \\
\hline $\mathrm{H}$ & 11.5344868 & 19.8635117 & 22.4055256 \\
\hline 0 & 11.8389398 & 11.8985507 & 22.6479204 \\
\hline $\mathrm{H}$ & 18.3963987 & 16.3474611 & 22.3437819 \\
\hline $\mathrm{O}$ & 8.9771452 & 16.2179892 & 27.4667641 \\
\hline $\mathrm{H}$ & 16.2965659 & 12.5157801 & 17.6369250 \\
\hline
\end{tabular}




\begin{tabular}{|c|c|c|c|}
\hline 0 & 9.3490446 & 15.8886894 & 17.4100730 \\
\hline $\mathrm{H}$ & 15.8767384 & 20.0987106 & 17.7201108 \\
\hline $\mathrm{O}$ & 9.2788108 & 16.4959219 & 22.3483649 \\
\hline $\mathrm{O}$ & 7.0558357 & 15.0329398 & 17.0070093 \\
\hline 0 & 9.4099489 & 13.4477568 & 27.9214577 \\
\hline $\mathrm{O}$ & 13.9399616 & 18.8849288 & 22.0265564 \\
\hline $\mathrm{O}$ & 11.1026096 & 14.8129823 & 22.1258637 \\
\hline $\mathrm{O}$ & 16.5631039 & 14.5955415 & 22.0217610 \\
\hline $\mathrm{O}$ & 16.4657059 & 17.5559825 & 18.0598173 \\
\hline 0 & 13.8621430 & 13.2908943 & 18.0998466 \\
\hline 0 & 11.4344790 & 17.6695178 & 18.0892301 \\
\hline $\mathrm{H}$ & 4.5049993 & 18.4857906 & 26.7954448 \\
\hline $\mathrm{H}$ & 9.3931237 & 18.5849033 & 26.9822640 \\
\hline 0 & 6.8463436 & 17.5407763 & 23.0720944 \\
\hline $\mathrm{H}$ & 5.1590738 & 15.0982213 & 15.1312459 \\
\hline 0 & 12.1178841 & 19.3181576 & 19.8910244 \\
\hline $\mathrm{O}$ & 17.5804860 & 16.2125455 & 19.8818640 \\
\hline 0 & 5.2795441 & 16.7608949 & 24.8950221 \\
\hline $\mathrm{H}$ & 8.6774077 & 15.1315915 & 29.8646386 \\
\hline $\mathrm{O}$ & 15.9234567 & 13.0196455 & 20.1710963 \\
\hline 0 & 15.6448774 & 19.2863803 & 20.2062693 \\
\hline $\mathrm{O}$ & 10.2218680 & 16.0586246 & 20.0992460 \\
\hline 0 & 8.7652892 & 17.0520956 & 25.1231692 \\
\hline $\mathrm{O}$ & 11.9506494 & 12.9961501 & 19.7524598 \\
\hline C & 9.5595313 & 10.7200614 & 20.3616549 \\
\hline $\mathrm{H}$ & 10.1920629 & 10.3292550 & 21.1651774 \\
\hline $\mathrm{H}$ & 9.2559518 & 9.8964019 & 19.7084852 \\
\hline $\mathrm{H}$ & 10.1390315 & 11.4574862 & 19.7950534 \\
\hline C & 7.8970314 & 13.5719706 & 22.1069604 \\
\hline C & 6.8908187 & 13.8530719 & 21.1635133 \\
\hline C & 6.5657386 & 12.9568785 & 20.1236431 \\
\hline C & 7.2571056 & 11.7739575 & 20.0128088 \\
\hline C & 8.3054673 & 11.4058607 & 20.9729352 \\
\hline C & 8.6038335 & 12.3952018 & 22.0141780 \\
\hline $\mathrm{H}$ & 8.1418529 & 14.3054564 & 22.8735713 \\
\hline $\mathrm{H}$ & 9.4210528 & 12.1713067 & 22.7063833 \\
\hline $\mathrm{H}$ & 6.3492760 & 14.8005486 & 21.2418987 \\
\hline $\mathrm{H}$ & 5.7851569 & 13.2081686 & 19.4047736 \\
\hline $\mathrm{H}$ & 7.0352937 & 11.0729907 & 19.2031810 \\
\hline $\mathrm{H}$ & 7.8247693 & 10.5699300 & 21.5607743 \\
\hline $\mathrm{H}$ & 5.1289485 & 15.1279498 & 29.8555678 \\
\hline $\mathrm{H}$ & 16.1072479 & 19.8670381 & 22.5441714 \\
\hline \multicolumn{4}{|c|}{ Al 22} \\
\hline \multicolumn{4}{|c|}{174} \\
\hline $\mathrm{H}$ & 8.7004653 & 8.9773625 & 15.1981981 \\
\hline $\mathrm{Si}$ & 5.4198512 & 9.3863227 & 16.6360469 \\
\hline $\mathrm{Si}$ & 5.3984797 & 9.3379165 & 28.5638241 \\
\hline $\mathrm{Si}$ & 5.3776345 & 6.9015896 & 21.6050718 \\
\hline $\mathrm{Si}$ & 5.4255617 & 6.9146204 & 18.5294139 \\
\hline $\mathrm{Si}$ & 3.2917567 & 8.0989733 & 26.6291938 \\
\hline $\mathrm{Si}$ & 3.3786838 & 8.1763326 & 23.5753508 \\
\hline $\mathrm{Si}$ & 8.5040241 & 9.2881738 & 28.5577665 \\
\hline $\mathrm{Si}$ & 8.5361919 & 9.3810496 & 16.6219859 \\
\hline $\mathrm{Si}$ & 8.5384207 & 6.9169892 & 18.5411452 \\
\hline $\mathrm{Si}$ & 8.5155311 & 6.8701592 & 21.6461739 \\
\hline $\mathrm{Si}$ & 1.7264454 & 10.8607809 & 23.5538294 \\
\hline $\mathrm{Si}$ & 1.6930453 & 10.8222922 & 26.6319330 \\
\hline 0 & 6.9810998 & 9.7941565 & 16.9194138 \\
\hline $\mathrm{O}$ & 4.9829911 & 10.8871092 & 28.2701749 \\
\hline $\mathrm{H}$ & 4.7945532 & 5.5387181 & 21.7454934 \\
\hline $\mathrm{H}$ & 9.0764636 & 5.5040217 & 21.8362888 \\
\hline 0 & 6.9870981 & 6.5083869 & 18.2672786 \\
\hline $\mathrm{O}$ & 2.1720801 & 9.2696029 & 26.7655303 \\
\hline $\mathrm{H}$ & 2.3459343 & 7.1282303 & 23.3472487 \\
\hline $\mathrm{H}$ & 0.3265259 & 10.4035111 & 23.3341701 \\
\hline 0 & 4.9895266 & 8.1275879 & 17.5483239 \\
\hline 0 & 4.4939168 & 8.3212072 & 27.6925470 \\
\hline 0 & 4.6477048 & 7.9769617 & 22.5805100 \\
\hline 0 & 2.5367597 & 11.7650191 & 27.6454164 \\
\hline $\mathrm{O}$ & 8.9778440 & 8.1653353 & 17.6004045 \\
\hline $\mathrm{O}$ & 2.1694055 & 12.0562231 & 22.5612237 \\
\hline 0 & 4.5089799 & 10.6537484 & 17.0656442 \\
\hline 0 & 6.9471672 & 9.1277673 & 28.1411681 \\
\hline $\mathrm{O}$ & 6.9468013 & 6.8654172 & 22.0258209 \\
\hline $\mathrm{H}$ & 9.4156043 & 5.7586479 & 18.2156997 \\
\hline $\mathrm{H}$ & 4.5536601 & 5.7460095 & 18.2273267 \\
\hline $\mathrm{H}$ & 0.2629507 & 10.8992479 & 27.0393979 \\
\hline $\mathrm{H}$ & 2.6560140 & 6.7907820 & 26.9479214 \\
\hline 0 & 2.7405222 & 9.6247064 & 23.2629021 \\
\hline
\end{tabular}

17.4100730

7.7201108

17.0070093

27.9214577

22.1258637

22.0217610

18.099176

18.0892301

23.0720944

1312459

19.8818640

50221

20.1710963

20.2062693

19.7524598

0.3616549

21.1651774

22.1069604

1.1635133

20.0128088

20.9729352

22.0141780

22.7063833

21.2418987

19.4047736

21.5607743

29.8555678 122

174 


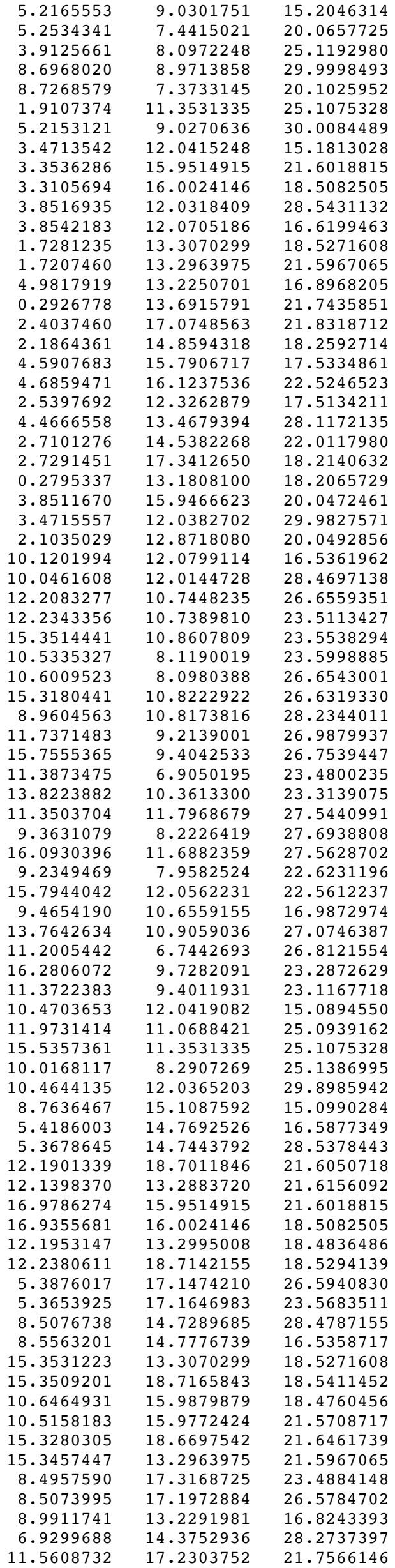




\begin{tabular}{|c|c|c|}
\hline 13.8251984 & 13.7171701 & 21.7530966 \\
\hline 15.9396074 & 17.1802733 & 21.8534535 \\
\hline 15.8114349 & 14.8594318 & 18.2592714 \\
\hline 11.7760832 & 14.8618450 & 18.1759759 \\
\hline 13.7995975 & 18.3079820 & 18.2672786 \\
\hline 6.9401575 & 17.5722688 & 26.8472723 \\
\hline 9.0160182 & 18.7041144 & 23.3400534 \\
\hline 4.7008135 & 18.4940538 & 23.4774157 \\
\hline 18.1101185 & 15.8081458 & 17.6139286 \\
\hline 11.8372516 & 19.8291919 & 17.6275825 \\
\hline 11.4621173 & 12.3368300 & 17.3780216 \\
\hline 4.9128452 & 16.0019551 & 27.6314194 \\
\hline 11.5213035 & 19.6865419 & 22.4988602 \\
\hline 11.7306324 & 11.9333151 & 22.6112828 \\
\hline 18.1958444 & 16.1088715 & 22.4449324 \\
\hline 8.9519966 & 15.9523959 & 27.5164186 \\
\hline 16.0957621 & 12.4096703 & 17.5996090 \\
\hline 9.4007725 & 15.8146734 & 17.4401760 \\
\hline 15.7538854 & 19.8613578 & 17.6784557 \\
\hline 9.1630301 & 16.3116272 & 22.4259656 \\
\hline 6.9899927 & 14.9226270 & 16.9418180 \\
\hline 9.3631544 & 13.4225180 & 28.0548379 \\
\hline 13.7593006 & 18.6650122 & 22.0258209 \\
\hline 11.1476791 & 14.6269182 & 22.0921265 \\
\hline 16.3351264 & 14.5382268 & 22.0117980 \\
\hline 16.3026882 & 17.4597522 & 18.1880279 \\
\hline 13.7903207 & 13.1708584 & 18.1812966 \\
\hline 11.2964117 & 17.4521215 & 18.2031612 \\
\hline 4.5110783 & 18.3319900 & 26.8076801 \\
\hline 9.3414656 & 18.3753341 & 26.9440690 \\
\hline 6.9110919 & 17.3440997 & 23.1610454 \\
\hline 5.1520779 & 15.1052310 & 15.1618300 \\
\hline 12.0659335 & 19.2410971 & 20.0657725 \\
\hline 17.4761658 & 15.9466623 & 20.0472461 \\
\hline 5.2198443 & 16.5629065 & 25.0771451 \\
\hline 8.7596503 & 15.1048592 & 29.8972833 \\
\hline 15.7285017 & 12.8718080 & 20.0492856 \\
\hline 15.5393573 & 19.1729096 & 20.1025952 \\
\hline 10.0649942 & 15.9161371 & 19.9906966 \\
\hline 8.7359556 & 16.7889414 & 25.0172350 \\
\hline 11.7820232 & 12.8541040 & 19.9543090 \\
\hline 9.2047204 & 10.8270322 & 20.4273584 \\
\hline 9.7106770 & 10.1247157 & 21.0975985 \\
\hline 9.2685962 & 10.4673571 & 19.3962280 \\
\hline 9.6813947 & 11.8096596 & 20.5015771 \\
\hline 6.9143052 & 12.3266233 & 22.7406574 \\
\hline 6.2925788 & 13.1911008 & 21.8166847 \\
\hline 6.3022267 & 12.9438531 & 20.4286296 \\
\hline 6.9601358 & 11.8374283 & 19.9465742 \\
\hline 7.6770852 & 10.9272810 & 20.8446518 \\
\hline 7.5738396 & 11.2138686 & 22.2771869 \\
\hline 6.8729531 & 12.5528858 & 23.8070223 \\
\hline 8.0731492 & 10.5241636 & 22.9620280 \\
\hline 5.7825881 & 14.0848822 & 22.1874408 \\
\hline 5.7956104 & 13.6345981 & 19.7540311 \\
\hline 6.9913294 & 11.6281175 & 18.8736727 \\
\hline 7.3125870 & 9.8887196 & 20.6647613 \\
\hline 5.1483060 & 15.1024226 & 29.9663818 \\
\hline 15.9853347 & 19.6639056 & 22.5387739 \\
\hline & & \\
\hline 8.6425059 & 9.1218048 & 15.1672663 \\
\hline 5.4035318 & 9.4862732 & 16.7137531 \\
\hline 5.3627031 & 9.4161456 & 28.5193930 \\
\hline 5.4285296 & 6.8815688 & 21.6342511 \\
\hline 5.4453543 & 6.8950220 & 18.4927303 \\
\hline 3.2236728 & 8.0632773 & 26.6546781 \\
\hline 3.3121692 & 8.1879925 & 23.5662060 \\
\hline 8.4843492 & 9.3142342 & 28.4284577 \\
\hline 8.5434439 & 9.4283268 & 16.6210034 \\
\hline 8.6003346 & 6.8530219 & 18.4462299 \\
\hline 8.5957487 & 6.8000566 & 21.6253272 \\
\hline 1.6734956 & 10.8979326 & 23.4701298 \\
\hline 1.6076781 & 10.8194622 & 26.6170766 \\
\hline 6.8778831 & 9.8505755 & 17.0209812 \\
\hline 4.8973636 & 11.0687211 & 28.1528898 \\
\hline 4.8902350 & 5.5024273 & 21.7933996 \\
\hline 9.1521086 & 5.4409821 & 21.8712965 \\
\hline 7.1276424 & 6.4896772 & 18.1798229 \\
\hline
\end{tabular}

21.7530966

8534535

8.1759759

18.2672786

23.4774157

17.6139286

.6275825

27.6314194

22.4988602

22.6112828

449324

17.5996090

4401760

22.4259656

.9418180

22.0258209

.0921265

18.1880279

.1812966

26.8076801

.9440690

1610454

20.0657725

20.0472461

25.0771451

9.8972833

20.1025952

19.9906966

25.0172350
19.9543090

20.4273584

21.0975985

19.3962280

20.5015771

21.8166847

20.4286296

19.9465742

20.8446518

22.2771869

23.8070223
22.9620280

22.1874408

19.7540311

29.9663818

22.5387739

15.1672663 16.7137531 28.5193930

18.4927303 26.6546781 3.5662060 16.6210034 18.4462299 21.6253272 701298 26.6170766
17.0209812 28.1528898 21.8712965 18.1798229 


\begin{tabular}{|c|c|c|}
\hline 2.1473264 & 9.1575499 & 26.7720731 \\
\hline 2.2196498 & 7.1983874 & 23.3559590 \\
\hline 0.3017751 & 10.4117952 & 23.1552109 \\
\hline 4.9736627 & 8.2725708 & 17.5361892 \\
\hline 4.3360067 & 8.2860478 & 27.6860802 \\
\hline 4.6847342 & 7.8789908 & 22.5347999 \\
\hline 2.5595026 & 11.8711174 & 27.6308144 \\
\hline 9.0207926 & 8.0597762 & 17.5942399 \\
\hline 2.0621930 & 12.0752071 & 22.5763007 \\
\hline 4.5278582 & 10.6757181 & 17.1237639 \\
\hline 7.0129361 & 9.1573729 & 28.0267339 \\
\hline 6.9089159 & 6.8861241 & 22.0421851 \\
\hline 9.4601154 & 5.6967060 & 18.0709550 \\
\hline 4.5680463 & 5.7511096 & 18.1200165 \\
\hline 0.2021777 & 10.8774687 & 27.1052613 \\
\hline 2.5993083 & 6.7425328 & 26.9426425 \\
\hline 2.6857747 & 9.7697357 & 23.2117337 \\
\hline 5.2330733 & 9.1693284 & 15.2688966 \\
\hline 5.2834039 & 7.3596736 & 20.1744237 \\
\hline 3.8421925 & 8.0816677 & 25.2413654 \\
\hline 8.6535951 & 9.0778237 & 29.8887955 \\
\hline 8.8028320 & 7.2215175 & 19.9310029 \\
\hline 1.7495500 & 11.3374719 & 24.9507072 \\
\hline 5.2479375 & 9.1978230 & 29.9878223 \\
\hline 3.5288684 & 12.1769605 & 15.1619292 \\
\hline 3.2966867 & 16.0680731 & 21.6196616 \\
\hline 3.2337575 & 16.1285789 & 18.4654047 \\
\hline 3.8311890 & 12.1501697 & 28.4306047 \\
\hline 3.8149751 & 12.1901563 & 16.6231237 \\
\hline 1.5854165 & 13.4155539 & 18.4397124 \\
\hline 1.5388159 & 13.4317197 & 21.5869104 \\
\hline 5.0016907 & 13.4365584 & 17.0114043 \\
\hline 0.1452740 & 13.8953646 & 21.8322572 \\
\hline 2.3465126 & 17.1786425 & 21.9041351 \\
\hline 2.0658739 & 14.8647266 & 18.1837870 \\
\hline 4.6713349 & 15.8892012 & 17.4996482 \\
\hline 4.5748982 & 16.2159456 & 22.4683596 \\
\hline 2.3530112 & 12.4524415 & 17.5158633 \\
\hline 4.3872020 & 13.5119247 & 27.9938601 \\
\hline 2.6665518 & 14.7307199 & 21.9730480 \\
\hline 2.6474858 & 17.4529213 & 18.1196831 \\
\hline 0.1395467 & 13.3275566 & 18.0949838 \\
\hline 3.7367738 & 16.1104295 & 20.1423316 \\
\hline 3.4911399 & 12.1739066 & 29.8800611 \\
\hline 1.8600212 & 13.0062643 & 19.8950717 \\
\hline 10.1498987 & 12.1166446 & 16.5600020 \\
\hline 10.0797143 & 12.0403471 & 28.3695303 \\
\hline 12.3808203 & 10.7335644 & 26.7300583 \\
\hline 12.4266957 & 10.7268773 & 23.4910798 \\
\hline 15.5484943 & 10.8979326 & 23.4701298 \\
\hline 10.6259039 & 8.1456181 & 23.5346379 \\
\hline 10.6892147 & 8.1289053 & 26.6260787 \\
\hline 15.4826768 & 10.8194622 & 26.6170766 \\
\hline 8.9447514 & 10.7362665 & 28.0499180 \\
\hline 11.8861299 & 9.3171536 & 27.1042048 \\
\hline 15.9407426 & 9.4087932 & 26.7486411 \\
\hline 11.4173629 & 6.8851616 & 23.4903345 \\
\hline 14.1275812 & 10.3943613 & 23.1439173 \\
\hline 11.5385851 & 11.7947661 & 27.4551815 \\
\hline 9.3007168 & 8.2564527 & 27.6765442 \\
\hline 16.2955867 & 11.7176329 & 27.4828638 \\
\hline 9.3985884 & 8.0104290 & 22.6109596 \\
\hline 15.9371917 & 12.0752071 & 22.5763007 \\
\hline 9.5659251 & 10.7752068 & 17.0441180 \\
\hline 13.8365778 & 10.8873984 & 27.1888305 \\
\hline 11.2847623 & 6.7701167 & 26.7531112 \\
\hline 16.5287585 & 9.8054168 & 23.2199059 \\
\hline 11.4942471 & 9.2974140 & 23.0335095 \\
\hline 10.4275218 & 12.0509210 & 15.0985896 \\
\hline 12.2642017 & 10.9432017 & 25.2233010 \\
\hline 15.6245487 & 11.3374719 & 24.9507072 \\
\hline 10.1425444 & 8.4072386 & 24.9756925 \\
\hline 10.3844985 & 12.0477267 & 29.8269845 \\
\hline 8.7683586 & 15.1192160 & 15.0479848 \\
\hline 5.4518515 & 14.8737015 & 16.6577389 \\
\hline 5.3936522 & 14.8486432 & 28.4817217 \\
\hline 12.3660290 & 18.8976701 & 21.6342511 \\
\hline 12.1390117 & 13.4295463 & 21.6858766 \\
\hline 17.1716854 & 16.0680731 & 21.6196616 \\
\hline 17.1087562 & 16.1285789 & 18.4654047 \\
\hline
\end{tabular}




\begin{tabular}{|c|c|c|c|}
\hline Al & 12.2699507 & 13.4481373 & 18.4441220 \\
\hline Al & 12.3828537 & 18.9111234 & 18.4927303 \\
\hline $\mathrm{P}$ & 5.3645283 & 17.3490690 & 26.6207224 \\
\hline Al & 5.3106426 & 17.3455029 & 23.5692374 \\
\hline $\mathrm{P}$ & 8.5478220 & 14.7929743 & 28.3339606 \\
\hline Al & 8.6143235 & 14.8627527 & 16.5066212 \\
\hline $\mathrm{P}$ & 15.4604152 & 13.4155539 & 18.4397124 \\
\hline $\mathrm{P}$ & 15.5378340 & 18.8691233 & 18.4462299 \\
\hline $\mathrm{P}$ & 10.7452692 & 16.2049161 & 18.3613035 \\
\hline Al & 10.6079405 & 16.2209226 & 21.5343643 \\
\hline Al & 15.5332480 & 18.8161579 & 21.6253272 \\
\hline Al & 15.4138146 & 13.4317197 & 21.5869104 \\
\hline $\mathrm{P}$ & 8.4518074 & 17.5932355 & 23.3940516 \\
\hline Al & 8.5041001 & 17.3730320 & 26.5151371 \\
\hline 0 & 9.1047901 & 13.2157601 & 16.8651443 \\
\hline 0 & 7.0591866 & 14.4512754 & 28.1209233 \\
\hline $\mathrm{O}$ & 11.8130414 & 17.4808843 & 21.7977436 \\
\hline $\mathrm{O}$ & 13.8146783 & 13.9637679 & 21.8684541 \\
\hline 0 & 16.1871530 & 17.2188007 & 21.9144217 \\
\hline 0 & 15.9408726 & 14.8647266 & 18.1837870 \\
\hline $\mathrm{O}$ & 11.8046682 & 15.1231808 & 18.1004979 \\
\hline $\mathrm{O}$ & 14.0651418 & 18.5057786 & 18.1798229 \\
\hline $\mathrm{O}$ & 6.8261224 & 17.7830704 & 26.8610727 \\
\hline $\mathrm{H}$ & 8.9487273 & 18.9949831 & 23.3212853 \\
\hline $\mathrm{H}$ & 4.6121303 & 18.6586776 & 23.5001455 \\
\hline $\mathrm{H}$ & 18.3331058 & 15.9247068 & 17.6428934 \\
\hline $\mathrm{H}$ & 11.9797043 & 20.0884984 & 17.6751857 \\
\hline $\mathrm{O}$ & 11.4602556 & 12.3900606 & 17.2864532 \\
\hline 0 & 4.9260962 & 16.2979973 & 27.6439909 \\
\hline $\mathrm{H}$ & 11.6449585 & 19.8646182 & 22.5072857 \\
\hline $\mathrm{O}$ & 11.7085368 & 12.0435442 & 22.6887441 \\
\hline $\mathrm{H}$ & 18.4064270 & 16.2109167 & 22.4394967 \\
\hline 0 & 8.9630196 & 15.9747522 & 27.4511953 \\
\hline $\mathrm{H}$ & 16.2027955 & 12.4840785 & 17.5462105 \\
\hline O & 9.5465419 & 16.0169717 & 17.4134624 \\
\hline $\mathrm{H}$ & 15.9454582 & 20.0390434 & 17.6202455 \\
\hline O & 9.1264680 & 16.7157310 & 22.3448406 \\
\hline $\mathrm{O}$ & 6.9397603 & 15.0137642 & 16.9952482 \\
\hline 0 & 9.3813775 & 13.5750169 & 27.9218720 \\
\hline 0 & 13.8464152 & 18.9022255 & 22.0421851 \\
\hline $\mathrm{O}$ & 11.0391547 & 14.7119753 & 22.1978162 \\
\hline $\mathrm{O}$ & 16.5415505 & 14.7307199 & 21.9730480 \\
\hline 0 & 16.4218866 & 17.6801642 & 18.0603609 \\
\hline 0 & 13.9804805 & 13.3254834 & 18.0868619 \\
\hline $\mathrm{O}$ & 11.3619639 & 17.5799962 & 18.0590175 \\
\hline $\mathrm{H}$ & 4.4694909 & 18.5295894 & 26.7703898 \\
\hline $\mathrm{H}$ & 9.3713899 & 18.5245389 & 26.8879115 \\
\hline 0 & 6.9530746 & 17.5927725 & 23.0758007 \\
\hline $\mathrm{H}$ & 5.2043850 & 15.1494635 & 15.2155751 \\
\hline 0 & 12.2209033 & 19.3757750 & 20.1744237 \\
\hline $\mathrm{O}$ & 17.6117725 & 16.1104295 & 20.1423316 \\
\hline $\mathrm{O}$ & 5.2311364 & 16.7350334 & 25.2094765 \\
\hline $\mathrm{H}$ & 8.7873714 & 15.1522218 & 29.7589791 \\
\hline $\mathrm{O}$ & 15.7350199 & 13.0062643 & 19.8950717 \\
\hline 0 & 15.7403313 & 19.2376189 & 19.9310029 \\
\hline 0 & 10.2317114 & 16.1637110 & 19.8094311 \\
\hline 0 & 8.6940741 & 17.0094947 & 24.8048696 \\
\hline $\mathrm{O}$ & 11.7934937 & 12.9549959 & 20.0105066 \\
\hline C & 9.4542607 & 10.6479723 & 20.3963552 \\
\hline $\mathrm{H}$ & 10.0710806 & 10.2489041 & 21.2075830 \\
\hline $\mathrm{H}$ & 9.1106124 & 9.8202178 & 19.7672014 \\
\hline $\mathrm{H}$ & 10.0637538 & 11.3458138 & 19.8122256 \\
\hline C & 7.9149385 & 13.6072846 & 22.0905547 \\
\hline C & 6.9164714 & 13.9070930 & 21.1472894 \\
\hline C & 6.5595228 & 13.0076821 & 20.1194074 \\
\hline C & 7.2030991 & 11.7976658 & 20.0263743 \\
\hline $\mathrm{C}$ & 8.2376647 & 11.4066230 & 20.9929132 \\
\hline $\mathrm{C}$ & 8.5798287 & 12.4030387 & 22.0137463 \\
\hline $\mathrm{H}$ & 8.1927279 & 14.3412234 & 22.8463901 \\
\hline $\mathrm{H}$ & 9.3967868 & 12.1645523 & 22.7024814 \\
\hline $\mathrm{H}$ & 6.4019322 & 14.8703499 & 21.2097477 \\
\hline $\mathrm{H}$ & 5.7922977 & 13.2821154 & 19.3951330 \\
\hline $\mathrm{H}$ & 6.9504439 & 11.0921956 & 19.2297457 \\
\hline $\mathrm{H}$ & 7.7179063 & 10.6133731 & 21.6070744 \\
\hline $\mathrm{H}$ & 5.2260135 & 15.1120979 & 29.9376096 \\
\hline $\mathrm{H}$ & 16.2142932 & 19.8429113 & 22.4614346 \\
\hline \multicolumn{4}{|c|}{$\mathrm{Ga} 22$} \\
\hline & & & \\
\hline
\end{tabular}




\begin{tabular}{|c|c|c|c|}
\hline $\mathrm{Si}$ & 5.4524252 & 9.3655694 & 16.6926353 \\
\hline $\mathrm{Si}$ & 5.4393609 & 9.3056192 & 28.6229493 \\
\hline $\mathrm{Si}$ & 5.4135852 & 6.8855276 & 21.6516769 \\
\hline $\mathrm{Si}$ & 5.4566388 & 6.9028840 & 18.5920228 \\
\hline $\mathrm{Si}$ & 3.3370098 & 8.0698513 & 26.6839529 \\
\hline $\mathrm{Si}$ & 3.4097865 & 8.1797701 & 23.6361627 \\
\hline $\mathrm{Si}$ & 8.5457925 & 9.2593354 & 28.6159651 \\
\hline $\mathrm{Si}$ & 8.5727418 & 9.3742459 & 16.6985582 \\
\hline $\mathrm{Si}$ & 8.5659643 & 6.8745710 & 18.5823590 \\
\hline $\mathrm{Si}$ & 8.5493316 & 6.8427571 & 21.7074843 \\
\hline $\mathrm{Si}$ & 1.7623994 & 10.8579742 & 23.6155792 \\
\hline $\mathrm{Si}$ & 1.7246576 & 10.7833128 & 26.7070536 \\
\hline 0 & 7.0114107 & 9.7753003 & 16.9844703 \\
\hline $\mathrm{O}$ & 5.0255269 & 10.8558503 & 28.3306166 \\
\hline $\mathrm{H}$ & 4.8256493 & 5.5206186 & 21.7437380 \\
\hline $\mathrm{H}$ & 9.1067907 & 5.4798088 & 21.9282369 \\
\hline $\mathrm{O}$ & 7.0084926 & 6.4775085 & 18.3165492 \\
\hline 0 & 2.2109937 & 9.2329865 & 26.8320502 \\
\hline $\mathrm{H}$ & 2.3459051 & 7.1582512 & 23.4317708 \\
\hline $\mathrm{H}$ & 0.3676516 & 10.4129071 & 23.3440754 \\
\hline 0 & 5.0183385 & 8.1048931 & 17.6022110 \\
\hline 0 & 4.5346383 & 8.2867321 & 27.7527314 \\
\hline $\mathrm{O}$ & 4.6617342 & 7.9423462 & 22.6288511 \\
\hline $\mathrm{O}$ & 2.5763754 & 11.7295681 & 27.7097540 \\
\hline 0 & 9.0001918 & 8.1408504 & 17.6610894 \\
\hline $\mathrm{O}$ & 2.2129084 & 12.0748248 & 22.6473483 \\
\hline $\mathrm{O}$ & 4.5310119 & 10.6225278 & 17.1282997 \\
\hline 0 & 6.9878351 & 9.0764519 & 28.2144163 \\
\hline $\mathrm{O}$ & 6.9761479 & 6.8289580 & 22.0795439 \\
\hline $\mathrm{H}$ & 9.4304103 & 5.7182252 & 18.2180540 \\
\hline $\mathrm{H}$ & 4.5669922 & 5.7386939 & 18.3268607 \\
\hline $\mathrm{H}$ & 0.2982683 & 10.8499468 & 27.1290657 \\
\hline $\mathrm{H}$ & 2.7065590 & 6.7536107 & 26.9791866 \\
\hline 0 & 2.8028177 & 9.6426773 & 23.3054187 \\
\hline $\mathrm{H}$ & 5.2493081 & 9.0043415 & 15.2624680 \\
\hline $\mathrm{O}$ & 5.3013566 & 7.4601318 & 20.1211292 \\
\hline $\mathrm{O}$ & 3.9577606 & 8.1006416 & 25.1733027 \\
\hline $\mathrm{H}$ & 8.7508705 & 8.9961124 & 30.0670947 \\
\hline $\mathrm{O}$ & 8.7689058 & 7.2949787 & 20.1491266 \\
\hline $\mathrm{O}$ & 1.9220381 & 11.3156457 & 25.1790798 \\
\hline $\mathrm{H}$ & 5.2490436 & 9.0007396 & 30.0679227 \\
\hline $\mathrm{H}$ & 3.5156318 & 12.0201993 & 15.2414950 \\
\hline $\mathrm{Si}$ & 3.3987528 & 15.9491655 & 21.6538282 \\
\hline $\mathrm{Si}$ & 3.3495759 & 15.9850223 & 18.5620016 \\
\hline $\mathrm{Si}$ & 3.8946851 & 12.0029248 & 28.6015594 \\
\hline $\mathrm{Si}$ & 3.8917527 & 12.0460345 & 16.6819762 \\
\hline $\mathrm{Si}$ & 1.7678505 & 13.2697397 & 18.6012181 \\
\hline $\mathrm{Si}$ & 1.7503546 & 13.2861401 & 21.6500006 \\
\hline 0 & 5.0237822 & 13.1906460 & 16.9684709 \\
\hline $\mathrm{H}$ & 0.3374607 & 13.7326514 & 21.7965577 \\
\hline $\mathrm{H}$ & 2.4349347 & 17.0516084 & 21.9236333 \\
\hline $\mathrm{O}$ & 2.2356414 & 14.8208392 & 18.3631242 \\
\hline $\mathrm{O}$ & 4.6275621 & 15.7592905 & 17.5899304 \\
\hline 0 & 4.7348575 & 16.0750575 & 22.5778109 \\
\hline $\mathrm{O}$ & 2.5697770 & 12.3022753 & 17.5691986 \\
\hline 0 & 4.5030334 & 13.4402607 & 28.1694322 \\
\hline 0 & 2.7636525 & 14.5179998 & 22.0211977 \\
\hline $\mathrm{H}$ & 2.7454580 & 17.3017283 & 18.2178394 \\
\hline $\mathrm{H}$ & 0.3136668 & 13.1567128 & 18.3017264 \\
\hline $\mathrm{O}$ & 3.8895521 & 15.9993678 & 20.0998263 \\
\hline $\mathrm{H}$ & 3.5165042 & 12.0165547 & 30.0416685 \\
\hline 0 & 2.1273338 & 12.7983320 & 20.1191336 \\
\hline $\mathrm{Si}$ & 10.1538633 & 12.0529088 & 16.5793225 \\
\hline $\mathrm{Si}$ & 10.0660158 & 11.9731829 & 28.4972906 \\
\hline $\mathrm{Si}$ & 12.2510712 & 10.7019502 & 26.7139343 \\
\hline $\mathrm{Si}$ & 12.2690818 & 10.6749695 & 23.5676418 \\
\hline $\mathrm{Si}$ & 15.3873982 & 10.8579742 & 23.6155792 \\
\hline $\mathrm{Si}$ & 10.5358554 & 8.0707981 & 23.6806809 \\
\hline $\mathrm{Si}$ & 10.6218046 & 8.0599346 & 26.7071851 \\
\hline $\mathrm{Si}$ & 15.3496563 & 10.7833128 & 26.7070536 \\
\hline 0 & 8.9825706 & 10.7813146 & 28.2354295 \\
\hline $\mathrm{O}$ & 11.7674259 & 9.1722237 & 27.0262011 \\
\hline $\mathrm{H}$ & 15.7940266 & 9.3667636 & 26.8212643 \\
\hline $\mathrm{H}$ & 11.3287570 & 6.8128454 & 23.6033316 \\
\hline $\mathrm{O}$ & 13.8678601 & 10.3730862 & 23.3197835 \\
\hline 0 & 11.3861315 & 11.7562865 & 27.5945057 \\
\hline $\mathrm{O}$ & 9.4160833 & 8.1733732 & 27.7881283 \\
\hline $\mathrm{H}$ & 16.1322277 & 11.6527467 & 27.6283501 \\
\hline $\mathrm{O}$ & 9.2685989 & 7.9434021 & 22.6636152 \\
\hline $\mathrm{O}$ & 15.8379071 & 12.0748248 & 22.6473483 \\
\hline
\end{tabular}


6.8327183

列1801

5.1239920

列 3720

5.2108038

9.9356543

5.1400700
16.6552550

8.6014521

1.6516769
1.6704048

1.6538282

5620016

6.6499098

49754

6.5785357

8.5247477

1.6219762

.

5.5386908

6136449

. 3342924

.7512469

8. 3631242

8.2053658

3.4237643

. 6005709

17.6693396

7.3553983

77.7161283
22.5476817

2.6542185

2.4982222
7.5504597

17.6561992

.4822489

6.9941714

2.2433790

8.2780102

6.9735074

3.2296848

1.2278246
0.1211292

20.0998263

480400

.9367137

0.1491266

20.0357960

0.5140455

0.1429312

21.1687012 


\begin{tabular}{|c|c|c|c|}
\hline $\mathrm{C}$ & 5.7630177 & 12.9261365 & 21.5706858 \\
\hline $\mathrm{C}$ & 6.9105509 & 13.6591729 & 21.2071246 \\
\hline $\mathrm{C}$ & 7.8940649 & 13.0389737 & 20.4718804 \\
\hline C & 7.7753586 & 11.6372308 & 20.0656378 \\
\hline C & 6.5271743 & 10.9599715 & 20.4278820 \\
\hline $\mathrm{H}$ & 4.6382671 & 11.0737169 & 21.4576804 \\
\hline $\mathrm{H}$ & 6.3961420 & 9.9210987 & 20.1129271 \\
\hline $\mathrm{H}$ & 4.9991057 & 13.4123399 & 22.1833988 \\
\hline $\mathrm{H}$ & 7.0171063 & 14.6979419 & 21.5231464 \\
\hline $\mathrm{H}$ & 8.8089079 & 13.5724400 & 20.1990774 \\
\hline $\mathrm{H}$ & 7.8554986 & 11.6130858 & 18.9492168 \\
\hline $\mathrm{H}$ & 5.1852084 & 15.0568937 & 30.0331896 \\
\hline $\mathrm{H}$ & 16.0206110 & 19.6504376 & 22.5832087 \\
\hline \multicolumn{4}{|c|}{$\mathrm{Ti} 22$} \\
\hline \multicolumn{4}{|c|}{174} \\
\hline $\mathrm{H}$ & 8.6388292 & 9.1440108 & 15.1757980 \\
\hline $\mathrm{P}$ & 5.4089494 & 9.5049366 & 16.7299471 \\
\hline Al & 5.3561964 & 9.4048352 & 28.5357528 \\
\hline$P$ & 5.4201124 & 6.8891708 & 21.6463890 \\
\hline Al & 5.4535526 & 6.9079458 & 18.5046351 \\
\hline $\mathrm{P}$ & 3.2332065 & 8.0526590 & 26.6574986 \\
\hline Al & 3.3742033 & 8.2129213 & 23.5827262 \\
\hline $\mathrm{P}$ & 8.4765163 & 9.2990418 & 28.4319285 \\
\hline Al & 8.5473298 & 9.4520122 & 16.6297181 \\
\hline $\mathrm{P}$ & 8.5990524 & 6.8765148 & 18.4613955 \\
\hline Al & 8.5897807 & 6.7868038 & 21.6318878 \\
\hline $\mathrm{P}$ & 1.6780787 & 10.9002894 & 23.4826394 \\
\hline Al & 1.5975936 & 10.8051379 & 26.6273078 \\
\hline 0 & 6.8824927 & 9.8778140 & 17.0321351 \\
\hline 0 & 4.8945790 & 11.0557530 & 28.1577724 \\
\hline $\mathrm{H}$ & 4.7547515 & 5.5670430 & 21.8088491 \\
\hline $\mathrm{H}$ & 9.2028711 & 5.4444522 & 21.8302127 \\
\hline 0 & 7.1331493 & 6.4962055 & 18.1768465 \\
\hline 0 & 2.1541556 & 9.1460970 & 26.7487501 \\
\hline $\mathrm{H}$ & 2.2967289 & 7.2153069 & 23.3358761 \\
\hline $\mathrm{H}$ & 0.3208799 & 10.3968802 & 23.1337679 \\
\hline 0 & 4.9848915 & 8.2964610 & 17.5626079 \\
\hline 0 & 4.3169559 & 8.2710970 & 27.7205346 \\
\hline $\mathrm{O}$ & 4.7625757 & 7.9447826 & 22.5529410 \\
\hline $\mathrm{O}$ & 2.5530621 & 11.8517091 & 27.6440204 \\
\hline 0 & 9.0197680 & 8.0814173 & 17.6055331 \\
\hline 0 & 2.0871651 & 12.0744917 & 22.5922387 \\
\hline 0 & 4.5279679 & 10.6934319 & 17.1312939 \\
\hline $\mathrm{O}$ & 7.0036633 & 9.1365486 & 28.0372406 \\
\hline 0 & 6.8981471 & 6.7605508 & 22.0460005 \\
\hline $\mathrm{H}$ & 9.4763822 & 5.7259379 & 18.1098479 \\
\hline $\mathrm{H}$ & 4.5620412 & 5.7737203 & 18.1360426 \\
\hline $\mathrm{H}$ & 0.2022966 & 10.8363436 & 27.1462422 \\
\hline $\mathrm{H}$ & 2.6015674 & 6.7302603 & 26.9209641 \\
\hline $\mathrm{O}$ & 2.7144687 & 9.7864485 & 23.2594607 \\
\hline $\mathrm{H}$ & 5.2380026 & 9.1749591 & 15.2880689 \\
\hline 0 & 5.3122762 & 7.3777362 & 20.1872023 \\
\hline 0 & 3.8888548 & 8.0772868 & 25.2607065 \\
\hline $\mathrm{H}$ & 8.6485534 & 9.0985660 & 29.8973067 \\
\hline 0 & 8.7745338 & 7.2615012 & 19.9465431 \\
\hline 0 & 1.7049365 & 11.3457587 & 24.9644469 \\
\hline $\mathrm{H}$ & 5.2511143 & 9.2005236 & 30.0069208 \\
\hline $\mathrm{H}$ & 3.5427081 & 12.1933852 & 15.1640495 \\
\hline $\mathrm{P}$ & 3.3532680 & 16.0644539 & 21.5952501 \\
\hline Al & 3.2461616 & 16.1414621 & 18.4495025 \\
\hline $\mathrm{P}$ & 3.8317943 & 12.1421365 & 28.4287805 \\
\hline Al & 3.8201690 & 12.2091197 & 16.6268853 \\
\hline $\mathrm{P}$ & 1.5918003 & 13.4433183 & 18.4418921 \\
\hline Al & 1.5896061 & 13.4409493 & 21.6011609 \\
\hline 0 & 5.0105920 & 13.4521411 & 17.0216051 \\
\hline $\mathrm{H}$ & 0.1786762 & 13.8496184 & 21.8448553 \\
\hline $\mathrm{H}$ & 2.4071340 & 17.1843183 & 21.8557400 \\
\hline 0 & 2.0579673 & 14.8949296 & 18.1673398 \\
\hline 0 & 4.6676629 & 15.9136250 & 17.4543036 \\
\hline 0 & 4.6435486 & 16.2267779 & 22.4264661 \\
\hline 0 & 2.3548804 & 12.4800140 & 17.5128130 \\
\hline 0 & 4.3856700 & 13.4966554 & 27.9655531 \\
\hline 0 & 2.7205250 & 14.7382850 & 21.9904317 \\
\hline $\mathrm{H}$ & 2.6640268 & 17.4790914 & 18.1511948 \\
\hline $\mathrm{H}$ & 0.1423902 & 13.3421570 & 18.1161663 \\
\hline $\mathrm{O}$ & 3.7833265 & 16.0655220 & 20.1150925 \\
\hline $\mathrm{H}$ & 3.5058612 & 12.1891099 & 29.8809106 \\
\hline 0 & 1.8918369 & 13.0467280 & 19.8960377 \\
\hline $\mathrm{P}$ & 10.1525858 & 12.1320675 & 16.5279334 \\
\hline
\end{tabular}




\begin{tabular}{|c|c|c|c|}
\hline Al & 10.0716397 & 12.0204303 & 28.3342262 \\
\hline $\mathrm{P}$ & 12.3876523 & 10.6776504 & 26.7534369 \\
\hline Al & 12.4350774 & 10.6338819 & 23.5029792 \\
\hline $\mathrm{P}$ & 15.5530774 & 10.9002894 & 23.4826394 \\
\hline $\mathrm{P}$ & 10.5715050 & 8.1161676 & 23.5688716 \\
\hline Al & 10.6708415 & 8.1087092 & 26.6405990 \\
\hline Al & 15.4725924 & 10.8051379 & 26.6273078 \\
\hline 0 & 8.9404029 & 10.7105528 & 28.0167479 \\
\hline $\mathrm{O}$ & 11.8730885 & 9.2772882 & 27.1610251 \\
\hline $\mathrm{H}$ & 15.9450356 & 9.3968443 & 26.7303954 \\
\hline $\mathrm{H}$ & 11.2567827 & 6.7942413 & 23.5739542 \\
\hline $\mathrm{O}$ & 14.1460339 & 10.3783919 & 23.1209552 \\
\hline 0 & 11.5327753 & 11.7675606 & 27.4221130 \\
\hline $\mathrm{O}$ & 9.2891812 & 8.2196543 & 27.7043848 \\
\hline $\mathrm{H}$ & 16.2883027 & 11.6986252 & 27.4953041 \\
\hline $\mathrm{O}$ & 9.3408745 & 8.0233629 & 22.6390124 \\
\hline $\mathrm{O}$ & 15.9621638 & 12.0744917 & 22.5922387 \\
\hline $\mathrm{O}$ & 9.5746644 & 10.7995656 & 17.0470114 \\
\hline $\mathrm{O}$ & 13.8355408 & 10.8417504 & 27.2361547 \\
\hline $\mathrm{H}$ & 11.2709304 & 6.7477633 & 26.7101711 \\
\hline $\mathrm{H}$ & 16.5566371 & 9.8217323 & 23.2665305 \\
\hline 0 & 11.5303787 & 9.1837404 & 23.0403244 \\
\hline $\mathrm{H}$ & 10.4065310 & 12.0341945 & 15.0640163 \\
\hline $\mathrm{O}$ & 12.3110385 & 10.8302870 & 25.2384995 \\
\hline $\mathrm{O}$ & 15.5799352 & 11.3457587 & 24.9644469 \\
\hline $\mathrm{O}$ & 10.1087817 & 8.4535751 & 25.0022850 \\
\hline $\mathrm{H}$ & 10.3648438 & 12.0297804 & 29.7940428 \\
\hline $\mathrm{H}$ & 8.7697335 & 15.1284236 & 15.0058097 \\
\hline $\mathrm{P}$ & 5.4556431 & 14.8833703 & 16.6360353 \\
\hline Al & 5.3935862 & 14.8318982 & 28.4557874 \\
\hline $\mathrm{P}$ & 12.3576118 & 18.9052722 & 21.6463890 \\
\hline $\mathrm{Ti}$ & 12.0936604 & 13.4252590 & 21.7290346 \\
\hline $\mathrm{P}$ & 17.2282667 & 16.0644539 & 21.5952501 \\
\hline Al & 17.1211603 & 16.1414621 & 18.4495025 \\
\hline Al & 12.2622308 & 13.4669219 & 18.4096627 \\
\hline Al & 12.3910519 & 18.9240472 & 18.5046351 \\
\hline $\mathrm{P}$ & 5.3682780 & 17.3316302 & 26.6054678 \\
\hline Al & 5.3002931 & 17.3523286 & 23.5810007 \\
\hline $\mathrm{P}$ & 8.5474822 & 14.7834546 & 28.2929237 \\
\hline Al & 8.6191590 & 14.8836573 & 16.4668153 \\
\hline $\mathrm{P}$ & 15.4667990 & 13.4433183 & 18.4418921 \\
\hline$P$ & 15.5365517 & 18.8926162 & 18.4613955 \\
\hline $\mathrm{P}$ & 10.7325706 & 16.2226479 & 18.3435617 \\
\hline Al & 10.4969688 & 16.2713797 & 21.5183156 \\
\hline Al & 15.5272800 & 18.8029052 & 21.6318878 \\
\hline Al & 15.4646048 & 13.4409493 & 21.6011609 \\
\hline $\mathrm{P}$ & 8.4173280 & 17.6616444 & 23.3700409 \\
\hline Al & 8.4965899 & 17.3706577 & 26.4816636 \\
\hline 0 & 9.1132030 & 13.2377576 & 16.8291037 \\
\hline $\mathrm{O}$ & 7.0583505 & 14.4374101 & 28.0881552 \\
\hline $\mathrm{O}$ & 11.6748354 & 17.5485384 & 21.8131014 \\
\hline $\mathrm{O}$ & 13.8422599 & 13.9108538 & 21.8813707 \\
\hline $\mathrm{O}$ & 16.2481809 & 17.2245044 & 21.8650876 \\
\hline $\mathrm{O}$ & 15.9329660 & 14.8949296 & 18.1673398 \\
\hline $\mathrm{O}$ & 11.7988802 & 15.1475322 & 18.0840848 \\
\hline 0 & 14.0706486 & 18.5123069 & 18.1768465 \\
\hline 0 & 6.8233419 & 17.7834863 & 26.8575979 \\
\hline $\mathrm{H}$ & 9.0285882 & 19.0173293 & 23.2952069 \\
\hline $\mathrm{H}$ & 4.4660995 & 18.5857004 & 23.5750122 \\
\hline $\mathrm{H}$ & 18.3305567 & 15.9476210 & 17.6027991 \\
\hline $\mathrm{H}$ & 11.9904880 & 20.1108091 & 17.6994858 \\
\hline 0 & 11.4776524 & 12.4214671 & 17.2223763 \\
\hline 0 & 4.9243865 & 16.2939107 & 27.6399636 \\
\hline $\mathrm{H}$ & 11.7214357 & 19.9265915 & 22.5234908 \\
\hline 0 & 11.6789696 & 11.9563674 & 22.7325369 \\
\hline $\mathrm{H}$ & 18.4730664 & 16.2210562 & 22.3971666 \\
\hline $\mathrm{O}$ & 8.9575587 & 15.9549121 & 27.3931428 \\
\hline $\mathrm{H}$ & 16.2043230 & 12.5122757 & 17.5439285 \\
\hline 0 & 9.5542189 & 16.0439150 & 17.3668896 \\
\hline $\mathrm{H}$ & 15.9442214 & 20.0601560 & 17.6320724 \\
\hline $\mathrm{O}$ & 8.9732787 & 16.7521971 & 22.2732562 \\
\hline $\mathrm{O}$ & 6.9450534 & 15.0367101 & 16.9642707 \\
\hline 0 & 9.3812493 & 13.5614657 & 27.8910148 \\
\hline 0 & 13.8356465 & 18.7766521 & 22.0460005 \\
\hline $\mathrm{O}$ & 10.9791063 & 14.7876089 & 22.2093866 \\
\hline 0 & 16.5955237 & 14.7382850 & 21.9904317 \\
\hline $\mathrm{O}$ & 16.4388301 & 17.7093205 & 18.0998510 \\
\hline $\mathrm{O}$ & 13.9831891 & 13.3397700 & 18.1084806 \\
\hline $\mathrm{O}$ & 11.3533753 & 17.6038628 & 18.0756111 \\
\hline $\mathrm{H}$ & 4.4581490 & 18.5046327 & 26.7188295 \\
\hline
\end{tabular}




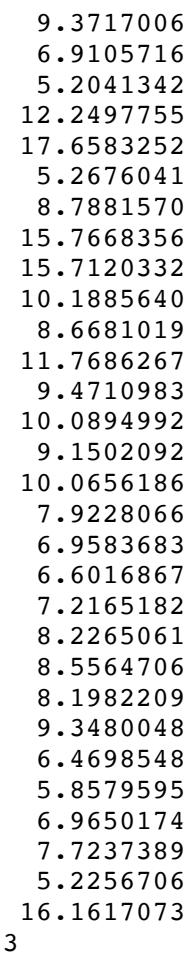

3.7684804
18.5131329

17.8031703

15.1245639

19.3938376

16.0655220

16.6873797

15.1589196

13.0467280

19.2776026

16.1638578

17.0325645

13.0006414

10.6619922

10.2584445

9.8424431

11.3906389

13.5787890

13.9040995

13.0122881

11.7863641

11.3754611

12.3574918

14.3061281

12.0971862

14.8815997

13.3048537

11.0866644

10.5492088

15.0876416

19.8473910

8.9674755

9.2872611

9.2830539

6.7005648

6.7127426

8.0715718

8.1765435

9.2674165

9.3250806

6.7688303

6.7239106

10.7943365

10.7774658

9.6700561

10.7425861

5.3074494

5.3417697

6.4359815

9.3079112

7.1854807

10.2227357

7.8722833

8.3097559

7.8599121

11.6951996

8.1486825

12.2252150

10.6402428

9.0783229

6.8118468

5.5964280

5.4915777

10.9036329

6.7561361

9.5710479

9.0178221

7.0880819

8.1458355

9.0027294

7.1044613

11.2232418

8.9811552

11.9518026

16.0533564

16.0778393

11.9836964

11.9833652
26.8638314

23.1239788

15.1883856

20.1872023

20.1150925

25.2031015

29.7135652

19.8960377

19.9465431

19.7809640

24.7614267

19.9823124

20.4153016

21.2232158

19.7642036

19.8531573

22.1231735

21.1522436

20.1176330

20.0415139

21.0248340

22.0632680

22.8863652

22.7730603

21.1988714

19.3760269

19.2394995

21.6032823

29.9130177

22.4825769

15.3010162

16.6897647

28.5075363

21.6196368

18.4772823

26.6519047

23.5235718

28.5591267

16.7375164

18.5541648

21.7040334

23.5699620

26.7220506

17.0428579

28.2073000

21.9008750

22.0013365

18.3209761

26.9018229

23.3383817

23.3764102

17.5693685

27.7053884

22.6122533

27.6324746

17.6038347

22.6197025

17.1496958

28.0935327

21.9426238

18.1073376

18.0562045

27.1193802

27.0013095

23.1539075

15.2341536

19.9314317

24.9901445

30.0146227

20.2470227

25.2636858

29.9552646

15.2739226

21.6414412

18.4595820

28.5394751

16.7140244 


\begin{tabular}{|c|c|c|c|}
\hline Al & 1.6091408 & 13.2973633 & 18.5774248 \\
\hline $\mathrm{P}$ & 1.6216707 & 13.4081850 & 21.6439074 \\
\hline 0 & 4.8143702 & 13.0879945 & 16.9711318 \\
\hline $\mathrm{H}$ & 0.2943000 & 14.0827989 & 21.6337245 \\
\hline $\mathrm{H}$ & 2.1867560 & 17.1140222 & 21.9540206 \\
\hline 0 & 2.0693422 & 14.9599843 & 18.2489917 \\
\hline 0 & 4.3524565 & 15.8427936 & 17.5924962 \\
\hline 0 & 4.6425247 & 16.3572515 & 22.5381147 \\
\hline 0 & 2.4972308 & 12.2245244 & 17.5311088 \\
\hline $\mathrm{O}$ & 4.3933739 & 13.5426689 & 28.0940477 \\
\hline 0 & 2.6869532 & 14.4410991 & 22.0698343 \\
\hline $\mathrm{H}$ & 2.5044689 & 17.3730915 & 18.0442169 \\
\hline $\mathrm{H}$ & 0.1656755 & 13.1184582 & 18.2588004 \\
\hline 0 & 3.5482419 & 16.1389918 & 19.9300728 \\
\hline $\mathrm{H}$ & 3.4350174 & 11.9556564 & 29.9931187 \\
\hline $\mathrm{O}$ & 1.9673602 & 12.8630908 & 20.2303374 \\
\hline Al & 10.0519373 & 12.0592504 & 16.5546834 \\
\hline $\mathrm{P}$ & 9.9982496 & 12.0355648 & 28.4012875 \\
\hline Al & 12.2171365 & 10.6723682 & 26.6761058 \\
\hline $\mathrm{P}$ & 12.2883028 & 10.6037539 & 23.4843817 \\
\hline Al & 15.3658326 & 10.7943365 & 23.5699620 \\
\hline Al & 10.5475251 & 8.0279366 & 23.6127903 \\
\hline $\mathrm{P}$ & 10.6407872 & 7.9952313 & 26.7408520 \\
\hline$P$ & 15.3535194 & 10.7774658 & 26.7220506 \\
\hline $\mathrm{O}$ & 8.9753321 & 10.9052439 & 28.1709442 \\
\hline 0 & 11.7126787 & 9.0436030 & 27.1043590 \\
\hline $\mathrm{H}$ & 15.7676188 & 9.3577895 & 26.8957213 \\
\hline $\mathrm{H}$ & 11.4818716 & 6.8771635 & 23.4719419 \\
\hline $\mathrm{O}$ & 13.7526823 & 10.1169476 & 23.3405889 \\
\hline $\mathrm{O}$ & 11.2361000 & 11.8391360 & 27.5234275 \\
\hline 0 & 9.4445848 & 8.1032672 & 27.6937608 \\
\hline $\mathrm{H}$ & 16.1526535 & 11.6694098 & 27.6068903 \\
\hline $\mathrm{O}$ & 9.1372906 & 7.7457502 & 22.6292763 \\
\hline 0 & 15.5724591 & 12.2252150 & 22.6197025 \\
\hline $\mathrm{O}$ & 9.4001989 & 10.5306219 & 17.0855140 \\
\hline $\mathrm{O}$ & 13.8806 & 10.9074655 & 27.1314502 \\
\hline $\mathrm{H}$ & 11.2260347 & 6.6342130 & 26.8899668 \\
\hline $\mathrm{H}$ & 16.3709571 & 9.7542804 & 23.2162269 \\
\hline $\mathrm{O}$ & 11.3544777 & 9.4558039 & 22.9759067 \\
\hline $\mathrm{H}$ & 10.3860615 & 12.0407730 & 15.1037732 \\
\hline $\mathrm{O}$ & 11.9851689 & 10.8916626 & 24.9644173 \\
\hline $\mathrm{O}$ & 15.5522888 & 11.2232418 & 25.2636858 \\
\hline 0 & 10.1364222 & 8.2284937 & 25.3004156 \\
\hline $\mathrm{H}$ & 10.4276376 & 12.0375872 & 29.8270303 \\
\hline $\mathrm{H}$ & 8.6567337 & 15.1239754 & 15.2093414 \\
\hline Al & 5.3080215 & 14.7389056 & 16.6451183 \\
\hline $\mathrm{P}$ & 5.2581754 & 14.7460232 & 28.4841424 \\
\hline Al & 12.1819390 & 18.7166662 & 21.6196368 \\
\hline $\mathrm{Zn}$ & 12.3527774 & 13.4667794 & 21.7705168 \\
\hline Al & 17.0589521 & 16.0533564 & 21.6414412 \\
\hline $\mathrm{P}$ & 16.9852020 & 16.0778393 & 18.4595820 \\
\hline$P$ & 12.2842118 & 13.1949676 & 18.4389395 \\
\hline$P$ & 12.2212310 & 18.7288440 & 18.4772823 \\
\hline Al & 5.3396742 & 17.2490945 & 26.6117642 \\
\hline $\mathrm{P}$ & 5.3266512 & 17.3085123 & 23.5178606 \\
\hline Al & 8.4226386 & 14.7738135 & 28.4821600 \\
\hline $\mathrm{P}$ & 8.4642427 & 14.7764876 & 16.6443745 \\
\hline Al & 15.4841395 & 13.2973633 & 18.5774248 \\
\hline Al & 15.4225452 & 18.7849316 & 18.5541648 \\
\hline Al & 10.6956493 & 15.9791199 & 18.5303395 \\
\hline $\mathrm{P}$ & 10.5402780 & 16.0441724 & 21.6866817 \\
\hline $\mathrm{P}$ & 15.3941323 & 18.7400120 & 21.7040334 \\
\hline $\mathrm{P}$ & 15.4966694 & 13.4081850 & 21.6439074 \\
\hline Al & 8.4672869 & 17.5101189 & 23.5342932 \\
\hline $\mathrm{P}$ & 8.4888122 & 17.3438766 & 26.6753436 \\
\hline $\mathrm{O}$ & 8.8828053 & 13.3111655 & 16.9000825 \\
\hline $\mathrm{O}$ & 6.7340700 & 14.4028598 & 28.2043605 \\
\hline $\mathrm{O}$ & 11.6620469 & 17.0859205 & 21.9488471 \\
\hline $\mathrm{O}$ & 14.1347909 & 14.1003369 & 21.6334598 \\
\hline 0 & 15.8777653 & 17.3097220 & 22.0116936 \\
\hline $\mathrm{O}$ & 15.9443409 & 14.9599843 & 18.2489917 \\
\hline $\mathrm{O}$ & 11.8537896 & 14.6604607 & 18.3484356 \\
\hline 0 & 13.7283819 & 18.4520828 & 18.3209761 \\
\hline $\mathrm{O}$ & 7.0073747 & 17.6875943 & 26.9461681 \\
\hline $\mathrm{H}$ & 8.9240273 & 18.9168776 & 23.3624249 \\
\hline $\mathrm{H}$ & 4.7152031 & 18.6645303 & 23.4510250 \\
\hline $\mathrm{H}$ & 18.1917517 & 15.8495490 & 17.6174170 \\
\hline $\mathrm{H}$ & 11.8076543 & 19.8550888 & 17.5954390 \\
\hline 0 & 11.5568531 & 12.3166110 & 17.4126210 \\
\hline 0 & 4.8169950 & 15.9489780 & 27.6450348 \\
\hline
\end{tabular}




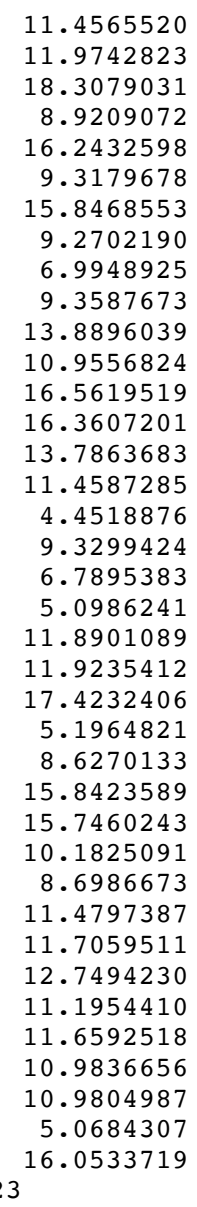

$\begin{array}{lrrr}\mathrm{H} & 8.6196415 & 8.9821846 & 15.2015323 \\ \mathrm{P} & 5.3085202 & 9.3486538 & 16.7279294 \\ \mathrm{Al} & 5.2782222 & 9.3222446 & 28.5563222 \\ \mathrm{P} & 5.3236485 & 6.7701110 & 21.6786239 \\ \mathrm{Al} & 5.3633820 & 6.7675393 & 18.5316049 \\ \mathrm{P} & 3.1278319 & 7.9759372 & 26.7062535 \\ \mathrm{Al} & 3.1839752 & 8.0352826 & 23.5748858 \\ \mathrm{P} & 8.4225955 & 9.2539777 & 28.4785965 \\ \mathrm{Al} & 8.4621130 & 9.2978515 & 16.6481351 \\ \mathrm{P} & 8.5622462 & 6.7516153 & 18.4969629 \\ \mathrm{Al} & 8.5116270 & 6.7209141 & 21.6439058 \\ \mathrm{P} & 1.5620540 & 10.7533543 & 23.5106429 \\ \mathrm{Al} & 1.5566492 & 10.7536074 & 26.6511275 \\ \mathrm{O} & 6.7901348 & 9.7037631 & 16.9770822 \\ \mathrm{O} & 4.8032184 & 10.9706681 & 28.1930841 \\ \mathrm{H} & 4.8851913 & 5.3749989 & 21.9588701 \\ \mathrm{H} & 8.9527201 & 5.3288682 & 21.9350512 \\ \mathrm{O} & 7.0704319 & 6.4256860 & 18.3225383 \\ \mathrm{O} & 2.0851601 & 9.0984341 & 26.8640944 \\ \mathrm{H} & 2.1407424 & 7.0051560 & 23.3148374 \\ \mathrm{H} & 0.1758694 & 10.2578382 & 23.2868652 \\ \mathrm{O} & 4.8950866 & 8.1391949 & 17.5691168 \\ \mathrm{O} & 4.3070989 & 8.1939691 & 27.6591285 \\ \mathrm{O} & 4.5845248 & 7.7707275 & 22.5750188 \\ \mathrm{O} & 2.4940854 & 11.8362887 & 27.6382723 \\ \mathrm{O} & 8.9692018 & 7.9380686 & 17.6141881 \\ \mathrm{O} & 1.8902241 & 11.9228272 & 22.5849686 \\ \mathrm{O} & 4.4415286 & 10.5418485 & 17.1434186 \\ \mathrm{O} & 6.9451521 & 9.1126576 & 28.1080244 \\ \mathrm{O} & 6.8217849 & 6.8926671 & 21.9793827 \\ \mathrm{H} & 9.3683755 & 5.5720268 & 18.0776216 \\ \mathrm{H} & 4.5988918 & 5.5726490 & 18.0789322 \\ \mathrm{H} & 0.1381428 & 10.8369424 & 27.0961169 \\ \mathrm{H} & 2.4888864 & 6.6802407 & 27.0668639 \\ \mathrm{O} & 2.5400567 & 9.6119013 & 23.2083695 \\ \mathrm{H} & 5.0904568 & 9.0173696 & 15.2927222 \\ \mathrm{O} & 5.0417149 & 7.1379935 & 20.2085718 \\ \mathrm{O} & 3.6599415 & 7.9437118 & 25.2619929 \\ \mathrm{H} & 8.6396903 & 8.9379519 & 29.9173870 \\ & & & \end{array}$

22.4653542

22.6138403

22.4092481

27.5301245

17.6830563

17.4909933

17.7446063

22.4409200

17.0503986

28.0295611

21.9426238

22.1620569

22.0698343

18.0313613

18.2026660

18.0437839

26.8534071

27.0500540

23. 1117206

15.2026083

19.9314317

19.8632885

19.9300728

24.9428085

29.9246837

20.2303374

20.2470227

20.1805862

25.1931686

20.0010039

19.5977490

19.9442388

19.8401145

18.5183430

20.2301902

21.2099001

$\begin{array}{ll}15.0847108 & 29.9216431 \\ 19.7296976 & 22.6001619\end{array}$

$\begin{array}{ll}15.0847108 & 29.9216431 \\ 19.7296976 & 22.6001619\end{array}$

15.2015323

18.5316049

6.7062535

16.6481351

18.4969629

21.6439058

5106429

16.9770822

(950841

21.9350512

.

3.3148374

.2868652

27.6591285

.5750188

17.6141881

.5849686

28.1080244

9793827

18.0789322

27.0961169

7.0668639

29.9173870 


\begin{tabular}{|c|c|c|c|}
\hline 0 & 8.8671769 & 7.1143620 & 19.9664948 \\
\hline $\mathrm{O}$ & 1.7161110 & 11.2237725 & 24.9726899 \\
\hline $\mathrm{H}$ & 5.1121732 & 9.0532579 & 30.0113804 \\
\hline $\mathrm{H}$ & 3.4147283 & 12.0380751 & 15.1985798 \\
\hline $\mathrm{P}$ & 3.1238866 & 15.9874056 & 21.7023365 \\
\hline Al & 3.1218120 & 16.0057568 & 18.5187994 \\
\hline $\mathrm{P}$ & 3.7512961 & 12.0612738 & 28.4808213 \\
\hline Al & 3.7554540 & 12.0670833 & 16.6477814 \\
\hline $\mathrm{P}$ & 1.5470228 & 13.2898153 & 18.4812308 \\
\hline Al & 1.4968216 & 13.3082530 & 21.5902341 \\
\hline 0 & 4.9360703 & 13.3279881 & 16.9602071 \\
\hline $\mathrm{H}$ & 0.0599914 & 13.6963069 & 21.6355516 \\
\hline $\mathrm{H}$ & 2.1295709 & 17.0615375 & 21.9756447 \\
\hline $\mathrm{O}$ & 1.9408488 & 14.7539566 & 18.1875444 \\
\hline 0 & 4.5747549 & 15.7491081 & 17.5886889 \\
\hline $\mathrm{O}$ & 4.3886216 & 16.2149104 & 22.5383755 \\
\hline $\mathrm{O}$ & 2.2754699 & 12.3415733 & 17.5204254 \\
\hline 0 & 4.3367479 & 13.4245009 & 28.1034619 \\
\hline 0 & 2.5289807 & 14.6362341 & 22.0938733 \\
\hline $\mathrm{H}$ & 2.5524534 & 17.3261628 & 18.1321739 \\
\hline $\mathrm{H}$ & 0.0857484 & 13.1415984 & 18.2366305 \\
\hline 0 & 3.5257133 & 16.0096245 & 20.2165954 \\
\hline $\mathrm{H}$ & 3.3682336 & 12.0339472 & 29.9194446 \\
\hline $\mathrm{O}$ & 1.9190377 & 12.9030966 & 19.9198919 \\
\hline $\mathrm{P}$ & 10.0605972 & 11.9988033 & 16.6459701 \\
\hline Al & 10.0226425 & 11.9853871 & 28.4744774 \\
\hline $\mathrm{P}$ & 12.2973045 & 10.6942318 & 26.7893667 \\
\hline Al & 12.3292113 & 10.7195471 & 23.5829953 \\
\hline $\mathrm{P}$ & 15.4370527 & 10.7533543 & 23.5106429 \\
\hline $\mathrm{P}$ & 10.6313979 & 8.0934049 & 23.5059030 \\
\hline Al & 10.6521811 & 8.0599602 & 26.6756721 \\
\hline Al & 15.4316479 & 10.7536074 & 26.6511275 \\
\hline 0 & 8.8728046 & 10.6967769 & 28.1718060 \\
\hline 0 & 11.8337868 & 9.2661733 & 27.1496463 \\
\hline $\mathrm{H}$ & 15.8812047 & 9.3457000 & 26.8322793 \\
\hline $\mathrm{H}$ & 11.6002086 & 6.9747454 & 23.3411990 \\
\hline $\mathrm{O}$ & 13.9972703 & 10.2386787 & 23.2782127 \\
\hline $\mathrm{O}$ & 11.4885578 & 11.7345310 & 27.5730923 \\
\hline $\mathrm{O}$ & 9.2120546 & 8.2467992 & 27.6354112 \\
\hline $\mathrm{H}$ & 16.2341425 & 11.6804394 & 27.4961752 \\
\hline $\mathrm{O}$ & 9.3799833 & 7.8596165 & 22.6528887 \\
\hline $\mathrm{O}$ & 15.7652229 & 11.9228272 & 22.5849686 \\
\hline $\mathrm{O}$ & 9.4976763 & 10.6375230 & 17.0741618 \\
\hline $\mathrm{O}$ & 13.7706639 & 10.8511876 & 27.1721828 \\
\hline $\mathrm{H}$ & 11.2150784 & 6.7050335 & 26.9295242 \\
\hline $\mathrm{H}$ & 16.3868465 & 9.6448247 & 23.2170881 \\
\hline $\mathrm{O}$ & 11.2912777 & 9.3966712 & 22.9908257 \\
\hline $\mathrm{H}$ & 10.4135612 & 11.9948975 & 15.1994149 \\
\hline $\mathrm{O}$ & 12.0873237 & 10.9402896 & 25.2918648 \\
\hline $\mathrm{O}$ & 15.5911097 & 11.2237725 & 24.9726899 \\
\hline 0 & 10.2331754 & 8.2535375 & 24.9797718 \\
\hline $\mathrm{H}$ & 10.3647621 & 11.9933986 & 29.9236187 \\
\hline $\mathrm{H}$ & 8.7110801 & 15.0253485 & 15.1554257 \\
\hline $\mathrm{P}$ & 5.3714408 & 14.7850010 & 16.7033887 \\
\hline Al & 5.3301528 & 14.7801139 & 28.5499933 \\
\hline$P$ & 12.2611479 & 18.7862124 & 21.6786239 \\
\hline $\mathrm{Si}$ & 12.1730242 & 13.3096550 & 21.7080170 \\
\hline$P$ & 16.9988853 & 15.9874056 & 21.7023365 \\
\hline Al & 16.9968107 & 16.0057568 & 18.5187994 \\
\hline Al & 12.2183174 & 13.2860344 & 18.5363754 \\
\hline Al & 12.3008814 & 18.7836407 & 18.5316049 \\
\hline$P$ & 5.2674616 & 17.2947853 & 26.6789509 \\
\hline Al & 5.2695700 & 17.3144168 & 23.5507633 \\
\hline $\mathrm{P}$ & 8.4880385 & 14.7241080 & 28.4405547 \\
\hline Al & 8.5289160 & 14.7418279 & 16.6057887 \\
\hline $\mathrm{P}$ & 15.4220215 & 13.2898153 & 18.4812308 \\
\hline$P$ & 15.4997456 & 18.7677166 & 18.4969629 \\
\hline $\mathrm{P}$ & 10.6912931 & 16.1083734 & 18.4724741 \\
\hline Al & 10.6045262 & 16.1108186 & 21.5925207 \\
\hline Al & 15.4491264 & 18.7370155 & 21.6439058 \\
\hline Al & 15.3718203 & 13.3082530 & 21.5902341 \\
\hline $\mathrm{P}$ & 8.4208527 & 17.3844507 & 23.4629459 \\
\hline Al & 8.4194938 & 17.3000071 & 26.6231244 \\
\hline 0 & 9.0132830 & 13.0866936 & 16.9479116 \\
\hline $\mathrm{O}$ & 7.0027728 & 14.3749979 & 28.2261822 \\
\hline $\mathrm{O}$ & 11.8089896 & 17.3475054 & 21.9676273 \\
\hline $\mathrm{O}$ & 13.7154973 & 13.7555868 & 21.6424744 \\
\hline $\mathrm{O}$ & 15.9672578 & 17.1018445 & 21.9859006 \\
\hline $\mathrm{O}$ & 15.8158475 & 14.7539566 & 18.1875444 \\
\hline $\mathrm{O}$ & 11.7072213 & 14.9444462 & 18.4279358 \\
\hline
\end{tabular}




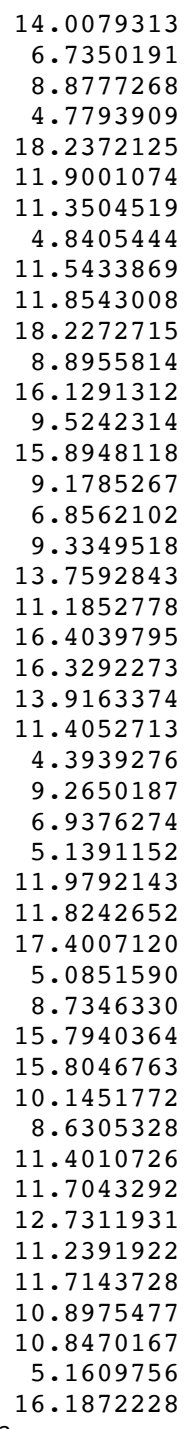

18.4417873

17.6912766

18.7891907

18.7085763

15.7866515

19.9575234

12.2446449

16.1583648

19.7579083

12.0963126

16.2083718

15.9199885

12.3693489

15.8392821

19.9195072

16.4312096

14.9301799

13.5181657

18.9087684

14.5435372

14.6362341

17.5539571

13.1370940

17.3838114

18.4666009

18.4624680

17.3120293

15.1472839

19.1540948

12.6265213

16.0096245

16.8303455

15.0635198

12.9030966

19.1304634

16.2920217

16.9451757

11.6298215

9.3549718

9.3281136

8.3640277

9.6617921

10.3266825

10.0528173

15.1028572

19.7049041

8.9630579

9.2986735

9.2975676

6.7327253

6.7066750

8.0627230

8.1677923

9.2696001

9.3357344

6.7831910

6.7363824

10.8015673

10.7890799

9.6818686

10.7515423

5.3680185

5.3570107

6.4478908

9.3267929

7.1673104

10.2135462

7.8616500

8.3112380

7.9259043

11.7035897

8.1695541

12.1926612

10.6462027

9.0956404

6.8130436

5.6155015
18.3225383

26.9363154

23.2756166

23.3686526

17.7247485

17.7078936

17.4411787

27.6107078

22.5491105

22.7044964

22.5143475

27.5757435

17.5485690

17.5156369

17.6399788

22.5468436

17.0582322

28.0178014

21.9793827

21.9029774

22.0938733

18.0654739

18.2291968

18.0012930

26.9633927

27.0115739

23.0885308

15.2779426

20.2085718

20.1529755

20.2165954

25.2223707

29.8692294

19.9198919

19.9664948

19.8933725

24.9252906

20.2189964

19.5991047

19.9967595

19.6818883

18.5473142

20.3093319

21.2567019

29.9937164

22.5015338

15.3033820

16.6916505

28.5036392

21.6066158

18.4595470

26.6464502

23.5238958

28.5624862

16.7366672

18.5566789

21.7019176

23.5763610

26.7172015

17.0444001

28.1870768

21.9255590

22.0058207

18.3220926

26.8429607

23.2792282

23.3666096

17.5452735

27.7120209

22.5980053

27.6295136

17.6119128

22.5913288

17.1646739

28.0919433

21.9166374

18.1064923 


\begin{tabular}{|c|c|c|c|}
\hline $\mathrm{H}$ & 4.5855409 & 5.4725472 & 18.0280912 \\
\hline $\mathrm{H}$ & 0.0502976 & 10.8683992 & 27.1608456 \\
\hline $\mathrm{H}$ & 2.5017328 & 6.7687174 & 27.0268884 \\
\hline 0 & 2.6831426 & 9.5692367 & 23.2281055 \\
\hline $\mathrm{H}$ & 5.1962927 & 9.0457516 & 15.2333101 \\
\hline 0 & 4.9500026 & 7.0845786 & 19.9090853 \\
\hline 0 & 3.7067237 & 8.0654343 & 24.9891987 \\
\hline $\mathrm{H}$ & 8.6414471 & 8.9988735 & 30.0167408 \\
\hline $\mathrm{O}$ & 8.8313117 & 7.1193406 & 20.2494234 \\
\hline $\mathrm{O}$ & 1.6123253 & 11.2778917 & 25.2662440 \\
\hline $\mathrm{H}$ & 5.1738457 & 9.0114031 & 29.9547688 \\
\hline $\mathrm{H}$ & 3.3885041 & 11.9393034 & 15.2730912 \\
\hline Al & 3.1821340 & 16.0594451 & 21.6443724 \\
\hline $\mathrm{P}$ & 3.1123735 & 16.0878442 & 18.4552237 \\
\hline Al & 3.7462979 & 11.9884153 & 28.5379656 \\
\hline $\mathrm{P}$ & 3.7588109 & 11.9868582 & 16.7145253 \\
\hline Al & 1.6031279 & 13.3206361 & 18.5726384 \\
\hline $\mathrm{P}$ & 1.6365622 & 13.3963650 & 21.6430061 \\
\hline 0 & 4.8055119 & 13.0934151 & 16.9624639 \\
\hline $\mathrm{H}$ & 0.2678004 & 13.9825027 & 21.6503727 \\
\hline $\mathrm{H}$ & 2.1931563 & 17.1274730 & 21.9579961 \\
\hline 0 & 2.0632570 & 14.9819170 & 18.2258200 \\
\hline $\mathrm{O}$ & 4.3598715 & 15.8482612 & 17.5965829 \\
\hline 0 & 4.6495680 & 16.3784864 & 22.5259322 \\
\hline 0 & 2.4820791 & 12.2400916 & 17.5206226 \\
\hline 0 & 4.3796875 & 13.5494687 & 28.0999403 \\
\hline 0 & 2.6674324 & 14.4598287 & 22.0881049 \\
\hline $\mathrm{H}$ & 2.5252605 & 17.3926483 & 18.0430280 \\
\hline $\mathrm{H}$ & 0.1529866 & 13.1653613 & 18.2724706 \\
\hline 0 & 3.5371146 & 16.1361622 & 19.9300111 \\
\hline $\mathrm{H}$ & 3.4311039 & 11.9452402 & 29.9925822 \\
\hline 0 & 2.0064931 & 12.8968680 & 20.2157439 \\
\hline Al & 10.0552108 & 12.0753744 & 16.5542671 \\
\hline $\mathrm{P}$ & 10.0038039 & 12.0414048 & 28.4044876 \\
\hline Al & 12.2196513 & 10.6366817 & 26.7186435 \\
\hline $\mathrm{P}$ & 12.3046516 & 10.5953212 & 23.5097294 \\
\hline Al & 15.3701596 & 10.8015673 & 23.5763610 \\
\hline Al & 10.5399782 & 8.0512380 & 23.6120841 \\
\hline $\mathrm{P}$ & 10.6212922 & 7.9933606 & 26.7495397 \\
\hline$P$ & 15.3444542 & 10.7890799 & 26.7172015 \\
\hline $\mathrm{O}$ & 8.9828893 & 10.9061751 & 28.1915116 \\
\hline 0 & 11.6930663 & 9.0212998 & 27.1699580 \\
\hline $\mathrm{H}$ & 15.7963066 & 9.3755132 & 26.8387707 \\
\hline $\mathrm{H}$ & 11.4659554 & 6.8934522 & 23.4734518 \\
\hline 0 & 13.7630963 & 10.1025076 & 23.3270014 \\
\hline 0 & 11.2382308 & 11.8344647 & 27.5228689 \\
\hline 0 & 9.4060803 & 8.0936878 & 27.6789484 \\
\hline $\mathrm{H}$ & 16.1442303 & 11.6782577 & 27.6042424 \\
\hline 0 & 9.1242597 & 7.7645211 & 22.6353300 \\
\hline 0 & 15.6545154 & 12.1926612 & 22.5913288 \\
\hline 0 & 9.4007663 & 10.5433031 & 17.0717149 \\
\hline 0 & 13.8813339 & 10.8708563 & 27.1745887 \\
\hline $\mathrm{H}$ & 11.1886424 & 6.6224510 & 26.8754014 \\
\hline $\mathrm{H}$ & 16.3828287 & 9.7510939 & 23.2794982 \\
\hline 0 & 11.3523402 & 9.4763805 & 22.9429463 \\
\hline $\mathrm{H}$ & 10.3981806 & 12.0653449 & 15.1053393 \\
\hline 0 & 12.0015292 & 10.7886223 & 25.0011732 \\
\hline 0 & 15.4873240 & 11.2778917 & 25.2662440 \\
\hline 0 & 10.1530757 & 8.2688206 & 25.3032316 \\
\hline $\mathrm{H}$ & 10.4410205 & 12.0629006 & 29.8276883 \\
\hline $\mathrm{H}$ & 8.6460815 & 15.1193083 & 15.1962273 \\
\hline Al & 5.3066471 & 14.7439865 & 16.6415068 \\
\hline$P$ & 5.2529990 & 14.7492795 & 28.4798800 \\
\hline Al & 12.1751761 & 18.7488267 & 21.6066158 \\
\hline Mg & 12.3116706 & 13.4088317 & 21.7072465 \\
\hline $\mathrm{Al}$ & 17.0571328 & 16.0594451 & 21.6443724 \\
\hline$P$ & 16.9873722 & 16.0878442 & 18.4552237 \\
\hline$P$ & 12.2671884 & 13.1808129 & 18.4912936 \\
\hline $\mathrm{P}$ & 12.2357078 & 18.7227764 & 18.4595470 \\
\hline Al & 5.3256143 & 17.2531603 & 26.6055352 \\
\hline $\mathrm{P}$ & 5.3259333 & 17.3316641 & 23.5100616 \\
\hline Al & 8.4143848 & 14.7717612 & 28.4687705 \\
\hline $\mathrm{P}$ & 8.4608704 & 14.7819082 & 16.6346218 \\
\hline Al & 15.4781266 & 13.3206361 & 18.5726384 \\
\hline Al & 15.4381831 & 18.7992923 & 18.5566789 \\
\hline Al & 10.6689454 & 16.0065394 & 18.5436458 \\
\hline $\mathrm{P}$ & 10.4966072 & 16.0979646 & 21.6477171 \\
\hline $\mathrm{P}$ & 15.3970592 & 18.7524838 & 21.7019176 \\
\hline$P$ & 15.5115610 & 13.3963650 & 21.6430061 \\
\hline Al & 8.4672225 & 17.5162096 & 23.5268093 \\
\hline
\end{tabular}




\begin{tabular}{|c|c|c|c|}
\hline $\mathrm{P}$ & 8.4681050 & 17.3635755 & 26.6856651 \\
\hline $\mathrm{O}$ & 8.8767451 & 13.3174053 & 16.8979824 \\
\hline $\mathrm{O}$ & 6.7257159 & 14.3967955 & 28.1931059 \\
\hline 0 & 11.5877584 & 17.1549638 & 21.9791146 \\
\hline 0 & 14.1168504 & 13.9936145 & 21.6505124 \\
\hline $\mathrm{O}$ & 15.8844889 & 17.3258198 & 22.0162402 \\
\hline 0 & 15.9382557 & 14.9819170 & 18.2258200 \\
\hline 0 & 11.7815418 & 14.6344539 & 18.4896667 \\
\hline 0 & 13.7474806 & 18.4639921 & 18.3220926 \\
\hline $\mathrm{O}$ & 6.9861270 & 17.7027450 & 26.9612898 \\
\hline $\mathrm{H}$ & 8.9668564 & 18.9019104 & 23.3092781 \\
\hline $\mathrm{H}$ & 4.6977838 & 18.6804658 & 23.4527669 \\
\hline $\mathrm{H}$ & 18.1988516 & 15.8551786 & 17.6213742 \\
\hline $\mathrm{H}$ & 11.8196957 & 19.8437687 & 17.5721740 \\
\hline 0 & 11.5473307 & 12.3352718 & 17.4320178 \\
\hline $\mathrm{O}$ & 4.8109442 & 15.9489491 & 27.6367222 \\
\hline $\mathrm{H}$ & 11.4875746 & 19.7646629 & 22.4506546 \\
\hline $\mathrm{O}$ & 12.0170565 & 11.8423773 & 22.7235319 \\
\hline $\mathrm{H}$ & 18.3119119 & 16.3322522 & 22.3981801 \\
\hline 0 & 8.9007899 & 16.1502997 & 27.5205995 \\
\hline $\mathrm{H}$ & 16.2279044 & 12.3988919 & 17.6752302 \\
\hline $\mathrm{O}$ & 9.3241765 & 15.7319894 & 17.4664537 \\
\hline $\mathrm{H}$ & 15.8551479 & 19.9805147 & 17.7517103 \\
\hline 0 & 9.2416685 & 16.3879126 & 22.4841578 \\
\hline $\mathrm{O}$ & 6.9937442 & 14.9479371 & 17.0480066 \\
\hline $\mathrm{O}$ & 9.3600000 & 13.3761067 & 28.0190257 \\
\hline 0 & 13.8888670 & 18.8291450 & 21.9166374 \\
\hline 0 & 10.9948884 & 14.7127401 & 21.9498665 \\
\hline 0 & 16.5424311 & 14.4598287 & 22.0881049 \\
\hline 0 & 16.3818735 & 17.4335089 & 18.0301198 \\
\hline 0 & 13.7690608 & 13.1376368 & 18.2188753 \\
\hline 0 & 11.5015914 & 17.4515055 & 18.0151058 \\
\hline $\mathrm{H}$ & 4.4176733 & 18.4099063 & 26.8394206 \\
\hline $\mathrm{H}$ & 9.3066007 & 18.5289452 & 27.0805819 \\
\hline 0 & 6.7862515 & 17.4916328 & 23.1037214 \\
\hline $\mathrm{H}$ & 5.1025583 & 15.0525846 & 15.1992046 \\
\hline 0 & 11.8875019 & 19.1006800 & 19.9090853 \\
\hline 0 & 11.9668432 & 12.5467604 & 19.8927243 \\
\hline $\mathrm{O}$ & 17.4121133 & 16.1361622 & 19.9300111 \\
\hline 0 & 5.2051236 & 16.7500276 & 24.9319329 \\
\hline $\mathrm{H}$ & 8.6165231 & 15.0766223 & 29.9121417 \\
\hline $\mathrm{O}$ & 15.8814918 & 12.8968680 & 20.2157439 \\
\hline 0 & 15.7688111 & 19.1354419 & 20.2494234 \\
\hline $\mathrm{O}$ & 10.0866213 & 16.2524166 & 20.1582736 \\
\hline $\mathrm{O}$ & 8.6784478 & 17.0366330 & 25.1991096 \\
\hline $\mathrm{H}$ & 11.5067737 & 11.4112737 & 20.0517572 \\
\hline C & 11.7426918 & 9.2582086 & 19.5806586 \\
\hline $\mathrm{H}$ & 12.7932592 & 9.2056665 & 19.8994230 \\
\hline $\mathrm{H}$ & 11.2210339 & 8.3201938 & 19.8018945 \\
\hline $\mathrm{H}$ & 11.6661329 & 9.4814320 & 18.5118824 \\
\hline 0 & 11.0508209 & 10.3328517 & 20.2827884 \\
\hline $\mathrm{H}$ & 11.0619990 & 10.1393112 & 21.2636433 \\
\hline $\mathrm{H}$ & 5.0728708 & 15.0950511 & 29.9169313 \\
\hline $\mathrm{H}$ & 16.0399423 & 19.7468769 & 22.6046935 \\
\hline \multicolumn{4}{|c|}{ Al 23} \\
\hline \multicolumn{4}{|c|}{165} \\
\hline $\mathrm{H}$ & 8.6537439 & 8.7489655 & 15.2316232 \\
\hline $\mathrm{Si}$ & 5.3587655 & 9.1943593 & 16.6432813 \\
\hline $\mathrm{Si}$ & 5.3613993 & 9.1592408 & 28.5688945 \\
\hline $\mathrm{Si}$ & 5.3327702 & 6.7784723 & 21.6062191 \\
\hline $\mathrm{Si}$ & 5.3658516 & 6.7384397 & 18.5414949 \\
\hline $\mathrm{Si}$ & 3.2662534 & 7.9101509 & 26.6556204 \\
\hline $\mathrm{Si}$ & 3.3296250 & 7.9662306 & 23.6014084 \\
\hline $\mathrm{Si}$ & 8.4699629 & 9.1083297 & 28.6000876 \\
\hline $\mathrm{Si}$ & 8.4751567 & 9.1739940 & 16.6474544 \\
\hline $\mathrm{Si}$ & 8.4905594 & 6.6967229 & 18.5413713 \\
\hline $\mathrm{Si}$ & 8.4759005 & 6.6415731 & 21.6623901 \\
\hline $\mathrm{Si}$ & 1.6696407 & 10.6579738 & 23.5669044 \\
\hline $\mathrm{Si}$ & 1.6521062 & 10.6379505 & 26.6549137 \\
\hline 0 & 6.9214691 & 9.5881870 & 16.9240261 \\
\hline 0 & 4.9199586 & 10.6948229 & 28.2492486 \\
\hline $\mathrm{H}$ & 4.7539857 & 5.4148850 & 21.7570794 \\
\hline $\mathrm{H}$ & 8.9551497 & 5.2543349 & 21.9134097 \\
\hline 0 & 6.9254269 & 6.3278050 & 18.2972045 \\
\hline 0 & 2.1676502 & 9.1012757 & 26.8019362 \\
\hline $\mathrm{H}$ & 2.3282448 & 6.8885570 & 23.3712395 \\
\hline $\mathrm{H}$ & 0.2585047 & 10.2718552 & 23.2899054 \\
\hline $\mathrm{O}$ & 4.9199765 & 7.9116550 & 17.5217710 \\
\hline 0 & 4.4875225 & 8.1140978 & 27.6986570 \\
\hline
\end{tabular}

26.6856651

16.8979824

21.9791146

21.6505124

0162402

18.4896667

18.3220926

12898

23.4527669

17.6213742

17.5721740

22.4506546

.7235319

27.5205995

6752302

17.7517103

22.4841578

21.9166374

21.9498665

22.0881049

.0301198

18.0151058

6.8394206

23.1037214

.1992046

19.8927243

19.9300111

24.9319329

20.2157439

20.2494234

20.1582736

20.0517572

19.5806586

(9)

18.5118824

20.2827884

21.2636433

29.9169313

Al 23

165 


\begin{tabular}{|c|c|c|}
\hline 4.5954772 & 7.8296728 & 22.5960535 \\
\hline 2.4928994 & 11.6239466 & 27.6245972 \\
\hline 8.9261272 & 7.9778119 & 17.6434003 \\
\hline 2.1799364 & 11.8362665 & 22.5888185 \\
\hline 4.4279394 & 10.4457926 & 17.0777184 \\
\hline 6.9177227 & 8.9747153 & 28.1683400 \\
\hline 6.9024161 & 6.7334713 & 22.0056768 \\
\hline 9.3251308 & 5.5348681 & 18.1282076 \\
\hline 4.5207990 & 5.5451653 & 18.2602428 \\
\hline 0.2283129 & 10.6933400 & 27.0871927 \\
\hline 2.6072632 & 6.6173321 & 26.9894950 \\
\hline 2.6222695 & 9.3823628 & 23.3015686 \\
\hline 5.1593219 & 8.8568929 & 15.2068067 \\
\hline 5.1664951 & 7.2865853 & 20.0627141 \\
\hline 3.8696957 & 7.8943022 & 25.1408001 \\
\hline 8.6526218 & 8.7448343 & 30.0324379 \\
\hline 8.7501519 & 7.0688180 & 20.1084182 \\
\hline 1.8084115 & 11.1499655 & 25.1181646 \\
\hline 5.1597735 & 8.8543420 & 30.0123294 \\
\hline 3.3921874 & 11.8052865 & 15.1738221 \\
\hline 3.3053731 & 15.7749720 & 21.6286823 \\
\hline 3.2353044 & 15.8092946 & 18.5128662 \\
\hline 3.8024355 & 11.8447374 & 28.5453852 \\
\hline 3.7839770 & 11.8582167 & 16.6093777 \\
\hline 1.7194410 & 13.0836949 & 18.5679124 \\
\hline 1.7955112 & 13.0596396 & 21.5925290 \\
\hline 4.9007107 & 13.0197593 & 16.8584024 \\
\hline 0.3542409 & 13.4257586 & 21.6688009 \\
\hline 2.2864212 & 16.8239183 & 21.9089847 \\
\hline 2.1108555 & 14.6466335 & 18.3032554 \\
\hline 4.5219926 & 15.5654145 & 17.5600055 \\
\hline 4.6277376 & 16.0144302 & 22.5293873 \\
\hline 2.4438029 & 12.1304838 & 17.4753355 \\
\hline 4.4336802 & 13.2853422 & 28.1754358 \\
\hline 2.7247288 & 14.3246239 & 22.0185878 \\
\hline 2.6378921 & 17.1174998 & 18.1270965 \\
\hline 0.2489809 & 12.9368210 & 18.3854408 \\
\hline 3.7355963 & 15.8440129 & 20.0584315 \\
\hline 3.3940282 & 11.8041826 & 29.9767060 \\
\hline 2.1798986 & 12.6174063 & 20.0542021 \\
\hline 10.0702272 & 11.8749997 & 16.5653192 \\
\hline 10.0300118 & 11.8430688 & 28.5254585 \\
\hline 12.1773962 & 10.5664676 & 26.6852319 \\
\hline 12.1739782 & 10.5763397 & 23.5480700 \\
\hline 15.2946394 & 10.6579738 & 23.5669044 \\
\hline 10.5089959 & 7.9283238 & 23.6077570 \\
\hline 10.5581428 & 7.9049891 & 26.6687217 \\
\hline 15.2771050 & 10.6379505 & 26.6549137 \\
\hline 8.9410324 & 10.6460172 & 28.3403798 \\
\hline 11.6927122 & 9.0354909 & 26.9614144 \\
\hline 15.7487749 & 9.2320504 & 26.7894242 \\
\hline 11.4696524 & 6.7973797 & 23.4843665 \\
\hline 13.7470168 & 10.2345094 & 23.2631137 \\
\hline 11.3178734 & 11.6087720 & 27.5807536 \\
\hline 9.3249463 & 8.0679783 & 27.7051583 \\
\hline 16.0506441 & 11.5450780 & 27.5470334 \\
\hline 9.2417041 & 7.7115248 & 22.6169287 \\
\hline 15.8049352 & 11.8362665 & 22.5888185 \\
\hline 9.4199451 & 10.4502274 & 16.9816049 \\
\hline 13.7283476 & 10.6982015 & 27.1251331 \\
\hline 11.1657838 & 6.5627712 & 26.8839985 \\
\hline 16.1734740 & 9.4811764 & 23.3221225 \\
\hline 11.2644864 & 9.2835010 & 23.1516016 \\
\hline 10.4887713 & 11.8884017 & 15.1364169 \\
\hline 11.9725415 & 10.9441192 & 25.1227866 \\
\hline 15.4334102 & 11.1499655 & 25.1181646 \\
\hline 9.9832201 & 8.0503136 & 25.1472003 \\
\hline 10.4828167 & 11.8855621 & 29.9433029 \\
\hline 8.7108916 & 14.9131713 & 15.1566916 \\
\hline 5.3672254 & 14.5621082 & 16.6142110 \\
\hline 5.3426370 & 14.5619375 & 28.5697725 \\
\hline 12.1452696 & 18.5780673 & 21.6062191 \\
\hline 12.1978375 & 13.1554681 & 21.7290524 \\
\hline 16.9303718 & 15.7749720 & 21.6286823 \\
\hline 16.8603031 & 15.8092946 & 18.5128662 \\
\hline 12.1503666 & 13.0966615 & 18.5018378 \\
\hline 12.1783510 & 18.5380348 & 18.5414949 \\
\hline 5.3423448 & 16.9667370 & 26.6219613 \\
\hline 5.3473135 & 17.0034757 & 23.5821891 \\
\hline 8.4724413 & 14.5474528 & 28.5314846 \\
\hline
\end{tabular}

22.5960535

7.6245972

22.5888185

17.0777184

22.0056768

18.1282076

27.0871927

26.9894950

068067

20.0627141

1408001

20.1084182

15.1738221

21.6286823

16.6093777

18.5679124

21.5925290

8584024

21.9089847

8.3032554

00055

17.4753355

28.1754358

22.0185878

18.3854408

20.0584315

29.9767060

20.0542021
16.5653192

28.5254585

26.6852319

. 5480700

23.6077570

26.6549137

28.3403798

4144

23.4843665

1137

27.7051583

(160334

22.5888185

16.9816049

26.8839985

. 3221225

15.1364169

25.1227866

25.1472003

29.9433029

16.6142110

28.5697725

21.6062191

21.6286823

18.5128662

18.5414949

23.5821891

28.5314846 


\begin{tabular}{|c|c|c|c|}
\hline $\mathrm{Si}$ & 8.4990059 & 14.5746202 & 16.5911281 \\
\hline $\mathrm{Si}$ & 15.3444397 & 13.0836949 & 18.5679124 \\
\hline $\mathrm{Si}$ & 15.3030587 & 18.4963180 & 18.5413713 \\
\hline $\mathrm{Si}$ & 10.5932346 & 15.8009898 & 18.5311849 \\
\hline $\mathrm{Si}$ & 10.5148049 & 15.8271487 & 21.6182581 \\
\hline $\mathrm{Si}$ & 15.2883999 & 18.4411682 & 21.6623901 \\
\hline $\mathrm{Si}$ & 15.4205099 & 13.0596396 & 21.5925290 \\
\hline$i$ & 8.4821633 & 17.0807634 & 23.5474967 \\
\hline $\mathrm{Si}$ & 8.4720395 & 17.0108022 & 26.6322116 \\
\hline 0 & 8.9733175 & 13.0367758 & 16.8753762 \\
\hline $\mathrm{O}$ & 6.9030264 & 14.1834240 & 28.3029170 \\
\hline $\mathrm{O}$ & 11.5191711 & 17.1030107 & 21.7694118 \\
\hline $\mathrm{O}$ & 13.8746148 & 13.4523360 & 21.6743377 \\
\hline $\mathrm{O}$ & 15.8116174 & 16.9266587 & 21.9364393 \\
\hline $\mathrm{O}$ & 15.7358542 & 14.6466335 & 18.3032554 \\
\hline $\mathrm{O}$ & 11.7288683 & 14.6461192 & 18.2667000 \\
\hline $\mathrm{O}$ & 13.7379263 & 18.1274000 & 18.2972045 \\
\hline 0 & 6.9000754 & 17.3788269 & 26.8714618 \\
\hline $\mathrm{H}$ & 9.0027234 & 18.4640847 & 23.3670532 \\
\hline $\mathrm{H}$ & 4.7879229 & 18.3798104 & 23.4826628 \\
\hline $\mathrm{H}$ & 18.0432626 & 15.5850754 & 17.6368221 \\
\hline $\mathrm{H}$ & 11.7678012 & 19.6182996 & 17.6025607 \\
\hline $\mathrm{O}$ & 11.3989939 & 12.0976155 & 17.4730085 \\
\hline 0 & 4.8808630 & 15.8029529 & 27.6444889 \\
\hline $\mathrm{H}$ & 11.4681126 & 19.5435286 & 22.5153195 \\
\hline 0 & 11.6392112 & 11.7816174 & 22.6337573 \\
\hline $\mathrm{H}$ & 18.1474616 & 15.9953667 & 22.4576813 \\
\hline 0 & 8.9230314 & 15.7881440 & 27.5965462 \\
\hline $\mathrm{H}$ & 16.0098926 & 12.2080042 & 17.5641899 \\
\hline 0 & 9.3579886 & 15.6041928 & 17.4971263 \\
\hline $\mathrm{H}$ & 15.7024274 & 19.6709382 & 17.7180289 \\
\hline 0 & 9.1804393 & 16.0667985 & 22.5115765 \\
\hline 0 & 6.9362211 & 14.7011673 & 16.9967717 \\
\hline 0 & 9.3505957 & 13.2519800 & 28.1145996 \\
\hline 0 & 13.7149154 & 18.5330663 & 22.0056768 \\
\hline $\mathrm{O}$ & 11.2515843 & 14.5142808 & 22.1159025 \\
\hline 0 & 16.3497276 & 14.3246239 & 22.0185878 \\
\hline 0 & 16.2095065 & 17.2344000 & 18.0926244 \\
\hline 0 & 13.7401688 & 12.9234556 & 18.3688360 \\
\hline 0 & 11.2616212 & 17.2435471 & 18.2363871 \\
\hline $\mathrm{H}$ & 4.4769939 & 18.1506621 & 26.8800502 \\
\hline $\mathrm{H}$ & 9.2917852 & 18.2019310 & 26.9876688 \\
\hline 0 & 6.9071138 & 17.0962222 & 23.2036912 \\
\hline $\mathrm{H}$ & 5.1426698 & 14.9435523 & 15.1925234 \\
\hline $\mathrm{O}$ & 11.9789945 & 19.0861804 & 20.0627141 \\
\hline $\mathrm{O}$ & 11.6711251 & 12.6244687 & 20.0256245 \\
\hline $\mathrm{O}$ & 17.3605951 & 15.8440129 & 20.0584315 \\
\hline 0 & 5.1420768 & 16.4298548 & 25.0954121 \\
\hline $\mathrm{H}$ & 8.7083062 & 14.9103571 & 29.9561911 \\
\hline $\mathrm{O}$ & 15.8048973 & 12.6174063 & 20.0542021 \\
\hline 0 & 15.5626513 & 18.8684131 & 20.1084182 \\
\hline 0 & 10.0359202 & 15.7134438 & 20.0496968 \\
\hline 0 & 8.7262349 & 16.5796140 & 25.0825188 \\
\hline $\mathrm{H}$ & 10.7029277 & 12.0971164 & 20.1907426 \\
\hline C & 8.9708276 & 10.3724339 & 20.3436681 \\
\hline $\mathrm{H}$ & 9.7032254 & 9.6152747 & 20.0333571 \\
\hline $\mathrm{H}$ & 8.3362447 & 9.9687115 & 21.1425453 \\
\hline $\mathrm{H}$ & 8.3490577 & 10.6676058 & 19.4915192 \\
\hline 0 & 9.6271379 & 11.5724916 & 20.8210807 \\
\hline $\mathrm{H}$ & 10.0752864 & 11.4030783 & 21.6925128 \\
\hline $\mathrm{H}$ & 5.1406682 & 14.9433768 & 29.9948456 \\
\hline $\mathrm{H}$ & 15.9898764 & 19.4212445 & 22.5367480 \\
\hline \multicolumn{4}{|c|}{$\begin{array}{l}\mathrm{Ge} 23 \\
165\end{array}$} \\
\hline $\mathrm{H}$ & 8.6096274 & 9.0182106 & 15.2232255 \\
\hline$P$ & 5.3160781 & 9.3606188 & 16.7465719 \\
\hline Al & 5.2809605 & 9.3158348 & 28.5714666 \\
\hline $\mathrm{P}$ & 5.3178784 & 6.7577443 & 21.6682339 \\
\hline $\mathrm{Al}$ & 5.3872835 & 6.7725733 & 18.5250127 \\
\hline $\mathrm{P}$ & 3.1480367 & 7.9690818 & 26.7024773 \\
\hline Al & 3.2247223 & 8.1064951 & 23.5995390 \\
\hline $\mathrm{P}$ & 8.4172261 & 9.2202528 & 28.4872986 \\
\hline Al & 8.4667122 & 9.3198680 & 16.6743280 \\
\hline $\mathrm{P}$ & 8.5837961 & 6.7668922 & 18.5104045 \\
\hline Al & 8.5119143 & 6.7162057 & 21.6624253 \\
\hline $\mathrm{P}$ & 1.5585186 & 10.7763779 & 23.5301981 \\
\hline Al & 1.5398700 & 10.7260296 & 26.6839812 \\
\hline 0 & 6.7943528 & 9.7178110 & 17.0105607 \\
\hline & & & \\
\hline
\end{tabular}




\begin{tabular}{|c|c|c|}
\hline 4.8556838 & 5.3657674 & 21.9249379 \\
\hline 9.0044016 & 5.3411128 & 21.9517287 \\
\hline 7.0948082 & 6.4370071 & 18.3188939 \\
\hline 2.0799365 & 9.0695550 & 26.8465353 \\
\hline 2.1178043 & 7.1327272 & 23.3906631 \\
\hline 0.2123516 & 10.2063158 & 23.2473831 \\
\hline 4.8991805 & 8.1487805 & 17.5816027 \\
\hline 4.2851048 & 8.1851010 & 27.7054025 \\
\hline 4.5837813 & 7.7614947 & 22.5666894 \\
\hline 2.5000639 & 11.8004534 & 27.6599488 \\
\hline 8.9891799 & 7.9636479 & 17.6398933 \\
\hline 1.8261922 & 11.9840065 & 22.6338262 \\
\hline 4.4421340 & 10.5500550 & 17.1565168 \\
\hline 6.9406302 & 9.0703872 & 28.1149864 \\
\hline 6.8144604 & 6.8424190 & 21.9834785 \\
\hline 9.3975349 & 5.5946473 & 18.0852085 \\
\hline 4.6411297 & 5.5748568 & 18.0497758 \\
\hline 0.1394343 & 10.7829180 & 27.1866383 \\
\hline 2.5208813 & 6.6537357 & 27.0085187 \\
\hline 2.6235045 & 9.7083909 & 23.2430143 \\
\hline 5.1081835 & 9.0301739 & 15.3096632 \\
\hline 5.0555638 & 7.1448536 & 20.1997866 \\
\hline 3.7362594 & 7.9907470 & 25.2777787 \\
\hline 8.6273829 & 8.9741685 & 29.9407074 \\
\hline 8.8726050 & 7.1166791 & 19.9864674 \\
\hline 1.6339170 & 11.2247515 & 25.0059153 \\
\hline 5.1279212 & 9.0631637 & 30.0308695 \\
\hline 3.4439011 & 12.0639289 & 15.2128576 \\
\hline 3.1741624 & 15.9954965 & 21.6949645 \\
\hline 3.1564829 & 16.0271118 & 18.5223877 \\
\hline 3.7624004 & 12.0575871 & 28.4859322 \\
\hline 3.7755771 & 12.0838073 & 16.6643108 \\
\hline 1.5438847 & 13.3076901 & 18.4885580 \\
\hline 1.4762301 & 13.3556273 & 21.6053360 \\
\hline 4.9696313 & 13.3290762 & 16.9964810 \\
\hline 0.0887860 & 13.8906774 & 21.6817623 \\
\hline 2.1910973 & 17.0738302 & 21.9914438 \\
\hline 1.9703683 & 14.7697688 & 18.2375812 \\
\hline 4.6010836 & 15.7593190 & 17.5808225 \\
\hline 4.4414636 & 16.1827082 & 22.5363679 \\
\hline 2.3015325 & 12.3659258 & 17.5444197 \\
\hline 4.3300926 & 13.4204111 & 28.0748939 \\
\hline 2.5778501 & 14.6385361 & 22.0565598 \\
\hline 2.5835700 & 17.3469619 & 18.1391291 \\
\hline 0.0928895 & 13.1860509 & 18.1772102 \\
\hline 3.5827300 & 16.0501581 & 20.2129640 \\
\hline 3.3980555 & 12.0603743 & 29.9296654 \\
\hline 1.8371926 & 12.8865754 & 19.9368179 \\
\hline 10.0668338 & 12.0018122 & 16.6039973 \\
\hline 10.0017284 & 11.9495686 & 28.4192163 \\
\hline 12.3133413 & 10.6313058 & 26.8326097 \\
\hline 12.3635111 & 10.6180603 & 23.6008527 \\
\hline 15.4335174 & 10.7763779 & 23.5301981 \\
\hline 10.5540223 & 8.0850447 & 23.5674367 \\
\hline 10.6272811 & 8.0441452 & 26.6984405 \\
\hline 15.4148687 & 10.7260296 & 26.6839812 \\
\hline 8.8763905 & 10.6423774 & 28.1043584 \\
\hline 11.8111022 & 9.2267844 & 27.2322440 \\
\hline 15.8744253 & 9.3164923 & 26.8223027 \\
\hline 11.4392764 & 6.8907516 & 23.4831183 \\
\hline 14.0339133 & 10.1836868 & 23.2361565 \\
\hline 11.4786563 & 11.7154306 & 27.5274908 \\
\hline 9.2091940 & 8.1664496 & 27.7032661 \\
\hline 16.2363793 & 11.6452716 & 27.5189873 \\
\hline 9.3073378 & 7.8899795 & 22.6960672 \\
\hline 15.7011909 & 11.9840065 & 22.6338262 \\
\hline 9.4987007 & 10.6643279 & 17.0963039 \\
\hline 13.7719113 & 10.7927697 & 27.2736864 \\
\hline 11.2142157 & 6.6839740 & 26.8486491 \\
\hline 16.4663602 & 9.7406245 & 23.2516819 \\
\hline 11.3192081 & 9.3072554 & 23.0059856 \\
\hline 10.3657170 & 11.9463512 & 15.1463575 \\
\hline 12.1863854 & 10.8010485 & 25.3181041 \\
\hline 15.5089157 & 11.2247515 & 25.0059153 \\
\hline 10.1489303 & 8.3417002 & 25.0281775 \\
\hline 10.3197236 & 11.9454946 & 29.8738582 \\
\hline 8.7254835 & 15.0253450 & 15.0964077 \\
\hline 5.3940384 & 14.7832738 & 16.7045149 \\
\hline 5.3268279 & 14.7685893 & 28.5456358 \\
\hline 12.2553778 & 18.7738457 & 21.6682339 \\
\hline
\end{tabular}




\begin{tabular}{|c|c|c|c|}
\hline $\mathrm{Ge}$ & 12.1045775 & 13.3594615 & 21.7624892 \\
\hline $\mathrm{P}$ & 17.0491611 & 15.9954965 & 21.6949645 \\
\hline Al & 17.0314817 & 16.0271118 & 18.5223877 \\
\hline Al & 12.2222303 & 13.2855369 & 18.4690629 \\
\hline Al & 12.3247829 & 18.7886747 & 18.5250127 \\
\hline $\mathrm{P}$ & 5.2833220 & 17.2681992 & 26.6735256 \\
\hline Al & 5.2378980 & 17.2920383 & 23.6002522 \\
\hline $\mathrm{P}$ & 8.4838105 & 14.7045773 & 28.3871250 \\
\hline Al & 8.5519728 & 14.7609538 & 16.5514375 \\
\hline $\mathrm{P}$ & 15.4188834 & 13.3076901 & 18.4885580 \\
\hline$P$ & 15.5212954 & 18.7829936 & 18.5104045 \\
\hline$P$ & 10.7023475 & 16.1245277 & 18.4182933 \\
\hline $\mathrm{Al}$ & 10.5035615 & 16.1807000 & 21.5439027 \\
\hline Al & 15.4494136 & 18.7323070 & 21.6624253 \\
\hline Al & 15.3512288 & 13.3556273 & 21.6053360 \\
\hline $\mathrm{P}$ & 8.3738926 & 17.5199386 & 23.4455720 \\
\hline Al & 8.4270055 & 17.2868850 & 26.5706974 \\
\hline 0 & 9.0483835 & 13.1148876 & 16.9115812 \\
\hline 0 & 6.9934413 & 14.3652918 & 28.1969535 \\
\hline 0 & 11.7785682 & 17.3378534 & 21.9330550 \\
\hline 0 & 13.7404786 & 13.9767926 & 21.6940630 \\
\hline 0 & 16.0287052 & 17.1148447 & 22.0027204 \\
\hline 0 & 15.8453670 & 14.7697688 & 18.2375812 \\
\hline 0 & 11.6944519 & 14.9409197 & 18.4056889 \\
\hline 0 & 14.0323076 & 18.4531085 & 18.3188939 \\
\hline 0 & 6.7478284 & 17.6889584 & 26.9179059 \\
\hline $\mathrm{H}$ & 8.8453006 & 18.9295779 & 23.3571864 \\
\hline $\mathrm{H}$ & 4.6279947 & 18.6465586 & 23.4982068 \\
\hline $\mathrm{H}$ & 18.2641312 & 15.7986094 & 17.7189685 \\
\hline $\mathrm{H}$ & 11.9067181 & 19.9674090 & 17.7169732 \\
\hline 0 & 11.3914146 & 12.2552925 & 17.3377874 \\
\hline 0 & 4.8480960 & 16.1892336 & 27.6669669 \\
\hline $\mathrm{H}$ & 11.5428882 & 19.7480516 & 22.5402442 \\
\hline 0 & 11.7804112 & 11.9992876 & 22.7939528 \\
\hline $\mathrm{H}$ & 18.2803578 & 16.1773747 & 22.5123969 \\
\hline $\mathrm{O}$ & 8.8918366 & 15.8852333 & 27.5004830 \\
\hline $\mathrm{H}$ & 16.1544319 & 12.3933955 & 17.5719587 \\
\hline 0 & 9.5565428 & 15.8765254 & 17.4307733 \\
\hline $\mathrm{H}$ & 15.9146875 & 19.9443476 & 17.6656442 \\
\hline 0 & 9.0716003 & 16.6436917 & 22.4162699 \\
\hline 0 & 6.8841180 & 14.9467599 & 17.0294405 \\
\hline 0 & 9.3123258 & 13.4840477 & 27.9703415 \\
\hline 0 & 13.7519597 & 18.8585203 & 21.9834785 \\
\hline 0 & 10.8943794 & 14.5772913 & 21.9881940 \\
\hline 0 & 16.4528488 & 14.6385361 & 22.0565598 \\
\hline 0 & 16.3591383 & 17.5760252 & 18.0726136 \\
\hline 0 & 13.9243438 & 13.1824005 & 18.1678666 \\
\hline 0 & 11.4510860 & 17.3862277 & 17.9685417 \\
\hline $\mathrm{H}$ & 4.3955786 & 18.4476984 & 26.8679834 \\
\hline $\mathrm{H}$ & 9.2930188 & 18.4364193 & 26.9524203 \\
\hline $\mathrm{O}$ & 6.8814595 & 17.5041047 & 23.1184166 \\
\hline $\mathrm{H}$ & 5.1364780 & 15.1113587 & 15.2751292 \\
\hline 0 & 11.9930631 & 19.1609550 & 20.1997866 \\
\hline 0 & 11.8156827 & 12.5972704 & 20.0656780 \\
\hline $\mathrm{O}$ & 17.4577287 & 16.0501581 & 20.2129640 \\
\hline $\mathrm{O}$ & 5.1254296 & 16.7086112 & 25.2462990 \\
\hline $\mathrm{H}$ & 8.7469229 & 15.0595902 & 29.8090456 \\
\hline 0 & 15.7121913 & 12.8865754 & 19.9368179 \\
\hline 0 & 15.8101044 & 19.1327805 & 19.9864674 \\
\hline $\mathrm{O}$ & 10.1253916 & 16.3200063 & 19.8249882 \\
\hline 0 & 8.6247735 & 16.9587687 & 24.8615071 \\
\hline $\mathrm{H}$ & 11.4282390 & 11.6027593 & 20.1606907 \\
\hline C & 11.7452076 & 9.2759472 & 19.6094874 \\
\hline $\mathrm{H}$ & 12.7672279 & 9.2431463 & 20.0192567 \\
\hline $\mathrm{H}$ & 11.2708378 & 8.2897021 & 19.6982692 \\
\hline $\mathrm{H}$ & 11.7723803 & 9.5676222 & 18.5534528 \\
\hline 0 & 10.9400799 & 10.2650872 & 20.2935113 \\
\hline $\mathrm{H}$ & 10.8759259 & 10.0111660 & 21.2440601 \\
\hline $\mathrm{H}$ & 5.1574657 & 15.0697876 & 29.9939854 \\
\hline $\mathrm{H}$ & 16.1244049 & 19.7283640 & 22.5395672 \\
\hline \multicolumn{4}{|c|}{ Ga 23} \\
\hline \multicolumn{4}{|c|}{165} \\
\hline $\mathrm{H}$ & 8.6513543 & 8.7603108 & 15.2487775 \\
\hline $\mathrm{Si}$ & 5.3614839 & 9.1904115 & 16.6664941 \\
\hline $\mathrm{Si}$ & 5.3635848 & 9.1398758 & 28.5968321 \\
\hline $\mathrm{Si}$ & 5.3465611 & 6.7239690 & 21.6262408 \\
\hline $\mathrm{Si}$ & 5.3663240 & 6.7364173 & 18.5651528 \\
\hline $\mathrm{Si}$ & 3.2687436 & 7.9081282 & 26.6642588 \\
\hline $\mathrm{Si}$ & 3.3833281 & 8.0177074 & 23.6123605 \\
\hline
\end{tabular}




\begin{tabular}{|c|c|c|c|}
\hline $\mathrm{Si}$ & 8.4673172 & 9.0833550 & 28.6087775 \\
\hline $\mathrm{Si}$ & 8.4747506 & 9.1781607 & 16.6669923 \\
\hline $\mathrm{Si}$ & 8.4874232 & 6.6897868 & 18.5480019 \\
\hline $\mathrm{Si}$ & 8.4889566 & 6.6108059 & 21.6733464 \\
\hline $\mathrm{Si}$ & 1.6769250 & 10.6461323 & 23.5803526 \\
\hline $\mathrm{Si}$ & 1.6456920 & 10.6081690 & 26.6780133 \\
\hline 0 & 6.9217483 & 9.5892705 & 16.9486427 \\
\hline $\mathrm{O}$ & 4.9388366 & 10.6844544 & 28.2933614 \\
\hline $\mathrm{H}$ & 4.7353631 & 5.3721815 & 21.7536307 \\
\hline $\mathrm{H}$ & 9.0369671 & 5.2506362 & 21.9316936 \\
\hline 0 & 6.9215977 & 6.3214447 & 18.2985927 \\
\hline $\mathrm{O}$ & 2.1338002 & 9.0630059 & 26.8312423 \\
\hline $\mathrm{H}$ & 2.3533915 & 6.9624479 & 23.4055309 \\
\hline $\mathrm{H}$ & 0.2916773 & 10.1628357 & 23.3261203 \\
\hline $\mathrm{O}$ & 4.9157471 & 7.9245394 & 17.5653598 \\
\hline $\mathrm{O}$ & 4.4655663 & 8.1096420 & 27.7344007 \\
\hline $\mathrm{O}$ & 4.6537505 & 7.7934233 & 22.6304819 \\
\hline 0 & 2.5035398 & 11.5824444 & 27.6445715 \\
\hline 0 & 8.9245302 & 7.9773455 & 17.6590302 \\
\hline $\mathrm{O}$ & 2.0371758 & 11.8948213 & 22.6258360 \\
\hline 0 & 4.4297491 & 10.4474594 & 17.0763764 \\
\hline 0 & 6.9143307 & 8.9322984 & 28.1799710 \\
\hline $\mathrm{O}$ & 6.9132050 & 6.6103008 & 22.0146434 \\
\hline $\mathrm{H}$ & 9.3216375 & 5.5309513 & 18.1257372 \\
\hline $\mathrm{H}$ & 4.5028896 & 5.5561906 & 18.2846771 \\
\hline $\mathrm{H}$ & 0.2222883 & 10.6869548 & 27.1079377 \\
\hline $\mathrm{H}$ & 2.6392216 & 6.5884741 & 26.9459245 \\
\hline $\mathrm{O}$ & 2.7275567 & 9.4553134 & 23.2604506 \\
\hline $\mathrm{H}$ & 5.1708878 & 8.8313303 & 15.2340646 \\
\hline $\mathrm{O}$ & 5.1872844 & 7.2673671 & 20.0944575 \\
\hline $\mathrm{O}$ & 3.8993262 & 7.9716502 & 25.1610312 \\
\hline $\mathrm{H}$ & 8.6500896 & 8.7535388 & 30.0492413 \\
\hline $\mathrm{O}$ & 8.7457534 & 7.0464887 & 20.1190158 \\
\hline 0 & 1.8163560 & 11.1129216 & 25.1390728 \\
\hline $\mathrm{H}$ & 5.1712772 & 8.8274995 & 30.0399396 \\
\hline $\mathrm{H}$ & 3.4057728 & 11.8374774 & 15.1859313 \\
\hline $\mathrm{Si}$ & 3.3841885 & 15.7723121 & 21.6144366 \\
\hline $\mathrm{Si}$ & 3.2557242 & 15.8162901 & 18.5080259 \\
\hline $\mathrm{Si}$ & 3.8139815 & 11.8369511 & 28.5552289 \\
\hline $\mathrm{Si}$ & 3.7979968 & 11.8679297 & 16.6220210 \\
\hline $\mathrm{Si}$ & 1.7159355 & 13.0840790 & 18.5753042 \\
\hline $\mathrm{Si}$ & 1.7803970 & 13.1239367 & 21.6010451 \\
\hline 0 & 4.9221080 & 13.0201783 & 16.8841619 \\
\hline $\mathrm{H}$ & 0.4057629 & 13.6917660 & 21.6722602 \\
\hline $\mathrm{H}$ & 2.3742102 & 16.8213516 & 21.9252102 \\
\hline 0 & 2.1382218 & 14.6418038 & 18.3368598 \\
\hline $\mathrm{O}$ & 4.5274918 & 15.5765699 & 17.5354571 \\
\hline $\mathrm{O}$ & 4.7213238 & 15.9911528 & 22.5016063 \\
\hline $\mathrm{O}$ & 2.4643322 & 12.1322794 & 17.4993598 \\
\hline $\mathrm{O}$ & 4.4364335 & 13.2717978 & 28.1407936 \\
\hline 0 & 2.8307931 & 14.3036693 & 21.9857450 \\
\hline $\mathrm{H}$ & 2.6364187 & 17.1146623 & 18.1235638 \\
\hline $\mathrm{H}$ & 0.2511795 & 12.9518108 & 18.3426771 \\
\hline 0 & 3.7912271 & 15.8688337 & 20.0406900 \\
\hline $\mathrm{H}$ & 3.4074788 & 11.8348695 & 29.9876646 \\
\hline 0 & 2.1040535 & 12.5954898 & 20.0769651 \\
\hline $\mathrm{Si}$ & 10.0641510 & 11.8718418 & 16.5444664 \\
\hline $\mathrm{Si}$ & 10.0119013 & 11.8171073 & 28.5029076 \\
\hline $\mathrm{Si}$ & 12.1770607 & 10.5487067 & 26.6844125 \\
\hline $\mathrm{Si}$ & 12.2112849 & 10.5019317 & 23.5518489 \\
\hline $\mathrm{Si}$ & 15.3019237 & 10.6461323 & 23.5803526 \\
\hline $\mathrm{Si}$ & 10.4438361 & 7.9193768 & 23.6374944 \\
\hline $\mathrm{Si}$ & 10.5462936 & 7.8951265 & 26.6724279 \\
\hline $\mathrm{Si}$ & 15.2706908 & 10.6081690 & 26.6780133 \\
\hline 0 & 8.9266292 & 10.6178080 & 28.3067564 \\
\hline $\mathrm{O}$ & 11.6893333 & 9.0188076 & 26.9648630 \\
\hline $\mathrm{H}$ & 15.7172187 & 9.1946330 & 26.8181892 \\
\hline $\mathrm{H}$ & 11.3316465 & 6.7276612 & 23.5440741 \\
\hline $\mathrm{O}$ & 13.7812139 & 10.1155746 & 23.3012591 \\
\hline 0 & 11.2999266 & 11.5972085 & 27.5542783 \\
\hline $\mathrm{O}$ & 9.3409144 & 8.0271547 & 27.7474634 \\
\hline $\mathrm{H}$ & 16.0599290 & 11.5045231 & 27.5672675 \\
\hline $\mathrm{O}$ & 9.1843477 & 7.7313223 & 22.6291359 \\
\hline $\mathrm{O}$ & 15.6621746 & 11.8948213 & 22.6258360 \\
\hline $\mathrm{O}$ & 9.4171779 & 10.4569487 & 17.0009094 \\
\hline 0 & 13.7219447 & 10.6938925 & 27.1457961 \\
\hline $\mathrm{H}$ & 11.1662055 & 6.5497933 & 26.8237833 \\
\hline $\mathrm{H}$ & 16.2676311 & 9.5515693 & 23.2863088 \\
\hline $\mathrm{O}$ & 11.2782519 & 9.2233252 & 23.1704596 \\
\hline $\mathrm{H}$ & 10.4725483 & 11.8473598 & 15.1127776 \\
\hline
\end{tabular}




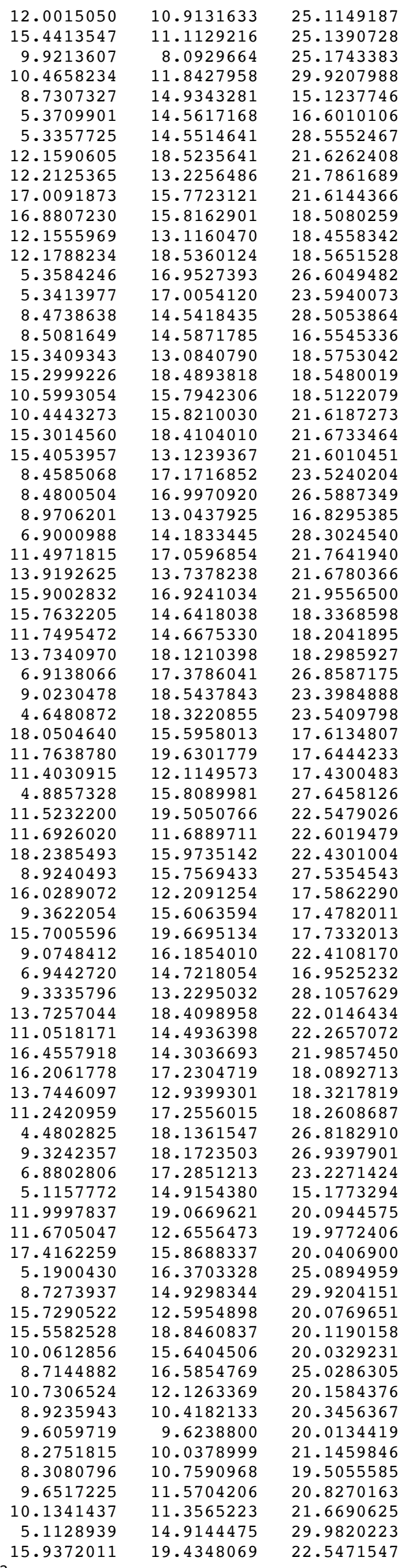




\begin{tabular}{|c|c|c|c|}
\hline $\mathrm{H}$ & 8.5955885 & 9.0591650 & 15.2360825 \\
\hline$P$ & 5.3180608 & 9.3766747 & 16.7716062 \\
\hline Al & 5.2683388 & 9.3229870 & 28.5898704 \\
\hline $\mathrm{P}$ & 5.2992036 & 6.7828733 & 21.6840880 \\
\hline Al & 5.3971728 & 6.7756901 & 18.5363486 \\
\hline $\mathrm{P}$ & 3.1419104 & 7.9730151 & 26.7074169 \\
\hline Al & 3.2766704 & 8.1443205 & 23.6215457 \\
\hline $\mathrm{P}$ & 8.3976059 & 9.2092509 & 28.4905833 \\
\hline Al & 8.4701881 & 9.3487221 & 16.6912636 \\
\hline $\mathrm{P}$ & 8.5897881 & 6.7907951 & 18.5287132 \\
\hline Al & 8.5039084 & 6.7173121 & 21.6817343 \\
\hline $\mathrm{P}$ & 1.5618272 & 10.7996644 & 23.5548750 \\
\hline Al & 1.5153949 & 10.7306991 & 26.7021411 \\
\hline 0 & 6.7955756 & 9.7378793 & 17.0366600 \\
\hline 0 & 4.8275111 & 10.9799859 & 28.2092363 \\
\hline $\mathrm{H}$ & 4.7240047 & 5.4388931 & 21.9669025 \\
\hline $\mathrm{H}$ & 9.0458191 & 5.3590698 & 21.9621470 \\
\hline 0 & 7.1054233 & 6.4449492 & 18.3270405 \\
\hline 0 & 2.0674114 & 9.0725633 & 26.8013345 \\
\hline $\mathrm{H}$ & 2.1821737 & 7.1664832 & 23.3704848 \\
\hline $\mathrm{H}$ & 0.2347581 & 10.2094353 & 23.2267932 \\
\hline 0 & 4.9068899 & 8.1530138 & 17.5932531 \\
\hline 0 & 4.2442287 & 8.2010556 & 27.7454888 \\
\hline $\mathrm{O}$ & 4.6408483 & 7.8513258 & 22.5715691 \\
\hline 0 & 2.4890553 & 11.7824926 & 27.6911239 \\
\hline $\mathrm{O}$ & 8.9887827 & 7.9918469 & 17.6606332 \\
\hline 0 & 1.8580594 & 11.9998478 & 22.6566555 \\
\hline 0 & 4.4397075 & 10.5603999 & 17.1929917 \\
\hline $\mathrm{O}$ & 6.9204192 & 9.0428119 & 28.1253174 \\
\hline 0 & 6.7991455 & 6.7511990 & 21.9935739 \\
\hline $\mathrm{H}$ & 9.4195024 & 5.6288028 & 18.1062578 \\
\hline $\mathrm{H}$ & 4.6638120 & 5.5672864 & 18.0683071 \\
\hline $\mathrm{H}$ & 0.1276260 & 10.7630382 & 27.2408174 \\
\hline $\mathrm{H}$ & 2.5072157 & 6.6602477 & 27.0089546 \\
\hline 0 & 2.6531012 & 9.7463026 & 23.3197156 \\
\hline $\mathrm{H}$ & 5.1072550 & 9.0604994 & 15.3319136 \\
\hline $\mathrm{O}$ & 5.0653967 & 7.1620252 & 20.2090621 \\
\hline $\mathrm{O}$ & 3.7748537 & 7.9783029 & 25.3008024 \\
\hline $\mathrm{H}$ & 8.6103993 & 9.0151525 & 29.9514616 \\
\hline 0 & 8.8617929 & 7.1379370 & 20.0091106 \\
\hline 0 & 1.5719434 & 11.2621907 & 25.0298969 \\
\hline $\mathrm{H}$ & 5.1251409 & 9.0903753 & 30.0536008 \\
\hline $\mathrm{H}$ & 3.4647477 & 12.0699368 & 15.2308328 \\
\hline$P$ & 3.2166787 & 16.0106335 & 21.6948577 \\
\hline Al & 3.1729308 & 16.0517180 & 18.5223533 \\
\hline $\mathrm{P}$ & 3.7609728 & 12.0582861 & 28.4972560 \\
\hline Al & 3.7854546 & 12.0963778 & 16.6846445 \\
\hline $\mathrm{P}$ & 1.5491631 & 13.3400109 & 18.4940193 \\
\hline Al & 1.5183769 & 13.3707932 & 21.6217360 \\
\hline 0 & 4.9846456 & 13.3386740 & 17.0193744 \\
\hline $\mathrm{H}$ & 0.1099344 & 13.8462314 & 21.7075773 \\
\hline $\mathrm{H}$ & 2.2413038 & 17.0934474 & 22.0002727 \\
\hline 0 & 1.9779136 & 14.8016643 & 18.2406345 \\
\hline $\mathrm{O}$ & 4.6147010 & 15.7764762 & 17.5771447 \\
\hline 0 & 4.4980824 & 16.1902519 & 22.5195083 \\
\hline $\mathrm{O}$ & 2.3057193 & 12.3969282 & 17.5491818 \\
\hline 0 & 4.3090742 & 13.4254791 & 28.0712448 \\
\hline 0 & 2.6179390 & 14.6570899 & 22.0676480 \\
\hline $\mathrm{H}$ & 2.6056782 & 17.3790682 & 18.1569955 \\
\hline $\mathrm{H}$ & 0.0971668 & 13.2220321 & 18.1859471 \\
\hline 0 & 3.6102639 & 16.0600940 & 20.2099730 \\
\hline $\mathrm{H}$ & 3.4198682 & 12.0650969 & 29.9466427 \\
\hline $\mathrm{O}$ & 1.8498713 & 12.9203231 & 19.9418542 \\
\hline$P$ & 10.0690587 & 12.0158851 & 16.5597383 \\
\hline Al & 9.9658947 & 11.9369136 & 28.3667076 \\
\hline $\mathrm{P}$ & 12.3095579 & 10.5911109 & 26.8620486 \\
\hline Al & 12.3754767 & 10.5470316 & 23.6203337 \\
\hline $\mathrm{P}$ & 15.4368259 & 10.7996644 & 23.5548750 \\
\hline $\mathrm{P}$ & 10.4937099 & 8.0815905 & 23.6099580 \\
\hline Al & 10.5992459 & 8.0402959 & 26.7163018 \\
\hline Al & 15.3903936 & 10.7306991 & 26.7021411 \\
\hline 0 & 8.8520831 & 10.6178877 & 28.0520645 \\
\hline 0 & 11.7863040 & 9.2034436 & 27.2947870 \\
\hline $\mathrm{H}$ & 15.8599676 & 9.3202024 & 26.7865201 \\
\hline $\mathrm{H}$ & 11.2968923 & 6.8281170 & 23.581277 \\
\hline 0 & 14.0557934 & 10.1854345 & 23.213452 \\
\hline 0 & 11.4519452 & 11.7029252 & 27.484433 \\
\hline 0 & 9.1916752 & 8.1297067 & 27.741421 \\
\hline $\mathrm{H}$ & 16.2229449 & 11.6300600 & 27.547794 \\
\hline
\end{tabular}




\begin{tabular}{|c|c|c|}
\hline 9.2447092 & 7.9201979 & 22.7317176 \\
\hline 15.7330581 & 11.9998478 & 22.6566555 \\
\hline 9.5192751 & 10.6874135 & 17.1005163 \\
\hline 13.7576503 & 10.7687468 & 27.3359066 \\
\hline 11.1926479 & 6.6771534 & 26.7989891 \\
\hline 16.4955039 & 9.7777662 & 23.3267398 \\
\hline 11.3402170 & 9.2349409 & 23.0130617 \\
\hline 10.3085731 & 11.9285347 & 15.0927266 \\
\hline 12.2371669 & 10.6945838 & 25.3396702 \\
\hline 15.4469421 & 11.2621907 & 25.0298969 \\
\hline 10.1007952 & 8.4113146 & 25.0610685 \\
\hline 10.2647420 & 11.9277430 & 29.8253805 \\
\hline 8.7235856 & 15.0261521 & 15.0625560 \\
\hline 5.4035659 & 14.7907434 & 16.7070288 \\
\hline 5.3078806 & 14.7731951 & 28.5441321 \\
\hline 12.2367029 & 18.7989747 & 21.6840880 \\
\hline 12.0523480 & 13.3409635 & 21.7503883 \\
\hline 17.0916774 & 16.0106335 & 21.6948577 \\
\hline 17.0479295 & 16.0517180 & 18.5223533 \\
\hline 12.2143376 & 13.2698128 & 18.4334814 \\
\hline 12.3346721 & 18.7917915 & 18.5363486 \\
\hline 5.2735883 & 17.2589335 & 26.6741862 \\
\hline 5.2203191 & 17.3007008 & 23.6336203 \\
\hline 8.4674330 & 14.7055744 & 28.3518371 \\
\hline 8.5612843 & 14.7752505 & 16.5212634 \\
\hline 15.4241618 & 13.3400109 & 18.4940193 \\
\hline 15.5272874 & 18.8068965 & 18.5287132 \\
\hline 10.6937540 & 16.1264920 & 18.4191873 \\
\hline 10.3943753 & 16.2480833 & 21.5375480 \\
\hline 15.4414077 & 18.7334135 & 21.6817343 \\
\hline 15.3933757 & 13.3707932 & 21.6217360 \\
\hline 8.3381874 & 17.5975598 & 23.4377203 \\
\hline 8.4093572 & 17.2998321 & 26.5593021 \\
\hline 9.0570870 & 13.1303898 & 16.8858770 \\
\hline 6.9723535 & 14.3820566 & 28.1722811 \\
\hline 11.6437927 & 17.4136108 & 21.9756109 \\
\hline 13.7540191 & 13.9241794 & 21.7216509 \\
\hline 16.0793558 & 17.1344639 & 22.0118417 \\
\hline 15.8529123 & 14.8016643 & 18.2406345 \\
\hline 11.6632682 & 14.9255502 & 18.4515526 \\
\hline 14.0429227 & 18.4610506 & 18.3270405 \\
\hline 6.7323162 & 17.6926271 & 26.9355908 \\
\hline 8.9107873 & 18.9678620 & 23.3303804 \\
\hline 4.4969074 & 18.6013639 & 23.5881049 \\
\hline 18.2776088 & 15.8169655 & 17.7161891 \\
\hline 11.9150604 & 19.9705827 & 17.7291944 \\
\hline 11.4248486 & 12.2962995 & 17.2227739 \\
\hline 4.8205627 & 16.2087116 & 27.6909364 \\
\hline 11.5989452 & 19.8339992 & 22.5438030 \\
\hline 11.7796972 & 11.9673119 & 22.8631209 \\
\hline 18.3351869 & 16.1849401 & 22.4951214 \\
\hline 8.8817616 & 15.8810177 & 27.4603357 \\
\hline 16.1583147 & 12.4248551 & 17.5771606 \\
\hline 9.5771186 & 15.8888224 & 17.3944136 \\
\hline 15.9144024 & 19.9721882 & 17.6864794 \\
\hline 8.9256760 & 16.6776071 & 22.3729632 \\
\hline 6.8966501 & 14.9635063 & 17.0144803 \\
\hline 9.2793840 & 13.4759930 & 27.9262226 \\
\hline 13.7366449 & 18.7673003 & 21.9935739 \\
\hline 10.8681705 & 14.6607782 & 21.9849696 \\
\hline 16.4929377 & 14.6570899 & 22.0676480 \\
\hline 16.3820784 & 17.6097850 & 18.0934898 \\
\hline 13.9291954 & 13.2185406 & 18.1768301 \\
\hline 11.4753995 & 17.3759149 & 17.9879483 \\
\hline 4.3759125 & 18.4392494 & 26.8089194 \\
\hline 9.2784430 & 18.4436576 & 26.9510593 \\
\hline 6.8360394 & 17.7042714 & 23.1747506 \\
\hline 5.1314198 & 15.1005524 & 15.2762684 \\
\hline 12.0028961 & 19.1781266 & 20.2090621 \\
\hline 11.7872866 & 12.5204377 & 19.9847469 \\
\hline 17.4852626 & 16.0600940 & 20.2099730 \\
\hline 5.1548142 & 16.6532218 & 25.2598303 \\
\hline 8.7427157 & 15.0582625 & 29.7720311 \\
\hline 15.7248700 & 12.9203231 & 19.9418542 \\
\hline 15.7992923 & 19.1540383 & 20.0091106 \\
\hline 10.0716503 & 16.3488328 & 19.8046919 \\
\hline 8.5996256 & 17.0075458 & 24.8405694 \\
\hline 11.4662719 & 11.5262830 & 20.0551338 \\
\hline 11.8730933 & 9.1458477 & 19.5417261 \\
\hline 12.8949410 & 9.1348423 & 19.9538260 \\
\hline
\end{tabular}




\begin{tabular}{|c|c|c|c|}
\hline $\mathrm{H}$ & 11.4283378 & 8.1436250 & 19.6148642 \\
\hline $\mathrm{H}$ & 11.8994329 & 9.4478937 & 18.4879978 \\
\hline 0 & 11.0406318 & 10.1057541 & 20.2283312 \\
\hline $\mathrm{H}$ & 10.9698869 & 9.8424003 & 21.1739564 \\
\hline $\mathrm{H}$ & 5.1498567 & 15.0609621 & 29.9964886 \\
\hline $\mathrm{H}$ & 16.0680829 & 19.7509860 & 22.5699601 \\
\hline \multicolumn{4}{|c|}{$\mathrm{Zn} 24$} \\
\hline \multicolumn{4}{|c|}{168} \\
\hline $\mathrm{H}$ & 8.7151216 & 8.9057245 & 15.2301295 \\
\hline Al & 5.4366564 & 9.2629161 & 16.5980043 \\
\hline $\mathrm{P}$ & 5.4429076 & 9.2221698 & 28.4123547 \\
\hline Al & 5.3452827 & 6.6593396 & 21.5459719 \\
\hline $\mathrm{P}$ & 5.3674643 & 6.6994042 & 18.4079190 \\
\hline Al & 3.2117135 & 8.0074292 & 26.5743576 \\
\hline $\mathrm{P}$ & 3.2696003 & 8.1000210 & 23.4501765 \\
\hline Al & 8.5662909 & 9.2126054 & 28.4861449 \\
\hline$P$ & 8.5697914 & 9.2826932 & 16.6632709 \\
\hline $\mathrm{Al}$ & 8.5196315 & 6.6907269 & 18.4579363 \\
\hline $\mathrm{P}$ & 8.5148390 & 6.6479881 & 21.6372062 \\
\hline Al & 1.5578120 & 10.7197792 & 23.4770600 \\
\hline $\mathrm{P}$ & 1.5600623 & 10.7017341 & 26.6384889 \\
\hline 0 & 7.1087208 & 9.6796549 & 16.9686075 \\
\hline 0 & 5.0237706 & 10.6743650 & 28.1031622 \\
\hline $\mathrm{H}$ & 4.8734560 & 5.2569378 & 21.7126136 \\
\hline $\mathrm{H}$ & 9.0225421 & 5.2739466 & 21.9043543 \\
\hline $\mathrm{O}$ & 6.8378890 & 6.3103154 & 18.1535294 \\
\hline $\mathrm{O}$ & 1.9990630 & 9.2392481 & 26.8595057 \\
\hline $\mathrm{H}$ & 2.1983336 & 7.0776862 & 23.2941644 \\
\hline $\mathrm{H}$ & 0.1749313 & 10.2086110 & 23.2685681 \\
\hline 0 & 4.9508570 & 7.8511331 & 17.4893080 \\
\hline 0 & 4.5812533 & 8.2306879 & 27.6274538 \\
\hline $\mathrm{O}$ & 4.4638070 & 7.7852806 & 22.5417276 \\
\hline 0 & 2.3700181 & 11.6425440 & 27.5400018 \\
\hline 0 & 8.9966885 & 8.1026172 & 17.5448349 \\
\hline $\mathrm{O}$ & 1.8346827 & 12.1517759 & 22.5419817 \\
\hline 0 & 4.4046841 & 10.5875957 & 17.0591391 \\
\hline 0 & 6.9050641 & 9.0256414 & 27.9926307 \\
\hline 0 & 7.0285401 & 6.7103479 & 21.9873423 \\
\hline $\mathrm{H}$ & 9.3616552 & 5.5366395 & 18.0381757 \\
\hline $\mathrm{H}$ & 4.5061998 & 5.5272499 & 18.0894876 \\
\hline $\mathrm{H}$ & 0.1252640 & 10.8241175 & 27.0172988 \\
\hline $\mathrm{H}$ & 2.6228936 & 6.6752705 & 26.8838170 \\
\hline 0 & 2.7104477 & 9.4708449 & 23.0468881 \\
\hline $\mathrm{H}$ & 5.2991913 & 8.9770489 & 15.1431834 \\
\hline 0 & 5.1745205 & 7.1469837 & 19.8670770 \\
\hline 0 & 3.7603575 & 8.1166828 & 24.9122562 \\
\hline $\mathrm{H}$ & 8.6965698 & 8.9419398 & 29.9445304 \\
\hline 0 & 8.7447254 & 7.0339837 & 20.1603401 \\
\hline $\mathrm{O}$ & 1.7789180 & 11.1173500 & 25.1748440 \\
\hline $\mathrm{H}$ & 5.2809886 & 8.9375076 & 29.8648940 \\
\hline $\mathrm{H}$ & 3.4751562 & 11.9169686 & 15.1737502 \\
\hline Al & 3.2829552 & 15.9869811 & 21.5547581 \\
\hline $\mathrm{P}$ & 3.1975234 & 16.0215142 & 18.3783528 \\
\hline $\mathrm{Al}$ & 3.8332404 & 11.9229475 & 28.4367941 \\
\hline $\mathrm{P}$ & 3.8118006 & 11.9340395 & 16.6240949 \\
\hline Al & 1.6937616 & 13.2427148 & 18.5140750 \\
\hline $\mathrm{P}$ & 1.7361961 & 13.3271082 & 21.5620393 \\
\hline 0 & 4.8510863 & 13.0350571 & 16.9248171 \\
\hline $\mathrm{H}$ & 0.3931283 & 13.9695008 & 21.5371168 \\
\hline $\mathrm{H}$ & 2.2845315 & 17.0491405 & 21.8582185 \\
\hline 0 & 2.1569459 & 14.9019900 & 18.1710419 \\
\hline 0 & 4.4296049 & 15.7980697 & 17.4932866 \\
\hline 0 & 4.7437154 & 16.2551534 & 22.4594007 \\
\hline 0 & 2.5199969 & 12.1709707 & 17.4127296 \\
\hline 0 & 4.4916720 & 13.4713839 & 27.9816950 \\
\hline 0 & 2.7732552 & 14.3839152 & 21.9954524 \\
\hline $\mathrm{H}$ & 2.5847444 & 17.3186774 & 17.9796171 \\
\hline $\mathrm{H}$ & 0.2302466 & 13.0941808 & 18.2834619 \\
\hline 0 & 3.6537239 & 16.0665686 & 19.8440247 \\
\hline $\mathrm{H}$ & 3.5193294 & 11.9174030 & 29.8923180 \\
\hline 0 & 2.1123233 & 12.7969125 & 20.1493815 \\
\hline Al & 10.1461041 & 11.9993805 & 16.4936731 \\
\hline $\mathrm{P}$ & 10.0889812 & 11.9753792 & 28.3365579 \\
\hline Al & 12.2959463 & 10.6639616 & 26.5231051 \\
\hline $\mathrm{P}$ & 12.3302186 & 10.5796244 & 23.3839631 \\
\hline Al & 15.4328107 & 10.7197792 & 23.4770600 \\
\hline Al & 10.6204964 & 7.9069802 & 23.5524911 \\
\hline $\mathrm{P}$ & 10.7165441 & 7.9056603 & 26.6431543 \\
\hline $\mathrm{P}$ & 15.4350610 & 10.7017341 & 26.6384889 \\
\hline
\end{tabular}


9. 0551262

11.7705752

15.8587349

11.5818026

13.8038914

11.3281405

9.5815035

16.2211362

9.2416643

15.7096814

9. 4865256

13.9577927

11.3668393

16.4117897

11.4205953

10.4690089

12.1116552

15.6539167

10.1061544

10.5091665

8.7258781

5.3731972

5. 3527522

12.2827820

12.4584306

17.1579540

17.0725221

12.3439358

12.3049636

5.4358835

5.4146755

8.5150440

8.5338626

15.5687603

15.4571308

10.7645309

10.6526688

15.4523384

15.6111948

8.5739624

8.6043105

8.9919508

6.8305427

11.7314705

14.2324118

15.9775047

16.0319446

11.9672032

13.7753884

7. 1201884

9.0203458

4.8201836

18.2689337

11.8997788

11.6604827

4.9161850

11.5295398

11.9476760

18.4087152

9.0287035

16.2738712

9. 3478114

15.8635513

9.3576034

7.0595594

9.4590759

13.9660394

11.1113427

16.6482539

16.4410373

13.8481950

11.4191361

4.5882830

9.4365305

6.8896527

5.1830372

12.1120198

11.8536250

17.5287226

5.2396842
10.8541051

9.0146053

9.2903079

6.7866151

0.1176652

11.7650364

8.0665815

11.6148053

7. 6832621

12.1517759

10.4668942

10.8277400

6.5885727

9.6590100

9.3698796

11.9895123

11.0676034

11.1173500

7.9618598

11.9874493

15.0482228

14.6700583

14.6702865

18.6754410

13.3679875

15.9869811

16.0215142

13.2456519

18.7155055

17.1860128

17.2177284

14.7061086

14.7129737

13.2427148

18.7068283

15.9390611

15.9367834

18.6640895

13.3271082

17.3961211

17.2481070

13.2645115

14.3332244

17.0367876

13.9865835

17.2427859

14.9019900

14.7063266

18.3264168

17.5942584

18.8098232

18.5784450

15.8045386

19.8356565

12.2882211

15.8854539

19.6375847

11.6597710

16.2166009

16.0777376

12.3280862

15.6959695

19.9096637

16.3846232

14.8376096

13.3172132

18.7264492

14.6313489

14.3839152

17.3582748

13.0680925

17.5099216

18.3713787

18.4311635

17.3150126

14.9496433

19.1630851

12.8457299

16.0665686

16.6765857
28.1101860

26.8197622

26.8517893

23.3580868

23.2314737

27.4679769

27.6612876

27.5134217

22.5071290

22.5419817

17.0018217

27.0285116

26.8871153

23.1116980

23.1038762

15.0401409

24.8384753

25.1748440

25.2278780

29.7649903

15.1445659

16.5634628

28.3925384

21.5459719

21.7475139

21.5547581

18.3783528

18.3080536

18.4079190

26.5367337

23.4394032

28.4116561

16.5825710

18.5140750

18.4579363

18.4227578

21.5965399

21.6372062

21.5620393

23.4521819

26.5728663

16.8633814

28.1152275

21.7406864

21.5364541

21.9135433

18.1710419

18.0218042

18.1535294

26.8148778

23.3132259

23. 3291748

17.5189101

17.5144944

17.3267769

27.5711749

22.3968691

22.3950202

22.3293493

27.4693719

17.5741846

17.4302408

17.6800354

22.2915499

16.9847601

27.9537421

21.9873423

22.2134393

21.9954524

17.9674452

18.2429572

18.0804060

26.8426778

26.9262890

23.0672070

15.1133621

19.8670770

19.7558309

19.8440247

24.8721599 
$8.6993426 \quad 15.0058111$

$15.9873220 \quad 12.7969125$

$15.6822248 \quad 19.0500850$

$10.3123967 \quad 15.7632905$

$8.8360354 \quad 16.8517993$

$10.8476252 \quad 12.3898020$

$9.5564008 \quad 10.4934231$

$9.7095370 \quad 10.4414775$

$8.5819561 \quad 10.0700751$

$10.3564113 \quad 9.9545817$

$9.6155960 \quad 11.8676922$

$8.6158229 \quad 12.7118580$

$8.7587260 \quad 13.7220298$

$7.6189604 \quad 12.3358340$

$8.7450619 \quad 12.7206398$

$5.1568121 \quad 14.9872544$

$16.1572916 \quad 19.6682094$ Si 24

168

$\mathrm{H} \quad 8.7080194$

$\mathrm{P}$

Al $\quad 5.4011504$

P $\quad 5.4509344$

$\mathrm{Al} \quad 5.4738798$

$\mathrm{P} \quad 3.2299416$

Al $\quad 3.2854655$

P $\quad 8.5340784$

Al 8.5694801

P $\quad 8.6379327$

Al 8.6161920

$\mathrm{P} \quad 1.6716414$

Al $\quad 1.6684534$

0 6.9003345

O 4.9305156

4.9541906

9.0919472

7. 1562878

2.1747147

2. 2513401

0.2789667

4.9963220

4.4081584

4.6970503

2.6093525

9.0561516

1.9865538

4.5474772

7.0633388

6.9342219

9.4754110

4.6213648

0.2411806

2.6091428

2. 6425559

5.2347508

5.2608808

3. 7599423

8.7252757

8.8698819

1.8734316

5. 2543339

3.5596727

3. 2378983

3. 2274747

3. 8782750

3. 8681398

1.6715304

1. 6079739

5. 0535519

0.1642510

2. 2722032

2. 0323843

4.6767314

4.5019287

2. 3711706

4.4555282

2.5958642

2. 6595744

0.2033674
8.9324645

9.2907903

9.2517938

6.7363384

6.7276324

7. 9080595

7.9706075

9. 1799577

9.2336922

6.6711972

6.6448907

10.6772850

10.6771767

9. 6475512

10.9010760

5.3458823

5. 2605180

6.3193283

9.0157642

6.9303768

10.1887590

8.0723273

8.1249264

7. 7168172

11.7536827

7.8596970

11.8548269

10.4758274

9. 0153717

6.7861601

5.4995169

5.5617642

10.7857132

6.5975692

9. 5372880

8.9762504

7.1794954

7.9042051

8.8906529

7.0534903

11.1331619

9.0086652

11.9797306

15.8926502

15.9272419

11.9904808

12.0007032

13.2089483

13.2126232

13.2464806

13.5751227

16.9962136

14.6830686

15.6748871

16.0803354

12.2838759

13.3541963

14.5619674

17.2539032

13.0331168
29.8584916

20.1493815

20.1603401

20.0914825

25.1021408

19.8236273

20.3184350

21.4047442

20.0373009

19.7995998

19.8690042

20.4842417

20.0850895

20.2120226

21.5775543

29.8341554

22.4809508

15.1269094

16.6495735

28.4627726

21.6033783

18.4637479

26.6320704

23.4970602

28.3978918

16.5785255

18.4099478

21.5760956

23.4338409

26.5709757

16.9366558

28.0929079

21.7957268

21.8486571

18.1757382

26.8096990

23.2408858

23. 2365595

17.4700050

27.5876793

22.5072461

27.5661439

17.5346555

22.5118964

17.0678230

28.0037949

21.9824103

18.0319056

18.1016839

26.9811378

26.9702193

23.0989593

15.2065843

20.1388586

25.1860155

29.8459480

19.8855361

24.8946073

29.9244339

15.1100235

21.6282531

18.4509986

28.3871331

16.5665704

18.4109426

21.4828634

16.9299354

21.4457279

21.8865191

18.1177903

17.5083274

22.4782218

17.4079892

27.9943187

22.0169895

18.0841477

18.2357244 


\begin{tabular}{|c|c|c|c|}
\hline $\mathrm{O}$ & 3.6531827 & 15.8965641 & 20.1446531 \\
\hline $\mathrm{H}$ & 3.5185528 & 11.9765955 & 29.8319611 \\
\hline 0 & 2.1102670 & 12.8160337 & 19.8303121 \\
\hline $\mathrm{P}$ & 10.1690430 & 11.9256100 & 16.5669982 \\
\hline Al & 10.1320156 & 11.8994301 & 28.3951868 \\
\hline $\mathrm{P}$ & 12.4015491 & 10.6542834 & 26.6566164 \\
\hline Al & 12.4200870 & 10.6350322 & 23.4662326 \\
\hline $\mathrm{P}$ & 15.5466402 & 10.6772850 & 23.4338409 \\
\hline$P$ & 10.7128723 & 7.9949725 & 23.4394087 \\
\hline Al & 10.7606015 & 7.9839528 & 26.5795922 \\
\hline Al & 15.5434521 & 10.6771767 & 26.5709757 \\
\hline 0 & 8.9707620 & 10.6239209 & 28.0763433 \\
\hline $\mathrm{O}$ & 11.9494378 & 9.2109794 & 26.9686133 \\
\hline $\mathrm{H}$ & 15.9734309 & 9.2661027 & 26.7737286 \\
\hline $\mathrm{H}$ & 11.6392700 & 6.8408545 & 23.2753375 \\
\hline 0 & 14.1056677 & 10.1718170 & 23.2297178 \\
\hline 0 & 11.5913501 & 11.6582030 & 27.4868564 \\
\hline 0 & 9.3557465 & 8.1691869 & 27.5936906 \\
\hline $\mathrm{H}$ & 16.3477057 & 11.5973432 & 27.4216170 \\
\hline 0 & 9.4733801 & 7.8112470 & 22.5506528 \\
\hline 0 & 15.8615525 & 11.8548269 & 22.5118964 \\
\hline $\mathrm{O}$ & 9.5945570 & 10.5767641 & 17.0221123 \\
\hline 0 & 13.8744393 & 10.8040962 & 27.0506077 \\
\hline $\mathrm{H}$ & 11.3538541 & 6.64 & 26.8470988 \\
\hline $\mathrm{H}$ & 16.4888209 & 9.5710256 & 23.1088699 \\
\hline 0 & 11.4249759 & 9.2713977 & 22.9917986 \\
\hline $\mathrm{H}$ & 10.5200466 & 11.8844516 & 15.1205463 \\
\hline $\mathrm{O}$ & 12.1868963 & 10.9657366 & 25.1728896 \\
\hline 0 & 15.7484303 & 11.13 & 24.8946073 \\
\hline $\mathrm{O}$ & 10.2574094 & 8.1115945 & 24.9059773 \\
\hline $\mathrm{H}$ & 10.4716383 & 11.8856323 & 29.8448718 \\
\hline $\mathrm{H}$ & 8.8133878 & 14.9830134 & 15.0643615 \\
\hline$P$ & 5.4823214 & 14.7010439 & 16.6414060 \\
\hline Al & 5.4455214 & 14.7041 & 28.4718004 \\
\hline $\mathrm{P}$ & 12.3884338 & 18.7524398 & 21.6033783 \\
\hline $\mathrm{Si}$ & 12.2667022 & 13.2657907 & 21.6379100 \\
\hline $\mathrm{P}$ & 17.1128970 & 15.8926502 & 21.6282531 \\
\hline Al & 17.1024734 & 15.9272419 & 18.4509986 \\
\hline Al & 12.3336195 & 13.2639191 & 18.4160140 \\
\hline Al & 12.4113792 & 18.7437337 & 537479 \\
\hline $\mathrm{P}$ & 5.3910535 & 17.2200220 & 26.6093820 \\
\hline Al & 5.3574273 & 17.2097435 & 23.4895024 \\
\hline $\mathrm{P}$ & 8.6039440 & 14.6561391 & 28.3565725 \\
\hline Al & 8.6361527 & 14.6813322 & 16.5116682 \\
\hline $\mathrm{P}$ & 15.5465291 & 13.2089483 & 18.4109426 \\
\hline $\mathrm{P}$ & 15.5754320 & 18.6872986 & 18.4099478 \\
\hline $\mathrm{P}$ & 10.8085529 & 16.0161575 & 18.3774531 \\
\hline Al & 10.7253018 & 16.0218069 & 21.5447519 \\
\hline Al & 15.5536914 & 18.6609921 & 21.5760956 \\
\hline Al & 15.4829726 & 13.2126232 & 21.4828634 \\
\hline $\mathrm{P}$ & 8.5204971 & 17.3103321 & 23.3738837 \\
\hline Al & 8.5479075 & 17.2127489 & 26.5226526 \\
\hline 0 & 9.1218947 & 13.0251126 & 16.8392015 \\
\hline 0 & 7.1187246 & 14.3102365 & 28.1368623 \\
\hline 0 & 11.8769343 & 17.3206804 & 21.8014405 \\
\hline 0 & 13.8162243 & 13.6311214 & 21.4399912 \\
\hline $\mathrm{O}$ & 16.1119777 & 17.0364666 & 21.8959395 \\
\hline 0 & 15.9073830 & 14.6830686 & 18.1177903 \\
\hline 0 & 11.8924499 & 14.9355245 & 18.1537319 \\
\hline $\mathrm{O}$ & 14.0937871 & 18.3354297 & 18.1757382 \\
\hline 0 & 6.8664582 & 17.6020907 & 26.8411280 \\
\hline $\mathrm{H}$ & 8.9892809 & 18.71 & 23.2015715 \\
\hline $\mathrm{H}$ & 4.8218678 & 18.5864070 & 23.3021674 \\
\hline $\mathrm{H}$ & 18.3375702 & 15.7121781 & 17.6476281 \\
\hline $\mathrm{H}$ & 12.0024532 & 19.8951770 & 17.6128199 \\
\hline 0 & 11.4567384 & 12.1946559 & 17.3559683 \\
\hline 0 & 4.9609324 & 16.1075080 & 27.5700035 \\
\hline $\mathrm{H}$ & 11.6556524 & 19.7054730 & 22.4819451 \\
\hline 0 & 11.9542109 & 11.9859824 & 22.5393683 \\
\hline $\mathrm{H}$ & 18.3392505 & 16.0747411 & 22.4528868 \\
\hline 0 & 9.0274512 & 15.8332270 & 27.4747948 \\
\hline $\mathrm{H}$ & 16.2259318 & 12.3106341 & 17.4370001 \\
\hline 0 & 9.6177174 & 15.7777147 & 17.4404963 \\
\hline $\mathrm{H}$ & 15.9813463 & 19.8408307 & 17.5604080 \\
\hline 0 & 9.2525455 & 16.3707604 & 22.4176706 \\
\hline $\mathrm{O}$ & 6.9676631 & 14.8559598 & 16.9965087 \\
\hline 0 & 9.4473360 & 13.4398716 & 27.9646073 \\
\hline 0 & 13.8717212 & 18.8022615 & 21.9824103 \\
\hline $\mathrm{O}$ & 11.3550054 & 14.5164648 & 22.0411416 \\
\hline 0 & 16.4708630 & 14.5619674 & 22.0169895 \\
\hline
\end{tabular}




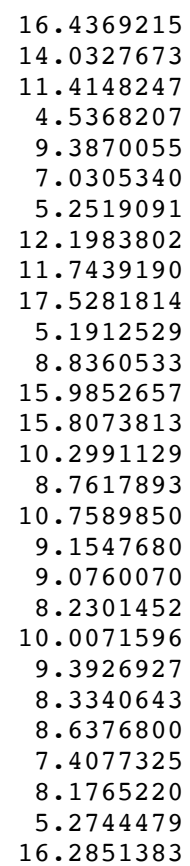

17.4820254 13.0276557 17.3808825 18.4082715 18.3789500 17.2453082 15.0303806 19.1955967 12.7925962 15.8965641 16.7234025 15.0225880 12.8160337 19.0695917 15.9804635 16.8458324 12.4073161 10.5874228 10.5500710 10.2049386 9.9828246 11.9335335 12.8470936 13.8398583 12.5403705 12.8756464 14.9907666 19.6562553

8.8877316 9.2935221

9.2272956

6.6765667

6.7168486

7.9856175

8.0899547

9.1831294

9.2986040

6.7128543

6.6432215

10.7306804

10.7011065

9.7139191

10.6787703

5.3102166

5.2811144

6.3276827

9.2353953

7.0663922

10.2023525

7.8757412

8.2327772

7.8466883

11.6117186

8.1362905

12.1098253

10.6066607

9.0099165

6.6460204

5.5620729

5.5483103

10.7936883

6.6720879

9.4745720

9.0103359

7.1549330

8.0192267

8.9214593

7.0577813

11.1807618

8.9704277

11.9219439

15.9806743

16.0363265

11.9163148

11.9491107

13.2661967

13.2995606
18.0210669

18.2302824

18.0405102

26.8841001

26.9138178

23.0309172

15.2076807

20.1388586

20.0469773

20.1446531

25.1648260

29.7809885

19.8303121

19.8855361

19.8258880

24.8246358

20.0566715

20.4394068

21.5370557

19.9786827

20.1100489

19.9917139

20.3282732

19.9744976

19.8173611

21.4189682

29.9229032

22.4076948

15.2479028

16.6113994

28.4218225

21.5474909

18.4048510

26.5826484

23.4630958

28.5003600

16.6728144

18.4785442

21.6520298

23.4979921

26.6414666

16.9749972

28.0905791

21.7329690

21.9047063

18.1582235

26.7923456

23.2273686

23.2748120

17.4940184

27.6562252

22.5488655

27.5717641

17.5792940

22.5162742

17.0895638

28.0043457

21.9806415

18.0606925

18.0676750

27.0489603

26.9241895

23.1391073

15.1571342

19.8652340

24.9280271

29.9602188

20.1824808

25.1932422

29.8796847

15.1804513

21.5535353

18.3754492

28.4388363

16.6373411

18.5111399

21.5627850 


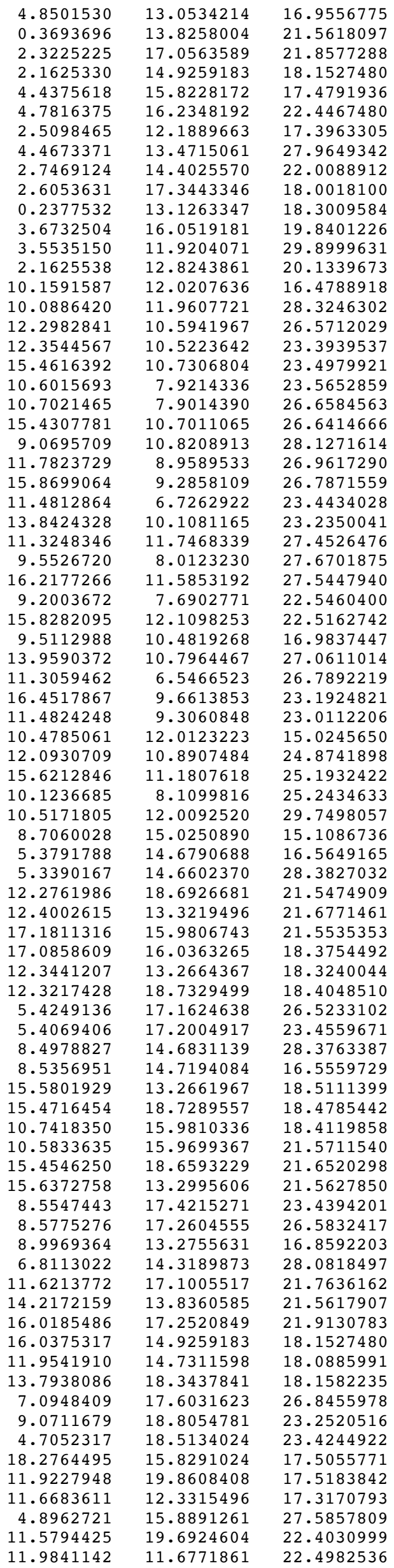




\begin{tabular}{|c|c|c|}
\hline 18.4413095 & 16.1977307 & 22.3163976 \\
\hline 9.0054975 & 16.0598810 & 27.4388604 \\
\hline 16.2661609 & 12.3478553 & 17.5607623 \\
\hline 9.3669493 & 15.7176710 & 17.3679996 \\
\hline 15.8738736 & 19.9409938 & 17.7128440 \\
\hline 9.2871559 & 16.3239968 & 22.3205975 \\
\hline 7.0679071 & 14.8518183 & 16.9803644 \\
\hline 9.4385241 & 13.2883584 & 27.9222555 \\
\hline 13.9624482 & 18.6621218 & 21.9806415 \\
\hline 11.1249384 & 14.6578637 & 22.0757468 \\
\hline 16.6219112 & 14.4025570 & 22.0088912 \\
\hline 16.4617917 & 17.3844501 & 17.9903508 \\
\hline 13.8499311 & 13.1012853 & 18.2633145 \\
\hline 11.4382440 & 17.5311421 & 18.0580752 \\
\hline 4.5329333 & 18.3321491 & 26.7542390 \\
\hline 9.4137941 & 18.4297170 & 26.9713224 \\
\hline 6.8634858 & 17.4315409 & 23.0640003 \\
\hline 5.1887121 & 14.9261048 & 15.1089576 \\
\hline 12.1217749 & 19.1710344 & 19.8652340 \\
\hline 11.8483094 & 12.8230517 & 19.7606773 \\
\hline 17.5482492 & 16.0519181 & 19.8401226 \\
\hline 5.3056197 & 16.5904198 & 24.8691558 \\
\hline 8.6791850 & 14.9817095 & 29.8237815 \\
\hline 16.0375525 & 12.8243861 & 20.1339673 \\
\hline 15.6898515 & 19.0738827 & 20.1824808 \\
\hline 10.2094545 & 15.8794055 & 20.0628307 \\
\hline 8.8004194 & 16.9087769 & 25.1011238 \\
\hline 10.8141281 & 12.3682731 & 19.8016373 \\
\hline 9.5578197 & 10.4975935 & 20.3252398 \\
\hline 9.7215692 & 10.4711119 & 21.4108251 \\
\hline 8.5805030 & 10.0711914 & 20.0620935 \\
\hline 10.3521505 & 9.9476001 & 19.8099040 \\
\hline 9.6135704 & 11.8635771 & 19.8430707 \\
\hline 8.6022316 & 12.7226409 & 20.4237398 \\
\hline 8.7596718 & 13.7265178 & 20.0144533 \\
\hline 7.6126383 & 12.3455840 & 20.1294049 \\
\hline 8.7046574 & 12.7444413 & 21.5193558 \\
\hline 5.1619545 & 14.9585855 & 29.8307218 \\
\hline 16.1165250 & 19.6736728 & 22.5181148 \\
\hline & & \\
\hline 8.6812915 & 8.7702327 & 15.1999848 \\
\hline 5.3890119 & 9.1937074 & 16.6171666 \\
\hline 5.3761045 & 9.1422821 & 28.5465344 \\
\hline 5.3524964 & 6.7182840 & 21.5860273 \\
\hline 5.3822091 & 6.7274399 & 18.5158227 \\
\hline 3.2709142 & 7.8961889 & 26.6276489 \\
\hline 3.3428562 & 7.9780177 & 23.5645706 \\
\hline 8.4834301 & 9.0899054 & 28.5607822 \\
\hline 8.5019009 & 9.1742230 & 16.6218609 \\
\hline 8.5079032 & 6.6920354 & 18.5217971 \\
\hline 8.4980470 & 6.6473725 & 21.6299581 \\
\hline 1.6785710 & 10.6324174 & 23.5506160 \\
\hline 1.6669341 & 10.6146915 & 26.6301886 \\
\hline 6.9491491 & 9.5971759 & 16.8920964 \\
\hline 4.9487447 & 10.6857932 & 28.2418996 \\
\hline 4.8149302 & 5.3382799 & 21.7400785 \\
\hline 9.0012674 & 5.2662200 & 21.8672500 \\
\hline 6.9425899 & 6.3103407 & 18.2897950 \\
\hline 2.1543748 & 9.0684185 & 26.7875466 \\
\hline 2.3021077 & 6.9372059 & 23.3394614 \\
\hline 0.2900520 & 10.1331355 & 23.3509834 \\
\hline 4.9578301 & 7.9263176 & 17.5200373 \\
\hline 4.4887422 & 8.1120747 & 27.6725906 \\
\hline 4.6100526 & 7.7597191 & 22.5783272 \\
\hline 2.5079843 & 11.5843364 & 27.6174243 \\
\hline 8.9358854 & 7.9543192 & 17.5962644 \\
\hline 2.0351814 & 11.8567527 & 22.5627708 \\
\hline 4.4563383 & 10.4443303 & 17.0458775 \\
\hline 6.9286743 & 8.9378293 & 28.1408321 \\
\hline 6.9228715 & 6.6993376 & 21.9687346 \\
\hline 9.3457148 & 5.5243823 & 18.1322092 \\
\hline 4.5278600 & 5.5529715 & 18.1874447 \\
\hline 0.2372663 & 10.6907339 & 27.0393196 \\
\hline 2.6367300 & 6.5884433 & 26.9512727 \\
\hline 2.7165158 & 9.4287657 & 23.2307592 \\
\hline 5.1811776 & 8.8377826 & 15.1863476 \\
\hline 5.1552041 & 7.2304241 & 20.0473684 \\
\hline 3.8665494 & 7.9030914 & 25.1096232 \\
\hline
\end{tabular}




\begin{tabular}{|c|c|c|c|}
\hline $\mathrm{H}$ & 8.6790172 & 8.7644159 & 30.0005471 \\
\hline 0 & 8.7685256 & 7.0970723 & 20.0808395 \\
\hline 0 & 1.8685463 & 11.1275205 & 25.0981058 \\
\hline $\mathrm{H}$ & 5.1804922 & 8.8341226 & 29.9901044 \\
\hline $\mathrm{H}$ & 3.4245642 & 11.8227032 & 15.1515033 \\
\hline $\mathrm{Si}$ & 3.3141964 & 15.7492762 & 21.6029438 \\
\hline $\mathrm{Si}$ & 3.2566358 & 15.7917287 & 18.4889388 \\
\hline $\mathrm{Si}$ & 3.8232042 & 11.8335132 & 28.5203392 \\
\hline $\mathrm{Si}$ & 3.8089382 & 11.8571966 & 16.5896227 \\
\hline $\mathrm{Si}$ & 1.7375028 & 13.0724578 & 18.5364955 \\
\hline $\mathrm{Si}$ & 1.7311231 & 13.0842513 & 21.5463496 \\
\hline 0 & 4.9216887 & 13.0183157 & 16.8654294 \\
\hline $\mathrm{H}$ & 0.3049296 & 13.5117855 & 21.5288205 \\
\hline $\mathrm{H}$ & 2.3294594 & 16.8352633 & 21.8637997 \\
\hline 0 & 2.1355633 & 14.6308677 & 18.2525608 \\
\hline 0 & 4.5465561 & 15.5712445 & 17.5318972 \\
\hline 0 & 4.6426645 & 15.9555248 & 22.5074758 \\
\hline 0 & 2.4653348 & 12.1085523 & 17.4560581 \\
\hline 0 & 4.4415362 & 13.2736474 & 28.1209973 \\
\hline 0 & 2.6858499 & 14.3216302 & 22.0060426 \\
\hline $\mathrm{H}$ & 2.6581656 & 17.1072030 & 18.1304958 \\
\hline $\mathrm{H}$ & 0.2681995 & 12.9244458 & 18.3458102 \\
\hline 0 & 3.7596877 & 15.7860508 & 20.0344170 \\
\hline $\mathrm{H}$ & 3.4264616 & 11.8207592 & 29.9554535 \\
\hline 0 & 2.1838980 & 12.6179050 & 20.0304551 \\
\hline $\mathrm{Si}$ & 10.0751078 & 11.8613523 & 16.5243102 \\
\hline $\mathrm{Si}$ & 10.0291279 & 11.8153297 & 28.4742149 \\
\hline $\mathrm{Si}$ & 12.1838292 & 10.5556588 & 26.6440232 \\
\hline $\mathrm{Si}$ & 12.2138255 & 10.5238168 & 23.5188740 \\
\hline $\mathrm{Si}$ & 15.3035697 & 10.6324174 & 23.5506160 \\
\hline $\mathrm{Si}$ & 10.5041087 & 7.9116803 & 23.5886445 \\
\hline $\mathrm{Si}$ & 10.5724721 & 7.8912762 & 26.6431270 \\
\hline $\mathrm{Si}$ & 15.2919328 & 10.6146915 & 26.6301886 \\
\hline 0 & 8.9408582 & 10.6231876 & 28.2540071 \\
\hline 0 & 11.7025140 & 9.0249839 & 26.9403186 \\
\hline H & 15.7375086 & 9.2012234 & 26.7740316 \\
\hline $\mathrm{H}$ & 11.4192900 & 6.7441805 & 23.4601607 \\
\hline O & 13.7845714 & 10.0862179 & 23.3322239 \\
\hline 0 & 11.3298315 & 11.6007204 & 27.5437170 \\
\hline O & 9.34 & 8.0329493 & 27.6902529 \\
\hline $\mathrm{H}$ & 16.0652947 & 11.5062986 & 27.5379709 \\
\hline 0 & 9.2300417 & 7.7241642 & 22.5987504 \\
\hline 0 & 15.6601801 & 11.8567527 & 22.5627708 \\
\hline 0 & 9.4558037 & 10.4358328 & 16.9855444 \\
\hline O & 13.7377350 & 10.6973575 & 27.0749567 \\
\hline $\mathrm{H}$ & 11.1886761 & 6.5500337 & 26.8392950 \\
\hline $\mathrm{H}$ & 16.2568529 & 9.5269434 & 23.2568489 \\
\hline $\mathrm{O}$ & 11.2938076 & 9.2378765 & 23.1292125 \\
\hline $\mathrm{H}$ & 10.4710283 & 11.8353102 & 15.0891484 \\
\hline 0 & 11.9628437 & 10.9231767 & 25.0845009 \\
\hline 0 & 15.4935451 & 11.1275205 & 25.0981058 \\
\hline 0 & 9.9822696 & 8.0434457 & 25.1288618 \\
\hline H & 10.4652122 & 11.8315196 & 29.8978332 \\
\hline $\mathrm{H}$ & 8.7310875 & 14.9235760 & 15.0981109 \\
\hline $\mathrm{Si}$ & 5.3801820 & 14.5575759 & 16.5857157 \\
\hline $\mathrm{Si}$ & 5.3475931 & 14.5469590 & 28.5362975 \\
\hline $\mathrm{Si}$ & 12.1649958 & 18.5178791 & 21.5860273 \\
\hline Al & 12.1657305 & 13.1232975 & 21.6631407 \\
\hline $\mathrm{Si}$ & 16.9391952 & 15.7492762 & 21.6029438 \\
\hline $\mathrm{Si}$ & 16.8816345 & 15.7917287 & 18.4889388 \\
\hline $\mathrm{Si}$ & 12.1734016 & 13.1103375 & 18.4347226 \\
\hline $\mathrm{Si}$ & 12.1947085 & 18.5270350 & 18.5158227 \\
\hline $\mathrm{Si}$ & 5.3637825 & 16.9524083 & 26.5874951 \\
\hline $\mathrm{Si}$ & 5.3409634 & 16.9712981 & 23.5530216 \\
\hline $\mathrm{Si}$ & 8.4819569 & 14.5328381 & 28.4801946 \\
\hline $\mathrm{Si}$ & 8.5140216 & 14.5673792 & 16.5274908 \\
\hline $\mathrm{Si}$ & 15.3625016 & 13.0724578 & 18.5364955 \\
\hline $\mathrm{Si}$ & 15.3204026 & 18.4916304 & 18.5217971 \\
\hline $\mathrm{Si}$ & 10.6186898 & 15.8065477 & 18.4698020 \\
\hline $\mathrm{Si}$ & 10.5116642 & 15.8046980 & 21.5726871 \\
\hline $\mathrm{Si}$ & 15.3105463 & 18.4469675 & 21.6299581 \\
\hline $\mathrm{Si}$ & 15.3561218 & 13.0842513 & 21.5463496 \\
\hline $\mathrm{Si}$ & 8.4728792 & 17.1175649 & 23.4906016 \\
\hline $\mathrm{Si}$ & 8.4901704 & 16.9953734 & 26.5735527 \\
\hline 0 & 8.9676440 & 13.0229044 & 16.8025364 \\
\hline 0 & 6.9092240 & 14.1691574 & 28.2783863 \\
\hline 0 & 11.5819999 & 17.0212510 & 21.7530973 \\
\hline 0 & 13.8239325 & 13.5435602 & 21.5275177 \\
\hline 0 & 15.8596884 & 16.9397772 & 21.8889042 \\
\hline 0 & 15.7605621 & 14.6308677 & 18.2525608 \\
\hline
\end{tabular}




\begin{tabular}{|c|c|c|c|}
\hline 0 & 11.7699641 & 14.6670507 & 18.2152423 \\
\hline 0 & 13.7550892 & 18.1099357 & 18.2897950 \\
\hline 0 & 6.9220300 & 17.3681595 & 26.8273288 \\
\hline $\mathrm{H}$ & 8.9720929 & 18.5115253 & 23.3331829 \\
\hline $\mathrm{H}$ & 4.7362779 & 18.3286221 & 23.4573775 \\
\hline $\mathrm{H}$ & 18.0663357 & 15.5892294 & 17.6099634 \\
\hline $\mathrm{H}$ & 11.8034966 & 19.6322149 & 17.5978624 \\
\hline 0 & 11.4248566 & 12.1355315 & 17.3845298 \\
\hline 0 & 4.8997809 & 15.8017904 & 27.6243852 \\
\hline $\mathrm{H}$ & 11.4820775 & 19.4758170 & 22.4987695 \\
\hline 0 & 11.7901509 & 11.7275058 & 22.5737475 \\
\hline $\mathrm{H}$ & 18.1599715 & 15.9388054 & 22.4341503 \\
\hline 0 & 8.9306042 & 15.7516846 & 27.5161139 \\
\hline $\mathrm{H}$ & 16.0312489 & 12.1868012 & 17.5437669 \\
\hline 0 & 9.3788644 & 15.5774643 & 17.4501789 \\
\hline $\mathrm{H}$ & 15.7131230 & 19.6499134 & 17.6725199 \\
\hline 0 & 9.1696231 & 16.1245669 & 22.4296421 \\
\hline 0 & 6.9545133 & 14.7070866 & 16.9451582 \\
\hline $\mathrm{O}$ & 9.3525222 & 13.2299740 & 28.0791797 \\
\hline 0 & 13.7353709 & 18.4989326 & 21.9687346 \\
\hline $\mathrm{O}$ & 11.1319598 & 14.4281280 & 22.0616220 \\
\hline 0 & 16.3108487 & 14.3216302 & 22.0060426 \\
\hline 0 & 16.2301638 & 17.2237015 & 18.0987521 \\
\hline 0 & 13.7587670 & 12.9109037 & 18.3283638 \\
\hline 0 & 11.2672228 & 17.2520260 & 18.1593339 \\
\hline $\mathrm{H}$ & 4.4993787 & 18.1392793 & 26.8350105 \\
\hline $\mathrm{H}$ & 9.3220832 & 18.1724555 & 26.9470756 \\
\hline 0 & 6.8954641 & 17.1091021 & 23.1580622 \\
\hline $\mathrm{H}$ & 5.1345914 & 14.9136546 & 15.1609302 \\
\hline $\mathrm{O}$ & 11.9677035 & 19.0300191 & 20.0473684 \\
\hline 0 & 11.6398625 & 12.6298188 & 19.9458063 \\
\hline 0 & 17.3846865 & 15.7860508 & 20.0344170 \\
\hline $\mathrm{O}$ & 5.1683592 & 16.3921272 & 25.0683319 \\
\hline $\mathrm{H}$ & 8.7275998 & 14.9194349 & 29.8969948 \\
\hline 0 & 15.8088967 & 12.6179050 & 20.0304551 \\
\hline 0 & 15.5810250 & 18.8966673 & 20.0808395 \\
\hline 0 & 10.0568608 & 15.7249209 & 19.9900023 \\
\hline $\mathrm{O}$ & 8.7384521 & 16.5915885 & 25.0145026 \\
\hline $\mathrm{H}$ & 10.6238645 & 12.2412572 & 19.9624107 \\
\hline C & 9.1657804 & 10.4159849 & 20.3946902 \\
\hline $\mathrm{H}$ & 9.2304982 & 10.3548160 & 21.4908021 \\
\hline $\mathrm{H}$ & 8.1955061 & 10.0346957 & 20.0437479 \\
\hline $\mathrm{H}$ & 9.9750334 & 9.8358218 & 19.9386455 \\
\hline $\mathrm{O}$ & 9.3234095 & 11.7808762 & 19.9524300 \\
\hline $\mathrm{C}$ & 8.3035574 & 12.6673063 & 20.4598937 \\
\hline $\mathrm{H}$ & 8.5252436 & 13.6693605 & 20.0755785 \\
\hline $\mathrm{H}$ & 7.3224413 & 12.3334699 & 20.0900199 \\
\hline $\mathrm{H}$ & 8.3161217 & 12.6792195 & 21.5614312 \\
\hline $\mathrm{H}$ & 5.1321671 & 14.9122231 & 29.9636357 \\
\hline $\mathrm{H}$ & 15.9821402 & 19.4349072 & 22.5188100 \\
\hline \multicolumn{4}{|c|}{ Ge 24} \\
\hline \multicolumn{4}{|c|}{168} \\
\hline $\mathrm{H}$ & 8.6953435 & 8.9617651 & 15.1523579 \\
\hline$P$ & 5.4307518 & 9.3048032 & 16.6697746 \\
\hline Al & 5.4080111 & 9.2447346 & 28.4747197 \\
\hline$P$ & 5.4625332 & 6.7225273 & 21.5950644 \\
\hline Al & 5.4859940 & 6.7395009 & 18.4708353 \\
\hline$P$ & 3.2562514 & 7.8988106 & 26.6287805 \\
\hline Al & 3.3439702 & 8.0271389 & 23.5226758 \\
\hline$P$ & 8.5340762 & 9.1507028 & 28.4120269 \\
\hline Al & 8.5715249 & 9.2541687 & 16.6071052 \\
\hline$P$ & 8.6449869 & 6.6744596 & 18.4172889 \\
\hline Al & 8.6294163 & 6.6216144 & 21.5926509 \\
\hline $\mathrm{P}$ & 1.6946446 & 10.6983547 & 23.4588573 \\
\hline Al & 1.6623000 & 10.6602730 & 26.5935926 \\
\hline 0 & 6.9028640 & 9.6635461 & 16.9730284 \\
\hline 0 & 4.9404259 & 10.8919936 & 28.0847741 \\
\hline $\mathrm{H}$ & 4.9249092 & 5.3410197 & 21.7347707 \\
\hline $\mathrm{H}$ & 9.1546875 & 5.2553758 & 21.8657859 \\
\hline 0 & 7.1645283 & 6.3218569 & 18.1712652 \\
\hline 0 & 2.1887315 & 8.9989646 & 26.7777526 \\
\hline $\mathrm{H}$ & 2.2551747 & 7.0377341 & 23.2930609 \\
\hline $\mathrm{H}$ & 0.3370917 & 10.1318102 & 23.2282102 \\
\hline 0 & 5.0002478 & 8.0760871 & 17.4725743 \\
\hline 0 & 4.3935101 & 8.1082886 & 27.6350508 \\
\hline 0 & 4.7267421 & 7.7018549 & 22.5156283 \\
\hline $\mathrm{O}$ & 2.6028583 & 11.7238298 & 27.6032743 \\
\hline 0 & 9.0620834 & 7.8812517 & 17.5652863 \\
\hline $\mathrm{O}$ & 1.9480292 & 11.8931404 & 22.5405155 \\
\hline
\end{tabular}

18.2152423

18.2897950

23.3331829

23.4573775

17.6099634

17.3845298

22.4987695

22.5737475

17.5437669

22.4296421

21.9687346

2.0616220

18.0987521

.3283638

26.8350105

.9470756

15.1609302

.0473684

458063

25.0683319

29.8969948

20.0304551

25.0145026

19.9624107

20.3946902
21.4908021

20.0437479

19.9386455

20.4598937

20.0755785

20.0900199

(2)

29.9636357
22.5188100

$\mathrm{Ge} 2$

168 


\begin{tabular}{|c|c|c|c|}
\hline 0 & 4.5457746 & 10.4817581 & 17.0927793 \\
\hline 0 & 7.0652738 & 8.9792817 & 28.0099612 \\
\hline 0 & 6.9413841 & 6.7078816 & 21.9922858 \\
\hline $\mathrm{H}$ & 9.4851392 & 5.5115834 & 18.0185614 \\
\hline $\mathrm{H}$ & 4.6108534 & 5.5836271 & 18.1314163 \\
\hline $\mathrm{H}$ & 0.2431139 & 10.7322112 & 27.0384032 \\
\hline $\mathrm{H}$ & 2.6307504 & 6.5804462 & 26.9250649 \\
\hline $\mathrm{O}$ & 2.7453486 & 9.6218019 & 23.1478391 \\
\hline $\mathrm{H}$ & 5.2529325 & 9.0047790 & 15.2221951 \\
\hline 0 & 5.3023476 & 7.2165442 & 20.1431613 \\
\hline 0 & 3.8434825 & 7.9241794 & 25.2039813 \\
\hline $\mathrm{H}$ & 8.7106422 & 8.9194736 & 29.8723276 \\
\hline 0 & 8.8736937 & 7.0293776 & 19.9001427 \\
\hline $\mathrm{O}$ & 1.8322092 & 11.1654439 & 24.9241686 \\
\hline $\mathrm{H}$ & 5.2711020 & 9.0322451 & 29.9421067 \\
\hline $\mathrm{H}$ & 3.6050933 & 11.9966058 & 15.1208045 \\
\hline $\mathrm{P}$ & 3.3059850 & 15.8926078 & 21.6100716 \\
\hline Al & 3.2473120 & 15.9418334 & 18.4339205 \\
\hline $\mathrm{P}$ & 3.8907365 & 11.9821737 & 28.3875800 \\
\hline Al & 3.8837303 & 12.0109369 & 16.5834312 \\
\hline$P$ & 1.6725896 & 13.2185957 & 18.4123385 \\
\hline Al & 1.6262967 & 13.2509768 & 21.4948339 \\
\hline 0 & 5.0684545 & 13.2509836 & 16.9715278 \\
\hline $\mathrm{H}$ & 0.2255098 & 13.7558082 & 21.4869619 \\
\hline $\mathrm{H}$ & 2.3447179 & 16.9913970 & 21.9028998 \\
\hline $\mathrm{O}$ & 2.0534563 & 14.6895328 & 18.1320054 \\
\hline $\mathrm{O}$ & 4.6906663 & 15.6936396 & 17.4809081 \\
\hline $\mathrm{O}$ & 4.5902291 & 16.0601435 & 22.4337267 \\
\hline 0 & 2.3794419 & 12.2929298 & 17.4141912 \\
\hline 0 & 4.4520157 & 13.3431426 & 27.9573382 \\
\hline $\mathrm{O}$ & 2.6848685 & 14.5525563 & 21.9970005 \\
\hline $\mathrm{H}$ & 2.6713006 & 17.2657394 & 18.0697714 \\
\hline $\mathrm{H}$ & 0.2053923 & 13.0601257 & 18.2139958 \\
\hline 0 & 3.6929745 & 15.9198204 & 20.1207620 \\
\hline $\mathrm{H}$ & 3.5678489 & 11.9937833 & 29.8411031 \\
\hline $\mathrm{O}$ & 2.0761079 & 12.8087735 & 19.8382139 \\
\hline$P$ & 10.1740199 & 11.9344048 & 16.5388571 \\
\hline Al & 10.1181710 & 11.8733537 & 28.3547507 \\
\hline $\mathrm{P}$ & 12.4129868 & 10.5954876 & 26.6828656 \\
\hline Al & 12.4668089 & 10.5223067 & 23.4797786 \\
\hline $\mathrm{P}$ & 15.5696433 & 10.6983547 & 23.4588573 \\
\hline $\mathrm{P}$ & 10.6520597 & 7.9664740 & 23.5027300 \\
\hline Al & 10.7340598 & 7.9620061 & 26.5920745 \\
\hline Al & 15.5372987 & 10.6602730 & 26.5935926 \\
\hline 0 & 8.9792589 & 10.5781849 & 28.0319628 \\
\hline $\mathrm{O}$ & 11.9366519 & 9.1657317 & 27.0206295 \\
\hline $\mathrm{H}$ & 15.9845970 & 9.2486925 & 26.7500697 \\
\hline $\mathrm{H}$ & 11.4735050 & 6.7257842 & 23.4476221 \\
\hline $\mathrm{O}$ & 14.1636703 & 10.1116031 & 23.2199837 \\
\hline $\mathrm{O}$ & 11.5868182 & 11.6318120 & 27.4578368 \\
\hline 0 & 9.3628891 & 8.1025299 & 27.6614924 \\
\hline $\mathrm{H}$ & 16.3411624 & 11.5692594 & 27.4565338 \\
\hline 0 & 9.4330793 & 7.8249821 & 22.5763228 \\
\hline 0 & 15.8230279 & 11.8931404 & 22.5405155 \\
\hline 0 & 9.6004788 & 10.5997512 & 17.0364692 \\
\hline $\mathrm{O}$ & 13.8765175 & 10.7444576 & 27.1141255 \\
\hline $\mathrm{H}$ & 11.3386478 & 6.6096069 & 26.7424421 \\
\hline $\mathrm{H}$ & 16.5881145 & 9.6548276 & 23.1573803 \\
\hline $\mathrm{O}$ & 11.4977406 & 9.1410458 & 23.0124929 \\
\hline $\mathrm{H}$ & 10.4783255 & 11.8633974 & 15.0830148 \\
\hline 0 & 12.2526986 & 10.8636446 & 25.1848595 \\
\hline 0 & 15.7072079 & 11.1654439 & 24.9241686 \\
\hline $\mathrm{O}$ & 10.1671096 & 8.2082495 & 24.9464202 \\
\hline $\mathrm{H}$ & 10.4330452 & 11.8631422 & 29.8100412 \\
\hline $\mathrm{H}$ & 8.8235809 & 14.9780394 & 15.0218909 \\
\hline $\mathrm{P}$ & 5.4927009 & 14.6972714 & 16.6363609 \\
\hline Al & 5.4433610 & 14.6862750 & 28.4593818 \\
\hline $\mathrm{P}$ & 12.4000325 & 18.7386287 & 21.5950644 \\
\hline $\mathrm{Ge}$ & 12.2247190 & 13.3086081 & 21.7042806 \\
\hline $\mathrm{P}$ & 17.1809837 & 15.8926078 & 21.6100716 \\
\hline Al & 17.1223107 & 15.9418334 & 18.4339205 \\
\hline Al & 12.3332423 & 13.2910193 & 18.3494371 \\
\hline Al & 12.4234934 & 18.7556023 & 18.4708353 \\
\hline $\mathrm{P}$ & 5.4048402 & 17.1820641 & 26.5904488 \\
\hline Al & 5.3469577 & 17.1721639 & 23.5321089 \\
\hline $\mathrm{P}$ & 8.6023575 & 14.6403647 & 28.3134890 \\
\hline Al & 8.6489775 & 14.6983921 & 16.4739348 \\
\hline$P$ & 15.5475884 & 13.2185957 & 18.4123385 \\
\hline$P$ & 15.5824863 & 18.6905610 & 18.4172889 \\
\hline $\mathrm{P}$ & 10.8104898 & 16.0200170 & 18.3408789 \\
\hline
\end{tabular}




\begin{tabular}{|c|c|c|c|}
\hline Al & 10.6410642 & 16.0617747 & 21.5194379 \\
\hline Al & 15.5669156 & 18.6377158 & 21.5926509 \\
\hline $\mathrm{Al}$ & 15.5012954 & 13.2509768 & 21.4948339 \\
\hline $\mathrm{P}$ & 8.4923624 & 17.4311952 & 23.3553333 \\
\hline Al & 8.5526982 & 17.2054188 & 26.4766361 \\
\hline 0 & 9.1481796 & 13.0506721 & 16.8258497 \\
\hline 0 & 7.1142399 & 14.2970641 & 28.1102549 \\
\hline 0 & 11.8465361 & 17.3163345 & 21.7388953 \\
\hline 0 & 13.8753718 & 13.8369455 & 21.4856967 \\
\hline 0 & 16.1843062 & 17.0318735 & 21.9136868 \\
\hline 0 & 15.9284550 & 14.6895328 & 18.1320054 \\
\hline 0 & 11.9031472 & 14.9624109 & 18.0598876 \\
\hline 0 & 14.1020277 & 18.3379583 & 18.1712652 \\
\hline 0 & 6.8725421 & 17.6022451 & 26.8167134 \\
\hline $\mathrm{H}$ & 8.9850939 & 18.8328033 & 23.2561823 \\
\hline $\mathrm{H}$ & 4.6675959 & 18.4950839 & 23.4581454 \\
\hline $\mathrm{H}$ & 18.3522871 & 15.7303313 & 17.6217964 \\
\hline $\mathrm{H}$ & 12.0072215 & 19.9010218 & 17.6153516 \\
\hline 0 & 11.4908354 & 12.2064708 & 17.2767548 \\
\hline 0 & 4.9712324 & 16.1307055 & 27.6164031 \\
\hline $\mathrm{H}$ & 11.6850284 & 19.6902891 & 22.4896213 \\
\hline 0 & 11.8918994 & 11.8371108 & 22.5570493 \\
\hline $\mathrm{H}$ & 18.4268655 & 16.0551389 & 22.4091229 \\
\hline 0 & 9.0198044 & 15.8103703 & 27.4174479 \\
\hline $\mathrm{H}$ & 16.2337576 & 12.3200156 & 17.4433978 \\
\hline 0 & 9.6207794 & 15.8158125 & 17.3930109 \\
\hline $\mathrm{H}$ & 15.9870835 & 19.8611885 & 17.5908187 \\
\hline 0 & 9.1601981 & 16.5486328 & 22.3031230 \\
\hline 0 & 6.9816159 & 14.8663188 & 16.9681792 \\
\hline 0 & 9.4373515 & 13.4171132 & 27.9217498 \\
\hline 0 & 13.8788835 & 18.7239829 & 21.9922858 \\
\hline 0 & 11.1254952 & 14.5634773 & 22.2053417 \\
\hline 0 & 16.5598672 & 14.5525563 & 21.9970005 \\
\hline 0 & 16.4470040 & 17.4939599 & 18.0069979 \\
\hline 0 & 14.0359108 & 13.0553214 & 18.2079827 \\
\hline 0 & 11.4013912 & 17.4056236 & 18.0744179 \\
\hline $\mathrm{H}$ & 4.5244150 & 18.3704465 & 26.7628414 \\
\hline $\mathrm{H}$ & 9.4053128 & 18.3619623 & 26.8672460 \\
\hline 0 & 6.9927029 & 17.4309203 & 23.0626187 \\
\hline $\mathrm{H}$ & 5.2449468 & 14.9822201 & 15.1960336 \\
\hline $\mathrm{O}$ & 12.2398469 & 19.2326455 & 20.1431613 \\
\hline 0 & 11.6990250 & 12.8332578 & 19.9582893 \\
\hline 0 & 17.5679732 & 15.9198204 & 20.1207620 \\
\hline 0 & 5.2465469 & 16.5781650 & 25.1793804 \\
\hline $\mathrm{H}$ & 8.8454661 & 15.0136634 & 29.7342870 \\
\hline 0 & 15.9511067 & 12.8087735 & 19.8382139 \\
\hline 0 & 15.8111931 & 19.0454790 & 19.9001427 \\
\hline 0 & 10.3082244 & 15.9022937 & 19.7887542 \\
\hline 0 & 8.7679109 & 16.8675476 & 24.7670641 \\
\hline $\mathrm{H}$ & 10.7277196 & 12.4313082 & 19.9883060 \\
\hline C & 9.1389013 & 10.5883849 & 20.4529566 \\
\hline $\mathrm{H}$ & 9.0717048 & 10.5639723 & 21.5518514 \\
\hline $\mathrm{H}$ & 8.2137094 & 10.1884237 & 20.0073920 \\
\hline $\mathrm{H}$ & 9.9950298 & 9.9891290 & 20.1233295 \\
\hline 0 & 9.3562278 & 11.9305019 & 19.9852706 \\
\hline C & 8.2924019 & 12.8367191 & 20.3226535 \\
\hline $\mathrm{H}$ & 8.5822253 & 13.8272647 & 19.9515325 \\
\hline $\mathrm{H}$ & 7.3620817 & 12.5144708 & 19.8282683 \\
\hline $\mathrm{H}$ & 8.1489552 & 12.8793294 & 21.4150409 \\
\hline $\mathrm{H}$ & 5.2676284 & 14.9461151 & 29.9149648 \\
\hline $\mathrm{H}$ & 16.2508209 & 19.6617638 & 22.4297410 \\
\hline \multicolumn{4}{|c|}{ Ga 24} \\
\hline \multicolumn{4}{|c|}{168} \\
\hline $\mathrm{H}$ & 8.6735296 & 8.7739835 & 15.2132473 \\
\hline $\mathrm{Si}$ & 5.3926885 & 9.1964441 & 16.6325688 \\
\hline $\mathrm{Si}$ & 5.3789415 & 9.1329013 & 28.5637034 \\
\hline $\mathrm{Si}$ & 5.3592331 & 6.6886472 & 21.5991343 \\
\hline $\mathrm{Si}$ & 5.3852024 & 6.7291873 & 18.5291353 \\
\hline $\mathrm{Si}$ & 3.2744740 & 7.8985321 & 26.6295498 \\
\hline $\mathrm{Si}$ & 3.3802788 & 8.0124474 & 23.5724673 \\
\hline $\mathrm{Si}$ & 8.4823734 & 9.0701897 & 28.5681039 \\
\hline $\mathrm{Si}$ & 8.5020659 & 9.1805971 & 16.6353535 \\
\hline $\mathrm{Si}$ & 8.5051212 & 6.6902227 & 18.5264194 \\
\hline $\mathrm{Si}$ & 8.5031529 & 6.6211645 & 21.6408746 \\
\hline $\mathrm{Si}$ & 1.6888336 & 10.6337911 & 23.5530980 \\
\hline $\mathrm{Si}$ & 1.6615602 & 10.6004091 & 26.6392104 \\
\hline 0 & 6.9505910 & 9.6054645 & 16.9106270 \\
\hline $\mathrm{O}$ & 4.9609354 & 10.6816582 & 28.2680029 \\
\hline $\mathrm{H}$ & 4.7853553 & 5.3217650 & 21.7384819 \\
\hline
\end{tabular}




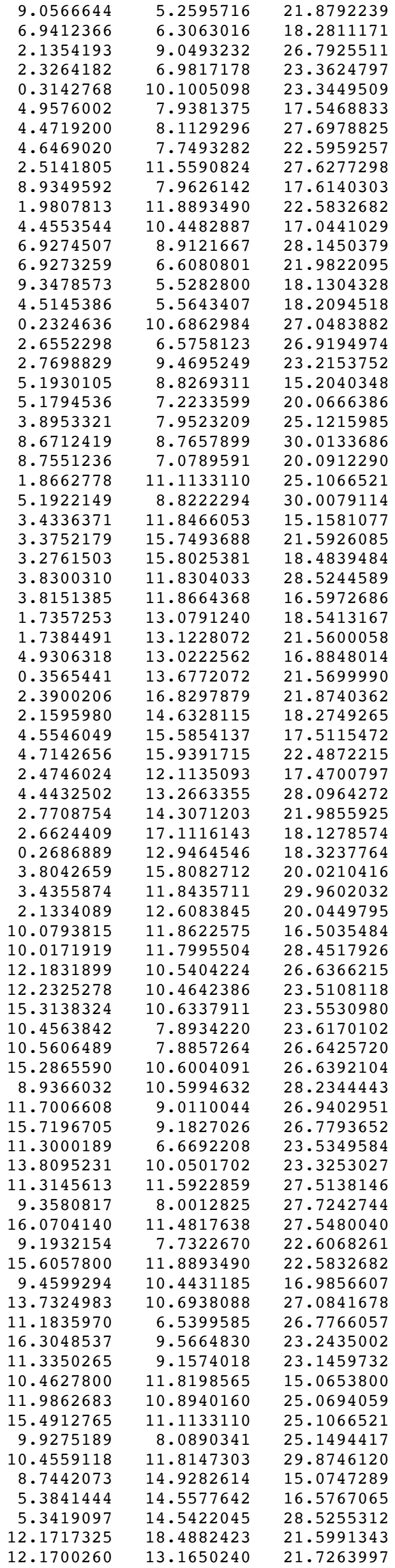




\begin{tabular}{|c|c|c|c|}
\hline $\mathrm{Si}$ & 17.0002166 & 15.7493688 & 21.5926085 \\
\hline $\mathrm{Si}$ & 16.9011490 & 15.8025381 & 18.4839484 \\
\hline $\mathrm{Si}$ & 12.1744559 & 13.1265356 & 18.3966097 \\
\hline $\mathrm{Si}$ & 12.1977017 & 18.5287823 & 18.5291353 \\
\hline $\mathrm{Si}$ & 5.3742430 & 16.9393491 & 26.5771194 \\
\hline $\mathrm{Si}$ & 5.3376853 & 16.9624828 & 23.5721641 \\
\hline $\mathrm{Si}$ & 8.4824093 & 14.5284531 & 28.4586264 \\
\hline $\mathrm{Si}$ & 8.5227702 & 14.5749448 & 16.5041531 \\
\hline $\mathrm{Si}$ & 15.3607240 & 13.0791240 & 18.5413167 \\
\hline $\mathrm{Si}$ & 15.3176205 & 18.4898178 & 18.5264194 \\
\hline $\mathrm{Si}$ & 10.6203819 & 15.8038781 & 18.4547539 \\
\hline $\mathrm{Si}$ & 10.4539322 & 15.8081425 & 21.5753501 \\
\hline $\mathrm{Si}$ & 15.3156523 & 18.4207596 & 21.6408746 \\
\hline $\mathrm{Si}$ & 15.3634478 & 13.1228072 & 21.5600058 \\
\hline $\mathrm{Si}$ & 8.4522987 & 17.1801102 & 23.4784610 \\
\hline $\mathrm{Si}$ & 8.4925834 & 16.9897429 & 26.5496764 \\
\hline 0 & 8.9787382 & 13.0314223 & 16.7799388 \\
\hline 0 & 6.9058699 & 14.1761402 & 28.2689271 \\
\hline $\mathrm{O}$ & 11.5487595 & 17.0044236 & 21.7504030 \\
\hline $\mathrm{O}$ & 13.8698395 & 13.7220209 & 21.5708068 \\
\hline $\mathrm{O}$ & 15.9200900 & 16.9338924 & 21.9011534 \\
\hline 0 & 15.7845967 & 14.6328115 & 18.2749265 \\
\hline 0 & 11.7779082 & 14.6832529 & 18.1582448 \\
\hline 0 & 13.7537360 & 18.1058967 & 18.2811171 \\
\hline 0 & 6.9285498 & 17.3694875 & 26.8302315 \\
\hline $\mathrm{H}$ & 8.9937228 & 18.5616510 & 23.3546646 \\
\hline $\mathrm{H}$ & 4.6148131 & 18.2636093 & 23.5315880 \\
\hline $\mathrm{H}$ & 18.0756064 & 15.6030759 & 17.5906482 \\
\hline $\mathrm{H}$ & 11.8035359 & 19.6431987 & 17.6236905 \\
\hline 0 & 11.4402407 & 12.1440184 & 17.3424653 \\
\hline $\mathrm{O}$ & 4.8948041 & 15.8118712 & 27.6328240 \\
\hline $\mathrm{H}$ & 11.5172096 & 19.4628452 & 22.5150325 \\
\hline 0 & 11.7542404 & 11.6278595 & 22.5347584 \\
\hline $\mathrm{H}$ & 18.2298110 & 15.9236571 & 22.4140961 \\
\hline 0 & 8.9346964 & 15.7357368 & 27.4794280 \\
\hline $\mathrm{H}$ & 16.0396584 & 12.1918466 & 17.5569857 \\
\hline 0 & 9.3768583 & 15.5891768 & 17.4346453 \\
\hline $\mathrm{H}$ & 15.7118152 & 19.6566990 & 17.6896881 \\
\hline 0 & 9.0867108 & 16.2069565 & 22.3589360 \\
\hline 0 & 6.9616271 & 14.7139780 & 16.9155611 \\
\hline 0 & 9.3352420 & 13.2127815 & 28.0609221 \\
\hline 0 & 13.7398252 & 18.4076751 & 21.9822095 \\
\hline 0 & 10.9834950 & 14.4301422 & 22.1832086 \\
\hline 0 & 16.3958741 & 14.3071203 & 21.9855925 \\
\hline $\mathrm{O}$ & 16.2330276 & 17.2276782 & 18.0962860 \\
\hline $\mathrm{O}$ & 13.7615178 & 12.9345020 & 18.3041776 \\
\hline 0 & 11.2524694 & 17.2641717 & 18.1820723 \\
\hline $\mathrm{H}$ & 4.4971043 & 18.1267624 & 26.7715362 \\
\hline $\mathrm{H}$ & 9.3402000 & 18.1587400 & 26.9131489 \\
\hline 0 & 6.8707081 & 17.2561434 & 23.1809095 \\
\hline $\mathrm{H}$ & 5.1201662 & 14.8930992 & 15.1501769 \\
\hline 0 & 11.9919530 & 19.0229550 & 20.0666386 \\
\hline 0 & 11.6295964 & 12.6544539 & 19.9000160 \\
\hline 0 & 17.4292646 & 15.8082712 & 20.0210416 \\
\hline 0 & 5.2194409 & 16.3276114 & 25.0708941 \\
\hline $\mathrm{H}$ & 8.7400052 & 14.9231376 & 29.8710672 \\
\hline 0 & 15.7584076 & 12.6083845 & 20.0449795 \\
\hline 0 & 15.5676230 & 18.8785541 & 20.0912290 \\
\hline $\mathrm{O}$ & 10.0759388 & 15.6683223 & 19.9786989 \\
\hline 0 & 8.7219154 & 16.5965956 & 24.9823154 \\
\hline $\mathrm{H}$ & 10.6278005 & 12.2676769 & 19.9366413 \\
\hline C & 9.1748426 & 10.4264687 & 20.4102252 \\
\hline $\mathrm{H}$ & 9.2459249 & 10.3813818 & 21.5067795 \\
\hline $\mathrm{H}$ & 8.2093396 & 10.0228555 & 20.0702038 \\
\hline $\mathrm{H}$ & 9.9919235 & 9.8525835 & 19.9599010 \\
\hline 0 & 9.3087051 & 11.7859947 & 19.9485805 \\
\hline $\mathrm{C}$ & 8.2793418 & 12.6603995 & 20.4535995 \\
\hline $\mathrm{H}$ & 8.4757087 & 13.6592261 & 20.0478453 \\
\hline $\mathrm{H}$ & 7.2988298 & 12.3017594 & 20.1049325 \\
\hline $\mathrm{H}$ & 8.3068517 & 12.6943048 & 21.5545734 \\
\hline $\mathrm{H}$ & 5.1169748 & 14.8912982 & 29.9554468 \\
\hline $\mathrm{H}$ & 15.9475823 & 19.4382602 & 22.5254522 \\
\hline \multicolumn{4}{|c|}{ Ti 24} \\
\hline \multicolumn{4}{|c|}{168} \\
\hline $\mathrm{H}$ & 8.6907038 & 8.9788175 & 15.156202 \\
\hline $\mathrm{P}$ & 5.4543464 & 9.3298639 & 16.6956705 \\
\hline Al & 5.4023290 & 9.2431048 & 28.4991896 \\
\hline $\mathrm{P}$ & 5.4553264 & 6.7441450 & 21.6100113 \\
\hline & & & \\
\hline
\end{tabular}




\begin{tabular}{|c|c|c|c|}
\hline $\mathrm{P}$ & 3.2613416 & 7.8854964 & 26.6397048 \\
\hline Al & 3.4087821 & 8.0542772 & 23.5564662 \\
\hline$P$ & 8.5199067 & 9.1202554 & 28.4084484 \\
\hline Al & 8.5885519 & 9.2791046 & 16.6110268 \\
\hline $\mathrm{P}$ & 8.6676008 & 6.6986123 & 18.4409171 \\
\hline Al & 8.6350137 & 6.6285914 & 21.6099788 \\
\hline $\mathrm{P}$ & 1.7096283 & 10.7167942 & 23.4794453 \\
\hline Al & 1.6383352 & 10.6432663 & 26.6199849 \\
\hline 0 & 6.9247398 & 9.7082426 & 16.9869049 \\
\hline $\mathrm{O}$ & 4.9569393 & 10.8951492 & 28.1004397 \\
\hline $\mathrm{H}$ & 4.8251696 & 5.4063947 & 21.7845018 \\
\hline $\mathrm{H}$ & 9.1954471 & 5.2726816 & 21.8640328 \\
\hline $\mathrm{O}$ & 7.1916314 & 6.3215571 & 18.2026174 \\
\hline $\mathrm{O}$ & 2.1833452 & 8.9816316 & 26.7267496 \\
\hline $\mathrm{H}$ & 2.3267803 & 7.0675149 & 23.2868497 \\
\hline $\mathrm{H}$ & 0.3774146 & 10.1405118 & 23.1474427 \\
\hline 0 & 5.0445499 & 8.0959939 & 17.4999712 \\
\hline $\mathrm{O}$ & 4.3555891 & 8.1153856 & 27.6877342 \\
\hline $\mathrm{O}$ & 4.7927804 & 7.7809461 & 22.5279576 \\
\hline $\mathrm{O}$ & 2.6074608 & 11.6900159 & 27.6193113 \\
\hline $\mathrm{O}$ & 9.0637442 & 7.9083407 & 17.5827070 \\
\hline $\mathrm{O}$ & 2.0295246 & 11.9114893 & 22.5801099 \\
\hline $\mathrm{O}$ & 4.5557622 & 10.4964231 & 17.1215644 \\
\hline $\mathrm{O}$ & 7.0483839 & 8.9438042 & 28.0179630 \\
\hline $\mathrm{O}$ & 6.9374270 & 6.6373745 & 21.9821412 \\
\hline $\mathrm{H}$ & 9.5233684 & 5.5470355 & 18.0426040 \\
\hline $\mathrm{H}$ & 4.6422077 & 5.5867822 & 18.1129327 \\
\hline $\mathrm{H}$ & 0.2442689 & 10.6855500 & 27.1414363 \\
\hline $\mathrm{H}$ & 2.6306209 & 6.5686702 & 26.9317338 \\
\hline $\mathrm{O}$ & 2.7924663 & 9.6534643 & 23.2469338 \\
\hline $\mathrm{H}$ & 5.2697821 & 9.0250340 & 15.2499405 \\
\hline 0 & 5.3036709 & 7.2188021 & 20.1513154 \\
\hline $\mathrm{O}$ & 3.9024528 & 7.8919271 & 25.2367746 \\
\hline $\mathrm{H}$ & 8.7022095 & 8.9333995 & 29.8743854 \\
\hline 0 & 8.8943257 & 7.0620727 & 19.9235124 \\
\hline $\mathrm{O}$ & 1.7286050 & 11.1823911 & 24.9528905 \\
\hline $\mathrm{H}$ & 5.2843834 & 9.0490261 & 29.9707679 \\
\hline $\mathrm{H}$ & 3.6120940 & 11.9930023 & 15.1356189 \\
\hline$P$ & 3.3552937 & 15.9138733 & 21.6051181 \\
\hline Al & 3.2758217 & 15.9644288 & 18.4317853 \\
\hline $\mathrm{P}$ & 3.8923930 & 11.9723477 & 28.3997695 \\
\hline Al & 3.8923573 & 12.0221269 & 16.5977149 \\
\hline$P$ & 1.6857959 & 13.2507160 & 18.4275660 \\
\hline Al & 1.6931768 & 13.2621068 & 21.5248290 \\
\hline 0 & 5.0848989 & 13.2603574 & 16.9720221 \\
\hline $\mathrm{H}$ & 0.2692658 & 13.6966735 & 21.5522116 \\
\hline $\mathrm{H}$ & 2.3915980 & 17.0105265 & 21.8979711 \\
\hline $\mathrm{O}$ & 2.0686928 & 14.7208476 & 18.1417802 \\
\hline 0 & 4.7157409 & 15.7054991 & 17.4745074 \\
\hline $\mathrm{O}$ & 4.6504493 & 16.0908239 & 22.4113086 \\
\hline $\mathrm{O}$ & 2.3909045 & 12.3234137 & 17.4276537 \\
\hline $\mathrm{O}$ & 4.4324987 & 13.3389132 & 27.9597928 \\
\hline $\mathrm{O}$ & 2.7432631 & 14.5750220 & 22.0119012 \\
\hline $\mathrm{H}$ & 2.7091764 & 17.2983068 & 18.0900208 \\
\hline $\mathrm{H}$ & 0.2173168 & 13.0941866 & 18.2373343 \\
\hline $\mathrm{O}$ & 3.7317083 & 15.9277279 & 20.1145938 \\
\hline $\mathrm{H}$ & 3.5742255 & 11.9875068 & 29.8543004 \\
\hline 0 & 2.0997686 & 12.8421246 & 19.8514926 \\
\hline$P$ & 10.1988913 & 11.9429641 & 16.4780852 \\
\hline Al & 10.0912360 & 11.8482596 & 28.2852841 \\
\hline $\mathrm{P}$ & 12.4308792 & 10.5190001 & 26.7440996 \\
\hline Al & 12.5046415 & 10.4409409 & 23.5037409 \\
\hline$P$ & 15.5846270 & 10.7167942 & 23.4794453 \\
\hline $\mathrm{P}$ & 10.6183867 & 7.9720258 & 23.5396367 \\
\hline Al & 10.7201364 & 7.9480988 & 26.6210455 \\
\hline Al & 15.5133340 & 10.6432663 & 26.6199849 \\
\hline $\mathrm{O}$ & 8.9709975 & 10.5323767 & 27.9777944 \\
\hline 0 & 11.9175101 & 9.1204293 & 27.1531118 \\
\hline $\mathrm{H}$ & 15.9765331 & 9.2310575 & 26.7107233 \\
\hline $\mathrm{H}$ & 11.3630365 & 6.6826100 & 23.5347137 \\
\hline $\mathrm{O}$ & 14.2027042 & 10.1190088 & 23.1350546 \\
\hline $\mathrm{O}$ & 11.5670660 & 11.6125031 & 27.3923407 \\
\hline $\mathrm{O}$ & 9.3376535 & 8.0436347 & 27.6833971 \\
\hline $\mathrm{H}$ & 16.3418476 & 11.5381414 & 27.4743175 \\
\hline $\mathrm{O}$ & 9.3833947 & 7.8465527 & 22.6289267 \\
\hline 0 & 15.9045233 & 11.9114893 & 22.5801099 \\
\hline $\mathrm{O}$ & 9.6497973 & 10.6107227 & 17.0135564 \\
\hline 0 & 13.8758543 & 10.6929331 & 27.2324852 \\
\hline $\mathrm{H}$ & 11.3228132 & 6.5888013 & 26.6998599 \\
\hline $\mathrm{H}$ & 16.6347822 & 9.6855584 & 23.2539516 \\
\hline
\end{tabular}




\begin{tabular}{|c|c|c|c|}
\hline 0 & 11.5233152 & 9.0801465 & 22.9906496 \\
\hline $\mathrm{H}$ & 10.4383621 & 11.8532053 & 15.0112118 \\
\hline 0 & 12.3645017 & 10.6648984 & 25.2260881 \\
\hline $\mathrm{O}$ & 15.6036037 & 11.1823911 & 24.9528905 \\
\hline 0 & 10.1731295 & 8.2969246 & 24.9812394 \\
\hline $\mathrm{H}$ & 10.3937142 & 11.8504471 & 29.7432357 \\
\hline $\mathrm{H}$ & 8.8377508 & 14.9536223 & 14.9788142 \\
\hline $\mathrm{P}$ & 5.5089683 & 14.7041059 & 16.6263517 \\
\hline Al & 5.4288858 & 14.6823624 & 28.4522290 \\
\hline $\mathrm{P}$ & 12.3928258 & 18.7602464 & 21.6100113 \\
\hline $\mathrm{Ti}$ & 12.1867920 & 13.2797382 & 21.6980055 \\
\hline $\mathrm{P}$ & 17.2302924 & 15.9138733 & 21.6051181 \\
\hline Al & 17.1508204 & 15.9644288 & 18.4317853 \\
\hline Al & 12.3314983 & 13.2722826 & 18.3118386 \\
\hline Al & 12.4465014 & 18.7563199 & 18.4808631 \\
\hline $\mathrm{P}$ & 5.4062752 & 17.1675427 & 26.5837711 \\
\hline Al & 5.3485911 & 17.1970894 & 23.5511640 \\
\hline $\mathrm{P}$ & 8.5896374 & 14.6206408 & 28.2691030 \\
\hline Al & 8.6710538 & 14.7013858 & 16.4367955 \\
\hline $\mathrm{P}$ & 15.5607947 & 13.2507160 & 18.4275660 \\
\hline $\mathrm{P}$ & 15.6051002 & 18.7147137 & 18.4409171 \\
\hline$P$ & 10.8088853 & 16.0367450 & 18.3264502 \\
\hline$A 1$ & 10.5535735 & 16.1298566 & 21.5012131 \\
\hline Al & 15.5725131 & 18.6446928 & 21.6099788 \\
\hline Al & 15.5681755 & 13.2621068 & 21.5248290 \\
\hline $\mathrm{P}$ & 8.4710174 & 17.5026778 & 23.3477936 \\
\hline Al & 8.5406407 & 17.2078281 & 26.4666575 \\
\hline $\mathrm{O}$ & 9.1818727 & 13.0589379 & 16.8005086 \\
\hline $\mathrm{O}$ & 7.0955576 & 14.2943800 & 28.0879783 \\
\hline 0 & 11.7444183 & 17.3837522 & 21.7895554 \\
\hline $\mathrm{O}$ & 13.9099679 & 13.7681790 & 21.5567172 \\
\hline 0 & 16.2314045 & 17.0505741 & 21.9086655 \\
\hline $\mathrm{O}$ & 15.9436915 & 14.7208476 & 18.1417802 \\
\hline $\mathrm{O}$ & 11.8894034 & 14.9559007 & 18.1023423 \\
\hline $\mathrm{O}$ & 14.1291307 & 18.3376585 & 18.2026174 \\
\hline $\mathrm{O}$ & 6.8652107 & 17.6039745 & 26.8397221 \\
\hline $\mathrm{H}$ & 9.0569618 & 18.8675504 & 23.2433314 \\
\hline $\mathrm{H}$ & 4.5681383 & 18.4650838 & 23.5368716 \\
\hline $\mathrm{H}$ & 18.3771290 & 15.7439111 & 17.6165186 \\
\hline $\mathrm{H}$ & 12.0482837 & 19.9187513 & 17.6398539 \\
\hline 0 & 11.5490476 & 12.2368323 & 17.1453981 \\
\hline $\mathrm{O}$ & 4.9534386 & 16.1287969 & 27.6139828 \\
\hline $\mathrm{H}$ & 11.7501788 & 19.7659080 & 22.5003878 \\
\hline 0 & 11.8956479 & 11.8464081 & 22.7221252 \\
\hline $\mathrm{H}$ & 18.4859807 & 16.0854317 & 22.3867416 \\
\hline 0 & 9.0078214 & 15.7897128 & 27.3717275 \\
\hline $\mathrm{H}$ & 16.2446761 & 12.3513300 & 17.4577558 \\
\hline 0 & 9.6454854 & 15.8299254 & 17.3444978 \\
\hline $\mathrm{H}$ & 15.9893174 & 19.8880222 & 17.6085441 \\
\hline $\mathrm{O}$ & 9.0494055 & 16.5863697 & 22.2680822 \\
\hline 0 & 7.0032198 & 14.8716353 & 16.9369418 \\
\hline 0 & 9.4027545 & 13.3895707 & 27.8536050 \\
\hline 0 & 13.8749263 & 18.6534758 & 21.9821412 \\
\hline 0 & 11.0865551 & 14.6260355 & 22.1441733 \\
\hline 0 & 16.6182618 & 14.5750220 & 22.0119012 \\
\hline 0 & 16.4860922 & 17.5291932 & 18.0308634 \\
\hline $\mathrm{O}$ & 14.0486911 & 13.0895365 & 18.2316831 \\
\hline $\mathrm{O}$ & 11.4334042 & 17.4081995 & 18.0508312 \\
\hline $\mathrm{H}$ & 4.5086461 & 18.3488763 & 26.7096020 \\
\hline $\mathrm{H}$ & 9.4031978 & 18.3520807 & 26.8713816 \\
\hline $\mathrm{O}$ & 6.9666699 & 17.6173369 & 23.0990892 \\
\hline $\mathrm{H}$ & 5.2433372 & 14.9835180 & 15.1881272 \\
\hline 0 & 12.2411703 & 19.2349034 & 20.1513154 \\
\hline O & 11.6825639 & 12.7338565 & 19.8778357 \\
\hline 0 & 17.6067070 & 15.9277279 & 20.1145938 \\
\hline 0 & 5.2948511 & 16.5400332 & 25.1771833 \\
\hline $\mathrm{H}$ & 8.8574889 & 14.9849638 & 29.6877802 \\
\hline 0 & 15.9747673 & 12.8421246 & 19.8514926 \\
\hline 0 & 15.8318251 & 19.0781741 & 19.9235124 \\
\hline 0 & 10.2602187 & 15.9723425 & 19.7620324 \\
\hline 0 & 8.7413753 & 16.9062644 & 24.7474280 \\
\hline $\mathrm{H}$ & 10.7172011 & 12.3519695 & 19.8837001 \\
\hline C & 9.0544961 & 10.5529580 & 20.4373505 \\
\hline $\mathrm{H}$ & 9.0071147 & 10.5573608 & 21.5382976 \\
\hline $\mathrm{H}$ & 8.1112513 & 10.1604608 & 20.0227511 \\
\hline $\mathrm{H}$ & 9.8892291 & 9.9237448 & 20.1079476 \\
\hline 0 & 9.2952291 & 11.8743926 & 19.9305898 \\
\hline $\mathrm{C}$ & 8.2611016 & 12.8136897 & 20.2619882 \\
\hline $\mathrm{H}$ & 8.5708912 & 13.7883370 & 19.8653009 \\
\hline $\mathrm{H}$ & 7.3138548 & 12.5075196 & 19.7891162 \\
\hline
\end{tabular}




\begin{tabular}{|c|c|c|c|}
\hline $\mathrm{H}$ & 8.1338953 & 12.8857313 & 21.3552424 \\
\hline $\mathrm{H}$ & 5.2635561 & 14.9466322 & 29.9082332 \\
\hline $\mathrm{H}$ & 16.2072855 & 19.6777606 & 22.4742446 \\
\hline \multicolumn{4}{|c|}{$\mathrm{Zn} 25$} \\
\hline \multicolumn{4}{|c|}{171} \\
\hline $\mathrm{H}$ & 8.7318077 & 8.7531916 & 15.1715510 \\
\hline Al & 5.4514661 & 9.1297902 & 16.5325359 \\
\hline $\mathrm{P}$ & 5.4843787 & 9.1245799 & 28.3440039 \\
\hline Al & 5.3932822 & 6.5881329 & 21.4766466 \\
\hline $\mathrm{P}$ & 5.4066252 & 6.5808497 & 18.3478158 \\
\hline Al & 3.2450815 & 7.9094974 & 26.5125077 \\
\hline$P$ & 3.3302524 & 8.0141060 & 23.3723356 \\
\hline Al & 8.6070375 & 9.1060032 & 28.4341176 \\
\hline $\mathrm{P}$ & 8.5861039 & 9.1581637 & 16.5969943 \\
\hline Al & 8.5716217 & 6.5882923 & 18.4093246 \\
\hline $\mathrm{P}$ & 8.5683550 & 6.5322333 & 21.5876313 \\
\hline Al & 1.6177994 & 10.6228525 & 23.4376481 \\
\hline $\mathrm{P}$ & 1.6114259 & 10.6187051 & 26.5825682 \\
\hline $\mathrm{O}$ & 7.1232736 & 9.5389020 & 16.9058470 \\
\hline $\mathrm{O}$ & 5.0707067 & 10.5801957 & 28.0431129 \\
\hline $\mathrm{H}$ & 4.8810081 & 5.2021774 & 21.6605573 \\
\hline $\mathrm{H}$ & 9.0662417 & 5.1594792 & 21.8787936 \\
\hline $\mathrm{O}$ & 6.8848986 & 6.2191273 & 18.1039756 \\
\hline 0 & 2.0408408 & 9.1515875 & 26.7884652 \\
\hline $\mathrm{H}$ & 2.2650882 & 6.9960259 & 23.1577230 \\
\hline $\mathrm{H}$ & 0.2570576 & 10.0383043 & 23.2833570 \\
\hline $\mathrm{O}$ & 4.9639765 & 7.6990352 & 17.3976600 \\
\hline $\mathrm{O}$ & 4.6274759 & 8.1409677 & 27.5450805 \\
\hline $\mathrm{O}$ & 4.5467114 & 7.7286189 & 22.4852560 \\
\hline 0 & 2.4125441 & 11.5460344 & 27.5032703 \\
\hline $\mathrm{O}$ & 9.0439353 & 8.0076321 & 17.4999388 \\
\hline 0 & 1.8163468 & 12.0568500 & 22.4841226 \\
\hline $\mathrm{O}$ & 4.4215871 & 10.4582470 & 16.9984146 \\
\hline $\mathrm{O}$ & 6.9482513 & 8.9325573 & 27.9285925 \\
\hline 0 & 7.0757800 & 6.5946491 & 21.9091148 \\
\hline $\mathrm{H}$ & 9.3911204 & 5.4245223 & 17.9720811 \\
\hline $\mathrm{H}$ & 4.5727098 & 5.3806828 & 18.0626756 \\
\hline $\mathrm{H}$ & 0.1741892 & 10.7453172 & 26.9505907 \\
\hline $\mathrm{H}$ & 2.6513192 & 6.5877901 & 26.8555190 \\
\hline 0 & 2.7897952 & 9.4000010 & 22.9964613 \\
\hline $\mathrm{H}$ & 5.3255692 & 8.8655016 & 15.0725969 \\
\hline $\mathrm{O}$ & 5.2031976 & 7.0606637 & 19.7954064 \\
\hline $\mathrm{O}$ & 3.7814362 & 7.9850989 & 24.8463723 \\
\hline $\mathrm{H}$ & 8.7169063 & 8.7955161 & 29.8862358 \\
\hline $\mathrm{O}$ & 8.8242080 & 6.8937523 & 20.1111618 \\
\hline 0 & 1.8501887 & 11.0534531 & 25.1266989 \\
\hline $\mathrm{H}$ & 5.3096508 & 8.8297657 & 29.7930296 \\
\hline $\mathrm{H}$ & 3.5192708 & 11.8169943 & 15.1205570 \\
\hline Al & 3.3244078 & 15.8772949 & 21.5069512 \\
\hline $\mathrm{P}$ & 3.2137959 & 15.9016834 & 18.3191260 \\
\hline Al & 3.8827643 & 11.8266126 & 28.3853013 \\
\hline $\mathrm{P}$ & 3.8446717 & 11.8153633 & 16.5735650 \\
\hline Al & 1.7217034 & 13.1225536 & 18.4642208 \\
\hline $\mathrm{P}$ & 1.7824063 & 13.2320045 & 21.4993939 \\
\hline 0 & 4.8907517 & 12.9069036 & 16.8884409 \\
\hline $\mathrm{H}$ & 0.4562586 & 13.9058147 & 21.4328152 \\
\hline $\mathrm{H}$ & 2.3273320 & 16.9347728 & 21.8305263 \\
\hline 0 & 2.1668856 & 14.7850213 & 18.1068773 \\
\hline $\mathrm{O}$ & 4.4536733 & 15.6653905 & 17.4467183 \\
\hline $\mathrm{O}$ & 4.7978881 & 16.1655933 & 22.3877603 \\
\hline 0 & 2.5465845 & 12.0568789 & 17.3544355 \\
\hline $\mathrm{O}$ & 4.5361824 & 13.3738302 & 27.9173388 \\
\hline 0 & 2.8342106 & 14.2650539 & 21.9556559 \\
\hline $\mathrm{H}$ & 2.6127690 & 17.2009622 & 17.9095388 \\
\hline $\mathrm{H}$ & 0.2552608 & 12.9466486 & 18.2752125 \\
\hline 0 & 3.6581296 & 15.9460250 & 19.7880642 \\
\hline $\mathrm{H}$ & 3.5644245 & 11.8184604 & 29.8398507 \\
\hline 0 & 2.1754820 & 12.6907079 & 20.0954592 \\
\hline Al & 10.1944426 & 11.8846358 & 16.4044127 \\
\hline $\mathrm{P}$ & 10.1500088 & 11.8775350 & 28.2903040 \\
\hline Al & 12.3441611 & 10.5408802 & 26.4788110 \\
\hline $\mathrm{P}$ & 12.4243986 & 10.4391794 & 23.3370890 \\
\hline Al & 15.4927981 & 10.6228525 & 23.4376481 \\
\hline Al & 10.6708529 & 7.8344930 & 23.4787555 \\
\hline $\mathrm{P}$ & 10.7705701 & 7.8212796 & 26.5844125 \\
\hline $\mathrm{P}$ & 15.4864246 & 10.6187051 & 26.5825682 \\
\hline $\mathrm{O}$ & 9.1018464 & 10.7604880 & 28.1142969 \\
\hline 0 & 11.8505348 & 8.8929226 & 26.8357334 \\
\hline $\mathrm{H}$ & 15.9009528 & 9.2024489 & 26.7813273 \\
\hline
\end{tabular}




\begin{tabular}{|c|c|c|}
\hline 11.6080451 & 6.6867521 & 23.3321875 \\
\hline 13.8893350 & 9.9340360 & 23.2558354 \\
\hline 11.3487656 & 11.6647940 & 27.3690577 \\
\hline 9.6204518 & 7.9741514 & 27.5878715 \\
\hline 16.2646596 & 11.5195460 & 27.4769712 \\
\hline 9.2783504 & 7.5703948 & 22.4661547 \\
\hline 15.6913455 & 12.0568500 & 22.4841226 \\
\hline 9.4793874 & 10.3741008 & 16.8919462 \\
\hline 14.0062648 & 10.7490985 & 26.9615817 \\
\hline 11.3777547 & 6.4763947 & 26.7837417 \\
\hline 16.4898223 & 9.5825650 & 23.0623277 \\
\hline 11.4907019 & 9.2720283 & 22.9641368 \\
\hline 10.5912221 & 11.8842041 & 14.9692519 \\
\hline 12.1303515 & 10.8918321 & 24.7885803 \\
\hline 15.7251874 & 11.0534531 & 25.1266989 \\
\hline 10.1919917 & 7.9628958 & 25.1628824 \\
\hline 10.6395573 & 11.8839019 & 29.6965125 \\
\hline 8.7659513 & 15.0055481 & 15.0905266 \\
\hline 5.4065455 & 14.5442451 & 16.5180214 \\
\hline 5.3952446 & 14.5683521 & 28.3461811 \\
\hline 12.3307815 & 18.6042343 & 21.4766466 \\
\hline 12.5390364 & 13.3187068 & 21.7899313 \\
\hline 17.1994065 & 15.8772949 & 21.5069512 \\
\hline 17.0887946 & 15.9016834 & 18.3191260 \\
\hline 12.3583336 & 13.0945105 & 18.2897908 \\
\hline 12.3441246 & 18.5969511 & 18.3478158 \\
\hline 5.4698896 & 17.0798846 & 26.4701204 \\
\hline 5.4559680 & 17.1198626 & 23.3856502 \\
\hline 8.5586226 & 14.6229184 & 28.3622535 \\
\hline 8.5760126 & 14.6189199 & 16.5158555 \\
\hline 15.5967021 & 13.1225536 & 18.4642208 \\
\hline 15.5091210 & 18.6043937 & 18.4093246 \\
\hline 10.7950236 & 15.8065263 & 18.4005685 \\
\hline 10.6970565 & 15.8483698 & 21.5704124 \\
\hline 15.5058544 & 18.5483347 & 21.5876313 \\
\hline 15.6574050 & 13.2320045 & 21.4993939 \\
\hline 8.6160823 & 17.3274064 & 23.3774833 \\
\hline 8.6372663 & 17.1681731 & 26.5122727 \\
\hline 9.0533804 & 13.1658460 & 16.7396482 \\
\hline 6.8755312 & 14.2311049 & 28.0801684 \\
\hline 11.7329156 & 16.9867103 & 21.6912855 \\
\hline 14.2939072 & 13.9247921 & 21.4309401 \\
\hline 16.0215343 & 17.1265217 & 21.8891990 \\
\hline 16.0418843 & 14.7850213 & 18.1068773 \\
\hline 11.9792168 & 14.5480192 & 17.9975308 \\
\hline 13.8223979 & 18.2352287 & 18.1039756 \\
\hline 7.1506305 & 17.5064176 & 26.7499969 \\
\hline 9.0824295 & 18.7282391 & 23.1843292 \\
\hline 4.8430047 & 18.4747340 & 23.3100180 \\
\hline 18.2920266 & 15.6723743 & 17.4725028 \\
\hline 11.9140878 & 19.6832774 & 17.4247318 \\
\hline 11.6601844 & 12.1178260 & 17.3448045 \\
\hline 4.9685938 & 15.7925673 & 27.5319560 \\
\hline 11.6071771 & 19.5790621 & 22.3387533 \\
\hline 12.1510166 & 11.5671095 & 22.3697410 \\
\hline 18.4598158 & 16.1239042 & 22.2603918 \\
\hline 9.0558766 & 15.9739250 & 27.3816444 \\
\hline 16.3002584 & 12.2136200 & 17.5176644 \\
\hline 9.3802655 & 15.5772352 & 17.4006453 \\
\hline 15.9108554 & 19.8116375 & 17.6358309 \\
\hline 9.3825284 & 16.2602281 & 22.2521706 \\
\hline 7.0999271 & 14.7099278 & 16.9196350 \\
\hline 9.5100712 & 13.2243476 & 27.9442968 \\
\hline 14.0132794 & 18.6107505 & 21.9091148 \\
\hline 11.2058385 & 14.5824368 & 22.2327726 \\
\hline 16.7092093 & 14.2650539 & 21.9556559 \\
\hline 16.4693558 & 17.2407645 & 17.8969914 \\
\hline 13.8617817 & 12.9144437 & 18.2406087 \\
\hline 11.4855235 & 17.3612567 & 18.0542349 \\
\hline 4.6020789 & 18.2585945 & 26.7433753 \\
\hline 9.4633315 & 18.3438747 & 26.9027372 \\
\hline 6.9285819 & 17.2480282 & 23.0109460 \\
\hline 5.2107943 & 14.8284907 & 15.0695717 \\
\hline 12.1406970 & 19.0767650 & 19.7954064 \\
\hline 11.8825217 & 12.7199517 & 19.7690388 \\
\hline 17.5331283 & 15.9460250 & 19.7880642 \\
\hline 5.2949250 & 16.5463979 & 24.8090106 \\
\hline 8.7396472 & 14.9580102 & 29.8017202 \\
\hline 16.0504807 & 12.6907079 & 20.0954592 \\
\hline 15.7617074 & 18.9098537 & 20.1111618 \\
\hline
\end{tabular}




\begin{tabular}{|c|c|c|c|}
\hline 0 & 10.3692114 & 15.6177113 & 20.0724485 \\
\hline 0 & 8.8870295 & 16.8126449 & 25.0349852 \\
\hline $\mathrm{H}$ & 10.9941677 & 12.2232386 & 19.8833843 \\
\hline C & 8.7262636 & 12.0018049 & 20.7984728 \\
\hline $\mathrm{H}$ & 8.8059079 & 13.4112551 & 22.4291312 \\
\hline C & 8.7173964 & 12.3272215 & 22.2617937 \\
\hline $\mathrm{C}$ & 7.7335975 & 12.7500100 & 19.9582412 \\
\hline $\mathrm{H}$ & 7.9411419 & 13.8329892 & 19.9885807 \\
\hline $\mathrm{H}$ & 7.7292266 & 12.4184112 & 18.9127579 \\
\hline $\mathrm{H}$ & 6.7185449 & 12.6236358 & 20.3704976 \\
\hline $\mathrm{H}$ & 9.5256582 & 11.8230617 & 22.8046659 \\
\hline C & 9.5547143 & 11.0669110 & 20.2761887 \\
\hline $\mathrm{H}$ & 10.2191816 & 10.4855751 & 20.9195046 \\
\hline $\mathrm{H}$ & 9.4637101 & 10.7569087 & 19.2333552 \\
\hline $\mathrm{H}$ & 7.7506684 & 12.0189259 & 22.6952529 \\
\hline $\mathrm{H}$ & 5.1839518 & 14.8677124 & 29.7893926 \\
\hline $\mathrm{H}$ & 16.1949458 & 19.5559302 & 22.4402889 \\
\hline \multicolumn{4}{|c|}{$\begin{array}{l}\text { Si } 25 \\
171\end{array}$} \\
\hline $\mathrm{H}$ & 8.7257547 & 8.8021856 & 15.0591931 \\
\hline $\mathrm{P}$ & 5.4296772 & 9.1838826 & 16.5785394 \\
\hline Al & 5.4168941 & 9.1620470 & 28.3996193 \\
\hline $\mathrm{P}$ & 5.4777813 & 6.6447697 & 21.5440066 \\
\hline Al & 5.5028784 & 6.6196387 & 18.4017517 \\
\hline $\mathrm{P}$ & 3.2580376 & 7.8030871 & 26.5670557 \\
\hline Al & 3.3188106 & 7.8752577 & 23.4280839 \\
\hline $\mathrm{P}$ & 8.5566591 & 9.0818360 & 28.3390987 \\
\hline Al & 8.5754909 & 9.1274743 & 16.5044366 \\
\hline $\mathrm{P}$ & 8.6752963 & 6.5812426 & 18.3537292 \\
\hline Al & 8.6511125 & 6.5685899 & 21.5134166 \\
\hline$P$ & 1.7079525 & 10.5857527 & 23.3704187 \\
\hline Al & 1.6910085 & 10.5821668 & 26.5092178 \\
\hline 0 & 6.9067949 & 9.5514534 & 16.8431593 \\
\hline 0 & 4.9425445 & 10.8098331 & 28.0321088 \\
\hline $\mathrm{H}$ & 4.9884350 & 5.2574220 & 21.7740656 \\
\hline $\mathrm{H}$ & 9.1128480 & 5.1805295 & 21.7912823 \\
\hline 0 & 7.1912201 & 6.2273031 & 18.1373602 \\
\hline 0 & 2.2144715 & 8.9243995 & 26.7280623 \\
\hline $\mathrm{H}$ & 2.2834933 & 6.8430010 & 23.1457992 \\
\hline $\mathrm{H}$ & 0.3284436 & 10.0716301 & 23.1473629 \\
\hline 0 & 5.0219675 & 7.9626439 & 17.4050624 \\
\hline 0 & 4.4450299 & 8.0291631 & 27.5087110 \\
\hline 0 & 4.7340052 & 7.6382603 & 22.4424828 \\
\hline 0 & 2.6276938 & 11.6679440 & 27.4964103 \\
\hline 0 & 9.0780611 & 7.7734446 & 17.4761733 \\
\hline 0 & 2.0183000 & 11.7675559 & 22.4518312 \\
\hline 0 & 4.5473931 & 10.3648332 & 17.0001180 \\
\hline 0 & 7.0831340 & 8.9523477 & 27.9453708 \\
\hline 0 & 6.9649887 & 6.7074147 & 21.8984016 \\
\hline $\mathrm{H}$ & 9.5069019 & 5.4115992 & 17.9568828 \\
\hline $\mathrm{H}$ & 4.6768754 & 5.4396835 & 18.0241997 \\
\hline $\mathrm{H}$ & 0.2714380 & 10.6739404 & 26.9491243 \\
\hline $\mathrm{H}$ & 2.6278471 & 6.5058667 & 26.9374606 \\
\hline 0 & 2.7027344 & 9.4609400 & 23.0590853 \\
\hline $\mathrm{H}$ & 5.2262406 & 8.8665621 & 15.1380389 \\
\hline 0 & 5.2555617 & 7.0558843 & 20.0753605 \\
\hline 0 & 3.7769739 & 7.7648348 & 25.1182007 \\
\hline $\mathrm{H}$ & 8.7451643 & 8.7573557 & 29.7800355 \\
\hline 0 & 8.9307581 & 6.9542714 & 19.8249663 \\
\hline 0 & 1.8677366 & 11.0521705 & 24.8330044 \\
\hline $\mathrm{H}$ & 5.2488932 & 8.9016152 & 29.8560092 \\
\hline $\mathrm{H}$ & 3.5677933 & 11.8857977 & 15.0472179 \\
\hline $\mathrm{P}$ & 3.2615828 & 15.8143897 & 21.5664658 \\
\hline Al & 3.2415585 & 15.8331895 & 18.3864114 \\
\hline $\mathrm{P}$ & 3.8922152 & 11.9009363 & 28.3250629 \\
\hline Al & 3.8849353 & 11.8996562 & 16.5019857 \\
\hline $\mathrm{P}$ & 1.6896463 & 13.1184997 & 18.3564761 \\
\hline Al & 1.6512218 & 13.1296126 & 21.4242401 \\
\hline $\mathrm{O}$ & 5.0873459 & 13.1350748 & 16.8453497 \\
\hline $\mathrm{H}$ & 0.2101792 & 13.5008802 & 21.3724993 \\
\hline $\mathrm{H}$ & 2.2914895 & 16.9126517 & 21.8307766 \\
\hline 0 & 2.0300414 & 14.5975397 & 18.0636954 \\
\hline 0 & 4.6939925 & 15.5519875 & 17.4573665 \\
\hline 0 & 4.5314193 & 16.0118742 & 22.4054078 \\
\hline 0 & 2.3910717 & 12.2029478 & 17.3459063 \\
\hline 0 & 4.4746195 & 13.2634536 & 27.9360238 \\
\hline 0 & 2.6323856 & 14.4788522 & 21.9654294 \\
\hline $\mathrm{H}$ & 2.6892957 & 17.1637311 & 18.0098673 \\
\hline $\mathrm{H}$ & 0.2221903 & 12.9234702 & 18.1962975 \\
\hline
\end{tabular}




\begin{tabular}{|c|c|c|c|}
\hline 0 & 3.6651125 & 15.8107726 & 20.0804958 \\
\hline $\mathrm{H}$ & 3.5251004 & 11.8839621 & 29.7679971 \\
\hline 0 & 2.1462142 & 12.7286530 & 19.7713146 \\
\hline $\mathrm{P}$ & 10.2047392 & 11.8274386 & 16.4883480 \\
\hline Al & 10.1781918 & 11.8066171 & 28.3426835 \\
\hline $\mathrm{P}$ & 12.4347994 & 10.5380923 & 26.6198054 \\
\hline Al & 12.4784973 & 10.5239137 & 23.4129499 \\
\hline $\mathrm{P}$ & 15.5829512 & 10.5857527 & 23.3704187 \\
\hline $\mathrm{P}$ & 10.7533571 & 7.9226127 & 23.3759739 \\
\hline Al & 10.7842088 & 7.8944961 & 26.5257428 \\
\hline Al & 15.5660072 & 10.5821668 & 26.5092178 \\
\hline $\mathrm{O}$ & 9.0184557 & 10.5251935 & 28.0506364 \\
\hline 0 & 11.9651339 & 9.1108287 & 26.9753661 \\
\hline $\mathrm{H}$ & 16.0108479 & 9.1733905 & 26.6951926 \\
\hline $\mathrm{H}$ & 11.6869528 & 6.7721868 & 23.2275152 \\
\hline $\mathrm{O}$ & 14.1547335 & 10.0534771 & 23.1394871 \\
\hline $\mathrm{O}$ & 11.6193841 & 11.5780956 & 27.4008971 \\
\hline 0 & 9.3580864 & 8.0751744 & 27.5103030 \\
\hline $\mathrm{H}$ & 16.3671443 & 11.5108206 & 27.3535531 \\
\hline $\mathrm{O}$ & 9.5055488 & 7.7162718 & 22.5096014 \\
\hline 0 & 15.8932987 & 11.7675559 & 22.4518312 \\
\hline 0 & 9.5938786 & 10.4873960 & 16.9188596 \\
\hline $\mathrm{O}$ & 13.9047812 & 10.6895632 & 27.0240103 \\
\hline $\mathrm{H}$ & 11.3656414 & 6.5473128 & 26.7790289 \\
\hline $\mathrm{H}$ & 16.5488452 & 9.4936040 & 23.0681262 \\
\hline $\mathrm{O}$ & 11.4544291 & 9.1971597 & 22.8951200 \\
\hline $\mathrm{H}$ & 10.6195611 & 11.7894475 & 15.0588026 \\
\hline 0 & 12.2442666 & 10.7964781 & 25.1245128 \\
\hline $\mathrm{O}$ & 15.7427353 & 11.0521705 & 24.8330044 \\
\hline $\mathrm{O}$ & 10.3196854 & 8.0681319 & 24.8463000 \\
\hline $\mathrm{H}$ & 10.5635524 & 11.7910903 & 29.7808688 \\
\hline $\mathrm{H}$ & 8.8366265 & 14.9216756 & 15.0023485 \\
\hline $\mathrm{P}$ & 5.5043117 & 14.5966675 & 16.5756313 \\
\hline Al & 5.4645735 & 14.6133867 & 28.4138511 \\
\hline $\mathrm{P}$ & 12.4152807 & 18.6608711 & 21.5440066 \\
\hline $\mathrm{Si}$ & 12.3226097 & 13.1857722 & 21.6200096 \\
\hline $\mathrm{P}$ & 17.1365815 & 15.8143897 & 21.5664658 \\
\hline Al & 17.1165572 & 15.8331895 & 18.3864114 \\
\hline Al & 12.3488902 & 13.1373026 & 18.3902471 \\
\hline Al & 12.4403778 & 18.6357400 & 18.4017517 \\
\hline $\mathrm{P}$ & 5.4104909 & 17.1264371 & 26.5448865 \\
\hline Al & 5.3887747 & 17.1312289 & 23.4240909 \\
\hline $\mathrm{P}$ & 8.6248310 & 14.5668184 & 28.3016351 \\
\hline Al & 8.6624271 & 14.5982654 & 16.4453250 \\
\hline $\mathrm{P}$ & 15.5646450 & 13.1184997 & 18.3564761 \\
\hline$P$ & 15.6127957 & 18.5973440 & 18.3537292 \\
\hline$P$ & 10.8343587 & 15.9150328 & 18.3363287 \\
\hline Al & 10.7550346 & 15.9438048 & 21.4924437 \\
\hline Al & 15.5886118 & 18.5846913 & 21.5134166 \\
\hline Al & 15.5262205 & 13.1296126 & 21.4242401 \\
\hline $\mathrm{P}$ & 8.5486841 & 17.2284285 & 23.3084434 \\
\hline Al & 8.5649467 & 17.1272164 & 26.4705597 \\
\hline 0 & 9.1602858 & 12.9353704 & 16.7260334 \\
\hline $\mathrm{O}$ & 7.1398918 & 14.2146004 & 28.0918006 \\
\hline $\mathrm{O}$ & 11.9109110 & 17.2309306 & 21.7811286 \\
\hline 0 & 13.8588559 & 13.5591894 & 21.3643732 \\
\hline 0 & 16.1317181 & 16.9520156 & 21.8402500 \\
\hline $\mathrm{O}$ & 15.9050401 & 14.5975397 & 18.0636954 \\
\hline $\mathrm{O}$ & 11.8988460 & 14.8052085 & 18.1623557 \\
\hline $\mathrm{O}$ & 14.1287195 & 18.2434044 & 18.1373602 \\
\hline $\mathrm{O}$ & 6.8827400 & 17.5144627 & 26.7896262 \\
\hline $\mathrm{H}$ & 9.0199667 & 18.6258303 & 23.1028186 \\
\hline $\mathrm{H}$ & 4.8678733 & 18.5155115 & 23.2522075 \\
\hline $\mathrm{H}$ & 18.3545429 & 15.5935063 & 17.5945377 \\
\hline $\mathrm{H}$ & 12.0288891 & 19.7848747 & 17.5489403 \\
\hline $\mathrm{O}$ & 11.4555484 & 12.0729860 & 17.3434628 \\
\hline $\mathrm{O}$ & 4.9801303 & 16.0097728 & 27.5002832 \\
\hline $\mathrm{H}$ & 11.6924520 & 19.6263814 & 22.4171784 \\
\hline $\mathrm{O}$ & 12.0420620 & 11.9352905 & 22.5641468 \\
\hline $\mathrm{H}$ & 18.3686038 & 16.0059934 & 22.3804251 \\
\hline $\mathrm{O}$ & 9.0428945 & 15.7257837 & 27.3928007 \\
\hline $\mathrm{H}$ & 16.2457360 & 12.2294898 & 17.3752029 \\
\hline 0 & 9.6507853 & 15.6699826 & 17.3929708 \\
\hline $\mathrm{H}$ & 16.0037027 & 19.7544464 & 17.5020095 \\
\hline $\mathrm{O}$ & 9.2845341 & 16.2625500 & 22.3801148 \\
\hline 0 & 6.9908196 & 14.7570127 & 16.9248446 \\
\hline $\mathrm{O}$ & 9.4705090 & 13.3434979 & 27.9357714 \\
\hline $\mathrm{O}$ & 13.9024881 & 18.7235161 & 21.8984016 \\
\hline $\mathrm{O}$ & 11.3960370 & 14.4354845 & 21.9674864 \\
\hline $\mathrm{O}$ & 16.5073843 & 14.4788522 & 21.9654294 \\
\hline
\end{tabular}




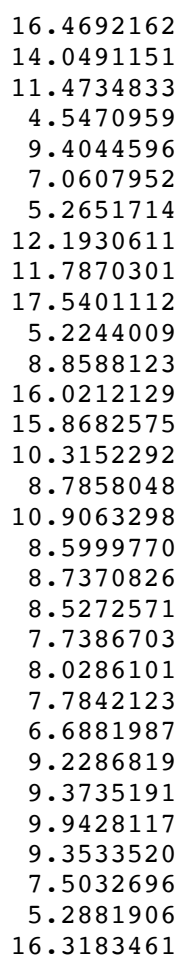

17.3927987

12.9170810

17.2545197

18.3093753

18.2871720

17.1564709

14.9453756

19.0719857

12.6272403

15.8107726

16.6338288

14.9641698

12.7286530

18.9703728

15.9368982

16.7942088

12.1286563

11.9828818

13.4090112

12.3392926

12.8025317

13.8666314

12.4570997

12.7656322

11.7537095

10.9703443

10.3432679

10.6712313

12.1626789

14.9056547

19.5648730

8.7494250

9.1726034

9.1368565

6.6028896

6.6030502

7.8846224

8.0003183

9.0792825

9.1774588

6.6154807

6.5364814

10.6234870

10.6107417

9.5862894

10.5888420

5.2489639

5.1735924

6.2371310

9.1443977

6.9939864

10.0116845

7.7319607

8.1420745

7.7760585

11.5134647

8.0348593

12.0148637

10.4871624

8.9224294

6.5401132

5.4530269

5.4086179

10.6969593

6.5817392

9.4037301

8.9138861

7.0723771

7.8796330

8.7878381

6.9342024

11.1115132

8.8780308

11.8096627

15.8735775

15.9201352

11.8207605
17.9450411

18.1910501

17.9598006

26.8138229

26.8790222

22.9606252

15.1479286

20.0753605

20.0378281

20.0804958

25.0971626

29.7174336

19.7713146

19.8249663

19.7799045

24.7681773

20.1126244

20.8491135

22.4628584

22.3049828

19.9320542

19.9695064

18.8921467

20.2655355

22.9117379

20.3960469

21.0864448

19.3459397

22.6754322

29.8631920

22.3642116

15.1792381

16.5527855

28.3582233

21.4785182

18.3475903

26.5268959

23.4039524

28.4368847

16.5996719

18.4286814

21.5952125

23.4566469

26.5864184

16.9146214

28.0270034

21.6720450

21.8685847

18.1210252

26.7136076

23.1216493

23.2661843

17.4039024

27.5931876

22.5003108

27.5243677

17.5155355

22.4636191

17.0348225

27.9345046

21.8929953

17.9968437

18.0331741

27.0042189

26.8987763

23.1144561

15.0928279

19.7956270

24.8741337

29.8925390

20.1286186

25.1440778

29.8155342

15.1252558

21.5054973

18.3191376

28.3864467 


\begin{tabular}{|c|c|c|c|}
\hline $\mathrm{P}$ & 3.8477927 & 11.8345989 & 16.5816085 \\
\hline Al & 1.7303456 & 13.1504011 & 18.4644306 \\
\hline $\mathrm{P}$ & 1.8018475 & 13.2076543 & 21.5024234 \\
\hline 0 & 4.8875879 & 12.9331345 & 16.8923489 \\
\hline $\mathrm{H}$ & 0.4305831 & 13.7865207 & 21.4615808 \\
\hline $\mathrm{H}$ & 2.3622662 & 16.9472884 & 21.8208640 \\
\hline $\mathrm{O}$ & 2.1645213 & 14.8149206 & 18.0987819 \\
\hline 0 & 4.4519803 & 15.6900244 & 17.4291409 \\
\hline 0 & 4.8275048 & 16.1507282 & 22.3811235 \\
\hline 0 & 2.5384150 & 12.0857190 & 17.3404573 \\
\hline 0 & 4.4969052 & 13.3788141 & 27.9160188 \\
\hline 0 & 2.8144810 & 14.2798442 & 21.9637472 \\
\hline H & 2.6292254 & 17.2304081 & 17.9346366 \\
\hline $\mathrm{H}$ & 0.2622588 & 12.9838681 & 18.2797458 \\
\hline 0 & 3.6807193 & 15.9359210 & 19.7846419 \\
\hline $\mathrm{H}$ & 3.5801242 & 11.8106504 & 29.8460326 \\
\hline 0 & 2.2105766 & 12.7110520 & 20.0823448 \\
\hline Al & 10.1964955 & 11.9078119 & 16.3834934 \\
\hline $\mathrm{P}$ & 10.1378207 & 11.8637518 & 28.2661653 \\
\hline Al & 12.3409436 & 10.4764271 & 26.5254087 \\
\hline $\mathrm{P}$ & 12.4527931 & 10.3828683 & 23.3466828 \\
\hline Al & 15.5112728 & 10.6234870 & 23.4566469 \\
\hline Al & 10.6501871 & 7.8479732 & 23.4864372 \\
\hline $\mathrm{P}$ & 10.7439507 & 7.8118840 & 26.5967245 \\
\hline $\mathrm{P}$ & 15.4670135 & 10.6107417 & 26.5864184 \\
\hline 0 & 9.1094661 & 10.7263206 & 28.1127913 \\
\hline $\mathrm{O}$ & 11.8285055 & 8.8496218 & 26.9546162 \\
\hline $\mathrm{H}$ & 15.9096584 & 9.1943756 & 26.7092726 \\
\hline $\mathrm{H}$ & 11.5234263 & 6.6464314 & 23.3821723 \\
\hline 0 & 13.9248010 & 9.9013501 & 23.2318356 \\
\hline $\mathrm{O}$ & 11.3402715 & 11.6495978 & 27.3496197 \\
\hline 0 & 9.5714175 & 7.9198683 & 27.5821994 \\
\hline $\mathrm{H}$ & 16.2525511 & 11.4879050 & 27.4978106 \\
\hline 0 & 9.2343812 & 7.5823416 & 22.5017352 \\
\hline 0 & 15.7957309 & 12.0148637 & 22.4636191 \\
\hline 0 & 9.5133287 & 10.3835364 & 16.8734568 \\
\hline 0 & 13.9974390 & 10.6995577 & 27.0168107 \\
\hline H & 11.3252323 & 6.4461737 & 26.7153318 \\
\hline $\mathrm{H}$ & 16.5368406 & 9.5841083 & 23.1650595 \\
\hline $\mathrm{O}$ & 11.5307378 & 9.2263434 & 22.8987813 \\
\hline $\mathrm{H}$ & 10.5809363 & 11.9122608 & 14.9449851 \\
\hline 0 & 12.1455313 & 10.7243349 & 24.8232513 \\
\hline 0 & 15.6515650 & 11.1115132 & 25.1440778 \\
\hline 0 & 10.2063926 & 8.0616495 & 25.1732965 \\
\hline $\mathrm{H}$ & 10.6265521 & 11.9112439 & 29.6718704 \\
\hline $\mathrm{H}$ & 8.7420229 & 14.9741633 & 15.0450442 \\
\hline Al & 5.4095520 & 14.5648952 & 16.5097663 \\
\hline $\mathrm{P}$ & 5.3732869 & 14.5655824 & 28.3304718 \\
\hline Al & 12.3217055 & 18.6189910 & 21.4785182 \\
\hline $\mathrm{Mg}$ & 12.4768646 & 13.2600101 & 21.6901751 \\
\hline Al & 17.2195120 & 15.8735775 & 21.5054973 \\
\hline $\mathrm{P}$ & 17.0979115 & 15.9201352 & 18.3191376 \\
\hline$P$ & 12.3583637 & 13.1195387 & 18.2975421 \\
\hline $\mathrm{P}$ & 12.3572806 & 18.6191516 & 18.3475903 \\
\hline Al & 5.4571244 & 17.0686428 & 26.4589046 \\
\hline $\mathrm{P}$ & 5.4516243 & 17.1199375 & 23.3885726 \\
\hline Al & 8.5314716 & 14.5963784 & 28.3181713 \\
\hline $\mathrm{P}$ & 8.5725821 & 14.6257703 & 16.4827621 \\
\hline Al & 15.6053443 & 13.1504011 & 18.4644306 \\
\hline Al & 15.5209337 & 18.6315820 & 18.4286814 \\
\hline Al & 10.7646901 & 15.8585332 & 18.3848028 \\
\hline $\mathrm{P}$ & 10.6249694 & 15.8873829 & 21.5340937 \\
\hline$P$ & 15.5065766 & 18.5525828 & 21.5952125 \\
\hline $\mathrm{P}$ & 15.6768462 & 13.2076543 & 21.5024234 \\
\hline Al & 8.5953743 & 17.3584323 & 23.3707666 \\
\hline $\mathrm{P}$ & 8.6053056 & 17.1812189 & 26.5284851 \\
\hline O & 9.0431003 & 13.1740693 & 16.7359160 \\
\hline 0 & 6.8458394 & 14.2162783 & 28.0374184 \\
\hline 0 & 11.6361650 & 17.0423133 & 21.7038846 \\
\hline 0 & 14.2769505 & 13.7986072 & 21.4607281 \\
\hline 0 & 16.0589597 & 17.1421969 & 21.8781118 \\
\hline 0 & 16.0395201 & 14.8149206 & 18.0987819 \\
\hline O & 11.9615493 & 14.5788297 & 18.0844748 \\
\hline 0 & 13.8373326 & 18.2532324 & 18.1210252 \\
\hline $\mathrm{O}$ & 7.1225383 & 17.5178674 & 26.7951403 \\
\hline $\mathrm{H}$ & 9.1257660 & 18.7322242 & 23.1505372 \\
\hline $\mathrm{H}$ & 4.7472285 & 18.4315873 & 23.3657242 \\
\hline $\mathrm{H}$ & 18.2902919 & 15.6968931 & 17.4557069 \\
\hline $\mathrm{H}$ & 11.9432124 & 19.7165127 & 17.4302754 \\
\hline 0 & 11.6613345 & 12.1754096 & 17.3225268 \\
\hline
\end{tabular}




\begin{tabular}{|c|c|c|c|}
\hline 0 & 4.9389296 & 15.7918858 & 27.5244876 \\
\hline $\mathrm{H}$ & 11.6503444 & 19.6212089 & 22.3514180 \\
\hline 0 & 12.1896073 & 11.5870967 & 22.4824066 \\
\hline $\mathrm{H}$ & 18.4854044 & 16.1101554 & 22.2529382 \\
\hline 0 & 9.0298674 & 15.9555189 & 27.3510109 \\
\hline $\mathrm{H}$ & 16.2943214 & 12.2426306 & 17.5061072 \\
\hline $\mathrm{O}$ & 9.4033416 & 15.6003651 & 17.3233134 \\
\hline $\mathrm{H}$ & 15.9163957 & 19.8388479 & 17.6519965 \\
\hline $\mathrm{O}$ & 9.3277194 & 16.2173444 & 22.2937357 \\
\hline 0 & 7.1042940 & 14.7369259 & 16.9113626 \\
\hline 0 & 9.4759442 & 13.1935846 & 27.8940322 \\
\hline $\mathrm{O}$ & 14.0079410 & 18.5562145 & 21.8929953 \\
\hline $\mathrm{O}$ & 11.2068591 & 14.5986871 & 22.0551534 \\
\hline 0 & 16.6894797 & 14.2798442 & 21.9637472 \\
\hline 0 & 16.4861838 & 17.2702232 & 17.9229528 \\
\hline 0 & 13.8620942 & 12.9526548 & 18.2451303 \\
\hline $\mathrm{O}$ & 11.5008876 & 17.3891410 & 18.0238086 \\
\hline $\mathrm{H}$ & 4.5541275 & 18.2315010 & 26.6813408 \\
\hline $\mathrm{H}$ & 9.4399100 & 18.3399482 & 26.9502701 \\
\hline $\mathrm{O}$ & 6.9059855 & 17.3579287 & 22.9900535 \\
\hline $\mathrm{H}$ & 5.2187517 & 14.8315492 & 15.0573161 \\
\hline $\mathrm{O}$ & 12.1372351 & 19.0884785 & 19.7956270 \\
\hline 0 & 11.8899866 & 12.6754603 & 19.7692684 \\
\hline 0 & 17.5557180 & 15.9359210 & 19.7846419 \\
\hline 0 & 5.3598263 & 16.5039428 & 24.8010059 \\
\hline $\mathrm{H}$ & 8.7146212 & 14.9261922 & 29.7585878 \\
\hline $\mathrm{O}$ & 16.0855753 & 12.7110520 & 20.0823448 \\
\hline $\mathrm{O}$ & 15.7719796 & 18.9503038 & 20.1286186 \\
\hline 0 & 10.2365297 & 15.7655641 & 20.0336129 \\
\hline 0 & 8.8357381 & 16.8714180 & 25.0395157 \\
\hline $\mathrm{H}$ & 10.9902410 & 12.1759064 & 19.8572748 \\
\hline $\mathrm{C}$ & 8.7614186 & 11.9844377 & 20.7982716 \\
\hline $\mathrm{H}$ & 8.8278418 & 13.3830314 & 22.4384106 \\
\hline C & 8.7478971 & 12.2993905 & 22.2635790 \\
\hline C & 7.7771422 & 12.7445435 & 19.9600156 \\
\hline $\mathrm{H}$ & 7.9910978 & 13.8260548 & 19.9993696 \\
\hline $\mathrm{H}$ & 7.7722830 & 12.4202387 & 18.9124071 \\
\hline $\mathrm{H}$ & 6.7610504 & 12.6220278 & 20.3705604 \\
\hline $\mathrm{H}$ & 9.5562139 & 11.7947030 & 22.8061700 \\
\hline C & 9.5889555 & 11.0484337 & 20.2723111 \\
\hline $\mathrm{H}$ & 10.2413429 & 10.4537240 & 20.9167422 \\
\hline $\mathrm{H}$ & 9.4934524 & 10.7394031 & 19.2291960 \\
\hline $\mathrm{H}$ & 7.7811861 & 11.9816993 & 22.6902325 \\
\hline $\mathrm{H}$ & 5.1918564 & 14.8675554 & 29.7771977 \\
\hline $\mathrm{H}$ & 16.1516678 & 19.5666684 & 22.4741939 \\
\hline \multicolumn{4}{|c|}{ Al 25} \\
\hline \multicolumn{4}{|c|}{171} \\
\hline $\mathrm{H}$ & 8.7131658 & 8.6417710 & 15.1355563 \\
\hline $\mathrm{Si}$ & 5.4100711 & 9.0853690 & 16.5630716 \\
\hline $\mathrm{Si}$ & 5.4006621 & 9.0512423 & 28.4983241 \\
\hline $\mathrm{Si}$ & 5.3786240 & 6.6240285 & 21.5291984 \\
\hline $\mathrm{Si}$ & 5.4110694 & 6.6173121 & 18.4619332 \\
\hline $\mathrm{Si}$ & 3.2972638 & 7.8058598 & 26.5741421 \\
\hline $\mathrm{Si}$ & 3.3876460 & 7.8893318 & 23.5087756 \\
\hline $\mathrm{Si}$ & 8.5127426 & 8.9902267 & 28.5044253 \\
\hline $\mathrm{Si}$ & 8.5258347 & 9.0621835 & 16.5516358 \\
\hline $\mathrm{Si}$ & 8.5626950 & 6.6074034 & 18.4795507 \\
\hline $\mathrm{Si}$ & 8.5443536 & 6.5614552 & 21.5703217 \\
\hline $\mathrm{Si}$ & 1.7139239 & 10.5325288 & 23.5028785 \\
\hline $\mathrm{Si}$ & 1.6956729 & 10.5318524 & 26.5767763 \\
\hline $\mathrm{O}$ & 6.9739621 & 9.4837251 & 16.8180633 \\
\hline 0 & 4.9785637 & 10.5972498 & 28.2006819 \\
\hline $\mathrm{H}$ & 4.8602603 & 5.2440923 & 21.7394265 \\
\hline $\mathrm{H}$ & 9.0207080 & 5.1744784 & 21.8282021 \\
\hline $\mathrm{O}$ & 6.9873299 & 6.2469163 & 18.2869998 \\
\hline 0 & 2.1865378 & 8.9854679 & 26.7162439 \\
\hline $\mathrm{H}$ & 2.3407439 & 6.8598570 & 23.2611908 \\
\hline $\mathrm{H}$ & 0.3447618 & 9.9792788 & 23.3120112 \\
\hline 0 & 4.9841266 & 7.8161155 & 17.4654858 \\
\hline $\mathrm{O}$ & 4.5180650 & 8.0285083 & 27.6125500 \\
\hline $\mathrm{O}$ & 4.6598221 & 7.6764296 & 22.5288801 \\
\hline 0 & 2.5438456 & 11.4986180 & 27.5587659 \\
\hline 0 & 8.9788041 & 7.8640350 & 17.5404537 \\
\hline $\mathrm{O}$ & 2.0207921 & 11.7640219 & 22.5069737 \\
\hline $\mathrm{O}$ & 4.4831058 & 10.3412919 & 16.9927371 \\
\hline 0 & 6.9544913 & 8.8563129 & 28.0942453 \\
\hline 0 & 6.9596631 & 6.6293151 & 21.8516910 \\
\hline $\mathrm{H}$ & 9.3700743 & 5.4278388 & 18.0625534 \\
\hline $\mathrm{H}$ & 4.6089789 & 5.4187716 & 18.0914310 \\
\hline
\end{tabular}

27.5244876

3514180

22.2529382

27.3510109

5061072

17.6519965

22.2937357

21.8929953

22.0551534

21.9637472

18.0238086

13408

22.9900535

0573161

19.7692684

.7846419

29.7585878

20.0823448

286186

25.0395157

19.8572748

20.7982716

22.4384106

19.9600156

19.9993696

20.3705604

22.8061700

20.2723111
20.9167422

19.2291960

22.6902325

29.7771977

Al 25

171 


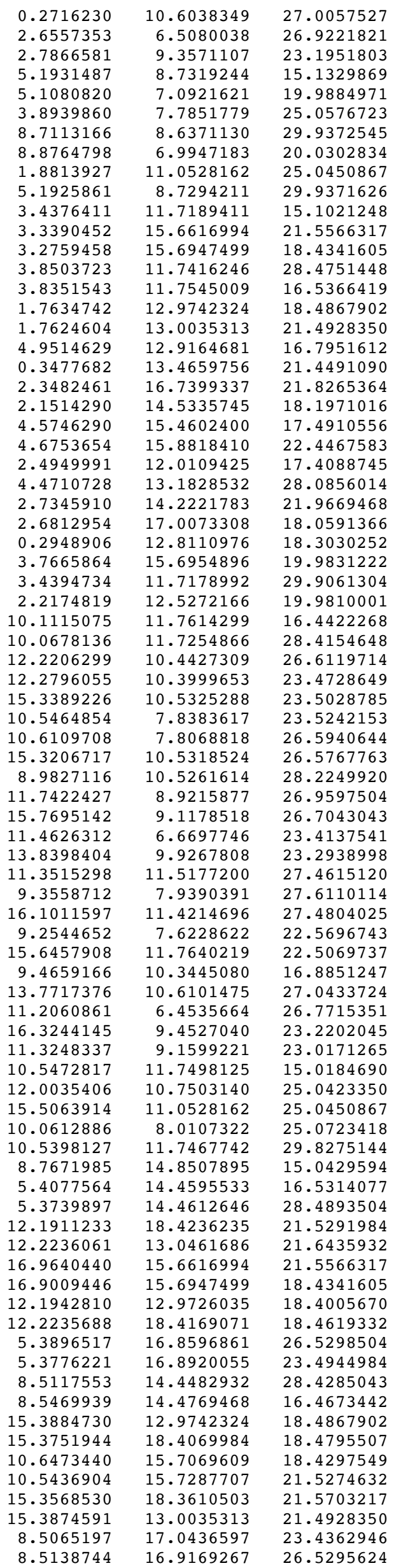




\begin{tabular}{|c|c|c|c|}
\hline 0 & 9.0103074 & 12.9286205 & 16.7120461 \\
\hline $\mathrm{O}$ & 6.9375408 & 14.0858177 & 28.2362364 \\
\hline 0 & 11.6280312 & 16.9246158 & 21.7575666 \\
\hline $\mathrm{O}$ & 13.8648214 & 13.5012616 & 21.4457726 \\
\hline 0 & 15.8780381 & 16.8435422 & 21.8524718 \\
\hline $\mathrm{O}$ & 15.7764277 & 14.5335745 & 18.1971016 \\
\hline $\mathrm{O}$ & 11.7679769 & 14.5226812 & 18.2375189 \\
\hline 0 & 13.7998292 & 18.0465113 & 18.2869998 \\
\hline $\mathrm{O}$ & 6.9442118 & 17.2808044 & 26.7868407 \\
\hline $\mathrm{H}$ & 9.0085912 & 18.4336805 & 23.2549466 \\
\hline $\mathrm{H}$ & 4.7796179 & 18.2531100 & 23.4113956 \\
\hline $\mathrm{H}$ & 18.0931080 & 15.4794749 & 17.5684103 \\
\hline $\mathrm{H}$ & 11.8302439 & 19.5213155 & 17.5439472 \\
\hline 0 & 11.4327624 & 12.0044295 & 17.3594425 \\
\hline $\mathrm{O}$ & 4.9243455 & 15.7055693 & 27.5630139 \\
\hline $\mathrm{H}$ & 11.5303446 & 19.3910727 & 22.4481838 \\
\hline 0 & 11.9174730 & 11.6643664 & 22.5862902 \\
\hline $\mathrm{H}$ & 18.1918033 & 15.8639570 & 22.3744456 \\
\hline 0 & 8.9583647 & 15.6585169 & 27.4522580 \\
\hline $\mathrm{H}$ & 16.0607721 & 12.0889324 & 17.4961447 \\
\hline 0 & 9.4128647 & 15.4703181 & 17.4059983 \\
\hline $\mathrm{H}$ & 15.7569450 & 19.5598689 & 17.6179958 \\
\hline $\mathrm{O}$ & 9.2068666 & 16.0259032 & 22.4006038 \\
\hline 0 & 6.9859323 & 14.6035609 & 16.8813323 \\
\hline $\mathrm{O}$ & 9.3765601 & 13.1373989 & 28.0369360 \\
\hline $\mathrm{O}$ & 13.7721625 & 18.4289101 & 21.8516910 \\
\hline 0 & 11.1547305 & 14.3327591 & 21.9730461 \\
\hline $\mathrm{O}$ & 16.3595897 & 14.2221783 & 21.9669468 \\
\hline $\mathrm{O}$ & 16.2535697 & 17.1237101 & 18.0258852 \\
\hline $\mathrm{O}$ & 13.7807230 & 12.7956386 & 18.2856112 \\
\hline 0 & 11.3511549 & 17.1132845 & 18.0589471 \\
\hline $\mathrm{H}$ & 4.5159781 & 18.0419686 & 26.7665425 \\
\hline $\mathrm{H}$ & 9.3406537 & 18.0924986 & 26.9189046 \\
\hline 0 & 6.9313692 & 17.0296730 & 23.0962487 \\
\hline $\mathrm{H}$ & 5.1584517 & 14.8347827 & 15.1121929 \\
\hline 0 & 11.9205814 & 18.8917572 & 19.9884971 \\
\hline $\mathrm{O}$ & 11.7027063 & 12.4463144 & 19.9308028 \\
\hline 0 & 17.3915852 & 15.6954896 & 19.9831222 \\
\hline $\mathrm{O}$ & 5.2111264 & 16.3026331 & 25.0074828 \\
\hline $\mathrm{H}$ & 8.7633853 & 14.8470624 & 29.8408732 \\
\hline 0 & 15.8424806 & 12.5272166 & 19.9810001 \\
\hline 0 & 15.6889792 & 18.7943134 & 20.0302834 \\
\hline $\mathrm{O}$ & 10.0823746 & 15.7070817 & 19.9477510 \\
\hline 0 & 8.7665395 & 16.5363121 & 24.9665420 \\
\hline $\mathrm{H}$ & 10.8144312 & 11.9446711 & 20.0013836 \\
\hline C & 8.5165089 & 11.8100573 & 20.8279443 \\
\hline $\mathrm{H}$ & 8.6210302 & 13.2036702 & 22.4697733 \\
\hline C & 8.4463909 & 12.1311736 & 22.2908535 \\
\hline C & 7.6153059 & 12.6164446 & 19.9395026 \\
\hline $\mathrm{H}$ & 7.8557536 & 13.6906103 & 20.0123703 \\
\hline $\mathrm{H}$ & 7.6726851 & 12.3081712 & 18.8884854 \\
\hline $\mathrm{H}$ & 6.5694132 & 12.5177810 & 20.2752827 \\
\hline $\mathrm{H}$ & 9.1721428 & 11.5561378 & 22.8781543 \\
\hline C & 9.3210004 & 10.8341449 & 20.3447922 \\
\hline $\mathrm{H}$ & 9.9118718 & 10.2093320 & 21.0190066 \\
\hline $\mathrm{H}$ & 9.2829470 & 10.5427385 & 19.2929932 \\
\hline $\mathrm{H}$ & 7.4315803 & 11.9115686 & 22.6636526 \\
\hline $\mathrm{H}$ & 5.1558166 & 14.8345395 & 29.9141967 \\
\hline $\mathrm{H}$ & 16.0089026 & 19.3356718 & 22.4879626 \\
\hline \multicolumn{4}{|c|}{$\mathrm{Ge} 25$} \\
\hline \multicolumn{4}{|c|}{171} \\
\hline $\mathrm{H}$ & 8.6852884 & 8.8150166 & 15.0787353 \\
\hline $\mathrm{P}$ & 5.4179105 & 9.1896101 & 16.6059082 \\
\hline Al & 5.3977590 & 9.1452786 & 28.4179742 \\
\hline $\mathrm{P}$ & 5.4617008 & 6.6366044 & 21.5379962 \\
\hline Al & 5.4896968 & 6.6228583 & 18.4102861 \\
\hline $\mathrm{P}$ & 3.2549657 & 7.7853583 & 26.5706574 \\
\hline Al & 3.3643435 & 7.9290222 & 23.4646991 \\
\hline$P$ & 8.5247755 & 9.0384552 & 28.3466111 \\
\hline Al & 8.5565133 & 9.1308703 & 16.5281400 \\
\hline $\mathrm{P}$ & 8.6578598 & 6.5723018 & 18.3618829 \\
\hline Al & 8.6388241 & 6.5366656 & 21.5287023 \\
\hline $\mathrm{P}$ & 1.6922646 & 10.5910008 & 23.3952239 \\
\hline Al & 1.6459210 & 10.5473151 & 26.5396825 \\
\hline $\mathrm{O}$ & 6.8920030 & 9.5531930 & 16.8902785 \\
\hline $\mathrm{O}$ & 4.9357929 & 10.7946192 & 28.0342899 \\
\hline $\mathrm{H}$ & 4.9127996 & 5.2650670 & 21.7243110 \\
\hline $\mathrm{H}$ & 9.1521716 & 5.1664377 & 21.8045115 \\
\hline 0 & 7.1742003 & 6.2207784 & 18.1363769 \\
\hline
\end{tabular}

16.7120461

28.2362364

21.4457726

21.8524718

18. 1375189

18.2869998

.7868407

23.4113956

4103

17.3594425

(1)

22.5862902

4456

17.4961447

4059983

22.4006038

21.8516910

9730461

18.0258852

8.2856112

26.7665425

.9189046

962487

19.9884971

19.9308028

19.9831222

29.8408732

19.9810001

20.0302834

19.9477510
24.9665420

20.0013836

20.8279443

2.0975

19.9395026

20.2752827

21.0190066

19.2929932

29.9141967

Ge 25

171 


\begin{tabular}{|c|c|c|}
\hline 2.1892848 & 8.8900183 & 26.6968331 \\
\hline 2.2854951 & 6.9363646 & 23.2042426 \\
\hline 0.3576934 & 9.9972601 & 23.1062387 \\
\hline 4.9993271 & 7.9597466 & 17.4130947 \\
\hline 4.3893133 & 8.0075705 & 27.5752694 \\
\hline 4.7522099 & 7.6403868 & 22.4540920 \\
\hline 2.6040468 & 11.6190197 & 27.5208377 \\
\hline 9.0627451 & 7.7751448 & 17.4983711 \\
\hline 1.9549653 & 11.7969172 & 22.4924337 \\
\hline 4.5301610 & 10.3654581 & 17.0285210 \\
\hline 7.0536574 & 8.8959154 & 27.9449969 \\
\hline 6.9464161 & 6.6154404 & 21.9043408 \\
\hline 9.4882957 & 5.4065625 & 17.9513362 \\
\hline 4.6489666 & 5.4484830 & 18.0481591 \\
\hline 0.2451446 & 10.6065378 & 27.0411192 \\
\hline 2.6248170 & 6.4741544 & 26.8881121 \\
\hline 2.7750996 & 9.5367769 & 23.1259012 \\
\hline 5.2300845 & 8.8849134 & 15.1605702 \\
\hline 5.2682125 & 7.0930037 & 20.0789928 \\
\hline 3.8462404 & 7.7863458 & 25.1477047 \\
\hline 8.7014304 & 8.7699878 & 29.8005158 \\
\hline 8.9102157 & 6.9274125 & 19.8387633 \\
\hline 1.7544285 & 11.0575295 & 24.8660063 \\
\hline 5.2496490 & 8.9149469 & 29.8815764 \\
\hline 3.5699082 & 11.8772243 & 15.0590510 \\
\hline 3.3073634 & 15.8043761 & 21.5494281 \\
\hline 3.2370638 & 15.8317538 & 18.3734855 \\
\hline 3.8759665 & 11.8765469 & 28.3301035 \\
\hline 3.8728601 & 11.8971069 & 16.5167703 \\
\hline 1.6678640 & 13.1111322 & 18.3667097 \\
\hline 1.6506319 & 13.1531730 & 21.4388087 \\
\hline 5.0778745 & 13.1290321 & 16.8674719 \\
\hline 0.2530647 & 13.6651692 & 21.3965411 \\
\hline 2.3412445 & 16.8987182 & 21.8429414 \\
\hline 2.0248888 & 14.5884927 & 18.0871809 \\
\hline 4.6810035 & 15.5564719 & 17.4285874 \\
\hline 4.5942474 & 15.9879585 & 22.3653932 \\
\hline 2.3761784 & 12.1998793 & 17.3564543 \\
\hline 4.4361785 & 13.2421991 & 27.9161762 \\
\hline 2.7002270 & 14.4590873 & 21.9474686 \\
\hline 2.6729337 & 17.1589761 & 18.0028661 \\
\hline 0.2006571 & 12.9287887 & 18.1901449 \\
\hline 3.6868834 & 15.8196739 & 20.0588562 \\
\hline 3.5288768 & 11.8738828 & 29.7780822 \\
\hline 2.0999197 & 12.7020518 & 19.7850591 \\
\hline 10.1828354 & 11.8242600 & 16.4492679 \\
\hline 10.1317326 & 11.7676854 & 28.2863689 \\
\hline 12.4270724 & 10.4508692 & 26.6596795 \\
\hline 12.5037776 & 10.3996977 & 23.4268509 \\
\hline 15.5672633 & 10.5910008 & 23.3952239 \\
\hline 10.6624046 & 7.8964352 & 23.4352258 \\
\hline 10.7340498 & 7.8593012 & 26.5392274 \\
\hline 15.5209197 & 10.5473151 & 26.5396825 \\
\hline 8.9885867 & 10.4690398 & 28.0011394 \\
\hline 11.9278335 & 9.0424964 & 27.0509405 \\
\hline 15.9829375 & 9.1381292 & 26.6733064 \\
\hline 11.5014724 & 6.6673882 & 23.3849327 \\
\hline 14.1838924 & 9.9755495 & 23.0956717 \\
\hline 11.5768584 & 11.5286976 & 27.3499617 \\
\hline 9.3333613 & 7.9949388 & 27.5690104 \\
\hline 16.3406136 & 11.4641776 & 27.3790784 \\
\hline 9.4259352 & 7.7234268 & 22.5427414 \\
\hline 15.8299641 & 11.7969172 & 22.4924337 \\
\hline 9.5837936 & 10.4916109 & 16.9192995 \\
\hline 13.8785358 & 10.6167526 & 27.1276075 \\
\hline 11.3223518 & 6.4981252 & 26.6742132 \\
\hline 16.6175973 & 9.5684192 & 23.1339848 \\
\hline 11.4761645 & 9.0804677 & 22.9030577 \\
\hline 10.5471210 & 11.7679799 & 15.0066144 \\
\hline 12.3256091 & 10.6344306 & 25.1474093 \\
\hline 15.6294273 & 11.0575295 & 24.8660063 \\
\hline 10.2146077 & 8.1583601 & 24.8872996 \\
\hline 10.4938419 & 11.7666055 & 29.7306667 \\
\hline 8.8164732 & 14.8892436 & 14.9545802 \\
\hline 5.4924613 & 14.5849094 & 16.5651052 \\
\hline 5.4359564 & 14.5842462 & 28.3982706 \\
\hline 12.3992002 & 18.6527057 & 21.5379962 \\
\hline 12.2629682 & 13.2266902 & 21.6935083 \\
\hline 17.1823621 & 15.8043761 & 21.5494281 \\
\hline 17.1120625 & 15.8317538 & 18.3734855 \\
\hline
\end{tabular}




\begin{tabular}{|c|c|c|c|}
\hline Al & 12.3220066 & 13.1399665 & 18.3335246 \\
\hline Al & 12.4271962 & 18.6389596 & 18.4102861 \\
\hline $\mathrm{P}$ & 5.3985196 & 17.0790703 & 26.5212615 \\
\hline Al & 5.3542421 & 17.1002441 & 23.4594461 \\
\hline $\mathrm{P}$ & 8.5924318 & 14.5336422 & 28.2504411 \\
\hline Al & 8.6499659 & 14.5967555 & 16.4050445 \\
\hline $\mathrm{P}$ & 15.5428628 & 13.1111322 & 18.3667097 \\
\hline $\mathrm{P}$ & 15.5953592 & 18.5884032 & 18.3618829 \\
\hline $\mathrm{P}$ & 10.8129467 & 15.9059974 & 18.2989013 \\
\hline Al & 10.6408536 & 15.9864901 & 21.4650741 \\
\hline Al & 15.5763235 & 18.5527669 & 21.5287023 \\
\hline Al & 15.5256306 & 13.1531730 & 21.4388087 \\
\hline $\mathrm{P}$ & 8.4951103 & 17.3414968 & 23.2915827 \\
\hline Al & 8.5391024 & 17.1094314 & 26.4262488 \\
\hline 0 & 9.1517948 & 12.9394093 & 16.7154862 \\
\hline $\mathrm{O}$ & 7.1056458 & 14.1811789 & 28.0533308 \\
\hline $\mathrm{O}$ & 11.8337975 & 17.2399361 & 21.7299122 \\
\hline 0 & 13.8991835 & 13.7490189 & 21.3896190 \\
\hline 0 & 16.1810810 & 16.9385472 & 21.8536239 \\
\hline 0 & 15.8998875 & 14.5884927 & 18.0871809 \\
\hline 0 & 11.8864163 & 14.8118084 & 18.0904801 \\
\hline $\mathrm{O}$ & 14.1116996 & 18.2368797 & 18.1363769 \\
\hline $\mathrm{O}$ & 6.8602149 & 17.5085112 & 26.7714076 \\
\hline $\mathrm{H}$ & 9.0155718 & 18.7306199 & 23.1628292 \\
\hline $\mathrm{H}$ & 4.6940881 & 18.4333082 & 23.3941963 \\
\hline $\mathrm{H}$ & 18.3424431 & 15.5971862 & 17.5683381 \\
\hline $\mathrm{H}$ & 12.0071837 & 19.7840340 & 17.5561697 \\
\hline 0 & 11.4664658 & 12.0783805 & 17.2522713 \\
\hline 0 & 4.9627185 & 16.0138426 & 27.5311944 \\
\hline $\mathrm{H}$ & 11.7100876 & 19.6276571 & 22.4277795 \\
\hline $\mathrm{O}$ & 11.9657326 & 11.8164540 & 22.6454166 \\
\hline $\mathrm{H}$ & 18.4308544 & 15.9824817 & 22.3410505 \\
\hline 0 & 9.0024517 & 15.6946226 & 27.3391541 \\
\hline $\mathrm{H}$ & 16.2304642 & 12.2265266 & 17.3859967 \\
\hline 0 & 9.6404042 & 15.6884201 & 17.3334106 \\
\hline $\mathrm{H}$ & 15.9880951 & 19.7551526 & 17.5242823 \\
\hline 0 & 9.1531389 & 16.4194126 & 22.2665710 \\
\hline $\mathrm{O}$ & 6.9813859 & 14.7571211 & 16.8992027 \\
\hline 0 & 9.4331299 & 13.3091369 & 27.8727875 \\
\hline 0 & 13.8839155 & 18.6315417 & 21.9043408 \\
\hline 0 & 11.1548307 & 14.4894132 & 22.1295150 \\
\hline 0 & 16.5752258 & 14.4590873 & 21.9474686 \\
\hline $\mathrm{O}$ & 16.4507321 & 17.3876581 & 17.9390080 \\
\hline 0 & 14.0285121 & 12.9229297 & 18.1844716 \\
\hline 0 & 11.4435076 & 17.2648927 & 17.9865827 \\
\hline $\mathrm{H}$ & 4.5055415 & 18.2582849 & 26.6920356 \\
\hline $\mathrm{H}$ & 9.3980480 & 18.2571152 & 26.8289333 \\
\hline 0 & 6.9985310 & 17.3629244 & 22.9878856 \\
\hline $\mathrm{H}$ & 5.2447365 & 14.9028809 & 15.1317012 \\
\hline 0 & 12.2057119 & 19.1091051 & 20.0789928 \\
\hline 0 & 11.7186034 & 12.6381224 & 19.9608835 \\
\hline 0 & 17.5618821 & 15.8196739 & 20.0588562 \\
\hline 0 & 5.2613320 & 16.4904651 & 25.1018657 \\
\hline $\mathrm{H}$ & 8.8369923 & 14.9266014 & 29.6656774 \\
\hline 0 & 15.9749184 & 12.7020518 & 19.7850591 \\
\hline 0 & 15.8477151 & 18.9435138 & 19.8387633 \\
\hline 0 & 10.2850460 & 15.8628207 & 19.7400488 \\
\hline 0 & 8.7528924 & 16.7989209 & 24.7137699 \\
\hline $\mathrm{H}$ & 9.8346040 & 10.3072719 & 21.0158635 \\
\hline $\mathrm{C}$ & 8.5522126 & 12.0083835 & 20.9128645 \\
\hline $\mathrm{H}$ & 8.8095056 & 13.2820973 & 22.6311756 \\
\hline $\mathrm{C}$ & 8.4945604 & 12.2538720 & 22.3916700 \\
\hline C & 7.7298540 & 12.9335752 & 20.0630837 \\
\hline $\mathrm{H}$ & 7.7739913 & 12.6741998 & 18.9978795 \\
\hline $\mathrm{H}$ & 6.6751577 & 12.9077543 & 20.3839071 \\
\hline $\mathrm{H}$ & 8.0582374 & 13.9790396 & 20.1907505 \\
\hline $\mathrm{H}$ & 9.1310466 & 11.5583725 & 22.9524786 \\
\hline C & 9.2848266 & 11.0048033 & 20.3793209 \\
\hline $\mathrm{H}$ & 10.8425301 & 12.1409573 & 20.0557644 \\
\hline $\mathrm{H}$ & 9.2489223 & 10.7879896 & 19.3093974 \\
\hline $\mathrm{H}$ & 7.4546035 & 12.1499220 & 22.7441602 \\
\hline $\mathrm{H}$ & 5.2662129 & 14.8644983 & 29.8507741 \\
\hline $\mathrm{H}$ & 16.2467301 & 19.5635678 & 22.3923904 \\
\hline \multicolumn{4}{|c|}{$\mathrm{Ga} 25$} \\
\hline \multicolumn{4}{|c|}{171} \\
\hline $\mathrm{H}$ & 8.6987813 & 8.6492403 & 15.1531407 \\
\hline $\mathrm{Si}$ & 5.4109223 & 9.0879339 & 16.5758146 \\
\hline $\mathrm{Si}$ & 5.4061212 & 9.0447347 & 28.507581 \\
\hline & & & \\
\hline
\end{tabular}




\begin{tabular}{|c|c|c|c|}
\hline $\mathrm{Si}$ & 5.4200741 & 6.6293504 & 18.4769144 \\
\hline $\mathrm{Si}$ & 3.3002934 & 7.8116554 & 26.5766830 \\
\hline $\mathrm{Si}$ & 3.4220942 & 7.9314938 & 23.5155072 \\
\hline $\mathrm{Si}$ & 8.5119034 & 8.9770953 & 28.5155226 \\
\hline $\mathrm{Si}$ & 8.5222431 & 9.0713633 & 16.5700976 \\
\hline $\mathrm{Si}$ & 8.5523705 & 6.6010167 & 18.4772532 \\
\hline $\mathrm{Si}$ & 8.5437577 & 6.5305286 & 21.5865285 \\
\hline $\mathrm{Si}$ & 1.7231703 & 10.5382167 & 23.5112026 \\
\hline $\mathrm{Si}$ & 1.6938069 & 10.5235536 & 26.5877101 \\
\hline 0 & 6.9710968 & 9.4913648 & 16.8455125 \\
\hline 0 & 4.9888811 & 10.5934767 & 28.2120598 \\
\hline $\mathrm{H}$ & 4.8138994 & 5.2499075 & 21.6879121 \\
\hline $\mathrm{H}$ & 9.0802500 & 5.1654154 & 21.8429707 \\
\hline 0 & 6.9831310 & 6.2285292 & 18.2434342 \\
\hline 0 & 2.1703583 & 8.9725236 & 26.7302862 \\
\hline $\mathrm{H}$ & 2.3614265 & 6.9123221 & 23.2844364 \\
\hline $\mathrm{H}$ & 0.3696660 & 9.9447501 & 23.3296978 \\
\hline 0 & 4.9772354 & 7.8180856 & 17.4750099 \\
\hline 0 & 4.5046434 & 8.0259276 & 27.6359244 \\
\hline 0 & 4.6933863 & 7.6732795 & 22.5449995 \\
\hline 0 & 2.5444767 & 11.4803210 & 27.5773283 \\
\hline 0 & 8.9770484 & 7.8741564 & 17.5616087 \\
\hline 0 & 1.9491111 & 11.7985698 & 22.5289202 \\
\hline 0 & 4.4761647 & 10.3405812 & 16.9964992 \\
\hline 0 & 6.9563760 & 8.8321119 & 28.0919852 \\
\hline 0 & 6.9630868 & 6.5245376 & 21.9036157 \\
\hline $\mathrm{H}$ & 9.3800443 & 5.4339674 & 18.0648546 \\
\hline $\mathrm{H}$ & 4.5737489 & 5.4442231 & 18.1665475 \\
\hline $\mathrm{H}$ & 0.2664120 & 10.6061200 & 27.0034591 \\
\hline $\mathrm{H}$ & 2.6717598 & 6.4977855 & 26.8862181 \\
\hline 0 & 2.8371853 & 9.4050840 & 23.1755359 \\
\hline $\mathrm{H}$ & 5.2085322 & 8.7315893 & 15.1443198 \\
\hline 0 & 5.1915507 & 7.1383369 & 20.0059210 \\
\hline 0 & 3.9194480 & 7.8436026 & 25.0683694 \\
\hline $\mathrm{H}$ & 8.6972919 & 8.6424957 & 29.9545483 \\
\hline 0 & 8.8262922 & 6.9701065 & 20.0394444 \\
\hline 0 & 1.8954153 & 11.0446456 & 25.0570357 \\
\hline $\mathrm{H}$ & 5.2083534 & 8.7283506 & 29.9490775 \\
\hline $\mathrm{H}$ & 3.4554193 & 11.7395524 & 15.1101735 \\
\hline $\mathrm{Si}$ & 3.4015208 & 15.6566614 & 21.5498505 \\
\hline $\mathrm{Si}$ & 3.2937300 & 15.7025208 & 18.4315287 \\
\hline $\mathrm{Si}$ & 3.8589676 & 11.7395551 & 28.4788946 \\
\hline $\mathrm{Si}$ & 3.8432703 & 11.7622576 & 16.5475937 \\
\hline $\mathrm{Si}$ & 1.7605239 & 12.9832198 & 18.4938682 \\
\hline $\mathrm{Si}$ & 1.7712055 & 13.0432299 & 21.5062799 \\
\hline 0 & 4.9679863 & 12.9141561 & 16.8170460 \\
\hline $\mathrm{H}$ & 0.4053384 & 13.6355202 & 21.4794510 \\
\hline $\mathrm{H}$ & 2.4135514 & 16.7324025 & 21.8393642 \\
\hline 0 & 2.1661067 & 14.5402166 & 18.2186510 \\
\hline 0 & 4.5808491 & 15.4658764 & 17.4741527 \\
\hline 0 & 4.7489560 & 15.8641260 & 22.4279630 \\
\hline 0 & 2.5050498 & 12.0221010 & 17.4222717 \\
\hline 0 & 4.4739505 & 13.1772947 & 28.0615552 \\
\hline 0 & 2.8202750 & 14.2045194 & 21.9557896 \\
\hline $\mathrm{H}$ & 2.6938339 & 17.0141012 & 18.0613907 \\
\hline $\mathrm{H}$ & 0.2937416 & 12.8269344 & 18.2907793 \\
\hline 0 & 3.8084593 & 15.7074589 & 19.9725826 \\
\hline $\mathrm{H}$ & 3.4572730 & 11.7376540 & 29.9126862 \\
\hline 0 & 2.1760345 & 12.5221317 & 19.9965136 \\
\hline $\mathrm{Si}$ & 10.1166597 & 11.7653384 & 16.4277923 \\
\hline $\mathrm{Si}$ & 10.0578081 & 11.7132220 & 28.4003291 \\
\hline $\mathrm{Si}$ & 12.2189537 & 10.4368537 & 26.5952095 \\
\hline $\mathrm{Si}$ & 12.2984910 & 10.3486699 & 23.4665686 \\
\hline $\mathrm{Si}$ & 15.3481691 & 10.5382167 & 23.5112026 \\
\hline $\mathrm{Si}$ & 10.4962967 & 7.8202340 & 23.5522628 \\
\hline $\mathrm{Si}$ & 10.6004092 & 7.8023910 & 26.5904111 \\
\hline $\mathrm{Si}$ & 15.3188057 & 10.5235536 & 26.5877101 \\
\hline $\mathrm{O}$ & 8.9726448 & 10.5124588 & 28.2156982 \\
\hline 0 & 11.7463811 & 8.9109691 & 26.9319156 \\
\hline $\mathrm{H}$ & 15.7544436 & 9.1056845 & 26.7180456 \\
\hline $\mathrm{H}$ & 11.3461254 & 6.5994548 & 23.4843652 \\
\hline 0 & 13.8655203 & 9.8881245 & 23.3123795 \\
\hline $\mathrm{O}$ & 11.3364347 & 11.5044540 & 27.4393966 \\
\hline 0 & 9.3798504 & 7.9195199 & 27.6513954 \\
\hline $\mathrm{H}$ & 16.1015839 & 11.4039619 & 27.4983473 \\
\hline 0 & 9.2221040 & 7.6343801 & 22.5663900 \\
\hline 0 & 15.5741098 & 11.7985698 & 22.5289202 \\
\hline 0 & 9.4638652 & 10.3563870 & 16.8894621 \\
\hline 0 & 13.7660639 & 10.6133706 & 27.0399681 \\
\hline $\mathrm{H}$ & 11.2031015 & 6.4467223 & 26.7170804 \\
\hline
\end{tabular}




\begin{tabular}{|c|c|c|}
\hline 16.3695170 & 9.4993414 & 23.2034576 \\
\hline 11.3589470 & 9.0875050 & 23.0460094 \\
\hline 10.5424076 & 11.7352370 & 15.0012744 \\
\hline 12.0177486 & 10.7536352 & 25.0233443 \\
\hline 15.5204140 & 11.0446456 & 25.0570357 \\
\hline 9.9963386 & 8.0398670 & 25.0914019 \\
\hline 10.5340685 & 11.7309502 & 29.8109965 \\
\hline 8.7736368 & 14.8618413 & 15.0195092 \\
\hline 5.4164720 & 14.4551597 & 16.5270585 \\
\hline 5.3725781 & 14.4559009 & 28.4797919 \\
\hline 12.2060570 & 18.4128879 & 21.5385895 \\
\hline 12.2347284 & 13.1129676 & 21.7198217 \\
\hline 17.0265195 & 15.6566614 & 21.5498505 \\
\hline 16.9187287 & 15.7025208 & 18.4315287 \\
\hline 12.1945295 & 12.9987484 & 18.3631301 \\
\hline 12.2325735 & 18.4289454 & 18.4769144 \\
\hline 5.3979849 & 16.8482023 & 26.5204297 \\
\hline 5.3725239 & 16.8851397 & 23.5146312 \\
\hline 8.5129081 & 14.4474247 & 28.4065483 \\
\hline 8.5577896 & 14.4909289 & 16.4453263 \\
\hline 15.3855226 & 12.9832198 & 18.4938682 \\
\hline 15.3648698 & 18.4006117 & 18.4772532 \\
\hline 10.6503137 & 15.6958678 & 18.4201769 \\
\hline 10.4893400 & 15.7308457 & 21.5320043 \\
\hline 15.3562570 & 18.3301236 & 21.5865285 \\
\hline 15.3962042 & 13.0432299 & 21.5062799 \\
\hline 8.4867257 & 17.1112460 & 23.4219956 \\
\hline 8.5167468 & 16.9118773 & 26.4999762 \\
\hline 9.0266052 & 12.9446321 & 16.6927563 \\
\hline 6.9369518 & 14.0897055 & 28.2209798 \\
\hline 11.5764696 & 16.9320668 & 21.7007741 \\
\hline 13.9169506 & 13.6846888 & 21.4772238 \\
\hline 15.9434848 & 16.8359135 & 21.8672221 \\
\hline 15.7911054 & 14.5402166 & 18.2186510 \\
\hline 11.7932479 & 14.5515239 & 18.1446660 \\
\hline 13.7956304 & 18.0281242 & 18.2434342 \\
\hline 6.9506708 & 17.2819759 & 26.7795067 \\
\hline 9.0266678 & 18.4912553 & 23.2765397 \\
\hline 4.6610644 & 18.1927514 & 23.4815025 \\
\hline 18.1006754 & 15.4852130 & 17.5523814 \\
\hline 11.8246585 & 19.5239331 & 17.5540233 \\
\hline 11.4488718 & 12.0108461 & 17.3266916 \\
\hline 4.9226921 & 15.7180760 & 27.5762811 \\
\hline 11.5627829 & 19.3867379 & 22.4632166 \\
\hline 11.9005008 & 11.5635550 & 22.5231990 \\
\hline 18.2637456 & 15.8471571 & 22.3561406 \\
\hline 8.9611358 & 15.6460514 & 27.4146085 \\
\hline 16.0695841 & 12.1001554 & 17.5092983 \\
\hline 9.4154722 & 15.4916679 & 17.3869908 \\
\hline 15.7540780 & 19.5674168 & 17.6380848 \\
\hline 9.1225147 & 16.1178177 & 22.3207999 \\
\hline 6.9962182 & 14.6119401 & 16.8612011 \\
\hline 9.3685807 & 13.1273172 & 28.0255202 \\
\hline 13.7755862 & 18.3241326 & 21.9036157 \\
\hline 11.0371635 & 14.3642416 & 22.1551489 \\
\hline 16.4452738 & 14.2045194 & 21.9557896 \\
\hline 16.2655170 & 17.1306676 & 18.0284948 \\
\hline 13.7823453 & 12.8124016 & 18.2718942 \\
\hline 11.3127598 & 17.1409106 & 18.1395976 \\
\hline 4.5157425 & 18.0323560 & 26.7116074 \\
\hline 9.3565021 & 18.0812220 & 26.8801926 \\
\hline 6.9059115 & 17.1768601 & 23.1236826 \\
\hline 5.1534478 & 14.8098477 & 15.1050405 \\
\hline 12.0040501 & 18.9379319 & 20.0059210 \\
\hline 11.6733074 & 12.5210816 & 19.8891602 \\
\hline 17.4334581 & 15.7074589 & 19.9725826 \\
\hline 5.2509622 & 16.2423671 & 25.0110027 \\
\hline 8.7689421 & 14.8567624 & 29.8150972 \\
\hline 15.8010333 & 12.5221317 & 19.9965136 \\
\hline 15.6387916 & 18.7697015 & 20.0394444 \\
\hline 10.1017617 & 15.5742126 & 19.9417585 \\
\hline 8.7577520 & 16.5408723 & 24.9300280 \\
\hline 10.8053224 & 11.9984486 & 19.9816527 \\
\hline 8.5087514 & 11.7834688 & 20.8237720 \\
\hline 8.5852523 & 13.1794542 & 22.4658065 \\
\hline 8.4318950 & 12.1037996 & 22.2869694 \\
\hline 7.5889204 & 12.5690165 & 19.9348560 \\
\hline 7.8124271 & 13.6473520 & 19.9996998 \\
\hline 7.6470010 & 12.2562744 & 18.8848812 \\
\hline 6.5461545 & 12.4544370 & 20.2753122 \\
\hline
\end{tabular}

23.2034576

3.0460094

25.0233443

25.0570357

25.0914019

. 8109965

16.5270585

28.4797919

21.5385895

4

18.4315287

.3631301

26.5204297

5146312

16.4453263

.4938682

18.4201769

5320043

21.5062799

.4219956

(299962

8. 2209798

21.7007741

21.4772238

1.8672221

18.1446660

2434342

6.7795067

23.4815025

17.5523814

7.3266916

27.5762811

22.5231990

22.3561406

27.4146085

092983

7.6380848

22.3207999

16.8612011

55202

22.1551489

1.9557896

18.2718942

18.1395976

23.1236826

15.1050405

20.0059210

9.8891602

25.0110027

29.8150972

19.9965136
20.0394444

19.9417585

24.9300280

20.8237720

22.4658065

19.9348560

18.8848812

20.2753122 


\begin{tabular}{|c|c|c|c|}
\hline $\mathrm{H}$ & 9.1715728 & 11.5453935 & 22.8732552 \\
\hline $\mathrm{C}$ & 9.3344041 & 10.8261836 & 20.3416048 \\
\hline $\mathrm{H}$ & 9.9471424 & 10.2216866 & 21.0141213 \\
\hline $\mathrm{H}$ & 9.3055010 & 10.5358194 & 19.2895541 \\
\hline $\mathrm{H}$ & 7.4229921 & 11.8622216 & 22.6621210 \\
\hline $\mathrm{H}$ & 5.1499481 & 14.8096061 & 29.9089347 \\
\hline $\mathrm{H}$ & 15.9780493 & 19.3419465 & 22.4846985 \\
\hline \multicolumn{4}{|c|}{ Ti 25} \\
\hline \multicolumn{4}{|c|}{171} \\
\hline $\mathrm{H}$ & 8.7134474 & 8.8737480 & 15.0776360 \\
\hline$P$ & 5.4637244 & 9.2244729 & 16.6275348 \\
\hline Al & 5.4206034 & 9.1557413 & 28.4358580 \\
\hline $\mathrm{P}$ & 5.4828838 & 6.6657459 & 21.5459731 \\
\hline Al & 5.5300743 & 6.6417864 & 18.4196997 \\
\hline$P$ & 3.2907192 & 7.7886078 & 26.5831473 \\
\hline Al & 3.4463063 & 7.9718122 & 23.4951014 \\
\hline $\mathrm{P}$ & 8.5410371 & 9.0336340 & 28.3349434 \\
\hline Al & 8.5982592 & 9.1697514 & 16.5323643 \\
\hline $\mathrm{P}$ & 8.6964292 & 6.6038846 & 18.3714702 \\
\hline Al & 8.6687311 & 6.5571199 & 21.5349162 \\
\hline $\mathrm{P}$ & 1.7371917 & 10.6258984 & 23.4238756 \\
\hline Al & 1.6590805 & 10.5439468 & 26.5712916 \\
\hline 0 & 6.9366628 & 9.5991045 & 16.9070836 \\
\hline $\mathrm{O}$ & 4.9680432 & 10.8052411 & 28.0397234 \\
\hline $\mathrm{H}$ & 4.8537927 & 5.3304604 & 21.7418751 \\
\hline $\mathrm{H}$ & 9.2242641 & 5.2007199 & 21.7969902 \\
\hline 0 & 7.2155976 & 6.2363146 & 18.1503268 \\
\hline 0 & 2.2161456 & 8.8873666 & 26.6791085 \\
\hline $\mathrm{H}$ & 2.3677865 & 6.9833425 & 23.2178953 \\
\hline $\mathrm{H}$ & 0.4148836 & 10.0396279 & 23.0704513 \\
\hline 0 & 5.0551571 & 7.9872693 & 17.4277394 \\
\hline 0 & 4.3909047 & 8.0143647 & 27.6242677 \\
\hline 0 & 4.8322140 & 7.7076504 & 22.4675691 \\
\hline 0 & 2.6243121 & 11.6090634 & 27.5533402 \\
\hline 0 & 9.0901884 & 7.8047621 & 17.4991043 \\
\hline 0 & 2.0523054 & 11.8353020 & 22.5416947 \\
\hline 0 & 4.5687581 & 10.3921889 & 17.0585729 \\
\hline 0 & 7.0672554 & 8.8762939 & 27.9492715 \\
\hline 0 & 6.9689497 & 6.5587381 & 21.8960738 \\
\hline $\mathrm{H}$ & 9.5373892 & 5.4439434 & 17.9659541 \\
\hline $\mathrm{H}$ & 4.6902064 & 5.4687089 & 18.0514175 \\
\hline $\mathrm{H}$ & 0.2716675 & 10.5753814 & 27.1109375 \\
\hline $\mathrm{H}$ & 2.6582946 & 6.4733263 & 26.8784339 \\
\hline 0 & 2.8324009 & 9.5751784 & 23.1941637 \\
\hline $\mathrm{H}$ & 5.2718167 & 8.9244330 & 15.1817589 \\
\hline 0 & 5.3037249 & 7.1247388 & 20.0857609 \\
\hline 0 & 3.9253430 & 7.7969653 & 25.1776819 \\
\hline $\mathrm{H}$ & 8.7270017 & 8.8299062 & 29.7981703 \\
\hline 0 & 8.9439010 & 6.9694249 & 19.8480218 \\
\hline 0 & 1.7319438 & 11.0776638 & 24.9015682 \\
\hline $\mathrm{H}$ & 5.2884504 & 8.9502481 & 29.9046769 \\
\hline $\mathrm{H}$ & 3.6183748 & 11.8939366 & 15.0786871 \\
\hline$P$ & 3.3836076 & 15.8372711 & 21.5408068 \\
\hline Al & 3.2870892 & 15.8631015 & 18.3682737 \\
\hline $\mathrm{P}$ & 3.9054486 & 11.8828631 & 28.3431676 \\
\hline Al & 3.9083369 & 11.9207336 & 16.5389352 \\
\hline $\mathrm{P}$ & 1.7023543 & 13.1469958 & 18.3836485 \\
\hline Al & 1.7295087 & 13.1807460 & 21.4749406 \\
\hline $\mathrm{O}$ & 5.1129708 & 13.1541912 & 16.8888610 \\
\hline $\mathrm{H}$ & 0.3080297 & 13.6239571 & 21.4840057 \\
\hline $\mathrm{H}$ & 2.4208475 & 16.9348745 & 21.8331768 \\
\hline 0 & 2.0696100 & 14.6210407 & 18.0964673 \\
\hline 0 & 4.7273055 & 15.5906167 & 17.4147212 \\
\hline 0 & 4.6824996 & 16.0215108 & 22.3394095 \\
\hline $\mathrm{O}$ & 2.4113949 & 12.2283397 & 17.3784264 \\
\hline 0 & 4.4511444 & 13.2492597 & 27.9109994 \\
\hline $\mathrm{O}$ & 2.7765370 & 14.4974084 & 21.9578829 \\
\hline $\mathrm{H}$ & 2.7228006 & 17.1949119 & 18.0147484 \\
\hline $\mathrm{H}$ & 0.2342186 & 12.9730233 & 18.2063580 \\
\hline 0 & 3.7515406 & 15.8389432 & 20.0485769 \\
\hline $\mathrm{H}$ & 3.5787849 & 11.8890970 & 29.7958798 \\
\hline 0 & 2.1306563 & 12.7421536 & 19.8049765 \\
\hline $\mathrm{P}$ & 10.2254158 & 11.8407215 & 16.4020382 \\
\hline Al & 10.1312709 & 11.7563710 & 28.2222761 \\
\hline $\mathrm{P}$ & 12.4637627 & 10.4062473 & 26.7022335 \\
\hline Al & 12.5514746 & 10.3485196 & 23.4563080 \\
\hline $\mathrm{P}$ & 15.6121904 & 10.6258984 & 23.4238756 \\
\hline $\mathrm{P}$ & 10.6512597 & 7.9039935 & 23.4682821 \\
\hline Al & 10.7439112 & 7.8549993 & 26.5586429 \\
\hline
\end{tabular}




\begin{tabular}{|c|c|c|c|}
\hline Al & 15.5340792 & 10.5439468 & 26.5712916 \\
\hline 0 & 9.0042849 & 10.4465628 & 27.9193261 \\
\hline $\mathrm{O}$ & 11.9325992 & 9.0202056 & 27.1296405 \\
\hline $\mathrm{H}$ & 16.0077756 & 9.1352854 & 26.6629729 \\
\hline $\mathrm{H}$ & 11.4194527 & 6.6284991 & 23.4575987 \\
\hline 0 & 14.2398151 & 10.0174296 & 23.0570694 \\
\hline 0 & 11.5966190 & 11.5200517 & 27.3119031 \\
\hline 0 & 9.3437273 & 7.9559178 & 27.5961274 \\
\hline $\mathrm{H}$ & 16.3596691 & 11.4549712 & 27.4112656 \\
\hline 0 & 9.4111507 & 7.7615528 & 22.5719667 \\
\hline 0 & 15.9273041 & 11.8353020 & 22.5416947 \\
\hline 0 & 9.6469296 & 10.5169645 & 16.9281481 \\
\hline 0 & 13.9034224 & 10.5808925 & 27.2055492 \\
\hline $\mathrm{H}$ & 11.3395889 & 6.4928529 & 26.6413813 \\
\hline $\mathrm{H}$ & 16.6745703 & 9.6066741 & 23.2010494 \\
\hline 0 & 11.5312904 & 9.0306258 & 22.9093880 \\
\hline $\mathrm{H}$ & 10.5115082 & 11.7492826 & 14.9436450 \\
\hline $\mathrm{O}$ & 12.4243730 & 10.5159673 & 25.1818963 \\
\hline 0 & 15.6069425 & 11.0776638 & 24.9015682 \\
\hline 0 & 10.2209822 & 8.2227128 & 24.9159385 \\
\hline $\mathrm{H}$ & 10.4621866 & 11.7482990 & 29.6740165 \\
\hline $\mathrm{H}$ & 8.8587332 & 14.8778639 & 14.9223765 \\
\hline$P$ & 5.5308373 & 14.6034784 & 16.5603309 \\
\hline Al & 5.4582967 & 14.5878520 & 28.3911403 \\
\hline $\mathrm{P}$ & 12.4203831 & 18.6818473 & 21.5459731 \\
\hline $\mathrm{Ti}$ & 12.2300229 & 13.2088691 & 21.6779563 \\
\hline $\mathrm{P}$ & 17.2586063 & 15.8372711 & 21.5408068 \\
\hline Al & 17.1620879 & 15.8631015 & 18.3682737 \\
\hline $\mathrm{Al}$ & 12.3437736 & 13.1438522 & 18.2843288 \\
\hline Al & 12.4675736 & 18.6578878 & 18.4196997 \\
\hline $\mathrm{P}$ & 5.4291042 & 17.0772257 & 26.5148495 \\
\hline $\mathrm{Al}$ & 5.3795174 & 17.1267073 & 23.4800797 \\
\hline $\mathrm{P}$ & 8.6153163 & 14.5295994 & 28.2156909 \\
\hline Al & 8.6935744 & 14.6118648 & 16.3780852 \\
\hline $\mathrm{P}$ & 15.5773530 & 13.1469958 & 18.3836485 \\
\hline $\mathrm{P}$ & 15.6339285 & 18.6199860 & 18.3714702 \\
\hline $\mathrm{P}$ & 10.8366355 & 15.9290731 & 18.2862622 \\
\hline $\mathrm{Al}$ & 10.5834130 & 16.0571800 & 21.4491638 \\
\hline $\mathrm{Al}$ & 15.6062304 & 18.5732213 & 21.5349162 \\
\hline Al & 15.6045074 & 13.1807460 & 21.4749406 \\
\hline $\mathrm{P}$ & 8.5039506 & 17.4225025 & 23.2882430 \\
\hline $\mathrm{Al}$ & 8.5630029 & 17.1189032 & 26.4075933 \\
\hline 0 & 9.2082651 & 12.9607822 & 16.7022686 \\
\hline 0 & 7.1246277 & 14.1858756 & 28.0351454 \\
\hline 0 & 11.7727325 & 17.3071681 & 21.7476546 \\
\hline $\mathrm{O}$ & 13.9460128 & 13.6978575 & 21.4855172 \\
\hline 0 & 16.2609402 & 16.9746695 & 21.8437770 \\
\hline $\mathrm{O}$ & 15.9446087 & 14.6210407 & 18.0964673 \\
\hline 0 & 11.9039493 & 14.8264320 & 18.0996802 \\
\hline 0 & 14.1530969 & 18.2524160 & 18.1503268 \\
\hline 0 & 6.8864461 & 17.5202202 & 26.7711240 \\
\hline $\mathrm{H}$ & 9.0979380 & 18.7830449 & 23.1732479 \\
\hline $\mathrm{H}$ & 4.6219134 & 18.4084141 & 23.4604661 \\
\hline $\mathrm{H}$ & 18.3884609 & 15.6310752 & 17.5563047 \\
\hline $\mathrm{H}$ & 12.0606439 & 19.8107562 & 17.5697448 \\
\hline $\mathrm{O}$ & 11.5538376 & 12.1166954 & 17.1197213 \\
\hline 0 & 4.9875825 & 16.0274189 & 27.5380292 \\
\hline $\mathrm{H}$ & 11.7894867 & 19.6920890 & 22.4395624 \\
\hline 0 & 11.9733355 & 11.8051112 & 22.7447267 \\
\hline $\mathrm{H}$ & 18.5178775 & 16.0158908 & 22.3150493 \\
\hline 0 & 9.0212618 & 15.6932752 & 27.3057838 \\
\hline $\mathrm{H}$ & 16.2650120 & 12.2560423 & 17.4087395 \\
\hline 0 & 9.6823305 & 15.7180474 & 17.2950891 \\
\hline $\mathrm{H}$ & 16.0157298 & 19.7843944 & 17.5255969 \\
\hline 0 & 9.0748731 & 16.4935806 & 22.2151689 \\
\hline 0 & 7.0244778 & 14.7752953 & 16.8751172 \\
\hline 0 & 9.4421641 & 13.3028855 & 27.8137447 \\
\hline 0 & 13.9064491 & 18.5748395 & 21.8960738 \\
\hline 0 & 11.1356554 & 14.5627724 & 22.1008522 \\
\hline 0 & 16.6515357 & 14.4974084 & 21.9578829 \\
\hline 0 & 16.5003318 & 17.4249508 & 17.9536852 \\
\hline 0 & 14.0631363 & 12.9675628 & 18.2007933 \\
\hline $\mathrm{O}$ & 11.4844917 & 17.2847772 & 17.9886181 \\
\hline $\mathrm{H}$ & 4.5247381 & 18.2522074 & 26.6514534 \\
\hline $\mathrm{H}$ & 9.4301757 & 18.2578447 & 26.8174031 \\
\hline 0 & 7.0010321 & 17.5435182 & 23.0396141 \\
\hline $\mathrm{H}$ & 5.2704292 & 14.9001849 & 15.1246174 \\
\hline 0 & 12.2412243 & 19.1408402 & 20.0857609 \\
\hline 0 & 11.7104824 & 12.5850053 & 19.8642739 \\
\hline $\mathrm{O}$ & 17.6265393 & 15.8389432 & 20.0485769 \\
\hline
\end{tabular}




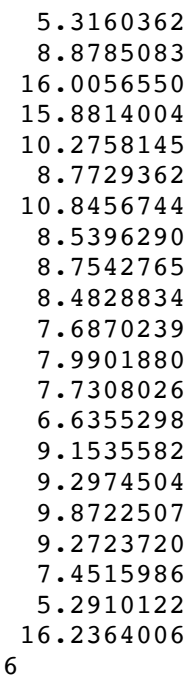

16.4620868

14.9112335

12.7421536

18.9855263

15.8997396

16.8284002

12.0759619

11.9369246

13.3543505

2.2976998

12.7688168

13.8291072

12.4279529

12.7428757

11.6772904

10.9148806

10.2883897

10.6175645

12.1789241

14.8622692

19.5955510

8.9684426

9.4045695

9.3975459

6.8516494

6.8671052

8.1733693

8.2701741

9.3647812

9.4036735

6.8399226

6.7927990

10.8897591

10.8781799

9.7983473

10.8469053

5.4104153

5.3907314

6.4779075

9.4139888

7.3314861

10.3122870

7.9769837

8.3985319

7.8536948

11.8135224

8.2657972

12.3233691

10.7406225

9.2160425

6.9778958

5.6772503

5.6778376

10.9935325

6.8437648

9.6737127

.1458086

7.3786448

8.2713759

9.0168040

7.1251527

11.3153256

9.1109898

12.0824103

16.1523511

16.1664462

12.0957383

12.0889850

13.3803354

13.4924355

13.1926128

14.1728099

17.1702087

15.0403782

15.9339158

16.4940149

12.3204636
25.1031743

29.6306841

19.8049765

19.8480218

19.7164277

24.6888065

19.9214975

20.8281835

22.4398145

22.2838086

19.9134924

19.9545261

18.8716532

20.2447333

22.8914461

20.3732043

21.0594769

19.3229328

22.6565148

29.8450426

22.4151708

15.2519059

16.6228212

28.4326237

21.5544672

18.4400687

26.6040257

23.4952980

28.5222122

16.6695885

18.4802644

21.6785486

23.5392695

26.6837309

16.9846050

28.1226951

21.6245955

21.9589677

18.1527667

26.8908825

23.3973929

23.3933473

17.4838945

27.6448351

22.5608591

27.6095369

17.5915470

22.5863111

17.0966342

28.0157322

22.0580140

18.0429580

18.2018023

27.0451410

26.9241570

23.0871346

15.1615907

19.8844106

24.9431997

29.9665545

20.1890199

25.2301573

29.8836001

15.2128907

21.5965506

18.4095643

28.4771200

16.6663545

18.5622891

21.5970731

16.9759602

21.5411444

21.9115399

18.2020379

17.5504860

22.4805714

17.4455995 


\begin{tabular}{|c|c|c|c|}
\hline 0 & 4.5525837 & 13.6405001 & 28.0084733 \\
\hline $\mathrm{O}$ & 2.8623671 & 14.5244178 & 22.0385883 \\
\hline $\mathrm{H}$ & 2.6052226 & 17.4559659 & 17.9814413 \\
\hline $\mathrm{H}$ & 0.2581624 & 13.2186913 & 18.3901199 \\
\hline $\mathrm{O}$ & 3.6468718 & 16.2310968 & 19.8814815 \\
\hline $\mathrm{H}$ & 3.5775695 & 12.0842141 & 29.9321180 \\
\hline 0 & 2.1780206 & 12.9447480 & 20.1911356 \\
\hline Al & 10.1918984 & 12.1602524 & 16.5034723 \\
\hline $\mathrm{P}$ & 10.1700548 & 12.1534011 & 28.3988438 \\
\hline Al & 12.3588327 & 10.8291034 & 26.5608579 \\
\hline $\mathrm{P}$ & 12.4610996 & 10.7331413 & 23.4397719 \\
\hline Al & 15.5274474 & 10.8897591 & 23.5392695 \\
\hline Al & 10.7526918 & 8.0829399 & 23.5533682 \\
\hline $\mathrm{P}$ & 10.7884411 & 8.0776080 & 26.6542839 \\
\hline $\mathrm{P}$ & 15.5042263 & 10.8781799 & 26.6837309 \\
\hline $\mathrm{O}$ & 9.1350245 & 11.0213061 & 28.2533331 \\
\hline $\mathrm{O}$ & 11.8462982 & 9.1781327 & 26.8633149 \\
\hline $\mathrm{H}$ & 15.9292707 & 9.4652059 & 26.8836363 \\
\hline $\mathrm{H}$ & 11.7705442 & 7.0068812 & 23.4010698 \\
\hline $\mathrm{O}$ & 13.9187703 & 10.2090386 & 23.3672573 \\
\hline 0 & 11.3683598 & 11.9330077 & 27.4785942 \\
\hline 0 & 9.6287342 & 8.2512639 & 27.6423611 \\
\hline $\mathrm{H}$ & 16.2679359 & 11.7866433 & 27.5829319 \\
\hline $\mathrm{O}$ & 9.3936446 & 7.7809550 & 22.5118521 \\
\hline 0 & 15.7175147 & 12.3233691 & 22.5863111 \\
\hline $\mathrm{O}$ & 9.5056963 & 10.6204883 & 16.9330350 \\
\hline $\mathrm{O}$ & 14.0215010 & 10.9969666 & 27.0559003 \\
\hline $\mathrm{H}$ & 11.4208465 & 6.7553269 & 26.9164993 \\
\hline $\mathrm{H}$ & 16.5279296 & 9.8560994 & 23.1549473 \\
\hline $\mathrm{O}$ & 11.5138648 & 9.5692299 & 23.1039334 \\
\hline $\mathrm{H}$ & 10.6127786 & 12.1966257 & 15.0756567 \\
\hline $\mathrm{O}$ & 12.1745694 & 11.2356657 & 24.8772909 \\
\hline $\mathrm{O}$ & 15.7519761 & 11.3153256 & 25.2301573 \\
\hline 0 & 10.2182179 & 8.1392418 & 25.2241916 \\
\hline $\mathrm{H}$ & 10.6653293 & 12.2009931 & 29.8022534 \\
\hline $\mathrm{H}$ & 8.8180171 & 15.2655547 & 15.1917196 \\
\hline Al & 5.4076013 & 14.8281108 & 16.5953929 \\
\hline$P$ & 5.4022102 & 14.8416085 & 28.4381264 \\
\hline Al & 12.3729414 & 18.8677508 & 21.5544672 \\
\hline $\mathrm{Zn}$ & 12.5683522 & 13.6240151 & 21.9634918 \\
\hline Al & 17.1698543 & 16.1523511 & 21.5965506 \\
\hline $\mathrm{P}$ & 17.0892945 & 16.1664462 & 18.4095643 \\
\hline $\mathrm{P}$ & 12.3594660 & 13.3947984 & 18.3784072 \\
\hline$P$ & 12.3516677 & 18.8832066 & 18.4400687 \\
\hline Al & 5.4974853 & 17.3572478 & 26.5613981 \\
\hline$P$ & 5.5012623 & 17.3912167 & 23.4640594 \\
\hline Al & 8.5779533 & 14.8866768 & 28.4675180 \\
\hline $\mathrm{P}$ & 8.5869030 & 14.8881430 & 16.6134324 \\
\hline Al & 15.6033140 & 13.3803354 & 18.5622891 \\
\hline Al & 15.5007387 & 18.8560240 & 18.4802644 \\
\hline Al & 10.7941165 & 16.0855118 & 18.5035789 \\
\hline $\mathrm{P}$ & 10.7993318 & 16.1393904 & 21.6456046 \\
\hline $\mathrm{P}$ & 15.5090989 & 18.8089004 & 21.6785486 \\
\hline $\mathrm{P}$ & 15.6787242 & 13.4924355 & 21.5970731 \\
\hline Al & 8.6405601 & 17.6067387 & 23.4901685 \\
\hline$P$ & 8.6669528 & 17.4188027 & 26.6010734 \\
\hline 0 & 9.0448283 & 13.4312742 & 16.8513158 \\
\hline $\mathrm{O}$ & 6.8886058 & 14.5040903 & 28.2110170 \\
\hline $\mathrm{O}$ & 11.9430958 & 17.1819563 & 21.6364955 \\
\hline $\mathrm{O}$ & 14.3177906 & 14.1921672 & 21.5395532 \\
\hline $\mathrm{O}$ & 15.9396702 & 17.3561944 & 21.9690955 \\
\hline 0 & 16.0516387 & 15.0403782 & 18.2020379 \\
\hline $\mathrm{O}$ & 11.9894072 & 14.8423437 & 18.0552257 \\
\hline $\mathrm{O}$ & 13.8162690 & 18.4940089 & 18.1527667 \\
\hline $\mathrm{O}$ & 7.1819753 & 17.7683965 & 26.8339105 \\
\hline $\mathrm{H}$ & 8.9803512 & 19.0541412 & 23.4083855 \\
\hline $\mathrm{H}$ & 5.0205817 & 18.7978496 & 23.3777420 \\
\hline $\mathrm{H}$ & 18.3018669 & 15.9406625 & 17.5754118 \\
\hline $\mathrm{H}$ & 11.9125731 & 19.9611346 & 17.5114203 \\
\hline 0 & 11.6451695 & 12.3976393 & 17.4696280 \\
\hline $\mathrm{O}$ & 4.9918787 & 16.0530131 & 27.5985640 \\
\hline $\mathrm{H}$ & 11.5155905 & 19.7267197 & 22.4171620 \\
\hline 0 & 12.2000370 & 11.8373009 & 22.4377746 \\
\hline $\mathrm{H}$ & 18.4178605 & 16.4451347 & 22.3540986 \\
\hline $\mathrm{O}$ & 9.0790895 & 16.2381876 & 27.4902100 \\
\hline $\mathrm{H}$ & 16.3063835 & 12.4767511 & 17.6102653 \\
\hline $\mathrm{O}$ & 9.3785692 & 15.8468993 & 17.5097159 \\
\hline $\mathrm{H}$ & 15.9211858 & 20.0682470 & 17.7247115 \\
\hline $\mathrm{O}$ & 9.5639026 & 16.7322550 & 22.3298456 \\
\hline $\mathrm{O}$ & 7.1022956 & 15.0006208 & 16.9720735 \\
\hline
\end{tabular}


9.5109501

14.0379482
11.2298718

16.7373658

16.4616989

13.8575989

11.4621295

4.6438749

9.4984021

6.9768961

5.1866597

12.2064305

17.5218705

5.2992456

8.7882258

16.0530194

15.7270077

10.4071910

8.9093191

11.8830380

9.5957012

9.9515507

10.4604172

8.9980494

6.9097608

7.0888953

8.1046039

8.9332154

8.7644345

7.7398667

6.1075218

7.5752656

6.4423699

8.2616214

9.7174871

10.9370341

5.1567071 26

$\mathrm{H} \quad 8.7065960$

P $\quad 5.4474900$

Al $\quad 5.4416144$

$\mathrm{P} \quad 5.5239886$

Al $\quad 5.5014651$

P $\quad 3.2898630$

Al $\quad 3.3084212$

$\mathrm{P} \quad 8.5739671$

Al 8.5873070

P $\quad 8.6681840$

Al 8.6572939

$\mathrm{P} \quad 1.7279104$

Al $\quad 1.7105078$

O 6.9255215

4.9399071

5.1634625

9.0600950

7.1804539

2.2445262

2.1827635

0.3597406

5.0055119

4.4689791

4.6619997

2.6273700

9.0993520

1.9747518

4.5764643

7.1077487

6.9904252

9.4837940

4.6481141

0.2866355

2. 6570564

2.7526743

5. 2668979

5. 3220225

3.8253971

8.7221137
13.4829977

18.9939972

14.8846302

14.5244178

17.4951811

13.1883932

17.6583729

18.5371423

18.5981843

17.3587800

15.1193237

19.3947462

16.2310968

16.8507805

15.2189006

2.9447480

19.1412540

15.8294415

7.0306349

13.0540825

10.5868387

10.5423405

10.5234059

9.6773724

13.2897448

14.0031466

13.6244663

12.5419510

11.8150291

12.2135543

13.5647068

11.6578838

14.8477810

14.1714614

12.2449913

12.7888412

15.1590089

19.7694065

8.9921846

9.4470752

9.4253403

6.9192742

6.8943655

8.0725406

8.1572120

9.3333990

9. 3613182

6.8083107

6.8030742

10.8452711

10.8414475

9.7876347

11.0580374

5.4788106

5.3990125

6.4879893

9. 1889346

7.1969618

10.2893369

8. 2143164

8.2669966

7.7808242

11.9449198

8.0252519

12.0412421

10.6331909

9.2374428

7.0895765

5.6400094

5.7156150

10.9331451

6.7651314

9.7556341

9.1617949

7.4053339

8.0818982

8.9418747
28.0234381

22.0580140

22.3874874

22.0385883

17.9684218

18.3578488

18.1946768

26. 8717505

26.9683222

23.0709310

15.1519593

19.8844106

19.8814815

24.8942046

29.9036703

20.1911356

20.1890199

20.1775927

25.1295535

19.8787802

20.3508917

19.3126541

21.0224016

20.5079529

20.0597839

21.2485832

22.1253691

21.8173047

20.6270753

19.7478184

19.3735945

18.8221869

21.4887985

23.0566478

22.5158956

19.9789638

29.8720391

22.4885352

15.1612692

16.6794139

28.4864188

21.6052701

18.4906345

26.6679444

23.5475104

28.4522476

16.5988474

18.4245889

21.6144007

23.4796835

26.6161724

16.9771084

28.0952733

21.7157514

21.9033343

18.1830026

26.8550769

23.3803731

23.2895016

17.4707163

27.6277697

22.5285323

27.6012809

17.5936307

22.5637255

17.1106003

28.0212078

22.0222690

17.9921852

18.1752618

27.0419655

26.9955989

23.1360486

15.2291994

20.1549710

25.2238313

29.8811919 


\begin{tabular}{|c|c|c|c|}
\hline 0 & 8.9194967 & 7.1186404 & 19.9096857 \\
\hline 0 & 1.9064859 & 11.3059420 & 24.9410874 \\
\hline $\mathrm{H}$ & 5.2878092 & 9.1929975 & 29.9491154 \\
\hline $\mathrm{H}$ & 3.5945056 & 12.1304002 & 15.1383150 \\
\hline $\mathrm{P}$ & 3.2552277 & 16.0832496 & 21.6609621 \\
\hline Al & 3.2283110 & 16.0833007 & 18.4736622 \\
\hline $\mathrm{P}$ & 3.9062696 & 12.1561597 & 28.4135507 \\
\hline Al & 3.8972255 & 12.1552031 & 16.5960070 \\
\hline $\mathrm{P}$ & 1.6935886 & 13.3537619 & 18.4551660 \\
\hline Al & 1.6773847 & 13.3944974 & 21.5108691 \\
\hline 0 & 5.0948421 & 13.4002430 & 16.9232682 \\
\hline $\mathrm{H}$ & 0.2488468 & 13.8062059 & 21.4278267 \\
\hline $\mathrm{H}$ & 2.2319715 & 17.1272195 & 21.9441483 \\
\hline $\mathrm{O}$ & 2.0237003 & 14.8362058 & 18.1687670 \\
\hline $\mathrm{O}$ & 4.6949043 & 15.8014413 & 17.5677635 \\
\hline $\mathrm{O}$ & 4.5238423 & 16.3425922 & 22.4832406 \\
\hline $\mathrm{O}$ & 2.3933168 & 12.4514677 & 17.4309373 \\
\hline 0 & 4.4992747 & 13.5142477 & 28.0268207 \\
\hline $\mathrm{O}$ & 2.6968019 & 14.7149959 & 22.0544567 \\
\hline $\mathrm{H}$ & 2.6668086 & 17.3962393 & 18.0517286 \\
\hline $\mathrm{H}$ & 0.2254539 & 13.1511429 & 18.3114762 \\
\hline $\mathrm{O}$ & 3.6431260 & 16.1096402 & 20.1701431 \\
\hline $\mathrm{H}$ & 3.5541313 & 12.1270989 & 29.8600205 \\
\hline 0 & 2.1637948 & 12.9585859 & 19.8638575 \\
\hline$P$ & 10.2068131 & 12.1048624 & 16.5918168 \\
\hline Al & 10.2081817 & 12.0835096 & 28.4698418 \\
\hline $\mathrm{P}$ & 12.4487539 & 10.8021346 & 26.7146589 \\
\hline Al & 12.5161989 & 10.7862079 & 23.5187837 \\
\hline $\mathrm{P}$ & 15.6029091 & 10.8452711 & 23.4796835 \\
\hline$P$ & 10.8158177 & 8.1794434 & 23.4670954 \\
\hline Al & 10.8035799 & 8.1509787 & 26.6134371 \\
\hline Al & 15.5855065 & 10.8414475 & 26.6161724 \\
\hline 0 & 9.0565368 & 10.7825843 & 28.2428014 \\
\hline 0 & 11.9859761 & 9.3685534 & 27.0519035 \\
\hline $\mathrm{H}$ & 16.0390993 & 9.4378108 & 26.8190967 \\
\hline $\mathrm{H}$ & 11.8185229 & 7.0863189 & 23.3375509 \\
\hline 0 & 14.1849645 & 10.2691118 & 23.2825827 \\
\hline 0 & 11.6345026 & 11.8292337 & 27.5130459 \\
\hline $\mathrm{O}$ & 9.3809344 & 8.3535977 & 27.5973836 \\
\hline $\mathrm{H}$ & 16.3699628 & 11.7855651 & 27.4590193 \\
\hline $\mathrm{O}$ & 9.6002511 & 7.9041488 & 22.5780775 \\
\hline 0 & 15.8497505 & 12.0412421 & 22.5637255 \\
\hline 0 & 9.6040989 & 10.7392230 & 16.9342462 \\
\hline 0 & 13.9198868 & 10.9487136 & 27.1142573 \\
\hline $\mathrm{H}$ & 11.3793248 & 6.8030299 & 26.8754910 \\
\hline $\mathrm{H}$ & 16.5971090 & 9.7881330 & 23.1462977 \\
\hline $\mathrm{O}$ & 11.4531247 & 9.4916364 & 22.9969741 \\
\hline $\mathrm{H}$ & 10.6807709 & 12.1382607 & 15.1806580 \\
\hline 0 & 12.2504176 & 11.0834297 & 25.2233123 \\
\hline 0 & 15.7814847 & 11.3059420 & 24.9410874 \\
\hline 0 & 10.3465663 & 8.3011483 & 24.9287408 \\
\hline $\mathrm{H}$ & 10.6213768 & 12.1308259 & 29.8995801 \\
\hline $\mathrm{H}$ & 8.8997738 & 15.1821324 & 15.1169018 \\
\hline $\mathrm{P}$ & 5.4862748 & 14.8680495 & 16.6453901 \\
\hline Al & 5.4674035 & 14.8764106 & 28.5096383 \\
\hline $\mathrm{P}$ & 12.4614879 & 18.9353756 & 21.6052701 \\
\hline $\mathrm{Si}$ & 12.3761204 & 13.5012828 & 21.7575006 \\
\hline$P$ & 17.1302264 & 16.0832496 & 21.6609621 \\
\hline Al & 17.1033097 & 16.0833007 & 18.4736622 \\
\hline Al & 12.3539889 & 13.4219868 & 18.4840976 \\
\hline Al & 12.4389645 & 18.9104669 & 18.4906345 \\
\hline $\mathrm{P}$ & 5.4342455 & 17.3916079 & 26.6297946 \\
\hline Al & 5.4372398 & 17.4110604 & 23.5057395 \\
\hline $\mathrm{P}$ & 8.6490898 & 14.8310339 & 28.4225710 \\
\hline Al & 8.6679905 & 14.8616987 & 16.5524224 \\
\hline $\mathrm{P}$ & 15.5685873 & 13.3537619 & 18.4551660 \\
\hline $\mathrm{P}$ & 15.6056833 & 18.8244121 & 18.4245889 \\
\hline $\mathrm{P}$ & 10.8417504 & 16.1596909 & 18.4434691 \\
\hline Al & 10.8452770 & 16.2151216 & 21.5989374 \\
\hline Al & 15.5947932 & 18.8191756 & 21.6144007 \\
\hline Al & 15.5523834 & 13.3944974 & 21.5108691 \\
\hline $\mathrm{P}$ & 8.5715912 & 17.5384737 & 23.4348673 \\
\hline Al & 8.5815258 & 17.3845550 & 26.5676754 \\
\hline 0 & 9.1440587 & 13.1924796 & 16.8359620 \\
\hline 0 & 7.1560787 & 14.4877375 & 28.2594626 \\
\hline 0 & 12.0899287 & 17.4508296 & 21.7191325 \\
\hline 0 & 13.8951489 & 13.8721169 & 21.4145323 \\
\hline 0 & 16.0691029 & 17.1658534 & 21.9546281 \\
\hline 0 & 15.8986990 & 14.8362058 & 18.168767 \\
\hline & & & \\
\hline
\end{tabular}




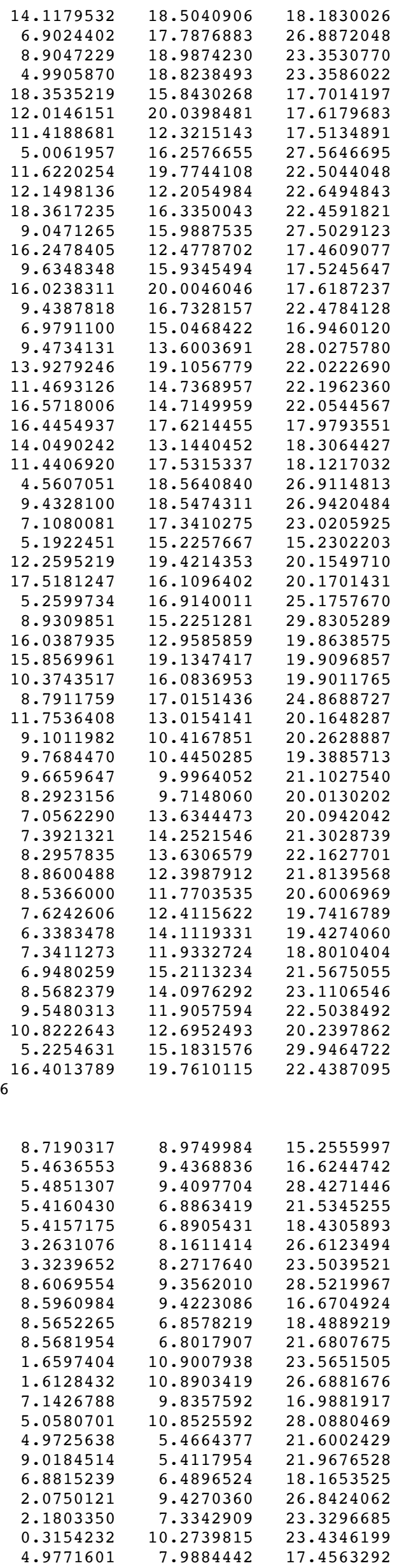

7.9884442

18.1830026

26.8872048

23.3530770

23.3586022

17.7014197

17.6179683

17.5134891

27.5646695

22.5044048

22.6494843

22.4591821

27.5029123

17.4609077

17.5245647

17.6187237

22.4784128

16.9460120

28.0275780

22.0222690

22.1962360

22.0544567

17.9793551

18.3064427

18.1217032

26.9114813

26.9420484

23.0205925

15.2302203

20.1549710

20.1701431

25.1757670

29.8305289

19.8638575

19.9096857

19.9011765

24.8688727

20.1648287

20.2628887

19.3885713

21.1027540

20.0130202

20.0942042

21.3028739

22.1627701

21.8139568

20.6006969

19.7416789

19.4274060

18.8010404

21.5675055

23.1106546

22.5038492

20.2397862

29.9464722

22.4387095

15.2555997

16.6244742

28.4271446

21.5345255

18.4305893

26.6123494

23.5039521

28.5219967

16.6704924

18.4889219

21.6807675

23.5651505

26.6881676

16.9881917

28.0880469

21.6002429

21.9676528

18.1653525

26.8424062

23.3296685

23.4346199

17.4563292 


\begin{tabular}{|c|c|c|}
\hline 4.6307450 & 8.3948431 & $\begin{array}{l}27.6650758 \\
22.5640283\end{array}$ \\
\hline & & \\
\hline 2.3865379 & 11.8054720 & 27.6438623 \\
\hline 9.0459466 & 8.2888739 & 17.5990531 \\
\hline 1.8806360 & 12.2903239 & 22.5590499 \\
\hline 4.4300944 & 10.7526730 & 17.1214194 \\
\hline 6.9480193 & 9.2191680 & 28.0110253 \\
\hline 7.0859517 & 6.9399555 & 22.0275703 \\
\hline 9.3847914 & 5.6944618 & 18.0507128 \\
\hline 4.5506188 & 5.7020207 & 18.1936517 \\
\hline 0.1744461 & 10.9715409 & 27.0643868 \\
\hline 2.6462864 & 6.8513944 & 26.9605087 \\
\hline 2.8614752 & 9.6937639 & 23.1711539 \\
\hline 5.3345628 & 9.1919115 & 15.1614485 \\
\hline 5.2601870 & 7.4233466 & 19.8657941 \\
\hline 3.8368831 & 8.1879209 & 24.9567285 \\
\hline 8.7052969 & 9.0209387 & 29.9694251 \\
\hline 8.8082267 & 7.1448418 & 20.1959230 \\
\hline 1.8444123 & 11.3828919 & 25.2495297 \\
\hline 5.3180067 & 9.1584216 & 29.8852303 \\
\hline 3.5657959 & 12.0936324 & 15.2142022 \\
\hline 3.2916765 & 16.1422055 & 21.5976204 \\
\hline 3.2065541 & 16.17 & 18.4084512 \\
\hline 3.8829571 & 12.0978631 & 28.4722535 \\
\hline 3.8496902 & 12.1022356 & 16.6758624 \\
\hline 1.7258526 & 13.3939333 & 18.5591687 \\
\hline 1.7946921 & 13.4663250 & 21.5771598 \\
\hline 4.8785381 & 13.20 & 128928 \\
\hline 0.433 & 14.06 & 5016764 \\
\hline 2.2813734 & 17.1876866 & 21.9191439 \\
\hline 2.1619406 & 15.0571162 & 18.1918652 \\
\hline 4.4533490 & 15.9463546 & 17.5443148 \\
\hline 4.7644078 & 16.440 & 22.4766886 \\
\hline 2.52 & 12.33 & 17.4178018 \\
\hline 4.5200580 & 13.6458066 & 27.9883935 \\
\hline 2.8103460 & 14.5328153 & 22.0424019 \\
\hline 2.6054163 & 17.4725704 & 17.9888263 \\
\hline 0.2525025 & 13.23 & 18.4123768 \\
\hline 3.639 & 16.22 & 19.8803974 \\
\hline 3.6052971 & 12.09 & 351311 \\
\hline 2.2187963 & 12.9461523 & 20.1700133 \\
\hline 0.1834617 & 12.1775895 & 16.4875522 \\
\hline 0.1568574 & 12.15 & 28.3826092 \\
\hline 2.3450826 & 10.77 & 26.5956179 \\
\hline 2.4841782 & 10.67 & 23.4561678 \\
\hline 15.5347392 & 10.9007938 & 23.5651505 \\
\hline .7217416 & 8.0914150 & 23.5583814 \\
\hline .7605853 & 8.0763208 & 26.6680836 \\
\hline 5.4878420 & 10.89 & 26.6881676 \\
\hline 9.1312687 & 11.008 & 28.2512920 \\
\hline 11.8346083 & 9.1395117 & 26.9740202 \\
\hline 15.9340421 & 9.4775956 & 26.8370770 \\
\hline 11.6706871 & 6.9502896 & 23.4381500 \\
\hline 3.9486617 & 10.16 & 454 \\
\hline 1.35 & 11.9260421 & 27.4671857 \\
\hline 9.5856936 & 8.2179439 & 27.6450951 \\
\hline 16.2394372 & 11.7793327 & 27.6165643 \\
\hline 9.3400969 & 7.8128383 & 22.5364818 \\
\hline 15.7556348 & 12.29 & 22.5590499 \\
\hline 9.5094456 & 10.6342 & 16.9218107 \\
\hline 14.0068381 & 10.9739461 & 27.0755308 \\
\hline 11.3579350 & 6.7254425 & 26.8562900 \\
\hline 16.5582768 & 9.8727462 & 23.2295770 \\
\hline 11.5581473 & 9.5143953 & 23.0352593 \\
\hline 0.5994108 & 12.21 & 15.0583699 \\
\hline 2.1344549 & 11.0962352 & 24.9036844 \\
\hline 15.7194110 & 11.3828919 & 25.2495297 \\
\hline 10.2208081 & 8.2427134 & 25.2344558 \\
\hline 10.6502903 & 12.2208231 & 29.7857109 \\
\hline 8.7787846 & 15.2554481 & 15.1589180 \\
\hline 5.4006919 & 14.8311693 & 16.602589 \\
\hline 5.3810811 & 14.8339175 & 28.429688 \\
\hline 12.3535423 & 18.9024433 & 21.5345255 \\
\hline & 13.5561365 & 21.8217182 \\
\hline 17.1666752 & 16.1422055 & 21.5976204 \\
\hline 7.0815528 & 16.1765500 & 18.4084512 \\
\hline & 13.4198029 & 18.370543 \\
\hline 12.3532168 & 18.9066445 & 18.430589 \\
\hline 5.4670526 & 17.3402381 & 26.5522886 \\
\hline 5.4718754 & 17.3611930 & 23.472306 \\
\hline
\end{tabular}




\begin{tabular}{|c|c|c|c|}
\hline Al & 8.5498544 & 14.8752384 & 28.4349273 \\
\hline $\mathrm{P}$ & 8.5748082 & 14.9024134 & 16.5910077 \\
\hline $\mathrm{Al}$ & 15.6008514 & 13.3939333 & 18.5591687 \\
\hline Al & 15.5027259 & 18.8739233 & 18.4889219 \\
\hline Al & 10.7686296 & 16.1208604 & 18.4850429 \\
\hline $\mathrm{P}$ & 10.7411446 & 16.1582043 & 21.6168268 \\
\hline $\mathrm{P}$ & 15.5056947 & 18.8178920 & 21.6807675 \\
\hline $\mathrm{P}$ & 15.6696908 & 13.4663250 & 21.5771598 \\
\hline $\mathrm{Al}$ & 8.6173526 & 17.6293791 & 23.4747531 \\
\hline $\mathrm{P}$ & 8.6286295 & 17.4362526 & 26.6051165 \\
\hline 0 & 9.0430637 & 13.4508780 & 16.8463107 \\
\hline 0 & 6.8618179 & 14.4924521 & 28.1733754 \\
\hline 0 & 11.8372474 & 17.2494018 & 21.6110332 \\
\hline 0 & 14.2791893 & 14.0766767 & 21.5000788 \\
\hline 0 & 15.9719378 & 17.3785429 & 21.9778391 \\
\hline 0 & 16.0369393 & 15.0571162 & 18.1918652 \\
\hline 0 & 11.9766128 & 14.8689638 & 18.0687507 \\
\hline 0 & 13.8190232 & 18.5057537 & 18.1653525 \\
\hline 0 & 7.1423375 & 17.7770406 & 26.8435402 \\
\hline $\mathrm{H}$ & 9.0064849 & 19.0608697 & 23.3461785 \\
\hline $\mathrm{H}$ & 4.9070265 & 18.7378875 & 23.4195921 \\
\hline $\mathrm{H}$ & 18.2914995 & 15.9531579 & 17.5698538 \\
\hline $\mathrm{H}$ & 11.9269578 & 19.9737575 & 17.4836501 \\
\hline 0 & 11.6393155 & 12.4263182 & 17.4556688 \\
\hline 0 & 4.9621687 & 16.0627497 & 27.6211677 \\
\hline $\mathrm{H}$ & 11.5496253 & 19.7914573 & 22.4179800 \\
\hline 0 & 12.2729611 & 11.8345579 & 22.5217988 \\
\hline $\mathrm{H}$ & 18.4262616 & 16.3977345 & 22.3494632 \\
\hline 0 & 9.0430693 & 16.2330133 & 27.4636169 \\
\hline $\mathrm{H}$ & 16.2819048 & 12.4951711 & 17.5867936 \\
\hline 0 & 9.3823070 & 15.8789153 & 17.4525434 \\
\hline $\mathrm{H}$ & 15.9111923 & 20.0898839 & 17.7328031 \\
\hline 0 & 9.4943901 & 16.6770906 & 22.3413960 \\
\hline 0 & 7.0965826 & 15.0128048 & 16.9782404 \\
\hline 0 & 9.4876722 & 13.4721439 & 27.9941368 \\
\hline 0 & 14.0234511 & 18.9560569 & 22.0275703 \\
\hline 0 & 11.2615520 & 14.9086940 & 22.2835722 \\
\hline 0 & 16.6853447 & 14.5328153 & 22.0424019 \\
\hline 0 & 16.4620330 & 17.5122011 & 17.9759947 \\
\hline 0 & 13.8421631 & 13.2059089 & 18.3839482 \\
\hline $\mathrm{O}$ & 11.4623698 & 17.6827474 & 18.1865996 \\
\hline $\mathrm{H}$ & 4.5841185 & 18.5095969 & 26.8171435 \\
\hline $\mathrm{H}$ & 9.4537201 & 18.6082603 & 27.0085321 \\
\hline 0 & 6.9435660 & 17.4271612 & 23.0701800 \\
\hline $\mathrm{H}$ & 5.1881281 & 15.0913205 & 15.1519833 \\
\hline $\mathrm{O}$ & 12.1976863 & 19.4394480 & 19.8657941 \\
\hline 0 & 17.5145953 & 16.2253636 & 19.8803974 \\
\hline $\mathrm{O}$ & 5.3127339 & 16.7854729 & 24.8948381 \\
\hline $\mathrm{H}$ & 8.7498042 & 15.2077141 & 29.8724948 \\
\hline 0 & 16.0937950 & 12.9461523 & 20.1700133 \\
\hline 0 & 15.7457260 & 19.1609432 & 20.1959230 \\
\hline 0 & 10.3251315 & 15.8812125 & 20.1434680 \\
\hline 0 & 8.8773907 & 17.0867084 & 25.1264210 \\
\hline 0 & 11.8279418 & 13.0687241 & 19.8701802 \\
\hline C & 9.6934323 & 10.5771444 & 20.3425269 \\
\hline $\mathrm{H}$ & 10.0037768 & 10.5229164 & 19.2907751 \\
\hline $\mathrm{H}$ & 10.5842299 & 10.5177384 & 20.9794865 \\
\hline $\mathrm{H}$ & 9.1033910 & 9.6699575 & 20.5361370 \\
\hline C & 7.0445083 & 13.3213522 & 20.0850560 \\
\hline $\mathrm{C}$ & 7.1887190 & 13.9762249 & 21.3110722 \\
\hline C & 8.1724108 & 13.5490804 & 22.2025910 \\
\hline C & 9.0037345 & 12.4762777 & 21.8717653 \\
\hline C & 8.8711478 & 11.8065532 & 20.6424928 \\
\hline C & 7.8773037 & 12.2535583 & 19.7507773 \\
\hline $\mathrm{H}$ & 6.2680753 & 13.6353291 & 19.3864068 \\
\hline $\mathrm{H}$ & 7.7349510 & 11.7387974 & 18.7985418 \\
\hline $\mathrm{H}$ & 6.5404689 & 14.8148704 & 21.5676941 \\
\hline $\mathrm{H}$ & 8.3040364 & 14.0540029 & 23.1611920 \\
\hline $\mathrm{H}$ & 9.7616854 & 12.1401743 & 22.5820590 \\
\hline $\mathrm{H}$ & 10.8748069 & 12.7973319 & 19.9244641 \\
\hline $\mathrm{H}$ & 5.1590447 & 15.1262349 & 29.8727306 \\
\hline $\mathrm{H}$ & 16.2554081 & 19.7998773 & 22.5118844 \\
\hline \multicolumn{4}{|c|}{ Al 26} \\
\hline \multicolumn{4}{|c|}{174} \\
\hline $\mathrm{H}$ & 8.6883737 & 8.8618575 & 15.2225320 \\
\hline $\mathrm{Si}$ & 5.4017473 & 9.3452994 & 16.6349849 \\
\hline $\mathrm{Si}$ & 5.4059453 & 9.3143646 & 28.5635450 \\
\hline $\mathrm{Si}$ & 5.4047014 & 6.8748106 & 21.5883166 \\
\hline $\mathrm{Si}$ & 5.4050220 & 6.8828622 & 18.5316880 \\
\hline
\end{tabular}




\begin{tabular}{|c|c|c|c|}
\hline $\mathrm{Si}$ & 3.3000133 & 8.0665817 & 26.6519350 \\
\hline $\mathrm{Si}$ & 3.3386257 & 8.1496672 & 23.5972223 \\
\hline $\mathrm{Si}$ & 8.5136586 & 9.2441821 & 28.5953559 \\
\hline $\mathrm{Si}$ & 8.5127081 & 9.3072360 & 16.6324612 \\
\hline $\mathrm{Si}$ & 8.5265246 & 6.8252014 & 18.5274767 \\
\hline $\mathrm{Si}$ & 8.5198660 & 6.7804853 & 21.6652303 \\
\hline $\mathrm{Si}$ & 1.7149251 & 10.7823847 & 23.5888138 \\
\hline $\mathrm{Si}$ & 1.6991298 & 10.7910042 & 26.6564492 \\
\hline 0 & 6.9647668 & 9.7431302 & 16.9035972 \\
\hline 0 & 4.9765956 & 10.8565240 & 28.2579897 \\
\hline $\mathrm{H}$ & 4.9861036 & 5.4479728 & 21.6659720 \\
\hline $\mathrm{H}$ & 8.9347664 & 5.3744951 & 21.9263239 \\
\hline 0 & 6.9595174 & 6.4565696 & 18.2783763 \\
\hline 0 & 2.1881886 & 9.2445994 & 26.8135066 \\
\hline $\mathrm{H}$ & 2.2094319 & 7.1917303 & 23.4410211 \\
\hline $\mathrm{H}$ & 0.3580057 & 10.1862535 & 23.4455729 \\
\hline 0 & 4.9676983 & 8.0669133 & 17.5215015 \\
\hline 0 & 4.5265471 & 8.2810221 & 27.6860399 \\
\hline 0 & 4.5519133 & 7.8149800 & 22.5859457 \\
\hline 0 & 2.5374027 & 11.7639036 & 27.6406228 \\
\hline 0 & 8.9554999 & 8.1181165 & 17.6404185 \\
\hline 0 & 1.9454430 & 12.0196832 & 22.5837124 \\
\hline 0 & 4.4681421 & 10.5947074 & 17.0689589 \\
\hline 0 & 6.9609594 & 9.1229914 & 28.1599382 \\
\hline 0 & 6.9592573 & 6.9689143 & 22.0275658 \\
\hline $\mathrm{H}$ & 9.3590973 & 5.6669576 & 18.1003765 \\
\hline $\mathrm{H}$ & 4.5361927 & 5.7089284 & 18.2416270 \\
\hline $\mathrm{H}$ & 0.2706065 & 10.8681677 & 27.0693506 \\
\hline $\mathrm{H}$ & 2.6640345 & 6.7632435 & 26.9895165 \\
\hline 0 & 2.8166881 & 9.6411929 & 23.2505526 \\
\hline $\mathrm{H}$ & 5.1979797 & 9.0037857 & 15.2000745 \\
\hline 0 & 5.2136682 & 7.4163590 & 20.0581292 \\
\hline $\mathrm{O}$ & 3.8922783 & 8.0649914 & 25.1323762 \\
\hline $\mathrm{H}$ & 8.6878368 & 8.8579102 & 30.0227930 \\
\hline 0 & 8.7919752 & 7.1558362 & 20.0993391 \\
\hline 0 & 1.9062262 & 11.3075321 & 25.1261165 \\
\hline $\mathrm{H}$ & 5.1985748 & 9.0015856 & 30.0044778 \\
\hline $\mathrm{H}$ & 3.4457208 & 11.9802718 & 15.1715483 \\
\hline $\mathrm{Si}$ & 3.2979019 & 15.9105467 & 21.6441228 \\
\hline $\mathrm{Si}$ & 3.2582815 & 15.9438721 & 18.5147441 \\
\hline $\mathrm{Si}$ & 3.8537358 & 12.0030202 & 28.5433734 \\
\hline $\mathrm{Si}$ & 3.8276247 & 12.0098297 & 16.6104355 \\
\hline $\mathrm{Si}$ & 1.7517015 & 13.2175874 & 18.5641403 \\
\hline $\mathrm{Si}$ & 1.7526340 & 13.2557356 & 21.5561159 \\
\hline 0 & 4.9465351 & 13.1667556 & 16.8773166 \\
\hline $\mathrm{H}$ & 0.3558183 & 13.7661028 & 21.4816060 \\
\hline $\mathrm{H}$ & 2.2614304 & 16.9423585 & 21.9237864 \\
\hline $\mathrm{O}$ & 2.1341329 & 14.7804518 & 18.2861705 \\
\hline 0 & 4.5722461 & 15.6946588 & 17.5966355 \\
\hline 0 & 4.6182677 & 16.1857176 & 22.5393833 \\
\hline 0 & 2.4767428 & 12.2699974 & 17.4684929 \\
\hline 0 & 4.4773813 & 13.4424192 & 28.1505008 \\
\hline 0 & 2.7570925 & 14.4436602 & 22.0410597 \\
\hline $\mathrm{H}$ & 2.6721293 & 17.2482598 & 18.0998723 \\
\hline $\mathrm{H}$ & 0.2816243 & 13.0507634 & 18.3963211 \\
\hline 0 & 3.7275173 & 15.9781839 & 20.0710854 \\
\hline $\mathrm{H}$ & 3.4485785 & 11.9797463 & 29.9760026 \\
\hline 0 & 2.2100509 & 12.7574507 & 20.0521314 \\
\hline $\mathrm{Si}$ & 10.1045348 & 12.0189216 & 16.5139883 \\
\hline $\mathrm{Si}$ & 10.0772717 & 11.9868020 & 28.5147408 \\
\hline $\mathrm{Si}$ & 12.2185138 & 10.7256479 & 26.6683744 \\
\hline $\mathrm{Si}$ & 12.3058518 & 10.6583453 & 23.5583552 \\
\hline $\mathrm{Si}$ & 15.3399238 & 10.7823847 & 23.5888138 \\
\hline $\mathrm{Si}$ & 10.5819451 & 8.0784386 & 23.6046715 \\
\hline $\mathrm{Si}$ & 10.6096801 & 8.0659080 & 26.6591580 \\
\hline $\mathrm{Si}$ & 15.3241285 & 10.7910042 & 26.6564492 \\
\hline 0 & 8.9897562 & 10.7850719 & 28.3576330 \\
\hline O & 11.7393458 & 9.1964068 & 26.9725117 \\
\hline $\mathrm{H}$ & 15.7710241 & 9.3779197 & 26.7999662 \\
\hline $\mathrm{H}$ & 11.5646338 & 6.9630927 & 23.5183754 \\
\hline 0 & 13.8528435 & 10.1290703 & 23.4318327 \\
\hline 0 & 11.3435695 & 11.7783071 & 27.5388047 \\
\hline 0 & 9.3693236 & 8.2150701 & 27.6898704 \\
\hline $\mathrm{H}$ & 16.0955810 & 11.6863518 & 27.5621723 \\
\hline 0 & 9.3399363 & 7.8146547 & 22.6028912 \\
\hline 0 & 15.5704417 & 12.0196832 & 22.5837124 \\
\hline 0 & 9.4618597 & 10.5924688 & 16.9289549 \\
\hline 0 & 13.7697355 & 10.8749667 & 27.1057321 \\
\hline $\mathrm{H}$ & 11.2177037 & 6.7228040 & 26.8677230 \\
\hline $\mathrm{H}$ & 16.3513955 & 9.7347155 & 23.2782737 \\
\hline
\end{tabular}




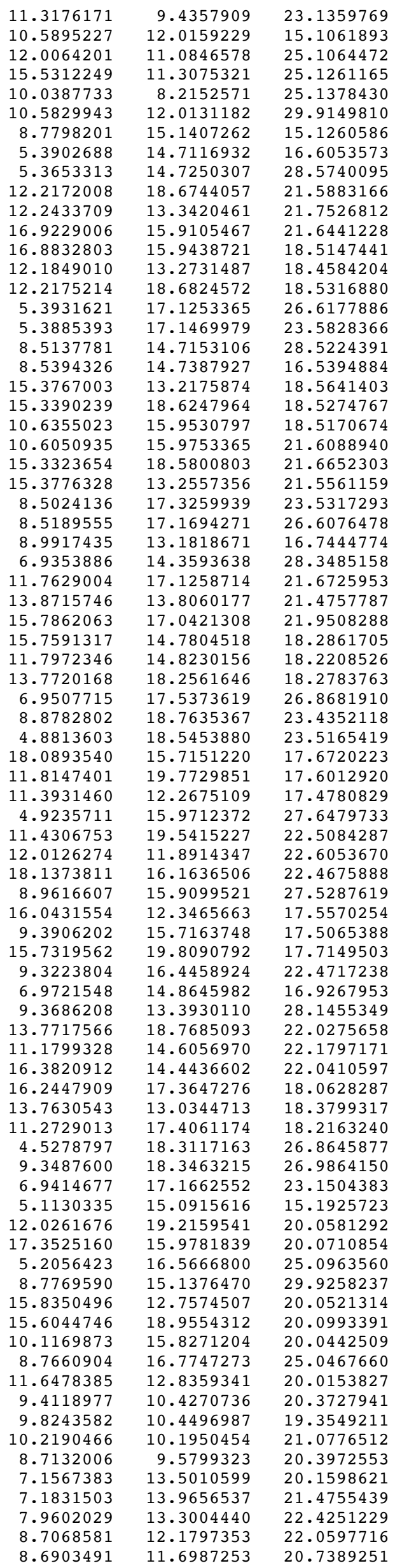

20.7389251 


\begin{tabular}{|c|c|c|c|}
\hline C & 7.8999808 & 12.3782122 & 19.7941852 \\
\hline $\mathrm{H}$ & 6.5525563 & 14.0188603 & 19.4145907 \\
\hline $\mathrm{H}$ & 7.8436711 & 12.0058370 & 18.7698502 \\
\hline $\mathrm{H}$ & 6.6070474 & 14.8472492 & 21.7530700 \\
\hline $\mathrm{H}$ & 7.9961007 & 13.6608215 & 23.4553022 \\
\hline $\mathrm{H}$ & 9.3126646 & 11.6646084 & 22.8069145 \\
\hline $\mathrm{H}$ & 10.7153816 & 12.5049305 & 20.0640173 \\
\hline $\mathrm{H}$ & 5.1115170 & 15.0918362 & 29.9946264 \\
\hline $\mathrm{H}$ & 16.0865770 & 19.5311970 & 22.5275890 \\
\hline \multicolumn{4}{|c|}{ Ge 26} \\
\hline \multicolumn{4}{|c|}{174} \\
\hline $\mathrm{H}$ & 8.6915240 & 9.0281639 & 15.1829454 \\
\hline $\mathrm{P}$ & 5.4476279 & 9.4554755 & 16.6903711 \\
\hline Al & 5.4507946 & 9.4183269 & 28.4883549 \\
\hline $\mathrm{P}$ & 5.5287886 & 6.9292516 & 21.5778811 \\
\hline Al & 5.5108169 & 6.9101093 & 18.4980008 \\
\hline $\mathrm{P}$ & 3.3134244 & 8.0527898 & 26.6667341 \\
\hline Al & 3.3476325 & 8.1873330 & 23.5770654 \\
\hline$P$ & 8.5724327 & 9.3040273 & 28.4562684 \\
\hline Al & 8.5817350 & 9.3815011 & 16.6252421 \\
\hline $\mathrm{P}$ & 8.6697240 & 6.8098398 & 18.4311905 \\
\hline Al & 8.6610092 & 6.7779833 & 21.6260487 \\
\hline $\mathrm{P}$ & 1.7382978 & 10.8546531 & 23.4947099 \\
\hline Al & 1.7005464 & 10.8161629 & 26.6380605 \\
\hline 0 & 6.9195572 & 9.8011354 & 17.0125113 \\
\hline 0 & 4.9603627 & 11.0507303 & 28.0770416 \\
\hline $\mathrm{H}$ & 5.1388641 & 5.4923559 & 21.5981341 \\
\hline $\mathrm{H}$ & 9.1033895 & 5.3844906 & 21.9081804 \\
\hline O & 7.1837923 & 6.4822342 & 18.1833655 \\
\hline 0 & 2.2575111 & 9.1648211 & 26.8156688 \\
\hline $\mathrm{H}$ & 2.1750741 & 7.2790362 & 23.4458241 \\
\hline $\mathrm{H}$ & 0.4003532 & 10.2550358 & 23.2349331 \\
\hline 0 & 5.0049539 & 8.2044140 & 17.4518420 \\
\hline 0 & 4.4542586 & 8.2509893 & 27.6701480 \\
\hline 0 & 4.6590407 & 7.7594693 & 22.5232372 \\
\hline 0 & 2.6325854 & 11.9126035 & 27.6164875 \\
\hline 0 & 9.0940403 & 8.0389473 & 17.6135918 \\
\hline 0 & 1.9755288 & 12.0611081 & 22.5878881 \\
\hline 0 & 4.5614111 & 10.6278653 & 17.1289475 \\
\hline 0 & 7.1097541 & 9.1924900 & 28.0147496 \\
\hline 0 & 6.9885209 & 7.0401174 & 22.0345616 \\
\hline $\mathrm{H}$ & 9.4912619 & 5.6507189 & 17.9855059 \\
\hline $\mathrm{H}$ & 4.6388945 & 5.7341209 & 18.2261124 \\
\hline $\mathrm{H}$ & 0.2939847 & 10.8739484 & 27.1232052 \\
\hline $\mathrm{H}$ & 2.6752421 & 6.7415370 & 26.9674995 \\
\hline 0 & 2.8220506 & 9.8073543 & 23.2000071 \\
\hline $\mathrm{H}$ & 5.2873379 & 9.1926271 & 15.2335464 \\
\hline 0 & 5.3689537 & 7.4875683 & 20.1475382 \\
\hline 0 & 3.9017573 & 8.0722986 & 25.2415350 \\
\hline $\mathrm{H}$ & 8.7059108 & 8.9783601 & 29.9030735 \\
\hline $\mathrm{O}$ & 8.9174080 & 7.1050622 & 19.9209726 \\
\hline 0 & 1.8278062 & 11.3190785 & 24.9637324 \\
\hline $\mathrm{H}$ & 5.3070349 & 9.2187647 & 29.9569013 \\
\hline $\mathrm{H}$ & 3.6349111 & 12.1321664 & 15.1377573 \\
\hline $\mathrm{P}$ & 3.3097416 & 16.0776133 & 21.6376709 \\
\hline Al & 3.2462288 & 16.0936965 & 18.4569597 \\
\hline $\mathrm{P}$ & 3.9233298 & 12.1439982 & 28.4041765 \\
\hline Al & 3.9047298 & 12.1560928 & 16.6019110 \\
\hline $\mathrm{P}$ & 1.6974289 & 13.3571357 & 18.4550998 \\
\hline Al & 1.7195515 & 13.4023650 & 21.5098308 \\
\hline 0 & 5.1080145 & 13.3911021 & 16.9539371 \\
\hline $\mathrm{H}$ & 0.3310607 & 13.9354313 & 21.4387388 \\
\hline $\mathrm{H}$ & 2.2839653 & 17.1116135 & 21.9471010 \\
\hline 0 & 2.0406747 & 14.8399832 & 18.1893633 \\
\hline 0 & 4.7048707 & 15.8071030 & 17.5387074 \\
\hline 0 & 4.5857798 & 16.3270844 & 22.4486366 \\
\hline $\mathrm{O}$ & 2.3914498 & 12.4655277 & 17.4164438 \\
\hline 0 & 4.4971008 & 13.5039872 & 27.9925618 \\
\hline 0 & 2.7815114 & 14.6961960 & 22.0213286 \\
\hline $\mathrm{H}$ & 2.6766804 & 17.4058013 & 18.0432977 \\
\hline $\mathrm{H}$ & 0.2273837 & 13.1702768 & 18.3095950 \\
\hline $\mathrm{O}$ & 3.6838085 & 16.1310442 & 20.1456816 \\
\hline $\mathrm{H}$ & 3.5991446 & 12.1285666 & 29.8573752 \\
\hline 0 & 2.1597646 & 12.9312300 & 19.8589993 \\
\hline $\mathrm{P}$ & 10.2164689 & 12.1039112 & 16.5645959 \\
\hline Al & 10.1992239 & 12.0497535 & 28.4252549 \\
\hline $\mathrm{P}$ & 12.4705793 & 10.7355418 & 26.7532188 \\
\hline Al & 12.5511498 & 10.6928676 & 23.5313031 \\
\hline $\mathrm{P}$ & 15.6132965 & 10.8546531 & \\
\hline
\end{tabular}




\begin{tabular}{|c|c|c|c|}
\hline $\mathrm{P}$ & 10.7651904 & 8.1565979 & 23.5201835 \\
\hline Al & 10.7873577 & 8.1243005 & 26.6332586 \\
\hline Al & 15.5755451 & 10.8161629 & 26.6380605 \\
\hline 0 & 9.0594782 & 10.7410149 & 28.1799300 \\
\hline 0 & 11.9737699 & 9.3213525 & 27.1215103 \\
\hline $\mathrm{H}$ & 16.0489647 & 9.4125235 & 26.7890274 \\
\hline $\mathrm{H}$ & 11.7169598 & 7.0128787 & 23.4639530 \\
\hline 0 & 14.2258737 & 10.2328615 & 23.2253264 \\
\hline 0 & 11.6333588 & 11.8015102 & 27.4752648 \\
\hline 0 & 9.3867257 & 8.2812055 & 27.6585813 \\
\hline $\mathrm{H}$ & 16.3730560 & 11.7543461 & 27.4752638 \\
\hline 0 & 9.5570606 & 7.8989147 & 22.6154331 \\
\hline 0 & 15.8505275 & 12.0611081 & 22.5878881 \\
\hline 0 & 9.6006226 & 10.7582883 & 16.9631400 \\
\hline 0 & 13.9276553 & 10.8838629 & 27.2064430 \\
\hline $\mathrm{H}$ & 11.3794185 & 6.7689660 & 26.8054591 \\
\hline $\mathrm{H}$ & 16.6641305 & 9.8391658 & 23.2089587 \\
\hline 0 & 11.4811506 & 9.4094762 & 23.0079694 \\
\hline $\mathrm{H}$ & 10.6467227 & 12.0913376 & 15.1391682 \\
\hline 0 & 12.3475158 & 10.9540072 & 25.2461162 \\
\hline 0 & 15.7028049 & 11.3190785 & 24.9637324 \\
\hline 0 & 10.2811737 & 8.3631698 & 24.9690605 \\
\hline $\mathrm{H}$ & 10.5903471 & 12.0847965 & 29.8615401 \\
\hline $\mathrm{H}$ & 8.8982728 & 15.1755792 & 15.0769870 \\
\hline $\mathrm{P}$ & 5.5008502 & 14.8520325 & 16.6422614 \\
\hline Al & 5.4780723 & 14.8507010 & 28.4967445 \\
\hline $\mathrm{P}$ & 12.4662880 & 18.9453529 & 21.5778811 \\
\hline $\mathrm{Ge}$ & 12.3485992 & 13.5569423 & 21.8305553 \\
\hline$P$ & 17.1847403 & 16.0776133 & 21.6376709 \\
\hline Al & 17.1212275 & 16.0936965 & 18.4569597 \\
\hline Al & 12.3521294 & 13.4416585 & 18.4326647 \\
\hline Al & 12.4483163 & 18.9262106 & 18.4980008 \\
\hline $\mathrm{P}$ & 5.4477154 & 17.3533092 & 26.6119447 \\
\hline Al & 5.4250752 & 17.3773488 & 23.5405668 \\
\hline$P$ & 8.6515907 & 14.8082184 & 28.3818381 \\
\hline Al & 8.6817920 & 14.8745061 & 16.5190729 \\
\hline$P$ & 15.5724276 & 13.3571357 & 18.4550998 \\
\hline $\mathrm{P}$ & 15.6072234 & 18.8259412 & 18.4311905 \\
\hline $\mathrm{P}$ & 10.8411669 & 16.1578851 & 18.4158389 \\
\hline Al & 10.7804855 & 16.2684217 & 21.5603233 \\
\hline Al & 15.5985086 & 18.7940847 & 21.6260487 \\
\hline Al & 15.5945502 & 13.4023650 & 21.5098308 \\
\hline$P$ & 8.5576247 & 17.6265121 & 23.4219917 \\
\hline Al & 8.5960613 & 17.3665766 & 26.5225560 \\
\hline 0 & 9.1805524 & 13.2152502 & 16.8175525 \\
\hline 0 & 7.1603922 & 14.4553867 & 28.2211421 \\
\hline 0 & 12.0645535 & 17.4649365 & 21.5987475 \\
\hline 0 & 13.9778623 & 14.0230402 & 21.4270549 \\
\hline 0 & 16.1202347 & 17.1506534 & 21.9587839 \\
\hline 0 & 15.9156734 & 14.8399832 & 18.1893633 \\
\hline 0 & 11.9325461 & 15.1032361 & 18.0957185 \\
\hline 0 & 14.1212917 & 18.4983356 & 18.1833655 \\
\hline 0 & 6.9149427 & 17.7740066 & 26.8398253 \\
\hline $\mathrm{H}$ & 8.8881475 & 19.0783644 & 23.4220313 \\
\hline $\mathrm{H}$ & 4.8944965 & 18.7669861 & 23.4733725 \\
\hline $\mathrm{H}$ & 18.3642610 & 15.8494656 & 17.6744384 \\
\hline $\mathrm{H}$ & 12.0152803 & 20.0341795 & 17.6024533 \\
\hline 0 & 11.4632113 & 12.3258782 & 17.4358110 \\
\hline $\mathrm{O}$ & 5.0273613 & 16.2701328 & 27.6070931 \\
\hline $\mathrm{H}$ & 11.6195796 & 19.7535783 & 22.4981948 \\
\hline 0 & 12.0583160 & 12.1064746 & 22.7168738 \\
\hline $\mathrm{H}$ & 18.4246588 & 16.3200228 & 22.4256813 \\
\hline 0 & 9.0450086 & 15.9601820 & 27.4523145 \\
\hline $\mathrm{H}$ & 16.2457632 & 12.4921022 & 17.4474010 \\
\hline 0 & 9.6422695 & 15.9719961 & 17.4757043 \\
\hline $\mathrm{H}$ & 16.0185628 & 20.0174591 & 17.6385963 \\
\hline 0 & 9.3849664 & 16.9019808 & 22.3706279 \\
\hline $\mathrm{O}$ & 6.9944173 & 15.0400911 & 16.9352816 \\
\hline 0 & 9.4801304 & 13.5777955 & 27.9953561 \\
\hline 0 & 13.9260203 & 19.0562188 & 22.0345616 \\
\hline 0 & 11.3133399 & 14.8427424 & 22.3644228 \\
\hline 0 & 16.6565101 & 14.6961960 & 22.0213286 \\
\hline 0 & 16.4535748 & 17.6318105 & 17.9720446 \\
\hline 0 & 14.0521253 & 13.1638886 & 18.3046206 \\
\hline $\mathrm{O}$ & 11.4286520 & 17.5509583 & 18.1800425 \\
\hline $\mathrm{H}$ & 4.5625327 & 18.5309217 & 26.8282804 \\
\hline $\mathrm{H}$ & 9.4495183 & 18.5233855 & 26.9105313 \\
\hline 0 & 7.0861570 & 17.4474201 & 23.0435087 \\
\hline $\mathrm{H}$ & 5.2064020 & 15.1746382 & 15.2187635 \\
\hline 0 & 12.3064530 & 19.5036697 & 20.1475382 \\
\hline
\end{tabular}




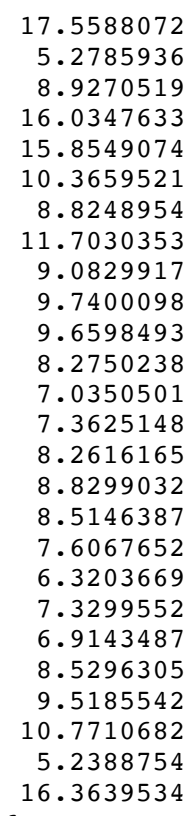

0.4338873
16.1310442 16.7924974 15.2147736 12.9312300 19.1211636 15.9930831 17.0169980 13.0544906 10.4398950 10.4594805 10.0348136

9.7296406

13.6543566 14.2828971 13.6698211 12.4355553 11.7961914 12.4293055 14.1252418 11.9437706 15.2434320 14.1445967 11.9512688 12.7422045 15.1351484 19.7516315

8.8800970

9.3310238

9. 2955050

6.8633947

6.8815929

8.0613205

8.1573212

9.2355953

9.3071349

6.8135751

6.7515984

10.7733522

10.7751911

9.7286485

10.8390023

5.4230920

5.3359350

6.4489526

.2282521

7.2304712

10.1647035

8.0575355

8.2663912

7.7529361

11.7521095

8. 1107548

12.0322139

10.5846574

9.1005832

6.9785667

5.6578412

5.7081770

10.8568671

6.7464438

9. 6524935

8.9800431

7.4335062

8.0998329

8.8752977

7.1332877

11.2829544

8.9774774

11.9932950

15.9069185

15.9421434

11.9949553

12.0075091

13.2096880

13.2705752

13.1589172

13.8996111
20.1456816

25.1854772

29.7875246

19.8589993

19.9209726

19.8663905

24.8160541

20.0884469

20.3020073

19.4196895

21.1414611

20.0716439

20.0945485

21.2999541

22.1705079

21.8355055

20.6254984

19.7553752

19.4199476

18.8165117

21.5529340

23.1160143

22.5311312

20.1709446

29.9386166

22.4712226

15.2364588

16.6412483

28.5726965

21.5902717

18.5448493

26.6517931

23.6055445

28.6024110

16.6507509

18.5282504

21.6700260

23.5942475

26.6674019

16.9187391

28.2749848

21.6186625

21.9147638

18.2697354

26.8347925

23.5070071

23.4623134

17.5310061

27.6907098

22.5875709

27.6454412

17.6500516

22.6025637

17.0622462

28.1700060

22.0575346

18.0952149

18.2860227

27.0761522

26.9639269

23.2248976

15.2072618

20.0689683

25.1325362

30.0365954

20.1038883

25.1338178

30.0121944

15.1756416

21.6365631

18.5127708

28.5461025

16.6165428

18.5727962

21.5673175

16.8979094

21.5031639 


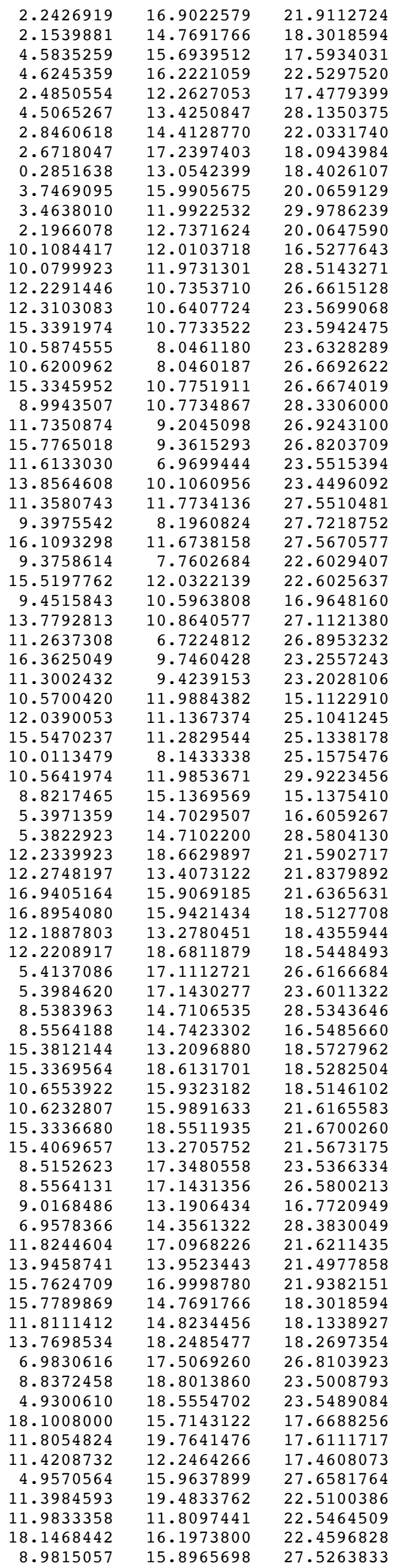

16.9022579

14.7691766

15.6939512

16.2221059

12.2627053

13.4250847

14.4128770

17.2397403

13.0542399

15.9905675

11.9922532

12.7371624

12.0103718

11.9731301

10.7353710

10.6407724

10.7733522

8.0461180

8.0460187

10.7751911

10.7734867

9.2045098

9.3615293

6.9699444

10.1060956

11.7734136

8.1960824

11.6738158

7. 7602684

12.0322139

10.5963808

10.8640577

6.7224812

9.7460428

9.4239153

11.9884382

11.1367374

11.2829544

8.1433338

11.9853671

15.1369569

14.7029507

14.7102200

18.6629897

13.4073122

15.9069185

15.9421434

3.2780451

18.6811879

17.1112721

17.1430277

14.7106535

14.7423302

13.2096880

18.6131701

15.9323182

15.9891633

18.5511935

13.2705752

17.3480558

17.1431356

13.1906434

14.3561322

17.0968226

13.9523443

16.9998780

14.7691766

14.8234456

18.2485477

17.5069260

18.8013860

18.5554702

15.7143122

19.7641476

12.2464266

15.9637899

19.4833762

11.8097441

16.1973800

15.8965698

21.9112724

18.3018594

17.5934031

22.5297520

17.4779399

28.1350375

22.0331740

18.0943984

18.4026107

20.0659129

29.9786239

20.0647590

16.5277643

28.5143271

26.6615128

23.5699068

23.5942475

23.6328289

26.6692622

26.6674019

28.3306000

26.9243100

26.8203709

23.5515394

23.4496092

27.5510481

27.7218752

27.5670577

22.6029407

22.6025637

16.9648160

27.1121380

26.8953232

23.2557243

23.2028106

15.1122910

25.1041245

25.1338178

25.1575476

29.9223456

15.1375410

16.6059267

28.5804130

21.5902717

21.8379892

21.6365631

18.5127708

18.4355944

18.5448493

26.6166684

23.6011322

28.5343646

16.5485660

18.5727962

18.5282504

18.5146102

21.6165583

21.6700260

21.5673175

23.5366334

26.5800213

16.7720949

28.3830049

21.6211435

21.4977858

21.9382151

18.3018594

18.1338927

18.2697354

26.8103923

23.5008793

23.5489084

17.6688256

17.6111717

17.4608073

27.6581764

22.5100386

22.5464509

22.4596828

27.5263833 


\begin{tabular}{|c|c|c|c|}
\hline $\mathrm{H}$ & 16.0508245 & 12.3396625 & 17.5669141 \\
\hline $\mathrm{O}$ & 9.3791995 & 15.7298991 & 17.5333226 \\
\hline $\mathrm{H}$ & 15.7346314 & 19.8013893 & 17.7238186 \\
\hline $\mathrm{O}$ & 9.3364492 & 16.5788340 & 22.3934014 \\
\hline 0 & 6.9814273 & 14.8627574 & 16.9029791 \\
\hline $\mathrm{O}$ & 9.3818676 & 13.3844224 & 28.1481730 \\
\hline $\mathrm{O}$ & 13.7807757 & 18.7781618 & 22.0575346 \\
\hline 0 & 11.1043091 & 14.6509646 & 22.3544646 \\
\hline 0 & 16.4710605 & 14.4128770 & 22.0331740 \\
\hline 0 & 16.2433656 & 17.3555775 & 18.0570501 \\
\hline 0 & 13.7694345 & 13.0393690 & 18.3863299 \\
\hline 0 & 11.2651578 & 17.4058182 & 18.2635342 \\
\hline $\mathrm{H}$ & 4.5753193 & 18.3107687 & 26.8913172 \\
\hline $\mathrm{H}$ & 9.3751840 & 18.3278411 & 26.9584494 \\
\hline 0 & 6.9559033 & 17.1296706 & 23.1906394 \\
\hline $\mathrm{H}$ & 5.0988177 & 15.0678067 & 15.1934796 \\
\hline $\mathrm{O}$ & 12.0562725 & 19.2331012 & 20.0689683 \\
\hline 0 & 17.3719082 & 15.9905675 & 20.0659129 \\
\hline 0 & 5.1729782 & 16.5491298 & 25.1033622 \\
\hline $\mathrm{H}$ & 8.8196960 & 15.1334757 & 29.9340833 \\
\hline 0 & 15.8216066 & 12.7371624 & 20.0647590 \\
\hline 0 & 15.5933619 & 18.9328827 & 20.1038883 \\
\hline 0 & 10.1911787 & 15.7228419 & 20.0535890 \\
\hline 0 & 8.8372015 & 16.7411046 & 25.0221894 \\
\hline 0 & 11.6295553 & 12.8944857 & 19.9854309 \\
\hline C & 9.3328411 & 10.4376306 & 20.4043739 \\
\hline $\mathrm{H}$ & 9.8020418 & 10.4453370 & 19.4103339 \\
\hline $\mathrm{H}$ & 10.1011150 & 10.2112282 & 21.1528250 \\
\hline $\mathrm{H}$ & 8.6246243 & 9.5975926 & 20.3970370 \\
\hline $\mathrm{C}$ & 7.0084774 & 13.4508139 & 20.1028618 \\
\hline C & 7.1180954 & 14.0249402 & 21.3712932 \\
\hline $\mathrm{C}$ & 7.9672554 & 13.4482108 & 22.3151035 \\
\hline $\mathrm{C}$ & 8.7044893 & 12.3074673 & 21.9903560 \\
\hline C & 8.6080739 & 11.7211338 & 20.7174524 \\
\hline C & 7.7452647 & 12.3132317 & 19.7759963 \\
\hline $\mathrm{H}$ & 6.3398519 & 13.8949375 & 19.3656187 \\
\hline $\mathrm{H}$ & 7.6329216 & 11.8630195 & 18.7874723 \\
\hline $\mathrm{H}$ & 6.5488102 & 14.9204345 & 21.6160441 \\
\hline $\mathrm{H}$ & 8.0697395 & 13.8907108 & 23.3079257 \\
\hline $\mathrm{H}$ & 9.3684195 & 11.8609534 & 22.7324504 \\
\hline $\mathrm{H}$ & 10.6995437 & 12.5716738 & 20.0596831 \\
\hline $\mathrm{H}$ & 5.0981652 & 15.0676693 & 29.9976718 \\
\hline $\mathrm{H}$ & 16.1201695 & 19.4793872 & 22.5285085 \\
\hline \multicolumn{4}{|c|}{$\mathrm{Ti} 26$} \\
\hline \multicolumn{4}{|c|}{174} \\
\hline $\mathrm{H}$ & 8.7131908 & 9.1094171 & 15.1735068 \\
\hline $\mathrm{P}$ & 5.4710744 & 9.4726572 & 16.7029094 \\
\hline Al & 5.4501120 & 9.4075247 & 28.5003084 \\
\hline $\mathrm{P}$ & 5.5243135 & 6.9450248 & 21.5815735 \\
\hline Al & 5.5277845 & 6.9128029 & 18.5013020 \\
\hline $\mathrm{P}$ & 3.3184595 & 8.0407417 & 26.6697018 \\
\hline Al & 3.3983265 & 8.2174088 & 23.6081329 \\
\hline $\mathrm{P}$ & 8.5660928 & 9.2796671 & 28.4275419 \\
\hline Al & 8.6037751 & 9.4081771 & 16.6281171 \\
\hline $\mathrm{P}$ & 8.6950962 & 6.8259264 & 18.4416750 \\
\hline Al & 8.6795270 & 6.8056925 & 21.6283940 \\
\hline $\mathrm{P}$ & 1.7582612 & 10.8809092 & 23.5136209 \\
\hline Al & 1.6852684 & 10.7990311 & 26.6582613 \\
\hline 0 & 6.9422179 & 9.8291093 & 17.0180310 \\
\hline 0 & 4.9866658 & 11.0476717 & 28.0825108 \\
\hline $\mathrm{H}$ & 5.0875968 & 5.5224335 & 21.6328897 \\
\hline $\mathrm{H}$ & 9.1574560 & 5.4242548 & 21.9118271 \\
\hline 0 & 7.2076869 & 6.4848780 & 18.2235568 \\
\hline 0 & 2.2483550 & 9.1439845 & 26.7731492 \\
\hline $\mathrm{H}$ & 2.2211425 & 7.3168366 & 23.4655564 \\
\hline $\mathrm{H}$ & 0.4388792 & 10.2807039 & 23.1728788 \\
\hline 0 & 5.0412203 & 8.2165424 & 17.4611683 \\
\hline 0 & 4.4152957 & 8.2493601 & 27.7184623 \\
\hline 0 & 4.7019865 & 7.8178407 & 22.5326603 \\
\hline $\mathrm{O}$ & 2.6448666 & 11.8753677 & 27.6324726 \\
\hline 0 & 9.0984494 & 8.0448379 & 17.5979180 \\
\hline 0 & 2.0527500 & 12.0884126 & 22.6251361 \\
\hline 0 & 4.5783678 & 10.6371415 & 17.1491738 \\
\hline 0 & 7.0977809 & 9.1246855 & 28.0183859 \\
\hline 0 & 6.9946550 & 7.0131837 & 22.0059127 \\
\hline $\mathrm{H}$ & 9.5179366 & 5.6671702 & 17.9974472 \\
\hline $\mathrm{H}$ & 4.6623336 & 5.7393258 & 18.1995289 \\
\hline $\mathrm{H}$ & 0.3007765 & 10.8314223 & 27.2053021 \\
\hline $\mathrm{H}$ & 2.6805629 & 6.7240236 & 26.9462198 \\
\hline
\end{tabular}

17.5669141

7.5333226

22.3934014

16.9029791

1481730

22.3544646

22.0331740

0570501

18.2635342

26.8913172

26.9584494

.1906394

20.0689683

.0659129

29.9340833

0.0647590

20.0535890

5.0221894

20.4043739

19.4103339

20.3970370

. 1028618

22.3151035

1.9903560

19.7759963

19.3656187

18.7874723

23.3079257

22.7324504

20.0596831

29.9976718 Ti 26

17 


\begin{tabular}{|c|c|c|c|}
\hline 0 & 2.8639439 & 9.8422048 & 23.2780907 \\
\hline $\mathrm{H}$ & 5.3037450 & 9.2104334 & 15.2467637 \\
\hline $\mathrm{O}$ & 5.3520885 & 7.4886891 & 20.1476435 \\
\hline 0 & 3.9620640 & 8.0634598 & 25.2676452 \\
\hline $\mathrm{H}$ & 8.7266034 & 9.0653311 & 29.8922662 \\
\hline 0 & 8.9629467 & 7.1425672 & 19.9255311 \\
\hline 0 & 1.7566548 & 11.3356038 & 24.9900283 \\
\hline $\mathrm{H}$ & 5.3207199 & 9.2323774 & 29.9732992 \\
\hline $\mathrm{H}$ & 3.6575009 & 12.1250856 & 15.1481183 \\
\hline $\mathrm{P}$ & 3.3354937 & 16.0900920 & 21.6345007 \\
\hline Al & 3.2729053 & 16.1036795 & 18.4522899 \\
\hline $\mathrm{P}$ & 3.9364194 & 12.1294516 & 28.4109249 \\
\hline Al & 3.9196043 & 12.1613891 & 16.6134184 \\
\hline $\mathrm{P}$ & 1.7097618 & 13.3735323 & 18.4570523 \\
\hline Al & 1.7411063 & 13.4058725 & 21.5279782 \\
\hline 0 & 5.1231094 & 13.3980041 & 16.9637815 \\
\hline $\mathrm{H}$ & 0.3182381 & 13.8437464 & 21.4991138 \\
\hline $\mathrm{H}$ & 2.3425150 & 17.1536466 & 21.9506738 \\
\hline 0 & 2.0662322 & 14.8518635 & 18.1798456 \\
\hline 0 & 4.7397543 & 15.8187846 & 17.5418667 \\
\hline 0 & 4.6275383 & 16.2986852 & 22.4340125 \\
\hline 0 & 2.4055074 & 12.4716284 & 17.4270955 \\
\hline 0 & 4.4907090 & 13.4951817 & 27.9891902 \\
\hline 0 & 2.7674393 & 14.7291213 & 22.0277219 \\
\hline $\mathrm{H}$ & 2.7038566 & 17.4204168 & 18.0529066 \\
\hline $\mathrm{H}$ & 0.2386345 & 13.1966684 & 18.3100005 \\
\hline 0 & 3.7024151 & 16.1304408 & 20.1417930 \\
\hline $\mathrm{H}$ & 3.6226082 & 12.1191812 & 29.8664446 \\
\hline 0 & 2.1636228 & 12.9557467 & 19.8664091 \\
\hline$P$ & 10.2272040 & 12.0948436 & 16.5056848 \\
\hline Al & 10.1549835 & 12.0117559 & 28.3277127 \\
\hline $\mathrm{P}$ & 12.4907687 & 10.6644266 & 26.8054386 \\
\hline $\mathrm{Al}$ & 12.5835021 & 10.6160164 & 23.5607151 \\
\hline $\mathrm{P}$ & 15.6332599 & 10.8809092 & 23.5136209 \\
\hline $\mathrm{P}$ & 10.7262316 & 8.1509565 & 23.5594932 \\
\hline $\mathrm{Al}$ & 10.7812189 & 8.1035729 & 26.6570025 \\
\hline Al & 15.5602671 & 10.7990311 & 26.6582613 \\
\hline 0 & 9.0353062 & 10.6951223 & 28.0295628 \\
\hline 0 & 11.9629209 & 9.2756205 & 27.2284654 \\
\hline $\mathrm{H}$ & 16.0388310 & 9.3924170 & 26.7559038 \\
\hline $\mathrm{H}$ & 11.5774217 & 6.9293229 & 23.5450912 \\
\hline 0 & 14.2638525 & 10.2579467 & 23.1599593 \\
\hline 0 & 11.6254642 & 11.7743795 & 27.4250047 \\
\hline 0 & 9.3794200 & 8.2075099 & 27.6924183 \\
\hline $\mathrm{H}$ & 16.3813297 & 11.7199788 & 27.4918273 \\
\hline 0 & 9.5001239 & 7.9525211 & 22.6613532 \\
\hline 0 & 15.9277487 & 12.0884126 & 22.6251361 \\
\hline $\mathrm{O}$ & 9.6417603 & 10.7667923 & 17.0097487 \\
\hline 0 & 13.9328109 & 10.8371066 & 27.3013022 \\
\hline $\mathrm{H}$ & 11.3726104 & 6.7400207 & 26.7470150 \\
\hline $\mathrm{H}$ & 16.7056510 & 9.8734798 & 23.2851824 \\
\hline 0 & 11.5411356 & 9.3244318 & 23.0025542 \\
\hline $\mathrm{H}$ & 10.5288124 & 12.0193308 & 15.0495080 \\
\hline 0 & 12.4426420 & 10.7809789 & 25.2855780 \\
\hline 0 & 15.6316535 & 11.3356038 & 24.9900283 \\
\hline 0 & 10.2731595 & 8.4428193 & 25.0051406 \\
\hline $\mathrm{H}$ & 10.4809050 & 12.0165592 & 29.7805970 \\
\hline $\mathrm{H}$ & 8.9347866 & 15.1378478 & 15.0370729 \\
\hline $\mathrm{P}$ & 5.5163406 & 14.8553060 & 16.6358099 \\
\hline Al & 5.4698938 & 14.8429686 & 28.4967504 \\
\hline $\mathrm{P}$ & 12.4618129 & 18.9611261 & 21.5815735 \\
\hline $\mathrm{Ti}$ & 12.2397087 & 13.4840102 & 21.7797601 \\
\hline $\mathrm{P}$ & 17.2104924 & 16.0900920 & 21.6345007 \\
\hline $\mathrm{Al}$ & 17.1479040 & 16.1036795 & 18.4522899 \\
\hline $\mathrm{Al}$ & 12.3518891 & 13.4261281 & 18.3544613 \\
\hline Al & 12.4652838 & 18.9289043 & 18.5013020 \\
\hline $\mathrm{P}$ & 5.4556328 & 17.3255579 & 26.6000023 \\
\hline Al & 5.4090109 & 17.3567501 & 23.5599269 \\
\hline $\mathrm{P}$ & 8.6502101 & 14.7869257 & 28.3409029 \\
\hline $\mathrm{Al}$ & 8.7080164 & 14.8698850 & 16.4841015 \\
\hline $\mathrm{P}$ & 15.5847605 & 13.3735323 & 18.4570523 \\
\hline $\mathrm{P}$ & 15.6325955 & 18.8420278 & 18.4416750 \\
\hline $\mathrm{P}$ & 10.8493641 & 16.1689708 & 18.3886910 \\
\hline Al & 10.7188608 & 16.3159058 & 21.5417982 \\
\hline Al & 15.6170264 & 18.8217939 & 21.6283940 \\
\hline Al & 15.6161050 & 13.4058725 & 21.5279782 \\
\hline $\mathrm{P}$ & 8.5376142 & 17.6858913 & 23.4064323 \\
\hline $\mathrm{Al}$ & 8.5927568 & 17.3580207 & 26.4933924 \\
\hline 0 & 9.2167852 & 13.2179619 & 16.8122009 \\
\hline $\mathrm{O}$ & 7.1517125 & 14.4521031 & 28.2166842 \\
\hline
\end{tabular}




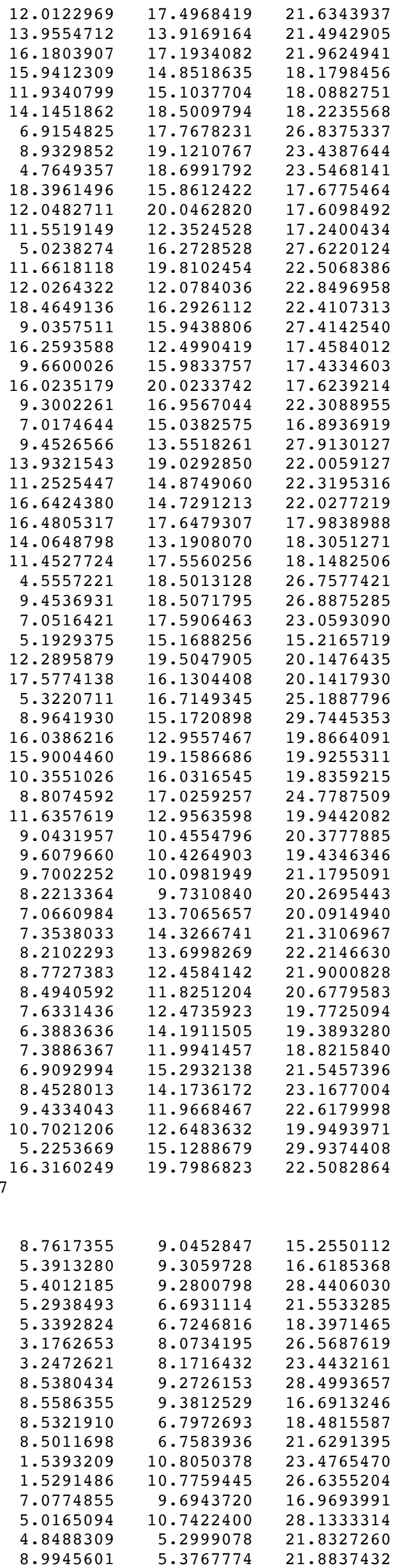




\begin{tabular}{|c|c|c|c|}
\hline 0 & 6.8479619 & 6.4585335 & 18.2111360 \\
\hline $\mathrm{O}$ & 1.9550729 & 9.3052821 & 26.8186592 \\
\hline $\mathrm{H}$ & 2.1646612 & 7.1649947 & 23.2650174 \\
\hline $\mathrm{H}$ & 0.1658286 & 10.2709618 & 23.2634687 \\
\hline $\mathrm{O}$ & 4.9011198 & 7.8978501 & 17.5123733 \\
\hline $\mathrm{O}$ & 4.5399453 & 8.3131229 & 27.6263280 \\
\hline 0 & 4.4407573 & 7.8651110 & 22.5295928 \\
\hline $\mathrm{O}$ & 2.3586470 & 11.6895455 & 27.5448937 \\
\hline 0 & 9.0357238 & 8.2154051 & 17.5766584 \\
\hline 0 & 1.8137999 & 12.2251818 & 22.5308932 \\
\hline $\mathrm{O}$ & 4.4057092 & 10.6616264 & 17.0843453 \\
\hline $\mathrm{O}$ & 6.8692480 & 9.0565858 & 28.0577829 \\
\hline 0 & 7.0013593 & 6.8258005 & 21.8978138 \\
\hline $\mathrm{H}$ & 9.3575254 & 5.6340119 & 18.0540356 \\
\hline $\mathrm{H}$ & 4.5961599 & 5.5070542 & 17.9702121 \\
\hline $\mathrm{H}$ & 0.1002523 & 10.9059289 & 27.0336160 \\
\hline $\mathrm{H}$ & 2.5757619 & 6.7544018 & 26.9103885 \\
\hline $\mathrm{O}$ & 2.7008335 & 9.5568504 & 23.0704504 \\
\hline $\mathrm{H}$ & 5.2275447 & 9.0240827 & 15.1656659 \\
\hline $\mathrm{O}$ & 5.0381318 & 7.0853839 & 19.8608363 \\
\hline $\mathrm{O}$ & 3.7348391 & 8.1524394 & 24.9079708 \\
\hline $\mathrm{H}$ & 8.7326169 & 9.0714983 & 29.9618341 \\
\hline $\mathrm{O}$ & 8.8199701 & 7.1916402 & 20.1743372 \\
\hline $\mathrm{O}$ & 1.7255360 & 11.2172611 & 25.1761931 \\
\hline $\mathrm{H}$ & 5.2058867 & 8.9854535 & 29.8870336 \\
\hline $\mathrm{H}$ & 3.4495286 & 11.9643431 & 15.1958230 \\
\hline Al & 3.2428443 & 16.0683855 & 21.5544041 \\
\hline $\mathrm{P}$ & 3.1708323 & 16.1037896 & 18.3852312 \\
\hline Al & 3.8101512 & 11.9806794 & 28.4592264 \\
\hline$P$ & 3.8176672 & 12.0080239 & 16.6379348 \\
\hline Al & 1.6400197 & 13.3339645 & 18.4936447 \\
\hline $\mathrm{P}$ & 1.6663618 & 13.4170659 & 21.5712218 \\
\hline 0 & 4.8777989 & 13.1006669 & 16.8920144 \\
\hline $\mathrm{H}$ & 0.3193977 & 14.0504695 & 21.6113233 \\
\hline $\mathrm{H}$ & 2.2567685 & 17.1471864 & 21.8389448 \\
\hline 0 & 2.1141692 & 15.0027580 & 18.1805200 \\
\hline 0 & 4.3958834 & 15.8657017 & 17.4950412 \\
\hline $\mathrm{O}$ & 4.6914186 & 16.3528926 & 22.4736803 \\
\hline 0 & 2.5492124 & 12.2721710 & 17.4476024 \\
\hline 0 & 4.4509961 & 13.5366758 & 28.0096697 \\
\hline $\mathrm{O}$ & 2.7141454 & 14.4741690 & 21.9886767 \\
\hline $\mathrm{H}$ & 2.5774839 & 17.4126418 & 17.9954052 \\
\hline $\mathrm{H}$ & 0.1976507 & 13.1611216 & 18.1668149 \\
\hline 0 & 3.6348388 & 16.1499702 & 19.8489610 \\
\hline $\mathrm{H}$ & 3.4926817 & 11.9655538 & 29.9139102 \\
\hline 0 & 2.0057407 & 12.9005968 & 20.1456525 \\
\hline Al & 10.1107691 & 12.0933307 & 16.4767051 \\
\hline $\mathrm{P}$ & 10.0293250 & 12.0245375 & 28.3065892 \\
\hline Al & 12.2655045 & 10.6711728 & 26.5954415 \\
\hline $\mathrm{P}$ & 12.3124547 & 10.6125981 & 23.3920359 \\
\hline Al & 15.4143196 & 10.8050378 & 23.4765470 \\
\hline $\mathrm{Al}$ & 10.5973549 & 8.0138995 & 23.5691876 \\
\hline $\mathrm{P}$ & 10.6906519 & 7.9899973 & 26.6841895 \\
\hline$P$ & 15.4041473 & 10.7759445 & 26.6355204 \\
\hline 0 & 9.0092996 & 10.8983738 & 28.0387075 \\
\hline $\mathrm{O}$ & 11.7639419 & 9.0410289 & 27.0324233 \\
\hline $\mathrm{H}$ & 15.8154291 & 9.3558408 & 26.8123632 \\
\hline $\mathrm{H}$ & 11.5246691 & 6.8569303 & 23.4326912 \\
\hline 0 & 13.7871641 & 10.1723261 & 23.2241163 \\
\hline 0 & 11.2837482 & 11.8353141 & 27.4499854 \\
\hline 0 & 9.5092952 & 8.0925267 & 27.6589751 \\
\hline $\mathrm{H}$ & 16.2099052 & 11.6633979 & 27.5188671 \\
\hline 0 & 9.1914113 & 7.7754746 & 22.5575887 \\
\hline 0 & 15.6887986 & 12.2251818 & 22.5308932 \\
\hline 0 & 9.4177793 & 10.5960226 & 17.0953637 \\
\hline 0 & 13.9311283 & 10.9099427 & 27.0459087 \\
\hline $\mathrm{H}$ & 11.2806046 & 6.6290421 & 26.8141025 \\
\hline $\mathrm{H}$ & 16.4010719 & 9.7446517 & 23.1315514 \\
\hline 0 & 11.4051441 & 9.4269309 & 22.9032033 \\
\hline $\mathrm{H}$ & 10.3897322 & 12.0094168 & 15.0164795 \\
\hline 0 & 12.0246756 & 10.8715743 & 24.8825994 \\
\hline 0 & 15.6005348 & 11.2172611 & 25.1761931 \\
\hline $\mathrm{O}$ & 10.1626454 & 8.2250409 & 25.2498212 \\
\hline $\mathrm{H}$ & 10.4228631 & 11.9964123 & 29.7423669 \\
\hline $\mathrm{H}$ & 8.7022291 & 15.1308009 & 15.1270201 \\
\hline Al & 5.3595251 & 14.7544591 & 16.5635952 \\
\hline $\mathrm{P}$ & 5.3083150 & 14.7447300 & 28.4001111 \\
\hline $\mathrm{Al}$ & 12.2313487 & 18.7092128 & 21.5533285 \\
\hline $\mathrm{Zn}$ & 12.3763664 & 13.4006870 & 21.5674060 \\
\hline Al & 17.1178431 & 16.0683855 & 21.554404 \\
\hline
\end{tabular}




\begin{tabular}{|c|c|c|c|}
\hline $\mathrm{P}$ & 17.0458310 & 16.1037896 & 18.3852312 \\
\hline $\mathrm{P}$ & 12.3205717 & 13.2041176 & 18.3672990 \\
\hline $\mathrm{P}$ & 12.2767817 & 18.7407830 & 18.3971465 \\
\hline Al & 5.3973786 & 17.2443078 & 26.5413434 \\
\hline $\mathrm{P}$ & 5.3838183 & 17.2972707 & 23.4536875 \\
\hline Al & 8.4735124 & 14.7766614 & 28.4011021 \\
\hline $\mathrm{P}$ & 8.5144679 & 14.8056301 & 16.5678985 \\
\hline Al & 15.5150184 & 13.3339645 & 18.4936447 \\
\hline Al & 15.4696904 & 18.8133706 & 18.4815587 \\
\hline Al & 10.7457267 & 15.9938266 & 18.4415100 \\
\hline $\mathrm{P}$ & 10.5947507 & 16.0361032 & 21.5951995 \\
\hline$P$ & 15.4386692 & 18.7744950 & 21.6291395 \\
\hline $\mathrm{P}$ & 15.5413606 & 13.4170659 & 21.5712218 \\
\hline Al & 8.5216263 & 17.4917233 & 23.4536070 \\
\hline$P$ & 8.5416553 & 17.3401441 & 26.5986917 \\
\hline $\mathrm{O}$ & 8.9440694 & 13.3453218 & 16.8384145 \\
\hline $\mathrm{O}$ & 6.7854028 & 14.4131458 & 28.1124158 \\
\hline 0 & 11.7114364 & 17.0815416 & 21.8797469 \\
\hline $\mathrm{O}$ & 14.1631080 & 14.0651827 & 21.6122548 \\
\hline 0 & 15.9480043 & 17.3482294 & 21.8919712 \\
\hline 0 & 15.9891679 & 15.0027580 & 18.1805200 \\
\hline 0 & 11.8802385 & 14.6758780 & 18.2336617 \\
\hline 0 & 13.7854613 & 18.4746349 & 18.2111360 \\
\hline 0 & 7.0625729 & 17.6841547 & 26.8864971 \\
\hline $\mathrm{H}$ & 8.9832796 & 18.8976512 & 23.2881873 \\
\hline $\mathrm{H}$ & 4.7549610 & 18.6463189 & 23.4121201 \\
\hline $\mathrm{H}$ & 18.2357751 & 15.8725247 & 17.5205519 \\
\hline $\mathrm{H}$ & 11.8512900 & 19.8800259 & 17.5379591 \\
\hline 0 & 11.6249622 & 12.3437236 & 17.2891185 \\
\hline 0 & 4.8555831 & 15.9468591 & 27.5660349 \\
\hline $\mathrm{H}$ & 11.5045324 & 19.7077316 & 22.3850850 \\
\hline 0 & 11.9293381 & 11.7915057 & 22.5376290 \\
\hline $\mathrm{H}$ & 18.3581158 & 16.3119812 & 22.3414906 \\
\hline 0 & 8.9849340 & 16.1465795 & 27.4549174 \\
\hline $\mathrm{H}$ & 16.2904186 & 12.4284195 & 17.6015330 \\
\hline 0 & 9.3553763 & 15.7708156 & 17.4031812 \\
\hline $\mathrm{H}$ & 15.8966635 & 20.0158858 & 17.7142440 \\
\hline 0 & 9.3276082 & 16.4269573 & 22.3718254 \\
\hline $\mathrm{O}$ & 7.0434267 & 14.9583714 & 16.9737871 \\
\hline $\mathrm{O}$ & 9.4019375 & 13.3724296 & 27.9459695 \\
\hline $\mathrm{O}$ & 13.9388586 & 18.8419019 & 21.8978138 \\
\hline 0 & 11.0174981 & 14.6523705 & 22.0277810 \\
\hline 0 & 16.5891441 & 14.4741690 & 21.9886767 \\
\hline 0 & 16.4329653 & 17.4556946 & 17.9825824 \\
\hline 0 & 13.8295720 & 13.1319930 & 18.1117354 \\
\hline $\mathrm{O}$ & 11.5135044 & 17.4901313 & 17.9586328 \\
\hline $\mathrm{H}$ & 4.5073599 & 18.4143979 & 26.7777256 \\
\hline $\mathrm{H}$ & 9.3866989 & 18.5122411 & 26.9581505 \\
\hline 0 & 6.8401472 & 17.4466554 & 23.0299143 \\
\hline $\mathrm{H}$ & 5.1522483 & 15.0433684 & 15.1176739 \\
\hline 0 & 11.9756311 & 19.1014853 & 19.8608363 \\
\hline $\mathrm{O}$ & 11.9447200 & 12.6257250 & 19.7448442 \\
\hline $\mathrm{O}$ & 17.5098375 & 16.1499702 & 19.8489610 \\
\hline 0 & 5.2744685 & 16.7154967 & 24.8756265 \\
\hline $\mathrm{H}$ & 8.6733626 & 15.0870695 & 29.8436093 \\
\hline 0 & 15.8807395 & 12.9005968 & 20.1456525 \\
\hline $\mathrm{O}$ & 15.7574695 & 19.2077416 & 20.1743372 \\
\hline $\mathrm{O}$ & 10.2256937 & 16.1031205 & 20.0917958 \\
\hline 0 & 8.7334121 & 16.9780141 & 25.1169679 \\
\hline $\mathrm{H}$ & 11.0636714 & 11.2958644 & 20.0220678 \\
\hline $\mathrm{N}$ & 10.4289106 & 10.4709204 & 20.3059341 \\
\hline $\mathrm{H}$ & 10.3393364 & 9.7914579 & 19.5388156 \\
\hline $\mathrm{H}$ & 9.4953430 & 10.8383100 & 20.5227783 \\
\hline $\mathrm{H}$ & 10.8077955 & 10.0230450 & 21.1703357 \\
\hline $\mathrm{H}$ & 5.1223579 & 15.0825069 & 29.8383208 \\
\hline $\mathrm{H}$ & 16.1058684 & 19.7576229 & 22.5265944 \\
\hline \multicolumn{4}{|c|}{ Si 27} \\
\hline & & & \\
\hline $\mathrm{H}$ & 8.7277111 & 9.0379834 & 15.1260374 \\
\hline $\mathrm{P}$ & 5.3522570 & 9.3636974 & 16.6582607 \\
\hline Al & 5.3235906 & 9.3171956 & 28.4930183 \\
\hline $\mathrm{P}$ & 5.3843895 & 6.7593363 & 21.6217811 \\
\hline Al & 5.4264192 & 6.7825640 & 18.4565175 \\
\hline $\mathrm{P}$ & 3.1726347 & 7.9825348 & 26.6268864 \\
\hline Al & 3.2166072 & 8.0399181 & 23.4972277 \\
\hline $\mathrm{P}$ & 8.4826879 & 9.2570657 & 28.4019595 \\
\hline Al & 8.5241382 & 9.3235194 & 16.5731545 \\
\hline $\mathrm{P}$ & 8.6116328 & 6.7902534 & 18.4373238 \\
\hline & & & \\
\hline
\end{tabular}

18.3852312

3672990

23.4536875

18.4815587

4415100

21.5951995

6291395

23.4536070

5986917

28.1124158

8797469

1.8919712

.1805200

8.2111360

.8864971

3. 4121201

. 5205519

(2)

7.5660349

22.3850850

22.5376290

4906

17.6015330

.4031812

22.3718254

.9737871

21.8978138

22.0277810

21.9886767

17.9825824

117354

6.7777256

26.9581505

23.0299143

19.7448442

29.8436093

20.1456525

1743372

0.0917958

169679

0.3059341

5388156

1.1703357

29.8383208

15.1260374

6582607

28.4930183
21.6217811

18.4565175

26.6268864

28.4019595

18.4373238

21.5943015 


\begin{tabular}{|c|c|c|c|}
\hline $\mathrm{P}$ & 1.6277993 & 10.7742348 & 23.4350943 \\
\hline Al & 1.6155392 & 10.7591422 & 26.5713121 \\
\hline 0 & 6.8446087 & 9.7025733 & 16.8811332 \\
\hline 0 & 4.8740994 & 10.9718051 & 28.1232586 \\
\hline $\mathrm{H}$ & 4.9357345 & 5.3613762 & 21.8698470 \\
\hline $\mathrm{H}$ & 9.0376556 & 5.3480702 & 21.8540601 \\
\hline 0 & 7.1339572 & 6.4544964 & 18.1877843 \\
\hline 0 & 2.1202569 & 9.0953429 & 26.7959906 \\
\hline $\mathrm{H}$ & 2.1627838 & 7.0151635 & 23.2596255 \\
\hline $\mathrm{H}$ & 0.2276339 & 10.3092099 & 23.2340738 \\
\hline 0 & 4.9426238 & 8.1702532 & 17.5221850 \\
\hline 0 & 4.3505615 & 8.2017006 & 27.5830299 \\
\hline 0 & 4.6121100 & 7.7568670 & 22.4933856 \\
\hline 0 & 2.5562849 & 11.8241416 & 27.5778193 \\
\hline 0 & 9.0504080 & 7.9896427 & 17.5765421 \\
\hline 0 & 1.9708449 & 11.9372415 & 22.5083171 \\
\hline 0 & 4.5102736 & 10.5718962 & 17.0779948 \\
\hline 0 & 6.9985681 & 9.0689538 & 28.0862669 \\
\hline 0 & 6.8717612 & 6.8779357 & 21.9865361 \\
\hline $\mathrm{H}$ & 9.4489609 & 5.6158472 & 18.0674961 \\
\hline $\mathrm{H}$ & 4.6402939 & 5.5997401 & 18.0092424 \\
\hline $\mathrm{H}$ & 0.1884553 & 10.8644712 & 26.9829646 \\
\hline $\mathrm{H}$ & 2.5457856 & 6.6771088 & 26.9733596 \\
\hline 0 & 2.5778891 & 9.6125808 & 23.1145205 \\
\hline $\mathrm{H}$ & 5.1104055 & 9.0214674 & 15.2294475 \\
\hline 0 & 5.1756275 & 7.1479579 & 20.1447189 \\
\hline 0 & 3.7071527 & 7.9699668 & 25.1829358 \\
\hline $\mathrm{H}$ & 8.7526260 & 8.9986506 & 29.8433046 \\
\hline 0 & 8.8421350 & 7.1873671 & 5755 \\
\hline 0 & 1.8176563 & 11.2295170 & 24.8988161 \\
\hline $\mathrm{H}$ & 5.1355443 & 9.0561567 & 29.9468470 \\
\hline $\mathrm{H}$ & 3.4944140 & 12.0603771 & 15.1302391 \\
\hline $\mathrm{P}$ & 3.1755078 & 15.9759608 & 21.6319060 \\
\hline Al & 3.1848351 & 16.0238368 & 18.4591126 \\
\hline $\mathrm{P}$ & 3.8199339 & 12.0637780 & 28.4067499 \\
\hline Al & 3.8078043 & 12.0929300 & 16.5855217 \\
\hline $\mathrm{P}$ & 1.5822961 & 13.3200159 & 18.3988950 \\
\hline Al & 1.5041179 & 13.3061282 & 21.5155780 \\
\hline 0 & 4.9833398 & 13.3522865 & 16.9280687 \\
\hline $\mathrm{H}$ & 0.0580170 & 13.6502300 & 21.6022203 \\
\hline $\mathrm{H}$ & 2.2187651 & 17.0877501 & 21.8882038 \\
\hline 0 & 1.9982007 & 14.7839830 & 18.1151137 \\
\hline 0 & 4.6299274 & 15.7867566 & 17.5082911 \\
\hline 0 & 4.4317813 & 16.1565313 & 22.4937007 \\
\hline 0 & 2.3230375 & 12.3710413 & 17.4437731 \\
\hline 0 & 4.4019219 & 13.4240290 & 28.0097532 \\
\hline 0 & 2.5220056 & 14.6525796 & 22.0098522 \\
\hline $\mathrm{H}$ & 2.6318354 & 17.3635262 & 18.1177268 \\
\hline $\mathrm{H}$ & 0.1240593 & 13.1861998 & 18.1291557 \\
\hline O & 3.6056484 & 15.9940100 & 20.1534727 \\
\hline $\mathrm{H}$ & 3.4519229 & 12.0550246 & 29.8495291 \\
\hline 0 & 1.9374793 & 12.9281234 & 19.8402612 \\
\hline $\mathrm{P}$ & 10.0994802 & 12.0092318 & 16.5872352 \\
\hline Al & 10.0490311 & 11.9707674 & 28.3886699 \\
\hline $\mathrm{P}$ & 12.3413344 & 10.7128827 & 26.6910726 \\
\hline Al & 12.3669069 & 10.7344703 & 23.4890958 \\
\hline $\mathrm{P}$ & 15.5027980 & 10.7742348 & 23.4350943 \\
\hline $\mathrm{P}$ & 10.6827539 & 8.0794900 & 23.4324336 \\
\hline Al & 10.7106208 & 8.0661888 & 26.5956513 \\
\hline Al & 15.4905380 & 10.7591422 & 26.5713121 \\
\hline 0 & 8.8934951 & 10.6969451 & 28.0330045 \\
\hline 0 & 11.8998880 & 9.2739265 & 27.0409362 \\
\hline $\mathrm{H}$ & 15.9192150 & 9.3460105 & 26.7621406 \\
\hline $\mathrm{H}$ & 11.5968824 & 6.9154491 & 23.2696503 \\
\hline 0 & 14.0505494 & 10.2919120 & 23.2265963 \\
\hline 0 & 11.5319433 & 11.7265310 & 27.5117149 \\
\hline 0 & 9.2761481 & 8.2424740 & 27.5716220 \\
\hline $\mathrm{H}$ & 16.2949564 & 11.6698083 & 27.4319623 \\
\hline 0 & 9.4247958 & 7.9046088 & 22.5641834 \\
\hline 0 & 15.8458437 & 11.9372415 & 22.5083171 \\
\hline 0 & 9.5182334 & 10.6718707 & 17.1108087 \\
\hline 0 & 13.8187193 & 10.8825344 & 27.0535601 \\
\hline $\mathrm{H}$ & 11.2812765 & 6.7138723 & 26.8460759 \\
\hline $\mathrm{H}$ & 16.4246795 & 9.6470705 & 23.1240383 \\
\hline 0 & 11.3928257 & 9.3497416 & 22.9146519 \\
\hline $\mathrm{H}$ & 10.3734797 & 11.9137992 & 15.1267772 \\
\hline 0 & 12.1004869 & 10.9775300 & 25.2001221 \\
\hline 0 & 15.6926551 & 11.2295170 & 24.8988161 \\
\hline 0 & 10.2731747 & 8.2522351 & 24.9019599 \\
\hline $\mathrm{H}$ & 10.3320183 & 11.9199560 & 29.8496480 \\
\hline
\end{tabular}




\begin{tabular}{|c|c|c|c|}
\hline $\mathrm{H}$ & 8.7702458 & 15.0438683 & 15.0755818 \\
\hline $\mathrm{P}$ & 5.4210210 & 14.8024750 & 16.6387517 \\
\hline Al & 5.3820363 & 14.7839048 & 28.4790194 \\
\hline $\mathrm{P}$ & 12.3218889 & 18.7754377 & 21.6217811 \\
\hline $\mathrm{Si}$ & 12.1635234 & 13.2715013 & 21.5687804 \\
\hline $\mathrm{P}$ & 17.0505065 & 15.9759608 & 21.6319060 \\
\hline Al & 17.0598339 & 16.0238368 & 18.4591126 \\
\hline Al & 12.2561851 & 13.3005946 & 18.4695560 \\
\hline Al & 12.3639186 & 18.7986654 & 18.4565175 \\
\hline $\mathrm{P}$ & 5.3259482 & 17.2949387 & 26.6156339 \\
\hline Al & 5.3069535 & 17.2762099 & 23.4907262 \\
\hline $\mathrm{P}$ & 8.5452216 & 14.7331714 & 28.3637052 \\
\hline Al & 8.5841636 & 14.7761025 & 16.5284395 \\
\hline $\mathrm{P}$ & 15.4572948 & 13.3200159 & 18.3988950 \\
\hline$P$ & 15.5491322 & 18.8063548 & 18.4373238 \\
\hline$P$ & 10.7450329 & 16.1230700 & 18.3754105 \\
\hline Al & 10.6564644 & 16.0887737 & 21.5178965 \\
\hline Al & 15.4898080 & 18.7476760 & 21.5943015 \\
\hline Al & 15.3791166 & 13.3061282 & 21.5155780 \\
\hline $\mathrm{P}$ & 8.4583844 & 17.3872212 & 23.3825325 \\
\hline Al & 8.4781087 & 17.2932510 & 26.5347984 \\
\hline 0 & 9.0745032 & 13.1208652 & 16.8833040 \\
\hline 0 & 7.0573313 & 14.3952460 & 28.1519631 \\
\hline 0 & 11.8601831 & 17.3368129 & 21.8770628 \\
\hline 0 & 13.7212450 & 13.7006212 & 21.6149084 \\
\hline 0 & 16.0572348 & 17.1301990 & 21.8979894 \\
\hline 0 & 15.8731994 & 14.7839830 & 18.1151137 \\
\hline 0 & 11.7530293 & 14.9652971 & 18.2522520 \\
\hline 0 & 14.0714565 & 18.4705977 & 18.1877843 \\
\hline 0 & 6.7962909 & 17.6845197 & 26.8651823 \\
\hline H & 8.8992034 & 18.8005556 & 23.2235198 \\
\hline $\mathrm{H}$ & 4.7785468 & 18.6550255 & 23.2989592 \\
\hline $\mathrm{H}$ & 18.2922088 & 15.8216548 & 17.6482519 \\
\hline $\mathrm{H}$ & 11.9502615 & 19.9851742 & 17.6576399 \\
\hline 0 & 11.4176304 & 12.2606478 & 17.3200278 \\
\hline 0 & 4.8883753 & 16.1783082 & 27.5661285 \\
\hline $\mathrm{H}$ & 11.5719490 & 19.7441129 & 22.4681728 \\
\hline 0 & 11.8099972 & 12.0360820 & 22.5525655 \\
\hline $\mathrm{H}$ & 18.2698330 & 16.1512207 & 22.4683553 \\
\hline 0 & 8.9646450 & 15.9167653 & 27.4887426 \\
\hline $\mathrm{H}$ & 16.1750338 & 12.4005101 & 17.4734328 \\
\hline 0 & 9.5533316 & 15.8967483 & 17.4331530 \\
\hline $\mathrm{H}$ & 15.9733403 & 19.9659253 & 17.6051193 \\
\hline 0 & 9.2178421 & 16.4622532 & 22.4417196 \\
\hline $\mathrm{O}$ & 6.9085655 & 14.9478914 & 16.9803015 \\
\hline 0 & 9.3820512 & 13.5160952 & 27.9524333 \\
\hline 0 & 13.8092606 & 18.8940371 & 21.9865361 \\
\hline 0 & 11.2085582 & 14.5259762 & 21.8770679 \\
\hline 0 & 16.3970043 & 14.6525796 & 22.0098522 \\
\hline O & 16.4091988 & 17.6000564 & 18.0574530 \\
\hline 0 & 13.9588208 & 13.1825074 & 18.1217128 \\
\hline 0 & 11.4465694 & 17.4183986 & 17.9345810 \\
\hline $\mathrm{H}$ & 4.4603112 & 18.4773131 & 26.8798004 \\
\hline $\mathrm{H}$ & 9.3222706 & 18.4583240 & 26.9183554 \\
\hline 0 & 6.9720582 & 17.3066227 & 23.0188064 \\
\hline $\mathrm{H}$ & 5.1802006 & 15.1343931 & 15.2073341 \\
\hline 0 & 12.1131268 & 19.1640592 & 20.1447189 \\
\hline 0 & 11.8177171 & 12.6778121 & 20.0371772 \\
\hline 0 & 17.4806471 & 15.9940100 & 20.1534727 \\
\hline 0 & 5.1405865 & 16.8061976 & 25.1674999 \\
\hline $\mathrm{H}$ & 8.7944059 & 15.0790608 & 29.7903755 \\
\hline 0 & 15.8124780 & 12.9281234 & 19.8402612 \\
\hline 0 & 15.7796343 & 19.2034684 & 19.9145755 \\
\hline 0 & 10.2224221 & 16.2619827 & 19.8100971 \\
\hline 0 & 8.6785912 & 16.9255353 & 24.8380239 \\
\hline $\mathrm{H}$ & 10.9974431 & 11.3890247 & 20.1468322 \\
\hline $\mathrm{N}$ & 10.3907645 & 10.4755852 & 20.2868886 \\
\hline $\mathrm{H}$ & 10.4033219 & 9.8903590 & 19.4418263 \\
\hline $\mathrm{H}$ & 9.4195451 & 10.7474474 & 20.4740341 \\
\hline $\mathrm{H}$ & 10.7435845 & 9.9554253 & 21.1138003 \\
\hline H & 5.2033484 & 15.0917584 & 29.9248469 \\
\hline $\mathrm{H}$ & 16.2303087 & 19.7432581 & 22.4174635 \\
\hline \\
\hline \multicolumn{4}{|c|}{$\begin{array}{l}\operatorname{Mg~} 27 \\
163\end{array}$} \\
\hline $\mathrm{H}$ & 8.7615028 & 9.0456635 & 15.2641161 \\
\hline Al & 5.3955183 & 9.3221000 & 16.6264342 \\
\hline $\mathrm{P}$ & 5.4010377 & 9.2872999 & 28.4431171 \\
\hline Al & 5.2863088 & 6.7190307 & 21.5484242 \\
\hline $\mathrm{P}$ & 5.3532222 & 6.7303220 & 18.3888490 \\
\hline
\end{tabular}




\begin{tabular}{|c|c|c|c|}
\hline Al & 3.1831461 & 8.0626790 & 26.5723128 \\
\hline $\mathrm{P}$ & 3.2743942 & 8.1629131 & 23.4526531 \\
\hline Al & 8.5354647 & 9.2674621 & 28.5080394 \\
\hline $\mathrm{P}$ & 8.5641216 & 9.3932867 & 16.6984519 \\
\hline Al & 8.5445943 & 6.8111650 & 18.4883556 \\
\hline $\mathrm{P}$ & 8.5009448 & 6.7665991 & 21.6329621 \\
\hline Al & 1.5507190 & 10.8124898 & 23.4882673 \\
\hline $\mathrm{P}$ & 1.5251412 & 10.7816605 & 26.6349264 \\
\hline 0 & 7.0834423 & 9.7063704 & 16.9790985 \\
\hline 0 & 5.0205495 & 10.7465519 & 28.1171045 \\
\hline $\mathrm{H}$ & 4.7788915 & 5.3522697 & 21.8510998 \\
\hline $\mathrm{H}$ & 9.0144637 & 5.3922880 & 21.8873005 \\
\hline 0 & 6.8636324 & 6.4700101 & 18.2090843 \\
\hline 0 & 1.9719045 & 9.3125249 & 26.7722744 \\
\hline $\mathrm{H}$ & 2.2065333 & 7.1511296 & 23.2222450 \\
\hline $\mathrm{H}$ & 0.1811249 & 10.2726634 & 23.2648394 \\
\hline 0 & 4.9127412 & 7.9014602 & 17.5027430 \\
\hline 0 & 4.5347185 & 8.3126993 & 27.6430408 \\
\hline 0 & 4.4744593 & 7.9174831 & 22.5278406 \\
\hline 0 & 2.3548517 & 11.6817928 & 27.5566312 \\
\hline 0 & 9.0486287 & 8.2342830 & 17.5901384 \\
\hline 0 & 1.9005601 & 12.1909204 & 22.5068517 \\
\hline 0 & 4.4041457 & 10.6707241 & 17.1057505 \\
\hline 0 & 6.8678258 & 9.0536898 & 28.0618356 \\
\hline 0 & 6.9982307 & 6.8032479 & 21.8870919 \\
\hline $\mathrm{H}$ & 9.3749987 & 5.6500713 & 18.0647869 \\
\hline $\mathrm{H}$ & 4.6205750 & 5.5082991 & 17.9564041 \\
\hline $\mathrm{H}$ & 0.1011138 & 10.8830638 & 27.0579913 \\
\hline $\mathrm{H}$ & 2.5641348 & 6.7573410 & 26.9329210 \\
\hline 0 & 2.7136377 & 9.5540764 & 23.1403423 \\
\hline $\mathrm{H}$ & 5.2297751 & 9.0508321 & 15.1717646 \\
\hline 0 & 5.0461531 & 7.0934612 & 19.8504725 \\
\hline 0 & 3.7598119 & 8.0831319 & 24.9163740 \\
\hline $\mathrm{H}$ & 8.7318838 & 9.0707049 & 29.9708541 \\
\hline 0 & 8.8259539 & 7.2103384 & 20.1818192 \\
\hline 0 & 1.6902457 & 11.2645306 & 25.1846772 \\
\hline $\mathrm{H}$ & 5.2077116 & 9.0133553 & 29.8938755 \\
\hline $\mathrm{H}$ & 3.4686497 & 11.9585127 & 15.1976150 \\
\hline Al & 3.2438209 & 16.0665139 & 21.5590858 \\
\hline$P$ & 3.1759734 & 16.1114878 & 18.3852758 \\
\hline Al & 3.8121702 & 11.9792385 & 28.4582952 \\
\hline $\mathrm{P}$ & 3.8188134 & 12.0142820 & 16.6437809 \\
\hline Al & 1.6422658 & 13.3515229 & 18.4901444 \\
\hline $\mathrm{P}$ & 1.6745378 & 13.3946477 & 21.5721188 \\
\hline 0 & 4.8759264 & 13.1093625 & 16.9021510 \\
\hline $\mathrm{H}$ & 0.2805649 & 13.9155399 & 21.6234158 \\
\hline $\mathrm{H}$ & 2.2743223 & 17.1605527 & 21.8424095 \\
\hline $\mathrm{O}$ & 2.1132584 & 15.0200611 & 18.1617681 \\
\hline 0 & 4.4035504 & 15.8760391 & 17.4971919 \\
\hline 0 & 4.7051799 & 16.3391529 & 22.4680747 \\
\hline 0 & 2.5390377 & 12.2849434 & 17.4343389 \\
\hline 0 & 4.4393974 & 13.5387232 & 28.0045718 \\
\hline 0 & 2.6685233 & 14.4967187 & 22.0099833 \\
\hline $\mathrm{H}$ & 2.5949972 & 17.4291987 & 18.0068248 \\
\hline $\mathrm{H}$ & 0.1947535 & 13.1907567 & 18.1803333 \\
\hline $\mathrm{O}$ & 3.6322233 & 16.1385583 & 19.8519040 \\
\hline $\mathrm{H}$ & 3.5096519 & 11.9600352 & 29.9161136 \\
\hline 0 & 2.0464075 & 12.9311865 & 20.1344900 \\
\hline Al & 10.1148496 & 12.1086060 & 16.4732803 \\
\hline $\mathrm{P}$ & 10.0288049 & 12.0221159 & 28.3044431 \\
\hline Al & 12.2675693 & 10.6493898 & 26.6162488 \\
\hline$P$ & 12.3210852 & 10.5920606 & 23.4067587 \\
\hline Al & 15.4257177 & 10.8124898 & 23.4882673 \\
\hline Al & 10.5782752 & 8.0167495 & 23.5806657 \\
\hline$P$ & 10.6795199 & 7.9860561 & 26.6927370 \\
\hline $\mathrm{P}$ & 15.4001400 & 10.7816605 & 26.6349264 \\
\hline 0 & 9.0112355 & 10.8915387 & 28.0464883 \\
\hline 0 & 11.7568930 & 9.0252895 & 27.0640249 \\
\hline $\mathrm{H}$ & 15.8316331 & 9.3627393 & 26.7675799 \\
\hline $\mathrm{H}$ & 11.4737150 & 6.8345285 & 23.4477689 \\
\hline 0 & 13.8002405 & 10.1718069 & 23.2230961 \\
\hline 0 & 11.2821320 & 11.8284442 & 27.4466780 \\
\hline $\mathrm{O}$ & 9.4981385 & 8.0791170 & 27.6685352 \\
\hline $\mathrm{H}$ & 16.2063606 & 11.6563093 & 27.5305370 \\
\hline 0 & 9.1677221 & 7.7940755 & 22.5692139 \\
\hline $\mathrm{O}$ & 15.7755588 & 12.1909204 & 22.5068517 \\
\hline 0 & 9.4243430 & 10.6105319 & 17.0918601 \\
\hline 0 & 13.9315183 & 10.8862393 & 27.0712398 \\
\hline $\mathrm{H}$ & 11.2611492 & 6.6192695 & 26.7962847 \\
\hline $\mathrm{H}$ & 16.4160792 & 9.7408034 & 23.1919684 \\
\hline
\end{tabular}




\begin{tabular}{|c|c|c|c|}
\hline 0 & 11.4219793 & 9.4054422 & 22.9008763 \\
\hline $\mathrm{H}$ & 10.3934717 & 12.0200430 & 15.0132642 \\
\hline $\mathrm{O}$ & 12.0343621 & 10.8225221 & 24.9007284 \\
\hline $\mathrm{O}$ & 15.5652444 & 11.2645306 & 25.1846772 \\
\hline 0 & 10.1550692 & 8.2503003 & 25.2614957 \\
\hline $\mathrm{H}$ & 10.4264335 & 12.0058638 & 29.7392769 \\
\hline $\mathrm{H}$ & 8.6972019 & 15.1334004 & 15.1078595 \\
\hline Al & 5.3607999 & 14.7607847 & 16.5633275 \\
\hline $\mathrm{P}$ & 5.3010928 & 14.7428827 & 28.3969368 \\
\hline Al & 12.2238082 & 18.7351321 & 21.5484242 \\
\hline Mg & 12.3178320 & 13.3538616 & 21.5620190 \\
\hline Al & 17.1188196 & 16.0665139 & 21.5590858 \\
\hline $\mathrm{P}$ & 17.0509721 & 16.1114878 & 18.3852758 \\
\hline $\mathrm{P}$ & 12.3136026 & 13.2106728 & 18.3870936 \\
\hline $\mathrm{P}$ & 12.2907216 & 18.7464233 & 18.3888490 \\
\hline Al & 5.3895422 & 17.2403290 & 26.5368912 \\
\hline $\mathrm{P}$ & 5.3734860 & 17.2962175 & 23.4542542 \\
\hline Al & 8.4661847 & 14.7718485 & 28.3843358 \\
\hline $\mathrm{P}$ & 8.5156405 & 14.8166665 & 16.5514092 \\
\hline Al & 15.5172646 & 13.3515229 & 18.4901444 \\
\hline Al & 15.4820936 & 18.8272664 & 18.4883556 \\
\hline Al & 10.7299959 & 16.0201650 & 18.4419798 \\
\hline $\mathrm{P}$ & 10.5470257 & 16.0769603 & 21.5672431 \\
\hline $\mathrm{P}$ & 15.4384442 & 18.7827005 & 21.6329621 \\
\hline $\mathrm{P}$ & 15.5495366 & 13.3946477 & 21.5721188 \\
\hline Al & 8.5110602 & 17.5017130 & 23.4426844 \\
\hline $\mathrm{P}$ & 8.5284709 & 17.3502198 & 26.6006263 \\
\hline $\mathrm{O}$ & 8.9431339 & 13.3571131 & 16.8287743 \\
\hline 0 & 6.7765421 & 14.4068450 & 28.1050866 \\
\hline $\mathrm{O}$ & 11.6321375 & 17.1414293 & 21.9013571 \\
\hline 0 & 14.1318348 & 13.9244068 & 21.6242890 \\
\hline 0 & 15.9681966 & 17.3649440 & 21.8953408 \\
\hline O & 15.9882571 & 15.0200611 & 18.1617681 \\
\hline 0 & 11.8509285 & 14.6800715 & 18.3004619 \\
\hline 0 & 13.8011317 & 18.4861115 & 18.2090843 \\
\hline 0 & 7.0495079 & 17.6882344 & 26.8955616 \\
\hline $\mathrm{H}$ & 9.0181346 & 18.8881924 & 23.2485937 \\
\hline $\mathrm{H}$ & 4.6985455 & 18.6231915 & 23.4274972 \\
\hline $\mathrm{H}$ & 18.2430653 & 15.8828449 & 17.5228625 \\
\hline $\mathrm{H}$ & 11.8629454 & 19.8837823 & 17.5283010 \\
\hline 0 & 11.6265133 & 12.3729809 & 17.2859280 \\
\hline 0 & 4.8485421 & 15.9474343 & 27.5666913 \\
\hline $\mathrm{H}$ & 11.5321526 & 19.7561541 & 22.3828384 \\
\hline O & 11.9413905 & 11.7889817 & 22.5796180 \\
\hline $\mathrm{H}$ & 18.3676086 & 16.2994947 & 22.3358526 \\
\hline $\mathrm{O}$ & 8.9728022 & 16.1399498 & 27.4333960 \\
\hline $\mathrm{H}$ & 16.2810357 & 12.4431284 & 17.5909260 \\
\hline 0 & 9.3644092 & 15.7854393 & 17.3743638 \\
\hline $\mathrm{H}$ & 15.9093113 & 20.0334957 & 17.7270302 \\
\hline 0 & 9.2770779 & 16.3848883 & 22.3797966 \\
\hline O & 7.0465354 & 14.9733107 & 16.9637184 \\
\hline $\mathrm{O}$ & 9.3969154 & 13.3658883 & 27.9348472 \\
\hline 0 & 13.9357300 & 18.8193493 & 21.8870919 \\
\hline 0 & 11.0393624 & 14.6963752 & 21.8996170 \\
\hline $\mathrm{O}$ & 16.5435220 & 14.4967187 & 22.0099833 \\
\hline O & 16.4507329 & 17.4728891 & 17.9942768 \\
\hline O & 13.8236973 & 13.1634289 & 18.1276702 \\
\hline 0 & 11.5382507 & 17.4913354 & 17.9447032 \\
\hline $\mathrm{H}$ & 4.4895584 & 18.4051621 & 26.7611984 \\
\hline $\mathrm{H}$ & 9.3713545 & 18.5164606 & 26.9834451 \\
\hline 0 & 6.8237521 & 17.5022499 & 23.0311094 \\
\hline $\mathrm{H}$ & 5.1491338 & 15.0401455 & 15.1161662 \\
\hline 0 & 11.9836525 & 19.1095626 & 19.8504725 \\
\hline 0 & 11.9552450 & 12.6027583 & 19.7540928 \\
\hline 0 & 17.5072220 & 16.1385583 & 19.8519040 \\
\hline 0 & 5.2867561 & 16.7006030 & 24.8725707 \\
\hline $\mathrm{H}$ & 8.6677892 & 15.0882717 & 29.8252912 \\
\hline 0 & 15.9214062 & 12.9311865 & 20.1344900 \\
\hline 0 & 15.7634532 & 19.2264398 & 20.1818192 \\
\hline 0 & 10.1603274 & 16.2143422 & 20.0705485 \\
\hline 0 & 8.7198581 & 17.0144977 & 25.1135453 \\
\hline $\mathrm{H}$ & 11.0847114 & 11.2336545 & 19.9988244 \\
\hline $\mathrm{N}$ & 10.4655992 & 10.4014544 & 20.2876316 \\
\hline $\mathrm{H}$ & 10.4007429 & 9.7059579 & 19.5322858 \\
\hline $\mathrm{H}$ & 9.5195959 & 10.7493744 & 20.4825922 \\
\hline $\mathrm{H}$ & 10.8407422 & 9.9746557 & 21.1657814 \\
\hline $\mathrm{H}$ & 5.1183518 & 15.0777590 & 29.8362367 \\
\hline $\mathrm{H}$ & 16.0824251 & 19.7750486 & 22.5372045 \\
\hline
\end{tabular}




\begin{tabular}{|c|c|c|c|}
\hline $\mathrm{H}$ & 8.7276931 & 8.9361382 & 15.2139197 \\
\hline $\mathrm{Si}$ & 5.3030833 & 9.2571673 & 16.6274719 \\
\hline $\mathrm{Si}$ & 5.3074618 & 9.2057208 & 28.5840836 \\
\hline $\mathrm{Si}$ & 5.2824259 & 6.7567003 & 21.6067120 \\
\hline $\mathrm{Si}$ & 5.3247195 & 6.7813531 & 18.5185867 \\
\hline $\mathrm{Si}$ & 3.2169534 & 7.9840990 & 26.6258295 \\
\hline $\mathrm{Si}$ & 3.2807670 & 8.0588780 & 23.5591976 \\
\hline $\mathrm{Si}$ & 8.4421977 & 9.1899122 & 28.5735061 \\
\hline $\mathrm{Si}$ & 8.4517811 & 9.2844949 & 16.6350604 \\
\hline $\mathrm{Si}$ & 8.4858392 & 6.8122547 & 18.5453242 \\
\hline $\mathrm{Si}$ & 8.4561373 & 6.7574592 & 21.6309567 \\
\hline $\mathrm{Si}$ & 1.6394722 & 10.7350541 & 23.5494805 \\
\hline $\mathrm{Si}$ & 1.6231702 & 10.7052785 & 26.6314000 \\
\hline 0 & 6.8807294 & 9.6347840 & 16.8439153 \\
\hline $\mathrm{O}$ & 4.9096291 & 10.7585751 & 28.2889672 \\
\hline $\mathrm{H}$ & 4.8014140 & 5.3704441 & 21.8597771 \\
\hline $\mathrm{H}$ & 8.9542381 & 5.3740290 & 21.8657699 \\
\hline $\mathrm{O}$ & 6.9172629 & 6.4664732 & 18.3441829 \\
\hline $\mathrm{O}$ & 2.0994972 & 9.1554377 & 26.7876319 \\
\hline $\mathrm{H}$ & 2.2325870 & 7.0251033 & 23.3361523 \\
\hline $\mathrm{H}$ & 0.2442697 & 10.2530665 & 23.3539846 \\
\hline $\mathrm{O}$ & 4.8868604 & 8.0152882 & 17.5690524 \\
\hline $\mathrm{O}$ & 4.4479029 & 8.2025417 & 27.6556594 \\
\hline $\mathrm{O}$ & 4.5500807 & 7.8297908 & 22.5768112 \\
\hline O & 2.4724008 & 11.6586218 & 27.6271477 \\
\hline $\mathrm{O}$ & 8.9238716 & 8.0827772 & 17.6236873 \\
\hline 0 & 2.0127337 & 11.9496753 & 22.5577705 \\
\hline $\mathrm{O}$ & 4.4140533 & 10.5374789 & 17.0539658 \\
\hline $\mathrm{O}$ & 6.8747785 & 8.9861702 & 28.2451277 \\
\hline 0 & 6.8735588 & 6.8207681 & 21.9085539 \\
\hline $\mathrm{H}$ & 9.3092352 & 5.6390336 & 18.1419732 \\
\hline $\mathrm{H}$ & 4.5689997 & 5.5733601 & 18.0864281 \\
\hline $\mathrm{H}$ & 0.1928197 & 10.7901586 & 27.0363857 \\
\hline $\mathrm{H}$ & 2.5822185 & 6.6809829 & 26.9665945 \\
\hline $\mathrm{O}$ & 2.6568213 & 9.5125894 & 23.2297537 \\
\hline $\mathrm{H}$ & 5.0509324 & 8.8786676 & 15.2096290 \\
\hline 0 & 5.0033014 & 7.1916878 & 20.0575822 \\
\hline 0 & 3.8028037 & 7.9826699 & 25.1055098 \\
\hline $\mathrm{H}$ & 8.7242795 & 8.9308440 & 30.0124065 \\
\hline $\mathrm{O}$ & 8.7991617 & 7.2390151 & 20.0960276 \\
\hline $\mathrm{O}$ & 1.8287638 & 11.2210562 & 25.1012336 \\
\hline $\mathrm{H}$ & 5.0518329 & 8.8750508 & 30.0132203 \\
\hline $\mathrm{H}$ & 3.3680666 & 11.9140585 & 15.1706834 \\
\hline $\mathrm{Si}$ & 3.2595264 & 15.8479904 & 21.6001522 \\
\hline $\mathrm{Si}$ & 3.2251518 & 15.9034321 & 18.4965617 \\
\hline $\mathrm{Si}$ & 3.7798976 & 11.9101313 & 28.5418336 \\
\hline $\mathrm{Si}$ & 3.7622644 & 11.9532180 & 16.6060214 \\
\hline $\mathrm{Si}$ & 1.6517786 & 13.1902697 & 18.5146357 \\
\hline $\mathrm{Si}$ & 1.6266333 & 13.1860856 & 21.5693893 \\
\hline 0 & 4.8739752 & 13.1174168 & 16.8688849 \\
\hline $\mathrm{H}$ & 0.2034741 & 13.6096433 & 21.6804626 \\
\hline $\mathrm{H}$ & 2.2831437 & 16.9415304 & 21.8608582 \\
\hline $\mathrm{O}$ & 2.1139036 & 14.7398112 & 18.2719346 \\
\hline 0 & 4.5063708 & 15.6848842 & 17.5284639 \\
\hline 0 & 4.5708954 & 16.0324111 & 22.5332695 \\
\hline $\mathrm{O}$ & 2.4341040 & 12.2069522 & 17.4872376 \\
\hline $\mathrm{O}$ & 4.4076234 & 13.3432444 & 28.1321874 \\
\hline 0 & 2.6162024 & 14.4217045 & 21.9622223 \\
\hline $\mathrm{H}$ & 2.6222729 & 17.2176114 & 18.1407666 \\
\hline $\mathrm{H}$ & 0.2016248 & 13.0955477 & 18.1902868 \\
\hline $\mathrm{O}$ & 3.7339580 & 15.9247551 & 20.0405890 \\
\hline $\mathrm{H}$ & 3.3697104 & 11.9104269 & 29.9732200 \\
\hline 0 & 1.9861508 & 12.7154078 & 20.0305195 \\
\hline $\mathrm{Si}$ & 10.0120685 & 11.9550963 & 16.5445575 \\
\hline $\mathrm{Si}$ & 9.9578474 & 11.8872150 & 28.4737893 \\
\hline $\mathrm{Si}$ & 12.1335893 & 10.6344589 & 26.6667325 \\
\hline $\mathrm{Si}$ & 12.1574843 & 10.6122193 & 23.5317870 \\
\hline $\mathrm{Si}$ & 15.2644709 & 10.7350541 & 23.5494805 \\
\hline $\mathrm{Si}$ & 10.4573435 & 7.9964567 & 23.6097413 \\
\hline $\mathrm{Si}$ & 10.5273315 & 7.9812105 & 26.6678613 \\
\hline $\mathrm{Si}$ & 15.2481689 & 10.7052785 & 26.6314000 \\
\hline 0 & 8.8578011 & 10.7170023 & 28.1841568 \\
\hline 0 & 11.6640732 & 9.1027108 & 26.9882704 \\
\hline $\mathrm{H}$ & 15.6835871 & 9.2885443 & 26.7742141 \\
\hline $\mathrm{H}$ & 11.3523173 & 6.8134697 & 23.4805748 \\
\hline 0 & 13.7342296 & 10.2064159 & 23.3350629 \\
\hline 0 & 11.2784546 & 11.6808061 & 27.5662159 \\
\hline $\mathrm{O}$ & 9.2876877 & 8.1180388 & 27.7045253 \\
\hline $\mathrm{H}$ & 16.0291483 & 11.5820033 & 27.5471212 \\
\hline
\end{tabular}




\begin{tabular}{|c|c|c|}
\hline 9.1769069 & 7.8342455 & 22.6165479 \\
\hline 15.6377324 & 11.9496753 & 22.5577705 \\
\hline 9.3499657 & 10.5649215 & 17.1143679 \\
\hline 13.6913609 & 10.7976629 & 27.0721905 \\
\hline 11.1238435 & 6.6282907 & 26.8436516 \\
\hline 16.1982649 & 9.6129907 & 23.2560130 \\
\hline 11.2679526 & 9.3002384 & 23.0983273 \\
\hline 10.3559155 & 11.8276854 & 15.1014164 \\
\hline 11.8862496 & 10.9672258 & 25.1014817 \\
\hline 15.4537625 & 11.2210562 & 25.1012336 \\
\hline 9.9527249 & 8.1662208 & 25.1480287 \\
\hline 10.3487778 & 11.8227686 & 29.9091083 \\
\hline 8.6868389 & 15.0432063 & 15.1093722 \\
\hline 5.3297613 & 14.6557191 & 16.5869519 \\
\hline 5.2994715 & 14.6275128 & 28.5437717 \\
\hline 12.0949252 & 18.5562954 & 21.6067120 \\
\hline 12.0719730 & 13.1503297 & 21.5928233 \\
\hline 16.8845251 & 15.8479904 & 21.6001522 \\
\hline 16.8501505 & 15.9034321 & 18.4965617 \\
\hline 12.1181144 & 13.1358864 & 18.4824069 \\
\hline 12.1372189 & 18.5809482 & 18.5185867 \\
\hline 5.3113928 & 17.0354026 & 26.6054335 \\
\hline 5.2888682 & 17.0456815 & 23.5645088 \\
\hline 8.4375883 & 14.6321107 & 28.4979034 \\
\hline 8.4663622 & 14.6847519 & 16.5376653 \\
\hline 15.2767774 & 13.1902697 & 18.5146357 \\
\hline 15.2983385 & 18.6118497 & 18.5453242 \\
\hline 10.5554857 & 15.9060331 & 18.4885346 \\
\hline 10.4456801 & 15.8971227 & 21.5688434 \\
\hline 15.2686367 & 18.5570542 & 21.6309567 \\
\hline 15.2516320 & 13.1860856 & 21.5693893 \\
\hline 8.4103040 & 17.2034219 & 23.4987385 \\
\hline 8.4271179 & 17.0925639 & 26.5957018 \\
\hline 8.9312443 & 13.1398622 & 16.7988922 \\
\hline 6.8660651 & 14.2613049 & 28.2952402 \\
\hline 11.5728465 & 17.0516859 & 21.8813829 \\
\hline 13.7283325 & 13.6394469 & 21.6882783 \\
\hline 15.8112172 & 17.0500859 & 21.8867384 \\
\hline 15.7389023 & 14.7398112 & 18.2719346 \\
\hline 11.6106855 & 14.6748043 & 18.3487088 \\
\hline 13.7297622 & 18.2660682 & 18.3441829 \\
\hline 6.8613584 & 17.4638331 & 26.8769567 \\
\hline 8.9023101 & 18.5987680 & 23.3312282 \\
\hline 4.6684387 & 18.3964661 & 23.4775092 \\
\hline 18.0272941 & 15.7026372 & 17.6071040 \\
\hline 11.7341161 & 19.7169362 & 17.6444243 \\
\hline 11.3778088 & 12.1908480 & 17.3729113 \\
\hline 4.8396038 & 15.8754130 & 27.6269421 \\
\hline 11.4223828 & 19.5417582 & 22.4975937 \\
\hline 11.6825644 & 11.7860701 & 22.5781803 \\
\hline 18.0898495 & 16.0174978 & 22.4578124 \\
\hline 8.8827543 & 15.8399868 & 27.5192892 \\
\hline 15.9944618 & 12.2882004 & 17.5721281 \\
\hline 9.3121910 & 15.6997843 & 17.4645429 \\
\hline 15.6985841 & 19.7727708 & 17.7031922 \\
\hline 9.1302968 & 16.1957431 & 22.4762648 \\
\hline 6.9029094 & 14.8065387 & 16.9369599 \\
\hline 9.3173064 & 13.3266184 & 28.1192797 \\
\hline 13.6860582 & 18.6203631 & 21.9085539 \\
\hline 11.0026463 & 14.4542753 & 21.8972290 \\
\hline 16.2412011 & 14.4217045 & 21.9622223 \\
\hline 16.1914494 & 17.3392951 & 18.1078225 \\
\hline 13.7019843 & 13.0874064 & 18.1624093 \\
\hline 11.3178194 & 17.2711653 & 18.0500128 \\
\hline 4.4347783 & 18.2162361 & 26.8384573 \\
\hline 9.2668096 & 18.2656569 & 26.9643357 \\
\hline 6.8341135 & 17.1994048 & 23.1430109 \\
\hline 5.0755374 & 15.0063876 & 15.1623388 \\
\hline 11.8158008 & 18.9912829 & 20.0575822 \\
\hline 11.7654187 & 12.5074008 & 19.9373072 \\
\hline 17.3589568 & 15.9247551 & 20.0405890 \\
\hline 5.1419351 & 16.4757721 & 25.0838468 \\
\hline 8.6841084 & 15.0382598 & 29.9090700 \\
\hline 15.6111496 & 12.7154078 & 20.0305195 \\
\hline 15.6116610 & 19.0386102 & 20.0960276 \\
\hline 9.9817029 & 16.0401414 & 19.9967192 \\
\hline 8.6472763 & 16.6996242 & 25.0331817 \\
\hline 11.0855527 & 11.1204980 & 20.0063355 \\
\hline 10.5776180 & 10.1480647 & 20.0610182 \\
\hline 11.2673569 & 9.3883742 & 20.0613700 \\
\hline
\end{tabular}




\begin{tabular}{|c|c|c|c|}
\hline $\mathrm{H}$ & 9.9553850 & 10.0330258 & 19.2454730 \\
\hline $\mathrm{H}$ & 10.0538594 & 10.0830975 & 20.9444818 \\
\hline $\mathrm{H}$ & 5.0731388 & 15.0037617 & 29.9665615 \\
\hline $\mathrm{H}$ & 15.9278683 & 19.5419066 & 22.5324000 \\
\hline \multicolumn{4}{|c|}{ Ge 27} \\
\hline \multicolumn{4}{|c|}{163} \\
\hline $\mathrm{H}$ & 8.7010728 & 9.0675737 & 15.1438719 \\
\hline $\mathrm{P}$ & 5.3752161 & 9.3822686 & 16.6843922 \\
\hline Al & 5.3318475 & 9.3134289 & 28.5048100 \\
\hline $\mathrm{P}$ & 5.3768355 & 6.7428389 & 21.6117713 \\
\hline Al & 5.4425775 & 6.7906159 & 18.4539204 \\
\hline $\mathrm{P}$ & 3.1956390 & 7.9790388 & 26.6270284 \\
\hline Al & 3.2629077 & 8.0990897 & 23.5272355 \\
\hline $\mathrm{P}$ & 8.4772422 & 9.2271789 & 28.4063240 \\
\hline Al & 8.5373589 & 9.3461087 & 16.5973975 \\
\hline $\mathrm{P}$ & 8.6369393 & 6.8044511 & 18.4479734 \\
\hline Al & 8.5561599 & 6.7132555 & 21.6057237 \\
\hline $\mathrm{P}$ & 1.6293650 & 10.7889885 & 23.4578698 \\
\hline Al & 1.6053875 & 10.7446560 & 26.5971713 \\
\hline 0 & 6.8625203 & 9.7205649 & 16.9393066 \\
\hline $\mathrm{O}$ & 4.8841462 & 10.9667312 & 28.1206449 \\
\hline $\mathrm{H}$ & 4.9148010 & 5.3473725 & 21.8490858 \\
\hline $\mathrm{H}$ & 9.0708992 & 5.3417813 & 21.8725989 \\
\hline $\mathrm{O}$ & 7.1556868 & 6.4831898 & 18.2039947 \\
\hline 0 & 2.1296430 & 9.0818510 & 26.7712110 \\
\hline $\mathrm{H}$ & 2.1508934 & 7.1280272 & 23.3333737 \\
\hline $\mathrm{H}$ & 0.2669290 & 10.2357694 & 23.2236960 \\
\hline $\mathrm{O}$ & 4.9520651 & 8.1790708 & 17.5273804 \\
\hline 0 & 4.3299768 & 8.1884583 & 27.6371222 \\
\hline 0 & 4.6195878 & 7.7435615 & 22.4937432 \\
\hline $\mathrm{O}$ & 2.5527552 & 11.7991732 & 27.6099685 \\
\hline 0 & 9.0775577 & 8.0160327 & 17.6034111 \\
\hline $\mathrm{O}$ & 1.9004454 & 11.9747616 & 22.5362816 \\
\hline $\mathrm{O}$ & 4.5228448 & 10.5829136 & 17.1029962 \\
\hline 0 & 6.9964489 & 9.0388561 & 28.0714209 \\
\hline 0 & 6.8673231 & 6.8348743 & 21.9661443 \\
\hline $\mathrm{H}$ & 9.4631561 & 5.6305221 & 18.0525280 \\
\hline $\mathrm{H}$ & 4.6721143 & 5.6065053 & 17.9834001 \\
\hline $\mathrm{H}$ & 0.1899536 & 10.8106440 & 27.0546786 \\
\hline $\mathrm{H}$ & 2.5652389 & 6.6634111 & 26.9250889 \\
\hline 0 & 2.6683171 & 9.6976456 & 23.1588402 \\
\hline $\mathrm{H}$ & 5.1570475 & 9.0538039 & 15.2485531 \\
\hline 0 & 5.1619598 & 7.1460553 & 20.1396651 \\
\hline $\mathrm{O}$ & 3.7888433 & 8.0020631 & 25.2041623 \\
\hline $\mathrm{H}$ & 8.7201635 & 9.0274294 & 29.8617312 \\
\hline 0 & 8.8784716 & 7.1749614 & 19.9310069 \\
\hline 0 & 1.7555629 & 11.2529742 & 24.9267514 \\
\hline $\mathrm{H}$ & 5.1770424 & 9.0833842 & 29.9677643 \\
\hline $\mathrm{H}$ & 3.5336703 & 12.0743066 & 15.1429644 \\
\hline $\mathrm{P}$ & 3.2213245 & 15.9818004 & 21.6198321 \\
\hline Al & 3.2057672 & 16.0414830 & 18.4517848 \\
\hline $\mathrm{P}$ & 3.8306696 & 12.0579793 & 28.4113549 \\
\hline Al & 3.8385958 & 12.1074599 & 16.6000306 \\
\hline $\mathrm{P}$ & 1.5871584 & 13.3290393 & 18.4000917 \\
\hline Al & 1.5000563 & 13.3462577 & 21.5203219 \\
\hline 0 & 5.0267790 & 13.3539210 & 16.9518135 \\
\hline $\mathrm{H}$ & 0.1001374 & 13.8422179 & 21.6269581 \\
\hline $\mathrm{H}$ & 2.2587224 & 17.0809066 & 21.9070312 \\
\hline $\mathrm{O}$ & 2.0161309 & 14.7945422 & 18.1481976 \\
\hline $\mathrm{O}$ & 4.6454874 & 15.7927793 & 17.4955798 \\
\hline 0 & 4.4859940 & 16.1446300 & 22.4714088 \\
\hline 0 & 2.3552555 & 12.3919442 & 17.4563146 \\
\hline $\mathrm{O}$ & 4.3976569 & 13.4179554 & 27.9875440 \\
\hline 0 & 2.5924561 & 14.6419181 & 21.9770349 \\
\hline $\mathrm{H}$ & 2.6475169 & 17.3771977 & 18.1034408 \\
\hline $\mathrm{H}$ & 0.1375244 & 13.2023185 & 18.0844591 \\
\hline $\mathrm{O}$ & 3.6409861 & 16.0369090 & 20.1405520 \\
\hline $\mathrm{H}$ & 3.4917232 & 12.0682373 & 29.8612275 \\
\hline 0 & 1.8886761 & 12.9113642 & 19.8474819 \\
\hline $\mathrm{P}$ & 10.1042299 & 12.0200086 & 16.5394072 \\
\hline Al & 10.0317324 & 11.9450833 & 28.3347665 \\
\hline $\mathrm{P}$ & 12.3536834 & 10.6563079 & 26.7249306 \\
\hline Al & 12.4025439 & 10.6295511 & 23.5073123 \\
\hline $\mathrm{P}$ & 15.5043637 & 10.7889885 & 23.4578698 \\
\hline $\mathrm{P}$ & 10.6119430 & 8.0629774 & 23.4915737 \\
\hline Al & 10.6845656 & 8.0461873 & 26.6113859 \\
\hline Al & 15.4803862 & 10.7446560 & 26.5971713 \\
\hline 0 & 8.9044557 & 10.6460181 & 27.9769971 \\
\hline 0 & 11.8771875 & 9.2356514 & 27.1033394 \\
\hline
\end{tabular}




\begin{tabular}{|c|c|c|}
\hline 15.9259035 & 9.3315883 & 26.7450719 \\
\hline 11.4507800 & 6.8349542 & 23.4178722 \\
\hline 14.0897659 & 10.2145891 & 23.2147306 \\
\hline 11.5280083 & 11.7096110 & 27.4779358 \\
\hline 9.2788397 & 8.1685057 & 27.6388332 \\
\hline 16.2900684 & 11.6459151 & 27.4627737 \\
\hline 9.3684344 & 7.9153763 & 22.5970031 \\
\hline 15.7754441 & 11.9747616 & 22.5362816 \\
\hline 9.5483244 & 10.6912321 & 17.1112067 \\
\hline 13.8203946 & 10.8220454 & 27.1337264 \\
\hline 11.2722256 & 6.6858976 & 26.7576334 \\
\hline 16.5114025 & 9.7311682 & 23.1680254 \\
\hline 11.4177621 & 9.2561111 & 22.9344230 \\
\hline 10.3244480 & 11.8916411 & 15.0723877 \\
\hline 12.1753134 & 10.8692311 & 25.2196614 \\
\hline 15.6305617 & 11.2529742 & 24.9267514 \\
\hline 10.1842907 & 8.3311072 & 24.9439080 \\
\hline 10.2867094 & 11.8965636 & 29.8009702 \\
\hline 8.7810512 & 15.0360636 & 15.0280777 \\
\hline 5.4432898 & 14.8052710 & 16.6355038 \\
\hline 5.3811979 & 14.7726470 & 28.4721159 \\
\hline 12.3143349 & 18.7589403 & 21.6117713 \\
\hline 12.1099322 & 13.3074070 & 21.5925699 \\
\hline 17.0963232 & 15.9818004 & 21.6198321 \\
\hline 17.0807659 & 16.0414830 & 18.4517848 \\
\hline 12.2655731 & 13.2982231 & 18.4042091 \\
\hline 12.3800769 & 18.8067172 & 18.4539204 \\
\hline 5.3390183 & 17.2643484 & 26.6014162 \\
\hline 5.2866739 & 17.2558250 & 23.5309039 \\
\hline 8.5426791 & 14.7171525 & 28.3175658 \\
\hline 8.6022867 & 14.7855659 & 16.4849287 \\
\hline 15.4621571 & 13.3290393 & 18.4000917 \\
\hline 15.5744386 & 18.8205524 & 18.4479734 \\
\hline 10.7682520 & 16.1323471 & 18.3349313 \\
\hline 10.5694101 & 16.1462222 & 21.4845993 \\
\hline 15.4936593 & 18.7293569 & 21.6057237 \\
\hline 15.3750550 & 13.3462577 & 21.5203219 \\
\hline 8.4213648 & 17.5086063 & 23.3707054 \\
\hline 8.4823752 & 17.2874012 & 26.4920173 \\
\hline 9.0811771 & 13.1301777 & 16.8493719 \\
\hline 7.0513441 & 14.3843011 & 28.1225662 \\
\hline 11.8387502 & 17.3225489 & 21.8560456 \\
\hline 13.7588059 & 13.9188589 & 21.6434366 \\
\hline 16.0963284 & 17.1236020 & 21.9181876 \\
\hline 15.8911297 & 14.7945422 & 18.1481976 \\
\hline 11.7786662 & 14.9746716 & 18.2457962 \\
\hline 14.0931862 & 18.4992912 & 18.2039947 \\
\hline 6.8030034 & 17.6842096 & 26.8470209 \\
\hline 8.8775488 & 18.9243293 & 23.3018215 \\
\hline 4.6426059 & 18.5947249 & 23.4327000 \\
\hline 18.3084759 & 15.8294030 & 17.6363886 \\
\hline 11.9602728 & 19.9950236 & 17.6609430 \\
\hline 11.4508782 & 12.3017540 & 17.2048419 \\
\hline 4.8954499 & 16.2004291 & 27.6077749 \\
\hline 11.5792368 & 19.7303915 & 22.4679453 \\
\hline 11.7626580 & 11.9203833 & 22.6082267 \\
\hline 18.3244339 & 16.1399229 & 22.4467916 \\
\hline 8.9586887 & 15.8962531 & 27.4332841 \\
\hline 16.2068238 & 12.4205298 & 17.4851040 \\
\hline 9.5973971 & 15.9020788 & 17.3679473 \\
\hline 16.0001278 & 19.9910827 & 17.6320270 \\
\hline 9.1307424 & 16.6517804 & 22.3341885 \\
\hline 6.9327762 & 14.9791985 & 16.9562567 \\
\hline 9.3675934 & 13.4932908 & 27.9012623 \\
\hline 13.8048225 & 18.8509757 & 21.9661443 \\
\hline 10.9437014 & 14.5532992 & 21.9646812 \\
\hline 16.4674548 & 14.6419181 & 21.9770349 \\
\hline 16.4234440 & 17.6142444 & 18.0416209 \\
\hline 13.9730146 & 13.1988648 & 18.0758568 \\
\hline 11.4808677 & 17.4247393 & 17.9047752 \\
\hline 4.4540457 & 18.4489175 & 26.7767446 \\
\hline 9.3391833 & 18.4451850 & 26.8695585 \\
\hline 6.9272990 & 17.4819326 & 23.0423795 \\
\hline 5.1821817 & 15.1070923 & 15.2009840 \\
\hline 12.0994591 & 19.1621567 & 20.1396651 \\
\hline 11.7834151 & 12.6190821 & 19.9372389 \\
\hline 17.5159848 & 16.0369090 & 20.1405520 \\
\hline 5.1863742 & 16.6836294 & 25.1817645 \\
\hline 8.8035692 & 15.0681143 & 29.7409009 \\
\hline 15.7636748 & 12.9113642 & 19.8474819 \\
\hline
\end{tabular}




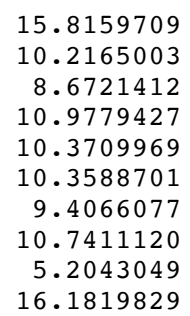

12.1982036
19.1910627

16.2776248

16.9398816

11.3296840

10.4258267

9.7992520

10.7122593

9.9403264

15.0661360

19.7480373

8.9009345

9.2534801

9.1981683

6.7258792

6.7804117

7.9830138

8.0912129

9.1545392

9.2729039

6.8094766

6.7273033

10.7252375

10.6927433

9.6181338

10.7524931

5.3443120

5.3564440

6.4808007

9. 1394595

7.0799672

10.1812660

8.0153813

8.1950078

7.8070760

11.6393152

8.0803593

11.9728846

10.5395742

8.9656911

6.7494744

5.6285400

5.5687292

10.7830775

6.6679480

9.5585349

8.8776358

7.1842459

8.0241058

8.8929983

7.2262659

11.2082943

8.8735832

11.9157749

15.8362245

15.8940110

11.9030616

11.9538358

13.1782742

13.2201440

13.1151401

13.7774452

16.9241914

14.7297914

15.6775291

16.0293612

12.2039939

13.3382712

14.3972813

17.2072467

13.0644773

15.9157848

11.9114615

12.7061352

11.9526917

11.8716519

10.5989432

10.5480515
19.9310069

19.7577939

24.7852171

20.1107728

20.3079997

19.4931261

20.5086232

21.1478955

29.9211478

22.4457365

15.2063667

16.6351986

28.5822573

21.6000089

18.5136609

26.6208153

23.5632360

28.5599832

16.6301326

18.5397981

21.6290944

23.5467317

26.6337050

16.8788956

28.2888362

21.8361711

21.8643277

18.3297388

26.7803221

23.3624325

23.3490650

17.5712466

27.6822507

22.5820344

27.6281515

17.6280517

22.5685224

17.0483315

28.2071749

21.9012956

18.1388391

18.0842390

27.0433805

26.9256243

23.2146287

15.2139829

20.0564251

25.1119345

30.0027371

20.0985569

25.1011489

30.0183969

15.1718142

21.5867169

18.4858912

28.5394667

16.6037300

18.5158642

21.5650513

16.8559569

21.6551271

21.8582119

18.2769148

17.5132892

22.5010618

17.5000417

28.1183118

21.9602722

18.1371410

18.1846869

20.0240170

29.9729074

20.0387511

16.4942802

28.4256162

26.6669381

23.5158414 


\begin{tabular}{|c|c|c|c|}
\hline $\mathrm{Si}$ & 15.2777729 & 10.7252375 & 23.5467317 \\
\hline $\mathrm{Si}$ & 10.4355970 & 7.9909545 & 23.6109335 \\
\hline $\mathrm{Si}$ & 10.5365828 & 7.9746278 & 26.6625411 \\
\hline Si & 15.2515206 & 10.6927433 & 26.6337050 \\
\hline 0 & 8.8749064 & 10.6759617 & 28.1634357 \\
\hline $\mathrm{O}$ & 11.6754227 & 9.0780371 & 27.0396680 \\
\hline $\mathrm{H}$ & 15.6791168 & 9.2727725 & 26.7677384 \\
\hline $\mathrm{H}$ & 11.2819085 & 6.7685113 & 23.5302495 \\
\hline 0 & 13.7703476 & 10.1275343 & 23.3295402 \\
\hline 0 & 11.2691197 & 11.6764039 & 27.5067147 \\
\hline 0 & 9.2942086 & 8.0724101 & 27.7009397 \\
\hline $\mathrm{H}$ & 16.0406647 & 11.5633094 & 27.5483016 \\
\hline $\mathrm{O}$ & 9.1489181 & 7.8253395 & 22.6276171 \\
\hline $\mathrm{O}$ & 15.5604211 & 11.9728846 & 22.5685224 \\
\hline $\mathrm{O}$ & 9.3875646 & 10.5588726 & 17.0531077 \\
\hline $\mathrm{O}$ & 13.6960440 & 10.7910947 & 27.0797395 \\
\hline $\mathrm{H}$ & 11.1313698 & 6.6138414 & 26.7702871 \\
\hline $\mathrm{H}$ & 16.2685343 & 9.6561692 & 23.2424204 \\
\hline 0 & 11.2835381 & 9.2556288 & 23.0294289 \\
\hline $\mathrm{H}$ & 10.3670458 & 11.8452618 & 15.0472336 \\
\hline $\mathrm{O}$ & 11.9106424 & 10.8610186 & 25.0864882 \\
\hline $\mathrm{O}$ & 15.4487502 & 11.2082943 & 25.1011489 \\
\hline 0 & 9.9687962 & 8.2446451 & 25.1487108 \\
\hline $\mathrm{H}$ & 10.3588271 & 11.8389658 & 29.8580057 \\
\hline $\mathrm{H}$ & 8.7169765 & 15.0187612 & 15.0644860 \\
\hline $\mathrm{Si}$ & 5.3555735 & 14.6580666 & 16.5692068 \\
\hline $\mathrm{Si}$ & 5.2979613 & 14.6280483 & 28.5285136 \\
\hline $\mathrm{Si}$ & 12.1078021 & 18.5254742 & 21.6000089 \\
\hline $\mathrm{Ga}$ & 12.0870523 & 13.1963956 & 21.5892935 \\
\hline $\mathrm{Si}$ & 16.9401919 & 15.8362245 & 21.5867169 \\
\hline $\mathrm{Si}$ & 16.8710212 & 15.8940110 & 18.4858912 \\
\hline $\mathrm{Si}$ & 12.1345805 & 13.1166017 & 18.4410172 \\
\hline $\mathrm{Si}$ & 12.1575954 & 18.5800068 & 18.5136609 \\
\hline $\mathrm{Si}$ & 5.3267005 & 17.0165571 & 26.5781755 \\
\hline $\mathrm{Si}$ & 5.2959737 & 17.0463219 & 23.5668176 \\
\hline $\mathrm{Si}$ & 8.4426821 & 14.6168464 & 28.4530808 \\
\hline $\mathrm{Si}$ & 8.4953496 & 14.6756687 & 16.4963692 \\
\hline $\mathrm{Si}$ & 15.2963984 & 13.1782742 & 18.5158642 \\
\hline $\mathrm{Si}$ & 15.3236353 & 18.6090716 & 18.5397981 \\
\hline $\mathrm{Si}$ & 10.5925601 & 15.8860252 & 18.4550100 \\
\hline $\mathrm{Si}$ & 10.4043907 & 15.8996214 & 21.5513549 \\
\hline $\mathrm{Si}$ & 15.2832163 & 18.5268984 & 21.6290944 \\
\hline $\mathrm{Si}$ & 15.2689520 & 13.2201440 & 21.5650513 \\
\hline $\mathrm{Si}$ & 8.4043316 & 17.2677753 & 23.4775269 \\
\hline $\mathrm{Si}$ & 8.4410068 & 17.0799266 & 26.5564209 \\
\hline 0 & 8.9389815 & 13.1263415 & 16.7666693 \\
\hline 0 & 6.8637470 & 14.2722385 & 28.2691922 \\
\hline 0 & 11.5621016 & 17.0254708 & 21.8564163 \\
\hline 0 & 13.7851752 & 13.8202972 & 21.6620533 \\
\hline 0 & 15.8623891 & 17.0331811 & 21.8854095 \\
\hline O & 15.7566299 & 14.7297914 & 18.2769148 \\
\hline $\mathrm{O}$ & 11.6658792 & 14.6722681 & 18.3168909 \\
\hline 0 & 13.7520685 & 18.2803957 & 18.3297388 \\
\hline 0 & 6.8756891 & 17.4500489 & 26.8526637 \\
\hline $\mathrm{H}$ & 8.9205643 & 18.6590779 & 23.3554565 \\
\hline $\mathrm{H}$ & 4.5957290 & 18.3597969 & 23.5273022 \\
\hline $\mathrm{H}$ & 18.0452129 & 15.6950763 & 17.5921243 \\
\hline $\mathrm{H}$ & 11.7427923 & 19.7168590 & 17.6461206 \\
\hline $\mathrm{O}$ & 11.4106460 & 12.2115855 & 17.2928576 \\
\hline O & 4.8351750 & 15.8811664 & 27.6182683 \\
\hline $\mathrm{H}$ & 11.4584096 & 19.5173435 & 22.5009003 \\
\hline 0 & 11.7068914 & 11.7316750 & 22.5838531 \\
\hline $\mathrm{H}$ & 18.1564789 & 16.0137397 & 22.4271067 \\
\hline $\mathrm{O}$ & 8.8969139 & 15.8206509 & 27.4709318 \\
\hline $\mathrm{H}$ & 16.0373314 & 12.2842590 & 17.5837292 \\
\hline 0 & 9.3624746 & 15.6835786 & 17.4133035 \\
\hline $\mathrm{H}$ & 15.7425673 & 19.7700568 & 17.7068935 \\
\hline 0 & 9.0674703 & 16.2937023 & 22.3872733 \\
\hline O & 6.9326421 & 14.8266872 & 16.8984638 \\
\hline 0 & 9.2871934 & 13.2949504 & 28.0521668 \\
\hline 0 & 13.6993761 & 18.5490694 & 21.9012956 \\
\hline O & 10.8621495 & 14.4451198 & 22.0003805 \\
\hline 0 & 16.3270060 & 14.3972813 & 21.9602722 \\
\hline 0 & 16.2058224 & 17.3283841 & 18.1049711 \\
\hline 0 & 13.7264726 & 13.0548302 & 18.1566113 \\
\hline 0 & 11.3432603 & 17.2667683 & 18.0482474 \\
\hline $\mathrm{H}$ & 4.4430702 & 18.2006259 & 26.7633766 \\
\hline $\mathrm{H}$ & 9.2847312 & 18.2515411 & 26.9205215 \\
\hline 0 & 6.8240454 & 17.3250415 & 23.1559412 \\
\hline & 5.0790929 & 15.0038523 & \\
\hline
\end{tabular}




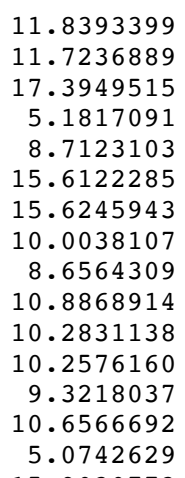

18.9838409 12.4771321 15.9157848 16.4197726 15.0135049 12.7061352 19.0258610 15.9834836 16.6978804 11.1430374 10.2767306

9.5817326

10.5851061

9.8579808

15.0012813

19.5288602

9.0915611

9.3995648

9.3149074

6.7751296

6.7961204

7.9688301

8.1313725

9.2093603

9.3731620

6.8294561

6.7102015

10.8065708

10.7313365

9.7465809

10.9681698

5.4312782

5.3522795

6.5001836

9.0713052

7.1485882

10.2453586

8.1840506

8.1887203

7.8454344

11.7745275

8.0471035

11.9883602

10.5914107

9.0170167

6.7420517

5.6618394

5.5979883

10.7649866

6.6557553

9.7254099

9.0817496

7.1675476

7.9783840

9.0494468

7.1992377

11. 2750808

9.1076645

12.0775767

15.9914193

16.0596373

12.0519178

12.1205288

13.3564203

13.3486946

13.3590911

13.7749483

17.0923102

14.8278277

15.8020142

16.1558973

12.4320977

13.4146061

14.6551204

17.4052215

13.2178722

16.0361476
20.0564251

19.8770104

20.0240170

25.0667823

29.8627202

20.0387511

20.0985569

19.9606362

24.9881087

20.0854866

20.3495420

19.5920390

20.5334938

21.2259392

29.9525139

22.5402498

15.1573581

16.7019282

28.5157526

21.6175507

18.4598174

26.6287687

23.5456805

28.4131808

16.6119684

18.4667342

21.6183703

23.4776678

26.6161258

16.9631518

28.1156326

21.8877610

21.8669876

18.2245320

26.7274687

23.3025602

23.1758605

17.5311716

27.6708050

22.4978916

27.6278373

17.6252823

22.5650558

17.1270953

28.0754907

21.9475297

18.0681804

17.9855408

27.1258645

26.9214941

23.2373393

15.2629327

20.1408786

25.2224990

29.8750033

19.9511766

24.9508730

29.9829585

15.1504929

21.6065945

18.4414398

28.4127939

16.6101923

18.4064689

21.5284389

16.9624856

21.6269685

21.8983071

18.1524571

17.4744339

22.4393717

17.4425078

27.9721872

21.9824898

18.1152386

18.1206869

20.1237550 


\begin{tabular}{|c|c|c|c|}
\hline $\mathrm{H}$ & 3.5149244 & 12.0695395 & 29.8670181 \\
\hline 0 & 1.9333072 & 12.9353996 & 19.8452882 \\
\hline $\mathrm{P}$ & 10.1065518 & 12.0352177 & 16.5091428 \\
\hline Al & 10.0159032 & 11.9279014 & 28.2985309 \\
\hline $\mathrm{P}$ & 12.3644925 & 10.6017141 & 26.7670750 \\
\hline Al & 12.4129976 & 10.5541257 & 23.5307435 \\
\hline $\mathrm{P}$ & 15.5065504 & 10.8065708 & 23.4776678 \\
\hline $\mathrm{P}$ & 10.5564270 & 8.0505261 & 23.5394244 \\
\hline Al & 10.6650741 & 8.0298611 & 26.6343801 \\
\hline Al & 15.4640258 & 10.7313365 & 26.6161258 \\
\hline 0 & 8.9042418 & 10.6131494 & 27.9426693 \\
\hline 0 & 11.8604875 & 9.1984513 & 27.1744152 \\
\hline $\mathrm{H}$ & 15.9295869 & 9.3201616 & 26.7107772 \\
\hline $\mathrm{H}$ & 11.3090484 & 6.7659393 & 23.5166545 \\
\hline $\mathrm{O}$ & 14.1078458 & 10.2232801 & 23.1639872 \\
\hline 0 & 11.5208441 & 11.6873069 & 27.4537888 \\
\hline 0 & 9.2697400 & 8.1239923 & 27.6804194 \\
\hline $\mathrm{H}$ & 16.2853689 & 11.6228984 & 27.4807838 \\
\hline $\mathrm{O}$ & 9.3119433 & 7.9342559 & 22.6374617 \\
\hline 0 & 15.8266770 & 11.9883602 & 22.5650558 \\
\hline $\mathrm{O}$ & 9.5668630 & 10.7116983 & 17.1110476 \\
\hline $\mathrm{O}$ & 13.8206597 & 10.7708749 & 27.2150617 \\
\hline $\mathrm{H}$ & 11.2587649 & 6.6665076 & 26.7113157 \\
\hline $\mathrm{H}$ & 16.5378317 & 9.7581132 & 23.2446088 \\
\hline $\mathrm{O}$ & 11.4424857 & 9.1728847 & 22.9528593 \\
\hline $\mathrm{H}$ & 10.2818309 & 11.8845028 & 15.0381966 \\
\hline 0 & 12.2465703 & 10.7554460 & 25.2505858 \\
\hline 0 & 15.5512632 & 11.2750808 & 24.9508730 \\
\hline 0 & 10.1426138 & 8.3882252 & 24.9827422 \\
\hline $\mathrm{H}$ & 10.2472776 & 11.8874451 & 29.7688879 \\
\hline $\mathrm{H}$ & 8.7831814 & 15.0280634 & 14.9931083 \\
\hline$P$ & 5.4519871 & 14.8095964 & 16.6267353 \\
\hline Al & 5.3741145 & 14.7636021 & 28.4599138 \\
\hline $\mathrm{P}$ & 12.2963060 & 18.7912310 & 21.6175507 \\
\hline $\mathrm{Ti}$ & 12.0679820 & 13.2869507 & 21.6065264 \\
\hline $\mathrm{P}$ & 17.1446831 & 15.9914193 & 21.6065945 \\
\hline Al & 17.0893029 & 16.0596373 & 18.4414398 \\
\hline Al & 12.2507991 & 13.2779380 & 18.3906180 \\
\hline Al & 12.3898533 & 18.8122218 & 18.4598174 \\
\hline $\mathrm{P}$ & 5.3419444 & 17.2480609 & 26.5936641 \\
\hline Al & 5.2761409 & 17.2648187 & 23.5540495 \\
\hline $\mathrm{P}$ & 8.5349248 & 14.7043361 & 28.2801568 \\
\hline Al & 8.6113283 & 14.7983775 & 16.4542145 \\
\hline $\mathrm{P}$ & 15.4667099 & 13.3564203 & 18.4064689 \\
\hline$P$ & 15.5867914 & 18.8455575 & 18.4667342 \\
\hline $\mathrm{P}$ & 10.7625972 & 16.1404100 & 18.3264346 \\
\hline Al & 10.4614902 & 16.2197343 & 21.4634546 \\
\hline Al & 15.4942934 & 18.7263029 & 21.6183703 \\
\hline Al & 15.4359595 & 13.3486946 & 21.5284389 \\
\hline $\mathrm{P}$ & 8.3935189 & 17.5780303 & 23.3562090 \\
\hline Al & 8.4750130 & 17.2914437 & 26.4748719 \\
\hline 0 & 9.0872351 & 13.1453107 & 16.8336538 \\
\hline 0 & 7.0412154 & 14.3755922 & 28.0965502 \\
\hline 0 & 11.6981005 & 17.4088308 & 21.8955121 \\
\hline $\mathrm{O}$ & 13.7892541 & 13.8418620 & 21.6424358 \\
\hline $\mathrm{O}$ & 16.1480987 & 17.1352177 & 21.9096766 \\
\hline 0 & 15.8786986 & 14.8278277 & 18.1524571 \\
\hline $\mathrm{O}$ & 11.7473426 & 14.9593969 & 18.2947870 \\
\hline $\mathrm{O}$ & 14.1075442 & 18.5162849 & 18.2245320 \\
\hline $\mathrm{O}$ & 6.7987848 & 17.6869593 & 26.8536080 \\
\hline $\mathrm{H}$ & 8.9643301 & 18.9501509 & 23.2635803 \\
\hline $\mathrm{H}$ & 4.5136170 & 18.5433412 & 23.5215184 \\
\hline $\mathrm{H}$ & 18.3097553 & 15.8400450 & 17.6171851 \\
\hline $\mathrm{H}$ & 11.9705368 & 19.9996762 & 17.6653073 \\
\hline 0 & 11.4746675 & 12.3372620 & 17.1197375 \\
\hline 0 & 4.8887443 & 16.2052169 & 27.6175428 \\
\hline $\mathrm{H}$ & 11.6528080 & 19.8282721 & 22.4705317 \\
\hline $\mathrm{O}$ & 11.7342294 & 11.8822025 & 22.6950827 \\
\hline $\mathrm{H}$ & 18.3854452 & 16.1509212 & 22.4141768 \\
\hline 0 & 8.9482665 & 15.8795283 & 27.3882020 \\
\hline $\mathrm{H}$ & 16.2040903 & 12.4611085 & 17.4727626 \\
\hline 0 & 9.6223429 & 15.9185423 & 17.3194493 \\
\hline $\mathrm{H}$ & 16.0050746 & 20.0211974 & 17.6543115 \\
\hline $\mathrm{O}$ & 8.9830033 & 16.6695223 & 22.2838534 \\
\hline 0 & 6.9427469 & 15.0000137 & 16.9367639 \\
\hline $\mathrm{O}$ & 9.3527672 & 13.4764450 & 27.8582900 \\
\hline 0 & 13.7947688 & 18.7581530 & 21.9475297 \\
\hline 0 & 10.9222035 & 14.6402474 & 21.9237284 \\
\hline $\mathrm{O}$ & 16.5171671 & 14.6551204 & 21.9824898 \\
\hline $\mathrm{O}$ & 16.4437315 & 17.6452984 & 18.0570383 \\
\hline
\end{tabular}




\begin{tabular}{|c|c|c|c|}
\hline 0 & 13.9726868 & 13.2141304 & 18.1129687 \\
\hline $\mathrm{O}$ & 11.5185780 & 17.4130712 & 17.9059683 \\
\hline $\mathrm{H}$ & 4.4425770 & 18.4279687 & 26.7204568 \\
\hline $\mathrm{H}$ & 9.3410028 & 18.4385741 & 26.8638113 \\
\hline 0 & 6.8886293 & 17.6869763 & 23.0962629 \\
\hline $\mathrm{H}$ & 5.1828569 & 15.0900085 & 15.1893562 \\
\hline $\mathrm{O}$ & 12.0939105 & 19.1836490 & 20.1408786 \\
\hline $\mathrm{O}$ & 11.7474769 & 12.5536279 & 19.8930135 \\
\hline 0 & 17.5481229 & 16.0361476 & 20.1237550 \\
\hline 0 & 5.2255966 & 16.6278952 & 25.1853521 \\
\hline $\mathrm{H}$ & 8.8043461 & 15.0566208 & 29.7015745 \\
\hline $\mathrm{O}$ & 15.8083059 & 12.9353996 & 19.8452882 \\
\hline 0 & 15.8279663 & 19.2153391 & 19.9511766 \\
\hline 0 & 10.1607524 & 16.3304801 & 19.7255715 \\
\hline 0 & 8.6540431 & 16.9815121 & 24.7577278 \\
\hline $\mathrm{H}$ & 11.0029790 & 11.2755164 & 20.0519131 \\
\hline $\mathrm{N}$ & 10.4089525 & 10.3487841 & 20.2605366 \\
\hline $\mathrm{H}$ & 10.3952411 & 9.7220821 & 19.4460459 \\
\hline $\mathrm{H}$ & 9.4419985 & 10.6186659 & 20.4711450 \\
\hline $\mathrm{H}$ & 10.7885913 & 9.8630855 & 21.0932115 \\
\hline $\mathrm{H}$ & 5.2035784 & 15.0497773 & 29.9111690 \\
\hline $\mathrm{H}$ & 16.1321886 & 19.7602951 & 22.4792247 \\
\hline \multicolumn{4}{|c|}{$\begin{array}{l}\operatorname{Zn} 28 \\
161\end{array}$} \\
\hline $\mathrm{H}$ & 8.7286007 & 8.9688137 & 15.2605371 \\
\hline Al & 5.4049001 & 9.2847126 & 16.6119918 \\
\hline $\mathrm{P}$ & 5.4271201 & 9.2560409 & 28.4319254 \\
\hline Al & 5.3208939 & 6.6806118 & 21.5642624 \\
\hline $\mathrm{P}$ & 5.3480932 & 6.7283222 & 18.4207643 \\
\hline Al & 3.1922278 & 8.0550434 & 26.5838755 \\
\hline $\mathrm{P}$ & 3.2572892 & 8.1489950 & 23.4566303 \\
\hline Al & 8.5584548 & 9.2541419 & 28.5130878 \\
\hline $\mathrm{P}$ & 8.5481266 & 9.3316592 & 16.6933290 \\
\hline Al & 8.5085653 & 6.7424862 & 18.4818445 \\
\hline $\mathrm{P}$ & 8.4943631 & 6.6654974 & 21.6609190 \\
\hline Al & 1.5532169 & 10.7647407 & 23.4894179 \\
\hline $\mathrm{P}$ & 1.5474532 & 10.7522513 & 26.6474060 \\
\hline $\mathrm{O}$ & 7.0773902 & 9.6973346 & 16.9748014 \\
\hline 0 & 5.0173293 & 10.7132822 & 28.1315590 \\
\hline $\mathrm{H}$ & 4.8371979 & 5.2846866 & 21.7501432 \\
\hline $\mathrm{H}$ & 9.0094303 & 5.2939925 & 21.9270026 \\
\hline 0 & 6.8263383 & 6.3734411 & 18.1639004 \\
\hline $\mathrm{O}$ & 1.9777364 & 9.2871356 & 26.8680868 \\
\hline $\mathrm{H}$ & 2.1739248 & 7.1405768 & 23.2937357 \\
\hline $\mathrm{H}$ & 0.1746260 & 10.2400093 & 23.2862812 \\
\hline $\mathrm{O}$ & 4.9101899 & 7.8803953 & 17.5108930 \\
\hline $\mathrm{O}$ & 4.5712303 & 8.2777573 & 27.6253805 \\
\hline 0 & 4.4514780 & 7.8221212 & 22.5538958 \\
\hline 0 & 2.3591044 & 11.6849304 & 27.5551391 \\
\hline 0 & 8.9912523 & 8.1613975 & 17.5781021 \\
\hline $\mathrm{O}$ & 1.8143275 & 12.2062903 & 22.5639972 \\
\hline $\mathrm{O}$ & 4.3849993 & 10.6224299 & 17.0587759 \\
\hline 0 & 6.8949841 & 9.0586387 & 28.0317296 \\
\hline $\mathrm{O}$ & 7.0045706 & 6.7100852 & 21.9970001 \\
\hline $\mathrm{H}$ & 9.3415019 & 5.5885945 & 18.0438136 \\
\hline $\mathrm{H}$ & 4.5148083 & 5.5398405 & 18.0886976 \\
\hline $\mathrm{H}$ & 0.1112625 & 10.8862324 & 27.0169001 \\
\hline $\mathrm{H}$ & 2.5970608 & 6.7288346 & 26.9064701 \\
\hline 0 & 2.7150356 & 9.5278017 & 23.0548188 \\
\hline $\mathrm{H}$ & 5.2643211 & 8.9951486 & 15.1581999 \\
\hline $\mathrm{O}$ & 5.1397922 & 7.1545353 & 19.8828825 \\
\hline $\mathrm{O}$ & 3.7391516 & 8.1572012 & 24.9218990 \\
\hline $\mathrm{H}$ & 8.7077136 & 9.0022388 & 29.9730149 \\
\hline 0 & 8.7366114 & 7.0511073 & 20.1870290 \\
\hline 0 & 1.7742344 & 11.1687764 & 25.1854175 \\
\hline $\mathrm{H}$ & 5.2461365 & 8.9553424 & 29.8789727 \\
\hline $\mathrm{H}$ & 3.4668375 & 11.9752737 & 15.1840498 \\
\hline Al & 3.2857270 & 16.0285202 & 21.5556213 \\
\hline $\mathrm{P}$ & 3.1903471 & 16.0807171 & 18.3911748 \\
\hline Al & 3.8255263 & 11.9654018 & 28.4470654 \\
\hline $\mathrm{P}$ & 3.8101930 & 11.9779065 & 16.6329185 \\
\hline Al & 1.6766709 & 13.2912010 & 18.5080345 \\
\hline $\mathrm{P}$ & 1.7013981 & 13.3751755 & 21.5792398 \\
\hline 0 & 4.8575114 & 13.0686397 & 16.9397181 \\
\hline $\mathrm{H}$ & 0.3781856 & 14.0563355 & 21.6266789 \\
\hline $\mathrm{H}$ & 2.2738690 & 17.0722941 & 21.8778013 \\
\hline $\mathrm{O}$ & 2.1496564 & 14.9537257 & 18.2198988 \\
\hline 0 & 4.4054686 & 15.8417745 & 17.4877425 \\
\hline 0 & 4.7299078 & 16.2930482 & 22.4856926 \\
\hline
\end{tabular}

18.1129687

17.9059683

26.8638113

23.0962629

15.1893562

.1408786

9.8930135

25.1853521

29.7015745

(2882

19.7255715

(1)

20.2605366

60459

21.0932115

29.9111690

Zn 28

161 


\begin{tabular}{|c|c|c|c|}
\hline 0 & 2.5230564 & 12.2226446 & 17.4271205 \\
\hline 0 & 4.4792944 & 13.5111398 & 27.9763441 \\
\hline 0 & 2.7874851 & 14.4064058 & 21.9395898 \\
\hline $\mathrm{H}$ & 2.5651583 & 17.3685554 & 17.9816238 \\
\hline $\mathrm{H}$ & 0.2287237 & 13.1553769 & 18.1884700 \\
\hline $\mathrm{O}$ & 3.6693259 & 16.1508487 & 19.8483061 \\
\hline $\mathrm{H}$ & 3.5109865 & 11.9737391 & 29.9024402 \\
\hline 0 & 1.9793803 & 12.8162058 & 20.1563994 \\
\hline Al & 10.1123561 & 12.0449522 & 16.4857411 \\
\hline $\mathrm{P}$ & 10.0767448 & 12.0164761 & 28.3417931 \\
\hline Al & 12.2815485 & 10.7005424 & 26.5316119 \\
\hline $\mathrm{P}$ & 12.3243950 & 10.5976943 & 23.3814566 \\
\hline Al & 15.4282157 & 10.7647407 & 23.4894179 \\
\hline Al & 10.5850624 & 7.9649892 & 23.5675215 \\
\hline $\mathrm{P}$ & 10.7045096 & 7.9671743 & 26.6582996 \\
\hline$P$ & 15.4224520 & 10.7522513 & 26.6474060 \\
\hline $\mathrm{O}$ & 9.0414232 & 10.8961523 & 28.1227944 \\
\hline $\mathrm{O}$ & 11.7760975 & 9.0539527 & 26.8745112 \\
\hline $\mathrm{H}$ & 15.8377151 & 9.3382790 & 26.8603834 \\
\hline $\mathrm{H}$ & 11.5171543 & 6.8126284 & 23.4247284 \\
\hline $\mathrm{O}$ & 13.8028671 & 10.1460862 & 23.2499212 \\
\hline 0 & 11.3074984 & 11.8142358 & 27.4597556 \\
\hline 0 & 9.5748205 & 8.1094787 & 27.6867880 \\
\hline $\mathrm{H}$ & 16.2103784 & 11.6576680 & 27.5286059 \\
\hline 0 & 9.2004115 & 7.7023871 & 22.5444759 \\
\hline 0 & 15.6893262 & 12.2062903 & 22.5639972 \\
\hline 0 & 9.4330789 & 10.5406161 & 17.0495274 \\
\hline $\mathrm{O}$ & 13.9432649 & 10.8902435 & 27.0279620 \\
\hline $\mathrm{H}$ & 11.3342155 & 6.6322122 & 26.8544304 \\
\hline $\mathrm{H}$ & 16.4157554 & 9.7133491 & 23.1200110 \\
\hline $\mathrm{O}$ & 11.4219683 & 9.3940380 & 23.0587331 \\
\hline $\mathrm{H}$ & 10.4686151 & 12.0193137 & 15.0402160 \\
\hline 0 & 12.0782932 & 11.0666912 & 24.8382232 \\
\hline 0 & 15.6492331 & 11.1687764 & 25.1854175 \\
\hline 0 & 10.0939752 & 8.0913804 & 25.2480355 \\
\hline $\mathrm{H}$ & 10.5118512 & 12.0151130 & 29.7658019 \\
\hline $\mathrm{H}$ & 8.6996824 & 15.1087385 & 15.1404742 \\
\hline Al & 5.3599676 & 14.7091855 & 16.5750440 \\
\hline $\mathrm{P}$ & 5.3325199 & 14.7119188 & 28.3983520 \\
\hline Al & 12.2583933 & 18.6967132 & 21.5642624 \\
\hline $\mathrm{Zn}$ & 12.4543644 & 13.4611337 & 21.8929993 \\
\hline Al & 17.1607258 & 16.0285202 & 21.5556213 \\
\hline $\mathrm{P}$ & 17.0653458 & 16.0807171 & 18.3911748 \\
\hline $\mathrm{P}$ & 12.3462343 & 13.2686940 & 18.2972867 \\
\hline$P$ & 12.2855925 & 18.7444235 & 18.4207643 \\
\hline Al & 5.4142874 & 17.2259334 & 26.5545528 \\
\hline $\mathrm{P}$ & 5.3854081 & 17.2578241 & 23.4739028 \\
\hline Al & 8.4948305 & 14.7568630 & 28.4104389 \\
\hline $\mathrm{P}$ & 8.5148477 & 14.7734602 & 16.5794132 \\
\hline Al & 15.5516696 & 13.2912010 & 18.5080345 \\
\hline Al & 15.4460646 & 18.7585875 & 18.4818445 \\
\hline Al & 10.7233825 & 15.9800376 & 18.4524293 \\
\hline $\mathrm{P}$ & 10.5970788 & 15.9824495 & 21.6181385 \\
\hline$P$ & 15.4318625 & 18.6815988 & 21.6609190 \\
\hline $\mathrm{P}$ & 15.5763968 & 13.3751755 & 21.5792398 \\
\hline Al & 8.5353536 & 17.4656344 & 23.4647735 \\
\hline $\mathrm{P}$ & 8.5783759 & 17.3034319 & 26.5908999 \\
\hline $\mathrm{O}$ & 8.9788151 & 13.3232375 & 16.8519773 \\
\hline 0 & 6.8113241 & 14.3894914 & 28.1074196 \\
\hline 0 & 11.6927421 & 17.0642690 & 21.7816380 \\
\hline $\mathrm{O}$ & 14.2157451 & 14.0756083 & 21.6280212 \\
\hline 0 & 15.9650094 & 17.2619516 & 21.9363426 \\
\hline 0 & 16.0246552 & 14.9537257 & 18.2198988 \\
\hline 0 & 11.9190742 & 14.7190188 & 18.0989736 \\
\hline 0 & 13.7638377 & 18.3895425 & 18.1639004 \\
\hline 0 & 7.0950367 & 17.6384917 & 26.8550819 \\
\hline $\mathrm{H}$ & 8.9936797 & 18.8743559 & 23.3145683 \\
\hline $\mathrm{H}$ & 4.7500248 & 18.6025998 & 23.4032832 \\
\hline $\mathrm{H}$ & 18.2456626 & 15.8486185 & 17.5136195 \\
\hline $\mathrm{H}$ & 11.8599688 & 19.8641905 & 17.5364074 \\
\hline $\mathrm{O}$ & 11.6070380 & 12.3011927 & 17.3759218 \\
\hline 0 & 4.8825273 & 15.9372139 & 27.5987712 \\
\hline $\mathrm{H}$ & 11.5157046 & 19.6718346 & 22.4096454 \\
\hline 0 & 11.9668935 & 11.6977630 & 22.3976804 \\
\hline $\mathrm{H}$ & 18.3979969 & 16.2551490 & 22.3524401 \\
\hline 0 & 9.0192967 & 16.1230123 & 27.4674826 \\
\hline $\mathrm{H}$ & 16.2760863 & 12.3766294 & 17.5828860 \\
\hline 0 & 9.3380369 & 15.7536780 & 17.4189880 \\
\hline $\mathrm{H}$ & 15.8567257 & 19.9657706 & 17.7129575 \\
\hline & & & \\
\hline
\end{tabular}




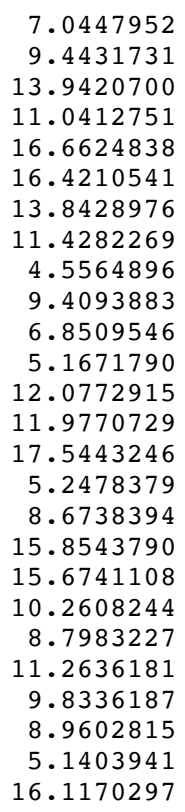

14.8973659

13.3612205

18.7261866

14.6647769

14.4064058

17.4079058

13.1309104

17.5215964

18.4145952

18.4853446

17.4112086

14.9727429

19.1706367

12.8276130

16.1508487

16.6835422

15.0648248

12.8162058

19.0672087

15.8317065

16.9258764

12.1257295

10.9951232

10.3578764

15.0082815

19.6878229

8.9976779

9.3389312

9.2895930

6.7673275

6.7649888

7.9530426

8.0235497

9.2285338

9.2925099

6.7375662

6.7039355

10.7332565

10.7243481

9.7006870

10.9391840

5.3858254

5.3162420

6.3888492

9.0679553

6.9785916

10.2527289

8.1351387

8.1656229

7.7848682

11.8054826

7.9374900

11.9117135

10.5311284

9.0609184

6.8387738

5.5719244

5.5886267

10.8215548

6.6486915

9.5900925

8.9992995

7.1435604

7.9422068

8.9565965

7.0993505

11.1885688

9.0330556

12.0395058

15.9631450

16.0031752

12.0375261

12.0619877

13.2842921

13.2772172

13.3109449

13.6548833
16.9902683

27.9800901

21.9970001

22.2252137

21.9395898

17.9691098

18.1309056

18.0791014

26.8160614

26.9509295

23.0840472

15.1222912

19.8828825

19.7920153

19.8483061

24.8977886

29.8562037

20.1563994

20.1870290

20.1136161

25.1148658

19.8779661

20.2514822

20.6070722

29.8448573

22.5183451

15.1493517

16.6589019

28.4852332

21.6238520

18.4632394

26.6348108

23.4968899

28.4218149

16.5987472

18.4301716

21.5940099

23.4408344

26.5825845

16.9169771

28.1171707

21.8889352

21.8656794

18.1956775

26.8127744

23.2333409

23.2233773

17.5077389

27.5833988

22.4978335

27.5642992

17.5669366

22.5246774

17.0647874

28.0513329

21.9741382

18.0301495

18.0341688

27.0142665

26.9846647

23.1184611

15.2243115

20.1459914

25.1863728

29.8695325

19.9068364

24.9046565

29.9419944

15.1155288

21.6378734

18.4617505

28.3953177

16.5697320

18.4146725

21.5050123

16.9208801

21.5067923 


\begin{tabular}{|c|c|c|c|}
\hline $\mathrm{H}$ & 2.2201289 & 17.0502749 & 21.9035497 \\
\hline 0 & 2.0096847 & 14.7552556 & 18.1384241 \\
\hline 0 & 4.6429533 & 15.7393866 & 17.5130546 \\
\hline 0 & 4.4604178 & 16.1608974 & 22.4914899 \\
\hline 0 & 2.3390906 & 12.3535382 & 17.4229901 \\
\hline 0 & 4.4320196 & 13.3932250 & 27.9985857 \\
\hline 0 & 2.5792012 & 14.6199902 & 22.0163496 \\
\hline $\mathrm{H}$ & 2.6358802 & 17.3269377 & 18.0836220 \\
\hline $\mathrm{H}$ & 0.1673369 & 13.1314970 & 18.1995315 \\
\hline 0 & 3.6218162 & 15.9831054 & 20.1559229 \\
\hline $\mathrm{H}$ & 3.4663052 & 12.0357093 & 29.8365638 \\
\hline $\mathrm{O}$ & 2.0274038 & 12.8756850 & 19.8408359 \\
\hline $\mathrm{P}$ & 10.1148815 & 11.9824846 & 16.5844587 \\
\hline Al & 10.0868284 & 11.9461711 & 28.4063637 \\
\hline $\mathrm{P}$ & 12.3663659 & 10.6891175 & 26.6939180 \\
\hline Al & 12.3735376 & 10.6901794 & 23.4946989 \\
\hline $\mathrm{P}$ & 15.4961872 & 10.7332565 & 23.4408344 \\
\hline $\mathrm{P}$ & 10.6675226 & 8.0657985 & 23.4623623 \\
\hline Al & 10.7174049 & 8.0318722 & 26.6054633 \\
\hline Al & 15.5033085 & 10.7243481 & 26.5825845 \\
\hline 0 & 8.9319035 & 10.6691331 & 28.0790929 \\
\hline 0 & 11.9095405 & 9.2502382 & 27.0162228 \\
\hline $\mathrm{H}$ & 15.9470927 & 9.3165483 & 26.7782273 \\
\hline $\mathrm{H}$ & 11.6095152 & 6.9233869 & 23.3053072 \\
\hline 0 & 14.0541639 & 10.2356226 & 23.2156360 \\
\hline 0 & 11.5573785 & 11.7026187 & 27.5154547 \\
\hline 0 & 9.3091322 & 8.2106354 & 27.6161114 \\
\hline $\mathrm{H}$ & 16.3144585 & 11.6487658 & 27.4219939 \\
\hline 0 & 9.4237011 & 7.8572879 & 22.5888515 \\
\hline 0 & 15.8265676 & 11.9117135 & 22.5246774 \\
\hline 0 & 9.5275929 & 10.6486687 & 17.0689271 \\
\hline 0 & 13.8393147 & 10.8381187 & 27.0878247 \\
\hline $\mathrm{H}$ & 11.2996204 & 6.6855808 & 26.8616765 \\
\hline $\mathrm{H}$ & 16.4378263 & 9.6231088 & 23.1277717 \\
\hline 0 & 11.3603107 & 9.3489346 & 22.9934408 \\
\hline $\mathrm{H}$ & 10.4587573 & 11.9244769 & 15.1368727 \\
\hline 0 & 12.1581913 & 10.9892616 & 25.2065767 \\
\hline $\mathrm{O}$ & 15.6743848 & 11.1885688 & 24.9046565 \\
\hline 0 & 10.2266345 & 8.1950514 & 24.9320157 \\
\hline $\mathrm{H}$ & 10.4112360 & 11.9263676 & 29.8594598 \\
\hline $\mathrm{H}$ & 8.7929210 & 15.0410794 & 15.0752976 \\
\hline$P$ & 5.4368998 & 14.7664658 & 16.6363538 \\
\hline Al & 5.4046777 & 14.7540309 & 28.4782341 \\
\hline $\mathrm{P}$ & 12.3365900 & 18.7834289 & 21.6238520 \\
\hline $\mathrm{Si}$ & 12.2455518 & 13.3147536 & 21.6651363 \\
\hline $\mathrm{P}$ & 17.0773115 & 15.9631450 & 21.6378734 \\
\hline Al & 17.0781464 & 16.0031752 & 18.4617505 \\
\hline Al & 12.2992213 & 13.3042129 & 18.4188629 \\
\hline Al & 12.3803682 & 18.7810901 & 18.4632394 \\
\hline $\mathrm{P}$ & 5.3481386 & 17.2702096 & 26.6224114 \\
\hline Al & 5.3223808 & 17.2859474 & 23.4978905 \\
\hline $\mathrm{P}$ & 8.5703774 & 14.7098569 & 28.3701426 \\
\hline $\mathrm{Al}$ & 8.5963670 & 14.7499865 & 16.5222779 \\
\hline $\mathrm{P}$ & 15.5077668 & 13.2842921 & 18.4146725 \\
\hline $\mathrm{P}$ & 15.5536227 & 18.7536676 & 18.4301716 \\
\hline$P$ & 10.7564951 & 16.1021593 & 18.3935923 \\
\hline Al & 10.6585570 & 16.0999089 & 21.5376973 \\
\hline $\mathrm{Al}$ & 15.5114416 & 18.7200368 & 21.5940099 \\
\hline Al & 15.4522302 & 13.2772172 & 21.5050123 \\
\hline $\mathrm{P}$ & 8.4746881 & 17.3680769 & 23.3839584 \\
\hline Al & 8.4959274 & 17.2716078 & 26.5437934 \\
\hline 0 & 9.0882867 & 13.0958116 & 16.8656364 \\
\hline 0 & 7.0832900 & 14.3646131 & 28.1673940 \\
\hline 0 & 11.8332190 & 17.3588892 & 21.8971933 \\
\hline 0 & 13.7862248 & 13.7140641 & 21.5070712 \\
\hline 0 & 16.0595142 & 17.0896937 & 21.9131830 \\
\hline 0 & 15.8846834 & 14.7552556 & 18.1384241 \\
\hline 0 & 11.7949430 & 14.9590460 & 18.2863256 \\
\hline 0 & 14.0721311 & 18.4049505 & 18.1956775 \\
\hline 0 & 6.8174506 & 17.6592599 & 26.8843758 \\
\hline $\mathrm{H}$ & 8.9611646 & 18.7624349 & 23.1936243 \\
\hline $\mathrm{H}$ & 4.7922622 & 18.6671324 & 23.3292995 \\
\hline $\mathrm{H}$ & 18.3072051 & 15.7779978 & 17.6519169 \\
\hline $\mathrm{H}$ & 11.9647402 & 19.9538887 & 17.6453657 \\
\hline 0 & 11.4095706 & 12.2370596 & 17.3733878 \\
\hline 0 & 4.9110232 & 16.1430186 & 27.5612975 \\
\hline $\mathrm{H}$ & 11.6153126 & 19.7716033 & 22.4726104 \\
\hline 0 & 11.9068141 & 12.0690452 & 22.5998885 \\
\hline $\mathrm{H}$ & 18.2991748 & 16.1552009 & 22.4669001 \\
\hline $\mathrm{O}$ & 8.9857415 & 15.8824577 & 27.4789026 \\
\hline
\end{tabular}




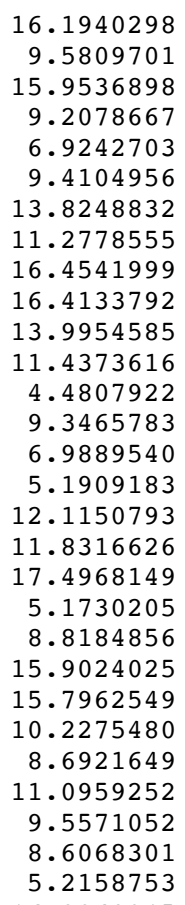

12.3799716

15.8442203

19.9179356

16.4006480

14.9225385

13.4902214

18.8548752

14.5538888

14.6199902

17.5544609

13.1266093

17.4042948

18.4490367

18.4312222

17.3223100

15.1011502

19.1596618

12.6933547

15.9831054

16.7903647

15.0788850

12.8756850

19.1154519

16.2104092

16.9215214

12.0213821

10.8887195

10.2895478

15.0588096

19.7046725

8.9799013

9.3123109

9.2638632

6.6871840

6.7230127

8.0327914

8.1355264

9.2383758

9.3568109

6.7818051

6.6756709

10.7716754

10.7486952

9.7242523

10.7205937

5.3344554

5.3100699

6.4177335

9.2835508

7.1149817

10.2370325

7.8989648

8.2826558

7.8961835

11.6579998

8.2002815

12.1604320

10.6435933

9.0492579

6.6707854

5.6273056

5.5217188

10.8420189

6.7272450

9.5236942

9.0258138

7.0843045

8.0546534

9.0091122

7.1018813

11.2284603

8.9857694

11.9645084

16.0259140

16.1009933

11.9578072

11.9904897
17.4511539

17.4460248

17.5925876

22.4580807

16.9773983

27.9772193

21.9741382

21.9046194

22.0163496

18.0186308

18.1926495

17.9610620

26.8966332

26.9295497

23.0227365

15.2064587

20.1459914

20.0624307

20.1559229

25.1706724

29.7911920

19.8408359

19.9068364

19.8275036

24.8431744

20.1023160

20.3176609

20.5024343

29.9234276

22.4433223

15.2713038

16.6267640

28.4440374

21.5623562

18.4009446

26.5811854

23. 4562911

28.5220994

16.7005005

18.5106486

21.6674427

23.5000321

26.6437613

16.9762030

28.1243951

21.8366468

21.9231075

18.2009738

26.7904729

23.2124918

23.2756738

17.5198150

27.6462651

22.5414699

27.5694880

17.5977515

22.5247492

17.0931060

28.0522741

21.9351270

18.0740263

17.9758568

27.0609751

26.9449772

23.1424311

15.1744586

19.8652083

24.9233470

29.9837328

20.2127772

25.1940890

29.8948957

15.1931210

21.5663018

18.3934465

28.4533006

16.6451650 


\begin{tabular}{|c|c|c|c|}
\hline Al & 1.6924508 & 13.3335853 & 18.5022674 \\
\hline $\mathrm{P}$ & 1.7150570 & 13.3560365 & 21.5810943 \\
\hline 0 & 4.8511648 & 13.0910008 & 16.9494501 \\
\hline $\mathrm{H}$ & 0.3368982 & 13.9168339 & 21.6385854 \\
\hline $\mathrm{H}$ & 2.3004333 & 17.0870705 & 21.8756559 \\
\hline 0 & 2.1651209 & 14.9909767 & 18.1803090 \\
\hline 0 & 4.4365556 & 15.8704160 & 17.4919278 \\
\hline 0 & 4.7564732 & 16.2807478 & 22.4845022 \\
\hline 0 & 2.5130134 & 12.2427214 & 17.4190004 \\
\hline $\mathrm{O}$ & 4.4501871 & 13.5130985 & 27.9802762 \\
\hline 0 & 2.7423920 & 14.4344367 & 21.9811222 \\
\hline $\mathrm{H}$ & 2.6127045 & 17.4067213 & 18.0113223 \\
\hline $\mathrm{H}$ & 0.2367564 & 13.2341025 & 18.2053204 \\
\hline 0 & 3.6832394 & 16.1236506 & 19.8561899 \\
\hline $\mathrm{H}$ & 3.5258169 & 11.9628356 & 29.9120501 \\
\hline $\mathrm{O}$ & 2.0394981 & 12.8649083 & 20.1390608 \\
\hline Al & 10.1214955 & 12.0736269 & 16.4714953 \\
\hline$P$ & 10.0738010 & 12.0072227 & 28.3218867 \\
\hline Al & 12.2880002 & 10.6311782 & 26.5874793 \\
\hline $\mathrm{P}$ & 12.3309565 & 10.5480259 & 23.4027669 \\
\hline Al & 15.4379735 & 10.7716754 & 23.5000321 \\
\hline Al & 10.5614044 & 7.9735980 & 23.5909347 \\
\hline$P$ & 10.6872966 & 7.9556336 & 26.6853451 \\
\hline$P$ & 15.4179379 & 10.7486952 & 26.6437613 \\
\hline $\mathrm{O}$ & 9.0513948 & 10.8731687 & 28.1161798 \\
\hline 0 & 11.7741787 & 9.0025140 & 27.0058219 \\
\hline $\mathrm{H}$ & 15.8590045 & 9.3335973 & 26.7854615 \\
\hline $\mathrm{H}$ & 11.4292189 & 6.7679231 & 23.4891178 \\
\hline $\mathrm{O}$ & 13.8200646 & 10.1409646 & 23.2353597 \\
\hline $\mathrm{O}$ & 11.3144646 & 11.7958922 & 27.4565196 \\
\hline 0 & 9.5382226 & 8.0593347 & 27.6987801 \\
\hline $\mathrm{H}$ & 16.2110058 & 11.6317979 & 27.5428128 \\
\hline $\mathrm{O}$ & 9.1468172 & 7.7094482 & 22.6030178 \\
\hline 0 & 15.7871028 & 12.1604320 & 22.5247492 \\
\hline 0 & 9.4552239 & 10.5695765 & 17.0479304 \\
\hline $\mathrm{O}$ & 13.9484089 & 10.8448471 & 27.0736189 \\
\hline $\mathrm{H}$ & 11.2794560 & 6.5942330 & 26.7996090 \\
\hline $\mathrm{H}$ & 16.4353262 & 9.7088229 & 23.1954785 \\
\hline $\mathrm{O}$ & 11.4571815 & 9.3395359 & 23.0039242 \\
\hline $\mathrm{H}$ & 10.4585171 & 12.0454702 & 15.0214111 \\
\hline $\mathrm{O}$ & 12.0749725 & 10.9016517 & 24.8871903 \\
\hline $\mathrm{O}$ & 15.5948298 & 11.2284603 & 25.1940890 \\
\hline 0 & 10.1126289 & 8.1933792 & 25.2743086 \\
\hline $\mathrm{H}$ & 10.4979576 & 12.0396724 & 29.7488270 \\
\hline $\mathrm{H}$ & 8.6936565 & 15.0794610 & 15.1005703 \\
\hline Al & 5.3699212 & 14.7242114 & 16.5733820 \\
\hline $\mathrm{P}$ & 5.3208978 & 14.7038024 & 28.3934005 \\
\hline Al & 12.2394278 & 18.7032853 & 21.5623562 \\
\hline $\mathrm{Mg}$ & 12.3783338 & 13.3820808 & 21.7466178 \\
\hline Al & 17.1731131 & 16.0259140 & 21.5663018 \\
\hline $\mathrm{P}$ & 17.0928280 & 16.1009933 & 18.3934465 \\
\hline$P$ & 12.3428510 & 13.2695781 & 18.3351655 \\
\hline $\mathrm{P}$ & 12.3177709 & 18.7391141 & 18.4009446 \\
\hline Al & 5.4095329 & 17.2154980 & 26.5496643 \\
\hline $\mathrm{P}$ & 5.3812176 & 17.2571514 & 23.4834904 \\
\hline Al & 8.4794677 & 14.7331148 & 28.3726184 \\
\hline $\mathrm{P}$ & 8.5232774 & 14.7849592 & 16.5501772 \\
\hline Al & 15.5674496 & 13.3335853 & 18.5022674 \\
\hline Al & 15.4944365 & 18.7979065 & 18.5106486 \\
\hline Al & 10.6889465 & 16.0544112 & 18.4431483 \\
\hline $\mathrm{P}$ & 10.5098468 & 16.0536175 & 21.5614317 \\
\hline $\mathrm{P}$ & 15.4404822 & 18.6917723 & 21.6674427 \\
\hline $\mathrm{P}$ & 15.5900557 & 13.3560365 & 21.5810943 \\
\hline Al & 8.5139165 & 17.4836958 & 23.4535990 \\
\hline $\mathrm{P}$ & 8.5493005 & 17.3246059 & 26.6077871 \\
\hline $\mathrm{O}$ & 8.9888197 & 13.3428724 & 16.8604328 \\
\hline $\mathrm{O}$ & 6.7931975 & 14.3621390 & 28.0893353 \\
\hline $\mathrm{O}$ & 11.5866656 & 17.1224711 & 21.8828954 \\
\hline 0 & 14.1834495 & 13.9284097 & 21.639772 \\
\hline $\mathrm{O}$ & 15.9943342 & 17.2796903 & 21.9318095 \\
\hline $\mathrm{O}$ & 16.0401196 & 14.9909767 & 18.1803090 \\
\hline $\mathrm{O}$ & 11.8359459 & 14.7028306 & 18.3120652 \\
\hline 0 & 13.8139136 & 18.4338348 & 18.2009738 \\
\hline 0 & 7.0719352 & 17.6663465 & 26.9015482 \\
\hline $\mathrm{H}$ & 9.0505810 & 18.8562970 & 23.241283 \\
\hline $\mathrm{H}$ & 4.6512721 & 18.5549142 & 23.4729220 \\
\hline $\mathrm{H}$ & 18.2762958 & 15.8770868 & 17.5180093 \\
\hline $\mathrm{H}$ & 11.8978220 & 19.8823457 & 17.544332 \\
\hline 0 & 11.6258600 & 12.3586278 & 17.345069 \\
\hline 0 & 4.8749859 & 15.9316362 & 27.5969224 \\
\hline
\end{tabular}




\begin{tabular}{|c|c|c|}
\hline 11.5626450 & 19.7339826 & 22.3970710 \\
\hline 11.9615695 & 11.7181365 & 22.5217611 \\
\hline 18.4196093 & 16.2437269 & 22.3511109 \\
\hline 8.9887804 & 16.1099762 & 27.4386518 \\
\hline 16.2685821 & 12.4014929 & 17.5766662 \\
\hline 9.3632454 & 15.7854460 & 17.3474172 \\
\hline 15.8902227 & 20.0049688 & 17.7338125 \\
\hline 9.2474098 & 16.3359175 & 22.3899369 \\
\hline 7.0583997 & 14.9179844 & 16.9756046 \\
\hline 9.4317668 & 13.3407657 & 27.9306415 \\
\hline 13.9372155 & 18.6868868 & 21.9351270 \\
\hline 11.0282059 & 14.6732609 & 21.8700471 \\
\hline 16.6173908 & 14.4344367 & 21.9811222 \\
\hline 16.4691830 & 17.4466838 & 17.9996272 \\
\hline 13.8413249 & 13.2156212 & 18.1501553 \\
\hline 11.5242502 & 17.5015569 & 17.9630247 \\
\hline 4.5077860 & 18.3803817 & 26.7665030 \\
\hline 9.3970150 & 18.4855284 & 26.9960648 \\
\hline 6.8253596 & 17.5234643 & 23.0662153 \\
\hline 5.1732706 & 14.9726138 & 15.1184781 \\
\hline 12.0270613 & 19.1004059 & 19.8652083 \\
\hline 12.0325228 & 12.6589012 & 19.7947622 \\
\hline 17.5582381 & 16.1236506 & 19.8561899 \\
\hline 5.3202114 & 16.6404314 & 24.8960207 \\
\hline 8.6659487 & 15.0351468 & 29.8186897 \\
\hline 15.9144968 & 12.8649083 & 20.1390608 \\
\hline 15.7367589 & 19.1179827 & 20.2127772 \\
\hline 10.1048074 & 16.1808305 & 20.0668981 \\
\hline 8.7457509 & 16.9918319 & 25.1203830 \\
\hline 11.2983626 & 11.9709322 & 19.8316603 \\
\hline 9.8336415 & 10.9033088 & 20.2338322 \\
\hline 8.9144509 & 10.3326097 & 20.5856698 \\
\hline 5.1453748 & 15.0052906 & 29.8409561 \\
\hline 16.0647187 & 19.6940820 & 22.5745395 \\
\hline \\
\hline 8.6983261 & 8.8381383 & 15.2165805 \\
\hline 5.3429762 & 9.2282406 & 16.6273428 \\
\hline 5.3374491 & 9.1856381 & 28.5737193 \\
\hline 5.3039650 & 6.7381137 & 21.5997483 \\
\hline 5.3561371 & 6.7555654 & 18.5139293 \\
\hline 3.2441441 & 7.9565803 & 26.6294067 \\
\hline 3.3073060 & 8.0295777 & 23.5655460 \\
\hline 8.4590072 & 9.1482204 & 28.5819742 \\
\hline 8.4751537 & 9.2267953 & 16.6365314 \\
\hline 8.5111184 & 6.7654246 & 18.5461527 \\
\hline 8.4701315 & 6.7000214 & 21.6402825 \\
\hline 1.6369214 & 10.6836866 & 23.5551891 \\
\hline 1.6383530 & 10.6760512 & 26.6366519 \\
\hline 6.9114129 & 9.6137641 & 16.8728050 \\
\hline 4.9196903 & 10.7337514 & 28.2805466 \\
\hline 4.8076691 & 5.3547510 & 21.8387433 \\
\hline 8.9441942 & 5.3102797 & 21.8872707 \\
\hline 6.9382676 & 6.4158164 & 18.3348315 \\
\hline 2.1313039 & 9.1319640 & 26.7887837 \\
\hline 2.2621688 & 6.9918298 & 23.3467121 \\
\hline 0.2503995 & 10.1799934 & 23.3527764 \\
\hline 4.9126477 & 7.9775272 & 17.5530564 \\
\hline 4.4702774 & 8.1704341 & 27.6643961 \\
\hline 4.5685762 & 7.8044006 & 22.5736811 \\
\hline 2.4901675 & 11.6440233 & 27.6152904 \\
\hline 8.9381156 & 8.0274021 & 17.6195323 \\
\hline 1.9818888 & 11.9122063 & 22.5670179 \\
\hline 4.4336769 & 10.5000486 & 17.0439022 \\
\hline 6.8977465 & 8.9866243 & 28.2007075 \\
\hline 6.8859127 & 6.7728861 & 21.9206369 \\
\hline 9.3232746 & 5.5899170 & 18.1269809 \\
\hline 4.5880384 & 5.5499847 & 18.0971317 \\
\hline 0.2133501 & 10.7488673 & 27.0623105 \\
\hline 2.6027438 & 6.6564188 & 26.9689745 \\
\hline 2.6803347 & 9.4839173 & 23.2402202 \\
\hline 5.1107396 & 8.8573278 & 15.2041034 \\
\hline 5.0322200 & 7.1750840 & 20.0504506 \\
\hline 3.8341562 & 7.9521543 & 25.1100286 \\
\hline 8.6959045 & 8.8330517 & 30.0178255 \\
\hline 8.8083086 & 7.1452432 & 20.1029876 \\
\hline 1.8173658 & 11.1864136 & 25.1014283 \\
\hline 5.1106143 & 8.8542523 & 30.0075428 \\
\hline 3.3784498 & 11.8807838 & 15.1626372 \\
\hline
\end{tabular}




\begin{tabular}{|c|c|c|c|}
\hline $\mathrm{Si}$ & 3.2795450 & 15.8136674 & 21.6152826 \\
\hline $\mathrm{Si}$ & 3.2478199 & 15.8676654 & 18.5023688 \\
\hline $\mathrm{Si}$ & 3.7945432 & 11.8862246 & 28.5360354 \\
\hline $\mathrm{Si}$ & 3.7808363 & 11.9126771 & 16.5958813 \\
\hline $\mathrm{Si}$ & 1.7064626 & 13.1439575 & 18.5286186 \\
\hline $\mathrm{Si}$ & 1.6826847 & 13.1508925 & 21.5629866 \\
\hline 0 & 4.8867885 & 13.0811262 & 16.8629223 \\
\hline $\mathrm{H}$ & 0.2692809 & 13.6182248 & 21.5947773 \\
\hline $\mathrm{H}$ & 2.2731605 & 16.8776077 & 21.8842468 \\
\hline 0 & 2.1415095 & 14.6925228 & 18.2723474 \\
\hline $\mathrm{O}$ & 4.5392154 & 15.6390040 & 17.5508020 \\
\hline $\mathrm{O}$ & 4.5928513 & 16.0270242 & 22.5359578 \\
\hline 0 & 2.4453482 & 12.1610275 & 17.4761769 \\
\hline $\mathrm{O}$ & 4.4232791 & 13.3213546 & 28.1378061 \\
\hline $\mathrm{O}$ & 2.6791809 & 14.3645855 & 21.9870780 \\
\hline $\mathrm{H}$ & 2.6358625 & 17.1713285 & 18.1240947 \\
\hline $\mathrm{H}$ & 0.2448405 & 13.0470020 & 18.2614462 \\
\hline 0 & 3.7364830 & 15.8844939 & 20.0510014 \\
\hline $\mathrm{H}$ & 3.3802525 & 11.8785867 & 29.9662191 \\
\hline 0 & 2.0647521 & 12.6641931 & 20.0354647 \\
\hline $\mathrm{Si}$ & 10.0311821 & 11.9177942 & 16.5306327 \\
\hline $\mathrm{Si}$ & 9.9924844 & 11.8728054 & 28.4773958 \\
\hline $\mathrm{Si}$ & 12.1590601 & 10.6003486 & 26.6754824 \\
\hline $\mathrm{Si}$ & 12.1758583 & 10.5714681 & 23.5396359 \\
\hline $\mathrm{Si}$ & 15.2619201 & 10.6836866 & 23.5551891 \\
\hline $\mathrm{Si}$ & 10.4696627 & 7.9775007 & 23.6035230 \\
\hline $\mathrm{Si}$ & 10.5431001 & 7.9533756 & 26.6670314 \\
\hline $\mathrm{Si}$ & 15.2633517 & 10.6760512 & 26.6366519 \\
\hline 0 & 8.9048421 & 10.6816059 & 28.2551889 \\
\hline $\mathrm{O}$ & 11.6773741 & 9.0752953 & 26.9967820 \\
\hline $\mathrm{H}$ & 15.7142169 & 9.2637905 & 26.7757955 \\
\hline $\mathrm{H}$ & 11.3993603 & 6.8207386 & 23.4823436 \\
\hline $\mathrm{O}$ & 13.7433919 & 10.1320384 & 23.3335053 \\
\hline 0 & 11.3025281 & 11.6577854 & 27.5603507 \\
\hline $\mathrm{O}$ & 9.3008331 & 8.0897327 & 27.6977202 \\
\hline $\mathrm{H}$ & 16.0468985 & 11.5664462 & 27.5368585 \\
\hline $\mathrm{O}$ & 9.1828951 & 7.7578574 & 22.6417074 \\
\hline $\mathrm{O}$ & 15.6068875 & 11.9122063 & 22.5670179 \\
\hline $\mathrm{O}$ & 9.3903031 & 10.5145588 & 17.0242467 \\
\hline 0 & 13.7133650 & 10.7552539 & 27.0996441 \\
\hline $\mathrm{H}$ & 11.1447777 & 6.6050890 & 26.8599766 \\
\hline $\mathrm{H}$ & 16.2204176 & 9.5815578 & 23.2658533 \\
\hline $\mathrm{O}$ & 11.2415513 & 9.3074030 & 23.1134562 \\
\hline $\mathrm{H}$ & 10.4262771 & 11.8865663 & 15.0953469 \\
\hline 0 & 11.9333107 & 10.9410757 & 25.1112217 \\
\hline 0 & 15.4423645 & 11.1864136 & 25.1014283 \\
\hline $\mathrm{O}$ & 9.9737168 & 8.1299100 & 25.1496403 \\
\hline $\mathrm{H}$ & 10.4192012 & 11.8829387 & 29.9039058 \\
\hline $\mathrm{H}$ & 8.7254944 & 14.9759936 & 15.1066295 \\
\hline $\mathrm{Si}$ & 5.3478089 & 14.6203030 & 16.5887153 \\
\hline $\mathrm{Si}$ & 5.3132517 & 14.6064526 & 28.5495228 \\
\hline $\mathrm{Si}$ & 12.1164643 & 18.5377087 & 21.5997483 \\
\hline Al & 12.1435724 & 13.1782444 & 21.6932831 \\
\hline $\mathrm{Si}$ & 16.9045437 & 15.8136674 & 21.6152826 \\
\hline $\mathrm{Si}$ & 16.8728187 & 15.8676654 & 18.5023688 \\
\hline $\mathrm{Si}$ & 12.1519056 & 13.1295166 & 18.4368605 \\
\hline $\mathrm{Si}$ & 12.1686365 & 18.5551605 & 18.5139293 \\
\hline $\mathrm{Si}$ & 5.3284292 & 17.0149595 & 26.6077130 \\
\hline $\mathrm{Si}$ & 5.3096116 & 17.0415469 & 23.5674380 \\
\hline $\mathrm{Si}$ & 8.4558678 & 14.5948017 & 28.4918487 \\
\hline $\mathrm{Si}$ & 8.4884067 & 14.6337784 & 16.5362444 \\
\hline $\mathrm{Si}$ & 15.3314613 & 13.1439575 & 18.5286186 \\
\hline $\mathrm{Si}$ & 15.3236178 & 18.5650196 & 18.5461527 \\
\hline $\mathrm{Si}$ & 10.5617504 & 15.8905512 & 18.4931882 \\
\hline $\mathrm{Si}$ & 10.4480312 & 15.8877427 & 21.5623283 \\
\hline $\mathrm{Si}$ & 15.2826308 & 18.4996164 & 21.6402825 \\
\hline $\mathrm{Si}$ & 15.3076835 & 13.1508925 & 21.5629866 \\
\hline $\mathrm{Si}$ & 8.4313995 & 17.1746129 & 23.5122542 \\
\hline $\mathrm{Si}$ & 8.4476071 & 17.0667463 & 26.6026151 \\
\hline 0 & 8.9529456 & 13.0953908 & 16.8309456 \\
\hline $\mathrm{O}$ & 6.8800956 & 14.2394220 & 28.3058989 \\
\hline $\mathrm{O}$ & 11.5767715 & 17.0333824 & 21.8596414 \\
\hline 0 & 13.7859165 & 13.6540544 & 21.5972147 \\
\hline 0 & 15.8008210 & 16.9805128 & 21.9102613 \\
\hline $\mathrm{O}$ & 15.7665082 & 14.6925228 & 18.2723474 \\
\hline 0 & 11.6375766 & 14.6541325 & 18.3946246 \\
\hline $\mathrm{O}$ & 13.7507669 & 18.2154114 & 18.3348315 \\
\hline $\mathrm{O}$ & 6.8816462 & 17.4373151 & 26.8749160 \\
\hline $\mathrm{H}$ & 8.9318416 & 18.5666558 & 23.3422694 \\
\hline $\mathrm{H}$ & 4.7170172 & 18.4047148 & 23.4795413 \\
\hline
\end{tabular}




\begin{tabular}{|c|c|c|c|}
\hline $\mathrm{H}$ & 18.0595450 & 15.6575373 & 17.6279276 \\
\hline $\mathrm{H}$ & 11.7601330 & 19.6807242 & 17.6288577 \\
\hline 0 & 11.3856814 & 12.1611568 & 17.4015642 \\
\hline $\mathrm{O}$ & 4.8596108 & 15.8507507 & 27.6270986 \\
\hline $\mathrm{H}$ & 11.4407880 & 19.5174148 & 22.4945992 \\
\hline $\mathrm{O}$ & 11.7581345 & 11.8060732 & 22.6272278 \\
\hline $\mathrm{H}$ & 18.1131395 & 16.0100132 & 22.4625519 \\
\hline $\mathrm{O}$ & 8.9014327 & 15.8183812 & 27.5337736 \\
\hline $\mathrm{H}$ & 16.0112017 & 12.2397077 & 17.5604213 \\
\hline $\mathrm{O}$ & 9.3451804 & 15.6536792 & 17.4522439 \\
\hline $\mathrm{H}$ & 15.7154046 & 19.7229338 & 17.6959419 \\
\hline $\mathrm{O}$ & 9.1462125 & 16.1609613 & 22.4871363 \\
\hline $\mathrm{O}$ & 6.9255272 & 14.7641143 & 16.9273638 \\
\hline 0 & 9.3200994 & 13.2885862 & 28.0818804 \\
\hline 0 & 13.6984121 & 18.5724812 & 21.9206369 \\
\hline $\mathrm{O}$ & 11.0224046 & 14.4418787 & 21.8741057 \\
\hline 0 & 16.3041796 & 14.3645855 & 21.9870780 \\
\hline 0 & 16.2064874 & 17.2871620 & 18.0904841 \\
\hline 0 & 13.7329387 & 13.0379208 & 18.2364220 \\
\hline $\mathrm{O}$ & 11.3331712 & 17.2438435 & 18.0605762 \\
\hline $\mathrm{H}$ & 4.4547138 & 18.1949614 & 26.8553765 \\
\hline $\mathrm{H}$ & 9.2869447 & 18.2413790 & 26.9671299 \\
\hline 0 & 6.8598128 & 17.1678573 & 23.1550323 \\
\hline $\mathrm{H}$ & 5.0847001 & 14.9829013 & 15.1687093 \\
\hline 0 & 11.8447193 & 18.9746790 & 20.0504506 \\
\hline $\mathrm{O}$ & 11.7820029 & 12.4919345 & 19.9622594 \\
\hline $\mathrm{O}$ & 17.3614817 & 15.8844939 & 20.0510014 \\
\hline $\mathrm{O}$ & 5.1508744 & 16.4645606 & 25.0845303 \\
\hline $\mathrm{H}$ & 8.7219145 & 14.9715212 & 29.9076249 \\
\hline 0 & 15.6897509 & 12.6641931 & 20.0354647 \\
\hline $\mathrm{O}$ & 15.6208079 & 18.9448382 & 20.1029876 \\
\hline 0 & 9.9680692 & 16.0059868 & 19.9935284 \\
\hline $\mathrm{O}$ & 8.6770267 & 16.6640338 & 25.0429117 \\
\hline $\mathrm{H}$ & 11.0483281 & 11.8113928 & 19.9916954 \\
\hline $\mathrm{C}$ & 9.4976185 & 10.7899468 & 20.3289166 \\
\hline 0 & 8.5153457 & 10.2954884 & 20.6213465 \\
\hline $\mathrm{H}$ & 5.0821093 & 14.9812123 & 29.9719323 \\
\hline $\mathrm{H}$ & 15.9370718 & 19.4708938 & 22.5597648 \\
\hline \multicolumn{4}{|c|}{$\begin{array}{l}\mathrm{Ge} 28 \\
161\end{array}$} \\
\hline $\mathrm{H}$ & 8.6811918 & 9.0225938 & 15.1671553 \\
\hline $\mathrm{P}$ & 5.3881019 & 9.3599318 & 16.6871274 \\
\hline Al & 5.3603630 & 9.2918609 & 28.5041761 \\
\hline $\mathrm{P}$ & 5.4111930 & 6.7509624 & 21.6267379 \\
\hline Al & 5.4531125 & 6.7829010 & 18.4806383 \\
\hline $\mathrm{P}$ & 3.2113226 & 7.9510438 & 26.6442979 \\
\hline Al & 3.3084565 & 8.0813329 & 23.5377703 \\
\hline $\mathrm{P}$ & 8.4942679 & 9.1973605 & 28.4290006 \\
\hline Al & 8.5328311 & 9.3104462 & 16.6205138 \\
\hline $\mathrm{P}$ & 8.6154874 & 6.7349190 & 18.4353004 \\
\hline Al & 8.5838603 & 6.6733993 & 21.6106877 \\
\hline $\mathrm{P}$ & 1.6501265 & 10.7506255 & 23.4729733 \\
\hline Al & 1.6180399 & 10.7134961 & 26.6082984 \\
\hline $\mathrm{O}$ & 6.8638689 & 9.7254286 & 16.9578541 \\
\hline $\mathrm{O}$ & 4.9077612 & 10.9443956 & 28.1175462 \\
\hline $\mathrm{H}$ & 4.8772047 & 5.3753487 & 21.8258962 \\
\hline $\mathrm{H}$ & 9.1024420 & 5.3056104 & 21.8888015 \\
\hline $\mathrm{O}$ & 7.1358980 & 6.3833163 & 18.1870776 \\
\hline 0 & 2.1413479 & 9.0508215 & 26.7838352 \\
\hline $\mathrm{H}$ & 2.2204416 & 7.0926498 & 23.3014445 \\
\hline $\mathrm{H}$ & 0.2970611 & 10.1780620 & 23.2310938 \\
\hline 0 & 4.9718277 & 8.1465187 & 17.5185540 \\
\hline 0 & 4.3463665 & 8.1670771 & 27.6505851 \\
\hline $\mathrm{O}$ & 4.6881840 & 7.7599475 & 22.5261936 \\
\hline 0 & 2.5721116 & 11.7706545 & 27.6110086 \\
\hline 0 & 9.0277517 & 7.9517770 & 17.5937925 \\
\hline $\mathrm{O}$ & 1.9014603 & 11.9460847 & 22.5543280 \\
\hline $\mathrm{O}$ & 4.5081962 & 10.5424127 & 17.1026141 \\
\hline 0 & 7.0203283 & 9.0160026 & 28.0543205 \\
\hline 0 & 6.8949133 & 6.7511186 & 21.9997787 \\
\hline $\mathrm{H}$ & 9.4563814 & 5.5782407 & 18.0204350 \\
\hline $\mathrm{H}$ & 4.6048070 & 5.6260841 & 18.0815481 \\
\hline $\mathrm{H}$ & 0.2014624 & 10.7884074 & 27.0608655 \\
\hline $\mathrm{H}$ & 2.5852845 & 6.6349399 & 26.9493675 \\
\hline 0 & 2.7078968 & 9.6791373 & 23.1734063 \\
\hline $\mathrm{H}$ & 5.1881120 & 9.0350866 & 15.2478219 \\
\hline 0 & 5.2246322 & 7.1922842 & 20.1621874 \\
\hline $\mathrm{O}$ & 3.8013748 & 7.9686180 & 25.2207748 \\
\hline $\mathrm{H}$ & 8.6995425 & 8.9808810 & 29.8878082 \\
\hline
\end{tabular}

17.6279276

7.6288577

27.6270986

22.4945992

22.4625519

27.5337736

17.4522439

17.6959419

(2)

28.0818804

(2)6369

21.9870780

18.0904841

64220

26.8553765

26.9671299

23.1550323

19.9622594

.0510014

45303

20.0354647

20.1029876

19.9935284

.0429117

20.3289166

13465

29.9719323
22.5597648

$\mathrm{Ge}$

161 


\begin{tabular}{|c|c|c|c|}
\hline 0 & 8.8474576 & 7.0705591 & 19.9198068 \\
\hline 0 & 1.7705789 & 11.2220348 & 24.9380356 \\
\hline $\mathrm{H}$ & 5.2081321 & 9.0642216 & 29.9677767 \\
\hline $\mathrm{H}$ & 3.5566659 & 12.0548886 & 15.1353137 \\
\hline $\mathrm{P}$ & 3.2648461 & 15.9536476 & 21.6270666 \\
\hline Al & 3.2194246 & 16.0130556 & 18.4531144 \\
\hline $\mathrm{P}$ & 3.8532257 & 12.0344886 & 28.4050399 \\
\hline Al & 3.8534097 & 12.0730989 & 16.5943312 \\
\hline $\mathrm{P}$ & 1.6347178 & 13.2871272 & 18.4208821 \\
\hline Al & 1.5835001 & 13.3088626 & 21.5154768 \\
\hline 0 & 5.0400660 & 13.3132206 & 16.9661864 \\
\hline $\mathrm{H}$ & 0.1883925 & 13.8288053 & 21.5368036 \\
\hline $\mathrm{H}$ & 2.2921485 & 17.0404228 & 21.9268992 \\
\hline $\mathrm{O}$ & 2.0254768 & 14.7575921 & 18.1638922 \\
\hline $\mathrm{O}$ & 4.6564685 & 15.7518744 & 17.4984796 \\
\hline $\mathrm{O}$ & 4.5418348 & 16.1207718 & 22.4598451 \\
\hline $\mathrm{O}$ & 2.3587965 & 12.3631661 & 17.4364199 \\
\hline $\mathrm{O}$ & 4.4161962 & 13.3940835 & 27.9741356 \\
\hline 0 & 2.6534119 & 14.6039149 & 21.9967149 \\
\hline $\mathrm{H}$ & 2.6430987 & 17.3325412 & 18.0737373 \\
\hline $\mathrm{H}$ & 0.1737780 & 13.1392476 & 18.1740883 \\
\hline 0 & 3.6587518 & 16.0005198 & 20.1403068 \\
\hline $\mathrm{H}$ & 3.5166014 & 12.0512266 & 29.8553931 \\
\hline 0 & 1.9896045 & 12.8598289 & 19.8527849 \\
\hline $\mathrm{P}$ & 10.1235106 & 11.9917825 & 16.5378394 \\
\hline Al & 10.0618531 & 11.9224491 & 28.3491904 \\
\hline $\mathrm{P}$ & 12.3716196 & 10.6454415 & 26.7005362 \\
\hline Al & 12.4276184 & 10.5596010 & 23.4949132 \\
\hline $\mathrm{P}$ & 15.5251252 & 10.7506255 & 23.4729733 \\
\hline$P$ & 10.6002880 & 8.0230142 & 23.5239633 \\
\hline Al & 10.6886052 & 8.0187587 & 26.6061699 \\
\hline Al & 15.4930386 & 10.7134961 & 26.6082984 \\
\hline 0 & 8.9282341 & 10.6234424 & 28.0288871 \\
\hline 0 & 11.8933004 & 9.2184882 & 27.0466273 \\
\hline $\mathrm{H}$ & 15.9378162 & 9.3003314 & 26.7574932 \\
\hline $\mathrm{H}$ & 11.4189558 & 6.7797242 & 23.4902964 \\
\hline $\mathrm{O}$ & 14.1229397 & 10.1572763 & 23.2223129 \\
\hline 0 & 11.5378880 & 11.6867961 & 27.4621330 \\
\hline $\mathrm{O}$ & 9.3160034 & 8.1464469 & 27.6753742 \\
\hline $\mathrm{H}$ & 16.3087200 & 11.6173112 & 27.4655631 \\
\hline $\mathrm{O}$ & 9.3819796 & 7.8723010 & 22.6021664 \\
\hline 0 & 15.7764590 & 11.9460847 & 22.5543280 \\
\hline 0 & 9.5527100 & 10.6655655 & 17.0658373 \\
\hline 0 & 13.8329203 & 10.8012863 & 27.1386717 \\
\hline $\mathrm{H}$ & 11.2926716 & 6.6649079 & 26.7451396 \\
\hline $\mathrm{H}$ & 16.5510922 & 9.7113531 & 23.1824132 \\
\hline $\mathrm{O}$ & 11.4514754 & 9.1889928 & 23.0163059 \\
\hline $\mathrm{H}$ & 10.4152891 & 11.9072241 & 15.0801577 \\
\hline 0 & 12.2214463 & 10.9024163 & 25.1988599 \\
\hline 0 & 15.6455776 & 11.2220348 & 24.9380356 \\
\hline 0 & 10.1211634 & 8.2897408 & 24.9653896 \\
\hline $\mathrm{H}$ & 10.3694954 & 11.9075912 & 29.8059869 \\
\hline $\mathrm{H}$ & 8.7941466 & 15.0258870 & 15.0282068 \\
\hline $\mathrm{P}$ & 5.4531671 & 14.7636868 & 16.6408690 \\
\hline Al & 5.3935347 & 14.7487091 & 28.4728525 \\
\hline $\mathrm{P}$ & 12.3486924 & 18.7670638 & 21.6267379 \\
\hline $\mathrm{Ge}$ & 12.1940455 & 13.3552162 & 21.7343205 \\
\hline$P$ & 17.1398449 & 15.9536476 & 21.6270666 \\
\hline Al & 17.0944233 & 16.0130556 & 18.4531144 \\
\hline Al & 12.3038556 & 13.3343725 & 18.3355054 \\
\hline Al & 12.3906118 & 18.7990023 & 18.4806383 \\
\hline $\mathrm{P}$ & 5.3603720 & 17.2374831 & 26.6103965 \\
\hline Al & 5.3051501 & 17.2320311 & 23.5517488 \\
\hline $\mathrm{P}$ & 8.5586674 & 14.6961543 & 28.3200401 \\
\hline Al & 8.6091584 & 14.7598921 & 16.4815294 \\
\hline $\mathrm{P}$ & 15.5097165 & 13.2871272 & 18.4208821 \\
\hline $\mathrm{P}$ & 15.5529868 & 18.7510203 & 18.4353004 \\
\hline $\mathrm{P}$ & 10.7686026 & 16.0946162 & 18.3517011 \\
\hline Al & 10.5760505 & 16.1251332 & 21.5276686 \\
\hline Al & 15.5213597 & 18.6895006 & 21.6106877 \\
\hline Al & 15.4584989 & 13.3088626 & 21.5154768 \\
\hline $\mathrm{P}$ & 8.4394086 & 17.4940358 & 23.3721699 \\
\hline Al & 8.4998286 & 17.2657896 & 26.5019354 \\
\hline 0 & 9.1073471 & 13.1100250 & 16.8389547 \\
\hline 0 & 7.0665709 & 14.3697156 & 28.1254963 \\
\hline 0 & 11.7982825 & 17.3491462 & 21.8320208 \\
\hline 0 & 13.8338464 & 13.9143543 & 21.5403126 \\
\hline 0 & 16.1314803 & 17.0802728 & 21.9378935 \\
\hline 0 & 15.9004755 & 14.7575921 & 18.163892 \\
\hline & & & \\
\hline
\end{tabular}




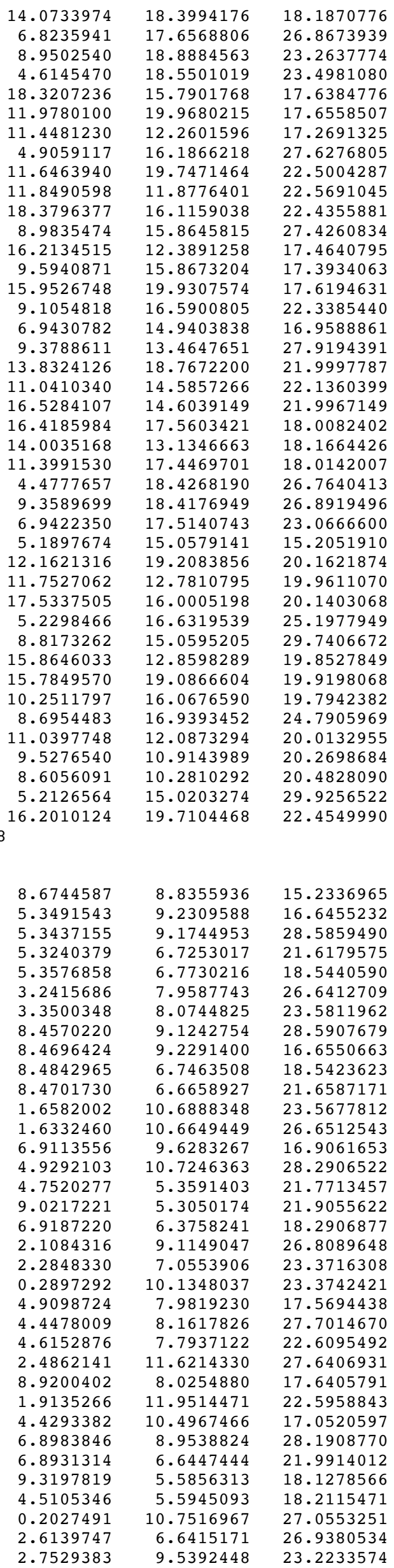

8.8355936

9.2309588

9.1744953

6.7253017

6.7730216

7.9587743

8.0744825

9.1242754

.2291400

6.7463508

6.6658927

10.6888348

10.6649449

9.6283267

10.7246363

5.3591403

5.3050174

6.3758241

9. 1149047

7.0553906

10.1348037

7.9819230

8.1617826

7.7937122

11.6214330

8.0254880

11.9514471

10.4967466

8.9538824

6.6447444

5.5856313

5.5945093

10.7516967

6.6415171

16.6455232

28.5859490

21.6179575

18.5440590

26.6412709

23. 5811962

28.5907679

16.6550663

18.5423623

21.6587171

23.5677812

26.6512543

16.9061653

28.2906522

21.7713457

21.9055622

18.2906877

26.8089648

23.3716308

23.3742421

17.5694438

27.7014670

22.6095492

27.6406931

17.6405791

22.5958843

17.0520597

28.1908770

21.9914012

18.1278566

18.2115471

27.0553251

26.9380534

23. 2233574 


\begin{tabular}{|c|c|c|}
\hline 5.1355628 & 8.8566586 & 15.2202518 \\
\hline 5.1352325 & 7.2478835 & 20.0832092 \\
\hline 3.8581794 & 8.0102167 & 25.1323110 \\
\hline 8.6725448 & 8.8280407 & 30.0339989 \\
\hline 8.7382643 & 7.1111396 & 20.1093399 \\
\hline 1.8391773 & 11.1760760 & 25.1183764 \\
\hline 5.1354126 & 8.8524233 & 30.0246985 \\
\hline 3.4028697 & 11.8993704 & 15.1718150 \\
\hline 3.3498617 & 15.8056960 & 21.6033648 \\
\hline 3.2533328 & 15.8662878 & 18.4973684 \\
\hline 3.8035662 & 11.8801391 & 28.5397384 \\
\hline 3.8001787 & 11.9190630 & 16.6066943 \\
\hline 1.7050001 & 13.1394138 & 18.5402358 \\
\hline 1.6901335 & 13.1888677 & 21.5736951 \\
\hline 4.9202915 & 13.0731110 & 16.8795923 \\
\hline 0.3243747 & 13.7805832 & 21.6148828 \\
\hline 2.3565039 & 16.8745139 & 21.8999944 \\
\hline 2.1377950 & 14.6925112 & 18.3043197 \\
\hline 4.5280647 & 15.6337731 & 17.5253520 \\
\hline 4.6830686 & 15.9932034 & 22.5052156 \\
\hline 2.4700496 & 12.1735360 & 17.4921783 \\
\hline 4.4261666 & 13.3112924 & 28.1105767 \\
\hline 2.7567499 & 14.3501095 & 21.9687582 \\
\hline 2.6349279 & 17.1685587 & 18.1248277 \\
\hline 0.2489964 & 13.0186652 & 18.2528447 \\
\hline 3.7796683 & 15.8913177 & 20.0335154 \\
\hline 3.4037852 & 11.8960841 & 29.9739774 \\
\hline 2.0289053 & 12.6522140 & 20.0545995 \\
\hline 10.0337140 & 11.9142111 & 16.5089819 \\
\hline 9.9802467 & 11.8524994 & 28.4591040 \\
\hline 12.1526886 & 10.5952003 & 26.6467608 \\
\hline 12.2076114 & 10.5035655 & 23.5243377 \\
\hline 15.2831990 & 10.6888348 & 23.5677812 \\
\hline 10.4133141 & 7.9514210 & 23.6306883 \\
\hline 10.5303438 & 7.9452172 & 26.6549236 \\
\hline 15.2582448 & 10.6649449 & 26.6512543 \\
\hline 8.8962097 & 10.6560753 & 28.2447058 \\
\hline 11.6768018 & 9.0649074 & 26.9555160 \\
\hline 15.6926198 & 9.2480274 & 26.7954201 \\
\hline 11.2506090 & 6.7221542 & 23.5602550 \\
\hline 13.7840053 & 10.0818801 & 23.3557544 \\
\hline 11.2791813 & 11.6447864 & 27.5236528 \\
\hline 9.3307602 & 8.0599783 & 27.7403139 \\
\hline 16.0426847 & 11.5445880 & 27.5612008 \\
\hline 9.1490579 & 7.7806636 & 22.6275294 \\
\hline 15.5385253 & 11.9514471 & 22.5958843 \\
\hline 9.3973748 & 10.5142009 & 17.0234251 \\
\hline 13.7018678 & 10.7593306 & 27.0908822 \\
\hline 11.1463295 & 6.5956957 & 26.7832746 \\
\hline 16.2866937 & 9.6350599 & 23.2520642 \\
\hline 11.2999963 & 9.2085807 & 23.1477839 \\
\hline 10.4265649 & 11.8612920 & 15.0737159 \\
\hline 11.9500720 & 10.9454572 & 25.0778645 \\
\hline 15.4641761 & 11.1760760 & 25.1183764 \\
\hline 9.8955252 & 8.1625723 & 25.1652988 \\
\hline 10.4186452 & 11.8563761 & 29.8820981 \\
\hline 8.7306233 & 14.9899390 & 15.0799850 \\
\hline 5.3566669 & 14.6154530 & 16.5807369 \\
\hline 5.3079914 & 14.5994924 & 28.5365270 \\
\hline 12.1365372 & 18.5248967 & 21.6179575 \\
\hline 12.1512621 & 13.2450662 & 21.7959956 \\
\hline 16.9748604 & 15.8056960 & 21.6033648 \\
\hline 16.8783315 & 15.8662878 & 18.4973684 \\
\hline 12.1584389 & 13.1626813 & 18.3876969 \\
\hline 12.1701851 & 18.5726166 & 18.5440590 \\
\hline 5.3372421 & 16.9933921 & 26.5900149 \\
\hline 5.3002880 & 17.0224734 & 23.5871978 \\
\hline 8.4553620 & 14.5909932 & 28.4672590 \\
\hline 8.4968812 & 14.6411434 & 16.5085601 \\
\hline 15.3299988 & 13.1394138 & 18.5402358 \\
\hline 15.2967959 & 18.5459459 & 18.5423623 \\
\hline 10.5770817 & 15.8574585 & 18.4812891 \\
\hline 10.3968891 & 15.8668975 & 21.5887411 \\
\hline 15.2826724 & 18.4654878 & 21.6587171 \\
\hline 15.3151322 & 13.1888677 & 21.5736951 \\
\hline 8.4085753 & 17.2557618 & 23.4931372 \\
\hline 8.4539361 & 17.0541408 & 26.5661717 \\
\hline 8.9515571 & 13.0959344 & 16.7892232 \\
\hline 6.8766840 & 14.2463701 & 28.2878446 \\
\hline 11.5149115 & 17.0402359 & 21.7846504 \\
\hline
\end{tabular}




\begin{tabular}{|c|c|c|c|}
\hline 0 & 13.8351299 & 13.8300793 & 21.6183281 \\
\hline $\mathrm{O}$ & 15.8857013 & 16.9775928 & 21.9286019 \\
\hline $\mathrm{O}$ & 15.7627938 & 14.6925112 & 18.3043197 \\
\hline $\mathrm{O}$ & 11.7219290 & 14.7083860 & 18.2335834 \\
\hline 0 & 13.7312214 & 18.1754192 & 18.2906877 \\
\hline $\mathrm{O}$ & 6.8895536 & 17.4225866 & 26.8595688 \\
\hline $\mathrm{H}$ & 8.9510414 & 18.6364357 & 23.3643316 \\
\hline $\mathrm{H}$ & 4.5655224 & 18.3172040 & 23.5569865 \\
\hline $\mathrm{H}$ & 18.0501125 & 15.6525516 & 17.6038548 \\
\hline $\mathrm{H}$ & 11.7575965 & 19.6864265 & 17.6461065 \\
\hline 0 & 11.3894474 & 12.1738445 & 17.3707006 \\
\hline $\mathrm{O}$ & 4.8505653 & 15.8619032 & 27.6387290 \\
\hline $\mathrm{H}$ & 11.4854322 & 19.5064095 & 22.5288995 \\
\hline 0 & 11.7530932 & 11.6693486 & 22.5327557 \\
\hline $\mathrm{H}$ & 18.1999004 & 15.9779904 & 22.4320459 \\
\hline $\mathrm{O}$ & 8.9085520 & 15.7938133 & 27.4833164 \\
\hline $\mathrm{H}$ & 16.0342244 & 12.2503264 & 17.5755023 \\
\hline 0 & 9.3569405 & 15.6507723 & 17.4353596 \\
\hline $\mathrm{H}$ & 15.6961731 & 19.7183282 & 17.7158406 \\
\hline $\mathrm{O}$ & 9.0434651 & 16.2738439 & 22.3843959 \\
\hline 0 & 6.9350485 & 14.7853354 & 16.9057445 \\
\hline 0 & 9.3031649 & 13.2688621 & 28.0749667 \\
\hline 0 & 13.7056307 & 18.4443395 & 21.9914012 \\
\hline $\mathrm{O}$ & 10.9125802 & 14.4698798 & 22.1724006 \\
\hline 0 & 16.3817486 & 14.3501095 & 21.9687582 \\
\hline $\mathrm{O}$ & 16.2050368 & 17.2841489 & 18.0917608 \\
\hline 0 & 13.7402864 & 13.0075765 & 18.2264527 \\
\hline $\mathrm{O}$ & 11.2503703 & 17.2930184 & 18.1830262 \\
\hline $\mathrm{H}$ & 4.4597001 & 18.1815130 & 26.7781889 \\
\hline $\mathrm{H}$ & 9.2984218 & 18.2246223 & 26.9321466 \\
\hline $\mathrm{O}$ & 6.8281530 & 17.3380018 & 23.1936396 \\
\hline $\mathrm{H}$ & 5.0773370 & 14.9553446 & 15.1582148 \\
\hline $\mathrm{O}$ & 11.9477319 & 19.0474785 & 20.0832092 \\
\hline 0 & 11.7090608 & 12.6339725 & 19.9219338 \\
\hline 0 & 17.4046671 & 15.8913177 & 20.0335154 \\
\hline 0 & 5.1938913 & 16.3815306 & 25.0840771 \\
\hline $\mathrm{H}$ & 8.7262974 & 14.9845228 & 29.8775246 \\
\hline 0 & 15.6539040 & 12.6522140 & 20.0545995 \\
\hline 0 & 15.5507636 & 18.9107346 & 20.1093399 \\
\hline $\mathrm{O}$ & 10.0141029 & 15.7574583 & 19.9954322 \\
\hline 0 & 8.6776034 & 16.6736586 & 24.9967714 \\
\hline $\mathrm{H}$ & 10.9870729 & 11.9457937 & 19.9754152 \\
\hline C & 9.4535819 & 10.8728904 & 20.3041717 \\
\hline $\mathrm{O}$ & 8.5062912 & 10.3109735 & 20.5915475 \\
\hline $\mathrm{H}$ & 5.0735419 & 14.9536023 & 29.9636781 \\
\hline $\mathrm{H}$ & 15.9045548 & 19.4866571 & 22.5461832 \\
\hline \multicolumn{4}{|c|}{$\mathrm{Ti} 28$} \\
\hline \multicolumn{4}{|c|}{161} \\
\hline $\mathrm{H}$ & 8.6859539 & 9.0655117 & 15.1647753 \\
\hline$P$ & 5.4050911 & 9.3745031 & 16.7085379 \\
\hline Al & 5.3551956 & 9.2868695 & 28.5222298 \\
\hline $\mathrm{P}$ & 5.3953349 & 6.7688416 & 21.6273817 \\
\hline Al & 5.4716807 & 6.7814091 & 18.4814390 \\
\hline $\mathrm{P}$ & 3.2253641 & 7.9397399 & 26.6495205 \\
\hline Al & 3.3596565 & 8.1126134 & 23.5637931 \\
\hline $\mathrm{P}$ & 8.4854384 & 9.1781556 & 28.4185759 \\
\hline Al & 8.5526971 & 9.3315925 & 16.6237353 \\
\hline $\mathrm{P}$ & 8.6482548 & 6.7646921 & 18.4533527 \\
\hline Al & 8.5908477 & 6.6923715 & 21.6152409 \\
\hline $\mathrm{P}$ & 1.6537428 & 10.7738719 & 23.4951701 \\
\hline Al & 1.6011201 & 10.6991190 & 26.6360024 \\
\hline $\mathrm{O}$ & 6.8828622 & 9.7369544 & 16.9747053 \\
\hline $\mathrm{O}$ & 4.9098248 & 10.9376119 & 28.1192384 \\
\hline $\mathrm{H}$ & 4.7989578 & 5.4265062 & 21.8714932 \\
\hline $\mathrm{H}$ & 9.1399621 & 5.3333562 & 21.8772933 \\
\hline 0 & 7.1665487 & 6.4147538 & 18.2255230 \\
\hline $\mathrm{O}$ & 2.1540804 & 9.0415294 & 26.7478399 \\
\hline $\mathrm{H}$ & 2.2691336 & 7.1314022 & 23.3086366 \\
\hline $\mathrm{H}$ & 0.3173716 & 10.2008396 & 23.1744419 \\
\hline 0 & 4.9914528 & 8.1544268 & 17.5316523 \\
\hline $\mathrm{O}$ & 4.3266549 & 8.1576263 & 27.6921172 \\
\hline 0 & 4.7337344 & 7.8241944 & 22.5260777 \\
\hline 0 & 2.5666679 & 11.7510551 & 27.6330706 \\
\hline 0 & 9.0544591 & 7.9711869 & 17.5932522 \\
\hline 0 & 1.9623037 & 11.9703689 & 22.5938289 \\
\hline 0 & 4.5271909 & 10.5561264 & 17.1323534 \\
\hline 0 & 7.0078487 & 8.9923295 & 28.0631405 \\
\hline $\mathrm{O}$ & 6.8885339 & 6.7062186 & 21.9585782 \\
\hline $\mathrm{H}$ & 9.4823293 & 5.6025437 & 18.0400111 \\
\hline
\end{tabular}

21.6183281

1.9286019

18.2335834

18.2906877

26.8595688

23.5569865

17.6038548

27.6387290

22.5288995

22.5327557

17.5755023

1353596

22.3843959

9057445

21.9914012

1724006

18.0917608

.2264527

26.7781889

.9321466

936396

20.0832092

19.9219338

20.0335154

.0840771

20.0545995

20.1093399

19.9954322

19.9754152

20.3041717

20.5915475

29.9636781 $\mathrm{Ti} 28$

161 


\begin{tabular}{|c|c|c|c|}
\hline $\mathrm{H}$ & 4.6773942 & 5.6004282 & 18.0438162 \\
\hline $\mathrm{H}$ & 0.2061856 & 10.7300965 & 27.1559240 \\
\hline $\mathrm{H}$ & 2.5875919 & 6.6264466 & 26.9421429 \\
\hline 0 & 2.7344976 & 9.7106180 & 23.2548229 \\
\hline $\mathrm{H}$ & 5.1975926 & 9.0565503 & 15.2687563 \\
\hline $\mathrm{O}$ & 5.1898209 & 7.1838706 & 20.1577526 \\
\hline 0 & 3.8590296 & 7.9498270 & 25.2433610 \\
\hline $\mathrm{H}$ & 8.7014032 & 9.0253049 & 29.8838801 \\
\hline 0 & 8.8940674 & 7.1154518 & 19.9339161 \\
\hline 0 & 1.6831522 & 11.2385307 & 24.9687848 \\
\hline $\mathrm{H}$ & 5.2151491 & 9.0818201 & 29.9903791 \\
\hline $\mathrm{H}$ & 3.5736205 & 12.0484357 & 15.1511491 \\
\hline $\mathrm{P}$ & 3.3020645 & 15.9758706 & 21.6178113 \\
\hline Al & 3.2400698 & 16.0274892 & 18.4472178 \\
\hline $\mathrm{P}$ & 3.8530170 & 12.0231337 & 28.4157654 \\
\hline Al & 3.8710297 & 12.0834063 & 16.6097255 \\
\hline $\mathrm{P}$ & 1.6444372 & 13.3091047 & 18.4283154 \\
\hline Al & 1.6282756 & 13.3221176 & 21.5393540 \\
\hline 0 & 5.0654509 & 13.3236858 & 16.9655081 \\
\hline $\mathrm{H}$ & 0.2064798 & 13.7625678 & 21.5796183 \\
\hline $\mathrm{H}$ & 2.3350299 & 17.0689947 & 21.9128442 \\
\hline 0 & 2.0379796 & 14.7784414 & 18.1632159 \\
\hline $\mathrm{O}$ & 4.6760944 & 15.7639546 & 17.4891084 \\
\hline $\mathrm{O}$ & 4.5894110 & 16.1440679 & 22.4362584 \\
\hline 0 & 2.3758646 & 12.3824701 & 17.4495977 \\
\hline $\mathrm{O}$ & 4.4041667 & 13.3847482 & 27.9751969 \\
\hline 0 & 2.6847260 & 14.6336552 & 22.0068617 \\
\hline $\mathrm{H}$ & 2.6682345 & 17.3549865 & 18.0896204 \\
\hline $\mathrm{H}$ & 0.1836395 & 13.1631465 & 18.1795445 \\
\hline 0 & 3.6891707 & 16.0032723 & 20.1304578 \\
\hline $\mathrm{H}$ & 3.5326592 & 12.0418037 & 29.8697746 \\
\hline $\mathrm{O}$ & 2.0020550 & 12.8896311 & 19.8628818 \\
\hline $\mathrm{P}$ & 10.1227598 & 12.0018059 & 16.4978462 \\
\hline Al & 10.0326823 & 11.9008843 & 28.2874204 \\
\hline $\mathrm{P}$ & 12.3876686 & 10.5744036 & 26.7722101 \\
\hline Al & 12.4458563 & 10.5008075 & 23.5380590 \\
\hline $\mathrm{P}$ & 15.5287415 & 10.7738719 & 23.4951701 \\
\hline $\mathrm{P}$ & 10.5645450 & 8.0284264 & 23.5574861 \\
\hline Al & 10.6728115 & 7.9994218 & 26.6361771 \\
\hline Al & 15.4761189 & 10.6991190 & 26.6360024 \\
\hline $\mathrm{O}$ & 8.9278117 & 10.5806395 & 27.9474363 \\
\hline $\mathrm{O}$ & 11.8715619 & 9.1727568 & 27.1649972 \\
\hline $\mathrm{H}$ & 15.9463499 & 9.2895239 & 26.7311077 \\
\hline $\mathrm{H}$ & 11.3136842 & 6.7416264 & 23.5499564 \\
\hline 0 & 14.1417658 & 10.1791406 & 23.1622968 \\
\hline $\mathrm{O}$ & 11.5396457 & 11.6631133 & 27.4497643 \\
\hline $\mathrm{O}$ & 9.2919250 & 8.0879353 & 27.7018317 \\
\hline $\mathrm{H}$ & 16.3016480 & 11.5985089 & 27.4884811 \\
\hline $\mathrm{O}$ & 9.3313405 & 7.9031038 & 22.6474310 \\
\hline $\mathrm{O}$ & 15.8373024 & 11.9703689 & 22.5938289 \\
\hline 0 & 9.5862657 & 10.6793294 & 17.0765051 \\
\hline 0 & 13.8377620 & 10.7355022 & 27.2466527 \\
\hline $\mathrm{H}$ & 11.2733096 & 6.6392380 & 26.7163171 \\
\hline $\mathrm{H}$ & 16.5770906 & 9.7424989 & 23.2620296 \\
\hline $\mathrm{O}$ & 11.4681046 & 9.1427817 & 23.0143948 \\
\hline $\mathrm{H}$ & 10.3138744 & 11.8933855 & 15.0251477 \\
\hline 0 & 12.3016122 & 10.7462775 & 25.2567831 \\
\hline $\mathrm{O}$ & 15.5581509 & 11.2385307 & 24.9687848 \\
\hline $\mathrm{O}$ & 10.1212743 & 8.3503717 & 25.0002095 \\
\hline $\mathrm{H}$ & 10.2769038 & 11.8922312 & 29.7562300 \\
\hline $\mathrm{H}$ & 8.8205860 & 14.9865633 & 14.9927235 \\
\hline $\mathrm{P}$ & 5.4709969 & 14.7747515 & 16.6299208 \\
\hline Al & 5.3883548 & 14.7373008 & 28.4653994 \\
\hline $\mathrm{P}$ & 12.3328342 & 18.7849430 & 21.6273817 \\
\hline $\mathrm{Ti}$ & 12.1311883 & 13.3125185 & 21.6948549 \\
\hline $\mathrm{P}$ & 17.1770632 & 15.9758706 & 21.6178113 \\
\hline Al & 17.1150685 & 16.0274892 & 18.4472178 \\
\hline Al & 12.2988818 & 13.2899545 & 18.3062934 \\
\hline Al & 12.4091801 & 18.7975105 & 18.4814390 \\
\hline $\mathrm{P}$ & 5.3588357 & 17.2219715 & 26.5998239 \\
\hline Al & 5.2973683 & 17.2543688 & 23.5643766 \\
\hline $\mathrm{P}$ & 8.5549183 & 14.6729894 & 28.2812930 \\
\hline Al & 8.6320299 & 14.7637903 & 16.4528397 \\
\hline $\mathrm{P}$ & 15.5194359 & 13.3091047 & 18.4283154 \\
\hline $\mathrm{P}$ & 15.5857541 & 18.7807934 & 18.4533527 \\
\hline$P$ & 10.7725742 & 16.1086708 & 18.3418943 \\
\hline Al & 10.4851129 & 16.2079749 & 21.4951876 \\
\hline Al & 15.5283471 & 18.7084728 & 21.6152409 \\
\hline Al & 15.5032743 & 13.3221176 & 21.5393540 \\
\hline $\mathrm{P}$ & 8.4142999 & 17.5671238 & 23.3690502 \\
\hline
\end{tabular}




\begin{tabular}{|c|c|c|c|}
\hline Al & 8.4891829 & 17.2689969 & 26.4881741 \\
\hline 0 & 9.1216101 & 13.1194223 & 16.8513576 \\
\hline 0 & 7.0585742 & 14.3515002 & 28.1148292 \\
\hline 0 & 11.7181173 & 17.4013278 & 21.8790002 \\
\hline 0 & 13.8437903 & 13.8361999 & 21.5863495 \\
\hline 0 & 16.1746034 & 17.1090388 & 21.9236521 \\
\hline 0 & 15.9129783 & 14.7784414 & 18.1632159 \\
\hline 0 & 11.8032789 & 14.9595200 & 18.2567650 \\
\hline 0 & 14.1040481 & 18.4308552 & 18.2255230 \\
\hline 0 & 6.8147910 & 17.6615420 & 26.8693336 \\
\hline $\mathrm{H}$ & 8.9983795 & 18.9330219 & 23.2675900 \\
\hline $\mathrm{H}$ & 4.5188427 & 18.5235654 & 23.5517858 \\
\hline $\mathrm{H}$ & 18.3395036 & 15.8027848 & 17.6302800 \\
\hline $\mathrm{H}$ & 11.9975659 & 19.9743548 & 17.6673555 \\
\hline 0 & 11.4952666 & 12.2938294 & 17.1247181 \\
\hline 0 & 4.9032718 & 16.1766448 & 27.6214742 \\
\hline $\mathrm{H}$ & 11.6914568 & 19.8080370 & 22.4986074 \\
\hline $\mathrm{O}$ & 11.8333036 & 11.9062768 & 22.7488031 \\
\hline $\mathrm{H}$ & 18.4260479 & 16.1390557 & 22.4118694 \\
\hline 0 & 8.9642521 & 15.8531182 & 27.3948628 \\
\hline $\mathrm{H}$ & 16.2296528 & 12.4093415 & 17.4779794 \\
\hline 0 & 9.6373437 & 15.8796489 & 17.3353520 \\
\hline $\mathrm{H}$ & 15.9794365 & 19.9500960 & 17.6197663 \\
\hline 0 & 9.0001443 & 16.6488325 & 22.2976929 \\
\hline 0 & 6.9646971 & 14.9617123 & 16.9283474 \\
\hline 0 & 9.3621765 & 13.4451932 & 27.8407924 \\
\hline 0 & 13.8260333 & 18.7223200 & 21.9585782 \\
\hline 0 & 10.9856744 & 14.6470837 & 22.0203370 \\
\hline 0 & 16.5597247 & 14.6336552 & 22.0068617 \\
\hline 0 & 16.4444172 & 17.5843848 & 18.0278257 \\
\hline 0 & 14.0135661 & 13.1586431 & 18.1718688 \\
\hline 0 & 11.4798949 & 17.4158076 & 17.9694370 \\
\hline $\mathrm{H}$ & 4.4580674 & 18.4008538 & 26.7262098 \\
\hline $\mathrm{H}$ & 9.3591210 & 18.4109312 & 26.8835402 \\
\hline 0 & 6.9119218 & 17.6821303 & 23.1099859 \\
\hline $\mathrm{H}$ & 5.1905940 & 15.0594694 & 15.1955462 \\
\hline 0 & 12.1273203 & 19.1999720 & 20.1577526 \\
\hline $\mathrm{O}$ & 11.7506162 & 12.6084226 & 19.8697674 \\
\hline $\mathrm{O}$ & 17.5641694 & 16.0032723 & 20.1304578 \\
\hline 0 & 5.2563289 & 16.5999535 & 25.1911220 \\
\hline $\mathrm{H}$ & 8.8435193 & 15.0136687 & 29.7017745 \\
\hline 0 & 15.8770537 & 12.8896311 & 19.8628818 \\
\hline 0 & 15.8315668 & 19.1315532 & 19.9339161 \\
\hline 0 & 10.1831244 & 16.1995423 & 19.7552441 \\
\hline 0 & 8.6776079 & 16.9692391 & 24.7692263 \\
\hline $\mathrm{H}$ & 11.0335270 & 11.9242202 & 19.8758940 \\
\hline C & 9.4557675 & 10.8125279 & 20.2253346 \\
\hline $\mathrm{O}$ & 8.4823157 & 10.2562057 & 20.4262447 \\
\hline $\mathrm{H}$ & 5.2121204 & 15.0197528 & 29.9167032 \\
\hline $\mathrm{H}$ & 16.1566470 & 19.7357658 & 22.4910428 \\
\hline \multicolumn{4}{|c|}{$\mathrm{Zn} 29$} \\
\hline \multicolumn{4}{|c|}{162} \\
\hline $\mathrm{H}$ & 8.7230537 & 8.9454854 & 15.2472310 \\
\hline Al & 5.4125843 & 9.2786404 & 16.6215330 \\
\hline$P$ & 5.4181979 & 9.2450788 & 28.4390496 \\
\hline Al & 5.3230844 & 6.6655808 & 21.5613735 \\
\hline$P$ & 5.3498705 & 6.7027403 & 18.4231759 \\
\hline Al & 3.1861145 & 8.0320579 & 26.5917020 \\
\hline $\mathrm{P}$ & 3.2683098 & 8.1282396 & 23.4613385 \\
\hline Al & 8.5483230 & 9.2262393 & 28.4991998 \\
\hline $\mathrm{P}$ & 8.5547997 & 9.3109578 & 16.6808422 \\
\hline Al & 8.5214668 & 6.7246276 & 18.4915161 \\
\hline $\mathrm{P}$ & 8.5081472 & 6.6620221 & 21.6599163 \\
\hline Al & 1.5563713 & 10.7375186 & 23.5025083 \\
\hline $\mathrm{P}$ & 1.5443760 & 10.7368603 & 26.6540068 \\
\hline 0 & 7.0888305 & 9.6984847 & 16.9674116 \\
\hline $\mathrm{O}$ & 5.0141384 & 10.7031527 & 28.1345557 \\
\hline $\mathrm{H}$ & 4.8560673 & 5.2660957 & 21.7625129 \\
\hline $\mathrm{H}$ & 9.0035010 & 5.2856673 & 21.9381116 \\
\hline 0 & 6.8341895 & 6.3489350 & 18.2115285 \\
\hline 0 & 1.9759244 & 9.2700596 & 26.8563438 \\
\hline $\mathrm{H}$ & 2.1843755 & 7.1244191 & 23.2754583 \\
\hline $\mathrm{H}$ & 0.1928666 & 10.1677335 & 23.3199698 \\
\hline 0 & 4.9377192 & 7.8590565 & 17.5079259 \\
\hline 0 & 4.5549729 & 8.2650080 & 27.6425271 \\
\hline 0 & 4.4675155 & 7.8069194 & 22.5631541 \\
\hline 0 & 2.3581968 & 11.6651330 & 27.5622258 \\
\hline 0 & 8.9836726 & 8.1320285 & 17.5608299 \\
\hline $\mathrm{O}$ & 1.7640134 & 12.1788758 & 22.5577763 \\
\hline
\end{tabular}




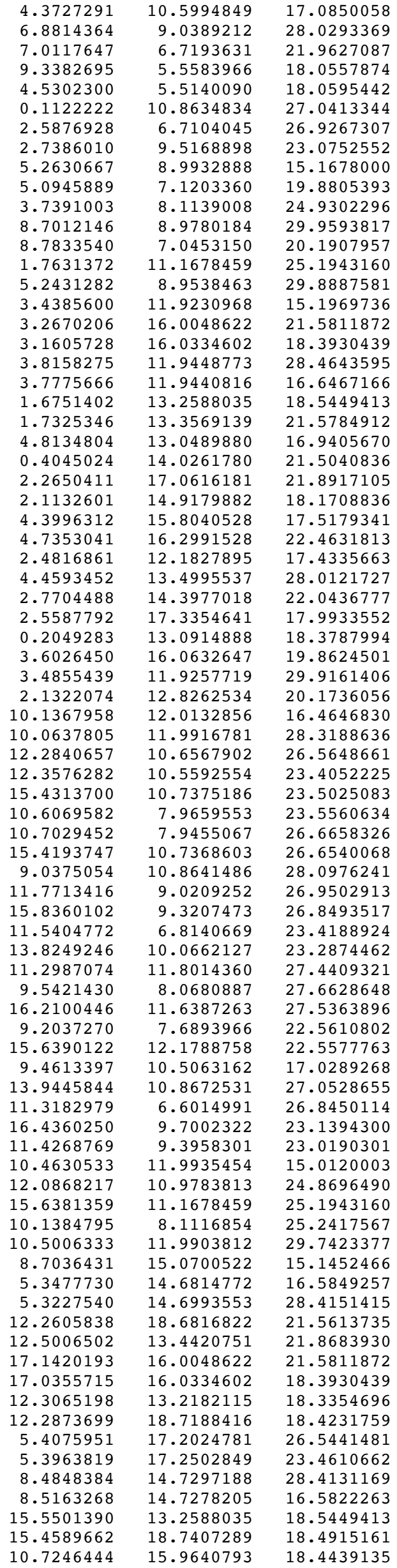

Al $\quad 5.3477730$ 


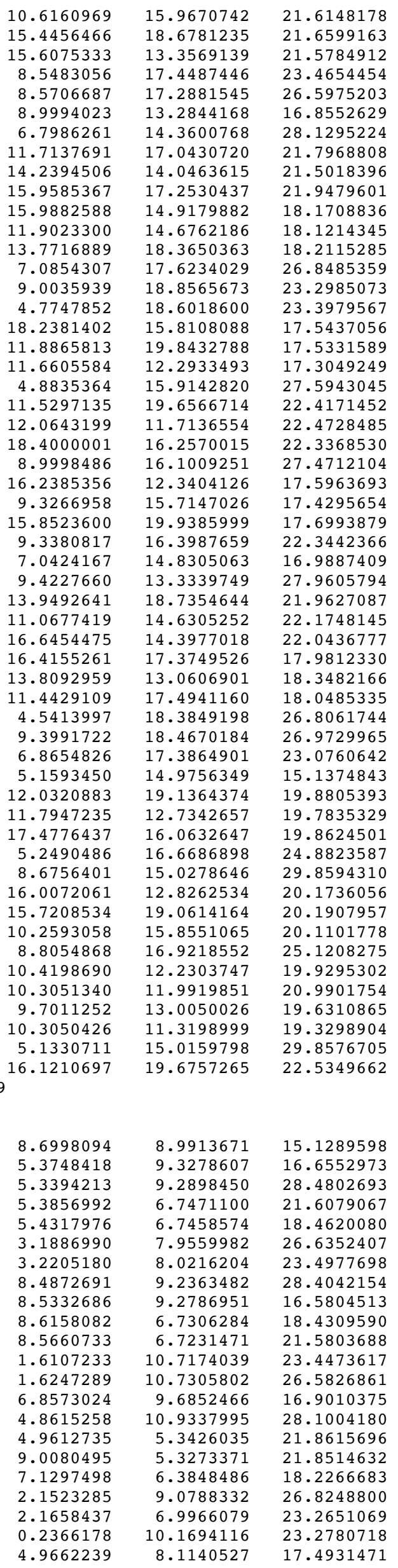




\begin{tabular}{|c|c|c|c|}
\hline 0 & 4.3790578 & 8.1530598 & 27.5805082 \\
\hline 0 & 4.6156856 & 7.7236618 & 22.5019943 \\
\hline 0 & 2.5562375 & 11.8225916 & 27.5672462 \\
\hline $\mathrm{O}$ & 9.0248017 & 7.9071557 & 17.5347552 \\
\hline 0 & 1.8502853 & 11.9081016 & 22.5184650 \\
\hline 0 & 4.5080194 & 10.5187757 & 17.0804341 \\
\hline 0 & 7.0089354 & 9.0732601 & 28.0485846 \\
\hline $\mathrm{O}$ & 6.8747931 & 6.8797663 & 21.9362183 \\
\hline $\mathrm{H}$ & 9.4367943 & 5.5500712 & 18.0444525 \\
\hline $\mathrm{H}$ & 4.6499963 & 5.5517915 & 18.0376096 \\
\hline $\mathrm{H}$ & 0.2015805 & 10.8170180 & 27.0119851 \\
\hline $\mathrm{H}$ & 2.5506947 & 6.6557916 & 26.9809774 \\
\hline 0 & 2.6180231 & 9.6114872 & 23.1014788 \\
\hline $\mathrm{H}$ & 5.1481293 & 9.0038227 & 15.2197760 \\
\hline $\mathrm{O}$ & 5.1239816 & 7.1302364 & 20.1378044 \\
\hline 0 & 3.7037139 & 7.9501268 & 25.1843509 \\
\hline $\mathrm{H}$ & 8.7204913 & 8.9516662 & 29.8470196 \\
\hline 0 & 8.8787713 & 7.1220100 & 19.8976336 \\
\hline $\mathrm{O}$ & 1.8126442 & 11.1889057 & 24.9033171 \\
\hline $\mathrm{H}$ & 5.1702670 & 9.0373294 & 29.9379192 \\
\hline $\mathrm{H}$ & 3.4919774 & 12.0050866 & 15.1211574 \\
\hline$P$ & 3.1540232 & 15.9555650 & 21.6468923 \\
\hline Al & 3.1678448 & 15.9701259 & 18.4670002 \\
\hline$P$ & 3.8211579 & 12.0316932 & 28.4022949 \\
\hline Al & 3.8232818 & 12.0404243 & 16.5724014 \\
\hline $\mathrm{P}$ & 1.6230745 & 13.2547246 & 18.4234493 \\
\hline Al & 1.5405601 & 13.2765223 & 21.4804937 \\
\hline 0 & 5.0125007 & 13.2923418 & 16.8929920 \\
\hline $\mathrm{H}$ & 0.1062498 & 13.6584864 & 21.3622649 \\
\hline $\mathrm{H}$ & 2.1833633 & 17.0581438 & 21.8903261 \\
\hline $\mathrm{O}$ & 1.9608323 & 14.7336530 & 18.1286215 \\
\hline $\mathrm{O}$ & 4.6179449 & 15.7024356 & 17.5313427 \\
\hline 0 & 4.4133169 & 16.1572025 & 22.4996898 \\
\hline 0 & 2.3304534 & 12.3371592 & 17.4201657 \\
\hline 0 & 4.4169887 & 13.3918019 & 28.0310070 \\
\hline $\mathrm{O}$ & 2.5099933 & 14.6250246 & 22.0462660 \\
\hline $\mathrm{H}$ & 2.6175310 & 17.3032330 & 18.0967289 \\
\hline $\mathrm{H}$ & 0.1570730 & 13.0573285 & 18.2531707 \\
\hline $\mathrm{O}$ & 3.5751903 & 15.9392972 & 20.1652312 \\
\hline $\mathrm{H}$ & 3.4471865 & 12.0000448 & 29.8432197 \\
\hline 0 & 2.0712306 & 12.8679487 & 19.8418637 \\
\hline $\mathrm{P}$ & 10.1169739 & 11.9776068 & 16.5718688 \\
\hline Al & 10.0748378 & 11.9560939 & 28.3902578 \\
\hline $\mathrm{P}$ & 12.3587680 & 10.6734379 & 26.7124572 \\
\hline Al & 12.3945058 & 10.6654368 & 23.5174955 \\
\hline $\mathrm{P}$ & 15.4857221 & 10.7174039 & 23.4473617 \\
\hline $\mathrm{P}$ & 10.6810565 & 8.0696542 & 23.4356742 \\
\hline Al & 10.7179342 & 8.0301055 & 26.6085899 \\
\hline Al & 15.4997276 & 10.7305802 & 26.5826861 \\
\hline 0 & 8.9187867 & 10.6792271 & 28.0687440 \\
\hline 0 & 11.9026485 & 9.2412808 & 27.0650779 \\
\hline $\mathrm{H}$ & 15.9484354 & 9.3258188 & 26.7886648 \\
\hline $\mathrm{H}$ & 11.6263971 & 6.9363698 & 23.2378912 \\
\hline $\mathrm{O}$ & 14.0619728 & 10.1496137 & 23.2719556 \\
\hline 0 & 11.5573100 & 11.7024157 & 27.5216216 \\
\hline $\mathrm{O}$ & 9.2817575 & 8.2248350 & 27.5749409 \\
\hline $\mathrm{H}$ & 16.2966060 & 11.6647640 & 27.4249485 \\
\hline $\mathrm{O}$ & 9.4143321 & 7.8597854 & 22.5960670 \\
\hline $\mathrm{O}$ & 15.7252841 & 11.9081016 & 22.5184650 \\
\hline $\mathrm{O}$ & 9.5609087 & 10.6236827 & 17.0394901 \\
\hline $\mathrm{O}$ & 13.8353534 & 10.8316693 & 27.0847520 \\
\hline $\mathrm{H}$ & 11.2822576 & 6.6823610 & 26.8953731 \\
\hline $\mathrm{H}$ & 16.4626045 & 9.6448824 & 23.1119234 \\
\hline 0 & 11.3492446 & 9.3677026 & 22.9650101 \\
\hline $\mathrm{H}$ & 10.4396631 & 11.9516917 & 15.1184863 \\
\hline 0 & 12.1316879 & 10.9413853 & 25.2228763 \\
\hline $\mathrm{O}$ & 15.6876429 & 11.1889057 & 24.9033171 \\
\hline $\mathrm{O}$ & 10.2839887 & 8.1781862 & 24.9191642 \\
\hline $\mathrm{H}$ & 10.3929119 & 11.9517639 & 29.8448816 \\
\hline $\mathrm{H}$ & 8.7861550 & 15.0002475 & 15.0857134 \\
\hline $\mathrm{P}$ & 5.4280349 & 14.7563160 & 16.6396191 \\
\hline Al & 5.3937600 & 14.7558821 & 28.4866745 \\
\hline $\mathrm{P}$ & 12.3231985 & 18.7632113 & 21.6079067 \\
\hline $\mathrm{Si}$ & 12.2337744 & 13.2992992 & 21.6445978 \\
\hline $\mathrm{P}$ & 17.0290219 & 15.9555650 & 21.6468923 \\
\hline Al & 17.0428435 & 15.9701259 & 18.4670002 \\
\hline Al & 12.2864366 & 13.2567574 & 18.4649168 \\
\hline Al & 12.3692969 & 18.7619587 & 18.4620080 \\
\hline $\mathrm{P}$ & 5.3270228 & 17.2745565 & 26.6237297 \\
\hline Al & 5.3043432 & 17.2874669 & 23.4799556 \\
\hline
\end{tabular}




\begin{tabular}{|c|c|c|c|}
\hline$P$ & 8.5572117 & 14.7037142 & 28.3730622 \\
\hline Al & 8.5873575 & 14.7217224 & 16.5348593 \\
\hline$P$ & 15.4980732 & 13.2547246 & 18.4234493 \\
\hline $\mathrm{P}$ & 15.5533076 & 18.7467298 & 18.4309590 \\
\hline $\mathrm{P}$ & 10.7589265 & 16.0715374 & 18.4130872 \\
\hline Al & 10.6646859 & 16.0870145 & 21.5404088 \\
\hline Al & 15.5035727 & 18.7392484 & 21.5803688 \\
\hline Al & 15.4155588 & 13.2765223 & 21.4804937 \\
\hline $\mathrm{P}$ & 8.4585641 & 17.3674970 & 23.3988504 \\
\hline Al & 8.4776959 & 17.2741443 & 26.5537420 \\
\hline 0 & 9.0704871 & 13.0650670 & 16.8882042 \\
\hline 0 & 7.0698508 & 14.3613393 & 28.1700863 \\
\hline $\mathrm{O}$ & 11.8850373 & 17.3132511 & 21.8697788 \\
\hline $\mathrm{O}$ & 13.7489610 & 13.7203458 & 21.3431176 \\
\hline 0 & 16.0232608 & 17.0980155 & 21.8991293 \\
\hline 0 & 15.8358311 & 14.7336530 & 18.1286215 \\
\hline 0 & 11.7923104 & 14.9193373 & 18.3531538 \\
\hline 0 & 14.0672492 & 18.4009500 & 18.2266683 \\
\hline 0 & 6.7975303 & 17.6599071 & 26.8824898 \\
\hline $\mathrm{H}$ & 8.8998856 & 18.7795129 & 23.2298321 \\
\hline $\mathrm{H}$ & 4.8061891 & 18.6746016 & 23.2682475 \\
\hline $\mathrm{H}$ & 18.2792167 & 15.7418899 & 17.6692471 \\
\hline $\mathrm{H}$ & 11.9708711 & 19.9328248 & 17.6328820 \\
\hline 0 & 11.4224458 & 12.2498095 & 17.3378363 \\
\hline 0 & 4.8998745 & 16.1252362 & 27.5405837 \\
\hline $\mathrm{H}$ & 11.5746291 & 19.7125671 & 22.4770948 \\
\hline 0 & 12.0302017 & 12.1030495 & 22.6731465 \\
\hline $\mathrm{H}$ & 18.2512219 & 16.1512631 & 22.4745698 \\
\hline $\mathrm{O}$ & 8.9664919 & 15.8995666 & 27.5099625 \\
\hline $\mathrm{H}$ & 16.1853245 & 12.3632675 & 17.4487130 \\
\hline $\mathrm{O}$ & 9.5969184 & 15.8009229 & 17.4517619 \\
\hline $\mathrm{H}$ & 15.9501752 & 19.8883754 & 17.5613258 \\
\hline 0 & 9.2355095 & 16.4346358 & 22.4744836 \\
\hline 0 & 6.9145868 & 14.9167515 & 16.9902759 \\
\hline $\mathrm{O}$ & 9.3968252 & 13.4956031 & 27.9433264 \\
\hline $\mathrm{O}$ & 13.8122925 & 18.8958676 & 21.9362183 \\
\hline 0 & 11.2417856 & 14.5185277 & 21.8986800 \\
\hline 0 & 16.3849920 & 14.6250246 & 22.0462660 \\
\hline $\mathrm{O}$ & 16.3981453 & 17.5318745 & 18.0332235 \\
\hline 0 & 13.9835313 & 13.0507926 & 18.2475327 \\
\hline 0 & 11.4529309 & 17.3623685 & 17.9645616 \\
\hline $\mathrm{H}$ & 4.4607919 & 18.4451146 & 26.9344678 \\
\hline $\mathrm{H}$ & 9.3269288 & 18.4386000 & 26.9278635 \\
\hline 0 & 6.9783166 & 17.2712306 & 23.0203372 \\
\hline $\mathrm{H}$ & 5.1899394 & 15.1189319 & 15.2152102 \\
\hline 0 & 12.0614809 & 19.1463377 & 20.1378044 \\
\hline 0 & 11.7194151 & 12.6078854 & 20.0896418 \\
\hline 0 & 17.4501890 & 15.9392972 & 20.1652312 \\
\hline 0 & 5.1375898 & 16.8310985 & 25.1624967 \\
\hline $\mathrm{H}$ & 8.8118575 & 15.0370677 & 29.8017510 \\
\hline 0 & 15.9462293 & 12.8679487 & 19.8418637 \\
\hline 0 & 15.8162707 & 19.1381114 & 19.8976336 \\
\hline 0 & 10.2060746 & 16.2086948 & 19.8368060 \\
\hline 0 & 8.6752409 & 16.9117331 & 24.8553778 \\
\hline $\mathrm{C}$ & 10.4705233 & 11.8217030 & 20.1263187 \\
\hline $\mathrm{H}$ & 10.3255876 & 11.4658471 & 21.1512792 \\
\hline $\mathrm{H}$ & 9.6299459 & 12.4586029 & 19.8197089 \\
\hline $\mathrm{H}$ & 10.5810870 & 10.9714678 & 19.4463186 \\
\hline $\mathrm{H}$ & 5.2136732 & 15.0748984 & 29.9299063 \\
\hline $\mathrm{H}$ & 16.2276127 & 19.7094379 & 22.4473285 \\
\hline \multicolumn{4}{|c|}{ Mg 29} \\
\hline \multicolumn{4}{|c|}{162} \\
\hline $\mathrm{H}$ & 8.7290007 & 8.9394733 & 15.2558258 \\
\hline Al & 5.4159787 & 9.3076235 & 16.6322975 \\
\hline $\mathrm{P}$ & 5.4096202 & 9.2610431 & 28.4472219 \\
\hline Al & 5.3036775 & 6.6790710 & 21.5572337 \\
\hline $\mathrm{P}$ & 5.3695627 & 6.7093377 & 18.4048682 \\
\hline Al & 3.1941879 & 8.0227644 & 26.5915321 \\
\hline $\mathrm{P}$ & 3.2948586 & 8.1150056 & 23.4712824 \\
\hline Al & 8.5395414 & 9.2200450 & 28.5090804 \\
\hline $\mathrm{P}$ & 8.5652899 & 9.3335762 & 16.6823609 \\
\hline Al & 8.5546387 & 6.7705683 & 18.5177338 \\
\hline $\mathrm{P}$ & 8.5084429 & 6.6792611 & 21.6677035 \\
\hline Al & 1.5559761 & 10.7466221 & 23.5113062 \\
\hline $\mathrm{P}$ & 1.5326326 & 10.7495214 & 26.6511332 \\
\hline 0 & 7.0988578 & 9.7198888 & 16.9671951 \\
\hline 0 & 5.0151254 & 10.7168019 & 28.1211648 \\
\hline $\mathrm{H}$ & 4.7858301 & 5.3084532 & 21.8224910 \\
\hline $\mathrm{H}$ & 9.0059961 & 5.3007244 & 21.9307589 \\
\hline
\end{tabular}




\begin{tabular}{|c|c|c|c|}
\hline 0 & 6.8689739 & 6.4070366 & 18.2350700 \\
\hline 0 & 2.0001039 & 9.2868118 & 26.7836358 \\
\hline $\mathrm{H}$ & 2.2255724 & 7.1086611 & 23.2242635 \\
\hline $\mathrm{H}$ & 0.2046368 & 10.1574187 & 23.3019214 \\
\hline $\mathrm{O}$ & 4.9519533 & 7.8824681 & 17.5130738 \\
\hline $\mathrm{O}$ & 4.5443614 & 8.2745897 & 27.6614482 \\
\hline 0 & 4.4958396 & 7.8656798 & 22.5504053 \\
\hline 0 & 2.3576910 & 11.6647808 & 27.5613332 \\
\hline 0 & 9.0116367 & 8.1790890 & 17.5853459 \\
\hline 0 & 1.8518126 & 12.1415541 & 22.5236870 \\
\hline 0 & 4.3788248 & 10.6292404 & 17.1082685 \\
\hline $\mathrm{O}$ & 6.8720867 & 9.0436102 & 28.0453889 \\
\hline 0 & 7.0025365 & 6.7141163 & 21.9189578 \\
\hline $\mathrm{H}$ & 9.3633409 & 5.5994021 & 18.0801367 \\
\hline $\mathrm{H}$ & 4.6101066 & 5.5046760 & 17.9699692 \\
\hline $\mathrm{H}$ & 0.1156055 & 10.8315726 & 27.1010471 \\
\hline $\mathrm{H}$ & 2.5679349 & 6.7250098 & 26.9667130 \\
\hline $\mathrm{O}$ & 2.7515416 & 9.5160920 & 23.1710883 \\
\hline $\mathrm{H}$ & 5.2510851 & 9.0305133 & 15.1786330 \\
\hline $\mathrm{O}$ & 5.0519120 & 7.0729341 & 19.8635205 \\
\hline 0 & 3.7707432 & 8.0169939 & 24.9365651 \\
\hline $\mathrm{H}$ & 8.7047003 & 8.9714122 & 29.9678555 \\
\hline $\mathrm{O}$ & 8.8275764 & 7.0968433 & 20.2149198 \\
\hline $\mathrm{O}$ & 1.6826337 & 11.2338483 & 25.1998083 \\
\hline $\mathrm{H}$ & 5.2287458 & 8.9918506 & 29.9004736 \\
\hline $\mathrm{H}$ & 3.4513262 & 11.9227324 & 15.1961515 \\
\hline Al & 3.2641449 & 16.0111995 & 21.5853134 \\
\hline $\mathrm{P}$ & 3.1763028 & 16.0647584 & 18.3987575 \\
\hline Al & 3.8126277 & 11.9504800 & 28.4616748 \\
\hline $\mathrm{P}$ & 3.7782486 & 11.9654858 & 16.6481896 \\
\hline Al & 1.6839026 & 13.2985574 & 18.5321694 \\
\hline $\mathrm{P}$ & 1.7342746 & 13.3397419 & 21.5702096 \\
\hline 0 & 4.8062400 & 13.0788844 & 16.9401193 \\
\hline $\mathrm{H}$ & 0.3606710 & 13.9124047 & 21.5213105 \\
\hline $\mathrm{H}$ & 2.2670050 & 17.0755351 & 21.8853506 \\
\hline 0 & 2.1241188 & 14.9572338 & 18.1594925 \\
\hline 0 & 4.4115461 & 15.8407974 & 17.5163814 \\
\hline $\mathrm{O}$ & 4.7289553 & 16.3085570 & 22.4752132 \\
\hline 0 & 2.4720073 & 12.2116458 & 17.4165718 \\
\hline 0 & 4.4351717 & 13.5124457 & 28.0142946 \\
\hline $\mathrm{O}$ & 2.7355589 & 14.4162252 & 22.0418908 \\
\hline $\mathrm{H}$ & 2.5820458 & 17.3755819 & 18.0170233 \\
\hline $\mathrm{H}$ & 0.2118026 & 13.1725050 & 18.3473643 \\
\hline $\mathrm{O}$ & 3.6186315 & 16.0711810 & 19.8680579 \\
\hline $\mathrm{H}$ & 3.4962415 & 11.9257231 & 29.9164626 \\
\hline 0 & 2.1498958 & 12.8520347 & 20.1494562 \\
\hline Al & 10.1239515 & 12.0591646 & 16.4552788 \\
\hline $\mathrm{P}$ & 10.0529558 & 12.0015675 & 28.3069944 \\
\hline Al & 12.2888898 & 10.6052454 & 26.6313371 \\
\hline $\mathrm{P}$ & 12.3686842 & 10.5320206 & 23.4352486 \\
\hline Al & 15.4309748 & 10.7466221 & 23.5113062 \\
\hline Al & 10.5969301 & 7.9955842 & 23.5663935 \\
\hline $\mathrm{P}$ & 10.6856919 & 7.9499434 & 26.6905187 \\
\hline$P$ & 15.4076313 & 10.7495214 & 26.6511332 \\
\hline 0 & 9.0416382 & 10.8558093 & 28.1166643 \\
\hline 0 & 11.7571296 & 8.9906179 & 27.0792784 \\
\hline $\mathrm{H}$ & 15.8592401 & 9.3364452 & 26.7791396 \\
\hline $\mathrm{H}$ & 11.5000315 & 6.8173443 & 23.4511581 \\
\hline 0 & 13.8358902 & 10.0511422 & 23.2641539 \\
\hline 0 & 11.2965877 & 11.7941951 & 27.4450368 \\
\hline 0 & 9.4940025 & 8.0430642 & 27.6546599 \\
\hline $\mathrm{H}$ & 16.2095557 & 11.6391176 & 27.5358119 \\
\hline 0 & 9.1672833 & 7.6951893 & 22.6107577 \\
\hline 0 & 15.7268113 & 12.1415541 & 22.5236870 \\
\hline 0 & 9.4693448 & 10.5396248 & 17.0042444 \\
\hline 0 & 13.9472451 & 10.8340833 & 27.1148138 \\
\hline $\mathrm{H}$ & 11.2704128 & 6.5862736 & 26.8155254 \\
\hline $\mathrm{H}$ & 16.4487572 & 9.6990745 & 23.2216794 \\
\hline 0 & 11.4313079 & 9.3978073 & 22.9619974 \\
\hline $\mathrm{H}$ & 10.4438708 & 12.0579856 & 15.0010537 \\
\hline 0 & 12.1002436 & 10.8175044 & 24.9275248 \\
\hline 0 & 15.5576324 & 11.2338483 & 25.1998083 \\
\hline $\mathrm{O}$ & 10.1753007 & 8.2040519 & 25.2590319 \\
\hline $\mathrm{H}$ & 10.4798811 & 12.0558305 & 29.7324456 \\
\hline $\mathrm{H}$ & 8.6883710 & 15.0350041 & 15.1162588 \\
\hline Al & 5.3470194 & 14.7088474 & 16.5825881 \\
\hline $\mathrm{P}$ & 5.3053200 & 14.7091597 & 28.4080648 \\
\hline $\mathrm{Al}$ & 12.2411768 & 18.6951724 & 21.5572337 \\
\hline $\mathrm{Mg}$ & 12.4133177 & 13.3720029 & 21.7084367 \\
\hline $\mathrm{Al}$ & 17.1391436 & 16.0111995 & 21.585313 \\
\hline
\end{tabular}




\begin{tabular}{|c|c|c|c|}
\hline $\mathrm{P}$ & 17.0513015 & 16.0647584 & 18.3987575 \\
\hline $\mathrm{P}$ & 12.3014492 & 13.2302867 & 18.3608231 \\
\hline $\mathrm{P}$ & 12.3070621 & 18.7254391 & 18.4048682 \\
\hline Al & 5.3930200 & 17.2087487 & 26.5478378 \\
\hline $\mathrm{P}$ & 5.3878817 & 17.2677093 & 23.4678549 \\
\hline Al & 8.4652855 & 14.7207517 & 28.3816337 \\
\hline $\mathrm{P}$ & 8.5102836 & 14.7507196 & 16.5669786 \\
\hline Al & 15.5589013 & 13.2985574 & 18.5321694 \\
\hline Al & 15.4921381 & 18.7866696 & 18.5177338 \\
\hline Al & 10.6780827 & 16.0427391 & 18.4448511 \\
\hline $\mathrm{P}$ & 10.5383349 & 16.0405240 & 21.5558834 \\
\hline$P$ & 15.4459423 & 18.6953625 & 21.6677035 \\
\hline$P$ & 15.6092733 & 13.3397419 & 21.5702096 \\
\hline Al & 8.5291107 & 17.4617034 & 23.4659576 \\
\hline $\mathrm{P}$ & 8.5397660 & 17.3163376 & 26.6240713 \\
\hline $\mathrm{O}$ & 8.9888529 & 13.3148331 & 16.8908891 \\
\hline 0 & 6.7762599 & 14.3657832 & 28.1022835 \\
\hline 0 & 11.6353567 & 17.0917117 & 21.8675534 \\
\hline 0 & 14.2058826 & 13.9248231 & 21.5202501 \\
\hline 0 & 15.9607597 & 17.2689928 & 21.9398865 \\
\hline 0 & 15.9991175 & 14.9572338 & 18.1594925 \\
\hline $\mathrm{O}$ & 11.8081135 & 14.6706925 & 18.3269735 \\
\hline 0 & 13.8064732 & 18.4231379 & 18.2350700 \\
\hline 0 & 7.0574220 & 17.6474733 & 26.9012519 \\
\hline $\mathrm{H}$ & 9.0362246 & 18.8454238 & 23.2531808 \\
\hline $\mathrm{H}$ & 4.7293828 & 18.6027348 & 23.4331190 \\
\hline $\mathrm{H}$ & 18.2499481 & 15.8474327 & 17.5425236 \\
\hline $\mathrm{H}$ & 11.9010794 & 19.8659080 & 17.5379025 \\
\hline $\mathrm{O}$ & 11.6532520 & 12.3600689 & 17.2895317 \\
\hline $\mathrm{O}$ & 4.8555749 & 15.9232349 & 27.5930617 \\
\hline $\mathrm{H}$ & 11.5520799 & 19.7073662 & 22.4044229 \\
\hline 0 & 12.0923512 & 11.7746881 & 22.6286257 \\
\hline $\mathrm{H}$ & 18.3929795 & 16.2657290 & 22.3470422 \\
\hline 0 & 8.9787714 & 16.1073729 & 27.4637411 \\
\hline $\mathrm{H}$ & 16.2311644 & 12.3714084 & 17.5805509 \\
\hline 0 & 9.3396766 & 15.7627106 & 17.3637445 \\
\hline $\mathrm{H}$ & 15.8810018 & 19.9851928 & 17.7243564 \\
\hline $\mathrm{O}$ & 9.3015296 & 16.3228898 & 22.4202524 \\
\hline 0 & 7.0416680 & 14.8724544 & 16.9844161 \\
\hline 0 & 9.3975079 & 13.3256505 & 27.9051165 \\
\hline 0 & 13.9400359 & 18.7302177 & 21.9189578 \\
\hline 0 & 11.0473933 & 14.6484262 & 21.8274012 \\
\hline 0 & 16.6105577 & 14.4162252 & 22.0418908 \\
\hline 0 & 16.4389536 & 17.4154873 & 18.0054022 \\
\hline 0 & 13.8082144 & 13.1486503 & 18.3123909 \\
\hline 0 & 11.5236488 & 17.4827761 & 17.9562502 \\
\hline $\mathrm{H}$ & 4.4962516 & 18.3744572 & 26.7803260 \\
\hline $\mathrm{H}$ & 9.3738441 & 18.4846764 & 27.0195694 \\
\hline $\mathrm{O}$ & 6.8465818 & 17.4490235 & 23.0582346 \\
\hline $\mathrm{H}$ & 5.1617641 & 14.9897112 & 15.1320997 \\
\hline 0 & 11.9894114 & 19.0890354 & 19.8635205 \\
\hline 0 & 11.8779947 & 12.5871155 & 19.7903125 \\
\hline 0 & 17.4936302 & 16.0711810 & 19.8680579 \\
\hline 0 & 5.2844834 & 16.6675690 & 24.8853626 \\
\hline $\mathrm{H}$ & 8.6594394 & 14.9951161 & 29.8322022 \\
\hline 0 & 16.0248945 & 12.8520347 & 20.1494562 \\
\hline 0 & 15.7650757 & 19.1129446 & 20.2149198 \\
\hline 0 & 10.0998653 & 16.1905655 & 20.0715735 \\
\hline 0 & 8.7531300 & 16.9835245 & 25.1386675 \\
\hline $\mathrm{C}$ & 10.5683837 & 11.9135905 & 19.9084270 \\
\hline $\mathrm{H}$ & 10.4918419 & 11.5964988 & 20.9532067 \\
\hline $\mathrm{H}$ & 9.7639823 & 12.6186360 & 19.6596627 \\
\hline $\mathrm{H}$ & 10.5578992 & 11.0385121 & 19.2502304 \\
\hline $\mathrm{H}$ & 5.1354746 & 15.0275794 & 29.8526693 \\
\hline $\mathrm{H}$ & 16.0851328 & 19.6809908 & 22.5826313 \\
\hline \multicolumn{4}{|c|}{ Al 29} \\
\hline \multicolumn{4}{|c|}{162} \\
\hline $\mathrm{H}$ & 8.6849178 & 8.8358768 & 15.1989728 \\
\hline $\mathrm{Si}$ & 5.3366841 & 9.2184471 & 16.6279099 \\
\hline $\mathrm{Si}$ & 5.3218547 & 9.1856497 & 28.5682353 \\
\hline $\mathrm{Si}$ & 5.2977434 & 6.7283413 & 21.5925954 \\
\hline $\mathrm{Si}$ & 5.3471536 & 6.7396174 & 18.5110550 \\
\hline $\mathrm{Si}$ & 3.2328614 & 7.9564146 & 26.6340373 \\
\hline $\mathrm{Si}$ & 3.2820269 & 8.0286101 & 23.5669232 \\
\hline $\mathrm{Si}$ & 8.4443633 & 9.1523794 & 28.5648288 \\
\hline $\mathrm{Si}$ & 8.4702891 & 9.2144232 & 16.6229664 \\
\hline $\mathrm{Si}$ & 8.5075863 & 6.7625625 & 18.5469804 \\
\hline $\mathrm{Si}$ & 8.4639102 & 6.7178989 & 21.6327033 \\
\hline $\mathrm{Si}$ & 1.6271905 & 10.6733091 & 23.5722991 \\
\hline
\end{tabular}

18.3987575

3608231

23.4678549

18.5321694

21.5558834

21.6677035

1. 5702096

6.6240713

16.8908891

28.1022835

.8675534

21.9398865

1594925

8.2350700

012519

3. 4331190

. 5425236

7.2895317

7.5930617

.4044229

22.3470422

27.4637411

17.5805509

22.4202524

.9844161

7.9051165

22.0418908

18.0054022

3123909

6. 7803260

27.0195694

23.0582346

19.7903125

.8680579

29.8322022

20.1494562

0.2149198

25.1386675

19.9084270

20.9532067

6596627

29.8526693

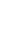

099

28.5682353

21.5925954

26.6340373

23.5669232

16.6229664

21.6327033

23.5722991 


\begin{tabular}{|c|c|c|c|}
\hline $\mathrm{Si}$ & 1.6363183 & 10.6870020 & 26.6407410 \\
\hline 0 & 6.9071002 & 9.6017434 & 16.8698791 \\
\hline 0 & 4.8911515 & 10.7272999 & 28.2615521 \\
\hline $\mathrm{H}$ & 4.8517989 & 5.3277369 & 21.8304221 \\
\hline $\mathrm{H}$ & 8.9078301 & 5.3171585 & 21.8734977 \\
\hline 0 & 6.9328535 & 6.4154962 & 18.3514941 \\
\hline 0 & 2.1395686 & 9.1478526 & 26.7986564 \\
\hline $\mathrm{H}$ & 2.2089960 & 7.0165183 & 23.3634645 \\
\hline $\mathrm{H}$ & 0.2579966 & 10.1051548 & 23.4321938 \\
\hline 0 & 4.9077530 & 7.9573069 & 17.5419204 \\
\hline 0 & 4.4653925 & 8.1554454 & 27.6646925 \\
\hline 0 & 4.5307474 & 7.7670240 & 22.5699906 \\
\hline 0 & 2.4660181 & 11.6667135 & 27.6256633 \\
\hline 0 & 8.9345596 & 8.0053723 & 17.5943789 \\
\hline 0 & 1.8763223 & 11.9078077 & 22.5632785 \\
\hline 0 & 4.4254700 & 10.4852806 & 17.0605385 \\
\hline 0 & 6.8814539 & 8.9999142 & 28.1909650 \\
\hline 0 & 6.8789243 & 6.8232484 & 21.9055614 \\
\hline $\mathrm{H}$ & 9.3064863 & 5.5736232 & 18.1404061 \\
\hline $\mathrm{H}$ & 4.5961440 & 5.5247966 & 18.0899663 \\
\hline $\mathrm{H}$ & 0.2084817 & 10.7445721 & 27.0591774 \\
\hline $\mathrm{H}$ & 2.5754678 & 6.6660870 & 26.9804599 \\
\hline 0 & 2.7015016 & 9.5041972 & 23.2360542 \\
\hline $\mathrm{H}$ & 5.0996129 & 8.8641636 & 15.2012351 \\
\hline 0 & 5.0016062 & 7.1563779 & 20.0443883 \\
\hline 0 & 3.8125859 & 7.9424932 & 25.1102257 \\
\hline $\mathrm{H}$ & 8.6817654 & 8.8320418 & 29.9994523 \\
\hline 0 & 8.8154623 & 7.1625835 & 20.0974348 \\
\hline O & 1.8348041 & 11.2002958 & 25.1076100 \\
\hline $\mathrm{H}$ & 5.0986638 & 8.8618412 & 30.0043601 \\
\hline $\mathrm{H}$ & 3.3625792 & 11.8489872 & 15.1703837 \\
\hline $\mathrm{Si}$ & 3.2320998 & 15.8046852 & 21.6273616 \\
\hline $\mathrm{Si}$ & 3.2010135 & 15.8344300 & 18.5051538 \\
\hline $\mathrm{Si}$ & 3.7758173 & 11.8821588 & 28.5446817 \\
\hline $\mathrm{Si}$ & 3.7691706 & 11.8941641 & 16.6020831 \\
\hline $\mathrm{Si}$ & 1.6968765 & 13.1179577 & 18.5484617 \\
\hline $\mathrm{Si}$ & 1.6610841 & 13.1516776 & 21.5449780 \\
\hline 0 & 4.8810701 & 13.0626238 & 16.8464310 \\
\hline $\mathrm{H}$ & 0.2516110 & 13.6228468 & 21.4527506 \\
\hline $\mathrm{H}$ & 2.2333584 & 16.8815287 & 21.8724014 \\
\hline 0 & 2.0764822 & 14.6768583 & 18.2495448 \\
\hline 0 & 4.5008353 & 15.6010156 & 17.5649722 \\
\hline 0 & 4.5542334 & 16.0418012 & 22.5304927 \\
\hline 0 & 2.4299623 & 12.1493503 & 17.4776361 \\
\hline 0 & 4.4082195 & 13.3204736 & 28.1697773 \\
\hline 0 & 2.6209543 & 14.3687685 & 22.0462891 \\
\hline H & 2.6153642 & 17.1531062 & 18.1374192 \\
\hline $\mathrm{H}$ & 0.2276808 & 12.9584677 & 18.3663971 \\
\hline 0 & 3.6763400 & 15.8220181 & 20.0581649 \\
\hline H & 3.3637263 & 11.8480365 & 29.9751142 \\
\hline $\mathrm{O}$ & 2.1479366 & 12.6745463 & 20.0440178 \\
\hline $\mathrm{Si}$ & 10.0189774 & 11.9123807 & 16.5250806 \\
\hline $\mathrm{Si}$ & 9.9801255 & 11.8792561 & 28.4684310 \\
\hline $\mathrm{Si}$ & 12.1494873 & 10.5854099 & 26.7026975 \\
\hline $\mathrm{Si}$ & 12.1981293 & 10.5526871 & 23.5756054 \\
\hline $\mathrm{Si}$ & 15.2521892 & 10.6733091 & 23.5722991 \\
\hline $\mathrm{Si}$ & 10.4885989 & 7.9901305 & 23.5880913 \\
\hline $\mathrm{Si}$ & 10.5412799 & 7.9516681 & 26.6743901 \\
\hline $\mathrm{Si}$ & 15.2613170 & 10.6870020 & 26.6407410 \\
\hline 0 & 8.8990579 & 10.6838279 & 28.2387278 \\
\hline 0 & 11.6694388 & 9.0659162 & 27.0528310 \\
\hline $\mathrm{H}$ & 15.7218779 & 9.2784147 & 26.7852609 \\
\hline $\mathrm{H}$ & 11.4305289 & 6.8444450 & 23.4565873 \\
\hline $\mathrm{O}$ & 13.7520751 & 10.0508287 & 23.4187971 \\
\hline 0 & 11.3056930 & 11.6615776 & 27.5757506 \\
\hline 0 & 9.2709163 & 8.0905509 & 27.6702599 \\
\hline $\mathrm{H}$ & 16.0248104 & 11.5885368 & 27.5470707 \\
\hline 0 & 9.1898537 & 7.7524573 & 22.6474949 \\
\hline 0 & 15.5013211 & 11.9078077 & 22.5632785 \\
\hline 0 & 9.3983056 & 10.4952523 & 17.0045644 \\
\hline 0 & 13.7091189 & 10.7495863 & 27.0956223 \\
\hline $\mathrm{H}$ & 11.1274358 & 6.5983988 & 26.8798263 \\
\hline $\mathrm{H}$ & 16.2378207 & 9.6007022 & 23.2638097 \\
\hline 0 & 11.2294032 & 9.3364669 & 23.0833639 \\
\hline $\mathrm{H}$ & 10.3989888 & 11.9031311 & 15.0854187 \\
\hline 0 & 11.8946864 & 10.8960361 & 25.1391718 \\
\hline 0 & 15.4598028 & 11.2002958 & 25.1076100 \\
\hline 0 & 10.0176703 & 8.1387700 & 25.1424276 \\
\hline $\mathrm{H}$ & 10.3919911 & 11.9003875 & 29.8991794 \\
\hline $\mathrm{H}$ & 8.7092674 & 14.9469021 & 15.1212662 \\
\hline
\end{tabular}




\begin{tabular}{|c|c|c|c|}
\hline $\mathrm{Si}$ & 5.3356551 & 14.6086883 & 16.5985326 \\
\hline $\mathrm{Si}$ & 5.3053575 & 14.6051724 & 28.5611809 \\
\hline $\mathrm{Si}$ & 12.1102428 & 18.5279363 & 21.5925954 \\
\hline Al & 12.1398487 & 13.1713237 & 21.6750973 \\
\hline $\mathrm{Si}$ & 16.8570985 & 15.8046852 & 21.6273616 \\
\hline $\mathrm{Si}$ & 16.8260122 & 15.8344300 & 18.5051538 \\
\hline $\mathrm{Si}$ & 12.1253139 & 13.0860887 & 18.4707307 \\
\hline $\mathrm{Si}$ & 12.1596530 & 18.5392124 & 18.5110550 \\
\hline $\mathrm{Si}$ & 5.3073762 & 17.0110311 & 26.6076119 \\
\hline $\mathrm{Si}$ & 5.2952974 & 17.0427345 & 23.5592716 \\
\hline $\mathrm{Si}$ & 8.4424818 & 14.5899888 & 28.4977438 \\
\hline $\mathrm{Si}$ & 8.4734939 & 14.6135044 & 16.5531801 \\
\hline $\mathrm{Si}$ & 15.3218752 & 13.1179577 & 18.5484617 \\
\hline $\mathrm{Si}$ & 15.3200856 & 18.5621576 & 18.5469804 \\
\hline $\mathrm{Si}$ & 10.5728174 & 15.8657199 & 18.4996704 \\
\hline $\mathrm{Si}$ & 10.4661677 & 15.8807609 & 21.5710423 \\
\hline $\mathrm{Si}$ & 15.2764095 & 18.5174940 & 21.6327033 \\
\hline $\mathrm{Si}$ & 15.2860828 & 13.1516776 & 21.5449780 \\
\hline $\mathrm{Si}$ & 8.4220501 & 17.1792833 & 23.5214233 \\
\hline $\mathrm{Si}$ & 8.4318830 & 17.0701562 & 26.6096072 \\
\hline 0 & 8.9272634 & 13.0717206 & 16.8556789 \\
\hline $\mathrm{O}$ & 6.8685986 & 14.2280253 & 28.3099750 \\
\hline $\mathrm{O}$ & 11.6246138 & 17.0026925 & 21.8515863 \\
\hline 0 & 13.7655962 & 13.6599572 & 21.4454866 \\
\hline $\mathrm{O}$ & 15.7619258 & 16.9855010 & 21.8960607 \\
\hline $\mathrm{O}$ & 15.7014810 & 14.6768583 & 18.2495448 \\
\hline $\mathrm{O}$ & 11.6482656 & 14.6251960 & 18.4184566 \\
\hline $\mathrm{O}$ & 13.7453529 & 18.2150912 & 18.3514941 \\
\hline 0 & 6.8617956 & 17.4325187 & 26.8622439 \\
\hline $\mathrm{H}$ & 8.8774714 & 18.5876639 & 23.3596324 \\
\hline $\mathrm{H}$ & 4.7479232 & 18.4234906 & 23.4543218 \\
\hline $\mathrm{H}$ & 18.0199153 & 15.6200359 & 17.6415850 \\
\hline $\mathrm{H}$ & 11.7550638 & 19.6604307 & 17.6186999 \\
\hline $\mathrm{O}$ & 11.3909532 & 12.1672146 & 17.3685084 \\
\hline $\mathrm{O}$ & 4.8517749 & 15.8389029 & 27.6242426 \\
\hline $\mathrm{H}$ & 11.4050067 & 19.4829823 & 22.4912889 \\
\hline $\mathrm{O}$ & 11.8882306 & 11.8393378 & 22.6991645 \\
\hline $\mathrm{H}$ & 18.0733603 & 16.0228138 & 22.4581731 \\
\hline $\mathrm{O}$ & 8.8786541 & 15.8299705 & 27.5556753 \\
\hline $\mathrm{H}$ & 15.9959526 & 12.2273167 & 17.5638304 \\
\hline 0 & 9.3507125 & 15.6200344 & 17.4657835 \\
\hline $\mathrm{H}$ & 15.7117916 & 19.7023130 & 17.6730625 \\
\hline 0 & 9.1743226 & 16.1944470 & 22.4955537 \\
\hline 0 & 6.9120571 & 14.7606802 & 16.9527572 \\
\hline $\mathrm{O}$ & 9.3116239 & 13.2946400 & 28.0619790 \\
\hline $\mathrm{O}$ & 13.6914236 & 18.6228434 & 21.9055614 \\
\hline 0 & 11.0060232 & 14.4212394 & 21.8944953 \\
\hline $\mathrm{O}$ & 16.2459530 & 14.3687685 & 22.0462891 \\
\hline $\mathrm{O}$ & 16.1886540 & 17.2695365 & 18.1049507 \\
\hline $\mathrm{O}$ & 13.7119723 & 12.9431931 & 18.3489605 \\
\hline $\mathrm{O}$ & 11.3419267 & 17.2164719 & 18.0525585 \\
\hline $\mathrm{H}$ & 4.4357554 & 18.1883519 & 26.8746580 \\
\hline $\mathrm{H}$ & 9.2594838 & 18.2516212 & 26.9788468 \\
\hline $\mathrm{O}$ & 6.8527606 & 17.1123069 & 23.1577827 \\
\hline $\mathrm{H}$ & 5.0904205 & 14.9927598 & 15.1809750 \\
\hline $\mathrm{O}$ & 11.8141056 & 18.9559730 & 20.0443883 \\
\hline 0 & 11.6405327 & 12.4392674 & 19.9774743 \\
\hline $\mathrm{O}$ & 17.3013387 & 15.8220181 & 20.0581649 \\
\hline 0 & 5.1106578 & 16.4805569 & 25.0796877 \\
\hline $\mathrm{H}$ & 8.7057300 & 14.9436800 & 29.9199687 \\
\hline $\mathrm{O}$ & 15.7729354 & 12.6745463 & 20.0440178 \\
\hline 0 & 15.6279616 & 18.9621785 & 20.0974348 \\
\hline 0 & 9.9834899 & 15.9933745 & 20.0016774 \\
\hline 0 & 8.6800040 & 16.6696644 & 25.0515058 \\
\hline C & 10.3992141 & 11.6351189 & 20.0365890 \\
\hline $\mathrm{H}$ & 10.2863738 & 11.3045789 & 21.0736947 \\
\hline $\mathrm{H}$ & 9.5464346 & 12.2586922 & 19.7366173 \\
\hline $\mathrm{H}$ & 10.5079566 & 10.7714959 & 19.3733249 \\
\hline $\mathrm{H}$ & 5.0880986 & 14.9920114 & 29.9825446 \\
\hline $\mathrm{H}$ & 15.9433063 & 19.4679035 & 22.5649538 \\
\hline \multicolumn{4}{|c|}{ Ge 29} \\
\hline \multicolumn{4}{|c|}{162} \\
\hline $\mathrm{H}$ & 8.6567946 & 9.0043713 & 15.1421752 \\
\hline$P$ & 5.3836629 & 9.3354500 & 16.6744085 \\
\hline $\mathrm{Al}$ & 5.3432986 & 9.2965646 & 28.4882235 \\
\hline $\mathrm{P}$ & 5.3796244 & 6.7484295 & 21.5918362 \\
\hline Al & 5.4466543 & 6.7463575 & 18.4524634 \\
\hline $\mathrm{P}$ & 3.2094305 & 7.9440511 & 26.631618 \\
\hline Al & 3.2768344 & 8.0863677 & 23.5322977 \\
\hline
\end{tabular}




\begin{tabular}{|c|c|c|c|}
\hline $\mathrm{P}$ & 8.4746681 & 9.2044216 & 28.4067683 \\
\hline Al & 8.5300658 & 9.2924361 & 16.5975373 \\
\hline $\mathrm{P}$ & 8.6394270 & 6.7450800 & 18.4399426 \\
\hline Al & 8.5733717 & 6.7206681 & 21.5920145 \\
\hline $\mathrm{P}$ & 1.6149239 & 10.7505106 & 23.4687316 \\
\hline Al & 1.5941625 & 10.7061028 & 26.6173139 \\
\hline 0 & 6.8599718 & 9.6930234 & 16.9554556 \\
\hline 0 & 4.8760332 & 10.9441544 & 28.1079980 \\
\hline $\mathrm{H}$ & 4.9311983 & 5.3504317 & 21.8401037 \\
\hline $\mathrm{H}$ & 9.0538514 & 5.3390368 & 21.8701418 \\
\hline 0 & 7.1510611 & 6.4095678 & 18.2385619 \\
\hline 0 & 2.1512113 & 9.0541760 & 26.7673612 \\
\hline $\mathrm{H}$ & 2.1619505 & 7.1208097 & 23.3277196 \\
\hline $\mathrm{H}$ & 0.2837209 & 10.1484046 & 23.1815250 \\
\hline 0 & 4.9630146 & 8.1077660 & 17.4850107 \\
\hline 0 & 4.3466471 & 8.1553359 & 27.6362433 \\
\hline $\mathrm{O}$ & 4.6268596 & 7.7381765 & 22.4889628 \\
\hline 0 & 2.5521411 & 11.7860669 & 27.5897443 \\
\hline 0 & 9.0485308 & 7.9317935 & 17.5561185 \\
\hline 0 & 1.8568168 & 11.9629810 & 22.5677021 \\
\hline 0 & 4.5036405 & 10.5160684 & 17.1005045 \\
\hline 0 & 7.0005624 & 9.0580414 & 28.0236306 \\
\hline 0 & 6.8720013 & 6.8449901 & 21.9139976 \\
\hline $\mathrm{H}$ & 9.4502479 & 5.5647366 & 18.0319236 \\
\hline $\mathrm{H}$ & 4.6900105 & 5.5436643 & 18.0073347 \\
\hline $\mathrm{H}$ & 0.2003277 & 10.7465376 & 27.1395308 \\
\hline $\mathrm{H}$ & 2.5708885 & 6.6359838 & 26.9452179 \\
\hline $\mathrm{O}$ & 2.7054890 & 9.7041880 & 23.1929329 \\
\hline $\mathrm{H}$ & 5.1863020 & 9.0296955 & 15.2305652 \\
\hline 0 & 5.1171828 & 7.1372999 & 20.1235337 \\
\hline 0 & 3.7982260 & 7.9510741 & 25.2068352 \\
\hline $\mathrm{H}$ & 8.6718507 & 8.9632771 & 29.8628208 \\
\hline 0 & 8.9118510 & 7.1158129 & 19.9111589 \\
\hline 0 & 1.6778384 & 11.2137803 & 24.9405631 \\
\hline $\mathrm{H}$ & 5.2041085 & 9.0607459 & 29.9518274 \\
\hline $\mathrm{H}$ & 3.5104043 & 12.0123175 & 15.1368177 \\
\hline $\mathrm{P}$ & 3.2047635 & 15.9720120 & 21.6360187 \\
\hline Al & 3.1839237 & 15.9832650 & 18.4541156 \\
\hline $\mathrm{P}$ & 3.8206417 & 12.0279688 & 28.4100883 \\
\hline Al & 3.8333664 & 12.0428189 & 16.5900506 \\
\hline$P$ & 1.6281469 & 13.2619398 & 18.4381767 \\
\hline Al & 1.5684016 & 13.3164964 & 21.5056437 \\
\hline 0 & 5.0323264 & 13.2847902 & 16.9201471 \\
\hline $\mathrm{H}$ & 0.1691398 & 13.8161781 & 21.4081502 \\
\hline $\mathrm{H}$ & 2.2369968 & 17.0701178 & 21.9093537 \\
\hline 0 & 1.9776087 & 14.7381565 & 18.1448735 \\
\hline 0 & 4.6328525 & 15.7038456 & 17.5181888 \\
\hline 0 & 4.4829328 & 16.1618369 & 22.4608501 \\
\hline 0 & 2.3433067 & 12.3417948 & 17.4421202 \\
\hline 0 & 4.3868494 & 13.3959301 & 28.0163237 \\
\hline 0 & 2.5850782 & 14.6346569 & 22.0434181 \\
\hline $\mathrm{H}$ & 2.6321387 & 17.3157185 & 18.0836811 \\
\hline $\mathrm{H}$ & 0.1628678 & 13.0712502 & 18.2545599 \\
\hline 0 & 3.5962950 & 15.9687497 & 20.1483763 \\
\hline $\mathrm{H}$ & 3.4661581 & 12.0077102 & 29.8561352 \\
\hline 0 & 2.0545021 & 12.8688886 & 19.8625389 \\
\hline$P$ & 10.1295650 & 11.9808412 & 16.5227451 \\
\hline Al & 10.0690843 & 11.9296184 & 28.3397157 \\
\hline$P$ & 12.3800705 & 10.5947105 & 26.7696097 \\
\hline Al & 12.4394083 & 10.5689756 & 23.5320028 \\
\hline $\mathrm{P}$ & 15.4899226 & 10.7505106 & 23.4687316 \\
\hline $\mathrm{P}$ & 10.6094984 & 8.0745027 & 23.4998691 \\
\hline Al & 10.6828400 & 8.0173343 & 26.6267363 \\
\hline Al & 15.4691612 & 10.7061028 & 26.6173139 \\
\hline 0 & 8.9386630 & 10.6266451 & 28.0285793 \\
\hline 0 & 11.8644795 & 9.1970974 & 27.1764126 \\
\hline $\mathrm{H}$ & 15.9431936 & 9.3003610 & 26.7449998 \\
\hline $\mathrm{H}$ & 11.4775369 & 6.8679414 & 23.4113270 \\
\hline 0 & 14.1089849 & 10.1259095 & 23.1707948 \\
\hline 0 & 11.5429454 & 11.6903428 & 27.4481486 \\
\hline 0 & 9.2672971 & 8.1444050 & 27.6359348 \\
\hline $\mathrm{H}$ & 16.2886689 & 11.6299637 & 27.4491845 \\
\hline 0 & 9.3553878 & 7.8861201 & 22.6349912 \\
\hline 0 & 15.7318156 & 11.9629810 & 22.5677021 \\
\hline 0 & 9.5693156 & 10.6387376 & 17.0186472 \\
\hline 0 & 13.8342648 & 10.7535308 & 27.2298474 \\
\hline $\mathrm{H}$ & 11.2653750 & 6.6560470 & 26.7838046 \\
\hline $\mathrm{H}$ & 16.5469176 & 9.7363962 & 23.2014226 \\
\hline $\mathrm{O}$ & 11.3826259 & 9.2878883 & 22.9663577 \\
\hline $\mathrm{H}$ & 10.4389055 & 11.9289702 & 15.0671565 \\
\hline
\end{tabular}




\begin{tabular}{|c|c|c|c|}
\hline 0 & 12.2763150 & 10.7527192 & 25.2555121 \\
\hline 0 & 15.5528371 & 11.2137803 & 24.9405631 \\
\hline $\mathrm{O}$ & 10.1925227 & 8.3072090 & 24.9654700 \\
\hline $\mathrm{H}$ & 10.3909719 & 11.9279175 & 29.7935059 \\
\hline $\mathrm{H}$ & 8.7690209 & 15.0049349 & 15.0332430 \\
\hline $\mathrm{P}$ & 5.4465640 & 14.7451122 & 16.6422610 \\
\hline Al & 5.3867876 & 14.7434194 & 28.4790031 \\
\hline $\mathrm{P}$ & 12.3171238 & 18.7645309 & 21.5918362 \\
\hline $\mathrm{Ge}$ & 12.1879449 & 13.3507213 & 21.7256693 \\
\hline $\mathrm{P}$ & 17.0797622 & 15.9720120 & 21.6360187 \\
\hline Al & 17.0589224 & 15.9832650 & 18.4541156 \\
\hline Al & 12.2848963 & 13.2440950 & 18.4304368 \\
\hline Al & 12.3841537 & 18.7624589 & 18.4524634 \\
\hline $\mathrm{P}$ & 5.3351961 & 17.2414892 & 26.6031891 \\
\hline Al & 5.2826643 & 17.2742745 & 23.5254750 \\
\hline $\mathrm{P}$ & 8.5403335 & 14.6854165 & 28.3212639 \\
\hline Al & 8.5994355 & 14.7312179 & 16.4870106 \\
\hline $\mathrm{P}$ & 15.5031456 & 13.2619398 & 18.4381767 \\
\hline $\mathrm{P}$ & 15.5769264 & 18.7611814 & 18.4399426 \\
\hline $\mathrm{P}$ & 10.7738870 & 16.0736423 & 18.3663769 \\
\hline Al & 10.5751225 & 16.1621739 & 21.4979288 \\
\hline Al & 15.5108710 & 18.7367695 & 21.5920145 \\
\hline Al & 15.4434004 & 13.3164964 & 21.5056437 \\
\hline $\mathrm{P}$ & 8.4233729 & 17.5038727 & 23.3806972 \\
\hline Al & 8.4785327 & 17.2686667 & 26.5062121 \\
\hline 0 & 9.0923199 & 13.0776405 & 16.8338419 \\
\hline $\mathrm{O}$ & 7.0529197 & 14.3380388 & 28.1223632 \\
\hline $\mathrm{O}$ & 11.8540317 & 17.3208111 & 21.8482233 \\
\hline 0 & 13.8087706 & 13.9002288 & 21.3917510 \\
\hline 0 & 16.0764400 & 17.1104619 & 21.9193960 \\
\hline 0 & 15.8526074 & 14.7381565 & 18.1448735 \\
\hline 0 & 11.7917706 & 14.9085541 & 18.3412080 \\
\hline $\mathrm{O}$ & 14.0885604 & 18.4256692 & 18.2385619 \\
\hline 0 & 6.7991116 & 17.6625244 & 26.8533141 \\
\hline $\mathrm{H}$ & 8.8861128 & 18.9165222 & 23.2945938 \\
\hline $\mathrm{H}$ & 4.6665377 & 18.6261237 & 23.4254144 \\
\hline $\mathrm{H}$ & 18.2935836 & 15.7451661 & 17.6565937 \\
\hline $\mathrm{H}$ & 11.9699866 & 19.9283073 & 17.6239808 \\
\hline 0 & 11.4452984 & 12.2561407 & 17.2697167 \\
\hline $\mathrm{O}$ & 4.9028120 & 16.1579797 & 27.5946531 \\
\hline $\mathrm{H}$ & 11.5861205 & 19.7256655 & 22.4630280 \\
\hline 0 & 11.9392147 & 12.0433348 & 22.8271240 \\
\hline $\mathrm{H}$ & 18.3212433 & 16.1563882 & 22.4371745 \\
\hline 0 & 8.9490303 & 15.8687374 & 27.4389646 \\
\hline $\mathrm{H}$ & 16.1977553 & 12.3682352 & 17.4707419 \\
\hline 0 & 9.6306984 & 15.8125330 & 17.3796108 \\
\hline $\mathrm{H}$ & 15.9737219 & 19.9121916 & 17.5827091 \\
\hline 0 & 9.1388608 & 16.6335300 & 22.3549668 \\
\hline 0 & 6.9347937 & 14.9168748 & 16.9831806 \\
\hline 0 & 9.3796576 & 13.4701485 & 27.9102447 \\
\hline 0 & 13.8095007 & 18.8610914 & 21.9139976 \\
\hline 0 & 10.9891581 & 14.5720697 & 21.9916447 \\
\hline 0 & 16.4600769 & 14.6346569 & 22.0434181 \\
\hline 0 & 16.4119212 & 17.5456470 & 18.0197589 \\
\hline 0 & 13.9900218 & 13.0650238 & 18.2485644 \\
\hline 0 & 11.4971975 & 17.3526328 & 17.9306727 \\
\hline $\mathrm{H}$ & 4.4461825 & 18.4189095 & 26.8043283 \\
\hline $\mathrm{H}$ & 9.3430741 & 18.4188729 & 26.8892452 \\
\hline 0 & 6.9334271 & 17.4683376 & 23.0467432 \\
\hline $\mathrm{H}$ & 5.2053334 & 15.0820142 & 15.2120773 \\
\hline 0 & 12.0546821 & 19.1534013 & 20.1235337 \\
\hline 0 & 11.7094774 & 12.5677569 & 20.0287536 \\
\hline 0 & 17.4712938 & 15.9687497 & 20.1483763 \\
\hline 0 & 5.1805037 & 16.6864142 & 25.1737820 \\
\hline $\mathrm{H}$ & 8.7898437 & 15.0402380 & 29.7456821 \\
\hline 0 & 15.9295008 & 12.8688886 & 19.8625389 \\
\hline 0 & 15.8493504 & 19.1319143 & 19.9111589 \\
\hline 0 & 10.1922222 & 16.2304364 & 19.7762017 \\
\hline 0 & 8.6769299 & 16.9422643 & 24.7962964 \\
\hline C & 10.4954557 & 11.7379628 & 20.0836431 \\
\hline $\mathrm{H}$ & 10.3761613 & 11.3746232 & 21.1104981 \\
\hline $\mathrm{H}$ & 9.6244210 & 12.3394371 & 19.7900317 \\
\hline $\mathrm{H}$ & 10.6250042 & 10.8910466 & 19.4021120 \\
\hline $\mathrm{H}$ & 5.2255940 & 15.0410535 & 29.9290208 \\
\hline $\mathrm{H}$ & 16.1767849 & 19.7291922 & 22.4801454 \\
\hline \multicolumn{4}{|c|}{ Ga 29} \\
\hline $\mathrm{H}$ & 8.6576707 & 8.8245326 & 15.2158320 \\
\hline $\mathrm{Si}$ & 5.3491541 & 9.2291920 & 16.6537177 \\
\hline
\end{tabular}




\begin{tabular}{|c|c|c|c|}
\hline $\mathrm{Si}$ & 5.3260108 & 9.1816539 & 28.5905373 \\
\hline $\mathrm{Si}$ & 5.2967156 & 6.7012986 & 21.6078103 \\
\hline $\mathrm{Si}$ & 5.3519999 & 6.7411013 & 18.5249507 \\
\hline $\mathrm{Si}$ & 3.2281308 & 7.9570099 & 26.6411445 \\
\hline $\mathrm{Si}$ & 3.3251996 & 8.0692300 & 23.5868719 \\
\hline $\mathrm{Si}$ & 8.4351836 & 9.1183137 & 28.5748947 \\
\hline $\mathrm{Si}$ & 8.4718228 & 9.2215884 & 16.6388316 \\
\hline $\mathrm{Si}$ & 8.5092785 & 6.7654011 & 18.5592275 \\
\hline $\mathrm{Si}$ & 8.4677765 & 6.7026211 & 21.6512444 \\
\hline $\mathrm{Si}$ & 1.6383376 & 10.6816894 & 23.5763350 \\
\hline $\mathrm{Si}$ & 1.6186015 & 10.6689632 & 26.6581447 \\
\hline 0 & 6.9151180 & 9.6230020 & 16.9072047 \\
\hline 0 & 4.9220229 & 10.7344395 & 28.2971603 \\
\hline $\mathrm{H}$ & 4.8111554 & 5.3119517 & 21.8337905 \\
\hline $\mathrm{H}$ & 8.9716371 & 5.3241302 & 21.9022578 \\
\hline $\mathrm{O}$ & 6.9362069 & 6.4103844 & 18.3550403 \\
\hline $\mathrm{O}$ & 2.1001794 & 9.1195567 & 26.7861299 \\
\hline $\mathrm{H}$ & 2.2327720 & 7.0764265 & 23.3917731 \\
\hline $\mathrm{H}$ & 0.2907360 & 10.0788822 & 23.3821346 \\
\hline $\mathrm{O}$ & 4.9166726 & 7.9710014 & 17.5699557 \\
\hline 0 & 4.4249956 & 8.1715531 & 27.7087937 \\
\hline 0 & 4.5655211 & 7.7640385 & 22.5904883 \\
\hline $\mathrm{O}$ & 2.4848244 & 11.6240318 & 27.6352970 \\
\hline $\mathrm{O}$ & 8.9362607 & 8.0188954 & 17.6194346 \\
\hline 0 & 1.8479254 & 11.9452545 & 22.5920916 \\
\hline $\mathrm{O}$ & 4.4268150 & 10.4923295 & 17.0711511 \\
\hline $\mathrm{O}$ & 6.8751123 & 8.9581808 & 28.1827079 \\
\hline $\mathrm{O}$ & 6.8792591 & 6.7321735 & 21.9193305 \\
\hline $\mathrm{H}$ & 9.3164451 & 5.5840041 & 18.1470333 \\
\hline $\mathrm{H}$ & 4.5883329 & 5.5360474 & 18.0985959 \\
\hline $\mathrm{H}$ & 0.2008079 & 10.7436276 & 27.1069288 \\
\hline $\mathrm{H}$ & 2.5921929 & 6.6480263 & 26.9562085 \\
\hline $\mathrm{O}$ & 2.7654220 & 9.5561409 & 23.2511181 \\
\hline $\mathrm{H}$ & 5.1272433 & 8.8648262 & 15.2271435 \\
\hline $\mathrm{O}$ & 5.0129564 & 7.1475607 & 20.0630753 \\
\hline $\mathrm{O}$ & 3.8511530 & 7.9822653 & 25.1328023 \\
\hline $\mathrm{H}$ & 8.6537721 & 8.8171068 & 30.0166347 \\
\hline $\mathrm{O}$ & 8.8058731 & 7.1536560 & 20.1150756 \\
\hline $\mathrm{O}$ & 1.7895627 & 11.1920976 & 25.1237895 \\
\hline $\mathrm{H}$ & 5.1255280 & 8.8612025 & 30.0307589 \\
\hline $\mathrm{H}$ & 3.3739390 & 11.8678386 & 15.1828230 \\
\hline $\mathrm{Si}$ & 3.2905524 & 15.8100308 & 21.6284700 \\
\hline $\mathrm{Si}$ & 3.2231734 & 15.8482174 & 18.5081117 \\
\hline $\mathrm{Si}$ & 3.7877240 & 11.8784593 & 28.5543078 \\
\hline $\mathrm{Si}$ & 3.7764166 & 11.9043208 & 16.6159320 \\
\hline $\mathrm{Si}$ & 1.6975456 & 13.1297909 & 18.5580941 \\
\hline $\mathrm{Si}$ & 1.6756659 & 13.1885253 & 21.5668381 \\
\hline 0 & 4.8899881 & 13.0691568 & 16.8706009 \\
\hline $\mathrm{H}$ & 0.3048762 & 13.7662718 & 21.5015306 \\
\hline $\mathrm{H}$ & 2.3018958 & 16.8898961 & 21.8997073 \\
\hline 0 & 2.1007800 & 14.6848083 & 18.2720844 \\
\hline $\mathrm{O}$ & 4.5183155 & 15.6164788 & 17.5601208 \\
\hline $\mathrm{O}$ & 4.6270649 & 16.0204930 & 22.5173643 \\
\hline 0 & 2.4395224 & 12.1583078 & 17.4956087 \\
\hline $\mathrm{O}$ & 4.3987697 & 13.3203471 & 28.1513623 \\
\hline 0 & 2.6935786 & 14.3657183 & 22.0401230 \\
\hline $\mathrm{H}$ & 2.6276286 & 17.1632451 & 18.1432157 \\
\hline $\mathrm{H}$ & 0.2302755 & 12.9810512 & 18.3528738 \\
\hline $\mathrm{O}$ & 3.7145236 & 15.8445832 & 20.0555372 \\
\hline $\mathrm{H}$ & 3.3754791 & 11.8656851 & 29.9850459 \\
\hline $\mathrm{O}$ & 2.1091016 & 12.6747689 & 20.0633051 \\
\hline $\mathrm{Si}$ & 10.0332005 & 11.9130680 & 16.4866176 \\
\hline $\mathrm{Si}$ & 9.9566491 & 11.8559172 & 28.4334563 \\
\hline $\mathrm{Si}$ & 12.1539124 & 10.5622458 & 26.7042083 \\
\hline $\mathrm{Si}$ & 12.2263341 & 10.4909418 & 23.5568651 \\
\hline $\mathrm{Si}$ & 15.2633364 & 10.6816894 & 23.5763350 \\
\hline $\mathrm{Si}$ & 10.4310934 & 7.9844594 & 23.6230942 \\
\hline $\mathrm{Si}$ & 10.5283335 & 7.9489516 & 26.6771469 \\
\hline $\mathrm{Si}$ & 15.2436002 & 10.6689632 & 26.6581447 \\
\hline 0 & 8.8872614 & 10.6459463 & 28.2263648 \\
\hline $\mathrm{O}$ & 11.6675331 & 9.0480837 & 27.0730869 \\
\hline $\mathrm{H}$ & 15.6841791 & 9.2514650 & 26.7752339 \\
\hline $\mathrm{H}$ & 11.2911446 & 6.7710823 & 23.5513401 \\
\hline $\mathrm{O}$ & 13.7863611 & 10.0210110 & 23.3634908 \\
\hline $\mathrm{O}$ & 11.2688103 & 11.6530905 & 27.5166858 \\
\hline 0 & 9.2850951 & 8.0444506 & 27.7138173 \\
\hline $\mathrm{H}$ & 16.0408520 & 11.5479866 & 27.5574934 \\
\hline $\mathrm{O}$ & 9.1384054 & 7.7804915 & 22.6637176 \\
\hline $\mathrm{O}$ & 15.4729241 & 11.9452545 & 22.5920916 \\
\hline $\mathrm{O}$ & 9.4166606 & 10.4995393 & 16.9857763 \\
\hline
\end{tabular}




\begin{tabular}{|c|c|c|}
\hline 13.7003876 & 10.7502324 & 27.1466285 \\
\hline 11.1237151 & 6.5894500 & 26.7971326 \\
\hline 16.2956391 & 9.6507934 & 23.2784671 \\
\hline 11.2708396 & 9.2575663 & 23.0873502 \\
\hline 10.4001264 & 11.8875608 & 15.0437610 \\
\hline 11.9622837 & 10.8328273 & 25.1263046 \\
\hline 15.4145615 & 11.1920976 & 25.1237895 \\
\hline 9.9598646 & 8.2133309 & 25.1695401 \\
\hline 10.3902036 & 11.8829168 & 29.8576831 \\
\hline 8.7197550 & 14.9514708 & 15.0840011 \\
\hline 5.3416430 & 14.6114928 & 16.5955241 \\
\hline 5.2877328 & 14.6088644 & 28.5559429 \\
\hline 12.1092150 & 18.5008937 & 21.6078103 \\
\hline 12.1413218 & 13.2272031 & 21.7365425 \\
\hline 16.9155511 & 15.8100308 & 21.6284700 \\
\hline 16.8481722 & 15.8482174 & 18.5081117 \\
\hline 12.1267823 & 13.0923273 & 18.4347540 \\
\hline 12.1644993 & 18.5406963 & 18.5249507 \\
\hline 5.3162073 & 16.9942346 & 26.5975235 \\
\hline 5.2859712 & 17.0361365 & 23.5861415 \\
\hline 8.4332983 & 14.5820383 & 28.4655137 \\
\hline 8.4857155 & 14.6176078 & 16.5160911 \\
\hline 15.3225444 & 13.1297909 & 18.5580941 \\
\hline 15.3217778 & 18.5649961 & 18.5592275 \\
\hline 10.5741930 & 15.8630841 & 18.4771691 \\
\hline 10.3980720 & 15.8913825 & 21.5666712 \\
\hline 15.2802758 & 18.5022162 & 21.6512444 \\
\hline 15.3006647 & 13.1885253 & 21.5668381 \\
\hline 8.3972149 & 17.2575154 & 23.5076183 \\
\hline 8.4330402 & 17.0613431 & 26.5837950 \\
\hline 8.9416785 & 13.0751927 & 16.8122752 \\
\hline 6.8520425 & 14.2477300 & 28.2957326 \\
\hline 11.5799859 & 16.9865956 & 21.8541141 \\
\hline 13.8129262 & 13.8155622 & 21.4959589 \\
\hline 15.8315329 & 16.9940553 & 21.9258697 \\
\hline 15.7257788 & 14.6848083 & 18.2720844 \\
\hline 11.6580317 & 14.6352170 & 18.3798582 \\
\hline 13.7487063 & 18.2099794 & 18.3550403 \\
\hline 6.8668744 & 17.4254321 & 26.8717626 \\
\hline 8.8978652 & 18.6544661 & 23.3851501 \\
\hline 4.6062607 & 18.3604089 & 23.5484994 \\
\hline 18.0373646 & 15.6354363 & 17.6376715 \\
\hline 11.7635930 & 19.6733491 & 17.6454665 \\
\hline 11.4140179 & 12.1825653 & 17.3090027 \\
\hline 4.8290842 & 15.8585960 & 27.6416327 \\
\hline 11.4378278 & 19.4767078 & 22.5101111 \\
\hline 11.8357443 & 11.7646573 & 22.6912556 \\
\hline 18.1448560 & 16.0036109 & 22.4460621 \\
\hline 8.8855763 & 15.8023695 & 27.5033588 \\
\hline 16.0046797 & 12.2366592 & 17.5812995 \\
\hline 9.3608823 & 15.6264818 & 17.4297977 \\
\hline 15.7133107 & 19.7144213 & 17.6974592 \\
\hline 9.0814412 & 16.2874542 & 22.4215630 \\
\hline 6.9243512 & 14.7654800 & 16.9187276 \\
\hline 9.2685589 & 13.2634657 & 28.0344939 \\
\hline 13.6917584 & 18.5317685 & 21.9193305 \\
\hline 10.8459558 & 14.4194945 & 21.9974393 \\
\hline 16.3185773 & 14.3657183 & 22.0401230 \\
\hline 16.1998016 & 17.2798902 & 18.1108489 \\
\hline 13.7174957 & 12.9670844 & 18.3336034 \\
\hline 11.3332919 & 17.2290649 & 18.0608881 \\
\hline 4.4339287 & 18.1779939 & 26.7909632 \\
\hline 9.2762358 & 18.2321104 & 26.9518245 \\
\hline 6.8217690 & 17.2826068 & 23.1768576 \\
\hline 5.0701516 & 14.9777325 & 15.1780328 \\
\hline 11.8254558 & 18.9471558 & 20.0630753 \\
\hline 11.6331546 & 12.4390958 & 19.9218226 \\
\hline 17.3395223 & 15.8445832 & 20.0555372 \\
\hline 5.1691218 & 16.4014673 & 25.0851211 \\
\hline 8.7144011 & 14.9472811 & 29.8813878 \\
\hline 15.7341004 & 12.6747689 & 20.0633051 \\
\hline 15.6183725 & 18.9532510 & 20.1150756 \\
\hline 9.9794453 & 15.9537283 & 19.9794889 \\
\hline 8.6605034 & 16.6840326 & 25.0149728 \\
\hline 10.4135760 & 11.6129422 & 19.9911188 \\
\hline 10.3150626 & 11.2786206 & 21.0282343 \\
\hline 9.5431694 & 12.2162971 & 19.6992892 \\
\hline 10.5320285 & 10.7508131 & 19.3270303 \\
\hline 5.0658211 & 14.9771487 & 29.9815103 \\
\hline 15.8952413 & 19.4906212 & 22.5796804 \\
\hline
\end{tabular}




\begin{tabular}{|c|c|c|}
\hline 9.2523045 & 8.0991153 & 27.6664464 \\
\hline 16.2807531 & 11.6065629 & 27.4804434 \\
\hline 9.3111032 & 7.9167490 & 22.6601622 \\
\hline 15.7999460 & 11.9785158 & 22.5998087 \\
\hline 9.5874807 & 10.6531274 & 16.9910161 \\
\hline 13.8242031 & 10.7293387 & 27.2889664 \\
\hline 11.2530915 & 6.6468816 & 26.7300129 \\
\hline 16.5936888 & 9.7674491 & 23.2771983 \\
\hline 11.4321341 & 9.1926815 & 22.9806002 \\
\hline 10.4032462 & 11.9204822 & 15.0038204 \\
\hline 12.3399685 & 10.6445783 & 25.2713308 \\
\hline 15.5138924 & 11.2406836 & 24.9702639 \\
\hline 10.1439337 & 8.3763012 & 24.9968892 \\
\hline 10.3554328 & 11.9176987 & 29.7356638 \\
\hline 8.7834324 & 14.9963322 & 14.9975534 \\
\hline 5.4539976 & 14.7487509 & 16.6419693 \\
\hline 5.3684395 & 14.7439211 & 28.4775353 \\
\hline 12.3111412 & 18.7846933 & 21.6150163 \\
\hline 12.1356479 & 13.3174229 & 21.7014139 \\
\hline 17.1390598 & 15.9853840 & 21.6332933 \\
\hline 17.0825237 & 16.0060564 & 18.4527283 \\
\hline 12.2746021 & 13.2389492 & 18.3732970 \\
\hline 12.3955554 & 18.7683087 & 18.4702354 \\
\hline 5.3352288 & 17.2292852 & 26.6017866 \\
\hline 5.2774585 & 17.2755221 & 23.5600902 \\
\hline 8.5282918 & 14.6776058 & 28.2858682 \\
\hline 8.6149186 & 14.7422410 & 16.4550037 \\
\hline 15.5068791 & 13.2925117 & 18.4499482 \\
\hline 15.5832640 & 18.7802568 & 18.4558463 \\
\hline 10.7614330 & 16.0809351 & 18.3603966 \\
\hline 10.4792256 & 16.2145102 & 21.4996702 \\
\hline 15.5154397 & 18.7334899 & 21.6103765 \\
\hline 15.4959933 & 13.3323814 & 21.5394597 \\
\hline 8.4019172 & 17.5778651 & 23.3719381 \\
\hline 8.4696850 & 17.2750160 & 26.4928703 \\
\hline 9.1219155 & 13.0934369 & 16.8080675 \\
\hline 7.0340417 & 14.3494264 & 28.1102981 \\
\hline 11.7264437 & 17.3920064 & 21.8934197 \\
\hline 13.8357995 & 13.8541837 & 21.4987520 \\
\hline 16.1447430 & 17.1283203 & 21.9279782 \\
\hline 15.8707925 & 14.7643802 & 18.1504807 \\
\hline 11.7651202 & 14.9043618 & 18.3353097 \\
\hline 14.0993791 & 18.4290834 & 18.2443364 \\
\hline 6.7930766 & 17.6653919 & 26.8654063 \\
\hline 8.9677116 & 18.9510371 & 23.2651867 \\
\hline 4.5331317 & 18.5647373 & 23.5281194 \\
\hline 18.3156958 & 15.7662297 & 17.6534221 \\
\hline 11.9816584 & 19.9373208 & 17.6460869 \\
\hline 11.4860139 & 12.2686932 & 17.1612170 \\
\hline 4.8860265 & 16.1767346 & 27.6194085 \\
\hline 11.6615796 & 19.8080757 & 22.4798161 \\
\hline 11.9238971 & 11.9657234 & 22.8449749 \\
\hline 18.3960167 & 16.1618548 & 22.4117777 \\
\hline 8.9393128 & 15.8551333 & 27.3963369 \\
\hline 16.1977729 & 12.3897232 & 17.4883042 \\
\hline 9.6328846 & 15.8396612 & 17.3490281 \\
\hline 15.9732582 & 19.9374909 & 17.6038873 \\
\hline 9.0017558 & 16.6616568 & 22.3077166 \\
\hline 6.9488207 & 14.9190451 & 16.9536822 \\
\hline 9.3431084 & 13.4508088 & 27.8571008 \\
\hline 13.8085682 & 18.7586511 & 21.9288302 \\
\hline 10.9684025 & 14.6414620 & 21.9988181 \\
\hline 16.5214097 & 14.6516979 & 22.0551445 \\
\hline 16.4350876 & 17.5748255 & 18.0384597 \\
\hline 13.9926386 & 13.1115106 & 18.2573748 \\
\hline 11.5051225 & 17.3586237 & 17.9530991 \\
\hline 4.4363743 & 18.4081786 & 26.7410407 \\
\hline 9.3374144 & 18.4169410 & 26.8930872 \\
\hline 6.8999516 & 17.6702608 & 23.1076446 \\
\hline 5.1897120 & 15.0660431 & 15.2113753 \\
\hline 12.0778327 & 19.1720544 & 20.1413119 \\
\hline 11.6829465 & 12.5232249 & 19.9293608 \\
\hline 17.5099292 & 15.9775615 & 20.1417628 \\
\hline 5.2202435 & 16.6222916 & 25.1876773 \\
\hline 8.8032636 & 15.0285226 & 29.7065611 \\
\hline 15.9270874 & 12.9005423 & 19.8762485 \\
\hline 15.8404349 & 19.1506148 & 19.9305409 \\
\hline 10.1584965 & 16.2346855 & 19.7623990 \\
\hline 8.6692214 & 16.9875340 & 24.7741001 \\
\hline 10.5169649 & 5405466 & 19.9639444 \\
\hline
\end{tabular}




\begin{tabular}{|c|c|c|c|}
\hline $\mathrm{H}$ & 10.3616847 & 11.3029555 & 20.9962994 \\
\hline $\mathrm{H}$ & 9.6275005 & 12.1838175 & 19.6144851 \\
\hline $\mathrm{H}$ & 10.7057078 & 10.7730854 & 19.3208639 \\
\hline $\mathrm{H}$ & 5.2088402 & 15.0272007 & 29.9306015 \\
\hline $\mathrm{H}$ & 16.1376795 & 19.7513944 & 22.5013360 \\
\hline \multicolumn{4}{|c|}{$\mathrm{Zn} \mathrm{ZOH}$} \\
\hline $\mathrm{H}$ & 8.6852020 & 8.9787900 & 15.2357514 \\
\hline Al & 5.3913999 & 9.2567708 & 16.6144388 \\
\hline $\mathrm{P}$ & 5.4042959 & 9.2752948 & 28.4333076 \\
\hline Al & 5.3023424 & 6.6904366 & 21.5677513 \\
\hline $\mathrm{P}$ & 5.3238104 & 6.7064964 & 18.4209372 \\
\hline Al & 3.1542194 & 8.0806140 & 26.5909323 \\
\hline $\mathrm{P}$ & 3.2281834 & 8.1726182 & 23.4612259 \\
\hline Al & 8.5269663 & 9.2923015 & 28.4936666 \\
\hline $\mathrm{P}$ & 8.5289351 & 9.3116815 & 16.6786250 \\
\hline Al & 8.4913239 & 6.7324816 & 18.4659053 \\
\hline $\mathrm{P}$ & 8.4761963 & 6.6955914 & 21.6462382 \\
\hline Al & 1.5454245 & 10.7754566 & 23.5150972 \\
\hline $\mathrm{P}$ & 1.5254155 & 10.7790027 & 26.6559377 \\
\hline $\mathrm{O}$ & 7.0605488 & 9.6601581 & 16.9929930 \\
\hline 0 & 4.9900125 & 10.7374651 & 28.1643328 \\
\hline $\mathrm{H}$ & 4.8428964 & 5.2891326 & 21.7736079 \\
\hline $\mathrm{H}$ & 8.9842984 & 5.3261643 & 21.9354135 \\
\hline 0 & 6.8048833 & 6.3653791 & 18.1663856 \\
\hline $\mathrm{O}$ & 1.9342327 & 9.3077625 & 26.8794876 \\
\hline $\mathrm{H}$ & 2.1195161 & 7.1910504 & 23.3046947 \\
\hline $\mathrm{H}$ & 0.1827734 & 10.1964749 & 23.3567217 \\
\hline 0 & 4.8762166 & 7.8470587 & 17.4996557 \\
\hline $\mathrm{O}$ & 4.5367265 & 8.3105418 & 27.6236313 \\
\hline $\mathrm{O}$ & 4.4144603 & 7.8143373 & 22.5607589 \\
\hline 0 & 2.3244921 & 11.6995817 & 27.5872419 \\
\hline 0 & 8.9889387 & 8.1212815 & 17.5273822 \\
\hline 0 & 1.7188780 & 12.2297281 & 22.5920975 \\
\hline $\mathrm{O}$ & 4.3780490 & 10.6003897 & 17.0587558 \\
\hline 0 & 6.8658377 & 9.0861008 & 28.0059420 \\
\hline 0 & 6.9870948 & 6.7524427 & 21.9861874 \\
\hline $\mathrm{H}$ & 9.3185681 & 5.5686092 & 18.0437813 \\
\hline $\mathrm{H}$ & 4.5055445 & 5.5044756 & 18.1004569 \\
\hline $\mathrm{H}$ & 0.0808625 & 10.9287060 & 26.9845352 \\
\hline $\mathrm{H}$ & 2.5633129 & 6.7547180 & 26.9225193 \\
\hline 0 & 2.7220153 & 9.5638119 & 23.0514572 \\
\hline $\mathrm{H}$ & 5.2614921 & 8.9834872 & 15.1565086 \\
\hline 0 & 5.1052947 & 7.1399710 & 19.8803293 \\
\hline 0 & 3.7043686 & 8.1767552 & 24.9284101 \\
\hline $\mathrm{H}$ & 8.6657105 & 9.0167811 & 29.9503612 \\
\hline $\mathrm{O}$ & 8.7177084 & 7.0551002 & 20.1672231 \\
\hline 0 & 1.7980126 & 11.1971553 & 25.2014743 \\
\hline $\mathrm{H}$ & 5.2444200 & 8.9473027 & 29.8769078 \\
\hline $\mathrm{H}$ & 3.4166837 & 11.9682112 & 15.2148008 \\
\hline Al & 3.2394438 & 16.0367868 & 21.5786732 \\
\hline$P$ & 3.1451371 & 16.0529793 & 18.4027425 \\
\hline Al & 3.7921213 & 11.9832729 & 28.4798515 \\
\hline$P$ & 3.8033629 & 11.9609480 & 16.6526975 \\
\hline Al & 1.6539229 & 13.2733489 & 18.5324699 \\
\hline $\mathrm{P}$ & 1.6365382 & 13.4037550 & 21.6107341 \\
\hline 0 & 4.8658565 & 13.0456606 & 16.9261433 \\
\hline $\mathrm{H}$ & 0.3136451 & 14.0869834 & 21.6272677 \\
\hline $\mathrm{H}$ & 2.2451522 & 17.1007431 & 21.8893206 \\
\hline 0 & 2.0895642 & 14.9399220 & 18.2136344 \\
\hline 0 & 4.3710824 & 15.7987962 & 17.5198290 \\
\hline 0 & 4.6942761 & 16.2973252 & 22.4944804 \\
\hline 0 & 2.5431639 & 12.2062741 & 17.4885714 \\
\hline $\mathrm{O}$ & 4.4465772 & 13.5351789 & 28.0232544 \\
\hline 0 & 2.7172299 & 14.4297345 & 22.0000051 \\
\hline $\mathrm{H}$ & 2.5402503 & 17.3475863 & 17.9841432 \\
\hline $\mathrm{H}$ & 0.2153315 & 13.0676554 & 18.2080233 \\
\hline 0 & 3.6045630 & 16.1130946 & 19.8659807 \\
\hline $\mathrm{H}$ & 3.4621876 & 11.9706526 & 29.9317830 \\
\hline 0 & 1.9439782 & 12.8443929 & 20.1946235 \\
\hline Al & 10.0905278 & 12.0203563 & 16.4768198 \\
\hline $\mathrm{P}$ & 10.0545827 & 12.0392591 & 28.3448414 \\
\hline Al & 12.2522127 & 10.7561236 & 26.4813838 \\
\hline $\mathrm{P}$ & 12.3468353 & 10.6046463 & 23.3709140 \\
\hline Al & 15.4204232 & 10.7754566 & 23.5150972 \\
\hline Al & 10.5635088 & 7.9839898 & 23.5470730 \\
\hline $\mathrm{P}$ & 10.6837720 & 7.9986963 & 26.6273157 \\
\hline $\mathrm{P}$ & 15.4004142 & 10.7790027 & 26.6559377 \\
\hline $\mathrm{O}$ & 8.9938993 & 10.9435016 & 28.1210230 \\
\hline
\end{tabular}




\begin{tabular}{|c|c|c|}
\hline 11.7554557 & 9.0972926 & 26.7767914 \\
\hline 15.7948574 & 9.3594912 & 26.8716276 \\
\hline 11.4958361 & 6.8339580 & 23.3879717 \\
\hline 13.8111386 & 10.0916818 & 23.3280564 \\
\hline 11.2631746 & 11.8373448 & 27.4306858 \\
\hline 9.5689934 & 8.1747251 & 27.6648140 \\
\hline 16.1760233 & 11.6725458 & 27.5598911 \\
\hline 9.1872670 & 7.7445781 & 22.5100622 \\
\hline 15.5938767 & 12.2297281 & 22.5920975 \\
\hline 9.4161722 & 10.5161761 & 17.0367889 \\
\hline 13.9121590 & 10.9332350 & 26.9944763 \\
\hline 11.3203687 & 6.6745016 & 26.8689219 \\
\hline 16.4207321 & 9.7453458 & 23.1209217 \\
\hline 11.4094647 & 9.4237219 & 23.0853085 \\
\hline 10.4714985 & 11.9955148 & 15.0375961 \\
\hline 12.0668304 & 11.1763895 & 24.7876402 \\
\hline 15.6730113 & 11.1971553 & 25.2014743 \\
\hline 10.0509959 & 8.0662124 & 25.2233157 \\
\hline 10.5188482 & 11.9930165 & 29.7588568 \\
\hline 8.6647900 & 15.1587304 & 15.1652523 \\
\hline 5.3501941 & 14.6991348 & 16.5948473 \\
\hline 5.3114500 & 14.7362155 & 28.4239396 \\
\hline 12.2398417 & 18.7065380 & 21.5677513 \\
\hline 12.3931711 & 13.5118649 & 21.9798714 \\
\hline 17.1144425 & 16.0367868 & 21.5786732 \\
\hline 17.0201358 & 16.0529793 & 18.4027425 \\
\hline 12.3316918 & 13.2203282 & 18.3185946 \\
\hline 12.2613097 & 18.7225978 & 18.4209372 \\
\hline 5.3813177 & 17.2522302 & 26.5655077 \\
\hline 5.3505439 & 17.2745766 & 23.4708467 \\
\hline 8.4690763 & 14.7889912 & 28.4353080 \\
\hline 8.4966052 & 14.7614167 & 16.5903756 \\
\hline 15.5289216 & 13.2733489 & 18.5324699 \\
\hline 15.4288233 & 18.7485830 & 18.4659053 \\
\hline 10.7243796 & 15.9446263 & 18.4936897 \\
\hline 10.5830464 & 16.0061413 & 21.6616369 \\
\hline 15.4136956 & 18.7116927 & 21.6462382 \\
\hline 15.5115369 & 13.4037550 & 21.6107341 \\
\hline 8.5003240 & 17.5077966 & 23.4769313 \\
\hline 8.5484665 & 17.3290936 & 26.6011892 \\
\hline 8.9420111 & 13.2963336 & 16.7931187 \\
\hline 6.7879304 & 14.4039488 & 28.1257913 \\
\hline 11.7017942 & 17.0655004 & 21.8088257 \\
\hline 14.1510973 & 14.1063748 & 21.6277370 \\
\hline 15.9398099 & 17.2937196 & 21.9456647 \\
\hline 15.9645629 & 14.9399220 & 18.2136344 \\
\hline 11.9371957 & 14.6818011 & 18.1852400 \\
\hline 13.7423827 & 18.3814804 & 18.1663856 \\
\hline 7.0640033 & 17.6592604 & 26.8609354 \\
\hline 8.9402052 & 18.9223006 & 23.3259233 \\
\hline 4.7289182 & 18.6234462 & 23.3647666 \\
\hline 18.2116553 & 15.8059339 & 17.5446222 \\
\hline 11.8265529 & 19.8304488 & 17.5260779 \\
\hline 11.5838168 & 12.2885494 & 17.3725022 \\
\hline 4.8627515 & 15.9566218 & 27.6130901 \\
\hline 11.4812849 & 19.6667359 & 22.4161215 \\
\hline 12.0948816 & 11.6569069 & 22.2966592 \\
\hline 18.3603330 & 16.2599069 & 22.3629529 \\
\hline 8.9881458 & 16.1450056 & 27.4733475 \\
\hline 16.2909546 & 12.3589216 & 17.6379035 \\
\hline 9.3477678 & 15.6910599 & 17.4593612 \\
\hline 15.8525884 & 19.9312748 & 17.6666659 \\
\hline 9.2946958 & 16.5043389 & 22.3214960 \\
\hline 7.0326561 & 14.8930268 & 17.0237479 \\
\hline 9.4392665 & 13.4026002 & 28.0257363 \\
\hline 13.9245942 & 18.7685440 & 21.9861874 \\
\hline 10.9890165 & 14.6982930 & 22.3245909 \\
\hline 16.5922286 & 14.4297345 & 22.0000051 \\
\hline 16.3972930 & 17.3860165 & 17.9717171 \\
\hline 13.8254524 & 13.0297824 & 18.1482852 \\
\hline 11.4185864 & 17.4846493 & 18.0908779 \\
\hline 4.5413706 & 18.4527044 & 26.8309723 \\
\hline 9.3763251 & 18.5110365 & 26.9683154 \\
\hline 6.8203301 & 17.4077085 & 23.0904820 \\
\hline 5.1607745 & 15.0028241 & 15.1495053 \\
\hline 12.0427941 & 19.1560724 & 19.8803293 \\
\hline 11.8976321 & 12.8104228 & 19.8159699 \\
\hline 17.4795617 & 16.1130946 & 19.8659807 \\
\hline 5.1975871 & 16.7273498 & 24.9042643 \\
\hline 8.6398203 & 15.1137603 & 29.8783922 \\
\hline
\end{tabular}




\begin{tabular}{|c|c|c|c|}
\hline 0 & 15.8189769 & 12.8443929 & 20.1946235 \\
\hline $\mathrm{O}$ & 15.6552078 & 19.0712016 & 20.1672231 \\
\hline 0 & 10.2723762 & 15.8119609 & 20.1583848 \\
\hline 0 & 8.7740232 & 16.9618512 & 25.1228957 \\
\hline $\mathrm{H}$ & 11.8684750 & 11.8512214 & 20.0217634 \\
\hline $\mathrm{H}$ & 5.1338469 & 15.0452051 & 29.8696585 \\
\hline $\mathrm{H}$ & 16.1040492 & 19.7301170 & 22.4848946 \\
\hline \multicolumn{4}{|c|}{$\mathrm{Si} \mathrm{ZOH}$} \\
\hline $\mathrm{H}$ & 8.6799336 & 9.0097584 & 15.1554013 \\
\hline $\mathrm{P}$ & 5.3404391 & 9.3419058 & 16.6664900 \\
\hline Al & 5.3267278 & 9.2953447 & 28.4940467 \\
\hline $\mathrm{P}$ & 5.3765137 & 6.7636573 & 21.6286503 \\
\hline Al & 5.4110995 & 6.7760803 & 18.4750599 \\
\hline $\mathrm{P}$ & 3.1776131 & 7.9661357 & 26.6489979 \\
\hline Al & 3.2136854 & 8.0284798 & 23.5058561 \\
\hline $\mathrm{P}$ & 8.4762263 & 9.2485216 & 28.4297129 \\
\hline Al & 8.4983114 & 9.2921320 & 16.6060560 \\
\hline $\mathrm{P}$ & 8.5830974 & 6.7389498 & 18.4331820 \\
\hline Al & 8.5512742 & 6.7129442 & 21.5926020 \\
\hline$P$ & 1.5997084 & 10.7341728 & 23.4499619 \\
\hline Al & 1.6137818 & 10.7355548 & 26.5925399 \\
\hline 0 & 6.8222597 & 9.6922451 & 16.9180526 \\
\hline 0 & 4.8454837 & 10.9384259 & 28.1165277 \\
\hline $\mathrm{H}$ & 4.9052094 & 5.3719506 & 21.8697838 \\
\hline $\mathrm{H}$ & 9.0199131 & 5.3244937 & 21.8566157 \\
\hline 0 & 7.0996032 & 6.3960980 & 18.2017205 \\
\hline 0 & 2.1408488 & 9.0861491 & 26.8545440 \\
\hline $\mathrm{H}$ & 2.1776938 & 6.9873185 & 23.2612647 \\
\hline $\mathrm{H}$ & 0.2017580 & 10.2573772 & 23.2614913 \\
\hline 0 & 4.9214124 & 8.1394920 & 17.5138368 \\
\hline 0 & 4.3748013 & 8.1586421 & 27.5864239 \\
\hline 0 & 4.6220700 & 7.7578783 & 22.5180761 \\
\hline 0 & 2.5427712 & 11.8323725 & 27.5757983 \\
\hline 0 & 9.0034042 & 7.9228415 & 17.5531175 \\
\hline 0 & 1.9109287 & 11.9182069 & 22.5343569 \\
\hline 0 & 4.4786400 & 10.5391476 & 17.0800056 \\
\hline 0 & 6.9993368 & 9.0807053 & 28.0693961 \\
\hline $\mathrm{O}$ & 6.8639060 & 6.8447560 & 21.9790443 \\
\hline $\mathrm{H}$ & 9.4119403 & 5.5638707 & 18.0467509 \\
\hline $\mathrm{H}$ & 4.6040008 & 5.5993472 & 18.0496054 \\
\hline $\mathrm{H}$ & 0.1864011 & 10.8287721 & 27.0060800 \\
\hline $\mathrm{H}$ & 2.5444384 & 6.6623352 & 26.9900473 \\
\hline 0 & 2.5608494 & 9.5915949 & 23.0986021 \\
\hline $\mathrm{H}$ & 5.1212471 & 9.0078274 & 15.2321027 \\
\hline 0 & 5.1484001 & 7.1610825 & 20.1570020 \\
\hline 0 & 3.6842862 & 7.9716767 & 25.1954196 \\
\hline $\mathrm{H}$ & 8.7034581 & 8.9706465 & 29.8747983 \\
\hline 0 & 8.8244565 & 7.1155998 & 19.9058312 \\
\hline 0 & 1.8112236 & 11.1788703 & 24.9121862 \\
\hline $\mathrm{H}$ & 5.1456929 & 9.0412854 & 29.9500003 \\
\hline $\mathrm{H}$ & 3.4855861 & 12.0436631 & 15.1249316 \\
\hline $\mathrm{P}$ & 3.1819115 & 15.9654281 & 21.6395238 \\
\hline Al & 3.1793344 & 16.0030734 & 18.4708314 \\
\hline$P$ & 3.8115992 & 12.0456650 & 28.4041752 \\
\hline Al & 3.8088846 & 12.0666297 & 16.5782282 \\
\hline $\mathrm{P}$ & 1.6029414 & 13.2831832 & 18.4173152 \\
\hline Al & 1.5429929 & 13.2844485 & 21.5143338 \\
\hline 0 & 4.9904984 & 13.3178807 & 16.9221279 \\
\hline $\mathrm{H}$ & 0.1064988 & 13.6760083 & 21.5312489 \\
\hline $\mathrm{H}$ & 2.2006917 & 17.0561157 & 21.8939428 \\
\hline 0 & 1.9878256 & 14.7526349 & 18.1527560 \\
\hline 0 & 4.6082063 & 15.7461822 & 17.5060623 \\
\hline 0 & 4.4324075 & 16.1556863 & 22.5054419 \\
\hline 0 & 2.3199643 & 12.3532678 & 17.4341447 \\
\hline 0 & 4.4154954 & 13.3966983 & 28.0120196 \\
\hline $\mathrm{O}$ & 2.5521646 & 14.6234979 & 22.0127464 \\
\hline $\mathrm{H}$ & 2.5971267 & 17.3221070 & 18.0989371 \\
\hline $\mathrm{H}$ & 0.1407770 & 13.1379267 & 18.1762830 \\
\hline 0 & 3.6134609 & 15.9797657 & 20.1608031 \\
\hline $\mathrm{H}$ & 3.4421310 & 12.0399157 & 29.8465970 \\
\hline 0 & 1.9690699 & 12.8658159 & 19.8482203 \\
\hline $\mathrm{P}$ & 10.0772434 & 11.9857080 & 16.6040142 \\
\hline Al & 10.0666720 & 11.9605476 & 28.4214831 \\
\hline $\mathrm{P}$ & 12.3420208 & 10.7094985 & 26.6973951 \\
\hline Al & 12.3436146 & 10.6964736 & 23.5175714 \\
\hline $\mathrm{P}$ & 15.4747071 & 10.7341728 & 23.4499619 \\
\hline $\mathrm{P}$ & 10.6450197 & 8.0544463 & 23.4619592 \\
\hline Al & 10.6943856 & 8.0337031 & 26.6146350 \\
\hline
\end{tabular}




\begin{tabular}{|c|c|c|c|}
\hline Al & 15.4887806 & 10.7355548 & 26.5925399 \\
\hline 0 & 8.9057298 & 10.6911455 & 28.0893085 \\
\hline $\mathrm{O}$ & 11.8831683 & 9.2660256 & 26.9900440 \\
\hline $\mathrm{H}$ & 15.9369112 & 9.3331728 & 26.8153049 \\
\hline $\mathrm{H}$ & 11.5933282 & 6.9243898 & 23.2599590 \\
\hline 0 & 14.0267449 & 10.2403197 & 23.2547488 \\
\hline 0 & 11.5481554 & 11.7059427 & 27.5523630 \\
\hline 0 & 9.2816721 & 8.2360554 & 27.6127959 \\
\hline $\mathrm{H}$ & 16.2830751 & 11.6733440 & 27.4332350 \\
\hline 0 & 9.3984378 & 7.8651492 & 22.5893745 \\
\hline 0 & 15.7859274 & 11.9182069 & 22.5343569 \\
\hline 0 & 9.5023936 & 10.6466004 & 17.0797281 \\
\hline 0 & 13.8194854 & 10.8445708 & 27.0761674 \\
\hline $\mathrm{H}$ & 11.2862436 & 6.7021056 & 26.9206951 \\
\hline $\mathrm{H}$ & 16.4077373 & 9.6250122 & 23.1088784 \\
\hline 0 & 11.3342543 & 9.3521427 & 23.0360598 \\
\hline $\mathrm{H}$ & 10.4205866 & 11.9461387 & 15.1556805 \\
\hline 0 & 12.1172985 & 11.0471389 & 25.2188520 \\
\hline 0 & 15.6862223 & 11.1788703 & 24.9121862 \\
\hline 0 & 10.2097674 & 8.1311551 & 24.9367595 \\
\hline $\mathrm{H}$ & 10.3758384 & 11.9473646 & 29.8779730 \\
\hline $\mathrm{H}$ & 8.7614073 & 15.0240735 & 15.0890700 \\
\hline$P$ & 5.4160389 & 14.7739115 & 16.6419864 \\
\hline Al & 5.3944360 & 14.7552538 & 28.4807212 \\
\hline $\mathrm{P}$ & 12.3140130 & 18.7797586 & 21.6286503 \\
\hline $\mathrm{Si}$ & 12.2186388 & 13.3213005 & 21.6822413 \\
\hline $\mathrm{P}$ & 17.0569102 & 15.9654281 & 21.6395238 \\
\hline Al & 17.0543331 & 16.0030734 & 18.4708314 \\
\hline $\mathrm{Al}$ & 12.2757560 & 13.3194369 & 18.4038909 \\
\hline Al & 12.3485989 & 18.7921816 & 18.4750599 \\
\hline $\mathrm{P}$ & 5.3209056 & 17.2877818 & 26.6416924 \\
\hline $\mathrm{Al}$ & 5.2923744 & 17.2894156 & 23.5045099 \\
\hline $\mathrm{P}$ & 8.5531470 & 14.7126281 & 28.3776742 \\
\hline Al & 8.5653757 & 14.7472552 & 16.5389196 \\
\hline $\mathrm{P}$ & 15.4779401 & 13.2831832 & 18.4173152 \\
\hline $\mathrm{P}$ & 15.5205968 & 18.7550512 & 18.4331820 \\
\hline $\mathrm{P}$ & 10.7234028 & 16.1117369 & 18.4035707 \\
\hline $\mathrm{Al}$ & 10.6306973 & 16.1021169 & 21.5382210 \\
\hline $\mathrm{Al}$ & 15.4887736 & 18.7290456 & 21.5926020 \\
\hline Al & 15.4179916 & 13.2844485 & 21.5143338 \\
\hline $\mathrm{P}$ & 8.4529013 & 17.3674386 & 23.4074260 \\
\hline $\mathrm{Al}$ & 8.4785094 & 17.2779239 & 26.5566640 \\
\hline 0 & 9.0531048 & 13.0964243 & 16.8987471 \\
\hline 0 & 7.0700811 & 14.3611003 & 28.1568137 \\
\hline 0 & 11.8277827 & 17.3439769 & 21.8774205 \\
\hline 0 & 13.7543832 & 13.7379151 & 21.5339233 \\
\hline 0 & 16.0400662 & 17.0957142 & 21.9031797 \\
\hline $\mathrm{O}$ & 15.8628243 & 14.7526349 & 18.1527560 \\
\hline 0 & 11.7700598 & 14.9716516 & 18.3099621 \\
\hline 0 & 14.0371025 & 18.4121993 & 18.2017205 \\
\hline 0 & 6.7975611 & 17.6627054 & 26.8781195 \\
\hline $\mathrm{H}$ & 8.9162727 & 18.7706361 & 23.2245485 \\
\hline $\mathrm{H}$ & 4.7744181 & 18.6688759 & 23.2901938 \\
\hline $\mathrm{H}$ & 18.2749014 & 15.7836323 & 17.6467081 \\
\hline $\mathrm{H}$ & 11.9292066 & 19.9598751 & 17.6518207 \\
\hline $\mathrm{O}$ & 11.3765080 & 12.2364818 & 17.3910858 \\
\hline 0 & 4.8970876 & 16.1440706 & 27.5665833 \\
\hline $\mathrm{H}$ & 11.5810128 & 19.7457211 & 22.4927960 \\
\hline 0 & 11.8832200 & 12.0503300 & 22.5786958 \\
\hline $\mathrm{H}$ & 18.2716014 & 16.1502387 & 22.4806486 \\
\hline 0 & 8.9684761 & 15.9028236 & 27.5105015 \\
\hline $\mathrm{H}$ & 16.1750657 & 12.3790729 & 17.4614276 \\
\hline 0 & 9.5618715 & 15.8476975 & 17.4427879 \\
\hline $\mathrm{H}$ & 15.9286071 & 19.9043073 & 17.5788645 \\
\hline 0 & 9.1950248 & 16.4192587 & 22.4701880 \\
\hline 0 & 6.8981963 & 14.9350292 & 17.0026402 \\
\hline 0 & 9.4056713 & 13.5057116 & 27.9722825 \\
\hline 0 & 13.8014053 & 18.8608574 & 21.9790443 \\
\hline 0 & 11.2338356 & 14.5465829 & 21.9002024 \\
\hline 0 & 16.4271633 & 14.6234979 & 22.0127464 \\
\hline 0 & 16.3731332 & 17.5463810 & 18.0357043 \\
\hline 0 & 13.9676217 & 13.1331429 & 18.1683449 \\
\hline $\mathrm{O}$ & 11.4038017 & 17.4146871 & 17.9770190 \\
\hline $\mathrm{H}$ & 4.4694167 & 18.4663187 & 26.9628434 \\
\hline $\mathrm{H}$ & 9.3219571 & 18.4449255 & 26.9359048 \\
\hline 0 & 6.9663852 & 17.2971475 & 23.0557365 \\
\hline $\mathrm{H}$ & 5.1901989 & 15.1067018 & 15.2083311 \\
\hline 0 & 12.0858995 & 19.1771839 & 20.1570020 \\
\hline 0 & 11.8275747 & 12.6945309 & 20.0589528 \\
\hline $\mathrm{O}$ & 17.4884596 & 15.9797657 & 20.1608031 \\
\hline
\end{tabular}




\begin{tabular}{|c|c|c|c|}
\hline $\mathrm{O}$ & 5.1085980 & 16.8374642 & 25.1856427 \\
\hline $\mathrm{H}$ & 8.7872577 & 15.0600017 & 29.8065354 \\
\hline 0 & 15.8440686 & 12.8658159 & 19.8482203 \\
\hline 0 & 15.7619558 & 19.1317011 & 19.9058312 \\
\hline 0 & 10.1819189 & 16.2146224 & 19.8327681 \\
\hline 0 & 8.6882414 & 16.9122360 & 24.8610578 \\
\hline $\mathrm{H}$ & 11.2661801 & 11.8984738 & 20.0992129 \\
\hline $\mathrm{H}$ & 5.2143326 & 15.0636303 & 29.9262616 \\
\hline $\mathrm{H}$ & 16.2123920 & 19.7132200 & 22.4440113 \\
\hline \multicolumn{4}{|c|}{$\begin{array}{l}\mathrm{Mg} \mathrm{ZOH} \\
159\end{array}$} \\
\hline $\mathrm{H}$ & 8.7004817 & 8.9841939 & 15.2669374 \\
\hline Al & 5.4060183 & 9.2992630 & 16.6326608 \\
\hline $\mathrm{P}$ & 5.4080426 & 9.2815217 & 28.4439215 \\
\hline Al & 5.2756433 & 6.6874716 & 21.5685080 \\
\hline $\mathrm{P}$ & 5.3522300 & 6.7150620 & 18.4116467 \\
\hline Al & 3.1694896 & 8.0550900 & 26.5963583 \\
\hline $\mathrm{P}$ & 3.2760454 & 8.1523683 & 23.4652865 \\
\hline Al & 8.5320928 & 9.2622831 & 28.5209251 \\
\hline $\mathrm{P}$ & 8.5462832 & 9.3471732 & 16.7027610 \\
\hline Al & 8.5368338 & 6.7826123 & 18.5150178 \\
\hline $\mathrm{P}$ & 8.4809162 & 6.6881490 & 21.6662259 \\
\hline Al & 1.5638666 & 10.7794797 & 23.5289384 \\
\hline $\mathrm{P}$ & 1.5270808 & 10.7766643 & 26.6518175 \\
\hline 0 & 7.0782702 & 9.7086611 & 17.0042208 \\
\hline 0 & 5.0109941 & 10.7411703 & 28.1378135 \\
\hline $\mathrm{H}$ & 4.7265199 & 5.3325899 & 21.8511380 \\
\hline $\mathrm{H}$ & 9.0164065 & 5.3245919 & 21.9328392 \\
\hline 0 & 6.8514645 & 6.4201031 & 18.2264511 \\
\hline $\mathrm{O}$ & 1.9584711 & 9.3039977 & 26.8063464 \\
\hline $\mathrm{H}$ & 2.1954091 & 7.1591097 & 23.2147213 \\
\hline $\mathrm{H}$ & 0.2096145 & 10.1821020 & 23.3668834 \\
\hline 0 & 4.9195199 & 7.8784192 & 17.5124946 \\
\hline 0 & 4.5334438 & 8.3088792 & 27.6508042 \\
\hline 0 & 4.4851187 & 7.8854281 & 22.5603703 \\
\hline $\mathrm{O}$ & 2.3259982 & 11.6677046 & 27.6110907 \\
\hline 0 & 9.0106901 & 8.1781189 & 17.5762582 \\
\hline $\mathrm{O}$ & 1.8121934 & 12.1752926 & 22.5363196 \\
\hline 0 & 4.3836132 & 10.6329594 & 17.0970111 \\
\hline $\mathrm{O}$ & 6.8703161 & 9.0660756 & 28.0325152 \\
\hline 0 & 6.9756377 & 6.6791722 & 21.9227092 \\
\hline $\mathrm{H}$ & 9.3613814 & 5.6208055 & 18.0820664 \\
\hline $\mathrm{H}$ & 4.5965665 & 5.5019359 & 17.9940124 \\
\hline $\mathrm{H}$ & 0.0876134 & 10.8914565 & 27.0149662 \\
\hline $\mathrm{H}$ & 2.5562552 & 6.7509139 & 26.9707763 \\
\hline 0 & 2.7521092 & 9.5562799 & 23.1432567 \\
\hline $\mathrm{H}$ & 5.2579259 & 9.0302270 & 15.1756746 \\
\hline 0 & 5.0428758 & 7.0833481 & 19.8711649 \\
\hline 0 & 3.7326016 & 8.0627861 & 24.9368048 \\
\hline $\mathrm{H}$ & 8.6793450 & 9.0162387 & 29.9820547 \\
\hline $\mathrm{O}$ & 8.7877609 & 7.1078857 & 20.2131099 \\
\hline $\mathrm{O}$ & 1.7658703 & 11.2609204 & 25.2114980 \\
\hline $\mathrm{H}$ & 5.2380775 & 8.9934880 & 29.8948761 \\
\hline $\mathrm{H}$ & 3.4765478 & 11.9795971 & 15.2112274 \\
\hline Al & 3.2612257 & 16.0245735 & 21.5820847 \\
\hline $\mathrm{P}$ & 3.1824054 & 16.0929792 & 18.4066662 \\
\hline Al & 3.8058454 & 11.9762817 & 28.4695826 \\
\hline $\mathrm{P}$ & 3.8155546 & 11.9887718 & 16.6610931 \\
\hline Al & 1.6674663 & 13.3271914 & 18.5034149 \\
\hline $\mathrm{P}$ & 1.6379276 & 13.3731629 & 21.5915798 \\
\hline 0 & 4.8638005 & 13.0797713 & 16.9661583 \\
\hline $\mathrm{H}$ & 0.2685088 & 13.9553506 & 21.6451540 \\
\hline $\mathrm{H}$ & 2.2761006 & 17.0987265 & 21.8867885 \\
\hline 0 & 2.1228373 & 14.9884310 & 18.1907399 \\
\hline 0 & 4.4025553 & 15.8530206 & 17.5101999 \\
\hline 0 & 4.7211568 & 16.2593316 & 22.5077387 \\
\hline 0 & 2.5230883 & 12.2424067 & 17.4467701 \\
\hline 0 & 4.4282957 & 13.5328605 & 27.9920467 \\
\hline 0 & 2.6829524 & 14.4361507 & 21.9867736 \\
\hline $\mathrm{H}$ & 2.5825144 & 17.3996768 & 18.0196354 \\
\hline $\mathrm{H}$ & 0.2244283 & 13.1875709 & 18.1639033 \\
\hline 0 & 3.6445367 & 16.1130603 & 19.8702893 \\
\hline $\mathrm{H}$ & 3.5164844 & 11.9788678 & 29.9301934 \\
\hline 0 & 1.9542823 & 12.8660708 & 20.1524632 \\
\hline Al & 10.0851115 & 12.0642341 & 16.4661530 \\
\hline $\mathrm{P}$ & 10.0490459 & 12.0277360 & 28.3260875 \\
\hline Al & 12.2569832 & 10.6855648 & 26.5367590 \\
\hline $\mathrm{P}$ & 12.3551617 & 10.5268765 & 23.3955618 \\
\hline & & & \\
\hline
\end{tabular}




\begin{tabular}{|c|c|c|c|}
\hline Al & 10.5238850 & 7.9711643 & 23.5980598 \\
\hline $\mathrm{P}$ & 10.6711435 & 7.9833749 & 26.6722487 \\
\hline $\mathrm{P}$ & 15.4020795 & 10.7766643 & 26.6518175 \\
\hline 0 & 9.0149534 & 10.9034164 & 28.1253582 \\
\hline $\mathrm{O}$ & 11.7648068 & 9.0420222 & 26.9246982 \\
\hline $\mathrm{H}$ & 15.8185584 & 9.3549017 & 26.8010050 \\
\hline $\mathrm{H}$ & 11.3686399 & 6.7488643 & 23.5006319 \\
\hline $\mathrm{O}$ & 13.8397440 & 10.0740870 & 23.3375815 \\
\hline 0 & 11.2748416 & 11.8182133 & 27.4381404 \\
\hline 0 & 9.5538659 & 8.1058941 & 27.7172952 \\
\hline $\mathrm{H}$ & 16.1776807 & 11.6416998 & 27.5830945 \\
\hline $\mathrm{O}$ & 9.1147308 & 7.7290192 & 22.6000863 \\
\hline $\mathrm{O}$ & 15.6871921 & 12.1752926 & 22.5363196 \\
\hline $\mathrm{O}$ & 9.4406335 & 10.5545247 & 17.0403178 \\
\hline $\mathrm{O}$ & 13.9190096 & 10.8949337 & 27.0259663 \\
\hline $\mathrm{H}$ & 11.2726964 & 6.6274376 & 26.8014333 \\
\hline $\mathrm{H}$ & 16.4508174 & 9.7377567 & 23.2004774 \\
\hline $\mathrm{O}$ & 11.4717509 & 9.3147255 & 23.0487277 \\
\hline $\mathrm{H}$ & 10.4510859 & 12.0447612 & 15.0229606 \\
\hline $\mathrm{O}$ & 12.0396857 & 11.0096777 & 24.8363754 \\
\hline $\mathrm{O}$ & 15.6408691 & 11.2609204 & 25.2114980 \\
\hline 0 & 10.0499579 & 8.1842671 & 25.2753161 \\
\hline $\mathrm{H}$ & 10.4951768 & 12.0410240 & 29.7466195 \\
\hline $\mathrm{H}$ & 8.6649251 & 15.1203276 & 15.1121534 \\
\hline Al & 5.3572330 & 14.7230334 & 16.5942890 \\
\hline $\mathrm{P}$ & 5.2950120 & 14.7257778 & 28.4110124 \\
\hline Al & 12.2131426 & 18.7035730 & 21.5685080 \\
\hline Mg & 12.3134316 & 13.3976508 & 21.7859939 \\
\hline Al & 17.1362244 & 16.0245735 & 21.5820847 \\
\hline $\mathrm{P}$ & 17.0574041 & 16.0929792 & 18.4066662 \\
\hline $\mathrm{P}$ & 12.3329748 & 13.2544125 & 18.3287359 \\
\hline $\mathrm{P}$ & 12.2897293 & 18.7311634 & 18.4116467 \\
\hline Al & 5.3818283 & 17.2295726 & 26.5660064 \\
\hline $\mathrm{P}$ & 5.3386009 & 17.2492155 & 23.5000378 \\
\hline Al & 8.4551095 & 14.7627786 & 28.3846964 \\
\hline $\mathrm{P}$ & 8.5010467 & 14.7851940 & 16.5536630 \\
\hline Al & 15.5424650 & 13.3271914 & 18.5034149 \\
\hline Al & 15.4743332 & 18.7987136 & 18.5150178 \\
\hline Al & 10.6801808 & 16.0359526 & 18.4772947 \\
\hline $\mathrm{P}$ & 10.4771433 & 16.0632666 & 21.5966438 \\
\hline $\mathrm{P}$ & 15.4184156 & 18.7042504 & 21.6662259 \\
\hline $\mathrm{P}$ & 15.5129263 & 13.3731629 & 21.5915798 \\
\hline Al & 8.4685716 & 17.5255939 & 23.4636912 \\
\hline $\mathrm{P}$ & 8.5230016 & 17.3481919 & 26.6217743 \\
\hline 0 & 8.9336968 & 13.3251076 & 16.8167612 \\
\hline 0 & 6.7680287 & 14.3970898 & 28.0954070 \\
\hline $\mathrm{O}$ & 11.5710873 & 17.1193952 & 21.8989695 \\
\hline $\mathrm{O}$ & 14.1150419 & 13.9674524 & 21.6462676 \\
\hline $\mathrm{O}$ & 15.9724172 & 17.2935565 & 21.9420558 \\
\hline $\mathrm{O}$ & 15.9978360 & 14.9884310 & 18.1907399 \\
\hline 0 & 11.8476366 & 14.6877294 & 18.3904689 \\
\hline 0 & 13.7889639 & 18.4362044 & 18.2264511 \\
\hline $\mathrm{O}$ & 7.0443779 & 17.6739690 & 26.9240742 \\
\hline $\mathrm{H}$ & 9.0013042 & 18.8986552 & 23.2445582 \\
\hline $\mathrm{H}$ & 4.5869522 & 18.5344882 & 23.4852435 \\
\hline $\mathrm{H}$ & 18.2425563 & 15.8599034 & 17.5359133 \\
\hline $\mathrm{H}$ & 11.8693516 & 19.8613647 & 17.5381205 \\
\hline $\mathrm{O}$ & 11.5887179 & 12.3663709 & 17.3442467 \\
\hline $\mathrm{O}$ & 4.8378847 & 15.9596645 & 27.6285849 \\
\hline $\mathrm{H}$ & 11.5384584 & 19.7259857 & 22.4150268 \\
\hline $\mathrm{O}$ & 12.0753996 & 11.6297708 & 22.3977141 \\
\hline $\mathrm{H}$ & 18.3823201 & 16.2249467 & 22.3721586 \\
\hline $\mathrm{O}$ & 8.9739466 & 16.1265579 & 27.4365287 \\
\hline $\mathrm{H}$ & 16.2749338 & 12.3985442 & 17.5988573 \\
\hline 0 & 9.3749495 & 15.7404055 & 17.3695305 \\
\hline $\mathrm{H}$ & 15.8781275 & 19.9878879 & 17.7150583 \\
\hline 0 & 9.2107068 & 16.3837431 & 22.4013886 \\
\hline 0 & 7.0435207 & 14.9434992 & 16.9969159 \\
\hline 0 & 9.4095138 & 13.3684346 & 27.9576979 \\
\hline $\mathrm{O}$ & 13.9131370 & 18.6952736 & 21.9227092 \\
\hline $\mathrm{O}$ & 10.9690469 & 14.6819527 & 21.9470297 \\
\hline $\mathrm{O}$ & 16.5579512 & 14.4361507 & 21.9867736 \\
\hline 0 & 16.4396850 & 17.4385105 & 18.0081333 \\
\hline 0 & 13.8249977 & 13.1610186 & 18.0993368 \\
\hline 0 & 11.5104303 & 17.4800933 & 17.9809497 \\
\hline $\mathrm{H}$ & 4.4984716 & 18.4106306 & 26.7707096 \\
\hline $\mathrm{H}$ & 9.3640373 & 18.5094974 & 27.0232081 \\
\hline $\mathrm{O}$ & 6.7785378 & 17.5365173 & 23.0787924 \\
\hline $\mathrm{H}$ & 5.1552598 & 14.9758308 & 15.1408720 \\
\hline $\mathrm{O}$ & 11.9803752 & 19.0994495 & 19.871164 \\
\hline
\end{tabular}




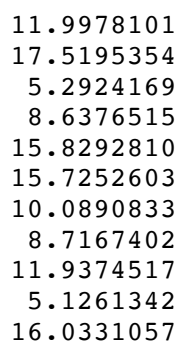

12.6581565

16.1130603

16.6392724

15.0753119

12.8660708

19.1239871

16.1613554

17.0379064

11.6820961

15.0099538

19.7137137

8.8579555

9.2307916

9.1977685

6.7409379

6.7596372

7.9690105

8.0409380

9.1640049

9.2355988

6.7738559

6.7147063

10.6957946

10.6948827

9.6207948

10.7446680

5.3564275

5.3266830

6.4207180

9.1495195

7. 0153219

10.1701720

7.9756598

8.1831925

7.8023164

11.6596201

8.0244565

11.9262077

10.4990986

9.0008368

6.7764643

5.5963353

5.5500378

10.7729011

6.6739546

9.5057441

8.8674481

7.1805454

7.9543111

8.8530717

7.1590998

11.2071503

8.8651446

11.8964803

15.8232705

15.8754442

11.8994375

11.9183044

13.1528981

13.1703107

13.0822708

13.6508423

16.8927206

14.7015022

15.6431978

16.0233136

12.1671471

13.3333732

14.3760086

17.1783787

13.0515769

15.8892806

11.8949153

12.6732086

11.9195242

11.8839612

10.6286487
19.8055005

19.8702893

24.9166421

29.8290378

20.1524632

20.2131099

20.0956311

25.1293324

19.8609776

29.8628543

22.5719083

15.2238359

16.6377201

28.5790088

21.6092153

18.5258004

26.6445618

23.5739085

28.5867792

16.6482954

18.5524858

21.6429400

23.5702598

26.6441470

16.8956617

28.2870521

21.8473695

21.8901118

18.3492409

26.8007926

23.3474906

23.3943773

17.5572237

27.6740134

22.5892408

27.6341157

17.6128382

22.5720637

17.0514938

28.1943631

21.9212447

18.1361253

18.1118960

27.0505715

26.9963486

23. 2453678

15.2108982

20.0609545

25.1222151

30.0255815

20.1063314

25.1117618

30.0139129

15.1749606

21.6214636

18.5101733

28.5464436

16.6081519

18.5307748

21.5716074

16.8808231

21.6086458

21.8877102

18.2814584

17.5539133

22.5453966

17.4913551

28.1434109

21.9887243

18.1329571

18.2377150

20.0572352

29.9784692

20.0437172

16.5339859

28.4851506

26.6651642 


\begin{tabular}{|c|c|c|c|}
\hline $\mathrm{Si}$ & 12.1631473 & 10.5661671 & 23.5467174 \\
\hline $\mathrm{Si}$ & 15.2470195 & 10.6957946 & 23.5702598 \\
\hline $\mathrm{Si}$ & 10.4356866 & 7.9778354 & 23.6165866 \\
\hline $\mathrm{Si}$ & 10.5174959 & 7.9687243 & 26.6697717 \\
\hline $\mathrm{Si}$ & 15.2412448 & 10.6948827 & 26.6441470 \\
\hline 0 & 8.8805563 & 10.6959917 & 28.2559448 \\
\hline $\mathrm{O}$ & 11.6508494 & 9.0997101 & 26.9739276 \\
\hline $\mathrm{H}$ & 15.6869072 & 9.2813847 & 26.7874261 \\
\hline $\mathrm{H}$ & 11.3509602 & 6.8090073 & 23.5015402 \\
\hline 0 & 13.7333372 & 10.1200861 & 23.3776177 \\
\hline 0 & 11.2768581 & 11.6783656 & 27.5623641 \\
\hline $\mathrm{O}$ & 9.2879953 & 8.1052271 & 27.7159696 \\
\hline $\mathrm{H}$ & 16.0163005 & 11.5822065 & 27.5546775 \\
\hline 0 & 9.1539485 & 7.7739046 & 22.6462448 \\
\hline 0 & 15.5547501 & 11.9262077 & 22.5720637 \\
\hline $\mathrm{O}$ & 9.3680599 & 10.5177683 & 17.0325643 \\
\hline 0 & 13.6852737 & 10.7797541 & 27.0862711 \\
\hline $\mathrm{H}$ & 11.1277565 & 6.6241790 & 26.8618669 \\
\hline $\mathrm{H}$ & 16.2137353 & 9.6032665 & 23.2719921 \\
\hline 0 & 11.2382478 & 9.2932619 & 23.1416038 \\
\hline $\mathrm{H}$ & 10.4071088 & 11.8853671 & 15.1018045 \\
\hline 0 & 11.9000494 & 10.9880460 & 25.1031283 \\
\hline 0 & 15.4440848 & 11.2071503 & 25.1117618 \\
\hline 0 & 9.9277861 & 8.1338615 & 25.1590038 \\
\hline $\mathrm{H}$ & 10.4006098 & 11.8825803 & 29.9103203 \\
\hline $\mathrm{H}$ & 8.6813034 & 14.9943629 & 15.1159880 \\
\hline $\mathrm{Si}$ & 5.3297072 & 14.6226040 & 16.6045314 \\
\hline $\mathrm{Si}$ & 5.2889800 & 14.6174766 & 28.5566192 \\
\hline $\mathrm{Si}$ & 12.0909473 & 18.5405330 & 21.6092153 \\
\hline Al & 12.1094887 & 13.1935056 & 21.7130376 \\
\hline $\mathrm{Si}$ & 16.8818478 & 15.8232705 & 21.6214636 \\
\hline $\mathrm{Si}$ & 16.8471157 & 15.8754442 & 18.5101733 \\
\hline $\mathrm{Si}$ & 12.1307078 & 13.1382070 & 18.4270518 \\
\hline $\mathrm{Si}$ & 12.1418130 & 18.5592323 & 18.5258004 \\
\hline $\mathrm{Si}$ & 5.2989917 & 17.0222026 & 26.6209124 \\
\hline $\mathrm{Si}$ & 5.2759812 & 17.0376683 & 23.5859928 \\
\hline $\mathrm{Si}$ & 8.4280647 & 14.6091168 & 28.4989107 \\
\hline $\mathrm{Si}$ & 8.4609940 & 14.6408449 & 16.5455366 \\
\hline $\mathrm{Si}$ & 15.3044820 & 13.1528981 & 18.5307748 \\
\hline $\mathrm{Si}$ & 15.2973944 & 18.5734509 & 18.5524858 \\
\hline $\mathrm{Si}$ & 10.5341899 & 15.8958749 & 18.5126301 \\
\hline $\mathrm{Si}$ & 10.4148001 & 15.8973527 & 21.5765262 \\
\hline $\mathrm{Si}$ & 15.2601223 & 18.5143013 & 21.6429400 \\
\hline $\mathrm{Si}$ & 15.2650316 & 13.1703107 & 21.5716074 \\
\hline $\mathrm{Si}$ & 8.4015976 & 17.1955226 & 23.5265000 \\
\hline $\mathrm{Si}$ & 8.4238389 & 17.0800643 & 26.6174441 \\
\hline 0 & 8.9267429 & 13.1008263 & 16.8233567 \\
\hline 0 & 6.8541935 & 14.2553496 & 28.2931263 \\
\hline 0 & 11.5539047 & 17.0338393 & 21.8683867 \\
\hline 0 & 13.7470196 & 13.6880779 & 21.6115158 \\
\hline 0 & 15.7841442 & 16.9957394 & 21.9133574 \\
\hline 0 & 15.7378116 & 14.7015022 & 18.2814584 \\
\hline 0 & 11.6139116 & 14.6565410 & 18.4392245 \\
\hline 0 & 13.7235193 & 18.2203130 & 18.3492409 \\
\hline 0 & 6.8545537 & 17.4347374 & 26.8848952 \\
\hline $\mathrm{H}$ & 8.8925000 & 18.5893137 & 23.3435204 \\
\hline $\mathrm{H}$ & 4.6679559 & 18.3940886 & 23.4991026 \\
\hline $\mathrm{H}$ & 18.0298797 & 15.6619652 & 17.6311871 \\
\hline $\mathrm{H}$ & 11.7322782 & 19.6790058 & 17.6338872 \\
\hline 0 & 11.3596095 & 12.1641389 & 17.4055218 \\
\hline 0 & 4.8220736 & 15.8700992 & 27.6511939 \\
\hline $\mathrm{H}$ & 11.4162548 & 19.5157554 & 22.5096884 \\
\hline 0 & 11.7706604 & 11.7700481 & 22.5815109 \\
\hline $\mathrm{H}$ & 18.0905778 & 16.0072725 & 22.4713081 \\
\hline $\mathrm{O}$ & 8.8850039 & 15.8293747 & 27.5416169 \\
\hline $\mathrm{H}$ & 15.9955981 & 12.2453331 & 17.5737979 \\
\hline 0 & 9.3330705 & 15.6495252 & 17.4591218 \\
\hline $\mathrm{H}$ & 15.6896184 & 19.7218324 & 17.6896412 \\
\hline 0 & 9.1174026 & 16.1801746 & 22.5030038 \\
\hline 0 & 6.9039018 & 14.7750225 & 16.9573457 \\
\hline 0 & 9.2975505 & 13.3030738 & 28.1034727 \\
\hline 0 & 13.6741777 & 18.5760593 & 21.9212447 \\
\hline 0 & 10.9805349 & 14.4460007 & 21.8873628 \\
\hline 0 & 16.2720446 & 14.3760086 & 21.9887243 \\
\hline 0 & 16.1788978 & 17.2930664 & 18.0997536 \\
\hline 0 & 13.7089442 & 13.0418938 & 18.2097076 \\
\hline $\mathrm{O}$ & 11.3111612 & 17.2429528 & 18.0753919 \\
\hline $\mathrm{H}$ & 4.4374596 & 18.2132611 & 26.8581096 \\
\hline $\mathrm{H}$ & 9.2513552 & 18.2591220 & 26.9944858 \\
\hline 0 & 6.8275566 & 17.1791160 & 23.1827246 \\
\hline
\end{tabular}


5.0770332

11.8114096

11.7629129

17.3409388

5.1172523

8.6776608

15.6331080

15.5973213

9.9332787

8.6654636

11.4021368

5.0738937

15.9089584 $\mathrm{Ge} \mathrm{zOH}$

159

$\mathrm{H} \quad 8.6532157$

P $\quad 5.3585167$

$\mathrm{Al} \quad 5.3375333$

P $\quad 5.3870304$

Al $\quad 5.4267352$

P $\quad 3.1805720$

Al $\quad 3.2797446$

P $\quad 8.4683021$

Al $\quad 8.5051281$

P $\quad 8.5906039$

Al 8.5632851

P $\quad 1.6343154$

Al $\quad 1.5964617$

O 6.8334502

O 4.8878735

$\mathrm{H} \quad 4.8680087$

9.0877788

7.1100238

2.1041854

2.1835341

0.2770381

4.9352998

4.3155120

4.6566234

2.5479235

9.0072914

1.8697249

4.4812943

6.9960707

6.8725580

9.4280134

4.5885111

0.1735830

2.5618141

2.6864389

5.1611614

5.1870681

3.7713068

8.6718208

8.8201421

1.7787899

5.1818713

3.5365514

3.2443511

Al $\quad 3.2017786$

P $\quad 3.8308610$

Al $\quad 3.8369386$

P $\quad 1.6039141$

Al $\quad 1.5419948$

5.0208521

0.1509018

2.2783350

2.0102515

4.6317862

4.5152652

2.3472963

4.3904774

2.6173654

2.6153163

0.1500056

3.6533057

3.4957726

1.9090823

10.0895364
14.9802775

18.9801404

12.4968273

15.8892806

16.4586029

14.9903590

12.6732086

18.9586948

16.0170528

16.6934090

11.5905597

14.9793730

19.4872891

9.0484590

9.3553696

9.2959121

6.7380624

6.7844737

7.9658062

8.0911197

9.2108541

9.3168320

6.7429754

6.6921907

10.7621703

10.7251434

9.7170698

10.9518369

5.3574059

5.3250772

6.3918605

9.0586695

7.1078596

10.1904281

8.1458912

8.1823812

7.7406950

11.7709261

7.9432711

11.9576734

10.5413052

9.0141415

6.7530726

5.5784030

5.6243873

10.8118217

6.6455377

9.6893532

9.0285105

7.1752108

7.9928133

9.0092594

7.0979795

11.2332738

9.0591732

12.0692763

15.9629956

16.0174690

12.0408301

12.0780102

13.2932381

13.3250633

13.3191962

13.8530626

17.0589279

14.7599546

15.7611420

16.1158154

12.3616208

13.3988792

14.6184296

17.3350493

13.1563692

16.0016007

12.0669359

12.8640478

11.9908611
15.1813849

20.0609545

19.9648209

20.0572352

25.1025872

29.9164709

20.0437172

20.1063314

20.0081941

25.0562662

19.9833839

29.9848662

22.5645836

15.1770399

16.6957044

28.5144042

21.6384663

18.4898615

26.6519858

23.5450736

28.4362436

16.6341489

18.4417227

21.6110497

23.4821741

26.6130802

16.9699797

28.1365684

21.8422421

21.8812860

18.1969878

26.7957666

23.3245227

23.2630172

17.5297964

27.6575483

22.5392745

27.6291766

17.5806852

22.5595801

17.1064487

28.0602870

22.0033017

18.0421768

18.0791298

27.0432237

26.9538972

23.1646631

15.2564912

20.1741996

25.2290082

29.8974281

19.9218164

24.9451284

29.9761992

15.1490386

21.6309319

18.4642369

28.4183640

16.6073979

18.4213419

21.5304866

16.9825640

21.5870327

21.9187964

18.1757700

17.4995482

22.4753034

17.4604731

27.9770963

21.9947859

18.0938792

18.1305887

20.1478841

29.8689345

19.8635582

16.5454076 


\begin{tabular}{|c|c|c|c|}
\hline Al & 10.0270459 & 11.9299631 & 28.3536282 \\
\hline $\mathrm{P}$ & 12.3412770 & 10.6706858 & 26.6881937 \\
\hline Al & 12.4015024 & 10.5627001 & 23.5018468 \\
\hline $\mathrm{P}$ & 15.5093141 & 10.7621703 & 23.4821741 \\
\hline $\mathrm{P}$ & 10.5684272 & 8.0201343 & 23.5384129 \\
\hline Al & 10.6635953 & 8.0268506 & 26.6096894 \\
\hline Al & 15.4714604 & 10.7251434 & 26.6130802 \\
\hline 0 & 8.8908326 & 10.6368053 & 28.0225632 \\
\hline 0 & 11.8772669 & 9.2330961 & 27.0069747 \\
\hline $\mathrm{H}$ & 15.9030527 & 9.3085515 & 26.7683734 \\
\hline $\mathrm{H}$ & 11.3669044 & 6.7637002 & 23.5079475 \\
\hline 0 & 14.1028352 & 10.1697024 & 23.2550728 \\
\hline 0 & 11.5093877 & 11.6902970 & 27.4787873 \\
\hline 0 & 9.3041148 & 8.1620318 & 27.6946870 \\
\hline $\mathrm{H}$ & 16.2851615 & 11.6195088 & 27.4820575 \\
\hline 0 & 9.3585524 & 7.8910066 & 22.6032455 \\
\hline 0 & 15.7447236 & 11.9576734 & 22.5595801 \\
\hline 0 & 9.5262145 & 10.6685147 & 17.0835414 \\
\hline 0 & 13.8049264 & 10.8266646 & 27.1168820 \\
\hline $\mathrm{H}$ & 11.2671269 & 6.6731563 & 26.7524540 \\
\hline $\mathrm{H}$ & 16.5293695 & 9.7220520 & 23.1743407 \\
\hline 0 & 11.4508179 & 9.1703185 & 23.0517832 \\
\hline $\mathrm{H}$ & 10.3699993 & 11.9053211 & 15.0855638 \\
\hline 0 & 12.1758685 & 10.9643497 & 25.1921916 \\
\hline 0 & 15.6537886 & 11.2332738 & 24.9451284 \\
\hline 0 & 10.0749430 & 8.2861934 & 24.9752341 \\
\hline $\mathrm{H}$ & 10.3256950 & 11.9070466 & 29.8121905 \\
\hline $\mathrm{H}$ & 8.7682950 & 15.0267227 & 15.0380275 \\
\hline $\mathrm{P}$ & 5.4307127 & 14.7688753 & 16.6489861 \\
\hline Al & 5.3684289 & 14.7524013 & 28.4784796 \\
\hline $\mathrm{P}$ & 12.3245298 & 18.7541638 & 21.6384663 \\
\hline $\mathrm{Ge}$ & 12.1604513 & 13.3570909 & 21.7471650 \\
\hline $\mathrm{P}$ & 17.1193498 & 15.9629956 & 21.6309319 \\
\hline Al & 17.0767773 & 16.0174690 & 18.4642369 \\
\hline Al & 12.2810517 & 13.3374879 & 18.3154843 \\
\hline Al & 12.3642345 & 18.8005751 & 18.4898615 \\
\hline $\mathrm{P}$ & 5.3365439 & 17.2450319 & 26.6240777 \\
\hline Al & 5.2764272 & 17.2299862 & 23.5656229 \\
\hline $\mathrm{P}$ & 8.5335509 & 14.7039284 & 28.3285160 \\
\hline Al & 8.5842065 & 14.7625717 & 16.4918006 \\
\hline $\mathrm{P}$ & 15.4789129 & 13.2932381 & 18.4213419 \\
\hline$P$ & 15.5281033 & 18.7590768 & 18.4417227 \\
\hline $\mathrm{P}$ & 10.7362891 & 16.1065767 & 18.3676694 \\
\hline Al & 10.5410531 & 16.1328360 & 21.5357830 \\
\hline Al & 15.5007845 & 18.7082921 & 21.6110497 \\
\hline Al & 15.4169935 & 13.3250633 & 21.5304866 \\
\hline $\mathrm{P}$ & 8.4072099 & 17.5072085 & 23.3909150 \\
\hline Al & 8.4728289 & 17.2768284 & 26.5175829 \\
\hline 0 & 9.0833111 & 13.1152261 & 16.8508736 \\
\hline 0 & 7.0422041 & 14.3772524 & 28.1299885 \\
\hline 0 & 11.7890569 & 17.3297454 & 21.8487010 \\
\hline 0 & 13.7947768 & 13.9407872 & 21.5964275 \\
\hline 0 & 16.1183273 & 17.0986422 & 21.9292280 \\
\hline 0 & 15.8852502 & 14.7599546 & 18.1757700 \\
\hline 0 & 11.8066317 & 14.9992615 & 18.2033715 \\
\hline 0 & 14.0475232 & 18.4079619 & 18.1969878 \\
\hline O & 6.7979203 & 17.6675950 & 26.8864730 \\
\hline $\mathrm{H}$ & 8.9118845 & 18.9043852 & 23.2893204 \\
\hline $\mathrm{H}$ & 4.5646706 & 18.5368858 & 23.5152575 \\
\hline $\mathrm{H}$ & 18.2977529 & 15.7986107 & 17.6405620 \\
\hline H & 11.9429305 & 19.9677086 & 17.6668045 \\
\hline 0 & 11.4259937 & 12.2581627 & 17.2609091 \\
\hline 0 & 4.8802167 & 16.1952926 & 27.6419166 \\
\hline $\mathrm{H}$ & 11.6151070 & 19.7279913 & 22.5133948 \\
\hline 0 & 11.8253988 & 11.8352686 & 22.5046680 \\
\hline $\mathrm{H}$ & 18.3534054 & 16.1113834 & 22.4508152 \\
\hline O & 8.9595686 & 15.8769605 & 27.4412226 \\
\hline H & 16.2019270 & 12.3871462 & 17.4867999 \\
\hline 0 & 9.5740641 & 15.8695099 & 17.3988062 \\
\hline H & 15.9323466 & 19.9235265 & 17.6063995 \\
\hline 0 & 9.0835151 & 16.6089717 & 22.3590352 \\
\hline 0 & 6.9195778 & 14.9516298 & 16.9672332 \\
\hline 0 & 9.3558569 & 13.4760239 & 27.9219553 \\
\hline 0 & 13.8100574 & 18.7691740 & 22.0033017 \\
\hline $\mathrm{O}$ & 10.9817131 & 14.5702293 & 22.1106230 \\
\hline 0 & 16.4923641 & 14.6184296 & 21.9947859 \\
\hline 0 & 16.3899678 & 17.5604951 & 18.0305088 \\
\hline 0 & 13.9788987 & 13.1520288 & 18.1213684 \\
\hline 0 & 11.3842704 & 17.4443232 & 18.0096769 \\
\hline $\mathrm{H}$ & 4.4526740 & 18.4341340 & 26.7721678 \\
\hline
\end{tabular}




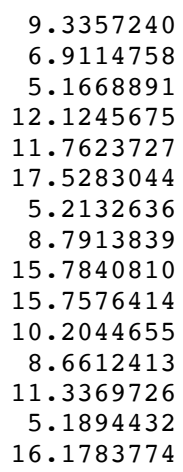

\begin{tabular}{|c|c|c|c|}
\hline$H$ & 8.6380512 & 8.8467172 & 15.2344958 \\
\hline $\mathrm{Si}$ & 5.3301892 & 9.2334077 & 16.6594032 \\
\hline $\mathrm{Si}$ & 5.3149497 & 9.1898192 & 28.6018676 \\
\hline $\mathrm{Si}$ & 5.2928286 & 6.7049602 & 21.6353123 \\
\hline $\mathrm{Si}$ & 5.3328798 & 6.7664644 & 18.5468471 \\
\hline $\mathrm{Si}$ & 3.2023121 & 7.9740352 & 26.6543520 \\
\hline $\mathrm{Si}$ & 3.3229294 & 8.0831554 & 23.5887937 \\
\hline $\mathrm{Si}$ & 8.4242338 & 9.1424150 & 28.5929115 \\
\hline $\mathrm{Si}$ & 8.4485145 & 9.2365520 & 16.6590046 \\
\hline $\mathrm{Si}$ & 8.4716383 & 6.7626676 & 18.5496373 \\
\hline $\mathrm{Si}$ & 8.4502334 & 6.6823492 & 21.6569823 \\
\hline $\mathrm{Si}$ & 1.6521101 & 10.7034926 & 23.5830488 \\
\hline $\mathrm{Si}$ & 1.6042565 & 10.6816084 & 26.6575652 \\
\hline 0 & 6.8911655 & 9.6312430 & 16.9228155 \\
\hline 0 & 4.9011896 & 10.7449177 & 28.3309663 \\
\hline $\mathrm{H}$ & 4.7420098 & 5.3359154 & 21.8338962 \\
\hline $\mathrm{H}$ & 9.0007554 & 5.3212883 & 21.9050938 \\
\hline 0 & 6.9024723 & 6.3989538 & 18.3127320 \\
\hline 0 & 2.0630599 & 9.1262739 & 26.8100353 \\
\hline $\mathrm{H}$ & 2.2424886 & 7.0822971 & 23.3695886 \\
\hline $\mathrm{H}$ & 0.2885625 & 10.1332961 & 23.4021220 \\
\hline 0 & 4.8847433 & 7.9937268 & 17.5944015 \\
\hline 0 & 4.4084856 & 8.1931693 & 27.7108884 \\
\hline 0 & 4.5879513 & 7.7825618 & 22.6216775 \\
\hline 0 & 2.4534795 & 11.6225556 & 27.6653281 \\
\hline 0 & 8.9100130 & 8.0265926 & 17.6305591 \\
\hline 0 & 1.8891132 & 11.9669557 & 22.6077333 \\
\hline 0 & 4.4097371 & 10.5024797 & 17.0523756 \\
\hline 0 & 6.8659676 & 8.9715700 & 28.1886862 \\
\hline 0 & 6.8697896 & 6.6539118 & 21.9754112 \\
\hline $\mathrm{H}$ & 9.2974380 & 5.5936407 & 18.1390870 \\
\hline $\mathrm{H}$ & 4.5191034 & 5.5801077 & 18.1628596 \\
\hline $\mathrm{H}$ & 0.1680481 & 10.7820952 & 27.0374713 \\
\hline $\mathrm{H}$ & 2.5793465 & 6.6589552 & 26.9699450 \\
\hline 0 & 2.7528600 & 9.5602861 & 23.2336095 \\
\hline $\mathrm{H}$ & 5.1209812 & 8.8517736 & 15.2354271 \\
\hline 0 & 5.0628911 & 7.1901235 & 20.0935009 \\
\hline 0 & 3.8175221 & 8.0072477 & 25.1441692 \\
\hline $\mathrm{H}$ & 8.6354568 & 8.8396438 & 30.0354214 \\
\hline 0 & 8.7328217 & 7.1333199 & 20.1129068 \\
\hline 0 & 1.8387002 & 11.1986964 & 25.1303585 \\
\hline $\mathrm{H}$ & 5.1199425 & 8.8485340 & 30.0380490 \\
\hline $\mathrm{H}$ & 3.3622994 & 11.9229119 & 15.1959922 \\
\hline $\mathrm{Si}$ & 3.3301847 & 15.8201416 & 21.6084548 \\
\hline $\mathrm{Si}$ & 3.2451602 & 15.8830210 & 18.5150546 \\
\hline $\mathrm{Si}$ & 3.7679875 & 11.8959500 & 28.5649447 \\
\hline $\mathrm{Si}$ & 3.7801807 & 11.9286077 & 16.6251399 \\
\hline $\mathrm{Si}$ & 1.6696075 & 13.1561664 & 18.5436380 \\
\hline $\mathrm{Si}$ & 1.6350298 & 13.2091895 & 21.5983129 \\
\hline 0 & 4.9016438 & 13.0819433 & 16.8911730 \\
\hline $\mathrm{H}$ & 0.2804620 & 13.8175354 & 21.7086855 \\
\hline $\mathrm{H}$ & 2.3359943 & 16.8894901 & 21.9003450 \\
\hline 0 & 2.1347077 & 14.7015460 & 18.3411550 \\
\hline 0 & 4.5098109 & 15.6460608 & 17.5328121 \\
\hline 0 & 4.6489168 & 15.9839766 & 22.5359495 \\
\hline 0 & 2.4666807 & 12.1756883 & 17.5364357 \\
\hline 0 & 4.3858406 & 13.3274178 & 28.1271915 \\
\hline 0 & 2.7278444 & 14.3600798 & 21.9386176 \\
\hline $\mathrm{H}$ & 2.6129166 & 17.1768995 & 18.1365483 \\
\hline $\mathrm{H}$ & 0.2305771 & 13.0609031 & 18.1731828 \\
\hline 0 & 3.7853354 & 15.9239438 & 20.0461915 \\
\hline $\mathrm{H}$ & 3.3619579 & 11.9201218 & 29.9973121 \\
\hline
\end{tabular}

26.8981625

23.0778473

15.2115480

20.1741996

19.9523710

20.1478841

25.2134655

29.7510561

19.8635582

19.9218164

19.8043683

24.8066894

20.0281521

29.9327541

22.4564319
15.0172982

19.7297211

15.2344958 (2) 5944015 27.6216775 7.6653281 7.0523756 28.1886862 18.1390870 18.1628596 27.0374713 23.2336095 5.2354271 25.1441692 25.1303585 21.6084548 271915 


\begin{tabular}{|c|c|c|c|}
\hline 0 & 1.8947712 & 12.6558226 & 20.0704189 \\
\hline $\mathrm{Si}$ & 10.0099338 & 11.9184941 & 16.4963881 \\
\hline $\mathrm{Si}$ & 9.9519733 & 11.8670806 & 28.4557369 \\
\hline $\mathrm{Si}$ & 12.1179267 & 10.6241560 & 26.6226846 \\
\hline $\mathrm{Si}$ & 12.2011529 & 10.4944129 & 23.5164367 \\
\hline $\mathrm{Si}$ & 15.2771088 & 10.7034926 & 23.5830488 \\
\hline $\mathrm{Si}$ & 10.3792701 & 7.9555105 & 23.6384296 \\
\hline $\mathrm{Si}$ & 10.4988099 & 7.9671194 & 26.6514944 \\
\hline $\mathrm{Si}$ & 15.2292552 & 10.6816084 & 26.6575652 \\
\hline 0 & 8.8624897 & 10.6750132 & 28.2495962 \\
\hline $\mathrm{O}$ & 11.6482301 & 9.0910891 & 26.9278660 \\
\hline $\mathrm{H}$ & 15.6486934 & 9.2597213 & 26.7969534 \\
\hline $\mathrm{H}$ & 11.1916484 & 6.7088386 & 23.5839194 \\
\hline $\mathrm{O}$ & 13.7826050 & 10.0785340 & 23.3847457 \\
\hline 0 & 11.2372977 & 11.6673460 & 27.4992368 \\
\hline $\mathrm{O}$ & 9.3072384 & 8.0843793 & 27.7443146 \\
\hline $\mathrm{H}$ & 16.0101416 & 11.5468380 & 27.5842339 \\
\hline 0 & 9.1185738 & 7.7984106 & 22.6307905 \\
\hline 0 & 15.5141120 & 11.9669557 & 22.6077333 \\
\hline $\mathrm{O}$ & 9.3849231 & 10.5176916 & 17.0129391 \\
\hline 0 & 13.6663692 & 10.7909584 & 27.0709801 \\
\hline $\mathrm{H}$ & 11.1155899 & 6.6183510 & 26.7838841 \\
\hline $\mathrm{H}$ & 16.2857240 & 9.6559745 & 23.2628582 \\
\hline $\mathrm{O}$ & 11.3077065 & 9.1859765 & 23.1646368 \\
\hline $\mathrm{H}$ & 10.4178044 & 11.8648275 & 15.0653458 \\
\hline $\mathrm{O}$ & 11.9194375 & 10.9848230 & 25.0523164 \\
\hline $\mathrm{O}$ & 15.4636990 & 11.1986964 & 25.1303585 \\
\hline 0 & 9.8514319 & 8.1808612 & 25.1673114 \\
\hline $\mathrm{H}$ & 10.4096680 & 11.8607580 & 29.8726336 \\
\hline $\mathrm{H}$ & 8.6838802 & 15.0130889 & 15.0805238 \\
\hline $\mathrm{Si}$ & 5.3386073 & 14.6236558 & 16.5931740 \\
\hline $\mathrm{Si}$ & 5.2749606 & 14.6144920 & 28.5444147 \\
\hline $\mathrm{Si}$ & 12.1053279 & 18.5045553 & 21.6353123 \\
\hline $\mathrm{Ga}$ & 12.1104794 & 13.2544551 & 21.8203363 \\
\hline $\mathrm{Si}$ & 16.9551835 & 15.8201416 & 21.6084548 \\
\hline $\mathrm{Si}$ & 16.8701590 & 15.8830210 & 18.5150546 \\
\hline $\mathrm{Si}$ & 12.1434827 & 13.1588873 & 18.3807474 \\
\hline $\mathrm{Si}$ & 12.1453791 & 18.5660595 & 18.5468471 \\
\hline $\mathrm{Si}$ & 5.3051476 & 17.0112340 & 26.6119625 \\
\hline $\mathrm{Si}$ & 5.2654798 & 17.0244821 & 23.6081398 \\
\hline $\mathrm{Si}$ & 8.4188374 & 14.6067484 & 28.4688394 \\
\hline $\mathrm{Si}$ & 8.4697356 & 14.6452242 & 16.5073869 \\
\hline $\mathrm{Si}$ & 15.2946062 & 13.1561664 & 18.5436380 \\
\hline $\mathrm{Si}$ & 15.2841377 & 18.5622627 & 18.5496373 \\
\hline $\mathrm{Si}$ & 10.5398901 & 15.8800310 & 18.4999489 \\
\hline $\mathrm{Si}$ & 10.3471920 & 15.8889672 & 21.5961272 \\
\hline $\mathrm{Si}$ & 15.2627327 & 18.4819442 & 21.6569823 \\
\hline $\mathrm{Si}$ & 15.2600285 & 13.2091895 & 21.5983129 \\
\hline $\mathrm{Si}$ & 8.3650878 & 17.2844236 & 23.5078331 \\
\hline $\mathrm{Si}$ & 8.4168326 & 17.0776294 & 26.5902760 \\
\hline 0 & 8.9228331 & 13.0967324 & 16.7590499 \\
\hline $\mathrm{O}$ & 6.8410180 & 14.2631373 & 28.2744690 \\
\hline $\mathrm{O}$ & 11.5054850 & 17.0136621 & 21.8515707 \\
\hline 0 & 13.7903338 & 13.8692397 & 21.7180662 \\
\hline $\mathrm{O}$ & 15.8651526 & 16.9925759 & 21.9284833 \\
\hline 0 & 15.7597065 & 14.7015460 & 18.3411550 \\
\hline 0 & 11.6634427 & 14.6913801 & 18.3627166 \\
\hline $\mathrm{O}$ & 13.7149717 & 18.1985488 & 18.3127320 \\
\hline $\mathrm{O}$ & 6.8543934 & 17.4403003 & 26.8997900 \\
\hline $\mathrm{H}$ & 8.9064956 & 18.6639043 & 23.3628111 \\
\hline $\mathrm{H}$ & 4.5058299 & 18.3048530 & 23.5816234 \\
\hline $\mathrm{H}$ & 18.0334554 & 15.6650517 & 17.6115330 \\
\hline $\mathrm{H}$ & 11.7326743 & 19.6962891 & 17.6697061 \\
\hline $\mathrm{O}$ & 11.3654620 & 12.1888687 & 17.3592576 \\
\hline 0 & 4.8055905 & 15.8832919 & 27.6598999 \\
\hline $\mathrm{H}$ & 11.4582624 & 19.4937755 & 22.5407790 \\
\hline $\mathrm{O}$ & 11.7701730 & 11.6240088 & 22.4675439 \\
\hline $\mathrm{H}$ & 18.1668750 & 15.9706783 & 22.4606655 \\
\hline $\mathrm{O}$ & 8.8813590 & 15.8059557 & 27.4854844 \\
\hline $\mathrm{H}$ & 16.0290854 & 12.2526851 & 17.6155311 \\
\hline $\mathrm{O}$ & 9.3470296 & 15.6387325 & 17.4345071 \\
\hline $\mathrm{H}$ & 15.6862994 & 19.7217779 & 17.7064819 \\
\hline 0 & 9.0112689 & 16.2854835 & 22.4221507 \\
\hline 0 & 6.9148722 & 14.7928683 & 16.9267288 \\
\hline $\mathrm{O}$ & 9.2712375 & 13.2854099 & 28.0885244 \\
\hline 0 & 13.6822890 & 18.4535068 & 21.9754112 \\
\hline $\mathrm{O}$ & 10.8213076 & 14.4430425 & 22.0942070 \\
\hline $\mathrm{O}$ & 16.3528431 & 14.3600798 & 21.9386176 \\
\hline $\mathrm{O}$ & 16.1821710 & 17.2909796 & 18.1031757 \\
\hline $\mathrm{O}$ & 13.7206232 & 13.0519693 & 18.1384414 \\
\hline
\end{tabular}




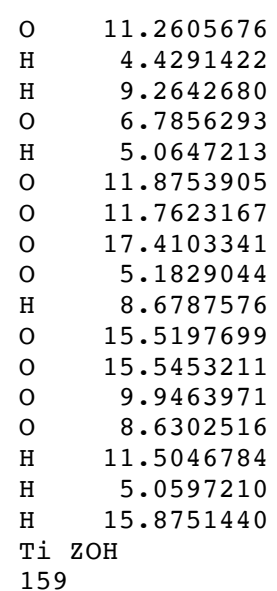

$\mathrm{H} \quad 8.6663920$

P $\quad 5.3824577$

Al $\quad 5.3324455$

$\mathrm{P} \quad 5.3668618$

Al $\quad 5.4613809$

$\mathrm{P} \quad 3.2013584$

Al $\quad 3.3200311$

P $\quad 8.4627914$

Al 8.5329371

P $\quad 8.6285257$

Al $\quad 8.5573136$

$\mathrm{P} \quad 1.6288606$

$\mathrm{Al} \quad 1.5812783$

O 6.8580809

O 4.8885957

$\mathrm{H} \quad 4.7779022$

9. 1144814

7.1552724

2.1300429

2. 2207067

0.2891027

4.9753775

4.3085637

4.6843757

2.5484633

9.0374789

1.9323840

4.4990706

6.9860592

6.8567433

9.4834115

4.6788984

0.1851273

2.5648965

2.7048314

5.1732088

5.1765590

3. 8260657

8.6820385

8.8374645

1. 6680514

5. 1909773

3.5445159

3. 2626619

3.2333677

3. 8308788

3. 8493287

1. 6188168

1.5715105

5. 0405401

0.1430760

2.3093894

2.0315549

4.6628615

4.5381185

2. 3579581

4.3850623

2. 6119915

2. 6682966

0.1625891
17.2761446

18.2033861

18.2432166

17.3619969

14.9643205

18.9897186

12.5706149

15.9239438

16.3884416

15.0085932

12.6558226

18.9329149

15.8903274

16.7171133

11.6325902

14.9630915

19.5046095

9.0960089

9.3729314

9. 2861617

6.7457501

6.7687330

7. 9496865

8.1149802

9.1896279

9.3497787

6.7799923

6.7169239

10.7837460

10.7091561

9.7451752

10.9409747

5.4023663

5. 3578495

6.4088894

9.0507762

7.1403881

10.2145031

8.1574956

8.1671507

7.8086302

11.7548747

7.9771347

11.9805864

10.5543049

8.9918290

6.7029476

5.6225216

5.5855896

10.7442158

6.6366568

9. 7174200

9.0432886

7.1376800

7. 9600659

9.0568393

7.1534553

11.2463819

9.0701078

12.0602103

15.9830168

16.0399387

12.0285898

12.0878995

13.3312567

13.3331568

13.3299664

13.7505115

17.0942316

14.7949217

15.7748223

16.1304795

12.3899856

13.3880556

14.6549458

17.3749171

13.2060242
18.1293410

26.7808073

26.9649494

23.1989334

15.1697786

20.0935009

19.9212672

20.0461915

25.1083234

29.8788334

20.0704189

20.1129068

20.0040900

25.0161205

20.0068759

29.9759421

22.5492987

15.1816909

16.7188404

28.5347412

21.6397332

18.4793861

26.6485570

23.5595362

28.4324332

16.6428245

18.4629502

21.6256341

23.4966174

26.6390458

16.9813740

28.1445946

21.8957944

21.8697681

18.2103148

26.7534807

23.3170975

23.1833573

17.5533577

27.6850445

22.5143691

27.6409092

17.5923740

22.5935943

17.1337921

28.0801299

21.9897880

18.0801288

18.0266018

27.1554312

26.9451878

23.2468123

15.2819440

20.1619984

25.2384586

29.8992047

19.9436611

24.9707196

30.0011749

15.1639423

21.6319554

18.4673899

28.4296915

16.6211462

18.4253732

21.5484236

16.9824877

21.5985295

21.9032373

18.1654247

17.5014442

22.4726717

17.4678316

27.9861388

22.0153132

18.1273194

18.1410522 


\begin{tabular}{|c|c|c|c|}
\hline 0 & 3.6782127 & 15.9934058 & 20.1514379 \\
\hline $\mathrm{H}$ & 3.5024986 & 12.0545783 & 29.8817975 \\
\hline 0 & 1.9353964 & 12.9105909 & 19.8682648 \\
\hline$P$ & 10.0970097 & 12.0092762 & 16.4986315 \\
\hline Al & 10.0001901 & 11.9076740 & 28.2870400 \\
\hline $\mathrm{P}$ & 12.3637863 & 10.5898681 & 26.7773315 \\
\hline Al & 12.4165343 & 10.4984742 & 23.5496183 \\
\hline $\mathrm{P}$ & 15.5038593 & 10.7837460 & 23.4966174 \\
\hline $\mathrm{P}$ & 10.5336202 & 8.0260088 & 23.5783243 \\
\hline Al & 10.6477293 & 8.0096302 & 26.6504804 \\
\hline Al & 15.4562770 & 10.7091561 & 26.6390458 \\
\hline 0 & 8.8974409 & 10.5880703 & 27.9406319 \\
\hline 0 & 11.8525388 & 9.1848007 & 27.1632651 \\
\hline $\mathrm{H}$ & 15.9230478 & 9.2985636 & 26.7363823 \\
\hline $\mathrm{H}$ & 11.2572862 & 6.7246943 & 23.5812641 \\
\hline 0 & 14.1136150 & 10.1930521 & 23.1715526 \\
\hline 0 & 11.5164159 & 11.6727776 & 27.4646488 \\
\hline 0 & 9.2754044 & 8.0961060 & 27.7270515 \\
\hline $\mathrm{H}$ & 16.2832458 & 11.6032733 & 27.4956657 \\
\hline 0 & 9.3044095 & 7.9194844 & 22.6613355 \\
\hline 0 & 15.8073827 & 11.9805864 & 22.5935943 \\
\hline $\mathrm{O}$ & 9.5765232 & 10.6908102 & 17.0978477 \\
\hline 0 & 13.8161102 & 10.7503434 & 27.2456838 \\
\hline $\mathrm{H}$ & 11.2496036 & 6.6499895 & 26.7295059 \\
\hline $\mathrm{H}$ & 16.5473774 & 9.7495818 & 23.2543468 \\
\hline $\mathrm{O}$ & 11.4687528 & 9.1167536 & 23.0418234 \\
\hline $\mathrm{H}$ & 10.2696053 & 11.8921189 & 15.0243163 \\
\hline 0 & 12.2710512 & 10.7751258 & 25.2629928 \\
\hline 0 & 15.5430501 & 11.2463819 & 24.9707196 \\
\hline 0 & 10.0869024 & 8.3602885 & 25.0174962 \\
\hline $\mathrm{H}$ & 10.2340547 & 11.8920115 & 29.7574763 \\
\hline $\mathrm{H}$ & 8.7960156 & 14.9924611 & 14.9964077 \\
\hline $\mathrm{P}$ & 5.4494902 & 14.7790561 & 16.6424570 \\
\hline Al & 5.3627878 & 14.7448540 & 28.4769965 \\
\hline $\mathrm{P}$ & 12.3043612 & 18.7618514 & 21.6397332 \\
\hline $\mathrm{Ti}$ & 12.0682585 & 13.2836682 & 21.6748360 \\
\hline $\mathrm{P}$ & 17.1376606 & 15.9830168 & 21.6319554 \\
\hline Al & 17.1083664 & 16.0399387 & 18.4673899 \\
\hline Al & 12.2786600 & 13.2977564 & 18.2868731 \\
\hline Al & 12.3988802 & 18.7848344 & 18.4793861 \\
\hline$P$ & 5.3347414 & 17.2313086 & 26.6218268 \\
\hline Al & 5.2582796 & 17.2484283 & 23.5861803 \\
\hline $\mathrm{P}$ & 8.5300672 & 14.6831794 & 28.2844855 \\
\hline Al & 8.6083781 & 14.7691049 & 16.4565532 \\
\hline $\mathrm{P}$ & 15.4938155 & 13.3312567 & 18.4253732 \\
\hline $\mathrm{P}$ & 15.5660250 & 18.7960937 & 18.4629502 \\
\hline $\mathrm{P}$ & 10.7362202 & 16.1243986 & 18.3563487 \\
\hline Al & 10.4391911 & 16.2139748 & 21.4919265 \\
\hline Al & 15.4948130 & 18.7330252 & 21.6256341 \\
\hline Al & 15.4465092 & 13.3331568 & 21.5484236 \\
\hline $\mathrm{P}$ & 8.3706458 & 17.5734858 & 23.3803360 \\
\hline Al & 8.4605652 & 17.2805655 & 26.5016968 \\
\hline 0 & 9.1021427 & 13.1286198 & 16.8566378 \\
\hline 0 & 7.0328334 & 14.3680379 & 28.1164565 \\
\hline 0 & 11.6966431 & 17.3756808 & 21.9039499 \\
\hline $\mathrm{O}$ & 13.7776710 & 13.8207517 & 21.6069623 \\
\hline 0 & 16.1504238 & 17.1338232 & 21.9129028 \\
\hline $\mathrm{O}$ & 15.9065536 & 14.7949217 & 18.1654247 \\
\hline $\mathrm{O}$ & 11.7413902 & 14.9477847 & 18.3411766 \\
\hline $\mathrm{O}$ & 14.0927718 & 18.4249908 & 18.2103148 \\
\hline 0 & 6.7894963 & 17.6713635 & 26.8975613 \\
\hline $\mathrm{H}$ & 8.9479214 & 18.9422214 & 23.2781780 \\
\hline $\mathrm{H}$ & 4.4641766 & 18.5079931 & 23.5820024 \\
\hline $\mathrm{H}$ & 18.3277930 & 15.8137818 & 17.6433920 \\
\hline $\mathrm{H}$ & 11.9826259 & 19.9742878 & 17.6862573 \\
\hline 0 & 11.4822561 & 12.3096275 & 17.0992220 \\
\hline $\mathrm{O}$ & 4.8728563 & 16.1889928 & 27.6441542 \\
\hline $\mathrm{H}$ & 11.6429258 & 19.7919479 & 22.4873917 \\
\hline 0 & 11.7817175 & 11.8813545 & 22.7327688 \\
\hline $\mathrm{H}$ & 18.3751277 & 16.1260873 & 22.4476309 \\
\hline 0 & 8.9452712 & 15.8637903 & 27.4016100 \\
\hline $\mathrm{H}$ & 16.2118768 & 12.4168304 & 17.4951403 \\
\hline 0 & 9.6188174 & 15.8837732 & 17.3346516 \\
\hline $\mathrm{H}$ & 15.9625488 & 19.9568508 & 17.6188338 \\
\hline 0 & 8.9676021 & 16.6540643 & 22.3164020 \\
\hline $\mathrm{O}$ & 6.9439901 & 14.9640736 & 16.9361827 \\
\hline 0 & 9.3337217 & 13.4538407 & 27.8414309 \\
\hline 0 & 13.7942426 & 18.7190490 & 21.9897880 \\
\hline $\mathrm{O}$ & 10.9138886 & 14.6213478 & 21.9469526 \\
\hline 0 & 16.4869902 & 14.6549458 & 22.0153132 \\
\hline
\end{tabular}




$\begin{array}{rll}16.4461225 & 17.6044877 & 18.0688389 \\ 13.9915119 & 13.2020617 & 18.1320561 \\ 11.4825007 & 17.3992335 & 17.9491222 \\ 4.4345798 & 18.4115588 & 26.7394669 \\ 9.3357341 & 18.4215116 & 26.8882738 \\ 6.8682679 & 17.6799168 & 23.1136829 \\ 5.1662239 & 15.0596808 & 15.2078384 \\ 12.1140584 & 19.1537813 & 20.1619984 \\ 11.7622420 & 12.5359939 & 19.8360571 \\ 17.5532114 & 15.9934058 & 20.1514379 \\ 5.2404054 & 16.6022478 & 25.2159896 \\ 8.8187141 & 15.0197317 & 29.7059412 \\ 15.8103951 & 12.9105909 & 19.8682648 \\ 15.7749639 & 19.1695567 & 19.9436611 \\ 10.1258867 & 16.2803409 & 19.7541653 \\ 8.6314212 & 16.9801848 & 24.7821027 \\ 11.2877235 & 11.6879132 & 19.7866945 \\ 5.1874885 & 15.0209765 & 29.9296310 \\ 16.1289872 & 19.7538217 & 22.5047918\end{array}$

S5 Cartesian coordinates of periodic structures in cif-format for all structures

Structures are labeled according to Fig. S2 and corresponding to Tables S2-S4.

$\mathrm{Zn} 1$

data_image 0

$\begin{array}{ll}\text {-celi__length_a } & 13.875 \\ \text {-cell_length_b } & 13.875 \\ \text {-cell_length_c } & 15.017 \\ \text {-cell_angle_alpha } & 90 \\ \text {-cell_angle_beta } & 90 \\ \text { _cell_angle_gamma } & 120\end{array}$

$\begin{array}{ll}\text { _symmetry_space_group_name_H-M } & \text { "P } 1 " \\ \text { _symmetry_int_tables_number } & 1\end{array}$

loop

symmetry_equiv_pos_as_xyz

' $\mathrm{x}, \mathrm{y}, \mathrm{z}$ '

loop_

atom_site_label

-atom_site_occupancy

atom site fract $x$

-atom_site_fract_y

-atom_site_fract_z

-atom_site_thermal_displace_type

-atom_site_B_iso_or_equiv

-atom_site_type_symbol

\begin{tabular}{|c|c|c|c|c|c|c|}
\hline $\bar{A} 11$ & 1.0000 & 0.99924 & 0.23211 & 0.10497 & Biso & 1.000 \\
\hline Al2 & 1.0000 & 0.77776 & 0.78085 & 0.10936 & Biso & 1.000 \\
\hline Al3 & 1.0000 & 0.23265 & 0.01092 & 0.09747 & Biso & 1.000 \\
\hline P1 & 1.0000 & 0.22463 & 0.00742 & 0.88599 & Biso & 1.000 \\
\hline P2 & 1.0000 & 0.77672 & 0.77903 & 0.89501 & Biso & 1.000 \\
\hline P3 & 1.0000 & 0.99631 & 0.23200 & 0.89233 & Biso & 1.000 \\
\hline Al4 & 1.0000 & 0.65999 & 0.56364 & 0.43684 & Biso & 1.000 \\
\hline Zn1 & 1.0000 & 0.44840 & 0.12116 & 0.44238 & Biso & 1.000 \\
\hline Al5 & 1.0000 & 0.90410 & 0.34140 & 0.43586 & Biso & 1.000 \\
\hline P4 & 1.0000 & 0.89703 & 0.34181 & 0.22699 & Biso & 1.000 \\
\hline P5 & 1.0000 & 0.43557 & 0.10489 & 0.22597 & Biso & 1.000 \\
\hline P6 & 1.0000 & 0.66527 & 0.56577 & 0.22769 & Biso & 1.000 \\
\hline Al6 & 1.0000 & 0.32847 & 0.89321 & 0.77250 & Biso & 1.000 \\
\hline Al 7 & 1.0000 & 0.10596 & 0.44037 & 0.76909 & Biso & 1.000 \\
\hline Al8 & 1.0000 & 0.56503 & 0.67764 & 0.77206 & Biso & 1.000 \\
\hline P7 & 1.0000 & 0.57586 & 0.68642 & 0.56475 & Biso & 1.000 \\
\hline P8 & 1.0000 & 0.10666 & 0.44502 & 0.56445 & Biso & 1.000 \\
\hline P9 & 1.0000 & 0.32897 & 0.88773 & 0.55984 & Biso & 1.000 \\
\hline Al9 & 1.0000 & 0.99903 & 0.77746 & 0.89686 & Biso & 1.000 \\
\hline Al10 & 1.0000 & 0.22455 & 0.23425 & 0.89212 & Biso & 1.000 \\
\hline Al11 & 1.0000 & 0.77245 & 0.00343 & 0.89746 & Biso & 1.000 \\
\hline $\mathrm{P} 10$ & 1.0000 & 0.77293 & 0.00440 & 0.11063 & Biso & 1.000 \\
\hline P11 & 1.0000 & 0.22759 & 0.23457 & 0.10575 & Biso & 1.000 \\
\hline P12 & 1.0000 & 0.00420 & 0.78359 & 0.11114 & Biso & 1.000 \\
\hline Al12 & 1.0000 & 0.67235 & 0.11394 & 0.23600 & Biso & 1.000 \\
\hline Al13 & 1.0000 & 0.89730 & 0.57150 & 0.23308 & Biso & 1.000 \\
\hline Al14 & 1.0000 & 0.43863 & 0.33510 & 0.22969 & Biso & 1.000 \\
\hline P13 & 1.0000 & 0.42806 & 0.33885 & 0.43992 & Biso & 1.000 \\
\hline P14 & 1.0000 & 0.89426 & 0.57021 & 0.44077 & Biso & 1.000 \\
\hline P15 & 1.0000 & 0.67908 & 0.12303 & 0.43972 & Biso & 1.000 \\
\hline
\end{tabular}




\begin{tabular}{|c|c|c|c|c|c|c|c|}
\hline Al15 & 1.0000 & 0.34194 & 0.46201 & 0.56412 & Biso & 1.000 & $\mathrm{Al}$ \\
\hline Al16 & 1.0000 & 0.56032 & 0.90492 & 0.56587 & Biso & 1.000 & $\mathrm{Al}$ \\
\hline Al17 & 1.0000 & 0.09622 & 0.67327 & 0.57197 & Biso & 1.000 & Al \\
\hline P16 & 1.0000 & 0.10212 & 0.67008 & 0.77873 & Biso & 1.000 & \\
\hline P 17 & 1.0000 & 0.55808 & 0.90248 & 0.77639 & Biso & 1.000 & \\
\hline P18 & 1.0000 & 0.33684 & 0.44816 & 0.77265 & Biso & 1.000 & $P$ \\
\hline 01 & 1.0000 & 0.89458 & 0.09534 & 0.12867 & Biso & 1.000 & 0 \\
\hline $\mathrm{O} 2$ & 1.0000 & 0.91500 & 0.81381 & 0.13920 & Biso & 1.000 & \\
\hline 03 & 1.0000 & 0.19915 & 0.11348 & 0.12544 & Biso & 1.000 & \\
\hline 04 & 1.0000 & 0.10374 & 0.91312 & 0.87129 & Biso & 1.000 & \\
\hline 05 & 1.0000 & 0.80730 & 0.90013 & 0.87566 & Biso & 1.000 & \\
\hline 06 & 1.0000 & 0.08808 & 0.20385 & 0.87101 & Biso & 1.000 & 0 \\
\hline 07 & 1.0000 & 0.55205 & 0.42873 & 0.45423 & Biso & 1.000 & 0 \\
\hline 08 & 1.0000 & 0.60405 & 0.17405 & 0.43779 & Biso & 1.000 & 0 \\
\hline 09 & 1.0000 & 0.87714 & 0.45247 & 0.44797 & Biso & 1.000 & 0 \\
\hline 010 & 1.0000 & 0.77433 & 0.25277 & 0.21128 & Biso & 1.000 & 0 \\
\hline 011 & 1.0000 & 0.46882 & 0.22776 & 0.21173 & Biso & 1.000 & 0 \\
\hline 012 & 1.0000 & 0.76058 & 0.53998 & 0.21484 & Biso & 1.000 & 0 \\
\hline 013 & 1.0000 & 0.22349 & 0.75767 & 0.80078 & Biso & 1.000 & 0 \\
\hline 014 & 1.0000 & 0.24457 & 0.47703 & 0.79088 & Biso & 1.000 & 0 \\
\hline 015 & 1.0000 & 0.52874 & 0.78036 & 0.78816 & Biso & 1.000 & 0 \\
\hline 016 & 1.0000 & 0.45190 & 0.59916 & 0.55308 & Biso & 1.000 & 0 \\
\hline 017 & 1.0000 & 0.11300 & 0.55831 & 0.56213 & Biso & 1.000 & 0 \\
\hline 018 & 1.0000 & 0.41769 & 0.85199 & 0.54723 & Biso & 1.000 & 0 \\
\hline 019 & 1.0000 & 0.97440 & 0.32620 & 0.16311 & Biso & 1.000 & 0 \\
\hline 020 & 1.0000 & 0.68271 & 0.66148 & 0.16621 & Biso & 1.000 & 0 \\
\hline 021 & 1.0000 & 0.35106 & 0.03133 & 0.15410 & Biso & 1.000 & 0 \\
\hline $\mathrm{O} 22$ & 1.0000 & 0.30563 & 0.99017 & 0.82869 & Biso & 1.000 & 0 \\
\hline 023 & 1.0000 & 0.67047 & 0.69696 & 0.84570 & Biso & 1.000 & 0 \\
\hline 024 & 1.0000 & 0.01389 & 0.33336 & 0.83867 & Biso & 1.000 & 0 \\
\hline 025 & 1.0000 & 0.64874 & 0.66074 & 0.50340 & Biso & 1.000 & 0 \\
\hline 026 & 1.0000 & 0.35016 & 0.98625 & 0.50342 & Biso & 1.000 & 0 \\
\hline 027 & 1.0000 & 0.01987 & 0.36564 & 0.49781 & Biso & 1.000 & 0 \\
\hline 028 & 1.0000 & 0.02249 & 0.67887 & 0.84501 & Biso & 1.000 & 0 \\
\hline O29 & 1.0000 & 0.31935 & 0.35001 & 0.83124 & Biso & 1.000 & 0 \\
\hline 030 & 1.0000 & 0.65601 & 0.97912 & 0.83664 & Biso & 1.000 & 0 \\
\hline 031 & 1.0000 & 0.69167 & 0.02517 & 0.16473 & Biso & 1.000 & 0 \\
\hline 032 & 1.0000 & 0.32984 & 0.31646 & 0.15939 & Biso & 1.000 & 0 \\
\hline 033 & 1.0000 & 0.99028 & 0.68488 & 0.16746 & Biso & 1.000 & 0 \\
\hline 034 & 1.0000 & 0.35363 & 0.37420 & 0.48932 & Biso & 1.000 & 0 \\
\hline 035 & 1.0000 & 0.98318 & 0.65152 & 0.50551 & Biso & 1.000 & 0 \\
\hline 036 & 1.0000 & 0.63982 & 0.02409 & 0.50373 & Biso & 1.000 & 0 \\
\hline 037 & 1.0000 & 0.12810 & 0.24704 & 0.13412 & Biso & 1.000 & 0 \\
\hline 038 & 1.0000 & 0.75962 & 0.89194 & 0.13926 & Biso & 1.000 & 0 \\
\hline 039 & 1.0000 & 0.11937 & 0.88352 & 0.13282 & Biso & 1.000 & 0 \\
\hline 040 & 1.0000 & 0.23437 & 0.11865 & 0.86037 & Biso & 1.000 & 0 \\
\hline 041 & 1.0000 & 0.87189 & 0.76158 & 0.86284 & Biso & 1.000 & 0 \\
\hline 042 & 1.0000 & 0.88345 & 0.13243 & 0.86666 & Biso & 1.000 & 0 \\
\hline 043 & 1.0000 & 0.78533 & 0.56766 & 0.46064 & Biso & 1.000 & 0 \\
\hline O4 4 & 1.0000 & 0.40488 & 0.22705 & 0.47464 & Biso & 1.000 & 0 \\
\hline 045 & 1.0000 & 0.79619 & 0.21341 & 0.47064 & Biso & 1.000 & 0 \\
\hline 046 & 1.0000 & 0.91111 & 0.45716 & 0.20865 & Biso & 1.000 & 0 \\
\hline 047 & 1.0000 & 0.53967 & 0.09437 & 0.21660 & Biso & 1.000 & 0 \\
\hline 048 & 1.0000 & 0.55571 & 0.46222 & 0.20222 & Biso & 1.000 & 0 \\
\hline 049 & 1.0000 & 0.45731 & 0.91231 & 0.80527 & Biso & 1.000 & 0 \\
\hline 050 & 1.0000 & 0.08802 & 0.55405 & 0.78772 & Biso & 1.000 & 0 \\
\hline 051 & 1.0000 & 0.44963 & 0.54887 & 0.79674 & Biso & 1.000 & 0 \\
\hline 052 & 1.0000 & 0.59374 & 0.80157 & 0.54012 & Biso & 1.000 & 0 \\
\hline 053 & 1.0000 & 0.22010 & 0.46178 & 0.53773 & Biso & 1.000 & 0 \\
\hline 054 & 1.0000 & 0.21493 & 0.78851 & 0.53181 & Biso & 1.000 & 0 \\
\hline 055 & 1.0000 & 0.99845 & 0.25913 & 0.99174 & Biso & 1.000 & 0 \\
\hline 056 & 1.0000 & 0.75828 & 0.75519 & 0.99548 & Biso & 1.000 & 0 \\
\hline 057 & 1.0000 & 0.25626 & 0.00885 & 0.98450 & Biso & 1.000 & 0 \\
\hline 058 & 1.0000 & 0.66343 & 0.60103 & 0.32448 & Biso & 1.000 & 0 \\
\hline 059 & 1.0000 & 0.93250 & 0.33603 & 0.32281 & Biso & 1.000 & 0 \\
\hline 060 & 1.0000 & 0.32442 & 0.91355 & 0.65925 & Biso & 1.000 & 0 \\
\hline 061 & 1.0000 & 0.07378 & 0.39466 & 0.65859 & Biso & 1.000 & 0 \\
\hline 062 & 1.0000 & 0.61114 & 0.68503 & 0.66210 & Biso & 1.000 & 0 \\
\hline 063 & 1.0000 & 0.99446 & 0.75412 & 0.01227 & Biso & 1.000 & 0 \\
\hline 064 & 1.0000 & 0.25269 & 0.26014 & 0.00612 & Biso & 1.000 & 0 \\
\hline 065 & 1.0000 & 0.74499 & 0.00208 & 0.01134 & Biso & 1.000 & 0 \\
\hline 066 & 1.0000 & 0.68808 & 0.08167 & 0.34545 & Biso & 1.000 & 0 \\
\hline 067 & 1.0000 & 0.93580 & 0.61792 & 0.34487 & Biso & 1.000 & 0 \\
\hline 068 & 1.0000 & 0.40007 & 0.33491 & 0.33952 & Biso & 1.000 & 0 \\
\hline 069 & 1.0000 & 0.33562 & 0.41648 & 0.67429 & Biso & 1.000 & 0 \\
\hline 070 & 1.0000 & 0.58968 & 0.93953 & 0.67923 & Biso & 1.000 & 0 \\
\hline 071 & 1.0000 & 0.07129 & 0.68880 & 0.68407 & Biso & 1.000 & 0 \\
\hline 072 & 1.0000 & 0.38026 & 0.06250 & 0.31849 & Biso & 1.000 & 0 \\
\hline $\mathrm{H} 1$ & 1.0000 & 0.01637 & 0.86921 & 0.29170 & Biso & 1.000 & $\mathrm{H}$ \\
\hline $\mathrm{C} 1$ & 1.0000 & 0.21392 & 0.95793 & 0.33131 & Biso & 1.000 & $\mathrm{C}$ \\
\hline
\end{tabular}




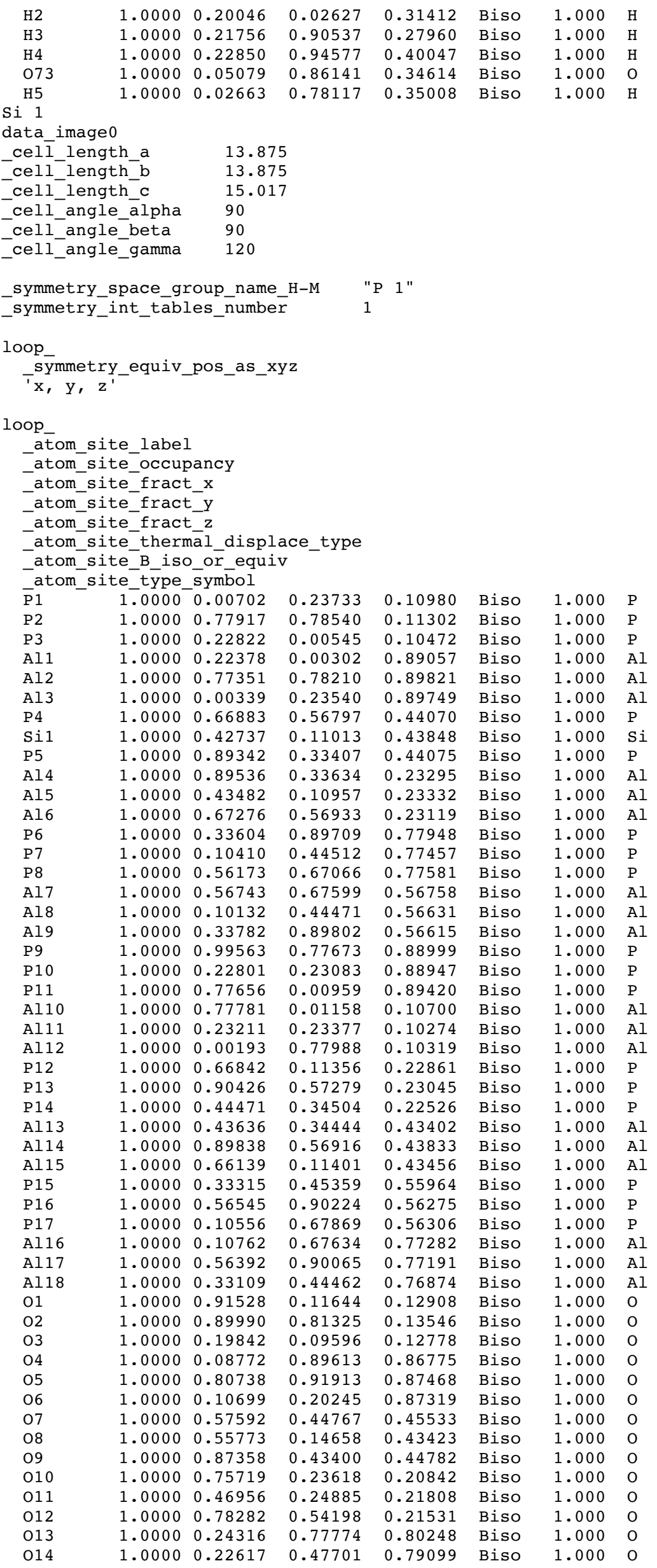




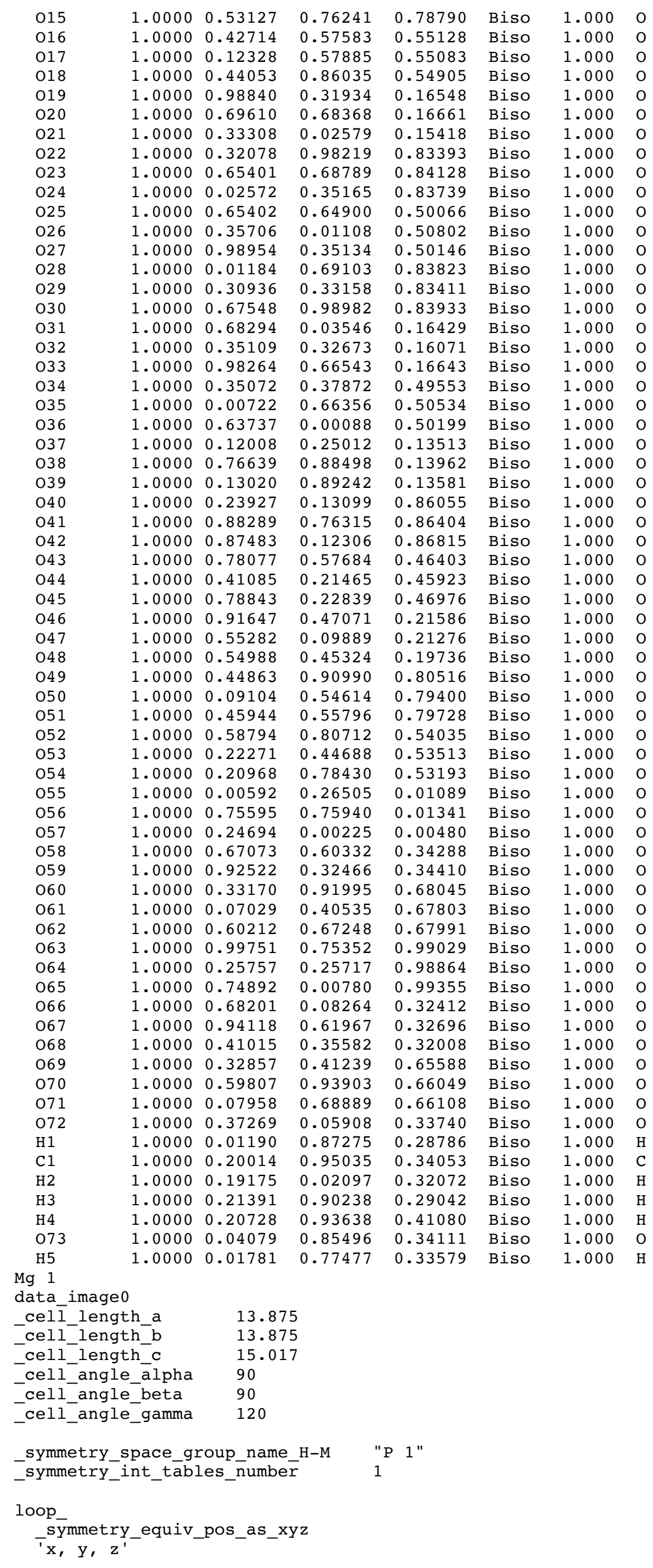




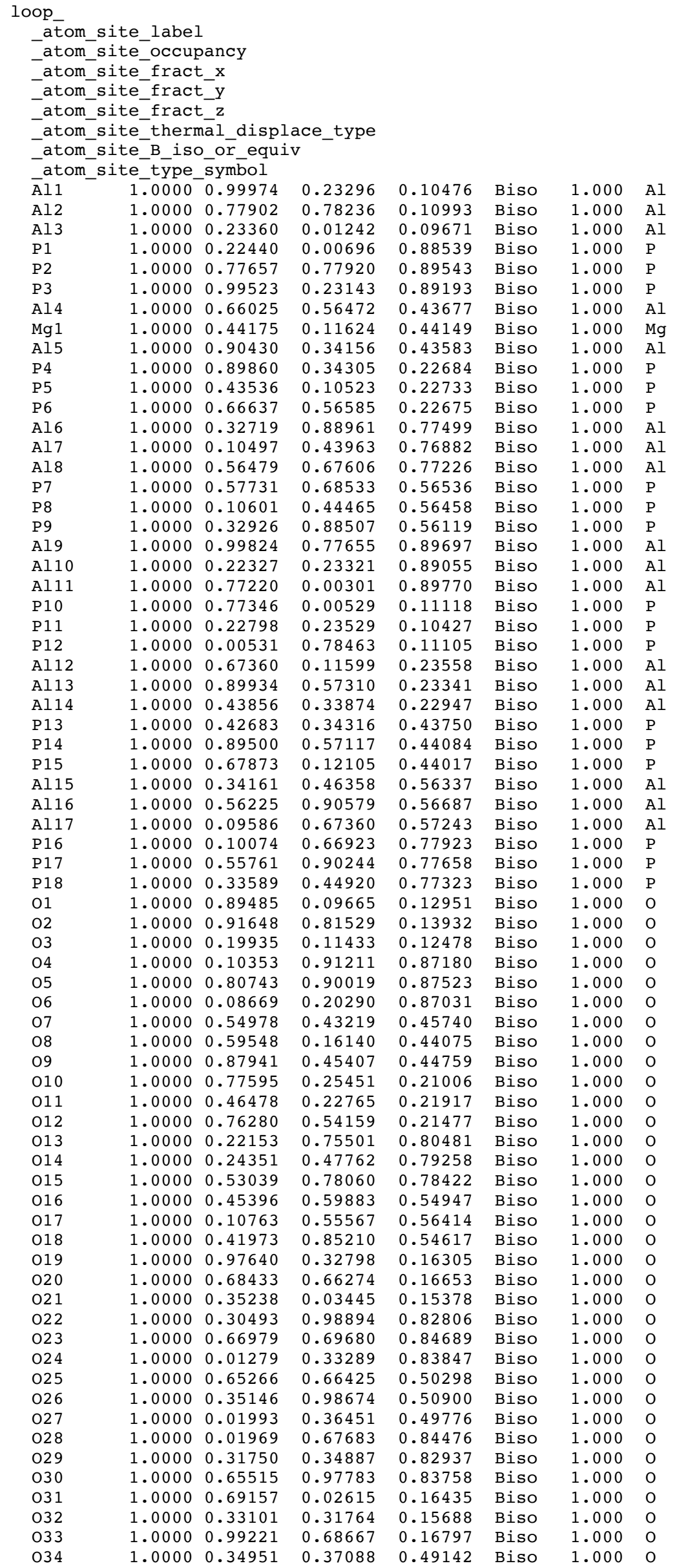




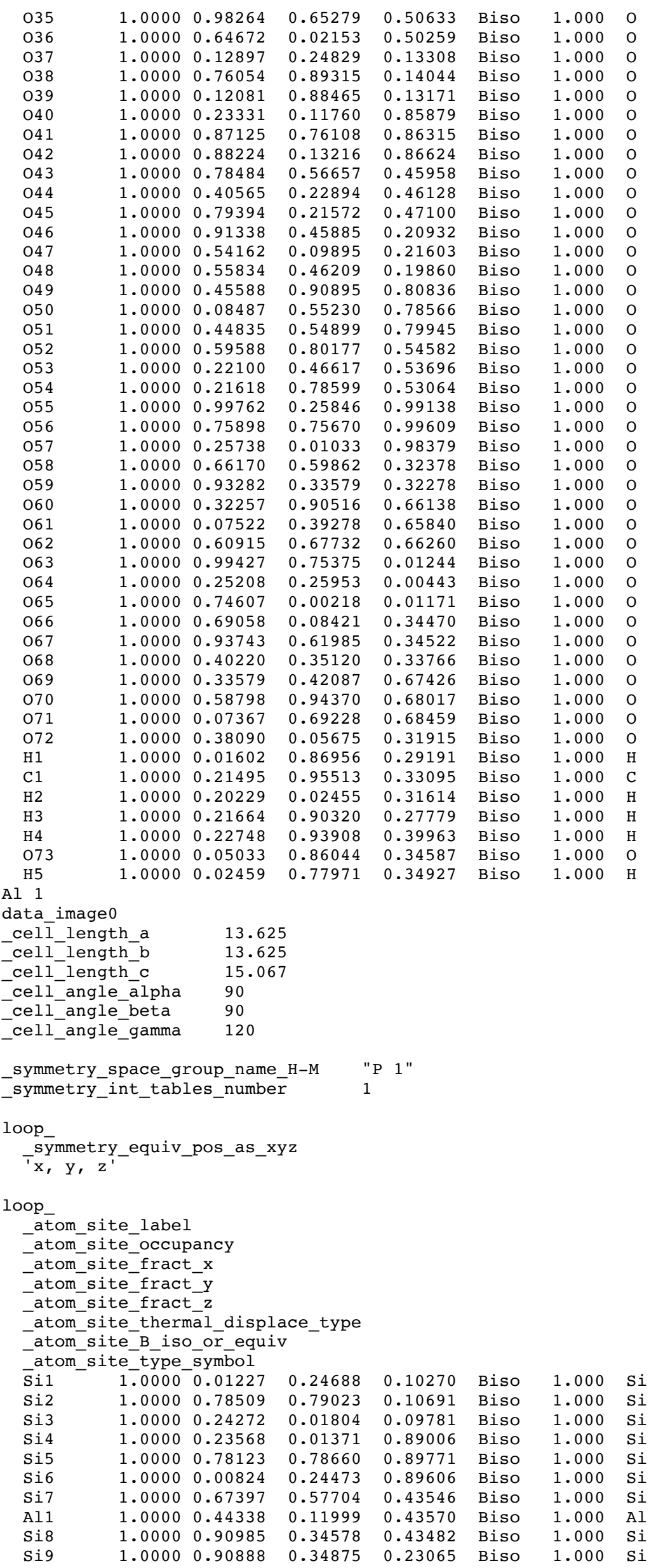




\begin{tabular}{|c|c|c|c|c|c|c|c|}
\hline Silo & 1.0000 & 0.44404 & 0.11636 & 0.22972 & Biso & 1.000 & $\mathrm{Si}$ \\
\hline Si11 & 1.0000 & 0.67858 & 0.57912 & 0.23040 & Biso & 1.000 & $\mathrm{Si}$ \\
\hline Si12 & 1.0000 & 0.34047 & 0.90438 & 0.77242 & Biso & 1.000 & $\mathrm{Si}$ \\
\hline Si13 & 1.0000 & 0.11077 & 0.44826 & 0.76718 & Biso & 1.000 & \\
\hline Si14 & 1.0000 & 0.57426 & 0.68152 & 0.76969 & Biso & 1.000 & \\
\hline Si15 & 1.0000 & 0.58274 & 0.68798 & 0.56708 & Biso & 1.000 & \\
\hline Si16 & 1.0000 & 0.11066 & 0.45045 & 0.56590 & Biso & 1.000 & \\
\hline Si17 & 1.0000 & 0.34241 & 0.90289 & 0.56397 & Biso & 1.000 & \\
\hline Si18 & 1.0000 & 0.00621 & 0.78262 & 0.89552 & Biso & 1.000 & \\
\hline Si19 & 1.0000 & 0.23701 & 0.24284 & 0.89174 & Biso & 1.000 & \\
\hline Si20 & 1.0000 & 0.78051 & 0.01461 & 0.89677 & Biso & 1.000 & \\
\hline Si21 & 1.0000 & 0.78180 & 0.01725 & 0.10438 & Biso & 1.000 & \\
\hline Si22 & 1.0000 & 0.24157 & 0.24579 & 0.09981 & Biso & 1.000 & \\
\hline Si23 & 1.0000 & 0.01269 & 0.78874 & 0.10397 & Biso & 1.000 & \\
\hline Si24 & 1.0000 & 0.68043 & 0.12165 & 0.23220 & Biso & 1.000 & \\
\hline Si25 & 1.0000 & 0.91117 & 0.58235 & 0.23240 & Biso & 1.000 & \\
\hline Si26 & 1.0000 & 0.44798 & 0.35089 & 0.22843 & Biso & 1.000 & \\
\hline Si27 & 1.0000 & 0.43904 & 0.35129 & 0.43246 & Biso & 1.000 & \\
\hline Si28 & 1.0000 & 0.90656 & 0.57880 & 0.43672 & Biso & 1.000 & \\
\hline Si29 & 1.0000 & 0.67876 & 0.12327 & 0.43360 & Biso & 1.000 & \\
\hline $\mathrm{Si} 30$ & 1.0000 & 0.34628 & 0.46305 & 0.56235 & Biso & 1.000 & \\
\hline Si31 & 1.0000 & 0.57422 & 0.91381 & 0.56527 & Biso & 1.000 & \\
\hline Si32 & 1.0000 & 0.10761 & 0.68388 & 0.56796 & Biso & 1.000 & \\
\hline Si33 & 1.0000 & 0.11051 & 0.68095 & 0.77140 & Biso & 1.000 & \\
\hline Si34 & 1.0000 & 0.57211 & 0.91219 & 0.76952 & Biso & 1.000 & \\
\hline Si35 & 1.0000 & 0.34204 & 0.45285 & 0.76690 & Biso & 1.000 & \\
\hline 01 & 1.0000 & 0.91279 & 0.11656 & 0.12090 & Biso & 1.000 & \\
\hline $\mathrm{O} 2$ & 1.0000 & 0.91623 & 0.82235 & 0.12886 & Biso & 1.000 & \\
\hline 03 & 1.0000 & 0.20944 & 0.11491 & 0.12015 & Biso & 1.000 & \\
\hline O4 & 1.0000 & 0.10552 & 0.91203 & 0.87531 & Biso & 1.000 & \\
\hline 05 & 1.0000 & 0.81489 & 0.91746 & 0.87921 & Biso & 1.000 & \\
\hline 06 & 1.0000 & 0.10641 & 0.21248 & 0.87761 & Biso & 1.000 & \\
\hline 07 & 1.0000 & 0.57139 & 0.44903 & 0.44976 & Biso & 1.000 & \\
\hline 08 & 1.0000 & 0.58562 & 0.16156 & 0.43405 & Biso & 1.000 & \\
\hline 09 & 1.0000 & 0.88495 & 0.45112 & 0.44412 & Biso & 1.000 & \\
\hline 010 & 1.0000 & 0.77744 & 0.25327 & 0.21171 & Biso & 1.000 & \\
\hline 011 & 1.0000 & 0.47583 & 0.24809 & 0.21917 & Biso & 1.000 & \\
\hline 012 & 1.0000 & 0.78090 & 0.55065 & 0.21682 & Biso & 1.000 & \\
\hline 013 & 1.0000 & 0.24071 & 0.77537 & 0.79553 & Biso & 1.000 & \\
\hline 014 & 1.0000 & 0.24271 & 0.48432 & 0.78456 & Biso & 1.000 & \\
\hline 015 & 1.0000 & 0.54229 & 0.78109 & 0.77904 & Biso & 1.000 & \\
\hline 016 & 1.0000 & 0.45002 & 0.59315 & 0.55295 & Biso & 1.000 & \\
\hline 017 & 1.0000 & 0.12528 & 0.57558 & 0.55981 & Biso & 1.000 & \\
\hline 018 & 1.0000 & 0.43907 & 0.86577 & 0.55123 & Biso & 1.000 & \\
\hline 019 & 1.0000 & 0.99422 & 0.33420 & 0.16410 & Biso & 1.000 & 0 \\
\hline 020 & 1.0000 & 0.69830 & 0.68306 & 0.16651 & Biso & 1.000 & \\
\hline $\mathrm{O} 21$ & 1.0000 & 0.35234 & 0.03830 & 0.15404 & Biso & 1.000 & \\
\hline $\mathrm{O} 22$ & 1.0000 & 0.32299 & 0.99503 & 0.83014 & Biso & 1.000 & O \\
\hline 023 & 1.0000 & 0.67094 & 0.69960 & 0.84111 & Biso & 1.000 & 0 \\
\hline $\mathrm{O} 24$ & 1.0000 & 0.02702 & 0.35032 & 0.83528 & Biso & 1.000 & 0 \\
\hline 025 & 1.0000 & 0.66330 & 0.66603 & 0.50037 & Biso & 1.000 & 0 \\
\hline 026 & 1.0000 & 0.36372 & 0.00818 & 0.50539 & Biso & 1.000 & O \\
\hline 027 & 1.0000 & 0.01467 & 0.36555 & 0.49725 & Biso & 1.000 & 0 \\
\hline 028 & 1.0000 & 0.02397 & 0.69174 & 0.83929 & Biso & 1.000 & 0 \\
\hline 029 & 1.0000 & 0.32276 & 0.34827 & 0.83004 & Biso & 1.000 & \\
\hline 030 & 1.0000 & 0.67452 & 0.99360 & 0.83565 & Biso & 1.000 & 0 \\
\hline 031 & 1.0000 & 0.69485 & 0.03765 & 0.16365 & Biso & 1.000 & 0 \\
\hline 032 & 1.0000 & 0.34919 & 0.33283 & 0.15888 & Biso & 1.000 & 0 \\
\hline 033 & 1.0000 & 0.99668 & 0.68534 & 0.16762 & Biso & 1.000 & O \\
\hline 034 & 1.0000 & 0.35791 & 0.38019 & 0.49271 & Biso & 1.000 & 0 \\
\hline 035 & 1.0000 & 0.00392 & 0.66625 & 0.50375 & Biso & 1.000 & 0 \\
\hline 036 & 1.0000 & 0.65081 & 0.01762 & 0.49929 & Biso & 1.000 & o \\
\hline 037 & 1.0000 & 0.13336 & 0.25825 & 0.12743 & Biso & 1.000 & 0 \\
\hline 038 & 1.0000 & 0.77182 & 0.89787 & 0.13372 & Biso & 1.000 & 0 \\
\hline 039 & 1.0000 & 0.13544 & 0.89677 & 0.12858 & Biso & 1.000 & o \\
\hline 040 & 1.0000 & 0.24586 & 0.13313 & 0.86273 & Biso & 1.000 & 0 \\
\hline 041 & 1.0000 & 0.88590 & 0.76982 & 0.86744 & Biso & 1.000 & 0 \\
\hline 042 & 1.0000 & 0.88713 & 0.13654 & 0.87065 & Biso & 1.000 & 0 \\
\hline 043 & 1.0000 & 0.79189 & 0.58044 & 0.45852 & Biso & 1.000 & 0 \\
\hline O4 4 & 1.0000 & 0.41892 & 0.22968 & 0.45691 & Biso & 1.000 & 0 \\
\hline 045 & 1.0000 & 0.80087 & 0.22882 & 0.46524 & Biso & 1.000 & 0 \\
\hline 046 & 1.0000 & 0.92451 & 0.47353 & 0.21311 & Biso & 1.000 & 0 \\
\hline 047 & 1.0000 & 0.55736 & 0.10872 & 0.21449 & Biso & 1.000 & O \\
\hline 048 & 1.0000 & 0.56131 & 0.46843 & 0.20186 & Biso & 1.000 & 0 \\
\hline 049 & 1.0000 & 0.46148 & 0.91842 & 0.80020 & Biso & 1.000 & 0 \\
\hline 050 & 1.0000 & 0.09534 & 0.55669 & 0.78415 & Biso & 1.000 & 0 \\
\hline 051 & 1.0000 & 0.46289 & 0.56145 & 0.79275 & Biso & 1.000 & 0 \\
\hline 052 & 1.0000 & 0.60044 & 0.81201 & 0.54507 & Biso & 1.000 & 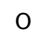 \\
\hline 053 & 1.0000 & 0.22996 & 0.46155 & 0.53864 & Biso & 1.000 & 0 \\
\hline 054 & 1.0000 & 0.22082 & 0.79496 & 0.53393 & Biso & 1.000 & 0 \\
\hline
\end{tabular}




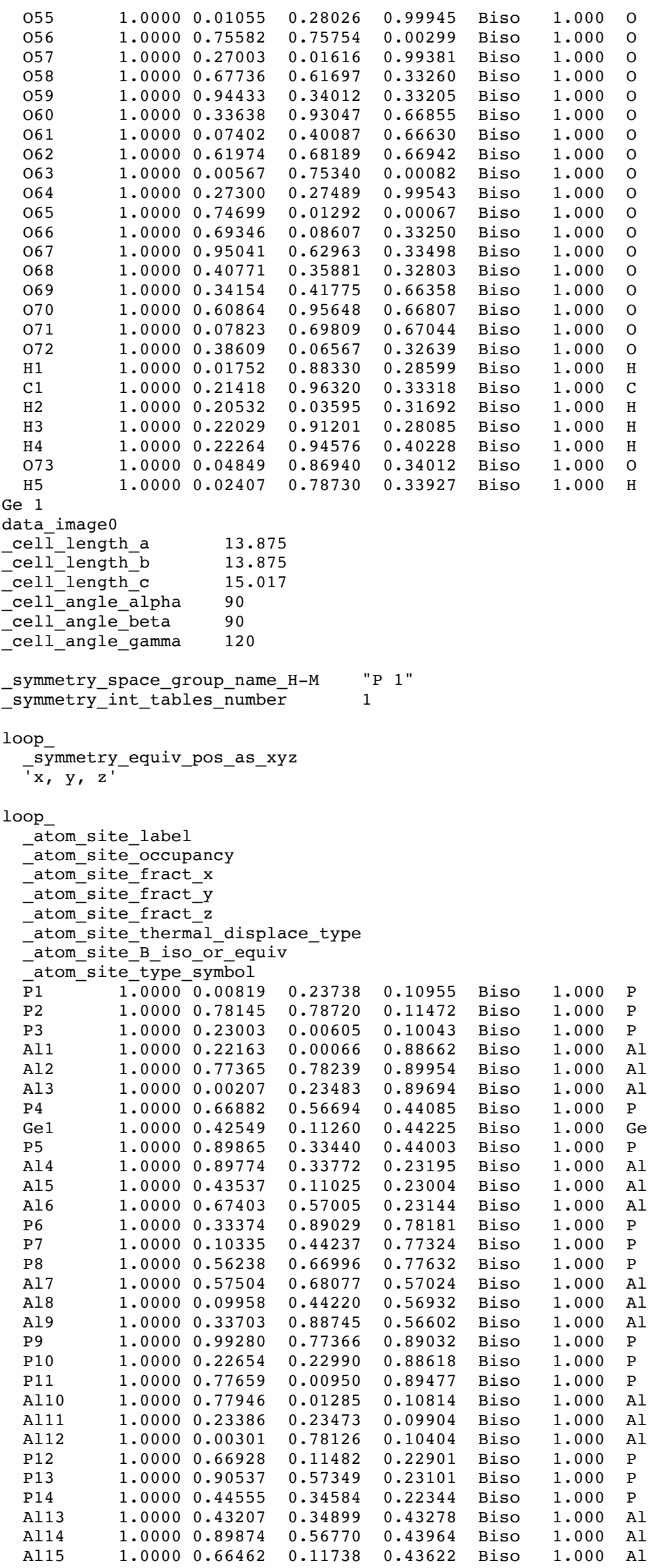




\begin{tabular}{|c|c|c|c|c|c|c|c|}
\hline P15 & 1.0000 & 0.33668 & 0.46512 & 0.55850 & Biso & 1.000 & $\mathrm{P}$ \\
\hline P16 & 1.0000 & 0.56797 & 0.90413 & 0.56413 & Biso & 1.000 & $\mathrm{P}$ \\
\hline P17 & 1.0000 & 0.10072 & 0.67735 & 0.56698 & Biso & 1.000 & $\mathrm{P}$ \\
\hline Al16 & 1.0000 & 0.10466 & 0.67523 & 0.77339 & Biso & 1.000 & $\mathrm{Al}$ \\
\hline Al17 & 1.0000 & 0.56130 & 0.89936 & 0.77369 & Biso & 1.000 & Al \\
\hline Al18 & 1.0000 & 0.33062 & 0.44518 & 0.76636 & Biso & 1.000 & $\mathrm{Al}$ \\
\hline 01 & 1.0000 & 0.91696 & 0.11701 & 0.13121 & Biso & 1.000 & 0 \\
\hline $\mathrm{O} 2$ & 1.0000 & 0.90209 & 0.81547 & 0.13850 & Biso & 1.000 & 0 \\
\hline 03 & 1.0000 & 0.19980 & 0.09648 & 0.12247 & Biso & 1.000 & 0 \\
\hline 04 & 1.0000 & 0.08566 & 0.89197 & 0.86599 & Biso & 1.000 & 0 \\
\hline 05 & 1.0000 & 0.80869 & 0.91979 & 0.87578 & Biso & 1.000 & 0 \\
\hline 06 & 1.0000 & 0.10531 & 0.20182 & 0.87155 & Biso & 1.000 & 0 \\
\hline 07 & 1.0000 & 0.57304 & 0.44777 & 0.45442 & Biso & 1.000 & 0 \\
\hline 08 & 1.0000 & 0.56960 & 0.16242 & 0.43909 & Biso & 1.000 & 0 \\
\hline 09 & 1.0000 & 0.87944 & 0.43453 & 0.44982 & Biso & 1.000 & 0 \\
\hline 010 & 1.0000 & 0.75926 & 0.23703 & 0.20907 & Biso & 1.000 & 0 \\
\hline 011 & 1.0000 & 0.47144 & 0.25029 & 0.21752 & Biso & 1.000 & 0 \\
\hline 012 & 1.0000 & 0.78402 & 0.54264 & 0.21523 & Biso & 1.000 & 0 \\
\hline 013 & 1.0000 & 0.23911 & 0.77345 & 0.80911 & Biso & 1.000 & 0 \\
\hline 014 & 1.0000 & 0.22639 & 0.47830 & 0.79089 & Biso & 1.000 & 0 \\
\hline 015 & 1.0000 & 0.53033 & 0.76100 & 0.78409 & Biso & 1.000 & 0 \\
\hline 016 & 1.0000 & 0.43329 & 0.58633 & 0.55427 & Biso & 1.000 & 0 \\
\hline 017 & 1.0000 & 0.10513 & 0.56960 & 0.56395 & Biso & 1.000 & 0 \\
\hline 018 & 1.0000 & 0.44303 & 0.85549 & 0.54398 & Biso & 1.000 & 0 \\
\hline 019 & 1.0000 & 0.99088 & 0.32072 & 0.16459 & Biso & 1.000 & 0 \\
\hline 020 & 1.0000 & 0.69789 & 0.68506 & 0.16762 & Biso & 1.000 & 0 \\
\hline 021 & 1.0000 & 0.33615 & 0.02839 & 0.14887 & Biso & 1.000 & 0 \\
\hline 022 & 1.0000 & 0.31759 & 0.98041 & 0.82745 & Biso & 1.000 & 0 \\
\hline 023 & 1.0000 & 0.65131 & 0.68846 & 0.84571 & Biso & 1.000 & 0 \\
\hline 024 & 1.0000 & 0.02672 & 0.35441 & 0.84061 & Biso & 1.000 & 0 \\
\hline 025 & 1.0000 & 0.65706 & 0.64959 & 0.50129 & Biso & 1.000 & 0 \\
\hline 026 & 1.0000 & 0.34812 & 0.00176 & 0.51472 & Biso & 1.000 & 0 \\
\hline 027 & 1.0000 & 0.99570 & 0.34958 & 0.49855 & Biso & 1.000 & 0 \\
\hline 028 & 1.0000 & 0.00790 & 0.68533 & 0.84139 & Biso & 1.000 & 0 \\
\hline 029 & 1.0000 & 0.30670 & 0.32903 & 0.82872 & Biso & 1.000 & 0 \\
\hline 030 & 1.0000 & 0.67372 & 0.98683 & 0.84112 & Biso & 1.000 & 0 \\
\hline 031 & 1.0000 & 0.68444 & 0.03615 & 0.16579 & Biso & 1.000 & 0 \\
\hline 032 & 1.0000 & 0.35323 & 0.32692 & 0.15721 & Biso & 1.000 & 0 \\
\hline 033 & 1.0000 & 0.98440 & 0.66761 & 0.16828 & Biso & 1.000 & 0 \\
\hline 034 & 1.0000 & 0.35101 & 0.39310 & 0.48932 & Biso & 1.000 & 0 \\
\hline 035 & 1.0000 & 0.00502 & 0.66553 & 0.50729 & Biso & 1.000 & 0 \\
\hline 036 & 1.0000 & 0.63872 & 0.00406 & 0.50413 & Biso & 1.000 & 0 \\
\hline 037 & 1.0000 & 0.12210 & 0.25095 & 0.13294 & Biso & 1.000 & 0 \\
\hline 038 & 1.0000 & 0.76760 & 0.88618 & 0.14095 & Biso & 1.000 & 0 \\
\hline 039 & 1.0000 & 0.13299 & 0.89345 & 0.13341 & Biso & 1.000 & 0 \\
\hline 040 & 1.0000 & 0.23609 & 0.12876 & 0.85821 & Biso & 1.000 & 0 \\
\hline 041 & 1.0000 & 0.88053 & 0.76060 & 0.86320 & Biso & 1.000 & 0 \\
\hline 042 & 1.0000 & 0.87323 & 0.12317 & 0.86662 & Biso & 1.000 & 0 \\
\hline 043 & 1.0000 & 0.77839 & 0.57075 & 0.46421 & Biso & 1.000 & 0 \\
\hline 044 & 1.0000 & 0.39501 & 0.21774 & 0.46676 & Biso & 1.000 & 0 \\
\hline 045 & 1.0000 & 0.79461 & 0.22828 & 0.46940 & Biso & 1.000 & 0 \\
\hline 046 & 1.0000 & 0.91812 & 0.47191 & 0.21515 & Biso & 1.000 & 0 \\
\hline 047 & 1.0000 & 0.55453 & 0.10119 & 0.21106 & Biso & 1.000 & 0 \\
\hline 048 & 1.0000 & 0.55094 & 0.45465 & 0.19694 & Biso & 1.000 & 0 \\
\hline 049 & 1.0000 & 0.44554 & 0.90472 & 0.81278 & Biso & 1.000 & 0 \\
\hline 050 & 1.0000 & 0.08745 & 0.54313 & 0.78366 & Biso & 1.000 & 0 \\
\hline 051 & 1.0000 & 0.45961 & 0.55697 & 0.79623 & Biso & 1.000 & 0 \\
\hline 052 & 1.0000 & 0.60001 & 0.81454 & 0.54630 & Biso & 1.000 & 0 \\
\hline 053 & 1.0000 & 0.22887 & 0.46498 & 0.53655 & Biso & 1.000 & 0 \\
\hline 054 & 1.0000 & 0.20994 & 0.77297 & 0.53094 & Biso & 1.000 & 0 \\
\hline 055 & 1.0000 & 0.00391 & 0.26235 & 0.01053 & Biso & 1.000 & 0 \\
\hline 056 & 1.0000 & 0.75999 & 0.76168 & 0.01499 & Biso & 1.000 & 0 \\
\hline 057 & 1.0000 & 0.24723 & 0.00048 & 0.00053 & Biso & 1.000 & $\mathrm{O}$ \\
\hline 058 & 1.0000 & 0.67250 & 0.60390 & 0.34327 & Biso & 1.000 & 0 \\
\hline 059 & 1.0000 & 0.92870 & 0.32648 & 0.34266 & Biso & 1.000 & 0 \\
\hline 060 & 1.0000 & 0.33286 & 0.90360 & 0.68111 & Biso & 1.000 & 0 \\
\hline 061 & 1.0000 & 0.06976 & 0.39257 & 0.67898 & Biso & 1.000 & 0 \\
\hline 062 & 1.0000 & 0.60810 & 0.67182 & 0.68229 & Biso & 1.000 & 0 \\
\hline 063 & 1.0000 & 0.99419 & 0.75348 & 0.99121 & Biso & 1.000 & 0 \\
\hline 064 & 1.0000 & 0.25871 & 0.25883 & 0.98479 & Biso & 1.000 & $\mathrm{O}$ \\
\hline 065 & 1.0000 & 0.75131 & 0.00964 & 0.99450 & Biso & 1.000 & 0 \\
\hline 066 & 1.0000 & 0.67966 & 0.08331 & 0.32514 & Biso & 1.000 & 0 \\
\hline 067 & 1.0000 & 0.94107 & 0.61854 & 0.32813 & Biso & 1.000 & 0 \\
\hline 068 & 1.0000 & 0.40864 & 0.35577 & 0.31759 & Biso & 1.000 & 0 \\
\hline 069 & 1.0000 & 0.32987 & 0.41700 & 0.65258 & Biso & 1.000 & 0 \\
\hline 070 & 1.0000 & 0.59204 & 0.94197 & 0.66248 & Biso & 1.000 & 0 \\
\hline 071 & 1.0000 & 0.08014 & 0.70074 & 0.66339 & Biso & 1.000 & 0 \\
\hline 072 & 1.0000 & 0.36931 & 0.05580 & 0.33225 & Biso & 1.000 & 0 \\
\hline H 1 & 1.0000 & 0.00697 & 0.87016 & 0.28870 & Biso & 1.000 & $\mathrm{H}$ \\
\hline C1 & 1.0000 & 0.19660 & 0.94734 & 0.33813 & Biso & 1.000 & C \\
\hline
\end{tabular}




$\begin{array}{llllllll}\text { H2 } & 1.0000 & 0.18859 & 0.01912 & 0.32157 & \text { Biso } & 1.000 & \mathrm{H} \\ \text { H3 } & 1.0000 & 0.20906 & 0.90118 & 0.28561 & \text { Biso } & 1.000 & \mathrm{H} \\ \text { H4 } & 1.0000 & 0.20578 & 0.93102 & 0.40753 & \text { Biso } & 1.000 & \mathrm{H} \\ \text { O73 } & 1.0000 & 0.03802 & 0.85307 & 0.34100 & \text { Biso } & 1.000 & \text { O } \\ \text { H5 } & 1.0000 & 0.01508 & 0.77284 & 0.33595 & \text { Biso } & 1.000 & \text { H }\end{array}$

Ga 1

data image 0

$\begin{array}{ll}\text {-celi__length_a } & 13.625 \\ \text {-cell_length_b } & 13.625 \\ \text {-cell_length_c } & 15.067 \\ \text {-cell_angle_alpha } & 90 \\ \text {-cell_angle_beta } & 90 \\ \text { _cell_angle_gamma } & 120\end{array}$

_cell_angle_gamma 120

symmetry_space_group_name_H-M "P 1 "

-symmetry_int_tables_number $\bar{r} 1$

loop

_symmetry_equiv_pos_as_xyz

$' \mathrm{x}, \mathrm{y}, \mathrm{z}$ '

loop_

_atom_site_label

-atom_site_occupancy

-atom_site_fract_x

-atom_site_fract_y

-atom_site_fract_z

_atom_site_thermal_displace_type

-atom_site_B_iso_or_equiv

atom site type symbol

\begin{tabular}{|c|c|c|c|c|c|c|c|}
\hline$\overline{\mathrm{S}} \mathrm{i} 1$ & 1.0000 & 0.01290 & 0.24712 & 0.10223 & Biso & 1.000 & $\mathrm{Si}$ \\
\hline $\mathrm{Si2}$ & 1.0000 & 0.78620 & 0.79092 & 0.10819 & Biso & 1.000 & $\mathrm{Si}$ \\
\hline $\mathrm{Si3}$ & 1.0000 & 0.24329 & 0.01819 & 0.09550 & Biso & 1.000 & $\mathrm{Si}$ \\
\hline $\mathrm{Si} 4$ & 1.0000 & 0.23391 & 0.01192 & 0.88816 & Biso & 1.000 & $\mathrm{Si}$ \\
\hline Si5 & 1.0000 & 0.78138 & 0.78607 & 0.89906 & Biso & 1.000 & $\mathrm{Si}$ \\
\hline Si6 & 1.0000 & 0.00761 & 0.24448 & 0.89524 & Biso & 1.000 & $\mathrm{Si}$ \\
\hline Si 7 & 1.0000 & 0.67401 & 0.57530 & 0.43668 & Biso & 1.000 & $\mathrm{Si}$ \\
\hline Ga 1 & 1.0000 & 0.44400 & 0.12328 & 0.43842 & Biso & 1.000 & $\mathrm{Ga}$ \\
\hline Si8 & 1.0000 & 0.91542 & 0.34607 & 0.43434 & Biso & 1.000 & $\mathrm{Si}$ \\
\hline $\operatorname{Si9}$ & 1.0000 & 0.91002 & 0.34923 & 0.23055 & Biso & 1.000 & $\mathrm{Si}$ \\
\hline Si 10 & 1.0000 & 0.44487 & 0.11798 & 0.22737 & Biso & 1.000 & $\mathrm{Si}$ \\
\hline Si11 & 1.0000 & 0.67940 & 0.57991 & 0.23175 & Biso & 1.000 & $\mathrm{Si}$ \\
\hline Si12 & 1.0000 & 0.33981 & 0.90231 & 0.77193 & Biso & 1.000 & $\mathrm{Si}$ \\
\hline Si13 & 1.0000 & 0.11102 & 0.44699 & 0.76626 & Biso & 1.000 & $\mathrm{Si}$ \\
\hline Si14 & 1.0000 & 0.57449 & 0.68140 & 0.77027 & Biso & 1.000 & $\mathrm{Si}$ \\
\hline Si15 & 1.0000 & 0.58871 & 0.69143 & 0.56811 & Biso & 1.000 & $\mathrm{Si}$ \\
\hline Si16 & 1.0000 & 0.11007 & 0.44972 & 0.56707 & Biso & 1.000 & $\mathrm{Si}$ \\
\hline Si17 & 1.0000 & 0.34190 & 0.89692 & 0.56272 & Biso & 1.000 & $\mathrm{Si}$ \\
\hline Si18 & 1.0000 & 0.00499 & 0.78045 & 0.89599 & Biso & 1.000 & $\mathrm{Si}$ \\
\hline Si19 & 1.0000 & 0.23627 & 0.24236 & 0.88975 & Biso & 1.000 & $\mathrm{Si}$ \\
\hline Si20 & 1.0000 & 0.78085 & 0.01415 & 0.89751 & Biso & 1.000 & $\mathrm{Si}$ \\
\hline Si21 & 1.0000 & 0.78285 & 0.01806 & 0.10524 & Biso & 1.000 & $\mathrm{Si}$ \\
\hline Si22 & 1.0000 & 0.24229 & 0.24646 & 0.09765 & Biso & 1.000 & $\mathrm{Si}$ \\
\hline Si23 & 1.0000 & 0.01321 & 0.78912 & 0.10470 & Biso & 1.000 & $\mathrm{Si}$ \\
\hline Si24 & 1.0000 & 0.68053 & 0.12206 & 0.23330 & Biso & 1.000 & $\mathrm{Si}$ \\
\hline Si25 & 1.0000 & 0.91071 & 0.58221 & 0.23293 & Biso & 1.000 & $\mathrm{Si}$ \\
\hline Si26 & 1.0000 & 0.44817 & 0.35031 & 0.22750 & Biso & 1.000 & $\mathrm{Si}$ \\
\hline Si27 & 1.0000 & 0.43416 & 0.35168 & 0.43310 & Biso & 1.000 & $\mathrm{Si}$ \\
\hline Si28 & 1.0000 & 0.90666 & 0.57738 & 0.43769 & Biso & 1.000 & $\mathrm{Si}$ \\
\hline Si29 & 1.0000 & 0.68129 & 0.12663 & 0.43532 & Biso & 1.000 & $\mathrm{Si}$ \\
\hline Si30 & 1.0000 & 0.34806 & 0.46992 & 0.56118 & Biso & 1.000 & $\mathrm{Si}$ \\
\hline Si31 & 1.0000 & 0.57628 & 0.91445 & 0.56566 & Biso & 1.000 & $\mathrm{Si}$ \\
\hline Si32 & 1.0000 & 0.10316 & 0.68233 & 0.56974 & Biso & 1.000 & $\mathrm{Si}$ \\
\hline Si33 & 1.0000 & 0.10941 & 0.68036 & 0.77113 & Biso & 1.000 & $\mathrm{Si}$ \\
\hline Si34 & 1.0000 & 0.57062 & 0.91052 & 0.77065 & Biso & 1.000 & $\mathrm{Si}$ \\
\hline Si35 & 1.0000 & 0.34199 & 0.45245 & 0.76513 & Biso & 1.000 & $\mathrm{Si}$ \\
\hline 01 & 1.0000 & 0.91406 & 0.11690 & 0.12175 & Biso & 1.000 & 0 \\
\hline $\mathrm{O} 2$ & 1.0000 & 0.91749 & 0.82358 & 0.13039 & Biso & 1.000 & 0 \\
\hline 03 & 1.0000 & 0.20954 & 0.11506 & 0.11658 & Biso & 1.000 & $\mathrm{O}$ \\
\hline 04 & 1.0000 & 0.10376 & 0.90969 & 0.87437 & Biso & 1.000 & 0 \\
\hline 05 & 1.0000 & 0.81648 & 0.91756 & 0.88126 & Biso & 1.000 & $\mathrm{O}$ \\
\hline 06 & 1.0000 & 0.10588 & 0.21270 & 0.87583 & Biso & 1.000 & $\mathrm{O}$ \\
\hline 07 & 1.0000 & 0.56682 & 0.44944 & 0.44907 & Biso & 1.000 & 0 \\
\hline 08 & 1.0000 & 0.59448 & 0.17369 & 0.43791 & Biso & 1.000 & 0 \\
\hline 09 & 1.0000 & 0.89295 & 0.45278 & 0.44531 & Biso & 1.000 & 0 \\
\hline 010 & 1.0000 & 0.77805 & 0.25371 & 0.21354 & Biso & 1.000 & 0 \\
\hline 011 & 1.0000 & 0.48007 & 0.25061 & 0.21541 & Biso & 1.000 & $\mathrm{O}$ \\
\hline 012 & 1.0000 & 0.78028 & 0.54967 & 0.21611 & Biso & 1.000 & 0 \\
\hline 013 & 1.0000 & 0.23990 & 0.77360 & 0.79594 & Biso & 1.000 & $\mathrm{O}$ \\
\hline 014 & 1.0000 & 0.24322 & 0.48437 & 0.78502 & Biso & 1.000 & 0 \\
\hline
\end{tabular}




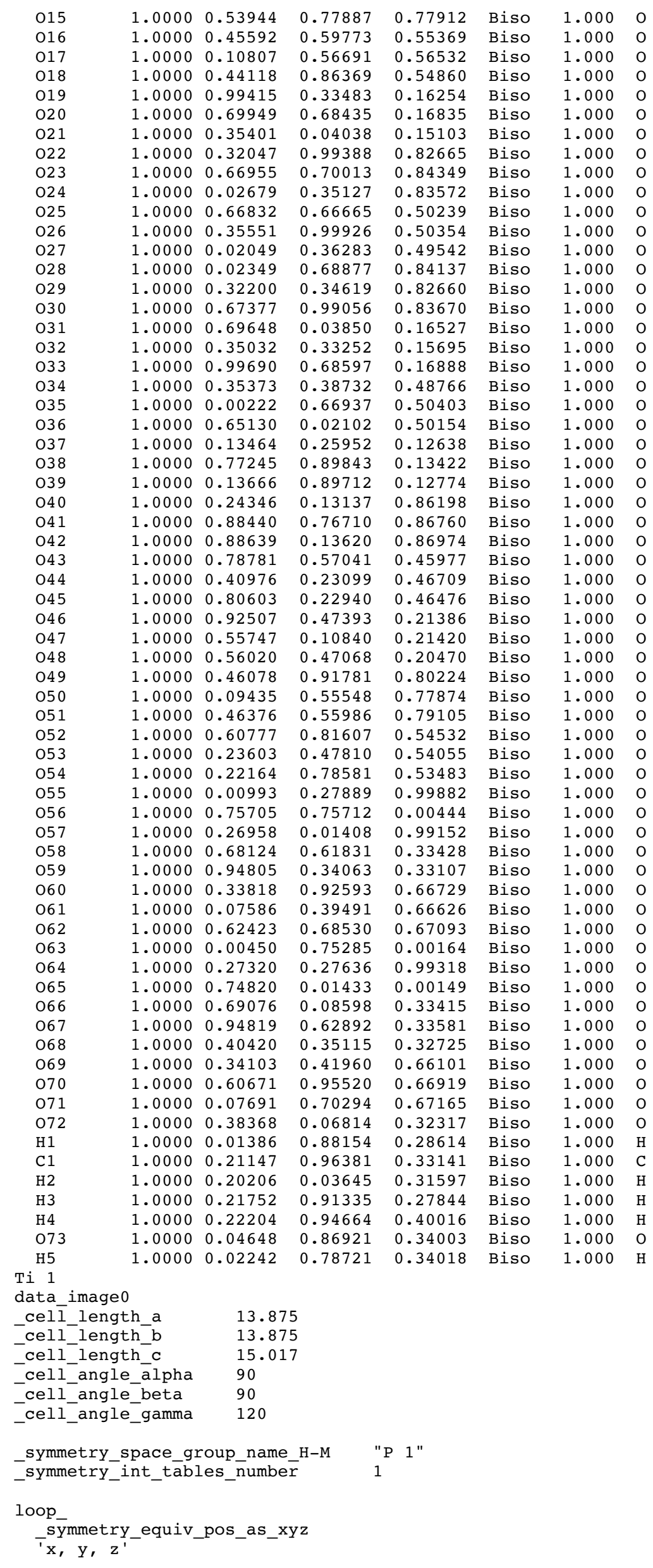




\begin{tabular}{|c|c|c|c|c|c|c|c|}
\hline \multicolumn{8}{|c|}{$\begin{array}{l}\text { oop_- } \\
\text {-atom_site_label } \\
\text {-atom_site_occupancy } \\
\text {-atom_site_fract_x } \\
\text {-atom_site_fract_y } \\
\text {-atom_site_fract_z } \\
\text {-atom_site_thermal_displace_type } \\
\text {-atom_site_B_iso_or_equiv } \\
\text { atom_site_type symbol }\end{array}$} \\
\hline$\overline{\mathrm{P}} 1$ & 1.0000 & 0.00873 & 0.23732 & 0.10943 & Biso & 1.000 & $\mathrm{P}$ \\
\hline P2 & 1.0000 & 0.78364 & 0.78870 & 0.11585 & Biso & 1.000 & $\mathrm{P}$ \\
\hline P3 & 1.0000 & 0.23185 & 0.00676 & 0.09751 & Biso & 1.000 & $\mathrm{P}$ \\
\hline Al1 & 1.0000 & 0.22045 & 0.99950 & 0.88357 & Biso & 1.000 & Al \\
\hline Al2 & 1.0000 & 0.77394 & 0.78252 & 0.90046 & Biso & 1.000 & Al \\
\hline Al3 & 1.0000 & 0.00123 & 0.23431 & 0.89645 & Biso & 1.000 & Al \\
\hline P 4 & 1.0000 & 0.67006 & 0.56871 & 0.44169 & Biso & 1.000 & $\mathrm{P}$ \\
\hline Til & 1.0000 & 0.42086 & 0.11041 & 0.44399 & Biso & 1.000 & $\mathrm{Ti}$ \\
\hline P5 & 1.0000 & 0.90289 & 0.33526 & 0.43929 & Biso & 1.000 & $\mathrm{P}$ \\
\hline Al4 & 1.0000 & 0.89916 & 0.33842 & 0.23149 & Biso & 1.000 & Al \\
\hline Al5 & 1.0000 & 0.43470 & 0.11055 & 0.22832 & Biso & 1.000 & Al \\
\hline Al6 & 1.0000 & 0.67520 & 0.57083 & 0.23231 & Biso & 1.000 & Al \\
\hline P6 & 1.0000 & 0.33284 & 0.88698 & 0.78278 & Biso & 1.000 & $\mathrm{P}$ \\
\hline P7 & 1.0000 & 0.10333 & 0.44138 & 0.77312 & Biso & 1.000 & $\mathrm{P}$ \\
\hline P8 & 1.0000 & 0.56285 & 0.66936 & 0.77721 & Biso & 1.000 & $\mathrm{P}$ \\
\hline Al 7 & 1.0000 & 0.58046 & 0.68294 & 0.57204 & Biso & 1.000 & Al \\
\hline Al8 & 1.0000 & 0.09876 & 0.44144 & 0.57115 & Biso & 1.000 & Al \\
\hline Al9 & 1.0000 & 0.33546 & 0.88010 & 0.56637 & Biso & 1.000 & Al \\
\hline P9 & 1.0000 & 0.99161 & 0.77206 & 0.89019 & Biso & 1.000 & $\mathrm{P}$ \\
\hline P10 & 1.0000 & 0.22546 & 0.22891 & 0.88411 & Biso & 1.000 & $\mathrm{P}$ \\
\hline P11 & 1.0000 & 0.77654 & 0.00925 & 0.89538 & Biso & 1.000 & $\mathrm{P}$ \\
\hline Al10 & 1.0000 & 0.78005 & 0.01362 & 0.10921 & Biso & 1.000 & Al \\
\hline Al11 & 1.0000 & 0.23473 & 0.23486 & 0.09733 & Biso & 1.000 & Al \\
\hline Al12 & 1.0000 & 0.00455 & 0.78238 & 0.10416 & Biso & 1.000 & Al \\
\hline P12 & 1.0000 & 0.67051 & 0.11603 & 0.23020 & Biso & 1.000 & $P$ \\
\hline P13 & 1.0000 & 0.90570 & 0.57392 & 0.23132 & Biso & 1.000 & $P$ \\
\hline $\mathrm{P} 14$ & 1.0000 & 0.44515 & 0.34621 & 0.22302 & Biso & 1.000 & $P$ \\
\hline Al13 & 1.0000 & 0.42813 & 0.35334 & 0.43278 & Biso & 1.000 & Al \\
\hline Al14 & 1.0000 & 0.89953 & 0.56778 & 0.44019 & Biso & 1.000 & Al \\
\hline Al15 & 1.0000 & 0.66937 & 0.11754 & 0.43788 & Biso & 1.000 & Al \\
\hline P15 & 1.0000 & 0.33767 & 0.47084 & 0.55812 & Biso & 1.000 & $P$ \\
\hline P16 & 1.0000 & 0.57108 & 0.90585 & 0.56560 & Biso & 1.000 & $\mathrm{P}$ \\
\hline P17 & 1.0000 & 0.09718 & 0.67452 & 0.56915 & Biso & 1.000 & $P$ \\
\hline Al16 & 1.0000 & 0.10314 & 0.67429 & 0.77382 & Biso & 1.000 & Al \\
\hline Al17 & 1.0000 & 0.55992 & 0.89822 & 0.77521 & Biso & 1.000 & Al \\
\hline Al18 & 1.0000 & 0.33053 & 0.44537 & 0.76551 & Biso & 1.000 & Al \\
\hline 01 & 1.0000 & 0.91752 & 0.11759 & 0.13295 & Biso & 1.000 & 0 \\
\hline $\mathrm{O} 2$ & 1.0000 & 0.90461 & 0.81776 & 0.13993 & Biso & 1.000 & 0 \\
\hline 03 & 1.0000 & 0.20119 & 0.09668 & 0.12068 & Biso & 1.000 & 0 \\
\hline 04 & 1.0000 & 0.08465 & 0.88961 & 0.86419 & Biso & 1.000 & 0 \\
\hline 05 & 1.0000 & 0.80923 & 0.91995 & 0.87638 & Biso & 1.000 & $\mathrm{O}$ \\
\hline 06 & 1.0000 & 0.10435 & 0.20150 & 0.87008 & Biso & 1.000 & 0 \\
\hline 07 & 1.0000 & 0.56854 & 0.45309 & 0.45515 & Biso & 1.000 & 0 \\
\hline 08 & 1.0000 & 0.56729 & 0.15344 & 0.44241 & Biso & 1.000 & 0 \\
\hline 09 & 1.0000 & 0.88551 & 0.43651 & 0.44906 & Biso & 1.000 & 0 \\
\hline 010 & 1.0000 & 0.76021 & 0.23817 & 0.20930 & Biso & 1.000 & 0 \\
\hline 011 & 1.0000 & 0.47222 & 0.25152 & 0.21652 & Biso & 1.000 & 0 \\
\hline 012 & 1.0000 & 0.78407 & 0.54184 & 0.21500 & Biso & 1.000 & 0 \\
\hline 013 & 1.0000 & 0.23698 & 0.77161 & 0.81187 & Biso & 1.000 & 0 \\
\hline 014 & 1.0000 & 0.22665 & 0.47873 & 0.79138 & Biso & 1.000 & 0 \\
\hline 015 & 1.0000 & 0.52989 & 0.75990 & 0.78291 & Biso & 1.000 & 0 \\
\hline 016 & 1.0000 & 0.43930 & 0.58891 & 0.55374 & Biso & 1.000 & 0 \\
\hline 017 & 1.0000 & 0.08877 & 0.56069 & 0.57053 & Biso & 1.000 & 0 \\
\hline 018 & 1.0000 & 0.44733 & 0.85789 & 0.54099 & Biso & 1.000 & 0 \\
\hline 019 & 1.0000 & 0.99232 & 0.32192 & 0.16357 & Biso & 1.000 & 0 \\
\hline 020 & 1.0000 & 0.70025 & 0.68622 & 0.16848 & Biso & 1.000 & 0 \\
\hline 021 & 1.0000 & 0.33980 & 0.03066 & 0.14363 & Biso & 1.000 & 0 \\
\hline 022 & 1.0000 & 0.31616 & 0.97933 & 0.82357 & Biso & 1.000 & 0 \\
\hline 023 & 1.0000 & 0.65005 & 0.68856 & 0.84847 & Biso & 1.000 & $\mathrm{O}$ \\
\hline $\mathrm{O} 24$ & 1.0000 & 0.02698 & 0.35545 & 0.84189 & Biso & 1.000 & 0 \\
\hline 025 & 1.0000 & 0.66468 & 0.65487 & 0.50255 & Biso & 1.000 & 0 \\
\hline 026 & 1.0000 & 0.33999 & 0.99310 & 0.51627 & Biso & 1.000 & 0 \\
\hline 027 & 1.0000 & 0.00064 & 0.34910 & 0.49647 & Biso & 1.000 & 0 \\
\hline 028 & 1.0000 & 0.00576 & 0.68224 & 0.84265 & Biso & 1.000 & 0 \\
\hline 029 & 1.0000 & 0.30563 & 0.32787 & 0.82643 & Biso & 1.000 & 0 \\
\hline 030 & 1.0000 & 0.67242 & 0.98497 & 0.84286 & Biso & 1.000 & 0 \\
\hline 031 & 1.0000 & 0.68468 & 0.03713 & 0.16631 & Biso & 1.000 & 0 \\
\hline 032 & 1.0000 & 0.35428 & 0.32777 & 0.15527 & Biso & 1.000 & 0 \\
\hline 033 & 1.0000 & 0.98468 & 0.66843 & 0.16877 & Biso & 1.000 & 0 \\
\hline 034 & 1.0000 & 0.34409 & 0.39684 & 0.48601 & Biso & 1.000 & 0 \\
\hline
\end{tabular}




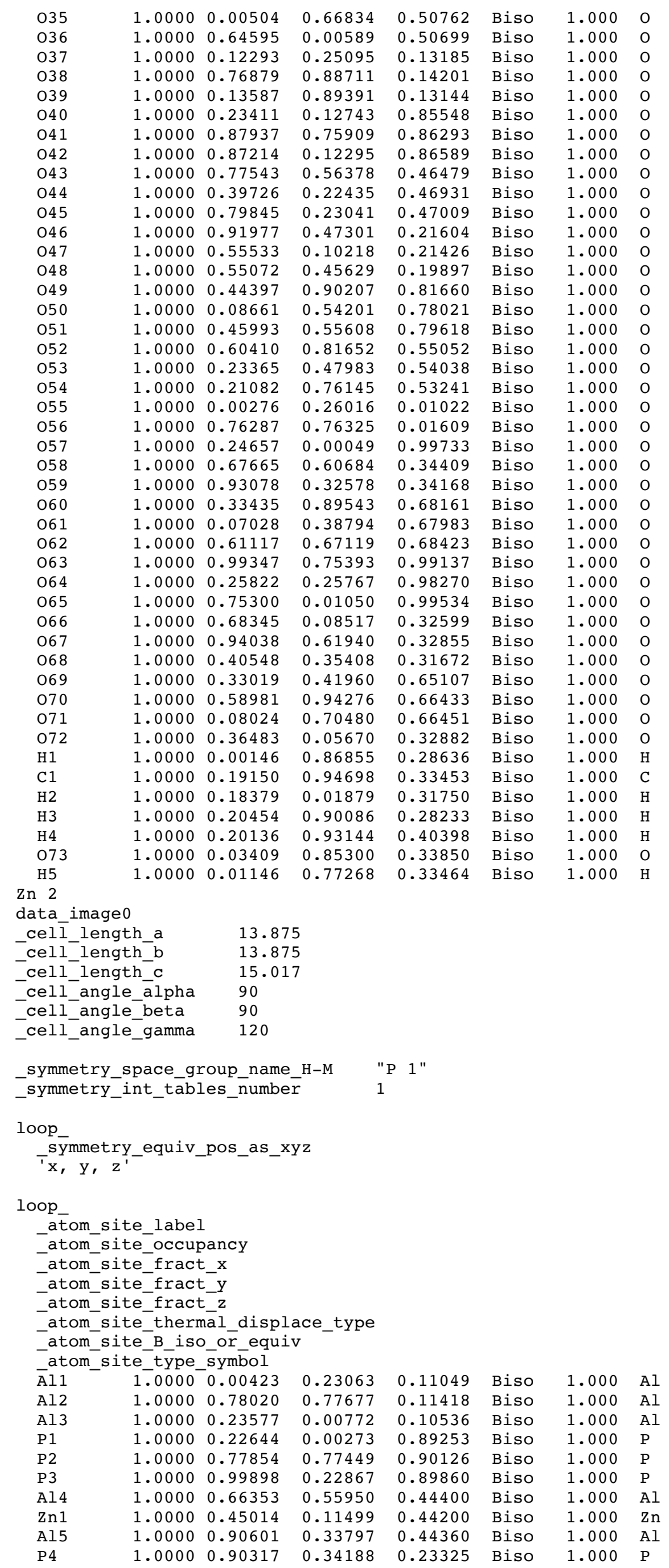




\begin{tabular}{|c|c|c|c|c|c|c|c|}
\hline P5 & 1.0000 & 0.44319 & 0.10395 & 0.23020 & Biso & 1.000 & $\mathrm{P}$ \\
\hline P6 & 1.0000 & 0.66994 & 0.56295 & 0.23396 & Biso & 1.000 & $\mathrm{P}$ \\
\hline Al6 & 1.0000 & 0.33075 & 0.88956 & 0.77943 & Biso & 1.000 & Al \\
\hline Al7 & 1.0000 & 0.10929 & 0.43714 & 0.77519 & Biso & 1.000 & Al \\
\hline A18 & 1.0000 & 0.56753 & 0.67300 & 0.77747 & Biso & 1.000 & Al \\
\hline P7 & 1.0000 & 0.57874 & 0.68188 & 0.56911 & Biso & 1.000 & $\mathrm{P}$ \\
\hline P8 & 1.0000 & 0.11027 & 0.44135 & 0.56960 & Biso & 1.000 & $\mathrm{P}$ \\
\hline P9 & 1.0000 & 0.33232 & 0.88602 & 0.56676 & Biso & 1.000 & $\mathrm{P}$ \\
\hline Al9 & 1.0000 & 0.00364 & 0.77330 & 0.90449 & Biso & 1.000 & Al \\
\hline Al10 & 1.0000 & 0.22759 & 0.23033 & 0.89818 & Biso & 1.000 & Al \\
\hline Al11 & 1.0000 & 0.77567 & 0.99888 & 0.90392 & Biso & 1.000 & Al \\
\hline P10 & 1.0000 & 0.77941 & 0.00157 & 0.11695 & Biso & 1.000 & $P$ \\
\hline P11 & 1.0000 & 0.23219 & 0.23234 & 0.11090 & Biso & 1.000 & $P$ \\
\hline P12 & 1.0000 & 0.00949 & 0.78145 & 0.11804 & Biso & 1.000 & $\mathrm{P}$ \\
\hline Al12 & 1.0000 & 0.67661 & 0.11188 & 0.24030 & Biso & 1.000 & Al \\
\hline Al13 & 1.0000 & 0.89983 & 0.56694 & 0.23854 & Biso & 1.000 & Al \\
\hline Al1 14 & 1.0000 & 0.44247 & 0.33241 & 0.23659 & Biso & 1.000 & Al \\
\hline P13 & 1.0000 & 0.42887 & 0.33412 & 0.44544 & Biso & 1.000 & $\mathrm{P}$ \\
\hline P14 & 1.0000 & 0.89377 & 0.56168 & 0.45002 & Biso & 1.000 & $P$ \\
\hline P15 & 1.0000 & 0.68140 & 0.11739 & 0.44575 & Biso & 1.000 & $\mathrm{P}$ \\
\hline Al15 & 1.0000 & 0.34522 & 0.45751 & 0.56900 & Biso & 1.000 & Al \\
\hline Al16 & 1.0000 & 0.56378 & 0.90137 & 0.57258 & Biso & 1.000 & Al \\
\hline Al17 & 1.0000 & 0.09970 & 0.66935 & 0.57616 & Biso & 1.000 & Al \\
\hline P16 & 1.0000 & 0.10504 & 0.66649 & 0.78404 & Biso & 1.000 & $\mathrm{P}$ \\
\hline P 17 & 1.0000 & 0.56139 & 0.89830 & 0.78253 & Biso & 1.000 & P \\
\hline P18 & 1.0000 & 0.33970 & 0.44461 & 0.77876 & Biso & 1.000 & $\mathrm{P}$ \\
\hline 01 & 1.0000 & 0.90181 & 0.09250 & 0.13314 & Biso & 1.000 & 0 \\
\hline $\mathrm{O} 2$ & 1.0000 & 0.91824 & 0.81142 & 0.13835 & Biso & 1.000 & 0 \\
\hline 03 & 1.0000 & 0.20057 & 0.11048 & 0.12978 & Biso & 1.000 & 0 \\
\hline 04 & 1.0000 & 0.10636 & 0.90836 & 0.87445 & Biso & 1.000 & 0 \\
\hline 05 & 1.0000 & 0.81075 & 0.89595 & 0.88073 & Biso & 1.000 & 0 \\
\hline 06 & 1.0000 & 0.09084 & 0.20027 & 0.87836 & Biso & 1.000 & 0 \\
\hline 07 & 1.0000 & 0.55131 & 0.42720 & 0.46147 & Biso & 1.000 & 0 \\
\hline 08 & 1.0000 & 0.60740 & 0.16915 & 0.45037 & Biso & 1.000 & 0 \\
\hline 09 & 1.0000 & 0.87608 & 0.44465 & 0.46685 & Biso & 1.000 & 0 \\
\hline 010 & 1.0000 & 0.78129 & 0.25046 & 0.21955 & Biso & 1.000 & 0 \\
\hline 011 & 1.0000 & 0.47592 & 0.22784 & 0.22115 & Biso & 1.000 & 0 \\
\hline 012 & 1.0000 & 0.76291 & 0.53505 & 0.21708 & Biso & 1.000 & 0 \\
\hline 013 & 1.0000 & 0.22585 & 0.75399 & 0.80783 & Biso & 1.000 & 0 \\
\hline 014 & 1.0000 & 0.24759 & 0.47345 & 0.79773 & Biso & 1.000 & 0 \\
\hline 015 & 1.0000 & 0.53157 & 0.77594 & 0.79372 & Biso & 1.000 & 0 \\
\hline 016 & 1.0000 & 0.45599 & 0.59311 & 0.55386 & Biso & 1.000 & 0 \\
\hline 017 & 1.0000 & 0.11780 & 0.55504 & 0.56576 & Biso & 1.000 & 0 \\
\hline 018 & 1.0000 & 0.42106 & 0.84999 & 0.55604 & Biso & 1.000 & 0 \\
\hline 019 & 1.0000 & 0.98136 & 0.32260 & 0.17306 & Biso & 1.000 & 0 \\
\hline 020 & 1.0000 & 0.68689 & 0.66011 & 0.17442 & Biso & 1.000 & 0 \\
\hline 021 & 1.0000 & 0.35835 & 0.03503 & 0.15687 & Biso & 1.000 & 0 \\
\hline $\mathrm{O} 22$ & 1.0000 & 0.30968 & 0.98702 & 0.83656 & Biso & 1.000 & 0 \\
\hline 023 & 1.0000 & 0.67559 & 0.69322 & 0.84806 & Biso & 1.000 & 0 \\
\hline $\mathrm{O} 24$ & 1.0000 & 0.01626 & 0.32875 & 0.84322 & Biso & 1.000 & 0 \\
\hline 025 & 1.0000 & 0.65549 & 0.66057 & 0.50856 & Biso & 1.000 & 0 \\
\hline 026 & 1.0000 & 0.35390 & 0.98439 & 0.51066 & Biso & 1.000 & 0 \\
\hline 027 & 1.0000 & 0.02251 & 0.35997 & 0.50439 & Biso & 1.000 & 0 \\
\hline 028 & 1.0000 & 0.02356 & 0.67451 & 0.84858 & Biso & 1.000 & 0 \\
\hline 029 & 1.0000 & 0.32133 & 0.34484 & 0.83548 & Biso & 1.000 & 0 \\
\hline 030 & 1.0000 & 0.65820 & 0.97403 & 0.84409 & Biso & 1.000 & 0 \\
\hline 031 & 1.0000 & 0.69986 & 0.02386 & 0.17142 & Biso & 1.000 & 0 \\
\hline 032 & 1.0000 & 0.33423 & 0.31287 & 0.16516 & Biso & 1.000 & 0 \\
\hline 033 & 1.0000 & 0.99186 & 0.68293 & 0.17570 & Biso & 1.000 & 0 \\
\hline 034 & 1.0000 & 0.35094 & 0.36358 & 0.49712 & Biso & 1.000 & 0 \\
\hline 035 & 1.0000 & 0.98731 & 0.64881 & 0.50961 & Biso & 1.000 & 0 \\
\hline 036 & 1.0000 & 0.64576 & 0.01792 & 0.50892 & Biso & 1.000 & 0 \\
\hline 037 & 1.0000 & 0.13354 & 0.24658 & 0.13948 & Biso & 1.000 & 0 \\
\hline 038 & 1.0000 & 0.76641 & 0.88979 & 0.14687 & Biso & 1.000 & 0 \\
\hline 039 & 1.0000 & 0.12265 & 0.88216 & 0.14266 & Biso & 1.000 & 0 \\
\hline 040 & 1.0000 & 0.23630 & 0.11413 & 0.86673 & Biso & 1.000 & 0 \\
\hline 041 & 1.0000 & 0.87502 & 0.75671 & 0.87422 & Biso & 1.000 & 0 \\
\hline 042 & 1.0000 & 0.88628 & 0.12846 & 0.87339 & Biso & 1.000 & 0 \\
\hline 043 & 1.0000 & 0.78704 & 0.56286 & 0.47319 & Biso & 1.000 & 0 \\
\hline 044 & 1.0000 & 0.40928 & 0.22265 & 0.47714 & Biso & 1.000 & 0 \\
\hline 045 & 1.0000 & 0.80114 & 0.20599 & 0.47302 & Biso & 1.000 & 0 \\
\hline 046 & 1.0000 & 0.91558 & 0.45470 & 0.20797 & Biso & 1.000 & 0 \\
\hline 047 & 1.0000 & 0.54825 & 0.09630 & 0.21273 & Biso & 1.000 & 0 \\
\hline 048 & 1.0000 & 0.55804 & 0.46137 & 0.21038 & Biso & 1.000 & 0 \\
\hline 049 & 1.0000 & 0.46015 & 0.90811 & 0.80970 & Biso & 1.000 & 0 \\
\hline 050 & 1.0000 & 0.09095 & 0.55045 & 0.79327 & Biso & 1.000 & 0 \\
\hline 051 & 1.0000 & 0.45251 & 0.54460 & 0.80387 & Biso & 1.000 & 0 \\
\hline 052 & 1.0000 & 0.59529 & 0.79685 & 0.54621 & Biso & 1.000 & 0 \\
\hline 053 & 1.0000 & 0.22272 & 0.45599 & 0.54193 & Biso & 1.000 & 0 \\
\hline 054 & 1.0000 & 0.21876 & 0.78588 & 0.53540 & Biso & 1.000 & 0 \\
\hline
\end{tabular}




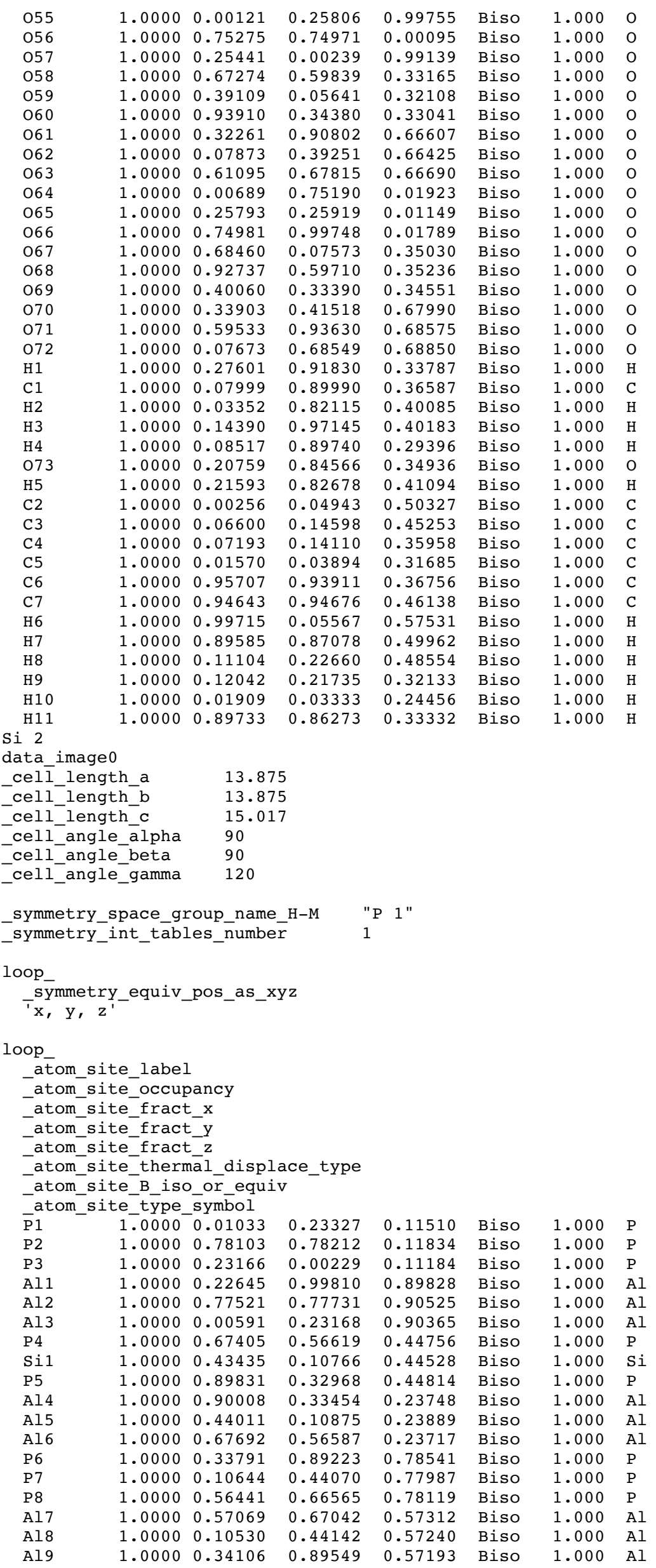




\begin{tabular}{|c|c|c|c|c|c|c|c|}
\hline P9 & 1.0000 & 0.99894 & 0.77152 & 0.89928 & Biso & 1.000 & $\mathrm{P}$ \\
\hline P10 & 1.0000 & 0.23094 & 0.22665 & 0.89498 & Biso & 1.000 & $\mathrm{P}$ \\
\hline P11 & 1.0000 & 0.77930 & 0.00494 & 0.89948 & Biso & 1.000 & $\mathrm{P}$ \\
\hline Al10 & 1.0000 & 0.78015 & 0.00754 & 0.11218 & Biso & 1.000 & Al \\
\hline Al11 & 1.0000 & 0.23684 & 0.23086 & 0.10719 & Biso & 1.000 & Al \\
\hline Al12 & 1.0000 & 0.00582 & 0.77653 & 0.11206 & Biso & 1.000 & Al \\
\hline P12 & 1.0000 & 0.67107 & 0.11005 & 0.23320 & Biso & 1.000 & $P$ \\
\hline P13 & 1.0000 & 0.90381 & 0.56441 & 0.23515 & Biso & 1.000 & $\mathrm{P}$ \\
\hline P14 & 1.0000 & 0.44680 & 0.34267 & 0.23184 & Biso & 1.000 & $\mathrm{P}$ \\
\hline Al13 & 1.0000 & 0.43935 & 0.34008 & 0.44030 & Biso & 1.000 & Al \\
\hline Al14 & 1.0000 & 0.89887 & 0.55970 & 0.44572 & Biso & 1.000 & Al \\
\hline Al15 & 1.0000 & 0.66542 & 0.10878 & 0.44142 & Biso & 1.000 & Al \\
\hline P15 & 1.0000 & 0.33614 & 0.44807 & 0.56464 & Biso & 1.000 & $\mathrm{P}$ \\
\hline P16 & 1.0000 & 0.56805 & 0.89752 & 0.56844 & Biso & 1.000 & $\mathrm{P}$ \\
\hline P17 & 1.0000 & 0.10786 & 0.67472 & 0.56906 & Biso & 1.000 & $\mathrm{P}$ \\
\hline Al16 & 1.0000 & 0.10953 & 0.67256 & 0.77885 & Biso & 1.000 & Al \\
\hline Al17 & 1.0000 & 0.56663 & 0.89665 & 0.77698 & Biso & 1.000 & Al \\
\hline Al18 & 1.0000 & 0.33343 & 0.44086 & 0.77474 & Biso & 1.000 & $\mathrm{Al}$ \\
\hline 01 & 1.0000 & 0.91839 & 0.11205 & 0.13318 & Biso & 1.000 & 0 \\
\hline $\mathrm{O} 2$ & 1.0000 & 0.90269 & 0.81158 & 0.13557 & Biso & 1.000 & 0 \\
\hline 03 & 1.0000 & 0.20117 & 0.09318 & 0.13201 & Biso & 1.000 & 0 \\
\hline 04 & 1.0000 & 0.09012 & 0.89114 & 0.87596 & Biso & 1.000 & 0 \\
\hline 05 & 1.0000 & 0.81019 & 0.91450 & 0.87976 & Biso & 1.000 & 0 \\
\hline 06 & 1.0000 & 0.10969 & 0.19869 & 0.88013 & Biso & 1.000 & 0 \\
\hline 07 & 1.0000 & 0.57682 & 0.44823 & 0.46228 & Biso & 1.000 & 0 \\
\hline 08 & 1.0000 & 0.56530 & 0.14485 & 0.45142 & Biso & 1.000 & 0 \\
\hline 09 & 1.0000 & 0.87388 & 0.42519 & 0.46540 & Biso & 1.000 & 0 \\
\hline 010 & 1.0000 & 0.76334 & 0.23143 & 0.21467 & Biso & 1.000 & 0 \\
\hline 011 & 1.0000 & 0.47380 & 0.24834 & 0.22296 & Biso & 1.000 & 0 \\
\hline 012 & 1.0000 & 0.78238 & 0.53373 & 0.21744 & Biso & 1.000 & 0 \\
\hline 013 & 1.0000 & 0.24542 & 0.77276 & 0.80868 & Biso & 1.000 & 0 \\
\hline 014 & 1.0000 & 0.22862 & 0.47345 & 0.79711 & Biso & 1.000 & 0 \\
\hline 015 & 1.0000 & 0.53511 & 0.75844 & 0.79129 & Biso & 1.000 & 0 \\
\hline 016 & 1.0000 & 0.43198 & 0.56869 & 0.55319 & Biso & 1.000 & 0 \\
\hline 017 & 1.0000 & 0.12658 & 0.57530 & 0.55886 & Biso & 1.000 & 0 \\
\hline 018 & 1.0000 & 0.44345 & 0.85715 & 0.55467 & Biso & 1.000 & 0 \\
\hline 019 & 1.0000 & 0.99380 & 0.31419 & 0.17363 & Biso & 1.000 & 0 \\
\hline 020 & 1.0000 & 0.70107 & 0.68190 & 0.17472 & Biso & 1.000 & 0 \\
\hline $\mathrm{O} 21$ & 1.0000 & 0.33665 & 0.02473 & 0.16140 & Biso & 1.000 & 0 \\
\hline $\mathrm{O} 22$ & 1.0000 & 0.32264 & 0.97730 & 0.83979 & Biso & 1.000 & 0 \\
\hline $\mathrm{O} 23$ & 1.0000 & 0.65734 & 0.68369 & 0.84606 & Biso & 1.000 & 0 \\
\hline $\mathrm{O} 24$ & 1.0000 & 0.02807 & 0.34768 & 0.84299 & Biso & 1.000 & 0 \\
\hline 025 & 1.0000 & 0.66239 & 0.65089 & 0.50592 & Biso & 1.000 & 0 \\
\hline 026 & 1.0000 & 0.35845 & 0.00655 & 0.51251 & Biso & 1.000 & 0 \\
\hline $\mathrm{O} 27$ & 1.0000 & 0.99710 & 0.34614 & 0.50569 & Biso & 1.000 & 0 \\
\hline 028 & 1.0000 & 0.01391 & 0.68652 & 0.84486 & Biso & 1.000 & 0 \\
\hline O29 & 1.0000 & 0.31089 & 0.32572 & 0.83740 & Biso & 1.000 & 0 \\
\hline 030 & 1.0000 & 0.67859 & 0.98553 & 0.84419 & Biso & 1.000 & 0 \\
\hline 031 & 1.0000 & 0.68585 & 0.03080 & 0.17034 & Biso & 1.000 & 0 \\
\hline 032 & 1.0000 & 0.35293 & 0.32446 & 0.16744 & Biso & 1.000 & 0 \\
\hline 033 & 1.0000 & 0.98340 & 0.66315 & 0.17680 & Biso & 1.000 & 0 \\
\hline O34 & 1.0000 & 0.34915 & 0.36885 & 0.50211 & Biso & 1.000 & 0 \\
\hline 035 & 1.0000 & 0.00963 & 0.65826 & 0.51065 & Biso & 1.000 & 0 \\
\hline 036 & 1.0000 & 0.64193 & 0.99341 & 0.50616 & Biso & 1.000 & 0 \\
\hline 037 & 1.0000 & 0.12307 & 0.24461 & 0.13931 & Biso & 1.000 & 0 \\
\hline 038 & 1.0000 & 0.76947 & 0.88211 & 0.14653 & Biso & 1.000 & 0 \\
\hline 039 & 1.0000 & 0.13330 & 0.89049 & 0.14306 & Biso & 1.000 & 0 \\
\hline 040 & 1.0000 & 0.24073 & 0.12565 & 0.86726 & Biso & 1.000 & 0 \\
\hline 041 & 1.0000 & 0.88546 & 0.75783 & 0.87538 & Biso & 1.000 & 0 \\
\hline 042 & 1.0000 & 0.87791 & 0.11861 & 0.87386 & Biso & 1.000 & 0 \\
\hline 043 & 1.0000 & 0.78331 & 0.57095 & 0.47401 & Biso & 1.000 & 0 \\
\hline O4 4 & 1.0000 & 0.41772 & 0.21237 & 0.46662 & Biso & 1.000 & 0 \\
\hline 045 & 1.0000 & 0.79738 & 0.21873 & 0.47350 & Biso & 1.000 & 0 \\
\hline 046 & 1.0000 & 0.91790 & 0.46495 & 0.21119 & Biso & 1.000 & 0 \\
\hline 047 & 1.0000 & 0.55854 & 0.10002 & 0.21302 & Biso & 1.000 & 0 \\
\hline 048 & 1.0000 & 0.55045 & 0.45297 & 0.20562 & Biso & 1.000 & 0 \\
\hline 049 & 1.0000 & 0.45084 & 0.90513 & 0.81018 & Biso & 1.000 & 0 \\
\hline 050 & 1.0000 & 0.09226 & 0.54142 & 0.79703 & Biso & 1.000 & 0 \\
\hline 051 & 1.0000 & 0.46151 & 0.55398 & 0.80423 & Biso & 1.000 & 0 \\
\hline 052 & 1.0000 & 0.58874 & 0.80076 & 0.54825 & Biso & 1.000 & 0 \\
\hline 053 & 1.0000 & 0.22635 & 0.44322 & 0.54023 & Biso & 1.000 & 0 \\
\hline 054 & 1.0000 & 0.21231 & 0.78020 & 0.53631 & Biso & 1.000 & 0 \\
\hline 055 & 1.0000 & 0.00842 & 0.26291 & 0.01678 & Biso & 1.000 & 0 \\
\hline 056 & 1.0000 & 0.75082 & 0.75415 & 0.01967 & Biso & 1.000 & 0 \\
\hline 057 & 1.0000 & 0.25131 & 0.99814 & 0.01185 & Biso & 1.000 & 0 \\
\hline 058 & 1.0000 & 0.68021 & 0.60187 & 0.34944 & Biso & 1.000 & 0 \\
\hline 059 & 1.0000 & 0.38783 & 0.06013 & 0.34379 & Biso & 1.000 & 0 \\
\hline 060 & 1.0000 & 0.93083 & 0.33074 & 0.34992 & Biso & 1.000 & 0 \\
\hline 061 & 1.0000 & 0.33248 & 0.91444 & 0.68629 & Biso & 1.000 & 0 \\
\hline 062 & 1.0000 & 0.07362 & 0.39917 & 0.68344 & & 1.000 & 0 \\
\hline
\end{tabular}




\begin{tabular}{|c|c|c|c|c|c|c|c|}
\hline 063 & 1.0000 & 0.60344 & 0.66414 & 0.68532 & Biso & 1.000 & 0 \\
\hline 064 & 1.0000 & 0.00384 & 0.74777 & 0.99883 & Biso & 1.000 & 0 \\
\hline 065 & 1.0000 & 0.26335 & 0.25623 & 0.99336 & Biso & 1.000 & 0 \\
\hline 066 & 1.0000 & 0.75110 & 0.00287 & 0.99867 & Biso & 1.000 & 0 \\
\hline 067 & 1.0000 & 0.67922 & 0.07722 & 0.32940 & Biso & 1.000 & 0 \\
\hline 068 & 1.0000 & 0.93363 & 0.59713 & 0.33373 & Biso & 1.000 & 0 \\
\hline 069 & 1.0000 & 0.41059 & 0.35069 & 0.32694 & Biso & 1.000 & 0 \\
\hline 070 & 1.0000 & 0.33171 & 0.40972 & 0.66166 & Biso & 1.000 & 0 \\
\hline 071 & 1.0000 & 0.60123 & 0.93647 & 0.66577 & Biso & 1.000 & 0 \\
\hline 072 & 1.0000 & 0.08328 & 0.68794 & 0.66673 & Biso & 1.000 & 0 \\
\hline H1 & 1.0000 & 0.27589 & 0.92497 & 0.34853 & Biso & 1.000 & $\mathrm{H}$ \\
\hline $\mathrm{C} 1$ & 1.0000 & 0.07747 & 0.90167 & 0.36569 & Biso & 1.000 & C \\
\hline H2 & 1.0000 & 0.03172 & 0.82284 & 0.40060 & Biso & 1.000 & $\mathrm{H}$ \\
\hline H3 & 1.0000 & 0.14136 & 0.97296 & 0.40188 & Biso & 1.000 & $\mathrm{H}$ \\
\hline H4 & 1.0000 & 0.08442 & 0.89919 & 0.29390 & Biso & 1.000 & $\mathrm{H}$ \\
\hline 073 & 1.0000 & 0.20765 & 0.84942 & 0.35137 & Biso & 1.000 & 0 \\
\hline H5 & 1.0000 & 0.20864 & 0.82250 & 0.41163 & Biso & 1.000 & $\mathrm{H}$ \\
\hline $\mathrm{C} 2$ & 1.0000 & 0.00168 & 0.05030 & 0.50274 & Biso & 1.000 & $\mathrm{C}$ \\
\hline $\mathrm{C} 3$ & 1.0000 & 0.06491 & 0.14680 & 0.45185 & Biso & 1.000 & C \\
\hline $\mathrm{C} 4$ & 1.0000 & 0.06996 & 0.14189 & 0.35884 & Biso & 1.000 & C \\
\hline $\mathrm{C} 5$ & 1.0000 & 0.01351 & 0.03971 & 0.31620 & Biso & 1.000 & C \\
\hline $\mathrm{C} 6$ & 1.0000 & 0.95550 & 0.93982 & 0.36702 & Biso & 1.000 & $\mathrm{C}$ \\
\hline C7 & 1.0000 & 0.94511 & 0.94765 & 0.46091 & Biso & 1.000 & $\mathrm{C}$ \\
\hline H6 & 1.0000 & 0.99688 & 0.05652 & 0.57484 & Biso & 1.000 & $\mathrm{H}$ \\
\hline H7 & 1.0000 & 0.89492 & 0.87161 & 0.49919 & Biso & 1.000 & $\mathrm{H}$ \\
\hline H8 & 1.0000 & 0.11070 & 0.22739 & 0.48484 & Biso & 1.000 & $\mathrm{H}$ \\
\hline H9 & 1.0000 & 0.11766 & 0.21814 & 0.32043 & Biso & 1.000 & $\mathrm{H}$ \\
\hline $\mathrm{H} 10$ & 1.0000 & 0.01652 & 0.03408 & 0.24389 & Biso & 1.000 & $\mathrm{H}$ \\
\hline H11 & 1.0000 & 0.89524 & 0.86354 & 0.33290 & Biso & 1.000 & $\mathrm{H}$ \\
\hline \\
\hline \multicolumn{8}{|c|}{ data image 0} \\
\hline \multicolumn{8}{|c|}{ celílength_a } \\
\hline \multicolumn{8}{|c|}{ _cell_length_b $\quad 13.875$} \\
\hline \multicolumn{8}{|c|}{ cell- length ${ }^{-} \mathrm{c} \quad 15.017$} \\
\hline \multicolumn{8}{|c|}{ _cell_angle_àlpha 90} \\
\hline \multicolumn{8}{|c|}{ _cell_angle_beta 90} \\
\hline -cell_ & e_gamma & 120 & & & & & \\
\hline symme & space_gr & coup_name & $\mathrm{H}-\mathrm{M}$ & $1 "$ & & & \\
\hline _symme & int_tab] & Les_numbe & & & & & \\
\hline loop_ & & & & & & & \\
\hline -sym & I_equiv & pos_as_x & & & & & \\
\hline ' $\mathrm{x}$, & & & & & & & \\
\hline loop_ & & & & & & & \\
\hline _ato & Ee_labe & & & & & & \\
\hline ato & te occup & pancy & & & & & \\
\hline -ato & te_frac & $=x$ & & & & & \\
\hline -ato & te_fract & & & & & & \\
\hline -ato & te_fract & $=z$ & & & & & \\
\hline -ato & te_therr & nàl_displ & ace_type & & & & \\
\hline -ato & ee_B_is & _or_equi & & & & & \\
\hline -ato & $-+-+\infty$ & symbol & & & & & \\
\hline$\overline{\mathrm{A}} 11$ & 1.0000 & 0.00460 & 0.23096 & 0.11056 & Biso & 1.000 & $\mathrm{Al}$ \\
\hline Al2 & 1.0000 & 0.78150 & 0.77800 & 0.11442 & Biso & 1.000 & Al \\
\hline Al3 & 1.0000 & 0.23698 & 0.00858 & 0.10524 & Biso & 1.000 & Al \\
\hline $\mathrm{P} 1$ & 1.0000 & 0.22653 & 0.00242 & 0.89246 & Biso & 1.000 & $\mathrm{P}$ \\
\hline $\mathrm{P} 2$ & 1.0000 & 0.77885 & 0.77495 & 0.90121 & Biso & 1.000 & $P$ \\
\hline P3 & 1.0000 & 0.99864 & 0.22845 & 0.89856 & Biso & 1.000 & $\mathrm{P}$ \\
\hline Al4 & 1.0000 & 0.66389 & 0.56095 & 0.44355 & Biso & 1.000 & Al \\
\hline $\operatorname{Mg} 1$ & 1.0000 & 0.44552 & 0.11171 & 0.44299 & Biso & 1.000 & $\mathrm{Mg}$ \\
\hline Al5 & 1.0000 & 0.90528 & 0.33755 & 0.44394 & Biso & 1.000 & Al \\
\hline $\mathrm{P} 4$ & 1.0000 & 0.90404 & 0.34229 & 0.23316 & Biso & 1.000 & $\mathrm{P}$ \\
\hline P5 & 1.0000 & 0.44325 & 0.10423 & 0.23144 & Biso & 1.000 & $\mathrm{P}$ \\
\hline P6 & 1.0000 & 0.67110 & 0.56305 & 0.23317 & Biso & 1.000 & $\mathrm{P}$ \\
\hline Al 6 & 1.0000 & 0.32995 & 0.88704 & 0.78133 & Biso & 1.000 & Al \\
\hline A 17 & 1.0000 & 0.10854 & 0.43646 & 0.77482 & Biso & 1.000 & $\mathrm{Al}$ \\
\hline Al8 & 1.0000 & 0.56743 & 0.67182 & 0.77767 & Biso & 1.000 & Al \\
\hline P7 & 1.0000 & 0.57939 & 0.68082 & 0.56987 & Biso & 1.000 & $\mathrm{P}$ \\
\hline P8 & 1.0000 & 0.10978 & 0.44099 & 0.56967 & Biso & 1.000 & $\mathrm{P}$ \\
\hline P9 & 1.0000 & 0.33246 & 0.88367 & 0.56812 & Biso & 1.000 & $P$ \\
\hline Al9 & 1.0000 & 0.00321 & 0.77261 & 0.90476 & Biso & 1.000 & Al \\
\hline Al10 & 1.0000 & 0.22697 & 0.22963 & 0.89734 & Biso & 1.000 & Al \\
\hline Al11 & 1.0000 & 0.77576 & 0.99864 & 0.90380 & Biso & 1.000 & Al \\
\hline $\mathrm{P} 10$ & 1.0000 & 0.77943 & 0.00173 & 0.11711 & Biso & 1.000 & $\mathrm{P}$ \\
\hline P11 & 1.0000 & 0.23259 & 0.23261 & 0.11014 & Biso & 1.000 & $\mathrm{P}$ \\
\hline P12 & 1.0000 & 0.01036 & 0.78207 & 0.11815 & Biso & 1.000 & $\mathrm{P}$ \\
\hline Al12 & 1.0000 & 0.67770 & 0.11313 & 0.23972 & Biso & 1.000 & Al \\
\hline Al13 & 1.0000 & 0.90146 & 0.56784 & 0.23896 & Biso & 1.000 & Al \\
\hline
\end{tabular}




\begin{tabular}{|c|c|c|c|c|c|c|}
\hline Al14 & 1.0000 & 0.44259 & 0.33444 & 0.23617 & Biso & 1.000 \\
\hline P13 & 1.0000 & 0.42841 & 0.33743 & 0.44347 & Biso & 1.000 \\
\hline P14 & 1.0000 & 0.89397 & 0.56212 & 0.45016 & Biso & 1.000 \\
\hline P15 & 1.0000 & 0.68129 & 0.11535 & 0.44529 & Biso & 1.000 \\
\hline Al15 & 1.0000 & 0.34536 & 0.45844 & 0.56868 & Biso & 1.000 \\
\hline Al16 & 1.0000 & 0.56467 & 0.90172 & 0.57328 & Biso & 1.000 \\
\hline Al17 & 1.0000 & 0.09934 & 0.66931 & 0.57669 & Biso & 1.000 \\
\hline P16 & 1.0000 & 0.10397 & 0.66567 & 0.78455 & Biso & 1.000 \\
\hline P17 & 1.0000 & 0.56150 & 0.89885 & 0.78233 & Biso & 1.000 \\
\hline P18 & 1.0000 & 0.33947 & 0.44526 & 0.77922 & Biso & 1.000 \\
\hline 01 & 1.0000 & 0.90157 & 0.09319 & 0.13352 & Biso & 1.000 \\
\hline $\mathrm{O} 2$ & 1.0000 & 0.91958 & 0.81268 & 0.13858 & Biso & 1.000 \\
\hline 03 & 1.0000 & 0.20135 & 0.11100 & 0.12968 & Biso & 1.000 \\
\hline O4 & 1.0000 & 0.10641 & 0.90765 & 0.87522 & Biso & 1.000 \\
\hline 05 & 1.0000 & 0.81110 & 0.89616 & 0.87958 & Biso & 1.000 \\
\hline 06 & 1.0000 & 0.09019 & 0.19967 & 0.87803 & Biso & 1.000 \\
\hline 07 & 1.0000 & 0.55013 & 0.43029 & 0.46252 & Biso & 1.000 \\
\hline 08 & 1.0000 & 0.60074 & 0.15872 & 0.44970 & Biso & 1.000 \\
\hline 09 & 1.0000 & 0.87639 & 0.44512 & 0.46671 & Biso & 1.000 \\
\hline 010 & 1.0000 & 0.78235 & 0.25147 & 0.21751 & Biso & 1.000 \\
\hline 011 & 1.0000 & 0.47364 & 0.22771 & 0.22443 & Biso & 1.000 \\
\hline 012 & 1.0000 & 0.76457 & 0.53566 & 0.21732 & Biso & 1.000 \\
\hline 013 & 1.0000 & 0.22440 & 0.75207 & 0.81047 & Biso & 1.000 \\
\hline 014 & 1.0000 & 0.24679 & 0.47333 & 0.79803 & Biso & 1.000 \\
\hline 015 & 1.0000 & 0.53364 & 0.77676 & 0.79011 & Biso & 1.000 \\
\hline 016 & 1.0000 & 0.45697 & 0.59314 & 0.55162 & Biso & 1.000 \\
\hline 017 & 1.0000 & 0.11579 & 0.55402 & 0.56694 & Biso & 1.000 \\
\hline 018 & 1.0000 & 0.42137 & 0.84798 & 0.55628 & Biso & 1.000 \\
\hline 019 & 1.0000 & 0.98315 & 0.32359 & 0.17358 & Biso & 1.000 \\
\hline $\mathrm{O} 20$ & 1.0000 & 0.68847 & 0.66046 & 0.17379 & Biso & 1.000 \\
\hline 021 & 1.0000 & 0.35926 & 0.03609 & 0.15733 & Biso & 1.000 \\
\hline $\mathrm{O} 22$ & 1.0000 & 0.30933 & 0.98610 & 0.83638 & Biso & 1.000 \\
\hline 023 & 1.0000 & 0.67524 & 0.69305 & 0.84896 & Biso & 1.000 \\
\hline $\mathrm{O} 24$ & 1.0000 & 0.01586 & 0.32853 & 0.84327 & Biso & 1.000 \\
\hline 025 & 1.0000 & 0.65758 & 0.66290 & 0.50823 & Biso & 1.000 \\
\hline 026 & 1.0000 & 0.35688 & 0.98457 & 0.51447 & Biso & 1.000 \\
\hline 027 & 1.0000 & 0.02248 & 0.35983 & 0.50405 & Biso & 1.000 \\
\hline 028 & 1.0000 & 0.02174 & 0.67302 & 0.84869 & Biso & 1.000 \\
\hline O29 & 1.0000 & 0.32034 & 0.34414 & 0.83444 & Biso & 1.000 \\
\hline 030 & 1.0000 & 0.65796 & 0.97355 & 0.84450 & Biso & 1.000 \\
\hline 031 & 1.0000 & 0.69910 & 0.02404 & 0.17045 & Biso & 1.000 \\
\hline 032 & 1.0000 & 0.33509 & 0.31389 & 0.16354 & Biso & 1.000 \\
\hline 033 & 1.0000 & 0.99312 & 0.68404 & 0.17625 & Biso & 1.000 \\
\hline 034 & 1.0000 & 0.34891 & 0.36219 & 0.49797 & Biso & 1.000 \\
\hline 035 & 1.0000 & 0.98672 & 0.64905 & 0.51050 & Biso & 1.000 \\
\hline 036 & 1.0000 & 0.64896 & 0.01483 & 0.50694 & Biso & 1.000 \\
\hline 037 & 1.0000 & 0.13393 & 0.24664 & 0.13902 & Biso & 1.000 \\
\hline 038 & 1.0000 & 0.76699 & 0.89041 & 0.14791 & Biso & 1.000 \\
\hline 039 & 1.0000 & 0.12385 & 0.88274 & 0.14208 & Biso & 1.000 \\
\hline O40 & 1.0000 & 0.23588 & 0.11343 & 0.86589 & Biso & 1.000 \\
\hline 041 & 1.0000 & 0.87494 & 0.75659 & 0.87413 & Biso & 1.000 \\
\hline 042 & 1.0000 & 0.88581 & 0.12847 & 0.87339 & Biso & 1.000 \\
\hline 043 & 1.0000 & 0.78676 & 0.56276 & 0.47248 & Biso & 1.000 \\
\hline O4 4 & 1.0000 & 0.41143 & 0.22522 & 0.46847 & Biso & 1.000 \\
\hline 045 & 1.0000 & 0.79908 & 0.20693 & 0.47455 & Biso & 1.000 \\
\hline 046 & 1.0000 & 0.91768 & 0.45585 & 0.20867 & Biso & 1.000 \\
\hline 047 & 1.0000 & 0.54959 & 0.09906 & 0.21314 & Biso & 1.000 \\
\hline 048 & 1.0000 & 0.55998 & 0.46129 & 0.20830 & Biso & 1.000 \\
\hline 049 & 1.0000 & 0.45930 & 0.90574 & 0.81182 & Biso & 1.000 \\
\hline 050 & 1.0000 & 0.08892 & 0.54912 & 0.79210 & Biso & 1.000 \\
\hline 051 & 1.0000 & 0.45153 & 0.54496 & 0.80638 & Biso & 1.000 \\
\hline 052 & 1.0000 & 0.59688 & 0.79692 & 0.55116 & Biso & 1.000 \\
\hline 053 & 1.0000 & 0.22296 & 0.45750 & 0.54198 & Biso & 1.000 \\
\hline 054 & 1.0000 & 0.21900 & 0.78483 & 0.53493 & Biso & 1.000 \\
\hline 055 & 1.0000 & 0.00120 & 0.25785 & 0.99753 & Biso & 1.000 \\
\hline 056 & 1.0000 & 0.75408 & 0.75173 & 0.00114 & Biso & 1.000 \\
\hline 057 & 1.0000 & 0.25562 & 0.00351 & 0.99122 & Biso & 1.000 \\
\hline 058 & 1.0000 & 0.67241 & 0.59798 & 0.33082 & Biso & 1.000 \\
\hline 059 & 1.0000 & 0.39277 & 0.05551 & 0.32216 & Biso & 1.000 \\
\hline 060 & 1.0000 & 0.93774 & 0.34228 & 0.33071 & Biso & 1.000 \\
\hline 061 & 1.0000 & 0.32135 & 0.90257 & 0.66771 & Biso & 1.000 \\
\hline 062 & 1.0000 & 0.07853 & 0.39103 & 0.66402 & Biso & 1.000 \\
\hline 063 & 1.0000 & 0.60916 & 0.67144 & 0.66734 & Biso & 1.000 \\
\hline 064 & 1.0000 & 0.00664 & 0.75142 & 0.01950 & Biso & 1.000 \\
\hline 065 & 1.0000 & 0.25756 & 0.25859 & 0.01056 & Biso & 1.000 \\
\hline 066 & 1.0000 & 0.75047 & 0.99652 & 0.01784 & Biso & 1.000 \\
\hline 067 & 1.0000 & 0.68931 & 0.07792 & 0.34921 & Biso & 1.000 \\
\hline 068 & 1.0000 & 0.92878 & 0.59836 & 0.35279 & Biso & 1.000 \\
\hline 069 & 1.0000 & 0.40141 & 0.34345 & 0.34399 & Biso & 1.000 \\
\hline 070 & 1.0000 & 0.34077 & 0.41831 & 0.68001 & Biso & 1.000 \\
\hline
\end{tabular}




\begin{tabular}{|c|c|c|c|c|c|c|}
\hline 071 & 1.0000 & 0.59447 & 0.94057 & 0.68616 & Biso & 1.000 \\
\hline 072 & 1.0000 & 0.07783 & 0.68723 & 0.68903 & Biso & 1.000 \\
\hline $\mathrm{H} 1$ & 1.0000 & 0.27531 & 0.91746 & 0.33781 & Biso & 1.000 \\
\hline $\mathrm{C} 1$ & 1.0000 & 0.07926 & 0.89975 & 0.36580 & Biso & 1.000 \\
\hline $\mathrm{H} 2$ & 1.0000 & 0.03224 & 0.82089 & 0.40049 & Biso & 1.000 \\
\hline H3 & 1.0000 & 0.14238 & 0.97132 & 0.40218 & Biso & 1.000 \\
\hline H4 & 1.0000 & 0.08484 & 0.89785 & 0.29390 & Biso & 1.000 \\
\hline 073 & 1.0000 & 0.20636 & 0.84564 & 0.35021 & Biso & 1.000 \\
\hline H5 & 1.0000 & 0.21514 & 0.82640 & 0.41161 & Biso & 1.000 \\
\hline $\mathrm{C} 2$ & 1.0000 & 0.00177 & 0.04959 & 0.50287 & Biso & 1.000 \\
\hline C3 & 1.0000 & 0.06588 & 0.14596 & 0.45210 & Biso & 1.000 \\
\hline $\mathrm{C} 4$ & 1.0000 & 0.07188 & 0.14091 & 0.35918 & Biso & 1.000 \\
\hline C5 & 1.0000 & 0.01502 & 0.03873 & 0.31649 & Biso & 1.000 \\
\hline $\mathrm{C} 6$ & 1.0000 & 0.95566 & 0.93911 & 0.36727 & Biso & 1.000 \\
\hline C7 & 1.0000 & 0.94504 & 0.94690 & 0.46104 & Biso & 1.000 \\
\hline H6 & 1.0000 & 0.99631 & 0.05593 & 0.57490 & Biso & 1.000 \\
\hline H7 & 1.0000 & 0.89397 & 0.87107 & 0.49932 & Biso & 1.000 \\
\hline H8 & 1.0000 & 0.11157 & 0.22652 & 0.48508 & Biso & 1.000 \\
\hline H9 & 1.0000 & 0.12094 & 0.21701 & 0.32090 & Biso & 1.000 \\
\hline $\mathrm{H} 10$ & 1.0000 & 0.01852 & 0.03300 & 0.24422 & Biso & 1.000 \\
\hline H 11 & 1.0000 & 0.89603 & 0.86269 & 0.33305 & Biso & 1.000 \\
\hline
\end{tabular}

Al 2

data_image 0

$\begin{array}{ll}\text {-celi__length_a } & 13.625 \\ \text { _cell_length_b } & 13.625 \\ \text {-cell_length_c } & 15.067 \\ \text { _cell_angle_alpha } & 90 \\ \text {-cell_angle_beta } & 90 \\ \text {-cell_angle_gamma } & 120\end{array}$

symmetry_space_group_name_H-M "P 1"

-symmetry_int_tables_number 1

loop_

_symmetry_equiv_pos_as_xyz

' $\mathrm{x}, \mathrm{y}, \mathrm{z}$ '

loop

atom site label

-atom_site_occupancy

-atom_site_fract_x

atom site fract $y$

-atom_site_fract_z

-atom_site_thermal_displace_type

atom_site_B_iso_or_equiv

_atom_site_type_symbol

Sil_t.0000-0.01542

$1.0000 \quad 0.78641$

$\mathrm{Si3} \quad 1.0000 \quad 0.24537$

Si4 $1.0000 \quad 0.23778$

0.24277

0.10859

Biso

$1.000 \mathrm{Si}$

$\begin{array}{lllll}.78611 & 0.11201 & \text { Biso } & 1.000 & \mathrm{Si}\end{array}$

$\begin{array}{ll}1.0000 & 0.23778 \\ 1.0000 & 0.78298\end{array}$

0.10526 Biso

$1.000 \mathrm{Si}$

0.009030 .89753 Biso $1.000 \mathrm{Si}$

Si5

0.782210 .90436

$1.000 \mathrm{Si}$

Si6

$1.0000 \quad 0.01067$

$1.0000 \quad 0.67785$

0.24084

436 Biso

$1.000 \mathrm{Si}$

$\begin{array}{lll}0.57411 & 0.44220 & \text { Biso }\end{array}$

$1.000 \mathrm{Si}$

$1.0000 \quad 0.44817$

0.44107

$1.000 \mathrm{Al}$

Si8

0.341480 .44186 Biso

$1.000 \mathrm{Si}$

$1.0000 \quad 0.91351$

0.34760

0.23641 Biso

$1.000 \mathrm{Si}$

Si 10

$0.11529 \quad 0.23535 \quad \mathrm{Biso}$

$1.0000 \quad 0.44932$

$1.0000 \quad 0.68255$

0.57586

Biso

$.000 \mathrm{Si}$

Si12

$0.90077 \quad 0.77814 \quad$ Biso

$1.000 \mathrm{Si}$

$1.0000 \quad 0.11364$

0.44488

77814

Biso

$1.000 \mathrm{Si}$

$1.0000 \quad 0.57660$

0.67744

0.77541

$1.000 \mathrm{Si}$

Si 14

$0.68367 \quad 0.57224$ Biso

$1.000 \mathrm{Si}$

$.0000 \quad 0.58572$

0.44710

0.57224

Biso

$1.000 \mathrm{Si}$

Sil6

$1.0000 \quad 0.34500$

0.90000

0.56987 Biso

$1.000 \mathrm{Si}$

Si18

0.77839

0.90389

$1.000 \mathrm{Si}$

1.00000 .00977

0.23924

$1.0000 \quad 0.78349$

0.01030

$1.000 \mathrm{Si}$

Si20

0.01339

0.90258 Biso

$1.000 \mathrm{Si}$

$1.0000 \quad 0.78525$

$1.0000 \quad 0.24541$

0.24329

Si22

$1.0000 \quad 0.01580$

0.78575

.11040 Biso

$1.000 \mathrm{Si}$

$1.000 \mathrm{Si}$

Si23

0.11870

0.10498 Biso

$1.0000 \quad 0.68244$

0.57618

0.11153 Biso

$1.000 \mathrm{Si}$

Si25

Si26

Si27

0.34716

0.23718 Biso

$1.000 \mathrm{Si}$

$1.0000 \quad 0.91158$

$1.0000 \quad 0.44940$

0.23832 Biso

$1.000 \mathrm{Si}$

$1.0000 \quad 0.43940$

0.34609

0.23547 Biso

$1.000 \mathrm{Si}$

$1.0000 \quad 0.90581$

0.56954

$1.0000 \quad 0.68096$

0.43867 Biso

$1.000 \mathrm{Si}$

Si29

0.11828

0.44486 Biso

$.000 \mathrm{Si}$

$1.0000 \quad 0.34900$

0.45905

Biso

$1.000 \mathrm{Si}$

$1.0000 \quad 0.57679$

0.90964

0.56769 Biso

$1.000 \mathrm{Si}$

Si32

0.67989

0.57139 Biso

$1.000 \mathrm{Si}$

$1.0000 \quad 0.11324$

0.67788

Biso

$1.000 \mathrm{Si}$

$1.000 \mathrm{Si}$ 


\begin{tabular}{|c|c|c|c|c|c|c|}
\hline $\mathrm{Si} 34$ & 1.0000 & 0.57490 & 0.90834 & 0.77512 & Biso & 1.000 \\
\hline Si35 & 1.0000 & 0.34461 & 0.44952 & 0.77324 & Biso & 1.000 \\
\hline 01 & 1.0000 & 0.91715 & 0.11168 & 0.12623 & Biso & 1.000 \\
\hline $\mathrm{O} 2$ & 1.0000 & 0.91832 & 0.82015 & 0.12891 & Biso & 1.000 \\
\hline 03 & 1.0000 & 0.21204 & 0.11221 & 0.12376 & Biso & 1.000 \\
\hline 04 & 1.0000 & 0.10740 & 0.90808 & 0.88163 & Biso & 1.000 \\
\hline 05 & 1.0000 & 0.81826 & 0.91346 & 0.88445 & Biso & 1.000 \\
\hline 06 & 1.0000 & 0.10899 & 0.20886 & 0.88306 & Biso & 1.000 \\
\hline 07 & 1.0000 & 0.57012 & 0.44885 & 0.45403 & Biso & 1.000 \\
\hline 08 & 1.0000 & 0.59161 & 0.16071 & 0.44780 & Biso & 1.000 \\
\hline 09 & 1.0000 & 0.88457 & 0.44256 & 0.46021 & Biso & 1.000 \\
\hline 010 & 1.0000 & 0.78252 & 0.24997 & 0.22110 & Biso & 1.000 \\
\hline 011 & 1.0000 & 0.48076 & 0.24751 & 0.22415 & Biso & 1.000 \\
\hline 012 & 1.0000 & 0.78047 & 0.54240 & 0.22050 & Biso & 1.000 \\
\hline 013 & 1.0000 & 0.24370 & 0.77133 & 0.80152 & Biso & 1.000 \\
\hline 014 & 1.0000 & 0.24553 & 0.48120 & 0.79169 & Biso & 1.000 \\
\hline 015 & 1.0000 & 0.54436 & 0.77690 & 0.78447 & Biso & 1.000 \\
\hline 016 & 1.0000 & 0.45426 & 0.58746 & 0.55525 & Biso & 1.000 \\
\hline 017 & 1.0000 & 0.12706 & 0.57154 & 0.56625 & Biso & 1.000 \\
\hline 018 & 1.0000 & 0.44143 & 0.86217 & 0.55902 & Biso & 1.000 \\
\hline 019 & 1.0000 & 0.99777 & 0.32867 & 0.17168 & Biso & 1.000 \\
\hline $\mathrm{O} 20$ & 1.0000 & 0.70242 & 0.67997 & 0.17357 & Biso & 1.000 \\
\hline 021 & 1.0000 & 0.35565 & 0.03731 & 0.16073 & Biso & 1.000 \\
\hline $\mathrm{O} 22$ & 1.0000 & 0.32479 & 0.99083 & 0.83642 & Biso & 1.000 \\
\hline $\mathrm{O} 23$ & 1.0000 & 0.67498 & 0.69626 & 0.84507 & Biso & 1.000 \\
\hline $\mathrm{O} 24$ & 1.0000 & 0.02945 & 0.34675 & 0.84136 & Biso & 1.000 \\
\hline 025 & 1.0000 & 0.66998 & 0.66583 & 0.50645 & Biso & 1.000 \\
\hline 026 & 1.0000 & 0.36601 & 0.00362 & 0.50972 & Biso & 1.000 \\
\hline 027 & 1.0000 & 0.01886 & 0.35995 & 0.50376 & Biso & 1.000 \\
\hline 028 & 1.0000 & 0.02663 & 0.68853 & 0.84496 & Biso & 1.000 \\
\hline 029 & 1.0000 & 0.32473 & 0.34329 & 0.83442 & Biso & 1.000 \\
\hline 030 & 1.0000 & 0.67679 & 0.98880 & 0.84198 & Biso & 1.000 \\
\hline 031 & 1.0000 & 0.70006 & 0.03577 & 0.16963 & Biso & 1.000 \\
\hline 032 & 1.0000 & 0.35210 & 0.33036 & 0.16466 & Biso & 1.000 \\
\hline 033 & 1.0000 & 0.99605 & 0.68303 & 0.17669 & Biso & 1.000 \\
\hline 034 & 1.0000 & 0.35587 & 0.37197 & 0.49942 & Biso & 1.000 \\
\hline 035 & 1.0000 & 0.00573 & 0.66182 & 0.50911 & Biso & 1.000 \\
\hline 036 & 1.0000 & 0.65406 & 0.01172 & 0.50455 & Biso & 1.000 \\
\hline 037 & 1.0000 & 0.13675 & 0.25492 & 0.13362 & Biso & 1.000 \\
\hline 038 & 1.0000 & 0.77398 & 0.89388 & 0.14080 & Biso & 1.000 \\
\hline 039 & 1.0000 & 0.13716 & 0.89477 & 0.13693 & Biso & 1.000 \\
\hline 040 & 1.0000 & 0.24834 & 0.12894 & 0.87064 & Biso & 1.000 \\
\hline 041 & 1.0000 & 0.88814 & 0.76440 & 0.87818 & Biso & 1.000 \\
\hline 042 & 1.0000 & 0.88973 & 0.13254 & 0.87599 & Biso & 1.000 \\
\hline 043 & 1.0000 & 0.79206 & 0.57248 & 0.46977 & Biso & 1.000 \\
\hline 044 & 1.0000 & 0.42449 & 0.22729 & 0.46540 & Biso & 1.000 \\
\hline 045 & 1.0000 & 0.80770 & 0.21980 & 0.46728 & Biso & 1.000 \\
\hline 046 & 1.0000 & 0.92755 & 0.46995 & 0.21231 & Biso & 1.000 \\
\hline 047 & 1.0000 & 0.56301 & 0.10976 & 0.21303 & Biso & 1.000 \\
\hline 048 & 1.0000 & 0.56118 & 0.46800 & 0.21330 & Biso & 1.000 \\
\hline 049 & 1.0000 & 0.46430 & 0.91558 & 0.80404 & Biso & 1.000 \\
\hline 050 & 1.0000 & 0.09728 & 0.55302 & 0.78869 & Biso & 1.000 \\
\hline 051 & 1.0000 & 0.46559 & 0.55753 & 0.79959 & Biso & 1.000 \\
\hline 052 & 1.0000 & 0.60193 & 0.80712 & 0.55105 & Biso & 1.000 \\
\hline 053 & 1.0000 & 0.23328 & 0.45905 & 0.54402 & Biso & 1.000 \\
\hline 054 & 1.0000 & 0.22321 & 0.79085 & 0.53792 & Biso & 1.000 \\
\hline 055 & 1.0000 & 0.01298 & 0.27616 & 0.00542 & Biso & 1.000 \\
\hline 056 & 1.0000 & 0.75132 & 0.75265 & 0.00878 & Biso & 1.000 \\
\hline 057 & 1.0000 & 0.27165 & 0.00976 & 0.00090 & Biso & 1.000 \\
\hline 058 & 1.0000 & 0.68876 & 0.61786 & 0.33973 & Biso & 1.000 \\
\hline 059 & 1.0000 & 0.39872 & 0.06622 & 0.33217 & Biso & 1.000 \\
\hline 060 & 1.0000 & 0.95167 & 0.34624 & 0.33864 & Biso & 1.000 \\
\hline 061 & 1.0000 & 0.33560 & 0.92592 & 0.67420 & Biso & 1.000 \\
\hline 062 & 1.0000 & 0.07833 & 0.39686 & 0.67251 & Biso & 1.000 \\
\hline 063 & 1.0000 & 0.62059 & 0.67636 & 0.67482 & Biso & 1.000 \\
\hline 064 & 1.0000 & 0.01337 & 0.74940 & 0.00849 & Biso & 1.000 \\
\hline 065 & 1.0000 & 0.27643 & 0.27459 & 0.00076 & Biso & 1.000 \\
\hline 066 & 1.0000 & 0.75079 & 0.00884 & 0.00655 & Biso & 1.000 \\
\hline 067 & 1.0000 & 0.68778 & 0.07873 & 0.33779 & Biso & 1.000 \\
\hline 068 & 1.0000 & 0.94337 & 0.61082 & 0.34249 & Biso & 1.000 \\
\hline 069 & 1.0000 & 0.40416 & 0.34979 & 0.33475 & Biso & 1.000 \\
\hline 070 & 1.0000 & 0.34425 & 0.41597 & 0.66947 & Biso & 1.000 \\
\hline 071 & 1.0000 & 0.61324 & 0.95288 & 0.67387 & Biso & 1.000 \\
\hline 072 & 1.0000 & 0.08220 & 0.69652 & 0.67596 & Biso & 1.000 \\
\hline H 1 & 1.0000 & 0.28530 & 0.92532 & 0.34055 & Biso & 1.000 \\
\hline $\mathrm{C} 1$ & 1.0000 & 0.08525 & 0.90400 & 0.36183 & Biso & 1.000 \\
\hline $\mathrm{H} 2$ & 1.0000 & 0.03831 & 0.82346 & 0.39607 & Biso & 1.000 \\
\hline H3 & 1.0000 & 0.14938 & 0.97688 & 0.39821 & Biso & 1.000 \\
\hline $\mathrm{H} 4$ & 1.0000 & 0.09208 & 0.90224 & 0.29022 & Biso & 1.000 \\
\hline 073 & 1.0000 & 0.21615 & 0.84948 & 0.34856 & Biso & 1.000 \\
\hline
\end{tabular}




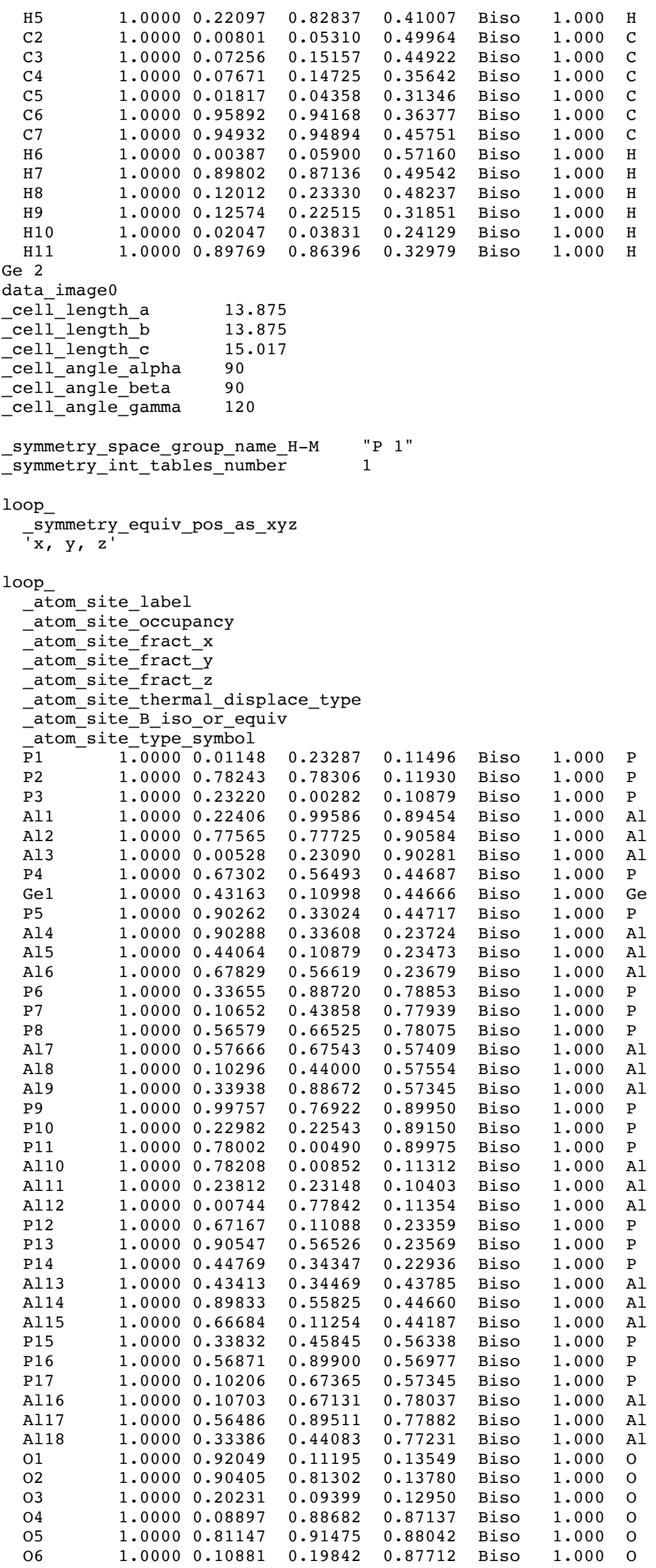




\begin{tabular}{|c|c|c|c|c|c|c|c|}
\hline 07 & 1.0000 & 0.57322 & 0.44818 & 0.46056 & Biso & 1.000 & 0 \\
\hline 08 & 1.0000 & 0.57671 & 0.16250 & 0.45332 & Biso & 1.000 & 0 \\
\hline 09 & 1.0000 & 0.87763 & 0.42510 & 0.46599 & Biso & 1.000 & 0 \\
\hline 010 & 1.0000 & 0.76559 & 0.23214 & 0.21761 & Biso & 1.000 & 0 \\
\hline 011 & 1.0000 & 0.47472 & 0.24897 & 0.22321 & Biso & 1.000 & 0 \\
\hline 012 & 1.0000 & 0.78415 & 0.53464 & 0.21745 & Biso & 1.000 & 0 \\
\hline 013 & 1.0000 & 0.24196 & 0.76980 & 0.81456 & Biso & 1.000 & 0 \\
\hline 014 & 1.0000 & 0.22930 & 0.47347 & 0.79697 & Biso & 1.000 & 0 \\
\hline 015 & 1.0000 & 0.53486 & 0.75702 & 0.78921 & Biso & 1.000 & 0 \\
\hline 016 & 1.0000 & 0.43640 & 0.57831 & 0.55556 & Biso & 1.000 & 0 \\
\hline 017 & 1.0000 & 0.11163 & 0.56869 & 0.56957 & Biso & 1.000 & 0 \\
\hline 018 & 1.0000 & 0.44321 & 0.85105 & 0.55265 & Biso & 1.000 & 0 \\
\hline 019 & 1.0000 & 0.99523 & 0.31499 & 0.17215 & Biso & 1.000 & 0 \\
\hline 020 & 1.0000 & 0.70198 & 0.68235 & 0.17493 & Biso & 1.000 & 0 \\
\hline 021 & 1.0000 & 0.34053 & 0.02779 & 0.15410 & Biso & 1.000 & 0 \\
\hline 022 & 1.0000 & 0.32202 & 0.97648 & 0.83720 & Biso & 1.000 & $\mathrm{O}$ \\
\hline 023 & 1.0000 & 0.65649 & 0.68364 & 0.84810 & Biso & 1.000 & 0 \\
\hline $\mathrm{O} 24$ & 1.0000 & 0.02928 & 0.35017 & 0.84616 & Biso & 1.000 & 0 \\
\hline 025 & 1.0000 & 0.66414 & 0.65112 & 0.50555 & Biso & 1.000 & 0 \\
\hline 026 & 1.0000 & 0.35126 & 0.99867 & 0.51861 & Biso & 1.000 & 0 \\
\hline 027 & 1.0000 & 0.00051 & 0.34488 & 0.50497 & Biso & 1.000 & 0 \\
\hline 028 & 1.0000 & 0.01038 & 0.68005 & 0.84921 & Biso & 1.000 & 0 \\
\hline 029 & 1.0000 & 0.30993 & 0.32376 & 0.83323 & Biso & 1.000 & 0 \\
\hline 030 & 1.0000 & 0.67747 & 0.98304 & 0.84592 & Biso & 1.000 & 0 \\
\hline 031 & 1.0000 & 0.68816 & 0.03222 & 0.17136 & Biso & 1.000 & 0 \\
\hline 032 & 1.0000 & 0.35596 & 0.32509 & 0.16261 & Biso & 1.000 & 0 \\
\hline 033 & 1.0000 & 0.98531 & 0.66491 & 0.17816 & Biso & 1.000 & 0 \\
\hline 034 & 1.0000 & 0.34775 & 0.38208 & 0.49545 & Biso & 1.000 & 0 \\
\hline 035 & 1.0000 & 0.00560 & 0.65906 & 0.51350 & Biso & 1.000 & $\mathrm{O}$ \\
\hline 036 & 1.0000 & 0.63921 & 0.99738 & 0.50852 & Biso & 1.000 & 0 \\
\hline 037 & 1.0000 & 0.12530 & 0.24604 & 0.13801 & Biso & 1.000 & 0 \\
\hline 038 & 1.0000 & 0.76978 & 0.88244 & 0.14730 & Biso & 1.000 & 0 \\
\hline 039 & 1.0000 & 0.13581 & 0.89195 & 0.14395 & Biso & 1.000 & 0 \\
\hline 040 & 1.0000 & 0.23810 & 0.12346 & 0.86402 & Biso & 1.000 & 0 \\
\hline 041 & 1.0000 & 0.88420 & 0.75553 & 0.87513 & Biso & 1.000 & 0 \\
\hline 042 & 1.0000 & 0.87722 & 0.11847 & 0.87181 & Biso & 1.000 & 0 \\
\hline 043 & 1.0000 & 0.77985 & 0.56493 & 0.47345 & Biso & 1.000 & 0 \\
\hline 044 & 1.0000 & 0.39980 & 0.21442 & 0.47131 & Biso & 1.000 & 0 \\
\hline 045 & 1.0000 & 0.80204 & 0.21823 & 0.47069 & Biso & 1.000 & 0 \\
\hline 046 & 1.0000 & 0.91986 & 0.46618 & 0.21077 & Biso & 1.000 & 0 \\
\hline 047 & 1.0000 & 0.56072 & 0.10270 & 0.21003 & Biso & 1.000 & $\mathrm{O}$ \\
\hline 048 & 1.0000 & 0.55228 & 0.45344 & 0.20425 & Biso & 1.000 & 0 \\
\hline 049 & 1.0000 & 0.44848 & 0.89987 & 0.81678 & Biso & 1.000 & 0 \\
\hline 050 & 1.0000 & 0.09139 & 0.53970 & 0.78987 & Biso & 1.000 & 0 \\
\hline 051 & 1.0000 & 0.46281 & 0.55280 & 0.80196 & Biso & 1.000 & 0 \\
\hline 052 & 1.0000 & 0.59899 & 0.80823 & 0.55118 & Biso & 1.000 & 0 \\
\hline 053 & 1.0000 & 0.23091 & 0.45958 & 0.54219 & Biso & 1.000 & 0 \\
\hline 054 & 1.0000 & 0.21020 & 0.77248 & 0.53753 & Biso & 1.000 & 0 \\
\hline 055 & 1.0000 & 0.00696 & 0.25916 & 0.01629 & Biso & 1.000 & 0 \\
\hline 056 & 1.0000 & 0.75353 & 0.75553 & 0.02047 & Biso & 1.000 & O \\
\hline 057 & 1.0000 & 0.24596 & 0.99502 & 0.00841 & Biso & 1.000 & 0 \\
\hline 058 & 1.0000 & 0.68093 & 0.60205 & 0.34901 & Biso & 1.000 & 0 \\
\hline 059 & 1.0000 & 0.38235 & 0.05382 & 0.33725 & Biso & 1.000 & 0 \\
\hline 060 & 1.0000 & 0.93678 & 0.33418 & 0.34909 & Biso & 1.000 & 0 \\
\hline 061 & 1.0000 & 0.33351 & 0.90323 & 0.68820 & Biso & 1.000 & 0 \\
\hline 062 & 1.0000 & 0.07288 & 0.38943 & 0.68481 & Biso & 1.000 & 0 \\
\hline 063 & 1.0000 & 0.60884 & 0.66560 & 0.68594 & Biso & 1.000 & 0 \\
\hline 064 & 1.0000 & 0.00430 & 0.75140 & 0.99993 & Biso & 1.000 & $\mathrm{O}$ \\
\hline 065 & 1.0000 & 0.26278 & 0.25541 & 0.98980 & Biso & 1.000 & 0 \\
\hline 066 & 1.0000 & 0.75469 & 0.00521 & 0.99935 & Biso & 1.000 & 0 \\
\hline 067 & 1.0000 & 0.67412 & 0.07540 & 0.33010 & Biso & 1.000 & 0 \\
\hline 068 & 1.0000 & 0.93416 & 0.59635 & 0.33469 & Biso & 1.000 & 0 \\
\hline 069 & 1.0000 & 0.40880 & 0.35204 & 0.32329 & Biso & 1.000 & 0 \\
\hline 070 & 1.0000 & 0.33287 & 0.41329 & 0.65831 & Biso & 1.000 & 0 \\
\hline 071 & 1.0000 & 0.59629 & 0.93792 & 0.66769 & Biso & 1.000 & 0 \\
\hline 072 & 1.0000 & 0.08118 & 0.69571 & 0.67004 & Biso & 1.000 & 0 \\
\hline H 1 & 1.0000 & 0.27208 & 0.91932 & 0.34627 & Biso & 1.000 & $\mathrm{H}$ \\
\hline $\mathrm{C} 1$ & 1.0000 & 0.07594 & 0.89966 & 0.36638 & Biso & 1.000 & $\mathrm{C}$ \\
\hline $\mathrm{H} 2$ & 1.0000 & 0.02885 & 0.82046 & 0.40054 & Biso & 1.000 & $\mathrm{H}$ \\
\hline H3 & 1.0000 & 0.13998 & 0.96999 & 0.40334 & Biso & 1.000 & $\mathrm{H}$ \\
\hline H 4 & 1.0000 & 0.08381 & 0.89822 & 0.29462 & Biso & 1.000 & $\mathrm{H}$ \\
\hline 073 & 1.0000 & 0.20366 & 0.84418 & 0.35213 & Biso & 1.000 & 0 \\
\hline H5 & 1.0000 & 0.20683 & 0.81980 & 0.41288 & Biso & 1.000 & $\mathrm{H}$ \\
\hline $\mathrm{C} 2$ & 1.0000 & 0.00292 & 0.05067 & 0.50318 & Biso & 1.000 & $\mathrm{C}$ \\
\hline C3 & 1.0000 & 0.06717 & 0.14686 & 0.45225 & Biso & 1.000 & C \\
\hline $\mathrm{C} 4$ & 1.0000 & 0.07213 & 0.14184 & 0.35925 & Biso & 1.000 & C \\
\hline C5 & 1.0000 & 0.01465 & 0.03972 & 0.31665 & Biso & 1.000 & C \\
\hline C6 & 1.0000 & 0.95552 & 0.93999 & 0.36750 & Biso & 1.000 & C \\
\hline C7 & 1.0000 & 0.94525 & 0.94809 & 0.46138 & Biso & 1.000 & C \\
\hline H6 & 1.0000 & 0.99831 & 0.05708 & 0.57527 & Biso & 1.000 & $\mathrm{H}$ \\
\hline
\end{tabular}




$\begin{array}{llllllll}\text { H7 } & 1.0000 & 0.89435 & 0.87227 & 0.49969 & \text { Biso } & 1.000 & \mathrm{H} \\ \text { H8 } & 1.0000 & 0.11396 & 0.22734 & 0.48522 & \text { Biso } & 1.000 & \mathrm{H} \\ \text { H9 } & 1.0000 & 0.12066 & 0.21792 & 0.32083 & \text { Biso } & 1.000 & \mathrm{H} \\ \text { H10 } & 1.0000 & 0.01762 & 0.03392 & 0.24436 & \text { Biso } & 1.000 & \mathrm{H} \\ \text { H11 } & 1.0000 & 0.89462 & 0.86405 & 0.33338 & \text { Biso } & 1.000 & \mathrm{H}\end{array}$

$\mathrm{Ga} 2$

data image 0

cel' length a

cell_length_b 13.625

cell length_c 15.067

cell_angle_àlpha 90

_cell_angle_beta 90

cell_angle_gamma 120

symmetry_space_group_name_H-M "P 1 "

_symmetry_int_tables_number 1

loop

_symmetry_equiv_pos_as_xyz

$' \mathrm{x}, \mathrm{y}, \mathrm{z}$ '

loop_

_atom_site_label

-atom_site_occupancy

atom_site_fract_x

-atom_site_fract_y

-atom_site_fract_z

_atom_site_thermal_displace_type

-atom_site_B_iso_or_equiv

-atom_site_type_symbol

\begin{tabular}{|c|c|c|c|c|c|c|c|}
\hline$\overline{\mathrm{S}} \mathrm{i} 1$ & 1.0000 & 0.01652 & 0.24384 & 0.10797 & Biso & 1.000 & $\mathrm{Si}$ \\
\hline $\mathrm{Si2}$ & 1.0000 & 0.78767 & 0.78713 & 0.11306 & Biso & 1.000 & $\mathrm{Si}$ \\
\hline $\mathrm{Si3}$ & 1.0000 & 0.24555 & 0.01503 & 0.10349 & Biso & 1.000 & $\mathrm{Si}$ \\
\hline $\mathrm{Si} 4$ & 1.0000 & 0.23567 & 0.00772 & 0.89555 & Biso & 1.000 & $\mathrm{Si}$ \\
\hline Si5 & 1.0000 & 0.78248 & 0.78162 & 0.90563 & Biso & 1.000 & $\mathrm{Si}$ \\
\hline Si6 & 1.0000 & 0.01000 & 0.24089 & 0.90126 & Biso & 1.000 & $\mathrm{Si}$ \\
\hline Si7 & 1.0000 & 0.67692 & 0.57261 & 0.44314 & Biso & 1.000 & $\mathrm{Si}$ \\
\hline Ga 1 & 1.0000 & 0.44875 & 0.12047 & 0.44208 & Biso & 1.000 & $\mathrm{Ga}$ \\
\hline Si8 & 1.0000 & 0.91765 & 0.34231 & 0.44128 & Biso & 1.000 & $\mathrm{Si}$ \\
\hline Si9 & 1.0000 & 0.91523 & 0.34889 & 0.23632 & Biso & 1.000 & $\mathrm{Si}$ \\
\hline Si 10 & 1.0000 & 0.45063 & 0.11670 & 0.23281 & Biso & 1.000 & $\mathrm{Si}$ \\
\hline Si11 & 1.0000 & 0.68320 & 0.57656 & 0.23821 & Biso & 1.000 & $\mathrm{Si}$ \\
\hline Si12 & 1.0000 & 0.34144 & 0.89885 & 0.77867 & Biso & 1.000 & $\mathrm{Si}$ \\
\hline Si13 & 1.0000 & 0.11323 & 0.44383 & 0.77267 & Biso & 1.000 & $\mathrm{Si}$ \\
\hline Si14 & 1.0000 & 0.57679 & 0.67761 & 0.77585 & Biso & 1.000 & $\mathrm{Si}$ \\
\hline Si15 & 1.0000 & 0.59007 & 0.68715 & 0.57309 & Biso & 1.000 & $\mathrm{Si}$ \\
\hline Si16 & 1.0000 & 0.11294 & 0.44746 & 0.57323 & Biso & 1.000 & $\mathrm{Si}$ \\
\hline Si17 & 1.0000 & 0.34400 & 0.89589 & 0.56964 & Biso & 1.000 & $\mathrm{Si}$ \\
\hline Si18 & 1.0000 & 0.00858 & 0.77663 & 0.90426 & Biso & 1.000 & $\mathrm{Si}$ \\
\hline Si19 & 1.0000 & 0.23902 & 0.23882 & 0.89564 & Biso & 1.000 & $\mathrm{Si}$ \\
\hline Si20 & 1.0000 & 0.78349 & 0.01012 & 0.90335 & Biso & 1.000 & $\mathrm{Si}$ \\
\hline Si21 & 1.0000 & 0.78695 & 0.01474 & 0.11125 & Biso & 1.000 & $\mathrm{Si}$ \\
\hline Si22 & 1.0000 & 0.24625 & 0.24392 & 0.10299 & Biso & 1.000 & $\mathrm{Si}$ \\
\hline Si23 & 1.0000 & 0.01685 & 0.78672 & 0.11220 & Biso & 1.000 & $\mathrm{Si}$ \\
\hline Si24 & 1.0000 & 0.68296 & 0.11969 & 0.23784 & Biso & 1.000 & $\mathrm{Si}$ \\
\hline Si25 & 1.0000 & 0.91175 & 0.57667 & 0.23885 & Biso & 1.000 & $\mathrm{Si}$ \\
\hline Si26 & 1.0000 & 0.45018 & 0.34775 & 0.23443 & Biso & 1.000 & $\mathrm{Si}$ \\
\hline Si27 & 1.0000 & 0.43503 & 0.34771 & 0.43849 & Biso & 1.000 & $\mathrm{Si}$ \\
\hline Si28 & 1.0000 & 0.90520 & 0.56842 & 0.44565 & Biso & 1.000 & $\mathrm{Si}$ \\
\hline Si29 & 1.0000 & 0.68274 & 0.12183 & 0.44108 & Biso & 1.000 & $\mathrm{Si}$ \\
\hline Si30 & 1.0000 & 0.35003 & 0.46525 & 0.56677 & Biso & 1.000 & $\mathrm{Si}$ \\
\hline Si31 & 1.0000 & 0.57752 & 0.91066 & 0.57195 & Biso & 1.000 & $\mathrm{Si}$ \\
\hline Si32 & 1.0000 & 0.10521 & 0.67940 & 0.57520 & Biso & 1.000 & $\mathrm{Si}$ \\
\hline Si33 & 1.0000 & 0.11161 & 0.67721 & 0.77742 & Biso & 1.000 & $\mathrm{Si}$ \\
\hline Si34 & 1.0000 & 0.57352 & 0.90741 & 0.77646 & Biso & 1.000 & $\mathrm{Si}$ \\
\hline Si35 & 1.0000 & 0.34428 & 0.44927 & 0.77151 & Biso & 1.000 & $\mathrm{Si}$ \\
\hline 01 & 1.0000 & 0.91906 & 0.11270 & 0.12679 & Biso & 1.000 & 0 \\
\hline $\mathrm{O} 2$ & 1.0000 & 0.91979 & 0.82170 & 0.12957 & Biso & 1.000 & 0 \\
\hline 03 & 1.0000 & 0.21132 & 0.11240 & 0.12197 & Biso & 1.000 & $\mathrm{O}$ \\
\hline 04 & 1.0000 & 0.10572 & 0.90578 & 0.87977 & Biso & 1.000 & 0 \\
\hline 05 & 1.0000 & 0.81842 & 0.91318 & 0.88599 & Biso & 1.000 & $\mathrm{O}$ \\
\hline 06 & 1.0000 & 0.10867 & 0.20967 & 0.88184 & Biso & 1.000 & 0 \\
\hline 07 & 1.0000 & 0.56630 & 0.44905 & 0.45443 & Biso & 1.000 & 0 \\
\hline 08 & 1.0000 & 0.60040 & 0.17334 & 0.45115 & Biso & 1.000 & $\mathrm{O}$ \\
\hline 09 & 1.0000 & 0.88929 & 0.44344 & 0.46111 & Biso & 1.000 & 0 \\
\hline 010 & 1.0000 & 0.78400 & 0.25076 & 0.22300 & Biso & 1.000 & 0 \\
\hline 011 & 1.0000 & 0.48368 & 0.24957 & 0.22365 & Biso & 1.000 & $\mathrm{O}$ \\
\hline 012 & 1.0000 & 0.78059 & 0.54256 & 0.22055 & Biso & 1.000 & $\mathrm{O}$ \\
\hline 013 & 1.0000 & 0.24201 & 0.76996 & 0.80280 & Biso & 1.000 & 0 \\
\hline 014 & 1.0000 & 0.24529 & 0.48081 & 0.79152 & Biso & 1.000 & 0 \\
\hline
\end{tabular}




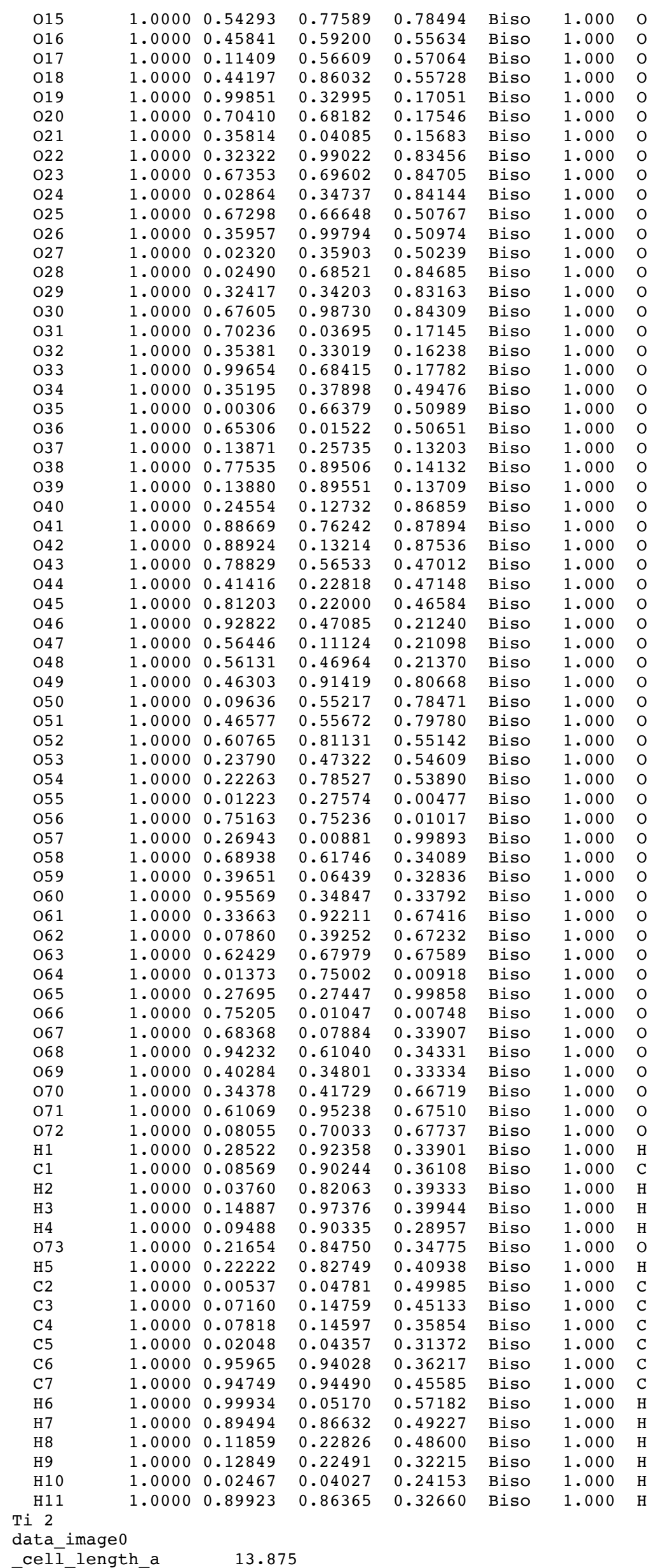




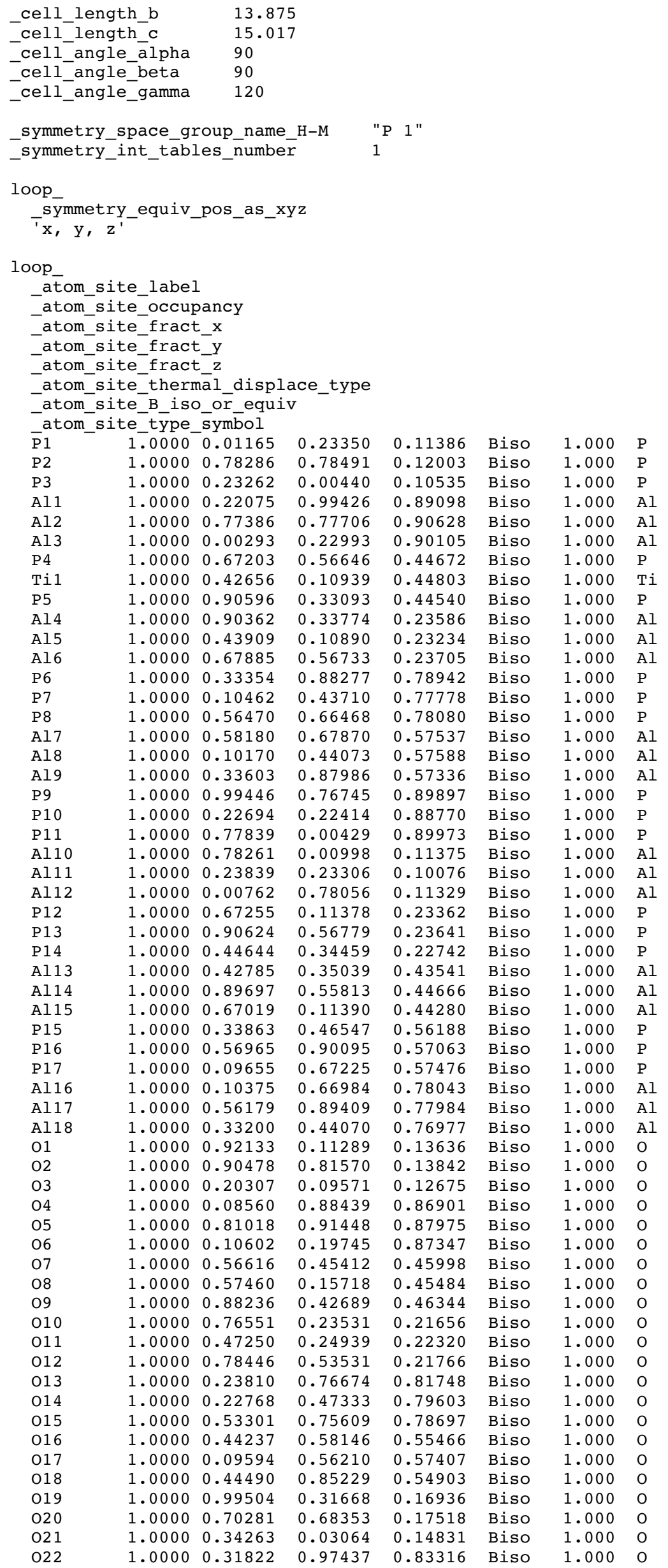




\begin{tabular}{|c|c|c|c|c|c|c|c|}
\hline 023 & 1.0000 & 0.65267 & 0.68304 & 0.85088 & Biso & 1.000 & 0 \\
\hline 024 & 1.0000 & 0.02760 & 0.35030 & 0.84567 & Biso & 1.000 & 0 \\
\hline 025 & 1.0000 & 0.67070 & 0.65635 & 0.50631 & Biso & 1.000 & 0 \\
\hline 026 & 1.0000 & 0.34427 & 0.99279 & 0.52121 & Biso & 1.000 & 0 \\
\hline 027 & 1.0000 & 0.00521 & 0.34572 & 0.50165 & Biso & 1.000 & 0 \\
\hline 028 & 1.0000 & 0.00680 & 0.67701 & 0.85015 & Biso & 1.000 & 0 \\
\hline 029 & 1.0000 & 0.30706 & 0.32208 & 0.82898 & Biso & 1.000 & 0 \\
\hline 030 & 1.0000 & 0.67428 & 0.98095 & 0.84750 & Biso & 1.000 & 0 \\
\hline 031 & 1.0000 & 0.68917 & 0.03522 & 0.17123 & Biso & 1.000 & 0 \\
\hline 032 & 1.0000 & 0.35786 & 0.32735 & 0.15770 & Biso & 1.000 & 0 \\
\hline 033 & 1.0000 & 0.98546 & 0.66736 & 0.17853 & Biso & 1.000 & 0 \\
\hline 034 & 1.0000 & 0.33909 & 0.38751 & 0.49030 & Biso & 1.000 & 0 \\
\hline 035 & 1.0000 & 0.00137 & 0.66140 & 0.51475 & Biso & 1.000 & 0 \\
\hline 036 & 1.0000 & 0.64315 & 0.99939 & 0.51031 & Biso & 1.000 & 0 \\
\hline 037 & 1.0000 & 0.12620 & 0.24801 & 0.13648 & Biso & 1.000 & 0 \\
\hline 038 & 1.0000 & 0.76913 & 0.88353 & 0.14849 & Biso & 1.000 & 0 \\
\hline 039 & 1.0000 & 0.13717 & 0.89383 & 0.14211 & Biso & 1.000 & 0 \\
\hline 040 & 1.0000 & 0.23470 & 0.12184 & 0.86024 & Biso & 1.000 & 0 \\
\hline 041 & 1.0000 & 0.88082 & 0.75320 & 0.87461 & Biso & 1.000 & 0 \\
\hline 042 & 1.0000 & 0.87442 & 0.11789 & 0.87027 & Biso & 1.000 & 0 \\
\hline 043 & 1.0000 & 0.77356 & 0.55609 & 0.47262 & Biso & 1.000 & 0 \\
\hline 044 & 1.0000 & 0.39851 & 0.22156 & 0.46984 & Biso & 1.000 & 0 \\
\hline 045 & 1.0000 & 0.80522 & 0.22013 & 0.47140 & Biso & 1.000 & 0 \\
\hline 046 & 1.0000 & 0.92230 & 0.46938 & 0.21273 & Biso & 1.000 & 0 \\
\hline 047 & 1.0000 & 0.56087 & 0.10441 & 0.21096 & Biso & 1.000 & 0 \\
\hline 048 & 1.0000 & 0.55271 & 0.45441 & 0.20489 & Biso & 1.000 & 0 \\
\hline 049 & 1.0000 & 0.44508 & 0.89663 & 0.82061 & Biso & 1.000 & 0 \\
\hline 050 & 1.0000 & 0.08837 & 0.53791 & 0.78544 & Biso & 1.000 & 0 \\
\hline 051 & 1.0000 & 0.46120 & 0.55187 & 0.80007 & Biso & 1.000 & 0 \\
\hline 052 & 1.0000 & 0.60208 & 0.81113 & 0.55505 & Biso & 1.000 & 0 \\
\hline 053 & 1.0000 & 0.23628 & 0.47774 & 0.54554 & Biso & 1.000 & 0 \\
\hline 054 & 1.0000 & 0.20787 & 0.76450 & 0.53682 & Biso & 1.000 & 0 \\
\hline 055 & 1.0000 & 0.00571 & 0.25703 & 0.01475 & Biso & 1.000 & 0 \\
\hline 056 & 1.0000 & 0.75417 & 0.75778 & 0.02117 & Biso & 1.000 & 0 \\
\hline 057 & 1.0000 & 0.24339 & 0.99497 & 0.00478 & Biso & 1.000 & 0 \\
\hline 058 & 1.0000 & 0.68278 & 0.60505 & 0.34905 & Biso & 1.000 & 0 \\
\hline 059 & 1.0000 & 0.37916 & 0.05293 & 0.33408 & Biso & 1.000 & 0 \\
\hline 060 & 1.0000 & 0.93750 & 0.33192 & 0.34706 & Biso & 1.000 & 0 \\
\hline 061 & 1.0000 & 0.33252 & 0.89351 & 0.68841 & Biso & 1.000 & 0 \\
\hline 062 & 1.0000 & 0.07184 & 0.38524 & 0.68385 & Biso & 1.000 & 0 \\
\hline 063 & 1.0000 & 0.61169 & 0.66587 & 0.68733 & Biso & 1.000 & 0 \\
\hline 064 & 1.0000 & 0.00219 & 0.75215 & 0.99971 & Biso & 1.000 & 0 \\
\hline 065 & 1.0000 & 0.26023 & 0.25456 & 0.98595 & Biso & 1.000 & 0 \\
\hline 066 & 1.0000 & 0.75562 & 0.00572 & 0.99973 & Biso & 1.000 & 0 \\
\hline 067 & 1.0000 & 0.67701 & 0.07926 & 0.33010 & Biso & 1.000 & 0 \\
\hline 068 & 1.0000 & 0.93411 & 0.60021 & 0.33540 & Biso & 1.000 & 0 \\
\hline 069 & 1.0000 & 0.40385 & 0.35328 & 0.31996 & Biso & 1.000 & 0 \\
\hline 070 & 1.0000 & 0.33167 & 0.41534 & 0.65515 & Biso & 1.000 & 0 \\
\hline 071 & 1.0000 & 0.59167 & 0.93934 & 0.66901 & Biso & 1.000 & 0 \\
\hline 072 & 1.0000 & 0.08012 & 0.70020 & 0.67091 & Biso & 1.000 & 0 \\
\hline $\mathrm{H} 1$ & 1.0000 & 0.27383 & 0.91637 & 0.34226 & Biso & 1.000 & $\mathrm{H}$ \\
\hline $\mathrm{C} 1$ & 1.0000 & 0.08064 & 0.89870 & 0.36372 & Biso & 1.000 & C \\
\hline H2 & 1.0000 & 0.02940 & 0.81559 & 0.39063 & Biso & 1.000 & $\mathrm{H}$ \\
\hline H3 & 1.0000 & 0.14246 & 0.96293 & 0.40672 & Biso & 1.000 & $\mathrm{H}$ \\
\hline $\mathrm{H} 4$ & 1.0000 & 0.09388 & 0.90666 & 0.29227 & Biso & 1.000 & $\mathrm{H}$ \\
\hline 073 & 1.0000 & 0.20607 & 0.84053 & 0.34784 & Biso & 1.000 & 0 \\
\hline H5 & 1.0000 & 0.20894 & 0.81568 & 0.40841 & Biso & 1.000 & $\mathrm{H}$ \\
\hline $\mathrm{C} 2$ & 1.0000 & 0.00499 & 0.03644 & 0.51111 & Biso & 1.000 & C \\
\hline $\mathrm{C} 3$ & 1.0000 & 0.07377 & 0.13793 & 0.46795 & Biso & 1.000 & C \\
\hline $\mathrm{C} 4$ & 1.0000 & 0.08368 & 0.14437 & 0.37491 & Biso & 1.000 & C \\
\hline $\mathrm{C} 5$ & 1.0000 & 0.02667 & 0.04824 & 0.32448 & Biso & 1.000 & C \\
\hline $\mathrm{C} 6$ & 1.0000 & 0.96278 & 0.94300 & 0.36726 & Biso & 1.000 & C \\
\hline C7 & 1.0000 & 0.94756 & 0.93976 & 0.46140 & Biso & 1.000 & C \\
\hline H6 & 1.0000 & 0.99682 & 0.03400 & 0.58344 & Biso & 1.000 & $\mathrm{H}$ \\
\hline $\mathrm{H} 7$ & 1.0000 & 0.89327 & 0.85997 & 0.49365 & Biso & 1.000 & $\mathrm{H}$ \\
\hline H8 & 1.0000 & 0.12071 & 0.21357 & 0.50719 & Biso & 1.000 & $\mathrm{H}$ \\
\hline H9 & 1.0000 & 0.13585 & 0.22458 & 0.34273 & Biso & 1.000 & $\mathrm{H}$ \\
\hline $\mathrm{H} 10$ & 1.0000 & 0.03336 & 0.05116 & 0.25201 & Biso & 1.000 & $\mathrm{H}$ \\
\hline H11 & 1.0000 & 0.90312 & 0.87226 & 0.32731 & Biso & 1.000 & $\mathrm{H}$ \\
\hline \\
\hline \multicolumn{8}{|c|}{$\begin{array}{l}\mathrm{Zn} 3 \\
\text { data image } 0\end{array}$} \\
\hline \multicolumn{2}{|c|}{ celī_length_a } & \multicolumn{2}{|c|}{13.875} & & & & \\
\hline \multicolumn{2}{|c|}{ cell_length_b } & \multicolumn{2}{|c|}{$\begin{array}{l}13.875 \\
13.875\end{array}$} & & & & \\
\hline $\mathrm{cell}$ & $=h \_c$ & 15.01 & & & & & \\
\hline $\operatorname{cell}$ & - & 90 & & & & & \\
\hline $\mathrm{cell}$ & -beta & 90 & & & & & \\
\hline $\mathrm{cell}$ & gamma & 120 & & & & & \\
\hline & & & & $1 "$ & & & \\
\hline symme & $n t \_t a b l$ & & & & & & \\
\hline
\end{tabular}




\begin{tabular}{|c|c|c|c|c|c|c|c|}
\hline \multicolumn{8}{|c|}{ 'symmetry_equiv_pos_as_xyz } \\
\hline \multicolumn{8}{|c|}{ loop_ _ _ _ n } \\
\hline \multicolumn{8}{|c|}{ atom_site_label } \\
\hline \multicolumn{8}{|c|}{ atom_site_occupancy } \\
\hline \multicolumn{8}{|c|}{ _atom_site_fract_x } \\
\hline \multicolumn{8}{|c|}{ _atom_site_fract_y } \\
\hline \multicolumn{8}{|c|}{ _atom_site_fract_z } \\
\hline -ato & $\begin{array}{l}\text { te ther } \\
\text { te_B_is }\end{array}$ & $\begin{array}{l}\text { nall_displ } \\
\text { onor_equi }\end{array}$ & ace_type & & & & \\
\hline $\bar{A} 11$ & 1.0000 & 0.99887 & 0.22446 & 0.10917 & Biso & 1.000 & Al \\
\hline Al2 & 1.0000 & 0.77601 & 0.77166 & 0.11262 & Biso & 1.000 & Al \\
\hline Al3 & 1.0000 & 0.23145 & 0.00201 & 0.10396 & Biso & 1.000 & Al \\
\hline $\mathrm{P} 1$ & 1.0000 & 0.22198 & 0.99788 & 0.89081 & Biso & 1.000 & $\mathrm{P}$ \\
\hline $\mathrm{P} 2$ & 1.0000 & 0.77411 & 0.76936 & 0.89942 & Biso & 1.000 & $\mathrm{P}$ \\
\hline P3 & 1.0000 & 0.99423 & 0.22298 & 0.89693 & Biso & 1.000 & $\mathrm{P}$ \\
\hline Al4 & 1.0000 & 0.65956 & 0.55515 & 0.44183 & Biso & 1.000 & Al \\
\hline $\mathrm{Zn} 1$ & 1.0000 & 0.44583 & 0.11094 & 0.44111 & Biso & 1.000 & $\mathrm{Zn}$ \\
\hline Al5 & 1.0000 & 0.90114 & 0.33277 & 0.44218 & Biso & 1.000 & Al \\
\hline $\mathrm{P} 4$ & 1.0000 & 0.89792 & 0.33566 & 0.23163 & Biso & 1.000 & $P$ \\
\hline P5 & 1.0000 & 0.43779 & 0.09876 & 0.22862 & Biso & 1.000 & $\mathrm{P}$ \\
\hline P 6 & 1.0000 & 0.66554 & 0.55792 & 0.23253 & Biso & 1.000 & $\mathrm{P}$ \\
\hline Al 6 & 1.0000 & 0.32603 & 0.88428 & 0.77782 & Biso & 1.000 & Al \\
\hline Al7 & 1.0000 & 0.10447 & 0.43176 & 0.77328 & Biso & 1.000 & Al \\
\hline Al8 & 1.0000 & 0.56318 & 0.66795 & 0.77593 & Biso & 1.000 & Al \\
\hline P7 & 1.0000 & 0.57333 & 0.67659 & 0.56805 & Biso & 1.000 & $P$ \\
\hline P8 & 1.0000 & 0.10539 & 0.43569 & 0.56789 & Biso & 1.000 & $\mathrm{P}$ \\
\hline P9 & 1.0000 & 0.32736 & 0.88099 & 0.56526 & Biso & 1.000 & $\mathrm{P}$ \\
\hline Al9 & 1.0000 & 0.99893 & 0.76846 & 0.90258 & Biso & 1.000 & Al \\
\hline Al10 & 1.0000 & 0.22275 & 0.22475 & 0.89693 & Biso & 1.000 & Al \\
\hline Al11 & 1.0000 & 0.77117 & 0.99384 & 0.90207 & Biso & 1.000 & Al \\
\hline $\mathrm{P} 10$ & 1.0000 & 0.77401 & 0.99590 & 0.11579 & Biso & 1.000 & $P$ \\
\hline P11 & 1.0000 & 0.22682 & 0.22584 & 0.11045 & Biso & 1.000 & $\mathrm{P}$ \\
\hline P12 & 1.0000 & 0.00468 & 0.77627 & 0.11650 & Biso & 1.000 & $\mathrm{P}$ \\
\hline Al12 & 1.0000 & 0.67195 & 0.10617 & 0.23913 & Biso & 1.000 & Al \\
\hline Al13 & 1.0000 & 0.89495 & 0.56179 & 0.23717 & Biso & 1.000 & Al \\
\hline Al14 & 1.0000 & 0.43778 & 0.32657 & 0.23452 & Biso & 1.000 & Al \\
\hline P13 & 1.0000 & 0.42515 & 0.32868 & 0.44380 & Biso & 1.000 & $P$ \\
\hline P14 & 1.0000 & 0.88965 & 0.55759 & 0.44803 & Biso & 1.000 & $\mathrm{P}$ \\
\hline P15 & 1.0000 & 0.67709 & 0.11242 & 0.44391 & Biso & 1.000 & $\mathrm{P}$ \\
\hline Al15 & 1.0000 & 0.34028 & 0.45160 & 0.56811 & Biso & 1.000 & Al \\
\hline Al16 & 1.0000 & 0.55860 & 0.89600 & 0.57112 & Biso & 1.000 & Al \\
\hline Al17 & 1.0000 & 0.09513 & 0.66385 & 0.57461 & Biso & 1.000 & Al \\
\hline $\mathrm{P} 16$ & 1.0000 & 0.10036 & 0.66110 & 0.78255 & Biso & 1.000 & $\mathrm{P}$ \\
\hline P17 & 1.0000 & 0.55673 & 0.89307 & 0.78111 & Biso & 1.000 & $\mathrm{P}$ \\
\hline P18 & 1.0000 & 0.33522 & 0.43908 & 0.77708 & Biso & 1.000 & $\mathrm{P}$ \\
\hline 01 & 1.0000 & 0.89602 & 0.08697 & 0.13401 & Biso & 1.000 & 0 \\
\hline $\mathrm{O} 2$ & 1.0000 & 0.91401 & 0.80681 & 0.13763 & Biso & 1.000 & 0 \\
\hline 03 & 1.0000 & 0.19699 & 0.10477 & 0.13104 & Biso & 1.000 & 0 \\
\hline 04 & 1.0000 & 0.10193 & 0.90354 & 0.87278 & Biso & 1.000 & 0 \\
\hline 05 & 1.0000 & 0.80569 & 0.89061 & 0.87879 & Biso & 1.000 & 0 \\
\hline 06 & 1.0000 & 0.08597 & 0.19437 & 0.87703 & Biso & 1.000 & 0 \\
\hline 07 & 1.0000 & 0.54817 & 0.42152 & 0.45652 & Biso & 1.000 & 0 \\
\hline 08 & 1.0000 & 0.60279 & 0.16396 & 0.44582 & Biso & 1.000 & 0 \\
\hline 09 & 1.0000 & 0.87199 & 0.44025 & 0.46346 & Biso & 1.000 & 0 \\
\hline 010 & 1.0000 & 0.77608 & 0.24459 & 0.21665 & Biso & 1.000 & 0 \\
\hline 011 & 1.0000 & 0.47147 & 0.22251 & 0.21604 & Biso & 1.000 & 0 \\
\hline 012 & 1.0000 & 0.75754 & 0.52856 & 0.21586 & Biso & 1.000 & 0 \\
\hline 013 & 1.0000 & 0.22126 & 0.74871 & 0.80601 & Biso & 1.000 & 0 \\
\hline 014 & 1.0000 & 0.24310 & 0.46832 & 0.79467 & Biso & 1.000 & 0 \\
\hline 015 & 1.0000 & 0.52724 & 0.77087 & 0.79256 & Biso & 1.000 & 0 \\
\hline 016 & 1.0000 & 0.45010 & 0.58816 & 0.55469 & Biso & 1.000 & 0 \\
\hline 017 & 1.0000 & 0.11364 & 0.54987 & 0.56364 & Biso & 1.000 & 0 \\
\hline 018 & 1.0000 & 0.41565 & 0.84440 & 0.55473 & Biso & 1.000 & 0 \\
\hline 019 & 1.0000 & 0.97661 & 0.31746 & 0.17111 & Biso & 1.000 & 0 \\
\hline 020 & 1.0000 & 0.68238 & 0.65396 & 0.17168 & Biso & 1.000 & 0 \\
\hline 021 & 1.0000 & 0.35370 & 0.02769 & 0.15552 & Biso & 1.000 & 0 \\
\hline 022 & 1.0000 & 0.30533 & 0.98160 & 0.83555 & Biso & 1.000 & 0 \\
\hline 023 & 1.0000 & 0.67056 & 0.68752 & 0.84710 & Biso & 1.000 & 0 \\
\hline $\mathrm{O} 24$ & 1.0000 & 0.01255 & 0.32393 & 0.84234 & Biso & 1.000 & 0 \\
\hline 025 & 1.0000 & 0.64827 & 0.65372 & 0.50680 & Biso & 1.000 & 0 \\
\hline 026 & 1.0000 & 0.34954 & 0.97944 & 0.50882 & Biso & 1.000 & 0 \\
\hline 027 & 1.0000 & 0.01821 & 0.35495 & 0.50201 & Biso & 1.000 & 0 \\
\hline 028 & 1.0000 & 0.01920 & 0.66962 & 0.84715 & Biso & 1.000 & 0 \\
\hline 029 & 1.0000 & 0.31665 & 0.34041 & 0.83541 & Biso & 1.000 & 0 \\
\hline 030 & 1.0000 & 0.65337 & 0.96907 & 0.84275 & Biso & 1.000 & 0 \\
\hline
\end{tabular}




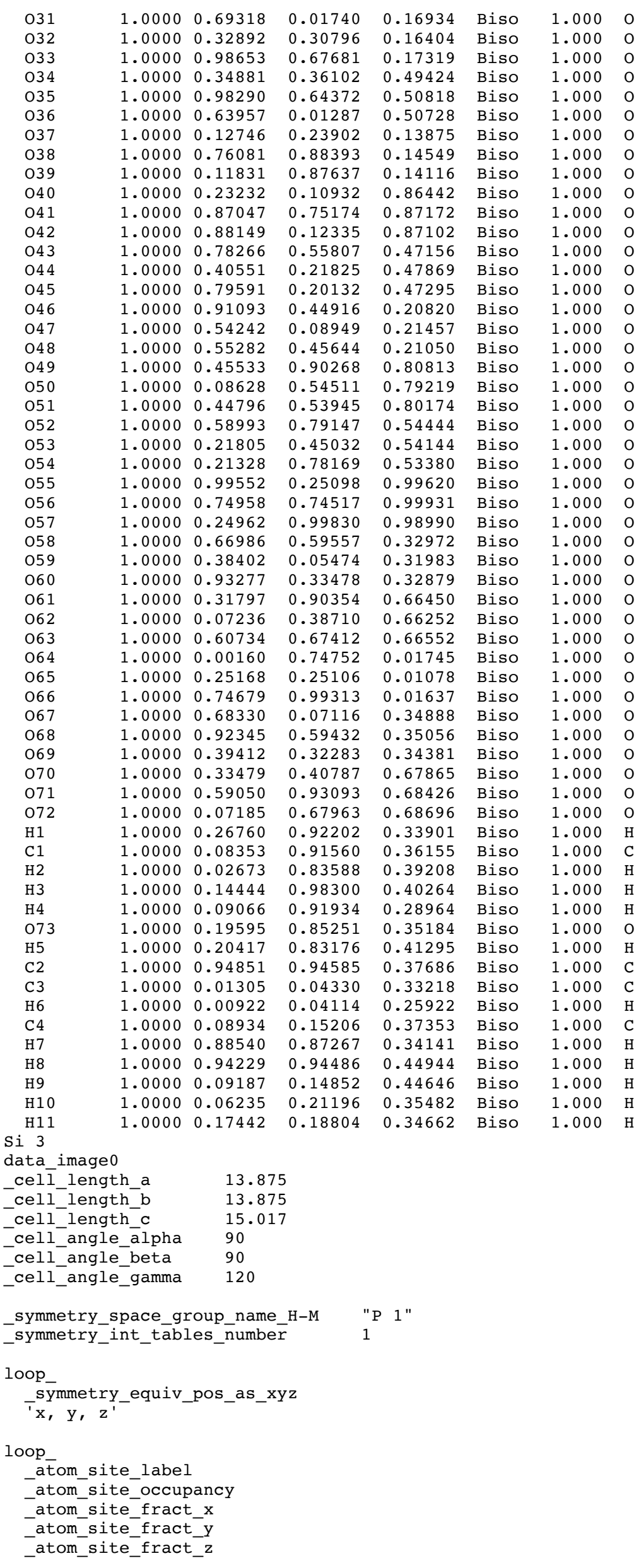




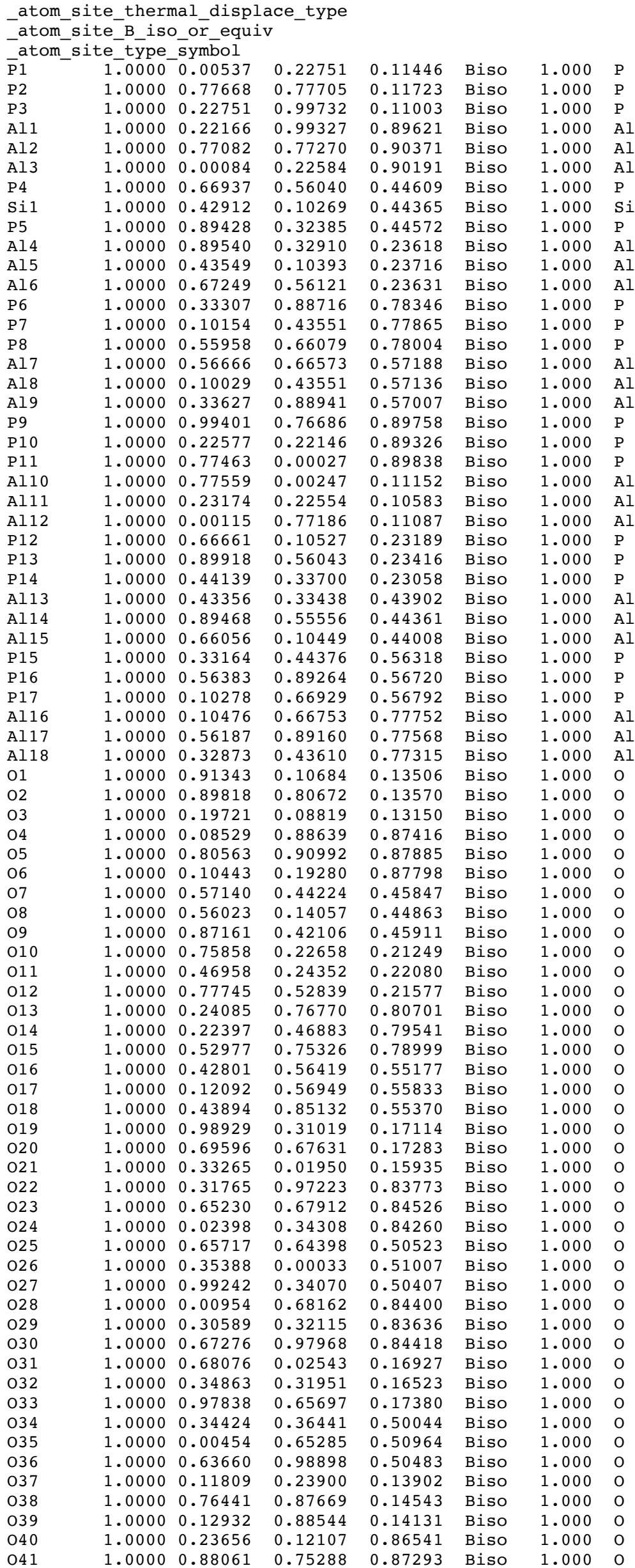




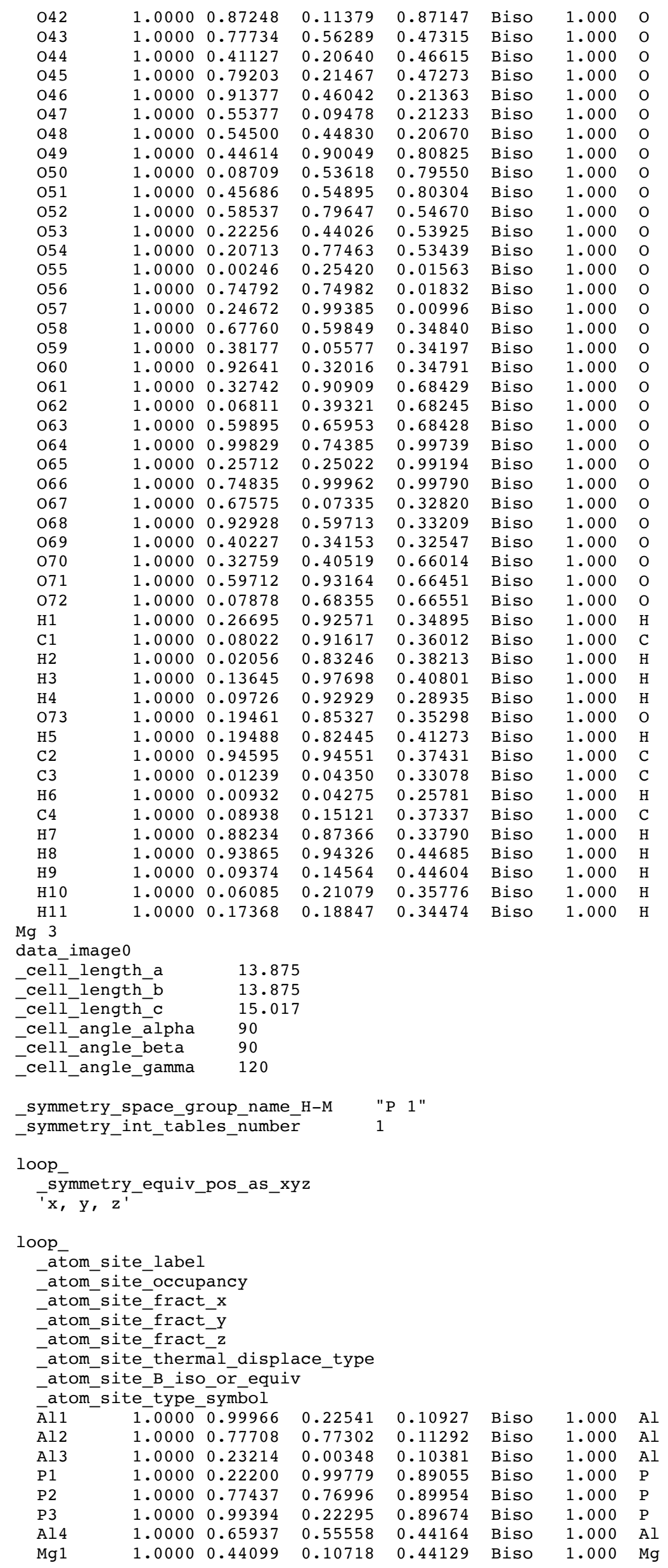




\begin{tabular}{|c|c|c|c|c|c|c|c|}
\hline Al5 & 1.0000 & 0.90112 & 0.33239 & 0.44244 & Biso & 1.000 & $\mathrm{Al}$ \\
\hline P4 & 1.0000 & 0.89933 & 0.33652 & 0.23221 & Biso & 1.000 & $\mathrm{P}$ \\
\hline P5 & 1.0000 & 0.43797 & 0.09888 & 0.22966 & Biso & 1.000 & $\mathrm{P}$ \\
\hline P6 & 1.0000 & 0.66689 & 0.55798 & 0.23144 & Biso & 1.000 & $\mathrm{P}$ \\
\hline Al6 & 1.0000 & 0.32542 & 0.88238 & 0.77948 & Biso & 1.000 & $\mathrm{Al}$ \\
\hline Al7 & 1.0000 & 0.10427 & 0.43170 & 0.77349 & Biso & 1.000 & Al \\
\hline Al8 & 1.0000 & 0.56341 & 0.66725 & 0.77573 & Biso & 1.000 & Al \\
\hline P7 & 1.0000 & 0.57419 & 0.67580 & 0.56813 & Biso & 1.000 & $\mathrm{P}$ \\
\hline P8 & 1.0000 & 0.10478 & 0.43561 & 0.56844 & Biso & 1.000 & $P$ \\
\hline P9 & 1.0000 & 0.32721 & 0.87903 & 0.56656 & Biso & 1.000 & $\mathrm{P}$ \\
\hline Al9 & 1.0000 & 0.99882 & 0.76830 & 0.90289 & Biso & 1.000 & $\mathrm{Al}$ \\
\hline Al10 & 1.0000 & 0.22204 & 0.22417 & 0.89565 & Biso & 1.000 & Al \\
\hline Al11 & 1.0000 & 0.77146 & 0.99400 & 0.90202 & Biso & 1.000 & $\mathrm{Al}$ \\
\hline $\mathrm{P} 10$ & 1.0000 & 0.77507 & 0.99700 & 0.11605 & Biso & 1.000 & $\mathrm{P}$ \\
\hline P 11 & 1.0000 & 0.22730 & 0.22677 & 0.10930 & Biso & 1.000 & $P$ \\
\hline P12 & 1.0000 & 0.00583 & 0.77739 & 0.11679 & Biso & 1.000 & $\mathrm{P}$ \\
\hline Al12 & 1.0000 & 0.67307 & 0.10809 & 0.23854 & Biso & 1.000 & Al \\
\hline Al13 & 1.0000 & 0.89703 & 0.56356 & 0.23786 & Biso & 1.000 & Al \\
\hline Al 14 & 1.0000 & 0.43792 & 0.32927 & 0.23397 & Biso & 1.000 & Al \\
\hline P13 & 1.0000 & 0.42340 & 0.33188 & 0.44138 & Biso & 1.000 & $\mathrm{P}$ \\
\hline P 14 & 1.0000 & 0.88977 & 0.55820 & 0.44823 & Biso & 1.000 & $\mathrm{P}$ \\
\hline P15 & 1.0000 & 0.67657 & 0.11079 & 0.44377 & Biso & 1.000 & $\mathrm{P}$ \\
\hline Al15 & 1.0000 & 0.33974 & 0.45233 & 0.56765 & Biso & 1.000 & Al \\
\hline A116 & 1.0000 & 0.55951 & 0.89627 & 0.57160 & Biso & 1.000 & Al \\
\hline Al17 & 1.0000 & 0.09436 & 0.66407 & 0.57544 & Biso & 1.000 & $\mathrm{Al}$ \\
\hline P16 & 1.0000 & 0.09969 & 0.66087 & 0.78330 & Biso & 1.000 & $P$ \\
\hline P 17 & 1.0000 & 0.55697 & 0.89345 & 0.78089 & Biso & 1.000 & $\mathrm{P}$ \\
\hline P 18 & 1.0000 & 0.33492 & 0.43990 & 0.77739 & Biso & 1.000 & $P$ \\
\hline 01 & 1.0000 & 0.89700 & 0.08803 & 0.13462 & Biso & 1.000 & 0 \\
\hline $\mathrm{O} 2$ & 1.0000 & 0.91501 & 0.80772 & 0.13792 & Biso & 1.000 & 0 \\
\hline 03 & 1.0000 & 0.19714 & 0.10581 & 0.13085 & Biso & 1.000 & 0 \\
\hline 04 & 1.0000 & 0.10208 & 0.90308 & 0.87270 & Biso & 1.000 & 0 \\
\hline 05 & 1.0000 & 0.80627 & 0.89111 & 0.87813 & Biso & 1.000 & 0 \\
\hline 06 & 1.0000 & 0.08525 & 0.19394 & 0.87607 & Biso & 1.000 & 0 \\
\hline 07 & 1.0000 & 0.54567 & 0.42406 & 0.45870 & Biso & 1.000 & 0 \\
\hline 08 & 1.0000 & 0.59602 & 0.15427 & 0.44662 & Biso & 1.000 & 0 \\
\hline 09 & 1.0000 & 0.87362 & 0.44129 & 0.46229 & Biso & 1.000 & 0 \\
\hline 010 & 1.0000 & 0.77731 & 0.24663 & 0.21606 & Biso & 1.000 & 0 \\
\hline 011 & 1.0000 & 0.46880 & 0.22239 & 0.22164 & Biso & 1.000 & 0 \\
\hline 012 & 1.0000 & 0.75993 & 0.53004 & 0.21520 & Biso & 1.000 & 0 \\
\hline 013 & 1.0000 & 0.22029 & 0.74740 & 0.80871 & Biso & 1.000 & 0 \\
\hline 014 & 1.0000 & 0.24290 & 0.46905 & 0.79583 & Biso & 1.000 & 0 \\
\hline 015 & 1.0000 & 0.52860 & 0.77133 & 0.78980 & Biso & 1.000 & 0 \\
\hline 016 & 1.0000 & 0.45145 & 0.58744 & 0.55238 & Biso & 1.000 & 0 \\
\hline 017 & 1.0000 & 0.10999 & 0.54841 & 0.56532 & Biso & 1.000 & 0 \\
\hline 018 & 1.0000 & 0.41605 & 0.84320 & 0.55546 & Biso & 1.000 & 0 \\
\hline 019 & 1.0000 & 0.97787 & 0.31878 & 0.17110 & Biso & 1.000 & 0 \\
\hline 020 & 1.0000 & 0.68391 & 0.65505 & 0.17179 & Biso & 1.000 & 0 \\
\hline 021 & 1.0000 & 0.35472 & 0.03021 & 0.15531 & Biso & 1.000 & 0 \\
\hline 022 & 1.0000 & 0.30550 & 0.98118 & 0.83573 & Biso & 1.000 & 0 \\
\hline 023 & 1.0000 & 0.67055 & 0.68787 & 0.84762 & Biso & 1.000 & 0 \\
\hline $\mathrm{O} 24$ & 1.0000 & 0.01234 & 0.32432 & 0.84276 & Biso & 1.000 & 0 \\
\hline 025 & 1.0000 & 0.65080 & 0.65616 & 0.50612 & Biso & 1.000 & 0 \\
\hline 026 & 1.0000 & 0.35177 & 0.97949 & 0.51209 & Biso & 1.000 & 0 \\
\hline 027 & 1.0000 & 0.01797 & 0.35422 & 0.50262 & Biso & 1.000 & 0 \\
\hline 028 & 1.0000 & 0.01780 & 0.66850 & 0.84764 & Biso & 1.000 & 0 \\
\hline 029 & 1.0000 & 0.31594 & 0.34004 & 0.83436 & Biso & 1.000 & 0 \\
\hline 030 & 1.0000 & 0.65308 & 0.96847 & 0.84330 & Biso & 1.000 & 0 \\
\hline 031 & 1.0000 & 0.69397 & 0.01903 & 0.16866 & Biso & 1.000 & 0 \\
\hline 032 & 1.0000 & 0.33056 & 0.30938 & 0.16139 & Biso & 1.000 & 0 \\
\hline 033 & 1.0000 & 0.98846 & 0.67836 & 0.17367 & Biso & 1.000 & 0 \\
\hline 034 & 1.0000 & 0.34503 & 0.35823 & 0.49557 & Biso & 1.000 & 0 \\
\hline 035 & 1.0000 & 0.98171 & 0.64413 & 0.50951 & Biso & 1.000 & 0 \\
\hline 036 & 1.0000 & 0.64298 & 0.01022 & 0.50560 & Biso & 1.000 & 0 \\
\hline 037 & 1.0000 & 0.12875 & 0.24088 & 0.13829 & Biso & 1.000 & 0 \\
\hline 038 & 1.0000 & 0.76172 & 0.88510 & 0.14630 & Biso & 1.000 & 0 \\
\hline 039 & 1.0000 & 0.11943 & 0.87771 & 0.14124 & Biso & 1.000 & 0 \\
\hline 040 & 1.0000 & 0.23197 & 0.10885 & 0.86330 & Biso & 1.000 & 0 \\
\hline 041 & 1.0000 & 0.87042 & 0.75173 & 0.87211 & Biso & 1.000 & 0 \\
\hline 042 & 1.0000 & 0.88099 & 0.12376 & 0.87068 & Biso & 1.000 & 0 \\
\hline 043 & 1.0000 & 0.78147 & 0.55627 & 0.47134 & Biso & 1.000 & 0 \\
\hline 044 & 1.0000 & 0.40537 & 0.21946 & 0.46735 & Biso & 1.000 & 0 \\
\hline 045 & 1.0000 & 0.79384 & 0.20251 & 0.47388 & Biso & 1.000 & 0 \\
\hline 046 & 1.0000 & 0.91383 & 0.45105 & 0.21054 & Biso & 1.000 & 0 \\
\hline 047 & 1.0000 & 0.54421 & 0.09304 & 0.21322 & Biso & 1.000 & 0 \\
\hline 048 & 1.0000 & 0.55538 & 0.45626 & 0.20720 & Biso & 1.000 & 0 \\
\hline 049 & 1.0000 & 0.45489 & 0.90112 & 0.80935 & Biso & 1.000 & 0 \\
\hline 050 & 1.0000 & 0.08471 & 0.54439 & 0.79120 & Biso & 1.000 & 0 \\
\hline 051 & 1.0000 & 0.44761 & 0.53972 & 0.80305 & Biso & 1.000 & 0 \\
\hline 052 & 1.0000 & 0.59068 & 0.79121 & 0.54756 & Biso & 1.000 & 0 \\
\hline
\end{tabular}




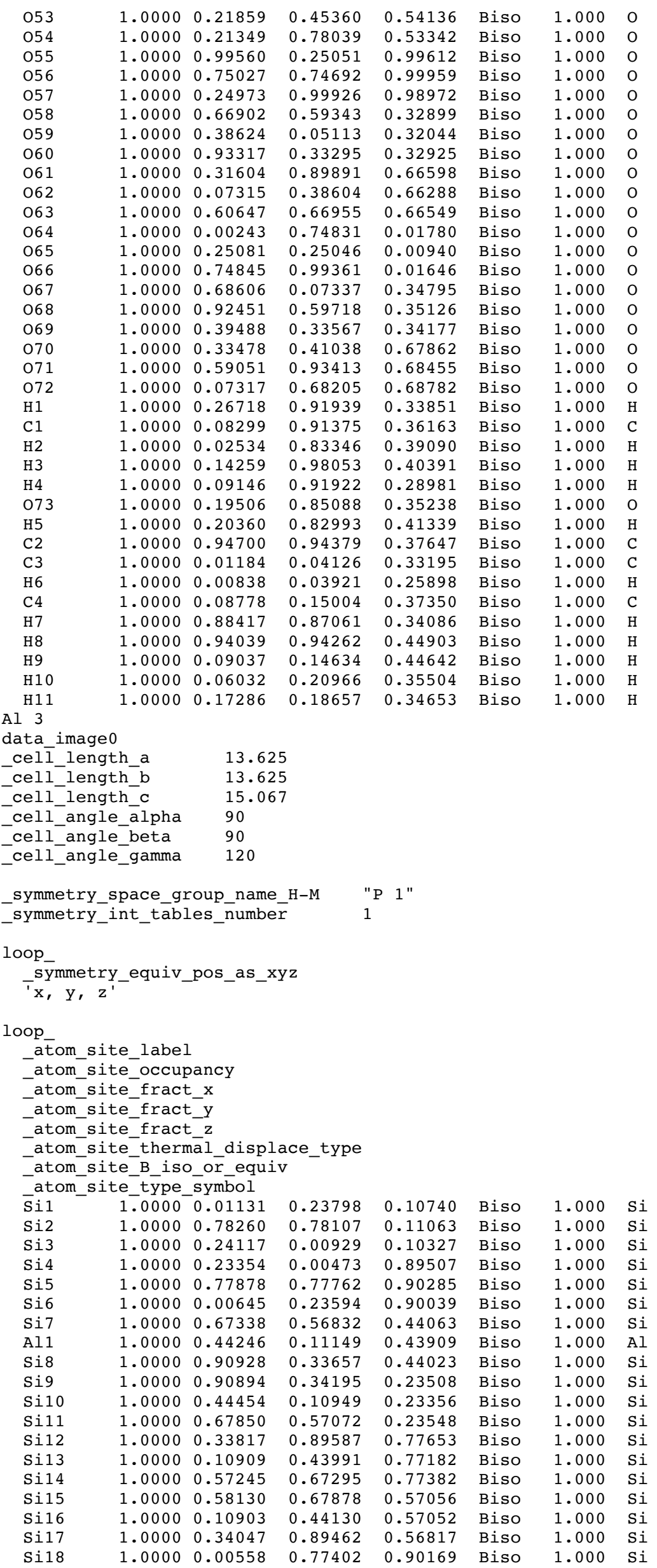




\begin{tabular}{|c|c|c|c|c|c|c|c|}
\hline Si19 & 1.0000 & 0.23540 & 0.23435 & 0.89591 & Biso & 1.000 & $\mathrm{Si}$ \\
\hline Si20 & 1.0000 & 0.77945 & 0.00599 & 0.90133 & Biso & 1.000 & $\mathrm{Si}$ \\
\hline Si21 & 1.0000 & 0.78144 & 0.00865 & 0.10941 & Biso & 1.000 & $\mathrm{Si}$ \\
\hline Si22 & 1.0000 & 0.24087 & 0.23770 & 0.10371 & Biso & 1.000 & \\
\hline Si23 & 1.0000 & 0.01195 & 0.78072 & 0.10963 & Biso & 1.000 & \\
\hline Si24 & 1.0000 & 0.67863 & 0.11394 & 0.23578 & Biso & 1.000 & \\
\hline Si25 & 1.0000 & 0.90817 & 0.57252 & 0.23704 & Biso & 1.000 & \\
\hline Si26 & 1.0000 & 0.44579 & 0.34203 & 0.23335 & Biso & 1.000 & \\
\hline Si27 & 1.0000 & 0.43533 & 0.34111 & 0.43689 & Biso & 1.000 & \\
\hline Si28 & 1.0000 & 0.90280 & 0.56683 & 0.44260 & Biso & 1.000 & \\
\hline Si29 & 1.0000 & 0.67655 & 0.11427 & 0.43878 & Biso & 1.000 & \\
\hline Si30 & 1.0000 & 0.34463 & 0.45391 & 0.56625 & Biso & 1.000 & \\
\hline Si31 & 1.0000 & 0.57286 & 0.90499 & 0.56989 & Biso & 1.000 & \\
\hline Si32 & 1.0000 & 0.10512 & 0.67454 & 0.57185 & Biso & 1.000 & \\
\hline Si33 & 1.0000 & 0.10914 & 0.67299 & 0.77581 & Biso & 1.000 & \\
\hline $\operatorname{Si} 34$ & 1.0000 & 0.57091 & 0.90382 & 0.77380 & Biso & 1.000 & \\
\hline Si35 & 1.0000 & 0.34044 & 0.44481 & 0.77146 & Biso & 1.000 & \\
\hline 01 & 1.0000 & 0.91308 & 0.10714 & 0.12665 & Biso & 1.000 & \\
\hline $\mathrm{O} 2$ & 1.0000 & 0.91426 & 0.81455 & 0.12805 & Biso & 1.000 & \\
\hline $\mathrm{O} 3$ & 1.0000 & 0.20768 & 0.10682 & 0.12386 & Biso & 1.000 & \\
\hline 04 & 1.0000 & 0.10334 & 0.90356 & 0.87917 & Biso & 1.000 & \\
\hline 05 & 1.0000 & 0.81386 & 0.90890 & 0.88353 & Biso & 1.000 & \\
\hline 06 & 1.0000 & 0.10475 & 0.20401 & 0.88159 & Biso & 1.000 & \\
\hline 07 & 1.0000 & 0.56649 & 0.44231 & 0.45242 & Biso & 1.000 & \\
\hline 08 & 1.0000 & 0.58575 & 0.15499 & 0.44518 & Biso & 1.000 & \\
\hline 09 & 1.0000 & 0.88339 & 0.44009 & 0.45523 & Biso & 1.000 & \\
\hline 010 & 1.0000 & 0.77795 & 0.24518 & 0.21778 & Biso & 1.000 & \\
\hline 011 & 1.0000 & 0.47652 & 0.24184 & 0.22249 & Biso & 1.000 & \\
\hline 012 & 1.0000 & 0.77704 & 0.53812 & 0.21851 & Biso & 1.000 & \\
\hline 013 & 1.0000 & 0.23950 & 0.76661 & 0.80037 & Biso & 1.000 & \\
\hline 014 & 1.0000 & 0.24113 & 0.47631 & 0.78925 & Biso & 1.000 & \\
\hline 015 & 1.0000 & 0.54027 & 0.77242 & 0.78330 & Biso & 1.000 & \\
\hline 016 & 1.0000 & 0.44960 & 0.58273 & 0.55439 & Biso & 1.000 & \\
\hline 017 & 1.0000 & 0.12173 & 0.56563 & 0.56402 & Biso & 1.000 & \\
\hline 018 & 1.0000 & 0.43755 & 0.85780 & 0.55735 & Biso & 1.000 & \\
\hline 019 & 1.0000 & 0.99384 & 0.32469 & 0.16976 & Biso & 1.000 & \\
\hline 020 & 1.0000 & 0.69800 & 0.67506 & 0.17210 & Biso & 1.000 & 0 \\
\hline 021 & 1.0000 & 0.35182 & 0.03197 & 0.15824 & Biso & 1.000 & \\
\hline 022 & 1.0000 & 0.32090 & 0.98628 & 0.83466 & Biso & 1.000 & $\mathrm{O}$ \\
\hline 023 & 1.0000 & 0.67061 & 0.69162 & 0.84374 & Biso & 1.000 & 0 \\
\hline $\mathrm{O} 24$ & 1.0000 & 0.02563 & 0.34234 & 0.84035 & Biso & 1.000 & 0 \\
\hline 025 & 1.0000 & 0.66431 & 0.65943 & 0.50457 & Biso & 1.000 & 0 \\
\hline 026 & 1.0000 & 0.36051 & 0.99799 & 0.50790 & Biso & 1.000 & 0 \\
\hline $\mathrm{O} 27$ & 1.0000 & 0.01459 & 0.35426 & 0.50171 & Biso & 1.000 & 0 \\
\hline 028 & 1.0000 & 0.02220 & 0.68381 & 0.84306 & Biso & 1.000 & 0 \\
\hline 029 & 1.0000 & 0.32078 & 0.33944 & 0.83370 & Biso & 1.000 & 0 \\
\hline 030 & 1.0000 & 0.67236 & 0.98422 & 0.84108 & Biso & 1.000 & 0 \\
\hline 031 & 1.0000 & 0.69562 & 0.03003 & 0.16884 & Biso & 1.000 & O \\
\hline 032 & 1.0000 & 0.34813 & 0.32503 & 0.16285 & Biso & 1.000 & 0 \\
\hline 033 & 1.0000 & 0.99265 & 0.67704 & 0.17352 & Biso & 1.000 & 0 \\
\hline 034 & 1.0000 & 0.35239 & 0.36794 & 0.49731 & Biso & 1.000 & 0 \\
\hline 035 & 1.0000 & 0.00173 & 0.65785 & 0.50789 & Biso & 1.000 & O \\
\hline 036 & 1.0000 & 0.64980 & 0.00751 & 0.50314 & Biso & 1.000 & 0 \\
\hline 037 & 1.0000 & 0.13256 & 0.24990 & 0.13237 & Biso & 1.000 & 0 \\
\hline 038 & 1.0000 & 0.77056 & 0.88917 & 0.13934 & Biso & 1.000 & 0 \\
\hline 039 & 1.0000 & 0.13349 & 0.88960 & 0.13504 & Biso & 1.000 & 0 \\
\hline 040 & 1.0000 & 0.24437 & 0.12456 & 0.86758 & Biso & 1.000 & 0 \\
\hline 041 & 1.0000 & 0.88397 & 0.76010 & 0.87620 & Biso & 1.000 & 0 \\
\hline 042 & 1.0000 & 0.88549 & 0.12796 & 0.87408 & Biso & 1.000 & O \\
\hline 043 & 1.0000 & 0.78778 & 0.56696 & 0.46800 & Biso & 1.000 & 0 \\
\hline O4 4 & 1.0000 & 0.41793 & 0.22106 & 0.46303 & Biso & 1.000 & 0 \\
\hline 045 & 1.0000 & 0.80187 & 0.21696 & 0.46780 & Biso & 1.000 & 0 \\
\hline 046 & 1.0000 & 0.92414 & 0.46543 & 0.21438 & Biso & 1.000 & 0 \\
\hline 047 & 1.0000 & 0.55828 & 0.10353 & 0.21277 & Biso & 1.000 & 0 \\
\hline 048 & 1.0000 & 0.55768 & 0.46241 & 0.21064 & Biso & 1.000 & 0 \\
\hline 049 & 1.0000 & 0.46020 & 0.91108 & 0.80235 & Biso & 1.000 & 0 \\
\hline 050 & 1.0000 & 0.09308 & 0.54818 & 0.78760 & Biso & 1.000 & 0 \\
\hline 051 & 1.0000 & 0.46127 & 0.55310 & 0.79777 & Biso & 1.000 & 0 \\
\hline 052 & 1.0000 & 0.59764 & 0.80234 & 0.54895 & Biso & 1.000 & 0 \\
\hline 053 & 1.0000 & 0.22922 & 0.45458 & 0.54324 & Biso & 1.000 & 0 \\
\hline 054 & 1.0000 & 0.21892 & 0.78550 & 0.53586 & Biso & 1.000 & 0 \\
\hline 055 & 1.0000 & 0.00814 & 0.27013 & 0.00412 & Biso & 1.000 & 0 \\
\hline 056 & 1.0000 & 0.74770 & 0.74777 & 0.00737 & Biso & 1.000 & 0 \\
\hline 057 & 1.0000 & 0.26697 & 0.00625 & 0.99873 & Biso & 1.000 & 0 \\
\hline 058 & 1.0000 & 0.68350 & 0.61148 & 0.33802 & Biso & 1.000 & 0 \\
\hline 059 & 1.0000 & 0.39218 & 0.06015 & 0.33011 & Biso & 1.000 & 0 \\
\hline 060 & 1.0000 & 0.94560 & 0.33569 & 0.33701 & Biso & 1.000 & 0 \\
\hline 061 & 1.0000 & 0.33093 & 0.92046 & 0.67249 & Biso & 1.000 & 0 \\
\hline 062 & 1.0000 & 0.07278 & 0.39173 & 0.67097 & Biso & 1.000 & 0 \\
\hline 063 & 1.0000 & 0.61660 & 0.67231 & 0.67322 & Biso & 1.000 & 0 \\
\hline
\end{tabular}




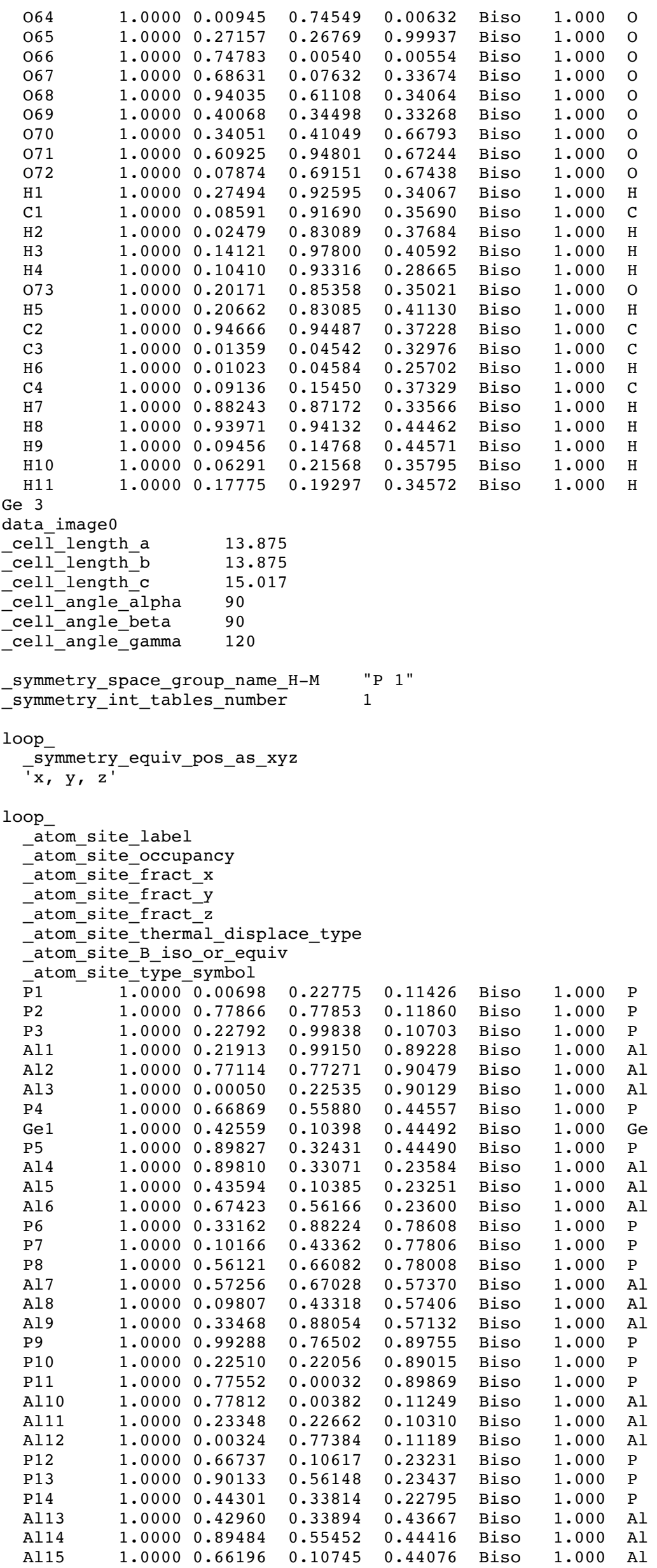




\begin{tabular}{|c|c|c|c|c|c|c|c|}
\hline P15 & 1.0000 & 0.33413 & 0.45346 & 0.56260 & Biso & 1.000 & $\mathrm{P}$ \\
\hline P16 & 1.0000 & 0.56536 & 0.89421 & 0.56867 & Biso & 1.000 & $\mathrm{P}$ \\
\hline P17 & 1.0000 & 0.09771 & 0.66735 & 0.57138 & Biso & 1.000 & $\mathrm{P}$ \\
\hline Al16 & 1.0000 & 0.10224 & 0.66611 & 0.77844 & Biso & 1.000 & $\mathrm{Al}$ \\
\hline Al17 & 1.0000 & 0.56054 & 0.89061 & 0.77759 & Biso & 1.000 & Al \\
\hline Al18 & 1.0000 & 0.32915 & 0.43628 & 0.77090 & Biso & 1.000 & $\mathrm{Al}$ \\
\hline 01 & 1.0000 & 0.91616 & 0.10727 & 0.13704 & Biso & 1.000 & 0 \\
\hline $\mathrm{O} 2$ & 1.0000 & 0.90010 & 0.80827 & 0.13754 & Biso & 1.000 & 0 \\
\hline 03 & 1.0000 & 0.19857 & 0.08951 & 0.13004 & Biso & 1.000 & 0 \\
\hline 04 & 1.0000 & 0.08380 & 0.88285 & 0.86946 & Biso & 1.000 & 0 \\
\hline 05 & 1.0000 & 0.80676 & 0.91009 & 0.87918 & Biso & 1.000 & 0 \\
\hline 06 & 1.0000 & 0.10387 & 0.19268 & 0.87570 & Biso & 1.000 & 0 \\
\hline 07 & 1.0000 & 0.56948 & 0.44109 & 0.45707 & Biso & 1.000 & 0 \\
\hline 08 & 1.0000 & 0.57038 & 0.15575 & 0.45161 & Biso & 1.000 & 0 \\
\hline 09 & 1.0000 & 0.87581 & 0.42141 & 0.46008 & Biso & 1.000 & 0 \\
\hline 010 & 1.0000 & 0.76064 & 0.22750 & 0.21533 & Biso & 1.000 & 0 \\
\hline 011 & 1.0000 & 0.47065 & 0.24412 & 0.22044 & Biso & 1.000 & 0 \\
\hline 012 & 1.0000 & 0.77973 & 0.52969 & 0.21569 & Biso & 1.000 & 0 \\
\hline 013 & 1.0000 & 0.23763 & 0.76445 & 0.81183 & Biso & 1.000 & 0 \\
\hline 014 & 1.0000 & 0.22485 & 0.46951 & 0.79489 & Biso & 1.000 & 0 \\
\hline 015 & 1.0000 & 0.52999 & 0.75242 & 0.78831 & Biso & 1.000 & 0 \\
\hline 016 & 1.0000 & 0.43189 & 0.57373 & 0.55615 & Biso & 1.000 & 0 \\
\hline 017 & 1.0000 & 0.10589 & 0.56168 & 0.56754 & Biso & 1.000 & 0 \\
\hline 018 & 1.0000 & 0.43985 & 0.84663 & 0.55176 & Biso & 1.000 & 0 \\
\hline 019 & 1.0000 & 0.99084 & 0.31114 & 0.16987 & Biso & 1.000 & 0 \\
\hline 020 & 1.0000 & 0.69765 & 0.67746 & 0.17367 & Biso & 1.000 & 0 \\
\hline 021 & 1.0000 & 0.33664 & 0.02264 & 0.15141 & Biso & 1.000 & 0 \\
\hline 022 & 1.0000 & 0.31642 & 0.97079 & 0.83532 & Biso & 1.000 & 0 \\
\hline 023 & 1.0000 & 0.65099 & 0.67887 & 0.84828 & Biso & 1.000 & 0 \\
\hline 024 & 1.0000 & 0.02559 & 0.34549 & 0.84557 & Biso & 1.000 & 0 \\
\hline 025 & 1.0000 & 0.65778 & 0.64286 & 0.50521 & Biso & 1.000 & 0 \\
\hline 026 & 1.0000 & 0.34425 & 0.99089 & 0.51504 & Biso & 1.000 & 0 \\
\hline 027 & 1.0000 & 0.99558 & 0.33858 & 0.50313 & Biso & 1.000 & 0 \\
\hline 028 & 1.0000 & 0.00645 & 0.67626 & 0.84738 & Biso & 1.000 & 0 \\
\hline 029 & 1.0000 & 0.30525 & 0.32017 & 0.83313 & Biso & 1.000 & 0 \\
\hline 030 & 1.0000 & 0.67195 & 0.97787 & 0.84609 & Biso & 1.000 & 0 \\
\hline 031 & 1.0000 & 0.68363 & 0.02720 & 0.17028 & Biso & 1.000 & 0 \\
\hline 032 & 1.0000 & 0.35196 & 0.32081 & 0.16085 & Biso & 1.000 & 0 \\
\hline 033 & 1.0000 & 0.98079 & 0.65894 & 0.17482 & Biso & 1.000 & 0 \\
\hline 034 & 1.0000 & 0.34516 & 0.37866 & 0.49407 & Biso & 1.000 & 0 \\
\hline 035 & 1.0000 & 0.00181 & 0.65412 & 0.51150 & Biso & 1.000 & 0 \\
\hline 036 & 1.0000 & 0.63556 & 0.99245 & 0.50710 & Biso & 1.000 & 0 \\
\hline 037 & 1.0000 & 0.12091 & 0.24139 & 0.13754 & Biso & 1.000 & 0 \\
\hline 038 & 1.0000 & 0.76591 & 0.87783 & 0.14692 & Biso & 1.000 & 0 \\
\hline 039 & 1.0000 & 0.13196 & 0.88720 & 0.14206 & Biso & 1.000 & 0 \\
\hline 040 & 1.0000 & 0.23467 & 0.11965 & 0.86156 & Biso & 1.000 & 0 \\
\hline 041 & 1.0000 & 0.87911 & 0.75041 & 0.87328 & Biso & 1.000 & 0 \\
\hline 042 & 1.0000 & 0.87212 & 0.11377 & 0.86983 & Biso & 1.000 & 0 \\
\hline 043 & 1.0000 & 0.77529 & 0.55850 & 0.47237 & Biso & 1.000 & 0 \\
\hline 044 & 1.0000 & 0.39345 & 0.20806 & 0.47050 & Biso & 1.000 & 0 \\
\hline 045 & 1.0000 & 0.79612 & 0.21439 & 0.47038 & Biso & 1.000 & 0 \\
\hline 046 & 1.0000 & 0.91599 & 0.46175 & 0.21263 & Biso & 1.000 & 0 \\
\hline 047 & 1.0000 & 0.55584 & 0.09700 & 0.20949 & Biso & 1.000 & 0 \\
\hline 048 & 1.0000 & 0.54756 & 0.44888 & 0.20467 & Biso & 1.000 & 0 \\
\hline 049 & 1.0000 & 0.44387 & 0.89566 & 0.81423 & Biso & 1.000 & 0 \\
\hline 050 & 1.0000 & 0.08569 & 0.53423 & 0.78881 & Biso & 1.000 & 0 \\
\hline 051 & 1.0000 & 0.45806 & 0.54826 & 0.80051 & Biso & 1.000 & 0 \\
\hline 052 & 1.0000 & 0.59514 & 0.80314 & 0.54990 & Biso & 1.000 & 0 \\
\hline 053 & 1.0000 & 0.22686 & 0.45469 & 0.54136 & Biso & 1.000 & 0 \\
\hline 054 & 1.0000 & 0.20625 & 0.76566 & 0.53535 & Biso & 1.000 & 0 \\
\hline 055 & 1.0000 & 0.00132 & 0.25134 & 0.01521 & Biso & 1.000 & 0 \\
\hline 056 & 1.0000 & 0.75045 & 0.75181 & 0.01962 & Biso & 1.000 & 0 \\
\hline 057 & 1.0000 & 0.24073 & 0.99201 & 0.00643 & Biso & 1.000 & $\mathrm{O}$ \\
\hline 058 & 1.0000 & 0.67779 & 0.59806 & 0.34816 & Biso & 1.000 & 0 \\
\hline 059 & 1.0000 & 0.37605 & 0.04959 & 0.33490 & Biso & 1.000 & 0 \\
\hline 060 & 1.0000 & 0.93155 & 0.32324 & 0.34705 & Biso & 1.000 & 0 \\
\hline 061 & 1.0000 & 0.32855 & 0.89895 & 0.68582 & Biso & 1.000 & 0 \\
\hline 062 & 1.0000 & 0.06735 & 0.38391 & 0.68374 & Biso & 1.000 & 0 \\
\hline 063 & 1.0000 & 0.60550 & 0.66184 & 0.68564 & Biso & 1.000 & 0 \\
\hline 064 & 1.0000 & 0.99982 & 0.74768 & 0.99808 & Biso & 1.000 & $\mathrm{O}$ \\
\hline 065 & 1.0000 & 0.25713 & 0.24900 & 0.98880 & Biso & 1.000 & 0 \\
\hline 066 & 1.0000 & 0.75200 & 0.00148 & 0.99865 & Biso & 1.000 & 0 \\
\hline 067 & 1.0000 & 0.67112 & 0.07170 & 0.32892 & Biso & 1.000 & 0 \\
\hline 068 & 1.0000 & 0.93046 & 0.59630 & 0.33273 & Biso & 1.000 & 0 \\
\hline 069 & 1.0000 & 0.40225 & 0.34367 & 0.32196 & Biso & 1.000 & 0 \\
\hline 070 & 1.0000 & 0.32828 & 0.40719 & 0.65722 & Biso & 1.000 & 0 \\
\hline 071 & 1.0000 & 0.59332 & 0.93338 & 0.66650 & Biso & 1.000 & 0 \\
\hline 072 & 1.0000 & 0.07705 & 0.68997 & 0.66787 & Biso & 1.000 & 0 \\
\hline H 1 & 1.0000 & 0.26214 & 0.92088 & 0.34579 & Biso & 1.000 & $\mathrm{H}$ \\
\hline C1 & 1.0000 & 0.07699 & 0.91381 & 0.36108 & Biso & 1.000 & C \\
\hline
\end{tabular}




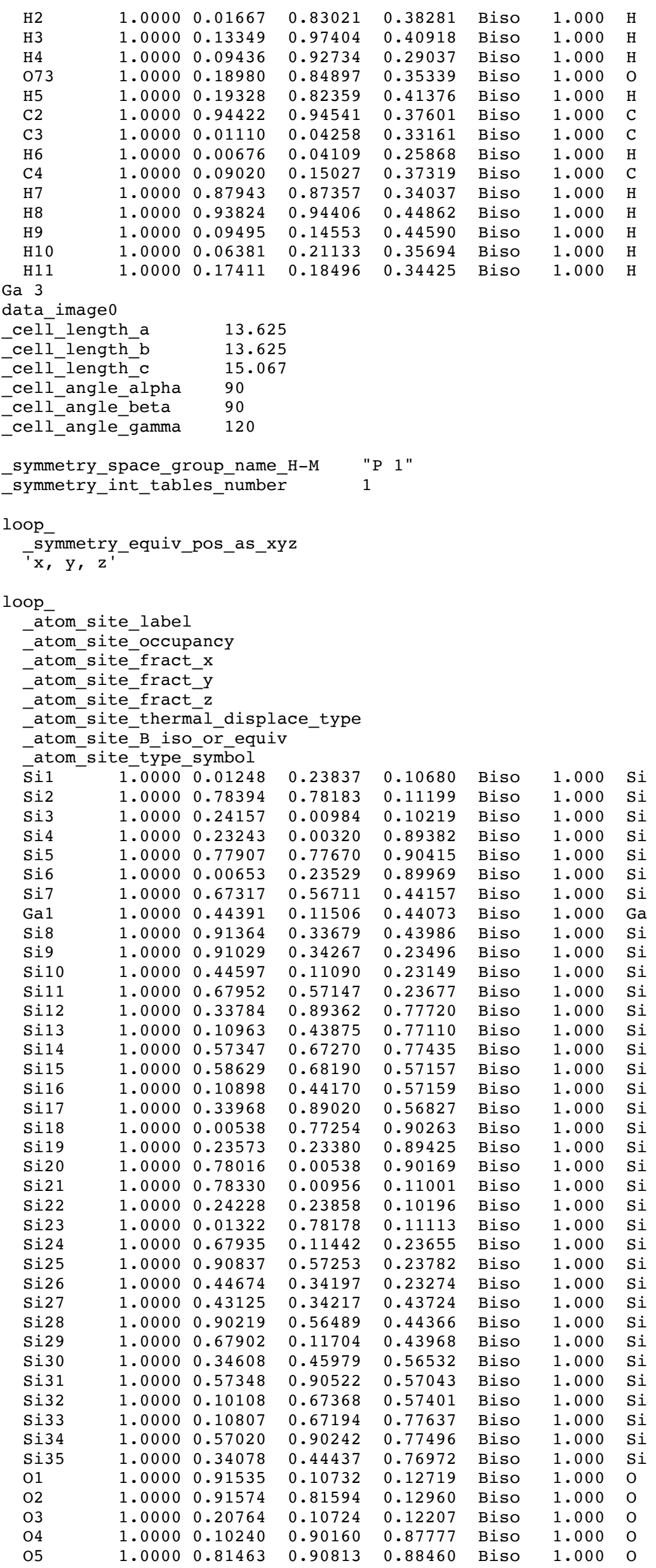




\begin{tabular}{|c|c|c|c|c|c|c|}
\hline 06 & 1.0000 & 0.10507 & 0.20378 & 0.88081 & Biso & 1.000 \\
\hline 07 & 1.0000 & 0.56273 & 0.44312 & 0.45205 & Biso & 1.000 \\
\hline 08 & 1.0000 & 0.59543 & 0.16736 & 0.44719 & Biso & 1.000 \\
\hline 09 & 1.0000 & 0.88777 & 0.44006 & 0.45643 & Biso & 1.000 \\
\hline 010 & 1.0000 & 0.77881 & 0.24583 & 0.21976 & Biso & 1.000 \\
\hline 011 & 1.0000 & 0.48062 & 0.24409 & 0.22096 & Biso & 1.000 \\
\hline 012 & 1.0000 & 0.77720 & 0.53788 & 0.21873 & Biso & 1.000 \\
\hline 013 & 1.0000 & 0.23869 & 0.76464 & 0.80132 & Biso & 1.000 \\
\hline 014 & 1.0000 & 0.24200 & 0.47635 & 0.78917 & Biso & 1.000 \\
\hline 015 & 1.0000 & 0.53969 & 0.77102 & 0.78384 & Biso & 1.000 \\
\hline 016 & 1.0000 & 0.45452 & 0.58668 & 0.55551 & Biso & 1.000 \\
\hline 017 & 1.0000 & 0.10974 & 0.56033 & 0.56872 & Biso & 1.000 \\
\hline 018 & 1.0000 & 0.43783 & 0.85491 & 0.55616 & Biso & 1.000 \\
\hline 019 & 1.0000 & 0.99391 & 0.32486 & 0.16857 & Biso & 1.000 \\
\hline 020 & 1.0000 & 0.69940 & 0.67622 & 0.17379 & Biso & 1.000 \\
\hline 021 & 1.0000 & 0.35445 & 0.03504 & 0.15499 & Biso & 1.000 \\
\hline 022 & 1.0000 & 0.32001 & 0.98491 & 0.83359 & Biso & 1.000 \\
\hline 023 & 1.0000 & 0.66988 & 0.69081 & 0.84588 & Biso & 1.000 \\
\hline 024 & 1.0000 & 0.02613 & 0.34246 & 0.84047 & Biso & 1.000 \\
\hline 025 & 1.0000 & 0.66835 & 0.66033 & 0.50605 & Biso & 1.000 \\
\hline 026 & 1.0000 & 0.35507 & 0.99200 & 0.50791 & Biso & 1.000 \\
\hline 027 & 1.0000 & 0.01958 & 0.35358 & 0.50033 & Biso & 1.000 \\
\hline 028 & 1.0000 & 0.02196 & 0.68081 & 0.84592 & Biso & 1.000 \\
\hline 029 & 1.0000 & 0.32053 & 0.33782 & 0.83085 & Biso & 1.000 \\
\hline 030 & 1.0000 & 0.67233 & 0.98249 & 0.84189 & Biso & 1.000 \\
\hline 031 & 1.0000 & 0.69817 & 0.03155 & 0.16983 & Biso & 1.000 \\
\hline 032 & 1.0000 & 0.35017 & 0.32498 & 0.16108 & Biso & 1.000 \\
\hline 033 & 1.0000 & 0.99331 & 0.67800 & 0.17518 & Biso & 1.000 \\
\hline 034 & 1.0000 & 0.34857 & 0.37452 & 0.49260 & Biso & 1.000 \\
\hline 035 & 1.0000 & 0.99902 & 0.65889 & 0.50904 & Biso & 1.000 \\
\hline 036 & 1.0000 & 0.64823 & 0.00996 & 0.50479 & Biso & 1.000 \\
\hline 037 & 1.0000 & 0.13487 & 0.25235 & 0.13085 & Biso & 1.000 \\
\hline 038 & 1.0000 & 0.77147 & 0.88980 & 0.14016 & Biso & 1.000 \\
\hline 039 & 1.0000 & 0.13509 & 0.89054 & 0.13631 & Biso & 1.000 \\
\hline 040 & 1.0000 & 0.24346 & 0.12316 & 0.86648 & Biso & 1.000 \\
\hline 041 & 1.0000 & 0.88335 & 0.75780 & 0.87712 & Biso & 1.000 \\
\hline 042 & 1.0000 & 0.88574 & 0.12711 & 0.87308 & Biso & 1.000 \\
\hline 043 & 1.0000 & 0.78410 & 0.55903 & 0.46856 & Biso & 1.000 \\
\hline 044 & 1.0000 & 0.40963 & 0.22264 & 0.47131 & Biso & 1.000 \\
\hline 045 & 1.0000 & 0.80691 & 0.21620 & 0.46688 & Biso & 1.000 \\
\hline 046 & 1.0000 & 0.92492 & 0.46595 & 0.21434 & Biso & 1.000 \\
\hline 047 & 1.0000 & 0.55913 & 0.10342 & 0.21218 & Biso & 1.000 \\
\hline 048 & 1.0000 & 0.55767 & 0.46412 & 0.21277 & Biso & 1.000 \\
\hline 049 & 1.0000 & 0.45962 & 0.90924 & 0.80478 & Biso & 1.000 \\
\hline 050 & 1.0000 & 0.09237 & 0.54677 & 0.78406 & Biso & 1.000 \\
\hline 051 & 1.0000 & 0.46234 & 0.55177 & 0.79594 & Biso & 1.000 \\
\hline 052 & 1.0000 & 0.60342 & 0.80588 & 0.54934 & Biso & 1.000 \\
\hline 053 & 1.0000 & 0.23442 & 0.46865 & 0.54515 & Biso & 1.000 \\
\hline 054 & 1.0000 & 0.21808 & 0.78011 & 0.53749 & Biso & 1.000 \\
\hline 055 & 1.0000 & 0.00747 & 0.26885 & 0.00344 & Biso & 1.000 \\
\hline 056 & 1.0000 & 0.74899 & 0.74775 & 0.00888 & Biso & 1.000 \\
\hline 057 & 1.0000 & 0.26502 & 0.00430 & 0.99755 & Biso & 1.000 \\
\hline 058 & 1.0000 & 0.68596 & 0.61248 & 0.33940 & Biso & 1.000 \\
\hline 059 & 1.0000 & 0.38938 & 0.06010 & 0.32688 & Biso & 1.000 \\
\hline 060 & 1.0000 & 0.94926 & 0.33722 & 0.33626 & Biso & 1.000 \\
\hline 061 & 1.0000 & 0.33252 & 0.91705 & 0.67272 & Biso & 1.000 \\
\hline 062 & 1.0000 & 0.07409 & 0.38739 & 0.67087 & Biso & 1.000 \\
\hline 063 & 1.0000 & 0.62113 & 0.67545 & 0.67439 & Biso & 1.000 \\
\hline 064 & 1.0000 & 0.01042 & 0.74675 & 0.00773 & Biso & 1.000 \\
\hline 065 & 1.0000 & 0.27299 & 0.26830 & 0.99751 & Biso & 1.000 \\
\hline 066 & 1.0000 & 0.74982 & 0.00648 & 0.00610 & Biso & 1.000 \\
\hline 067 & 1.0000 & 0.68407 & 0.07566 & 0.33779 & Biso & 1.000 \\
\hline 068 & 1.0000 & 0.93927 & 0.60970 & 0.34175 & Biso & 1.000 \\
\hline 069 & 1.0000 & 0.39860 & 0.34021 & 0.33178 & Biso & 1.000 \\
\hline 070 & 1.0000 & 0.34021 & 0.41147 & 0.66564 & Biso & 1.000 \\
\hline 071 & 1.0000 & 0.60729 & 0.94706 & 0.67349 & Biso & 1.000 \\
\hline 072 & 1.0000 & 0.07682 & 0.69454 & 0.67628 & Biso & 1.000 \\
\hline H 1 & 1.0000 & 0.27289 & 0.92709 & 0.33975 & Biso & 1.000 \\
\hline $\mathrm{C} 1$ & 1.0000 & 0.08298 & 0.91659 & 0.35744 & Biso & 1.000 \\
\hline H2 & 1.0000 & 0.02268 & 0.83075 & 0.37833 & Biso & 1.000 \\
\hline H3 & 1.0000 & 0.13878 & 0.97870 & 0.40568 & Biso & 1.000 \\
\hline $\mathrm{H} 4$ & 1.0000 & 0.10026 & 0.93173 & 0.28701 & Biso & 1.000 \\
\hline 073 & 1.0000 & 0.20005 & 0.85454 & 0.35031 & Biso & 1.000 \\
\hline H5 & 1.0000 & 0.20647 & 0.83304 & 0.41140 & Biso & 1.000 \\
\hline $\mathrm{C} 2$ & 1.0000 & 0.94357 & 0.94412 & 0.37396 & Biso & 1.000 \\
\hline C3 & 1.0000 & 0.00867 & 0.04196 & 0.32757 & Biso & 1.000 \\
\hline H6 & 1.0000 & 0.00210 & 0.03801 & 0.25495 & Biso & 1.000 \\
\hline C 4 & 1.0000 & 0.08835 & 0.15361 & 0.36661 & Biso & 1.000 \\
\hline $\mathrm{H} 7$ & 1.0000 & 0.87781 & 0.86877 & 0.34045 & Biso & 1.000 \\
\hline H8 & 1.0000 & 0.93983 & 0.94484 & 0.44641 & Biso & 1.000 \\
\hline
\end{tabular}




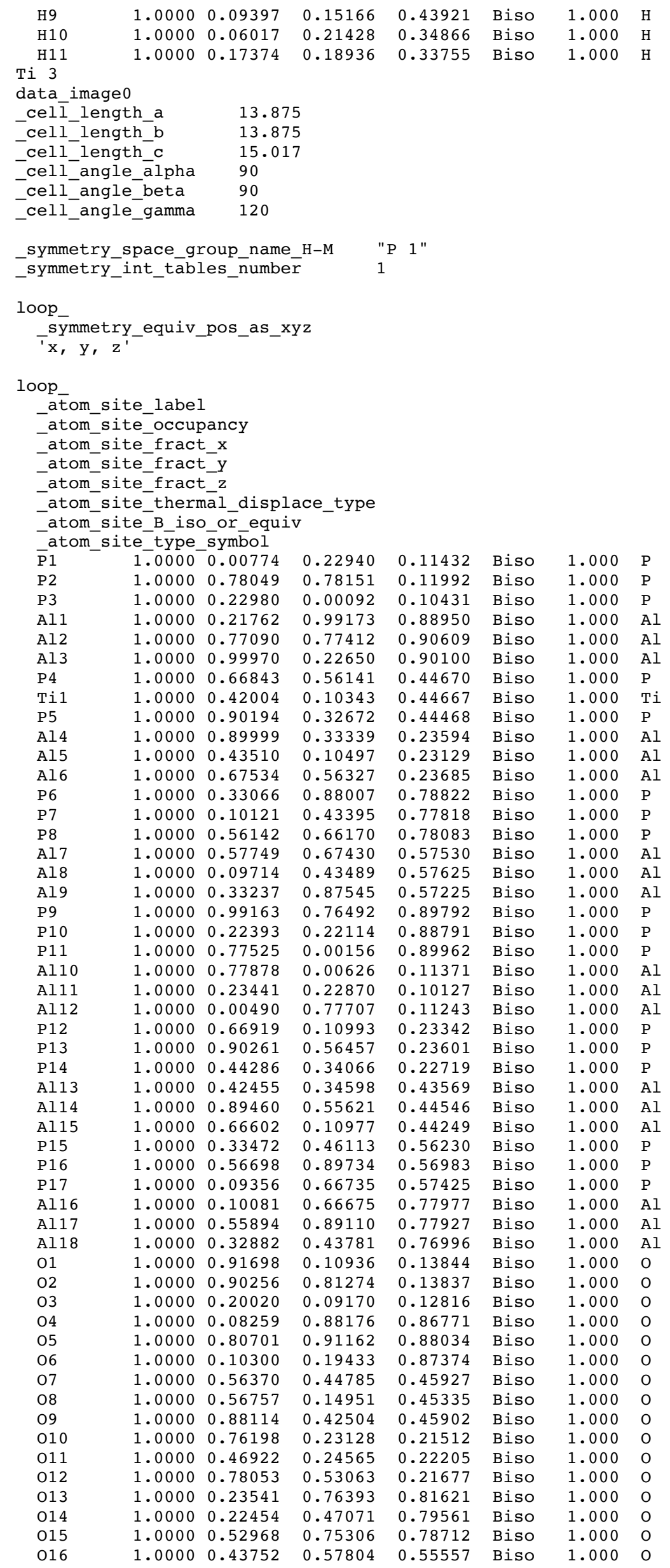




\begin{tabular}{|c|c|c|c|c|c|c|c|}
\hline 017 & 1.0000 & 0.09118 & 0.55636 & 0.57425 & Biso & 1.000 & 0 \\
\hline 018 & 1.0000 & 0.44255 & 0.85012 & 0.54784 & Biso & 1.000 & 0 \\
\hline 019 & 1.0000 & 0.99220 & 0.31388 & 0.16904 & Biso & 1.000 & O \\
\hline $\mathrm{O} 20$ & 1.0000 & 0.70066 & 0.68031 & 0.17541 & Biso & 1.000 & 0 \\
\hline 021 & 1.0000 & 0.34050 & 0.02704 & 0.14605 & Biso & 1.000 & 0 \\
\hline 022 & 1.0000 & 0.31510 & 0.97146 & 0.83213 & Biso & 1.000 & 0 \\
\hline 023 & 1.0000 & 0.64960 & 0.68023 & 0.85080 & Biso & 1.000 & 0 \\
\hline $\mathrm{O} 24$ & 1.0000 & 0.02521 & 0.34790 & 0.84701 & Biso & 1.000 & 0 \\
\hline 025 & 1.0000 & 0.66477 & 0.64992 & 0.50618 & Biso & 1.000 & O \\
\hline 026 & 1.0000 & 0.33651 & 0.98601 & 0.51878 & Biso & 1.000 & 0 \\
\hline 027 & 1.0000 & 0.00007 & 0.34064 & 0.50180 & Biso & 1.000 & 0 \\
\hline 028 & 1.0000 & 0.00396 & 0.67443 & 0.84924 & Biso & 1.000 & 0 \\
\hline 029 & 1.0000 & 0.30438 & 0.32028 & 0.83050 & Biso & 1.000 & 0 \\
\hline 030 & 1.0000 & 0.67095 & 0.97780 & 0.84749 & Biso & 1.000 & $\mathrm{O}$ \\
\hline 031 & 1.0000 & 0.68450 & 0.03050 & 0.17106 & Biso & 1.000 & 0 \\
\hline 032 & 1.0000 & 0.35379 & 0.32353 & 0.15802 & Biso & 1.000 & 0 \\
\hline 033 & 1.0000 & 0.98138 & 0.66230 & 0.17631 & Biso & 1.000 & 0 \\
\hline 034 & 1.0000 & 0.33726 & 0.38451 & 0.49060 & Biso & 1.000 & 0 \\
\hline 035 & 1.0000 & 0.99930 & 0.65789 & 0.51389 & Biso & 1.000 & 0 \\
\hline 036 & 1.0000 & 0.64127 & 0.99583 & 0.50971 & Biso & 1.000 & 0 \\
\hline 037 & 1.0000 & 0.12199 & 0.24324 & 0.13684 & Biso & 1.000 & 0 \\
\hline 038 & 1.0000 & 0.76647 & 0.88011 & 0.14811 & Biso & 1.000 & 0 \\
\hline 039 & 1.0000 & 0.13508 & 0.88982 & 0.14105 & Biso & 1.000 & 0 \\
\hline 040 & 1.0000 & 0.23228 & 0.11961 & 0.85904 & Biso & 1.000 & 0 \\
\hline O4 1 & 1.0000 & 0.87784 & 0.75048 & 0.87392 & Biso & 1.000 & 0 \\
\hline 042 & 1.0000 & 0.87110 & 0.11497 & 0.86972 & Biso & 1.000 & 0 \\
\hline 043 & 1.0000 & 0.77076 & 0.55250 & 0.47280 & Biso & 1.000 & 0 \\
\hline O4 4 & 1.0000 & 0.39296 & 0.21600 & 0.46929 & Biso & 1.000 & 0 \\
\hline 045 & 1.0000 & 0.79927 & 0.21825 & 0.47219 & Biso & 1.000 & 0 \\
\hline 046 & 1.0000 & 0.91935 & 0.46579 & 0.21563 & Biso & 1.000 & 0 \\
\hline 047 & 1.0000 & 0.55707 & 0.10025 & 0.21222 & Biso & 1.000 & 0 \\
\hline O48 & 1.0000 & 0.54881 & 0.45079 & 0.20472 & Biso & 1.000 & 0 \\
\hline 049 & 1.0000 & 0.44228 & 0.89422 & 0.81942 & Biso & 1.000 & 0 \\
\hline 050 & 1.0000 & 0.08487 & 0.53470 & 0.78574 & Biso & 1.000 & 0 \\
\hline 051 & 1.0000 & 0.45795 & 0.54901 & 0.80038 & Biso & 1.000 & 0 \\
\hline 052 & 1.0000 & 0.59833 & 0.80687 & 0.55406 & Biso & 1.000 & 0 \\
\hline 053 & 1.0000 & 0.23166 & 0.47208 & 0.54583 & Biso & 1.000 & 0 \\
\hline 054 & 1.0000 & 0.20541 & 0.75847 & 0.53612 & Biso & 1.000 & 0 \\
\hline 055 & 1.0000 & 0.00091 & 0.25127 & 0.01508 & Biso & 1.000 & 0 \\
\hline 056 & 1.0000 & 0.75176 & 0.75407 & 0.02111 & Biso & 1.000 & 0 \\
\hline 057 & 1.0000 & 0.23940 & 0.99297 & 0.00355 & Biso & 1.000 & 0 \\
\hline 058 & 1.0000 & 0.67920 & 0.60024 & 0.34900 & Biso & 1.000 & 0 \\
\hline 059 & 1.0000 & 0.37183 & 0.04852 & 0.33215 & Biso & 1.000 & 0 \\
\hline 060 & 1.0000 & 0.93290 & 0.32301 & 0.34669 & Biso & 1.000 & 0 \\
\hline 061 & 1.0000 & 0.32979 & 0.89119 & 0.68716 & Biso & 1.000 & 0 \\
\hline 062 & 1.0000 & 0.06724 & 0.38098 & 0.68473 & Biso & 1.000 & 0 \\
\hline 063 & 1.0000 & 0.60810 & 0.66269 & 0.68732 & Biso & 1.000 & 0 \\
\hline 064 & 1.0000 & 0.99973 & 0.74996 & 0.99869 & Biso & 1.000 & 0 \\
\hline 065 & 1.0000 & 0.25638 & 0.24958 & 0.98654 & Biso & 1.000 & 0 \\
\hline 066 & 1.0000 & 0.75284 & 0.00364 & 0.99971 & Biso & 1.000 & 0 \\
\hline 067 & 1.0000 & 0.67554 & 0.07655 & 0.32990 & Biso & 1.000 & 0 \\
\hline 068 & 1.0000 & 0.93075 & 0.60090 & 0.33437 & Biso & 1.000 & 0 \\
\hline 069 & 1.0000 & 0.40041 & 0.34827 & 0.32007 & Biso & 1.000 & 0 \\
\hline 070 & 1.0000 & 0.32852 & 0.41137 & 0.65562 & Biso & 1.000 & 0 \\
\hline 071 & 1.0000 & 0.58891 & 0.93550 & 0.66825 & Biso & 1.000 & 0 \\
\hline 072 & 1.0000 & 0.07751 & 0.69653 & 0.67008 & Biso & 1.000 & 0 \\
\hline $\mathrm{H} 1$ & 1.0000 & 0.26399 & 0.91641 & 0.34241 & Biso & 1.000 & $\mathrm{H}$ \\
\hline $\mathrm{C} 1$ & 1.0000 & 0.07743 & 0.90309 & 0.35798 & Biso & 1.000 & $\mathrm{C}$ \\
\hline $\mathrm{H} 2$ & 1.0000 & 0.01572 & 0.81604 & 0.36817 & Biso & 1.000 & $\mathrm{H}$ \\
\hline H3 & 1.0000 & 0.12608 & 0.95463 & 0.41348 & Biso & 1.000 & $\mathrm{H}$ \\
\hline H4 & 1.0000 & 0.10430 & 0.92994 & 0.29015 & Biso & 1.000 & $\mathrm{H}$ \\
\hline 073 & 1.0000 & 0.19339 & 0.84260 & 0.34976 & Biso & 1.000 & 0 \\
\hline H5 & 1.0000 & 0.19703 & 0.81754 & 0.41015 & Biso & 1.000 & $\mathrm{H}$ \\
\hline $\mathrm{C} 2$ & 1.0000 & 0.94178 & 0.93143 & 0.37528 & Biso & 1.000 & C \\
\hline C3 & 1.0000 & 0.00812 & 0.02757 & 0.32953 & Biso & 1.000 & $\mathrm{C}$ \\
\hline H6 & 1.0000 & 0.00129 & 0.02513 & 0.25673 & Biso & 1.000 & $\mathrm{H}$ \\
\hline $\mathrm{C} 4$ & 1.0000 & 0.08955 & 0.13562 & 0.36954 & Biso & 1.000 & $\mathrm{C}$ \\
\hline $\mathrm{H} 7$ & 1.0000 & 0.87592 & 0.85905 & 0.34097 & Biso & 1.000 & $\mathrm{H}$ \\
\hline H8 & 1.0000 & 0.93827 & 0.93090 & 0.44800 & Biso & 1.000 & $\mathrm{H}$ \\
\hline H9 & 1.0000 & 0.09574 & 0.13208 & 0.44221 & Biso & 1.000 & $\mathrm{H}$ \\
\hline $\mathrm{H} 10$ & 1.0000 & 0.06471 & 0.19774 & 0.35302 & Biso & 1.000 & $\mathrm{H}$ \\
\hline $\mathrm{H} 11$ & 1.0000 & 0.17270 & 0.16788 & 0.33968 & Biso & 1.000 & $\mathrm{H}$ \\
\hline \\
\hline \multicolumn{8}{|c|}{$\begin{array}{l}\mathrm{Zn} 4 \\
\text { data image } 0\end{array}$} \\
\hline \multicolumn{2}{|c|}{ cel' length a } & \multicolumn{2}{|c|}{13.875} & & & & \\
\hline \multicolumn{2}{|c|}{ cell length b } & 13.87 & & & & & \\
\hline cell & $=h-c$ & 15.01 & & & & & \\
\hline :el1 & $\bar{a} l p h a$ & 90 & & & & & \\
\hline ell & beta & 90 & & & & & \\
\hline ell & gamma & 120 & & & & & \\
\hline
\end{tabular}




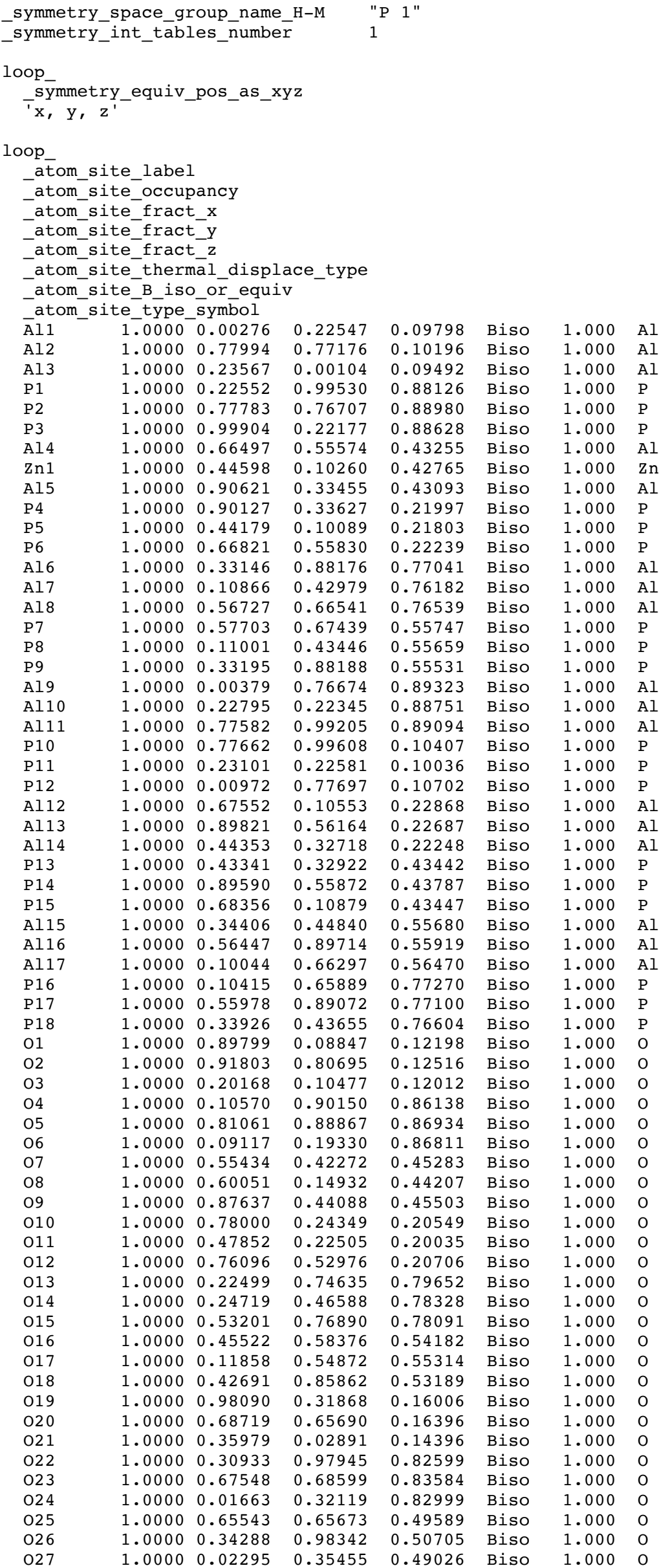




\begin{tabular}{|c|c|c|c|c|c|c|c|}
\hline 028 & 1.0000 & 0.02306 & 0.66718 & 0.83758 & Biso & 1.000 & 0 \\
\hline 029 & 1.0000 & 0.32083 & 0.33791 & 0.82421 & Biso & 1.000 & O \\
\hline 030 & 1.0000 & 0.66011 & 0.96772 & 0.82894 & Biso & 1.000 & O \\
\hline 031 & 1.0000 & 0.69496 & 0.01604 & 0.15795 & Biso & 1.000 & O \\
\hline 032 & 1.0000 & 0.33108 & 0.30770 & 0.15605 & Biso & 1.000 & $\mathrm{O}$ \\
\hline 033 & 1.0000 & 0.99000 & 0.67702 & 0.16378 & Biso & 1.000 & 0 \\
\hline 034 & 1.0000 & 0.35165 & 0.35562 & 0.48391 & Biso & 1.000 & $\mathrm{O}$ \\
\hline 035 & 1.0000 & 0.98875 & 0.64441 & 0.49834 & Biso & 1.000 & O \\
\hline 036 & 1.0000 & 0.65821 & 0.01039 & 0.49660 & Biso & 1.000 & O \\
\hline 037 & 1.0000 & 0.13035 & 0.23760 & 0.12699 & Biso & 1.000 & O \\
\hline 038 & 1.0000 & 0.76621 & 0.88528 & 0.13442 & Biso & 1.000 & O \\
\hline 039 & 1.0000 & 0.12246 & 0.87653 & 0.13353 & Biso & 1.000 & 0 \\
\hline 040 & 1.0000 & 0.23702 & 0.10752 & 0.85592 & Biso & 1.000 & O \\
\hline 041 & 1.0000 & 0.87431 & 0.74887 & 0.86400 & Biso & 1.000 & O \\
\hline 042 & 1.0000 & 0.88674 & 0.12127 & 0.86080 & Biso & 1.000 & 0 \\
\hline 043 & 1.0000 & 0.78942 & 0.56104 & 0.46016 & Biso & 1.000 & O \\
\hline 044 & 1.0000 & 0.41403 & 0.21814 & 0.46913 & Biso & 1.000 & 0 \\
\hline 045 & 1.0000 & 0.80023 & 0.20380 & 0.46137 & Biso & 1.000 & O \\
\hline 046 & 1.0000 & 0.91210 & 0.44850 & 0.19514 & Biso & 1.000 & O \\
\hline 047 & 1.0000 & 0.54573 & 0.08911 & 0.20789 & Biso & 1.000 & $\mathrm{O}$ \\
\hline 048 & 1.0000 & 0.55646 & 0.45796 & 0.19650 & Biso & 1.000 & O \\
\hline 049 & 1.0000 & 0.45966 & 0.89927 & 0.80378 & Biso & 1.000 & O \\
\hline 050 & 1.0000 & 0.09036 & 0.54289 & 0.78174 & Biso & 1.000 & 0 \\
\hline 051 & 1.0000 & 0.45188 & 0.53704 & 0.79095 & Biso & 1.000 & O \\
\hline 052 & 1.0000 & 0.59013 & 0.78817 & 0.53581 & Biso & 1.000 & O \\
\hline 053 & 1.0000 & 0.22270 & 0.44872 & 0.53023 & Biso & 1.000 & O \\
\hline 054 & 1.0000 & 0.22062 & 0.77968 & 0.52793 & Biso & 1.000 & O \\
\hline 055 & 1.0000 & 0.99972 & 0.25193 & 0.98492 & Biso & 1.000 & 0 \\
\hline 056 & 1.0000 & 0.75021 & 0.74222 & 0.98930 & Biso & 1.000 & $\mathrm{O}$ \\
\hline 057 & 1.0000 & 0.25110 & 0.99359 & 0.98049 & Biso & 1.000 & 0 \\
\hline 058 & 1.0000 & 0.66832 & 0.59158 & 0.32028 & Biso & 1.000 & 0 \\
\hline 059 & 1.0000 & 0.38547 & 0.06174 & 0.30828 & Biso & 1.000 & O \\
\hline 060 & 1.0000 & 0.93643 & 0.33783 & 0.31734 & Biso & 1.000 & O \\
\hline 061 & 1.0000 & 0.33134 & 0.90073 & 0.65641 & Biso & 1.000 & O \\
\hline 062 & 1.0000 & 0.07684 & 0.38520 & 0.65101 & Biso & 1.000 & O \\
\hline 063 & 1.0000 & 0.61034 & 0.67027 & 0.65475 & Biso & 1.000 & 0 \\
\hline 064 & 1.0000 & 0.00923 & 0.74831 & 0.00810 & Biso & 1.000 & O \\
\hline 065 & 1.0000 & 0.25844 & 0.25253 & 0.00102 & Biso & 1.000 & O \\
\hline 066 & 1.0000 & 0.74836 & 0.99150 & 0.00476 & Biso & 1.000 & O \\
\hline 067 & 1.0000 & 0.69004 & 0.07119 & 0.33812 & Biso & 1.000 & O \\
\hline 068 & 1.0000 & 0.92970 & 0.59257 & 0.34009 & Biso & 1.000 & 0 \\
\hline 069 & 1.0000 & 0.40793 & 0.32588 & 0.33408 & Biso & 1.000 & 0 \\
\hline 070 & 1.0000 & 0.33932 & 0.40561 & 0.66750 & Biso & 1.000 & O \\
\hline 071 & 1.0000 & 0.58683 & 0.92819 & 0.67339 & Biso & 1.000 & $\mathrm{O}$ \\
\hline 072 & 1.0000 & 0.07559 & 0.67768 & 0.67721 & Biso & 1.000 & O \\
\hline $\mathrm{H} 1$ & 1.0000 & 0.27525 & 0.14504 & 0.53211 & Biso & 1.000 & $\mathrm{H}$ \\
\hline $\mathrm{C} 1$ & 1.0000 & 0.09492 & 0.00164 & 0.44957 & Biso & 1.000 & $\mathrm{C}$ \\
\hline $\mathrm{H} 2$ & 1.0000 & 0.16273 & 0.01661 & 0.40490 & Biso & 1.000 & $\mathrm{H}$ \\
\hline H3 & 1.0000 & 0.06058 & 0.92853 & 0.49205 & Biso & 1.000 & $\mathrm{H}$ \\
\hline $\mathrm{H} 4$ & 1.0000 & 0.08068 & 0.06966 & 0.46644 & Biso & 1.000 & $\mathrm{H}$ \\
\hline 073 & 1.0000 & 0.21536 & 0.07215 & 0.55380 & Biso & 1.000 & O \\
\hline H5 & 1.0000 & 0.25436 & 0.02840 & 0.54808 & Biso & 1.000 & $\mathrm{H}$ \\
\hline H6 & 1.0000 & 0.91617 & 0.90939 & 0.39495 & Biso & 1.000 & $\mathrm{H}$ \\
\hline 074 & 1.0000 & 0.98824 & 0.93759 & 0.36530 & Biso & 1.000 & 0 \\
\hline $\mathrm{C} 2$ & 1.0000 & 0.99818 & 0.01414 & 0.29394 & Biso & 1.000 & C \\
\hline $\mathrm{H} 7$ & 1.0000 & 0.92735 & 0.96963 & 0.24886 & Biso & 1.000 & $\mathrm{H}$ \\
\hline H8 & 1.0000 & 0.00026 & 0.08844 & 0.32181 & Biso & 1.000 & $\mathrm{H}$ \\
\hline H9 & 1.0000 & 0.07559 & 0.03635 & 0.25866 & Biso & 1.000 & $\mathrm{H}$ \\
\hline \multicolumn{8}{|c|}{$\mathrm{Si} 4$} \\
\hline \multicolumn{8}{|c|}{ data image 0} \\
\hline \multicolumn{2}{|c|}{ celli length a } & & & & & \\
\hline cell & th_b & $\begin{array}{l}13.875 \\
13.875\end{array}$ & 13.875 & & & & \\
\hline cell & $\operatorname{th}^{-} \mathrm{c}$ & \multicolumn{2}{|c|}{15.017} & & & & \\
\hline cell & e $\bar{a}$ lpha & 90 & & & & & \\
\hline cell & e beta & 90 & & & & & \\
\hline cell & e_gamma & 120 & & & & & \\
\hline symme & space & coup nam & $\mathrm{H}-\mathrm{M}$ & $1 "$ & & & \\
\hline symme & int_tab. & les_numbe & & & & & \\
\hline .00p & & & & & & & \\
\hline sy & equi & pos_as & & & & & \\
\hline$T^{\prime} \mathrm{x}$, & & & & & & & \\
\hline oop & & & & & & & \\
\hline atc & e_labe & & & & & & \\
\hline$-a t$ & e_occu & pancy & & & & & \\
\hline atc & $e^{-}$fract & t $x$ & & & & & \\
\hline -at & e_fract & & & & & & \\
\hline & $e_{-}^{-}$fract & & & & & & \\
\hline
\end{tabular}




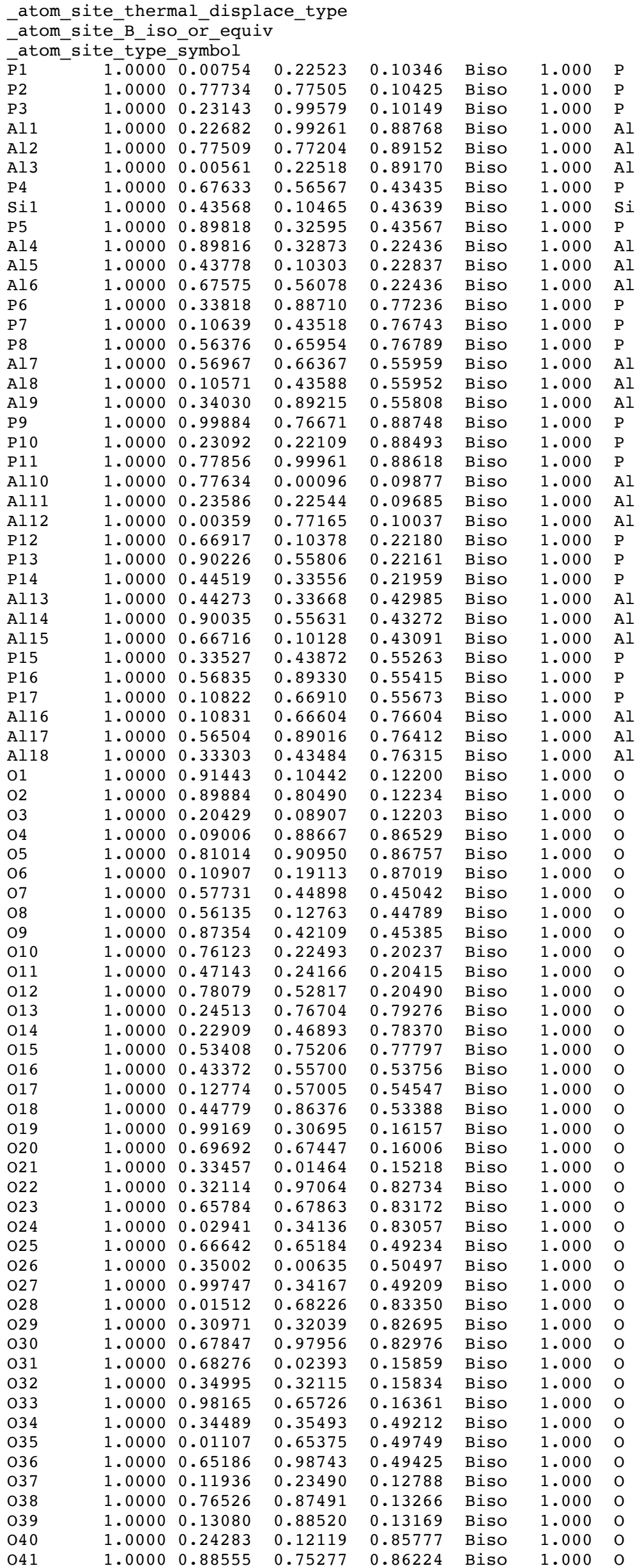




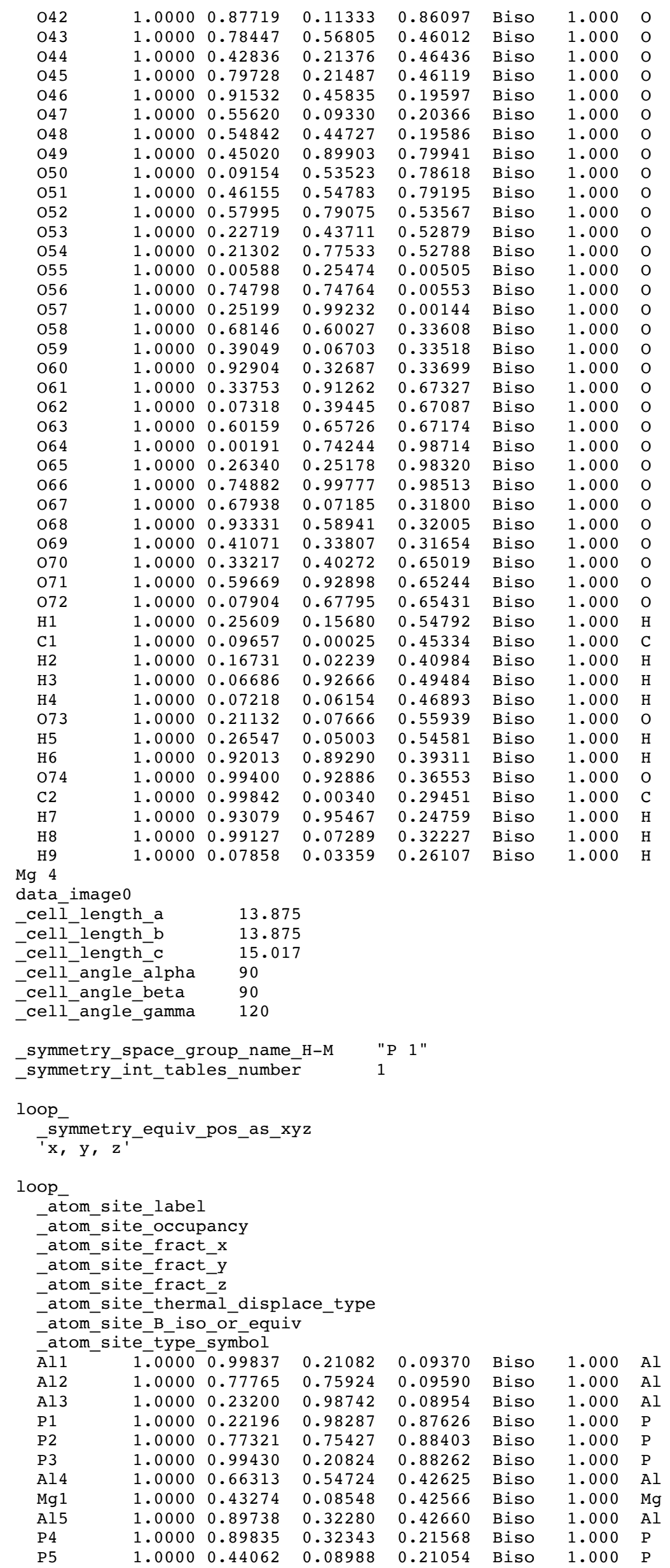




\begin{tabular}{|c|c|c|c|c|c|c|c|}
\hline P 6 & 1.0000 & 0.66488 & 0.54439 & 0.21603 & Biso & 1.000 & $P$ \\
\hline Al 6 & 1.0000 & 0.32653 & 0.86859 & 0.76489 & Biso & 1.000 & Al \\
\hline Al 7 & 1.0000 & 0.10334 & 0.41633 & 0.75746 & Biso & 1.000 & Al \\
\hline Al8 & 1.0000 & 0.56271 & 0.65237 & 0.75948 & Biso & 1.000 & $\mathrm{Al}$ \\
\hline P7 & 1.0000 & 0.56934 & 0.66153 & 0.55234 & Biso & 1.000 & $\mathrm{P}$ \\
\hline P8 & 1.0000 & 0.10161 & 0.41591 & 0.55049 & Biso & 1.000 & $P$ \\
\hline P9 & 1.0000 & 0.32677 & 0.87009 & 0.54985 & Biso & 1.000 & $\mathrm{P}$ \\
\hline A19 & 1.0000 & 0.99933 & 0.75383 & 0.88663 & Biso & 1.000 & Al \\
\hline Al10 & 1.0000 & 0.22415 & 0.21086 & 0.88352 & Biso & 1.000 & $\mathrm{Al}$ \\
\hline Al11 & 1.0000 & 0.77077 & 0.97896 & 0.88696 & Biso & 1.000 & Al \\
\hline $\mathrm{P} 10$ & 1.0000 & 0.77305 & 0.98219 & 0.09979 & Biso & 1.000 & $P$ \\
\hline P11 & 1.0000 & 0.22738 & 0.21256 & 0.09529 & Biso & 1.000 & $\mathrm{P}$ \\
\hline P 12 & 1.0000 & 0.00628 & 0.76254 & 0.09920 & Biso & 1.000 & $P$ \\
\hline Al12 & 1.0000 & 0.67208 & 0.09284 & 0.22322 & Biso & 1.000 & Al \\
\hline Al13 & 1.0000 & 0.89401 & 0.54775 & 0.22056 & Biso & 1.000 & $\mathrm{Al}$ \\
\hline Al 14 & 1.0000 & 0.44057 & 0.31381 & 0.21607 & Biso & 1.000 & $\mathrm{Al}$ \\
\hline P13 & 1.0000 & 0.43384 & 0.31915 & 0.42912 & Biso & 1.000 & $P$ \\
\hline P 14 & 1.0000 & 0.89328 & 0.54936 & 0.43238 & Biso & 1.000 & $P$ \\
\hline P15 & 1.0000 & 0.67581 & 0.09361 & 0.43109 & Biso & 1.000 & $\mathrm{P}$ \\
\hline Al15 & 1.0000 & 0.33969 & 0.43625 & 0.55135 & Biso & 1.000 & Al \\
\hline Al16 & 1.0000 & 0.56322 & 0.88872 & 0.55485 & Biso & 1.000 & $\mathrm{Al}$ \\
\hline Al1 17 & 1.0000 & 0.09795 & 0.64765 & 0.55649 & Biso & 1.000 & Al \\
\hline P16 & 1.0000 & 0.09945 & 0.64495 & 0.76609 & Biso & 1.000 & $\mathrm{P}$ \\
\hline P 17 & 1.0000 & 0.55565 & 0.87873 & 0.76591 & Biso & 1.000 & $P$ \\
\hline P18 & 1.0000 & 0.33462 & 0.42329 & 0.76003 & Biso & 1.000 & $\mathrm{P}$ \\
\hline 01 & 1.0000 & 0.89461 & 0.07406 & 0.11727 & Biso & 1.000 & 0 \\
\hline $\mathrm{O} 2$ & 1.0000 & 0.91617 & 0.79472 & 0.11577 & Biso & 1.000 & 0 \\
\hline $\mathrm{O} 3$ & 1.0000 & 0.19818 & 0.09150 & 0.11294 & Biso & 1.000 & 0 \\
\hline O4 & 1.0000 & 0.10183 & 0.88927 & 0.85683 & Biso & 1.000 & 0 \\
\hline 05 & 1.0000 & 0.80536 & 0.87580 & 0.86387 & Biso & 1.000 & 0 \\
\hline 06 & 1.0000 & 0.08675 & 0.17989 & 0.86541 & Biso & 1.000 & 0 \\
\hline 07 & 1.0000 & 0.55426 & 0.41263 & 0.44696 & Biso & 1.000 & 0 \\
\hline 08 & 1.0000 & 0.58271 & 0.11915 & 0.44231 & Biso & 1.000 & 0 \\
\hline 09 & 1.0000 & 0.87322 & 0.43157 & 0.45254 & Biso & 1.000 & 0 \\
\hline 010 & 1.0000 & 0.77743 & 0.23108 & 0.20060 & Biso & 1.000 & 0 \\
\hline 011 & 1.0000 & 0.47604 & 0.21326 & 0.18973 & Biso & 1.000 & 0 \\
\hline 012 & 1.0000 & 0.75557 & 0.51248 & 0.20202 & Biso & 1.000 & 0 \\
\hline 013 & 1.0000 & 0.21976 & 0.73302 & 0.79046 & Biso & 1.000 & 0 \\
\hline 014 & 1.0000 & 0.24231 & 0.45270 & 0.77554 & Biso & 1.000 & 0 \\
\hline 015 & 1.0000 & 0.52854 & 0.75683 & 0.77335 & Biso & 1.000 & 0 \\
\hline 016 & 1.0000 & 0.44598 & 0.57305 & 0.53718 & Biso & 1.000 & 0 \\
\hline 017 & 1.0000 & 0.10934 & 0.52884 & 0.53999 & Biso & 1.000 & 0 \\
\hline 018 & 1.0000 & 0.42888 & 0.85886 & 0.52532 & Biso & 1.000 & 0 \\
\hline 019 & 1.0000 & 0.97892 & 0.30404 & 0.15857 & Biso & 1.000 & 0 \\
\hline 020 & 1.0000 & 0.68609 & 0.64254 & 0.15652 & Biso & 1.000 & 0 \\
\hline 021 & 1.0000 & 0.35520 & 0.01457 & 0.13965 & Biso & 1.000 & 0 \\
\hline 022 & 1.0000 & 0.30488 & 0.96687 & 0.81984 & Biso & 1.000 & 0 \\
\hline 023 & 1.0000 & 0.67105 & 0.67315 & 0.82968 & Biso & 1.000 & 0 \\
\hline 024 & 1.0000 & 0.01266 & 0.30740 & 0.82544 & Biso & 1.000 & 0 \\
\hline 025 & 1.0000 & 0.64524 & 0.64327 & 0.48876 & Biso & 1.000 & 0 \\
\hline 026 & 1.0000 & 0.32679 & 0.96677 & 0.50197 & Biso & 1.000 & 0 \\
\hline 027 & 1.0000 & 0.01211 & 0.33050 & 0.48616 & Biso & 1.000 & 0 \\
\hline 028 & 1.0000 & 0.01701 & 0.65505 & 0.82789 & Biso & 1.000 & 0 \\
\hline 029 & 1.0000 & 0.31510 & 0.32453 & 0.81828 & Biso & 1.000 & o \\
\hline 030 & 1.0000 & 0.65445 & 0.95443 & 0.82564 & Biso & 1.000 & 0 \\
\hline 031 & 1.0000 & 0.69241 & 0.00266 & 0.15461 & Biso & 1.000 & 0 \\
\hline 032 & 1.0000 & 0.32583 & 0.29386 & 0.15284 & Biso & 1.000 & 0 \\
\hline 033 & 1.0000 & 0.98456 & 0.66260 & 0.15697 & Biso & 1.000 & 0 \\
\hline 034 & 1.0000 & 0.35166 & 0.34732 & 0.47664 & Biso & 1.000 & 0 \\
\hline 035 & 1.0000 & 0.98827 & 0.63521 & 0.49095 & Biso & 1.000 & 0 \\
\hline 036 & 1.0000 & 0.66247 & 0.99777 & 0.49161 & Biso & 1.000 & 0 \\
\hline 037 & 1.0000 & 0.12672 & 0.22455 & 0.12130 & Biso & 1.000 & 0 \\
\hline 038 & 1.0000 & 0.76081 & 0.87043 & 0.12813 & Biso & 1.000 & 0 \\
\hline 039 & 1.0000 & 0.11983 & 0.86077 & 0.12531 & Biso & 1.000 & 0 \\
\hline 040 & 1.0000 & 0.23316 & 0.09516 & 0.85124 & Biso & 1.000 & 0 \\
\hline 041 & 1.0000 & 0.87019 & 0.73702 & 0.85777 & Biso & 1.000 & 0 \\
\hline 042 & 1.0000 & 0.88236 & 0.10792 & 0.85628 & Biso & 1.000 & 0 \\
\hline 043 & 1.0000 & 0.78795 & 0.55355 & 0.45518 & Biso & 1.000 & 0 \\
\hline 044 & 1.0000 & 0.41492 & 0.20927 & 0.46649 & Biso & 1.000 & 0 \\
\hline 045 & 1.0000 & 0.78852 & 0.19559 & 0.45773 & Biso & 1.000 & 0 \\
\hline 046 & 1.0000 & 0.91085 & 0.43588 & 0.18954 & Biso & 1.000 & 0 \\
\hline 047 & 1.0000 & 0.54415 & 0.07787 & 0.19736 & Biso & 1.000 & 0 \\
\hline 048 & 1.0000 & 0.55196 & 0.44541 & 0.19052 & Biso & 1.000 & 0 \\
\hline 049 & 1.0000 & 0.45422 & 0.88514 & 0.79839 & Biso & 1.000 & 0 \\
\hline 050 & 1.0000 & 0.08556 & 0.52918 & 0.77865 & Biso & 1.000 & 0 \\
\hline 051 & 1.0000 & 0.44672 & 0.52396 & 0.78528 & Biso & 1.000 & 0 \\
\hline 052 & 1.0000 & 0.58271 & 0.77565 & 0.53385 & Biso & 1.000 & 0 \\
\hline 053 & 1.0000 & 0.21203 & 0.42452 & 0.52407 & Biso & 1.000 & 0 \\
\hline 054 & 1.0000 & 0.22228 & 0.76044 & 0.52275 & Biso & 1.000 & 0 \\
\hline 055 & 1.0000 & 0.99403 & 0.23911 & 0.98093 & Biso & 1.000 & 0 \\
\hline
\end{tabular}




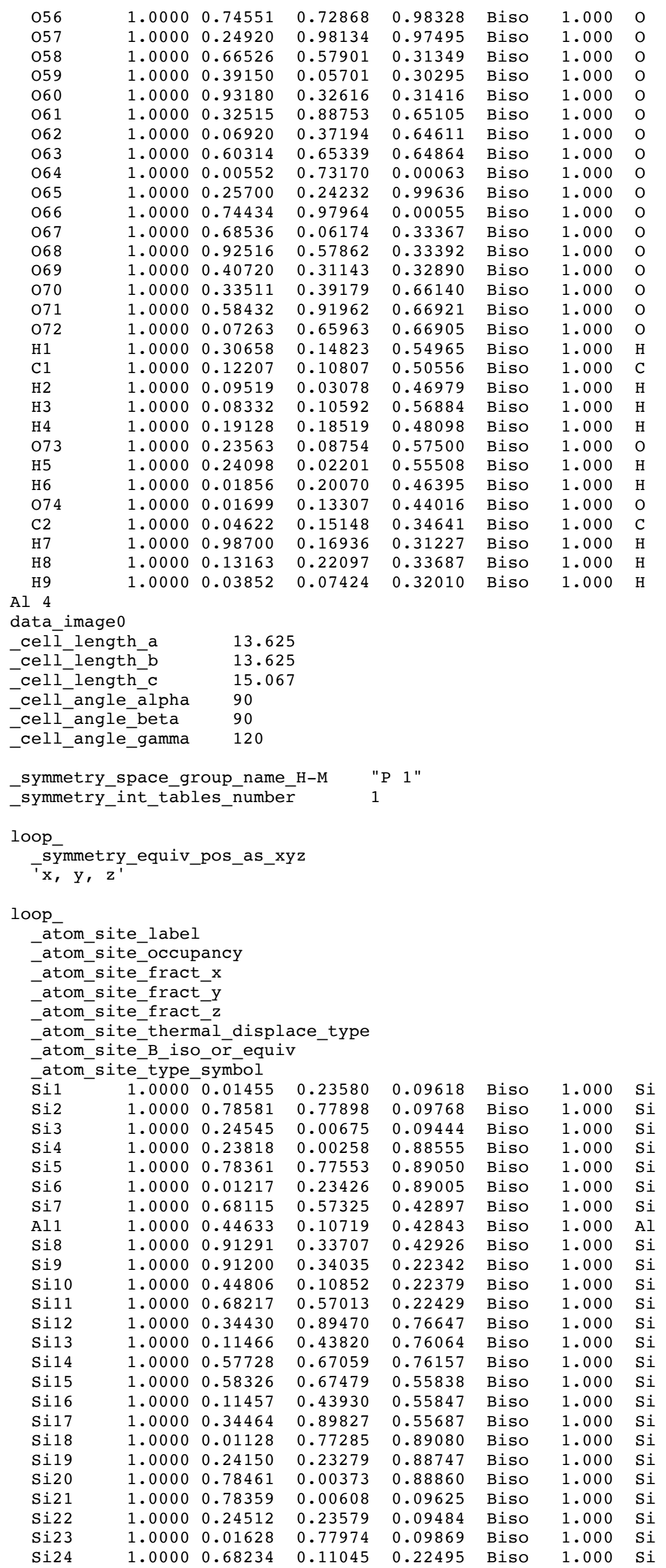




\begin{tabular}{|c|c|c|c|c|c|c|c|}
\hline Si25 & 1.0000 & 0.91117 & 0.56965 & 0.22503 & Biso & 1.000 & $\mathrm{Si}$ \\
\hline Si26 & 1.0000 & 0.45045 & 0.33959 & 0.22305 & Biso & 1.000 & $\mathrm{Si}$ \\
\hline Si27 & 1.0000 & 0.44589 & 0.34077 & 0.42810 & Biso & 1.000 & $\mathrm{Si}$ \\
\hline Si28 & 1.0000 & 0.90913 & 0.56719 & 0.43119 & Biso & 1.000 & \\
\hline Si29 & 1.0000 & 0.68395 & 0.10685 & 0.42789 & Biso & 1.000 & \\
\hline $\mathrm{Si} 30$ & 1.0000 & 0.34792 & 0.44612 & 0.55561 & Biso & 1.000 & \\
\hline Si31 & 1.0000 & 0.57816 & 0.90540 & 0.55644 & Biso & 1.000 & \\
\hline Si32 & 1.0000 & 0.11192 & 0.67266 & 0.56037 & Biso & 1.000 & \\
\hline Si33 & 1.0000 & 0.11363 & 0.67028 & 0.76420 & Biso & 1.000 & \\
\hline Si34 & 1.0000 & 0.57495 & 0.90140 & 0.76215 & Biso & 1.000 & \\
\hline Si35 & 1.0000 & 0.34537 & 0.44197 & 0.76130 & Biso & 1.000 & \\
\hline 01 & 1.0000 & 0.91494 & 0.10493 & 0.11346 & Biso & 1.000 & \\
\hline $\mathrm{O} 2$ & 1.0000 & 0.91754 & 0.81287 & 0.11406 & Biso & 1.000 & \\
\hline 03 & 1.0000 & 0.21333 & 0.10540 & 0.11474 & Biso & 1.000 & \\
\hline 04 & 1.0000 & 0.10786 & 0.90268 & 0.86755 & Biso & 1.000 & \\
\hline 05 & 1.0000 & 0.81927 & 0.90685 & 0.87067 & Biso & 1.000 & \\
\hline 06 & 1.0000 & 0.11061 & 0.20194 & 0.87347 & Biso & 1.000 & \\
\hline 07 & 1.0000 & 0.57267 & 0.44889 & 0.44401 & Biso & 1.000 & \\
\hline 08 & 1.0000 & 0.58347 & 0.13291 & 0.43977 & Biso & 1.000 & \\
\hline 09 & 1.0000 & 0.88541 & 0.43902 & 0.44719 & Biso & 1.000 & \\
\hline 010 & 1.0000 & 0.78140 & 0.24179 & 0.20736 & Biso & 1.000 & \\
\hline 011 & 1.0000 & 0.48267 & 0.24141 & 0.20642 & Biso & 1.000 & \\
\hline 012 & 1.0000 & 0.77983 & 0.53613 & 0.20886 & Biso & 1.000 & \\
\hline 013 & 1.0000 & 0.24453 & 0.76479 & 0.78629 & Biso & 1.000 & \\
\hline 014 & 1.0000 & 0.24677 & 0.47458 & 0.77780 & Biso & 1.000 & \\
\hline 015 & 1.0000 & 0.54553 & 0.77030 & 0.77113 & Biso & 1.000 & 0 \\
\hline 016 & 1.0000 & 0.45461 & 0.57279 & 0.54019 & Biso & 1.000 & \\
\hline 017 & 1.0000 & 0.13125 & 0.56514 & 0.55082 & Biso & 1.000 & 0 \\
\hline 018 & 1.0000 & 0.44901 & 0.87537 & 0.53478 & Biso & 1.000 & 0 \\
\hline 019 & 1.0000 & 0.99729 & 0.32172 & 0.15960 & Biso & 1.000 & 0 \\
\hline 020 & 1.0000 & 0.70151 & 0.67282 & 0.15908 & Biso & 1.000 & O \\
\hline 021 & 1.0000 & 0.35701 & 0.02937 & 0.14784 & Biso & 1.000 & 0 \\
\hline 022 & 1.0000 & 0.32548 & 0.98339 & 0.82547 & Biso & 1.000 & 0 \\
\hline 023 & 1.0000 & 0.67663 & 0.68969 & 0.83020 & Biso & 1.000 & 0 \\
\hline 024 & 1.0000 & 0.03151 & 0.33928 & 0.82824 & Biso & 1.000 & 0 \\
\hline 025 & 1.0000 & 0.67285 & 0.66590 & 0.49210 & Biso & 1.000 & 0 \\
\hline 026 & 1.0000 & 0.35213 & 0.00332 & 0.50302 & Biso & 1.000 & 0 \\
\hline 027 & 1.0000 & 0.01800 & 0.35303 & 0.49053 & Biso & 1.000 & 0 \\
\hline 028 & 1.0000 & 0.02835 & 0.68300 & 0.83201 & Biso & 1.000 & 0 \\
\hline 029 & 1.0000 & 0.32608 & 0.33797 & 0.82481 & Biso & 1.000 & 0 \\
\hline 030 & 1.0000 & 0.67939 & 0.98318 & 0.82650 & Biso & 1.000 & 0 \\
\hline 031 & 1.0000 & 0.69763 & 0.02741 & 0.15563 & Biso & 1.000 & 0 \\
\hline 032 & 1.0000 & 0.34989 & 0.32381 & 0.15598 & Biso & 1.000 & 0 \\
\hline 033 & 1.0000 & 0.99490 & 0.67485 & 0.16193 & Biso & 1.000 & 0 \\
\hline 034 & 1.0000 & 0.35475 & 0.35552 & 0.49004 & Biso & 1.000 & 0 \\
\hline 035 & 1.0000 & 0.00925 & 0.65692 & 0.49602 & Biso & 1.000 & 0 \\
\hline 036 & 1.0000 & 0.66984 & 0.00337 & 0.49188 & Biso & 1.000 & 0 \\
\hline 037 & 1.0000 & 0.13491 & 0.24589 & 0.12107 & Biso & 1.000 & O \\
\hline 038 & 1.0000 & 0.77376 & 0.88712 & 0.12722 & Biso & 1.000 & 0 \\
\hline 039 & 1.0000 & 0.13706 & 0.88768 & 0.12629 & Biso & 1.000 & 0 \\
\hline 040 & 1.0000 & 0.25120 & 0.12358 & 0.85869 & Biso & 1.000 & 0 \\
\hline 041 & 1.0000 & 0.88887 & 0.75743 & 0.86575 & Biso & 1.000 & 0 \\
\hline 042 & 1.0000 & 0.89148 & 0.12599 & 0.86357 & Biso & 1.000 & 0 \\
\hline 043 & 1.0000 & 0.79563 & 0.57167 & 0.45533 & Biso & 1.000 & 0 \\
\hline 044 & 1.0000 & 0.43920 & 0.22634 & 0.45835 & Biso & 1.000 & 0 \\
\hline 045 & 1.0000 & 0.80540 & 0.21661 & 0.45506 & Biso & 1.000 & 0 \\
\hline 046 & 1.0000 & 0.92521 & 0.46215 & 0.19894 & Biso & 1.000 & 0 \\
\hline 047 & 1.0000 & 0.56142 & 0.10003 & 0.20610 & Biso & 1.000 & 0 \\
\hline 048 & 1.0000 & 0.56048 & 0.46199 & 0.20140 & Biso & 1.000 & 0 \\
\hline 049 & 1.0000 & 0.46510 & 0.90795 & 0.79449 & Biso & 1.000 & 0 \\
\hline 050 & 1.0000 & 0.09865 & 0.54609 & 0.77828 & Biso & 1.000 & 0 \\
\hline 051 & 1.0000 & 0.46652 & 0.55071 & 0.78606 & Biso & 1.000 & 0 \\
\hline 052 & 1.0000 & 0.58896 & 0.79378 & 0.53880 & Biso & 1.000 & 0 \\
\hline 053 & 1.0000 & 0.23280 & 0.44678 & 0.53136 & Biso & 1.000 & 0 \\
\hline 054 & 1.0000 & 0.22676 & 0.78468 & 0.53011 & Biso & 1.000 & 0 \\
\hline 055 & 1.0000 & 0.01258 & 0.27014 & 0.99317 & Biso & 1.000 & 0 \\
\hline 056 & 1.0000 & 0.74969 & 0.74590 & 0.99461 & Biso & 1.000 & 0 \\
\hline 057 & 1.0000 & 0.26930 & 0.00234 & 0.98942 & Biso & 1.000 & 0 \\
\hline 058 & 1.0000 & 0.68835 & 0.61390 & 0.32612 & Biso & 1.000 & 0 \\
\hline 059 & 1.0000 & 0.39567 & 0.06678 & 0.32052 & Biso & 1.000 & 0 \\
\hline 060 & 1.0000 & 0.94949 & 0.33913 & 0.32588 & Biso & 1.000 & 0 \\
\hline 061 & 1.0000 & 0.34354 & 0.92372 & 0.66255 & Biso & 1.000 & 0 \\
\hline 062 & 1.0000 & 0.07855 & 0.39153 & 0.65940 & Biso & 1.000 & 0 \\
\hline 063 & 1.0000 & 0.61972 & 0.66885 & 0.66057 & Biso & 1.000 & 0 \\
\hline 064 & 1.0000 & 0.01650 & 0.74524 & 0.99535 & Biso & 1.000 & 0 \\
\hline 065 & 1.0000 & 0.27831 & 0.26683 & 0.99075 & Biso & 1.000 & 0 \\
\hline 066 & 1.0000 & 0.74974 & 0.00110 & 0.99230 & Biso & 1.000 & 0 \\
\hline 067 & 1.0000 & 0.69437 & 0.07207 & 0.32497 & Biso & 1.000 & 0 \\
\hline 068 & 1.0000 & 0.94627 & 0.60576 & 0.32843 & Biso & 1.000 & 0 \\
\hline 069 & 1.0000 & 0.40864 & 0.33916 & 0.32445 & Biso & 1.000 & 0 \\
\hline
\end{tabular}




$\begin{array}{llllllll}\text { O70 } & 1.0000 & 0.34420 & 0.40537 & 0.65803 & \text { Biso } & 1.000 & \text { O } \\ \text { O71 } & 1.0000 & 0.60872 & 0.94467 & 0.66008 & \text { Biso } & 1.000 & \text { O } \\ \text { O72 } & 1.0000 & 0.08019 & 0.68447 & 0.66282 & \text { Biso } & 1.000 & \text { O } \\ \text { H1 } & 1.0000 & 0.26770 & 0.16924 & 0.54253 & \text { Biso } & 1.000 & \mathrm{H} \\ \text { C1 } & 1.0000 & 0.09566 & 0.01420 & 0.45482 & \text { Biso } & 1.000 & \mathrm{C} \\ \text { H2 } & 1.0000 & 0.16298 & 0.02564 & 0.40984 & \text { Biso } & 1.000 & \mathrm{H} \\ \text { H3 } & 1.0000 & 0.05971 & 0.94178 & 0.49927 & \text { Biso } & 1.000 & \mathrm{H} \\ \text { H4 } & 1.0000 & 0.08083 & 0.08428 & 0.46732 & \text { Biso } & 1.000 & \mathrm{H} \\ \text { O73 } & 1.0000 & 0.21875 & 0.08838 & 0.55578 & \text { Biso } & 1.000 & \text { O } \\ \text { H5 } & 1.0000 & 0.26947 & 0.05609 & 0.54343 & \text { Biso } & 1.000 & \mathrm{H} \\ \text { H6 } & 1.0000 & 0.91123 & 0.91863 & 0.39953 & \text { Biso } & 1.000 & \mathrm{H} \\ \text { O74 } & 1.0000 & 0.98446 & 0.94346 & 0.37076 & \text { Biso } & 1.000 & \mathrm{O} \\ \text { C2 } & 1.0000 & 0.99652 & 0.01584 & 0.29488 & \text { Biso } & 1.000 & \mathrm{C} \\ \text { H7 } & 1.0000 & 0.92366 & 0.96848 & 0.25092 & \text { Biso } & 1.000 & \mathrm{H} \\ \text { H8 } & 1.0000 & 0.00165 & 0.09512 & 0.31723 & \text { Biso } & 1.000 & \mathrm{H} \\ \text { H9 } & 1.0000 & 0.07438 & 0.03299 & 0.26057 & \text { Biso } & 1.000 & \mathrm{H}\end{array}$

Ge 4

data image 0

$\begin{array}{ll}\text {-cel1__length_a } & 13.875 \\ \text { _cell_length_b } & 13.875 \\ \text {-cell_length_c } & 15.017 \\ \text {-cell_angle_alpha } & 90 \\ \text {-cell_angle_beta } & 90 \\ \text {-cell_angle_gamma } & 120\end{array}$

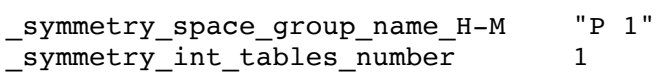

loop

symmetry_equiv_pos_as $\mathrm{xyz}$

' $\mathrm{x}, \mathrm{y}, \mathrm{z}$ '

loop

atom_site_label

_atom_site_occupancy

atom site fract $x$

-atom_site_fract_y

_atom_site_fract_z

-atom_site_thermal_displace_type

-atom_site_B_iso_or_equiv

-atom_site_tȳpe_symbol

P1 - 1.0000-0.00935

$\begin{array}{lll}1.0000 & 0.00935 & 0.22562\end{array}$

P3 $1.0000 \quad 0.23245$

Al1 $1.0000 \quad 0.22430$

Al2 $1.0000 \quad 0.77544$

Al3 $1.0000 \quad 0.00519$

$\begin{array}{lll}\text { P4 } & 1.0000 & 0.67465\end{array}$

Ge1 $1.0000 \quad 0.43083$

P5 $1.0000 \quad 0.90312$

Al4 $1.0000 \quad 0.90096$

$1.0000 \quad 0.43864$

$1.0000 \quad 0.67740$

$1.0000 \quad 0.33668$

$1.0000 \quad 0.10601$

$1.0000 \quad 0.56524$

$1.0000 \quad 0.57668$

$1.0000 \quad 0.10241$

$1.0000 \quad 0.33865$

$1.0000 \quad 0.99754$

$1.0000 \quad 0.22987$

$1.0000 \quad 0.77948$

$1.0000 \quad 0.77913$

$1.0000 \quad 0.23735$

$\begin{array}{lll}\text { Al12 } & 1.0000 & 0.00609 \\ \text { P12 } & 1.0000 & 0.67060\end{array}$

0.10327

0.77741
0.99678

0.10630

Biso

$1.000 \mathrm{P}$

$\begin{array}{llll}0.99054 & 0.88291 & \text { Biso } & 1.000\end{array}$

$0.77205 \quad 0.89298$ Biso $1.000 \mathrm{Al}$

$0.22464 \quad 0.89067$ Biso $1.000 \mathrm{Al}$

$\begin{array}{lllll}0.56261 & 0.43442 & \text { Biso } & 1.000 & \mathrm{P}\end{array}$

0.105150 .43609 Biso 1.000 Ge

0.326580 .43440 Biso $1.000 \quad \mathrm{P}$

$0.33055 \quad 0.22395$ Biso $1.000 \mathrm{Al}$

0.104210 .22341 Biso $1.000 \mathrm{Al}$

0.561830 .22498 Biso $1.000 \mathrm{Al}$

$0.88182 \quad 0.77495$ Biso $1.000 \quad \mathrm{P}$

$\begin{array}{lllll}0.43294 & 0.76683 & \text { Biso } & 1.000 & \mathrm{P}\end{array}$

0.659540 .76855 Biso $1.000 \quad \mathrm{P}$

0.669160 .56206 Biso $1.000 \mathrm{Al}$

$\begin{array}{lllll}0.43376 & 0.56315 & \text { Biso } & 1.000 & \mathrm{Al}\end{array}$

$0.88093 \quad 0.55914$ Biso $1.000 \mathrm{Al}$

0.764660 .88790 Biso $1.000 \quad \mathrm{P}$

$0.22008 \quad 0.88055$ Biso $1.000 \quad \mathrm{P}$

0.999590 .88649 Biso $1.000 \quad \mathrm{P}$

$0.00276 \quad 0.09991$ Biso $1.000 \mathrm{Al}$

$\begin{array}{lllll}0.22629 & 0.09311 & \text { Biso } & 1.000 \mathrm{Al}\end{array}$

$0.77437 \quad 0.10211$ Biso 1.000 Al

$1.0000 \quad 0.90414$

0.1053

0.22228

$1.000 \mathrm{P}$

0.559770 .22289 Biso $1.000 \quad \mathrm{P}$

$\begin{array}{llllll}1.0000 & 0.44698 & 0.33666 & 0.21658 & \text { Biso } & 1.000\end{array}$

P14 $1.0000 \quad 0.44698$

$1.0000 \quad 0.43571$

$1.0000 \quad 0.90041$

0.55562

0.42744 Biso

Al14

Al15

$1.0000 \quad 0.66895$

0.10620

0.43386 Biso

$1.000 \mathrm{~A}]$

$1.0000 \quad 0.33781$

0.45104

$\begin{array}{lll}\mathrm{P} 16 & 1.0000 & 0.57041 \\ \mathrm{P} 17 & 1.0000 & 0.10168\end{array}$

0.89522

0.43080

Biso

$1.000 \mathrm{Al}$

$1.000 \mathrm{Al}$

$1.000 \mathrm{P}$

$1.0000 \quad 0.10610$

06780

0.56152

$1.000 \mathrm{P}$

Al 16

$\begin{array}{lll}\text { Al17 } & 1.0000 & 0.56383\end{array}$

0.88935

0.76796 Biso

$1.000 \mathrm{P}$

Biso

$1.000 \mathrm{Al}$

Al18

$\begin{array}{llll}01 & 1.0000 & 0.91732 & 0.10514\end{array}$

0.76001

Biso

$1.000 \mathrm{Al}$

$\begin{array}{llll}02 & 1.0000 & 0.90169 & 0.80795\end{array}$

0.12460 Biso

$1.000 \mathrm{Al}$

03

$1.0000 \quad 0.20512$

$0.08980 \quad 0.11862$ Biso

$1.000 \quad 0$

$1.000 \quad 0$ 


\begin{tabular}{|c|c|c|c|c|c|c|c|}
\hline 04 & 1.0000 & 0.08859 & 0.88249 & 0.86001 & Biso & 1.000 & 0 \\
\hline 05 & 1.0000 & 0.81101 & 0.90945 & 0.86768 & Biso & 1.000 & 0 \\
\hline 06 & 1.0000 & 0.10833 & 0.19127 & 0.86604 & Biso & 1.000 & 0 \\
\hline 07 & 1.0000 & 0.57325 & 0.44674 & 0.44826 & Biso & 1.000 & 0 \\
\hline 08 & 1.0000 & 0.57305 & 0.14797 & 0.44656 & Biso & 1.000 & 0 \\
\hline 09 & 1.0000 & 0.87965 & 0.42226 & 0.45353 & Biso & 1.000 & 0 \\
\hline 010 & 1.0000 & 0.76321 & 0.22665 & 0.20450 & Biso & 1.000 & 0 \\
\hline 011 & 1.0000 & 0.47587 & 0.24438 & 0.20242 & Biso & 1.000 & 0 \\
\hline 012 & 1.0000 & 0.78248 & 0.52917 & 0.20600 & Biso & 1.000 & 0 \\
\hline 013 & 1.0000 & 0.24215 & 0.76398 & 0.79964 & Biso & 1.000 & $\mathrm{O}$ \\
\hline 014 & 1.0000 & 0.22939 & 0.46887 & 0.78286 & Biso & 1.000 & 0 \\
\hline 015 & 1.0000 & 0.53445 & 0.75146 & 0.77657 & Biso & 1.000 & 0 \\
\hline 016 & 1.0000 & 0.43811 & 0.56929 & 0.54162 & Biso & 1.000 & 0 \\
\hline 017 & 1.0000 & 0.10820 & 0.56109 & 0.55745 & Biso & 1.000 & 0 \\
\hline 018 & 1.0000 & 0.44770 & 0.85532 & 0.53293 & Biso & 1.000 & 0 \\
\hline 019 & 1.0000 & 0.99329 & 0.30860 & 0.15953 & Biso & 1.000 & $\mathrm{O}$ \\
\hline 020 & 1.0000 & 0.69958 & 0.67642 & 0.16161 & Biso & 1.000 & 0 \\
\hline 021 & 1.0000 & 0.34000 & 0.01946 & 0.14307 & Biso & 1.000 & 0 \\
\hline 022 & 1.0000 & 0.32035 & 0.97015 & 0.82336 & Biso & 1.000 & 0 \\
\hline 023 & 1.0000 & 0.65589 & 0.67802 & 0.83589 & Biso & 1.000 & 0 \\
\hline 024 & 1.0000 & 0.03068 & 0.34460 & 0.83445 & Biso & 1.000 & 0 \\
\hline 025 & 1.0000 & 0.66760 & 0.64943 & 0.49372 & Biso & 1.000 & 0 \\
\hline 026 & 1.0000 & 0.34441 & 0.99557 & 0.51027 & Biso & 1.000 & 0 \\
\hline 027 & 1.0000 & 0.00160 & 0.33988 & 0.49066 & Biso & 1.000 & 0 \\
\hline 028 & 1.0000 & 0.01163 & 0.67584 & 0.83831 & Biso & 1.000 & 0 \\
\hline 029 & 1.0000 & 0.30914 & 0.31886 & 0.82225 & Biso & 1.000 & 0 \\
\hline 030 & 1.0000 & 0.67742 & 0.97785 & 0.83204 & Biso & 1.000 & 0 \\
\hline 031 & 1.0000 & 0.68553 & 0.02644 & 0.15897 & Biso & 1.000 & 0 \\
\hline 032 & 1.0000 & 0.35362 & 0.32160 & 0.15286 & Biso & 1.000 & 0 \\
\hline 033 & 1.0000 & 0.98330 & 0.65933 & 0.16502 & Biso & 1.000 & 0 \\
\hline 034 & 1.0000 & 0.34413 & 0.37249 & 0.48324 & Biso & 1.000 & $\mathrm{O}$ \\
\hline 035 & 1.0000 & 0.00650 & 0.65595 & 0.50124 & Biso & 1.000 & 0 \\
\hline 036 & 1.0000 & 0.64906 & 0.99287 & 0.49682 & Biso & 1.000 & 0 \\
\hline 037 & 1.0000 & 0.12242 & 0.23750 & 0.12674 & Biso & 1.000 & 0 \\
\hline 038 & 1.0000 & 0.76687 & 0.87658 & 0.13471 & Biso & 1.000 & 0 \\
\hline 039 & 1.0000 & 0.13474 & 0.88688 & 0.13256 & Biso & 1.000 & 0 \\
\hline 040 & 1.0000 & 0.24032 & 0.11928 & 0.85354 & Biso & 1.000 & 0 \\
\hline 041 & 1.0000 & 0.88391 & 0.75004 & 0.86273 & Biso & 1.000 & 0 \\
\hline 042 & 1.0000 & 0.87680 & 0.11317 & 0.85902 & Biso & 1.000 & 0 \\
\hline 043 & 1.0000 & 0.78014 & 0.55978 & 0.45999 & Biso & 1.000 & 0 \\
\hline 044 & 1.0000 & 0.40593 & 0.21346 & 0.46983 & Biso & 1.000 & $\mathrm{O}$ \\
\hline 045 & 1.0000 & 0.80191 & 0.21551 & 0.45923 & Biso & 1.000 & 0 \\
\hline 046 & 1.0000 & 0.91780 & 0.46045 & 0.19698 & Biso & 1.000 & 0 \\
\hline 047 & 1.0000 & 0.55801 & 0.09501 & 0.20280 & Biso & 1.000 & 0 \\
\hline 048 & 1.0000 & 0.54996 & 0.44945 & 0.19509 & Biso & 1.000 & 0 \\
\hline 049 & 1.0000 & 0.44818 & 0.89469 & 0.80513 & Biso & 1.000 & 0 \\
\hline 050 & 1.0000 & 0.09027 & 0.53361 & 0.77826 & Biso & 1.000 & 0 \\
\hline 051 & 1.0000 & 0.46219 & 0.54720 & 0.78966 & Biso & 1.000 & 0 \\
\hline 052 & 1.0000 & 0.59474 & 0.80015 & 0.53914 & Biso & 1.000 & 0 \\
\hline 053 & 1.0000 & 0.23227 & 0.45613 & 0.53200 & Biso & 1.000 & O \\
\hline 054 & 1.0000 & 0.21142 & 0.76491 & 0.52790 & Biso & 1.000 & 0 \\
\hline 055 & 1.0000 & 0.00506 & 0.25108 & 0.00438 & Biso & 1.000 & 0 \\
\hline 056 & 1.0000 & 0.75160 & 0.75048 & 0.00748 & Biso & 1.000 & 0 \\
\hline 057 & 1.0000 & 0.24624 & 0.98918 & 0.99698 & Biso & 1.000 & 0 \\
\hline 058 & 1.0000 & 0.68199 & 0.60035 & 0.33682 & Biso & 1.000 & 0 \\
\hline 059 & 1.0000 & 0.37962 & 0.06084 & 0.32701 & Biso & 1.000 & 0 \\
\hline 060 & 1.0000 & 0.93450 & 0.32850 & 0.33580 & Biso & 1.000 & 0 \\
\hline 061 & 1.0000 & 0.33714 & 0.89928 & 0.67444 & Biso & 1.000 & $\mathrm{O}$ \\
\hline 062 & 1.0000 & 0.07100 & 0.38327 & 0.67254 & Biso & 1.000 & 0 \\
\hline 063 & 1.0000 & 0.60848 & 0.65965 & 0.67384 & Biso & 1.000 & 0 \\
\hline 064 & 1.0000 & 0.00330 & 0.74721 & 0.98847 & Biso & 1.000 & 0 \\
\hline 065 & 1.0000 & 0.26240 & 0.25082 & 0.97892 & Biso & 1.000 & 0 \\
\hline 066 & 1.0000 & 0.75306 & 0.99972 & 0.98602 & Biso & 1.000 & 0 \\
\hline 067 & 1.0000 & 0.67759 & 0.07136 & 0.31861 & Biso & 1.000 & 0 \\
\hline 068 & 1.0000 & 0.93481 & 0.59097 & 0.32147 & Biso & 1.000 & 0 \\
\hline 069 & 1.0000 & 0.40873 & 0.33676 & 0.31268 & Biso & 1.000 & 0 \\
\hline 070 & 1.0000 & 0.33367 & 0.40619 & 0.64619 & Biso & 1.000 & 0 \\
\hline 071 & 1.0000 & 0.59306 & 0.93131 & 0.65463 & Biso & 1.000 & 0 \\
\hline 072 & 1.0000 & 0.07868 & 0.68880 & 0.65806 & Biso & 1.000 & O \\
\hline H 1 & 1.0000 & 0.26353 & 0.14472 & 0.54053 & Biso & 1.000 & $\mathrm{H}$ \\
\hline $\mathrm{C} 1$ & 1.0000 & 0.09212 & 0.99477 & 0.45341 & Biso & 1.000 & C \\
\hline H2 & 1.0000 & 0.16355 & 0.01654 & 0.41083 & Biso & 1.000 & $\mathrm{H}$ \\
\hline H3 & 1.0000 & 0.06080 & 0.92052 & 0.49436 & Biso & 1.000 & $\mathrm{H}$ \\
\hline H 4 & 1.0000 & 0.07038 & 0.05763 & 0.47043 & Biso & 1.000 & $\mathrm{H}$ \\
\hline 073 & 1.0000 & 0.20717 & 0.06984 & 0.56140 & Biso & 1.000 & 0 \\
\hline H5 & 1.0000 & 0.25180 & 0.03146 & 0.55415 & Biso & 1.000 & $\mathrm{H}$ \\
\hline H 6 & 1.0000 & 0.91719 & 0.89369 & 0.39173 & Biso & 1.000 & $\mathrm{H}$ \\
\hline 074 & 1.0000 & 0.99160 & 0.92817 & 0.36516 & Biso & 1.000 & 0 \\
\hline $\mathrm{C} 2$ & 1.0000 & 0.00043 & 0.00557 & 0.29490 & Biso & 1.000 & C \\
\hline $\mathrm{H} 7$ & 1.0000 & 0.93357 & 0.95937 & 0.24680 & Biso & 1.000 & $\mathrm{H}$ \\
\hline
\end{tabular}




\begin{tabular}{|c|c|c|c|c|c|c|c|}
\hline H8 & 1.0000 & 0.99502 & 0.07574 & 0.32334 & Biso & 1.000 & $\mathrm{H}$ \\
\hline H9 & 1.0000 & 0.08114 & 0.03430 & 0.26280 & Biso & 1.000 & $\mathrm{H}$ \\
\hline \multicolumn{8}{|l|}{$\mathrm{Ga} 4$} \\
\hline \multicolumn{8}{|c|}{ data_image 0} \\
\hline \multicolumn{8}{|c|}{13.625} \\
\hline \multicolumn{8}{|c|}{13.625} \\
\hline \multicolumn{8}{|c|}{15.067} \\
\hline \multicolumn{8}{|c|}{ àlpha } \\
\hline cell_e & beta & 90 & & & & & \\
\hline cell_c & gamma & 120 & & & & & \\
\hline symmet & pace_g & us_llat & & $1 "$ & & & \\
\hline symmet & $n t \_t \overline{a b}$ & les_numbe & & & & & \\
\hline oop_ & & & & & & & \\
\hline $\begin{array}{l}\text { symm } \\
\text { ' } x, y\end{array}$ & _equiv & pos_as_x & & & & & \\
\hline oop_ & & & & & & & \\
\hline aton & e_label & & & & & & \\
\hline aton & ee_occup & pancy & & & & & \\
\hline aton & $=e^{-}$fract & 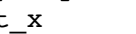 & & & & & \\
\hline aton & $e^{-}$fract & $t^{-} y$ & & & & & \\
\hline -aton & $=e_{-}^{-}$fract & -z & & & & & \\
\hline -aton & e_thern & nàl_displ & ace_type & & & & \\
\hline $\begin{array}{l}\text {-aton } \\
\text { aton }\end{array}$ & $\begin{array}{l}e^{-} \mathrm{B} \text { is } \\
e^{-} \text {type }\end{array}$ & $\begin{array}{l}\text { o_or_equi } \\
\text { symbol }\end{array}$ & & & & & \\
\hline$\overline{\mathrm{S}} \mathrm{i} 1$ & 1.0000 & 0.01560 & 0.23629 & 0.09576 & Biso & 1.000 & $\mathrm{Si}$ \\
\hline Si2 & 1.0000 & 0.78740 & 0.78011 & 0.09952 & Biso & 1.000 & $\mathrm{Si}$ \\
\hline $\mathrm{Si3}$ & 1.0000 & 0.24600 & 0.00688 & 0.09170 & Biso & 1.000 & $\mathrm{Si}$ \\
\hline $\mathrm{Si4}$ & 1.0000 & 0.23618 & 0.00076 & 0.88286 & Biso & 1.000 & $\mathrm{Si}$ \\
\hline Si5 & 1.0000 & 0.78312 & 0.77465 & 0.89219 & Biso & 1.000 & $\mathrm{Si}$ \\
\hline Si6 & 1.0000 & 0.01154 & 0.23406 & 0.88928 & Biso & 1.000 & $\mathrm{Si}$ \\
\hline Si7 & 1.0000 & 0.67921 & 0.56845 & 0.42991 & Biso & 1.000 & $\mathrm{Si}$ \\
\hline Gal & 1.0000 & 0.44363 & 0.10806 & 0.42796 & Biso & 1.000 & $\mathrm{Ga}$ \\
\hline Si8 & 1.0000 & 0.91739 & 0.33807 & 0.42836 & Biso & 1.000 & $\mathrm{Si}$ \\
\hline Si9 & 1.0000 & 0.91376 & 0.34136 & 0.22311 & Biso & 1.000 & $\mathrm{Si}$ \\
\hline Silo & 1.0000 & 0.44859 & 0.10939 & 0.22043 & Biso & 1.000 & $\mathrm{Si}$ \\
\hline Si11 & 1.0000 & 0.68253 & 0.57012 & 0.22491 & Biso & 1.000 & $\mathrm{Si}$ \\
\hline Sil12 & 1.0000 & 0.34331 & 0.89185 & 0.76678 & Biso & 1.000 & $\mathrm{Si}$ \\
\hline Si13 & 1.0000 & 0.11387 & 0.43648 & 0.75957 & Biso & 1.000 & $\mathrm{Si}$ \\
\hline $\operatorname{Si} 14$ & 1.0000 & 0.57751 & 0.67042 & 0.76239 & Biso & 1.000 & $\mathrm{Si}$ \\
\hline Si15 & 1.0000 & 0.58845 & 0.67866 & 0.56010 & Biso & 1.000 & $\mathrm{Si}$ \\
\hline Si16 & 1.0000 & 0.11231 & 0.43807 & 0.56005 & Biso & 1.000 & $\mathrm{Si}$ \\
\hline $\operatorname{Si} 17$ & 1.0000 & 0.34423 & 0.89071 & 0.55629 & Biso & 1.000 & $\mathrm{Si}$ \\
\hline $\operatorname{si} 18$ & 1.0000 & 0.00988 & 0.77103 & 0.89078 & Biso & 1.000 & $\mathrm{Si}$ \\
\hline Si19 & 1.0000 & 0.24087 & 0.23243 & 0.88488 & Biso & 1.000 & $\mathrm{Si}$ \\
\hline $\mathrm{Si} 20$ & 1.0000 & 0.78468 & 0.00340 & 0.88944 & Biso & 1.000 & $\mathrm{Si}$ \\
\hline Si21 & 1.0000 & 0.78495 & 0.00724 & 0.09727 & Biso & 1.000 & $\mathrm{Si}$ \\
\hline Si22 & 1.0000 & 0.24602 & 0.23635 & 0.09222 & Biso & 1.000 & $\mathrm{Si}$ \\
\hline Si23 & 1.0000 & 0.01738 & 0.78087 & 0.09944 & Biso & 1.000 & $\mathrm{Si}$ \\
\hline Si24 & 1.0000 & 0.68273 & 0.11139 & 0.22568 & Biso & 1.000 & $\mathrm{Si}$ \\
\hline Si25 & 1.0000 & 0.91203 & 0.57049 & 0.22539 & Biso & 1.000 & $\mathrm{Si}$ \\
\hline Si26 & 1.0000 & 0.45170 & 0.34001 & 0.22062 & Biso & 1.000 & $\mathrm{Si}$ \\
\hline Si27 & 1.0000 & 0.44055 & 0.34168 & 0.42726 & Biso & 1.000 & $\mathrm{Si}$ \\
\hline Si28 & 1.0000 & 0.90981 & 0.56717 & 0.43146 & Biso & 1.000 & $\mathrm{Si}$ \\
\hline $\operatorname{Si} 29$ & 1.0000 & 0.68462 & 0.11202 & 0.42882 & Biso & 1.000 & $\mathrm{Si}$ \\
\hline Si30 & 1.0000 & 0.34928 & 0.45482 & 0.55440 & Biso & 1.000 & $\mathrm{Si}$ \\
\hline Si31 & 1.0000 & 0.58032 & 0.90646 & 0.55731 & Biso & 1.000 & $\mathrm{Si}$ \\
\hline $\mathrm{Si} 32$ & 1.0000 & 0.10739 & 0.67163 & 0.56248 & Biso & 1.000 & $\mathrm{Si}$ \\
\hline Si33 & 1.0000 & 0.11217 & 0.66977 & 0.76447 & Biso & 1.000 & $\mathrm{Si}$ \\
\hline $\mathrm{Si} 34$ & 1.0000 & 0.57380 & 0.90029 & 0.76344 & Biso & 1.000 & $\mathrm{Si}$ \\
\hline Si35 & 1.0000 & 0.34489 & 0.44148 & 0.75880 & Biso & 1.000 & $\mathrm{Si}$ \\
\hline 01 & 1.0000 & 0.91640 & 0.10569 & 0.11466 & Biso & 1.000 & 0 \\
\hline $\mathrm{O} 2$ & 1.0000 & 0.91925 & 0.81457 & 0.11615 & Biso & 1.000 & 0 \\
\hline 03 & 1.0000 & 0.21391 & 0.10569 & 0.11128 & Biso & 1.000 & 0 \\
\hline 04 & 1.0000 & 0.10615 & 0.90006 & 0.86485 & Biso & 1.000 & 0 \\
\hline 05 & 1.0000 & 0.81934 & 0.90625 & 0.87260 & Biso & 1.000 & 0 \\
\hline 06 & 1.0000 & 0.11024 & 0.20256 & 0.87135 & Biso & 1.000 & 0 \\
\hline 07 & 1.0000 & 0.57073 & 0.44347 & 0.44422 & Biso & 1.000 & 0 \\
\hline 08 & 1.0000 & 0.59160 & 0.14933 & 0.44142 & Biso & 1.000 & 0 \\
\hline 09 & 1.0000 & 0.89202 & 0.44117 & 0.44724 & Biso & 1.000 & 0 \\
\hline 010 & 1.0000 & 0.78280 & 0.24244 & 0.20877 & Biso & 1.000 & 0 \\
\hline 011 & 1.0000 & 0.48526 & 0.24281 & 0.20405 & Biso & 1.000 & 0 \\
\hline 012 & 1.0000 & 0.78067 & 0.53688 & 0.20907 & Biso & 1.000 & 0 \\
\hline 013 & 1.0000 & 0.24298 & 0.76279 & 0.78881 & Biso & 1.000 & 0 \\
\hline 014 & 1.0000 & 0.24630 & 0.47389 & 0.77725 & Biso & 1.000 & 0 \\
\hline 015 & 1.0000 & 0.54415 & 0.76907 & 0.77127 & Biso & 1.000 & 0 \\
\hline 016 & 1.0000 & 0.45742 & 0.58169 & 0.54374 & Biso & 1.000 & 0 \\
\hline 017 & 1.0000 & 0.11427 & 0.55712 & 0.55717 & Biso & 1.000 & 0 \\
\hline
\end{tabular}




\begin{tabular}{|c|c|c|c|c|c|c|c|}
\hline 018 & 1.0000 & 0.44955 & 0.86938 & 0.53375 & Biso & 1.000 & 0 \\
\hline 019 & 1.0000 & 0.99825 & 0.32300 & 0.15815 & Biso & 1.000 & 0 \\
\hline $\mathrm{O} 20$ & 1.0000 & 0.70326 & 0.67497 & 0.16177 & Biso & 1.000 & 0 \\
\hline 021 & 1.0000 & 0.35977 & 0.03178 & 0.14285 & Biso & 1.000 & 0 \\
\hline $\mathrm{O} 22$ & 1.0000 & 0.32380 & 0.98283 & 0.82203 & Biso & 1.000 & 0 \\
\hline 023 & 1.0000 & 0.67429 & 0.68894 & 0.83349 & Biso & 1.000 & 0 \\
\hline $\mathrm{O} 24$ & 1.0000 & 0.03075 & 0.34043 & 0.82918 & Biso & 1.000 & 0 \\
\hline 025 & 1.0000 & 0.67286 & 0.66159 & 0.49374 & Biso & 1.000 & 0 \\
\hline 026 & 1.0000 & 0.34701 & 0.99402 & 0.50308 & Biso & 1.000 & 0 \\
\hline $\mathrm{O} 27$ & 1.0000 & 0.02180 & 0.35071 & 0.48899 & Biso & 1.000 & 0 \\
\hline 028 & 1.0000 & 0.02657 & 0.67910 & 0.83431 & Biso & 1.000 & $\mathrm{O}$ \\
\hline O29 & 1.0000 & 0.32543 & 0.33619 & 0.82099 & Biso & 1.000 & 0 \\
\hline 030 & 1.0000 & 0.67862 & 0.98133 & 0.82777 & Biso & 1.000 & 0 \\
\hline 031 & 1.0000 & 0.69930 & 0.02826 & 0.15739 & Biso & 1.000 & O \\
\hline 032 & 1.0000 & 0.35142 & 0.32378 & 0.15313 & Biso & 1.000 & 0 \\
\hline 033 & 1.0000 & 0.99603 & 0.67565 & 0.16231 & Biso & 1.000 & $\mathrm{O}$ \\
\hline 034 & 1.0000 & 0.35376 & 0.36914 & 0.48261 & Biso & 1.000 & 0 \\
\hline 035 & 1.0000 & 0.00725 & 0.66003 & 0.49684 & Biso & 1.000 & 0 \\
\hline 036 & 1.0000 & 0.66776 & 0.00874 & 0.49400 & Biso & 1.000 & 0 \\
\hline 037 & 1.0000 & 0.13648 & 0.24704 & 0.11988 & Biso & 1.000 & $\mathrm{O}$ \\
\hline 038 & 1.0000 & 0.77492 & 0.88823 & 0.12801 & Biso & 1.000 & $\mathrm{O}$ \\
\hline 039 & 1.0000 & 0.13885 & 0.88851 & 0.12636 & Biso & 1.000 & $\mathrm{O}$ \\
\hline 040 & 1.0000 & 0.24871 & 0.12186 & 0.85723 & Biso & 1.000 & 0 \\
\hline 041 & 1.0000 & 0.88720 & 0.75522 & 0.86575 & Biso & 1.000 & 0 \\
\hline 042 & 1.0000 & 0.89097 & 0.12544 & 0.86277 & Biso & 1.000 & $\mathrm{O}$ \\
\hline 043 & 1.0000 & 0.79292 & 0.56500 & 0.45511 & Biso & 1.000 & $\mathrm{O}$ \\
\hline 044 & 1.0000 & 0.41984 & 0.22301 & 0.46443 & Biso & 1.000 & 0 \\
\hline 045 & 1.0000 & 0.80925 & 0.21805 & 0.45382 & Biso & 1.000 & 0 \\
\hline 046 & 1.0000 & 0.92603 & 0.46293 & 0.19934 & Biso & 1.000 & 0 \\
\hline 047 & 1.0000 & 0.56214 & 0.10083 & 0.20502 & Biso & 1.000 & 0 \\
\hline 048 & 1.0000 & 0.56123 & 0.46286 & 0.19946 & Biso & 1.000 & 0 \\
\hline 049 & 1.0000 & 0.46408 & 0.90646 & 0.79696 & Biso & 1.000 & 0 \\
\hline 050 & 1.0000 & 0.09712 & 0.54479 & 0.77250 & Biso & 1.000 & 0 \\
\hline 051 & 1.0000 & 0.46640 & 0.54962 & 0.78402 & Biso & 1.000 & O \\
\hline 052 & 1.0000 & 0.60184 & 0.80113 & 0.53912 & Biso & 1.000 & 0 \\
\hline 053 & 1.0000 & 0.23688 & 0.46182 & 0.53330 & Biso & 1.000 & 0 \\
\hline 054 & 1.0000 & 0.22724 & 0.77575 & 0.53025 & Biso & 1.000 & 0 \\
\hline 055 & 1.0000 & 0.01205 & 0.26873 & 0.99263 & Biso & 1.000 & $\mathrm{O}$ \\
\hline 056 & 1.0000 & 0.75135 & 0.74563 & 0.99664 & Biso & 1.000 & 0 \\
\hline 057 & 1.0000 & 0.26710 & 0.99940 & 0.98662 & Biso & 1.000 & 0 \\
\hline 058 & 1.0000 & 0.68591 & 0.61017 & 0.32746 & Biso & 1.000 & 0 \\
\hline 059 & 1.0000 & 0.38990 & 0.06435 & 0.31536 & Biso & 1.000 & 0 \\
\hline 060 & 1.0000 & 0.95347 & 0.34038 & 0.32486 & Biso & 1.000 & 0 \\
\hline 061 & 1.0000 & 0.34393 & 0.91663 & 0.66191 & Biso & 1.000 & 0 \\
\hline 062 & 1.0000 & 0.07785 & 0.38435 & 0.65956 & Biso & 1.000 & 0 \\
\hline 063 & 1.0000 & 0.62464 & 0.67222 & 0.66235 & Biso & 1.000 & 0 \\
\hline 064 & 1.0000 & 0.01618 & 0.74667 & 0.99589 & Biso & 1.000 & $\mathrm{O}$ \\
\hline 065 & 1.0000 & 0.27836 & 0.26776 & 0.98801 & Biso & 1.000 & 0 \\
\hline 066 & 1.0000 & 0.75119 & 0.00286 & 0.99334 & Biso & 1.000 & 0 \\
\hline 067 & 1.0000 & 0.69038 & 0.07239 & 0.32650 & Biso & 1.000 & 0 \\
\hline 068 & 1.0000 & 0.94680 & 0.60684 & 0.32883 & Biso & 1.000 & 0 \\
\hline 069 & 1.0000 & 0.40929 & 0.33767 & 0.32198 & Biso & 1.000 & 0 \\
\hline 070 & 1.0000 & 0.34392 & 0.40708 & 0.65484 & Biso & 1.000 & 0 \\
\hline 071 & 1.0000 & 0.60683 & 0.94449 & 0.66146 & Biso & 1.000 & 0 \\
\hline 072 & 1.0000 & 0.07992 & 0.69115 & 0.66446 & Biso & 1.000 & 0 \\
\hline $\mathrm{H} 1$ & 1.0000 & 0.27691 & 0.15739 & 0.53763 & Biso & 1.000 & $\mathrm{H}$ \\
\hline $\mathrm{C} 1$ & 1.0000 & 0.09202 & 0.01262 & 0.45668 & Biso & 1.000 & $\mathrm{C}$ \\
\hline $\mathrm{H} 2$ & 1.0000 & 0.15728 & 0.01497 & 0.41371 & Biso & 1.000 & $\mathrm{H}$ \\
\hline H3 & 1.0000 & 0.05033 & 0.94328 & 0.50364 & Biso & 1.000 & $\mathrm{H}$ \\
\hline $\mathrm{H} 4$ & 1.0000 & 0.08757 & 0.08930 & 0.46672 & Biso & 1.000 & $\mathrm{H}$ \\
\hline 073 & 1.0000 & 0.21758 & 0.08213 & 0.55850 & Biso & 1.000 & 0 \\
\hline H5 & 1.0000 & 0.25815 & 0.03871 & 0.54916 & Biso & 1.000 & $\mathrm{H}$ \\
\hline H6 & 1.0000 & 0.90970 & 0.93159 & 0.40092 & Biso & 1.000 & $\mathrm{H}$ \\
\hline 074 & 1.0000 & 0.98157 & 0.94815 & 0.37341 & Biso & 1.000 & 0 \\
\hline $\mathrm{C} 2$ & 1.0000 & 0.00219 & 0.01947 & 0.29496 & Biso & 1.000 & C \\
\hline $\mathrm{H} 7$ & 1.0000 & 0.92958 & 0.97529 & 0.25025 & Biso & 1.000 & $\mathrm{H}$ \\
\hline H8 & 1.0000 & 0.01467 & 0.10281 & 0.31416 & Biso & 1.000 & $\mathrm{H}$ \\
\hline H9 & 1.0000 & 0.07839 & 0.02809 & 0.26315 & Biso & 1.000 & $\mathrm{H}$ \\
\hline \\
\hline \multicolumn{8}{|c|}{$\begin{array}{l}\mathrm{Ti} 4 \\
\text { data image } 0\end{array}$} \\
\hline \multicolumn{2}{|c|}{ cell_length_a } & \multicolumn{2}{|c|}{13.875} & & & & \\
\hline \multicolumn{2}{|c|}{ cell length b } & \multicolumn{2}{|c|}{ } & & & & \\
\hline cell & $\mathrm{th}^{-} \mathrm{C}$ & 15.01 & & & & & \\
\hline cell & e_lpha & 90 & & & & & \\
\hline $\operatorname{cell}$ & e_beta & 90 & & & & & \\
\hline cell & -gamma & 120 & & & & & \\
\hline & & & & $1 "$ & & & \\
\hline symme & $\left.n t \_t \overline{a b}\right]$ & es_numbe & & & & & \\
\hline
\end{tabular}


loop

_symmetry_equiv_pos_as_xyz

' $\mathrm{x}, \mathrm{y}, \mathrm{z}$ '

loop

atom_site_label

-atom_site_occupancy

-atom_site_fract_x

_atom_site_fract_y

atom site fract $z$

-atom_site_thermä_displace_type

_atom_site_B_iso_or_equiv

atom site type symbol

$\overline{\mathrm{P} 1} \quad 1.0000^{-} 0.00928 \quad 0.22575$

$1.0000 \quad 0.78127$

0.77855

0.10265 Biso

$1.000 \quad \mathrm{P}$

$1.0000 \quad 0.23319$

0.99722

.10744 Biso

$1.000 \mathrm{P}$

Al1

$1.0000 \quad 0.22217$

0.98863

0.09545 Biso

$.000 \mathrm{P}$

Al2 $1.0000 \quad 0.77444$

0.770620 .89398 Biso $1.000 \mathrm{Al}$

Al3 $1.0000 \quad 0.00409$

0.22349

P4 $1.0000 \quad 0.67416$

0.88994 Biso

0.562190 .43525 Biso

$1.000 \mathrm{Al}$

$1.0000 \quad 0.42632$

0.10434

0.43816

Biso

$1.000 \mathrm{P}$

$1.000 \mathrm{Ti}$

$1.0000 \quad 0.90584$

32693

0.43346 Biso

$1.000 \mathrm{P}$

Al4 $\quad 1.0000 \quad 0.90176$

$1.0000 \quad 0.43884$

0.22316 Biso

$1.000 \mathrm{Al}$

$1.0000 \quad 0.67787$

.22010 Biso

$1.000 \mathrm{Al}$

$1.0000 \quad 0.33507$

$1.0000 \quad 0.10524$

0.22590 Biso

$1.000 \mathrm{Al}$

$\begin{array}{llllllll}\text { P8 } & 1.0000 & 0.56527 & 0.65884 & 0.76894 & \text { Biso } & 1.000 & \text { P } \\ \text { Al7 } & 1.0000 & 0.58067 & 0.67160 & 0.56380 & \text { Biso } & 1.000 & \text { Al }\end{array}$

0.43091

$1.000 \mathrm{P}$

$1.000 \mathrm{P}$

0.658840 .76894 Biso $1.000 \quad \mathrm{P}$

Al8 $\quad 1.0000 \quad 0.10087$

$1.0000 \quad 0.33596$

$\begin{array}{lll}\text { P9 } & 1.0000 & 0.99605 \\ \text { P10 } & 1.0000 & 0.22922\end{array}$

0.43253

0.56442 Biso

$1.000 \mathrm{Al}$

$0.87380 \quad 0.56016$ Biso $1.000 \mathrm{Al}$

$\begin{array}{lll}\mathrm{P} 11 & 1.0000 & 0.77924\end{array}$

Al10 $\quad 1.0000 \quad 0.77952$

$1.0000 \quad 0.23810$

0.76270

0.88804 Biso

$\begin{array}{ll}1.000 & \mathrm{~A} 1 \\ 1.000 & \mathrm{P}\end{array}$

$\begin{array}{lllll}0.21926 & 0.87879 & \text { Biso } & 1.000 \mathrm{P}\end{array}$

0.998430 .88659 Biso $1.000 \quad \mathrm{P}$

0.003290 .10043 Biso $1.000 \mathrm{Al}$

$0.22722 \quad 0.09129$ Biso $1.000 \quad \mathrm{Al}$

Al12 $1.0000 \quad 0.00703$

P12 $1.0000 \quad 0.67150$

0.10258

$\begin{array}{lllll}0.77561 & 0.10258 & \text { Biso } & 1.000 & \mathrm{~A} 1 \\ 0.10617 & 0.22245 & \text { Biso } & 1.000 & \mathrm{P}\end{array}$

$1.0000 \quad 0.90441$

0.56067

0.22357 Biso

$1.0000 \quad 0.44673$

0.33767

0.21536 Biso

$1.000 \mathrm{P}$

$0.34350 \quad 0.42719$ Biso $1.000 \mathrm{Al}$

Al13 1.00000 .43159

$1.0000 \quad 0.90036$

0.55555

0.43443 Biso

$1.000 \mathrm{~A}$

Al15 $\quad 1.0000 \quad 0.67212$

P15 $1.0000 \quad 0.33800$

$1.0000 \quad 0.57158$

0.10661

0.43095 Biso

1.000

0.456840 .55074 Biso $1.000 \mathrm{P}$

$0.89597 \quad 0.55723$ Biso $1.000 \quad \mathrm{P}$

$1.0000 \quad 0.09766$

$1.0000 \quad 0.10433$

0.66491

$0.66361 \quad 0.76875$ Biso $1.000 \mathrm{Al}$

Al16

Al17

$1.0000 \quad 0.56237$

0.88790

1.000 A

$1.0000 \quad 0.33241$

0.43383

$1.000 \mathrm{AI}$

0.91742

0.10586

$1.000 \quad 0$

$1.0000 \quad 0.90319$

.80994

0.09102

1.0000

$1.0000 \quad 0.20708$

0.87978

$1.000 \quad 0$

$.0000 \quad 0.08667$

0.90800

$1.000 \quad 0$

$1.0000 \quad 0.81040$

$1.0000 \quad 0.10773$

$1.0000 \quad 0.56985$

0.19094

1.0000

Biso $1.000 \quad 0$

$1.0000 \quad 0.57164$

$1.0000 \quad 0.88331$

0.14321

0.44871 Biso

1.0000

$\begin{array}{lllll}0.22756 & 0.20392 & \text { Biso } & 1.000 & 0\end{array}$

$.0000 \quad 0.76376$

0.24633

0.19885 Biso

000

$1.0000 \quad 0.47647$

$1.0000 \quad 0.78246$

$1.0000 \quad 0.23998$

0.52905

0.76105

0.20654 Biso

O

$1.0000 \quad 0.22883$

$1.0000 \quad 0.53319$

0.46786

Biso

$1.000 \quad 0$

$\begin{array}{llll}0.78283 & \text { Biso } 1.000 & 0\end{array}$

$\begin{array}{lllll}0.74990 & 0.77629 & \text { Biso } & 1.000 & 0 \\ 0.57330 & 0.54456 & \text { Biso } & 1.000 & 0\end{array}$

$1.0000 \quad 0.44141$

0.57330

0.54456 Biso

$1.0000 \quad 0.09333$

$1.0000 \quad 0.44902$

0.55286

0.56376 Biso

$1.000 \quad 0$

$\begin{array}{lllll}0.85461 & 0.53240 & \text { Biso } & 1.000 & 0\end{array}$

$1.0000 \quad 0.99427$

0.30997

0.15821 Biso

1.0000

$1.0000 \quad 0.70130$

$1.0000 \quad 0.34243$

0.67774

0.16310 Biso

1.0000

0.020750 .13852 Biso $1.000 \quad 0$

$1.0000 \quad 0.31847$

96807

0.82158 Biso

$1.000 \quad 0$

$1.0000 \quad 0.65318$

$1.0000 \quad 0.02999$

0.67637

0.83876 Biso

$1.000 \quad 0$

0.344430 .83501 Biso $1.000 \quad 0$

$1.0000 \quad 0.67047$

0.65057

0.49501 Biso

1.0000

$1.0000 \quad 0.33717$

0.98671

0.51170 Biso

1.0000

1.00000 .00950

$1.0000 \quad 0.30815$

0.33951

0.48860

Biso

$1.000 \quad 0$

$\begin{array}{lllll}.67247 & 0.84000 & \text { Biso } & 1.000 & 0\end{array}$

$030 \quad 1.00000 .67616$

0.31711

1.0000

0.02720

0.83329 Biso

$1.000 \quad 0$

$1.000 \quad 0$ 


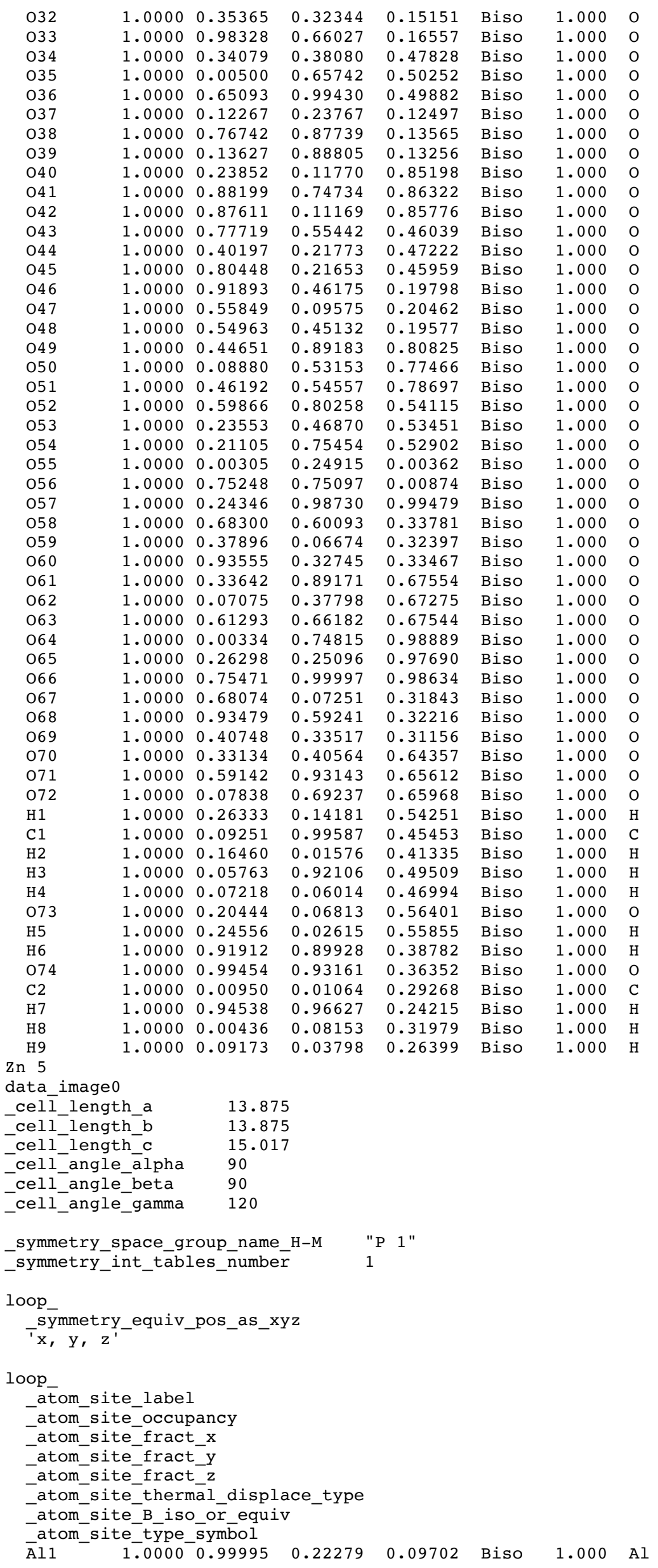




\begin{tabular}{|c|c|c|c|c|c|c|c|}
\hline Al2 & 1.0000 & 0.77735 & 0.77029 & 0.10052 & Biso & 1.000 & $\mathrm{Al}$ \\
\hline Al3 & 1.0000 & 0.23221 & 0.99912 & 0.09099 & Biso & 1.000 & Al \\
\hline $\mathrm{P} 1$ & 1.0000 & 0.22598 & 0.99509 & 0.88191 & Biso & 1.000 & $\mathrm{P}$ \\
\hline P2 & 1.0000 & 0.77578 & 0.76712 & 0.88794 & Biso & 1.000 & $\mathrm{P}$ \\
\hline P3 & 1.0000 & 0.99832 & 0.22193 & 0.88540 & Biso & 1.000 & $\mathrm{P}$ \\
\hline Al4 & 1.0000 & 0.66280 & 0.55716 & 0.43062 & Biso & 1.000 & Al \\
\hline $\mathrm{Zn} 1$ & 1.0000 & 0.44866 & 0.10469 & 0.42995 & Biso & 1.000 & $\mathrm{Zn}$ \\
\hline Al5 & 1.0000 & 0.90357 & 0.33578 & 0.42934 & Biso & 1.000 & Al \\
\hline P 4 & 1.0000 & 0.89636 & 0.33419 & 0.21837 & Biso & 1.000 & $P$ \\
\hline P5 & 1.0000 & 0.43871 & 0.09692 & 0.22050 & Biso & 1.000 & $P$ \\
\hline P6 & 1.0000 & 0.66408 & 0.55520 & 0.22038 & Biso & 1.000 & $P$ \\
\hline Al 6 & 1.0000 & 0.32980 & 0.88037 & 0.77260 & Biso & 1.000 & Al \\
\hline Al 7 & 1.0000 & 0.10690 & 0.43108 & 0.76105 & Biso & 1.000 & $\mathrm{Al}$ \\
\hline A18 & 1.0000 & 0.56504 & 0.66617 & 0.76412 & Biso & 1.000 & Al \\
\hline P7 & 1.0000 & 0.57477 & 0.67582 & 0.55566 & Biso & 1.000 & $\mathrm{P}$ \\
\hline P8 & 1.0000 & 0.11100 & 0.44018 & 0.55411 & Biso & 1.000 & $\mathrm{P}$ \\
\hline P9 & 1.0000 & 0.33137 & 0.88379 & 0.55598 & Biso & 1.000 & $\mathrm{P}$ \\
\hline A19 & 1.0000 & 0.00141 & 0.76807 & 0.89100 & Biso & 1.000 & Al \\
\hline Al 10 & 1.0000 & 0.22781 & 0.22667 & 0.88828 & Biso & 1.000 & Al \\
\hline Al11 & 1.0000 & 0.77349 & 0.99255 & 0.88956 & Biso & 1.000 & Al \\
\hline P 10 & 1.0000 & 0.77297 & 0.99404 & 0.10149 & Biso & 1.000 & $\mathrm{P}$ \\
\hline P11 & 1.0000 & 0.22816 & 0.22597 & 0.09599 & Biso & 1.000 & $P$ \\
\hline P12 & 1.0000 & 0.00620 & 0.77489 & 0.10437 & Biso & 1.000 & $\mathrm{P}$ \\
\hline Al12 & 1.0000 & 0.67316 & 0.10298 & 0.22872 & Biso & 1.000 & Al \\
\hline Al13 & 1.0000 & 0.89609 & 0.56019 & 0.22525 & Biso & 1.000 & $\mathrm{Al}$ \\
\hline Al14 & 1.0000 & 0.44106 & 0.32520 & 0.22371 & Biso & 1.000 & Al \\
\hline P13 & 1.0000 & 0.43361 & 0.33072 & 0.43477 & Biso & 1.000 & $\mathrm{P}$ \\
\hline P 14 & 1.0000 & 0.89467 & 0.55986 & 0.43547 & Biso & 1.000 & $P$ \\
\hline P15 & 1.0000 & 0.68321 & 0.11066 & 0.43294 & Biso & 1.000 & $\mathrm{P}$ \\
\hline Al15 & 1.0000 & 0.34273 & 0.45005 & 0.55526 & Biso & 1.000 & $\mathrm{Al}$ \\
\hline Al16 & 1.0000 & 0.55966 & 0.89649 & 0.55732 & Biso & 1.000 & Al \\
\hline Al17 & 1.0000 & 0.10197 & 0.66764 & 0.56203 & Biso & 1.000 & Al \\
\hline P16 & 1.0000 & 0.10330 & 0.66000 & 0.77250 & Biso & 1.000 & $\mathrm{P}$ \\
\hline P 17 & 1.0000 & 0.55691 & 0.89099 & 0.77039 & Biso & 1.000 & $\mathrm{P}$ \\
\hline P18 & 1.0000 & 0.33731 & 0.43688 & 0.76449 & Biso & 1.000 & $P$ \\
\hline 01 & 1.0000 & 0.89504 & 0.08508 & 0.11745 & Biso & 1.000 & 0 \\
\hline $\mathrm{O} 2$ & 1.0000 & 0.91563 & 0.80577 & 0.12427 & Biso & 1.000 & 0 \\
\hline $\mathrm{O} 3$ & 1.0000 & 0.19535 & 0.10236 & 0.10028 & Biso & 1.000 & 0 \\
\hline 04 & 1.0000 & 0.10460 & 0.90404 & 0.86276 & Biso & 1.000 & 0 \\
\hline 05 & 1.0000 & 0.80729 & 0.88853 & 0.86858 & Biso & 1.000 & 0 \\
\hline 06 & 1.0000 & 0.09023 & 0.19305 & 0.86680 & Biso & 1.000 & 0 \\
\hline 07 & 1.0000 & 0.55431 & 0.42357 & 0.45499 & Biso & 1.000 & 0 \\
\hline 08 & 1.0000 & 0.60393 & 0.15664 & 0.43544 & Biso & 1.000 & 0 \\
\hline 09 & 1.0000 & 0.87127 & 0.44078 & 0.45310 & Biso & 1.000 & 0 \\
\hline 010 & 1.0000 & 0.77414 & 0.24222 & 0.20565 & Biso & 1.000 & 0 \\
\hline 011 & 1.0000 & 0.47795 & 0.22217 & 0.21075 & Biso & 1.000 & 0 \\
\hline 012 & 1.0000 & 0.75839 & 0.52811 & 0.20882 & Biso & 1.000 & 0 \\
\hline 013 & 1.0000 & 0.22283 & 0.74633 & 0.80094 & Biso & 1.000 & 0 \\
\hline 014 & 1.0000 & 0.24516 & 0.46585 & 0.78245 & Biso & 1.000 & 0 \\
\hline 015 & 1.0000 & 0.52971 & 0.76946 & 0.78106 & Biso & 1.000 & 0 \\
\hline 016 & 1.0000 & 0.45265 & 0.58550 & 0.53989 & Biso & 1.000 & 0 \\
\hline 017 & 1.0000 & 0.12701 & 0.55776 & 0.54912 & Biso & 1.000 & 0 \\
\hline 018 & 1.0000 & 0.42148 & 0.85577 & 0.52726 & Biso & 1.000 & 0 \\
\hline 019 & 1.0000 & 0.97418 & 0.31381 & 0.15877 & Biso & 1.000 & 0 \\
\hline 020 & 1.0000 & 0.68447 & 0.65342 & 0.16096 & Biso & 1.000 & 0 \\
\hline 021 & 1.0000 & 0.35451 & 0.03076 & 0.14650 & Biso & 1.000 & 0 \\
\hline 022 & 1.0000 & 0.30616 & 0.98171 & 0.81964 & Biso & 1.000 & 0 \\
\hline 023 & 1.0000 & 0.67310 & 0.68595 & 0.83426 & Biso & 1.000 & 0 \\
\hline $\mathrm{O} 24$ & 1.0000 & 0.01552 & 0.32065 & 0.82804 & Biso & 1.000 & 0 \\
\hline 025 & 1.0000 & 0.65259 & 0.65717 & 0.49455 & Biso & 1.000 & 0 \\
\hline 026 & 1.0000 & 0.35215 & 0.99498 & 0.51835 & Biso & 1.000 & 0 \\
\hline 027 & 1.0000 & 0.02179 & 0.36185 & 0.48882 & Biso & 1.000 & 0 \\
\hline 028 & 1.0000 & 0.01942 & 0.66882 & 0.83359 & Biso & 1.000 & 0 \\
\hline 029 & 1.0000 & 0.31934 & 0.33717 & 0.82085 & Biso & 1.000 & 0 \\
\hline 030 & 1.0000 & 0.66050 & 0.96986 & 0.82428 & Biso & 1.000 & 0 \\
\hline 031 & 1.0000 & 0.69310 & 0.01557 & 0.15671 & Biso & 1.000 & 0 \\
\hline 032 & 1.0000 & 0.32685 & 0.29698 & 0.15712 & Biso & 1.000 & 0 \\
\hline 033 & 1.0000 & 0.98713 & 0.67530 & 0.16151 & Biso & 1.000 & 0 \\
\hline 034 & 1.0000 & 0.35131 & 0.35406 & 0.48690 & Biso & 1.000 & 0 \\
\hline 035 & 1.0000 & 0.98739 & 0.64394 & 0.49709 & Biso & 1.000 & 0 \\
\hline 036 & 1.0000 & 0.65156 & 0.01353 & 0.49781 & Biso & 1.000 & 0 \\
\hline 037 & 1.0000 & 0.12849 & 0.23728 & 0.12640 & Biso & 1.000 & 0 \\
\hline 038 & 1.0000 & 0.75988 & 0.88193 & 0.13038 & Biso & 1.000 & 0 \\
\hline 039 & 1.0000 & 0.12019 & 0.87366 & 0.12954 & Biso & 1.000 & 0 \\
\hline 040 & 1.0000 & 0.23895 & 0.10973 & 0.86500 & Biso & 1.000 & 0 \\
\hline 041 & 1.0000 & 0.87281 & 0.75079 & 0.85995 & Biso & 1.000 & 0 \\
\hline 042 & 1.0000 & 0.88579 & 0.12138 & 0.86052 & Biso & 1.000 & 0 \\
\hline 043 & 1.0000 & 0.78959 & 0.56572 & 0.45525 & Biso & 1.000 & 0 \\
\hline 044 & 1.0000 & 0.41342 & 0.21810 & 0.46591 & Biso & 1.000 & 0 \\
\hline 045 & 1.0000 & 0.80024 & 0.20385 & 0.46077 & Biso & 1.000 & 0 \\
\hline
\end{tabular}




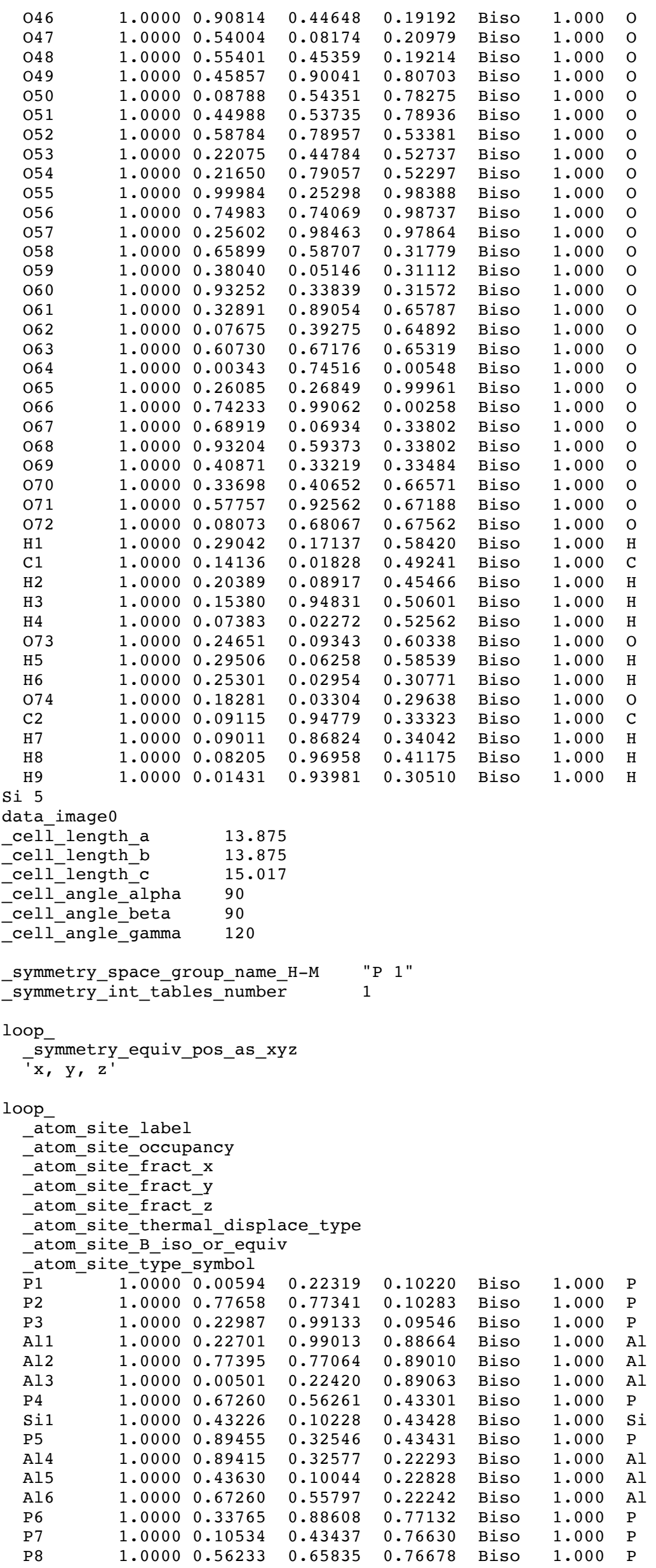




\begin{tabular}{|c|c|c|c|c|c|c|c|}
\hline Al7 & 1.0000 & 0.56785 & 0.66286 & 0.55858 & Biso & 1.000 & Al \\
\hline Al8 & 1.0000 & 0.10359 & 0.43575 & 0.55761 & Biso & 1.000 & Al \\
\hline Al9 & 1.0000 & 0.33955 & 0.88862 & 0.55602 & Biso & 1.000 & Al \\
\hline P9 & 1.0000 & 0.99787 & 0.76663 & 0.88477 & Biso & 1.000 & $\mathrm{P}$ \\
\hline P10 & 1.0000 & 0.23040 & 0.22224 & 0.88546 & Biso & 1.000 & $\mathrm{P}$ \\
\hline P11 & 1.0000 & 0.77715 & 0.99842 & 0.88478 & Biso & 1.000 & $P$ \\
\hline Al10 & 1.0000 & 0.77493 & 0.99869 & 0.09686 & Biso & 1.000 & Al \\
\hline Al11 & 1.0000 & 0.23237 & 0.22248 & 0.09424 & Biso & 1.000 & Al \\
\hline Al12 & 1.0000 & 0.00203 & 0.77056 & 0.09815 & Biso & 1.000 & Al \\
\hline P12 & 1.0000 & 0.66807 & 0.10059 & 0.22147 & Biso & 1.000 & $\mathrm{P}$ \\
\hline P13 & 1.0000 & 0.90112 & 0.55711 & 0.22056 & Biso & 1.000 & $\mathrm{P}$ \\
\hline P14 & 1.0000 & 0.44608 & 0.33331 & 0.21888 & Biso & 1.000 & $\mathrm{P}$ \\
\hline Al13 & 1.0000 & 0.44202 & 0.33649 & 0.42859 & Biso & 1.000 & Al \\
\hline Al14 & 1.0000 & 0.89898 & 0.55697 & 0.43038 & Biso & 1.000 & Al \\
\hline Al15 & 1.0000 & 0.66640 & 0.10006 & 0.42781 & Biso & 1.000 & Al \\
\hline P15 & 1.0000 & 0.33295 & 0.43760 & 0.55166 & Biso & 1.000 & $\mathrm{P}$ \\
\hline P16 & 1.0000 & 0.56578 & 0.89131 & 0.55247 & Biso & 1.000 & $P$ \\
\hline P17 & 1.0000 & 0.10739 & 0.66889 & 0.55467 & Biso & 1.000 & $\mathrm{P}$ \\
\hline Al16 & 1.0000 & 0.10817 & 0.66552 & 0.76559 & Biso & 1.000 & Al \\
\hline Al17 & 1.0000 & 0.56305 & 0.88852 & 0.76355 & Biso & 1.000 & $\mathrm{Al}$ \\
\hline Al18 & 1.0000 & 0.33172 & 0.43250 & 0.76148 & Biso & 1.000 & Al \\
\hline 01 & 1.0000 & 0.91307 & 0.10195 & 0.11827 & Biso & 1.000 & 0 \\
\hline $\mathrm{O} 2$ & 1.0000 & 0.89833 & 0.80460 & 0.12155 & Biso & 1.000 & 0 \\
\hline 03 & 1.0000 & 0.19881 & 0.08326 & 0.10176 & Biso & 1.000 & 0 \\
\hline O4 & 1.0000 & 0.08986 & 0.88626 & 0.86219 & Biso & 1.000 & 0 \\
\hline 05 & 1.0000 & 0.80838 & 0.90800 & 0.86648 & Biso & 1.000 & 0 \\
\hline 06 & 1.0000 & 0.10833 & 0.19001 & 0.86765 & Biso & 1.000 & 0 \\
\hline 07 & 1.0000 & 0.57717 & 0.44467 & 0.45322 & Biso & 1.000 & 0 \\
\hline 08 & 1.0000 & 0.55811 & 0.12545 & 0.43465 & Biso & 1.000 & 0 \\
\hline 09 & 1.0000 & 0.87061 & 0.42133 & 0.45102 & Biso & 1.000 & 0 \\
\hline 010 & 1.0000 & 0.75589 & 0.22318 & 0.20122 & Biso & 1.000 & 0 \\
\hline 011 & 1.0000 & 0.47682 & 0.24139 & 0.21013 & Biso & 1.000 & 0 \\
\hline 012 & 1.0000 & 0.77906 & 0.52644 & 0.20662 & Biso & 1.000 & 0 \\
\hline 013 & 1.0000 & 0.24385 & 0.76750 & 0.79464 & Biso & 1.000 & 0 \\
\hline 014 & 1.0000 & 0.22771 & 0.46637 & 0.78199 & Biso & 1.000 & 0 \\
\hline 015 & 1.0000 & 0.53199 & 0.75039 & 0.77765 & Biso & 1.000 & 0 \\
\hline 016 & 1.0000 & 0.43023 & 0.55707 & 0.53919 & Biso & 1.000 & 0 \\
\hline 017 & 1.0000 & 0.12890 & 0.57127 & 0.54208 & Biso & 1.000 & 0 \\
\hline 018 & 1.0000 & 0.44476 & 0.85852 & 0.52936 & Biso & 1.000 & 0 \\
\hline 019 & 1.0000 & 0.98697 & 0.30320 & 0.16007 & Biso & 1.000 & o \\
\hline 020 & 1.0000 & 0.69642 & 0.67245 & 0.15850 & Biso & 1.000 & 0 \\
\hline 021 & 1.0000 & 0.33240 & 0.01856 & 0.15122 & Biso & 1.000 & 0 \\
\hline 022 & 1.0000 & 0.32092 & 0.97334 & 0.82079 & Biso & 1.000 & 0 \\
\hline 023 & 1.0000 & 0.65603 & 0.67700 & 0.83081 & Biso & 1.000 & 0 \\
\hline 024 & 1.0000 & 0.02785 & 0.33974 & 0.82855 & Biso & 1.000 & 0 \\
\hline 025 & 1.0000 & 0.66164 & 0.64799 & 0.49077 & Biso & 1.000 & 0 \\
\hline 026 & 1.0000 & 0.35389 & 0.00795 & 0.50787 & Biso & 1.000 & 0 \\
\hline 027 & 1.0000 & 0.99400 & 0.34227 & 0.49105 & Biso & 1.000 & 0 \\
\hline 028 & 1.0000 & 0.01347 & 0.68134 & 0.83122 & Biso & 1.000 & 0 \\
\hline 029 & 1.0000 & 0.30875 & 0.31630 & 0.82270 & Biso & 1.000 & 0 \\
\hline 030 & 1.0000 & 0.67827 & 0.97913 & 0.82688 & Biso & 1.000 & 0 \\
\hline 031 & 1.0000 & 0.68129 & 0.02309 & 0.15573 & Biso & 1.000 & 0 \\
\hline 032 & 1.0000 & 0.34788 & 0.30969 & 0.15809 & Biso & 1.000 & 0 \\
\hline 033 & 1.0000 & 0.97859 & 0.65465 & 0.16029 & Biso & 1.000 & 0 \\
\hline 034 & 1.0000 & 0.34489 & 0.35588 & 0.49037 & Biso & 1.000 & 0 \\
\hline 035 & 1.0000 & 0.00828 & 0.65219 & 0.49760 & Biso & 1.000 & 0 \\
\hline 036 & 1.0000 & 0.64855 & 0.98828 & 0.49466 & Biso & 1.000 & 0 \\
\hline 037 & 1.0000 & 0.11785 & 0.23393 & 0.12810 & Biso & 1.000 & 0 \\
\hline 038 & 1.0000 & 0.76150 & 0.87170 & 0.12949 & Biso & 1.000 & 0 \\
\hline 039 & 1.0000 & 0.13074 & 0.88210 & 0.13017 & Biso & 1.000 & 0 \\
\hline 040 & 1.0000 & 0.24358 & 0.12106 & 0.86661 & Biso & 1.000 & 0 \\
\hline 041 & 1.0000 & 0.88505 & 0.75328 & 0.85876 & Biso & 1.000 & 0 \\
\hline 042 & 1.0000 & 0.87642 & 0.11212 & 0.86040 & Biso & 1.000 & 0 \\
\hline 043 & 1.0000 & 0.78359 & 0.56965 & 0.45596 & Biso & 1.000 & 0 \\
\hline 044 & 1.0000 & 0.42442 & 0.21105 & 0.46110 & Biso & 1.000 & 0 \\
\hline 045 & 1.0000 & 0.79295 & 0.21558 & 0.46160 & Biso & 1.000 & 0 \\
\hline 046 & 1.0000 & 0.91330 & 0.45664 & 0.19580 & Biso & 1.000 & 0 \\
\hline 047 & 1.0000 & 0.55165 & 0.08488 & 0.20887 & Biso & 1.000 & 0 \\
\hline 048 & 1.0000 & 0.54660 & 0.44433 & 0.18966 & Biso & 1.000 & 0 \\
\hline 049 & 1.0000 & 0.44924 & 0.89859 & 0.80049 & Biso & 1.000 & $\mathrm{O}$ \\
\hline 050 & 1.0000 & 0.09217 & 0.53517 & 0.78659 & Biso & 1.000 & 0 \\
\hline 051 & 1.0000 & 0.46011 & 0.54596 & 0.78966 & Biso & 1.000 & 0 \\
\hline 052 & 1.0000 & 0.58099 & 0.79109 & 0.53401 & Biso & 1.000 & 0 \\
\hline 053 & 1.0000 & 0.22419 & 0.43443 & 0.52785 & Biso & 1.000 & 0 \\
\hline 054 & 1.0000 & 0.21005 & 0.77654 & 0.52362 & Biso & 1.000 & 0 \\
\hline 055 & 1.0000 & 0.00678 & 0.25479 & 0.00378 & Biso & 1.000 & 0 \\
\hline 056 & 1.0000 & 0.74839 & 0.74462 & 0.00392 & Biso & 1.000 & 0 \\
\hline 057 & 1.0000 & 0.25465 & 0.97675 & 0.99811 & Biso & 1.000 & 0 \\
\hline 058 & 1.0000 & 0.67081 & 0.59216 & 0.33445 & Biso & 1.000 & 0 \\
\hline 059 & 1.0000 & 0.37684 & 0.05951 & 0.33412 & Biso & 1.000 & 0 \\
\hline
\end{tabular}




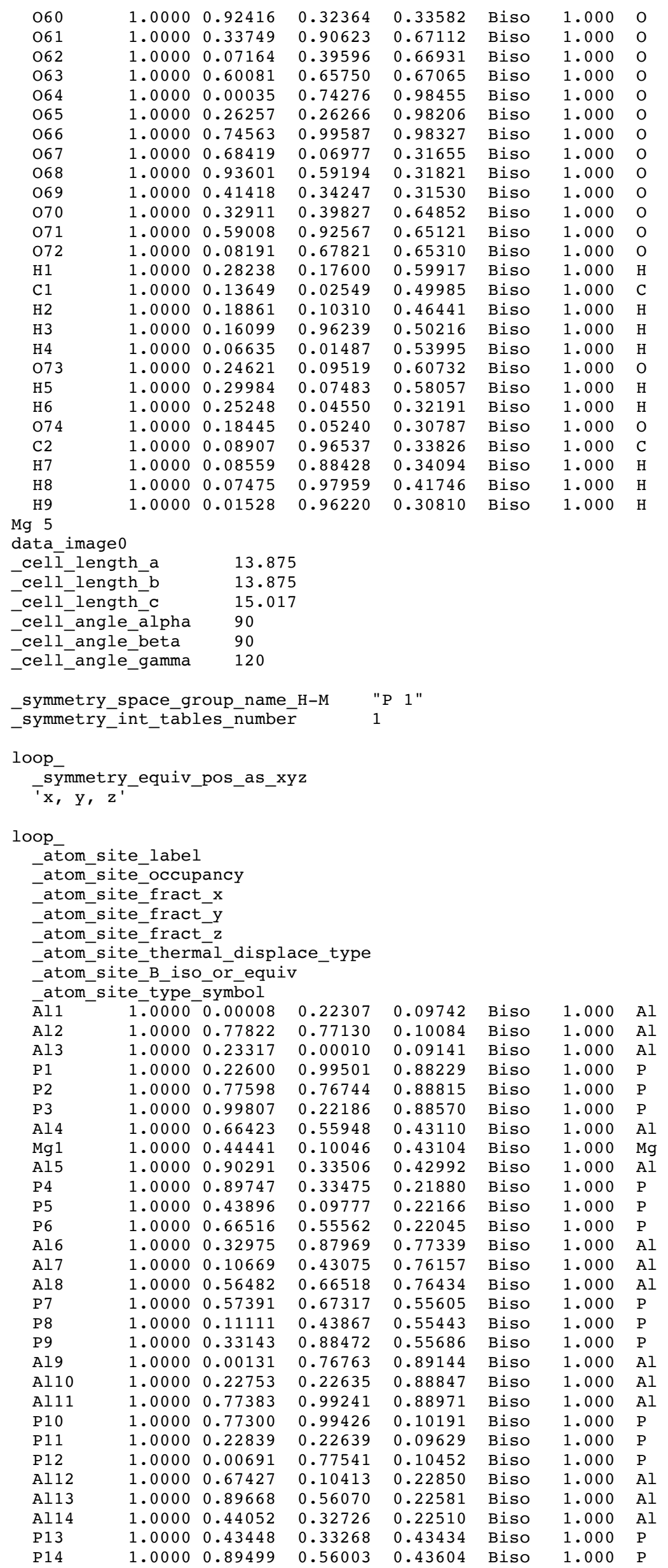




\begin{tabular}{|c|c|c|c|c|c|c|c|}
\hline P15 & 1.0000 & 0.68407 & 0.10630 & 0.43341 & Biso & 1.000 & $\mathrm{P}$ \\
\hline Al15 & 1.0000 & 0.34227 & 0.44774 & 0.55561 & Biso & 1.000 & Al \\
\hline Al16 & 1.0000 & 0.56176 & 0.89763 & 0.55800 & Biso & 1.000 & Al \\
\hline Al17 & 1.0000 & 0.10292 & 0.66666 & 0.56233 & Biso & 1.000 & Al \\
\hline P16 & 1.0000 & 0.10310 & 0.65964 & 0.77267 & Biso & 1.000 & $P$ \\
\hline P 17 & 1.0000 & 0.55752 & 0.89164 & 0.77007 & Biso & 1.000 & $\mathrm{P}$ \\
\hline P18 & 1.0000 & 0.33726 & 0.43750 & 0.76606 & Biso & 1.000 & $\mathrm{P}$ \\
\hline 01 & 1.0000 & 0.89479 & 0.08572 & 0.11837 & Biso & 1.000 & 0 \\
\hline $\mathrm{O} 2$ & 1.0000 & 0.91683 & 0.80717 & 0.12395 & Biso & 1.000 & 0 \\
\hline 03 & 1.0000 & 0.19571 & 0.10286 & 0.10114 & Biso & 1.000 & 0 \\
\hline 04 & 1.0000 & 0.10459 & 0.90371 & 0.86360 & Biso & 1.000 & 0 \\
\hline 05 & 1.0000 & 0.80805 & 0.88882 & 0.86804 & Biso & 1.000 & 0 \\
\hline 06 & 1.0000 & 0.09009 & 0.19316 & 0.86706 & Biso & 1.000 & 0 \\
\hline 07 & 1.0000 & 0.55339 & 0.42776 & 0.45653 & Biso & 1.000 & 0 \\
\hline 08 & 1.0000 & 0.59532 & 0.13915 & 0.43870 & Biso & 1.000 & 0 \\
\hline 09 & 1.0000 & 0.87124 & 0.44072 & 0.45293 & Biso & 1.000 & 0 \\
\hline 010 & 1.0000 & 0.77535 & 0.24327 & 0.20471 & Biso & 1.000 & 0 \\
\hline 011 & 1.0000 & 0.47615 & 0.22298 & 0.21504 & Biso & 1.000 & 0 \\
\hline 012 & 1.0000 & 0.75881 & 0.52762 & 0.20856 & Biso & 1.000 & 0 \\
\hline 013 & 1.0000 & 0.22254 & 0.74568 & 0.80157 & Biso & 1.000 & 0 \\
\hline 014 & 1.0000 & 0.24466 & 0.46572 & 0.78426 & Biso & 1.000 & 0 \\
\hline 015 & 1.0000 & 0.53121 & 0.77013 & 0.77796 & Biso & 1.000 & 0 \\
\hline 016 & 1.0000 & 0.45337 & 0.58141 & 0.53643 & Biso & 1.000 & 0 \\
\hline 017 & 1.0000 & 0.12772 & 0.55653 & 0.54968 & Biso & 1.000 & 0 \\
\hline 018 & 1.0000 & 0.42521 & 0.86240 & 0.52702 & Biso & 1.000 & 0 \\
\hline 019 & 1.0000 & 0.97588 & 0.31500 & 0.15939 & Biso & 1.000 & 0 \\
\hline 020 & 1.0000 & 0.68595 & 0.65396 & 0.16102 & Biso & 1.000 & 0 \\
\hline 021 & 1.0000 & 0.35635 & 0.03340 & 0.14618 & Biso & 1.000 & 0 \\
\hline 022 & 1.0000 & 0.30596 & 0.98118 & 0.82004 & Biso & 1.000 & 0 \\
\hline 023 & 1.0000 & 0.67318 & 0.68624 & 0.83463 & Biso & 1.000 & 0 \\
\hline 024 & 1.0000 & 0.01496 & 0.32057 & 0.82852 & Biso & 1.000 & 0 \\
\hline 025 & 1.0000 & 0.65543 & 0.66074 & 0.49448 & Biso & 1.000 & 0 \\
\hline 026 & 1.0000 & 0.34791 & 0.99413 & 0.51912 & Biso & 1.000 & 0 \\
\hline 027 & 1.0000 & 0.02091 & 0.36059 & 0.48966 & Biso & 1.000 & 0 \\
\hline 028 & 1.0000 & 0.01906 & 0.66858 & 0.83345 & Biso & 1.000 & 0 \\
\hline 029 & 1.0000 & 0.31921 & 0.33695 & 0.82127 & Biso & 1.000 & 0 \\
\hline 030 & 1.0000 & 0.66021 & 0.96937 & 0.82526 & Biso & 1.000 & 0 \\
\hline 031 & 1.0000 & 0.69235 & 0.01581 & 0.15600 & Biso & 1.000 & 0 \\
\hline 032 & 1.0000 & 0.32712 & 0.29805 & 0.15717 & Biso & 1.000 & 0 \\
\hline 033 & 1.0000 & 0.98753 & 0.67635 & 0.16249 & Biso & 1.000 & 0 \\
\hline 034 & 1.0000 & 0.34929 & 0.34727 & 0.49128 & Biso & 1.000 & 0 \\
\hline 035 & 1.0000 & 0.98831 & 0.64348 & 0.49756 & Biso & 1.000 & 0 \\
\hline 036 & 1.0000 & 0.66042 & 0.00858 & 0.49589 & Biso & 1.000 & 0 \\
\hline 037 & 1.0000 & 0.12860 & 0.23750 & 0.12659 & Biso & 1.000 & 0 \\
\hline 038 & 1.0000 & 0.76031 & 0.88248 & 0.13150 & Biso & 1.000 & 0 \\
\hline 039 & 1.0000 & 0.12125 & 0.87401 & 0.12920 & Biso & 1.000 & 0 \\
\hline 040 & 1.0000 & 0.23855 & 0.10938 & 0.86471 & Biso & 1.000 & 0 \\
\hline 041 & 1.0000 & 0.87266 & 0.75034 & 0.86059 & Biso & 1.000 & 0 \\
\hline 042 & 1.0000 & 0.88567 & 0.12134 & 0.86058 & Biso & 1.000 & 0 \\
\hline 043 & 1.0000 & 0.79005 & 0.56599 & 0.45653 & Biso & 1.000 & 0 \\
\hline 044 & 1.0000 & 0.42067 & 0.22085 & 0.45808 & Biso & 1.000 & 0 \\
\hline 045 & 1.0000 & 0.79799 & 0.20454 & 0.46200 & Biso & 1.000 & 0 \\
\hline 046 & 1.0000 & 0.91014 & 0.44766 & 0.19316 & Biso & 1.000 & 0 \\
\hline 047 & 1.0000 & 0.54189 & 0.08525 & 0.21005 & Biso & 1.000 & 0 \\
\hline 048 & 1.0000 & 0.55468 & 0.45441 & 0.19249 & Biso & 1.000 & 0 \\
\hline 049 & 1.0000 & 0.45834 & 0.89903 & 0.80753 & Biso & 1.000 & 0 \\
\hline 050 & 1.0000 & 0.08719 & 0.54294 & 0.78274 & Biso & 1.000 & 0 \\
\hline 051 & 1.0000 & 0.44925 & 0.53784 & 0.79229 & Biso & 1.000 & 0 \\
\hline 052 & 1.0000 & 0.58383 & 0.78620 & 0.53833 & Biso & 1.000 & 0 \\
\hline 053 & 1.0000 & 0.22027 & 0.44534 & 0.52692 & Biso & 1.000 & 0 \\
\hline 054 & 1.0000 & 0.21848 & 0.78859 & 0.52348 & Biso & 1.000 & 0 \\
\hline 055 & 1.0000 & 0.99943 & 0.25265 & 0.98423 & Biso & 1.000 & 0 \\
\hline 056 & 1.0000 & 0.75003 & 0.74194 & 0.98769 & Biso & 1.000 & 0 \\
\hline 057 & 1.0000 & 0.25670 & 0.98560 & 0.97899 & Biso & 1.000 & 0 \\
\hline 058 & 1.0000 & 0.66118 & 0.58807 & 0.31789 & Biso & 1.000 & 0 \\
\hline 059 & 1.0000 & 0.38153 & 0.04978 & 0.31168 & Biso & 1.000 & 0 \\
\hline 060 & 1.0000 & 0.93222 & 0.33731 & 0.31638 & Biso & 1.000 & 0 \\
\hline 061 & 1.0000 & 0.32914 & 0.89012 & 0.65873 & Biso & 1.000 & 0 \\
\hline 062 & 1.0000 & 0.07770 & 0.39176 & 0.64946 & Biso & 1.000 & 0 \\
\hline 063 & 1.0000 & 0.60417 & 0.66462 & 0.65340 & Biso & 1.000 & 0 \\
\hline 064 & 1.0000 & 0.00358 & 0.74443 & 0.00588 & Biso & 1.000 & 0 \\
\hline 065 & 1.0000 & 0.26080 & 0.26821 & 0.99975 & Biso & 1.000 & 0 \\
\hline 066 & 1.0000 & 0.74320 & 0.99012 & 0.00277 & Biso & 1.000 & 0 \\
\hline 067 & 1.0000 & 0.69378 & 0.07109 & 0.33699 & Biso & 1.000 & 0 \\
\hline 068 & 1.0000 & 0.93191 & 0.59459 & 0.33862 & Biso & 1.000 & 0 \\
\hline 069 & 1.0000 & 0.40816 & 0.34020 & 0.33543 & Biso & 1.000 & 0 \\
\hline 070 & 1.0000 & 0.33788 & 0.40886 & 0.66706 & Biso & 1.000 & 0 \\
\hline 071 & 1.0000 & 0.57898 & 0.92954 & 0.67228 & Biso & 1.000 & 0 \\
\hline 072 & 1.0000 & 0.08122 & 0.68053 & 0.67567 & Biso & 1.000 & 0 \\
\hline $\mathrm{H} 1$ & 1.0000 & 0.28711 & 0.17877 & 0.57748 & Biso & 1.000 & $\mathrm{H}$ \\
\hline
\end{tabular}




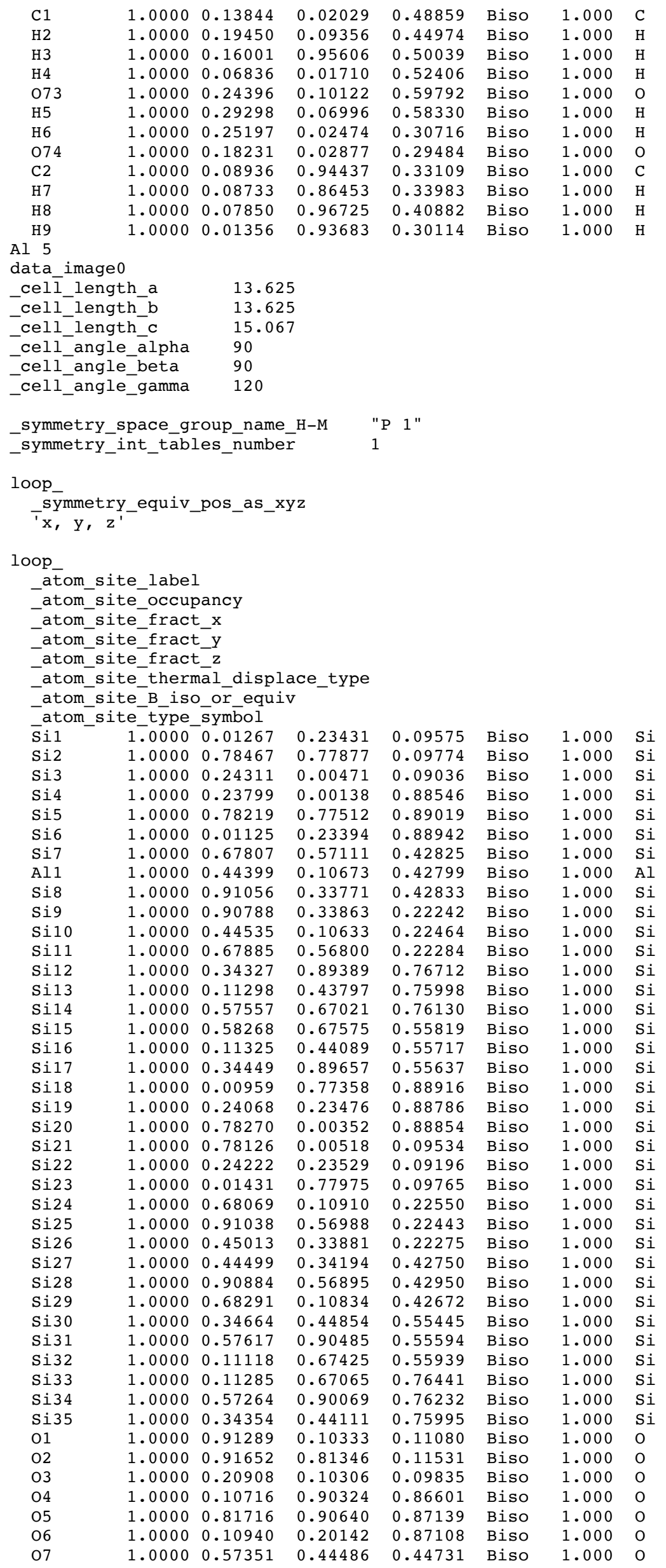




\begin{tabular}{|c|c|c|c|c|c|c|c|}
\hline 08 & 1.0000 & 0.58184 & 0.13508 & 0.43214 & Biso & 1.000 & 0 \\
\hline 09 & 1.0000 & 0.88411 & 0.44064 & 0.44521 & Biso & 1.000 & 0 \\
\hline 010 & 1.0000 & 0.77604 & 0.24164 & 0.20671 & Biso & 1.000 & 0 \\
\hline 011 & 1.0000 & 0.48430 & 0.24059 & 0.21351 & Biso & 1.000 & 0 \\
\hline 012 & 1.0000 & 0.77883 & 0.53654 & 0.21073 & Biso & 1.000 & 0 \\
\hline 013 & 1.0000 & 0.24299 & 0.76503 & 0.78906 & Biso & 1.000 & 0 \\
\hline 014 & 1.0000 & 0.24488 & 0.47338 & 0.77732 & Biso & 1.000 & 0 \\
\hline 015 & 1.0000 & 0.54318 & 0.76955 & 0.77086 & Biso & 1.000 & 0 \\
\hline 016 & 1.0000 & 0.45235 & 0.57606 & 0.54101 & Biso & 1.000 & 0 \\
\hline 017 & 1.0000 & 0.13189 & 0.56770 & 0.54950 & Biso & 1.000 & 0 \\
\hline 018 & 1.0000 & 0.44571 & 0.87000 & 0.53236 & Biso & 1.000 & 0 \\
\hline 019 & 1.0000 & 0.99201 & 0.31889 & 0.15828 & Biso & 1.000 & $\mathrm{O}$ \\
\hline 020 & 1.0000 & 0.70026 & 0.67211 & 0.15876 & Biso & 1.000 & 0 \\
\hline 021 & 1.0000 & 0.35413 & 0.03289 & 0.14768 & Biso & 1.000 & $\mathrm{O}$ \\
\hline 022 & 1.0000 & 0.32425 & 0.98610 & 0.82077 & Biso & 1.000 & $\mathrm{O}$ \\
\hline 023 & 1.0000 & 0.67419 & 0.68923 & 0.83063 & Biso & 1.000 & 0 \\
\hline 024 & 1.0000 & 0.02954 & 0.33848 & 0.82707 & Biso & 1.000 & 0 \\
\hline 025 & 1.0000 & 0.66908 & 0.66270 & 0.49169 & Biso & 1.000 & 0 \\
\hline 026 & 1.0000 & 0.35665 & 0.00669 & 0.50711 & Biso & 1.000 & 0 \\
\hline 027 & 1.0000 & 0.01615 & 0.35523 & 0.48955 & Biso & 1.000 & $\mathrm{O}$ \\
\hline 028 & 1.0000 & 0.02624 & 0.68285 & 0.83103 & Biso & 1.000 & 0 \\
\hline 029 & 1.0000 & 0.32456 & 0.33545 & 0.82122 & Biso & 1.000 & 0 \\
\hline 030 & 1.0000 & 0.67884 & 0.98320 & 0.82474 & Biso & 1.000 & O \\
\hline 031 & 1.0000 & 0.69589 & 0.02769 & 0.15483 & Biso & 1.000 & 0 \\
\hline 032 & 1.0000 & 0.34727 & 0.31521 & 0.15604 & Biso & 1.000 & 0 \\
\hline 033 & 1.0000 & 0.99305 & 0.67400 & 0.16000 & Biso & 1.000 & 0 \\
\hline 034 & 1.0000 & 0.35547 & 0.35857 & 0.48960 & Biso & 1.000 & $\mathrm{O}$ \\
\hline 035 & 1.0000 & 0.00755 & 0.65773 & 0.49591 & Biso & 1.000 & $\mathrm{O}$ \\
\hline 036 & 1.0000 & 0.66562 & 0.00620 & 0.49310 & Biso & 1.000 & 0 \\
\hline 037 & 1.0000 & 0.13318 & 0.24540 & 0.12201 & Biso & 1.000 & 0 \\
\hline 038 & 1.0000 & 0.76943 & 0.88529 & 0.12512 & Biso & 1.000 & 0 \\
\hline 039 & 1.0000 & 0.13611 & 0.88645 & 0.12535 & Biso & 1.000 & O \\
\hline 040 & 1.0000 & 0.25214 & 0.12461 & 0.86653 & Biso & 1.000 & 0 \\
\hline 041 & 1.0000 & 0.88769 & 0.75845 & 0.86278 & Biso & 1.000 & O \\
\hline 042 & 1.0000 & 0.89009 & 0.12565 & 0.86395 & Biso & 1.000 & O \\
\hline 043 & 1.0000 & 0.79568 & 0.57447 & 0.45155 & Biso & 1.000 & 0 \\
\hline 044 & 1.0000 & 0.43137 & 0.22326 & 0.45480 & Biso & 1.000 & $\mathrm{O}$ \\
\hline 045 & 1.0000 & 0.80223 & 0.21885 & 0.45629 & Biso & 1.000 & $\mathrm{O}$ \\
\hline 046 & 1.0000 & 0.92292 & 0.46149 & 0.19862 & Biso & 1.000 & O \\
\hline 047 & 1.0000 & 0.55612 & 0.09329 & 0.21074 & Biso & 1.000 & 0 \\
\hline 048 & 1.0000 & 0.55939 & 0.45911 & 0.19507 & Biso & 1.000 & 0 \\
\hline 049 & 1.0000 & 0.46369 & 0.90770 & 0.79696 & Biso & 1.000 & 0 \\
\hline 050 & 1.0000 & 0.09767 & 0.54632 & 0.77801 & Biso & 1.000 & 0 \\
\hline 051 & 1.0000 & 0.46470 & 0.54977 & 0.78474 & Biso & 1.000 & 0 \\
\hline 052 & 1.0000 & 0.59188 & 0.79630 & 0.53837 & Biso & 1.000 & 0 \\
\hline 053 & 1.0000 & 0.23104 & 0.44767 & 0.52966 & Biso & 1.000 & O \\
\hline 054 & 1.0000 & 0.22396 & 0.78775 & 0.52683 & Biso & 1.000 & 0 \\
\hline 055 & 1.0000 & 0.01363 & 0.27044 & 0.99254 & Biso & 1.000 & O \\
\hline 056 & 1.0000 & 0.75063 & 0.74423 & 0.99436 & Biso & 1.000 & 0 \\
\hline 057 & 1.0000 & 0.27055 & 0.99130 & 0.98748 & Biso & 1.000 & 0 \\
\hline 058 & 1.0000 & 0.67758 & 0.60668 & 0.32507 & Biso & 1.000 & 0 \\
\hline 059 & 1.0000 & 0.38510 & 0.05948 & 0.32055 & Biso & 1.000 & 0 \\
\hline 060 & 1.0000 & 0.94506 & 0.33716 & 0.32490 & Biso & 1.000 & O \\
\hline 061 & 1.0000 & 0.34307 & 0.91852 & 0.66228 & Biso & 1.000 & $\mathrm{O}$ \\
\hline 062 & 1.0000 & 0.07754 & 0.39331 & 0.65820 & Biso & 1.000 & 0 \\
\hline 063 & 1.0000 & 0.61880 & 0.66925 & 0.66043 & Biso & 1.000 & O \\
\hline 064 & 1.0000 & 0.01328 & 0.74614 & 0.99395 & Biso & 1.000 & O \\
\hline 065 & 1.0000 & 0.27737 & 0.27826 & 0.98961 & Biso & 1.000 & $\mathrm{O}$ \\
\hline 066 & 1.0000 & 0.74576 & 0.00070 & 0.99159 & Biso & 1.000 & O \\
\hline 067 & 1.0000 & 0.69671 & 0.07266 & 0.32505 & Biso & 1.000 & 0 \\
\hline 068 & 1.0000 & 0.94925 & 0.60906 & 0.32720 & Biso & 1.000 & 0 \\
\hline 069 & 1.0000 & 0.41224 & 0.34682 & 0.32376 & Biso & 1.000 & 0 \\
\hline 070 & 1.0000 & 0.34177 & 0.40500 & 0.65629 & Biso & 1.000 & 0 \\
\hline 071 & 1.0000 & 0.60300 & 0.94340 & 0.65989 & Biso & 1.000 & $\mathrm{O}$ \\
\hline 072 & 1.0000 & 0.08240 & 0.68686 & 0.66246 & Biso & 1.000 & 0 \\
\hline H 1 & 1.0000 & 0.28980 & 0.18878 & 0.58610 & Biso & 1.000 & $\mathrm{H}$ \\
\hline $\mathrm{C} 1$ & 1.0000 & 0.13962 & 0.03140 & 0.49196 & Biso & 1.000 & C \\
\hline H2 & 1.0000 & 0.19305 & 0.10879 & 0.45481 & Biso & 1.000 & $\mathrm{H}$ \\
\hline H3 & 1.0000 & 0.16446 & 0.96724 & 0.49742 & Biso & 1.000 & $\mathrm{H}$ \\
\hline $\mathrm{H} 4$ & 1.0000 & 0.06823 & 0.02279 & 0.53079 & Biso & 1.000 & $\mathrm{H}$ \\
\hline 073 & 1.0000 & 0.24996 & 0.10738 & 0.59956 & Biso & 1.000 & $\mathrm{O}$ \\
\hline H5 & 1.0000 & 0.30287 & 0.08183 & 0.57814 & Biso & 1.000 & $\mathrm{H}$ \\
\hline H6 & 1.0000 & 0.25359 & 0.03923 & 0.31185 & Biso & 1.000 & $\mathrm{H}$ \\
\hline 074 & 1.0000 & 0.18469 & 0.04682 & 0.29925 & Biso & 1.000 & O \\
\hline $\mathrm{C} 2$ & 1.0000 & 0.08784 & 0.96115 & 0.33298 & Biso & 1.000 & C \\
\hline H7 & 1.0000 & 0.08241 & 0.87790 & 0.33841 & Biso & 1.000 & $\mathrm{H}$ \\
\hline H8 & 1.0000 & 0.07644 & 0.98081 & 0.41131 & Biso & 1.000 & $\mathrm{H}$ \\
\hline H9 & 1.0000 & 0.01252 & 0.95806 & 0.30342 & Biso & 1.000 & $\mathrm{H}$ \\
\hline
\end{tabular}




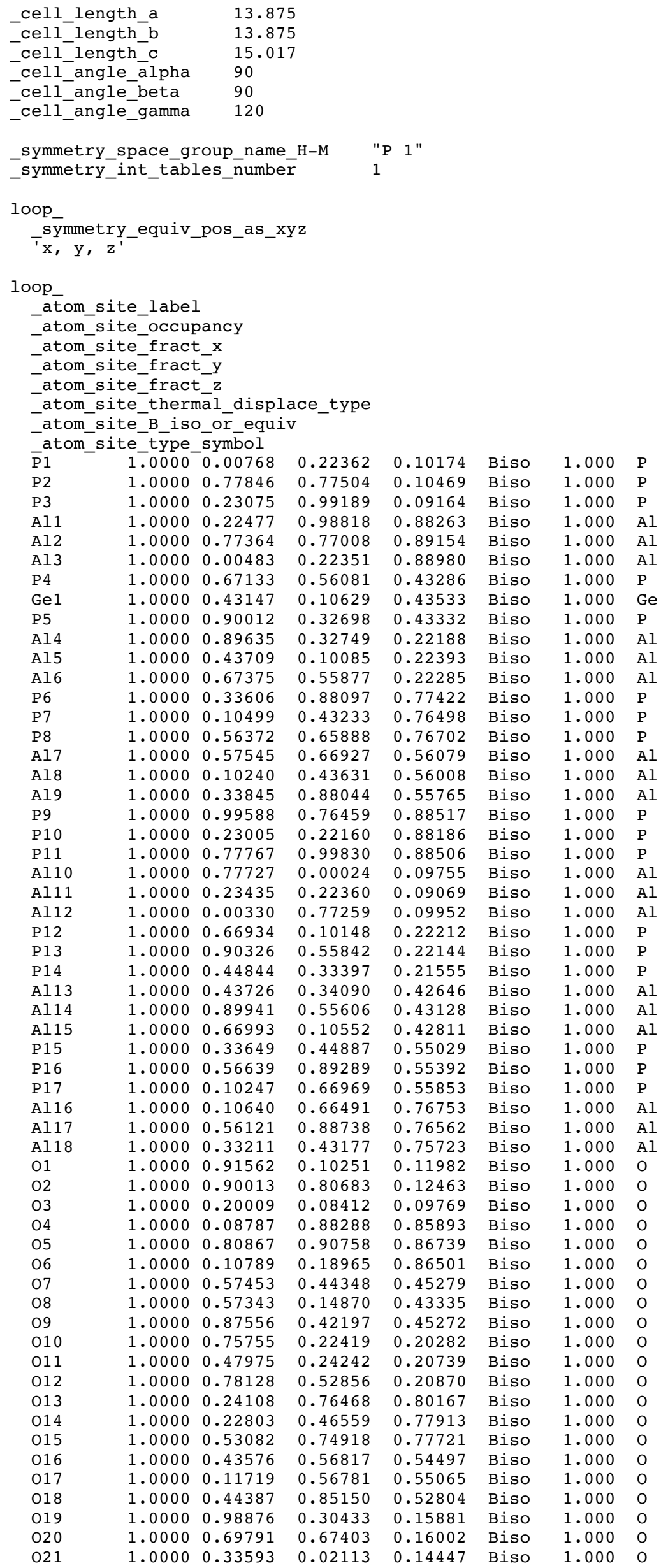




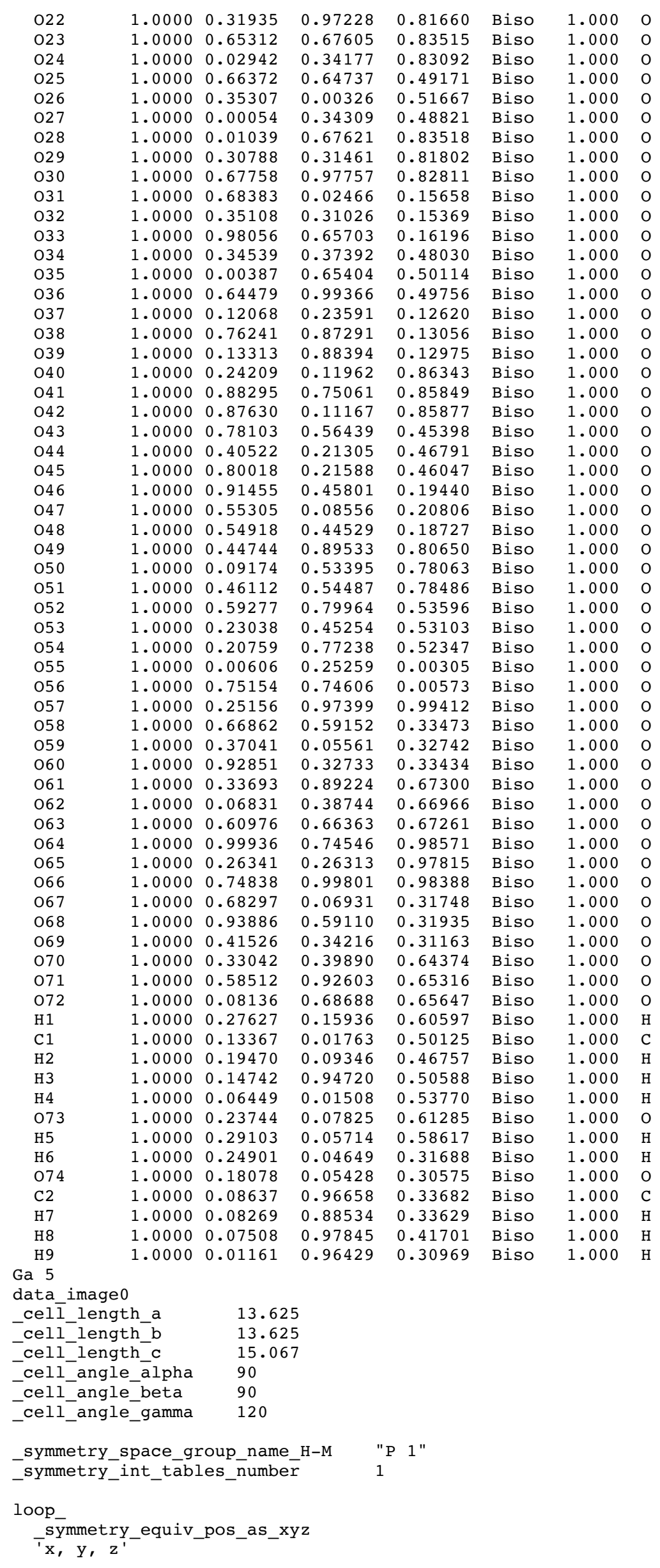




\begin{tabular}{|c|c|c|c|c|c|c|c|}
\hline \multicolumn{8}{|l|}{ oop } \\
\hline \multicolumn{8}{|c|}{ _atom_site_label } \\
\hline \multicolumn{8}{|c|}{ atom_site_occupancy } \\
\hline \multicolumn{8}{|c|}{ atom_site_fract_x } \\
\hline \multicolumn{8}{|c|}{ atom site fract $y$} \\
\hline \multicolumn{8}{|c|}{-atom_site_fract_z } \\
\hline -ato & e_thers & nàl_displ & ace_type & & & & \\
\hline - ato & $\begin{array}{l}e^{-} \mathrm{B} \text { is } \\
e^{-} \text {ype }\end{array}$ & $\begin{array}{l}\text { o_or_equ } \\
\text { symbol }\end{array}$ & & & & & \\
\hline$\overline{\mathrm{S}} \mathrm{i} 1$ & 1.0000 & 0.01366 & 0.23593 & 0.09417 & Biso & 1.000 & $\mathrm{Si}$ \\
\hline Si2 & 1.0000 & 0.78569 & 0.78035 & 0.09852 & Biso & 1.000 & $\mathrm{Si}$ \\
\hline $\mathrm{Si3}$ & 1.0000 & 0.24354 & 0.00590 & 0.08820 & Biso & 1.000 & $\mathrm{Si}$ \\
\hline $\mathrm{Si} 4$ & 1.0000 & 0.23638 & 0.00095 & 0.88309 & Biso & 1.000 & $\mathrm{Si}$ \\
\hline Si5 & 1.0000 & 0.78138 & 0.77509 & 0.89104 & Biso & 1.000 & $\mathrm{Si}$ \\
\hline Si6 & 1.0000 & 0.01079 & 0.23447 & 0.88775 & Biso & 1.000 & $\mathrm{Si}$ \\
\hline Si7 & 1.0000 & 0.67601 & 0.56856 & 0.42815 & Biso & 1.000 & $\mathrm{Si}$ \\
\hline $\mathrm{Ga} 1$ & 1.0000 & 0.44727 & 0.11235 & 0.42806 & Biso & 1.000 & $\mathrm{Ga}$ \\
\hline Si8 & 1.0000 & 0.91531 & 0.33975 & 0.42686 & Biso & 1.000 & $\mathrm{Si}$ \\
\hline Si9 & 1.0000 & 0.90916 & 0.34070 & 0.22084 & Biso & 1.000 & $\mathrm{Si}$ \\
\hline Silo & 1.0000 & 0.44596 & 0.10729 & 0.22189 & Biso & 1.000 & $\mathrm{Si}$ \\
\hline $\operatorname{sil} 1$ & 1.0000 & 0.67900 & 0.56914 & 0.22296 & Biso & 1.000 & $\mathrm{Si}$ \\
\hline $\operatorname{si} 12$ & 1.0000 & 0.34190 & 0.89101 & 0.76872 & Biso & 1.000 & $\mathrm{Si}$ \\
\hline Sil13 & 1.0000 & 0.11226 & 0.43774 & 0.75789 & Biso & 1.000 & $\mathrm{Si}$ \\
\hline Sil 14 & 1.0000 & 0.57611 & 0.67123 & 0.76120 & Biso & 1.000 & $\mathrm{Si}$ \\
\hline Si15 & 1.0000 & 0.58799 & 0.68088 & 0.55911 & Biso & 1.000 & $\mathrm{Si}$ \\
\hline Sil 6 & 1.0000 & 0.11372 & 0.44437 & 0.55721 & Biso & 1.000 & $\mathrm{Si}$ \\
\hline $\operatorname{sil} 17$ & 1.0000 & 0.34447 & 0.89256 & 0.55661 & Biso & 1.000 & $\mathrm{Si}$ \\
\hline $\operatorname{sil} 18$ & 1.0000 & 0.00777 & 0.77233 & 0.88924 & Biso & 1.000 & $\mathrm{Si}$ \\
\hline Sil 19 & 1.0000 & 0.23981 & 0.23456 & 0.88481 & Biso & 1.000 & $\mathrm{Si}$ \\
\hline Si20 & 1.0000 & 0.78237 & 0.00395 & 0.88831 & Biso & 1.000 & $\mathrm{Si}$ \\
\hline Si21 & 1.0000 & 0.78234 & 0.00689 & 0.09504 & Biso & 1.000 & $\mathrm{Si}$ \\
\hline Si22 & 1.0000 & 0.24281 & 0.23623 & 0.08945 & Biso & 1.000 & $\mathrm{Si}$ \\
\hline Si23 & 1.0000 & 0.01472 & 0.78087 & 0.09779 & Biso & 1.000 & $\mathrm{Si}$ \\
\hline Si24 & 1.0000 & 0.68121 & 0.11052 & 0.22531 & Biso & 1.000 & $\mathrm{Si}$ \\
\hline Si25 & 1.0000 & 0.91108 & 0.57117 & 0.22459 & Biso & 1.000 & $\mathrm{Si}$ \\
\hline Si26 & 1.0000 & 0.45101 & 0.33973 & 0.22003 & Biso & 1.000 & $\mathrm{Si}$ \\
\hline Si27 & 1.0000 & 0.44016 & 0.34385 & 0.42583 & Biso & 1.000 & $\mathrm{Si}$ \\
\hline Si28 & 1.0000 & 0.90821 & 0.56805 & 0.42985 & Biso & 1.000 & $\mathrm{Si}$ \\
\hline Si29 & 1.0000 & 0.68563 & 0.11492 & 0.42656 & Biso & 1.000 & $\mathrm{Si}$ \\
\hline $\operatorname{Si30}$ & 1.0000 & 0.34890 & 0.45658 & 0.55333 & Biso & 1.000 & $\mathrm{Si}$ \\
\hline Si31 & 1.0000 & 0.57527 & 0.90533 & 0.55582 & Biso & 1.000 & $\mathrm{Si}$ \\
\hline $\mathrm{Si} 32$ & 1.0000 & 0.10825 & 0.67689 & 0.56036 & Biso & 1.000 & $\mathrm{Si}$ \\
\hline $\mathrm{Si33}$ & 1.0000 & 0.11147 & 0.67095 & 0.76489 & Biso & 1.000 & $\mathrm{Si}$ \\
\hline $\operatorname{Si34}$ & 1.0000 & 0.57093 & 0.90020 & 0.76304 & Biso & 1.000 & $\mathrm{Si}$ \\
\hline $\operatorname{Si35}$ & 1.0000 & 0.34323 & 0.44119 & 0.75683 & Biso & 1.000 & $\mathrm{Si}$ \\
\hline 01 & 1.0000 & 0.91411 & 0.10502 & 0.10985 & Biso & 1.000 & 0 \\
\hline $\mathrm{O} 2$ & 1.0000 & 0.91750 & 0.81513 & 0.11629 & Biso & 1.000 & $\mathrm{O}$ \\
\hline 03 & 1.0000 & 0.20913 & 0.10392 & 0.09733 & Biso & 1.000 & $\mathrm{O}$ \\
\hline 04 & 1.0000 & 0.10564 & 0.90158 & 0.86518 & Biso & 1.000 & 0 \\
\hline 05 & 1.0000 & 0.81659 & 0.90646 & 0.87213 & Biso & 1.000 & 0 \\
\hline 06 & 1.0000 & 0.10875 & 0.20204 & 0.86849 & Biso & 1.000 & 0 \\
\hline 07 & 1.0000 & 0.57085 & 0.44227 & 0.44641 & Biso & 1.000 & 0 \\
\hline 08 & 1.0000 & 0.59647 & 0.15896 & 0.43098 & Biso & 1.000 & 0 \\
\hline 09 & 1.0000 & 0.88704 & 0.44104 & 0.44638 & Biso & 1.000 & 0 \\
\hline 010 & 1.0000 & 0.77726 & 0.24283 & 0.20704 & Biso & 1.000 & 0 \\
\hline 011 & 1.0000 & 0.48539 & 0.24161 & 0.21148 & Biso & 1.000 & 0 \\
\hline 012 & 1.0000 & 0.77980 & 0.53882 & 0.21138 & Biso & 1.000 & 0 \\
\hline 013 & 1.0000 & 0.24098 & 0.76337 & 0.79326 & Biso & 1.000 & 0 \\
\hline 014 & 1.0000 & 0.24456 & 0.47360 & 0.77467 & Biso & 1.000 & 0 \\
\hline 015 & 1.0000 & 0.54177 & 0.76914 & 0.77104 & Biso & 1.000 & 0 \\
\hline 016 & 1.0000 & 0.45621 & 0.58399 & 0.54490 & Biso & 1.000 & 0 \\
\hline 017 & 1.0000 & 0.12438 & 0.56778 & 0.55268 & Biso & 1.000 & 0 \\
\hline 018 & 1.0000 & 0.44284 & 0.86226 & 0.53104 & Biso & 1.000 & 0 \\
\hline 019 & 1.0000 & 0.99271 & 0.32080 & 0.15614 & Biso & 1.000 & $\mathrm{O}$ \\
\hline 020 & 1.0000 & 0.70112 & 0.67448 & 0.16013 & Biso & 1.000 & 0 \\
\hline 021 & 1.0000 & 0.35552 & 0.03453 & 0.14438 & Biso & 1.000 & 0 \\
\hline 022 & 1.0000 & 0.32237 & 0.98556 & 0.81809 & Biso & 1.000 & $\mathrm{O}$ \\
\hline 023 & 1.0000 & 0.67191 & 0.68892 & 0.83294 & Biso & 1.000 & 0 \\
\hline 024 & 1.0000 & 0.02910 & 0.33941 & 0.82590 & Biso & 1.000 & 0 \\
\hline 025 & 1.0000 & 0.66995 & 0.66124 & 0.49238 & Biso & 1.000 & 0 \\
\hline 026 & 1.0000 & 0.36114 & 0.00741 & 0.51263 & Biso & 1.000 & 0 \\
\hline 027 & 1.0000 & 0.02272 & 0.35852 & 0.48613 & Biso & 1.000 & 0 \\
\hline 028 & 1.0000 & 0.02358 & 0.68028 & 0.83206 & Biso & 1.000 & 0 \\
\hline 029 & 1.0000 & 0.32380 & 0.33520 & 0.81804 & Biso & 1.000 & $\mathrm{O}$ \\
\hline 030 & 1.0000 & 0.67857 & 0.98299 & 0.82414 & Biso & 1.000 & 0 \\
\hline 031 & 1.0000 & 0.69754 & 0.02913 & 0.15548 & Biso & 1.000 & 0 \\
\hline 032 & 1.0000 & 0.34908 & 0.31654 & 0.15243 & Biso & 1.000 & 0 \\
\hline 033 & 1.0000 & 0.99434 & 0.67623 & 0.16116 & Biso & 1.000 & 0 \\
\hline 034 & 1.0000 & 0.35421 & 0.37114 & 0.48209 & Biso & 1.000 & 0 \\
\hline 035 & 1.0000 & 0.00402 & 0.65964 & 0.49709 & Biso & 1.000 & 0 \\
\hline
\end{tabular}




\begin{tabular}{|c|c|c|c|c|c|c|c|}
\hline 036 & 1.0000 & 0.65904 & 0.01132 & 0.49432 & Biso & 1.000 & 0 \\
\hline 037 & 1.0000 & 0.13465 & 0.24772 & 0.11994 & Biso & 1.000 & 0 \\
\hline 038 & 1.0000 & 0.77059 & 0.88715 & 0.12487 & Biso & 1.000 & 0 \\
\hline 039 & 1.0000 & 0.13739 & 0.88744 & 0.12355 & Biso & 1.000 & 0 \\
\hline 040 & 1.0000 & 0.24975 & 0.12365 & 0.86306 & Biso & 1.000 & 0 \\
\hline 041 & 1.0000 & 0.88615 & 0.75776 & 0.86251 & Biso & 1.000 & 0 \\
\hline 042 & 1.0000 & 0.88952 & 0.12592 & 0.86285 & Biso & 1.000 & 0 \\
\hline 043 & 1.0000 & 0.79261 & 0.56941 & 0.45005 & Biso & 1.000 & 0 \\
\hline 044 & 1.0000 & 0.41585 & 0.22264 & 0.45960 & Biso & 1.000 & 0 \\
\hline 045 & 1.0000 & 0.81006 & 0.21861 & 0.45493 & Biso & 1.000 & 0 \\
\hline 046 & 1.0000 & 0.92278 & 0.46287 & 0.19665 & Biso & 1.000 & 0 \\
\hline 047 & 1.0000 & 0.55699 & 0.09473 & 0.20869 & Biso & 1.000 & 0 \\
\hline 048 & 1.0000 & 0.56051 & 0.46026 & 0.19320 & Biso & 1.000 & 0 \\
\hline 049 & 1.0000 & 0.46262 & 0.90677 & 0.80024 & Biso & 1.000 & 0 \\
\hline 050 & 1.0000 & 0.09609 & 0.54599 & 0.77392 & Biso & 1.000 & 0 \\
\hline 051 & 1.0000 & 0.46492 & 0.54957 & 0.78106 & Biso & 1.000 & 0 \\
\hline 052 & 1.0000 & 0.60158 & 0.80337 & 0.53741 & Biso & 1.000 & $\mathrm{O}$ \\
\hline 053 & 1.0000 & 0.23642 & 0.46260 & 0.53172 & Biso & 1.000 & 0 \\
\hline 054 & 1.0000 & 0.22168 & 0.78823 & 0.52487 & Biso & 1.000 & 0 \\
\hline 055 & 1.0000 & 0.01397 & 0.27117 & 0.99085 & Biso & 1.000 & 0 \\
\hline 056 & 1.0000 & 0.75143 & 0.74468 & 0.99540 & Biso & 1.000 & 0 \\
\hline 057 & 1.0000 & 0.27039 & 0.99299 & 0.98509 & Biso & 1.000 & 0 \\
\hline 058 & 1.0000 & 0.67510 & 0.60551 & 0.32541 & Biso & 1.000 & 0 \\
\hline 059 & 1.0000 & 0.38311 & 0.05757 & 0.31690 & Biso & 1.000 & 0 \\
\hline 060 & 1.0000 & 0.94835 & 0.34121 & 0.32290 & Biso & 1.000 & 0 \\
\hline 061 & 1.0000 & 0.34219 & 0.90943 & 0.66302 & Biso & 1.000 & 0 \\
\hline 062 & 1.0000 & 0.07616 & 0.39100 & 0.65658 & Biso & 1.000 & 0 \\
\hline 063 & 1.0000 & 0.62496 & 0.67556 & 0.66139 & Biso & 1.000 & 0 \\
\hline 064 & 1.0000 & 0.01139 & 0.74572 & 0.99422 & Biso & 1.000 & 0 \\
\hline 065 & 1.0000 & 0.27695 & 0.27752 & 0.98663 & Biso & 1.000 & 0 \\
\hline 066 & 1.0000 & 0.74597 & 0.00237 & 0.99144 & Biso & 1.000 & 0 \\
\hline 067 & 1.0000 & 0.69361 & 0.07328 & 0.32560 & Biso & 1.000 & 0 \\
\hline 068 & 1.0000 & 0.94993 & 0.60820 & 0.32773 & Biso & 1.000 & 0 \\
\hline 069 & 1.0000 & 0.41192 & 0.34618 & 0.32075 & Biso & 1.000 & 0 \\
\hline 070 & 1.0000 & 0.34169 & 0.40531 & 0.65297 & Biso & 1.000 & 0 \\
\hline 071 & 1.0000 & 0.59831 & 0.94248 & 0.66025 & Biso & 1.000 & 0 \\
\hline 072 & 1.0000 & 0.08373 & 0.69380 & 0.66370 & Biso & 1.000 & 0 \\
\hline $\mathrm{H} 1$ & 1.0000 & 0.28739 & 0.17777 & 0.59385 & Biso & 1.000 & $\mathrm{H}$ \\
\hline $\mathrm{C} 1$ & 1.0000 & 0.14006 & 0.02166 & 0.49788 & Biso & 1.000 & $\mathrm{C}$ \\
\hline $\mathrm{H} 2$ & 1.0000 & 0.20238 & 0.09385 & 0.45947 & Biso & 1.000 & $\mathrm{H}$ \\
\hline H3 & 1.0000 & 0.15261 & 0.95005 & 0.50999 & Biso & 1.000 & $\mathrm{H}$ \\
\hline $\mathrm{H} 4$ & 1.0000 & 0.07101 & 0.02511 & 0.53152 & Biso & 1.000 & $\mathrm{H}$ \\
\hline 073 & 1.0000 & 0.24851 & 0.09623 & 0.60640 & Biso & 1.000 & 0 \\
\hline H5 & 1.0000 & 0.30234 & 0.07246 & 0.58309 & Biso & 1.000 & $\mathrm{H}$ \\
\hline $\mathrm{H} 6$ & 1.0000 & 0.25149 & 0.03458 & 0.31106 & Biso & 1.000 & $\mathrm{H}$ \\
\hline 074 & 1.0000 & 0.17996 & 0.03847 & 0.30109 & Biso & 1.000 & 0 \\
\hline C2 & 1.0000 & 0.08720 & 0.95090 & 0.33797 & Biso & 1.000 & $\mathrm{C}$ \\
\hline H 7 & 1.0000 & 0.08659 & 0.86994 & 0.34361 & Biso & 1.000 & $\mathrm{H}$ \\
\hline $\mathrm{H} 8$ & 1.0000 & 0.07851 & 0.97160 & 0.41642 & Biso & 1.000 & $\mathrm{H}$ \\
\hline H9 & 1.0000 & 0.00850 & 0.94273 & 0.31083 & Biso & 1.000 & $\mathrm{H}$ \\
\hline \multicolumn{8}{|c|}{$\operatorname{Ti} 5$} \\
\hline \multicolumn{8}{|c|}{ data_image 0} \\
\hline \multicolumn{8}{|c|}{ celil length a $\quad 13.875$} \\
\hline \multicolumn{8}{|c|}{ cell_length_b $\quad 13.875$} \\
\hline \multicolumn{2}{|c|}{ cell_length_c } & \multicolumn{6}{|c|}{$\begin{array}{l}13.8 / 5 \\
15.017\end{array}$} \\
\hline \multicolumn{8}{|c|}{ cell angle àlpha } \\
\hline cell & beta & 90 & & & & & \\
\hline - cell_ & E_gamma & 120 & & & & & \\
\hline symme & pace gr & oup name & $-M$ & $1 "$ & & & \\
\hline symme & int_tabl & es_numbe & & & & & \\
\hline 1oop_ & & & & & & & \\
\hline _sym & _equiv & _pos_as_x & & & & & \\
\hline $\mathrm{x}$, & & & & & & & \\
\hline 1oop_ & & & & & & & \\
\hline ato & e_label & & & & & & \\
\hline -ato & e_occup & bancy & & & & & \\
\hline -ato & e_fract & $=x^{\prime}$ & & & & & \\
\hline -ato & e_fract & & & & & & \\
\hline -ato & e_fract & & & & & & \\
\hline -ato & e_therm & nàl_displ & ce_type & & & & \\
\hline $\begin{array}{l}\text {-ato } \\
\text { ato }\end{array}$ & $\begin{array}{l}e^{-} \text {B_iso } \\
e^{-} \text {type }\end{array}$ & $\begin{array}{l}\text { or_equi } \\
\text { symbol }\end{array}$ & & & & & \\
\hline$\overline{\mathrm{P}} 1$ & 1.0000 & 0.00821 & 0.22380 & 0.10194 & Biso & 1.000 & $\mathrm{P}$ \\
\hline $\mathrm{P} 2$ & 1.0000 & 0.78057 & 0.77711 & 0.10629 & Biso & 1.000 & $\mathrm{P}$ \\
\hline P3 & 1.0000 & 0.23282 & 0.99261 & 0.08945 & Biso & 1.000 & $\mathrm{P}$ \\
\hline Al1 & 1.0000 & 0.22335 & 0.98649 & 0.87996 & Biso & 1.000 & Al \\
\hline Al2 & 1.0000 & 0.77378 & 0.77005 & 0.89274 & Biso & 1.000 & Al \\
\hline
\end{tabular}




\begin{tabular}{|c|c|c|c|c|c|c|c|}
\hline A13 & 1.0000 & 0.00437 & 0.22263 & 0.88967 & Biso & 1.000 & $\mathrm{Al}$ \\
\hline P4 & 1.0000 & 0.67269 & 0.56201 & 0.43411 & Biso & 1.000 & $\mathrm{P}$ \\
\hline Ti1 & 1.0000 & 0.42686 & 0.10366 & 0.43783 & Biso & 1.000 & $\mathrm{Ti}$ \\
\hline P5 & 1.0000 & 0.90387 & 0.32759 & 0.43287 & Biso & 1.000 & $P$ \\
\hline Al4 & 1.0000 & 0.89832 & 0.32889 & 0.22169 & Biso & 1.000 & $\mathrm{Al}$ \\
\hline Al5 & 1.0000 & 0.43752 & 0.10282 & 0.22108 & Biso & 1.000 & Al \\
\hline Al6 & 1.0000 & 0.67528 & 0.56013 & 0.22405 & Biso & 1.000 & Al \\
\hline P6 & 1.0000 & 0.33465 & 0.87606 & 0.77623 & Biso & 1.000 & $\mathrm{P}$ \\
\hline P7 & 1.0000 & 0.10491 & 0.43044 & 0.76477 & Biso & 1.000 & $P$ \\
\hline P8 & 1.0000 & 0.56428 & 0.65822 & 0.76796 & Biso & 1.000 & $\mathrm{P}$ \\
\hline Al7 & 1.0000 & 0.57990 & 0.67091 & 0.56292 & Biso & 1.000 & $\mathrm{Al}$ \\
\hline Al8 & 1.0000 & 0.10148 & 0.43380 & 0.56215 & Biso & 1.000 & Al \\
\hline Al9 & 1.0000 & 0.33673 & 0.87367 & 0.55931 & Biso & 1.000 & Al \\
\hline P9 & 1.0000 & 0.99483 & 0.76305 & 0.88553 & Biso & 1.000 & $\mathrm{P}$ \\
\hline P 10 & 1.0000 & 0.22969 & 0.22054 & 0.88029 & Biso & 1.000 & $\mathrm{P}$ \\
\hline P11 & 1.0000 & 0.77812 & 0.99796 & 0.88559 & Biso & 1.000 & $\mathrm{P}$ \\
\hline Al10 & 1.0000 & 0.77815 & 0.00127 & 0.09884 & Biso & 1.000 & Al \\
\hline Al11 & 1.0000 & 0.23576 & 0.22456 & 0.08957 & Biso & 1.000 & Al \\
\hline Al12 & 1.0000 & 0.00503 & 0.77446 & 0.10034 & Biso & 1.000 & Al \\
\hline P 12 & 1.0000 & 0.67079 & 0.10321 & 0.22274 & Biso & 1.000 & $\mathrm{P}$ \\
\hline P13 & 1.0000 & 0.90378 & 0.55961 & 0.22231 & Biso & 1.000 & $\mathrm{P}$ \\
\hline P14 & 1.0000 & 0.44831 & 0.33482 & 0.21514 & Biso & 1.000 & $\mathrm{P}$ \\
\hline Al13 & 1.0000 & 0.43451 & 0.34387 & 0.42713 & Biso & 1.000 & Al \\
\hline Al14 & 1.0000 & 0.90016 & 0.55628 & 0.43250 & Biso & 1.000 & Al \\
\hline Al15 & 1.0000 & 0.67416 & 0.10502 & 0.42924 & Biso & 1.000 & $\mathrm{Al}$ \\
\hline P15 & 1.0000 & 0.33767 & 0.45382 & 0.55003 & Biso & 1.000 & $\mathrm{P}$ \\
\hline P16 & 1.0000 & 0.56950 & 0.89477 & 0.55584 & Biso & 1.000 & $\mathrm{P}$ \\
\hline P 17 & 1.0000 & 0.09929 & 0.66705 & 0.56146 & Biso & 1.000 & $\mathrm{P}$ \\
\hline Al16 & 1.0000 & 0.10468 & 0.66338 & 0.76846 & Biso & 1.000 & Al \\
\hline A117 & 1.0000 & 0.56060 & 0.88667 & 0.76700 & Biso & 1.000 & $\mathrm{Al}$ \\
\hline Al18 & 1.0000 & 0.33196 & 0.43186 & 0.75652 & Biso & 1.000 & Al \\
\hline 01 & 1.0000 & 0.91618 & 0.10342 & 0.12246 & Biso & 1.000 & 0 \\
\hline $\mathrm{O} 2$ & 1.0000 & 0.90249 & 0.80957 & 0.12614 & Biso & 1.000 & 0 \\
\hline $\mathrm{O} 3$ & 1.0000 & 0.20334 & 0.08560 & 0.09685 & Biso & 1.000 & 0 \\
\hline 04 & 1.0000 & 0.08650 & 0.88045 & 0.85684 & Biso & 1.000 & 0 \\
\hline 05 & 1.0000 & 0.80927 & 0.90743 & 0.86738 & Biso & 1.000 & 0 \\
\hline 06 & 1.0000 & 0.10737 & 0.18879 & 0.86458 & Biso & 1.000 & 0 \\
\hline 07 & 1.0000 & 0.57147 & 0.44715 & 0.45284 & Biso & 1.000 & 0 \\
\hline 08 & 1.0000 & 0.57066 & 0.13937 & 0.43614 & Biso & 1.000 & 0 \\
\hline 09 & 1.0000 & 0.88106 & 0.42361 & 0.45258 & Biso & 1.000 & 0 \\
\hline 010 & 1.0000 & 0.75918 & 0.22584 & 0.20312 & Biso & 1.000 & 0 \\
\hline 011 & 1.0000 & 0.48079 & 0.24455 & 0.20306 & Biso & 1.000 & 0 \\
\hline 012 & 1.0000 & 0.78148 & 0.52816 & 0.20830 & Biso & 1.000 & 0 \\
\hline 013 & 1.0000 & 0.23896 & 0.76111 & 0.80575 & Biso & 1.000 & 0 \\
\hline 014 & 1.0000 & 0.22853 & 0.46636 & 0.78005 & Biso & 1.000 & 0 \\
\hline 015 & 1.0000 & 0.53097 & 0.74843 & 0.77569 & Biso & 1.000 & 0 \\
\hline 016 & 1.0000 & 0.44049 & 0.57073 & 0.54547 & Biso & 1.000 & 0 \\
\hline 017 & 1.0000 & 0.10235 & 0.55871 & 0.55876 & Biso & 1.000 & 0 \\
\hline 018 & 1.0000 & 0.44811 & 0.85463 & 0.52720 & Biso & 1.000 & 0 \\
\hline 019 & 1.0000 & 0.99079 & 0.30627 & 0.15805 & Biso & 1.000 & 0 \\
\hline 020 & 1.0000 & 0.70026 & 0.67559 & 0.16120 & Biso & 1.000 & 0 \\
\hline 021 & 1.0000 & 0.34007 & 0.02214 & 0.13930 & Biso & 1.000 & 0 \\
\hline 022 & 1.0000 & 0.31764 & 0.96937 & 0.81427 & Biso & 1.000 & 0 \\
\hline 023 & 1.0000 & 0.65162 & 0.67578 & 0.83827 & Biso & 1.000 & o \\
\hline 024 & 1.0000 & 0.03021 & 0.34266 & 0.83289 & Biso & 1.000 & 0 \\
\hline 025 & 1.0000 & 0.66901 & 0.65067 & 0.49321 & Biso & 1.000 & 0 \\
\hline 026 & 1.0000 & 0.34321 & 0.99364 & 0.51918 & Biso & 1.000 & 0 \\
\hline 027 & 1.0000 & 0.00433 & 0.34171 & 0.48681 & Biso & 1.000 & 0 \\
\hline 028 & 1.0000 & 0.00853 & 0.67292 & 0.83745 & Biso & 1.000 & 0 \\
\hline 029 & 1.0000 & 0.30682 & 0.31339 & 0.81597 & Biso & 1.000 & 0 \\
\hline 030 & 1.0000 & 0.67650 & 0.97605 & 0.83026 & Biso & 1.000 & 0 \\
\hline 031 & 1.0000 & 0.68402 & 0.02623 & 0.15642 & Biso & 1.000 & 0 \\
\hline 032 & 1.0000 & 0.35167 & 0.31311 & 0.15293 & Biso & 1.000 & 0 \\
\hline 033 & 1.0000 & 0.98121 & 0.65867 & 0.16317 & Biso & 1.000 & 0 \\
\hline 034 & 1.0000 & 0.34169 & 0.37851 & 0.47756 & Biso & 1.000 & 0 \\
\hline 035 & 1.0000 & 0.00345 & 0.65613 & 0.50257 & Biso & 1.000 & 0 \\
\hline 036 & 1.0000 & 0.65093 & 0.99455 & 0.49974 & Biso & 1.000 & 0 \\
\hline 037 & 1.0000 & 0.12155 & 0.23608 & 0.12502 & Biso & 1.000 & 0 \\
\hline 038 & 1.0000 & 0.76356 & 0.87427 & 0.13266 & Biso & 1.000 & 0 \\
\hline 039 & 1.0000 & 0.13580 & 0.88551 & 0.12959 & Biso & 1.000 & 0 \\
\hline 040 & 1.0000 & 0.24115 & 0.11831 & 0.86101 & Biso & 1.000 & 0 \\
\hline 041 & 1.0000 & 0.88155 & 0.74843 & 0.85903 & Biso & 1.000 & 0 \\
\hline 042 & 1.0000 & 0.87583 & 0.11128 & 0.85782 & Biso & 1.000 & 0 \\
\hline 043 & 1.0000 & 0.77858 & 0.55839 & 0.45630 & Biso & 1.000 & 0 \\
\hline 044 & 1.0000 & 0.40687 & 0.21803 & 0.47144 & Biso & 1.000 & 0 \\
\hline 045 & 1.0000 & 0.80313 & 0.21746 & 0.46082 & Biso & 1.000 & 0 \\
\hline 046 & 1.0000 & 0.91682 & 0.46000 & 0.19595 & Biso & 1.000 & 0 \\
\hline 047 & 1.0000 & 0.55452 & 0.08783 & 0.21033 & Biso & 1.000 & 0 \\
\hline 048 & 1.0000 & 0.54884 & 0.44801 & 0.19022 & Biso & 1.000 & 0 \\
\hline 049 & 1.0000 & 0.44604 & 0.89188 & 0.81023 & Biso & 1.000 & 0 \\
\hline
\end{tabular}




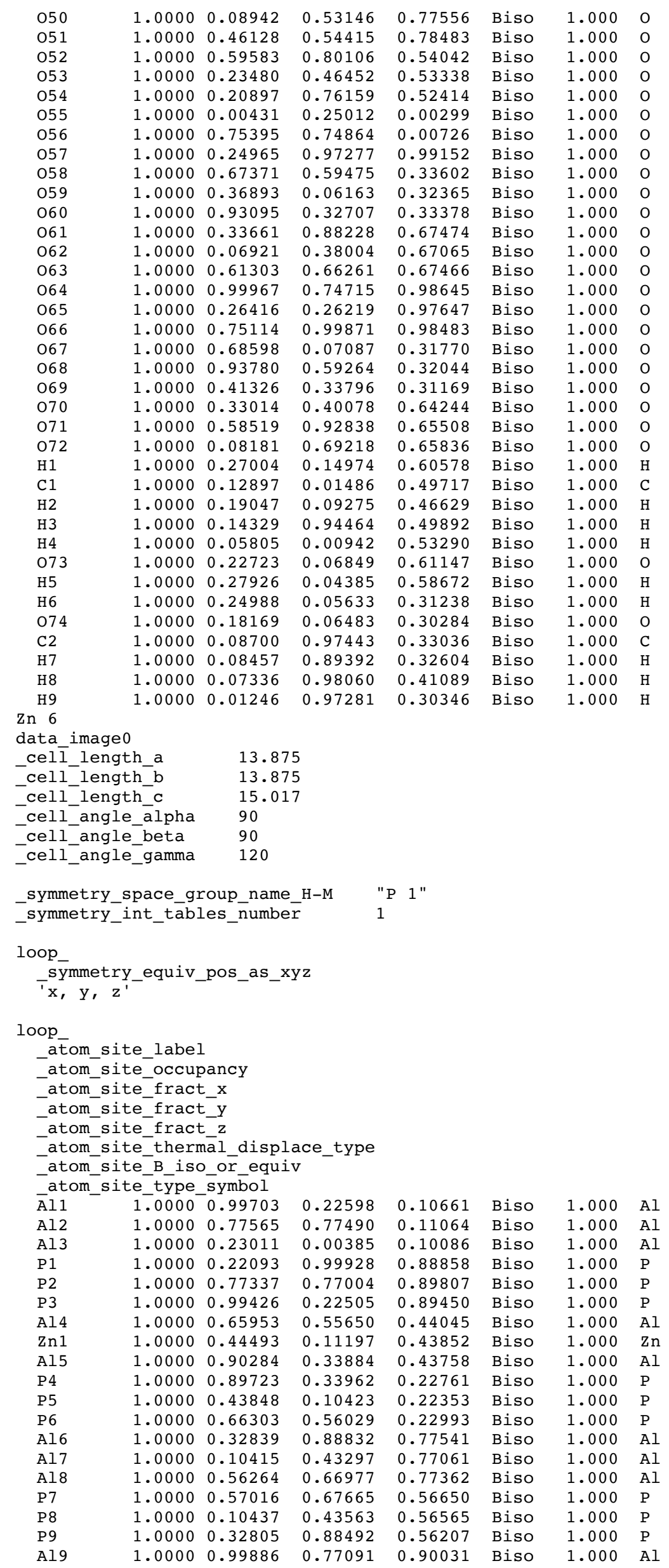




\begin{tabular}{|c|c|c|c|c|c|c|c|}
\hline Al10 & 1.0000 & 0.22341 & 0.22803 & 0.89608 & Biso & 1.000 & $\mathrm{Al}$ \\
\hline Al11 & 1.0000 & 0.77112 & 0.99562 & 0.89896 & Biso & 1.000 & $\mathrm{Al}$ \\
\hline P10 & 1.0000 & 0.77085 & 0.99825 & 0.11153 & Biso & 1.000 & $\mathrm{P}$ \\
\hline P11 & 1.0000 & 0.22599 & 0.22915 & 0.10819 & Biso & 1.000 & $\mathrm{P}$ \\
\hline P12 & 1.0000 & 0.00470 & 0.77980 & 0.11428 & Biso & 1.000 & $\mathrm{P}$ \\
\hline Al12 & 1.0000 & 0.67155 & 0.10832 & 0.23690 & Biso & 1.000 & Al \\
\hline Al13 & 1.0000 & 0.89300 & 0.56396 & 0.23311 & Biso & 1.000 & Al \\
\hline Al14 & 1.0000 & 0.43837 & 0.33065 & 0.23061 & Biso & 1.000 & Al \\
\hline P13 & 1.0000 & 0.42958 & 0.33080 & 0.44279 & Biso & 1.000 & $P$ \\
\hline P 14 & 1.0000 & 0.89250 & 0.56338 & 0.44387 & Biso & 1.000 & $P$ \\
\hline P15 & 1.0000 & 0.67876 & 0.11178 & 0.44380 & Biso & 1.000 & $P$ \\
\hline Al15 & 1.0000 & 0.33863 & 0.45006 & 0.56626 & Biso & 1.000 & Al \\
\hline A116 & 1.0000 & 0.56273 & 0.90076 & 0.56623 & Biso & 1.000 & $\mathrm{Al}$ \\
\hline Al17 & 1.0000 & 0.09425 & 0.66328 & 0.57322 & Biso & 1.000 & Al \\
\hline P 16 & 1.0000 & 0.10010 & 0.66276 & 0.77929 & Biso & 1.000 & $\mathrm{P}$ \\
\hline P17 & 1.0000 & 0.55502 & 0.89382 & 0.77877 & Biso & 1.000 & $\mathrm{P}$ \\
\hline P18 & 1.0000 & 0.33478 & 0.43935 & 0.77420 & Biso & 1.000 & $P$ \\
\hline 01 & 1.0000 & 0.89238 & 0.08923 & 0.12938 & Biso & 1.000 & 0 \\
\hline $\mathrm{O} 2$ & 1.0000 & 0.91389 & 0.81004 & 0.13431 & Biso & 1.000 & 0 \\
\hline $\mathrm{O} 3$ & 1.0000 & 0.19768 & 0.10795 & 0.12555 & Biso & 1.000 & 0 \\
\hline 04 & 1.0000 & 0.10056 & 0.90633 & 0.86968 & Biso & 1.000 & 0 \\
\hline 05 & 1.0000 & 0.80586 & 0.89185 & 0.87888 & Biso & 1.000 & 0 \\
\hline 06 & 1.0000 & 0.08690 & 0.19752 & 0.87514 & Biso & 1.000 & 0 \\
\hline 07 & 1.0000 & 0.55309 & 0.42068 & 0.45920 & Biso & 1.000 & 0 \\
\hline 08 & 1.0000 & 0.59462 & 0.15048 & 0.45647 & Biso & 1.000 & 0 \\
\hline 09 & 1.0000 & 0.87273 & 0.44552 & 0.46080 & Biso & 1.000 & 0 \\
\hline 010 & 1.0000 & 0.77524 & 0.24681 & 0.21607 & Biso & 1.000 & 0 \\
\hline 011 & 1.0000 & 0.47257 & 0.22718 & 0.20781 & Biso & 1.000 & 0 \\
\hline 012 & 1.0000 & 0.75580 & 0.53167 & 0.21425 & Biso & 1.000 & 0 \\
\hline 013 & 1.0000 & 0.22224 & 0.75177 & 0.79751 & Biso & 1.000 & 0 \\
\hline 014 & 1.0000 & 0.24270 & 0.46881 & 0.79140 & Biso & 1.000 & 0 \\
\hline 015 & 1.0000 & 0.52533 & 0.77177 & 0.79094 & Biso & 1.000 & 0 \\
\hline 016 & 1.0000 & 0.44664 & 0.58796 & 0.55643 & Biso & 1.000 & 0 \\
\hline 017 & 1.0000 & 0.11452 & 0.55082 & 0.56200 & Biso & 1.000 & 0 \\
\hline 018 & 1.0000 & 0.42652 & 0.86915 & 0.53702 & Biso & 1.000 & 0 \\
\hline 019 & 1.0000 & 0.97456 & 0.32015 & 0.16678 & Biso & 1.000 & 0 \\
\hline 020 & 1.0000 & 0.68266 & 0.65933 & 0.17196 & Biso & 1.000 & 0 \\
\hline 021 & 1.0000 & 0.35292 & 0.02995 & 0.15283 & Biso & 1.000 & 0 \\
\hline 022 & 1.0000 & 0.30337 & 0.98361 & 0.83124 & Biso & 1.000 & 0 \\
\hline 023 & 1.0000 & 0.66981 & 0.68957 & 0.84507 & Biso & 1.000 & 0 \\
\hline 024 & 1.0000 & 0.01189 & 0.32567 & 0.83972 & Biso & 1.000 & 0 \\
\hline 025 & 1.0000 & 0.64356 & 0.65257 & 0.50471 & Biso & 1.000 & 0 \\
\hline 026 & 1.0000 & 0.32918 & 0.97911 & 0.50579 & Biso & 1.000 & 0 \\
\hline 027 & 1.0000 & 0.01687 & 0.35710 & 0.49930 & Biso & 1.000 & 0 \\
\hline 028 & 1.0000 & 0.02247 & 0.67323 & 0.84634 & Biso & 1.000 & 0 \\
\hline 029 & 1.0000 & 0.31786 & 0.34259 & 0.83406 & Biso & 1.000 & 0 \\
\hline 030 & 1.0000 & 0.65578 & 0.97123 & 0.83601 & Biso & 1.000 & 0 \\
\hline 031 & 1.0000 & 0.69006 & 0.01921 & 0.16604 & Biso & 1.000 & 0 \\
\hline 032 & 1.0000 & 0.32588 & 0.31007 & 0.16445 & Biso & 1.000 & 0 \\
\hline 033 & 1.0000 & 0.98599 & 0.67979 & 0.17072 & Biso & 1.000 & 0 \\
\hline 034 & 1.0000 & 0.35332 & 0.36489 & 0.49080 & Biso & 1.000 & 0 \\
\hline 035 & 1.0000 & 0.98768 & 0.64931 & 0.50289 & Biso & 1.000 & 0 \\
\hline 036 & 1.0000 & 0.65811 & 0.01517 & 0.50606 & Biso & 1.000 & 0 \\
\hline 037 & 1.0000 & 0.12552 & 0.24050 & 0.13515 & Biso & 1.000 & o \\
\hline 038 & 1.0000 & 0.75737 & 0.88600 & 0.14003 & Biso & 1.000 & 0 \\
\hline 039 & 1.0000 & 0.11856 & 0.87866 & 0.14055 & Biso & 1.000 & 0 \\
\hline 040 & 1.0000 & 0.23285 & 0.11201 & 0.86514 & Biso & 1.000 & 0 \\
\hline 041 & 1.0000 & 0.86944 & 0.75202 & 0.86974 & Biso & 1.000 & 0 \\
\hline 042 & 1.0000 & 0.88226 & 0.12462 & 0.86814 & Biso & 1.000 & 0 \\
\hline 043 & 1.0000 & 0.78712 & 0.56700 & 0.46713 & Biso & 1.000 & 0 \\
\hline 044 & 1.0000 & 0.40572 & 0.21872 & 0.47797 & Biso & 1.000 & 0 \\
\hline 045 & 1.0000 & 0.79537 & 0.20873 & 0.46648 & Biso & 1.000 & 0 \\
\hline 046 & 1.0000 & 0.90720 & 0.45118 & 0.20133 & Biso & 1.000 & 0 \\
\hline 047 & 1.0000 & 0.54157 & 0.09233 & 0.21376 & Biso & 1.000 & 0 \\
\hline 048 & 1.0000 & 0.55164 & 0.46001 & 0.20289 & Biso & 1.000 & 0 \\
\hline 049 & 1.0000 & 0.45571 & 0.90508 & 0.80996 & Biso & 1.000 & 0 \\
\hline 050 & 1.0000 & 0.08782 & 0.54766 & 0.78993 & Biso & 1.000 & 0 \\
\hline 051 & 1.0000 & 0.44760 & 0.54060 & 0.79719 & Biso & 1.000 & 0 \\
\hline 052 & 1.0000 & 0.58380 & 0.78982 & 0.54104 & Biso & 1.000 & 0 \\
\hline 053 & 1.0000 & 0.21637 & 0.44855 & 0.53949 & Biso & 1.000 & 0 \\
\hline 054 & 1.0000 & 0.21800 & 0.77935 & 0.53908 & Biso & 1.000 & 0 \\
\hline 055 & 1.0000 & 0.99466 & 0.25321 & 0.99347 & Biso & 1.000 & 0 \\
\hline 056 & 1.0000 & 0.74839 & 0.74410 & 0.99766 & Biso & 1.000 & 0 \\
\hline 057 & 1.0000 & 0.24875 & 0.99586 & 0.98717 & Biso & 1.000 & 0 \\
\hline 058 & 1.0000 & 0.66202 & 0.59171 & 0.32798 & Biso & 1.000 & 0 \\
\hline 059 & 1.0000 & 0.38366 & 0.06389 & 0.31618 & Biso & 1.000 & 0 \\
\hline 060 & 1.0000 & 0.93530 & 0.34452 & 0.32442 & Biso & 1.000 & 0 \\
\hline 061 & 1.0000 & 0.33228 & 0.91362 & 0.66113 & Biso & 1.000 & 0 \\
\hline 062 & 1.0000 & 0.07047 & 0.38730 & 0.66023 & Biso & 1.000 & 0 \\
\hline 063 & 1.0000 & 0.60801 & 0.67838 & 0.66339 & Biso & 1.000 & 0 \\
\hline
\end{tabular}




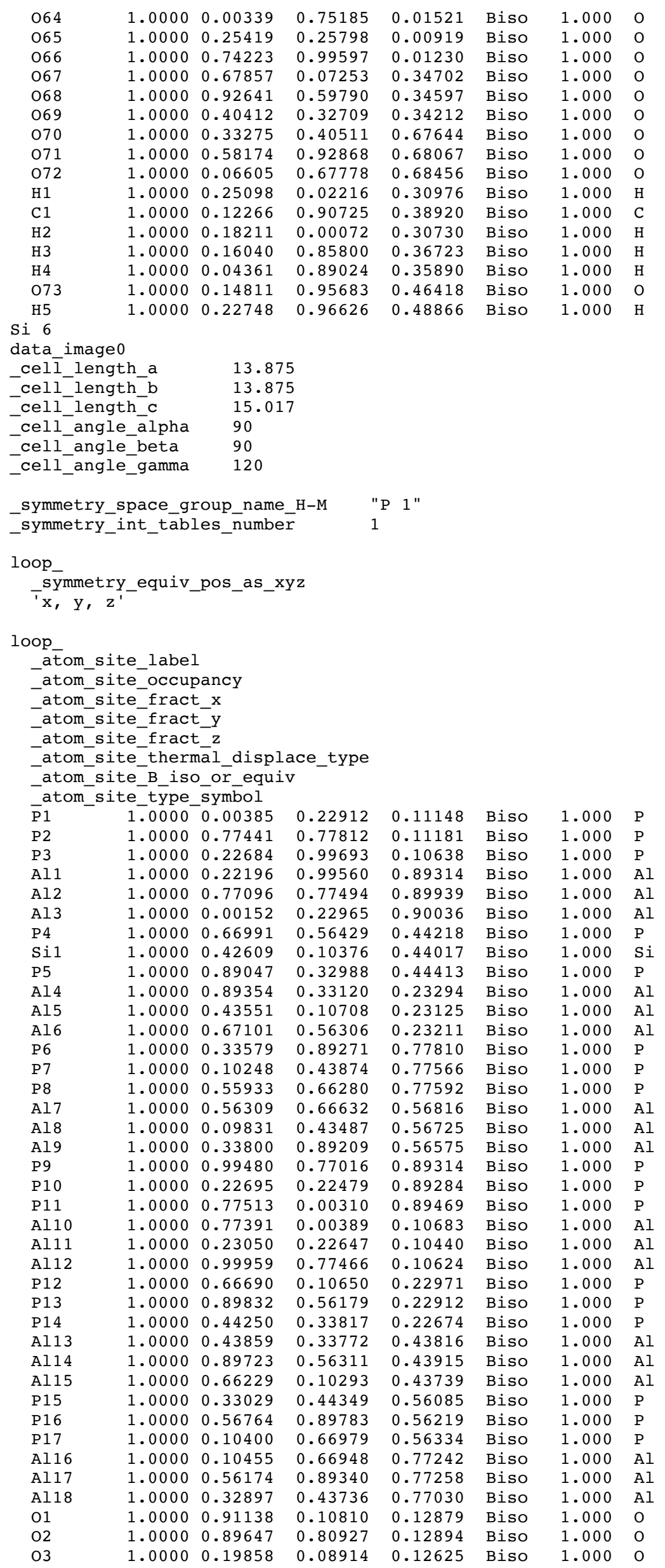




\begin{tabular}{|c|c|c|c|c|c|c|c|}
\hline 04 & 1.0000 & 0.08571 & 0.88984 & 0.86964 & Biso & 1.000 & 0 \\
\hline 05 & 1.0000 & 0.80662 & 0.91285 & 0.87641 & Biso & 1.000 & 0 \\
\hline 06 & 1.0000 & 0.10550 & 0.19628 & 0.87874 & Biso & 1.000 & 0 \\
\hline 07 & 1.0000 & 0.57715 & 0.44380 & 0.45758 & Biso & 1.000 & 0 \\
\hline 08 & 1.0000 & 0.54739 & 0.11751 & 0.44848 & Biso & 1.000 & 0 \\
\hline 09 & 1.0000 & 0.87103 & 0.42867 & 0.46029 & Biso & 1.000 & 0 \\
\hline 010 & 1.0000 & 0.75605 & 0.22841 & 0.20942 & Biso & 1.000 & 0 \\
\hline 011 & 1.0000 & 0.47207 & 0.24607 & 0.21127 & Biso & 1.000 & 0 \\
\hline 012 & 1.0000 & 0.77608 & 0.52973 & 0.21399 & Biso & 1.000 & 0 \\
\hline 013 & 1.0000 & 0.24175 & 0.77258 & 0.79597 & Biso & 1.000 & 0 \\
\hline 014 & 1.0000 & 0.22479 & 0.47103 & 0.79133 & Biso & 1.000 & 0 \\
\hline 015 & 1.0000 & 0.52899 & 0.75494 & 0.78654 & Biso & 1.000 & 0 \\
\hline 016 & 1.0000 & 0.42343 & 0.56580 & 0.55055 & Biso & 1.000 & 0 \\
\hline 017 & 1.0000 & 0.12046 & 0.56931 & 0.55122 & Biso & 1.000 & 0 \\
\hline 018 & 1.0000 & 0.44718 & 0.86872 & 0.54009 & Biso & 1.000 & 0 \\
\hline 019 & 1.0000 & 0.98741 & 0.30980 & 0.17063 & Biso & 1.000 & 0 \\
\hline 020 & 1.0000 & 0.69511 & 0.67758 & 0.16817 & Biso & 1.000 & 0 \\
\hline 021 & 1.0000 & 0.33184 & 0.01846 & 0.15639 & Biso & 1.000 & 0 \\
\hline 022 & 1.0000 & 0.31762 & 0.97571 & 0.83255 & Biso & 1.000 & 0 \\
\hline 023 & 1.0000 & 0.65314 & 0.68191 & 0.84003 & Biso & 1.000 & 0 \\
\hline $\mathrm{O} 24$ & 1.0000 & 0.02502 & 0.34583 & 0.83925 & Biso & 1.000 & 0 \\
\hline 025 & 1.0000 & 0.65288 & 0.64506 & 0.50076 & Biso & 1.000 & 0 \\
\hline 026 & 1.0000 & 0.33601 & 0.99835 & 0.50409 & Biso & 1.000 & 0 \\
\hline 027 & 1.0000 & 0.98680 & 0.34150 & 0.50215 & Biso & 1.000 & 0 \\
\hline 028 & 1.0000 & 0.01118 & 0.68550 & 0.83951 & Biso & 1.000 & 0 \\
\hline 029 & 1.0000 & 0.30637 & 0.32363 & 0.83483 & Biso & 1.000 & 0 \\
\hline 030 & 1.0000 & 0.67512 & 0.98292 & 0.83789 & Biso & 1.000 & 0 \\
\hline 031 & 1.0000 & 0.67959 & 0.02738 & 0.16559 & Biso & 1.000 & 0 \\
\hline 032 & 1.0000 & 0.34536 & 0.31969 & 0.16645 & Biso & 1.000 & 0 \\
\hline 033 & 1.0000 & 0.97599 & 0.65893 & 0.16859 & Biso & 1.000 & 0 \\
\hline 034 & 1.0000 & 0.34874 & 0.36821 & 0.49766 & Biso & 1.000 & 0 \\
\hline 035 & 1.0000 & 0.01067 & 0.66038 & 0.50223 & Biso & 1.000 & 0 \\
\hline 036 & 1.0000 & 0.65099 & 0.99362 & 0.50379 & Biso & 1.000 & 0 \\
\hline 037 & 1.0000 & 0.11641 & 0.23989 & 0.13461 & Biso & 1.000 & 0 \\
\hline 038 & 1.0000 & 0.76021 & 0.87675 & 0.13898 & Biso & 1.000 & 0 \\
\hline 039 & 1.0000 & 0.12879 & 0.88557 & 0.13867 & Biso & 1.000 & 0 \\
\hline 040 & 1.0000 & 0.23724 & 0.12406 & 0.86498 & Biso & 1.000 & 0 \\
\hline 041 & 1.0000 & 0.88116 & 0.75559 & 0.86866 & Biso & 1.000 & 0 \\
\hline 042 & 1.0000 & 0.87374 & 0.11682 & 0.86948 & Biso & 1.000 & 0 \\
\hline 043 & 1.0000 & 0.78215 & 0.57505 & 0.46742 & Biso & 1.000 & 0 \\
\hline O4 4 & 1.0000 & 0.42064 & 0.21171 & 0.46990 & Biso & 1.000 & 0 \\
\hline 045 & 1.0000 & 0.78502 & 0.22270 & 0.47007 & Biso & 1.000 & 0 \\
\hline 046 & 1.0000 & 0.91223 & 0.46195 & 0.20616 & Biso & 1.000 & 0 \\
\hline 047 & 1.0000 & 0.55176 & 0.09304 & 0.21477 & Biso & 1.000 & 0 \\
\hline 048 & 1.0000 & 0.54375 & 0.45032 & 0.20119 & Biso & 1.000 & 0 \\
\hline 049 & 1.0000 & 0.44681 & 0.90352 & 0.80644 & Biso & 1.000 & 0 \\
\hline 050 & 1.0000 & 0.08981 & 0.54015 & 0.79451 & Biso & 1.000 & 0 \\
\hline 051 & 1.0000 & 0.45723 & 0.55074 & 0.79935 & Biso & 1.000 & 0 \\
\hline 052 & 1.0000 & 0.57950 & 0.79594 & 0.54293 & Biso & 1.000 & 0 \\
\hline 053 & 1.0000 & 0.21916 & 0.43532 & 0.53643 & Biso & 1.000 & 0 \\
\hline 054 & 1.0000 & 0.21167 & 0.77497 & 0.53588 & Biso & 1.000 & 0 \\
\hline 055 & 1.0000 & 0.00170 & 0.26014 & 0.01341 & Biso & 1.000 & 0 \\
\hline 056 & 1.0000 & 0.74458 & 0.74885 & 0.01319 & Biso & 1.000 & 0 \\
\hline 057 & 1.0000 & 0.24674 & 0.99158 & 0.00656 & Biso & 1.000 & 0 \\
\hline 058 & 1.0000 & 0.67210 & 0.59805 & 0.34413 & Biso & 1.000 & 0 \\
\hline 059 & 1.0000 & 0.37686 & 0.06651 & 0.33750 & Biso & 1.000 & 0 \\
\hline 060 & 1.0000 & 0.92127 & 0.32764 & 0.34602 & Biso & 1.000 & 0 \\
\hline 061 & 1.0000 & 0.33825 & 0.92091 & 0.67883 & Biso & 1.000 & 0 \\
\hline 062 & 1.0000 & 0.06777 & 0.39782 & 0.67942 & Biso & 1.000 & 0 \\
\hline 063 & 1.0000 & 0.59785 & 0.66177 & 0.67989 & Biso & 1.000 & 0 \\
\hline 064 & 1.0000 & 0.99957 & 0.74726 & 0.99284 & Biso & 1.000 & 0 \\
\hline 065 & 1.0000 & 0.26035 & 0.25465 & 0.99101 & Biso & 1.000 & 0 \\
\hline 066 & 1.0000 & 0.74473 & 0.00134 & 0.99336 & Biso & 1.000 & 0 \\
\hline 067 & 1.0000 & 0.67977 & 0.07564 & 0.32552 & Biso & 1.000 & 0 \\
\hline 068 & 1.0000 & 0.93217 & 0.59836 & 0.32668 & Biso & 1.000 & 0 \\
\hline 069 & 1.0000 & 0.40946 & 0.33988 & 0.32401 & Biso & 1.000 & 0 \\
\hline 070 & 1.0000 & 0.32726 & 0.40460 & 0.65755 & Biso & 1.000 & 0 \\
\hline 071 & 1.0000 & 0.59299 & 0.93195 & 0.66080 & Biso & 1.000 & 0 \\
\hline 072 & 1.0000 & 0.07401 & 0.67884 & 0.66041 & Biso & 1.000 & 0 \\
\hline H 1 & 1.0000 & 0.24474 & 0.01345 & 0.32234 & Biso & 1.000 & $\mathrm{H}$ \\
\hline $\mathrm{C} 1$ & 1.0000 & 0.11598 & 0.90975 & 0.40494 & Biso & 1.000 & C \\
\hline H2 & 1.0000 & 0.17468 & 0.98665 & 0.31562 & Biso & 1.000 & $\mathrm{H}$ \\
\hline H3 & 1.0000 & 0.14628 & 0.85233 & 0.38842 & Biso & 1.000 & $\mathrm{H}$ \\
\hline $\mathrm{H} 4$ & 1.0000 & 0.03595 & 0.89309 & 0.37677 & Biso & 1.000 & $\mathrm{H}$ \\
\hline 073 & 1.0000 & 0.14984 & 0.96979 & 0.47498 & Biso & 1.000 & 0 \\
\hline H5 & 1.0000 & 0.23324 & 0.98211 & 0.49510 & Biso & 1.000 & $\mathrm{H}$ \\
\hline
\end{tabular}

data_image 0

_celī_length_a $\quad 13.875$

_cell_length_b 13.875 


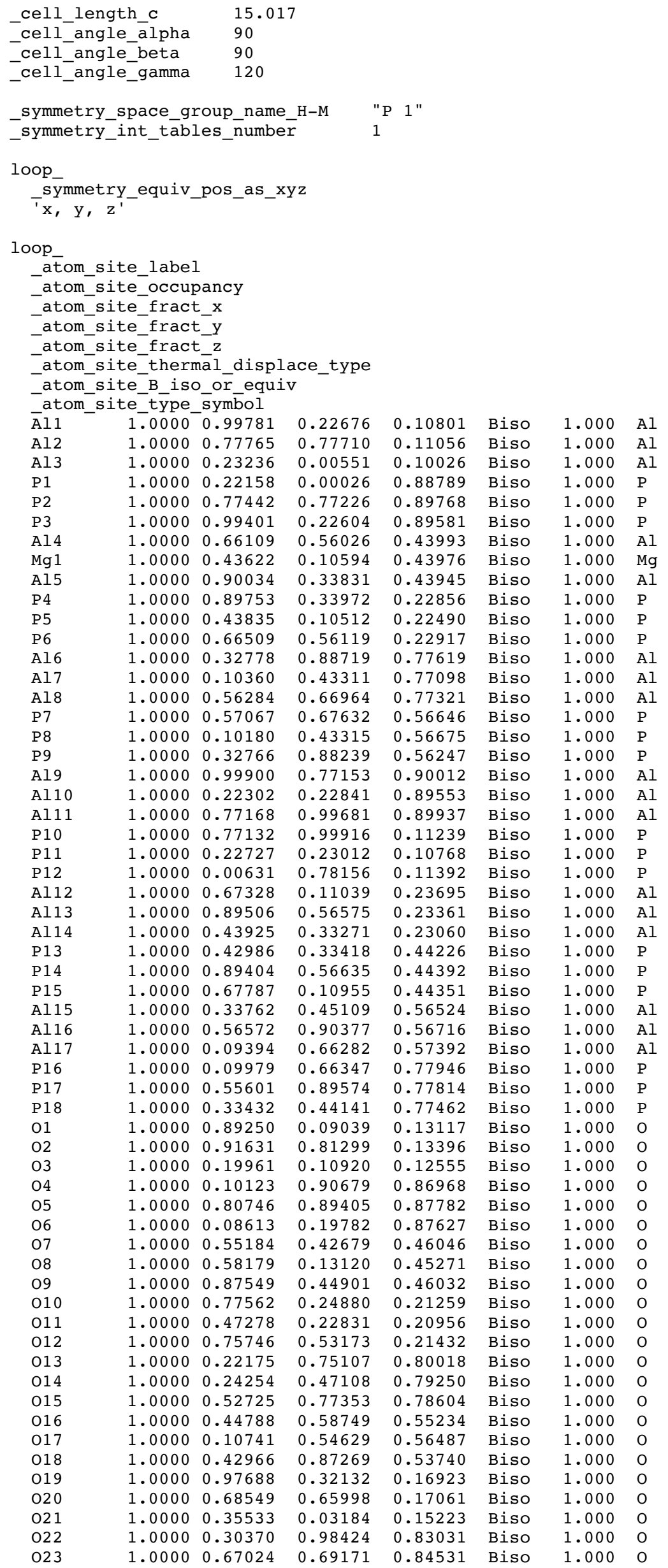




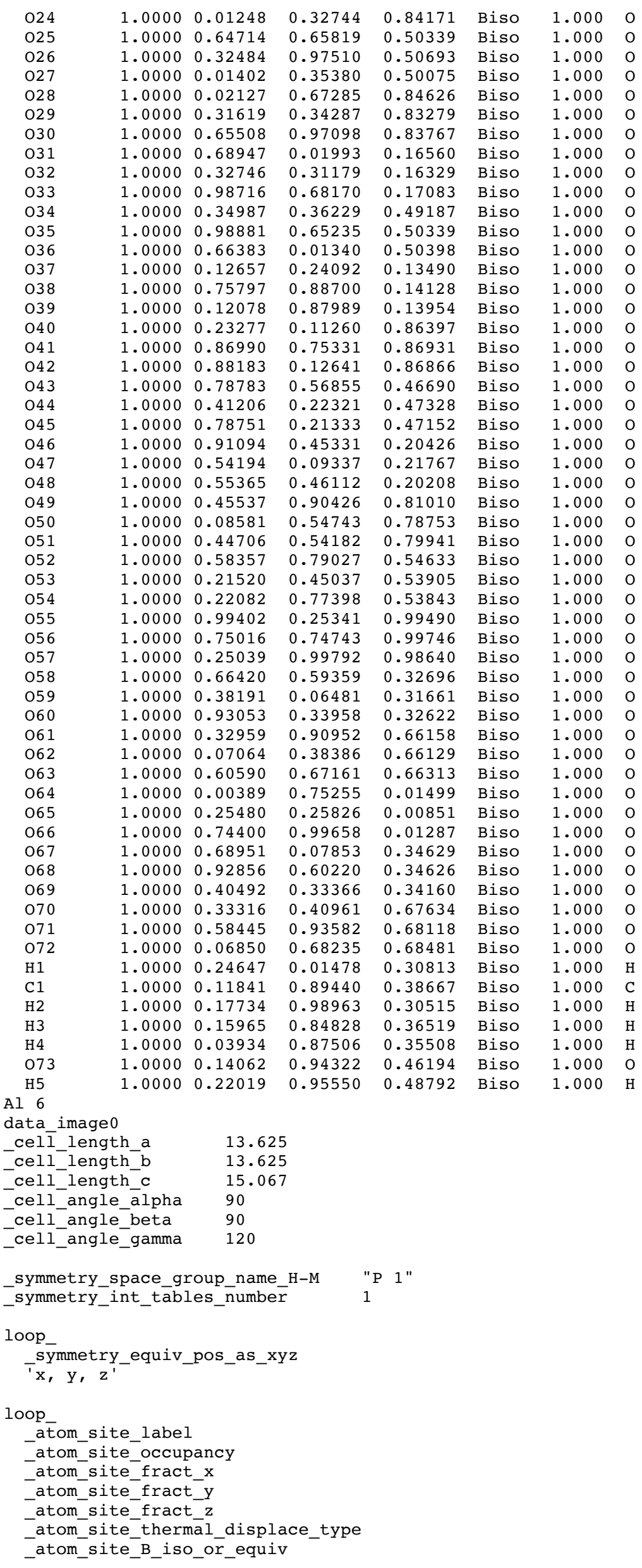




\begin{tabular}{|c|c|c|c|c|c|c|}
\hline$\overline{\mathrm{S}} \mathrm{i} 1$ & 1.0000 & 0.01291 & 0.23792 & 0.10311 & Biso & 1.000 \\
\hline $\mathrm{Si} 2$ & 1.0000 & 0.78557 & 0.78202 & 0.10436 & Biso & 1.000 \\
\hline $\operatorname{Si3}$ & 1.0000 & 0.24425 & 0.00901 & 0.09690 & Biso & 1.000 \\
\hline Si 4 & 1.0000 & 0.23634 & 0.00585 & 0.88937 & Biso & 1.000 \\
\hline Si5 & 1.0000 & 0.78181 & 0.77811 & 0.89675 & Biso & 1.000 \\
\hline Si6 & 1.0000 & 0.00983 & 0.23801 & 0.89702 & Biso & 1.000 \\
\hline Si7 & 1.0000 & 0.67770 & 0.57181 & 0.43505 & Biso & 1.000 \\
\hline Al1 & 1.0000 & 0.44057 & 0.10852 & 0.43325 & Biso & 1.000 \\
\hline Si8 & 1.0000 & 0.90907 & 0.34064 & 0.43564 & Biso & 1.000 \\
\hline Si9 & 1.0000 & 0.90992 & 0.34255 & 0.22980 & Biso & 1.000 \\
\hline Silo & 1.0000 & 0.44680 & 0.11084 & 0.22723 & Biso & 1.000 \\
\hline Si11 & 1.0000 & 0.68024 & 0.57172 & 0.22967 & Biso & 1.000 \\
\hline Si12 & 1.0000 & 0.34350 & 0.89912 & 0.77048 & Biso & 1.000 \\
\hline Si13 & 1.0000 & 0.11169 & 0.44012 & 0.76709 & Biso & 1.000 \\
\hline $\operatorname{Si} 14$ & 1.0000 & 0.57499 & 0.67367 & 0.76829 & Biso & 1.000 \\
\hline Si15 & 1.0000 & 0.57995 & 0.67757 & 0.56557 & Biso & \\
\hline Si16 & 1.0000 & 0.10912 & 0.43749 & 0.56523 & Biso & 1.000 \\
\hline Si17 & 1.0000 & 0.34467 & 0.89667 & 0.56220 & Biso & 1.000 \\
\hline Si18 & 1.0000 & 0.00881 & 0.77570 & 0.89515 & Biso & 1.000 \\
\hline Si19 & 1.0000 & 0.23981 & 0.23698 & 0.89300 & Biso & 1.000 \\
\hline Si20 & 1.0000 & 0.78274 & 0.00698 & 0.89578 & Biso & 1.000 \\
\hline Si21 & 1.0000 & 0.78240 & 0.00862 & 0.10310 & Biso & 1.000 \\
\hline Si22 & 1.0000 & 0.24338 & 0.23802 & 0.09972 & Biso & 1.000 \\
\hline Si23 & 1.0000 & 0.01483 & 0.78226 & 0.10316 & Biso & 1.000 \\
\hline Si24 & 1.0000 & 0.68192 & 0.11322 & 0.23172 & Biso & \\
\hline Si25 & 1.0000 & 0.91081 & 0.57327 & 0.23027 & Biso & \\
\hline Si26 & 1.0000 & 0.45016 & 0.34269 & 0.22818 & Biso & 1.000 \\
\hline Si27 & 1.0000 & 0.44450 & 0.34284 & 0.43405 & Biso & 1.000 \\
\hline Si28 & 1.0000 & 0.90957 & 0.57364 & 0.43582 & Biso & 1.000 \\
\hline Si29 & 1.0000 & 0.68067 & 0.11017 & 0.43425 & Biso & \\
\hline Si30 & 1.0000 & 0.34557 & 0.45147 & 0.56153 & Biso & \\
\hline Si31 & 1.0000 & 0.58088 & 0.91017 & 0.56303 & Biso & 1.000 \\
\hline Si32 & 1.0000 & 0.10924 & 0.67262 & 0.56652 & Biso & 1.000 \\
\hline Si33 & 1.0000 & 0.11175 & 0.67347 & 0.76902 & Biso & 1.000 \\
\hline Si34 & 1.0000 & 0.57369 & 0.90499 & 0.76897 & Biso & \\
\hline Si35 & 1.0000 & 0.34316 & 0.44490 & 0.76664 & Biso & \\
\hline 01 & 1.0000 & 0.91343 & 0.10736 & 0.11987 & Biso & 1.000 \\
\hline $\mathrm{O} 2$ & 1.0000 & 0.91750 & 0.81623 & 0.12119 & Biso & 1.000 \\
\hline 03 & 1.0000 & 0.21183 & 0.10703 & 0.11648 & Biso & 1.000 \\
\hline 04 & 1.0000 & 0.10620 & 0.90535 & 0.87238 & Biso & 1.000 \\
\hline 05 & 1.0000 & 0.81652 & 0.90942 & 0.87811 & Biso & 1.000 \\
\hline 06 & 1.0000 & 0.10938 & 0.20748 & 0.87938 & Biso & 1.000 \\
\hline 07 & 1.0000 & 0.57623 & 0.44307 & 0.44990 & Biso & 1.000 \\
\hline 08 & 1.0000 & 0.57424 & 0.12817 & 0.44380 & Biso & 1.000 \\
\hline 09 & 1.0000 & 0.88682 & 0.44643 & 0.45221 & Biso & 1.000 \\
\hline 010 & 1.0000 & 0.77872 & 0.24501 & 0.21262 & Biso & 1. \\
\hline 011 & 1.0000 & 0.48231 & 0.24347 & 0.21365 & Biso & 1.000 \\
\hline 012 & 1.0000 & 0.77948 & 0.53943 & 0.21527 & Biso & 1.000 \\
\hline 013 & 1.0000 & 0.24290 & 0.76940 & 0.78905 & Biso & 1.000 \\
\hline 014 & 1.0000 & 0.24352 & 0.47585 & 0.78424 & Biso & 1.000 \\
\hline 015 & 1.0000 & 0.54371 & 0.77388 & 0.77795 & Biso & 1.000 \\
\hline 016 & 1.0000 & 0.44766 & 0.58214 & 0.55087 & Biso & 1.000 \\
\hline 017 & 1.0000 & 0.12399 & 0.56290 & 0.55772 & Biso & 1.000 \\
\hline 018 & 1.0000 & 0.45145 & 0.87977 & 0.53905 & Biso & 1.000 \\
\hline 019 & 1.0000 & 0.99556 & 0.32390 & 0.16666 & Biso & 1.000 \\
\hline $\mathrm{O} 20$ & 1.0000 & 0.70129 & 0.67582 & 0.16575 & Biso & 1.000 \\
\hline 021 & 1.0000 & 0.35585 & 0.03221 & 0.15160 & Biso & 1.000 \\
\hline 022 & 1.0000 & 0.32318 & 0.98833 & 0.82716 & Biso & 1.000 \\
\hline 023 & 1.0000 & 0.67355 & 0.69224 & 0.83760 & Biso & 1.000 \\
\hline $\mathrm{O} 24$ & 1.0000 & 0.02808 & 0.34351 & 0.83608 & Biso & 1.000 \\
\hline 025 & 1.0000 & 0.66265 & 0.65947 & 0.49861 & Biso & \\
\hline 026 & 1.0000 & 0.34189 & 0.99430 & 0.50137 & Biso & 1.000 \\
\hline $\mathrm{O} 27$ & 1.0000 & 0.01134 & 0.35218 & 0.49791 & Biso & 1.000 \\
\hline 028 & 1.0000 & 0.02685 & 0.68588 & 0.83720 & Biso & 1.000 \\
\hline 029 & 1.0000 & 0.32507 & 0.34085 & 0.82974 & Biso & 1.000 \\
\hline 030 & 1.0000 & 0.67745 & 0.98674 & 0.83366 & Biso & 1.000 \\
\hline 031 & 1.0000 & 0.69603 & 0.02981 & 0.16253 & Biso & 1.000 \\
\hline 032 & 1.0000 & 0.34849 & 0.32379 & 0.16154 & Biso & 1.000 \\
\hline 033 & 1.0000 & 0.99484 & 0.67765 & 0.16646 & Biso & 1.000 \\
\hline 034 & 1.0000 & 0.36078 & 0.36951 & 0.49320 & Biso & 1.000 \\
\hline 035 & 1.0000 & 0.01219 & 0.66437 & 0.49898 & Biso & 1.000 \\
\hline 036 & 1.0000 & 0.67102 & 0.01040 & 0.49983 & Biso & 1.000 \\
\hline 037 & 1.0000 & 0.13409 & 0.24903 & 0.12630 & Biso & 1.000 \\
\hline 038 & 1.0000 & 0.77098 & 0.88875 & 0.13196 & Biso & 1.000 \\
\hline 039 & 1.0000 & 0.13749 & 0.88906 & 0.12943 & Biso & 1.000 \\
\hline 040 & 1.0000 & 0.24764 & 0.12646 & 0.86463 & Biso & 1.000 \\
\hline 041 & 1.0000 & 0.88700 & 0.76085 & 0.86913 & Biso & 1.000 \\
\hline 042 & 1.0000 & 0.88988 & 0.12889 & 0.87022 & Biso & 1.000 \\
\hline 043 & 1.0000 & 0.79743 & 0.57983 & 0.46027 & Biso & 1.000 \\
\hline
\end{tabular}




\begin{tabular}{|c|c|c|c|c|c|c|c|}
\hline 044 & 1.0000 & 0.42898 & 0.22372 & 0.46248 & Biso & 1.000 & 0 \\
\hline 045 & 1.0000 & 0.79649 & 0.22498 & 0.46209 & Biso & 1.000 & 0 \\
\hline 046 & 1.0000 & 0.92464 & 0.46533 & 0.20596 & Biso & 1.000 & 0 \\
\hline 047 & 1.0000 & 0.55882 & 0.10008 & 0.21507 & Biso & 1.000 & 0 \\
\hline 048 & 1.0000 & 0.56030 & 0.46320 & 0.20276 & Biso & 1.000 & 0 \\
\hline 049 & 1.0000 & 0.46339 & 0.91189 & 0.80020 & Biso & 1.000 & 0 \\
\hline 050 & 1.0000 & 0.09800 & 0.54992 & 0.78279 & Biso & 1.000 & 0 \\
\hline 051 & 1.0000 & 0.46352 & 0.55423 & 0.79233 & Biso & 1.000 & 0 \\
\hline 052 & 1.0000 & 0.59314 & 0.79988 & 0.54502 & Biso & 1.000 & 0 \\
\hline 053 & 1.0000 & 0.22759 & 0.44664 & 0.53728 & Biso & 1.000 & 0 \\
\hline 054 & 1.0000 & 0.22797 & 0.78167 & 0.53689 & Biso & 1.000 & 0 \\
\hline 055 & 1.0000 & 0.01008 & 0.27294 & 0.00028 & Biso & 1.000 & 0 \\
\hline 056 & 1.0000 & 0.75103 & 0.74743 & 0.00108 & Biso & 1.000 & 0 \\
\hline 057 & 1.0000 & 0.27007 & 0.00400 & 0.99250 & Biso & 1.000 & 0 \\
\hline 058 & 1.0000 & 0.68122 & 0.61056 & 0.33206 & Biso & 1.000 & 0 \\
\hline 059 & 1.0000 & 0.38731 & 0.06470 & 0.32368 & Biso & 1.000 & 0 \\
\hline 060 & 1.0000 & 0.94513 & 0.34054 & 0.33264 & Biso & 1.000 & $\mathrm{O}$ \\
\hline 061 & 1.0000 & 0.34564 & 0.92913 & 0.66587 & Biso & 1.000 & 0 \\
\hline 062 & 1.0000 & 0.07433 & 0.39120 & 0.66657 & Biso & 1.000 & 0 \\
\hline 063 & 1.0000 & 0.61790 & 0.67210 & 0.66750 & Biso & 1.000 & 0 \\
\hline 064 & 1.0000 & 0.01288 & 0.74753 & 0.99975 & Biso & 1.000 & 0 \\
\hline 065 & 1.0000 & 0.27777 & 0.27142 & 0.99601 & Biso & 1.000 & 0 \\
\hline 066 & 1.0000 & 0.74787 & 0.00518 & 0.99926 & Biso & 1.000 & 0 \\
\hline 067 & 1.0000 & 0.69429 & 0.07673 & 0.33201 & Biso & 1.000 & 0 \\
\hline 068 & 1.0000 & 0.94817 & 0.61364 & 0.33314 & Biso & 1.000 & 0 \\
\hline 069 & 1.0000 & 0.41136 & 0.34500 & 0.32956 & Biso & 1.000 & 0 \\
\hline 070 & 1.0000 & 0.34219 & 0.40899 & 0.66343 & Biso & 1.000 & 0 \\
\hline 071 & 1.0000 & 0.60742 & 0.94835 & 0.66694 & Biso & 1.000 & 0 \\
\hline 072 & 1.0000 & 0.07698 & 0.68724 & 0.66780 & Biso & 1.000 & 0 \\
\hline $\mathrm{H} 1$ & 1.0000 & 0.24871 & 0.00085 & 0.30884 & Biso & 1.000 & $\mathrm{H}$ \\
\hline $\mathrm{C} 1$ & 1.0000 & 0.12153 & 0.89536 & 0.39491 & Biso & 1.000 & $\mathrm{C}$ \\
\hline $\mathrm{H} 2$ & 1.0000 & 0.17820 & 0.97083 & 0.30253 & Biso & 1.000 & $\mathrm{H}$ \\
\hline H3 & 1.0000 & 0.15819 & 0.84109 & 0.38179 & Biso & 1.000 & $\mathrm{H}$ \\
\hline $\mathrm{H} 4$ & 1.0000 & 0.03941 & 0.87248 & 0.36477 & Biso & 1.000 & $\mathrm{H}$ \\
\hline 073 & 1.0000 & 0.15192 & 0.96021 & 0.46259 & Biso & 1.000 & 0 \\
\hline H5 & 1.0000 & 0.23483 & 0.97516 & 0.48677 & Biso & 1.000 & $\mathrm{H}$ \\
\hline \multirow{2}{*}{\multicolumn{8}{|c|}{$\begin{array}{l}\text { Ge } 6 \\
\text { data image } 0\end{array}$}} \\
\hline \multirow{2}{*}{\multicolumn{8}{|c|}{$\begin{array}{l}\text { data_image0 } \\
\text { celil_length_a }\end{array}$}} \\
\hline & & & & & & & \\
\hline \multicolumn{8}{|c|}{ _cell_length_b $\quad 13.875$} \\
\hline \multicolumn{8}{|c|}{ cell_length_c $\quad 15.017$} \\
\hline \multicolumn{8}{|c|}{ cell_angle_alpha $\quad 90$} \\
\hline \multicolumn{8}{|c|}{ cell_angle_beta 90} \\
\hline \multicolumn{8}{|c|}{ _cell_angle_gamma $\quad 120$} \\
\hline symme & pace_gr & oup_name & & $1 "$ & & & \\
\hline symme & int_tābl & es_numbe & & & & & \\
\hline $100 p_{-}$ & & & & & & & \\
\hline -sym & equiv & pos_as_x & & & & & \\
\hline $\bar{x}$, & & & & & & & \\
\hline loop & & & & & & & \\
\hline ato & e label & & & & & & \\
\hline ato & e_occup & ancy & & & & & \\
\hline -ato & $=e$ fract & $=x$ & & & & & \\
\hline -ato & $=e$ fract & $-y$ & & & & & \\
\hline -ato & $e_{-}^{-}$fract & -2 & & & & & \\
\hline ato & e_therm & nàl_displ & ce_type & & & & \\
\hline ato & e_B_isc & or_equi & & & & & \\
\hline -ato & =e_type & symbol & & & & & \\
\hline$\overline{\mathrm{P}} 1$ & 1.0000 & 0.00533 & 0.23006 & 0.11199 & Biso & 1.000 & $\mathrm{P}$ \\
\hline P2 & 1.0000 & 0.77743 & 0.78082 & 0.11381 & Biso & 1.000 & $\mathrm{P}$ \\
\hline P3 & 1.0000 & 0.22811 & 0.99855 & 0.10299 & Biso & 1.000 & $\mathrm{P}$ \\
\hline Al1 & 1.0000 & 0.21989 & 0.99457 & 0.88936 & Biso & 1.000 & Al \\
\hline Al2 & 1.0000 & 0.77167 & 0.77581 & 0.90086 & Biso & 1.000 & Al \\
\hline A13 & 1.0000 & 0.00091 & 0.22965 & 0.90008 & Biso & 1.000 & Al \\
\hline P 4 & 1.0000 & 0.66969 & 0.56278 & 0.44252 & Biso & 1.000 & $\mathrm{P}$ \\
\hline $\mathrm{Ge} 1$ & 1.0000 & 0.42236 & 0.10633 & 0.44279 & Biso & 1.000 & $\mathrm{Ge}$ \\
\hline P5 & 1.0000 & 0.89519 & 0.33081 & 0.44308 & Biso & 1.000 & $\mathrm{P}$ \\
\hline Al4 & 1.0000 & 0.89617 & 0.33341 & 0.23267 & Biso & 1.000 & Al \\
\hline Al5 & 1.0000 & 0.43667 & 0.10934 & 0.22702 & Biso & 1.000 & Al \\
\hline Al 6 & 1.0000 & 0.67280 & 0.56535 & 0.23324 & Biso & 1.000 & Al \\
\hline P6 & 1.0000 & 0.33435 & 0.88858 & 0.78011 & Biso & 1.000 & $\mathrm{P}$ \\
\hline P7 & 1.0000 & 0.10196 & 0.43661 & 0.77530 & Biso & 1.000 & $\mathrm{P}$ \\
\hline P8 & 1.0000 & 0.56019 & 0.66350 & 0.77701 & Biso & 1.000 & $\mathrm{P}$ \\
\hline Al7 & 1.0000 & 0.56825 & 0.67049 & 0.57125 & Biso & 1.000 & Al \\
\hline Al 8 & 1.0000 & 0.09518 & 0.43144 & 0.57135 & Biso & 1.000 & Al \\
\hline Al9 & 1.0000 & 0.33614 & 0.88282 & 0.56609 & Biso & 1.000 & Al \\
\hline P9 & 1.0000 & 0.99335 & 0.76864 & 0.89334 & Biso & 1.000 & $\mathrm{P}$ \\
\hline
\end{tabular}




\begin{tabular}{|c|c|c|c|c|c|c|c|}
\hline P10 & 1.0000 & 0.22603 & 0.22464 & 0.88994 & Biso & 1.000 & $\mathrm{P}$ \\
\hline P11 & 1.0000 & 0.77606 & 0.00400 & 0.89539 & Biso & 1.000 & $\mathrm{P}$ \\
\hline Al10 & 1.0000 & 0.77644 & 0.00622 & 0.10835 & Biso & 1.000 & Al \\
\hline Al11 & 1.0000 & 0.23200 & 0.22800 & 0.10189 & Biso & 1.000 & Al \\
\hline Al12 & 1.0000 & 0.00158 & 0.77700 & 0.10743 & Biso & 1.000 & Al \\
\hline P12 & 1.0000 & 0.66749 & 0.10778 & 0.23046 & Biso & 1.000 & $\mathrm{P}$ \\
\hline P13 & 1.0000 & 0.89972 & 0.56360 & 0.23002 & Biso & 1.000 & $\mathrm{P}$ \\
\hline P14 & 1.0000 & 0.44386 & 0.33969 & 0.22500 & Biso & 1.000 & $\mathrm{P}$ \\
\hline Al13 & 1.0000 & 0.43429 & 0.34189 & 0.43682 & Biso & 1.000 & Al \\
\hline Al14 & 1.0000 & 0.89793 & 0.56273 & 0.44040 & Biso & 1.000 & Al \\
\hline Al15 & 1.0000 & 0.66463 & 0.10564 & 0.43880 & Biso & 1.000 & Al \\
\hline P 15 & 1.0000 & 0.33252 & 0.45400 & 0.56067 & Biso & 1.000 & $\mathrm{P}$ \\
\hline P16 & 1.0000 & 0.57049 & 0.90041 & 0.56357 & Biso & 1.000 & $\mathrm{P}$ \\
\hline P17 & 1.0000 & 0.10002 & 0.66836 & 0.56763 & Biso & 1.000 & $\mathrm{P}$ \\
\hline Al16 & 1.0000 & 0.10316 & 0.66962 & 0.77349 & Biso & 1.000 & Al \\
\hline Al17 & 1.0000 & 0.56067 & 0.89337 & 0.77419 & Biso & 1.000 & Al \\
\hline Al18 & 1.0000 & 0.32896 & 0.43808 & 0.76824 & Biso & 1.000 & Al \\
\hline 01 & 1.0000 & 0.91364 & 0.10965 & 0.13257 & Biso & 1.000 & 0 \\
\hline $\mathrm{O} 2$ & 1.0000 & 0.89932 & 0.81224 & 0.13231 & Biso & 1.000 & 0 \\
\hline 03 & 1.0000 & 0.19958 & 0.09045 & 0.12349 & Biso & 1.000 & 0 \\
\hline 04 & 1.0000 & 0.08425 & 0.88697 & 0.86639 & Biso & 1.000 & 0 \\
\hline 05 & 1.0000 & 0.80802 & 0.91394 & 0.87759 & Biso & 1.000 & 0 \\
\hline 06 & 1.0000 & 0.10475 & 0.19689 & 0.87637 & Biso & 1.000 & 0 \\
\hline 07 & 1.0000 & 0.57567 & 0.44197 & 0.45414 & Biso & 1.000 & 0 \\
\hline 08 & 1.0000 & 0.55753 & 0.13165 & 0.45641 & Biso & 1.000 & 0 \\
\hline 09 & 1.0000 & 0.87618 & 0.42964 & 0.46064 & Biso & 1.000 & 0 \\
\hline 010 & 1.0000 & 0.75819 & 0.22962 & 0.21212 & Biso & 1.000 & 0 \\
\hline 011 & 1.0000 & 0.47598 & 0.24946 & 0.20925 & Biso & 1.000 & 0 \\
\hline 012 & 1.0000 & 0.77762 & 0.53183 & 0.21448 & Biso & 1.000 & 0 \\
\hline 013 & 1.0000 & 0.23991 & 0.76993 & 0.80235 & Biso & 1.000 & 0 \\
\hline 014 & 1.0000 & 0.22529 & 0.47240 & 0.79101 & Biso & 1.000 & 0 \\
\hline 015 & 1.0000 & 0.52806 & 0.75461 & 0.78510 & Biso & 1.000 & 0 \\
\hline 016 & 1.0000 & 0.42625 & 0.57658 & 0.55657 & Biso & 1.000 & 0 \\
\hline 017 & 1.0000 & 0.10308 & 0.56010 & 0.56480 & Biso & 1.000 & 0 \\
\hline 018 & 1.0000 & 0.44996 & 0.86783 & 0.53747 & Biso & 1.000 & 0 \\
\hline 019 & 1.0000 & 0.98971 & 0.31273 & 0.16923 & Biso & 1.000 & 0 \\
\hline 020 & 1.0000 & 0.69734 & 0.68016 & 0.16970 & Biso & 1.000 & 0 \\
\hline 021 & 1.0000 & 0.33598 & 0.02266 & 0.14959 & Biso & 1.000 & 0 \\
\hline $\mathrm{O} 22$ & 1.0000 & 0.31603 & 0.97543 & 0.82859 & Biso & 1.000 & 0 \\
\hline 023 & 1.0000 & 0.65084 & 0.68290 & 0.84462 & Biso & 1.000 & 0 \\
\hline $\mathrm{O} 24$ & 1.0000 & 0.02682 & 0.34997 & 0.84401 & Biso & 1.000 & 0 \\
\hline 025 & 1.0000 & 0.65194 & 0.64179 & 0.50275 & Biso & 1.000 & 0 \\
\hline 026 & 1.0000 & 0.32518 & 0.98612 & 0.50716 & Biso & 1.000 & 0 \\
\hline $\mathrm{O} 27$ & 1.0000 & 0.99054 & 0.33972 & 0.50080 & Biso & 1.000 & 0 \\
\hline 028 & 1.0000 & 0.00876 & 0.68105 & 0.84306 & Biso & 1.000 & 0 \\
\hline O29 & 1.0000 & 0.30549 & 0.32305 & 0.83153 & Biso & 1.000 & 0 \\
\hline 030 & 1.0000 & 0.67397 & 0.98126 & 0.84033 & Biso & 1.000 & 0 \\
\hline 031 & 1.0000 & 0.68151 & 0.02917 & 0.16673 & Biso & 1.000 & 0 \\
\hline 032 & 1.0000 & 0.34837 & 0.32131 & 0.16273 & Biso & 1.000 & 0 \\
\hline 033 & 1.0000 & 0.97805 & 0.66145 & 0.17024 & Biso & 1.000 & 0 \\
\hline 034 & 1.0000 & 0.35127 & 0.38488 & 0.49138 & Biso & 1.000 & 0 \\
\hline 035 & 1.0000 & 0.00936 & 0.66171 & 0.50460 & Biso & 1.000 & 0 \\
\hline 036 & 1.0000 & 0.65370 & 0.99739 & 0.50615 & Biso & 1.000 & 0 \\
\hline 037 & 1.0000 & 0.11893 & 0.24247 & 0.13387 & Biso & 1.000 & 0 \\
\hline 038 & 1.0000 & 0.76221 & 0.87895 & 0.14031 & Biso & 1.000 & 0 \\
\hline 039 & 1.0000 & 0.13212 & 0.88743 & 0.13807 & Biso & 1.000 & 0 \\
\hline 040 & 1.0000 & 0.23507 & 0.12322 & 0.86190 & Biso & 1.000 & 0 \\
\hline 041 & 1.0000 & 0.87961 & 0.75363 & 0.86824 & Biso & 1.000 & 0 \\
\hline 042 & 1.0000 & 0.87324 & 0.11756 & 0.86751 & Biso & 1.000 & 0 \\
\hline 043 & 1.0000 & 0.78044 & 0.57066 & 0.46852 & Biso & 1.000 & 0 \\
\hline 044 & 1.0000 & 0.40294 & 0.21459 & 0.47922 & Biso & 1.000 & 0 \\
\hline 045 & 1.0000 & 0.78998 & 0.22342 & 0.46795 & Biso & 1.000 & 0 \\
\hline 046 & 1.0000 & 0.91342 & 0.46379 & 0.20641 & Biso & 1.000 & 0 \\
\hline 047 & 1.0000 & 0.55342 & 0.09573 & 0.21291 & Biso & 1.000 & 0 \\
\hline 048 & 1.0000 & 0.54482 & 0.45338 & 0.20260 & Biso & 1.000 & 0 \\
\hline 049 & 1.0000 & 0.44550 & 0.90156 & 0.81101 & Biso & 1.000 & 0 \\
\hline 050 & 1.0000 & 0.08732 & 0.53820 & 0.78535 & Biso & 1.000 & 0 \\
\hline 051 & 1.0000 & 0.45768 & 0.55061 & 0.79774 & Biso & 1.000 & 0 \\
\hline 052 & 1.0000 & 0.58865 & 0.80184 & 0.54654 & Biso & 1.000 & 0 \\
\hline 053 & 1.0000 & 0.22268 & 0.44933 & 0.53825 & Biso & 1.000 & 0 \\
\hline 054 & 1.0000 & 0.21279 & 0.76301 & 0.53529 & Biso & 1.000 & 0 \\
\hline 055 & 1.0000 & 0.00004 & 0.25684 & 0.01344 & Biso & 1.000 & 0 \\
\hline 056 & 1.0000 & 0.74911 & 0.75156 & 0.01507 & Biso & 1.000 & 0 \\
\hline 057 & 1.0000 & 0.24374 & 0.99075 & 0.00284 & Biso & 1.000 & 0 \\
\hline 058 & 1.0000 & 0.67494 & 0.60081 & 0.34533 & Biso & 1.000 & 0 \\
\hline 059 & 1.0000 & 0.37151 & 0.06452 & 0.33093 & Biso & 1.000 & 0 \\
\hline 060 & 1.0000 & 0.92694 & 0.33074 & 0.34500 & Biso & 1.000 & 0 \\
\hline 061 & 1.0000 & 0.33732 & 0.90926 & 0.67946 & Biso & 1.000 & 0 \\
\hline 062 & 1.0000 & 0.06574 & 0.38501 & 0.68177 & Biso & 1.000 & 0 \\
\hline 063 & 1.0000 & 0.60410 & 0.66431 & 0.68253 & Biso & 1.000 & 0 \\
\hline
\end{tabular}




\begin{tabular}{|c|c|c|c|c|c|c|c|}
\hline 064 & 1.0000 & 0.99904 & 0.75014 & 0.99378 & Biso & 1.000 & $\mathrm{O}$ \\
\hline 065 & 1.0000 & 0.26001 & 0.25473 & 0.98805 & Biso & 1.000 & 0 \\
\hline 066 & 1.0000 & 0.74909 & 0.00502 & 0.99459 & Biso & 1.000 & 0 \\
\hline 067 & 1.0000 & 0.67543 & 0.07447 & 0.32661 & Biso & 1.000 & 0 \\
\hline 068 & 1.0000 & 0.93283 & 0.59917 & 0.32792 & Biso & 1.000 & 0 \\
\hline 069 & 1.0000 & 0.40706 & 0.33733 & 0.32176 & Biso & 1.000 & 0 \\
\hline 070 & 1.0000 & 0.32749 & 0.40685 & 0.65481 & Biso & 1.000 & 0 \\
\hline 071 & 1.0000 & 0.59035 & 0.93440 & 0.66256 & Biso & 1.000 & 0 \\
\hline 072 & 1.0000 & 0.07606 & 0.69148 & 0.66302 & Biso & 1.000 & 0 \\
\hline H 1 & 1.0000 & 0.24039 & 0.00949 & 0.31766 & Biso & 1.000 & $\mathrm{H}$ \\
\hline $\mathrm{C} 1$ & 1.0000 & 0.11086 & 0.89527 & 0.39772 & Biso & 1.000 & $\mathrm{C}$ \\
\hline $\mathrm{H} 2$ & 1.0000 & 0.16969 & 0.98008 & 0.31213 & Biso & 1.000 & $\mathrm{H}$ \\
\hline H3 & 1.0000 & 0.14662 & 0.84327 & 0.37838 & Biso & 1.000 & $\mathrm{H}$ \\
\hline H 4 & 1.0000 & 0.03070 & 0.87617 & 0.36810 & Biso & 1.000 & $\mathrm{H}$ \\
\hline 073 & 1.0000 & 0.13904 & 0.94995 & 0.47038 & Biso & 1.000 & 0 \\
\hline H5 & 1.0000 & 0.22426 & 0.96525 & 0.49308 & Biso & 1.000 & $\mathrm{H}$ \\
\hline \multirow{2}{*}{\multicolumn{8}{|c|}{$\mathrm{Ga} 6$}} \\
\hline & \multicolumn{7}{|c|}{ data_image 0} \\
\hline \multicolumn{8}{|c|}{13.625} \\
\hline \multicolumn{8}{|c|}{13.625} \\
\hline \multicolumn{8}{|c|}{15.067} \\
\hline \multicolumn{8}{|c|}{ alpha } \\
\hline \multicolumn{8}{|c|}{90} \\
\hline $\mathrm{cell}_{-}^{-}$ & gamma & 120 & & & & & \\
\hline symme & pace $g$ & nam & & 1" & & & \\
\hline symme & nt_tab. & les_ñumbe & & & & & \\
\hline op_ & & & & & & & \\
\hline -sym & equiv & oos as & & & & & \\
\hline ' $\mathrm{x}$ & & & & & & & \\
\hline op_ & & & & & & & \\
\hline ato & labe & & & & & & \\
\hline -ato & te_occup & pancy & & & & & \\
\hline -ato & te_fract & E $x$ & & & & & \\
\hline -ato & $=e^{-}$fract & ty & & & & & \\
\hline ato & $=e^{-}$fract & $z$ & & & & & \\
\hline -ato & e-thern & nàl_displ & ace_type & & & & \\
\hline -ato & e_B_is & o_or_equi & & & & & \\
\hline -ato & ze_type & symbol & & & & & \\
\hline$\overline{\mathrm{S}} \mathrm{i} 1$ & 1.0000 & 0.01359 & 0.23767 & 0.10260 & Biso & 1.000 & $\mathrm{Si}$ \\
\hline $\mathrm{Si2}$ & 1.0000 & 0.78638 & 0.78242 & 0.10593 & Biso & 1.000 & $\mathrm{Si}$ \\
\hline $\mathrm{Si3}$ & 1.0000 & 0.24409 & 0.00893 & 0.09580 & Biso & 1.000 & $\mathrm{Si}$ \\
\hline Si4 & 1.0000 & 0.23463 & 0.00386 & 0.88815 & Biso & 1.000 & $\mathrm{Si}$ \\
\hline Si5 & 1.0000 & 0.78170 & 0.77713 & 0.89812 & Biso & 1.000 & $\mathrm{Si}$ \\
\hline Si6 & 1.0000 & 0.00921 & 0.23666 & 0.89585 & Biso & 1.000 & $\mathrm{Si}$ \\
\hline Si7 & 1.0000 & 0.67701 & 0.56934 & 0.43581 & Biso & 1.000 & $\mathrm{Si}$ \\
\hline Ga 1 & 1.0000 & 0.44283 & 0.11336 & 0.43498 & Biso & 1.000 & $\mathrm{Ga}$ \\
\hline Si8 & 1.0000 & 0.91494 & 0.34070 & 0.43428 & Biso & 1.000 & $\mathrm{Si}$ \\
\hline Si9 & 1.0000 & 0.91171 & 0.34330 & 0.22951 & Biso & 1.000 & $\mathrm{Si}$ \\
\hline Si 10 & 1.0000 & 0.44855 & 0.11292 & 0.22418 & Biso & 1.000 & $\mathrm{Si}$ \\
\hline Si11 & 1.0000 & 0.68077 & 0.57261 & 0.23119 & Biso & 1.000 & $\mathrm{Si}$ \\
\hline Si 12 & 1.0000 & 0.34249 & 0.89674 & 0.77078 & Biso & 1.000 & $\mathrm{Si}$ \\
\hline Sil3 & 1.0000 & 0.11160 & 0.43867 & 0.76645 & Biso & 1.000 & $\mathrm{Si}$ \\
\hline Si 14 & 1.0000 & 0.57531 & 0.67310 & 0.76918 & Biso & 1.000 & $\mathrm{Si}$ \\
\hline $\operatorname{Si} 15$ & 1.0000 & 0.58492 & 0.68004 & 0.56728 & Biso & 1.000 & $\mathrm{Si}$ \\
\hline Si 16 & 1.0000 & 0.10874 & 0.43770 & 0.56696 & Biso & 1.000 & $\mathrm{Si}$ \\
\hline $\operatorname{Si} 17$ & 1.0000 & 0.34325 & 0.89119 & 0.56210 & Biso & 1.000 & $\mathrm{Si}$ \\
\hline Si18 & 1.0000 & 0.00781 & 0.77393 & 0.89599 & Biso & 1.000 & $\mathrm{Si}$ \\
\hline Sil19 & 1.0000 & 0.23881 & 0.23568 & 0.89123 & Biso & 1.000 & $\mathrm{Si}$ \\
\hline Si20 & 1.0000 & 0.78283 & 0.00616 & 0.89616 & Biso & 1.000 & $\mathrm{Si}$ \\
\hline Si21 & 1.0000 & 0.78376 & 0.00918 & 0.10387 & Biso & 1.000 & $\mathrm{Si}$ \\
\hline $\mathrm{Si} 22$ & 1.0000 & 0.24380 & 0.23842 & 0.09816 & Biso & 1.000 & $\mathrm{Si}$ \\
\hline Si23 & 1.0000 & 0.01531 & 0.78284 & 0.10475 & Biso & 1.000 & $\mathrm{Si}$ \\
\hline $\mathrm{Si} 24$ & 1.0000 & 0.68180 & 0.11297 & 0.23255 & Biso & 1.000 & $\mathrm{Si}$ \\
\hline Si25 & 1.0000 & 0.91009 & 0.57273 & 0.23078 & Biso & 1.000 & $\mathrm{Si}$ \\
\hline Si26 & 1.0000 & 0.45007 & 0.34216 & 0.22724 & Biso & 1.000 & $\mathrm{Si}$ \\
\hline Si27 & 1.0000 & 0.43899 & 0.34266 & 0.43388 & Biso & 1.000 & $\mathrm{Si}$ \\
\hline Si28 & 1.0000 & 0.90862 & 0.57059 & 0.43667 & Biso & 1.000 & $\mathrm{Si}$ \\
\hline $\operatorname{Si} 29$ & 1.0000 & 0.68299 & 0.11283 & 0.43557 & Biso & 1.000 & $\mathrm{Si}$ \\
\hline Si30 & 1.0000 & 0.34690 & 0.45701 & 0.56128 & Biso & 1.000 & $\mathrm{Si}$ \\
\hline $\operatorname{Si} 31$ & 1.0000 & 0.58113 & 0.90946 & 0.56378 & Biso & 1.000 & $\mathrm{Si}$ \\
\hline $\operatorname{Si} 32$ & 1.0000 & 0.10488 & 0.67169 & 0.56885 & Biso & 1.000 & $\mathrm{Si}$ \\
\hline $\mathrm{Si} 33$ & 1.0000 & 0.11042 & 0.67253 & 0.76964 & Biso & 1.000 & $\mathrm{Si}$ \\
\hline $\mathrm{Si} 34$ & 1.0000 & 0.57214 & 0.90295 & 0.77016 & Biso & 1.000 & $\mathrm{Si}$ \\
\hline Si35 & 1.0000 & 0.34283 & 0.44372 & 0.76503 & Biso & 1.000 & $\mathrm{Si}$ \\
\hline 01 & 1.0000 & 0.91496 & 0.10721 & 0.12109 & Biso & 1.000 & 0 \\
\hline $\mathrm{O} 2$ & 1.0000 & 0.91823 & 0.81698 & 0.12365 & Biso & 1.000 & 0 \\
\hline 03 & 1.0000 & 0.21182 & 0.10723 & 0.11467 & Biso & 1.000 & 0 \\
\hline
\end{tabular}




\begin{tabular}{|c|c|c|c|c|c|c|c|}
\hline 04 & 1.0000 & 0.10459 & 0.90310 & 0.87106 & Biso & 1.000 & 0 \\
\hline 05 & 1.0000 & 0.81706 & 0.90868 & 0.87939 & Biso & 1.000 & O \\
\hline 06 & 1.0000 & 0.10843 & 0.20602 & 0.87704 & Biso & 1.000 & 0 \\
\hline 07 & 1.0000 & 0.57168 & 0.44177 & 0.44734 & Biso & 1.000 & 0 \\
\hline 08 & 1.0000 & 0.58606 & 0.14504 & 0.44933 & Biso & 1.000 & 0 \\
\hline 09 & 1.0000 & 0.89073 & 0.44495 & 0.45235 & Biso & 1.000 & 0 \\
\hline 010 & 1.0000 & 0.78013 & 0.24468 & 0.21610 & Biso & 1.000 & 0 \\
\hline 011 & 1.0000 & 0.48572 & 0.24589 & 0.21015 & Biso & 1.000 & 0 \\
\hline 012 & 1.0000 & 0.77882 & 0.53902 & 0.21491 & Biso & 1.000 & 0 \\
\hline 013 & 1.0000 & 0.24186 & 0.76730 & 0.79036 & Biso & 1.000 & 0 \\
\hline 014 & 1.0000 & 0.24386 & 0.47556 & 0.78384 & Biso & 1.000 & $\mathrm{O}$ \\
\hline 015 & 1.0000 & 0.54159 & 0.77160 & 0.77870 & Biso & 1.000 & 0 \\
\hline 016 & 1.0000 & 0.45218 & 0.58618 & 0.55390 & Biso & 1.000 & 0 \\
\hline 017 & 1.0000 & 0.11158 & 0.55750 & 0.56391 & Biso & 1.000 & 0 \\
\hline 018 & 1.0000 & 0.45096 & 0.87573 & 0.53841 & Biso & 1.000 & 0 \\
\hline 019 & 1.0000 & 0.99537 & 0.32460 & 0.16416 & Biso & 1.000 & 0 \\
\hline 020 & 1.0000 & 0.70142 & 0.67652 & 0.16728 & Biso & 1.000 & 0 \\
\hline 021 & 1.0000 & 0.35746 & 0.03418 & 0.14878 & Biso & 1.000 & 0 \\
\hline 022 & 1.0000 & 0.32160 & 0.98684 & 0.82570 & Biso & 1.000 & 0 \\
\hline 023 & 1.0000 & 0.67176 & 0.69133 & 0.84054 & Biso & 1.000 & 0 \\
\hline 024 & 1.0000 & 0.02830 & 0.34391 & 0.83679 & Biso & 1.000 & 0 \\
\hline 025 & 1.0000 & 0.66537 & 0.65796 & 0.50079 & Biso & 1.000 & 0 \\
\hline 026 & 1.0000 & 0.33799 & 0.98727 & 0.50079 & Biso & 1.000 & O \\
\hline 027 & 1.0000 & 0.01716 & 0.35165 & 0.49627 & Biso & 1.000 & 0 \\
\hline 028 & 1.0000 & 0.02632 & 0.68267 & 0.84030 & Biso & 1.000 & 0 \\
\hline 029 & 1.0000 & 0.32421 & 0.33893 & 0.82749 & Biso & 1.000 & 0 \\
\hline 030 & 1.0000 & 0.67633 & 0.98402 & 0.83478 & Biso & 1.000 & 0 \\
\hline 031 & 1.0000 & 0.69782 & 0.03059 & 0.16367 & Biso & 1.000 & 0 \\
\hline 032 & 1.0000 & 0.35002 & 0.32418 & 0.15915 & Biso & 1.000 & 0 \\
\hline 033 & 1.0000 & 0.99506 & 0.67797 & 0.16789 & Biso & 1.000 & 0 \\
\hline 034 & 1.0000 & 0.35745 & 0.37706 & 0.48800 & Biso & 1.000 & 0 \\
\hline 035 & 1.0000 & 0.00913 & 0.66402 & 0.50012 & Biso & 1.000 & 0 \\
\hline 036 & 1.0000 & 0.66938 & 0.01213 & 0.50163 & Biso & 1.000 & 0 \\
\hline 037 & 1.0000 & 0.13537 & 0.25032 & 0.12614 & Biso & 1.000 & 0 \\
\hline 038 & 1.0000 & 0.77128 & 0.88898 & 0.13277 & Biso & 1.000 & 0 \\
\hline 039 & 1.0000 & 0.13835 & 0.88957 & 0.13068 & Biso & 1.000 & 0 \\
\hline 040 & 1.0000 & 0.24636 & 0.12475 & 0.86394 & Biso & 1.000 & 0 \\
\hline 041 & 1.0000 & 0.88570 & 0.75828 & 0.86953 & Biso & 1.000 & 0 \\
\hline 042 & 1.0000 & 0.88898 & 0.12799 & 0.86869 & Biso & 1.000 & 0 \\
\hline 043 & 1.0000 & 0.79316 & 0.57025 & 0.46143 & Biso & 1.000 & 0 \\
\hline 044 & 1.0000 & 0.41760 & 0.22410 & 0.47168 & Biso & 1.000 & 0 \\
\hline 045 & 1.0000 & 0.80448 & 0.22275 & 0.45943 & Biso & 1.000 & 0 \\
\hline 046 & 1.0000 & 0.92400 & 0.46504 & 0.20566 & Biso & 1.000 & 0 \\
\hline 047 & 1.0000 & 0.55990 & 0.10116 & 0.21265 & Biso & 1.000 & 0 \\
\hline 048 & 1.0000 & 0.55922 & 0.46505 & 0.20631 & Biso & 1.000 & 0 \\
\hline 049 & 1.0000 & 0.46232 & 0.91038 & 0.80201 & Biso & 1.000 & 0 \\
\hline 050 & 1.0000 & 0.09668 & 0.54833 & 0.77876 & Biso & 1.000 & 0 \\
\hline 051 & 1.0000 & 0.46405 & 0.55225 & 0.79027 & Biso & 1.000 & 0 \\
\hline 052 & 1.0000 & 0.59956 & 0.80280 & 0.54519 & Biso & 1.000 & 0 \\
\hline 053 & 1.0000 & 0.23268 & 0.46061 & 0.53970 & Biso & 1.000 & 0 \\
\hline 054 & 1.0000 & 0.22677 & 0.77536 & 0.53804 & Biso & 1.000 & 0 \\
\hline 055 & 1.0000 & 0.00975 & 0.27015 & 0.99939 & Biso & 1.000 & 0 \\
\hline 056 & 1.0000 & 0.75261 & 0.74733 & 0.00270 & Biso & 1.000 & 0 \\
\hline 057 & 1.0000 & 0.26766 & 0.00124 & 0.99134 & Biso & 1.000 & 0 \\
\hline 058 & 1.0000 & 0.68470 & 0.61253 & 0.33366 & Biso & 1.000 & 0 \\
\hline 059 & 1.0000 & 0.38671 & 0.06656 & 0.32016 & Biso & 1.000 & 0 \\
\hline 060 & 1.0000 & 0.95186 & 0.34354 & 0.33115 & Biso & 1.000 & 0 \\
\hline 061 & 1.0000 & 0.34572 & 0.92482 & 0.66568 & Biso & 1.000 & 0 \\
\hline 062 & 1.0000 & 0.07442 & 0.38560 & 0.66688 & Biso & 1.000 & 0 \\
\hline 063 & 1.0000 & 0.62302 & 0.67563 & 0.66937 & Biso & 1.000 & 0 \\
\hline 064 & 1.0000 & 0.01254 & 0.74862 & 0.00114 & Biso & 1.000 & 0 \\
\hline 065 & 1.0000 & 0.27655 & 0.27133 & 0.99417 & Biso & 1.000 & 0 \\
\hline 066 & 1.0000 & 0.74980 & 0.00646 & 0.99994 & Biso & 1.000 & 0 \\
\hline 067 & 1.0000 & 0.68749 & 0.07346 & 0.33329 & Biso & 1.000 & O \\
\hline 068 & 1.0000 & 0.94614 & 0.61171 & 0.33401 & Biso & 1.000 & 0 \\
\hline 069 & 1.0000 & 0.40673 & 0.33665 & 0.32835 & Biso & 1.000 & 0 \\
\hline 070 & 1.0000 & 0.34126 & 0.40835 & 0.66143 & Biso & 1.000 & 0 \\
\hline 071 & 1.0000 & 0.60520 & 0.94638 & 0.66806 & Biso & 1.000 & 0 \\
\hline 072 & 1.0000 & 0.07547 & 0.69169 & 0.66979 & Biso & 1.000 & 0 \\
\hline $\mathrm{H} 1$ & 1.0000 & 0.25106 & 0.01268 & 0.30762 & Biso & 1.000 & $\mathrm{H}$ \\
\hline $\mathrm{C} 1$ & 1.0000 & 0.12160 & 0.89959 & 0.38909 & Biso & 1.000 & $\mathrm{C}$ \\
\hline $\mathrm{H} 2$ & 1.0000 & 0.18003 & 0.98559 & 0.30263 & Biso & 1.000 & $\mathrm{H}$ \\
\hline H 3 & 1.0000 & 0.15821 & 0.84670 & 0.37035 & Biso & 1.000 & $\mathrm{H}$ \\
\hline H 4 & 1.0000 & 0.04003 & 0.88002 & 0.35955 & Biso & 1.000 & $\mathrm{H}$ \\
\hline 073 & 1.0000 & 0.15048 & 0.95632 & 0.46105 & Biso & 1.000 & 0 \\
\hline H5 & 1.0000 & 0.23375 & 0.96901 & 0.48487 & Biso & 1.000 & $\mathrm{H}$ \\
\hline
\end{tabular}

data_image 0

_cel̄_length_a $\quad 13.875$

_cell_length_b 13.875 


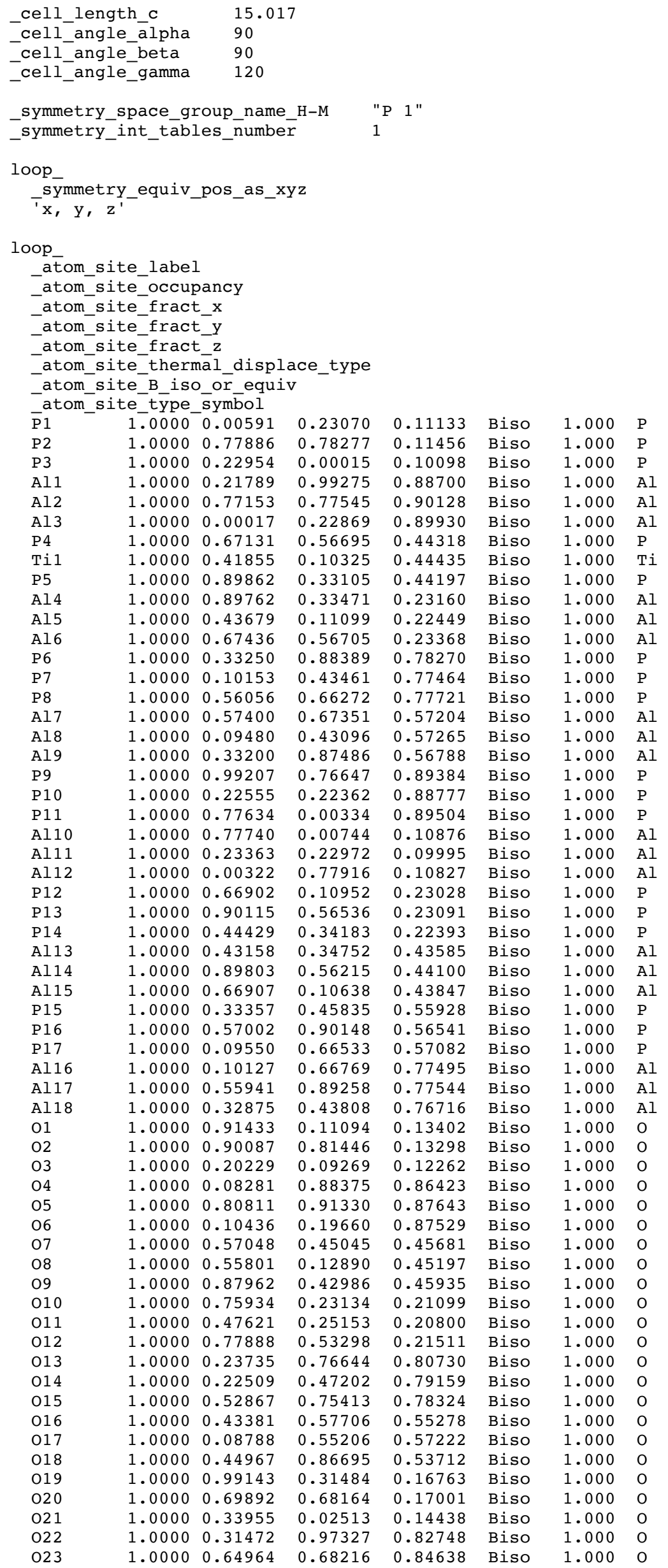




\begin{tabular}{|c|c|c|c|c|c|c|c|}
\hline 024 & 1.0000 & 0.02633 & 0.34979 & 0.84438 & Biso & 1.000 & 0 \\
\hline 025 & 1.0000 & 0.66277 & 0.65211 & 0.50304 & Biso & 1.000 & 0 \\
\hline 026 & 1.0000 & 0.31768 & 0.97791 & 0.51231 & Biso & 1.000 & 0 \\
\hline 027 & 1.0000 & 0.99527 & 0.34010 & 0.49817 & Biso & 1.000 & \\
\hline 028 & 1.0000 & 0.00628 & 0.67681 & 0.84559 & Biso & 1.000 & \\
\hline 029 & 1.0000 & 0.30462 & 0.32140 & 0.82854 & Biso & 1.000 & \\
\hline 030 & 1.0000 & 0.67294 & 0.97991 & 0.84156 & Biso & 1.000 & \\
\hline 031 & 1.0000 & 0.68149 & 0.03086 & 0.16539 & Biso & 1.000 & \\
\hline 032 & 1.0000 & 0.34989 & 0.32433 & 0.16057 & Biso & 1.000 & \\
\hline 033 & 1.0000 & 0.97940 & 0.66360 & 0.17139 & Biso & 1.000 & \\
\hline 034 & 1.0000 & 0.34168 & 0.38361 & 0.48856 & Biso & 1.000 & \\
\hline 035 & 1.0000 & 0.00702 & 0.66217 & 0.50697 & Biso & 1.000 & \\
\hline 036 & 1.0000 & 0.65386 & 0.99814 & 0.50788 & Biso & 1.000 & \\
\hline 037 & 1.0000 & 0.11999 & 0.24350 & 0.13184 & Biso & 1.000 & \\
\hline 038 & 1.0000 & 0.76312 & 0.88043 & 0.14164 & Biso & 1.000 & \\
\hline 039 & 1.0000 & 0.13440 & 0.88960 & 0.13799 & Biso & 1.000 & \\
\hline 040 & 1.0000 & 0.23321 & 0.12151 & 0.85936 & Biso & 1.000 & \\
\hline 041 & 1.0000 & 0.87813 & 0.75111 & 0.86888 & Biso & 1.000 & \\
\hline 042 & 1.0000 & 0.87279 & 0.11675 & 0.86593 & Biso & 1.000 & \\
\hline 043 & 1.0000 & 0.77734 & 0.56452 & 0.46826 & Biso & 1.000 & \\
\hline 044 & 1.0000 & 0.40933 & 0.22222 & 0.47719 & Biso & 1.000 & \\
\hline 045 & 1.0000 & 0.79383 & 0.22394 & 0.46868 & Biso & 1.000 & \\
\hline 046 & 1.0000 & 0.91539 & 0.46582 & 0.20735 & Biso & 1.000 & \\
\hline 047 & 1.0000 & 0.55448 & 0.09754 & 0.21546 & Biso & 1.000 & \\
\hline 048 & 1.0000 & 0.54603 & 0.45564 & 0.20301 & Biso & 1.000 & \\
\hline 049 & 1.0000 & 0.44348 & 0.89763 & 0.81518 & Biso & 1.000 & \\
\hline 050 & 1.0000 & 0.08555 & 0.53573 & 0.78136 & Biso & 1.000 & \\
\hline 051 & 1.0000 & 0.45746 & 0.55008 & 0.79747 & Biso & 1.000 & ) \\
\hline 052 & 1.0000 & 0.59067 & 0.80409 & 0.55098 & Biso & 1.000 & $\mathrm{O}$ \\
\hline 053 & 1.0000 & 0.22808 & 0.46429 & 0.54075 & Biso & 1.000 & \\
\hline 054 & 1.0000 & 0.21137 & 0.75208 & 0.53686 & Biso & 1.000 & \\
\hline 055 & 1.0000 & 0.99836 & 0.25501 & 0.01258 & Biso & 1.000 & \\
\hline 056 & 1.0000 & 0.75056 & 0.75405 & 0.01578 & Biso & 1.000 & ) \\
\hline 057 & 1.0000 & 0.24100 & 0.99041 & 0.00058 & Biso & 1.000 & \\
\hline 058 & 1.0000 & 0.67784 & 0.60398 & 0.34559 & Biso & 1.000 & 0 \\
\hline 059 & 1.0000 & 0.36932 & 0.06788 & 0.32761 & Biso & 1.000 & \\
\hline 060 & 1.0000 & 0.92812 & 0.32937 & 0.34359 & Biso & 1.000 & 0 \\
\hline 061 & 1.0000 & 0.33579 & 0.89991 & 0.68155 & Biso & 1.000 & \\
\hline 062 & 1.0000 & 0.06677 & 0.37966 & 0.68193 & Biso & 1.000 & ) \\
\hline 063 & 1.0000 & 0.60619 & 0.66284 & 0.68351 & Biso & 1.000 & \\
\hline 064 & 1.0000 & 0.99931 & 0.75145 & 0.99465 & Biso & 1.000 & 0 \\
\hline 065 & 1.0000 & 0.26082 & 0.25426 & 0.98566 & Biso & 1.000 & 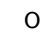 \\
\hline 066 & 1.0000 & 0.75170 & 0.00525 & 0.99463 & Biso & 1.000 & \\
\hline 067 & 1.0000 & 0.68025 & 0.07650 & 0.32592 & Biso & 1.000 & 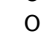 \\
\hline 068 & 1.0000 & 0.93384 & 0.60082 & 0.32892 & Biso & 1.000 & 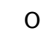 \\
\hline 069 & 1.0000 & 0.40619 & 0.33939 & 0.32037 & Biso & 1.000 & ( \\
\hline 070 & 1.0000 & 0.32816 & 0.41006 & 0.65303 & Biso & 1.000 & ( \\
\hline 071 & 1.0000 & 0.58737 & 0.93668 & 0.66422 & Biso & 1.000 & $\mathrm{O}$ \\
\hline 072 & 1.0000 & 0.07610 & 0.69562 & 0.66535 & Biso & 1.000 & 0 \\
\hline $\mathrm{H} 1$ & 1.0000 & 0.24021 & 0.01046 & 0.31612 & Biso & 1.000 & $\mathrm{H}$ \\
\hline $\mathrm{C} 1$ & 1.0000 & 0.10779 & 0.89181 & 0.39723 & Biso & 1.000 & $c$ \\
\hline H2 & 1.0000 & 0.16822 & 0.97832 & 0.31351 & Biso & 1.000 & 1 \\
\hline $\mathrm{H} 3$ & 1.0000 & 0.14369 & 0.84016 & 0.37707 & Biso & 1.000 & $\mathrm{r}$ \\
\hline $\mathrm{H} 4$ & 1.0000 & 0.02834 & 0.87361 & 0.36662 & Biso & 1.000 & $\mathrm{H}$ \\
\hline 073 & 1.0000 & 0.13427 & 0.94380 & 0.47105 & Biso & 1.000 & 0 \\
\hline H5 & 1.0000 & 0.22032 & 0.95726 & 0.49659 & Biso & 1.000 & $\mathrm{H}$ \\
\hline \multicolumn{8}{|c|}{$\mathrm{Zn} 7$} \\
\hline \multicolumn{8}{|c|}{ data_image 0} \\
\hline \multicolumn{8}{|c|}{13.875} \\
\hline \multicolumn{2}{|c|}{ cell length b } & \multicolumn{2}{|c|}{13.875} & & & & \\
\hline $\mathrm{cell}$ & $t h \mathrm{c}$ & \multicolumn{2}{|c|}{15.017} & & & & \\
\hline cell & e_alpha & 90 & & & & & \\
\hline cell & e_beta & 90 & & & & & \\
\hline$[\mathrm{cell}]$ & e_gamma & 120 & & & & & \\
\hline symme & pace_g & coup_name & H-M & P $1 "$ & & & \\
\hline symme & nt_t $\bar{a} b$ & Les_numbe & & & & & \\
\hline Loop_ & & & & & & & \\
\hline$=-$ & $-c q u+v$ & pos_ds_ & & & & & \\
\hline ' $\mathrm{x}$, & & & & & & & \\
\hline loop_ & & & & & & & \\
\hline at & e labe & & & & & & \\
\hline at & $e^{-}$occur & pancy & & & & & \\
\hline$-a t$ & efra & $x$ & & & & & \\
\hline$-a t$ & $e^{-} f r a$ & $\begin{array}{l}x \\
y\end{array}$ & & & & & \\
\hline- at & $e^{-11 d}$ & 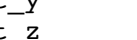 & & & & & \\
\hline$-a t$ & $\begin{array}{l}\text { Ira } \\
\text { the }\end{array}$ & $z$ & & & & & \\
\hline at & & & & & & & \\
\hline
\end{tabular}




\begin{tabular}{|c|c|c|c|c|c|c|c|}
\hline$\overline{\mathrm{A}} 11$ & 1.0000 & 0.99260 & 0.22604 & 0.10794 & Biso & 1.000 & Al \\
\hline Al2 & 1.0000 & 0.77064 & 0.77490 & 0.11196 & Biso & 1.000 & Al \\
\hline Al3 & 1.0000 & 0.22588 & 0.00511 & 0.10228 & Biso & 1.000 & Al \\
\hline P1 & 1.0000 & 0.21499 & 0.99871 & 0.88891 & Biso & 1.000 & $P$ \\
\hline P2 & 1.0000 & 0.76772 & 0.76945 & 0.89957 & Biso & 1.000 & $P$ \\
\hline P3 & 1.0000 & 0.98809 & 0.22410 & 0.89540 & Biso & 1.000 & $\mathrm{P}$ \\
\hline Al4 & 1.0000 & 0.65180 & 0.55295 & 0.44139 & Biso & 1.000 & Al \\
\hline Zn1 & 1.0000 & 0.43930 & 0.10862 & 0.43911 & Biso & 1.000 & $\mathrm{Zn}$ \\
\hline Al5 & 1.0000 & 0.89643 & 0.33422 & 0.43943 & Biso & 1.000 & Al \\
\hline P4 & 1.0000 & 0.89447 & 0.33987 & 0.23018 & Biso & 1.000 & $P$ \\
\hline P5 & 1.0000 & 0.43394 & 0.10356 & 0.22420 & Biso & 1.000 & $\mathrm{P}$ \\
\hline P6 & 1.0000 & 0.65897 & 0.56006 & 0.23132 & Biso & 1.000 & P \\
\hline Al6 & 1.0000 & 0.32197 & 0.88839 & 0.77439 & Biso & 1.000 & Al \\
\hline Al 7 & 1.0000 & 0.09896 & 0.43235 & 0.77333 & Biso & 1.000 & Al \\
\hline Al8 & 1.0000 & 0.55718 & 0.66899 & 0.77511 & Biso & 1.000 & Al \\
\hline P7 & 1.0000 & 0.56467 & 0.67532 & 0.56740 & Biso & 1.000 & $\mathrm{P}$ \\
\hline P8 & 1.0000 & 0.09822 & 0.43414 & 0.56765 & Biso & 1.000 & $\mathrm{P}$ \\
\hline P9 & 1.0000 & 0.32034 & 0.88302 & 0.56234 & Biso & 1.000 & $\mathrm{P}$ \\
\hline Al9 & 1.0000 & 0.99344 & 0.76897 & 0.90308 & Biso & 1.000 & Al \\
\hline Al10 & 1.0000 & 0.21681 & 0.22566 & 0.89527 & Biso & 1.000 & Al \\
\hline Al11 & 1.0000 & 0.76523 & 0.99469 & 0.90019 & Biso & 1.000 & Al \\
\hline P10 & 1.0000 & 0.76717 & 0.99848 & 0.11333 & Biso & 1.000 & $P$ \\
\hline P11 & 1.0000 & 0.22136 & 0.22900 & 0.10889 & Biso & 1.000 & P \\
\hline P12 & 1.0000 & 0.00027 & 0.78009 & 0.11641 & Biso & 1.000 & $\mathrm{P}$ \\
\hline Al12 & 1.0000 & 0.66626 & 0.10917 & 0.23675 & Biso & 1.000 & Al \\
\hline Al13 & 1.0000 & 0.88886 & 0.56412 & 0.23588 & Biso & 1.000 & Al \\
\hline Al1 14 & 1.0000 & 0.43249 & 0.33143 & 0.23104 & Biso & 1.000 & Al \\
\hline P13 & 1.0000 & 0.41999 & 0.32880 & 0.44131 & Biso & 1.000 & $\mathrm{P}$ \\
\hline P14 & 1.0000 & 0.88411 & 0.55838 & 0.44657 & Biso & 1.000 & $P$ \\
\hline P15 & 1.0000 & 0.67014 & 0.11134 & 0.44318 & Biso & 1.000 & $\mathrm{P}$ \\
\hline Al15 & 1.0000 & 0.33264 & 0.44929 & 0.56769 & Biso & 1.000 & Al \\
\hline Al16 & 1.0000 & 0.55304 & 0.89622 & 0.56798 & Biso & 1.000 & Al \\
\hline Al17 & 1.0000 & 0.08748 & 0.66130 & 0.57566 & Biso & 1.000 & Al \\
\hline P16 & 1.0000 & 0.09447 & 0.66159 & 0.78176 & Biso & 1.000 & $P$ \\
\hline P17 & 1.0000 & 0.55005 & 0.89292 & 0.77940 & Biso & 1.000 & $\mathrm{P}$ \\
\hline P18 & 1.0000 & 0.32946 & 0.43829 & 0.77604 & Biso & 1.000 & P \\
\hline 01 & 1.0000 & 0.88879 & 0.08926 & 0.13186 & Biso & 1.000 & 0 \\
\hline $\mathrm{O} 2$ & 1.0000 & 0.90914 & 0.81028 & 0.13441 & Biso & 1.000 & 0 \\
\hline $\mathrm{O3}$ & 1.0000 & 0.19408 & 0.10903 & 0.13140 & Biso & 1.000 & 0 \\
\hline 04 & 1.0000 & 0.09526 & 0.90369 & 0.87125 & Biso & 1.000 & 0 \\
\hline 05 & 1.0000 & 0.80008 & 0.89103 & 0.87933 & Biso & 1.000 & 0 \\
\hline 06 & 1.0000 & 0.08114 & 0.19766 & 0.87458 & Biso & 1.000 & 0 \\
\hline 07 & 1.0000 & 0.54392 & 0.41706 & 0.45771 & Biso & 1.000 & 0 \\
\hline 08 & 1.0000 & 0.59404 & 0.16032 & 0.45332 & Biso & 1.000 & 0 \\
\hline 09 & 1.0000 & 0.86544 & 0.44073 & 0.46126 & Biso & 1.000 & 0 \\
\hline 010 & 1.0000 & 0.77251 & 0.24760 & 0.21851 & Biso & 1.000 & 0 \\
\hline 011 & 1.0000 & 0.46400 & 0.22609 & 0.21165 & Biso & 1.000 & 0 \\
\hline 012 & 1.0000 & 0.75189 & 0.53152 & 0.21581 & Biso & 1.000 & 0 \\
\hline 013 & 1.0000 & 0.21611 & 0.75210 & 0.79889 & Biso & 1.000 & 0 \\
\hline 014 & 1.0000 & 0.23698 & 0.46672 & 0.79451 & Biso & 1.000 & 0 \\
\hline 015 & 1.0000 & 0.51983 & 0.77077 & 0.79300 & Biso & 1.000 & 0 \\
\hline 016 & 1.0000 & 0.44102 & 0.58678 & 0.55687 & Biso & 1.000 & 0 \\
\hline 017 & 1.0000 & 0.10786 & 0.54895 & 0.56237 & Biso & 1.000 & 0 \\
\hline 018 & 1.0000 & 0.41256 & 0.85304 & 0.54710 & Biso & 1.000 & 0 \\
\hline 019 & 1.0000 & 0.97144 & 0.32103 & 0.16827 & Biso & 1.000 & 0 \\
\hline $\mathrm{O} 20$ & 1.0000 & 0.67857 & 0.65903 & 0.17339 & Biso & 1.000 & 0 \\
\hline 021 & 1.0000 & 0.34875 & 0.03011 & 0.15254 & Biso & 1.000 & 0 \\
\hline $\mathrm{O} 22$ & 1.0000 & 0.29894 & 0.98289 & 0.83407 & Biso & 1.000 & 0 \\
\hline 023 & 1.0000 & 0.66498 & 0.68851 & 0.84590 & Biso & 1.000 & 0 \\
\hline $\mathrm{O} 24$ & 1.0000 & 0.00486 & 0.32505 & 0.84155 & Biso & 1.000 & 0 \\
\hline 025 & 1.0000 & 0.63767 & 0.64937 & 0.50658 & Biso & 1.000 & 0 \\
\hline 026 & 1.0000 & 0.33122 & 0.97566 & 0.50201 & Biso & 1.000 & 0 \\
\hline $\mathrm{O} 27$ & 1.0000 & 0.00963 & 0.35340 & 0.50287 & Biso & 1.000 & 0 \\
\hline 028 & 1.0000 & 0.01622 & 0.67105 & 0.84886 & Biso & 1.000 & 0 \\
\hline 029 & 1.0000 & 0.31332 & 0.34117 & 0.83518 & Biso & 1.000 & 0 \\
\hline 030 & 1.0000 & 0.64855 & 0.97000 & 0.83906 & Biso & 1.000 & 0 \\
\hline 031 & 1.0000 & 0.68642 & 0.02007 & 0.16706 & Biso & 1.000 & 0 \\
\hline 032 & 1.0000 & 0.32297 & 0.31331 & 0.16183 & Biso & 1.000 & 0 \\
\hline 033 & 1.0000 & 0.98230 & 0.68203 & 0.17544 & Biso & 1.000 & 0 \\
\hline 034 & 1.0000 & 0.34504 & 0.36180 & 0.49294 & Biso & 1.000 & 0 \\
\hline 035 & 1.0000 & 0.97759 & 0.64388 & 0.50706 & Biso & 1.000 & 0 \\
\hline 036 & 1.0000 & 0.64049 & 0.01276 & 0.50591 & Biso & 1.000 & 0 \\
\hline 037 & 1.0000 & 0.12148 & 0.24115 & 0.13646 & Biso & 1.000 & 0 \\
\hline 038 & 1.0000 & 0.75313 & 0.88615 & 0.14232 & Biso & 1.000 & 0 \\
\hline 039 & 1.0000 & 0.11409 & 0.87975 & 0.14144 & Biso & 1.000 & 0 \\
\hline 040 & 1.0000 & 0.22448 & 0.10951 & 0.86184 & Biso & 1.000 & 0 \\
\hline 041 & 1.0000 & 0.86432 & 0.75139 & 0.87310 & Biso & 1.000 & 0 \\
\hline 042 & 1.0000 & 0.87627 & 0.12362 & 0.86897 & Biso & 1.000 & 0 \\
\hline 043 & 1.0000 & 0.77755 & 0.55989 & 0.46893 & Biso & 1.000 & $\mathrm{O}$ \\
\hline
\end{tabular}




\begin{tabular}{|c|c|c|c|c|c|c|c|}
\hline 044 & 1.0000 & 0.39401 & 0.21441 & 0.47193 & Biso & 1.000 & 0 \\
\hline 045 & 1.0000 & 0.79011 & 0.20231 & 0.46638 & Biso & 1.000 & 0 \\
\hline 046 & 1.0000 & 0.90517 & 0.45225 & 0.20537 & Biso & 1.000 & 0 \\
\hline 047 & 1.0000 & 0.53971 & 0.09729 & 0.20826 & Biso & 1.000 & 0 \\
\hline 048 & 1.0000 & 0.54779 & 0.45965 & 0.20421 & Biso & 1.000 & 0 \\
\hline 049 & 1.0000 & 0.44980 & 0.90442 & 0.80694 & Biso & 1.000 & 0 \\
\hline 050 & 1.0000 & 0.08426 & 0.54751 & 0.79350 & Biso & 1.000 & 0 \\
\hline 051 & 1.0000 & 0.44225 & 0.53960 & 0.79886 & Biso & 1.000 & 0 \\
\hline 052 & 1.0000 & 0.58000 & 0.78889 & 0.54101 & Biso & 1.000 & 0 \\
\hline 053 & 1.0000 & 0.20988 & 0.44670 & 0.54066 & Biso & 1.000 & 0 \\
\hline 054 & 1.0000 & 0.20689 & 0.77933 & 0.53965 & Biso & 1.000 & 0 \\
\hline 055 & 1.0000 & 0.98921 & 0.25137 & 0.99467 & Biso & 1.000 & 0 \\
\hline 056 & 1.0000 & 0.74141 & 0.74425 & 0.99914 & Biso & 1.000 & 0 \\
\hline 057 & 1.0000 & 0.24246 & 0.00019 & 0.98818 & Biso & 1.000 & 0 \\
\hline 058 & 1.0000 & 0.65762 & 0.59122 & 0.32940 & Biso & 1.000 & 0 \\
\hline 059 & 1.0000 & 0.38218 & 0.05895 & 0.31601 & Biso & 1.000 & 0 \\
\hline 060 & 1.0000 & 0.93288 & 0.34299 & 0.32674 & Biso & 1.000 & 0 \\
\hline 061 & 1.0000 & 0.32091 & 0.91423 & 0.66112 & Biso & 1.000 & 0 \\
\hline 062 & 1.0000 & 0.06591 & 0.38753 & 0.66279 & Biso & 1.000 & 0 \\
\hline 063 & 1.0000 & 0.60160 & 0.67714 & 0.66461 & Biso & 1.000 & 0 \\
\hline 064 & 1.0000 & 0.99891 & 0.74927 & 0.01797 & Biso & 1.000 & 0 \\
\hline 065 & 1.0000 & 0.24575 & 0.25159 & 0.00900 & Biso & 1.000 & 0 \\
\hline 066 & 1.0000 & 0.73954 & 0.99616 & 0.01396 & Biso & 1.000 & 0 \\
\hline 067 & 1.0000 & 0.66850 & 0.07001 & 0.34679 & Biso & 1.000 & 0 \\
\hline 068 & 1.0000 & 0.92087 & 0.59723 & 0.34943 & Biso & 1.000 & 0 \\
\hline 069 & 1.0000 & 0.39272 & 0.32974 & 0.34122 & Biso & 1.000 & 0 \\
\hline 070 & 1.0000 & 0.32685 & 0.40479 & 0.67795 & Biso & 1.000 & 0 \\
\hline 071 & 1.0000 & 0.58147 & 0.92766 & 0.68176 & Biso & 1.000 & 0 \\
\hline 072 & 1.0000 & 0.05838 & 0.67378 & 0.68707 & Biso & 1.000 & 0 \\
\hline $\mathrm{H} 1$ & 1.0000 & 0.26080 & 0.91713 & 0.31249 & Biso & 1.000 & $\mathrm{H}$ \\
\hline $\mathrm{C} 1$ & 1.0000 & 0.11842 & 0.88084 & 0.38809 & Biso & 1.000 & $\mathrm{C}$ \\
\hline $\mathrm{H} 2$ & 1.0000 & 0.20434 & 0.85936 & 0.30622 & Biso & 1.000 & $\mathrm{H}$ \\
\hline H3 & 1.0000 & 0.06640 & 0.79049 & 0.37990 & Biso & 1.000 & $\mathrm{H}$ \\
\hline 073 & 1.0000 & 0.07835 & 0.93712 & 0.35322 & Biso & 1.000 & 0 \\
\hline $\mathrm{H} 4$ & 1.0000 & 0.18809 & 0.91847 & 0.43601 & Biso & 1.000 & $\mathrm{H}$ \\
\hline $\mathrm{C} 2$ & 1.0000 & 0.13647 & 0.05870 & 0.36478 & Biso & 1.000 & $\mathrm{C}$ \\
\hline H5 & 1.0000 & 0.20663 & 0.08605 & 0.41106 & Biso & 1.000 & $\mathrm{H}$ \\
\hline H6 & 1.0000 & 0.16413 & 0.09371 & 0.29803 & Biso & 1.000 & $\mathrm{H}$ \\
\hline H7 & 1.0000 & 0.07342 & 0.07757 & 0.38948 & Biso & 1.000 & $\mathrm{H}$ \\
\hline \\
\hline & \multicolumn{7}{|c|}{ data_image0 } \\
\hline \multicolumn{8}{|c|}{13.875} \\
\hline \multicolumn{8}{|c|}{ cell_length_b $\quad 13.875$} \\
\hline \multicolumn{8}{|c|}{ cell_length_c $\quad 15.017$} \\
\hline \multicolumn{8}{|c|}{ cell angle alpha 90} \\
\hline \multicolumn{8}{|c|}{ _cell_angle_beta } \\
\hline cell_ & e_gamma & 120 & & & & & \\
\hline symme & pace_gr & coup_name & $-11-1 M$ & $1 "$ & & & \\
\hline symme & nt_tabl & les_numbe & & & & & \\
\hline loop_ & & & & & & & \\
\hline sym & $-c q u+v$ & _ & & & & & \\
\hline ' $\mathrm{x}$, & & & & & & & \\
\hline 1oop_ & & & & & & & \\
\hline ato & e_label & & & & & & \\
\hline -ato & =e_occup & pancy & & & & & \\
\hline -ato & $=e_{-}^{-}$fract & E & & & & & \\
\hline -ato & $e_{-}^{-}$fract & & & & & & \\
\hline -ato & $e_{-}^{-}$fract & & & & & & \\
\hline -ato & e_therm & nàl_displ & ace_type & & & & \\
\hline $\begin{array}{l}\text {-ato } \\
\text { ato }\end{array}$ & $\begin{array}{l}={ }^{\text {E_tiso }} \\
\text { =e_type }\end{array}$ & $\begin{array}{l}\text { or_equi } \\
\text { symbol }\end{array}$ & & & & & \\
\hline$\overline{\mathrm{P}} 1$ & 1.0000 & 0.99932 & 0.22925 & 0.11262 & Biso & 1.000 & $\mathrm{P}$ \\
\hline $\mathrm{P} 2$ & 1.0000 & 0.76927 & 0.77816 & 0.11451 & Biso & 1.000 & $\mathrm{P}$ \\
\hline P3 & 1.0000 & 0.22206 & 0.99953 & 0.10933 & Biso & 1.000 & $\mathrm{P}$ \\
\hline Al1 & 1.0000 & 0.21527 & 0.99420 & 0.89450 & Biso & 1.000 & $\mathrm{Al}$ \\
\hline Al2 & 1.0000 & 0.76403 & 0.77206 & 0.90273 & Biso & 1.000 & Al \\
\hline A13 & 1.0000 & 0.99513 & 0.22659 & 0.90079 & Biso & 1.000 & Al \\
\hline P4 & 1.0000 & 0.66198 & 0.55930 & 0.44562 & Biso & 1.000 & $P$ \\
\hline Sil & 1.0000 & 0.42007 & 0.10108 & 0.44080 & Biso & 1.000 & $\mathrm{Si}$ \\
\hline P5 & 1.0000 & 0.88688 & 0.32532 & 0.44508 & Biso & 1.000 & $\mathrm{P}$ \\
\hline Al4 & 1.0000 & 0.89167 & 0.33264 & 0.23487 & Biso & 1.000 & $\mathrm{Al}$ \\
\hline Al5 & 1.0000 & 0.43209 & 0.10844 & 0.23157 & Biso & 1.000 & Al \\
\hline Al6 & 1.0000 & 0.66704 & 0.56320 & 0.23513 & Biso & 1.000 & Al \\
\hline P6 & 1.0000 & 0.32881 & 0.89117 & 0.77946 & Biso & 1.000 & $P$ \\
\hline P7 & 1.0000 & 0.09665 & 0.43683 & 0.77792 & Biso & 1.000 & $\mathrm{P}$ \\
\hline P8 & 1.0000 & 0.55379 & 0.66175 & 0.77801 & Biso & 1.000 & $\mathrm{P}$ \\
\hline Al7 & 1.0000 & 0.55785 & 0.66535 & 0.56955 & Biso & 1.000 & Al \\
\hline
\end{tabular}




\begin{tabular}{|c|c|c|c|c|c|c|c|}
\hline Al8 & 1.0000 & 0.09261 & 0.43414 & 0.56994 & Biso & 1.000 & Al \\
\hline Al9 & 1.0000 & 0.32951 & 0.89204 & 0.56757 & Biso & 1.000 & Al \\
\hline P9 & 1.0000 & 0.98945 & 0.76818 & 0.89726 & Biso & 1.000 & $P$ \\
\hline P10 & 1.0000 & 0.22113 & 0.22244 & 0.89216 & Biso & 1.000 & $\mathrm{P}$ \\
\hline P11 & 1.0000 & 0.76929 & 0.00123 & 0.89649 & Biso & 1.000 & $\mathrm{P}$ \\
\hline Al10 & 1.0000 & 0.77029 & 0.00488 & 0.10929 & Biso & 1.000 & Al \\
\hline Al11 & 1.0000 & 0.22705 & 0.22858 & 0.10441 & Biso & 1.000 & Al \\
\hline Al12 & 1.0000 & 0.99597 & 0.77607 & 0.10993 & Biso & 1.000 & Al \\
\hline P12 & 1.0000 & 0.66156 & 0.10867 & 0.22945 & Biso & 1.000 & $\mathrm{P}$ \\
\hline P13 & 1.0000 & 0.89499 & 0.56348 & 0.23361 & Biso & 1.000 & $\mathrm{P}$ \\
\hline P14 & 1.0000 & 0.43688 & 0.34036 & 0.22703 & Biso & 1.000 & $\mathrm{P}$ \\
\hline Al13 & 1.0000 & 0.42883 & 0.33452 & 0.43780 & Biso & 1.000 & Al \\
\hline Al1 14 & 1.0000 & 0.88823 & 0.55636 & 0.44339 & Biso & 1.000 & Al \\
\hline Al15 & 1.0000 & 0.65297 & 0.10362 & 0.43928 & Biso & 1.000 & Al \\
\hline P15 & 1.0000 & 0.32414 & 0.44194 & 0.56168 & Biso & 1.000 & $P$ \\
\hline P16 & 1.0000 & 0.55849 & 0.89376 & 0.56424 & Biso & 1.000 & $\mathrm{P}$ \\
\hline P17 & 1.0000 & 0.09546 & 0.66747 & 0.56733 & Biso & 1.000 & $\mathrm{P}$ \\
\hline Al16 & 1.0000 & 0.09829 & 0.66739 & 0.77588 & Biso & 1.000 & Al \\
\hline Al17 & 1.0000 & 0.55633 & 0.89176 & 0.77372 & Biso & 1.000 & Al \\
\hline Al18 & 1.0000 & 0.32351 & 0.43591 & 0.77095 & Biso & 1.000 & Al \\
\hline 01 & 1.0000 & 0.90768 & 0.10885 & 0.13328 & Biso & 1.000 & 0 \\
\hline $\mathrm{O} 2$ & 1.0000 & 0.89175 & 0.80969 & 0.12964 & Biso & 1.000 & 0 \\
\hline 03 & 1.0000 & 0.19570 & 0.09262 & 0.13275 & Biso & 1.000 & 0 \\
\hline 04 & 1.0000 & 0.07911 & 0.88757 & 0.87162 & Biso & 1.000 & 0 \\
\hline 05 & 1.0000 & 0.79928 & 0.90970 & 0.87902 & Biso & 1.000 & 0 \\
\hline 06 & 1.0000 & 0.09985 & 0.19457 & 0.87864 & Biso & 1.000 & 0 \\
\hline 07 & 1.0000 & 0.56672 & 0.43987 & 0.46010 & Biso & 1.000 & 0 \\
\hline O8 & 1.0000 & 0.54815 & 0.13257 & 0.45459 & Biso & 1.000 & 0 \\
\hline 09 & 1.0000 & 0.86449 & 0.42243 & 0.46097 & Biso & 1.000 & 0 \\
\hline 010 & 1.0000 & 0.75475 & 0.22986 & 0.21189 & Biso & 1.000 & 0 \\
\hline 011 & 1.0000 & 0.46350 & 0.24639 & 0.21260 & Biso & 1.000 & 0 \\
\hline 012 & 1.0000 & 0.77308 & 0.53103 & 0.21655 & Biso & 1.000 & 0 \\
\hline 013 & 1.0000 & 0.23576 & 0.77048 & 0.79783 & Biso & 1.000 & 0 \\
\hline 014 & 1.0000 & 0.21898 & 0.46882 & 0.79296 & Biso & 1.000 & 0 \\
\hline 015 & 1.0000 & 0.52329 & 0.75346 & 0.79067 & Biso & 1.000 & 0 \\
\hline 016 & 1.0000 & 0.41903 & 0.56321 & 0.55113 & Biso & 1.000 & 0 \\
\hline 017 & 1.0000 & 0.11294 & 0.56772 & 0.55427 & Biso & 1.000 & 0 \\
\hline 018 & 1.0000 & 0.43541 & 0.85958 & 0.54957 & Biso & 1.000 & 0 \\
\hline 019 & 1.0000 & 0.98462 & 0.31251 & 0.16989 & Biso & 1.000 & $\mathrm{O}$ \\
\hline $\mathrm{O} 20$ & 1.0000 & 0.69184 & 0.67921 & 0.17308 & Biso & 1.000 & 0 \\
\hline O21 & 1.0000 & 0.32835 & 0.01979 & 0.15586 & Biso & 1.000 & 0 \\
\hline 022 & 1.0000 & 0.31189 & 0.97252 & 0.83758 & Biso & 1.000 & 0 \\
\hline 023 & 1.0000 & 0.64757 & 0.67933 & 0.84173 & Biso & 1.000 & 0 \\
\hline $\mathrm{O} 24$ & 1.0000 & 0.01909 & 0.34387 & 0.84136 & Biso & 1.000 & 0 \\
\hline 025 & 1.0000 & 0.64791 & 0.64196 & 0.50414 & Biso & 1.000 & 0 \\
\hline 026 & 1.0000 & 0.33432 & 0.99461 & 0.50133 & Biso & 1.000 & 0 \\
\hline $\mathrm{O} 27$ & 1.0000 & 0.98318 & 0.33897 & 0.50415 & Biso & 1.000 & 0 \\
\hline 028 & 1.0000 & 0.00521 & 0.68293 & 0.84392 & Biso & 1.000 & 0 \\
\hline 029 & 1.0000 & 0.30106 & 0.32211 & 0.83527 & Biso & 1.000 & 0 \\
\hline 030 & 1.0000 & 0.66802 & 0.98056 & 0.84127 & Biso & 1.000 & 0 \\
\hline 031 & 1.0000 & 0.67652 & 0.02856 & 0.16802 & Biso & 1.000 & 0 \\
\hline 032 & 1.0000 & 0.34183 & 0.32471 & 0.16506 & Biso & 1.000 & 0 \\
\hline 033 & 1.0000 & 0.97403 & 0.66249 & 0.17505 & Biso & 1.000 & 0 \\
\hline 034 & 1.0000 & 0.33858 & 0.36471 & 0.49771 & Biso & 1.000 & 0 \\
\hline 035 & 1.0000 & 0.00034 & 0.65561 & 0.50665 & Biso & 1.000 & 0 \\
\hline 036 & 1.0000 & 0.63561 & 0.98987 & 0.50322 & Biso & 1.000 & 0 \\
\hline 037 & 1.0000 & 0.11263 & 0.24121 & 0.13513 & Biso & 1.000 & $\mathrm{O}$ \\
\hline 038 & 1.0000 & 0.75606 & 0.87748 & 0.14113 & Biso & 1.000 & 0 \\
\hline 039 & 1.0000 & 0.12414 & 0.88854 & 0.14273 & Biso & 1.000 & 0 \\
\hline $\mathrm{O} 40$ & 1.0000 & 0.23083 & 0.12187 & 0.86283 & Biso & 1.000 & 0 \\
\hline 041 & 1.0000 & 0.87489 & 0.75246 & 0.87462 & Biso & 1.000 & 0 \\
\hline 042 & 1.0000 & 0.86811 & 0.11374 & 0.86866 & Biso & 1.000 & 0 \\
\hline 043 & 1.0000 & 0.77202 & 0.56566 & 0.47180 & Biso & 1.000 & 0 \\
\hline O4 4 & 1.0000 & 0.40236 & 0.20469 & 0.46522 & Biso & 1.000 & 0 \\
\hline 045 & 1.0000 & 0.78332 & 0.21624 & 0.46969 & Biso & 1.000 & 0 \\
\hline 046 & 1.0000 & 0.91044 & 0.46446 & 0.21109 & Biso & 1.000 & 0 \\
\hline 047 & 1.0000 & 0.55023 & 0.09994 & 0.20649 & Biso & 1.000 & 0 \\
\hline 048 & 1.0000 & 0.54029 & 0.45136 & 0.20242 & Biso & 1.000 & 0 \\
\hline 049 & 1.0000 & 0.44090 & 0.90233 & 0.80459 & Biso & 1.000 & 0 \\
\hline 050 & 1.0000 & 0.08428 & 0.53823 & 0.79734 & Biso & 1.000 & 0 \\
\hline 051 & 1.0000 & 0.45169 & 0.54907 & 0.80011 & Biso & 1.000 & 0 \\
\hline 052 & 1.0000 & 0.57357 & 0.79409 & 0.54203 & Biso & 1.000 & 0 \\
\hline 053 & 1.0000 & 0.21404 & 0.43665 & 0.53852 & Biso & 1.000 & 0 \\
\hline 054 & 1.0000 & 0.20128 & 0.77354 & 0.53951 & Biso & 1.000 & 0 \\
\hline 055 & 1.0000 & 0.99462 & 0.25604 & 0.01395 & Biso & 1.000 & 0 \\
\hline 056 & 1.0000 & 0.73636 & 0.74643 & 0.01659 & Biso & 1.000 & 0 \\
\hline 057 & 1.0000 & 0.23700 & 0.99483 & 0.00880 & Biso & 1.000 & 0 \\
\hline 058 & 1.0000 & 0.66682 & 0.59460 & 0.34773 & Biso & 1.000 & 0 \\
\hline 059 & 1.0000 & 0.38005 & 0.06307 & 0.33695 & Biso & 1.000 & 0 \\
\hline 060 & 1.0000 & 0.92073 & 0.32591 & 0.34729 & Biso & 1.000 & 0 \\
\hline
\end{tabular}




\begin{tabular}{|c|c|c|c|c|c|c|c|}
\hline 061 & 1.0000 & 0.32726 & 0.92071 & 0.68124 & Biso & 1.000 & 0 \\
\hline 062 & 1.0000 & 0.06143 & 0.39593 & 0.68173 & Biso & 1.000 & 0 \\
\hline 063 & 1.0000 & 0.59247 & 0.66295 & 0.68169 & Biso & 1.000 & 0 \\
\hline 064 & 1.0000 & 0.99743 & 0.74728 & 0.99702 & Biso & 1.000 & 0 \\
\hline 065 & 1.0000 & 0.25440 & 0.25050 & 0.99061 & Biso & 1.000 & 0 \\
\hline 066 & 1.0000 & 0.74269 & 0.00316 & 0.99562 & Biso & 1.000 & 0 \\
\hline 067 & 1.0000 & 0.66536 & 0.07530 & 0.32628 & Biso & 1.000 & 0 \\
\hline 068 & 1.0000 & 0.92651 & 0.59887 & 0.33199 & Biso & 1.000 & 0 \\
\hline 069 & 1.0000 & 0.40181 & 0.34297 & 0.32363 & Biso & 1.000 & 0 \\
\hline 070 & 1.0000 & 0.32118 & 0.40257 & 0.65826 & Biso & 1.000 & 0 \\
\hline 071 & 1.0000 & 0.59139 & 0.92914 & 0.66213 & Biso & 1.000 & 0 \\
\hline 072 & 1.0000 & 0.06465 & 0.67508 & 0.66441 & Biso & 1.000 & 0 \\
\hline $\mathrm{H} 1$ & 1.0000 & 0.25870 & 0.91266 & 0.32248 & Biso & 1.000 & $\mathrm{H}$ \\
\hline $\mathrm{C} 1$ & 1.0000 & 0.11479 & 0.88299 & 0.39303 & Biso & 1.000 & C \\
\hline $\mathrm{H} 2$ & 1.0000 & 0.20598 & 0.85467 & 0.31136 & Biso & 1.000 & $\mathrm{H}$ \\
\hline H3 & 1.0000 & 0.06506 & 0.79242 & 0.38616 & Biso & 1.000 & $\mathrm{H}$ \\
\hline 073 & 1.0000 & 0.07497 & 0.93653 & 0.35362 & Biso & 1.000 & O \\
\hline $\mathrm{H} 4$ & 1.0000 & 0.18483 & 0.92403 & 0.44060 & Biso & 1.000 & $\mathrm{H}$ \\
\hline $\mathrm{C} 2$ & 1.0000 & 0.13041 & 0.05845 & 0.36192 & Biso & 1.000 & C \\
\hline H5 & 1.0000 & 0.19851 & 0.08864 & 0.41051 & Biso & 1.000 & $\mathrm{H}$ \\
\hline H6 & 1.0000 & 0.16076 & 0.09077 & 0.29495 & Biso & 1.000 & $\mathrm{H}$ \\
\hline $\mathrm{H} 7$ & 1.0000 & 0.06493 & 0.07621 & 0.38190 & Biso & 1.000 & $\mathrm{H}$ \\
\hline \multicolumn{8}{|c|}{$\lg 7$} \\
\hline \multirow{2}{*}{\multicolumn{8}{|c|}{ ata_image 0}} \\
\hline & & & & & & & \\
\hline \multicolumn{8}{|c|}{13.875} \\
\hline \multicolumn{8}{|c|}{15.017} \\
\hline \multicolumn{8}{|c|}{ e $\bar{l}$ lpha } \\
\hline \multicolumn{8}{|c|}{90} \\
\hline \multicolumn{8}{|c|}{120} \\
\hline ymme & pace_g & מבת מרור & & $1 "$ & & & \\
\hline ymme & nt_t $\overline{a b}$ & les_numbe & & & & & \\
\hline op_ & & & & & & & \\
\hline _sym & equiv & as as $\mathrm{x}$ & & & & & \\
\hline ' $x$, & & & & & & & \\
\hline op & & & & & & & \\
\hline ato & e_labe & & & & & & \\
\hline -ato & ee_occul & pancy & & & & & \\
\hline -ato & $e^{-}$frac & t $x$ & & & & & \\
\hline ato & $=e$ frac & $y$ & & & & & \\
\hline ato & $e^{-f r a c}$ & -2 & & & & & \\
\hline ato & $e^{-}$ther & nal displ & ace type & & & & \\
\hline -ato & e_B_is & D_or_equi & & & & & \\
\hline -ato & $=e_{-}^{-}$type & symb̄ol & & & & & \\
\hline $\bar{A} 11$ & 1.0000 & 0.99318 & 0.22642 & 0.10810 & Biso & 1.000 & Al \\
\hline Al2 & 1.0000 & 0.77179 & 0.77601 & 0.11218 & Biso & 1.000 & Al \\
\hline Al3 & 1.0000 & 0.22716 & 0.00631 & 0.10226 & Biso & 1.000 & Al \\
\hline $\mathrm{P} 1$ & 1.0000 & 0.21549 & 0.99856 & 0.88890 & Biso & 1.000 & $\mathrm{P}$ \\
\hline P2 & 1.0000 & 0.76834 & 0.77013 & 0.89964 & Biso & 1.000 & $P$ \\
\hline P3 & 1.0000 & 0.98780 & 0.22378 & 0.89519 & Biso & 1.000 & $\mathrm{P}$ \\
\hline Al4 & 1.0000 & 0.65221 & 0.55451 & 0.44120 & Biso & 1.000 & $\mathrm{Al}$ \\
\hline Mg 1 & 1.0000 & 0.43383 & 0.10571 & 0.44001 & Biso & 1.000 & Mg \\
\hline Al5 & 1.0000 & 0.89644 & 0.33359 & 0.43991 & Biso & 1.000 & Al \\
\hline P 4 & 1.0000 & 0.89529 & 0.33999 & 0.23018 & Biso & 1.000 & $\mathrm{P}$ \\
\hline P5 & 1.0000 & 0.43407 & 0.10371 & 0.22562 & Biso & 1.000 & $\mathrm{P}$ \\
\hline P6 & 1.0000 & 0.66056 & 0.55998 & 0.23059 & Biso & 1.000 & $\mathrm{P}$ \\
\hline Al 6 & 1.0000 & 0.32109 & 0.88580 & 0.77612 & Biso & 1.000 & Al \\
\hline Al 7 & 1.0000 & 0.09854 & 0.43184 & 0.77299 & Biso & 1.000 & Al \\
\hline Al 8 & 1.0000 & 0.55754 & 0.66813 & 0.77494 & Biso & 1.000 & $\mathrm{Al}$ \\
\hline P7 & 1.0000 & 0.56637 & 0.67496 & 0.56729 & Biso & 1.000 & $\mathrm{P}$ \\
\hline P8 & 1.0000 & 0.09733 & 0.43372 & 0.56825 & Biso & 1.000 & $P$ \\
\hline P9 & 1.0000 & 0.31944 & 0.88074 & 0.56304 & Biso & 1.000 & $\mathrm{P}$ \\
\hline Al9 & 1.0000 & 0.99346 & 0.76851 & 0.90352 & Biso & 1.000 & Al \\
\hline Al10 & 1.0000 & 0.21610 & 0.22499 & 0.89417 & Biso & 1.000 & Al \\
\hline Al11 & 1.0000 & 0.76549 & 0.99474 & 0.90022 & Biso & 1.000 & Al \\
\hline P10 & 1.0000 & 0.76763 & 0.99906 & 0.11375 & Biso & 1.000 & $\mathrm{P}$ \\
\hline P 11 & 1.0000 & 0.22203 & 0.22987 & 0.10803 & Biso & 1.000 & $P$ \\
\hline P 12 & 1.0000 & 0.00135 & 0.78105 & 0.11668 & Biso & 1.000 & $\mathrm{P}$ \\
\hline Al12 & 1.0000 & 0.66762 & 0.11103 & 0.23632 & Biso & 1.000 & $\mathrm{Al}$ \\
\hline Al13 & 1.0000 & 0.89091 & 0.56551 & 0.23674 & Biso & 1.000 & Al \\
\hline Al14 & 1.0000 & 0.43257 & 0.33360 & 0.23073 & Biso & 1.000 & Al \\
\hline P13 & 1.0000 & 0.41814 & 0.33212 & 0.43963 & Biso & 1.000 & $\mathrm{P}$ \\
\hline P14 & 1.0000 & 0.88455 & 0.55911 & 0.44691 & Biso & 1.000 & $P$ \\
\hline P15 & 1.0000 & 0.67010 & 0.10999 & 0.44359 & Biso & 1.000 & $\mathrm{P}$ \\
\hline Al15 & 1.0000 & 0.33230 & 0.45044 & 0.56688 & Biso & 1.000 & Al \\
\hline Al16 & 1.0000 & 0.55416 & 0.89706 & 0.56835 & Biso & 1.000 & Al \\
\hline Al17 & 1.0000 & 0.08660 & 0.66174 & 0.57649 & Biso & 1.000 & Al \\
\hline
\end{tabular}




\begin{tabular}{|c|c|c|c|c|c|c|c|}
\hline P16 & 1.0000 & 0.09402 & 0.66150 & 0.78247 & Biso & 1.000 & $P$ \\
\hline P17 & 1.0000 & 0.55025 & 0.89314 & 0.77913 & Biso & 1.000 & $P$ \\
\hline P18 & 1.0000 & 0.32926 & 0.43924 & 0.77616 & Biso & 1.000 & $\mathrm{P}$ \\
\hline 01 & 1.0000 & 0.88910 & 0.08999 & 0.13280 & Biso & 1.000 & 0 \\
\hline $\mathrm{O} 2$ & 1.0000 & 0.91042 & 0.81158 & 0.13453 & Biso & 1.000 & 0 \\
\hline 03 & 1.0000 & 0.19538 & 0.11026 & 0.13131 & Biso & 1.000 & 0 \\
\hline 04 & 1.0000 & 0.09579 & 0.90308 & 0.87186 & Biso & 1.000 & 0 \\
\hline 05 & 1.0000 & 0.80098 & 0.89164 & 0.87880 & Biso & 1.000 & 0 \\
\hline 06 & 1.0000 & 0.08024 & 0.19665 & 0.87364 & Biso & 1.000 & 0 \\
\hline 07 & 1.0000 & 0.54071 & 0.42141 & 0.45984 & Biso & 1.000 & 0 \\
\hline 08 & 1.0000 & 0.58622 & 0.14869 & 0.45370 & Biso & 1.000 & 0 \\
\hline 09 & 1.0000 & 0.86834 & 0.44232 & 0.46042 & Biso & 1.000 & 0 \\
\hline 010 & 1.0000 & 0.77326 & 0.24933 & 0.21570 & Biso & 1.000 & 0 \\
\hline 011 & 1.0000 & 0.46161 & 0.22585 & 0.21569 & Biso & 1.000 & 0 \\
\hline 012 & 1.0000 & 0.75394 & 0.53197 & 0.21570 & Biso & 1.000 & 0 \\
\hline 013 & 1.0000 & 0.21548 & 0.75012 & 0.80295 & Biso & 1.000 & 0 \\
\hline 014 & 1.0000 & 0.23686 & 0.46773 & 0.79504 & Biso & 1.000 & 0 \\
\hline 015 & 1.0000 & 0.52109 & 0.77097 & 0.78987 & Biso & 1.000 & 0 \\
\hline 016 & 1.0000 & 0.44365 & 0.58575 & 0.55319 & Biso & 1.000 & 0 \\
\hline 017 & 1.0000 & 0.10163 & 0.54611 & 0.56527 & Biso & 1.000 & 0 \\
\hline 018 & 1.0000 & 0.41357 & 0.85361 & 0.54697 & Biso & 1.000 & 0 \\
\hline 019 & 1.0000 & 0.97298 & 0.32218 & 0.16827 & Biso & 1.000 & 0 \\
\hline $\mathrm{O} 20$ & 1.0000 & 0.68042 & 0.65934 & 0.17306 & Biso & 1.000 & 0 \\
\hline 021 & 1.0000 & 0.34968 & 0.03135 & 0.15308 & Biso & 1.000 & 0 \\
\hline $\mathrm{O} 22$ & 1.0000 & 0.29919 & 0.98230 & 0.83405 & Biso & 1.000 & 0 \\
\hline 023 & 1.0000 & 0.66531 & 0.68898 & 0.84632 & Biso & 1.000 & 0 \\
\hline $\mathrm{O} 24$ & 1.0000 & 0.00508 & 0.32542 & 0.84212 & Biso & 1.000 & 0 \\
\hline 025 & 1.0000 & 0.64244 & 0.65397 & 0.50583 & Biso & 1.000 & 0 \\
\hline 026 & 1.0000 & 0.33133 & 0.97577 & 0.50559 & Biso & 1.000 & 0 \\
\hline 027 & 1.0000 & 0.01046 & 0.35255 & 0.50249 & Biso & 1.000 & 0 \\
\hline 028 & 1.0000 & 0.01468 & 0.66943 & 0.84939 & Biso & 1.000 & 0 \\
\hline 029 & 1.0000 & 0.31205 & 0.34056 & 0.83381 & Biso & 1.000 & 0 \\
\hline 030 & 1.0000 & 0.64818 & 0.96905 & 0.83967 & Biso & 1.000 & 0 \\
\hline 031 & 1.0000 & 0.68636 & 0.02074 & 0.16664 & Biso & 1.000 & 0 \\
\hline 032 & 1.0000 & 0.32449 & 0.31505 & 0.15964 & Biso & 1.000 & 0 \\
\hline 033 & 1.0000 & 0.98390 & 0.68359 & 0.17626 & Biso & 1.000 & 0 \\
\hline O34 & 1.0000 & 0.33959 & 0.35852 & 0.49346 & Biso & 1.000 & 0 \\
\hline 035 & 1.0000 & 0.97621 & 0.64491 & 0.50861 & Biso & 1.000 & 0 \\
\hline 036 & 1.0000 & 0.64443 & 0.01011 & 0.50397 & Biso & 1.000 & 0 \\
\hline 037 & 1.0000 & 0.12228 & 0.24182 & 0.13636 & Biso & 1.000 & 0 \\
\hline 038 & 1.0000 & 0.75366 & 0.88679 & 0.14311 & Biso & 1.000 & 0 \\
\hline 039 & 1.0000 & 0.11527 & 0.88091 & 0.14119 & Biso & 1.000 & 0 \\
\hline 040 & 1.0000 & 0.22443 & 0.10896 & 0.86115 & Biso & 1.000 & 0 \\
\hline 041 & 1.0000 & 0.86465 & 0.75155 & 0.87333 & Biso & 1.000 & 0 \\
\hline 042 & 1.0000 & 0.87560 & 0.12399 & 0.86854 & Biso & 1.000 & 0 \\
\hline 043 & 1.0000 & 0.77612 & 0.55723 & 0.46843 & Biso & 1.000 & 0 \\
\hline O4 4 & 1.0000 & 0.39611 & 0.21744 & 0.46374 & Biso & 1.000 & 0 \\
\hline 045 & 1.0000 & 0.78748 & 0.20454 & 0.46961 & Biso & 1.000 & 0 \\
\hline 046 & 1.0000 & 0.90842 & 0.45401 & 0.20777 & Biso & 1.000 & 0 \\
\hline 047 & 1.0000 & 0.54111 & 0.10002 & 0.20854 & Biso & 1.000 & 0 \\
\hline 048 & 1.0000 & 0.55012 & 0.45946 & 0.20235 & Biso & 1.000 & 0 \\
\hline 049 & 1.0000 & 0.44931 & 0.90265 & 0.80818 & Biso & 1.000 & 0 \\
\hline 050 & 1.0000 & 0.08173 & 0.54619 & 0.79085 & Biso & 1.000 & 0 \\
\hline 051 & 1.0000 & 0.44194 & 0.53980 & 0.80061 & Biso & 1.000 & 0 \\
\hline 052 & 1.0000 & 0.58068 & 0.78891 & 0.54460 & Biso & 1.000 & 0 \\
\hline 053 & 1.0000 & 0.21129 & 0.45225 & 0.54098 & Biso & 1.000 & 0 \\
\hline 054 & 1.0000 & 0.20733 & 0.77660 & 0.53771 & Biso & 1.000 & 0 \\
\hline 055 & 1.0000 & 0.98933 & 0.25039 & 0.99464 & Biso & 1.000 & 0 \\
\hline 056 & 1.0000 & 0.74236 & 0.74579 & 0.99932 & Biso & 1.000 & 0 \\
\hline 057 & 1.0000 & 0.24369 & 0.00130 & 0.98814 & Biso & 1.000 & 0 \\
\hline 058 & 1.0000 & 0.65805 & 0.59044 & 0.32868 & Biso & 1.000 & 0 \\
\hline 059 & 1.0000 & 0.38428 & 0.05737 & 0.31728 & Biso & 1.000 & 0 \\
\hline 060 & 1.0000 & 0.93082 & 0.33877 & 0.32701 & Biso & 1.000 & 0 \\
\hline 061 & 1.0000 & 0.31730 & 0.90755 & 0.66251 & Biso & 1.000 & 0 \\
\hline 062 & 1.0000 & 0.06628 & 0.38464 & 0.66281 & Biso & 1.000 & 0 \\
\hline 063 & 1.0000 & 0.60067 & 0.67202 & 0.66459 & Biso & 1.000 & 0 \\
\hline 064 & 1.0000 & 0.99932 & 0.74923 & 0.01844 & Biso & 1.000 & 0 \\
\hline 065 & 1.0000 & 0.24485 & 0.25118 & 0.00788 & Biso & 1.000 & 0 \\
\hline 066 & 1.0000 & 0.74087 & 0.99639 & 0.01415 & Biso & 1.000 & 0 \\
\hline 067 & 1.0000 & 0.67439 & 0.07425 & 0.34619 & Biso & 1.000 & 0 \\
\hline 068 & 1.0000 & 0.92238 & 0.60004 & 0.35026 & Biso & 1.000 & 0 \\
\hline 069 & 1.0000 & 0.39317 & 0.33951 & 0.33985 & Biso & 1.000 & 0 \\
\hline 070 & 1.0000 & 0.32760 & 0.40795 & 0.67763 & Biso & 1.000 & 0 \\
\hline 071 & 1.0000 & 0.58148 & 0.93112 & 0.68203 & Biso & 1.000 & 0 \\
\hline 072 & 1.0000 & 0.06139 & 0.67890 & 0.68794 & Biso & 1.000 & 0 \\
\hline $\mathrm{H} 1$ & 1.0000 & 0.26077 & 0.91567 & 0.31285 & Biso & 1.000 & $\mathrm{H}$ \\
\hline $\mathrm{C} 1$ & 1.0000 & 0.11676 & 0.87891 & 0.38795 & Biso & 1.000 & C \\
\hline H2 & 1.0000 & 0.20428 & 0.85798 & 0.30681 & Biso & 1.000 & $\mathrm{H}$ \\
\hline H3 & 1.0000 & 0.06563 & 0.78846 & 0.37985 & Biso & 1.000 & $\mathrm{H}$ \\
\hline 073 & 1.0000 & 0.07634 & 0.93430 & 0.35214 & & 1.000 & 0 \\
\hline
\end{tabular}




$\begin{array}{llllllll}\text { H4 } & 1.0000 & 0.18575 & 0.91711 & 0.43637 & \text { Biso } & 1.000 & \text { H } \\ \text { C2 } & 1.0000 & 0.13285 & 0.05585 & 0.36296 & \text { Biso } & 1.000 & \text { C } \\ \text { H5 } & 1.0000 & 0.20276 & 0.08465 & 0.40968 & \text { Biso } & 1.000 & \text { H } \\ \text { H6 } & 1.0000 & 0.16068 & 0.09042 & 0.29610 & \text { Biso } & 1.000 & \text { H } \\ \text { H7 } & 1.0000 & 0.06883 & 0.07381 & 0.38678 & \text { Biso } & 1.000 & \text { H }\end{array}$

Al 7

data image 0

cel̄ length a

cell_length_b 13.625

cell length_c $\quad 15.067$

cell_angle_ālpha 90

_cell_angle_beta 90

_cell_angle_gamma 120

_symmetry_space_group_name_H-M "P 1 "

-symmetry_int_tables_number $\bar{r} 1$

loop

_symmetry_equiv_pos_as_xyz

$' \mathrm{x}, \mathrm{y}, \mathrm{z}$ '

loop_

_atom_site_label

-atom_site_occupancy

atom_site_fract_x

-atom_site_fract_y

-atom_site_fract_z

-atom_site_thermäldisplace_type

-atom_site_B_iso_or_equiv

atom_site_type_symbol

\begin{tabular}{|c|c|c|c|c|c|c|c|}
\hline Sil & 1.0000 & 0.00480 & 0.23863 & 0.10554 & Biso & 1.000 & $\mathrm{Si}$ \\
\hline Si2 & 1.0000 & 0.77631 & 0.78239 & 0.10869 & Biso & 1.000 & $\mathrm{Si}$ \\
\hline Si3 & 1.0000 & 0.23578 & 0.01098 & 0.10243 & Biso & 1.000 & $\mathrm{Si}$ \\
\hline Si4 & 1.0000 & 0.22714 & 0.00476 & 0.89353 & Biso & 1.000 & $\mathrm{Si}$ \\
\hline & 1.0000 & 0.77268 & 0.77677 & 0.90194 & Biso & 1.000 & $\mathrm{Si}$ \\
\hline i6 & 1.0000 & 0.00082 & 0.23605 & 0.89905 & Biso & 1.000 & $\mathrm{Si}$ \\
\hline i7 & 1.0000 & 0.66669 & 0.56802 & 0.43953 & Biso & 1.000 & $\mathrm{Si}$ \\
\hline 11 & 1.0000 & 0.43534 & 0.10987 & 0.43705 & Biso & 1.000 & Al \\
\hline 1 & 1.0000 & 0.90342 & 0.33756 & 0.43839 & Biso & 1.000 & $\mathrm{Si}$ \\
\hline i9 & 1.0000 & 0.90487 & 0.34459 & 0.23319 & Biso & 1.000 & $\mathrm{Si}$ \\
\hline iilo & 1.0000 & 0.44027 & 0.11280 & 0.22992 & Biso & 1.000 & $\mathrm{Si}$ \\
\hline i 11 & 1.0000 & 0.67252 & 0.57218 & 0.23426 & Biso & 1.000 & $\mathrm{Si}$ \\
\hline i 12 & 1.0000 & 0.33410 & 0.89857 & 0.77357 & Biso & 1.000 & $\mathrm{Si}$ \\
\hline 13 & 1.0000 & 0.10433 & 0.44017 & 0.77088 & Biso & 1.000 & $\mathrm{Si}$ \\
\hline i14 & 1.0000 & 0.56696 & 0.67313 & 0.77209 & Biso & 1.000 & $\mathrm{Si}$ \\
\hline i15 & 1.0000 & 0.57351 & 0.67798 & 0.56904 & Biso & 1.000 & $\mathrm{Si}$ \\
\hline i16 & 1.0000 & 0.10240 & 0.44011 & 0.56907 & Biso & 1.000 & $\mathrm{Si}$ \\
\hline 17 & 1.0000 & 0.33367 & 0.89683 & 0.56561 & Biso & 1.000 & $\mathrm{Si}$ \\
\hline 18 & 1.0000 & 0.00064 & 0.77414 & 0.90157 & Biso & 1.000 & $\mathrm{Si}$ \\
\hline Si19 & 1.0000 & 0.23089 & 0.23490 & 0.89474 & Biso & 1.000 & $\mathrm{Si}$ \\
\hline Si20 & 1.0000 & 0.77425 & 0.00602 & 0.89901 & Biso & 1.000 & $\mathrm{Si}$ \\
\hline $5 i 21$ & 1.0000 & 0.77508 & 0.01006 & 0.10686 & Biso & 1.000 & $\mathrm{Si}$ \\
\hline Si22 & 1.0000 & 0.23614 & 0.24015 & 0.10211 & Biso & 1.000 & $\mathrm{Si}$ \\
\hline i23 & 1.0000 & 0.00685 & 0.78377 & 0.10914 & Biso & 1.000 & $\mathrm{Si}$ \\
\hline Si24 & 1.0000 & 0.67327 & 0.11579 & 0.23347 & Biso & 1.000 & $\mathrm{Si}$ \\
\hline Si25 & 1.0000 & 0.90286 & 0.57386 & 0.23589 & Biso & 1.000 & $\mathrm{Si}$ \\
\hline Si26 & 1.0000 & 0.44042 & 0.34501 & 0.23064 & Biso & 1.000 & $\mathrm{Si}$ \\
\hline Si27 & 1.0000 & 0.43089 & 0.34142 & 0.43545 & Biso & 1.000 & $\mathrm{Si}$ \\
\hline Si28 & 1.0000 & 0.89681 & 0.56664 & 0.44182 & Biso & 1.000 & $\mathrm{Si}$ \\
\hline Si29 & 1.0000 & 0.67041 & 0.11241 & 0.43742 & Biso & 1.000 & $\mathrm{Si}$ \\
\hline Si30 & 1.0000 & 0.33774 & 0.45206 & 0.56486 & Biso & 1.000 & $\mathrm{Si}$ \\
\hline Si31 & 1.0000 & 0.56715 & 0.90571 & 0.56675 & Biso & 1.000 & $\mathrm{Si}$ \\
\hline Si32 & 1.0000 & 0.09805 & 0.67258 & 0.57198 & Biso & 1.000 & $\mathrm{Si}$ \\
\hline Si33 & 1.0000 & 0.10288 & 0.67232 & 0.77459 & Biso & 1.000 & $\mathrm{Si}$ \\
\hline Si34 & 1.0000 & 0.56470 & 0.90329 & 0.77190 & Biso & 1.000 & $\mathrm{Si}$ \\
\hline Si35 & 1.0000 & 0.33541 & 0.44411 & 0.76964 & Biso & 1.000 & $\mathrm{Si}$ \\
\hline 01 & 1.0000 & 0.90627 & 0.10836 & 0.12488 & Biso & 1.000 & $\mathrm{O}$ \\
\hline $\mathrm{O} 2$ & 1.0000 & 0.90839 & 0.81664 & 0.12410 & Biso & 1.000 & 0 \\
\hline 03 & 1.0000 & 0.20543 & 0.11035 & 0.12448 & Biso & 1.000 & 0 \\
\hline $\mathrm{O} 4$ & 1.0000 & 0.09718 & 0.90351 & 0.87710 & Biso & 1.000 & 0 \\
\hline 05 & 1.0000 & 0.80833 & 0.90830 & 0.88296 & Biso & 1.000 & 0 \\
\hline 06 & 1.0000 & 0.10050 & 0.20564 & 0.88198 & Biso & 1.000 & 0 \\
\hline 07 & 1.0000 & 0.56226 & 0.44056 & 0.45308 & Biso & 1.000 & 0 \\
\hline 08 & 1.0000 & 0.57610 & 0.14794 & 0.44946 & Biso & 1.000 & 0 \\
\hline 09 & 1.0000 & 0.87594 & 0.43986 & 0.45583 & Biso & 1.000 & 0 \\
\hline 010 & 1.0000 & 0.77401 & 0.24675 & 0.21743 & Biso & 1.000 & $\mathrm{O}$ \\
\hline 011 & 1.0000 & 0.46925 & 0.24385 & 0.21718 & Biso & 1.000 & $\mathrm{O}$ \\
\hline 012 & 1.0000 & 0.77180 & 0.53989 & 0.21928 & Biso & 1.000 & 0 \\
\hline 013 & 1.0000 & 0.23400 & 0.76867 & 0.79319 & Biso & 1.000 & 0 \\
\hline 01 & 1.0000 & 0.23617 & 0.47555 & 0.78755 & Biso & 1.000 & 0 \\
\hline
\end{tabular}




\begin{tabular}{|c|c|c|c|c|c|c|}
\hline 015 & 1.0000 & 0.53388 & 0.77191 & 0.78242 & Biso & 1.000 \\
\hline 016 & 1.0000 & 0.44188 & 0.58127 & 0.55379 & Biso & 1.000 \\
\hline 017 & 1.0000 & 0.11572 & 0.56466 & 0.56132 & Biso & 1.000 \\
\hline 018 & 1.0000 & 0.43401 & 0.86579 & 0.55009 & Biso & 1.000 \\
\hline 019 & 1.0000 & 0.98929 & 0.32662 & 0.16804 & Biso & 1.000 \\
\hline 020 & 1.0000 & 0.69368 & 0.67735 & 0.17167 & Biso & 1.000 \\
\hline 021 & 1.0000 & 0.34720 & 0.03224 & 0.15573 & Biso & 1.000 \\
\hline 022 & 1.0000 & 0.31511 & 0.98631 & 0.83383 & Biso & 1.000 \\
\hline 023 & 1.0000 & 0.66572 & 0.69168 & 0.84131 & Biso & 1.000 \\
\hline $\mathrm{O} 24$ & 1.0000 & 0.02023 & 0.34217 & 0.83865 & Biso & 1.000 \\
\hline 025 & 1.0000 & 0.65632 & 0.65810 & 0.50344 & Biso & 1.000 \\
\hline 026 & 1.0000 & 0.34288 & 0.99488 & 0.50233 & Biso & 1.000 \\
\hline 027 & 1.0000 & 0.00681 & 0.35301 & 0.50110 & Biso & 1.000 \\
\hline 028 & 1.0000 & 0.01832 & 0.68394 & 0.84387 & Biso & 1.000 \\
\hline 029 & 1.0000 & 0.31641 & 0.33935 & 0.83223 & Biso & 1.000 \\
\hline 030 & 1.0000 & 0.66793 & 0.98421 & 0.83762 & Biso & 1.000 \\
\hline 031 & 1.0000 & 0.68915 & 0.03168 & 0.16614 & Biso & 1.000 \\
\hline 032 & 1.0000 & 0.34127 & 0.32942 & 0.16227 & Biso & 1.000 \\
\hline 033 & 1.0000 & 0.98792 & 0.68131 & 0.17490 & Biso & 1.000 \\
\hline 034 & 1.0000 & 0.34715 & 0.36734 & 0.49553 & Biso & 1.000 \\
\hline 035 & 1.0000 & 0.99681 & 0.65854 & 0.50609 & Biso & 1.000 \\
\hline 036 & 1.0000 & 0.65023 & 0.00735 & 0.50136 & Biso & 1.000 \\
\hline 037 & 1.0000 & 0.12653 & 0.25074 & 0.12834 & Biso & 1.000 \\
\hline 038 & 1.0000 & 0.76277 & 0.88984 & 0.13581 & Biso & 1.000 \\
\hline 039 & 1.0000 & 0.12832 & 0.89205 & 0.13585 & Biso & 1.000 \\
\hline 040 & 1.0000 & 0.23826 & 0.12449 & 0.86556 & Biso & 1.000 \\
\hline 041 & 1.0000 & 0.87821 & 0.75880 & 0.87699 & Biso & 1.000 \\
\hline 042 & 1.0000 & 0.88116 & 0.12725 & 0.87134 & Biso & 1.000 \\
\hline 043 & 1.0000 & 0.78297 & 0.56947 & 0.46530 & Biso & 1.000 \\
\hline 044 & 1.0000 & 0.41064 & 0.21971 & 0.46051 & Biso & 1.000 \\
\hline 045 & 1.0000 & 0.79515 & 0.21771 & 0.46335 & Biso & 1.000 \\
\hline 046 & 1.0000 & 0.91878 & 0.46747 & 0.21052 & Biso & 1.000 \\
\hline 047 & 1.0000 & 0.55472 & 0.10866 & 0.20905 & Biso & 1.000 \\
\hline 048 & 1.0000 & 0.55265 & 0.46432 & 0.20663 & Biso & 1.000 \\
\hline 049 & 1.0000 & 0.45459 & 0.91124 & 0.80152 & Biso & 1.000 \\
\hline 050 & 1.0000 & 0.09028 & 0.54926 & 0.78856 & Biso & 1.000 \\
\hline 051 & 1.0000 & 0.45631 & 0.55258 & 0.79536 & Biso & 1.000 \\
\hline 052 & 1.0000 & 0.58689 & 0.79990 & 0.54654 & Biso & 1.000 \\
\hline 053 & 1.0000 & 0.22183 & 0.45158 & 0.54177 & Biso & 1.000 \\
\hline 054 & 1.0000 & 0.21260 & 0.78443 & 0.54089 & Biso & 1.000 \\
\hline 055 & 1.0000 & 0.99999 & 0.27045 & 0.00232 & Biso & 1.000 \\
\hline 056 & 1.0000 & 0.73924 & 0.74601 & 0.00599 & Biso & 1.000 \\
\hline 057 & 1.0000 & 0.25895 & 0.00649 & 0.99759 & Biso & 1.000 \\
\hline 058 & 1.0000 & 0.67316 & 0.60923 & 0.33702 & Biso & 1.000 \\
\hline 059 & 1.0000 & 0.38898 & 0.06470 & 0.32684 & Biso & 1.000 \\
\hline 060 & 1.0000 & 0.94229 & 0.34209 & 0.33540 & Biso & 1.000 \\
\hline 061 & 1.0000 & 0.33271 & 0.92924 & 0.66988 & Biso & 1.000 \\
\hline 062 & 1.0000 & 0.06685 & 0.39282 & 0.67003 & Biso & 1.000 \\
\hline 063 & 1.0000 & 0.61082 & 0.67347 & 0.67134 & Biso & 1.000 \\
\hline 064 & 1.0000 & 0.00707 & 0.74758 & 0.00638 & Biso & 1.000 \\
\hline 065 & 1.0000 & 0.26892 & 0.26827 & 0.99791 & Biso & 1.000 \\
\hline 066 & 1.0000 & 0.74196 & 0.00751 & 0.00278 & Biso & 1.000 \\
\hline 067 & 1.0000 & 0.67660 & 0.07566 & 0.33439 & Biso & 1.000 \\
\hline 068 & 1.0000 & 0.93786 & 0.61102 & 0.33986 & Biso & 1.000 \\
\hline 069 & 1.0000 & 0.39846 & 0.34766 & 0.33114 & Biso & 1.000 \\
\hline 070 & 1.0000 & 0.33410 & 0.40831 & 0.66632 & Biso & 1.000 \\
\hline 071 & 1.0000 & 0.60052 & 0.94606 & 0.67002 & Biso & 1.000 \\
\hline 072 & 1.0000 & 0.06547 & 0.68437 & 0.67387 & Biso & 1.000 \\
\hline H 1 & 1.0000 & 0.26057 & 0.91804 & 0.31586 & Biso & 1.000 \\
\hline $\mathrm{C} 1$ & 1.0000 & 0.11750 & 0.88945 & 0.38922 & Biso & 1.000 \\
\hline $\mathrm{H} 2$ & 1.0000 & 0.20454 & 0.85985 & 0.30646 & Biso & 1.000 \\
\hline H3 & 1.0000 & 0.06543 & 0.79730 & 0.38250 & Biso & 1.000 \\
\hline 073 & 1.0000 & 0.07687 & 0.94512 & 0.35169 & Biso & 1.000 \\
\hline $\mathrm{H} 4$ & 1.0000 & 0.18888 & 0.92973 & 0.43650 & Biso & 1.000 \\
\hline $\mathrm{C} 2$ & 1.0000 & 0.13476 & 0.06928 & 0.35985 & Biso & 1.000 \\
\hline H5 & 1.0000 & 0.20615 & 0.09969 & 0.40632 & Biso & 1.000 \\
\hline H6 & 1.0000 & 0.16289 & 0.10200 & 0.29260 & Biso & 1.000 \\
\hline H7 & 1.0000 & 0.06981 & 0.08856 & 0.38244 & Biso & 1.000 \\
\hline \multicolumn{7}{|c|}{$\mathrm{Ge} 7$} \\
\hline \multicolumn{7}{|c|}{ data_image 0} \\
\hline \multicolumn{2}{|c|}{ celì length a } & \multicolumn{2}{|c|}{13.875} & & & \\
\hline \multicolumn{2}{|c|}{ cell length b } & \multicolumn{2}{|c|}{13.875} & & & \\
\hline \multicolumn{2}{|c|}{ cell length $\mathrm{C}$} & 15.01 & & & & \\
\hline cell & alpha & 90 & & & & \\
\hline cell & _beta & 90 & & & & \\
\hline cell & gamma & 120 & & & & \\
\hline & & & & $1 "$ & & \\
\hline symme & $\left.i t \_t \overline{a b}\right]$ & Les_numb & & & & \\
\hline
\end{tabular}


loop

_symmetry_equiv_pos_as_xyz

' $\mathrm{x}, \mathrm{y}, \mathrm{z}$ '

loop

atom_site_label

-atom_site_occupancy

-atom_site_fract_x

_atom_site_fract_y

atom site fract $z$

-atom_site_thermä_displace_type

_atom_site_B_iso_or_equiv

atom site type symbol

$\overline{\mathrm{P} 1} \quad 1.0000^{-} 0.00133 \quad 0.23015$

$1.0000 \quad 0.77173$

P3 $1.0000 \quad 0.22342$

Al1 1.00000 .21266

Al2 1.00000 .76454

0.78093

0.11305

Biso

$1.000 \mathrm{P}$

$1.000 \mathrm{P}$

$0.99337 \quad 0.89123$ Biso $1.000 \mathrm{Al}$

0.22699

0.90480 Biso

$\begin{array}{ll}1.000 & \mathrm{Al} \\ 1.000 & \mathrm{Al}\end{array}$

$1.0000 \quad 0.66046$

0.55751

0.90051 Biso

$1.000 \mathrm{Al}$

Ge1 $1.0000 \quad 0.41913$

0.10333

0.44605 Biso

$1.0000 \quad 0.89257$

0.32705

0.44270 Biso

$1.000 \mathrm{P}$

$1.000 \mathrm{Ge}$

A14 $\quad 1.00000 .89656$

Al5 $\quad 1.0000 \quad 0.43478$

0.33650

0.44391 Biso

$1.000 \mathrm{P}$

$1.0000 \quad 0.66877$

0.11070

0.23544 Biso

$1.000 \mathrm{Al}$

$\begin{array}{lll}\text { Al6 } & 1.0000 & 0.66877 \\ \text { P6 } & 1.0000 & 0.32684\end{array}$

$1.0000 \quad 0.09641$

0.88762

2653 Biso

$1.000 \mathrm{Al}$

0.78170 Biso $1.000 \mathrm{P}$

P8 $1.0000 \quad 0.55492$

$\begin{array}{lll}\text { P } 817 & 1.00000 & 0.55492 \\ \text { Al } & 1.0000 & 0.56366\end{array}$

$\begin{array}{llll}0.77837 & \text { Biso } & 1.000 & \mathrm{P} \\ 0.77873 & \text { Biso } & 1.000 & \mathrm{P}\end{array}$

$1.0000 \quad 0.09004$

$1.0000 \quad 0.32703$

$1.0000 \quad 0.98760$

$1.0000 \quad 0.21934$

$1.0000 \quad 0.76961$

$1.0000 \quad 0.77300$

$1.0000 \quad 0.22876$

$1.0000 \quad 0.99782$

$1.0000 \quad 0.66156$

$1.0000 \quad 0.89688$

$\begin{array}{ll}0.77873 & \text { Biso } \\ 0.57212 & \text { Biso }\end{array}$

$1.000 \mathrm{AI}$

$0.43144 \quad 0.57434$ Biso $1.000 \quad A$

0.883650 .56822 Biso $1.000 \mathrm{Al}$

$0.76646 \quad 0.89841$ Biso $1.000 \quad \mathrm{P}$

$0.22210 \quad 0.88875$ Biso $1.000 \quad \mathrm{P}$

0.002280 .89805 Biso $1.000 \mathrm{P}$

$0.00744 \quad 0.11127$ Biso $1.000 \mathrm{Al}$

$0.23047 \quad 0.10168$ Biso $1.000 \mathrm{Al}$

0.778920 .11199 Biso $1.000 \mathrm{Al}$

0.111160 .22986 Biso $1.000 \quad \mathrm{P}$

$\begin{array}{lllll}0.56500 & 0.23460 & \text { Biso } & 1.000 & \mathrm{P}\end{array}$

$1.0000 \quad 0.43807$

0.34366

$1.0000 \quad 0.42296$

0.33931

0.43514 Biso

$\begin{array}{ll}1.000 & \mathrm{P} \\ 1.000 & \mathrm{Al}\end{array}$

$1.0000 \quad 0.88721$

$1.0000 \quad 0.65396$

$1.0000 \quad 0.32608$

0.55412

0.44535 Biso

$1.000 \mathrm{Al}$

$0.10704 \quad 0.44029$ Biso $1.000 \mathrm{Al}$

$\begin{array}{lllll}0.45222 & 0.56157 & \text { Biso } & 1.000 & \mathrm{P}\end{array}$

$0.89691 \quad 0.56602$ Biso $1.000 \quad \mathrm{P}$

$1.0000 \quad 0.560$

$1.0000 \quad 0.09020$

$1.0000 \quad 0.09596$

0.66599

$\begin{array}{lllll}0.66765 & 0.77729 & \text { Biso } & 1.000 & \mathrm{Al}\end{array}$

Al16

A 117

$1.0000 \quad 0.55514$

0.89249

0.77540 Biso

1.000 A

$1.0000 \quad 0.32351$

0.43763

$1.0000 \quad 0.91062$

0.11019

0.76999 Biso

$1.0000 \quad 0.89424$

$1.0000 \quad 0.19735$

0.81306

.13619 Biso

$1.000 \mathrm{AI}$

$1.0000 \quad 0.07739$

$1.0000 \quad 0.80083$

$1.0000 \quad 0.09845$

$1.0000 \quad 0.56271$

$\begin{array}{ll}1.0000 & 0.56017\end{array}$

$1.0000 \quad 0.86684$

$1.0000 \quad 0.75909$

$1.0000 \quad 0.46381$

$1.0000 \quad 0.77537$

$1.0000 \quad 0.23309$

$1.0000 \quad 0.21948$

$1.0000 \quad 0.52302$

$1.0000 \quad 0.42329$

$1.0000 \quad 0.09546$

$1.0000 \quad 0.43689$

$1.0000 \quad 0.98681$

$1.0000 \quad 0.69399$

$1.0000 \quad 0.33249$

$1.0000 \quad 0.31033$

$1.0000 \quad 0.64578$

$1.0000 \quad 0.02001$

$1.0000 \quad 0.64905$

$1.0000 \quad 0.32386$

$1.0000 \quad 0.98575$

$1.0000 \quad 0.00213$

$1.0000 \quad 0.30002$

$\begin{array}{llllllll}030 & 1.0000 & 0.66639 & 0.97883 & 0.84436 & \text { Biso } & 1.000 & 0 \\ 031 & 1.0000 & 0.68017 & 0.03173 & 0.17065 & \text { Biso } & 1.000 & \text { o }\end{array}$

0.88431

$.000 \quad 0$

0.86928 Biso 1.000 o

$\begin{array}{lllll}0.91148 & 0.88110 & \text { Biso } & 1.000 & 0\end{array}$

0.195390 .87506 Biso $1.000 \quad 0$

0.439020 .45935 Biso $1.000 \quad 0$

$0.14977 \quad 0.46541$ Biso $1.000 \quad 0$

0.421280 .46366 Biso $1.000 \quad 0$

$0.23155 \quad 0.21908$ Biso $1.000 \quad 0$

$\begin{array}{lllll}0.24868 & 0.21431 & \text { Biso } & 1.000 & 0\end{array}$

0.533440 .21702 Biso $1.000 \quad 0$

0.768390 .80388 Biso $1.000 \quad 0$

$\begin{array}{lllll}0.47079 & 0.79498 & \text { Biso } & 1.000 & 0\end{array}$

$\begin{array}{lllll}0.75388 & 0.78773 & \text { Biso } & 1.000 & 0\end{array}$

$\begin{array}{lllll}0.57264 & 0.55458 & \text { Biso } & 1.000 & 0\end{array}$

$\begin{array}{lllll}0.55886 & 0.56774 & \text { Biso } & 1.000 & 0\end{array}$

$\begin{array}{lllll}0.85744 & 0.54778 & \text { Biso } & 1.000 & 0\end{array}$

0.314780 .16855 Biso $1.000 \quad 0$

$0.68190 \quad 0.17535$ Biso $1.000 \quad 0$

0.024150 .14908 Biso $1.000 \quad 0$

$0.97293 \quad 0.83468$ Biso $1.000 \quad 0$

0.681290 .84593 Biso $1.000 \quad 0$

0.348210 .84621 Biso $1.000 \quad 0$

$\begin{array}{lllll}0.64151 & 0.50507 & \text { Biso } & 1.000 & 0\end{array}$

$\begin{array}{lllll}0.98449 & 0.50437 & \text { Biso } & 1.000 & 0\end{array}$

$\begin{array}{lllll}0.33670 & 0.50485 & \text { Biso } & 1.000 & 0\end{array}$

$0.67820 \quad 0.84834$ Biso $1.000 \quad 0$

0.321540 .83189 Biso $1.000 \quad 0$

$\begin{array}{lllll}0.32154 & 0.83189 & \text { Biso } & 1.000 & 0 \\ 0.97883 & 0.84436 & \text { Biso } & 1.000 & 0\end{array}$ 


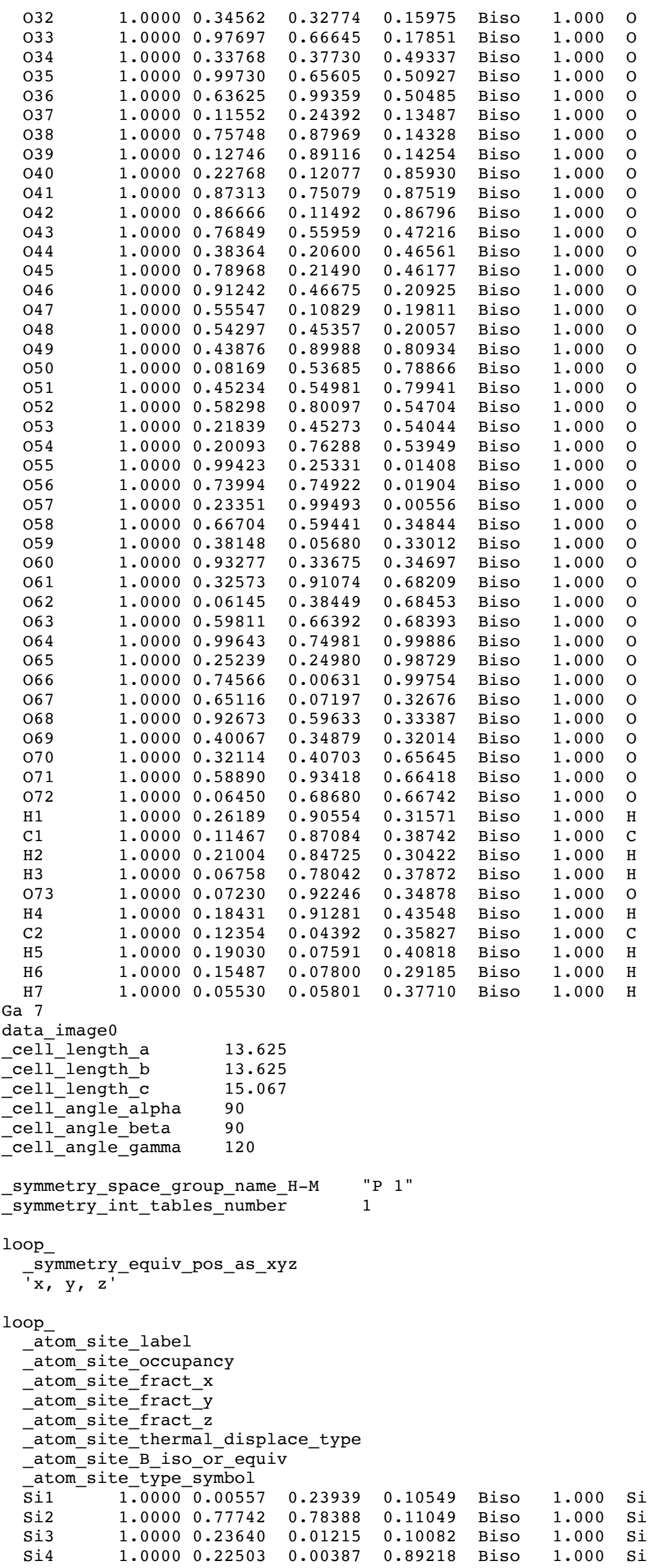




\begin{tabular}{|c|c|c|c|c|c|c|c|}
\hline Si5 & 1.0000 & 0.77220 & 0.77671 & 0.90367 & Biso & 1.000 & $\mathrm{Si}$ \\
\hline Si6 & 1.0000 & 0.99970 & 0.23642 & 0.89872 & Biso & 1.000 & $\mathrm{Si}$ \\
\hline Si7 & 1.0000 & 0.66529 & 0.56571 & 0.44096 & Biso & 1.000 & $\mathrm{Si}$ \\
\hline Ga 1 & 1.0000 & 0.43725 & 0.11368 & 0.43850 & Biso & 1.000 & \\
\hline Si 8 & 1.0000 & 0.90816 & 0.33861 & 0.43787 & Biso & 1.000 & \\
\hline Si9 & 1.0000 & 0.90748 & 0.34686 & 0.23370 & Biso & 1.000 & \\
\hline Si10 & 1.0000 & 0.44212 & 0.11519 & 0.22715 & Biso & 1.000 & \\
\hline Sil1 & 1.0000 & 0.67306 & 0.57336 & 0.23577 & Biso & 1.000 & \\
\hline Si12 & 1.0000 & 0.33286 & 0.89739 & 0.77359 & Biso & 1.000 & \\
\hline Si13 & 1.0000 & 0.10379 & 0.43947 & 0.77084 & Biso & 1.000 & \\
\hline Si14 & 1.0000 & 0.56664 & 0.67370 & 0.77308 & Biso & 1.000 & $\mathrm{Si}$ \\
\hline Si15 & 1.0000 & 0.57752 & 0.68123 & 0.57035 & Biso & 1.000 & \\
\hline $\operatorname{Si} 16$ & 1.0000 & 0.10107 & 0.43972 & 0.57118 & Biso & 1.000 & $\mathrm{Si}$ \\
\hline Si17 & 1.0000 & 0.33255 & 0.89216 & 0.56532 & Biso & 1.000 & $\mathrm{Si}$ \\
\hline Si18 & 1.0000 & 0.99904 & 0.77264 & 0.90269 & Biso & 1.000 & \\
\hline Si19 & 1.0000 & 0.22990 & 0.23494 & 0.89311 & Biso & 1.000 & $\mathrm{Si}$ \\
\hline Si20 & 1.0000 & 0.77424 & 0.00624 & 0.90003 & Biso & 1.000 & \\
\hline Si21 & 1.0000 & 0.77659 & 0.01167 & 0.10808 & Biso & 1.000 & \\
\hline Si22 & 1.0000 & 0.23700 & 0.24141 & 0.10046 & Biso & 1.000 & $\mathrm{Si}$ \\
\hline Si23 & 1.0000 & 0.00741 & 0.78515 & 0.11050 & Biso & 1.000 & $\mathrm{Si}$ \\
\hline $\mathrm{Si} 24$ & 1.0000 & 0.67318 & 0.11714 & 0.23418 & Biso & 1.000 & $\mathrm{Si}$ \\
\hline Si25 & 1.0000 & 0.90261 & 0.57416 & 0.23658 & Biso & 1.000 & \\
\hline Si26 & 1.0000 & 0.44059 & 0.34620 & 0.22986 & Biso & 1.000 & $\mathrm{Si}$ \\
\hline Si27 & 1.0000 & 0.42560 & 0.34245 & 0.43545 & Biso & 1.000 & $\mathrm{Si}$ \\
\hline Si28 & 1.0000 & 0.89574 & 0.56456 & 0.44323 & Biso & 1.000 & $\mathrm{Si}$ \\
\hline Si29 & 1.0000 & 0.67160 & 0.11595 & 0.43823 & Biso & 1.000 & $\mathrm{Si}$ \\
\hline $\mathrm{Si} 30$ & 1.0000 & 0.33834 & 0.45865 & 0.56439 & Biso & 1.000 & $\mathrm{Si}$ \\
\hline Si31 & 1.0000 & 0.56841 & 0.90678 & 0.56770 & Biso & 1.000 & $\mathrm{Si}$ \\
\hline Si32 & 1.0000 & 0.09390 & 0.67200 & 0.57412 & Biso & 1.000 & $\mathrm{Si}$ \\
\hline Si33 & 1.0000 & 0.10163 & 0.67272 & 0.77486 & Biso & 1.000 & $\mathrm{Si}$ \\
\hline $\mathrm{Si} 34$ & 1.0000 & 0.56355 & 0.90294 & 0.77314 & Biso & 1.000 & $\mathrm{Si}$ \\
\hline Si35 & 1.0000 & 0.33469 & 0.44440 & 0.76875 & Biso & 1.000 & $\mathrm{Si}$ \\
\hline 01 & 1.0000 & 0.90803 & 0.10917 & 0.12637 & Biso & 1.000 & 0 \\
\hline $\mathrm{O} 2$ & 1.0000 & 0.90980 & 0.81915 & 0.12590 & Biso & 1.000 & 0 \\
\hline 03 & 1.0000 & 0.20572 & 0.11137 & 0.12266 & Biso & 1.000 & 0 \\
\hline 04 & 1.0000 & 0.09515 & 0.90177 & 0.87700 & Biso & 1.000 & 0 \\
\hline 05 & 1.0000 & 0.80877 & 0.90861 & 0.88492 & Biso & 1.000 & 0 \\
\hline 06 & 1.0000 & 0.09993 & 0.20712 & 0.88068 & Biso & 1.000 & 0 \\
\hline 07 & 1.0000 & 0.55796 & 0.43946 & 0.45327 & Biso & 1.000 & 0 \\
\hline 08 & 1.0000 & 0.58663 & 0.16350 & 0.45457 & Biso & 1.000 & 0 \\
\hline 09 & 1.0000 & 0.87942 & 0.43954 & 0.45808 & Biso & 1.000 & 0 \\
\hline 010 & 1.0000 & 0.77642 & 0.24762 & 0.22214 & Biso & 1.000 & 0 \\
\hline 011 & 1.0000 & 0.47111 & 0.24635 & 0.21606 & Biso & 1.000 & 0 \\
\hline 012 & 1.0000 & 0.77168 & 0.54041 & 0.21959 & Biso & 1.000 & 0 \\
\hline 013 & 1.0000 & 0.23307 & 0.76767 & 0.79464 & Biso & 1.000 & 0 \\
\hline 014 & 1.0000 & 0.23575 & 0.47581 & 0.78915 & Biso & 1.000 & 0 \\
\hline 015 & 1.0000 & 0.53156 & 0.77112 & 0.78302 & Biso & 1.000 & 0 \\
\hline 016 & 1.0000 & 0.44539 & 0.58638 & 0.55538 & Biso & 1.000 & 0 \\
\hline 017 & 1.0000 & 0.10152 & 0.55824 & 0.56790 & Biso & 1.000 & 0 \\
\hline 018 & 1.0000 & 0.43456 & 0.86337 & 0.55021 & Biso & 1.000 & 0 \\
\hline 019 & 1.0000 & 0.98998 & 0.32797 & 0.16714 & Biso & 1.000 & 0 \\
\hline 020 & 1.0000 & 0.69515 & 0.67961 & 0.17420 & Biso & 1.000 & 0 \\
\hline 021 & 1.0000 & 0.34934 & 0.03523 & 0.15262 & Biso & 1.000 & 0 \\
\hline 022 & 1.0000 & 0.31279 & 0.98602 & 0.83170 & Biso & 1.000 & 0 \\
\hline 023 & 1.0000 & 0.66377 & 0.69231 & 0.84404 & Biso & 1.000 & 0 \\
\hline 024 & 1.0000 & 0.01900 & 0.34389 & 0.84002 & Biso & 1.000 & 0 \\
\hline 025 & 1.0000 & 0.65844 & 0.65740 & 0.50555 & Biso & 1.000 & 0 \\
\hline 026 & 1.0000 & 0.33766 & 0.98810 & 0.50132 & Biso & 1.000 & 0 \\
\hline 027 & 1.0000 & 0.01021 & 0.35131 & 0.50102 & Biso & 1.000 & 0 \\
\hline 028 & 1.0000 & 0.01754 & 0.68184 & 0.84634 & Biso & 1.000 & 0 \\
\hline 029 & 1.0000 & 0.31569 & 0.33823 & 0.82966 & Biso & 1.000 & 0 \\
\hline 030 & 1.0000 & 0.66670 & 0.98258 & 0.83942 & Biso & 1.000 & 0 \\
\hline 031 & 1.0000 & 0.69135 & 0.03368 & 0.16791 & Biso & 1.000 & 0 \\
\hline 032 & 1.0000 & 0.34280 & 0.33066 & 0.16008 & Biso & 1.000 & 0 \\
\hline 033 & 1.0000 & 0.98841 & 0.68336 & 0.17725 & Biso & 1.000 & 0 \\
\hline 034 & 1.0000 & 0.34369 & 0.37479 & 0.49177 & Biso & 1.000 & 0 \\
\hline 035 & 1.0000 & 0.99432 & 0.65987 & 0.50697 & Biso & 1.000 & 0 \\
\hline 036 & 1.0000 & 0.64853 & 0.01077 & 0.50304 & Biso & 1.000 & 0 \\
\hline 037 & 1.0000 & 0.12806 & 0.25287 & 0.12738 & Biso & 1.000 & 0 \\
\hline 038 & 1.0000 & 0.76318 & 0.89105 & 0.13687 & Biso & 1.000 & 0 \\
\hline 039 & 1.0000 & 0.12982 & 0.89329 & 0.13563 & Biso & 1.000 & 0 \\
\hline 040 & 1.0000 & 0.23506 & 0.12318 & 0.86444 & Biso & 1.000 & 0 \\
\hline 041 & 1.0000 & 0.87641 & 0.75688 & 0.87769 & Biso & 1.000 & 0 \\
\hline 042 & 1.0000 & 0.88029 & 0.12733 & 0.87059 & Biso & 1.000 & 0 \\
\hline 043 & 1.0000 & 0.77904 & 0.56191 & 0.46625 & Biso & 1.000 & 0 \\
\hline 044 & 1.0000 & 0.39833 & 0.21936 & 0.46585 & Biso & 1.000 & 0 \\
\hline 045 & 1.0000 & 0.80058 & 0.21657 & 0.45885 & Biso & 1.000 & o \\
\hline 046 & 1.0000 & 0.91885 & 0.46839 & 0.20950 & Biso & 1.000 & 0 \\
\hline 047 & 1.0000 & 0.55728 & 0.11289 & 0.20509 & Biso & 1.000 & 0 \\
\hline 048 & 1.0000 & 0.55256 & 0.46659 & 0.20790 & Biso & 1.000 & 0 \\
\hline
\end{tabular}




\begin{tabular}{|c|c|c|c|c|c|c|c|}
\hline 049 & 1.0000 & 0.45376 & 0.91164 & 0.80263 & Biso & 1.000 & 0 \\
\hline 050 & 1.0000 & 0.08867 & 0.54879 & 0.78361 & Biso & 1.000 & 0 \\
\hline 051 & 1.0000 & 0.45619 & 0.55217 & 0.79441 & Biso & 1.000 & 0 \\
\hline 052 & 1.0000 & 0.59351 & 0.80429 & 0.54687 & Biso & 1.000 & 0 \\
\hline 053 & 1.0000 & 0.22580 & 0.46560 & 0.54345 & Biso & 1.000 & 0 \\
\hline 054 & 1.0000 & 0.21252 & 0.77780 & 0.54137 & Biso & 1.000 & 0 \\
\hline 055 & 1.0000 & 0.99849 & 0.26926 & 0.00225 & Biso & 1.000 & 0 \\
\hline 056 & 1.0000 & 0.74020 & 0.74639 & 0.00799 & Biso & 1.000 & 0 \\
\hline 057 & 1.0000 & 0.25816 & 0.00625 & 0.99595 & Biso & 1.000 & 0 \\
\hline 058 & 1.0000 & 0.67400 & 0.60917 & 0.33890 & Biso & 1.000 & 0 \\
\hline 059 & 1.0000 & 0.38898 & 0.06401 & 0.32318 & Biso & 1.000 & 0 \\
\hline 060 & 1.0000 & 0.94965 & 0.34863 & 0.33507 & Biso & 1.000 & 0 \\
\hline 061 & 1.0000 & 0.33187 & 0.92564 & 0.66931 & Biso & 1.000 & 0 \\
\hline 062 & 1.0000 & 0.06786 & 0.38720 & 0.67096 & Biso & 1.000 & 0 \\
\hline 063 & 1.0000 & 0.61391 & 0.67687 & 0.67301 & Biso & 1.000 & 0 \\
\hline 064 & 1.0000 & 0.00559 & 0.74748 & 0.00784 & Biso & 1.000 & 0 \\
\hline 065 & 1.0000 & 0.26893 & 0.26910 & 0.99606 & Biso & 1.000 & 0 \\
\hline 066 & 1.0000 & 0.74364 & 0.00976 & 0.00401 & Biso & 1.000 & 0 \\
\hline 067 & 1.0000 & 0.66768 & 0.07354 & 0.33540 & Biso & 1.000 & 0 \\
\hline 068 & 1.0000 & 0.93625 & 0.60866 & 0.34110 & Biso & 1.000 & 0 \\
\hline 069 & 1.0000 & 0.39613 & 0.34581 & 0.32999 & Biso & 1.000 & 0 \\
\hline 070 & 1.0000 & 0.33270 & 0.41060 & 0.66471 & Biso & 1.000 & 0 \\
\hline 071 & 1.0000 & 0.60002 & 0.94620 & 0.67134 & Biso & 1.000 & 0 \\
\hline 072 & 1.0000 & 0.06460 & 0.69070 & 0.67546 & Biso & 1.000 & 0 \\
\hline $\mathrm{H} 1$ & 1.0000 & 0.26514 & 0.91372 & 0.31182 & Biso & 1.000 & $\mathrm{H}$ \\
\hline $\mathrm{C} 1$ & 1.0000 & 0.12055 & 0.88300 & 0.38504 & Biso & 1.000 & $\mathrm{C}$ \\
\hline $\mathrm{H} 2$ & 1.0000 & 0.21017 & 0.85487 & 0.30220 & Biso & 1.000 & $\mathrm{H}$ \\
\hline H3 & 1.0000 & 0.06989 & 0.79080 & 0.37781 & Biso & 1.000 & $\mathrm{H}$ \\
\hline 073 & 1.0000 & 0.07848 & 0.93715 & 0.34725 & Biso & 1.000 & $\mathrm{O}$ \\
\hline $\mathrm{H} 4$ & 1.0000 & 0.19193 & 0.92437 & 0.43240 & Biso & 1.000 & $\mathrm{H}$ \\
\hline $\mathrm{C} 2$ & 1.0000 & 0.13359 & 0.06107 & 0.35601 & Biso & 1.000 & $\mathrm{C}$ \\
\hline $\mathrm{H} 5$ & 1.0000 & 0.20315 & 0.09257 & 0.40430 & Biso & 1.000 & $\mathrm{H}$ \\
\hline H6 & 1.0000 & 0.16386 & 0.09491 & 0.28933 & Biso & 1.000 & $\mathrm{H}$ \\
\hline $\mathrm{H} 7$ & 1.0000 & 0.06631 & 0.07797 & 0.37653 & Biso & 1.000 & $\mathrm{H}$ \\
\hline \multicolumn{8}{|l|}{ Ti 7} \\
\hline \multicolumn{8}{|c|}{ data_image 0} \\
\hline \multicolumn{8}{|c|}{ _celì_length_a $\quad 13.875$} \\
\hline \multicolumn{8}{|c|}{ cell_length_b $\quad 13.875$} \\
\hline \multicolumn{8}{|c|}{ cell_length_c $\quad 15.017$} \\
\hline \multicolumn{8}{|c|}{ cell angle àlpha 90} \\
\hline \multicolumn{8}{|c|}{ _cell_angle_beta 90} \\
\hline \multicolumn{8}{|c|}{ _cell_angle_gamma 120} \\
\hline symme & space_g & coup_name & $\mathrm{H}-\mathrm{M}$ & $1 "$ & & & \\
\hline - symme & int_tāb. & les_numbe & & & & & \\
\hline loop_ & & & & & & & \\
\hline $\begin{array}{c}\text { syn } \\
\text { 'x, }\end{array}$ & _equiv & pos_as_x & & & & & \\
\hline loop_ & & & & & & & \\
\hline$-a \overline{t c}$ & Ee_labe. & & & & & & \\
\hline -atc & ce_occur & pancy & & & & & \\
\hline - atc & ce fract & E & & & & & \\
\hline -atc & ce_fract & E-y & & & & & \\
\hline -atc & ce_fract & - & & & & & \\
\hline atc & ee_therr & nàl_displ & ce_type & & & & \\
\hline $\begin{array}{l}\text {-atc } \\
\text { atc }\end{array}$ & $\begin{array}{l}\text { te_B_is } \\
\text { te type }\end{array}$ & $\begin{array}{l}\text { or_or_equi } \\
\text { symbol }\end{array}$ & & & & & \\
\hline$\overline{\mathrm{P}} 1$ & 1.0000 & 0.00195 & 0.23104 & 0.11263 & Biso & 1.000 & $\mathrm{P}$ \\
\hline $\mathrm{P} 2$ & 1.0000 & 0.77372 & 0.78330 & 0.11841 & Biso & 1.000 & $\mathrm{P}$ \\
\hline P3 & 1.0000 & 0.22447 & 0.00304 & 0.10395 & Biso & 1.000 & $\mathrm{P}$ \\
\hline Al1 & 1.0000 & 0.21082 & 0.99240 & 0.88852 & Biso & 1.000 & Al \\
\hline Al2 & 1.0000 & 0.76421 & 0.77353 & 0.90558 & Biso & 1.000 & Al \\
\hline Al3 & 1.0000 & 0.99360 & 0.22669 & 0.89967 & Biso & 1.000 & Al \\
\hline $\mathrm{P} 4$ & 1.0000 & 0.66101 & 0.55973 & 0.44672 & Biso & 1.000 & $\mathrm{P}$ \\
\hline Til & 1.0000 & 0.41393 & 0.10255 & 0.44429 & Biso & 1.000 & $\mathrm{Ti}$ \\
\hline P5 & 1.0000 & 0.89546 & 0.32709 & 0.44320 & Biso & 1.000 & $\mathrm{P}$ \\
\hline Al4 & 1.0000 & 0.89640 & 0.33698 & 0.23403 & Biso & 1.000 & Al \\
\hline Al5 & 1.0000 & 0.43300 & 0.11134 & 0.22515 & Biso & 1.000 & $\mathrm{Al}$ \\
\hline Al 6 & 1.0000 & 0.66989 & 0.56628 & 0.23662 & Biso & 1.000 & Al \\
\hline $\mathrm{P} 6$ & 1.0000 & 0.32495 & 0.88325 & 0.78342 & Biso & 1.000 & $P$ \\
\hline P7 & 1.0000 & 0.09518 & 0.43398 & 0.77751 & Biso & 1.000 & $\mathrm{P}$ \\
\hline P8 & 1.0000 & 0.55517 & 0.66240 & 0.77956 & Biso & 1.000 & $\mathrm{P}$ \\
\hline Al 7 & 1.0000 & 0.56935 & 0.67312 & 0.57410 & Biso & 1.000 & Al \\
\hline Al8 & 1.0000 & 0.08912 & 0.43162 & 0.57562 & Biso & 1.000 & Al \\
\hline Al9 & 1.0000 & 0.32440 & 0.87534 & 0.56884 & Biso & 1.000 & Al \\
\hline P9 & 1.0000 & 0.98634 & 0.76535 & 0.89843 & Biso & 1.000 & $P$ \\
\hline $\mathrm{P} 10$ & 1.0000 & 0.21868 & 0.22183 & 0.88661 & Biso & 1.000 & $\mathrm{P}$ \\
\hline P11 & 1.0000 & 0.76988 & 0.00198 & 0.89769 & Biso & 1.000 & $\mathrm{P}$ \\
\hline
\end{tabular}




\begin{tabular}{|c|c|c|c|c|c|c|c|}
\hline Al10 & 1.0000 & 0.77406 & 0.00869 & 0.11172 & Biso & 1.000 & $\mathrm{Al}$ \\
\hline Al11 & 1.0000 & 0.22956 & 0.23147 & 0.10003 & Biso & 1.000 & Al \\
\hline Al12 & 1.0000 & 0.99944 & 0.78085 & 0.11243 & Biso & 1.000 & Al \\
\hline P12 & 1.0000 & 0.66353 & 0.11259 & 0.23019 & Biso & 1.000 & $P$ \\
\hline P13 & 1.0000 & 0.89763 & 0.56651 & 0.23528 & Biso & 1.000 & $\mathrm{P}$ \\
\hline P 14 & 1.0000 & 0.43810 & 0.34464 & 0.22406 & Biso & 1.000 & $P$ \\
\hline Al13 & 1.0000 & 0.41850 & 0.34464 & 0.43485 & Biso & 1.000 & Al \\
\hline Al1 14 & 1.0000 & 0.88707 & 0.55402 & 0.44582 & Biso & 1.000 & Al \\
\hline Al15 & 1.0000 & 0.65873 & 0.10792 & 0.44039 & Biso & 1.000 & Al \\
\hline P15 & 1.0000 & 0.32722 & 0.45975 & 0.56099 & Biso & 1.000 & $\mathrm{P}$ \\
\hline P16 & 1.0000 & 0.56179 & 0.89807 & 0.56764 & Biso & 1.000 & $\mathrm{P}$ \\
\hline P 17 & 1.0000 & 0.08586 & 0.66386 & 0.57419 & Biso & 1.000 & $\mathrm{P}$ \\
\hline Al16 & 1.0000 & 0.09394 & 0.66652 & 0.77798 & Biso & 1.000 & Al \\
\hline Al1 17 & 1.0000 & 0.55408 & 0.89241 & 0.77669 & Biso & 1.000 & Al \\
\hline Al18 & 1.0000 & 0.32269 & 0.43831 & 0.76887 & Biso & 1.000 & $\mathrm{Al}$ \\
\hline 01 & 1.0000 & 0.91143 & 0.11162 & 0.13752 & Biso & 1.000 & 0 \\
\hline $\mathrm{O} 2$ & 1.0000 & 0.89631 & 0.81559 & 0.13446 & Biso & 1.000 & 0 \\
\hline 03 & 1.0000 & 0.19859 & 0.09591 & 0.12964 & Biso & 1.000 & 0 \\
\hline $\mathrm{O} 4$ & 1.0000 & 0.07579 & 0.88228 & 0.86699 & Biso & 1.000 & 0 \\
\hline 05 & 1.0000 & 0.80064 & 0.91110 & 0.87942 & Biso & 1.000 & 0 \\
\hline 06 & 1.0000 & 0.09794 & 0.19572 & 0.87323 & Biso & 1.000 & 0 \\
\hline 07 & 1.0000 & 0.55770 & 0.44497 & 0.45981 & Biso & 1.000 & 0 \\
\hline 08 & 1.0000 & 0.55945 & 0.14530 & 0.45916 & Biso & 1.000 & 0 \\
\hline 09 & 1.0000 & 0.87168 & 0.42278 & 0.46202 & Biso & 1.000 & 0 \\
\hline 010 & 1.0000 & 0.75845 & 0.23375 & 0.21566 & Biso & 1.000 & 0 \\
\hline 011 & 1.0000 & 0.46522 & 0.25063 & 0.21310 & Biso & 1.000 & 0 \\
\hline 012 & 1.0000 & 0.77590 & 0.53408 & 0.21753 & Biso & 1.000 & 0 \\
\hline 013 & 1.0000 & 0.23064 & 0.76522 & 0.80815 & Biso & 1.000 & 0 \\
\hline 014 & 1.0000 & 0.21855 & 0.47109 & 0.79514 & Biso & 1.000 & 0 \\
\hline 015 & 1.0000 & 0.52392 & 0.75415 & 0.78603 & Biso & 1.000 & 0 \\
\hline 016 & 1.0000 & 0.42933 & 0.57706 & 0.55428 & Biso & 1.000 & 0 \\
\hline 017 & 1.0000 & 0.07909 & 0.55093 & 0.57466 & Biso & 1.000 & 0 \\
\hline 018 & 1.0000 & 0.43789 & 0.85506 & 0.54636 & Biso & 1.000 & 0 \\
\hline 019 & 1.0000 & 0.98767 & 0.31667 & 0.16699 & Biso & 1.000 & 0 \\
\hline 020 & 1.0000 & 0.69593 & 0.68348 & 0.17594 & Biso & 1.000 & 0 \\
\hline 021 & 1.0000 & 0.33586 & 0.02735 & 0.14335 & Biso & 1.000 & 0 \\
\hline 022 & 1.0000 & 0.30833 & 0.97124 & 0.83221 & Biso & 1.000 & 0 \\
\hline 023 & 1.0000 & 0.64367 & 0.68042 & 0.84900 & Biso & 1.000 & 0 \\
\hline 024 & 1.0000 & 0.01909 & 0.34865 & 0.84665 & Biso & 1.000 & 0 \\
\hline 025 & 1.0000 & 0.65639 & 0.64720 & 0.50646 & Biso & 1.000 & 0 \\
\hline 026 & 1.0000 & 0.31947 & 0.97761 & 0.50781 & Biso & 1.000 & 0 \\
\hline 027 & 1.0000 & 0.99157 & 0.33799 & 0.50128 & Biso & 1.000 & 0 \\
\hline 028 & 1.0000 & 0.99984 & 0.67539 & 0.84998 & Biso & 1.000 & 0 \\
\hline 029 & 1.0000 & 0.29921 & 0.32116 & 0.82946 & Biso & 1.000 & 0 \\
\hline 030 & 1.0000 & 0.66536 & 0.97830 & 0.84579 & Biso & 1.000 & 0 \\
\hline 031 & 1.0000 & 0.67987 & 0.03360 & 0.16846 & Biso & 1.000 & 0 \\
\hline 032 & 1.0000 & 0.34722 & 0.32920 & 0.15735 & Biso & 1.000 & 0 \\
\hline 033 & 1.0000 & 0.97759 & 0.66803 & 0.17914 & Biso & 1.000 & 0 \\
\hline 034 & 1.0000 & 0.33128 & 0.38344 & 0.48963 & Biso & 1.000 & 0 \\
\hline 035 & 1.0000 & 0.99526 & 0.65810 & 0.51064 & Biso & 1.000 & 0 \\
\hline 036 & 1.0000 & 0.63775 & 0.99464 & 0.50656 & Biso & 1.000 & 0 \\
\hline 037 & 1.0000 & 0.11659 & 0.24538 & 0.13379 & Biso & 1.000 & 0 \\
\hline 038 & 1.0000 & 0.75895 & 0.88156 & 0.14545 & Biso & 1.000 & 0 \\
\hline 039 & 1.0000 & 0.13010 & 0.89258 & 0.14204 & Biso & 1.000 & o \\
\hline 040 & 1.0000 & 0.22633 & 0.12018 & 0.85676 & Biso & 1.000 & 0 \\
\hline 041 & 1.0000 & 0.87158 & 0.74921 & 0.87556 & Biso & 1.000 & 0 \\
\hline 042 & 1.0000 & 0.86619 & 0.11460 & 0.86668 & Biso & 1.000 & 0 \\
\hline 043 & 1.0000 & 0.76462 & 0.55272 & 0.47211 & Biso & 1.000 & 0 \\
\hline 044 & 1.0000 & 0.38447 & 0.21343 & 0.46844 & Biso & 1.000 & 0 \\
\hline 045 & 1.0000 & 0.79290 & 0.21641 & 0.46577 & Biso & 1.000 & 0 \\
\hline 046 & 1.0000 & 0.91410 & 0.46866 & 0.21060 & Biso & 1.000 & 0 \\
\hline 047 & 1.0000 & 0.55403 & 0.10629 & 0.20459 & Biso & 1.000 & 0 \\
\hline 048 & 1.0000 & 0.54323 & 0.45565 & 0.20247 & Biso & 1.000 & 0 \\
\hline 049 & 1.0000 & 0.43669 & 0.89660 & 0.81324 & Biso & 1.000 & 0 \\
\hline 050 & 1.0000 & 0.07893 & 0.53486 & 0.78423 & Biso & 1.000 & 0 \\
\hline 051 & 1.0000 & 0.45149 & 0.54990 & 0.79923 & Biso & 1.000 & 0 \\
\hline 052 & 1.0000 & 0.58862 & 0.80460 & 0.55187 & Biso & 1.000 & 0 \\
\hline 053 & 1.0000 & 0.22355 & 0.46958 & 0.54397 & Biso & 1.000 & 0 \\
\hline 054 & 1.0000 & 0.20021 & 0.75237 & 0.53966 & Biso & 1.000 & 0 \\
\hline 055 & 1.0000 & 0.99346 & 0.25185 & 0.01337 & Biso & 1.000 & 0 \\
\hline 056 & 1.0000 & 0.74215 & 0.75267 & 0.02023 & Biso & 1.000 & 0 \\
\hline 057 & 1.0000 & 0.23053 & 0.99465 & 0.00295 & Biso & 1.000 & 0 \\
\hline 058 & 1.0000 & 0.67017 & 0.59802 & 0.34924 & Biso & 1.000 & 0 \\
\hline 059 & 1.0000 & 0.37324 & 0.05929 & 0.32771 & Biso & 1.000 & 0 \\
\hline 060 & 1.0000 & 0.93051 & 0.33212 & 0.34530 & Biso & 1.000 & 0 \\
\hline 061 & 1.0000 & 0.32456 & 0.90129 & 0.68294 & Biso & 1.000 & 0 \\
\hline 062 & 1.0000 & 0.06132 & 0.37950 & 0.68456 & Biso & 1.000 & 0 \\
\hline 063 & 1.0000 & 0.60106 & 0.66288 & 0.68591 & Biso & 1.000 & 0 \\
\hline 064 & 1.0000 & 0.99659 & 0.75154 & 0.99916 & Biso & 1.000 & 0 \\
\hline 065 & 1.0000 & 0.25196 & 0.24931 & 0.98520 & Biso & 1.000 & 0 \\
\hline
\end{tabular}




\begin{tabular}{|c|c|c|c|c|c|c|c|}
\hline 066 & 1.0000 & 0.74833 & 0.00621 & 0.99762 & Biso & 1.000 & 0 \\
\hline 067 & 1.0000 & 0.66226 & 0.07564 & 0.32679 & Biso & 1.000 & 0 \\
\hline 068 & 1.0000 & 0.92707 & 0.59842 & 0.33462 & Biso & 1.000 & 0 \\
\hline 069 & 1.0000 & 0.39758 & 0.34765 & 0.31877 & Biso & 1.000 & 0 \\
\hline 070 & 1.0000 & 0.32125 & 0.41068 & 0.65458 & Biso & 1.000 & 0 \\
\hline 071 & 1.0000 & 0.58593 & 0.93677 & 0.66578 & Biso & 1.000 & 0 \\
\hline 072 & 1.0000 & 0.06527 & 0.69264 & 0.66884 & Biso & 1.000 & 0 \\
\hline $\mathrm{H} 1$ & 1.0000 & 0.26555 & 0.90407 & 0.31558 & Biso & 1.000 & $\mathrm{H}$ \\
\hline $\mathrm{C} 1$ & 1.0000 & 0.11347 & 0.86518 & 0.38593 & Biso & 1.000 & $\mathrm{C}$ \\
\hline H 2 & 1.0000 & 0.21803 & 0.84271 & 0.30665 & Biso & 1.000 & $\mathrm{H}$ \\
\hline H3 & 1.0000 & 0.06834 & 0.77541 & 0.37366 & Biso & 1.000 & $\mathrm{H}$ \\
\hline 073 & 1.0000 & 0.07393 & 0.91817 & 0.34559 & Biso & 1.000 & 0 \\
\hline $\mathrm{H} 4$ & 1.0000 & 0.17988 & 0.90543 & 0.43679 & Biso & 1.000 & $\mathrm{H}$ \\
\hline $\mathrm{C} 2$ & 1.0000 & 0.12271 & 0.03886 & 0.35841 & Biso & 1.000 & $\mathrm{C}$ \\
\hline H5 & 1.0000 & 0.18217 & 0.06818 & 0.41387 & Biso & 1.000 & $\mathrm{H}$ \\
\hline H6 & 1.0000 & 0.16320 & 0.07694 & 0.29512 & Biso & 1.000 & $\mathrm{H}$ \\
\hline $\mathrm{H} 7$ & 1.0000 & 0.05176 & 0.05119 & 0.37050 & Biso & 1.000 & $\mathrm{H}$ \\
\hline \multirow{2}{*}{\multicolumn{8}{|c|}{$\begin{array}{l}\text { Zn } 8 \\
\text { data image } 0\end{array}$}} \\
\hline & & & & & & & \\
\hline \multicolumn{8}{|c|}{13.875} \\
\hline \multicolumn{8}{|c|}{13.875} \\
\hline \multicolumn{8}{|c|}{15.017} \\
\hline \multicolumn{8}{|c|}{90} \\
\hline \multicolumn{8}{|c|}{90} \\
\hline \multicolumn{8}{|c|}{120} \\
\hline & space_g & coup_name & $\mathrm{H}-\mathrm{M}$ & $1 "$ & & & \\
\hline symme & int_t $\overline{a b}$ & les_numbe & $\bar{c}$ & & & & \\
\hline op & & & & & & & \\
\hline${ }^{\text {sym }} \mathrm{x}$ & equiv & pos_as_z & & & & & \\
\hline op & & & & & & & \\
\hline -ato & e_labe & & & & & & \\
\hline -ato & $e_{-}^{-}$occur & pancy & & & & & \\
\hline -ato & $=e^{-}$fract & $\mathrm{x}$ & & & & & \\
\hline -ato & $=e_{-}^{-}$rac & $y$ & & & & & \\
\hline -ato & eeffrac & - & & & & & \\
\hline -ato & e-ther & nàl_disp. & ace_type & & & & \\
\hline -ato & e_B_is & o_or_equ & & & & & \\
\hline -ato & $=e_{-}$type & symb̄ol & & & & & \\
\hline $\bar{A} 11$ & 1.0000 & 0.98899 & 0.22100 & 0.08566 & Biso & 1.000 & Al \\
\hline Al2 & 1.0000 & 0.76832 & 0.76999 & 0.08932 & Biso & 1.000 & Al \\
\hline Al3 & 1.0000 & 0.22279 & 0.99959 & 0.08152 & Biso & 1.000 & Al \\
\hline P1 & 1.0000 & 0.21463 & 0.99567 & 0.87020 & Biso & 1.000 & $\mathrm{P}$ \\
\hline P2 & 1.0000 & 0.76588 & 0.76603 & 0.87635 & Biso & 1.000 & $\mathrm{P}$ \\
\hline P3 & 1.0000 & 0.98580 & 0.22026 & 0.87338 & Biso & 1.000 & $\mathrm{P}$ \\
\hline Al4 & 1.0000 & 0.65235 & 0.55213 & 0.41984 & Biso & 1.000 & Al \\
\hline $\mathrm{Zn} 1$ & 1.0000 & 0.44296 & 0.11062 & 0.42049 & Biso & 1.000 & $\mathrm{Zn}$ \\
\hline Al5 & 1.0000 & 0.89493 & 0.33018 & 0.41776 & Biso & 1.000 & Al \\
\hline P4 & 1.0000 & 0.88928 & 0.33437 & 0.20693 & Biso & 1.000 & $\mathrm{P}$ \\
\hline P5 & 1.0000 & 0.43224 & 0.10193 & 0.20376 & Biso & 1.000 & $\mathrm{P}$ \\
\hline P6 & 1.0000 & 0.65502 & 0.55566 & 0.20952 & Biso & 1.000 & $P$ \\
\hline Al6 & 1.0000 & 0.31939 & 0.88413 & 0.75269 & Biso & 1.000 & Al \\
\hline Al 7 & 1.0000 & 0.09666 & 0.42866 & 0.74941 & Biso & 1.000 & Al \\
\hline Al8 & 1.0000 & 0.55468 & 0.66457 & 0.75323 & Biso & 1.000 & $\mathrm{Al}$ \\
\hline P7 & 1.0000 & 0.56623 & 0.67345 & 0.54514 & Biso & 1.000 & $\mathrm{P}$ \\
\hline P8 & 1.0000 & 0.09819 & 0.43211 & 0.54392 & Biso & 1.000 & $\mathrm{P}$ \\
\hline P9 & 1.0000 & 0.32110 & 0.88014 & 0.54188 & Biso & 1.000 & $P$ \\
\hline Al9 & 1.0000 & 0.98922 & 0.76314 & 0.88116 & Biso & 1.000 & $\mathrm{Al}$ \\
\hline Al10 & 1.0000 & 0.21513 & 0.22241 & 0.87546 & Biso & 1.000 & Al \\
\hline Al11 & 1.0000 & 0.76277 & 0.99130 & 0.87834 & Biso & 1.000 & $\mathrm{Al}$ \\
\hline P10 & 1.0000 & 0.76367 & 0.99338 & 0.09108 & Biso & 1.000 & $\mathrm{P}$ \\
\hline P11 & 1.0000 & 0.21786 & 0.22353 & 0.08755 & Biso & 1.000 & $\mathrm{P}$ \\
\hline P12 & 1.0000 & 0.99413 & 0.77103 & 0.09195 & Biso & 1.000 & $\mathrm{P}$ \\
\hline Al 12 & 1.0000 & 0.66266 & 0.10245 & 0.21574 & Biso & 1.000 & Al \\
\hline Al13 & 1.0000 & 0.88231 & 0.55611 & 0.21212 & Biso & 1.000 & Al \\
\hline Al14 & 1.0000 & 0.42971 & 0.32491 & 0.21021 & Biso & 1.000 & Al \\
\hline P13 & 1.0000 & 0.41974 & 0.32520 & 0.42266 & Biso & 1.000 & $\mathrm{P}$ \\
\hline P14 & 1.0000 & 0.88093 & 0.55146 & 0.42496 & Biso & 1.000 & $\mathrm{P}$ \\
\hline P15 & 1.0000 & 0.67068 & 0.10859 & 0.42109 & Biso & 1.000 & $\mathrm{P}$ \\
\hline Al15 & 1.0000 & 0.33291 & 0.44749 & 0.54411 & Biso & 1.000 & Al \\
\hline Al16 & 1.0000 & 0.55134 & 0.89268 & 0.54753 & Biso & 1.000 & $\mathrm{Al}$ \\
\hline Al17 & 1.0000 & 0.08634 & 0.65893 & 0.55098 & Biso & 1.000 & Al \\
\hline P16 & 1.0000 & 0.09093 & 0.65768 & 0.75681 & Biso & 1.000 & $P$ \\
\hline P 17 & 1.0000 & 0.54766 & 0.88891 & 0.75820 & Biso & 1.000 & $\mathrm{P}$ \\
\hline P18 & 1.0000 & 0.32690 & 0.43429 & 0.75288 & Biso & 1.000 & $\mathrm{P}$ \\
\hline 01 & 1.0000 & 0.88511 & 0.08428 & 0.10950 & Biso & 1.000 & 0 \\
\hline $\mathrm{O} 2$ & 1.0000 & 0.90672 & 0.80590 & 0.11198 & Biso & 1.000 & 0 \\
\hline
\end{tabular}




\begin{tabular}{|c|c|c|c|c|c|c|c|}
\hline 03 & 1.0000 & 0.18803 & 0.10226 & 0.10613 & Biso & 1.000 & 0 \\
\hline 04 & 1.0000 & 0.09392 & 0.89988 & 0.85740 & Biso & 1.000 & 0 \\
\hline 05 & 1.0000 & 0.79655 & 0.88721 & 0.85650 & Biso & 1.000 & 0 \\
\hline 06 & 1.0000 & 0.07882 & 0.19304 & 0.85446 & Biso & 1.000 & 0 \\
\hline 07 & 1.0000 & 0.54151 & 0.41902 & 0.43846 & Biso & 1.000 & 0 \\
\hline 08 & 1.0000 & 0.59886 & 0.16279 & 0.42802 & Biso & 1.000 & 0 \\
\hline 09 & 1.0000 & 0.86327 & 0.43504 & 0.44510 & Biso & 1.000 & 0 \\
\hline 010 & 1.0000 & 0.76784 & 0.24069 & 0.19594 & Biso & 1.000 & 0 \\
\hline 011 & 1.0000 & 0.46638 & 0.22439 & 0.18380 & Biso & 1.000 & 0 \\
\hline 012 & 1.0000 & 0.74518 & 0.52378 & 0.19212 & Biso & 1.000 & 0 \\
\hline 013 & 1.0000 & 0.21289 & 0.74725 & 0.77431 & Biso & 1.000 & 0 \\
\hline 014 & 1.0000 & 0.23507 & 0.46387 & 0.77058 & Biso & 1.000 & 0 \\
\hline 015 & 1.0000 & 0.51778 & 0.76670 & 0.77093 & Biso & 1.000 & 0 \\
\hline 016 & 1.0000 & 0.44362 & 0.58346 & 0.53151 & Biso & 1.000 & 0 \\
\hline 017 & 1.0000 & 0.10629 & 0.54621 & 0.53949 & Biso & 1.000 & 0 \\
\hline 018 & 1.0000 & 0.40918 & 0.84366 & 0.52995 & Biso & 1.000 & 0 \\
\hline 019 & 1.0000 & 0.96750 & 0.31484 & 0.14720 & Biso & 1.000 & 0 \\
\hline 020 & 1.0000 & 0.67524 & 0.65429 & 0.15077 & Biso & 1.000 & 0 \\
\hline O21 & 1.0000 & 0.34305 & 0.02394 & 0.13642 & Biso & 1.000 & 0 \\
\hline $\mathrm{O} 22$ & 1.0000 & 0.29439 & 0.97810 & 0.81107 & Biso & 1.000 & 0 \\
\hline 023 & 1.0000 & 0.66243 & 0.68414 & 0.82379 & Biso & 1.000 & 0 \\
\hline 024 & 1.0000 & 0.00419 & 0.32103 & 0.81828 & Biso & 1.000 & 0 \\
\hline 025 & 1.0000 & 0.64293 & 0.65166 & 0.48511 & Biso & 1.000 & 0 \\
\hline 026 & 1.0000 & 0.33956 & 0.97442 & 0.48092 & Biso & 1.000 & 0 \\
\hline $\mathrm{O} 27$ & 1.0000 & 0.01152 & 0.35132 & 0.47793 & Biso & 1.000 & 0 \\
\hline $\mathrm{O} 28$ & 1.0000 & 0.01329 & 0.66792 & 0.82386 & Biso & 1.000 & 0 \\
\hline 029 & 1.0000 & 0.30855 & 0.33569 & 0.81116 & Biso & 1.000 & 0 \\
\hline 030 & 1.0000 & 0.64514 & 0.96601 & 0.81852 & Biso & 1.000 & 0 \\
\hline 031 & 1.0000 & 0.68232 & 0.01366 & 0.14528 & Biso & 1.000 & 0 \\
\hline 032 & 1.0000 & 0.31762 & 0.30498 & 0.14369 & Biso & 1.000 & 0 \\
\hline 033 & 1.0000 & 0.97636 & 0.67508 & 0.15339 & Biso & 1.000 & 0 \\
\hline 034 & 1.0000 & 0.34026 & 0.35639 & 0.46978 & Biso & 1.000 & 0 \\
\hline 035 & 1.0000 & 0.97702 & 0.64094 & 0.48152 & Biso & 1.000 & 0 \\
\hline 036 & 1.0000 & 0.63547 & 0.01016 & 0.48532 & Biso & 1.000 & 0 \\
\hline 037 & 1.0000 & 0.11805 & 0.23668 & 0.11307 & Biso & 1.000 & 0 \\
\hline 038 & 1.0000 & 0.74973 & 0.88079 & 0.11896 & Biso & 1.000 & 0 \\
\hline 039 & 1.0000 & 0.11063 & 0.86948 & 0.10907 & Biso & 1.000 & 0 \\
\hline 040 & 1.0000 & 0.22143 & 0.10521 & 0.84197 & Biso & 1.000 & 0 \\
\hline 041 & 1.0000 & 0.86296 & 0.75001 & 0.84718 & Biso & 1.000 & 0 \\
\hline 042 & 1.0000 & 0.87414 & 0.11984 & 0.84611 & Biso & 1.000 & 0 \\
\hline 043 & 1.0000 & 0.77570 & 0.55504 & 0.44894 & Biso & 1.000 & 0 \\
\hline 044 & 1.0000 & 0.40000 & 0.21575 & 0.46099 & Biso & 1.000 & 0 \\
\hline 045 & 1.0000 & 0.79181 & 0.19634 & 0.44517 & Biso & 1.000 & 0 \\
\hline 046 & 1.0000 & 0.89858 & 0.44505 & 0.17859 & Biso & 1.000 & 0 \\
\hline 047 & 1.0000 & 0.53460 & 0.08897 & 0.19026 & Biso & 1.000 & 0 \\
\hline 048 & 1.0000 & 0.54130 & 0.45681 & 0.18558 & Biso & 1.000 & 0 \\
\hline 049 & 1.0000 & 0.44661 & 0.89917 & 0.78545 & Biso & 1.000 & 0 \\
\hline 050 & 1.0000 & 0.07974 & 0.54299 & 0.76787 & Biso & 1.000 & 0 \\
\hline 051 & 1.0000 & 0.43986 & 0.53477 & 0.77677 & Biso & 1.000 & 0 \\
\hline 052 & 1.0000 & 0.58099 & 0.78724 & 0.52030 & Biso & 1.000 & 0 \\
\hline 053 & 1.0000 & 0.21129 & 0.44747 & 0.51807 & Biso & 1.000 & 0 \\
\hline 054 & 1.0000 & 0.20603 & 0.77907 & 0.51949 & Biso & 1.000 & 0 \\
\hline 055 & 1.0000 & 0.98509 & 0.24781 & 0.97235 & Biso & 1.000 & 0 \\
\hline 056 & 1.0000 & 0.74146 & 0.74037 & 0.97598 & Biso & 1.000 & 0 \\
\hline 057 & 1.0000 & 0.25015 & 0.00166 & 0.96764 & Biso & 1.000 & 0 \\
\hline 058 & 1.0000 & 0.65856 & 0.58958 & 0.30767 & Biso & 1.000 & 0 \\
\hline 059 & 1.0000 & 0.38327 & 0.06779 & 0.29769 & Biso & 1.000 & 0 \\
\hline 060 & 1.0000 & 0.92715 & 0.34141 & 0.30416 & Biso & 1.000 & 0 \\
\hline 061 & 1.0000 & 0.32047 & 0.91381 & 0.64006 & Biso & 1.000 & 0 \\
\hline 062 & 1.0000 & 0.06487 & 0.38362 & 0.63861 & Biso & 1.000 & 0 \\
\hline 063 & 1.0000 & 0.59993 & 0.67279 & 0.64293 & Biso & 1.000 & 0 \\
\hline 064 & 1.0000 & 0.98384 & 0.73233 & 0.99456 & Biso & 1.000 & 0 \\
\hline 065 & 1.0000 & 0.24686 & 0.25144 & 0.98830 & Biso & 1.000 & 0 \\
\hline 066 & 1.0000 & 0.73625 & 0.99237 & 0.99176 & Biso & 1.000 & 0 \\
\hline 067 & 1.0000 & 0.66877 & 0.06452 & 0.32568 & Biso & 1.000 & 0 \\
\hline 068 & 1.0000 & 0.91161 & 0.58208 & 0.32629 & Biso & 1.000 & 0 \\
\hline 069 & 1.0000 & 0.39358 & 0.31738 & 0.32203 & Biso & 1.000 & 0 \\
\hline 070 & 1.0000 & 0.32561 & 0.40183 & 0.65448 & Biso & 1.000 & 0 \\
\hline 071 & 1.0000 & 0.58071 & 0.92514 & 0.66103 & Biso & 1.000 & 0 \\
\hline 072 & 1.0000 & 0.05507 & 0.67112 & 0.66228 & Biso & 1.000 & 0 \\
\hline $\mathrm{H} 1$ & 1.0000 & 0.24978 & 0.97236 & 0.30516 & Biso & 1.000 & $\mathrm{H}$ \\
\hline $\mathrm{C} 1$ & 1.0000 & 0.09872 & 0.92696 & 0.42412 & Biso & 1.000 & C \\
\hline H2 & 1.0000 & 0.04143 & 0.83771 & 0.42026 & Biso & 1.000 & $\mathrm{H}$ \\
\hline H3 & 1.0000 & 0.17937 & 0.95688 & 0.45537 & Biso & 1.000 & $\mathrm{H}$ \\
\hline $\mathrm{H} 4$ & 1.0000 & 0.08200 & 0.98167 & 0.38352 & Biso & 1.000 & $\mathrm{H}$ \\
\hline 073 & 1.0000 & 0.17232 & 0.90632 & 0.30587 & Biso & 1.000 & 0 \\
\hline $\mathrm{C} 2$ & 1.0000 & 0.00463 & 0.91447 & 0.53959 & Biso & 1.000 & C \\
\hline $\mathrm{C} 3$ & 1.0000 & 0.07352 & 0.02671 & 0.54907 & Biso & 1.000 & C \\
\hline $\mathrm{C} 4$ & 1.0000 & 0.17805 & 0.08094 & 0.60068 & Biso & 1.000 & C \\
\hline H5 & 1.0000 & 0.19487 & 0.02145 & 0.63563 & & 1.000 & $\mathrm{H}$ \\
\hline
\end{tabular}




\begin{tabular}{|c|c|c|c|c|c|c|c|}
\hline & & & & & & & \\
\hline H6 & 1.0000 & 0.17425 & 0.13833 & 0.64956 & Biso & 1.000 & $\mathrm{H}$ \\
\hline $\mathrm{H} 7$ & 1.0000 & 0.24947 & 0.13406 & 0.55714 & Biso & 1.000 & $\mathrm{H}$ \\
\hline C5 & 1.0000 & 0.18560 & 0.80983 & 0.30123 & Biso & 1.000 & C \\
\hline H8 & 1.0000 & 0.10589 & 0.73690 & 0.31898 & Biso & 1.000 & $\mathrm{H}$ \\
\hline $\mathrm{H} 9$ & 1.0000 & 0.25058 & 0.81740 & 0.34723 & Biso & 1.000 & $\mathrm{H}$ \\
\hline $\mathrm{H} 10$ & 1.0000 & 0.20705 & 0.80025 & 0.23253 & Biso & 1.000 & $\mathrm{H}$ \\
\hline H 11 & 1.0000 & 0.01868 & 0.85622 & 0.57875 & Biso & 1.000 & $\mathrm{H}$ \\
\hline H 12 & 1.0000 & 0.05110 & 0.08213 & 0.51399 & Biso & 1.000 & $\mathrm{H}$ \\
\hline H 13 & 1.0000 & 0.92321 & 0.88097 & 0.50802 & Biso & 1.000 & $\mathrm{H}$ \\
\hline $\mathrm{Si} 8$ & & & & & & & \\
\hline 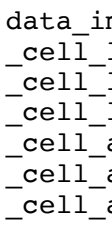 & $\begin{array}{l}\text { th_a } \\
\text { th_b } \\
\text { th_c } \\
\text { e_alpha } \\
\text { e_beta } \\
\text { e_gamma }\end{array}$ & $\begin{array}{l}13.87 \\
13.87 \\
15.01 \\
90 \\
90 \\
120\end{array}$ & & & & & \\
\hline _symmet & space_gr & roup_name & & P $1 "$ & & & \\
\hline symme & int_tab] & les_numbe & 1 & & & & \\
\hline loop_ & & & & & & & \\
\hline $\bar{T}^{\text {sym }}$ & _equiv & pos_as_x & & & & & \\
\hline loop_ & & & & & & & \\
\hline $\begin{array}{l}\text {-ator } \\
\text {-ator } \\
\text {-ator } \\
\text {-ator } \\
\text {-ator } \\
\text {-ator } \\
\text {-ator } \\
\text {-ator }\end{array}$ & $\begin{array}{l}\text { te_labe] } \\
\text { te_occup } \\
\text { te_fract } \\
\text { te_fract } \\
\text { te_fract } \\
\text { te_thern } \\
\text { te_B_isc } \\
\text { te_type }\end{array}$ & $\begin{array}{l}\text { oancy } \\
t \_x \\
\text { _y } \\
\text { na } \\
\text { nal_displ } \\
\text { _or_equi } \\
\text { symbol }\end{array}$ & ce_type & & & & \\
\hline$\overline{\mathrm{P}} 1$ & 1.0000 & 0.99613 & 0.22478 & 0.09053 & Biso & 1.000 & $\mathrm{P}$ \\
\hline P2 & 1.0000 & 0.76795 & 0.77495 & 0.09230 & Biso & 1.000 & $\mathrm{P}$ \\
\hline P3 & 1.0000 & 0.22211 & 0.99566 & 0.08588 & Biso & 1.000 & $\mathrm{P}$ \\
\hline Al1 & 1.0000 & 0.21636 & 0.99251 & 0.87496 & Biso & 1.000 & Al \\
\hline Al2 & 1.0000 & 0.76303 & 0.77014 & 0.87983 & Biso & 1.000 & Al \\
\hline Al3 & 1.0000 & 0.99269 & 0.22440 & 0.87893 & Biso & 1.000 & Al \\
\hline $\mathrm{P} 4$ & 1.0000 & 0.66237 & 0.55866 & 0.42318 & Biso & 1.000 & $\mathrm{P}$ \\
\hline Sil & 1.0000 & 0.42465 & 0.10456 & 0.42214 & Biso & 1.000 & $\mathrm{Si}$ \\
\hline P5 & 1.0000 & 0.88652 & 0.32293 & 0.42326 & Biso & 1.000 & $\mathrm{P}$ \\
\hline Al4 & 1.0000 & 0.88727 & 0.32790 & 0.21152 & Biso & 1.000 & Al \\
\hline Al5 & 1.0000 & 0.43023 & 0.10675 & 0.21188 & Biso & 1.000 & $\mathrm{Al}$ \\
\hline Al6 & 1.0000 & 0.66361 & 0.55947 & 0.21220 & Biso & 1.000 & Al \\
\hline P6 & 1.0000 & 0.32614 & 0.88720 & 0.75728 & Biso & 1.000 & $\mathrm{P}$ \\
\hline P7 & 1.0000 & 0.09423 & 0.43318 & 0.75491 & Biso & 1.000 & $P$ \\
\hline P8 & 1.0000 & 0.55262 & 0.65882 & 0.75615 & Biso & 1.000 & $\mathrm{P}$ \\
\hline Al7 & 1.0000 & 0.55928 & 0.66345 & 0.54822 & Biso & 1.000 & Al \\
\hline Al8 & 1.0000 & 0.09244 & 0.43228 & 0.54774 & Biso & 1.000 & Al \\
\hline Al9 & 1.0000 & 0.32985 & 0.88731 & 0.54510 & Biso & 1.000 & Al \\
\hline P9 & 1.0000 & 0.98557 & 0.76367 & 0.87586 & Biso & 1.000 & $\mathrm{P}$ \\
\hline $\mathrm{P} 10$ & 1.0000 & 0.21832 & 0.21935 & 0.87094 & Biso & 1.000 & $P$ \\
\hline $\mathrm{P} 11$ & 1.0000 & 0.76670 & 0.99871 & 0.87378 & Biso & 1.000 & $\mathrm{P}$ \\
\hline Al10 & 1.0000 & 0.76672 & 0.00053 & 0.08658 & Biso & 1.000 & $\mathrm{Al}$ \\
\hline Al11 & 1.0000 & 0.22268 & 0.22175 & 0.08355 & Biso & 1.000 & Al \\
\hline Al12 & 1.0000 & 0.99132 & 0.76962 & 0.08724 & Biso & 1.000 & Al \\
\hline $\mathrm{P} 12$ & 1.0000 & 0.65821 & 0.10227 & 0.20842 & Biso & 1.000 & $\mathrm{P}$ \\
\hline P13 & 1.0000 & 0.88821 & 0.55493 & 0.20880 & Biso & 1.000 & $\mathrm{P}$ \\
\hline P 14 & 1.0000 & 0.43441 & 0.33541 & 0.20561 & Biso & 1.000 & $\mathrm{P}$ \\
\hline Al13 & 1.0000 & 0.42819 & 0.33213 & 0.41744 & Biso & 1.000 & Al \\
\hline Al14 & 1.0000 & 0.88548 & 0.55047 & 0.42122 & Biso & 1.000 & Al \\
\hline Al15 & 1.0000 & 0.65391 & 0.10166 & 0.41625 & Biso & 1.000 & Al \\
\hline P15 & 1.0000 & 0.32392 & 0.44025 & 0.54033 & Biso & 1.000 & $\mathrm{P}$ \\
\hline P16 & 1.0000 & 0.55639 & 0.88975 & 0.54277 & Biso & 1.000 & $P$ \\
\hline P 17 & 1.0000 & 0.09391 & 0.66554 & 0.54495 & Biso & 1.000 & $\mathrm{P}$ \\
\hline Al16 & 1.0000 & 0.09545 & 0.66466 & 0.75254 & Biso & 1.000 & Al \\
\hline Al17 & 1.0000 & 0.55370 & 0.88893 & 0.75201 & Biso & 1.000 & Al \\
\hline Al18 & 1.0000 & 0.32128 & 0.43287 & 0.74965 & Biso & 1.000 & Al \\
\hline 01 & 1.0000 & 0.90395 & 0.10438 & 0.10998 & Biso & 1.000 & 0 \\
\hline $\mathrm{O} 2$ & 1.0000 & 0.89006 & 0.80687 & 0.10964 & Biso & 1.000 & 0 \\
\hline 03 & 1.0000 & 0.18976 & 0.08469 & 0.10725 & Biso & 1.000 & 0 \\
\hline 04 & 1.0000 & 0.07948 & 0.88393 & 0.85792 & Biso & 1.000 & 0 \\
\hline 05 & 1.0000 & 0.79606 & 0.90697 & 0.85529 & Biso & 1.000 & 0 \\
\hline 06 & 1.0000 & 0.09761 & 0.19281 & 0.85569 & Biso & 1.000 & 0 \\
\hline 07 & 1.0000 & 0.56528 & 0.44056 & 0.43833 & Biso & 1.000 & 0 \\
\hline 08 & 1.0000 & 0.55451 & 0.13902 & 0.42710 & Biso & 1.000 & 0 \\
\hline 09 & 1.0000 & 0.86094 & 0.41691 & 0.44443 & Biso & 1.000 & 0 \\
\hline 010 & 1.0000 & 0.75034 & 0.22371 & 0.19052 & Biso & 1.000 & 0 \\
\hline
\end{tabular}




\begin{tabular}{|c|c|c|c|c|c|c|}
\hline 011 & 1.0000 & 0.46598 & 0.24520 & 0.18851 & Biso & 1.000 \\
\hline 012 & 1.0000 & 0.76683 & 0.52415 & 0.19123 & Biso & 1.000 \\
\hline 013 & 1.0000 & 0.23262 & 0.76701 & 0.77655 & Biso & 1.000 \\
\hline 014 & 1.0000 & 0.21646 & 0.46553 & 0.77149 & Biso & 1.000 \\
\hline 015 & 1.0000 & 0.52250 & 0.75096 & 0.76752 & Biso & 1.000 \\
\hline 016 & 1.0000 & 0.42051 & 0.56077 & 0.53063 & Biso & 1.000 \\
\hline 017 & 1.0000 & 0.11247 & 0.56607 & 0.53556 & Biso & 1.000 \\
\hline 018 & 1.0000 & 0.43178 & 0.84902 & 0.52789 & Biso & 1.000 \\
\hline 019 & 1.0000 & 0.98103 & 0.30719 & 0.14847 & Biso & 1.000 \\
\hline 020 & 1.0000 & 0.68882 & 0.67513 & 0.14942 & Biso & 1.000 \\
\hline 021 & 1.0000 & 0.32348 & 0.01501 & 0.13997 & Biso & 1.000 \\
\hline 022 & 1.0000 & 0.30897 & 0.97040 & 0.81246 & Biso & 1.000 \\
\hline 023 & 1.0000 & 0.64492 & 0.67575 & 0.82116 & Biso & 1.000 \\
\hline $\mathrm{O} 24$ & 1.0000 & 0.01619 & 0.34159 & 0.81915 & Biso & 1.000 \\
\hline 025 & 1.0000 & 0.65025 & 0.64319 & 0.48118 & Biso & 1.000 \\
\hline 026 & 1.0000 & 0.34589 & 0.99697 & 0.48334 & Biso & 1.000 \\
\hline $\mathrm{O} 27$ & 1.0000 & 0.98567 & 0.33798 & 0.47951 & Biso & 1.000 \\
\hline 028 & 1.0000 & 0.00279 & 0.68087 & 0.82026 & Biso & 1.000 \\
\hline 029 & 1.0000 & 0.29895 & 0.31847 & 0.81345 & Biso & 1.000 \\
\hline 030 & 1.0000 & 0.66571 & 0.97900 & 0.81855 & Biso & 1.000 \\
\hline 031 & 1.0000 & 0.67184 & 0.02309 & 0.14489 & Biso & 1.000 \\
\hline 032 & 1.0000 & 0.33746 & 0.31691 & 0.14485 & Biso & 1.000 \\
\hline 033 & 1.0000 & 0.96879 & 0.65699 & 0.15378 & Biso & 1.000 \\
\hline 034 & 1.0000 & 0.33703 & 0.36217 & 0.47644 & Biso & 1.000 \\
\hline 035 & 1.0000 & 0.99891 & 0.65095 & 0.48299 & Biso & 1.000 \\
\hline 036 & 1.0000 & 0.63029 & 0.98685 & 0.48158 & Biso & 1.000 \\
\hline 037 & 1.0000 & 0.10912 & 0.23641 & 0.11291 & Biso & 1.000 \\
\hline 038 & 1.0000 & 0.75281 & 0.87330 & 0.11816 & Biso & 1.000 \\
\hline 039 & 1.0000 & 0.12361 & 0.88064 & 0.10864 & Biso & 1.000 \\
\hline 040 & 1.0000 & 0.22649 & 0.11776 & 0.84143 & Biso & 1.000 \\
\hline 041 & 1.0000 & 0.87484 & 0.75391 & 0.84760 & Biso & 1.000 \\
\hline 042 & 1.0000 & 0.86593 & 0.11123 & 0.84638 & Biso & 1.000 \\
\hline 043 & 1.0000 & 0.77148 & 0.56363 & 0.45047 & Biso & 1.000 \\
\hline 044 & 1.0000 & 0.40667 & 0.20630 & 0.45294 & Biso & 1.000 \\
\hline 045 & 1.0000 & 0.78620 & 0.21082 & 0.44723 & Biso & 1.000 \\
\hline 046 & 1.0000 & 0.90374 & 0.45714 & 0.18182 & Biso & 1.000 \\
\hline 047 & 1.0000 & 0.54552 & 0.09232 & 0.18914 & Biso & 1.000 \\
\hline 048 & 1.0000 & 0.53460 & 0.44926 & 0.18185 & Biso & 1.000 \\
\hline 049 & 1.0000 & 0.43774 & 0.89813 & 0.78395 & Biso & 1.000 \\
\hline 050 & 1.0000 & 0.08140 & 0.53493 & 0.77129 & Biso & 1.000 \\
\hline 051 & 1.0000 & 0.44970 & 0.54641 & 0.77748 & Biso & 1.000 \\
\hline 052 & 1.0000 & 0.57743 & 0.79351 & 0.52173 & Biso & 1.000 \\
\hline 053 & 1.0000 & 0.21530 & 0.43763 & 0.51665 & Biso & 1.000 \\
\hline 054 & 1.0000 & 0.19967 & 0.77168 & 0.51760 & Biso & 1.000 \\
\hline 055 & 1.0000 & 0.99207 & 0.25312 & 0.99200 & Biso & 1.000 \\
\hline 056 & 1.0000 & 0.73814 & 0.74439 & 0.99371 & Biso & 1.000 \\
\hline 057 & 1.0000 & 0.25172 & 0.00048 & 0.98672 & Biso & 1.000 \\
\hline 058 & 1.0000 & 0.66829 & 0.59331 & 0.32503 & Biso & 1.000 \\
\hline 059 & 1.0000 & 0.37880 & 0.06915 & 0.31883 & Biso & 1.000 \\
\hline 060 & 1.0000 & 0.91822 & 0.32824 & 0.32445 & Biso & 1.000 \\
\hline 061 & 1.0000 & 0.32540 & 0.91505 & 0.65865 & Biso & 1.000 \\
\hline 062 & 1.0000 & 0.06024 & 0.39007 & 0.65890 & Biso & 1.000 \\
\hline 063 & 1.0000 & 0.59320 & 0.65982 & 0.66042 & Biso & 1.000 \\
\hline 064 & 1.0000 & 0.98267 & 0.73330 & 0.97462 & Biso & 1.000 \\
\hline 065 & 1.0000 & 0.25079 & 0.24736 & 0.96934 & Biso & 1.000 \\
\hline 066 & 1.0000 & 0.73960 & 0.99953 & 0.97281 & Biso & 1.000 \\
\hline 067 & 1.0000 & 0.66569 & 0.06853 & 0.30448 & Biso & 1.000 \\
\hline 068 & 1.0000 & 0.91697 & 0.58293 & 0.30825 & Biso & 1.000 \\
\hline 069 & 1.0000 & 0.40029 & 0.33461 & 0.30304 & Biso & 1.000 \\
\hline 070 & 1.0000 & 0.31854 & 0.39902 & 0.63679 & Biso & 1.000 \\
\hline 071 & 1.0000 & 0.58796 & 0.92716 & 0.64046 & Biso & 1.000 \\
\hline 072 & 1.0000 & 0.06182 & 0.67569 & 0.64143 & Biso & 1.000 \\
\hline H 1 & 1.0000 & 0.24750 & 0.96982 & 0.31430 & Biso & 1.000 \\
\hline $\mathrm{C} 1$ & 1.0000 & 0.09308 & 0.92045 & 0.42748 & Biso & 1.000 \\
\hline H2 & 1.0000 & 0.04088 & 0.83031 & 0.42649 & Biso & 1.000 \\
\hline H3 & 1.0000 & 0.17527 & 0.95652 & 0.45734 & Biso & 1.000 \\
\hline $\mathrm{H} 4$ & 1.0000 & 0.07144 & 0.96945 & 0.38425 & Biso & 1.000 \\
\hline 073 & 1.0000 & 0.17074 & 0.90234 & 0.30951 & Biso & 1.000 \\
\hline $\mathrm{C} 2$ & 1.0000 & 0.99872 & 0.90754 & 0.54152 & Biso & 1.000 \\
\hline C3 & 1.0000 & 0.06626 & 0.02025 & 0.54931 & Biso & 1.000 \\
\hline $\mathrm{C} 4$ & 1.0000 & 0.17117 & 0.07732 & 0.60046 & Biso & 1.000 \\
\hline H5 & 1.0000 & 0.18948 & 0.01946 & 0.63642 & Biso & 1.000 \\
\hline H6 & 1.0000 & 0.16633 & 0.13488 & 0.64855 & Biso & 1.000 \\
\hline H7 & 1.0000 & 0.24225 & 0.13029 & 0.55657 & Biso & 1.000 \\
\hline C5 & 1.0000 & 0.18751 & 0.80853 & 0.30053 & Biso & 1.000 \\
\hline H8 & 1.0000 & 0.10711 & 0.73268 & 0.30971 & Biso & 1.000 \\
\hline H9 & 1.0000 & 0.24711 & 0.81102 & 0.35002 & Biso & 1.000 \\
\hline $\mathrm{H} 10$ & 1.0000 & 0.21832 & 0.80840 & 0.23299 & Biso & 1.000 \\
\hline $\mathrm{H} 11$ & 1.0000 & 0.01418 & 0.85084 & 0.58157 & Biso & 1.000 \\
\hline $\mathrm{H} 12$ & 1.0000 & 0.04239 & 0.07380 & 0.51302 & & 1.000 \\
\hline
\end{tabular}




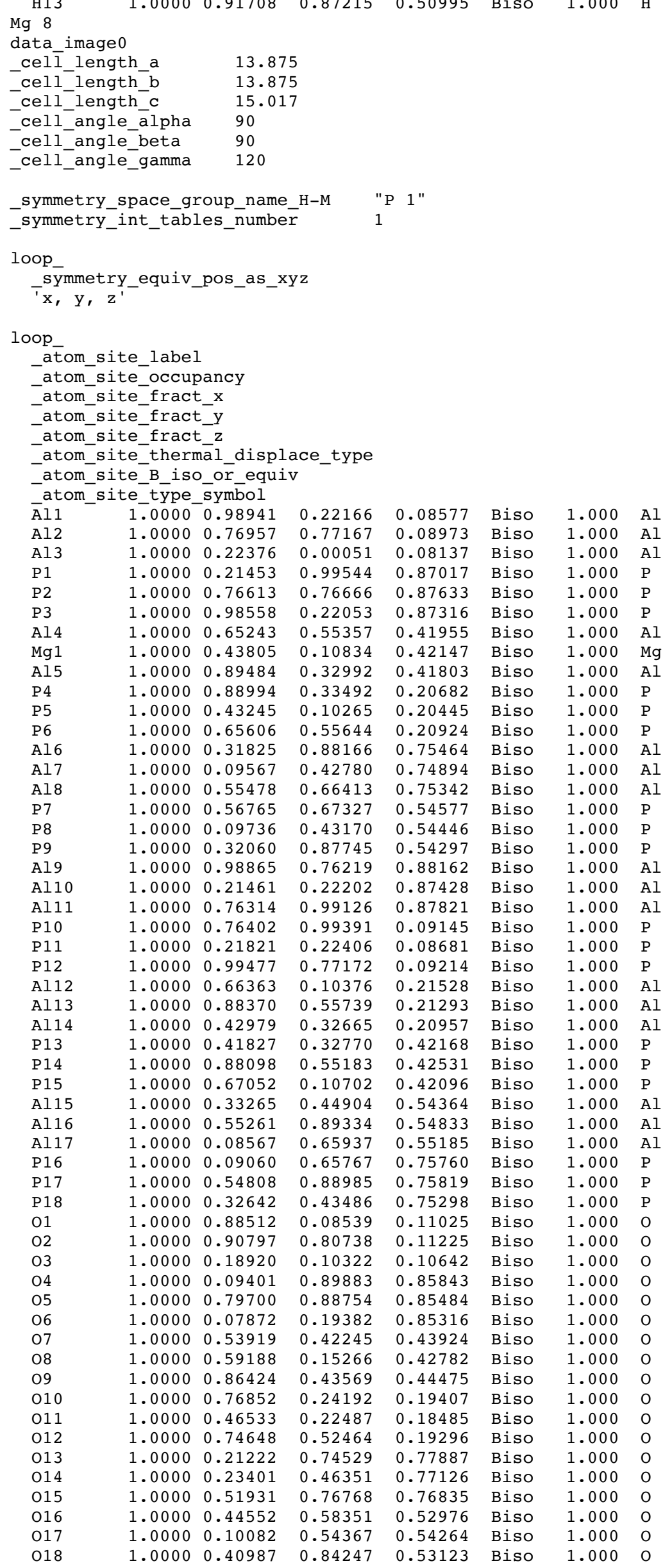




\begin{tabular}{|c|c|c|c|c|c|c|c|}
\hline 019 & 1.0000 & 0.96884 & 0.31624 & 0.14716 & Biso & 1.000 & 0 \\
\hline 020 & 1.0000 & 0.67677 & 0.65503 & 0.15026 & Biso & 1.000 & O \\
\hline 021 & 1.0000 & 0.34341 & 0.02436 & 0.13707 & Biso & 1.000 & O \\
\hline 022 & 1.0000 & 0.29409 & 0.97754 & 0.81101 & Biso & 1.000 & 0 \\
\hline 023 & 1.0000 & 0.66188 & 0.68400 & 0.82493 & Biso & 1.000 & 0 \\
\hline 024 & 1.0000 & 0.00306 & 0.32145 & 0.81870 & Biso & 1.000 & 0 \\
\hline 025 & 1.0000 & 0.64598 & 0.65449 & 0.48517 & Biso & 1.000 & 0 \\
\hline 026 & 1.0000 & 0.34211 & 0.97469 & 0.48468 & Biso & 1.000 & 0 \\
\hline 027 & 1.0000 & 0.01219 & 0.35104 & 0.47742 & Biso & 1.000 & 0 \\
\hline 028 & 1.0000 & 0.01144 & 0.66596 & 0.82434 & Biso & 1.000 & O \\
\hline 029 & 1.0000 & 0.30826 & 0.33535 & 0.81006 & Biso & 1.000 & 0 \\
\hline 030 & 1.0000 & 0.64482 & 0.96591 & 0.81948 & Biso & 1.000 & 0 \\
\hline 031 & 1.0000 & 0.68178 & 0.01436 & 0.14419 & Biso & 1.000 & O \\
\hline 032 & 1.0000 & 0.31865 & 0.30667 & 0.14177 & Biso & 1.000 & 0 \\
\hline 033 & 1.0000 & 0.97746 & 0.67652 & 0.15427 & Biso & 1.000 & 0 \\
\hline 034 & 1.0000 & 0.33688 & 0.35572 & 0.46974 & Biso & 1.000 & 0 \\
\hline 035 & 1.0000 & 0.97554 & 0.64122 & 0.48318 & Biso & 1.000 & O \\
\hline 036 & 1.0000 & 0.63872 & 0.00760 & 0.48368 & Biso & 1.000 & O \\
\hline 037 & 1.0000 & 0.11842 & 0.23697 & 0.11287 & Biso & 1.000 & O \\
\hline 038 & 1.0000 & 0.75051 & 0.88184 & 0.12060 & Biso & 1.000 & 0 \\
\hline 039 & 1.0000 & 0.11163 & 0.87009 & 0.10819 & Biso & 1.000 & 0 \\
\hline 040 & 1.0000 & 0.22017 & 0.10423 & 0.84102 & Biso & 1.000 & 0 \\
\hline 041 & 1.0000 & 0.86269 & 0.74966 & 0.84739 & Biso & 1.000 & O \\
\hline 042 & 1.0000 & 0.87394 & 0.12005 & 0.84601 & Biso & 1.000 & 0 \\
\hline 043 & 1.0000 & 0.77448 & 0.55349 & 0.44813 & Biso & 1.000 & 0 \\
\hline 044 & 1.0000 & 0.40148 & 0.21834 & 0.45657 & Biso & 1.000 & O \\
\hline 045 & 1.0000 & 0.78993 & 0.19777 & 0.44694 & Biso & 1.000 & 0 \\
\hline 046 & 1.0000 & 0.90038 & 0.44650 & 0.17977 & Biso & 1.000 & $\mathrm{O}$ \\
\hline 047 & 1.0000 & 0.53543 & 0.09072 & 0.19063 & Biso & 1.000 & 0 \\
\hline 048 & 1.0000 & 0.54280 & 0.45753 & 0.18445 & Biso & 1.000 & 0 \\
\hline 049 & 1.0000 & 0.44624 & 0.89815 & 0.78658 & Biso & 1.000 & 0 \\
\hline 050 & 1.0000 & 0.07760 & 0.54187 & 0.76504 & Biso & 1.000 & 0 \\
\hline 051 & 1.0000 & 0.43888 & 0.53538 & 0.77797 & Biso & 1.000 & O \\
\hline 052 & 1.0000 & 0.58247 & 0.78762 & 0.52377 & Biso & 1.000 & 0 \\
\hline 053 & 1.0000 & 0.21239 & 0.45230 & 0.51828 & Biso & 1.000 & O \\
\hline 054 & 1.0000 & 0.20660 & 0.77664 & 0.51723 & Biso & 1.000 & 0 \\
\hline 055 & 1.0000 & 0.98540 & 0.24753 & 0.97230 & Biso & 1.000 & O \\
\hline 056 & 1.0000 & 0.74277 & 0.74322 & 0.97628 & Biso & 1.000 & 0 \\
\hline 057 & 1.0000 & 0.25129 & 0.00334 & 0.96746 & Biso & 1.000 & O \\
\hline 058 & 1.0000 & 0.65854 & 0.59041 & 0.30725 & Biso & 1.000 & O \\
\hline 059 & 1.0000 & 0.38521 & 0.06903 & 0.29869 & Biso & 1.000 & 0 \\
\hline 060 & 1.0000 & 0.92612 & 0.33962 & 0.30430 & Biso & 1.000 & O \\
\hline 061 & 1.0000 & 0.31606 & 0.90695 & 0.64161 & Biso & 1.000 & 0 \\
\hline 062 & 1.0000 & 0.06506 & 0.38048 & 0.63847 & Biso & 1.000 & O \\
\hline 063 & 1.0000 & 0.59966 & 0.66890 & 0.64347 & Biso & 1.000 & 0 \\
\hline 064 & 1.0000 & 0.98309 & 0.73154 & 0.99509 & Biso & 1.000 & $\mathrm{O}$ \\
\hline 065 & 1.0000 & 0.24577 & 0.25054 & 0.98724 & Biso & 1.000 & O \\
\hline 066 & 1.0000 & 0.73756 & 0.99156 & 0.99181 & Biso & 1.000 & 0 \\
\hline 067 & 1.0000 & 0.67328 & 0.06692 & 0.32478 & Biso & 1.000 & O \\
\hline 068 & 1.0000 & 0.91339 & 0.58413 & 0.32706 & Biso & 1.000 & 0 \\
\hline 069 & 1.0000 & 0.39310 & 0.32289 & 0.32090 & Biso & 1.000 & O \\
\hline 070 & 1.0000 & 0.32588 & 0.40423 & 0.65422 & Biso & 1.000 & 0 \\
\hline 071 & 1.0000 & 0.58125 & 0.92910 & 0.66157 & Biso & 1.000 & O \\
\hline 072 & 1.0000 & 0.05851 & 0.67663 & 0.66322 & Biso & 1.000 & 0 \\
\hline $\mathrm{H} 1$ & 1.0000 & 0.25053 & 0.97229 & 0.30444 & Biso & 1.000 & $\mathrm{H}$ \\
\hline $\mathrm{C} 1$ & 1.0000 & 0.09899 & 0.92499 & 0.42345 & Biso & 1.000 & C \\
\hline $\mathrm{H} 2$ & 1.0000 & 0.04092 & 0.83601 & 0.41872 & Biso & 1.000 & $\mathrm{H}$ \\
\hline $\mathrm{H} 3$ & 1.0000 & 0.17871 & 0.95365 & 0.45591 & Biso & 1.000 & $\mathrm{H}$ \\
\hline $\mathrm{H} 4$ & 1.0000 & 0.08340 & 0.98101 & 0.38356 & Biso & 1.000 & $\mathrm{H}$ \\
\hline 073 & 1.0000 & 0.17339 & 0.90589 & 0.30560 & Biso & 1.000 & O \\
\hline $\mathrm{C} 2$ & 1.0000 & 0.00388 & 0.91112 & 0.53942 & Biso & 1.000 & $\mathrm{C}$ \\
\hline $\mathrm{C} 3$ & 1.0000 & 0.07079 & 0.02372 & 0.54801 & Biso & 1.000 & C \\
\hline $\mathrm{C} 4$ & 1.0000 & 0.17559 & 0.08058 & 0.59925 & Biso & 1.000 & C \\
\hline H5 & 1.0000 & 0.19531 & 0.02270 & 0.63350 & Biso & 1.000 & $\mathrm{H}$ \\
\hline $\mathrm{H} 6$ & 1.0000 & 0.16937 & 0.13590 & 0.64887 & Biso & 1.000 & $\mathrm{H}$ \\
\hline H 7 & 1.0000 & 0.24600 & 0.13612 & 0.55580 & Biso & 1.000 & $\mathrm{H}$ \\
\hline C5 & 1.0000 & 0.18755 & 0.80986 & 0.30061 & Biso & 1.000 & C \\
\hline H 8 & 1.0000 & 0.10793 & 0.73656 & 0.31790 & Biso & 1.000 & $\mathrm{H}$ \\
\hline H9 & 1.0000 & 0.25235 & 0.81748 & 0.34683 & Biso & 1.000 & $\mathrm{H}$ \\
\hline $\mathrm{H} 10$ & 1.0000 & 0.20962 & 0.80111 & 0.23190 & Biso & 1.000 & $\mathrm{H}$ \\
\hline H 11 & 1.0000 & 0.02004 & 0.85447 & 0.57882 & Biso & 1.000 & $\mathrm{H}$ \\
\hline $\mathrm{H} 12$ & 1.0000 & 0.04629 & 0.07747 & 0.51280 & Biso & 1.000 & $\mathrm{H}$ \\
\hline H 13 & 1.0000 & 0.92210 & 0.87556 & 0.50813 & Biso & 1.000 & $\mathrm{H}$ \\
\hline
\end{tabular}

data_image 0

$\begin{array}{ll}\text {-cell_length_a } & 13.625 \\ \text {-cell_length_b } & 13.625 \\ \text {-cell_length_c } & 15.067 \\ \text {-cell_angle_alpha } & 90 \\ \text { cell_angle beta } & 90\end{array}$


loop

symmetry equiv pos as $x y z$

' $\mathrm{x}, \mathrm{y}, \mathrm{z}$ '

loop

_atom_site_label

-atom_site_occupancy

atom site fract $x$

-atom_site_fract_y

-atom_site_fract_z

atom site thermal displace type

-atom_site_B_iso_or_equiv

atom_site_type_symbol

Sil_site-

Si2 1.00000 .77548

Si3 $1.0000 \quad 0.23457$

0.23922

0.08846

Biso

$1.000 \mathrm{Si}$

Si4 $\quad 1.0000 \quad 0.22568$

$\begin{array}{lll}\text { Si5 } & 1.0000 & 0.77130 \\ \text { Si6 } & 1.0000 & 0.99787\end{array}$

0.78260

0.09297

Biso

$1.000 \mathrm{Si}$

$\begin{array}{lllll}0.01159 & 0.08485 & \text { Biso } & 1.000 & \mathrm{Si}\end{array}$

$0.00518 \quad 0.87786$ Biso $1.000 \mathrm{Si}$

Si7 $1.0000 \quad 0.66470$

Al1 1.00000 .43613

0.77695

$\begin{array}{ll}1.000 & \mathrm{Si} \\ 1.000 & \mathrm{Si}\end{array}$

$0.23691 \quad 0.88245$ Biso $1.000 \mathrm{Si}$

$0.56745 \quad 0.42344$ Biso $1.000 \quad \mathrm{Si}$

$\begin{array}{lll}\text { Si8 } & 1.0000 & 0.90222 \\ \text { Si9 } & 1.0000 & 0.90345\end{array}$

Si10 1.00000 .44014

Sil1

0.11195

0.33698

9.42211 Biso $1.000 \mathrm{Si}$

$1.0000 \quad 0.67011$

0.57234

0.21244 Biso

$1.000 \mathrm{Si}$

$1.0000 \quad 0.33195$

0.89875

0.21768 Biso

$1.000 \mathrm{Si}$

$1.000 \mathrm{Si}$

Si13 $1.0000 \quad 0.10248$

Sil

0.44011

0.75707 Biso

$1.000 \mathrm{Si}$

$1.0000 \quad 0.56509$

0.67287

0.75416 Biso

$1.000 \mathrm{Si}$

$1.0000 \quad 0.57344$

0.67840

.75609 Biso

$1.000 \mathrm{Si}$

Si16 $1.0000 \quad 0.10150$

Si17

0.44123

0.55309 Biso

$1.0000 \quad 0.33296$

0.89599

0.55236 Biso

$1.000 \mathrm{Si}$

$1.0000 \quad 0.99683$

0.77159

.55004 Biso

$1.000 \mathrm{Si}$

$1.0000 \quad 0.22829$

0.23424

0.88620 Biso

$1.000 \mathrm{Si}$

Si19

$1.0000 \quad 0.77239$

0.00599

0.87806 Biso

$1.000 \mathrm{Si}$

$1.0000 \quad 0.77418$

$1.0000 \quad 0.23380$

0.01020

0.88241 Biso

$1.000 \mathrm{Si}$

Si21

0.23879

0.09034 Biso

$1.000 \mathrm{Si}$

Si22

$\mathrm{Si} 23$

0.78148

0.08511 Biso

$1.000 \mathrm{Si}$

$1.0000 \quad 0.00380$

$1.0000 \quad 0.67111$

0.11474

0.09252 Biso

$1.000 \mathrm{Si}$

$1.0000 \quad 0.89884$

0.57203

0.21677 Biso

$1.000 \mathrm{Si}$

Si25

Si26

$1.0000 \quad 0.43782$

$1.0000 \quad 0.42730$

0.34455

$1.000 \mathrm{Si}$

$\begin{array}{lllll} & 0.21859 & \text { Biso } & 1.000 & \mathrm{Si} \\ 55 & 0.21444 & \text { Biso } & 1.000 & \mathrm{Si}\end{array}$

Si28 $\quad 1.0000 \quad 0.89295$

$1.0000 \quad 0.66832$

0.41925 Biso

$1.0000 \quad 0.33614$

$1.0000 \quad 0.56428$

0.42606 Biso

$1.000 \mathrm{Si}$

$\begin{array}{llll}0.42010 & \text { Biso } & 1.000 & \mathrm{Si}\end{array}$

Si31

Si32

$1.0000 \quad 0.09509$

0.90429

0.54822 Biso

0.67290

0.55118 Biso

$1.000 \mathrm{Si}$

$290 \quad 0.55545$ Biso $1.000 \mathrm{Si}$

Si33 $1.0000 \quad 0.100110 .67236$

Si34 $1.0000 \quad 0.56235$

0.90285

0.75734 Biso

$1.0000 \quad 0.33299$

0.44327

0.75598 Biso

$1.000 \mathrm{Si}$

$\begin{array}{lll}\mathrm{O} 1 & 1.0000 & 0.90516 \\ \mathrm{O} 2 & 1.0000 & 0.90700\end{array}$

0.10874

0.75327 Biso

$00 \mathrm{Si}$

$1.0000 \quad 0.20121$

$1.0000 \quad 0.09594$

$1.0000 \quad 0.80605$

81635

$1.000 \mathrm{Si}$

0.11008 Biso 1.000 O

0.901360 .86600 Biso $1.000 \quad 0$

$0.90810 \quad 0.86567$ Biso $1.000 \quad 0$

$1.0000 \quad 0.09880$

$1.0000 \quad 0.55819$

0.20819

1.0000

$\begin{array}{lllll}0.44130 & 0.43666 & \text { Biso } & 1.000 & 0\end{array}$

$\begin{array}{lllll}0.15463 & 0.43102 & \text { Biso } & 1.000 & 0\end{array}$

$1.0000 \quad 0.87235$

$1.0000 \quad 0.77290$

0.43712

0.44220

1.0000

0.245480 .20293 Biso $1.000 \quad$ O

$0.24566 \quad 0.20078$ Biso $1.000 \quad 0$

$1.0000 \quad 0.47001$

0.53915

0.20033

1.0000

$1.0000 \quad 0.23124$

0.76888

0.77566 Biso

$\begin{array}{ll}1.000 & 0 \\ 1.000 & 0\end{array}$

$1.0000 \quad 0.23376$

0.47439

0.77255 Biso

1.0000

$1.0000 \quad 0.53160$

0.77140

$1.0000 \quad 0.442110 .58096$

0.76614 Biso

1.0000

$1.0000 \quad 0.11354$

$1.0000 \quad 0.42953$

527

0.54567 Biso

1.0000

$1.0000 \quad 0.98800$

0.32665

0.53672 Biso

1.0000

$1.0000 \quad 0.69083$

$1.0000 \quad 0.34498$

0.67778

0.15203 Biso

$1.000 \quad 0$

$1.0000 \quad 0.31219$

1.0000

$1.0000 \quad 0.66275$

$\begin{array}{llll}024 & 1.0000 & 0.01660 & 0.34247\end{array}$

$\begin{array}{llll}025 & 1.0000 & 0.65662 & 0.65925\end{array}$

0.98652

0.81641 Biso

$1.000 \quad 0$

$\begin{array}{lllll}69104 & 0.82628 & \text { Biso } & 1.000 & 0\end{array}$

026

0.99576

0.82146 Biso

$1.000 \quad 0$

0.48723 Biso 1.0000

0.48627 Biso $1.000 \quad 0$ 


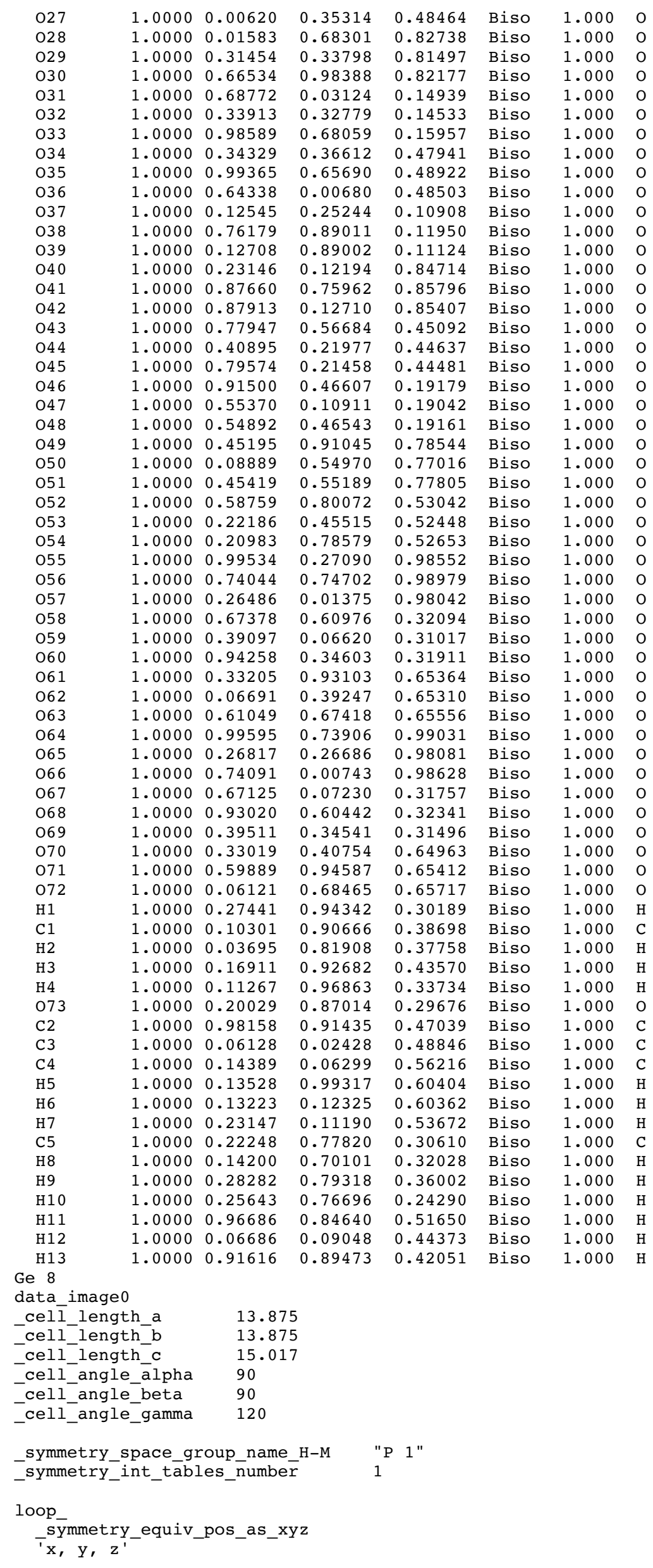




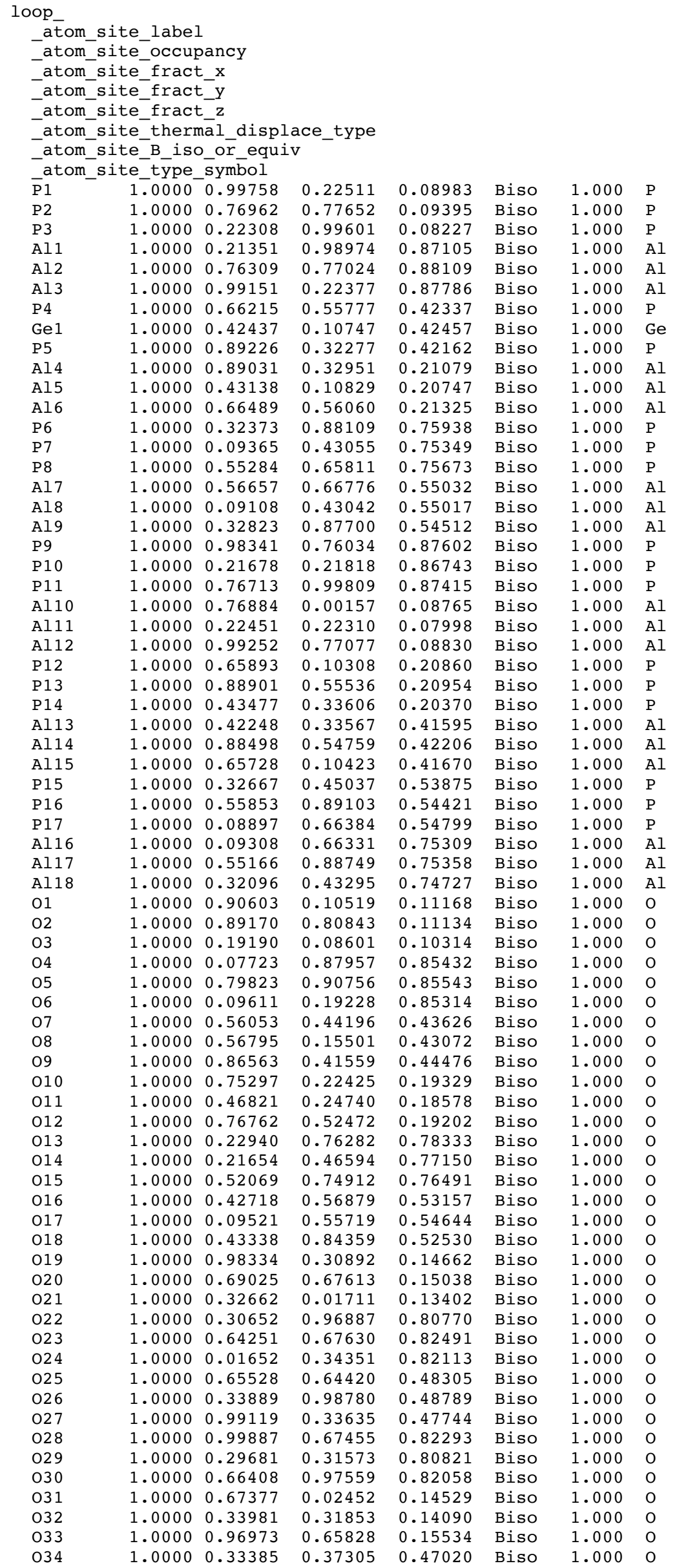




\begin{tabular}{|c|c|c|c|c|c|c|c|}
\hline 035 & 1.0000 & 0.99512 & 0.65106 & 0.48535 & Biso & 1.000 & 0 \\
\hline 036 & 1.0000 & 0.63020 & 0.98961 & 0.48356 & Biso & 1.000 & 0 \\
\hline 037 & 1.0000 & 0.11130 & 0.23772 & 0.11085 & Biso & 1.000 & 0 \\
\hline 038 & 1.0000 & 0.75425 & 0.87452 & 0.12053 & Biso & 1.000 & $\mathrm{O}$ \\
\hline 039 & 1.0000 & 0.12528 & 0.88195 & 0.10837 & Biso & 1.000 & 0 \\
\hline 040 & 1.0000 & 0.22321 & 0.11529 & 0.83897 & Biso & 1.000 & 0 \\
\hline 041 & 1.0000 & 0.87223 & 0.74999 & 0.84821 & Biso & 1.000 & 0 \\
\hline 042 & 1.0000 & 0.86430 & 0.11119 & 0.84500 & Biso & 1.000 & 0 \\
\hline 043 & 1.0000 & 0.76709 & 0.55428 & 0.45028 & Biso & 1.000 & 0 \\
\hline 044 & 1.0000 & 0.39392 & 0.21026 & 0.46021 & Biso & 1.000 & $\mathrm{O}$ \\
\hline 045 & 1.0000 & 0.79294 & 0.20923 & 0.44375 & Biso & 1.000 & $\mathrm{O}$ \\
\hline 046 & 1.0000 & 0.90456 & 0.45792 & 0.18124 & Biso & 1.000 & 0 \\
\hline 047 & 1.0000 & 0.54788 & 0.09543 & 0.18650 & Biso & 1.000 & $\mathrm{O}$ \\
\hline 048 & 1.0000 & 0.53507 & 0.45120 & 0.18354 & Biso & 1.000 & 0 \\
\hline 049 & 1.0000 & 0.43524 & 0.89399 & 0.78930 & Biso & 1.000 & 0 \\
\hline 050 & 1.0000 & 0.07856 & 0.53200 & 0.76219 & Biso & 1.000 & $\mathrm{O}$ \\
\hline 051 & 1.0000 & 0.44990 & 0.54503 & 0.77644 & Biso & 1.000 & 0 \\
\hline 052 & 1.0000 & 0.58826 & 0.79996 & 0.52609 & Biso & 1.000 & 0 \\
\hline 053 & 1.0000 & 0.22184 & 0.45652 & 0.51845 & Biso & 1.000 & 0 \\
\hline 054 & 1.0000 & 0.19915 & 0.76111 & 0.51545 & Biso & 1.000 & $\mathrm{O}$ \\
\hline 055 & 1.0000 & 0.99089 & 0.25060 & 0.99111 & Biso & 1.000 & $\mathrm{O}$ \\
\hline 056 & 1.0000 & 0.74016 & 0.74698 & 0.99526 & Biso & 1.000 & $\mathrm{O}$ \\
\hline 057 & 1.0000 & 0.24888 & 0.99721 & 0.98269 & Biso & 1.000 & $\mathrm{O}$ \\
\hline 058 & 1.0000 & 0.67107 & 0.59588 & 0.32590 & Biso & 1.000 & 0 \\
\hline 059 & 1.0000 & 0.37428 & 0.06734 & 0.31273 & Biso & 1.000 & $\mathrm{O}$ \\
\hline 060 & 1.0000 & 0.92500 & 0.33140 & 0.32288 & Biso & 1.000 & $\mathrm{O}$ \\
\hline 061 & 1.0000 & 0.32376 & 0.90045 & 0.65918 & Biso & 1.000 & $\mathrm{O}$ \\
\hline 062 & 1.0000 & 0.06033 & 0.37933 & 0.65945 & Biso & 1.000 & $\mathrm{O}$ \\
\hline 063 & 1.0000 & 0.59806 & 0.65990 & 0.66255 & Biso & 1.000 & $\mathrm{O}$ \\
\hline 064 & 1.0000 & 0.98275 & 0.73444 & 0.97557 & Biso & 1.000 & $\mathrm{O}$ \\
\hline 065 & 1.0000 & 0.25102 & 0.24819 & 0.96540 & Biso & 1.000 & $\mathrm{O}$ \\
\hline 066 & 1.0000 & 0.74249 & 0.99995 & 0.97364 & Biso & 1.000 & $\mathrm{O}$ \\
\hline 067 & 1.0000 & 0.66093 & 0.06629 & 0.30479 & Biso & 1.000 & $\mathrm{O}$ \\
\hline 068 & 1.0000 & 0.91730 & 0.58165 & 0.30927 & Biso & 1.000 & $\mathrm{O}$ \\
\hline 069 & 1.0000 & 0.39676 & 0.33106 & 0.30055 & Biso & 1.000 & $\mathrm{O}$ \\
\hline 070 & 1.0000 & 0.31958 & 0.40334 & 0.63342 & Biso & 1.000 & $\mathrm{O}$ \\
\hline 071 & 1.0000 & 0.58416 & 0.92934 & 0.64227 & Biso & 1.000 & $\mathrm{O}$ \\
\hline 072 & 1.0000 & 0.06358 & 0.68661 & 0.64338 & Biso & 1.000 & $\mathrm{O}$ \\
\hline $\mathrm{H} 1$ & 1.0000 & 0.24381 & 0.96984 & 0.31112 & Biso & 1.000 & $\mathrm{H}$ \\
\hline $\mathrm{C} 1$ & 1.0000 & 0.09203 & 0.91992 & 0.42798 & Biso & 1.000 & C \\
\hline $\mathrm{H} 2$ & 1.0000 & 0.03547 & 0.83060 & 0.42408 & Biso & 1.000 & $\mathrm{H}$ \\
\hline H3 & 1.0000 & 0.17294 & 0.95036 & 0.45912 & Biso & 1.000 & $\mathrm{H}$ \\
\hline $\mathrm{H} 4$ & 1.0000 & 0.07523 & 0.97405 & 0.38668 & Biso & 1.000 & $\mathrm{H}$ \\
\hline 073 & 1.0000 & 0.16718 & 0.90142 & 0.30897 & Biso & 1.000 & $\mathrm{O}$ \\
\hline $\mathrm{C} 2$ & 1.0000 & 0.99874 & 0.90802 & 0.54278 & Biso & 1.000 & C \\
\hline $\mathrm{C} 3$ & 1.0000 & 0.06608 & 0.02068 & 0.55128 & Biso & 1.000 & C \\
\hline $\mathrm{C} 4$ & 1.0000 & 0.17113 & 0.07746 & 0.60209 & Biso & 1.000 & $\mathrm{C}$ \\
\hline H5 & 1.0000 & 0.18981 & 0.01941 & 0.63731 & Biso & 1.000 & $\mathrm{H}$ \\
\hline H6 & 1.0000 & 0.16650 & 0.13469 & 0.65066 & Biso & 1.000 & $\mathrm{H}$ \\
\hline H 7 & 1.0000 & 0.24188 & 0.13090 & 0.55797 & Biso & 1.000 & $\mathrm{H}$ \\
\hline $\mathrm{C} 5$ & 1.0000 & 0.18593 & 0.80878 & 0.30082 & Biso & 1.000 & C \\
\hline H8 & 1.0000 & 0.10708 & 0.73231 & 0.31331 & Biso & 1.000 & $\mathrm{H}$ \\
\hline H9 & 1.0000 & 0.24884 & 0.81495 & 0.34855 & Biso & 1.000 & $\mathrm{H}$ \\
\hline $\mathrm{H} 10$ & 1.0000 & 0.21354 & 0.80658 & 0.23249 & Biso & 1.000 & $\mathrm{H}$ \\
\hline H 11 & 1.0000 & 0.01419 & 0.85099 & 0.58237 & Biso & 1.000 & $\mathrm{H}$ \\
\hline H 12 & 1.0000 & 0.04194 & 0.07449 & 0.51571 & Biso & 1.000 & $\mathrm{H}$ \\
\hline $\mathrm{H} 13$ & 1.0000 & 0.91692 & 0.87303 & 0.51161 & Biso & 1.000 & $\mathrm{H}$ \\
\hline \multirow{2}{*}{\multicolumn{8}{|c|}{$\begin{array}{l}\text { Ga } 8 \\
\text { data image } 0\end{array}$}} \\
\hline & & & & & & & \\
\hline \multicolumn{2}{|c|}{ celī_length_a } & \multicolumn{2}{|l|}{13.62} & & & & \\
\hline $\mathrm{cell}$ & $=h \_b$ & \multicolumn{2}{|c|}{13.625} & & & & \\
\hline $\mathrm{cell}$ & $=\mathrm{h}_{-}^{-} \mathrm{c}$ & \multicolumn{2}{|c|}{15.067} & & & & \\
\hline $\mathrm{cell}$ & alpha & \multicolumn{2}{|c|}{90} & & & & \\
\hline $\mathrm{cell}$ & beta & 90 & & & & & \\
\hline $\mathrm{cell}$ & _gamma & 120 & & & & & \\
\hline symme & pace_g & - & $\mathrm{M}$ & $1 "$ & & & \\
\hline symme & $\left.n t \_t \overline{a b}\right]$ & es_numbe & & & & & \\
\hline DOp_ & & & & & & & \\
\hline sy & equiv & חc & & & & & \\
\hline ' $x$, & & & & & & & \\
\hline oop_ & & & & & & & \\
\hline$-a \bar{t}$ & e_label & & & & & & \\
\hline at & e_occup & ancy & & & & & \\
\hline -at & $e_{-}^{-}$fract & & & & & & \\
\hline -atc & $e_{-}^{-}$fract & & & & & & \\
\hline atc & $e_{-}^{-}$fract & & & & & & \\
\hline atc & - & $d \perp$ _u & & & & & \\
\hline
\end{tabular}




\begin{tabular}{|c|c|c|c|c|c|c|c|}
\hline$\overline{\mathrm{S}} \mathrm{i} 1$ & 1.0000 & 0.00222 & 0.23473 & 0.08324 & Biso & 1.000 & $\mathrm{Si}$ \\
\hline $\mathrm{Si} 2$ & 1.0000 & 0.77584 & 0.77950 & 0.08849 & Biso & 1.000 & $\mathrm{Si}$ \\
\hline Si3 & 1.0000 & 0.23414 & 0.00660 & 0.07917 & Biso & 1.000 & $\mathrm{Si}$ \\
\hline Si4 & 1.0000 & 0.22450 & 0.00013 & 0.87276 & Biso & 1.000 & $\mathrm{Si}$ \\
\hline Si5 & 1.0000 & 0.77069 & 0.77310 & 0.88085 & Biso & 1.000 & $\mathrm{Si}$ \\
\hline Si6 & 1.0000 & 0.99694 & 0.23287 & 0.87734 & Biso & 1.000 & $\mathrm{Si}$ \\
\hline Si7 & 1.0000 & 0.66574 & 0.56471 & 0.41882 & Biso & 1.000 & $\mathrm{Si}$ \\
\hline Ga 1 & 1.0000 & 0.44104 & 0.11556 & 0.41963 & Biso & 1.000 & $\mathrm{Ga}$ \\
\hline Si 8 & 1.0000 & 0.90629 & 0.33393 & 0.41677 & Biso & 1.000 & $\mathrm{Si}$ \\
\hline Si9 & 1.0000 & 0.90258 & 0.34087 & 0.21125 & Biso & 1.000 & $\mathrm{Si}$ \\
\hline Silo & 1.0000 & 0.44029 & 0.11337 & 0.20622 & Biso & 1.000 & $\mathrm{Si}$ \\
\hline Si11 & 1.0000 & 0.66952 & 0.56919 & 0.21387 & Biso & 1.000 & $\mathrm{Si}$ \\
\hline Si12 & 1.0000 & 0.33012 & 0.89250 & 0.75238 & Biso & 1.000 & $\mathrm{Si}$ \\
\hline Si13 & 1.0000 & 0.10160 & 0.43525 & 0.74768 & Biso & 1.000 & $\mathrm{Si}$ \\
\hline Si14 & 1.0000 & 0.56477 & 0.66886 & 0.75173 & Biso & 1.000 & $\mathrm{Si}$ \\
\hline Si15 & 1.0000 & 0.57829 & 0.67798 & 0.54914 & Biso & 1.000 & $\mathrm{Si}$ \\
\hline Si16 & 1.0000 & 0.10138 & 0.43788 & 0.54819 & Biso & 1.000 & $\mathrm{Si}$ \\
\hline Si17 & 1.0000 & 0.33281 & 0.88816 & 0.54459 & Biso & 1.000 & $\mathrm{Si}$ \\
\hline Si18 & 1.0000 & 0.99511 & 0.76624 & 0.88139 & Biso & 1.000 & $\mathrm{Si}$ \\
\hline Si19 & 1.0000 & 0.22719 & 0.23010 & 0.87274 & Biso & 1.000 & $\mathrm{Si}$ \\
\hline Si20 & 1.0000 & 0.77145 & 0.00206 & 0.87791 & Biso & 1.000 & $\mathrm{Si}$ \\
\hline Si21 & 1.0000 & 0.77330 & 0.00618 & 0.08588 & Biso & 1.000 & $\mathrm{Si}$ \\
\hline Si22 & 1.0000 & 0.23323 & 0.23443 & 0.07942 & Biso & 1.000 & $\mathrm{Si}$ \\
\hline Si23 & 1.0000 & 0.00252 & 0.77705 & 0.08770 & Biso & 1.000 & $\mathrm{Si}$ \\
\hline $\mathrm{Si} 24$ & 1.0000 & 0.67012 & 0.10953 & 0.21365 & Biso & 1.000 & $\mathrm{Si}$ \\
\hline Si25 & 1.0000 & 0.89565 & 0.56562 & 0.21310 & Biso & 1.000 & $\mathrm{Si}$ \\
\hline Si26 & 1.0000 & 0.43768 & 0.33915 & 0.20872 & Biso & 1.000 & $\mathrm{Si}$ \\
\hline Si27 & 1.0000 & 0.42490 & 0.33778 & 0.41591 & Biso & 1.000 & $\mathrm{Si}$ \\
\hline Si28 & 1.0000 & 0.89189 & 0.55726 & 0.42157 & Biso & 1.000 & $\mathrm{Si}$ \\
\hline Si29 & 1.0000 & 0.67234 & 0.11174 & 0.41619 & Biso & 1.000 & $\mathrm{Si}$ \\
\hline Si30 & 1.0000 & 0.33778 & 0.45477 & 0.54233 & Biso & 1.000 & $\mathrm{Si}$ \\
\hline Si31 & 1.0000 & 0.56522 & 0.90101 & 0.54725 & Biso & 1.000 & $\mathrm{Si}$ \\
\hline Si32 & 1.0000 & 0.09229 & 0.66904 & 0.55091 & Biso & 1.000 & $\mathrm{Si}$ \\
\hline Si33 & 1.0000 & 0.09804 & 0.66800 & 0.75152 & Biso & 1.000 & $\mathrm{Si}$ \\
\hline Si34 & 1.0000 & 0.56053 & 0.89789 & 0.75234 & Biso & 1.000 & $\mathrm{Si}$ \\
\hline Si35 & 1.0000 & 0.33204 & 0.43915 & 0.74650 & Biso & 1.000 & $\mathrm{Si}$ \\
\hline 01 & 1.0000 & 0.90444 & 0.10439 & 0.10317 & Biso & 1.000 & 0 \\
\hline $\mathrm{O} 2$ & 1.0000 & 0.90789 & 0.81485 & 0.10505 & Biso & 1.000 & 0 \\
\hline 03 & 1.0000 & 0.20022 & 0.10368 & 0.09940 & Biso & 1.000 & 0 \\
\hline 04 & 1.0000 & 0.09471 & 0.89606 & 0.86158 & Biso & 1.000 & 0 \\
\hline 05 & 1.0000 & 0.80525 & 0.90425 & 0.86096 & Biso & 1.000 & 0 \\
\hline 06 & 1.0000 & 0.09736 & 0.20329 & 0.86088 & Biso & 1.000 & 0 \\
\hline 07 & 1.0000 & 0.55535 & 0.44079 & 0.43000 & Biso & 1.000 & 0 \\
\hline 08 & 1.0000 & 0.59143 & 0.16501 & 0.42719 & Biso & 1.000 & 0 \\
\hline 09 & 1.0000 & 0.87527 & 0.43249 & 0.44048 & Biso & 1.000 & $\mathrm{O}$ \\
\hline 010 & 1.0000 & 0.77190 & 0.24031 & 0.20022 & Biso & 1.000 & 0 \\
\hline 011 & 1.0000 & 0.47506 & 0.24523 & 0.18766 & Biso & 1.000 & 0 \\
\hline 012 & 1.0000 & 0.76474 & 0.53225 & 0.19533 & Biso & 1.000 & 0 \\
\hline 013 & 1.0000 & 0.22934 & 0.76286 & 0.77188 & Biso & 1.000 & 0 \\
\hline 014 & 1.0000 & 0.23362 & 0.47157 & 0.76613 & Biso & 1.000 & 0 \\
\hline 015 & 1.0000 & 0.52987 & 0.76639 & 0.76198 & Biso & 1.000 & 0 \\
\hline 016 & 1.0000 & 0.44689 & 0.58129 & 0.53387 & Biso & 1.000 & 0 \\
\hline 017 & 1.0000 & 0.10277 & 0.55680 & 0.54559 & Biso & 1.000 & 0 \\
\hline 018 & 1.0000 & 0.43012 & 0.85219 & 0.53130 & Biso & 1.000 & 0 \\
\hline 019 & 1.0000 & 0.98666 & 0.32187 & 0.14661 & Biso & 1.000 & 0 \\
\hline 020 & 1.0000 & 0.69151 & 0.67411 & 0.15065 & Biso & 1.000 & 0 \\
\hline 021 & 1.0000 & 0.34433 & 0.02916 & 0.13536 & Biso & 1.000 & 0 \\
\hline $\mathrm{O} 22$ & 1.0000 & 0.30957 & 0.98164 & 0.80925 & Biso & 1.000 & 0 \\
\hline 023 & 1.0000 & 0.66096 & 0.68655 & 0.82315 & Biso & 1.000 & 0 \\
\hline $\mathrm{O} 24$ & 1.0000 & 0.01700 & 0.33930 & 0.81673 & Biso & 1.000 & $\mathrm{O}$ \\
\hline 025 & 1.0000 & 0.66130 & 0.65761 & 0.48397 & Biso & 1.000 & 0 \\
\hline 026 & 1.0000 & 0.34734 & 0.98831 & 0.48188 & Biso & 1.000 & 0 \\
\hline $\mathrm{O} 27$ & 1.0000 & 0.01204 & 0.34969 & 0.47711 & Biso & 1.000 & 0 \\
\hline 028 & 1.0000 & 0.01406 & 0.67722 & 0.82285 & Biso & 1.000 & 0 \\
\hline 029 & 1.0000 & 0.31171 & 0.33246 & 0.80753 & Biso & 1.000 & 0 \\
\hline 030 & 1.0000 & 0.66375 & 0.97917 & 0.81781 & Biso & 1.000 & 0 \\
\hline 031 & 1.0000 & 0.68700 & 0.02708 & 0.14538 & Biso & 1.000 & 0 \\
\hline 032 & 1.0000 & 0.33776 & 0.32258 & 0.14084 & Biso & 1.000 & 0 \\
\hline 033 & 1.0000 & 0.98243 & 0.67584 & 0.15529 & Biso & 1.000 & 0 \\
\hline 034 & 1.0000 & 0.34037 & 0.36987 & 0.46916 & Biso & 1.000 & 0 \\
\hline 035 & 1.0000 & 0.99236 & 0.65437 & 0.48323 & Biso & 1.000 & 0 \\
\hline 036 & 1.0000 & 0.64242 & 0.00625 & 0.48280 & Biso & 1.000 & 0 \\
\hline 037 & 1.0000 & 0.12473 & 0.24785 & 0.10338 & Biso & 1.000 & 0 \\
\hline 038 & 1.0000 & 0.76054 & 0.88599 & 0.11495 & Biso & 1.000 & 0 \\
\hline 039 & 1.0000 & 0.12765 & 0.88386 & 0.10508 & Biso & 1.000 & 0 \\
\hline 040 & 1.0000 & 0.23004 & 0.11717 & 0.84294 & Biso & 1.000 & 0 \\
\hline 041 & 1.0000 & 0.87551 & 0.75540 & 0.85233 & Biso & 1.000 & 0 \\
\hline 042 & 1.0000 & 0.87782 & 0.12333 & 0.84893 & Biso & 1.000 & 0 \\
\hline
\end{tabular}




\begin{tabular}{|c|c|c|c|c|c|c|c|}
\hline 043 & 1.0000 & 0.77660 & 0.55689 & 0.44655 & Biso & 1.000 & 0 \\
\hline 044 & 1.0000 & 0.40608 & 0.22132 & 0.45642 & Biso & 1.000 & 0 \\
\hline 045 & 1.0000 & 0.80229 & 0.20950 & 0.43885 & Biso & 1.000 & 0 \\
\hline 046 & 1.0000 & 0.91213 & 0.46054 & 0.18378 & Biso & 1.000 & 0 \\
\hline 047 & 1.0000 & 0.55173 & 0.10261 & 0.18887 & Biso & 1.000 & 0 \\
\hline 048 & 1.0000 & 0.54564 & 0.46409 & 0.19097 & Biso & 1.000 & 0 \\
\hline 049 & 1.0000 & 0.45005 & 0.90512 & 0.78233 & Biso & 1.000 & 0 \\
\hline 050 & 1.0000 & 0.08576 & 0.54425 & 0.75983 & Biso & 1.000 & 0 \\
\hline 051 & 1.0000 & 0.45392 & 0.54683 & 0.77147 & Biso & 1.000 & 0 \\
\hline 052 & 1.0000 & 0.59395 & 0.80105 & 0.52607 & Biso & 1.000 & 0 \\
\hline 053 & 1.0000 & 0.22688 & 0.46473 & 0.52192 & Biso & 1.000 & 0 \\
\hline 054 & 1.0000 & 0.21023 & 0.77738 & 0.52074 & Biso & 1.000 & 0 \\
\hline 055 & 1.0000 & 0.99437 & 0.26661 & 0.98038 & Biso & 1.000 & 0 \\
\hline 056 & 1.0000 & 0.74099 & 0.74366 & 0.98535 & Biso & 1.000 & 0 \\
\hline 057 & 1.0000 & 0.26541 & 0.00834 & 0.97480 & Biso & 1.000 & 0 \\
\hline 058 & 1.0000 & 0.67769 & 0.60951 & 0.31686 & Biso & 1.000 & 0 \\
\hline 059 & 1.0000 & 0.38717 & 0.07320 & 0.30428 & Biso & 1.000 & 0 \\
\hline 060 & 1.0000 & 0.94457 & 0.34602 & 0.31313 & Biso & 1.000 & 0 \\
\hline 061 & 1.0000 & 0.33118 & 0.92255 & 0.64835 & Biso & 1.000 & 0 \\
\hline 062 & 1.0000 & 0.06653 & 0.38344 & 0.64747 & Biso & 1.000 & 0 \\
\hline 063 & 1.0000 & 0.61394 & 0.67351 & 0.65200 & Biso & 1.000 & 0 \\
\hline 064 & 1.0000 & 0.99297 & 0.73337 & 0.98556 & Biso & 1.000 & 0 \\
\hline 065 & 1.0000 & 0.26827 & 0.26455 & 0.97513 & Biso & 1.000 & 0 \\
\hline 066 & 1.0000 & 0.74017 & 0.00376 & 0.98179 & Biso & 1.000 & 0 \\
\hline 067 & 1.0000 & 0.66990 & 0.06659 & 0.31446 & Biso & 1.000 & 0 \\
\hline 068 & 1.0000 & 0.92646 & 0.59453 & 0.31822 & Biso & 1.000 & 0 \\
\hline 069 & 1.0000 & 0.39312 & 0.32921 & 0.31019 & Biso & 1.000 & 0 \\
\hline 070 & 1.0000 & 0.32998 & 0.40451 & 0.64241 & Biso & 1.000 & 0 \\
\hline 071 & 1.0000 & 0.59697 & 0.94144 & 0.65061 & Biso & 1.000 & 0 \\
\hline 072 & 1.0000 & 0.06071 & 0.68650 & 0.65223 & Biso & 1.000 & 0 \\
\hline $\mathrm{H} 1$ & 1.0000 & 0.25355 & 0.97362 & 0.30430 & Biso & 1.000 & $\mathrm{H}$ \\
\hline $\mathrm{C} 1$ & 1.0000 & 0.09846 & 0.92819 & 0.41834 & Biso & 1.000 & $\mathrm{C}$ \\
\hline H2 & 1.0000 & 0.03803 & 0.83789 & 0.41450 & Biso & 1.000 & $\mathrm{H}$ \\
\hline H3 & 1.0000 & 0.17841 & 0.95630 & 0.45252 & Biso & 1.000 & $\mathrm{H}$ \\
\hline $\mathrm{H} 4$ & 1.0000 & 0.08669 & 0.98519 & 0.37509 & Biso & 1.000 & $\mathrm{H}$ \\
\hline 073 & 1.0000 & 0.17667 & 0.90296 & 0.30407 & Biso & 1.000 & 0 \\
\hline $\mathrm{C} 2$ & 1.0000 & 0.99737 & 0.92200 & 0.52748 & Biso & 1.000 & $\mathrm{C}$ \\
\hline C3 & 1.0000 & 0.07248 & 0.03494 & 0.53917 & Biso & 1.000 & $\mathrm{C}$ \\
\hline $\mathrm{C} 4$ & 1.0000 & 0.17422 & 0.08340 & 0.59619 & Biso & 1.000 & $\mathrm{C}$ \\
\hline H5 & 1.0000 & 0.18357 & 0.01880 & 0.63261 & Biso & 1.000 & $\mathrm{H}$ \\
\hline H6 & 1.0000 & 0.17015 & 0.14263 & 0.64402 & Biso & 1.000 & $\mathrm{H}$ \\
\hline H 7 & 1.0000 & 0.25157 & 0.13568 & 0.55664 & Biso & 1.000 & $\mathrm{H}$ \\
\hline C5 & 1.0000 & 0.19952 & 0.81060 & 0.30141 & Biso & 1.000 & $\mathrm{C}$ \\
\hline H 8 & 1.0000 & 0.12198 & 0.73299 & 0.32003 & Biso & 1.000 & $\mathrm{H}$ \\
\hline H9 & 1.0000 & 0.26822 & 0.82508 & 0.34726 & Biso & 1.000 & $\mathrm{H}$ \\
\hline $\mathrm{H} 10$ & 1.0000 & 0.22303 & 0.80182 & 0.23317 & Biso & 1.000 & $\mathrm{H}$ \\
\hline $\mathrm{H} 11$ & 1.0000 & 0.00301 & 0.85875 & 0.56841 & Biso & 1.000 & $\mathrm{H}$ \\
\hline $\mathrm{H} 12$ & 1.0000 & 0.05808 & 0.09572 & 0.50172 & Biso & 1.000 & $\mathrm{H}$ \\
\hline $\mathrm{H} 13$ & 1.0000 & 0.91802 & 0.89362 & 0.49162 & Biso & 1.000 & $\mathrm{H}$ \\
\hline \multirow{2}{*}{\multicolumn{8}{|c|}{$\begin{array}{l}\text { Ti } 8 \\
\text { data image } 0\end{array}$}} \\
\hline & & & & & & & \\
\hline \multicolumn{8}{|c|}{ cel̄̄ length a $\quad 13.875$} \\
\hline \multicolumn{8}{|c|}{ cell_length_b $\quad 13.875$} \\
\hline \multicolumn{8}{|c|}{ cell_length_c $\quad 15.017$} \\
\hline \multicolumn{8}{|c|}{ cell_angle_alpha 90} \\
\hline \multicolumn{8}{|c|}{ cell angle beta } \\
\hline \multicolumn{8}{|c|}{ cell_angle_gamma } \\
\hline \multicolumn{8}{|c|}{ _symmetry_space_group_name_H-M "P 1" } \\
\hline symme & int_t $\bar{a} \bar{a} l$ & es_numbe & & & & & \\
\hline loop_ & & & & & & & \\
\hline $\bar{s}_{\mathrm{x}}^{\mathrm{sym}}$ & _equiv & pos_as_x & & & & & \\
\hline loop_ & & & & & & & \\
\hline ato & e_label & & & & & & \\
\hline -ato & =e_occup & ancy & & & & & \\
\hline -ato & $=e-f r a c t$ & $\mathrm{x}$ & & & & & \\
\hline -ato & $e_{-}^{-}$fract & & & & & & \\
\hline -ato & e_fract & & & & & & \\
\hline -ato & $e^{-}$therm & $\bar{a}$ l_displ & ce_type & & & & \\
\hline -ato & $\begin{array}{l}=e^{-} \mathrm{B} \text {-iso } \\
=e^{-} \text {type }\end{array}$ & $\begin{array}{l}\text { or_equi } \\
\text { symbol }\end{array}$ & & & & & \\
\hline$\overline{\mathrm{P}} 1$ & 1.0000 & 0.99824 & 0.22511 & 0.08924 & Biso & 1.000 & $\mathrm{P}$ \\
\hline $\mathrm{P} 2$ & 1.0000 & 0.77089 & 0.77787 & 0.09491 & Biso & 1.000 & $\mathrm{P}$ \\
\hline P3 & 1.0000 & 0.22455 & 0.99625 & 0.07966 & Biso & 1.000 & $P$ \\
\hline Al1 & 1.0000 & 0.21186 & 0.98793 & 0.86823 & Biso & 1.000 & Al \\
\hline Al2 & 1.0000 & 0.76271 & 0.77008 & 0.88161 & Biso & 1.000 & Al \\
\hline A13 & 1.0000 & 0.99078 & 0.22279 & 0.87718 & Biso & 1.000 & Al \\
\hline
\end{tabular}




\begin{tabular}{|c|c|c|c|c|c|c|c|}
\hline P4 & 1.0000 & 0.66236 & 0.55946 & 0.42329 & Biso & 1.000 & $\mathrm{P}$ \\
\hline Til & 1.0000 & 0.42118 & 0.10691 & 0.42651 & Biso & 1.000 & $\mathrm{Ti}$ \\
\hline P5 & 1.0000 & 0.89547 & 0.32289 & 0.42093 & Biso & 1.000 & $\mathrm{P}$ \\
\hline Al4 & 1.0000 & 0.89139 & 0.33004 & 0.21003 & Biso & 1.000 & Al \\
\hline Al5 & 1.0000 & 0.43069 & 0.10816 & 0.20610 & Biso & 1.000 & $\mathrm{Al}$ \\
\hline Al 6 & 1.0000 & 0.66612 & 0.56155 & 0.21378 & Biso & 1.000 & \\
\hline P6 & 1.0000 & 0.32189 & 0.87632 & 0.76137 & Biso & 1.000 & $\mathrm{P}$ \\
\hline P7 & 1.0000 & 0.09331 & 0.42926 & 0.75295 & Biso & 1.000 & $\mathrm{P}$ \\
\hline P8 & 1.0000 & 0.55290 & 0.65728 & 0.75713 & Biso & 1.000 & $\mathrm{P}$ \\
\hline Al7 & 1.0000 & 0.57113 & 0.66986 & 0.55173 & Biso & 1.000 & Al \\
\hline Al 8 & 1.0000 & 0.09090 & 0.43066 & 0.55126 & Biso & 1.000 & \\
\hline Al9 & 1.0000 & 0.32561 & 0.86913 & 0.54581 & Biso & 1.000 & ᄀ \\
\hline P9 & 1.0000 & 0.98195 & 0.75884 & 0.87611 & Biso & 1.000 & $\mathrm{P}$ \\
\hline P10 & 1.0000 & 0.21581 & 0.21716 & 0.86515 & Biso & 1.000 & $\mathrm{P}$ \\
\hline P11 & 1.0000 & 0.76669 & 0.99741 & 0.87400 & Biso & 1.000 & $\mathrm{P}$ \\
\hline Al10 & 1.0000 & 0.76921 & 0.00204 & 0.08791 & Biso & 1.000 & $\mathrm{Al}$ \\
\hline Al11 & 1.0000 & 0.22589 & 0.22395 & 0.07776 & Biso & 1.000 & \\
\hline Al12 & 1.0000 & 0.99362 & 0.77219 & 0.08904 & Biso & 1.000 & \\
\hline P12 & 1.0000 & 0.66048 & 0.10408 & 0.20913 & Biso & 1.000 & $\mathrm{P}$ \\
\hline P13 & 1.0000 & 0.89048 & 0.55665 & 0.21057 & Biso & 1.000 & $\mathrm{P}$ \\
\hline P 14 & 1.0000 & 0.43482 & 0.33658 & 0.20285 & Biso & 1.000 & $\mathrm{P}$ \\
\hline Al13 & 1.0000 & 0.41864 & 0.34039 & 0.41480 & Biso & 1.000 & \\
\hline Al14 & 1.0000 & 0.88425 & 0.54655 & 0.42271 & Biso & 1.000 & \\
\hline Al15 & 1.0000 & 0.66171 & 0.10439 & 0.41706 & Biso & 1.000 & Al \\
\hline P15 & 1.0000 & 0.32774 & 0.45627 & 0.53777 & Biso & 1.000 & $\mathrm{P}$ \\
\hline P16 & 1.0000 & 0.55904 & 0.89143 & 0.54511 & Biso & 1.000 & $P$ \\
\hline P17 & 1.0000 & 0.08479 & 0.66156 & 0.55025 & Biso & 1.000 & $\mathrm{P}$ \\
\hline Al16 & 1.0000 & 0.09128 & 0.66174 & 0.75458 & Biso & 1.000 & $\mathrm{Al}$ \\
\hline Al17 & 1.0000 & 0.54974 & 0.88634 & 0.75467 & Biso & 1.000 & Al \\
\hline Al18 & 1.0000 & 0.32056 & 0.43280 & 0.74557 & Biso & 1.000 & \\
\hline 01 & 1.0000 & 0.90650 & 0.10557 & 0.11205 & Biso & 1.000 & 0 \\
\hline $\mathrm{O} 2$ & 1.0000 & 0.89298 & 0.81002 & 0.11280 & Biso & 1.000 & 0 \\
\hline 03 & 1.0000 & 0.19452 & 0.08711 & 0.10055 & Biso & 1.000 & 0 \\
\hline 04 & 1.0000 & 0.07572 & 0.87723 & 0.85194 & Biso & 1.000 & 0 \\
\hline 05 & 1.0000 & 0.79812 & 0.90720 & 0.85473 & Biso & 1.000 & 0 \\
\hline 06 & 1.0000 & 0.09492 & 0.19092 & 0.85165 & Biso & 1.000 & 0 \\
\hline 07 & 1.0000 & 0.55617 & 0.44717 & 0.43562 & Biso & 1.000 & 0 \\
\hline 08 & 1.0000 & 0.56787 & 0.15031 & 0.42903 & Biso & 1.000 & 0 \\
\hline 09 & 1.0000 & 0.86869 & 0.41564 & 0.44392 & Biso & 1.000 & 0 \\
\hline 010 & 1.0000 & 0.75360 & 0.22546 & 0.19240 & Biso & 1.000 & 0 \\
\hline 011 & 1.0000 & 0.46836 & 0.24791 & 0.18542 & Biso & 1.000 & 0 \\
\hline 012 & 1.0000 & 0.76889 & 0.52548 & 0.19308 & Biso & 1.000 & 0 \\
\hline 013 & 1.0000 & 0.22668 & 0.75988 & 0.78862 & Biso & 1.000 & 0 \\
\hline 014 & 1.0000 & 0.21654 & 0.46603 & 0.77124 & Biso & 1.000 & 0 \\
\hline 015 & 1.0000 & 0.52044 & 0.74821 & 0.76325 & Biso & 1.000 & 0 \\
\hline 016 & 1.0000 & 0.43189 & 0.57212 & 0.53122 & Biso & 1.000 & 0 \\
\hline 017 & 1.0000 & 0.08289 & 0.55093 & 0.55176 & Biso & 1.000 & 0 \\
\hline 018 & 1.0000 & 0.43448 & 0.84193 & 0.52216 & Biso & 1.000 & 0 \\
\hline 019 & 1.0000 & 0.98451 & 0.30964 & 0.14558 & Biso & 1.000 & 0 \\
\hline 020 & 1.0000 & 0.69130 & 0.67670 & 0.15050 & Biso & 1.000 & 0 \\
\hline 021 & 1.0000 & 0.32981 & 0.01832 & 0.12926 & Biso & 1.000 & 0 \\
\hline 022 & 1.0000 & 0.30455 & 0.96730 & 0.80390 & Biso & 1.000 & 0 \\
\hline 023 & 1.0000 & 0.64066 & 0.67568 & 0.82728 & Biso & 1.000 & 0 \\
\hline 024 & 1.0000 & 0.01656 & 0.34338 & 0.82141 & Biso & 1.000 & 0 \\
\hline 025 & 1.0000 & 0.66112 & 0.64832 & 0.48398 & Biso & 1.000 & 0 \\
\hline 026 & 1.0000 & 0.33590 & 0.98297 & 0.49256 & Biso & 1.000 & 0 \\
\hline 027 & 1.0000 & 0.99592 & 0.33742 & 0.47528 & Biso & 1.000 & 0 \\
\hline 028 & 1.0000 & 0.99615 & 0.67099 & 0.82483 & Biso & 1.000 & 0 \\
\hline 029 & 1.0000 & 0.29503 & 0.31391 & 0.80484 & Biso & 1.000 & 0 \\
\hline 030 & 1.0000 & 0.66290 & 0.97419 & 0.82118 & Biso & 1.000 & 0 \\
\hline 031 & 1.0000 & 0.67383 & 0.02570 & 0.14444 & Biso & 1.000 & 0 \\
\hline 032 & 1.0000 & 0.34171 & 0.32004 & 0.13815 & Biso & 1.000 & 0 \\
\hline 033 & 1.0000 & 0.97086 & 0.65968 & 0.15624 & Biso & 1.000 & 0 \\
\hline 034 & 1.0000 & 0.32865 & 0.37871 & 0.46600 & Biso & 1.000 & 0 \\
\hline 035 & 1.0000 & 0.99152 & 0.65124 & 0.48796 & Biso & 1.000 & 0 \\
\hline 036 & 1.0000 & 0.63271 & 0.99028 & 0.48528 & Biso & 1.000 & 0 \\
\hline 037 & 1.0000 & 0.11212 & 0.23753 & 0.10956 & Biso & 1.000 & 0 \\
\hline 038 & 1.0000 & 0.75475 & 0.87532 & 0.12182 & Biso & 1.000 & 0 \\
\hline 039 & 1.0000 & 0.12705 & 0.88305 & 0.10816 & Biso & 1.000 & 0 \\
\hline 040 & 1.0000 & 0.22193 & 0.11396 & 0.83709 & Biso & 1.000 & 0 \\
\hline 041 & 1.0000 & 0.87063 & 0.74816 & 0.84826 & Biso & 1.000 & 0 \\
\hline 042 & 1.0000 & 0.86320 & 0.11068 & 0.84432 & Biso & 1.000 & 0 \\
\hline 043 & 1.0000 & 0.76305 & 0.54783 & 0.44950 & Biso & 1.000 & 0 \\
\hline 044 & 1.0000 & 0.39436 & 0.21709 & 0.46090 & Biso & 1.000 & 0 \\
\hline 045 & 1.0000 & 0.79698 & 0.20953 & 0.44502 & Biso & 1.000 & 0 \\
\hline 046 & 1.0000 & 0.90645 & 0.45940 & 0.18235 & Biso & 1.000 & 0 \\
\hline 047 & 1.0000 & 0.54835 & 0.09551 & 0.19025 & Biso & 1.000 & 0 \\
\hline 048 & 1.0000 & 0.53608 & 0.45190 & 0.18475 & Biso & 1.000 & 0 \\
\hline 049 & 1.0000 & 0.43317 & 0.89066 & 0.79390 & Biso & 1.000 & 0 \\
\hline 050 & 1.0000 & 0.07703 & 0.53020 & 0.75959 & Biso & 1.000 & 0 \\
\hline
\end{tabular}




\begin{tabular}{|c|c|c|c|c|c|c|c|}
\hline 051 & 1.0000 & 0.44956 & 0.54409 & 0.77583 & Biso & 1.000 & 0 \\
\hline 052 & 1.0000 & 0.59225 & 0.80230 & 0.53008 & Biso & 1.000 & 0 \\
\hline 053 & 1.0000 & 0.22622 & 0.46988 & 0.52153 & Biso & 1.000 & 0 \\
\hline 054 & 1.0000 & 0.19713 & 0.75299 & 0.51507 & Biso & 1.000 & 0 \\
\hline 055 & 1.0000 & 0.99061 & 0.24947 & 0.99043 & Biso & 1.000 & 0 \\
\hline 056 & 1.0000 & 0.74218 & 0.74914 & 0.99606 & Biso & 1.000 & 0 \\
\hline 057 & 1.0000 & 0.24714 & 0.99479 & 0.97974 & Biso & 1.000 & 0 \\
\hline 058 & 1.0000 & 0.67363 & 0.59917 & 0.32610 & Biso & 1.000 & 0 \\
\hline 059 & 1.0000 & 0.37071 & 0.06824 & 0.31053 & Biso & 1.000 & 0 \\
\hline 060 & 1.0000 & 0.92604 & 0.32997 & 0.32187 & Biso & 1.000 & 0 \\
\hline 061 & 1.0000 & 0.32291 & 0.88872 & 0.66036 & Biso & 1.000 & 0 \\
\hline 062 & 1.0000 & 0.06064 & 0.37574 & 0.65950 & Biso & 1.000 & 0 \\
\hline 063 & 1.0000 & 0.60067 & 0.65892 & 0.66398 & Biso & 1.000 & 0 \\
\hline 064 & 1.0000 & 0.98256 & 0.73604 & 0.97616 & Biso & 1.000 & 0 \\
\hline 065 & 1.0000 & 0.25110 & 0.24845 & 0.96285 & Biso & 1.000 & 0 \\
\hline 066 & 1.0000 & 0.74321 & 0.99940 & 0.97371 & Biso & 1.000 & 0 \\
\hline 067 & 1.0000 & 0.66674 & 0.06800 & 0.30480 & Biso & 1.000 & 0 \\
\hline 068 & 1.0000 & 0.91867 & 0.58307 & 0.31037 & Biso & 1.000 & 0 \\
\hline 069 & 1.0000 & 0.39400 & 0.33080 & 0.29895 & Biso & 1.000 & 0 \\
\hline 070 & 1.0000 & 0.32009 & 0.40554 & 0.63110 & Biso & 1.000 & 0 \\
\hline 071 & 1.0000 & 0.57928 & 0.92978 & 0.64341 & Biso & 1.000 & 0 \\
\hline 072 & 1.0000 & 0.06435 & 0.69032 & 0.64533 & Biso & 1.000 & 0 \\
\hline $\mathrm{H} 1$ & 1.0000 & 0.24032 & 0.97026 & 0.30852 & Biso & 1.000 & $\mathrm{H}$ \\
\hline $\mathrm{C} 1$ & 1.0000 & 0.09116 & 0.91974 & 0.42797 & Biso & 1.000 & $\mathrm{C}$ \\
\hline $\mathrm{H} 2$ & 1.0000 & 0.03174 & 0.83125 & 0.42227 & Biso & 1.000 & $\mathrm{H}$ \\
\hline H3 & 1.0000 & 0.17097 & 0.94630 & 0.45989 & Biso & 1.000 & $\mathrm{H}$ \\
\hline $\mathrm{H} 4$ & 1.0000 & 0.07784 & 0.97718 & 0.38792 & Biso & 1.000 & $\mathrm{H}$ \\
\hline 073 & 1.0000 & 0.16459 & 0.90045 & 0.30843 & Biso & 1.000 & 0 \\
\hline $\mathrm{C} 2$ & 1.0000 & 0.99877 & 0.90820 & 0.54352 & Biso & 1.000 & $\mathrm{C}$ \\
\hline $\mathrm{C} 3$ & 1.0000 & 0.06626 & 0.02088 & 0.55157 & Biso & 1.000 & $\mathrm{C}$ \\
\hline $\mathrm{C} 4$ & 1.0000 & 0.17211 & 0.07790 & 0.60134 & Biso & 1.000 & $\mathrm{C}$ \\
\hline H5 & 1.0000 & 0.19196 & 0.01999 & 0.63537 & Biso & 1.000 & $\mathrm{H}$ \\
\hline H6 & 1.0000 & 0.16750 & 0.13421 & 0.65088 & Biso & 1.000 & $\mathrm{H}$ \\
\hline H 7 & 1.0000 & 0.24204 & 0.13249 & 0.55695 & Biso & 1.000 & $\mathrm{H}$ \\
\hline $\mathrm{C} 5$ & 1.0000 & 0.18665 & 0.80979 & 0.30193 & Biso & 1.000 & $\mathrm{C}$ \\
\hline H8 & 1.0000 & 0.11025 & 0.73275 & 0.31878 & Biso & 1.000 & $\mathrm{H}$ \\
\hline H9 & 1.0000 & 0.25376 & 0.82145 & 0.34737 & Biso & 1.000 & $\mathrm{H}$ \\
\hline $\mathrm{H} 10$ & 1.0000 & 0.21026 & 0.80433 & 0.23292 & Biso & 1.000 & $\mathrm{H}$ \\
\hline $\mathrm{H} 11$ & 1.0000 & 0.01484 & 0.85127 & 0.58266 & Biso & 1.000 & $\mathrm{H}$ \\
\hline $\mathrm{H} 12$ & 1.0000 & 0.04146 & 0.07455 & 0.51659 & Biso & 1.000 & $\mathrm{H}$ \\
\hline H13 & 1.0000 & 0.91652 & 0.87314 & 0.51309 & Biso & 1.000 & $\mathrm{H}$ \\
\hline \multirow{2}{*}{\multicolumn{8}{|c|}{$\begin{array}{l}\text { Zn } 9 \\
\text { data image } 0\end{array}$}} \\
\hline & & & & & & & \\
\hline \multicolumn{8}{|c|}{ celil length a $\quad 13.875$} \\
\hline \multicolumn{8}{|c|}{ cell length b $\quad 13.875$} \\
\hline \multicolumn{8}{|c|}{ _cell_length_c $\quad 15.017$} \\
\hline \multicolumn{8}{|c|}{ _cell_angle_ālpha } \\
\hline \multicolumn{8}{|c|}{ cell_angle_beta 90} \\
\hline \multicolumn{8}{|c|}{ cell_angle_gamma } \\
\hline \multicolumn{8}{|c|}{ _symmetry_space_group_name_H-M } \\
\hline symme & int_tabl & les_numbe & & & & & \\
\hline loop_ & & & & & & & \\
\hline $\begin{array}{c}\text { sym } \\
\text { 'x, }\end{array}$ & equiv & pos_as_x & & & & & \\
\hline loop_ & & & & & & & \\
\hline -ato & e_label & & & & & & \\
\hline -ato & e_occup & pancy & & & & & \\
\hline -ato & e_fract & & & & & & \\
\hline -ato & e_fract & & & & & & \\
\hline -ato & e_fract & - z & & & & & \\
\hline -ato & $e^{-}$therm & nāl_displ & ace_type & & & & \\
\hline -ato & $\begin{array}{l}e^{-} B \text { iso } \\
e^{-} \text {type }\end{array}$ & $\begin{array}{l}\text { _or_equi } \\
\text { symbol }\end{array}$ & & & & & \\
\hline $\bar{A} 11$ & 1.0000 & 0.99514 & 0.23286 & 0.11073 & Biso & 1.000 & Al \\
\hline Al2 & 1.0000 & 0.77047 & 0.78032 & 0.11404 & Biso & 1.000 & Al \\
\hline Al3 & 1.0000 & 0.22752 & 0.01354 & 0.10674 & Biso & 1.000 & Al \\
\hline P1 & 1.0000 & 0.21968 & 0.00813 & 0.89399 & Biso & 1.000 & $\mathrm{P}$ \\
\hline P2 & 1.0000 & 0.76998 & 0.77767 & 0.90147 & Biso & 1.000 & $\mathrm{P}$ \\
\hline P3 & 1.0000 & 0.99110 & 0.23116 & 0.89834 & Biso & 1.000 & $\mathrm{P}$ \\
\hline Al4 & 1.0000 & 0.65428 & 0.56254 & 0.44405 & Biso & 1.000 & Al \\
\hline $\mathrm{Zn} 1$ & 1.0000 & 0.44249 & 0.11664 & 0.44406 & Biso & 1.000 & $\mathrm{Zn}$ \\
\hline Al5 & 1.0000 & 0.89831 & 0.34197 & 0.44174 & Biso & 1.000 & Al \\
\hline P4 & 1.0000 & 0.89865 & 0.34893 & 0.23362 & Biso & 1.000 & $\mathrm{P}$ \\
\hline P5 & 1.0000 & 0.43840 & 0.10871 & 0.22858 & Biso & 1.000 & $\mathrm{P}$ \\
\hline P6 & 1.0000 & 0.66068 & 0.56566 & 0.23262 & Biso & 1.000 & $P$ \\
\hline Al6 & 1.0000 & 0.32490 & 0.89731 & 0.77681 & Biso & 1.000 & Al \\
\hline Al7 & 1.0000 & 0.10221 & 0.44211 & 0.77759 & Biso & 1.000 & Al \\
\hline
\end{tabular}




\begin{tabular}{|c|c|c|c|c|c|c|c|}
\hline Al8 & 1.0000 & 0.56044 & 0.67709 & 0.77674 & Biso & 1.000 & $\mathrm{Al}$ \\
\hline P7 & 1.0000 & 0.56666 & 0.68444 & 0.56869 & Biso & 1.000 & $\mathrm{P}$ \\
\hline P8 & 1.0000 & 0.10086 & 0.44353 & 0.56980 & Biso & 1.000 & $\mathrm{P}$ \\
\hline P9 & 1.0000 & 0.32241 & 0.89532 & 0.56688 & Biso & 1.000 & $\mathrm{P}$ \\
\hline Al9 & 1.0000 & 0.99634 & 0.77922 & 0.90557 & Biso & 1.000 & $\mathrm{Al}$ \\
\hline Al10 & 1.0000 & 0.21993 & 0.23426 & 0.89896 & Biso & 1.000 & Al \\
\hline Al11 & 1.0000 & 0.76621 & 0.00309 & 0.90362 & Biso & 1.000 & Al \\
\hline $\mathrm{P} 10$ & 1.0000 & 0.77007 & 0.00594 & 0.11645 & Biso & 1.000 & $\mathrm{P}$ \\
\hline P 11 & 1.0000 & 0.22333 & 0.23698 & 0.11231 & Biso & 1.000 & $P$ \\
\hline P12 & 1.0000 & 0.00023 & 0.78643 & 0.11879 & Biso & 1.000 & $\mathrm{P}$ \\
\hline Al12 & 1.0000 & 0.66728 & 0.11824 & 0.23851 & Biso & 1.000 & $\mathrm{Al}$ \\
\hline Al13 & 1.0000 & 0.89091 & 0.57049 & 0.23756 & Biso & 1.000 & Al \\
\hline Al14 & 1.0000 & 0.43312 & 0.33860 & 0.23694 & Biso & 1.000 & $\mathrm{Al}$ \\
\hline P13 & 1.0000 & 0.42246 & 0.33967 & 0.44435 & Biso & 1.000 & $\mathrm{P}$ \\
\hline P 14 & 1.0000 & 0.88450 & 0.56392 & 0.44930 & Biso & 1.000 & $P$ \\
\hline P15 & 1.0000 & 0.66974 & 0.11952 & 0.44614 & Biso & 1.000 & $\mathrm{P}$ \\
\hline Al15 & 1.0000 & 0.33493 & 0.45829 & 0.57103 & Biso & 1.000 & Al \\
\hline A116 & 1.0000 & 0.55320 & 0.90560 & 0.57089 & Biso & 1.000 & Al \\
\hline Al 17 & 1.0000 & 0.08944 & 0.66893 & 0.57804 & Biso & 1.000 & Al \\
\hline P16 & 1.0000 & 0.09476 & 0.66816 & 0.78408 & Biso & 1.000 & $\mathrm{P}$ \\
\hline P 17 & 1.0000 & 0.55225 & 0.90141 & 0.78236 & Biso & 1.000 & $\mathrm{P}$ \\
\hline P18 & 1.0000 & 0.33215 & 0.44808 & 0.78014 & Biso & 1.000 & $P$ \\
\hline 01 & 1.0000 & 0.89296 & 0.09481 & 0.13344 & Biso & 1.000 & 0 \\
\hline $\mathrm{O} 2$ & 1.0000 & 0.90887 & 0.81590 & 0.13899 & Biso & 1.000 & 0 \\
\hline 03 & 1.0000 & 0.19345 & 0.11603 & 0.13308 & Biso & 1.000 & 0 \\
\hline 04 & 1.0000 & 0.09890 & 0.91475 & 0.87685 & Biso & 1.000 & 0 \\
\hline 05 & 1.0000 & 0.79998 & 0.89879 & 0.88272 & Biso & 1.000 & 0 \\
\hline 06 & 1.0000 & 0.08319 & 0.20310 & 0.87777 & Biso & 1.000 & 0 \\
\hline 07 & 1.0000 & 0.54551 & 0.42842 & 0.46384 & Biso & 1.000 & 0 \\
\hline 08 & 1.0000 & 0.59819 & 0.17218 & 0.46385 & Biso & 1.000 & 0 \\
\hline 09 & 1.0000 & 0.86357 & 0.44563 & 0.46555 & Biso & 1.000 & 0 \\
\hline 010 & 1.0000 & 0.77649 & 0.25627 & 0.22574 & Biso & 1.000 & 0 \\
\hline 011 & 1.0000 & 0.45962 & 0.22899 & 0.22595 & Biso & 1.000 & 0 \\
\hline 012 & 1.0000 & 0.75510 & 0.53988 & 0.21544 & Biso & 1.000 & 0 \\
\hline 013 & 1.0000 & 0.21664 & 0.76055 & 0.79603 & Biso & 1.000 & 0 \\
\hline 014 & 1.0000 & 0.24033 & 0.47716 & 0.79928 & Biso & 1.000 & 0 \\
\hline 015 & 1.0000 & 0.52538 & 0.78015 & 0.79513 & Biso & 1.000 & 0 \\
\hline 016 & 1.0000 & 0.44348 & 0.59482 & 0.55673 & Biso & 1.000 & 0 \\
\hline 017 & 1.0000 & 0.11393 & 0.55942 & 0.56049 & Biso & 1.000 & 0 \\
\hline 018 & 1.0000 & 0.41310 & 0.86275 & 0.55051 & Biso & 1.000 & 0 \\
\hline 019 & 1.0000 & 0.97312 & 0.32667 & 0.17163 & Biso & 1.000 & 0 \\
\hline 020 & 1.0000 & 0.67764 & 0.66428 & 0.17508 & Biso & 1.000 & 0 \\
\hline 021 & 1.0000 & 0.34762 & 0.03618 & 0.15998 & Biso & 1.000 & 0 \\
\hline 022 & 1.0000 & 0.30205 & 0.98986 & 0.83957 & Biso & 1.000 & 0 \\
\hline 023 & 1.0000 & 0.66843 & 0.69602 & 0.84711 & Biso & 1.000 & 0 \\
\hline 024 & 1.0000 & 0.00866 & 0.33182 & 0.84380 & Biso & 1.000 & 0 \\
\hline 025 & 1.0000 & 0.64138 & 0.66188 & 0.50672 & Biso & 1.000 & 0 \\
\hline 026 & 1.0000 & 0.33263 & 0.98665 & 0.50627 & Biso & 1.000 & 0 \\
\hline 027 & 1.0000 & 0.00948 & 0.36062 & 0.50783 & Biso & 1.000 & 0 \\
\hline 028 & 1.0000 & 0.01934 & 0.68184 & 0.85145 & Biso & 1.000 & 0 \\
\hline 029 & 1.0000 & 0.31519 & 0.35007 & 0.83849 & Biso & 1.000 & 0 \\
\hline 030 & 1.0000 & 0.65041 & 0.97964 & 0.84202 & Biso & 1.000 & 0 \\
\hline 031 & 1.0000 & 0.69226 & 0.02932 & 0.17244 & Biso & 1.000 & 0 \\
\hline 032 & 1.0000 & 0.32549 & 0.31952 & 0.16540 & Biso & 1.000 & o \\
\hline 033 & 1.0000 & 0.98459 & 0.68927 & 0.17769 & Biso & 1.000 & 0 \\
\hline 034 & 1.0000 & 0.34549 & 0.36631 & 0.50024 & Biso & 1.000 & 0 \\
\hline 035 & 1.0000 & 0.97926 & 0.64958 & 0.50866 & Biso & 1.000 & 0 \\
\hline 036 & 1.0000 & 0.64291 & 0.02080 & 0.50808 & Biso & 1.000 & 0 \\
\hline 037 & 1.0000 & 0.12446 & 0.25043 & 0.14085 & Biso & 1.000 & 0 \\
\hline 038 & 1.0000 & 0.75425 & 0.89244 & 0.14429 & Biso & 1.000 & 0 \\
\hline 039 & 1.0000 & 0.11398 & 0.88714 & 0.14288 & Biso & 1.000 & 0 \\
\hline 040 & 1.0000 & 0.23102 & 0.11966 & 0.86649 & Biso & 1.000 & 0 \\
\hline 041 & 1.0000 & 0.86827 & 0.76283 & 0.87419 & Biso & 1.000 & 0 \\
\hline 042 & 1.0000 & 0.87857 & 0.13127 & 0.87258 & Biso & 1.000 & 0 \\
\hline 043 & 1.0000 & 0.77991 & 0.56934 & 0.47214 & Biso & 1.000 & 0 \\
\hline 044 & 1.0000 & 0.39786 & 0.22410 & 0.46767 & Biso & 1.000 & 0 \\
\hline 045 & 1.0000 & 0.79304 & 0.20753 & 0.46218 & Biso & 1.000 & 0 \\
\hline 046 & 1.0000 & 0.90863 & 0.46003 & 0.20515 & Biso & 1.000 & 0 \\
\hline 047 & 1.0000 & 0.54613 & 0.11178 & 0.19908 & Biso & 1.000 & 0 \\
\hline 048 & 1.0000 & 0.55059 & 0.46365 & 0.20604 & Biso & 1.000 & 0 \\
\hline 049 & 1.0000 & 0.45036 & 0.90903 & 0.81151 & Biso & 1.000 & 0 \\
\hline 050 & 1.0000 & 0.08654 & 0.55579 & 0.80189 & Biso & 1.000 & 0 \\
\hline 051 & 1.0000 & 0.44543 & 0.54865 & 0.80297 & Biso & 1.000 & 0 \\
\hline 052 & 1.0000 & 0.58054 & 0.79797 & 0.54500 & Biso & 1.000 & 0 \\
\hline 053 & 1.0000 & 0.21046 & 0.45129 & 0.54248 & Biso & 1.000 & 0 \\
\hline 054 & 1.0000 & 0.20767 & 0.79123 & 0.55114 & Biso & 1.000 & 0 \\
\hline 055 & 1.0000 & 0.99299 & 0.25937 & 0.99754 & Biso & 1.000 & 0 \\
\hline 056 & 1.0000 & 0.74383 & 0.75058 & 0.00094 & Biso & 1.000 & 0 \\
\hline 057 & 1.0000 & 0.24748 & 0.00951 & 0.99315 & Biso & 1.000 & 0 \\
\hline 058 & 1.0000 & 0.66059 & 0.59704 & 0.33088 & Biso & 1.000 & 0 \\
\hline
\end{tabular}




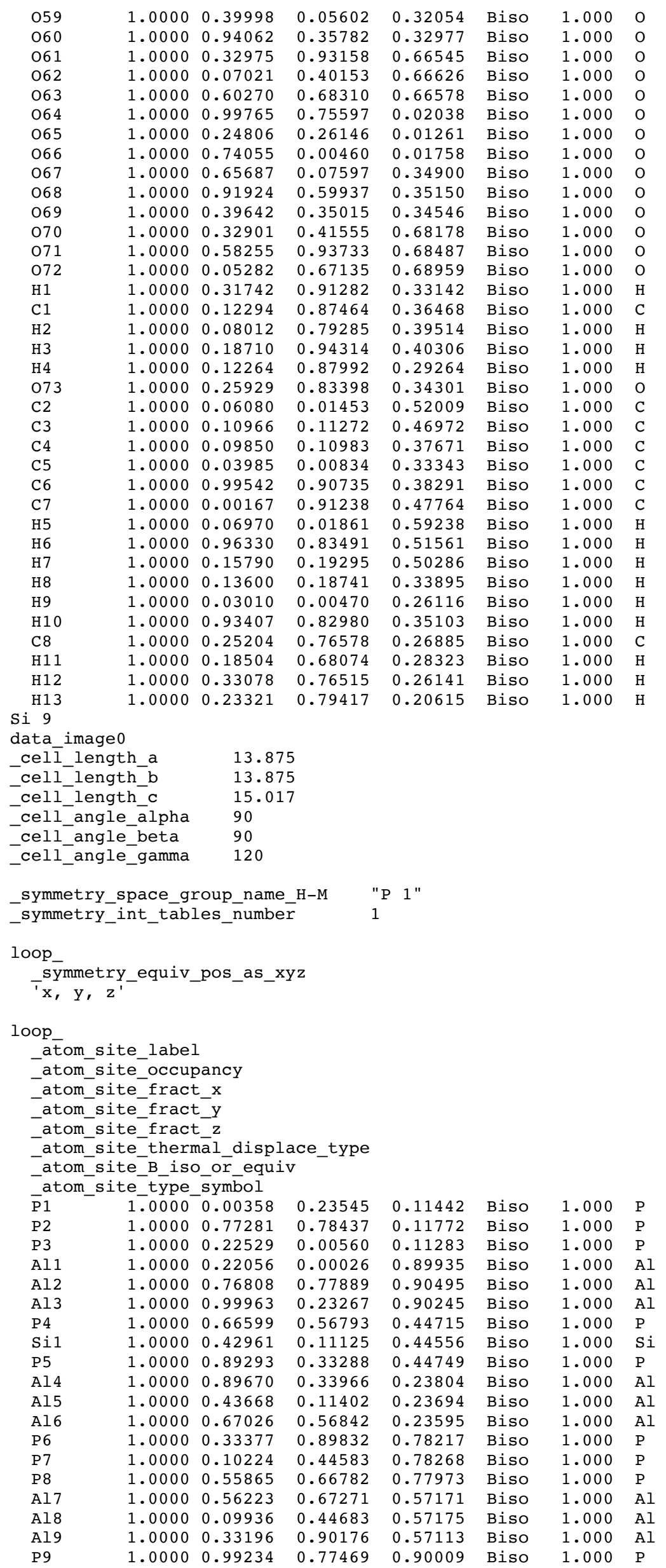




\begin{tabular}{|c|c|c|c|c|c|c|c|}
\hline P 10 & 1.0000 & 0.22470 & 0.22828 & 0.89482 & Biso & 1.000 & $\mathrm{P}$ \\
\hline P11 & 1.0000 & 0.77158 & 0.00717 & 0.89908 & Biso & 1.000 & $\mathrm{P}$ \\
\hline Al10 & 1.0000 & 0.77287 & 0.01102 & 0.11130 & Biso & 1.000 & Al \\
\hline Al11 & 1.0000 & 0.22964 & 0.23398 & 0.10735 & Biso & 1.000 & $\mathrm{Al}$ \\
\hline Al12 & 1.0000 & 0.99768 & 0.78025 & 0.11250 & Biso & 1.000 & $\mathrm{Al}$ \\
\hline P12 & 1.0000 & 0.66341 & 0.11518 & 0.23211 & Biso & 1.000 & $\mathrm{P}$ \\
\hline P13 & 1.0000 & 0.89790 & 0.56804 & 0.23507 & Biso & 1.000 & $P$ \\
\hline P14 & 1.0000 & 0.43968 & 0.34825 & 0.23072 & Biso & 1.000 & $\mathrm{P}$ \\
\hline Al13 & 1.0000 & 0.43208 & 0.34442 & 0.43780 & Biso & 1.000 & $\mathrm{Al}$ \\
\hline Al14 & 1.0000 & 0.89050 & 0.56087 & 0.44634 & Biso & 1.000 & $\mathrm{Al}$ \\
\hline Al15 & 1.0000 & 0.65646 & 0.11144 & 0.44277 & Biso & 1.000 & $\mathrm{Al}$ \\
\hline P 15 & 1.0000 & 0.32810 & 0.44829 & 0.56509 & Biso & 1.000 & $\mathrm{P}$ \\
\hline P16 & 1.0000 & 0.55724 & 0.89908 & 0.56643 & Biso & 1.000 & $\mathrm{P}$ \\
\hline P17 & 1.0000 & 0.09645 & 0.67298 & 0.57150 & Biso & 1.000 & $\mathrm{P}$ \\
\hline Al16 & 1.0000 & 0.10016 & 0.67115 & 0.77917 & Biso & 1.000 & $\mathrm{Al}$ \\
\hline Al17 & 1.0000 & 0.55849 & 0.89740 & 0.77611 & Biso & 1.000 & $\mathrm{Al}$ \\
\hline Al18 & 1.0000 & 0.32797 & 0.44181 & 0.77454 & Biso & 1.000 & $\mathrm{Al}$ \\
\hline 01 & 1.0000 & 0.91132 & 0.11453 & 0.13264 & Biso & 1.000 & 0 \\
\hline $\mathrm{O} 2$ & 1.0000 & 0.89477 & 0.81504 & 0.13598 & Biso & 1.000 & 0 \\
\hline 03 & 1.0000 & 0.19592 & 0.09697 & 0.13308 & Biso & 1.000 & 0 \\
\hline 04 & 1.0000 & 0.08346 & 0.89468 & 0.87795 & Biso & 1.000 & 0 \\
\hline 05 & 1.0000 & 0.80243 & 0.91624 & 0.88178 & Biso & 1.000 & 0 \\
\hline 06 & 1.0000 & 0.10359 & 0.19986 & 0.87861 & Biso & 1.000 & 0 \\
\hline 07 & 1.0000 & 0.56945 & 0.44976 & 0.46313 & Biso & 1.000 & 0 \\
\hline 08 & 1.0000 & 0.55948 & 0.15004 & 0.46323 & Biso & 1.000 & 0 \\
\hline 09 & 1.0000 & 0.86473 & 0.42594 & 0.46508 & Biso & 1.000 & 0 \\
\hline 010 & 1.0000 & 0.75953 & 0.23590 & 0.21900 & Biso & 1.000 & 0 \\
\hline 011 & 1.0000 & 0.46249 & 0.25088 & 0.22517 & Biso & 1.000 & 0 \\
\hline 012 & 1.0000 & 0.77707 & 0.53797 & 0.21584 & Biso & 1.000 & 0 \\
\hline 013 & 1.0000 & 0.23715 & 0.77787 & 0.79437 & Biso & 1.000 & 0 \\
\hline 014 & 1.0000 & 0.22322 & 0.47358 & 0.79806 & Biso & 1.000 & 0 \\
\hline 015 & 1.0000 & 0.52852 & 0.75975 & 0.79160 & Biso & 1.000 & 0 \\
\hline 016 & 1.0000 & 0.42382 & 0.56881 & 0.55388 & Biso & 1.000 & 0 \\
\hline 017 & 1.0000 & 0.12351 & 0.58066 & 0.54976 & Biso & 1.000 & 0 \\
\hline 018 & 1.0000 & 0.43397 & 0.86303 & 0.55070 & Biso & 1.000 & 0 \\
\hline 019 & 1.0000 & 0.98702 & 0.31755 & 0.17146 & Biso & 1.000 & 0 \\
\hline 020 & 1.0000 & 0.69333 & 0.68501 & 0.17503 & Biso & 1.000 & 0 \\
\hline 021 & 1.0000 & 0.32858 & 0.02570 & 0.16410 & Biso & 1.000 & 0 \\
\hline 022 & 1.0000 & 0.31581 & 0.97751 & 0.84225 & Biso & 1.000 & 0 \\
\hline 023 & 1.0000 & 0.65188 & 0.68550 & 0.84419 & Biso & 1.000 & 0 \\
\hline 024 & 1.0000 & 0.02147 & 0.34744 & 0.84053 & Biso & 1.000 & 0 \\
\hline 025 & 1.0000 & 0.65338 & 0.65303 & 0.50394 & Biso & 1.000 & 0 \\
\hline 026 & 1.0000 & 0.34557 & 0.01085 & 0.51009 & Biso & 1.000 & 0 \\
\hline 027 & 1.0000 & 0.98856 & 0.34838 & 0.50845 & Biso & 1.000 & 0 \\
\hline 028 & 1.0000 & 0.00913 & 0.69043 & 0.84671 & Biso & 1.000 & 0 \\
\hline 029 & 1.0000 & 0.30598 & 0.32748 & 0.83804 & Biso & 1.000 & 0 \\
\hline 030 & 1.0000 & 0.67181 & 0.98711 & 0.84221 & Biso & 1.000 & 0 \\
\hline 031 & 1.0000 & 0.68113 & 0.03569 & 0.17190 & Biso & 1.000 & 0 \\
\hline 032 & 1.0000 & 0.34608 & 0.32985 & 0.16609 & Biso & 1.000 & 0 \\
\hline 033 & 1.0000 & 0.97900 & 0.66899 & 0.17888 & Biso & 1.000 & 0 \\
\hline 034 & 1.0000 & 0.34098 & 0.36940 & 0.50187 & Biso & 1.000 & 0 \\
\hline 035 & 1.0000 & 0.00176 & 0.66061 & 0.50990 & Biso & 1.000 & 0 \\
\hline 036 & 1.0000 & 0.63481 & 0.99512 & 0.50539 & Biso & 1.000 & 0 \\
\hline 037 & 1.0000 & 0.11586 & 0.24679 & 0.14021 & Biso & 1.000 & 0 \\
\hline 038 & 1.0000 & 0.75993 & 0.88409 & 0.14367 & Biso & 1.000 & 0 \\
\hline 039 & 1.0000 & 0.12624 & 0.89347 & 0.14355 & Biso & 1.000 & 0 \\
\hline 040 & 1.0000 & 0.23546 & 0.12766 & 0.86770 & Biso & 1.000 & 0 \\
\hline 041 & 1.0000 & 0.87919 & 0.76075 & 0.87487 & Biso & 1.000 & 0 \\
\hline 042 & 1.0000 & 0.87104 & 0.12014 & 0.87323 & Biso & 1.000 & 0 \\
\hline 043 & 1.0000 & 0.77572 & 0.57385 & 0.47391 & Biso & 1.000 & 0 \\
\hline 044 & 1.0000 & 0.40826 & 0.21448 & 0.45669 & Biso & 1.000 & 0 \\
\hline 045 & 1.0000 & 0.79206 & 0.21978 & 0.46758 & Biso & 1.000 & 0 \\
\hline 046 & 1.0000 & 0.91331 & 0.46962 & 0.21013 & Biso & 1.000 & $\mathrm{O}$ \\
\hline 047 & 1.0000 & 0.55546 & 0.11048 & 0.20275 & Biso & 1.000 & 0 \\
\hline 048 & 1.0000 & 0.54524 & 0.45529 & 0.20188 & Biso & 1.000 & 0 \\
\hline 049 & 1.0000 & 0.44225 & 0.90375 & 0.81164 & Biso & 1.000 & 0 \\
\hline 050 & 1.0000 & 0.09197 & 0.54649 & 0.80989 & Biso & 1.000 & 0 \\
\hline 051 & 1.0000 & 0.45652 & 0.55529 & 0.80216 & Biso & 1.000 & 0 \\
\hline 052 & 1.0000 & 0.57461 & 0.80029 & 0.54581 & Biso & 1.000 & 0 \\
\hline 053 & 1.0000 & 0.21814 & 0.44313 & 0.54150 & Biso & 1.000 & 0 \\
\hline 054 & 1.0000 & 0.19854 & 0.78594 & 0.55539 & Biso & 1.000 & 0 \\
\hline 055 & 1.0000 & 0.00317 & 0.26436 & 0.01568 & Biso & 1.000 & 0 \\
\hline 056 & 1.0000 & 0.74334 & 0.75384 & 0.01924 & Biso & 1.000 & 0 \\
\hline 057 & 1.0000 & 0.24606 & 0.00141 & 0.01321 & Biso & 1.000 & 0 \\
\hline 058 & 1.0000 & 0.67151 & 0.60121 & 0.34848 & Biso & 1.000 & 0 \\
\hline 059 & 1.0000 & 0.39601 & 0.06110 & 0.34268 & Biso & 1.000 & 0 \\
\hline 060 & 1.0000 & 0.93159 & 0.33997 & 0.35008 & Biso & 1.000 & 0 \\
\hline 061 & 1.0000 & 0.34095 & 0.93530 & 0.68546 & Biso & 1.000 & 0 \\
\hline 062 & 1.0000 & 0.06950 & 0.41504 & 0.68454 & Biso & 1.000 & 0 \\
\hline 063 & 1.0000 & 0.59777 & 0.66842 & 0.68355 & Biso & 1.000 & 0 \\
\hline
\end{tabular}




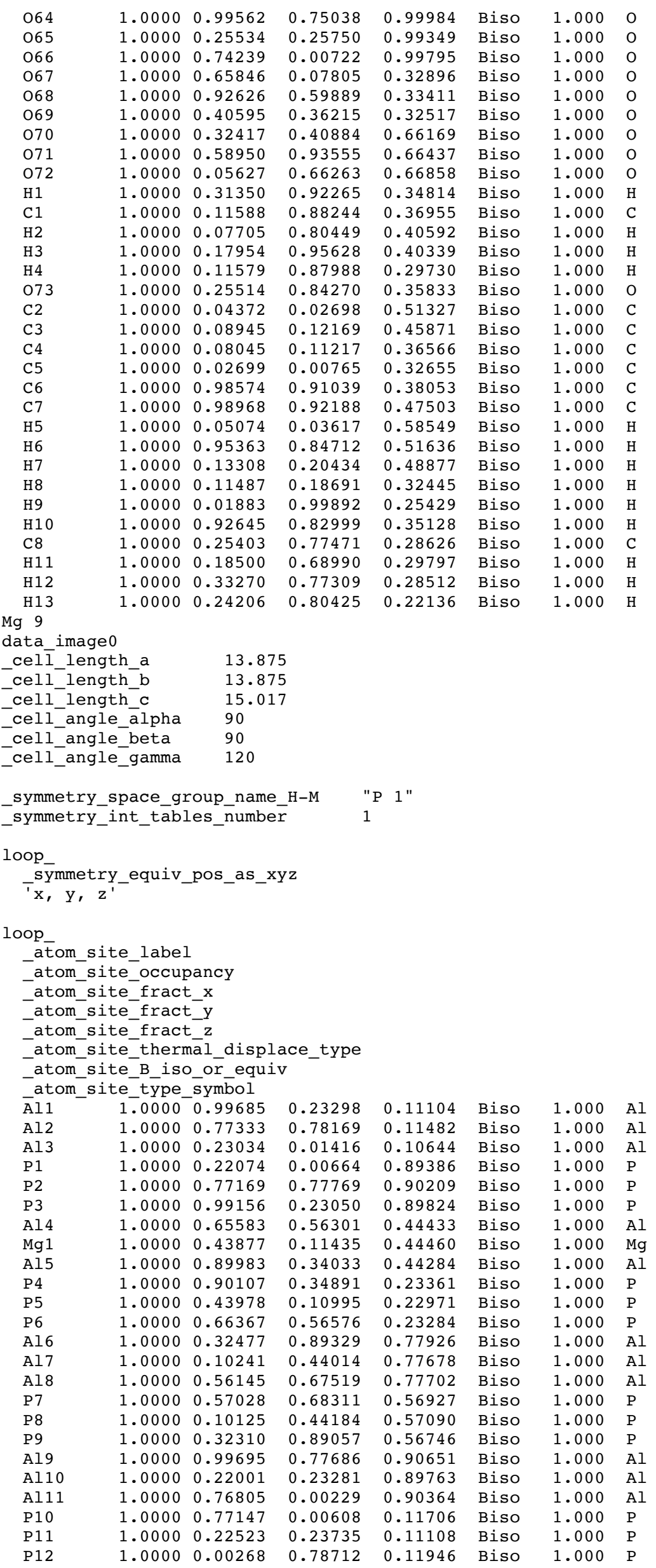




\begin{tabular}{|c|c|c|c|c|c|c|c|}
\hline Al12 & 1.0000 & 0.67005 & 0.11969 & 0.23805 & Biso & 1.000 & Al \\
\hline Al13 & 1.0000 & 0.89386 & 0.57125 & 0.23917 & Biso & 1.000 & Al \\
\hline Al14 & 1.0000 & 0.43437 & 0.34059 & 0.23616 & Biso & 1.000 & Al \\
\hline P13 & 1.0000 & 0.42115 & 0.34192 & 0.44222 & Biso & 1.000 & $\mathrm{P}$ \\
\hline P14 & 1.0000 & 0.88582 & 0.56318 & 0.45065 & Biso & 1.000 & $P$ \\
\hline P 15 & 1.0000 & 0.67103 & 0.11756 & 0.44636 & Biso & 1.000 & $P$ \\
\hline Al15 & 1.0000 & 0.33652 & 0.45925 & 0.56977 & Biso & 1.000 & Al \\
\hline Al16 & 1.0000 & 0.55573 & 0.90510 & 0.57180 & Biso & 1.000 & Al \\
\hline Al1 17 & 1.0000 & 0.08976 & 0.66924 & 0.57921 & Biso & 1.000 & Al \\
\hline P16 & 1.0000 & 0.09563 & 0.66783 & 0.78535 & Biso & 1.000 & $\mathrm{P}$ \\
\hline P 17 & 1.0000 & 0.55381 & 0.90117 & 0.78193 & Biso & 1.000 & $\mathrm{P}$ \\
\hline P18 & 1.0000 & 0.33292 & 0.44801 & 0.77991 & Biso & 1.000 & $\mathrm{P}$ \\
\hline 01 & 1.0000 & 0.89386 & 0.09568 & 0.13513 & Biso & 1.000 & 0 \\
\hline $\mathrm{O} 2$ & 1.0000 & 0.91219 & 0.81808 & 0.13906 & Biso & 1.000 & 0 \\
\hline 03 & 1.0000 & 0.19646 & 0.11687 & 0.13243 & Biso & 1.000 & 0 \\
\hline 04 & 1.0000 & 0.10029 & 0.91200 & 0.87765 & Biso & 1.000 & 0 \\
\hline 05 & 1.0000 & 0.80312 & 0.89899 & 0.88217 & Biso & 1.000 & 0 \\
\hline 06 & 1.0000 & 0.08339 & 0.20238 & 0.87681 & Biso & 1.000 & 0 \\
\hline 07 & 1.0000 & 0.54270 & 0.43205 & 0.46503 & Biso & 1.000 & 0 \\
\hline 08 & 1.0000 & 0.59294 & 0.16225 & 0.46249 & Biso & 1.000 & 0 \\
\hline 09 & 1.0000 & 0.86789 & 0.44598 & 0.46635 & Biso & 1.000 & 0 \\
\hline 010 & 1.0000 & 0.77893 & 0.25747 & 0.22216 & Biso & 1.000 & 0 \\
\hline 011 & 1.0000 & 0.45948 & 0.22977 & 0.22714 & Biso & 1.000 & 0 \\
\hline 012 & 1.0000 & 0.75776 & 0.53930 & 0.21632 & Biso & 1.000 & 0 \\
\hline 013 & 1.0000 & 0.21728 & 0.75746 & 0.80346 & Biso & 1.000 & 0 \\
\hline 014 & 1.0000 & 0.24079 & 0.47663 & 0.79943 & Biso & 1.000 & 0 \\
\hline 015 & 1.0000 & 0.52729 & 0.77959 & 0.79088 & Biso & 1.000 & 0 \\
\hline 016 & 1.0000 & 0.44806 & 0.59357 & 0.55277 & Biso & 1.000 & 0 \\
\hline 017 & 1.0000 & 0.10695 & 0.55468 & 0.56603 & Biso & 1.000 & 0 \\
\hline 018 & 1.0000 & 0.41483 & 0.85916 & 0.55173 & Biso & 1.000 & 0 \\
\hline 019 & 1.0000 & 0.97713 & 0.32825 & 0.17209 & Biso & 1.000 & 0 \\
\hline 020 & 1.0000 & 0.68171 & 0.66496 & 0.17559 & Biso & 1.000 & 0 \\
\hline 021 & 1.0000 & 0.35010 & 0.03709 & 0.16045 & Biso & 1.000 & 0 \\
\hline 022 & 1.0000 & 0.30325 & 0.98910 & 0.83886 & Biso & 1.000 & 0 \\
\hline 023 & 1.0000 & 0.66931 & 0.69617 & 0.84844 & Biso & 1.000 & 0 \\
\hline 024 & 1.0000 & 0.00926 & 0.33197 & 0.84481 & Biso & 1.000 & 0 \\
\hline 025 & 1.0000 & 0.64815 & 0.66533 & 0.50710 & Biso & 1.000 & 0 \\
\hline 026 & 1.0000 & 0.33806 & 0.98636 & 0.51062 & Biso & 1.000 & 0 \\
\hline 027 & 1.0000 & 0.01290 & 0.35896 & 0.50678 & Biso & 1.000 & 0 \\
\hline 028 & 1.0000 & 0.01786 & 0.67773 & 0.85279 & Biso & 1.000 & 0 \\
\hline 029 & 1.0000 & 0.31474 & 0.34798 & 0.83622 & Biso & 1.000 & 0 \\
\hline 030 & 1.0000 & 0.65117 & 0.97718 & 0.84305 & Biso & 1.000 & 0 \\
\hline 031 & 1.0000 & 0.69211 & 0.02925 & 0.17111 & Biso & 1.000 & 0 \\
\hline 032 & 1.0000 & 0.32804 & 0.32111 & 0.16293 & Biso & 1.000 & 0 \\
\hline 033 & 1.0000 & 0.98660 & 0.69075 & 0.17957 & Biso & 1.000 & 0 \\
\hline 034 & 1.0000 & 0.34106 & 0.36303 & 0.49944 & Biso & 1.000 & 0 \\
\hline 035 & 1.0000 & 0.97857 & 0.64985 & 0.51095 & Biso & 1.000 & o \\
\hline 036 & 1.0000 & 0.64555 & 0.01710 & 0.50605 & Biso & 1.000 & 0 \\
\hline 037 & 1.0000 & 0.12619 & 0.25006 & 0.14048 & Biso & 1.000 & 0 \\
\hline 038 & 1.0000 & 0.75618 & 0.89307 & 0.14602 & Biso & 1.000 & 0 \\
\hline 039 & 1.0000 & 0.11688 & 0.88768 & 0.14269 & Biso & 1.000 & 0 \\
\hline 040 & 1.0000 & 0.23016 & 0.11732 & 0.86611 & Biso & 1.000 & 0 \\
\hline 041 & 1.0000 & 0.86902 & 0.76108 & 0.87525 & Biso & 1.000 & 0 \\
\hline 042 & 1.0000 & 0.87895 & 0.13105 & 0.87200 & Biso & 1.000 & 0 \\
\hline 043 & 1.0000 & 0.77890 & 0.56456 & 0.47253 & Biso & 1.000 & 0 \\
\hline 044 & 1.0000 & 0.40152 & 0.22714 & 0.46019 & Biso & 1.000 & 0 \\
\hline 045 & 1.0000 & 0.79249 & 0.20819 & 0.46657 & Biso & 1.000 & 0 \\
\hline 046 & 1.0000 & 0.91342 & 0.46173 & 0.20743 & Biso & 1.000 & 0 \\
\hline 047 & 1.0000 & 0.54836 & 0.11421 & 0.20125 & Biso & 1.000 & 0 \\
\hline 048 & 1.0000 & 0.55364 & 0.46430 & 0.20537 & Biso & 1.000 & 0 \\
\hline 049 & 1.0000 & 0.45152 & 0.90718 & 0.81264 & Biso & 1.000 & 0 \\
\hline 050 & 1.0000 & 0.08424 & 0.55314 & 0.79679 & Biso & 1.000 & 0 \\
\hline 051 & 1.0000 & 0.44572 & 0.54788 & 0.80519 & Biso & 1.000 & 0 \\
\hline 052 & 1.0000 & 0.58428 & 0.79755 & 0.54982 & Biso & 1.000 & 0 \\
\hline 053 & 1.0000 & 0.21416 & 0.45791 & 0.54291 & Biso & 1.000 & 0 \\
\hline 054 & 1.0000 & 0.20960 & 0.78693 & 0.54648 & Biso & 1.000 & 0 \\
\hline 055 & 1.0000 & 0.99348 & 0.25760 & 0.99768 & Biso & 1.000 & 0 \\
\hline 056 & 1.0000 & 0.74588 & 0.75227 & 0.00177 & Biso & 1.000 & 0 \\
\hline 057 & 1.0000 & 0.25006 & 0.00943 & 0.99285 & Biso & 1.000 & 0 \\
\hline 058 & 1.0000 & 0.66304 & 0.59696 & 0.33105 & Biso & 1.000 & 0 \\
\hline 059 & 1.0000 & 0.40169 & 0.05802 & 0.32172 & Biso & 1.000 & 0 \\
\hline 060 & 1.0000 & 0.93941 & 0.35322 & 0.33036 & Biso & 1.000 & 0 \\
\hline 061 & 1.0000 & 0.32478 & 0.92035 & 0.66707 & Biso & 1.000 & 0 \\
\hline 062 & 1.0000 & 0.07148 & 0.39484 & 0.66617 & Biso & 1.000 & 0 \\
\hline 063 & 1.0000 & 0.60265 & 0.67590 & 0.66646 & Biso & 1.000 & 0 \\
\hline 064 & 1.0000 & 0.99896 & 0.75460 & 0.02147 & Biso & 1.000 & 0 \\
\hline 065 & 1.0000 & 0.24836 & 0.26092 & 0.01115 & Biso & 1.000 & 0 \\
\hline 066 & 1.0000 & 0.74360 & 0.00377 & 0.01774 & Biso & 1.000 & 0 \\
\hline 067 & 1.0000 & 0.66540 & 0.07893 & 0.34824 & Biso & 1.000 & 0 \\
\hline 068 & 1.0000 & 0.92141 & 0.60024 & 0.35318 & Biso & 1.000 & 0 \\
\hline
\end{tabular}




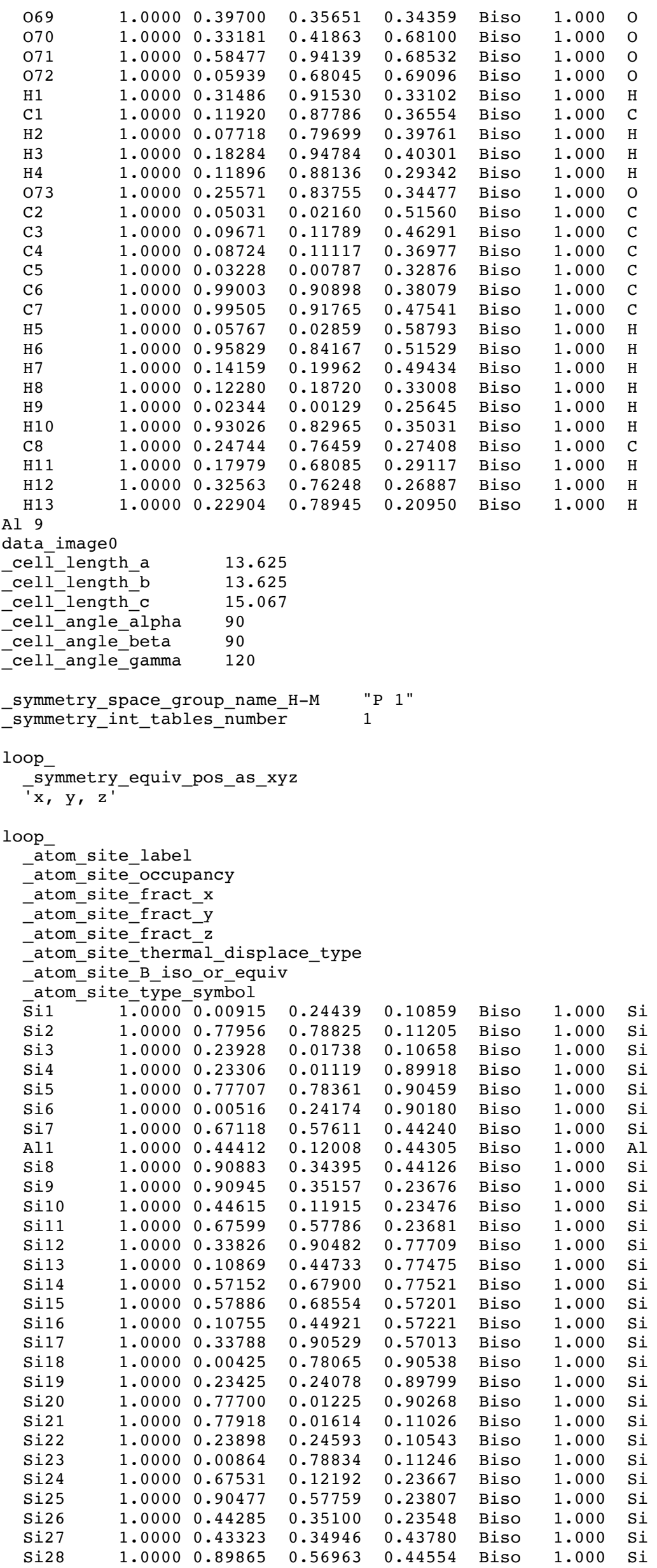




\begin{tabular}{|c|c|c|c|c|c|c|c|}
\hline Si29 & 1.0000 & 0.67346 & 0.11966 & 0.44113 & Biso & 1.000 & $\mathrm{Si}$ \\
\hline Si30 & 1.0000 & 0.34253 & 0.45983 & 0.56837 & Biso & 1.000 & $\mathrm{Si}$ \\
\hline Si31 & 1.0000 & 0.56857 & 0.91160 & 0.57077 & Biso & 1.000 & $\mathrm{Si}$ \\
\hline Si32 & 1.0000 & 0.10066 & 0.67964 & 0.57544 & Biso & 1.000 & \\
\hline Si33 & 1.0000 & 0.10491 & 0.67761 & 0.77739 & Biso & 1.000 & \\
\hline $\mathrm{Si} 34$ & 1.0000 & 0.56792 & 0.90922 & 0.77566 & Biso & 1.000 & \\
\hline Si35 & 1.0000 & 0.33954 & 0.45078 & 0.77351 & Biso & 1.000 & $\mathrm{Si}$ \\
\hline 01 & 1.0000 & 0.91132 & 0.11330 & 0.12638 & Biso & 1.000 & \\
\hline $\mathrm{O} 2$ & 1.0000 & 0.91167 & 0.82302 & 0.12979 & Biso & 1.000 & \\
\hline 03 & 1.0000 & 0.20601 & 0.11506 & 0.12513 & Biso & 1.000 & \\
\hline 04 & 1.0000 & 0.10231 & 0.91054 & 0.88459 & Biso & 1.000 & \\
\hline 05 & 1.0000 & 0.81100 & 0.91463 & 0.88583 & Biso & 1.000 & \\
\hline 06 & 1.0000 & 0.10342 & 0.20958 & 0.88306 & Biso & 1.000 & \\
\hline 07 & 1.0000 & 0.56387 & 0.45077 & 0.45559 & Biso & 1.000 & \\
\hline 08 & 1.0000 & 0.58687 & 0.16422 & 0.45776 & Biso & 1.000 & \\
\hline 09 & 1.0000 & 0.87663 & 0.44249 & 0.46187 & Biso & 1.000 & 0 \\
\hline 010 & 1.0000 & 0.77839 & 0.25264 & 0.22565 & Biso & 1.000 & 0 \\
\hline 011 & 1.0000 & 0.47144 & 0.24924 & 0.22654 & Biso & 1.000 & 0 \\
\hline 012 & 1.0000 & 0.77447 & 0.54513 & 0.21968 & Biso & 1.000 & \\
\hline 013 & 1.0000 & 0.23607 & 0.77497 & 0.79336 & Biso & 1.000 & 0 \\
\hline 014 & 1.0000 & 0.24033 & 0.48211 & 0.79188 & Biso & 1.000 & \\
\hline 015 & 1.0000 & 0.53978 & 0.77856 & 0.78535 & Biso & 1.000 & 0 \\
\hline 016 & 1.0000 & 0.44772 & 0.58798 & 0.55558 & Biso & 1.000 & 0 \\
\hline 017 & 1.0000 & 0.12198 & 0.57384 & 0.56296 & Biso & 1.000 & 0 \\
\hline 018 & 1.0000 & 0.43472 & 0.86826 & 0.55502 & Biso & 1.000 & 0 \\
\hline 019 & 1.0000 & 0.99137 & 0.33082 & 0.17094 & Biso & 1.000 & 0 \\
\hline 020 & 1.0000 & 0.69576 & 0.68254 & 0.17395 & Biso & 1.000 & 0 \\
\hline 021 & 1.0000 & 0.34725 & 0.03795 & 0.16437 & Biso & 1.000 & 0 \\
\hline 022 & 1.0000 & 0.31937 & 0.99146 & 0.83894 & Biso & 1.000 & 0 \\
\hline 023 & 1.0000 & 0.67017 & 0.69731 & 0.84455 & Biso & 1.000 & 0 \\
\hline 024 & 1.0000 & 0.02415 & 0.34748 & 0.84118 & Biso & 1.000 & 0 \\
\hline 025 & 1.0000 & 0.66322 & 0.66837 & 0.50574 & Biso & 1.000 & 0 \\
\hline 026 & 1.0000 & 0.35410 & 0.00680 & 0.50898 & Biso & 1.000 & 0 \\
\hline 027 & 1.0000 & 0.01201 & 0.36031 & 0.50484 & Biso & 1.000 & 0 \\
\hline 028 & 1.0000 & 0.02235 & 0.69105 & 0.84767 & Biso & 1.000 & 0 \\
\hline 029 & 1.0000 & 0.31981 & 0.34490 & 0.83511 & Biso & 1.000 & 0 \\
\hline 030 & 1.0000 & 0.67109 & 0.99107 & 0.84125 & Biso & 1.000 & 0 \\
\hline 031 & 1.0000 & 0.69541 & 0.03919 & 0.17084 & Biso & 1.000 & 0 \\
\hline 032 & 1.0000 & 0.34579 & 0.33379 & 0.16449 & Biso & 1.000 & 0 \\
\hline 033 & 1.0000 & 0.99088 & 0.68733 & 0.17921 & Biso & 1.000 & 0 \\
\hline 034 & 1.0000 & 0.34902 & 0.37248 & 0.50005 & Biso & 1.000 & 0 \\
\hline 035 & 1.0000 & 0.99934 & 0.66300 & 0.50842 & Biso & 1.000 & 0 \\
\hline 036 & 1.0000 & 0.65053 & 0.01355 & 0.50498 & Biso & 1.000 & 0 \\
\hline 037 & 1.0000 & 0.13063 & 0.25755 & 0.13427 & Biso & 1.000 & 0 \\
\hline 038 & 1.0000 & 0.76602 & 0.89557 & 0.13950 & Biso & 1.000 & 0 \\
\hline 039 & 1.0000 & 0.13089 & 0.89703 & 0.13725 & Biso & 1.000 & 0 \\
\hline 040 & 1.0000 & 0.24379 & 0.13084 & 0.87131 & Biso & 1.000 & 0 \\
\hline 041 & 1.0000 & 0.88337 & 0.76752 & 0.87853 & Biso & 1.000 & 0 \\
\hline 042 & 1.0000 & 0.88422 & 0.13361 & 0.87582 & Biso & 1.000 & 0 \\
\hline 043 & 1.0000 & 0.78571 & 0.57459 & 0.46932 & Biso & 1.000 & 0 \\
\hline 044 & 1.0000 & 0.41700 & 0.22909 & 0.45981 & Biso & 1.000 & 0 \\
\hline 045 & 1.0000 & 0.80341 & 0.22003 & 0.46092 & Biso & 1.000 & 0 \\
\hline 046 & 1.0000 & 0.92164 & 0.47261 & 0.20959 & Biso & 1.000 & 0 \\
\hline 047 & 1.0000 & 0.56010 & 0.11799 & 0.20472 & Biso & 1.000 & 0 \\
\hline 048 & 1.0000 & 0.55571 & 0.46974 & 0.21089 & Biso & 1.000 & 0 \\
\hline 049 & 1.0000 & 0.45669 & 0.91384 & 0.80714 & Biso & 1.000 & 0 \\
\hline 050 & 1.0000 & 0.09427 & 0.55573 & 0.79440 & Biso & 1.000 & 0 \\
\hline 051 & 1.0000 & 0.46059 & 0.55896 & 0.79945 & Biso & 1.000 & 0 \\
\hline 052 & 1.0000 & 0.59167 & 0.80752 & 0.55126 & Biso & 1.000 & 0 \\
\hline 053 & 1.0000 & 0.22669 & 0.45951 & 0.54527 & Biso & 1.000 & 0 \\
\hline 054 & 1.0000 & 0.21416 & 0.79466 & 0.55061 & Biso & 1.000 & 0 \\
\hline 055 & 1.0000 & 0.00726 & 0.27722 & 0.00524 & Biso & 1.000 & 0 \\
\hline 056 & 1.0000 & 0.74528 & 0.75305 & 0.00894 & Biso & 1.000 & 0 \\
\hline 057 & 1.0000 & 0.26765 & 0.01365 & 0.00275 & Biso & 1.000 & $\mathrm{O}$ \\
\hline 058 & 1.0000 & 0.68081 & 0.61771 & 0.33944 & Biso & 1.000 & 0 \\
\hline 059 & 1.0000 & 0.40528 & 0.06783 & 0.33264 & Biso & 1.000 & 0 \\
\hline 060 & 1.0000 & 0.95191 & 0.35626 & 0.33849 & Biso & 1.000 & 0 \\
\hline 061 & 1.0000 & 0.34163 & 0.94053 & 0.67467 & Biso & 1.000 & 0 \\
\hline 062 & 1.0000 & 0.07210 & 0.40228 & 0.67329 & Biso & 1.000 & 0 \\
\hline 063 & 1.0000 & 0.61492 & 0.67846 & 0.67434 & Biso & 1.000 & 0 \\
\hline 064 & 1.0000 & 0.00581 & 0.75039 & 0.01007 & Biso & 1.000 & 0 \\
\hline 065 & 1.0000 & 0.27006 & 0.27612 & 0.00121 & Biso & 1.000 & 0 \\
\hline 066 & 1.0000 & 0.74428 & 0.01264 & 0.00657 & Biso & 1.000 & 0 \\
\hline 067 & 1.0000 & 0.66882 & 0.07783 & 0.33768 & Biso & 1.000 & 0 \\
\hline 068 & 1.0000 & 0.93658 & 0.60929 & 0.34261 & Biso & 1.000 & 0 \\
\hline 069 & 1.0000 & 0.39954 & 0.35826 & 0.33432 & Biso & 1.000 & 0 \\
\hline 070 & 1.0000 & 0.33869 & 0.41648 & 0.66993 & Biso & 1.000 & 0 \\
\hline 071 & 1.0000 & 0.60287 & 0.95301 & 0.67394 & Biso & 1.000 & 0 \\
\hline 072 & 1.0000 & 0.06237 & 0.68414 & 0.67740 & Biso & 1.000 & 0 \\
\hline H 1 & 1.0000 & 0.31923 & 0.92433 & 0.33944 & Biso & 1.000 & $\mathrm{H}$ \\
\hline
\end{tabular}




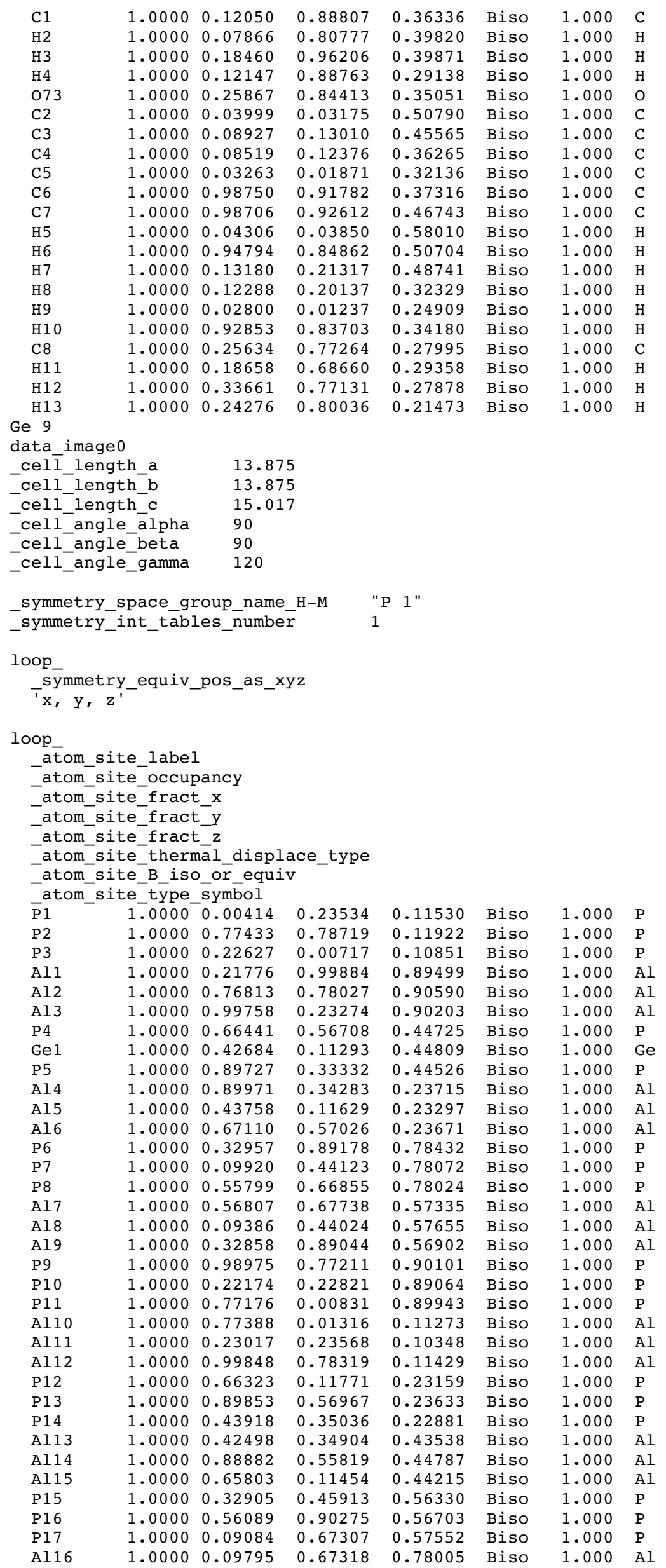




\begin{tabular}{|c|c|c|c|c|c|c|c|}
\hline Al17 & 1.0000 & 0.55693 & 0.89829 & 0.77668 & Biso & 1.000 & Al \\
\hline Al18 & 1.0000 & 0.32634 & 0.44380 & 0.77266 & Biso & 1.000 & Al \\
\hline 01 & 1.0000 & 0.91199 & 0.11550 & 0.13720 & Biso & 1.000 & 0 \\
\hline $\mathrm{O} 2$ & 1.0000 & 0.89647 & 0.81917 & 0.13857 & Biso & 1.000 & 0 \\
\hline 03 & 1.0000 & 0.19652 & 0.09843 & 0.12789 & Biso & 1.000 & 0 \\
\hline 04 & 1.0000 & 0.08153 & 0.89033 & 0.87478 & Biso & 1.000 & 0 \\
\hline 05 & 1.0000 & 0.80385 & 0.91813 & 0.88244 & Biso & 1.000 & 0 \\
\hline 06 & 1.0000 & 0.10097 & 0.20070 & 0.87401 & Biso & 1.000 & 0 \\
\hline 07 & 1.0000 & 0.56334 & 0.45102 & 0.46112 & Biso & 1.000 & 0 \\
\hline 08 & 1.0000 & 0.56960 & 0.16343 & 0.46878 & Biso & 1.000 & O \\
\hline 09 & 1.0000 & 0.86835 & 0.42509 & 0.46644 & Biso & 1.000 & 0 \\
\hline 010 & 1.0000 & 0.76236 & 0.23740 & 0.22201 & Biso & 1.000 & 0 \\
\hline 011 & 1.0000 & 0.46263 & 0.25329 & 0.22696 & Biso & 1.000 & 0 \\
\hline 012 & 1.0000 & 0.77759 & 0.53928 & 0.21716 & Biso & 1.000 & 0 \\
\hline 013 & 1.0000 & 0.23463 & 0.77349 & 0.80793 & Biso & 1.000 & 0 \\
\hline 014 & 1.0000 & 0.22189 & 0.47593 & 0.79880 & Biso & 1.000 & 0 \\
\hline 015 & 1.0000 & 0.52673 & 0.76009 & 0.78842 & Biso & 1.000 & O \\
\hline 016 & 1.0000 & 0.42903 & 0.57739 & 0.55353 & Biso & 1.000 & 0 \\
\hline 017 & 1.0000 & 0.09805 & 0.56674 & 0.57125 & Biso & 1.000 & 0 \\
\hline 018 & 1.0000 & 0.43739 & 0.86198 & 0.54698 & Biso & 1.000 & O \\
\hline 019 & 1.0000 & 0.98895 & 0.32030 & 0.16961 & Biso & 1.000 & 0 \\
\hline 020 & 1.0000 & 0.69488 & 0.68695 & 0.17576 & Biso & 1.000 & 0 \\
\hline 021 & 1.0000 & 0.33213 & 0.03054 & 0.15737 & Biso & 1.000 & 0 \\
\hline $\mathrm{O} 22$ & 1.0000 & 0.31338 & 0.97887 & 0.83521 & Biso & 1.000 & 0 \\
\hline 023 & 1.0000 & 0.64920 & 0.68763 & 0.84740 & Biso & 1.000 & 0 \\
\hline 024 & 1.0000 & 0.02165 & 0.35337 & 0.84775 & Biso & 1.000 & O \\
\hline 025 & 1.0000 & 0.65704 & 0.65415 & 0.50563 & Biso & 1.000 & 0 \\
\hline 026 & 1.0000 & 0.33415 & 0.00159 & 0.51572 & Biso & 1.000 & 0 \\
\hline 027 & 1.0000 & 0.99119 & 0.34454 & 0.50624 & Biso & 1.000 & 0 \\
\hline 028 & 1.0000 & 0.00470 & 0.68378 & 0.85181 & Biso & 1.000 & 0 \\
\hline 029 & 1.0000 & 0.30311 & 0.32622 & 0.83269 & Biso & 1.000 & O \\
\hline 030 & 1.0000 & 0.66950 & 0.98510 & 0.84461 & Biso & 1.000 & 0 \\
\hline 031 & 1.0000 & 0.68129 & 0.03785 & 0.17214 & Biso & 1.000 & 0 \\
\hline 032 & 1.0000 & 0.34882 & 0.33115 & 0.16048 & Biso & 1.000 & 0 \\
\hline 033 & 1.0000 & 0.97953 & 0.67250 & 0.18178 & Biso & 1.000 & $\mathrm{O}$ \\
\hline 034 & 1.0000 & 0.33574 & 0.37960 & 0.49666 & Biso & 1.000 & 0 \\
\hline 035 & 1.0000 & 0.99650 & 0.66021 & 0.51318 & Biso & 1.000 & 0 \\
\hline 036 & 1.0000 & 0.63735 & 0.99959 & 0.50623 & Biso & 1.000 & 0 \\
\hline 037 & 1.0000 & 0.11725 & 0.24800 & 0.14012 & Biso & 1.000 & 0 \\
\hline 038 & 1.0000 & 0.75926 & 0.88559 & 0.14511 & Biso & 1.000 & 0 \\
\hline 039 & 1.0000 & 0.12889 & 0.89585 & 0.14264 & Biso & 1.000 & 0 \\
\hline 040 & 1.0000 & 0.23100 & 0.12625 & 0.86512 & Biso & 1.000 & 0 \\
\hline 041 & 1.0000 & 0.87689 & 0.75859 & 0.87487 & Biso & 1.000 & 0 \\
\hline 042 & 1.0000 & 0.86907 & 0.12141 & 0.87069 & Biso & 1.000 & 0 \\
\hline 043 & 1.0000 & 0.77011 & 0.56478 & 0.47372 & Biso & 1.000 & 0 \\
\hline 044 & 1.0000 & 0.39139 & 0.21679 & 0.46061 & Biso & 1.000 & 0 \\
\hline 045 & 1.0000 & 0.79640 & 0.21905 & 0.46115 & Biso & 1.000 & 0 \\
\hline 046 & 1.0000 & 0.91456 & 0.47220 & 0.20908 & Biso & 1.000 & 0 \\
\hline 047 & 1.0000 & 0.55871 & 0.11745 & 0.19844 & Biso & 1.000 & 0 \\
\hline 048 & 1.0000 & 0.54587 & 0.45760 & 0.20221 & Biso & 1.000 & 0 \\
\hline 049 & 1.0000 & 0.44065 & 0.90344 & 0.81437 & Biso & 1.000 & 0 \\
\hline 050 & 1.0000 & 0.08443 & 0.54254 & 0.79110 & Biso & 1.000 & 0 \\
\hline 051 & 1.0000 & 0.45538 & 0.55593 & 0.80199 & Biso & 1.000 & 0 \\
\hline 052 & 1.0000 & 0.58507 & 0.80758 & 0.54973 & Biso & 1.000 & 0 \\
\hline 053 & 1.0000 & 0.22301 & 0.46304 & 0.54257 & Biso & 1.000 & 0 \\
\hline 054 & 1.0000 & 0.20048 & 0.77105 & 0.54470 & Biso & 1.000 & 0 \\
\hline 055 & 1.0000 & 0.00080 & 0.25908 & 0.01592 & Biso & 1.000 & 0 \\
\hline 056 & 1.0000 & 0.74624 & 0.75716 & 0.02055 & Biso & 1.000 & 0 \\
\hline 057 & 1.0000 & 0.24355 & 0.99936 & 0.00875 & Biso & 1.000 & 0 \\
\hline 058 & 1.0000 & 0.67269 & 0.60358 & 0.34919 & Biso & 1.000 & 0 \\
\hline 059 & 1.0000 & 0.39375 & 0.05663 & 0.33668 & Biso & 1.000 & 0 \\
\hline 060 & 1.0000 & 0.93875 & 0.34633 & 0.34831 & Biso & 1.000 & 0 \\
\hline 061 & 1.0000 & 0.33014 & 0.91250 & 0.68464 & Biso & 1.000 & 0 \\
\hline 062 & 1.0000 & 0.06595 & 0.39129 & 0.68639 & Biso & 1.000 & 0 \\
\hline 063 & 1.0000 & 0.60045 & 0.66835 & 0.68533 & Biso & 1.000 & 0 \\
\hline 064 & 1.0000 & 0.99374 & 0.75286 & 0.00161 & Biso & 1.000 & 0 \\
\hline 065 & 1.0000 & 0.25250 & 0.25909 & 0.98917 & Biso & 1.000 & 0 \\
\hline 066 & 1.0000 & 0.74626 & 0.01093 & 0.99886 & Biso & 1.000 & 0 \\
\hline 067 & 1.0000 & 0.65094 & 0.07743 & 0.32827 & Biso & 1.000 & 0 \\
\hline 068 & 1.0000 & 0.92601 & 0.59764 & 0.33589 & Biso & 1.000 & 0 \\
\hline 069 & 1.0000 & 0.40098 & 0.36415 & 0.32161 & Biso & 1.000 & 0 \\
\hline 070 & 1.0000 & 0.32388 & 0.41541 & 0.65872 & Biso & 1.000 & 0 \\
\hline 071 & 1.0000 & 0.58754 & 0.94028 & 0.66537 & Biso & 1.000 & 0 \\
\hline 072 & 1.0000 & 0.06318 & 0.69161 & 0.67130 & Biso & 1.000 & 0 \\
\hline $\mathrm{H} 1$ & 1.0000 & 0.31366 & 0.92007 & 0.34171 & Biso & 1.000 & $\mathrm{H}$ \\
\hline $\mathrm{C} 1$ & 1.0000 & 0.11650 & 0.87849 & 0.36733 & Biso & 1.000 & $\mathrm{C}$ \\
\hline $\mathrm{H} 2$ & 1.0000 & 0.07327 & 0.79576 & 0.39614 & Biso & 1.000 & $\mathrm{H}$ \\
\hline H3 & 1.0000 & 0.17844 & 0.94582 & 0.40806 & Biso & 1.000 & $\mathrm{H}$ \\
\hline $\mathrm{H} 4$ & 1.0000 & 0.12217 & 0.88610 & 0.29535 & Biso & 1.000 & $\mathrm{H}$ \\
\hline 073 & 1.0000 & 0.25636 & 0.83970 & 0.35260 & Biso & 1.000 & 0 \\
\hline
\end{tabular}




\begin{tabular}{|c|c|c|c|c|c|c|c|}
\hline $\mathrm{C} 2$ & 1.0000 & 0.04740 & 0.01555 & 0.51898 & Biso & 1.000 & $\mathrm{C}$ \\
\hline $\mathrm{C} 3$ & 1.0000 & 0.09880 & 0.11443 & 0.46946 & Biso & 1.000 & $\mathrm{C}$ \\
\hline $\mathrm{C} 4$ & 1.0000 & 0.09186 & 0.11285 & 0.37616 & Biso & 1.000 & $\mathrm{C}$ \\
\hline C5 & 1.0000 & 0.03545 & 0.01195 & 0.33178 & Biso & 1.000 & $\mathrm{C}$ \\
\hline $\mathrm{C} 6$ & 1.0000 & 0.98907 & 0.91016 & 0.38051 & Biso & 1.000 & $\mathrm{C}$ \\
\hline $\mathrm{C} 7$ & 1.0000 & 0.99036 & 0.91397 & 0.47543 & Biso & 1.000 & $\mathrm{C}$ \\
\hline H5 & 1.0000 & 0.05279 & 0.01868 & 0.59149 & Biso & 1.000 & $\mathrm{H}$ \\
\hline H6 & 1.0000 & 0.95039 & 0.83608 & 0.51287 & Biso & 1.000 & $\mathrm{H}$ \\
\hline $\mathrm{H} 7$ & 1.0000 & 0.14561 & 0.19418 & 0.50363 & Biso & 1.000 & $\mathrm{H}$ \\
\hline H8 & 1.0000 & 0.13065 & 0.19093 & 0.33904 & Biso & 1.000 & $\mathrm{H}$ \\
\hline H9 & 1.0000 & 0.02904 & 0.00927 & 0.25926 & Biso & 1.000 & $\mathrm{H}$ \\
\hline H 10 & 1.0000 & 0.92858 & 0.83330 & 0.34723 & Biso & 1.000 & $\mathrm{H}$ \\
\hline $\mathrm{C} 8$ & 1.0000 & 0.25453 & 0.77180 & 0.28026 & Biso & 1.000 & $\mathrm{C}$ \\
\hline H 11 & 1.0000 & 0.18687 & 0.68652 & 0.29292 & Biso & 1.000 & $\mathrm{H}$ \\
\hline Н 12 & 1.0000 & 0.33394 & 0.77174 & 0.27735 & Biso & 1.000 & $\mathrm{H}$ \\
\hline $\mathrm{H} 13$ & 1.0000 & 0.23986 & 0.80013 & 0.21576 & Biso & 1.000 & $\mathrm{H}$ \\
\hline \multicolumn{8}{|c|}{$\mathrm{Ga} 9$} \\
\hline \multicolumn{8}{|c|}{ data image0 } \\
\hline \multicolumn{8}{|c|}{13.625} \\
\hline \multicolumn{8}{|c|}{13.625} \\
\hline \multicolumn{8}{|c|}{15.067} \\
\hline \multicolumn{8}{|c|}{ lpha } \\
\hline \multicolumn{8}{|c|}{90} \\
\hline cell_c & gamma & 120 & & & & & \\
\hline symmet & pace_g & nam & & $1 "$ & & & \\
\hline symmet & nt_tab & les_ñumbe & & & & & \\
\hline op_ & & & & & & & \\
\hline symn & equiv & Dos as $y$ & & & & & \\
\hline ' $\mathrm{x}$ & & & & & & & \\
\hline op_ & & & & & & & \\
\hline _aton & e_labe & & & & & & \\
\hline aton & te_occup & pancy & & & & & \\
\hline -aton & te_fract & E $x$ & & & & & \\
\hline -aton & ce-fract & ty & & & & & \\
\hline aton & $=e^{-}$fract & $z$ & & & & & \\
\hline -aton & e-thern & nàl_displ & ace_type & & & & \\
\hline -aton & e_B_is & o_or_equi & & & & & \\
\hline -aton & ze_type & symbol & & & & & \\
\hline$\overline{\mathrm{S}} \mathrm{i} 1$ & 1.0000 & 0.00992 & 0.24491 & 0.10858 & Biso & 1.000 & $\mathrm{Si}$ \\
\hline Si2 & 1.0000 & 0.78067 & 0.78914 & 0.11336 & Biso & 1.000 & $\mathrm{Si}$ \\
\hline $\mathrm{Si3}$ & 1.0000 & 0.23965 & 0.01768 & 0.10450 & Biso & 1.000 & $\mathrm{Si}$ \\
\hline Si4 & 1.0000 & 0.23093 & 0.00985 & 0.89701 & Biso & 1.000 & $\mathrm{Si}$ \\
\hline Si5 & 1.0000 & 0.77668 & 0.78332 & 0.90605 & Biso & 1.000 & $\mathrm{Si}$ \\
\hline Si6 & 1.0000 & 0.00417 & 0.24192 & 0.90149 & Biso & 1.000 & $\mathrm{Si}$ \\
\hline Si7 & 1.0000 & 0.66976 & 0.57360 & 0.44357 & Biso & 1.000 & $\mathrm{Si}$ \\
\hline Ga 1 & 1.0000 & 0.44337 & 0.12140 & 0.44463 & Biso & 1.000 & $\mathrm{Ga}$ \\
\hline Si8 & 1.0000 & 0.91253 & 0.34483 & 0.44065 & Biso & 1.000 & $\mathrm{Si}$ \\
\hline Si9 & 1.0000 & 0.91145 & 0.35300 & 0.23702 & Biso & 1.000 & $\mathrm{Si}$ \\
\hline $\operatorname{Si} 10$ & 1.0000 & 0.44734 & 0.12010 & 0.23248 & Biso & 1.000 & $\mathrm{Si}$ \\
\hline Si11 & 1.0000 & 0.67622 & 0.57810 & 0.23776 & Biso & 1.000 & $\mathrm{Si}$ \\
\hline Si12 & 1.0000 & 0.33682 & 0.90229 & 0.77734 & Biso & 1.000 & $\mathrm{Si}$ \\
\hline Si13 & 1.0000 & 0.10803 & 0.44587 & 0.77385 & Biso & 1.000 & $\mathrm{Si}$ \\
\hline Sil14 & 1.0000 & 0.57126 & 0.67924 & 0.77563 & Biso & 1.000 & $\mathrm{Si}$ \\
\hline $\operatorname{Si} 15$ & 1.0000 & 0.58249 & 0.68830 & 0.57302 & Biso & 1.000 & $\mathrm{Si}$ \\
\hline Si 16 & 1.0000 & 0.10557 & 0.44739 & 0.57387 & Biso & 1.000 & $\mathrm{Si}$ \\
\hline $\operatorname{Si} 17$ & 1.0000 & 0.33653 & 0.90007 & 0.56890 & Biso & 1.000 & $\mathrm{Si}$ \\
\hline Si18 & 1.0000 & 0.00287 & 0.77895 & 0.90559 & Biso & 1.000 & $\mathrm{Si}$ \\
\hline Si19 & 1.0000 & 0.23310 & 0.24041 & 0.89611 & Biso & 1.000 & $\mathrm{Si}$ \\
\hline Si20 & 1.0000 & 0.77704 & 0.01226 & 0.90364 & Biso & 1.000 & $\mathrm{Si}$ \\
\hline $\mathrm{Si} 21$ & 1.0000 & 0.78027 & 0.01727 & 0.11128 & Biso & 1.000 & $\mathrm{Si}$ \\
\hline Si22 & 1.0000 & 0.23950 & 0.24617 & 0.10352 & Biso & 1.000 & $\mathrm{Si}$ \\
\hline Si23 & 1.0000 & 0.00943 & 0.78933 & 0.11317 & Biso & 1.000 & $\mathrm{Si}$ \\
\hline Si24 & 1.0000 & 0.67580 & 0.12311 & 0.23739 & Biso & 1.000 & $\mathrm{Si}$ \\
\hline Si25 & 1.0000 & 0.90503 & 0.57815 & 0.23876 & Biso & 1.000 & $\mathrm{Si}$ \\
\hline Si26 & 1.0000 & 0.44341 & 0.35150 & 0.23451 & Biso & 1.000 & $\mathrm{Si}$ \\
\hline Si27 & 1.0000 & 0.42898 & 0.35052 & 0.43774 & Biso & 1.000 & $\mathrm{Si}$ \\
\hline Si28 & 1.0000 & 0.89847 & 0.56895 & 0.44637 & Biso & 1.000 & $\mathrm{Si}$ \\
\hline Si29 & 1.0000 & 0.67497 & 0.12258 & 0.44201 & Biso & 1.000 & $\mathrm{Si}$ \\
\hline Si30 & 1.0000 & 0.34270 & 0.46567 & 0.56748 & Biso & 1.000 & $\mathrm{Si}$ \\
\hline Si31 & 1.0000 & 0.57095 & 0.91325 & 0.57093 & Biso & 1.000 & $\mathrm{Si}$ \\
\hline Si32 & 1.0000 & 0.09718 & 0.67892 & 0.57711 & Biso & 1.000 & $\mathrm{Si}$ \\
\hline Si33 & 1.0000 & 0.10395 & 0.67785 & 0.77744 & Biso & 1.000 & $\mathrm{Si}$ \\
\hline $\mathrm{Si} 34$ & 1.0000 & 0.56673 & 0.90842 & 0.77646 & Biso & 1.000 & $\mathrm{Si}$ \\
\hline Si35 & 1.0000 & 0.33857 & 0.45082 & 0.77208 & Biso & 1.000 & $\mathrm{Si}$ \\
\hline 01 & 1.0000 & 0.91256 & 0.11397 & 0.12766 & Biso & 1.000 & 0 \\
\hline $\mathrm{O} 2$ & 1.0000 & 0.91310 & 0.82485 & 0.13089 & Biso & 1.000 & 0 \\
\hline 03 & 1.0000 & 0.20554 & 0.11488 & 0.12260 & Biso & 1.000 & 0 \\
\hline
\end{tabular}




\begin{tabular}{|c|c|c|c|c|c|c|c|}
\hline 04 & 1.0000 & 0.10042 & 0.90842 & 0.88270 & Biso & 1.000 & 0 \\
\hline 05 & 1.0000 & 0.81199 & 0.91499 & 0.88821 & Biso & 1.000 & 0 \\
\hline 06 & 1.0000 & 0.10251 & 0.21021 & 0.88172 & Biso & 1.000 & 0 \\
\hline 07 & 1.0000 & 0.56059 & 0.44916 & 0.45661 & Biso & 1.000 & 0 \\
\hline 08 & 1.0000 & 0.59382 & 0.17371 & 0.46189 & Biso & 1.000 & 0 \\
\hline 09 & 1.0000 & 0.88117 & 0.44357 & 0.46279 & Biso & 1.000 & 0 \\
\hline 010 & 1.0000 & 0.78036 & 0.25332 & 0.22815 & Biso & 1.000 & 0 \\
\hline 011 & 1.0000 & 0.47333 & 0.25058 & 0.22702 & Biso & 1.000 & 0 \\
\hline 012 & 1.0000 & 0.77459 & 0.54528 & 0.22033 & Biso & 1.000 & 0 \\
\hline 013 & 1.0000 & 0.23533 & 0.77282 & 0.79688 & Biso & 1.000 & $\mathrm{O}$ \\
\hline 014 & 1.0000 & 0.24015 & 0.48293 & 0.79263 & Biso & 1.000 & 0 \\
\hline 015 & 1.0000 & 0.53706 & 0.77716 & 0.78519 & Biso & 1.000 & 0 \\
\hline 016 & 1.0000 & 0.45082 & 0.59239 & 0.55725 & Biso & 1.000 & 0 \\
\hline 017 & 1.0000 & 0.10595 & 0.56554 & 0.57023 & Biso & 1.000 & 0 \\
\hline 018 & 1.0000 & 0.43753 & 0.86932 & 0.55232 & Biso & 1.000 & 0 \\
\hline 019 & 1.0000 & 0.99231 & 0.33205 & 0.17019 & Biso & 1.000 & 0 \\
\hline 020 & 1.0000 & 0.69744 & 0.68431 & 0.17623 & Biso & 1.000 & 0 \\
\hline 021 & 1.0000 & 0.34999 & 0.04118 & 0.16029 & Biso & 1.000 & 0 \\
\hline 022 & 1.0000 & 0.31726 & 0.99112 & 0.83584 & Biso & 1.000 & 0 \\
\hline 023 & 1.0000 & 0.66837 & 0.69811 & 0.84675 & Biso & 1.000 & 0 \\
\hline 024 & 1.0000 & 0.02356 & 0.34914 & 0.84251 & Biso & 1.000 & 0 \\
\hline 025 & 1.0000 & 0.66487 & 0.66750 & 0.50714 & Biso & 1.000 & 0 \\
\hline 026 & 1.0000 & 0.34471 & 0.00004 & 0.50941 & Biso & 1.000 & 0 \\
\hline 027 & 1.0000 & 0.01473 & 0.35783 & 0.50406 & Biso & 1.000 & 0 \\
\hline 028 & 1.0000 & 0.02100 & 0.68794 & 0.84960 & Biso & 1.000 & 0 \\
\hline 029 & 1.0000 & 0.31851 & 0.34371 & 0.83241 & Biso & 1.000 & 0 \\
\hline 030 & 1.0000 & 0.67023 & 0.98877 & 0.84237 & Biso & 1.000 & 0 \\
\hline 031 & 1.0000 & 0.69702 & 0.04013 & 0.17274 & Biso & 1.000 & 0 \\
\hline 032 & 1.0000 & 0.34710 & 0.33313 & 0.16239 & Biso & 1.000 & 0 \\
\hline 033 & 1.0000 & 0.99107 & 0.68826 & 0.18014 & Biso & 1.000 & 0 \\
\hline 034 & 1.0000 & 0.34570 & 0.37945 & 0.49597 & Biso & 1.000 & $\mathrm{O}$ \\
\hline 035 & 1.0000 & 0.99719 & 0.66489 & 0.50948 & Biso & 1.000 & 0 \\
\hline 036 & 1.0000 & 0.65248 & 0.01716 & 0.50646 & Biso & 1.000 & 0 \\
\hline 037 & 1.0000 & 0.13203 & 0.25891 & 0.13333 & Biso & 1.000 & 0 \\
\hline 038 & 1.0000 & 0.76659 & 0.89636 & 0.13990 & Biso & 1.000 & 0 \\
\hline 039 & 1.0000 & 0.13250 & 0.89751 & 0.13727 & Biso & 1.000 & 0 \\
\hline 040 & 1.0000 & 0.24104 & 0.12945 & 0.86985 & Biso & 1.000 & 0 \\
\hline 041 & 1.0000 & 0.88162 & 0.76534 & 0.87887 & Biso & 1.000 & 0 \\
\hline 042 & 1.0000 & 0.88325 & 0.13373 & 0.87520 & Biso & 1.000 & 0 \\
\hline 043 & 1.0000 & 0.78261 & 0.56849 & 0.46965 & Biso & 1.000 & 0 \\
\hline 044 & 1.0000 & 0.40504 & 0.22829 & 0.46507 & Biso & 1.000 & $\mathrm{O}$ \\
\hline 045 & 1.0000 & 0.80649 & 0.22074 & 0.45838 & Biso & 1.000 & 0 \\
\hline 046 & 1.0000 & 0.92220 & 0.47345 & 0.20983 & Biso & 1.000 & 0 \\
\hline 047 & 1.0000 & 0.56225 & 0.12061 & 0.20268 & Biso & 1.000 & 0 \\
\hline 048 & 1.0000 & 0.55590 & 0.47083 & 0.21045 & Biso & 1.000 & 0 \\
\hline 049 & 1.0000 & 0.45622 & 0.91415 & 0.80842 & Biso & 1.000 & 0 \\
\hline 050 & 1.0000 & 0.09141 & 0.55410 & 0.78734 & Biso & 1.000 & 0 \\
\hline 051 & 1.0000 & 0.46062 & 0.55796 & 0.79765 & Biso & 1.000 & 0 \\
\hline 052 & 1.0000 & 0.59737 & 0.81117 & 0.55139 & Biso & 1.000 & 0 \\
\hline 053 & 1.0000 & 0.23032 & 0.47286 & 0.54613 & Biso & 1.000 & O \\
\hline 054 & 1.0000 & 0.21587 & 0.78578 & 0.54857 & Biso & 1.000 & $\mathrm{O}$ \\
\hline 055 & 1.0000 & 0.00626 & 0.27612 & 0.00516 & Biso & 1.000 & 0 \\
\hline 056 & 1.0000 & 0.74588 & 0.75251 & 0.01052 & Biso & 1.000 & 0 \\
\hline 057 & 1.0000 & 0.26574 & 0.01182 & 0.00045 & Biso & 1.000 & 0 \\
\hline 058 & 1.0000 & 0.67976 & 0.61586 & 0.34079 & Biso & 1.000 & 0 \\
\hline 059 & 1.0000 & 0.40346 & 0.06463 & 0.32899 & Biso & 1.000 & 0 \\
\hline 060 & 1.0000 & 0.95655 & 0.35930 & 0.33806 & Biso & 1.000 & 0 \\
\hline 061 & 1.0000 & 0.33918 & 0.93288 & 0.67385 & Biso & 1.000 & $\mathrm{O}$ \\
\hline 062 & 1.0000 & 0.07296 & 0.39445 & 0.67365 & Biso & 1.000 & 0 \\
\hline 063 & 1.0000 & 0.61833 & 0.68162 & 0.67553 & Biso & 1.000 & 0 \\
\hline 064 & 1.0000 & 0.00554 & 0.75115 & 0.01072 & Biso & 1.000 & 0 \\
\hline 065 & 1.0000 & 0.26992 & 0.27649 & 0.99917 & Biso & 1.000 & 0 \\
\hline 066 & 1.0000 & 0.74540 & 0.01466 & 0.00762 & Biso & 1.000 & 0 \\
\hline 067 & 1.0000 & 0.66424 & 0.07815 & 0.33875 & Biso & 1.000 & 0 \\
\hline 068 & 1.0000 & 0.93621 & 0.60925 & 0.34348 & Biso & 1.000 & 0 \\
\hline 069 & 1.0000 & 0.39889 & 0.35792 & 0.33306 & Biso & 1.000 & 0 \\
\hline 070 & 1.0000 & 0.33644 & 0.41774 & 0.66790 & Biso & 1.000 & 0 \\
\hline 071 & 1.0000 & 0.60178 & 0.95278 & 0.67481 & Biso & 1.000 & 0 \\
\hline 072 & 1.0000 & 0.06416 & 0.69364 & 0.67863 & Biso & 1.000 & O \\
\hline H 1 & 1.0000 & 0.31902 & 0.92279 & 0.33706 & Biso & 1.000 & $\mathrm{H}$ \\
\hline $\mathrm{C} 1$ & 1.0000 & 0.12112 & 0.88717 & 0.36289 & Biso & 1.000 & C \\
\hline H2 & 1.0000 & 0.07773 & 0.80530 & 0.39537 & Biso & 1.000 & $\mathrm{H}$ \\
\hline H3 & 1.0000 & 0.18483 & 0.95901 & 0.40044 & Biso & 1.000 & $\mathrm{H}$ \\
\hline H 4 & 1.0000 & 0.12396 & 0.88996 & 0.29096 & Biso & 1.000 & $\mathrm{H}$ \\
\hline 073 & 1.0000 & 0.25892 & 0.84244 & 0.34879 & Biso & 1.000 & 0 \\
\hline $\mathrm{C} 2$ & 1.0000 & 0.04217 & 0.03125 & 0.50838 & Biso & 1.000 & C \\
\hline $\mathrm{C} 3$ & 1.0000 & 0.09161 & 0.12973 & 0.45631 & Biso & 1.000 & C \\
\hline C 4 & 1.0000 & 0.08705 & 0.12370 & 0.36332 & Biso & 1.000 & C \\
\hline C5 & 1.0000 & 0.03396 & 0.01880 & 0.32184 & Biso & 1.000 & C \\
\hline C6 & 1.0000 & 0.98873 & 0.91772 & 0.37343 & Biso & 1.000 & C \\
\hline
\end{tabular}




\begin{tabular}{|c|c|c|c|c|c|c|c|}
\hline $\mathrm{C} 7$ & 1.0000 & 0.98866 & 0.92575 & 0.46772 & Biso & 1.000 & $\mathrm{C}$ \\
\hline H5 & 1.0000 & 0.04575 & 0.03782 & 0.58059 & Biso & 1.000 & $\mathrm{H}$ \\
\hline H6 & 1.0000 & 0.94953 & 0.84815 & 0.50721 & Biso & 1.000 & $\mathrm{H}$ \\
\hline H 7 & 1.0000 & 0.13481 & 0.21268 & 0.48822 & Biso & 1.000 & $\mathrm{H}$ \\
\hline H8 & 1.0000 & 0.12488 & 0.20146 & 0.32413 & Biso & 1.000 & $\mathrm{H}$ \\
\hline $\mathrm{H} 9$ & 1.0000 & 0.02894 & 0.01266 & 0.24957 & Biso & 1.000 & $\mathrm{H}$ \\
\hline $\mathrm{H} 10$ & 1.0000 & 0.92937 & 0.83717 & 0.34196 & Biso & 1.000 & $\mathrm{H}$ \\
\hline C8 & 1.0000 & 0.25589 & 0.77068 & 0.27827 & Biso & 1.000 & $\mathrm{C}$ \\
\hline $\mathrm{H} 11$ & 1.0000 & 0.18646 & 0.68461 & 0.29235 & Biso & 1.000 & $\mathrm{H}$ \\
\hline $\mathrm{H} 12$ & 1.0000 & 0.33624 & 0.76952 & 0.27643 & Biso & 1.000 & $\mathrm{H}$ \\
\hline H13 & 1.0000 & 0.24139 & \multirow[t]{2}{*}{0.79789} & 0.21313 & Biso & 1.000 & $\mathrm{H}$ \\
\hline \multicolumn{7}{|c|}{$\begin{array}{l}\text { Ti } 9 \\
\text { data image } 0\end{array}$} & \\
\hline $\begin{array}{l}\text { data_in } \\
\text { cell___ } \\
\text { cell__ } \\
\text { cell__- } \\
\text { cell_o } \\
\text { cell__o } \\
\text { cell__o }\end{array}$ & $\begin{array}{l}=h \_a \\
=h \_b \\
=h \_c \\
\text {-alpha } \\
\text {-beta } \\
\text {-gamma }\end{array}$ & $\begin{array}{l}13.87 \\
13.87 \\
15.01 \\
90 \\
90 \\
120\end{array}$ & & & & & \\
\hline symmet & pace gr & oup name & & $1 "$ & & & \\
\hline symmet & nt_tabl & es_numbe & & & & & \\
\hline $\begin{array}{l}\text { loop_- } \\
{ }_{\text {symn }} \\
x_{,}, y\end{array}$ & _equiv & pos_as_x & & & & & \\
\hline $\begin{array}{l}\text { loop_- } \\
\text {-aton } \\
\text {-aton } \\
\text {-aton } \\
\text {-aton } \\
\text {-aton } \\
\text {-aton } \\
\text {-aton } \\
\text {-aton }\end{array}$ & 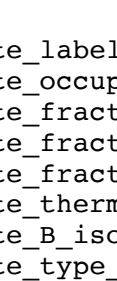 & $\begin{array}{l}\text { ancy } \\
-x \\
-y \\
-z \\
\text { aly_displ } \\
\text { or_equi } \\
\text { symbol }\end{array}$ & ce_type & & & & \\
\hline$\overline{\mathrm{P}} 1$ & 1.0000 & 0.00521 & 0.23582 & 0.11484 & Biso & 1.000 & $\mathrm{P}$ \\
\hline P2 & 1.0000 & 0.77550 & 0.78810 & 0.12057 & Biso & 1.000 & $\mathrm{P}$ \\
\hline P3 & 1.0000 & 0.22668 & 0.00764 & 0.10639 & Biso & 1.000 & $\mathrm{P}$ \\
\hline Al1 & 1.0000 & 0.21587 & 0.99668 & 0.89265 & Biso & 1.000 & Al \\
\hline Al2 & 1.0000 & 0.76763 & 0.77974 & 0.90729 & Biso & 1.000 & Al \\
\hline A13 & 1.0000 & 0.99656 & 0.23135 & 0.90126 & Biso & 1.000 & Al \\
\hline P 4 & 1.0000 & 0.66427 & 0.56760 & 0.44789 & Biso & 1.000 & $P$ \\
\hline Til & 1.0000 & 0.42407 & 0.11391 & 0.45084 & Biso & 1.000 & $\mathrm{Ti}$ \\
\hline P5 & 1.0000 & 0.90160 & 0.33358 & 0.44459 & Biso & 1.000 & $\mathrm{P}$ \\
\hline Al4 & 1.0000 & 0.90092 & 0.34356 & 0.23652 & Biso & 1.000 & Al \\
\hline Al5 & 1.0000 & 0.43729 & 0.11620 & 0.23164 & Biso & 1.000 & Al \\
\hline Al6 & 1.0000 & 0.67197 & 0.57077 & 0.23771 & Biso & 1.000 & Al \\
\hline P6 & 1.0000 & 0.32745 & 0.88638 & 0.78690 & Biso & 1.000 & $P$ \\
\hline P7 & 1.0000 & 0.09873 & 0.43943 & 0.78012 & Biso & 1.000 & $\mathrm{P}$ \\
\hline P8 & 1.0000 & 0.55818 & 0.66755 & 0.78113 & Biso & 1.000 & $P$ \\
\hline Al7 & 1.0000 & 0.57411 & 0.68058 & 0.57533 & Biso & 1.000 & Al \\
\hline A18 & 1.0000 & 0.09363 & 0.44076 & 0.57823 & Biso & 1.000 & Al \\
\hline Al9 & 1.0000 & 0.32654 & 0.88178 & 0.57039 & Biso & 1.000 & Al \\
\hline P9 & 1.0000 & 0.98816 & 0.76968 & 0.90136 & Biso & 1.000 & $P$ \\
\hline P 10 & 1.0000 & 0.22037 & 0.22649 & 0.88821 & Biso & 1.000 & $\mathrm{P}$ \\
\hline P 11 & 1.0000 & 0.77158 & 0.00753 & 0.90049 & Biso & 1.000 & $\mathrm{P}$ \\
\hline Al10 & 1.0000 & 0.77586 & 0.01419 & 0.11425 & Biso & 1.000 & Al \\
\hline Al11 & 1.0000 & 0.23116 & 0.23618 & 0.10117 & Biso & 1.000 & Al \\
\hline Al12 & 1.0000 & 0.99953 & 0.78387 & 0.11486 & Biso & 1.000 & Al \\
\hline P12 & 1.0000 & 0.66488 & 0.11888 & 0.23279 & Biso & 1.000 & $P$ \\
\hline $\mathrm{P} 13$ & 1.0000 & 0.89915 & 0.57044 & 0.23752 & Biso & 1.000 & $\mathrm{P}$ \\
\hline $\mathrm{P} 14$ & 1.0000 & 0.43906 & 0.35029 & 0.22777 & Biso & 1.000 & $\mathrm{P}$ \\
\hline Al13 & 1.0000 & 0.41970 & 0.35391 & 0.43473 & Biso & 1.000 & Al \\
\hline Al14 & 1.0000 & 0.88806 & 0.55691 & 0.44900 & Biso & 1.000 & Al \\
\hline Al15 & 1.0000 & 0.66212 & 0.11635 & 0.44385 & Biso & 1.000 & Al \\
\hline P15 & 1.0000 & 0.33071 & 0.46719 & 0.56302 & Biso & 1.000 & $P$ \\
\hline P16 & 1.0000 & 0.56221 & 0.90327 & 0.56912 & Biso & 1.000 & $\mathrm{P}$ \\
\hline P17 & 1.0000 & 0.08667 & 0.67111 & 0.57792 & Biso & 1.000 & $P$ \\
\hline Al16 & 1.0000 & 0.09613 & 0.67143 & 0.78143 & Biso & 1.000 & Al \\
\hline Al17 & 1.0000 & 0.55525 & 0.89660 & 0.77877 & Biso & 1.000 & Al \\
\hline Al18 & 1.0000 & 0.32593 & 0.44338 & 0.77118 & Biso & 1.000 & Al \\
\hline 01 & 1.0000 & 0.91415 & 0.11622 & 0.13889 & Biso & 1.000 & 0 \\
\hline $\mathrm{O} 2$ & 1.0000 & 0.89783 & 0.82024 & 0.13931 & Biso & 1.000 & 0 \\
\hline 03 & 1.0000 & 0.19637 & 0.09858 & 0.12572 & Biso & 1.000 & 0 \\
\hline 04 & 1.0000 & 0.08000 & 0.88695 & 0.87295 & Biso & 1.000 & 0 \\
\hline 05 & 1.0000 & 0.80413 & 0.91771 & 0.88325 & Biso & 1.000 & 0 \\
\hline 06 & 1.0000 & 0.09942 & 0.19892 & 0.87245 & Biso & 1.000 & 0 \\
\hline 07 & 1.0000 & 0.55797 & 0.45547 & 0.46100 & Biso & 1.000 & 0 \\
\hline 08 & 1.0000 & 0.57122 & 0.16296 & 0.46833 & Biso & 1.000 & 0 \\
\hline
\end{tabular}




\begin{tabular}{|c|c|c|c|c|c|c|}
\hline 09 & 1.0000 & 0.87296 & 0.42549 & 0.46595 & Biso & 1.000 \\
\hline 010 & 1.0000 & 0.76307 & 0.23899 & 0.22188 & Biso & 1.000 \\
\hline 011 & 1.0000 & 0.46354 & 0.25397 & 0.22636 & Biso & 1.000 \\
\hline 012 & 1.0000 & 0.77807 & 0.53921 & 0.21780 & Biso & 1.000 \\
\hline 013 & 1.0000 & 0.23190 & 0.76983 & 0.81400 & Biso & 1.000 \\
\hline 014 & 1.0000 & 0.22183 & 0.47581 & 0.79859 & Biso & 1.000 \\
\hline 015 & 1.0000 & 0.52575 & 0.75836 & 0.78751 & Biso & 1.000 \\
\hline 016 & 1.0000 & 0.43496 & 0.58242 & 0.55435 & Biso & 1.000 \\
\hline 017 & 1.0000 & 0.08350 & 0.55960 & 0.57777 & Biso & 1.000 \\
\hline 018 & 1.0000 & 0.43838 & 0.85814 & 0.54667 & Biso & 1.000 \\
\hline 019 & 1.0000 & 0.98983 & 0.32148 & 0.16797 & Biso & 1.000 \\
\hline $\mathrm{O} 20$ & 1.0000 & 0.69631 & 0.68780 & 0.17710 & Biso & 1.000 \\
\hline 021 & 1.0000 & 0.33438 & 0.03309 & 0.15316 & Biso & 1.000 \\
\hline 022 & 1.0000 & 0.31158 & 0.97679 & 0.83263 & Biso & 1.000 \\
\hline $\mathrm{O} 23$ & 1.0000 & 0.64728 & 0.68689 & 0.85048 & Biso & 1.000 \\
\hline $\mathrm{O} 24$ & 1.0000 & 0.02176 & 0.35321 & 0.84838 & Biso & 1.000 \\
\hline 025 & 1.0000 & 0.66323 & 0.65755 & 0.50722 & Biso & 1.000 \\
\hline 026 & 1.0000 & 0.33381 & 0.99606 & 0.52023 & Biso & 1.000 \\
\hline $\mathrm{O} 27$ & 1.0000 & 0.99747 & 0.34558 & 0.50374 & Biso & 1.000 \\
\hline 028 & 1.0000 & 0.00136 & 0.67949 & 0.85332 & Biso & 1.000 \\
\hline 029 & 1.0000 & 0.30099 & 0.32389 & 0.82930 & Biso & 1.000 \\
\hline 030 & 1.0000 & 0.66762 & 0.98246 & 0.84727 & Biso & 1.000 \\
\hline 031 & 1.0000 & 0.68327 & 0.03923 & 0.17327 & Biso & 1.000 \\
\hline 032 & 1.0000 & 0.35086 & 0.33143 & 0.15731 & Biso & 1.000 \\
\hline 033 & 1.0000 & 0.98014 & 0.67367 & 0.18328 & Biso & 1.000 \\
\hline 034 & 1.0000 & 0.32998 & 0.38769 & 0.49211 & Biso & 1.000 \\
\hline 035 & 1.0000 & 0.99317 & 0.66113 & 0.51564 & Biso & 1.000 \\
\hline 036 & 1.0000 & 0.63832 & 0.00117 & 0.50909 & Biso & 1.000 \\
\hline 037 & 1.0000 & 0.11934 & 0.25017 & 0.13864 & Biso & 1.000 \\
\hline 038 & 1.0000 & 0.76060 & 0.88647 & 0.14689 & Biso & 1.000 \\
\hline 039 & 1.0000 & 0.13054 & 0.89652 & 0.14236 & Biso & 1.000 \\
\hline 040 & 1.0000 & 0.22909 & 0.12416 & 0.86274 & Biso & 1.000 \\
\hline 041 & 1.0000 & 0.87520 & 0.75641 & 0.87591 & Biso & 1.000 \\
\hline 042 & 1.0000 & 0.86761 & 0.12052 & 0.86987 & Biso & 1.000 \\
\hline 043 & 1.0000 & 0.76519 & 0.55620 & 0.47390 & Biso & 1.000 \\
\hline 044 & 1.0000 & 0.38987 & 0.22322 & 0.46388 & Biso & 1.000 \\
\hline 045 & 1.0000 & 0.80131 & 0.21943 & 0.46254 & Biso & 1.000 \\
\hline 046 & 1.0000 & 0.91627 & 0.47363 & 0.21034 & Biso & 1.000 \\
\hline 047 & 1.0000 & 0.55928 & 0.11692 & 0.20042 & Biso & 1.000 \\
\hline 048 & 1.0000 & 0.54617 & 0.45858 & 0.20373 & Biso & 1.000 \\
\hline 049 & 1.0000 & 0.43856 & 0.89960 & 0.81886 & Biso & 1.000 \\
\hline 050 & 1.0000 & 0.08255 & 0.54025 & 0.78752 & Biso & 1.000 \\
\hline 051 & 1.0000 & 0.45539 & 0.55441 & 0.80134 & Biso & 1.000 \\
\hline 052 & 1.0000 & 0.59179 & 0.81145 & 0.55358 & Biso & 1.000 \\
\hline 053 & 1.0000 & 0.22879 & 0.48029 & 0.54711 & Biso & 1.000 \\
\hline 054 & 1.0000 & 0.19912 & 0.76207 & 0.54382 & Biso & 1.000 \\
\hline 055 & 1.0000 & 0.99966 & 0.25673 & 0.01521 & Biso & 1.000 \\
\hline 056 & 1.0000 & 0.74681 & 0.75807 & 0.02204 & Biso & 1.000 \\
\hline 057 & 1.0000 & 0.24130 & 0.99792 & 0.00646 & Biso & 1.000 \\
\hline 058 & 1.0000 & 0.67540 & 0.60582 & 0.35008 & Biso & 1.000 \\
\hline 059 & 1.0000 & 0.39096 & 0.05744 & 0.33521 & Biso & 1.000 \\
\hline 060 & 1.0000 & 0.94071 & 0.34510 & 0.34713 & Biso & 1.000 \\
\hline 061 & 1.0000 & 0.32796 & 0.90019 & 0.68629 & Biso & 1.000 \\
\hline 062 & 1.0000 & 0.06598 & 0.38642 & 0.68659 & Biso & 1.000 \\
\hline 063 & 1.0000 & 0.60414 & 0.66840 & 0.68737 & Biso & 1.000 \\
\hline 064 & 1.0000 & 0.99382 & 0.75292 & 0.00220 & Biso & 1.000 \\
\hline 065 & 1.0000 & 0.25228 & 0.25831 & 0.98650 & Biso & 1.000 \\
\hline 066 & 1.0000 & 0.74866 & 0.01177 & 0.00026 & Biso & 1.000 \\
\hline 067 & 1.0000 & 0.65476 & 0.07975 & 0.32964 & Biso & 1.000 \\
\hline 068 & 1.0000 & 0.92579 & 0.59831 & 0.33726 & Biso & 1.000 \\
\hline 069 & 1.0000 & 0.39718 & 0.36244 & 0.31956 & Biso & 1.000 \\
\hline 070 & 1.0000 & 0.32468 & 0.41807 & 0.65654 & Biso & 1.000 \\
\hline 071 & 1.0000 & 0.58475 & 0.94084 & 0.66776 & Biso & 1.000 \\
\hline 072 & 1.0000 & 0.06498 & 0.69738 & 0.67328 & Biso & 1.000 \\
\hline H 1 & 1.0000 & 0.31382 & 0.92093 & 0.34094 & Biso & 1.000 \\
\hline $\mathrm{C} 1$ & 1.0000 & 0.11696 & 0.87821 & 0.36722 & Biso & 1.000 \\
\hline $\mathrm{H} 2$ & 1.0000 & 0.07520 & 0.79693 & 0.39859 & Biso & 1.000 \\
\hline Н3 & 1.0000 & 0.17952 & 0.94788 & 0.40560 & Biso & 1.000 \\
\hline $\mathrm{H} 4$ & 1.0000 & 0.12060 & 0.88272 & 0.29507 & Biso & 1.000 \\
\hline 073 & 1.0000 & 0.25736 & 0.84043 & 0.35281 & Biso & 1.000 \\
\hline $\mathrm{C} 2$ & 1.0000 & 0.04930 & 0.02123 & 0.51517 & Biso & 1.000 \\
\hline C3 & 1.0000 & 0.09731 & 0.11763 & 0.46257 & Biso & 1.000 \\
\hline $\mathrm{C} 4$ & 1.0000 & 0.08781 & 0.11125 & 0.36941 & Biso & 1.000 \\
\hline C5 & 1.0000 & 0.03200 & 0.00811 & 0.32825 & Biso & 1.000 \\
\hline $\mathrm{C} 6$ & 1.0000 & 0.98870 & 0.90892 & 0.38015 & Biso & 1.000 \\
\hline $\mathrm{C} 7$ & 1.0000 & 0.99284 & 0.91745 & 0.47487 & Biso & 1.000 \\
\hline H5 & 1.0000 & 0.05673 & 0.02801 & 0.58751 & Biso & 1.000 \\
\hline H6 & 1.0000 & 0.95541 & 0.84145 & 0.51475 & Biso & 1.000 \\
\hline H 7 & 1.0000 & 0.14332 & 0.19916 & 0.49423 & Biso & 1.000 \\
\hline$H$ & 1.0000 & 0.12397 & 0.18737 & 0.32980 & & 1.000 \\
\hline
\end{tabular}




$\begin{array}{llllllll}\text { H9 } & 1.0000 & 0.02347 & 0.00178 & 0.25591 & \text { Biso } & 1.000 & \mathrm{H} \\ \text { H10 } & 1.0000 & 0.92813 & 0.83005 & 0.34947 & \text { Biso } & 1.000 & \mathrm{H} \\ \text { C8 } & 1.0000 & 0.25529 & 0.77220 & 0.28066 & \text { Biso } & 1.000 & \mathrm{C} \\ \text { H11 } & 1.0000 & 0.18794 & 0.68688 & 0.29368 & \text { Biso } & 1.000 & \mathrm{H} \\ \text { H12 } & 1.0000 & 0.33486 & 0.77245 & 0.27754 & \text { Biso } & 1.000 & \mathrm{H} \\ \text { H13 } & 1.0000 & 0.24013 & 0.80010 & 0.21614 & \text { Biso } & 1.000 & \mathrm{H}\end{array}$

data_image 0

celillength_a 13.875

cell length ${ }^{-} \mathrm{b} \quad 13.875$

cell_length_c 15.017

cell_angle_ālpha 90

cell angle beta 90

_cell_angle_gamma 120

symmetry_space_group name_H-M "P 1"

_symmetry_int_tables_number 1

loop_

symmetry_equiv_pos_as_xyz

' $\mathrm{x}, \mathrm{y}, \mathrm{z}$ '

loop

atom_site label

-atom_site_occupancy

-atom_site_fract_x

-atom_site_fract_y

-atom_site_fract_z

_atom_site_thermal_displace_type

-atom_site_B_iso_or_equiv

atom_site_type_symbol

Al1 $1.0000 \quad 0.99124 \quad 0.24519$

Al2 $1.0000 \quad 0.76683$

Al3 $1.0000 \quad 0.22015$

P1 $1.0000 \quad 0.21172$

P2 $1.0000 \quad 0.76371$

0.78836

0.1054

Biso

$1.000 \mathrm{Al}$

$\begin{array}{lllll}0.02243 & 0.11321 & \text { Biso } & 1.000 & \mathrm{Al}\end{array}$

P3 1.00000 .98381

$0.01160 \quad 0.89053$ Biso $1.000 \mathrm{P}$

0.782790 .90129 Biso $1.000 \quad \mathrm{P}$

$\begin{array}{lllllll}1.0000 & 0.64729 & 0.56658 & 0.44190 & \text { Biso } & 1.000 & \mathrm{P}\end{array}$

$\begin{array}{lllllll}1.0000 & 0.43508 & 0.12533 & 0.44381 & \text { Biso } & 1.000 & \mathrm{Al}\end{array}$

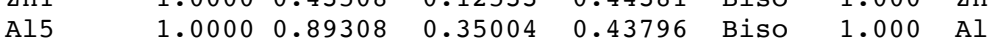

$\begin{array}{llllllll}\text { P4 } & 1.0000 & 0.89276 & 0.35731 & 0.22923 & \text { Biso } & 1.000 & \text { P }\end{array}$

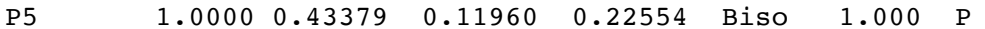

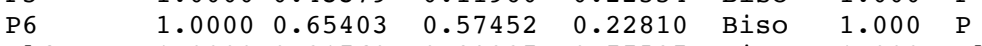

$\begin{array}{llllllll}\text { Al6 } & 1.0000 & 0.31760 & 0.89937 & 0.77527 & \text { Biso } & 1.000 & \text { Al }\end{array}$

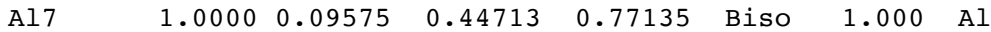

Al8 $\quad 1.0000 \quad 0.55391 \quad 0.68158 \quad 0.77389$ Biso $1.000 \mathrm{Al}$

$\begin{array}{llllllll}\text { P7 } & 1.0000 & 0.56212 & 0.69091 & 0.56562 & \text { Biso } & 1.000 & \text { P }\end{array}$

$\begin{array}{lllllll}\text { P8 } & 1.0000 & 0.09523 & 0.45105 & 0.56487 & \text { Biso } & 1.000\end{array}$

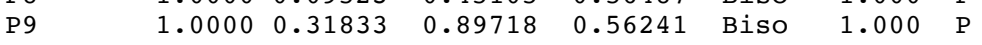

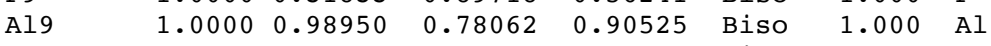

Al10 $\quad 1.0000 \quad 0.21329 \quad 0.24005 \quad 0.89306$ Biso 1.000 Al

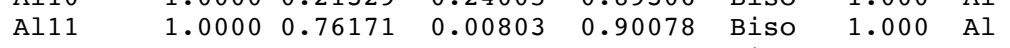

$\begin{array}{llllllll}\text { P10 } & 1.0000 & 0.76690 & 0.01516 & 0.11336 & \text { Biso } & 1.000 & \text { P }\end{array}$

$\begin{array}{llllllll}\text { P11 } & 1.0000 & 0.21806 & 0.24557 & 0.10463 & \text { Biso } & 1.000 & \mathrm{P}\end{array}$

$\begin{array}{llllllll}\mathrm{P} 12 & 1.0000 & 0.99854 & 0.79148 & 0.11781 & \text { Biso } & 1.000 & \mathrm{P}\end{array}$

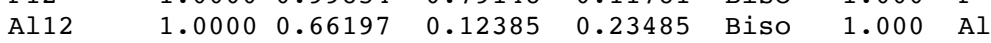

Al13 $\quad 1.0000 \quad 0.88197 \quad 0.57709 \quad 0.23454$ Biso $1.000 \mathrm{Al}$

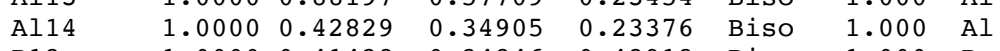

$\begin{array}{llllllll}\mathrm{P} 13 & 1.0000 & 0.41428 & 0.34846 & 0.43913 & \text { Biso } & 1.000 & \mathrm{P}\end{array}$

$\begin{array}{llllllll}\mathrm{P} 14 & 1.0000 & 0.87700 & 0.56998 & 0.44755 & \text { Biso } & 1.000 & \mathrm{P}\end{array}$

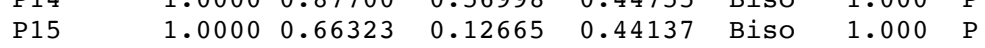

$\begin{array}{llllllll}\text { Al15 } & 1.0000 & 0.32829 & 0.46867 & 0.56477 & \text { Biso } & 1.000 & \text { AI }\end{array}$

Al16 $\quad 1.0000 \quad 0.55116 \quad 0.91353 \quad 0.56862$ Biso $1.000 \mathrm{Al}$

$\begin{array}{llllllll}\text { Al17 } & 1.0000 & 0.08320 & 0.67886 & 0.57291 & \text { Biso } & 1.000 & \text { Al }\end{array}$

$\begin{array}{llllllll}\text { P16 } & 1.0000 & 0.08942 & 0.67538 & 0.77972 & \text { Biso } & 1.000 & \text { P }\end{array}$

$\begin{array}{llllllll}\text { P17 } & 1.0000 & 0.54613 & 0.90680 & 0.77931 & \text { Biso } & 1.000 & \mathrm{P}\end{array}$

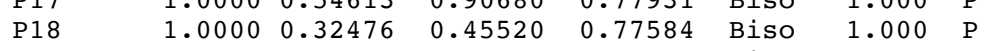

$\begin{array}{llllllll}01 & 1.0000 & 0.88754 & 0.10877 & 0.13015 & \text { Biso } & 1.000 & 0\end{array}$

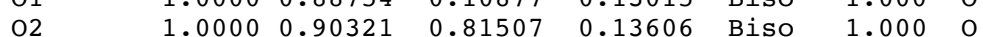

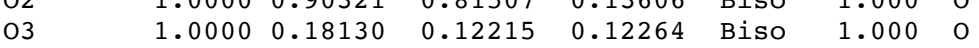

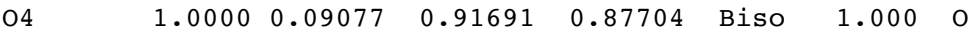

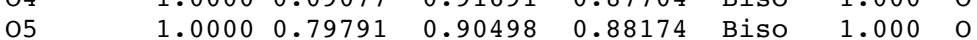

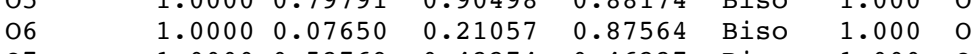

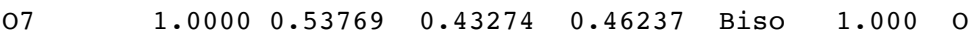

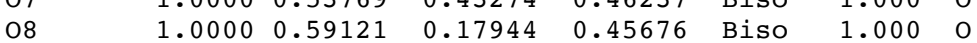

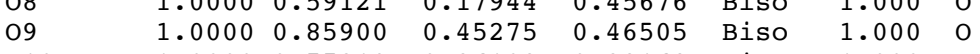

$\begin{array}{llllllll}010 & 1.0000 & 0.77219 & 0.26102 & 0.22168 & \text { Biso } & 1.000 & 0\end{array}$

$011 \quad 1.0000 \quad 0.45879 \quad 0.24031 \quad 0.23236$ Biso $1.000 \quad 0$

$\begin{array}{llllllll}012 & 1.0000 & 0.75104 & 0.55406 & 0.20535 & \text { Biso } & 1.000 & 0 \\ 013 & 1.0000 & 0.21133 & 0.76320 & 0.79990 & \text { Biso } & 1.000 & 0\end{array}$ 


\begin{tabular}{|c|c|c|c|c|c|c|c|}
\hline 014 & 1.0000 & 0.23315 & 0.48364 & 0.79874 & Biso & 1.000 & 0 \\
\hline 015 & 1.0000 & 0.51759 & 0.78464 & 0.78828 & Biso & 1.000 & O \\
\hline 016 & 1.0000 & 0.43828 & 0.60510 & 0.55052 & Biso & 1.000 & 0 \\
\hline 017 & 1.0000 & 0.09922 & 0.56315 & 0.56160 & Biso & 1.000 & 0 \\
\hline 018 & 1.0000 & 0.41061 & 0.86686 & 0.54493 & Biso & 1.000 & 0 \\
\hline 019 & 1.0000 & 0.97053 & 0.33944 & 0.16761 & Biso & 1.000 & O \\
\hline 020 & 1.0000 & 0.66915 & 0.67645 & 0.17614 & Biso & 1.000 & O \\
\hline 021 & 1.0000 & 0.34434 & 0.05464 & 0.15442 & Biso & 1.000 & O \\
\hline 022 & 1.0000 & 0.29252 & 0.99386 & 0.83321 & Biso & 1.000 & 0 \\
\hline 023 & 1.0000 & 0.66215 & 0.70359 & 0.84564 & Biso & 1.000 & $\mathrm{O}$ \\
\hline $\mathrm{O} 24$ & 1.0000 & 0.00040 & 0.33703 & 0.83691 & Biso & 1.000 & O \\
\hline 025 & 1.0000 & 0.63548 & 0.66759 & 0.50296 & Biso & 1.000 & O \\
\hline 026 & 1.0000 & 0.33188 & 0.99283 & 0.50560 & Biso & 1.000 & O \\
\hline 027 & 1.0000 & 0.00512 & 0.36754 & 0.50224 & Biso & 1.000 & O \\
\hline 028 & 1.0000 & 0.01124 & 0.68456 & 0.84730 & Biso & 1.000 & O \\
\hline 029 & 1.0000 & 0.30679 & 0.35303 & 0.82907 & Biso & 1.000 & 0 \\
\hline 030 & 1.0000 & 0.64434 & 0.98161 & 0.84010 & Biso & 1.000 & O \\
\hline 031 & 1.0000 & 0.68486 & 0.03387 & 0.16850 & Biso & 1.000 & 0 \\
\hline 032 & 1.0000 & 0.32074 & 0.32214 & 0.15992 & Biso & 1.000 & O \\
\hline 033 & 1.0000 & 0.98833 & 0.69767 & 0.18057 & Biso & 1.000 & O \\
\hline 034 & 1.0000 & 0.33838 & 0.37415 & 0.49679 & Biso & 1.000 & o \\
\hline 035 & 1.0000 & 0.97242 & 0.65781 & 0.50449 & Biso & 1.000 & 0 \\
\hline 036 & 1.0000 & 0.63716 & 0.03001 & 0.50538 & Biso & 1.000 & O \\
\hline 037 & 1.0000 & 0.12247 & 0.26490 & 0.13173 & Biso & 1.000 & O \\
\hline 038 & 1.0000 & 0.75778 & 0.90489 & 0.14231 & Biso & 1.000 & O \\
\hline 039 & 1.0000 & 0.11150 & 0.89422 & 0.14039 & Biso & 1.000 & O \\
\hline 040 & 1.0000 & 0.22063 & 0.12228 & 0.86392 & Biso & 1.000 & 0 \\
\hline 041 & 1.0000 & 0.86023 & 0.76369 & 0.87706 & Biso & 1.000 & O \\
\hline 042 & 1.0000 & 0.87184 & 0.13701 & 0.86889 & Biso & 1.000 & 0 \\
\hline 043 & 1.0000 & 0.77113 & 0.57189 & 0.47194 & Biso & 1.000 & O \\
\hline 044 & 1.0000 & 0.38601 & 0.23003 & 0.45557 & Biso & 1.000 & O \\
\hline 045 & 1.0000 & 0.78641 & 0.21540 & 0.45570 & Biso & 1.000 & O \\
\hline 046 & 1.0000 & 0.89765 & 0.46598 & 0.19994 & Biso & 1.000 & O \\
\hline 047 & 1.0000 & 0.54005 & 0.11938 & 0.19755 & Biso & 1.000 & O \\
\hline 048 & 1.0000 & 0.54551 & 0.47218 & 0.19840 & Biso & 1.000 & $\mathrm{O}$ \\
\hline 049 & 1.0000 & 0.44503 & 0.91532 & 0.80982 & Biso & 1.000 & 0 \\
\hline 050 & 1.0000 & 0.07587 & 0.55956 & 0.78941 & Biso & 1.000 & 0 \\
\hline 051 & 1.0000 & 0.43834 & 0.55381 & 0.80166 & Biso & 1.000 & 0 \\
\hline 052 & 1.0000 & 0.58102 & 0.80733 & 0.54497 & Biso & 1.000 & 0 \\
\hline 053 & 1.0000 & 0.20801 & 0.46936 & 0.53353 & Biso & 1.000 & 0 \\
\hline 054 & 1.0000 & 0.20629 & 0.79324 & 0.53820 & Biso & 1.000 & 0 \\
\hline 055 & 1.0000 & 0.98486 & 0.26950 & 0.99223 & Biso & 1.000 & 0 \\
\hline 056 & 1.0000 & 0.73507 & 0.75670 & 0.00066 & Biso & 1.000 & O \\
\hline 057 & 1.0000 & 0.24415 & 0.01434 & 0.98894 & Biso & 1.000 & O \\
\hline 058 & 1.0000 & 0.65294 & 0.59739 & 0.32789 & Biso & 1.000 & 0 \\
\hline 059 & 1.0000 & 0.93536 & 0.36937 & 0.32548 & Biso & 1.000 & O \\
\hline 060 & 1.0000 & 0.31897 & 0.92435 & 0.66219 & Biso & 1.000 & O \\
\hline 061 & 1.0000 & 0.06968 & 0.40394 & 0.66017 & Biso & 1.000 & O \\
\hline 062 & 1.0000 & 0.59470 & 0.68404 & 0.66285 & Biso & 1.000 & O \\
\hline 063 & 1.0000 & 0.99586 & 0.75692 & 0.02026 & Biso & 1.000 & O \\
\hline 064 & 1.0000 & 0.24718 & 0.27271 & 0.00566 & Biso & 1.000 & 0 \\
\hline 065 & 1.0000 & 0.73593 & 0.01069 & 0.01458 & Biso & 1.000 & O \\
\hline 066 & 1.0000 & 0.64911 & 0.07994 & 0.34507 & Biso & 1.000 & O \\
\hline 067 & 1.0000 & 0.90634 & 0.60076 & 0.34841 & Biso & 1.000 & 0 \\
\hline 068 & 1.0000 & 0.39321 & 0.36777 & 0.34074 & Biso & 1.000 & 0 \\
\hline 069 & 1.0000 & 0.32174 & 0.42905 & 0.67622 & Biso & 1.000 & 0 \\
\hline 070 & 1.0000 & 0.57698 & 0.94676 & 0.68257 & Biso & 1.000 & O \\
\hline 071 & 1.0000 & 0.05636 & 0.69218 & 0.68537 & Biso & 1.000 & O \\
\hline 072 & 1.0000 & 0.38985 & 0.05927 & 0.31630 & Biso & 1.000 & O \\
\hline $\mathrm{H} 1$ & 1.0000 & 0.11400 & 0.73013 & 0.26382 & Biso & 1.000 & $\mathrm{H}$ \\
\hline $\mathrm{C} 1$ & 1.0000 & 0.28022 & 0.89949 & 0.31393 & Biso & 1.000 & C \\
\hline $\mathrm{H} 2$ & 1.0000 & 0.29218 & 0.89471 & 0.24311 & Biso & 1.000 & $\mathrm{H}$ \\
\hline H3 & 1.0000 & 0.32885 & 0.88288 & 0.36155 & Biso & 1.000 & $\mathrm{H}$ \\
\hline $\mathrm{H} 4$ & 1.0000 & 0.21826 & 0.91851 & 0.33858 & Biso & 1.000 & $\mathrm{H}$ \\
\hline 073 & 1.0000 & 0.16259 & 0.74022 & 0.31513 & Biso & 1.000 & $\mathrm{O}$ \\
\hline $\mathrm{C} 2$ & 1.0000 & 0.20136 & 0.66102 & 0.31138 & Biso & 1.000 & $\mathrm{C}$ \\
\hline H5 & 1.0000 & 0.12947 & 0.57611 & 0.30874 & Biso & 1.000 & $\mathrm{H}$ \\
\hline H 6 & 1.0000 & 0.25558 & 0.67582 & 0.25336 & Biso & 1.000 & $\mathrm{H}$ \\
\hline $\mathrm{H} 7$ & 1.0000 & 0.24767 & 0.67128 & 0.37320 & Biso & 1.000 & $\mathrm{H}$ \\
\hline \multicolumn{8}{|c|}{ i 10} \\
\hline \multicolumn{8}{|c|}{ data image 0} \\
\hline \multicolumn{2}{|c|}{ celī_length_a } & \multicolumn{2}{|c|}{13.875} & & & & \\
\hline \multicolumn{2}{|c|}{ cell length $b$} & & & & & \\
\hline cell & $\mathrm{th}^{-} \mathrm{C}$ & 15.01 & & & & & \\
\hline cell & _-alpha & 90 & & & & & \\
\hline cell & beta & 90 & & & & & \\
\hline cell & gamma & 120 & & & & & \\
\hline & & & & P $1 "$ & & & \\
\hline & & & & & & & \\
\hline
\end{tabular}




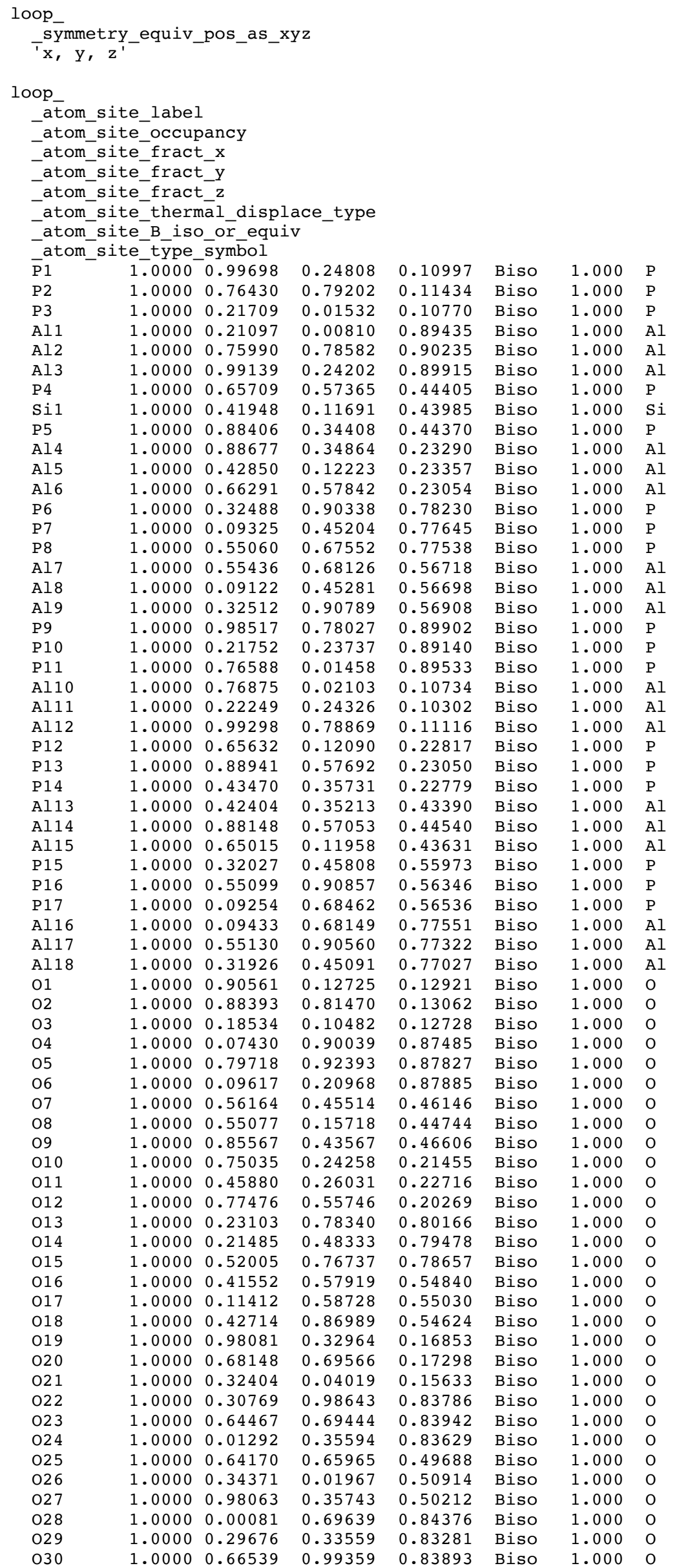




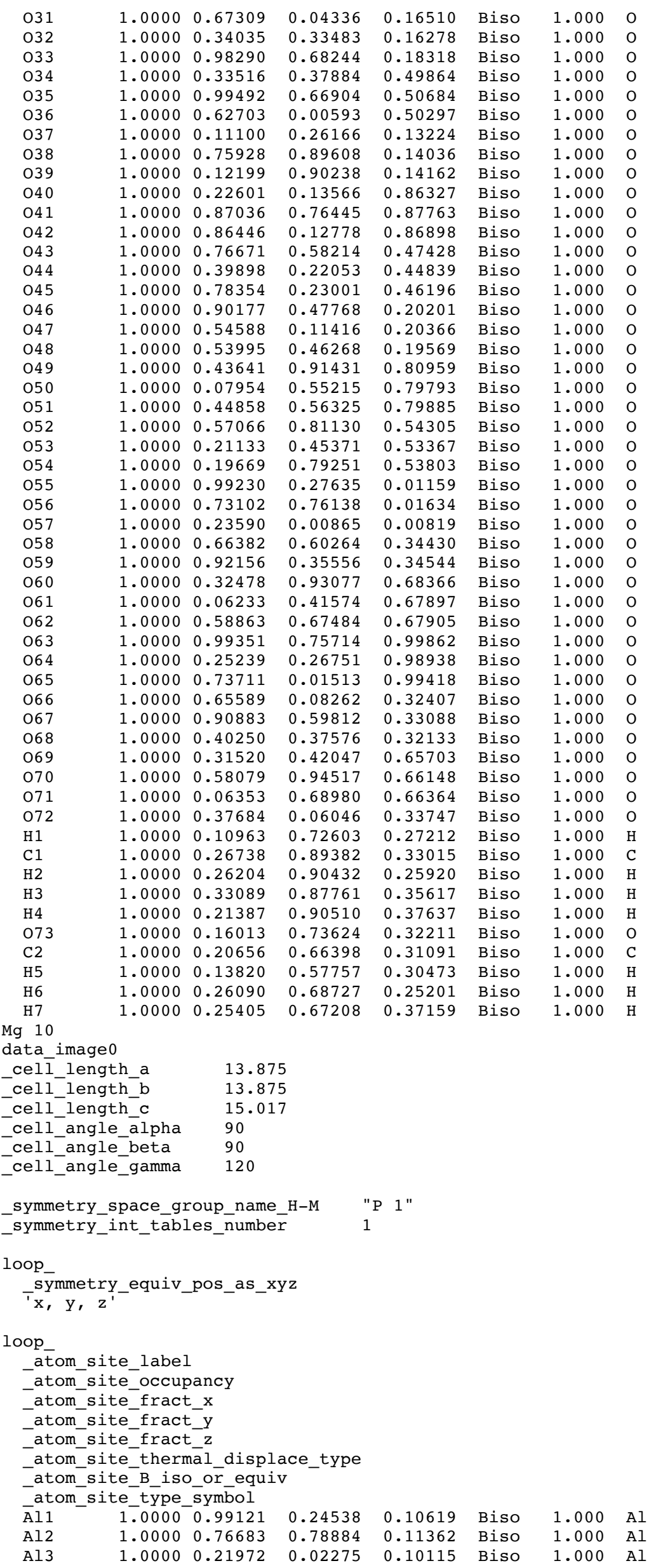




\begin{tabular}{|c|c|c|c|c|c|c|c|}
\hline P1 & 1.0000 & 0.21136 & 0.01120 & 0.89007 & Biso & 1.000 & $\mathrm{P}$ \\
\hline P2 & 1.0000 & 0.76372 & 0.78288 & 0.90133 & Biso & 1.000 & $\mathrm{P}$ \\
\hline P3 & 1.0000 & 0.98351 & 0.23826 & 0.89411 & Biso & 1.000 & $\mathrm{P}$ \\
\hline Al4 & 1.0000 & 0.64802 & 0.56821 & 0.44225 & Biso & 1.000 & Al \\
\hline $\operatorname{Mg} 1$ & 1.0000 & 0.42899 & 0.12269 & 0.44172 & Biso & 1.000 & $\mathrm{Mg}$ \\
\hline Al5 & 1.0000 & 0.89147 & 0.34825 & 0.43969 & Biso & 1.000 & Al \\
\hline P4 & 1.0000 & 0.89138 & 0.35618 & 0.22935 & Biso & 1.000 & $P$ \\
\hline P5 & 1.0000 & 0.43219 & 0.11963 & 0.22603 & Biso & 1.000 & $P$ \\
\hline P6 & 1.0000 & 0.65492 & 0.57489 & 0.22831 & Biso & 1.000 & P \\
\hline Al6 & 1.0000 & 0.31669 & 0.89767 & 0.77721 & Biso & 1.000 & Al \\
\hline Al7 & 1.0000 & 0.09513 & 0.44638 & 0.77111 & Biso & 1.000 & Al \\
\hline A18 & 1.0000 & 0.55380 & 0.68079 & 0.77423 & Biso & 1.000 & Al \\
\hline P7 & 1.0000 & 0.56412 & 0.69116 & 0.56617 & Biso & 1.000 & $\mathrm{P}$ \\
\hline P8 & 1.0000 & 0.09447 & 0.45082 & 0.56555 & Biso & 1.000 & $P$ \\
\hline P9 & 1.0000 & 0.31880 & 0.89222 & 0.56542 & Biso & 1.000 & $\mathrm{P}$ \\
\hline Al9 & 1.0000 & 0.98932 & 0.78033 & 0.90485 & Biso & 1.000 & Al \\
\hline Al10 & 1.0000 & 0.21347 & 0.24012 & 0.89262 & Biso & 1.000 & Al \\
\hline Al11 & 1.0000 & 0.76273 & 0.00817 & 0.90090 & Biso & 1.000 & Al \\
\hline P10 & 1.0000 & 0.76782 & 0.01568 & 0.11420 & Biso & 1.000 & $\mathrm{P}$ \\
\hline P11 & 1.0000 & 0.21861 & 0.24630 & 0.10413 & Biso & 1.000 & $\mathrm{P}$ \\
\hline P12 & 1.0000 & 0.99859 & 0.79195 & 0.11774 & Biso & 1.000 & $\mathrm{P}$ \\
\hline Al12 & 1.0000 & 0.66295 & 0.12429 & 0.23488 & Biso & 1.000 & Al \\
\hline Al13 & 1.0000 & 0.88299 & 0.57815 & 0.23558 & Biso & 1.000 & Al \\
\hline Al1 14 & 1.0000 & 0.42855 & 0.34990 & 0.23387 & Biso & 1.000 & Al \\
\hline P13 & 1.0000 & 0.41304 & 0.35062 & 0.43911 & Biso & 1.000 & $\mathrm{P}$ \\
\hline P 14 & 1.0000 & 0.87708 & 0.57037 & 0.44819 & Biso & 1.000 & P \\
\hline P15 & 1.0000 & 0.66212 & 0.12596 & 0.44124 & Biso & 1.000 & $\mathrm{P}$ \\
\hline Al15 & 1.0000 & 0.32893 & 0.47105 & 0.56403 & Biso & 1.000 & Al \\
\hline Al16 & 1.0000 & 0.55171 & 0.91285 & 0.57117 & Biso & 1.000 & Al \\
\hline Al17 & 1.0000 & 0.08241 & 0.67897 & 0.57396 & Biso & 1.000 & Al \\
\hline P16 & 1.0000 & 0.08918 & 0.67517 & 0.78082 & Biso & 1.000 & $\mathrm{P}$ \\
\hline P17 & 1.0000 & 0.54735 & 0.90768 & 0.77985 & Biso & 1.000 & $P$ \\
\hline P18 & 1.0000 & 0.32486 & 0.45575 & 0.77572 & Biso & 1.000 & $P$ \\
\hline 01 & 1.0000 & 0.88802 & 0.10930 & 0.13278 & Biso & 1.000 & 0 \\
\hline $\mathrm{O} 2$ & 1.0000 & 0.90297 & 0.81484 & 0.13638 & Biso & 1.000 & 0 \\
\hline 03 & 1.0000 & 0.18122 & 0.12274 & 0.12249 & Biso & 1.000 & 0 \\
\hline 04 & 1.0000 & 0.09096 & 0.91596 & 0.87518 & Biso & 1.000 & 0 \\
\hline 05 & 1.0000 & 0.79821 & 0.90486 & 0.88058 & Biso & 1.000 & 0 \\
\hline 06 & 1.0000 & 0.07674 & 0.21120 & 0.87631 & Biso & 1.000 & 0 \\
\hline 07 & 1.0000 & 0.53532 & 0.43694 & 0.46367 & Biso & 1.000 & 0 \\
\hline 08 & 1.0000 & 0.58477 & 0.17299 & 0.44968 & Biso & 1.000 & 0 \\
\hline 09 & 1.0000 & 0.86072 & 0.45373 & 0.46485 & Biso & 1.000 & 0 \\
\hline 010 & 1.0000 & 0.77035 & 0.26208 & 0.21713 & Biso & 1.000 & 0 \\
\hline 011 & 1.0000 & 0.45958 & 0.24118 & 0.23224 & Biso & 1.000 & 0 \\
\hline 012 & 1.0000 & 0.75205 & 0.55463 & 0.20557 & Biso & 1.000 & 0 \\
\hline 013 & 1.0000 & 0.21052 & 0.76212 & 0.80392 & Biso & 1.000 & 0 \\
\hline 014 & 1.0000 & 0.23255 & 0.48316 & 0.79857 & Biso & 1.000 & 0 \\
\hline 015 & 1.0000 & 0.51937 & 0.78548 & 0.78635 & Biso & 1.000 & 0 \\
\hline 016 & 1.0000 & 0.44076 & 0.60617 & 0.54773 & Biso & 1.000 & 0 \\
\hline 017 & 1.0000 & 0.09487 & 0.56116 & 0.56441 & Biso & 1.000 & 0 \\
\hline 018 & 1.0000 & 0.40803 & 0.85653 & 0.55430 & Biso & 1.000 & 0 \\
\hline 019 & 1.0000 & 0.97078 & 0.33979 & 0.16843 & Biso & 1.000 & 0 \\
\hline 020 & 1.0000 & 0.66935 & 0.67639 & 0.17608 & Biso & 1.000 & $\mathrm{O}$ \\
\hline 021 & 1.0000 & 0.34444 & 0.05573 & 0.15373 & Biso & 1.000 & 0 \\
\hline 022 & 1.0000 & 0.29368 & 0.99437 & 0.83398 & Biso & 1.000 & 0 \\
\hline 023 & 1.0000 & 0.66173 & 0.70307 & 0.84641 & Biso & 1.000 & 0 \\
\hline $\mathrm{O} 24$ & 1.0000 & 0.00042 & 0.33761 & 0.83805 & Biso & 1.000 & 0 \\
\hline 025 & 1.0000 & 0.63958 & 0.67090 & 0.50350 & Biso & 1.000 & 0 \\
\hline 026 & 1.0000 & 0.34293 & 0.99026 & 0.50746 & Biso & 1.000 & 0 \\
\hline 027 & 1.0000 & 0.00611 & 0.36753 & 0.50161 & Biso & 1.000 & 0 \\
\hline 028 & 1.0000 & 0.00942 & 0.68247 & 0.84795 & Biso & 1.000 & 0 \\
\hline 029 & 1.0000 & 0.30624 & 0.35231 & 0.82750 & Biso & 1.000 & 0 \\
\hline 030 & 1.0000 & 0.64331 & 0.98088 & 0.84303 & Biso & 1.000 & 0 \\
\hline 031 & 1.0000 & 0.68408 & 0.03406 & 0.16718 & Biso & 1.000 & 0 \\
\hline 032 & 1.0000 & 0.32136 & 0.32259 & 0.15948 & Biso & 1.000 & $\mathrm{O}$ \\
\hline 033 & 1.0000 & 0.98864 & 0.69752 & 0.17960 & Biso & 1.000 & 0 \\
\hline 034 & 1.0000 & 0.33469 & 0.37377 & 0.49607 & Biso & 1.000 & 0 \\
\hline 035 & 1.0000 & 0.97151 & 0.65838 & 0.50588 & Biso & 1.000 & 0 \\
\hline 036 & 1.0000 & 0.63194 & 0.02734 & 0.50437 & Biso & 1.000 & 0 \\
\hline 037 & 1.0000 & 0.12334 & 0.26626 & 0.13086 & Biso & 1.000 & 0 \\
\hline 038 & 1.0000 & 0.75803 & 0.90526 & 0.14373 & Biso & 1.000 & 0 \\
\hline 039 & 1.0000 & 0.11116 & 0.89495 & 0.14115 & Biso & 1.000 & 0 \\
\hline 040 & 1.0000 & 0.21996 & 0.12177 & 0.86353 & Biso & 1.000 & 0 \\
\hline 041 & 1.0000 & 0.85984 & 0.76310 & 0.87732 & Biso & 1.000 & 0 \\
\hline 042 & 1.0000 & 0.87214 & 0.13697 & 0.86781 & Biso & 1.000 & 0 \\
\hline 043 & 1.0000 & 0.76997 & 0.56983 & 0.47258 & Biso & 1.000 & 0 \\
\hline 044 & 1.0000 & 0.38977 & 0.23386 & 0.45450 & Biso & 1.000 & 0 \\
\hline 045 & 1.0000 & 0.78307 & 0.21610 & 0.46308 & Biso & 1.000 & 0 \\
\hline 046 & 1.0000 & 0.89990 & 0.46729 & 0.20276 & Biso & 1.000 & 0 \\
\hline 047 & 1.0000 & 0.53758 & 0.11594 & 0.20176 & Biso & 1.000 & 0 \\
\hline
\end{tabular}




\begin{tabular}{|c|c|c|c|c|c|c|c|}
\hline 048 & 1.0000 & 0.54648 & 0.47236 & 0.19876 & Biso & 1.000 & 0 \\
\hline 049 & 1.0000 & 0.44490 & 0.91425 & 0.80958 & Biso & 1.000 & 0 \\
\hline 050 & 1.0000 & 0.07507 & 0.55892 & 0.78805 & Biso & 1.000 & 0 \\
\hline 051 & 1.0000 & 0.43766 & 0.55409 & 0.80363 & Biso & 1.000 & 0 \\
\hline 052 & 1.0000 & 0.58467 & 0.80873 & 0.54869 & Biso & 1.000 & 0 \\
\hline 053 & 1.0000 & 0.20892 & 0.47344 & 0.53455 & Biso & 1.000 & 0 \\
\hline 054 & 1.0000 & 0.20602 & 0.79161 & 0.53701 & Biso & 1.000 & 0 \\
\hline 055 & 1.0000 & 0.98283 & 0.26769 & 0.99281 & Biso & 1.000 & 0 \\
\hline 056 & 1.0000 & 0.73565 & 0.75833 & 0.00092 & Biso & 1.000 & 0 \\
\hline 057 & 1.0000 & 0.24216 & 0.01339 & 0.98882 & Biso & 1.000 & 0 \\
\hline 058 & 1.0000 & 0.65413 & 0.59817 & 0.32803 & Biso & 1.000 & 0 \\
\hline 059 & 1.0000 & 0.92927 & 0.36195 & 0.32636 & Biso & 1.000 & 0 \\
\hline 060 & 1.0000 & 0.31315 & 0.91985 & 0.66413 & Biso & 1.000 & 0 \\
\hline 061 & 1.0000 & 0.06904 & 0.40144 & 0.66023 & Biso & 1.000 & 0 \\
\hline 062 & 1.0000 & 0.59330 & 0.67945 & 0.66343 & Biso & 1.000 & 0 \\
\hline 063 & 1.0000 & 0.99694 & 0.75875 & 0.02003 & Biso & 1.000 & 0 \\
\hline 064 & 1.0000 & 0.24817 & 0.27301 & 0.00515 & Biso & 1.000 & 0 \\
\hline 065 & 1.0000 & 0.73964 & 0.01163 & 0.01491 & Biso & 1.000 & 0 \\
\hline 066 & 1.0000 & 0.65951 & 0.08317 & 0.34478 & Biso & 1.000 & 0 \\
\hline 067 & 1.0000 & 0.90668 & 0.60285 & 0.34936 & Biso & 1.000 & 0 \\
\hline 068 & 1.0000 & 0.39267 & 0.36948 & 0.34031 & Biso & 1.000 & 0 \\
\hline 069 & 1.0000 & 0.32409 & 0.43248 & 0.67572 & Biso & 1.000 & 0 \\
\hline 070 & 1.0000 & 0.58119 & 0.95131 & 0.68422 & Biso & 1.000 & 0 \\
\hline 071 & 1.0000 & 0.05881 & 0.69554 & 0.68656 & Biso & 1.000 & 0 \\
\hline 072 & 1.0000 & 0.38435 & 0.06037 & 0.31672 & Biso & 1.000 & 0 \\
\hline $\mathrm{H} 1$ & 1.0000 & 0.11671 & 0.72744 & 0.25338 & Biso & 1.000 & $\mathrm{H}$ \\
\hline $\mathrm{C} 1$ & 1.0000 & 0.27816 & 0.90098 & 0.30936 & Biso & 1.000 & C \\
\hline H2 & 1.0000 & 0.32546 & 0.88825 & 0.25780 & Biso & 1.000 & $\mathrm{H}$ \\
\hline H3 & 1.0000 & 0.29199 & 0.89178 & 0.37909 & Biso & 1.000 & $\mathrm{H}$ \\
\hline $\mathrm{H} 4$ & 1.0000 & 0.21258 & 0.91808 & 0.29134 & Biso & 1.000 & $\mathrm{H}$ \\
\hline 073 & 1.0000 & 0.16306 & 0.73963 & 0.30667 & Biso & 1.000 & 0 \\
\hline $\mathrm{C} 2$ & 1.0000 & 0.20438 & 0.66257 & 0.30900 & Biso & 1.000 & C \\
\hline H5 & 1.0000 & 0.13402 & 0.57680 & 0.30604 & Biso & 1.000 & $\mathrm{H}$ \\
\hline H6 & 1.0000 & 0.26217 & 0.67706 & 0.25363 & Biso & 1.000 & $\mathrm{H}$ \\
\hline $\mathrm{H} 7$ & 1.0000 & 0.24757 & 0.67552 & 0.37287 & Biso & 1.000 & $\mathrm{H}$ \\
\hline \multicolumn{8}{|c|}{110} \\
\hline \multicolumn{8}{|c|}{ ata_image 0} \\
\hline \multicolumn{8}{|c|}{13.625} \\
\hline \multicolumn{8}{|c|}{13.625} \\
\hline \multicolumn{8}{|c|}{15.067} \\
\hline \multicolumn{8}{|c|}{90} \\
\hline \multicolumn{8}{|c|}{ e_beta } \\
\hline sell_- & e_gamma & 120 & & & & & \\
\hline symme & pace_g & coup_name & & $1 "$ & & & \\
\hline symme & $\mathrm{n}+\mathrm{t} \overrightarrow{\mathrm{a}}$ & les_ñumbe & & & & & \\
\hline & & & & & & & \\
\hline sym & equiv & pos_as_x & & & & & \\
\hline ' $x$, & & & & & & & \\
\hline op_ & & & & & & & \\
\hline ato & te labe. & & & & & & \\
\hline ato & ce occup & pancy & & & & & \\
\hline ato & te fract & $\mathrm{x}$ & & & & & \\
\hline ato & te_fract & $y$ & & & & & \\
\hline ato & te fract & $z$ & & & & & \\
\hline -ato & te-thern & nāl_displ & dce_cype & & & & \\
\hline -ato & ee_B_is & o_or_equi & & & & & \\
\hline -ato & ce t'ype & symb̄ol & & & & & \\
\hline$\overline{\mathrm{S}} \mathrm{i} 1$ & 1.0000 & 0.00114 & 0.25580 & 0.10498 & Biso & 1.000 & $\mathrm{Si}$ \\
\hline Si2 & 1.0000 & 0.77173 & 0.79696 & 0.10835 & Biso & 1.000 & $\mathrm{Si}$ \\
\hline Si3 & 1.0000 & 0.22845 & 0.02637 & 0.10192 & Biso & 1.000 & $\mathrm{Si}$ \\
\hline Si4 & 1.0000 & 0.22287 & 0.02067 & 0.89352 & Biso & 1.000 & $\mathrm{Si}$ \\
\hline Si5 & 1.0000 & 0.76900 & 0.79310 & 0.90104 & Biso & 1.000 & $\mathrm{Si}$ \\
\hline Si6 & 1.0000 & 0.99698 & 0.25279 & 0.89914 & Biso & 1.000 & $\mathrm{Si}$ \\
\hline Si7 & 1.0000 & 0.66118 & 0.58574 & 0.43682 & Biso & 1.000 & $\mathrm{Si}$ \\
\hline Al1 & 1.0000 & 0.43086 & 0.12674 & 0.43670 & Biso & 1.000 & Al \\
\hline Si8 & 1.0000 & 0.89779 & 0.35616 & 0.43777 & Biso & 1.000 & $\mathrm{Si}$ \\
\hline Si9 & 1.0000 & 0.89780 & 0.35918 & 0.23249 & Biso & 1.000 & $\mathrm{Si}$ \\
\hline Silo & 1.0000 & 0.43360 & 0.12388 & 0.23145 & Biso & 1.000 & $\mathrm{Si}$ \\
\hline Sil1 & 1.0000 & 0.66512 & 0.58706 & 0.23336 & Biso & 1.000 & $\mathrm{Si}$ \\
\hline Sil 12 & 1.0000 & 0.33042 & 0.91378 & 0.77635 & Biso & 1.000 & $\mathrm{Si}$ \\
\hline Sil13 & 1.0000 & 0.10109 & 0.45721 & 0.77044 & Biso & 1.000 & $\mathrm{Si}$ \\
\hline Si 14 & 1.0000 & 0.56325 & 0.68888 & 0.77176 & Biso & 1.000 & $\mathrm{Si}$ \\
\hline Si15 & 1.0000 & 0.57026 & 0.69581 & 0.56827 & Biso & 1.000 & $\mathrm{Si}$ \\
\hline Si 16 & 1.0000 & 0.10026 & 0.45995 & 0.56761 & Biso & 1.000 & $\mathrm{Si}$ \\
\hline $\operatorname{Si} 17$ & 1.0000 & 0.33103 & 0.91418 & 0.56859 & Biso & 1.000 & $\mathrm{Si}$ \\
\hline Si18 & 1.0000 & 0.99695 & 0.79069 & 0.90045 & Biso & 1.000 & $\mathrm{Si}$ \\
\hline Si19 & 1.0000 & 0.22735 & 0.25167 & 0.89517 & Biso & 1.000 & $\mathrm{Si}$ \\
\hline
\end{tabular}




\begin{tabular}{|c|c|c|c|c|c|c|}
\hline Si20 & 1.0000 & 0.77071 & 0.02180 & 0.89882 & Biso & 1.000 \\
\hline Si21 & 1.0000 & 0.77233 & 0.02533 & 0.10667 & Biso & 1.000 \\
\hline Si22 & 1.0000 & 0.23143 & 0.25558 & 0.10165 & Biso & 1.000 \\
\hline Si23 & 1.0000 & 0.00305 & 0.79825 & 0.10857 & Biso & 1.000 \\
\hline Si24 & 1.0000 & 0.66714 & 0.12756 & 0.23369 & Biso & 1.000 \\
\hline Si25 & 1.0000 & 0.90002 & 0.58935 & 0.23463 & Biso & 1.000 \\
\hline Si26 & 1.0000 & 0.43770 & 0.36064 & 0.23217 & Biso & 1.000 \\
\hline Si27 & 1.0000 & 0.42948 & 0.36195 & 0.43379 & Biso & 1.000 \\
\hline Si28 & 1.0000 & 0.89544 & 0.58547 & 0.43922 & Biso & 1.000 \\
\hline Si29 & 1.0000 & 0.66484 & 0.12947 & 0.43543 & Biso & 1.000 \\
\hline Si30 & 1.0000 & 0.33441 & 0.47044 & 0.56392 & Biso & 1.000 \\
\hline Si31 & 1.0000 & 0.56119 & 0.92165 & 0.56803 & Biso & 1.000 \\
\hline Si32 & 1.0000 & 0.09551 & 0.69169 & 0.57138 & Biso & 1.000 \\
\hline Si33 & 1.0000 & 0.09854 & 0.68817 & 0.77468 & Biso & 1.000 \\
\hline $\mathrm{Si} 34$ & 1.0000 & 0.56034 & 0.91892 & 0.77320 & Biso & 1.000 \\
\hline Si35 & 1.0000 & 0.33135 & 0.46107 & 0.76964 & Biso & 1.000 \\
\hline 01 & 1.0000 & 0.90312 & 0.12509 & 0.12364 & Biso & 1.000 \\
\hline $\mathrm{O} 2$ & 1.0000 & 0.90248 & 0.82741 & 0.12513 & Biso & 1.000 \\
\hline 03 & 1.0000 & 0.19538 & 0.12378 & 0.12082 & Biso & 1.000 \\
\hline 04 & 1.0000 & 0.09319 & 0.91985 & 0.87525 & Biso & 1.000 \\
\hline 05 & 1.0000 & 0.80483 & 0.92444 & 0.88131 & Biso & 1.000 \\
\hline 06 & 1.0000 & 0.09652 & 0.22173 & 0.88402 & Biso & 1.000 \\
\hline 07 & 1.0000 & 0.56185 & 0.45703 & 0.45625 & Biso & 1.000 \\
\hline 08 & 1.0000 & 0.57422 & 0.17082 & 0.44053 & Biso & 1.000 \\
\hline 09 & 1.0000 & 0.86626 & 0.45585 & 0.45560 & Biso & 1.000 \\
\hline 010 & 1.0000 & 0.76755 & 0.25890 & 0.21961 & Biso & 1.000 \\
\hline 011 & 1.0000 & 0.46127 & 0.25447 & 0.23099 & Biso & 1.000 \\
\hline 012 & 1.0000 & 0.77132 & 0.56372 & 0.22680 & Biso & 1.000 \\
\hline 013 & 1.0000 & 0.22912 & 0.78434 & 0.79557 & Biso & 1.000 \\
\hline 014 & 1.0000 & 0.23270 & 0.49297 & 0.78896 & Biso & 1.000 \\
\hline 015 & 1.0000 & 0.53075 & 0.78790 & 0.78300 & Biso & 1.000 \\
\hline 016 & 1.0000 & 0.43805 & 0.60031 & 0.55252 & Biso & 1.000 \\
\hline 017 & 1.0000 & 0.11729 & 0.58604 & 0.56011 & Biso & 1.000 \\
\hline 018 & 1.0000 & 0.42651 & 0.87566 & 0.55260 & Biso & 1.000 \\
\hline 019 & 1.0000 & 0.98362 & 0.34203 & 0.16840 & Biso & 1.000 \\
\hline $\mathrm{O} 20$ & 1.0000 & 0.68561 & 0.69062 & 0.16904 & Biso & 1.000 \\
\hline 021 & 1.0000 & 0.34143 & 0.05031 & 0.15509 & Biso & 1.000 \\
\hline $\mathrm{O} 22$ & 1.0000 & 0.31238 & 0.00279 & 0.83572 & Biso & 1.000 \\
\hline 023 & 1.0000 & 0.66225 & 0.70720 & 0.84068 & Biso & 1.000 \\
\hline $\mathrm{O} 24$ & 1.0000 & 0.01628 & 0.35721 & 0.83669 & Biso & 1.000 \\
\hline 025 & 1.0000 & 0.65294 & 0.67530 & 0.50283 & Biso & 1.000 \\
\hline 026 & 1.0000 & 0.35092 & 0.01803 & 0.50871 & Biso & 1.000 \\
\hline 027 & 1.0000 & 0.00160 & 0.37415 & 0.50088 & Biso & 1.000 \\
\hline 028 & 1.0000 & 0.01307 & 0.69932 & 0.84332 & Biso & 1.000 \\
\hline 029 & 1.0000 & 0.31139 & 0.35495 & 0.83105 & Biso & 1.000 \\
\hline 030 & 1.0000 & 0.66427 & 0.00066 & 0.83804 & Biso & 1.000 \\
\hline 031 & 1.0000 & 0.68470 & 0.04559 & 0.16533 & Biso & 1.000 \\
\hline 032 & 1.0000 & 0.33832 & 0.33994 & 0.16253 & Biso & 1.000 \\
\hline 033 & 1.0000 & 0.98608 & 0.69399 & 0.17176 & Biso & 1.000 \\
\hline O34 & 1.0000 & 0.34692 & 0.38575 & 0.49681 & Biso & 1.000 \\
\hline 035 & 1.0000 & 0.99233 & 0.67373 & 0.50630 & Biso & 1.000 \\
\hline 036 & 1.0000 & 0.63961 & 0.02630 & 0.50317 & Biso & 1.000 \\
\hline 037 & 1.0000 & 0.12442 & 0.27115 & 0.12709 & Biso & 1.000 \\
\hline 038 & 1.0000 & 0.76119 & 0.90586 & 0.13658 & Biso & 1.000 \\
\hline 039 & 1.0000 & 0.12430 & 0.90599 & 0.13706 & Biso & 1.000 \\
\hline 040 & 1.0000 & 0.23476 & 0.14100 & 0.86680 & Biso & 1.000 \\
\hline 041 & 1.0000 & 0.87427 & 0.77477 & 0.87675 & Biso & 1.000 \\
\hline 042 & 1.0000 & 0.87728 & 0.14358 & 0.87219 & Biso & 1.000 \\
\hline 043 & 1.0000 & 0.78342 & 0.59494 & 0.45182 & Biso & 1.000 \\
\hline 044 & 1.0000 & 0.40647 & 0.23748 & 0.44917 & Biso & 1.000 \\
\hline 045 & 1.0000 & 0.79123 & 0.23355 & 0.45944 & Biso & 1.000 \\
\hline 046 & 1.0000 & 0.90707 & 0.47906 & 0.20520 & Biso & 1.000 \\
\hline 047 & 1.0000 & 0.54789 & 0.12016 & 0.20886 & Biso & 1.000 \\
\hline 048 & 1.0000 & 0.55290 & 0.47348 & 0.20019 & Biso & 1.000 \\
\hline 049 & 1.0000 & 0.45012 & 0.92515 & 0.80524 & Biso & 1.000 \\
\hline 050 & 1.0000 & 0.08566 & 0.56513 & 0.78962 & Biso & 1.000 \\
\hline 051 & 1.0000 & 0.45276 & 0.56853 & 0.79591 & Biso & 1.000 \\
\hline 052 & 1.0000 & 0.58616 & 0.81925 & 0.54650 & Biso & 1.000 \\
\hline 053 & 1.0000 & 0.21787 & 0.46797 & 0.53856 & Biso & 1.000 \\
\hline 054 & 1.0000 & 0.20819 & 0.80607 & 0.54202 & Biso & 1.000 \\
\hline 055 & 1.0000 & 0.99551 & 0.28875 & 0.00206 & Biso & 1.000 \\
\hline 056 & 1.0000 & 0.73577 & 0.76340 & 0.00524 & Biso & 1.000 \\
\hline 057 & 1.0000 & 0.25259 & 0.01958 & 0.99780 & Biso & 1.000 \\
\hline 058 & 1.0000 & 0.65329 & 0.62116 & 0.33454 & Biso & 1.000 \\
\hline 059 & 1.0000 & 0.93917 & 0.36532 & 0.33467 & Biso & 1.000 \\
\hline 060 & 1.0000 & 0.33070 & 0.94495 & 0.67306 & Biso & 1.000 \\
\hline 061 & 1.0000 & 0.06594 & 0.41277 & 0.66876 & Biso & 1.000 \\
\hline 062 & 1.0000 & 0.60614 & 0.68934 & 0.67069 & Biso & 1.000 \\
\hline 063 & 1.0000 & 0.00487 & 0.76528 & 0.00535 & Biso & 1.000 \\
\hline 064 & 1.0000 & 0.26707 & 0.28665 & 0.99796 & Biso & 1.000 \\
\hline
\end{tabular}




\begin{tabular}{|c|c|c|c|c|c|c|c|}
\hline 065 & 1.0000 & 0.73802 & 0.02113 & 0.00282 & Biso & 1.000 & 0 \\
\hline 066 & 1.0000 & 0.66863 & 0.08513 & 0.33414 & Biso & 1.000 & 0 \\
\hline 067 & 1.0000 & 0.94732 & 0.62545 & 0.33733 & Biso & 1.000 & 0 \\
\hline 068 & 1.0000 & 0.40260 & 0.38062 & 0.33048 & Biso & 1.000 & 0 \\
\hline 069 & 1.0000 & 0.32967 & 0.42769 & 0.66582 & Biso & 1.000 & 0 \\
\hline 070 & 1.0000 & 0.59461 & 0.96212 & 0.67126 & Biso & 1.000 & 0 \\
\hline 071 & 1.0000 & 0.06210 & 0.70023 & 0.67387 & Biso & 1.000 & 0 \\
\hline 072 & 1.0000 & 0.38034 & 0.06357 & 0.32723 & Biso & 1.000 & 0 \\
\hline $\mathrm{H} 1$ & 1.0000 & 0.10570 & 0.70357 & 0.33572 & Biso & 1.000 & $\mathrm{H}$ \\
\hline $\mathrm{C} 1$ & 1.0000 & 0.28210 & 0.89531 & 0.32801 & Biso & 1.000 & $\mathrm{C}$ \\
\hline $\mathrm{H} 2$ & 1.0000 & 0.23440 & 0.90315 & 0.38238 & Biso & 1.000 & $\mathrm{H}$ \\
\hline H3 & 1.0000 & 0.25625 & 0.89433 & 0.25974 & Biso & 1.000 & $\mathrm{H}$ \\
\hline $\mathrm{H} 4$ & 1.0000 & 0.35496 & 0.88612 & 0.34295 & Biso & 1.000 & $\mathrm{H}$ \\
\hline 073 & 1.0000 & 0.18726 & 0.72724 & 0.33844 & Biso & 1.000 & 0 \\
\hline $\mathrm{C} 2$ & 1.0000 & 0.21098 & 0.66316 & 0.27414 & Biso & 1.000 & $\mathrm{C}$ \\
\hline H5 & 1.0000 & 0.16406 & 0.57289 & 0.29225 & Biso & 1.000 & $\mathrm{H}$ \\
\hline $\mathrm{H} 6$ & 1.0000 & 0.18794 & 0.67486 & 0.20653 & Biso & 1.000 & $\mathrm{H}$ \\
\hline H7 & 1.0000 & 0.30214 & 0.69358 & 0.27781 & Biso & 1.000 & $\mathrm{H}$ \\
\hline \\
\hline \multirow{2}{*}{\multicolumn{8}{|c|}{$\begin{array}{l}\text { data_image } 0 \\
\text { celi__length_a }\end{array}$}} \\
\hline & & & & & & & \\
\hline \multicolumn{8}{|c|}{ cell_length_b $\quad 13.875$} \\
\hline \multicolumn{8}{|c|}{ cell_length_c $\quad 15.017$} \\
\hline \multicolumn{8}{|c|}{ cell_angle_alpha 90} \\
\hline \multicolumn{8}{|c|}{ _cell_angle_beta 90} \\
\hline \multicolumn{8}{|c|}{ _cell_angle_gamma $\quad 120$} \\
\hline \multicolumn{4}{|c|}{$\begin{array}{l}\text {-symmetry_space_group_name_H-M } \\
\text { symmetry int tables number }\end{array}$} & P $1 "$ & & & \\
\hline _symme & int_tab. & les_numbe & $\bar{c}$ & & & & \\
\hline loop_ & & & & & & & \\
\hline $\bar{'}^{\mathrm{s} y \mathrm{~m}}$ & equiv & pos_as_x & & & & & \\
\hline 1oop_ & & & & & & & \\
\hline _ator & Ee_labe & & & & & & \\
\hline -ator & ce_occul & pancy & & & & & \\
\hline -ator & ee_frac & E_ & & & & & \\
\hline -ator & ee_frac & & & & & & \\
\hline -ator & ee_frac & & & & & & \\
\hline $\begin{array}{l}\text {-ator } \\
\text {-ator } \\
\text {-ator }\end{array}$ & $\begin{array}{l}\text { Ce_thers } \\
\text { ce_B_is } \\
\text { ce_type }\end{array}$ & $\begin{array}{l}\text { nāl_displ } \\
\text { o_or_equi } \\
\text { symbol }\end{array}$ & ce_type & & & & \\
\hline$\overline{\mathrm{P}} 1$ & 1.0000 & 0.99798 & 0.24744 & 0.11054 & Biso & 1.000 & $\mathrm{P}$ \\
\hline P2 & 1.0000 & 0.76535 & 0.79290 & 0.11556 & Biso & 1.000 & $\mathrm{P}$ \\
\hline P3 & 1.0000 & 0.21801 & 0.01566 & 0.10431 & Biso & 1.000 & $\mathrm{P}$ \\
\hline Al1 & 1.0000 & 0.20947 & 0.00629 & 0.89109 & Biso & 1.000 & $\mathrm{Al}$ \\
\hline Al2 & 1.0000 & 0.76044 & 0.78630 & 0.90326 & Biso & 1.000 & Al \\
\hline Al3 & 1.0000 & 0.99050 & 0.24164 & 0.89886 & Biso & 1.000 & Al \\
\hline $\mathrm{P} 4$ & 1.0000 & 0.65657 & 0.57228 & 0.44388 & Biso & 1.000 & $\mathrm{P}$ \\
\hline Ge1 & 1.0000 & 0.41627 & 0.11855 & 0.44333 & Biso & 1.000 & $\mathrm{Ge}$ \\
\hline P5 & 1.0000 & 0.88931 & 0.34528 & 0.44181 & Biso & 1.000 & $\mathrm{P}$ \\
\hline Al4 & 1.0000 & 0.89075 & 0.35074 & 0.23355 & Biso & 1.000 & Al \\
\hline Al5 & 1.0000 & 0.42989 & 0.12310 & 0.22970 & Biso & 1.000 & Al \\
\hline Al6 & 1.0000 & 0.66386 & 0.57878 & 0.23055 & Biso & 1.000 & Al \\
\hline P6 & 1.0000 & 0.32303 & 0.89802 & 0.78418 & Biso & 1.000 & $\mathrm{P}$ \\
\hline P7 & 1.0000 & 0.09300 & 0.44930 & 0.77618 & Biso & 1.000 & $\mathrm{P}$ \\
\hline P8 & 1.0000 & 0.55170 & 0.67582 & 0.77532 & Biso & 1.000 & $\mathrm{P}$ \\
\hline Al7 & 1.0000 & 0.56015 & 0.68633 & 0.56855 & Biso & 1.000 & Al \\
\hline A18 & 1.0000 & 0.08750 & 0.44803 & 0.57130 & Biso & 1.000 & Al \\
\hline Al9 & 1.0000 & 0.32337 & 0.89831 & 0.56881 & Biso & 1.000 & Al \\
\hline P9 & 1.0000 & 0.98363 & 0.77783 & 0.89933 & Biso & 1.000 & $\mathrm{P}$ \\
\hline $\mathrm{P} 10$ & 1.0000 & 0.21638 & 0.23701 & 0.88814 & Biso & 1.000 & $\mathrm{P}$ \\
\hline P11 & 1.0000 & 0.76634 & 0.01517 & 0.89608 & Biso & 1.000 & $\mathrm{P}$ \\
\hline Al10 & 1.0000 & 0.77023 & 0.02233 & 0.10890 & Biso & 1.000 & Al \\
\hline Al11 & 1.0000 & 0.22389 & 0.24428 & 0.09977 & Biso & 1.000 & Al \\
\hline Al12 & 1.0000 & 0.99370 & 0.78983 & 0.11220 & Biso & 1.000 & Al \\
\hline $\mathrm{P} 12$ & 1.0000 & 0.65598 & 0.12220 & 0.22906 & Biso & 1.000 & $\mathrm{P}$ \\
\hline P13 & 1.0000 & 0.89036 & 0.57743 & 0.23091 & Biso & 1.000 & $\mathrm{P}$ \\
\hline P14 & 1.0000 & 0.43506 & 0.35857 & 0.22604 & Biso & 1.000 & $\mathrm{P}$ \\
\hline Al13 & 1.0000 & 0.41966 & 0.35731 & 0.43174 & Biso & 1.000 & Al \\
\hline Al14 & 1.0000 & 0.88173 & 0.56946 & 0.44611 & Biso & 1.000 & Al \\
\hline Al15 & 1.0000 & 0.65091 & 0.12294 & 0.43712 & Biso & 1.000 & Al \\
\hline P 15 & 1.0000 & 0.32224 & 0.46928 & 0.55882 & Biso & 1.000 & $\mathrm{P}$ \\
\hline P16 & 1.0000 & 0.55465 & 0.91219 & 0.56431 & Biso & 1.000 & $\mathrm{P}$ \\
\hline P17 & 1.0000 & 0.08788 & 0.68277 & 0.56931 & Biso & 1.000 & $\mathrm{P}$ \\
\hline Al16 & 1.0000 & 0.09237 & 0.68134 & 0.77586 & Biso & 1.000 & Al \\
\hline Al17 & 1.0000 & 0.54990 & 0.90514 & 0.77467 & Biso & 1.000 & Al \\
\hline Al18 & 1.0000 & 0.31926 & 0.45190 & 0.76869 & Biso & 1.000 & Al \\
\hline 01 & 1.0000 & 0.90718 & 0.12730 & 0.13275 & Biso & 1.000 & 0 \\
\hline
\end{tabular}




\begin{tabular}{|c|c|c|c|c|c|c|c|}
\hline $\mathrm{O} 2$ & 1.0000 & 0.88499 & 0.81610 & 0.13305 & Biso & 1.000 & 0 \\
\hline 03 & 1.0000 & 0.18645 & 0.10552 & 0.12276 & Biso & 1.000 & 0 \\
\hline 04 & 1.0000 & 0.07348 & 0.89660 & 0.87243 & Biso & 1.000 & 0 \\
\hline 05 & 1.0000 & 0.79826 & 0.92480 & 0.87976 & Biso & 1.000 & 0 \\
\hline 06 & 1.0000 & 0.09526 & 0.21017 & 0.87571 & Biso & 1.000 & 0 \\
\hline 07 & 1.0000 & 0.55912 & 0.45437 & 0.45982 & Biso & 1.000 & 0 \\
\hline 08 & 1.0000 & 0.56055 & 0.17165 & 0.45652 & Biso & 1.000 & 0 \\
\hline 09 & 1.0000 & 0.86020 & 0.43584 & 0.46642 & Biso & 1.000 & 0 \\
\hline 010 & 1.0000 & 0.75410 & 0.24278 & 0.22129 & Biso & 1.000 & 0 \\
\hline 011 & 1.0000 & 0.45757 & 0.26059 & 0.22905 & Biso & 1.000 & 0 \\
\hline 012 & 1.0000 & 0.77612 & 0.55857 & 0.20263 & Biso & 1.000 & 0 \\
\hline 013 & 1.0000 & 0.22814 & 0.78011 & 0.80838 & Biso & 1.000 & 0 \\
\hline 014 & 1.0000 & 0.21536 & 0.48444 & 0.79648 & Biso & 1.000 & 0 \\
\hline 015 & 1.0000 & 0.51982 & 0.76693 & 0.78436 & Biso & 1.000 & 0 \\
\hline 016 & 1.0000 & 0.41923 & 0.58995 & 0.55128 & Biso & 1.000 & 0 \\
\hline 017 & 1.0000 & 0.09480 & 0.57619 & 0.56506 & Biso & 1.000 & 0 \\
\hline 018 & 1.0000 & 0.43107 & 0.86976 & 0.54187 & Biso & 1.000 & 0 \\
\hline 019 & 1.0000 & 0.98279 & 0.33096 & 0.16732 & Biso & 1.000 & 0 \\
\hline $\mathrm{O} 20$ & 1.0000 & 0.68205 & 0.69630 & 0.17375 & Biso & 1.000 & 0 \\
\hline 021 & 1.0000 & 0.32625 & 0.04228 & 0.15164 & Biso & 1.000 & 0 \\
\hline 022 & 1.0000 & 0.30611 & 0.98600 & 0.83269 & Biso & 1.000 & 0 \\
\hline 023 & 1.0000 & 0.64365 & 0.69523 & 0.84180 & Biso & 1.000 & 0 \\
\hline 024 & 1.0000 & 0.01394 & 0.36024 & 0.84173 & Biso & 1.000 & 0 \\
\hline 025 & 1.0000 & 0.64287 & 0.65904 & 0.49729 & Biso & 1.000 & 0 \\
\hline 026 & 1.0000 & 0.33036 & 0.00953 & 0.51480 & Biso & 1.000 & 0 \\
\hline 027 & 1.0000 & 0.98194 & 0.35330 & 0.50250 & Biso & 1.000 & 0 \\
\hline 028 & 1.0000 & 0.99775 & 0.69087 & 0.84697 & Biso & 1.000 & 0 \\
\hline 029 & 1.0000 & 0.29554 & 0.33376 & 0.82813 & Biso & 1.000 & 0 \\
\hline 030 & 1.0000 & 0.66398 & 0.99163 & 0.84114 & Biso & 1.000 & 0 \\
\hline 031 & 1.0000 & 0.67518 & 0.04505 & 0.16739 & Biso & 1.000 & 0 \\
\hline 032 & 1.0000 & 0.34274 & 0.33561 & 0.15873 & Biso & 1.000 & 0 \\
\hline 033 & 1.0000 & 0.98428 & 0.68356 & 0.18425 & Biso & 1.000 & 0 \\
\hline 034 & 1.0000 & 0.33539 & 0.39297 & 0.49337 & Biso & 1.000 & 0 \\
\hline 035 & 1.0000 & 0.99313 & 0.67038 & 0.50848 & Biso & 1.000 & 0 \\
\hline 036 & 1.0000 & 0.63080 & 0.01161 & 0.50559 & Biso & 1.000 & 0 \\
\hline 037 & 1.0000 & 0.11281 & 0.26229 & 0.13158 & Biso & 1.000 & 0 \\
\hline 038 & 1.0000 & 0.75920 & 0.89648 & 0.14107 & Biso & 1.000 & 0 \\
\hline 039 & 1.0000 & 0.12370 & 0.90363 & 0.14055 & Biso & 1.000 & 0 \\
\hline 040 & 1.0000 & 0.22336 & 0.13397 & 0.86155 & Biso & 1.000 & 0 \\
\hline 041 & 1.0000 & 0.86933 & 0.76295 & 0.87711 & Biso & 1.000 & 0 \\
\hline 042 & 1.0000 & 0.86357 & 0.12814 & 0.86712 & Biso & 1.000 & 0 \\
\hline 043 & 1.0000 & 0.76447 & 0.57718 & 0.47434 & Biso & 1.000 & 0 \\
\hline O4 4 & 1.0000 & 0.38068 & 0.22215 & 0.45183 & Biso & 1.000 & 0 \\
\hline 045 & 1.0000 & 0.78808 & 0.23023 & 0.45378 & Biso & 1.000 & 0 \\
\hline 046 & 1.0000 & 0.90260 & 0.47830 & 0.20166 & Biso & 1.000 & 0 \\
\hline 047 & 1.0000 & 0.55024 & 0.12130 & 0.19783 & Biso & 1.000 & 0 \\
\hline 048 & 1.0000 & 0.54179 & 0.46280 & 0.19446 & Biso & 1.000 & 0 \\
\hline 049 & 1.0000 & 0.43442 & 0.91076 & 0.81470 & Biso & 1.000 & 0 \\
\hline 050 & 1.0000 & 0.07714 & 0.55001 & 0.78626 & Biso & 1.000 & 0 \\
\hline 051 & 1.0000 & 0.44943 & 0.56304 & 0.79741 & Biso & 1.000 & 0 \\
\hline 052 & 1.0000 & 0.58106 & 0.81878 & 0.54626 & Biso & 1.000 & 0 \\
\hline 053 & 1.0000 & 0.21512 & 0.46953 & 0.53440 & Biso & 1.000 & 0 \\
\hline 054 & 1.0000 & 0.19818 & 0.77975 & 0.53621 & Biso & 1.000 & 0 \\
\hline 055 & 1.0000 & 0.99050 & 0.27193 & 0.01184 & Biso & 1.000 & 0 \\
\hline 056 & 1.0000 & 0.73338 & 0.76227 & 0.01741 & Biso & 1.000 & 0 \\
\hline 057 & 1.0000 & 0.23474 & 0.00621 & 0.00483 & Biso & 1.000 & 0 \\
\hline 058 & 1.0000 & 0.66475 & 0.60285 & 0.34436 & Biso & 1.000 & 0 \\
\hline 059 & 1.0000 & 0.93253 & 0.36334 & 0.34484 & Biso & 1.000 & 0 \\
\hline 060 & 1.0000 & 0.32387 & 0.91627 & 0.68390 & Biso & 1.000 & 0 \\
\hline 061 & 1.0000 & 0.06226 & 0.40069 & 0.68140 & Biso & 1.000 & 0 \\
\hline 062 & 1.0000 & 0.59350 & 0.67617 & 0.68009 & Biso & 1.000 & 0 \\
\hline 063 & 1.0000 & 0.99207 & 0.75795 & 0.99957 & Biso & 1.000 & 0 \\
\hline 064 & 1.0000 & 0.25199 & 0.26909 & 0.98584 & Biso & 1.000 & 0 \\
\hline 065 & 1.0000 & 0.74058 & 0.01852 & 0.99536 & Biso & 1.000 & 0 \\
\hline 066 & 1.0000 & 0.64373 & 0.07909 & 0.32491 & Biso & 1.000 & 0 \\
\hline 067 & 1.0000 & 0.90891 & 0.59738 & 0.33148 & Biso & 1.000 & 0 \\
\hline 068 & 1.0000 & 0.40129 & 0.37954 & 0.31812 & Biso & 1.000 & 0 \\
\hline 069 & 1.0000 & 0.31516 & 0.42564 & 0.65443 & Biso & 1.000 & 0 \\
\hline 070 & 1.0000 & 0.57737 & 0.94761 & 0.66317 & Biso & 1.000 & 0 \\
\hline 071 & 1.0000 & 0.06469 & 0.70360 & 0.66585 & Biso & 1.000 & 0 \\
\hline 072 & 1.0000 & 0.37831 & 0.05639 & 0.33197 & Biso & 1.000 & 0 \\
\hline H 1 & 1.0000 & 0.10960 & 0.72243 & 0.26976 & Biso & 1.000 & $\mathrm{H}$ \\
\hline $\mathrm{C} 1$ & 1.0000 & 0.26697 & 0.88979 & 0.32666 & Biso & 1.000 & C \\
\hline H2 & 1.0000 & 0.26005 & 0.90071 & 0.25599 & Biso & 1.000 & $\mathrm{H}$ \\
\hline H3 & 1.0000 & 0.33138 & 0.87393 & 0.35105 & Biso & 1.000 & $\mathrm{H}$ \\
\hline H4 & 1.0000 & 0.21541 & 0.90218 & 0.37422 & Biso & 1.000 & $\mathrm{H}$ \\
\hline 073 & 1.0000 & 0.15960 & 0.73346 & 0.32041 & Biso & 1.000 & 0 \\
\hline C2 & 1.0000 & 0.20482 & 0.65972 & 0.31273 & Biso & 1.000 & C \\
\hline H5 & 1.0000 & 0.13577 & 0.57337 & 0.30902 & Biso & 1.000 & $\mathrm{H}$ \\
\hline H6 & 1.0000 & 0.25864 & 0.67961 & 0.25379 & & 1.000 & $\mathrm{H}$ \\
\hline
\end{tabular}




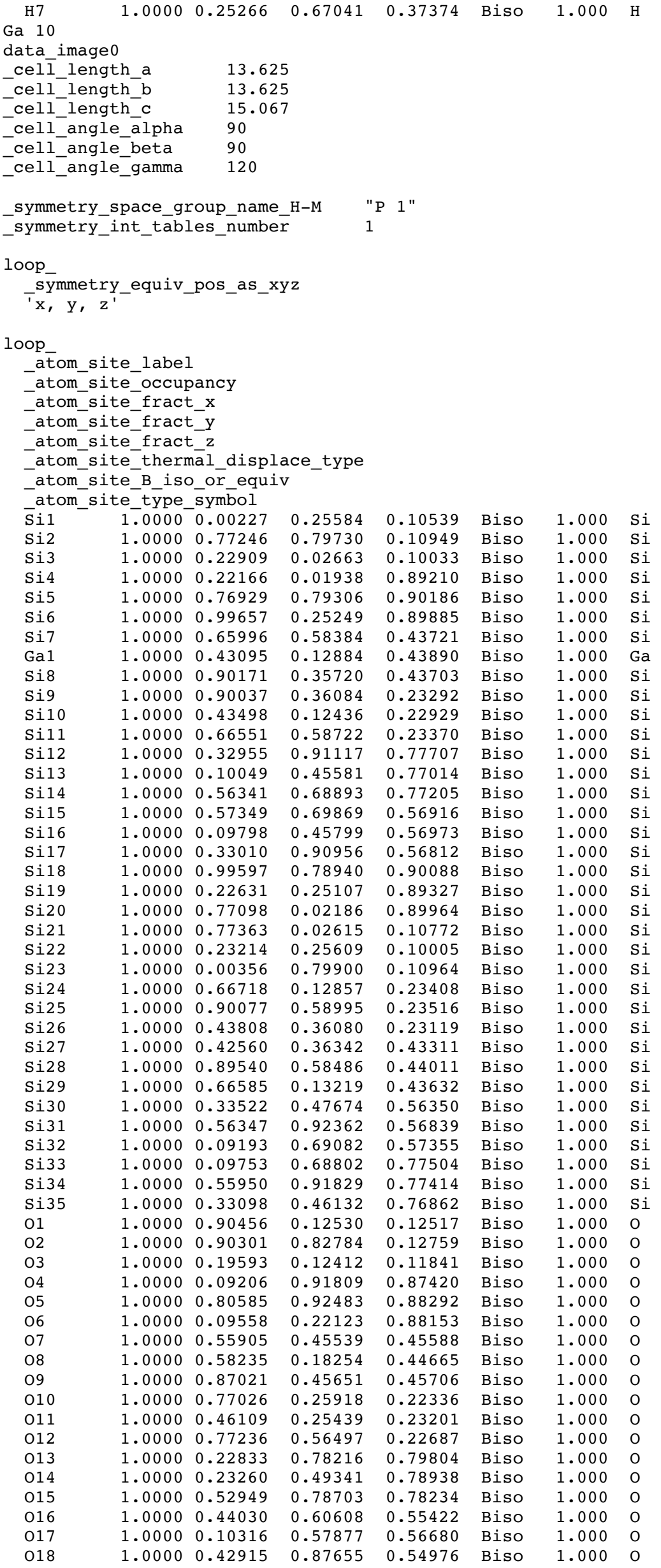




\begin{tabular}{|c|c|c|c|c|c|c|c|}
\hline 019 & 1.0000 & 0.98463 & 0.34302 & 0.16756 & Biso & 1.000 & 0 \\
\hline 020 & 1.0000 & 0.68550 & 0.69112 & 0.16997 & Biso & 1.000 & 0 \\
\hline 021 & 1.0000 & 0.34315 & 0.05200 & 0.15241 & Biso & 1.000 & 0 \\
\hline 022 & 1.0000 & 0.31088 & 0.00194 & 0.83347 & Biso & 1.000 & 0 \\
\hline 023 & 1.0000 & 0.66122 & 0.70782 & 0.84240 & Biso & 1.000 & 0 \\
\hline 024 & 1.0000 & 0.01619 & 0.35887 & 0.83870 & Biso & 1.000 & 0 \\
\hline 025 & 1.0000 & 0.65334 & 0.67430 & 0.50340 & Biso & 1.000 & 0 \\
\hline 026 & 1.0000 & 0.34180 & 0.01186 & 0.50988 & Biso & 1.000 & 0 \\
\hline 027 & 1.0000 & 0.00353 & 0.37116 & 0.50078 & Biso & 1.000 & 0 \\
\hline 028 & 1.0000 & 0.01245 & 0.69670 & 0.84577 & Biso & 1.000 & 0 \\
\hline 029 & 1.0000 & 0.31041 & 0.35377 & 0.82858 & Biso & 1.000 & 0 \\
\hline 030 & 1.0000 & 0.66368 & 0.99887 & 0.83919 & Biso & 1.000 & 0 \\
\hline 031 & 1.0000 & 0.68666 & 0.04659 & 0.16714 & Biso & 1.000 & 0 \\
\hline 032 & 1.0000 & 0.34035 & 0.34018 & 0.15989 & Biso & 1.000 & 0 \\
\hline 033 & 1.0000 & 0.98757 & 0.69498 & 0.17279 & Biso & 1.000 & 0 \\
\hline 034 & 1.0000 & 0.34542 & 0.39391 & 0.49305 & Biso & 1.000 & 0 \\
\hline 035 & 1.0000 & 0.99064 & 0.67571 & 0.50724 & Biso & 1.000 & 0 \\
\hline 036 & 1.0000 & 0.64150 & 0.02994 & 0.50475 & Biso & 1.000 & 0 \\
\hline 037 & 1.0000 & 0.12587 & 0.27199 & 0.12761 & Biso & 1.000 & 0 \\
\hline 038 & 1.0000 & 0.76155 & 0.90615 & 0.13703 & Biso & 1.000 & 0 \\
\hline 039 & 1.0000 & 0.12538 & 0.90682 & 0.13695 & Biso & 1.000 & 0 \\
\hline 040 & 1.0000 & 0.23336 & 0.13985 & 0.86606 & Biso & 1.000 & 0 \\
\hline 041 & 1.0000 & 0.87342 & 0.77339 & 0.87614 & Biso & 1.000 & 0 \\
\hline 042 & 1.0000 & 0.87649 & 0.14381 & 0.87169 & Biso & 1.000 & 0 \\
\hline 043 & 1.0000 & 0.78093 & 0.59009 & 0.45196 & Biso & 1.000 & 0 \\
\hline 044 & 1.0000 & 0.39408 & 0.23679 & 0.45329 & Biso & 1.000 & 0 \\
\hline 045 & 1.0000 & 0.79520 & 0.23340 & 0.45495 & Biso & 1.000 & 0 \\
\hline 046 & 1.0000 & 0.90731 & 0.47953 & 0.20500 & Biso & 1.000 & 0 \\
\hline 047 & 1.0000 & 0.55077 & 0.12442 & 0.20454 & Biso & 1.000 & o \\
\hline 048 & 1.0000 & 0.55393 & 0.47342 & 0.19996 & Biso & 1.000 & 0 \\
\hline 049 & 1.0000 & 0.44957 & 0.92430 & 0.80752 & Biso & 1.000 & 0 \\
\hline 050 & 1.0000 & 0.08354 & 0.56376 & 0.78412 & Biso & 1.000 & 0 \\
\hline 051 & 1.0000 & 0.45295 & 0.56801 & 0.79515 & Biso & 1.000 & 0 \\
\hline 052 & 1.0000 & 0.59234 & 0.82352 & 0.54749 & Biso & 1.000 & 0 \\
\hline 053 & 1.0000 & 0.22054 & 0.47883 & 0.54006 & Biso & 1.000 & 0 \\
\hline 054 & 1.0000 & 0.20933 & 0.79835 & 0.54196 & Biso & 1.000 & 0 \\
\hline 055 & 1.0000 & 0.99608 & 0.28695 & 0.00221 & Biso & 1.000 & 0 \\
\hline 056 & 1.0000 & 0.73767 & 0.76343 & 0.00627 & Biso & 1.000 & 0 \\
\hline 057 & 1.0000 & 0.25178 & 0.01782 & 0.99621 & Biso & 1.000 & 0 \\
\hline 058 & 1.0000 & 0.65301 & 0.62031 & 0.33506 & Biso & 1.000 & 0 \\
\hline 059 & 1.0000 & 0.94557 & 0.37049 & 0.33430 & Biso & 1.000 & 0 \\
\hline 060 & 1.0000 & 0.33053 & 0.93869 & 0.67297 & Biso & 1.000 & 0 \\
\hline 061 & 1.0000 & 0.06577 & 0.40562 & 0.66968 & Biso & 1.000 & 0 \\
\hline 062 & 1.0000 & 0.60898 & 0.69106 & 0.67155 & Biso & 1.000 & 0 \\
\hline 063 & 1.0000 & 0.00353 & 0.76592 & 0.00622 & Biso & 1.000 & 0 \\
\hline 064 & 1.0000 & 0.26569 & 0.28723 & 0.99602 & Biso & 1.000 & 0 \\
\hline 065 & 1.0000 & 0.73960 & 0.02287 & 0.00383 & Biso & 1.000 & 0 \\
\hline 066 & 1.0000 & 0.66017 & 0.08345 & 0.33499 & Biso & 1.000 & o \\
\hline 067 & 1.0000 & 0.94724 & 0.62503 & 0.33817 & Biso & 1.000 & 0 \\
\hline 068 & 1.0000 & 0.40148 & 0.38091 & 0.32882 & Biso & 1.000 & 0 \\
\hline 069 & 1.0000 & 0.32951 & 0.42994 & 0.66424 & Biso & 1.000 & 0 \\
\hline 070 & 1.0000 & 0.59306 & 0.96265 & 0.67229 & Biso & 1.000 & 0 \\
\hline 071 & 1.0000 & 0.06227 & 0.70709 & 0.67554 & Biso & 1.000 & 0 \\
\hline 072 & 1.0000 & 0.38200 & 0.06064 & 0.32394 & Biso & 1.000 & 0 \\
\hline H 1 & 1.0000 & 0.10610 & 0.70241 & 0.33535 & Biso & 1.000 & $\mathrm{H}$ \\
\hline $\mathrm{C} 1$ & 1.0000 & 0.28259 & 0.89241 & 0.32611 & Biso & 1.000 & $\mathrm{C}$ \\
\hline $\mathrm{H} 2$ & 1.0000 & 0.23729 & 0.90161 & 0.38168 & Biso & 1.000 & $\mathrm{H}$ \\
\hline H3 & 1.0000 & 0.25496 & 0.89185 & 0.25845 & Biso & 1.000 & $\mathrm{H}$ \\
\hline H4 & 1.0000 & 0.35585 & 0.88321 & 0.33921 & Biso & 1.000 & $\mathrm{H}$ \\
\hline 073 & 1.0000 & 0.18755 & 0.72552 & 0.33717 & Biso & 1.000 & 0 \\
\hline $\mathrm{C} 2$ & 1.0000 & 0.20995 & 0.66127 & 0.27208 & Biso & 1.000 & $\mathrm{C}$ \\
\hline H5 & 1.0000 & 0.15942 & 0.57057 & 0.28818 & Biso & 1.000 & $\mathrm{H}$ \\
\hline $\mathrm{H} 6$ & 1.0000 & 0.19024 & 0.67673 & 0.20443 & Biso & 1.000 & $\mathrm{H}$ \\
\hline H 7 & 1.0000 & 0.30020 & 0.68809 & 0.27739 & Biso & 1.000 & $\mathrm{H}$ \\
\hline \\
\hline \multicolumn{8}{|c|}{$\begin{array}{l}\mathrm{Ti} 10 \\
\text { data image } 0\end{array}$} \\
\hline \multicolumn{2}{|c|}{ celì length a } & \multicolumn{2}{|c|}{13.875} & & & & \\
\hline \multicolumn{2}{|c|}{ cell length b } & \multicolumn{2}{|c|}{13.875} & & & & \\
\hline cell & $t h c$ & 15.01 & & & & & \\
\hline cell & e àlpha & 90 & & & & & \\
\hline cell & beta & 90 & & & & & \\
\hline cell & gamma & 120 & & & & & \\
\hline & & & & $1 "$ & & & \\
\hline symm & nt tal & es numb & & & & & \\
\hline & $\mathrm{Ld}$ & 5 & & & & & \\
\hline op & & & & & & & \\
\hline & & & & & & & \\
\hline
\end{tabular}




\begin{tabular}{|c|c|c|c|c|c|c|c|}
\hline \multicolumn{8}{|l|}{-oop } \\
\hline \multicolumn{8}{|c|}{$\begin{array}{l}\text { oop_- } \\
\text { atom site label }\end{array}$} \\
\hline \multicolumn{8}{|c|}{ atom site occupancy } \\
\hline \multicolumn{8}{|c|}{ atom_site_fract_x } \\
\hline \multicolumn{8}{|c|}{ atom site fract y } \\
\hline \multicolumn{8}{|c|}{ _atom_site_fract_z } \\
\hline -ato & te ther & nāl displ & ace type & & & & \\
\hline $\begin{array}{l}\text {-ato } \\
\text { ato }\end{array}$ & $\begin{array}{l}\text { te_B_is } \\
\text { te type }\end{array}$ & $\begin{array}{l}\text { oror_equ } \\
\text { symb̄ol }\end{array}$ & & & & & \\
\hline$\overline{\mathrm{P}} 1$ & 1.0000 & 0.99920 & 0.24843 & 0.10997 & Biso & 1.000 & $\mathrm{P}$ \\
\hline $\mathrm{P} 2$ & 1.0000 & 0.76690 & 0.79441 & 0.11724 & Biso & 1.000 & $\mathrm{P}$ \\
\hline P3 & 1.0000 & 0.21865 & 0.01666 & 0.10249 & Biso & 1.000 & $\mathrm{P}$ \\
\hline Al1 & 1.0000 & 0.20701 & 0.00450 & 0.88867 & Biso & 1.000 & $\mathrm{Al}$ \\
\hline Al2 & 1.0000 & 0.76016 & 0.78601 & 0.90464 & Biso & 1.000 & Al \\
\hline Al3 & 1.0000 & 0.98947 & 0.24091 & 0.89803 & Biso & 1.000 & A] \\
\hline $\mathrm{P} 4$ & 1.0000 & 0.65606 & 0.57371 & 0.44479 & Biso & 1.000 & $\mathrm{P}$ \\
\hline Til & 1.0000 & 0.41326 & 0.11825 & 0.44375 & Biso & 1.000 & $\mathrm{Ti}$ \\
\hline P5 & 1.0000 & 0.89265 & 0.34517 & 0.44101 & Biso & 1.000 & $\mathrm{P}$ \\
\hline Al4 & 1.0000 & 0.89234 & 0.35194 & 0.23274 & Biso & 1.000 & Al \\
\hline Al5 & 1.0000 & 0.42965 & 0.12292 & 0.22708 & Biso & 1.000 & $A l$ \\
\hline Al 6 & 1.0000 & 0.66481 & 0.57993 & 0.23173 & Biso & 1.000 & $\mathrm{Al}$ \\
\hline P6 & 1.0000 & 0.32122 & 0.89454 & 0.78585 & Biso & 1.000 & $\mathrm{P}$ \\
\hline P7 & 1.0000 & 0.09208 & 0.44771 & 0.77543 & Biso & 1.000 & $\mathrm{P}$ \\
\hline P8 & 1.0000 & 0.55150 & 0.67495 & 0.77672 & Biso & 1.000 & $\mathrm{P}$ \\
\hline Al 7 & 1.0000 & 0.56544 & 0.68894 & 0.57056 & Biso & 1.000 & Al \\
\hline Al 8 & 1.0000 & 0.08651 & 0.44825 & 0.57293 & Biso & 1.000 & Al \\
\hline Al9 & 1.0000 & 0.32103 & 0.89083 & 0.57019 & Biso & 1.000 & Al \\
\hline P9 & 1.0000 & 0.98219 & 0.77563 & 0.90000 & Biso & 1.000 & $\mathrm{P}$ \\
\hline P10 & 1.0000 & 0.21484 & 0.23543 & 0.88545 & Biso & 1.000 & $\mathrm{P}$ \\
\hline $\mathrm{P} 11$ & 1.0000 & 0.76615 & 0.01453 & 0.89674 & Biso & 1.000 & $\mathrm{P}$ \\
\hline Al 10 & 1.0000 & 0.77199 & 0.02353 & 0.11004 & Biso & 1.000 & Al \\
\hline Al11 & 1.0000 & 0.22507 & 0.24524 & 0.09762 & Biso & 1.000 & $\mathrm{Al}$ \\
\hline Al 12 & 1.0000 & 0.99514 & 0.79118 & 0.11319 & Biso & 1.000 & $\mathrm{Al}$ \\
\hline $\mathrm{P} 12$ & 1.0000 & 0.65747 & 0.12358 & 0.22939 & Biso & 1.000 & $\mathrm{P}$ \\
\hline $\mathrm{P} 13$ & 1.0000 & 0.89161 & 0.57873 & 0.23218 & Biso & 1.000 & $\mathrm{P}$ \\
\hline P 14 & 1.0000 & 0.43491 & 0.35906 & 0.22449 & Biso & 1.000 & $\mathrm{P}$ \\
\hline Al13 & 1.0000 & 0.41438 & 0.36220 & 0.43080 & Biso & 1.000 & Al \\
\hline Al1 14 & 1.0000 & 0.88083 & 0.56784 & 0.44712 & Biso & 1.000 & $\mathrm{Al}$ \\
\hline Al15 & 1.0000 & 0.65427 & 0.12342 & 0.43812 & Biso & 1.000 & Al \\
\hline $\mathrm{P} 15$ & 1.0000 & 0.32330 & 0.47581 & 0.55825 & Biso & 1.000 & $\mathrm{P}$ \\
\hline P16 & 1.0000 & 0.55558 & 0.91247 & 0.56638 & Biso & 1.000 & $\mathrm{P}$ \\
\hline P17 & 1.0000 & 0.08312 & 0.68085 & 0.57205 & Biso & 1.000 & $\mathrm{P}$ \\
\hline Al16 & 1.0000 & 0.09034 & 0.67996 & 0.77694 & Biso & 1.000 & Al \\
\hline Al1 17 & 1.0000 & 0.54859 & 0.90413 & 0.77633 & Biso & 1.000 & Al \\
\hline Al18 & 1.0000 & 0.31878 & 0.45167 & 0.76739 & Biso & 1.000 & Al \\
\hline 01 & 1.0000 & 0.90889 & 0.12873 & 0.13399 & Biso & 1.000 & 0 \\
\hline 02 & 1.0000 & 0.88641 & 0.81722 & 0.13465 & Biso & 1.000 & 0 \\
\hline 03 & 1.0000 & 0.18809 & 0.10698 & 0.12250 & Biso & 1.000 & 0 \\
\hline 04 & 1.0000 & 0.07166 & 0.89337 & 0.87035 & Biso & 1.000 & 0 \\
\hline 05 & 1.0000 & 0.79825 & 0.92434 & 0.87979 & Biso & 1.000 & 0 \\
\hline 06 & 1.0000 & 0.09393 & 0.20948 & 0.87363 & Biso & 1.000 & 0 \\
\hline 07 & 1.0000 & 0.55273 & 0.45988 & 0.46103 & Biso & 1.000 & 0 \\
\hline 08 & 1.0000 & 0.56102 & 0.16882 & 0.45683 & Biso & 1.000 & 0 \\
\hline 09 & 1.0000 & 0.86319 & 0.43533 & 0.46626 & Biso & 1.000 & 0 \\
\hline 010 & 1.0000 & 0.75559 & 0.24415 & 0.22096 & Biso & 1.000 & 0 \\
\hline 011 & 1.0000 & 0.45635 & 0.26047 & 0.22782 & Biso & 1.000 & 0 \\
\hline 012 & 1.0000 & 0.77742 & 0.56010 & 0.20403 & Biso & 1.000 & 0 \\
\hline 013 & 1.0000 & 0.22568 & 0.77765 & 0.81180 & Biso & 1.000 & 0 \\
\hline 014 & 1.0000 & 0.21469 & 0.48381 & 0.79588 & Biso & 1.000 & 0 \\
\hline 015 & 1.0000 & 0.51927 & 0.76596 & 0.78406 & Biso & 1.000 & 0 \\
\hline 016 & 1.0000 & 0.42525 & 0.59321 & 0.55045 & Biso & 1.000 & 0 \\
\hline 017 & 1.0000 & 0.08065 & 0.56962 & 0.57164 & Biso & 1.000 & 0 \\
\hline 018 & 1.0000 & 0.43167 & 0.86668 & 0.54262 & Biso & 1.000 & 0 \\
\hline 019 & 1.0000 & 0.98453 & 0.33297 & 0.16588 & Biso & 1.000 & 0 \\
\hline 020 & 1.0000 & 0.68326 & 0.69760 & 0.17507 & Biso & 1.000 & 0 \\
\hline 021 & 1.0000 & 0.32911 & 0.04402 & 0.14613 & Biso & 1.000 & 0 \\
\hline 022 & 1.0000 & 0.30460 & 0.98448 & 0.83131 & Biso & 1.000 & 0 \\
\hline 023 & 1.0000 & 0.64174 & 0.69439 & 0.84498 & Biso & 1.000 & 0 \\
\hline 024 & 1.0000 & 0.01339 & 0.36068 & 0.84242 & Biso & 1.000 & 0 \\
\hline 025 & 1.0000 & 0.65062 & 0.66459 & 0.49939 & Biso & 1.000 & 0 \\
\hline 026 & 1.0000 & 0.32844 & 0.00313 & 0.51658 & Biso & 1.000 & 0 \\
\hline 027 & 1.0000 & 0.98683 & 0.35372 & 0.50020 & Biso & 1.000 & 0 \\
\hline 028 & 1.0000 & 0.99510 & 0.68680 & 0.84928 & Biso & 1.000 & 0 \\
\hline 029 & 1.0000 & 0.29399 & 0.33204 & 0.82524 & Biso & 1.000 & 0 \\
\hline 030 & 1.0000 & 0.66235 & 0.98989 & 0.84339 & Biso & 1.000 & 0 \\
\hline 031 & 1.0000 & 0.67648 & 0.04624 & 0.16773 & Biso & 1.000 & 0 \\
\hline 032 & 1.0000 & 0.34511 & 0.33787 & 0.15501 & Biso & 1.000 & 0 \\
\hline 033 & 1.0000 & 0.98575 & 0.68513 & 0.18576 & Biso & 1.000 & 0 \\
\hline 034 & 1.0000 & 0.32723 & 0.39755 & 0.48898 & Biso & 1.000 & 0 \\
\hline 035 & 1.0000 & 0.98997 & 0.67134 & 0.51044 & Biso & 1.000 & 0 \\
\hline
\end{tabular}




\begin{tabular}{|c|c|c|c|c|c|c|c|}
\hline 036 & 1.0000 & 0.63139 & 0.01193 & 0.50756 & Biso & 1.000 & 0 \\
\hline 037 & 1.0000 & 0.11458 & 0.26405 & 0.13008 & Biso & 1.000 & 0 \\
\hline 038 & 1.0000 & 0.76112 & 0.89806 & 0.14315 & Biso & 1.000 & 0 \\
\hline 039 & 1.0000 & 0.12549 & 0.90513 & 0.14072 & Biso & 1.000 & 0 \\
\hline 040 & 1.0000 & 0.22068 & 0.13192 & 0.85829 & Biso & 1.000 & $\mathrm{O}$ \\
\hline 041 & 1.0000 & 0.86764 & 0.76053 & 0.87830 & Biso & 1.000 & 0 \\
\hline 042 & 1.0000 & 0.86235 & 0.12748 & 0.86641 & Biso & 1.000 & 0 \\
\hline 043 & 1.0000 & 0.75959 & 0.56887 & 0.47385 & Biso & 1.000 & 0 \\
\hline O4 4 & 1.0000 & 0.38152 & 0.22885 & 0.45406 & Biso & 1.000 & 0 \\
\hline 045 & 1.0000 & 0.79217 & 0.22979 & 0.45397 & Biso & 1.000 & 0 \\
\hline 046 & 1.0000 & 0.90400 & 0.47989 & 0.20232 & Biso & 1.000 & 0 \\
\hline 047 & 1.0000 & 0.55176 & 0.12268 & 0.19825 & Biso & 1.000 & 0 \\
\hline 048 & 1.0000 & 0.54313 & 0.46359 & 0.19555 & Biso & 1.000 & 0 \\
\hline 049 & 1.0000 & 0.43245 & 0.90784 & 0.81761 & Biso & 1.000 & 0 \\
\hline 050 & 1.0000 & 0.07592 & 0.54854 & 0.78262 & Biso & 1.000 & 0 \\
\hline 051 & 1.0000 & 0.44876 & 0.56205 & 0.79772 & Biso & 1.000 & 0 \\
\hline 052 & 1.0000 & 0.58577 & 0.82139 & 0.55013 & Biso & 1.000 & $\mathrm{O}$ \\
\hline 053 & 1.0000 & 0.22009 & 0.48568 & 0.53884 & Biso & 1.000 & 0 \\
\hline 054 & 1.0000 & 0.19632 & 0.77161 & 0.53720 & Biso & 1.000 & 0 \\
\hline 055 & 1.0000 & 0.98992 & 0.27063 & 0.01109 & Biso & 1.000 & 0 \\
\hline 056 & 1.0000 & 0.73496 & 0.76431 & 0.01907 & Biso & 1.000 & 0 \\
\hline 057 & 1.0000 & 0.23072 & 0.00556 & 0.00257 & Biso & 1.000 & 0 \\
\hline 058 & 1.0000 & 0.66546 & 0.60516 & 0.34540 & Biso & 1.000 & 0 \\
\hline 059 & 1.0000 & 0.93459 & 0.36334 & 0.34373 & Biso & 1.000 & 0 \\
\hline 060 & 1.0000 & 0.32246 & 0.90908 & 0.68511 & Biso & 1.000 & 0 \\
\hline 061 & 1.0000 & 0.06120 & 0.39576 & 0.68160 & Biso & 1.000 & 0 \\
\hline 062 & 1.0000 & 0.59571 & 0.67548 & 0.68233 & Biso & 1.000 & 0 \\
\hline 063 & 1.0000 & 0.99241 & 0.75882 & 0.00055 & Biso & 1.000 & 0 \\
\hline 064 & 1.0000 & 0.25106 & 0.26714 & 0.98313 & Biso & 1.000 & 0 \\
\hline 065 & 1.0000 & 0.74271 & 0.01879 & 0.99637 & Biso & 1.000 & 0 \\
\hline 066 & 1.0000 & 0.64612 & 0.08090 & 0.32531 & Biso & 1.000 & 0 \\
\hline 067 & 1.0000 & 0.91002 & 0.59811 & 0.33284 & Biso & 1.000 & 0 \\
\hline 068 & 1.0000 & 0.39810 & 0.37908 & 0.31571 & Biso & 1.000 & 0 \\
\hline 069 & 1.0000 & 0.31655 & 0.42849 & 0.65251 & Biso & 1.000 & 0 \\
\hline 070 & 1.0000 & 0.57587 & 0.94865 & 0.66522 & Biso & 1.000 & 0 \\
\hline 071 & 1.0000 & 0.06384 & 0.70789 & 0.66793 & Biso & 1.000 & 0 \\
\hline 072 & 1.0000 & 0.37590 & 0.05543 & 0.32818 & Biso & 1.000 & 0 \\
\hline $\mathrm{H} 1$ & 1.0000 & 0.11001 & 0.72124 & 0.26855 & Biso & 1.000 & $\mathrm{H}$ \\
\hline $\mathrm{C} 1$ & 1.0000 & 0.26653 & 0.88792 & 0.32225 & Biso & 1.000 & $\mathrm{C}$ \\
\hline $\mathrm{H} 2$ & 1.0000 & 0.26162 & 0.89721 & 0.25105 & Biso & 1.000 & $\mathrm{H}$ \\
\hline H3 & 1.0000 & 0.33143 & 0.87462 & 0.34945 & Biso & 1.000 & $\mathrm{H}$ \\
\hline $\mathrm{H} 4$ & 1.0000 & 0.21412 & 0.90210 & 0.36756 & Biso & 1.000 & $\mathrm{H}$ \\
\hline 073 & 1.0000 & 0.16096 & 0.73314 & 0.31879 & Biso & 1.000 & 0 \\
\hline C2 & 1.0000 & 0.20649 & 0.65961 & 0.31148 & Biso & 1.000 & $\mathrm{C}$ \\
\hline H5 & 1.0000 & 0.13751 & 0.57321 & 0.30841 & Biso & 1.000 & $\mathrm{H}$ \\
\hline H6 & 1.0000 & 0.25987 & 0.67900 & 0.25232 & Biso & 1.000 & $\mathrm{H}$ \\
\hline H7 & 1.0000 & 0.25479 & 0.67112 & 0.37235 & Biso & 1.000 & $\mathrm{H}$ \\
\hline \multirow{2}{*}{\multicolumn{8}{|c|}{$\begin{array}{l}\mathrm{Zn} 11 \\
\text { data image } 0\end{array}$}} \\
\hline & & & & & & & \\
\hline \multicolumn{8}{|c|}{ celì length a $\quad 13.875$} \\
\hline \multicolumn{8}{|c|}{ cell length b $\quad 13.875$} \\
\hline \multicolumn{8}{|c|}{ _cell_length_c $\quad 15.017$} \\
\hline \multicolumn{8}{|c|}{ cell_angle_ālpha $\quad 90$} \\
\hline \multicolumn{8}{|c|}{ cell_angle_beta 90} \\
\hline \multicolumn{8}{|c|}{ _cell_angle_gamma } \\
\hline \multicolumn{8}{|c|}{ symmetry_space_group_name_H-M "P $1 "$} \\
\hline symme & int_tabl & Les_numbe & & & & & \\
\hline loop_ & & & & & & & \\
\hline $\begin{array}{l}\text { sym } \\
\text { 'x, }\end{array}$ & equiv & pos_as_x & & & & & \\
\hline loop_ & & & & & & & \\
\hline -ato & e_label & & & & & & \\
\hline ato & e_occup & pancy & & & & & \\
\hline -ato & e_fract & & & & & & \\
\hline -ato & e_fract & & & & & & \\
\hline -ato & $e_{-}^{-}$fract & $=-z$ & & & & & \\
\hline -ato & $e^{-}$therm & nàl_displ & ace_type & & & & \\
\hline -ato & e_B_iso & or_equi & & & & & \\
\hline $\bar{A} 11$ & 1.0000 & 0.00193 & 0.22036 & 0.10848 & Biso & 1.000 & Al \\
\hline Al2 & 1.0000 & 0.78012 & 0.76990 & 0.11130 & Biso & 1.000 & Al \\
\hline Al3 & 1.0000 & 0.23811 & 0.99959 & 0.10149 & Biso & 1.000 & Al \\
\hline P1 & 1.0000 & 0.23000 & 0.99669 & 0.89106 & Biso & 1.000 & $\mathrm{P}$ \\
\hline P2 & 1.0000 & 0.78015 & 0.76730 & 0.89801 & Biso & 1.000 & $\mathrm{P}$ \\
\hline P3 & 1.0000 & 0.00016 & 0.22055 & 0.89648 & Biso & 1.000 & $P$ \\
\hline Al4 & 1.0000 & 0.66586 & 0.55204 & 0.44062 & Biso & 1.000 & Al \\
\hline $\mathrm{Zn} 1$ & 1.0000 & 0.45783 & 0.11100 & 0.44635 & Biso & 1.000 & $\mathrm{Zn}$ \\
\hline
\end{tabular}




\begin{tabular}{|c|c|c|c|c|c|c|c|}
\hline Al5 & 1.0000 & 0.90685 & 0.33047 & 0.44120 & Biso & 1.000 & $\mathrm{Al}$ \\
\hline P4 & 1.0000 & 0.90209 & 0.33368 & 0.22980 & Biso & 1.000 & $\mathrm{P}$ \\
\hline P5 & 1.0000 & 0.44167 & 0.09864 & 0.22797 & Biso & 1.000 & $\mathrm{P}$ \\
\hline P6 & 1.0000 & 0.67006 & 0.55574 & 0.23084 & Biso & 1.000 & $\mathrm{P}$ \\
\hline Al6 & 1.0000 & 0.33365 & 0.88438 & 0.77363 & Biso & 1.000 & $\mathrm{Al}$ \\
\hline Al7 & 1.0000 & 0.11067 & 0.42955 & 0.77228 & Biso & 1.000 & Al \\
\hline Al8 & 1.0000 & 0.56923 & 0.66586 & 0.77470 & Biso & 1.000 & Al \\
\hline P7 & 1.0000 & 0.57814 & 0.67357 & 0.56681 & Biso & 1.000 & $\mathrm{P}$ \\
\hline P8 & 1.0000 & 0.11131 & 0.43237 & 0.56674 & Biso & 1.000 & $P$ \\
\hline P9 & 1.0000 & 0.33435 & 0.87915 & 0.56319 & Biso & 1.000 & $\mathrm{P}$ \\
\hline Al9 & 1.0000 & 0.00450 & 0.76580 & 0.90274 & Biso & 1.000 & $\mathrm{Al}$ \\
\hline Al10 & 1.0000 & 0.22953 & 0.22336 & 0.89696 & Biso & 1.000 & Al \\
\hline Al11 & 1.0000 & 0.77677 & 0.99203 & 0.90001 & Biso & 1.000 & Al \\
\hline P10 & 1.0000 & 0.77610 & 0.99327 & 0.11352 & Biso & 1.000 & $\mathrm{P}$ \\
\hline P11 & 1.0000 & 0.23239 & 0.22431 & 0.10963 & Biso & 1.000 & $\mathrm{P}$ \\
\hline P12 & 1.0000 & 0.00775 & 0.77342 & 0.11486 & Biso & 1.000 & $\mathrm{P}$ \\
\hline Al12 & 1.0000 & 0.67650 & 0.10328 & 0.23848 & Biso & 1.000 & Al \\
\hline Al13 & 1.0000 & 0.89905 & 0.55850 & 0.23534 & Biso & 1.000 & Al \\
\hline Al 14 & 1.0000 & 0.44320 & 0.32500 & 0.23203 & Biso & 1.000 & Al \\
\hline P13 & 1.0000 & 0.43388 & 0.32550 & 0.44346 & Biso & 1.000 & $\mathrm{P}$ \\
\hline P 14 & 1.0000 & 0.89559 & 0.55383 & 0.44690 & Biso & 1.000 & $\mathrm{P}$ \\
\hline P15 & 1.0000 & 0.68511 & 0.10944 & 0.44204 & Biso & 1.000 & $\mathrm{P}$ \\
\hline Al15 & 1.0000 & 0.34660 & 0.44824 & 0.56710 & Biso & 1.000 & Al \\
\hline Al16 & 1.0000 & 0.56421 & 0.89253 & 0.56916 & Biso & 1.000 & Al \\
\hline Al1 17 & 1.0000 & 0.10031 & 0.65936 & 0.57415 & Biso & 1.000 & $\mathrm{Al}$ \\
\hline P16 & 1.0000 & 0.10599 & 0.65813 & 0.78055 & Biso & 1.000 & $P$ \\
\hline P 17 & 1.0000 & 0.56249 & 0.89065 & 0.77956 & Biso & 1.000 & $\mathrm{P}$ \\
\hline P 18 & 1.0000 & 0.34167 & 0.43630 & 0.77544 & Biso & 1.000 & $P$ \\
\hline 01 & 1.0000 & 0.89764 & 0.08379 & 0.13345 & Biso & 1.000 & 0 \\
\hline $\mathrm{O} 2$ & 1.0000 & 0.91846 & 0.80555 & 0.13583 & Biso & 1.000 & 0 \\
\hline $\mathrm{O} 3$ & 1.0000 & 0.20664 & 0.10412 & 0.12926 & Biso & 1.000 & 0 \\
\hline 04 & 1.0000 & 0.10865 & 0.90247 & 0.87862 & Biso & 1.000 & 0 \\
\hline 05 & 1.0000 & 0.81098 & 0.88840 & 0.87787 & Biso & 1.000 & 0 \\
\hline 06 & 1.0000 & 0.09236 & 0.19206 & 0.87828 & Biso & 1.000 & 0 \\
\hline 07 & 1.0000 & 0.55746 & 0.41641 & 0.45590 & Biso & 1.000 & 0 \\
\hline 08 & 1.0000 & 0.61334 & 0.16425 & 0.44266 & Biso & 1.000 & 0 \\
\hline 09 & 1.0000 & 0.87528 & 0.43581 & 0.46476 & Biso & 1.000 & 0 \\
\hline 010 & 1.0000 & 0.78015 & 0.24174 & 0.21587 & Biso & 1.000 & 0 \\
\hline 011 & 1.0000 & 0.47408 & 0.22004 & 0.20599 & Biso & 1.000 & 0 \\
\hline 012 & 1.0000 & 0.76235 & 0.52680 & 0.21387 & Biso & 1.000 & 0 \\
\hline 013 & 1.0000 & 0.22810 & 0.74771 & 0.79741 & Biso & 1.000 & 0 \\
\hline 014 & 1.0000 & 0.24951 & 0.46563 & 0.79190 & Biso & 1.000 & 0 \\
\hline 015 & 1.0000 & 0.53347 & 0.76875 & 0.79247 & Biso & 1.000 & 0 \\
\hline 016 & 1.0000 & 0.45426 & 0.58602 & 0.55500 & Biso & 1.000 & 0 \\
\hline 017 & 1.0000 & 0.12261 & 0.54778 & 0.56142 & Biso & 1.000 & 0 \\
\hline 018 & 1.0000 & 0.42177 & 0.84129 & 0.55231 & Biso & 1.000 & 0 \\
\hline 019 & 1.0000 & 0.98093 & 0.31409 & 0.17065 & Biso & 1.000 & 0 \\
\hline 020 & 1.0000 & 0.68705 & 0.65242 & 0.17088 & Biso & 1.000 & 0 \\
\hline 021 & 1.0000 & 0.35478 & 0.01910 & 0.15998 & Biso & 1.000 & 0 \\
\hline 022 & 1.0000 & 0.30939 & 0.97866 & 0.83239 & Biso & 1.000 & 0 \\
\hline 023 & 1.0000 & 0.67704 & 0.68521 & 0.84536 & Biso & 1.000 & 0 \\
\hline $\mathrm{O} 24$ & 1.0000 & 0.01975 & 0.32181 & 0.84180 & Biso & 1.000 & 0 \\
\hline 025 & 1.0000 & 0.65122 & 0.64804 & 0.50582 & Biso & 1.000 & 0 \\
\hline 026 & 1.0000 & 0.35450 & 0.97333 & 0.50174 & Biso & 1.000 & o \\
\hline 027 & 1.0000 & 0.02385 & 0.35248 & 0.50070 & Biso & 1.000 & 0 \\
\hline 028 & 1.0000 & 0.02895 & 0.66993 & 0.84745 & Biso & 1.000 & 0 \\
\hline 029 & 1.0000 & 0.32290 & 0.33827 & 0.83471 & Biso & 1.000 & 0 \\
\hline 030 & 1.0000 & 0.65972 & 0.96801 & 0.84016 & Biso & 1.000 & 0 \\
\hline 031 & 1.0000 & 0.69414 & 0.01459 & 0.16600 & Biso & 1.000 & 0 \\
\hline 032 & 1.0000 & 0.33113 & 0.30741 & 0.16598 & Biso & 1.000 & 0 \\
\hline 033 & 1.0000 & 0.99241 & 0.67763 & 0.17552 & Biso & 1.000 & 0 \\
\hline 034 & 1.0000 & 0.35874 & 0.36131 & 0.49135 & Biso & 1.000 & 0 \\
\hline 035 & 1.0000 & 0.99015 & 0.63998 & 0.50569 & Biso & 1.000 & 0 \\
\hline 036 & 1.0000 & 0.64475 & 0.01059 & 0.50617 & Biso & 1.000 & 0 \\
\hline 037 & 1.0000 & 0.13004 & 0.23277 & 0.13620 & Biso & 1.000 & 0 \\
\hline 038 & 1.0000 & 0.76164 & 0.88063 & 0.14233 & Biso & 1.000 & 0 \\
\hline 039 & 1.0000 & 0.12274 & 0.87410 & 0.13493 & Biso & 1.000 & 0 \\
\hline 040 & 1.0000 & 0.23896 & 0.10763 & 0.86516 & Biso & 1.000 & 0 \\
\hline 041 & 1.0000 & 0.87732 & 0.75091 & 0.87005 & Biso & 1.000 & 0 \\
\hline 042 & 1.0000 & 0.88809 & 0.12103 & 0.86913 & Biso & 1.000 & 0 \\
\hline 043 & 1.0000 & 0.79015 & 0.55756 & 0.46961 & Biso & 1.000 & 0 \\
\hline 044 & 1.0000 & 0.41121 & 0.21487 & 0.48100 & Biso & 1.000 & 0 \\
\hline 045 & 1.0000 & 0.80427 & 0.19707 & 0.47074 & Biso & 1.000 & 0 \\
\hline 046 & 1.0000 & 0.91438 & 0.44620 & 0.20329 & Biso & 1.000 & 0 \\
\hline 047 & 1.0000 & 0.54534 & 0.08717 & 0.21975 & Biso & 1.000 & 0 \\
\hline 048 & 1.0000 & 0.55768 & 0.45440 & 0.20733 & Biso & 1.000 & 0 \\
\hline 049 & 1.0000 & 0.46123 & 0.90041 & 0.80688 & Biso & 1.000 & 0 \\
\hline 050 & 1.0000 & 0.09406 & 0.54339 & 0.79376 & Biso & 1.000 & 0 \\
\hline 051 & 1.0000 & 0.45424 & 0.53695 & 0.80002 & Biso & 1.000 & 0 \\
\hline 052 & 1.0000 & 0.59574 & 0.78843 & 0.54174 & Biso & 1.000 & 0 \\
\hline
\end{tabular}




\begin{tabular}{|c|c|c|c|c|c|c|c|}
\hline 053 & 1.0000 & 0.22267 & 0.44335 & 0.54102 & Biso & 1.000 & 0 \\
\hline 054 & 1.0000 & 0.21932 & 0.77857 & 0.54042 & Biso & 1.000 & 0 \\
\hline 055 & 1.0000 & 0.99908 & 0.24791 & 0.99562 & Biso & 1.000 & 0 \\
\hline 056 & 1.0000 & 0.75536 & 0.74236 & 0.99780 & Biso & 1.000 & 0 \\
\hline 057 & 1.0000 & 0.26489 & 0.00009 & 0.98882 & Biso & 1.000 & 0 \\
\hline 058 & 1.0000 & 0.67271 & 0.59075 & 0.32841 & Biso & 1.000 & 0 \\
\hline 059 & 1.0000 & 0.39033 & 0.06499 & 0.32211 & Biso & 1.000 & 0 \\
\hline 060 & 1.0000 & 0.93719 & 0.33619 & 0.32726 & Biso & 1.000 & 0 \\
\hline 061 & 1.0000 & 0.33414 & 0.91298 & 0.66127 & Biso & 1.000 & 0 \\
\hline 062 & 1.0000 & 0.07687 & 0.38503 & 0.66164 & Biso & 1.000 & 0 \\
\hline 063 & 1.0000 & 0.61317 & 0.67272 & 0.66422 & Biso & 1.000 & 0 \\
\hline 064 & 1.0000 & 0.00077 & 0.73827 & 0.01713 & Biso & 1.000 & 0 \\
\hline 065 & 1.0000 & 0.26019 & 0.25169 & 0.01058 & Biso & 1.000 & 0 \\
\hline 066 & 1.0000 & 0.75079 & 0.99222 & 0.01388 & Biso & 1.000 & 0 \\
\hline 067 & 1.0000 & 0.68983 & 0.06681 & 0.34727 & Biso & 1.000 & 0 \\
\hline 068 & 1.0000 & 0.92902 & 0.58704 & 0.34879 & Biso & 1.000 & 0 \\
\hline 069 & 1.0000 & 0.40419 & 0.31692 & 0.34301 & Biso & 1.000 & 0 \\
\hline 070 & 1.0000 & 0.34184 & 0.40381 & 0.67740 & Biso & 1.000 & 0 \\
\hline 071 & 1.0000 & 0.59551 & 0.92687 & 0.68238 & Biso & 1.000 & 0 \\
\hline 072 & 1.0000 & 0.06974 & 0.66950 & 0.68589 & Biso & 1.000 & 0 \\
\hline $\mathrm{C} 1$ & 1.0000 & 0.21454 & 0.99356 & 0.34431 & Biso & 1.000 & $\mathrm{C}$ \\
\hline $\mathrm{H} 1$ & 1.0000 & 0.21154 & 0.03332 & 0.28293 & Biso & 1.000 & $\mathrm{H}$ \\
\hline $\mathrm{H} 2$ & 1.0000 & 0.23926 & 0.04510 & 0.40392 & Biso & 1.000 & $\mathrm{H}$ \\
\hline $\mathrm{C} 2$ & 1.0000 & 0.02503 & 0.95279 & 0.38480 & Biso & 1.000 & $\mathrm{C}$ \\
\hline C3 & 1.0000 & 0.04741 & 0.04384 & 0.33615 & Biso & 1.000 & $\mathrm{C}$ \\
\hline $\mathrm{H} 3$ & 1.0000 & 0.02512 & 0.03227 & 0.26532 & Biso & 1.000 & $\mathrm{H}$ \\
\hline $\mathrm{C} 4$ & 1.0000 & 0.10105 & 0.15965 & 0.37042 & Biso & 1.000 & $\mathrm{C}$ \\
\hline $\mathrm{H} 4$ & 1.0000 & 0.98077 & 0.86970 & 0.35571 & Biso & 1.000 & $\mathrm{H}$ \\
\hline H5 & 1.0000 & 0.04069 & 0.95836 & 0.45648 & Biso & 1.000 & $\mathrm{H}$ \\
\hline H6 & 1.0000 & 0.12053 & 0.16530 & 0.44176 & Biso & 1.000 & $\mathrm{H}$ \\
\hline H7 & 1.0000 & 0.04613 & 0.19471 & 0.35908 & Biso & 1.000 & $\mathrm{H}$ \\
\hline H8 & 1.0000 & 0.17827 & 0.21456 & 0.33369 & Biso & 1.000 & $\mathrm{H}$ \\
\hline C5 & 1.0000 & 0.18129 & 0.87476 & 0.34784 & Biso & 1.000 & C \\
\hline H9 & 1.0000 & 0.12774 & 0.82726 & 0.29215 & Biso & 1.000 & $\mathrm{H}$ \\
\hline $\mathrm{H} 10$ & 1.0000 & 0.14430 & 0.83703 & 0.41204 & Biso & 1.000 & $\mathrm{H}$ \\
\hline H 11 & 1.0000 & 0.25815 & 0.87005 & 0.34309 & Biso & 1.000 & $\mathrm{H}$ \\
\hline \\
\hline \\
\hline & & \\
\hline cell & & \multicolumn{6}{|c|}{$\begin{array}{l}13.875 \\
13.875\end{array}$} \\
\hline _cell & th_c & \multicolumn{6}{|c|}{15.017} \\
\hline -cell & e_talpha & \multicolumn{6}{|c|}{90} \\
\hline cell & e_beta & \multicolumn{6}{|l|}{90} \\
\hline cell & e_gamma & \multicolumn{6}{|l|}{120} \\
\hline _symme & space_g & coup_name & & $1 "$ & & & \\
\hline symm & int_tab. & les_numbe & & & & & \\
\hline loop_ & & & & & & & \\
\hline $\begin{array}{c}\text { syr } \\
\text { 'x, }\end{array}$ & _equiv & pos_as_x & & & & & \\
\hline loop_ & & & & & & & \\
\hline atc & Ce_labe & & & & & & \\
\hline -atc & ce_occur & bancy & & & & & \\
\hline -atc & ee_fract & E_ $x$ & & & & & \\
\hline atc & ce_fract & & & & & & \\
\hline -atc & ee_fract & $z$ & & & & & \\
\hline $\begin{array}{l}- \text { atc } \\
\text {-atc }\end{array}$ & $\begin{array}{l}\text { Ce-therr } \\
\text { ce_B_isc }\end{array}$ & $\begin{array}{l}\text { nàl_displ } \\
\text { onor_equi }\end{array}$ & ce_type & & & & \\
\hline -atc & te_type & symb̄ol & & & & & \\
\hline$\overline{\mathrm{P}} 1$ & 1.0000 & 0.01028 & 0.22416 & 0.11359 & Biso & 1.000 & $\mathrm{P}$ \\
\hline P2 & 1.0000 & 0.78121 & 0.77496 & 0.11491 & Biso & 1.000 & $\mathrm{P}$ \\
\hline P3 & 1.0000 & 0.23544 & 0.99586 & 0.10827 & Biso & 1.000 & $\mathrm{P}$ \\
\hline Al1 & 1.0000 & 0.22967 & 0.99209 & 0.89564 & Biso & 1.000 & Al \\
\hline Al2 & 1.0000 & 0.77771 & 0.77104 & 0.90155 & Biso & 1.000 & Al \\
\hline A13 & 1.0000 & 0.00749 & 0.22467 & 0.90153 & Biso & 1.000 & Al \\
\hline P 4 & 1.0000 & 0.67720 & 0.56028 & 0.44449 & Biso & 1.000 & $\mathrm{P}$ \\
\hline Sil & 1.0000 & 0.43810 & 0.10409 & 0.44399 & Biso & 1.000 & $\mathrm{Si}$ \\
\hline P5 & 1.0000 & 0.90053 & 0.32400 & 0.44554 & Biso & 1.000 & $\mathrm{P}$ \\
\hline Al4 & 1.0000 & 0.90089 & 0.32831 & 0.23424 & Biso & 1.000 & Al \\
\hline Al5 & 1.0000 & 0.44214 & 0.10411 & 0.23531 & Biso & 1.000 & Al \\
\hline Al 6 & 1.0000 & 0.67882 & 0.56021 & 0.23521 & Biso & 1.000 & Al \\
\hline P6 & 1.0000 & 0.34103 & 0.88706 & 0.78111 & Biso & 1.000 & $\mathrm{P}$ \\
\hline P7 & 1.0000 & 0.10848 & 0.43364 & 0.77735 & Biso & 1.000 & $\mathrm{P}$ \\
\hline P8 & 1.0000 & 0.56618 & 0.65890 & 0.77861 & Biso & 1.000 & $\mathrm{P}$ \\
\hline Al7 & 1.0000 & 0.57329 & 0.66471 & 0.57040 & Biso & 1.000 & Al \\
\hline Al8 & 1.0000 & 0.10620 & 0.43259 & 0.57039 & Biso & 1.000 & Al \\
\hline Al9 & 1.0000 & 0.34394 & 0.88745 & 0.56859 & Biso & 1.000 & Al \\
\hline P9 & 1.0000 & 0.00023 & 0.76437 & 0.89692 & Biso & 1.000 & $\mathrm{P}$ \\
\hline
\end{tabular}




\begin{tabular}{|c|c|c|c|c|c|c|c|}
\hline P10 & 1.0000 & 0.23323 & 0.22014 & 0.89273 & Biso & 1.000 & $\mathrm{P}$ \\
\hline P11 & 1.0000 & 0.78191 & 0.99909 & 0.89634 & Biso & 1.000 & $\mathrm{P}$ \\
\hline Al10 & 1.0000 & 0.78083 & 0.00047 & 0.10942 & Biso & 1.000 & Al \\
\hline Al11 & 1.0000 & 0.23892 & 0.22478 & 0.10469 & Biso & 1.000 & Al \\
\hline Al12 & 1.0000 & 0.00497 & 0.77038 & 0.10881 & Biso & 1.000 & Al \\
\hline P12 & 1.0000 & 0.67365 & 0.10375 & 0.23128 & Biso & 1.000 & $\mathrm{P}$ \\
\hline P13 & 1.0000 & 0.90530 & 0.55812 & 0.23227 & Biso & 1.000 & $\mathrm{P}$ \\
\hline P14 & 1.0000 & 0.44793 & 0.33430 & 0.22871 & Biso & 1.000 & $\mathrm{P}$ \\
\hline Al13 & 1.0000 & 0.44269 & 0.33271 & 0.43982 & Biso & 1.000 & Al \\
\hline Al14 & 1.0000 & 0.90236 & 0.55491 & 0.44336 & Biso & 1.000 & Al \\
\hline Al15 & 1.0000 & 0.66897 & 0.10270 & 0.43740 & Biso & 1.000 & Al \\
\hline P15 & 1.0000 & 0.33915 & 0.44263 & 0.56187 & Biso & 1.000 & $\mathrm{P}$ \\
\hline P16 & 1.0000 & 0.57132 & 0.89142 & 0.56611 & Biso & 1.000 & $\mathrm{P}$ \\
\hline P17 & 1.0000 & 0.10936 & 0.66668 & 0.56757 & Biso & 1.000 & $\mathrm{P}$ \\
\hline Al16 & 1.0000 & 0.11113 & 0.66540 & 0.77564 & Biso & 1.000 & Al \\
\hline Al17 & 1.0000 & 0.56882 & 0.88994 & 0.77437 & Biso & 1.000 & Al \\
\hline Al18 & 1.0000 & 0.33618 & 0.43385 & 0.77132 & Biso & 1.000 & Al \\
\hline 01 & 1.0000 & 0.91894 & 0.10324 & 0.13379 & Biso & 1.000 & 0 \\
\hline $\mathrm{O} 2$ & 1.0000 & 0.90329 & 0.80658 & 0.13366 & Biso & 1.000 & 0 \\
\hline 03 & 1.0000 & 0.20739 & 0.08810 & 0.13064 & Biso & 1.000 & 0 \\
\hline 04 & 1.0000 & 0.09289 & 0.88447 & 0.87700 & Biso & 1.000 & 0 \\
\hline 05 & 1.0000 & 0.81247 & 0.90834 & 0.87733 & Biso & 1.000 & 0 \\
\hline 06 & 1.0000 & 0.11192 & 0.19228 & 0.87938 & Biso & 1.000 & 0 \\
\hline 07 & 1.0000 & 0.58038 & 0.44129 & 0.45658 & Biso & 1.000 & 0 \\
\hline 08 & 1.0000 & 0.56800 & 0.13887 & 0.43997 & Biso & 1.000 & 0 \\
\hline 09 & 1.0000 & 0.87786 & 0.42045 & 0.46326 & Biso & 1.000 & 0 \\
\hline 010 & 1.0000 & 0.76316 & 0.22595 & 0.21171 & Biso & 1.000 & 0 \\
\hline 011 & 1.0000 & 0.47655 & 0.24203 & 0.21108 & Biso & 1.000 & 0 \\
\hline 012 & 1.0000 & 0.78376 & 0.52710 & 0.21478 & Biso & 1.000 & 0 \\
\hline 013 & 1.0000 & 0.24774 & 0.76720 & 0.80199 & Biso & 1.000 & 0 \\
\hline 014 & 1.0000 & 0.23089 & 0.46592 & 0.79252 & Biso & 1.000 & 0 \\
\hline 015 & 1.0000 & 0.53678 & 0.75163 & 0.78899 & Biso & 1.000 & 0 \\
\hline 016 & 1.0000 & 0.43408 & 0.56385 & 0.55062 & Biso & 1.000 & 0 \\
\hline 017 & 1.0000 & 0.12599 & 0.56594 & 0.55730 & Biso & 1.000 & 0 \\
\hline 018 & 1.0000 & 0.44631 & 0.84890 & 0.55262 & Biso & 1.000 & 0 \\
\hline 019 & 1.0000 & 0.99439 & 0.30586 & 0.17185 & Biso & 1.000 & 0 \\
\hline 020 & 1.0000 & 0.70121 & 0.67358 & 0.17018 & Biso & 1.000 & 0 \\
\hline 021 & 1.0000 & 0.33698 & 0.01337 & 0.16128 & Biso & 1.000 & 0 \\
\hline $\mathrm{O} 22$ & 1.0000 & 0.32483 & 0.97079 & 0.83661 & Biso & 1.000 & 0 \\
\hline 023 & 1.0000 & 0.65941 & 0.67708 & 0.84319 & Biso & 1.000 & 0 \\
\hline $\mathrm{O} 24$ & 1.0000 & 0.03162 & 0.34214 & 0.84227 & Biso & 1.000 & 0 \\
\hline 025 & 1.0000 & 0.66315 & 0.64223 & 0.50394 & Biso & 1.000 & 0 \\
\hline 026 & 1.0000 & 0.36405 & 0.99839 & 0.50702 & Biso & 1.000 & 0 \\
\hline $\mathrm{O} 27$ & 1.0000 & 0.99942 & 0.33855 & 0.50174 & Biso & 1.000 & 0 \\
\hline 028 & 1.0000 & 0.01721 & 0.68039 & 0.84310 & Biso & 1.000 & 0 \\
\hline O29 & 1.0000 & 0.31281 & 0.31894 & 0.83487 & Biso & 1.000 & 0 \\
\hline 030 & 1.0000 & 0.68037 & 0.97880 & 0.84188 & Biso & 1.000 & 0 \\
\hline 031 & 1.0000 & 0.68637 & 0.02564 & 0.16580 & Biso & 1.000 & 0 \\
\hline 032 & 1.0000 & 0.35317 & 0.31958 & 0.16666 & Biso & 1.000 & 0 \\
\hline 033 & 1.0000 & 0.98514 & 0.65849 & 0.17497 & Biso & 1.000 & 0 \\
\hline 034 & 1.0000 & 0.35284 & 0.36519 & 0.49757 & Biso & 1.000 & 0 \\
\hline 035 & 1.0000 & 0.01390 & 0.65321 & 0.50699 & Biso & 1.000 & 0 \\
\hline 036 & 1.0000 & 0.64306 & 0.98842 & 0.50393 & Biso & 1.000 & 0 \\
\hline 037 & 1.0000 & 0.12363 & 0.23601 & 0.13619 & Biso & 1.000 & 0 \\
\hline 038 & 1.0000 & 0.76633 & 0.87315 & 0.14235 & Biso & 1.000 & 0 \\
\hline 039 & 1.0000 & 0.13474 & 0.88395 & 0.13599 & Biso & 1.000 & 0 \\
\hline 040 & 1.0000 & 0.24237 & 0.11887 & 0.86465 & Biso & 1.000 & 0 \\
\hline 041 & 1.0000 & 0.88815 & 0.75227 & 0.87037 & Biso & 1.000 & 0 \\
\hline 042 & 1.0000 & 0.88027 & 0.11227 & 0.86942 & Biso & 1.000 & 0 \\
\hline 043 & 1.0000 & 0.78593 & 0.56442 & 0.47135 & Biso & 1.000 & 0 \\
\hline 044 & 1.0000 & 0.42228 & 0.20704 & 0.47398 & Biso & 1.000 & 0 \\
\hline 045 & 1.0000 & 0.79862 & 0.21386 & 0.47147 & Biso & 1.000 & 0 \\
\hline 046 & 1.0000 & 0.92011 & 0.45928 & 0.20708 & Biso & 1.000 & 0 \\
\hline 047 & 1.0000 & 0.55864 & 0.09065 & 0.21646 & Biso & 1.000 & 0 \\
\hline 048 & 1.0000 & 0.55047 & 0.44718 & 0.20722 & Biso & 1.000 & 0 \\
\hline 049 & 1.0000 & 0.45303 & 0.89859 & 0.80734 & Biso & 1.000 & 0 \\
\hline 050 & 1.0000 & 0.09577 & 0.53518 & 0.79490 & Biso & 1.000 & 0 \\
\hline 051 & 1.0000 & 0.46356 & 0.54716 & 0.80205 & Biso & 1.000 & 0 \\
\hline 052 & 1.0000 & 0.59404 & 0.79618 & 0.54529 & Biso & 1.000 & 0 \\
\hline 053 & 1.0000 & 0.22876 & 0.43701 & 0.53945 & Biso & 1.000 & 0 \\
\hline 054 & 1.0000 & 0.21564 & 0.77136 & 0.53868 & Biso & 1.000 & 0 \\
\hline 055 & 1.0000 & 0.00611 & 0.25212 & 0.01520 & Biso & 1.000 & 0 \\
\hline 056 & 1.0000 & 0.75360 & 0.74711 & 0.01590 & Biso & 1.000 & 0 \\
\hline 057 & 1.0000 & 0.25968 & 0.99603 & 0.00895 & Biso & 1.000 & 0 \\
\hline 058 & 1.0000 & 0.68448 & 0.59816 & 0.34691 & Biso & 1.000 & 0 \\
\hline 059 & 1.0000 & 0.38520 & 0.06571 & 0.34146 & Biso & 1.000 & 0 \\
\hline 060 & 1.0000 & 0.93095 & 0.32399 & 0.34674 & Biso & 1.000 & 0 \\
\hline 061 & 1.0000 & 0.33910 & 0.91334 & 0.68247 & Biso & 1.000 & 0 \\
\hline 062 & 1.0000 & 0.07296 & 0.39055 & 0.68157 & Biso & 1.000 & 0 \\
\hline 063 & 1.0000 & 0.60482 & 0.65746 & 0.68271 & Biso & 1.000 & 0 \\
\hline
\end{tabular}




\begin{tabular}{|c|c|c|c|c|c|c|c|}
\hline 064 & 1.0000 & 0.00024 & 0.73762 & 0.99647 & Biso & 1.000 & 0 \\
\hline 065 & 1.0000 & 0.26680 & 0.24963 & 0.99109 & Biso & 1.000 & 0 \\
\hline 066 & 1.0000 & 0.75521 & 0.99903 & 0.99567 & Biso & 1.000 & 0 \\
\hline 067 & 1.0000 & 0.68713 & 0.07117 & 0.32632 & Biso & 1.000 & 0 \\
\hline 068 & 1.0000 & 0.93600 & 0.59017 & 0.33070 & Biso & 1.000 & 0 \\
\hline 069 & 1.0000 & 0.41040 & 0.33133 & 0.32537 & Biso & 1.000 & 0 \\
\hline 070 & 1.0000 & 0.33704 & 0.40332 & 0.65836 & Biso & 1.000 & 0 \\
\hline 071 & 1.0000 & 0.60445 & 0.93044 & 0.66338 & Biso & 1.000 & 0 \\
\hline 072 & 1.0000 & 0.07982 & 0.67718 & 0.66456 & Biso & 1.000 & 0 \\
\hline $\mathrm{C} 1$ & 1.0000 & 0.20081 & 0.98813 & 0.35285 & Biso & 1.000 & $\mathrm{C}$ \\
\hline H 1 & 1.0000 & 0.20896 & 0.03299 & 0.29155 & Biso & 1.000 & $\mathrm{H}$ \\
\hline H 2 & 1.0000 & 0.22019 & 0.03553 & 0.41443 & Biso & 1.000 & $\mathrm{H}$ \\
\hline $\mathrm{C} 2$ & 1.0000 & 0.01430 & 0.94421 & 0.38166 & Biso & 1.000 & $\mathrm{C}$ \\
\hline C3 & 1.0000 & 0.04087 & 0.03565 & 0.33166 & Biso & 1.000 & $\mathrm{C}$ \\
\hline H3 & 1.0000 & 0.02362 & 0.02421 & 0.25999 & Biso & 1.000 & $\mathrm{H}$ \\
\hline $\mathrm{C} 4$ & 1.0000 & 0.09285 & 0.15141 & 0.36570 & Biso & 1.000 & $\mathrm{C}$ \\
\hline H4 & 1.0000 & 0.97088 & 0.86118 & 0.35243 & Biso & 1.000 & $\mathrm{H}$ \\
\hline H5 & 1.0000 & 0.02385 & 0.94941 & 0.45405 & Biso & 1.000 & $\mathrm{H}$ \\
\hline H6 & 1.0000 & 0.10858 & 0.15713 & 0.43771 & Biso & 1.000 & $\mathrm{H}$ \\
\hline H7 & 1.0000 & 0.03845 & 0.18632 & 0.35114 & Biso & 1.000 & $\mathrm{H}$ \\
\hline H8 & 1.0000 & 0.17163 & 0.20638 & 0.33081 & Biso & 1.000 & $\mathrm{H}$ \\
\hline $\mathrm{C} 5$ & 1.0000 & 0.17120 & 0.87009 & 0.35192 & Biso & 1.000 & $\mathrm{C}$ \\
\hline H9 & 1.0000 & 0.12160 & 0.82558 & 0.29358 & Biso & 1.000 & $\mathrm{H}$ \\
\hline H10 & 1.0000 & 0.13108 & 0.82673 & 0.41363 & Biso & 1.000 & $\mathrm{H}$ \\
\hline Н11 & 1.0000 & 0.24983 & 0.86877 & 0.34706 & Biso & 1.000 & $\mathrm{H}$ \\
\hline \multicolumn{8}{|c|}{$\operatorname{Mg} 11$} \\
\hline \multicolumn{8}{|c|}{ data_image 0} \\
\hline \\
\hline $\mathrm{cell}$ & & & & & \\
\hline $\mathrm{cell}$ & \multicolumn{6}{|c|}{15.017} & \\
\hline $\mathrm{cell}$ & \multicolumn{7}{|l|}{ - } \\
\hline cell & beta & 90 & & & & & \\
\hline $\mathrm{cell}_{2}$ & gamma & 120 & & & & & \\
\hline symme & pace_g & coup_nam & & $1 "$ & & & \\
\hline symme & at $t \bar{a} b$ & les_numbe & & & & & \\
\hline & & & & & & & \\
\hline $\begin{array}{c}\text { sym } \\
\text { 'x, }\end{array}$ & equiv & pos_as_r & & & & & \\
\hline op_ & & & & & & & \\
\hline ato & Ee_labe & & & & & & \\
\hline -ato & ee_occur & pancy & & & & & \\
\hline -ato & $=e_{-}^{-}$frac & E $x$ & & & & & \\
\hline ato & $=e_{-}^{-}$frac & - $y$ & & & & & \\
\hline -ato & $=e_{-}^{-} f r a c$ & - $z$ & & & & & \\
\hline -ato & e-therr & nāl_displ & ace_type & & & & \\
\hline -ato & e_B_is & o_or_equi & & & & & \\
\hline -ato & =e_type & symbol & & & & & \\
\hline $\bar{A} 11$ & 1.0000 & 0.00255 & 0.22109 & 0.10885 & Biso & 1.000 & Al \\
\hline Al2 & 1.0000 & 0.78202 & 0.77189 & 0.11217 & Biso & 1.000 & Al \\
\hline Al3 & 1.0000 & 0.23942 & 0.00080 & 0.10082 & Biso & 1.000 & Al \\
\hline P1 & 1.0000 & 0.22957 & 0.99617 & 0.89046 & Biso & 1.000 & $P$ \\
\hline P2 & 1.0000 & 0.78066 & 0.76818 & 0.89861 & Biso & 1.000 & $\mathrm{P}$ \\
\hline P3 & 1.0000 & 0.99942 & 0.22097 & 0.89656 & Biso & 1.000 & $\mathrm{P}$ \\
\hline Al4 & 1.0000 & 0.66648 & 0.55371 & 0.44057 & Biso & 1.000 & Al \\
\hline $\operatorname{Mg} 1$ & 1.0000 & 0.45220 & 0.10825 & 0.44588 & Biso & 1.000 & $\mathrm{Mg}$ \\
\hline Al5 & 1.0000 & 0.90734 & 0.33024 & 0.44186 & Biso & 1.000 & $\mathrm{Al}$ \\
\hline P 4 & 1.0000 & 0.90286 & 0.33421 & 0.23020 & Biso & 1.000 & $P$ \\
\hline P5 & 1.0000 & 0.44213 & 0.09993 & 0.22861 & Biso & 1.000 & $\mathrm{P}$ \\
\hline P6 & 1.0000 & 0.67155 & 0.55683 & 0.23086 & Biso & 1.000 & $\mathrm{P}$ \\
\hline Al6 & 1.0000 & 0.33241 & 0.88163 & 0.77573 & Biso & 1.000 & $\mathrm{Al}$ \\
\hline Al7 & 1.0000 & 0.10985 & 0.42871 & 0.77200 & Biso & 1.000 & Al \\
\hline Al 8 & 1.0000 & 0.56903 & 0.66490 & 0.77546 & Biso & 1.000 & Al \\
\hline P7 & 1.0000 & 0.58088 & 0.67338 & 0.56816 & Biso & 1.000 & $P$ \\
\hline P8 & 1.0000 & 0.11044 & 0.43172 & 0.56769 & Biso & 1.000 & $\mathrm{P}$ \\
\hline P9 & 1.0000 & 0.33491 & 0.87494 & 0.56407 & Biso & 1.000 & $\mathrm{P}$ \\
\hline Al9 & 1.0000 & 0.00367 & 0.76439 & 0.90312 & Biso & 1.000 & $\mathrm{Al}$ \\
\hline Al10 & 1.0000 & 0.22845 & 0.22274 & 0.89564 & Biso & 1.000 & $\mathrm{Al}$ \\
\hline Al11 & 1.0000 & 0.77718 & 0.99212 & 0.90053 & Biso & 1.000 & Al \\
\hline $\mathrm{P} 10$ & 1.0000 & 0.77692 & 0.99411 & 0.11447 & Biso & 1.000 & $\mathrm{P}$ \\
\hline P 11 & 1.0000 & 0.23306 & 0.22507 & 0.10851 & Biso & 1.000 & $\mathrm{P}$ \\
\hline $\mathrm{P} 12$ & 1.0000 & 0.00898 & 0.77432 & 0.11518 & Biso & 1.000 & $\mathrm{P}$ \\
\hline Al 12 & 1.0000 & 0.67762 & 0.10463 & 0.23873 & Biso & 1.000 & Al \\
\hline Al13 & 1.0000 & 0.90090 & 0.55990 & 0.23643 & Biso & 1.000 & Al \\
\hline Al14 & 1.0000 & 0.44343 & 0.32747 & 0.23162 & Biso & 1.000 & Al \\
\hline P13 & 1.0000 & 0.43200 & 0.32825 & 0.44241 & Biso & 1.000 & $\mathrm{P}$ \\
\hline P14 & 1.0000 & 0.89644 & 0.55458 & 0.44744 & Biso & 1.000 & $\mathrm{P}$ \\
\hline P15 & 1.0000 & 0.68488 & 0.10798 & 0.44232 & Biso & 1.000 & $\mathrm{P}$ \\
\hline
\end{tabular}




\begin{tabular}{|c|c|c|c|c|c|c|c|}
\hline Al15 & 1.0000 & 0.34680 & 0.45063 & 0.56651 & Biso & 1.000 & Al \\
\hline Al16 & 1.0000 & 0.56654 & 0.89317 & 0.57070 & Biso & 1.000 & Al \\
\hline Al17 & 1.0000 & 0.09997 & 0.66019 & 0.57502 & Biso & 1.000 & Al \\
\hline P16 & 1.0000 & 0.10563 & 0.65841 & 0.78147 & Biso & 1.000 & $\mathrm{P}$ \\
\hline P 17 & 1.0000 & 0.56258 & 0.89112 & 0.77990 & Biso & 1.000 & $\mathrm{P}$ \\
\hline P18 & 1.0000 & 0.34114 & 0.43692 & 0.77580 & Biso & 1.000 & $\mathrm{P}$ \\
\hline 01 & 1.0000 & 0.89821 & 0.08492 & 0.13478 & Biso & 1.000 & $\mathrm{O}$ \\
\hline $\mathrm{O} 2$ & 1.0000 & 0.92045 & 0.80742 & 0.13651 & Biso & 1.000 & 0 \\
\hline 03 & 1.0000 & 0.20779 & 0.10514 & 0.12887 & Biso & 1.000 & 0 \\
\hline 04 & 1.0000 & 0.10865 & 0.90070 & 0.87900 & Biso & 1.000 & 0 \\
\hline 05 & 1.0000 & 0.81225 & 0.88927 & 0.87742 & Biso & 1.000 & 0 \\
\hline 06 & 1.0000 & 0.09161 & 0.19273 & 0.87743 & Biso & 1.000 & 0 \\
\hline 07 & 1.0000 & 0.55465 & 0.42050 & 0.45682 & Biso & 1.000 & 0 \\
\hline 08 & 1.0000 & 0.60608 & 0.15392 & 0.44308 & Biso & 1.000 & $\mathrm{O}$ \\
\hline 09 & 1.0000 & 0.87799 & 0.43723 & 0.46487 & Biso & 1.000 & 0 \\
\hline 010 & 1.0000 & 0.78086 & 0.24308 & 0.21497 & Biso & 1.000 & 0 \\
\hline 011 & 1.0000 & 0.47374 & 0.22136 & 0.20820 & Biso & 1.000 & 0 \\
\hline 012 & 1.0000 & 0.76407 & 0.52791 & 0.21502 & Biso & 1.000 & 0 \\
\hline 013 & 1.0000 & 0.22701 & 0.74613 & 0.80345 & Biso & 1.000 & 0 \\
\hline 014 & 1.0000 & 0.24856 & 0.46543 & 0.79332 & Biso & 1.000 & 0 \\
\hline 015 & 1.0000 & 0.53415 & 0.76899 & 0.78923 & Biso & 1.000 & 0 \\
\hline 016 & 1.0000 & 0.45749 & 0.58656 & 0.55257 & Biso & 1.000 & 0 \\
\hline 017 & 1.0000 & 0.11507 & 0.54411 & 0.56556 & Biso & 1.000 & 0 \\
\hline 018 & 1.0000 & 0.42330 & 0.83817 & 0.55400 & Biso & 1.000 & 0 \\
\hline 019 & 1.0000 & 0.98211 & 0.31520 & 0.17101 & Biso & 1.000 & 0 \\
\hline 020 & 1.0000 & 0.68912 & 0.65351 & 0.17072 & Biso & 1.000 & 0 \\
\hline 021 & 1.0000 & 0.35607 & 0.02100 & 0.15993 & Biso & 1.000 & 0 \\
\hline $\mathrm{O} 22$ & 1.0000 & 0.30912 & 0.97869 & 0.83142 & Biso & 1.000 & 0 \\
\hline 023 & 1.0000 & 0.67639 & 0.68583 & 0.84728 & Biso & 1.000 & 0 \\
\hline 024 & 1.0000 & 0.01861 & 0.32265 & 0.84267 & Biso & 1.000 & 0 \\
\hline 025 & 1.0000 & 0.65621 & 0.65156 & 0.50668 & Biso & 1.000 & 0 \\
\hline 026 & 1.0000 & 0.35949 & 0.97270 & 0.50567 & Biso & 1.000 & 0 \\
\hline 027 & 1.0000 & 0.02486 & 0.35138 & 0.50060 & Biso & 1.000 & 0 \\
\hline $\mathrm{O} 28$ & 1.0000 & 0.02603 & 0.66699 & 0.84782 & Biso & 1.000 & 0 \\
\hline 029 & 1.0000 & 0.32201 & 0.33711 & 0.83298 & Biso & 1.000 & 0 \\
\hline 030 & 1.0000 & 0.65882 & 0.96646 & 0.84204 & Biso & 1.000 & 0 \\
\hline 031 & 1.0000 & 0.69423 & 0.01558 & 0.16573 & Biso & 1.000 & 0 \\
\hline 032 & 1.0000 & 0.33258 & 0.30906 & 0.16369 & Biso & 1.000 & 0 \\
\hline 033 & 1.0000 & 0.99392 & 0.67907 & 0.17638 & Biso & 1.000 & 0 \\
\hline 034 & 1.0000 & 0.35448 & 0.35992 & 0.49182 & Biso & 1.000 & 0 \\
\hline 035 & 1.0000 & 0.98901 & 0.64125 & 0.50753 & Biso & 1.000 & 0 \\
\hline 036 & 1.0000 & 0.64862 & 0.00807 & 0.50504 & Biso & 1.000 & 0 \\
\hline 037 & 1.0000 & 0.13091 & 0.23353 & 0.13572 & Biso & 1.000 & 0 \\
\hline 038 & 1.0000 & 0.76268 & 0.88181 & 0.14421 & Biso & 1.000 & 0 \\
\hline 039 & 1.0000 & 0.12448 & 0.87488 & 0.13423 & Biso & 1.000 & 0 \\
\hline 040 & 1.0000 & 0.23663 & 0.10615 & 0.86410 & Biso & 1.000 & 0 \\
\hline 041 & 1.0000 & 0.87684 & 0.75036 & 0.87036 & Biso & 1.000 & 0 \\
\hline 042 & 1.0000 & 0.88727 & 0.12160 & 0.86912 & Biso & 1.000 & 0 \\
\hline 043 & 1.0000 & 0.78912 & 0.55528 & 0.46862 & Biso & 1.000 & 0 \\
\hline 044 & 1.0000 & 0.41313 & 0.21768 & 0.47576 & Biso & 1.000 & 0 \\
\hline 045 & 1.0000 & 0.80222 & 0.19880 & 0.47256 & Biso & 1.000 & 0 \\
\hline 046 & 1.0000 & 0.91627 & 0.44753 & 0.20482 & Biso & 1.000 & 0 \\
\hline 047 & 1.0000 & 0.54628 & 0.08916 & 0.22085 & Biso & 1.000 & 0 \\
\hline 048 & 1.0000 & 0.55957 & 0.45547 & 0.20649 & Biso & 1.000 & 0 \\
\hline 049 & 1.0000 & 0.46066 & 0.89906 & 0.80853 & Biso & 1.000 & 0 \\
\hline 050 & 1.0000 & 0.09201 & 0.54246 & 0.79014 & Biso & 1.000 & 0 \\
\hline 051 & 1.0000 & 0.45322 & 0.53706 & 0.80231 & Biso & 1.000 & 0 \\
\hline 052 & 1.0000 & 0.59963 & 0.78948 & 0.54708 & Biso & 1.000 & 0 \\
\hline 053 & 1.0000 & 0.22460 & 0.45009 & 0.54127 & Biso & 1.000 & 0 \\
\hline 054 & 1.0000 & 0.22099 & 0.77489 & 0.53733 & Biso & 1.000 & 0 \\
\hline 055 & 1.0000 & 0.99871 & 0.24750 & 0.99591 & Biso & 1.000 & 0 \\
\hline 056 & 1.0000 & 0.75724 & 0.74508 & 0.99868 & Biso & 1.000 & 0 \\
\hline 057 & 1.0000 & 0.26585 & 0.00123 & 0.98808 & Biso & 1.000 & 0 \\
\hline 058 & 1.0000 & 0.67307 & 0.59183 & 0.32826 & Biso & 1.000 & 0 \\
\hline 059 & 1.0000 & 0.39089 & 0.06541 & 0.32277 & Biso & 1.000 & 0 \\
\hline 060 & 1.0000 & 0.93662 & 0.33461 & 0.32775 & Biso & 1.000 & 0 \\
\hline 061 & 1.0000 & 0.32967 & 0.90391 & 0.66268 & Biso & 1.000 & 0 \\
\hline 062 & 1.0000 & 0.07768 & 0.38107 & 0.66183 & Biso & 1.000 & 0 \\
\hline 063 & 1.0000 & 0.61261 & 0.66684 & 0.66559 & Biso & 1.000 & 0 \\
\hline 064 & 1.0000 & 0.00045 & 0.73784 & 0.01769 & Biso & 1.000 & 0 \\
\hline 065 & 1.0000 & 0.25953 & 0.25118 & 0.00920 & Biso & 1.000 & 0 \\
\hline 066 & 1.0000 & 0.75254 & 0.99219 & 0.01459 & Biso & 1.000 & 0 \\
\hline 067 & 1.0000 & 0.69410 & 0.06920 & 0.34693 & Biso & 1.000 & 0 \\
\hline 068 & 1.0000 & 0.93156 & 0.58935 & 0.34976 & Biso & 1.000 & 0 \\
\hline 069 & 1.0000 & 0.40316 & 0.32312 & 0.34185 & Biso & 1.000 & 0 \\
\hline 070 & 1.0000 & 0.34248 & 0.40745 & 0.67715 & Biso & 1.000 & 0 \\
\hline 071 & 1.0000 & 0.59640 & 0.93154 & 0.68360 & Biso & 1.000 & 0 \\
\hline 072 & 1.0000 & 0.07455 & 0.67680 & 0.68686 & Biso & 1.000 & 0 \\
\hline $\mathrm{C} 1$ & 1.0000 & 0.21541 & 0.99310 & 0.34323 & Biso & 1.000 & $\mathrm{C}$ \\
\hline $\mathrm{H} 1$ & 1.0000 & 0.21218 & 0.03204 & 0.28146 & Biso & 1.000 & $\mathrm{H}$ \\
\hline
\end{tabular}




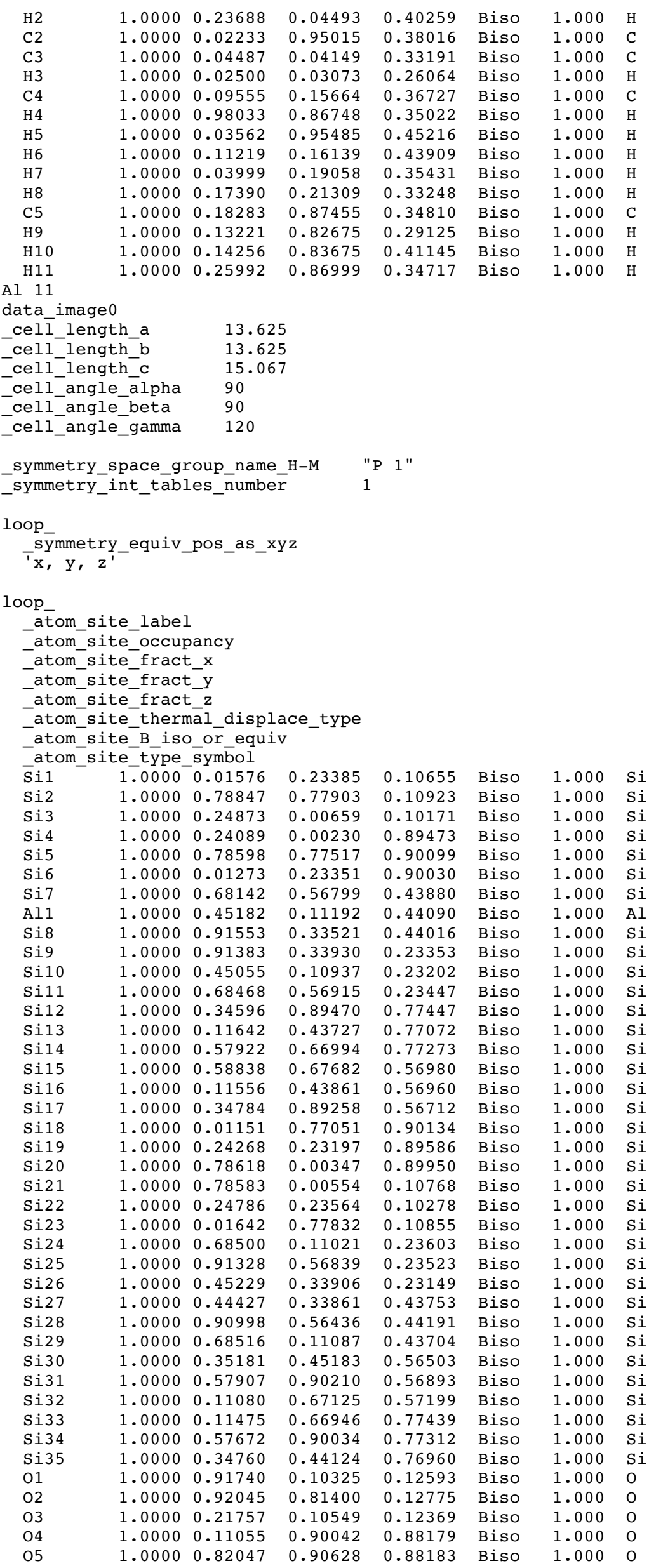




\begin{tabular}{|c|c|c|c|c|c|c|}
\hline 06 & 1.0000 & 0.11189 & 0.20205 & 0.88431 & Biso & 1.000 \\
\hline 07 & 1.0000 & 0.57506 & 0.44127 & 0.44960 & Biso & 1.000 \\
\hline 08 & 1.0000 & 0.59356 & 0.15117 & 0.43908 & Biso & 1.000 \\
\hline 09 & 1.0000 & 0.88820 & 0.43716 & 0.45830 & Biso & 1.000 \\
\hline 010 & 1.0000 & 0.78254 & 0.24189 & 0.21709 & Biso & 1.000 \\
\hline 011 & 1.0000 & 0.48422 & 0.24056 & 0.21232 & Biso & 1.000 \\
\hline 012 & 1.0000 & 0.78235 & 0.53512 & 0.21774 & Biso & 1.000 \\
\hline 013 & 1.0000 & 0.24570 & 0.76505 & 0.79469 & Biso & 1.000 \\
\hline 014 & 1.0000 & 0.24853 & 0.47311 & 0.78686 & Biso & 1.000 \\
\hline 015 & 1.0000 & 0.54662 & 0.76907 & 0.78276 & Biso & 1.000 \\
\hline 016 & 1.0000 & 0.45632 & 0.58102 & 0.55428 & Biso & 1.000 \\
\hline 017 & 1.0000 & 0.12808 & 0.56270 & 0.56319 & Biso & 1.000 \\
\hline 018 & 1.0000 & 0.44418 & 0.85481 & 0.55497 & Biso & 1.000 \\
\hline 019 & 1.0000 & 0.99940 & 0.31997 & 0.17057 & Biso & 1.000 \\
\hline 020 & 1.0000 & 0.70366 & 0.67167 & 0.16940 & Biso & 1.000 \\
\hline 021 & 1.0000 & 0.35648 & 0.02549 & 0.15984 & Biso & 1.000 \\
\hline 022 & 1.0000 & 0.32715 & 0.98346 & 0.83357 & Biso & 1.000 \\
\hline 023 & 1.0000 & 0.67720 & 0.68852 & 0.84279 & Biso & 1.000 \\
\hline 024 & 1.0000 & 0.03360 & 0.33993 & 0.83967 & Biso & 1.000 \\
\hline 025 & 1.0000 & 0.67078 & 0.65703 & 0.50373 & Biso & 1.000 \\
\hline 026 & 1.0000 & 0.36806 & 0.99472 & 0.50493 & Biso & 1.000 \\
\hline 027 & 1.0000 & 0.02180 & 0.35217 & 0.50001 & Biso & 1.000 \\
\hline 028 & 1.0000 & 0.03024 & 0.68106 & 0.84382 & Biso & 1.000 \\
\hline 029 & 1.0000 & 0.32698 & 0.33588 & 0.83233 & Biso & 1.000 \\
\hline 030 & 1.0000 & 0.67916 & 0.98167 & 0.83929 & Biso & 1.000 \\
\hline 031 & 1.0000 & 0.69922 & 0.02761 & 0.16587 & Biso & 1.000 \\
\hline 032 & 1.0000 & 0.35207 & 0.32394 & 0.16432 & Biso & 1.000 \\
\hline 033 & 1.0000 & 0.99869 & 0.67649 & 0.17448 & Biso & 1.000 \\
\hline 034 & 1.0000 & 0.36060 & 0.36804 & 0.49425 & Biso & 1.000 \\
\hline 035 & 1.0000 & 0.00997 & 0.65625 & 0.50569 & Biso & 1.000 \\
\hline 036 & 1.0000 & 0.65666 & 0.00552 & 0.50304 & Biso & 1.000 \\
\hline 037 & 1.0000 & 0.13736 & 0.24500 & 0.12879 & Biso & 1.000 \\
\hline 038 & 1.0000 & 0.77321 & 0.88531 & 0.13726 & Biso & 1.000 \\
\hline 039 & 1.0000 & 0.13969 & 0.88668 & 0.13100 & Biso & 1.000 \\
\hline 040 & 1.0000 & 0.24983 & 0.12125 & 0.86720 & Biso & 1.000 \\
\hline 041 & 1.0000 & 0.89123 & 0.75807 & 0.87325 & Biso & 1.000 \\
\hline 042 & 1.0000 & 0.89269 & 0.12529 & 0.87241 & Biso & 1.000 \\
\hline 043 & 1.0000 & 0.79599 & 0.56707 & 0.46570 & Biso & 1.000 \\
\hline 044 & 1.0000 & 0.42917 & 0.22132 & 0.47056 & Biso & 1.000 \\
\hline 045 & 1.0000 & 0.80907 & 0.21453 & 0.46709 & Biso & 1.000 \\
\hline 046 & 1.0000 & 0.92871 & 0.46188 & 0.20848 & Biso & 1.000 \\
\hline 047 & 1.0000 & 0.56208 & 0.09781 & 0.21926 & Biso & 1.000 \\
\hline 048 & 1.0000 & 0.56278 & 0.46102 & 0.21125 & Biso & 1.000 \\
\hline 049 & 1.0000 & 0.46615 & 0.90711 & 0.80312 & Biso & 1.000 \\
\hline 050 & 1.0000 & 0.10156 & 0.54598 & 0.78778 & Biso & 1.000 \\
\hline 051 & 1.0000 & 0.46840 & 0.54945 & 0.79612 & Biso & 1.000 \\
\hline 052 & 1.0000 & 0.60485 & 0.80026 & 0.54807 & Biso & 1.000 \\
\hline 053 & 1.0000 & 0.23585 & 0.45159 & 0.54290 & Biso & 1.000 \\
\hline 054 & 1.0000 & 0.22584 & 0.78267 & 0.54156 & Biso & 1.000 \\
\hline 055 & 1.0000 & 0.01088 & 0.26718 & 0.00378 & Biso & 1.000 \\
\hline 056 & 1.0000 & 0.75612 & 0.74574 & 0.00564 & Biso & 1.000 \\
\hline 057 & 1.0000 & 0.27822 & 0.00651 & 0.99788 & Biso & 1.000 \\
\hline 058 & 1.0000 & 0.69075 & 0.61143 & 0.33644 & Biso & 1.000 \\
\hline 059 & 1.0000 & 0.39541 & 0.07025 & 0.33048 & Biso & 1.000 \\
\hline 060 & 1.0000 & 0.95025 & 0.33738 & 0.33611 & Biso & 1.000 \\
\hline 061 & 1.0000 & 0.34514 & 0.92538 & 0.67109 & Biso & 1.000 \\
\hline 062 & 1.0000 & 0.07867 & 0.38893 & 0.67004 & Biso & 1.000 \\
\hline 063 & 1.0000 & 0.62405 & 0.67028 & 0.67230 & Biso & 1.000 \\
\hline 064 & 1.0000 & 0.01080 & 0.73942 & 0.00603 & Biso & 1.000 \\
\hline 065 & 1.0000 & 0.28180 & 0.26606 & 0.99893 & Biso & 1.000 \\
\hline 066 & 1.0000 & 0.75396 & 0.00319 & 0.00352 & Biso & 1.000 \\
\hline 067 & 1.0000 & 0.69746 & 0.07230 & 0.33574 & Biso & 1.000 \\
\hline 068 & 1.0000 & 0.94739 & 0.60325 & 0.33894 & Biso & 1.000 \\
\hline 069 & 1.0000 & 0.40808 & 0.33331 & 0.33248 & Biso & 1.000 \\
\hline 070 & 1.0000 & 0.34808 & 0.40662 & 0.66614 & Biso & 1.000 \\
\hline 071 & 1.0000 & 0.61393 & 0.94447 & 0.67170 & Biso & 1.000 \\
\hline 072 & 1.0000 & 0.07809 & 0.68325 & 0.67401 & Biso & 1.000 \\
\hline C1 & 1.0000 & 0.21267 & 0.99623 & 0.34533 & Biso & 1.000 \\
\hline $\mathrm{H} 1$ & 1.0000 & 0.21542 & 0.03784 & 0.28320 & Biso & 1.000 \\
\hline $\mathrm{H} 2$ & 1.0000 & 0.23265 & 0.04759 & 0.40512 & Biso & 1.000 \\
\hline $\mathrm{C} 2$ & 1.0000 & 0.01807 & 0.95263 & 0.37668 & Biso & 1.000 \\
\hline C3 & 1.0000 & 0.04599 & 0.04647 & 0.32779 & Biso & 1.000 \\
\hline H3 & 1.0000 & 0.02838 & 0.03591 & 0.25633 & Biso & 1.000 \\
\hline $\mathrm{C} 4$ & 1.0000 & 0.09972 & 0.16398 & 0.36270 & Biso & 1.000 \\
\hline $\mathrm{H} 4$ & 1.0000 & 0.97386 & 0.86843 & 0.34690 & Biso & 1.000 \\
\hline H5 & 1.0000 & 0.02840 & 0.95702 & 0.44878 & Biso & 1.000 \\
\hline H 6 & 1.0000 & 0.11398 & 0.16847 & 0.43468 & Biso & 1.000 \\
\hline H7 & 1.0000 & 0.04612 & 0.20134 & 0.34753 & Biso & 1.000 \\
\hline H8 & 1.0000 & 0.18128 & 0.21947 & 0.32946 & Biso & 1.000 \\
\hline C5 & 1.0000 & 0.17981 & 0.87549 & 0.34874 & & 1.000 \\
\hline
\end{tabular}




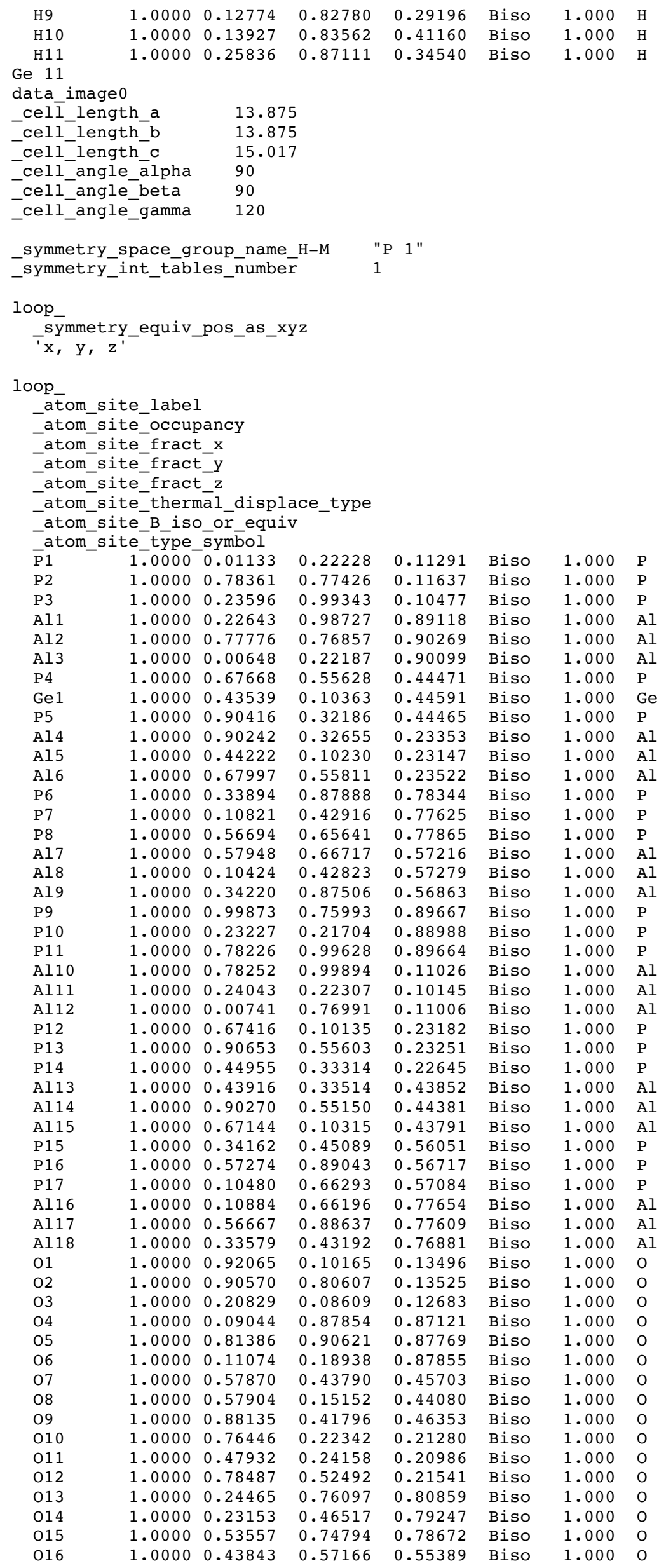




\begin{tabular}{|c|c|c|c|c|c|c|c|}
\hline 017 & 1.0000 & 0.10979 & 0.55542 & 0.56818 & Biso & 1.000 & 0 \\
\hline 018 & 1.0000 & 0.44738 & 0.84112 & 0.54901 & Biso & 1.000 & O \\
\hline 019 & 1.0000 & 0.99638 & 0.30463 & 0.17111 & Biso & 1.000 & 0 \\
\hline 020 & 1.0000 & 0.70364 & 0.67266 & 0.17139 & Biso & 1.000 & 0 \\
\hline 021 & 1.0000 & 0.34178 & 0.01494 & 0.15315 & Biso & 1.000 & 0 \\
\hline 022 & 1.0000 & 0.32244 & 0.96710 & 0.83197 & Biso & 1.000 & 0 \\
\hline 023 & 1.0000 & 0.65733 & 0.67509 & 0.84641 & Biso & 1.000 & 0 \\
\hline $\mathrm{O} 24$ & 1.0000 & 0.03278 & 0.34184 & 0.84451 & Biso & 1.000 & 0 \\
\hline 025 & 1.0000 & 0.66469 & 0.63943 & 0.50436 & Biso & 1.000 & 0 \\
\hline 026 & 1.0000 & 0.35527 & 0.98689 & 0.51214 & Biso & 1.000 & 0 \\
\hline 027 & 1.0000 & 0.00341 & 0.33534 & 0.49981 & Biso & 1.000 & 0 \\
\hline 028 & 1.0000 & 0.01380 & 0.67233 & 0.84631 & Biso & 1.000 & 0 \\
\hline 029 & 1.0000 & 0.31040 & 0.31478 & 0.83039 & Biso & 1.000 & 0 \\
\hline 030 & 1.0000 & 0.67917 & 0.97380 & 0.84340 & Biso & 1.000 & 0 \\
\hline 031 & 1.0000 & 0.68749 & 0.02360 & 0.16637 & Biso & 1.000 & 0 \\
\hline 032 & 1.0000 & 0.35461 & 0.31709 & 0.16401 & Biso & 1.000 & 0 \\
\hline 033 & 1.0000 & 0.98613 & 0.65691 & 0.17556 & Biso & 1.000 & 0 \\
\hline 034 & 1.0000 & 0.35369 & 0.37718 & 0.49125 & Biso & 1.000 & 0 \\
\hline 035 & 1.0000 & 0.01078 & 0.65161 & 0.50948 & Biso & 1.000 & 0 \\
\hline 036 & 1.0000 & 0.64238 & 0.98961 & 0.50627 & Biso & 1.000 & 0 \\
\hline 037 & 1.0000 & 0.12549 & 0.23488 & 0.13355 & Biso & 1.000 & 0 \\
\hline 038 & 1.0000 & 0.76827 & 0.87209 & 0.14407 & Biso & 1.000 & 0 \\
\hline 039 & 1.0000 & 0.13784 & 0.88258 & 0.13792 & Biso & 1.000 & 0 \\
\hline 040 & 1.0000 & 0.24008 & 0.11500 & 0.86183 & Biso & 1.000 & 0 \\
\hline 041 & 1.0000 & 0.88571 & 0.74619 & 0.87091 & Biso & 1.000 & 0 \\
\hline 042 & 1.0000 & 0.87917 & 0.10977 & 0.86815 & Biso & 1.000 & 0 \\
\hline 043 & 1.0000 & 0.78423 & 0.55778 & 0.47080 & Biso & 1.000 & 0 \\
\hline 044 & 1.0000 & 0.40609 & 0.20746 & 0.47992 & Biso & 1.000 & 0 \\
\hline 045 & 1.0000 & 0.80318 & 0.21117 & 0.47057 & Biso & 1.000 & 0 \\
\hline 046 & 1.0000 & 0.92124 & 0.45736 & 0.20626 & Biso & 1.000 & 0 \\
\hline 047 & 1.0000 & 0.55949 & 0.08891 & 0.21649 & Biso & 1.000 & 0 \\
\hline 048 & 1.0000 & 0.55169 & 0.44630 & 0.20492 & Biso & 1.000 & 0 \\
\hline 049 & 1.0000 & 0.45068 & 0.89230 & 0.81350 & Biso & 1.000 & 0 \\
\hline 050 & 1.0000 & 0.09263 & 0.53005 & 0.78665 & Biso & 1.000 & 0 \\
\hline 051 & 1.0000 & 0.46418 & 0.54374 & 0.79980 & Biso & 1.000 & 0 \\
\hline 052 & 1.0000 & 0.60464 & 0.80091 & 0.54868 & Biso & 1.000 & 0 \\
\hline 053 & 1.0000 & 0.23336 & 0.45037 & 0.53994 & Biso & 1.000 & 0 \\
\hline 054 & 1.0000 & 0.21506 & 0.75880 & 0.53695 & Biso & 1.000 & 0 \\
\hline 055 & 1.0000 & 0.00418 & 0.24831 & 0.01463 & Biso & 1.000 & 0 \\
\hline 056 & 1.0000 & 0.75608 & 0.74679 & 0.01735 & Biso & 1.000 & 0 \\
\hline 057 & 1.0000 & 0.25323 & 0.98855 & 0.00478 & Biso & 1.000 & 0 \\
\hline 058 & 1.0000 & 0.68365 & 0.59422 & 0.34720 & Biso & 1.000 & 0 \\
\hline 059 & 1.0000 & 0.37717 & 0.05977 & 0.33497 & Biso & 1.000 & 0 \\
\hline 060 & 1.0000 & 0.93416 & 0.32290 & 0.34565 & Biso & 1.000 & 0 \\
\hline 061 & 1.0000 & 0.33855 & 0.89668 & 0.68320 & Biso & 1.000 & 0 \\
\hline 062 & 1.0000 & 0.07315 & 0.37809 & 0.68235 & Biso & 1.000 & 0 \\
\hline 063 & 1.0000 & 0.61057 & 0.65681 & 0.68415 & Biso & 1.000 & 0 \\
\hline 064 & 1.0000 & 0.00266 & 0.73988 & 0.99711 & Biso & 1.000 & 0 \\
\hline 065 & 1.0000 & 0.26845 & 0.24807 & 0.98773 & Biso & 1.000 & 0 \\
\hline 066 & 1.0000 & 0.75757 & 0.99742 & 0.99632 & Biso & 1.000 & 0 \\
\hline 067 & 1.0000 & 0.68579 & 0.06774 & 0.32705 & Biso & 1.000 & 0 \\
\hline 068 & 1.0000 & 0.93723 & 0.58689 & 0.33115 & Biso & 1.000 & 0 \\
\hline 069 & 1.0000 & 0.41157 & 0.33064 & 0.32294 & Biso & 1.000 & 0 \\
\hline 070 & 1.0000 & 0.33687 & 0.40443 & 0.65491 & Biso & 1.000 & 0 \\
\hline 071 & 1.0000 & 0.59913 & 0.92939 & 0.66509 & Biso & 1.000 & 0 \\
\hline 072 & 1.0000 & 0.08144 & 0.68536 & 0.66676 & Biso & 1.000 & 0 \\
\hline $\mathrm{C} 1$ & 1.0000 & 0.19507 & 0.99464 & 0.35054 & Biso & 1.000 & $\mathrm{C}$ \\
\hline $\mathrm{H} 1$ & 1.0000 & 0.20194 & 0.03223 & 0.28575 & Biso & 1.000 & $\mathrm{H}$ \\
\hline $\mathrm{H} 2$ & 1.0000 & 0.22079 & 0.04995 & 0.40789 & Biso & 1.000 & $\mathrm{H}$ \\
\hline $\mathrm{C} 2$ & 1.0000 & 0.01362 & 0.96604 & 0.38120 & Biso & 1.000 & C \\
\hline C3 & 1.0000 & 0.04656 & 0.05896 & 0.33141 & Biso & 1.000 & C \\
\hline H3 & 1.0000 & 0.02789 & 0.04867 & 0.25994 & Biso & 1.000 & $\mathrm{H}$ \\
\hline $\mathrm{C} 4$ & 1.0000 & 0.10719 & 0.17477 & 0.36550 & Biso & 1.000 & $\mathrm{C}$ \\
\hline H 4 & 1.0000 & 0.96408 & 0.88350 & 0.35201 & Biso & 1.000 & $\mathrm{H}$ \\
\hline H5 & 1.0000 & 0.02430 & 0.97069 & 0.45348 & Biso & 1.000 & $\mathrm{H}$ \\
\hline H6 & 1.0000 & 0.12419 & 0.17911 & 0.43724 & Biso & 1.000 & $\mathrm{H}$ \\
\hline $\mathrm{H} 7$ & 1.0000 & 0.05830 & 0.21613 & 0.35237 & Biso & 1.000 & $\mathrm{H}$ \\
\hline $\mathrm{H} 8$ & 1.0000 & 0.18641 & 0.22498 & 0.32970 & Biso & 1.000 & $\mathrm{H}$ \\
\hline $\mathrm{C} 5$ & 1.0000 & 0.15770 & 0.87498 & 0.35900 & Biso & 1.000 & C \\
\hline H9 & 1.0000 & 0.09940 & 0.82514 & 0.30628 & Biso & 1.000 & $\mathrm{H}$ \\
\hline $\mathrm{H} 10$ & 1.0000 & 0.12392 & 0.84157 & 0.42491 & Biso & 1.000 & $\mathrm{H}$ \\
\hline H 11 & 1.0000 & 0.23202 & 0.86647 & 0.35031 & Biso & 1.000 & $\mathrm{H}$ \\
\hline \multicolumn{8}{|c|}{$a^{n+1} 11$} \\
\hline \multicolumn{8}{|c|}{$\begin{array}{l}\text { a } 11 \\
\text { ata image } 0\end{array}$} \\
\hline \multicolumn{2}{|c|}{ celil length a } & \multicolumn{2}{|c|}{13.625} & & & & \\
\hline \multicolumn{2}{|c|}{ cell length b } & 13.62 & & & & & \\
\hline cell & the & 15.06 & & & & & \\
\hline $\mathrm{ell}^{-}$ & $\bar{a} l p h a$ & 90 & & & & & \\
\hline$e 11$ & beta & 90 & & & & & \\
\hline ell & - & 120 & & & & & \\
\hline
\end{tabular}




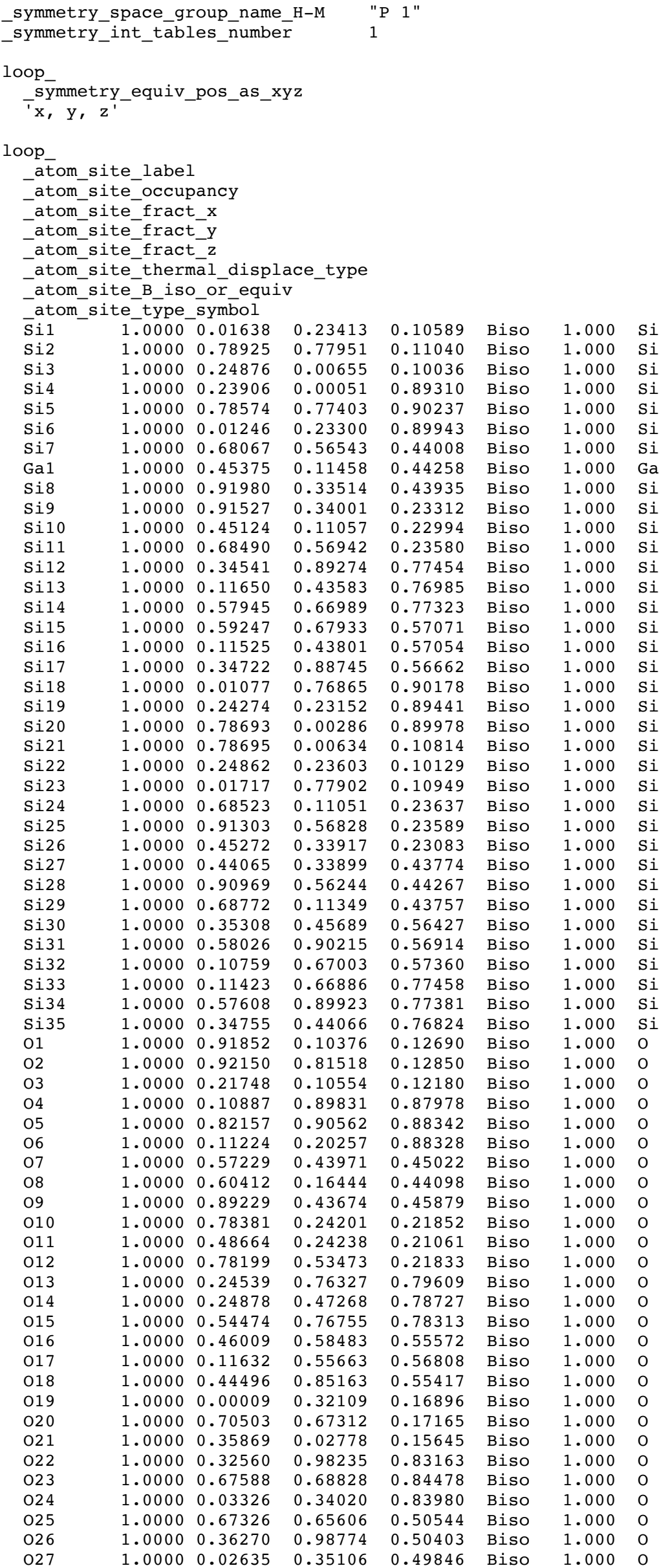




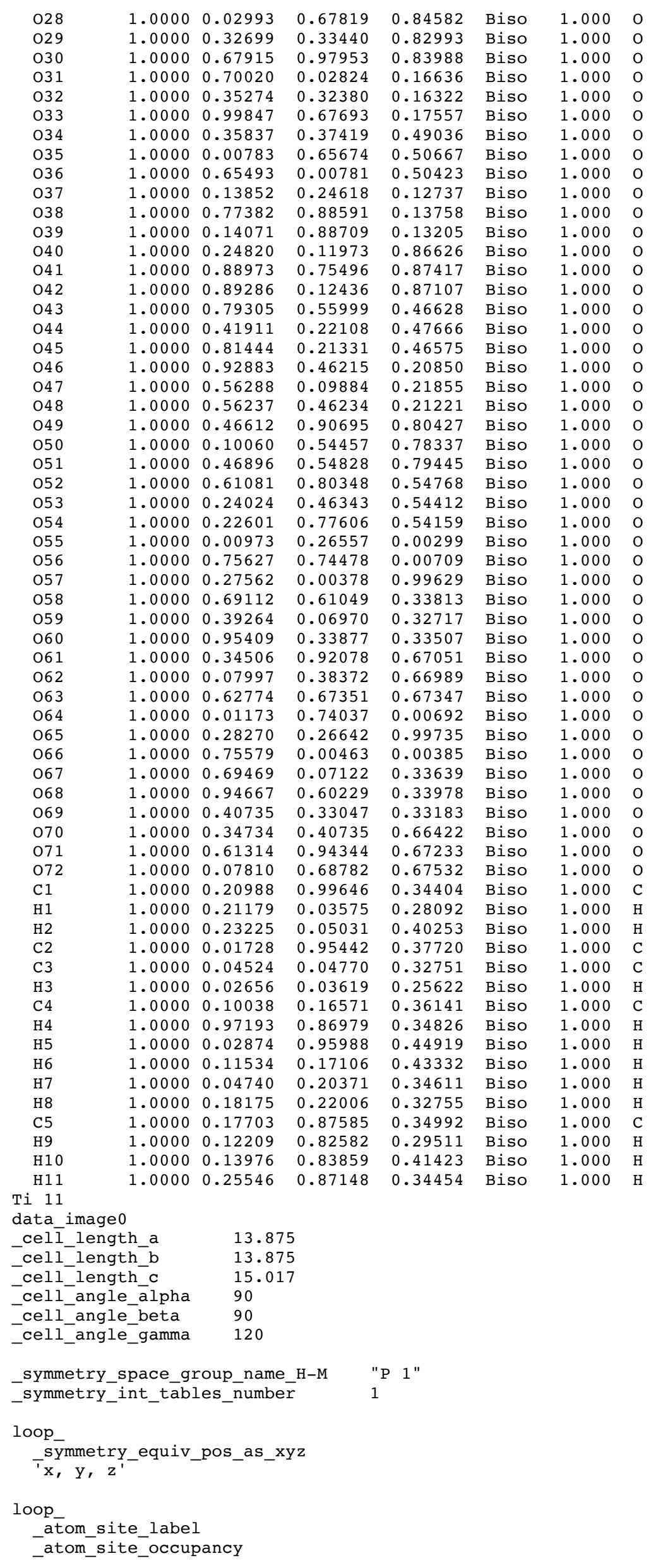




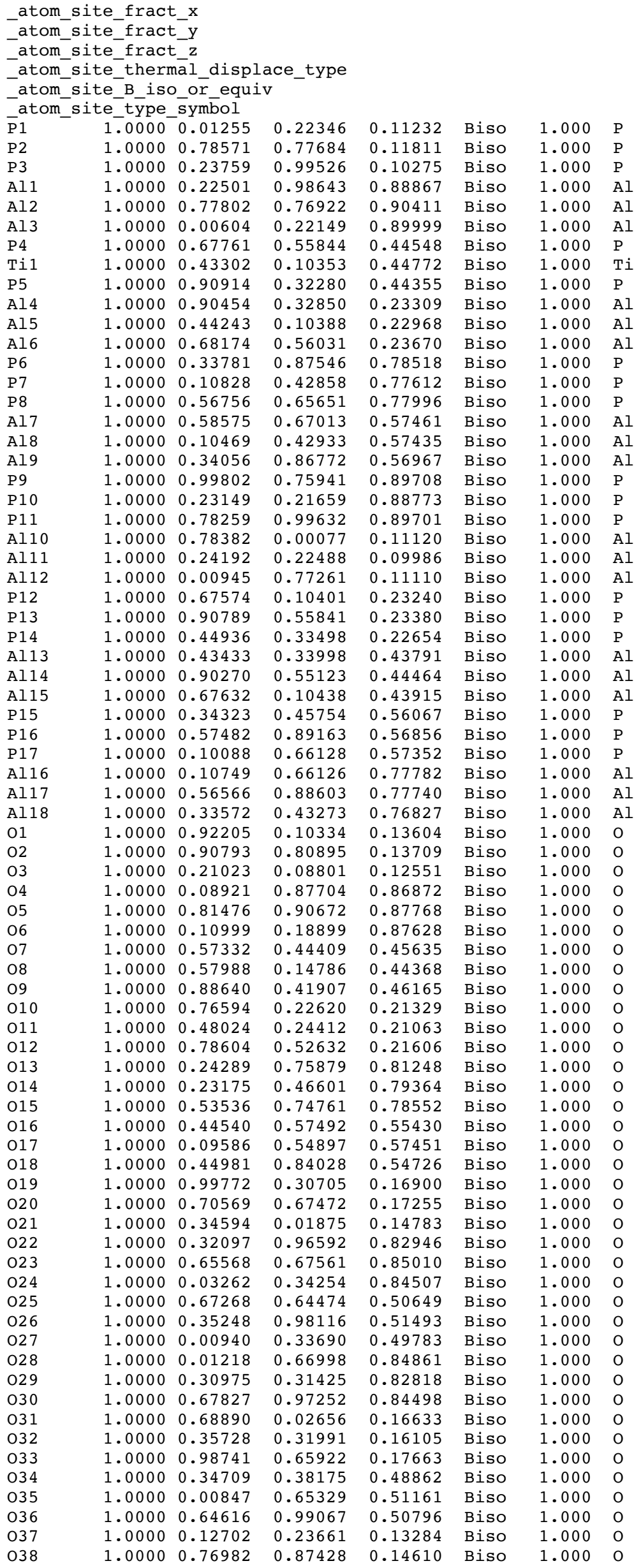




\begin{tabular}{|c|c|c|c|c|c|c|c|}
\hline 039 & 1.0000 & 0.14074 & 0.88488 & 0.13844 & Biso & 1.000 & 0 \\
\hline 040 & 1.0000 & 0.23916 & 0.11447 & 0.85958 & Biso & 1.000 & 0 \\
\hline 041 & 1.0000 & 0.88446 & 0.74472 & 0.87175 & Biso & 1.000 & 0 \\
\hline 042 & 1.0000 & 0.87837 & 0.10986 & 0.86724 & Biso & 1.000 & 0 \\
\hline 043 & 1.0000 & 0.77983 & 0.54944 & 0.47121 & Biso & 1.000 & 0 \\
\hline O4 4 & 1.0000 & 0.40636 & 0.21404 & 0.48037 & Biso & 1.000 & 0 \\
\hline 045 & 1.0000 & 0.80861 & 0.21237 & 0.47093 & Biso & 1.000 & 0 \\
\hline 046 & 1.0000 & 0.92357 & 0.46007 & 0.20844 & Biso & 1.000 & 0 \\
\hline 047 & 1.0000 & 0.56099 & 0.09159 & 0.21782 & Biso & 1.000 & 0 \\
\hline 048 & 1.0000 & 0.55232 & 0.44890 & 0.20827 & Biso & 1.000 & 0 \\
\hline 049 & 1.0000 & 0.44940 & 0.89011 & 0.81727 & Biso & 1.000 & 0 \\
\hline 050 & 1.0000 & 0.09137 & 0.52899 & 0.78369 & Biso & 1.000 & 0 \\
\hline 051 & 1.0000 & 0.46444 & 0.54362 & 0.79982 & Biso & 1.000 & 0 \\
\hline 052 & 1.0000 & 0.60967 & 0.80373 & 0.55310 & Biso & 1.000 & 0 \\
\hline 053 & 1.0000 & 0.23952 & 0.46725 & 0.54392 & Biso & 1.000 & 0 \\
\hline 054 & 1.0000 & 0.21415 & 0.75031 & 0.53779 & Biso & 1.000 & 0 \\
\hline 055 & 1.0000 & 0.00441 & 0.24713 & 0.01370 & Biso & 1.000 & 0 \\
\hline 056 & 1.0000 & 0.75862 & 0.74995 & 0.01903 & Biso & 1.000 & 0 \\
\hline 057 & 1.0000 & 0.25042 & 0.98783 & 0.00244 & Biso & 1.000 & 0 \\
\hline 058 & 1.0000 & 0.68858 & 0.59917 & 0.34841 & Biso & 1.000 & 0 \\
\hline 059 & 1.0000 & 0.37562 & 0.06078 & 0.33219 & Biso & 1.000 & 0 \\
\hline 060 & 1.0000 & 0.93769 & 0.32218 & 0.34443 & Biso & 1.000 & 0 \\
\hline 061 & 1.0000 & 0.33852 & 0.88832 & 0.68431 & Biso & 1.000 & 0 \\
\hline 062 & 1.0000 & 0.07475 & 0.37493 & 0.68282 & Biso & 1.000 & 0 \\
\hline 063 & 1.0000 & 0.61456 & 0.65713 & 0.68673 & Biso & 1.000 & 0 \\
\hline 064 & 1.0000 & 0.00389 & 0.74307 & 0.99795 & Biso & 1.000 & 0 \\
\hline 065 & 1.0000 & 0.26754 & 0.24771 & 0.98561 & Biso & 1.000 & 0 \\
\hline 066 & 1.0000 & 0.75977 & 0.99822 & 0.99698 & Biso & 1.000 & 0 \\
\hline 067 & 1.0000 & 0.68845 & 0.07016 & 0.32731 & Biso & 1.000 & 0 \\
\hline 068 & 1.0000 & 0.93793 & 0.59015 & 0.33247 & Biso & 1.000 & 0 \\
\hline 069 & 1.0000 & 0.40686 & 0.33056 & 0.32188 & Biso & 1.000 & 0 \\
\hline 070 & 1.0000 & 0.33698 & 0.40735 & 0.65382 & Biso & 1.000 & 0 \\
\hline 071 & 1.0000 & 0.59674 & 0.93103 & 0.66663 & Biso & 1.000 & 0 \\
\hline 072 & 1.0000 & 0.08201 & 0.69018 & 0.66880 & Biso & 1.000 & 0 \\
\hline C1 & 1.0000 & 0.19214 & 0.99153 & 0.34839 & Biso & 1.000 & C \\
\hline H 1 & 1.0000 & 0.19896 & 0.02620 & 0.28243 & Biso & 1.000 & $\mathrm{H}$ \\
\hline H2 & 1.0000 & 0.21626 & 0.04921 & 0.40410 & Biso & 1.000 & $\mathrm{H}$ \\
\hline $\mathrm{C} 2$ & 1.0000 & 0.00837 & 0.95662 & 0.37360 & Biso & 1.000 & C \\
\hline C3 & 1.0000 & 0.04134 & 0.05097 & 0.32570 & Biso & 1.000 & C \\
\hline H3 & 1.0000 & 0.02642 & 0.04292 & 0.25369 & Biso & 1.000 & $\mathrm{H}$ \\
\hline $\mathrm{C} 4$ & 1.0000 & 0.09774 & 0.16553 & 0.36241 & Biso & 1.000 & C \\
\hline H4 & 1.0000 & 0.96220 & 0.87503 & 0.34219 & Biso & 1.000 & $\mathrm{H}$ \\
\hline H5 & 1.0000 & 0.01522 & 0.95874 & 0.44616 & Biso & 1.000 & $\mathrm{H}$ \\
\hline H6 & 1.0000 & 0.11084 & 0.16780 & 0.43467 & Biso & 1.000 & $\mathrm{H}$ \\
\hline H7 & 1.0000 & 0.04810 & 0.20571 & 0.34783 & Biso & 1.000 & $\mathrm{H}$ \\
\hline H8 & 1.0000 & 0.17856 & 0.21820 & 0.32942 & Biso & 1.000 & $\mathrm{H}$ \\
\hline C5 & 1.0000 & 0.15938 & 0.87356 & 0.36121 & Biso & 1.000 & C \\
\hline H9 & 1.0000 & 0.11005 & 0.82082 & 0.30568 & Biso & 1.000 & $\mathrm{H}$ \\
\hline $\mathrm{H} 10$ & 1.0000 & 0.11765 & 0.83998 & 0.42494 & Biso & 1.000 & $\mathrm{H}$ \\
\hline H 11 & 1.0000 & 0.23726 & 0.87043 & 0.36352 & Biso & 1.000 & $\mathrm{H}$ \\
\hline
\end{tabular}

data_image 0

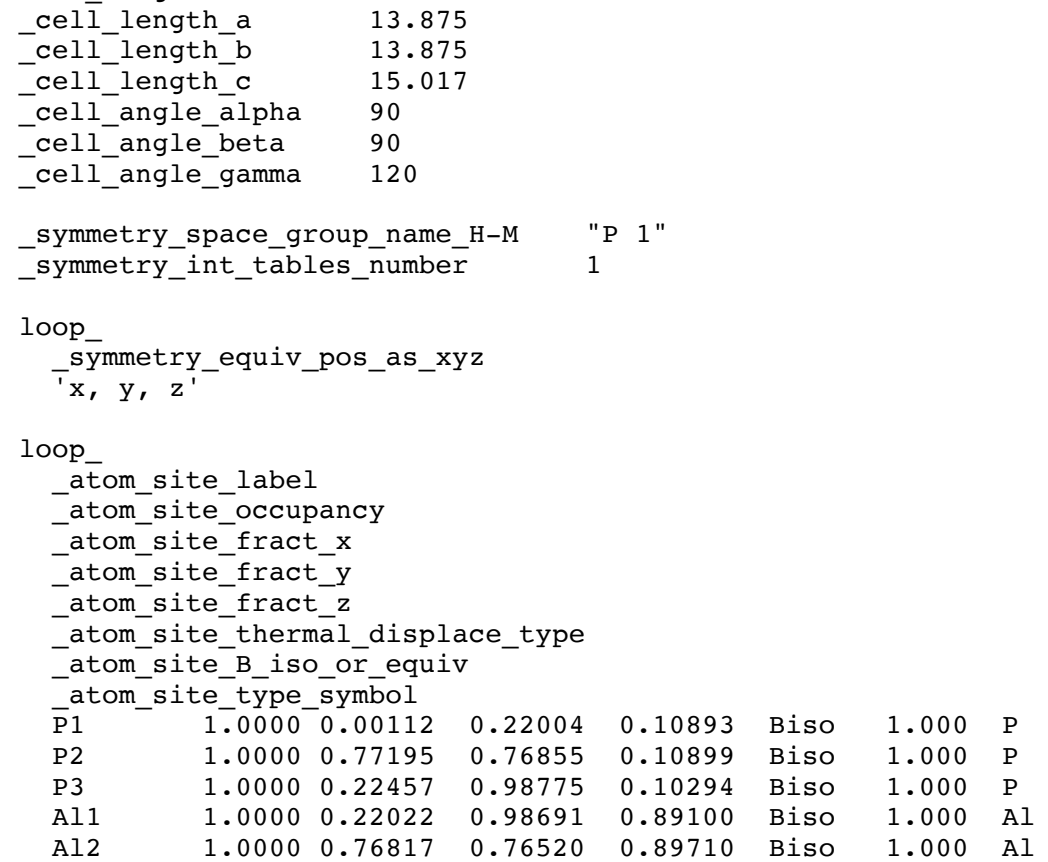




\begin{tabular}{|c|c|c|c|c|c|c|c|}
\hline A13 & 1.0000 & 0.99902 & 0.22087 & 0.89769 & Biso & 1.000 & $\mathrm{Al}$ \\
\hline P4 & 1.0000 & 0.66655 & 0.55317 & 0.44051 & Biso & 1.000 & $\mathrm{P}$ \\
\hline Sil & 1.0000 & 0.42424 & 0.09490 & 0.43857 & Biso & 1.000 & $\mathrm{Si}$ \\
\hline P5 & 1.0000 & 0.88882 & 0.32065 & 0.44146 & Biso & 1.000 & $P$ \\
\hline Al4 & 1.0000 & 0.89140 & 0.32223 & 0.23037 & Biso & 1.000 & $\mathrm{Al}$ \\
\hline Al5 & 1.0000 & 0.43445 & 0.09962 & 0.22795 & Biso & 1.000 & Al \\
\hline Al6 & 1.0000 & 0.66743 & 0.55394 & 0.22996 & Biso & 1.000 & Al \\
\hline P6 & 1.0000 & 0.33331 & 0.88515 & 0.77318 & Biso & 1.000 & $\mathrm{P}$ \\
\hline P7 & 1.0000 & 0.09974 & 0.42924 & 0.77355 & Biso & 1.000 & $P$ \\
\hline P8 & 1.0000 & 0.55637 & 0.65473 & 0.77410 & Biso & 1.000 & $\mathrm{P}$ \\
\hline Al7 & 1.0000 & 0.56013 & 0.65695 & 0.56521 & Biso & 1.000 & $\mathrm{Al}$ \\
\hline Al8 & 1.0000 & 0.09502 & 0.42445 & 0.56551 & Biso & 1.000 & Al \\
\hline Al9 & 1.0000 & 0.33543 & 0.88250 & 0.56094 & Biso & 1.000 & Al \\
\hline P9 & 1.0000 & 0.99232 & 0.76130 & 0.89065 & Biso & 1.000 & $\mathrm{P}$ \\
\hline P 10 & 1.0000 & 0.22506 & 0.21675 & 0.89029 & Biso & 1.000 & $\mathrm{P}$ \\
\hline P11 & 1.0000 & 0.77254 & 0.99442 & 0.89207 & Biso & 1.000 & $\mathrm{P}$ \\
\hline Al10 & 1.0000 & 0.77144 & 0.99496 & 0.10406 & Biso & 1.000 & Al \\
\hline Al11 & 1.0000 & 0.22721 & 0.21681 & 0.10170 & Biso & 1.000 & Al \\
\hline Al 12 & 1.0000 & 0.99701 & 0.76528 & 0.10374 & Biso & 1.000 & Al \\
\hline P 12 & 1.0000 & 0.66353 & 0.09664 & 0.22706 & Biso & 1.000 & $\mathrm{P}$ \\
\hline P13 & 1.0000 & 0.89429 & 0.55174 & 0.22626 & Biso & 1.000 & $\mathrm{P}$ \\
\hline P14 & 1.0000 & 0.44004 & 0.32915 & 0.22414 & Biso & 1.000 & $\mathrm{P}$ \\
\hline Al13 & 1.0000 & 0.43530 & 0.32709 & 0.43622 & Biso & 1.000 & Al \\
\hline Al14 & 1.0000 & 0.89463 & 0.55324 & 0.43642 & Biso & 1.000 & Al \\
\hline Al15 & 1.0000 & 0.65896 & 0.09405 & 0.43587 & Biso & 1.000 & $\mathrm{Al}$ \\
\hline P15 & 1.0000 & 0.32715 & 0.43369 & 0.55819 & Biso & 1.000 & $\mathrm{P}$ \\
\hline P16 & 1.0000 & 0.56535 & 0.88749 & 0.55853 & Biso & 1.000 & $\mathrm{P}$ \\
\hline P 17 & 1.0000 & 0.10075 & 0.65986 & 0.56110 & Biso & 1.000 & $\mathrm{P}$ \\
\hline Al16 & 1.0000 & 0.10267 & 0.66122 & 0.76948 & Biso & 1.000 & Al \\
\hline A117 & 1.0000 & 0.55938 & 0.88450 & 0.76993 & Biso & 1.000 & $\mathrm{Al}$ \\
\hline Al18 & 1.0000 & 0.32648 & 0.42805 & 0.76773 & Biso & 1.000 & Al \\
\hline 01 & 1.0000 & 0.90855 & 0.09928 & 0.12666 & Biso & 1.000 & 0 \\
\hline $\mathrm{O} 2$ & 1.0000 & 0.89403 & 0.80021 & 0.12587 & Biso & 1.000 & 0 \\
\hline $\mathrm{O} 3$ & 1.0000 & 0.19405 & 0.07878 & 0.12004 & Biso & 1.000 & 0 \\
\hline 04 & 1.0000 & 0.08365 & 0.88121 & 0.86797 & Biso & 1.000 & 0 \\
\hline 05 & 1.0000 & 0.80272 & 0.90300 & 0.87491 & Biso & 1.000 & 0 \\
\hline 06 & 1.0000 & 0.10416 & 0.18948 & 0.87486 & Biso & 1.000 & 0 \\
\hline 07 & 1.0000 & 0.57391 & 0.43271 & 0.45656 & Biso & 1.000 & 0 \\
\hline 08 & 1.0000 & 0.54585 & 0.11057 & 0.45184 & Biso & 1.000 & 0 \\
\hline 09 & 1.0000 & 0.86960 & 0.41937 & 0.45877 & Biso & 1.000 & 0 \\
\hline 010 & 1.0000 & 0.75435 & 0.21817 & 0.20801 & Biso & 1.000 & 0 \\
\hline 011 & 1.0000 & 0.47189 & 0.23895 & 0.20748 & Biso & 1.000 & 0 \\
\hline 012 & 1.0000 & 0.77206 & 0.52008 & 0.21154 & Biso & 1.000 & 0 \\
\hline 013 & 1.0000 & 0.24023 & 0.76468 & 0.79162 & Biso & 1.000 & 0 \\
\hline 014 & 1.0000 & 0.22173 & 0.46064 & 0.78974 & Biso & 1.000 & 0 \\
\hline 015 & 1.0000 & 0.52558 & 0.74620 & 0.78755 & Biso & 1.000 & 0 \\
\hline 016 & 1.0000 & 0.42061 & 0.55577 & 0.54799 & Biso & 1.000 & 0 \\
\hline 017 & 1.0000 & 0.11559 & 0.55833 & 0.55059 & Biso & 1.000 & 0 \\
\hline 018 & 1.0000 & 0.44503 & 0.85925 & 0.53706 & Biso & 1.000 & 0 \\
\hline 019 & 1.0000 & 0.98520 & 0.30142 & 0.16758 & Biso & 1.000 & 0 \\
\hline 020 & 1.0000 & 0.69295 & 0.66937 & 0.16674 & Biso & 1.000 & 0 \\
\hline 021 & 1.0000 & 0.32864 & 0.01101 & 0.15502 & Biso & 1.000 & 0 \\
\hline 022 & 1.0000 & 0.31444 & 0.96784 & 0.82739 & Biso & 1.000 & 0 \\
\hline 023 & 1.0000 & 0.65069 & 0.67246 & 0.83707 & Biso & 1.000 & o \\
\hline 024 & 1.0000 & 0.02152 & 0.33770 & 0.83776 & Biso & 1.000 & 0 \\
\hline 025 & 1.0000 & 0.65016 & 0.63406 & 0.49957 & Biso & 1.000 & 0 \\
\hline 026 & 1.0000 & 0.98450 & 0.33096 & 0.49975 & Biso & 1.000 & 0 \\
\hline 027 & 1.0000 & 0.00942 & 0.67729 & 0.83658 & Biso & 1.000 & 0 \\
\hline 028 & 1.0000 & 0.30560 & 0.31458 & 0.83178 & Biso & 1.000 & 0 \\
\hline 029 & 1.0000 & 0.67301 & 0.97478 & 0.83476 & Biso & 1.000 & 0 \\
\hline 030 & 1.0000 & 0.67733 & 0.01690 & 0.16451 & Biso & 1.000 & 0 \\
\hline 031 & 1.0000 & 0.34141 & 0.30883 & 0.16498 & Biso & 1.000 & 0 \\
\hline 032 & 1.0000 & 0.97201 & 0.64892 & 0.16588 & Biso & 1.000 & 0 \\
\hline 033 & 1.0000 & 0.34496 & 0.35792 & 0.49502 & Biso & 1.000 & 0 \\
\hline 034 & 1.0000 & 0.00776 & 0.65098 & 0.49982 & Biso & 1.000 & 0 \\
\hline 035 & 1.0000 & 0.64913 & 0.98462 & 0.50145 & Biso & 1.000 & 0 \\
\hline 036 & 1.0000 & 0.11365 & 0.23093 & 0.13197 & Biso & 1.000 & 0 \\
\hline 037 & 1.0000 & 0.75755 & 0.86745 & 0.13444 & Biso & 1.000 & 0 \\
\hline 038 & 1.0000 & 0.12714 & 0.87554 & 0.13372 & Biso & 1.000 & 0 \\
\hline 039 & 1.0000 & 0.23420 & 0.11505 & 0.86330 & Biso & 1.000 & 0 \\
\hline 040 & 1.0000 & 0.87915 & 0.74744 & 0.86517 & Biso & 1.000 & 0 \\
\hline 041 & 1.0000 & 0.87207 & 0.10726 & 0.86603 & Biso & 1.000 & 0 \\
\hline 042 & 1.0000 & 0.77911 & 0.56429 & 0.46519 & Biso & 1.000 & 0 \\
\hline 043 & 1.0000 & 0.41428 & 0.20031 & 0.46990 & Biso & 1.000 & 0 \\
\hline 044 & 1.0000 & 0.78334 & 0.21315 & 0.46639 & Biso & 1.000 & 0 \\
\hline 045 & 1.0000 & 0.90768 & 0.45171 & 0.20274 & Biso & 1.000 & 0 \\
\hline 046 & 1.0000 & 0.54976 & 0.08475 & 0.20852 & Biso & 1.000 & 0 \\
\hline 047 & 1.0000 & 0.53950 & 0.44254 & 0.19837 & Biso & 1.000 & 0 \\
\hline 048 & 1.0000 & 0.44503 & 0.89725 & 0.80092 & Biso & 1.000 & 0 \\
\hline 049 & 1.0000 & 0.08831 & 0.53178 & 0.79042 & Biso & 1.000 & 0 \\
\hline
\end{tabular}




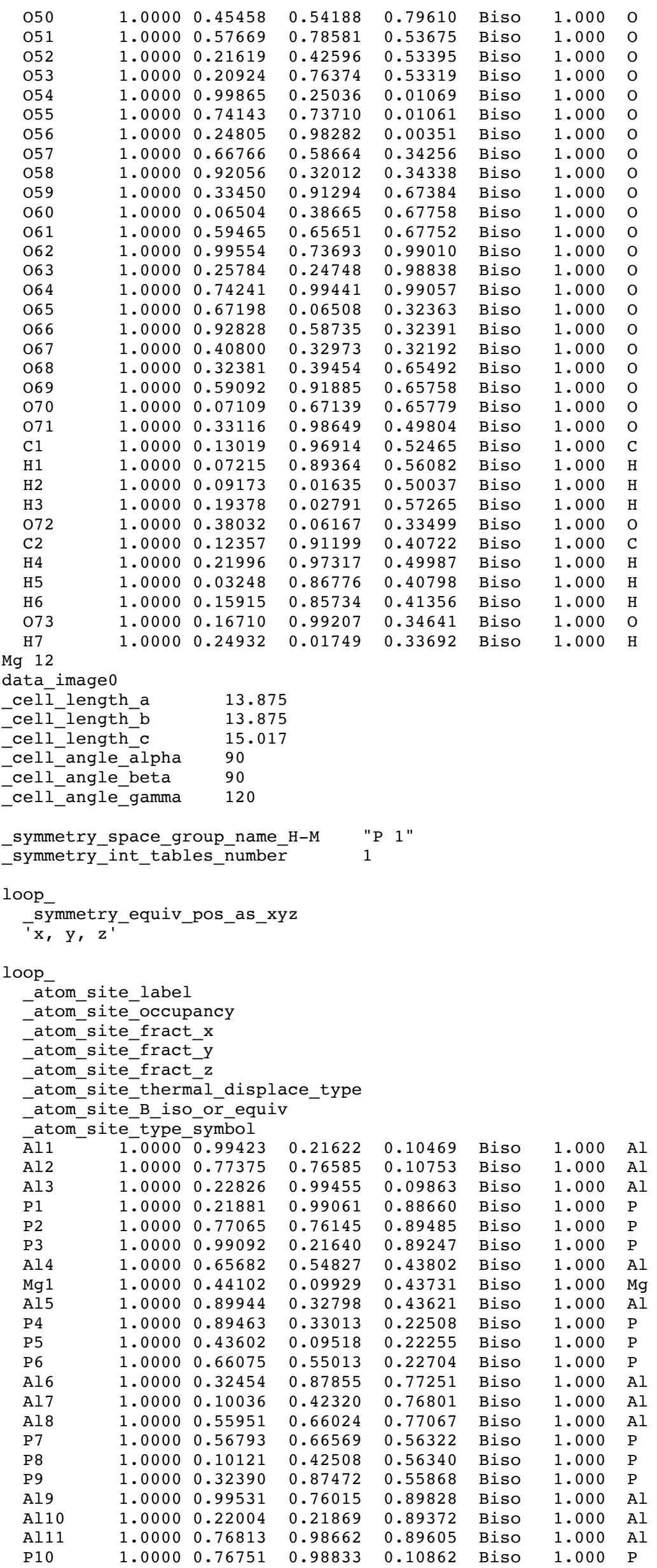




\begin{tabular}{|c|c|c|c|c|c|c|c|}
\hline P11 & 1.0000 & 0.22309 & 0.21913 & 0.10554 & Biso & 1.000 & $\mathrm{P}$ \\
\hline P12 & 1.0000 & 0.00177 & 0.76918 & 0.11066 & Biso & 1.000 & $\mathrm{P}$ \\
\hline Al12 & 1.0000 & 0.66953 & 0.09935 & 0.23334 & Biso & 1.000 & Al \\
\hline Al13 & 1.0000 & 0.89031 & 0.55400 & 0.23098 & Biso & 1.000 & Al \\
\hline Al1 14 & 1.0000 & 0.43518 & 0.32171 & 0.22834 & Biso & 1.000 & Al \\
\hline P13 & 1.0000 & 0.42528 & 0.32189 & 0.44056 & Biso & 1.000 & $P$ \\
\hline P14 & 1.0000 & 0.88844 & 0.55195 & 0.44239 & Biso & 1.000 & $\mathrm{P}$ \\
\hline P15 & 1.0000 & 0.67776 & 0.09925 & 0.44061 & Biso & 1.000 & $\mathrm{P}$ \\
\hline Al15 & 1.0000 & 0.33519 & 0.43884 & 0.56337 & Biso & 1.000 & Al \\
\hline Al16 & 1.0000 & 0.56061 & 0.89146 & 0.56325 & Biso & 1.000 & Al \\
\hline Al17 & 1.0000 & 0.09129 & 0.65315 & 0.56967 & Biso & 1.000 & Al \\
\hline P16 & 1.0000 & 0.09730 & 0.65413 & 0.77564 & Biso & 1.000 & $\mathrm{P}$ \\
\hline P 17 & 1.0000 & 0.55288 & 0.88577 & 0.77482 & Biso & 1.000 & $\mathrm{P}$ \\
\hline P18 & 1.0000 & 0.33140 & 0.43029 & 0.77225 & Biso & 1.000 & $P$ \\
\hline 01 & 1.0000 & 0.88870 & 0.07973 & 0.12685 & Biso & 1.000 & 0 \\
\hline $\mathrm{O} 2$ & 1.0000 & 0.91249 & 0.80199 & 0.12911 & Biso & 1.000 & 0 \\
\hline 03 & 1.0000 & 0.19503 & 0.09818 & 0.12209 & Biso & 1.000 & 0 \\
\hline 04 & 1.0000 & 0.09835 & 0.89616 & 0.87014 & Biso & 1.000 & 0 \\
\hline 05 & 1.0000 & 0.80294 & 0.88309 & 0.87493 & Biso & 1.000 & 0 \\
\hline 06 & 1.0000 & 0.08399 & 0.18966 & 0.87237 & Biso & 1.000 & 0 \\
\hline 07 & 1.0000 & 0.54630 & 0.41568 & 0.46006 & Biso & 1.000 & 0 \\
\hline 08 & 1.0000 & 0.58769 & 0.12931 & 0.45332 & Biso & 1.000 & 0 \\
\hline 09 & 1.0000 & 0.87031 & 0.43502 & 0.46111 & Biso & 1.000 & 0 \\
\hline 010 & 1.0000 & 0.77293 & 0.23777 & 0.21117 & Biso & 1.000 & 0 \\
\hline 011 & 1.0000 & 0.46949 & 0.21817 & 0.20687 & Biso & 1.000 & 0 \\
\hline 012 & 1.0000 & 0.75246 & 0.51991 & 0.21194 & Biso & 1.000 & 0 \\
\hline 013 & 1.0000 & 0.21913 & 0.74215 & 0.79627 & Biso & 1.000 & 0 \\
\hline 014 & 1.0000 & 0.23877 & 0.45892 & 0.78945 & Biso & 1.000 & 0 \\
\hline 015 & 1.0000 & 0.52340 & 0.76356 & 0.78546 & Biso & 1.000 & 0 \\
\hline 016 & 1.0000 & 0.44632 & 0.57399 & 0.54938 & Biso & 1.000 & 0 \\
\hline 017 & 1.0000 & 0.10906 & 0.53925 & 0.56034 & Biso & 1.000 & 0 \\
\hline 018 & 1.0000 & 0.42430 & 0.86136 & 0.53530 & Biso & 1.000 & 0 \\
\hline 019 & 1.0000 & 0.97348 & 0.31077 & 0.16600 & Biso & 1.000 & 0 \\
\hline 020 & 1.0000 & 0.68208 & 0.64975 & 0.16911 & Biso & 1.000 & 0 \\
\hline 021 & 1.0000 & 0.35010 & 0.02072 & 0.15217 & Biso & 1.000 & 0 \\
\hline 022 & 1.0000 & 0.29993 & 0.97473 & 0.82742 & Biso & 1.000 & 0 \\
\hline 023 & 1.0000 & 0.66720 & 0.68077 & 0.84167 & Biso & 1.000 & 0 \\
\hline $\mathrm{O} 24$ & 1.0000 & 0.00803 & 0.31723 & 0.83804 & Biso & 1.000 & 0 \\
\hline 025 & 1.0000 & 0.64618 & 0.64826 & 0.50167 & Biso & 1.000 & 0 \\
\hline 026 & 1.0000 & 0.01466 & 0.34611 & 0.49659 & Biso & 1.000 & 0 \\
\hline 027 & 1.0000 & 0.01820 & 0.66341 & 0.84174 & Biso & 1.000 & 0 \\
\hline 028 & 1.0000 & 0.31478 & 0.33311 & 0.83142 & Biso & 1.000 & 0 \\
\hline 029 & 1.0000 & 0.65237 & 0.96225 & 0.83352 & Biso & 1.000 & 0 \\
\hline 030 & 1.0000 & 0.68599 & 0.00887 & 0.16245 & Biso & 1.000 & 0 \\
\hline 031 & 1.0000 & 0.32288 & 0.30038 & 0.16174 & Biso & 1.000 & 0 \\
\hline 032 & 1.0000 & 0.98230 & 0.67084 & 0.16959 & Biso & 1.000 & 0 \\
\hline 033 & 1.0000 & 0.34316 & 0.34728 & 0.49010 & Biso & 1.000 & 0 \\
\hline 034 & 1.0000 & 0.98329 & 0.63944 & 0.50117 & Biso & 1.000 & 0 \\
\hline 035 & 1.0000 & 0.65927 & 0.00109 & 0.50053 & Biso & 1.000 & 0 \\
\hline 036 & 1.0000 & 0.12252 & 0.23028 & 0.13248 & Biso & 1.000 & 0 \\
\hline 037 & 1.0000 & 0.75430 & 0.87621 & 0.13714 & Biso & 1.000 & 0 \\
\hline 038 & 1.0000 & 0.11684 & 0.86733 & 0.13345 & Biso & 1.000 & 0 \\
\hline 039 & 1.0000 & 0.22804 & 0.10197 & 0.86165 & Biso & 1.000 & 0 \\
\hline 040 & 1.0000 & 0.86701 & 0.74375 & 0.86667 & Biso & 1.000 & 0 \\
\hline 041 & 1.0000 & 0.87921 & 0.11586 & 0.86557 & Biso & 1.000 & 0 \\
\hline 042 & 1.0000 & 0.78230 & 0.55433 & 0.46541 & Biso & 1.000 & 0 \\
\hline 043 & 1.0000 & 0.40814 & 0.21099 & 0.47191 & Biso & 1.000 & 0 \\
\hline 044 & 1.0000 & 0.79196 & 0.19839 & 0.46639 & Biso & 1.000 & 0 \\
\hline 045 & 1.0000 & 0.90616 & 0.44229 & 0.19866 & Biso & 1.000 & 0 \\
\hline 046 & 1.0000 & 0.53973 & 0.08418 & 0.21139 & Biso & 1.000 & 0 \\
\hline 047 & 1.0000 & 0.54876 & 0.45080 & 0.19981 & Biso & 1.000 & 0 \\
\hline 048 & 1.0000 & 0.45267 & 0.89601 & 0.80517 & Biso & 1.000 & 0 \\
\hline 049 & 1.0000 & 0.08411 & 0.53846 & 0.78437 & Biso & 1.000 & 0 \\
\hline 050 & 1.0000 & 0.44375 & 0.53195 & 0.79569 & Biso & 1.000 & 0 \\
\hline 051 & 1.0000 & 0.57732 & 0.77758 & 0.54051 & Biso & 1.000 & 0 \\
\hline 052 & 1.0000 & 0.21441 & 0.44083 & 0.53743 & Biso & 1.000 & 0 \\
\hline 053 & 1.0000 & 0.21526 & 0.76834 & 0.53380 & Biso & 1.000 & 0 \\
\hline 054 & 1.0000 & 0.99122 & 0.24385 & 0.99151 & Biso & 1.000 & 0 \\
\hline 055 & 1.0000 & 0.74516 & 0.73569 & 0.99435 & Biso & 1.000 & 0 \\
\hline 056 & 1.0000 & 0.25060 & 0.99053 & 0.98448 & Biso & 1.000 & 0 \\
\hline 057 & 1.0000 & 0.65957 & 0.58145 & 0.32519 & Biso & 1.000 & 0 \\
\hline 058 & 1.0000 & 0.92960 & 0.33372 & 0.32271 & Biso & 1.000 & 0 \\
\hline 059 & 1.0000 & 0.32424 & 0.90151 & 0.65792 & Biso & 1.000 & 0 \\
\hline 060 & 1.0000 & 0.06764 & 0.37582 & 0.65779 & Biso & 1.000 & 0 \\
\hline 061 & 1.0000 & 0.60333 & 0.66479 & 0.66045 & Biso & 1.000 & 0 \\
\hline 062 & 1.0000 & 0.99727 & 0.73600 & 0.01229 & Biso & 1.000 & 0 \\
\hline 063 & 1.0000 & 0.25133 & 0.24882 & 0.00651 & Biso & 1.000 & 0 \\
\hline 064 & 1.0000 & 0.73937 & 0.98606 & 0.00926 & Biso & 1.000 & 0 \\
\hline 065 & 1.0000 & 0.68238 & 0.06546 & 0.34291 & Biso & 1.000 & 0 \\
\hline 066 & 1.0000 & 0.92172 & 0.58504 & 0.34445 & Biso & 1.000 & 0 \\
\hline
\end{tabular}




$\begin{array}{llllllll}\text { 067 } & 1.0000 & 0.40162 & 0.32170 & 0.33990 & \text { Biso } & 1.000 & \text { O } \\ \text { O68 } & 1.0000 & 0.33001 & 0.39670 & 0.67431 & \text { Biso } & 1.000 & \text { O } \\ \text { O69 } & 1.0000 & 0.58134 & 0.92282 & 0.67722 & \text { Biso } & 1.000 & \text { O } \\ \text { O70 } & 1.0000 & 0.06607 & 0.67233 & 0.68072 & \text { Biso } & 1.000 & \text { O } \\ \text { O71 } & 1.0000 & 0.32618 & 0.96972 & 0.50308 & \text { Biso } & 1.000 & \text { O } \\ \text { C1 } & 1.0000 & 0.13712 & 0.97998 & 0.51300 & \text { Biso } & 1.000 & \mathrm{C} \\ \text { H1 } & 1.0000 & 0.07880 & 0.91391 & 0.55737 & \text { Biso } & 1.000 & \mathrm{H} \\ \text { H2 } & 1.0000 & 0.10065 & 0.02569 & 0.48192 & \text { Biso } & 1.000 & \mathrm{H} \\ \text { H3 } & 1.0000 & 0.20624 & 0.04724 & 0.55240 & \text { Biso } & 1.000 & \mathrm{H} \\ \text { O72 } & 1.0000 & 0.38485 & 0.05660 & 0.31571 & \text { Biso } & 1.000 & \text { O } \\ \text { C2 } & 1.0000 & 0.12870 & 0.91298 & 0.40214 & \text { Biso } & 1.000 & \mathrm{C} \\ \text { H4 } & 1.0000 & 0.22016 & 0.96836 & 0.49643 & \text { Biso } & 1.000 & \mathrm{H} \\ \text { H5 } & 1.0000 & 0.03757 & 0.86794 & 0.40231 & \text { Biso } & 1.000 & \mathrm{H} \\ \text { H6 } & 1.0000 & 0.16347 & 0.85780 & 0.41055 & \text { Biso } & 1.000 & \mathrm{H} \\ \text { O73 } & 1.0000 & 0.17217 & 0.98924 & 0.33772 & \text { Biso } & 1.000 & \mathrm{O} \\ \mathrm{H} 7 & 1.0000 & 0.25300 & 0.01248 & 0.32635 & \text { Biso } & 1.000 & \mathrm{H}\end{array}$

Al 12

data_image 0

$\begin{array}{ll}\text { _cel1_length_a } & 13.625 \\ \text {-cell_length_b } & 13.625 \\ \text { _cell_length_c } & 15.067 \\ \text {-cell_angle_alpha } & 90 \\ \text {-cell_angle_beta } & 90 \\ \text { _cell_angle_gamma } & 120\end{array}$

_symmetry_space_group_name_H-M "P 1 "

symmetry_int_tables_number $\bar{n}$

loop

symmetry_equiv_pos_as_xyz

' $\mathrm{x}, \mathrm{y}, \mathrm{z}$ '

loop

atom_site_label

-atom_site_occupancy

atom site fract $x$

-atom_site_fract_y

-atom_site_thermāl_displace_type

-atom_site_B_iso_or_equiv

-atom_site_type_symbol

\begin{tabular}{|c|c|c|c|c|c|c|}
\hline Si1 & 1.0000 & 0.00717 & 0.22955 & 0.10226 & Biso & 1.000 \\
\hline $\mathrm{Si} 2$ & 1.0000 & 0.78033 & 0.77429 & 0.10396 & Biso & 1.000 \\
\hline Si3 & 1.0000 & 0.23842 & 0.00053 & 0.09682 & Biso & 1.000 \\
\hline Si 4 & 1.0000 & 0.23104 & 0.99748 & 0.88969 & Biso & 1.000 \\
\hline Si5 & 1.0000 & 0.77657 & 0.77017 & 0.89660 & Biso & 1.000 \\
\hline Si6 & 1.0000 & 0.00405 & 0.22967 & 0.89602 & Biso & 1.000 \\
\hline $\operatorname{Si7}$ & 1.0000 & 0.67174 & 0.56283 & 0.43504 & Biso & 1.000 \\
\hline Al1 & 1.0000 & 0.43785 & 0.10221 & 0.43335 & Biso & 1.000 \\
\hline $\operatorname{Si} 8$ & 1.0000 & 0.90532 & 0.33251 & 0.43480 & Biso & 1.000 \\
\hline Si9 & 1.0000 & 0.90497 & 0.33494 & 0.22899 & Biso & 1.000 \\
\hline Silo & 1.0000 & 0.44258 & 0.10446 & 0.22597 & Biso & 1.000 \\
\hline Si11 & 1.0000 & 0.67433 & 0.56374 & 0.22984 & Biso & 1.000 \\
\hline Si12 & 1.0000 & 0.33784 & 0.89226 & 0.76854 & Biso & 1.000 \\
\hline Si13 & 1.0000 & 0.10719 & 0.43254 & 0.76655 & Biso & 1.000 \\
\hline Si14 & 1.0000 & 0.56927 & 0.66568 & 0.76794 & Biso & 1.000 \\
\hline Si15 & 1.0000 & 0.57532 & 0.66943 & 0.56505 & Biso & 1.000 \\
\hline Si16 & 1.0000 & 0.10438 & 0.43002 & 0.56494 & Biso & 1.000 \\
\hline Si17 & 1.0000 & 0.33851 & 0.88891 & 0.56043 & Biso & 1.000 \\
\hline Si18 & 1.0000 & 0.00313 & 0.76720 & 0.89533 & Biso & 1.000 \\
\hline Si19 & 1.0000 & 0.23392 & 0.22858 & 0.89275 & Biso & 1.000 \\
\hline Si20 & 1.0000 & 0.77727 & 0.99904 & 0.89491 & Biso & 1.000 \\
\hline Si21 & 1.0000 & 0.77695 & 0.00075 & 0.10221 & Biso & 1.000 \\
\hline Si22 & 1.0000 & 0.23744 & 0.22968 & 0.09909 & Biso & 1.000 \\
\hline Si23 & 1.0000 & 0.00888 & 0.77443 & 0.10322 & Biso & 1.000 \\
\hline Si24 & 1.0000 & 0.67626 & 0.10519 & 0.23092 & Biso & 1.000 \\
\hline Si25 & 1.0000 & 0.90421 & 0.56441 & 0.23007 & Biso & 1.000 \\
\hline Si26 & 1.0000 & 0.44461 & 0.33437 & 0.22719 & Biso & 1.000 \\
\hline Si27 & 1.0000 & 0.43789 & 0.33332 & 0.43410 & Biso & 1.000 \\
\hline Si28 & 1.0000 & 0.90351 & 0.56395 & 0.43565 & Biso & 1.000 \\
\hline Si29 & 1.0000 & 0.67610 & 0.10222 & 0.43403 & Biso & 1.000 \\
\hline Si30 & 1.0000 & 0.34008 & 0.44252 & 0.56103 & Biso & 1.000 \\
\hline Si31 & 1.0000 & 0.57478 & 0.90099 & 0.56183 & Biso & 1.000 \\
\hline Si32 & 1.0000 & 0.10281 & 0.66425 & 0.56626 & Biso & 1.000 \\
\hline Si33 & 1.0000 & 0.10655 & 0.66583 & 0.76844 & Biso & 1.000 \\
\hline Si34 & 1.0000 & 0.56746 & 0.89583 & 0.76798 & Biso & 1.000 \\
\hline Si35 & 1.0000 & 0.33781 & 0.43589 & 0.76579 & Biso & 1.000 \\
\hline 01 & 1.0000 & 0.90806 & 0.09894 & 0.11921 & Biso & 1.000 \\
\hline $\mathrm{O} 2$ & 1.0000 & 0.91252 & 0.80996 & 0.12024 & Biso & 1.000 \\
\hline $\mathrm{O3}$ & 1.0000 & 0.20572 & 0.09866 & 0.11445 & Biso & 1.000 \\
\hline
\end{tabular}




\begin{tabular}{|c|c|c|c|c|c|c|c|}
\hline 04 & 1.0000 & 0.10085 & 0.89686 & 0.87263 & Biso & 1.000 & 0 \\
\hline 05 & 1.0000 & 0.81174 & 0.90174 & 0.87819 & Biso & 1.000 & 0 \\
\hline 06 & 1.0000 & 0.10347 & 0.19891 & 0.87837 & Biso & 1.000 & 0 \\
\hline 07 & 1.0000 & 0.56886 & 0.43477 & 0.45040 & Biso & 1.000 & 0 \\
\hline 08 & 1.0000 & 0.57171 & 0.12313 & 0.44630 & Biso & 1.000 & 0 \\
\hline 09 & 1.0000 & 0.88175 & 0.43711 & 0.45296 & Biso & 1.000 & 0 \\
\hline 010 & 1.0000 & 0.77374 & 0.23691 & 0.21311 & Biso & 1.000 & 0 \\
\hline 011 & 1.0000 & 0.47878 & 0.23708 & 0.21018 & Biso & 1.000 & 0 \\
\hline 012 & 1.0000 & 0.77230 & 0.52960 & 0.21602 & Biso & 1.000 & 0 \\
\hline 013 & 1.0000 & 0.23786 & 0.76227 & 0.78712 & Biso & 1.000 & 0 \\
\hline 014 & 1.0000 & 0.23908 & 0.46816 & 0.78340 & Biso & 1.000 & 0 \\
\hline 015 & 1.0000 & 0.53543 & 0.76413 & 0.77813 & Biso & 1.000 & 0 \\
\hline 016 & 1.0000 & 0.44378 & 0.57215 & 0.55073 & Biso & 1.000 & 0 \\
\hline 017 & 1.0000 & 0.11799 & 0.55485 & 0.55791 & Biso & 1.000 & 0 \\
\hline 018 & 1.0000 & 0.44534 & 0.87147 & 0.53879 & Biso & 1.000 & 0 \\
\hline 019 & 1.0000 & 0.98983 & 0.31580 & 0.16541 & Biso & 1.000 & 0 \\
\hline 020 & 1.0000 & 0.69691 & 0.66831 & 0.16594 & Biso & 1.000 & 0 \\
\hline 021 & 1.0000 & 0.34961 & 0.02437 & 0.15225 & Biso & 1.000 & 0 \\
\hline 022 & 1.0000 & 0.31736 & 0.98080 & 0.82598 & Biso & 1.000 & 0 \\
\hline 023 & 1.0000 & 0.66794 & 0.68508 & 0.83735 & Biso & 1.000 & 0 \\
\hline 024 & 1.0000 & 0.02351 & 0.33609 & 0.83559 & Biso & 1.000 & 0 \\
\hline 025 & 1.0000 & 0.65913 & 0.65169 & 0.49911 & Biso & 1.000 & 0 \\
\hline 026 & 1.0000 & 0.00782 & 0.34423 & 0.49704 & Biso & 1.000 & 0 \\
\hline 027 & 1.0000 & 0.02200 & 0.67784 & 0.83724 & Biso & 1.000 & 0 \\
\hline 028 & 1.0000 & 0.31918 & 0.33177 & 0.82888 & Biso & 1.000 & 0 \\
\hline 029 & 1.0000 & 0.67136 & 0.97711 & 0.83275 & Biso & 1.000 & 0 \\
\hline 030 & 1.0000 & 0.69094 & 0.02204 & 0.16194 & Biso & 1.000 & 0 \\
\hline 031 & 1.0000 & 0.34216 & 0.31522 & 0.16139 & Biso & 1.000 & 0 \\
\hline 032 & 1.0000 & 0.98702 & 0.66913 & 0.16632 & Biso & 1.000 & o \\
\hline 033 & 1.0000 & 0.35250 & 0.35934 & 0.49198 & Biso & 1.000 & 0 \\
\hline 034 & 1.0000 & 0.00485 & 0.65525 & 0.49957 & Biso & 1.000 & 0 \\
\hline 035 & 1.0000 & 0.66533 & 0.00137 & 0.49895 & Biso & 1.000 & 0 \\
\hline 036 & 1.0000 & 0.12845 & 0.24122 & 0.12545 & Biso & 1.000 & 0 \\
\hline 037 & 1.0000 & 0.76418 & 0.88029 & 0.13064 & Biso & 1.000 & 0 \\
\hline 038 & 1.0000 & 0.13220 & 0.88019 & 0.12823 & Biso & 1.000 & 0 \\
\hline 039 & 1.0000 & 0.24153 & 0.11780 & 0.86482 & Biso & 1.000 & 0 \\
\hline 040 & 1.0000 & 0.88163 & 0.75284 & 0.86827 & Biso & 1.000 & 0 \\
\hline 041 & 1.0000 & 0.88400 & 0.12100 & 0.86830 & Biso & 1.000 & 0 \\
\hline 042 & 1.0000 & 0.79046 & 0.56864 & 0.45996 & Biso & 1.000 & 0 \\
\hline 043 & 1.0000 & 0.42231 & 0.21476 & 0.46530 & Biso & 1.000 & 0 \\
\hline 044 & 1.0000 & 0.79392 & 0.21545 & 0.46072 & Biso & 1.000 & 0 \\
\hline 045 & 1.0000 & 0.91857 & 0.45702 & 0.20449 & Biso & 1.000 & 0 \\
\hline 046 & 1.0000 & 0.55389 & 0.09273 & 0.21256 & Biso & 1.000 & 0 \\
\hline 047 & 1.0000 & 0.55335 & 0.45648 & 0.20304 & Biso & 1.000 & 0 \\
\hline 048 & 1.0000 & 0.45803 & 0.90525 & 0.79748 & Biso & 1.000 & 0 \\
\hline 049 & 1.0000 & 0.09372 & 0.54257 & 0.78169 & Biso & 1.000 & 0 \\
\hline 050 & 1.0000 & 0.45890 & 0.54476 & 0.79058 & Biso & 1.000 & 0 \\
\hline 051 & 1.0000 & 0.58594 & 0.79025 & 0.54260 & Biso & 1.000 & o \\
\hline 052 & 1.0000 & 0.22356 & 0.44077 & 0.53723 & Biso & 1.000 & 0 \\
\hline 053 & 1.0000 & 0.22131 & 0.77363 & 0.53662 & Biso & 1.000 & 0 \\
\hline 054 & 1.0000 & 0.00373 & 0.26393 & 0.99929 & Biso & 1.000 & 0 \\
\hline 055 & 1.0000 & 0.74545 & 0.73870 & 0.00072 & Biso & 1.000 & 0 \\
\hline 056 & 1.0000 & 0.26585 & 0.99572 & 0.99237 & Biso & 1.000 & 0 \\
\hline 057 & 1.0000 & 0.67500 & 0.60220 & 0.33238 & Biso & 1.000 & 0 \\
\hline 058 & 1.0000 & 0.94167 & 0.33419 & 0.33168 & Biso & 1.000 & 0 \\
\hline 059 & 1.0000 & 0.33881 & 0.92295 & 0.66396 & Biso & 1.000 & 0 \\
\hline 060 & 1.0000 & 0.06956 & 0.38301 & 0.66612 & Biso & 1.000 & 0 \\
\hline 061 & 1.0000 & 0.61382 & 0.66669 & 0.66725 & Biso & 1.000 & 0 \\
\hline 062 & 1.0000 & 0.00590 & 0.73842 & 0.99976 & Biso & 1.000 & 0 \\
\hline 063 & 1.0000 & 0.27213 & 0.26432 & 0.99543 & Biso & 1.000 & 0 \\
\hline 064 & 1.0000 & 0.74279 & 0.99843 & 0.99830 & Biso & 1.000 & 0 \\
\hline 065 & 1.0000 & 0.68623 & 0.06764 & 0.33146 & Biso & 1.000 & 0 \\
\hline 066 & 1.0000 & 0.94170 & 0.60298 & 0.33308 & Biso & 1.000 & 0 \\
\hline 067 & 1.0000 & 0.40568 & 0.33315 & 0.32923 & Biso & 1.000 & 0 \\
\hline 068 & 1.0000 & 0.33564 & 0.39865 & 0.66266 & Biso & 1.000 & 0 \\
\hline 069 & 1.0000 & 0.60240 & 0.93814 & 0.66583 & Biso & 1.000 & 0 \\
\hline 070 & 1.0000 & 0.07068 & 0.67967 & 0.66751 & Biso & 1.000 & 0 \\
\hline 071 & 1.0000 & 0.33614 & 0.98569 & 0.49820 & Biso & 1.000 & 0 \\
\hline $\mathrm{C} 1$ & 1.0000 & 0.13400 & 0.97687 & 0.51689 & Biso & 1.000 & C \\
\hline $\mathrm{H} 1$ & 1.0000 & 0.07491 & 0.90402 & 0.55684 & Biso & 1.000 & $\mathrm{H}$ \\
\hline $\mathrm{H} 2$ & 1.0000 & 0.09560 & 0.02423 & 0.48960 & Biso & 1.000 & $\mathrm{H}$ \\
\hline Н3 & 1.0000 & 0.20077 & 0.04096 & 0.56141 & Biso & 1.000 & $\mathrm{H}$ \\
\hline 072 & 1.0000 & 0.38658 & 0.06240 & 0.32357 & Biso & 1.000 & 0 \\
\hline $\mathrm{C} 2$ & 1.0000 & 0.12680 & 0.91356 & 0.40385 & Biso & 1.000 & C \\
\hline $\mathrm{H} 4$ & 1.0000 & 0.22400 & 0.97560 & 0.49632 & Biso & 1.000 & $\mathrm{H}$ \\
\hline H5 & 1.0000 & 0.03401 & 0.86675 & 0.40467 & Biso & 1.000 & $\mathrm{H}$ \\
\hline H6 & 1.0000 & 0.16383 & 0.85870 & 0.41105 & Biso & 1.000 & $\mathrm{H}$ \\
\hline 073 & 1.0000 & 0.16941 & 0.99252 & 0.34072 & Biso & 1.000 & 0 \\
\hline H 7 & 1.0000 & 0.25220 & 0.01743 & 0.32934 & Biso & 1.000 & $\mathrm{H}$ \\
\hline
\end{tabular}




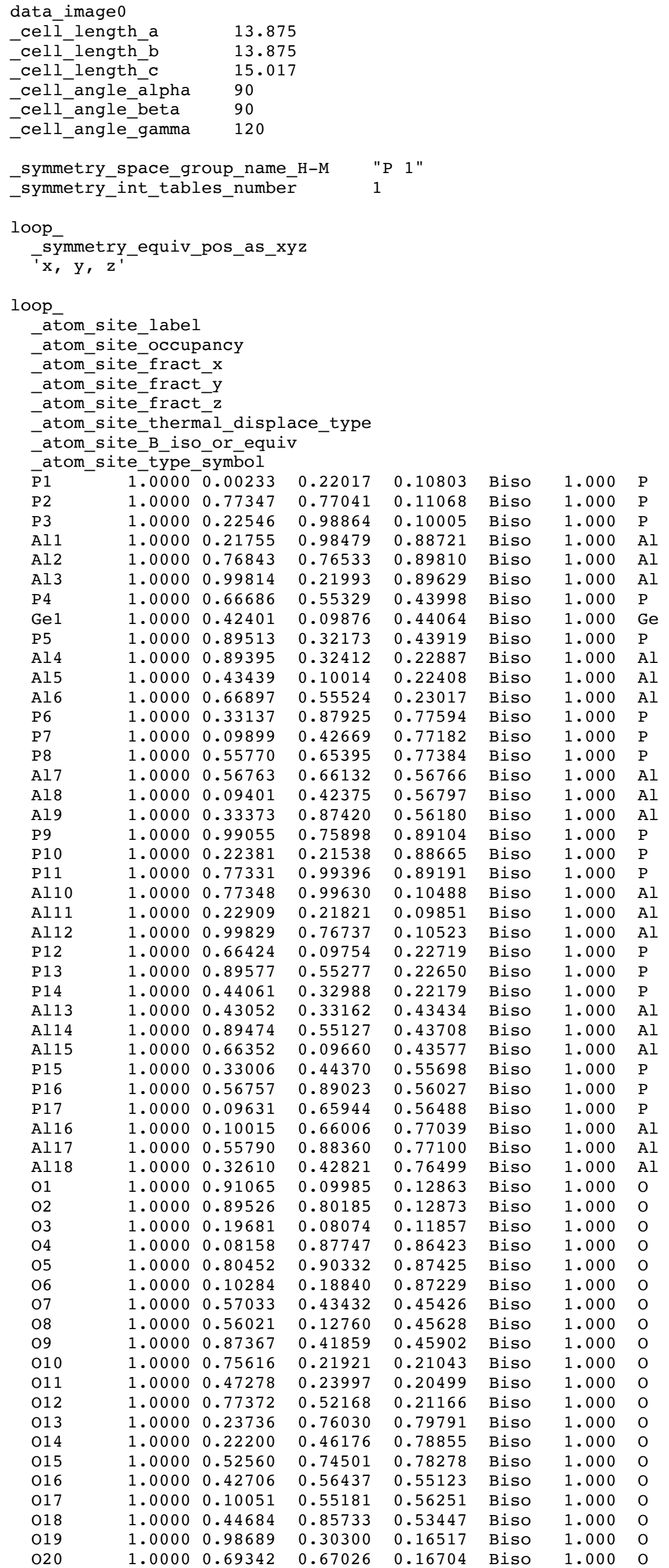




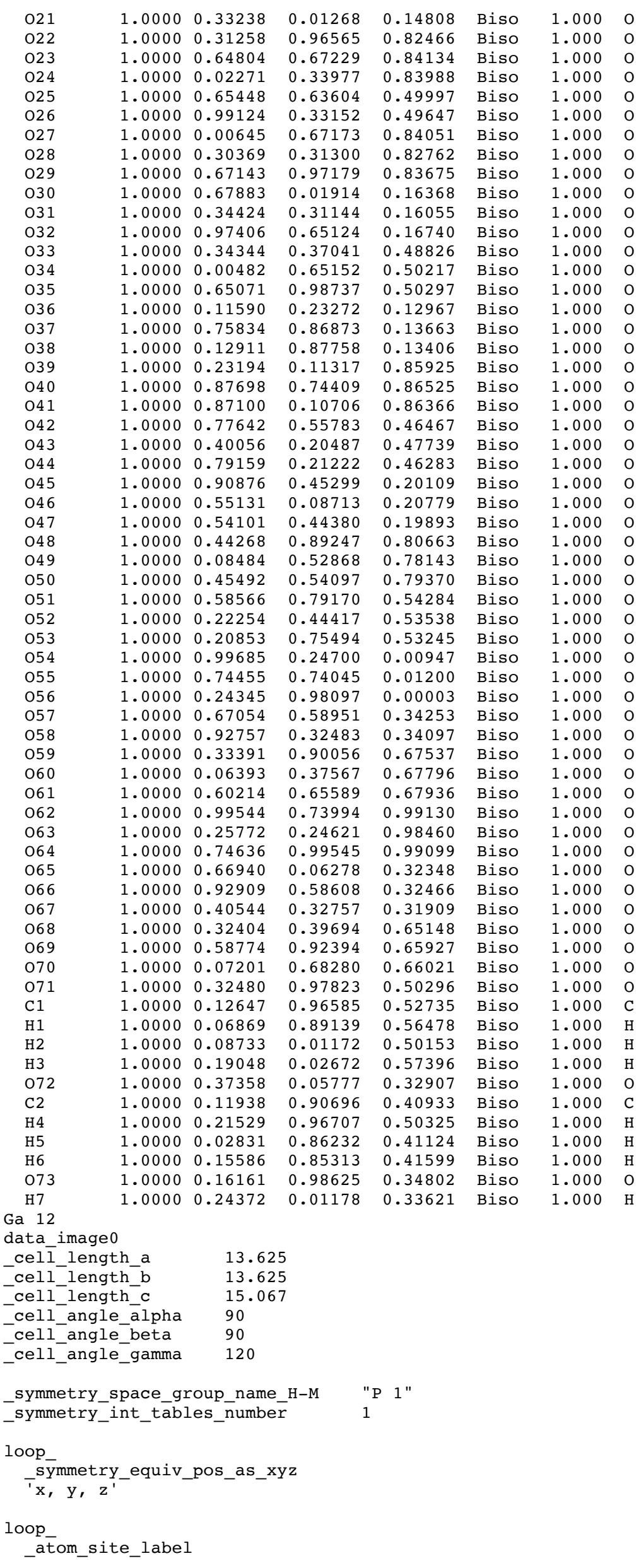




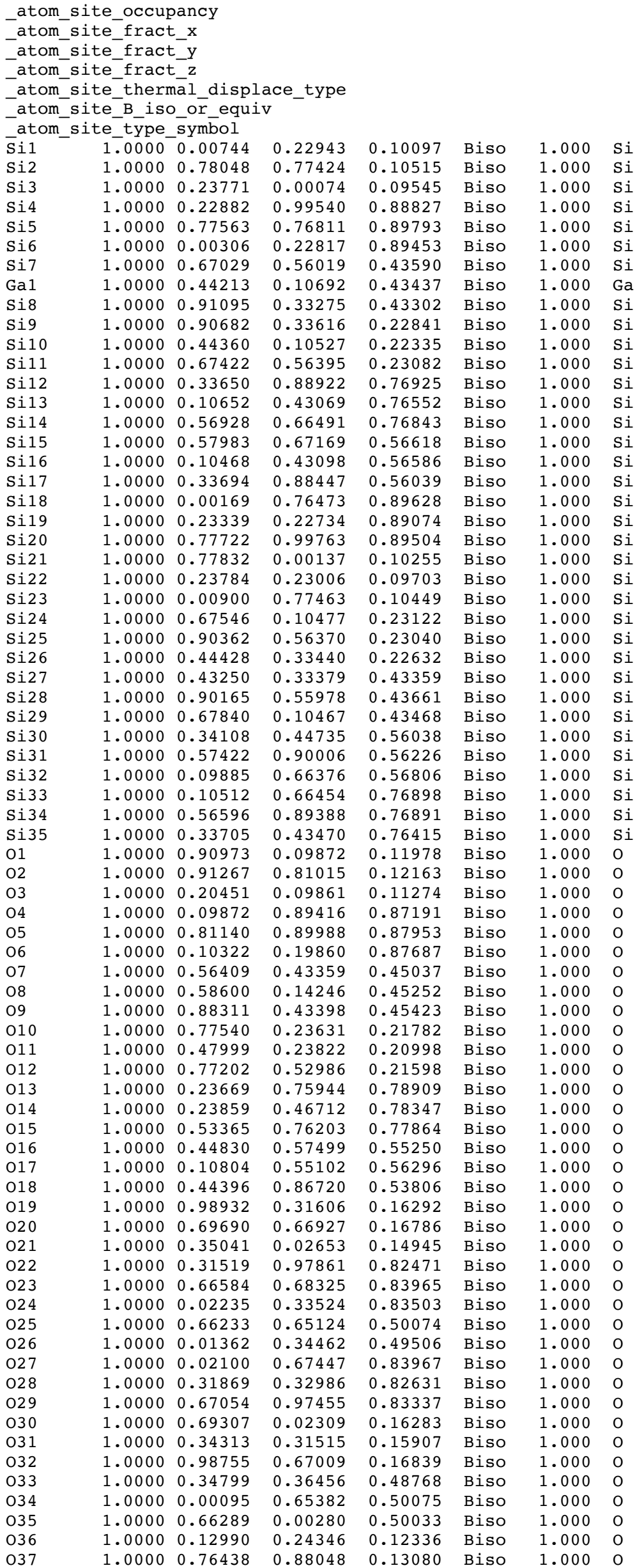




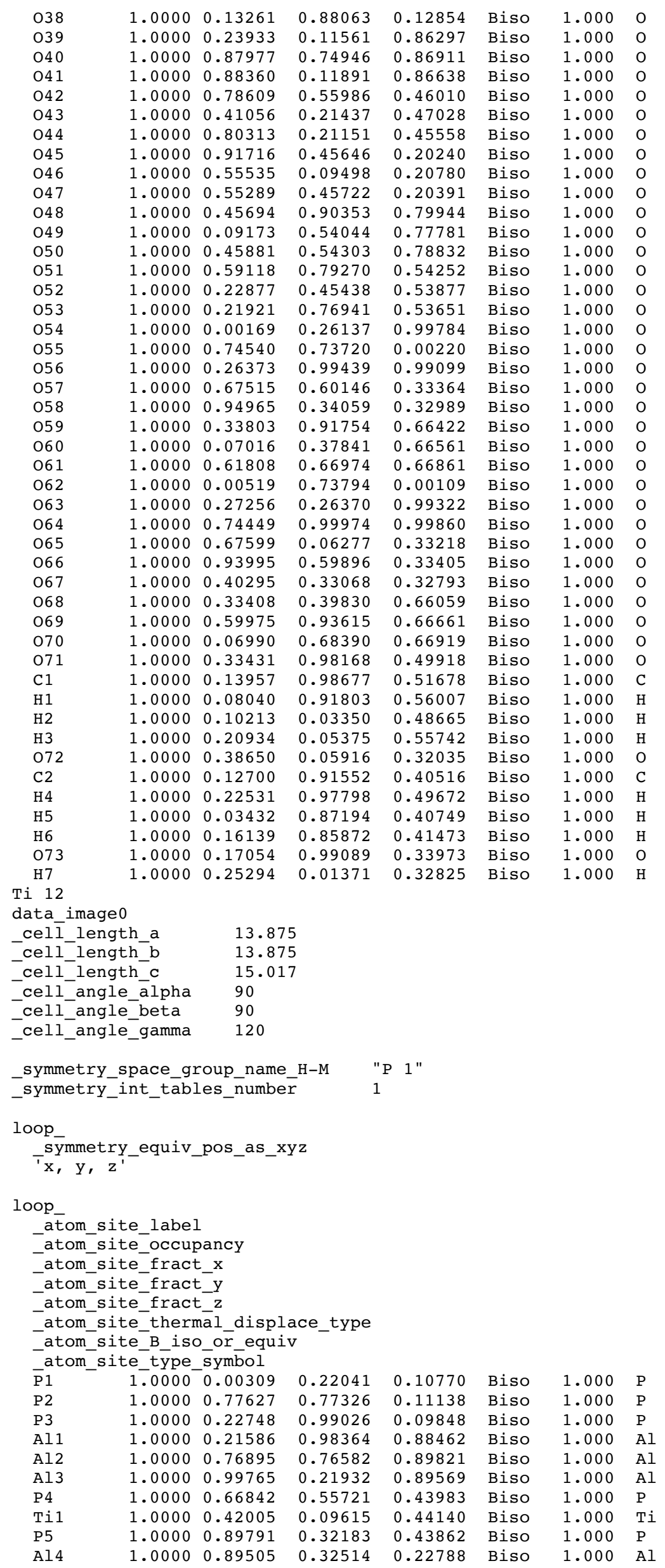




\begin{tabular}{|c|c|c|c|c|c|c|}
\hline Al5 & 1.0000 & 0.43394 & 0.10086 & 0.22229 & Biso & 1.000 \\
\hline Al6 & 1.0000 & 0.67149 & 0.55678 & 0.23024 & Biso & 1.000 \\
\hline P6 & 1.0000 & 0.32991 & 0.87551 & 0.77834 & Biso & 1.000 \\
\hline P7 & 1.0000 & 0.09893 & 0.42531 & 0.77119 & Biso & 1.000 \\
\hline P8 & 1.0000 & 0.55870 & 0.65379 & 0.77361 & Biso & 1.000 \\
\hline Al 7 & 1.0000 & 0.57261 & 0.66413 & 0.56856 & Biso & 1.000 \\
\hline A18 & 1.0000 & 0.09399 & 0.42362 & 0.56911 & Biso & 1.000 \\
\hline Al9 & 1.0000 & 0.33005 & 0.86799 & 0.56336 & Biso & 1.000 \\
\hline P9 & 1.0000 & 0.98996 & 0.75741 & 0.89133 & Biso & 1.000 \\
\hline P10 & 1.0000 & 0.22310 & 0.21429 & 0.88454 & Biso & 1.000 \\
\hline P11 & 1.0000 & 0.77383 & 0.99354 & 0.89138 & Biso & 1.000 \\
\hline Al10 & 1.0000 & 0.77445 & 0.99728 & 0.10526 & Biso & 1.000 \\
\hline Al11 & 1.0000 & 0.23080 & 0.21937 & 0.09713 & Biso & 1.000 \\
\hline Al12 & 1.0000 & 0.00084 & 0.77012 & 0.10601 & Biso & 1.000 \\
\hline P12 & 1.0000 & 0.66640 & 0.09959 & 0.22702 & Biso & 1.000 \\
\hline P13 & 1.0000 & 0.89799 & 0.55464 & 0.22751 & Biso & 1.000 \\
\hline P14 & 1.0000 & 0.44177 & 0.33183 & 0.22038 & Biso & 1.000 \\
\hline Al13 & 1.0000 & 0.42843 & 0.33743 & 0.43276 & Biso & 1.000 \\
\hline Al14 & 1.0000 & 0.89476 & 0.55087 & 0.43782 & Biso & 1.000 \\
\hline Al15 & 1.0000 & 0.66851 & 0.09719 & 0.43473 & Biso & 1.000 \\
\hline P15 & 1.0000 & 0.33140 & 0.44832 & 0.55611 & Biso & 1.000 \\
\hline P16 & 1.0000 & 0.56712 & 0.89154 & 0.56172 & Biso & 1.000 \\
\hline P17 & 1.0000 & 0.09277 & 0.65714 & 0.56761 & Biso & 1.000 \\
\hline Al16 & 1.0000 & 0.09881 & 0.65862 & 0.77192 & Biso & 1.000 \\
\hline Al17 & 1.0000 & 0.55722 & 0.88355 & 0.77159 & Biso & 1.000 \\
\hline Al18 & 1.0000 & 0.32633 & 0.42851 & 0.76384 & Biso & 1.000 \\
\hline 01 & 1.0000 & 0.91160 & 0.10052 & 0.12986 & Biso & 1.000 \\
\hline $\mathrm{O} 2$ & 1.0000 & 0.89850 & 0.80587 & 0.12911 & Biso & 1.000 \\
\hline 03 & 1.0000 & 0.20029 & 0.08286 & 0.11974 & Biso & 1.000 \\
\hline 04 & 1.0000 & 0.08076 & 0.87461 & 0.86127 & Biso & 1.000 \\
\hline 05 & 1.0000 & 0.80529 & 0.90338 & 0.87213 & Biso & 1.000 \\
\hline 06 & 1.0000 & 0.10223 & 0.18795 & 0.87109 & Biso & 1.000 \\
\hline 07 & 1.0000 & 0.56665 & 0.44174 & 0.45484 & Biso & 1.000 \\
\hline 08 & 1.0000 & 0.56066 & 0.12415 & 0.44872 & Biso & 1.000 \\
\hline 09 & 1.0000 & 0.87657 & 0.41885 & 0.45808 & Biso & 1.000 \\
\hline 010 & 1.0000 & 0.75664 & 0.22166 & 0.20845 & Biso & 1.000 \\
\hline 011 & 1.0000 & 0.47335 & 0.24141 & 0.20413 & Biso & 1.000 \\
\hline 012 & 1.0000 & 0.77548 & 0.52191 & 0.21258 & Biso & 1.000 \\
\hline 013 & 1.0000 & 0.23519 & 0.75784 & 0.80291 & Biso & 1.000 \\
\hline 014 & 1.0000 & 0.22227 & 0.46191 & 0.78845 & Biso & 1.000 \\
\hline 015 & 1.0000 & 0.52680 & 0.74519 & 0.77979 & Biso & 1.000 \\
\hline 016 & 1.0000 & 0.43311 & 0.56595 & 0.54966 & Biso & 1.000 \\
\hline 017 & 1.0000 & 0.08813 & 0.54530 & 0.56864 & Biso & 1.000 \\
\hline 018 & 1.0000 & 0.44653 & 0.85700 & 0.53418 & Biso & 1.000 \\
\hline 019 & 1.0000 & 0.98826 & 0.30415 & 0.16420 & Biso & 1.000 \\
\hline 020 & 1.0000 & 0.69697 & 0.67167 & 0.16666 & Biso & 1.000 \\
\hline 021 & 1.0000 & 0.33733 & 0.01499 & 0.14187 & Biso & 1.000 \\
\hline $\mathrm{O} 22$ & 1.0000 & 0.31225 & 0.96456 & 0.82387 & Biso & 1.000 \\
\hline 023 & 1.0000 & 0.64709 & 0.67236 & 0.84317 & Biso & 1.000 \\
\hline $\mathrm{O} 24$ & 1.0000 & 0.02298 & 0.34002 & 0.84034 & Biso & 1.000 \\
\hline 025 & 1.0000 & 0.66239 & 0.64402 & 0.49963 & Biso & 1.000 \\
\hline 026 & 1.0000 & 0.99602 & 0.33265 & 0.49390 & Biso & 1.000 \\
\hline 027 & 1.0000 & 0.00422 & 0.66778 & 0.84292 & Biso & 1.000 \\
\hline 028 & 1.0000 & 0.30297 & 0.31231 & 0.82572 & Biso & 1.000 \\
\hline 029 & 1.0000 & 0.67055 & 0.97080 & 0.83794 & Biso & 1.000 \\
\hline 030 & 1.0000 & 0.67895 & 0.02169 & 0.16134 & Biso & 1.000 \\
\hline 031 & 1.0000 & 0.34688 & 0.31453 & 0.15765 & Biso & 1.000 \\
\hline 032 & 1.0000 & 0.97551 & 0.65376 & 0.16859 & Biso & 1.000 \\
\hline 033 & 1.0000 & 0.33727 & 0.37249 & 0.48519 & Biso & 1.000 \\
\hline 034 & 1.0000 & 0.00251 & 0.65194 & 0.50462 & Biso & 1.000 \\
\hline 035 & 1.0000 & 0.65081 & 0.98766 & 0.50376 & Biso & 1.000 \\
\hline 036 & 1.0000 & 0.11716 & 0.23341 & 0.12832 & Biso & 1.000 \\
\hline 037 & 1.0000 & 0.75940 & 0.87017 & 0.13877 & Biso & 1.000 \\
\hline 038 & 1.0000 & 0.13248 & 0.87958 & 0.13477 & Biso & 1.000 \\
\hline 039 & 1.0000 & 0.23027 & 0.11190 & 0.85579 & Biso & 1.000 \\
\hline 040 & 1.0000 & 0.87610 & 0.74213 & 0.86594 & Biso & 1.000 \\
\hline 041 & 1.0000 & 0.87051 & 0.10693 & 0.86241 & Biso & 1.000 \\
\hline 042 & 1.0000 & 0.77396 & 0.55349 & 0.46434 & Biso & 1.000 \\
\hline 043 & 1.0000 & 0.40590 & 0.21258 & 0.47527 & Biso & 1.000 \\
\hline 044 & 1.0000 & 0.79519 & 0.21273 & 0.46497 & Biso & 1.000 \\
\hline 045 & 1.0000 & 0.91258 & 0.45575 & 0.20215 & Biso & 1.000 \\
\hline 046 & 1.0000 & 0.55186 & 0.08757 & 0.21276 & Biso & 1.000 \\
\hline 047 & 1.0000 & 0.54328 & 0.44568 & 0.19903 & Biso & 1.000 \\
\hline 048 & 1.0000 & 0.44108 & 0.88910 & 0.81000 & Biso & 1.000 \\
\hline 049 & 1.0000 & 0.08361 & 0.52684 & 0.77823 & Biso & 1.000 \\
\hline 050 & 1.0000 & 0.45523 & 0.54105 & 0.79289 & Biso & 1.000 \\
\hline 051 & 1.0000 & 0.58716 & 0.79375 & 0.54726 & Biso & 1.000 \\
\hline 052 & 1.0000 & 0.22745 & 0.45714 & 0.53800 & Biso & 1.000 \\
\hline 053 & 1.0000 & 0.20729 & 0.74624 & 0.53314 & Biso & 1.000 \\
\hline 054 & 1.0000 & 0.99594 & 0.24534 & 0.00897 & Biso & 1.000 \\
\hline
\end{tabular}




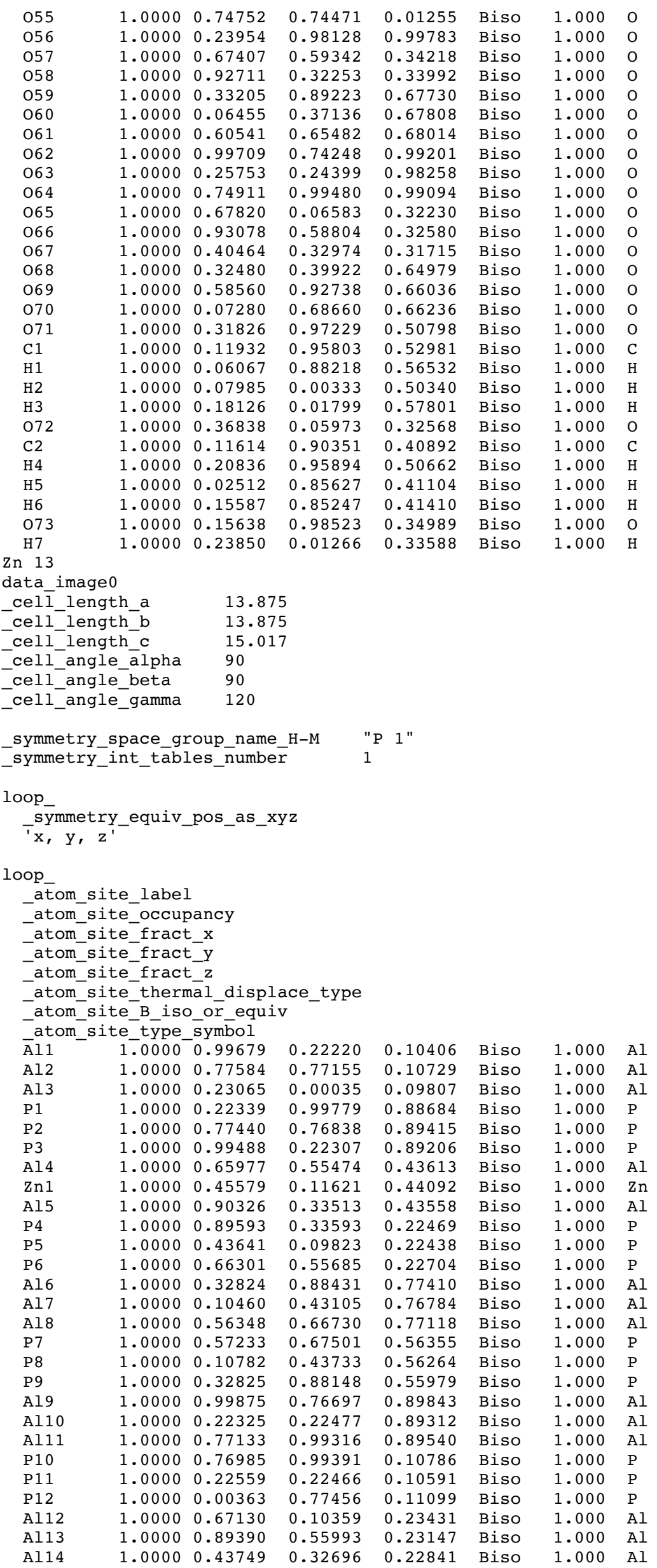




\begin{tabular}{|c|c|c|c|c|c|c|c|}
\hline P13 & 1.0000 & 0.42924 & 0.32879 & 0.43957 & Biso & 1.000 & $\mathrm{P}$ \\
\hline P14 & 1.0000 & 0.89066 & 0.55582 & 0.44205 & Biso & 1.000 & $\mathrm{P}$ \\
\hline P15 & 1.0000 & 0.68258 & 0.11030 & 0.43873 & Biso & 1.000 & $\mathrm{P}$ \\
\hline Al15 & 1.0000 & 0.34057 & 0.44873 & 0.56412 & Biso & 1.000 & $\mathrm{Al}$ \\
\hline Al16 & 1.0000 & 0.55995 & 0.89552 & 0.56372 & Biso & 1.000 & Al \\
\hline Al17 & 1.0000 & 0.09589 & 0.66345 & 0.56926 & Biso & 1.000 & $\mathrm{Al}$ \\
\hline P16 & 1.0000 & 0.10097 & 0.66070 & 0.77693 & Biso & 1.000 & $\mathrm{P}$ \\
\hline P17 & 1.0000 & 0.55536 & 0.89125 & 0.77640 & Biso & 1.000 & $\mathrm{P}$ \\
\hline P18 & 1.0000 & 0.33539 & 0.43721 & 0.77209 & Biso & 1.000 & $P$ \\
\hline 01 & 1.0000 & 0.89136 & 0.08525 & 0.12526 & Biso & 1.000 & 0 \\
\hline $\mathrm{O} 2$ & 1.0000 & 0.91407 & 0.80666 & 0.13040 & Biso & 1.000 & 0 \\
\hline 03 & 1.0000 & 0.19859 & 0.10414 & 0.12487 & Biso & 1.000 & 0 \\
\hline 04 & 1.0000 & 0.10284 & 0.90313 & 0.87222 & Biso & 1.000 & 0 \\
\hline 05 & 1.0000 & 0.80554 & 0.88951 & 0.87355 & Biso & 1.000 & 0 \\
\hline 06 & 1.0000 & 0.08699 & 0.19491 & 0.87218 & Biso & 1.000 & 0 \\
\hline 07 & 1.0000 & 0.55265 & 0.41896 & 0.45465 & Biso & 1.000 & 0 \\
\hline 08 & 1.0000 & 0.60787 & 0.16184 & 0.44399 & Biso & 1.000 & 0 \\
\hline 09 & 1.0000 & 0.86738 & 0.43700 & 0.46166 & Biso & 1.000 & 0 \\
\hline 010 & 1.0000 & 0.77395 & 0.24238 & 0.21363 & Biso & 1.000 & 0 \\
\hline 011 & 1.0000 & 0.46896 & 0.22048 & 0.20899 & Biso & 1.000 & 0 \\
\hline 012 & 1.0000 & 0.75670 & 0.52904 & 0.21478 & Biso & 1.000 & 0 \\
\hline 013 & 1.0000 & 0.22226 & 0.74879 & 0.79908 & Biso & 1.000 & 0 \\
\hline 014 & 1.0000 & 0.24300 & 0.46629 & 0.78878 & Biso & 1.000 & 0 \\
\hline 015 & 1.0000 & 0.52712 & 0.76979 & 0.78961 & Biso & 1.000 & 0 \\
\hline 016 & 1.0000 & 0.44887 & 0.58627 & 0.55284 & Biso & 1.000 & 0 \\
\hline 017 & 1.0000 & 0.12175 & 0.55413 & 0.55913 & Biso & 1.000 & 0 \\
\hline 018 & 1.0000 & 0.42081 & 0.85527 & 0.53686 & Biso & 1.000 & 0 \\
\hline 019 & 1.0000 & 0.97362 & 0.31502 & 0.16542 & Biso & 1.000 & 0 \\
\hline 020 & 1.0000 & 0.68235 & 0.65372 & 0.16641 & Biso & 1.000 & 0 \\
\hline 021 & 1.0000 & 0.34901 & 0.02198 & 0.15589 & Biso & 1.000 & 0 \\
\hline 022 & 1.0000 & 0.30425 & 0.98140 & 0.82813 & Biso & 1.000 & 0 \\
\hline 023 & 1.0000 & 0.67107 & 0.68626 & 0.84165 & Biso & 1.000 & 0 \\
\hline 024 & 1.0000 & 0.01242 & 0.32330 & 0.83674 & Biso & 1.000 & 0 \\
\hline 025 & 1.0000 & 0.64605 & 0.65060 & 0.50253 & Biso & 1.000 & 0 \\
\hline 026 & 1.0000 & 0.34356 & 0.98377 & 0.50682 & Biso & 1.000 & 0 \\
\hline 027 & 1.0000 & 0.02052 & 0.36006 & 0.49565 & Biso & 1.000 & 0 \\
\hline 028 & 1.0000 & 0.02072 & 0.66999 & 0.84184 & Biso & 1.000 & 0 \\
\hline 029 & 1.0000 & 0.31805 & 0.34023 & 0.83196 & Biso & 1.000 & 0 \\
\hline 030 & 1.0000 & 0.65672 & 0.97048 & 0.83228 & Biso & 1.000 & 0 \\
\hline 031 & 1.0000 & 0.68874 & 0.01549 & 0.16153 & Biso & 1.000 & 0 \\
\hline 032 & 1.0000 & 0.32625 & 0.30691 & 0.16095 & Biso & 1.000 & 0 \\
\hline 033 & 1.0000 & 0.98599 & 0.67678 & 0.16973 & Biso & 1.000 & 0 \\
\hline 034 & 1.0000 & 0.35317 & 0.36161 & 0.48925 & Biso & 1.000 & 0 \\
\hline 035 & 1.0000 & 0.98376 & 0.64093 & 0.50267 & Biso & 1.000 & 0 \\
\hline 036 & 1.0000 & 0.64891 & 0.01345 & 0.50397 & Biso & 1.000 & 0 \\
\hline 037 & 1.0000 & 0.12492 & 0.23561 & 0.13297 & Biso & 1.000 & 0 \\
\hline 038 & 1.0000 & 0.75644 & 0.88197 & 0.13736 & Biso & 1.000 & 0 \\
\hline 039 & 1.0000 & 0.11869 & 0.87390 & 0.13329 & Biso & 1.000 & 0 \\
\hline 040 & 1.0000 & 0.23237 & 0.10877 & 0.86134 & Biso & 1.000 & 0 \\
\hline 041 & 1.0000 & 0.87128 & 0.75158 & 0.86619 & Biso & 1.000 & 0 \\
\hline 042 & 1.0000 & 0.88250 & 0.12283 & 0.86637 & Biso & 1.000 & 0 \\
\hline 043 & 1.0000 & 0.78582 & 0.56209 & 0.46125 & Biso & 1.000 & 0 \\
\hline 044 & 1.0000 & 0.40659 & 0.21675 & 0.47426 & Biso & 1.000 & 0 \\
\hline 045 & 1.0000 & 0.80180 & 0.20060 & 0.46336 & Biso & 1.000 & 0 \\
\hline 046 & 1.0000 & 0.90548 & 0.44652 & 0.19588 & Biso & 1.000 & 0 \\
\hline 047 & 1.0000 & 0.53974 & 0.08695 & 0.21490 & Biso & 1.000 & 0 \\
\hline 048 & 1.0000 & 0.55257 & 0.45465 & 0.20029 & Biso & 1.000 & 0 \\
\hline 049 & 1.0000 & 0.45597 & 0.90190 & 0.80829 & Biso & 1.000 & 0 \\
\hline 050 & 1.0000 & 0.08771 & 0.54519 & 0.78738 & Biso & 1.000 & 0 \\
\hline 051 & 1.0000 & 0.44805 & 0.53852 & 0.79545 & Biso & 1.000 & 0 \\
\hline 052 & 1.0000 & 0.58687 & 0.78855 & 0.53772 & Biso & 1.000 & 0 \\
\hline 053 & 1.0000 & 0.21880 & 0.44753 & 0.53711 & Biso & 1.000 & 0 \\
\hline 054 & 1.0000 & 0.21448 & 0.78372 & 0.53201 & Biso & 1.000 & $\mathrm{O}$ \\
\hline 055 & 1.0000 & 0.99635 & 0.25185 & 0.99105 & Biso & 1.000 & 0 \\
\hline 056 & 1.0000 & 0.74964 & 0.74359 & 0.99383 & Biso & 1.000 & 0 \\
\hline 057 & 1.0000 & 0.25657 & 0.99956 & 0.98491 & Biso & 1.000 & 0 \\
\hline 058 & 1.0000 & 0.65939 & 0.59044 & 0.32409 & Biso & 1.000 & 0 \\
\hline 059 & 1.0000 & 0.38384 & 0.05874 & 0.31868 & Biso & 1.000 & 0 \\
\hline 060 & 1.0000 & 0.93362 & 0.34316 & 0.32182 & Biso & 1.000 & 0 \\
\hline 061 & 1.0000 & 0.32958 & 0.90549 & 0.65961 & Biso & 1.000 & 0 \\
\hline 062 & 1.0000 & 0.07185 & 0.38808 & 0.65683 & Biso & 1.000 & 0 \\
\hline 063 & 1.0000 & 0.60872 & 0.67651 & 0.66084 & Biso & 1.000 & 0 \\
\hline 064 & 1.0000 & 0.99917 & 0.74198 & 0.01261 & Biso & 1.000 & 0 \\
\hline 065 & 1.0000 & 0.25268 & 0.25196 & 0.00664 & Biso & 1.000 & 0 \\
\hline 066 & 1.0000 & 0.74108 & 0.99068 & 0.00863 & Biso & 1.000 & 0 \\
\hline 067 & 1.0000 & 0.68159 & 0.06616 & 0.34358 & Biso & 1.000 & 0 \\
\hline 068 & 1.0000 & 0.92817 & 0.58745 & 0.34456 & Biso & 1.000 & 0 \\
\hline 069 & 1.0000 & 0.40136 & 0.32437 & 0.33935 & Biso & 1.000 & 0 \\
\hline 070 & 1.0000 & 0.33444 & 0.40358 & 0.67426 & Biso & 1.000 & 0 \\
\hline 071 & 1.0000 & 0.58037 & 0.92469 & 0.67790 & Biso & 1.000 & 0 \\
\hline
\end{tabular}




$\begin{array}{llllllll}\text { 072 } & 1.0000 & 0.07140 & 0.67844 & 0.68152 & \text { Biso } & 1.000 & \text { O } \\ \text { H1 } & 1.0000 & 0.23903 & 0.98055 & 0.48386 & \text { Biso } & 1.000 & \text { H } \\ \text { C1 } & 1.0000 & 0.17069 & 0.93891 & 0.35407 & \text { Biso } & 1.000 & \text { C } \\ \text { H2 } & 1.0000 & 0.18189 & 0.97973 & 0.45612 & \text { Biso } & 1.000 & \text { H } \\ \text { O73 } & 1.0000 & 0.07875 & 0.87593 & 0.33778 & \text { Biso } & 1.000 & \text { O } \\ \text { H3 } & 1.0000 & 0.26960 & 0.99344 & 0.33078 & \text { Biso } & 1.000 & \text { H }\end{array}$

$\mathrm{Si} 13$

data_image 0

cel̄_length_a 13.875

cell-length_b 13.875

cell_length_c 15.017

cell_angle_ālpha 90

cell angle beta 90

_cell_angle_gamma 120

$\begin{array}{ll}\text {-symmetry_space_group_name_H-M } & \text { "P } 1 " \\ \text { symmetry_int tables_number } & 1\end{array}$

loop_

symmetry_equiv_pos_as_xyz

' $\mathrm{x}, \mathrm{y}, \mathrm{z}$ '

loop

atom_site_label

-atom_site_occupancy

-atom_site_fract_x

-atom_site_fract_y

-atom_site_fract_z

_atom_site_thermal_displace_type

-atom_site_B_iso_or_equiv

-atom_site_type_symbol

P1 $1.0000 \quad 0.00437-0.22699$

$\begin{array}{lll}\text { P2 } & 1.0000 & 0.77419 \\ \text { P3 } & 1.0000 & 0.22748\end{array}$

Al1 1.00000 .22349

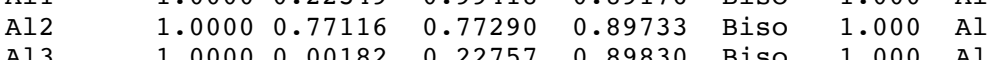

0.22699

0.10927

Biso

$1.000 \quad P$

0.10973 Biso $1.000 \quad \mathrm{P}$

$\begin{array}{llll}0.22757 & 0.89830 & \text { Biso }\end{array}$

$\begin{array}{llllllll}\text { P4 } & 1.0000 & 0.67061 & 0.56294 & 0.44011 & \text { Biso } & 1.000 & \text { P }\end{array}$

$\begin{array}{llllllll}\text { Si1 } & 1.0000 & 0.43032 & 0.10277 & 0.43978 & \text { Biso } & 1.000 & \mathrm{Si}\end{array}$

$\begin{array}{llllllll}\text { P5 } & 1.0000 & 0.89216 & 0.32857 & 0.44184 & \text { Biso } & 1.000 & \text { P }\end{array}$

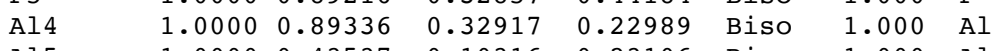

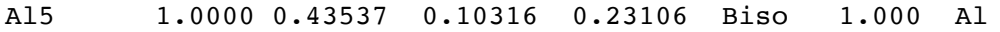

Al6 $\quad 1.0000 \quad 0.67140 \quad 0.56102 \quad 0.22957$ Biso 1.000 Al

$\begin{array}{llllllll}\text { P6 } & 1.0000 & 0.33550 & 0.88866 & 0.77754 & \text { Biso } & 1.000 & \text { P }\end{array}$

$\begin{array}{llllllll}\text { P7 } & 1.0000 & 0.10187 & 0.43604 & 0.77314 & \text { Biso } & 1.000 & \text { P }\end{array}$

$\begin{array}{llllllll}\text { P8 } & 1.0000 & 0.55964 & 0.66023 & 0.77427 & \text { Biso } & 1.000 & \text { P }\end{array}$

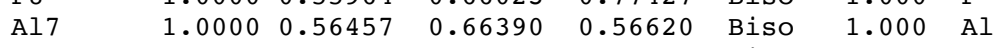

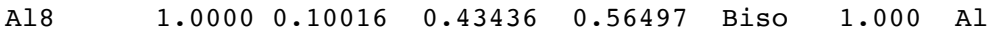

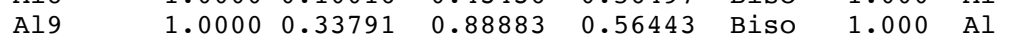

$\begin{array}{llllllll}\mathrm{P} 9 & 1.0000 & 0.99477 & 0.76750 & 0.89189 & \text { Biso } & 1.000 & \mathrm{P}\end{array}$

$\begin{array}{llllllll}\text { P10 } & 1.0000 & 0.22740 & 0.22280 & 0.89078 & \text { Biso } & 1.000 & \text { P }\end{array}$

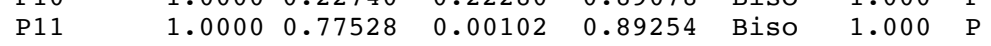

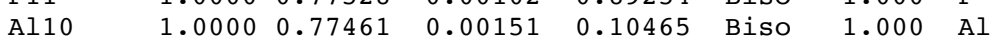

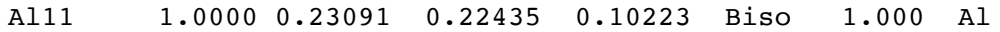

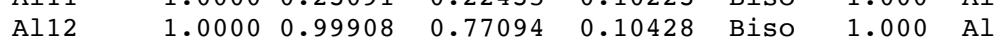

$\begin{array}{llllllll}\mathrm{P} 12 & 1.0000 & 0.66703 & 0.10310 & 0.22777 & \text { Biso } & 1.000 & \mathrm{P}\end{array}$

$\begin{array}{llllllll}\text { P13 } & 1.0000 & 0.89876 & 0.55836 & 0.22604 & \text { Biso } & 1.000 & \text { P }\end{array}$

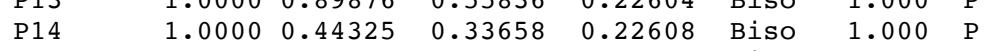

Al13 $\quad 1.0000 \quad 0.43942 \quad 0.33769 \quad 0.43595$ Biso 1.000 Al

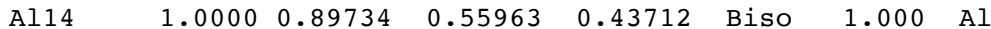

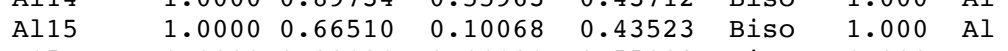

$\begin{array}{llllllll}\text { P15 } & 1.0000 & 0.33121 & 0.44131 & 0.55888 & \text { Biso } & 1.000 & \text { P }\end{array}$

$\begin{array}{llllllll}\text { P16 } & 1.0000 & 0.56726 & 0.89504 & 0.56067 & \text { Biso } & 1.000 & \text { P }\end{array}$

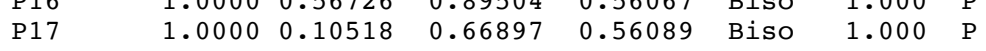

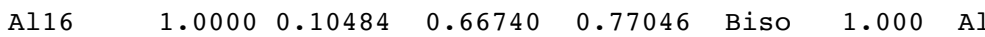

$\begin{array}{llllllll}\text { Al17 } & 1.0000 & 0.56210 & 0.89154 & 0.77093 & \text { Biso } & 1.000 & \text { Al }\end{array}$

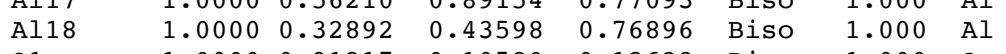

$\begin{array}{llllllll}01 & 1.0000 & 0.91217 & 0.10580 & 0.12623 & \text { Biso } & 1.000 & 0\end{array}$

$\begin{array}{llllllll}02 & 1.0000 & 0.89571 & 0.80510 & 0.12675 & \text { Biso } & 1.000 & 0\end{array}$

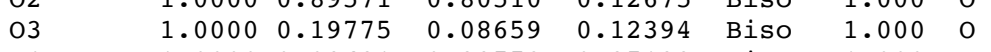

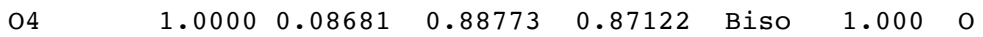

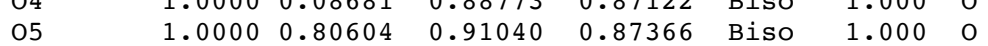

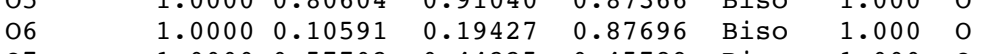

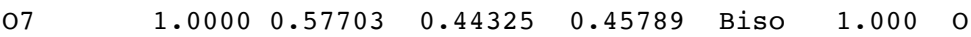

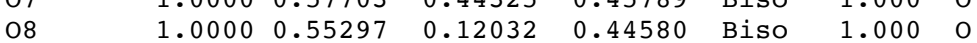

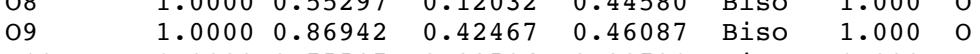

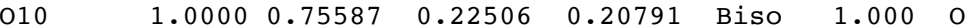

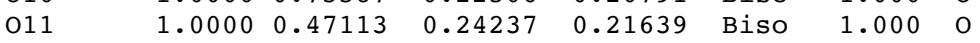

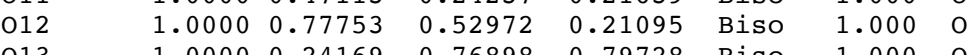

$\begin{array}{llllllll}013 & 1.0000 & 0.24169 & 0.76898 & 0.79728 & \text { Biso } & 1.000 & 0\end{array}$ 


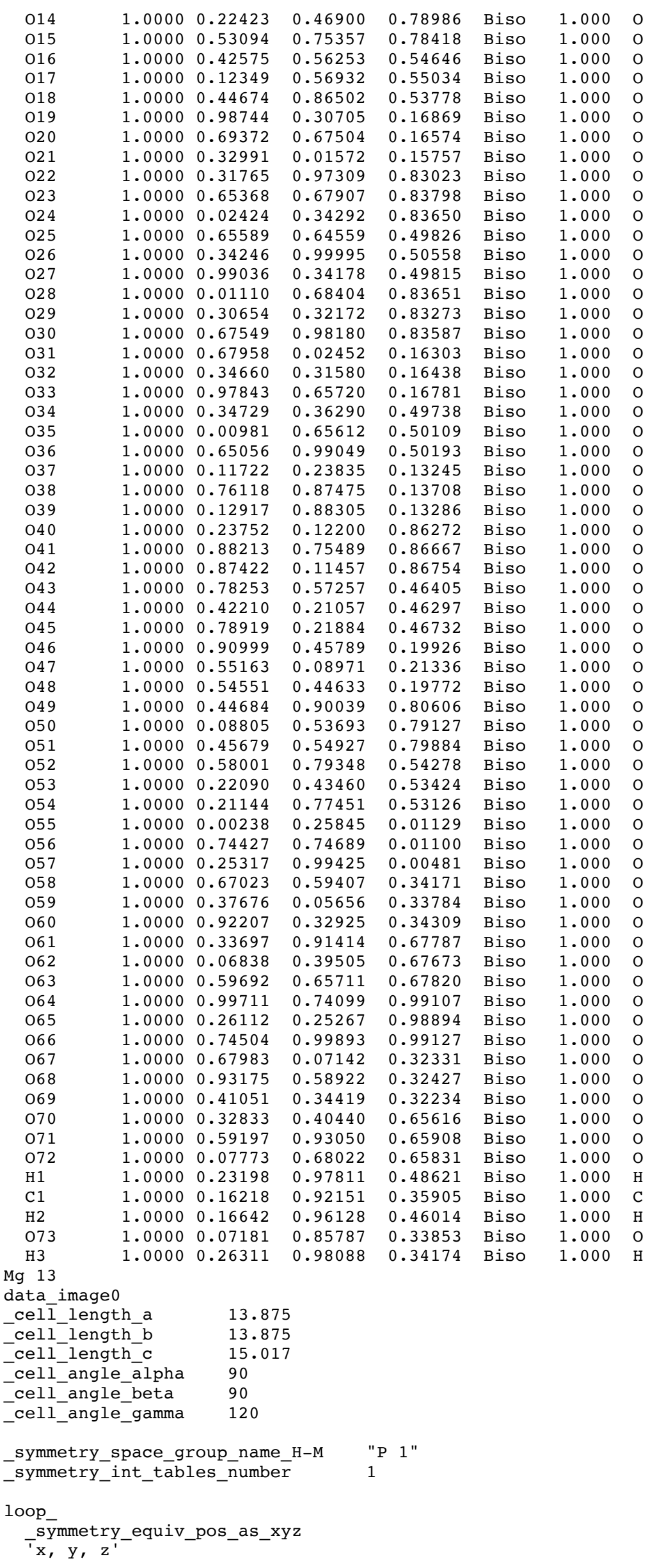




\begin{tabular}{|c|c|c|c|c|c|c|c|}
\hline \multicolumn{8}{|l|}{-oop } \\
\hline \multicolumn{8}{|c|}{ atom_site_label } \\
\hline \multicolumn{8}{|c|}{ atom_site_occupancy } \\
\hline \multicolumn{8}{|c|}{ atom_site_fract_x } \\
\hline \multicolumn{8}{|c|}{ atom site fract $y$} \\
\hline ato & te_frac & $t-z$ & & & & & \\
\hline -ato & Eclield & nàl_displ & ace_type & & & & \\
\hline - ato & $\begin{array}{l}e^{-} \mathrm{B} \text { is } \\
e^{-} \text {ype }\end{array}$ & $\begin{array}{l}\text { o_or_equ } \\
\text { symbol }\end{array}$ & & & & & \\
\hline $\bar{A} 11$ & 1.0000 & 0.99733 & 0.22247 & 0.10498 & Biso & 1.000 & Al \\
\hline Al2 & 1.0000 & 0.77735 & 0.77301 & 0.10773 & Biso & 1.000 & Al \\
\hline Al3 & 1.0000 & 0.23237 & 0.00165 & 0.09673 & Biso & 1.000 & $\mathrm{Al}$ \\
\hline $\mathrm{P} 1$ & 1.0000 & 0.22324 & 0.99808 & 0.88560 & Biso & 1.000 & $\mathrm{P}$ \\
\hline $\mathrm{P} 2$ & 1.0000 & 0.77475 & 0.76958 & 0.89443 & Biso & 1.000 & $\mathrm{P}$ \\
\hline P3 & 1.0000 & 0.99456 & 0.22366 & 0.89273 & Biso & 1.000 & $P$ \\
\hline Al4 & 1.0000 & 0.66098 & 0.55766 & 0.43616 & Biso & 1.000 & Al \\
\hline $\operatorname{Mg} 1$ & 1.0000 & 0.44671 & 0.10839 & 0.43961 & Biso & 1.000 & $\mathrm{Mg}$ \\
\hline Al5 & 1.0000 & 0.90242 & 0.33522 & 0.43666 & Biso & 1.000 & Al \\
\hline P4 & 1.0000 & 0.89661 & 0.33635 & 0.22481 & Biso & 1.000 & $P$ \\
\hline P5 & 1.0000 & 0.43538 & 0.09752 & 0.22620 & Biso & & P \\
\hline P6 & 1.0000 & 0.66458 & 0.55643 & 0.22601 & Biso & 1.000 & D \\
\hline A 16 & 1 & 0.32750 & & & Bian & 1.000 & \\
\hline $\mathrm{H} \perp \mathrm{O}$ & 1.0000 & $0.32 / 59$ & 0.88240 & 0.77528 & Blso & 1.000 & Al \\
\hline Al7 & 1.0000 & 0.10347 & 0.43058 & 0.76809 & Biso & 1.000 & $\mathrm{Al}$ \\
\hline Al 8 & 1.0000 & 0.56344 & 0.66682 & 0.77080 & Biso & 1.000 & $\mathrm{Al}$ \\
\hline P7 & 1.0000 & 0.57288 & 0.67313 & 0.56387 & Biso & 1.000 & $P$ \\
\hline P8 & 1.0000 & 0.10600 & 0.43509 & 0.56364 & Biso & 1.000 & $\mathrm{P}$ \\
\hline P9 & 1.0000 & 0.32845 & 0.87955 & 0.56024 & Biso & 1.000 & $P$ \\
\hline Al9 & 1.0000 & 0.99837 & 0.76703 & 0.89808 & Biso & 1.000 & Al \\
\hline Al10 & 1.0000 & 0.22283 & 0.22495 & 0.89251 & Biso & 1.000 & Al \\
\hline Al11 & 1.0000 & 0.77166 & 0.99371 & 0.89589 & Biso & 1.000 & $\mathrm{Al}$ \\
\hline $\mathrm{P} 10$ & 1.0000 & 0.76995 & 0.99437 & 0.10870 & Biso & 1.000 & $P$ \\
\hline P 11 & 1.0000 & 0.22622 & 0.22490 & 0.10545 & Biso & 1.000 & $P$ \\
\hline P 12 & 1.0000 & 0.00511 & 0.77585 & 0.11050 & Biso & 1.000 & $\mathrm{P}$ \\
\hline Al12 & 1.0000 & 0.67295 & 0.10575 & 0.23409 & Biso & 1.000 & Al \\
\hline Al13 & 1.0000 & 0.89649 & 0.56176 & 0.23182 & Biso & 1.000 & Al \\
\hline Al14 & 1.0000 & 0.43803 & 0.33006 & 0.22920 & Biso & 1.000 & Al \\
\hline P13 & 1.0000 & 0.42966 & 0.33358 & 0.43866 & Biso & 1.000 & $P$ \\
\hline $\mathrm{P} 14$ & 1.0000 & 0.89241 & 0.55845 & 0.44206 & Biso & 1.000 & $P$ \\
\hline P 15 & 1.0000 & 0.68279 & 0.10706 & 0.43932 & Biso & 1.000 & $P$ \\
\hline Al15 & 1.0000 & 0.34006 & 0.44879 & 0.56405 & Biso & 1.000 & Al \\
\hline Al16 & 1.0000 & 0.56326 & 0.89811 & 0.56464 & Biso & 1.000 & Al \\
\hline Al17 & 1.0000 & 0.09590 & 0.66315 & 0.56985 & Biso & 1.000 & $\mathrm{Al}$ \\
\hline P16 & 1.0000 & 0.10048 & 0.66100 & 0.77717 & Biso & 1.000 & $P$ \\
\hline P 17 & 1.0000 & 0.55634 & 0.89370 & 0.77530 & Biso & 1.000 & $P$ \\
\hline P18 & 1.0000 & 0.33518 & 0.43932 & 0.77360 & Biso & 1.000 & $P$ \\
\hline 01 & 1.0000 & 0.89123 & 0.08597 & 0.12669 & Biso & 1.000 & 0 \\
\hline 02 & 1.0000 & 0.91607 & 0.80864 & 0.13012 & Biso & 1.000 & O \\
\hline 03 & 1.0000 & 0.19936 & 0.10445 & 0.12452 & Biso & 1.000 & 0 \\
\hline 04 & 1.0000 & 0.10265 & 0.90312 & 0.87177 & Biso & 1.000 & 0 \\
\hline 05 & 1.0000 & 0.80682 & 0.89088 & 0.87344 & Biso & 1.000 & 0 \\
\hline 06 & 1.0000 & 0.08666 & 0.19573 & 0.87202 & Biso & 1.000 & 0 \\
\hline 07 & 1.0000 & 0.55109 & 0.42507 & 0.45944 & Biso & 1.000 & 0 \\
\hline 08 & 1.0000 & 0.59499 & 0.14128 & 0.44624 & Biso & 1.000 & 0 \\
\hline 09 & 1.0000 & 0.87027 & 0.44009 & 0.46157 & Biso & 1.000 & 0 \\
\hline 010 & 1.0000 & 0.77460 & 0.24434 & 0.21026 & Biso & 1.000 & 0 \\
\hline 011 & 1.0000 & 0.46600 & 0.22001 & 0.21682 & Biso & 1.000 & 0 \\
\hline 012 & 1.0000 & 0.75909 & 0.52966 & 0.21480 & Biso & 1.000 & 0 \\
\hline 013 & 1.0000 & 0.22134 & 0.74761 & 0.80226 & Biso & 1.000 & 0 \\
\hline 014 & 1.0000 & 0.24183 & 0.46698 & 0.79037 & Biso & 1.000 & 0 \\
\hline 015 & 1.0000 & 0.52974 & 0.77211 & 0.78265 & Biso & 1.000 & 0 \\
\hline 016 & 1.0000 & 0.45057 & 0.58420 & 0.54772 & Biso & 1.000 & $\mathrm{O}$ \\
\hline 017 & 1.0000 & 0.11594 & 0.55018 & 0.56158 & Biso & 1.000 & 0 \\
\hline 018 & 1.0000 & 0.42526 & 0.86052 & 0.53540 & Biso & 1.000 & 0 \\
\hline 019 & 1.0000 & 0.97564 & 0.31604 & 0.16669 & Biso & 1.000 & $\mathrm{O}$ \\
\hline 020 & 1.0000 & 0.68477 & 0.65433 & 0.16628 & Biso & 1.000 & 0 \\
\hline 021 & 1.0000 & 0.35201 & 0.02536 & 0.15382 & Biso & 1.000 & 0 \\
\hline 022 & 1.0000 & 0.30361 & 0.98126 & 0.82651 & Biso & 1.000 & 0 \\
\hline 023 & 1.0000 & 0.67072 & 0.68793 & 0.84246 & Biso & 1.000 & 0 \\
\hline 024 & 1.0000 & 0.01174 & 0.32439 & 0.83833 & Biso & 1.000 & 0 \\
\hline 025 & 1.0000 & 0.65074 & 0.65683 & 0.50108 & Biso & 1.000 & 0 \\
\hline 026 & 1.0000 & 0.33976 & 0.98189 & 0.51008 & Biso & 1.000 & 0 \\
\hline 027 & 1.0000 & 0.01963 & 0.35758 & 0.49606 & Biso & 1.000 & 0 \\
\hline 028 & 1.0000 & 0.01902 & 0.66916 & 0.84148 & Biso & 1.000 & 0 \\
\hline 029 & 1.0000 & 0.31755 & 0.34084 & 0.83175 & Biso & 1.000 & 0 \\
\hline 030 & 1.0000 & 0.65639 & 0.97024 & 0.83343 & Biso & 1.000 & 0 \\
\hline 031 & 1.0000 & 0.68806 & 0.01594 & 0.16130 & Biso & 1.000 & 0 \\
\hline 032 & 1.0000 & 0.32737 & 0.30735 & 0.15990 & Biso & 1.000 & O \\
\hline 033 & 1.0000 & 0.98778 & 0.67846 & 0.16958 & Biso & 1.000 & 0 \\
\hline 034 & 1.0000 & 0.34870 & 0.35609 & 0.49262 & Biso & 1.000 & 0 \\
\hline 035 & 1.0000 & 0.98466 & 0.64384 & 0.50329 & Biso & 1.000 & 0 \\
\hline
\end{tabular}




\begin{tabular}{|c|c|c|c|c|c|c|c|}
\hline 036 & 1.0000 & 0.65846 & 0.00864 & 0.50081 & Biso & 1.000 & 0 \\
\hline 037 & 1.0000 & 0.12563 & 0.23568 & 0.13308 & Biso & 1.000 & 0 \\
\hline 038 & 1.0000 & 0.75683 & 0.88261 & 0.13865 & Biso & 1.000 & $\mathrm{O}$ \\
\hline 039 & 1.0000 & 0.12074 & 0.87494 & 0.13210 & Biso & 1.000 & 0 \\
\hline 040 & 1.0000 & 0.23174 & 0.10887 & 0.86004 & Biso & 1.000 & 0 \\
\hline 041 & 1.0000 & 0.87081 & 0.75162 & 0.86619 & Biso & 1.000 & 0 \\
\hline 042 & 1.0000 & 0.88216 & 0.12366 & 0.86676 & Biso & 1.000 & 0 \\
\hline 043 & 1.0000 & 0.78658 & 0.56322 & 0.46037 & Biso & 1.000 & 0 \\
\hline 044 & 1.0000 & 0.41223 & 0.22057 & 0.46264 & Biso & 1.000 & 0 \\
\hline 045 & 1.0000 & 0.79716 & 0.20423 & 0.46732 & Biso & 1.000 & 0 \\
\hline 046 & 1.0000 & 0.90907 & 0.44861 & 0.19738 & Biso & 1.000 & 0 \\
\hline 047 & 1.0000 & 0.54066 & 0.08934 & 0.21758 & Biso & 1.000 & 0 \\
\hline 048 & 1.0000 & 0.55545 & 0.45413 & 0.19690 & Biso & 1.000 & 0 \\
\hline 049 & 1.0000 & 0.45558 & 0.90060 & 0.80945 & Biso & 1.000 & 0 \\
\hline 050 & 1.0000 & 0.08564 & 0.54464 & 0.78513 & Biso & 1.000 & 0 \\
\hline 051 & 1.0000 & 0.44676 & 0.54065 & 0.79932 & Biso & 1.000 & 0 \\
\hline 052 & 1.0000 & 0.58617 & 0.78758 & 0.54535 & Biso & 1.000 & 0 \\
\hline 053 & 1.0000 & 0.21869 & 0.44933 & 0.53793 & Biso & 1.000 & 0 \\
\hline 054 & 1.0000 & 0.21731 & 0.77922 & 0.53081 & Biso & 1.000 & 0 \\
\hline 055 & 1.0000 & 0.99624 & 0.25149 & 0.99194 & Biso & 1.000 & 0 \\
\hline 056 & 1.0000 & 0.75064 & 0.74558 & 0.99425 & Biso & 1.000 & 0 \\
\hline 057 & 1.0000 & 0.25750 & 0.00062 & 0.98350 & Biso & 1.000 & 0 \\
\hline 058 & 1.0000 & 0.65841 & 0.58811 & 0.32312 & Biso & 1.000 & 0 \\
\hline 059 & 1.0000 & 0.37982 & 0.05140 & 0.31862 & Biso & 1.000 & 0 \\
\hline 060 & 1.0000 & 0.93042 & 0.33987 & 0.32266 & Biso & 1.000 & 0 \\
\hline 061 & 1.0000 & 0.32806 & 0.89945 & 0.66049 & Biso & 1.000 & 0 \\
\hline 062 & 1.0000 & 0.07121 & 0.38454 & 0.65760 & Biso & 1.000 & 0 \\
\hline 063 & 1.0000 & 0.60561 & 0.66599 & 0.66087 & Biso & 1.000 & 0 \\
\hline 064 & 1.0000 & 0.99965 & 0.74248 & 0.01225 & Biso & 1.000 & 0 \\
\hline 065 & 1.0000 & 0.25254 & 0.25166 & 0.00605 & Biso & 1.000 & 0 \\
\hline 066 & 1.0000 & 0.74209 & 0.99074 & 0.00923 & Biso & 1.000 & 0 \\
\hline 067 & 1.0000 & 0.69031 & 0.07181 & 0.34251 & Biso & 1.000 & 0 \\
\hline 068 & 1.0000 & 0.93091 & 0.59094 & 0.34481 & Biso & 1.000 & 0 \\
\hline 069 & 1.0000 & 0.40484 & 0.34061 & 0.33890 & Biso & 1.000 & 0 \\
\hline 070 & 1.0000 & 0.33635 & 0.40860 & 0.67536 & Biso & 1.000 & 0 \\
\hline 071 & 1.0000 & 0.58195 & 0.93354 & 0.67810 & Biso & 1.000 & 0 \\
\hline 072 & 1.0000 & 0.07415 & 0.68264 & 0.68181 & Biso & 1.000 & 0 \\
\hline H 1 & 1.0000 & 0.23292 & 0.97159 & 0.48309 & Biso & 1.000 & $\mathrm{H}$ \\
\hline $\mathrm{C} 1$ & 1.0000 & 0.16491 & 0.93213 & 0.35005 & Biso & 1.000 & C \\
\hline H2 & 1.0000 & 0.17568 & 0.96796 & 0.45335 & Biso & 1.000 & $\mathrm{H}$ \\
\hline 073 & 1.0000 & 0.07261 & 0.87249 & 0.33257 & Biso & 1.000 & $\mathrm{O}$ \\
\hline & & & & & & & \\
\hline
\end{tabular}

Al 13

data_image 0

$\begin{array}{ll}\text {-cell_length_a } & 13.625 \\ \text { _cell_length_b } & 13.625 \\ \text {-cell_length_c } & 15.067 \\ \text { _cell_angle_alpha } & 90 \\ \text {-cell_angle_beta } & 90 \\ \text { _cell_angle_gamma } & 120\end{array}$

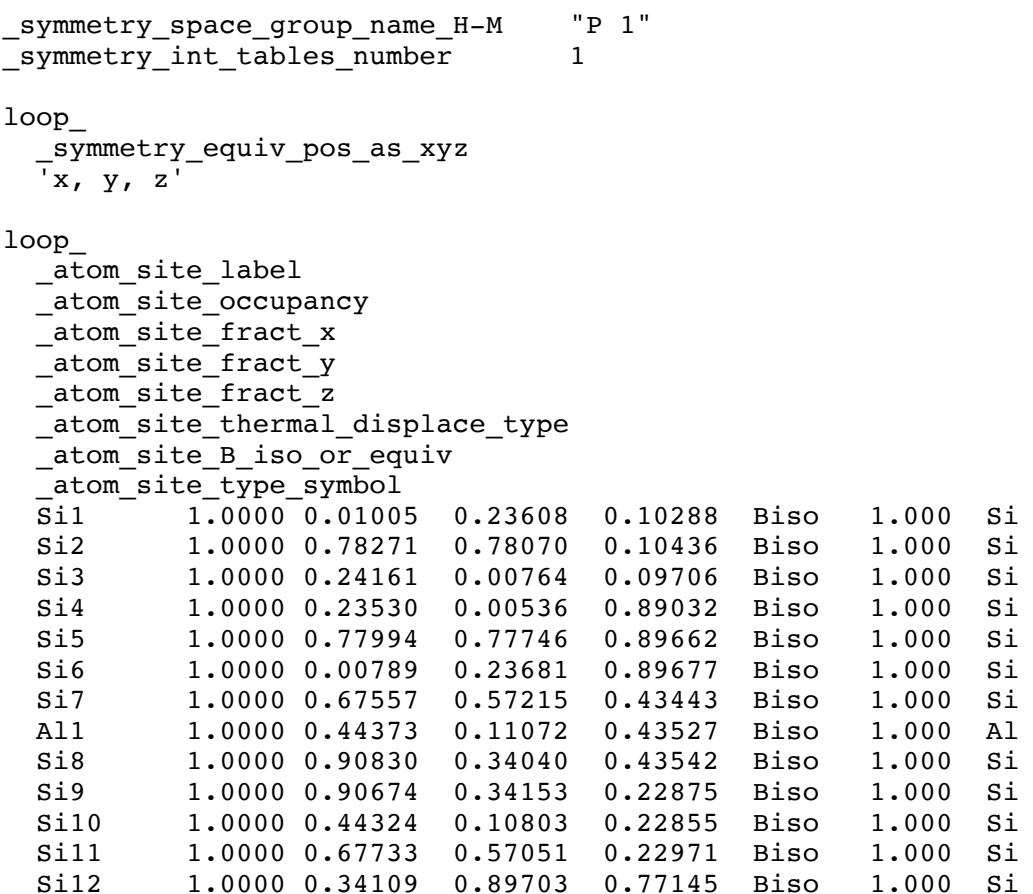




\begin{tabular}{|c|c|c|c|c|c|c|c|}
\hline Sil3 & 1.0000 & 0.10947 & 0.43941 & 0.76669 & Biso & 1.000 & $\mathrm{Si}$ \\
\hline Si14 & 1.0000 & 0.57322 & 0.67251 & 0.76860 & Biso & 1.000 & $\mathrm{Si}$ \\
\hline Sil15 & 1.0000 & 0.57957 & 0.67664 & 0.56583 & Biso & 1.000 & $\mathrm{Si}$ \\
\hline Si16 & 1.0000 & 0.10898 & 0.43937 & 0.56498 & Biso & 1.000 & \\
\hline Si17 & 1.0000 & 0.34220 & 0.89542 & 0.56282 & Biso & 1.000 & \\
\hline Si18 & 1.0000 & 0.00656 & 0.77436 & 0.89605 & Biso & 1.000 & \\
\hline Si19 & 1.0000 & 0.23759 & 0.23564 & 0.89314 & Biso & 1.000 & \\
\hline Si20 & 1.0000 & 0.78057 & 0.00594 & 0.89525 & Biso & 1.000 & \\
\hline Si21 & 1.0000 & 0.77926 & 0.00678 & 0.10256 & Biso & 1.000 & \\
\hline Si22 & 1.0000 & 0.24067 & 0.23648 & 0.10007 & Biso & 1.000 & \\
\hline Si23 & 1.0000 & 0.01130 & 0.78010 & 0.10342 & Biso & 1.000 & \\
\hline Si24 & 1.0000 & 0.67911 & 0.11074 & 0.23178 & Biso & 1.000 & \\
\hline Si25 & 1.0000 & 0.90872 & 0.57100 & 0.23023 & Biso & 1.000 & \\
\hline Si26 & 1.0000 & 0.44758 & 0.34191 & 0.22876 & Biso & 1.000 & \\
\hline Si27 & 1.0000 & 0.44246 & 0.34378 & 0.43411 & Biso & 1.000 & \\
\hline $\operatorname{Si} 28$ & 1.0000 & 0.90694 & 0.57040 & 0.43568 & Biso & 1.000 & \\
\hline Si29 & 1.0000 & 0.68119 & 0.10895 & 0.43334 & Biso & 1.000 & \\
\hline Si30 & 1.0000 & 0.34437 & 0.45062 & 0.56204 & Biso & 1.000 & \\
\hline Si31 & 1.0000 & 0.57722 & 0.90772 & 0.56347 & Biso & 1.000 & \\
\hline $\mathrm{Si} 32$ & 1.0000 & 0.10707 & 0.67322 & 0.56614 & Biso & 1.000 & \\
\hline Si33 & 1.0000 & 0.10966 & 0.67255 & 0.76929 & Biso & 1.000 & \\
\hline Si34 & 1.0000 & 0.57142 & 0.90395 & 0.76908 & Biso & 1.000 & \\
\hline Si35 & 1.0000 & 0.34120 & 0.44440 & 0.76719 & Biso & 1.000 & \\
\hline 01 & 1.0000 & 0.91029 & 0.10554 & 0.11922 & Biso & 1.000 & \\
\hline $\mathrm{O} 2$ & 1.0000 & 0.91456 & 0.81489 & 0.12098 & Biso & 1.000 & \\
\hline 03 & 1.0000 & 0.20970 & 0.10575 & 0.11772 & Biso & 1.000 & \\
\hline 04 & 1.0000 & 0.10488 & 0.90450 & 0.87567 & Biso & 1.000 & \\
\hline 05 & 1.0000 & 0.81426 & 0.90848 & 0.87713 & Biso & 1.000 & \\
\hline 06 & 1.0000 & 0.10703 & 0.20560 & 0.87936 & Biso & 1.000 & \\
\hline 07 & 1.0000 & 0.57314 & 0.44428 & 0.45180 & Biso & 1.000 & \\
\hline 08 & 1.0000 & 0.57854 & 0.13357 & 0.44091 & Biso & 1.000 & \\
\hline 09 & 1.0000 & 0.88100 & 0.44219 & 0.45511 & Biso & 1.000 & \\
\hline 010 & 1.0000 & 0.77548 & 0.24262 & 0.21345 & Biso & 1.000 & \\
\hline 011 & 1.0000 & 0.47694 & 0.24002 & 0.21747 & Biso & 1.000 & \\
\hline 012 & 1.0000 & 0.77776 & 0.53977 & 0.21785 & Biso & 1.000 & \\
\hline 013 & 1.0000 & 0.24078 & 0.76750 & 0.79071 & Biso & 1.000 & \\
\hline 014 & 1.0000 & 0.24142 & 0.47536 & 0.78384 & Biso & 1.000 & \\
\hline 015 & 1.0000 & 0.54263 & 0.77322 & 0.77773 & Biso & 1.000 & \\
\hline 016 & 1.0000 & 0.44806 & 0.58006 & 0.54966 & Biso & 1.000 & \\
\hline 017 & 1.0000 & 0.12541 & 0.56538 & 0.55808 & Biso & 1.000 & 0 \\
\hline 018 & 1.0000 & 0.44696 & 0.87475 & 0.53995 & Biso & 1.000 & \\
\hline 019 & 1.0000 & 0.99220 & 0.32144 & 0.16659 & Biso & 1.000 & \\
\hline 020 & 1.0000 & 0.69795 & 0.67362 & 0.16481 & Biso & 1.000 & U \\
\hline 021 & 1.0000 & 0.35083 & 0.02849 & 0.15462 & Biso & 1.000 & \\
\hline 022 & 1.0000 & 0.32101 & 0.98675 & 0.82773 & Biso & 1.000 & 0 \\
\hline 023 & 1.0000 & 0.67174 & 0.69084 & 0.83778 & Biso & 1.000 & 0 \\
\hline $\mathrm{O} 24$ & 1.0000 & 0.02640 & 0.34209 & 0.83547 & Biso & 1.000 & 0 \\
\hline 025 & 1.0000 & 0.66410 & 0.66111 & 0.49911 & Biso & 1.000 & O \\
\hline 026 & 1.0000 & 0.34720 & 0.99782 & 0.50368 & Biso & 1.000 & 0 \\
\hline 027 & 1.0000 & 0.01284 & 0.35484 & 0.49624 & Biso & 1.000 & 0 \\
\hline 028 & 1.0000 & 0.02472 & 0.68545 & 0.83709 & Biso & 1.000 & 0 \\
\hline 029 & 1.0000 & 0.32264 & 0.34022 & 0.83039 & Biso & 1.000 & O \\
\hline 030 & 1.0000 & 0.67555 & 0.98641 & 0.83315 & Biso & 1.000 & 0 \\
\hline 031 & 1.0000 & 0.69223 & 0.02836 & 0.16100 & Biso & 1.000 & 0 \\
\hline 032 & 1.0000 & 0.34607 & 0.32228 & 0.16174 & Biso & 1.000 & 0 \\
\hline 033 & 1.0000 & 0.99232 & 0.67643 & 0.16716 & Biso & 1.000 & 0 \\
\hline 034 & 1.0000 & 0.35648 & 0.36608 & 0.49420 & Biso & 1.000 & 0 \\
\hline 035 & 1.0000 & 0.00720 & 0.66058 & 0.50035 & Biso & 1.000 & 0 \\
\hline 036 & 1.0000 & 0.66613 & 0.00801 & 0.49970 & Biso & 1.000 & 0 \\
\hline 037 & 1.0000 & 0.13116 & 0.24705 & 0.12657 & Biso & 1.000 & 0 \\
\hline 038 & 1.0000 & 0.76751 & 0.88705 & 0.13225 & Biso & 1.000 & 0 \\
\hline 039 & 1.0000 & 0.13470 & 0.88735 & 0.12745 & Biso & 1.000 & O \\
\hline 040 & 1.0000 & 0.24607 & 0.12553 & 0.86452 & Biso & 1.000 & 0 \\
\hline 041 & 1.0000 & 0.88557 & 0.76092 & 0.86920 & Biso & 1.000 & 0 \\
\hline 042 & 1.0000 & 0.88770 & 0.12800 & 0.87016 & Biso & 1.000 & 0 \\
\hline 043 & 1.0000 & 0.79482 & 0.57814 & 0.45625 & Biso & 1.000 & 0 \\
\hline 044 & 1.0000 & 0.42832 & 0.22439 & 0.45978 & Biso & 1.000 & 0 \\
\hline 045 & 1.0000 & 0.79951 & 0.22080 & 0.46100 & Biso & 1.000 & 0 \\
\hline 046 & 1.0000 & 0.91937 & 0.46234 & 0.20123 & Biso & 1.000 & 0 \\
\hline 047 & 1.0000 & 0.55541 & 0.09792 & 0.21711 & Biso & 1.000 & 0 \\
\hline 048 & 1.0000 & 0.55896 & 0.46021 & 0.20149 & Biso & 1.000 & 0 \\
\hline 049 & 1.0000 & 0.46107 & 0.91011 & 0.80129 & Biso & 1.000 & 0 \\
\hline 050 & 1.0000 & 0.09492 & 0.54856 & 0.78315 & Biso & 1.000 & 0 \\
\hline 051 & 1.0000 & 0.46137 & 0.55366 & 0.79331 & Biso & 1.000 & 0 \\
\hline 052 & 1.0000 & 0.59149 & 0.79858 & 0.54622 & Biso & 1.000 & 0 \\
\hline 053 & 1.0000 & 0.22759 & 0.44813 & 0.53825 & Biso & 1.000 & 0 \\
\hline 054 & 1.0000 & 0.22377 & 0.78411 & 0.53536 & Biso & 1.000 & 0 \\
\hline 055 & 1.0000 & 0.00836 & 0.27182 & 0.00007 & Biso & 1.000 & 0 \\
\hline 056 & 1.0000 & 0.74871 & 0.74721 & 0.00086 & Biso & 1.000 & 0 \\
\hline 057 & 1.0000 & 0.27180 & 0.00637 & 0.99326 & Biso & 1.000 & 0 \\
\hline
\end{tabular}




\begin{tabular}{|c|c|c|c|c|c|c|}
\hline 058 & 1.0000 & 0.67408 & 0.60876 & 0.33153 & Biso & 1.000 \\
\hline 059 & 1.0000 & 0.38370 & 0.06001 & 0.32611 & Biso & 1.000 \\
\hline 060 & 1.0000 & 0.94354 & 0.34380 & 0.33170 & Biso & 1.000 \\
\hline 061 & 1.0000 & 0.34283 & 0.92621 & 0.66683 & Biso & 1.000 \\
\hline 062 & 1.0000 & 0.07230 & 0.39151 & 0.66588 & Biso & 1.000 \\
\hline 063 & 1.0000 & 0.61598 & 0.67004 & 0.66797 & Biso & 1.000 \\
\hline 064 & 1.0000 & 0.00830 & 0.74359 & 0.00027 & Biso & 1.000 \\
\hline 065 & 1.0000 & 0.27503 & 0.26937 & 0.99637 & Biso & 1.000 \\
\hline 066 & 1.0000 & 0.74513 & 0.00318 & 0.99866 & Biso & 1.000 \\
\hline 067 & 1.0000 & 0.69221 & 0.07273 & 0.33135 & Biso & 1.000 \\
\hline 068 & 1.0000 & 0.94828 & 0.60588 & 0.33312 & Biso & 1.000 \\
\hline 069 & 1.0000 & 0.40961 & 0.34776 & 0.32975 & Biso & 1.000 \\
\hline 070 & 1.0000 & 0.34132 & 0.40874 & 0.66406 & Biso & 1.000 \\
\hline 071 & 1.0000 & 0.60412 & 0.94754 & 0.66701 & Biso & 1.000 \\
\hline 072 & 1.0000 & 0.07639 & 0.68771 & 0.66809 & Biso & 1.000 \\
\hline H1 & 1.0000 & 0.23505 & 0.97716 & 0.48043 & Biso & 1.000 \\
\hline $\mathrm{C} 1$ & 1.0000 & 0.16353 & 0.93699 & 0.34888 & Biso & 1.000 \\
\hline H2 & 1.0000 & 0.17131 & 0.96475 & 0.45296 & Biso & 1.000 \\
\hline 073 & 1.0000 & 0.06977 & 0.88153 & 0.32793 & Biso & 1.000 \\
\hline H3 & 1.0000 & 0.26677 & 0.99167 & 0.33068 & Biso & 1.000 \\
\hline
\end{tabular}

Ge 13

data image 0

$\begin{array}{ll}\text { _cel-_length_a } & 13.875 \\ \text {-cell_length_b } & 13.875 \\ \text {-cell_length_c } & 15.017 \\ \text {-cell_angle_alpha } & 90 \\ \text { _cell_angle_beta } & 90 \\ \text {-cell_angle_gamma } & 120\end{array}$

_symmetry_space_group_name_H-M "P 1"

-symmetry_int_tables_number $\bar{r} 1$

loop

-symmetry_equiv_pos_as_xyz

' $\mathrm{x}, \mathrm{y}, \mathrm{z}$ '

loop

_atom_site_label

atom site occupancy

-atom_site_fract_x

-atom_site_fract_y

atom site fract $z$

-atom_site_thermal_displace_type

-atom_site_B_iso_or_equiv

atom site type symbol

\begin{tabular}{|c|c|c|c|c|c|c|c|}
\hline P1 & 1.0000 & 0.00521 & 0.22577 & 0.10971 & Biso & 1.000 & $P$ \\
\hline P2 & 1.0000 & 0.77651 & 0.77714 & 0.11136 & Biso & 1.000 & $\mathrm{P}$ \\
\hline P3 & 1.0000 & 0.22907 & 0.99559 & 0.10059 & Biso & 1.000 & $\mathrm{P}$ \\
\hline Al1 & 1.0000 & 0.22127 & 0.99205 & 0.88765 & Biso & 1.000 & Al \\
\hline Al2 & 1.0000 & 0.77184 & 0.77307 & 0.89824 & Biso & 1.000 & Al \\
\hline Al3 & 1.0000 & 0.00117 & 0.22634 & 0.89750 & Biso & 1.000 & Al \\
\hline P4 & 1.0000 & 0.67022 & 0.56150 & 0.43955 & Biso & 1.000 & $\mathrm{P}$ \\
\hline Ge1 & 1.0000 & 0.42703 & 0.10587 & 0.44249 & Biso & 1.000 & $\mathrm{Ge}$ \\
\hline P5 & 1.0000 & 0.89704 & 0.32940 & 0.44059 & Biso & 1.000 & $\mathrm{P}$ \\
\hline Al4 & 1.0000 & 0.89528 & 0.33004 & 0.22928 & Biso & 1.000 & Al \\
\hline Al5 & 1.0000 & 0.43568 & 0.10377 & 0.22696 & Biso & 1.000 & Al \\
\hline Al6 & 1.0000 & 0.67284 & 0.56190 & 0.23055 & Biso & 1.000 & Al \\
\hline P6 & 1.0000 & 0.33421 & 0.88372 & 0.77993 & Biso & 1.000 & $\mathrm{P}$ \\
\hline 7 & 1.0000 & 0.10147 & 0.43348 & 0.77264 & Biso & 1.000 & $P$ \\
\hline P8 & 1.0000 & 0.56069 & 0.66000 & 0.77502 & Biso & 1.000 & $\mathrm{P}$ \\
\hline Al 7 & 1.0000 & 0.57109 & 0.66883 & 0.56895 & Biso & 1.000 & Al \\
\hline Al8 & 1.0000 & 0.09717 & 0.43137 & 0.56871 & Biso & 1.000 & Al \\
\hline Al9 & 1.0000 & 0.33668 & 0.87876 & 0.56539 & Biso & 1.000 & Al \\
\hline P9 & 1.0000 & 0.99335 & 0.76563 & 0.89185 & Biso & 1.000 & $\mathrm{P}$ \\
\hline P10 & 1.0000 & 0.22602 & 0.22156 & 0.88733 & Biso & 1.000 & $\mathrm{P}$ \\
\hline P11 & 1.0000 & 0.77608 & 0.00072 & 0.89286 & Biso & 1.000 & $P$ \\
\hline Al10 & 1.0000 & 0.77607 & 0.00197 & 0.10614 & Biso & 1.000 & Al \\
\hline Al11 & 1.0000 & 0.23208 & 0.22462 & 0.09952 & Biso & 1.000 & Al \\
\hline Al12 & 1.0000 & 0.00080 & 0.77331 & 0.10574 & Biso & 1.000 & Al \\
\hline P12 & 1.0000 & 0.66781 & 0.10320 & 0.22888 & Biso & 1.000 & $\mathrm{P}$ \\
\hline P13 & 1.0000 & 0.90039 & 0.55933 & 0.22706 & Biso & 1.000 & $\mathrm{P}$ \\
\hline $\mathrm{P} 14$ & 1.0000 & 0.44426 & 0.33617 & 0.22338 & Biso & 1.000 & $\mathrm{P}$ \\
\hline Al13 & 1.0000 & 0.43497 & 0.34127 & 0.43448 & Biso & 1.000 & Al \\
\hline Al1 14 & 1.0000 & 0.89875 & 0.55952 & 0.43762 & Biso & 1.000 & Al \\
\hline Al15 & 1.0000 & 0.66816 & 0.10383 & 0.43539 & Biso & 1.000 & Al \\
\hline P15 & 1.0000 & 0.33411 & 0.45258 & 0.55820 & Biso & 1.000 & $P$ \\
\hline P16 & 1.0000 & 0.57014 & 0.89746 & 0.56279 & Biso & 1.000 & $P$ \\
\hline P 17 & 1.0000 & 0.10014 & 0.66731 & 0.56561 & Biso & 1.000 & $\mathrm{P}$ \\
\hline Al16 & 1.0000 & 0.10281 & 0.66650 & 0.77185 & Biso & 1.000 & Al \\
\hline Al1 17 & 1.0000 & 0.56055 & 0.89035 & 0.77308 & Biso & 1.000 & Al \\
\hline
\end{tabular}




\begin{tabular}{|c|c|c|c|c|c|c|c|}
\hline Al18 & 1.0000 & 0.32904 & 0.43582 & 0.76633 & Biso & 1.000 & Al \\
\hline 01 & 1.0000 & 0.91351 & 0.10525 & 0.12980 & Biso & 1.000 & 0 \\
\hline $\mathrm{O} 2$ & 1.0000 & 0.89823 & 0.80827 & 0.12966 & Biso & 1.000 & 0 \\
\hline 03 & 1.0000 & 0.20057 & 0.08737 & 0.12152 & Biso & 1.000 & 0 \\
\hline 04 & 1.0000 & 0.08539 & 0.88417 & 0.86639 & Biso & 1.000 & 0 \\
\hline 05 & 1.0000 & 0.80736 & 0.91058 & 0.87335 & Biso & 1.000 & 0 \\
\hline 06 & 1.0000 & 0.10466 & 0.19322 & 0.87316 & Biso & 1.000 & 0 \\
\hline 07 & 1.0000 & 0.57513 & 0.44166 & 0.45418 & Biso & 1.000 & 0 \\
\hline 08 & 1.0000 & 0.56473 & 0.13735 & 0.44548 & Biso & 1.000 & 0 \\
\hline 09 & 1.0000 & 0.87523 & 0.42586 & 0.46073 & Biso & 1.000 & 0 \\
\hline 010 & 1.0000 & 0.75697 & 0.22540 & 0.21012 & Biso & 1.000 & 0 \\
\hline 011 & 1.0000 & 0.47434 & 0.24370 & 0.21190 & Biso & 1.000 & 0 \\
\hline 012 & 1.0000 & 0.77857 & 0.52971 & 0.21363 & Biso & 1.000 & 0 \\
\hline 013 & 1.0000 & 0.23904 & 0.76587 & 0.80310 & Biso & 1.000 & 0 \\
\hline 014 & 1.0000 & 0.22481 & 0.46943 & 0.78880 & Biso & 1.000 & 0 \\
\hline 015 & 1.0000 & 0.53017 & 0.75227 & 0.78268 & Biso & 1.000 & 0 \\
\hline 016 & 1.0000 & 0.42978 & 0.57401 & 0.55184 & Biso & 1.000 & 0 \\
\hline 017 & 1.0000 & 0.10585 & 0.56033 & 0.56311 & Biso & 1.000 & 0 \\
\hline 018 & 1.0000 & 0.44881 & 0.86099 & 0.53612 & Biso & 1.000 & 0 \\
\hline 019 & 1.0000 & 0.98858 & 0.30782 & 0.16684 & Biso & 1.000 & 0 \\
\hline $\mathrm{O} 20$ & 1.0000 & 0.69589 & 0.67528 & 0.16586 & Biso & 1.000 & 0 \\
\hline 021 & 1.0000 & 0.33490 & 0.01767 & 0.14995 & Biso & 1.000 & 0 \\
\hline $\mathrm{O} 22$ & 1.0000 & 0.31664 & 0.97219 & 0.82647 & Biso & 1.000 & $\mathrm{O}$ \\
\hline 023 & 1.0000 & 0.65138 & 0.67880 & 0.84231 & Biso & 1.000 & 0 \\
\hline $\mathrm{O} 24$ & 1.0000 & 0.02624 & 0.34606 & 0.84087 & Biso & 1.000 & 0 \\
\hline 025 & 1.0000 & 0.65656 & 0.64290 & 0.50015 & Biso & 1.000 & 0 \\
\hline 026 & 1.0000 & 0.33460 & 0.98878 & 0.50998 & Biso & 1.000 & 0 \\
\hline $\mathrm{O} 27$ & 1.0000 & 0.99466 & 0.34023 & 0.49635 & Biso & 1.000 & 0 \\
\hline 028 & 1.0000 & 0.00823 & 0.67813 & 0.84093 & Biso & 1.000 & 0 \\
\hline 029 & 1.0000 & 0.30538 & 0.32019 & 0.82903 & Biso & 1.000 & 0 \\
\hline 030 & 1.0000 & 0.67389 & 0.97929 & 0.83856 & Biso & 1.000 & 0 \\
\hline 031 & 1.0000 & 0.68050 & 0.02564 & 0.16311 & Biso & 1.000 & 0 \\
\hline 032 & 1.0000 & 0.34937 & 0.31676 & 0.16009 & Biso & 1.000 & 0 \\
\hline 033 & 1.0000 & 0.97860 & 0.65810 & 0.16809 & Biso & 1.000 & 0 \\
\hline 034 & 1.0000 & 0.34905 & 0.37997 & 0.48975 & Biso & 1.000 & 0 \\
\hline 035 & 1.0000 & 0.00759 & 0.65800 & 0.50391 & Biso & 1.000 & 0 \\
\hline 036 & 1.0000 & 0.65119 & 0.99543 & 0.50515 & Biso & 1.000 & 0 \\
\hline 037 & 1.0000 & 0.11886 & 0.23847 & 0.13229 & Biso & 1.000 & 0 \\
\hline 038 & 1.0000 & 0.76097 & 0.87475 & 0.13919 & Biso & 1.000 & 0 \\
\hline 039 & 1.0000 & 0.13237 & 0.88408 & 0.13329 & Biso & 1.000 & 0 \\
\hline 040 & 1.0000 & 0.23579 & 0.12042 & 0.85967 & Biso & 1.000 & 0 \\
\hline 041 & 1.0000 & 0.88051 & 0.75216 & 0.86584 & Biso & 1.000 & 0 \\
\hline 042 & 1.0000 & 0.87328 & 0.11442 & 0.86546 & Biso & 1.000 & 0 \\
\hline 043 & 1.0000 & 0.78061 & 0.56744 & 0.46272 & Biso & 1.000 & 0 \\
\hline O4 4 & 1.0000 & 0.40443 & 0.21315 & 0.47468 & Biso & 1.000 & 0 \\
\hline 045 & 1.0000 & 0.79423 & 0.21972 & 0.46575 & Biso & 1.000 & 0 \\
\hline 046 & 1.0000 & 0.91155 & 0.45897 & 0.19955 & Biso & 1.000 & 0 \\
\hline 047 & 1.0000 & 0.55235 & 0.08985 & 0.21511 & Biso & 1.000 & 0 \\
\hline O48 & 1.0000 & 0.54646 & 0.44780 & 0.19888 & Biso & 1.000 & 0 \\
\hline O49 & 1.0000 & 0.44487 & 0.89631 & 0.81182 & Biso & 1.000 & 0 \\
\hline 050 & 1.0000 & 0.08624 & 0.53466 & 0.78321 & Biso & 1.000 & 0 \\
\hline 051 & 1.0000 & 0.45740 & 0.54812 & 0.79671 & Biso & 1.000 & 0 \\
\hline 052 & 1.0000 & 0.59215 & 0.80119 & 0.54678 & Biso & 1.000 & 0 \\
\hline 053 & 1.0000 & 0.22540 & 0.45047 & 0.53654 & Biso & 1.000 & 0 \\
\hline O54 & 1.0000 & 0.21160 & 0.76325 & 0.53213 & Biso & 1.000 & 0 \\
\hline 055 & 1.0000 & 0.00112 & 0.25307 & 0.01107 & Biso & 1.000 & 0 \\
\hline 056 & 1.0000 & 0.74861 & 0.74986 & 0.01232 & Biso & 1.000 & 0 \\
\hline 057 & 1.0000 & 0.24896 & 0.99105 & 0.00083 & Biso & 1.000 & 0 \\
\hline 058 & 1.0000 & 0.67127 & 0.59696 & 0.34219 & Biso & 1.000 & 0 \\
\hline 059 & 1.0000 & 0.36836 & 0.05644 & 0.33137 & Biso & 1.000 & 0 \\
\hline 060 & 1.0000 & 0.92693 & 0.33105 & 0.34180 & Biso & 1.000 & 0 \\
\hline 061 & 1.0000 & 0.33779 & 0.90234 & 0.67906 & Biso & 1.000 & 0 \\
\hline 062 & 1.0000 & 0.06612 & 0.38290 & 0.67868 & Biso & 1.000 & 0 \\
\hline 063 & 1.0000 & 0.60365 & 0.65927 & 0.68049 & Biso & 1.000 & 0 \\
\hline 064 & 1.0000 & 0.99731 & 0.74539 & 0.99206 & Biso & 1.000 & $\mathrm{O}$ \\
\hline 065 & 1.0000 & 0.25922 & 0.25164 & 0.98563 & Biso & 1.000 & 0 \\
\hline 066 & 1.0000 & 0.74954 & 0.00038 & 0.99226 & Biso & 1.000 & 0 \\
\hline 067 & 1.0000 & 0.67951 & 0.06956 & 0.32413 & Biso & 1.000 & 0 \\
\hline 068 & 1.0000 & 0.93508 & 0.59075 & 0.32503 & Biso & 1.000 & 0 \\
\hline 069 & 1.0000 & 0.40778 & 0.33821 & 0.31954 & Biso & 1.000 & 0 \\
\hline 070 & 1.0000 & 0.32947 & 0.40666 & 0.65274 & Biso & 1.000 & 0 \\
\hline 071 & 1.0000 & 0.58883 & 0.93259 & 0.66154 & Biso & 1.000 & 0 \\
\hline 072 & 1.0000 & 0.07756 & 0.69050 & 0.66149 & Biso & 1.000 & 0 \\
\hline H 1 & 1.0000 & 0.22575 & 0.96234 & 0.48617 & Biso & 1.000 & $\mathrm{H}$ \\
\hline C1 & 1.0000 & 0.15484 & 0.92504 & 0.35365 & Biso & 1.000 & $\mathrm{C}$ \\
\hline $\mathrm{H} 2$ & 1.0000 & 0.16086 & 0.94588 & 0.45817 & Biso & 1.000 & $\mathrm{H}$ \\
\hline 073 & 1.0000 & 0.06374 & 0.86530 & 0.33185 & Biso & 1.000 & 0 \\
\hline H3 & 1.0000 & 0.25846 & 0.98704 & 0.33589 & Biso & 1.000 & $\mathrm{H}$ \\
\hline
\end{tabular}
Ga 13

data_image 0 


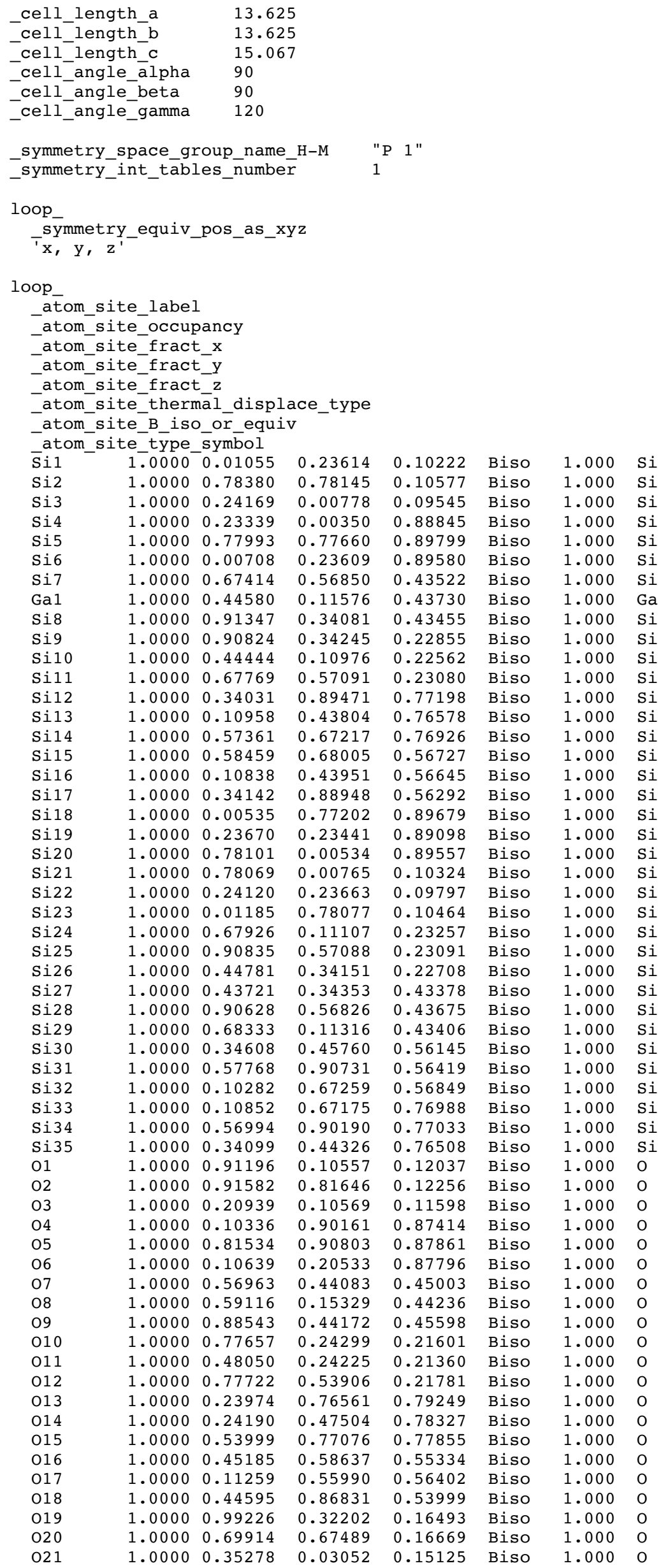




\begin{tabular}{|c|c|c|c|c|c|c|c|}
\hline $\mathrm{O} 22$ & 1.0000 & 0.31959 & 0.98566 & 0.82581 & Biso & 1.000 & 0 \\
\hline 023 & 1.0000 & 0.67011 & 0.69039 & 0.84045 & Biso & 1.000 & 0 \\
\hline 024 & 1.0000 & 0.02651 & 0.34283 & 0.83596 & Biso & 1.000 & 0 \\
\hline 025 & 1.0000 & 0.66501 & 0.65801 & 0.50085 & Biso & 1.000 & O \\
\hline 026 & 1.0000 & 0.34487 & 0.99124 & 0.50373 & Biso & 1.000 & $\mathrm{O}$ \\
\hline 027 & 1.0000 & 0.01823 & 0.35425 & 0.49459 & Biso & 1.000 & 0 \\
\hline 028 & 1.0000 & 0.02372 & 0.68154 & 0.83998 & Biso & 1.000 & $\mathrm{O}$ \\
\hline 029 & 1.0000 & 0.32177 & 0.33816 & 0.82750 & Biso & 1.000 & O \\
\hline 030 & 1.0000 & 0.67476 & 0.98357 & 0.83412 & Biso & 1.000 & 0 \\
\hline 031 & 1.0000 & 0.69417 & 0.02966 & 0.16201 & Biso & 1.000 & 0 \\
\hline 032 & 1.0000 & 0.34721 & 0.32232 & 0.15925 & Biso & 1.000 & 0 \\
\hline 033 & 1.0000 & 0.99245 & 0.67725 & 0.16876 & Biso & 1.000 & 0 \\
\hline 034 & 1.0000 & 0.35486 & 0.37637 & 0.48827 & Biso & 1.000 & 0 \\
\hline 035 & 1.0000 & 0.00440 & 0.66142 & 0.50158 & Biso & 1.000 & $\mathrm{O}$ \\
\hline 036 & 1.0000 & 0.66223 & 0.01160 & 0.50173 & Biso & 1.000 & 0 \\
\hline 037 & 1.0000 & 0.13263 & 0.24874 & 0.12488 & Biso & 1.000 & $\mathrm{O}$ \\
\hline 038 & 1.0000 & 0.76780 & 0.88751 & 0.13283 & Biso & 1.000 & O \\
\hline 039 & 1.0000 & 0.13598 & 0.88763 & 0.12764 & Biso & 1.000 & 0 \\
\hline 040 & 1.0000 & 0.24341 & 0.12329 & 0.86250 & Biso & 1.000 & 0 \\
\hline 041 & 1.0000 & 0.88417 & 0.75814 & 0.86957 & Biso & 1.000 & 0 \\
\hline 042 & 1.0000 & 0.88709 & 0.12732 & 0.86843 & Biso & 1.000 & 0 \\
\hline 043 & 1.0000 & 0.79097 & 0.56988 & 0.45746 & Biso & 1.000 & 0 \\
\hline 044 & 1.0000 & 0.41345 & 0.22297 & 0.46895 & Biso & 1.000 & 0 \\
\hline 045 & 1.0000 & 0.80647 & 0.21960 & 0.45937 & Biso & 1.000 & 0 \\
\hline 046 & 1.0000 & 0.91961 & 0.46277 & 0.20113 & Biso & 1.000 & 0 \\
\hline 047 & 1.0000 & 0.55593 & 0.09827 & 0.21595 & Biso & 1.000 & O \\
\hline 048 & 1.0000 & 0.55816 & 0.46195 & 0.20289 & Biso & 1.000 & 0 \\
\hline 049 & 1.0000 & 0.46031 & 0.90889 & 0.80339 & Biso & 1.000 & $\mathrm{O}$ \\
\hline 050 & 1.0000 & 0.09407 & 0.54723 & 0.77859 & Biso & 1.000 & $\mathrm{O}$ \\
\hline 051 & 1.0000 & 0.46216 & 0.55158 & 0.79075 & Biso & 1.000 & 0 \\
\hline 052 & 1.0000 & 0.60063 & 0.80355 & 0.54551 & Biso & 1.000 & 0 \\
\hline 053 & 1.0000 & 0.23250 & 0.46224 & 0.54021 & Biso & 1.000 & O \\
\hline 054 & 1.0000 & 0.22278 & 0.77801 & 0.53621 & Biso & 1.000 & 0 \\
\hline 055 & 1.0000 & 0.00662 & 0.26968 & 0.99925 & Biso & 1.000 & O \\
\hline 056 & 1.0000 & 0.74994 & 0.74693 & 0.00242 & Biso & 1.000 & 0 \\
\hline 057 & 1.0000 & 0.26988 & 0.00503 & 0.99141 & Biso & 1.000 & 0 \\
\hline 058 & 1.0000 & 0.67540 & 0.60855 & 0.33299 & Biso & 1.000 & 0 \\
\hline 059 & 1.0000 & 0.38203 & 0.06225 & 0.32249 & Biso & 1.000 & 0 \\
\hline 060 & 1.0000 & 0.94850 & 0.34637 & 0.33063 & Biso & 1.000 & 0 \\
\hline 061 & 1.0000 & 0.34330 & 0.92131 & 0.66679 & Biso & 1.000 & O \\
\hline 062 & 1.0000 & 0.07262 & 0.38587 & 0.66593 & Biso & 1.000 & O \\
\hline 063 & 1.0000 & 0.62141 & 0.67454 & 0.66953 & Biso & 1.000 & 0 \\
\hline 064 & 1.0000 & 0.00764 & 0.74378 & 0.00150 & Biso & 1.000 & O \\
\hline 065 & 1.0000 & 0.27509 & 0.26864 & 0.99405 & Biso & 1.000 & 0 \\
\hline 066 & 1.0000 & 0.74724 & 0.00487 & 0.99922 & Biso & 1.000 & 0 \\
\hline 067 & 1.0000 & 0.68768 & 0.07112 & 0.33264 & Biso & 1.000 & 0 \\
\hline 068 & 1.0000 & 0.94671 & 0.60475 & 0.33414 & Biso & 1.000 & $\mathrm{O}$ \\
\hline 069 & 1.0000 & 0.40670 & 0.34096 & 0.32816 & Biso & 1.000 & 0 \\
\hline 070 & 1.0000 & 0.34053 & 0.40856 & 0.66144 & Biso & 1.000 & O \\
\hline 071 & 1.0000 & 0.60205 & 0.94550 & 0.66818 & Biso & 1.000 & 0 \\
\hline 072 & 1.0000 & 0.07529 & 0.69270 & 0.67009 & Biso & 1.000 & 0 \\
\hline $\mathrm{H} 1$ & 1.0000 & 0.23421 & 0.97037 & 0.47949 & Biso & 1.000 & $\mathrm{H}$ \\
\hline $\mathrm{C} 1$ & 1.0000 & 0.16303 & 0.94333 & 0.34660 & Biso & 1.000 & C \\
\hline $\mathrm{H} 2$ & 1.0000 & 0.17087 & 0.95955 & 0.45190 & Biso & 1.000 & $\mathrm{H}$ \\
\hline 073 & 1.0000 & 0.06903 & 0.89110 & 0.32510 & Biso & 1.000 & O \\
\hline H3 & 1.0000 & 0.26781 & 0.99846 & 0.32800 & Biso & 1.000 & $\mathrm{H}$ \\
\hline
\end{tabular}

Ti 13

data_image 0

$\begin{array}{ll}\text {-cel'_length_a } & 13.875 \\ \text {-cell_length_b } & 13.875 \\ \text {-cell_length_c } & 15.017 \\ \text {-cell_angle_alpha } & 90 \\ \text {-cell_angle_beta } & 90 \\ \text {-cell_angle_gamma } & 120\end{array}$

_symmetry_space_group_name_H-M "P 1 "

_symmetry_int_tables_number 1

loop_

_symmetry_equiv_pos_as_xyz

' $\mathrm{x}, \mathrm{y}, \mathrm{z}$ '

loop

atom site label

-atom_site_occupancy

-atom_site_fract_x

atom site fract $y$

-atom_site_fract_z

-atom_site_thermal_displace_type

-atom_site_B_iso_or_equiv 


\begin{tabular}{|c|c|c|c|c|c|c|c|}
\hline$\overline{\mathrm{P}} 1$ & 1.0000 & 0.00641 & 0.22670 & 0.10908 & Biso & 1.000 & $\mathrm{P}$ \\
\hline P2 & 1.0000 & 0.77876 & 0.77926 & 0.11279 & Biso & 1.000 & $\mathrm{P}$ \\
\hline P3 & 1.0000 & 0.23017 & 0.99705 & 0.09834 & Biso & 1.000 & $\mathrm{P}$ \\
\hline Al1 & 1.0000 & 0.21847 & 0.99018 & 0.88408 & Biso & 1.000 & Al \\
\hline Al2 & 1.0000 & 0.77163 & 0.77238 & 0.89965 & Biso & 1.000 & Al \\
\hline A13 & 1.0000 & 0.00052 & 0.22543 & 0.89681 & Biso & 1.000 & Al \\
\hline P4 & 1.0000 & 0.67028 & 0.56289 & 0.44053 & Biso & 1.000 & $\mathrm{P}$ \\
\hline Til & 1.0000 & 0.42331 & 0.10170 & 0.44181 & Biso & 1.000 & $\mathrm{Ti}$ \\
\hline P5 & 1.0000 & 0.90096 & 0.32946 & 0.43974 & Biso & 1.000 & $\mathrm{P}$ \\
\hline Al4 & 1.0000 & 0.89784 & 0.33182 & 0.22869 & Biso & 1.000 & Al \\
\hline Al5 & 1.0000 & 0.43466 & 0.10302 & 0.22432 & Biso & 1.000 & Al \\
\hline Al6 & 1.0000 & 0.67443 & 0.56234 & 0.23087 & Biso & 1.000 & Al \\
\hline P6 & 1.0000 & 0.33245 & 0.87929 & 0.78218 & Biso & 1.000 & $\mathrm{P}$ \\
\hline P7 & 1.0000 & 0.10118 & 0.43172 & 0.77247 & Biso & 1.000 & $\mathrm{P}$ \\
\hline P8 & 1.0000 & 0.56142 & 0.65950 & 0.77521 & Biso & 1.000 & $\mathrm{P}$ \\
\hline Al7 & 1.0000 & 0.57622 & 0.67094 & 0.57001 & Biso & 1.000 & Al \\
\hline A18 & 1.0000 & 0.09701 & 0.43115 & 0.57030 & Biso & 1.000 & Al \\
\hline Al9 & 1.0000 & 0.33307 & 0.87108 & 0.56701 & Biso & 1.000 & $\mathrm{Al}$ \\
\hline P9 & 1.0000 & 0.99242 & 0.76369 & 0.89227 & Biso & 1.000 & $\mathrm{P}$ \\
\hline P10 & 1.0000 & 0.22539 & 0.22000 & 0.88489 & Biso & 1.000 & $P$ \\
\hline P11 & 1.0000 & 0.77619 & 0.99990 & 0.89320 & Biso & 1.000 & $\mathrm{P}$ \\
\hline Al10 & 1.0000 & 0.77732 & 0.00335 & 0.10687 & Biso & 1.000 & Al \\
\hline Al11 & 1.0000 & 0.23341 & 0.22517 & 0.09778 & Biso & 1.000 & Al \\
\hline Al12 & 1.0000 & 0.00344 & 0.77609 & 0.10692 & Biso & 1.000 & Al \\
\hline P12 & 1.0000 & 0.66960 & 0.10600 & 0.22862 & Biso & 1.000 & $\mathrm{P}$ \\
\hline P13 & 1.0000 & 0.90247 & 0.56150 & 0.22848 & Biso & 1.000 & $\mathrm{P}$ \\
\hline P14 & 1.0000 & 0.44451 & 0.33845 & 0.22234 & Biso & 1.000 & $\mathrm{P}$ \\
\hline Al13 & 1.0000 & 0.43106 & 0.34685 & 0.43246 & Biso & 1.000 & Al \\
\hline Al1 14 & 1.0000 & 0.89851 & 0.55877 & 0.43864 & Biso & 1.000 & Al \\
\hline Al15 & 1.0000 & 0.67226 & 0.10495 & 0.43586 & Biso & 1.000 & Al \\
\hline P15 & 1.0000 & 0.33481 & 0.45654 & 0.55795 & Biso & 1.000 & $\mathrm{P}$ \\
\hline P16 & 1.0000 & 0.56995 & 0.89762 & 0.56407 & Biso & 1.000 & $P$ \\
\hline P17 & 1.0000 & 0.09552 & 0.66458 & 0.56895 & Biso & 1.000 & $\mathrm{P}$ \\
\hline Al16 & 1.0000 & 0.10107 & 0.66468 & 0.77361 & Biso & 1.000 & $\mathrm{Al}$ \\
\hline Al17 & 1.0000 & 0.55970 & 0.88957 & 0.77380 & Biso & 1.000 & Al \\
\hline Al18 & 1.0000 & 0.32887 & 0.43593 & 0.76603 & Biso & 1.000 & Al \\
\hline 01 & 1.0000 & 0.91475 & 0.10671 & 0.13093 & Biso & 1.000 & 0 \\
\hline $\mathrm{O} 2$ & 1.0000 & 0.90099 & 0.81157 & 0.13024 & Biso & 1.000 & 0 \\
\hline 03 & 1.0000 & 0.20235 & 0.08862 & 0.12231 & Biso & 1.000 & 0 \\
\hline $\mathrm{O} 4$ & 1.0000 & 0.08352 & 0.88065 & 0.86213 & Biso & 1.000 & 0 \\
\hline 05 & 1.0000 & 0.80771 & 0.90988 & 0.87383 & Biso & 1.000 & 0 \\
\hline 06 & 1.0000 & 0.10439 & 0.19322 & 0.87169 & Biso & 1.000 & 0 \\
\hline 07 & 1.0000 & 0.56946 & 0.44696 & 0.45764 & Biso & 1.000 & 0 \\
\hline 08 & 1.0000 & 0.56526 & 0.13504 & 0.44531 & Biso & 1.000 & 0 \\
\hline 09 & 1.0000 & 0.87904 & 0.42595 & 0.45933 & Biso & 1.000 & 0 \\
\hline 010 & 1.0000 & 0.75917 & 0.22802 & 0.20945 & Biso & 1.000 & 0 \\
\hline 011 & 1.0000 & 0.47160 & 0.24359 & 0.21534 & Biso & 1.000 & 0 \\
\hline 012 & 1.0000 & 0.78025 & 0.53012 & 0.21443 & Biso & 1.000 & 0 \\
\hline 013 & 1.0000 & 0.23681 & 0.76260 & 0.80777 & Biso & 1.000 & 0 \\
\hline 014 & 1.0000 & 0.22460 & 0.46904 & 0.79029 & Biso & 1.000 & 0 \\
\hline 015 & 1.0000 & 0.53056 & 0.75167 & 0.78050 & Biso & 1.000 & 0 \\
\hline 016 & 1.0000 & 0.43628 & 0.57423 & 0.55009 & Biso & 1.000 & 0 \\
\hline 017 & 1.0000 & 0.09151 & 0.55286 & 0.57017 & Biso & 1.000 & 0 \\
\hline 018 & 1.0000 & 0.44846 & 0.85887 & 0.53634 & Biso & 1.000 & 0 \\
\hline 019 & 1.0000 & 0.99101 & 0.31011 & 0.16548 & Biso & 1.000 & 0 \\
\hline 020 & 1.0000 & 0.69921 & 0.67740 & 0.16777 & Biso & 1.000 & 0 \\
\hline 021 & 1.0000 & 0.34050 & 0.02179 & 0.14127 & Biso & 1.000 & 0 \\
\hline 022 & 1.0000 & 0.31551 & 0.96997 & 0.82555 & Biso & 1.000 & 0 \\
\hline 023 & 1.0000 & 0.65026 & 0.67857 & 0.84443 & Biso & 1.000 & 0 \\
\hline 024 & 1.0000 & 0.02536 & 0.34578 & 0.84134 & Biso & 1.000 & 0 \\
\hline 025 & 1.0000 & 0.66458 & 0.64984 & 0.50025 & Biso & 1.000 & 0 \\
\hline 026 & 1.0000 & 0.32891 & 0.98089 & 0.51338 & Biso & 1.000 & 0 \\
\hline 027 & 1.0000 & 0.99957 & 0.34066 & 0.49446 & Biso & 1.000 & 0 \\
\hline 028 & 1.0000 & 0.00573 & 0.67347 & 0.84402 & Biso & 1.000 & 0 \\
\hline 029 & 1.0000 & 0.30528 & 0.31931 & 0.82734 & Biso & 1.000 & 0 \\
\hline 030 & 1.0000 & 0.67303 & 0.97740 & 0.83978 & Biso & 1.000 & 0 \\
\hline 031 & 1.0000 & 0.68167 & 0.02798 & 0.16282 & Biso & 1.000 & 0 \\
\hline 032 & 1.0000 & 0.35165 & 0.31921 & 0.15672 & Biso & 1.000 & 0 \\
\hline 033 & 1.0000 & 0.98009 & 0.66054 & 0.16948 & Biso & 1.000 & 0 \\
\hline 034 & 1.0000 & 0.34044 & 0.37940 & 0.48810 & Biso & 1.000 & 0 \\
\hline 035 & 1.0000 & 0.00453 & 0.65842 & 0.50682 & Biso & 1.000 & 0 \\
\hline 036 & 1.0000 & 0.65101 & 0.99525 & 0.50594 & Biso & 1.000 & 0 \\
\hline 037 & 1.0000 & 0.12049 & 0.23971 & 0.13046 & Biso & 1.000 & 0 \\
\hline 038 & 1.0000 & 0.76235 & 0.87636 & 0.14062 & Biso & 1.000 & 0 \\
\hline 039 & 1.0000 & 0.13604 & 0.88581 & 0.13450 & Biso & 1.000 & 0 \\
\hline 040 & 1.0000 & 0.23358 & 0.11860 & 0.85503 & Biso & 1.000 & 0 \\
\hline 041 & 1.0000 & 0.87874 & 0.74897 & 0.86736 & Biso & 1.000 & 0 \\
\hline 042 & 1.0000 & 0.87275 & 0.11344 & 0.86459 & Biso & 1.000 & 0 \\
\hline 043 & 1.0000 & 0.77663 & 0.56016 & 0.46296 & Biso & 1.000 & 0 \\
\hline
\end{tabular}




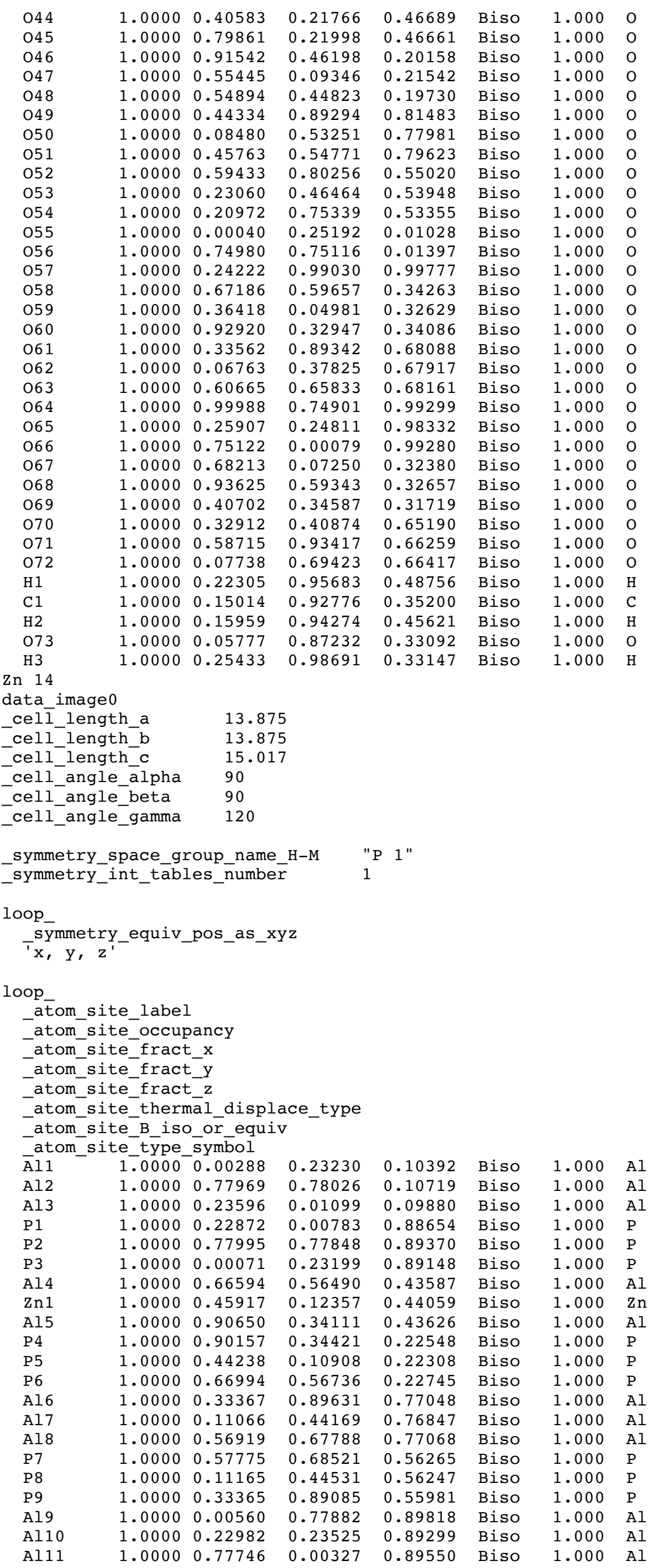




\begin{tabular}{|c|c|c|c|c|c|c|c|}
\hline P10 & 1.0000 & 0.77777 & 0.00444 & 0.10937 & Biso & 1.000 & $\mathrm{P}$ \\
\hline P11 & 1.0000 & 0.23210 & 0.23610 & 0.10600 & Biso & 1.000 & $\mathrm{P}$ \\
\hline P12 & 1.0000 & 0.00915 & 0.78539 & 0.11205 & Biso & 1.000 & $\mathrm{P}$ \\
\hline Al12 & 1.0000 & 0.67634 & 0.11351 & 0.23365 & Biso & 1.000 & Al \\
\hline Al13 & 1.0000 & 0.89853 & 0.56954 & 0.23145 & Biso & 1.000 & $\mathrm{Al}$ \\
\hline Al14 & 1.0000 & 0.44209 & 0.33494 & 0.22950 & Biso & 1.000 & Al \\
\hline P13 & 1.0000 & 0.43274 & 0.33604 & 0.43948 & Biso & 1.000 & $\mathrm{P}$ \\
\hline P14 & 1.0000 & 0.89473 & 0.56481 & 0.44266 & Biso & 1.000 & $\mathrm{P}$ \\
\hline P15 & 1.0000 & 0.68493 & 0.12047 & 0.43700 & Biso & 1.000 & $\mathrm{P}$ \\
\hline Al15 & 1.0000 & 0.34627 & 0.45897 & 0.56321 & Biso & 1.000 & Al \\
\hline Al16 & 1.0000 & 0.56320 & 0.90373 & 0.56513 & Biso & 1.000 & Al \\
\hline Al17 & 1.0000 & 0.10087 & 0.67209 & 0.56919 & Biso & 1.000 & Al \\
\hline P16 & 1.0000 & 0.10679 & 0.67044 & 0.77690 & Biso & 1.000 & $P$ \\
\hline P17 & 1.0000 & 0.56311 & 0.90268 & 0.77542 & Biso & 1.000 & $\mathrm{P}$ \\
\hline P18 & 1.0000 & 0.34154 & 0.44779 & 0.77150 & Biso & 1.000 & $\mathrm{P}$ \\
\hline 01 & 1.0000 & 0.89922 & 0.09538 & 0.12898 & Biso & 1.000 & 0 \\
\hline $\mathrm{O} 2$ & 1.0000 & 0.91775 & 0.81502 & 0.13202 & Biso & 1.000 & 0 \\
\hline 03 & 1.0000 & 0.20439 & 0.11541 & 0.12523 & Biso & 1.000 & 0 \\
\hline 04 & 1.0000 & 0.10790 & 0.91472 & 0.86923 & Biso & 1.000 & 0 \\
\hline 05 & 1.0000 & 0.81121 & 0.89946 & 0.87237 & Biso & 1.000 & 0 \\
\hline 06 & 1.0000 & 0.09299 & 0.20396 & 0.87195 & Biso & 1.000 & 0 \\
\hline 07 & 1.0000 & 0.55561 & 0.43003 & 0.44850 & Biso & 1.000 & 0 \\
\hline 08 & 1.0000 & 0.61497 & 0.17723 & 0.43678 & Biso & 1.000 & 0 \\
\hline 09 & 1.0000 & 0.87505 & 0.44671 & 0.45897 & Biso & 1.000 & 0 \\
\hline 010 & 1.0000 & 0.77964 & 0.25230 & 0.21194 & Biso & 1.000 & 0 \\
\hline 011 & 1.0000 & 0.47556 & 0.23147 & 0.20464 & Biso & 1.000 & 0 \\
\hline 012 & 1.0000 & 0.76160 & 0.53754 & 0.21024 & Biso & 1.000 & 0 \\
\hline 013 & 1.0000 & 0.22863 & 0.75969 & 0.79522 & Biso & 1.000 & 0 \\
\hline 014 & 1.0000 & 0.24922 & 0.47691 & 0.78803 & Biso & 1.000 & 0 \\
\hline 015 & 1.0000 & 0.53348 & 0.78070 & 0.78918 & Biso & 1.000 & 0 \\
\hline 016 & 1.0000 & 0.45421 & 0.59646 & 0.55098 & Biso & 1.000 & 0 \\
\hline 017 & 1.0000 & 0.12454 & 0.56127 & 0.55600 & Biso & 1.000 & 0 \\
\hline 018 & 1.0000 & 0.41988 & 0.85123 & 0.55092 & Biso & 1.000 & 0 \\
\hline 019 & 1.0000 & 0.97989 & 0.32538 & 0.16511 & Biso & 1.000 & 0 \\
\hline 020 & 1.0000 & 0.68552 & 0.66182 & 0.16527 & Biso & 1.000 & 0 \\
\hline 021 & 1.0000 & 0.35536 & 0.03265 & 0.15395 & Biso & 1.000 & 0 \\
\hline 022 & 1.0000 & 0.31090 & 0.99082 & 0.83052 & Biso & 1.000 & 0 \\
\hline 023 & 1.0000 & 0.67692 & 0.69618 & 0.84105 & Biso & 1.000 & 0 \\
\hline $\mathrm{O} 24$ & 1.0000 & 0.01933 & 0.33330 & 0.83727 & Biso & 1.000 & 0 \\
\hline 025 & 1.0000 & 0.65170 & 0.66028 & 0.50222 & Biso & 1.000 & 0 \\
\hline 026 & 1.0000 & 0.35792 & 0.98708 & 0.49934 & Biso & 1.000 & 0 \\
\hline 027 & 1.0000 & 0.02370 & 0.36490 & 0.49678 & Biso & 1.000 & 0 \\
\hline 028 & 1.0000 & 0.02868 & 0.68190 & 0.84293 & Biso & 1.000 & 0 \\
\hline 029 & 1.0000 & 0.32365 & 0.35044 & 0.83116 & Biso & 1.000 & 0 \\
\hline 030 & 1.0000 & 0.66025 & 0.98005 & 0.83612 & Biso & 1.000 & 0 \\
\hline 031 & 1.0000 & 0.69556 & 0.02578 & 0.16133 & Biso & 1.000 & 0 \\
\hline 032 & 1.0000 & 0.33281 & 0.31858 & 0.16076 & Biso & 1.000 & 0 \\
\hline 033 & 1.0000 & 0.99161 & 0.68653 & 0.16949 & Biso & 1.000 & 0 \\
\hline 034 & 1.0000 & 0.35709 & 0.37028 & 0.48865 & Biso & 1.000 & 0 \\
\hline 035 & 1.0000 & 0.98836 & 0.65024 & 0.50260 & Biso & 1.000 & 0 \\
\hline 036 & 1.0000 & 0.64245 & 0.02183 & 0.50169 & Biso & 1.000 & 0 \\
\hline 037 & 1.0000 & 0.13144 & 0.24718 & 0.13337 & Biso & 1.000 & 0 \\
\hline 038 & 1.0000 & 0.76360 & 0.89218 & 0.13912 & Biso & 1.000 & 0 \\
\hline 039 & 1.0000 & 0.12262 & 0.88589 & 0.13719 & Biso & 1.000 & 0 \\
\hline 040 & 1.0000 & 0.24036 & 0.12008 & 0.86122 & Biso & 1.000 & 0 \\
\hline 041 & 1.0000 & 0.87691 & 0.76123 & 0.86692 & Biso & 1.000 & 0 \\
\hline 042 & 1.0000 & 0.88855 & 0.13233 & 0.86450 & Biso & 1.000 & 0 \\
\hline 043 & 1.0000 & 0.78861 & 0.56717 & 0.46551 & Biso & 1.000 & 0 \\
\hline 044 & 1.0000 & 0.41519 & 0.22797 & 0.47860 & Biso & 1.000 & 0 \\
\hline 045 & 1.0000 & 0.80462 & 0.20711 & 0.46583 & Biso & 1.000 & 0 \\
\hline 046 & 1.0000 & 0.91343 & 0.45685 & 0.20031 & Biso & 1.000 & 0 \\
\hline 047 & 1.0000 & 0.54575 & 0.09740 & 0.21251 & Biso & 1.000 & 0 \\
\hline 048 & 1.0000 & 0.55672 & 0.46538 & 0.20745 & Biso & 1.000 & 0 \\
\hline 049 & 1.0000 & 0.46210 & 0.91325 & 0.80190 & Biso & 1.000 & 0 \\
\hline 050 & 1.0000 & 0.09436 & 0.55554 & 0.79034 & Biso & 1.000 & 0 \\
\hline 051 & 1.0000 & 0.45410 & 0.54884 & 0.79531 & Biso & 1.000 & 0 \\
\hline 052 & 1.0000 & 0.59392 & 0.79931 & 0.53686 & Biso & 1.000 & 0 \\
\hline 053 & 1.0000 & 0.22220 & 0.45412 & 0.53710 & Biso & 1.000 & 0 \\
\hline 054 & 1.0000 & 0.21796 & 0.79280 & 0.53406 & Biso & 1.000 & 0 \\
\hline 055 & 1.0000 & 0.00058 & 0.25890 & 0.99078 & Biso & 1.000 & 0 \\
\hline 056 & 1.0000 & 0.75487 & 0.75467 & 0.99355 & Biso & 1.000 & 0 \\
\hline 057 & 1.0000 & 0.25705 & 0.00697 & 0.98545 & Biso & 1.000 & 0 \\
\hline 058 & 1.0000 & 0.67600 & 0.60662 & 0.32419 & Biso & 1.000 & 0 \\
\hline 059 & 1.0000 & 0.93763 & 0.34588 & 0.32260 & Biso & 1.000 & 0 \\
\hline 060 & 1.0000 & 0.33026 & 0.92287 & 0.65800 & Biso & 1.000 & 0 \\
\hline 061 & 1.0000 & 0.07668 & 0.39870 & 0.65748 & Biso & 1.000 & 0 \\
\hline 062 & 1.0000 & 0.61302 & 0.68558 & 0.66014 & Biso & 1.000 & 0 \\
\hline 063 & 1.0000 & 0.00767 & 0.75686 & 0.01311 & Biso & 1.000 & 0 \\
\hline 064 & 1.0000 & 0.25848 & 0.26294 & 0.00660 & Biso & 1.000 & 0 \\
\hline 065 & 1.0000 & 0.75248 & 0.00243 & 0.00961 & Biso & 1.000 & 0 \\
\hline
\end{tabular}




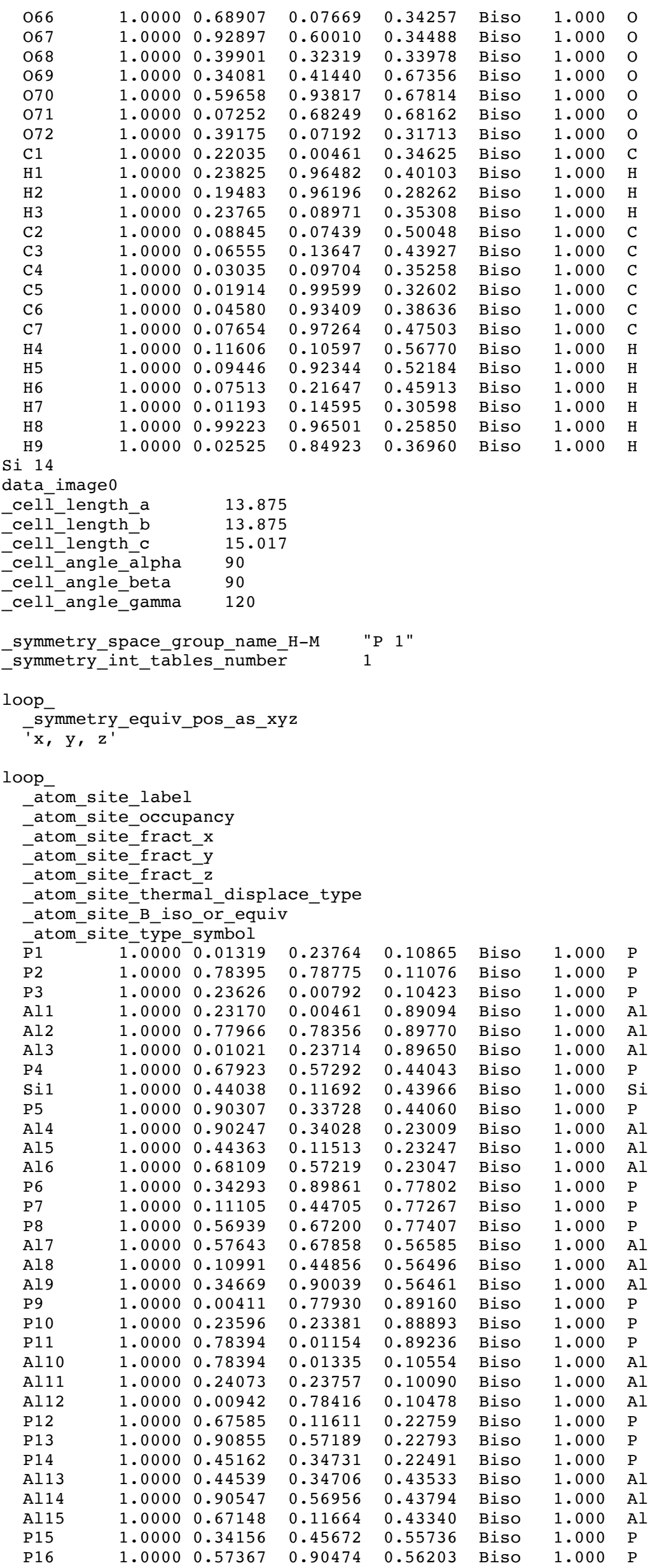




\begin{tabular}{|c|c|c|c|c|c|c|c|}
\hline P17 & 1.0000 & 0.11256 & 0.68213 & 0.56217 & Biso & 1.000 & $\mathrm{P}$ \\
\hline Al16 & 1.0000 & 0.11370 & 0.67846 & 0.77181 & Biso & 1.000 & $\mathrm{Al}$ \\
\hline Al17 & 1.0000 & 0.57122 & 0.90283 & 0.77054 & Biso & 1.000 & Al \\
\hline Al18 & 1.0000 & 0.33834 & 0.44740 & 0.76713 & Biso & 1.000 & $\mathrm{Al}$ \\
\hline 01 & 1.0000 & 0.92231 & 0.11639 & 0.12848 & Biso & 1.000 & 0 \\
\hline $\mathrm{O} 2$ & 1.0000 & 0.90615 & 0.81875 & 0.12804 & Biso & 1.000 & 0 \\
\hline 03 & 1.0000 & 0.20688 & 0.09966 & 0.12327 & Biso & 1.000 & 0 \\
\hline 04 & 1.0000 & 0.09524 & 0.89871 & 0.86743 & Biso & 1.000 & 0 \\
\hline 05 & 1.0000 & 0.81398 & 0.92056 & 0.87264 & Biso & 1.000 & 0 \\
\hline 06 & 1.0000 & 0.11424 & 0.20412 & 0.87393 & Biso & 1.000 & 0 \\
\hline 07 & 1.0000 & 0.58318 & 0.45413 & 0.45507 & Biso & 1.000 & 0 \\
\hline 08 & 1.0000 & 0.57074 & 0.15316 & 0.43476 & Biso & 1.000 & 0 \\
\hline 09 & 1.0000 & 0.88168 & 0.43496 & 0.45576 & Biso & 1.000 & 0 \\
\hline 010 & 1.0000 & 0.76439 & 0.23867 & 0.20764 & Biso & 1.000 & 0 \\
\hline 011 & 1.0000 & 0.48031 & 0.25441 & 0.21173 & Biso & 1.000 & 0 \\
\hline 012 & 1.0000 & 0.78673 & 0.53997 & 0.21094 & Biso & 1.000 & 0 \\
\hline 013 & 1.0000 & 0.24978 & 0.77928 & 0.80071 & Biso & 1.000 & 0 \\
\hline 014 & 1.0000 & 0.23346 & 0.48005 & 0.78900 & Biso & 1.000 & 0 \\
\hline 015 & 1.0000 & 0.54043 & 0.76495 & 0.78510 & Biso & 1.000 & 0 \\
\hline 016 & 1.0000 & 0.43697 & 0.57785 & 0.54693 & Biso & 1.000 & 0 \\
\hline 017 & 1.0000 & 0.12996 & 0.58192 & 0.55071 & Biso & 1.000 & 0 \\
\hline 018 & 1.0000 & 0.44843 & 0.86113 & 0.54829 & Biso & 1.000 & 0 \\
\hline 019 & 1.0000 & 0.99521 & 0.31858 & 0.16610 & Biso & 1.000 & 0 \\
\hline 020 & 1.0000 & 0.70451 & 0.68665 & 0.16641 & Biso & 1.000 & 0 \\
\hline 021 & 1.0000 & 0.34049 & 0.02964 & 0.15519 & Biso & 1.000 & 0 \\
\hline 022 & 1.0000 & 0.32764 & 0.98388 & 0.83226 & Biso & 1.000 & 0 \\
\hline 023 & 1.0000 & 0.66224 & 0.68919 & 0.83870 & Biso & 1.000 & 0 \\
\hline 024 & 1.0000 & 0.03356 & 0.35360 & 0.83592 & Biso & 1.000 & 0 \\
\hline 025 & 1.0000 & 0.66608 & 0.65617 & 0.49903 & Biso & 1.000 & 0 \\
\hline 026 & 1.0000 & 0.36944 & 0.01432 & 0.50631 & Biso & 1.000 & 0 \\
\hline 027 & 1.0000 & 0.00192 & 0.35276 & 0.49771 & Biso & 1.000 & 0 \\
\hline 028 & 1.0000 & 0.01910 & 0.69349 & 0.83848 & Biso & 1.000 & 0 \\
\hline 029 & 1.0000 & 0.31501 & 0.33235 & 0.83051 & Biso & 1.000 & 0 \\
\hline 030 & 1.0000 & 0.68253 & 0.99207 & 0.83811 & Biso & 1.000 & 0 \\
\hline 031 & 1.0000 & 0.68981 & 0.03858 & 0.16230 & Biso & 1.000 & 0 \\
\hline 032 & 1.0000 & 0.35660 & 0.32976 & 0.16215 & Biso & 1.000 & 0 \\
\hline 033 & 1.0000 & 0.98724 & 0.66961 & 0.16810 & Biso & 1.000 & 0 \\
\hline 034 & 1.0000 & 0.35567 & 0.37904 & 0.49383 & Biso & 1.000 & 0 \\
\hline 035 & 1.0000 & 0.01479 & 0.66733 & 0.50387 & Biso & 1.000 & 0 \\
\hline 036 & 1.0000 & 0.64520 & 0.00262 & 0.50052 & Biso & 1.000 & 0 \\
\hline 037 & 1.0000 & 0.12663 & 0.25077 & 0.13272 & Biso & 1.000 & 0 \\
\hline 038 & 1.0000 & 0.77034 & 0.88649 & 0.13893 & Biso & 1.000 & 0 \\
\hline 039 & 1.0000 & 0.13764 & 0.89694 & 0.13738 & Biso & 1.000 & 0 \\
\hline 040 & 1.0000 & 0.24724 & 0.13325 & 0.86242 & Biso & 1.000 & 0 \\
\hline 041 & 1.0000 & 0.89059 & 0.76524 & 0.86754 & Biso & 1.000 & 0 \\
\hline 042 & 1.0000 & 0.88251 & 0.12462 & 0.86542 & Biso & 1.000 & 0 \\
\hline 043 & 1.0000 & 0.78878 & 0.57823 & 0.46637 & Biso & 1.000 & 0 \\
\hline 044 & 1.0000 & 0.42379 & 0.22019 & 0.46668 & Biso & 1.000 & 0 \\
\hline 045 & 1.0000 & 0.80091 & 0.22818 & 0.46825 & Biso & 1.000 & 0 \\
\hline 046 & 1.0000 & 0.92304 & 0.47222 & 0.20550 & Biso & 1.000 & 0 \\
\hline 047 & 1.0000 & 0.56014 & 0.10132 & 0.21307 & Biso & 1.000 & 0 \\
\hline 048 & 1.0000 & 0.55406 & 0.45902 & 0.20006 & Biso & 1.000 & 0 \\
\hline 049 & 1.0000 & 0.45520 & 0.91069 & 0.80395 & Biso & 1.000 & 0 \\
\hline 050 & 1.0000 & 0.09679 & 0.54755 & 0.79108 & Biso & 1.000 & 0 \\
\hline 051 & 1.0000 & 0.46638 & 0.56032 & 0.79694 & Biso & 1.000 & 0 \\
\hline 052 & 1.0000 & 0.59748 & 0.81029 & 0.54087 & Biso & 1.000 & 0 \\
\hline 053 & 1.0000 & 0.23180 & 0.45196 & 0.53371 & Biso & 1.000 & 0 \\
\hline 054 & 1.0000 & 0.21696 & 0.78780 & 0.53141 & Biso & 1.000 & 0 \\
\hline 055 & 1.0000 & 0.01004 & 0.26552 & 0.01004 & Biso & 1.000 & 0 \\
\hline 056 & 1.0000 & 0.75475 & 0.75999 & 0.01194 & Biso & 1.000 & 0 \\
\hline 057 & 1.0000 & 0.25576 & 0.00136 & 0.00470 & Biso & 1.000 & 0 \\
\hline 058 & 1.0000 & 0.68413 & 0.60812 & 0.34239 & Biso & 1.000 & 0 \\
\hline 059 & 1.0000 & 0.93305 & 0.33367 & 0.34227 & Biso & 1.000 & $\mathrm{O}$ \\
\hline 060 & 1.0000 & 0.33934 & 0.92198 & 0.67895 & Biso & 1.000 & 0 \\
\hline 061 & 1.0000 & 0.07742 & 0.40630 & 0.67613 & Biso & 1.000 & 0 \\
\hline 062 & 1.0000 & 0.60840 & 0.67141 & 0.67813 & Biso & 1.000 & 0 \\
\hline 063 & 1.0000 & 0.00946 & 0.75732 & 0.99150 & Biso & 1.000 & 0 \\
\hline 064 & 1.0000 & 0.26828 & 0.26476 & 0.98720 & Biso & 1.000 & 0 \\
\hline 065 & 1.0000 & 0.75748 & 0.01101 & 0.99177 & Biso & 1.000 & 0 \\
\hline 066 & 1.0000 & 0.69073 & 0.08470 & 0.32274 & Biso & 1.000 & 0 \\
\hline 067 & 1.0000 & 0.94062 & 0.60793 & 0.32578 & Biso & 1.000 & 0 \\
\hline 068 & 1.0000 & 0.41566 & 0.35010 & 0.32106 & Biso & 1.000 & 0 \\
\hline 069 & 1.0000 & 0.33747 & 0.41688 & 0.65398 & Biso & 1.000 & 0 \\
\hline 070 & 1.0000 & 0.60618 & 0.94326 & 0.65948 & Biso & 1.000 & 0 \\
\hline 071 & 1.0000 & 0.08590 & 0.69260 & 0.66008 & Biso & 1.000 & 0 \\
\hline 072 & 1.0000 & 0.38566 & 0.07310 & 0.33817 & Biso & 1.000 & 0 \\
\hline $\mathrm{C} 1$ & 1.0000 & 0.20376 & 0.99751 & 0.35697 & Biso & 1.000 & C \\
\hline H 1 & 1.0000 & 0.21364 & 0.94566 & 0.40611 & Biso & 1.000 & $\mathrm{H}$ \\
\hline H2 & 1.0000 & 0.19469 & 0.97324 & 0.28748 & Biso & 1.000 & $\mathrm{H}$ \\
\hline $\mathrm{H} 3$ & 1.0000 & 0.22253 & 0.08075 & 0.37554 & Biso & 1.000 & $\mathrm{H}$ \\
\hline
\end{tabular}




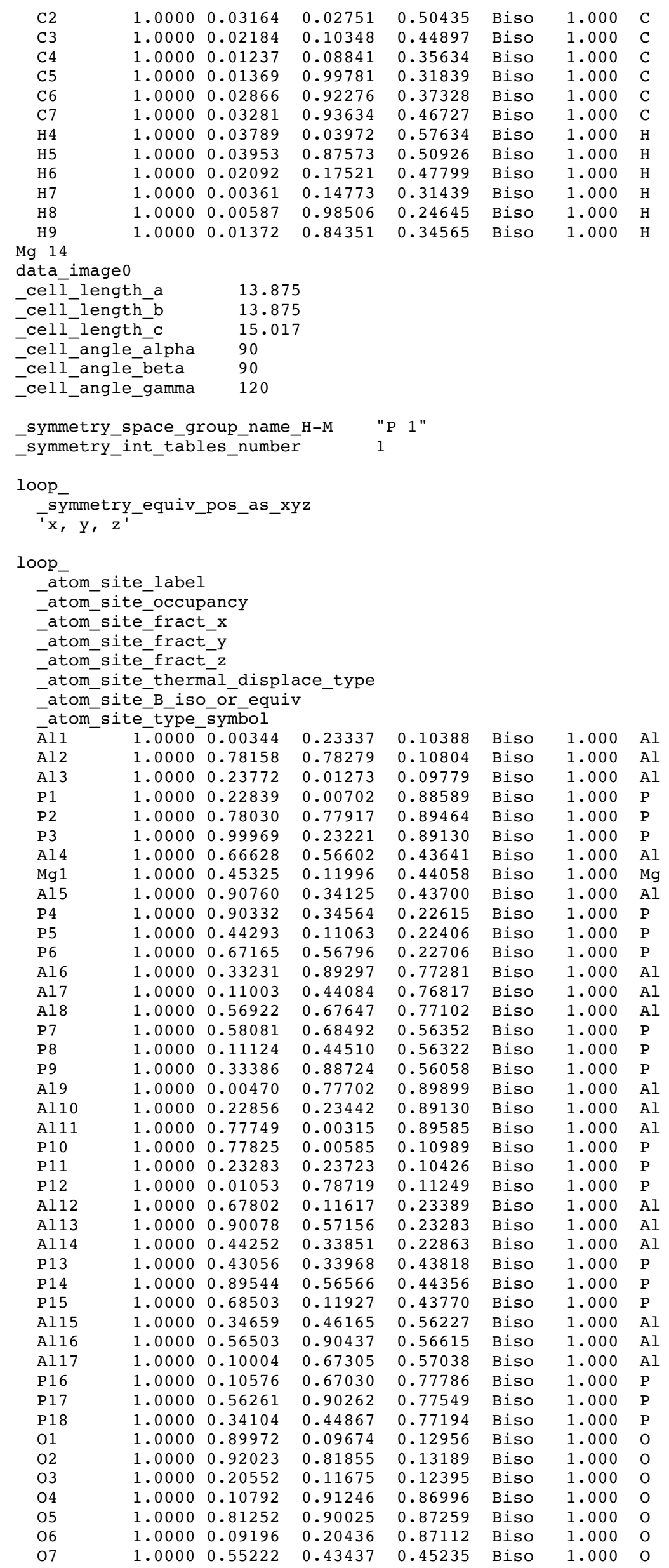




\begin{tabular}{|c|c|c|c|c|c|c|c|}
\hline 08 & 1.0000 & 0.60742 & 0.16659 & 0.43881 & Biso & 1.000 & 0 \\
\hline 09 & 1.0000 & 0.87851 & 0.44857 & 0.45922 & Biso & 1.000 & 0 \\
\hline 010 & 1.0000 & 0.78108 & 0.25504 & 0.21135 & Biso & 1.000 & 0 \\
\hline 011 & 1.0000 & 0.47445 & 0.23294 & 0.20830 & Biso & 1.000 & 0 \\
\hline 012 & 1.0000 & 0.76368 & 0.53838 & 0.21095 & Biso & 1.000 & 0 \\
\hline 013 & 1.0000 & 0.22681 & 0.75776 & 0.80104 & Biso & 1.000 & 0 \\
\hline 014 & 1.0000 & 0.24839 & 0.47695 & 0.79016 & Biso & 1.000 & 0 \\
\hline 015 & 1.0000 & 0.53439 & 0.78057 & 0.78482 & Biso & 1.000 & 0 \\
\hline 016 & 1.0000 & 0.45807 & 0.59667 & 0.54718 & Biso & 1.000 & 0 \\
\hline 017 & 1.0000 & 0.11656 & 0.55775 & 0.55997 & Biso & 1.000 & 0 \\
\hline 018 & 1.0000 & 0.42141 & 0.84945 & 0.55011 & Biso & 1.000 & 0 \\
\hline 019 & 1.0000 & 0.98146 & 0.32690 & 0.16541 & Biso & 1.000 & 0 \\
\hline 020 & 1.0000 & 0.68894 & 0.66400 & 0.16616 & Biso & 1.000 & 0 \\
\hline 021 & 1.0000 & 0.35700 & 0.03536 & 0.15387 & Biso & 1.000 & 0 \\
\hline 022 & 1.0000 & 0.31050 & 0.99072 & 0.82908 & Biso & 1.000 & 0 \\
\hline 023 & 1.0000 & 0.67656 & 0.69697 & 0.84268 & Biso & 1.000 & 0 \\
\hline 024 & 1.0000 & 0.01784 & 0.33363 & 0.83749 & Biso & 1.000 & 0 \\
\hline 025 & 1.0000 & 0.65774 & 0.66510 & 0.50232 & Biso & 1.000 & 0 \\
\hline 026 & 1.0000 & 0.36069 & 0.98722 & 0.50420 & Biso & 1.000 & 0 \\
\hline 027 & 1.0000 & 0.02515 & 0.36373 & 0.49674 & Biso & 1.000 & 0 \\
\hline 028 & 1.0000 & 0.02533 & 0.67843 & 0.84362 & Biso & 1.000 & 0 \\
\hline 029 & 1.0000 & 0.32248 & 0.34879 & 0.82870 & Biso & 1.000 & 0 \\
\hline 030 & 1.0000 & 0.65934 & 0.97807 & 0.83720 & Biso & 1.000 & 0 \\
\hline 031 & 1.0000 & 0.69601 & 0.02797 & 0.16101 & Biso & 1.000 & 0 \\
\hline 032 & 1.0000 & 0.33411 & 0.32034 & 0.15812 & Biso & 1.000 & 0 \\
\hline 033 & 1.0000 & 0.99299 & 0.68945 & 0.17138 & Biso & 1.000 & 0 \\
\hline 034 & 1.0000 & 0.35152 & 0.36770 & 0.48962 & Biso & 1.000 & 0 \\
\hline 035 & 1.0000 & 0.98693 & 0.65192 & 0.50468 & Biso & 1.000 & 0 \\
\hline 036 & 1.0000 & 0.64773 & 0.01922 & 0.50054 & Biso & 1.000 & 0 \\
\hline 037 & 1.0000 & 0.13228 & 0.24816 & 0.13226 & Biso & 1.000 & 0 \\
\hline 038 & 1.0000 & 0.76401 & 0.89374 & 0.14039 & Biso & 1.000 & 0 \\
\hline 039 & 1.0000 & 0.12471 & 0.88754 & 0.13629 & Biso & 1.000 & 0 \\
\hline 040 & 1.0000 & 0.23760 & 0.11815 & 0.86017 & Biso & 1.000 & 0 \\
\hline 041 & 1.0000 & 0.87645 & 0.76065 & 0.86790 & Biso & 1.000 & 0 \\
\hline 042 & 1.0000 & 0.88751 & 0.13257 & 0.86437 & Biso & 1.000 & 0 \\
\hline 043 & 1.0000 & 0.78711 & 0.56414 & 0.46518 & Biso & 1.000 & 0 \\
\hline 044 & 1.0000 & 0.41552 & 0.23008 & 0.46994 & Biso & 1.000 & 0 \\
\hline 045 & 1.0000 & 0.80299 & 0.20937 & 0.46772 & Biso & 1.000 & 0 \\
\hline 046 & 1.0000 & 0.91700 & 0.45945 & 0.20243 & Biso & 1.000 & 0 \\
\hline 047 & 1.0000 & 0.54736 & 0.10081 & 0.21333 & Biso & 1.000 & 0 \\
\hline 048 & 1.0000 & 0.55919 & 0.46659 & 0.20405 & Biso & 1.000 & 0 \\
\hline 049 & 1.0000 & 0.46080 & 0.91045 & 0.80466 & Biso & 1.000 & 0 \\
\hline 050 & 1.0000 & 0.09188 & 0.55427 & 0.78651 & Biso & 1.000 & 0 \\
\hline 051 & 1.0000 & 0.45323 & 0.54887 & 0.79800 & Biso & 1.000 & 0 \\
\hline 052 & 1.0000 & 0.59755 & 0.80030 & 0.54273 & Biso & 1.000 & 0 \\
\hline 053 & 1.0000 & 0.22489 & 0.46222 & 0.53673 & Biso & 1.000 & 0 \\
\hline 054 & 1.0000 & 0.21911 & 0.78971 & 0.53161 & Biso & 1.000 & 0 \\
\hline 055 & 1.0000 & 0.99993 & 0.25888 & 0.99068 & Biso & 1.000 & 0 \\
\hline 056 & 1.0000 & 0.75569 & 0.75653 & 0.99461 & Biso & 1.000 & 0 \\
\hline 057 & 1.0000 & 0.25892 & 0.00809 & 0.98455 & Biso & 1.000 & 0 \\
\hline 058 & 1.0000 & 0.67493 & 0.60478 & 0.32416 & Biso & 1.000 & 0 \\
\hline 059 & 1.0000 & 0.93809 & 0.34471 & 0.32325 & Biso & 1.000 & 0 \\
\hline 060 & 1.0000 & 0.32721 & 0.91345 & 0.65966 & Biso & 1.000 & 0 \\
\hline 061 & 1.0000 & 0.07857 & 0.39505 & 0.65751 & Biso & 1.000 & 0 \\
\hline 062 & 1.0000 & 0.61227 & 0.67838 & 0.66102 & Biso & 1.000 & 0 \\
\hline 063 & 1.0000 & 0.00757 & 0.75609 & 0.01403 & Biso & 1.000 & 0 \\
\hline 064 & 1.0000 & 0.25820 & 0.26317 & 0.00468 & Biso & 1.000 & 0 \\
\hline 065 & 1.0000 & 0.75327 & 0.00289 & 0.01001 & Biso & 1.000 & 0 \\
\hline 066 & 1.0000 & 0.69325 & 0.08004 & 0.34226 & Biso & 1.000 & 0 \\
\hline 067 & 1.0000 & 0.93091 & 0.60278 & 0.34623 & Biso & 1.000 & 0 \\
\hline 068 & 1.0000 & 0.40007 & 0.33493 & 0.33811 & Biso & 1.000 & 0 \\
\hline 069 & 1.0000 & 0.34147 & 0.41927 & 0.67318 & Biso & 1.000 & 0 \\
\hline 070 & 1.0000 & 0.59541 & 0.94284 & 0.67902 & Biso & 1.000 & 0 \\
\hline 071 & 1.0000 & 0.07619 & 0.68928 & 0.68283 & Biso & 1.000 & 0 \\
\hline 072 & 1.0000 & 0.39260 & 0.07127 & 0.31792 & Biso & 1.000 & 0 \\
\hline $\mathrm{C} 1$ & 1.0000 & 0.22108 & 0.00322 & 0.34525 & Biso & 1.000 & C \\
\hline $\mathrm{H} 1$ & 1.0000 & 0.23496 & 0.95925 & 0.39911 & Biso & 1.000 & $\mathrm{H}$ \\
\hline $\mathrm{H} 2$ & 1.0000 & 0.19743 & 0.96391 & 0.28028 & Biso & 1.000 & $\mathrm{H}$ \\
\hline H3 & 1.0000 & 0.23788 & 0.08774 & 0.35524 & Biso & 1.000 & $\mathrm{H}$ \\
\hline $\mathrm{C} 2$ & 1.0000 & 0.08102 & 0.06352 & 0.50044 & Biso & 1.000 & C \\
\hline C3 & 1.0000 & 0.06348 & 0.13173 & 0.44179 & Biso & 1.000 & C \\
\hline C4 & 1.0000 & 0.03337 & 0.09991 & 0.35292 & Biso & 1.000 & C \\
\hline C5 & 1.0000 & 0.02178 & 0.00035 & 0.32177 & Biso & 1.000 & C \\
\hline $\mathrm{C} 6$ & 1.0000 & 0.04302 & 0.93229 & 0.37965 & Biso & 1.000 & $\mathrm{C}$ \\
\hline C7 & 1.0000 & 0.06882 & 0.96324 & 0.47028 & Biso & 1.000 & C \\
\hline H4 & 1.0000 & 0.10438 & 0.08904 & 0.56945 & Biso & 1.000 & $\mathrm{H}$ \\
\hline H5 & 1.0000 & 0.08206 & 0.90905 & 0.51516 & Biso & 1.000 & $\mathrm{H}$ \\
\hline H6 & 1.0000 & 0.07304 & 0.21051 & 0.46529 & Biso & 1.000 & $\mathrm{H}$ \\
\hline H7 & 1.0000 & 0.01911 & 0.15356 & 0.30833 & Biso & 1.000 & $\mathrm{H}$ \\
\hline H8 & 1.0000 & 0.99855 & 0.97513 & 0.25265 & & 1.000 & $\mathrm{H}$ \\
\hline
\end{tabular}




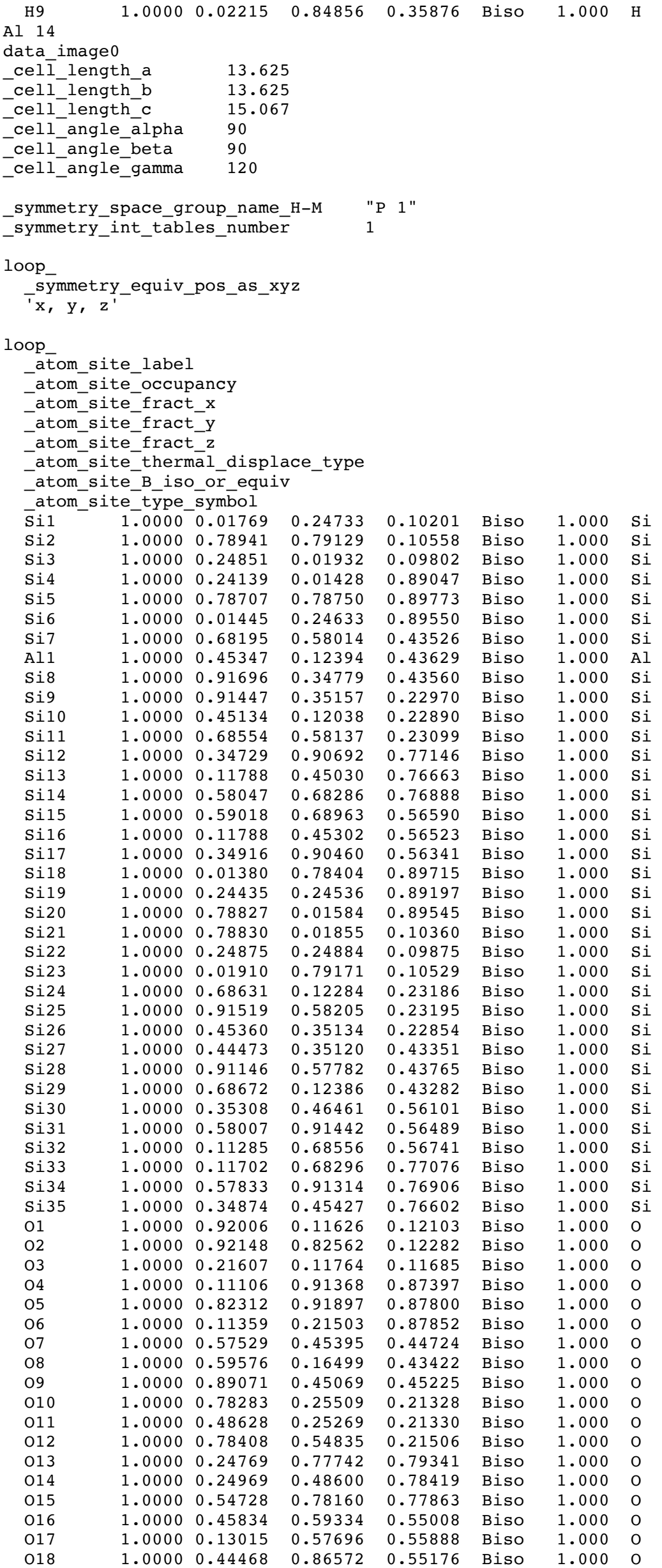




\begin{tabular}{|c|c|c|c|c|c|c|c|}
\hline 019 & 1.0000 & 0.99901 & 0.33257 & 0.16531 & Biso & 1.000 & 0 \\
\hline $\mathrm{O} 20$ & 1.0000 & 0.70497 & 0.68429 & 0.16611 & Biso & 1.000 & 0 \\
\hline 021 & 1.0000 & 0.35817 & 0.04106 & 0.15461 & Biso & 1.000 & 0 \\
\hline $\mathrm{O} 22$ & 1.0000 & 0.32884 & 0.99660 & 0.82970 & Biso & 1.000 & 0 \\
\hline 023 & 1.0000 & 0.67857 & 0.70169 & 0.83890 & Biso & 1.000 & 0 \\
\hline $\mathrm{O} 24$ & 1.0000 & 0.03406 & 0.35228 & 0.83472 & Biso & 1.000 & 0 \\
\hline 025 & 1.0000 & 0.67319 & 0.67018 & 0.50033 & Biso & 1.000 & 0 \\
\hline 026 & 1.0000 & 0.37226 & 0.00933 & 0.50345 & Biso & 1.000 & 0 \\
\hline 027 & 1.0000 & 0.02345 & 0.36588 & 0.49612 & Biso & 1.000 & 0 \\
\hline 028 & 1.0000 & 0.03141 & 0.69374 & 0.83963 & Biso & 1.000 & 0 \\
\hline $\mathrm{O} 29$ & 1.0000 & 0.32891 & 0.34858 & 0.82795 & Biso & 1.000 & 0 \\
\hline 030 & 1.0000 & 0.68130 & 0.99377 & 0.83504 & Biso & 1.000 & 0 \\
\hline 031 & 1.0000 & 0.70211 & 0.04122 & 0.16171 & Biso & 1.000 & 0 \\
\hline 032 & 1.0000 & 0.35460 & 0.33485 & 0.15969 & Biso & 1.000 & 0 \\
\hline 033 & 1.0000 & 0.99980 & 0.68815 & 0.16949 & Biso & 1.000 & 0 \\
\hline 034 & 1.0000 & 0.36084 & 0.37894 & 0.49170 & Biso & 1.000 & 0 \\
\hline 035 & 1.0000 & 0.00970 & 0.66893 & 0.50314 & Biso & 1.000 & 0 \\
\hline 036 & 1.0000 & 0.65679 & 0.01806 & 0.49886 & Biso & 1.000 & 0 \\
\hline 037 & 1.0000 & 0.13968 & 0.26037 & 0.12573 & Biso & 1.000 & 0 \\
\hline 038 & 1.0000 & 0.77574 & 0.89849 & 0.13382 & Biso & 1.000 & 0 \\
\hline 039 & 1.0000 & 0.14089 & 0.90025 & 0.13165 & Biso & 1.000 & 0 \\
\hline 040 & 1.0000 & 0.25238 & 0.13464 & 0.86486 & Biso & 1.000 & 0 \\
\hline 041 & 1.0000 & 0.89183 & 0.76904 & 0.87134 & Biso & 1.000 & 0 \\
\hline 042 & 1.0000 & 0.89438 & 0.13778 & 0.86814 & Biso & 1.000 & 0 \\
\hline 043 & 1.0000 & 0.79647 & 0.57852 & 0.46121 & Biso & 1.000 & 0 \\
\hline 044 & 1.0000 & 0.43017 & 0.23333 & 0.46387 & Biso & 1.000 & 0 \\
\hline 045 & 1.0000 & 0.81069 & 0.22738 & 0.46372 & Biso & 1.000 & 0 \\
\hline 046 & 1.0000 & 0.93023 & 0.47494 & 0.20685 & Biso & 1.000 & 0 \\
\hline 047 & 1.0000 & 0.56283 & 0.10884 & 0.21456 & Biso & 1.000 & 0 \\
\hline 048 & 1.0000 & 0.56443 & 0.47278 & 0.20689 & Biso & 1.000 & 0 \\
\hline 049 & 1.0000 & 0.46836 & 0.92090 & 0.79931 & Biso & 1.000 & 0 \\
\hline 050 & 1.0000 & 0.10238 & 0.55873 & 0.78300 & Biso & 1.000 & 0 \\
\hline 051 & 1.0000 & 0.46976 & 0.56230 & 0.79220 & Biso & 1.000 & 0 \\
\hline 052 & 1.0000 & 0.60644 & 0.81298 & 0.54399 & Biso & 1.000 & 0 \\
\hline 053 & 1.0000 & 0.23778 & 0.46555 & 0.53792 & Biso & 1.000 & 0 \\
\hline 054 & 1.0000 & 0.22642 & 0.79730 & 0.53461 & Biso & 1.000 & 0 \\
\hline 055 & 1.0000 & 0.01363 & 0.28031 & 0.99898 & Biso & 1.000 & 0 \\
\hline 056 & 1.0000 & 0.75567 & 0.75813 & 0.00215 & Biso & 1.000 & 0 \\
\hline 057 & 1.0000 & 0.27450 & 0.01352 & 0.99407 & Biso & 1.000 & 0 \\
\hline 058 & 1.0000 & 0.69018 & 0.62309 & 0.33293 & Biso & 1.000 & 0 \\
\hline 059 & 1.0000 & 0.95136 & 0.34748 & 0.33187 & Biso & 1.000 & 0 \\
\hline 060 & 1.0000 & 0.34384 & 0.93437 & 0.66770 & Biso & 1.000 & 0 \\
\hline 061 & 1.0000 & 0.08160 & 0.40272 & 0.66554 & Biso & 1.000 & 0 \\
\hline 062 & 1.0000 & 0.62557 & 0.68335 & 0.66853 & Biso & 1.000 & 0 \\
\hline 063 & 1.0000 & 0.01805 & 0.75692 & 0.00211 & Biso & 1.000 & 0 \\
\hline 064 & 1.0000 & 0.28224 & 0.28098 & 0.99488 & Biso & 1.000 & 0 \\
\hline 065 & 1.0000 & 0.75586 & 0.01539 & 0.99944 & Biso & 1.000 & 0 \\
\hline 066 & 1.0000 & 0.69969 & 0.08552 & 0.33163 & Biso & 1.000 & 0 \\
\hline 067 & 1.0000 & 0.95041 & 0.61976 & 0.33532 & Biso & 1.000 & 0 \\
\hline 068 & 1.0000 & 0.40903 & 0.34892 & 0.32882 & Biso & 1.000 & 0 \\
\hline 069 & 1.0000 & 0.34800 & 0.41983 & 0.66242 & Biso & 1.000 & 0 \\
\hline 070 & 1.0000 & 0.61535 & 0.95720 & 0.66757 & Biso & 1.000 & 0 \\
\hline 071 & 1.0000 & 0.08319 & 0.69937 & 0.67002 & Biso & 1.000 & 0 \\
\hline 072 & 1.0000 & 0.39582 & 0.07671 & 0.32675 & Biso & 1.000 & 0 \\
\hline C1 & 1.0000 & 0.21591 & 0.00375 & 0.34767 & Biso & 1.000 & C \\
\hline H 1 & 1.0000 & 0.22612 & 0.95513 & 0.40033 & Biso & 1.000 & $\mathrm{H}$ \\
\hline $\mathrm{H} 2$ & 1.0000 & 0.20009 & 0.97027 & 0.28060 & Biso & 1.000 & $\mathrm{H}$ \\
\hline H3 & 1.0000 & 0.23364 & 0.08944 & 0.36075 & Biso & 1.000 & $\mathrm{H}$ \\
\hline $\mathrm{C} 2$ & 1.0000 & 0.05649 & 0.05099 & 0.49678 & Biso & 1.000 & C \\
\hline C3 & 1.0000 & 0.04722 & 0.12714 & 0.43977 & Biso & 1.000 & C \\
\hline $\mathrm{C} 4$ & 1.0000 & 0.02846 & 0.10468 & 0.34863 & Biso & 1.000 & C \\
\hline $\mathrm{C} 5$ & 1.0000 & 0.02036 & 0.00659 & 0.31361 & Biso & 1.000 & C \\
\hline $\mathrm{C} 6$ & 1.0000 & 0.03443 & 0.93101 & 0.36999 & Biso & 1.000 & C \\
\hline C7 & 1.0000 & 0.04796 & 0.95221 & 0.46267 & Biso & 1.000 & C \\
\hline H4 & 1.0000 & 0.07024 & 0.06914 & 0.56765 & Biso & 1.000 & $\mathrm{H}$ \\
\hline H5 & 1.0000 & 0.05430 & 0.89143 & 0.50603 & Biso & 1.000 & $\mathrm{H}$ \\
\hline H6 & 1.0000 & 0.05425 & 0.20489 & 0.46639 & Biso & 1.000 & $\mathrm{H}$ \\
\hline H7 & 1.0000 & 0.02037 & 0.16452 & 0.30552 & Biso & 1.000 & $\mathrm{H}$ \\
\hline H8 & 1.0000 & 0.00590 & 0.98845 & 0.24275 & Biso & 1.000 & $\mathrm{H}$ \\
\hline H9 & 1.0000 & 0.01503 & 0.84780 & 0.34518 & Biso & 1.000 & $\mathrm{H}$ \\
\hline
\end{tabular}

data_image 0

$\begin{array}{ll}\text {-cell_length_a } & 13.875 \\ \text {-cell_length_b } & 13.875 \\ \text {-cell_length_c } & 15.017 \\ \text {-cell_angle_alpha } & 90 \\ \text {-cell_angle_beta } & 90 \\ \text {-cell_angle_gamma } & 120\end{array}$




\begin{tabular}{|c|c|c|c|c|c|c|c|}
\hline \multicolumn{8}{|l|}{ loop } \\
\hline \multicolumn{2}{|c|}{ ' $\mathrm{x}, \mathrm{y}, \mathrm{z}$ ' } & & & & & & \\
\hline \multicolumn{8}{|c|}{ loop_ } \\
\hline \multicolumn{8}{|c|}{ atom_site_label } \\
\hline \multicolumn{8}{|c|}{ atom_site_occupancy } \\
\hline \multicolumn{8}{|c|}{ atom site fract $x$} \\
\hline \multicolumn{8}{|c|}{ _atom_site_fract_y } \\
\hline -ato & te_fract & $t z$ & & & & & \\
\hline -ato & te_thern & nàl_disp. & ace_type & & & & \\
\hline -ato & $\begin{array}{l}\text { te_B_isc } \\
\text { te_type }\end{array}$ & $\begin{array}{l}\text { o_or_equ } \\
\text { symbol }\end{array}$ & & & & & \\
\hline$\overline{\mathrm{P}} 1$ & 1.0000 & 0.01465 & 0.23818 & 0.10831 & Biso & 1.000 & $\mathrm{P}$ \\
\hline $\mathrm{P} 2$ & 1.0000 & 0.78639 & 0.78962 & 0.11234 & Biso & 1.000 & $\mathrm{P}$ \\
\hline P3 & 1.0000 & 0.23756 & 0.00885 & 0.10123 & Biso & 1.000 & $P$ \\
\hline Al1 & 1.0000 & 0.22934 & 0.00225 & 0.88746 & Biso & 1.000 & Al \\
\hline A 12 & 1.0000 & 0.78017 & 0.78334 & 0.89884 & Biso & 1.000 & Al \\
\hline Al3 & 1.0000 & 0.00962 & 0.23669 & 0.89585 & Biso & 1.000 & Al \\
\hline P 4 & 1.0000 & 0.67925 & 0.57230 & 0.44047 & Biso & 1.000 & $\mathrm{P}$ \\
\hline $\mathrm{Ge} 1$ & 1.0000 & 0.43866 & 0.11972 & 0.44233 & Biso & 1.000 & $\mathrm{Ge}$ \\
\hline P5 & 1.0000 & 0.90791 & 0.33778 & 0.43977 & Biso & 1.000 & $\mathrm{P}$ \\
\hline Al 4 & 1.0000 & 0.90496 & 0.34179 & 0.22940 & Biso & 1.000 & Al \\
\hline Al5 & 1.0000 & 0.44473 & 0.11671 & 0.22841 & Biso & 1.000 & Al \\
\hline Al 6 & 1.0000 & 0.68285 & 0.57368 & 0.23114 & Biso & 1.000 & Al \\
\hline P6 & 1.0000 & 0.34169 & 0.89360 & 0.78029 & Biso & 1.000 & $\mathrm{P}$ \\
\hline P7 & 1.0000 & 0.11084 & 0.44452 & 0.77160 & Biso & 1.000 & $\mathrm{P}$ \\
\hline P8 & 1.0000 & 0.57037 & 0.67153 & 0.77468 & Biso & 1.000 & $P$ \\
\hline Al7 & 1.0000 & 0.58320 & 0.68314 & 0.56830 & Biso & 1.000 & Al \\
\hline Al 8 & 1.0000 & 0.10823 & 0.44652 & 0.56780 & Biso & 1.000 & Al \\
\hline Al9 & 1.0000 & 0.34540 & 0.89152 & 0.56508 & Biso & 1.000 & Al \\
\hline P9 & 1.0000 & 0.00241 & 0.77622 & 0.89222 & Biso & 1.000 & $\mathrm{P}$ \\
\hline $\mathrm{P} 10$ & 1.0000 & 0.23505 & 0.23246 & 0.88575 & Biso & 1.000 & $\mathrm{P}$ \\
\hline P11 & 1.0000 & 0.78492 & 0.01115 & 0.89252 & Biso & 1.000 & $P$ \\
\hline Al10 & 1.0000 & 0.78605 & 0.01468 & 0.10637 & Biso & 1.000 & Al \\
\hline Al11 & 1.0000 & 0.24243 & 0.23839 & 0.09797 & Biso & 1.000 & Al \\
\hline Al12 & 1.0000 & 0.01114 & 0.78565 & 0.10611 & Biso & 1.000 & Al \\
\hline $\mathrm{P} 12$ & 1.0000 & 0.67683 & 0.11687 & 0.22807 & Biso & 1.000 & $\mathrm{P}$ \\
\hline $\mathrm{P} 13$ & 1.0000 & 0.90994 & 0.57263 & 0.22878 & Biso & 1.000 & $\mathrm{P}$ \\
\hline P14 & 1.0000 & 0.45301 & 0.34857 & 0.22246 & Biso & 1.000 & $P$ \\
\hline Al13 & 1.0000 & 0.44091 & 0.35145 & 0.43340 & Biso & 1.000 & Al \\
\hline Al14 & 1.0000 & 0.90564 & 0.56802 & 0.43922 & Biso & 1.000 & Al \\
\hline Al15 & 1.0000 & 0.67458 & 0.11938 & 0.43449 & Biso & 1.000 & Al \\
\hline P15 & 1.0000 & 0.34449 & 0.46659 & 0.55652 & Biso & 1.000 & $\mathrm{P}$ \\
\hline P16 & 1.0000 & 0.57540 & 0.90615 & 0.56335 & Biso & 1.000 & $\mathrm{P}$ \\
\hline $\mathrm{P} 17$ & 1.0000 & 0.10768 & 0.68056 & 0.56605 & Biso & 1.000 & $\mathrm{P}$ \\
\hline Al16 & 1.0000 & 0.11170 & 0.67734 & 0.77270 & Biso & 1.000 & Al \\
\hline Al17 & 1.0000 & 0.56946 & 0.90140 & 0.77251 & Biso & 1.000 & Al \\
\hline Al18 & 1.0000 & 0.33851 & 0.44681 & 0.76460 & Biso & 1.000 & Al \\
\hline 01 & 1.0000 & 0.92429 & 0.11742 & 0.13044 & Biso & 1.000 & 0 \\
\hline 02 & 1.0000 & 0.90847 & 0.82076 & 0.13054 & Biso & 1.000 & 0 \\
\hline 03 & 1.0000 & 0.20837 & 0.10057 & 0.12113 & Biso & 1.000 & 0 \\
\hline 04 & 1.0000 & 0.09353 & 0.89431 & 0.86479 & Biso & 1.000 & 0 \\
\hline 05 & 1.0000 & 0.81563 & 0.92057 & 0.87289 & Biso & 1.000 & 0 \\
\hline 06 & 1.0000 & 0.11362 & 0.20423 & 0.87183 & Biso & 1.000 & 0 \\
\hline 07 & 1.0000 & 0.58028 & 0.45469 & 0.45305 & Biso & 1.000 & 0 \\
\hline 08 & 1.0000 & 0.58254 & 0.16802 & 0.43838 & Biso & 1.000 & 0 \\
\hline 09 & 1.0000 & 0.88611 & 0.43483 & 0.45722 & Biso & 1.000 & 0 \\
\hline 010 & 1.0000 & 0.76661 & 0.23926 & 0.20924 & Biso & 1.000 & 0 \\
\hline 011 & 1.0000 & 0.48341 & 0.25688 & 0.20931 & Biso & 1.000 & 0 \\
\hline 012 & 1.0000 & 0.78827 & 0.54117 & 0.21161 & Biso & 1.000 & 0 \\
\hline 013 & 1.0000 & 0.24710 & 0.77600 & 0.80578 & Biso & 1.000 & 0 \\
\hline 014 & 1.0000 & 0.23384 & 0.47963 & 0.78826 & Biso & 1.000 & 0 \\
\hline 015 & 1.0000 & 0.53957 & 0.76341 & 0.78346 & Biso & 1.000 & 0 \\
\hline 016 & 1.0000 & 0.44245 & 0.58679 & 0.55067 & Biso & 1.000 & 0 \\
\hline 017 & 1.0000 & 0.11385 & 0.57371 & 0.56165 & Biso & 1.000 & 0 \\
\hline 018 & 1.0000 & 0.45011 & 0.85714 & 0.54472 & Biso & 1.000 & 0 \\
\hline 019 & 1.0000 & 0.99760 & 0.32039 & 0.16491 & Biso & 1.000 & 0 \\
\hline 020 & 1.0000 & 0.70641 & 0.68824 & 0.16738 & Biso & 1.000 & 0 \\
\hline 021 & 1.0000 & 0.34453 & 0.03263 & 0.14876 & Biso & 1.000 & 0 \\
\hline 022 & 1.0000 & 0.32582 & 0.98243 & 0.82850 & Biso & 1.000 & 0 \\
\hline 023 & 1.0000 & 0.66008 & 0.68886 & 0.84270 & Biso & 1.000 & 0 \\
\hline 024 & 1.0000 & 0.03458 & 0.35601 & 0.83879 & Biso & 1.000 & 0 \\
\hline 025 & 1.0000 & 0.66903 & 0.65646 & 0.50029 & Biso & 1.000 & 0 \\
\hline 026 & 1.0000 & 0.35949 & 0.00529 & 0.51126 & Biso & 1.000 & 0 \\
\hline 027 & 1.0000 & 0.00713 & 0.35180 & 0.49562 & Biso & 1.000 & 0 \\
\hline 028 & 1.0000 & 0.01632 & 0.68764 & 0.84218 & Biso & 1.000 & 0 \\
\hline 029 & 1.0000 & 0.31415 & 0.33025 & 0.82659 & Biso & 1.000 & 0 \\
\hline
\end{tabular}




\begin{tabular}{|c|c|c|c|c|c|c|c|}
\hline 030 & 1.0000 & 0.68181 & 0.98950 & 0.83969 & Biso & 1.000 & 0 \\
\hline 031 & 1.0000 & 0.69160 & 0.03962 & 0.16302 & Biso & 1.000 & O \\
\hline 032 & 1.0000 & 0.35953 & 0.33123 & 0.15797 & Biso & 1.000 & O \\
\hline 033 & 1.0000 & 0.98920 & 0.67166 & 0.17022 & Biso & 1.000 & O \\
\hline 034 & 1.0000 & 0.35523 & 0.39254 & 0.48700 & Biso & 1.000 & $\mathrm{O}$ \\
\hline 035 & 1.0000 & 0.01222 & 0.66871 & 0.50606 & Biso & 1.000 & 0 \\
\hline 036 & 1.0000 & 0.64574 & 0.00573 & 0.50293 & Biso & 1.000 & $\mathrm{O}$ \\
\hline 037 & 1.0000 & 0.12892 & 0.25229 & 0.13074 & Biso & 1.000 & O \\
\hline 038 & 1.0000 & 0.77217 & 0.88800 & 0.14042 & Biso & 1.000 & O \\
\hline 039 & 1.0000 & 0.14058 & 0.89826 & 0.13695 & Biso & 1.000 & O \\
\hline 040 & 1.0000 & 0.24409 & 0.13066 & 0.85896 & Biso & 1.000 & O \\
\hline 041 & 1.0000 & 0.88883 & 0.76184 & 0.86761 & Biso & 1.000 & 0 \\
\hline 042 & 1.0000 & 0.88208 & 0.12433 & 0.86375 & Biso & 1.000 & O \\
\hline 043 & 1.0000 & 0.78614 & 0.57217 & 0.46633 & Biso & 1.000 & O \\
\hline 044 & 1.0000 & 0.40928 & 0.22402 & 0.47391 & Biso & 1.000 & 0 \\
\hline 045 & 1.0000 & 0.80685 & 0.22761 & 0.46681 & Biso & 1.000 & O \\
\hline 046 & 1.0000 & 0.92434 & 0.47329 & 0.20468 & Biso & 1.000 & 0 \\
\hline 047 & 1.0000 & 0.56194 & 0.10334 & 0.21182 & Biso & 1.000 & O \\
\hline 048 & 1.0000 & 0.55548 & 0.46136 & 0.20024 & Biso & 1.000 & O \\
\hline 049 & 1.0000 & 0.45326 & 0.90665 & 0.81028 & Biso & 1.000 & $\mathrm{O}$ \\
\hline 050 & 1.0000 & 0.09557 & 0.54551 & 0.78301 & Biso & 1.000 & O \\
\hline 051 & 1.0000 & 0.46703 & 0.55896 & 0.79483 & Biso & 1.000 & O \\
\hline 052 & 1.0000 & 0.60715 & 0.81652 & 0.54495 & Biso & 1.000 & 0 \\
\hline 053 & 1.0000 & 0.23745 & 0.46860 & 0.53607 & Biso & 1.000 & O \\
\hline 054 & 1.0000 & 0.21665 & 0.77800 & 0.53172 & Biso & 1.000 & O \\
\hline 055 & 1.0000 & 0.00870 & 0.26317 & 0.00952 & Biso & 1.000 & O \\
\hline 056 & 1.0000 & 0.75824 & 0.76233 & 0.01342 & Biso & 1.000 & O \\
\hline 057 & 1.0000 & 0.25267 & 0.99999 & 0.00133 & Biso & 1.000 & 0 \\
\hline 058 & 1.0000 & 0.68647 & 0.61030 & 0.34298 & Biso & 1.000 & $\mathrm{O}$ \\
\hline 059 & 1.0000 & 0.93757 & 0.33648 & 0.34112 & Biso & 1.000 & 0 \\
\hline 060 & 1.0000 & 0.34088 & 0.91044 & 0.67995 & Biso & 1.000 & 0 \\
\hline 061 & 1.0000 & 0.07627 & 0.39549 & 0.67705 & Biso & 1.000 & O \\
\hline 062 & 1.0000 & 0.61483 & 0.67313 & 0.68027 & Biso & 1.000 & O \\
\hline 063 & 1.0000 & 0.00873 & 0.75838 & 0.99275 & Biso & 1.000 & O \\
\hline 064 & 1.0000 & 0.26872 & 0.26368 & 0.98385 & Biso & 1.000 & O \\
\hline 065 & 1.0000 & 0.76094 & 0.01232 & 0.99231 & Biso & 1.000 & 0 \\
\hline 066 & 1.0000 & 0.68833 & 0.08376 & 0.32355 & Biso & 1.000 & O \\
\hline 067 & 1.0000 & 0.94127 & 0.60654 & 0.32707 & Biso & 1.000 & O \\
\hline 068 & 1.0000 & 0.41393 & 0.34856 & 0.31807 & Biso & 1.000 & O \\
\hline 069 & 1.0000 & 0.33848 & 0.41895 & 0.65070 & Biso & 1.000 & O \\
\hline 070 & 1.0000 & 0.60118 & 0.94450 & 0.66146 & Biso & 1.000 & 0 \\
\hline 071 & 1.0000 & 0.08517 & 0.70146 & 0.66272 & Biso & 1.000 & 0 \\
\hline 072 & 1.0000 & 0.38098 & 0.07119 & 0.33201 & Biso & 1.000 & O \\
\hline $\mathrm{C} 1$ & 1.0000 & 0.19972 & 0.99533 & 0.35418 & Biso & 1.000 & $\mathrm{C}$ \\
\hline $\mathrm{H} 1$ & 1.0000 & 0.21108 & 0.94474 & 0.40371 & Biso & 1.000 & $\mathrm{H}$ \\
\hline $\mathrm{H} 2$ & 1.0000 & 0.18937 & 0.96972 & 0.28496 & Biso & 1.000 & $\mathrm{H}$ \\
\hline H3 & 1.0000 & 0.21895 & 0.07899 & 0.37182 & Biso & 1.000 & $\mathrm{H}$ \\
\hline $\mathrm{C} 2$ & 1.0000 & 0.03056 & 0.02645 & 0.50450 & Biso & 1.000 & C \\
\hline $\mathrm{C} 3$ & 1.0000 & 0.02007 & 0.10231 & 0.44950 & Biso & 1.000 & C \\
\hline $\mathrm{C} 4$ & 1.0000 & 0.00938 & 0.08708 & 0.35693 & Biso & 1.000 & C \\
\hline C5 & 1.0000 & 0.01006 & 0.99634 & 0.31864 & Biso & 1.000 & C \\
\hline C6 & 1.0000 & 0.02560 & 0.92128 & 0.37310 & Biso & 1.000 & C \\
\hline C7 & 1.0000 & 0.03106 & 0.93511 & 0.46710 & Biso & 1.000 & C \\
\hline $\mathrm{H} 4$ & 1.0000 & 0.03793 & 0.03891 & 0.57645 & Biso & 1.000 & $\mathrm{H}$ \\
\hline H5 & 1.0000 & 0.03820 & 0.87453 & 0.50880 & Biso & 1.000 & $\mathrm{H}$ \\
\hline H6 & 1.0000 & 0.01955 & 0.17412 & 0.47879 & Biso & 1.000 & $\mathrm{H}$ \\
\hline $\mathrm{H} 7$ & 1.0000 & 0.00018 & 0.14636 & 0.31526 & Biso & 1.000 & $\mathrm{H}$ \\
\hline H8 & 1.0000 & 0.00132 & 0.98341 & 0.24674 & Biso & 1.000 & $\mathrm{H}$ \\
\hline H9 & 1.0000 & 0.00971 & 0.84173 & 0.34542 & Biso & 1.000 & $\mathrm{H}$ \\
\hline \\
\hline \multicolumn{8}{|c|}{$\begin{array}{l}\text { Ga } 14 \\
\text { data image } 0\end{array}$} \\
\hline \multicolumn{2}{|c|}{ celil length a } & & & & & \\
\hline cell] & th_b & 13.625 & 13.625 & & & & \\
\hline cell] & th_c & \multicolumn{2}{|c|}{15.067} & & & & \\
\hline $\mathrm{Cell}$ & e_- $\bar{a} l p h a$ & 90 & & & & & \\
\hline $\mathrm{cell}$ & e- beta & 90 & & & & & \\
\hline$[\mathrm{cell}$ & e_gamma & 120 & & & & & \\
\hline symme & space_g & coup_nam & $n-11$ & $1 "$ & & & \\
\hline symme & int_t $\bar{a} b$ & les_numbe & & & & & \\
\hline $00 p_{-}$ & & & & & & & \\
\hline & equi & pos as & & & & & \\
\hline$T^{\circ} \mathrm{x}$, & & & & & & & \\
\hline .oop_ & & & & & & & \\
\hline $5-$ & e $l a b c$ & & & & & & \\
\hline & e_occur & pancy & & & & & \\
\hline at & efrac & & & & & & \\
\hline & $e_{-}^{-}$fract & & & & & & \\
\hline
\end{tabular}




\begin{tabular}{|c|c|c|c|c|c|c|c|}
\hline$\overline{\mathrm{S}} i 1$ & 1.0000 & 0.01864 & 0.24796 & 0.10157 & Biso & 1.000 & $\mathrm{Si}$ \\
\hline $\mathrm{Si} 2$ & 1.0000 & 0.79028 & 0.79225 & 0.10652 & Biso & 1.000 & $\mathrm{Si}$ \\
\hline Si3 & 1.0000 & 0.24933 & 0.02021 & 0.09654 & Biso & 1.000 & $\mathrm{Si}$ \\
\hline Si 4 & 1.0000 & 0.23999 & 0.01326 & 0.88892 & Biso & 1.000 & $\mathrm{Si}$ \\
\hline Si5 & 1.0000 & 0.78705 & 0.78718 & 0.89874 & Biso & 1.000 & $\mathrm{Si}$ \\
\hline Si6 & 1.0000 & 0.01400 & 0.24620 & 0.89479 & Biso & 1.000 & Si \\
\hline Si7 & 1.0000 & 0.68201 & 0.57928 & 0.43593 & Biso & 1.000 & $\mathrm{Si}$ \\
\hline Gal & 1.0000 & 0.45570 & 0.12814 & 0.43840 & Biso & 1.000 & $\mathrm{Ga}$ \\
\hline Si8 & 1.0000 & 0.92172 & 0.34851 & 0.43492 & Biso & 1.000 & $\mathrm{Si}$ \\
\hline Si9 & 1.0000 & 0.91661 & 0.35304 & 0.22945 & Biso & 1.000 & $\mathrm{Si}$ \\
\hline Silo & 1.0000 & 0.45259 & 0.12248 & 0.22653 & Biso & 1.000 & $\mathrm{Si}$ \\
\hline Si11 & 1.0000 & 0.68661 & 0.58251 & 0.23194 & Biso & 1.000 & $\mathrm{Si}$ \\
\hline Si12 & 1.0000 & 0.34668 & 0.90555 & 0.77138 & Biso & 1.000 & $\mathrm{Si}$ \\
\hline Si13 & 1.0000 & 0.11806 & 0.44945 & 0.76586 & Biso & 1.000 & $\mathrm{Si}$ \\
\hline Si14 & 1.0000 & 0.58090 & 0.68317 & 0.76921 & Biso & 1.000 & $\mathrm{Si}$ \\
\hline Si15 & 1.0000 & 0.59463 & 0.69291 & 0.56664 & Biso & 1.000 & $\mathrm{Si}$ \\
\hline Si16 & 1.0000 & 0.11764 & 0.45299 & 0.56640 & Biso & 1.000 & $\mathrm{Si}$ \\
\hline Si17 & 1.0000 & 0.34847 & 0.90050 & 0.56281 & Biso & 1.000 & $\mathrm{Si}$ \\
\hline Si18 & 1.0000 & 0.01298 & 0.78251 & 0.89771 & Biso & 1.000 & $\mathrm{Si}$ \\
\hline Si19 & 1.0000 & 0.24407 & 0.24510 & 0.89017 & Biso & 1.000 & $\mathrm{Si}$ \\
\hline Si20 & 1.0000 & 0.78872 & 0.01584 & 0.89596 & Biso & 1.000 & $\mathrm{Si}$ \\
\hline Si21 & 1.0000 & 0.78971 & 0.01987 & 0.10443 & Biso & 1.000 & $\mathrm{Si}$ \\
\hline $\mathrm{Si} 22$ & 1.0000 & 0.25016 & 0.25013 & 0.09700 & Biso & 1.000 & $\mathrm{Si}$ \\
\hline Si23 & 1.0000 & 0.01980 & 0.79276 & 0.10605 & Biso & 1.000 & $\mathrm{Si}$ \\
\hline Si24 & 1.0000 & 0.68695 & 0.12396 & 0.23255 & Biso & 1.000 & $\mathrm{Si}$ \\
\hline Si25 & 1.0000 & 0.91533 & 0.58252 & 0.23237 & Biso & 1.000 & $\mathrm{Si}$ \\
\hline Si26 & 1.0000 & 0.45413 & 0.35177 & 0.22755 & Biso & 1.000 & $\mathrm{Si}$ \\
\hline Si27 & 1.0000 & 0.44109 & 0.35246 & 0.43345 & Biso & 1.000 & $\mathrm{Si}$ \\
\hline Si28 & 1.0000 & 0.91099 & 0.57632 & 0.43849 & Biso & 1.000 & $\mathrm{Si}$ \\
\hline Si29 & 1.0000 & 0.68948 & 0.12727 & 0.43398 & Biso & 1.000 & $\mathrm{Si}$ \\
\hline Si30 & 1.0000 & 0.35462 & 0.47050 & 0.56006 & Biso & 1.000 & $\mathrm{Si}$ \\
\hline Si31 & 1.0000 & 0.58143 & 0.91547 & 0.56545 & Biso & 1.000 & $\mathrm{Si}$ \\
\hline Si32 & 1.0000 & 0.10925 & 0.68456 & 0.56919 & Biso & 1.000 & $\mathrm{Si}$ \\
\hline Si33 & 1.0000 & 0.11599 & 0.68258 & 0.77085 & Biso & 1.000 & $\mathrm{Si}$ \\
\hline Si34 & 1.0000 & 0.57741 & 0.91238 & 0.77014 & Biso & 1.000 & $\mathrm{Si}$ \\
\hline Si35 & 1.0000 & 0.34886 & 0.45423 & 0.76432 & Biso & 1.000 & $\mathrm{Si}$ \\
\hline 01 & 1.0000 & 0.92157 & 0.11714 & 0.12235 & Biso & 1.000 & 0 \\
\hline $\mathrm{O} 2$ & 1.0000 & 0.92248 & 0.82704 & 0.12377 & Biso & 1.000 & 0 \\
\hline 03 & 1.0000 & 0.21735 & 0.11891 & 0.11535 & Biso & 1.000 & 0 \\
\hline O4 & 1.0000 & 0.10988 & 0.91180 & 0.87302 & Biso & 1.000 & 0 \\
\hline 05 & 1.0000 & 0.82383 & 0.91896 & 0.87922 & Biso & 1.000 & 0 \\
\hline 06 & 1.0000 & 0.11347 & 0.21555 & 0.87747 & Biso & 1.000 & 0 \\
\hline 07 & 1.0000 & 0.57218 & 0.45469 & 0.44601 & Biso & 1.000 & $\mathrm{O}$ \\
\hline 08 & 1.0000 & 0.60632 & 0.17867 & 0.43748 & Biso & 1.000 & 0 \\
\hline 09 & 1.0000 & 0.89528 & 0.45103 & 0.45302 & Biso & 1.000 & 0 \\
\hline 010 & 1.0000 & 0.78473 & 0.25596 & 0.21510 & Biso & 1.000 & 0 \\
\hline 011 & 1.0000 & 0.48891 & 0.25506 & 0.21002 & Biso & 1.000 & 0 \\
\hline 012 & 1.0000 & 0.78425 & 0.54854 & 0.21449 & Biso & 1.000 & 0 \\
\hline 013 & 1.0000 & 0.24682 & 0.77634 & 0.79403 & Biso & 1.000 & 0 \\
\hline 014 & 1.0000 & 0.25018 & 0.48628 & 0.78399 & Biso & 1.000 & 0 \\
\hline 015 & 1.0000 & 0.54586 & 0.78059 & 0.77892 & Biso & 1.000 & 0 \\
\hline 016 & 1.0000 & 0.46261 & 0.59774 & 0.55103 & Biso & 1.000 & 0 \\
\hline 017 & 1.0000 & 0.11809 & 0.57123 & 0.56378 & Biso & 1.000 & 0 \\
\hline 018 & 1.0000 & 0.44590 & 0.86428 & 0.55048 & Biso & 1.000 & 0 \\
\hline 019 & 1.0000 & 0.00021 & 0.33414 & 0.16392 & Biso & 1.000 & 0 \\
\hline $\mathrm{O} 20$ & 1.0000 & 0.70592 & 0.68567 & 0.16743 & Biso & 1.000 & 0 \\
\hline 021 & 1.0000 & 0.36030 & 0.04295 & 0.15172 & Biso & 1.000 & 0 \\
\hline $\mathrm{O} 22$ & 1.0000 & 0.32743 & 0.99605 & 0.82773 & Biso & 1.000 & $\mathrm{O}$ \\
\hline $\mathrm{O} 23$ & 1.0000 & 0.67757 & 0.70185 & 0.84063 & Biso & 1.000 & 0 \\
\hline $\mathrm{O} 24$ & 1.0000 & 0.03415 & 0.35326 & 0.83516 & Biso & 1.000 & 0 \\
\hline 025 & 1.0000 & 0.67644 & 0.67081 & 0.50158 & Biso & 1.000 & 0 \\
\hline 026 & 1.0000 & 0.36568 & 0.00290 & 0.50215 & Biso & 1.000 & 0 \\
\hline 027 & 1.0000 & 0.02835 & 0.36519 & 0.49471 & Biso & 1.000 & 0 \\
\hline 028 & 1.0000 & 0.03078 & 0.69119 & 0.84161 & Biso & 1.000 & 0 \\
\hline 029 & 1.0000 & 0.32838 & 0.34741 & 0.82523 & Biso & 1.000 & 0 \\
\hline 030 & 1.0000 & 0.68062 & 0.99214 & 0.83627 & Biso & 1.000 & 0 \\
\hline 031 & 1.0000 & 0.70371 & 0.04250 & 0.16287 & Biso & 1.000 & 0 \\
\hline 032 & 1.0000 & 0.35615 & 0.33636 & 0.15791 & Biso & 1.000 & 0 \\
\hline 033 & 1.0000 & 0.00058 & 0.68976 & 0.17098 & Biso & 1.000 & 0 \\
\hline 034 & 1.0000 & 0.35812 & 0.38608 & 0.48697 & Biso & 1.000 & 0 \\
\hline 035 & 1.0000 & 0.00775 & 0.67025 & 0.50375 & Biso & 1.000 & 0 \\
\hline 036 & 1.0000 & 0.65609 & 0.02135 & 0.50065 & Biso & 1.000 & 0 \\
\hline 037 & 1.0000 & 0.14130 & 0.26201 & 0.12417 & Biso & 1.000 & 0 \\
\hline 038 & 1.0000 & 0.77643 & 0.89944 & 0.13431 & Biso & 1.000 & 0 \\
\hline 039 & 1.0000 & 0.14205 & 0.90146 & 0.13135 & Biso & 1.000 & 0 \\
\hline 040 & 1.0000 & 0.25040 & 0.13338 & 0.86335 & Biso & 1.000 & 0 \\
\hline
\end{tabular}




\begin{tabular}{|c|c|c|c|c|c|c|c|}
\hline 041 & 1.0000 & 0.89086 & 0.76731 & 0.87181 & Biso & 1.000 & 0 \\
\hline 042 & 1.0000 & 0.89411 & 0.13755 & 0.86690 & Biso & 1.000 & 0 \\
\hline 043 & 1.0000 & 0.79326 & 0.57152 & 0.46212 & Biso & 1.000 & 0 \\
\hline 044 & 1.0000 & 0.42201 & 0.23530 & 0.47176 & Biso & 1.000 & 0 \\
\hline 045 & 1.0000 & 0.81646 & 0.22701 & 0.46242 & Biso & 1.000 & 0 \\
\hline 046 & 1.0000 & 0.93113 & 0.47598 & 0.20677 & Biso & 1.000 & 0 \\
\hline 047 & 1.0000 & 0.56424 & 0.11086 & 0.21362 & Biso & 1.000 & 0 \\
\hline 048 & 1.0000 & 0.56434 & 0.47481 & 0.20914 & Biso & 1.000 & 0 \\
\hline 049 & 1.0000 & 0.46765 & 0.92029 & 0.80088 & Biso & 1.000 & 0 \\
\hline 050 & 1.0000 & 0.10168 & 0.55795 & 0.77892 & Biso & 1.000 & 0 \\
\hline 051 & 1.0000 & 0.47044 & 0.56156 & 0.79054 & Biso & 1.000 & 0 \\
\hline 052 & 1.0000 & 0.61225 & 0.81696 & 0.54420 & Biso & 1.000 & 0 \\
\hline 053 & 1.0000 & 0.24262 & 0.47876 & 0.53980 & Biso & 1.000 & 0 \\
\hline 054 & 1.0000 & 0.22651 & 0.79106 & 0.53555 & Biso & 1.000 & 0 \\
\hline 055 & 1.0000 & 0.01241 & 0.27889 & 0.99842 & Biso & 1.000 & 0 \\
\hline 056 & 1.0000 & 0.75637 & 0.75820 & 0.00327 & Biso & 1.000 & 0 \\
\hline 057 & 1.0000 & 0.27359 & 0.01300 & 0.99242 & Biso & 1.000 & 0 \\
\hline 058 & 1.0000 & 0.69348 & 0.62468 & 0.33404 & Biso & 1.000 & 0 \\
\hline 059 & 1.0000 & 0.95591 & 0.34990 & 0.33098 & Biso & 1.000 & 0 \\
\hline 060 & 1.0000 & 0.34472 & 0.93134 & 0.66709 & Biso & 1.000 & 0 \\
\hline 061 & 1.0000 & 0.08246 & 0.39805 & 0.66555 & Biso & 1.000 & 0 \\
\hline 062 & 1.0000 & 0.62930 & 0.68667 & 0.66952 & Biso & 1.000 & 0 \\
\hline 063 & 1.0000 & 0.01772 & 0.75710 & 0.00298 & Biso & 1.000 & 0 \\
\hline 064 & 1.0000 & 0.28314 & 0.28157 & 0.99289 & Biso & 1.000 & 0 \\
\hline 065 & 1.0000 & 0.75795 & 0.01744 & 0.00014 & Biso & 1.000 & 0 \\
\hline 066 & 1.0000 & 0.69655 & 0.08518 & 0.33279 & Biso & 1.000 & 0 \\
\hline 067 & 1.0000 & 0.94897 & 0.61892 & 0.33613 & Biso & 1.000 & 0 \\
\hline 068 & 1.0000 & 0.40714 & 0.34397 & 0.32782 & Biso & 1.000 & 0 \\
\hline 069 & 1.0000 & 0.34804 & 0.42127 & 0.66020 & Biso & 1.000 & 0 \\
\hline 070 & 1.0000 & 0.61420 & 0.95695 & 0.66866 & Biso & 1.000 & 0 \\
\hline 071 & 1.0000 & 0.08174 & 0.70326 & 0.67134 & Biso & 1.000 & 0 \\
\hline 072 & 1.0000 & 0.39451 & 0.07852 & 0.32356 & Biso & 1.000 & 0 \\
\hline $\mathrm{C} 1$ & 1.0000 & 0.21419 & 0.00318 & 0.34581 & Biso & 1.000 & $\mathrm{C}$ \\
\hline $\mathrm{H} 1$ & 1.0000 & 0.22650 & 0.95538 & 0.39803 & Biso & 1.000 & $\mathrm{H}$ \\
\hline $\mathrm{H} 2$ & 1.0000 & 0.19862 & 0.97023 & 0.27859 & Biso & 1.000 & $\mathrm{H}$ \\
\hline H3 & 1.0000 & 0.23157 & 0.08870 & 0.35919 & Biso & 1.000 & $\mathrm{H}$ \\
\hline $\mathrm{C} 2$ & 1.0000 & 0.05328 & 0.04453 & 0.49743 & Biso & 1.000 & $\mathrm{C}$ \\
\hline C3 & 1.0000 & 0.04238 & 0.12098 & 0.44194 & Biso & 1.000 & $\mathrm{C}$ \\
\hline $\mathrm{C} 4$ & 1.0000 & 0.02411 & 0.10055 & 0.35052 & Biso & 1.000 & $\mathrm{C}$ \\
\hline C5 & 1.0000 & 0.01803 & 0.00420 & 0.31376 & Biso & 1.000 & $\mathrm{C}$ \\
\hline C6 & 1.0000 & 0.03374 & 0.92836 & 0.36861 & Biso & 1.000 & $\mathrm{C}$ \\
\hline C7 & 1.0000 & 0.04681 & 0.94748 & 0.46157 & Biso & 1.000 & $\mathrm{C}$ \\
\hline $\mathrm{H} 4$ & 1.0000 & 0.06673 & 0.06110 & 0.56851 & Biso & 1.000 & $\mathrm{H}$ \\
\hline H5 & 1.0000 & 0.05425 & 0.88638 & 0.50369 & Biso & 1.000 & $\mathrm{H}$ \\
\hline H6 & 1.0000 & 0.04767 & 0.19736 & 0.46996 & Biso & 1.000 & $\mathrm{H}$ \\
\hline $\mathrm{H} 7$ & 1.0000 & 0.01475 & 0.16059 & 0.30857 & Biso & 1.000 & $\mathrm{H}$ \\
\hline H8 & 1.0000 & 0.00394 & 0.98761 & 0.24270 & Biso & 1.000 & $\mathrm{H}$ \\
\hline H9 & 1.0000 & 0.01522 & 0.84593 & 0.34260 & Biso & 1.000 & $\mathrm{H}$ \\
\hline \multicolumn{8}{|c|}{ Ti 14} \\
\hline \multicolumn{8}{|c|}{ data_image 0} \\
\hline \multicolumn{8}{|c|}{ cell length a } \\
\hline \multicolumn{8}{|c|}{ _cell_length_b $\quad 13.875$} \\
\hline \multicolumn{8}{|c|}{-cell_length_c $\quad 15.017$} \\
\hline \multicolumn{8}{|c|}{ cell_angle_alpha $\quad 90$} \\
\hline \multicolumn{8}{|c|}{ cell_angle_beta 90} \\
\hline - cell_ & e_gamma & 120 & & & & & \\
\hline symme & space_g & coup_name & & P $1 "$ & & & \\
\hline symme & int_t $\bar{a} b$ & les_numbe & & & & & \\
\hline loop_ & & & & & & & \\
\hline- syn & I_equiv & pos_as_x & & & & & \\
\hline ' $\mathrm{x}$, & & & & & & & \\
\hline loop_ & & & & & & & \\
\hline atc & =e_labe & & & & & & \\
\hline atc & e- occur & pancy & & & & & \\
\hline atc & te_fract & E $x$ & & & & & \\
\hline -atc & ce_fract & & & & & & \\
\hline -atc & ce_fract & & & & & & \\
\hline -atc & $=e$ therr & nàl_displ & ce_type & & & & \\
\hline -atc & $\begin{array}{l}\text { ee_B_is } \\
\text { ce type }\end{array}$ & $\begin{array}{l}\text { or_er_equi } \\
\text { symbol }\end{array}$ & & & & & \\
\hline$\overline{\mathrm{P}} 1$ & 1.0000 & 0.01554 & 0.23874 & 0.10769 & Biso & 1.000 & $\mathrm{P}$ \\
\hline P2 & 1.0000 & 0.78829 & 0.79132 & 0.11358 & Biso & 1.000 & $\mathrm{P}$ \\
\hline P3 & 1.0000 & 0.23919 & 0.00996 & 0.09854 & Biso & 1.000 & $\mathrm{P}$ \\
\hline Al1 & 1.0000 & 0.22787 & 0.00090 & 0.88447 & Biso & 1.000 & Al \\
\hline Al2 & 1.0000 & 0.78001 & 0.78322 & 0.89998 & Biso & 1.000 & Al \\
\hline Al3 & 1.0000 & 0.00884 & 0.23554 & 0.89494 & Biso & 1.000 & $\mathrm{Al}$ \\
\hline $\mathrm{P} 4$ & 1.0000 & 0.68001 & 0.57315 & 0.44125 & Biso & 1.000 & $\mathrm{P}$ \\
\hline
\end{tabular}




\begin{tabular}{|c|c|c|c|c|c|c|}
\hline Til & 1.0000 & 0.43502 & 0.11803 & 0.44427 & Biso & 1.000 \\
\hline P5 & 1.0000 & 0.91253 & 0.33807 & 0.43841 & Biso & 1.000 \\
\hline Al4 & 1.0000 & 0.90699 & 0.34296 & 0.22870 & Biso & 1.000 \\
\hline Al5 & 1.0000 & 0.44436 & 0.11715 & 0.22628 & Biso & 1.000 \\
\hline Al6 & 1.0000 & 0.68424 & 0.57462 & 0.23195 & Biso & 1.000 \\
\hline P6 & 1.0000 & 0.34021 & 0.88880 & 0.78194 & Biso & 1.000 \\
\hline P7 & 1.0000 & 0.11053 & 0.44302 & 0.77084 & Biso & 1.000 \\
\hline P8 & 1.0000 & 0.57089 & 0.67090 & 0.77522 & Biso & 1.000 \\
\hline Al 7 & 1.0000 & 0.58966 & 0.68582 & 0.57008 & Biso & 1.000 \\
\hline A18 & 1.0000 & 0.10843 & 0.44615 & 0.56905 & Biso & 1.000 \\
\hline Al9 & 1.0000 & 0.34386 & 0.88349 & 0.56584 & Biso & 1.000 \\
\hline P9 & 1.0000 & 0.00130 & 0.77504 & 0.89210 & Biso & 1.000 \\
\hline P10 & 1.0000 & 0.23432 & 0.23156 & 0.88333 & Biso & 1.000 \\
\hline P11 & 1.0000 & 0.78489 & 0.01082 & 0.89303 & Biso & 1.000 \\
\hline Al10 & 1.0000 & 0.78724 & 0.01607 & 0.10737 & Biso & 1.000 \\
\hline Al11 & 1.0000 & 0.24400 & 0.23968 & 0.09573 & Biso & 1.000 \\
\hline Al12 & 1.0000 & 0.01284 & 0.78743 & 0.10638 & Biso & 1.000 \\
\hline P12 & 1.0000 & 0.67828 & 0.11874 & 0.22864 & Biso & 1.000 \\
\hline P13 & 1.0000 & 0.91138 & 0.57434 & 0.22960 & Biso & 1.000 \\
\hline P14 & 1.0000 & 0.45291 & 0.34980 & 0.22179 & Biso & 1.000 \\
\hline Al13 & 1.0000 & 0.43680 & 0.35594 & 0.43278 & Biso & 1.000 \\
\hline Al1 14 & 1.0000 & 0.90619 & 0.56757 & 0.43949 & Biso & 1.000 \\
\hline Al15 & 1.0000 & 0.67914 & 0.12006 & 0.43582 & Biso & 1.000 \\
\hline P15 & 1.0000 & 0.34658 & 0.47350 & 0.55579 & Biso & 1.000 \\
\hline P16 & 1.0000 & 0.57819 & 0.90758 & 0.56486 & Biso & 1.000 \\
\hline P17 & 1.0000 & 0.10398 & 0.67774 & 0.56845 & Biso & 1.000 \\
\hline Al16 & 1.0000 & 0.10982 & 0.67568 & 0.77340 & Biso & 1.000 \\
\hline Al1 17 & 1.0000 & 0.56810 & 0.90043 & 0.77385 & Biso & 1.000 \\
\hline Al1 18 & 1.0000 & 0.33827 & 0.44736 & 0.76319 & Biso & 1.000 \\
\hline 01 & 1.0000 & 0.92537 & 0.11873 & 0.13225 & Biso & 1.000 \\
\hline $\mathrm{O} 2$ & 1.0000 & 0.91061 & 0.82304 & 0.13158 & Biso & 1.000 \\
\hline 03 & 1.0000 & 0.21066 & 0.10203 & 0.11915 & Biso & 1.000 \\
\hline 04 & 1.0000 & 0.09207 & 0.89230 & 0.86241 & Biso & 1.000 \\
\hline 05 & 1.0000 & 0.81596 & 0.92046 & 0.87350 & Biso & 1.000 \\
\hline 06 & 1.0000 & 0.11255 & 0.20280 & 0.87055 & Biso & 1.000 \\
\hline 07 & 1.0000 & 0.57565 & 0.45938 & 0.45414 & Biso & 1.000 \\
\hline 08 & 1.0000 & 0.58204 & 0.16249 & 0.44143 & Biso & 1.000 \\
\hline 09 & 1.0000 & 0.89150 & 0.43577 & 0.45485 & Biso & 1.000 \\
\hline 010 & 1.0000 & 0.76816 & 0.24102 & 0.20912 & Biso & 1.000 \\
\hline 011 & 1.0000 & 0.48306 & 0.25791 & 0.20911 & Biso & 1.000 \\
\hline 012 & 1.0000 & 0.78943 & 0.54174 & 0.21199 & Biso & 1.000 \\
\hline 013 & 1.0000 & 0.24471 & 0.77255 & 0.80947 & Biso & 1.000 \\
\hline 014 & 1.0000 & 0.23404 & 0.48054 & 0.78837 & Biso & 1.000 \\
\hline 015 & 1.0000 & 0.53956 & 0.76259 & 0.78122 & Biso & 1.000 \\
\hline 016 & 1.0000 & 0.44932 & 0.59053 & 0.54999 & Biso & 1.000 \\
\hline 017 & 1.0000 & 0.09905 & 0.56546 & 0.56836 & Biso & 1.000 \\
\hline 018 & 1.0000 & 0.45358 & 0.85713 & 0.54221 & Biso & 1.000 \\
\hline 019 & 1.0000 & 0.99948 & 0.32260 & 0.16294 & Biso & 1.000 \\
\hline 020 & 1.0000 & 0.70870 & 0.68993 & 0.16880 & Biso & 1.000 \\
\hline 021 & 1.0000 & 0.34810 & 0.03493 & 0.14336 & Biso & 1.000 \\
\hline 022 & 1.0000 & 0.32372 & 0.98001 & 0.82528 & Biso & 1.000 \\
\hline 023 & 1.0000 & 0.65835 & 0.68873 & 0.84562 & Biso & 1.000 \\
\hline $\mathrm{O} 24$ & 1.0000 & 0.03485 & 0.35610 & 0.83925 & Biso & 1.000 \\
\hline 025 & 1.0000 & 0.67689 & 0.66101 & 0.50171 & Biso & 1.000 \\
\hline 026 & 1.0000 & 0.35440 & 0.99811 & 0.51428 & Biso & 1.000 \\
\hline 027 & 1.0000 & 0.01274 & 0.35230 & 0.49322 & Biso & 1.000 \\
\hline 028 & 1.0000 & 0.01427 & 0.68484 & 0.84363 & Biso & 1.000 \\
\hline 029 & 1.0000 & 0.31233 & 0.32894 & 0.82332 & Biso & 1.000 \\
\hline 030 & 1.0000 & 0.68033 & 0.98746 & 0.84157 & Biso & 1.000 \\
\hline 031 & 1.0000 & 0.69234 & 0.04113 & 0.16332 & Biso & 1.000 \\
\hline 032 & 1.0000 & 0.36119 & 0.33338 & 0.15554 & Biso & 1.000 \\
\hline 033 & 1.0000 & 0.99030 & 0.67315 & 0.17062 & Biso & 1.000 \\
\hline 034 & 1.0000 & 0.34953 & 0.39766 & 0.48351 & Biso & 1.000 \\
\hline 035 & 1.0000 & 0.01086 & 0.66999 & 0.50735 & Biso & 1.000 \\
\hline 036 & 1.0000 & 0.65094 & 0.00708 & 0.50504 & Biso & 1.000 \\
\hline 037 & 1.0000 & 0.13027 & 0.25325 & 0.12894 & Biso & 1.000 \\
\hline 038 & 1.0000 & 0.77354 & 0.88944 & 0.14152 & Biso & 1.000 \\
\hline 039 & 1.0000 & 0.14310 & 0.89989 & 0.13617 & Biso & 1.000 \\
\hline 040 & 1.0000 & 0.24325 & 0.12972 & 0.85627 & Biso & 1.000 \\
\hline 041 & 1.0000 & 0.88738 & 0.76013 & 0.86786 & Biso & 1.000 \\
\hline 042 & 1.0000 & 0.88097 & 0.12378 & 0.86245 & Biso & 1.000 \\
\hline 043 & 1.0000 & 0.78256 & 0.56414 & 0.46614 & Biso & 1.000 \\
\hline 044 & 1.0000 & 0.40867 & 0.22945 & 0.47385 & Biso & 1.000 \\
\hline 045 & 1.0000 & 0.81164 & 0.22870 & 0.46733 & Biso & 1.000 \\
\hline 046 & 1.0000 & 0.92678 & 0.47529 & 0.20668 & Biso & 1.000 \\
\hline 047 & 1.0000 & 0.56334 & 0.10548 & 0.21338 & Biso & 1.000 \\
\hline 048 & 1.0000 & 0.55635 & 0.46274 & 0.20134 & Biso & 1.000 \\
\hline 049 & 1.0000 & 0.45139 & 0.90300 & 0.81464 & Biso & 1.000 \\
\hline 050 & 1.0000 & 0.09315 & 0.54313 & 0.77897 & Biso & 1.000 \\
\hline 051 & 1.0000 & 0.46708 & 0.55832 & 0.79444 & Biso & 1.000 \\
\hline
\end{tabular}




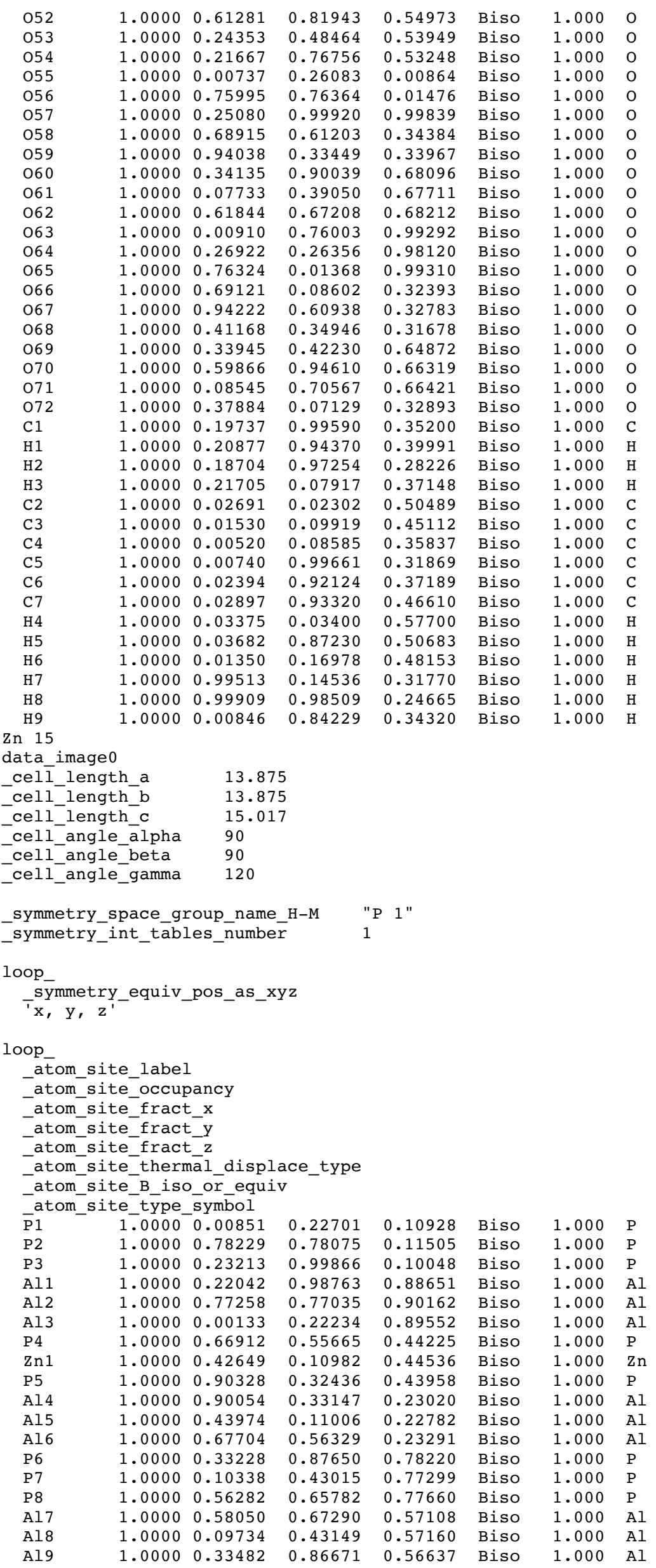




\begin{tabular}{|c|c|c|c|c|c|c|c|}
\hline P9 & 1.0000 & 0.99396 & 0.76141 & 0.89505 & Biso & 1.000 & $\mathrm{P}$ \\
\hline P10 & 1.0000 & 0.22559 & 0.21801 & 0.88258 & Biso & 1.000 & $\mathrm{P}$ \\
\hline P11 & 1.0000 & 0.77751 & 0.99806 & 0.89403 & Biso & 1.000 & $\mathrm{P}$ \\
\hline Al10 & 1.0000 & 0.78011 & 0.00482 & 0.10844 & Biso & 1.000 & Al \\
\hline Al11 & 1.0000 & 0.23540 & 0.22743 & 0.09507 & Biso & 1.000 & $\mathrm{Al}$ \\
\hline Al12 & 1.0000 & 0.00639 & 0.77589 & 0.10898 & Biso & 1.000 & $\mathrm{Al}$ \\
\hline P12 & 1.0000 & 0.67029 & 0.10653 & 0.22917 & Biso & 1.000 & $\mathrm{P}$ \\
\hline P13 & 1.0000 & 0.90272 & 0.56175 & 0.23146 & Biso & 1.000 & $\mathrm{P}$ \\
\hline P14 & 1.0000 & 0.44583 & 0.34031 & 0.21990 & Biso & 1.000 & $\mathrm{P}$ \\
\hline Al13 & 1.0000 & 0.42433 & 0.34377 & 0.43006 & Biso & 1.000 & Al \\
\hline Al14 & 1.0000 & 0.89601 & 0.55325 & 0.44171 & Biso & 1.000 & $\mathrm{Al}$ \\
\hline Al15 & 1.0000 & 0.66757 & 0.10665 & 0.43584 & Biso & 1.000 & $\mathrm{Al}$ \\
\hline P15 & 1.0000 & 0.33695 & 0.46284 & 0.55634 & Biso & 1.000 & $\mathrm{P}$ \\
\hline P16 & 1.0000 & 0.56945 & 0.89303 & 0.56582 & Biso & 1.000 & $\mathrm{P}$ \\
\hline P17 & 1.0000 & 0.09286 & 0.66283 & 0.57098 & Biso & 1.000 & $\mathrm{P}$ \\
\hline Al16 & 1.0000 & 0.10188 & 0.66272 & 0.77523 & Biso & 1.000 & $\mathrm{Al}$ \\
\hline Al17 & 1.0000 & 0.56029 & 0.88688 & 0.77488 & Biso & 1.000 & $\mathrm{Al}$ \\
\hline Al18 & 1.0000 & 0.33075 & 0.43387 & 0.76336 & Biso & 1.000 & Al \\
\hline 01 & 1.0000 & 0.91769 & 0.10773 & 0.13467 & Biso & 1.000 & 0 \\
\hline $\mathrm{O} 2$ & 1.0000 & 0.90493 & 0.81322 & 0.13235 & Biso & 1.000 & 0 \\
\hline 03 & 1.0000 & 0.20161 & 0.08982 & 0.11945 & Biso & 1.000 & 0 \\
\hline 04 & 1.0000 & 0.08468 & 0.87867 & 0.86532 & Biso & 1.000 & 0 \\
\hline 05 & 1.0000 & 0.80886 & 0.90776 & 0.87507 & Biso & 1.000 & 0 \\
\hline 06 & 1.0000 & 0.10417 & 0.18942 & 0.86806 & Biso & 1.000 & 0 \\
\hline 07 & 1.0000 & 0.56440 & 0.44229 & 0.45270 & Biso & 1.000 & 0 \\
\hline 08 & 1.0000 & 0.57826 & 0.15954 & 0.43855 & Biso & 1.000 & 0 \\
\hline 09 & 1.0000 & 0.88145 & 0.42134 & 0.45643 & Biso & 1.000 & 0 \\
\hline 010 & 1.0000 & 0.76205 & 0.22842 & 0.21142 & Biso & 1.000 & 0 \\
\hline 011 & 1.0000 & 0.47968 & 0.25097 & 0.20912 & Biso & 1.000 & 0 \\
\hline 012 & 1.0000 & 0.78085 & 0.52877 & 0.21232 & Biso & 1.000 & 0 \\
\hline 013 & 1.0000 & 0.23724 & 0.76014 & 0.81001 & Biso & 1.000 & 0 \\
\hline 014 & 1.0000 & 0.22687 & 0.46701 & 0.78993 & Biso & 1.000 & 0 \\
\hline 015 & 1.0000 & 0.53015 & 0.74851 & 0.78361 & Biso & 1.000 & 0 \\
\hline 016 & 1.0000 & 0.43915 & 0.58030 & 0.55168 & Biso & 1.000 & 0 \\
\hline 017 & 1.0000 & 0.08557 & 0.54935 & 0.57186 & Biso & 1.000 & 0 \\
\hline 018 & 1.0000 & 0.44375 & 0.83815 & 0.54583 & Biso & 1.000 & 0 \\
\hline 019 & 1.0000 & 0.99275 & 0.31235 & 0.16271 & Biso & 1.000 & 0 \\
\hline 020 & 1.0000 & 0.70370 & 0.68028 & 0.17152 & Biso & 1.000 & 0 \\
\hline 021 & 1.0000 & 0.34160 & 0.02645 & 0.14586 & Biso & 1.000 & 0 \\
\hline $\mathrm{O} 22$ & 1.0000 & 0.31614 & 0.96745 & 0.82643 & Biso & 1.000 & 0 \\
\hline $\mathrm{O} 23$ & 1.0000 & 0.65103 & 0.67626 & 0.84654 & Biso & 1.000 & 0 \\
\hline $\mathrm{O} 24$ & 1.0000 & 0.02782 & 0.34438 & 0.84215 & Biso & 1.000 & 0 \\
\hline 025 & 1.0000 & 0.66433 & 0.64311 & 0.50320 & Biso & 1.000 & 0 \\
\hline 026 & 1.0000 & 0.34838 & 0.98084 & 0.51185 & Biso & 1.000 & 0 \\
\hline $\mathrm{O} 27$ & 1.0000 & 0.00180 & 0.33711 & 0.49592 & Biso & 1.000 & 0 \\
\hline $\mathrm{O} 28$ & 1.0000 & 0.00694 & 0.67116 & 0.84670 & Biso & 1.000 & 0 \\
\hline 029 & 1.0000 & 0.30483 & 0.31465 & 0.82241 & Biso & 1.000 & 0 \\
\hline 030 & 1.0000 & 0.67251 & 0.97367 & 0.84273 & Biso & 1.000 & 0 \\
\hline 031 & 1.0000 & 0.68414 & 0.02904 & 0.16360 & Biso & 1.000 & 0 \\
\hline 032 & 1.0000 & 0.35485 & 0.32154 & 0.15221 & Biso & 1.000 & 0 \\
\hline 033 & 1.0000 & 0.98243 & 0.66159 & 0.17372 & Biso & 1.000 & 0 \\
\hline 034 & 1.0000 & 0.34044 & 0.38929 & 0.48192 & Biso & 1.000 & 0 \\
\hline 035 & 1.0000 & 0.00045 & 0.65567 & 0.50952 & Biso & 1.000 & 0 \\
\hline 036 & 1.0000 & 0.63722 & 0.99326 & 0.50528 & Biso & 1.000 & 0 \\
\hline 037 & 1.0000 & 0.12302 & 0.24132 & 0.13215 & Biso & 1.000 & 0 \\
\hline 038 & 1.0000 & 0.76716 & 0.87868 & 0.14267 & Biso & 1.000 & 0 \\
\hline 039 & 1.0000 & 0.13710 & 0.88832 & 0.13863 & Biso & 1.000 & 0 \\
\hline 040 & 1.0000 & 0.23504 & 0.11594 & 0.85782 & Biso & 1.000 & 0 \\
\hline 041 & 1.0000 & 0.87997 & 0.74651 & 0.87096 & Biso & 1.000 & 0 \\
\hline 042 & 1.0000 & 0.87310 & 0.11112 & 0.86304 & Biso & 1.000 & 0 \\
\hline 043 & 1.0000 & 0.77098 & 0.54722 & 0.46833 & Biso & 1.000 & 0 \\
\hline O4 4 & 1.0000 & 0.38378 & 0.21385 & 0.47207 & Biso & 1.000 & 0 \\
\hline 045 & 1.0000 & 0.80156 & 0.21407 & 0.46630 & Biso & 1.000 & 0 \\
\hline 046 & 1.0000 & 0.91903 & 0.46330 & 0.20819 & Biso & 1.000 & 0 \\
\hline 047 & 1.0000 & 0.55675 & 0.09592 & 0.21253 & Biso & 1.000 & 0 \\
\hline 048 & 1.0000 & 0.54779 & 0.45460 & 0.20076 & Biso & 1.000 & 0 \\
\hline 049 & 1.0000 & 0.44386 & 0.89095 & 0.81409 & Biso & 1.000 & 0 \\
\hline 050 & 1.0000 & 0.08695 & 0.53085 & 0.78052 & Biso & 1.000 & 0 \\
\hline 051 & 1.0000 & 0.45981 & 0.54432 & 0.79519 & Biso & 1.000 & 0 \\
\hline 052 & 1.0000 & 0.60761 & 0.80776 & 0.54878 & Biso & 1.000 & 0 \\
\hline 053 & 1.0000 & 0.23310 & 0.47278 & 0.54120 & Biso & 1.000 & 0 \\
\hline 054 & 1.0000 & 0.20681 & 0.75051 & 0.53529 & Biso & 1.000 & 0 \\
\hline 055 & 1.0000 & 0.00188 & 0.24701 & 0.00959 & Biso & 1.000 & 0 \\
\hline 056 & 1.0000 & 0.75242 & 0.75148 & 0.01656 & Biso & 1.000 & 0 \\
\hline 057 & 1.0000 & 0.24463 & 0.98707 & 0.00051 & Biso & 1.000 & 0 \\
\hline 058 & 1.0000 & 0.68043 & 0.59779 & 0.34536 & Biso & 1.000 & 0 \\
\hline 059 & 1.0000 & 0.93412 & 0.32314 & 0.34121 & Biso & 1.000 & 0 \\
\hline 060 & 1.0000 & 0.33230 & 0.88829 & 0.68119 & Biso & 1.000 & 0 \\
\hline 061 & 1.0000 & 0.06911 & 0.37632 & 0.67976 & Biso & 1.000 & 0 \\
\hline 062 & 1.0000 & 0.61006 & 0.66031 & 0.68308 & Biso & 1.000 & 0 \\
\hline
\end{tabular}




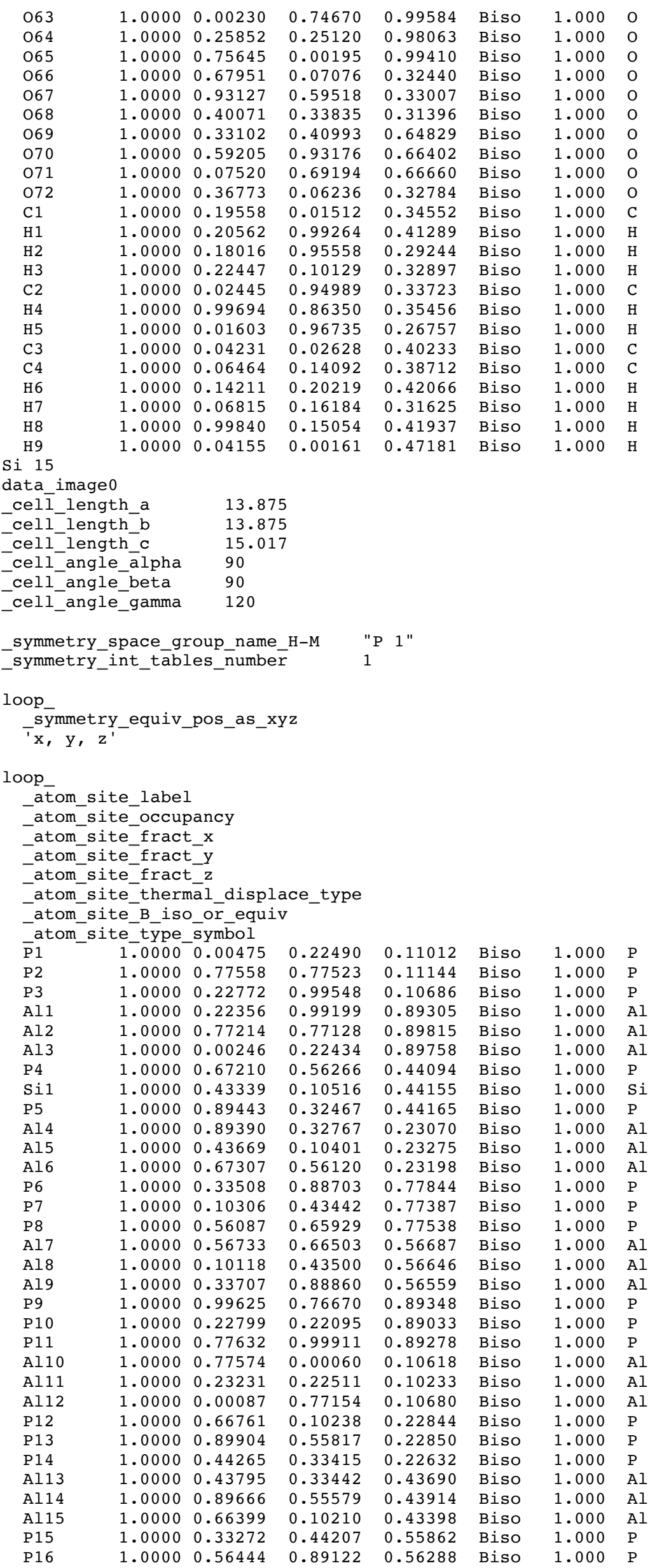




\begin{tabular}{|c|c|c|c|c|c|c|c|}
\hline P17 & 1.0000 & 0.10358 & 0.66837 & 0.56372 & Biso & 1.000 & $\mathrm{P}$ \\
\hline Al16 & 1.0000 & 0.10542 & 0.66572 & 0.77259 & Biso & 1.000 & $\mathrm{Al}$ \\
\hline Al17 & 1.0000 & 0.56297 & 0.88980 & 0.77161 & Biso & 1.000 & Al \\
\hline Al18 & 1.0000 & 0.33028 & 0.43432 & 0.76828 & Biso & 1.000 & $\mathrm{Al}$ \\
\hline 01 & 1.0000 & 0.91354 & 0.10399 & 0.13017 & Biso & 1.000 & 0 \\
\hline $\mathrm{O} 2$ & 1.0000 & 0.89728 & 0.80565 & 0.12991 & Biso & 1.000 & 0 \\
\hline 03 & 1.0000 & 0.19938 & 0.08786 & 0.12703 & Biso & 1.000 & 0 \\
\hline 04 & 1.0000 & 0.08708 & 0.88638 & 0.86977 & Biso & 1.000 & 0 \\
\hline 05 & 1.0000 & 0.80644 & 0.90823 & 0.87281 & Biso & 1.000 & 0 \\
\hline 06 & 1.0000 & 0.10628 & 0.19098 & 0.87511 & Biso & 1.000 & 0 \\
\hline 07 & 1.0000 & 0.57441 & 0.44422 & 0.45342 & Biso & 1.000 & 0 \\
\hline 08 & 1.0000 & 0.56215 & 0.13706 & 0.43545 & Biso & 1.000 & 0 \\
\hline 09 & 1.0000 & 0.87068 & 0.42051 & 0.45837 & Biso & 1.000 & 0 \\
\hline 010 & 1.0000 & 0.75601 & 0.22494 & 0.20882 & Biso & 1.000 & 0 \\
\hline 011 & 1.0000 & 0.47307 & 0.24289 & 0.20999 & Biso & 1.000 & 0 \\
\hline 012 & 1.0000 & 0.77745 & 0.52756 & 0.21171 & Biso & 1.000 & 0 \\
\hline 013 & 1.0000 & 0.24223 & 0.76694 & 0.79918 & Biso & 1.000 & 0 \\
\hline 014 & 1.0000 & 0.22565 & 0.46738 & 0.78933 & Biso & 1.000 & 0 \\
\hline 015 & 1.0000 & 0.53134 & 0.75174 & 0.78719 & Biso & 1.000 & 0 \\
\hline 016 & 1.0000 & 0.42872 & 0.56258 & 0.54705 & Biso & 1.000 & 0 \\
\hline 017 & 1.0000 & 0.12231 & 0.56877 & 0.55290 & Biso & 1.000 & 0 \\
\hline 018 & 1.0000 & 0.43995 & 0.85079 & 0.54921 & Biso & 1.000 & 0 \\
\hline 019 & 1.0000 & 0.98716 & 0.30661 & 0.16683 & Biso & 1.000 & 0 \\
\hline 020 & 1.0000 & 0.69481 & 0.67352 & 0.16604 & Biso & 1.000 & 0 \\
\hline 021 & 1.0000 & 0.33202 & 0.01648 & 0.15749 & Biso & 1.000 & 0 \\
\hline 022 & 1.0000 & 0.31921 & 0.97045 & 0.83480 & Biso & 1.000 & 0 \\
\hline 023 & 1.0000 & 0.65433 & 0.67675 & 0.83945 & Biso & 1.000 & 0 \\
\hline 024 & 1.0000 & 0.02640 & 0.34151 & 0.83788 & Biso & 1.000 & 0 \\
\hline 025 & 1.0000 & 0.65912 & 0.64496 & 0.50081 & Biso & 1.000 & 0 \\
\hline 026 & 1.0000 & 0.35831 & 0.00141 & 0.50589 & Biso & 1.000 & 0 \\
\hline 027 & 1.0000 & 0.99366 & 0.34060 & 0.49827 & Biso & 1.000 & 0 \\
\hline 028 & 1.0000 & 0.01242 & 0.68136 & 0.84082 & Biso & 1.000 & 0 \\
\hline 029 & 1.0000 & 0.30720 & 0.31994 & 0.83242 & Biso & 1.000 & 0 \\
\hline 030 & 1.0000 & 0.67456 & 0.97937 & 0.83885 & Biso & 1.000 & 0 \\
\hline 031 & 1.0000 & 0.68054 & 0.02512 & 0.16224 & Biso & 1.000 & 0 \\
\hline 032 & 1.0000 & 0.34815 & 0.31812 & 0.16357 & Biso & 1.000 & 0 \\
\hline 033 & 1.0000 & 0.97848 & 0.65670 & 0.16970 & Biso & 1.000 & 0 \\
\hline 034 & 1.0000 & 0.34540 & 0.36339 & 0.49474 & Biso & 1.000 & 0 \\
\hline 035 & 1.0000 & 0.00670 & 0.65292 & 0.50425 & Biso & 1.000 & 0 \\
\hline 036 & 1.0000 & 0.63790 & 0.98871 & 0.50158 & Biso & 1.000 & 0 \\
\hline 037 & 1.0000 & 0.11806 & 0.23772 & 0.13492 & Biso & 1.000 & 0 \\
\hline 038 & 1.0000 & 0.76170 & 0.87375 & 0.13980 & Biso & 1.000 & 0 \\
\hline 039 & 1.0000 & 0.12906 & 0.88449 & 0.13959 & Biso & 1.000 & 0 \\
\hline 040 & 1.0000 & 0.23997 & 0.12084 & 0.86387 & Biso & 1.000 & 0 \\
\hline 041 & 1.0000 & 0.88268 & 0.75204 & 0.86861 & Biso & 1.000 & 0 \\
\hline 042 & 1.0000 & 0.87467 & 0.11235 & 0.86592 & Biso & 1.000 & 0 \\
\hline 043 & 1.0000 & 0.78017 & 0.56529 & 0.46718 & Biso & 1.000 & 0 \\
\hline 044 & 1.0000 & 0.42075 & 0.21006 & 0.47088 & Biso & 1.000 & 0 \\
\hline 045 & 1.0000 & 0.79320 & 0.21409 & 0.46818 & Biso & 1.000 & 0 \\
\hline 046 & 1.0000 & 0.91241 & 0.45830 & 0.20414 & Biso & 1.000 & 0 \\
\hline 047 & 1.0000 & 0.55181 & 0.08804 & 0.21500 & Biso & 1.000 & 0 \\
\hline 048 & 1.0000 & 0.54444 & 0.44761 & 0.20525 & Biso & 1.000 & 0 \\
\hline 049 & 1.0000 & 0.44737 & 0.89885 & 0.80407 & Biso & 1.000 & 0 \\
\hline 050 & 1.0000 & 0.08924 & 0.53512 & 0.79240 & Biso & 1.000 & 0 \\
\hline 051 & 1.0000 & 0.45833 & 0.54720 & 0.79812 & Biso & 1.000 & 0 \\
\hline 052 & 1.0000 & 0.58538 & 0.79513 & 0.54089 & Biso & 1.000 & 0 \\
\hline 053 & 1.0000 & 0.22299 & 0.43755 & 0.53550 & Biso & 1.000 & 0 \\
\hline 054 & 1.0000 & 0.20844 & 0.77419 & 0.53437 & Biso & 1.000 & 0 \\
\hline 055 & 1.0000 & 0.00247 & 0.25219 & 0.01128 & Biso & 1.000 & 0 \\
\hline 056 & 1.0000 & 0.74760 & 0.74845 & 0.01241 & Biso & 1.000 & 0 \\
\hline 057 & 1.0000 & 0.24710 & 0.99014 & 0.00717 & Biso & 1.000 & 0 \\
\hline 058 & 1.0000 & 0.67890 & 0.60041 & 0.34342 & Biso & 1.000 & 0 \\
\hline 059 & 1.0000 & 0.92484 & 0.32350 & 0.34306 & Biso & 1.000 & $\mathrm{O}$ \\
\hline 060 & 1.0000 & 0.33233 & 0.91338 & 0.67989 & Biso & 1.000 & 0 \\
\hline 061 & 1.0000 & 0.06838 & 0.39278 & 0.67766 & Biso & 1.000 & 0 \\
\hline 062 & 1.0000 & 0.59935 & 0.65918 & 0.67919 & Biso & 1.000 & 0 \\
\hline 063 & 1.0000 & 0.00094 & 0.74477 & 0.99349 & Biso & 1.000 & 0 \\
\hline 064 & 1.0000 & 0.25970 & 0.25149 & 0.98881 & Biso & 1.000 & 0 \\
\hline 065 & 1.0000 & 0.75021 & 0.99853 & 0.99229 & Biso & 1.000 & 0 \\
\hline 066 & 1.0000 & 0.68272 & 0.07004 & 0.32319 & Biso & 1.000 & 0 \\
\hline 067 & 1.0000 & 0.93078 & 0.59167 & 0.32663 & Biso & 1.000 & 0 \\
\hline 068 & 1.0000 & 0.40350 & 0.33053 & 0.32268 & Biso & 1.000 & 0 \\
\hline 069 & 1.0000 & 0.32979 & 0.40290 & 0.65524 & Biso & 1.000 & 0 \\
\hline 070 & 1.0000 & 0.59791 & 0.92878 & 0.66032 & Biso & 1.000 & 0 \\
\hline 071 & 1.0000 & 0.07485 & 0.67777 & 0.66132 & Biso & 1.000 & 0 \\
\hline 072 & 1.0000 & 0.37827 & 0.06590 & 0.33914 & Biso & 1.000 & 0 \\
\hline $\mathrm{C} 1$ & 1.0000 & 0.20905 & 0.01967 & 0.35014 & Biso & 1.000 & C \\
\hline H 1 & 1.0000 & 0.21310 & 0.00206 & 0.42013 & Biso & 1.000 & $\mathrm{H}$ \\
\hline H2 & 1.0000 & 0.18942 & 0.95410 & 0.30177 & Biso & 1.000 & $\mathrm{H}$ \\
\hline $\mathrm{H} 3$ & 1.0000 & 0.23266 & 0.10295 & 0.32810 & Biso & 1.000 & $\mathrm{H}$ \\
\hline
\end{tabular}




\begin{tabular}{|c|c|c|c|c|c|c|c|}
\hline $\mathrm{C} 2$ & 1.0000 & 0.02792 & 0.95256 & 0.33786 & Biso & 1.000 & $\mathrm{C}$ \\
\hline $\mathrm{H} 4$ & 1.0000 & 0.00079 & 0.86685 & 0.35719 & Biso & 1.000 & $\mathrm{H}$ \\
\hline H5 & 1.0000 & 0.02394 & 0.96870 & 0.26711 & Biso & 1.000 & $\mathrm{H}$ \\
\hline C3 & 1.0000 & 0.04619 & 0.03109 & 0.40040 & Biso & 1.000 & $\mathrm{C}$ \\
\hline C4 & 1.0000 & 0.07111 & 0.14628 & 0.38186 & Biso & 1.000 & $\mathrm{C}$ \\
\hline H6 & 1.0000 & 0.14850 & 0.20796 & 0.41523 & Biso & 1.000 & $\mathrm{H}$ \\
\hline H7 & 1.0000 & 0.07655 & 0.16482 & 0.31035 & Biso & 1.000 & $\mathrm{H}$ \\
\hline H 8 & 1.0000 & 0.00518 & 0.15868 & 0.41122 & Biso & 1.000 & $\mathrm{H}$ \\
\hline H9 & 1.0000 & 0.04254 & 0.00819 & 0.47073 & Biso & 1.000 & $\mathrm{H}$ \\
\hline \multicolumn{8}{|c|}{$\begin{array}{l}\text { Mg } 15 \\
\text { data image } 0\end{array}$} \\
\hline $\begin{array}{l}\text { data_in } \\
\text { cell__ } \\
\text { cell__ } \\
\text { cell__ } \\
\text { cell__ } \\
\text { cell_- } \\
\text { cell__ }\end{array}$ & $\begin{array}{l}0 \\
t h \_a \\
t h \_b \\
t h \_c \\
\text { _alpha } \\
\text { _beta } \\
\text { __gamma }\end{array}$ & $\begin{array}{l}13.87 \\
13.87 \\
15.01 \\
90 \\
90 \\
120\end{array}$ & & & & & \\
\hline symmet & pace_gr & :oup_name & & $1 "$ & & & \\
\hline symmet & int_tabl & es_numbe & & & & & \\
\hline loop_ & & & & & & & \\
\hline $\bar{T}_{\mathrm{x}}^{\text {symn }}$ & _equiv & pos_as_y & & & & & \\
\hline loop_ & & & & & & & \\
\hline $\begin{array}{l}\text {-aton } \\
\text {-aton } \\
\text {-aton } \\
\text {-aton } \\
\text {-aton } \\
\text {-aton } \\
\text {-aton } \\
\text {-aton }\end{array}$ & $\begin{array}{l}\text { e_label } \\
\text { e_occup } \\
\text { e_fract } \\
\text { e_fract } \\
\text { e_fract } \\
\text { e_therm } \\
\text { e_B_iso } \\
\text { e-type }\end{array}$ & $\begin{array}{l}\text { bancy } \\
=\text { - } \\
\text { _y } \\
\text { zzal_displ } \\
\text { or_equi } \\
\text { symbol }\end{array}$ & ce_type & & & & \\
\hline$\overline{\mathrm{A}} 11$ & 1.0000 & 0.99736 & 0.22359 & 0.10463 & Biso & 1.000 & Al \\
\hline Al2 & 1.0000 & 0.77661 & 0.77450 & 0.10816 & Biso & 1.000 & Al \\
\hline A13 & 1.0000 & 0.23209 & 0.00305 & 0.09909 & Biso & 1.000 & Al \\
\hline P1 & 1.0000 & 0.22355 & 0.99774 & 0.88715 & Biso & 1.000 & $\mathrm{P}$ \\
\hline $\mathrm{P} 2$ & 1.0000 & 0.77503 & 0.76996 & 0.89456 & Biso & 1.000 & $\mathrm{P}$ \\
\hline P3 & 1.0000 & 0.99454 & 0.22220 & 0.89158 & Biso & 1.000 & $\mathrm{P}$ \\
\hline Al4 & 1.0000 & 0.66207 & 0.55931 & 0.43621 & Biso & 1.000 & Al \\
\hline $\operatorname{Mg} 1$ & 1.0000 & 0.44983 & 0.11135 & 0.44279 & Biso & 1.000 & $\mathrm{Mg}$ \\
\hline Al5 & 1.0000 & 0.90347 & 0.33271 & 0.43658 & Biso & 1.000 & Al \\
\hline P4 & 1.0000 & 0.89756 & 0.33686 & 0.22574 & Biso & 1.000 & $\mathrm{P}$ \\
\hline P5 & 1.0000 & 0.43783 & 0.10287 & 0.22519 & Biso & 1.000 & $\mathrm{P}$ \\
\hline P6 & 1.0000 & 0.66642 & 0.56054 & 0.22781 & Biso & 1.000 & $\mathrm{P}$ \\
\hline Al6 & 1.0000 & 0.32684 & 0.88334 & 0.77317 & Biso & 1.000 & Al \\
\hline Al7 & 1.0000 & 0.10446 & 0.43134 & 0.76835 & Biso & 1.000 & Al \\
\hline A18 & 1.0000 & 0.56380 & 0.66699 & 0.77190 & Biso & 1.000 & Al \\
\hline P7 & 1.0000 & 0.57519 & 0.67531 & 0.56418 & Biso & 1.000 & $\mathrm{P}$ \\
\hline P8 & 1.0000 & 0.10614 & 0.43613 & 0.56354 & Biso & 1.000 & $\mathrm{P}$ \\
\hline P9 & 1.0000 & 0.32771 & 0.87973 & 0.56037 & Biso & 1.000 & $\mathrm{P}$ \\
\hline Al9 & 1.0000 & 0.99947 & 0.76792 & 0.89955 & Biso & 1.000 & Al \\
\hline Al10 & 1.0000 & 0.22291 & 0.22447 & 0.89193 & Biso & 1.000 & Al \\
\hline Al11 & 1.0000 & 0.77204 & 0.99377 & 0.89571 & Biso & 1.000 & Al \\
\hline $\mathrm{P} 10$ & 1.0000 & 0.77193 & 0.99635 & 0.11003 & Biso & 1.000 & $\mathrm{P}$ \\
\hline P11 & 1.0000 & 0.22659 & 0.22731 & 0.10535 & Biso & 1.000 & $\mathrm{P}$ \\
\hline P12 & 1.0000 & 0.00476 & 0.77779 & 0.11302 & Biso & 1.000 & $\mathrm{P}$ \\
\hline Al12 & 1.0000 & 0.67263 & 0.10631 & 0.23457 & Biso & 1.000 & Al \\
\hline Al13 & 1.0000 & 0.89396 & 0.56167 & 0.23282 & Biso & 1.000 & Al \\
\hline Al14 & 1.0000 & 0.43684 & 0.33003 & 0.22913 & Biso & 1.000 & Al \\
\hline P13 & 1.0000 & 0.42557 & 0.33081 & 0.43825 & Biso & 1.000 & $\mathrm{P}$ \\
\hline P 14 & 1.0000 & 0.88908 & 0.55506 & 0.44382 & Biso & 1.000 & $\mathrm{P}$ \\
\hline P15 & 1.0000 & 0.68176 & 0.10861 & 0.43799 & Biso & 1.000 & $\mathrm{P}$ \\
\hline Al15 & 1.0000 & 0.34091 & 0.45095 & 0.56324 & Biso & 1.000 & Al \\
\hline Al16 & 1.0000 & 0.55956 & 0.89545 & 0.56631 & Biso & 1.000 & Al \\
\hline Al17 & 1.0000 & 0.09434 & 0.66383 & 0.57043 & Biso & 1.000 & Al \\
\hline P16 & 1.0000 & 0.09994 & 0.66052 & 0.77799 & Biso & 1.000 & $\mathrm{P}$ \\
\hline P17 & 1.0000 & 0.55683 & 0.89301 & 0.77633 & Biso & 1.000 & $\mathrm{P}$ \\
\hline P18 & 1.0000 & 0.33565 & 0.43901 & 0.77259 & Biso & 1.000 & $\mathrm{P}$ \\
\hline 01 & 1.0000 & 0.89295 & 0.08746 & 0.13048 & Biso & 1.000 & 0 \\
\hline $\mathrm{O} 2$ & 1.0000 & 0.91509 & 0.81004 & 0.13226 & Biso & 1.000 & 0 \\
\hline 03 & 1.0000 & 0.20025 & 0.10728 & 0.12614 & Biso & 1.000 & 0 \\
\hline 04 & 1.0000 & 0.10284 & 0.90368 & 0.87156 & Biso & 1.000 & 0 \\
\hline 05 & 1.0000 & 0.80638 & 0.89058 & 0.87161 & Biso & 1.000 & 0 \\
\hline 06 & 1.0000 & 0.08624 & 0.19361 & 0.87120 & Biso & 1.000 & 0 \\
\hline 07 & 1.0000 & 0.54595 & 0.42850 & 0.44927 & Biso & 1.000 & 0 \\
\hline 08 & 1.0000 & 0.60285 & 0.15442 & 0.44023 & Biso & 1.000 & 0 \\
\hline 09 & 1.0000 & 0.87162 & 0.43784 & 0.46006 & Biso & 1.000 & 0 \\
\hline 010 & 1.0000 & 0.77538 & 0.24514 & 0.21232 & Biso & 1.000 & 0 \\
\hline
\end{tabular}




\begin{tabular}{|c|c|c|c|c|c|c|c|}
\hline 011 & 1.0000 & 0.46971 & 0.22499 & 0.20805 & Biso & 1.000 & 0 \\
\hline 012 & 1.0000 & 0.75672 & 0.52869 & 0.21132 & Biso & 1.000 & 0 \\
\hline 013 & 1.0000 & 0.22127 & 0.74791 & 0.80045 & Biso & 1.000 & 0 \\
\hline 014 & 1.0000 & 0.24305 & 0.46760 & 0.78970 & Biso & 1.000 & 0 \\
\hline 015 & 1.0000 & 0.52946 & 0.77131 & 0.78640 & Biso & 1.000 & 0 \\
\hline 016 & 1.0000 & 0.45331 & 0.58524 & 0.54739 & Biso & 1.000 & 0 \\
\hline 017 & 1.0000 & 0.11200 & 0.54907 & 0.56019 & Biso & 1.000 & 0 \\
\hline 018 & 1.0000 & 0.41757 & 0.84542 & 0.54708 & Biso & 1.000 & 0 \\
\hline 019 & 1.0000 & 0.97547 & 0.31814 & 0.16472 & Biso & 1.000 & 0 \\
\hline 020 & 1.0000 & 0.68325 & 0.65502 & 0.16537 & Biso & 1.000 & 0 \\
\hline 021 & 1.0000 & 0.35159 & 0.02648 & 0.15577 & Biso & 1.000 & $\mathrm{O}$ \\
\hline $\mathrm{O} 22$ & 1.0000 & 0.30515 & 0.98049 & 0.83053 & Biso & 1.000 & 0 \\
\hline $\mathrm{O} 23$ & 1.0000 & 0.67117 & 0.68669 & 0.84322 & Biso & 1.000 & 0 \\
\hline $\mathrm{O} 24$ & 1.0000 & 0.01338 & 0.32413 & 0.83822 & Biso & 1.000 & 0 \\
\hline $\mathrm{O} 25$ & 1.0000 & 0.65390 & 0.65756 & 0.50339 & Biso & 1.000 & 0 \\
\hline 026 & 1.0000 & 0.35086 & 0.97974 & 0.50514 & Biso & 1.000 & 0 \\
\hline 027 & 1.0000 & 0.02090 & 0.35545 & 0.49634 & Biso & 1.000 & 0 \\
\hline 028 & 1.0000 & 0.02031 & 0.66960 & 0.84405 & Biso & 1.000 & 0 \\
\hline 029 & 1.0000 & 0.31691 & 0.33976 & 0.83028 & Biso & 1.000 & 0 \\
\hline 030 & 1.0000 & 0.65406 & 0.96953 & 0.83722 & Biso & 1.000 & 0 \\
\hline 031 & 1.0000 & 0.68884 & 0.01840 & 0.16014 & Biso & 1.000 & 0 \\
\hline 032 & 1.0000 & 0.32822 & 0.31130 & 0.15864 & Biso & 1.000 & 0 \\
\hline 033 & 1.0000 & 0.98635 & 0.67973 & 0.17181 & Biso & 1.000 & 0 \\
\hline 034 & 1.0000 & 0.34504 & 0.35674 & 0.48987 & Biso & 1.000 & 0 \\
\hline 035 & 1.0000 & 0.98090 & 0.64147 & 0.50452 & Biso & 1.000 & O \\
\hline 036 & 1.0000 & 0.64698 & 0.00954 & 0.50142 & Biso & 1.000 & 0 \\
\hline 037 & 1.0000 & 0.12593 & 0.23780 & 0.13383 & Biso & 1.000 & 0 \\
\hline 038 & 1.0000 & 0.75746 & 0.88433 & 0.14100 & Biso & 1.000 & 0 \\
\hline 039 & 1.0000 & 0.11939 & 0.87753 & 0.13703 & Biso & 1.000 & 0 \\
\hline 040 & 1.0000 & 0.23365 & 0.10914 & 0.86107 & Biso & 1.000 & 0 \\
\hline 041 & 1.0000 & 0.87141 & 0.75173 & 0.86805 & Biso & 1.000 & 0 \\
\hline 042 & 1.0000 & 0.88205 & 0.12320 & 0.86440 & Biso & 1.000 & 0 \\
\hline 043 & 1.0000 & 0.78080 & 0.55385 & 0.46544 & Biso & 1.000 & 0 \\
\hline 044 & 1.0000 & 0.41531 & 0.22387 & 0.47176 & Biso & 1.000 & 0 \\
\hline 045 & 1.0000 & 0.79994 & 0.19975 & 0.46628 & Biso & 1.000 & 0 \\
\hline 046 & 1.0000 & 0.90950 & 0.44963 & 0.20084 & Biso & 1.000 & 0 \\
\hline 047 & 1.0000 & 0.54156 & 0.09183 & 0.21675 & Biso & 1.000 & 0 \\
\hline 048 & 1.0000 & 0.55259 & 0.45938 & 0.20740 & Biso & 1.000 & 0 \\
\hline 049 & 1.0000 & 0.45501 & 0.90052 & 0.80587 & Biso & 1.000 & 0 \\
\hline 050 & 1.0000 & 0.08591 & 0.54446 & 0.78737 & Biso & 1.000 & 0 \\
\hline 051 & 1.0000 & 0.44775 & 0.53939 & 0.79859 & Biso & 1.000 & 0 \\
\hline 052 & 1.0000 & 0.58944 & 0.78957 & 0.54311 & Biso & 1.000 & 0 \\
\hline 053 & 1.0000 & 0.22019 & 0.45330 & 0.53820 & Biso & 1.000 & 0 \\
\hline 054 & 1.0000 & 0.21394 & 0.78035 & 0.53257 & Biso & 1.000 & 0 \\
\hline 055 & 1.0000 & 0.99495 & 0.24832 & 0.99111 & Biso & 1.000 & 0 \\
\hline 056 & 1.0000 & 0.75105 & 0.74863 & 0.99469 & Biso & 1.000 & 0 \\
\hline 057 & 1.0000 & 0.25424 & 0.99943 & 0.98592 & Biso & 1.000 & 0 \\
\hline 058 & 1.0000 & 0.67267 & 0.60040 & 0.32436 & Biso & 1.000 & 0 \\
\hline 059 & 1.0000 & 0.93380 & 0.33816 & 0.32268 & Biso & 1.000 & 0 \\
\hline 060 & 1.0000 & 0.32327 & 0.90494 & 0.66009 & Biso & 1.000 & 0 \\
\hline 061 & 1.0000 & 0.07226 & 0.38582 & 0.65770 & Biso & 1.000 & 0 \\
\hline 062 & 1.0000 & 0.60671 & 0.66961 & 0.66177 & Biso & 1.000 & 0 \\
\hline 063 & 1.0000 & 0.00178 & 0.74662 & 0.01458 & Biso & 1.000 & 0 \\
\hline 064 & 1.0000 & 0.25114 & 0.25222 & 0.00569 & Biso & 1.000 & 0 \\
\hline 065 & 1.0000 & 0.74804 & 0.99316 & 0.00994 & Biso & 1.000 & 0 \\
\hline 066 & 1.0000 & 0.68838 & 0.06881 & 0.34235 & Biso & 1.000 & 0 \\
\hline 067 & 1.0000 & 0.92398 & 0.59117 & 0.34630 & Biso & 1.000 & 0 \\
\hline 068 & 1.0000 & 0.39128 & 0.32120 & 0.33852 & Biso & 1.000 & 0 \\
\hline 069 & 1.0000 & 0.33668 & 0.40875 & 0.67410 & Biso & 1.000 & 0 \\
\hline 070 & 1.0000 & 0.58838 & 0.93221 & 0.67951 & Biso & 1.000 & 0 \\
\hline 071 & 1.0000 & 0.06965 & 0.67872 & 0.68304 & Biso & 1.000 & 0 \\
\hline 072 & 1.0000 & 0.38661 & 0.06520 & 0.31959 & Biso & 1.000 & 0 \\
\hline $\mathrm{C} 1$ & 1.0000 & 0.22442 & 0.01715 & 0.34032 & Biso & 1.000 & C \\
\hline $\mathrm{H} 1$ & 1.0000 & 0.23183 & 0.99213 & 0.40741 & Biso & 1.000 & $\mathrm{H}$ \\
\hline $\mathrm{H} 2$ & 1.0000 & 0.19648 & 0.95521 & 0.28762 & Biso & 1.000 & $\mathrm{H}$ \\
\hline H3 & 1.0000 & 0.24046 & 0.10063 & 0.32668 & Biso & 1.000 & $\mathrm{H}$ \\
\hline $\mathrm{C} 2$ & 1.0000 & 0.03427 & 0.93876 & 0.34876 & Biso & 1.000 & C \\
\hline $\mathrm{H} 4$ & 1.0000 & 0.01883 & 0.85733 & 0.37113 & Biso & 1.000 & $\mathrm{H}$ \\
\hline H5 & 1.0000 & 0.01572 & 0.94620 & 0.27919 & Biso & 1.000 & $\mathrm{H}$ \\
\hline $\mathrm{C} 3$ & 1.0000 & 0.05929 & 0.02238 & 0.40774 & Biso & 1.000 & $\mathrm{C}$ \\
\hline $\mathrm{C} 4$ & 1.0000 & 0.07027 & 0.13187 & 0.38607 & Biso & 1.000 & $\mathrm{C}$ \\
\hline H6 & 1.0000 & 0.15037 & 0.20116 & 0.40964 & Biso & 1.000 & $\mathrm{H}$ \\
\hline $\mathrm{H} 7$ & 1.0000 & 0.06103 & 0.14177 & 0.31454 & Biso & 1.000 & $\mathrm{H}$ \\
\hline H8 & 1.0000 & 0.00590 & 0.14048 & 0.42258 & Biso & 1.000 & $\mathrm{H}$ \\
\hline H9 & 1.0000 & 0.07202 & 0.00875 & 0.47766 & Biso & 1.000 & $\mathrm{H}$ \\
\hline \\
\hline \multicolumn{8}{|c|}{ ata ima } \\
\hline \\
\hline \multicolumn{2}{|c|}{ cell length b } & \multicolumn{2}{|c|}{13.875} & & & & \\
\hline cell & th_c & 15.01 & & & & & \\
\hline
\end{tabular}




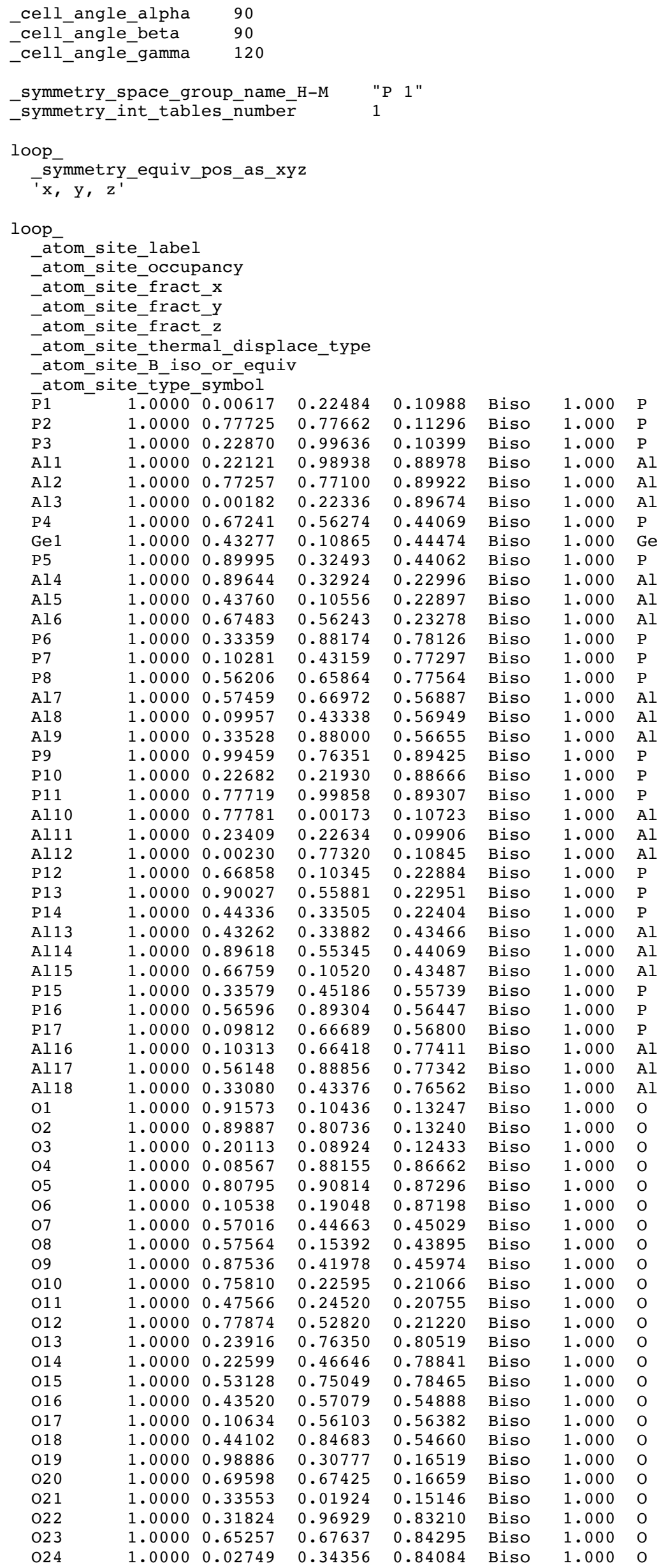




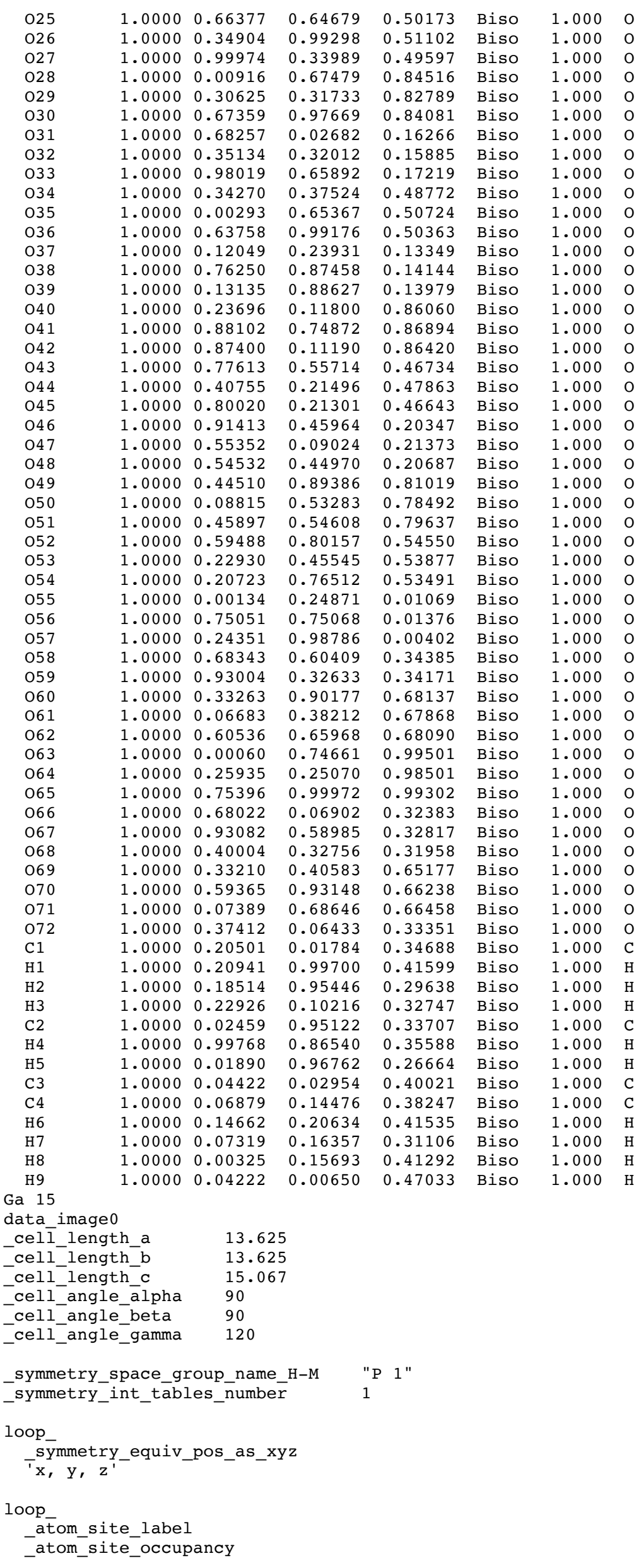




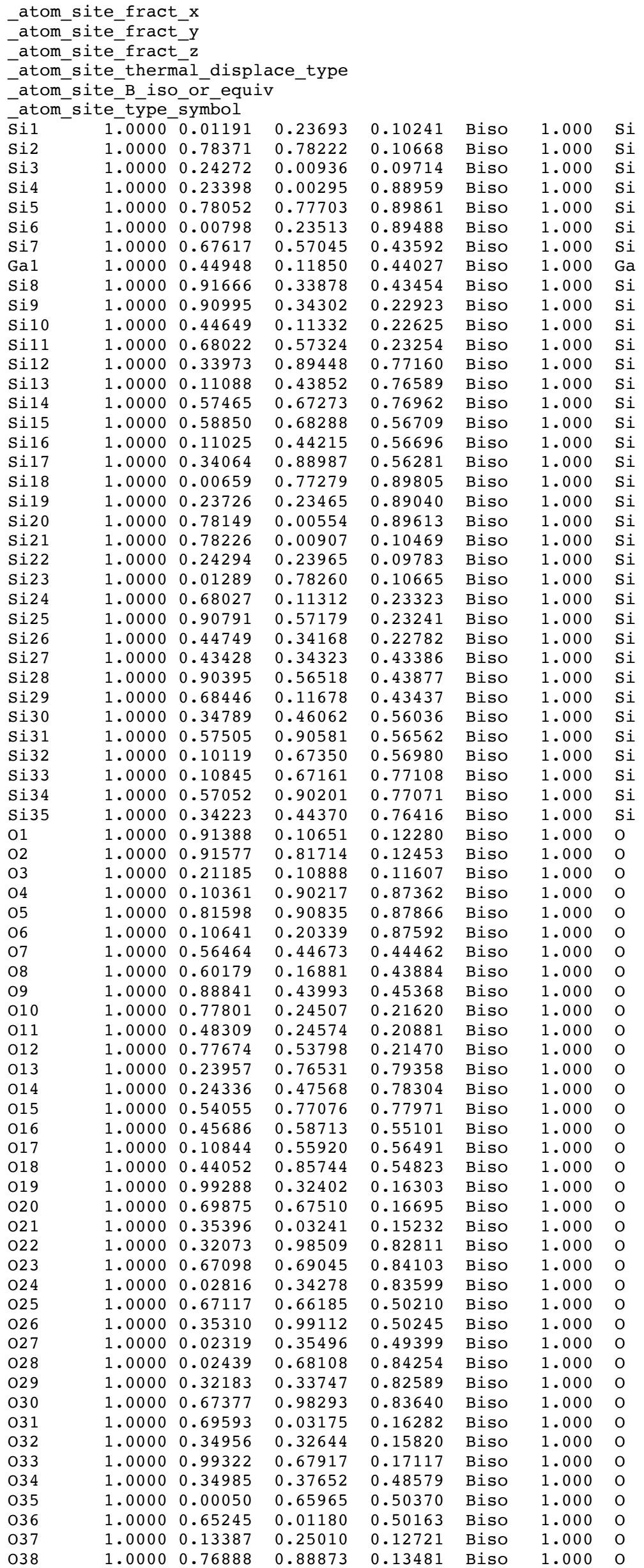




\begin{tabular}{|c|c|c|c|c|c|c|c|}
\hline 039 & 1.0000 & 0.13542 & 0.89099 & 0.13222 & Biso & 1.000 & 0 \\
\hline 040 & 1.0000 & 0.24595 & 0.12393 & 0.86479 & Biso & 1.000 & 0 \\
\hline 041 & 1.0000 & 0.88475 & 0.75790 & 0.87161 & Biso & 1.000 & 0 \\
\hline 042 & 1.0000 & 0.88714 & 0.12736 & 0.86777 & Biso & 1.000 & 0 \\
\hline 043 & 1.0000 & 0.78564 & 0.55966 & 0.46211 & Biso & 1.000 & 0 \\
\hline 044 & 1.0000 & 0.41655 & 0.22776 & 0.47498 & Biso & 1.000 & 0 \\
\hline 045 & 1.0000 & 0.81199 & 0.21634 & 0.46112 & Biso & 1.000 & 0 \\
\hline 046 & 1.0000 & 0.92310 & 0.46517 & 0.20569 & Biso & 1.000 & 0 \\
\hline 047 & 1.0000 & 0.55742 & 0.10053 & 0.21557 & Biso & 1.000 & 0 \\
\hline 048 & 1.0000 & 0.55699 & 0.46554 & 0.21168 & Biso & 1.000 & 0 \\
\hline 049 & 1.0000 & 0.46022 & 0.90860 & 0.80186 & Biso & 1.000 & 0 \\
\hline 050 & 1.0000 & 0.09432 & 0.54697 & 0.77915 & Biso & 1.000 & 0 \\
\hline 051 & 1.0000 & 0.46364 & 0.55135 & 0.79041 & Biso & 1.000 & 0 \\
\hline 052 & 1.0000 & 0.60480 & 0.80645 & 0.54484 & Biso & 1.000 & 0 \\
\hline 053 & 1.0000 & 0.23662 & 0.47058 & 0.54171 & Biso & 1.000 & 0 \\
\hline 054 & 1.0000 & 0.22005 & 0.77835 & 0.53715 & Biso & 1.000 & 0 \\
\hline 055 & 1.0000 & 0.00867 & 0.26771 & 0.99880 & Biso & 1.000 & 0 \\
\hline 056 & 1.0000 & 0.75051 & 0.74871 & 0.00329 & Biso & 1.000 & 0 \\
\hline 057 & 1.0000 & 0.26722 & 0.00190 & 0.99316 & Biso & 1.000 & 0 \\
\hline 058 & 1.0000 & 0.68895 & 0.61719 & 0.33431 & Biso & 1.000 & 0 \\
\hline 059 & 1.0000 & 0.95090 & 0.34188 & 0.33046 & Biso & 1.000 & 0 \\
\hline 060 & 1.0000 & 0.33934 & 0.92125 & 0.66733 & Biso & 1.000 & 0 \\
\hline 061 & 1.0000 & 0.07443 & 0.38637 & 0.66586 & Biso & 1.000 & 0 \\
\hline 062 & 1.0000 & 0.62313 & 0.67656 & 0.66989 & Biso & 1.000 & 0 \\
\hline 063 & 1.0000 & 0.01085 & 0.74752 & 0.00343 & Biso & 1.000 & 0 \\
\hline 064 & 1.0000 & 0.27390 & 0.27139 & 0.99358 & Biso & 1.000 & 0 \\
\hline 065 & 1.0000 & 0.75052 & 0.00634 & 0.00038 & Biso & 1.000 & 0 \\
\hline 066 & 1.0000 & 0.68938 & 0.07329 & 0.33321 & Biso & 1.000 & 0 \\
\hline 067 & 1.0000 & 0.94140 & 0.60706 & 0.33623 & Biso & 1.000 & 0 \\
\hline 068 & 1.0000 & 0.39869 & 0.32998 & 0.32814 & Biso & 1.000 & 0 \\
\hline 069 & 1.0000 & 0.34229 & 0.41055 & 0.66008 & Biso & 1.000 & 0 \\
\hline 070 & 1.0000 & 0.60617 & 0.94627 & 0.66907 & Biso & 1.000 & 0 \\
\hline 071 & 1.0000 & 0.07337 & 0.69222 & 0.67191 & Biso & 1.000 & 0 \\
\hline 072 & 1.0000 & 0.38711 & 0.07102 & 0.32361 & Biso & 1.000 & 0 \\
\hline $\mathrm{C} 1$ & 1.0000 & 0.21768 & 0.01841 & 0.34005 & Biso & 1.000 & $\mathrm{C}$ \\
\hline H 1 & 1.0000 & 0.22392 & 0.99184 & 0.40686 & Biso & 1.000 & $\mathrm{H}$ \\
\hline H2 & 1.0000 & 0.19506 & 0.95796 & 0.28604 & Biso & 1.000 & $\mathrm{H}$ \\
\hline H3 & 1.0000 & 0.23603 & 0.10414 & 0.32670 & Biso & 1.000 & $\mathrm{H}$ \\
\hline $\mathrm{C} 2$ & 1.0000 & 0.02788 & 0.93924 & 0.33922 & Biso & 1.000 & $\mathrm{C}$ \\
\hline $\mathrm{H} 4$ & 1.0000 & 0.00940 & 0.85416 & 0.35771 & Biso & 1.000 & $\mathrm{H}$ \\
\hline H5 & 1.0000 & 0.01450 & 0.95316 & 0.26989 & Biso & 1.000 & $\mathrm{H}$ \\
\hline $\mathrm{C} 3$ & 1.0000 & 0.04856 & 0.01899 & 0.40210 & Biso & 1.000 & $\mathrm{C}$ \\
\hline $\mathrm{C} 4$ & 1.0000 & 0.06229 & 0.13253 & 0.38531 & Biso & 1.000 & $\mathrm{C}$ \\
\hline H6 & 1.0000 & 0.14218 & 0.20042 & 0.41370 & Biso & 1.000 & $\mathrm{H}$ \\
\hline H 7 & 1.0000 & 0.05835 & 0.14903 & 0.31441 & Biso & 1.000 & $\mathrm{H}$ \\
\hline H8 & 1.0000 & 0.99454 & 0.13889 & 0.42034 & Biso & 1.000 & $\mathrm{H}$ \\
\hline H9 & 1.0000 & 0.05535 & 0.99853 & 0.47141 & Biso & 1.000 & $\mathrm{H}$ \\
\hline \\
\hline \multirow{2}{*}{\multicolumn{8}{|c|}{$\begin{array}{l}\text { data_image } 0 \\
\text { celil length a } \\
13.875\end{array}$}} \\
\hline & & & & & & & \\
\hline \multicolumn{8}{|c|}{ cell length b 13.875} \\
\hline \multicolumn{8}{|c|}{ cell_length_c $\quad 15.017$} \\
\hline \multicolumn{8}{|c|}{ cell-angle ālpha $\quad 90$} \\
\hline \multicolumn{8}{|c|}{ cell_angle_beta 90} \\
\hline \multicolumn{8}{|c|}{ _cell_angle_gamma } \\
\hline symme & space_gr & oup_name & & P $1 "$ & & & \\
\hline symme & int_t $\overline{a b}]$ & es_numbe & - & & & & \\
\hline oop_ & & & & & & & \\
\hline sym & equiv & pos as & & & & & \\
\hline ' $\mathrm{x}$, & & & & & & & \\
\hline oop & & & & & & & \\
\hline -ato & Ee_label & & & & & & \\
\hline atc & ce occup & ancy & & & & & \\
\hline atc & ce_fract & & & & & & \\
\hline -ato & ee_fract & $y$ & & & & & \\
\hline -ato & ee_fract & $z$ & & & & & \\
\hline -ato & ce_thern & $\bar{a} \bar{l}$ _displ & ace_type & & & & \\
\hline -ato & ee_B_isc & or_equi & & & & & \\
\hline ato & ce-type & symbol & & & & & \\
\hline$\overline{\mathrm{P}} 1$ & 1.0000 & 0.00740 & 0.22563 & 0.10948 & Biso & 1.000 & $\mathrm{P}$ \\
\hline $\mathrm{P} 2$ & 1.0000 & 0.77954 & 0.77874 & 0.11434 & Biso & 1.000 & $\mathrm{P}$ \\
\hline P3 & 1.0000 & 0.23094 & 0.99747 & 0.10098 & Biso & 1.000 & $\mathrm{P}$ \\
\hline Al1 & 1.0000 & 0.21970 & 0.98791 & 0.88677 & Biso & 1.000 & Al \\
\hline Al2 & 1.0000 & 0.77241 & 0.77075 & 0.90042 & Biso & 1.000 & Al \\
\hline A13 & 1.0000 & 0.00123 & 0.22282 & 0.89623 & Biso & 1.000 & Al \\
\hline P 4 & 1.0000 & 0.67251 & 0.56316 & 0.44149 & Biso & 1.000 & $\mathrm{P}$ \\
\hline Ti1 & 1.0000 & 0.42812 & 0.10647 & 0.44626 & Biso & 1.000 & $\mathrm{Ti}$ \\
\hline
\end{tabular}




\begin{tabular}{|c|c|c|c|c|c|c|c|}
\hline P5 & 1.0000 & 0.90396 & 0.32600 & 0.43980 & Biso & 1.000 & $\mathrm{P}$ \\
\hline Al4 & 1.0000 & 0.89889 & 0.33103 & 0.22963 & Biso & 1.000 & Al \\
\hline Al5 & 1.0000 & 0.43748 & 0.10606 & 0.22702 & Biso & 1.000 & Al \\
\hline Al6 & 1.0000 & 0.67629 & 0.56341 & 0.23353 & Biso & 1.000 & Al \\
\hline P6 & 1.0000 & 0.33245 & 0.87710 & 0.78319 & Biso & 1.000 & $P$ \\
\hline P7 & 1.0000 & 0.10281 & 0.43041 & 0.77270 & Biso & 1.000 & $P$ \\
\hline P8 & 1.0000 & 0.56230 & 0.65788 & 0.77634 & Biso & 1.000 & $\mathrm{P}$ \\
\hline Al7 & 1.0000 & 0.57924 & 0.67162 & 0.57082 & Biso & 1.000 & Al \\
\hline Al 8 & 1.0000 & 0.09941 & 0.43328 & 0.57084 & Biso & 1.000 & Al \\
\hline Al9 & 1.0000 & 0.33366 & 0.87298 & 0.56709 & Biso & 1.000 & Al \\
\hline P9 & 1.0000 & 0.99339 & 0.76183 & 0.89442 & Biso & 1.000 & $\mathrm{P}$ \\
\hline $\mathrm{P} 10$ & 1.0000 & 0.22609 & 0.21853 & 0.88463 & Biso & 1.000 & $P$ \\
\hline P11 & 1.0000 & 0.77717 & 0.99791 & 0.89354 & Biso & 1.000 & $\mathrm{P}$ \\
\hline Al10 & 1.0000 & 0.77886 & 0.00300 & 0.10799 & Biso & 1.000 & $\mathrm{Al}$ \\
\hline Al11 & 1.0000 & 0.23557 & 0.22725 & 0.09715 & Biso & 1.000 & Al \\
\hline Al12 & 1.0000 & 0.00431 & 0.77504 & 0.10878 & Biso & 1.000 & Al \\
\hline P12 & 1.0000 & 0.67012 & 0.10535 & 0.22956 & Biso & 1.000 & $\mathrm{P}$ \\
\hline P13 & 1.0000 & 0.90191 & 0.56063 & 0.23053 & Biso & 1.000 & $P$ \\
\hline P14 & 1.0000 & 0.44368 & 0.33675 & 0.22340 & Biso & 1.000 & $\mathrm{P}$ \\
\hline Al13 & 1.0000 & 0.42873 & 0.34353 & 0.43368 & Biso & 1.000 & Al \\
\hline Al14 & 1.0000 & 0.89632 & 0.55340 & 0.44154 & Biso & 1.000 & Al \\
\hline Al15 & 1.0000 & 0.67156 & 0.10543 & 0.43633 & Biso & 1.000 & Al \\
\hline P15 & 1.0000 & 0.33637 & 0.45760 & 0.55691 & Biso & 1.000 & $\mathrm{P}$ \\
\hline P16 & 1.0000 & 0.56804 & 0.89429 & 0.56537 & Biso & 1.000 & $P$ \\
\hline P 17 & 1.0000 & 0.09482 & 0.66506 & 0.57023 & Biso & 1.000 & $\mathrm{P}$ \\
\hline Al16 & 1.0000 & 0.10183 & 0.66301 & 0.77506 & Biso & 1.000 & Al \\
\hline Al17 & 1.0000 & 0.55975 & 0.88718 & 0.77486 & Biso & 1.000 & $\mathrm{Al}$ \\
\hline Al18 & 1.0000 & 0.33019 & 0.43374 & 0.76459 & Biso & 1.000 & Al \\
\hline 01 & 1.0000 & 0.91682 & 0.10564 & 0.13327 & Biso & 1.000 & 0 \\
\hline $\mathrm{O} 2$ & 1.0000 & 0.90154 & 0.81016 & 0.13321 & Biso & 1.000 & 0 \\
\hline 03 & 1.0000 & 0.20336 & 0.09024 & 0.12196 & Biso & 1.000 & 0 \\
\hline 04 & 1.0000 & 0.08413 & 0.87913 & 0.86479 & Biso & 1.000 & 0 \\
\hline 05 & 1.0000 & 0.80869 & 0.90799 & 0.87344 & Biso & 1.000 & 0 \\
\hline 06 & 1.0000 & 0.10466 & 0.19010 & 0.87069 & Biso & 1.000 & 0 \\
\hline 07 & 1.0000 & 0.56634 & 0.45012 & 0.45128 & Biso & 1.000 & 0 \\
\hline 08 & 1.0000 & 0.57392 & 0.14705 & 0.44310 & Biso & 1.000 & 0 \\
\hline 09 & 1.0000 & 0.87960 & 0.42097 & 0.45903 & Biso & 1.000 & 0 \\
\hline 010 & 1.0000 & 0.76019 & 0.22778 & 0.21146 & Biso & 1.000 & 0 \\
\hline 011 & 1.0000 & 0.47585 & 0.24659 & 0.20863 & Biso & 1.000 & 0 \\
\hline 012 & 1.0000 & 0.78012 & 0.52902 & 0.21285 & Biso & 1.000 & 0 \\
\hline 013 & 1.0000 & 0.23713 & 0.76044 & 0.80983 & Biso & 1.000 & 0 \\
\hline 014 & 1.0000 & 0.22619 & 0.46705 & 0.78987 & Biso & 1.000 & 0 \\
\hline 015 & 1.0000 & 0.53033 & 0.74907 & 0.78318 & Biso & 1.000 & 0 \\
\hline 016 & 1.0000 & 0.44000 & 0.57373 & 0.54973 & Biso & 1.000 & 0 \\
\hline 017 & 1.0000 & 0.09276 & 0.55401 & 0.57001 & Biso & 1.000 & 0 \\
\hline 018 & 1.0000 & 0.44434 & 0.84842 & 0.54209 & Biso & 1.000 & 0 \\
\hline 019 & 1.0000 & 0.99094 & 0.30961 & 0.16414 & Biso & 1.000 & 0 \\
\hline 020 & 1.0000 & 0.69890 & 0.67636 & 0.16822 & Biso & 1.000 & 0 \\
\hline 021 & 1.0000 & 0.33983 & 0.02206 & 0.14570 & Biso & 1.000 & 0 \\
\hline 022 & 1.0000 & 0.31614 & 0.96760 & 0.82808 & Biso & 1.000 & 0 \\
\hline 023 & 1.0000 & 0.65069 & 0.67620 & 0.84599 & Biso & 1.000 & 0 \\
\hline 024 & 1.0000 & 0.02710 & 0.34370 & 0.84125 & Biso & 1.000 & 0 \\
\hline 025 & 1.0000 & 0.66892 & 0.64983 & 0.50298 & Biso & 1.000 & 0 \\
\hline 026 & 1.0000 & 0.34298 & 0.98735 & 0.51554 & Biso & 1.000 & 0 \\
\hline 027 & 1.0000 & 0.00406 & 0.34033 & 0.49456 & Biso & 1.000 & 0 \\
\hline 028 & 1.0000 & 0.00704 & 0.67171 & 0.84657 & Biso & 1.000 & 0 \\
\hline 029 & 1.0000 & 0.30520 & 0.31593 & 0.82513 & Biso & 1.000 & 0 \\
\hline 030 & 1.0000 & 0.67276 & 0.97462 & 0.84182 & Biso & 1.000 & 0 \\
\hline 031 & 1.0000 & 0.68374 & 0.02870 & 0.16300 & Biso & 1.000 & 0 \\
\hline 032 & 1.0000 & 0.35327 & 0.32177 & 0.15632 & Biso & 1.000 & 0 \\
\hline 033 & 1.0000 & 0.98163 & 0.66109 & 0.17338 & Biso & 1.000 & 0 \\
\hline 034 & 1.0000 & 0.33778 & 0.38041 & 0.48476 & Biso & 1.000 & 0 \\
\hline 035 & 1.0000 & 0.00110 & 0.65536 & 0.50913 & Biso & 1.000 & 0 \\
\hline 036 & 1.0000 & 0.64404 & 0.99327 & 0.50616 & Biso & 1.000 & 0 \\
\hline 037 & 1.0000 & 0.12185 & 0.23985 & 0.13234 & Biso & 1.000 & 0 \\
\hline 038 & 1.0000 & 0.76427 & 0.87634 & 0.14298 & Biso & 1.000 & 0 \\
\hline 039 & 1.0000 & 0.13469 & 0.88765 & 0.13866 & Biso & 1.000 & O \\
\hline 040 & 1.0000 & 0.23530 & 0.11670 & 0.85840 & Biso & 1.000 & 0 \\
\hline 041 & 1.0000 & 0.87949 & 0.74659 & 0.86956 & Biso & 1.000 & 0 \\
\hline 042 & 1.0000 & 0.87311 & 0.11143 & 0.86393 & Biso & 1.000 & 0 \\
\hline 043 & 1.0000 & 0.77276 & 0.55087 & 0.46745 & Biso & 1.000 & 0 \\
\hline 044 & 1.0000 & 0.40537 & 0.21967 & 0.47701 & Biso & 1.000 & 0 \\
\hline 045 & 1.0000 & 0.80427 & 0.21431 & 0.46614 & Biso & 1.000 & 0 \\
\hline 046 & 1.0000 & 0.91673 & 0.46195 & 0.20466 & Biso & 1.000 & 0 \\
\hline 047 & 1.0000 & 0.55537 & 0.09295 & 0.21485 & Biso & 1.000 & 0 \\
\hline 048 & 1.0000 & 0.54650 & 0.45125 & 0.20711 & Biso & 1.000 & 0 \\
\hline 049 & 1.0000 & 0.44362 & 0.89085 & 0.81544 & Biso & 1.000 & 0 \\
\hline 050 & 1.0000 & 0.08633 & 0.53098 & 0.78130 & Biso & 1.000 & 0 \\
\hline 051 & 1.0000 & 0.45905 & 0.54486 & 0.79557 & Biso & 1.000 & 0 \\
\hline 052 & 1.0000 & 0.59859 & 0.80338 & 0.54961 & Biso & 1.000 & 0 \\
\hline
\end{tabular}




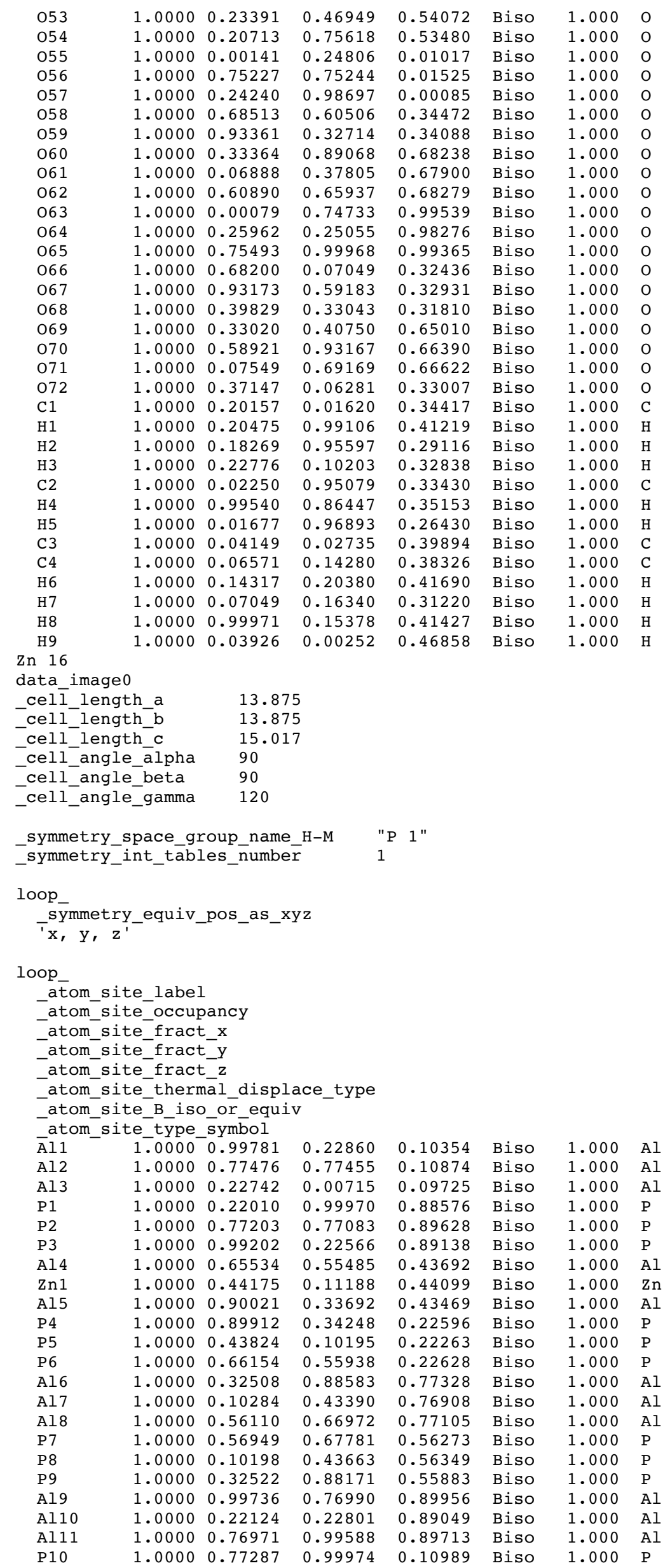




\begin{tabular}{|c|c|c|c|c|c|c|c|}
\hline P11 & 1.0000 & 0.22569 & 0.23172 & 0.10237 & Biso & 1.000 & $\mathrm{P}$ \\
\hline P12 & 1.0000 & 0.00508 & 0.77925 & 0.11280 & Biso & 1.000 & $\mathrm{P}$ \\
\hline Al12 & 1.0000 & 0.66938 & 0.11033 & 0.23151 & Biso & 1.000 & Al \\
\hline Al13 & 1.0000 & 0.89457 & 0.56570 & 0.23243 & Biso & 1.000 & Al \\
\hline Al1 14 & 1.0000 & 0.43601 & 0.33381 & 0.23020 & Biso & 1.000 & $\mathrm{Al}$ \\
\hline P13 & 1.0000 & 0.42433 & 0.33578 & 0.43662 & Biso & 1.000 & $P$ \\
\hline P14 & 1.0000 & 0.88893 & 0.55955 & 0.44245 & Biso & 1.000 & $\mathrm{P}$ \\
\hline P15 & 1.0000 & 0.67086 & 0.11329 & 0.43820 & Biso & 1.000 & $\mathrm{P}$ \\
\hline Al15 & 1.0000 & 0.33642 & 0.45555 & 0.56235 & Biso & 1.000 & Al \\
\hline Al16 & 1.0000 & 0.55905 & 0.89991 & 0.56488 & Biso & 1.000 & Al \\
\hline Al17 & 1.0000 & 0.09200 & 0.66550 & 0.57162 & Biso & 1.000 & Al \\
\hline P16 & 1.0000 & 0.09873 & 0.66365 & 0.77840 & Biso & 1.000 & $\mathrm{P}$ \\
\hline P 17 & 1.0000 & 0.55425 & 0.89504 & 0.77591 & Biso & 1.000 & $\mathrm{P}$ \\
\hline P18 & 1.0000 & 0.33275 & 0.44259 & 0.77299 & Biso & 1.000 & $P$ \\
\hline 01 & 1.0000 & 0.89433 & 0.09143 & 0.12708 & Biso & 1.000 & 0 \\
\hline $\mathrm{O} 2$ & 1.0000 & 0.91240 & 0.80685 & 0.13185 & Biso & 1.000 & 0 \\
\hline 03 & 1.0000 & 0.19188 & 0.10898 & 0.11953 & Biso & 1.000 & 0 \\
\hline 04 & 1.0000 & 0.09955 & 0.90538 & 0.86990 & Biso & 1.000 & 0 \\
\hline 05 & 1.0000 & 0.80531 & 0.89280 & 0.87690 & Biso & 1.000 & 0 \\
\hline 06 & 1.0000 & 0.08472 & 0.19848 & 0.87126 & Biso & 1.000 & 0 \\
\hline 07 & 1.0000 & 0.54834 & 0.41973 & 0.45852 & Biso & 1.000 & 0 \\
\hline 08 & 1.0000 & 0.59746 & 0.16465 & 0.45280 & Biso & 1.000 & 0 \\
\hline 09 & 1.0000 & 0.86671 & 0.44078 & 0.45990 & Biso & 1.000 & 0 \\
\hline 010 & 1.0000 & 0.77744 & 0.24804 & 0.21746 & Biso & 1.000 & 0 \\
\hline 011 & 1.0000 & 0.46274 & 0.22254 & 0.22683 & Biso & 1.000 & 0 \\
\hline 012 & 1.0000 & 0.75925 & 0.53758 & 0.21358 & Biso & 1.000 & 0 \\
\hline 013 & 1.0000 & 0.21996 & 0.75056 & 0.80191 & Biso & 1.000 & 0 \\
\hline 014 & 1.0000 & 0.24062 & 0.47063 & 0.79474 & Biso & 1.000 & 0 \\
\hline 015 & 1.0000 & 0.52488 & 0.77279 & 0.78604 & Biso & 1.000 & 0 \\
\hline 016 & 1.0000 & 0.44535 & 0.59266 & 0.54816 & Biso & 1.000 & 0 \\
\hline 017 & 1.0000 & 0.10809 & 0.54994 & 0.56147 & Biso & 1.000 & 0 \\
\hline 018 & 1.0000 & 0.41835 & 0.85317 & 0.54037 & Biso & 1.000 & 0 \\
\hline 019 & 1.0000 & 0.97538 & 0.32235 & 0.16443 & Biso & 1.000 & 0 \\
\hline 020 & 1.0000 & 0.67943 & 0.65840 & 0.16883 & Biso & 1.000 & 0 \\
\hline 021 & 1.0000 & 0.34940 & 0.03438 & 0.15185 & Biso & 1.000 & 0 \\
\hline 022 & 1.0000 & 0.30176 & 0.98329 & 0.82818 & Biso & 1.000 & 0 \\
\hline 023 & 1.0000 & 0.66948 & 0.69106 & 0.84189 & Biso & 1.000 & 0 \\
\hline $\mathrm{O} 24$ & 1.0000 & 0.00842 & 0.32579 & 0.83656 & Biso & 1.000 & 0 \\
\hline 025 & 1.0000 & 0.64284 & 0.65302 & 0.50139 & Biso & 1.000 & 0 \\
\hline 026 & 1.0000 & 0.33889 & 0.97954 & 0.50468 & Biso & 1.000 & 0 \\
\hline 027 & 1.0000 & 0.01194 & 0.35531 & 0.49986 & Biso & 1.000 & 0 \\
\hline 028 & 1.0000 & 0.01819 & 0.67148 & 0.84408 & Biso & 1.000 & 0 \\
\hline 029 & 1.0000 & 0.31546 & 0.34153 & 0.82737 & Biso & 1.000 & 0 \\
\hline 030 & 1.0000 & 0.65321 & 0.97069 & 0.83560 & Biso & 1.000 & 0 \\
\hline 031 & 1.0000 & 0.69211 & 0.02059 & 0.16483 & Biso & 1.000 & 0 \\
\hline 032 & 1.0000 & 0.32839 & 0.30957 & 0.15721 & Biso & 1.000 & 0 \\
\hline 033 & 1.0000 & 0.99062 & 0.68209 & 0.17142 & Biso & 1.000 & 0 \\
\hline 034 & 1.0000 & 0.34946 & 0.36401 & 0.49314 & Biso & 1.000 & 0 \\
\hline 035 & 1.0000 & 0.98016 & 0.64413 & 0.50453 & Biso & 1.000 & 0 \\
\hline 036 & 1.0000 & 0.64468 & 0.01642 & 0.50194 & Biso & 1.000 & 0 \\
\hline 037 & 1.0000 & 0.12882 & 0.24837 & 0.13074 & Biso & 1.000 & 0 \\
\hline 038 & 1.0000 & 0.75996 & 0.88779 & 0.13867 & Biso & 1.000 & 0 \\
\hline 039 & 1.0000 & 0.11906 & 0.87993 & 0.13688 & Biso & 1.000 & 0 \\
\hline 040 & 1.0000 & 0.22976 & 0.11110 & 0.86072 & Biso & 1.000 & 0 \\
\hline 041 & 1.0000 & 0.86833 & 0.75245 & 0.86978 & Biso & 1.000 & 0 \\
\hline 042 & 1.0000 & 0.87996 & 0.12496 & 0.86573 & Biso & 1.000 & 0 \\
\hline 043 & 1.0000 & 0.78273 & 0.56372 & 0.45996 & Biso & 1.000 & 0 \\
\hline 044 & 1.0000 & 0.39505 & 0.21761 & 0.45626 & Biso & 1.000 & 0 \\
\hline 045 & 1.0000 & 0.79321 & 0.20282 & 0.45425 & Biso & 1.000 & 0 \\
\hline 046 & 1.0000 & 0.90662 & 0.45240 & 0.19757 & Biso & 1.000 & 0 \\
\hline 047 & 1.0000 & 0.54467 & 0.10117 & 0.19646 & Biso & 1.000 & 0 \\
\hline 048 & 1.0000 & 0.55489 & 0.45556 & 0.19533 & Biso & 1.000 & 0 \\
\hline 049 & 1.0000 & 0.45396 & 0.90495 & 0.80646 & Biso & 1.000 & 0 \\
\hline 050 & 1.0000 & 0.08408 & 0.54729 & 0.78598 & Biso & 1.000 & 0 \\
\hline 051 & 1.0000 & 0.44576 & 0.54204 & 0.79863 & Biso & 1.000 & 0 \\
\hline 052 & 1.0000 & 0.58905 & 0.79415 & 0.54040 & Biso & 1.000 & 0 \\
\hline 053 & 1.0000 & 0.21436 & 0.45356 & 0.53265 & Biso & 1.000 & 0 \\
\hline 054 & 1.0000 & 0.21374 & 0.77826 & 0.53026 & Biso & 1.000 & 0 \\
\hline 055 & 1.0000 & 0.99324 & 0.25425 & 0.99039 & Biso & 1.000 & 0 \\
\hline 056 & 1.0000 & 0.74524 & 0.74476 & 0.99574 & Biso & 1.000 & 0 \\
\hline 057 & 1.0000 & 0.25079 & 0.99996 & 0.98437 & Biso & 1.000 & 0 \\
\hline 058 & 1.0000 & 0.65299 & 0.58687 & 0.32405 & Biso & 1.000 & 0 \\
\hline 059 & 1.0000 & 0.94041 & 0.35167 & 0.32228 & Biso & 1.000 & 0 \\
\hline 060 & 1.0000 & 0.32186 & 0.90291 & 0.65909 & Biso & 1.000 & 0 \\
\hline 061 & 1.0000 & 0.07456 & 0.38839 & 0.65841 & Biso & 1.000 & 0 \\
\hline 062 & 1.0000 & 0.60212 & 0.67267 & 0.66016 & Biso & 1.000 & 0 \\
\hline 063 & 1.0000 & 0.00300 & 0.74873 & 0.01423 & Biso & 1.000 & 0 \\
\hline 064 & 1.0000 & 0.25333 & 0.25980 & 0.00330 & Biso & 1.000 & 0 \\
\hline 065 & 1.0000 & 0.74301 & 0.99679 & 0.01093 & Biso & 1.000 & 0 \\
\hline 066 & 1.0000 & 0.65843 & 0.06699 & 0.34190 & Biso & 1.000 & 0 \\
\hline
\end{tabular}




$\begin{array}{llllllll}\text { O67 } & 1.0000 & 0.92943 & 0.59432 & 0.34547 & \text { Biso } & 1.000 & \text { O } \\ \text { O68 } & 1.0000 & 0.40231 & 0.35183 & 0.33782 & \text { Biso } & 1.000 & \text { O } \\ \text { O69 } & 1.0000 & 0.33058 & 0.41539 & 0.67363 & \text { Biso } & 1.000 & \text { O } \\ \text { O70 } & 1.0000 & 0.58392 & 0.93309 & 0.67865 & \text { Biso } & 1.000 & \text { O } \\ \text { O71 } & 1.0000 & 0.07008 & 0.68436 & 0.68352 & \text { Biso } & 1.000 & \text { O } \\ \text { O72 } & 1.0000 & 0.39343 & 0.04421 & 0.31428 & \text { Biso } & 1.000 & \text { O } \\ \text { C1 } & 1.0000 & 0.30097 & 0.87813 & 0.31784 & \text { Biso } & 1.000 & \text { C } \\ \text { H1 } & 1.0000 & 0.37731 & 0.87471 & 0.32515 & \text { Biso } & 1.000 & \text { H } \\ \text { H2 } & 1.0000 & 0.26187 & 0.88861 & 0.37703 & \text { Biso } & 1.000 & \text { H } \\ \text { H3 } & 1.0000 & 0.26659 & 0.87474 & 0.25203 & \text { Biso } & 1.000 & \text { H } \\ \text { C2 } & 1.0000 & 0.21435 & 0.71324 & 0.33149 & \text { Biso } & 1.000 & \text { C } \\ \text { O73 } & 1.0000 & 0.17959 & 0.62064 & 0.34295 & \text { Biso } & 1.000 & \text { O }\end{array}$

data_image0

celìllength_a $\quad 13.875$

cell_length_b 13.875

_cell_length_c 15.017

_cell_angle_ālpha 90

cell angle beta 90

_cell_angle_gamma 120

$\begin{array}{ll}\text { _symmetry_space_group_name_H-M } & \text { "P } 1 " \\ \text { _symmetry_int_tables_number } & 1\end{array}$

loop_

_symmetry_equiv_pos_as_xyz

' $\mathrm{x}, \mathrm{y}, \mathrm{z}$ '

loop

atom_site label

-atom_site_occupancy

-atom_site_fract_x

-atom_site_fract_y

-atom_site_fract_z

_atom_site_thermal_displace_type

-atom_site_B_iso_or_equiv

-atom_site_type_symbol

P1 $1.0000 \quad 0.00397$

P2 $1.0000 \quad 0.77327$

P3 $1.0000 \quad 0.22497$

Al1 $1.0000 \quad 0.21973$

0.77860

0.10808

Biso

$1.000 \mathrm{P}$

$\begin{array}{llll} & 0.11045 & \text { Biso } & 1.000 \quad \mathrm{P}\end{array}$

Al2 $1.0000 \quad 0.76926$

$0.00017 \quad 0.10423$ Biso

$\begin{array}{ll}0.10423 & \text { Biso } \\ 0.89053 & \text { Biso }\end{array}$

$1.000 \mathrm{P}$

0.89833 Biso

$1.000 \mathrm{Al}$

$\begin{array}{lll}\text { Al3 } & 1.0000 & 0.99986 \\ \mathrm{P} 4 & 1.0000 & 0.66515\end{array}$

$\begin{array}{lll}.77383 & 0.89833 & \text { Biso } \\ 0.22915 & 0.89708 & \text { Biso }\end{array}$

$1.000 \mathrm{AI}$

P4 $1.0000 \quad 0.66515$

0.560720 .44022 Biso

$1.000 \mathrm{Al}$

$1.0000 \quad 0.42549$

0.10227

0.43703 Biso

$1.000 \mathrm{P}$

P5 $1.0000 \quad 0.89118$

Al4 $1.0000 \quad 0.89415$

$0.32956 \quad 0.44134$ Biso

$1.000 \mathrm{Si}$

$1.0000 \quad 0.43505$

0.33325

0.23049 Biso

$1.000 \mathrm{P}$

$1.000 \mathrm{Al}$

Al6 $1.0000 \quad 0.67057$

P6 1.00000 .33306

$0.56340 \quad 0.22919$ Biso

$1.000 \mathrm{Al}$

$1.0000 \quad 0.10140$

0.88994

0.77969 Biso

$1.000 \mathrm{AI}$

P8 $\quad 1.00000 .55871$

Al7 $1.0000 \quad 0.56329$

0.66255

77347 Biso

0.667890 .56518 Biso

$1.000 \mathrm{P}$

$1.0000 \quad 0.09868$

Al9 $\quad 1.0000 \quad 0.33396 \quad 0.89291$

0.43702

$\begin{array}{lllll}6789 & 0.56518 & \text { Biso } & 1.000 & A \\ 3702 & 0.56548 & \text { Biso } & 1.000 & A\end{array}$

$1.000 \mathrm{P}$

P9 $1.0000 \quad 0.99397$

$1.000 \mathrm{~A}$

$1.0000 \quad 0.22604$

0.76873

0.89330 Biso

$1.000 \mathrm{Al}$

$1.0000 \quad 0.77458$

0.2246

0.88888 Biso

P11

$1.0000 \quad 0.77561$

0.00242

0.89227 Biso

$1.000 \mathrm{P}$

$1.000 \mathrm{P}$

$1.000 \mathrm{P}$

Al11 $\quad 1.0000 \quad 0.23047$

0.00590

.10474 Biso

$1.000 \mathrm{AI}$

Al12 $\quad 1.0000 \quad 0.00047$

$\begin{array}{lll}\mathrm{P} 12 & 1.0000 & 0.66527\end{array}$

0.77622

0.10037 Biso

$1.000 \mathrm{Al}$

$1.0000 \quad 0.90033$

0.10760

Biso

$1.000 \mathrm{Al}$

$\begin{array}{lll}\text { P13 } & 1.0000 & 0.90033 \\ \text { P14 } & 1.0000 & 0.44262\end{array}$

Al13 $1.0000 \quad 0.43338$

Al14 $\quad 1.0000 \quad 0.89317$

Al15 $1.0000 \quad 0.65903$

$\begin{array}{lll}\mathrm{P} 15 & 1.0000 & 0.32952\end{array}$

$\begin{array}{lll}\mathrm{P} 16 & 1.0000 & 0.56074\end{array}$

P17 $1.0000 \quad 0.10176$

Al16 $1.0000 \quad 0.10336$

Al17 $1.0000 \quad 0.56030$

Al18 $\quad 1.0000 \quad 0.32789$

$01 \quad 1.0000 \quad 0.91307$

0.342740 .22499 Biso

$0.33881 \quad 0.43191$ Biso

$.000 \mathrm{P}$

Biso $1.000 \quad A I$

$\begin{array}{lllll}0.44585 & 0.43392 & \text { Biso } & 1.000 & \mathrm{~A}\end{array}$

$\begin{array}{lllll}0.89530 & 0.56078 & \text { Biso } & 1.000 & \mathrm{P}\end{array}$

$\begin{array}{lllll}0.67122 & 0.56334 & \text { Biso } & 1.000 & \mathrm{P}\end{array}$

$0.66928 \quad 0.77267$ Biso $1.000 \mathrm{Al}$

0.892950 .77059 Biso $1.000 \mathrm{AI}$

0.438170 .76786 Biso $1.000 \mathrm{Al}$

$0.11038 \quad 0.12713$ Biso $1.000 \quad 0$

$1.0000 \quad 0.89475$

0.80731

0.12664

$1.0000 \quad 0.19462$

0.09063

0.12377 Biso

$1.000 \quad 0$

$\begin{array}{lll}04 & 1.0000 & 0.08415 \\ 05 & 1.0000 & 0.80553 \\ 06 & 1.0000 & 0.10477\end{array}$

$\begin{array}{lll}04 & 1.0000 & 0.08415 \\ 05 & 1.0000 & 0.80553 \\ 06 & 1.0000 & 0.10477\end{array}$

0.88774

0.86722

Biso

1.0000

$\begin{array}{lll}06 & 1.0000 & 0.10477 \\ 07 & 1.0000 & 0.57184\end{array}$

$\begin{array}{lllll}0.91168 & 0.87444 & \text { Biso } & 1.000 & 0 \\ 0.19710 & 0.87608 & \text { Biso } & 1.000 & 0\end{array}$

0.87444 Biso

$1.000 \quad 0$

0.44117

0.45831

Biso 


\begin{tabular}{|c|c|c|c|c|c|c|c|}
\hline 08 & 1.0000 & 0.55598 & 0.13943 & 0.44156 & Biso & 1.000 & 0 \\
\hline 09 & 1.0000 & 0.86615 & 0.42443 & 0.45951 & Biso & 1.000 & O \\
\hline 010 & 1.0000 & 0.75666 & 0.22960 & 0.20941 & Biso & 1.000 & O \\
\hline 011 & 1.0000 & 0.46689 & 0.24574 & 0.22299 & Biso & 1.000 & O \\
\hline 012 & 1.0000 & 0.78002 & 0.53633 & 0.21152 & Biso & 1.000 & 0 \\
\hline 013 & 1.0000 & 0.23946 & 0.77057 & 0.80131 & Biso & 1.000 & O \\
\hline 014 & 1.0000 & 0.22342 & 0.47080 & 0.79162 & Biso & 1.000 & O \\
\hline 015 & 1.0000 & 0.52875 & 0.75483 & 0.78461 & Biso & 1.000 & $\mathrm{O}$ \\
\hline 016 & 1.0000 & 0.42410 & 0.56722 & 0.54570 & Biso & 1.000 & O \\
\hline 017 & 1.0000 & 0.12033 & 0.57166 & 0.55251 & Biso & 1.000 & O \\
\hline 018 & 1.0000 & 0.43677 & 0.85644 & 0.54356 & Biso & 1.000 & O \\
\hline 019 & 1.0000 & 0.98738 & 0.31255 & 0.16674 & Biso & 1.000 & O \\
\hline 020 & 1.0000 & 0.69336 & 0.67943 & 0.16788 & Biso & 1.000 & 0 \\
\hline 021 & 1.0000 & 0.33208 & 0.02437 & 0.15260 & Biso & 1.000 & O \\
\hline 022 & 1.0000 & 0.31752 & 0.97495 & 0.83387 & Biso & 1.000 & O \\
\hline 023 & 1.0000 & 0.65292 & 0.68132 & 0.83717 & Biso & 1.000 & $\mathrm{O}$ \\
\hline 024 & 1.0000 & 0.02238 & 0.34495 & 0.83619 & Biso & 1.000 & O \\
\hline 025 & 1.0000 & 0.65161 & 0.64464 & 0.49758 & Biso & 1.000 & 0 \\
\hline 026 & 1.0000 & 0.35019 & 0.00363 & 0.50569 & Biso & 1.000 & O \\
\hline 027 & 1.0000 & 0.98832 & 0.34400 & 0.49957 & Biso & 1.000 & O \\
\hline 028 & 1.0000 & 0.00841 & 0.68249 & 0.84019 & Biso & 1.000 & O \\
\hline 029 & 1.0000 & 0.30530 & 0.32276 & 0.83024 & Biso & 1.000 & $\mathrm{O}$ \\
\hline 030 & 1.0000 & 0.67380 & 0.98174 & 0.83633 & Biso & 1.000 & O \\
\hline 031 & 1.0000 & 0.68069 & 0.02959 & 0.16246 & Biso & 1.000 & O \\
\hline 032 & 1.0000 & 0.34772 & 0.32045 & 0.16072 & Biso & 1.000 & O \\
\hline 033 & 1.0000 & 0.98228 & 0.66360 & 0.17131 & Biso & 1.000 & O \\
\hline 034 & 1.0000 & 0.34528 & 0.36717 & 0.49612 & Biso & 1.000 & O \\
\hline 035 & 1.0000 & 0.00504 & 0.65594 & 0.50379 & Biso & 1.000 & O \\
\hline 036 & 1.0000 & 0.63616 & 0.99259 & 0.50011 & Biso & 1.000 & O \\
\hline 037 & 1.0000 & 0.11814 & 0.24541 & 0.12998 & Biso & 1.000 & O \\
\hline 038 & 1.0000 & 0.76187 & 0.87894 & 0.13735 & Biso & 1.000 & O \\
\hline 039 & 1.0000 & 0.13006 & 0.88784 & 0.13898 & Biso & 1.000 & O \\
\hline 040 & 1.0000 & 0.23471 & 0.12299 & 0.86085 & Biso & 1.000 & 0 \\
\hline 041 & 1.0000 & 0.87969 & 0.75359 & 0.87078 & Biso & 1.000 & O \\
\hline 042 & 1.0000 & 0.87304 & 0.11558 & 0.86566 & Biso & 1.000 & $\mathrm{O}$ \\
\hline 043 & 1.0000 & 0.77724 & 0.57057 & 0.46426 & Biso & 1.000 & O \\
\hline 044 & 1.0000 & 0.40736 & 0.20691 & 0.44841 & Biso & 1.000 & $\mathrm{O}$ \\
\hline 045 & 1.0000 & 0.78911 & 0.21837 & 0.46462 & Biso & 1.000 & $\mathrm{O}$ \\
\hline 046 & 1.0000 & 0.91218 & 0.46361 & 0.20216 & Biso & 1.000 & O \\
\hline 047 & 1.0000 & 0.55210 & 0.09689 & 0.20529 & Biso & 1.000 & 0 \\
\hline 048 & 1.0000 & 0.54748 & 0.44843 & 0.19307 & Biso & 1.000 & 0 \\
\hline 049 & 1.0000 & 0.44506 & 0.90156 & 0.80589 & Biso & 1.000 & 0 \\
\hline 050 & 1.0000 & 0.08735 & 0.53882 & 0.79084 & Biso & 1.000 & 0 \\
\hline 051 & 1.0000 & 0.45657 & 0.55063 & 0.79740 & Biso & 1.000 & O \\
\hline 052 & 1.0000 & 0.58081 & 0.79834 & 0.54040 & Biso & 1.000 & 0 \\
\hline 053 & 1.0000 & 0.21981 & 0.44021 & 0.53181 & Biso & 1.000 & $\mathrm{O}$ \\
\hline 054 & 1.0000 & 0.20720 & 0.77627 & 0.53174 & Biso & 1.000 & O \\
\hline 055 & 1.0000 & 0.99909 & 0.26025 & 0.00986 & Biso & 1.000 & 0 \\
\hline 056 & 1.0000 & 0.74145 & 0.74854 & 0.01218 & Biso & 1.000 & O \\
\hline 057 & 1.0000 & 0.24262 & 0.99280 & 0.00452 & Biso & 1.000 & 0 \\
\hline 058 & 1.0000 & 0.66516 & 0.59165 & 0.34166 & Biso & 1.000 & O \\
\hline 059 & 1.0000 & 0.92505 & 0.33307 & 0.34314 & Biso & 1.000 & 0 \\
\hline 060 & 1.0000 & 0.33044 & 0.91411 & 0.68048 & Biso & 1.000 & 0 \\
\hline 061 & 1.0000 & 0.06927 & 0.39688 & 0.67702 & Biso & 1.000 & 0 \\
\hline 062 & 1.0000 & 0.59629 & 0.66139 & 0.67720 & Biso & 1.000 & O \\
\hline 063 & 1.0000 & 0.00216 & 0.74851 & 0.99322 & Biso & 1.000 & 0 \\
\hline 064 & 1.0000 & 0.26080 & 0.25472 & 0.98686 & Biso & 1.000 & 0 \\
\hline 065 & 1.0000 & 0.74622 & 0.00252 & 0.99124 & Biso & 1.000 & 0 \\
\hline 066 & 1.0000 & 0.67054 & 0.07238 & 0.32202 & Biso & 1.000 & O \\
\hline 067 & 1.0000 & 0.93269 & 0.59480 & 0.32692 & Biso & 1.000 & 0 \\
\hline 068 & 1.0000 & 0.41086 & 0.35976 & 0.31911 & Biso & 1.000 & 0 \\
\hline 069 & 1.0000 & 0.32536 & 0.40849 & 0.65457 & Biso & 1.000 & 0 \\
\hline 070 & 1.0000 & 0.59030 & 0.93209 & 0.65875 & Biso & 1.000 & $\mathrm{O}$ \\
\hline 071 & 1.0000 & 0.07572 & 0.68354 & 0.66079 & Biso & 1.000 & $\mathrm{O}$ \\
\hline 072 & 1.0000 & 0.37881 & 0.04703 & 0.33440 & Biso & 1.000 & 0 \\
\hline $\mathrm{C} 1$ & 1.0000 & 0.27990 & 0.87986 & 0.33033 & Biso & 1.000 & $\mathrm{C}$ \\
\hline $\mathrm{H} 1$ & 1.0000 & 0.35493 & 0.87482 & 0.34140 & Biso & 1.000 & $\mathrm{H}$ \\
\hline $\mathrm{H} 2$ & 1.0000 & 0.23440 & 0.88516 & 0.38723 & Biso & 1.000 & $\mathrm{H}$ \\
\hline H3 & 1.0000 & 0.25385 & 0.88501 & 0.26299 & Biso & 1.000 & $\mathrm{H}$ \\
\hline $\mathrm{C} 2$ & 1.0000 & 0.19794 & 0.71752 & 0.32995 & Biso & 1.000 & $\mathrm{C}$ \\
\hline 073 & 1.0000 & 0.18427 & 0.62947 & 0.33060 & Biso & 1.000 & $\mathrm{O}$ \\
\hline \\
\hline \multicolumn{8}{|c|}{$\begin{array}{l}\text { Mg } 16 \\
\text { data image } 0\end{array}$} \\
\hline \multicolumn{2}{|c|}{ cel' length a } & \multicolumn{2}{|c|}{13.875} & & & & \\
\hline \multicolumn{2}{|c|}{ cell_length_b } & \multicolumn{2}{|c|}{13.875} & & & & \\
\hline cell & $\operatorname{th}^{-} \mathrm{c}$ & 15.01 & & & & & \\
\hline cell & alpha & 90 & & & & & \\
\hline cell & e beta & 90 & & & & & \\
\hline cell & gamma & 120 & & & & & \\
\hline
\end{tabular}




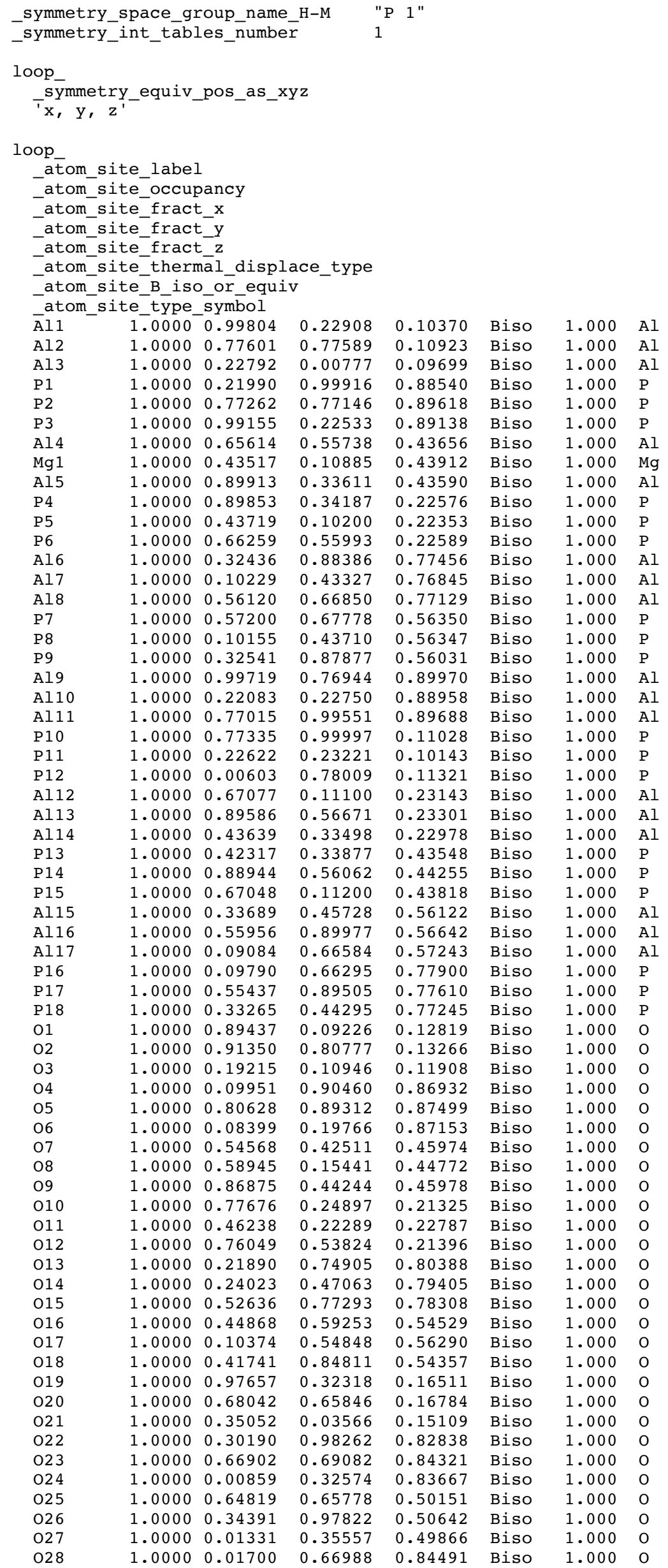




\begin{tabular}{|c|c|c|c|c|c|c|}
\hline 029 & 1.0000 & 0.31405 & 0.34039 & 0.82538 & Biso & 1.000 \\
\hline 030 & 1.0000 & 0.65217 & 0.96935 & 0.83723 & Biso & 1.000 \\
\hline 031 & 1.0000 & 0.69118 & 0.02079 & 0.16321 & Biso & 1.000 \\
\hline 032 & 1.0000 & 0.32926 & 0.31007 & 0.15596 & Biso & 1.000 \\
\hline 033 & 1.0000 & 0.99174 & 0.68276 & 0.17154 & Biso & 1.000 \\
\hline 034 & 1.0000 & 0.34469 & 0.36246 & 0.49180 & Biso & 1.000 \\
\hline 035 & 1.0000 & 0.97918 & 0.64558 & 0.50547 & Biso & 1.000 \\
\hline 036 & 1.0000 & 0.64409 & 0.01377 & 0.50071 & Biso & 1.000 \\
\hline 037 & 1.0000 & 0.12952 & 0.24913 & 0.12979 & Biso & 1.000 \\
\hline 038 & 1.0000 & 0.76072 & 0.88851 & 0.14043 & Biso & 1.000 \\
\hline 039 & 1.0000 & 0.12017 & 0.88062 & 0.13740 & Biso & 1.000 \\
\hline 040 & 1.0000 & 0.22941 & 0.11045 & 0.86005 & Biso & 1.000 \\
\hline 041 & 1.0000 & 0.86812 & 0.75176 & 0.86978 & Biso & 1.000 \\
\hline 042 & 1.0000 & 0.87941 & 0.12506 & 0.86526 & Biso & 1.000 \\
\hline 043 & 1.0000 & 0.78186 & 0.56243 & 0.45900 & Biso & 1.000 \\
\hline 044 & 1.0000 & 0.39974 & 0.22223 & 0.45227 & Biso & 1.000 \\
\hline 045 & 1.0000 & 0.78992 & 0.20489 & 0.46041 & Biso & 1.000 \\
\hline 046 & 1.0000 & 0.90869 & 0.45355 & 0.19938 & Biso & 1.000 \\
\hline 047 & 1.0000 & 0.54364 & 0.09977 & 0.20058 & Biso & 1.000 \\
\hline 048 & 1.0000 & 0.55629 & 0.45575 & 0.19485 & Biso & 1.000 \\
\hline 049 & 1.0000 & 0.45296 & 0.90237 & 0.80768 & Biso & 1.000 \\
\hline 050 & 1.0000 & 0.08267 & 0.54624 & 0.78482 & Biso & 1.000 \\
\hline 051 & 1.0000 & 0.44512 & 0.54177 & 0.80020 & Biso & 1.000 \\
\hline 052 & 1.0000 & 0.59143 & 0.79482 & 0.54524 & Biso & 1.000 \\
\hline 053 & 1.0000 & 0.21584 & 0.45855 & 0.53324 & Biso & 1.000 \\
\hline 054 & 1.0000 & 0.21349 & 0.77682 & 0.53024 & Biso & 1.000 \\
\hline 055 & 1.0000 & 0.99233 & 0.25359 & 0.99043 & Biso & 1.000 \\
\hline 056 & 1.0000 & 0.74729 & 0.74792 & 0.99603 & Biso & 1.000 \\
\hline 057 & 1.0000 & 0.25024 & 0.99974 & 0.98413 & Biso & 1.000 \\
\hline 058 & 1.0000 & 0.65373 & 0.58814 & 0.32337 & Biso & 1.000 \\
\hline 059 & 1.0000 & 0.93554 & 0.34623 & 0.32284 & Biso & 1.000 \\
\hline 060 & 1.0000 & 0.31996 & 0.89948 & 0.66038 & Biso & 1.000 \\
\hline 061 & 1.0000 & 0.07425 & 0.38696 & 0.65787 & Biso & 1.000 \\
\hline 062 & 1.0000 & 0.60155 & 0.66731 & 0.66080 & Biso & 1.000 \\
\hline 063 & 1.0000 & 0.00368 & 0.74986 & 0.01455 & Biso & 1.000 \\
\hline 064 & 1.0000 & 0.25372 & 0.25978 & 0.00228 & Biso & 1.000 \\
\hline 065 & 1.0000 & 0.74501 & 0.99577 & 0.01091 & Biso & 1.000 \\
\hline 066 & 1.0000 & 0.66892 & 0.07044 & 0.34145 & Biso & 1.000 \\
\hline 067 & 1.0000 & 0.93112 & 0.59658 & 0.34593 & Biso & 1.000 \\
\hline 068 & 1.0000 & 0.40251 & 0.35615 & 0.33652 & Biso & 1.000 \\
\hline 069 & 1.0000 & 0.33247 & 0.41829 & 0.67275 & Biso & 1.000 \\
\hline 070 & 1.0000 & 0.58471 & 0.93692 & 0.67971 & Biso & 1.000 \\
\hline 071 & 1.0000 & 0.07044 & 0.68602 & 0.68443 & Biso & 1.000 \\
\hline 072 & 1.0000 & 0.38932 & 0.04429 & 0.31474 & Biso & 1.000 \\
\hline $\mathrm{C} 1$ & 1.0000 & 0.29915 & 0.87766 & 0.31697 & Biso & 1.000 \\
\hline $\mathrm{H} 1$ & 1.0000 & 0.37616 & 0.87487 & 0.31950 & Biso & 1.000 \\
\hline $\mathrm{H} 2$ & 1.0000 & 0.26301 & 0.88588 & 0.37883 & Biso & 1.000 \\
\hline H3 & 1.0000 & 0.26032 & 0.87443 & 0.25323 & Biso & 1.000 \\
\hline $\mathrm{C} 2$ & 1.0000 & 0.21407 & 0.71176 & 0.32989 & Biso & 1.000 \\
\hline 073 & 1.0000 & 0.17933 & 0.61924 & 0.34170 & Biso & 1.000 \\
\hline
\end{tabular}

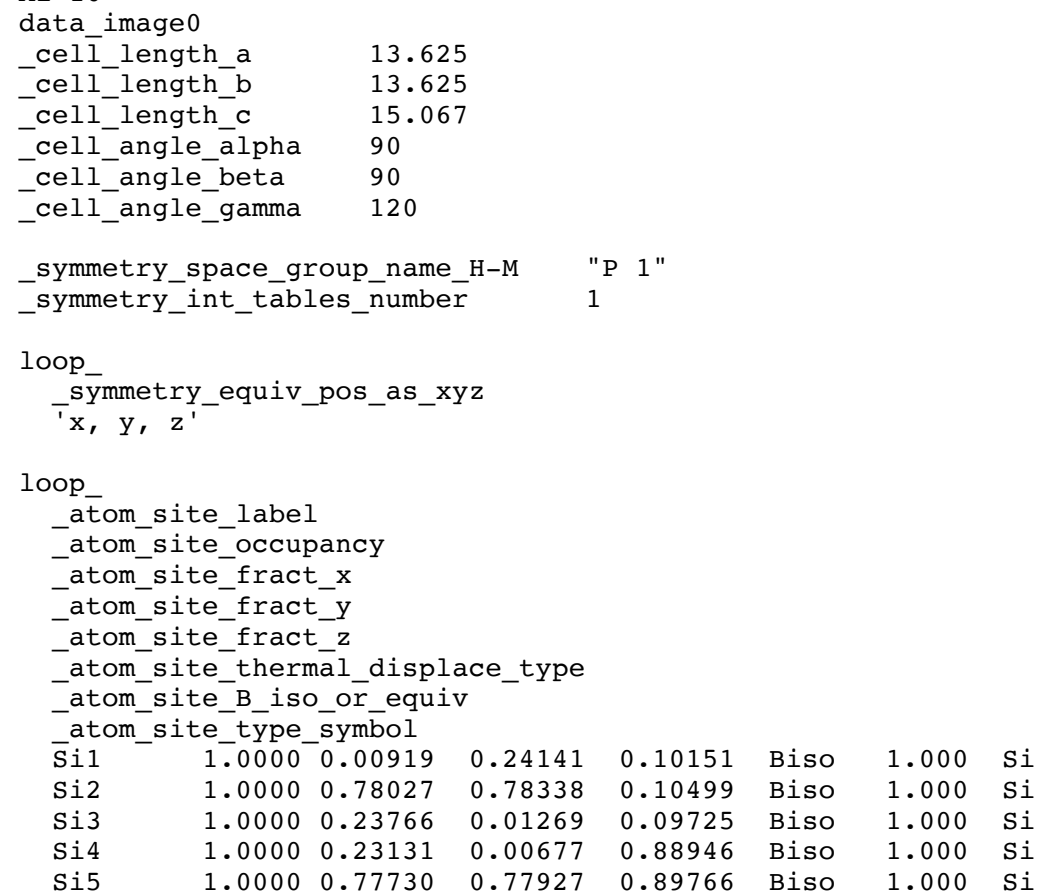




\begin{tabular}{|c|c|c|c|c|c|c|c|}
\hline Si6 & 1.0000 & 0.00506 & 0.23894 & 0.89566 & Biso & 1.000 & $\mathrm{Si}$ \\
\hline Si7 & 1.0000 & 0.66993 & 0.57026 & 0.43435 & Biso & 1.000 & $\mathrm{Si}$ \\
\hline Al1 & 1.0000 & 0.43841 & 0.11222 & 0.43369 & Biso & 1.000 & Al \\
\hline Si8 & 1.0000 & 0.90622 & 0.34151 & 0.43481 & Biso & 1.000 & $\mathrm{Si}$ \\
\hline Si9 & 1.0000 & 0.90716 & 0.34613 & 0.22908 & Biso & 1.000 & $\mathrm{Si}$ \\
\hline Silo & 1.0000 & 0.44284 & 0.11175 & 0.22732 & Biso & 1.000 & \\
\hline Si11 & 1.0000 & 0.67492 & 0.57289 & 0.22924 & Biso & 1.000 & $\mathrm{Si}$ \\
\hline Sil2 & 1.0000 & 0.33778 & 0.89859 & 0.77217 & Biso & 1.000 & $\mathrm{Si}$ \\
\hline Si13 & 1.0000 & 0.10855 & 0.44257 & 0.76663 & Biso & 1.000 & $\mathrm{Si}$ \\
\hline Si14 & 1.0000 & 0.57109 & 0.67507 & 0.76819 & Biso & 1.000 & $\mathrm{Si}$ \\
\hline Si15 & 1.0000 & 0.57825 & 0.68088 & 0.56482 & Biso & 1.000 & $\mathrm{Si}$ \\
\hline Sil 16 & 1.0000 & 0.10720 & 0.44336 & 0.56476 & Biso & 1.000 & $\mathrm{Si}$ \\
\hline $\operatorname{Sil} 17$ & 1.0000 & 0.33867 & 0.89736 & 0.56322 & Biso & 1.000 & $\mathrm{Si}$ \\
\hline Si18 & 1.0000 & 0.00486 & 0.77649 & 0.89710 & Biso & 1.000 & $\mathrm{Si}$ \\
\hline Si19 & 1.0000 & 0.23542 & 0.23805 & 0.89167 & Biso & 1.000 & $\mathrm{Si}$ \\
\hline Si20 & 1.0000 & 0.77900 & 0.00811 & 0.89506 & Biso & 1.000 & $\mathrm{Si}$ \\
\hline Si21 & 1.0000 & 0.78025 & 0.01157 & 0.10271 & Biso & 1.000 & $\mathrm{Si}$ \\
\hline $\mathrm{Si} 22$ & 1.0000 & 0.23974 & 0.24189 & 0.09784 & Biso & 1.000 & $\mathrm{Si}$ \\
\hline Si23 & 1.0000 & 0.01128 & 0.78450 & 0.10531 & Biso & 1.000 & $\mathrm{Si}$ \\
\hline Si24 & 1.0000 & 0.67662 & 0.11566 & 0.22947 & Biso & 1.000 & $\mathrm{Si}$ \\
\hline Si25 & 1.0000 & 0.90872 & 0.57577 & 0.23159 & Biso & 1.000 & $\mathrm{Si}$ \\
\hline Si26 & 1.0000 & 0.44571 & 0.34754 & 0.22868 & Biso & 1.000 & $\mathrm{Si}$ \\
\hline Si27 & 1.0000 & 0.43674 & 0.34700 & 0.43074 & Biso & 1.000 & $\mathrm{Si}$ \\
\hline Si28 & 1.0000 & 0.90303 & 0.57080 & 0.43671 & Biso & 1.000 & $\mathrm{Si}$ \\
\hline Si29 & 1.0000 & 0.67351 & 0.11546 & 0.43203 & Biso & 1.000 & $\mathrm{Si}$ \\
\hline $\mathrm{Si} 30$ & 1.0000 & 0.34236 & 0.45634 & 0.56067 & Biso & 1.000 & $\mathrm{Si}$ \\
\hline Si31 & 1.0000 & 0.57094 & 0.90770 & 0.56369 & Biso & 1.000 & $\mathrm{Si}$ \\
\hline Si32 & 1.0000 & 0.10368 & 0.67686 & 0.56775 & Biso & 1.000 & $\mathrm{Si}$ \\
\hline Si33 & 1.0000 & 0.10786 & 0.67512 & 0.77124 & Biso & 1.000 & $\mathrm{Si}$ \\
\hline Si34 & 1.0000 & 0.56895 & 0.90564 & 0.76865 & Biso & 1.000 & $\mathrm{Si}$ \\
\hline Si35 & 1.0000 & 0.33920 & 0.44755 & 0.76638 & Biso & 1.000 & $\mathrm{Si}$ \\
\hline 01 & 1.0000 & 0.91123 & 0.11053 & 0.11973 & Biso & 1.000 & 0 \\
\hline $\mathrm{O} 2$ & 1.0000 & 0.91146 & 0.81496 & 0.12158 & Biso & 1.000 & 0 \\
\hline 03 & 1.0000 & 0.20462 & 0.11008 & 0.11565 & Biso & 1.000 & 0 \\
\hline 04 & 1.0000 & 0.10134 & 0.90588 & 0.87248 & Biso & 1.000 & 0 \\
\hline 05 & 1.0000 & 0.81338 & 0.91080 & 0.87832 & Biso & 1.000 & 0 \\
\hline 06 & 1.0000 & 0.10459 & 0.20794 & 0.88006 & Biso & 1.000 & 0 \\
\hline 07 & 1.0000 & 0.56898 & 0.44197 & 0.45281 & Biso & 1.000 & 0 \\
\hline 08 & 1.0000 & 0.58107 & 0.15435 & 0.43885 & Biso & 1.000 & 0 \\
\hline 09 & 1.0000 & 0.87676 & 0.44211 & 0.45391 & Biso & 1.000 & 0 \\
\hline 010 & 1.0000 & 0.77629 & 0.24693 & 0.21471 & Biso & 1.000 & 0 \\
\hline 011 & 1.0000 & 0.47064 & 0.24216 & 0.22649 & Biso & 1.000 & 0 \\
\hline 012 & 1.0000 & 0.77914 & 0.54733 & 0.21839 & Biso & 1.000 & 0 \\
\hline 013 & 1.0000 & 0.23841 & 0.76933 & 0.79487 & Biso & 1.000 & 0 \\
\hline 014 & 1.0000 & 0.24047 & 0.47952 & 0.78531 & Biso & 1.000 & 0 \\
\hline 015 & 1.0000 & 0.53863 & 0.77437 & 0.77800 & Biso & 1.000 & 0 \\
\hline 016 & 1.0000 & 0.44577 & 0.58626 & 0.54892 & Biso & 1.000 & 0 \\
\hline 017 & 1.0000 & 0.12175 & 0.56868 & 0.55877 & Biso & 1.000 & 0 \\
\hline 018 & 1.0000 & 0.43638 & 0.86212 & 0.54718 & Biso & 1.000 & 0 \\
\hline 019 & 1.0000 & 0.99206 & 0.32735 & 0.16525 & Biso & 1.000 & 0 \\
\hline 020 & 1.0000 & 0.69487 & 0.67771 & 0.16650 & Biso & 1.000 & 0 \\
\hline 021 & 1.0000 & 0.35001 & 0.03669 & 0.15171 & Biso & 1.000 & 0 \\
\hline 022 & 1.0000 & 0.31940 & 0.98897 & 0.82938 & Biso & 1.000 & 0 \\
\hline 023 & 1.0000 & 0.67012 & 0.69415 & 0.83730 & Biso & 1.000 & 0 \\
\hline $\mathrm{O} 24$ & 1.0000 & 0.02440 & 0.34417 & 0.83415 & Biso & 1.000 & 0 \\
\hline 025 & 1.0000 & 0.66011 & 0.66032 & 0.49877 & Biso & 1.000 & 0 \\
\hline 026 & 1.0000 & 0.35641 & 0.00077 & 0.50348 & Biso & 1.000 & 0 \\
\hline 027 & 1.0000 & 0.01006 & 0.35761 & 0.49720 & Biso & 1.000 & 0 \\
\hline 028 & 1.0000 & 0.02161 & 0.68573 & 0.83939 & Biso & 1.000 & 0 \\
\hline 029 & 1.0000 & 0.31933 & 0.34126 & 0.82747 & Biso & 1.000 & 0 \\
\hline 030 & 1.0000 & 0.67275 & 0.98662 & 0.83378 & Biso & 1.000 & 0 \\
\hline 031 & 1.0000 & 0.69331 & 0.03277 & 0.16151 & Biso & 1.000 & 0 \\
\hline 032 & 1.0000 & 0.34606 & 0.32615 & 0.15918 & Biso & 1.000 & 0 \\
\hline 033 & 1.0000 & 0.99511 & 0.68165 & 0.16952 & Biso & 1.000 & 0 \\
\hline 034 & 1.0000 & 0.35440 & 0.37121 & 0.49371 & Biso & 1.000 & 0 \\
\hline 035 & 1.0000 & 0.00087 & 0.65995 & 0.50326 & Biso & 1.000 & 0 \\
\hline 036 & 1.0000 & 0.64954 & 0.01104 & 0.49800 & Biso & 1.000 & 0 \\
\hline 037 & 1.0000 & 0.13217 & 0.25609 & 0.12350 & Biso & 1.000 & 0 \\
\hline 038 & 1.0000 & 0.76835 & 0.89176 & 0.13243 & Biso & 1.000 & 0 \\
\hline 039 & 1.0000 & 0.13343 & 0.89245 & 0.13238 & Biso & 1.000 & 0 \\
\hline 040 & 1.0000 & 0.24293 & 0.12726 & 0.86374 & Biso & 1.000 & 0 \\
\hline 041 & 1.0000 & 0.88235 & 0.76075 & 0.87267 & Biso & 1.000 & 0 \\
\hline 042 & 1.0000 & 0.88550 & 0.12984 & 0.86821 & Biso & 1.000 & 0 \\
\hline 043 & 1.0000 & 0.79021 & 0.57770 & 0.45427 & Biso & 1.000 & 0 \\
\hline 044 & 1.0000 & 0.41374 & 0.22256 & 0.44701 & Biso & 1.000 & 0 \\
\hline 045 & 1.0000 & 0.79882 & 0.21973 & 0.45744 & Biso & 1.000 & 0 \\
\hline 046 & 1.0000 & 0.91909 & 0.46709 & 0.20231 & Biso & 1.000 & 0 \\
\hline 047 & 1.0000 & 0.55663 & 0.10712 & 0.20516 & Biso & 1.000 & 0 \\
\hline 048 & 1.0000 & 0.56007 & 0.46112 & 0.19709 & Biso & 1.000 & 0 \\
\hline 049 & 1.0000 & 0.45907 & 0.91309 & 0.79999 & Biso & 1.000 & 0 \\
\hline
\end{tabular}




\begin{tabular}{|c|c|c|c|c|c|c|c|}
\hline 050 & 1.0000 & 0.09229 & 0.55058 & 0.78302 & Biso & 1.000 & $\mathrm{O}$ \\
\hline 051 & 1.0000 & 0.46037 & 0.55518 & 0.79295 & Biso & 1.000 & $\mathrm{O}$ \\
\hline 052 & 1.0000 & 0.59510 & 0.80472 & 0.54334 & Biso & 1.000 & 0 \\
\hline 053 & 1.0000 & 0.22615 & 0.45462 & 0.53553 & Biso & 1.000 & 0 \\
\hline 054 & 1.0000 & 0.21837 & 0.78691 & 0.53293 & Biso & 1.000 & 0 \\
\hline 055 & 1.0000 & 0.00354 & 0.27440 & 0.99862 & Biso & 1.000 & 0 \\
\hline 056 & 1.0000 & 0.74442 & 0.74902 & 0.00186 & Biso & 1.000 & $\mathrm{O}$ \\
\hline 057 & 1.0000 & 0.26322 & 0.00566 & 0.99334 & Biso & 1.000 & 0 \\
\hline 058 & 1.0000 & 0.66648 & 0.60617 & 0.33145 & Biso & 1.000 & 0 \\
\hline 059 & 1.0000 & 0.94579 & 0.34909 & 0.33157 & Biso & 1.000 & 0 \\
\hline 060 & 1.0000 & 0.33417 & 0.92430 & 0.66786 & Biso & 1.000 & $\mathrm{O}$ \\
\hline 061 & 1.0000 & 0.07327 & 0.39506 & 0.66563 & Biso & 1.000 & 0 \\
\hline 062 & 1.0000 & 0.61379 & 0.67400 & 0.66727 & Biso & 1.000 & 0 \\
\hline 063 & 1.0000 & 0.01195 & 0.75059 & 0.00199 & Biso & 1.000 & 0 \\
\hline 064 & 1.0000 & 0.27542 & 0.27390 & 0.99424 & Biso & 1.000 & 0 \\
\hline 065 & 1.0000 & 0.74583 & 0.00780 & 0.99887 & Biso & 1.000 & 0 \\
\hline 066 & 1.0000 & 0.67813 & 0.07361 & 0.33006 & Biso & 1.000 & $\mathrm{O}$ \\
\hline 067 & 1.0000 & 0.94910 & 0.60978 & 0.33478 & Biso & 1.000 & $\mathrm{O}$ \\
\hline 068 & 1.0000 & 0.40971 & 0.36502 & 0.32737 & Biso & 1.000 & 0 \\
\hline 069 & 1.0000 & 0.33805 & 0.41410 & 0.66264 & Biso & 1.000 & 0 \\
\hline 070 & 1.0000 & 0.60351 & 0.94918 & 0.66674 & Biso & 1.000 & 0 \\
\hline 071 & 1.0000 & 0.07600 & 0.69267 & 0.67013 & Biso & 1.000 & 0 \\
\hline 072 & 1.0000 & 0.38939 & 0.05180 & 0.32331 & Biso & 1.000 & $\mathrm{O}$ \\
\hline $\mathrm{C} 1$ & 1.0000 & 0.29417 & 0.88151 & 0.32198 & Biso & 1.000 & $\mathrm{C}$ \\
\hline $\mathrm{H} 1$ & 1.0000 & 0.37245 & 0.87915 & 0.33021 & Biso & 1.000 & $\mathrm{H}$ \\
\hline $\mathrm{H} 2$ & 1.0000 & 0.25009 & 0.88661 & 0.38043 & Biso & 1.000 & $\mathrm{H}$ \\
\hline H3 & 1.0000 & 0.26234 & 0.88227 & 0.25590 & Biso & 1.000 & $\mathrm{H}$ \\
\hline $\mathrm{C} 2$ & 1.0000 & 0.21365 & 0.71439 & 0.32752 & Biso & 1.000 & $\mathrm{C}$ \\
\hline 073 & 1.0000 & 0.19846 & 0.62471 & 0.33487 & Biso & 1.000 & $\mathrm{O}$ \\
\hline \\
\hline & \multicolumn{7}{|c|}{ data_image 0} \\
\hline \multicolumn{8}{|c|}{13.875} \\
\hline \multicolumn{8}{|c|}{-cell_length_b $\quad 13.875$} \\
\hline \multicolumn{8}{|c|}{-cell_length_c $\quad 15.017$} \\
\hline \multicolumn{8}{|c|}{ _cell_angle_àlpha 90} \\
\hline \multicolumn{8}{|c|}{ _cell_angle_beta 90} \\
\hline \multicolumn{8}{|c|}{ cell_angle_gamma } \\
\hline symme & space_gr & coup_name & $\mathrm{H}-\mathrm{M}$ & P $1 "$ & & & \\
\hline _symme & int_tabl & les_numbe & & & & & \\
\hline loop_ & & & & & & & \\
\hline $\begin{array}{c}\text { sym } \\
\text { x, }\end{array}$ & _equiv & pos_as_x & & & & & \\
\hline loop & & & & & & & \\
\hline -ato & [e_labe] & & & & & & \\
\hline -ato & Ee_occup & oancy & & & & & \\
\hline -ato & ce_fract & t_ & & & & & \\
\hline -ato & te_fract & & & & & & \\
\hline -ato & te_fract & z & & & & & \\
\hline -ato & te_thern & nàl_displ & ace_type & & & & \\
\hline -ato & $\begin{array}{l}\text { ce_B_isc } \\
\text { te type }\end{array}$ & $\begin{array}{l}\text { o_or_equi } \\
\text { symbol }\end{array}$ & & & & & \\
\hline$\overline{\mathrm{P}} 1$ & 1.0000 & 0.00576 & 0.23151 & 0.10843 & Biso & 1.000 & $\mathrm{P}$ \\
\hline $\mathrm{P} 2$ & 1.0000 & 0.77479 & 0.77992 & 0.11201 & Biso & 1.000 & $\mathrm{P}$ \\
\hline P3 & 1.0000 & 0.22676 & 0.00064 & 0.10069 & Biso & 1.000 & $\mathrm{P}$ \\
\hline Al1 & 1.0000 & 0.21780 & 0.99327 & 0.88717 & Biso & 1.000 & Al \\
\hline Al2 & 1.0000 & 0.76932 & 0.77425 & 0.89965 & Biso & 1.000 & Al \\
\hline Al3 & 1.0000 & 0.99909 & 0.22880 & 0.89666 & Biso & 1.000 & $\mathrm{Al}$ \\
\hline $\mathrm{P} 4$ & 1.0000 & 0.66371 & 0.55868 & 0.44020 & Biso & 1.000 & $P$ \\
\hline $\mathrm{Ge} 1$ & 1.0000 & 0.42234 & 0.10356 & 0.44041 & Biso & 1.000 & $\mathrm{Ge}$ \\
\hline P5 & 1.0000 & 0.89633 & 0.33078 & 0.43965 & Biso & 1.000 & $P$ \\
\hline Al4 & 1.0000 & 0.89963 & 0.33637 & 0.23130 & Biso & 1.000 & Al \\
\hline Al5 & 1.0000 & 0.43720 & 0.10865 & 0.22583 & Biso & 1.000 & $\mathrm{Al}$ \\
\hline Al6 & 1.0000 & 0.67172 & 0.56383 & 0.22937 & Biso & 1.000 & $\mathrm{Al}$ \\
\hline P 6 & 1.0000 & 0.33154 & 0.88515 & 0.78124 & Biso & 1.000 & $P$ \\
\hline P7 & 1.0000 & 0.10097 & 0.43603 & 0.77368 & Biso & 1.000 & $\mathrm{P}$ \\
\hline P8 & 1.0000 & 0.55917 & 0.66270 & 0.77374 & Biso & 1.000 & $\mathrm{P}$ \\
\hline Al7 & 1.0000 & 0.56763 & 0.67161 & 0.56681 & Biso & 1.000 & Al \\
\hline A18 & 1.0000 & 0.09502 & 0.43317 & 0.56934 & Biso & 1.000 & Al \\
\hline Al9 & 1.0000 & 0.33163 & 0.88363 & 0.56606 & Biso & 1.000 & $\mathrm{Al}$ \\
\hline P9 & 1.0000 & 0.99194 & 0.76639 & 0.89375 & Biso & 1.000 & $P$ \\
\hline $\mathrm{P} 10$ & 1.0000 & 0.22432 & 0.22367 & 0.88549 & Biso & 1.000 & $\mathrm{P}$ \\
\hline P11 & 1.0000 & 0.77453 & 0.00274 & 0.89337 & Biso & 1.000 & $P$ \\
\hline Al10 & 1.0000 & 0.77710 & 0.00730 & 0.10624 & Biso & 1.000 & $\mathrm{Al}$ \\
\hline Al11 & 1.0000 & 0.23194 & 0.22949 & 0.09740 & Biso & 1.000 & $\mathrm{Al}$ \\
\hline Al12 & 1.0000 & 0.00159 & 0.77744 & 0.10738 & Biso & 1.000 & Al \\
\hline $\mathrm{P} 12$ & 1.0000 & 0.66485 & 0.10934 & 0.22640 & Biso & 1.000 & $\mathrm{P}$ \\
\hline $\mathrm{P} 13$ & 1.0000 & 0.90175 & 0.56476 & 0.22898 & Biso & 1.000 & $\mathrm{P}$ \\
\hline
\end{tabular}




\begin{tabular}{|c|c|c|c|c|c|c|c|}
\hline P14 & 1.0000 & 0.44286 & 0.34438 & 0.22326 & Biso & 1.000 & $\mathrm{P}$ \\
\hline Al13 & 1.0000 & 0.42820 & 0.34342 & 0.42918 & Biso & 1.000 & $\mathrm{Al}$ \\
\hline Al14 & 1.0000 & 0.89268 & 0.55800 & 0.44030 & Biso & 1.000 & Al \\
\hline Al15 & 1.0000 & 0.65876 & 0.10882 & 0.43512 & Biso & 1.000 & $\mathrm{Al}$ \\
\hline P15 & 1.0000 & 0.33052 & 0.45492 & 0.55679 & Biso & 1.000 & $\mathrm{P}$ \\
\hline P16 & 1.0000 & 0.56330 & 0.89795 & 0.56141 & Biso & 1.000 & $\mathrm{P}$ \\
\hline P17 & 1.0000 & 0.09659 & 0.66870 & 0.56694 & Biso & 1.000 & $\mathrm{P}$ \\
\hline Al16 & 1.0000 & 0.10141 & 0.66868 & 0.77336 & Biso & 1.000 & Al \\
\hline Al17 & 1.0000 & 0.55865 & 0.89237 & 0.77192 & Biso & 1.000 & $\mathrm{Al}$ \\
\hline Al18 & 1.0000 & 0.32751 & 0.43872 & 0.76646 & Biso & 1.000 & $\mathrm{Al}$ \\
\hline 01 & 1.0000 & 0.91460 & 0.11108 & 0.12949 & Biso & 1.000 & 0 \\
\hline $\mathrm{O} 2$ & 1.0000 & 0.89629 & 0.80895 & 0.12884 & Biso & 1.000 & 0 \\
\hline 03 & 1.0000 & 0.19674 & 0.09136 & 0.12011 & Biso & 1.000 & 0 \\
\hline 04 & 1.0000 & 0.08237 & 0.88445 & 0.86563 & Biso & 1.000 & 0 \\
\hline 05 & 1.0000 & 0.80666 & 0.91265 & 0.87637 & Biso & 1.000 & 0 \\
\hline 06 & 1.0000 & 0.10333 & 0.19690 & 0.87223 & Biso & 1.000 & 0 \\
\hline 07 & 1.0000 & 0.56826 & 0.43964 & 0.45681 & Biso & 1.000 & 0 \\
\hline 08 & 1.0000 & 0.56580 & 0.15442 & 0.45415 & Biso & 1.000 & 0 \\
\hline 09 & 1.0000 & 0.86959 & 0.42394 & 0.46063 & Biso & 1.000 & 0 \\
\hline 010 & 1.0000 & 0.76204 & 0.22988 & 0.21696 & Biso & 1.000 & 0 \\
\hline 011 & 1.0000 & 0.46461 & 0.24578 & 0.22584 & Biso & 1.000 & 0 \\
\hline 012 & 1.0000 & 0.78169 & 0.53765 & 0.21164 & Biso & 1.000 & 0 \\
\hline 013 & 1.0000 & 0.23696 & 0.76750 & 0.80642 & Biso & 1.000 & 0 \\
\hline 014 & 1.0000 & 0.22359 & 0.47159 & 0.79302 & Biso & 1.000 & 0 \\
\hline 015 & 1.0000 & 0.52757 & 0.75405 & 0.78257 & Biso & 1.000 & 0 \\
\hline 016 & 1.0000 & 0.42670 & 0.57598 & 0.54877 & Biso & 1.000 & 0 \\
\hline 017 & 1.0000 & 0.10258 & 0.56174 & 0.56388 & Biso & 1.000 & 0 \\
\hline 018 & 1.0000 & 0.43981 & 0.85638 & 0.53883 & Biso & 1.000 & 0 \\
\hline 019 & 1.0000 & 0.99046 & 0.31453 & 0.16549 & Biso & 1.000 & 0 \\
\hline 020 & 1.0000 & 0.69459 & 0.68067 & 0.16925 & Biso & 1.000 & 0 \\
\hline 021 & 1.0000 & 0.33523 & 0.02630 & 0.14739 & Biso & 1.000 & 0 \\
\hline 022 & 1.0000 & 0.31516 & 0.97392 & 0.82879 & Biso & 1.000 & 0 \\
\hline 023 & 1.0000 & 0.65127 & 0.68233 & 0.83998 & Biso & 1.000 & 0 \\
\hline 024 & 1.0000 & 0.02292 & 0.34821 & 0.84045 & Biso & 1.000 & 0 \\
\hline 025 & 1.0000 & 0.65163 & 0.64314 & 0.49818 & Biso & 1.000 & 0 \\
\hline 026 & 1.0000 & 0.33497 & 0.99214 & 0.50976 & Biso & 1.000 & 0 \\
\hline 027 & 1.0000 & 0.98876 & 0.33954 & 0.50093 & Biso & 1.000 & 0 \\
\hline 028 & 1.0000 & 0.00566 & 0.67815 & 0.84286 & Biso & 1.000 & 0 \\
\hline 029 & 1.0000 & 0.30405 & 0.32111 & 0.82635 & Biso & 1.000 & 0 \\
\hline 030 & 1.0000 & 0.67248 & 0.97961 & 0.83810 & Biso & 1.000 & 0 \\
\hline 031 & 1.0000 & 0.68316 & 0.03129 & 0.16515 & Biso & 1.000 & 0 \\
\hline 032 & 1.0000 & 0.35053 & 0.32182 & 0.15613 & Biso & 1.000 & 0 \\
\hline 033 & 1.0000 & 0.98434 & 0.66567 & 0.17321 & Biso & 1.000 & 0 \\
\hline 034 & 1.0000 & 0.34427 & 0.37911 & 0.49119 & Biso & 1.000 & 0 \\
\hline 035 & 1.0000 & 0.00215 & 0.65688 & 0.50601 & Biso & 1.000 & 0 \\
\hline 036 & 1.0000 & 0.63958 & 0.99692 & 0.50240 & Biso & 1.000 & 0 \\
\hline 037 & 1.0000 & 0.12004 & 0.24541 & 0.12993 & Biso & 1.000 & 0 \\
\hline 038 & 1.0000 & 0.76274 & 0.88000 & 0.13850 & Biso & 1.000 & 0 \\
\hline 039 & 1.0000 & 0.13262 & 0.88899 & 0.13738 & Biso & 1.000 & 0 \\
\hline 040 & 1.0000 & 0.23198 & 0.12118 & 0.85845 & Biso & 1.000 & 0 \\
\hline 041 & 1.0000 & 0.87786 & 0.75156 & 0.87061 & Biso & 1.000 & 0 \\
\hline 042 & 1.0000 & 0.87161 & 0.11606 & 0.86503 & Biso & 1.000 & 0 \\
\hline 043 & 1.0000 & 0.77410 & 0.56487 & 0.46440 & Biso & 1.000 & 0 \\
\hline 044 & 1.0000 & 0.38795 & 0.20774 & 0.44982 & Biso & 1.000 & 0 \\
\hline 045 & 1.0000 & 0.79378 & 0.21758 & 0.45537 & Biso & 1.000 & 0 \\
\hline 046 & 1.0000 & 0.91357 & 0.46481 & 0.20146 & Biso & 1.000 & 0 \\
\hline 047 & 1.0000 & 0.55785 & 0.10668 & 0.19635 & Biso & 1.000 & 0 \\
\hline 048 & 1.0000 & 0.54972 & 0.44842 & 0.19183 & Biso & 1.000 & 0 \\
\hline 049 & 1.0000 & 0.44327 & 0.89861 & 0.81117 & Biso & 1.000 & 0 \\
\hline 050 & 1.0000 & 0.08537 & 0.53704 & 0.78291 & Biso & 1.000 & 0 \\
\hline 051 & 1.0000 & 0.45693 & 0.55016 & 0.79617 & Biso & 1.000 & 0 \\
\hline 052 & 1.0000 & 0.58890 & 0.80405 & 0.54349 & Biso & 1.000 & 0 \\
\hline 053 & 1.0000 & 0.22249 & 0.45374 & 0.53328 & Biso & 1.000 & $\mathrm{O}$ \\
\hline 054 & 1.0000 & 0.20707 & 0.76439 & 0.53139 & Biso & 1.000 & 0 \\
\hline 055 & 1.0000 & 0.99950 & 0.25745 & 0.00987 & Biso & 1.000 & 0 \\
\hline 056 & 1.0000 & 0.74354 & 0.74969 & 0.01371 & Biso & 1.000 & 0 \\
\hline 057 & 1.0000 & 0.24207 & 0.99124 & 0.00092 & Biso & 1.000 & 0 \\
\hline 058 & 1.0000 & 0.66537 & 0.59139 & 0.34189 & Biso & 1.000 & 0 \\
\hline 059 & 1.0000 & 0.93784 & 0.34284 & 0.34285 & Biso & 1.000 & 0 \\
\hline 060 & 1.0000 & 0.33107 & 0.90176 & 0.68065 & Biso & 1.000 & 0 \\
\hline 061 & 1.0000 & 0.06888 & 0.38587 & 0.67947 & Biso & 1.000 & 0 \\
\hline 062 & 1.0000 & 0.60055 & 0.66250 & 0.67851 & Biso & 1.000 & 0 \\
\hline 063 & 1.0000 & 0.00033 & 0.74876 & 0.99412 & Biso & 1.000 & 0 \\
\hline 064 & 1.0000 & 0.25897 & 0.25471 & 0.98343 & Biso & 1.000 & 0 \\
\hline 065 & 1.0000 & 0.74790 & 0.00470 & 0.99261 & Biso & 1.000 & 0 \\
\hline 066 & 1.0000 & 0.65419 & 0.06751 & 0.32263 & Biso & 1.000 & 0 \\
\hline 067 & 1.0000 & 0.93282 & 0.59366 & 0.32806 & Biso & 1.000 & 0 \\
\hline 068 & 1.0000 & 0.40931 & 0.36475 & 0.31562 & Biso & 1.000 & 0 \\
\hline 069 & 1.0000 & 0.32492 & 0.41185 & 0.65243 & Biso & 1.000 & 0 \\
\hline 070 & 1.0000 & 0.58594 & 0.93367 & 0.66014 & Biso & 1.000 & 0 \\
\hline
\end{tabular}




$\begin{array}{llllllll}071 & 1.0000 & 0.07589 & 0.69277 & 0.66299 & \text { Biso } & 1.000 & \text { O } \\ \text { O72 } & 1.0000 & 0.38334 & 0.04200 & 0.32833 & \text { Biso } & 1.000 & \text { O } \\ \text { C1 } & 1.0000 & 0.28237 & 0.87552 & 0.32653 & \text { Biso } & 1.000 & \text { C } \\ \text { H1 } & 1.0000 & 0.35782 & 0.86992 & 0.33193 & \text { Biso } & 1.000 & \text { H } \\ \text { H2 } & 1.0000 & 0.24242 & 0.88217 & 0.38674 & \text { Biso } & 1.000 & \text { H } \\ \text { H3 } & 1.0000 & 0.25076 & 0.88057 & 0.26142 & \text { Biso } & 1.000 & \text { H } \\ \text { C2 } & 1.0000 & 0.19914 & 0.71372 & 0.32925 & \text { Biso } & 1.000 & \text { C } \\ \text { O73 } & 1.0000 & 0.18382 & 0.62529 & 0.33473 & \text { Biso } & 1.000 & \text { O }\end{array}$

Ga 16

data image 0

$\begin{array}{ll}\text { _celi__length_a } & 13.625 \\ \text {-cell_length_b } & 13.625 \\ \text { _cell_length_c } & 15.067 \\ \text {-cell_angle_alpha } & 90 \\ \text { _cell_angle_beta } & 90 \\ \text {-cell_angle_gamma } & 120\end{array}$

cell_angle_gamma 120

symmetry_space_group_name_H-M "P 1 "

symmetry_int_tables_number $\bar{r} 1$

loop_

_symmetry_equiv_pos_as_xyz

' $\mathrm{x}, \mathrm{y}, \mathrm{z}$ '

loop_

_atom_site_label

-atom_site_occupancy

_atom_site_fract_x

-atom_site_fract_y

atom_site_fract z

-atom_site_thermāldisplace_type

-atom_site_B_iso_or_equiv

atom site type symbol

\begin{tabular}{|c|c|c|c|c|c|c|c|}
\hline$\overline{\mathrm{S}} i 1$ & 1.0000 & 0.01010 & 0.24169 & 0.10148 & Biso & 1.000 & $\mathrm{Si}$ \\
\hline Si2 & 1.0000 & 0.78083 & 0.78367 & 0.10616 & Biso & 1.000 & $\mathrm{Si}$ \\
\hline $\mathrm{Si3}$ & 1.0000 & 0.23778 & 0.01277 & 0.09551 & Biso & 1.000 & $\mathrm{Si}$ \\
\hline $\mathrm{Si} 4$ & 1.0000 & 0.22959 & 0.00532 & 0.88797 & Biso & 1.000 & $\mathrm{Si}$ \\
\hline Si5 & 1.0000 & 0.77691 & 0.77887 & 0.89893 & Biso & 1.000 & $\mathrm{Si}$ \\
\hline Si6 & 1.0000 & 0.00409 & 0.23873 & 0.89514 & Biso & 1.000 & $\mathrm{Si}$ \\
\hline Si7 & 1.0000 & 0.66815 & 0.56735 & 0.43515 & Biso & 1.000 & $\mathrm{Si}$ \\
\hline Ga 1 & 1.0000 & 0.43880 & 0.11487 & 0.43595 & Biso & 1.000 & $\mathrm{Ga}$ \\
\hline Si8 & 1.0000 & 0.91028 & 0.34245 & 0.43354 & Biso & 1.000 & $\mathrm{Si}$ \\
\hline Si9 & 1.0000 & 0.91029 & 0.34801 & 0.22986 & Biso & 1.000 & $\mathrm{Si}$ \\
\hline Si10 & 1.0000 & 0.44515 & 0.11330 & 0.22425 & Biso & 1.000 & $\mathrm{Si}$ \\
\hline Si11 & 1.0000 & 0.67499 & 0.57300 & 0.22976 & Biso & 1.000 & $\mathrm{Si}$ \\
\hline Si12 & 1.0000 & 0.33682 & 0.89712 & 0.77195 & Biso & 1.000 & $\mathrm{Si}$ \\
\hline Si13 & 1.0000 & 0.10796 & 0.44139 & 0.76667 & Biso & 1.000 & $\mathrm{Si}$ \\
\hline $\operatorname{Sil} 4$ & 1.0000 & 0.57075 & 0.67509 & 0.76860 & Biso & 1.000 & $\mathrm{Si}$ \\
\hline Si15 & 1.0000 & 0.58084 & 0.68365 & 0.56559 & Biso & 1.000 & $\mathrm{Si}$ \\
\hline Si16 & 1.0000 & 0.10463 & 0.44136 & 0.56667 & Biso & 1.000 & $\mathrm{Si}$ \\
\hline Sil 7 & 1.0000 & 0.33736 & 0.89262 & 0.56266 & Biso & 1.000 & $\mathrm{Si}$ \\
\hline Si18 & 1.0000 & 0.00356 & 0.77479 & 0.89751 & Biso & 1.000 & $\mathrm{Si}$ \\
\hline Si19 & 1.0000 & 0.23419 & 0.23743 & 0.88945 & Biso & 1.000 & $\mathrm{Si}$ \\
\hline Si20 & 1.0000 & 0.77859 & 0.00790 & 0.89643 & Biso & 1.000 & $\mathrm{Si}$ \\
\hline Si21 & 1.0000 & 0.78141 & 0.01247 & 0.10408 & Biso & 1.000 & $\mathrm{Si}$ \\
\hline Si22 & 1.0000 & 0.23997 & 0.24202 & 0.09570 & Biso & 1.000 & $\mathrm{Si}$ \\
\hline Si23 & 1.0000 & 0.01168 & 0.78477 & 0.10602 & Biso & 1.000 & $\mathrm{Si}$ \\
\hline Si24 & 1.0000 & 0.67581 & 0.11649 & 0.23004 & Biso & 1.000 & $\mathrm{Si}$ \\
\hline Si25 & 1.0000 & 0.90844 & 0.57570 & 0.23172 & Biso & 1.000 & $\mathrm{Si}$ \\
\hline Si26 & 1.0000 & 0.44552 & 0.34790 & 0.22758 & Biso & 1.000 & $\mathrm{Si}$ \\
\hline Si27 & 1.0000 & 0.43208 & 0.34811 & 0.42988 & Biso & 1.000 & $\mathrm{Si}$ \\
\hline Si28 & 1.0000 & 0.90216 & 0.56935 & 0.43740 & Biso & 1.000 & $\mathrm{Si}$ \\
\hline Si29 & 1.0000 & 0.67323 & 0.11824 & 0.43323 & Biso & 1.000 & $\mathrm{Si}$ \\
\hline Si30 & 1.0000 & 0.34258 & 0.46265 & 0.55998 & Biso & 1.000 & $\mathrm{Si}$ \\
\hline Si31 & 1.0000 & 0.57301 & 0.90951 & 0.56424 & Biso & 1.000 & $\mathrm{Si}$ \\
\hline Si32 & 1.0000 & 0.09965 & 0.67513 & 0.56936 & Biso & 1.000 & $\mathrm{Si}$ \\
\hline Si33 & 1.0000 & 0.10645 & 0.67476 & 0.77104 & Biso & 1.000 & $\mathrm{Si}$ \\
\hline Si34 & 1.0000 & 0.56777 & 0.90481 & 0.76966 & Biso & 1.000 & $\mathrm{Si}$ \\
\hline Si35 & 1.0000 & 0.33862 & 0.44738 & 0.76525 & Biso & 1.000 & $\mathrm{Si}$ \\
\hline 01 & 1.0000 & 0.91257 & 0.11102 & 0.12095 & Biso & 1.000 & 0 \\
\hline $\mathrm{O} 2$ & 1.0000 & 0.91204 & 0.81538 & 0.12288 & Biso & 1.000 & $\mathrm{O}$ \\
\hline 03 & 1.0000 & 0.20393 & 0.10985 & 0.11280 & Biso & 1.000 & $\mathrm{O}$ \\
\hline O4 & 1.0000 & 0.09980 & 0.90376 & 0.87154 & Biso & 1.000 & 0 \\
\hline 05 & 1.0000 & 0.81377 & 0.91091 & 0.88075 & Biso & 1.000 & 0 \\
\hline 06 & 1.0000 & 0.10375 & 0.20844 & 0.87749 & Biso & 1.000 & 0 \\
\hline 07 & 1.0000 & 0.56552 & 0.43925 & 0.45231 & Biso & 1.000 & 0 \\
\hline 08 & 1.0000 & 0.58946 & 0.16764 & 0.44791 & Biso & 1.000 & 0 \\
\hline 09 & 1.0000 & 0.87990 & 0.44194 & 0.45496 & Biso & 1.000 & $\mathrm{O}$ \\
\hline 010 & 1.0000 & 0.77958 & 0.24661 & 0.22073 & Biso & 1.000 & $\mathrm{O}$ \\
\hline 011 & 1.0000 & 0.47097 & 0.24297 & 0.22750 & Biso & 1.000 & 0 \\
\hline
\end{tabular}




\begin{tabular}{|c|c|c|c|c|c|c|c|}
\hline 012 & 1.0000 & 0.77912 & 0.54765 & 0.21756 & Biso & 1.000 & 0 \\
\hline 013 & 1.0000 & 0.23715 & 0.76819 & 0.79538 & Biso & 1.000 & 0 \\
\hline 014 & 1.0000 & 0.23993 & 0.47892 & 0.78655 & Biso & 1.000 & 0 \\
\hline 015 & 1.0000 & 0.53645 & 0.77314 & 0.77800 & Biso & 1.000 & 0 \\
\hline 016 & 1.0000 & 0.44732 & 0.59213 & 0.55056 & Biso & 1.000 & 0 \\
\hline 017 & 1.0000 & 0.10757 & 0.56119 & 0.56442 & Biso & 1.000 & 0 \\
\hline 018 & 1.0000 & 0.43857 & 0.86259 & 0.54552 & Biso & 1.000 & 0 \\
\hline 019 & 1.0000 & 0.99297 & 0.32851 & 0.16410 & Biso & 1.000 & 0 \\
\hline $\mathrm{O} 20$ & 1.0000 & 0.69516 & 0.67895 & 0.16834 & Biso & 1.000 & O \\
\hline 021 & 1.0000 & 0.35141 & 0.03918 & 0.14900 & Biso & 1.000 & 0 \\
\hline 022 & 1.0000 & 0.31767 & 0.98842 & 0.82711 & Biso & 1.000 & 0 \\
\hline 023 & 1.0000 & 0.66880 & 0.69477 & 0.83894 & Biso & 1.000 & 0 \\
\hline 024 & 1.0000 & 0.02304 & 0.34535 & 0.83551 & Biso & 1.000 & 0 \\
\hline 025 & 1.0000 & 0.65951 & 0.65817 & 0.49967 & Biso & 1.000 & 0 \\
\hline 026 & 1.0000 & 0.34659 & 0.99247 & 0.50212 & Biso & 1.000 & 0 \\
\hline 027 & 1.0000 & 0.01080 & 0.35384 & 0.49784 & Biso & 1.000 & 0 \\
\hline 028 & 1.0000 & 0.02046 & 0.68311 & 0.84103 & Biso & 1.000 & 0 \\
\hline 029 & 1.0000 & 0.31866 & 0.33949 & 0.82443 & Biso & 1.000 & 0 \\
\hline 030 & 1.0000 & 0.67147 & 0.98442 & 0.83540 & Biso & 1.000 & 0 \\
\hline 031 & 1.0000 & 0.69555 & 0.03348 & 0.16451 & Biso & 1.000 & 0 \\
\hline 032 & 1.0000 & 0.34743 & 0.32567 & 0.15630 & Biso & 1.000 & 0 \\
\hline 033 & 1.0000 & 0.99581 & 0.68224 & 0.17053 & Biso & 1.000 & 0 \\
\hline 034 & 1.0000 & 0.35251 & 0.37935 & 0.48987 & Biso & 1.000 & 0 \\
\hline 035 & 1.0000 & 0.99920 & 0.66140 & 0.50332 & Biso & 1.000 & 0 \\
\hline 036 & 1.0000 & 0.65079 & 0.01494 & 0.49993 & Biso & 1.000 & 0 \\
\hline 037 & 1.0000 & 0.13347 & 0.25721 & 0.12323 & Biso & 1.000 & 0 \\
\hline 038 & 1.0000 & 0.76911 & 0.89232 & 0.13286 & Biso & 1.000 & 0 \\
\hline 039 & 1.0000 & 0.13437 & 0.89282 & 0.13206 & Biso & 1.000 & 0 \\
\hline 040 & 1.0000 & 0.24028 & 0.12554 & 0.86274 & Biso & 1.000 & 0 \\
\hline 041 & 1.0000 & 0.88101 & 0.75913 & 0.87293 & Biso & 1.000 & 0 \\
\hline 042 & 1.0000 & 0.88428 & 0.12957 & 0.86801 & Biso & 1.000 & 0 \\
\hline 043 & 1.0000 & 0.78697 & 0.57180 & 0.45546 & Biso & 1.000 & 0 \\
\hline 044 & 1.0000 & 0.39978 & 0.22113 & 0.45066 & Biso & 1.000 & 0 \\
\hline 045 & 1.0000 & 0.80283 & 0.21881 & 0.45036 & Biso & 1.000 & 0 \\
\hline 046 & 1.0000 & 0.91845 & 0.46696 & 0.20174 & Biso & 1.000 & 0 \\
\hline 047 & 1.0000 & 0.56039 & 0.11308 & 0.19802 & Biso & 1.000 & 0 \\
\hline 048 & 1.0000 & 0.56011 & 0.46179 & 0.19689 & Biso & 1.000 & 0 \\
\hline 049 & 1.0000 & 0.45810 & 0.91255 & 0.80127 & Biso & 1.000 & 0 \\
\hline 050 & 1.0000 & 0.09134 & 0.54990 & 0.77869 & Biso & 1.000 & 0 \\
\hline 051 & 1.0000 & 0.46032 & 0.55430 & 0.79204 & Biso & 1.000 & 0 \\
\hline 052 & 1.0000 & 0.60102 & 0.80891 & 0.54365 & Biso & 1.000 & 0 \\
\hline 053 & 1.0000 & 0.22809 & 0.46511 & 0.53653 & Biso & 1.000 & 0 \\
\hline 054 & 1.0000 & 0.21899 & 0.77873 & 0.53410 & Biso & 1.000 & 0 \\
\hline 055 & 1.0000 & 0.00349 & 0.27299 & 0.99845 & Biso & 1.000 & 0 \\
\hline 056 & 1.0000 & 0.74478 & 0.74819 & 0.00320 & Biso & 1.000 & 0 \\
\hline 057 & 1.0000 & 0.26221 & 0.00403 & 0.99161 & Biso & 1.000 & 0 \\
\hline 058 & 1.0000 & 0.66643 & 0.60469 & 0.33241 & Biso & 1.000 & 0 \\
\hline 059 & 1.0000 & 0.95483 & 0.35621 & 0.33119 & Biso & 1.000 & 0 \\
\hline 060 & 1.0000 & 0.33458 & 0.92103 & 0.66714 & Biso & 1.000 & 0 \\
\hline 061 & 1.0000 & 0.07369 & 0.38929 & 0.66669 & Biso & 1.000 & 0 \\
\hline 062 & 1.0000 & 0.61597 & 0.67618 & 0.66812 & Biso & 1.000 & 0 \\
\hline 063 & 1.0000 & 0.01103 & 0.75034 & 0.00265 & Biso & 1.000 & 0 \\
\hline 064 & 1.0000 & 0.27426 & 0.27435 & 0.99191 & Biso & 1.000 & 0 \\
\hline 065 & 1.0000 & 0.74650 & 0.00961 & 0.00037 & Biso & 1.000 & 0 \\
\hline 066 & 1.0000 & 0.66395 & 0.07023 & 0.33116 & Biso & 1.000 & 0 \\
\hline 067 & 1.0000 & 0.94708 & 0.60831 & 0.33530 & Biso & 1.000 & 0 \\
\hline 068 & 1.0000 & 0.40773 & 0.36521 & 0.32562 & Biso & 1.000 & 0 \\
\hline 069 & 1.0000 & 0.33717 & 0.41638 & 0.66080 & Biso & 1.000 & 0 \\
\hline 070 & 1.0000 & 0.60268 & 0.94921 & 0.66791 & Biso & 1.000 & 0 \\
\hline 071 & 1.0000 & 0.07443 & 0.69674 & 0.67112 & Biso & 1.000 & 0 \\
\hline 072 & 1.0000 & 0.39425 & 0.04989 & 0.31951 & Biso & 1.000 & 0 \\
\hline $\mathrm{C} 1$ & 1.0000 & 0.30083 & 0.87981 & 0.31852 & Biso & 1.000 & C \\
\hline $\mathrm{H} 1$ & 1.0000 & 0.38009 & 0.87831 & 0.31828 & Biso & 1.000 & $\mathrm{H}$ \\
\hline $\mathrm{H} 2$ & 1.0000 & 0.26475 & 0.88570 & 0.38148 & Biso & 1.000 & $\mathrm{H}$ \\
\hline H3 & 1.0000 & 0.26075 & 0.88017 & 0.25617 & Biso & 1.000 & $\mathrm{H}$ \\
\hline $\mathrm{C} 2$ & 1.0000 & 0.22067 & 0.71340 & 0.32708 & Biso & 1.000 & $\mathrm{C}$ \\
\hline 073 & 1.0000 & 0.20229 & 0.62394 & 0.34221 & Biso & 1.000 & 0 \\
\hline \\
\hline \multicolumn{8}{|c|}{$\begin{array}{l}\mathrm{Ti} 16 \\
\text { data image } 0\end{array}$} \\
\hline \multicolumn{2}{|c|}{ cel's_length_a } & \multicolumn{2}{|c|}{13.875} & & & & \\
\hline $\mathrm{cell}$ & $\operatorname{th}{ }^{-} b$ & \multicolumn{2}{|c|}{$\begin{array}{l}13.875 \\
13.875\end{array}$} & & & & \\
\hline cell & $=h^{-} c$ & \multicolumn{2}{|c|}{15.017} & & & & \\
\hline cell & alpha & 90 & & & & & \\
\hline cell & $e^{-b e t a}$ & 90 & & & & & \\
\hline cell & gamma & 120 & & & & & \\
\hline symme & oace g & nam & & $1 "$ & & & \\
\hline symme & at tab. & Les numb & & & & & \\
\hline
\end{tabular}




\begin{tabular}{|c|c|c|c|c|c|c|c|}
\hline \multicolumn{8}{|c|}{$\begin{array}{l}\text { 'symmetry_equiv_pos_as_xyz } \\
\text { op_y, } \\
\text {-atom_site_label } \\
\text {-atom_site_occupancy } \\
\text {-atom_site_fract_x } \\
\text {-atom_site_fract_y } \\
\text {-atom_site_fract_z } \\
\text {-atom_site_thermal_displace_type } \\
\text {-atom_site_B_iso_or_equiv } \\
\text {-atom_site_type_symbol }\end{array}$} \\
\hline$\overline{\mathrm{P}} 1$ & 1.0000 & 0.00664 & 0.23155 & 0.10820 & Biso & 1.000 & $\mathrm{P}$ \\
\hline P2 & 1.0000 & 0.77572 & 0.78038 & 0.11301 & Biso & 1.000 & $P$ \\
\hline P3 & 1.0000 & 0.22667 & 0.00129 & 0.09864 & Biso & 1.000 & $\mathrm{P}$ \\
\hline Al1 & 1.0000 & 0.21526 & 0.99197 & 0.88416 & Biso & 1.000 & A. \\
\hline Al2 & 1.0000 & 0.76928 & 0.77430 & 0.90000 & Biso & 1.000 & A. \\
\hline Al3 & 1.0000 & 0.99829 & 0.22823 & 0.89630 & Biso & 1.000 & A. \\
\hline P4 & 1.0000 & 0.66433 & 0.56140 & 0.44008 & Biso & 1.000 & $\mathrm{P}$ \\
\hline Til & 1.0000 & 0.41741 & 0.10247 & 0.43991 & Biso & 1.000 & \\
\hline P5 & 1.0000 & 0.89881 & 0.33146 & 0.43960 & Biso & 1.000 & $P$ \\
\hline Al4 & 1.0000 & 0.89877 & 0.33602 & 0.23001 & Biso & 1.000 & \\
\hline Al5 & 1.0000 & 0.43430 & 0.10510 & 0.22403 & Biso & 1.000 & \\
\hline Al 6 & 1.0000 & 0.67269 & 0.56391 & 0.22977 & Biso & 1.000 & \\
\hline P6 & 1.0000 & 0.32999 & 0.88140 & 0.78375 & Biso & 1.000 & \\
\hline P7 & 1.0000 & 0.10024 & 0.43479 & 0.77271 & Biso & 1.000 & $\mathrm{P}$ \\
\hline P8 & 1.0000 & 0.55969 & 0.66229 & 0.77418 & Biso & 1.000 & $\mathrm{P}$ \\
\hline Al 7 & 1.0000 & 0.57413 & 0.67550 & 0.56853 & Biso & 1.000 & \\
\hline Al8 & 1.0000 & 0.09464 & 0.43428 & 0.57057 & Biso & 1.000 & \\
\hline Al9 & 1.0000 & 0.33055 & 0.87673 & 0.56821 & Biso & 1.000 & \\
\hline P9 & 1.0000 & 0.99069 & 0.76511 & 0.89335 & Biso & 1.000 & $\mathrm{P}$ \\
\hline P 10 & 1.0000 & 0.22348 & 0.22275 & 0.88327 & Biso & 1.000 & $\mathrm{P}$ \\
\hline P11 & 1.0000 & 0.77498 & 0.00224 & 0.89364 & Biso & 1.000 & $P$ \\
\hline Al10 & 1.0000 & 0.77922 & 0.00756 & 0.10732 & Biso & 1.000 & \\
\hline Al11 & 1.0000 & 0.23358 & 0.23042 & 0.09562 & Biso & 1.000 & \\
\hline Al12 & 1.0000 & 0.00275 & 0.77872 & 0.10775 & Biso & 1.000 & \\
\hline $\mathrm{P} 12$ & 1.0000 & 0.66682 & 0.10974 & 0.22703 & Biso & 1.000 & \\
\hline P13 & 1.0000 & 0.90429 & 0.56642 & 0.22984 & Biso & 1.000 & $\mathrm{P}$ \\
\hline P14 & 1.0000 & 0.44394 & 0.34319 & 0.22186 & Biso & 1.000 & $\mathrm{P}$ \\
\hline Al13 & 1.0000 & 0.42537 & 0.34943 & 0.42882 & Biso & 1.000 & \\
\hline Al14 & 1.0000 & 0.89401 & 0.55910 & 0.44043 & Biso & 1.000 & \\
\hline Al15 & 1.0000 & 0.66333 & 0.11001 & 0.43579 & Biso & 1.000 & \\
\hline P15 & 1.0000 & 0.33255 & 0.46267 & 0.55604 & Biso & 1.000 & $\mathrm{P}$ \\
\hline P16 & 1.0000 & 0.56517 & 0.89933 & 0.56411 & Biso & 1.000 & $P$ \\
\hline P17 & 1.0000 & 0.09314 & 0.66794 & 0.56954 & Biso & 1.000 & $P$ \\
\hline Al16 & 1.0000 & 0.09960 & 0.66747 & 0.77449 & Biso & 1.000 & \\
\hline Al17 & 1.0000 & 0.55762 & 0.89176 & 0.77388 & Biso & 1.000 & \\
\hline Al18 & 1.0000 & 0.32724 & 0.43885 & 0.76447 & Biso & 1.000 & \\
\hline 01 & 1.0000 & 0.91710 & 0.11084 & 0.13068 & Biso & 1.000 & O \\
\hline $\mathrm{O} 2$ & 1.0000 & 0.89696 & 0.80906 & 0.13062 & Biso & 1.000 & 0 \\
\hline 03 & 1.0000 & 0.19811 & 0.09260 & 0.12031 & Biso & 1.000 & 0 \\
\hline 04 & 1.0000 & 0.08063 & 0.88180 & 0.86182 & Biso & 1.000 & 0 \\
\hline 05 & 1.0000 & 0.80710 & 0.91245 & 0.87493 & Biso & 1.000 & 0 \\
\hline 06 & 1.0000 & 0.10239 & 0.19628 & 0.87162 & Biso & 1.000 & 0 \\
\hline 07 & 1.0000 & 0.56469 & 0.44542 & 0.45864 & Biso & 1.000 & 0 \\
\hline 08 & 1.0000 & 0.56438 & 0.14944 & 0.44826 & Biso & 1.000 & 0 \\
\hline 09 & 1.0000 & 0.87421 & 0.42614 & 0.46027 & Biso & 1.000 & 0 \\
\hline 010 & 1.0000 & 0.76053 & 0.23152 & 0.21370 & Biso & 1.000 & $\mathrm{O}$ \\
\hline 011 & 1.0000 & 0.46359 & 0.24332 & 0.22491 & Biso & 1.000 & O \\
\hline 012 & 1.0000 & 0.78407 & 0.53948 & 0.21410 & Biso & 1.000 & 0 \\
\hline 013 & 1.0000 & 0.23455 & 0.76484 & 0.81045 & Biso & 1.000 & 0 \\
\hline 014 & 1.0000 & 0.22340 & 0.47184 & 0.79144 & Biso & 1.000 & O \\
\hline 015 & 1.0000 & 0.52773 & 0.75353 & 0.78097 & Biso & 1.000 & O \\
\hline 016 & 1.0000 & 0.43327 & 0.58110 & 0.54932 & Biso & 1.000 & O \\
\hline 017 & 1.0000 & 0.08975 & 0.55644 & 0.56988 & Biso & 1.000 & $\mathrm{O}$ \\
\hline 018 & 1.0000 & 0.44117 & 0.85332 & 0.54026 & Biso & 1.000 & 0 \\
\hline 019 & 1.0000 & 0.99050 & 0.31421 & 0.16509 & Biso & 1.000 & 0 \\
\hline 020 & 1.0000 & 0.69462 & 0.67966 & 0.16852 & Biso & 1.000 & $\mathrm{O}$ \\
\hline 021 & 1.0000 & 0.33790 & 0.02741 & 0.14041 & Biso & 1.000 & O \\
\hline 022 & 1.0000 & 0.31393 & 0.97222 & 0.82808 & Biso & 1.000 & $\mathrm{O}$ \\
\hline 023 & 1.0000 & 0.64924 & 0.68155 & 0.84289 & Biso & 1.000 & $\mathrm{O}$ \\
\hline $\mathrm{O} 24$ & 1.0000 & 0.02335 & 0.34869 & 0.84102 & Biso & 1.000 & O \\
\hline 025 & 1.0000 & 0.65920 & 0.64961 & 0.49860 & Biso & 1.000 & 0 \\
\hline 026 & 1.0000 & 0.33475 & 0.98712 & 0.51341 & Biso & 1.000 & O \\
\hline 027 & 1.0000 & 0.99469 & 0.34165 & 0.49741 & Biso & 1.000 & 0 \\
\hline 028 & 1.0000 & 0.00320 & 0.67453 & 0.84495 & Biso & 1.000 & \\
\hline 029 & 1.0000 & 0.30241 & 0.32035 & 0.82383 & Biso & 1.000 & \\
\hline 030 & 1.0000 & 0.67100 & 0.97822 & 0.84076 & Biso & 1.000 & \\
\hline 031 & 1.0000 & 0.68488 & 0.03250 & 0.16457 & Biso & 1.000 & $\mathrm{O}$ \\
\hline 032 & 1.0000 & 0.35348 & 0.32279 & 0.15330 & Biso & 1.000 & \\
\hline
\end{tabular}




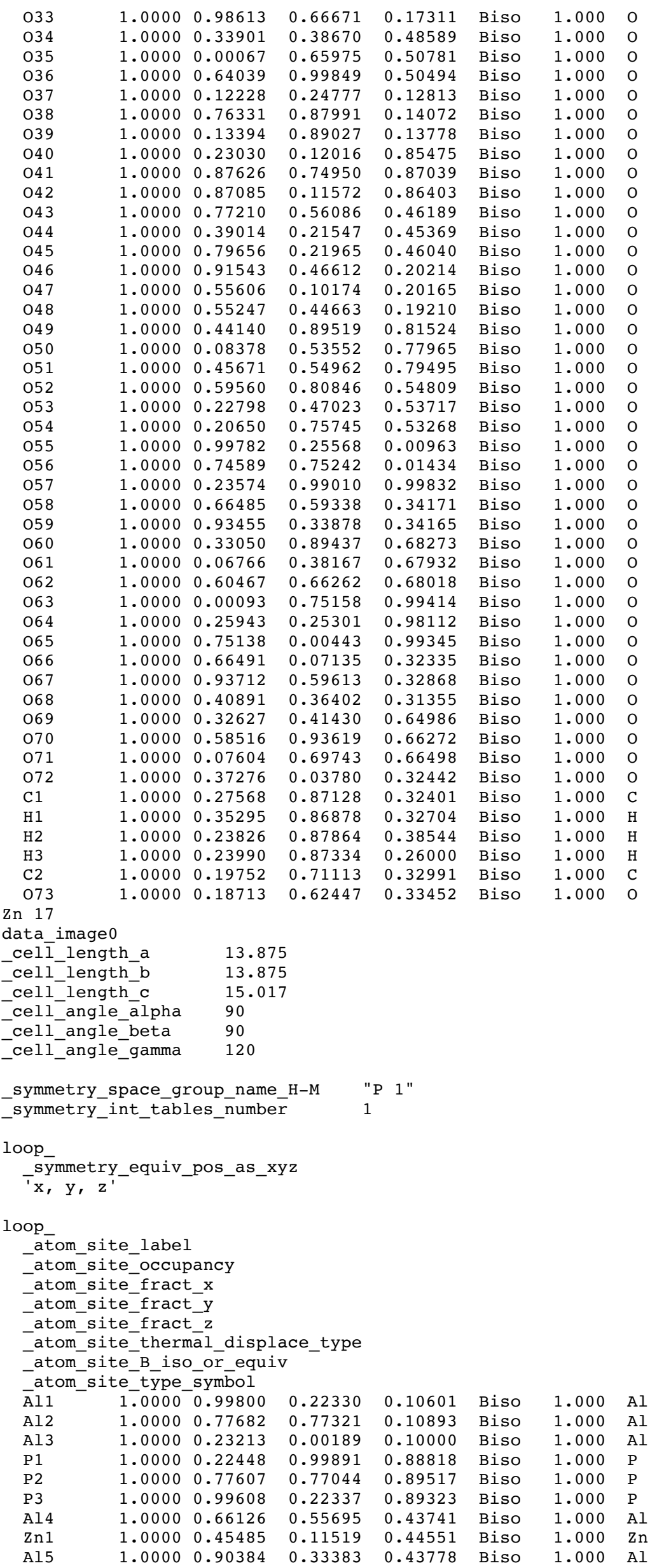




\begin{tabular}{|c|c|c|c|c|c|c|c|}
\hline $\mathrm{P} 4$ & 1.0000 & 0.89717 & 0.33615 & 0.22666 & Biso & 1.000 & $\mathrm{P}$ \\
\hline P5 & 1.0000 & 0.43819 & 0.10166 & 0.22550 & Biso & 1.000 & $\mathrm{P}$ \\
\hline P 6 & 1.0000 & 0.66558 & 0.55945 & 0.22878 & Biso & 1.000 & $\mathrm{P}$ \\
\hline Al6 & 1.0000 & 0.32882 & 0.88690 & 0.77179 & Biso & 1.000 & $\mathrm{Al}$ \\
\hline Al7 & 1.0000 & 0.10599 & 0.43271 & 0.76959 & Biso & 1.000 & Al \\
\hline A18 & 1.0000 & 0.56462 & 0.66915 & 0.77245 & Biso & 1.000 & $\mathrm{Al}$ \\
\hline P7 & 1.0000 & 0.57430 & 0.67716 & 0.56454 & Biso & 1.000 & $\mathrm{P}$ \\
\hline P8 & 1.0000 & 0.10721 & 0.43734 & 0.56443 & Biso & 1.000 & $\mathrm{P}$ \\
\hline P9 & 1.0000 & 0.32824 & 0.88293 & 0.56011 & Biso & 1.000 & $\mathrm{P}$ \\
\hline Al9 & 1.0000 & 0.00028 & 0.76963 & 0.89931 & Biso & 1.000 & $\mathrm{Al}$ \\
\hline Al10 & 1.0000 & 0.22440 & 0.22578 & 0.89379 & Biso & 1.000 & $\mathrm{Al}$ \\
\hline Al11 & 1.0000 & 0.77246 & 0.99484 & 0.89693 & Biso & 1.000 & $\mathrm{Al}$ \\
\hline P10 & 1.0000 & 0.77183 & 0.99579 & 0.11061 & Biso & 1.000 & $\mathrm{P}$ \\
\hline P 11 & 1.0000 & 0.22668 & 0.22592 & 0.10720 & Biso & 1.000 & $\mathrm{P}$ \\
\hline P12 & 1.0000 & 0.00443 & 0.77654 & 0.11332 & Biso & 1.000 & $P$ \\
\hline Al12 & 1.0000 & 0.67264 & 0.10532 & 0.23618 & Biso & 1.000 & $\mathrm{Al}$ \\
\hline Al13 & 1.0000 & 0.89350 & 0.56047 & 0.23279 & Biso & 1.000 & $\mathrm{Al}$ \\
\hline Al14 & 1.0000 & 0.43782 & 0.32797 & 0.23050 & Biso & 1.000 & $\mathrm{Al}$ \\
\hline P13 & 1.0000 & 0.42738 & 0.32864 & 0.44044 & Biso & 1.000 & $\mathrm{P}$ \\
\hline P 14 & 1.0000 & 0.89028 & 0.55656 & 0.44394 & Biso & 1.000 & $\mathrm{P}$ \\
\hline P15 & 1.0000 & 0.68174 & 0.11228 & 0.43916 & Biso & 1.000 & $P$ \\
\hline Al15 & 1.0000 & 0.34134 & 0.45073 & 0.56483 & Biso & 1.000 & $\mathrm{Al}$ \\
\hline Al16 & 1.0000 & 0.55856 & 0.89560 & 0.56605 & Biso & 1.000 & Al \\
\hline Al17 & 1.0000 & 0.09518 & 0.66427 & 0.57107 & Biso & 1.000 & Al \\
\hline P16 & 1.0000 & 0.10154 & 0.66166 & 0.77806 & Biso & 1.000 & $\mathrm{P}$ \\
\hline P17 & 1.0000 & 0.55757 & 0.89347 & 0.77700 & Biso & 1.000 & $\mathrm{P}$ \\
\hline P18 & 1.0000 & 0.33676 & 0.43916 & 0.77309 & Biso & 1.000 & $\mathrm{P}$ \\
\hline 01 & 1.0000 & 0.89312 & 0.08672 & 0.13017 & Biso & 1.000 & 0 \\
\hline $\mathrm{O} 2$ & 1.0000 & 0.91517 & 0.80885 & 0.13542 & Biso & 1.000 & 0 \\
\hline 03 & 1.0000 & 0.19946 & 0.10538 & 0.12739 & Biso & 1.000 & 0 \\
\hline 04 & 1.0000 & 0.10346 & 0.90570 & 0.87231 & Biso & 1.000 & 0 \\
\hline 05 & 1.0000 & 0.80699 & 0.89142 & 0.87436 & Biso & 1.000 & 0 \\
\hline 06 & 1.0000 & 0.08759 & 0.19444 & 0.87303 & Biso & 1.000 & 0 \\
\hline 07 & 1.0000 & 0.55017 & 0.42267 & 0.45023 & Biso & 1.000 & 0 \\
\hline 08 & 1.0000 & 0.60933 & 0.16648 & 0.43847 & Biso & 1.000 & 0 \\
\hline 09 & 1.0000 & 0.87167 & 0.43911 & 0.46095 & Biso & 1.000 & 0 \\
\hline 010 & 1.0000 & 0.77521 & 0.24378 & 0.21338 & Biso & 1.000 & 0 \\
\hline 011 & 1.0000 & 0.47148 & 0.22386 & 0.20737 & Biso & 1.000 & 0 \\
\hline 012 & 1.0000 & 0.75645 & 0.52843 & 0.21215 & Biso & 1.000 & 0 \\
\hline 013 & 1.0000 & 0.22356 & 0.75042 & 0.79654 & Biso & 1.000 & 0 \\
\hline 014 & 1.0000 & 0.24477 & 0.46871 & 0.78988 & Biso & 1.000 & 0 \\
\hline 015 & 1.0000 & 0.52838 & 0.77164 & 0.79062 & Biso & 1.000 & 0 \\
\hline 016 & 1.0000 & 0.45138 & 0.58740 & 0.55260 & Biso & 1.000 & 0 \\
\hline 017 & 1.0000 & 0.11639 & 0.55189 & 0.55996 & Biso & 1.000 & 0 \\
\hline 018 & 1.0000 & 0.41681 & 0.84688 & 0.54745 & Biso & 1.000 & 0 \\
\hline 019 & 1.0000 & 0.97548 & 0.31717 & 0.16642 & Biso & 1.000 & 0 \\
\hline 020 & 1.0000 & 0.68273 & 0.65452 & 0.16674 & Biso & 1.000 & 0 \\
\hline 021 & 1.0000 & 0.35179 & 0.02498 & 0.15624 & Biso & 1.000 & 0 \\
\hline 022 & 1.0000 & 0.30576 & 0.98146 & 0.83146 & Biso & 1.000 & 0 \\
\hline 023 & 1.0000 & 0.67178 & 0.68802 & 0.84388 & Biso & 1.000 & 0 \\
\hline 024 & 1.0000 & 0.01515 & 0.32509 & 0.83941 & Biso & 1.000 & 0 \\
\hline 025 & 1.0000 & 0.64934 & 0.65370 & 0.50395 & Biso & 1.000 & 0 \\
\hline 026 & 1.0000 & 0.34828 & 0.97962 & 0.50146 & Biso & 1.000 & 0 \\
\hline 027 & 1.0000 & 0.02095 & 0.35749 & 0.49773 & Biso & 1.000 & 0 \\
\hline 028 & 1.0000 & 0.02403 & 0.67256 & 0.84522 & Biso & 1.000 & 0 \\
\hline 029 & 1.0000 & 0.31864 & 0.34174 & 0.83290 & Biso & 1.000 & 0 \\
\hline 030 & 1.0000 & 0.65576 & 0.97121 & 0.83666 & Biso & 1.000 & 0 \\
\hline 031 & 1.0000 & 0.68952 & 0.01693 & 0.16286 & Biso & 1.000 & 0 \\
\hline 032 & 1.0000 & 0.32794 & 0.30873 & 0.16136 & Biso & 1.000 & 0 \\
\hline 033 & 1.0000 & 0.98634 & 0.67764 & 0.17082 & Biso & 1.000 & 0 \\
\hline 034 & 1.0000 & 0.35123 & 0.36203 & 0.48959 & Biso & 1.000 & 0 \\
\hline 035 & 1.0000 & 0.98350 & 0.64335 & 0.50350 & Biso & 1.000 & 0 \\
\hline 036 & 1.0000 & 0.64146 & 0.01418 & 0.50409 & Biso & 1.000 & 0 \\
\hline 037 & 1.0000 & 0.12612 & 0.23666 & 0.13525 & Biso & 1.000 & 0 \\
\hline 038 & 1.0000 & 0.75803 & 0.88360 & 0.14035 & Biso & 1.000 & 0 \\
\hline 039 & 1.0000 & 0.11931 & 0.87582 & 0.13737 & Biso & 1.000 & 0 \\
\hline 040 & 1.0000 & 0.23563 & 0.11085 & 0.86271 & Biso & 1.000 & 0 \\
\hline 041 & 1.0000 & 0.87239 & 0.75299 & 0.86659 & Biso & 1.000 & 0 \\
\hline 042 & 1.0000 & 0.88335 & 0.12424 & 0.86657 & Biso & 1.000 & 0 \\
\hline 043 & 1.0000 & 0.78356 & 0.55811 & 0.46623 & Biso & 1.000 & 0 \\
\hline 044 & 1.0000 & 0.41018 & 0.22035 & 0.47873 & Biso & 1.000 & 0 \\
\hline 045 & 1.0000 & 0.80051 & 0.20072 & 0.46772 & Biso & 1.000 & 0 \\
\hline 046 & 1.0000 & 0.90829 & 0.44823 & 0.20043 & Biso & 1.000 & 0 \\
\hline 047 & 1.0000 & 0.54106 & 0.08920 & 0.21814 & Biso & 1.000 & 0 \\
\hline 048 & 1.0000 & 0.55210 & 0.45817 & 0.20774 & Biso & 1.000 & 0 \\
\hline 049 & 1.0000 & 0.45688 & 0.90394 & 0.80480 & Biso & 1.000 & 0 \\
\hline 050 & 1.0000 & 0.08877 & 0.54644 & 0.78999 & Biso & 1.000 & $\mathrm{O}$ \\
\hline 051 & 1.0000 & 0.44965 & 0.53995 & 0.79685 & Biso & 1.000 & 0 \\
\hline 052 & 1.0000 & 0.58919 & 0.79082 & 0.53886 & Biso & 1.000 & 0 \\
\hline 053 & 1.0000 & 0.21997 & 0.45127 & 0.53942 & Biso & 1.000 & 0 \\
\hline
\end{tabular}




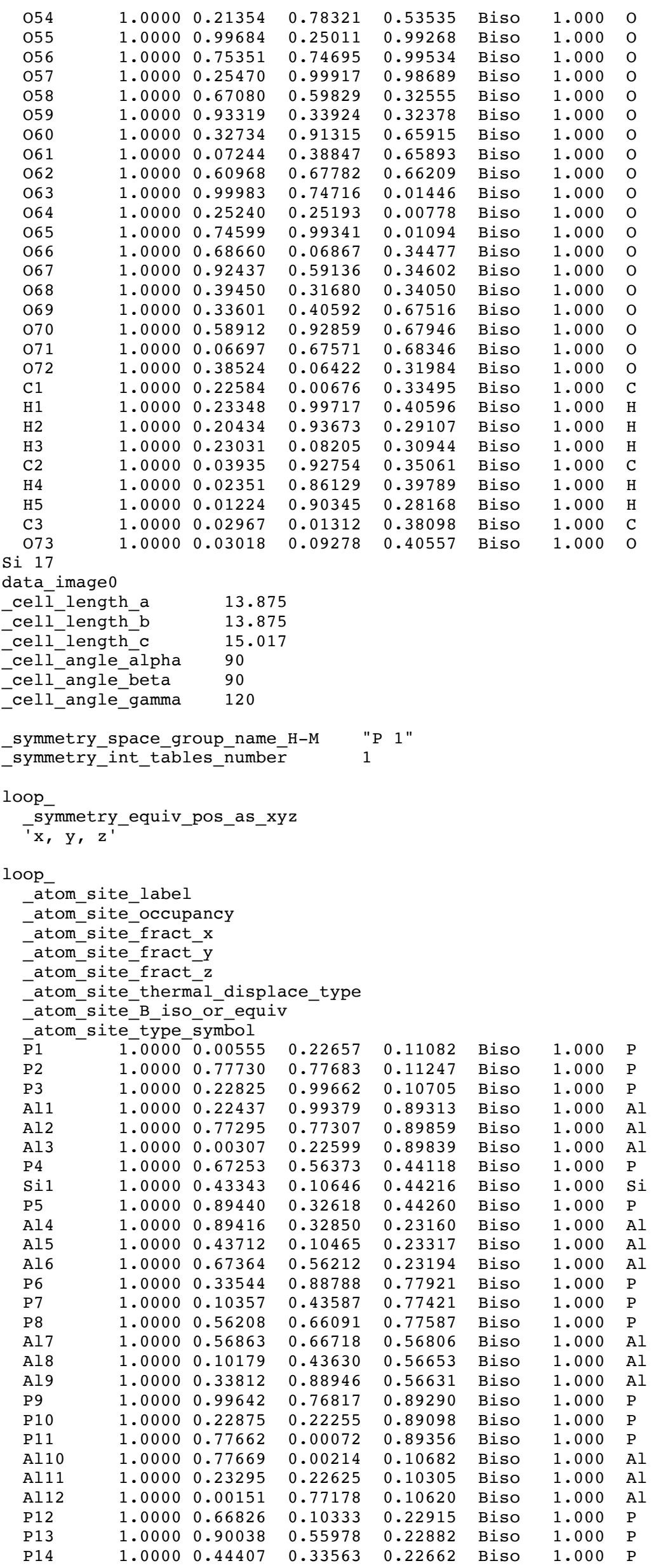




\begin{tabular}{|c|c|c|c|c|c|c|c|}
\hline Al13 & 1.0000 & 0.43880 & 0.33643 & 0.43743 & Biso & 1.000 & Al \\
\hline Al14 & 1.0000 & 0.89769 & 0.55779 & 0.43925 & Biso & 1.000 & Al \\
\hline Al15 & 1.0000 & 0.66440 & 0.10414 & 0.43434 & Biso & 1.000 & Al \\
\hline P15 & 1.0000 & 0.33390 & 0.44514 & 0.55946 & Biso & 1.000 & $\mathrm{P}$ \\
\hline P16 & 1.0000 & 0.56545 & 0.89342 & 0.56398 & Biso & 1.000 & $\mathrm{P}$ \\
\hline P17 & 1.0000 & 0.10437 & 0.67003 & 0.56365 & Biso & 1.000 & $\mathrm{P}$ \\
\hline Al16 & 1.0000 & 0.10567 & 0.66687 & 0.77257 & Biso & 1.000 & $\mathrm{Al}$ \\
\hline Al1 17 & 1.0000 & 0.56376 & 0.89184 & 0.77223 & Biso & 1.000 & Al \\
\hline Al18 & 1.0000 & 0.33071 & 0.43625 & 0.76889 & Biso & 1.000 & $\mathrm{Al}$ \\
\hline 01 & 1.0000 & 0.91438 & 0.10549 & 0.13073 & Biso & 1.000 & 0 \\
\hline $\mathrm{O} 2$ & 1.0000 & 0.89879 & 0.80654 & 0.13229 & Biso & 1.000 & 0 \\
\hline 03 & 1.0000 & 0.19977 & 0.08872 & 0.12791 & Biso & 1.000 & 0 \\
\hline 04 & 1.0000 & 0.08792 & 0.88784 & 0.87014 & Biso & 1.000 & 0 \\
\hline 05 & 1.0000 & 0.80639 & 0.90968 & 0.87323 & Biso & 1.000 & 0 \\
\hline 06 & 1.0000 & 0.10688 & 0.19243 & 0.87641 & Biso & 1.000 & 0 \\
\hline 07 & 1.0000 & 0.57657 & 0.44457 & 0.45444 & Biso & 1.000 & 0 \\
\hline 08 & 1.0000 & 0.56201 & 0.13872 & 0.43346 & Biso & 1.000 & $\mathrm{O}$ \\
\hline 09 & 1.0000 & 0.87120 & 0.42269 & 0.45875 & Biso & 1.000 & 0 \\
\hline 010 & 1.0000 & 0.75620 & 0.22585 & 0.20891 & Biso & 1.000 & 0 \\
\hline 011 & 1.0000 & 0.47363 & 0.24346 & 0.21147 & Biso & 1.000 & 0 \\
\hline 012 & 1.0000 & 0.77908 & 0.52998 & 0.21192 & Biso & 1.000 & 0 \\
\hline 013 & 1.0000 & 0.24215 & 0.76805 & 0.80005 & Biso & 1.000 & 0 \\
\hline 014 & 1.0000 & 0.22624 & 0.46951 & 0.79029 & Biso & 1.000 & 0 \\
\hline 015 & 1.0000 & 0.53337 & 0.75407 & 0.78658 & Biso & 1.000 & 0 \\
\hline 016 & 1.0000 & 0.42943 & 0.56629 & 0.54933 & Biso & 1.000 & 0 \\
\hline 017 & 1.0000 & 0.12216 & 0.57000 & 0.55273 & Biso & 1.000 & 0 \\
\hline 018 & 1.0000 & 0.44052 & 0.85100 & 0.55015 & Biso & 1.000 & 0 \\
\hline 019 & 1.0000 & 0.98771 & 0.30795 & 0.16769 & Biso & 1.000 & 0 \\
\hline 020 & 1.0000 & 0.69560 & 0.67508 & 0.16652 & Biso & 1.000 & 0 \\
\hline 021 & 1.0000 & 0.33237 & 0.01711 & 0.15788 & Biso & 1.000 & 0 \\
\hline 022 & 1.0000 & 0.31989 & 0.97181 & 0.83517 & Biso & 1.000 & 0 \\
\hline 023 & 1.0000 & 0.65446 & 0.67793 & 0.84101 & Biso & 1.000 & 0 \\
\hline 024 & 1.0000 & 0.02690 & 0.34270 & 0.83806 & Biso & 1.000 & 0 \\
\hline 025 & 1.0000 & 0.65858 & 0.64584 & 0.50059 & Biso & 1.000 & 0 \\
\hline 026 & 1.0000 & 0.36017 & 0.00286 & 0.50691 & Biso & 1.000 & $\mathrm{O}$ \\
\hline 027 & 1.0000 & 0.99332 & 0.34222 & 0.49932 & Biso & 1.000 & 0 \\
\hline 028 & 1.0000 & 0.01237 & 0.68276 & 0.84026 & Biso & 1.000 & 0 \\
\hline 029 & 1.0000 & 0.30763 & 0.32195 & 0.83329 & Biso & 1.000 & 0 \\
\hline 030 & 1.0000 & 0.67491 & 0.98145 & 0.83981 & Biso & 1.000 & 0 \\
\hline 031 & 1.0000 & 0.68099 & 0.02577 & 0.16312 & Biso & 1.000 & 0 \\
\hline 032 & 1.0000 & 0.34914 & 0.31876 & 0.16409 & Biso & 1.000 & 0 \\
\hline 033 & 1.0000 & 0.98019 & 0.65761 & 0.16945 & Biso & 1.000 & 0 \\
\hline 034 & 1.0000 & 0.34891 & 0.36815 & 0.49561 & Biso & 1.000 & o \\
\hline 035 & 1.0000 & 0.00788 & 0.65576 & 0.50402 & Biso & 1.000 & 0 \\
\hline 036 & 1.0000 & 0.63746 & 0.99063 & 0.50203 & Biso & 1.000 & 0 \\
\hline 037 & 1.0000 & 0.11896 & 0.23943 & 0.13495 & Biso & 1.000 & 0 \\
\hline 038 & 1.0000 & 0.76390 & 0.87568 & 0.14062 & Biso & 1.000 & 0 \\
\hline 039 & 1.0000 & 0.12943 & 0.88516 & 0.13911 & Biso & 1.000 & 0 \\
\hline 040 & 1.0000 & 0.24071 & 0.12255 & 0.86384 & Biso & 1.000 & 0 \\
\hline 041 & 1.0000 & 0.88336 & 0.75437 & 0.86757 & Biso & 1.000 & 0 \\
\hline 042 & 1.0000 & 0.87514 & 0.11391 & 0.86701 & Biso & 1.000 & 0 \\
\hline 043 & 1.0000 & 0.78214 & 0.56923 & 0.46691 & Biso & 1.000 & 0 \\
\hline 044 & 1.0000 & 0.42017 & 0.21105 & 0.47053 & Biso & 1.000 & 0 \\
\hline 045 & 1.0000 & 0.79237 & 0.21647 & 0.46960 & Biso & 1.000 & 0 \\
\hline 046 & 1.0000 & 0.91287 & 0.45931 & 0.20511 & Biso & 1.000 & 0 \\
\hline 047 & 1.0000 & 0.55200 & 0.08828 & 0.21614 & Biso & 1.000 & 0 \\
\hline 048 & 1.0000 & 0.54614 & 0.44816 & 0.20358 & Biso & 1.000 & 0 \\
\hline 049 & 1.0000 & 0.44738 & 0.89919 & 0.80523 & Biso & 1.000 & 0 \\
\hline 050 & 1.0000 & 0.08897 & 0.53619 & 0.79268 & Biso & 1.000 & 0 \\
\hline 051 & 1.0000 & 0.45885 & 0.54933 & 0.79846 & Biso & 1.000 & 0 \\
\hline 052 & 1.0000 & 0.58837 & 0.79834 & 0.54310 & Biso & 1.000 & 0 \\
\hline 053 & 1.0000 & 0.22436 & 0.44051 & 0.53571 & Biso & 1.000 & 0 \\
\hline 054 & 1.0000 & 0.20951 & 0.77570 & 0.53428 & Biso & 1.000 & 0 \\
\hline 055 & 1.0000 & 0.00274 & 0.25398 & 0.01202 & Biso & 1.000 & $\mathrm{O}$ \\
\hline 056 & 1.0000 & 0.75100 & 0.75076 & 0.01322 & Biso & 1.000 & $\mathrm{O}$ \\
\hline 057 & 1.0000 & 0.24801 & 0.99205 & 0.00737 & Biso & 1.000 & 0 \\
\hline 058 & 1.0000 & 0.67792 & 0.60042 & 0.34343 & Biso & 1.000 & 0 \\
\hline 059 & 1.0000 & 0.92405 & 0.32435 & 0.34399 & Biso & 1.000 & 0 \\
\hline 060 & 1.0000 & 0.33305 & 0.91400 & 0.68055 & Biso & 1.000 & 0 \\
\hline 061 & 1.0000 & 0.06960 & 0.39457 & 0.67793 & Biso & 1.000 & $\mathrm{O}$ \\
\hline 062 & 1.0000 & 0.60162 & 0.66028 & 0.68010 & Biso & 1.000 & $\mathrm{O}$ \\
\hline 063 & 1.0000 & 0.99992 & 0.74534 & 0.99295 & Biso & 1.000 & 0 \\
\hline 064 & 1.0000 & 0.26092 & 0.25237 & 0.98950 & Biso & 1.000 & 0 \\
\hline 065 & 1.0000 & 0.75036 & 0.99949 & 0.99313 & Biso & 1.000 & 0 \\
\hline 066 & 1.0000 & 0.68400 & 0.07163 & 0.32392 & Biso & 1.000 & 0 \\
\hline 067 & 1.0000 & 0.93247 & 0.59436 & 0.32677 & Biso & 1.000 & 0 \\
\hline 068 & 1.0000 & 0.40673 & 0.33469 & 0.32298 & Biso & 1.000 & $\mathrm{O}$ \\
\hline 069 & 1.0000 & 0.32995 & 0.40492 & 0.65594 & Biso & 1.000 & $\mathrm{O}$ \\
\hline 070 & 1.0000 & 0.59851 & 0.93247 & 0.66120 & Biso & 1.000 & 0 \\
\hline 071 & 1.0000 & 0.07582 & 0.67966 & 0.66124 & Biso & 1.000 & 0 \\
\hline
\end{tabular}




\begin{tabular}{|c|c|c|c|c|c|c|c|}
\hline 072 & 1.0000 & 0.37660 & 0.06525 & 0.33962 & Biso & 1.000 & 0 \\
\hline $\mathrm{C} 1$ & 1.0000 & 0.21243 & 0.00710 & 0.34592 & Biso & 1.000 & C \\
\hline H 1 & 1.0000 & 0.21330 & 0.99896 & 0.41782 & Biso & 1.000 & $\mathrm{H}$ \\
\hline $\mathrm{H} 2$ & 1.0000 & 0.19818 & 0.93765 & 0.30385 & Biso & 1.000 & $\mathrm{H}$ \\
\hline H3 & 1.0000 & 0.22278 & 0.08305 & 0.31647 & Biso & 1.000 & $\mathrm{H}$ \\
\hline $\mathrm{C} 2$ & 1.0000 & 0.02999 & 0.93130 & 0.34437 & Biso & 1.000 & C \\
\hline H4 & 1.0000 & 0.00538 & 0.85969 & 0.38814 & Biso & 1.000 & $\mathrm{H}$ \\
\hline H5 & 1.0000 & 0.01249 & 0.91417 & 0.27317 & Biso & 1.000 & $\mathrm{H}$ \\
\hline $\mathrm{C} 3$ & 1.0000 & 0.01322 & 0.01236 & 0.37574 & Biso & 1.000 & C \\
\hline 073 & 1.0000 & 0.00847 & 0.08844 & 0.40235 & Biso & 1.000 & 0 \\
\hline g 17 & & & & & & & \\
\hline & & & & & & & \\
\hline _celì__ & $=h \_a$ & 13.87 & & & & & \\
\hline cell_ & $\mathrm{ch} \_\mathrm{b}$ & 13.87 & & & & & \\
\hline cell_ & $=h \_c$ & 15.01 & & & & & \\
\hline _cell_e & _ēalpha & 90 & & & & & \\
\hline cell_ & beta & 90 & & & & & \\
\hline cell_e & gamma & 120 & & & & & \\
\hline symmet & pace_gr & oup_name & & $1 "$ & & & \\
\hline symmet & nt_tab] & es_numbe & & & & & \\
\hline loop_ & & & & & & & \\
\hline $\begin{array}{c}\text { symm } \\
\text { 'x, y }\end{array}$ & _equiv & pos_as_x & & & & & \\
\hline oop_ & & & & & & & \\
\hline _aton & e_labe] & & & & & & \\
\hline aton & e_occup & ancy & & & & & \\
\hline aton & $=e$ fract & $=x$ & & & & & \\
\hline aton & $=e^{-}$fract & & & & & & \\
\hline aton & $=e^{-}$fract & & & & & & \\
\hline -aton & e-thern & nàl_displ & ace_type & & & & \\
\hline -aton & $\begin{array}{l}e^{-} \text {B_isc } \\
\text { type }\end{array}$ & $\begin{array}{l}\text { or_equi } \\
\text { symbol }\end{array}$ & & & & & \\
\hline $\bar{A} 11$ & 1.0000 & 0.99826 & 0.22352 & 0.10628 & Biso & 1.000 & Al \\
\hline Al2 & 1.0000 & 0.77805 & 0.77486 & 0.10943 & Biso & 1.000 & $\mathrm{Al}$ \\
\hline Al3 & 1.0000 & 0.23352 & 0.00313 & 0.09927 & Biso & 1.000 & Al \\
\hline $\mathrm{P} 1$ & 1.0000 & 0.22467 & 0.99845 & 0.88765 & Biso & 1.000 & $\mathrm{P}$ \\
\hline P2 & 1.0000 & 0.77637 & 0.77118 & 0.89531 & Biso & 1.000 & $P$ \\
\hline P3 & 1.0000 & 0.99511 & 0.22301 & 0.89310 & Biso & 1.000 & $P$ \\
\hline Al4 & 1.0000 & 0.66214 & 0.55895 & 0.43695 & Biso & 1.000 & Al \\
\hline Mg1 & 1.0000 & 0.44917 & 0.11166 & 0.44434 & Biso & 1.000 & $\mathrm{Mg}$ \\
\hline Al5 & 1.0000 & 0.90409 & 0.33337 & 0.43800 & Biso & 1.000 & $\mathrm{Al}$ \\
\hline P4 & 1.0000 & 0.89784 & 0.33666 & 0.22670 & Biso & 1.000 & $P$ \\
\hline P5 & 1.0000 & 0.43827 & 0.10247 & 0.22613 & Biso & 1.000 & $P$ \\
\hline P6 & 1.0000 & 0.66698 & 0.56046 & 0.22844 & Biso & 1.000 & $\mathrm{P}$ \\
\hline Al6 & 1.0000 & 0.32734 & 0.88340 & 0.77381 & Biso & 1.000 & Al \\
\hline Al7 & 1.0000 & 0.10486 & 0.43168 & 0.76937 & Biso & 1.000 & $\mathrm{Al}$ \\
\hline Al8 & 1.0000 & 0.56446 & 0.66754 & 0.77299 & Biso & 1.000 & Al \\
\hline P7 & 1.0000 & 0.57610 & 0.67597 & 0.56576 & Biso & 1.000 & $\mathrm{P}$ \\
\hline P8 & 1.0000 & 0.10641 & 0.43639 & 0.56519 & Biso & 1.000 & $\mathrm{P}$ \\
\hline P9 & 1.0000 & 0.32850 & 0.87937 & 0.56081 & Biso & 1.000 & $P$ \\
\hline A19 & 1.0000 & 0.99937 & 0.76831 & 0.89958 & Biso & 1.000 & Al \\
\hline Al10 & 1.0000 & 0.22297 & 0.22462 & 0.89246 & Biso & 1.000 & Al \\
\hline Al11 & 1.0000 & 0.77231 & 0.99467 & 0.89700 & Biso & 1.000 & Al \\
\hline $\mathrm{P} 10$ & 1.0000 & 0.77210 & 0.99632 & 0.11123 & Biso & 1.000 & $\mathrm{P}$ \\
\hline P11 & 1.0000 & 0.22722 & 0.22676 & 0.10616 & Biso & 1.000 & $\mathrm{P}$ \\
\hline P12 & 1.0000 & 0.00508 & 0.77732 & 0.11334 & Biso & 1.000 & $P$ \\
\hline Al12 & 1.0000 & 0.67370 & 0.10653 & 0.23616 & Biso & 1.000 & $\mathrm{Al}$ \\
\hline Al13 & 1.0000 & 0.89506 & 0.56178 & 0.23347 & Biso & 1.000 & Al \\
\hline Al14 & 1.0000 & 0.43761 & 0.33015 & 0.22995 & Biso & 1.000 & Al \\
\hline P13 & 1.0000 & 0.42613 & 0.33135 & 0.43899 & Biso & 1.000 & $P$ \\
\hline P14 & 1.0000 & 0.89062 & 0.55674 & 0.44420 & Biso & 1.000 & $P$ \\
\hline P15 & 1.0000 & 0.68210 & 0.10966 & 0.43932 & Biso & 1.000 & $P$ \\
\hline Al15 & 1.0000 & 0.34141 & 0.45213 & 0.56439 & Biso & 1.000 & Al \\
\hline Al16 & 1.0000 & 0.56045 & 0.89605 & 0.56728 & Biso & 1.000 & Al \\
\hline Al17 & 1.0000 & 0.09470 & 0.66431 & 0.57178 & Biso & 1.000 & Al \\
\hline P16 & 1.0000 & 0.10008 & 0.66100 & 0.77876 & Biso & 1.000 & $P$ \\
\hline P17 & 1.0000 & 0.55715 & 0.89358 & 0.77720 & Biso & 1.000 & $P$ \\
\hline P18 & 1.0000 & 0.33605 & 0.43970 & 0.77362 & Biso & 1.000 & $P$ \\
\hline 01 & 1.0000 & 0.89313 & 0.08738 & 0.13154 & Biso & 1.000 & 0 \\
\hline $\mathrm{O} 2$ & 1.0000 & 0.91654 & 0.81054 & 0.13574 & Biso & 1.000 & 0 \\
\hline 03 & 1.0000 & 0.20125 & 0.10676 & 0.12730 & Biso & 1.000 & $\mathrm{O}$ \\
\hline 04 & 1.0000 & 0.10387 & 0.90403 & 0.87326 & Biso & 1.000 & 0 \\
\hline 05 & 1.0000 & 0.80715 & 0.89179 & 0.87312 & Biso & 1.000 & 0 \\
\hline 06 & 1.0000 & 0.08627 & 0.19385 & 0.87198 & Biso & 1.000 & 0 \\
\hline 07 & 1.0000 & 0.54784 & 0.42712 & 0.45005 & Biso & 1.000 & 0 \\
\hline 08 & 1.0000 & 0.60171 & 0.15375 & 0.43995 & Biso & 1.000 & 0 \\
\hline 09 & 1.0000 & 0.87317 & 0.43967 & 0.46061 & Biso & 1.000 & 0 \\
\hline
\end{tabular}




\begin{tabular}{|c|c|c|c|c|c|c|c|}
\hline 010 & 1.0000 & 0.77574 & 0.24504 & 0.21227 & Biso & 1.000 & 0 \\
\hline 011 & 1.0000 & 0.46996 & 0.22439 & 0.20930 & Biso & 1.000 & $\mathrm{O}$ \\
\hline 012 & 1.0000 & 0.75799 & 0.52948 & 0.21250 & Biso & 1.000 & 0 \\
\hline 013 & 1.0000 & 0.22141 & 0.74823 & 0.80141 & Biso & 1.000 & 0 \\
\hline 014 & 1.0000 & 0.24365 & 0.46859 & 0.79084 & Biso & 1.000 & 0 \\
\hline 015 & 1.0000 & 0.53007 & 0.77192 & 0.78664 & Biso & 1.000 & 0 \\
\hline 016 & 1.0000 & 0.45367 & 0.58710 & 0.54986 & Biso & 1.000 & 0 \\
\hline 017 & 1.0000 & 0.11113 & 0.54890 & 0.56330 & Biso & 1.000 & 0 \\
\hline 018 & 1.0000 & 0.41848 & 0.84529 & 0.54715 & Biso & 1.000 & 0 \\
\hline 019 & 1.0000 & 0.97634 & 0.31809 & 0.16630 & Biso & 1.000 & $\mathrm{O}$ \\
\hline 020 & 1.0000 & 0.68407 & 0.65507 & 0.16594 & Biso & 1.000 & $\mathrm{O}$ \\
\hline 021 & 1.0000 & 0.35265 & 0.02584 & 0.15651 & Biso & 1.000 & 0 \\
\hline 022 & 1.0000 & 0.30566 & 0.98102 & 0.83045 & Biso & 1.000 & O \\
\hline 023 & 1.0000 & 0.67114 & 0.68783 & 0.84550 & Biso & 1.000 & 0 \\
\hline 024 & 1.0000 & 0.01426 & 0.32539 & 0.84024 & Biso & 1.000 & 0 \\
\hline 025 & 1.0000 & 0.65339 & 0.65690 & 0.50420 & Biso & 1.000 & 0 \\
\hline 026 & 1.0000 & 0.35099 & 0.97919 & 0.50567 & Biso & 1.000 & 0 \\
\hline 027 & 1.0000 & 0.02158 & 0.35663 & 0.49753 & Biso & 1.000 & 0 \\
\hline 028 & 1.0000 & 0.02057 & 0.66960 & 0.84529 & Biso & 1.000 & 0 \\
\hline 029 & 1.0000 & 0.31714 & 0.34049 & 0.83151 & Biso & 1.000 & $\mathrm{O}$ \\
\hline 030 & 1.0000 & 0.65443 & 0.96993 & 0.83815 & Biso & 1.000 & 0 \\
\hline 031 & 1.0000 & 0.68896 & 0.01777 & 0.16193 & Biso & 1.000 & 0 \\
\hline 032 & 1.0000 & 0.32936 & 0.31091 & 0.15882 & Biso & 1.000 & $\mathrm{O}$ \\
\hline 033 & 1.0000 & 0.98770 & 0.67938 & 0.17177 & Biso & 1.000 & 0 \\
\hline 034 & 1.0000 & 0.34787 & 0.36003 & 0.49054 & Biso & 1.000 & 0 \\
\hline 035 & 1.0000 & 0.98243 & 0.64354 & 0.50483 & Biso & 1.000 & 0 \\
\hline 036 & 1.0000 & 0.64733 & 0.01050 & 0.50262 & Biso & 1.000 & 0 \\
\hline 037 & 1.0000 & 0.12662 & 0.23698 & 0.13508 & Biso & 1.000 & 0 \\
\hline 038 & 1.0000 & 0.75815 & 0.88431 & 0.14186 & Biso & 1.000 & $\mathrm{O}$ \\
\hline 039 & 1.0000 & 0.12047 & 0.87681 & 0.13589 & Biso & 1.000 & 0 \\
\hline 040 & 1.0000 & 0.23395 & 0.10943 & 0.86144 & Biso & 1.000 & O \\
\hline 041 & 1.0000 & 0.87219 & 0.75312 & 0.86647 & Biso & 1.000 & 0 \\
\hline 042 & 1.0000 & 0.88217 & 0.12441 & 0.86618 & Biso & 1.000 & 0 \\
\hline 043 & 1.0000 & 0.78259 & 0.55621 & 0.46541 & Biso & 1.000 & 0 \\
\hline 044 & 1.0000 & 0.41370 & 0.22345 & 0.47246 & Biso & 1.000 & 0 \\
\hline 045 & 1.0000 & 0.79896 & 0.20185 & 0.46889 & Biso & 1.000 & 0 \\
\hline 046 & 1.0000 & 0.91006 & 0.44952 & 0.20153 & Biso & 1.000 & 0 \\
\hline 047 & 1.0000 & 0.54191 & 0.09131 & 0.21944 & Biso & 1.000 & 0 \\
\hline 048 & 1.0000 & 0.55378 & 0.45895 & 0.20719 & Biso & 1.000 & 0 \\
\hline 049 & 1.0000 & 0.45522 & 0.90056 & 0.80735 & Biso & 1.000 & 0 \\
\hline 050 & 1.0000 & 0.08591 & 0.54483 & 0.78730 & Biso & 1.000 & $\mathrm{O}$ \\
\hline 051 & 1.0000 & 0.44831 & 0.53998 & 0.79960 & Biso & 1.000 & 0 \\
\hline 052 & 1.0000 & 0.59185 & 0.79095 & 0.54496 & Biso & 1.000 & 0 \\
\hline 053 & 1.0000 & 0.22109 & 0.45540 & 0.53975 & Biso & 1.000 & 0 \\
\hline 054 & 1.0000 & 0.21473 & 0.77981 & 0.53330 & Biso & 1.000 & 0 \\
\hline 055 & 1.0000 & 0.99622 & 0.24875 & 0.99279 & Biso & 1.000 & 0 \\
\hline 056 & 1.0000 & 0.75539 & 0.74981 & 0.99577 & Biso & 1.000 & $\mathrm{O}$ \\
\hline 057 & 1.0000 & 0.25680 & 0.00102 & 0.98622 & Biso & 1.000 & 0 \\
\hline 058 & 1.0000 & 0.67203 & 0.59996 & 0.32497 & Biso & 1.000 & 0 \\
\hline 059 & 1.0000 & 0.93278 & 0.33780 & 0.32387 & Biso & 1.000 & $\mathrm{O}$ \\
\hline 060 & 1.0000 & 0.32449 & 0.90450 & 0.66061 & Biso & 1.000 & 0 \\
\hline 061 & 1.0000 & 0.07270 & 0.38493 & 0.65906 & Biso & 1.000 & 0 \\
\hline 062 & 1.0000 & 0.60842 & 0.67007 & 0.66314 & Biso & 1.000 & 0 \\
\hline 063 & 1.0000 & 0.99863 & 0.74597 & 0.01480 & Biso & 1.000 & 0 \\
\hline 064 & 1.0000 & 0.25098 & 0.25108 & 0.00640 & Biso & 1.000 & 0 \\
\hline 065 & 1.0000 & 0.74763 & 0.99322 & 0.01126 & Biso & 1.000 & $\mathrm{O}$ \\
\hline 066 & 1.0000 & 0.69100 & 0.07052 & 0.34392 & Biso & 1.000 & 0 \\
\hline 067 & 1.0000 & 0.92600 & 0.59297 & 0.34666 & Biso & 1.000 & 0 \\
\hline 068 & 1.0000 & 0.39287 & 0.32273 & 0.33913 & Biso & 1.000 & 0 \\
\hline 069 & 1.0000 & 0.33699 & 0.40929 & 0.67519 & Biso & 1.000 & 0 \\
\hline 070 & 1.0000 & 0.58828 & 0.93335 & 0.68049 & Biso & 1.000 & 0 \\
\hline 071 & 1.0000 & 0.06971 & 0.68034 & 0.68414 & Biso & 1.000 & 0 \\
\hline 072 & 1.0000 & 0.38541 & 0.06430 & 0.32053 & Biso & 1.000 & 0 \\
\hline $\mathrm{C} 1$ & 1.0000 & 0.22651 & 0.00741 & 0.33437 & Biso & 1.000 & C \\
\hline $\mathrm{H} 1$ & 1.0000 & 0.23104 & 0.99468 & 0.40532 & Biso & 1.000 & $\mathrm{H}$ \\
\hline $\mathrm{H} 2$ & 1.0000 & 0.20469 & 0.93837 & 0.28928 & Biso & 1.000 & $\mathrm{H}$ \\
\hline $\mathrm{H} 3$ & 1.0000 & 0.23140 & 0.08354 & 0.31055 & Biso & 1.000 & $\mathrm{H}$ \\
\hline C2 & 1.0000 & 0.03820 & 0.92873 & 0.34799 & Biso & 1.000 & C \\
\hline $\mathrm{H} 4$ & 1.0000 & 0.02104 & 0.86176 & 0.39489 & Biso & 1.000 & $\mathrm{H}$ \\
\hline H5 & 1.0000 & 0.01232 & 0.90564 & 0.27870 & Biso & 1.000 & $\mathrm{H}$ \\
\hline $\mathrm{C} 3$ & 1.0000 & 0.02862 & 0.01430 & 0.37845 & Biso & 1.000 & C \\
\hline 073 & 1.0000 & 0.02912 & 0.09389 & 0.40322 & Biso & 1.000 & $\mathrm{O}$ \\
\hline
\end{tabular}

Al 17

data image

$\begin{array}{ll}\text {-cell_length_a } & 13.625 \\ \text {-cell_length_b } & 13.625 \\ \text {-cell_length_c } & 15.067 \\ \text {-cell_angle_alpha } & 90 \\ \text {-cell_angle_beta } & 90 \\ \text {-cell_angle_gamma } & 120\end{array}$




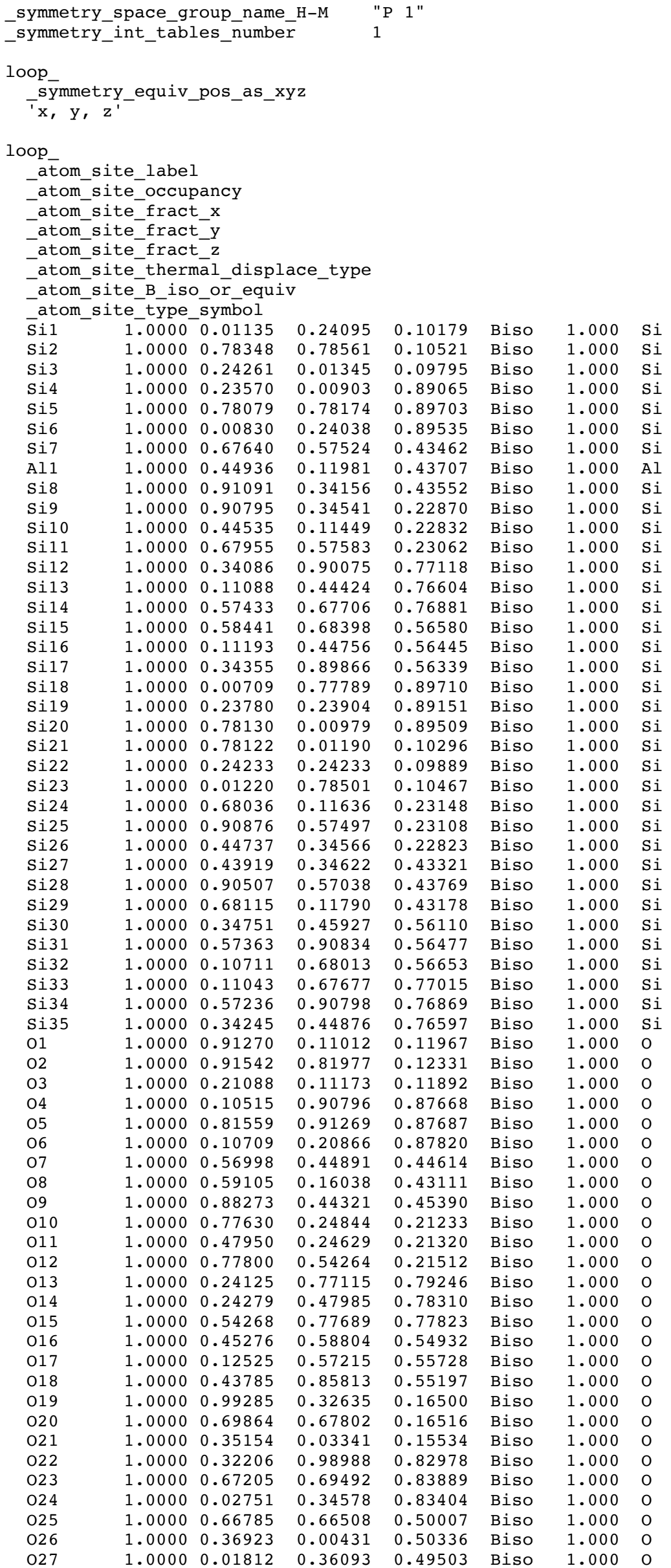




\begin{tabular}{|c|c|c|c|c|c|c|c|}
\hline 028 & 1.0000 & 0.02530 & 0.68868 & 0.83876 & Biso & 1.000 & 0 \\
\hline 029 & 1.0000 & 0.32256 & 0.34341 & 0.82844 & Biso & 1.000 & 0 \\
\hline 030 & 1.0000 & 0.67504 & 0.98938 & 0.83451 & Biso & 1.000 & 0 \\
\hline 031 & 1.0000 & 0.69456 & 0.03431 & 0.16088 & Biso & 1.000 & 0 \\
\hline 032 & 1.0000 & 0.34876 & 0.32937 & 0.15913 & Biso & 1.000 & 0 \\
\hline 033 & 1.0000 & 0.99405 & 0.68295 & 0.17039 & Biso & 1.000 & 0 \\
\hline 034 & 1.0000 & 0.35579 & 0.37403 & 0.49159 & Biso & 1.000 & 0 \\
\hline 035 & 1.0000 & 0.00414 & 0.66333 & 0.50166 & Biso & 1.000 & 0 \\
\hline 036 & 1.0000 & 0.64866 & 0.01184 & 0.49811 & Biso & 1.000 & 0 \\
\hline 037 & 1.0000 & 0.13310 & 0.25341 & 0.12568 & Biso & 1.000 & 0 \\
\hline 038 & 1.0000 & 0.76915 & 0.89224 & 0.13391 & Biso & 1.000 & 0 \\
\hline 039 & 1.0000 & 0.13496 & 0.89325 & 0.12928 & Biso & 1.000 & 0 \\
\hline 040 & 1.0000 & 0.24631 & 0.12879 & 0.86360 & Biso & 1.000 & 0 \\
\hline 041 & 1.0000 & 0.88591 & 0.76403 & 0.87037 & Biso & 1.000 & 0 \\
\hline 042 & 1.0000 & 0.88782 & 0.13184 & 0.86902 & Biso & 1.000 & 0 \\
\hline 043 & 1.0000 & 0.79127 & 0.57400 & 0.45994 & Biso & 1.000 & 0 \\
\hline 044 & 1.0000 & 0.42569 & 0.22875 & 0.46377 & Biso & 1.000 & 0 \\
\hline 045 & 1.0000 & 0.80494 & 0.22060 & 0.46326 & Biso & 1.000 & 0 \\
\hline 046 & 1.0000 & 0.92301 & 0.46817 & 0.20384 & Biso & 1.000 & 0 \\
\hline 047 & 1.0000 & 0.55637 & 0.10239 & 0.21595 & Biso & 1.000 & 0 \\
\hline 048 & 1.0000 & 0.55865 & 0.46671 & 0.20689 & Biso & 1.000 & 0 \\
\hline 049 & 1.0000 & 0.46179 & 0.91452 & 0.79914 & Biso & 1.000 & 0 \\
\hline 050 & 1.0000 & 0.09551 & 0.55261 & 0.78361 & Biso & 1.000 & 0 \\
\hline 051 & 1.0000 & 0.46290 & 0.55736 & 0.79268 & Biso & 1.000 & 0 \\
\hline 052 & 1.0000 & 0.60140 & 0.80778 & 0.54422 & Biso & 1.000 & 0 \\
\hline 053 & 1.0000 & 0.23243 & 0.46057 & 0.53867 & Biso & 1.000 & 0 \\
\hline 054 & 1.0000 & 0.22026 & 0.79278 & 0.53405 & Biso & 1.000 & 0 \\
\hline 055 & 1.0000 & 0.00862 & 0.27516 & 0.99880 & Biso & 1.000 & 0 \\
\hline 056 & 1.0000 & 0.75055 & 0.75296 & 0.00169 & Biso & 1.000 & 0 \\
\hline 057 & 1.0000 & 0.27116 & 0.01126 & 0.99415 & Biso & 1.000 & 0 \\
\hline 058 & 1.0000 & 0.68448 & 0.61852 & 0.33233 & Biso & 1.000 & 0 \\
\hline 059 & 1.0000 & 0.94404 & 0.34381 & 0.33126 & Biso & 1.000 & 0 \\
\hline 060 & 1.0000 & 0.33829 & 0.92905 & 0.66746 & Biso & 1.000 & 0 \\
\hline 061 & 1.0000 & 0.07427 & 0.39802 & 0.66482 & Biso & 1.000 & 0 \\
\hline 062 & 1.0000 & 0.61902 & 0.67667 & 0.66844 & Biso & 1.000 & 0 \\
\hline 063 & 1.0000 & 0.00868 & 0.74787 & 0.00189 & Biso & 1.000 & 0 \\
\hline 064 & 1.0000 & 0.27523 & 0.27288 & 0.99482 & Biso & 1.000 & 0 \\
\hline 065 & 1.0000 & 0.74770 & 0.00748 & 0.99899 & Biso & 1.000 & 0 \\
\hline 066 & 1.0000 & 0.69440 & 0.07877 & 0.33096 & Biso & 1.000 & 0 \\
\hline 067 & 1.0000 & 0.94467 & 0.61075 & 0.33485 & Biso & 1.000 & 0 \\
\hline 068 & 1.0000 & 0.40287 & 0.34284 & 0.32853 & Biso & 1.000 & 0 \\
\hline 069 & 1.0000 & 0.34367 & 0.41498 & 0.66248 & Biso & 1.000 & 0 \\
\hline 070 & 1.0000 & 0.60894 & 0.95218 & 0.66715 & Biso & 1.000 & 0 \\
\hline 071 & 1.0000 & 0.07666 & 0.69247 & 0.66920 & Biso & 1.000 & 0 \\
\hline 072 & 1.0000 & 0.38853 & 0.07070 & 0.32701 & Biso & 1.000 & 0 \\
\hline C1 & 1.0000 & 0.22395 & 0.99093 & 0.33989 & Biso & 1.000 & $\mathrm{C}$ \\
\hline H 1 & 1.0000 & 0.23078 & 0.96178 & 0.40546 & Biso & 1.000 & $\mathrm{H}$ \\
\hline H2 & 1.0000 & 0.21046 & 0.93715 & 0.28278 & Biso & 1.000 & $\mathrm{H}$ \\
\hline H3 & 1.0000 & 0.21943 & 0.06786 & 0.33275 & Biso & 1.000 & $\mathrm{H}$ \\
\hline $\mathrm{C} 2$ & 1.0000 & 0.03270 & 0.89136 & 0.34961 & Biso & 1.000 & $\mathrm{C}$ \\
\hline $\mathrm{H} 4$ & 1.0000 & 0.02001 & 0.80585 & 0.34180 & Biso & 1.000 & $\mathrm{H}$ \\
\hline H5 & 1.0000 & 0.00818 & 0.92628 & 0.29416 & Biso & 1.000 & $\mathrm{H}$ \\
\hline C3 & 1.0000 & 0.01391 & 0.91681 & 0.43140 & Biso & 1.000 & C \\
\hline 073 & 1.0000 & 0.00650 & 0.94373 & 0.50313 & Biso & 1.000 & 0 \\
\hline 17 & & & & & & & \\
\hline & & & & & & & \\
\hline celi & ch_a & 13.87 & & & & & \\
\hline $\mathrm{cell}$ & $=h-b$ & 13.87 & & & & & \\
\hline $\mathrm{Cell}$ & $\mathrm{Ch}_{-}^{-} \mathrm{c}$ & 15.01 & & & & & \\
\hline$[\mathrm{cell}$ & e_talpha & 90 & & & & & \\
\hline $\mathrm{cell}$ & beta & 90 & & & & & \\
\hline $\mathrm{cell}$ & _gamma & 120 & & & & & \\
\hline symme & pace g & coup name & $\mathrm{H}-\mathrm{M}$ & $1 "$ & & & \\
\hline symme & $n t \_t a b$ & Les_numbe & & & & & \\
\hline \multicolumn{8}{|c|}{ loop_ } \\
\hline \multicolumn{8}{|c|}{ symmetry equiv pos as xyz } \\
\hline \multicolumn{8}{|c|}{$' x, y, z{ }^{\prime}$} \\
\hline \multicolumn{8}{|c|}{ 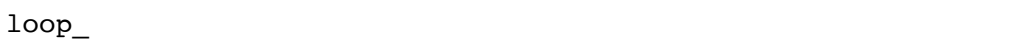 } \\
\hline \multicolumn{8}{|c|}{ atom_site_label } \\
\hline \multicolumn{8}{|c|}{ atom_site_occupancy } \\
\hline \multicolumn{8}{|c|}{-atom_site_fract_x } \\
\hline -atc & te_fract & $=-y$ & & & & & \\
\hline atc & $e_{-}^{-}$fract & & & & & & \\
\hline -atc & e_thern & nàl_disp. & ce_type & & & & \\
\hline & e_B_isc & or_equ. & & & & & \\
\hline & e_tȳpe & $\overline{\text { symbol }}$ & & & & & \\
\hline$\overline{\mathrm{P}} 1$ & 1.0000 & 0.00696 & 0.22697 & 0.11056 & Biso & 1.000 & \\
\hline
\end{tabular}




\begin{tabular}{|c|c|c|c|c|c|c|c|}
\hline P2 & 1.0000 & 0.78013 & 0.77926 & 0.11433 & Biso & 1.000 & $\mathrm{P}$ \\
\hline P3 & 1.0000 & 0.22999 & 0.99773 & 0.10314 & Biso & 1.000 & $\mathrm{P}$ \\
\hline Al1 & 1.0000 & 0.22229 & 0.99207 & 0.88919 & Biso & 1.000 & Al \\
\hline Al2 & 1.0000 & 0.77336 & 0.77334 & 0.89989 & Biso & 1.000 & Al \\
\hline A13 & 1.0000 & 0.00230 & 0.22576 & 0.89752 & Biso & 1.000 & Al \\
\hline P 4 & 1.0000 & 0.67242 & 0.56302 & 0.44161 & Biso & 1.000 & $\mathrm{P}$ \\
\hline Ge1 & 1.0000 & 0.43176 & 0.10934 & 0.44526 & Biso & 1.000 & $\mathrm{Ge}$ \\
\hline P5 & 1.0000 & 0.89993 & 0.32640 & 0.44127 & Biso & 1.000 & $\mathrm{P}$ \\
\hline Al4 & 1.0000 & 0.89677 & 0.33020 & 0.23063 & Biso & 1.000 & Al \\
\hline Al5 & 1.0000 & 0.43818 & 0.10675 & 0.22932 & Biso & 1.000 & Al \\
\hline Al 6 & 1.0000 & 0.67519 & 0.56363 & 0.23302 & Biso & 1.000 & $\mathrm{Al}$ \\
\hline P6 & 1.0000 & 0.33401 & 0.88308 & 0.78121 & Biso & 1.000 & $\mathrm{P}$ \\
\hline P7 & 1.0000 & 0.10323 & 0.43373 & 0.77337 & Biso & 1.000 & $P$ \\
\hline P8 & 1.0000 & 0.56286 & 0.66095 & 0.77678 & Biso & 1.000 & $\mathrm{P}$ \\
\hline Al7 & 1.0000 & 0.57594 & 0.67203 & 0.57062 & Biso & 1.000 & Al \\
\hline Al8 & 1.0000 & 0.09998 & 0.43412 & 0.56955 & Biso & 1.000 & Al \\
\hline Al9 & 1.0000 & 0.33661 & 0.88001 & 0.56624 & Biso & 1.000 & Al \\
\hline P9 & 1.0000 & 0.99465 & 0.76584 & 0.89323 & Biso & 1.000 & $\mathrm{P}$ \\
\hline P10 & 1.0000 & 0.22751 & 0.22183 & 0.88758 & Biso & 1.000 & $P$ \\
\hline P11 & 1.0000 & 0.77726 & 0.00070 & 0.89384 & Biso & 1.000 & $\mathrm{P}$ \\
\hline Al10 & 1.0000 & 0.77857 & 0.00367 & 0.10784 & Biso & 1.000 & $\mathrm{Al}$ \\
\hline Al11 & 1.0000 & 0.23434 & 0.22717 & 0.09989 & Biso & 1.000 & Al \\
\hline Al12 & 1.0000 & 0.00336 & 0.77369 & 0.10729 & Biso & 1.000 & Al \\
\hline P12 & 1.0000 & 0.66925 & 0.10451 & 0.22957 & Biso & 1.000 & $P$ \\
\hline P13 & 1.0000 & 0.90148 & 0.56070 & 0.22977 & Biso & 1.000 & $\mathrm{P}$ \\
\hline P14 & 1.0000 & 0.44507 & 0.33686 & 0.22455 & Biso & 1.000 & $P$ \\
\hline Al13 & 1.0000 & 0.43353 & 0.34056 & 0.43581 & Biso & 1.000 & $\mathrm{Al}$ \\
\hline Al14 & 1.0000 & 0.89764 & 0.55583 & 0.44047 & Biso & 1.000 & Al \\
\hline Al15 & 1.0000 & 0.66786 & 0.10712 & 0.43532 & Biso & 1.000 & Al \\
\hline P15 & 1.0000 & 0.33686 & 0.45524 & 0.55859 & Biso & 1.000 & $\mathrm{P}$ \\
\hline P16 & 1.0000 & 0.56738 & 0.89498 & 0.56506 & Biso & 1.000 & $P$ \\
\hline P 17 & 1.0000 & 0.09911 & 0.66824 & 0.56756 & Biso & 1.000 & $\mathrm{P}$ \\
\hline Al16 & 1.0000 & 0.10355 & 0.66623 & 0.77353 & Biso & 1.000 & $\mathrm{Al}$ \\
\hline Al17 & 1.0000 & 0.56180 & 0.89079 & 0.77410 & Biso & 1.000 & Al \\
\hline Al18 & 1.0000 & 0.33077 & 0.43628 & 0.76647 & Biso & 1.000 & Al \\
\hline 01 & 1.0000 & 0.91608 & 0.10661 & 0.13311 & Biso & 1.000 & 0 \\
\hline $\mathrm{O} 2$ & 1.0000 & 0.90172 & 0.80965 & 0.13502 & Biso & 1.000 & 0 \\
\hline 03 & 1.0000 & 0.20090 & 0.08941 & 0.12394 & Biso & 1.000 & 0 \\
\hline 04 & 1.0000 & 0.08635 & 0.88419 & 0.86725 & Biso & 1.000 & 0 \\
\hline 05 & 1.0000 & 0.80779 & 0.91012 & 0.87365 & Biso & 1.000 & 0 \\
\hline 06 & 1.0000 & 0.10597 & 0.19286 & 0.87331 & Biso & 1.000 & 0 \\
\hline 07 & 1.0000 & 0.57257 & 0.44569 & 0.45283 & Biso & 1.000 & 0 \\
\hline 08 & 1.0000 & 0.57424 & 0.15415 & 0.43691 & Biso & 1.000 & 0 \\
\hline 09 & 1.0000 & 0.87659 & 0.42247 & 0.45946 & Biso & 1.000 & 0 \\
\hline 010 & 1.0000 & 0.75849 & 0.22678 & 0.21022 & Biso & 1.000 & 0 \\
\hline 011 & 1.0000 & 0.47729 & 0.24665 & 0.20926 & Biso & 1.000 & 0 \\
\hline 012 & 1.0000 & 0.78006 & 0.53065 & 0.21291 & Biso & 1.000 & 0 \\
\hline 013 & 1.0000 & 0.23928 & 0.76523 & 0.80572 & Biso & 1.000 & 0 \\
\hline 014 & 1.0000 & 0.22651 & 0.46965 & 0.78990 & Biso & 1.000 & 0 \\
\hline 015 & 1.0000 & 0.53209 & 0.75289 & 0.78508 & Biso & 1.000 & 0 \\
\hline 016 & 1.0000 & 0.43568 & 0.57500 & 0.55244 & Biso & 1.000 & 0 \\
\hline 017 & 1.0000 & 0.10467 & 0.56106 & 0.56425 & Biso & 1.000 & 0 \\
\hline 018 & 1.0000 & 0.44236 & 0.84703 & 0.54610 & Biso & 1.000 & 0 \\
\hline 019 & 1.0000 & 0.99005 & 0.31014 & 0.16585 & Biso & 1.000 & 0 \\
\hline 020 & 1.0000 & 0.69830 & 0.67703 & 0.16778 & Biso & 1.000 & 0 \\
\hline 021 & 1.0000 & 0.33654 & 0.02092 & 0.15141 & Biso & 1.000 & 0 \\
\hline 022 & 1.0000 & 0.31816 & 0.97146 & 0.83021 & Biso & 1.000 & 0 \\
\hline 023 & 1.0000 & 0.65199 & 0.67824 & 0.84545 & Biso & 1.000 & 0 \\
\hline 024 & 1.0000 & 0.02771 & 0.34564 & 0.84118 & Biso & 1.000 & O \\
\hline 025 & 1.0000 & 0.66271 & 0.64672 & 0.50239 & Biso & 1.000 & 0 \\
\hline 026 & 1.0000 & 0.34944 & 0.99295 & 0.51109 & Biso & 1.000 & 0 \\
\hline 027 & 1.0000 & 0.99932 & 0.34107 & 0.49668 & Biso & 1.000 & 0 \\
\hline 028 & 1.0000 & 0.00933 & 0.67749 & 0.84377 & Biso & 1.000 & 0 \\
\hline 029 & 1.0000 & 0.30671 & 0.32027 & 0.82911 & Biso & 1.000 & 0 \\
\hline 030 & 1.0000 & 0.67390 & 0.97920 & 0.84142 & Biso & 1.000 & 0 \\
\hline 031 & 1.0000 & 0.68240 & 0.02702 & 0.16369 & Biso & 1.000 & 0 \\
\hline 032 & 1.0000 & 0.35169 & 0.31979 & 0.16009 & Biso & 1.000 & O \\
\hline 033 & 1.0000 & 0.98142 & 0.65974 & 0.17136 & Biso & 1.000 & 0 \\
\hline 034 & 1.0000 & 0.34706 & 0.38082 & 0.48895 & Biso & 1.000 & 0 \\
\hline 035 & 1.0000 & 0.00478 & 0.65690 & 0.50645 & Biso & 1.000 & 0 \\
\hline 036 & 1.0000 & 0.63828 & 0.99400 & 0.50432 & Biso & 1.000 & 0 \\
\hline 037 & 1.0000 & 0.12104 & 0.24075 & 0.13362 & Biso & 1.000 & 0 \\
\hline 038 & 1.0000 & 0.76549 & 0.87736 & 0.14236 & Biso & 1.000 & 0 \\
\hline 039 & 1.0000 & 0.13302 & 0.88645 & 0.13776 & Biso & 1.000 & 0 \\
\hline 040 & 1.0000 & 0.23767 & 0.12069 & 0.86078 & Biso & 1.000 & 0 \\
\hline 041 & 1.0000 & 0.88156 & 0.75178 & 0.86730 & Biso & 1.000 & 0 \\
\hline 042 & 1.0000 & 0.87429 & 0.11403 & 0.86540 & Biso & 1.000 & 0 \\
\hline 043 & 1.0000 & 0.77859 & 0.56141 & 0.46708 & Biso & 1.000 & 0 \\
\hline 044 & 1.0000 & 0.40599 & 0.21520 & 0.47871 & Biso & 1.000 & 0 \\
\hline 045 & 1.0000 & 0.79890 & 0.21594 & 0.46802 & Biso & 1.000 & 0 \\
\hline
\end{tabular}




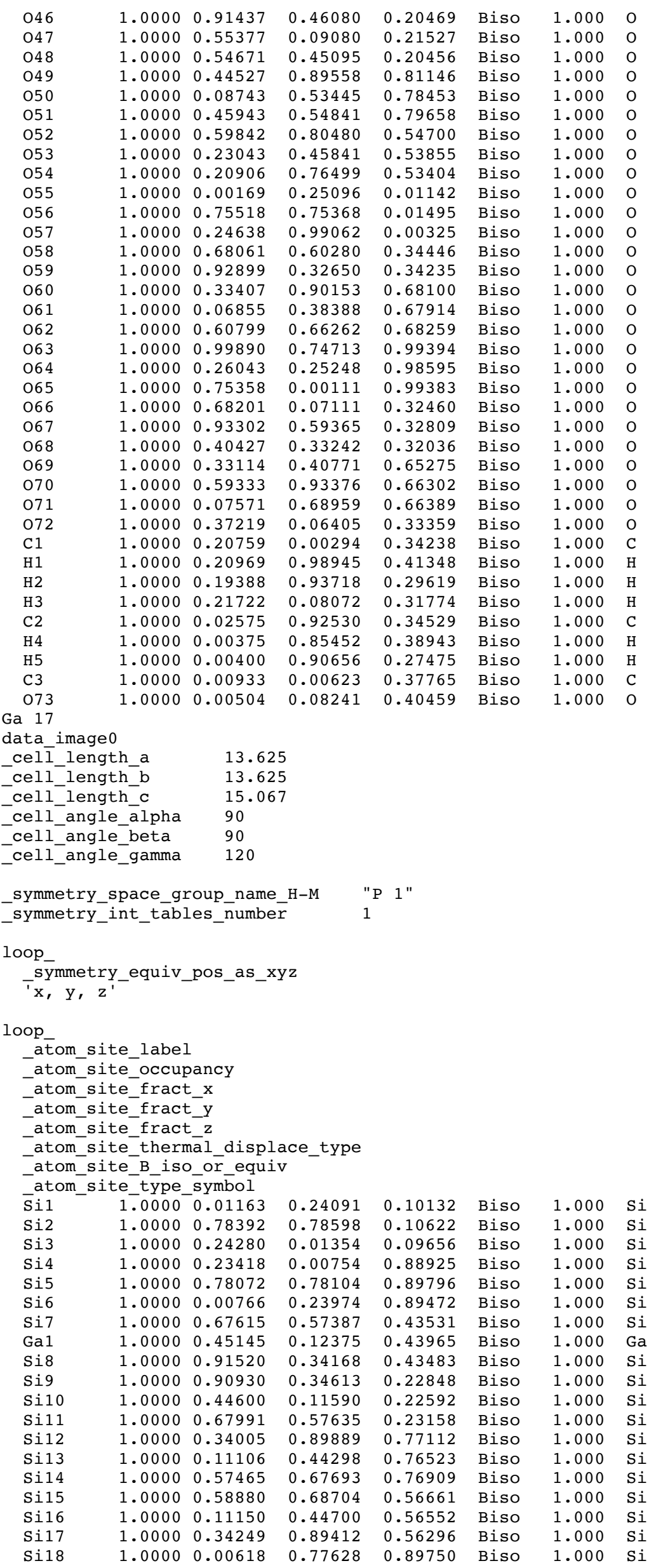




\begin{tabular}{|c|c|c|c|c|c|c|}
\hline Si19 & 1.0000 & 0.23755 & 0.23855 & 0.89012 & Biso & 1.000 \\
\hline Si20 & 1.0000 & 0.78161 & 0.00936 & 0.89541 & Biso & 1.000 \\
\hline Si21 & 1.0000 & 0.78212 & 0.01261 & 0.10361 & Biso & 1.000 \\
\hline Si22 & 1.0000 & 0.24328 & 0.24310 & 0.09726 & Biso & 1.000 \\
\hline Si23 & 1.0000 & 0.01241 & 0.78560 & 0.10556 & Biso & 1.000 \\
\hline $\mathrm{Si} 24$ & 1.0000 & 0.68032 & 0.11663 & 0.23210 & Biso & 1.000 \\
\hline Si25 & 1.0000 & 0.90824 & 0.57476 & 0.23132 & Biso & 1.000 \\
\hline Si26 & 1.0000 & 0.44747 & 0.34524 & 0.22737 & Biso & 1.000 \\
\hline Si27 & 1.0000 & 0.43561 & 0.34686 & 0.43343 & Biso & 1.000 \\
\hline Si28 & 1.0000 & 0.90426 & 0.56830 & 0.43834 & Biso & 1.000 \\
\hline Si29 & 1.0000 & 0.68346 & 0.12063 & 0.43284 & Biso & 1.000 \\
\hline Si30 & 1.0000 & 0.34880 & 0.46461 & 0.56016 & Biso & 1.000 \\
\hline Si31 & 1.0000 & 0.57449 & 0.90874 & 0.56524 & Biso & 1.000 \\
\hline Si32 & 1.0000 & 0.10308 & 0.67865 & 0.56830 & Biso & 1.000 \\
\hline Si33 & 1.0000 & 0.10911 & 0.67591 & 0.77015 & Biso & 1.000 \\
\hline $\mathrm{Si} 34$ & 1.0000 & 0.57107 & 0.90643 & 0.76970 & Biso & 1.000 \\
\hline Si35 & 1.0000 & 0.34230 & 0.44808 & 0.76418 & Biso & 1.000 \\
\hline 01 & 1.0000 & 0.91372 & 0.11023 & 0.12095 & Biso & 1.000 \\
\hline $\mathrm{O} 2$ & 1.0000 & 0.91588 & 0.82057 & 0.12484 & Biso & 1.000 \\
\hline 03 & 1.0000 & 0.21162 & 0.11235 & 0.11699 & Biso & 1.000 \\
\hline $\mathrm{O} 4$ & 1.0000 & 0.10377 & 0.90601 & 0.87532 & Biso & 1.000 \\
\hline 05 & 1.0000 & 0.81630 & 0.91232 & 0.87808 & Biso & 1.000 \\
\hline 06 & 1.0000 & 0.10686 & 0.20859 & 0.87777 & Biso & 1.000 \\
\hline 07 & 1.0000 & 0.56689 & 0.44894 & 0.44506 & Biso & 1.000 \\
\hline 08 & 1.0000 & 0.60140 & 0.17365 & 0.43403 & Biso & 1.000 \\
\hline 09 & 1.0000 & 0.88665 & 0.44283 & 0.45468 & Biso & 1.000 \\
\hline 010 & 1.0000 & 0.77744 & 0.24855 & 0.21419 & Biso & 1.000 \\
\hline 011 & 1.0000 & 0.48181 & 0.24802 & 0.20939 & Biso & 1.000 \\
\hline 012 & 1.0000 & 0.77749 & 0.54224 & 0.21454 & Biso & 1.000 \\
\hline 013 & 1.0000 & 0.24021 & 0.76948 & 0.79277 & Biso & 1.000 \\
\hline 014 & 1.0000 & 0.24336 & 0.47999 & 0.78293 & Biso & 1.000 \\
\hline 015 & 1.0000 & 0.54055 & 0.77502 & 0.77866 & Biso & 1.000 \\
\hline 016 & 1.0000 & 0.45684 & 0.59199 & 0.55097 & Biso & 1.000 \\
\hline 017 & 1.0000 & 0.11334 & 0.56618 & 0.56218 & Biso & 1.000 \\
\hline 018 & 1.0000 & 0.43854 & 0.85597 & 0.55090 & Biso & 1.000 \\
\hline 019 & 1.0000 & 0.99332 & 0.32707 & 0.16375 & Biso & 1.000 \\
\hline 020 & 1.0000 & 0.69884 & 0.67872 & 0.16639 & Biso & 1.000 \\
\hline 021 & 1.0000 & 0.35295 & 0.03448 & 0.15260 & Biso & 1.000 \\
\hline 022 & 1.0000 & 0.32050 & 0.98881 & 0.82796 & Biso & 1.000 \\
\hline 023 & 1.0000 & 0.67078 & 0.69470 & 0.84074 & Biso & 1.000 \\
\hline $\mathrm{O} 24$ & 1.0000 & 0.02778 & 0.34633 & 0.83450 & Biso & 1.000 \\
\hline 025 & 1.0000 & 0.67067 & 0.66515 & 0.50128 & Biso & 1.000 \\
\hline 026 & 1.0000 & 0.36241 & 0.99740 & 0.50200 & Biso & 1.000 \\
\hline $\mathrm{O} 27$ & 1.0000 & 0.02267 & 0.35983 & 0.49358 & Biso & 1.000 \\
\hline 028 & 1.0000 & 0.02480 & 0.68586 & 0.84100 & Biso & 1.000 \\
\hline 029 & 1.0000 & 0.32179 & 0.34179 & 0.82584 & Biso & 1.000 \\
\hline 030 & 1.0000 & 0.67422 & 0.98708 & 0.83545 & Biso & 1.000 \\
\hline 031 & 1.0000 & 0.69560 & 0.03499 & 0.16177 & Biso & 1.000 \\
\hline 032 & 1.0000 & 0.34936 & 0.32999 & 0.15803 & Biso & 1.000 \\
\hline 033 & 1.0000 & 0.99414 & 0.68356 & 0.17147 & Biso & 1.000 \\
\hline 034 & 1.0000 & 0.35318 & 0.38100 & 0.48673 & Biso & 1.000 \\
\hline 035 & 1.0000 & 0.00190 & 0.66398 & 0.50206 & Biso & 1.000 \\
\hline 036 & 1.0000 & 0.64724 & 0.01464 & 0.49994 & Biso & 1.000 \\
\hline 037 & 1.0000 & 0.13411 & 0.25439 & 0.12395 & Biso & 1.000 \\
\hline 038 & 1.0000 & 0.76913 & 0.89250 & 0.13422 & Biso & 1.000 \\
\hline 039 & 1.0000 & 0.13548 & 0.89390 & 0.12946 & Biso & 1.000 \\
\hline 040 & 1.0000 & 0.24467 & 0.12739 & 0.86271 & Biso & 1.000 \\
\hline 041 & 1.0000 & 0.88474 & 0.76181 & 0.87043 & Biso & 1.000 \\
\hline 042 & 1.0000 & 0.88745 & 0.13117 & 0.86752 & Biso & 1.000 \\
\hline 043 & 1.0000 & 0.78786 & 0.56675 & 0.46085 & Biso & 1.000 \\
\hline 044 & 1.0000 & 0.41731 & 0.23022 & 0.47253 & Biso & 1.000 \\
\hline 045 & 1.0000 & 0.81029 & 0.21954 & 0.46183 & Biso & 1.000 \\
\hline 046 & 1.0000 & 0.92302 & 0.46837 & 0.20364 & Biso & 1.000 \\
\hline 047 & 1.0000 & 0.55701 & 0.10344 & 0.21503 & Biso & 1.000 \\
\hline 048 & 1.0000 & 0.55782 & 0.46809 & 0.20922 & Biso & 1.000 \\
\hline 049 & 1.0000 & 0.46088 & 0.91341 & 0.80069 & Biso & 1.000 \\
\hline 050 & 1.0000 & 0.09444 & 0.55126 & 0.77935 & Biso & 1.000 \\
\hline 051 & 1.0000 & 0.46367 & 0.55580 & 0.79047 & Biso & 1.000 \\
\hline 052 & 1.0000 & 0.60673 & 0.81124 & 0.54397 & Biso & 1.000 \\
\hline 053 & 1.0000 & 0.23690 & 0.47290 & 0.54016 & Biso & 1.000 \\
\hline 054 & 1.0000 & 0.21984 & 0.78638 & 0.53509 & Biso & 1.000 \\
\hline 055 & 1.0000 & 0.00662 & 0.27321 & 0.99825 & Biso & 1.000 \\
\hline 056 & 1.0000 & 0.75149 & 0.75264 & 0.00276 & Biso & 1.000 \\
\hline 057 & 1.0000 & 0.26955 & 0.00929 & 0.99264 & Biso & 1.000 \\
\hline 058 & 1.0000 & 0.68712 & 0.61948 & 0.33345 & Biso & 1.000 \\
\hline 059 & 1.0000 & 0.94805 & 0.34574 & 0.33039 & Biso & 1.000 \\
\hline 060 & 1.0000 & 0.33902 & 0.92591 & 0.66693 & Biso & 1.000 \\
\hline 061 & 1.0000 & 0.07518 & 0.39271 & 0.66478 & & 1.000 \\
\hline 062 & 1.0000 & 0.62333 & 0.68049 & 0.66944 & Biso & 1.000 \\
\hline 063 & 1.0000 & 0.00812 & 0.74838 & 0.00273 & Biso & 1.000 \\
\hline
\end{tabular}




\begin{tabular}{|c|c|c|c|c|c|c|c|}
\hline 064 & 1.0000 & 0.27644 & 0.27370 & 0.99313 & Biso & 1.000 & 0 \\
\hline 065 & 1.0000 & 0.74950 & 0.00914 & 0.99948 & Biso & 1.000 & 0 \\
\hline 066 & 1.0000 & 0.69067 & 0.07753 & 0.33204 & Biso & 1.000 & 0 \\
\hline 067 & 1.0000 & 0.94279 & 0.60929 & 0.33545 & Biso & 1.000 & 0 \\
\hline 068 & 1.0000 & 0.40101 & 0.33668 & 0.32784 & Biso & 1.000 & 0 \\
\hline 069 & 1.0000 & 0.34276 & 0.41527 & 0.66017 & Biso & 1.000 & 0 \\
\hline 070 & 1.0000 & 0.60743 & 0.95100 & 0.66817 & Biso & 1.000 & 0 \\
\hline 071 & 1.0000 & 0.07456 & 0.69581 & 0.67052 & Biso & 1.000 & 0 \\
\hline 072 & 1.0000 & 0.38714 & 0.07282 & 0.32393 & Biso & 1.000 & 0 \\
\hline $\mathrm{C} 1$ & 1.0000 & 0.22253 & 0.99165 & 0.33846 & Biso & 1.000 & C \\
\hline $\mathrm{H} 1$ & 1.0000 & 0.23157 & 0.96273 & 0.40353 & Biso & 1.000 & $\mathrm{H}$ \\
\hline H2 & 1.0000 & 0.20897 & 0.93857 & 0.28087 & Biso & 1.000 & $\mathrm{H}$ \\
\hline Н3 & 1.0000 & 0.21790 & 0.06860 & 0.33213 & Biso & 1.000 & $\mathrm{H}$ \\
\hline $\mathrm{C} 2$ & 1.0000 & 0.03294 & 0.89112 & 0.35004 & Biso & 1.000 & C \\
\hline H 4 & 1.0000 & 0.02067 & 0.80568 & 0.34302 & Biso & 1.000 & $\mathrm{H}$ \\
\hline H5 & 1.0000 & 0.00669 & 0.92438 & 0.29451 & Biso & 1.000 & $\mathrm{H}$ \\
\hline $\mathrm{C} 3$ & 1.0000 & 0.01478 & 0.91751 & 0.43173 & Biso & 1.000 & C \\
\hline 073 & 1.0000 & 0.00805 & 0.94545 & 0.50324 & Biso & 1.000 & 0 \\
\hline \multicolumn{8}{|l|}{ Ti 17} \\
\hline \multicolumn{8}{|c|}{ data_image 0} \\
\hline \multicolumn{8}{|c|}{13.875} \\
\hline \multicolumn{8}{|c|}{13.875} \\
\hline \multicolumn{8}{|c|}{15.017} \\
\hline \multicolumn{8}{|c|}{90} \\
\hline \multicolumn{8}{|c|}{90} \\
\hline \multicolumn{8}{|c|}{120} \\
\hline vmm & pace_g & מוני nam מוני & & $1 "$ & & & \\
\hline symme & $n t \_t \overline{a b}$ & les_ñumb & & & & & \\
\hline op_ & & & & & & & \\
\hline $\begin{array}{c}\text { sym } \\
\bar{x},\end{array}$ & _equiv & pos_as_x & & & & & \\
\hline op & & & & & & & \\
\hline ator & e_labe & & & & & & \\
\hline -aton & e_occu & pancy & & & & & \\
\hline -ator & $=e_{-}^{-} f r a c$ & t $x$ & & & & & \\
\hline -ator & $e_{-}^{-}$frac & - & & & & & \\
\hline -ator & $e_{-}^{-} f r a c$ & $z$ & & & & & \\
\hline -ator & $e^{-}$ther & nàl_displ & ace_type & & & & \\
\hline $\begin{array}{l}\text { ator } \\
\text { ator }\end{array}$ & $\begin{array}{l}\text { e-B_is } \\
=e^{-} \text {type }\end{array}$ & $\begin{array}{l}\text { Dor_equi } \\
\text { symbol }\end{array}$ & & & & & \\
\hline$\overline{\mathrm{P}} 1$ & 1.0000 & 0.00768 & 0.22720 & 0.11002 & Biso & 1.000 & $P$ \\
\hline P2 & 1.0000 & 0.78126 & 0.78042 & 0.11524 & Biso & 1.000 & $P$ \\
\hline P3 & 1.0000 & 0.23083 & 0.99827 & 0.10113 & Biso & 1.000 & $\mathrm{P}$ \\
\hline Al1 & 1.0000 & 0.22044 & 0.98994 & 0.88682 & Biso & 1.000 & Al \\
\hline Al2 & 1.0000 & 0.77325 & 0.77302 & 0.90058 & Biso & 1.000 & Al \\
\hline Al3 & 1.0000 & 0.00163 & 0.22460 & 0.89680 & Biso & 1.000 & Al \\
\hline P4 & 1.0000 & 0.67302 & 0.56467 & 0.44165 & Biso & 1.000 & $\mathrm{P}$ \\
\hline Til & 1.0000 & 0.42913 & 0.10865 & 0.44664 & Biso & 1.000 & $\mathrm{Ti}$ \\
\hline P5 & 1.0000 & 0.90409 & 0.32706 & 0.44055 & Biso & 1.000 & $P$ \\
\hline Al4 & 1.0000 & 0.89825 & 0.33100 & 0.23033 & Biso & 1.000 & Al \\
\hline Al5 & 1.0000 & 0.43738 & 0.10652 & 0.22749 & Biso & 1.000 & Al \\
\hline Al6 & 1.0000 & 0.67632 & 0.56436 & 0.23356 & Biso & 1.000 & Al \\
\hline P6 & 1.0000 & 0.33260 & 0.87841 & 0.78380 & Biso & 1.000 & $\mathrm{P}$ \\
\hline P7 & 1.0000 & 0.10332 & 0.43228 & 0.77289 & Biso & 1.000 & $P$ \\
\hline P8 & 1.0000 & 0.56329 & 0.65981 & 0.77718 & Biso & 1.000 & $\mathrm{P}$ \\
\hline Al7 & 1.0000 & 0.58088 & 0.67409 & 0.57213 & Biso & 1.000 & Al \\
\hline Al 8 & 1.0000 & 0.10030 & 0.43483 & 0.57078 & Biso & 1.000 & Al \\
\hline Al9 & 1.0000 & 0.33503 & 0.87375 & 0.56784 & Biso & 1.000 & Al \\
\hline P9 & 1.0000 & 0.99326 & 0.76346 & 0.89342 & Biso & 1.000 & $\mathrm{P}$ \\
\hline P 10 & 1.0000 & 0.22644 & 0.22006 & 0.88535 & Biso & 1.000 & $\mathrm{P}$ \\
\hline P11 & 1.0000 & 0.77722 & 0.99981 & 0.89423 & Biso & 1.000 & $\mathrm{P}$ \\
\hline Al10 & 1.0000 & 0.77938 & 0.00431 & 0.10874 & Biso & 1.000 & Al \\
\hline Al11 & 1.0000 & 0.23544 & 0.22778 & 0.09801 & Biso & 1.000 & Al \\
\hline Al12 & 1.0000 & 0.00439 & 0.77463 & 0.10779 & Biso & 1.000 & $\mathrm{Al}$ \\
\hline P12 & 1.0000 & 0.67012 & 0.10560 & 0.23036 & Biso & 1.000 & $\mathrm{P}$ \\
\hline P13 & 1.0000 & 0.90236 & 0.56161 & 0.23071 & Biso & 1.000 & $P$ \\
\hline P14 & 1.0000 & 0.44466 & 0.33760 & 0.22379 & Biso & 1.000 & $\mathrm{P}$ \\
\hline Al13 & 1.0000 & 0.42953 & 0.34532 & 0.43447 & Biso & 1.000 & Al \\
\hline Al14 & 1.0000 & 0.89743 & 0.55516 & 0.44126 & Biso & 1.000 & Al \\
\hline Al15 & 1.0000 & 0.67235 & 0.10764 & 0.43674 & Biso & 1.000 & $\mathrm{Al}$ \\
\hline P15 & 1.0000 & 0.33799 & 0.46073 & 0.55795 & Biso & 1.000 & $P$ \\
\hline P16 & 1.0000 & 0.56901 & 0.89594 & 0.56652 & Biso & 1.000 & $P$ \\
\hline P 17 & 1.0000 & 0.09588 & 0.66688 & 0.56973 & Biso & 1.000 & $P$ \\
\hline Al16 & 1.0000 & 0.10204 & 0.66455 & 0.77474 & Biso & 1.000 & Al \\
\hline Al17 & 1.0000 & 0.56032 & 0.88914 & 0.77558 & Biso & 1.000 & Al \\
\hline Al 18 & 1.0000 & 0.33063 & 0.43572 & 0.76519 & Biso & 1.000 & $\mathrm{Al}$ \\
\hline 01 & 1.0000 & 0.91707 & 0.10718 & 0.13401 & Biso & 1.000 & 0 \\
\hline
\end{tabular}




\begin{tabular}{|c|c|c|c|c|c|c|c|}
\hline $\mathrm{O} 2$ & 1.0000 & 0.90299 & 0.81099 & 0.13576 & Biso & 1.000 & 0 \\
\hline 03 & 1.0000 & 0.20257 & 0.09034 & 0.12298 & Biso & 1.000 & 0 \\
\hline 04 & 1.0000 & 0.08498 & 0.88083 & 0.86511 & Biso & 1.000 & 0 \\
\hline 05 & 1.0000 & 0.80839 & 0.90980 & 0.87344 & Biso & 1.000 & 0 \\
\hline 06 & 1.0000 & 0.10489 & 0.19142 & 0.87179 & Biso & 1.000 & 0 \\
\hline 07 & 1.0000 & 0.56810 & 0.45089 & 0.45215 & Biso & 1.000 & 0 \\
\hline 08 & 1.0000 & 0.57479 & 0.14990 & 0.44042 & Biso & 1.000 & 0 \\
\hline 09 & 1.0000 & 0.88044 & 0.42295 & 0.45867 & Biso & 1.000 & 0 \\
\hline 010 & 1.0000 & 0.75947 & 0.22795 & 0.21104 & Biso & 1.000 & 0 \\
\hline 011 & 1.0000 & 0.47672 & 0.24717 & 0.20941 & Biso & 1.000 & 0 \\
\hline 012 & 1.0000 & 0.78077 & 0.53076 & 0.21337 & Biso & 1.000 & 0 \\
\hline 013 & 1.0000 & 0.23683 & 0.76206 & 0.81057 & Biso & 1.000 & 0 \\
\hline 014 & 1.0000 & 0.22681 & 0.46941 & 0.79015 & Biso & 1.000 & 0 \\
\hline 015 & 1.0000 & 0.53168 & 0.75128 & 0.78354 & Biso & 1.000 & 0 \\
\hline 016 & 1.0000 & 0.44110 & 0.57757 & 0.55228 & Biso & 1.000 & 0 \\
\hline 017 & 1.0000 & 0.09346 & 0.55575 & 0.56933 & Biso & 1.000 & 0 \\
\hline 018 & 1.0000 & 0.44463 & 0.84724 & 0.54398 & Biso & 1.000 & 0 \\
\hline 019 & 1.0000 & 0.99105 & 0.31113 & 0.16455 & Biso & 1.000 & 0 \\
\hline $\mathrm{O} 20$ & 1.0000 & 0.69946 & 0.67758 & 0.16808 & Biso & 1.000 & 0 \\
\hline 021 & 1.0000 & 0.33935 & 0.02238 & 0.14644 & Biso & 1.000 & 0 \\
\hline 022 & 1.0000 & 0.31694 & 0.96943 & 0.82846 & Biso & 1.000 & 0 \\
\hline 023 & 1.0000 & 0.65065 & 0.67763 & 0.84775 & Biso & 1.000 & 0 \\
\hline 024 & 1.0000 & 0.02786 & 0.34535 & 0.84145 & Biso & 1.000 & 0 \\
\hline 025 & 1.0000 & 0.66899 & 0.65119 & 0.50311 & Biso & 1.000 & 0 \\
\hline 026 & 1.0000 & 0.34706 & 0.98932 & 0.51626 & Biso & 1.000 & 0 \\
\hline 027 & 1.0000 & 0.00450 & 0.34221 & 0.49491 & Biso & 1.000 & 0 \\
\hline 028 & 1.0000 & 0.00663 & 0.67332 & 0.84546 & Biso & 1.000 & 0 \\
\hline 029 & 1.0000 & 0.30539 & 0.31827 & 0.82648 & Biso & 1.000 & 0 \\
\hline 030 & 1.0000 & 0.67265 & 0.97695 & 0.84299 & Biso & 1.000 & 0 \\
\hline 031 & 1.0000 & 0.68324 & 0.02840 & 0.16401 & Biso & 1.000 & 0 \\
\hline 032 & 1.0000 & 0.35347 & 0.32156 & 0.15719 & Biso & 1.000 & 0 \\
\hline 033 & 1.0000 & 0.98217 & 0.66089 & 0.17239 & Biso & 1.000 & 0 \\
\hline 034 & 1.0000 & 0.34128 & 0.38526 & 0.48540 & Biso & 1.000 & 0 \\
\hline 035 & 1.0000 & 0.00249 & 0.65792 & 0.50841 & Biso & 1.000 & 0 \\
\hline 036 & 1.0000 & 0.64264 & 0.99507 & 0.50669 & Biso & 1.000 & 0 \\
\hline 037 & 1.0000 & 0.12220 & 0.24146 & 0.13232 & Biso & 1.000 & 0 \\
\hline 038 & 1.0000 & 0.76631 & 0.87815 & 0.14401 & Biso & 1.000 & 0 \\
\hline 039 & 1.0000 & 0.13463 & 0.88739 & 0.13742 & Biso & 1.000 & 0 \\
\hline 040 & 1.0000 & 0.23587 & 0.11859 & 0.85816 & Biso & 1.000 & 0 \\
\hline 041 & 1.0000 & 0.88005 & 0.74939 & 0.86784 & Biso & 1.000 & 0 \\
\hline 042 & 1.0000 & 0.87317 & 0.11335 & 0.86483 & Biso & 1.000 & 0 \\
\hline 043 & 1.0000 & 0.77478 & 0.55462 & 0.46688 & Biso & 1.000 & 0 \\
\hline O4 4 & 1.0000 & 0.40623 & 0.22138 & 0.47796 & Biso & 1.000 & 0 \\
\hline 045 & 1.0000 & 0.80379 & 0.21657 & 0.46836 & Biso & 1.000 & 0 \\
\hline 046 & 1.0000 & 0.91609 & 0.46210 & 0.20594 & Biso & 1.000 & 0 \\
\hline 047 & 1.0000 & 0.55466 & 0.09216 & 0.21664 & Biso & 1.000 & 0 \\
\hline 048 & 1.0000 & 0.54738 & 0.45180 & 0.20593 & Biso & 1.000 & 0 \\
\hline 049 & 1.0000 & 0.44353 & 0.89163 & 0.81605 & Biso & 1.000 & 0 \\
\hline 050 & 1.0000 & 0.08639 & 0.53259 & 0.78168 & Biso & 1.000 & 0 \\
\hline 051 & 1.0000 & 0.45970 & 0.54693 & 0.79589 & Biso & 1.000 & 0 \\
\hline 052 & 1.0000 & 0.60199 & 0.80671 & 0.55103 & Biso & 1.000 & 0 \\
\hline 053 & 1.0000 & 0.23535 & 0.47224 & 0.54157 & Biso & 1.000 & 0 \\
\hline 054 & 1.0000 & 0.20821 & 0.75823 & 0.53439 & Biso & 1.000 & 0 \\
\hline 055 & 1.0000 & 0.00111 & 0.24943 & 0.01072 & Biso & 1.000 & 0 \\
\hline 056 & 1.0000 & 0.75647 & 0.75564 & 0.01580 & Biso & 1.000 & 0 \\
\hline 057 & 1.0000 & 0.24351 & 0.98954 & 0.00095 & Biso & 1.000 & 0 \\
\hline 058 & 1.0000 & 0.68417 & 0.60601 & 0.34469 & Biso & 1.000 & 0 \\
\hline 059 & 1.0000 & 0.93192 & 0.32626 & 0.34149 & Biso & 1.000 & 0 \\
\hline 060 & 1.0000 & 0.33369 & 0.89164 & 0.68295 & Biso & 1.000 & 0 \\
\hline 061 & 1.0000 & 0.06952 & 0.38021 & 0.67918 & Biso & 1.000 & 0 \\
\hline 062 & 1.0000 & 0.61115 & 0.66170 & 0.68403 & Biso & 1.000 & 0 \\
\hline 063 & 1.0000 & 0.99889 & 0.74757 & 0.99444 & Biso & 1.000 & 0 \\
\hline 064 & 1.0000 & 0.26002 & 0.25088 & 0.98363 & Biso & 1.000 & 0 \\
\hline 065 & 1.0000 & 0.75519 & 0.00071 & 0.99450 & Biso & 1.000 & 0 \\
\hline 066 & 1.0000 & 0.68368 & 0.07199 & 0.32515 & Biso & 1.000 & 0 \\
\hline 067 & 1.0000 & 0.93331 & 0.59482 & 0.32911 & Biso & 1.000 & 0 \\
\hline 068 & 1.0000 & 0.40095 & 0.33286 & 0.31868 & Biso & 1.000 & 0 \\
\hline 069 & 1.0000 & 0.33113 & 0.40950 & 0.65083 & Biso & 1.000 & 0 \\
\hline 070 & 1.0000 & 0.59025 & 0.93430 & 0.66482 & Biso & 1.000 & 0 \\
\hline 071 & 1.0000 & 0.07648 & 0.69345 & 0.66572 & Biso & 1.000 & 0 \\
\hline 072 & 1.0000 & 0.36960 & 0.06313 & 0.33049 & Biso & 1.000 & 0 \\
\hline C1 & 1.0000 & 0.20438 & 0.00299 & 0.33996 & Biso & 1.000 & C \\
\hline H 1 & 1.0000 & 0.20677 & 0.99066 & 0.41120 & Biso & 1.000 & $\mathrm{H}$ \\
\hline H2 & 1.0000 & 0.19078 & 0.93649 & 0.29463 & Biso & 1.000 & $\mathrm{H}$ \\
\hline H3 & 1.0000 & 0.21545 & 0.08099 & 0.31450 & Biso & 1.000 & $\mathrm{H}$ \\
\hline $\mathrm{C} 2$ & 1.0000 & 0.02422 & 0.92723 & 0.34311 & Biso & 1.000 & C \\
\hline $\mathrm{H} 4$ & 1.0000 & 0.00140 & 0.85580 & 0.38671 & Biso & 1.000 & $\mathrm{H}$ \\
\hline H5 & 1.0000 & 0.00176 & 0.90892 & 0.27261 & Biso & 1.000 & $\mathrm{H}$ \\
\hline $\mathrm{C} 3$ & 1.0000 & 0.00769 & 0.00783 & 0.37625 & Biso & 1.000 & C \\
\hline 073 & 1.0000 & 0.00357 & 0.08380 & 0.40384 & & 1.000 & 0 \\
\hline
\end{tabular}


Zn 18

data_image

$\begin{array}{ll}\text {-celí_length_a } & 13.875 \\ \text {-cell_length_b } & 13.875 \\ \text {-cell_length_c } & 15.017 \\ \text {-cell_angle_alpha } & 90 \\ \text {-cell_angle_beta } & 90 \\ \text { _cell_angle_gamma } & 120\end{array}$

symmetry_space_group_name_H-M "P 1"

_symmetry_int_tables_number

loop

_symmetry_equiv_pos_as_xyz

' $\mathrm{x}, \mathrm{y}, \mathrm{z}$ '

loop

atom_site_label

-atom_site_occupancy

-atom_site_fract_x

-atom_site_fract_y

atom site fract $z$

_atom_site_thermal_displace_type

atom_site_B_iso_or_equiv

atom site type symbol

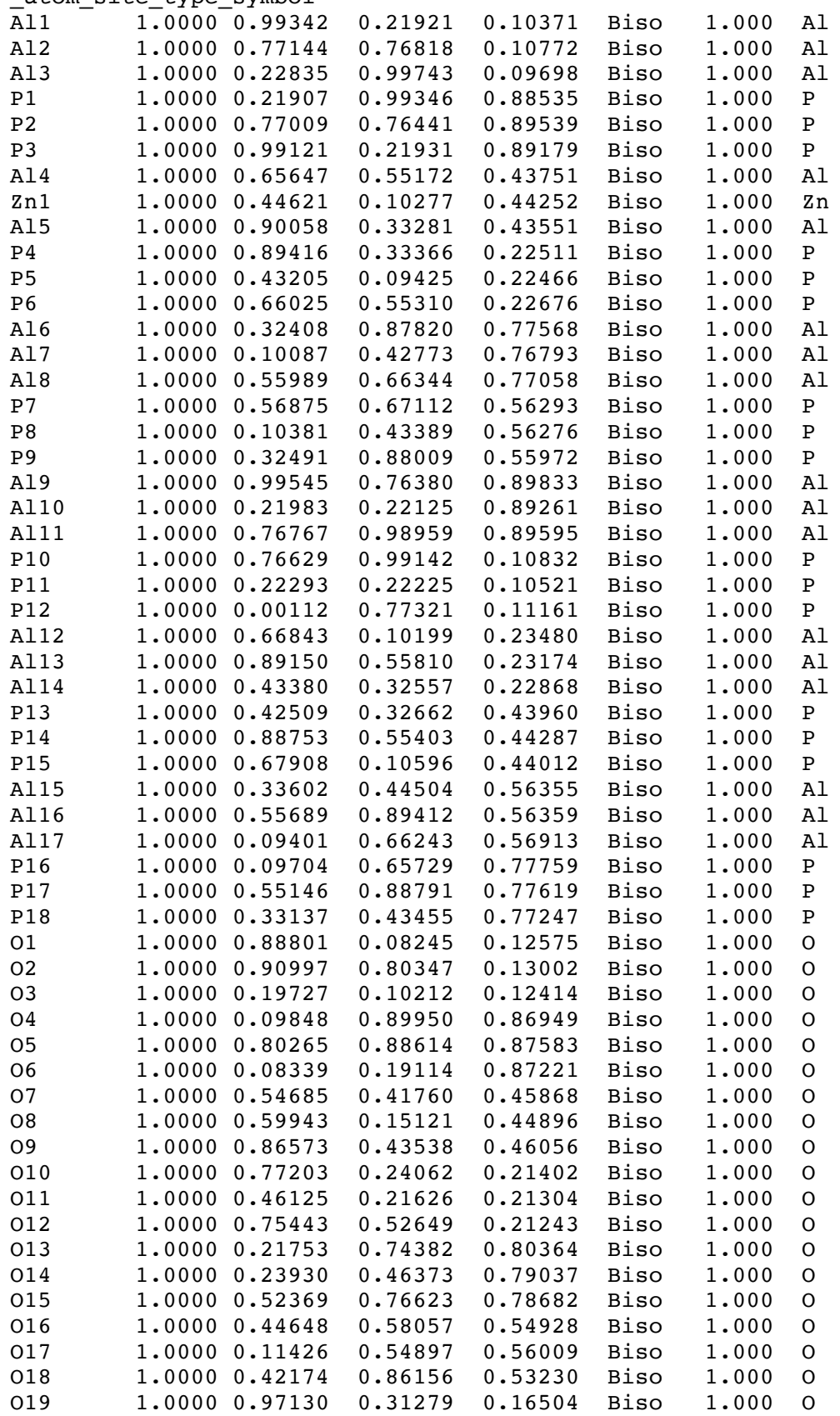




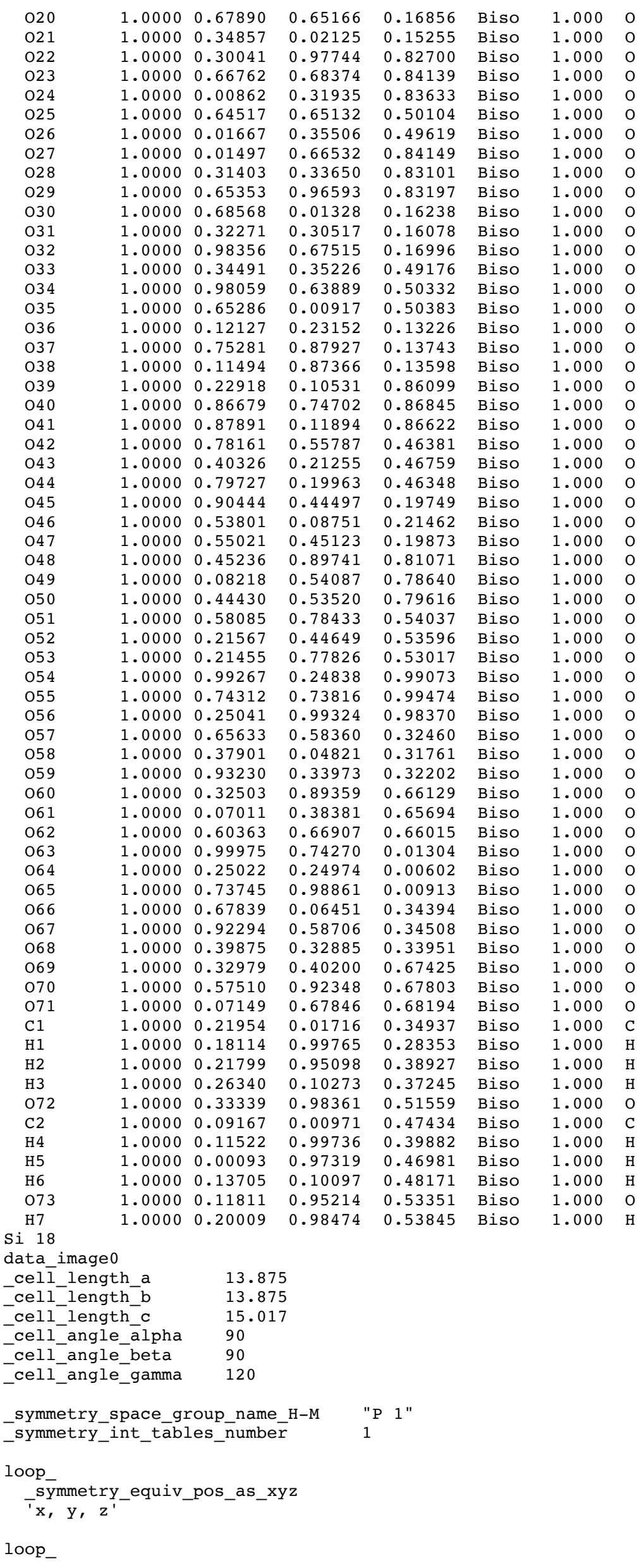




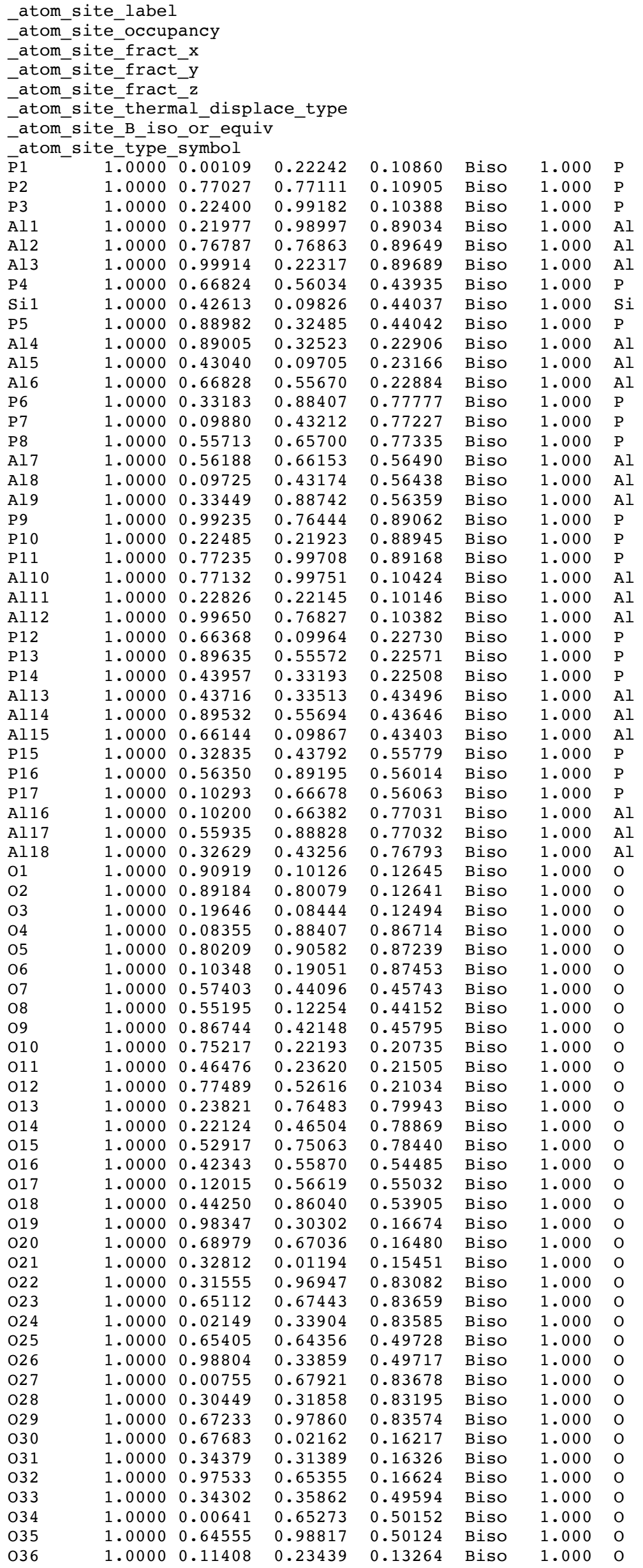




\begin{tabular}{|c|c|c|c|c|c|c|}
\hline 037 & 1.0000 & 0.75716 & 0.87028 & 0.13672 & Biso & 1.000 \\
\hline 038 & 1.0000 & 0.12493 & 0.88107 & 0.13586 & Biso & 1.000 \\
\hline 039 & 1.0000 & 0.23574 & 0.11881 & 0.86165 & Biso & 1.000 \\
\hline 040 & 1.0000 & 0.87894 & 0.75061 & 0.86653 & Biso & 1.000 \\
\hline 041 & 1.0000 & 0.87168 & 0.11014 & 0.86605 & Biso & 1.000 \\
\hline 042 & 1.0000 & 0.77980 & 0.56921 & 0.46328 & Biso & 1.000 \\
\hline 043 & 1.0000 & 0.41559 & 0.20647 & 0.46146 & Biso & 1.000 \\
\hline 044 & 1.0000 & 0.78693 & 0.21549 & 0.46666 & Biso & 1.000 \\
\hline 045 & 1.0000 & 0.90811 & 0.45513 & 0.20060 & Biso & 1.000 \\
\hline 046 & 1.0000 & 0.54803 & 0.08556 & 0.21334 & Biso & 1.000 \\
\hline 047 & 1.0000 & 0.54308 & 0.44109 & 0.19752 & Biso & 1.000 \\
\hline 048 & 1.0000 & 0.44364 & 0.89602 & 0.80528 & Biso & 1.000 \\
\hline 049 & 1.0000 & 0.08490 & 0.53290 & 0.79032 & Biso & 1.000 \\
\hline 050 & 1.0000 & 0.45405 & 0.54600 & 0.79749 & Biso & 1.000 \\
\hline 051 & 1.0000 & 0.57786 & 0.79128 & 0.54108 & Biso & 1.000 \\
\hline 052 & 1.0000 & 0.21797 & 0.43140 & 0.53371 & Biso & 1.000 \\
\hline 053 & 1.0000 & 0.20908 & 0.77113 & 0.53030 & Biso & 1.000 \\
\hline 054 & 1.0000 & 0.99954 & 0.25248 & 0.01021 & Biso & 1.000 \\
\hline 055 & 1.0000 & 0.74079 & 0.74299 & 0.01025 & Biso & 1.000 \\
\hline 056 & 1.0000 & 0.24433 & 0.98768 & 0.00416 & Biso & 1.000 \\
\hline 057 & 1.0000 & 0.66778 & 0.59110 & 0.34085 & Biso & 1.000 \\
\hline 058 & 1.0000 & 0.37291 & 0.05223 & 0.33819 & Biso & 1.000 \\
\hline 059 & 1.0000 & 0.91991 & 0.32386 & 0.34190 & Biso & 1.000 \\
\hline 060 & 1.0000 & 0.33104 & 0.90785 & 0.67827 & Biso & 1.000 \\
\hline 061 & 1.0000 & 0.06516 & 0.39080 & 0.67590 & Biso & 1.000 \\
\hline 062 & 1.0000 & 0.59395 & 0.65459 & 0.67696 & Biso & 1.000 \\
\hline 063 & 1.0000 & 0.99737 & 0.74164 & 0.99035 & Biso & 1.000 \\
\hline 064 & 1.0000 & 0.25705 & 0.24857 & 0.98793 & Biso & 1.000 \\
\hline 065 & 1.0000 & 0.74341 & 0.99555 & 0.99063 & Biso & 1.000 \\
\hline 066 & 1.0000 & 0.67779 & 0.06818 & 0.32261 & Biso & 1.000 \\
\hline 067 & 1.0000 & 0.92955 & 0.58911 & 0.32363 & Biso & 1.000 \\
\hline 068 & 1.0000 & 0.40652 & 0.33991 & 0.32139 & Biso & 1.000 \\
\hline 069 & 1.0000 & 0.32582 & 0.40083 & 0.65498 & Biso & 1.000 \\
\hline 070 & 1.0000 & 0.59031 & 0.92710 & 0.65858 & Biso & 1.000 \\
\hline 071 & 1.0000 & 0.07603 & 0.67797 & 0.65829 & Biso & 1.000 \\
\hline C1 & 1.0000 & 0.20247 & 0.01061 & 0.36124 & Biso & 1.000 \\
\hline H 1 & 1.0000 & 0.16942 & 0.99314 & 0.29346 & Biso & 1.000 \\
\hline H2 & 1.0000 & 0.20311 & 0.94469 & 0.39990 & Biso & 1.000 \\
\hline H3 & 1.0000 & 0.24545 & 0.09624 & 0.38421 & Biso & 1.000 \\
\hline 072 & 1.0000 & 0.34416 & 0.00208 & 0.51040 & Biso & 1.000 \\
\hline $\mathrm{C} 2$ & 1.0000 & 0.08113 & 0.00307 & 0.48810 & Biso & 1.000 \\
\hline H4 & 1.0000 & 0.09965 & 0.98792 & 0.41051 & Biso & 1.000 \\
\hline H5 & 1.0000 & 0.98974 & 0.95500 & 0.49028 & Biso & 1.000 \\
\hline H6 & 1.0000 & 0.11600 & 0.09399 & 0.48934 & Biso & 1.000 \\
\hline 073 & 1.0000 & 0.12554 & 0.96092 & 0.54618 & Biso & 1.000 \\
\hline H7 & 1.0000 & 0.20832 & 0.00186 & 0.54438 & Biso & 1.000 \\
\hline
\end{tabular}

Mg 18

data image 0

$\begin{array}{ll}\text { _cell_length_a } & 13.875 \\ \text {-cell_length_b } & 13.875 \\ \text { _cell_length_c } & 15.017 \\ \text {-cell_angle_alpha } & 90 \\ \text {-cell_angle_beta } & 90 \\ \text {-cell_angle_gamma } & 120\end{array}$

symmetry_space_group_name_H-M "P 1 "

_symmetry_int_tables_number $\bar{r} 1$

loop_

_symmetry_equiv_pos_as_xyz

$' \mathrm{x}, \mathrm{y}, \mathrm{z}$ '

loop

_atom_site_label

-atom_site_occupancy

_atom_site_fract_x

-atom_site_fract_y

atom site fract $z$

-atom_site_thermāl_displace_type

-atom_site_B_iso_or_equiv

atom site type symbol

\begin{tabular}{|c|c|c|c|c|c|c|}
\hline Al1 & 1.0000 & 0.99355 & 0.21957 & 0.10455 & Biso & 1.000 \\
\hline Al2 & 1.0000 & 0.77301 & 0.77007 & 0.10744 & Biso & 1.000 \\
\hline Al3 & 1.0000 & 0.22954 & 0.99845 & 0.09693 & Biso & 1.000 \\
\hline P1 & 1.0000 & 0.21974 & 0.99394 & 0.88507 & Biso & 1.000 \\
\hline P2 & 1.0000 & 0.77080 & 0.76556 & 0.89481 & Biso & 1.000 \\
\hline P3 & 1.0000 & 0.99126 & 0.21948 & 0.89225 & Biso & 1.000 \\
\hline Al4 & 1.0000 & 0.65783 & 0.55530 & 0.43674 & Biso & 1.000 \\
\hline Mg 1 & 1.0000 & 0.43972 & 0.09876 & 0.44187 & Biso & 1.000 \\
\hline Al5 & 1.0000 & 0.89812 & 0.33218 & 0.43621 & Biso & 1.000 \\
\hline
\end{tabular}




\begin{tabular}{|c|c|c|c|c|c|c|c|}
\hline $\mathrm{P} 4$ & 1.0000 & 0.89420 & 0.33385 & 0.22497 & Biso & 1.000 & $\mathrm{P}$ \\
\hline P5 & 1.0000 & 0.43201 & 0.09540 & 0.22550 & Biso & 1.000 & $\mathrm{P}$ \\
\hline P 6 & 1.0000 & 0.66145 & 0.55393 & 0.22619 & Biso & 1.000 & $\mathrm{P}$ \\
\hline Al6 & 1.0000 & 0.32411 & 0.87726 & 0.77671 & Biso & 1.000 & $\mathrm{Al}$ \\
\hline Al7 & 1.0000 & 0.10027 & 0.42736 & 0.76795 & Biso & 1.000 & Al \\
\hline A18 & 1.0000 & 0.56007 & 0.66282 & 0.77037 & Biso & 1.000 & $\mathrm{Al}$ \\
\hline P7 & 1.0000 & 0.56775 & 0.66940 & 0.56318 & Biso & 1.000 & $\mathrm{P}$ \\
\hline P8 & 1.0000 & 0.10220 & 0.43172 & 0.56297 & Biso & 1.000 & $\mathrm{P}$ \\
\hline P9 & 1.0000 & 0.32480 & 0.87938 & 0.56064 & Biso & 1.000 & $\mathrm{P}$ \\
\hline Al9 & 1.0000 & 0.99591 & 0.76426 & 0.89798 & Biso & 1.000 & $\mathrm{Al}$ \\
\hline Al10 & 1.0000 & 0.21976 & 0.22117 & 0.89248 & Biso & 1.000 & $\mathrm{Al}$ \\
\hline Al11 & 1.0000 & 0.76832 & 0.99003 & 0.89572 & Biso & 1.000 & $\mathrm{Al}$ \\
\hline P10 & 1.0000 & 0.76614 & 0.99182 & 0.10872 & Biso & 1.000 & $\mathrm{P}$ \\
\hline P 11 & 1.0000 & 0.22319 & 0.22246 & 0.10533 & Biso & 1.000 & $\mathrm{P}$ \\
\hline P12 & 1.0000 & 0.00230 & 0.77460 & 0.11120 & Biso & 1.000 & $P$ \\
\hline Al12 & 1.0000 & 0.66958 & 0.10320 & 0.23423 & Biso & 1.000 & $\mathrm{Al}$ \\
\hline Al13 & 1.0000 & 0.89302 & 0.55935 & 0.23211 & Biso & 1.000 & $\mathrm{Al}$ \\
\hline Al1 14 & 1.0000 & 0.43415 & 0.32798 & 0.22881 & Biso & 1.000 & $\mathrm{Al}$ \\
\hline P13 & 1.0000 & 0.42650 & 0.32999 & 0.43849 & Biso & 1.000 & $\mathrm{P}$ \\
\hline P 14 & 1.0000 & 0.88863 & 0.55579 & 0.44252 & Biso & 1.000 & $\mathrm{P}$ \\
\hline P15 & 1.0000 & 0.67881 & 0.10239 & 0.43969 & Biso & 1.000 & $P$ \\
\hline Al15 & 1.0000 & 0.33532 & 0.44381 & 0.56346 & Biso & 1.000 & $\mathrm{Al}$ \\
\hline Al16 & 1.0000 & 0.55871 & 0.89566 & 0.56411 & Biso & 1.000 & Al \\
\hline Al17 & 1.0000 & 0.09459 & 0.66154 & 0.56938 & Biso & 1.000 & Al \\
\hline P16 & 1.0000 & 0.09695 & 0.65716 & 0.77785 & Biso & 1.000 & $\mathrm{P}$ \\
\hline P 17 & 1.0000 & 0.55266 & 0.88933 & 0.77552 & Biso & 1.000 & $\mathrm{P}$ \\
\hline P18 & 1.0000 & 0.33145 & 0.43542 & 0.77318 & Biso & 1.000 & $\mathrm{P}$ \\
\hline 01 & 1.0000 & 0.88719 & 0.08354 & 0.12752 & Biso & 1.000 & 0 \\
\hline $\mathrm{O} 2$ & 1.0000 & 0.91195 & 0.80610 & 0.12924 & Biso & 1.000 & 0 \\
\hline 03 & 1.0000 & 0.19825 & 0.10271 & 0.12508 & Biso & 1.000 & 0 \\
\hline 04 & 1.0000 & 0.09928 & 0.89980 & 0.86902 & Biso & 1.000 & 0 \\
\hline 05 & 1.0000 & 0.80341 & 0.88701 & 0.87397 & Biso & 1.000 & 0 \\
\hline 06 & 1.0000 & 0.08332 & 0.19120 & 0.87237 & Biso & 1.000 & 0 \\
\hline 07 & 1.0000 & 0.54693 & 0.42265 & 0.45946 & Biso & 1.000 & 0 \\
\hline 08 & 1.0000 & 0.58903 & 0.13362 & 0.44813 & Biso & 1.000 & 0 \\
\hline 09 & 1.0000 & 0.86521 & 0.43652 & 0.45990 & Biso & 1.000 & 0 \\
\hline 010 & 1.0000 & 0.77233 & 0.24156 & 0.21057 & Biso & 1.000 & 0 \\
\hline 011 & 1.0000 & 0.46026 & 0.21730 & 0.21541 & Biso & 1.000 & 0 \\
\hline 012 & 1.0000 & 0.75543 & 0.52663 & 0.21385 & Biso & 1.000 & 0 \\
\hline 013 & 1.0000 & 0.21706 & 0.74332 & 0.80522 & Biso & 1.000 & 0 \\
\hline 014 & 1.0000 & 0.23875 & 0.46385 & 0.79032 & Biso & 1.000 & 0 \\
\hline 015 & 1.0000 & 0.52651 & 0.76792 & 0.78317 & Biso & 1.000 & 0 \\
\hline 016 & 1.0000 & 0.44633 & 0.57843 & 0.54643 & Biso & 1.000 & 0 \\
\hline 017 & 1.0000 & 0.11338 & 0.54716 & 0.56058 & Biso & 1.000 & 0 \\
\hline 018 & 1.0000 & 0.42421 & 0.86524 & 0.53251 & Biso & 1.000 & 0 \\
\hline 019 & 1.0000 & 0.97319 & 0.31426 & 0.16604 & Biso & 1.000 & 0 \\
\hline 020 & 1.0000 & 0.68130 & 0.65214 & 0.16708 & Biso & 1.000 & 0 \\
\hline 021 & 1.0000 & 0.35053 & 0.02333 & 0.15199 & Biso & 1.000 & 0 \\
\hline 022 & 1.0000 & 0.30136 & 0.97762 & 0.82729 & Biso & 1.000 & 0 \\
\hline 023 & 1.0000 & 0.66799 & 0.68418 & 0.84143 & Biso & 1.000 & 0 \\
\hline 024 & 1.0000 & 0.00893 & 0.32008 & 0.83753 & Biso & 1.000 & 0 \\
\hline 025 & 1.0000 & 0.64696 & 0.65511 & 0.50027 & Biso & 1.000 & 0 \\
\hline 026 & 1.0000 & 0.01450 & 0.35362 & 0.49641 & Biso & 1.000 & 0 \\
\hline 027 & 1.0000 & 0.01422 & 0.66501 & 0.84114 & Biso & 1.000 & 0 \\
\hline 028 & 1.0000 & 0.31373 & 0.33683 & 0.83121 & Biso & 1.000 & 0 \\
\hline 029 & 1.0000 & 0.65354 & 0.96640 & 0.83277 & Biso & 1.000 & 0 \\
\hline 030 & 1.0000 & 0.68383 & 0.01311 & 0.16095 & Biso & 1.000 & 0 \\
\hline 031 & 1.0000 & 0.32316 & 0.30632 & 0.16024 & Biso & 1.000 & 0 \\
\hline 032 & 1.0000 & 0.98368 & 0.67620 & 0.16955 & Biso & 1.000 & 0 \\
\hline 033 & 1.0000 & 0.34364 & 0.34901 & 0.49349 & Biso & 1.000 & 0 \\
\hline 034 & 1.0000 & 0.98120 & 0.63931 & 0.50403 & Biso & 1.000 & 0 \\
\hline 035 & 1.0000 & 0.65842 & 0.00487 & 0.50102 & Biso & 1.000 & 0 \\
\hline 036 & 1.0000 & 0.12128 & 0.23119 & 0.13246 & Biso & 1.000 & 0 \\
\hline 037 & 1.0000 & 0.75309 & 0.88002 & 0.13859 & Biso & 1.000 & 0 \\
\hline 038 & 1.0000 & 0.11654 & 0.87432 & 0.13589 & Biso & 1.000 & 0 \\
\hline 039 & 1.0000 & 0.22975 & 0.10565 & 0.86027 & Biso & 1.000 & 0 \\
\hline 040 & 1.0000 & 0.86729 & 0.74764 & 0.86830 & Biso & 1.000 & 0 \\
\hline 041 & 1.0000 & 0.87902 & 0.11956 & 0.86601 & Biso & 1.000 & 0 \\
\hline 042 & 1.0000 & 0.78302 & 0.56081 & 0.46218 & Biso & 1.000 & 0 \\
\hline 043 & 1.0000 & 0.41039 & 0.21687 & 0.46072 & Biso & 1.000 & 0 \\
\hline 044 & 1.0000 & 0.79272 & 0.20130 & 0.46655 & Biso & 1.000 & 0 \\
\hline 045 & 1.0000 & 0.90625 & 0.44626 & 0.19848 & Biso & 1.000 & 0 \\
\hline 046 & 1.0000 & 0.53865 & 0.08952 & 0.21728 & Biso & 1.000 & 0 \\
\hline 047 & 1.0000 & 0.55171 & 0.45209 & 0.19751 & Biso & 1.000 & 0 \\
\hline 048 & 1.0000 & 0.45234 & 0.89595 & 0.81109 & Biso & 1.000 & 0 \\
\hline 049 & 1.0000 & 0.08158 & 0.54053 & 0.78619 & Biso & 1.000 & 0 \\
\hline 050 & 1.0000 & 0.44358 & 0.53623 & 0.79843 & Biso & 1.000 & 0 \\
\hline 051 & 1.0000 & 0.57830 & 0.78265 & 0.54504 & Biso & 1.000 & 0 \\
\hline 052 & 1.0000 & 0.21378 & 0.44343 & 0.53620 & Biso & 1.000 & 0 \\
\hline 053 & 1.0000 & 0.21635 & 0.77579 & 0.53025 & Biso & 1.000 & 0 \\
\hline
\end{tabular}




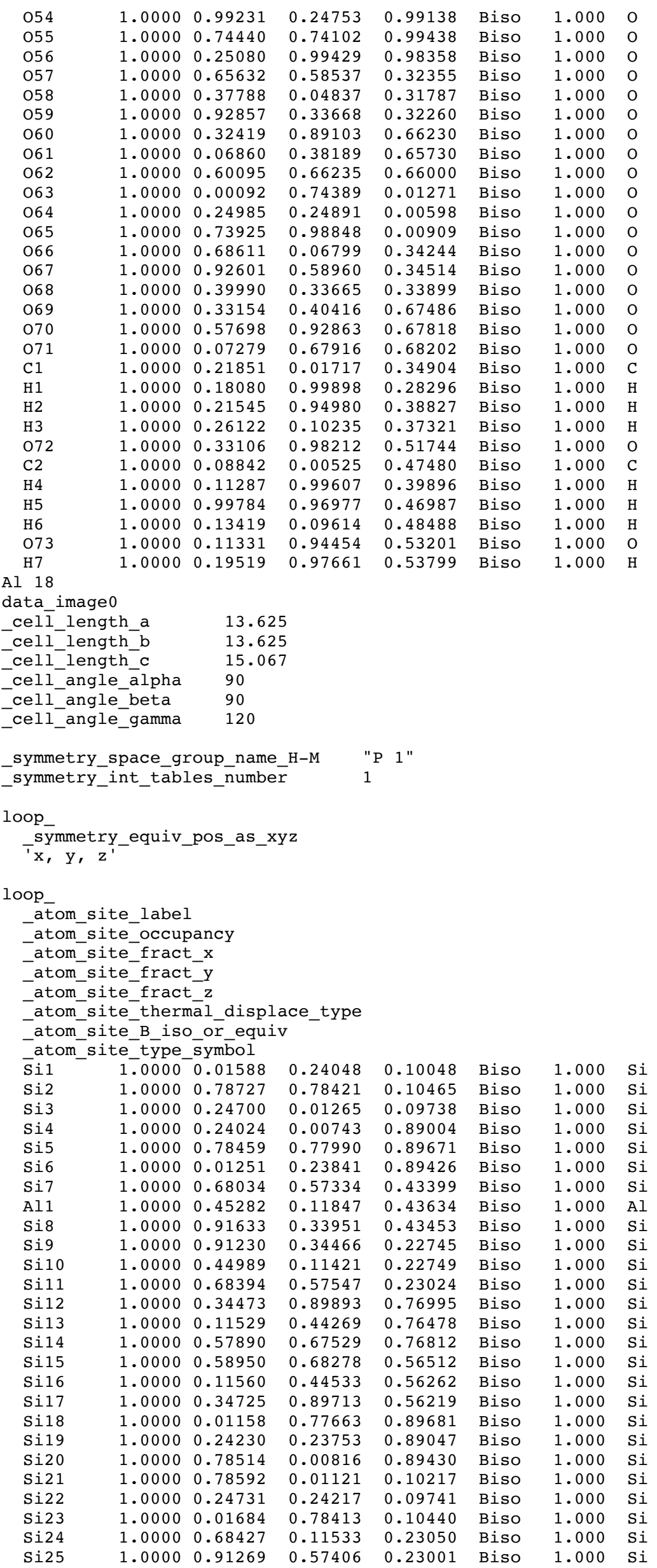




\begin{tabular}{|c|c|c|c|c|c|c|c|}
\hline Si26 & 1.0000 & 0.45102 & 0.34414 & 0.22750 & Biso & 1.000 & $\mathrm{Si}$ \\
\hline Si27 & 1.0000 & 0.44169 & 0.34380 & 0.43228 & Biso & 1.000 & $\mathrm{Si}$ \\
\hline Si28 & 1.0000 & 0.90807 & 0.56720 & 0.43687 & Biso & 1.000 & $\mathrm{Si}$ \\
\hline Si29 & 1.0000 & 0.68483 & 0.11653 & 0.43141 & Biso & 1.000 & \\
\hline $\mathrm{Si} 30$ & 1.0000 & 0.35173 & 0.45841 & 0.55975 & Biso & 1.000 & \\
\hline Si31 & 1.0000 & 0.57787 & 0.90678 & 0.56376 & Biso & 1.000 & \\
\hline $\mathrm{Si} 32$ & 1.0000 & 0.11025 & 0.67768 & 0.56562 & Biso & 1.000 & \\
\hline Si33 & 1.0000 & 0.11374 & 0.67462 & 0.76938 & Biso & 1.000 & \\
\hline Si34 & 1.0000 & 0.57634 & 0.90592 & 0.76794 & Biso & 1.000 & \\
\hline Si35 & 1.0000 & 0.34651 & 0.44712 & 0.76441 & Biso & 1.000 & \\
\hline 01 & 1.0000 & 0.91731 & 0.10974 & 0.11865 & Biso & 1.000 & \\
\hline $\mathrm{O} 2$ & 1.0000 & 0.91863 & 0.81687 & 0.12249 & Biso & 1.000 & \\
\hline 03 & 1.0000 & 0.21597 & 0.11166 & 0.11736 & Biso & 1.000 & \\
\hline 04 & 1.0000 & 0.10963 & 0.90649 & 0.87567 & Biso & 1.000 & \\
\hline 05 & 1.0000 & 0.81879 & 0.91059 & 0.87616 & Biso & 1.000 & \\
\hline 06 & 1.0000 & 0.11120 & 0.20633 & 0.87793 & Biso & 1.000 & \\
\hline 07 & 1.0000 & 0.57220 & 0.44796 & 0.44342 & Biso & 1.000 & \\
\hline 08 & 1.0000 & 0.59479 & 0.15895 & 0.43283 & Biso & 1.000 & \\
\hline 09 & 1.0000 & 0.89090 & 0.44279 & 0.45545 & Biso & 1.000 & \\
\hline 010 & 1.0000 & 0.78084 & 0.24731 & 0.21163 & Biso & 1.000 & \\
\hline 011 & 1.0000 & 0.48433 & 0.24604 & 0.21059 & Biso & 1.000 & \\
\hline 012 & 1.0000 & 0.78228 & 0.54250 & 0.21288 & Biso & 1.000 & \\
\hline 013 & 1.0000 & 0.24468 & 0.76927 & 0.79058 & Biso & 1.000 & \\
\hline 014 & 1.0000 & 0.24736 & 0.47899 & 0.78167 & Biso & 1.000 & \\
\hline 015 & 1.0000 & 0.54716 & 0.77502 & 0.77803 & Biso & 1.000 & \\
\hline 016 & 1.0000 & 0.45812 & 0.58643 & 0.54842 & Biso & 1.000 & 0 \\
\hline 017 & 1.0000 & 0.12367 & 0.56766 & 0.55322 & Biso & 1.000 & \\
\hline 018 & 1.0000 & 0.44220 & 0.85748 & 0.55064 & Biso & 1.000 & 0 \\
\hline 019 & 1.0000 & 0.99744 & 0.32598 & 0.16372 & Biso & 1.000 & 0 \\
\hline 020 & 1.0000 & 0.70153 & 0.67729 & 0.16498 & Biso & 1.000 & 0 \\
\hline 021 & 1.0000 & 0.35549 & 0.03236 & 0.15502 & Biso & 1.000 & 0 \\
\hline $\mathrm{O} 22$ & 1.0000 & 0.32639 & 0.98793 & 0.82910 & Biso & 1.000 & 0 \\
\hline 023 & 1.0000 & 0.67631 & 0.69257 & 0.83830 & Biso & 1.000 & 0 \\
\hline 024 & 1.0000 & 0.03216 & 0.34347 & 0.83224 & Biso & 1.000 & 0 \\
\hline 025 & 1.0000 & 0.67302 & 0.66340 & 0.49984 & Biso & 1.000 & 0 \\
\hline 026 & 1.0000 & 0.37090 & 0.00163 & 0.50148 & Biso & 1.000 & 0 \\
\hline 027 & 1.0000 & 0.02329 & 0.35645 & 0.49338 & Biso & 1.000 & 0 \\
\hline 028 & 1.0000 & 0.02904 & 0.68712 & 0.83798 & Biso & 1.000 & 0 \\
\hline 029 & 1.0000 & 0.32603 & 0.34143 & 0.82662 & Biso & 1.000 & 0 \\
\hline 030 & 1.0000 & 0.67877 & 0.98787 & 0.83380 & Biso & 1.000 & 0 \\
\hline 031 & 1.0000 & 0.69925 & 0.03328 & 0.16040 & Biso & 1.000 & 0 \\
\hline 032 & 1.0000 & 0.35343 & 0.32946 & 0.15789 & Biso & 1.000 & 0 \\
\hline 033 & 1.0000 & 0.99930 & 0.68236 & 0.17031 & Biso & 1.000 & 0 \\
\hline 034 & 1.0000 & 0.35828 & 0.37256 & 0.48989 & Biso & 1.000 & 0 \\
\hline 035 & 1.0000 & 0.00693 & 0.66471 & 0.50077 & Biso & 1.000 & 0 \\
\hline 036 & 1.0000 & 0.65365 & 0.01049 & 0.49748 & Biso & 1.000 & 0 \\
\hline 037 & 1.0000 & 0.13791 & 0.25326 & 0.12374 & Biso & 1.000 & 0 \\
\hline 038 & 1.0000 & 0.77415 & 0.89165 & 0.13296 & Biso & 1.000 & 0 \\
\hline 039 & 1.0000 & 0.13890 & 0.89305 & 0.12918 & Biso & 1.000 & 0 \\
\hline 040 & 1.0000 & 0.25125 & 0.12739 & 0.86300 & Biso & 1.000 & 0 \\
\hline 041 & 1.0000 & 0.89024 & 0.76275 & 0.87067 & Biso & 1.000 & 0 \\
\hline 042 & 1.0000 & 0.89200 & 0.12991 & 0.86789 & Biso & 1.000 & 0 \\
\hline 043 & 1.0000 & 0.79346 & 0.56860 & 0.46038 & Biso & 1.000 & 0 \\
\hline 044 & 1.0000 & 0.43007 & 0.22781 & 0.46486 & Biso & 1.000 & 0 \\
\hline 045 & 1.0000 & 0.80924 & 0.21938 & 0.46179 & Biso & 1.000 & 0 \\
\hline 046 & 1.0000 & 0.92670 & 0.46715 & 0.20265 & Biso & 1.000 & 0 \\
\hline 047 & 1.0000 & 0.56091 & 0.10211 & 0.21390 & Biso & 1.000 & 0 \\
\hline 048 & 1.0000 & 0.56219 & 0.46639 & 0.20893 & Biso & 1.000 & 0 \\
\hline 049 & 1.0000 & 0.46530 & 0.91188 & 0.79786 & Biso & 1.000 & 0 \\
\hline 050 & 1.0000 & 0.09912 & 0.55058 & 0.78289 & Biso & 1.000 & 0 \\
\hline 051 & 1.0000 & 0.46731 & 0.55527 & 0.79105 & Biso & 1.000 & 0 \\
\hline 052 & 1.0000 & 0.60522 & 0.80594 & 0.54302 & Biso & 1.000 & 0 \\
\hline 053 & 1.0000 & 0.23813 & 0.46297 & 0.53779 & Biso & 1.000 & 0 \\
\hline 054 & 1.0000 & 0.22401 & 0.78965 & 0.53381 & Biso & 1.000 & 0 \\
\hline 055 & 1.0000 & 0.01246 & 0.27419 & 0.99740 & Biso & 1.000 & 0 \\
\hline 056 & 1.0000 & 0.75364 & 0.75110 & 0.00125 & Biso & 1.000 & 0 \\
\hline 057 & 1.0000 & 0.27524 & 0.00925 & 0.99357 & Biso & 1.000 & 0 \\
\hline 058 & 1.0000 & 0.69245 & 0.61928 & 0.33215 & Biso & 1.000 & 0 \\
\hline 059 & 1.0000 & 0.39478 & 0.07232 & 0.32621 & Biso & 1.000 & 0 \\
\hline 060 & 1.0000 & 0.94883 & 0.34374 & 0.33006 & Biso & 1.000 & 0 \\
\hline 061 & 1.0000 & 0.34223 & 0.92774 & 0.66626 & Biso & 1.000 & 0 \\
\hline 062 & 1.0000 & 0.07882 & 0.39729 & 0.66333 & Biso & 1.000 & 0 \\
\hline 063 & 1.0000 & 0.62420 & 0.67598 & 0.66778 & Biso & 1.000 & 0 \\
\hline 064 & 1.0000 & 0.01426 & 0.74712 & 0.00156 & Biso & 1.000 & 0 \\
\hline 065 & 1.0000 & 0.28077 & 0.27283 & 0.99340 & Biso & 1.000 & 0 \\
\hline 066 & 1.0000 & 0.75207 & 0.00660 & 0.99823 & Biso & 1.000 & 0 \\
\hline 067 & 1.0000 & 0.69693 & 0.07757 & 0.33028 & Biso & 1.000 & 0 \\
\hline 068 & 1.0000 & 0.94644 & 0.60767 & 0.33440 & Biso & 1.000 & 0 \\
\hline 069 & 1.0000 & 0.40421 & 0.33758 & 0.32761 & Biso & 1.000 & 0 \\
\hline 070 & 1.0000 & 0.34700 & 0.41315 & 0.66089 & Biso & 1.000 & 0 \\
\hline
\end{tabular}




$\begin{array}{llllllll}\text { O71 } & 1.0000 & 0.61283 & 0.94980 & 0.66635 & \text { Biso } & 1.000 & \text { O } \\ \text { O72 } & 1.0000 & 0.07907 & 0.68894 & 0.66813 & \text { Biso } & 1.000 & \text { O } \\ \text { C1 } & 1.0000 & 0.21850 & 0.99109 & 0.34177 & \text { Biso } & 1.000 & \mathrm{C} \\ \text { H1 } & 1.0000 & 0.23266 & 0.97045 & 0.40882 & \text { Biso } & 1.000 & \mathrm{H} \\ \text { H2 } & 1.0000 & 0.22184 & 0.07136 & 0.32889 & \text { Biso } & 1.000 & \mathrm{H} \\ \text { H3 } & 1.0000 & 0.20828 & 0.93483 & 0.28685 & \text { Biso } & 1.000 & \mathrm{H} \\ \text { C2 } & 1.0000 & 0.00045 & 0.88623 & 0.38661 & \text { Biso } & 1.000 & \mathrm{C} \\ \text { H4 } & 1.0000 & 0.09686 & 0.93362 & 0.35882 & \text { Biso } & 1.000 & \mathrm{H} \\ \text { H5 } & 1.0000 & 0.96031 & 0.81053 & 0.34388 & \text { Biso } & 1.000 & \mathrm{H} \\ \text { H6 } & 1.0000 & 0.97358 & 0.94818 & 0.37175 & \text { Biso } & 1.000 & \mathrm{H} \\ \text { O73 } & 1.0000 & 0.99802 & 0.86719 & 0.47539 & \text { Biso } & 1.000 & \text { O } \\ \text { H7 } & 1.0000 & 0.00019 & 0.79682 & 0.48730 & \text { Biso } & 1.000 & \mathrm{H}\end{array}$

$\mathrm{Ge} 18$

data_image 0

celìllength_a $\quad 13.875$

cell_length_b 13.875

_cell_length_c 15.017

cell_angle_ālpha 90

cell_angle_beta 90

_cell_angle_gamma 120

symmetry_space_group_name_H-M "P 1"

_symmetry_int_tables_number 1

loop_

_symmetry_equiv_pos_as_xyz

' $\mathrm{x}, \mathrm{y}, \mathrm{z}$ '

loop

atom_site label

-atom_site_occupancy

-atom_site_fract_x

atom site fract $y$

-atom_site_fract_z

_atom_site_thermal_displace_type

atom_site_B_iso_or_equiv

-atom_site_tȳpe_symbol

P1 $1.0000 \quad 0.00393 \quad 0.22565$

$\begin{array}{llll}1.0000 & 0.77341 & 0.77526\end{array}$

P3 1.00000 .22583

Al1 $1.0000 \quad 0.21763$

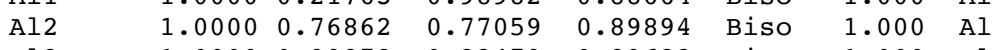

$\begin{array}{lllll}0.77526 & 0.11176 & \text { Biso } & 1.000 & \mathrm{P} \\ 0.99534 & 0.10061 & \text { Biso } & 1.000 & \mathrm{P}\end{array}$

0.10851

Biso

$1.000 \quad P$

0.989820 .88664 Biso $1.000 \mathrm{Al}$

$\begin{array}{lllll}1.0000 & 0.99878 & 0.22479 & 0.89633 & \text { Biso }\end{array}$

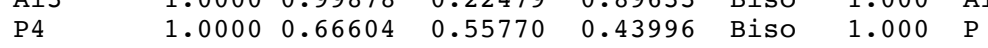

$\begin{array}{llllllll}\mathrm{Ge} 1 & 1.0000 & 0.42451 & 0.10164 & 0.44228 & \text { Biso } & 1.000 & \mathrm{Ge}\end{array}$

$\begin{array}{llllllll}\mathrm{P} 5 & 1.0000 & 0.89598 & 0.32755 & 0.43992 & \text { Biso } & 1.000 & \mathrm{P}\end{array}$

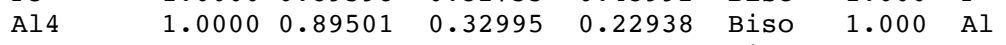

$\begin{array}{llllllll}\text { Al5 } & 1.0000 & 0.43167 & 0.09907 & 0.22807 & \text { Biso } & 1.000 & \text { Al }\end{array}$

Al6 $\quad 1.0000 \quad 0.67068 \quad 0.55892 \quad 0.22920$ Biso 1.000 Al

$\begin{array}{llllllll}\mathrm{P} 6 & 1.0000 & 0.33096 & 0.88062 & 0.78136 & \text { Biso } & 1.000 & \mathrm{P}\end{array}$

$\begin{array}{llllllll}\text { P7 } & 1.0000 & 0.09935 & 0.43243 & 0.77216 & \text { Biso } & 1.000 & \text { P }\end{array}$

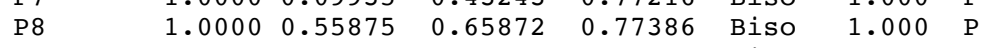

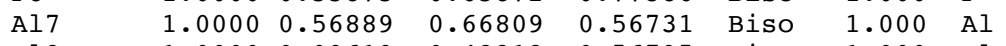

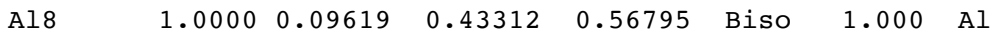

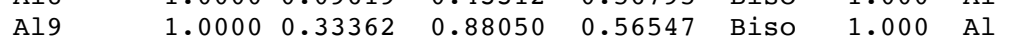

$\begin{array}{llllllll}\text { P9 } & 1.0000 & 0.99120 & 0.76387 & 0.89174 & \text { Biso } & 1.000 & \mathrm{P}\end{array}$

$\begin{array}{llllllll}\text { P10 } & 1.0000 & 0.22384 & 0.22004 & 0.88569 & \text { Biso } & 1.000 & \text { P }\end{array}$

$\begin{array}{llllllll}\text { P11 } & 1.0000 & 0.77377 & 0.99881 & 0.89293 & \text { Biso } & 1.000 & \text { P }\end{array}$

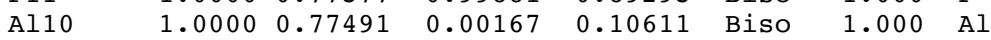

$\begin{array}{llllllll}\text { Al11 } & 1.0000 & 0.23108 & 0.22522 & 0.09793 & \text { Biso } & 1.000 & \text { Al }\end{array}$

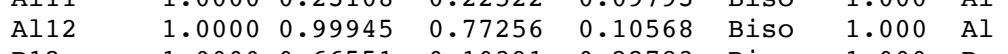

$\begin{array}{llllllll}\text { P12 } & 1.0000 & 0.66551 & 0.10391 & 0.22783 & \text { Biso } & 1.000 & \text { P }\end{array}$

$\begin{array}{llllllll}\mathrm{P} 13 & 1.0000 & 0.90018 & 0.56014 & 0.22768 & \text { Biso } & 1.000 & \mathrm{P}\end{array}$

$\begin{array}{llllllll}\text { P14 } & 1.0000 & 0.44193 & 0.33645 & 0.22254 & \text { Biso } & 1.000 & \text { P }\end{array}$

Al13 $\quad 1.0000 \quad 0.43075 \quad 0.34053 \quad 0.43165$ Biso 1.000 A]

$\begin{array}{llllllll}\text { Al14 } & 1.0000 & 0.89565 & 0.55737 & 0.43833 & \text { Biso } & 1.000 & \text { Al }\end{array}$

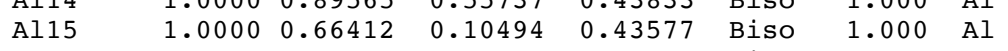

$\begin{array}{llllllll}\text { P15 } & 1.0000 & 0.33125 & 0.45083 & 0.55694 & \text { Biso } & 1.000 & \text { P }\end{array}$

$\begin{array}{llllllll}\text { P16 } & 1.0000 & 0.56540 & 0.89569 & 0.56218 & \text { Biso } & 1.000 & \mathrm{P}\end{array}$

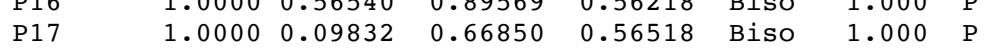

$\begin{array}{lllllll}\text { Al16 } & 1.0000 & 0.10058 & 0.66525 & 0.77218 & \text { Biso } & 1.000\end{array}$

$\begin{array}{llllllll}\text { Al17 } & 1.0000 & 0.55787 & 0.88871 & 0.77267 & \text { Biso } & 1.000 & \mathrm{Al}\end{array}$

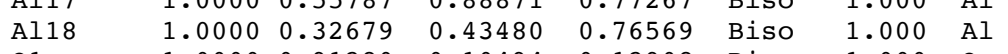

$01 \quad 1.0000 \quad 0.91280 \quad 0.10494 \quad 0.12908$ Biso $1.000 \quad 0$

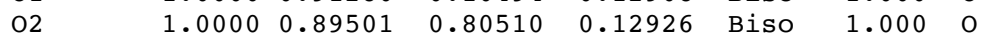

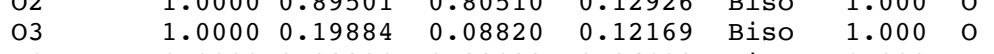

$\begin{array}{llllllll}04 & 1.0000 & 0.08204 & 0.88199 & 0.86403 & \text { Biso } & 1.000 & 0\end{array}$

$05 \quad 1.0000 \quad 0.80508 \quad 0.90845 \quad 0.87446$ Biso $1.000 \quad 0$

$\begin{array}{llllllll}06 & 1.0000 & 0.10262 & 0.19223 & 0.87171 & \text { Biso } & 1.000 & 0 \\ 07 & 1.0000 & 0.56999 & 0.43902 & 0.45774 & \text { Biso } & 1.000 & 0\end{array}$ 


\begin{tabular}{|c|c|c|c|c|c|c|c|}
\hline 08 & 1.0000 & 0.56642 & 0.14608 & 0.44790 & Biso & 1.000 & 0 \\
\hline 09 & 1.0000 & 0.87267 & 0.42336 & 0.45881 & Biso & 1.000 & $\mathrm{O}$ \\
\hline 010 & 1.0000 & 0.75686 & 0.22572 & 0.21041 & Biso & 1.000 & $\mathrm{O}$ \\
\hline 011 & 1.0000 & 0.46410 & 0.23831 & 0.21854 & Biso & 1.000 & 0 \\
\hline 012 & 1.0000 & 0.77893 & 0.53067 & 0.21155 & Biso & 1.000 & 0 \\
\hline 013 & 1.0000 & 0.23582 & 0.76349 & 0.80667 & Biso & 1.000 & 0 \\
\hline 014 & 1.0000 & 0.22239 & 0.46777 & 0.78945 & Biso & 1.000 & 0 \\
\hline 015 & 1.0000 & 0.52806 & 0.75073 & 0.78208 & Biso & 1.000 & 0 \\
\hline 016 & 1.0000 & 0.42864 & 0.57108 & 0.54897 & Biso & 1.000 & $\mathrm{O}$ \\
\hline 017 & 1.0000 & 0.10519 & 0.56189 & 0.56165 & Biso & 1.000 & 0 \\
\hline 018 & 1.0000 & 0.44353 & 0.85763 & 0.53700 & Biso & 1.000 & $\mathrm{O}$ \\
\hline 019 & 1.0000 & 0.98733 & 0.30783 & 0.16544 & Biso & 1.000 & 0 \\
\hline 020 & 1.0000 & 0.69302 & 0.67465 & 0.16768 & Biso & 1.000 & 0 \\
\hline 021 & 1.0000 & 0.33297 & 0.01775 & 0.14747 & Biso & 1.000 & O \\
\hline 022 & 1.0000 & 0.31446 & 0.97021 & 0.82751 & Biso & 1.000 & 0 \\
\hline 023 & 1.0000 & 0.64971 & 0.67730 & 0.84085 & Biso & 1.000 & 0 \\
\hline $\mathrm{O} 24$ & 1.0000 & 0.02288 & 0.34376 & 0.83913 & Biso & 1.000 & 0 \\
\hline 025 & 1.0000 & 0.65498 & 0.64286 & 0.49807 & Biso & 1.000 & $\mathrm{O}$ \\
\hline 026 & 1.0000 & 0.99349 & 0.33994 & 0.49669 & Biso & 1.000 & 0 \\
\hline 027 & 1.0000 & 0.00474 & 0.67549 & 0.84102 & Biso & 1.000 & $\mathrm{O}$ \\
\hline 028 & 1.0000 & 0.30340 & 0.31835 & 0.82721 & Biso & 1.000 & $\mathrm{O}$ \\
\hline 029 & 1.0000 & 0.67169 & 0.97694 & 0.83830 & Biso & 1.000 & $\mathrm{O}$ \\
\hline 030 & 1.0000 & 0.68049 & 0.02578 & 0.16414 & Biso & 1.000 & 0 \\
\hline 031 & 1.0000 & 0.34862 & 0.31793 & 0.15772 & Biso & 1.000 & 0 \\
\hline 032 & 1.0000 & 0.97970 & 0.65893 & 0.16914 & Biso & 1.000 & 0 \\
\hline 033 & 1.0000 & 0.34298 & 0.37488 & 0.48977 & Biso & 1.000 & 0 \\
\hline 034 & 1.0000 & 0.00307 & 0.65628 & 0.50516 & Biso & 1.000 & $\mathrm{O}$ \\
\hline 035 & 1.0000 & 0.64505 & 0.99429 & 0.50420 & Biso & 1.000 & 0 \\
\hline 036 & 1.0000 & 0.11793 & 0.23908 & 0.13095 & Biso & 1.000 & $\mathrm{O}$ \\
\hline 037 & 1.0000 & 0.76011 & 0.87437 & 0.13917 & Biso & 1.000 & 0 \\
\hline 038 & 1.0000 & 0.12866 & 0.88552 & 0.13661 & Biso & 1.000 & $\mathrm{O}$ \\
\hline 039 & 1.0000 & 0.23306 & 0.11850 & 0.85823 & Biso & 1.000 & 0 \\
\hline 040 & 1.0000 & 0.87736 & 0.74929 & 0.86803 & Biso & 1.000 & 0 \\
\hline 041 & 1.0000 & 0.87109 & 0.11216 & 0.86494 & Biso & 1.000 & 0 \\
\hline 042 & 1.0000 & 0.77627 & 0.56340 & 0.46340 & Biso & 1.000 & 0 \\
\hline 043 & 1.0000 & 0.39160 & 0.20658 & 0.46083 & Biso & 1.000 & $\mathrm{O}$ \\
\hline 044 & 1.0000 & 0.79411 & 0.21699 & 0.46470 & Biso & 1.000 & 0 \\
\hline 045 & 1.0000 & 0.91224 & 0.45988 & 0.20183 & Biso & 1.000 & 0 \\
\hline 046 & 1.0000 & 0.55210 & 0.09302 & 0.20886 & Biso & 1.000 & $\mathrm{O}$ \\
\hline 047 & 1.0000 & 0.54783 & 0.44298 & 0.19399 & Biso & 1.000 & 0 \\
\hline 048 & 1.0000 & 0.44224 & 0.89390 & 0.81258 & Biso & 1.000 & 0 \\
\hline 049 & 1.0000 & 0.08395 & 0.53333 & 0.78336 & Biso & 1.000 & 0 \\
\hline 050 & 1.0000 & 0.45566 & 0.54663 & 0.79557 & Biso & 1.000 & 0 \\
\hline 051 & 1.0000 & 0.58905 & 0.80032 & 0.54538 & Biso & 1.000 & 0 \\
\hline 052 & 1.0000 & 0.22380 & 0.45112 & 0.53518 & Biso & 1.000 & $\mathrm{O}$ \\
\hline 053 & 1.0000 & 0.20832 & 0.76500 & 0.53055 & Biso & 1.000 & 0 \\
\hline 054 & 1.0000 & 0.99923 & 0.25224 & 0.00981 & Biso & 1.000 & 0 \\
\hline 055 & 1.0000 & 0.74387 & 0.74682 & 0.01303 & Biso & 1.000 & 0 \\
\hline 056 & 1.0000 & 0.24079 & 0.98723 & 0.00059 & Biso & 1.000 & 0 \\
\hline 057 & 1.0000 & 0.66605 & 0.58931 & 0.34161 & Biso & 1.000 & 0 \\
\hline 058 & 1.0000 & 0.37053 & 0.04329 & 0.33209 & Biso & 1.000 & 0 \\
\hline 059 & 1.0000 & 0.92758 & 0.32931 & 0.34151 & Biso & 1.000 & 0 \\
\hline 060 & 1.0000 & 0.33230 & 0.89632 & 0.68055 & Biso & 1.000 & 0 \\
\hline 061 & 1.0000 & 0.06554 & 0.38354 & 0.67761 & Biso & 1.000 & $\mathrm{O}$ \\
\hline 062 & 1.0000 & 0.60127 & 0.65838 & 0.67901 & Biso & 1.000 & 0 \\
\hline 063 & 1.0000 & 0.99867 & 0.74620 & 0.99212 & Biso & 1.000 & 0 \\
\hline 064 & 1.0000 & 0.25737 & 0.25031 & 0.98390 & Biso & 1.000 & $\mathrm{O}$ \\
\hline 065 & 1.0000 & 0.74745 & 0.99958 & 0.99229 & Biso & 1.000 & $\mathrm{O}$ \\
\hline 066 & 1.0000 & 0.67187 & 0.06942 & 0.32398 & Biso & 1.000 & 0 \\
\hline 067 & 1.0000 & 0.93224 & 0.59227 & 0.32599 & Biso & 1.000 & 0 \\
\hline 068 & 1.0000 & 0.40803 & 0.35001 & 0.31709 & Biso & 1.000 & 0 \\
\hline 069 & 1.0000 & 0.32629 & 0.40612 & 0.65197 & Biso & 1.000 & 0 \\
\hline 070 & 1.0000 & 0.58582 & 0.93073 & 0.66104 & Biso & 1.000 & 0 \\
\hline 071 & 1.0000 & 0.07688 & 0.69033 & 0.66185 & Biso & 1.000 & 0 \\
\hline $\mathrm{C} 1$ & 1.0000 & 0.19760 & 0.98827 & 0.35742 & Biso & 1.000 & $\mathrm{C}$ \\
\hline $\mathrm{H} 1$ & 1.0000 & 0.16469 & 0.96416 & 0.28997 & Biso & 1.000 & $\mathrm{H}$ \\
\hline $\mathrm{H} 2$ & 1.0000 & 0.20581 & 0.92852 & 0.39886 & Biso & 1.000 & $\mathrm{H}$ \\
\hline H3 & 1.0000 & 0.23273 & 0.07456 & 0.37779 & Biso & 1.000 & $\mathrm{H}$ \\
\hline 072 & 1.0000 & 0.33738 & 0.99609 & 0.51838 & Biso & 1.000 & 0 \\
\hline $\mathrm{C} 2$ & 1.0000 & 0.06706 & 0.97062 & 0.48094 & Biso & 1.000 & $\mathrm{C}$ \\
\hline $\mathrm{H} 4$ & 1.0000 & 0.09165 & 0.95655 & 0.40492 & Biso & 1.000 & $\mathrm{H}$ \\
\hline H5 & 1.0000 & 0.97619 & 0.91585 & 0.48064 & Biso & 1.000 & $\mathrm{H}$ \\
\hline H6 & 1.0000 & 0.09423 & 0.06008 & 0.47995 & Biso & 1.000 & $\mathrm{H}$ \\
\hline 073 & 1.0000 & 0.11496 & 0.93687 & 0.54286 & Biso & 1.000 & 0 \\
\hline H7 & 1.0000 & 0.19786 & 0.98305 & 0.54268 & Biso & 1.000 & $\mathrm{H}$ \\
\hline
\end{tabular}

Ga 18

data image 0

$\begin{array}{ll}\text {-celi__length_a } & 13.625 \\ \text { cell_length b } & 13.625\end{array}$

_cell_length_c 15.067 


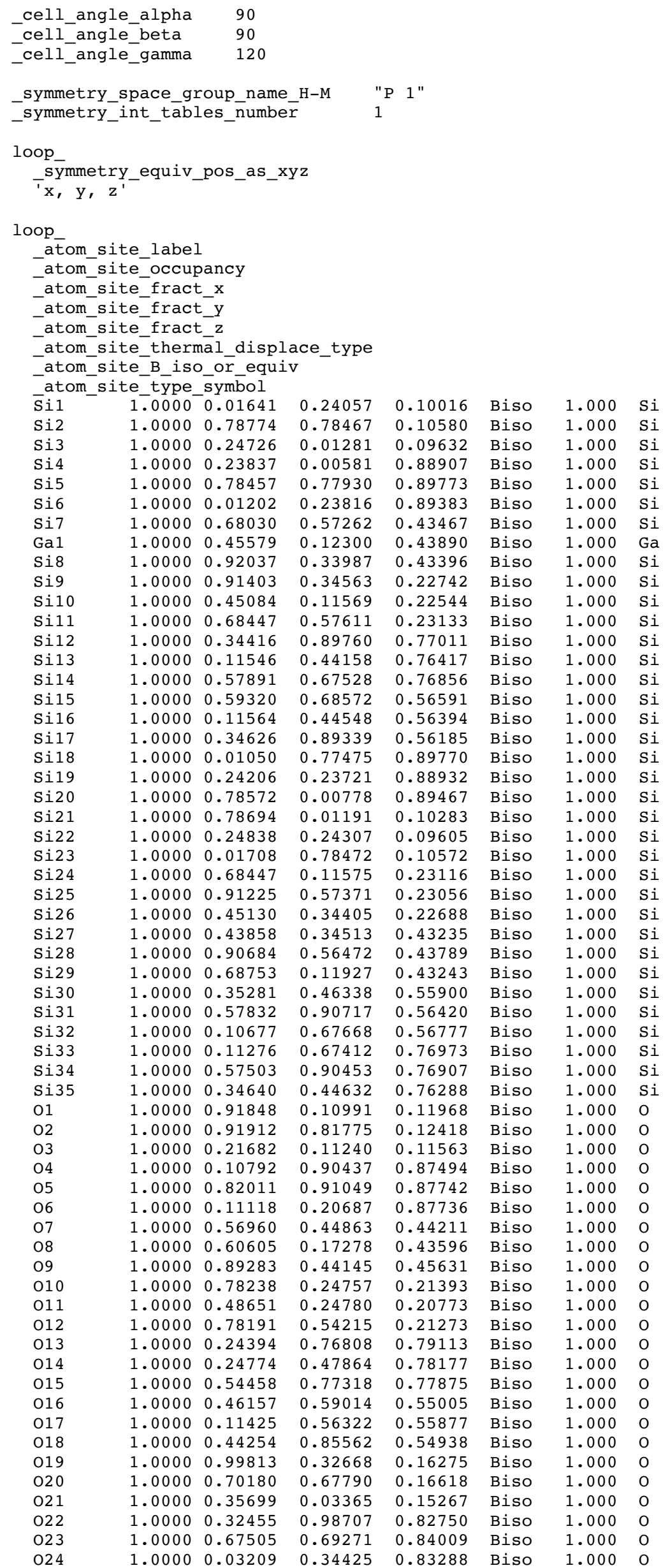




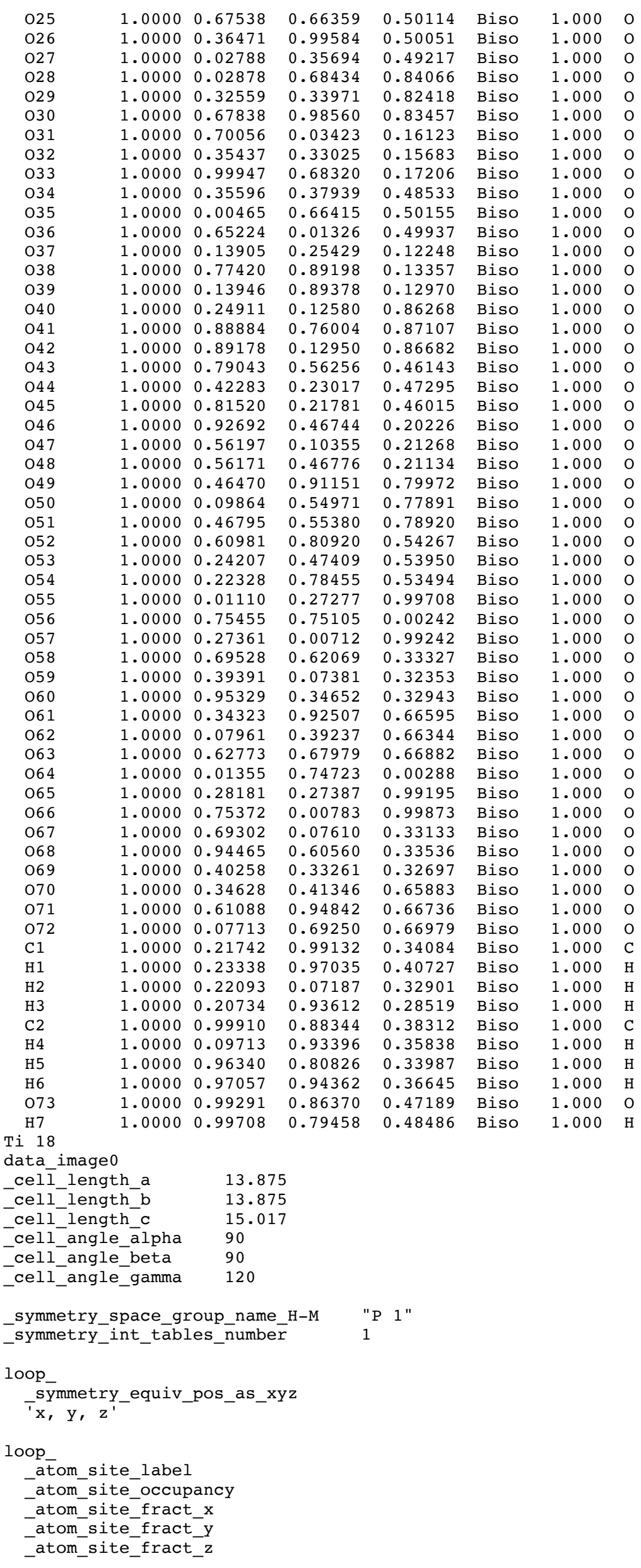




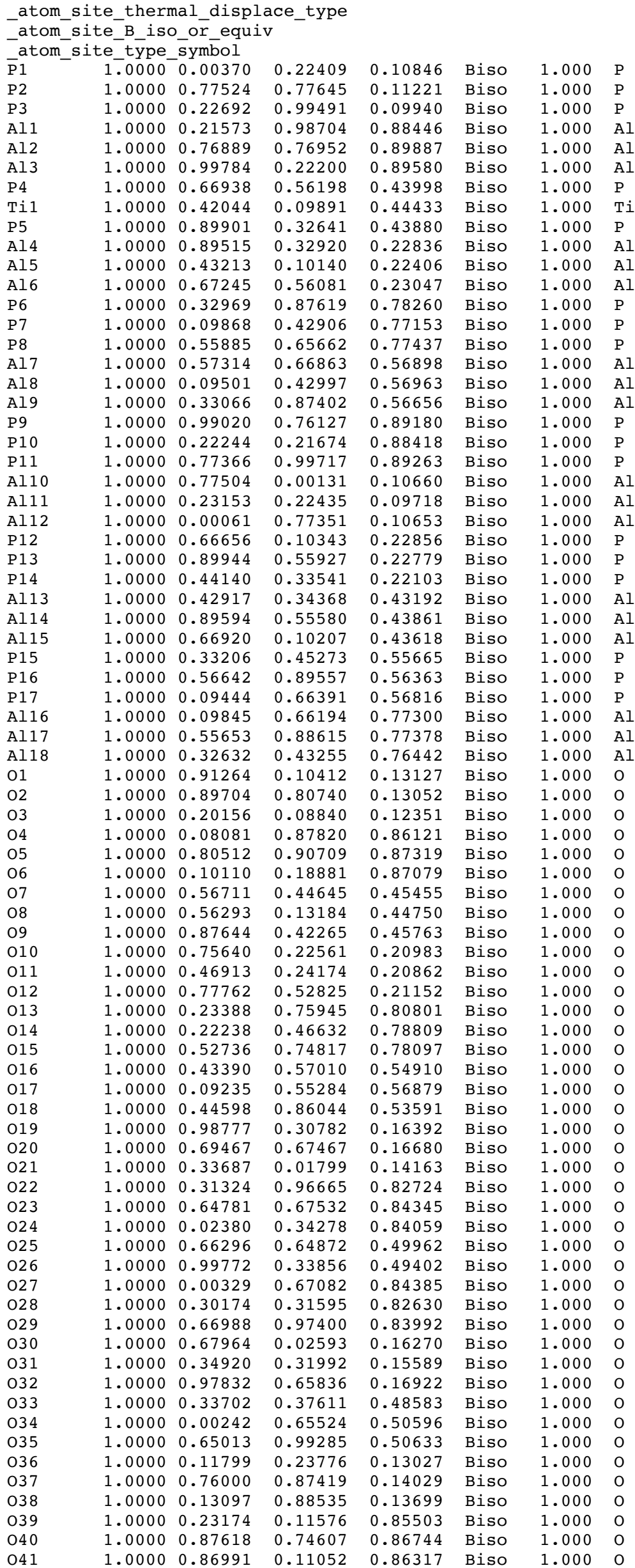




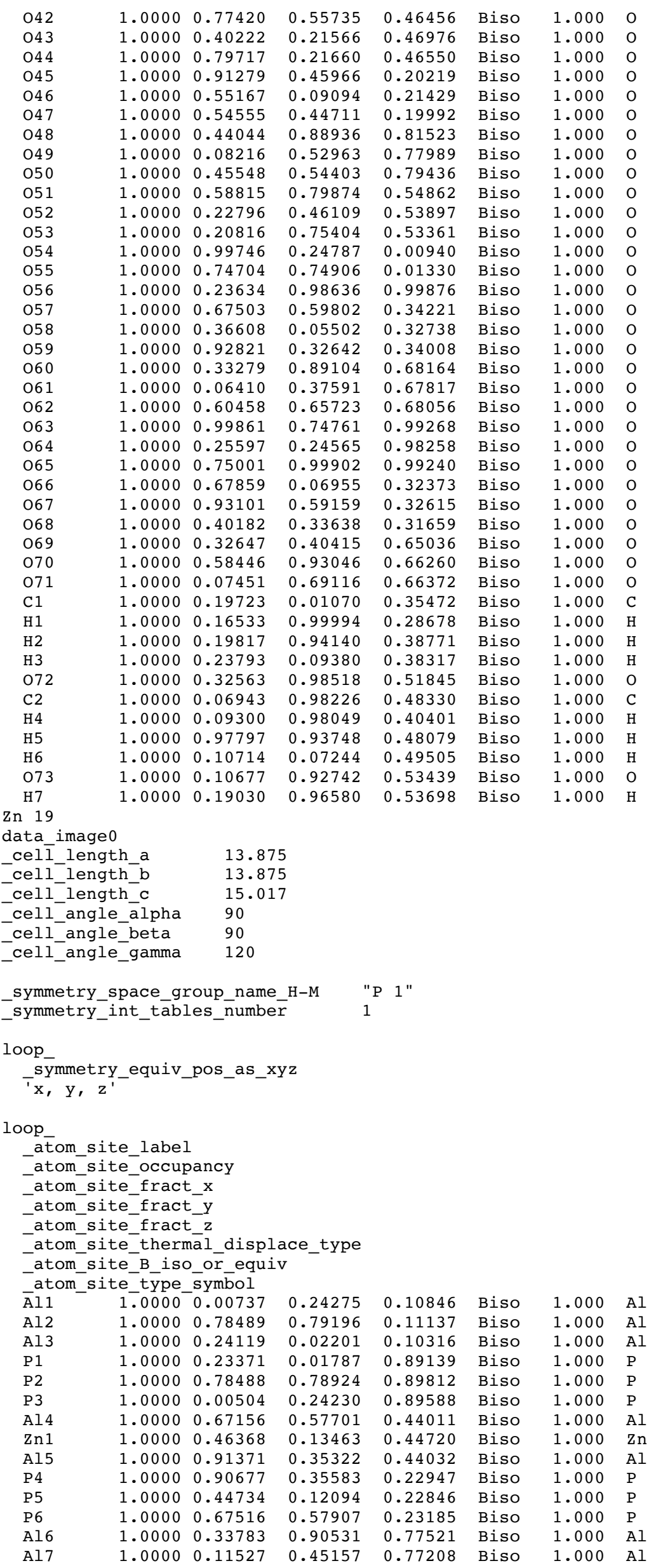




\begin{tabular}{|c|c|c|c|c|c|c|c|}
\hline Al8 & 1.0000 & 0.57390 & 0.68786 & 0.77504 & Biso & 1.000 & Al \\
\hline P7 & 1.0000 & 0.58467 & 0.69662 & 0.56728 & Biso & 1.000 & $\mathrm{P}$ \\
\hline P8 & 1.0000 & 0.11679 & 0.45592 & 0.56710 & Biso & 1.000 & $\mathrm{P}$ \\
\hline P9 & 1.0000 & 0.33810 & 0.90155 & 0.56308 & Biso & 1.000 & $\mathrm{P}$ \\
\hline Al9 & 1.0000 & 0.00984 & 0.78817 & 0.90302 & Biso & 1.000 & Al \\
\hline Al10 & 1.0000 & 0.23422 & 0.24526 & 0.89687 & Biso & 1.000 & Al \\
\hline Al11 & 1.0000 & 0.78209 & 0.01385 & 0.89985 & Biso & 1.000 & Al \\
\hline P10 & 1.0000 & 0.78185 & 0.01547 & 0.11361 & Biso & 1.000 & $\mathrm{P}$ \\
\hline P11 & 1.0000 & 0.23723 & 0.24717 & 0.10967 & Biso & 1.000 & $P$ \\
\hline $\mathrm{P} 12$ & 1.0000 & 0.01356 & 0.79623 & 0.11633 & Biso & 1.000 & $\mathrm{P}$ \\
\hline Al12 & 1.0000 & 0.68124 & 0.12480 & 0.23855 & Biso & 1.000 & $\mathrm{Al}$ \\
\hline Al13 & 1.0000 & 0.90296 & 0.58010 & 0.23560 & Biso & 1.000 & Al \\
\hline Al1 14 & 1.0000 & 0.44694 & 0.34679 & 0.23375 & Biso & 1.000 & Al \\
\hline P13 & 1.0000 & 0.43751 & 0.34809 & 0.44374 & Biso & 1.000 & $\mathrm{P}$ \\
\hline P 14 & 1.0000 & 0.89978 & 0.57545 & 0.44713 & Biso & 1.000 & $P$ \\
\hline P15 & 1.0000 & 0.69118 & 0.13124 & 0.44261 & Biso & 1.000 & $\mathrm{P}$ \\
\hline Al15 & 1.0000 & 0.35142 & 0.47069 & 0.56706 & Biso & 1.000 & Al \\
\hline Al16 & 1.0000 & 0.56848 & 0.91485 & 0.56917 & Biso & 1.000 & Al \\
\hline Al1 17 & 1.0000 & 0.10505 & 0.68344 & 0.57374 & Biso & 1.000 & Al \\
\hline P16 & 1.0000 & 0.11081 & 0.68078 & 0.78070 & Biso & 1.000 & $\mathrm{P}$ \\
\hline P 17 & 1.0000 & 0.56698 & 0.91248 & 0.77996 & Biso & 1.000 & $\mathrm{P}$ \\
\hline P18 & 1.0000 & 0.34591 & 0.45832 & 0.77549 & Biso & 1.000 & $P$ \\
\hline 01 & 1.0000 & 0.90325 & 0.10603 & 0.13331 & Biso & 1.000 & 0 \\
\hline $\mathrm{O} 2$ & 1.0000 & 0.92302 & 0.82709 & 0.13584 & Biso & 1.000 & 0 \\
\hline $\mathrm{O} 3$ & 1.0000 & 0.20974 & 0.12658 & 0.12935 & Biso & 1.000 & 0 \\
\hline 04 & 1.0000 & 0.11271 & 0.92432 & 0.87564 & Biso & 1.000 & 0 \\
\hline 05 & 1.0000 & 0.81636 & 0.91033 & 0.87680 & Biso & 1.000 & 0 \\
\hline 06 & 1.0000 & 0.09719 & 0.21395 & 0.87682 & Biso & 1.000 & 0 \\
\hline 07 & 1.0000 & 0.55990 & 0.44329 & 0.45272 & Biso & 1.000 & 0 \\
\hline 08 & 1.0000 & 0.61900 & 0.18532 & 0.44568 & Biso & 1.000 & 0 \\
\hline 09 & 1.0000 & 0.88125 & 0.45799 & 0.46435 & Biso & 1.000 & 0 \\
\hline 010 & 1.0000 & 0.78469 & 0.26350 & 0.21726 & Biso & 1.000 & 0 \\
\hline 011 & 1.0000 & 0.48036 & 0.24305 & 0.20923 & Biso & 1.000 & 0 \\
\hline 012 & 1.0000 & 0.76599 & 0.54812 & 0.21466 & Biso & 1.000 & 0 \\
\hline 013 & 1.0000 & 0.23277 & 0.76881 & 0.80040 & Biso & 1.000 & 0 \\
\hline 014 & 1.0000 & 0.25408 & 0.48805 & 0.79261 & Biso & 1.000 & 0 \\
\hline 015 & 1.0000 & 0.53780 & 0.79054 & 0.79269 & Biso & 1.000 & 0 \\
\hline 016 & 1.0000 & 0.46173 & 0.60720 & 0.55462 & Biso & 1.000 & 0 \\
\hline 017 & 1.0000 & 0.12438 & 0.56973 & 0.56340 & Biso & 1.000 & 0 \\
\hline 018 & 1.0000 & 0.42708 & 0.86610 & 0.55008 & Biso & 1.000 & 0 \\
\hline 019 & 1.0000 & 0.98448 & 0.33635 & 0.16897 & Biso & 1.000 & 0 \\
\hline 020 & 1.0000 & 0.69104 & 0.67334 & 0.16943 & Biso & 1.000 & 0 \\
\hline 021 & 1.0000 & 0.35965 & 0.04351 & 0.16015 & Biso & 1.000 & 0 \\
\hline 022 & 1.0000 & 0.31475 & 0.00033 & 0.83423 & Biso & 1.000 & 0 \\
\hline 023 & 1.0000 & 0.68170 & 0.70700 & 0.84561 & Biso & 1.000 & 0 \\
\hline $\mathrm{O} 24$ & 1.0000 & 0.02424 & 0.34384 & 0.84165 & Biso & 1.000 & 0 \\
\hline 025 & 1.0000 & 0.66021 & 0.67390 & 0.50682 & Biso & 1.000 & 0 \\
\hline 026 & 1.0000 & 0.03042 & 0.37547 & 0.50055 & Biso & 1.000 & 0 \\
\hline 027 & 1.0000 & 0.03272 & 0.69117 & 0.84753 & Biso & 1.000 & 0 \\
\hline 028 & 1.0000 & 0.32748 & 0.36029 & 0.83455 & Biso & 1.000 & 0 \\
\hline 029 & 1.0000 & 0.66494 & 0.98977 & 0.83996 & Biso & 1.000 & 0 \\
\hline 030 & 1.0000 & 0.69983 & 0.03704 & 0.16579 & Biso & 1.000 & 0 \\
\hline 031 & 1.0000 & 0.33772 & 0.32981 & 0.16466 & Biso & 1.000 & 0 \\
\hline 032 & 1.0000 & 0.99601 & 0.69836 & 0.17511 & Biso & 1.000 & o \\
\hline 033 & 1.0000 & 0.36083 & 0.38137 & 0.49233 & Biso & 1.000 & 0 \\
\hline 034 & 1.0000 & 0.99310 & 0.66229 & 0.50655 & Biso & 1.000 & 0 \\
\hline 035 & 1.0000 & 0.65388 & 0.03300 & 0.50734 & Biso & 1.000 & 0 \\
\hline 036 & 1.0000 & 0.13641 & 0.25806 & 0.13663 & Biso & 1.000 & 0 \\
\hline 037 & 1.0000 & 0.76707 & 0.90288 & 0.14317 & Biso & 1.000 & 0 \\
\hline 038 & 1.0000 & 0.12775 & 0.89637 & 0.14022 & Biso & 1.000 & 0 \\
\hline 039 & 1.0000 & 0.24440 & 0.12965 & 0.86587 & Biso & 1.000 & 0 \\
\hline 040 & 1.0000 & 0.88170 & 0.77181 & 0.87123 & Biso & 1.000 & 0 \\
\hline 041 & 1.0000 & 0.89292 & 0.14283 & 0.86827 & Biso & 1.000 & 0 \\
\hline 042 & 1.0000 & 0.79321 & 0.57716 & 0.46963 & Biso & 1.000 & 0 \\
\hline 043 & 1.0000 & 0.42199 & 0.24113 & 0.48346 & Biso & 1.000 & 0 \\
\hline 044 & 1.0000 & 0.81129 & 0.21912 & 0.46924 & Biso & 1.000 & 0 \\
\hline 045 & 1.0000 & 0.91788 & 0.46788 & 0.20315 & Biso & 1.000 & 0 \\
\hline 046 & 1.0000 & 0.55062 & 0.10912 & 0.21812 & Biso & 1.000 & 0 \\
\hline 047 & 1.0000 & 0.56149 & 0.47747 & 0.21234 & Biso & 1.000 & 0 \\
\hline 048 & 1.0000 & 0.46615 & 0.92262 & 0.80785 & Biso & 1.000 & 0 \\
\hline 049 & 1.0000 & 0.09725 & 0.56502 & 0.79131 & Biso & 1.000 & 0 \\
\hline 050 & 1.0000 & 0.45881 & 0.55888 & 0.79964 & Biso & 1.000 & 0 \\
\hline 051 & 1.0000 & 0.59998 & 0.81067 & 0.54233 & Biso & 1.000 & 0 \\
\hline 052 & 1.0000 & 0.22991 & 0.47123 & 0.54144 & Biso & 1.000 & 0 \\
\hline 053 & 1.0000 & 0.22382 & 0.80162 & 0.53737 & Biso & 1.000 & 0 \\
\hline 054 & 1.0000 & 0.00415 & 0.26883 & 0.99514 & Biso & 1.000 & 0 \\
\hline 055 & 1.0000 & 0.75966 & 0.76551 & 0.99789 & Biso & 1.000 & 0 \\
\hline 056 & 1.0000 & 0.26432 & 0.01849 & 0.98999 & Biso & 1.000 & 0 \\
\hline 057 & 1.0000 & 0.68231 & 0.61926 & 0.32848 & Biso & 1.000 & 0 \\
\hline 058 & 1.0000 & 0.39736 & 0.08469 & 0.32303 & Biso & 1.000 & 0 \\
\hline
\end{tabular}




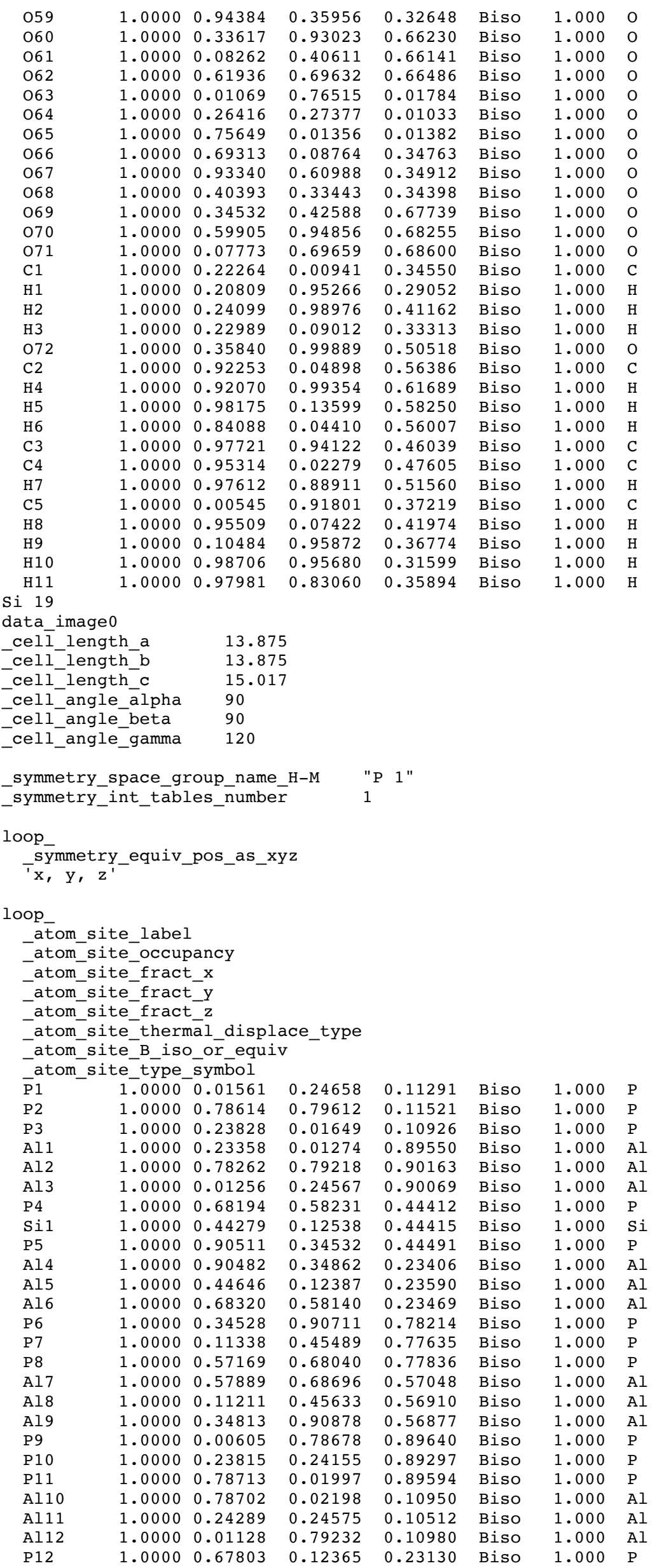




\begin{tabular}{|c|c|c|c|c|c|c|c|}
\hline P13 & 1.0000 & 0.91018 & 0.57977 & 0.23200 & Biso & 1.000 & $\mathrm{P}$ \\
\hline P14 & 1.0000 & 0.45345 & 0.35526 & 0.22890 & Biso & 1.000 & $\mathrm{P}$ \\
\hline Al13 & 1.0000 & 0.44754 & 0.35521 & 0.43915 & Biso & 1.000 & Al \\
\hline Al14 & 1.0000 & 0.90706 & 0.57661 & 0.44256 & Biso & 1.000 & $\mathrm{Al}$ \\
\hline Al15 & 1.0000 & 0.67378 & 0.12423 & 0.43718 & Biso & 1.000 & Al \\
\hline P15 & 1.0000 & 0.34392 & 0.46494 & 0.56166 & Biso & 1.000 & $\mathrm{P}$ \\
\hline P16 & 1.0000 & 0.57567 & 0.91294 & 0.56627 & Biso & 1.000 & $\mathrm{P}$ \\
\hline P17 & 1.0000 & 0.11406 & 0.69002 & 0.56680 & Biso & 1.000 & $\mathrm{P}$ \\
\hline Al16 & 1.0000 & 0.11571 & 0.68659 & 0.77568 & Biso & 1.000 & Al \\
\hline Al17 & 1.0000 & 0.57325 & 0.91078 & 0.77505 & Biso & 1.000 & Al \\
\hline Al18 & 1.0000 & 0.34048 & 0.45507 & 0.77111 & Biso & 1.000 & Al \\
\hline 01 & 1.0000 & 0.92467 & 0.12558 & 0.13322 & Biso & 1.000 & 0 \\
\hline $\mathrm{O} 2$ & 1.0000 & 0.90747 & 0.82565 & 0.13416 & Biso & 1.000 & 0 \\
\hline 03 & 1.0000 & 0.20958 & 0.10840 & 0.12975 & Biso & 1.000 & 0 \\
\hline $\mathrm{O} 4$ & 1.0000 & 0.09728 & 0.90623 & 0.87259 & Biso & 1.000 & 0 \\
\hline 05 & 1.0000 & 0.81736 & 0.92918 & 0.87572 & Biso & 1.000 & 0 \\
\hline 06 & 1.0000 & 0.11662 & 0.21265 & 0.87837 & Biso & 1.000 & $\mathrm{O}$ \\
\hline 07 & 1.0000 & 0.58541 & 0.46349 & 0.45698 & Biso & 1.000 & 0 \\
\hline 08 & 1.0000 & 0.57269 & 0.15999 & 0.43983 & Biso & 1.000 & 0 \\
\hline 09 & 1.0000 & 0.88162 & 0.44155 & 0.46122 & Biso & 1.000 & 0 \\
\hline 010 & 1.0000 & 0.76694 & 0.24609 & 0.21185 & Biso & 1.000 & 0 \\
\hline 011 & 1.0000 & 0.48284 & 0.26294 & 0.21475 & Biso & 1.000 & 0 \\
\hline 012 & 1.0000 & 0.78888 & 0.54948 & 0.21463 & Biso & 1.000 & 0 \\
\hline 013 & 1.0000 & 0.25220 & 0.78739 & 0.80374 & Biso & 1.000 & 0 \\
\hline 014 & 1.0000 & 0.23583 & 0.48805 & 0.79288 & Biso & 1.000 & 0 \\
\hline 015 & 1.0000 & 0.54175 & 0.77267 & 0.78944 & Biso & 1.000 & 0 \\
\hline 016 & 1.0000 & 0.43965 & 0.58609 & 0.55213 & Biso & 1.000 & 0 \\
\hline 017 & 1.0000 & 0.13145 & 0.58962 & 0.55650 & Biso & 1.000 & 0 \\
\hline 018 & 1.0000 & 0.45099 & 0.87087 & 0.55186 & Biso & 1.000 & 0 \\
\hline 019 & 1.0000 & 0.99820 & 0.32822 & 0.16991 & Biso & 1.000 & 0 \\
\hline 020 & 1.0000 & 0.70484 & 0.69458 & 0.16972 & Biso & 1.000 & $\mathrm{O}$ \\
\hline 021 & 1.0000 & 0.34259 & 0.03716 & 0.15972 & Biso & 1.000 & 0 \\
\hline 022 & 1.0000 & 0.32941 & 0.99151 & 0.83707 & Biso & 1.000 & 0 \\
\hline 023 & 1.0000 & 0.66415 & 0.69783 & 0.84351 & Biso & 1.000 & 0 \\
\hline 024 & 1.0000 & 0.03600 & 0.36223 & 0.84023 & Biso & 1.000 & 0 \\
\hline 025 & 1.0000 & 0.66864 & 0.66493 & 0.50345 & Biso & 1.000 & 0 \\
\hline 026 & 1.0000 & 0.00401 & 0.36126 & 0.50186 & Biso & 1.000 & 0 \\
\hline 027 & 1.0000 & 0.02195 & 0.70109 & 0.84392 & Biso & 1.000 & 0 \\
\hline 028 & 1.0000 & 0.31753 & 0.34054 & 0.83503 & Biso & 1.000 & 0 \\
\hline 029 & 1.0000 & 0.68510 & 0.99990 & 0.84219 & Biso & 1.000 & 0 \\
\hline 030 & 1.0000 & 0.69177 & 0.04613 & 0.16589 & Biso & 1.000 & 0 \\
\hline 031 & 1.0000 & 0.35931 & 0.33877 & 0.16561 & Biso & 1.000 & 0 \\
\hline 032 & 1.0000 & 0.99015 & 0.67805 & 0.17318 & Biso & 1.000 & 0 \\
\hline 033 & 1.0000 & 0.35848 & 0.38795 & 0.49766 & Biso & 1.000 & 0 \\
\hline 034 & 1.0000 & 0.01682 & 0.67476 & 0.50769 & Biso & 1.000 & 0 \\
\hline 035 & 1.0000 & 0.64882 & 0.01100 & 0.50514 & Biso & 1.000 & 0 \\
\hline 036 & 1.0000 & 0.12936 & 0.26006 & 0.13618 & Biso & 1.000 & 0 \\
\hline 037 & 1.0000 & 0.77285 & 0.89506 & 0.14343 & Biso & 1.000 & 0 \\
\hline 038 & 1.0000 & 0.13993 & 0.90492 & 0.14144 & Biso & 1.000 & 0 \\
\hline 039 & 1.0000 & 0.24877 & 0.14087 & 0.86556 & Biso & 1.000 & 0 \\
\hline 040 & 1.0000 & 0.89268 & 0.77254 & 0.87118 & Biso & 1.000 & 0 \\
\hline 041 & 1.0000 & 0.88514 & 0.13319 & 0.86861 & Biso & 1.000 & 0 \\
\hline 042 & 1.0000 & 0.79109 & 0.58706 & 0.47062 & Biso & 1.000 & 0 \\
\hline 043 & 1.0000 & 0.42805 & 0.22949 & 0.47163 & Biso & 1.000 & 0 \\
\hline 044 & 1.0000 & 0.80365 & 0.23497 & 0.47184 & Biso & 1.000 & 0 \\
\hline 045 & 1.0000 & 0.92350 & 0.47968 & 0.20868 & Biso & 1.000 & 0 \\
\hline 046 & 1.0000 & 0.56258 & 0.10952 & 0.21661 & Biso & 1.000 & 0 \\
\hline 047 & 1.0000 & 0.55600 & 0.46764 & 0.20595 & Biso & 1.000 & 0 \\
\hline 048 & 1.0000 & 0.45754 & 0.91920 & 0.80833 & Biso & 1.000 & 0 \\
\hline 049 & 1.0000 & 0.09923 & 0.55564 & 0.79376 & Biso & 1.000 & 0 \\
\hline 050 & 1.0000 & 0.46894 & 0.56814 & 0.80020 & Biso & 1.000 & 0 \\
\hline 051 & 1.0000 & 0.59911 & 0.81829 & 0.54496 & Biso & 1.000 & 0 \\
\hline 052 & 1.0000 & 0.23469 & 0.46109 & 0.53780 & Biso & 1.000 & 0 \\
\hline 053 & 1.0000 & 0.21912 & 0.79520 & 0.53636 & Biso & 1.000 & 0 \\
\hline 054 & 1.0000 & 0.01154 & 0.27359 & 0.01413 & Biso & 1.000 & 0 \\
\hline 055 & 1.0000 & 0.75874 & 0.76980 & 0.01600 & Biso & 1.000 & 0 \\
\hline 056 & 1.0000 & 0.25783 & 0.01165 & 0.00947 & Biso & 1.000 & 0 \\
\hline 057 & 1.0000 & 0.68861 & 0.61963 & 0.34643 & Biso & 1.000 & 0 \\
\hline 058 & 1.0000 & 0.38930 & 0.08264 & 0.34208 & Biso & 1.000 & 0 \\
\hline 059 & 1.0000 & 0.93515 & 0.34363 & 0.34643 & Biso & 1.000 & 0 \\
\hline 060 & 1.0000 & 0.34271 & 0.93171 & 0.68317 & Biso & 1.000 & 0 \\
\hline 061 & 1.0000 & 0.07960 & 0.41280 & 0.68011 & Biso & 1.000 & 0 \\
\hline 062 & 1.0000 & 0.61216 & 0.68122 & 0.68263 & Biso & 1.000 & 0 \\
\hline 063 & 1.0000 & 0.01006 & 0.76485 & 0.99648 & Biso & 1.000 & 0 \\
\hline 064 & 1.0000 & 0.27066 & 0.27137 & 0.99134 & Biso & 1.000 & 0 \\
\hline 065 & 1.0000 & 0.76138 & 0.01933 & 0.99551 & Biso & 1.000 & 0 \\
\hline 066 & 1.0000 & 0.69199 & 0.09153 & 0.32654 & Biso & 1.000 & 0 \\
\hline 067 & 1.0000 & 0.94151 & 0.61413 & 0.33020 & Biso & 1.000 & 0 \\
\hline 068 & 1.0000 & 0.41587 & 0.35553 & 0.32498 & Biso & 1.000 & 0 \\
\hline 069 & 1.0000 & 0.33918 & 0.42407 & 0.65802 & Biso & 1.000 & 0 \\
\hline
\end{tabular}




\begin{tabular}{|c|c|c|c|c|c|c|c|}
\hline 070 & 1.0000 & 0.60828 & 0.95100 & 0.66380 & Biso & 1.000 & 0 \\
\hline 071 & 1.0000 & 0.08656 & 0.70102 & 0.66441 & Biso & 1.000 & 0 \\
\hline $\mathrm{C} 1$ & 1.0000 & 0.20562 & 0.00023 & 0.35515 & Biso & 1.000 & $\mathrm{C}$ \\
\hline H 1 & 1.0000 & 0.20163 & 0.94559 & 0.30151 & Biso & 1.000 & $\mathrm{H}$ \\
\hline $\mathrm{H} 2$ & 1.0000 & 0.22021 & 0.98301 & 0.42326 & Biso & 1.000 & $\mathrm{H}$ \\
\hline H3 & 1.0000 & 0.21629 & 0.08151 & 0.33908 & Biso & 1.000 & $\mathrm{H}$ \\
\hline 072 & 1.0000 & 0.36982 & 0.02220 & 0.50989 & Biso & 1.000 & 0 \\
\hline $\mathrm{C} 2$ & 1.0000 & 0.92213 & 0.05510 & 0.56545 & Biso & 1.000 & $\mathrm{C}$ \\
\hline H4 & 1.0000 & 0.91361 & 0.99551 & 0.61732 & Biso & 1.000 & $\mathrm{H}$ \\
\hline H5 & 1.0000 & 0.98671 & 0.13946 & 0.58596 & Biso & 1.000 & $\mathrm{H}$ \\
\hline H6 & 1.0000 & 0.84445 & 0.05834 & 0.56154 & Biso & 1.000 & $\mathrm{H}$ \\
\hline $\mathrm{C} 3$ & 1.0000 & 0.96422 & 0.93965 & 0.45975 & Biso & 1.000 & $\mathrm{C}$ \\
\hline $\mathrm{C} 4$ & 1.0000 & 0.95022 & 0.02754 & 0.47724 & Biso & 1.000 & $\mathrm{C}$ \\
\hline H7 & 1.0000 & 0.95611 & 0.88291 & 0.51364 & Biso & 1.000 & $\mathrm{H}$ \\
\hline C5 & 1.0000 & 0.99060 & 0.91618 & 0.37138 & Biso & 1.000 & $\mathrm{C}$ \\
\hline H8 & 1.0000 & 0.95935 & 0.08350 & 0.42211 & Biso & 1.000 & $\mathrm{H}$ \\
\hline H9 & 1.0000 & 0.09098 & 0.95003 & 0.36775 & Biso & 1.000 & $\mathrm{H}$ \\
\hline H 10 & 1.0000 & 0.97944 & 0.96100 & 0.31580 & Biso & 1.000 & $\mathrm{H}$ \\
\hline H 11 & 1.0000 & 0.96017 & 0.82832 & 0.35578 & Biso & 1.000 & $\mathrm{H}$ \\
\hline \multicolumn{8}{|c|}{$\operatorname{Mg} 19$} \\
\hline \multicolumn{8}{|c|}{ data_image 0} \\
\hline \\
\hline $\mathrm{cell}_{-}^{-}$ & $t h \_b$ & \multicolumn{5}{|c|}{$\begin{array}{l}13.875 \\
13.875\end{array}$} & \\
\hline \multicolumn{8}{|c|}{15.017} \\
\hline \multicolumn{8}{|c|}{90} \\
\hline \multicolumn{8}{|c|}{90} \\
\hline $\mathrm{cell}_{-}^{-}$ & gamma & 120 & & & & & \\
\hline symme & pace-y & מרח & & $1 "$ & & & \\
\hline symme & $a t$ tab & les_numbe & & & & & \\
\hline op_ & & & & & & & \\
\hline $\begin{array}{c}\text { sym } \\
\text { 'x, }\end{array}$ & _equiv & pos_as_z & & & & & \\
\hline op & & & & & & & \\
\hline ato & e_labe. & & & & & & \\
\hline -ato & =e_occup & pancy & & & & & \\
\hline -ato & te_fract & E $x$ & & & & & \\
\hline -ato & ee_fract & Ey & & & & & \\
\hline -ato & e_fract & & & & & & \\
\hline -ato & $e^{-}$thern & nāl_displ & ace_type & & & & \\
\hline -ato & $e_{-}^{-} B$ is & D_or_equi & & & & & \\
\hline -ato & e-tȳpe & symbol & & & & & \\
\hline $\bar{A} 11$ & 1.0000 & 0.00828 & 0.24401 & 0.10874 & Biso & 1.000 & Al \\
\hline Al2 & 1.0000 & 0.78657 & 0.79416 & 0.11190 & Biso & 1.000 & Al \\
\hline Al3 & 1.0000 & 0.24263 & 0.02375 & 0.10269 & Biso & 1.000 & Al \\
\hline P1 & 1.0000 & 0.23366 & 0.01794 & 0.89101 & Biso & 1.000 & $\mathrm{P}$ \\
\hline P2 & 1.0000 & 0.78528 & 0.79057 & 0.89829 & Biso & 1.000 & $\mathrm{P}$ \\
\hline P3 & 1.0000 & 0.00436 & 0.24278 & 0.89579 & Biso & 1.000 & $\mathrm{P}$ \\
\hline Al4 & 1.0000 & 0.67174 & 0.57900 & 0.43965 & Biso & 1.000 & Al \\
\hline Mg 1 & 1.0000 & 0.45794 & 0.13176 & 0.44665 & Biso & 1.000 & $\mathrm{Mg}$ \\
\hline Al5 & 1.0000 & 0.91327 & 0.35254 & 0.44115 & Biso & 1.000 & $\mathrm{Al}$ \\
\hline P 4 & 1.0000 & 0.90802 & 0.35680 & 0.23005 & Biso & 1.000 & $\mathrm{P}$ \\
\hline P5 & 1.0000 & 0.44761 & 0.12198 & 0.22901 & Biso & 1.000 & $\mathrm{P}$ \\
\hline P6 & 1.0000 & 0.67694 & 0.58033 & 0.23136 & Biso & 1.000 & $\mathrm{P}$ \\
\hline Al6 & 1.0000 & 0.33647 & 0.90297 & 0.77703 & Biso & 1.000 & Al \\
\hline Al 7 & 1.0000 & 0.11446 & 0.45131 & 0.77226 & Biso & 1.000 & Al \\
\hline Al8 & 1.0000 & 0.57389 & 0.68706 & 0.77545 & Biso & 1.000 & Al \\
\hline P7 & 1.0000 & 0.58601 & 0.69616 & 0.56795 & Biso & 1.000 & $\mathrm{P}$ \\
\hline P8 & 1.0000 & 0.11575 & 0.45567 & 0.56774 & Biso & 1.000 & $\mathrm{P}$ \\
\hline P9 & 1.0000 & 0.33751 & 0.89836 & 0.56429 & Biso & 1.000 & $\mathrm{P}$ \\
\hline Al9 & 1.0000 & 0.00921 & 0.78732 & 0.90379 & Biso & 1.000 & Al \\
\hline Al10 & 1.0000 & 0.23295 & 0.24465 & 0.89509 & Biso & 1.000 & Al \\
\hline Al11 & 1.0000 & 0.78201 & 0.01406 & 0.90002 & Biso & 1.000 & Al \\
\hline $\mathrm{P} 10$ & 1.0000 & 0.78255 & 0.01646 & 0.11426 & Biso & 1.000 & $P$ \\
\hline P11 & 1.0000 & 0.23803 & 0.24835 & 0.10837 & Biso & 1.000 & $\mathrm{P}$ \\
\hline $\mathrm{P} 12$ & 1.0000 & 0.01484 & 0.79731 & 0.11676 & Biso & 1.000 & $\mathrm{P}$ \\
\hline Al12 & 1.0000 & 0.68275 & 0.12676 & 0.23832 & Biso & 1.000 & Al \\
\hline Al13 & 1.0000 & 0.90476 & 0.58184 & 0.23681 & Biso & 1.000 & Al \\
\hline Al14 & 1.0000 & 0.44670 & 0.34944 & 0.23303 & Biso & 1.000 & Al \\
\hline P13 & 1.0000 & 0.43506 & 0.35118 & 0.44184 & Biso & 1.000 & $P$ \\
\hline P 14 & 1.0000 & 0.89914 & 0.57546 & 0.44801 & Biso & 1.000 & $\mathrm{P}$ \\
\hline P15 & 1.0000 & 0.69040 & 0.12946 & 0.44248 & Biso & 1.000 & $\mathrm{P}$ \\
\hline Al15 & 1.0000 & 0.35108 & 0.47287 & 0.56640 & Biso & 1.000 & Al \\
\hline Al16 & 1.0000 & 0.56927 & 0.91535 & 0.57045 & Biso & 1.000 & Al \\
\hline Al17 & 1.0000 & 0.10375 & 0.68365 & 0.57460 & Biso & 1.000 & Al \\
\hline P16 & 1.0000 & 0.10966 & 0.68065 & 0.78161 & Biso & 1.000 & $\mathrm{P}$ \\
\hline P17 & 1.0000 & 0.56704 & 0.91341 & 0.77998 & Biso & 1.000 & $\mathrm{P}$ \\
\hline P18 & 1.0000 & 0.34547 & 0.45962 & 0.77620 & Biso & 1.000 & $\mathrm{P}$ \\
\hline
\end{tabular}




\begin{tabular}{|c|c|c|c|c|c|c|c|}
\hline 01 & 1.0000 & 0.90363 & 0.10771 & 0.13406 & Biso & 1.000 & O \\
\hline $\mathrm{O} 2$ & 1.0000 & 0.92470 & 0.82883 & 0.13604 & Biso & 1.000 & 0 \\
\hline 03 & 1.0000 & 0.21168 & 0.12843 & 0.12968 & Biso & 1.000 & 0 \\
\hline 04 & 1.0000 & 0.11297 & 0.92314 & 0.87666 & Biso & 1.000 & 0 \\
\hline 05 & 1.0000 & 0.81678 & 0.91126 & 0.87530 & Biso & 1.000 & 0 \\
\hline 06 & 1.0000 & 0.09622 & 0.21446 & 0.87527 & Biso & 1.000 & 0 \\
\hline 07 & 1.0000 & 0.55639 & 0.44799 & 0.45241 & Biso & 1.000 & 0 \\
\hline 08 & 1.0000 & 0.61132 & 0.17486 & 0.44535 & Biso & 1.000 & 0 \\
\hline 09 & 1.0000 & 0.88243 & 0.45862 & 0.46441 & Biso & 1.000 & O \\
\hline 010 & 1.0000 & 0.78586 & 0.26542 & 0.21592 & Biso & 1.000 & 0 \\
\hline 011 & 1.0000 & 0.47887 & 0.24392 & 0.21184 & Biso & 1.000 & 0 \\
\hline 012 & 1.0000 & 0.76794 & 0.54946 & 0.21466 & Biso & 1.000 & 0 \\
\hline 013 & 1.0000 & 0.23101 & 0.76750 & 0.80458 & Biso & 1.000 & 0 \\
\hline 014 & 1.0000 & 0.25303 & 0.48818 & 0.79453 & Biso & 1.000 & 0 \\
\hline 015 & 1.0000 & 0.53977 & 0.79168 & 0.78924 & Biso & 1.000 & 0 \\
\hline 016 & 1.0000 & 0.46362 & 0.60759 & 0.55128 & Biso & 1.000 & 0 \\
\hline 017 & 1.0000 & 0.11857 & 0.56724 & 0.56557 & Biso & 1.000 & 0 \\
\hline 018 & 1.0000 & 0.42695 & 0.86328 & 0.55185 & Biso & 1.000 & 0 \\
\hline 019 & 1.0000 & 0.98625 & 0.33809 & 0.16949 & Biso & 1.000 & 0 \\
\hline 020 & 1.0000 & 0.69282 & 0.67434 & 0.16866 & Biso & 1.000 & 0 \\
\hline 021 & 1.0000 & 0.36104 & 0.04503 & 0.15991 & Biso & 1.000 & 0 \\
\hline 022 & 1.0000 & 0.31474 & 0.00035 & 0.83392 & Biso & 1.000 & 0 \\
\hline 023 & 1.0000 & 0.68149 & 0.70745 & 0.84681 & Biso & 1.000 & 0 \\
\hline $\mathrm{O} 24$ & 1.0000 & 0.02285 & 0.34450 & 0.84220 & Biso & 1.000 & 0 \\
\hline 025 & 1.0000 & 0.66384 & 0.67760 & 0.50675 & Biso & 1.000 & 0 \\
\hline 026 & 1.0000 & 0.03025 & 0.37425 & 0.50106 & Biso & 1.000 & 0 \\
\hline 027 & 1.0000 & 0.02986 & 0.68910 & 0.84786 & Biso & 1.000 & 0 \\
\hline 028 & 1.0000 & 0.32668 & 0.35956 & 0.83285 & Biso & 1.000 & 0 \\
\hline 029 & 1.0000 & 0.66393 & 0.98947 & 0.84132 & Biso & 1.000 & $\mathrm{O}$ \\
\hline 030 & 1.0000 & 0.69977 & 0.03827 & 0.16509 & Biso & 1.000 & 0 \\
\hline 031 & 1.0000 & 0.33989 & 0.33268 & 0.16120 & Biso & 1.000 & 0 \\
\hline 032 & 1.0000 & 0.99798 & 0.70060 & 0.17674 & Biso & 1.000 & 0 \\
\hline 033 & 1.0000 & 0.35646 & 0.37961 & 0.49332 & Biso & 1.000 & 0 \\
\hline 034 & 1.0000 & 0.99078 & 0.66255 & 0.50857 & Biso & 1.000 & 0 \\
\hline 035 & 1.0000 & 0.65609 & 0.02979 & 0.50545 & Biso & 1.000 & O \\
\hline 036 & 1.0000 & 0.13744 & 0.25912 & 0.13631 & Biso & 1.000 & 0 \\
\hline 037 & 1.0000 & 0.76843 & 0.90450 & 0.14517 & Biso & 1.000 & 0 \\
\hline 038 & 1.0000 & 0.12939 & 0.89778 & 0.13937 & Biso & 1.000 & 0 \\
\hline 039 & 1.0000 & 0.24252 & 0.12859 & 0.86417 & Biso & 1.000 & 0 \\
\hline 040 & 1.0000 & 0.88169 & 0.77231 & 0.87187 & Biso & 1.000 & $\mathrm{O}$ \\
\hline 041 & 1.0000 & 0.89194 & 0.14352 & 0.86860 & Biso & 1.000 & 0 \\
\hline 042 & 1.0000 & 0.79089 & 0.57429 & 0.46943 & Biso & 1.000 & 0 \\
\hline 043 & 1.0000 & 0.42382 & 0.24413 & 0.47618 & Biso & 1.000 & 0 \\
\hline 044 & 1.0000 & 0.80854 & 0.22026 & 0.47134 & Biso & 1.000 & 0 \\
\hline 045 & 1.0000 & 0.92060 & 0.46992 & 0.20525 & Biso & 1.000 & 0 \\
\hline 046 & 1.0000 & 0.55196 & 0.11197 & 0.21908 & Biso & 1.000 & 0 \\
\hline 047 & 1.0000 & 0.56353 & 0.47853 & 0.21165 & Biso & 1.000 & 0 \\
\hline 048 & 1.0000 & 0.46491 & 0.92048 & 0.80935 & Biso & 1.000 & 0 \\
\hline 049 & 1.0000 & 0.09515 & 0.56428 & 0.78962 & Biso & 1.000 & 0 \\
\hline 050 & 1.0000 & 0.45777 & 0.55967 & 0.80253 & Biso & 1.000 & 0 \\
\hline 051 & 1.0000 & 0.60218 & 0.81146 & 0.54755 & Biso & 1.000 & 0 \\
\hline 052 & 1.0000 & 0.23064 & 0.47607 & 0.54137 & Biso & 1.000 & 0 \\
\hline 053 & 1.0000 & 0.22375 & 0.79926 & 0.53581 & Biso & 1.000 & 0 \\
\hline 054 & 1.0000 & 0.00466 & 0.26901 & 0.99526 & Biso & 1.000 & 0 \\
\hline 055 & 1.0000 & 0.76110 & 0.76916 & 0.99835 & Biso & 1.000 & 0 \\
\hline 056 & 1.0000 & 0.26585 & 0.02111 & 0.98952 & Biso & 1.000 & 0 \\
\hline 057 & 1.0000 & 0.68398 & 0.62096 & 0.32784 & Biso & 1.000 & 0 \\
\hline 058 & 1.0000 & 0.39763 & 0.08417 & 0.32347 & Biso & 1.000 & 0 \\
\hline 059 & 1.0000 & 0.94310 & 0.35764 & 0.32726 & Biso & 1.000 & 0 \\
\hline 060 & 1.0000 & 0.33226 & 0.92363 & 0.66380 & Biso & 1.000 & 0 \\
\hline 061 & 1.0000 & 0.08353 & 0.40447 & 0.66178 & Biso & 1.000 & 0 \\
\hline 062 & 1.0000 & 0.61740 & 0.68952 & 0.66545 & Biso & 1.000 & 0 \\
\hline 063 & 1.0000 & 0.01060 & 0.76431 & 0.01861 & Biso & 1.000 & 0 \\
\hline 064 & 1.0000 & 0.26254 & 0.27261 & 0.00858 & Biso & 1.000 & 0 \\
\hline 065 & 1.0000 & 0.75772 & 0.01288 & 0.01426 & Biso & 1.000 & 0 \\
\hline 066 & 1.0000 & 0.69761 & 0.09026 & 0.34679 & Biso & 1.000 & 0 \\
\hline 067 & 1.0000 & 0.93418 & 0.61176 & 0.35044 & Biso & 1.000 & 0 \\
\hline 068 & 1.0000 & 0.40130 & 0.34157 & 0.34213 & Biso & 1.000 & 0 \\
\hline 069 & 1.0000 & 0.34624 & 0.43074 & 0.67739 & Biso & 1.000 & 0 \\
\hline 070 & 1.0000 & 0.59920 & 0.95362 & 0.68335 & Biso & 1.000 & 0 \\
\hline 071 & 1.0000 & 0.07982 & 0.70050 & 0.68694 & Biso & 1.000 & 0 \\
\hline $\mathrm{C} 1$ & 1.0000 & 0.22426 & 0.00699 & 0.34457 & Biso & 1.000 & C \\
\hline $\mathrm{H} 1$ & 1.0000 & 0.21000 & 0.95145 & 0.28874 & Biso & 1.000 & $\mathrm{H}$ \\
\hline $\mathrm{H} 2$ & 1.0000 & 0.23989 & 0.98454 & 0.41055 & Biso & 1.000 & $\mathrm{H}$ \\
\hline H3 & 1.0000 & 0.22946 & 0.08710 & 0.33402 & Biso & 1.000 & $\mathrm{H}$ \\
\hline 072 & 1.0000 & 0.36179 & 0.99841 & 0.50871 & Biso & 1.000 & 0 \\
\hline $\mathrm{C} 2$ & 1.0000 & 0.92298 & 0.04797 & 0.56136 & Biso & 1.000 & C \\
\hline $\mathrm{H} 4$ & 1.0000 & 0.92457 & 0.99568 & 0.61561 & Biso & 1.000 & $\mathrm{H}$ \\
\hline H5 & 1.0000 & 0.98073 & 0.13621 & 0.57751 & Biso & 1.000 & $\mathrm{H}$ \\
\hline H 6 & 1.0000 & 0.84001 & 0.04016 & 0.55831 & Biso & 1.000 & $\mathrm{H}$ \\
\hline
\end{tabular}




\begin{tabular}{|c|c|c|c|c|c|c|c|}
\hline $\mathrm{C} 3$ & 1.0000 & 0.97846 & 0.93909 & 0.45990 & Biso & 1.000 & C \\
\hline $\mathrm{C} 4$ & 1.0000 & 0.95231 & 0.01948 & 0.47393 & Biso & 1.000 & C \\
\hline H7 & 1.0000 & 0.98014 & 0.88986 & 0.51627 & Biso & 1.000 & $\mathrm{H}$ \\
\hline $\mathrm{C} 5$ & 1.0000 & 0.00513 & 0.91315 & 0.37201 & Biso & 1.000 & C \\
\hline H8 & 1.0000 & 0.95113 & 0.06781 & 0.41646 & Biso & 1.000 & $\mathrm{H}$ \\
\hline H9 & 1.0000 & 0.10393 & 0.95416 & 0.36583 & Biso & 1.000 & $\mathrm{H}$ \\
\hline $\mathrm{H} 10$ & 1.0000 & 0.98439 & 0.94930 & 0.31527 & Biso & 1.000 & $\mathrm{H}$ \\
\hline H11 & 1.0000 & 0.97958 & \multirow[t]{2}{*}{0.82537} & 0.36076 & Biso & 1.000 & $\mathrm{H}$ \\
\hline L 19 & & & & & & & \\
\hline ata_in & & & & & & & \\
\hline $\operatorname{cel} \bar{l}$ & h_a & 13.62 & & & & & \\
\hline cell_- & Ch_b & 13.62 & & & & & \\
\hline cell_- & th_c & 15.06 & & & & & \\
\hline cell_c & e_alpha & 90 & & & & & \\
\hline cell_c & beta & 90 & & & & & \\
\hline $\mathrm{cell}^{-}$ & gamma & 120 & & & & & \\
\hline symme & pace_gl & coup_name & & $1 "$ & & & \\
\hline symme & nt_tab. & les_numb & & & & & \\
\hline op & & & & & & & \\
\hline 'symr & _equiv & _pos_as_x & & & & & \\
\hline op_ & & & & & & & \\
\hline ator & e_labe & & & & & & \\
\hline ator & e_occup & pancy & & & & & \\
\hline _aton & $=e_{-}^{-}$fract & - $x$ & & & & & \\
\hline -ator & $=e_{-}^{-}$fract & - $y$ & & & & & \\
\hline -ator & $e_{-}^{-}$fract & $z$ & & & & & \\
\hline -ator & e_thern & nāl_displ & ace_type & & & & \\
\hline $\begin{array}{l}\text { aton } \\
\text { aton }\end{array}$ & $\begin{array}{l}\text { e_B_isc } \\
\text { e type }\end{array}$ & $\begin{array}{l}\text { or_equi } \\
\text { symbol }\end{array}$ & & & & & \\
\hline$\overline{\mathrm{S}} i 1$ & 1.0000 & 0.02054 & 0.25629 & 0.10617 & Biso & 1.000 & $\mathrm{Si}$ \\
\hline Si2 & 1.0000 & 0.79222 & 0.80081 & 0.10927 & Biso & 1.000 & $\mathrm{Si}$ \\
\hline Si3 & 1.0000 & 0.25157 & 0.02906 & 0.10231 & Biso & 1.000 & $\mathrm{Si}$ \\
\hline Si4 & 1.0000 & 0.24480 & 0.02384 & 0.89455 & Biso & 1.000 & $\mathrm{Si}$ \\
\hline Si5 & 1.0000 & 0.79048 & 0.79722 & 0.90104 & Biso & 1.000 & $\mathrm{Si}$ \\
\hline Si6 & 1.0000 & 0.01744 & 0.25512 & 0.89921 & Biso & 1.000 & $\mathrm{Si}$ \\
\hline Si7 & 1.0000 & 0.68525 & 0.59025 & 0.43840 & Biso & 1.000 & $\mathrm{Si}$ \\
\hline Al1 & 1.0000 & 0.45549 & 0.13342 & 0.44089 & Biso & 1.000 & Al \\
\hline Si8 & 1.0000 & 0.92042 & 0.35693 & 0.43921 & Biso & 1.000 & $\mathrm{Si}$ \\
\hline Si9 & 1.0000 & 0.91796 & 0.36119 & 0.23339 & Biso & 1.000 & $\mathrm{Si}$ \\
\hline $\operatorname{Si} 10$ & 1.0000 & 0.45418 & 0.13014 & 0.23245 & Biso & 1.000 & $\mathrm{Si}$ \\
\hline Si11 & 1.0000 & 0.68908 & 0.59153 & 0.23450 & Biso & 1.000 & $\mathrm{Si}$ \\
\hline $\mathrm{Si} 12$ & 1.0000 & 0.34989 & 0.91546 & 0.77523 & Biso & 1.000 & $\mathrm{Si}$ \\
\hline $\operatorname{Si} 13$ & 1.0000 & 0.12106 & 0.45949 & 0.77020 & Biso & 1.000 & $\mathrm{Si}$ \\
\hline $\operatorname{Si} 14$ & 1.0000 & 0.58392 & 0.69201 & 0.77237 & Biso & 1.000 & $\mathrm{Si}$ \\
\hline Si15 & 1.0000 & 0.59327 & 0.69904 & 0.56946 & Biso & 1.000 & $\mathrm{Si}$ \\
\hline $\operatorname{Si} 16$ & 1.0000 & 0.12019 & 0.46162 & 0.56904 & Biso & 1.000 & $\mathrm{Si}$ \\
\hline $\operatorname{Si} 17$ & 1.0000 & 0.35116 & 0.91390 & 0.56704 & Biso & 1.000 & $\mathrm{Si}$ \\
\hline Si 18 & 1.0000 & 0.01662 & 0.79315 & 0.90137 & Biso & 1.000 & $\mathrm{Si}$ \\
\hline Si19 & 1.0000 & 0.24693 & 0.25390 & 0.89512 & Biso & 1.000 & $\mathrm{Si}$ \\
\hline $\mathrm{Si} 20$ & 1.0000 & 0.79120 & 0.02532 & 0.89896 & Biso & 1.000 & $\mathrm{Si}$ \\
\hline Si21 & 1.0000 & 0.79113 & 0.02791 & 0.10748 & Biso & 1.000 & $\mathrm{Si}$ \\
\hline Si22 & 1.0000 & 0.25197 & 0.25855 & 0.10245 & Biso & 1.000 & $\mathrm{Si}$ \\
\hline Si23 & 1.0000 & 0.02148 & 0.80093 & 0.10941 & Biso & 1.000 & $\mathrm{Si}$ \\
\hline $\mathrm{Si} 24$ & 1.0000 & 0.68916 & 0.13224 & 0.23557 & Biso & 1.000 & $\mathrm{Si}$ \\
\hline Si25 & 1.0000 & 0.91798 & 0.59136 & 0.23554 & Biso & 1.000 & $\mathrm{Si}$ \\
\hline Si26 & 1.0000 & 0.45591 & 0.36086 & 0.23212 & Biso & 1.000 & $\mathrm{Si}$ \\
\hline Si27 & 1.0000 & 0.44686 & 0.36071 & 0.43674 & Biso & 1.000 & $\mathrm{Si}$ \\
\hline Si28 & 1.0000 & 0.91372 & 0.58638 & 0.44171 & Biso & 1.000 & $\mathrm{Si}$ \\
\hline Si29 & 1.0000 & 0.68920 & 0.13267 & 0.43658 & Biso & 1.000 & $\mathrm{Si}$ \\
\hline $\mathrm{Si} 30$ & 1.0000 & 0.35569 & 0.47431 & 0.56453 & Biso & 1.000 & $\mathrm{Si}$ \\
\hline Si31 & 1.0000 & 0.58280 & 0.92390 & 0.56859 & Biso & 1.000 & $\mathrm{Si}$ \\
\hline $\mathrm{Si} 32$ & 1.0000 & 0.11463 & 0.69437 & 0.57145 & Biso & 1.000 & $\mathrm{Si}$ \\
\hline Si33 & 1.0000 & 0.11922 & 0.69177 & 0.77433 & Biso & 1.000 & $\mathrm{Si}$ \\
\hline $\mathrm{Si} 34$ & 1.0000 & 0.58109 & 0.92216 & 0.77290 & Biso & 1.000 & $\mathrm{Si}$ \\
\hline Si35 & 1.0000 & 0.35170 & 0.46379 & 0.76948 & Biso & 1.000 & $\mathrm{Si}$ \\
\hline 01 & 1.0000 & 0.92256 & 0.12557 & 0.12559 & Biso & 1.000 & 0 \\
\hline $\mathrm{O} 2$ & 1.0000 & 0.92371 & 0.83432 & 0.12769 & Biso & 1.000 & 0 \\
\hline 03 & 1.0000 & 0.22061 & 0.12810 & 0.12263 & Biso & 1.000 & 0 \\
\hline 04 & 1.0000 & 0.11438 & 0.92290 & 0.87928 & Biso & 1.000 & 0 \\
\hline 05 & 1.0000 & 0.82589 & 0.92843 & 0.88083 & Biso & 1.000 & 0 \\
\hline 06 & 1.0000 & 0.11595 & 0.22298 & 0.88193 & Biso & 1.000 & 0 \\
\hline 07 & 1.0000 & 0.57726 & 0.46474 & 0.44839 & Biso & 1.000 & 0 \\
\hline 08 & 1.0000 & 0.59720 & 0.17224 & 0.43933 & Biso & 1.000 & 0 \\
\hline 09 & 1.0000 & 0.89357 & 0.45949 & 0.45628 & Biso & 1.000 & 0 \\
\hline 010 & 1.0000 & 0.78621 & 0.26429 & 0.21757 & Biso & 1.000 & 0 \\
\hline 011 & 1.0000 & 0.48821 & 0.26197 & 0.21602 & Biso & 1.000 & 0 \\
\hline
\end{tabular}




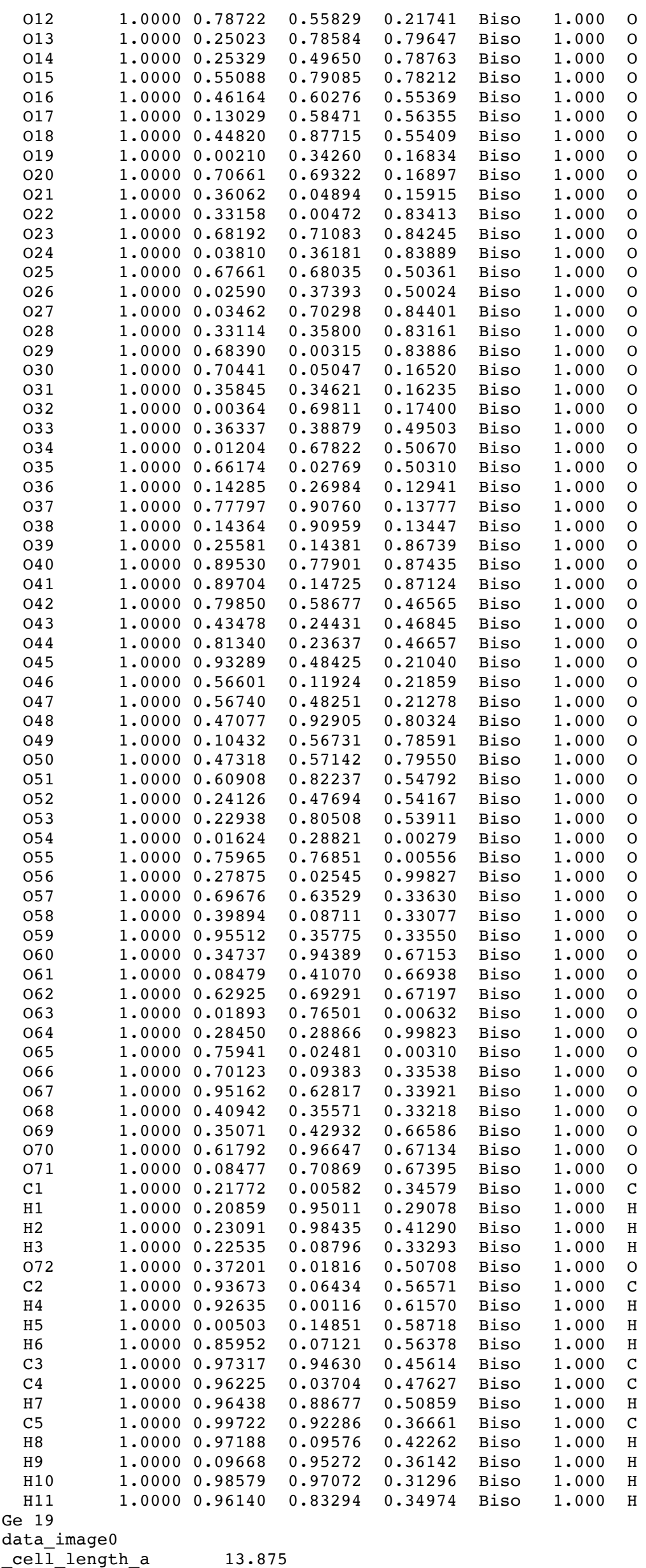




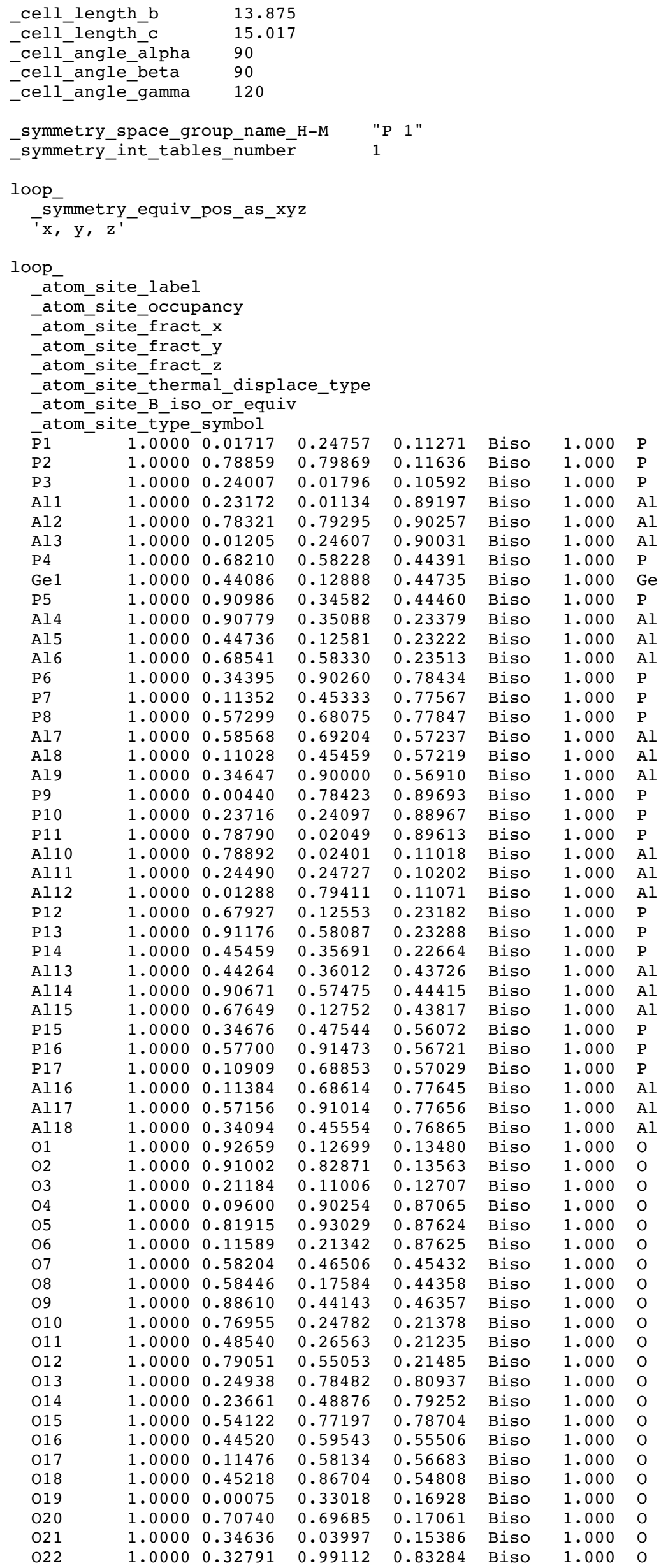




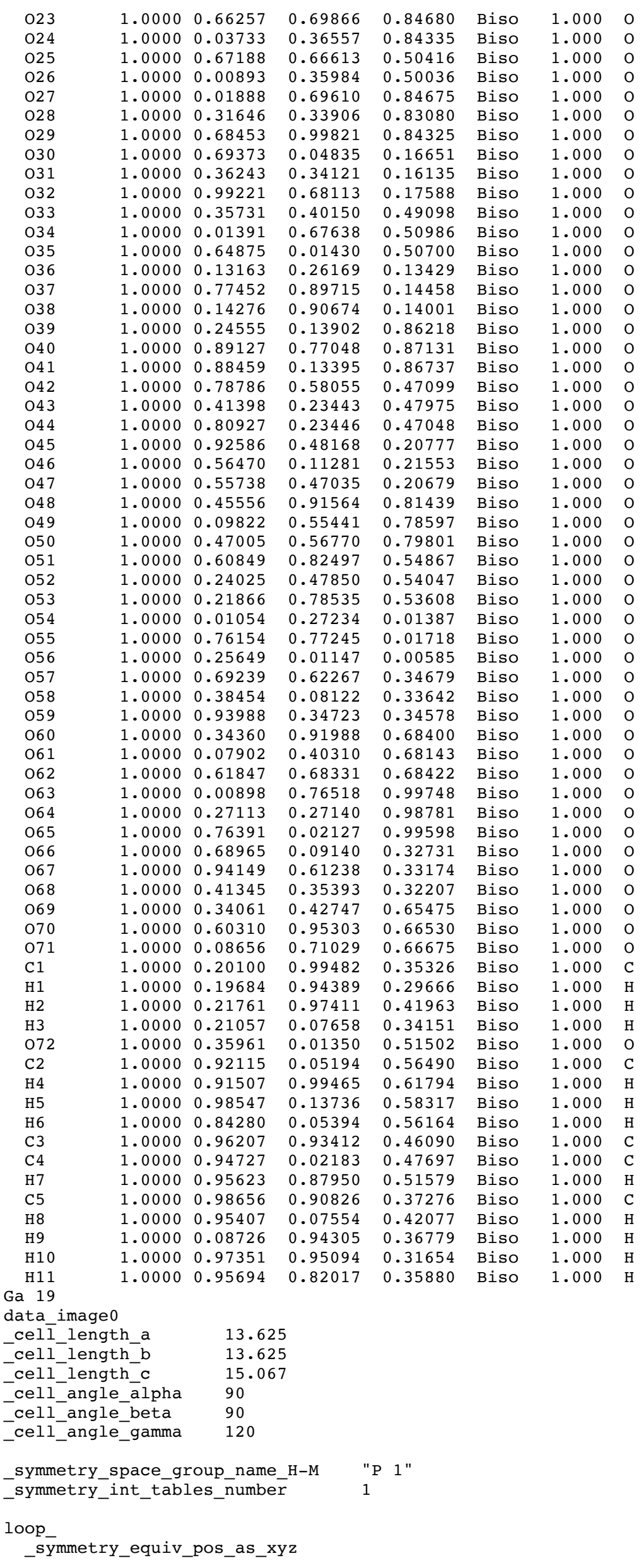


loop

āom site label

_atom_site_occupancy

-atom_site_fract_x

atom site fract $y$

-atom_site_fract_z

-atom_site_thermal_displace_type

-atom_site_B_iso_or_equiv

-atom_site_type_symbol

$\begin{array}{llll}\text { Sil } & 1.0000 & 0.02101 & 0.25604\end{array}$

$\begin{array}{llll}\text { Si2 } & 1.0000 & 0.79252 & 0.80084\end{array}$

$\begin{array}{llll}\mathrm{Si} 3 & 1.0000 & 0.25156 & 0.02896\end{array}$

$\begin{array}{llll}\mathrm{Si} 4 & 1.0000 & 0.24310 & 0.02218\end{array}$

Si5 $1.0000 \quad 0.78983$

Si6 1.00000 .01698

Si7 $1.0000 \quad 0.68498$

Ga1 $1.0000 \quad 0.45832$

Si8 $1.0000 \quad 0.92452$

Si9 $1.0000 \quad 0.91902$

Sil0 $\quad 1.0000 \quad 0.45509$

Si11 $1.0000 \quad 0.68948$

Si12 $\quad 1.0000 \quad 0.34906$

Sil

$1.0000 \quad 0.12060$

$1.0000 \quad 0.58405$

$1.0000 \quad 0.59698$

$1.0000 \quad 0.11982$

$1.0000 \quad 0.34976$

$1.0000 \quad 0.01568$

0.79571

0.25410

0.58892

0.13743

0.35658

0.36170

0.13147

0.59196

0.91380

0.45783

0.69174

0.70135

0.46137

0.90979

$1.0000 \quad 0.24669$

$1.0000 \quad 0.79103$

$1.0000 \quad 0.79181$

$1.0000 \quad 0.25257$

$1.0000 \quad 0.02168$

$1.0000 \quad 0.68917$

$1.0000 \quad 0.91734$

$1.0000 \quad 0.45603$

$1.0000 \quad 0.44315$

$1.0000 \quad 0.91240$

$1.0000 \quad 0.69185$

$1.0000 \quad 0.35656$

$1.0000 \quad 0.58283$

$1.0000 \quad 0.11061$

$1.0000 \quad 0.11798$

$1.0000 \quad 0.58003$

$1.0000 \quad 0.35135$

$1.0000 \quad 0.92346$

$1.0000 \quad 0.92414$

$1.0000 \quad 0.22088$

$1.0000 \quad 0.11276$

$1.0000 \quad 0.82553$

$1.0000 \quad 0.11594$

$1.0000 \quad 0.57379$

$1.0000 \quad 0.60861$

$1.0000 \quad 0.89645$

$1.0000 \quad 0.78707$

$1.0000 \quad 0.49088$

$1.0000 \quad 0.78655$

$1.0000 \quad 0.24932$

$1.0000 \quad 0.25300$

$1.0000 \quad 0.54928$

$1.0000 \quad 0.46532$

$1.0000 \quad 0.12007$

$1.0000 \quad 0.44790$

$1.0000 \quad 0.00205$

$1.0000 \quad 0.70693$

$1.0000 \quad 0.36212$

$1.0000 \quad 0.32992$

$1.0000 \quad 0.68028$

$1.0000 \quad 0.03741$

$1.0000 \quad 0.67944$

$1.0000 \quad 0.03082$

$1.0000 \quad 0.03424$

$1.0000 \quad 0.33118$

$1.0000 \quad 0.68333$

$1.0000 \quad 0.70558$

$1.0000 \quad 0.35942$

$\begin{array}{lll}032 & 1.0000 & 0.00341 \\ 033 & 1.0000 & 0.36003\end{array}$

0.79142

0.25324

0.02424

0.02813

0.25886

0.80127

0.13225

0.59069

0.36029

0.36122

0.58325

0.13508

0.47830

0.92349

0.69270

0.69057

0.92072

0.46246

0.12534

0.83498

0.12829

0.92092

0.92704

0.22284

0.10516

0.10976

.89304 Biso

0.90152 Biso

0.89796 Biso

0.43854 Biso

0.44253 Biso

0.43801 Biso

0.23242 Biso

0.22980 Biso

0.23530 Biso

0.77462 Biso

0.76903 Biso

0.77223 Biso

0.56972 Biso

0.56950 Biso

0.56633 Biso

0.90157 Biso

0.89344 Biso

0.89865 Biso

0.10730 Biso

0.10090 Biso

0.10999 Biso

0.23550 Biso

$1.000 \mathrm{Si}$

$1.000 \mathrm{Si}$

$1.000 \mathrm{Si}$

$1.000 \mathrm{Si}$

$1.000 \mathrm{Si}$

$1.000 \mathrm{Si}$

$1.000 \mathrm{Si}$

$1.000 \mathrm{Ga}$

$1.000 \mathrm{Si}$

$1.000 \mathrm{Si}$

$1.000 \mathrm{Si}$

$1.000 \mathrm{Si}$

$1.000 \mathrm{Si}$

$1.000 \mathrm{Si}$

$1.000 \mathrm{Si}$

$1.000 \mathrm{Si}$

$1.000 \mathrm{Si}$

$1.000 \mathrm{Si}$

$1.000 \mathrm{Si}$

$1.000 \mathrm{Si}$

$1.000 \mathrm{Si}$

$1.000 \mathrm{Si}$

$1.000 \mathrm{Si}$

$1.000 \mathrm{Si}$

0.23104 Biso $1.000 \mathrm{Si}$

0.43636 Biso $1.000 \mathrm{Si}$

0.44220 Biso $1.000 \mathrm{Si}$

0.43675 Biso $1.000 \mathrm{Si}$

0.56355 Biso $1.000 \mathrm{Si}$

0.56820 Biso $1.000 \mathrm{Si}$

0.57267 Biso $1.000 \mathrm{Si}$

0.77421 Biso $1.000 \mathrm{Si}$

0.77311 Biso $1.000 \mathrm{Si}$

0.76736 Biso $1.000 \mathrm{Si}$

0.12539 Biso 1.0000

0.12832 Biso 1.0000

0.12091 Biso $1.000 \quad 0$

0.87778 Biso 1.0000

0.88112 Biso $1.000 \quad 0$

$0.18620 \quad 0.44122$ Biso $1.000 \quad 0$

$\begin{array}{lllll}0.45795 & 0.45725 & \text { Biso } & 1.000 & 0\end{array}$

$0.26422 \quad 0.21882$ Biso $1.000 \quad 0$

$\begin{array}{lllll}0.26373 & 0.21245 & \text { Biso } & 1.000 & 0\end{array}$

0.557530 .21692 Biso $1.000 \quad 0$

$0.78423 \quad 0.79601$ Biso $1.000 \quad 0$

$\begin{array}{lllll}0.49512 & 0.78659 & \text { Biso } & 1.000 & 0\end{array}$

0.789290 .78270 Biso $1.000 \quad 0$

$0.60521 \quad 0.55502$ Biso $1.000 \quad 0$

$\begin{array}{lllll}0.57961 & 0.56677 & \text { Biso } & 1.000 & 0\end{array}$

$0.87453 \quad 0.55299$ Biso $1.000 \quad 0$

$0.34272 \quad 0.16641$ Biso $1.000 \quad 0$

0.693590 .16977 Biso $1.000 \quad 0$

$0.05026 \quad 0.15614$ Biso $1.000 \quad 0$

$0.00331 \quad 0.83244$ Biso $1.000 \quad 0$

$\begin{array}{lllll}0.70940 & 0.84377 & \text { Biso } & 1.000 & 0\end{array}$

$\begin{array}{lllll}0.36138 & 0.83847 & \text { Biso } & 1.000 & 0\end{array}$

0.680150 .50463 Biso $1.000 \quad 0$

0.373210 .49795 Biso $1.000 \quad 0$

0.700390 .84574 Biso $1.000 \quad 0$

$0.35660 \quad 0.82933$ Biso $1.000 \quad 0$

0.001540 .83880 Biso 1.0000

$0.05107 \quad 0.16532$ Biso $1.000 \quad 0$

0.346550 .16063 Biso 1.000 o

$\begin{array}{lllll}0.69864 & 0.17507 & \text { Biso } & 1.000 & 0\end{array}$

0.39448

0.48991 Biso

$1.000 \quad 0$ 


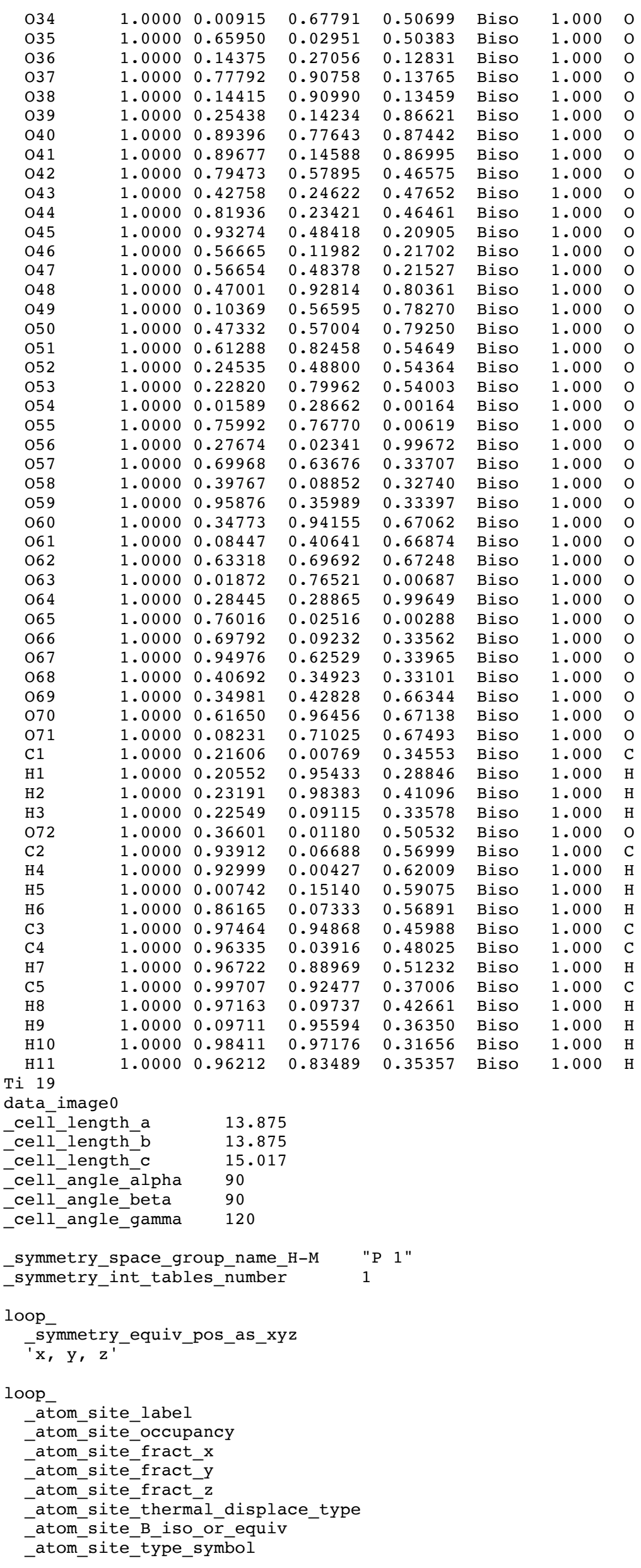




\begin{tabular}{|c|c|c|c|c|c|c|c|}
\hline P1 & 1.0000 & 0.01786 & 0.24774 & 0.11163 & Biso & 1.000 & $\mathrm{P}$ \\
\hline P2 & 1.0000 & 0.78979 & 0.80003 & 0.11725 & Biso & 1.000 & $\mathrm{P}$ \\
\hline P3 & 1.0000 & 0.24111 & 0.01860 & 0.10308 & Biso & 1.000 & $\mathrm{P}$ \\
\hline Al1 & 1.0000 & 0.22982 & 0.00932 & 0.88908 & Biso & 1.000 & Al \\
\hline Al2 & 1.0000 & 0.78240 & 0.79217 & 0.90330 & Biso & 1.000 & $\mathrm{Al}$ \\
\hline Al3 & 1.0000 & 0.01135 & 0.24476 & 0.89896 & Biso & 1.000 & $\mathrm{Al}$ \\
\hline P 4 & 1.0000 & 0.68219 & 0.58371 & 0.44418 & Biso & 1.000 & $\mathrm{P}$ \\
\hline Til & 1.0000 & 0.43852 & 0.12845 & 0.44865 & Biso & 1.000 & $\mathrm{Ti}$ \\
\hline P5 & 1.0000 & 0.91398 & 0.34642 & 0.44305 & Biso & 1.000 & $\mathrm{P}$ \\
\hline Al4 & 1.0000 & 0.90919 & 0.35195 & 0.23261 & Biso & 1.000 & Al \\
\hline Al5 & 1.0000 & 0.44684 & 0.12603 & 0.22995 & Biso & 1.000 & $\mathrm{Al}$ \\
\hline Al 6 & 1.0000 & 0.68631 & 0.58406 & 0.23570 & Biso & 1.000 & $\mathrm{Al}$ \\
\hline P6 & 1.0000 & 0.34221 & 0.89778 & 0.78625 & Biso & 1.000 & $\mathrm{P}$ \\
\hline P7 & 1.0000 & 0.11260 & 0.45161 & 0.77480 & Biso & 1.000 & $\mathrm{P}$ \\
\hline P8 & 1.0000 & 0.57290 & 0.67968 & 0.77866 & Biso & 1.000 & $\mathrm{P}$ \\
\hline Al 7 & 1.0000 & 0.59061 & 0.69410 & 0.57367 & Biso & 1.000 & $\mathrm{Al}$ \\
\hline Al8 & 1.0000 & 0.11015 & 0.45534 & 0.57303 & Biso & 1.000 & $\mathrm{Al}$ \\
\hline A19 & 1.0000 & 0.34450 & 0.89319 & 0.57000 & Biso & 1.000 & Al \\
\hline P9 & 1.0000 & 0.00287 & 0.78248 & 0.89696 & Biso & 1.000 & $\mathrm{P}$ \\
\hline P10 & 1.0000 & 0.23638 & 0.23991 & 0.88697 & Biso & 1.000 & $\mathrm{P}$ \\
\hline P11 & 1.0000 & 0.78748 & 0.01948 & 0.89605 & Biso & 1.000 & $\mathrm{P}$ \\
\hline Al10 & 1.0000 & 0.78959 & 0.02475 & 0.11048 & Biso & 1.000 & $\mathrm{Al}$ \\
\hline Al11 & 1.0000 & 0.24591 & 0.24826 & 0.09955 & Biso & 1.000 & Al \\
\hline Al12 & 1.0000 & 0.01406 & 0.79559 & 0.11115 & Biso & 1.000 & Al \\
\hline P12 & 1.0000 & 0.68021 & 0.12684 & 0.23191 & Biso & 1.000 & $\mathrm{P}$ \\
\hline P13 & 1.0000 & 0.91258 & 0.58202 & 0.23366 & Biso & 1.000 & $\mathrm{P}$ \\
\hline P14 & 1.0000 & 0.45423 & 0.35782 & 0.22558 & Biso & 1.000 & $\mathrm{P}$ \\
\hline Al13 & 1.0000 & 0.43813 & 0.36493 & 0.43591 & Biso & 1.000 & $\mathrm{Al}$ \\
\hline Al1 14 & 1.0000 & 0.90601 & 0.57367 & 0.44468 & Biso & 1.000 & Al \\
\hline Al15 & 1.0000 & 0.68098 & 0.12804 & 0.43876 & Biso & 1.000 & $\mathrm{Al}$ \\
\hline P15 & 1.0000 & 0.34766 & 0.48112 & 0.55966 & Biso & 1.000 & $\mathrm{P}$ \\
\hline P 16 & 1.0000 & 0.57835 & 0.91566 & 0.56824 & Biso & 1.000 & $\mathrm{P}$ \\
\hline P17 & 1.0000 & 0.10498 & 0.68694 & 0.57245 & Biso & 1.000 & $\mathrm{P}$ \\
\hline Al16 & 1.0000 & 0.11179 & 0.68439 & 0.77761 & Biso & 1.000 & $\mathrm{Al}$ \\
\hline Al17 & 1.0000 & 0.56995 & 0.90902 & 0.77748 & Biso & 1.000 & Al \\
\hline Al18 & 1.0000 & 0.34032 & 0.45518 & 0.76692 & Biso & 1.000 & $\mathrm{Al}$ \\
\hline 01 & 1.0000 & 0.92743 & 0.12757 & 0.13512 & Biso & 1.000 & 0 \\
\hline $\mathrm{O} 2$ & 1.0000 & 0.91145 & 0.83060 & 0.13628 & Biso & 1.000 & 0 \\
\hline 03 & 1.0000 & 0.21336 & 0.11108 & 0.12411 & Biso & 1.000 & 0 \\
\hline 04 & 1.0000 & 0.09418 & 0.89985 & 0.86806 & Biso & 1.000 & 0 \\
\hline 05 & 1.0000 & 0.81874 & 0.92935 & 0.87585 & Biso & 1.000 & 0 \\
\hline 06 & 1.0000 & 0.11510 & 0.21246 & 0.87360 & Biso & 1.000 & 0 \\
\hline 07 & 1.0000 & 0.57665 & 0.47060 & 0.45464 & Biso & 1.000 & 0 \\
\hline 08 & 1.0000 & 0.58533 & 0.17207 & 0.44525 & Biso & 1.000 & 0 \\
\hline 09 & 1.0000 & 0.88960 & 0.44155 & 0.46227 & Biso & 1.000 & 0 \\
\hline 010 & 1.0000 & 0.77041 & 0.24924 & 0.21377 & Biso & 1.000 & 0 \\
\hline 011 & 1.0000 & 0.48513 & 0.26654 & 0.21217 & Biso & 1.000 & 0 \\
\hline 012 & 1.0000 & 0.79110 & 0.55079 & 0.21541 & Biso & 1.000 & 0 \\
\hline 013 & 1.0000 & 0.24666 & 0.78158 & 0.81374 & Biso & 1.000 & 0 \\
\hline 014 & 1.0000 & 0.23585 & 0.48791 & 0.79218 & Biso & 1.000 & 0 \\
\hline 015 & 1.0000 & 0.54111 & 0.77106 & 0.78484 & Biso & 1.000 & 0 \\
\hline 016 & 1.0000 & 0.45076 & 0.59797 & 0.55387 & Biso & 1.000 & 0 \\
\hline 017 & 1.0000 & 0.10287 & 0.57590 & 0.57180 & Biso & 1.000 & 0 \\
\hline 018 & 1.0000 & 0.45405 & 0.86648 & 0.54563 & Biso & 1.000 & 0 \\
\hline 019 & 1.0000 & 0.00149 & 0.33132 & 0.16698 & Biso & 1.000 & 0 \\
\hline 020 & 1.0000 & 0.70891 & 0.69788 & 0.17132 & Biso & 1.000 & 0 \\
\hline $\mathrm{O} 21$ & 1.0000 & 0.34937 & 0.04225 & 0.14846 & Biso & 1.000 & 0 \\
\hline $\mathrm{O} 22$ & 1.0000 & 0.32603 & 0.98904 & 0.82978 & Biso & 1.000 & 0 \\
\hline 023 & 1.0000 & 0.66049 & 0.69772 & 0.84901 & Biso & 1.000 & 0 \\
\hline 024 & 1.0000 & 0.03643 & 0.36491 & 0.84311 & Biso & 1.000 & 0 \\
\hline 025 & 1.0000 & 0.67892 & 0.67114 & 0.50509 & Biso & 1.000 & 0 \\
\hline 026 & 1.0000 & 0.01435 & 0.36131 & 0.49761 & Biso & 1.000 & 0 \\
\hline $\mathrm{O} 27$ & 1.0000 & 0.01613 & 0.69251 & 0.84842 & Biso & 1.000 & 0 \\
\hline 028 & 1.0000 & 0.31548 & 0.33734 & 0.82739 & Biso & 1.000 & 0 \\
\hline 029 & 1.0000 & 0.68322 & 0.99646 & 0.84417 & Biso & 1.000 & 0 \\
\hline 030 & 1.0000 & 0.69443 & 0.04994 & 0.16601 & Biso & 1.000 & 0 \\
\hline 031 & 1.0000 & 0.36396 & 0.34269 & 0.15834 & Biso & 1.000 & 0 \\
\hline 032 & 1.0000 & 0.99277 & 0.68276 & 0.17691 & Biso & 1.000 & 0 \\
\hline 033 & 1.0000 & 0.35031 & 0.40556 & 0.48698 & Biso & 1.000 & 0 \\
\hline 034 & 1.0000 & 0.01062 & 0.67709 & 0.51188 & Biso & 1.000 & 0 \\
\hline 035 & 1.0000 & 0.65229 & 0.01510 & 0.50853 & Biso & 1.000 & 0 \\
\hline 036 & 1.0000 & 0.13265 & 0.26239 & 0.13293 & Biso & 1.000 & 0 \\
\hline 037 & 1.0000 & 0.77518 & 0.89811 & 0.14573 & Biso & 1.000 & 0 \\
\hline 038 & 1.0000 & 0.14471 & 0.90808 & 0.13954 & Biso & 1.000 & 0 \\
\hline 039 & 1.0000 & 0.24430 & 0.13752 & 0.85997 & Biso & 1.000 & 0 \\
\hline 040 & 1.0000 & 0.88939 & 0.76819 & 0.87179 & Biso & 1.000 & 0 \\
\hline 041 & 1.0000 & 0.88363 & 0.13278 & 0.86625 & Biso & 1.000 & 0 \\
\hline 042 & 1.0000 & 0.78327 & 0.57281 & 0.47043 & Biso & 1.000 & 0 \\
\hline 043 & 1.0000 & 0.41422 & 0.24074 & 0.47890 & Biso & 1.000 & 0 \\
\hline 044 & 1.0000 & 0.81439 & 0.23478 & 0.47001 & Biso & 1.000 & 0 \\
\hline
\end{tabular}




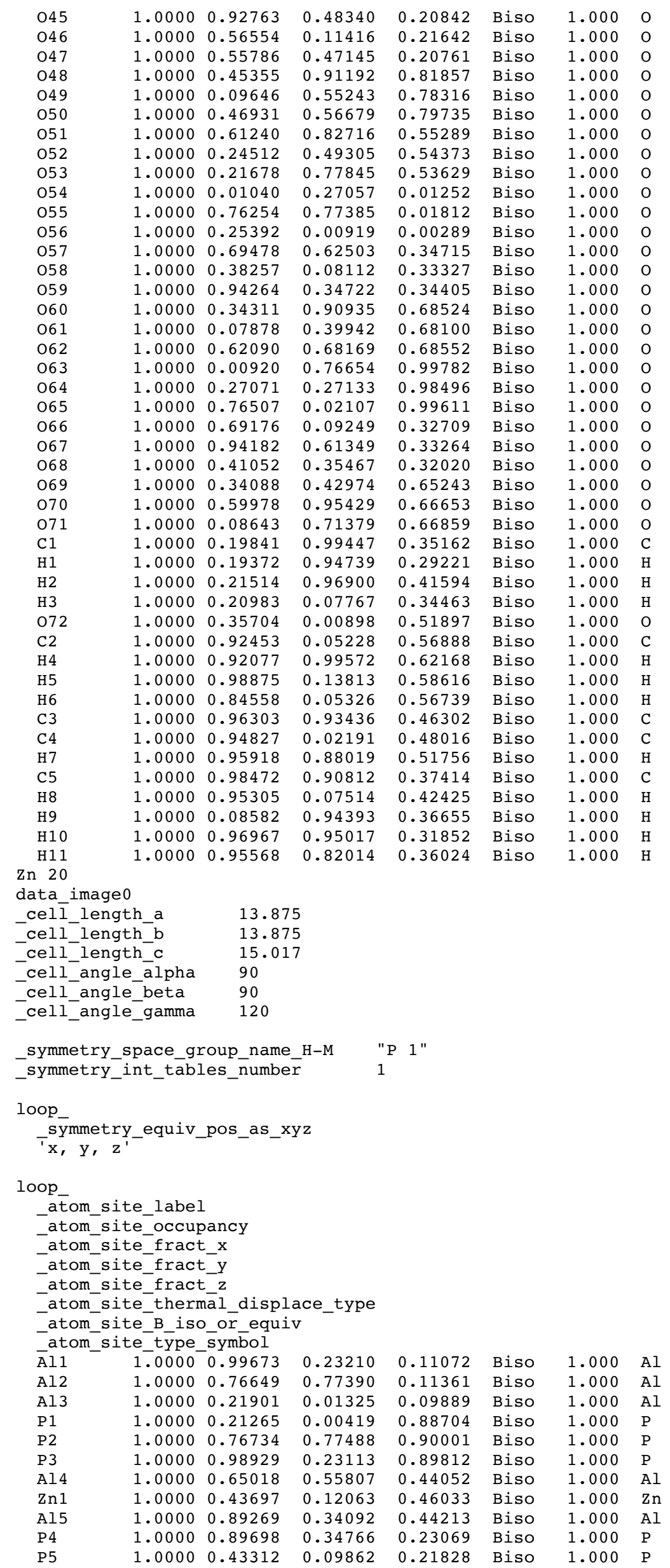




\begin{tabular}{|c|c|c|c|c|c|c|c|}
\hline P6 & 1.0000 & 0.65834 & 0.55593 & 0.22922 & Biso & 1.000 & $\mathrm{P}$ \\
\hline Al6 & 1.0000 & 0.32286 & 0.89526 & 0.77666 & Biso & 1.000 & Al \\
\hline Al7 & 1.0000 & 0.09823 & 0.43862 & 0.77552 & Biso & 1.000 & Al \\
\hline Al8 & 1.0000 & 0.55815 & 0.67651 & 0.77323 & Biso & 1.000 & Al \\
\hline P7 & 1.0000 & 0.56454 & 0.68396 & 0.56566 & Biso & 1.000 & $P$ \\
\hline P8 & 1.0000 & 0.09471 & 0.44023 & 0.56972 & Biso & 1.000 & $P$ \\
\hline P9 & 1.0000 & 0.32144 & 0.88664 & 0.56910 & Biso & 1.000 & $\mathrm{P}$ \\
\hline Al9 & 1.0000 & 0.99397 & 0.77758 & 0.90184 & Biso & 1.000 & Al \\
\hline Al10 & 1.0000 & 0.22075 & 0.23589 & 0.89566 & Biso & 1.000 & Al \\
\hline Al11 & 1.0000 & 0.76811 & 0.00134 & 0.90229 & Biso & 1.000 & Al \\
\hline P 10 & 1.0000 & 0.77263 & 0.00349 & 0.11589 & Biso & 1.000 & $\mathrm{P}$ \\
\hline P11 & 1.0000 & 0.22374 & 0.23659 & 0.10677 & Biso & 1.000 & $P$ \\
\hline P12 & 1.0000 & 0.00029 & 0.78655 & 0.11683 & Biso & 1.000 & $\mathrm{P}$ \\
\hline Al12 & 1.0000 & 0.67048 & 0.12161 & 0.23085 & Biso & 1.000 & $\mathrm{Al}$ \\
\hline Al13 & 1.0000 & 0.89663 & 0.57355 & 0.23697 & Biso & 1.000 & Al \\
\hline Al14 & 1.0000 & 0.43297 & 0.32823 & 0.23945 & Biso & 1.000 & Al \\
\hline P13 & 1.0000 & 0.41936 & 0.34132 & 0.44309 & Biso & 1.000 & $\mathrm{P}$ \\
\hline P14 & 1.0000 & 0.88524 & 0.56716 & 0.44711 & Biso & 1.000 & $P$ \\
\hline P15 & 1.0000 & 0.66464 & 0.12191 & 0.43954 & Biso & 1.000 & $\mathrm{P}$ \\
\hline Al15 & 1.0000 & 0.33154 & 0.46358 & 0.56759 & Biso & 1.000 & Al \\
\hline Al16 & 1.0000 & 0.55656 & 0.90703 & 0.57173 & Biso & 1.000 & Al \\
\hline Al17 & 1.0000 & 0.08509 & 0.66913 & 0.57825 & Biso & 1.000 & Al \\
\hline P16 & 1.0000 & 0.09549 & 0.66914 & 0.78371 & Biso & 1.000 & $\mathrm{P}$ \\
\hline P17 & 1.0000 & 0.55548 & 0.90492 & 0.77878 & Biso & 1.000 & $P$ \\
\hline P18 & 1.0000 & 0.32986 & 0.44905 & 0.77758 & Biso & 1.000 & $P$ \\
\hline 01 & 1.0000 & 0.89504 & 0.09302 & 0.13438 & Biso & 1.000 & 0 \\
\hline $\mathrm{O} 2$ & 1.0000 & 0.90452 & 0.80883 & 0.13812 & Biso & 1.000 & 0 \\
\hline 03 & 1.0000 & 0.17796 & 0.11083 & 0.12060 & Biso & 1.000 & 0 \\
\hline 04 & 1.0000 & 0.09358 & 0.91101 & 0.86416 & Biso & 1.000 & 0 \\
\hline 05 & 1.0000 & 0.80145 & 0.89704 & 0.88039 & Biso & 1.000 & 0 \\
\hline 06 & 1.0000 & 0.08439 & 0.20753 & 0.87814 & Biso & 1.000 & 0 \\
\hline 07 & 1.0000 & 0.54411 & 0.42220 & 0.46476 & Biso & 1.000 & 0 \\
\hline 08 & 1.0000 & 0.58953 & 0.17317 & 0.44443 & Biso & 1.000 & 0 \\
\hline 09 & 1.0000 & 0.86352 & 0.44829 & 0.46364 & Biso & 1.000 & 0 \\
\hline 010 & 1.0000 & 0.77435 & 0.25977 & 0.21234 & Biso & 1.000 & 0 \\
\hline 011 & 1.0000 & 0.44977 & 0.20962 & 0.25427 & Biso & 1.000 & 0 \\
\hline 012 & 1.0000 & 0.75926 & 0.53944 & 0.21667 & Biso & 1.000 & 0 \\
\hline 013 & 1.0000 & 0.21806 & 0.75828 & 0.80089 & Biso & 1.000 & 0 \\
\hline 014 & 1.0000 & 0.23589 & 0.47398 & 0.79972 & Biso & 1.000 & 0 \\
\hline 015 & 1.0000 & 0.52489 & 0.78202 & 0.78589 & Biso & 1.000 & 0 \\
\hline 016 & 1.0000 & 0.43918 & 0.60149 & 0.55304 & Biso & 1.000 & 0 \\
\hline 017 & 1.0000 & 0.09995 & 0.55292 & 0.56690 & Biso & 1.000 & 0 \\
\hline 018 & 1.0000 & 0.41226 & 0.85281 & 0.56344 & Biso & 1.000 & 0 \\
\hline 019 & 1.0000 & 0.97449 & 0.32494 & 0.17302 & Biso & 1.000 & 0 \\
\hline 020 & 1.0000 & 0.67121 & 0.65201 & 0.16954 & Biso & 1.000 & 0 \\
\hline 021 & 1.0000 & 0.35457 & 0.06080 & 0.13798 & Biso & 1.000 & 0 \\
\hline 022 & 1.0000 & 0.29987 & 0.99049 & 0.83517 & Biso & 1.000 & 0 \\
\hline 023 & 1.0000 & 0.66453 & 0.69583 & 0.84554 & Biso & 1.000 & 0 \\
\hline $\mathrm{O} 24$ & 1.0000 & 0.00480 & 0.33221 & 0.84506 & Biso & 1.000 & 0 \\
\hline 025 & 1.0000 & 0.63381 & 0.65651 & 0.50171 & Biso & 1.000 & 0 \\
\hline 026 & 1.0000 & 0.34025 & 0.97754 & 0.50357 & Biso & 1.000 & 0 \\
\hline 027 & 1.0000 & 0.00482 & 0.35804 & 0.50625 & Biso & 1.000 & 0 \\
\hline 028 & 1.0000 & 0.01889 & 0.67843 & 0.85264 & Biso & 1.000 & 0 \\
\hline 029 & 1.0000 & 0.31525 & 0.34890 & 0.83201 & Biso & 1.000 & 0 \\
\hline 030 & 1.0000 & 0.64936 & 0.97679 & 0.84406 & Biso & 1.000 & 0 \\
\hline 031 & 1.0000 & 0.69310 & 0.02782 & 0.16953 & Biso & 1.000 & 0 \\
\hline 032 & 1.0000 & 0.32791 & 0.30385 & 0.16364 & Biso & 1.000 & 0 \\
\hline 033 & 1.0000 & 0.98777 & 0.68755 & 0.17159 & Biso & 1.000 & 0 \\
\hline 034 & 1.0000 & 0.34643 & 0.37316 & 0.49798 & Biso & 1.000 & O \\
\hline 035 & 1.0000 & 0.97535 & 0.65097 & 0.51015 & Biso & 1.000 & 0 \\
\hline 036 & 1.0000 & 0.62602 & 0.01952 & 0.49987 & Biso & 1.000 & 0 \\
\hline 037 & 1.0000 & 0.13245 & 0.26190 & 0.13529 & Biso & 1.000 & 0 \\
\hline 038 & 1.0000 & 0.75378 & 0.88892 & 0.14448 & Biso & 1.000 & 0 \\
\hline 039 & 1.0000 & 0.11251 & 0.88849 & 0.14319 & Biso & 1.000 & 0 \\
\hline 040 & 1.0000 & 0.22559 & 0.11750 & 0.86392 & Biso & 1.000 & 0 \\
\hline 041 & 1.0000 & 0.86282 & 0.75536 & 0.87306 & Biso & 1.000 & 0 \\
\hline 042 & 1.0000 & 0.87893 & 0.12968 & 0.86991 & Biso & 1.000 & O \\
\hline 043 & 1.0000 & 0.77815 & 0.56975 & 0.46549 & Biso & 1.000 & 0 \\
\hline 044 & 1.0000 & 0.38521 & 0.22140 & 0.46442 & Biso & 1.000 & 0 \\
\hline 045 & 1.0000 & 0.78265 & 0.20986 & 0.46919 & Biso & 1.000 & 0 \\
\hline 046 & 1.0000 & 0.91498 & 0.46271 & 0.20574 & Biso & 1.000 & 0 \\
\hline 047 & 1.0000 & 0.54494 & 0.10977 & 0.19190 & Biso & 1.000 & 0 \\
\hline 048 & 1.0000 & 0.55406 & 0.44673 & 0.20156 & Biso & 1.000 & 0 \\
\hline 049 & 1.0000 & 0.45299 & 0.91343 & 0.80473 & Biso & 1.000 & 0 \\
\hline 050 & 1.0000 & 0.08356 & 0.55411 & 0.79349 & Biso & 1.000 & 0 \\
\hline 051 & 1.0000 & 0.44171 & 0.55049 & 0.80260 & Biso & 1.000 & 0 \\
\hline 052 & 1.0000 & 0.58738 & 0.80209 & 0.54506 & Biso & 1.000 & 0 \\
\hline 053 & 1.0000 & 0.20724 & 0.45713 & 0.53923 & Biso & 1.000 & 0 \\
\hline 054 & 1.0000 & 0.20957 & 0.78334 & 0.54556 & Biso & 1.000 & 0 \\
\hline 055 & 1.0000 & 0.98727 & 0.25556 & 0.99768 & Biso & 1.000 & 0 \\
\hline
\end{tabular}




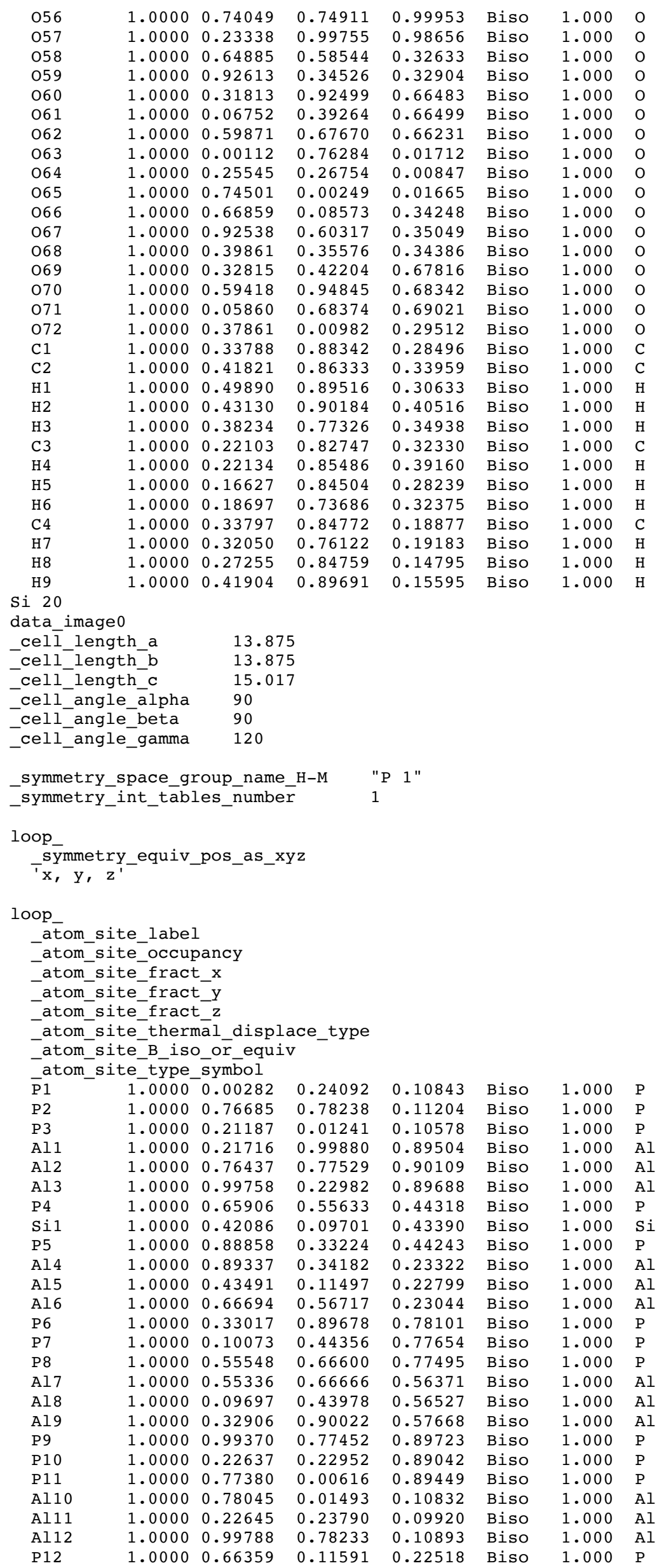




\begin{tabular}{|c|c|c|c|c|c|c|c|}
\hline P13 & 1.0000 & 0.89669 & 0.57104 & 0.23057 & Biso & 1.000 & $\mathrm{P}$ \\
\hline P14 & 1.0000 & 0.44164 & 0.34637 & 0.22866 & Biso & 1.000 & $\mathrm{P}$ \\
\hline Al13 & 1.0000 & 0.42738 & 0.33451 & 0.42967 & Biso & 1.000 & Al \\
\hline Al14 & 1.0000 & 0.88999 & 0.56289 & 0.44233 & Biso & 1.000 & Al \\
\hline Al15 & 1.0000 & 0.65468 & 0.10767 & 0.43417 & Biso & 1.000 & $\mathrm{Al}$ \\
\hline P15 & 1.0000 & 0.32452 & 0.44090 & 0.55743 & Biso & 1.000 & $P$ \\
\hline P16 & 1.0000 & 0.56058 & 0.89883 & 0.56903 & Biso & 1.000 & $\mathrm{P}$ \\
\hline P17 & 1.0000 & 0.09921 & 0.66934 & 0.56589 & Biso & 1.000 & $\mathrm{P}$ \\
\hline Al16 & 1.0000 & 0.10072 & 0.67000 & 0.77570 & Biso & 1.000 & Al \\
\hline Al17 & 1.0000 & 0.56207 & 0.89731 & 0.77289 & Biso & 1.000 & Al \\
\hline Al18 & 1.0000 & 0.32680 & 0.44203 & 0.76866 & Biso & 1.000 & Al \\
\hline 01 & 1.0000 & 0.91805 & 0.11898 & 0.13318 & Biso & 1.000 & 0 \\
\hline $\mathrm{O} 2$ & 1.0000 & 0.88800 & 0.80842 & 0.12328 & Biso & 1.000 & 0 \\
\hline 03 & 1.0000 & 0.16735 & 0.09356 & 0.11435 & Biso & 1.000 & 0 \\
\hline 04 & 1.0000 & 0.08074 & 0.89437 & 0.86961 & Biso & 1.000 & 0 \\
\hline 05 & 1.0000 & 0.80018 & 0.91257 & 0.87544 & Biso & 1.000 & 0 \\
\hline 06 & 1.0000 & 0.10367 & 0.19831 & 0.87993 & Biso & 1.000 & 0 \\
\hline 07 & 1.0000 & 0.56633 & 0.43505 & 0.45864 & Biso & 1.000 & 0 \\
\hline 08 & 1.0000 & 0.55208 & 0.14216 & 0.44153 & Biso & 1.000 & 0 \\
\hline 09 & 1.0000 & 0.86296 & 0.42672 & 0.45993 & Biso & 1.000 & 0 \\
\hline 010 & 1.0000 & 0.75479 & 0.23869 & 0.21524 & Biso & 1.000 & 0 \\
\hline 011 & 1.0000 & 0.47456 & 0.25527 & 0.23734 & Biso & 1.000 & 0 \\
\hline 012 & 1.0000 & 0.77697 & 0.54249 & 0.20844 & Biso & 1.000 & 0 \\
\hline 013 & 1.0000 & 0.23925 & 0.77406 & 0.79481 & Biso & 1.000 & 0 \\
\hline 014 & 1.0000 & 0.22274 & 0.47472 & 0.79197 & Biso & 1.000 & 0 \\
\hline 015 & 1.0000 & 0.52686 & 0.75856 & 0.79113 & Biso & 1.000 & 0 \\
\hline 016 & 1.0000 & 0.41589 & 0.56270 & 0.54080 & Biso & 1.000 & 0 \\
\hline 017 & 1.0000 & 0.12409 & 0.57530 & 0.54489 & Biso & 1.000 & 0 \\
\hline 018 & 1.0000 & 0.43708 & 0.86744 & 0.57348 & Biso & 1.000 & 0 \\
\hline 019 & 1.0000 & 0.98209 & 0.32131 & 0.16394 & Biso & 1.000 & 0 \\
\hline 020 & 1.0000 & 0.68842 & 0.68527 & 0.17215 & Biso & 1.000 & 0 \\
\hline 021 & 1.0000 & 0.32120 & 0.05717 & 0.15700 & Biso & 1.000 & 0 \\
\hline 022 & 1.0000 & 0.31619 & 0.97195 & 0.84841 & Biso & 1.000 & 0 \\
\hline 023 & 1.0000 & 0.65351 & 0.68395 & 0.83391 & Biso & 1.000 & 0 \\
\hline 024 & 1.0000 & 0.02172 & 0.34475 & 0.83454 & Biso & 1.000 & 0 \\
\hline 025 & 1.0000 & 0.64113 & 0.63859 & 0.49938 & Biso & 1.000 & 0 \\
\hline 026 & 1.0000 & 0.34711 & 0.00515 & 0.50641 & Biso & 1.000 & 0 \\
\hline 027 & 1.0000 & 0.98234 & 0.34433 & 0.50374 & Biso & 1.000 & 0 \\
\hline 028 & 1.0000 & 0.00893 & 0.69044 & 0.84170 & Biso & 1.000 & 0 \\
\hline 029 & 1.0000 & 0.30241 & 0.32487 & 0.82854 & Biso & 1.000 & 0 \\
\hline 030 & 1.0000 & 0.66858 & 0.98534 & 0.84489 & Biso & 1.000 & 0 \\
\hline 031 & 1.0000 & 0.68447 & 0.04149 & 0.16176 & Biso & 1.000 & 0 \\
\hline 032 & 1.0000 & 0.34597 & 0.31180 & 0.16247 & Biso & 1.000 & 0 \\
\hline 033 & 1.0000 & 0.98045 & 0.67165 & 0.17537 & Biso & 1.000 & 0 \\
\hline 034 & 1.0000 & 0.34141 & 0.35936 & 0.50018 & Biso & 1.000 & 0 \\
\hline 035 & 1.0000 & 0.00449 & 0.65813 & 0.50558 & Biso & 1.000 & 0 \\
\hline 036 & 1.0000 & 0.62658 & 0.99337 & 0.50269 & Biso & 1.000 & 0 \\
\hline 037 & 1.0000 & 0.12182 & 0.26649 & 0.12870 & Biso & 1.000 & 0 \\
\hline 038 & 1.0000 & 0.76036 & 0.88522 & 0.14059 & Biso & 1.000 & 0 \\
\hline 039 & 1.0000 & 0.12299 & 0.89922 & 0.14357 & Biso & 1.000 & 0 \\
\hline 040 & 1.0000 & 0.23719 & 0.12841 & 0.86455 & Biso & 1.000 & 0 \\
\hline 041 & 1.0000 & 0.87707 & 0.75612 & 0.87959 & Biso & 1.000 & 0 \\
\hline 042 & 1.0000 & 0.87192 & 0.11666 & 0.86228 & Biso & 1.000 & 0 \\
\hline 043 & 1.0000 & 0.77114 & 0.56840 & 0.47088 & Biso & 1.000 & 0 \\
\hline 044 & 1.0000 & 0.39538 & 0.19743 & 0.42813 & Biso & 1.000 & 0 \\
\hline 045 & 1.0000 & 0.78525 & 0.21996 & 0.46229 & Biso & 1.000 & 0 \\
\hline 046 & 1.0000 & 0.91073 & 0.47166 & 0.20600 & Biso & 1.000 & 0 \\
\hline 047 & 1.0000 & 0.55225 & 0.10686 & 0.19780 & Biso & 1.000 & 0 \\
\hline 048 & 1.0000 & 0.54303 & 0.45274 & 0.19327 & Biso & 1.000 & 0 \\
\hline 049 & 1.0000 & 0.44466 & 0.90825 & 0.79554 & Biso & 1.000 & 0 \\
\hline 050 & 1.0000 & 0.08749 & 0.54251 & 0.80392 & Biso & 1.000 & 0 \\
\hline 051 & 1.0000 & 0.45457 & 0.55393 & 0.80062 & Biso & 1.000 & 0 \\
\hline 052 & 1.0000 & 0.56728 & 0.79639 & 0.53836 & Biso & 1.000 & 0 \\
\hline 053 & 1.0000 & 0.21183 & 0.42930 & 0.53307 & Biso & 1.000 & 0 \\
\hline 054 & 1.0000 & 0.20471 & 0.78015 & 0.54713 & Biso & 1.000 & 0 \\
\hline 055 & 1.0000 & 0.99126 & 0.26030 & 0.00913 & Biso & 1.000 & 0 \\
\hline 056 & 1.0000 & 0.72935 & 0.75141 & 0.01454 & Biso & 1.000 & 0 \\
\hline 057 & 1.0000 & 0.23671 & 0.99797 & 0.00925 & Biso & 1.000 & 0 \\
\hline 058 & 1.0000 & 0.66236 & 0.58854 & 0.34450 & Biso & 1.000 & 0 \\
\hline 059 & 1.0000 & 0.92666 & 0.33796 & 0.34503 & Biso & 1.000 & 0 \\
\hline 060 & 1.0000 & 0.32036 & 0.93534 & 0.68721 & Biso & 1.000 & 0 \\
\hline 061 & 1.0000 & 0.06851 & 0.41161 & 0.67859 & Biso & 1.000 & 0 \\
\hline 062 & 1.0000 & 0.58609 & 0.66485 & 0.67654 & Biso & 1.000 & 0 \\
\hline 063 & 1.0000 & 0.00768 & 0.75541 & 0.99644 & Biso & 1.000 & 0 \\
\hline 064 & 1.0000 & 0.26457 & 0.26632 & 0.98702 & Biso & 1.000 & 0 \\
\hline 065 & 1.0000 & 0.75495 & 0.01244 & 0.99454 & Biso & 1.000 & 0 \\
\hline 066 & 1.0000 & 0.66032 & 0.07425 & 0.32070 & Biso & 1.000 & 0 \\
\hline 067 & 1.0000 & 0.92253 & 0.59991 & 0.32985 & Biso & 1.000 & 0 \\
\hline 068 & 1.0000 & 0.40642 & 0.36813 & 0.32001 & Biso & 1.000 & 0 \\
\hline 069 & 1.0000 & 0.32578 & 0.41120 & 0.65601 & Biso & 1.000 & 0 \\
\hline
\end{tabular}




$\begin{array}{llllllll}\text { O70 } & 1.0000 & 0.61110 & 0.93535 & 0.66308 & \text { Biso } & 1.000 & \text { O } \\ \text { O71 } & 1.0000 & 0.06354 & 0.66478 & 0.66360 & \text { Biso } & 1.000 & \text { O } \\ \text { O72 } & 1.0000 & 0.38290 & 0.02896 & 0.32752 & \text { Biso } & 1.000 & \text { O } \\ \text { C1 } & 1.0000 & 0.32724 & 0.89779 & 0.31444 & \text { Biso } & 1.000 & \text { C } \\ \text { C2 } & 1.0000 & 0.39611 & 0.86092 & 0.36759 & \text { Biso } & 1.000 & \text { C } \\ \text { H1 } & 1.0000 & 0.47352 & 0.88148 & 0.33252 & \text { Biso } & 1.000 & \mathrm{H} \\ \text { H2 } & 1.0000 & 0.41812 & 0.89831 & 0.43334 & \text { Biso } & 1.000 & \mathrm{H} \\ \text { H3 } & 1.0000 & 0.34788 & 0.77025 & 0.37684 & \text { Biso } & 1.000 & \mathrm{H} \\ \text { C3 } & 1.0000 & 0.20733 & 0.85105 & 0.34329 & \text { Biso } & 1.000 & \mathrm{C} \\ \text { H4 } & 1.0000 & 0.20007 & 0.87145 & 0.41226 & \text { Biso } & 1.000 & \mathrm{H} \\ \text { H5 } & 1.0000 & 0.16576 & 0.88218 & 0.29945 & \text { Biso } & 1.000 & \mathrm{H} \\ \text { H6 } & 1.0000 & 0.16347 & 0.75992 & 0.33668 & \text { Biso } & 1.000 & \mathrm{H} \\ \text { C4 } & 1.0000 & 0.33208 & 0.86552 & 0.21773 & \text { Biso } & 1.000 & \mathrm{C} \\ \text { H7 } & 1.0000 & 0.31304 & 0.77850 & 0.22098 & \text { Biso } & 1.000 & \mathrm{H} \\ \text { H8 } & 1.0000 & 0.26983 & 0.86712 & 0.17455 & \text { Biso } & 1.000 & \mathrm{H} \\ \text { H9 } & 1.0000 & 0.41526 & 0.91283 & 0.18800 & \text { Biso } & 1.000 & \mathrm{H}\end{array}$

Mg 20

data_image 0

$\begin{array}{ll}\text {-cel1__length_a } & 13.875 \\ \text { _cell_length_b } & 13.875 \\ \text {-cell_length_c } & 15.017 \\ \text {-cell_angle_alpha } & 90 \\ \text {-cell_angle_beta } & 90 \\ \text {-cell_angle_gamma } & 120\end{array}$

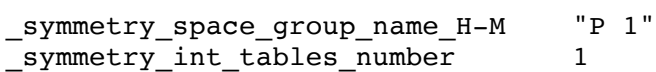

loop

_symmetry_equiv_pos_as_xyz

' $\mathrm{x}, \mathrm{y}, \mathrm{z}$ '

loop

atom_site_label

_atom_site_occupancy

atom site fract $x$

_atom_site_fract_y

-atom_site_fract_z

-atom_site_thermal_displace_type

-atom_site_B_iso_or_equiv

-atom_site_type_symbol

A 11 - $-000-0.99670$

Al1 $\quad 1.0000 \quad 0.99670 \quad 0.23298$

Al2 $\quad 1.0000 \quad 0.76805$

Al3 $1.0000 \quad 0.21879$

$\begin{array}{lll}\mathrm{P} 1 & 1.0000 & 0.21478\end{array}$

0.10990

0.775420 .11163

0.01500

0.10103

Biso

$1.000 \mathrm{Al}$

P2 $1.0000 \quad 0.76847$

P3 $1.0000 \quad 0.98965$

$1.000 \mathrm{AI}$

0.88782 Biso 1.000 A

$\begin{array}{lllll}0.77487 & 0.89820 & \text { Biso } & 1.000 & \mathrm{P}\end{array}$

0.229680 .89686 Biso $1.000 \quad \mathrm{P}$

$\begin{array}{lll}1.0000 & 0.65112 & 0.55909\end{array}$

0.43937 Biso

$1.000 \mathrm{Al}$

Mg1 $1.0000 \quad 0.42324$

Al5 $1.0000 \quad 0.88982$

$0.10498 \quad 0.43272$ Biso

0.338940 .44185 Biso

$1.000 \mathrm{Mg}$

$1.0000 \quad 0.89651$

0.34690

0.23058 Biso

$1.000 \mathrm{Al}$

$\begin{array}{lll}\text { P4 } & 1.0000 & 0.89651 \\ \text { P5 } & 1.0000 & 0.43487\end{array}$

P6 $1.0000 \quad 0.66049$

$0.10309 \quad 0.21927$ Biso

$1.000 \mathrm{P}$

$1.0000 \quad 0.32274$

0.22795 Biso

$1.000 \mathrm{P}$

$0.89370 \quad 0.77840$ Biso 1.000 A

Al6 $1.0000-3$.

$\begin{array}{lll}1.0000 & 0.09959 & 0.43824\end{array}$

0.675110 .77200 Biso

$.000 \mathrm{AI}$

Al8 $1.0000 \quad 0.55873$

$1.0000 \quad 0.56181$

$\begin{array}{lll}\text { P8 } & 1.0000 & 0.09505 \\ \text { P9 } & 1.0000 & 0.32048\end{array}$

0.68067

0.56366 Biso

$\begin{array}{lll}0.43852 & 0.56797 \quad \text { Biso }\end{array}$

$1.000 \mathrm{Al}$

$1.000 \mathrm{Al}$

A19 $1.0000 \quad 0.99576$

Al10 $\quad 1.0000 \quad 0.22073$

0.88871

0.57177 Biso

$1.000 \mathrm{P}$

$\begin{array}{lll}1.0000 & 0.76950 & 0.00072\end{array}$

0.90163 Biso

0.89431 Biso

0.90010 Biso

P10

$1.0000 \quad 0.77374$

$1.0000 \quad 0.22396$

0.00414

0.11443 Biso

0.237170 .10712 Biso

$0.78610 \quad 0.11612$ Biso

P12

$1.0000 \quad 0.00190$

0.12016

0.11612

$1.0000 \quad 0.67219$

0.57424

$1.0000 \quad 0.89751$

0.33443

0.23736 Biso

Al13

$1.0000 \quad 0.43403$

$1.0000 \quad 0.42045$

$1.0000 \quad 0.88588$

0.34054

0.23776 Biso

P13

0.56748

0.4391

$1.0000 \quad 0.66265$

0.11668

0.44696 Biso

$1.0000 \quad 0.33041$

0.45679

0.43671

Al15

Al16

$1.0000 \quad 0.55613$

0.90620

0.56616

$1.0000 \quad 0.08812$

0.66808

0.57195 Biso

$1.000 \mathrm{P}$

$1.000 \mathrm{Al}$

$1.000 \mathrm{Al}$

$1.000 \mathrm{Al}$

$1.000 \mathrm{P}$

$1.000 \quad \mathrm{P}$

$1.000 \mathrm{P}$

$1.000 \mathrm{Al}$

$1.000 \mathrm{Al}$

$1.000 \mathrm{Al}$

$1.000 \mathrm{P}$

$1.000 \mathrm{P}$

$1.000 \quad \mathrm{P}$

$1.000 \mathrm{AI}$

$1.000 \mathrm{Al}$

$1.000 \mathrm{Al}$

P16 $1.0000 \quad 0.09668$

$\begin{array}{lll}\mathrm{P} 17 & 1.0000 & 0.55675\end{array}$

$\begin{array}{lll}\mathrm{P} 18 & 1.0000 & 0.33088\end{array}$

0.66747

0.57708 Biso

0.903580 .77808 Biso

$1.000 \mathrm{P}$

$\begin{array}{llll}1.0000 & 0.33088 & 0.44775\end{array}$

0.77691 Biso

$1.000 \mathrm{P}$

Biso $\quad 1.000 \mathrm{P}$

$\begin{array}{lll}\mathrm{O} 1 & 1.0000 & 0.89499 \\ \mathrm{O} 2 & 1.0000 & 0.90577\end{array}$

O3 $1.0000 \quad 0.17987$

$\begin{array}{lll}0.80845 & 0.13525 & \text { Biso }\end{array}$

$1.000 \quad \mathrm{O}$

$1.000 \quad 0$

$1.000 \quad 0$ 


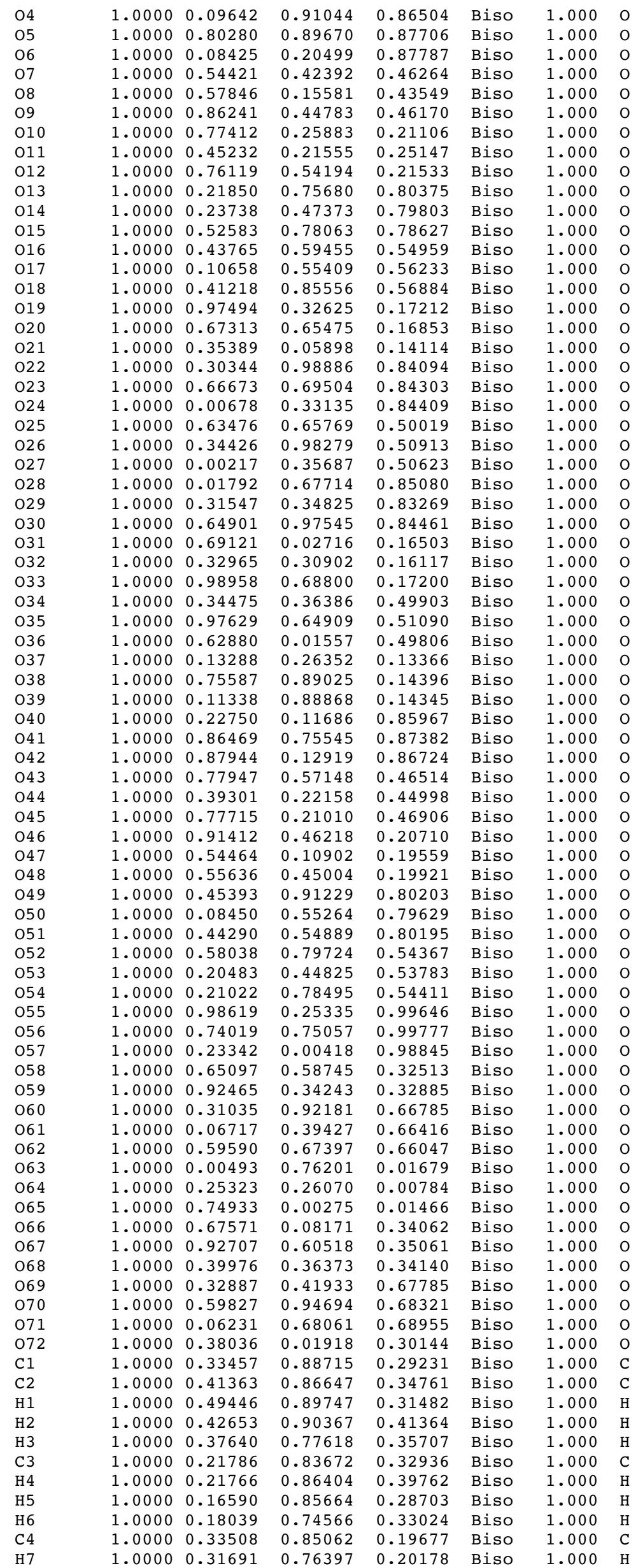




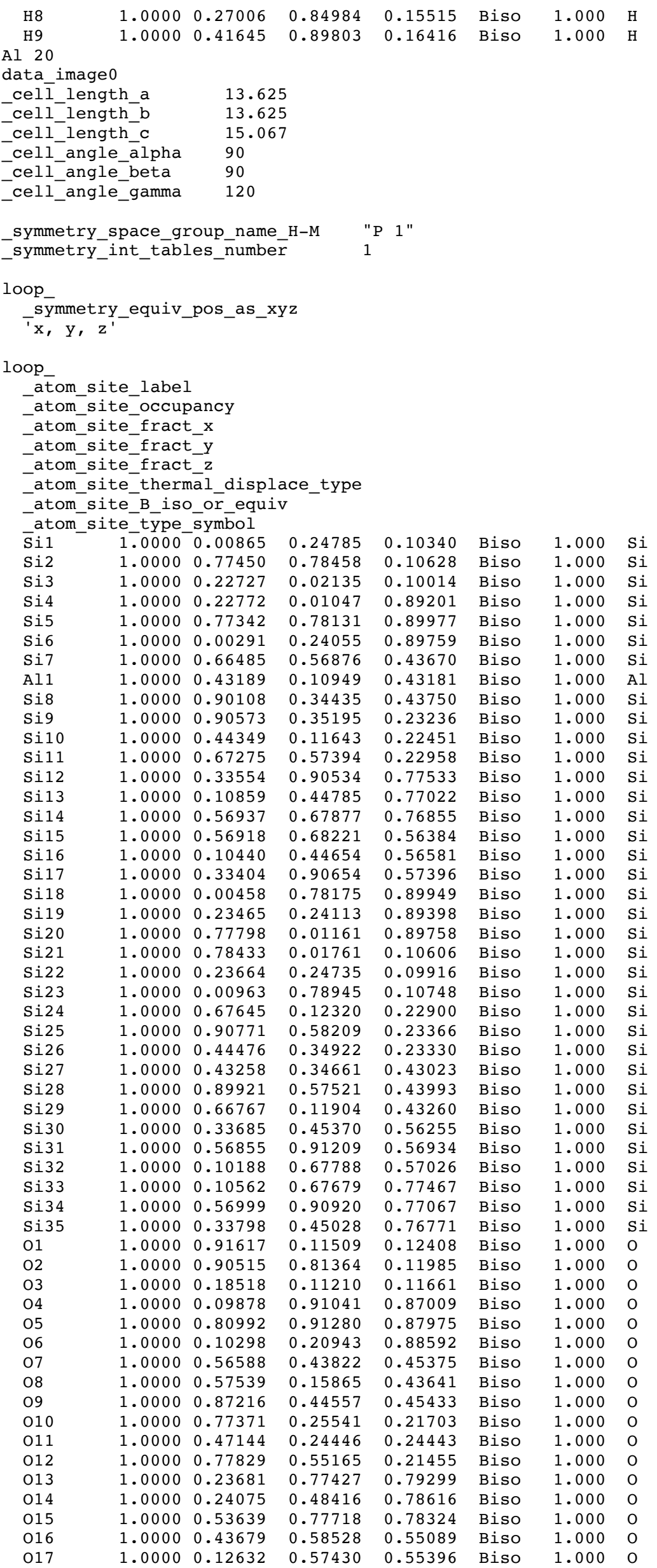




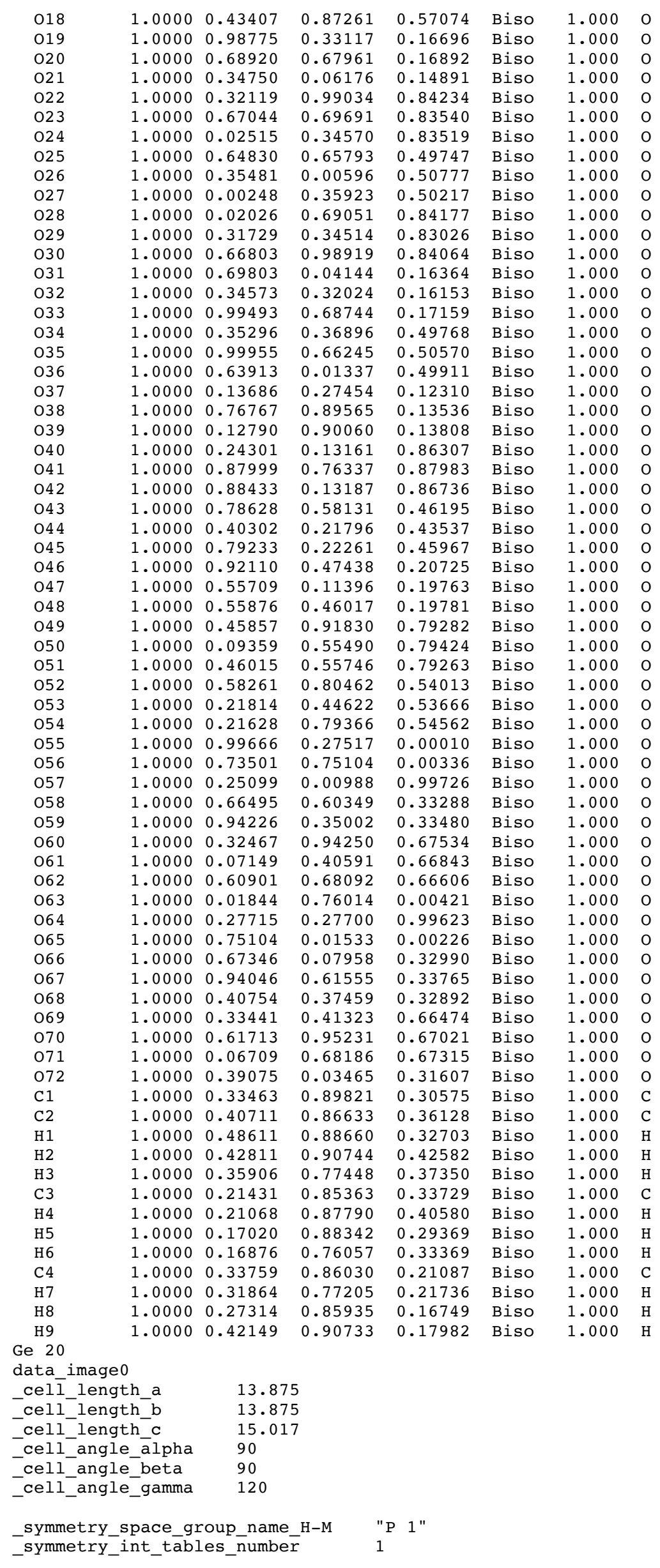




\begin{tabular}{|c|c|c|c|c|c|c|c|}
\hline \multicolumn{8}{|l|}{ loop_ } \\
\hline \multicolumn{8}{|c|}{-symmetry_equiv_pos_as_xyz } \\
\hline \multicolumn{8}{|c|}{ loop_ } \\
\hline \multicolumn{8}{|c|}{ _atom_site_label } \\
\hline \multicolumn{8}{|c|}{ _atom_site_occupancy } \\
\hline \multicolumn{8}{|c|}{ atom_site_fract_x } \\
\hline -ator & te_fract & $t_{-}^{-} y$ & & & & & \\
\hline -ator & te_fract & $t z$ & & & & & \\
\hline -ator & te_thern & nal_disp] & ace_type & & & & \\
\hline -ato & $\begin{array}{l}\text { te_B_isc } \\
\text { te_type }\end{array}$ & $\begin{array}{l}\text { o_or_equ } \\
\text { symbol }\end{array}$ & & & & & \\
\hline$\overline{\mathrm{P}} 1$ & 1.0000 & 0.00463 & 0.24026 & 0.10833 & Biso & 1.000 & $\mathrm{P}$ \\
\hline $\mathrm{P} 2$ & 1.0000 & 0.76938 & 0.78302 & 0.11362 & Biso & 1.000 & $\mathrm{P}$ \\
\hline P3 & 1.0000 & 0.21334 & 0.01390 & 0.10499 & Biso & 1.000 & $\mathrm{P}$ \\
\hline Al1 & 1.0000 & 0.21150 & 0.99742 & 0.88966 & Biso & 1.000 & Al \\
\hline Al2 & 1.0000 & 0.76425 & 0.77507 & 0.90169 & Biso & 1.000 & Al \\
\hline Al3 & 1.0000 & 0.99579 & 0.22781 & 0.89704 & Biso & 1.000 & Al \\
\hline $\mathrm{P} 4$ & 1.0000 & 0.65969 & 0.55828 & 0.44149 & Biso & 1.000 & $\mathrm{P}$ \\
\hline $\mathrm{Ge} 1$ & 1.0000 & 0.41796 & 0.10045 & 0.43453 & Biso & 1.000 & $\mathrm{Ge}$ \\
\hline P5 & 1.0000 & 0.89065 & 0.33284 & 0.44161 & Biso & 1.000 & $P$ \\
\hline Al4 & 1.0000 & 0.89622 & 0.34298 & 0.23266 & Biso & 1.000 & Al \\
\hline Al5 & 1.0000 & 0.43461 & 0.11143 & 0.22078 & Biso & 1.000 & Al \\
\hline Al6 & 1.0000 & 0.67110 & 0.56746 & 0.22976 & Biso & 1.000 & $\mathrm{Al}$ \\
\hline P6 & 1.0000 & 0.32703 & 0.89190 & 0.78612 & Biso & 1.000 & $P$ \\
\hline P7 & 1.0000 & 0.09889 & 0.44011 & 0.77568 & Biso & 1.000 & $\mathrm{P}$ \\
\hline P8 & 1.0000 & 0.55668 & 0.66606 & 0.77471 & Biso & 1.000 & $P$ \\
\hline Al7 & 1.0000 & 0.55881 & 0.67185 & 0.56551 & Biso & 1.000 & Al \\
\hline A18 & 1.0000 & 0.09460 & 0.43848 & 0.56767 & Biso & 1.000 & $\mathrm{Al}$ \\
\hline Al9 & 1.0000 & 0.32669 & 0.89518 & 0.58031 & Biso & 1.000 & Al \\
\hline P9 & 1.0000 & 0.99162 & 0.77163 & 0.89681 & Biso & 1.000 & $P$ \\
\hline $\mathrm{P} 10$ & 1.0000 & 0.22339 & 0.22532 & 0.88698 & Biso & 1.000 & $\mathrm{P}$ \\
\hline P11 & 1.0000 & 0.77318 & 0.00475 & 0.89534 & Biso & 1.000 & $\mathrm{P}$ \\
\hline Al10 & 1.0000 & 0.78357 & 0.01473 & 0.10991 & Biso & 1.000 & $\mathrm{Al}$ \\
\hline Al11 & 1.0000 & 0.22978 & 0.23874 & 0.09888 & Biso & 1.000 & Al \\
\hline Al12 & 1.0000 & 0.00116 & 0.78415 & 0.11005 & Biso & 1.000 & $\mathrm{Al}$ \\
\hline $\mathrm{P} 12$ & 1.0000 & 0.66551 & 0.11659 & 0.22507 & Biso & 1.000 & $P$ \\
\hline $\mathrm{P} 13$ & 1.0000 & 0.90276 & 0.57326 & 0.23089 & Biso & 1.000 & $\mathrm{P}$ \\
\hline P14 & 1.0000 & 0.44412 & 0.34782 & 0.22443 & Biso & 1.000 & $P$ \\
\hline Al13 & 1.0000 & 0.42610 & 0.34227 & 0.42569 & Biso & 1.000 & Al \\
\hline Al14 & 1.0000 & 0.89042 & 0.56249 & 0.44248 & Biso & 1.000 & Al \\
\hline Al15 & 1.0000 & 0.65546 & 0.11045 & 0.43380 & Biso & 1.000 & Al \\
\hline P15 & 1.0000 & 0.32630 & 0.44887 & 0.55769 & Biso & 1.000 & $P$ \\
\hline P16 & 1.0000 & 0.56050 & 0.90130 & 0.57109 & Biso & 1.000 & $\mathrm{P}$ \\
\hline P17 & 1.0000 & 0.09506 & 0.67018 & 0.56966 & Biso & 1.000 & $P$ \\
\hline Al16 & 1.0000 & 0.09750 & 0.66831 & 0.77769 & Biso & 1.000 & Al \\
\hline Al17 & 1.0000 & 0.56038 & 0.89671 & 0.77512 & Biso & 1.000 & Al \\
\hline Al18 & 1.0000 & 0.32553 & 0.44157 & 0.76713 & Biso & 1.000 & $\mathrm{Al}$ \\
\hline 01 & 1.0000 & 0.92152 & 0.11834 & 0.13452 & Biso & 1.000 & 0 \\
\hline $\mathrm{O} 2$ & 1.0000 & 0.88998 & 0.80787 & 0.12626 & Biso & 1.000 & 0 \\
\hline 03 & 1.0000 & 0.17802 & 0.09921 & 0.12988 & Biso & 1.000 & 0 \\
\hline 04 & 1.0000 & 0.07807 & 0.88837 & 0.86220 & Biso & 1.000 & 0 \\
\hline 05 & 1.0000 & 0.79985 & 0.91182 & 0.87385 & Biso & 1.000 & 0 \\
\hline 06 & 1.0000 & 0.10091 & 0.19548 & 0.87833 & Biso & 1.000 & 0 \\
\hline 07 & 1.0000 & 0.56600 & 0.43721 & 0.45625 & Biso & 1.000 & 0 \\
\hline 08 & 1.0000 & 0.56241 & 0.15859 & 0.44079 & Biso & 1.000 & 0 \\
\hline 09 & 1.0000 & 0.86378 & 0.42631 & 0.46047 & Biso & 1.000 & 0 \\
\hline 010 & 1.0000 & 0.75738 & 0.23932 & 0.21658 & Biso & 1.000 & 0 \\
\hline 011 & 1.0000 & 0.46457 & 0.24838 & 0.23509 & Biso & 1.000 & 0 \\
\hline 012 & 1.0000 & 0.78365 & 0.54673 & 0.20935 & Biso & 1.000 & 0 \\
\hline 013 & 1.0000 & 0.23572 & 0.76978 & 0.80203 & Biso & 1.000 & $\mathrm{O}$ \\
\hline 014 & 1.0000 & 0.22211 & 0.47535 & 0.79076 & Biso & 1.000 & 0 \\
\hline 015 & 1.0000 & 0.52684 & 0.75796 & 0.78947 & Biso & 1.000 & $\mathrm{O}$ \\
\hline 016 & 1.0000 & 0.41905 & 0.57130 & 0.54738 & Biso & 1.000 & 0 \\
\hline 017 & 1.0000 & 0.11445 & 0.57180 & 0.55447 & Biso & 1.000 & 0 \\
\hline 018 & 1.0000 & 0.43516 & 0.86331 & 0.57418 & Biso & 1.000 & $\mathrm{O}$ \\
\hline 019 & 1.0000 & 0.98435 & 0.32076 & 0.16407 & Biso & 1.000 & 0 \\
\hline 020 & 1.0000 & 0.68910 & 0.68410 & 0.17133 & Biso & 1.000 & 0 \\
\hline 021 & 1.0000 & 0.33000 & 0.05062 & 0.14130 & Biso & 1.000 & 0 \\
\hline 022 & 1.0000 & 0.31381 & 0.96930 & 0.85199 & Biso & 1.000 & 0 \\
\hline 023 & 1.0000 & 0.65079 & 0.68218 & 0.83761 & Biso & 1.000 & 0 \\
\hline 024 & 1.0000 & 0.02231 & 0.34531 & 0.83780 & Biso & 1.000 & 0 \\
\hline 025 & 1.0000 & 0.64210 & 0.64050 & 0.49815 & Biso & 1.000 & $\mathrm{O}$ \\
\hline 026 & 1.0000 & 0.34027 & 0.00269 & 0.51524 & Biso & 1.000 & 0 \\
\hline 027 & 1.0000 & 0.98404 & 0.34395 & 0.50274 & Biso & 1.000 & 0 \\
\hline 028 & 1.0000 & 0.00389 & 0.68225 & 0.84653 & Biso & 1.000 & 0 \\
\hline 029 & 1.0000 & 0.30039 & 0.32604 & 0.82997 & Biso & 1.000 & 0 \\
\hline 030 & 1.0000 & 0.66598 & 0.98297 & 0.84852 & Biso & 1.000 & 0 \\
\hline 031 & 1.0000 & 0.68835 & 0.04250 & 0.16295 & Biso & 1.000 & 0 \\
\hline
\end{tabular}




\begin{tabular}{|c|c|c|c|c|c|c|c|}
\hline 032 & 1.0000 & 0.35332 & 0.32277 & 0.15529 & Biso & 1.000 & 0 \\
\hline 033 & 1.0000 & 0.98703 & 0.67423 & 0.17622 & Biso & 1.000 & 0 \\
\hline 034 & 1.0000 & 0.34340 & 0.37242 & 0.49478 & Biso & 1.000 & 0 \\
\hline 035 & 1.0000 & 0.00140 & 0.65883 & 0.50810 & Biso & 1.000 & 0 \\
\hline 036 & 1.0000 & 0.62261 & 0.99675 & 0.50459 & Biso & 1.000 & 0 \\
\hline 037 & 1.0000 & 0.12466 & 0.26757 & 0.12600 & Biso & 1.000 & 0 \\
\hline 038 & 1.0000 & 0.76310 & 0.88546 & 0.14376 & Biso & 1.000 & 0 \\
\hline 039 & 1.0000 & 0.12683 & 0.90066 & 0.14429 & Biso & 1.000 & 0 \\
\hline 040 & 1.0000 & 0.23349 & 0.12616 & 0.85321 & Biso & 1.000 & 0 \\
\hline 041 & 1.0000 & 0.87483 & 0.75296 & 0.87966 & Biso & 1.000 & 0 \\
\hline 042 & 1.0000 & 0.86952 & 0.11582 & 0.86201 & Biso & 1.000 & 0 \\
\hline 043 & 1.0000 & 0.77115 & 0.56855 & 0.46860 & Biso & 1.000 & 0 \\
\hline 044 & 1.0000 & 0.37967 & 0.20171 & 0.42776 & Biso & 1.000 & 0 \\
\hline 045 & 1.0000 & 0.78837 & 0.21941 & 0.46011 & Biso & 1.000 & 0 \\
\hline 046 & 1.0000 & 0.91499 & 0.47323 & 0.20457 & Biso & 1.000 & 0 \\
\hline 047 & 1.0000 & 0.55556 & 0.10843 & 0.19478 & Biso & 1.000 & 0 \\
\hline 048 & 1.0000 & 0.55220 & 0.44886 & 0.19120 & Biso & 1.000 & 0 \\
\hline 049 & 1.0000 & 0.44159 & 0.90378 & 0.80116 & Biso & 1.000 & 0 \\
\hline 050 & 1.0000 & 0.08309 & 0.53881 & 0.79721 & Biso & 1.000 & 0 \\
\hline 051 & 1.0000 & 0.45455 & 0.55329 & 0.79664 & Biso & 1.000 & 0 \\
\hline 052 & 1.0000 & 0.57462 & 0.80283 & 0.54125 & Biso & 1.000 & 0 \\
\hline 053 & 1.0000 & 0.21530 & 0.44100 & 0.53371 & Biso & 1.000 & 0 \\
\hline 054 & 1.0000 & 0.20333 & 0.77668 & 0.54716 & Biso & 1.000 & 0 \\
\hline 055 & 1.0000 & 0.98952 & 0.25752 & 0.00934 & Biso & 1.000 & 0 \\
\hline 056 & 1.0000 & 0.73343 & 0.75517 & 0.01568 & Biso & 1.000 & 0 \\
\hline 057 & 1.0000 & 0.21863 & 0.00341 & 0.00460 & Biso & 1.000 & 0 \\
\hline 058 & 1.0000 & 0.66343 & 0.59112 & 0.34296 & Biso & 1.000 & 0 \\
\hline 059 & 1.0000 & 0.93009 & 0.34119 & 0.34444 & Biso & 1.000 & 0 \\
\hline 060 & 1.0000 & 0.31660 & 0.92725 & 0.69138 & Biso & 1.000 & 0 \\
\hline 061 & 1.0000 & 0.06495 & 0.39986 & 0.67933 & Biso & 1.000 & 0 \\
\hline 062 & 1.0000 & 0.59392 & 0.66848 & 0.67764 & Biso & 1.000 & 0 \\
\hline 063 & 1.0000 & 0.00931 & 0.76037 & 0.99675 & Biso & 1.000 & 0 \\
\hline 064 & 1.0000 & 0.26032 & 0.25245 & 0.98490 & Biso & 1.000 & 0 \\
\hline 065 & 1.0000 & 0.75784 & 0.01052 & 0.99602 & Biso & 1.000 & 0 \\
\hline 066 & 1.0000 & 0.65797 & 0.07356 & 0.32078 & Biso & 1.000 & 0 \\
\hline 067 & 1.0000 & 0.92829 & 0.59994 & 0.33054 & Biso & 1.000 & 0 \\
\hline 068 & 1.0000 & 0.41009 & 0.37464 & 0.31433 & Biso & 1.000 & 0 \\
\hline 069 & 1.0000 & 0.32372 & 0.40992 & 0.65425 & Biso & 1.000 & 0 \\
\hline 070 & 1.0000 & 0.60876 & 0.93981 & 0.66560 & Biso & 1.000 & 0 \\
\hline 071 & 1.0000 & 0.06180 & 0.67444 & 0.66677 & Biso & 1.000 & 0 \\
\hline 072 & 1.0000 & 0.37955 & 0.02474 & 0.31933 & Biso & 1.000 & 0 \\
\hline $\mathrm{C} 1$ & 1.0000 & 0.32554 & 0.89523 & 0.31231 & Biso & 1.000 & $\mathrm{C}$ \\
\hline $\mathrm{C} 2$ & 1.0000 & 0.39580 & 0.86260 & 0.36826 & Biso & 1.000 & $\mathrm{C}$ \\
\hline H 1 & 1.0000 & 0.47388 & 0.88334 & 0.33426 & Biso & 1.000 & $\mathrm{H}$ \\
\hline H2 & 1.0000 & 0.41666 & 0.90333 & 0.43299 & Biso & 1.000 & $\mathrm{H}$ \\
\hline H3 & 1.0000 & 0.34929 & 0.77247 & 0.38060 & Biso & 1.000 & $\mathrm{H}$ \\
\hline C3 & 1.0000 & 0.20610 & 0.84855 & 0.34280 & Biso & 1.000 & C \\
\hline H4 & 1.0000 & 0.20077 & 0.87212 & 0.41131 & Biso & 1.000 & $\mathrm{H}$ \\
\hline H5 & 1.0000 & 0.16281 & 0.87722 & 0.29847 & Biso & 1.000 & $\mathrm{H}$ \\
\hline H6 & 1.0000 & 0.16256 & 0.75721 & 0.33919 & Biso & 1.000 & $\mathrm{H}$ \\
\hline $\mathrm{C} 4$ & 1.0000 & 0.32959 & 0.85830 & 0.21704 & Biso & 1.000 & C \\
\hline $\mathrm{H} 7$ & 1.0000 & 0.31015 & 0.77131 & 0.22247 & Biso & 1.000 & $\mathrm{H}$ \\
\hline H8 & 1.0000 & 0.26779 & 0.85936 & 0.17291 & Biso & 1.000 & $\mathrm{H}$ \\
\hline H9 & 1.0000 & 0.41290 & 0.90477 & 0.18725 & Biso & 1.000 & $\mathrm{H}$ \\
\hline \multirow{2}{*}{\multicolumn{8}{|c|}{$\begin{array}{l}\text { Ga } 20 \\
\text { data_image } 0\end{array}$}} \\
\hline & & & & & & & \\
\hline \multicolumn{8}{|c|}{ cel' length a } \\
\hline \multicolumn{2}{|c|}{ cell length b } & \multicolumn{2}{|c|}{13.625} & & & & \\
\hline $\operatorname{cell}$ & $=\mathrm{h}^{-} \mathrm{C}$ & \multicolumn{2}{|c|}{$\begin{array}{l}13.625 \\
15.067\end{array}$} & & & & \\
\hline $\mathrm{cell}$ & e_alpha & \multicolumn{2}{|c|}{90} & & & & \\
\hline $\operatorname{cell}$ & -beta & 90 & & & & & \\
\hline $\operatorname{cell}$ & gamma & 120 & & & & & \\
\hline symme & pace $\mathrm{g}$ & up nam & & $1 "$ & & & \\
\hline symme & $+\bar{c} b$ & Les_numbe & & & & & \\
\hline $00 P_{-}$ & & & & & & & \\
\hline & equiv & os_as & & & & & \\
\hline$T^{\circ}{ }^{\prime}$, & & & & & & & \\
\hline oop & & & & & & & \\
\hline atc & e_labe] & & & & & & \\
\hline atc & $e^{-}$occup & bancy & & & & & \\
\hline ato & effract & $=x^{1}$ & & & & & \\
\hline -ato & $e_{-}^{-}$fract & & & & & & \\
\hline atc & e_fract & & & & & & \\
\hline atc & e_thern & nàl_displ & ce_type & & & & \\
\hline atc & $\begin{array}{l}e^{-} B \text { isc } \\
e^{-} \text {type }\end{array}$ & $\begin{array}{l}\text { or_equi } \\
\text { symbol }\end{array}$ & & & & & \\
\hline$\overline{\text { Sil }}$ & 1.0000 & 0.00939 & 0.24697 & 0.10451 & Biso & 1.000 & $\mathrm{Si}$ \\
\hline
\end{tabular}




\begin{tabular}{|c|c|c|c|c|c|c|c|}
\hline Si2 & 1.0000 & 0.77469 & 0.78477 & 0.10772 & Biso & 1.000 & $\mathrm{Si}$ \\
\hline Si3 & 1.0000 & 0.22768 & 0.02138 & 0.09837 & Biso & 1.000 & $\mathrm{Si}$ \\
\hline Si4 & 1.0000 & 0.22562 & 0.00933 & 0.89031 & Biso & 1.000 & $\mathrm{Si}$ \\
\hline Si5 & 1.0000 & 0.77346 & 0.78126 & 0.90068 & Biso & 1.000 & $\mathrm{Si}$ \\
\hline Si6 & 1.0000 & 0.00225 & 0.24143 & 0.89819 & Biso & 1.000 & \\
\hline Si7 & 1.0000 & 0.66352 & 0.56714 & 0.43686 & Biso & 1.000 & \\
\hline Ga 1 & 1.0000 & 0.43189 & 0.11217 & 0.43437 & Biso & 1.000 & \\
\hline Si8 & 1.0000 & 0.90300 & 0.34450 & 0.43765 & Biso & 1.000 & \\
\hline Si9 & 1.0000 & 0.90757 & 0.35326 & 0.23272 & Biso & 1.000 & \\
\hline Si10 & 1.0000 & 0.44366 & 0.11570 & 0.22211 & Biso & 1.000 & \\
\hline Si11 & 1.0000 & 0.67312 & 0.57281 & 0.22988 & Biso & 1.000 & \\
\hline Si12 & 1.0000 & 0.33457 & 0.90313 & 0.77661 & Biso & 1.000 & $\mathrm{Si}$ \\
\hline Sil3 & 1.0000 & 0.10688 & 0.44574 & 0.77049 & Biso & 1.000 & $\mathrm{Si}$ \\
\hline Si14 & 1.0000 & 0.56966 & 0.67922 & 0.76877 & Biso & 1.000 & $\mathrm{Si}$ \\
\hline Si15 & 1.0000 & 0.57221 & 0.68482 & 0.56492 & Biso & 1.000 & $\mathrm{Si}$ \\
\hline Si16 & 1.0000 & 0.10163 & 0.44421 & 0.56870 & Biso & 1.000 & \\
\hline Si17 & 1.0000 & 0.33254 & 0.90061 & 0.57360 & Biso & 1.000 & \\
\hline Si18 & 1.0000 & 0.00328 & 0.78017 & 0.90035 & Biso & 1.000 & $\mathrm{Si}$ \\
\hline Sil9 & 1.0000 & 0.23450 & 0.24195 & 0.89233 & Biso & 1.000 & $\mathrm{Si}$ \\
\hline Si20 & 1.0000 & 0.77876 & 0.01172 & 0.89817 & Biso & 1.000 & $\mathrm{Si}$ \\
\hline Si21 & 1.0000 & 0.78533 & 0.01782 & 0.10717 & Biso & 1.000 & $S \perp$ \\
\hline Si22 & 1.0000 & 0.23768 & 0.24780 & 0.09760 & Biso & 1.000 & \\
\hline Si23 & 1.0000 & 0.00987 & 0.79069 & 0.10898 & Biso & 1.000 & $\mathrm{Si}$ \\
\hline Si24 & 1.0000 & 0.67680 & 0.12503 & 0.22848 & Biso & 1.000 & $\mathrm{Si}$ \\
\hline Si25 & 1.0000 & 0.90889 & 0.58250 & 0.23461 & Biso & 1.000 & $\mathrm{Si}$ \\
\hline Si26 & 1.0000 & 0.44483 & 0.34825 & 0.23282 & Biso & 1.000 & $\mathrm{Si}$ \\
\hline Si27 & 1.0000 & 0.42937 & 0.34872 & 0.42998 & Biso & 1.000 & \\
\hline Si28 & 1.0000 & 0.89850 & 0.57407 & 0.44104 & Biso & 1.000 & $\mathrm{Si}$ \\
\hline Si29 & 1.0000 & 0.66822 & 0.12139 & 0.43244 & Biso & 1.000 & $\mathrm{Si}$ \\
\hline Si30 & 1.0000 & 0.33763 & 0.46069 & 0.56226 & Biso & 1.000 & $\mathrm{Si}$ \\
\hline Si31 & 1.0000 & 0.56967 & 0.91373 & 0.56980 & Biso & 1.000 & $\mathrm{Si}$ \\
\hline Si32 & 1.0000 & 0.09794 & 0.67754 & 0.57321 & Biso & 1.000 & $\mathrm{Si}$ \\
\hline Si33 & 1.0000 & 0.10450 & 0.67744 & 0.77554 & Biso & 1.000 & $\mathrm{Si}$ \\
\hline $\mathrm{Si} 34$ & 1.0000 & 0.56999 & 0.91051 & 0.77125 & Biso & 1.000 & $\mathrm{Si}$ \\
\hline Si35 & 1.0000 & 0.33751 & 0.45132 & 0.76765 & Biso & 1.000 & $\mathrm{Si}$ \\
\hline 01 & 1.0000 & 0.91751 & 0.11415 & 0.12591 & Biso & 1.000 & 0 \\
\hline $\mathrm{O} 2$ & 1.0000 & 0.90567 & 0.81525 & 0.12229 & Biso & 1.000 & 0 \\
\hline 03 & 1.0000 & 0.18579 & 0.11239 & 0.11417 & Biso & 1.000 & 0 \\
\hline 04 & 1.0000 & 0.09722 & 0.90788 & 0.86850 & Biso & 1.000 & 0 \\
\hline 05 & 1.0000 & 0.81087 & 0.91298 & 0.88033 & Biso & 1.000 & 0 \\
\hline 06 & 1.0000 & 0.10382 & 0.21314 & 0.88391 & Biso & 1.000 & 0 \\
\hline 07 & 1.0000 & 0.56350 & 0.43680 & 0.45363 & Biso & 1.000 & 0 \\
\hline 08 & 1.0000 & 0.58301 & 0.17060 & 0.43848 & Biso & 1.000 & 0 \\
\hline 09 & 1.0000 & 0.87375 & 0.44521 & 0.45612 & Biso & 1.000 & 0 \\
\hline 010 & 1.0000 & 0.77521 & 0.25705 & 0.21846 & Biso & 1.000 & 0 \\
\hline 011 & 1.0000 & 0.46903 & 0.24210 & 0.24632 & Biso & 1.000 & 0 \\
\hline 012 & 1.0000 & 0.77927 & 0.55137 & 0.21548 & Biso & 1.000 & 0 \\
\hline 013 & 1.0000 & 0.23572 & 0.77280 & 0.79709 & Biso & 1.000 & 0 \\
\hline 014 & 1.0000 & 0.23888 & 0.48263 & 0.78878 & Biso & 1.000 & 0 \\
\hline 015 & 1.0000 & 0.53759 & 0.77859 & 0.78066 & Biso & 1.000 & 0 \\
\hline 016 & 1.0000 & 0.43848 & 0.59206 & 0.55188 & Biso & 1.000 & 0 \\
\hline 017 & 1.0000 & 0.11395 & 0.56826 & 0.56349 & Biso & 1.000 & 0 \\
\hline 018 & 1.0000 & 0.43404 & 0.86902 & 0.56860 & Biso & 1.000 & 0 \\
\hline 019 & 1.0000 & 0.98860 & 0.33067 & 0.16769 & Biso & 1.000 & 0 \\
\hline 020 & 1.0000 & 0.68932 & 0.67855 & 0.16936 & Biso & 1.000 & 0 \\
\hline 021 & 1.0000 & 0.34950 & 0.06333 & 0.14498 & Biso & 1.000 & 0 \\
\hline 022 & 1.0000 & 0.31996 & 0.99126 & 0.83982 & Biso & 1.000 & 0 \\
\hline 023 & 1.0000 & 0.66912 & 0.69719 & 0.83726 & Biso & 1.000 & 0 \\
\hline $\mathrm{O} 24$ & 1.0000 & 0.02256 & 0.34818 & 0.83848 & Biso & 1.000 & 0 \\
\hline 025 & 1.0000 & 0.64815 & 0.65713 & 0.49765 & Biso & 1.000 & 0 \\
\hline 026 & 1.0000 & 0.34820 & 0.00035 & 0.50960 & Biso & 1.000 & 0 \\
\hline 027 & 1.0000 & 0.00329 & 0.35712 & 0.50254 & Biso & 1.000 & 0 \\
\hline 028 & 1.0000 & 0.01904 & 0.68690 & 0.84541 & Biso & 1.000 & 0 \\
\hline 029 & 1.0000 & 0.31839 & 0.34460 & 0.82781 & Biso & 1.000 & 0 \\
\hline 030 & 1.0000 & 0.66824 & 0.98877 & 0.84170 & Biso & 1.000 & 0 \\
\hline 031 & 1.0000 & 0.69987 & 0.04333 & 0.16429 & Biso & 1.000 & 0 \\
\hline 032 & 1.0000 & 0.34748 & 0.31979 & 0.15956 & Biso & 1.000 & 0 \\
\hline 033 & 1.0000 & 0.99563 & 0.68894 & 0.17322 & Biso & 1.000 & 0 \\
\hline 034 & 1.0000 & 0.35228 & 0.37715 & 0.49517 & Biso & 1.000 & 0 \\
\hline 035 & 1.0000 & 0.99688 & 0.66291 & 0.50750 & Biso & 1.000 & 0 \\
\hline 036 & 1.0000 & 0.63676 & 0.01510 & 0.49887 & Biso & 1.000 & 0 \\
\hline 037 & 1.0000 & 0.13825 & 0.27498 & 0.12313 & Biso & 1.000 & 0 \\
\hline 038 & 1.0000 & 0.76625 & 0.89500 & 0.13688 & Biso & 1.000 & 0 \\
\hline 039 & 1.0000 & 0.12891 & 0.90172 & 0.13847 & Biso & 1.000 & 0 \\
\hline 040 & 1.0000 & 0.23950 & 0.13024 & 0.86243 & Biso & 1.000 & 0 \\
\hline 041 & 1.0000 & 0.87870 & 0.76147 & 0.87978 & Biso & 1.000 & 0 \\
\hline 042 & 1.0000 & 0.88454 & 0.13203 & 0.86727 & Biso & 1.000 & o \\
\hline 043 & 1.0000 & 0.78404 & 0.57769 & 0.46196 & Biso & 1.000 & 0 \\
\hline 044 & 1.0000 & 0.39115 & 0.21770 & 0.43969 & Biso & 1.000 & 0 \\
\hline 045 & 1.0000 & 0.79493 & 0.22164 & 0.45808 & Biso & 1.000 & 0 \\
\hline
\end{tabular}




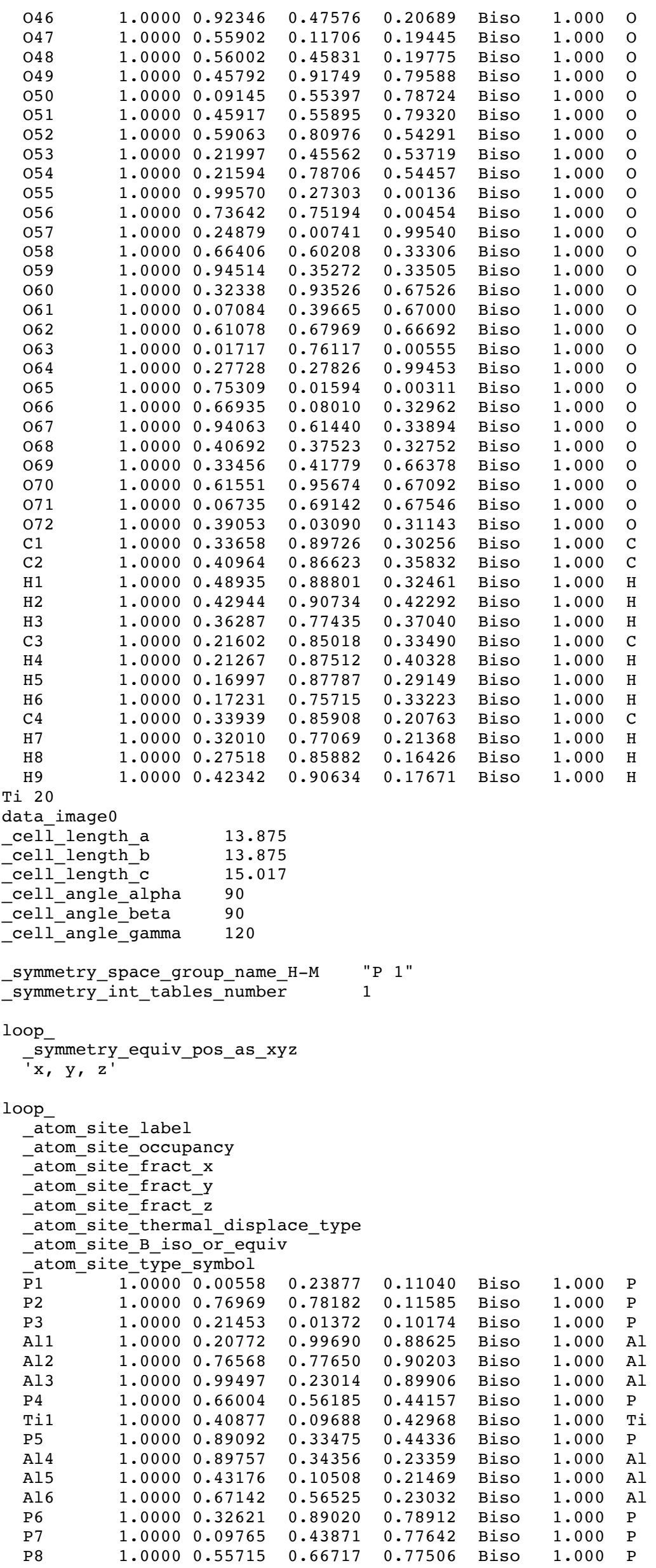




\begin{tabular}{|c|c|c|c|c|c|c|c|}
\hline A 17 & 1.0000 & 0.56395 & 0.67692 & 0.56789 & Biso & 1.000 & Al \\
\hline Al8 & 1.0000 & 0.09110 & 0.43748 & 0.57232 & Biso & 1.000 & Al \\
\hline Al9 & 1.0000 & 0.32568 & 0.88926 & 0.58150 & Biso & 1.000 & Al \\
\hline P9 & 1.0000 & 0.98937 & 0.77016 & 0.89660 & Biso & 1.000 & $\mathrm{P}$ \\
\hline $\mathrm{P} 10$ & 1.0000 & 0.22231 & 0.22608 & 0.88544 & Biso & 1.000 & $P$ \\
\hline P11 & 1.0000 & 0.77418 & 0.00515 & 0.89719 & Biso & 1.000 & $P$ \\
\hline Al10 & 1.0000 & 0.78449 & 0.01331 & 0.11215 & Biso & 1.000 & Al \\
\hline Al11 & 1.0000 & 0.23238 & 0.23939 & 0.09816 & Biso & 1.000 & Al \\
\hline Al12 & 1.0000 & 0.00144 & 0.78589 & 0.11180 & Biso & 1.000 & Al \\
\hline P12 & 1.0000 & 0.66768 & 0.11882 & 0.22511 & Biso & 1.000 & $\mathrm{P}$ \\
\hline P13 & 1.0000 & 0.90515 & 0.57471 & 0.23202 & Biso & 1.000 & $\mathrm{P}$ \\
\hline $\mathrm{P} 14$ & 1.0000 & 0.44261 & 0.34380 & 0.22530 & Biso & 1.000 & $\mathrm{P}$ \\
\hline Al13 & 1.0000 & 0.42350 & 0.34889 & 0.42808 & Biso & 1.000 & Al \\
\hline Al14 & 1.0000 & 0.89147 & 0.56565 & 0.44349 & Biso & 1.000 & Al \\
\hline Al15 & 1.0000 & 0.65625 & 0.11309 & 0.43508 & Biso & 1.000 & Al \\
\hline P15 & 1.0000 & 0.32680 & 0.45938 & 0.55833 & Biso & 1.000 & $\mathrm{P}$ \\
\hline P16 & 1.0000 & 0.56279 & 0.90512 & 0.57274 & Biso & 1.000 & $P$ \\
\hline P17 & 1.0000 & 0.09071 & 0.67184 & 0.57487 & Biso & 1.000 & $\mathrm{P}$ \\
\hline Al16 & 1.0000 & 0.09629 & 0.66992 & 0.77918 & Biso & 1.000 & Al \\
\hline Al17 & 1.0000 & 0.56007 & 0.89861 & 0.77687 & Biso & 1.000 & Al \\
\hline Al18 & 1.0000 & 0.32465 & 0.44367 & 0.76766 & Biso & 1.000 & Al \\
\hline 01 & 1.0000 & 0.92304 & 0.11645 & 0.13621 & Biso & 1.000 & 0 \\
\hline $\mathrm{O} 2$ & 1.0000 & 0.88998 & 0.80793 & 0.13323 & Biso & 1.000 & 0 \\
\hline 03 & 1.0000 & 0.18557 & 0.10186 & 0.13255 & Biso & 1.000 & 0 \\
\hline O4 & 1.0000 & 0.07631 & 0.88460 & 0.85823 & Biso & 1.000 & 0 \\
\hline 05 & 1.0000 & 0.80288 & 0.91386 & 0.87444 & Biso & 1.000 & 0 \\
\hline 06 & 1.0000 & 0.10081 & 0.19963 & 0.87774 & Biso & 1.000 & 0 \\
\hline 07 & 1.0000 & 0.56378 & 0.44253 & 0.45785 & Biso & 1.000 & 0 \\
\hline 08 & 1.0000 & 0.55598 & 0.15250 & 0.43941 & Biso & 1.000 & 0 \\
\hline 09 & 1.0000 & 0.86720 & 0.43038 & 0.46169 & Biso & 1.000 & 0 \\
\hline 010 & 1.0000 & 0.75873 & 0.24162 & 0.21426 & Biso & 1.000 & 0 \\
\hline 011 & 1.0000 & 0.45417 & 0.23888 & 0.23630 & Biso & 1.000 & 0 \\
\hline 012 & 1.0000 & 0.78563 & 0.54694 & 0.21071 & Biso & 1.000 & 0 \\
\hline 013 & 1.0000 & 0.23441 & 0.76881 & 0.80740 & Biso & 1.000 & 0 \\
\hline 014 & 1.0000 & 0.22098 & 0.47637 & 0.79461 & Biso & 1.000 & 0 \\
\hline 015 & 1.0000 & 0.52702 & 0.75944 & 0.78523 & Biso & 1.000 & 0 \\
\hline 016 & 1.0000 & 0.42286 & 0.58046 & 0.55031 & Biso & 1.000 & 0 \\
\hline 017 & 1.0000 & 0.09748 & 0.56533 & 0.56948 & Biso & 1.000 & 0 \\
\hline 018 & 1.0000 & 0.43617 & 0.86104 & 0.57151 & Biso & 1.000 & 0 \\
\hline 019 & 1.0000 & 0.98625 & 0.31887 & 0.16764 & Biso & 1.000 & 0 \\
\hline 020 & 1.0000 & 0.68671 & 0.67960 & 0.16948 & Biso & 1.000 & 0 \\
\hline 021 & 1.0000 & 0.33414 & 0.04753 & 0.12908 & Biso & 1.000 & 0 \\
\hline 022 & 1.0000 & 0.31236 & 0.97067 & 0.85117 & Biso & 1.000 & 0 \\
\hline 023 & 1.0000 & 0.64860 & 0.68434 & 0.84122 & Biso & 1.000 & 0 \\
\hline 024 & 1.0000 & 0.02104 & 0.35005 & 0.84312 & Biso & 1.000 & 0 \\
\hline 025 & 1.0000 & 0.64575 & 0.64662 & 0.49764 & Biso & 1.000 & 0 \\
\hline 026 & 1.0000 & 0.33883 & 0.99696 & 0.51578 & Biso & 1.000 & 0 \\
\hline 027 & 1.0000 & 0.98477 & 0.34448 & 0.50338 & Biso & 1.000 & 0 \\
\hline 028 & 1.0000 & 0.00256 & 0.67783 & 0.85224 & Biso & 1.000 & 0 \\
\hline 029 & 1.0000 & 0.30054 & 0.32692 & 0.82882 & Biso & 1.000 & 0 \\
\hline 030 & 1.0000 & 0.66592 & 0.98165 & 0.85126 & Biso & 1.000 & 0 \\
\hline 031 & 1.0000 & 0.69075 & 0.04322 & 0.16499 & Biso & 1.000 & 0 \\
\hline 032 & 1.0000 & 0.35647 & 0.32604 & 0.15354 & Biso & 1.000 & 0 \\
\hline 033 & 1.0000 & 0.98861 & 0.67507 & 0.17629 & Biso & 1.000 & 0 \\
\hline 034 & 1.0000 & 0.34062 & 0.38360 & 0.49233 & Biso & 1.000 & 0 \\
\hline 035 & 1.0000 & 0.99990 & 0.66287 & 0.51099 & Biso & 1.000 & 0 \\
\hline 036 & 1.0000 & 0.62453 & 0.99997 & 0.50583 & Biso & 1.000 & 0 \\
\hline 037 & 1.0000 & 0.12596 & 0.26604 & 0.12609 & Biso & 1.000 & 0 \\
\hline 038 & 1.0000 & 0.76023 & 0.88252 & 0.14631 & Biso & 1.000 & 0 \\
\hline 039 & 1.0000 & 0.12913 & 0.90170 & 0.14379 & Biso & 1.000 & 0 \\
\hline 040 & 1.0000 & 0.22913 & 0.12565 & 0.84994 & Biso & 1.000 & 0 \\
\hline 041 & 1.0000 & 0.87294 & 0.75067 & 0.87586 & Biso & 1.000 & 0 \\
\hline 042 & 1.0000 & 0.86891 & 0.11747 & 0.86412 & Biso & 1.000 & 0 \\
\hline 043 & 1.0000 & 0.77014 & 0.56865 & 0.46806 & Biso & 1.000 & 0 \\
\hline 044 & 1.0000 & 0.38072 & 0.20934 & 0.43876 & Biso & 1.000 & 0 \\
\hline 045 & 1.0000 & 0.78722 & 0.22324 & 0.46404 & Biso & 1.000 & 0 \\
\hline 046 & 1.0000 & 0.91861 & 0.47504 & 0.20665 & Biso & 1.000 & 0 \\
\hline 047 & 1.0000 & 0.55721 & 0.10875 & 0.19412 & Biso & 1.000 & 0 \\
\hline 048 & 1.0000 & 0.55508 & 0.44166 & 0.19532 & Biso & 1.000 & 0 \\
\hline 049 & 1.0000 & 0.44057 & 0.90269 & 0.80699 & Biso & 1.000 & 0 \\
\hline 050 & 1.0000 & 0.08045 & 0.53837 & 0.78732 & Biso & 1.000 & 0 \\
\hline 051 & 1.0000 & 0.45408 & 0.55502 & 0.79679 & Biso & 1.000 & 0 \\
\hline 052 & 1.0000 & 0.58410 & 0.80999 & 0.54693 & Biso & 1.000 & 0 \\
\hline 053 & 1.0000 & 0.21834 & 0.45755 & 0.53540 & Biso & 1.000 & 0 \\
\hline 054 & 1.0000 & 0.20389 & 0.76948 & 0.54749 & Biso & 1.000 & 0 \\
\hline 055 & 1.0000 & 0.98867 & 0.25683 & 0.01199 & Biso & 1.000 & 0 \\
\hline 056 & 1.0000 & 0.74012 & 0.75780 & 0.01661 & Biso & 1.000 & 0 \\
\hline 057 & 1.0000 & 0.20828 & 0.00249 & 0.00109 & Biso & 1.000 & 0 \\
\hline 058 & 1.0000 & 0.66366 & 0.59324 & 0.34265 & Biso & 1.000 & 0 \\
\hline 059 & 1.0000 & 0.92787 & 0.33975 & 0.34592 & Biso & 1.000 & 0 \\
\hline
\end{tabular}




\begin{tabular}{|c|c|c|c|c|c|c|c|}
\hline 060 & 1.0000 & 0.31711 & 0.92133 & 0.69267 & Biso & 1.000 & 0 \\
\hline 061 & 1.0000 & 0.06533 & 0.38869 & 0.68216 & Biso & 1.000 & 0 \\
\hline 062 & 1.0000 & 0.59788 & 0.66748 & 0.67942 & Biso & 1.000 & 0 \\
\hline 063 & 1.0000 & 0.00500 & 0.76457 & 0.99757 & Biso & 1.000 & 0 \\
\hline 064 & 1.0000 & 0.25983 & 0.25093 & 0.98349 & Biso & 1.000 & 0 \\
\hline 065 & 1.0000 & 0.75926 & 0.00930 & 0.99810 & Biso & 1.000 & 0 \\
\hline 066 & 1.0000 & 0.66210 & 0.07942 & 0.32175 & Biso & 1.000 & 0 \\
\hline 067 & 1.0000 & 0.93066 & 0.60277 & 0.33159 & Biso & 1.000 & 0 \\
\hline 068 & 1.0000 & 0.40757 & 0.37186 & 0.31419 & Biso & 1.000 & 0 \\
\hline 069 & 1.0000 & 0.32187 & 0.41574 & 0.65368 & Biso & 1.000 & 0 \\
\hline 070 & 1.0000 & 0.60632 & 0.94707 & 0.66790 & Biso & 1.000 & 0 \\
\hline 071 & 1.0000 & 0.06241 & 0.68980 & 0.67052 & Biso & 1.000 & 0 \\
\hline 072 & 1.0000 & 0.37167 & 0.01611 & 0.31000 & Biso & 1.000 & 0 \\
\hline C1 & 1.0000 & 0.32579 & 0.88991 & 0.30401 & Biso & 1.000 & C \\
\hline $\mathrm{C} 2$ & 1.0000 & 0.40076 & 0.86332 & 0.36016 & Biso & 1.000 & C \\
\hline H1 & 1.0000 & 0.48155 & 0.89217 & 0.32775 & Biso & 1.000 & $\mathrm{H}$ \\
\hline $\mathrm{H} 2$ & 1.0000 & 0.41570 & 0.90093 & 0.42618 & Biso & 1.000 & $\mathrm{H}$ \\
\hline н3 & 1.0000 & 0.36080 & 0.77288 & 0.36991 & Biso & 1.000 & $\mathrm{H}$ \\
\hline C3 & 1.0000 & 0.20675 & 0.83659 & 0.33766 & Biso & 1.000 & C \\
\hline H4 & 1.0000 & 0.20308 & 0.86069 & 0.40646 & Biso & 1.000 & $\mathrm{H}$ \\
\hline H5 & 1.0000 & 0.15789 & 0.86026 & 0.29500 & Biso & 1.000 & $\mathrm{H}$ \\
\hline H6 & 1.0000 & 0.16805 & 0.74552 & 0.33565 & Biso & 1.000 & $\mathrm{H}$ \\
\hline $\mathrm{C} 4$ & 1.0000 & 0.32923 & 0.85202 & 0.20891 & Biso & 1.000 & C \\
\hline H7 & 1.0000 & 0.31117 & 0.76546 & 0.21390 & Biso & 1.000 & $\mathrm{H}$ \\
\hline H8 & 1.0000 & 0.26657 & 0.85237 & 0.16525 & Biso & 1.000 & $\mathrm{H}$ \\
\hline $\mathrm{H} 9$ & 1.0000 & 0.41216 & 0.89986 & 0.17853 & Biso & 1.000 & $\mathrm{H}$ \\
\hline \multicolumn{8}{|l|}{121} \\
\hline \multicolumn{8}{|c|}{ data_image 0} \\
\hline \multicolumn{8}{|c|}{13.625} \\
\hline \multicolumn{8}{|c|}{13.625} \\
\hline \multicolumn{8}{|c|}{15.067} \\
\hline \multicolumn{8}{|c|}{$\operatorname{sel} 1^{-} \mathrm{a}$} \\
\hline \multicolumn{8}{|c|}{90} \\
\hline ell__ & -gamma & 120 & & & & & \\
\hline vmmo & חa & & & $1 "$ & & & \\
\hline ymme & $t \_t \bar{a} b$ & s_numbe & & & & & \\
\hline & & & & & & & \\
\hline $\bar{T}^{\mathrm{s} y \mathrm{~m}}$ & $-1+x^{-1}$ & pos_as_x & & & & & \\
\hline & & & & & & & \\
\hline ato & e labe & & & & & & \\
\hline -ato & ce_occu & pancy & & & & & \\
\hline -ato & ce-frac & $\mathrm{x}$ & & & & & \\
\hline -ato & ce_frac & - $y$ & & & & & \\
\hline ato & ce $\mathrm{frac}$ & $z$ & & & & & \\
\hline ato & e_ther & nal_displ & ace_type & & & & \\
\hline -ato & $e_{-}^{-} B$ is & o_or_equi & & & & & \\
\hline ato & ce_type & symbol & & & & & \\
\hline $\bar{S} i 1$ & 1.0000 & 0.00747 & 0.22464 & 0.09472 & Biso & 1.000 & $\mathrm{Si}$ \\
\hline Si2 & 1.0000 & 0.77954 & 0.76890 & 0.09810 & Biso & 1.000 & $\mathrm{Si}$ \\
\hline Si3 & 1.0000 & 0.23823 & 0.99643 & 0.09283 & Biso & 1.000 & $\mathrm{Si}$ \\
\hline $\mathrm{Si} 4$ & 1.0000 & 0.23094 & 0.99123 & 0.88397 & Biso & 1.000 & $\mathrm{Si}$ \\
\hline Si5 & 1.0000 & 0.77640 & 0.76351 & 0.89107 & Biso & 1.000 & $\mathrm{Si}$ \\
\hline Si6 & 1.0000 & 0.00455 & 0.22247 & 0.88810 & Biso & 1.000 & $\mathrm{Si}$ \\
\hline Si7 & 1.0000 & 0.67168 & 0.55531 & 0.42885 & Biso & 1.000 & $\mathrm{Si}$ \\
\hline Al1 & 1.0000 & 0.44175 & 0.10035 & 0.42633 & Biso & 1.000 & $\mathrm{Al}$ \\
\hline Si8 & 1.0000 & 0.90784 & 0.32498 & 0.42754 & Biso & 1.000 & $\mathrm{Si}$ \\
\hline Si9 & 1.0000 & 0.90615 & 0.33009 & 0.22197 & Biso & 1.000 & $\mathrm{Si}$ \\
\hline Si10 & 1.0000 & 0.44372 & 0.10132 & 0.21908 & Biso & 1.000 & $\mathrm{Si}$ \\
\hline Sil1 & 1.0000 & 0.67546 & 0.55945 & 0.22423 & Biso & 1.000 & $\mathrm{Si}$ \\
\hline Si 12 & 1.0000 & 0.33779 & 0.88644 & 0.76224 & Biso & 1.000 & $\mathrm{Si}$ \\
\hline Sil13 & 1.0000 & 0.10806 & 0.42734 & 0.75937 & Biso & 1.000 & $\mathrm{Si}$ \\
\hline $\operatorname{Si} 14$ & 1.0000 & 0.57048 & 0.66019 & 0.76171 & Biso & 1.000 & $\mathrm{Si}$ \\
\hline Sil 15 & 1.0000 & 0.57849 & 0.66612 & 0.55838 & Biso & 1.000 & $\mathrm{Si}$ \\
\hline Sil 6 & 1.0000 & 0.10636 & 0.42851 & 0.55780 & Biso & 1.000 & $\mathrm{Si}$ \\
\hline $\operatorname{Si} 17$ & 1.0000 & 0.33855 & 0.88420 & 0.55548 & Biso & 1.000 & $\mathrm{Si}$ \\
\hline Sil8 & 1.0000 & 0.00456 & 0.76202 & 0.89034 & Biso & 1.000 & $\mathrm{Si}$ \\
\hline Si19 & 1.0000 & 0.23495 & 0.22222 & 0.88507 & Biso & 1.000 & $\mathrm{Si}$ \\
\hline $\operatorname{Si} 20$ & 1.0000 & 0.77800 & 0.99297 & 0.88835 & Biso & 1.000 & $\mathrm{Si}$ \\
\hline Si21 & 1.0000 & 0.77842 & 0.99648 & 0.09636 & Biso & 1.000 & $\mathrm{Si}$ \\
\hline Si22 & 1.0000 & 0.23900 & 0.22656 & 0.09179 & Biso & 1.000 & $\mathrm{Si}$ \\
\hline Si23 & 1.0000 & 0.00955 & 0.77019 & 0.09869 & Biso & 1.000 & $\mathrm{Si}$ \\
\hline $\mathrm{Si} 24$ & 1.0000 & 0.67547 & 0.10066 & 0.22359 & Biso & 1.000 & $\mathrm{Si}$ \\
\hline Si25 & 1.0000 & 0.90414 & 0.55884 & 0.22428 & Biso & 1.000 & $\mathrm{Si}$ \\
\hline Si26 & 1.0000 & 0.44492 & 0.32942 & 0.21888 & Biso & 1.000 & $\mathrm{Si}$ \\
\hline Si27 & 1.0000 & 0.43536 & 0.32711 & 0.42634 & Biso & 1.000 & $\mathrm{Si}$ \\
\hline Si28 & 1.0000 & 0.90159 & 0.55420 & 0.43036 & Biso & 1.000 & $\mathrm{Si}$ \\
\hline
\end{tabular}




\begin{tabular}{|c|c|c|c|c|c|c|c|}
\hline Si29 & 1.0000 & 0.67494 & 0.10102 & 0.42637 & Biso & 1.000 & $\mathrm{Si}$ \\
\hline Si30 & 1.0000 & 0.34227 & 0.44018 & 0.55368 & Biso & 1.000 & $\mathrm{Si}$ \\
\hline Si31 & 1.0000 & 0.57077 & 0.89209 & 0.55689 & Biso & 1.000 & $\mathrm{Si}$ \\
\hline Si32 & 1.0000 & 0.10168 & 0.66076 & 0.56054 & Biso & 1.000 & \\
\hline Si33 & 1.0000 & 0.10661 & 0.65950 & 0.76326 & Biso & 1.000 & \\
\hline $\operatorname{Si} 34$ & 1.0000 & 0.56850 & 0.88987 & 0.76162 & Biso & 1.000 & \\
\hline Si35 & 1.0000 & 0.33908 & 0.43013 & 0.75764 & Biso & 1.000 & \\
\hline 01 & 1.0000 & 0.90993 & 0.09404 & 0.11463 & Biso & 1.000 & \\
\hline $\mathrm{O} 2$ & 1.0000 & 0.91162 & 0.80390 & 0.11442 & Biso & 1.000 & \\
\hline 03 & 1.0000 & 0.20744 & 0.09621 & 0.11184 & Biso & 1.000 & \\
\hline 04 & 1.0000 & 0.10072 & 0.89147 & 0.86531 & Biso & 1.000 & \\
\hline 05 & 1.0000 & 0.81155 & 0.89490 & 0.87202 & Biso & 1.000 & \\
\hline 06 & 1.0000 & 0.10404 & 0.19142 & 0.87189 & Biso & 1.000 & \\
\hline 07 & 1.0000 & 0.56630 & 0.42762 & 0.44076 & Biso & 1.000 & \\
\hline 08 & 1.0000 & 0.58388 & 0.14146 & 0.43504 & Biso & 1.000 & \\
\hline 09 & 1.0000 & 0.88142 & 0.42760 & 0.44625 & Biso & 1.000 & \\
\hline 010 & 1.0000 & 0.77514 & 0.23207 & 0.20708 & Biso & 1.000 & \\
\hline 011 & 1.0000 & 0.47854 & 0.23327 & 0.19747 & Biso & 1.000 & \\
\hline 012 & 1.0000 & 0.77268 & 0.52479 & 0.20810 & Biso & 1.000 & \\
\hline 013 & 1.0000 & 0.23798 & 0.75607 & 0.78071 & Biso & 1.000 & \\
\hline 014 & 1.0000 & 0.24013 & 0.46224 & 0.77425 & Biso & 1.000 & \\
\hline 015 & 1.0000 & 0.53653 & 0.75819 & 0.77339 & Biso & 1.000 & \\
\hline 016 & 1.0000 & 0.44666 & 0.56920 & 0.54384 & Biso & 1.000 & 0 \\
\hline 017 & 1.0000 & 0.11974 & 0.55287 & 0.54950 & Biso & 1.000 & 0 \\
\hline 018 & 1.0000 & 0.43632 & 0.84857 & 0.54402 & Biso & 1.000 & 0 \\
\hline 019 & 1.0000 & 0.99067 & 0.31180 & 0.15707 & Biso & 1.000 & 0 \\
\hline 020 & 1.0000 & 0.69634 & 0.66377 & 0.16074 & Biso & 1.000 & 0 \\
\hline 021 & 1.0000 & 0.34950 & 0.01857 & 0.14634 & Biso & 1.000 & 0 \\
\hline 022 & 1.0000 & 0.31891 & 0.97310 & 0.82401 & Biso & 1.000 & 0 \\
\hline 023 & 1.0000 & 0.66878 & 0.67797 & 0.83112 & Biso & 1.000 & 0 \\
\hline 024 & 1.0000 & 0.02529 & 0.32899 & 0.82753 & Biso & 1.000 & 0 \\
\hline 025 & 1.0000 & 0.66066 & 0.64419 & 0.49372 & Biso & 1.000 & 0 \\
\hline 026 & 1.0000 & 0.35411 & 0.98330 & 0.49106 & Biso & 1.000 & 0 \\
\hline 027 & 1.0000 & 0.01269 & 0.34059 & 0.48889 & Biso & 1.000 & 0 \\
\hline 028 & 1.0000 & 0.02306 & 0.67186 & 0.83321 & Biso & 1.000 & 0 \\
\hline 029 & 1.0000 & 0.31915 & 0.32562 & 0.82093 & Biso & 1.000 & 0 \\
\hline 030 & 1.0000 & 0.67095 & 0.97094 & 0.82788 & Biso & 1.000 & 0 \\
\hline 031 & 1.0000 & 0.69237 & 0.01783 & 0.15552 & Biso & 1.000 & 0 \\
\hline 032 & 1.0000 & 0.34287 & 0.31430 & 0.15387 & Biso & 1.000 & 0 \\
\hline 033 & 1.0000 & 0.98820 & 0.66532 & 0.16214 & Biso & 1.000 & 0 \\
\hline 034 & 1.0000 & 0.35069 & 0.35680 & 0.48184 & Biso & 1.000 & 0 \\
\hline 035 & 1.0000 & 0.00081 & 0.64693 & 0.49461 & Biso & 1.000 & 0 \\
\hline 036 & 1.0000 & 0.64997 & 0.99557 & 0.49164 & Biso & 1.000 & 0 \\
\hline 037 & 1.0000 & 0.12945 & 0.23750 & 0.11789 & Biso & 1.000 & 0 \\
\hline 038 & 1.0000 & 0.76531 & 0.87592 & 0.12506 & Biso & 1.000 & 0 \\
\hline 039 & 1.0000 & 0.13040 & 0.87811 & 0.12710 & Biso & 1.000 & 0 \\
\hline 040 & 1.0000 & 0.24365 & 0.11212 & 0.85729 & Biso & 1.000 & 0 \\
\hline 041 & 1.0000 & 0.88185 & 0.74580 & 0.86508 & Biso & 1.000 & 0 \\
\hline 042 & 1.0000 & 0.88490 & 0.11392 & 0.85971 & Biso & 1.000 & 0 \\
\hline 043 & 1.0000 & 0.78694 & 0.55545 & 0.45498 & Biso & 1.000 & 0 \\
\hline 044 & 1.0000 & 0.41421 & 0.20720 & 0.46076 & Biso & 1.000 & 0 \\
\hline 045 & 1.0000 & 0.80065 & 0.20439 & 0.45329 & Biso & 1.000 & 0 \\
\hline 046 & 1.0000 & 0.91944 & 0.45223 & 0.19807 & Biso & 1.000 & 0 \\
\hline 047 & 1.0000 & 0.55525 & 0.09039 & 0.20107 & Biso & 1.000 & 0 \\
\hline 048 & 1.0000 & 0.55333 & 0.45300 & 0.19931 & Biso & 1.000 & 0 \\
\hline 049 & 1.0000 & 0.45844 & 0.89882 & 0.78922 & Biso & 1.000 & 0 \\
\hline 050 & 1.0000 & 0.09460 & 0.53662 & 0.77792 & Biso & 1.000 & 0 \\
\hline 051 & 1.0000 & 0.46006 & 0.53860 & 0.78312 & Biso & 1.000 & 0 \\
\hline 052 & 1.0000 & 0.59296 & 0.78816 & 0.53409 & Biso & 1.000 & 0 \\
\hline 053 & 1.0000 & 0.22629 & 0.43990 & 0.53195 & Biso & 1.000 & 0 \\
\hline 054 & 1.0000 & 0.21641 & 0.77337 & 0.53150 & Biso & 1.000 & 0 \\
\hline 055 & 1.0000 & 0.00251 & 0.25614 & 0.99138 & Biso & 1.000 & 0 \\
\hline 056 & 1.0000 & 0.74382 & 0.73278 & 0.99520 & Biso & 1.000 & 0 \\
\hline 057 & 1.0000 & 0.26078 & 0.98962 & 0.98797 & Biso & 1.000 & 0 \\
\hline 058 & 1.0000 & 0.67903 & 0.59855 & 0.32690 & Biso & 1.000 & 0 \\
\hline 059 & 1.0000 & 0.39294 & 0.06557 & 0.31694 & Biso & 1.000 & 0 \\
\hline 060 & 1.0000 & 0.94479 & 0.32882 & 0.32408 & Biso & 1.000 & 0 \\
\hline 061 & 1.0000 & 0.33615 & 0.91945 & 0.65911 & Biso & 1.000 & 0 \\
\hline 062 & 1.0000 & 0.06923 & 0.38035 & 0.65849 & Biso & 1.000 & 0 \\
\hline 063 & 1.0000 & 0.61566 & 0.66316 & 0.66094 & Biso & 1.000 & 0 \\
\hline 064 & 1.0000 & 0.01080 & 0.73666 & 0.99531 & Biso & 1.000 & 0 \\
\hline 065 & 1.0000 & 0.27331 & 0.25785 & 0.98793 & Biso & 1.000 & 0 \\
\hline 066 & 1.0000 & 0.74651 & 0.99502 & 0.99217 & Biso & 1.000 & 0 \\
\hline 067 & 1.0000 & 0.68188 & 0.06155 & 0.32439 & Biso & 1.000 & 0 \\
\hline 068 & 1.0000 & 0.93914 & 0.59502 & 0.32788 & Biso & 1.000 & 0 \\
\hline 069 & 1.0000 & 0.40157 & 0.32177 & 0.32096 & Biso & 1.000 & 0 \\
\hline 070 & 1.0000 & 0.33841 & 0.39345 & 0.65431 & Biso & 1.000 & 0 \\
\hline 071 & 1.0000 & 0.60704 & 0.93192 & 0.65994 & Biso & 1.000 & 0 \\
\hline 072 & 1.0000 & 0.06785 & 0.67041 & 0.66276 & Biso & 1.000 & 0 \\
\hline H 1 & 1.0000 & 0.05511 & 0.83772 & 0.41736 & Biso & 1.000 & $\mathrm{H}$ \\
\hline
\end{tabular}




$\begin{array}{llllllll}\text { C1 } & 1.0000 & 0.12782 & 0.01493 & 0.40464 & \text { Biso } & 1.000 & \mathrm{C} \\ \mathrm{H} 2 & 1.0000 & 0.24796 & 0.10877 & 0.49477 & \text { Biso } & 1.000 & \mathrm{H} \\ \mathrm{C} 2 & 1.0000 & 0.15237 & 0.05134 & 0.49626 & \text { Biso } & 1.000 & \mathrm{C} \\ \mathrm{C} 3 & 1.0000 & 0.12477 & 0.09140 & 0.33807 & \text { Biso } & 1.000 & \mathrm{C} \\ \mathrm{H} 3 & 1.0000 & 0.21323 & 0.13711 & 0.31184 & \text { Biso } & 1.000 & \mathrm{H} \\ \mathrm{H} 4 & 1.0000 & 0.07167 & 0.04672 & 0.28043 & \text { Biso } & 1.000 & \mathrm{H} \\ \mathrm{H} 5 & 1.0000 & 0.10788 & 0.15639 & 0.36475 & \text { Biso } & 1.000 & \mathrm{H} \\ \mathrm{H} 6 & 1.0000 & 0.13584 & 0.98396 & 0.54380 & \text { Biso } & 1.000 & \mathrm{H} \\ \mathrm{C} 4 & 1.0000 & 0.12005 & 0.90877 & 0.37749 & \text { Biso } & 1.000 & \mathrm{C} \\ \mathrm{H} 7 & 1.0000 & 0.19954 & 0.91206 & 0.40016 & \text { Biso } & 1.000 & \mathrm{H} \\ \mathrm{H} 8 & 1.0000 & 0.10740 & 0.89089 & 0.30631 & \text { Biso } & 1.000 & \mathrm{H} \\ \mathrm{H} 9 & 1.0000 & 0.11973 & 0.10684 & 0.51715 & \text { Biso } & 1.000 & \mathrm{H}\end{array}$

$\mathrm{Ga} 21$

data_image 0

cell_length a 13.625

cell-length ${ }^{-} \mathrm{b} \quad 13.625$

-cell_length_c $\quad 15.067$

cell_angle_ālpha 90

cell angle beta 90

_cell_angle_gamma 120

symmetry space group name $\mathrm{H}-\mathrm{M}$ "P 1 "

_symmetry_int_tables_number 1

loop

_symmetry_equiv_pos_as_xyz

' $\mathrm{x}, \mathrm{y}, \mathrm{z}$ '

loop

atom_site label

-atom_site_occupancy

-atom_site_fract_x

-atom site fract $y$

atom_site_fract_z

_atom_site_thermal_displace_type

atom site_B_iso_or_equiv

-atom_site_type_symbol

Sil 1.00000 .008710 .22419

$\begin{array}{lll}\mathrm{Si3} & 1.0000 & 0.23917\end{array}$

$\begin{array}{lll}\mathrm{Si} & 1.0000 & 0.23046\end{array}$

0.22419

0.09547

0.10022

Biso

$1.000 \mathrm{Si}$

$0.99608 \quad 0.09188$ Biso

$1.000 \mathrm{Si}$

Si 5

$1.0000 \quad 0.77703$

0.98993

0.88334 Biso

$1.000 \mathrm{Si}$

$1.0000 \quad 0.00483$

$1.0000 \quad 0.67248$

0.76307

0.89267 Biso

$1.000 \mathrm{Si}$

Si 7

$0.22213 \quad 0.88875$ Biso

$1.000 \mathrm{Si}$

$1.0000 \quad 0.44567$

0.55548

0.43023 Biso

$1.000 \mathrm{Si}$

$1.0000 \quad 0.91236$

$1.0000 \quad 0.90699$

(10339

0.43046 Biso

$1.000 \mathrm{Si}$

0.32523

0.42841 Biso

$.000 \mathrm{Ga}$

Si9

0.32966

0.22275 Biso

$1.000 \mathrm{Si}$

$1.0000 \quad 0.44324$

.09903

.22015 Biso

$1.000 \mathrm{Si}$

Sil1

$1.0000 \quad 0.67654$

0.55890

0.22569 Biso

$1.000 \mathrm{Si}$

Si12

$1.0000 \quad 0.33696$

0.76549 Biso

$1.000 \mathrm{Si}$

$1.0000 \quad 0.10806$

$1.0000 \quad 0.57151$

0.65975

0.75937 Biso

$1.000 \mathrm{Si}$

Si14

$1.0000 \quad 0.58451$

0.66909

0.76297 Biso

$1.000 \mathrm{Si}$

Si16

$0.42934 \quad 0.55975$

$1.000 \mathrm{Si}$

$1.0000 \quad 0.10785$

$1.0000 \quad 0.33837$

0.87883

0.55975 Biso

Si

Sil1

Si19

$.0000 \quad 0.00371$

0.75973

0.55667 Biso

$1.000 \mathrm{Si}$

$1.0000 \quad 0.23489$

0.22129

.89139 Biso

$1.000 \mathrm{Si}$

$1.0000 \quad 0.77874$

0.99224

0.88444 Biso

Si

$\mathrm{Si} 21$

$1.0000 \quad 0.77961$

0.99606

0.88972 Biso

$.000 \mathrm{Si}$

$1.0000 \quad 0.24020$

0.22593

.09788 Biso

$1.000 \mathrm{Si}$

$1.0000 \quad 0.01018$

0.76927

0.09154 Biso

$.000 \mathrm{Si}$

Si23

Si24

0.10010

0.09985 Biso

$.000 \mathrm{Si}$

.00000 .67703

0.55868

.22599 Biso

$1.000 \mathrm{Si}$

$1.0000 \quad 0.90566$

$1.0000 \quad 0.44542$

0.32857

0.22589 Biso

$.000 \mathrm{Si}$

Si26

Si2

0.32954

0.22074 Biso

$1.000 \mathrm{Si}$

.00000 .43284

0.55274

.42753 Biso

$1.000 \mathrm{Si}$

$1.0000 \quad 0.67981$

0.10379

0.43189 Biso

$1.000 \mathrm{Si}$

Si29

0.44571

0.42781 Biso

$.000 \mathrm{Si}$

$1.0000 \quad 0.34469$

0.89203

0.55410 Biso

$1.000 \mathrm{Si}$

$1.0000 \quad 0.57128$

$1.0000 \quad 0.09997$

0.66118

0.55867 Biso

$.000 \mathrm{Si}$

$\mathrm{Si} 32$

Si33

$1.0000 \quad 0.10619$

0.65867

0.56274 Biso

$1.000 \mathrm{Si}$

$1.0000 \quad 0.56800$

0.88890

0.76474

Biso

$1.000 \mathrm{Si}$

Si35 $1.0000 \quad 0.33914$

$01 \quad 1.0000 \quad 0.91130$

0.43040

0.76381 Biso

$1.000 \mathrm{Si}$

0.09355

0.75795 Biso

$1.000 \mathrm{Si}$

$1.0000 \quad 0.91289$

0.80354

0.11577

Biso

$1.000 \mathrm{Si}$

$1.0000 \quad 0.20747$

0.09506

0.11719 Biso

.0000

$1.0000 \quad 0.10032$

.88905

0.86637

Biso

1.0000

$1.0000 \quad 0.81284$

$\begin{array}{lll}06 & 1.0000 & 0.10413 \\ 07 & 1.0000 & 0.56349\end{array}$

0.89461

Biso

$1.000 \quad 0$

1.0000

0.43034

0.87181 Biso

1.0000

1.0000

$1.000 \quad 0$ 


\begin{tabular}{|c|c|c|c|c|c|c|c|}
\hline 08 & 1.0000 & 0.59642 & 0.15488 & 0.43293 & Biso & 1.000 & 0 \\
\hline 09 & 1.0000 & 0.88508 & 0.42707 & 0.44761 & Biso & 1.000 & O \\
\hline 010 & 1.0000 & 0.77542 & 0.23178 & 0.20875 & Biso & 1.000 & O \\
\hline 011 & 1.0000 & 0.47972 & 0.23182 & 0.20291 & Biso & 1.000 & $\mathrm{O}$ \\
\hline 012 & 1.0000 & 0.77444 & 0.52523 & 0.20942 & Biso & 1.000 & $\mathrm{O}$ \\
\hline 013 & 1.0000 & 0.23728 & 0.75230 & 0.78741 & Biso & 1.000 & 0 \\
\hline 014 & 1.0000 & 0.24050 & 0.46273 & 0.77640 & Biso & 1.000 & 0 \\
\hline 015 & 1.0000 & 0.53690 & 0.75735 & 0.77353 & Biso & 1.000 & O \\
\hline 016 & 1.0000 & 0.45291 & 0.57257 & 0.54481 & Biso & 1.000 & 0 \\
\hline 017 & 1.0000 & 0.11071 & 0.54886 & 0.55651 & Biso & 1.000 & O \\
\hline 018 & 1.0000 & 0.43635 & 0.84360 & 0.54306 & Biso & 1.000 & $\mathrm{O}$ \\
\hline 019 & 1.0000 & 0.99090 & 0.31098 & 0.15743 & Biso & 1.000 & $\mathrm{O}$ \\
\hline 020 & 1.0000 & 0.69678 & 0.66293 & 0.16197 & Biso & 1.000 & 0 \\
\hline 021 & 1.0000 & 0.35128 & 0.01932 & 0.14523 & Biso & 1.000 & O \\
\hline 022 & 1.0000 & 0.31794 & 0.97164 & 0.82300 & Biso & 1.000 & O \\
\hline 023 & 1.0000 & 0.66795 & 0.67736 & 0.83421 & Biso & 1.000 & 0 \\
\hline 024 & 1.0000 & 0.02520 & 0.32894 & 0.82868 & Biso & 1.000 & 0 \\
\hline 025 & 1.0000 & 0.66692 & 0.64748 & 0.49542 & Biso & 1.000 & $\mathrm{O}$ \\
\hline 026 & 1.0000 & 0.35396 & 0.98181 & 0.49736 & Biso & 1.000 & O \\
\hline 027 & 1.0000 & 0.01905 & 0.34181 & 0.48790 & Biso & 1.000 & O \\
\hline 028 & 1.0000 & 0.02144 & 0.66837 & 0.83526 & Biso & 1.000 & O \\
\hline 029 & 1.0000 & 0.31886 & 0.32462 & 0.82007 & Biso & 1.000 & 0 \\
\hline 030 & 1.0000 & 0.67146 & 0.96965 & 0.82935 & Biso & 1.000 & 0 \\
\hline 031 & 1.0000 & 0.69363 & 0.01803 & 0.15690 & Biso & 1.000 & 0 \\
\hline 032 & 1.0000 & 0.34556 & 0.31262 & 0.15286 & Biso & 1.000 & O \\
\hline 033 & 1.0000 & 0.99020 & 0.66540 & 0.16396 & Biso & 1.000 & 0 \\
\hline 034 & 1.0000 & 0.34768 & 0.36098 & 0.48057 & Biso & 1.000 & O \\
\hline 035 & 1.0000 & 0.99863 & 0.64660 & 0.49719 & Biso & 1.000 & 0 \\
\hline 036 & 1.0000 & 0.64774 & 0.99786 & 0.49431 & Biso & 1.000 & 0 \\
\hline 037 & 1.0000 & 0.13123 & 0.23774 & 0.11838 & Biso & 1.000 & O \\
\hline 038 & 1.0000 & 0.76641 & 0.87566 & 0.12736 & Biso & 1.000 & 0 \\
\hline 039 & 1.0000 & 0.13213 & 0.87736 & 0.12627 & Biso & 1.000 & O \\
\hline 040 & 1.0000 & 0.24234 & 0.11047 & 0.85659 & Biso & 1.000 & O \\
\hline 041 & 1.0000 & 0.88142 & 0.74421 & 0.86560 & Biso & 1.000 & $\mathrm{O}$ \\
\hline 042 & 1.0000 & 0.88492 & 0.11354 & 0.86091 & Biso & 1.000 & 0 \\
\hline 043 & 1.0000 & 0.78463 & 0.54905 & 0.45497 & Biso & 1.000 & O \\
\hline 044 & 1.0000 & 0.41051 & 0.21050 & 0.46530 & Biso & 1.000 & $\mathrm{O}$ \\
\hline 045 & 1.0000 & 0.80707 & 0.20340 & 0.45532 & Biso & 1.000 & 0 \\
\hline 046 & 1.0000 & 0.92034 & 0.45180 & 0.19898 & Biso & 1.000 & 0 \\
\hline 047 & 1.0000 & 0.55501 & 0.08777 & 0.20631 & Biso & 1.000 & $\mathrm{O}$ \\
\hline 048 & 1.0000 & 0.55485 & 0.45150 & 0.20088 & Biso & 1.000 & $\mathrm{O}$ \\
\hline 049 & 1.0000 & 0.45809 & 0.89655 & 0.79438 & Biso & 1.000 & O \\
\hline 050 & 1.0000 & 0.09157 & 0.53394 & 0.77363 & Biso & 1.000 & $\mathrm{O}$ \\
\hline 051 & 1.0000 & 0.46073 & 0.53809 & 0.78346 & Biso & 1.000 & O \\
\hline 052 & 1.0000 & 0.60009 & 0.79214 & 0.53696 & Biso & 1.000 & 0 \\
\hline 053 & 1.0000 & 0.23273 & 0.45376 & 0.53402 & Biso & 1.000 & O \\
\hline 054 & 1.0000 & 0.21664 & 0.76902 & 0.52964 & Biso & 1.000 & $\mathrm{O}$ \\
\hline 055 & 1.0000 & 0.00345 & 0.25545 & 0.99220 & Biso & 1.000 & O \\
\hline 056 & 1.0000 & 0.74617 & 0.73357 & 0.99712 & Biso & 1.000 & O \\
\hline 057 & 1.0000 & 0.26223 & 0.99001 & 0.98722 & Biso & 1.000 & O \\
\hline 058 & 1.0000 & 0.68019 & 0.59868 & 0.32815 & Biso & 1.000 & 0 \\
\hline 059 & 1.0000 & 0.38517 & 0.05666 & 0.31670 & Biso & 1.000 & O \\
\hline 060 & 1.0000 & 0.94665 & 0.32809 & 0.32438 & Biso & 1.000 & O \\
\hline 061 & 1.0000 & 0.33488 & 0.90867 & 0.66136 & Biso & 1.000 & 0 \\
\hline 062 & 1.0000 & 0.07170 & 0.37493 & 0.65899 & Biso & 1.000 & O \\
\hline 063 & 1.0000 & 0.61983 & 0.66417 & 0.66308 & Biso & 1.000 & O \\
\hline 064 & 1.0000 & 0.00904 & 0.73464 & 0.99656 & Biso & 1.000 & 0 \\
\hline 065 & 1.0000 & 0.27353 & 0.25644 & 0.98743 & Biso & 1.000 & O \\
\hline 066 & 1.0000 & 0.74740 & 0.99400 & 0.99370 & Biso & 1.000 & $\mathrm{O}$ \\
\hline 067 & 1.0000 & 0.68548 & 0.06119 & 0.32654 & Biso & 1.000 & $\mathrm{O}$ \\
\hline 068 & 1.0000 & 0.94047 & 0.59395 & 0.32953 & Biso & 1.000 & O \\
\hline 069 & 1.0000 & 0.40068 & 0.32265 & 0.32179 & Biso & 1.000 & O \\
\hline 070 & 1.0000 & 0.33844 & 0.39596 & 0.65403 & Biso & 1.000 & O \\
\hline 071 & 1.0000 & 0.60407 & 0.93234 & 0.66202 & Biso & 1.000 & O \\
\hline 072 & 1.0000 & 0.07181 & 0.67850 & 0.66504 & Biso & 1.000 & $\mathrm{O}$ \\
\hline H 1 & 1.0000 & 0.13864 & 0.86516 & 0.40002 & Biso & 1.000 & $\mathrm{H}$ \\
\hline $\mathrm{C} 1$ & 1.0000 & 0.12427 & 0.01511 & 0.39415 & Biso & 1.000 & C \\
\hline $\mathrm{H} 2$ & 1.0000 & 0.23388 & 0.10296 & 0.49528 & Biso & 1.000 & $\mathrm{H}$ \\
\hline $\mathrm{C} 2$ & 1.0000 & 0.14100 & 0.04002 & 0.48903 & Biso & 1.000 & C \\
\hline C3 & 1.0000 & 0.09595 & 0.08562 & 0.33750 & Biso & 1.000 & $\mathrm{C}$ \\
\hline H3 & 1.0000 & 0.10978 & 0.07900 & 0.26658 & Biso & 1.000 & $\mathrm{H}$ \\
\hline $\mathrm{H} 4$ & 1.0000 & 0.00406 & 0.05346 & 0.34715 & Biso & 1.000 & $\mathrm{H}$ \\
\hline H5 & 1.0000 & 0.13847 & 0.17443 & 0.35997 & Biso & 1.000 & $\mathrm{H}$ \\
\hline H6 & 1.0000 & 0.12588 & 0.96719 & 0.52988 & Biso & 1.000 & $\mathrm{H}$ \\
\hline $\mathrm{C} 4$ & 1.0000 & 0.14383 & 0.93091 & 0.35521 & Biso & 1.000 & C \\
\hline H7 & 1.0000 & 0.24012 & 0.98449 & 0.33742 & Biso & 1.000 & $\mathrm{H}$ \\
\hline H8 & 1.0000 & 0.10487 & 0.90044 & 0.28980 & Biso & 1.000 & $\mathrm{H}$ \\
\hline H9 & 1.0000 & 0.09677 & 0.08341 & 0.51363 & Biso & 1.000 & $\mathrm{H}$ \\
\hline
\end{tabular}




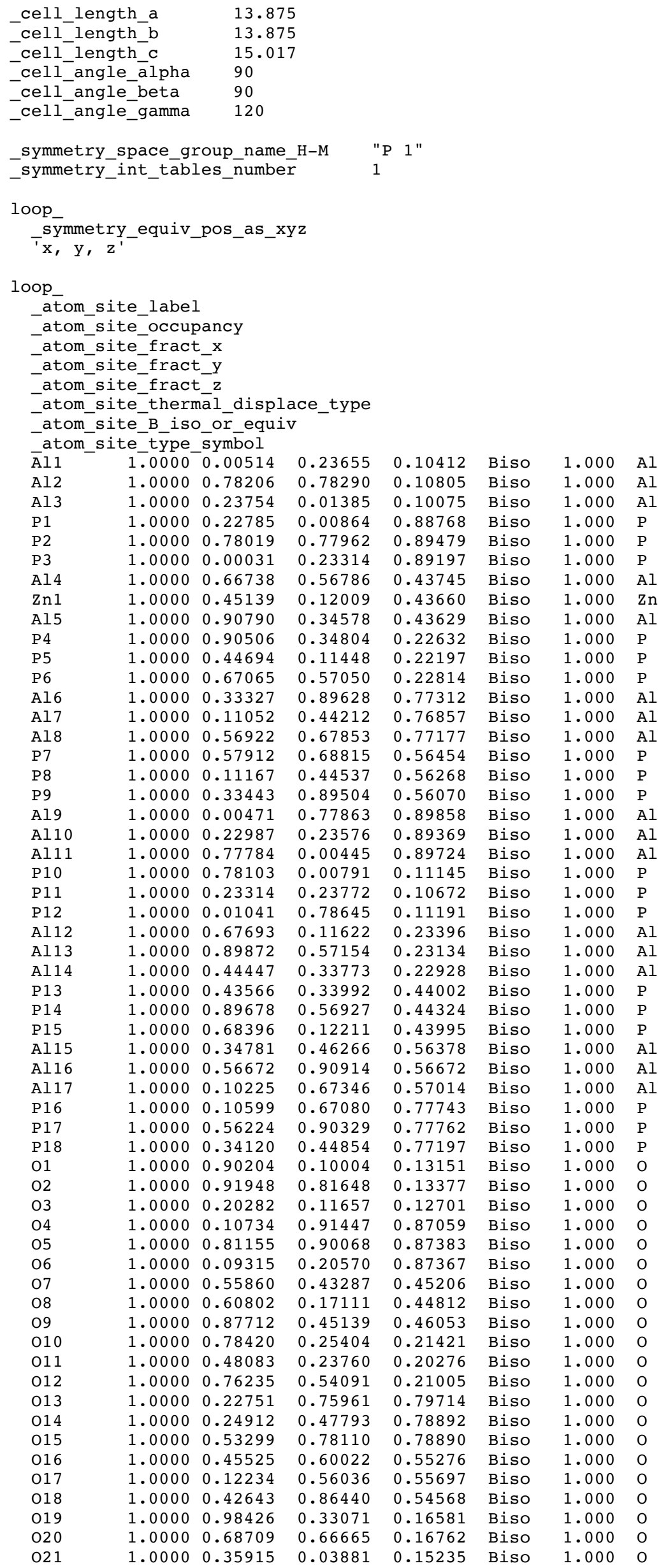




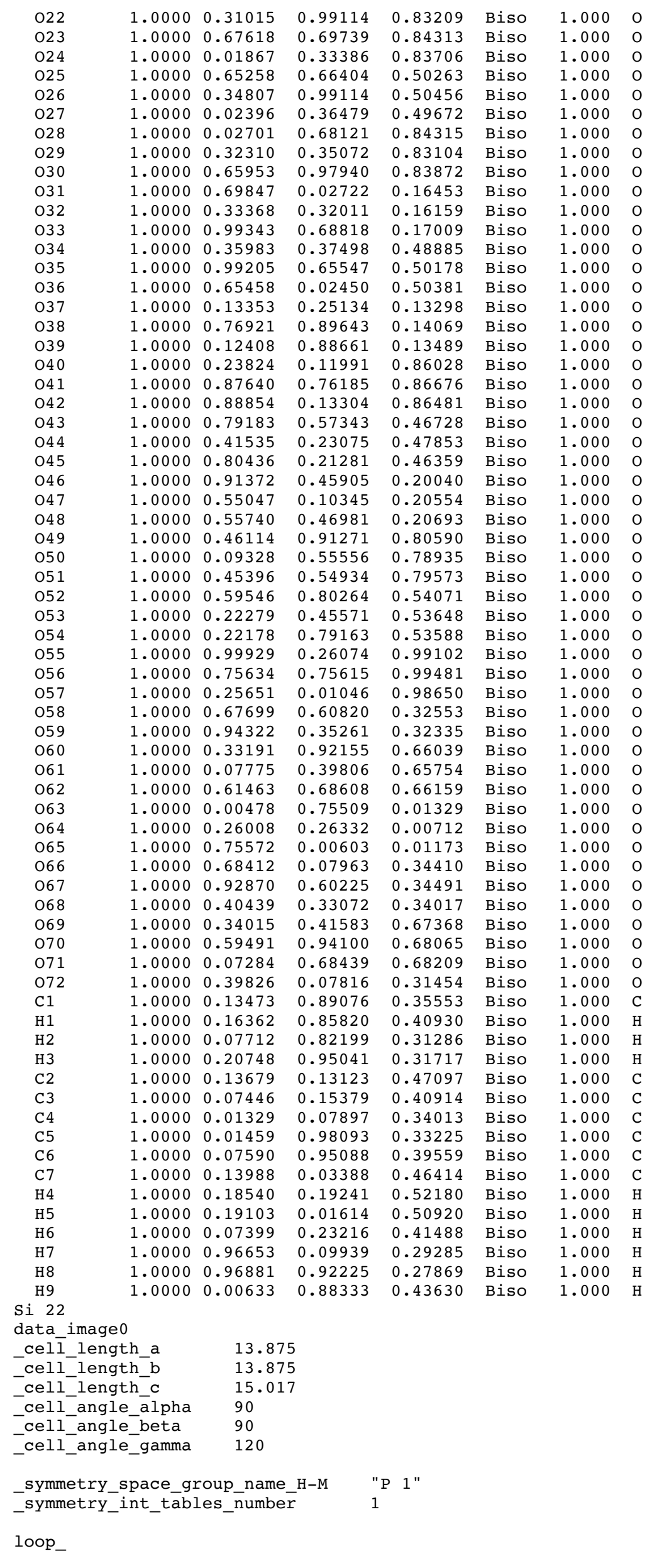




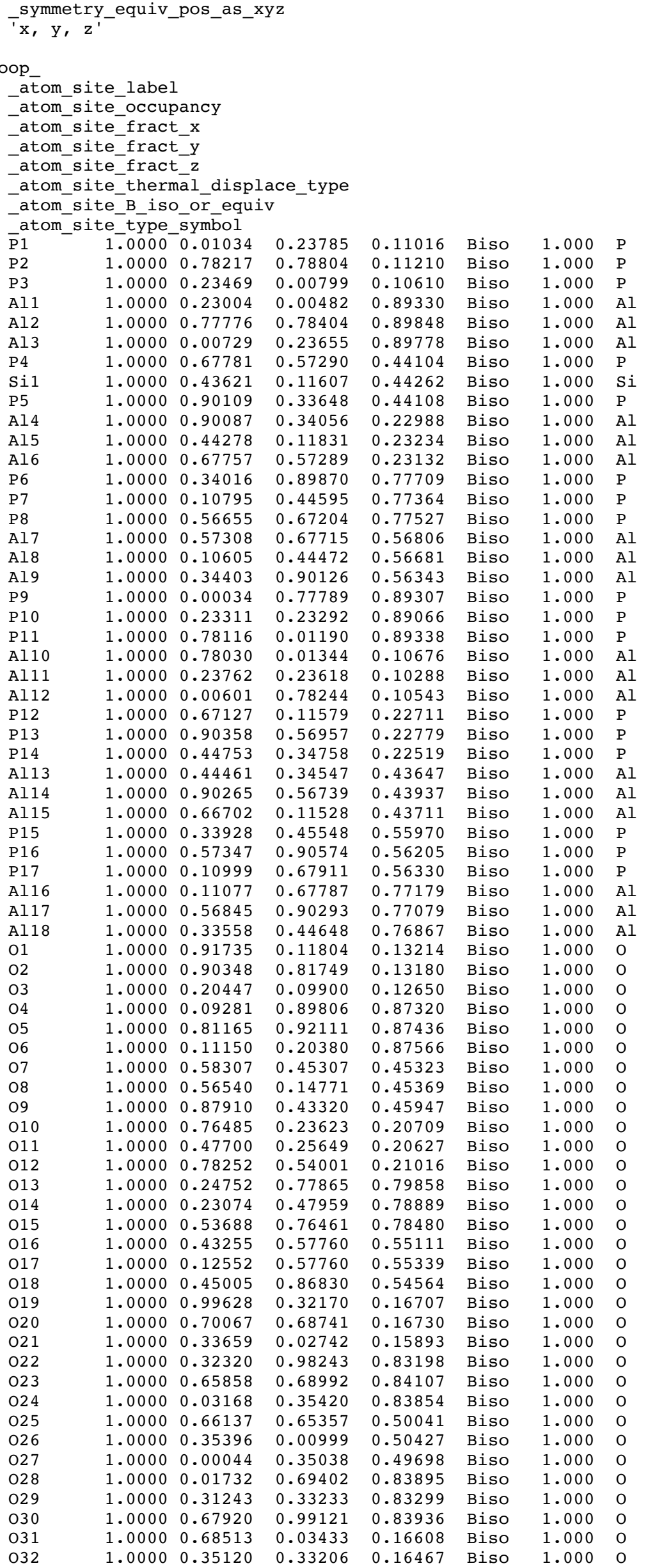




\begin{tabular}{|c|c|c|c|c|c|c|c|}
\hline 033 & 1.0000 & 0.98441 & 0.66926 & 0.17059 & Biso & 1.000 & 0 \\
\hline 034 & 1.0000 & 0.35663 & 0.38095 & 0.49485 & Biso & 1.000 & 0 \\
\hline 035 & 1.0000 & 0.01435 & 0.66585 & 0.50292 & Biso & 1.000 & 0 \\
\hline 036 & 1.0000 & 0.65050 & 0.00130 & 0.50055 & Biso & 1.000 & O \\
\hline 037 & 1.0000 & 0.12250 & 0.24812 & 0.13375 & Biso & 1.000 & $\mathrm{O}$ \\
\hline 038 & 1.0000 & 0.76982 & 0.88772 & 0.13965 & Biso & 1.000 & 0 \\
\hline 039 & 1.0000 & 0.13485 & 0.89531 & 0.13369 & Biso & 1.000 & $\mathrm{O}$ \\
\hline 040 & 1.0000 & 0.24393 & 0.13250 & 0.86280 & Biso & 1.000 & O \\
\hline 041 & 1.0000 & 0.88811 & 0.76560 & 0.86635 & Biso & 1.000 & 0 \\
\hline 042 & 1.0000 & 0.87939 & 0.12488 & 0.86576 & Biso & 1.000 & 0 \\
\hline 043 & 1.0000 & 0.78803 & 0.58011 & 0.46817 & Biso & 1.000 & 0 \\
\hline 044 & 1.0000 & 0.42105 & 0.22003 & 0.47325 & Biso & 1.000 & 0 \\
\hline 045 & 1.0000 & 0.79953 & 0.22644 & 0.46676 & Biso & 1.000 & 0 \\
\hline 046 & 1.0000 & 0.91711 & 0.47007 & 0.20281 & Biso & 1.000 & O \\
\hline 047 & 1.0000 & 0.55952 & 0.10650 & 0.20583 & Biso & 1.000 & 0 \\
\hline 048 & 1.0000 & 0.54900 & 0.46131 & 0.20267 & Biso & 1.000 & $\mathrm{O}$ \\
\hline 049 & 1.0000 & 0.45249 & 0.91119 & 0.80366 & Biso & 1.000 & O \\
\hline 050 & 1.0000 & 0.09379 & 0.54674 & 0.79056 & Biso & 1.000 & 0 \\
\hline 051 & 1.0000 & 0.46348 & 0.56013 & 0.79760 & Biso & 1.000 & 0 \\
\hline 052 & 1.0000 & 0.59227 & 0.80761 & 0.54268 & Biso & 1.000 & 0 \\
\hline 053 & 1.0000 & 0.22777 & 0.44695 & 0.53554 & Biso & 1.000 & 0 \\
\hline 054 & 1.0000 & 0.21660 & 0.78283 & 0.53382 & Biso & 1.000 & 0 \\
\hline 055 & 1.0000 & 0.00593 & 0.26375 & 0.01138 & Biso & 1.000 & 0 \\
\hline 056 & 1.0000 & 0.75515 & 0.76086 & 0.01304 & Biso & 1.000 & 0 \\
\hline 057 & 1.0000 & 0.25882 & 0.00700 & 0.00646 & Biso & 1.000 & 0 \\
\hline 058 & 1.0000 & 0.68470 & 0.61071 & 0.34347 & Biso & 1.000 & 0 \\
\hline 059 & 1.0000 & 0.93214 & 0.33685 & 0.34239 & Biso & 1.000 & 0 \\
\hline 060 & 1.0000 & 0.33792 & 0.92348 & 0.67816 & Biso & 1.000 & $\mathrm{O}$ \\
\hline 061 & 1.0000 & 0.07288 & 0.40224 & 0.67781 & Biso & 1.000 & 0 \\
\hline 062 & 1.0000 & 0.60711 & 0.67096 & 0.67989 & Biso & 1.000 & 0 \\
\hline 063 & 1.0000 & 0.00010 & 0.75089 & 0.99258 & Biso & 1.000 & 0 \\
\hline 064 & 1.0000 & 0.26521 & 0.26273 & 0.98904 & Biso & 1.000 & O \\
\hline 065 & 1.0000 & 0.75530 & 0.01246 & 0.99291 & Biso & 1.000 & 0 \\
\hline 066 & 1.0000 & 0.67894 & 0.08532 & 0.32417 & Biso & 1.000 & O \\
\hline 067 & 1.0000 & 0.93409 & 0.60114 & 0.32640 & Biso & 1.000 & 0 \\
\hline 068 & 1.0000 & 0.41258 & 0.34594 & 0.32252 & Biso & 1.000 & 0 \\
\hline 069 & 1.0000 & 0.33457 & 0.41353 & 0.65571 & Biso & 1.000 & 0 \\
\hline 070 & 1.0000 & 0.60440 & 0.94344 & 0.65987 & Biso & 1.000 & 0 \\
\hline 071 & 1.0000 & 0.08086 & 0.69033 & 0.66029 & Biso & 1.000 & 0 \\
\hline 072 & 1.0000 & 0.39680 & 0.08413 & 0.33911 & Biso & 1.000 & O \\
\hline $\mathrm{C} 1$ & 1.0000 & 0.12815 & 0.88742 & 0.35540 & Biso & 1.000 & C \\
\hline $\mathrm{H} 1$ & 1.0000 & 0.15576 & 0.85390 & 0.40934 & Biso & 1.000 & $\mathrm{H}$ \\
\hline $\mathrm{H} 2$ & 1.0000 & 0.06935 & 0.81883 & 0.31307 & Biso & 000 & $\mathrm{H}$ \\
\hline $\mathrm{H} 3$ & 1.0000 & 0.20130 & 0.94577 & 0.31687 & Biso & 1.000 & $\mathrm{H}$ \\
\hline $\mathrm{C} 2$ & 1.0000 & 0.13707 & 0.13187 & 0.46972 & Biso & 1.000 & $\mathrm{C}$ \\
\hline $\mathrm{C} 3$ & 1.0000 & 0.07594 & 0.15588 & 0.40781 & Biso & 1.000 & C \\
\hline C4 & 1.0000 & 0.01359 & 0.08133 & 0.33898 & Biso & 1.000 & C \\
\hline C5 & 1.0000 & 0.01210 & 0.98188 & 0.33153 & Biso & 1.000 & C \\
\hline C6 & 1.0000 & 0.07186 & 0.95019 & 0.39513 & Biso & 1.000 & C \\
\hline C7 & 1.0000 & 0.13743 & 0.03302 & 0.46331 & Biso & 1.000 & C \\
\hline $\mathrm{H} 4$ & 1.0000 & 0.18678 & 0.19282 & 0.52039 & Biso & 1.000 & $\mathrm{H}$ \\
\hline H5 & 1.0000 & 0.18783 & 0.01416 & 0.50834 & Biso & 1.000 & $\mathrm{H}$ \\
\hline $\mathrm{H} 6$ & 1.0000 & 0.07701 & 0.23506 & 0.41309 & Biso & 1.000 & $\mathrm{H}$ \\
\hline $\mathrm{H} 7$ & 1.0000 & 0.96834 & 0.10335 & 0.29146 & Biso & 1.000 & $\mathrm{H}$ \\
\hline $\mathrm{H} 8$ & 1.0000 & 0.96497 & 0.92330 & 0.27828 & Biso & 1.000 & $\mathrm{H}$ \\
\hline $\mathrm{H} 9$ & 1.0000 & 0.00156 & 0.88414 & 0.43628 & Biso & 1.000 & $\mathrm{H}$ \\
\hline
\end{tabular}

Mg 22

data_image 0

$\begin{array}{ll}\text {-cell_length_a } & 13.875 \\ \text {-cell_length_b } & 13.875 \\ \text {-cell_length_c } & 15.017 \\ \text {-cell_angle_alpha } & 90 \\ \text {-cell_angle_beta } & 90 \\ \text {-cell_angle_gamma } & 120\end{array}$

_symmetry_space_group_name_H-M "P 1 "

_symmetry_int_tables_number 1

loop_

-symmetry_equiv_pos_as_xyz

' $\mathrm{x}, \mathrm{y}, \mathrm{z}$ '

loop

atom site label

-atom_site_occupancy

-atom_site_fract_x

atom site fract $y$

-atom_site_fract_z

-atom_site_thermal_displace_type

-atom_site_B_iso_or_equiv 


\begin{tabular}{|c|c|c|c|c|c|c|c|}
\hline $\bar{A} 11$ & 1.0000 & 0.00575 & 0.23686 & 0.10446 & Biso & 1.000 & Al \\
\hline Al2 & 1.0000 & 0.78362 & 0.78455 & 0.10796 & Biso & 1.000 & Al \\
\hline Al3 & 1.0000 & 0.23956 & 0.01498 & 0.10007 & Biso & 1.000 & Al \\
\hline P1 & 1.0000 & 0.22893 & 0.00865 & 0.88717 & Biso & 1.000 & $P$ \\
\hline $\mathrm{P} 2$ & 1.0000 & 0.78093 & 0.78060 & 0.89455 & Biso & 1.000 & $P$ \\
\hline P3 & 1.0000 & 0.99993 & 0.23297 & 0.89201 & Biso & 1.000 & $\mathrm{P}$ \\
\hline Al4 & 1.0000 & 0.66746 & 0.56906 & 0.43689 & Biso & 1.000 & Al \\
\hline Mg1 & 1.0000 & 0.44595 & 0.11706 & 0.43831 & Biso & 1.000 & $\mathrm{Mg}$ \\
\hline Al5 & 1.0000 & 0.90735 & 0.34512 & 0.43691 & Biso & 1.000 & Al \\
\hline P 4 & 1.0000 & 0.90634 & 0.34849 & 0.22657 & Biso & 1.000 & $\mathrm{P}$ \\
\hline P5 & 1.0000 & 0.44779 & 0.11576 & 0.22212 & Biso & 1.000 & $\mathrm{P}$ \\
\hline P6 & 1.0000 & 0.67223 & 0.57088 & 0.22707 & Biso & 1.000 & $\mathrm{P}$ \\
\hline Al6 & 1.0000 & 0.33229 & 0.89328 & 0.77491 & Biso & 1.000 & Al \\
\hline Al 7 & 1.0000 & 0.11009 & 0.44153 & 0.76837 & Biso & 1.000 & Al \\
\hline Al 8 & 1.0000 & 0.56972 & 0.67719 & 0.77136 & Biso & 1.000 & Al \\
\hline P7 & 1.0000 & 0.58043 & 0.68696 & 0.56484 & Biso & 1.000 & $P$ \\
\hline P8 & 1.0000 & 0.11028 & 0.44428 & 0.56337 & Biso & 1.000 & $\mathrm{P}$ \\
\hline P9 & 1.0000 & 0.33383 & 0.89190 & 0.56140 & Biso & 1.000 & $\mathrm{P}$ \\
\hline Al9 & 1.0000 & 0.00462 & 0.77808 & 0.89875 & Biso & 1.000 & Al \\
\hline Al10 & 1.0000 & 0.22912 & 0.23509 & 0.89232 & Biso & 1.000 & Al \\
\hline Al11 & 1.0000 & 0.77791 & 0.00468 & 0.89721 & Biso & 1.000 & Al \\
\hline P10 & 1.0000 & 0.78138 & 0.00856 & 0.11175 & Biso & 1.000 & $\mathrm{P}$ \\
\hline P11 & 1.0000 & 0.23411 & 0.23861 & 0.10544 & Biso & 1.000 & $\mathrm{P}$ \\
\hline P 12 & 1.0000 & 0.01144 & 0.78777 & 0.11189 & Biso & 1.000 & $\mathrm{P}$ \\
\hline Al12 & 1.0000 & 0.67843 & 0.11824 & 0.23334 & Biso & 1.000 & Al \\
\hline Al13 & 1.0000 & 0.90066 & 0.57304 & 0.23201 & Biso & 1.000 & Al \\
\hline Al1 14 & 1.0000 & 0.44499 & 0.33963 & 0.22790 & Biso & 1.000 & Al \\
\hline P13 & 1.0000 & 0.43395 & 0.34204 & 0.43867 & Biso & 1.000 & $\mathrm{P}$ \\
\hline $\mathrm{P} 14$ & 1.0000 & 0.89695 & 0.57005 & 0.44344 & Biso & 1.000 & $\mathrm{P}$ \\
\hline P15 & 1.0000 & 0.68349 & 0.11981 & 0.44026 & Biso & 1.000 & $P$ \\
\hline Al15 & 1.0000 & 0.34732 & 0.46373 & 0.56256 & Biso & 1.000 & Al \\
\hline Al16 & 1.0000 & 0.56812 & 0.90979 & 0.56737 & Biso & 1.000 & $\mathrm{Al}$ \\
\hline Al1 17 & 1.0000 & 0.10127 & 0.67344 & 0.57090 & Biso & 1.000 & Al \\
\hline P16 & 1.0000 & 0.10502 & 0.67045 & 0.77824 & Biso & 1.000 & $P$ \\
\hline P17 & 1.0000 & 0.56249 & 0.90362 & 0.77712 & Biso & 1.000 & $P$ \\
\hline P18 & 1.0000 & 0.34104 & 0.44928 & 0.77176 & Biso & 1.000 & $\mathrm{P}$ \\
\hline 01 & 1.0000 & 0.90218 & 0.10078 & 0.13245 & Biso & 1.000 & 0 \\
\hline $\mathrm{O} 2$ & 1.0000 & 0.92124 & 0.81883 & 0.13380 & Biso & 1.000 & 0 \\
\hline 03 & 1.0000 & 0.20533 & 0.11804 & 0.12621 & Biso & 1.000 & 0 \\
\hline 04 & 1.0000 & 0.10864 & 0.91343 & 0.87102 & Biso & 1.000 & 0 \\
\hline 05 & 1.0000 & 0.81207 & 0.90143 & 0.87292 & Biso & 1.000 & 0 \\
\hline 06 & 1.0000 & 0.09220 & 0.20489 & 0.87293 & Biso & 1.000 & 0 \\
\hline 07 & 1.0000 & 0.55575 & 0.43635 & 0.45349 & Biso & 1.000 & 0 \\
\hline 08 & 1.0000 & 0.59937 & 0.15800 & 0.44929 & Biso & 1.000 & 0 \\
\hline 09 & 1.0000 & 0.87886 & 0.45263 & 0.45968 & Biso & 1.000 & 0 \\
\hline 010 & 1.0000 & 0.78542 & 0.25591 & 0.21173 & Biso & 1.000 & 0 \\
\hline 011 & 1.0000 & 0.47976 & 0.23821 & 0.20212 & Biso & 1.000 & 0 \\
\hline 012 & 1.0000 & 0.76409 & 0.54125 & 0.20984 & Biso & 1.000 & 0 \\
\hline 013 & 1.0000 & 0.22585 & 0.75791 & 0.80177 & Biso & 1.000 & 0 \\
\hline 014 & 1.0000 & 0.24890 & 0.47850 & 0.78918 & Biso & 1.000 & 0 \\
\hline 015 & 1.0000 & 0.53563 & 0.78180 & 0.78427 & Biso & 1.000 & 0 \\
\hline 016 & 1.0000 & 0.45716 & 0.59963 & 0.54920 & Biso & 1.000 & 0 \\
\hline 017 & 1.0000 & 0.11612 & 0.55712 & 0.55973 & Biso & 1.000 & 0 \\
\hline 018 & 1.0000 & 0.42772 & 0.86412 & 0.54521 & Biso & 1.000 & 0 \\
\hline 019 & 1.0000 & 0.98634 & 0.33192 & 0.16636 & Biso & 1.000 & 0 \\
\hline $\mathrm{O} 20$ & 1.0000 & 0.68948 & 0.66757 & 0.16698 & Biso & 1.000 & 0 \\
\hline 021 & 1.0000 & 0.35998 & 0.03873 & 0.15298 & Biso & 1.000 & 0 \\
\hline 022 & 1.0000 & 0.31110 & 0.99133 & 0.83113 & Biso & 1.000 & 0 \\
\hline 023 & 1.0000 & 0.67654 & 0.69778 & 0.84356 & Biso & 1.000 & 0 \\
\hline 024 & 1.0000 & 0.01882 & 0.33440 & 0.83790 & Biso & 1.000 & 0 \\
\hline 025 & 1.0000 & 0.65618 & 0.66771 & 0.50161 & Biso & 1.000 & 0 \\
\hline 026 & 1.0000 & 0.34837 & 0.99022 & 0.50815 & Biso & 1.000 & 0 \\
\hline 027 & 1.0000 & 0.02358 & 0.36318 & 0.49693 & Biso & 1.000 & 0 \\
\hline 028 & 1.0000 & 0.02419 & 0.67870 & 0.84340 & Biso & 1.000 & 0 \\
\hline 029 & 1.0000 & 0.32185 & 0.34969 & 0.82904 & Biso & 1.000 & 0 \\
\hline 030 & 1.0000 & 0.65888 & 0.97852 & 0.83936 & Biso & 1.000 & 0 \\
\hline 031 & 1.0000 & 0.69833 & 0.02794 & 0.16398 & Biso & 1.000 & 0 \\
\hline 032 & 1.0000 & 0.33495 & 0.32228 & 0.15936 & Biso & 1.000 & 0 \\
\hline 033 & 1.0000 & 0.99465 & 0.69016 & 0.17086 & Biso & 1.000 & 0 \\
\hline 034 & 1.0000 & 0.35515 & 0.37282 & 0.48820 & Biso & 1.000 & 0 \\
\hline 035 & 1.0000 & 0.99069 & 0.65624 & 0.50324 & Biso & 1.000 & 0 \\
\hline 036 & 1.0000 & 0.65893 & 0.02084 & 0.50148 & Biso & 1.000 & 0 \\
\hline 037 & 1.0000 & 0.13406 & 0.25107 & 0.13252 & Biso & 1.000 & 0 \\
\hline 038 & 1.0000 & 0.76950 & 0.89712 & 0.14131 & Biso & 1.000 & 0 \\
\hline 039 & 1.0000 & 0.12559 & 0.88779 & 0.13375 & Biso & 1.000 & 0 \\
\hline 040 & 1.0000 & 0.23777 & 0.11914 & 0.85932 & Biso & 1.000 & 0 \\
\hline 041 & 1.0000 & 0.87709 & 0.76284 & 0.86643 & Biso & 1.000 & 0 \\
\hline 042 & 1.0000 & 0.88782 & 0.13359 & 0.86451 & Biso & 1.000 & 0 \\
\hline 043 & 1.0000 & 0.79050 & 0.57164 & 0.46677 & Biso & 1.000 & 0 \\
\hline
\end{tabular}




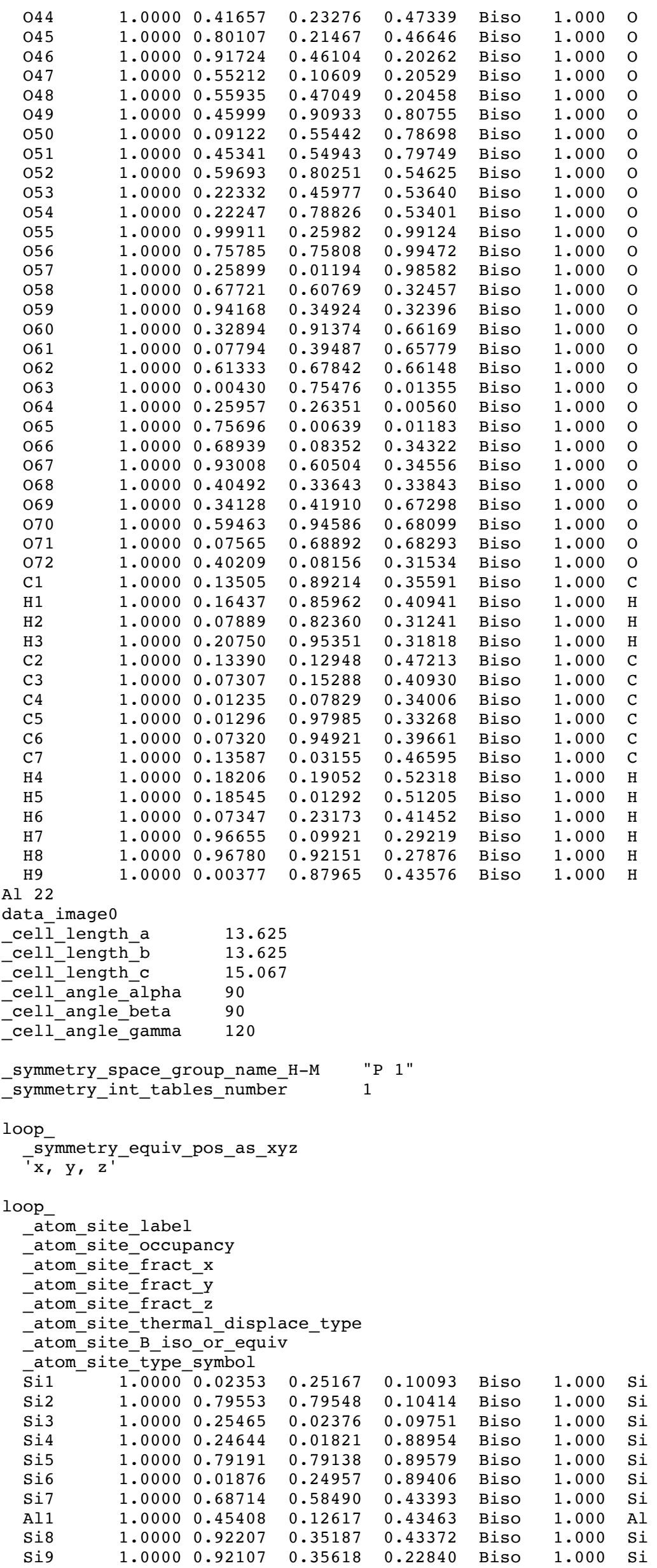




\begin{tabular}{|c|c|c|c|c|c|c|c|}
\hline Silo & 1.0000 & 0.45863 & 0.12712 & 0.22676 & Biso & 1.000 & $\mathrm{Si}$ \\
\hline Si11 & 1.0000 & 0.69121 & 0.58600 & 0.22980 & Biso & 1.000 & $\mathrm{Si}$ \\
\hline Si12 & 1.0000 & 0.35133 & 0.91061 & 0.76916 & Biso & 1.000 & $\mathrm{Si}$ \\
\hline Si13 & 1.0000 & 0.12203 & 0.45322 & 0.76506 & Biso & 1.000 & \\
\hline Si14 & 1.0000 & 0.58479 & 0.68638 & 0.76739 & Biso & 1.000 & \\
\hline Si15 & 1.0000 & 0.59444 & 0.69293 & 0.56470 & Biso & 1.000 & \\
\hline Si16 & 1.0000 & 0.12113 & 0.45469 & 0.56424 & Biso & 1.000 & $i$ \\
\hline Si17 & 1.0000 & 0.35299 & 0.91011 & 0.56045 & Biso & 1.000 & \\
\hline Si18 & 1.0000 & 0.01773 & 0.78716 & 0.89539 & Biso & 1.000 & \\
\hline Si19 & 1.0000 & 0.24855 & 0.24826 & 0.89014 & Biso & 1.000 & \\
\hline Si20 & 1.0000 & 0.79253 & 0.01968 & 0.89441 & Biso & 1.000 & \\
\hline Si21 & 1.0000 & 0.79436 & 0.02296 & 0.10307 & Biso & 1.000 & \\
\hline Si22 & 1.0000 & 0.25418 & 0.25239 & 0.09749 & Biso & 1.000 & $i$ \\
\hline Si23 & 1.0000 & 0.02403 & 0.79503 & 0.10320 & Biso & 1.000 & \\
\hline Si24 & 1.0000 & 0.69071 & 0.12775 & 0.22965 & Biso & 1.000 & \\
\hline $\mathrm{Si} 25$ & 1.0000 & 0.91978 & 0.58621 & 0.23058 & Biso & 1.000 & \\
\hline Si26 & 1.0000 & 0.45887 & 0.35496 & 0.22626 & Biso & 1.000 & \\
\hline Si27 & 1.0000 & 0.44883 & 0.35405 & 0.43166 & Biso & 1.000 & $5 i$ \\
\hline Si28 & 1.0000 & 0.91611 & 0.58224 & 0.43666 & Biso & 1.000 & $\mathrm{Si}$ \\
\hline Si29 & 1.0000 & 0.68972 & 0.12685 & 0.43338 & Biso & 1.000 & \\
\hline $\mathrm{Si} 30$ & 1.0000 & 0.35733 & 0.46758 & 0.55893 & Biso & 1.000 & \\
\hline Si31 & 1.0000 & 0.58693 & 0.92044 & 0.56327 & Biso & 1.000 & \\
\hline Si32 & 1.0000 & 0.11714 & 0.68807 & 0.56633 & Biso & 1.000 & $\mathrm{Si}$ \\
\hline Si33 & 1.0000 & 0.12120 & 0.68630 & 0.76905 & Biso & 1.000 & $\mathrm{Si}$ \\
\hline $\mathrm{Si} 34$ & 1.0000 & 0.58285 & 0.91717 & 0.76757 & Biso & 1.000 & $\mathrm{Si}$ \\
\hline Si35 & 1.0000 & 0.35312 & 0.45745 & 0.76402 & Biso & 1.000 & \\
\hline 01 & 1.0000 & 0.92604 & 0.12081 & 0.12145 & Biso & 1.000 & \\
\hline $\mathrm{O} 2$ & 1.0000 & 0.92740 & 0.83004 & 0.12295 & Biso & 1.000 & $\mathrm{O}$ \\
\hline 03 & 1.0000 & 0.22048 & 0.12116 & 0.11664 & Biso & 1.000 & 0 \\
\hline O4 & 1.0000 & 0.11603 & 0.91676 & 0.87392 & Biso & 1.000 & \\
\hline 05 & 1.0000 & 0.82706 & 0.92267 & 0.87630 & Biso & 1.000 & $\mathrm{O}$ \\
\hline 06 & 1.0000 & 0.11777 & 0.21829 & 0.87653 & Biso & 1.000 & 0 \\
\hline 07 & 1.0000 & 0.57863 & 0.46025 & 0.44399 & Biso & 1.000 & 0 \\
\hline 08 & 1.0000 & 0.59595 & 0.16251 & 0.44376 & Biso & 1.000 & 0 \\
\hline 09 & 1.0000 & 0.89788 & 0.45601 & 0.45042 & Biso & 1.000 & 0 \\
\hline 010 & 1.0000 & 0.79013 & 0.25932 & 0.21187 & Biso & 1.000 & 0 \\
\hline 011 & 1.0000 & 0.49406 & 0.25952 & 0.20634 & Biso & 1.000 & 0 \\
\hline 012 & 1.0000 & 0.78860 & 0.55158 & 0.21240 & Biso & 1.000 & 0 \\
\hline 013 & 1.0000 & 0.25188 & 0.78087 & 0.79120 & Biso & 1.000 & 0 \\
\hline 014 & 1.0000 & 0.25398 & 0.48923 & 0.78186 & Biso & 1.000 & 0 \\
\hline 015 & 1.0000 & 0.55221 & 0.78559 & 0.77643 & Biso & 1.000 & 0 \\
\hline 016 & 1.0000 & 0.46324 & 0.59598 & 0.54818 & Biso & 1.000 & $\mathrm{O}$ \\
\hline 017 & 1.0000 & 0.12931 & 0.57657 & 0.55771 & Biso & 1.000 & 0 \\
\hline 018 & 1.0000 & 0.45354 & 0.87811 & 0.54735 & Biso & 1.000 & 0 \\
\hline 019 & 1.0000 & 0.00606 & 0.33824 & 0.16370 & Biso & 1.000 & 0 \\
\hline $\mathrm{O} 20$ & 1.0000 & 0.71060 & 0.68880 & 0.16469 & Biso & 1.000 & 0 \\
\hline 021 & 1.0000 & 0.36402 & 0.04553 & 0.15338 & Biso & 1.000 & 0 \\
\hline $\mathrm{O} 22$ & 1.0000 & 0.33294 & 0.99977 & 0.82811 & Biso & 1.000 & 0 \\
\hline 023 & 1.0000 & 0.68243 & 0.70521 & 0.83796 & Biso & 1.000 & 0 \\
\hline 024 & 1.0000 & 0.03865 & 0.35614 & 0.83390 & Biso & 1.000 & 0 \\
\hline 025 & 1.0000 & 0.67913 & 0.67604 & 0.49867 & Biso & 1.000 & 0 \\
\hline 026 & 1.0000 & 0.36663 & 0.01133 & 0.50072 & Biso & 1.000 & $\mathrm{O}$ \\
\hline 027 & 1.0000 & 0.02716 & 0.36647 & 0.49497 & Biso & 1.000 & 0 \\
\hline 028 & 1.0000 & 0.03563 & 0.69686 & 0.83805 & Biso & 1.000 & 0 \\
\hline 029 & 1.0000 & 0.33300 & 0.35194 & 0.82627 & Biso & 1.000 & 0 \\
\hline 030 & 1.0000 & 0.68472 & 0.99707 & 0.83483 & Biso & 1.000 & 0 \\
\hline 031 & 1.0000 & 0.70872 & 0.04464 & 0.16237 & Biso & 1.000 & 0 \\
\hline 032 & 1.0000 & 0.36010 & 0.34027 & 0.15751 & Biso & 1.000 & 0 \\
\hline 033 & 1.0000 & 0.00493 & 0.69200 & 0.16814 & Biso & 1.000 & 0 \\
\hline 034 & 1.0000 & 0.36371 & 0.38239 & 0.48842 & Biso & 1.000 & 0 \\
\hline 035 & 1.0000 & 0.01502 & 0.67445 & 0.50150 & Biso & 1.000 & 0 \\
\hline 036 & 1.0000 & 0.67010 & 0.02175 & 0.49739 & Biso & 1.000 & 0 \\
\hline 037 & 1.0000 & 0.14536 & 0.26467 & 0.12443 & Biso & 1.000 & 0 \\
\hline 038 & 1.0000 & 0.78238 & 0.90289 & 0.13265 & Biso & 1.000 & 0 \\
\hline 039 & 1.0000 & 0.14625 & 0.90307 & 0.12745 & Biso & 1.000 & 0 \\
\hline 040 & 1.0000 & 0.25597 & 0.13754 & 0.86201 & Biso & 1.000 & 0 \\
\hline 041 & 1.0000 & 0.89667 & 0.77357 & 0.86774 & Biso & 1.000 & 0 \\
\hline 042 & 1.0000 & 0.89852 & 0.14139 & 0.86615 & Biso & 1.000 & 0 \\
\hline 043 & 1.0000 & 0.80077 & 0.58183 & 0.46186 & Biso & 1.000 & 0 \\
\hline 044 & 1.0000 & 0.43798 & 0.23961 & 0.46626 & Biso & 1.000 & 0 \\
\hline 045 & 1.0000 & 0.81496 & 0.23210 & 0.46093 & Biso & 1.000 & 0 \\
\hline 046 & 1.0000 & 0.93637 & 0.47969 & 0.20714 & Biso & 1.000 & 0 \\
\hline 047 & 1.0000 & 0.57024 & 0.11621 & 0.20670 & Biso & 1.000 & 0 \\
\hline 048 & 1.0000 & 0.56862 & 0.47904 & 0.20815 & Biso & 1.000 & 0 \\
\hline 049 & 1.0000 & 0.47235 & 0.92426 & 0.79695 & Biso & 1.000 & 0 \\
\hline 050 & 1.0000 & 0.10672 & 0.56194 & 0.78041 & Biso & 1.000 & 0 \\
\hline 051 & 1.0000 & 0.47383 & 0.56589 & 0.79038 & Biso & 1.000 & 0 \\
\hline 052 & 1.0000 & 0.60898 & 0.81568 & 0.54396 & Biso & 1.000 & 0 \\
\hline 053 & 1.0000 & 0.24218 & 0.46989 & 0.53720 & Biso & 1.000 & $\mathrm{O}$ \\
\hline 054 & 1.0000 & 0.23303 & 0.79674 & 0.53427 & Biso & 1.000 & 0 \\
\hline
\end{tabular}




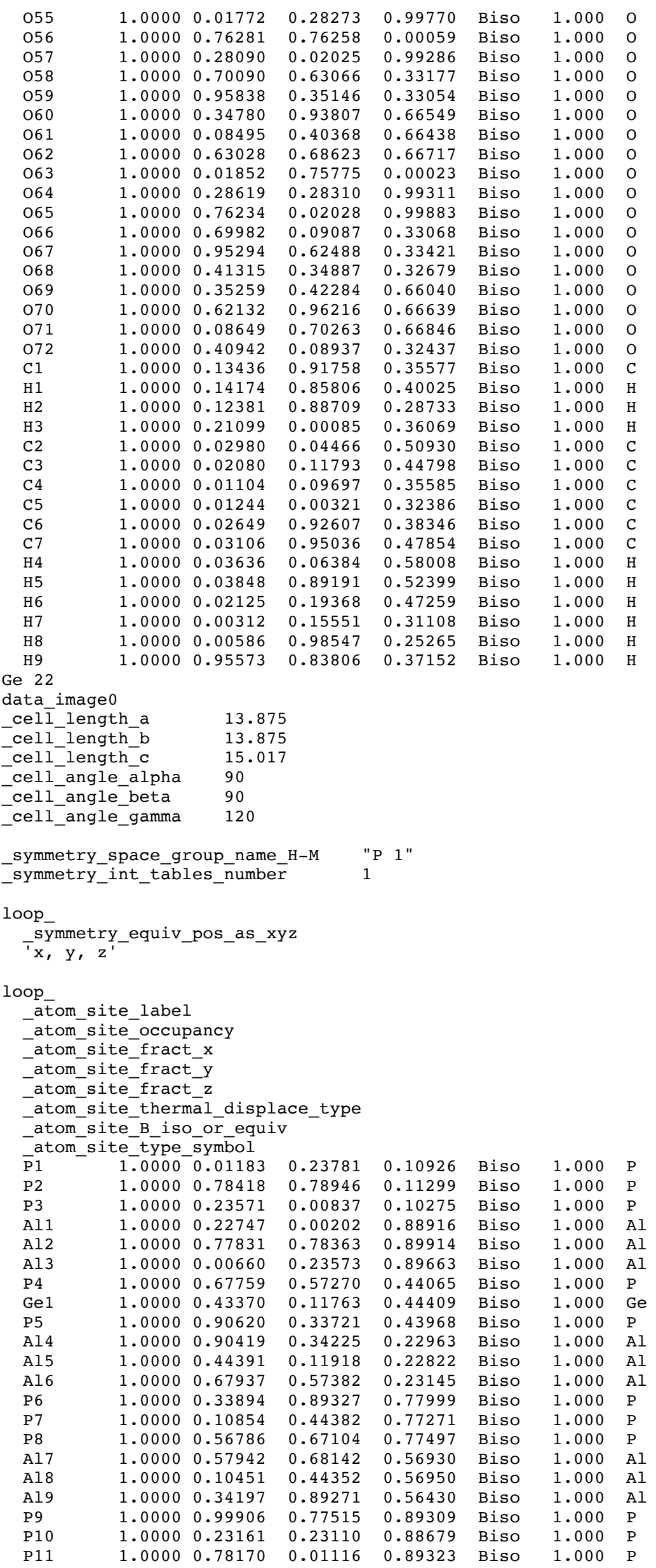




\begin{tabular}{|c|c|c|c|c|c|c|c|}
\hline Al10 & 1.0000 & 0.78220 & 0.01449 & 0.10695 & Biso & 1.000 & $\mathrm{Al}$ \\
\hline Al11 & 1.0000 & 0.23930 & 0.23690 & 0.09920 & Biso & 1.000 & $\mathrm{Al}$ \\
\hline Al12 & 1.0000 & 0.00806 & 0.78464 & 0.10681 & Biso & 1.000 & \\
\hline P12 & 1.0000 & 0.67250 & 0.11646 & 0.22792 & Biso & 1.000 & $\mathrm{P}$ \\
\hline P13 & 1.0000 & 0.90500 & 0.57032 & 0.22836 & Biso & 1.000 & \\
\hline P14 & 1.0000 & 0.44873 & 0.34860 & 0.22270 & Biso & 1.000 & $\mathrm{P}$ \\
\hline Al13 & 1.0000 & 0.43950 & 0.34993 & 0.43400 & Biso & 1.000 & \\
\hline Al1 14 & 1.0000 & 0.90247 & 0.56591 & 0.44006 & Biso & 1.000 & \\
\hline Al15 & 1.0000 & 0.66981 & 0.11781 & 0.43750 & Biso & 1.000 & \\
\hline P15 & 1.0000 & 0.34121 & 0.46414 & 0.55784 & Biso & 1.000 & \\
\hline P16 & 1.0000 & 0.57408 & 0.90694 & 0.56290 & Biso & 1.000 & \\
\hline P 17 & 1.0000 & 0.10478 & 0.67789 & 0.56720 & Biso & 1.000 & $\mathrm{P}$ \\
\hline Al16 & 1.0000 & 0.10864 & 0.67650 & 0.77306 & Biso & 1.000 & \\
\hline Al17 & 1.0000 & 0.56608 & 0.90041 & 0.77246 & Biso & 1.000 & Al \\
\hline Al18 & 1.0000 & 0.33581 & 0.44581 & 0.76567 & Biso & 1.000 & Al \\
\hline 01 & 1.0000 & 0.91959 & 0.11821 & 0.13281 & Biso & 1.000 & \\
\hline $\mathrm{O} 2$ & 1.0000 & 0.90559 & 0.81978 & 0.13345 & Biso & 1.000 & 0 \\
\hline 03 & 1.0000 & 0.20612 & 0.09984 & 0.12307 & Biso & 1.000 & 0 \\
\hline 04 & 1.0000 & 0.09141 & 0.89349 & 0.86788 & Biso & 1.000 & \\
\hline 05 & 1.0000 & 0.81354 & 0.92116 & 0.87473 & Biso & 1.000 & 0 \\
\hline 06 & 1.0000 & 0.11010 & 0.20266 & 0.87261 & Biso & 1.000 & 0 \\
\hline 07 & 1.0000 & 0.57878 & 0.45479 & 0.45154 & Biso & 1.000 & 0 \\
\hline 08 & 1.0000 & 0.57670 & 0.16209 & 0.45625 & Biso & 1.000 & 0 \\
\hline 09 & 1.0000 & 0.88313 & 0.43298 & 0.45931 & Biso & 1.000 & 0 \\
\hline 010 & 1.0000 & 0.76743 & 0.23707 & 0.21088 & Biso & 1.000 & 0 \\
\hline 011 & 1.0000 & 0.48008 & 0.25858 & 0.20533 & Biso & 1.000 & 0 \\
\hline 012 & 1.0000 & 0.78374 & 0.54008 & 0.21062 & Biso & 1.000 & 0 \\
\hline 013 & 1.0000 & 0.24435 & 0.77539 & 0.80490 & Biso & 1.000 & 0 \\
\hline 014 & 1.0000 & 0.23194 & 0.47994 & 0.78871 & Biso & 1.000 & 0 \\
\hline 015 & 1.0000 & 0.53582 & 0.76211 & 0.78278 & Biso & 1.000 & 0 \\
\hline 016 & 1.0000 & 0.43839 & 0.58456 & 0.55284 & Biso & 1.000 & 0 \\
\hline 017 & 1.0000 & 0.10949 & 0.57019 & 0.56417 & Biso & 1.000 & 0 \\
\hline 018 & 1.0000 & 0.45072 & 0.86504 & 0.54118 & Biso & 1.000 & 0 \\
\hline 019 & 1.0000 & 0.99784 & 0.32233 & 0.16532 & Biso & 1.000 & 0 \\
\hline 020 & 1.0000 & 0.70269 & 0.68846 & 0.16776 & Biso & 1.000 & 0 \\
\hline 021 & 1.0000 & 0.34153 & 0.03112 & 0.15113 & Biso & 1.000 & 0 \\
\hline 022 & 1.0000 & 0.32240 & 0.98158 & 0.82827 & Biso & 1.000 & 0 \\
\hline 023 & 1.0000 & 0.65729 & 0.68958 & 0.84365 & Biso & 1.000 & 0 \\
\hline $\mathrm{O} 24$ & 1.0000 & 0.03321 & 0.35635 & 0.84085 & Biso & 1.000 & 0 \\
\hline 025 & 1.0000 & 0.66549 & 0.65570 & 0.50062 & Biso & 1.000 & 0 \\
\hline 026 & 1.0000 & 0.34500 & 0.00228 & 0.51087 & Biso & 1.000 & 0 \\
\hline 027 & 1.0000 & 0.00448 & 0.34952 & 0.49620 & Biso & 1.000 & 0 \\
\hline 028 & 1.0000 & 0.01388 & 0.68712 & 0.84301 & Biso & 1.000 & 0 \\
\hline 029 & 1.0000 & 0.31071 & 0.32945 & 0.82801 & Biso & 1.000 & 0 \\
\hline 030 & 1.0000 & 0.67844 & 0.98793 & 0.83997 & Biso & 1.000 & 0 \\
\hline 031 & 1.0000 & 0.68774 & 0.03631 & 0.16640 & Biso & 1.000 & 0 \\
\hline 032 & 1.0000 & 0.35452 & 0.33296 & 0.15958 & Biso & 1.000 & 0 \\
\hline 033 & 1.0000 & 0.98552 & 0.67075 & 0.17162 & Biso & 1.000 & 0 \\
\hline O34 & 1.0000 & 0.35332 & 0.39111 & 0.48797 & Biso & 1.000 & 0 \\
\hline 035 & 1.0000 & 0.01070 & 0.66664 & 0.50569 & Biso & 1.000 & 0 \\
\hline 036 & 1.0000 & 0.65109 & 0.00492 & 0.50338 & Biso & 1.000 & 0 \\
\hline 037 & 1.0000 & 0.12490 & 0.24947 & 0.13173 & Biso & 1.000 & 0 \\
\hline 038 & 1.0000 & 0.77056 & 0.88845 & 0.14029 & Biso & 1.000 & 0 \\
\hline 039 & 1.0000 & 0.13780 & 0.89673 & 0.13499 & Biso & 1.000 & 0 \\
\hline 040 & 1.0000 & 0.24100 & 0.12974 & 0.85935 & Biso & 1.000 & 0 \\
\hline 041 & 1.0000 & 0.88648 & 0.76209 & 0.86633 & Biso & 1.000 & 0 \\
\hline 042 & 1.0000 & 0.87844 & 0.12448 & 0.86414 & Biso & 1.000 & 0 \\
\hline 043 & 1.0000 & 0.78448 & 0.57307 & 0.46782 & Biso & 1.000 & 0 \\
\hline 044 & 1.0000 & 0.40779 & 0.22436 & 0.47818 & Biso & 1.000 & 0 \\
\hline 045 & 1.0000 & 0.80514 & 0.22592 & 0.46321 & Biso & 1.000 & 0 \\
\hline 046 & 1.0000 & 0.91925 & 0.47137 & 0.20266 & Biso & 1.000 & 0 \\
\hline 047 & 1.0000 & 0.56209 & 0.10897 & 0.20443 & Biso & 1.000 & 0 \\
\hline 048 & 1.0000 & 0.55040 & 0.46304 & 0.20257 & Biso & 1.000 & 0 \\
\hline 049 & 1.0000 & 0.45026 & 0.90607 & 0.81054 & Biso & 1.000 & 0 \\
\hline 050 & 1.0000 & 0.09276 & 0.54460 & 0.78293 & Biso & 1.000 & 0 \\
\hline 051 & 1.0000 & 0.46496 & 0.55789 & 0.79471 & Biso & 1.000 & 0 \\
\hline 052 & 1.0000 & 0.60010 & 0.81305 & 0.54570 & Biso & 1.000 & 0 \\
\hline 053 & 1.0000 & 0.23317 & 0.46410 & 0.53665 & Biso & 1.000 & 0 \\
\hline 054 & 1.0000 & 0.21529 & 0.77375 & 0.53383 & Biso & 1.000 & 0 \\
\hline 055 & 1.0000 & 0.00528 & 0.26145 & 0.01036 & Biso & 1.000 & 0 \\
\hline 056 & 1.0000 & 0.75794 & 0.76230 & 0.01391 & Biso & 1.000 & 0 \\
\hline 057 & 1.0000 & 0.25350 & 0.00274 & 0.00254 & Biso & 1.000 & 0 \\
\hline 058 & 1.0000 & 0.68703 & 0.61248 & 0.34344 & Biso & 1.000 & 0 \\
\hline 059 & 1.0000 & 0.93969 & 0.34074 & 0.34130 & Biso & 1.000 & 0 \\
\hline 060 & 1.0000 & 0.33926 & 0.91071 & 0.67965 & Biso & 1.000 & 0 \\
\hline 061 & 1.0000 & 0.07338 & 0.39272 & 0.67873 & Biso & 1.000 & 0 \\
\hline 062 & 1.0000 & 0.61320 & 0.67257 & 0.68085 & Biso & 1.000 & 0 \\
\hline 063 & 1.0000 & 0.00150 & 0.75481 & 0.99360 & Biso & 1.000 & 0 \\
\hline 064 & 1.0000 & 0.26492 & 0.26201 & 0.98492 & Biso & 1.000 & 0 \\
\hline 065 & 1.0000 & 0.75740 & 0.01320 & 0.99297 & Biso & 1.000 & 0 \\
\hline
\end{tabular}




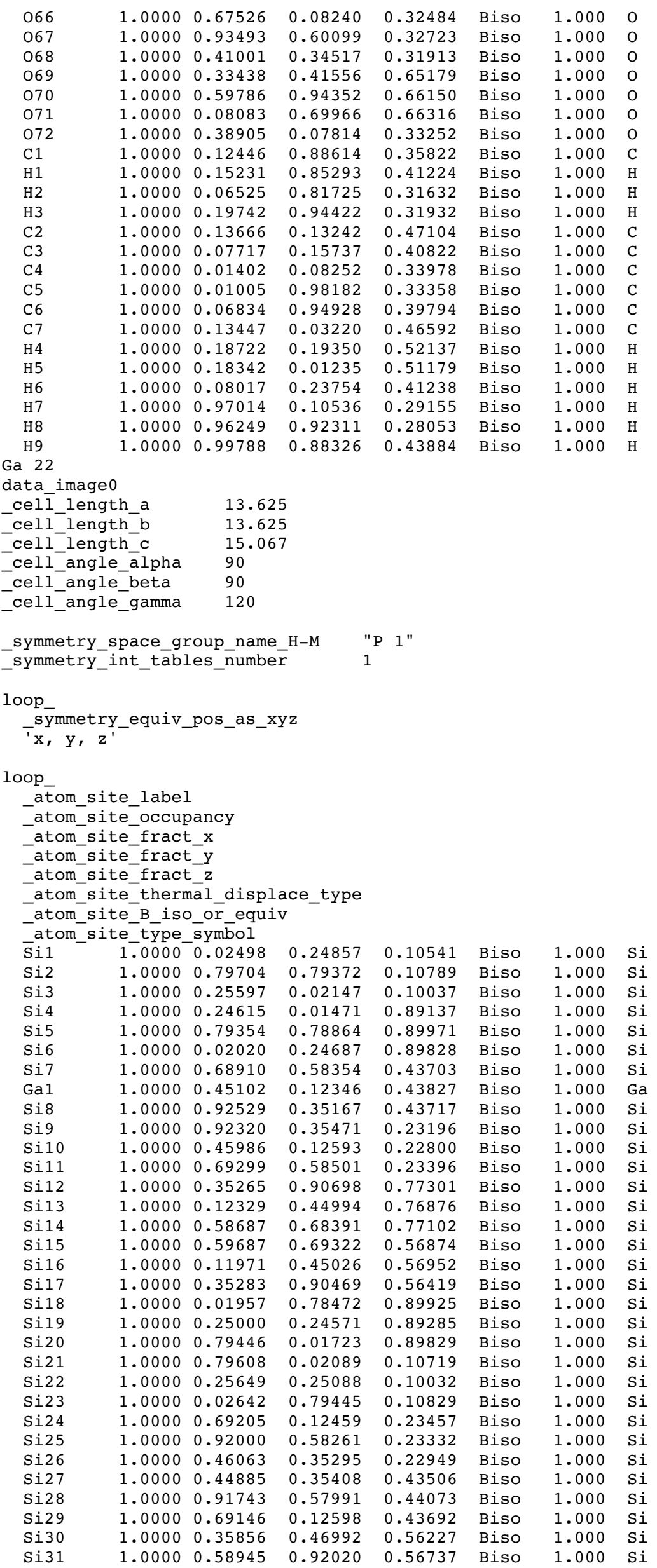




\begin{tabular}{|c|c|c|c|c|c|c|c|}
\hline Si32 & 1.0000 & 0.11527 & 0.68399 & 0.57169 & Biso & 1.000 & $\mathrm{Si}$ \\
\hline Si33 & 1.0000 & 0.12112 & 0.68307 & 0.77256 & Biso & 1.000 & $\mathrm{Si}$ \\
\hline Si34 & 1.0000 & 0.58352 & 0.91387 & 0.77255 & Biso & 1.000 & $\mathrm{Si}$ \\
\hline Si35 & 1.0000 & 0.35441 & 0.45494 & 0.76635 & Biso & 1.000 & \\
\hline 01 & 1.0000 & 0.92766 & 0.11789 & 0.12620 & Biso & 1.000 & \\
\hline $\mathrm{O} 2$ & 1.0000 & 0.92882 & 0.82844 & 0.12726 & Biso & 1.000 & \\
\hline $\mathrm{O3}$ & 1.0000 & 0.22379 & 0.12011 & 0.12096 & Biso & 1.000 & \\
\hline 04 & 1.0000 & 0.11612 & 0.91370 & 0.87399 & Biso & 1.000 & \\
\hline 05 & 1.0000 & 0.82886 & 0.92002 & 0.88031 & Biso & 1.000 & \\
\hline 06 & 1.0000 & 0.11912 & 0.21555 & 0.88055 & Biso & 1.000 & \\
\hline 07 & 1.0000 & 0.57987 & 0.45843 & 0.44364 & Biso & 1.000 & \\
\hline 08 & 1.0000 & 0.60101 & 0.16635 & 0.44729 & Biso & 1.000 & \\
\hline 09 & 1.0000 & 0.89904 & 0.45375 & 0.45673 & Biso & 1.000 & \\
\hline 010 & 1.0000 & 0.79211 & 0.25605 & 0.21876 & Biso & 1.000 & \\
\hline 011 & 1.0000 & 0.49789 & 0.25926 & 0.20829 & Biso & 1.000 & \\
\hline 012 & 1.0000 & 0.78886 & 0.54896 & 0.21567 & Biso & 1.000 & \\
\hline 013 & 1.0000 & 0.25233 & 0.77733 & 0.79373 & Biso & 1.000 & \\
\hline 014 & 1.0000 & 0.25597 & 0.48754 & 0.78487 & Biso & 1.000 & \\
\hline 015 & 1.0000 & 0.55352 & 0.78248 & 0.78085 & Biso & 1.000 & \\
\hline 016 & 1.0000 & 0.46444 & 0.59876 & 0.55394 & Biso & 1.000 & 0 \\
\hline 017 & 1.0000 & 0.12057 & 0.56846 & 0.56613 & Biso & 1.000 & \\
\hline 018 & 1.0000 & 0.45738 & 0.87911 & 0.54774 & Biso & 1.000 & \\
\hline 019 & 1.0000 & 0.00743 & 0.33558 & 0.16745 & Biso & 1.000 & 0 \\
\hline $\mathrm{O} 20$ & 1.0000 & 0.71176 & 0.68688 & 0.16826 & Biso & 1.000 & 0 \\
\hline 021 & 1.0000 & 0.36922 & 0.04574 & 0.15188 & Biso & 1.000 & 0 \\
\hline 022 & 1.0000 & 0.33384 & 0.99633 & 0.83145 & Biso & 1.000 & 0 \\
\hline 023 & 1.0000 & 0.68396 & 0.70229 & 0.84195 & Biso & 1.000 & 0 \\
\hline $\mathrm{O} 24$ & 1.0000 & 0.04132 & 0.35492 & 0.83953 & Biso & 1.000 & 0 \\
\hline 025 & 1.0000 & 0.67870 & 0.67310 & 0.50188 & Biso & 1.000 & $\mathrm{O}$ \\
\hline 026 & 1.0000 & 0.35612 & 0.00120 & 0.50357 & Biso & 1.000 & 0 \\
\hline 027 & 1.0000 & 0.02868 & 0.36234 & 0.49849 & Biso & 1.000 & O \\
\hline 028 & 1.0000 & 0.03743 & 0.69268 & 0.84430 & Biso & 1.000 & 0 \\
\hline 029 & 1.0000 & 0.33385 & 0.34918 & 0.82853 & Biso & 1.000 & 0 \\
\hline 030 & 1.0000 & 0.68612 & 0.99407 & 0.83910 & Biso & 1.000 & 0 \\
\hline 031 & 1.0000 & 0.70991 & 0.04260 & 0.16607 & Biso & 1.000 & 0 \\
\hline 032 & 1.0000 & 0.36261 & 0.33906 & 0.16030 & Biso & 1.000 & 0 \\
\hline 033 & 1.0000 & 0.00553 & 0.68993 & 0.17217 & Biso & 1.000 & 0 \\
\hline 034 & 1.0000 & 0.36594 & 0.38906 & 0.48777 & Biso & 1.000 & 0 \\
\hline 035 & 1.0000 & 0.01686 & 0.67319 & 0.50419 & Biso & 1.000 & 0 \\
\hline 036 & 1.0000 & 0.67408 & 0.02333 & 0.50311 & Biso & 1.000 & 0 \\
\hline 037 & 1.0000 & 0.14760 & 0.26259 & 0.12791 & Biso & 1.000 & 0 \\
\hline 038 & 1.0000 & 0.78267 & 0.90025 & 0.13681 & Biso & 1.000 & 0 \\
\hline 039 & 1.0000 & 0.14803 & 0.90279 & 0.13494 & Biso & 1.000 & 0 \\
\hline 040 & 1.0000 & 0.25773 & 0.13515 & 0.86483 & Biso & 1.000 & 0 \\
\hline 041 & 1.0000 & 0.89748 & 0.76922 & 0.87260 & Biso & 1.000 & 0 \\
\hline 042 & 1.0000 & 0.90002 & 0.13904 & 0.86961 & Biso & 1.000 & 0 \\
\hline 043 & 1.0000 & 0.80138 & 0.57875 & 0.46542 & Biso & 1.000 & 0 \\
\hline O4 4 & 1.0000 & 0.43215 & 0.23964 & 0.47630 & Biso & 1.000 & O \\
\hline 045 & 1.0000 & 0.81803 & 0.23038 & 0.46155 & Biso & 1.000 & 0 \\
\hline 046 & 1.0000 & 0.93568 & 0.47628 & 0.20708 & Biso & 1.000 & 0 \\
\hline 047 & 1.0000 & 0.57170 & 0.11426 & 0.21312 & Biso & 1.000 & 0 \\
\hline 048 & 1.0000 & 0.56916 & 0.47843 & 0.21495 & Biso & 1.000 & 0 \\
\hline 049 & 1.0000 & 0.47287 & 0.92001 & 0.80298 & Biso & 1.000 & 0 \\
\hline 050 & 1.0000 & 0.10718 & 0.55858 & 0.78160 & Biso & 1.000 & 0 \\
\hline 051 & 1.0000 & 0.47597 & 0.56268 & 0.79232 & Biso & 1.000 & 0 \\
\hline 052 & 1.0000 & 0.61431 & 0.81720 & 0.54679 & Biso & 1.000 & 0 \\
\hline 053 & 1.0000 & 0.24354 & 0.47279 & 0.54176 & Biso & 1.000 & 0 \\
\hline 054 & 1.0000 & 0.23615 & 0.78693 & 0.54167 & Biso & 1.000 & 0 \\
\hline 055 & 1.0000 & 0.01844 & 0.27875 & 0.00209 & Biso & 1.000 & 0 \\
\hline 056 & 1.0000 & 0.76414 & 0.76039 & 0.00456 & Biso & 1.000 & 0 \\
\hline 057 & 1.0000 & 0.27676 & 0.01435 & 0.99540 & Biso & 1.000 & 0 \\
\hline 058 & 1.0000 & 0.70521 & 0.63224 & 0.33544 & Biso & 1.000 & 0 \\
\hline 059 & 1.0000 & 0.96343 & 0.35593 & 0.33403 & Biso & 1.000 & 0 \\
\hline 060 & 1.0000 & 0.35297 & 0.93570 & 0.66917 & Biso & 1.000 & 0 \\
\hline 061 & 1.0000 & 0.08557 & 0.39655 & 0.66908 & Biso & 1.000 & 0 \\
\hline 062 & 1.0000 & 0.63374 & 0.68652 & 0.67076 & Biso & 1.000 & 0 \\
\hline 063 & 1.0000 & 0.02385 & 0.76026 & 0.00484 & Biso & 1.000 & 0 \\
\hline 064 & 1.0000 & 0.28839 & 0.28061 & 0.99592 & Biso & 1.000 & 0 \\
\hline 065 & 1.0000 & 0.76474 & 0.01850 & 0.00281 & Biso & 1.000 & 0 \\
\hline 066 & 1.0000 & 0.69846 & 0.08464 & 0.33531 & Biso & 1.000 & 0 \\
\hline 067 & 1.0000 & 0.95271 & 0.61824 & 0.33730 & Biso & 1.000 & 0 \\
\hline 068 & 1.0000 & 0.41137 & 0.34122 & 0.32978 & Biso & 1.000 & 0 \\
\hline 069 & 1.0000 & 0.35378 & 0.42114 & 0.66229 & Biso & 1.000 & 0 \\
\hline 070 & 1.0000 & 0.62056 & 0.95899 & 0.67114 & Biso & 1.000 & 0 \\
\hline 071 & 1.0000 & 0.08444 & 0.70126 & 0.67325 & Biso & 1.000 & 0 \\
\hline 072 & 1.0000 & 0.40091 & 0.08557 & 0.32302 & Biso & 1.000 & 0 \\
\hline $\mathrm{C} 1$ & 1.0000 & 0.12175 & 0.91605 & 0.36152 & Biso & 1.000 & $\mathrm{C}$ \\
\hline H 1 & 1.0000 & 0.07390 & 0.83008 & 0.33448 & Biso & 1.000 & $\mathrm{H}$ \\
\hline H2 & 1.0000 & 0.20921 & 0.95812 & 0.33689 & Biso & 1.000 & $\mathrm{H}$ \\
\hline H3 & 1.0000 & 0.12286 & 0.91219 & 0.43414 & Biso & 1.000 & $\mathrm{H}$ \\
\hline
\end{tabular}




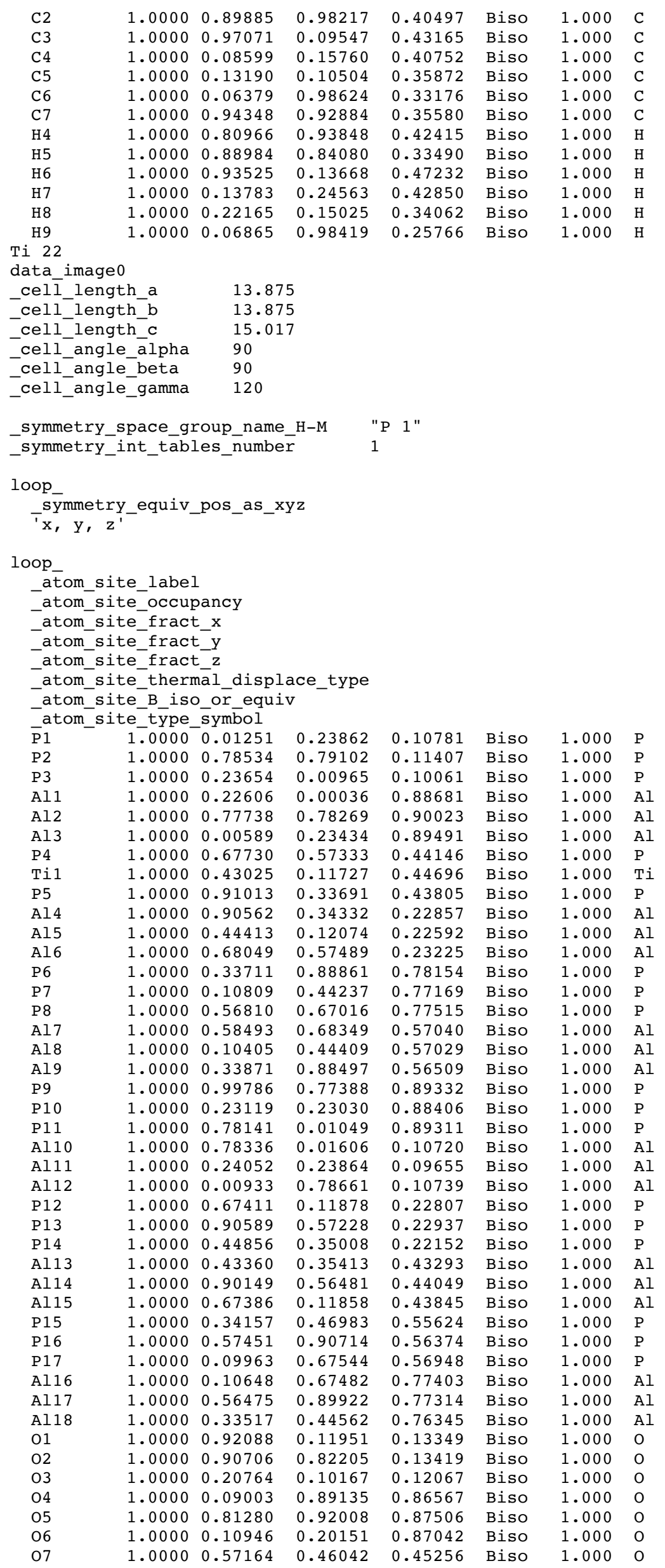




\begin{tabular}{|c|c|c|c|c|c|c|}
\hline 08 & 1.0000 & 0.57648 & 0.15768 & 0.45711 & Biso & 1.000 \\
\hline 09 & 1.0000 & 0.88777 & 0.43345 & 0.45602 & Biso & 1.000 \\
\hline 010 & 1.0000 & 0.76811 & 0.23958 & 0.20979 & Biso & 1.000 \\
\hline 011 & 1.0000 & 0.48067 & 0.26060 & 0.20424 & Biso & 1.000 \\
\hline 012 & 1.0000 & 0.78441 & 0.54063 & 0.21042 & Biso & 1.000 \\
\hline 013 & 1.0000 & 0.24175 & 0.77207 & 0.80869 & Biso & 1.000 \\
\hline 014 & 1.0000 & 0.23176 & 0.47997 & 0.78848 & Biso & 1.000 \\
\hline 015 & 1.0000 & 0.53583 & 0.76115 & 0.78123 & Biso & 1.000 \\
\hline 016 & 1.0000 & 0.44505 & 0.58604 & 0.55111 & Biso & 1.000 \\
\hline 017 & 1.0000 & 0.09388 & 0.56273 & 0.56983 & Biso & 1.000 \\
\hline 018 & 1.0000 & 0.45139 & 0.86371 & 0.53965 & Biso & 1.000 \\
\hline 019 & 1.0000 & 0.99859 & 0.32436 & 0.16230 & Biso & 1.000 \\
\hline 020 & 1.0000 & 0.70449 & 0.69045 & 0.16952 & Biso & 1.000 \\
\hline 021 & 1.0000 & 0.34409 & 0.03374 & 0.14686 & Biso & 1.000 \\
\hline 022 & 1.0000 & 0.32085 & 0.97932 & 0.82607 & Biso & 1.000 \\
\hline 023 & 1.0000 & 0.65530 & 0.68833 & 0.84594 & Biso & 1.000 \\
\hline 024 & 1.0000 & 0.03291 & 0.35601 & 0.84058 & Biso & 1.000 \\
\hline 025 & 1.0000 & 0.67384 & 0.66118 & 0.50183 & Biso & 1.000 \\
\hline 026 & 1.0000 & 0.33924 & 0.99503 & 0.51379 & Biso & 1.000 \\
\hline 027 & 1.0000 & 0.00988 & 0.35042 & 0.49341 & Biso & 1.000 \\
\hline 028 & 1.0000 & 0.01152 & 0.68405 & 0.84487 & Biso & 1.000 \\
\hline 029 & 1.0000 & 0.30949 & 0.32779 & 0.82414 & Biso & 1.000 \\
\hline 030 & 1.0000 & 0.67716 & 0.98632 & 0.84085 & Biso & 1.000 \\
\hline 031 & 1.0000 & 0.68902 & 0.03861 & 0.16620 & Biso & 1.000 \\
\hline 032 & 1.0000 & 0.35619 & 0.33520 & 0.15648 & Biso & 1.000 \\
\hline 033 & 1.0000 & 0.98635 & 0.67255 & 0.17237 & Biso & 1.000 \\
\hline 034 & 1.0000 & 0.34380 & 0.39415 & 0.48320 & Biso & 1.000 \\
\hline 035 & 1.0000 & 0.00708 & 0.66772 & 0.50756 & Biso & 1.000 \\
\hline 036 & 1.0000 & 0.65286 & 0.00486 & 0.50444 & Biso & 1.000 \\
\hline 037 & 1.0000 & 0.12623 & 0.25138 & 0.12967 & Biso & 1.000 \\
\hline 038 & 1.0000 & 0.77130 & 0.88993 & 0.14079 & Biso & 1.000 \\
\hline 039 & 1.0000 & 0.13944 & 0.89876 & 0.13518 & Biso & 1.000 \\
\hline 040 & 1.0000 & 0.24043 & 0.12861 & 0.85730 & Biso & 1.000 \\
\hline 041 & 1.0000 & 0.88495 & 0.76036 & 0.86703 & Biso & 1.000 \\
\hline 042 & 1.0000 & 0.87769 & 0.12321 & 0.86226 & Biso & 1.000 \\
\hline 043 & 1.0000 & 0.77848 & 0.56262 & 0.46807 & Biso & 1.000 \\
\hline 044 & 1.0000 & 0.40661 & 0.23065 & 0.47895 & Biso & 1.000 \\
\hline 045 & 1.0000 & 0.80935 & 0.22654 & 0.46437 & Biso & 1.000 \\
\hline 046 & 1.0000 & 0.92168 & 0.47380 & 0.20529 & Biso & 1.000 \\
\hline 047 & 1.0000 & 0.56288 & 0.11016 & 0.20587 & Biso & 1.000 \\
\hline 048 & 1.0000 & 0.55077 & 0.46502 & 0.20368 & Biso & 1.000 \\
\hline 049 & 1.0000 & 0.44829 & 0.90227 & 0.81369 & Biso & 1.000 \\
\hline 050 & 1.0000 & 0.09086 & 0.54257 & 0.77944 & Biso & 1.000 \\
\hline 051 & 1.0000 & 0.46458 & 0.55685 & 0.79322 & Biso & 1.000 \\
\hline 052 & 1.0000 & 0.60286 & 0.81444 & 0.54888 & Biso & 1.000 \\
\hline 053 & 1.0000 & 0.23886 & 0.48161 & 0.53985 & Biso & 1.000 \\
\hline 054 & 1.0000 & 0.21316 & 0.76429 & 0.53428 & Biso & 1.000 \\
\hline 055 & 1.0000 & 0.00418 & 0.25927 & 0.00861 & Biso & 1.000 \\
\hline 056 & 1.0000 & 0.75851 & 0.76273 & 0.01518 & Biso & 1.000 \\
\hline 057 & 1.0000 & 0.25119 & 0.00127 & 0.00029 & Biso & 1.000 \\
\hline 058 & 1.0000 & 0.68986 & 0.61399 & 0.34429 & Biso & 1.000 \\
\hline 059 & 1.0000 & 0.94117 & 0.33700 & 0.33949 & Biso & 1.000 \\
\hline 060 & 1.0000 & 0.33794 & 0.90131 & 0.68066 & Biso & 1.000 \\
\hline 061 & 1.0000 & 0.07402 & 0.38875 & 0.67830 & Biso & 1.000 \\
\hline 062 & 1.0000 & 0.61638 & 0.67221 & 0.68214 & Biso & 1.000 \\
\hline 063 & 1.0000 & 0.00205 & 0.75664 & 0.99417 & Biso & 1.000 \\
\hline 064 & 1.0000 & 0.26530 & 0.26264 & 0.98195 & Biso & 1.000 \\
\hline 065 & 1.0000 & 0.75915 & 0.01453 & 0.99303 & Biso & 1.000 \\
\hline 066 & 1.0000 & 0.67923 & 0.08577 & 0.32490 & Biso & 1.000 \\
\hline 067 & 1.0000 & 0.93456 & 0.60431 & 0.32826 & Biso & 1.000 \\
\hline 068 & 1.0000 & 0.40690 & 0.34518 & 0.31724 & Biso & 1.000 \\
\hline 069 & 1.0000 & 0.33347 & 0.41748 & 0.64889 & Biso & 1.000 \\
\hline 070 & 1.0000 & 0.59498 & 0.94421 & 0.66241 & Biso & 1.000 \\
\hline 071 & 1.0000 & 0.08032 & 0.70352 & 0.66493 & Biso & 1.000 \\
\hline 072 & 1.0000 & 0.38916 & 0.08194 & 0.33065 & Biso & 1.000 \\
\hline $\mathrm{C} 1$ & 1.0000 & 0.12626 & 0.88731 & 0.35948 & Biso & 1.000 \\
\hline $\mathrm{H} 1$ & 1.0000 & 0.15403 & 0.85372 & 0.41328 & Biso & 1.000 \\
\hline H2 & 1.0000 & 0.06903 & 0.81910 & 0.31612 & Biso & 1.000 \\
\hline H3 & 1.0000 & 0.19942 & 0.94795 & 0.32205 & Biso & 1.000 \\
\hline C2 & 1.0000 & 0.13604 & 0.13005 & 0.47321 & Biso & 1.000 \\
\hline C3 & 1.0000 & 0.08007 & 0.15712 & 0.40855 & Biso & 1.000 \\
\hline C4 & 1.0000 & 0.01725 & 0.08290 & 0.33966 & Biso & 1.000 \\
\hline C5 & 1.0000 & 0.01055 & 0.98088 & 0.33459 & Biso & 1.000 \\
\hline C6 & 1.0000 & 0.06624 & 0.94668 & 0.40007 & Biso & 1.000 \\
\hline C7 & 1.0000 & 0.13089 & 0.02841 & 0.46922 & Biso & 1.000 \\
\hline $\mathrm{H} 4$ & 1.0000 & 0.18615 & 0.19058 & 0.52403 & Biso & 1.000 \\
\hline H5 & 1.0000 & 0.17710 & 0.00675 & 0.51649 & Biso & 1.000 \\
\hline H6 & 1.0000 & 0.08553 & 0.23847 & 0.41166 & Biso & 1.000 \\
\hline $\mathrm{H} 7$ & 1.0000 & 0.97582 & 0.10725 & 0.29027 & Biso & 1.000 \\
\hline H8 & 1.0000 & 0.96331 & 0.92265 & 0.28118 & & 1.000 \\
\hline
\end{tabular}




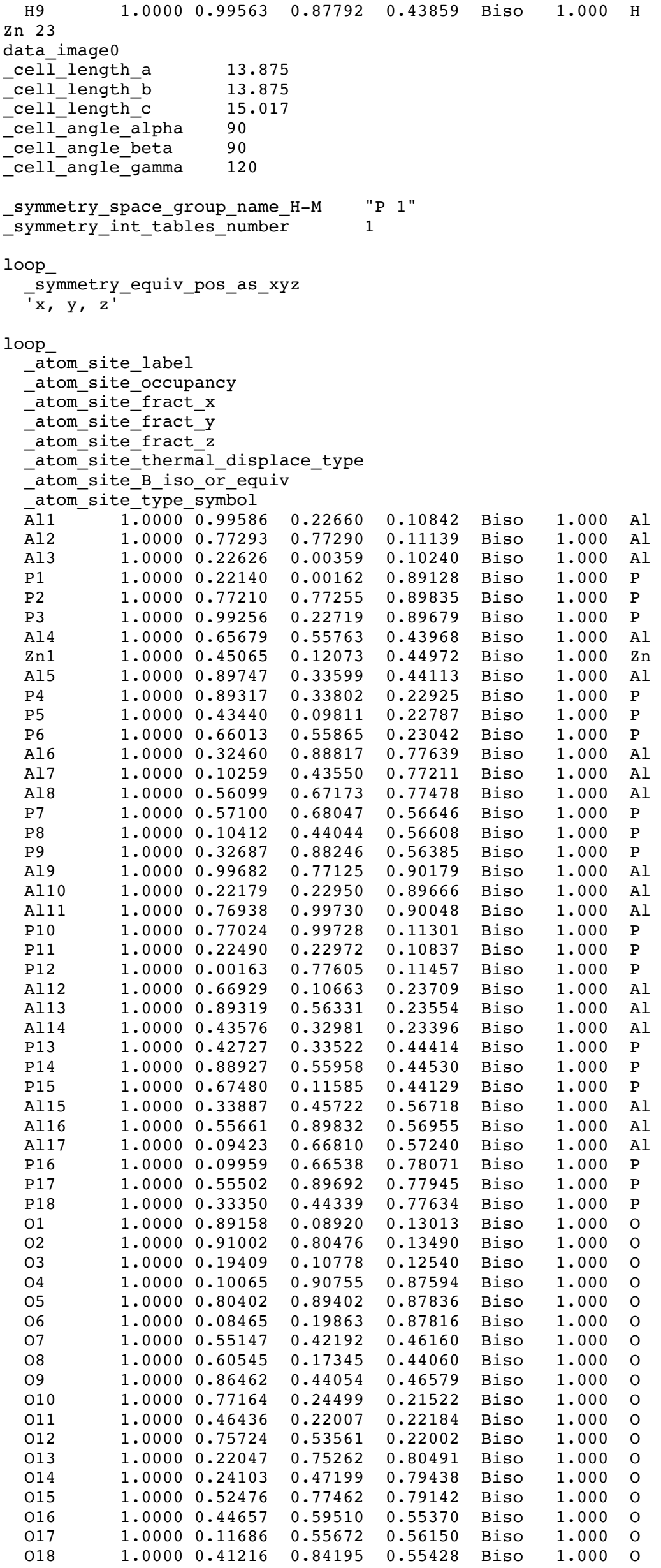




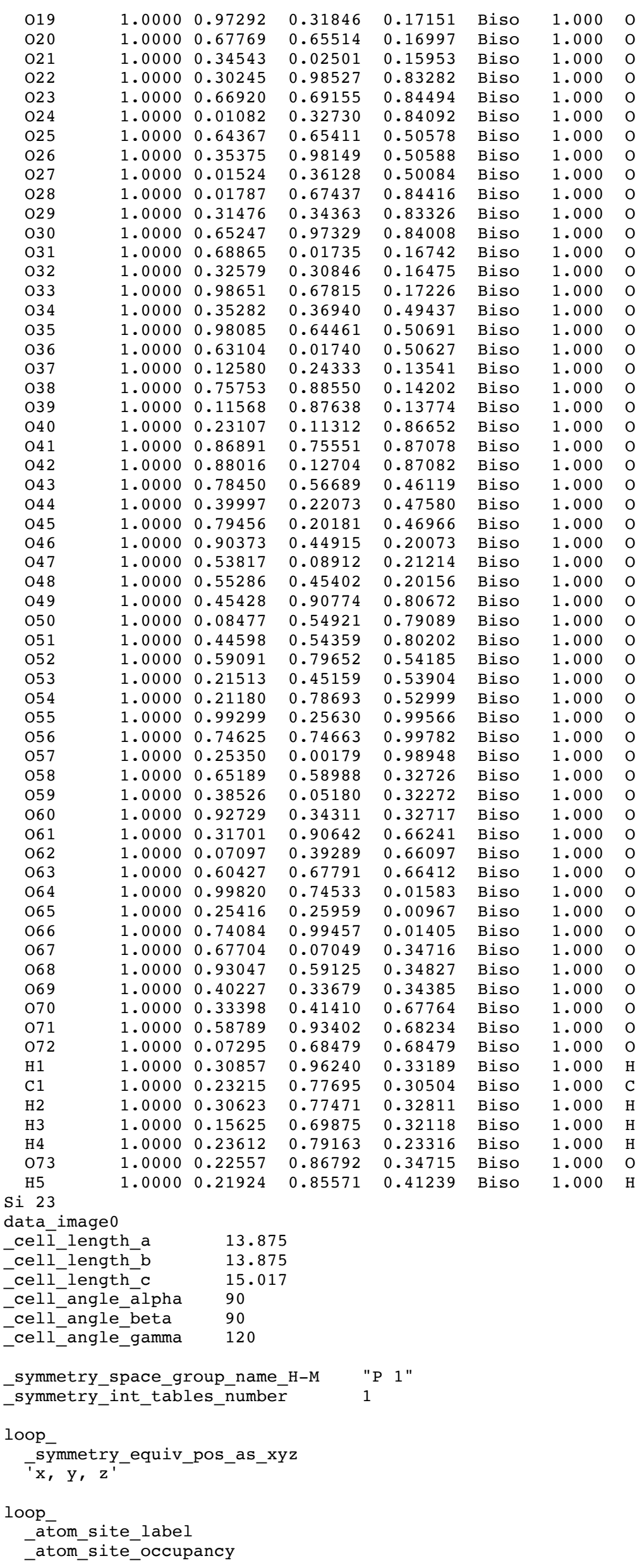




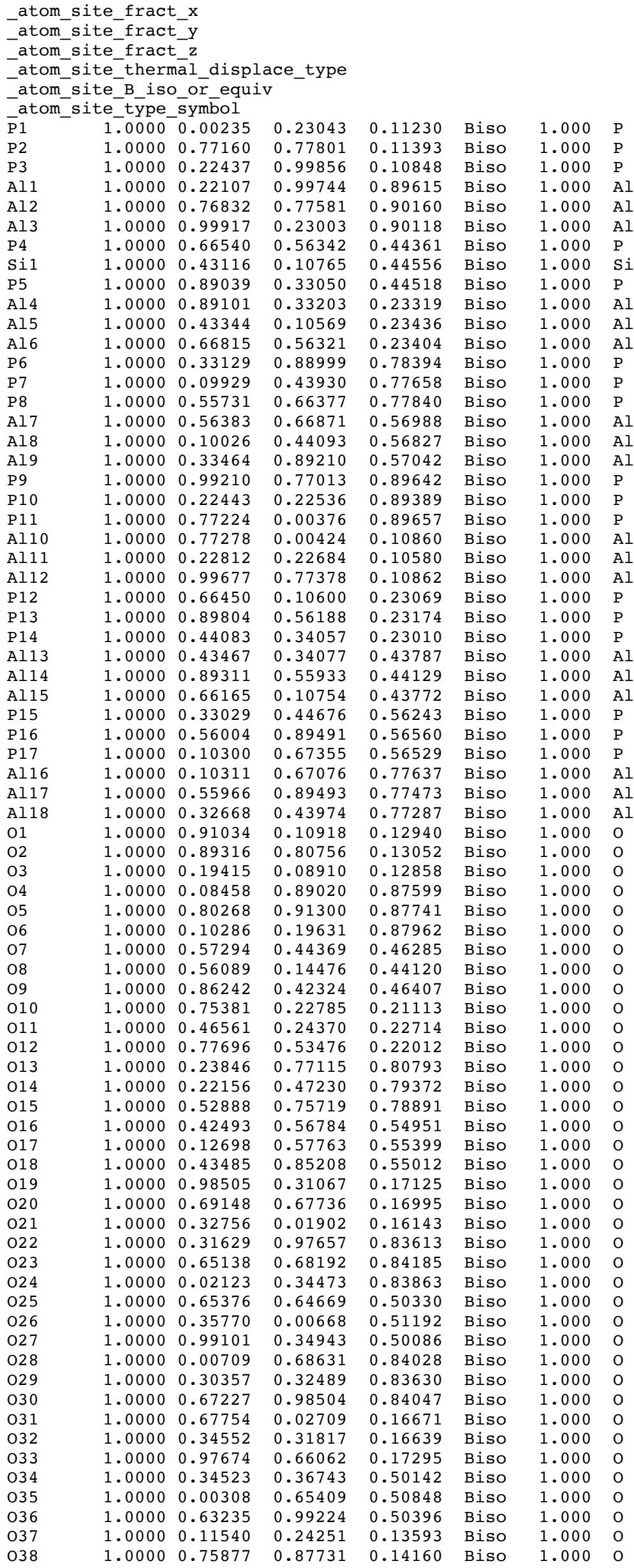




\begin{tabular}{|c|c|c|c|c|c|c|}
\hline 039 & 1.0000 & 0.12715 & 0.88527 & 0.13699 & Biso & 1.000 \\
\hline 040 & 1.0000 & 0.23529 & 0.12500 & 0.86574 & Biso & 1.000 \\
\hline 041 & 1.0000 & 0.87974 & 0.75837 & 0.87175 & Biso & 1.000 \\
\hline 042 & 1.0000 & 0.87116 & 0.11721 & 0.87144 & Biso & 1.000 \\
\hline 043 & 1.0000 & 0.77847 & 0.57362 & 0.46363 & Biso & 1.000 \\
\hline 044 & 1.0000 & 0.41131 & 0.21034 & 0.45855 & Biso & 1.000 \\
\hline 045 & 1.0000 & 0.79129 & 0.21805 & 0.47126 & Biso & 1.000 \\
\hline 046 & 1.0000 & 0.90732 & 0.46087 & 0.20300 & Biso & 1.000 \\
\hline 047 & 1.0000 & 0.54962 & 0.09329 & 0.21390 & Biso & 1.000 \\
\hline 048 & 1.0000 & 0.54536 & 0.44671 & 0.19873 & Biso & 1.000 \\
\hline 049 & 1.0000 & 0.44401 & 0.90305 & 0.80943 & Biso & 1.000 \\
\hline 050 & 1.0000 & 0.08470 & 0.53950 & 0.79604 & Biso & 1.000 \\
\hline 051 & 1.0000 & 0.45447 & 0.55283 & 0.80311 & Biso & 1.000 \\
\hline 052 & 1.0000 & 0.58303 & 0.79992 & 0.54547 & Biso & 1.000 \\
\hline 053 & 1.0000 & 0.22038 & 0.44074 & 0.53749 & Biso & 1.000 \\
\hline 054 & 1.0000 & 0.20479 & 0.78201 & 0.53099 & Biso & 1.000 \\
\hline 055 & 1.0000 & 0.00062 & 0.26160 & 0.01418 & Biso & 1.000 \\
\hline 056 & 1.0000 & 0.74115 & 0.74955 & 0.01527 & Biso & 1.000 \\
\hline 057 & 1.0000 & 0.25038 & 0.99823 & 0.00933 & Biso & 1.000 \\
\hline 058 & 1.0000 & 0.66038 & 0.59404 & 0.34571 & Biso & 1.000 \\
\hline 059 & 1.0000 & 0.37760 & 0.05080 & 0.34201 & Biso & 1.000 \\
\hline 060 & 1.0000 & 0.92028 & 0.33235 & 0.34625 & Biso & 1.000 \\
\hline 061 & 1.0000 & 0.32639 & 0.91047 & 0.68422 & Biso & 1.000 \\
\hline 062 & 1.0000 & 0.06682 & 0.40065 & 0.67959 & Biso & 1.000 \\
\hline 063 & 1.0000 & 0.59432 & 0.66109 & 0.68223 & Biso & 1.000 \\
\hline 064 & 1.0000 & 0.99468 & 0.74293 & 0.99550 & Biso & 1.000 \\
\hline 065 & 1.0000 & 0.25742 & 0.25457 & 0.99227 & Biso & 1.000 \\
\hline 066 & 1.0000 & 0.74258 & 0.00141 & 0.99544 & Biso & 1.000 \\
\hline 067 & 1.0000 & 0.67522 & 0.07382 & 0.32649 & Biso & 1.000 \\
\hline 068 & 1.0000 & 0.93511 & 0.59207 & 0.32959 & Biso & 1.000 \\
\hline 069 & 1.0000 & 0.40911 & 0.35585 & 0.32472 & Biso & 1.000 \\
\hline 070 & 1.0000 & 0.32712 & 0.41021 & 0.65981 & Biso & 1.000 \\
\hline 071 & 1.0000 & 0.59071 & 0.93406 & 0.66296 & Biso & 1.000 \\
\hline 072 & 1.0000 & 0.08096 & 0.68687 & 0.66343 & Biso & 1.000 \\
\hline H 1 & 1.0000 & 0.30563 & 0.96785 & 0.34641 & Biso & 1.000 \\
\hline $\mathrm{C} 1$ & 1.0000 & 0.23282 & 0.77854 & 0.30513 & Biso & 1.000 \\
\hline $\mathrm{H} 2$ & 1.0000 & 0.30571 & 0.77630 & 0.33161 & Biso & 1.000 \\
\hline H3 & 1.0000 & 0.15807 & 0.69607 & 0.31064 & Biso & 1.000 \\
\hline $\mathrm{H} 4$ & 1.0000 & 0.24631 & 0.80407 & 0.23509 & Biso & 1.000 \\
\hline 073 & 1.0000 & 0.21511 & 0.85940 & 0.35242 & Biso & 1.000 \\
\hline H5 & 1.0000 & 0.20007 & 0.83661 & 0.41551 & Biso & 1.000 \\
\hline
\end{tabular}

Mg 23

data_image 0

$\begin{array}{ll}\text { cel1_length_a } & 13.875 \\ \text {-cell_length_b } & 13.875 \\ \text { _cell_length_c } & 15.017 \\ \text {-cell_angle_alpha } & 90 \\ \text {-cell-angle_beta } & 90 \\ \text {-cell_anglangle_gamma } & 120\end{array}$

$\begin{array}{ll}\text { symmetry_space_group_name_H-M } & \text { "P } 1 " \\ \text { symmetry_int tables_number } & 1\end{array}$

loop_

_symmetry_equiv_pos_as_xyz

' $\mathrm{x}, \mathrm{y}, \mathrm{z}$ '

loop

atom_site label

-atom_site_occupancy

-atom_site_fract_x

atom site fract $y$

atom site_fract_z

_atom_site_thermal_displace_type

_atom_site_B_iso_or_equiv

-atom_site_type_symbol

\begin{tabular}{|c|c|c|c|c|c|c|c|}
\hline All & 1.0000 & 0.99597 & 0.22702 & 0.10818 & Biso & 1.000 & Al \\
\hline Al2 & 1.0000 & 0.77314 & 0.77385 & 0.11152 & Biso & 1.000 & Al \\
\hline Al3 & 1.0000 & 0.22717 & 0.00493 & 0.10237 & Biso & 1.000 & Al \\
\hline P1 & 1.0000 & 0.22205 & 0.00211 & 0.89149 & Biso & 1.000 & $\mathrm{P}$ \\
\hline P2 & 1.0000 & 0.77214 & 0.77376 & 0.89809 & Biso & 1.000 & $\mathrm{P}$ \\
\hline P3 & 1.0000 & 0.99232 & 0.22746 & 0.89651 & Biso & 1.000 & $\mathrm{P}$ \\
\hline Al4 & 1.0000 & 0.65764 & 0.56031 & 0.43881 & Biso & 1.000 & Al \\
\hline Mg 1 & 1.0000 & 0.44528 & 0.11591 & 0.44551 & Biso & 1.000 & $\mathrm{Mg}$ \\
\hline Al5 & 1.0000 & 0.89759 & 0.33649 & 0.44132 & Biso & 1.000 & Al \\
\hline P4 & 1.0000 & 0.89374 & 0.33886 & 0.22896 & Biso & 1.000 & $\mathrm{P}$ \\
\hline P5 & 1.0000 & 0.43259 & 0.09693 & 0.23136 & Biso & 1.000 & $\mathrm{P}$ \\
\hline P6 & 1.0000 & 0.66092 & 0.55814 & 0.22924 & Biso & 1.000 & $\mathrm{P}$ \\
\hline Al6 & 1.0000 & 0.32330 & 0.88520 & 0.77923 & Biso & 1.000 & Al \\
\hline Al 7 & 1.0000 & 0.10175 & 0.43584 & 0.77169 & Biso & 1.000 & Al \\
\hline
\end{tabular}




\begin{tabular}{|c|c|c|c|c|c|c|c|}
\hline Al8 & 1.0000 & 0.56127 & 0.67099 & 0.77442 & Biso & 1.000 & Al \\
\hline P7 & 1.0000 & 0.57276 & 0.67974 & 0.56648 & Biso & 1.000 & $\mathrm{P}$ \\
\hline P8 & 1.0000 & 0.10504 & 0.44237 & 0.56556 & Biso & 1.000 & $\mathrm{P}$ \\
\hline P9 & 1.0000 & 0.32770 & 0.88176 & 0.56554 & Biso & 1.000 & $\mathrm{P}$ \\
\hline Al9 & 1.0000 & 0.99626 & 0.77143 & 0.90201 & Biso & 1.000 & Al \\
\hline Al10 & 1.0000 & 0.22111 & 0.22933 & 0.89577 & Biso & 1.000 & Al \\
\hline Al11 & 1.0000 & 0.76885 & 0.99770 & 0.90038 & Biso & 1.000 & Al \\
\hline P10 & 1.0000 & 0.76969 & 0.99757 & 0.11304 & Biso & 1.000 & $\mathrm{P}$ \\
\hline P11 & 1.0000 & 0.22488 & 0.23018 & 0.10772 & Biso & 1.000 & $P$ \\
\hline $\mathrm{P} 12$ & 1.0000 & 0.00194 & 0.77694 & 0.11451 & Biso & 1.000 & $\mathrm{P}$ \\
\hline Al12 & 1.0000 & 0.66982 & 0.10857 & 0.23677 & Biso & 1.000 & Al \\
\hline Al13 & 1.0000 & 0.89492 & 0.56451 & 0.23571 & Biso & 1.000 & Al \\
\hline Al1 14 & 1.0000 & 0.43498 & 0.33209 & 0.23484 & Biso & 1.000 & Al \\
\hline P13 & 1.0000 & 0.42636 & 0.33970 & 0.44155 & Biso & 1.000 & $\mathrm{P}$ \\
\hline P14 & 1.0000 & 0.89000 & 0.56061 & 0.44516 & Biso & 1.000 & $\mathrm{P}$ \\
\hline P15 & 1.0000 & 0.67538 & 0.11487 & 0.44123 & Biso & 1.000 & $\mathrm{P}$ \\
\hline Al15 & 1.0000 & 0.33911 & 0.45773 & 0.56668 & Biso & 1.000 & Al \\
\hline Al16 & 1.0000 & 0.55722 & 0.89892 & 0.56998 & Biso & 1.000 & Al \\
\hline Al1 17 & 1.0000 & 0.09466 & 0.67004 & 0.57236 & Biso & 1.000 & Al \\
\hline P16 & 1.0000 & 0.09811 & 0.66522 & 0.78128 & Biso & 1.000 & $\mathrm{P}$ \\
\hline P 17 & 1.0000 & 0.55485 & 0.89789 & 0.77913 & Biso & 1.000 & $\mathrm{P}$ \\
\hline P18 & 1.0000 & 0.33283 & 0.44503 & 0.77703 & Biso & 1.000 & $P$ \\
\hline 01 & 1.0000 & 0.89117 & 0.08966 & 0.12955 & Biso & 1.000 & 0 \\
\hline $\mathrm{O} 2$ & 1.0000 & 0.91042 & 0.80574 & 0.13501 & Biso & 1.000 & 0 \\
\hline $\mathrm{O} 3$ & 1.0000 & 0.19391 & 0.10830 & 0.12526 & Biso & 1.000 & 0 \\
\hline 04 & 1.0000 & 0.10123 & 0.90763 & 0.87731 & Biso & 1.000 & 0 \\
\hline 05 & 1.0000 & 0.80348 & 0.89476 & 0.87701 & Biso & 1.000 & 0 \\
\hline 06 & 1.0000 & 0.08380 & 0.19813 & 0.87741 & Biso & 1.000 & 0 \\
\hline 07 & 1.0000 & 0.54899 & 0.42766 & 0.46362 & Biso & 1.000 & 0 \\
\hline 08 & 1.0000 & 0.59972 & 0.16457 & 0.44173 & Biso & 1.000 & 0 \\
\hline 09 & 1.0000 & 0.86577 & 0.44188 & 0.46609 & Biso & 1.000 & 0 \\
\hline 010 & 1.0000 & 0.77211 & 0.24682 & 0.21368 & Biso & 1.000 & 0 \\
\hline 011 & 1.0000 & 0.45807 & 0.21790 & 0.23125 & Biso & 1.000 & 0 \\
\hline 012 & 1.0000 & 0.75911 & 0.53660 & 0.22009 & Biso & 1.000 & 0 \\
\hline 013 & 1.0000 & 0.21813 & 0.75077 & 0.80928 & Biso & 1.000 & 0 \\
\hline 014 & 1.0000 & 0.24013 & 0.47325 & 0.79538 & Biso & 1.000 & 0 \\
\hline 015 & 1.0000 & 0.52769 & 0.77619 & 0.78751 & Biso & 1.000 & 0 \\
\hline 016 & 1.0000 & 0.44943 & 0.59354 & 0.54962 & Biso & 1.000 & 0 \\
\hline 017 & 1.0000 & 0.11622 & 0.55808 & 0.56163 & Biso & 1.000 & 0 \\
\hline 018 & 1.0000 & 0.41231 & 0.84075 & 0.55337 & Biso & 1.000 & 0 \\
\hline 019 & 1.0000 & 0.97368 & 0.31892 & 0.17178 & Biso & 1.000 & 0 \\
\hline 020 & 1.0000 & 0.67809 & 0.65426 & 0.16836 & Biso & 1.000 & 0 \\
\hline 021 & 1.0000 & 0.34552 & 0.02656 & 0.16082 & Biso & 1.000 & 0 \\
\hline $\mathrm{O} 22$ & 1.0000 & 0.30240 & 0.98488 & 0.83278 & Biso & 1.000 & 0 \\
\hline 023 & 1.0000 & 0.66906 & 0.69168 & 0.84538 & Biso & 1.000 & 0 \\
\hline $\mathrm{O} 24$ & 1.0000 & 0.01038 & 0.32730 & 0.84036 & Biso & 1.000 & 0 \\
\hline 025 & 1.0000 & 0.64909 & 0.65961 & 0.50483 & Biso & 1.000 & 0 \\
\hline 026 & 1.0000 & 0.35887 & 0.98554 & 0.51319 & Biso & 1.000 & 0 \\
\hline 027 & 1.0000 & 0.01663 & 0.36304 & 0.50003 & Biso & 1.000 & 0 \\
\hline 028 & 1.0000 & 0.01470 & 0.67357 & 0.84317 & Biso & 1.000 & 0 \\
\hline 029 & 1.0000 & 0.31353 & 0.34405 & 0.83263 & Biso & 1.000 & 0 \\
\hline 030 & 1.0000 & 0.65219 & 0.97399 & 0.83988 & Biso & 1.000 & 0 \\
\hline 031 & 1.0000 & 0.68821 & 0.01864 & 0.16672 & Biso & 1.000 & 0 \\
\hline 032 & 1.0000 & 0.32663 & 0.30924 & 0.16311 & Biso & 1.000 & o \\
\hline 033 & 1.0000 & 0.98787 & 0.67988 & 0.17280 & Biso & 1.000 & 0 \\
\hline 034 & 1.0000 & 0.34798 & 0.36383 & 0.49725 & Biso & 1.000 & 0 \\
\hline 035 & 1.0000 & 0.98069 & 0.64618 & 0.50731 & Biso & 1.000 & 0 \\
\hline 036 & 1.0000 & 0.63560 & 0.01469 & 0.50438 & Biso & 1.000 & 0 \\
\hline 037 & 1.0000 & 0.12605 & 0.24399 & 0.13525 & Biso & 1.000 & 0 \\
\hline 038 & 1.0000 & 0.75705 & 0.88599 & 0.14302 & Biso & 1.000 & 0 \\
\hline 039 & 1.0000 & 0.11625 & 0.87743 & 0.13683 & Biso & 1.000 & 0 \\
\hline 040 & 1.0000 & 0.23119 & 0.11318 & 0.86582 & Biso & 1.000 & 0 \\
\hline 041 & 1.0000 & 0.86909 & 0.75695 & 0.87068 & Biso & 1.000 & 0 \\
\hline 042 & 1.0000 & 0.87946 & 0.12761 & 0.87121 & Biso & 1.000 & 0 \\
\hline 043 & 1.0000 & 0.78450 & 0.56699 & 0.45946 & Biso & 1.000 & 0 \\
\hline 044 & 1.0000 & 0.40463 & 0.22442 & 0.46167 & Biso & 1.000 & 0 \\
\hline 045 & 1.0000 & 0.79393 & 0.20337 & 0.47087 & Biso & 1.000 & 0 \\
\hline 046 & 1.0000 & 0.90610 & 0.45085 & 0.20065 & Biso & 1.000 & 0 \\
\hline 047 & 1.0000 & 0.53903 & 0.09334 & 0.21322 & Biso & 1.000 & 0 \\
\hline 048 & 1.0000 & 0.55512 & 0.45234 & 0.19965 & Biso & 1.000 & 0 \\
\hline 049 & 1.0000 & 0.45280 & 0.90469 & 0.80959 & Biso & 1.000 & 0 \\
\hline 050 & 1.0000 & 0.08154 & 0.54823 & 0.78988 & Biso & 1.000 & 0 \\
\hline 051 & 1.0000 & 0.44493 & 0.54484 & 0.80410 & Biso & 1.000 & 0 \\
\hline 052 & 1.0000 & 0.59156 & 0.79637 & 0.54679 & Biso & 1.000 & 0 \\
\hline 053 & 1.0000 & 0.21694 & 0.45568 & 0.53850 & Biso & 1.000 & 0 \\
\hline 054 & 1.0000 & 0.21251 & 0.78864 & 0.52780 & Biso & 1.000 & 0 \\
\hline 055 & 1.0000 & 0.99378 & 0.25719 & 0.99536 & Biso & 1.000 & 0 \\
\hline 056 & 1.0000 & 0.74710 & 0.74920 & 0.99776 & Biso & 1.000 & 0 \\
\hline 057 & 1.0000 & 0.25558 & 0.00396 & 0.98956 & Biso & 1.000 & 0 \\
\hline 058 & 1.0000 & 0.65155 & 0.58959 & 0.32577 & Biso & 1.000 & 0 \\
\hline
\end{tabular}




$\begin{array}{llllllll}\text { 059 } & 1.0000 & 0.38456 & 0.04416 & 0.32468 & \text { Biso } & 1.000 & \text { O } \\ \text { O60 } & 1.0000 & 0.92637 & 0.34288 & 0.32716 & \text { Biso } & 1.000 & \text { O } \\ \text { O61 } & 1.0000 & 0.31390 & 0.89785 & 0.66486 & \text { Biso } & 1.000 & \text { O } \\ \text { O62 } & 1.0000 & 0.07213 & 0.39397 & 0.66025 & \text { Biso } & 1.000 & \text { O } \\ \text { O63 } & 1.0000 & 0.60276 & 0.67122 & 0.66406 & \text { Biso } & 1.000 & \text { O } \\ \text { O64 } & 1.0000 & 0.99743 & 0.74492 & 0.01598 & \text { Biso } & 1.000 & \text { O } \\ \text { O65 } & 1.0000 & 0.25316 & 0.25917 & 0.00881 & \text { Biso } & 1.000 & \text { O } \\ \text { O66 } & 1.0000 & 0.74010 & 0.99348 & 0.01398 & \text { Biso } & 1.000 & \text { O } \\ \text { O67 } & 1.0000 & 0.68126 & 0.07330 & 0.34619 & \text { Biso } & 1.000 & \text { O } \\ \text { O68 } & 1.0000 & 0.93273 & 0.59248 & 0.34843 & \text { Biso } & 1.000 & \text { O } \\ \text { O69 } & 1.0000 & 0.40324 & 0.35255 & 0.34236 & \text { Biso } & 1.000 & \text { O } \\ \text { O70 } & 1.0000 & 0.33438 & 0.41782 & 0.67804 & \text { Biso } & 1.000 & \text { O } \\ \text { O71 } & 1.0000 & 0.58549 & 0.93856 & 0.68251 & \text { Biso } & 1.000 & \text { O } \\ \text { O72 } & 1.0000 & 0.07583 & 0.68815 & 0.68497 & \text { Biso } & 1.000 & \text { O } \\ \text { H1 } & 1.0000 & 0.30415 & 0.94967 & 0.33527 & \text { Biso } & 1.000 & \text { H } \\ \text { C1 } & 1.0000 & 0.23156 & 0.77048 & 0.30390 & \text { Biso } & 1.000 & \text { C } \\ \text { H2 } & 1.0000 & 0.30509 & 0.76611 & 0.32513 & \text { Biso } & 1.000 & \mathrm{H} \\ \text { H3 } & 1.0000 & 0.15493 & 0.69242 & 0.31863 & \text { Biso } & 1.000 & \mathrm{H} \\ \text { H4 } & 1.0000 & 0.23533 & 0.78906 & 0.23273 & \text { Biso } & 1.000 & \mathrm{H} \\ \text { O73 } & 1.0000 & 0.22641 & 0.85992 & 0.35066 & \text { Biso } & 1.000 & \text { O } \\ \text { H5 } & 1.0000 & 0.21917 & 0.84381 & 0.41597 & \text { Biso } & 1.000 & \mathrm{H}\end{array}$

Al 23

data_image 0

$\begin{array}{ll}\text {-celí_length_a } & 13.625 \\ \text {-cell_length_b } & 13.625 \\ \text {-cell_length_c } & 15.067 \\ \text {-cell_angle_alpha } & 90 \\ \text {-cell_angle_beta } & 90 \\ \text {-cell_angle_gamma } & 120\end{array}$

$\begin{array}{lll}\text {-symmetry_space_group_name_H-M } & \text { "P } 1 " \\ \text { symmetry_int_tables_number } & 1\end{array}$

loop_

_symmetry_equiv_pos_as_xyz

' $\mathrm{x}, \mathrm{y}, \mathrm{z}$ '

loop

atom site label

-atom_site_occupancy

-atom_site_fract_x

atom site fract $y$

-atom_site_fract_z

-atom_site_thermal_displace_type

-atom_site_B_iso_or_equiv

_atom_site_type_symbol

Sil $1.0000-0.01098$

$1.0000 \quad 0.78291$

Si3 $1.0000 \quad 0.24229$

Si4 $1.0000 \quad 0.23799$

0.23412

0.10269

Biso

$1.000 \mathrm{Si}$

$\begin{array}{lllll}0.77921 & 0.10462 & \text { Biso } & 1.000 & \mathrm{Si}\end{array}$

0.09944 Biso

$1.000 \mathrm{Si}$

Si5 $\quad 1.0000 \quad 0.78161$

0.89324 Biso

$1.000 \mathrm{Si}$

Si6

$1.0000 \quad 0.00917$

$0.77623 \quad 0.89612$

$1.000 \mathrm{Si}$

Si7

$0.23410 \quad 0.89618$ Biso

$1.000 \mathrm{Si}$

$.0000 \quad 0.67863$

.57447

0.43401 Biso

$1.000 \mathrm{Si}$

Al1 $\quad 1.0000 \quad 0.45271$

Si8 $1.0000 \quad 0.91105$

Si9

$\begin{array}{lll}11491 & 0.44216 & \text { Biso }\end{array}$

$1.0000 \quad 0.90736$

0.33691

0.43550 Biso

$1.000 \mathrm{Al}$

Silo

0.33982

0.22870 Biso

$1.000 \mathrm{Si}$

$1.0000 \quad 0.44673$

$1.0000 \quad 0.67936$

0.10992

0.22797 Biso

Si

Si12

$\begin{array}{lll}0.57107 & 0.23060 & \text { Biso }\end{array}$

$.000 \mathrm{Si}$

$.0000 \quad 0.34150$

89549

0.77110 Biso

$1.000 \mathrm{Si}$

$1.0000 \quad 0.11105$

$1.0000 \quad 0.57491$

0.43791

Sil4

0.67037

0.76691 Biso

$1.000 \mathrm{Si}$

$1.0000 \quad 0.58194$

$1.0000 \quad 0.11297$

0.67513

0.76914 Biso

$1.000 \mathrm{Si}$

Sil6

0.441020 .56516

$1.0000 \quad 0.34167$

0.89633

0.56516 Biso

$1.000 \mathrm{Si}$

$1.000 \mathrm{Si}$

Sil 17

0.77192

0.56289 Biso

$1.000 \mathrm{Si}$

$.0000 \quad 0.00761$

$1.0000 \quad 0.23827$

$1.0000 \quad 0.78099$

0.23288

Si 19

0.00383

.89819 Biso

$1.000 \mathrm{Si}$

$1.000 \mathrm{Si}$

$1.0000 \quad 0.78021$

$1.0000 \quad 0.24137$

0.00497

0.89456 Biso

$1.000 \mathrm{Si}$

Si22

$\mathrm{Si} 23$

0.23518

$1.0000 \quad 0.01077$

0.77748

0.10237 Biso

$1.000 \mathrm{Si}$

$1.0000 \quad 0.68061$

0.10883

0.10116 Biso

$1.000 \mathrm{Si}$

Si24

0.56754

$1.0000 \quad 0.44704$

0.33911

Biso

$1.000 \mathrm{Si}$

Si26

Si27

0.34133

.23236 Biso

$1.000 \mathrm{Si}$

$1.0000 \quad 0.44239$

$1.0000 \quad 0.90352$

0.56286

$1.0000 \quad 0.68517 \quad 0.10679$

$1.000 \mathrm{Si}$

Si28

Si30

0.44757

$1.0000 \quad 0.34633$

0.90325

$1.0000 \quad 0.57417$

1.00000 .10726

0.67191

0.22992 Biso

$1.000 \mathrm{Si}$

0.43774 Biso $1.000 \mathrm{Si}$

Si31

$\begin{array}{ll}1.000 & \mathrm{Si} \\ 1.000 & \mathrm{Si}\end{array}$

0.56285 Biso $1.000 \mathrm{Si}$

Si33

0.66994

$1.000 \mathrm{Si}$

$1.000 \mathrm{Si}$

0.77001 Biso $1.000 \mathrm{Si}$ 


\begin{tabular}{|c|c|c|c|c|c|c|}
\hline $\mathrm{Si} 34$ & 1.0000 & 0.57203 & 0.90155 & 0.76909 & Biso & 1.000 \\
\hline Si35 & 1.0000 & 0.34262 & 0.44164 & 0.76759 & Biso & 1.000 \\
\hline 01 & 1.0000 & 0.91139 & 0.10341 & 0.11890 & Biso & 1.000 \\
\hline $\mathrm{O} 2$ & 1.0000 & 0.91429 & 0.81259 & 0.12325 & Biso & 1.000 \\
\hline 03 & 1.0000 & 0.21102 & 0.10485 & 0.12002 & Biso & 1.000 \\
\hline 04 & 1.0000 & 0.10734 & 0.90224 & 0.88096 & Biso & 1.000 \\
\hline 05 & 1.0000 & 0.81428 & 0.90637 & 0.87491 & Biso & 1.000 \\
\hline 06 & 1.0000 & 0.10766 & 0.20203 & 0.87847 & Biso & 1.000 \\
\hline 07 & 1.0000 & 0.57017 & 0.44946 & 0.44484 & Biso & 1.000 \\
\hline 08 & 1.0000 & 0.58835 & 0.14007 & 0.43853 & Biso & 1.000 \\
\hline 09 & 1.0000 & 0.87774 & 0.43451 & 0.45593 & Biso & 1.000 \\
\hline 010 & 1.0000 & 0.77557 & 0.24128 & 0.21479 & Biso & 1.000 \\
\hline 011 & 1.0000 & 0.48145 & 0.24124 & 0.21236 & Biso & 1.000 \\
\hline 012 & 1.0000 & 0.77642 & 0.53627 & 0.21439 & Biso & 1.000 \\
\hline 013 & 1.0000 & 0.24105 & 0.76575 & 0.78943 & Biso & 1.000 \\
\hline 014 & 1.0000 & 0.24284 & 0.47283 & 0.78346 & Biso & 1.000 \\
\hline 015 & 1.0000 & 0.54475 & 0.77132 & 0.77885 & Biso & 1.000 \\
\hline 016 & 1.0000 & 0.45204 & 0.57556 & 0.54978 & Biso & 1.000 \\
\hline 017 & 1.0000 & 0.13176 & 0.56794 & 0.55797 & Biso & 1.000 \\
\hline 018 & 1.0000 & 0.44264 & 0.86736 & 0.54398 & Biso & 1.000 \\
\hline 019 & 1.0000 & 0.99146 & 0.31915 & 0.16546 & Biso & 1.000 \\
\hline $\mathrm{O} 20$ & 1.0000 & 0.69635 & 0.67050 & 0.16292 & Biso & 1.000 \\
\hline 021 & 1.0000 & 0.34925 & 0.02526 & 0.15969 & Biso & 1.000 \\
\hline $\mathrm{O} 22$ & 1.0000 & 0.32258 & 0.98383 & 0.83054 & Biso & 1.000 \\
\hline $\mathrm{O} 23$ & 1.0000 & 0.67319 & 0.68766 & 0.83837 & Biso & 1.000 \\
\hline $\mathrm{O} 24$ & 1.0000 & 0.02787 & 0.33928 & 0.83477 & Biso & 1.000 \\
\hline 025 & 1.0000 & 0.66906 & 0.66355 & 0.49971 & Biso & 1.000 \\
\hline 026 & 1.0000 & 0.35349 & 0.99848 & 0.50221 & Biso & 1.000 \\
\hline 027 & 1.0000 & 0.01825 & 0.35720 & 0.49528 & Biso & 1.000 \\
\hline 028 & 1.0000 & 0.02628 & 0.68375 & 0.83880 & Biso & 1.000 \\
\hline 029 & 1.0000 & 0.32391 & 0.33802 & 0.83159 & Biso & 1.000 \\
\hline 030 & 1.0000 & 0.67552 & 0.98511 & 0.83345 & Biso & 1.000 \\
\hline 031 & 1.0000 & 0.69338 & 0.02804 & 0.15984 & Biso & 1.000 \\
\hline 032 & 1.0000 & 0.34804 & 0.32243 & 0.16129 & Biso & 1.000 \\
\hline 033 & 1.0000 & 0.99318 & 0.67611 & 0.17100 & Biso & 1.000 \\
\hline 034 & 1.0000 & 0.35461 & 0.36164 & 0.49410 & Biso & 1.000 \\
\hline 035 & 1.0000 & 0.00506 & 0.65354 & 0.50109 & Biso & 1.000 \\
\hline 036 & 1.0000 & 0.66155 & 0.00311 & 0.49922 & Biso & 1.000 \\
\hline 037 & 1.0000 & 0.13203 & 0.24590 & 0.12808 & Biso & 1.000 \\
\hline 038 & 1.0000 & 0.76762 & 0.88527 & 0.13345 & Biso & 1.000 \\
\hline 039 & 1.0000 & 0.13419 & 0.88564 & 0.12707 & Biso & 1.000 \\
\hline 040 & 1.0000 & 0.24783 & 0.12309 & 0.86597 & Biso & 1.000 \\
\hline 041 & 1.0000 & 0.88802 & 0.76060 & 0.86954 & Biso & 1.000 \\
\hline 042 & 1.0000 & 0.88837 & 0.12592 & 0.87001 & Biso & 1.000 \\
\hline 043 & 1.0000 & 0.79193 & 0.57065 & 0.46052 & Biso & 1.000 \\
\hline 044 & 1.0000 & 0.44084 & 0.23007 & 0.46784 & Biso & 1.000 \\
\hline 045 & 1.0000 & 0.80698 & 0.21399 & 0.46138 & Biso & 1.000 \\
\hline 046 & 1.0000 & 0.91998 & 0.46059 & 0.20081 & Biso & 1.000 \\
\hline 047 & 1.0000 & 0.55608 & 0.09525 & 0.21914 & Biso & 1.000 \\
\hline 048 & 1.0000 & 0.55722 & 0.46137 & 0.21035 & Biso & 1.000 \\
\hline 049 & 1.0000 & 0.46091 & 0.90666 & 0.80030 & Biso & 1.000 \\
\hline 050 & 1.0000 & 0.09658 & 0.54673 & 0.78548 & Biso & 1.000 \\
\hline 051 & 1.0000 & 0.46283 & 0.55132 & 0.79322 & Biso & 1.000 \\
\hline 052 & 1.0000 & 0.59003 & 0.79514 & 0.54653 & Biso & 1.000 \\
\hline 053 & 1.0000 & 0.23139 & 0.44888 & 0.54003 & Biso & 1.000 \\
\hline 054 & 1.0000 & 0.22013 & 0.78676 & 0.53658 & Biso & 1.000 \\
\hline 055 & 1.0000 & 0.01064 & 0.26944 & 0.99958 & Biso & 1.000 \\
\hline 056 & 1.0000 & 0.75136 & 0.74803 & 0.00068 & Biso & 1.000 \\
\hline 057 & 1.0000 & 0.27634 & 0.00763 & 0.99625 & Biso & 1.000 \\
\hline 058 & 1.0000 & 0.68796 & 0.61753 & 0.33157 & Biso & 1.000 \\
\hline 059 & 1.0000 & 0.39155 & 0.06991 & 0.32911 & Biso & 1.000 \\
\hline 060 & 1.0000 & 0.94555 & 0.34276 & 0.33128 & Biso & 1.000 \\
\hline 061 & 1.0000 & 0.34247 & 0.92750 & 0.66740 & Biso & 1.000 \\
\hline 062 & 1.0000 & 0.07360 & 0.39241 & 0.66559 & Biso & 1.000 \\
\hline 063 & 1.0000 & 0.61853 & 0.66903 & 0.66860 & Biso & 1.000 \\
\hline 064 & 1.0000 & 0.00542 & 0.73817 & 0.00234 & Biso & 1.000 \\
\hline 065 & 1.0000 & 0.27404 & 0.26653 & 0.99712 & Biso & 1.000 \\
\hline 066 & 1.0000 & 0.74637 & 0.00007 & 0.99835 & Biso & 1.000 \\
\hline 067 & 1.0000 & 0.69465 & 0.06931 & 0.33100 & Biso & 1.000 \\
\hline 068 & 1.0000 & 0.94175 & 0.59907 & 0.33460 & Biso & 1.000 \\
\hline 069 & 1.0000 & 0.40243 & 0.33169 & 0.33070 & Biso & 1.000 \\
\hline 070 & 1.0000 & 0.34301 & 0.40510 & 0.66473 & Biso & 1.000 \\
\hline 071 & 1.0000 & 0.60520 & 0.94494 & 0.66710 & Biso & 1.000 \\
\hline 072 & 1.0000 & 0.07384 & 0.68225 & 0.66903 & Biso & 1.000 \\
\hline H 1 & 1.0000 & 0.29814 & 0.02521 & 0.34006 & Biso & 1.000 \\
\hline $\mathrm{C} 1$ & 1.0000 & 0.09793 & 0.87905 & 0.35021 & Biso & 1.000 \\
\hline $\mathrm{H} 2$ & 1.0000 & 0.11960 & 0.81488 & 0.32962 & Biso & 1.000 \\
\hline H3 & 1.0000 & 0.03425 & 0.84484 & 0.40324 & Biso & 1.000 \\
\hline $\mathrm{H} 4$ & 1.0000 & 0.06481 & 0.90407 & 0.29366 & Biso & 1.000 \\
\hline 073 & 1.0000 & 0.19696 & 0.98075 & 0.38190 & Biso & 1.000 \\
\hline
\end{tabular}




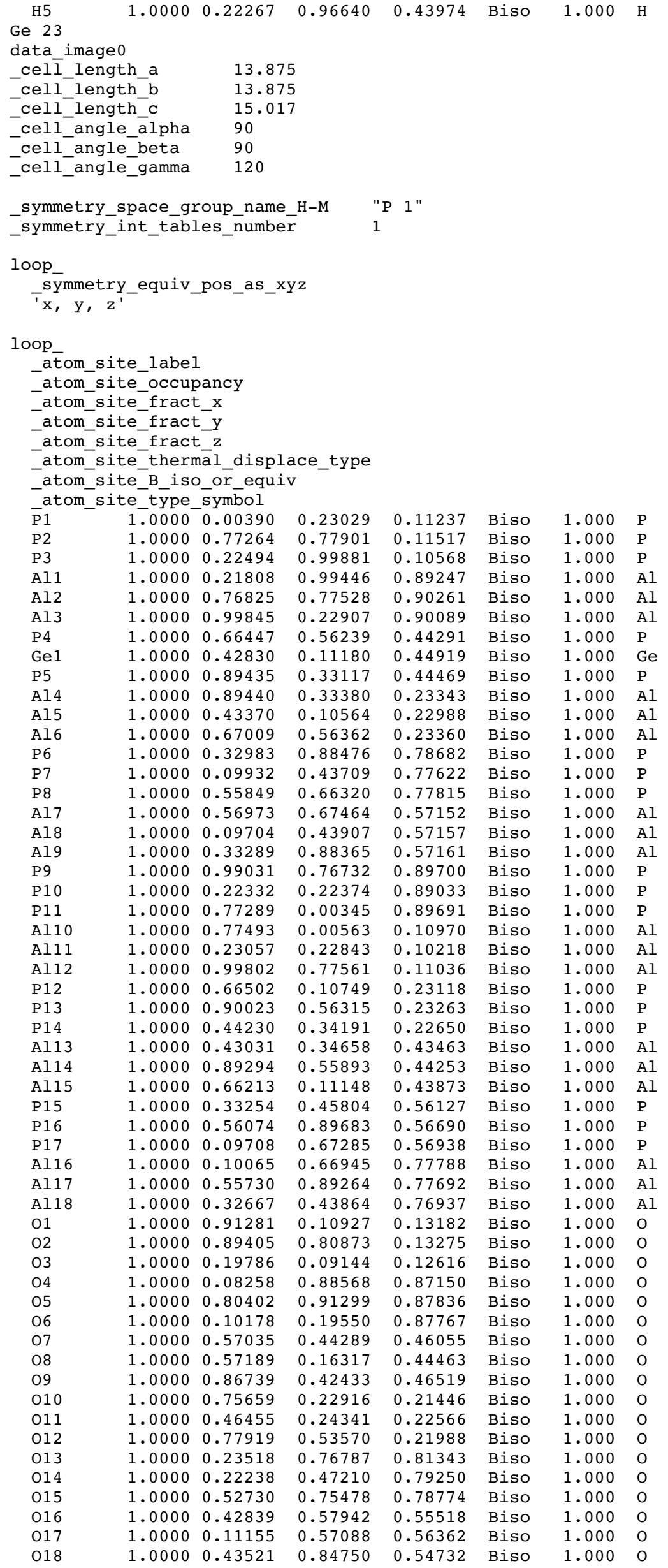




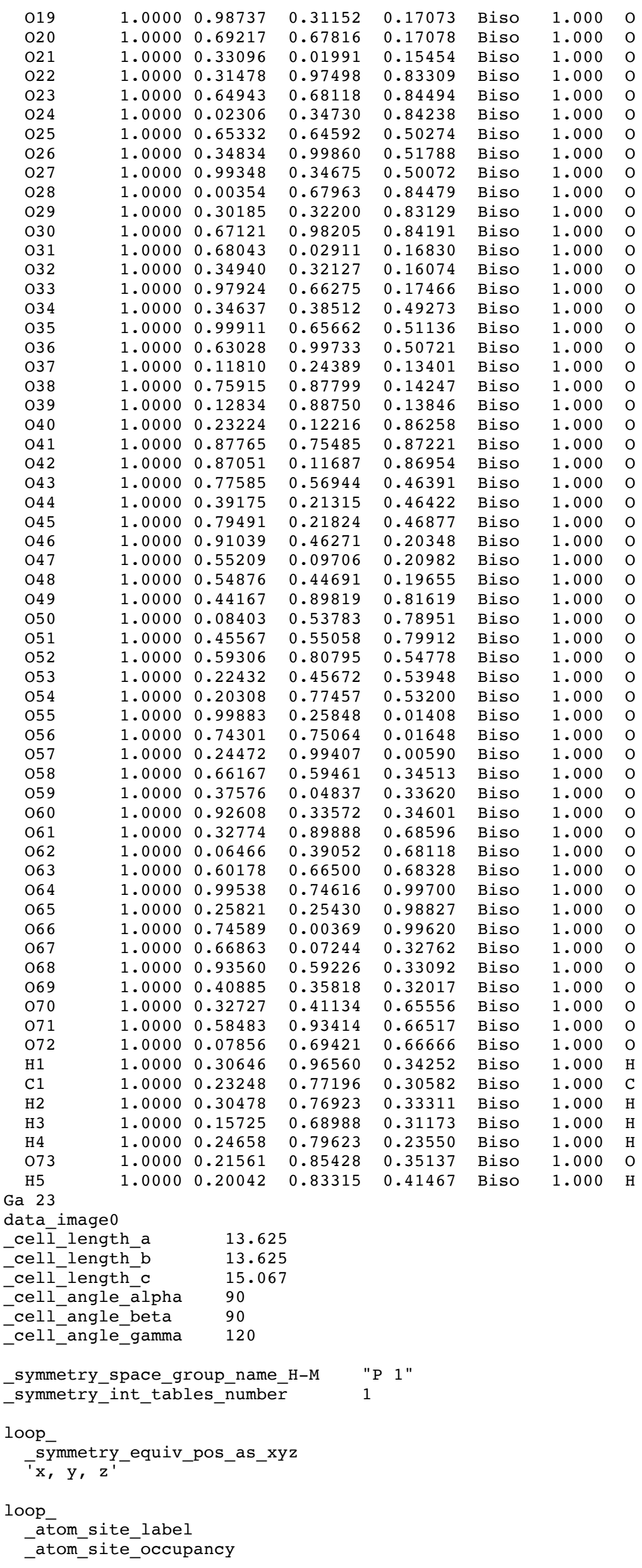




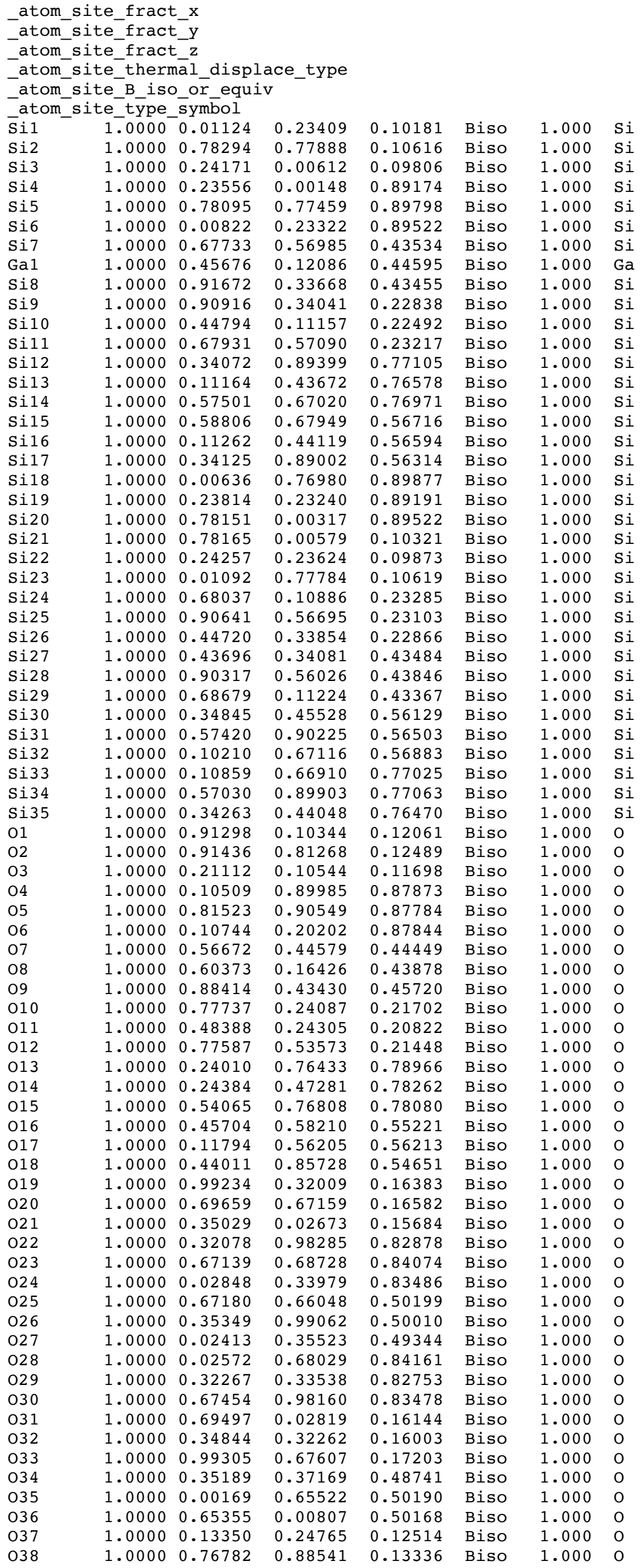




\begin{tabular}{|c|c|c|c|c|c|c|c|}
\hline 039 & 1.0000 & 0.13428 & 0.88621 & 0.12835 & Biso & 1.000 & 0 \\
\hline 040 & 1.0000 & 0.24562 & 0.12118 & 0.86539 & Biso & 1.000 & 0 \\
\hline 041 & 1.0000 & 0.88597 & 0.75700 & 0.87031 & Biso & 1.000 & 0 \\
\hline 042 & 1.0000 & 0.88799 & 0.12477 & 0.86771 & Biso & 1.000 & 0 \\
\hline 043 & 1.0000 & 0.78750 & 0.56021 & 0.46112 & Biso & 1.000 & 0 \\
\hline 044 & 1.0000 & 0.42530 & 0.22832 & 0.47778 & Biso & 1.000 & 0 \\
\hline 045 & 1.0000 & 0.81387 & 0.21222 & 0.45920 & Biso & 1.000 & 0 \\
\hline 046 & 1.0000 & 0.91957 & 0.46026 & 0.20059 & Biso & 1.000 & 0 \\
\hline 047 & 1.0000 & 0.55710 & 0.09664 & 0.21602 & Biso & 1.000 & 0 \\
\hline 048 & 1.0000 & 0.55630 & 0.46239 & 0.21198 & Biso & 1.000 & 0 \\
\hline 049 & 1.0000 & 0.46026 & 0.90629 & 0.80167 & Biso & 1.000 & 0 \\
\hline 050 & 1.0000 & 0.09612 & 0.54555 & 0.78114 & Biso & 1.000 & 0 \\
\hline 051 & 1.0000 & 0.46408 & 0.54872 & 0.79002 & Biso & 1.000 & 0 \\
\hline 052 & 1.0000 & 0.60085 & 0.80133 & 0.54380 & Biso & 1.000 & 0 \\
\hline 053 & 1.0000 & 0.23742 & 0.46489 & 0.54159 & Biso & 1.000 & 0 \\
\hline 054 & 1.0000 & 0.21859 & 0.78166 & 0.53783 & Biso & 1.000 & 0 \\
\hline 055 & 1.0000 & 0.00716 & 0.26682 & 0.99865 & Biso & 1.000 & 0 \\
\hline 056 & 1.0000 & 0.75110 & 0.74570 & 0.00251 & Biso & 1.000 & 0 \\
\hline 057 & 1.0000 & 0.27319 & 0.00387 & 0.99469 & Biso & 1.000 & 0 \\
\hline 058 & 1.0000 & 0.68867 & 0.61590 & 0.33367 & Biso & 1.000 & 0 \\
\hline 059 & 1.0000 & 0.39283 & 0.07255 & 0.32589 & Biso & 1.000 & 0 \\
\hline 060 & 1.0000 & 0.95069 & 0.34486 & 0.33010 & Biso & 1.000 & 0 \\
\hline 061 & 1.0000 & 0.34328 & 0.92488 & 0.66688 & Biso & 1.000 & 0 \\
\hline 062 & 1.0000 & 0.07460 & 0.38736 & 0.66520 & Biso & 1.000 & 0 \\
\hline 063 & 1.0000 & 0.62398 & 0.67559 & 0.66994 & Biso & 1.000 & 0 \\
\hline 064 & 1.0000 & 0.00574 & 0.73919 & 0.00347 & Biso & 1.000 & 0 \\
\hline 065 & 1.0000 & 0.27654 & 0.26844 & 0.99483 & Biso & 1.000 & 0 \\
\hline 066 & 1.0000 & 0.74880 & 0.00297 & 0.99913 & Biso & 1.000 & 0 \\
\hline 067 & 1.0000 & 0.68815 & 0.06745 & 0.33251 & Biso & 1.000 & 0 \\
\hline 068 & 1.0000 & 0.94048 & 0.59718 & 0.33530 & Biso & 1.000 & 0 \\
\hline 069 & 1.0000 & 0.40120 & 0.32551 & 0.32959 & Biso & 1.000 & 0 \\
\hline 070 & 1.0000 & 0.34239 & 0.40560 & 0.66116 & Biso & 1.000 & 0 \\
\hline 071 & 1.0000 & 0.60421 & 0.94181 & 0.66849 & Biso & 1.000 & 0 \\
\hline 072 & 1.0000 & 0.07111 & 0.68587 & 0.67083 & Biso & 1.000 & 0 \\
\hline $\mathrm{H} 1$ & 1.0000 & 0.30142 & 0.02769 & 0.33792 & Biso & 1.000 & $\mathrm{H}$ \\
\hline $\mathrm{C} 1$ & 1.0000 & 0.09641 & 0.88293 & 0.35034 & Biso & 1.000 & C \\
\hline $\mathrm{H} 2$ & 1.0000 & 0.11283 & 0.81561 & 0.32830 & Biso & 1.000 & $\mathrm{H}$ \\
\hline H3 & 1.0000 & 0.03270 & 0.85070 & 0.40346 & Biso & 1.000 & $\mathrm{H}$ \\
\hline $\mathrm{H} 4$ & 1.0000 & 0.06568 & 0.91182 & 0.29459 & Biso & 1.000 & $\mathrm{H}$ \\
\hline 073 & 1.0000 & 0.19867 & 0.98058 & 0.38229 & Biso & 1.000 & 0 \\
\hline H5 & 1.0000 & 0.22502 & 0.96245 & 0.43818 & Biso & 1.000 & $\mathrm{H}$ \\
\hline \multirow{2}{*}{\multicolumn{8}{|c|}{$\begin{array}{l}\text { i } 23 \\
\text { ata image } 0\end{array}$}} \\
\hline & & & & & & & \\
\hline \multicolumn{8}{|c|}{13.875} \\
\hline \multicolumn{8}{|c|}{13.875} \\
\hline \multicolumn{8}{|c|}{15.017} \\
\hline \multicolumn{8}{|c|}{ e $\bar{a}$ lpha } \\
\hline \multicolumn{8}{|c|}{90} \\
\hline cell & gamma & 120 & & & & & \\
\hline symme & space_gl & coup_nam & & $1 "$ & & & \\
\hline symme & int_t $\overline{a b}$ & les_numbe & & & & & \\
\hline Op_ & & & & & & & \\
\hline & equiv & pos as & & & & & \\
\hline${ }^{\prime} \mathrm{x}$, & & & & & & & \\
\hline op_ & & & & & & & \\
\hline$a \overline{t c}$ & ce_labe & & & & & & \\
\hline ato & ce occup & bancy & & & & & \\
\hline atc & te_fract & E $x$ & & & & & \\
\hline -atc & te_fract & & & & & & \\
\hline -atc & te_fract & $z$ & & & & & \\
\hline -atc & te-thern & nall_displ & ace_cype & & & & \\
\hline $\begin{array}{l}- \\
\text { atc } \\
\text { atc }\end{array}$ & $\begin{array}{l}\text { ee_B_is } \\
\text { ce type }\end{array}$ & $\begin{array}{l}\text { or_equi } \\
\text { symbol }\end{array}$ & & & & & \\
\hline$\overline{\mathrm{P}} 1$ & 1.0000 & 0.00490 & 0.23091 & 0.11254 & Biso & 1.000 & $P$ \\
\hline P2 & 1.0000 & 0.77345 & 0.78034 & 0.11684 & Biso & 1.000 & $\mathrm{P}$ \\
\hline P3 & 1.0000 & 0.22569 & 0.99998 & 0.10273 & Biso & 1.000 & $\mathrm{P}$ \\
\hline Al1 & 1.0000 & 0.21497 & 0.99341 & 0.88897 & Biso & 1.000 & Al \\
\hline Al2 & 1.0000 & 0.76764 & 0.77587 & 0.90383 & Biso & 1.000 & Al \\
\hline A13 & 1.0000 & 0.99727 & 0.22945 & 0.90079 & Biso & 1.000 & $\mathrm{Al}$ \\
\hline P4 & 1.0000 & 0.66417 & 0.56448 & 0.44397 & Biso & 1.000 & $P$ \\
\hline Til & 1.0000 & 0.42377 & 0.11026 & 0.44838 & Biso & 1.000 & $\mathrm{Ti}$ \\
\hline P5 & 1.0000 & 0.89805 & 0.33243 & 0.44469 & Biso & 1.000 & $\mathrm{P}$ \\
\hline Al4 & 1.0000 & 0.89661 & 0.33585 & 0.23343 & Biso & 1.000 & Al \\
\hline Al5 & 1.0000 & 0.43248 & 0.10434 & 0.22751 & Biso & 1.000 & Al \\
\hline Al 6 & 1.0000 & 0.67093 & 0.56388 & 0.23436 & Biso & 1.000 & Al \\
\hline P6 & 1.0000 & 0.32788 & 0.88141 & 0.78878 & Biso & 1.000 & $\mathrm{P}$ \\
\hline P7 & 1.0000 & 0.09824 & 0.43632 & 0.77627 & Biso & 1.000 & P \\
\hline
\end{tabular}




\begin{tabular}{|c|c|c|c|c|c|c|c|}
\hline P8 & 1.0000 & 0.55821 & 0.66353 & 0.77848 & Biso & 1.000 & $\mathrm{P}$ \\
\hline Al 7 & 1.0000 & 0.57505 & 0.67778 & 0.57299 & Biso & 1.000 & Al \\
\hline Al8 & 1.0000 & 0.09614 & 0.43979 & 0.57379 & Biso & 1.000 & Al \\
\hline Al9 & 1.0000 & 0.33080 & 0.87774 & 0.57291 & Biso & 1.000 & Al \\
\hline P9 & 1.0000 & 0.98844 & 0.76641 & 0.89722 & Biso & 1.000 & $\mathrm{P}$ \\
\hline P10 & 1.0000 & 0.22218 & 0.22382 & 0.88798 & Biso & 1.000 & $\mathrm{P}$ \\
\hline P11 & 1.0000 & 0.77282 & 0.00351 & 0.89767 & Biso & 1.000 & $\mathrm{P}$ \\
\hline Al10 & 1.0000 & 0.77617 & 0.00668 & 0.11105 & Biso & 1.000 & Al \\
\hline Al11 & 1.0000 & 0.23184 & 0.22962 & 0.10017 & Biso & 1.000 & Al \\
\hline Al12 & 1.0000 & 0.99947 & 0.77802 & 0.11149 & Biso & 1.000 & Al \\
\hline P12 & 1.0000 & 0.66674 & 0.11018 & 0.23154 & Biso & 1.000 & $\mathrm{P}$ \\
\hline P13 & 1.0000 & 0.90165 & 0.56514 & 0.23385 & Biso & 1.000 & $P$ \\
\hline P 14 & 1.0000 & 0.44176 & 0.34207 & 0.22656 & Biso & 1.000 & $\mathrm{P}$ \\
\hline Al13 & 1.0000 & 0.42524 & 0.35219 & 0.43421 & Biso & 1.000 & Al \\
\hline Al1 14 & 1.0000 & 0.89241 & 0.55903 & 0.44381 & Biso & 1.000 & Al \\
\hline Al15 & 1.0000 & 0.66580 & 0.11274 & 0.43982 & Biso & 1.000 & Al \\
\hline P15 & 1.0000 & 0.33320 & 0.46450 & 0.56075 & Biso & 1.000 & $\mathrm{P}$ \\
\hline P16 & 1.0000 & 0.56195 & 0.89877 & 0.56855 & Biso & 1.000 & $\mathrm{P}$ \\
\hline P17 & 1.0000 & 0.09259 & 0.67256 & 0.57222 & Biso & 1.000 & $\mathrm{P}$ \\
\hline Al16 & 1.0000 & 0.09847 & 0.66913 & 0.77907 & Biso & 1.000 & Al \\
\hline Al17 & 1.0000 & 0.55573 & 0.89303 & 0.77813 & Biso & 1.000 & $\mathrm{Al}$ \\
\hline Al18 & 1.0000 & 0.32594 & 0.43972 & 0.76862 & Biso & 1.000 & Al \\
\hline 01 & 1.0000 & 0.91429 & 0.11007 & 0.13334 & Biso & 1.000 & 0 \\
\hline $\mathrm{O} 2$ & 1.0000 & 0.89497 & 0.81040 & 0.13449 & Biso & 1.000 & 0 \\
\hline 03 & 1.0000 & 0.19913 & 0.09273 & 0.12445 & Biso & 1.000 & 0 \\
\hline 04 & 1.0000 & 0.07981 & 0.88364 & 0.86802 & Biso & 1.000 & 0 \\
\hline 05 & 1.0000 & 0.80482 & 0.91377 & 0.87849 & Biso & 1.000 & 0 \\
\hline 06 & 1.0000 & 0.10096 & 0.19690 & 0.87603 & Biso & 1.000 & 0 \\
\hline 07 & 1.0000 & 0.56379 & 0.44919 & 0.46338 & Biso & 1.000 & 0 \\
\hline 08 & 1.0000 & 0.57068 & 0.15879 & 0.44647 & Biso & 1.000 & 0 \\
\hline 09 & 1.0000 & 0.87185 & 0.42596 & 0.46580 & Biso & 1.000 & 0 \\
\hline 010 & 1.0000 & 0.75846 & 0.23182 & 0.21467 & Biso & 1.000 & 0 \\
\hline 011 & 1.0000 & 0.46166 & 0.24213 & 0.22871 & Biso & 1.000 & 0 \\
\hline 012 & 1.0000 & 0.78028 & 0.53636 & 0.22042 & Biso & 1.000 & 0 \\
\hline 013 & 1.0000 & 0.23243 & 0.76593 & 0.81759 & Biso & 1.000 & 0 \\
\hline 014 & 1.0000 & 0.22142 & 0.47241 & 0.79367 & Biso & 1.000 & 0 \\
\hline 015 & 1.0000 & 0.52652 & 0.75503 & 0.78473 & Biso & 1.000 & 0 \\
\hline 016 & 1.0000 & 0.43470 & 0.58227 & 0.55336 & Biso & 1.000 & 0 \\
\hline 017 & 1.0000 & 0.09845 & 0.56584 & 0.57026 & Biso & 1.000 & 0 \\
\hline 018 & 1.0000 & 0.43685 & 0.84765 & 0.54581 & Biso & 1.000 & 0 \\
\hline 019 & 1.0000 & 0.98906 & 0.31294 & 0.17048 & Biso & 1.000 & 0 \\
\hline 020 & 1.0000 & 0.69290 & 0.67851 & 0.17156 & Biso & 1.000 & 0 \\
\hline 021 & 1.0000 & 0.33507 & 0.02332 & 0.14689 & Biso & 1.000 & 0 \\
\hline $\mathrm{O} 22$ & 1.0000 & 0.31233 & 0.97394 & 0.83022 & Biso & 1.000 & 0 \\
\hline $\mathrm{O} 23$ & 1.0000 & 0.64714 & 0.68251 & 0.84761 & Biso & 1.000 & 0 \\
\hline $\mathrm{O} 24$ & 1.0000 & 0.02189 & 0.34892 & 0.84397 & Biso & 1.000 & 0 \\
\hline 025 & 1.0000 & 0.66118 & 0.65340 & 0.50307 & Biso & 1.000 & 0 \\
\hline 026 & 1.0000 & 0.34696 & 0.99594 & 0.52248 & Biso & 1.000 & 0 \\
\hline 027 & 1.0000 & 0.99788 & 0.34738 & 0.49960 & Biso & 1.000 & 0 \\
\hline 028 & 1.0000 & 0.00075 & 0.67657 & 0.84733 & Biso & 1.000 & 0 \\
\hline 029 & 1.0000 & 0.30095 & 0.32164 & 0.82862 & Biso & 1.000 & 0 \\
\hline 030 & 1.0000 & 0.66967 & 0.98056 & 0.84399 & Biso & 1.000 & 0 \\
\hline 031 & 1.0000 & 0.68202 & 0.03169 & 0.16862 & Biso & 1.000 & 0 \\
\hline 032 & 1.0000 & 0.35139 & 0.32229 & 0.15831 & Biso & 1.000 & 0 \\
\hline 033 & 1.0000 & 0.98039 & 0.66509 & 0.17604 & Biso & 1.000 & 0 \\
\hline 034 & 1.0000 & 0.33726 & 0.38794 & 0.48984 & Biso & 1.000 & 0 \\
\hline 035 & 1.0000 & 0.99585 & 0.65913 & 0.51373 & Biso & 1.000 & 0 \\
\hline 036 & 1.0000 & 0.63324 & 0.99865 & 0.50873 & Biso & 1.000 & 0 \\
\hline 037 & 1.0000 & 0.11970 & 0.24529 & 0.13301 & Biso & 1.000 & 0 \\
\hline 038 & 1.0000 & 0.75941 & 0.87885 & 0.14490 & Biso & 1.000 & 0 \\
\hline 039 & 1.0000 & 0.13079 & 0.88942 & 0.13874 & Biso & 1.000 & 0 \\
\hline 040 & 1.0000 & 0.22953 & 0.12149 & 0.85964 & Biso & 1.000 & 0 \\
\hline 041 & 1.0000 & 0.87505 & 0.75256 & 0.87290 & Biso & 1.000 & 0 \\
\hline 042 & 1.0000 & 0.86921 & 0.11729 & 0.86930 & Biso & 1.000 & 0 \\
\hline 043 & 1.0000 & 0.77095 & 0.56185 & 0.46458 & Biso & 1.000 & 0 \\
\hline 044 & 1.0000 & 0.39334 & 0.22009 & 0.46401 & Biso & 1.000 & 0 \\
\hline 045 & 1.0000 & 0.79857 & 0.21979 & 0.46951 & Biso & 1.000 & 0 \\
\hline 046 & 1.0000 & 0.91345 & 0.46552 & 0.20487 & Biso & 1.000 & 0 \\
\hline 047 & 1.0000 & 0.55394 & 0.10007 & 0.21042 & Biso & 1.000 & 0 \\
\hline 048 & 1.0000 & 0.55008 & 0.44605 & 0.19784 & Biso & 1.000 & 0 \\
\hline 049 & 1.0000 & 0.43964 & 0.89619 & 0.82033 & Biso & 1.000 & 0 \\
\hline 050 & 1.0000 & 0.08224 & 0.53715 & 0.78548 & Biso & 1.000 & 0 \\
\hline 051 & 1.0000 & 0.45493 & 0.55111 & 0.79914 & Biso & 1.000 & 0 \\
\hline 052 & 1.0000 & 0.59677 & 0.81110 & 0.55289 & Biso & 1.000 & 0 \\
\hline 053 & 1.0000 & 0.22938 & 0.47338 & 0.54323 & Biso & 1.000 & 0 \\
\hline 054 & 1.0000 & 0.20159 & 0.76855 & 0.53247 & Biso & 1.000 & 0 \\
\hline 055 & 1.0000 & 0.99796 & 0.25753 & 0.01418 & Biso & 1.000 & 0 \\
\hline 056 & 1.0000 & 0.74422 & 0.75321 & 0.01797 & Biso & 1.000 & 0 \\
\hline 057 & 1.0000 & 0.23968 & 0.99252 & 0.00243 & Biso & 1.000 & 0 \\
\hline 058 & 1.0000 & 0.66309 & 0.59604 & 0.34575 & Biso & 1.000 & 0 \\
\hline
\end{tabular}




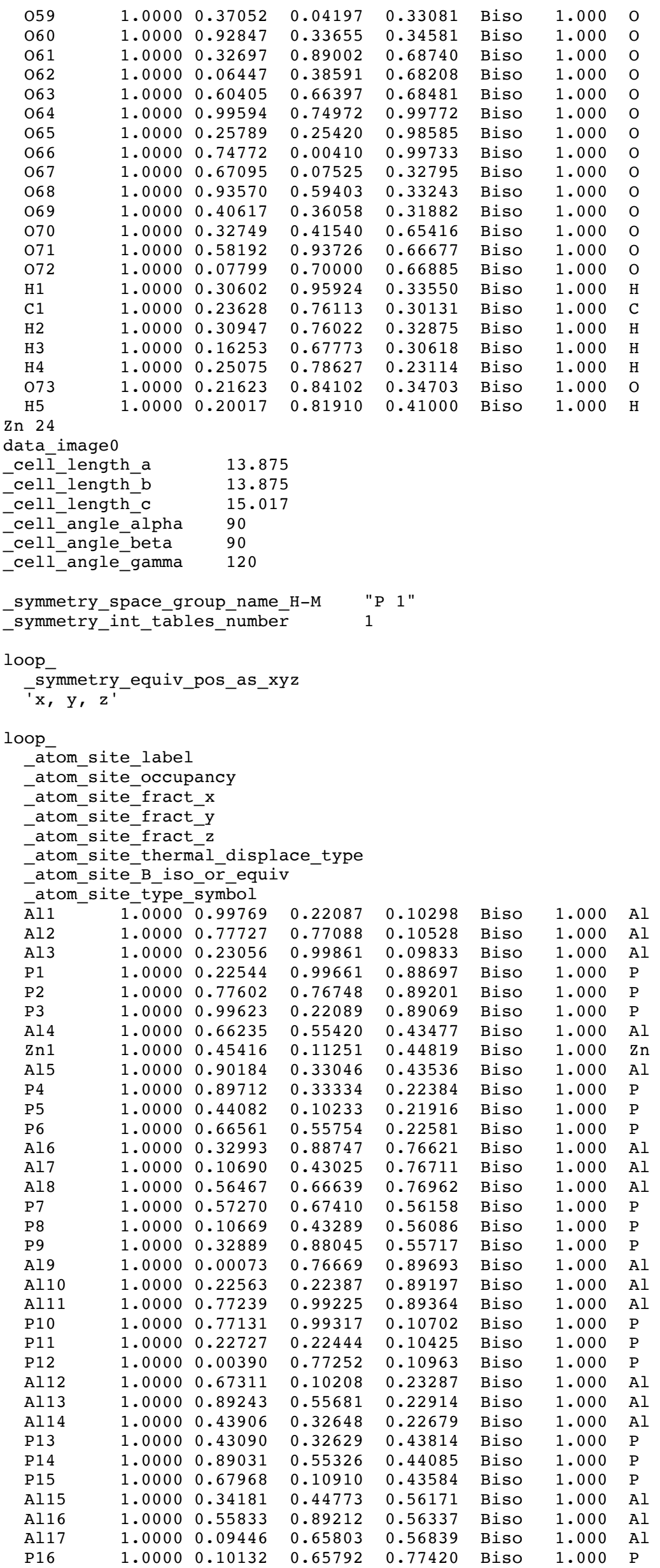




\begin{tabular}{|c|c|c|c|c|c|c|c|}
\hline P 17 & 1.0000 & 0.55775 & 0.89062 & 0.77389 & Biso & 1.000 & P \\
\hline P18 & 1.0000 & 0.33784 & 0.43542 & 0.76952 & Biso & 1.000 & $P$ \\
\hline 01 & 1.0000 & 0.89203 & 0.08480 & 0.12704 & Biso & 1.000 & 0 \\
\hline $\mathrm{O} 2$ & 1.0000 & 0.91512 & 0.80556 & 0.12996 & Biso & 1.000 & 0 \\
\hline 03 & 1.0000 & 0.20002 & 0.10389 & 0.12295 & Biso & 1.000 & 0 \\
\hline 04 & 1.0000 & 0.10427 & 0.90330 & 0.87189 & Biso & 1.000 & 0 \\
\hline 05 & 1.0000 & 0.80624 & 0.88834 & 0.87142 & Biso & 1.000 & 0 \\
\hline 06 & 1.0000 & 0.08871 & 0.19283 & 0.87223 & Biso & 1.000 & 0 \\
\hline 07 & 1.0000 & 0.55443 & 0.41783 & 0.44774 & Biso & 1.000 & 0 \\
\hline 08 & 1.0000 & 0.60775 & 0.16399 & 0.43414 & Biso & 1.000 & 0 \\
\hline 09 & 1.0000 & 0.86902 & 0.43497 & 0.45925 & Biso & 1.000 & 0 \\
\hline 010 & 1.0000 & 0.77554 & 0.24017 & 0.21003 & Biso & 1.000 & 0 \\
\hline 011 & 1.0000 & 0.47444 & 0.22389 & 0.20009 & Biso & 1.000 & 0 \\
\hline 012 & 1.0000 & 0.75540 & 0.52515 & 0.20887 & Biso & 1.000 & 0 \\
\hline 013 & 1.0000 & 0.22344 & 0.75021 & 0.78596 & Biso & 1.000 & 0 \\
\hline 014 & 1.0000 & 0.24528 & 0.46422 & 0.78563 & Biso & 1.000 & 0 \\
\hline 015 & 1.0000 & 0.52853 & 0.76891 & 0.78861 & Biso & 1.000 & 0 \\
\hline 016 & 1.0000 & 0.44882 & 0.58608 & 0.55083 & Biso & 1.000 & 0 \\
\hline 017 & 1.0000 & 0.12086 & 0.54940 & 0.55331 & Biso & 1.000 & 0 \\
\hline 018 & 1.0000 & 0.41588 & 0.84201 & 0.54701 & Biso & 1.000 & 0 \\
\hline 019 & 1.0000 & 0.97662 & 0.31474 & 0.16490 & Biso & 1.000 & 0 \\
\hline $\mathrm{O} 20$ & 1.0000 & 0.68351 & 0.65338 & 0.16463 & Biso & 1.000 & 0 \\
\hline 021 & 1.0000 & 0.35172 & 0.02265 & 0.15381 & Biso & 1.000 & 0 \\
\hline $\mathrm{O} 22$ & 1.0000 & 0.30600 & 0.97911 & 0.82913 & Biso & 1.000 & 0 \\
\hline 023 & 1.0000 & 0.67267 & 0.68497 & 0.83975 & Biso & 1.000 & 0 \\
\hline $\mathrm{O} 24$ & 1.0000 & 0.01533 & 0.32201 & 0.83600 & Biso & 1.000 & 0 \\
\hline $\mathrm{O} 25$ & 1.0000 & 0.64567 & 0.64790 & 0.50108 & Biso & 1.000 & 0 \\
\hline 026 & 1.0000 & 0.34627 & 0.97035 & 0.49131 & Biso & 1.000 & 0 \\
\hline $\mathrm{O} 27$ & 1.0000 & 0.01828 & 0.35278 & 0.49560 & Biso & 1.000 & 0 \\
\hline 028 & 1.0000 & 0.02622 & 0.67131 & 0.84200 & Biso & 1.000 & 0 \\
\hline 029 & 1.0000 & 0.31973 & 0.33802 & 0.82922 & Biso & 1.000 & 0 \\
\hline 030 & 1.0000 & 0.65527 & 0.96891 & 0.83392 & Biso & 1.000 & 0 \\
\hline 031 & 1.0000 & 0.68807 & 0.01289 & 0.15953 & Biso & 1.000 & 0 \\
\hline 032 & 1.0000 & 0.32684 & 0.30624 & 0.16070 & Biso & 1.000 & 0 \\
\hline 033 & 1.0000 & 0.98557 & 0.67431 & 0.16833 & Biso & 1.000 & 0 \\
\hline O34 & 1.0000 & 0.35620 & 0.36356 & 0.48442 & Biso & 1.000 & 0 \\
\hline 035 & 1.0000 & 0.98577 & 0.63941 & 0.49878 & Biso & 1.000 & 0 \\
\hline 036 & 1.0000 & 0.63787 & 0.01129 & 0.50110 & Biso & 1.000 & 0 \\
\hline 037 & 1.0000 & 0.12620 & 0.23481 & 0.13104 & Biso & 1.000 & 0 \\
\hline 038 & 1.0000 & 0.75801 & 0.88112 & 0.13599 & Biso & 1.000 & 0 \\
\hline 039 & 1.0000 & 0.11925 & 0.87107 & 0.13217 & Biso & 1.000 & 0 \\
\hline 040 & 1.0000 & 0.23588 & 0.10828 & 0.86147 & Biso & 1.000 & 0 \\
\hline 041 & 1.0000 & 0.87323 & 0.75113 & 0.86406 & Biso & 1.000 & 0 \\
\hline 042 & 1.0000 & 0.88428 & 0.12111 & 0.86333 & Biso & 1.000 & 0 \\
\hline 043 & 1.0000 & 0.78578 & 0.55845 & 0.46416 & Biso & 1.000 & 0 \\
\hline 044 & 1.0000 & 0.40964 & 0.21765 & 0.47922 & Biso & 1.000 & 0 \\
\hline 045 & 1.0000 & 0.79840 & 0.19705 & 0.46470 & Biso & 1.000 & 0 \\
\hline 046 & 1.0000 & 0.90723 & 0.44458 & 0.19647 & Biso & 1.000 & 0 \\
\hline 047 & 1.0000 & 0.54184 & 0.08755 & 0.21482 & Biso & 1.000 & 0 \\
\hline 048 & 1.0000 & 0.55160 & 0.45720 & 0.20400 & Biso & 1.000 & 0 \\
\hline 049 & 1.0000 & 0.45652 & 0.90110 & 0.79986 & Biso & 1.000 & 0 \\
\hline 050 & 1.0000 & 0.09317 & 0.54535 & 0.79088 & Biso & 1.000 & 0 \\
\hline 051 & 1.0000 & 0.45017 & 0.53669 & 0.79373 & Biso & 1.000 & 0 \\
\hline 052 & 1.0000 & 0.58944 & 0.78818 & 0.53472 & Biso & 1.000 & 0 \\
\hline 053 & 1.0000 & 0.21704 & 0.44098 & 0.53607 & Biso & 1.000 & 0 \\
\hline 054 & 1.0000 & 0.21299 & 0.77978 & 0.53851 & Biso & 1.000 & 0 \\
\hline 055 & 1.0000 & 0.99526 & 0.24813 & 0.98984 & Biso & 1.000 & 0 \\
\hline 056 & 1.0000 & 0.75175 & 0.74303 & 0.99188 & Biso & 1.000 & 0 \\
\hline 057 & 1.0000 & 0.25726 & 0.99765 & 0.98528 & Biso & 1.000 & 0 \\
\hline 058 & 1.0000 & 0.67033 & 0.59478 & 0.32297 & Biso & 1.000 & 0 \\
\hline 059 & 1.0000 & 0.38884 & 0.06904 & 0.31556 & Biso & 1.000 & 0 \\
\hline 060 & 1.0000 & 0.93187 & 0.33709 & 0.32144 & Biso & 1.000 & 0 \\
\hline 061 & 1.0000 & 0.33344 & 0.92106 & 0.65402 & Biso & 1.000 & 0 \\
\hline 062 & 1.0000 & 0.07156 & 0.38785 & 0.65627 & Biso & 1.000 & 0 \\
\hline 063 & 1.0000 & 0.60876 & 0.67548 & 0.65894 & Biso & 1.000 & 0 \\
\hline 064 & 1.0000 & 0.99853 & 0.74018 & 0.01123 & Biso & 1.000 & 0 \\
\hline 065 & 1.0000 & 0.25596 & 0.25324 & 0.00541 & Biso & 1.000 & 0 \\
\hline 066 & 1.0000 & 0.74556 & 0.99171 & 0.00744 & Biso & 1.000 & 0 \\
\hline 067 & 1.0000 & 0.68473 & 0.06498 & 0.34177 & Biso & 1.000 & 0 \\
\hline 068 & 1.0000 & 0.92294 & 0.58538 & 0.34250 & Biso & 1.000 & 0 \\
\hline 069 & 1.0000 & 0.39916 & 0.31185 & 0.33792 & Biso & 1.000 & 0 \\
\hline 070 & 1.0000 & 0.33805 & 0.40243 & 0.67158 & Biso & 1.000 & 0 \\
\hline 071 & 1.0000 & 0.59081 & 0.92520 & 0.67642 & Biso & 1.000 & 0 \\
\hline 072 & 1.0000 & 0.05967 & 0.66260 & 0.67995 & Biso & 1.000 & 0 \\
\hline $\mathrm{H} 1$ & 1.0000 & 0.29736 & 0.03110 & 0.32008 & Biso & 1.000 & $\mathrm{H}$ \\
\hline $\mathrm{C} 1$ & 1.0000 & 0.12539 & 0.87328 & 0.35303 & Biso & 1.000 & C \\
\hline H2 & 1.0000 & 0.13427 & 0.86896 & 0.42537 & Biso & 1.000 & $\mathrm{H}$ \\
\hline H3 & 1.0000 & 0.03754 & 0.83805 & 0.33431 & Biso & 1.000 & $\mathrm{H}$ \\
\hline H4 & 1.0000 & 0.16063 & 0.82844 & 0.31848 & Biso & 1.000 & $\mathrm{H}$ \\
\hline 073 & 1.0000 & 0.18684 & 0.98765 & 0.32310 & & 1.000 & 0 \\
\hline
\end{tabular}




\begin{tabular}{|c|c|c|c|c|c|c|c|}
\hline $\mathrm{C} 2$ & 1.0000 & 0.14991 & 0.05790 & 0.36407 & Biso & 1.000 & C \\
\hline H5 & 1.0000 & 0.20224 & 0.14197 & 0.33749 & Biso & 1.000 & $\mathrm{H}$ \\
\hline H6 & 1.0000 & 0.06242 & 0.02661 & 0.34594 & Biso & 1.000 & $\mathrm{H}$ \\
\hline H7 & 1.0000 & 0.15959 & 0.05863 & 0.43688 & Biso & 1.000 & $\mathrm{H}$ \\
\hline \multicolumn{8}{|c|}{$\begin{array}{l}\text { Si } 24 \\
\text { data image } 0\end{array}$} \\
\hline \multicolumn{2}{|c|}{ _celī_length_a } & & & & & \\
\hline cell_ & th_b & \multicolumn{2}{|c|}{$\begin{array}{l}13.875 \\
13.875\end{array}$} & & & & \\
\hline -cell_ & th_c & \multicolumn{2}{|c|}{$\begin{array}{l}13.875 \\
15.017\end{array}$} & & & & \\
\hline -cell__ & e_talpha & \multicolumn{2}{|c|}{90} & & & & \\
\hline _cell_e & e_beta & \multicolumn{2}{|l|}{90} & & & & \\
\hline _cell_e & e_gamma & \multicolumn{2}{|l|}{120} & & & & \\
\hline \multicolumn{4}{|c|}{ _symmetry_space_group_name_H-M } & P $1 "$ & & & \\
\hline \multicolumn{4}{|c|}{ _symmetry_int_tābles_number } & & & & \\
\hline \multicolumn{8}{|c|}{ loop_ } \\
\hline$T^{\text {symn }}$ & Y_equiv & pos_as_x & & & & & \\
\hline loop_ & & & & & & & \\
\hline $\begin{array}{l}\text {-ator } \\
\text {-ator } \\
\text {-ator } \\
\text {-ator } \\
\text {-ator } \\
\text {-ator } \\
\text {-ator } \\
\text {-ator }\end{array}$ & $\begin{array}{l}\text { te_labe } \\
\text { te_occur } \\
\text { te_fract } \\
\text { te_frac } \\
\text { te_frac } \\
\text { te_ther } \\
\text { te_B_is } \\
\text { te_type }\end{array}$ & $\begin{array}{l}\text { oncy } \\
\text { oancy } \\
t \text { _x } \\
\text { _y } \\
\text { nal_displ } \\
\text { o_or_equi } \\
\text { symbol }\end{array}$ & ce_type & & & & \\
\hline$\overline{\mathrm{P}} 1$ & 1.0000 & 0.00684 & 0.22345 & 0.10817 & Biso & 1.000 & $\mathrm{P}$ \\
\hline $\mathrm{P} 2$ & 1.0000 & 0.77755 & 0.77320 & 0.10872 & Biso & 1.000 & $\mathrm{P}$ \\
\hline P3 & 1.0000 & 0.22914 & 0.99247 & 0.10322 & Biso & 1.000 & $\mathrm{P}$ \\
\hline Al1 & 1.0000 & 0.22538 & 0.99029 & 0.89087 & Biso & 1.000 & Al \\
\hline Al2 & 1.0000 & 0.77425 & 0.76995 & 0.89537 & Biso & 1.000 & Al \\
\hline Al3 & 1.0000 & 0.00432 & 0.22370 & 0.89597 & Biso & 1.000 & Al \\
\hline $\mathrm{P} 4$ & 1.0000 & 0.67316 & 0.56061 & 0.43859 & Biso & 1.000 & $\mathrm{P}$ \\
\hline Sil & 1.0000 & 0.43609 & 0.10400 & 0.44089 & Biso & 1.000 & $\mathrm{Si}$ \\
\hline P5 & 1.0000 & 0.89467 & 0.32261 & 0.44025 & Biso & 1.000 & $\mathrm{P}$ \\
\hline Al4 & 1.0000 & 0.89536 & 0.32549 & 0.22867 & Biso & 1.000 & Al \\
\hline Al5 & 1.0000 & 0.44083 & 0.10385 & 0.22634 & Biso & 1.000 & Al \\
\hline Al6 & 1.0000 & 0.67446 & 0.55988 & 0.22952 & Biso & 1.000 & Al \\
\hline $\mathrm{P} 6$ & 1.0000 & 0.33714 & 0.88667 & 0.77510 & Biso & 1.000 & $\mathrm{P}$ \\
\hline P7 & 1.0000 & 0.10508 & 0.43308 & 0.77195 & Biso & 1.000 & $\mathrm{P}$ \\
\hline P8 & 1.0000 & 0.56185 & 0.65812 & 0.77346 & Biso & 1.000 & $\mathrm{P}$ \\
\hline Al7 & 1.0000 & 0.56845 & 0.66333 & 0.56470 & Biso & 1.000 & $\mathrm{Al}$ \\
\hline Al8 & 1.0000 & 0.10223 & 0.43222 & 0.56419 & Biso & 1.000 & Al \\
\hline Al9 & 1.0000 & 0.33767 & 0.88507 & 0.56264 & Biso & 1.000 & Al \\
\hline P9 & 1.0000 & 0.99705 & 0.76397 & 0.89105 & Biso & 1.000 & $\mathrm{P}$ \\
\hline $\mathrm{P} 10$ & 1.0000 & 0.22996 & 0.21971 & 0.88830 & Biso & 1.000 & $\mathrm{P}$ \\
\hline P11 & 1.0000 & 0.77845 & 0.99787 & 0.89033 & Biso & 1.000 & $\mathrm{P}$ \\
\hline Al10 & 1.0000 & 0.77814 & 0.99872 & 0.10319 & Biso & 1.000 & Al \\
\hline Al11 & 1.0000 & 0.23333 & 0.22180 & 0.09953 & Biso & 1.000 & Al \\
\hline Al12 & 1.0000 & 0.00184 & 0.76844 & 0.10398 & Biso & 1.000 & Al \\
\hline $\mathrm{P} 12$ & 1.0000 & 0.67011 & 0.09927 & 0.22601 & Biso & 1.000 & $\mathrm{P}$ \\
\hline P13 & 1.0000 & 0.90015 & 0.55519 & 0.22594 & Biso & 1.000 & $\mathrm{P}$ \\
\hline P14 & 1.0000 & 0.44544 & 0.33289 & 0.22378 & Biso & 1.000 & $\mathrm{P}$ \\
\hline Al13 & 1.0000 & 0.43968 & 0.33336 & 0.43469 & Biso & 1.000 & Al \\
\hline Al14 & 1.0000 & 0.89749 & 0.55300 & 0.43678 & Biso & 1.000 & Al \\
\hline Al15 & 1.0000 & 0.66568 & 0.09958 & 0.43057 & Biso & 1.000 & Al \\
\hline P15 & 1.0000 & 0.33439 & 0.44059 & 0.55650 & Biso & 1.000 & $\mathrm{P}$ \\
\hline P16 & 1.0000 & 0.56477 & 0.88858 & 0.56049 & Biso & 1.000 & $P$ \\
\hline P17 & 1.0000 & 0.10478 & 0.66535 & 0.56086 & Biso & 1.000 & $\mathrm{P}$ \\
\hline Al16 & 1.0000 & 0.10776 & 0.66444 & 0.76997 & Biso & 1.000 & Al \\
\hline Al17 & 1.0000 & 0.56454 & 0.88857 & 0.76939 & Biso & 1.000 & Al \\
\hline Al18 & 1.0000 & 0.33230 & 0.43247 & 0.76618 & Biso & 1.000 & Al \\
\hline 01 & 1.0000 & 0.91542 & 0.10239 & 0.12738 & Biso & 1.000 & 0 \\
\hline $\mathrm{O} 2$ & 1.0000 & 0.89876 & 0.80289 & 0.12783 & Biso & 1.000 & 0 \\
\hline 03 & 1.0000 & 0.19942 & 0.08397 & 0.12134 & Biso & 1.000 & 0 \\
\hline 04 & 1.0000 & 0.08861 & 0.88414 & 0.86964 & Biso & 1.000 & 0 \\
\hline 05 & 1.0000 & 0.80896 & 0.90721 & 0.87074 & Biso & 1.000 & 0 \\
\hline 06 & 1.0000 & 0.10852 & 0.19092 & 0.87367 & Biso & 1.000 & 0 \\
\hline 07 & 1.0000 & 0.57672 & 0.44146 & 0.45178 & Biso & 1.000 & 0 \\
\hline 08 & 1.0000 & 0.56297 & 0.13440 & 0.42771 & Biso & 1.000 & 0 \\
\hline 09 & 1.0000 & 0.87013 & 0.41780 & 0.45808 & Biso & 1.000 & 0 \\
\hline 010 & 1.0000 & 0.75745 & 0.22195 & 0.20649 & Biso & 1.000 & 0 \\
\hline 011 & 1.0000 & 0.47859 & 0.24296 & 0.20888 & Biso & 1.000 & 0 \\
\hline 012 & 1.0000 & 0.77872 & 0.52591 & 0.21034 & Biso & 1.000 & 0 \\
\hline 013 & 1.0000 & 0.24450 & 0.76655 & 0.79587 & Biso & 1.000 & 0 \\
\hline 014 & 1.0000 & 0.22732 & 0.46488 & 0.78738 & Biso & 1.000 & 0 \\
\hline 015 & 1.0000 & 0.53189 & 0.75031 & 0.78529 & Biso & 1.000 & 0 \\
\hline
\end{tabular}




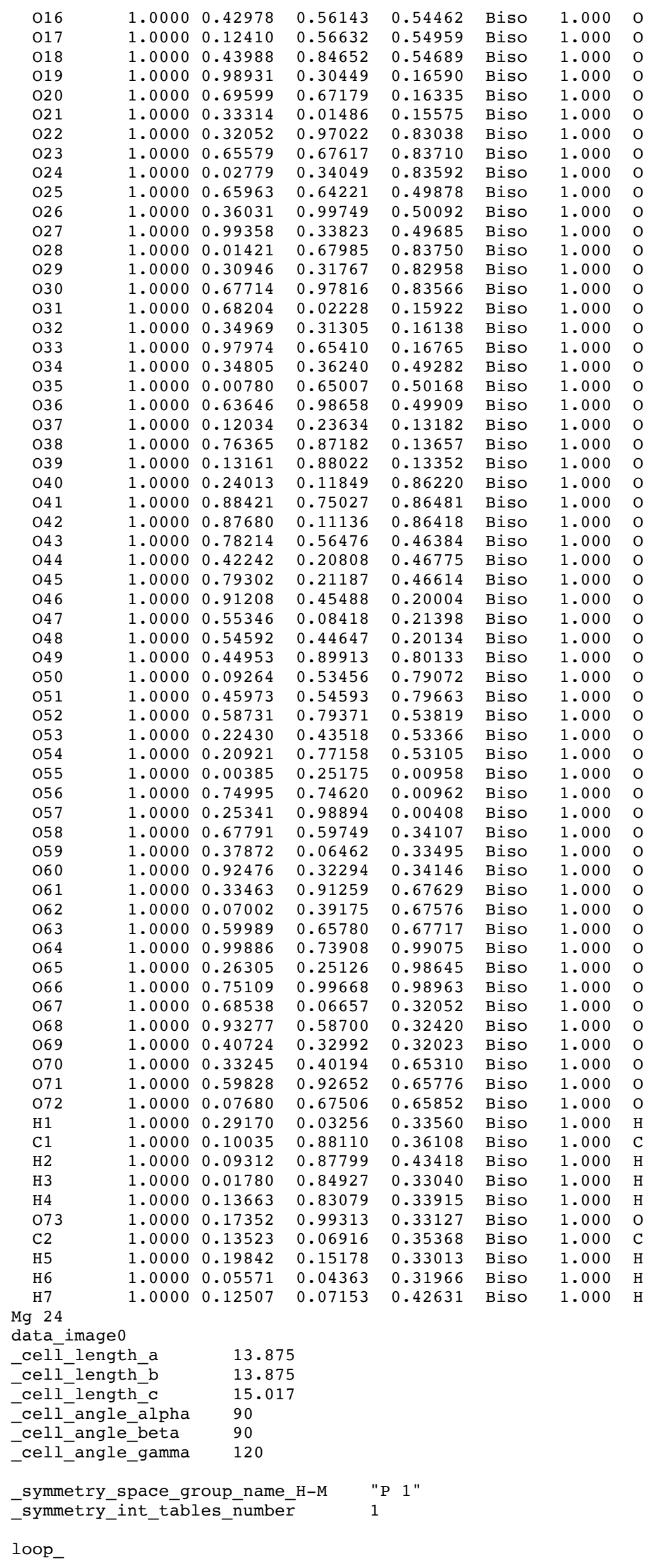




\begin{tabular}{|c|c|c|c|c|c|c|c|}
\hline \multicolumn{8}{|c|}{$\begin{array}{l}\text { 'symmetry_equiv_pos_as_xyz } \\
\text { x, y, z' } \\
\text {-atom_site_label } \\
\text { _atom_site_occupancy } \\
\text {-atom_site_fract_x } \\
\text {-atom_site_fract_y } \\
\text {-atom_site_fract_z } \\
\text {-atom_site_thermal_displace_type } \\
\text {-atom_site_B_iso_or_equiv } \\
\text {-atom_site_type_symbol }\end{array}$} \\
\hline $\bar{A} 11$ & 1.0000 & 0.99850 & 0.22162 & 0.10308 & Biso & 1.000 & Al \\
\hline Al2 & 1.0000 & 0.77959 & 0.77342 & 0.10617 & Biso & 1.000 & Al \\
\hline Al3 & 1.0000 & 0.23239 & 0.00039 & 0.09735 & Biso & 1.000 & Al \\
\hline P1 & 1.0000 & 0.22481 & 0.99540 & 0.88617 & Biso & 1.000 & $\mathrm{P}$ \\
\hline P2 & 1.0000 & 0.77626 & 0.76791 & 0.89264 & Biso & 1.000 & $\mathrm{P}$ \\
\hline P3 & 1.0000 & 0.99482 & 0.22005 & 0.89004 & Biso & 1.000 & $\mathrm{P}$ \\
\hline Al4 & 1.0000 & 0.66259 & 0.55564 & 0.43487 & Biso & 1.000 & Al \\
\hline Mg 1 & 1.0000 & 0.44805 & 0.10867 & 0.44351 & Biso & 1.000 & $\mathrm{Mg}$ \\
\hline Al5 & 1.0000 & 0.90325 & 0.32994 & 0.43528 & Biso & 1.000 & Al \\
\hline P 4 & 1.0000 & 0.89870 & 0.33457 & 0.22364 & Biso & 1.000 & $\mathrm{P}$ \\
\hline P5 & 1.0000 & 0.44169 & 0.10405 & 0.22022 & Biso & 1.000 & $\mathrm{P}$ \\
\hline P6 & 1.0000 & 0.66755 & 0.55899 & 0.22560 & Biso & 1.000 & $P$ \\
\hline Al6 & 1.0000 & 0.32720 & 0.88167 & 0.76941 & Biso & 1.000 & Al \\
\hline Al 7 & 1.0000 & 0.10513 & 0.42829 & 0.76622 & Biso & 1.000 & Al \\
\hline Al8 & 1.0000 & 0.56420 & 0.66458 & 0.77017 & Biso & 1.000 & Al \\
\hline P7 & 1.0000 & 0.57559 & 0.67326 & 0.56244 & Biso & 1.000 & $\mathrm{P}$ \\
\hline P8 & 1.0000 & 0.10542 & 0.43145 & 0.56196 & Biso & 1.000 & $P$ \\
\hline P9 & 1.0000 & 0.32826 & 0.87569 & 0.55783 & Biso & 1.000 & $\mathrm{P}$ \\
\hline Al9 & 1.0000 & 0.99944 & 0.76424 & 0.89787 & Biso & 1.000 & Al \\
\hline Al10 & 1.0000 & 0.22344 & 0.22195 & 0.88961 & Biso & 1.000 & Al \\
\hline Al11 & 1.0000 & 0.77262 & 0.99170 & 0.89378 & Biso & 1.000 & Al \\
\hline P10 & 1.0000 & 0.77250 & 0.99442 & 0.10790 & Biso & 1.000 & $\mathrm{P}$ \\
\hline P11 & 1.0000 & 0.22767 & 0.22497 & 0.10248 & Biso & 1.000 & $P$ \\
\hline P12 & 1.0000 & 0.00551 & 0.77385 & 0.11026 & Biso & 1.000 & $\mathrm{P}$ \\
\hline Al12 & 1.0000 & 0.67491 & 0.10404 & 0.23268 & Biso & 1.000 & Al \\
\hline Al13 & 1.0000 & 0.89440 & 0.55865 & 0.23051 & Biso & 1.000 & Al \\
\hline Al1 14 & 1.0000 & 0.43917 & 0.32997 & 0.22608 & Biso & 1.000 & Al \\
\hline P13 & 1.0000 & 0.42729 & 0.32904 & 0.43645 & Biso & 1.000 & $\mathrm{P}$ \\
\hline P14 & 1.0000 & 0.89028 & 0.55286 & 0.44183 & Biso & 1.000 & $P$ \\
\hline P15 & 1.0000 & 0.68042 & 0.10681 & 0.43589 & Biso & 1.000 & $\mathrm{P}$ \\
\hline Al15 & 1.0000 & 0.34148 & 0.44985 & 0.56086 & Biso & 1.000 & Al \\
\hline Al16 & 1.0000 & 0.56087 & 0.89303 & 0.56476 & Biso & 1.000 & Al \\
\hline Al17 & 1.0000 & 0.09369 & 0.65923 & 0.56924 & Biso & 1.000 & Al \\
\hline P16 & 1.0000 & 0.10011 & 0.65757 & 0.77522 & Biso & 1.000 & $\mathrm{P}$ \\
\hline P17 & 1.0000 & 0.55741 & 0.89056 & 0.77409 & Biso & 1.000 & $P$ \\
\hline P18 & 1.0000 & 0.33642 & 0.43644 & 0.77021 & Biso & 1.000 & $P$ \\
\hline 01 & 1.0000 & 0.89272 & 0.08633 & 0.12910 & Biso & 1.000 & 0 \\
\hline $\mathrm{O} 2$ & 1.0000 & 0.91776 & 0.80841 & 0.13039 & Biso & 1.000 & 0 \\
\hline 03 & 1.0000 & 0.20084 & 0.10481 & 0.12268 & Biso & 1.000 & 0 \\
\hline $\mathrm{O} 4$ & 1.0000 & 0.10393 & 0.90053 & 0.87302 & Biso & 1.000 & 0 \\
\hline 05 & 1.0000 & 0.80746 & 0.88871 & 0.87059 & Biso & 1.000 & 0 \\
\hline 06 & 1.0000 & 0.08673 & 0.19165 & 0.87000 & Biso & 1.000 & 0 \\
\hline 07 & 1.0000 & 0.54915 & 0.42314 & 0.44927 & Biso & 1.000 & 0 \\
\hline 08 & 1.0000 & 0.60039 & 0.15146 & 0.43583 & Biso & 1.000 & 0 \\
\hline 09 & 1.0000 & 0.87236 & 0.43575 & 0.45922 & Biso & 1.000 & 0 \\
\hline 010 & 1.0000 & 0.77694 & 0.24216 & 0.20881 & Biso & 1.000 & 0 \\
\hline 011 & 1.0000 & 0.47454 & 0.22595 & 0.20454 & Biso & 1.000 & 0 \\
\hline 012 & 1.0000 & 0.75745 & 0.52660 & 0.20918 & Biso & 1.000 & 0 \\
\hline 013 & 1.0000 & 0.22197 & 0.74558 & 0.79541 & Biso & 1.000 & 0 \\
\hline 014 & 1.0000 & 0.24382 & 0.46496 & 0.78768 & Biso & 1.000 & 0 \\
\hline 015 & 1.0000 & 0.52920 & 0.76859 & 0.78413 & Biso & 1.000 & 0 \\
\hline 016 & 1.0000 & 0.45286 & 0.58516 & 0.54620 & Biso & 1.000 & 0 \\
\hline 017 & 1.0000 & 0.10958 & 0.54365 & 0.55981 & Biso & 1.000 & 0 \\
\hline 018 & 1.0000 & 0.41826 & 0.84121 & 0.54725 & Biso & 1.000 & 0 \\
\hline 019 & 1.0000 & 0.97822 & 0.31680 & 0.16396 & Biso & 1.000 & 0 \\
\hline $\mathrm{O} 20$ & 1.0000 & 0.68623 & 0.65543 & 0.16495 & Biso & 1.000 & 0 \\
\hline 021 & 1.0000 & 0.35409 & 0.02625 & 0.15317 & Biso & 1.000 & 0 \\
\hline $\mathrm{O} 22$ & 1.0000 & 0.30500 & 0.97759 & 0.82810 & Biso & 1.000 & 0 \\
\hline $\mathrm{O} 23$ & 1.0000 & 0.67177 & 0.68515 & 0.84166 & Biso & 1.000 & 0 \\
\hline $\mathrm{O} 24$ & 1.0000 & 0.01404 & 0.32232 & 0.83697 & Biso & 1.000 & 0 \\
\hline 025 & 1.0000 & 0.65251 & 0.65301 & 0.50156 & Biso & 1.000 & 0 \\
\hline 026 & 1.0000 & 0.34962 & 0.97179 & 0.49819 & Biso & 1.000 & 0 \\
\hline $\mathrm{O} 27$ & 1.0000 & 0.02017 & 0.35109 & 0.49476 & Biso & 1.000 & 0 \\
\hline 028 & 1.0000 & 0.02188 & 0.66680 & 0.84259 & Biso & 1.000 & 0 \\
\hline 029 & 1.0000 & 0.31731 & 0.33653 & 0.82719 & Biso & 1.000 & 0 \\
\hline 030 & 1.0000 & 0.65371 & 0.96635 & 0.83604 & Biso & 1.000 & 0 \\
\hline 031 & 1.0000 & 0.68808 & 0.01439 & 0.15844 & Biso & 1.000 & 0 \\
\hline 032 & 1.0000 & 0.32912 & 0.30805 & 0.15656 & Biso & 1.000 & \\
\hline
\end{tabular}




\begin{tabular}{|c|c|c|c|c|c|c|}
\hline 033 & 1.0000 & 0.98768 & 0.67712 & 0.17063 & Biso & 1.000 \\
\hline 034 & 1.0000 & 0.34860 & 0.35851 & 0.48636 & Biso & 1.000 \\
\hline 035 & 1.0000 & 0.98309 & 0.64000 & 0.50137 & Biso & 1.000 \\
\hline 036 & 1.0000 & 0.64467 & 0.00780 & 0.49939 & Biso & 1.000 \\
\hline 037 & 1.0000 & 0.12740 & 0.23599 & 0.13074 & Biso & 1.000 \\
\hline 038 & 1.0000 & 0.75923 & 0.88270 & 0.13801 & Biso & 1.000 \\
\hline 039 & 1.0000 & 0.12166 & 0.87232 & 0.13097 & Biso & 1.000 \\
\hline 040 & 1.0000 & 0.23319 & 0.10588 & 0.85938 & Biso & 1.000 \\
\hline 041 & 1.0000 & 0.87241 & 0.74982 & 0.86484 & Biso & 1.000 \\
\hline 042 & 1.0000 & 0.88253 & 0.12112 & 0.86222 & Biso & 1.000 \\
\hline 043 & 1.0000 & 0.78285 & 0.55309 & 0.46372 & Biso & 1.000 \\
\hline 044 & 1.0000 & 0.41172 & 0.21985 & 0.47005 & Biso & 1.000 \\
\hline 045 & 1.0000 & 0.79728 & 0.19860 & 0.46560 & Biso & 1.000 \\
\hline 046 & 1.0000 & 0.90982 & 0.44676 & 0.19800 & Biso & 1.000 \\
\hline 047 & 1.0000 & 0.54335 & 0.09031 & 0.21618 & Biso & 1.000 \\
\hline 048 & 1.0000 & 0.55386 & 0.45897 & 0.20251 & Biso & 1.000 \\
\hline 049 & 1.0000 & 0.45531 & 0.89850 & 0.80203 & Biso & 1.000 \\
\hline 050 & 1.0000 & 0.08691 & 0.54184 & 0.78416 & Biso & 1.000 \\
\hline 051 & 1.0000 & 0.44851 & 0.53657 & 0.79680 & Biso & 1.000 \\
\hline 052 & 1.0000 & 0.59243 & 0.78849 & 0.54086 & Biso & 1.000 \\
\hline 053 & 1.0000 & 0.22001 & 0.45068 & 0.53586 & Biso & 1.000 \\
\hline 054 & 1.0000 & 0.21480 & 0.77447 & 0.53234 & Biso & 1.000 \\
\hline 055 & 1.0000 & 0.99446 & 0.24568 & 0.98959 & Biso & 1.000 \\
\hline 056 & 1.0000 & 0.75328 & 0.74584 & 0.99285 & Biso & 1.000 \\
\hline 057 & 1.0000 & 0.25884 & 0.99957 & 0.98433 & Biso & 1.000 \\
\hline 058 & 1.0000 & 0.67136 & 0.59545 & 0.32285 & Biso & 1.000 \\
\hline 059 & 1.0000 & 0.38751 & 0.06716 & 0.31589 & Biso & 1.000 \\
\hline 060 & 1.0000 & 0.93267 & 0.33587 & 0.32118 & Biso & 1.000 \\
\hline 061 & 1.0000 & 0.32475 & 0.90635 & 0.65640 & Biso & 1.000 \\
\hline 062 & 1.0000 & 0.07273 & 0.38068 & 0.65607 & Biso & 1.000 \\
\hline 063 & 1.0000 & 0.60715 & 0.66737 & 0.65999 & Biso & 1.000 \\
\hline 064 & 1.0000 & 0.99783 & 0.73858 & 0.01240 & Biso & 1.000 \\
\hline 065 & 1.0000 & 0.25345 & 0.25121 & 0.00309 & Biso & 1.000 \\
\hline 066 & 1.0000 & 0.74858 & 0.99210 & 0.00793 & Biso & 1.000 \\
\hline 067 & 1.0000 & 0.68949 & 0.06727 & 0.34075 & Biso & 1.000 \\
\hline 068 & 1.0000 & 0.92448 & 0.58736 & 0.34398 & Biso & 1.000 \\
\hline 069 & 1.0000 & 0.39657 & 0.32151 & 0.33601 & Biso & 1.000 \\
\hline 070 & 1.0000 & 0.33785 & 0.40718 & 0.67151 & Biso & 1.000 \\
\hline 071 & 1.0000 & 0.59110 & 0.93048 & 0.67765 & Biso & 1.000 \\
\hline 072 & 1.0000 & 0.06710 & 0.67493 & 0.68099 & Biso & 1.000 \\
\hline $\mathrm{H} 1$ & 1.0000 & 0.29405 & 0.02931 & 0.31861 & Biso & 1.000 \\
\hline $\mathrm{C} 1$ & 1.0000 & 0.12567 & 0.87363 & 0.35348 & Biso & 1.000 \\
\hline H2 & 1.0000 & 0.13637 & 0.87142 & 0.42577 & Biso & 1.000 \\
\hline $\mathrm{H} 3$ & 1.0000 & 0.03749 & 0.83814 & 0.33596 & Biso & 1.000 \\
\hline $\mathrm{H} 4$ & 1.0000 & 0.16003 & 0.82786 & 0.31917 & Biso & 1.000 \\
\hline 073 & 1.0000 & 0.18652 & 0.98731 & 0.32137 & Biso & 1.000 \\
\hline $\mathrm{C} 2$ & 1.0000 & 0.14938 & 0.05880 & 0.36004 & Biso & 1.000 \\
\hline H5 & 1.0000 & 0.20250 & 0.14234 & 0.33279 & Biso & 1.000 \\
\hline H6 & 1.0000 & 0.06237 & 0.02742 & 0.34044 & Biso & 1.000 \\
\hline H 7 & 1.0000 & 0.15767 & 0.06061 & 0.43300 & Biso & 1.000 \\
\hline
\end{tabular}

data_image 0

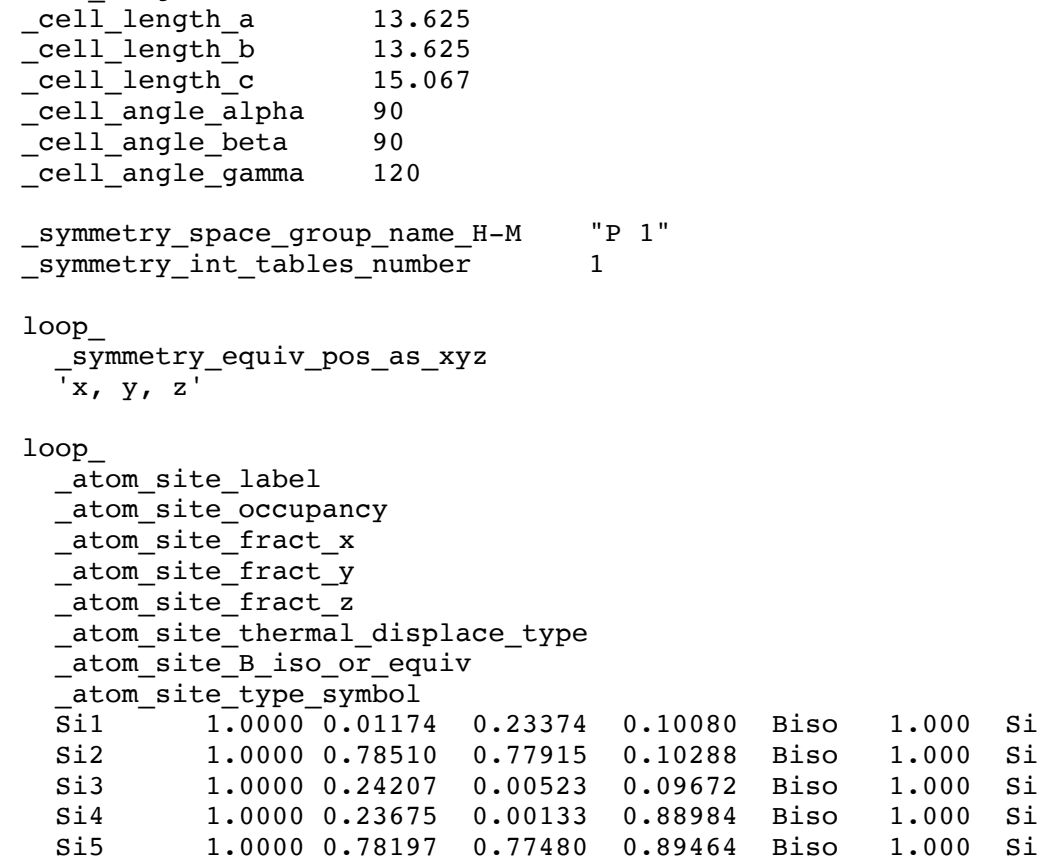




\begin{tabular}{|c|c|c|c|c|c|c|c|}
\hline Si6 & 1.0000 & 0.00890 & 0.23284 & 0.89396 & Biso & 1.000 & $\mathrm{Si}$ \\
\hline Si7 & 1.0000 & 0.67753 & 0.56937 & 0.43267 & Biso & 1.000 & $\mathrm{Si}$ \\
\hline Al1 & 1.0000 & 0.44899 & 0.11218 & 0.43779 & Biso & 1.000 & Al \\
\hline Si8 & 1.0000 & 0.91061 & 0.33473 & 0.43379 & Biso & 1.000 & $\mathrm{Si}$ \\
\hline Si9 & 1.0000 & 0.90818 & 0.33833 & 0.22711 & Biso & 1.000 & $\mathrm{Si}$ \\
\hline Silo & 1.0000 & 0.44900 & 0.11108 & 0.22352 & Biso & 1.000 & \\
\hline Si11 & 1.0000 & 0.68010 & 0.57014 & 0.22890 & Biso & 1.000 & $\mathrm{Si}$ \\
\hline Sil2 & 1.0000 & 0.34152 & 0.89458 & 0.76837 & Biso & 1.000 & $\mathrm{Si}$ \\
\hline Si13 & 1.0000 & 0.11202 & 0.43669 & 0.76462 & Biso & 1.000 & $\mathrm{Si}$ \\
\hline Si14 & 1.0000 & 0.57466 & 0.66919 & 0.76728 & Biso & 1.000 & $\mathrm{Si}$ \\
\hline Si15 & 1.0000 & 0.58341 & 0.67613 & 0.56399 & Biso & 1.000 & $\mathrm{Si}$ \\
\hline Si16 & 1.0000 & 0.11114 & 0.43829 & 0.56322 & Biso & 1.000 & $\mathrm{Si}$ \\
\hline $\operatorname{Sil} 17$ & 1.0000 & 0.34237 & 0.89188 & 0.56095 & Biso & 1.000 & $\mathrm{Si}$ \\
\hline Si18 & 1.0000 & 0.00782 & 0.77036 & 0.89559 & Biso & 1.000 & $\mathrm{Si}$ \\
\hline Si19 & 1.0000 & 0.23835 & 0.23164 & 0.89024 & Biso & 1.000 & $\mathrm{Si}$ \\
\hline Si20 & 1.0000 & 0.78204 & 0.00287 & 0.89290 & Biso & 1.000 & $\mathrm{Si}$ \\
\hline Si21 & 1.0000 & 0.78200 & 0.00488 & 0.10106 & Biso & 1.000 & $\mathrm{Si}$ \\
\hline $\mathrm{Si} 22$ & 1.0000 & 0.24217 & 0.23457 & 0.09693 & Biso & 1.000 & $\mathrm{Si}$ \\
\hline Si23 & 1.0000 & 0.01274 & 0.77750 & 0.10320 & Biso & 1.000 & $\mathrm{Si}$ \\
\hline Si24 & 1.0000 & 0.68146 & 0.10787 & 0.23027 & Biso & 1.000 & $\mathrm{Si}$ \\
\hline Si25 & 1.0000 & 0.90800 & 0.56714 & 0.22930 & Biso & 1.000 & $\mathrm{Si}$ \\
\hline Si26 & 1.0000 & 0.44915 & 0.33958 & 0.22584 & Biso & 1.000 & $\mathrm{Si}$ \\
\hline Si27 & 1.0000 & 0.44121 & 0.33943 & 0.43178 & Biso & 1.000 & $\mathrm{Si}$ \\
\hline Si28 & 1.0000 & 0.90539 & 0.56336 & 0.43559 & Biso & 1.000 & $\mathrm{Si}$ \\
\hline Si29 & 1.0000 & 0.68149 & 0.10887 & 0.43004 & Biso & 1.000 & $\mathrm{Si}$ \\
\hline $\mathrm{Si} 30$ & 1.0000 & 0.34721 & 0.45069 & 0.55908 & Biso & 1.000 & $\mathrm{Si}$ \\
\hline Si31 & 1.0000 & 0.57374 & 0.90108 & 0.56306 & Biso & 1.000 & $\mathrm{Si}$ \\
\hline Si32 & 1.0000 & 0.10620 & 0.67050 & 0.56558 & Biso & 1.000 & $\mathrm{Si}$ \\
\hline Si33 & 1.0000 & 0.11035 & 0.66878 & 0.76831 & Biso & 1.000 & $\mathrm{Si}$ \\
\hline Si34 & 1.0000 & 0.57213 & 0.89958 & 0.76745 & Biso & 1.000 & $\mathrm{Si}$ \\
\hline Si35 & 1.0000 & 0.34330 & 0.44034 & 0.76369 & Biso & 1.000 & $\mathrm{Si}$ \\
\hline 01 & 1.0000 & 0.91287 & 0.10328 & 0.11936 & Biso & 1.000 & 0 \\
\hline $\mathrm{O} 2$ & 1.0000 & 0.91670 & 0.81335 & 0.12113 & Biso & 1.000 & 0 \\
\hline 03 & 1.0000 & 0.21001 & 0.10367 & 0.11519 & Biso & 1.000 & 0 \\
\hline 04 & 1.0000 & 0.10636 & 0.90030 & 0.87522 & Biso & 1.000 & 0 \\
\hline 05 & 1.0000 & 0.81601 & 0.90561 & 0.87442 & Biso & 1.000 & 0 \\
\hline 06 & 1.0000 & 0.10751 & 0.20082 & 0.87684 & Biso & 1.000 & 0 \\
\hline 07 & 1.0000 & 0.57132 & 0.44253 & 0.44376 & Biso & 1.000 & 0 \\
\hline 08 & 1.0000 & 0.58850 & 0.14780 & 0.42879 & Biso & 1.000 & 0 \\
\hline 09 & 1.0000 & 0.88183 & 0.43562 & 0.45277 & Biso & 1.000 & 0 \\
\hline 010 & 1.0000 & 0.77671 & 0.23995 & 0.21143 & Biso & 1.000 & 0 \\
\hline 011 & 1.0000 & 0.48536 & 0.24301 & 0.20895 & Biso & 1.000 & 0 \\
\hline 012 & 1.0000 & 0.77694 & 0.53479 & 0.21390 & Biso & 1.000 & 0 \\
\hline 013 & 1.0000 & 0.24133 & 0.76486 & 0.78803 & Biso & 1.000 & 0 \\
\hline 014 & 1.0000 & 0.24400 & 0.47193 & 0.78054 & Biso & 1.000 & 0 \\
\hline 015 & 1.0000 & 0.54239 & 0.76854 & 0.77790 & Biso & 1.000 & 0 \\
\hline 016 & 1.0000 & 0.45177 & 0.57975 & 0.54766 & Biso & 1.000 & 0 \\
\hline 017 & 1.0000 & 0.12540 & 0.56314 & 0.55633 & Biso & 1.000 & 0 \\
\hline 018 & 1.0000 & 0.43911 & 0.85479 & 0.54856 & Biso & 1.000 & 0 \\
\hline 019 & 1.0000 & 0.99351 & 0.31964 & 0.16360 & Biso & 1.000 & 0 \\
\hline 020 & 1.0000 & 0.69975 & 0.67174 & 0.16281 & Biso & 1.000 & 0 \\
\hline 021 & 1.0000 & 0.35276 & 0.02847 & 0.15382 & Biso & 1.000 & 0 \\
\hline 022 & 1.0000 & 0.32312 & 0.98315 & 0.82808 & Biso & 1.000 & 0 \\
\hline 023 & 1.0000 & 0.67319 & 0.68749 & 0.83664 & Biso & 1.000 & 0 \\
\hline $\mathrm{O} 24$ & 1.0000 & 0.02921 & 0.33918 & 0.83344 & Biso & 1.000 & 0 \\
\hline 025 & 1.0000 & 0.66717 & 0.65763 & 0.49853 & Biso & 1.000 & 0 \\
\hline 026 & 1.0000 & 0.36228 & 0.99389 & 0.49822 & Biso & 1.000 & 0 \\
\hline 027 & 1.0000 & 0.01685 & 0.35221 & 0.49383 & Biso & 1.000 & 0 \\
\hline 028 & 1.0000 & 0.02619 & 0.68078 & 0.83781 & Biso & 1.000 & 0 \\
\hline 029 & 1.0000 & 0.32292 & 0.33493 & 0.82625 & Biso & 1.000 & 0 \\
\hline 030 & 1.0000 & 0.67495 & 0.98176 & 0.83297 & Biso & 1.000 & 0 \\
\hline 031 & 1.0000 & 0.69403 & 0.02618 & 0.15856 & Biso & 1.000 & 0 \\
\hline 032 & 1.0000 & 0.34844 & 0.32017 & 0.15817 & Biso & 1.000 & 0 \\
\hline 033 & 1.0000 & 0.99290 & 0.67412 & 0.16787 & Biso & 1.000 & 0 \\
\hline 034 & 1.0000 & 0.35627 & 0.36654 & 0.48866 & Biso & 1.000 & 0 \\
\hline 035 & 1.0000 & 0.00474 & 0.65461 & 0.49988 & Biso & 1.000 & 0 \\
\hline 036 & 1.0000 & 0.65179 & 0.00484 & 0.49750 & Biso & 1.000 & 0 \\
\hline 037 & 1.0000 & 0.13363 & 0.24641 & 0.12465 & Biso & 1.000 & 0 \\
\hline 038 & 1.0000 & 0.76964 & 0.88514 & 0.13134 & Biso & 1.000 & 0 \\
\hline 039 & 1.0000 & 0.13622 & 0.88442 & 0.12733 & Biso & 1.000 & 0 \\
\hline 040 & 1.0000 & 0.24704 & 0.12122 & 0.86362 & Biso & 1.000 & 0 \\
\hline 041 & 1.0000 & 0.88726 & 0.75747 & 0.86771 & Biso & 1.000 & 0 \\
\hline 042 & 1.0000 & 0.88845 & 0.12492 & 0.86640 & Biso & 1.000 & 0 \\
\hline 043 & 1.0000 & 0.79198 & 0.56776 & 0.45807 & Biso & 1.000 & 0 \\
\hline 044 & 1.0000 & 0.42841 & 0.22276 & 0.46423 & Biso & 1.000 & 0 \\
\hline 045 & 1.0000 & 0.80400 & 0.21374 & 0.46055 & Biso & 1.000 & 0 \\
\hline 046 & 1.0000 & 0.92105 & 0.45969 & 0.20122 & Biso & 1.000 & 0 \\
\hline 047 & 1.0000 & 0.55691 & 0.09418 & 0.21646 & Biso & 1.000 & 0 \\
\hline 048 & 1.0000 & 0.55800 & 0.46209 & 0.20524 & Biso & 1.000 & 0 \\
\hline 049 & 1.0000 & 0.46157 & 0.90659 & 0.79697 & Biso & 1.000 & 0 \\
\hline
\end{tabular}




\begin{tabular}{|c|c|c|c|c|c|c|c|}
\hline 050 & 1.0000 & 0.09778 & 0.54565 & 0.78241 & Biso & 1.000 & 0 \\
\hline 051 & 1.0000 & 0.46384 & 0.54873 & 0.79063 & Biso & 1.000 & 0 \\
\hline 052 & 1.0000 & 0.59892 & 0.79908 & 0.54183 & Biso & 1.000 & 0 \\
\hline 053 & 1.0000 & 0.23108 & 0.44997 & 0.53701 & Biso & 1.000 & 0 \\
\hline 054 & 1.0000 & 0.22035 & 0.78290 & 0.53509 & Biso & 1.000 & 0 \\
\hline 055 & 1.0000 & 0.00854 & 0.26668 & 0.99755 & Biso & 1.000 & 0 \\
\hline 056 & 1.0000 & 0.75202 & 0.74626 & 0.99933 & Biso & 1.000 & 0 \\
\hline 057 & 1.0000 & 0.27248 & 0.00283 & 0.99311 & Biso & 1.000 & 0 \\
\hline 058 & 1.0000 & 0.68475 & 0.61277 & 0.33055 & Biso & 1.000 & 0 \\
\hline 059 & 1.0000 & 0.38948 & 0.07036 & 0.32381 & Biso & 1.000 & 0 \\
\hline 060 & 1.0000 & 0.94486 & 0.33785 & 0.32969 & Biso & 1.000 & 0 \\
\hline 061 & 1.0000 & 0.34087 & 0.92572 & 0.66486 & Biso & 1.000 & 0 \\
\hline 062 & 1.0000 & 0.07393 & 0.38921 & 0.66379 & Biso & 1.000 & 0 \\
\hline 063 & 1.0000 & 0.61867 & 0.66978 & 0.66653 & Biso & 1.000 & 0 \\
\hline 064 & 1.0000 & 0.00843 & 0.74015 & 0.00023 & Biso & 1.000 & 0 \\
\hline 065 & 1.0000 & 0.27606 & 0.26755 & 0.99329 & Biso & 1.000 & 0 \\
\hline 066 & 1.0000 & 0.74964 & 0.00169 & 0.99696 & Biso & 1.000 & 0 \\
\hline 067 & 1.0000 & 0.69496 & 0.06935 & 0.32943 & Biso & 1.000 & 0 \\
\hline 068 & 1.0000 & 0.94430 & 0.60147 & 0.33277 & Biso & 1.000 & 0 \\
\hline 069 & 1.0000 & 0.40445 & 0.33267 & 0.32674 & Biso & 1.000 & 0 \\
\hline 070 & 1.0000 & 0.34441 & 0.40612 & 0.66022 & Biso & 1.000 & 0 \\
\hline 071 & 1.0000 & 0.60866 & 0.94304 & 0.66577 & Biso & 1.000 & 0 \\
\hline 072 & 1.0000 & 0.07348 & 0.68167 & 0.66781 & Biso & 1.000 & 0 \\
\hline $\mathrm{H} 1$ & 1.0000 & 0.29845 & 0.03743 & 0.32491 & Biso & 1.000 & $\mathrm{H}$ \\
\hline $\mathrm{C} 1$ & 1.0000 & 0.11409 & 0.88274 & 0.35360 & Biso & 1.000 & $\mathrm{C}$ \\
\hline $\mathrm{H} 2$ & 1.0000 & 0.11625 & 0.87756 & 0.42635 & Biso & 1.000 & $\mathrm{H}$ \\
\hline $\mathrm{H} 3$ & 1.0000 & 0.02672 & 0.85043 & 0.33031 & Biso & 1.000 & $\mathrm{H}$ \\
\hline $\mathrm{H} 4$ & 1.0000 & 0.14890 & 0.83357 & 0.32333 & Biso & 1.000 & $\mathrm{H}$ \\
\hline 073 & 1.0000 & 0.18349 & 0.99841 & 0.32425 & Biso & 1.000 & $\mathrm{O}$ \\
\hline $\mathrm{C} 2$ & 1.0000 & 0.14620 & 0.07354 & 0.35793 & Biso & 1.000 & $\mathrm{C}$ \\
\hline H5 & 1.0000 & 0.20494 & 0.15846 & 0.33242 & Biso & 1.000 & $\mathrm{H}$ \\
\hline H6 & 1.0000 & 0.06005 & 0.04525 & 0.33338 & Biso & 1.000 & $\mathrm{H}$ \\
\hline H7 & 1.0000 & 0.14763 & 0.07455 & 0.43104 & Biso & 1.000 & $\mathrm{H}$ \\
\hline \multicolumn{8}{|l|}{ Ge 24} \\
\hline \multicolumn{8}{|c|}{ data image 0} \\
\hline \multicolumn{8}{|c|}{ _celílength_a $\quad 13.875$} \\
\hline \multicolumn{8}{|c|}{ _cell_length_b $\quad 13.875$} \\
\hline \multicolumn{8}{|c|}{ cell_length_c $\quad 15.017$} \\
\hline \multicolumn{8}{|c|}{ cell-angle $\overline{\text { alpha }} \quad 90$} \\
\hline \multicolumn{8}{|c|}{ cell angle beta } \\
\hline \multicolumn{8}{|c|}{ _cell_angle_gamma } \\
\hline symme & space gr & coup name & $H-M$ & P $1 "$ & & & \\
\hline symme & int_t $\bar{a} \bar{b}]$ & les_ñumbe & & & & & \\
\hline loop_ & & & & & & & \\
\hline$\tau^{\text {sym }}$ & _equiv & pos_as_x & & & & & \\
\hline loop & & & & & & & \\
\hline$-\mathrm{atc}$ & [e_labe] & & & & & & \\
\hline -ato & ee_occup & pancy & & & & & \\
\hline -atc & te_fract & t & & & & & \\
\hline -atc & te fract & ty & & & & & \\
\hline -ato & ce_fract & $-z$ & & & & & \\
\hline ato & $e_{-}^{-}$thern & nàl_displ & ce_type & & & & \\
\hline $\begin{array}{l}\text {-atc } \\
\text {-atc }\end{array}$ & $\begin{array}{l}\text { te_B_isc } \\
\text { te_type }\end{array}$ & $\begin{array}{l}\text { or_or_equi } \\
\text { symbol }\end{array}$ & & & & & \\
\hline$\overline{\mathrm{P}} 1$ & 1.0000 & 0.00744 & 0.22313 & 0.10784 & Biso & 1.000 & $\mathrm{P}$ \\
\hline P2 & 1.0000 & 0.77859 & 0.77436 & 0.11006 & Biso & 1.000 & $P$ \\
\hline P3 & 1.0000 & 0.22986 & 0.99320 & 0.10134 & Biso & 1.000 & $\mathrm{P}$ \\
\hline Al1 & 1.0000 & 0.22330 & 0.98812 & 0.88818 & Biso & 1.000 & Al \\
\hline Al2 & 1.0000 & 0.77445 & 0.76936 & 0.89617 & Biso & 1.000 & Al \\
\hline Al3 & 1.0000 & 0.00342 & 0.22222 & 0.89514 & Biso & 1.000 & Al \\
\hline $\mathrm{P} 4$ & 1.0000 & 0.67343 & 0.55946 & 0.43804 & Biso & 1.000 & $P$ \\
\hline $\mathrm{Ge} 1$ & 1.0000 & 0.43484 & 0.10756 & 0.44531 & Biso & 1.000 & $\mathrm{Ge}$ \\
\hline P5 & 1.0000 & 0.89957 & 0.32261 & 0.43904 & Biso & 1.000 & $\mathrm{P}$ \\
\hline Al4 & 1.0000 & 0.89739 & 0.32671 & 0.22754 & Biso & 1.000 & Al \\
\hline Al5 & 1.0000 & 0.44193 & 0.10610 & 0.22191 & Biso & 1.000 & Al \\
\hline Al6 & 1.0000 & 0.67582 & 0.56087 & 0.23000 & Biso & 1.000 & $\mathrm{Al}$ \\
\hline P6 & 1.0000 & 0.33552 & 0.88177 & 0.77684 & Biso & 1.000 & $P$ \\
\hline P7 & 1.0000 & 0.10450 & 0.42992 & 0.77069 & Biso & 1.000 & $\mathrm{P}$ \\
\hline P8 & 1.0000 & 0.56336 & 0.65735 & 0.77324 & Biso & 1.000 & $\mathrm{P}$ \\
\hline A17 & 1.0000 & 0.57502 & 0.66803 & 0.56640 & Biso & 1.000 & Al \\
\hline Al8 & 1.0000 & 0.09991 & 0.42910 & 0.56703 & Biso & 1.000 & Al \\
\hline Al9 & 1.0000 & 0.33635 & 0.87568 & 0.56355 & Biso & 1.000 & Al \\
\hline P9 & 1.0000 & 0.99584 & 0.76154 & 0.89199 & Biso & 1.000 & $P$ \\
\hline $\mathrm{P} 10$ & 1.0000 & 0.22919 & 0.21840 & 0.88543 & Biso & 1.000 & $\mathrm{P}$ \\
\hline P11 & 1.0000 & 0.77900 & 0.99718 & 0.89036 & Biso & 1.000 & $\mathrm{P}$ \\
\hline Al10 & 1.0000 & 0.77969 & 0.99957 & 0.10431 & Biso & 1.000 & Al \\
\hline
\end{tabular}




\begin{tabular}{|c|c|c|c|c|c|c|c|}
\hline Al11 & 1.0000 & 0.23496 & 0.22322 & 0.09702 & Biso & 1.000 & Al \\
\hline Al12 & 1.0000 & 0.00284 & 0.77015 & 0.10589 & Biso & 1.000 & Al \\
\hline P 12 & 1.0000 & 0.67058 & 0.10007 & 0.22610 & Biso & 1.000 & $P$ \\
\hline P13 & 1.0000 & 0.90079 & 0.55546 & 0.22643 & Biso & 1.000 & $\mathrm{P}$ \\
\hline P14 & 1.0000 & 0.44574 & 0.33321 & 0.22134 & Biso & 1.000 & $P$ \\
\hline Al13 & 1.0000 & 0.43527 & 0.33669 & 0.43301 & Biso & 1.000 & Al \\
\hline Al14 & 1.0000 & 0.89747 & 0.55106 & 0.43788 & Biso & 1.000 & Al \\
\hline Al15 & 1.0000 & 0.66859 & 0.10277 & 0.43137 & Biso & 1.000 & Al \\
\hline P15 & 1.0000 & 0.33739 & 0.45065 & 0.55526 & Biso & 1.000 & $\mathrm{P}$ \\
\hline P16 & 1.0000 & 0.56730 & 0.89033 & 0.56215 & Biso & 1.000 & $\mathrm{P}$ \\
\hline P17 & 1.0000 & 0.09921 & 0.66298 & 0.56508 & Biso & 1.000 & $\mathrm{P}$ \\
\hline Al16 & 1.0000 & 0.10493 & 0.66261 & 0.77080 & Biso & 1.000 & Al \\
\hline Al17 & 1.0000 & 0.56339 & 0.88717 & 0.77090 & Biso & 1.000 & Al \\
\hline Al18 & 1.0000 & 0.33234 & 0.43186 & 0.76311 & Biso & 1.000 & Al \\
\hline 01 & 1.0000 & 0.91668 & 0.10277 & 0.13015 & Biso & 1.000 & 0 \\
\hline $\mathrm{O} 2$ & 1.0000 & 0.89961 & 0.80422 & 0.13025 & Biso & 1.000 & 0 \\
\hline 03 & 1.0000 & 0.20238 & 0.08610 & 0.12045 & Biso & 1.000 & 0 \\
\hline O4 & 1.0000 & 0.08732 & 0.88033 & 0.86668 & Biso & 1.000 & 0 \\
\hline 05 & 1.0000 & 0.80929 & 0.90645 & 0.87020 & Biso & 1.000 & 0 \\
\hline 06 & 1.0000 & 0.10765 & 0.18983 & 0.87190 & Biso & 1.000 & 0 \\
\hline 07 & 1.0000 & 0.57435 & 0.44109 & 0.44762 & Biso & 1.000 & 0 \\
\hline 08 & 1.0000 & 0.57579 & 0.15153 & 0.43076 & Biso & 1.000 & 0 \\
\hline 09 & 1.0000 & 0.87515 & 0.41742 & 0.45926 & Biso & 1.000 & 0 \\
\hline 010 & 1.0000 & 0.75924 & 0.22249 & 0.20743 & Biso & 1.000 & 0 \\
\hline 011 & 1.0000 & 0.48048 & 0.24520 & 0.20263 & Biso & 1.000 & 0 \\
\hline 012 & 1.0000 & 0.77942 & 0.52612 & 0.21005 & Biso & 1.000 & 0 \\
\hline 013 & 1.0000 & 0.24169 & 0.76279 & 0.79934 & Biso & 1.000 & 0 \\
\hline 014 & 1.0000 & 0.22776 & 0.46489 & 0.78576 & Biso & 1.000 & 0 \\
\hline 015 & 1.0000 & 0.53220 & 0.74891 & 0.78316 & Biso & 1.000 & 0 \\
\hline 016 & 1.0000 & 0.43441 & 0.57126 & 0.54843 & Biso & 1.000 & 0 \\
\hline 017 & 1.0000 & 0.10698 & 0.55701 & 0.56131 & Biso & 1.000 & 0 \\
\hline 018 & 1.0000 & 0.44156 & 0.84150 & 0.54625 & Biso & 1.000 & 0 \\
\hline 019 & 1.0000 & 0.99109 & 0.30605 & 0.16407 & Biso & 1.000 & 0 \\
\hline 020 & 1.0000 & 0.69643 & 0.67211 & 0.16352 & Biso & 1.000 & 0 \\
\hline 021 & 1.0000 & 0.33609 & 0.01584 & 0.15048 & Biso & 1.000 & 0 \\
\hline $\mathrm{O} 22$ & 1.0000 & 0.31910 & 0.96802 & 0.82845 & Biso & 1.000 & 0 \\
\hline 023 & 1.0000 & 0.65404 & 0.67479 & 0.84025 & Biso & 1.000 & 0 \\
\hline $\mathrm{O} 24$ & 1.0000 & 0.02950 & 0.34242 & 0.83901 & Biso & 1.000 & 0 \\
\hline 025 & 1.0000 & 0.66115 & 0.64096 & 0.49934 & Biso & 1.000 & 0 \\
\hline 026 & 1.0000 & 0.34963 & 0.98510 & 0.50210 & Biso & 1.000 & 0 \\
\hline 027 & 1.0000 & 0.99910 & 0.33655 & 0.49389 & Biso & 1.000 & 0 \\
\hline 028 & 1.0000 & 0.01196 & 0.67431 & 0.84201 & Biso & 1.000 & 0 \\
\hline 029 & 1.0000 & 0.30796 & 0.31577 & 0.82576 & Biso & 1.000 & 0 \\
\hline 030 & 1.0000 & 0.67543 & 0.97568 & 0.83814 & Biso & 1.000 & 0 \\
\hline 031 & 1.0000 & 0.68301 & 0.02304 & 0.15963 & Biso & 1.000 & 0 \\
\hline 032 & 1.0000 & 0.35150 & 0.31622 & 0.15822 & Biso & 1.000 & 0 \\
\hline 033 & 1.0000 & 0.98107 & 0.65589 & 0.16969 & Biso & 1.000 & 0 \\
\hline 034 & 1.0000 & 0.34880 & 0.37720 & 0.48519 & Biso & 1.000 & 0 \\
\hline 035 & 1.0000 & 0.00547 & 0.65121 & 0.50338 & Biso & 1.000 & 0 \\
\hline 036 & 1.0000 & 0.63528 & 0.98977 & 0.50100 & Biso & 1.000 & 0 \\
\hline 037 & 1.0000 & 0.12178 & 0.23720 & 0.12993 & Biso & 1.000 & 0 \\
\hline 038 & 1.0000 & 0.76378 & 0.87231 & 0.13823 & Biso & 1.000 & 0 \\
\hline 039 & 1.0000 & 0.13299 & 0.88213 & 0.13448 & Biso & 1.000 & 0 \\
\hline 040 & 1.0000 & 0.23847 & 0.11659 & 0.85934 & Biso & 1.000 & 0 \\
\hline 041 & 1.0000 & 0.88284 & 0.74727 & 0.86522 & Biso & 1.000 & 0 \\
\hline 042 & 1.0000 & 0.87609 & 0.11044 & 0.86171 & Biso & 1.000 & 0 \\
\hline 043 & 1.0000 & 0.77940 & 0.55824 & 0.46449 & Biso & 1.000 & 0 \\
\hline 044 & 1.0000 & 0.40784 & 0.21200 & 0.47868 & Biso & 1.000 & 0 \\
\hline 045 & 1.0000 & 0.79905 & 0.21109 & 0.46481 & Biso & 1.000 & 0 \\
\hline 046 & 1.0000 & 0.91331 & 0.45588 & 0.19911 & Biso & 1.000 & 0 \\
\hline 047 & 1.0000 & 0.55484 & 0.08649 & 0.21249 & Biso & 1.000 & 0 \\
\hline 048 & 1.0000 & 0.54598 & 0.44853 & 0.20360 & Biso & 1.000 & 0 \\
\hline 049 & 1.0000 & 0.44720 & 0.89417 & 0.80556 & Biso & 1.000 & 0 \\
\hline 050 & 1.0000 & 0.09013 & 0.53141 & 0.78247 & Biso & 1.000 & 0 \\
\hline 051 & 1.0000 & 0.46054 & 0.54447 & 0.79354 & Biso & 1.000 & 0 \\
\hline 052 & 1.0000 & 0.59823 & 0.80074 & 0.54144 & Biso & 1.000 & 0 \\
\hline 053 & 1.0000 & 0.22929 & 0.45063 & 0.53577 & Biso & 1.000 & 0 \\
\hline 054 & 1.0000 & 0.20903 & 0.76073 & 0.53243 & Biso & 1.000 & 0 \\
\hline 055 & 1.0000 & 0.00125 & 0.24759 & 0.00890 & Biso & 1.000 & 0 \\
\hline 056 & 1.0000 & 0.75251 & 0.74863 & 0.01072 & Biso & 1.000 & 0 \\
\hline 057 & 1.0000 & 0.24938 & 0.98713 & 0.00166 & Biso & 1.000 & 0 \\
\hline 058 & 1.0000 & 0.68244 & 0.60057 & 0.34136 & Biso & 1.000 & 0 \\
\hline 059 & 1.0000 & 0.37718 & 0.06801 & 0.32905 & Biso & 1.000 & 0 \\
\hline 060 & 1.0000 & 0.92860 & 0.32487 & 0.33987 & Biso & 1.000 & 0 \\
\hline 061 & 1.0000 & 0.33512 & 0.90409 & 0.67709 & Biso & 1.000 & 0 \\
\hline 062 & 1.0000 & 0.06796 & 0.37966 & 0.67673 & Biso & 1.000 & 0 \\
\hline 063 & 1.0000 & 0.60674 & 0.65946 & 0.67836 & Biso & 1.000 & 0 \\
\hline 064 & 1.0000 & 0.99904 & 0.74165 & 0.99246 & Biso & 1.000 & 0 \\
\hline 065 & 1.0000 & 0.26342 & 0.25057 & 0.98341 & Biso & 1.000 & 0 \\
\hline 066 & 1.0000 & 0.75548 & 0.99817 & 0.99027 & Biso & 1.000 & 0 \\
\hline
\end{tabular}




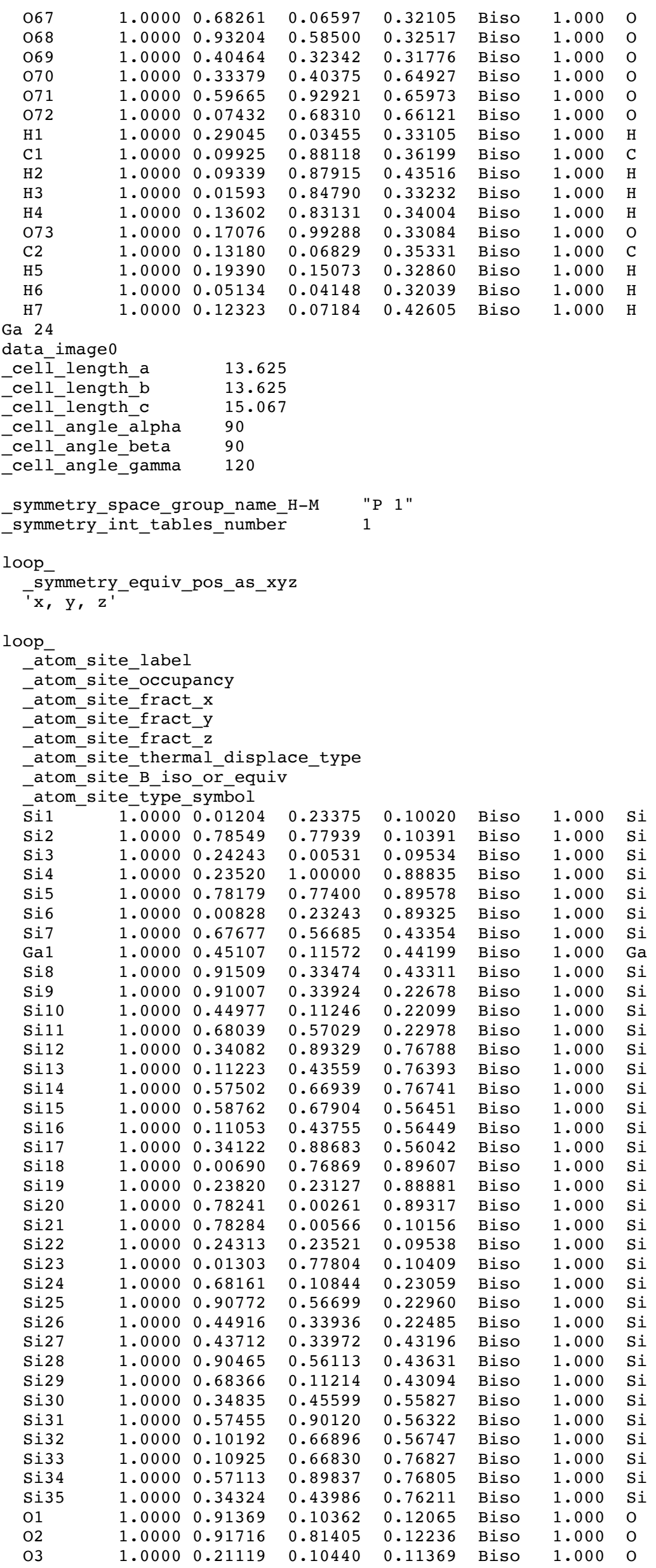




\begin{tabular}{|c|c|c|c|c|c|c|}
\hline 04 & 1.0000 & 0.10504 & 0.89829 & 0.87393 & Biso & 1.000 \\
\hline 05 & 1.0000 & 0.81673 & 0.90526 & 0.87615 & Biso & 1.000 \\
\hline 06 & 1.0000 & 0.10756 & 0.20141 & 0.87621 & Biso & 1.000 \\
\hline 07 & 1.0000 & 0.56817 & 0.44110 & 0.44358 & Biso & 1.000 \\
\hline 08 & 1.0000 & 0.59943 & 0.16292 & 0.43166 & Biso & 1.000 \\
\hline 09 & 1.0000 & 0.88601 & 0.43512 & 0.45358 & Biso & 1.000 \\
\hline 010 & 1.0000 & 0.77856 & 0.24011 & 0.21291 & Biso & 1.000 \\
\hline 011 & 1.0000 & 0.48663 & 0.24439 & 0.20517 & Biso & 1.000 \\
\hline 012 & 1.0000 & 0.77667 & 0.53445 & 0.21332 & Biso & 1.000 \\
\hline 013 & 1.0000 & 0.24060 & 0.76367 & 0.78803 & Biso & 1.000 \\
\hline 014 & 1.0000 & 0.24454 & 0.47204 & 0.78073 & Biso & 1.000 \\
\hline 015 & 1.0000 & 0.54019 & 0.76692 & 0.77823 & Biso & 1.000 \\
\hline 016 & 1.0000 & 0.45558 & 0.58375 & 0.54931 & Biso & 1.000 \\
\hline 017 & 1.0000 & 0.11278 & 0.55678 & 0.56158 & Biso & 1.000 \\
\hline 018 & 1.0000 & 0.43941 & 0.85174 & 0.54811 & Biso & 1.000 \\
\hline 019 & 1.0000 & 0.99470 & 0.32084 & 0.16225 & Biso & 1.000 \\
\hline 020 & 1.0000 & 0.70023 & 0.67275 & 0.16459 & Biso & 1.000 \\
\hline 021 & 1.0000 & 0.35425 & 0.02919 & 0.15102 & Biso & 1.000 \\
\hline 022 & 1.0000 & 0.32164 & 0.98243 & 0.82610 & Biso & 1.000 \\
\hline 023 & 1.0000 & 0.67199 & 0.68756 & 0.83831 & Biso & 1.000 \\
\hline $\mathrm{O} 24$ & 1.0000 & 0.02927 & 0.34004 & 0.83400 & Biso & 1.000 \\
\hline 025 & 1.0000 & 0.66943 & 0.65675 & 0.49970 & Biso & 1.000 \\
\hline 026 & 1.0000 & 0.35542 & 0.98545 & 0.49564 & Biso & 1.000 \\
\hline 027 & 1.0000 & 0.02141 & 0.35082 & 0.49248 & Biso & 1.000 \\
\hline 028 & 1.0000 & 0.02588 & 0.67810 & 0.84007 & Biso & 1.000 \\
\hline 029 & 1.0000 & 0.32255 & 0.33358 & 0.82382 & Biso & 1.000 \\
\hline 030 & 1.0000 & 0.67434 & 0.97962 & 0.83366 & Biso & 1.000 \\
\hline 031 & 1.0000 & 0.69492 & 0.02660 & 0.15949 & Biso & 1.000 \\
\hline 032 & 1.0000 & 0.34879 & 0.32116 & 0.15714 & Biso & 1.000 \\
\hline 033 & 1.0000 & 0.99319 & 0.67482 & 0.16905 & Biso & 1.000 \\
\hline 034 & 1.0000 & 0.35367 & 0.37352 & 0.48397 & Biso & 1.000 \\
\hline 035 & 1.0000 & 0.00238 & 0.65530 & 0.50042 & Biso & 1.000 \\
\hline 036 & 1.0000 & 0.64918 & 0.00761 & 0.49886 & Biso & 1.000 \\
\hline 037 & 1.0000 & 0.13444 & 0.24699 & 0.12269 & Biso & 1.000 \\
\hline 038 & 1.0000 & 0.76974 & 0.88548 & 0.13122 & Biso & 1.000 \\
\hline 039 & 1.0000 & 0.13683 & 0.88504 & 0.12734 & Biso & 1.000 \\
\hline 040 & 1.0000 & 0.24504 & 0.11977 & 0.86241 & Biso & 1.000 \\
\hline 041 & 1.0000 & 0.88608 & 0.75529 & 0.86799 & Biso & 1.000 \\
\hline 042 & 1.0000 & 0.88826 & 0.12430 & 0.86477 & Biso & 1.000 \\
\hline 043 & 1.0000 & 0.78844 & 0.56003 & 0.45896 & Biso & 1.000 \\
\hline 044 & 1.0000 & 0.41760 & 0.22294 & 0.47230 & Biso & 1.000 \\
\hline 045 & 1.0000 & 0.80962 & 0.21251 & 0.45919 & Biso & 1.000 \\
\hline 046 & 1.0000 & 0.92143 & 0.46002 & 0.20105 & Biso & 1.000 \\
\hline 047 & 1.0000 & 0.55811 & 0.09618 & 0.21485 & Biso & 1.000 \\
\hline 048 & 1.0000 & 0.55743 & 0.46312 & 0.20675 & Biso & 1.000 \\
\hline 049 & 1.0000 & 0.46103 & 0.90629 & 0.79758 & Biso & 1.000 \\
\hline 050 & 1.0000 & 0.09699 & 0.54467 & 0.77792 & Biso & 1.000 \\
\hline 051 & 1.0000 & 0.46469 & 0.54754 & 0.78833 & Biso & 1.000 \\
\hline 052 & 1.0000 & 0.60456 & 0.80253 & 0.54081 & Biso & 1.000 \\
\hline 053 & 1.0000 & 0.23549 & 0.46244 & 0.53852 & Biso & 1.000 \\
\hline 054 & 1.0000 & 0.21997 & 0.77608 & 0.53620 & Biso & 1.000 \\
\hline 055 & 1.0000 & 0.00641 & 0.26475 & 0.99692 & Biso & 1.000 \\
\hline 056 & 1.0000 & 0.75243 & 0.74523 & 0.00051 & Biso & 1.000 \\
\hline 057 & 1.0000 & 0.27108 & 0.00140 & 0.99151 & Biso & 1.000 \\
\hline 058 & 1.0000 & 0.68623 & 0.61217 & 0.33183 & Biso & 1.000 \\
\hline 059 & 1.0000 & 0.38977 & 0.07245 & 0.32077 & Biso & 1.000 \\
\hline 060 & 1.0000 & 0.94908 & 0.33973 & 0.32880 & Biso & 1.000 \\
\hline 061 & 1.0000 & 0.34135 & 0.92325 & 0.66386 & Biso & 1.000 \\
\hline 062 & 1.0000 & 0.07495 & 0.38374 & 0.66396 & Biso & 1.000 \\
\hline 063 & 1.0000 & 0.62287 & 0.67395 & 0.66733 & Biso & 1.000 \\
\hline 064 & 1.0000 & 0.00796 & 0.74044 & 0.00110 & Biso & 1.000 \\
\hline 065 & 1.0000 & 0.27728 & 0.26796 & 0.99163 & Biso & 1.000 \\
\hline 066 & 1.0000 & 0.75137 & 0.00383 & 0.99734 & Biso & 1.000 \\
\hline 067 & 1.0000 & 0.69085 & 0.06854 & 0.33039 & Biso & 1.000 \\
\hline 068 & 1.0000 & 0.94254 & 0.59993 & 0.33346 & Biso & 1.000 \\
\hline 069 & 1.0000 & 0.40345 & 0.32787 & 0.32599 & Biso & 1.000 \\
\hline 070 & 1.0000 & 0.34341 & 0.40654 & 0.65808 & Biso & 1.000 \\
\hline 071 & 1.0000 & 0.60789 & 0.94184 & 0.66633 & Biso & 1.000 \\
\hline 072 & 1.0000 & 0.07139 & 0.68553 & 0.66917 & Biso & 1.000 \\
\hline H 1 & 1.0000 & 0.29986 & 0.03967 & 0.32320 & Biso & 1.000 \\
\hline $\mathrm{C} 1$ & 1.0000 & 0.11520 & 0.88363 & 0.35463 & Biso & 1.000 \\
\hline $\mathrm{H} 2$ & 1.0000 & 0.11850 & 0.87981 & 0.42741 & Biso & 1.000 \\
\hline H3 & 1.0000 & 0.02723 & 0.84942 & 0.33206 & Biso & 1.000 \\
\hline H4 & 1.0000 & 0.15085 & 0.83499 & 0.32474 & Biso & 1.000 \\
\hline 073 & 1.0000 & 0.18263 & 0.99885 & 0.32399 & Biso & 1.000 \\
\hline $\mathrm{C} 2$ & 1.0000 & 0.14413 & 0.07295 & 0.35751 & Biso & 1.000 \\
\hline H5 & 1.0000 & 0.20087 & 0.15760 & 0.33058 & Biso & 1.000 \\
\hline H6 & 1.0000 & 0.05697 & 0.04256 & 0.33437 & Biso & 1.000 \\
\hline $\mathrm{H} 7$ & 1.0000 & 0.14759 & 0.07583 & 0.43058 & Biso & 1.000 \\
\hline
\end{tabular}




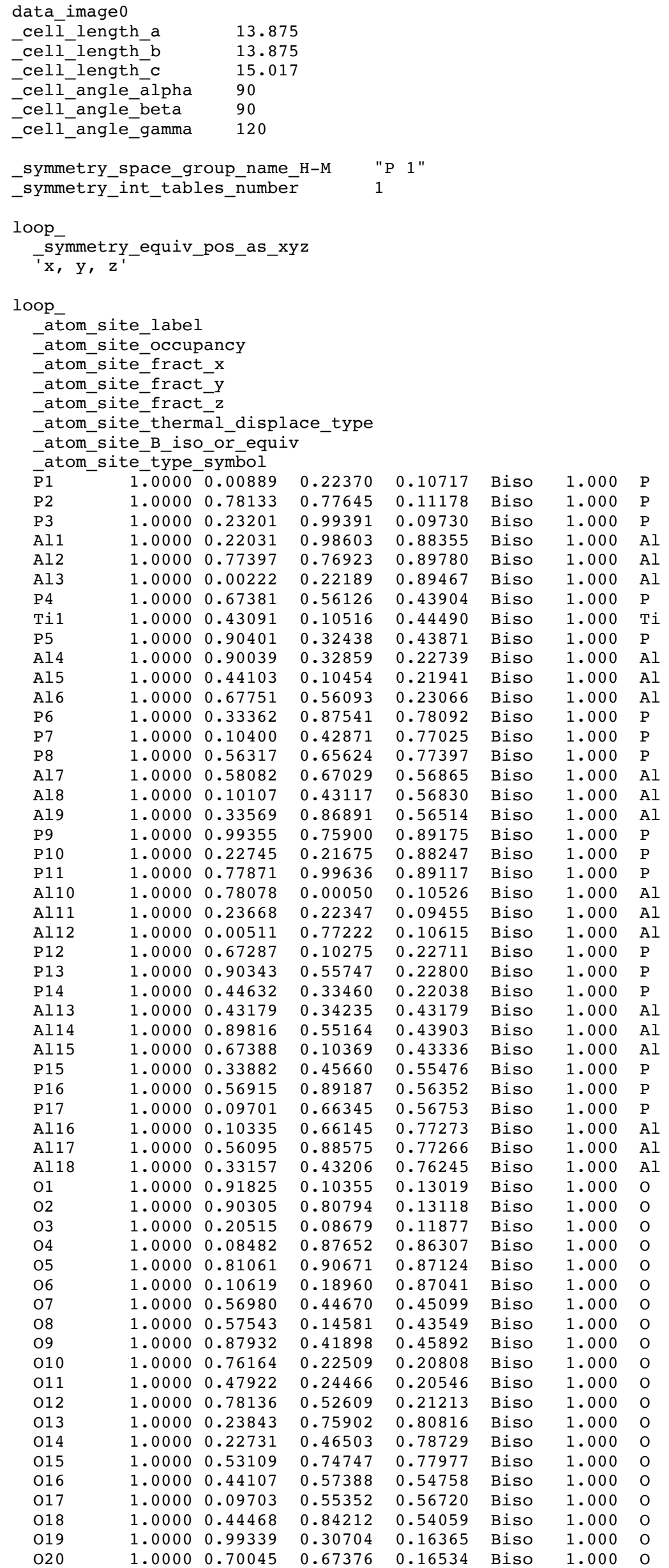




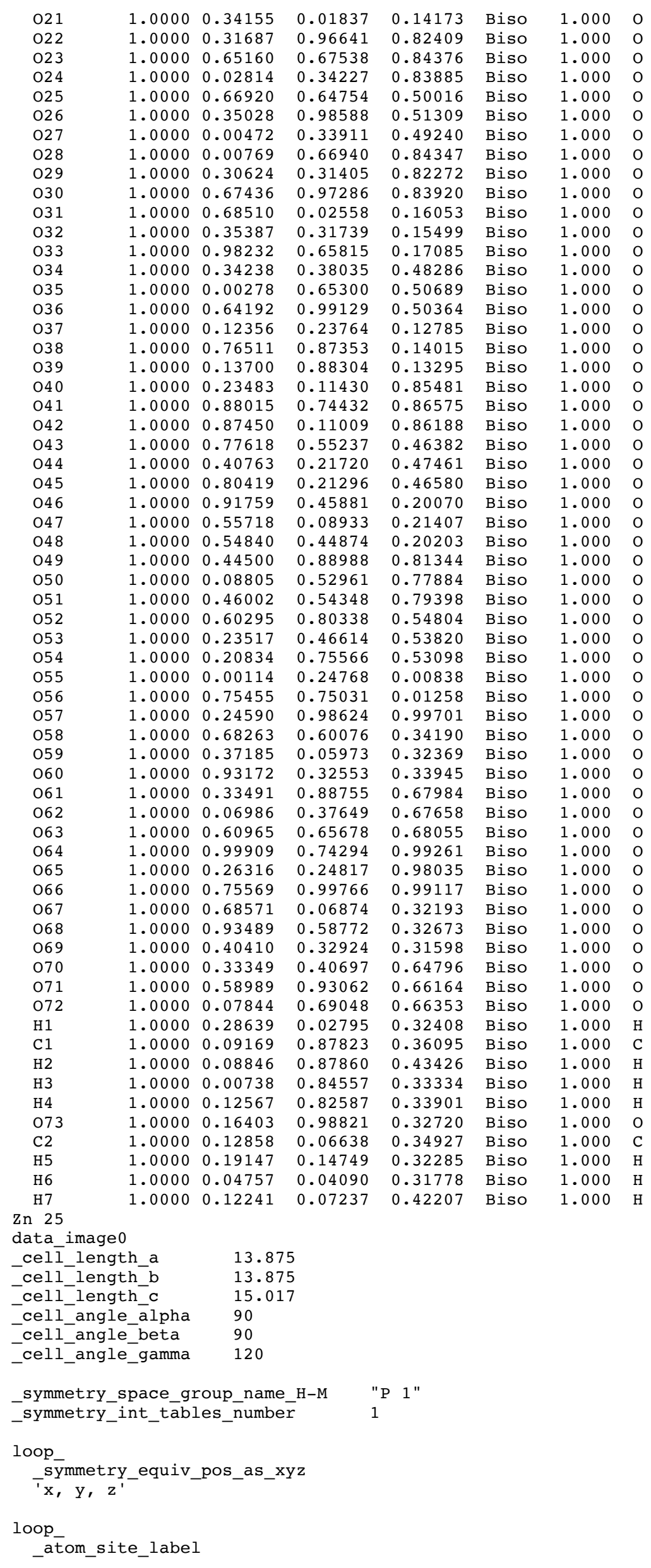




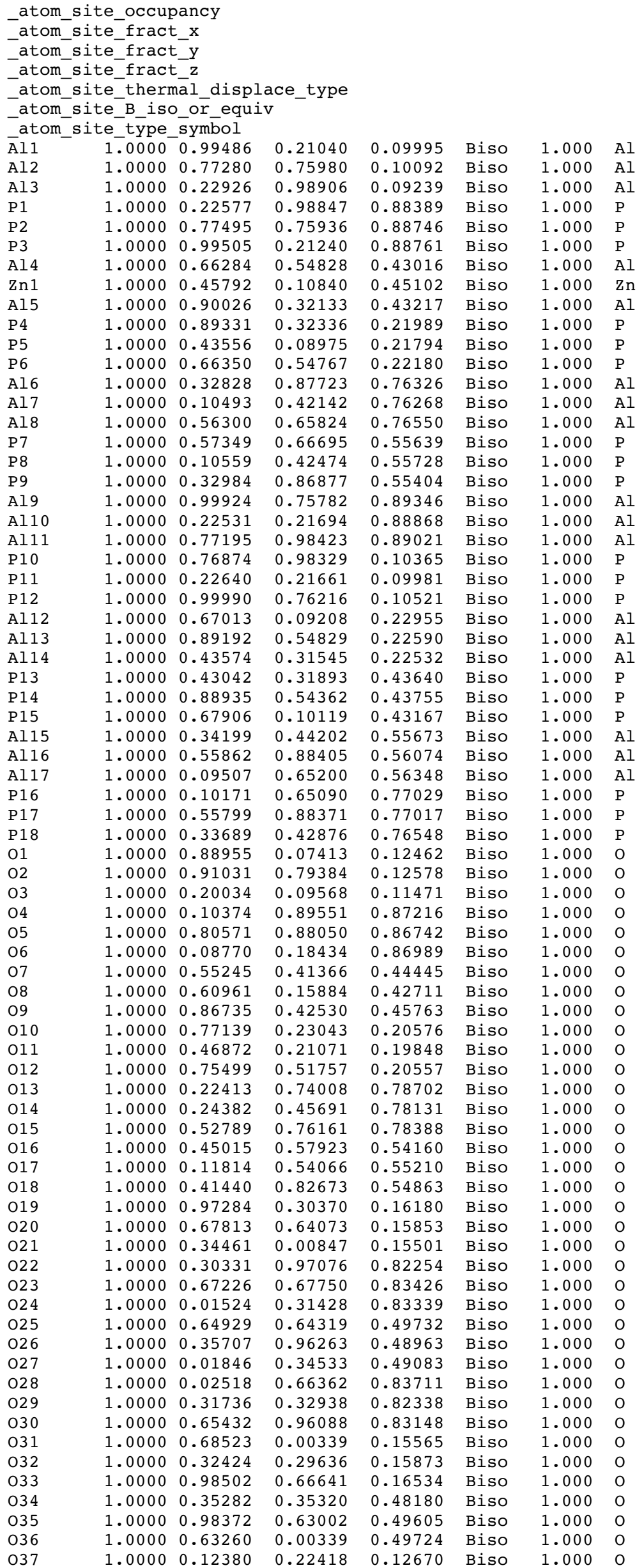




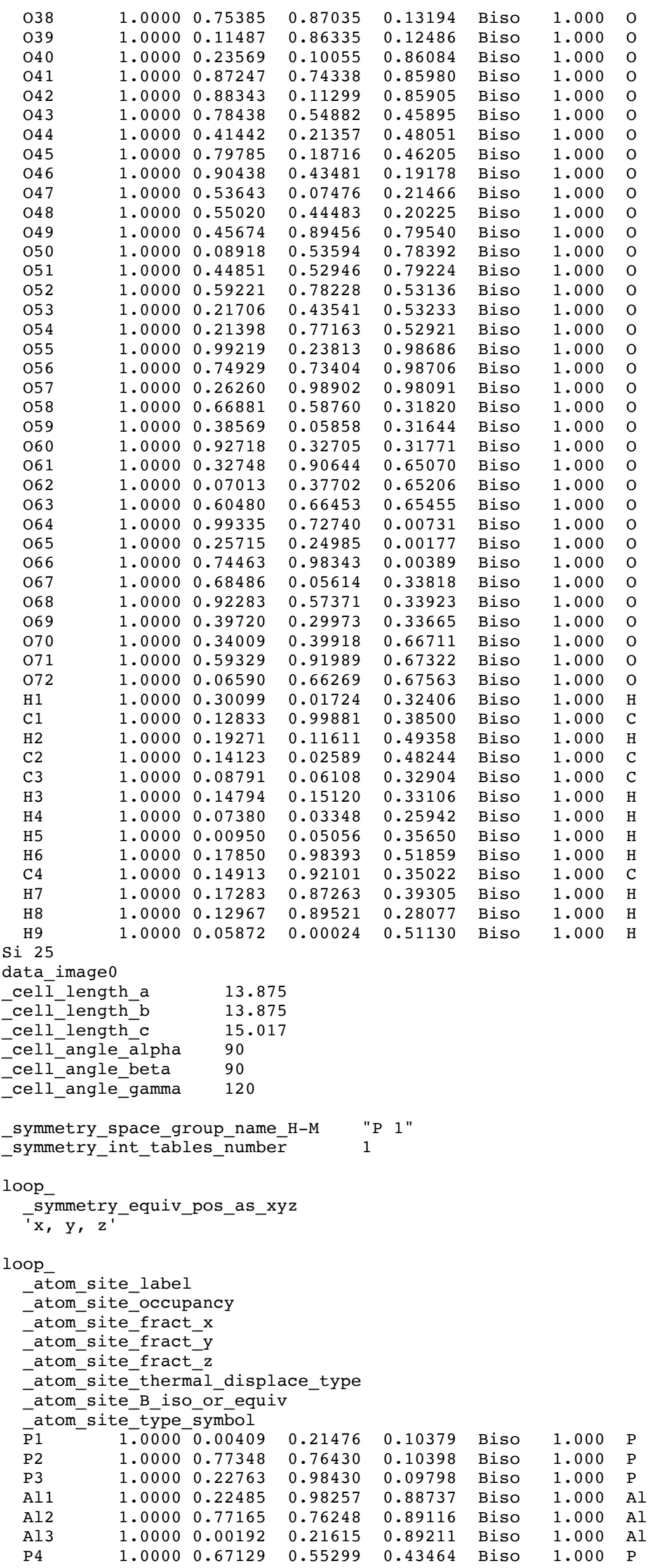




\begin{tabular}{|c|c|c|c|c|c|c|c|}
\hline Sil & 1.0000 & 0.43679 & 0.09734 & 0.43970 & Biso & 1.000 & $\mathrm{Si}$ \\
\hline P5 & 1.0000 & 0.89312 & 0.31610 & 0.43614 & Biso & 1.000 & $\mathrm{P}$ \\
\hline Al4 & 1.0000 & 0.89246 & 0.31766 & 0.22437 & Biso & 1.000 & Al \\
\hline Al5 & 1.0000 & 0.43666 & 0.09331 & 0.22463 & Biso & 1.000 & $\mathrm{Al}$ \\
\hline Al6 & 1.0000 & 0.67205 & 0.55090 & 0.22539 & Biso & 1.000 & $\mathrm{Al}$ \\
\hline P 6 & 1.0000 & 0.33470 & 0.87700 & 0.77264 & Biso & 1.000 & $P$ \\
\hline P7 & 1.0000 & 0.10259 & 0.42529 & 0.76766 & Biso & 1.000 & $\mathrm{P}$ \\
\hline P 8 & 1.0000 & 0.55951 & 0.64939 & 0.76913 & Biso & 1.000 & $\mathrm{P}$ \\
\hline Al7 & 1.0000 & 0.56689 & 0.65539 & 0.56010 & Biso & 1.000 & Al \\
\hline A18 & 1.0000 & 0.10122 & 0.42569 & 0.55984 & Biso & 1.000 & Al \\
\hline Al9 & 1.0000 & 0.33726 & 0.87582 & 0.55910 & Biso & 1.000 & $\mathrm{Al}$ \\
\hline P9 & 1.0000 & 0.99460 & 0.75581 & 0.88713 & Biso & 1.000 & $\mathrm{P}$ \\
\hline P 10 & 1.0000 & 0.22775 & 0.21227 & 0.88464 & Biso & 1.000 & $P$ \\
\hline P11 & 1.0000 & 0.77573 & 0.99042 & 0.88620 & Biso & 1.000 & $\mathrm{P}$ \\
\hline Al10 & 1.0000 & 0.77515 & 0.99031 & 0.09889 & Biso & 1.000 & $\mathrm{Al}$ \\
\hline Al11 & 1.0000 & 0.23177 & 0.21489 & 0.09511 & Biso & 1.000 & $\mathrm{Al}$ \\
\hline Al12 & 1.0000 & 0.99786 & 0.75960 & 0.09905 & Biso & 1.000 & Al \\
\hline P12 & 1.0000 & 0.66765 & 0.09174 & 0.22238 & Biso & 1.000 & $P$ \\
\hline P13 & 1.0000 & 0.89910 & 0.54770 & 0.22220 & Biso & 1.000 & $\mathrm{P}$ \\
\hline P 14 & 1.0000 & 0.44309 & 0.32448 & 0.22104 & Biso & 1.000 & $\mathrm{P}$ \\
\hline Al13 & 1.0000 & 0.43857 & 0.32687 & 0.43121 & Biso & 1.000 & $\mathrm{Al}$ \\
\hline Al14 & 1.0000 & 0.89683 & 0.54665 & 0.43260 & Biso & 1.000 & Al \\
\hline Al15 & 1.0000 & 0.66534 & 0.09267 & 0.42667 & Biso & 1.000 & Al \\
\hline P 15 & 1.0000 & 0.33301 & 0.43378 & 0.55214 & Biso & 1.000 & $P$ \\
\hline P16 & 1.0000 & 0.56358 & 0.88096 & 0.55626 & Biso & 1.000 & $\mathrm{P}$ \\
\hline $\mathrm{P} 17$ & 1.0000 & 0.10468 & 0.65933 & 0.55663 & Biso & 1.000 & $\mathrm{P}$ \\
\hline Al16 & 1.0000 & 0.10574 & 0.65699 & 0.76638 & Biso & 1.000 & $\mathrm{Al}$ \\
\hline Al1 17 & 1.0000 & 0.56221 & 0.88067 & 0.76528 & Biso & 1.000 & Al \\
\hline Al18 & 1.0000 & 0.32997 & 0.42536 & 0.76271 & Biso & 1.000 & Al \\
\hline 01 & 1.0000 & 0.91322 & 0.09312 & 0.12175 & Biso & 1.000 & 0 \\
\hline $\mathrm{O} 2$ & 1.0000 & 0.89523 & 0.79489 & 0.12161 & Biso & 1.000 & 0 \\
\hline 03 & 1.0000 & 0.19845 & 0.07650 & 0.11381 & Biso & 1.000 & 0 \\
\hline 04 & 1.0000 & 0.08794 & 0.87592 & 0.86793 & Biso & 1.000 & 0 \\
\hline 05 & 1.0000 & 0.80603 & 0.89961 & 0.86669 & Biso & 1.000 & 0 \\
\hline 06 & 1.0000 & 0.10607 & 0.18296 & 0.87067 & Biso & 1.000 & 0 \\
\hline 07 & 1.0000 & 0.57544 & 0.43399 & 0.45043 & Biso & 1.000 & 0 \\
\hline 08 & 1.0000 & 0.56305 & 0.12842 & 0.42268 & Biso & 1.000 & 0 \\
\hline 09 & 1.0000 & 0.86803 & 0.41078 & 0.45437 & Biso & 1.000 & 0 \\
\hline 010 & 1.0000 & 0.75373 & 0.21483 & 0.20288 & Biso & 1.000 & 0 \\
\hline 011 & 1.0000 & 0.47363 & 0.23211 & 0.20945 & Biso & 1.000 & 0 \\
\hline 012 & 1.0000 & 0.77741 & 0.51825 & 0.20779 & Biso & 1.000 & 0 \\
\hline 013 & 1.0000 & 0.24146 & 0.75822 & 0.79632 & Biso & 1.000 & 0 \\
\hline 014 & 1.0000 & 0.22484 & 0.45758 & 0.78395 & Biso & 1.000 & 0 \\
\hline 015 & 1.0000 & 0.53095 & 0.74270 & 0.77985 & Biso & 1.000 & 0 \\
\hline 016 & 1.0000 & 0.42839 & 0.55419 & 0.53796 & Biso & 1.000 & 0 \\
\hline 017 & 1.0000 & 0.12471 & 0.56058 & 0.54644 & Biso & 1.000 & 0 \\
\hline 018 & 1.0000 & 0.43849 & 0.83667 & 0.54089 & Biso & 1.000 & 0 \\
\hline 019 & 1.0000 & 0.98544 & 0.29426 & 0.16251 & Biso & 1.000 & 0 \\
\hline 020 & 1.0000 & 0.69328 & 0.66266 & 0.15902 & Biso & 1.000 & 0 \\
\hline 021 & 1.0000 & 0.32799 & 0.00473 & 0.15492 & Biso & 1.000 & 0 \\
\hline 022 & 1.0000 & 0.31921 & 0.96355 & 0.82466 & Biso & 1.000 & 0 \\
\hline 023 & 1.0000 & 0.65446 & 0.66820 & 0.83184 & Biso & 1.000 & 0 \\
\hline $\mathrm{O} 24$ & 1.0000 & 0.02511 & 0.33236 & 0.83128 & Biso & 1.000 & 0 \\
\hline 025 & 1.0000 & 0.65902 & 0.63567 & 0.49447 & Biso & 1.000 & o \\
\hline 026 & 1.0000 & 0.36453 & 0.99327 & 0.50257 & Biso & 1.000 & 0 \\
\hline 027 & 1.0000 & 0.99286 & 0.33253 & 0.49200 & Biso & 1.000 & 0 \\
\hline 028 & 1.0000 & 0.01047 & 0.67203 & 0.83194 & Biso & 1.000 & 0 \\
\hline 029 & 1.0000 & 0.30610 & 0.30873 & 0.82412 & Biso & 1.000 & 0 \\
\hline 030 & 1.0000 & 0.67490 & 0.97103 & 0.83102 & Biso & 1.000 & 0 \\
\hline 031 & 1.0000 & 0.68010 & 0.01555 & 0.15508 & Biso & 1.000 & 0 \\
\hline 032 & 1.0000 & 0.34759 & 0.30408 & 0.15822 & Biso & 1.000 & 0 \\
\hline 033 & 1.0000 & 0.97773 & 0.64692 & 0.16376 & Biso & 1.000 & 0 \\
\hline 034 & 1.0000 & 0.34585 & 0.35340 & 0.49032 & Biso & 1.000 & 0 \\
\hline 035 & 1.0000 & 0.00617 & 0.64216 & 0.49894 & Biso & 1.000 & 0 \\
\hline 036 & 1.0000 & 0.63512 & 0.97932 & 0.49509 & Biso & 1.000 & 0 \\
\hline 037 & 1.0000 & 0.11789 & 0.22810 & 0.12705 & Biso & 1.000 & 0 \\
\hline 038 & 1.0000 & 0.75903 & 0.86258 & 0.13206 & Biso & 1.000 & 0 \\
\hline 039 & 1.0000 & 0.12784 & 0.87278 & 0.12665 & Biso & 1.000 & 0 \\
\hline 040 & 1.0000 & 0.23779 & 0.11047 & 0.86028 & Biso & 1.000 & 0 \\
\hline 041 & 1.0000 & 0.88301 & 0.74503 & 0.86092 & Biso & 1.000 & 0 \\
\hline 042 & 1.0000 & 0.87440 & 0.10381 & 0.86029 & Biso & 1.000 & 0 \\
\hline 043 & 1.0000 & 0.78108 & 0.55820 & 0.45824 & Biso & 1.000 & 0 \\
\hline 044 & 1.0000 & 0.42201 & 0.20135 & 0.46284 & Biso & 1.000 & 0 \\
\hline 045 & 1.0000 & 0.79220 & 0.20495 & 0.46270 & Biso & 1.000 & 0 \\
\hline 046 & 1.0000 & 0.91070 & 0.44746 & 0.19498 & Biso & 1.000 & 0 \\
\hline 047 & 1.0000 & 0.55004 & 0.07498 & 0.21136 & Biso & 1.000 & 0 \\
\hline 048 & 1.0000 & 0.54489 & 0.43595 & 0.19596 & Biso & 1.000 & 0 \\
\hline 049 & 1.0000 & 0.44695 & 0.88960 & 0.79956 & Biso & 1.000 & 0 \\
\hline 050 & 1.0000 & 0.08924 & 0.52634 & 0.78604 & Biso & 1.000 & 0 \\
\hline 051 & 1.0000 & 0.45720 & 0.53827 & 0.79452 & Biso & 1.000 & 0 \\
\hline
\end{tabular}




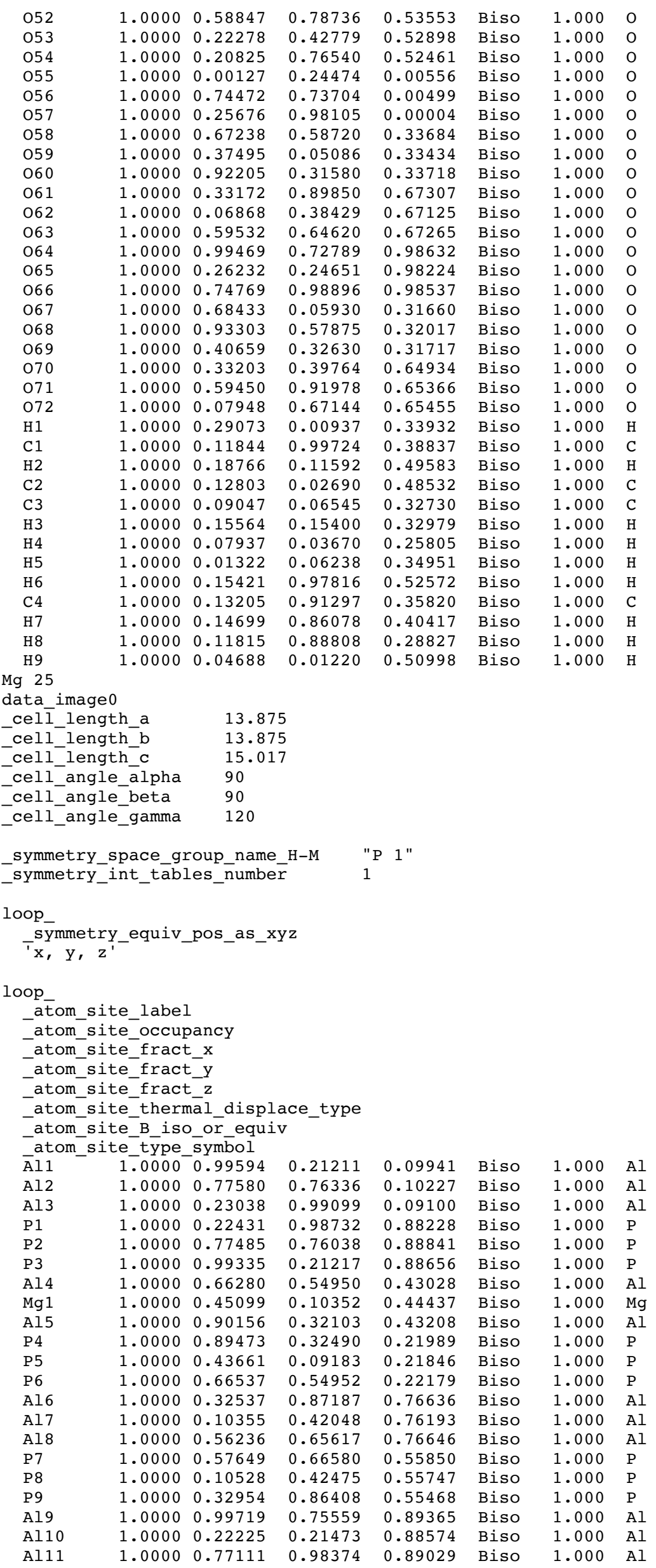




\begin{tabular}{|c|c|c|c|c|c|c|c|}
\hline P 10 & 1.0000 & 0.76977 & 0.98490 & 0.10419 & Biso & 1.000 & $\mathrm{P}$ \\
\hline P11 & 1.0000 & 0.22643 & 0.21718 & 0.09761 & Biso & 1.000 & $\mathrm{P}$ \\
\hline P12 & 1.0000 & 0.00157 & 0.76376 & 0.10539 & Biso & 1.000 & $\mathrm{P}$ \\
\hline Al12 & 1.0000 & 0.67191 & 0.09440 & 0.22957 & Biso & 1.000 & Al \\
\hline Al13 & 1.0000 & 0.89390 & 0.55055 & 0.22719 & Biso & 1.000 & Al \\
\hline Al14 & 1.0000 & 0.43572 & 0.31977 & 0.22427 & Biso & 1.000 & Al \\
\hline P13 & 1.0000 & 0.42685 & 0.32217 & 0.43398 & Biso & 1.000 & $\mathrm{P}$ \\
\hline P14 & 1.0000 & 0.88958 & 0.54398 & 0.43805 & Biso & 1.000 & $\mathrm{P}$ \\
\hline P15 & 1.0000 & 0.67944 & 0.09916 & 0.43187 & Biso & 1.000 & $\mathrm{P}$ \\
\hline Al15 & 1.0000 & 0.34179 & 0.44460 & 0.55629 & Biso & 1.000 & $\mathrm{Al}$ \\
\hline Al16 & 1.0000 & 0.55998 & 0.88410 & 0.56201 & Biso & 1.000 & Al \\
\hline Al1 17 & 1.0000 & 0.09414 & 0.65312 & 0.56399 & Biso & 1.000 & Al \\
\hline P16 & 1.0000 & 0.09940 & 0.65012 & 0.77111 & Biso & 1.000 & $\mathrm{P}$ \\
\hline P 17 & 1.0000 & 0.55626 & 0.88304 & 0.77042 & Biso & 1.000 & $\mathrm{P}$ \\
\hline P18 & 1.0000 & 0.33513 & 0.42985 & 0.76656 & Biso & 1.000 & $\mathrm{P}$ \\
\hline 01 & 1.0000 & 0.89042 & 0.07632 & 0.12488 & Biso & 1.000 & 0 \\
\hline $\mathrm{O} 2$ & 1.0000 & 0.91374 & 0.79779 & 0.12636 & Biso & 1.000 & 0 \\
\hline $\mathrm{O} 3$ & 1.0000 & 0.19994 & 0.09637 & 0.11446 & Biso & 1.000 & 0 \\
\hline $\mathrm{O} 4$ & 1.0000 & 0.10287 & 0.89266 & 0.87206 & Biso & 1.000 & 0 \\
\hline 05 & 1.0000 & 0.80623 & 0.88122 & 0.86635 & Biso & 1.000 & 0 \\
\hline 06 & 1.0000 & 0.08495 & 0.18310 & 0.86705 & Biso & 1.000 & 0 \\
\hline 07 & 1.0000 & 0.54779 & 0.41829 & 0.44529 & Biso & 1.000 & 0 \\
\hline 08 & 1.0000 & 0.60314 & 0.14834 & 0.42910 & Biso & 1.000 & $\mathrm{O}$ \\
\hline 09 & 1.0000 & 0.87070 & 0.42660 & 0.45689 & Biso & 1.000 & 0 \\
\hline 010 & 1.0000 & 0.77246 & 0.23292 & 0.20522 & Biso & 1.000 & 0 \\
\hline 011 & 1.0000 & 0.46873 & 0.21327 & 0.20427 & Biso & 1.000 & 0 \\
\hline 012 & 1.0000 & 0.75682 & 0.51906 & 0.20670 & Biso & 1.000 & 0 \\
\hline 013 & 1.0000 & 0.22075 & 0.73648 & 0.79494 & Biso & 1.000 & 0 \\
\hline 014 & 1.0000 & 0.24227 & 0.45787 & 0.78432 & Biso & 1.000 & $\mathrm{O}$ \\
\hline 015 & 1.0000 & 0.52827 & 0.76101 & 0.77889 & Biso & 1.000 & $\mathrm{O}$ \\
\hline 016 & 1.0000 & 0.45400 & 0.57910 & 0.53904 & Biso & 1.000 & 0 \\
\hline 017 & 1.0000 & 0.10920 & 0.53678 & 0.55591 & Biso & 1.000 & 0 \\
\hline 018 & 1.0000 & 0.41559 & 0.82401 & 0.54704 & Biso & 1.000 & 0 \\
\hline 019 & 1.0000 & 0.97374 & 0.30575 & 0.16063 & Biso & 1.000 & 0 \\
\hline 020 & 1.0000 & 0.68165 & 0.64347 & 0.15895 & Biso & 1.000 & $\mathrm{O}$ \\
\hline 021 & 1.0000 & 0.34709 & 0.01326 & 0.15353 & Biso & 1.000 & 0 \\
\hline 022 & 1.0000 & 0.30207 & 0.96950 & 0.82124 & Biso & 1.000 & 0 \\
\hline 023 & 1.0000 & 0.67044 & 0.67760 & 0.83746 & Biso & 1.000 & 0 \\
\hline 024 & 1.0000 & 0.01307 & 0.31423 & 0.83289 & Biso & 1.000 & 0 \\
\hline 025 & 1.0000 & 0.65498 & 0.64714 & 0.49832 & Biso & 1.000 & 0 \\
\hline 026 & 1.0000 & 0.36068 & 0.96430 & 0.49713 & Biso & 1.000 & 0 \\
\hline 027 & 1.0000 & 0.01997 & 0.34409 & 0.49039 & Biso & 1.000 & 0 \\
\hline 028 & 1.0000 & 0.01938 & 0.65910 & 0.83673 & Biso & 1.000 & $\mathrm{O}$ \\
\hline 029 & 1.0000 & 0.31472 & 0.32784 & 0.82134 & Biso & 1.000 & 0 \\
\hline 030 & 1.0000 & 0.65209 & 0.95817 & 0.83288 & Biso & 1.000 & 0 \\
\hline 031 & 1.0000 & 0.68585 & 0.00579 & 0.15472 & Biso & 1.000 & 0 \\
\hline 032 & 1.0000 & 0.32686 & 0.29829 & 0.15358 & Biso & 1.000 & $\mathrm{O}$ \\
\hline 033 & 1.0000 & 0.98647 & 0.66867 & 0.16638 & Biso & 1.000 & 0 \\
\hline 034 & 1.0000 & 0.34709 & 0.34963 & 0.48457 & Biso & 1.000 & 0 \\
\hline 035 & 1.0000 & 0.98105 & 0.63102 & 0.49842 & Biso & 1.000 & 0 \\
\hline 036 & 1.0000 & 0.63838 & 0.99990 & 0.49588 & Biso & 1.000 & 0 \\
\hline 037 & 1.0000 & 0.12524 & 0.22643 & 0.12615 & Biso & 1.000 & 0 \\
\hline 038 & 1.0000 & 0.75549 & 0.87276 & 0.13437 & Biso & 1.000 & 0 \\
\hline 039 & 1.0000 & 0.11771 & 0.86414 & 0.12362 & Biso & 1.000 & 0 \\
\hline 040 & 1.0000 & 0.23195 & 0.09799 & 0.85750 & Biso & 1.000 & 0 \\
\hline 041 & 1.0000 & 0.87100 & 0.74254 & 0.86019 & Biso & 1.000 & 0 \\
\hline 042 & 1.0000 & 0.88080 & 0.11341 & 0.85896 & Biso & 1.000 & 0 \\
\hline 043 & 1.0000 & 0.78172 & 0.54428 & 0.45788 & Biso & 1.000 & 0 \\
\hline 044 & 1.0000 & 0.41517 & 0.21493 & 0.46868 & Biso & 1.000 & 0 \\
\hline 045 & 1.0000 & 0.79704 & 0.18839 & 0.46259 & Biso & 1.000 & 0 \\
\hline 046 & 1.0000 & 0.90682 & 0.43726 & 0.19351 & Biso & 1.000 & 0 \\
\hline 047 & 1.0000 & 0.53804 & 0.07794 & 0.21497 & Biso & 1.000 & 0 \\
\hline 048 & 1.0000 & 0.55247 & 0.44715 & 0.20023 & Biso & 1.000 & 0 \\
\hline 049 & 1.0000 & 0.45404 & 0.89044 & 0.79908 & Biso & 1.000 & 0 \\
\hline 050 & 1.0000 & 0.08406 & 0.53342 & 0.77922 & Biso & 1.000 & 0 \\
\hline 051 & 1.0000 & 0.44668 & 0.52912 & 0.79548 & Biso & 1.000 & 0 \\
\hline 052 & 1.0000 & 0.59597 & 0.78259 & 0.53922 & Biso & 1.000 & 0 \\
\hline 053 & 1.0000 & 0.22001 & 0.44456 & 0.53094 & Biso & 1.000 & 0 \\
\hline 054 & 1.0000 & 0.21496 & 0.76783 & 0.52486 & Biso & 1.000 & 0 \\
\hline 055 & 1.0000 & 0.99282 & 0.23812 & 0.98605 & Biso & 1.000 & 0 \\
\hline 056 & 1.0000 & 0.75167 & 0.73817 & 0.98851 & Biso & 1.000 & 0 \\
\hline 057 & 1.0000 & 0.26289 & 0.99142 & 0.97934 & Biso & 1.000 & 0 \\
\hline 058 & 1.0000 & 0.66904 & 0.58858 & 0.31821 & Biso & 1.000 & 0 \\
\hline 059 & 1.0000 & 0.38437 & 0.05487 & 0.31646 & Biso & 1.000 & 0 \\
\hline 060 & 1.0000 & 0.92838 & 0.32621 & 0.31748 & Biso & 1.000 & 0 \\
\hline 061 & 1.0000 & 0.32160 & 0.89250 & 0.65301 & Biso & 1.000 & 0 \\
\hline 062 & 1.0000 & 0.07304 & 0.37349 & 0.65153 & Biso & 1.000 & 0 \\
\hline 063 & 1.0000 & 0.60402 & 0.65576 & 0.65640 & Biso & 1.000 & 0 \\
\hline 064 & 1.0000 & 0.99268 & 0.72702 & 0.00783 & Biso & 1.000 & 0 \\
\hline 065 & 1.0000 & 0.25399 & 0.24710 & 0.99883 & Biso & 1.000 & 0 \\
\hline
\end{tabular}




\begin{tabular}{|c|c|c|c|c|c|c|}
\hline 066 & 1.0000 & 0.74574 & 0.98276 & 0.00426 & Biso & 1.000 \\
\hline 067 & 1.0000 & 0.68824 & 0.05783 & 0.33731 & Biso & 1.000 \\
\hline 068 & 1.0000 & 0.92526 & 0.57708 & 0.34039 & Biso & 1.000 \\
\hline 069 & 1.0000 & 0.39379 & 0.31204 & 0.33406 & Biso & 1.000 \\
\hline 070 & 1.0000 & 0.33884 & 0.40407 & 0.66741 & Biso & 1.000 \\
\hline 071 & 1.0000 & 0.59040 & 0.92472 & 0.67437 & Biso & 1.000 \\
\hline 072 & 1.0000 & 0.07105 & 0.67090 & 0.67632 & Biso & 1.000 \\
\hline H 1 & 1.0000 & 0.29874 & 0.01330 & 0.32232 & Biso & 1.000 \\
\hline $\mathrm{C} 1$ & 1.0000 & 0.13014 & 0.99736 & 0.38498 & Biso & 1.000 \\
\hline H2 & 1.0000 & 0.19312 & 0.11376 & 0.49420 & Biso & 1.000 \\
\hline $\mathrm{C} 2$ & 1.0000 & 0.14227 & 0.02358 & 0.48256 & Biso & 1.000 \\
\hline $\mathrm{C} 3$ & 1.0000 & 0.09083 & 0.06062 & 0.32916 & Biso & 1.000 \\
\hline H3 & 1.0000 & 0.15125 & 0.15063 & 0.33178 & Biso & 1.000 \\
\hline H4 & 1.0000 & 0.07698 & 0.03363 & 0.25940 & Biso & 1.000 \\
\hline H5 & 1.0000 & 0.01250 & 0.05043 & 0.35650 & Biso & 1.000 \\
\hline H6 & 1.0000 & 0.17952 & 0.98157 & 0.51869 & Biso & 1.000 \\
\hline C4 & 1.0000 & 0.15083 & 0.91947 & 0.34996 & Biso & 1.000 \\
\hline H7 & 1.0000 & 0.17310 & 0.86998 & 0.39287 & Biso & 1.000 \\
\hline H8 & 1.0000 & 0.13109 & 0.89375 & 0.28050 & Biso & 1.000 \\
\hline H9 & 1.0000 & 0.05937 & 0.99714 & 0.51097 & Biso & 1.000 \\
\hline
\end{tabular}

Al 25

data image 0

$\begin{array}{ll}\text { _cel-_length_a } & 13.625 \\ \text {-cell_length_b } & 13.625 \\ \text {-cell_length_c } & 15.067 \\ \text {-cell_angle_alpha } & 90 \\ \text { _cell_angle_beta } & 90 \\ \text { _cell_angle_gamma } & 120\end{array}$

_symmetry_space_group_name_H-M "P 1"

_symmetry_int_tables_number 1

loop

-symmetry_equiv_pos_as_xyz

' $\mathrm{x}, \mathrm{y}, \mathrm{z}$ '

loop

_atom_site_label

atom site occupancy

-atom_site_fract_x

-atom_site_fract_y

atom site fract $z$

-atom_site_thermal_displace_type

-atom_site_B_iso_or_equiv

atom site type symbol

\begin{tabular}{|c|c|c|c|c|c|c|c|}
\hline Sil & 1.0000 & 0.00961 & 0.22543 & 0.09719 & Biso & 1.000 & $\mathrm{Si}$ \\
\hline $\mathrm{Si} 2$ & 1.0000 & 0.78206 & 0.76997 & 0.09929 & Biso & 1.000 & $\mathrm{Si}$ \\
\hline $\mathrm{Si3}$ & 1.0000 & 0.24051 & 0.99677 & 0.09127 & Biso & 1.000 & $\mathrm{Si}$ \\
\hline i4 & 1.0000 & 0.23578 & 0.99372 & 0.88594 & Biso & 1.000 & $\mathrm{Si}$ \\
\hline & 1.0000 & 0.77992 & 0.76708 & 0.89144 & Biso & 1.000 & $\mathrm{Si}$ \\
\hline & 1.0000 & 0.00721 & 0.22557 & 0.89084 & Biso & 1.000 & $\mathrm{Si}$ \\
\hline i 7 & 1.0000 & 0.67545 & 0.56138 & 0.42890 & Biso & 1.000 & $\mathrm{Si}$ \\
\hline 11 & 1.0000 & 0.44997 & 0.10565 & 0.43649 & Biso & 1.000 & Al \\
\hline & 1.0000 & 0.90872 & 0.32731 & 0.43072 & Biso & 1.000 & $\mathrm{Si}$ \\
\hline & 1.0000 & 0.90549 & 0.33011 & 0.22348 & Biso & 1.000 & $\mathrm{Si}$ \\
\hline 10 & 1.0000 & 0.44470 & 0.09941 & 0.22125 & Biso & 1.000 & $\mathrm{Si}$ \\
\hline i 11 & 1.0000 & 0.67755 & 0.56081 & 0.22532 & Biso & 1.000 & $\mathrm{Si}$ \\
\hline i 12 & 1.0000 & 0.33943 & 0.88501 & 0.76624 & Biso & 1.000 & $\mathrm{Si}$ \\
\hline$i 13$ & 1.0000 & 0.10999 & 0.42884 & 0.76079 & Biso & 1.000 & $\mathrm{Si}$ \\
\hline 14 & 1.0000 & 0.57277 & 0.66154 & 0.76373 & Biso & 1.000 & $\mathrm{Si}$ \\
\hline i 15 & 1.0000 & 0.58294 & 0.66861 & 0.56028 & Biso & 1.000 & $\mathrm{Si}$ \\
\hline i 16 & 1.0000 & 0.11048 & 0.43158 & 0.55934 & Biso & 1.000 & $\mathrm{Si}$ \\
\hline$i 17$ & 1.0000 & 0.34195 & 0.88138 & 0.55790 & Biso & 1.000 & $\mathrm{Si}$ \\
\hline i 18 & 1.0000 & 0.00574 & 0.76191 & 0.89184 & Biso & 1.000 & $\mathrm{Si}$ \\
\hline i 19 & 1.0000 & 0.23695 & 0.22447 & 0.88681 & Biso & 1.000 & $\mathrm{Si}$ \\
\hline$i 20$ & 1.0000 & 0.78014 & 0.99509 & 0.88990 & Biso & 1.000 & $\mathrm{Si}$ \\
\hline$i 21$ & 1.0000 & 0.77957 & 0.99618 & 0.09754 & Biso & 1.000 & $\mathrm{Si}$ \\
\hline$i 22$ & 1.0000 & 0.24075 & 0.22690 & 0.09294 & Biso & 1.000 & $\mathrm{Si}$ \\
\hline 23 & 1.0000 & 0.00975 & 0.76801 & 0.09854 & Biso & 1.000 & $\mathrm{Si}$ \\
\hline$i 24$ & 1.0000 & 0.67920 & 0.09955 & 0.22697 & Biso & 1.000 & $\mathrm{Si}$ \\
\hline$i 25$ & 1.0000 & 0.90844 & 0.55997 & 0.22649 & Biso & 1.000 & $\mathrm{Si}$ \\
\hline$i 26$ & 1.0000 & 0.44703 & 0.33114 & 0.22319 & Biso & 1.000 & $\mathrm{Si}$ \\
\hline$i 27$ & 1.0000 & 0.44035 & 0.33299 & 0.42878 & Biso & 1.000 & $\mathrm{Si}$ \\
\hline i28 & 1.0000 & 0.90515 & 0.55607 & 0.43163 & Biso & 1.000 & $\mathrm{Si}$ \\
\hline i29 & 1.0000 & 0.68037 & 0.10203 & 0.42648 & Biso & 1.000 & $\mathrm{Si}$ \\
\hline & 1.0000 & 0.34655 & 0.44443 & 0.55547 & Biso & 1.000 & $\mathrm{Si}$ \\
\hline & 1.0000 & 0.57210 & 0.89262 & 0.55989 & Biso & 1.000 & $\mathrm{Si}$ \\
\hline & 1.0000 & 0.10620 & 0.66429 & 0.56131 & Biso & 1.000 & $\mathrm{Si}$ \\
\hline i33 & 1.0000 & 0.10960 & 0.66162 & 0.76505 & Biso & 1.000 & $\mathrm{Si}$ \\
\hline i34 & 1.0000 & 0.57073 & 0.89256 & 0.76391 & Biso & 1.000 & $\mathrm{Si}$ \\
\hline
\end{tabular}




\begin{tabular}{|c|c|c|c|c|c|c|c|}
\hline Si35 & 1.0000 & 0.34172 & 0.43369 & 0.76077 & Biso & 1.000 & $\mathrm{Si}$ \\
\hline 01 & 1.0000 & 0.91074 & 0.09465 & 0.11470 & Biso & 1.000 & 0 \\
\hline $\mathrm{O} 2$ & 1.0000 & 0.91372 & 0.80373 & 0.11622 & Biso & 1.000 & 0 \\
\hline 03 & 1.0000 & 0.20915 & 0.09568 & 0.10918 & Biso & 1.000 & 0 \\
\hline O4 & 1.0000 & 0.10532 & 0.89208 & 0.87330 & Biso & 1.000 & 0 \\
\hline 05 & 1.0000 & 0.81445 & 0.89810 & 0.87169 & Biso & 1.000 & 0 \\
\hline 06 & 1.0000 & 0.10605 & 0.19375 & 0.87405 & Biso & 1.000 & 0 \\
\hline 07 & 1.0000 & 0.57060 & 0.43434 & 0.44405 & Biso & 1.000 & 0 \\
\hline 08 & 1.0000 & 0.58971 & 0.14421 & 0.42336 & Biso & 1.000 & 0 \\
\hline 09 & 1.0000 & 0.87909 & 0.42747 & 0.45035 & Biso & 1.000 & 0 \\
\hline 010 & 1.0000 & 0.77375 & 0.23170 & 0.20775 & Biso & 1.000 & 0 \\
\hline 011 & 1.0000 & 0.47909 & 0.23078 & 0.21043 & Biso & 1.000 & 0 \\
\hline 012 & 1.0000 & 0.77754 & 0.52942 & 0.21371 & Biso & 1.000 & 0 \\
\hline 013 & 1.0000 & 0.23986 & 0.75609 & 0.78932 & Biso & 1.000 & 0 \\
\hline 014 & 1.0000 & 0.24193 & 0.46453 & 0.77785 & Biso & 1.000 & 0 \\
\hline 015 & 1.0000 & 0.54123 & 0.76151 & 0.77316 & Biso & 1.000 & 0 \\
\hline 016 & 1.0000 & 0.45122 & 0.57321 & 0.54231 & Biso & 1.000 & 0 \\
\hline 017 & 1.0000 & 0.12544 & 0.55678 & 0.55335 & Biso & 1.000 & 0 \\
\hline 018 & 1.0000 & 0.43641 & 0.84128 & 0.54602 & Biso & 1.000 & 0 \\
\hline 019 & 1.0000 & 0.99087 & 0.31023 & 0.16089 & Biso & 1.000 & 0 \\
\hline $\mathrm{O} 20$ & 1.0000 & 0.69701 & 0.66241 & 0.15919 & Biso & 1.000 & 0 \\
\hline $\mathrm{O} 21$ & 1.0000 & 0.34778 & 0.01736 & 0.15215 & Biso & 1.000 & 0 \\
\hline 022 & 1.0000 & 0.32120 & 0.97611 & 0.82263 & Biso & 1.000 & 0 \\
\hline $\mathrm{O} 23$ & 1.0000 & 0.67180 & 0.68041 & 0.83265 & Biso & 1.000 & 0 \\
\hline $\mathrm{O} 24$ & 1.0000 & 0.02693 & 0.33103 & 0.82936 & Biso & 1.000 & 0 \\
\hline 025 & 1.0000 & 0.66729 & 0.65057 & 0.49525 & Biso & 1.000 & 0 \\
\hline 026 & 1.0000 & 0.36895 & 0.98854 & 0.49906 & Biso & 1.000 & 0 \\
\hline $\mathrm{O} 27$ & 1.0000 & 0.01613 & 0.34596 & 0.48980 & Biso & 1.000 & 0 \\
\hline 028 & 1.0000 & 0.02308 & 0.67282 & 0.83255 & Biso & 1.000 & 0 \\
\hline 029 & 1.0000 & 0.32101 & 0.32704 & 0.82201 & Biso & 1.000 & 0 \\
\hline 030 & 1.0000 & 0.67395 & 0.97449 & 0.82908 & Biso & 1.000 & 0 \\
\hline 031 & 1.0000 & 0.69207 & 0.01791 & 0.15543 & Biso & 1.000 & 0 \\
\hline 032 & 1.0000 & 0.34640 & 0.31109 & 0.15524 & Biso & 1.000 & 0 \\
\hline 033 & 1.0000 & 0.99223 & 0.66647 & 0.16416 & Biso & 1.000 & 0 \\
\hline 034 & 1.0000 & 0.35482 & 0.35817 & 0.48673 & Biso & 1.000 & 0 \\
\hline 035 & 1.0000 & 0.00224 & 0.64603 & 0.49795 & Biso & 1.000 & 0 \\
\hline 036 & 1.0000 & 0.64681 & 0.99699 & 0.49379 & Biso & 1.000 & 0 \\
\hline 037 & 1.0000 & 0.13155 & 0.23763 & 0.12042 & Biso & 1.000 & 0 \\
\hline 038 & 1.0000 & 0.76724 & 0.87641 & 0.12781 & Biso & 1.000 & 0 \\
\hline 039 & 1.0000 & 0.13309 & 0.87668 & 0.12067 & Biso & 1.000 & 0 \\
\hline 040 & 1.0000 & 0.24488 & 0.11338 & 0.86082 & Biso & 1.000 & 0 \\
\hline 041 & 1.0000 & 0.88570 & 0.75056 & 0.86462 & Biso & 1.000 & 0 \\
\hline 042 & 1.0000 & 0.88677 & 0.11723 & 0.86405 & Biso & 1.000 & 0 \\
\hline 043 & 1.0000 & 0.79171 & 0.56183 & 0.45030 & Biso & 1.000 & 0 \\
\hline 044 & 1.0000 & 0.42604 & 0.21468 & 0.45836 & Biso & 1.000 & 0 \\
\hline 045 & 1.0000 & 0.80336 & 0.20531 & 0.45795 & Biso & 1.000 & 0 \\
\hline 046 & 1.0000 & 0.91853 & 0.45121 & 0.19638 & Biso & 1.000 & 0 \\
\hline 047 & 1.0000 & 0.55364 & 0.08441 & 0.21362 & Biso & 1.000 & 0 \\
\hline 048 & 1.0000 & 0.55828 & 0.45033 & 0.19858 & Biso & 1.000 & 0 \\
\hline 049 & 1.0000 & 0.46037 & 0.89920 & 0.79487 & Biso & 1.000 & 0 \\
\hline 050 & 1.0000 & 0.09479 & 0.53739 & 0.77781 & Biso & 1.000 & 0 \\
\hline 051 & 1.0000 & 0.46177 & 0.54193 & 0.78885 & Biso & 1.000 & 0 \\
\hline 052 & 1.0000 & 0.60103 & 0.79300 & 0.53947 & Biso & 1.000 & 0 \\
\hline 053 & 1.0000 & 0.23035 & 0.44324 & 0.53290 & Biso & 1.000 & 0 \\
\hline 054 & 1.0000 & 0.21933 & 0.77629 & 0.52765 & Biso & 1.000 & 0 \\
\hline 055 & 1.0000 & 0.00699 & 0.26017 & 0.99428 & Biso & 1.000 & 0 \\
\hline 056 & 1.0000 & 0.74835 & 0.73729 & 0.99574 & Biso & 1.000 & 0 \\
\hline 057 & 1.0000 & 0.27472 & 0.99570 & 0.98862 & Biso & 1.000 & 0 \\
\hline 058 & 1.0000 & 0.67543 & 0.60105 & 0.32664 & Biso & 1.000 & 0 \\
\hline 059 & 1.0000 & 0.38632 & 0.05481 & 0.32281 & Biso & 1.000 & 0 \\
\hline 060 & 1.0000 & 0.94153 & 0.33017 & 0.32628 & Biso & 1.000 & 0 \\
\hline 061 & 1.0000 & 0.33653 & 0.91107 & 0.66207 & Biso & 1.000 & 0 \\
\hline 062 & 1.0000 & 0.07328 & 0.38163 & 0.65975 & Biso & 1.000 & 0 \\
\hline 063 & 1.0000 & 0.61569 & 0.65978 & 0.66308 & Biso & 1.000 & 0 \\
\hline 064 & 1.0000 & 0.00532 & 0.72914 & 0.99599 & Biso & 1.000 & 0 \\
\hline 065 & 1.0000 & 0.27574 & 0.26153 & 0.98960 & Biso & 1.000 & 0 \\
\hline 066 & 1.0000 & 0.74609 & 0.99289 & 0.99366 & Biso & 1.000 & 0 \\
\hline 067 & 1.0000 & 0.69358 & 0.06166 & 0.32614 & Biso & 1.000 & 0 \\
\hline 068 & 1.0000 & 0.94788 & 0.59279 & 0.32941 & Biso & 1.000 & 0 \\
\hline 069 & 1.0000 & 0.40557 & 0.33115 & 0.32394 & Biso & 1.000 & 0 \\
\hline 070 & 1.0000 & 0.34413 & 0.40143 & 0.65703 & Biso & 1.000 & 0 \\
\hline 071 & 1.0000 & 0.60644 & 0.93671 & 0.66225 & Biso & 1.000 & 0 \\
\hline 072 & 1.0000 & 0.07789 & 0.67890 & 0.66406 & Biso & 1.000 & 0 \\
\hline $\mathrm{H} 1$ & 1.0000 & 0.29987 & 0.01230 & 0.32750 & Biso & 1.000 & $\mathrm{H}$ \\
\hline $\mathrm{C} 1$ & 1.0000 & 0.12551 & 0.00089 & 0.38236 & Biso & 1.000 & $\mathrm{C}$ \\
\hline $\mathrm{H} 2$ & 1.0000 & 0.19223 & 0.11899 & 0.49132 & Biso & 1.000 & $\mathrm{H}$ \\
\hline $\mathrm{C} 2$ & 1.0000 & 0.13397 & 0.02810 & 0.47945 & Biso & 1.000 & $\mathrm{C}$ \\
\hline C3 & 1.0000 & 0.09354 & 0.06923 & 0.32339 & Biso & 1.000 & C \\
\hline H3 & 1.0000 & 0.15670 & 0.16026 & 0.32823 & Biso & 1.000 & $\mathrm{H}$ \\
\hline H4 & 1.0000 & 0.08468 & 0.04310 & 0.25363 & Biso & 1.000 & $\mathrm{H}$ \\
\hline
\end{tabular}




$\begin{array}{clllllll}\text { H5 } & 1.0000 & 0.01259 & 0.06087 & 0.34567 & \text { Biso } & 1.000 & \mathrm{H} \\ \text { H6 } & 1.0000 & 0.16287 & 0.97937 & 0.51843 & \text { Biso } & 1.000 & \mathrm{H} \\ \text { C4 } & 1.0000 & 0.14320 & 0.91818 & 0.35029 & \text { Biso } & 1.000 & \mathrm{C} \\ \mathrm{H} 7 & 1.0000 & 0.16009 & 0.86523 & 0.39504 & \text { Biso } & 1.000 & \mathrm{H} \\ \mathrm{H} 8 & 1.0000 & 0.12806 & 0.89348 & 0.28048 & \text { Biso } & 1.000 & \mathrm{H} \\ \mathrm{H} 9 & 1.0000 & 0.05018 & 0.00949 & 0.50419 & \text { Biso } & 1.000 & \mathrm{H} \\ \mathrm{Ge} & & & & & & \end{array}$

data_image 0

celīlength_a 13.875

cell-length_b 13.875

_cell_length_c 15.017

_cell_angle_àlpha 90

cell angle beta 90

_cell_angle_gamma 120

symmetry_space_group name_H-M "P 1"

_symmetry_int_tables_number 1

loop_

symmetry_equiv_pos_as_xyz

' $\mathrm{x}, \mathrm{y}, \mathrm{z}$ '

loop

atom_site label

-atom_site_occupancy

-atom_site_fract_x

-atom_site_fract_y

-atom_site_fract_z

_atom_site_thermal_displace_type

-atom_site_B_iso_or_equiv

-atom_site_type_symbol

\begin{tabular}{|c|c|c|c|c|c|c|c|}
\hline$\overline{\mathrm{P}} 1$ & 1.0000 & 0.00274 & 0.21378 & 0.10309 & Biso & 1.000 & P \\
\hline P2 & 1.0000 & 0.77287 & 0.76477 & 0.10581 & Biso & 1.000 & $P$ \\
\hline P3 & 1.0000 & 0.22592 & 0.98403 & 0.09538 & Biso & 1.000 & $\mathrm{P}$ \\
\hline Al1 & 1.0000 & 0.21988 & 0.97933 & 0.88362 & Biso & 1.000 & Al \\
\hline Al2 & 1.0000 & 0.76957 & 0.76109 & 0.89239 & Biso & 1.000 & $\mathrm{Al}$ \\
\hline Al3 & 1.0000 & 0.99864 & 0.21373 & 0.89107 & Biso & 1.000 & Al \\
\hline P4 & 1.0000 & 0.66979 & 0.55231 & 0.43424 & Biso & 1.000 & $\mathrm{P}$ \\
\hline Ge1 & 1.0000 & 0.43419 & 0.10075 & 0.44460 & Biso & 1.000 & $\mathrm{Ge}$ \\
\hline P5 & 1.0000 & 0.89600 & 0.31527 & 0.43500 & Biso & 1.000 & $\mathrm{P}$ \\
\hline Al4 & 1.0000 & 0.89207 & 0.31754 & 0.22351 & Biso & 1.000 & Al \\
\hline Al5 & 1.0000 & 0.43484 & 0.09353 & 0.22085 & Biso & 1.000 & Al \\
\hline Al6 & 1.0000 & 0.67124 & 0.55117 & 0.22596 & Biso & 1.000 & Al \\
\hline P6 & 1.0000 & 0.33051 & 0.86974 & 0.77530 & Biso & 1.000 & $\mathrm{P}$ \\
\hline P7 & 1.0000 & 0.09976 & 0.42135 & 0.76608 & Biso & 1.000 & $\mathrm{P}$ \\
\hline P8 & 1.0000 & 0.55855 & 0.64791 & 0.76937 & Biso & 1.000 & $\mathrm{P}$ \\
\hline Al 7 & 1.0000 & 0.57241 & 0.65987 & 0.56254 & Biso & 1.000 & Al \\
\hline Al8 & 1.0000 & 0.09745 & 0.42311 & 0.56219 & Biso & 1.000 & Al \\
\hline A19 & 1.0000 & 0.33391 & 0.86548 & 0.56002 & Biso & 1.000 & Al \\
\hline P9 & 1.0000 & 0.99050 & 0.75220 & 0.88763 & Biso & 1.000 & $\mathrm{P}$ \\
\hline P10 & 1.0000 & 0.22403 & 0.20951 & 0.88123 & Biso & 1.000 & $P$ \\
\hline P11 & 1.0000 & 0.77354 & 0.98839 & 0.88654 & Biso & 1.000 & $\mathrm{P}$ \\
\hline Al10 & 1.0000 & 0.77417 & 0.99010 & 0.09987 & Biso & 1.000 & Al \\
\hline A111 & 1.0000 & 0.23080 & 0.21477 & 0.09243 & Biso & 1.000 & Al \\
\hline Al1 12 & 1.0000 & 0.99663 & 0.75989 & 0.10063 & Biso & 1.000 & Al \\
\hline P12 & 1.0000 & 0.66577 & 0.09113 & 0.22306 & Biso & 1.000 & $\mathrm{P}$ \\
\hline P13 & 1.0000 & 0.89747 & 0.54696 & 0.22274 & Biso & 1.000 & P \\
\hline P14 & 1.0000 & 0.44117 & 0.32372 & 0.21855 & Biso & 1.000 & $\mathrm{P}$ \\
\hline Al13 & 1.0000 & 0.43212 & 0.33042 & 0.42939 & Biso & 1.000 & Al \\
\hline Al1 14 & 1.0000 & 0.89461 & 0.54399 & 0.43362 & Biso & 1.000 & Al \\
\hline Al15 & 1.0000 & 0.66628 & 0.09463 & 0.42764 & Biso & 1.000 & Al \\
\hline P15 & 1.0000 & 0.33385 & 0.44319 & 0.55101 & Biso & 1.000 & $\mathrm{P}$ \\
\hline P16 & 1.0000 & 0.56267 & 0.88140 & 0.55792 & Biso & 1.000 & $\mathrm{P}$ \\
\hline P 17 & 1.0000 & 0.09704 & 0.65715 & 0.56058 & Biso & 1.000 & $\mathrm{P}$ \\
\hline Al16 & 1.0000 & 0.10066 & 0.65406 & 0.76728 & Biso & 1.000 & Al \\
\hline Al17 & 1.0000 & 0.55751 & 0.87777 & 0.76731 & Biso & 1.000 & Al \\
\hline Al18 & 1.0000 & 0.32737 & 0.42388 & 0.75976 & Biso & 1.000 & Al \\
\hline 01 & 1.0000 & 0.91228 & 0.09262 & 0.12323 & Biso & 1.000 & 0 \\
\hline $\mathrm{O} 2$ & 1.0000 & 0.89424 & 0.79503 & 0.12474 & Biso & 1.000 & 0 \\
\hline 03 & 1.0000 & 0.19801 & 0.07684 & 0.11310 & Biso & 1.000 & 0 \\
\hline 04 & 1.0000 & 0.08345 & 0.87125 & 0.86463 & Biso & 1.000 & 0 \\
\hline 05 & 1.0000 & 0.80491 & 0.89835 & 0.86684 & Biso & 1.000 & 0 \\
\hline 06 & 1.0000 & 0.10221 & 0.18018 & 0.86811 & Biso & 1.000 & 0 \\
\hline 07 & 1.0000 & 0.57025 & 0.43474 & 0.44702 & Biso & 1.000 & 0 \\
\hline 08 & 1.0000 & 0.57385 & 0.14422 & 0.42436 & Biso & 1.000 & 0 \\
\hline 09 & 1.0000 & 0.87103 & 0.40965 & 0.45526 & Biso & 1.000 & 0 \\
\hline 010 & 1.0000 & 0.75298 & 0.21408 & 0.20445 & Biso & 1.000 & o \\
\hline 011 & 1.0000 & 0.47301 & 0.23266 & 0.20467 & Biso & 1.000 & 0 \\
\hline 012 & 1.0000 & 0.77591 & 0.51770 & 0.20772 & Biso & 1.000 & 0 \\
\hline 013 & 1.0000 & 0.23593 & 0.75253 & 0.80135 & Biso & 1.000 & 0 \\
\hline
\end{tabular}




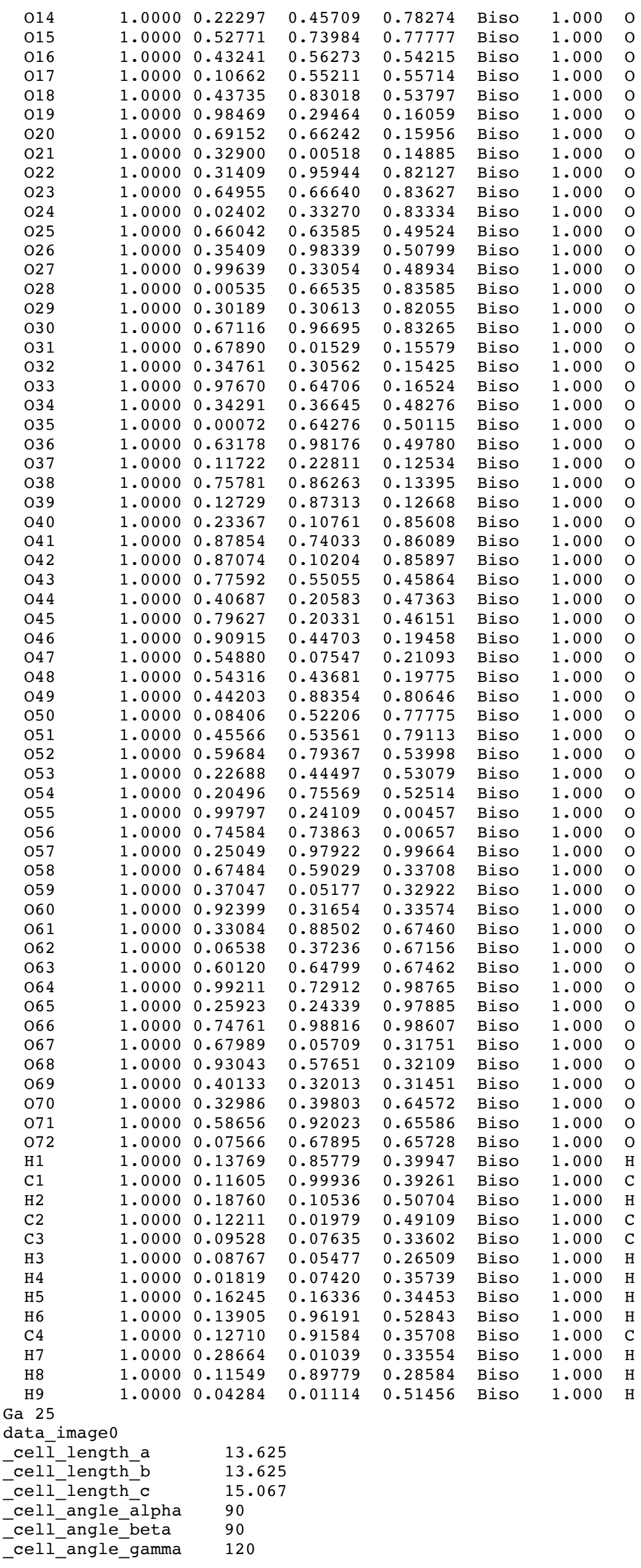




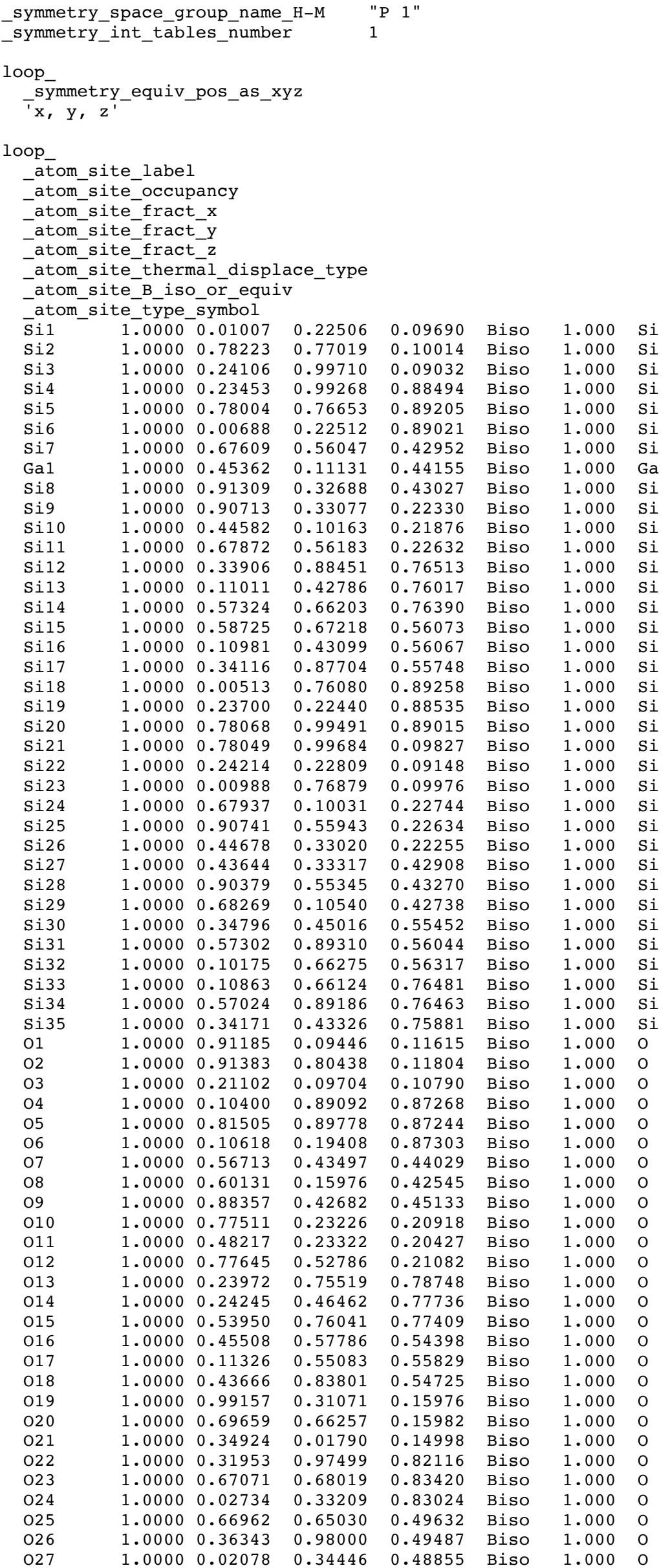




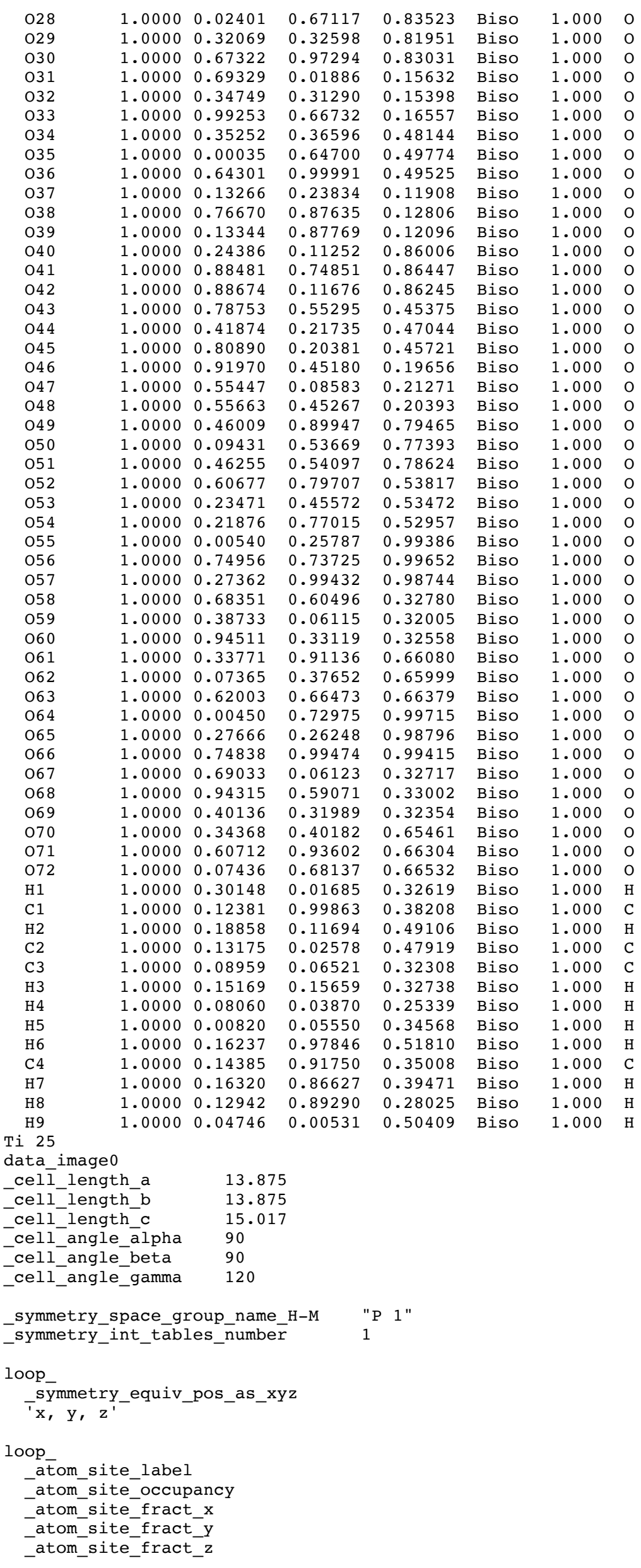




\begin{tabular}{|c|c|c|c|c|c|c|c|}
\hline$\overline{\mathrm{P}} 1$ & 1.0000 & 0.00628 & 0.21533 & 0.10277 & Biso & 1.000 & $\mathrm{P}$ \\
\hline P2 & 1.0000 & 0.77762 & 0.76768 & 0.10725 & Biso & 1.000 & $P$ \\
\hline P3 & 1.0000 & 0.22967 & 0.98540 & 0.09223 & Biso & 1.000 & P \\
\hline Al1 & 1.0000 & 0.21937 & 0.97838 & 0.87936 & Biso & 1.000 & $\mathrm{Al}$ \\
\hline Al2 & 1.0000 & 0.77165 & 0.76196 & 0.89358 & Biso & 1.000 & \\
\hline Al3 & 1.0000 & 0.00040 & 0.21403 & 0.89060 & Biso & 1.000 & \\
\hline P4 & 1.0000 & 0.67253 & 0.55473 & 0.43477 & Biso & 1.000 & ? \\
\hline Til & 1.0000 & 0.43108 & 0.09926 & 0.44356 & Biso & 1.000 & \\
\hline P5 & 1.0000 & 0.90287 & 0.31800 & 0.43443 & Biso & 1.000 & P \\
\hline Al4 & 1.0000 & 0.89698 & 0.32015 & 0.22317 & Biso & 1.000 & \\
\hline Al5 & 1.0000 & 0.43657 & 0.09385 & 0.21758 & Biso & 1.000 & \\
\hline Al6 & 1.0000 & 0.67493 & 0.55274 & 0.22659 & Biso & 1.000 & \\
\hline P6 & 1.0000 & 0.33130 & 0.86603 & 0.77813 & Biso & 1.000 & \\
\hline P7 & 1.0000 & 0.10188 & 0.42120 & 0.76566 & Biso & 1.000 & P \\
\hline P8 & 1.0000 & 0.56126 & 0.64818 & 0.77020 & Biso & 1.000 & \\
\hline Al 7 & 1.0000 & 0.58010 & 0.66343 & 0.56457 & Biso & 1.000 & \\
\hline Al8 & 1.0000 & 0.10037 & 0.42531 & 0.56357 & Biso & 1.000 & \\
\hline Al9 & 1.0000 & 0.33522 & 0.86122 & 0.56198 & Biso & 1.000 & \\
\hline P9 & 1.0000 & 0.99147 & 0.75179 & 0.88686 & Biso & 1.000 & \\
\hline P10 & 1.0000 & 0.22551 & 0.20918 & 0.87892 & Biso & 1.000 & \\
\hline P11 & 1.0000 & 0.77593 & 0.98891 & 0.88741 & Biso & 1.000 & \\
\hline Al10 & 1.0000 & 0.77771 & 0.99206 & 135 & Biso & & \\
\hline Al11 & 1.0000 & 0.23458 & 0.21602 & 0.09064 & Biso & 1.000 & \\
\hline Al12 & 1.0000 & 0.00126 & 0.76312 & 0.10091 & Biso & 1.000 & \\
\hline P12 & 1.0000 & 0.66975 & 0.09411 & 0.22419 & Biso & 1.000 & \\
\hline P13 & 1.0000 & 0.90156 & 0.54959 & 0.22338 & Biso & 1.000 & $?$ \\
\hline P14 & 1.0000 & 0.44384 & 0.32564 & 0.2 & Biso & & ? \\
\hline Al13 & 1.0000 & 0.43092 & 0.33631 & 0.42833 & Biso & 1.000 & A \\
\hline Al14 & 1.0000 & 0.89762 & 0.54569 & 0.43404 & Biso & 1.000 & \\
\hline Al15 & 1.0000 & 0.67311 & 0.09692 & 0.43004 & Biso & 1.000 & \\
\hline P15 & 1.0000 & 0.33786 & 0.44993 & 0.55079 & Biso & 1.000 & \\
\hline P16 & 1.0000 & 0.56736 & 0.88430 & 0.55 & Biso & & ? \\
\hline P17 & 1.0000 & 0.09655 & 0.65778 & 0.56278 & Biso & 1.000 & $?$ \\
\hline Al16 & 1.0000 & 0.10119 & 0.65371 & 0.76857 & Biso & 1.000 & A \\
\hline Al17 & 1.0000 & 0.55832 & 0.87748 & 0.76941 & Biso & 1.000 & \\
\hline Al18 & 1.0000 & 0.32949 & 0.42466 & 0.75851 & Biso & 1.000 & \\
\hline 01 & 1.0000 & 0.91586 & 0.09471 & 0.12465 & Biso & & \\
\hline $\mathrm{O} 2$ & 1.0000 & 0.89937 & 0.79885 & 0.12586 & Biso & & D \\
\hline 03 & 1.0000 & 0.20297 & 0.07862 & 0.11222 & Biso & 1.000 & $\mathrm{O}$ \\
\hline 04 & 1.0000 & 0.08365 & 0.86938 & 0.85918 & Biso & 1.000 & D \\
\hline 05 & 1.0000 & 0.80767 & 0.89923 & 0.86720 & Biso & 1.000 & $\mathrm{O}$ \\
\hline 06 & 1.0000 & 0.10377 & 0.18057 & 0.86689 & Biso & 1.000 & o \\
\hline 07 & 1.0000 & 0.56865 & 0.44033 & 0.44820 & Biso & 1.000 & 0 \\
\hline 08 & 1.0000 & 0.57510 & 0.13996 & 0.43075 & Biso & 1.000 & 0 \\
\hline 09 & 1.0000 & 0.87829 & 0.41266 & 0.45460 & Biso & 1.000 & 0 \\
\hline 010 & 1.0000 & 0.75755 & 0.21679 & 0.20507 & Biso & 1.000 & 0 \\
\hline 011 & 1.0000 & 0.47488 & 0.23388 & 0.20528 & Biso & 1.000 & 0 \\
\hline 012 & 1.0000 & 0.77954 & 0.51900 & 0.20865 & Biso & 000 & 0 \\
\hline 013 & 1.0000 & 0.23535 & 0.75068 & 0.80660 & Biso & 1.000 & 0 \\
\hline 014 & 1.0000 & 0.22535 & 0.45806 & 0.78272 & Biso & 1.000 & 0 \\
\hline 015 & 1.0000 & 0.52953 & 0.73962 & 0.77659 & Biso & 1.000 & 0 \\
\hline 016 & 1.0000 & 0.44050 & 0.56681 & 0.54289 & Biso & & 0 \\
\hline 017 & 1.0000 & 0.09890 & 0.54901 & 0.56205 & Biso & 1.000 & 0 \\
\hline 018 & 1.0000 & 0.44313 & 0.83367 & 0.53540 & Biso & 1.000 & 0 \\
\hline 019 & 1.0000 & 0.98945 & 0.29748 & 0.15967 & Biso & 1.000 & 0 \\
\hline $\mathrm{O} 20$ & 1.0000 & 0.69669 & 0.66471 & 0.16053 & Biso & 1.000 & $\mathrm{O}$ \\
\hline $\mathrm{O} 21$ & 1.0000 & 0.33689 & 0.00837 & 0.14002 & Biso & 1.000 & 0 \\
\hline $\mathrm{O} 22$ & 1.0000 & 0.31515 & 0.95872 & 0.81873 & Biso & 000 & 0 \\
\hline 023 & 1.0000 & 0.64995 & 0.66697 & 0.83953 & Biso & 1.000 & 0 \\
\hline $\mathrm{O} 24$ & 1.0000 & 0.02638 & 0.33383 & 0.83379 & Biso & 1.000 & 0 \\
\hline 025 & 1.0000 & 0.66899 & 0.64144 & 0.49614 & Biso & 1.000 & 0 \\
\hline 026 & 1.0000 & 0.35416 & 0.98244 & 0.51460 & Biso & 1.000 & 0 \\
\hline $\mathrm{O} 27$ & 1.0000 & 0.00415 & 0.33334 & 0.48761 & Biso & 1.000 & 0 \\
\hline 028 & 1.0000 & 0.00447 & 0.66210 & 0.83766 & Biso & 1.000 & 0 \\
\hline 029 & 1.0000 & 0.30319 & 0.30602 & 0.81832 & Biso & 1.000 & 0 \\
\hline 030 & 1.0000 & 0.67220 & 0.96613 & 0.83481 & Biso & 1.000 & \\
\hline 031 & 1.0000 & 0.68263 & 0.01766 & 0.15725 & Biso & 1.000 & 0 \\
\hline 032 & 1.0000 & 0.35187 & 0.30808 & 0.15170 & Biso & 1.000 & 0 \\
\hline 033 & 1.0000 & 0.97991 & 0.64953 & 0.16529 & Biso & 1.000 & 0 \\
\hline 034 & 1.0000 & 0.34036 & 0.37262 & 0.47933 & Biso & 1.000 & 0 \\
\hline 035 & 1.0000 & 0.00125 & 0.64593 & 0.50309 & Biso & 1.000 & \\
\hline 036 & 1.0000 & 0.64039 & 0.98495 & 0.50108 & Biso & 1.000 & \\
\hline 037 & 1.0000 & 0.12108 & 0.22962 & 0.12373 & Biso & 1.000 & $\mathrm{O}$ \\
\hline 038 & 1.0000 & 0.76171 & 0.86486 & 0.13595 & Biso & 1.000 & $\mathrm{O}$ \\
\hline 039 & 1.0000 & 0.13289 & 0.87524 & 0.12727 & Biso & 1.000 & $\mathrm{O}$ \\
\hline 040 & 1.0000 & 0.23406 & 0.10709 & 0.85215 & Biso & 1.000 & \\
\hline 041 & 1.0000 & 0.87870 & 0.73870 & 0.86118 & Biso & 1.000 & \\
\hline
\end{tabular}




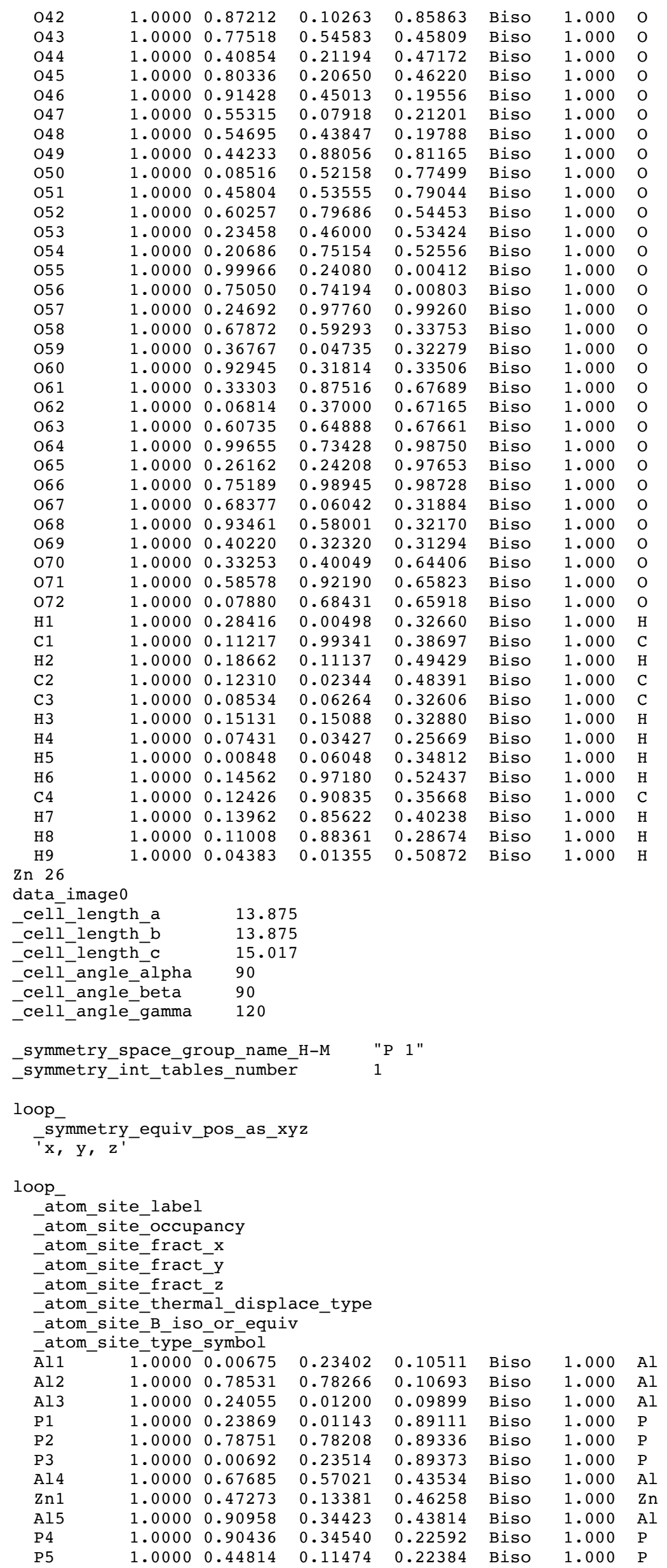




\begin{tabular}{|c|c|c|c|c|c|c|c|}
\hline P6 & 1.0000 & 0.67596 & 0.57149 & 0.22795 & Biso & 1.000 & $\mathrm{P}$ \\
\hline Al6 & 1.0000 & 0.34133 & 0.90122 & 0.76872 & Biso & 1.000 & Al \\
\hline Al7 & 1.0000 & 0.11846 & 0.44450 & 0.76876 & Biso & 1.000 & Al \\
\hline Al8 & 1.0000 & 0.57611 & 0.68020 & 0.77159 & Biso & 1.000 & Al \\
\hline P7 & 1.0000 & 0.58182 & 0.68826 & 0.56458 & Biso & 1.000 & $P$ \\
\hline P8 & 1.0000 & 0.12015 & 0.44733 & 0.56250 & Biso & 1.000 & $P$ \\
\hline P9 & 1.0000 & 0.34471 & 0.89323 & 0.56088 & Biso & 1.000 & $\mathrm{P}$ \\
\hline Al9 & 1.0000 & 0.01132 & 0.77935 & 0.89933 & Biso & 1.000 & Al \\
\hline Al10 & 1.0000 & 0.23768 & 0.23889 & 0.89569 & Biso & 1.000 & Al \\
\hline Al11 & 1.0000 & 0.78394 & 0.00663 & 0.89633 & Biso & 1.000 & Al \\
\hline P 10 & 1.0000 & 0.78093 & 0.00607 & 0.10983 & Biso & 1.000 & $\mathrm{P}$ \\
\hline P11 & 1.0000 & 0.23838 & 0.23902 & 0.10631 & Biso & 1.000 & $P$ \\
\hline P12 & 1.0000 & 0.01145 & 0.78259 & 0.11005 & Biso & 1.000 & $\mathrm{P}$ \\
\hline Al12 & 1.0000 & 0.68133 & 0.11353 & 0.23609 & Biso & 1.000 & $\mathrm{Al}$ \\
\hline Al13 & 1.0000 & 0.90179 & 0.56923 & 0.23062 & Biso & 1.000 & Al \\
\hline Al 14 & 1.0000 & 0.44729 & 0.33866 & 0.23218 & Biso & 1.000 & $\mathrm{Al}$ \\
\hline P13 & 1.0000 & 0.44990 & 0.34315 & 0.44141 & Biso & 1.000 & $\mathrm{P}$ \\
\hline P14 & 1.0000 & 0.90043 & 0.56531 & 0.44360 & Biso & 1.000 & $P$ \\
\hline P15 & 1.0000 & 0.69143 & 0.12286 & 0.43818 & Biso & 1.000 & $\mathrm{P}$ \\
\hline Al15 & 1.0000 & 0.35537 & 0.46526 & 0.56424 & Biso & 1.000 & Al \\
\hline Al16 & 1.0000 & 0.57223 & 0.90626 & 0.56751 & Biso & 1.000 & $\mathrm{Al}$ \\
\hline Al17 & 1.0000 & 0.11131 & 0.67268 & 0.56845 & Biso & 1.000 & Al \\
\hline P16 & 1.0000 & 0.11366 & 0.67223 & 0.77494 & Biso & 1.000 & $\mathrm{P}$ \\
\hline P17 & 1.0000 & 0.57007 & 0.90530 & 0.77690 & Biso & 1.000 & $P$ \\
\hline P18 & 1.0000 & 0.34946 & 0.44962 & 0.77140 & Biso & 1.000 & $P$ \\
\hline 01 & 1.0000 & 0.90141 & 0.09791 & 0.13045 & Biso & 1.000 & 0 \\
\hline $\mathrm{O} 2$ & 1.0000 & 0.92272 & 0.81543 & 0.13103 & Biso & 1.000 & 0 \\
\hline 03 & 1.0000 & 0.21077 & 0.11777 & 0.12215 & Biso & 1.000 & 0 \\
\hline 04 & 1.0000 & 0.11699 & 0.91721 & 0.88142 & Biso & 1.000 & 0 \\
\hline 05 & 1.0000 & 0.81708 & 0.90270 & 0.87272 & Biso & 1.000 & 0 \\
\hline 06 & 1.0000 & 0.10000 & 0.20705 & 0.87861 & Biso & 1.000 & 0 \\
\hline 07 & 1.0000 & 0.57572 & 0.42991 & 0.44080 & Biso & 1.000 & 0 \\
\hline 08 & 1.0000 & 0.62246 & 0.18110 & 0.43434 & Biso & 1.000 & 0 \\
\hline 09 & 1.0000 & 0.87101 & 0.44441 & 0.46295 & Biso & 1.000 & 0 \\
\hline 010 & 1.0000 & 0.78272 & 0.25169 & 0.21210 & Biso & 1.000 & 0 \\
\hline 011 & 1.0000 & 0.48170 & 0.23520 & 0.20232 & Biso & 1.000 & 0 \\
\hline 012 & 1.0000 & 0.76532 & 0.53910 & 0.20881 & Biso & 1.000 & 0 \\
\hline 013 & 1.0000 & 0.23570 & 0.76382 & 0.78886 & Biso & 1.000 & 0 \\
\hline 014 & 1.0000 & 0.25698 & 0.47872 & 0.78690 & Biso & 1.000 & 0 \\
\hline 015 & 1.0000 & 0.54089 & 0.78345 & 0.79070 & Biso & 1.000 & 0 \\
\hline 016 & 1.0000 & 0.45523 & 0.60725 & 0.55782 & Biso & 1.000 & 0 \\
\hline 017 & 1.0000 & 0.14475 & 0.56789 & 0.55658 & Biso & 1.000 & 0 \\
\hline 018 & 1.0000 & 0.42796 & 0.84961 & 0.55605 & Biso & 1.000 & 0 \\
\hline 019 & 1.0000 & 0.98469 & 0.32605 & 0.16871 & Biso & 1.000 & 0 \\
\hline 020 & 1.0000 & 0.68955 & 0.66386 & 0.16427 & Biso & 1.000 & 0 \\
\hline 021 & 1.0000 & 0.35517 & 0.03175 & 0.16332 & Biso & 1.000 & 0 \\
\hline 022 & 1.0000 & 0.31588 & 0.99308 & 0.82983 & Biso & 1.000 & 0 \\
\hline 023 & 1.0000 & 0.68472 & 0.69894 & 0.84090 & Biso & 1.000 & 0 \\
\hline $\mathrm{O} 24$ & 1.0000 & 0.02775 & 0.33596 & 0.83782 & Biso & 1.000 & 0 \\
\hline 025 & 1.0000 & 0.64646 & 0.65360 & 0.50235 & Biso & 1.000 & 0 \\
\hline 026 & 1.0000 & 0.37184 & 0.98512 & 0.49416 & Biso & 1.000 & 0 \\
\hline 027 & 1.0000 & 0.02876 & 0.37266 & 0.49701 & Biso & 1.000 & 0 \\
\hline 028 & 1.0000 & 0.03730 & 0.68668 & 0.84074 & Biso & 1.000 & 0 \\
\hline 029 & 1.0000 & 0.33003 & 0.35137 & 0.83061 & Biso & 1.000 & 0 \\
\hline 030 & 1.0000 & 0.66566 & 0.98314 & 0.83855 & Biso & 1.000 & 0 \\
\hline 031 & 1.0000 & 0.69666 & 0.02533 & 0.16172 & Biso & 1.000 & 0 \\
\hline 032 & 1.0000 & 0.33534 & 0.31881 & 0.16599 & Biso & 1.000 & 0 \\
\hline 033 & 1.0000 & 0.99676 & 0.68789 & 0.17144 & Biso & 1.000 & 0 \\
\hline 034 & 1.0000 & 0.38553 & 0.39249 & 0.48697 & Biso & 1.000 & O \\
\hline 035 & 1.0000 & 0.00079 & 0.64754 & 0.49909 & Biso & 1.000 & 0 \\
\hline 036 & 1.0000 & 0.64558 & 0.02557 & 0.50405 & Biso & 1.000 & 0 \\
\hline 037 & 1.0000 & 0.13607 & 0.24838 & 0.13019 & Biso & 1.000 & 0 \\
\hline 038 & 1.0000 & 0.76756 & 0.89385 & 0.13849 & Biso & 1.000 & 0 \\
\hline 039 & 1.0000 & 0.12702 & 0.88385 & 0.12759 & Biso & 1.000 & 0 \\
\hline 040 & 1.0000 & 0.24651 & 0.12208 & 0.86611 & Biso & 1.000 & 0 \\
\hline 041 & 1.0000 & 0.88550 & 0.76697 & 0.86560 & Biso & 1.000 & 0 \\
\hline 042 & 1.0000 & 0.89571 & 0.13519 & 0.86512 & Biso & 1.000 & O \\
\hline 043 & 1.0000 & 0.80210 & 0.58071 & 0.46887 & Biso & 1.000 & 0 \\
\hline 044 & 1.0000 & 0.42872 & 0.23872 & 0.49081 & Biso & 1.000 & 0 \\
\hline 045 & 1.0000 & 0.81067 & 0.20875 & 0.46758 & Biso & 1.000 & 0 \\
\hline 046 & 1.0000 & 0.91442 & 0.45598 & 0.19654 & Biso & 1.000 & 0 \\
\hline 047 & 1.0000 & 0.54753 & 0.09756 & 0.22247 & Biso & 1.000 & 0 \\
\hline 048 & 1.0000 & 0.56088 & 0.46956 & 0.21161 & Biso & 1.000 & 0 \\
\hline 049 & 1.0000 & 0.46815 & 0.91519 & 0.80168 & Biso & 1.000 & 0 \\
\hline 050 & 1.0000 & 0.10396 & 0.55915 & 0.79289 & Biso & 1.000 & 0 \\
\hline 051 & 1.0000 & 0.46161 & 0.55061 & 0.79656 & Biso & 1.000 & 0 \\
\hline 052 & 1.0000 & 0.60646 & 0.80506 & 0.53740 & Biso & 1.000 & 0 \\
\hline 053 & 1.0000 & 0.22515 & 0.44463 & 0.53632 & Biso & 1.000 & 0 \\
\hline 054 & 1.0000 & 0.22801 & 0.79637 & 0.53852 & Biso & 1.000 & 0 \\
\hline 055 & 1.0000 & 0.00228 & 0.26244 & 0.99240 & Biso & 1.000 & 0 \\
\hline
\end{tabular}




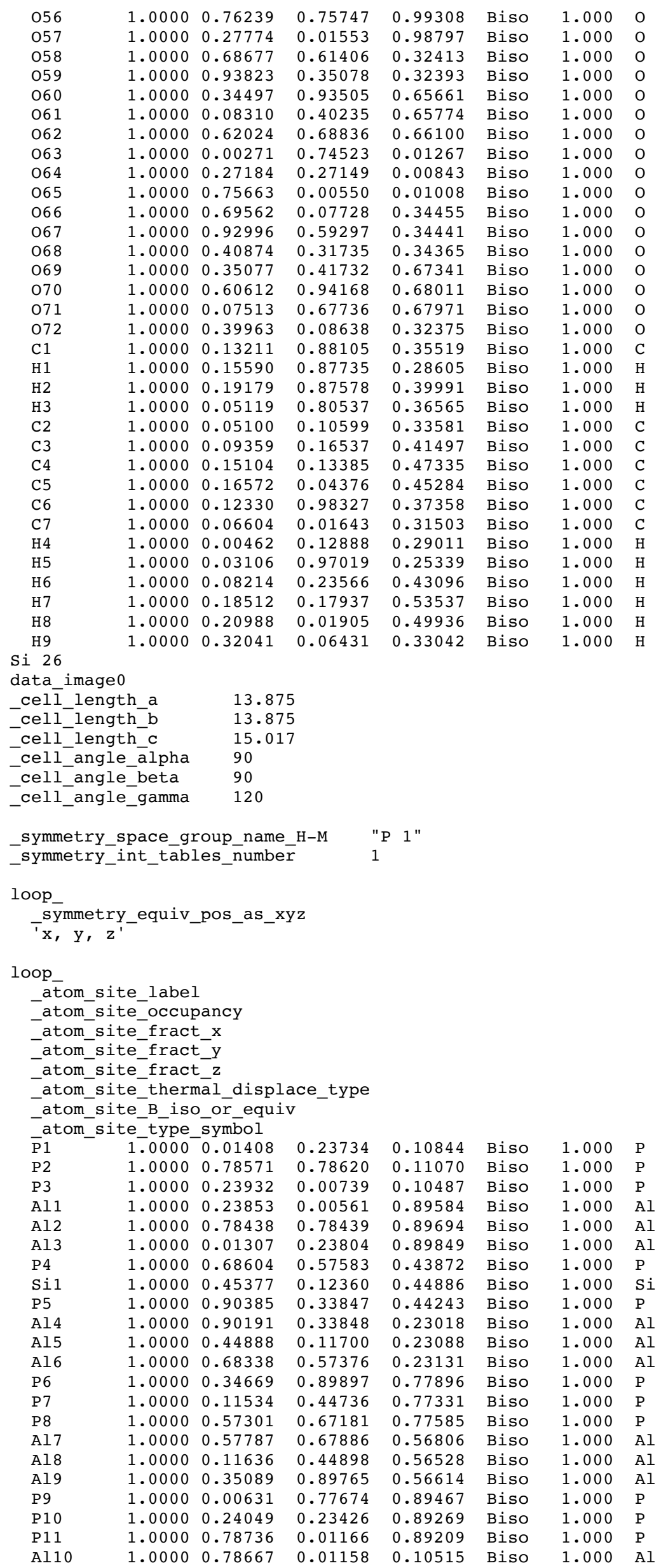




\begin{tabular}{|c|c|c|c|c|c|c|c|}
\hline Al11 & 1.0000 & 0.24313 & 0.23682 & 0.10225 & Biso & 1.000 & Al \\
\hline Al12 & 1.0000 & 0.00844 & 0.77906 & 0.10534 & Biso & 1.000 & Al \\
\hline P12 & 1.0000 & 0.67772 & 0.11132 & 0.22895 & Biso & 1.000 & $\mathrm{P}$ \\
\hline P13 & 1.0000 & 0.90803 & 0.56660 & 0.22692 & Biso & 1.000 & $P$ \\
\hline $\mathrm{P} 14$ & 1.0000 & 0.45381 & 0.34484 & 0.22817 & Biso & 1.000 & $\mathrm{P}$ \\
\hline Al13 & 1.0000 & 0.45637 & 0.34945 & 0.43830 & Biso & 1.000 & Al \\
\hline Al14 & 1.0000 & 0.90703 & 0.56616 & 0.43933 & Biso & 1.000 & Al \\
\hline Al15 & 1.0000 & 0.67825 & 0.11471 & 0.43243 & Biso & 1.000 & Al \\
\hline P15 & 1.0000 & 0.34756 & 0.45958 & 0.56056 & Biso & 1.000 & $\mathrm{P}$ \\
\hline P16 & 1.0000 & 0.57581 & 0.90256 & 0.56354 & Biso & 1.000 & $\mathrm{P}$ \\
\hline P17 & 1.0000 & 0.11987 & 0.68071 & 0.56270 & Biso & 1.000 & $\mathrm{P}$ \\
\hline Al16 & 1.0000 & 0.11781 & 0.67834 & 0.77222 & Biso & 1.000 & Al \\
\hline Al17 & 1.0000 & 0.57440 & 0.90224 & 0.77240 & Biso & 1.000 & Al \\
\hline Al18 & 1.0000 & 0.34187 & 0.44677 & 0.76917 & Biso & 1.000 & Al \\
\hline 01 & 1.0000 & 0.92479 & 0.11519 & 0.12694 & Biso & 1.000 & 0 \\
\hline $\mathrm{O} 2$ & 1.0000 & 0.90641 & 0.81454 & 0.13053 & Biso & 1.000 & 0 \\
\hline 03 & 1.0000 & 0.20798 & 0.09790 & 0.12113 & Biso & 1.000 & 0 \\
\hline 04 & 1.0000 & 0.10140 & 0.89734 & 0.88072 & Biso & 1.000 & 0 \\
\hline 05 & 1.0000 & 0.81616 & 0.92027 & 0.87090 & Biso & 1.000 & 0 \\
\hline 06 & 1.0000 & 0.11860 & 0.20569 & 0.88183 & Biso & 1.000 & 0 \\
\hline 07 & 1.0000 & 0.59749 & 0.45229 & 0.44630 & Biso & 1.000 & 0 \\
\hline 08 & 1.0000 & 0.57868 & 0.15446 & 0.42602 & Biso & 1.000 & 0 \\
\hline 09 & 1.0000 & 0.87242 & 0.42857 & 0.46199 & Biso & 1.000 & 0 \\
\hline 010 & 1.0000 & 0.76320 & 0.23469 & 0.20988 & Biso & 1.000 & 0 \\
\hline 011 & 1.0000 & 0.48709 & 0.25521 & 0.21021 & Biso & 1.000 & 0 \\
\hline 012 & 1.0000 & 0.78748 & 0.53994 & 0.21083 & Biso & 1.000 & 0 \\
\hline 013 & 1.0000 & 0.25369 & 0.77967 & 0.80142 & Biso & 1.000 & 0 \\
\hline 014 & 1.0000 & 0.23763 & 0.48032 & 0.79045 & Biso & 1.000 & 0 \\
\hline 015 & 1.0000 & 0.54413 & 0.76472 & 0.78831 & Biso & 1.000 & 0 \\
\hline 016 & 1.0000 & 0.43489 & 0.58449 & 0.55491 & Biso & 1.000 & 0 \\
\hline 017 & 1.0000 & 0.14753 & 0.58676 & 0.55379 & Biso & 1.000 & 0 \\
\hline 018 & 1.0000 & 0.44965 & 0.85461 & 0.55042 & Biso & 1.000 & 0 \\
\hline 019 & 1.0000 & 0.99588 & 0.31502 & 0.16986 & Biso & 1.000 & 0 \\
\hline 020 & 1.0000 & 0.70256 & 0.68361 & 0.16340 & Biso & 1.000 & o \\
\hline 021 & 1.0000 & 0.33569 & 0.02542 & 0.16624 & Biso & 1.000 & 0 \\
\hline 022 & 1.0000 & 0.33075 & 0.98445 & 0.83213 & Biso & 1.000 & 0 \\
\hline 023 & 1.0000 & 0.66609 & 0.68799 & 0.83977 & Biso & 1.000 & 0 \\
\hline 024 & 1.0000 & 0.03730 & 0.35299 & 0.83556 & Biso & 1.000 & 0 \\
\hline 025 & 1.0000 & 0.65977 & 0.64753 & 0.50020 & Biso & 1.000 & 0 \\
\hline 026 & 1.0000 & 0.38354 & 0.01576 & 0.50826 & Biso & 1.000 & 0 \\
\hline $\mathrm{O} 27$ & 1.0000 & 0.00607 & 0.36006 & 0.49719 & Biso & 1.000 & 0 \\
\hline 028 & 1.0000 & 0.02370 & 0.69520 & 0.83774 & Biso & 1.000 & 0 \\
\hline 029 & 1.0000 & 0.31735 & 0.33061 & 0.83145 & Biso & 1.000 & 0 \\
\hline 030 & 1.0000 & 0.68640 & 0.99408 & 0.83800 & Biso & 1.000 & 0 \\
\hline 031 & 1.0000 & 0.69061 & 0.03623 & 0.16075 & Biso & 1.000 & 0 \\
\hline 032 & 1.0000 & 0.35745 & 0.32610 & 0.16698 & Biso & 1.000 & 0 \\
\hline 033 & 1.0000 & 0.98975 & 0.66787 & 0.17158 & Biso & 1.000 & 0 \\
\hline 034 & 1.0000 & 0.37654 & 0.39253 & 0.49686 & Biso & 1.000 & 0 \\
\hline 035 & 1.0000 & 0.02081 & 0.65780 & 0.50350 & Biso & 1.000 & 0 \\
\hline 036 & 1.0000 & 0.64337 & 0.00209 & 0.50255 & Biso & 1.000 & 0 \\
\hline 037 & 1.0000 & 0.12911 & 0.25222 & 0.12846 & Biso & 1.000 & 0 \\
\hline 038 & 1.0000 & 0.77229 & 0.88491 & 0.13942 & Biso & 1.000 & 0 \\
\hline 039 & 1.0000 & 0.13906 & 0.89374 & 0.12767 & Biso & 1.000 & 0 \\
\hline 040 & 1.0000 & 0.24869 & 0.13185 & 0.86639 & Biso & 1.000 & 0 \\
\hline 041 & 1.0000 & 0.89665 & 0.76876 & 0.86597 & Biso & 1.000 & 0 \\
\hline 042 & 1.0000 & 0.88661 & 0.12468 & 0.86634 & Biso & 1.000 & 0 \\
\hline 043 & 1.0000 & 0.79882 & 0.59001 & 0.46649 & Biso & 1.000 & 0 \\
\hline 044 & 1.0000 & 0.43983 & 0.22643 & 0.47807 & Biso & 1.000 & 0 \\
\hline 045 & 1.0000 & 0.80667 & 0.22461 & 0.46863 & Biso & 1.000 & 0 \\
\hline 046 & 1.0000 & 0.91850 & 0.46649 & 0.19727 & Biso & 1.000 & 0 \\
\hline 047 & 1.0000 & 0.55948 & 0.09387 & 0.21905 & Biso & 1.000 & o \\
\hline 048 & 1.0000 & 0.55406 & 0.45900 & 0.20675 & Biso & 1.000 & 0 \\
\hline 049 & 1.0000 & 0.45882 & 0.91117 & 0.80557 & Biso & 1.000 & 0 \\
\hline 050 & 1.0000 & 0.10079 & 0.54754 & 0.79257 & Biso & 1.000 & 0 \\
\hline 051 & 1.0000 & 0.47010 & 0.55985 & 0.79830 & Biso & 1.000 & 0 \\
\hline 052 & 1.0000 & 0.60433 & 0.81188 & 0.54066 & Biso & 1.000 & 0 \\
\hline 053 & 1.0000 & 0.23386 & 0.44315 & 0.53297 & Biso & 1.000 & 0 \\
\hline 054 & 1.0000 & 0.22041 & 0.78991 & 0.53140 & Biso & 1.000 & 0 \\
\hline 055 & 1.0000 & 0.00757 & 0.26809 & 0.01111 & Biso & 1.000 & 0 \\
\hline 056 & 1.0000 & 0.76005 & 0.76172 & 0.01114 & Biso & 1.000 & 0 \\
\hline 057 & 1.0000 & 0.27595 & 0.01025 & 0.00805 & Biso & 1.000 & 0 \\
\hline 058 & 1.0000 & 0.69171 & 0.61628 & 0.34214 & Biso & 1.000 & 0 \\
\hline 059 & 1.0000 & 0.93290 & 0.34067 & 0.34315 & Biso & 1.000 & 0 \\
\hline 060 & 1.0000 & 0.34410 & 0.92238 & 0.67965 & Biso & 1.000 & 0 \\
\hline 061 & 1.0000 & 0.08290 & 0.40761 & 0.67648 & Biso & 1.000 & 0 \\
\hline 062 & 1.0000 & 0.61200 & 0.67259 & 0.67969 & Biso & 1.000 & 0 \\
\hline 063 & 1.0000 & 0.00051 & 0.74304 & 0.99308 & Biso & 1.000 & 0 \\
\hline 064 & 1.0000 & 0.27849 & 0.26821 & 0.98972 & Biso & 1.000 & 0 \\
\hline 065 & 1.0000 & 0.75992 & 0.00916 & 0.99151 & Biso & 1.000 & 0 \\
\hline 066 & 1.0000 & 0.69517 & 0.07844 & 0.32276 & Biso & 1.000 & 0 \\
\hline
\end{tabular}




\begin{tabular}{|c|c|c|c|c|c|c|c|}
\hline 067 & 1.0000 & 0.93906 & 0.59243 & 0.32581 & Biso & 1.000 & 0 \\
\hline 068 & 1.0000 & 0.41696 & 0.33851 & 0.32524 & Biso & 1.000 & 0 \\
\hline 069 & 1.0000 & 0.34161 & 0.41603 & 0.65605 & Biso & 1.000 & 0 \\
\hline 070 & 1.0000 & 0.60785 & 0.94090 & 0.66086 & Biso & 1.000 & 0 \\
\hline 071 & 1.0000 & 0.09112 & 0.69084 & 0.66003 & Biso & 1.000 & 0 \\
\hline 072 & 1.0000 & 0.38869 & 0.08316 & 0.34280 & Biso & 1.000 & 0 \\
\hline C1 & 1.0000 & 0.08939 & 0.86690 & 0.34933 & Biso & 1.000 & C \\
\hline H 1 & 1.0000 & 0.13866 & 0.86925 & 0.29111 & Biso & 1.000 & $\mathrm{H}$ \\
\hline $\mathrm{H} 2$ & 1.0000 & 0.11260 & 0.83192 & 0.40526 & Biso & 1.000 & $\mathrm{H}$ \\
\hline H3 & 1.0000 & 0.00189 & 0.80848 & 0.33269 & Biso & 1.000 & $\mathrm{H}$ \\
\hline $\mathrm{C} 2$ & 1.0000 & 0.07590 & 0.13468 & 0.33810 & Biso & 1.000 & C \\
\hline C3 & 1.0000 & 0.12581 & 0.18609 & 0.41858 & Biso & 1.000 & $\mathrm{C}$ \\
\hline $\mathrm{C} 4$ & 1.0000 & 0.16508 & 0.13437 & 0.47585 & Biso & 1.000 & C \\
\hline $\mathrm{C} 5$ & 1.0000 & 0.15449 & 0.03185 & 0.45262 & Biso & 1.000 & C \\
\hline $\mathrm{C} 6$ & 1.0000 & 0.10502 & 0.97955 & 0.37183 & Biso & 1.000 & C \\
\hline $\mathrm{C} 7$ & 1.0000 & 0.06595 & 0.03291 & 0.31462 & Biso & 1.000 & C \\
\hline H4 & 1.0000 & 0.04403 & 0.17442 & 0.29369 & Biso & 1.000 & $\mathrm{H}$ \\
\hline H5 & 1.0000 & 0.02564 & 0.99311 & 0.25198 & Biso & 1.000 & $\mathrm{H}$ \\
\hline H6 & 1.0000 & 0.13371 & 0.26591 & 0.43621 & Biso & 1.000 & $\mathrm{H}$ \\
\hline $\mathrm{H} 7$ & 1.0000 & 0.20414 & 0.17323 & 0.53897 & Biso & 1.000 & $\mathrm{H}$ \\
\hline H8 & 1.0000 & 0.18356 & 0.99082 & 0.49856 & Biso & 1.000 & $\mathrm{H}$ \\
\hline $\mathrm{H} 9$ & 1.0000 & 0.30824 & 0.05652 & 0.34779 & Biso & 1.000 & $\mathrm{H}$ \\
\hline \multicolumn{8}{|c|}{$\operatorname{Mg~} 26$} \\
\hline \multicolumn{8}{|c|}{ data_image0 } \\
\hline \multicolumn{8}{|c|}{13.875} \\
\hline \multicolumn{8}{|c|}{13.875} \\
\hline \multicolumn{8}{|c|}{15.017} \\
\hline \multicolumn{8}{|c|}{ e $\bar{l}$ lpha } \\
\hline \multicolumn{8}{|c|}{90} \\
\hline cell_ & gamma & 120 & & & & & \\
\hline symme & pace_g & nam & & $1 "$ & & & \\
\hline symme & nt_tab & les_ñumb & & & & & \\
\hline op_ & & & & & & & \\
\hline syn & еquіу & Pa & & & & & \\
\hline ' $\mathrm{x}$, & & & & & & & \\
\hline op_ & & & & & & & \\
\hline at̄o & ce_labe & & & & & & \\
\hline -ato & ee_occul & pancy & & & & & \\
\hline -ato & ce frac & t $x$ & & & & & \\
\hline ato & ce frac & $y$ & & & & & \\
\hline -ato & $=e^{-f r a c}$ & -2 & & & & & \\
\hline ato & ce therr & nal displ & ace type & & & & \\
\hline -ato & $=e_{-}^{-}$B_is & D_or_equi & & & & & \\
\hline -ato & $=e_{-}^{-}$type & symb̄ol & & & & & \\
\hline $\bar{A} 11$ & 1.0000 & 0.00638 & 0.23427 & 0.10559 & Biso & 1.000 & Al \\
\hline Al2 & 1.0000 & 0.78645 & 0.78535 & 0.10704 & Biso & 1.000 & Al \\
\hline Al3 & 1.0000 & 0.24066 & 0.01344 & 0.09793 & Biso & 1.000 & Al \\
\hline $\mathrm{P} 1$ & 1.0000 & 0.23762 & 0.01118 & 0.89003 & Biso & 1.000 & $\mathrm{P}$ \\
\hline P2 & 1.0000 & 0.78687 & 0.78310 & 0.89300 & Biso & 1.000 & $P$ \\
\hline P3 & 1.0000 & 0.00508 & 0.23450 & 0.89317 & Biso & 1.000 & $\mathrm{P}$ \\
\hline Al4 & 1.0000 & 0.67689 & 0.57309 & 0.43401 & Biso & 1.000 & $\mathrm{Al}$ \\
\hline Mg 1 & 1.0000 & 0.46426 & 0.12816 & 0.45313 & Biso & 1.000 & Mg \\
\hline Al5 & 1.0000 & 0.90893 & 0.34338 & 0.43821 & Biso & 1.000 & Al \\
\hline P 4 & 1.0000 & 0.90422 & 0.34624 & 0.22584 & Biso & 1.000 & $\mathrm{P}$ \\
\hline P5 & 1.0000 & 0.44824 & 0.11682 & 0.22332 & Biso & 1.000 & $\mathrm{P}$ \\
\hline P6 & 1.0000 & 0.67704 & 0.57344 & 0.22732 & Biso & 1.000 & $\mathrm{P}$ \\
\hline Al 6 & 1.0000 & 0.33820 & 0.89694 & 0.77103 & Biso & 1.000 & Al \\
\hline Al 7 & 1.0000 & 0.11556 & 0.44308 & 0.76815 & Biso & 1.000 & Al \\
\hline Al8 & 1.0000 & 0.57477 & 0.67918 & 0.77215 & Biso & 1.000 & Al \\
\hline P7 & 1.0000 & 0.58376 & 0.68839 & 0.56516 & Biso & 1.000 & $\mathrm{P}$ \\
\hline P8 & 1.0000 & 0.11678 & 0.44483 & 0.56305 & Biso & 1.000 & $P$ \\
\hline P9 & 1.0000 & 0.34383 & 0.88814 & 0.56197 & Biso & 1.000 & $\mathrm{P}$ \\
\hline Al9 & 1.0000 & 0.00964 & 0.77864 & 0.89931 & Biso & 1.000 & Al \\
\hline Al10 & 1.0000 & 0.23518 & 0.23794 & 0.89352 & Biso & 1.000 & Al \\
\hline Al11 & 1.0000 & 0.78325 & 0.00680 & 0.89600 & Biso & 1.000 & $\mathrm{Al}$ \\
\hline $\mathrm{P} 10$ & 1.0000 & 0.78104 & 0.00717 & 0.11047 & Biso & 1.000 & $\mathrm{P}$ \\
\hline P11 & 1.0000 & 0.23811 & 0.24020 & 0.10482 & Biso & 1.000 & $P$ \\
\hline $\mathrm{P} 12$ & 1.0000 & 0.01161 & 0.78414 & 0.11011 & Biso & 1.000 & $\mathrm{P}$ \\
\hline Al12 & 1.0000 & 0.68172 & 0.11467 & 0.23588 & Biso & 1.000 & $\mathrm{Al}$ \\
\hline Al13 & 1.0000 & 0.90267 & 0.57072 & 0.23120 & Biso & 1.000 & Al \\
\hline Al14 & 1.0000 & 0.44692 & 0.34160 & 0.23094 & Biso & 1.000 & Al \\
\hline P13 & 1.0000 & 0.44649 & 0.34471 & 0.43949 & Biso & 1.000 & $\mathrm{P}$ \\
\hline P14 & 1.0000 & 0.90056 & 0.56606 & 0.44375 & Biso & 1.000 & $P$ \\
\hline P15 & 1.0000 & 0.68969 & 0.12069 & 0.43685 & Biso & 1.000 & $\mathrm{P}$ \\
\hline Al15 & 1.0000 & 0.35464 & 0.46715 & 0.56321 & Biso & 1.000 & Al \\
\hline Al16 & 1.0000 & 0.57321 & 0.90718 & 0.56923 & Biso & 1.000 & Al \\
\hline Al17 & 1.0000 & 0.10943 & 0.67338 & 0.56878 & Biso & 1.000 & Al \\
\hline
\end{tabular}




\begin{tabular}{|c|c|c|c|c|c|c|c|}
\hline P 16 & 1.0000 & 0.11160 & 0.67212 & 0.77586 & Biso & 1.000 & $\mathrm{P}$ \\
\hline P 17 & 1.0000 & 0.56940 & 0.90631 & 0.77720 & Biso & 1.000 & $\mathrm{P}$ \\
\hline P18 & 1.0000 & 0.34742 & 0.45107 & 0.77167 & Biso & 1.000 & $\mathrm{P}$ \\
\hline 01 & 1.0000 & 0.90103 & 0.09884 & 0.13291 & Biso & 1.000 & 0 \\
\hline $\mathrm{O} 2$ & 1.0000 & 0.92406 & 0.81855 & 0.13126 & Biso & 1.000 & 0 \\
\hline 03 & 1.0000 & 0.21145 & 0.11940 & 0.12182 & Biso & 1.000 & 0 \\
\hline 04 & 1.0000 & 0.11617 & 0.91612 & 0.88129 & Biso & 1.000 & 0 \\
\hline 05 & 1.0000 & 0.81613 & 0.90317 & 0.87042 & Biso & 1.000 & 0 \\
\hline 06 & 1.0000 & 0.09759 & 0.20609 & 0.87610 & Biso & 1.000 & 0 \\
\hline 07 & 1.0000 & 0.57090 & 0.43552 & 0.43910 & Biso & 1.000 & 0 \\
\hline 08 & 1.0000 & 0.61487 & 0.17148 & 0.43172 & Biso & 1.000 & 0 \\
\hline 09 & 1.0000 & 0.87427 & 0.44627 & 0.46353 & Biso & 1.000 & 0 \\
\hline 010 & 1.0000 & 0.78235 & 0.25308 & 0.21142 & Biso & 1.000 & 0 \\
\hline 011 & 1.0000 & 0.48189 & 0.23742 & 0.20322 & Biso & 1.000 & 0 \\
\hline 012 & 1.0000 & 0.76601 & 0.54008 & 0.20965 & Biso & 1.000 & 0 \\
\hline 013 & 1.0000 & 0.23325 & 0.76061 & 0.79623 & Biso & 1.000 & 0 \\
\hline 014 & 1.0000 & 0.25448 & 0.47943 & 0.78754 & Biso & 1.000 & 0 \\
\hline 015 & 1.0000 & 0.54182 & 0.78453 & 0.78747 & Biso & 1.000 & 0 \\
\hline 016 & 1.0000 & 0.45787 & 0.60751 & 0.55312 & Biso & 1.000 & 0 \\
\hline 017 & 1.0000 & 0.13382 & 0.56259 & 0.55944 & Biso & 1.000 & 0 \\
\hline 018 & 1.0000 & 0.42813 & 0.84564 & 0.55898 & Biso & 1.000 & 0 \\
\hline 019 & 1.0000 & 0.98450 & 0.32708 & 0.16830 & Biso & 1.000 & 0 \\
\hline $\mathrm{O} 20$ & 1.0000 & 0.69112 & 0.66481 & 0.16244 & Biso & 1.000 & 0 \\
\hline 021 & 1.0000 & 0.35594 & 0.03414 & 0.16239 & Biso & 1.000 & 0 \\
\hline 022 & 1.0000 & 0.31482 & 0.99251 & 0.82907 & Biso & 1.000 & 0 \\
\hline 023 & 1.0000 & 0.68306 & 0.69863 & 0.84225 & Biso & 1.000 & 0 \\
\hline 024 & 1.0000 & 0.02602 & 0.33677 & 0.83933 & Biso & 1.000 & 0 \\
\hline 025 & 1.0000 & 0.65248 & 0.65931 & 0.50257 & Biso & 1.000 & 0 \\
\hline 026 & 1.0000 & 0.37698 & 0.98489 & 0.49975 & Biso & 1.000 & 0 \\
\hline 027 & 1.0000 & 0.02750 & 0.36825 & 0.49675 & Biso & 1.000 & 0 \\
\hline 028 & 1.0000 & 0.03282 & 0.68391 & 0.84092 & Biso & 1.000 & 0 \\
\hline 029 & 1.0000 & 0.32722 & 0.35094 & 0.82884 & Biso & 1.000 & 0 \\
\hline 030 & 1.0000 & 0.66324 & 0.98247 & 0.84084 & Biso & 1.000 & 0 \\
\hline 031 & 1.0000 & 0.69544 & 0.02687 & 0.15987 & Biso & 1.000 & 0 \\
\hline 032 & 1.0000 & 0.33694 & 0.32147 & 0.16219 & Biso & 1.000 & 0 \\
\hline 033 & 1.0000 & 0.99687 & 0.68981 & 0.17194 & Biso & 1.000 & 0 \\
\hline 034 & 1.0000 & 0.37823 & 0.38790 & 0.48774 & Biso & 1.000 & 0 \\
\hline 035 & 1.0000 & 0.99826 & 0.65020 & 0.50073 & Biso & 1.000 & 0 \\
\hline 036 & 1.0000 & 0.64695 & 0.02282 & 0.50223 & Biso & 1.000 & 0 \\
\hline 037 & 1.0000 & 0.13616 & 0.24939 & 0.13060 & Biso & 1.000 & $\mathrm{O}$ \\
\hline 038 & 1.0000 & 0.76671 & 0.89486 & 0.14014 & Biso & 1.000 & $\mathrm{O}$ \\
\hline 039 & 1.0000 & 0.12787 & 0.88500 & 0.12684 & Biso & 1.000 & 0 \\
\hline 040 & 1.0000 & 0.24438 & 0.12117 & 0.86416 & Biso & 1.000 & 0 \\
\hline 041 & 1.0000 & 0.88438 & 0.76723 & 0.86529 & Biso & 1.000 & 0 \\
\hline 042 & 1.0000 & 0.89358 & 0.13563 & 0.86378 & Biso & 1.000 & 0 \\
\hline 043 & 1.0000 & 0.79948 & 0.57755 & 0.46684 & Biso & 1.000 & 0 \\
\hline 044 & 1.0000 & 0.43201 & 0.24073 & 0.48389 & Biso & 1.000 & 0 \\
\hline 045 & 1.0000 & 0.80727 & 0.20945 & 0.46783 & Biso & 1.000 & 0 \\
\hline 046 & 1.0000 & 0.91515 & 0.45739 & 0.19704 & Biso & 1.000 & 0 \\
\hline 047 & 1.0000 & 0.54714 & 0.09902 & 0.22421 & Biso & 1.000 & 0 \\
\hline 048 & 1.0000 & 0.56191 & 0.47159 & 0.21107 & Biso & 1.000 & 0 \\
\hline 049 & 1.0000 & 0.46614 & 0.91327 & 0.80299 & Biso & 1.000 & 0 \\
\hline 050 & 1.0000 & 0.09808 & 0.55666 & 0.78873 & Biso & 1.000 & 0 \\
\hline 051 & 1.0000 & 0.45882 & 0.55146 & 0.79932 & Biso & 1.000 & 0 \\
\hline 052 & 1.0000 & 0.60960 & 0.80673 & 0.54300 & Biso & 1.000 & 0 \\
\hline 053 & 1.0000 & 0.22560 & 0.45032 & 0.53627 & Biso & 1.000 & 0 \\
\hline 054 & 1.0000 & 0.22892 & 0.79180 & 0.53395 & Biso & 1.000 & 0 \\
\hline 055 & 1.0000 & 0.00111 & 0.25963 & 0.99244 & Biso & 1.000 & $\mathrm{O}$ \\
\hline 056 & 1.0000 & 0.76366 & 0.76152 & 0.99315 & Biso & 1.000 & 0 \\
\hline 057 & 1.0000 & 0.27753 & 0.01725 & 0.98693 & Biso & 1.000 & 0 \\
\hline 058 & 1.0000 & 0.68800 & 0.61778 & 0.32289 & Biso & 1.000 & 0 \\
\hline 059 & 1.0000 & 0.93746 & 0.35030 & 0.32386 & Biso & 1.000 & 0 \\
\hline 060 & 1.0000 & 0.33628 & 0.92345 & 0.65837 & Biso & 1.000 & 0 \\
\hline 061 & 1.0000 & 0.08136 & 0.39692 & 0.65778 & Biso & 1.000 & 0 \\
\hline 062 & 1.0000 & 0.61724 & 0.68141 & 0.66190 & Biso & 1.000 & 0 \\
\hline 063 & 1.0000 & 0.00155 & 0.74575 & 0.01294 & Biso & 1.000 & 0 \\
\hline 064 & 1.0000 & 0.26846 & 0.27055 & 0.00632 & Biso & 1.000 & 0 \\
\hline 065 & 1.0000 & 0.75960 & 0.00643 & 0.01024 & Biso & 1.000 & 0 \\
\hline 066 & 1.0000 & 0.69861 & 0.07740 & 0.34315 & Biso & 1.000 & 0 \\
\hline 067 & 1.0000 & 0.93213 & 0.59461 & 0.34487 & Biso & 1.000 & 0 \\
\hline 068 & 1.0000 & 0.40498 & 0.32166 & 0.34138 & Biso & 1.000 & 0 \\
\hline 069 & 1.0000 & 0.35080 & 0.42198 & 0.67320 & Biso & 1.000 & 0 \\
\hline 070 & 1.0000 & 0.60658 & 0.94730 & 0.68140 & Biso & 1.000 & 0 \\
\hline 071 & 1.0000 & 0.07962 & 0.68597 & 0.68039 & Biso & 1.000 & O \\
\hline 072 & 1.0000 & 0.39626 & 0.08760 & 0.32318 & Biso & 1.000 & 0 \\
\hline $\mathrm{C} 1$ & 1.0000 & 0.13875 & 0.88025 & 0.35463 & Biso & 1.000 & C \\
\hline H 1 & 1.0000 & 0.15886 & 0.87573 & 0.28460 & Biso & 1.000 & $\mathrm{H}$ \\
\hline $\mathrm{H} 2$ & 1.0000 & 0.20048 & 0.87530 & 0.39705 & Biso & 1.000 & $\mathrm{H}$ \\
\hline H3 & 1.0000 & 0.05848 & 0.80475 & 0.36753 & Biso & 1.000 & $\mathrm{H}$ \\
\hline C2 & 1.0000 & 0.06202 & 0.10863 & 0.33749 & & 1.000 & C \\
\hline
\end{tabular}




$\begin{array}{llllllll}\text { C3 } & 1.0000 & 0.09967 & 0.16312 & 0.41913 & \text { Biso } & 1.000 & \mathrm{C} \\ \text { C4 } & 1.0000 & 0.15279 & 0.12758 & 0.47850 & \text { Biso } & 1.000 & \mathrm{C} \\ \text { C5 } & 1.0000 & 0.16807 & 0.03830 & 0.45647 & \text { Biso } & 1.000 & \mathrm{C} \\ \text { C6 } & 1.0000 & 0.13064 & 0.98256 & 0.37461 & \text { Biso } & 1.000 & \mathrm{C} \\ \text { C7 } & 1.0000 & 0.07761 & 0.01976 & 0.31523 & \text { Biso } & 1.000 & \mathrm{C} \\ \text { H4 } & 1.0000 & 0.01913 & 0.13475 & 0.29096 & \text { Biso } & 1.000 & \mathrm{H} \\ \text { H5 } & 1.0000 & 0.04594 & 0.97692 & 0.25182 & \text { Biso } & 1.000 & \mathrm{H} \\ \text { H6 } & 1.0000 & 0.08784 & 0.23292 & 0.43622 & \text { Biso } & 1.000 & \mathrm{H} \\ \text { H7 } & 1.0000 & 0.18329 & 0.16960 & 0.54233 & \text { Biso } & 1.000 & \mathrm{H} \\ \text { H8 } & 1.0000 & 0.20871 & 0.01033 & 0.50377 & \text { Biso } & 1.000 & \mathrm{H} \\ \text { H9 } & 1.0000 & 0.31628 & 0.06502 & 0.32679 & \text { Biso } & 1.000 & \mathrm{H}\end{array}$

Al 26

data imageo

celì length a 13.625

cell_length_b 13.625

cell_length_c 15.067

_cell_angle_ālpha 90

cell angle beta 90

_cell_angle_gamma 120

_symmetry_space_group_name_H-M "P 1 "

_symmetry_int_tables_number 1

loop

_symmetry_equiv_pos_as_xyz

' $\mathrm{x}, \mathrm{y}, \mathrm{z}$ '

loop

_atom_site_label

_atom_site_occupancy

-atom_site_fract_x

-atom_site_fract_y

atom site fract $z$

-atom_site_thermāldisplace_type

-atom_site_B_iso_or_equiv

-atom_site_type_symbol

\begin{tabular}{|c|c|c|c|c|c|c|}
\hline$\overline{\mathrm{S}} i 1$ & 1.0000 & 0.01901 & 0.24680 & 0.10210 & Biso & 1.000 \\
\hline Si2 & 1.0000 & 0.79246 & 0.79200 & 0.10407 & Biso & 1.000 \\
\hline Si3 & 1.0000 & 0.25091 & 0.01859 & 0.09604 & Biso & 1.000 \\
\hline Si 4 & 1.0000 & 0.24755 & 0.01587 & 0.89253 & Biso & 1.000 \\
\hline Si5 & 1.0000 & 0.79146 & 0.78938 & 0.89577 & Biso & 1.000 \\
\hline Si6 & 1.0000 & 0.01775 & 0.24793 & 0.89646 & Biso & 1.000 \\
\hline Si7 & 1.0000 & 0.68799 & 0.58263 & 0.43282 & Biso & 1.000 \\
\hline Al1 & 1.0000 & 0.46396 & 0.13072 & 0.44373 & Biso & 1.000 \\
\hline Si8 & 1.0000 & 0.91625 & 0.34840 & 0.43653 & Biso & 1.000 \\
\hline Si9 & 1.0000 & 0.91475 & 0.35122 & 0.22883 & Biso & 1.000 \\
\hline i 10 & 1.0000 & 0.45675 & 0.12488 & 0.22509 & Biso & 1.000 \\
\hline Si11 & 1.0000 & 0.68836 & 0.58331 & 0.22995 & Biso & 1.000 \\
\hline Si12 & 1.0000 & 0.35126 & 0.90898 & 0.76999 & Biso & 1.000 \\
\hline Si13 & 1.0000 & 0.12150 & 0.45135 & 0.76663 & Biso & 1.000 \\
\hline Si14 & 1.0000 & 0.58402 & 0.68363 & 0.76889 & Biso & 1.000 \\
\hline Si15 & 1.0000 & 0.59037 & 0.69067 & 0.56615 & Biso & 1.000 \\
\hline Si16 & 1.0000 & 0.12208 & 0.45319 & 0.56520 & Biso & 1.000 \\
\hline Sil 7 & 1.0000 & 0.35482 & 0.90328 & 0.56357 & Biso & 1.000 \\
\hline Si18 & 1.0000 & 0.01657 & 0.78343 & 0.89788 & Biso & 1.000 \\
\hline Si19 & 1.0000 & 0.24842 & 0.24710 & 0.89304 & Biso & 1.000 \\
\hline Si20 & 1.0000 & 0.79146 & 0.01724 & 0.89443 & Biso & 1.000 \\
\hline Si21 & 1.0000 & 0.78984 & 0.01782 & 0.10244 & Biso & 1.000 \\
\hline Si22 & 1.0000 & 0.25129 & 0.24909 & 0.09773 & Biso & 1.000 \\
\hline Si23 & 1.0000 & 0.01917 & 0.78878 & 0.10390 & Biso & 1.000 \\
\hline Si24 & 1.0000 & 0.68865 & 0.12017 & 0.23211 & Biso & 1.000 \\
\hline Si25 & 1.0000 & 0.91501 & 0.57843 & 0.22967 & Biso & 1.000 \\
\hline Si26 & 1.0000 & 0.45659 & 0.35200 & 0.22898 & Biso & 1.000 \\
\hline Si27 & 1.0000 & 0.45530 & 0.35389 & 0.43419 & Biso & 1.000 \\
\hline Si28 & 1.0000 & 0.91263 & 0.57464 & 0.43793 & Biso & 1.000 \\
\hline Si29 & 1.0000 & 0.69034 & 0.12341 & 0.43068 & Biso & 1.000 \\
\hline Si30 & 1.0000 & 0.35821 & 0.46835 & 0.56181 & Biso & 1.000 \\
\hline Si31 & 1.0000 & 0.58276 & 0.91379 & 0.56559 & Biso & 1.000 \\
\hline Si32 & 1.0000 & 0.11898 & 0.68464 & 0.56665 & Biso & 1.000 \\
\hline Si33 & 1.0000 & 0.12048 & 0.68357 & 0.76937 & Biso & 1.000 \\
\hline Si34 & 1.0000 & 0.58197 & 0.91452 & 0.76919 & Biso & 1.000 \\
\hline Si35 & 1.0000 & 0.35279 & 0.45509 & 0.76596 & Biso & 1.000 \\
\hline 01 & 1.0000 & 0.92098 & 0.11587 & 0.12015 & Biso & 1.000 \\
\hline $\mathrm{O} 2$ & 1.0000 & 0.92403 & 0.82572 & 0.12190 & Biso & 1.000 \\
\hline 03 & 1.0000 & 0.21852 & 0.11715 & 0.11133 & Biso & 1.000 \\
\hline O4 & 1.0000 & 0.11681 & 0.91402 & 0.88210 & Biso & 1.000 \\
\hline 05 & 1.0000 & 0.82529 & 0.92008 & 0.87549 & Biso & 1.000 \\
\hline 06 & 1.0000 & 0.11749 & 0.21694 & 0.88150 & Biso & 1.000 \\
\hline 07 & 1.0000 & 0.58903 & 0.45139 & 0.43841 & Biso & 1.000 \\
\hline 08 & 1.0000 & 0.60312 & 0.17004 & 0.42535 & Biso & 1.000 \\
\hline
\end{tabular}




\begin{tabular}{|c|c|c|c|c|c|c|}
\hline 09 & 1.0000 & 0.88077 & 0.44430 & 0.45688 & Biso & 1.000 \\
\hline 010 & 1.0000 & 0.78295 & 0.25262 & 0.21366 & Biso & 1.000 \\
\hline 011 & 1.0000 & 0.49397 & 0.25623 & 0.20932 & Biso & 1.000 \\
\hline 012 & 1.0000 & 0.78438 & 0.54719 & 0.21314 & Biso & 1.000 \\
\hline 013 & 1.0000 & 0.25130 & 0.77938 & 0.79017 & Biso & 1.000 \\
\hline 014 & 1.0000 & 0.25328 & 0.48627 & 0.78325 & Biso & 1.000 \\
\hline 015 & 1.0000 & 0.55233 & 0.78347 & 0.77962 & Biso & 1.000 \\
\hline 016 & 1.0000 & 0.45509 & 0.60172 & 0.55479 & Biso & 1.000 \\
\hline 017 & 1.0000 & 0.14600 & 0.58187 & 0.56042 & Biso & 1.000 \\
\hline 018 & 1.0000 & 0.44594 & 0.85843 & 0.55518 & Biso & 1.000 \\
\hline 019 & 1.0000 & 0.00063 & 0.33010 & 0.16789 & Biso & 1.000 \\
\hline $\mathrm{O} 20$ & 1.0000 & 0.70643 & 0.68366 & 0.16291 & Biso & 1.000 \\
\hline 021 & 1.0000 & 0.35602 & 0.03966 & 0.16002 & Biso & 1.000 \\
\hline 022 & 1.0000 & 0.33165 & 0.99820 & 0.82776 & Biso & 1.000 \\
\hline $\mathrm{O} 23$ & 1.0000 & 0.68313 & 0.70181 & 0.83753 & Biso & 1.000 \\
\hline $\mathrm{O} 24$ & 1.0000 & 0.03813 & 0.35354 & 0.83500 & Biso & 1.000 \\
\hline 025 & 1.0000 & 0.66524 & 0.66231 & 0.49903 & Biso & 1.000 \\
\hline 026 & 1.0000 & 0.38555 & 0.00778 & 0.50032 & Biso & 1.000 \\
\hline $\mathrm{O} 27$ & 1.0000 & 0.02481 & 0.37172 & 0.49594 & Biso & 1.000 \\
\hline 028 & 1.0000 & 0.03576 & 0.69622 & 0.83778 & Biso & 1.000 \\
\hline 029 & 1.0000 & 0.33191 & 0.34835 & 0.82709 & Biso & 1.000 \\
\hline 030 & 1.0000 & 0.68472 & 0.99698 & 0.83451 & Biso & 1.000 \\
\hline 031 & 1.0000 & 0.70171 & 0.03987 & 0.15939 & Biso & 1.000 \\
\hline 032 & 1.0000 & 0.35519 & 0.33194 & 0.16191 & Biso & 1.000 \\
\hline 033 & 1.0000 & 0.00128 & 0.68800 & 0.17080 & Biso & 1.000 \\
\hline 034 & 1.0000 & 0.38110 & 0.39377 & 0.49145 & Biso & 1.000 \\
\hline 035 & 1.0000 & 0.01664 & 0.66228 & 0.50016 & Biso & 1.000 \\
\hline 036 & 1.0000 & 0.65211 & 0.01865 & 0.49889 & Biso & 1.000 \\
\hline 037 & 1.0000 & 0.14160 & 0.25975 & 0.12344 & Biso & 1.000 \\
\hline 038 & 1.0000 & 0.77688 & 0.89789 & 0.13287 & Biso & 1.000 \\
\hline 039 & 1.0000 & 0.14330 & 0.89770 & 0.12358 & Biso & 1.000 \\
\hline 040 & 1.0000 & 0.25513 & 0.13504 & 0.86803 & Biso & 1.000 \\
\hline 041 & 1.0000 & 0.89748 & 0.77316 & 0.86898 & Biso & 1.000 \\
\hline 042 & 1.0000 & 0.89823 & 0.13923 & 0.86835 & Biso & 1.000 \\
\hline 043 & 1.0000 & 0.80607 & 0.59061 & 0.46197 & Biso & 1.000 \\
\hline 044 & 1.0000 & 0.43945 & 0.23781 & 0.47207 & Biso & 1.000 \\
\hline 045 & 1.0000 & 0.81440 & 0.22408 & 0.46287 & Biso & 1.000 \\
\hline 046 & 1.0000 & 0.92810 & 0.47164 & 0.19883 & Biso & 1.000 \\
\hline 047 & 1.0000 & 0.56246 & 0.10465 & 0.21988 & Biso & 1.000 \\
\hline 048 & 1.0000 & 0.56494 & 0.47515 & 0.20902 & Biso & 1.000 \\
\hline 049 & 1.0000 & 0.47144 & 0.92164 & 0.79901 & Biso & 1.000 \\
\hline 050 & 1.0000 & 0.10717 & 0.56026 & 0.78437 & Biso & 1.000 \\
\hline 051 & 1.0000 & 0.47315 & 0.56346 & 0.79327 & Biso & 1.000 \\
\hline 052 & 1.0000 & 0.61527 & 0.81708 & 0.54314 & Biso & 1.000 \\
\hline 053 & 1.0000 & 0.23687 & 0.45482 & 0.53650 & Biso & 1.000 \\
\hline 054 & 1.0000 & 0.23049 & 0.79967 & 0.53554 & Biso & 1.000 \\
\hline 055 & 1.0000 & 0.01437 & 0.28196 & 0.99969 & Biso & 1.000 \\
\hline 056 & 1.0000 & 0.76036 & 0.76043 & 0.00020 & Biso & 1.000 \\
\hline 057 & 1.0000 & 0.28948 & 0.01831 & 0.99444 & Biso & 1.000 \\
\hline 058 & 1.0000 & 0.69692 & 0.62853 & 0.33126 & Biso & 1.000 \\
\hline 059 & 1.0000 & 0.95064 & 0.35413 & 0.33212 & Biso & 1.000 \\
\hline 060 & 1.0000 & 0.35091 & 0.93941 & 0.66632 & Biso & 1.000 \\
\hline 061 & 1.0000 & 0.08407 & 0.40400 & 0.66565 & Biso & 1.000 \\
\hline 062 & 1.0000 & 0.62742 & 0.68350 & 0.66804 & Biso & 1.000 \\
\hline 063 & 1.0000 & 0.01264 & 0.74756 & 0.00171 & Biso & 1.000 \\
\hline 064 & 1.0000 & 0.28921 & 0.28634 & 0.99515 & Biso & 1.000 \\
\hline 065 & 1.0000 & 0.75790 & 0.01509 & 0.99830 & Biso & 1.000 \\
\hline 066 & 1.0000 & 0.70279 & 0.08118 & 0.33086 & Biso & 1.000 \\
\hline 067 & 1.0000 & 0.94851 & 0.60645 & 0.33400 & Biso & 1.000 \\
\hline 068 & 1.0000 & 0.41319 & 0.34133 & 0.33034 & Biso & 1.000 \\
\hline 069 & 1.0000 & 0.35420 & 0.42164 & 0.66236 & Biso & 1.000 \\
\hline 070 & 1.0000 & 0.61906 & 0.95830 & 0.66763 & Biso & 1.000 \\
\hline 071 & 1.0000 & 0.08491 & 0.69623 & 0.66840 & Biso & 1.000 \\
\hline 072 & 1.0000 & 0.39880 & 0.08783 & 0.32843 & Biso & 1.000 \\
\hline $\mathrm{C} 1$ & 1.0000 & 0.13262 & 0.88368 & 0.35215 & Biso & 1.000 \\
\hline $\mathrm{H} 1$ & 1.0000 & 0.16385 & 0.88560 & 0.28459 & Biso & 1.000 \\
\hline $\mathrm{H} 2$ & 1.0000 & 0.18203 & 0.86402 & 0.39893 & Biso & 1.000 \\
\hline Н3 & 1.0000 & 0.04544 & 0.81189 & 0.35377 & Biso & 1.000 \\
\hline $\mathrm{C} 2$ & 1.0000 & 0.09736 & 0.14420 & 0.33801 & Biso & 1.000 \\
\hline C3 & 1.0000 & 0.11899 & 0.18357 & 0.42534 & Biso & 1.000 \\
\hline $\mathrm{C} 4$ & 1.0000 & 0.14783 & 0.12719 & 0.48836 & Biso & 1.000 \\
\hline $\mathrm{C} 5$ & 1.0000 & 0.15514 & 0.03222 & 0.46411 & Biso & 1.000 \\
\hline C6 & 1.0000 & 0.13355 & 0.99145 & 0.37645 & Biso & 1.000 \\
\hline C7 & 1.0000 & 0.10433 & 0.04904 & 0.31374 & Biso & 1.000 \\
\hline $\mathrm{H} 4$ & 1.0000 & 0.07496 & 0.18808 & 0.28855 & Biso & 1.000 \\
\hline H5 & 1.0000 & 0.08442 & 0.01748 & 0.24576 & Biso & 1.000 \\
\hline H 6 & 1.0000 & 0.11406 & 0.25828 & 0.44376 & Biso & 1.000 \\
\hline H7 & 1.0000 & 0.16574 & 0.15774 & 0.55673 & Biso & 1.000 \\
\hline H8 & 1.0000 & 0.17778 & 0.98856 & 0.51370 & Biso & 1.000 \\
\hline H9 & 1.0000 & 0.31634 & 0.05978 & 0.33165 & & 1.000 \\
\hline
\end{tabular}


Ge 26

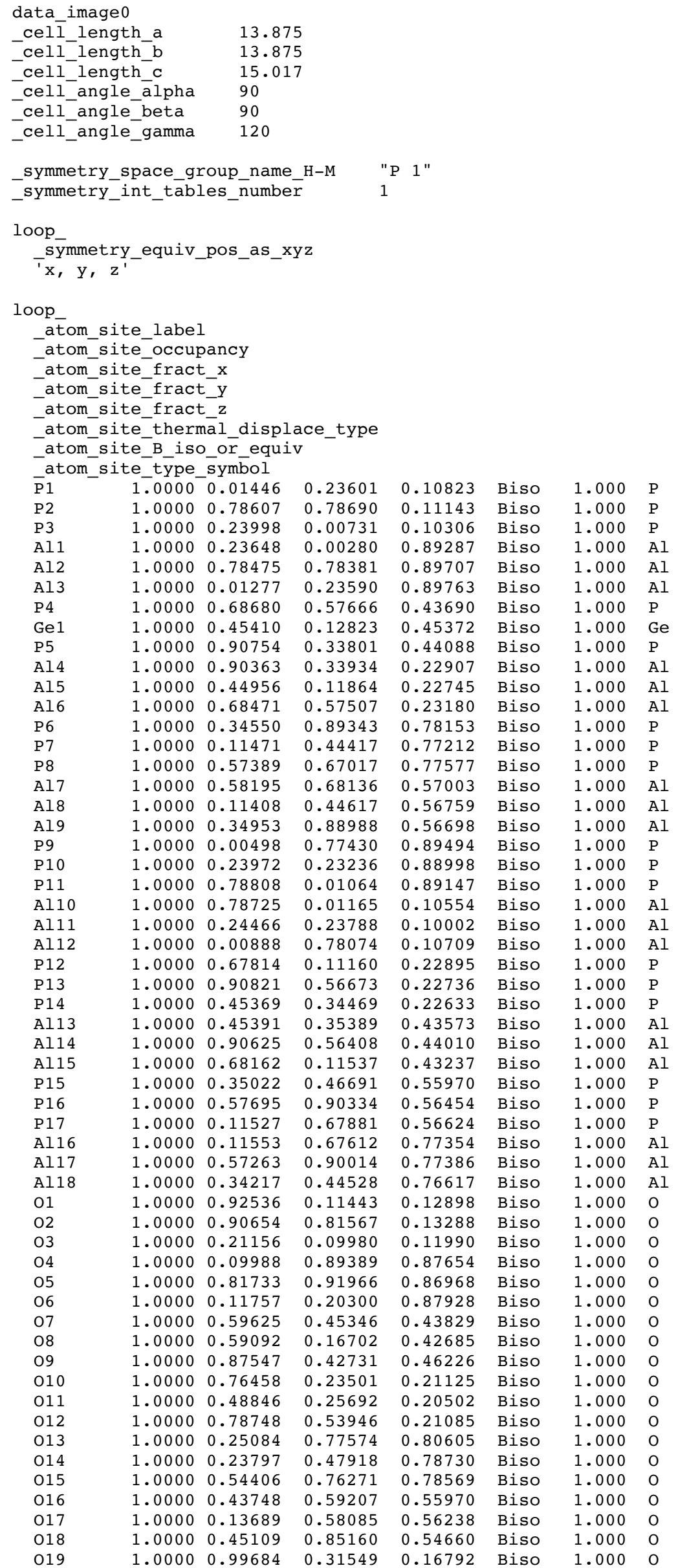




\begin{tabular}{|c|c|c|c|c|c|c|c|}
\hline 020 & 1.0000 & 0.70211 & 0.68279 & 0.16214 & Biso & 1.000 & 0 \\
\hline 021 & 1.0000 & 0.33907 & 0.02578 & 0.16107 & Biso & 1.000 & 0 \\
\hline $\mathrm{O} 22$ & 1.0000 & 0.32951 & 0.98214 & 0.82961 & Biso & 1.000 & 0 \\
\hline 023 & 1.0000 & 0.66436 & 0.68666 & 0.84259 & Biso & 1.000 & 0 \\
\hline 024 & 1.0000 & 0.03935 & 0.35403 & 0.83839 & Biso & 1.000 & 0 \\
\hline 025 & 1.0000 & 0.65866 & 0.64576 & 0.49985 & Biso & 1.000 & 0 \\
\hline 026 & 1.0000 & 0.37283 & 0.00752 & 0.51274 & Biso & 1.000 & 0 \\
\hline 027 & 1.0000 & 0.00989 & 0.35877 & 0.49488 & Biso & 1.000 & 0 \\
\hline 028 & 1.0000 & 0.02111 & 0.68918 & 0.84182 & Biso & 1.000 & 0 \\
\hline 029 & 1.0000 & 0.31601 & 0.32823 & 0.82808 & Biso & 1.000 & 0 \\
\hline 030 & 1.0000 & 0.68543 & 0.99139 & 0.83902 & Biso & 1.000 & 0 \\
\hline 031 & 1.0000 & 0.69106 & 0.03740 & 0.15978 & Biso & 1.000 & 0 \\
\hline 032 & 1.0000 & 0.35955 & 0.32922 & 0.16373 & Biso & 1.000 & 0 \\
\hline 033 & 1.0000 & 0.98993 & 0.66901 & 0.17291 & Biso & 1.000 & 0 \\
\hline 034 & 1.0000 & 0.37970 & 0.40661 & 0.48969 & Biso & 1.000 & 0 \\
\hline 035 & 1.0000 & 0.01748 & 0.65736 & 0.50599 & Biso & 1.000 & 0 \\
\hline 036 & 1.0000 & 0.64425 & 0.00375 & 0.50415 & Biso & 1.000 & 0 \\
\hline 037 & 1.0000 & 0.12993 & 0.25166 & 0.12774 & Biso & 1.000 & 0 \\
\hline 038 & 1.0000 & 0.77098 & 0.88447 & 0.14064 & Biso & 1.000 & 0 \\
\hline 039 & 1.0000 & 0.13960 & 0.89532 & 0.12960 & Biso & 1.000 & 0 \\
\hline 040 & 1.0000 & 0.24824 & 0.12997 & 0.86424 & Biso & 1.000 & 0 \\
\hline 041 & 1.0000 & 0.89492 & 0.76501 & 0.86554 & Biso & 1.000 & 0 \\
\hline 042 & 1.0000 & 0.88603 & 0.12382 & 0.86406 & Biso & 1.000 & 0 \\
\hline 043 & 1.0000 & 0.79662 & 0.58589 & 0.46731 & Biso & 1.000 & 0 \\
\hline 044 & 1.0000 & 0.43299 & 0.23524 & 0.48927 & Biso & 1.000 & 0 \\
\hline 045 & 1.0000 & 0.81199 & 0.22304 & 0.46643 & Biso & 1.000 & 0 \\
\hline 046 & 1.0000 & 0.91952 & 0.46735 & 0.19678 & Biso & 1.000 & 0 \\
\hline 047 & 1.0000 & 0.56053 & 0.09552 & 0.21893 & Biso & 1.000 & 0 \\
\hline 048 & 1.0000 & 0.55400 & 0.46062 & 0.21063 & Biso & 1.000 & 0 \\
\hline 049 & 1.0000 & 0.45668 & 0.90577 & 0.81171 & Biso & 1.000 & 0 \\
\hline 050 & 1.0000 & 0.09954 & 0.54471 & 0.78690 & Biso & 1.000 & 0 \\
\hline 051 & 1.0000 & 0.47040 & 0.55786 & 0.79638 & Biso & 1.000 & 0 \\
\hline 052 & 1.0000 & 0.61148 & 0.81618 & 0.54492 & Biso & 1.000 & 0 \\
\hline 053 & 1.0000 & 0.23672 & 0.45200 & 0.53449 & Biso & 1.000 & 0 \\
\hline 054 & 1.0000 & 0.21901 & 0.78307 & 0.53213 & Biso & 1.000 & 0 \\
\hline 055 & 1.0000 & 0.00642 & 0.26371 & 0.01043 & Biso & 1.000 & 0 \\
\hline 056 & 1.0000 & 0.76291 & 0.76437 & 0.01152 & Biso & 1.000 & 0 \\
\hline 057 & 1.0000 & 0.27135 & 0.00623 & 0.00537 & Biso & 1.000 & 0 \\
\hline 058 & 1.0000 & 0.69852 & 0.62313 & 0.34165 & Biso & 1.000 & 0 \\
\hline 059 & 1.0000 & 0.93673 & 0.34245 & 0.34153 & Biso & 1.000 & 0 \\
\hline 060 & 1.0000 & 0.34572 & 0.91161 & 0.68117 & Biso & 1.000 & 0 \\
\hline 061 & 1.0000 & 0.07919 & 0.39750 & 0.67713 & Biso & 1.000 & 0 \\
\hline 062 & 1.0000 & 0.61710 & 0.67179 & 0.68086 & Biso & 1.000 & 0 \\
\hline 063 & 1.0000 & 0.00092 & 0.74628 & 0.99453 & Biso & 1.000 & 0 \\
\hline 064 & 1.0000 & 0.27779 & 0.26740 & 0.98690 & Biso & 1.000 & 0 \\
\hline 065 & 1.0000 & 0.76331 & 0.00932 & 0.99135 & Biso & 1.000 & 0 \\
\hline 066 & 1.0000 & 0.69374 & 0.07616 & 0.32243 & Biso & 1.000 & 0 \\
\hline 067 & 1.0000 & 0.93834 & 0.59130 & 0.32656 & Biso & 1.000 & 0 \\
\hline 068 & 1.0000 & 0.41258 & 0.33097 & 0.32293 & Biso & 1.000 & 0 \\
\hline 069 & 1.0000 & 0.34412 & 0.41618 & 0.65253 & Biso & 1.000 & 0 \\
\hline 070 & 1.0000 & 0.60273 & 0.94199 & 0.66236 & Biso & 1.000 & 0 \\
\hline 071 & 1.0000 & 0.08898 & 0.69600 & 0.66272 & Biso & 1.000 & 0 \\
\hline 072 & 1.0000 & 0.38667 & 0.08642 & 0.33771 & Biso & 1.000 & 0 \\
\hline $\mathrm{C} 1$ & 1.0000 & 0.08904 & 0.86883 & 0.35194 & Biso & 1.000 & C \\
\hline $\mathrm{H} 1$ & 1.0000 & 0.13721 & 0.87046 & 0.29318 & Biso & 1.000 & $\mathrm{H}$ \\
\hline $\mathrm{H} 2$ & 1.0000 & 0.11376 & 0.83511 & 0.40784 & Biso & 1.000 & $\mathrm{H}$ \\
\hline H3 & 1.0000 & 0.00126 & 0.80972 & 0.33659 & Biso & 1.000 & $\mathrm{H}$ \\
\hline $\mathrm{C} 2$ & 1.0000 & 0.07520 & 0.13634 & 0.33812 & Biso & 1.000 & C \\
\hline $\mathrm{C} 3$ & 1.0000 & 0.12496 & 0.18865 & 0.41839 & Biso & 1.000 & C \\
\hline $\mathrm{C} 4$ & 1.0000 & 0.16424 & 0.13763 & 0.47636 & Biso & 1.000 & C \\
\hline C5 & 1.0000 & 0.15384 & 0.03491 & 0.45405 & Biso & 1.000 & C \\
\hline C 6 & 1.0000 & 0.10452 & 0.98170 & 0.37348 & Biso & 1.000 & C \\
\hline $\mathrm{C} 7$ & 1.0000 & 0.06543 & 0.03439 & 0.31553 & Biso & 1.000 & C \\
\hline H4 & 1.0000 & 0.04329 & 0.17553 & 0.29320 & Biso & 1.000 & $\mathrm{H}$ \\
\hline H5 & 1.0000 & 0.02528 & 0.99398 & 0.25301 & Biso & 1.000 & $\mathrm{H}$ \\
\hline H6 & 1.0000 & 0.13262 & 0.26858 & 0.43524 & Biso & 1.000 & $\mathrm{H}$ \\
\hline $\mathrm{H} 7$ & 1.0000 & 0.20332 & 0.17714 & 0.53932 & Biso & 1.000 & $\mathrm{H}$ \\
\hline H8 & 1.0000 & 0.18332 & 0.99460 & 0.50038 & Biso & 1.000 & $\mathrm{H}$ \\
\hline H9 & 1.0000 & 0.30651 & 0.06043 & 0.34321 & Biso & 1.000 & $\mathrm{H}$ \\
\hline \multicolumn{8}{|l|}{$\mathrm{Ga} 26$} \\
\hline \multicolumn{2}{|c|}{ cell length a } & \multicolumn{2}{|c|}{13.625} & & & & \\
\hline \multicolumn{2}{|c|}{ cell length b } & \multicolumn{2}{|c|}{$\begin{array}{l}13.023 \\
13.625\end{array}$} & & & & \\
\hline \multicolumn{2}{|c|}{ cell length $\mathrm{C}$} & 15.06 & & & & & \\
\hline cell & alpha & 90 & & & & & \\
\hline $\operatorname{cell}$ & beta & 90 & & & & & \\
\hline cell & gamma & 120 & & & & & \\
\hline & & & & $1 "$ & & & \\
\hline & $1 \tau_{-} \tau a b \perp$ & & & & & & \\
\hline
\end{tabular}




\begin{tabular}{|c|c|c|c|c|c|c|c|}
\hline \multicolumn{8}{|l|}{ loop } \\
\hline \multicolumn{8}{|c|}{ 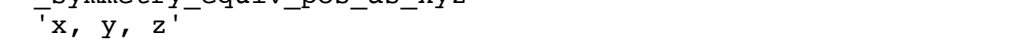 } \\
\hline \multicolumn{8}{|l|}{ loop } \\
\hline \\
\hline \multicolumn{8}{|c|}{ atom_site_occupancy } \\
\hline \multicolumn{8}{|c|}{ atom_site_fract_x } \\
\hline -ato & te_frac & E-y & & & & & \\
\hline -ato & te_frac & z & & & & & \\
\hline ato & te_ther & nàl_displ & ace_type & & & & \\
\hline -ato & $\begin{array}{l}\text { te_B_is } \\
\text { te type }\end{array}$ & $\begin{array}{l}\text { or_or_equi } \\
\text { symbol }\end{array}$ & & & & & \\
\hline$\overline{\mathrm{S}} \mathrm{i} 1$ & 1.0000 & 0.01915 & 0.24606 & 0.10214 & Biso & 1.000 & $\mathrm{Si}$ \\
\hline $\mathrm{Si2}$ & 1.0000 & 0.79178 & 0.79079 & 0.10448 & Biso & 1.000 & $\mathrm{Si}$ \\
\hline $\mathrm{Si3}$ & 1.0000 & 0.25084 & 0.01786 & 0.09695 & Biso & 1.000 & $\mathrm{Si}$ \\
\hline $\mathrm{Si4}$ & 1.0000 & 0.24717 & 0.01471 & 0.89250 & Biso & 1.000 & $\mathrm{Si}$ \\
\hline Si5 & 1.0000 & 0.79152 & 0.78778 & 0.89638 & Biso & 1.000 & $\mathrm{Si}$ \\
\hline Si6 & 1.0000 & 0.01837 & 0.24667 & 0.89689 & Biso & 1.000 & $\mathrm{Si}$ \\
\hline Si7 & 1.0000 & 0.68874 & 0.58166 & 0.43295 & Biso & 1.000 & $\mathrm{Si}$ \\
\hline $\mathrm{Ga} 1$ & 1.0000 & 0.46903 & 0.13625 & 0.44939 & Biso & 1.000 & $\mathrm{Ga}$ \\
\hline Si8 & 1.0000 & 0.91739 & 0.34809 & 0.43602 & Biso & 1.000 & $\mathrm{Si}$ \\
\hline Si9 & 1.0000 & 0.91557 & 0.35108 & 0.22870 & Biso & 1.000 & $\mathrm{Si}$ \\
\hline Silo & 1.0000 & 0.45724 & 0.12530 & 0.22357 & Biso & 1.000 & $\mathrm{Si}$ \\
\hline $\operatorname{Si} 11$ & 1.0000 & 0.68855 & 0.58321 & 0.23083 & Biso & 1.000 & $\mathrm{Si}$ \\
\hline $\operatorname{Si} 12$ & 1.0000 & 0.35246 & 0.90981 & 0.76953 & Biso & 1.000 & $\mathrm{Si}$ \\
\hline $\operatorname{Si} 13$ & 1.0000 & 0.12242 & 0.45016 & 0.76655 & Biso & 1.000 & $\mathrm{Si}$ \\
\hline Si 14 & 1.0000 & 0.58480 & 0.68319 & 0.76889 & Biso & 1.000 & $\mathrm{Si}$ \\
\hline Sil 15 & 1.0000 & 0.59001 & 0.69132 & 0.56671 & Biso & 1.000 & $\mathrm{Si}$ \\
\hline Sil 16 & 1.0000 & 0.12264 & 0.45285 & 0.56641 & Biso & 1.000 & $\mathrm{Si}$ \\
\hline $\operatorname{sil} 17$ & 1.0000 & 0.35440 & 0.90179 & 0.56434 & Biso & 1.000 & $\mathrm{Si}$ \\
\hline Si18 & 1.0000 & 0.01715 & 0.78270 & 0.89835 & Biso & 1.000 & $\mathrm{Si}$ \\
\hline Si19 & 1.0000 & 0.25003 & 0.24671 & 0.89383 & Biso & 1.000 & $\mathrm{Si}$ \\
\hline $\operatorname{Si} 20$ & 1.0000 & 0.79231 & 0.01656 & 0.89461 & Biso & 1.000 & $\mathrm{Si}$ \\
\hline Si21 & 1.0000 & 0.79030 & 0.01762 & 0.10284 & Biso & 1.000 & $\mathrm{Si}$ \\
\hline $\mathrm{Si} 22$ & 1.0000 & 0.25269 & 0.24939 & 0.09833 & Biso & 1.000 & $\mathrm{Si}$ \\
\hline Si23 & 1.0000 & 0.01932 & 0.78877 & 0.10511 & Biso & 1.000 & $\mathrm{Si}$ \\
\hline Si24 & 1.0000 & 0.68865 & 0.11950 & 0.23268 & Biso & 1.000 & $\mathrm{Si}$ \\
\hline Si25 & 1.0000 & 0.91437 & 0.57744 & 0.22972 & Biso & 1.000 & $\mathrm{Si}$ \\
\hline Si26 & 1.0000 & 0.45717 & 0.35024 & 0.22882 & Biso & 1.000 & $\mathrm{Si}$ \\
\hline Si27 & 1.0000 & 0.45722 & 0.35506 & 0.43470 & Biso & 1.000 & $\mathrm{Si}$ \\
\hline Si28 & 1.0000 & 0.91150 & 0.57219 & 0.43824 & Biso & 1.000 & $\mathrm{Si}$ \\
\hline $\operatorname{Si} 29$ & 1.0000 & 0.69312 & 0.12466 & 0.43143 & Biso & 1.000 & $\mathrm{Si}$ \\
\hline $\operatorname{Si30}$ & 1.0000 & 0.36009 & 0.47022 & 0.56213 & Biso & 1.000 & $\mathrm{Si}$ \\
\hline $\operatorname{Si} 31$ & 1.0000 & 0.58233 & 0.91303 & 0.56596 & Biso & 1.000 & $\mathrm{Si}$ \\
\hline $\operatorname{Si32}$ & 1.0000 & 0.11801 & 0.68190 & 0.56852 & Biso & 1.000 & $\mathrm{Si}$ \\
\hline Si33 & 1.0000 & 0.12040 & 0.68189 & 0.77004 & Biso & 1.000 & $\mathrm{Si}$ \\
\hline $\mathrm{Si} 34$ & 1.0000 & 0.58207 & 0.91318 & 0.76992 & Biso & 1.000 & $\mathrm{Si}$ \\
\hline Si35 & 1.0000 & 0.35442 & 0.45286 & 0.76412 & Biso & 1.000 & $\mathrm{Si}$ \\
\hline 01 & 1.0000 & 0.92149 & 0.11520 & 0.12152 & Biso & 1.000 & 0 \\
\hline $\mathrm{O} 2$ & 1.0000 & 0.92321 & 0.82449 & 0.12290 & Biso & 1.000 & 0 \\
\hline 03 & 1.0000 & 0.22073 & 0.11789 & 0.11317 & Biso & 1.000 & 0 \\
\hline 04 & 1.0000 & 0.11666 & 0.91304 & 0.88031 & Biso & 1.000 & 0 \\
\hline 05 & 1.0000 & 0.82533 & 0.91859 & 0.87662 & Biso & 1.000 & 0 \\
\hline 06 & 1.0000 & 0.11900 & 0.21666 & 0.88379 & Biso & 1.000 & 0 \\
\hline 07 & 1.0000 & 0.59232 & 0.44893 & 0.43500 & Biso & 1.000 & 0 \\
\hline 08 & 1.0000 & 0.61477 & 0.18244 & 0.42681 & Biso & 1.000 & 0 \\
\hline 09 & 1.0000 & 0.87724 & 0.44072 & 0.45604 & Biso & 1.000 & 0 \\
\hline 010 & 1.0000 & 0.78392 & 0.25167 & 0.21470 & Biso & 1.000 & 0 \\
\hline 011 & 1.0000 & 0.49501 & 0.25627 & 0.20355 & Biso & 1.000 & 0 \\
\hline 012 & 1.0000 & 0.78390 & 0.54654 & 0.21257 & Biso & 1.000 & 0 \\
\hline 013 & 1.0000 & 0.25133 & 0.78007 & 0.78697 & Biso & 1.000 & 0 \\
\hline 014 & 1.0000 & 0.25436 & 0.48369 & 0.77941 & Biso & 1.000 & 0 \\
\hline 015 & 1.0000 & 0.55201 & 0.78208 & 0.78103 & Biso & 1.000 & 0 \\
\hline 016 & 1.0000 & 0.45345 & 0.60516 & 0.55953 & Biso & 1.000 & 0 \\
\hline 017 & 1.0000 & 0.15029 & 0.58275 & 0.56265 & Biso & 1.000 & 0 \\
\hline 018 & 1.0000 & 0.44523 & 0.85648 & 0.55636 & Biso & 1.000 & 0 \\
\hline 019 & 1.0000 & 0.00143 & 0.33004 & 0.16768 & Biso & 1.000 & 0 \\
\hline 020 & 1.0000 & 0.70527 & 0.68287 & 0.16354 & Biso & 1.000 & 0 \\
\hline 021 & 1.0000 & 0.35716 & 0.03787 & 0.15888 & Biso & 1.000 & 0 \\
\hline 022 & 1.0000 & 0.33251 & 0.99778 & 0.82857 & Biso & 1.000 & 0 \\
\hline 023 & 1.0000 & 0.68333 & 0.70057 & 0.83784 & Biso & 1.000 & 0 \\
\hline $\mathrm{O} 24$ & 1.0000 & 0.04028 & 0.35291 & 0.83568 & Biso & 1.000 & 0 \\
\hline 025 & 1.0000 & 0.65994 & 0.65705 & 0.49914 & Biso & 1.000 & 0 \\
\hline 026 & 1.0000 & 0.37994 & 0.00086 & 0.49641 & Biso & 1.000 & 0 \\
\hline 027 & 1.0000 & 0.02682 & 0.37480 & 0.49530 & Biso & 1.000 & 0 \\
\hline 028 & 1.0000 & 0.03703 & 0.69461 & 0.83991 & Biso & 1.000 & 0 \\
\hline 029 & 1.0000 & 0.33280 & 0.34721 & 0.82693 & Biso & 1.000 & 0 \\
\hline 030 & 1.0000 & 0.68528 & 0.99598 & 0.83483 & Biso & 1.000 & 0 \\
\hline
\end{tabular}




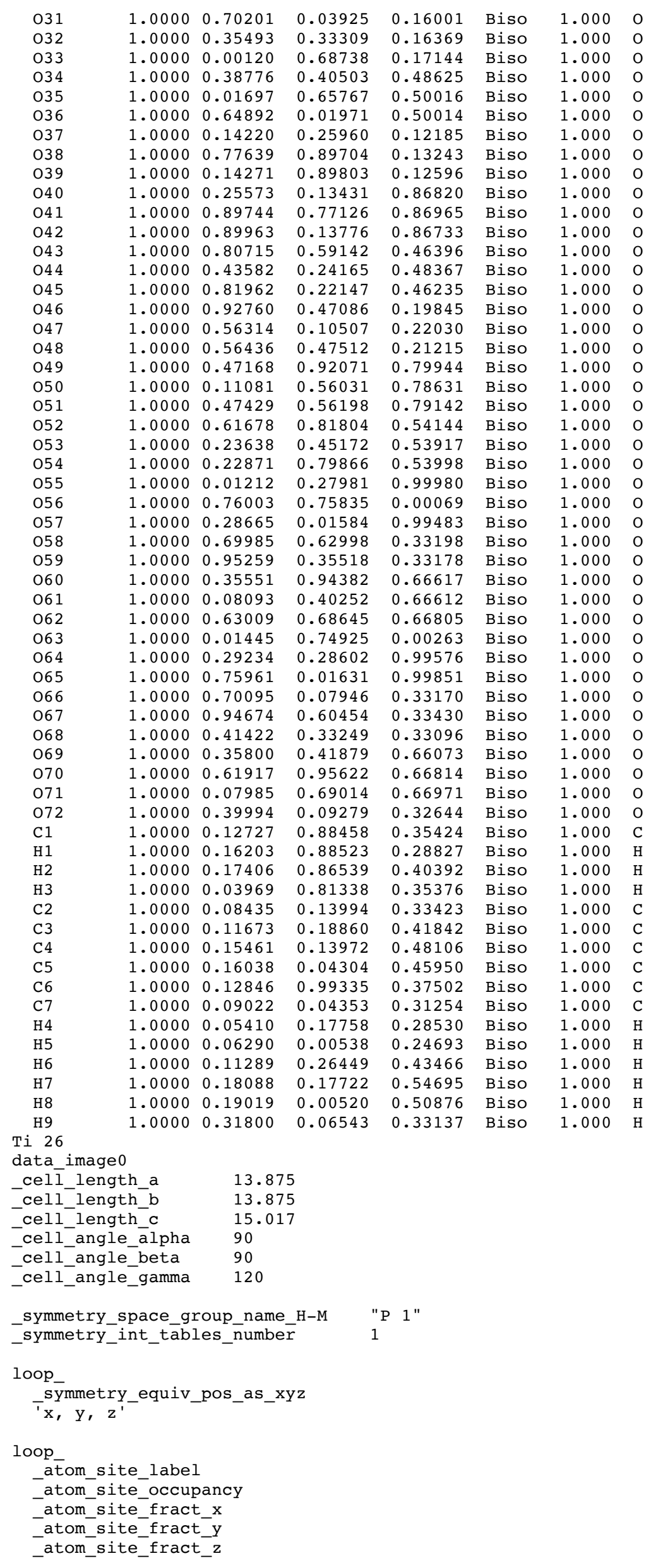




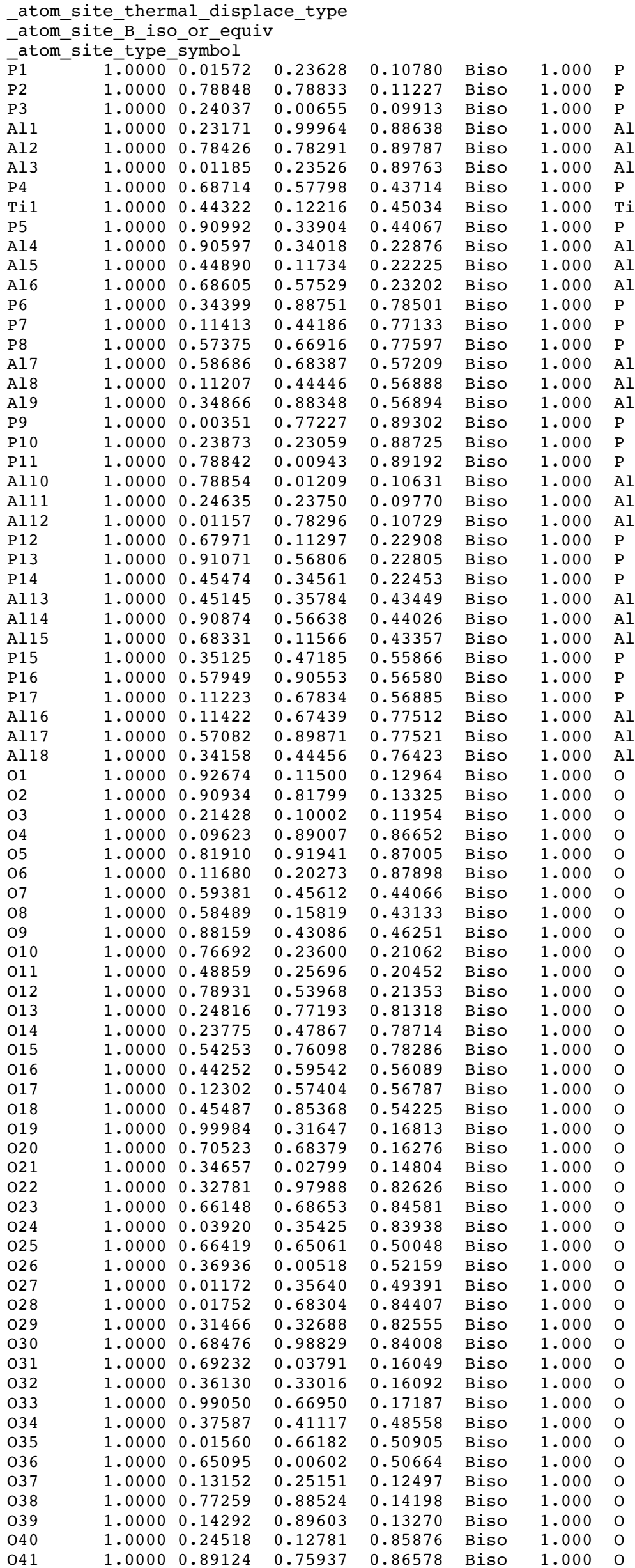




\begin{tabular}{|c|c|c|c|c|c|c|c|}
\hline 042 & 1.0000 & 0.88520 & 0.12309 & 0.86383 & Biso & 1.000 & 0 \\
\hline 043 & 1.0000 & 0.79594 & 0.58365 & 0.46540 & Biso & 1.000 & 0 \\
\hline 044 & 1.0000 & 0.42995 & 0.23791 & 0.48628 & Biso & 1.000 & 0 \\
\hline 045 & 1.0000 & 0.81235 & 0.22578 & 0.46685 & Biso & 1.000 & 0 \\
\hline 046 & 1.0000 & 0.92213 & 0.46869 & 0.19757 & Biso & 1.000 & 0 \\
\hline 047 & 1.0000 & 0.56257 & 0.09776 & 0.21896 & Biso & 1.000 & 0 \\
\hline 048 & 1.0000 & 0.55595 & 0.46104 & 0.20851 & Biso & 1.000 & 0 \\
\hline 049 & 1.0000 & 0.45511 & 0.90188 & 0.81803 & Biso & 1.000 & 0 \\
\hline 050 & 1.0000 & 0.09778 & 0.54224 & 0.78210 & Biso & 1.000 & 0 \\
\hline 051 & 1.0000 & 0.47005 & 0.55639 & 0.79492 & Biso & 1.000 & 0 \\
\hline 052 & 1.0000 & 0.61595 & 0.81908 & 0.55012 & Biso & 1.000 & 0 \\
\hline 053 & 1.0000 & 0.24019 & 0.46392 & 0.53555 & Biso & 1.000 & 0 \\
\hline 054 & 1.0000 & 0.21979 & 0.77599 & 0.53177 & Biso & 1.000 & 0 \\
\hline 055 & 1.0000 & 0.00513 & 0.26320 & 0.01030 & Biso & 1.000 & 0 \\
\hline 056 & 1.0000 & 0.76484 & 0.76588 & 0.01250 & Biso & 1.000 & 0 \\
\hline 057 & 1.0000 & 0.25945 & 0.00011 & 0.99966 & Biso & 1.000 & 0 \\
\hline 058 & 1.0000 & 0.69735 & 0.62322 & 0.34166 & Biso & 1.000 & 0 \\
\hline 059 & 1.0000 & 0.93804 & 0.34240 & 0.34127 & Biso & 1.000 & 0 \\
\hline 060 & 1.0000 & 0.34537 & 0.89721 & 0.68380 & Biso & 1.000 & 0 \\
\hline 061 & 1.0000 & 0.07910 & 0.39104 & 0.67735 & Biso & 1.000 & 0 \\
\hline 062 & 1.0000 & 0.62108 & 0.67105 & 0.68260 & Biso & 1.000 & 0 \\
\hline 063 & 1.0000 & 0.00625 & 0.75384 & 0.99381 & Biso & 1.000 & 0 \\
\hline 064 & 1.0000 & 0.27877 & 0.26379 & 0.98407 & Biso & 1.000 & 0 \\
\hline 065 & 1.0000 & 0.76463 & 0.00855 & 0.99197 & Biso & 1.000 & 0 \\
\hline 066 & 1.0000 & 0.69504 & 0.07820 & 0.32293 & Biso & 1.000 & 0 \\
\hline 067 & 1.0000 & 0.94319 & 0.59442 & 0.32687 & Biso & 1.000 & 0 \\
\hline 068 & 1.0000 & 0.41340 & 0.33418 & 0.32090 & Biso & 1.000 & 0 \\
\hline 069 & 1.0000 & 0.34323 & 0.41693 & 0.65005 & Biso & 1.000 & 0 \\
\hline 070 & 1.0000 & 0.59829 & 0.94337 & 0.66412 & Biso & 1.000 & 0 \\
\hline 071 & 1.0000 & 0.09172 & 0.70263 & 0.66512 & Biso & 1.000 & 0 \\
\hline 072 & 1.0000 & 0.37774 & 0.07825 & 0.32811 & Biso & 1.000 & 0 \\
\hline $\mathrm{C} 1$ & 1.0000 & 0.08682 & 0.87012 & 0.35698 & Biso & 1.000 & $\mathrm{C}$ \\
\hline $\mathrm{H} 1$ & 1.0000 & 0.12632 & 0.86771 & 0.29418 & Biso & 1.000 & $\mathrm{H}$ \\
\hline $\mathrm{H} 2$ & 1.0000 & 0.11931 & 0.84039 & 0.41037 & Biso & 1.000 & $\mathrm{H}$ \\
\hline H3 & 1.0000 & 0.99745 & 0.80984 & 0.34977 & Biso & 1.000 & $\mathrm{H}$ \\
\hline $\mathrm{C} 2$ & 1.0000 & 0.07961 & 0.14068 & 0.33792 & Biso & 1.000 & $\mathrm{C}$ \\
\hline C3 & 1.0000 & 0.12615 & 0.19229 & 0.41910 & Biso & 1.000 & $\mathrm{C}$ \\
\hline $\mathrm{C} 4$ & 1.0000 & 0.16179 & 0.14012 & 0.47930 & Biso & 1.000 & $\mathrm{C}$ \\
\hline C5 & 1.0000 & 0.15067 & 0.03681 & 0.45835 & Biso & 1.000 & $\mathrm{C}$ \\
\hline C6 & 1.0000 & 0.10424 & 0.98411 & 0.37697 & Biso & 1.000 & $\mathrm{C}$ \\
\hline C7 & 1.0000 & 0.06917 & 0.03807 & 0.31668 & Biso & 1.000 & $\mathrm{C}$ \\
\hline $\mathrm{H} 4$ & 1.0000 & 0.05093 & 0.18101 & 0.29116 & Biso & 1.000 & $\mathrm{H}$ \\
\hline H5 & 1.0000 & 0.03160 & 0.99817 & 0.25335 & Biso & 1.000 & $\mathrm{H}$ \\
\hline H6 & 1.0000 & 0.13433 & 0.27273 & 0.43476 & Biso & 1.000 & $\mathrm{H}$ \\
\hline $\mathrm{H} 7$ & 1.0000 & 0.19899 & 0.17955 & 0.54277 & Biso & 1.000 & $\mathrm{H}$ \\
\hline H8 & 1.0000 & 0.17784 & 0.99590 & 0.50616 & Biso & 1.000 & $\mathrm{H}$ \\
\hline H9 & 1.0000 & 0.29763 & 0.05262 & 0.32845 & Biso & 1.000 & $\mathrm{H}$ \\
\hline \multicolumn{8}{|c|}{ Zn 27} \\
\hline \multicolumn{8}{|c|}{ data_image 0} \\
\hline \multicolumn{8}{|c|}{13.875} \\
\hline \multicolumn{8}{|c|}{ cell length b $\quad 13.875$} \\
\hline \multicolumn{8}{|c|}{ _cell_length_c $\quad 15.017$} \\
\hline \multicolumn{8}{|c|}{ cell-angle ālpha $\quad 90$} \\
\hline \multicolumn{8}{|c|}{ cell_angle_beta 90} \\
\hline - cell] & e_gamma & 120 & & & & & \\
\hline symme & space_gr & roup_name & $\mathrm{H}-\mathrm{M}$ & $1 "$ & & & \\
\hline _symme & int_tab] & les_numbe & & & & & \\
\hline loop_ & & & & & & & \\
\hline $\begin{array}{c}\text { syn } \\
\text { x, }\end{array}$ & equiv & _pos_as_z & & & & & \\
\hline loop_ & & & & & & & \\
\hline$-a \overline{t c}$ & Ce_label & & & & & & \\
\hline -atc & =e_occup & pancy & & & & & \\
\hline -atc & ce_fract & $t \_x$ & & & & & \\
\hline -atc & ee_fract & & & & & & \\
\hline -atc & ee_fract & $t z z$ & & & & & \\
\hline -atc & =e_thern & māl_disp & ace_type & & & & \\
\hline atc & e_B_isc & o_or_equ & & & & & \\
\hline atc & ce-type & symbol & & & & & \\
\hline $\bar{A} 11$ & 1.0000 & 0.00022 & 0.22789 & 0.10299 & Biso & 1.000 & $\mathrm{Al}$ \\
\hline Al2 & 1.0000 & 0.77579 & 0.77446 & 0.10665 & Biso & 1.000 & Al \\
\hline Al3 & 1.0000 & 0.23192 & 0.00643 & 0.09720 & Biso & 1.000 & Al \\
\hline $\mathrm{P} 1$ & 1.0000 & 0.22319 & 0.00070 & 0.88497 & Biso & 1.000 & $P$ \\
\hline P2 & 1.0000 & 0.77543 & 0.77230 & 0.89389 & Biso & 1.000 & $P$ \\
\hline P3 & 1.0000 & 0.99612 & 0.22708 & 0.89120 & Biso & 1.000 & $\mathrm{P}$ \\
\hline Al4 & 1.0000 & 0.66004 & 0.55701 & 0.43526 & Biso & 1.000 & Al \\
\hline $\mathrm{Zn} 1$ & 1.0000 & 0.44960 & 0.11523 & 0.43620 & Biso & 1.000 & $\mathrm{Zn}$ \\
\hline
\end{tabular}




\begin{tabular}{|c|c|c|c|c|c|c|c|}
\hline Al5 & 1.0000 & 0.90234 & 0.33724 & 0.43533 & Biso & 1.000 & $\mathrm{Al}$ \\
\hline P4 & 1.0000 & 0.89862 & 0.34018 & 0.22429 & Biso & 1.000 & $\mathrm{P}$ \\
\hline P5 & 1.0000 & 0.43740 & 0.09887 & 0.22310 & Biso & 1.000 & $\mathrm{P}$ \\
\hline P6 & 1.0000 & 0.66463 & 0.55964 & 0.22509 & Biso & 1.000 & $\mathrm{P}$ \\
\hline Al6 & 1.0000 & 0.32804 & 0.88807 & 0.77102 & Biso & 1.000 & $\mathrm{Al}$ \\
\hline Al7 & 1.0000 & 0.10655 & 0.43510 & 0.76742 & Biso & 1.000 & Al \\
\hline Al8 & 1.0000 & 0.56486 & 0.67188 & 0.76925 & Biso & 1.000 & Al \\
\hline P7 & 1.0000 & 0.57407 & 0.68006 & 0.56111 & Biso & 1.000 & $\mathrm{P}$ \\
\hline P8 & 1.0000 & 0.10778 & 0.43951 & 0.56181 & Biso & 1.000 & $P$ \\
\hline P9 & 1.0000 & 0.32898 & 0.88320 & 0.55770 & Biso & 1.000 & $\mathrm{P}$ \\
\hline Al9 & 1.0000 & 0.00120 & 0.77168 & 0.89781 & Biso & 1.000 & $\mathrm{Al}$ \\
\hline Al10 & 1.0000 & 0.22557 & 0.22974 & 0.89126 & Biso & 1.000 & Al \\
\hline Al11 & 1.0000 & 0.77313 & 0.99705 & 0.89513 & Biso & 1.000 & Al \\
\hline $\mathrm{P} 10$ & 1.0000 & 0.77481 & 0.99933 & 0.10794 & Biso & 1.000 & $\mathrm{P}$ \\
\hline P 11 & 1.0000 & 0.22973 & 0.23215 & 0.10328 & Biso & 1.000 & $P$ \\
\hline P12 & 1.0000 & 0.00720 & 0.78072 & 0.11150 & Biso & 1.000 & $\mathrm{P}$ \\
\hline Al12 & 1.0000 & 0.67304 & 0.10967 & 0.23151 & Biso & 1.000 & Al \\
\hline Al13 & 1.0000 & 0.89777 & 0.56568 & 0.23071 & Biso & 1.000 & Al \\
\hline Al 14 & 1.0000 & 0.43998 & 0.33103 & 0.22804 & Biso & 1.000 & Al \\
\hline P13 & 1.0000 & 0.43086 & 0.33455 & 0.43805 & Biso & 1.000 & $\mathrm{P}$ \\
\hline P 14 & 1.0000 & 0.89392 & 0.56244 & 0.44031 & Biso & 1.000 & $\mathrm{P}$ \\
\hline P15 & 1.0000 & 0.67839 & 0.11659 & 0.43645 & Biso & 1.000 & $\mathrm{P}$ \\
\hline Al15 & 1.0000 & 0.34202 & 0.45569 & 0.56180 & Biso & 1.000 & Al \\
\hline A116 & 1.0000 & 0.56055 & 0.89921 & 0.56333 & Biso & 1.000 & Al \\
\hline Al17 & 1.0000 & 0.09724 & 0.66693 & 0.56950 & Biso & 1.000 & $\mathrm{Al}$ \\
\hline P16 & 1.0000 & 0.10297 & 0.66494 & 0.77693 & Biso & 1.000 & $P$ \\
\hline P 17 & 1.0000 & 0.55860 & 0.89679 & 0.77369 & Biso & 1.000 & $\mathrm{P}$ \\
\hline P 18 & 1.0000 & 0.33715 & 0.44308 & 0.77124 & Biso & 1.000 & $P$ \\
\hline 01 & 1.0000 & 0.89668 & 0.09026 & 0.12486 & Biso & 1.000 & 0 \\
\hline $\mathrm{O} 2$ & 1.0000 & 0.91348 & 0.80678 & 0.13001 & Biso & 1.000 & 0 \\
\hline 03 & 1.0000 & 0.19993 & 0.11062 & 0.12129 & Biso & 1.000 & 0 \\
\hline 04 & 1.0000 & 0.10281 & 0.90698 & 0.86713 & Biso & 1.000 & 0 \\
\hline 05 & 1.0000 & 0.80854 & 0.89399 & 0.87343 & Biso & 1.000 & 0 \\
\hline 06 & 1.0000 & 0.08878 & 0.19949 & 0.87204 & Biso & 1.000 & 0 \\
\hline 07 & 1.0000 & 0.55484 & 0.42155 & 0.45700 & Biso & 1.000 & 0 \\
\hline 08 & 1.0000 & 0.60603 & 0.17053 & 0.43919 & Biso & 1.000 & 0 \\
\hline 09 & 1.0000 & 0.87128 & 0.44375 & 0.45781 & Biso & 1.000 & 0 \\
\hline 010 & 1.0000 & 0.77665 & 0.24855 & 0.21066 & Biso & 1.000 & 0 \\
\hline 011 & 1.0000 & 0.46691 & 0.22135 & 0.21420 & Biso & 1.000 & 0 \\
\hline 012 & 1.0000 & 0.76229 & 0.53749 & 0.21270 & Biso & 1.000 & 0 \\
\hline 013 & 1.0000 & 0.22406 & 0.75241 & 0.80012 & Biso & 1.000 & 0 \\
\hline 014 & 1.0000 & 0.24487 & 0.47170 & 0.79040 & Biso & 1.000 & 0 \\
\hline 015 & 1.0000 & 0.52811 & 0.77440 & 0.78589 & Biso & 1.000 & 0 \\
\hline 016 & 1.0000 & 0.45004 & 0.59341 & 0.54884 & Biso & 1.000 & 0 \\
\hline 017 & 1.0000 & 0.11892 & 0.55523 & 0.55896 & Biso & 1.000 & 0 \\
\hline 018 & 1.0000 & 0.41695 & 0.84656 & 0.54652 & Biso & 1.000 & 0 \\
\hline 019 & 1.0000 & 0.97701 & 0.32037 & 0.16502 & Biso & 1.000 & 0 \\
\hline 020 & 1.0000 & 0.68187 & 0.65727 & 0.16617 & Biso & 1.000 & 0 \\
\hline 021 & 1.0000 & 0.35147 & 0.02727 & 0.15130 & Biso & 1.000 & 0 \\
\hline 022 & 1.0000 & 0.30572 & 0.98495 & 0.82793 & Biso & 1.000 & 0 \\
\hline 023 & 1.0000 & 0.67312 & 0.69183 & 0.83967 & Biso & 1.000 & 0 \\
\hline $\mathrm{O} 24$ & 1.0000 & 0.01351 & 0.32712 & 0.83566 & Biso & 1.000 & 0 \\
\hline 025 & 1.0000 & 0.64733 & 0.65455 & 0.50027 & Biso & 1.000 & 0 \\
\hline 026 & 1.0000 & 0.35043 & 0.98131 & 0.50081 & Biso & 1.000 & o \\
\hline 027 & 1.0000 & 0.01858 & 0.36092 & 0.49655 & Biso & 1.000 & 0 \\
\hline 028 & 1.0000 & 0.02209 & 0.67347 & 0.84184 & Biso & 1.000 & 0 \\
\hline 029 & 1.0000 & 0.31944 & 0.34375 & 0.82826 & Biso & 1.000 & 0 \\
\hline 030 & 1.0000 & 0.65640 & 0.97282 & 0.83425 & Biso & 1.000 & 0 \\
\hline 031 & 1.0000 & 0.69438 & 0.02131 & 0.16186 & Biso & 1.000 & 0 \\
\hline 032 & 1.0000 & 0.33050 & 0.31247 & 0.15890 & Biso & 1.000 & 0 \\
\hline 033 & 1.0000 & 0.99307 & 0.68370 & 0.17045 & Biso & 1.000 & 0 \\
\hline 034 & 1.0000 & 0.35580 & 0.36708 & 0.48977 & Biso & 1.000 & 0 \\
\hline 035 & 1.0000 & 0.98599 & 0.64709 & 0.50214 & Biso & 1.000 & 0 \\
\hline 036 & 1.0000 & 0.63942 & 0.01740 & 0.50036 & Biso & 1.000 & 0 \\
\hline 037 & 1.0000 & 0.13006 & 0.24486 & 0.13030 & Biso & 1.000 & 0 \\
\hline 038 & 1.0000 & 0.76117 & 0.88728 & 0.13767 & Biso & 1.000 & 0 \\
\hline 039 & 1.0000 & 0.11967 & 0.88182 & 0.13840 & Biso & 1.000 & 0 \\
\hline 040 & 1.0000 & 0.23406 & 0.11288 & 0.86096 & Biso & 1.000 & 0 \\
\hline 041 & 1.0000 & 0.87193 & 0.75370 & 0.86840 & Biso & 1.000 & 0 \\
\hline 042 & 1.0000 & 0.88406 & 0.12654 & 0.86520 & Biso & 1.000 & 0 \\
\hline 043 & 1.0000 & 0.78863 & 0.56805 & 0.45820 & Biso & 1.000 & 0 \\
\hline 044 & 1.0000 & 0.40375 & 0.21939 & 0.46686 & Biso & 1.000 & 0 \\
\hline 045 & 1.0000 & 0.79790 & 0.20456 & 0.46425 & Biso & 1.000 & 0 \\
\hline 046 & 1.0000 & 0.91070 & 0.45269 & 0.19748 & Biso & 1.000 & 0 \\
\hline 047 & 1.0000 & 0.54316 & 0.09287 & 0.20608 & Biso & 1.000 & 0 \\
\hline 048 & 1.0000 & 0.55758 & 0.45556 & 0.19589 & Biso & 1.000 & 0 \\
\hline 049 & 1.0000 & 0.45802 & 0.90794 & 0.80102 & Biso & 1.000 & 0 \\
\hline 050 & 1.0000 & 0.08850 & 0.54882 & 0.78580 & Biso & 1.000 & 0 \\
\hline 051 & 1.0000 & 0.44999 & 0.54343 & 0.79587 & Biso & 1.000 & 0 \\
\hline 052 & 1.0000 & 0.59232 & 0.79534 & 0.53629 & Biso & 1.000 & 0 \\
\hline
\end{tabular}




\begin{tabular}{|c|c|c|c|c|c|c|c|}
\hline 053 & 1.0000 & 0.21895 & 0.45194 & 0.53359 & Biso & 1.000 & 0 \\
\hline 054 & 1.0000 & 0.21425 & 0.78452 & 0.52515 & Biso & 1.000 & 0 \\
\hline 055 & 1.0000 & 0.99680 & 0.25609 & 0.99005 & Biso & 1.000 & 0 \\
\hline 056 & 1.0000 & 0.74823 & 0.74699 & 0.99335 & Biso & 1.000 & 0 \\
\hline 057 & 1.0000 & 0.25129 & 0.99828 & 0.98380 & Biso & 1.000 & 0 \\
\hline 058 & 1.0000 & 0.65794 & 0.58966 & 0.32256 & Biso & 1.000 & 0 \\
\hline 059 & 1.0000 & 0.38625 & 0.05073 & 0.31483 & Biso & 1.000 & 0 \\
\hline 060 & 1.0000 & 0.93398 & 0.34403 & 0.32177 & Biso & 1.000 & 0 \\
\hline 061 & 1.0000 & 0.31902 & 0.90475 & 0.65696 & Biso & 1.000 & 0 \\
\hline 062 & 1.0000 & 0.07569 & 0.39109 & 0.65650 & Biso & 1.000 & 0 \\
\hline 063 & 1.0000 & 0.60841 & 0.67846 & 0.65865 & Biso & 1.000 & 0 \\
\hline 064 & 1.0000 & 0.00788 & 0.75190 & 0.01290 & Biso & 1.000 & 0 \\
\hline 065 & 1.0000 & 0.25768 & 0.26010 & 0.00417 & Biso & 1.000 & 0 \\
\hline 066 & 1.0000 & 0.74554 & 0.99558 & 0.00880 & Biso & 1.000 & 0 \\
\hline 067 & 1.0000 & 0.68136 & 0.07361 & 0.34152 & Biso & 1.000 & 0 \\
\hline 068 & 1.0000 & 0.93492 & 0.59850 & 0.34343 & Biso & 1.000 & 0 \\
\hline 069 & 1.0000 & 0.40705 & 0.34013 & 0.33794 & Biso & 1.000 & 0 \\
\hline 070 & 1.0000 & 0.33590 & 0.41294 & 0.67257 & Biso & 1.000 & 0 \\
\hline 071 & 1.0000 & 0.59112 & 0.93352 & 0.67651 & Biso & 1.000 & 0 \\
\hline 072 & 1.0000 & 0.07469 & 0.68450 & 0.68142 & Biso & 1.000 & 0 \\
\hline H 1 & 1.0000 & 0.26741 & 0.94006 & 0.33329 & Biso & 1.000 & $\mathrm{H}$ \\
\hline N1 & 1.0000 & 0.18734 & 0.87141 & 0.35220 & Biso & 1.000 & $\mathrm{~N}$ \\
\hline H2 & 1.0000 & 0.15261 & 0.81486 & 0.30111 & Biso & 1.000 & $\mathrm{H}$ \\
\hline H3 & 1.0000 & 0.13534 & 0.90198 & 0.36664 & Biso & 1.000 & $\mathrm{H}$ \\
\hline H4 & 1.0000 & 0.19601 & 0.83413 & 0.40976 & Biso & 1.000 & $\mathrm{H}$ \\
\hline \multicolumn{8}{|l|}{ Si 27} \\
\hline \multicolumn{8}{|c|}{ _celī_length_a } \\
\hline $\mathrm{cell}$ & th_b & \multicolumn{6}{|c|}{13.875} \\
\hline$\left.{ }^{-} \mathrm{cell}\right]$ & $\mathrm{th}^{-} \mathrm{c}$ & \multicolumn{6}{|c|}{15.017} \\
\hline $\mathrm{cell}$ & e_talpha & \multicolumn{6}{|c|}{90} \\
\hline cell- & _beta & \multicolumn{6}{|l|}{90} \\
\hline$\left.{ }_{-} \mathrm{cell}\right]_{-}$ & e_gamma & \multicolumn{6}{|l|}{120} \\
\hline symme & space_gl & coup_name & $\mathrm{H}-\mathrm{M}$ & $1 "$ & & & \\
\hline symme & int_t $\overline{a b}$ & les_numbe & $\bar{c}$ & & & & \\
\hline & & & & & & & \\
\hline $\bar{T}_{\mathrm{x},}^{\mathrm{sym}}$ & _equiv & pos_as_x & & & & & \\
\hline op_ & & & & & & & \\
\hline ato & e_labe & & & & & & \\
\hline ato & e_occup & pancy & & & & & \\
\hline -ato & te_fract & E $x$ & & & & & \\
\hline -ato & te fract & ty & & & & & \\
\hline -ato & te_fract & $z$ & & & & & \\
\hline ato & e-thern & nal_displ & ace_type & & & & \\
\hline -ato & $=e^{-}$typisc & $\begin{array}{l}\text { or_equi } \\
\text { symbol }\end{array}$ & & & & & \\
\hline$\overline{\mathrm{P}} 1$ & 1.0000 & 0.00665 & 0.23189 & 0.10799 & Biso & 1.000 & $P$ \\
\hline P2 & 1.0000 & 0.77538 & 0.77926 & 0.10929 & Biso & 1.000 & $P$ \\
\hline P3 & 1.0000 & 0.22760 & 0.99943 & 0.10456 & Biso & 1.000 & $\mathrm{P}$ \\
\hline Al1 & 1.0000 & 0.22237 & 0.99623 & 0.89044 & Biso & 1.000 & $\mathrm{Al}$ \\
\hline Al2 & 1.0000 & 0.77138 & 0.77539 & 0.89738 & Biso & 1.000 & Al \\
\hline Al3 & 1.0000 & 0.00307 & 0.23034 & 0.89645 & Biso & 1.000 & Al \\
\hline P 4 & 1.0000 & 0.66933 & 0.56252 & 0.43982 & Biso & 1.000 & $\mathrm{P}$ \\
\hline Sil & 1.0000 & 0.42889 & 0.10448 & 0.43629 & Biso & 1.000 & $\mathrm{Si}$ \\
\hline P5 & 1.0000 & 0.89364 & 0.32955 & 0.44049 & Biso & 1.000 & $P$ \\
\hline Al4 & 1.0000 & 0.89630 & 0.33353 & 0.22921 & Biso & 1.000 & $\mathrm{Al}$ \\
\hline Al5 & 1.0000 & 0.43678 & 0.10690 & 0.22991 & Biso & 1.000 & Al \\
\hline Al6 & 1.0000 & 0.67332 & 0.56446 & 0.22904 & Biso & 1.000 & Al \\
\hline P 6 & 1.0000 & 0.33524 & 0.89154 & 0.77739 & Biso & 1.000 & $\mathrm{P}$ \\
\hline P7 & 1.0000 & 0.10351 & 0.43931 & 0.77237 & Biso & 1.000 & $P$ \\
\hline P8 & 1.0000 & 0.56082 & 0.66432 & 0.77312 & Biso & 1.000 & $P$ \\
\hline Al7 & 1.0000 & 0.56638 & 0.66910 & 0.56471 & Biso & 1.000 & Al \\
\hline Al8 & 1.0000 & 0.10136 & 0.43776 & 0.56428 & Biso & 1.000 & Al \\
\hline Al9 & 1.0000 & 0.33798 & 0.89334 & 0.56417 & Biso & 1.000 & $\mathrm{Al}$ \\
\hline P9 & 1.0000 & 0.99656 & 0.77039 & 0.89132 & Biso & 1.000 & $\mathrm{P}$ \\
\hline P 10 & 1.0000 & 0.22893 & 0.22612 & 0.88877 & Biso & 1.000 & $\mathrm{P}$ \\
\hline P11 & 1.0000 & 0.77729 & 0.00397 & 0.89164 & Biso & 1.000 & $P$ \\
\hline Al10 & 1.0000 & 0.77763 & 0.00639 & 0.10445 & Biso & 1.000 & Al \\
\hline Al11 & 1.0000 & 0.23352 & 0.22969 & 0.10065 & Biso & 1.000 & Al \\
\hline Al12 & 1.0000 & 0.00231 & 0.77592 & 0.10363 & Biso & 1.000 & Al \\
\hline P 12 & 1.0000 & 0.66830 & 0.10851 & 0.22520 & Biso & 1.000 & $P$ \\
\hline P13 & 1.0000 & 0.90321 & 0.56510 & 0.22776 & Biso & 1.000 & $P$ \\
\hline P14 & 1.0000 & 0.44531 & 0.34179 & 0.22364 & Biso & 1.000 & $\mathrm{P}$ \\
\hline Al13 & 1.0000 & 0.43750 & 0.33893 & 0.43290 & Biso & 1.000 & Al \\
\hline Al1 14 & 1.0000 & 0.89649 & 0.56021 & 0.43799 & Biso & 1.000 & Al \\
\hline Al15 & 1.0000 & 0.66208 & 0.10736 & 0.43275 & Biso & 1.000 & Al \\
\hline
\end{tabular}




\begin{tabular}{|c|c|c|c|c|c|c|c|}
\hline P15 & 1.0000 & 0.33311 & 0.44699 & 0.55707 & Biso & 1.000 & $\mathrm{P}$ \\
\hline P16 & 1.0000 & 0.56564 & 0.89665 & 0.56057 & Biso & 1.000 & $\mathrm{P}$ \\
\hline P17 & 1.0000 & 0.10612 & 0.67239 & 0.56039 & Biso & 1.000 & $\mathrm{P}$ \\
\hline Al16 & 1.0000 & 0.10758 & 0.67128 & 0.77104 & Biso & 1.000 & $\mathrm{Al}$ \\
\hline Al17 & 1.0000 & 0.56413 & 0.89539 & 0.76942 & Biso & 1.000 & Al \\
\hline Al18 & 1.0000 & 0.33062 & 0.43917 & 0.76698 & Biso & 1.000 & $\mathrm{Al}$ \\
\hline 01 & 1.0000 & 0.91476 & 0.11120 & 0.12726 & Biso & 1.000 & 0 \\
\hline $\mathrm{O} 2$ & 1.0000 & 0.89704 & 0.80746 & 0.12413 & Biso & 1.000 & 0 \\
\hline 03 & 1.0000 & 0.19999 & 0.09194 & 0.12428 & Biso & 1.000 & 0 \\
\hline 04 & 1.0000 & 0.08608 & 0.89022 & 0.86675 & Biso & 1.000 & 0 \\
\hline 05 & 1.0000 & 0.80783 & 0.91309 & 0.87276 & Biso & 1.000 & 0 \\
\hline 06 & 1.0000 & 0.10763 & 0.19800 & 0.87467 & Biso & 1.000 & 0 \\
\hline 07 & 1.0000 & 0.57619 & 0.44280 & 0.45682 & Biso & 1.000 & 0 \\
\hline 08 & 1.0000 & 0.55901 & 0.14019 & 0.43936 & Biso & 1.000 & 0 \\
\hline 09 & 1.0000 & 0.87008 & 0.42560 & 0.45821 & Biso & 1.000 & 0 \\
\hline 010 & 1.0000 & 0.75919 & 0.23035 & 0.20631 & Biso & 1.000 & 0 \\
\hline 011 & 1.0000 & 0.46978 & 0.24544 & 0.21544 & Biso & 1.000 & 0 \\
\hline 012 & 1.0000 & 0.78274 & 0.53715 & 0.21115 & Biso & 1.000 & 0 \\
\hline 013 & 1.0000 & 0.24355 & 0.77179 & 0.80069 & Biso & 1.000 & 0 \\
\hline 014 & 1.0000 & 0.22569 & 0.47174 & 0.78898 & Biso & 1.000 & 0 \\
\hline 015 & 1.0000 & 0.53128 & 0.75693 & 0.78438 & Biso & 1.000 & 0 \\
\hline 016 & 1.0000 & 0.42693 & 0.56882 & 0.54610 & Biso & 1.000 & 0 \\
\hline 017 & 1.0000 & 0.12406 & 0.57279 & 0.54925 & Biso & 1.000 & 0 \\
\hline 018 & 1.0000 & 0.44091 & 0.85651 & 0.54669 & Biso & 1.000 & 0 \\
\hline 019 & 1.0000 & 0.99059 & 0.31380 & 0.16590 & Biso & 1.000 & 0 \\
\hline 020 & 1.0000 & 0.69620 & 0.67994 & 0.16682 & Biso & 1.000 & 0 \\
\hline 021 & 1.0000 & 0.33307 & 0.02035 & 0.15336 & Biso & 1.000 & 0 \\
\hline 022 & 1.0000 & 0.31908 & 0.97590 & 0.83204 & Biso & 1.000 & 0 \\
\hline 023 & 1.0000 & 0.65483 & 0.68256 & 0.83679 & Biso & 1.000 & 0 \\
\hline 024 & 1.0000 & 0.02551 & 0.34639 & 0.83566 & Biso & 1.000 & 0 \\
\hline 025 & 1.0000 & 0.65517 & 0.64554 & 0.49786 & Biso & 1.000 & 0 \\
\hline 026 & 1.0000 & 0.35200 & 0.00166 & 0.50180 & Biso & 1.000 & 0 \\
\hline 027 & 1.0000 & 0.99169 & 0.34457 & 0.49788 & Biso & 1.000 & 0 \\
\hline 028 & 1.0000 & 0.01153 & 0.68595 & 0.83603 & Biso & 1.000 & 0 \\
\hline 029 & 1.0000 & 0.30841 & 0.32462 & 0.83051 & Biso & 1.000 & 0 \\
\hline 030 & 1.0000 & 0.67625 & 0.98402 & 0.83644 & Biso & 1.000 & 0 \\
\hline 031 & 1.0000 & 0.68220 & 0.02954 & 0.16160 & Biso & 1.000 & 0 \\
\hline 032 & 1.0000 & 0.35001 & 0.32295 & 0.16089 & Biso & 1.000 & 0 \\
\hline 033 & 1.0000 & 0.98474 & 0.66491 & 0.17044 & Biso & 1.000 & 0 \\
\hline 034 & 1.0000 & 0.34936 & 0.37002 & 0.49442 & Biso & 1.000 & 0 \\
\hline 035 & 1.0000 & 0.00818 & 0.65783 & 0.50258 & Biso & 1.000 & 0 \\
\hline 036 & 1.0000 & 0.63876 & 0.99344 & 0.49886 & Biso & 1.000 & 0 \\
\hline 037 & 1.0000 & 0.11991 & 0.24399 & 0.13074 & Biso & 1.000 & 0 \\
\hline 038 & 1.0000 & 0.76497 & 0.87981 & 0.13724 & Biso & 1.000 & 0 \\
\hline 039 & 1.0000 & 0.13006 & 0.88813 & 0.13943 & Biso & 1.000 & 0 \\
\hline 040 & 1.0000 & 0.23860 & 0.12483 & 0.86139 & Biso & 1.000 & 0 \\
\hline 041 & 1.0000 & 0.88177 & 0.75473 & 0.87030 & Biso & 1.000 & 0 \\
\hline 042 & 1.0000 & 0.87584 & 0.11717 & 0.86520 & Biso & 1.000 & 0 \\
\hline 043 & 1.0000 & 0.78146 & 0.57239 & 0.46411 & Biso & 1.000 & 0 \\
\hline 044 & 1.0000 & 0.41226 & 0.20888 & 0.45682 & Biso & 1.000 & 0 \\
\hline 045 & 1.0000 & 0.79147 & 0.21941 & 0.46566 & Biso & 1.000 & 0 \\
\hline 046 & 1.0000 & 0.91500 & 0.46471 & 0.20247 & Biso & 1.000 & 0 \\
\hline 047 & 1.0000 & 0.55458 & 0.09707 & 0.20675 & Biso & 1.000 & 0 \\
\hline 048 & 1.0000 & 0.54977 & 0.44959 & 0.19429 & Biso & 1.000 & 0 \\
\hline 049 & 1.0000 & 0.44878 & 0.90566 & 0.80153 & Biso & 1.000 & 0 \\
\hline 050 & 1.0000 & 0.08996 & 0.54037 & 0.79043 & Biso & 1.000 & 0 \\
\hline 051 & 1.0000 & 0.45846 & 0.55256 & 0.79685 & Biso & 1.000 & 0 \\
\hline 052 & 1.0000 & 0.58578 & 0.79998 & 0.53922 & Biso & 1.000 & 0 \\
\hline 053 & 1.0000 & 0.22263 & 0.44029 & 0.53285 & Biso & 1.000 & 0 \\
\hline 054 & 1.0000 & 0.21016 & 0.77810 & 0.52591 & Biso & 1.000 & 0 \\
\hline 055 & 1.0000 & 0.00298 & 0.26043 & 0.00951 & Biso & 1.000 & 0 \\
\hline 056 & 1.0000 & 0.74270 & 0.74987 & 0.01111 & Biso & 1.000 & 0 \\
\hline 057 & 1.0000 & 0.24382 & 0.99127 & 0.00460 & Biso & 1.000 & $\mathrm{O}$ \\
\hline 058 & 1.0000 & 0.67045 & 0.59486 & 0.34146 & Biso & 1.000 & 0 \\
\hline 059 & 1.0000 & 0.37926 & 0.05507 & 0.33430 & Biso & 1.000 & 0 \\
\hline 060 & 1.0000 & 0.92539 & 0.33105 & 0.34204 & Biso & 1.000 & 0 \\
\hline 061 & 1.0000 & 0.32889 & 0.91357 & 0.67811 & Biso & 1.000 & 0 \\
\hline 062 & 1.0000 & 0.06981 & 0.39864 & 0.67593 & Biso & 1.000 & 0 \\
\hline 063 & 1.0000 & 0.59882 & 0.66327 & 0.67696 & Biso & 1.000 & 0 \\
\hline 064 & 1.0000 & 0.00558 & 0.74810 & 0.99080 & Biso & 1.000 & 0 \\
\hline 065 & 1.0000 & 0.26237 & 0.25587 & 0.98698 & Biso & 1.000 & 0 \\
\hline 066 & 1.0000 & 0.74955 & 0.00322 & 0.99078 & Biso & 1.000 & 0 \\
\hline 067 & 1.0000 & 0.67759 & 0.07590 & 0.32119 & Biso & 1.000 & 0 \\
\hline 068 & 1.0000 & 0.93634 & 0.59814 & 0.32614 & Biso & 1.000 & 0 \\
\hline 069 & 1.0000 & 0.41343 & 0.35335 & 0.31918 & Biso & 1.000 & 0 \\
\hline 070 & 1.0000 & 0.32977 & 0.40857 & 0.65399 & Biso & 1.000 & 0 \\
\hline 071 & 1.0000 & 0.59827 & 0.93454 & 0.65804 & Biso & 1.000 & 0 \\
\hline 072 & 1.0000 & 0.08379 & 0.68676 & 0.65825 & Biso & 1.000 & 0 \\
\hline H 1 & 1.0000 & 0.26652 & 0.94781 & 0.34160 & Biso & 1.000 & $\mathrm{H}$ \\
\hline N1 & 1.0000 & 0.18478 & 0.87180 & 0.35093 & Biso & 1.000 & $\mathrm{~N}$ \\
\hline
\end{tabular}




\begin{tabular}{|c|c|c|c|c|c|c|c|}
\hline H2 & 1.0000 & 0.16134 & 0.82309 & 0.29465 & Biso & 1.000 & $\mathrm{H}$ \\
\hline H3 & 1.0000 & 0.12610 & 0.89442 & 0.36339 & Biso & 1.000 & $\mathrm{H}$ \\
\hline H4 & 1.0000 & 0.18857 & 0.82851 & 0.40599 & Biso & 1.000 & $\mathrm{H}$ \\
\hline \multicolumn{8}{|l|}{ Mg 27} \\
\hline \multicolumn{8}{|c|}{ data_image0 } \\
\hline \multicolumn{8}{|c|}{13.875} \\
\hline \multicolumn{8}{|c|}{13.875} \\
\hline cell_ & $=\mathrm{h}_{-}^{-} \mathrm{C}$ & 15.01 & & & & & \\
\hline $\mathrm{cell}^{-}$ & e-alpha & 90 & & & & & \\
\hline cell_ & beta & 90 & & & & & \\
\hline cell__ & gamma & 120 & & & & & \\
\hline symme & pace_g & oup_nalt & & $1 "$ & & & \\
\hline symme & $n t \_t \overline{a b}$ & Les_numbe & & & & & \\
\hline oop_ & & & & & & & \\
\hline 'sym & equiv & _pos_as_x & & & & & \\
\hline Loop_ & & & & & & & \\
\hline _ator & e_labe] & & & & & & \\
\hline -ator & e- occup & pancy & & & & & \\
\hline -ator & $=e^{-}$fract & $=x$ & & & & & \\
\hline -ator & $=e^{-}$fract & & & & & & \\
\hline ator & $e_{-}^{-}$fract & & & & & & \\
\hline -ator & e_thern & nàl_displ & ace_type & & & & \\
\hline _ator & e_B_isc & or_equi & & & & & \\
\hline & $e_{-}$type & symbol & & & & & \\
\hline $\bar{A} 11$ & 1.0000 & 0.00057 & 0.22842 & 0.10297 & Biso & 1.000 & Al \\
\hline Al2 & 1.0000 & 0.77677 & 0.77580 & 0.10717 & Biso & 1.000 & Al \\
\hline A13 & 1.0000 & 0.23285 & 0.00770 & 0.09698 & Biso & 1.000 & Al \\
\hline $\mathrm{P} 1$ & 1.0000 & 0.22305 & 0.00050 & 0.88483 & Biso & 1.000 & $P$ \\
\hline P2 & 1.0000 & 0.77572 & 0.77290 & 0.89406 & Biso & 1.000 & $P$ \\
\hline P3 & 1.0000 & 0.99552 & 0.22693 & 0.89099 & Biso & 1.000 & $\mathrm{P}$ \\
\hline Al4 & 1.0000 & 0.66058 & 0.55917 & 0.43494 & Biso & 1.000 & Al \\
\hline $\mathrm{Mg} 1$ & 1.0000 & 0.44344 & 0.11133 & 0.43584 & Biso & 1.000 & $\mathrm{Mg}$ \\
\hline Al5 & 1.0000 & 0.90233 & 0.33708 & 0.43565 & Biso & 1.000 & $\mathrm{Al}$ \\
\hline P 4 & 1.0000 & 0.89931 & 0.34082 & 0.22430 & Biso & 1.000 & $\mathrm{P}$ \\
\hline P5 & 1.0000 & 0.43717 & 0.09941 & 0.22442 & Biso & 1.000 & $\mathrm{P}$ \\
\hline P6 & 1.0000 & 0.66587 & 0.56011 & 0.22454 & Biso & 1.000 & $P$ \\
\hline Al6 & 1.0000 & 0.32728 & 0.88626 & 0.77241 & Biso & 1.000 & Al \\
\hline Al7 & 1.0000 & 0.10582 & 0.43477 & 0.76712 & Biso & 1.000 & Al \\
\hline Al8 & 1.0000 & 0.56491 & 0.67099 & 0.76948 & Biso & 1.000 & Al \\
\hline P7 & 1.0000 & 0.57566 & 0.67933 & 0.56174 & Biso & 1.000 & $\mathrm{P}$ \\
\hline P8 & 1.0000 & 0.10699 & 0.43942 & 0.56185 & Biso & 1.000 & $P$ \\
\hline P9 & 1.0000 & 0.32875 & 0.88149 & 0.55868 & Biso & 1.000 & $\mathrm{P}$ \\
\hline Al9 & 1.0000 & 0.00080 & 0.77125 & 0.89838 & Biso & 1.000 & Al \\
\hline Al10 & 1.0000 & 0.22484 & 0.22934 & 0.89015 & Biso & 1.000 & Al \\
\hline Al11 & 1.0000 & 0.77322 & 0.99693 & 0.89507 & Biso & 1.000 & Al \\
\hline P 10 & 1.0000 & 0.77515 & 0.99985 & 0.10833 & Biso & 1.000 & $\mathrm{P}$ \\
\hline P 11 & 1.0000 & 0.23027 & 0.23307 & 0.10218 & Biso & 1.000 & $\mathrm{P}$ \\
\hline P12 & 1.0000 & 0.00810 & 0.78172 & 0.11197 & Biso & 1.000 & $\mathrm{P}$ \\
\hline Al12 & 1.0000 & 0.67393 & 0.11114 & 0.23128 & Biso & 1.000 & Al \\
\hline Al13 & 1.0000 & 0.89924 & 0.56684 & 0.23116 & Biso & 1.000 & Al \\
\hline Al1 14 & 1.0000 & 0.43995 & 0.33322 & 0.22807 & Biso & 1.000 & Al \\
\hline P13 & 1.0000 & 0.42912 & 0.33795 & 0.43619 & Biso & 1.000 & $\mathrm{P}$ \\
\hline P 14 & 1.0000 & 0.89424 & 0.56313 & 0.44056 & Biso & 1.000 & $P$ \\
\hline P15 & 1.0000 & 0.67805 & 0.11472 & 0.43651 & Biso & 1.000 & $\mathrm{P}$ \\
\hline Al15 & 1.0000 & 0.34167 & 0.45652 & 0.56108 & Biso & 1.000 & Al \\
\hline Al16 & 1.0000 & 0.56168 & 0.89983 & 0.56411 & Biso & 1.000 & Al \\
\hline Al17 & 1.0000 & 0.09598 & 0.66717 & 0.57026 & Biso & 1.000 & Al \\
\hline P16 & 1.0000 & 0.10200 & 0.66461 & 0.77750 & Biso & 1.000 & $\mathrm{P}$ \\
\hline P 17 & 1.0000 & 0.55855 & 0.89727 & 0.77365 & Biso & 1.000 & $\mathrm{P}$ \\
\hline P18 & 1.0000 & 0.33662 & 0.44391 & 0.77137 & Biso & 1.000 & $P$ \\
\hline 01 & 1.0000 & 0.89691 & 0.09098 & 0.12553 & Biso & 1.000 & 0 \\
\hline $\mathrm{O} 2$ & 1.0000 & 0.91441 & 0.80778 & 0.13066 & Biso & 1.000 & 0 \\
\hline 03 & 1.0000 & 0.20035 & 0.11160 & 0.12065 & Biso & 1.000 & 0 \\
\hline 04 & 1.0000 & 0.10266 & 0.90641 & 0.86765 & Biso & 1.000 & 0 \\
\hline 05 & 1.0000 & 0.80901 & 0.89435 & 0.87235 & Biso & 1.000 & 0 \\
\hline 06 & 1.0000 & 0.08788 & 0.19896 & 0.87155 & Biso & 1.000 & 0 \\
\hline 07 & 1.0000 & 0.55162 & 0.42654 & 0.45844 & Biso & 1.000 & 0 \\
\hline 08 & 1.0000 & 0.59792 & 0.15881 & 0.43999 & Biso & 1.000 & 0 \\
\hline 09 & 1.0000 & 0.87343 & 0.44514 & 0.45804 & Biso & 1.000 & 0 \\
\hline 010 & 1.0000 & 0.77730 & 0.24999 & 0.20941 & Biso & 1.000 & 0 \\
\hline 011 & 1.0000 & 0.46497 & 0.22170 & 0.21865 & Biso & 1.000 & 0 \\
\hline 012 & 1.0000 & 0.76390 & 0.53845 & 0.21256 & Biso & 1.000 & 0 \\
\hline 013 & 1.0000 & 0.22289 & 0.75110 & 0.80223 & Biso & 1.000 & 0 \\
\hline 014 & 1.0000 & 0.24409 & 0.47204 & 0.79101 & Biso & 1.000 & 0 \\
\hline 015 & 1.0000 & 0.52962 & 0.77500 & 0.78280 & Biso & 1.000 & 0 \\
\hline 016 & 1.0000 & 0.45253 & 0.59225 & 0.54587 & Biso & 1.000 & 0 \\
\hline
\end{tabular}




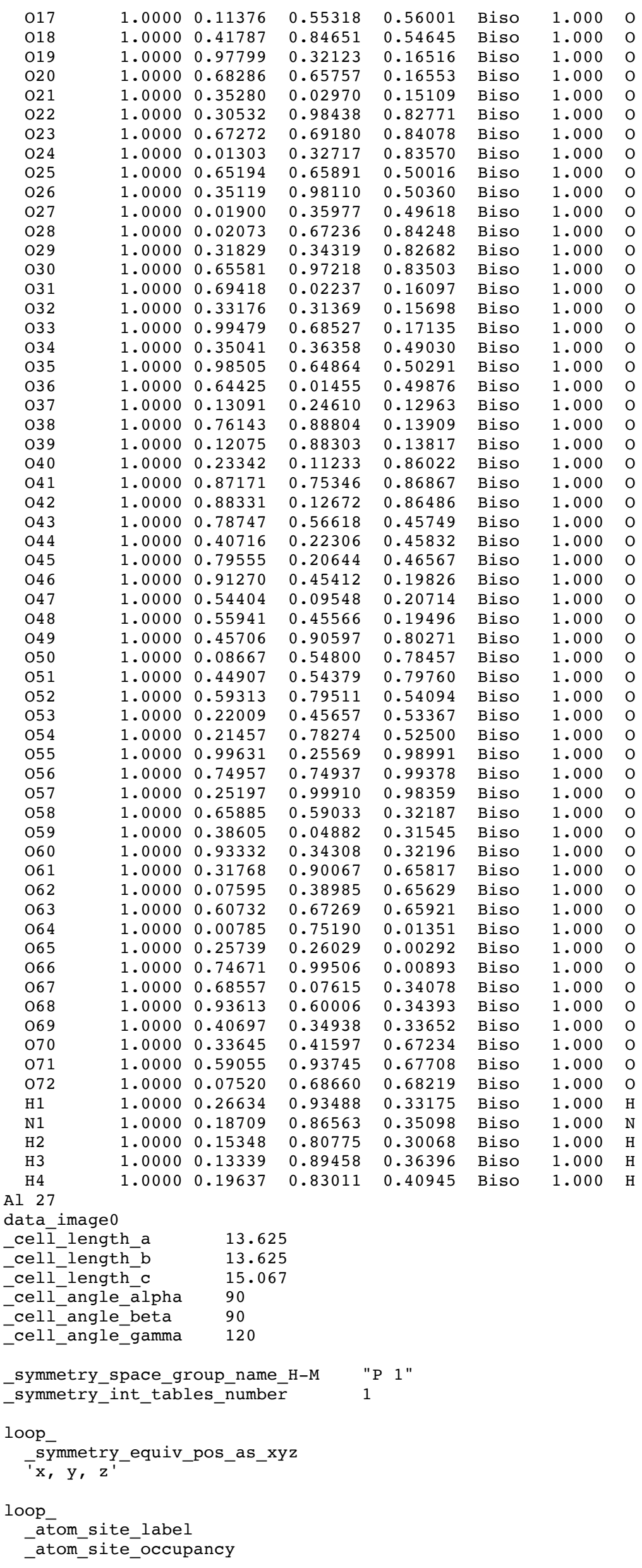




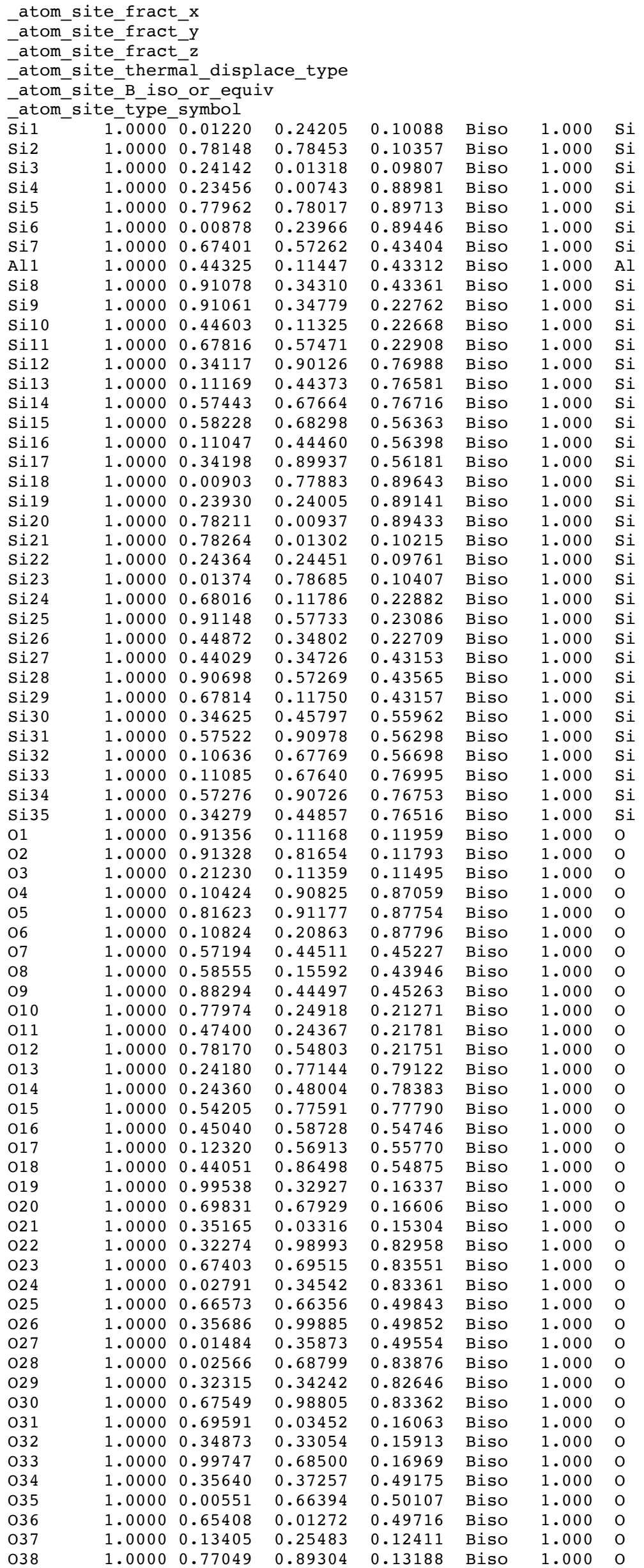




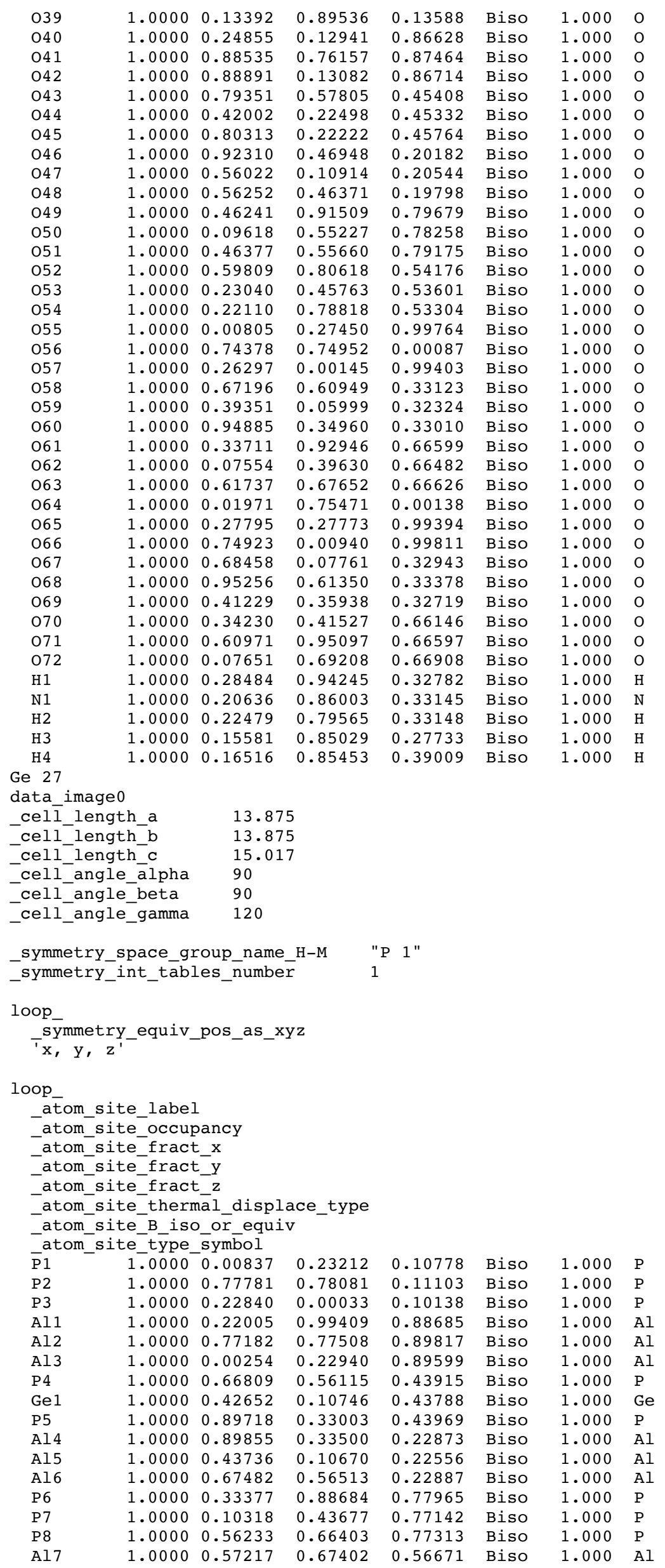




\begin{tabular}{|c|c|c|c|c|c|c|c|}
\hline Al8 & 1.0000 & 0.09905 & 0.43606 & 0.56695 & Biso & 1.000 & Al \\
\hline Al9 & 1.0000 & 0.33618 & 0.88461 & 0.56538 & Biso & 1.000 & Al \\
\hline P9 & 1.0000 & 0.99492 & 0.76790 & 0.89161 & Biso & 1.000 & $\mathrm{P}$ \\
\hline P10 & 1.0000 & 0.22808 & 0.22479 & 0.88570 & Biso & 1.000 & $\mathrm{P}$ \\
\hline P11 & 1.0000 & 0.77783 & 0.00349 & 0.89195 & Biso & 1.000 & $\mathrm{P}$ \\
\hline Al10 & 1.0000 & 0.78046 & 0.00760 & 0.10542 & Biso & 1.000 & Al \\
\hline Al11 & 1.0000 & 0.23522 & 0.23048 & 0.09775 & Biso & 1.000 & Al \\
\hline Al1 12 & 1.0000 & 0.00420 & 0.77780 & 0.10524 & Biso & 1.000 & Al \\
\hline P12 & 1.0000 & 0.66902 & 0.10926 & 0.22528 & Biso & 1.000 & $\mathrm{P}$ \\
\hline P13 & 1.0000 & 0.90562 & 0.56628 & 0.22847 & Biso & 1.000 & $\mathrm{P}$ \\
\hline P14 & 1.0000 & 0.44737 & 0.34256 & 0.22095 & Biso & 1.000 & $P$ \\
\hline Al13 & 1.0000 & 0.43362 & 0.34372 & 0.43069 & Biso & 1.000 & Al \\
\hline Al1 14 & 1.0000 & 0.89600 & 0.55869 & 0.43875 & Biso & 1.000 & Al \\
\hline Al15 & 1.0000 & 0.66346 & 0.11070 & 0.43306 & Biso & 1.000 & Al \\
\hline P15 & 1.0000 & 0.33549 & 0.45710 & 0.55628 & Biso & 1.000 & $P$ \\
\hline P16 & 1.0000 & 0.56637 & 0.89788 & 0.56209 & Biso & 1.000 & $\mathrm{P}$ \\
\hline P17 & 1.0000 & 0.10033 & 0.67101 & 0.56433 & Biso & 1.000 & $\mathrm{P}$ \\
\hline A116 & 1.0000 & 0.10487 & 0.66962 & 0.77208 & Biso & 1.000 & Al \\
\hline Al1 17 & 1.0000 & 0.56280 & 0.89419 & 0.77114 & Biso & 1.000 & $\mathrm{Al}$ \\
\hline Al18 & 1.0000 & 0.33069 & 0.43869 & 0.76414 & Biso & 1.000 & Al \\
\hline 01 & 1.0000 & 0.91796 & 0.11134 & 0.12884 & Biso & 1.000 & 0 \\
\hline $\mathrm{O} 2$ & 1.0000 & 0.89908 & 0.80896 & 0.12801 & Biso & 1.000 & 0 \\
\hline 03 & 1.0000 & 0.20086 & 0.09272 & 0.12202 & Biso & 1.000 & 0 \\
\hline 04 & 1.0000 & 0.08475 & 0.88598 & 0.86302 & Biso & 1.000 & 0 \\
\hline 05 & 1.0000 & 0.80835 & 0.91267 & 0.87259 & Biso & 1.000 & 0 \\
\hline 06 & 1.0000 & 0.10675 & 0.19709 & 0.87272 & Biso & 1.000 & 0 \\
\hline 07 & 1.0000 & 0.57405 & 0.44161 & 0.45542 & Biso & 1.000 & 0 \\
\hline O8 & 1.0000 & 0.57080 & 0.15835 & 0.44126 & Biso & 1.000 & 0 \\
\hline 09 & 1.0000 & 0.87262 & 0.42505 & 0.45956 & Biso & 1.000 & $\mathrm{O}$ \\
\hline 010 & 1.0000 & 0.76092 & 0.23123 & 0.20851 & Biso & 1.000 & 0 \\
\hline 011 & 1.0000 & 0.47202 & 0.24622 & 0.21501 & Biso & 1.000 & 0 \\
\hline 012 & 1.0000 & 0.78550 & 0.53954 & 0.21223 & Biso & 1.000 & 0 \\
\hline 013 & 1.0000 & 0.24032 & 0.76861 & 0.80484 & Biso & 1.000 & 0 \\
\hline 014 & 1.0000 & 0.22616 & 0.47171 & 0.78778 & Biso & 1.000 & 0 \\
\hline 015 & 1.0000 & 0.53139 & 0.75581 & 0.78273 & Biso & 1.000 & 0 \\
\hline 016 & 1.0000 & 0.43050 & 0.57905 & 0.55154 & Biso & 1.000 & 0 \\
\hline 017 & 1.0000 & 0.10992 & 0.56634 & 0.55931 & Biso & 1.000 & 0 \\
\hline 018 & 1.0000 & 0.44052 & 0.85008 & 0.54590 & Biso & 1.000 & 0 \\
\hline 019 & 1.0000 & 0.99196 & 0.31430 & 0.16505 & Biso & 1.000 & 0 \\
\hline 020 & 1.0000 & 0.69724 & 0.68068 & 0.16717 & Biso & 1.000 & 0 \\
\hline 021 & 1.0000 & 0.33717 & 0.02377 & 0.14569 & Biso & 1.000 & 0 \\
\hline 022 & 1.0000 & 0.31809 & 0.97449 & 0.82979 & Biso & 1.000 & 0 \\
\hline 023 & 1.0000 & 0.65280 & 0.68146 & 0.84039 & Biso & 1.000 & 0 \\
\hline 024 & 1.0000 & 0.02694 & 0.34823 & 0.83843 & Biso & 1.000 & 0 \\
\hline 025 & 1.0000 & 0.65516 & 0.64443 & 0.49789 & Biso & 1.000 & 0 \\
\hline 026 & 1.0000 & 0.34378 & 0.99203 & 0.50551 & Biso & 1.000 & 0 \\
\hline 027 & 1.0000 & 0.99511 & 0.34358 & 0.49640 & Biso & 1.000 & 0 \\
\hline 028 & 1.0000 & 0.00864 & 0.67980 & 0.84050 & Biso & 1.000 & 0 \\
\hline 029 & 1.0000 & 0.30713 & 0.32291 & 0.82682 & Biso & 1.000 & 0 \\
\hline 030 & 1.0000 & 0.67496 & 0.98195 & 0.83858 & Biso & 1.000 & 0 \\
\hline 031 & 1.0000 & 0.68539 & 0.03128 & 0.16244 & Biso & 1.000 & 0 \\
\hline 032 & 1.0000 & 0.35340 & 0.32340 & 0.15655 & Biso & 1.000 & 0 \\
\hline 033 & 1.0000 & 0.98779 & 0.66711 & 0.17223 & Biso & 1.000 & 0 \\
\hline 034 & 1.0000 & 0.35097 & 0.38579 & 0.48726 & Biso & 1.000 & 0 \\
\hline 035 & 1.0000 & 0.00457 & 0.65873 & 0.50476 & Biso & 1.000 & 0 \\
\hline 036 & 1.0000 & 0.63525 & 0.99656 & 0.50072 & Biso & 1.000 & 0 \\
\hline 037 & 1.0000 & 0.12296 & 0.24659 & 0.12914 & Biso & 1.000 & 0 \\
\hline 038 & 1.0000 & 0.76633 & 0.88073 & 0.13891 & Biso & 1.000 & 0 \\
\hline 039 & 1.0000 & 0.13304 & 0.88974 & 0.13946 & Biso & 1.000 & 0 \\
\hline 040 & 1.0000 & 0.23661 & 0.12293 & 0.85798 & Biso & 1.000 & 0 \\
\hline 041 & 1.0000 & 0.88036 & 0.75223 & 0.86931 & Biso & 1.000 & 0 \\
\hline 042 & 1.0000 & 0.87528 & 0.11666 & 0.86372 & Biso & 1.000 & 0 \\
\hline 043 & 1.0000 & 0.77935 & 0.56881 & 0.46275 & Biso & 1.000 & 0 \\
\hline 044 & 1.0000 & 0.39431 & 0.21115 & 0.46265 & Biso & 1.000 & 0 \\
\hline 045 & 1.0000 & 0.79611 & 0.21852 & 0.46348 & Biso & 1.000 & 0 \\
\hline 046 & 1.0000 & 0.91662 & 0.46589 & 0.20141 & Biso & 1.000 & 0 \\
\hline 047 & 1.0000 & 0.55628 & 0.09843 & 0.20369 & Biso & 1.000 & 0 \\
\hline 048 & 1.0000 & 0.55251 & 0.45012 & 0.19230 & Biso & 1.000 & 0 \\
\hline 049 & 1.0000 & 0.44638 & 0.90063 & 0.80687 & Biso & 1.000 & 0 \\
\hline 050 & 1.0000 & 0.08830 & 0.53799 & 0.78341 & Biso & 1.000 & 0 \\
\hline 051 & 1.0000 & 0.45928 & 0.55140 & 0.79354 & Biso & 1.000 & 0 \\
\hline 052 & 1.0000 & 0.59584 & 0.80705 & 0.54218 & Biso & 1.000 & 0 \\
\hline 053 & 1.0000 & 0.22670 & 0.45488 & 0.53442 & Biso & 1.000 & 0 \\
\hline 054 & 1.0000 & 0.20806 & 0.77031 & 0.52723 & Biso & 1.000 & 0 \\
\hline 055 & 1.0000 & 0.00191 & 0.25805 & 0.00916 & Biso & 1.000 & 0 \\
\hline 056 & 1.0000 & 0.74750 & 0.75262 & 0.01244 & Biso & 1.000 & 0 \\
\hline 057 & 1.0000 & 0.23920 & 0.98936 & 0.00114 & Biso & 1.000 & 0 \\
\hline 058 & 1.0000 & 0.66939 & 0.59471 & 0.34112 & Biso & 1.000 & 0 \\
\hline 059 & 1.0000 & 0.37435 & 0.05018 & 0.32764 & Biso & 1.000 & 0 \\
\hline 060 & 1.0000 & 0.92972 & 0.33462 & 0.34118 & Biso & 1.000 & 0 \\
\hline
\end{tabular}




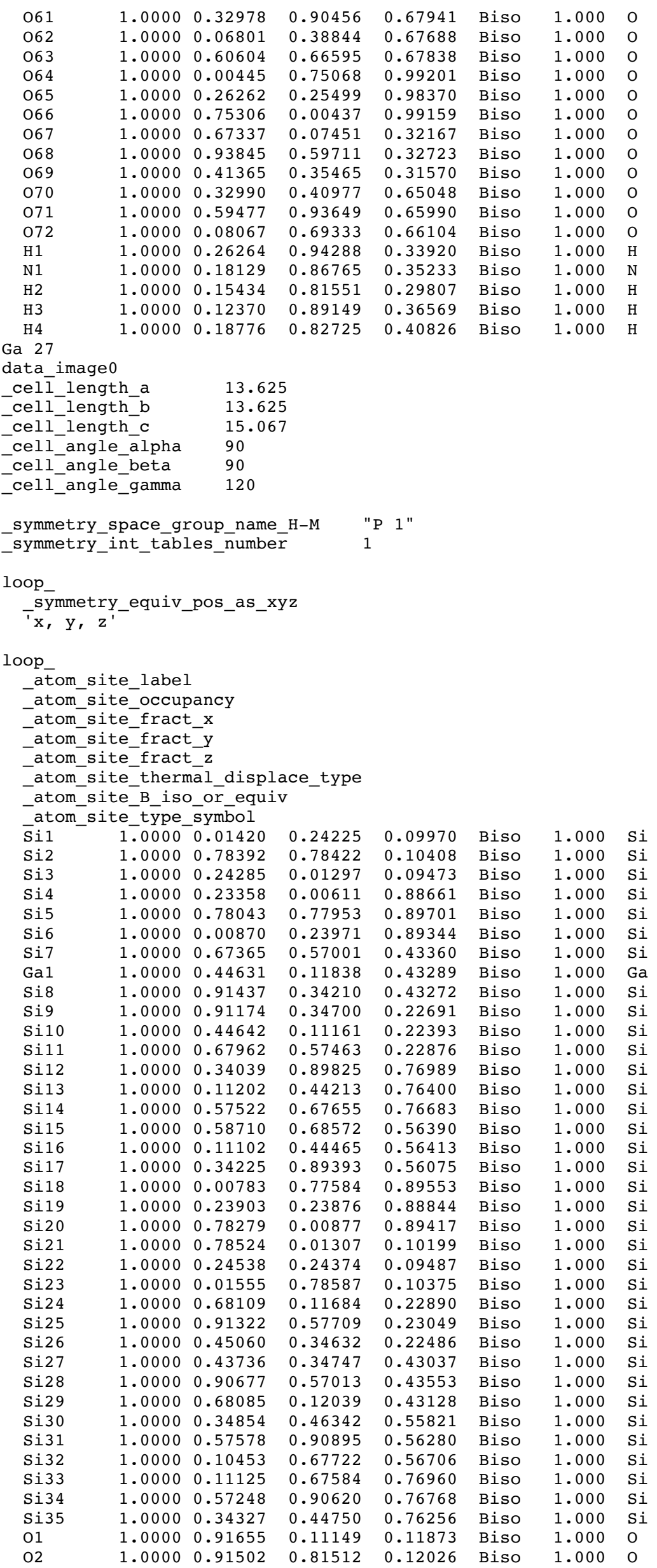




\begin{tabular}{|c|c|c|c|c|c|c|c|}
\hline 03 & 1.0000 & 0.21229 & 0.11244 & 0.11281 & Biso & 1.000 & 0 \\
\hline 04 & 1.0000 & 0.10376 & 0.90477 & 0.86921 & Biso & 1.000 & 0 \\
\hline 05 & 1.0000 & 0.81711 & 0.91126 & 0.87754 & Biso & 1.000 & 0 \\
\hline 06 & 1.0000 & 0.10854 & 0.20955 & 0.87623 & Biso & 1.000 & 0 \\
\hline 07 & 1.0000 & 0.57004 & 0.44289 & 0.45062 & Biso & 1.000 & 0 \\
\hline 08 & 1.0000 & 0.59738 & 0.17125 & 0.43772 & Biso & 1.000 & 0 \\
\hline 09 & 1.0000 & 0.88598 & 0.44354 & 0.45254 & Biso & 1.000 & 0 \\
\hline 010 & 1.0000 & 0.78062 & 0.24833 & 0.21304 & Biso & 1.000 & 0 \\
\hline 011 & 1.0000 & 0.47794 & 0.24346 & 0.21570 & Biso & 1.000 & O \\
\hline 012 & 1.0000 & 0.78395 & 0.54924 & 0.21655 & Biso & 1.000 & 0 \\
\hline 013 & 1.0000 & 0.24159 & 0.76935 & 0.79463 & Biso & 1.000 & 0 \\
\hline 014 & 1.0000 & 0.24407 & 0.47887 & 0.78222 & Biso & 1.000 & 0 \\
\hline 015 & 1.0000 & 0.54099 & 0.77456 & 0.77742 & Biso & 1.000 & 0 \\
\hline 016 & 1.0000 & 0.45433 & 0.59223 & 0.54936 & Biso & 1.000 & 0 \\
\hline 017 & 1.0000 & 0.11565 & 0.56550 & 0.56129 & Biso & 1.000 & 0 \\
\hline 018 & 1.0000 & 0.43982 & 0.85830 & 0.54839 & Biso & 1.000 & 0 \\
\hline 019 & 1.0000 & 0.99635 & 0.32865 & 0.16236 & Biso & 1.000 & 0 \\
\hline 020 & 1.0000 & 0.69888 & 0.67929 & 0.16621 & Biso & 1.000 & 0 \\
\hline 021 & 1.0000 & 0.35494 & 0.03492 & 0.14773 & Biso & 1.000 & 0 \\
\hline 022 & 1.0000 & 0.32187 & 0.98956 & 0.82563 & Biso & 1.000 & 0 \\
\hline 023 & 1.0000 & 0.67259 & 0.69452 & 0.83728 & Biso & 1.000 & 0 \\
\hline 024 & 1.0000 & 0.02783 & 0.34591 & 0.83303 & Biso & 1.000 & 0 \\
\hline 025 & 1.0000 & 0.66751 & 0.66164 & 0.49877 & Biso & 1.000 & 0 \\
\hline 026 & 1.0000 & 0.35634 & 0.99424 & 0.49890 & Biso & 1.000 & 0 \\
\hline 027 & 1.0000 & 0.01968 & 0.35847 & 0.49340 & Biso & 1.000 & 0 \\
\hline 028 & 1.0000 & 0.02421 & 0.68413 & 0.83852 & Biso & 1.000 & 0 \\
\hline 029 & 1.0000 & 0.32337 & 0.34078 & 0.82325 & Biso & 1.000 & 0 \\
\hline 030 & 1.0000 & 0.67556 & 0.98642 & 0.83369 & Biso & 1.000 & 0 \\
\hline 031 & 1.0000 & 0.69907 & 0.03427 & 0.16148 & Biso & 1.000 & 0 \\
\hline 032 & 1.0000 & 0.35174 & 0.32916 & 0.15572 & Biso & 1.000 & 0 \\
\hline 033 & 1.0000 & 0.00073 & 0.68480 & 0.16998 & Biso & 1.000 & 0 \\
\hline 034 & 1.0000 & 0.35594 & 0.38087 & 0.48585 & Biso & 1.000 & 0 \\
\hline 035 & 1.0000 & 0.00307 & 0.66319 & 0.50180 & Biso & 1.000 & 0 \\
\hline 036 & 1.0000 & 0.64939 & 0.01469 & 0.49788 & Biso & 1.000 & 0 \\
\hline 037 & 1.0000 & 0.13709 & 0.25654 & 0.12155 & Biso & 1.000 & 0 \\
\hline 038 & 1.0000 & 0.77337 & 0.89321 & 0.13150 & Biso & 1.000 & 0 \\
\hline 039 & 1.0000 & 0.13642 & 0.89485 & 0.13182 & Biso & 1.000 & 0 \\
\hline 040 & 1.0000 & 0.24499 & 0.12673 & 0.86183 & Biso & 1.000 & 0 \\
\hline 041 & 1.0000 & 0.88491 & 0.75983 & 0.87212 & Biso & 1.000 & 0 \\
\hline 042 & 1.0000 & 0.88898 & 0.13040 & 0.86622 & Biso & 1.000 & 0 \\
\hline 043 & 1.0000 & 0.79146 & 0.57201 & 0.45359 & Biso & 1.000 & 0 \\
\hline 044 & 1.0000 & 0.40932 & 0.22420 & 0.46017 & Biso & 1.000 & 0 \\
\hline 045 & 1.0000 & 0.80839 & 0.22015 & 0.45751 & Biso & 1.000 & 0 \\
\hline 046 & 1.0000 & 0.92370 & 0.46856 & 0.20163 & Biso & 1.000 & 0 \\
\hline 047 & 1.0000 & 0.56064 & 0.10638 & 0.20506 & Biso & 1.000 & 0 \\
\hline 048 & 1.0000 & 0.56420 & 0.46334 & 0.19787 & Biso & 1.000 & 0 \\
\hline 049 & 1.0000 & 0.46248 & 0.91453 & 0.79729 & Biso & 1.000 & 0 \\
\hline 050 & 1.0000 & 0.09609 & 0.55103 & 0.77734 & Biso & 1.000 & 0 \\
\hline 051 & 1.0000 & 0.46453 & 0.55541 & 0.78882 & Biso & 1.000 & 0 \\
\hline 052 & 1.0000 & 0.60570 & 0.81007 & 0.54076 & Biso & 1.000 & 0 \\
\hline 053 & 1.0000 & 0.23498 & 0.46827 & 0.53686 & Biso & 1.000 & 0 \\
\hline 054 & 1.0000 & 0.22035 & 0.78440 & 0.52847 & Biso & 1.000 & 0 \\
\hline 055 & 1.0000 & 0.00804 & 0.27425 & 0.99666 & Biso & 1.000 & 0 \\
\hline 056 & 1.0000 & 0.74760 & 0.74947 & 0.00118 & Biso & 1.000 & 0 \\
\hline 057 & 1.0000 & 0.26455 & 0.00308 & 0.99038 & Biso & 1.000 & 0 \\
\hline 058 & 1.0000 & 0.67337 & 0.60886 & 0.33115 & Biso & 1.000 & 0 \\
\hline 059 & 1.0000 & 0.38916 & 0.05742 & 0.31924 & Biso & 1.000 & 0 \\
\hline 060 & 1.0000 & 0.95111 & 0.34884 & 0.32900 & Biso & 1.000 & 0 \\
\hline 061 & 1.0000 & 0.33440 & 0.92046 & 0.66500 & Biso & 1.000 & 0 \\
\hline 062 & 1.0000 & 0.07609 & 0.39155 & 0.66369 & Biso & 1.000 & 0 \\
\hline 063 & 1.0000 & 0.62238 & 0.68003 & 0.66668 & Biso & 1.000 & 0 \\
\hline 064 & 1.0000 & 0.01656 & 0.75149 & 0.00070 & Biso & 1.000 & 0 \\
\hline 065 & 1.0000 & 0.27909 & 0.27556 & 0.99087 & Biso & 1.000 & 0 \\
\hline 066 & 1.0000 & 0.75087 & 0.00955 & 0.99813 & Biso & 1.000 & 0 \\
\hline 067 & 1.0000 & 0.68427 & 0.07683 & 0.32998 & Biso & 1.000 & 0 \\
\hline 068 & 1.0000 & 0.95297 & 0.61242 & 0.33395 & Biso & 1.000 & 0 \\
\hline 069 & 1.0000 & 0.41151 & 0.35458 & 0.32479 & Biso & 1.000 & 0 \\
\hline 070 & 1.0000 & 0.34290 & 0.41512 & 0.65847 & Biso & 1.000 & 0 \\
\hline 071 & 1.0000 & 0.60880 & 0.94989 & 0.66597 & Biso & 1.000 & 0 \\
\hline 072 & 1.0000 & 0.08102 & 0.69872 & 0.66913 & Biso & 1.000 & 0 \\
\hline $\mathrm{H} 1$ & 1.0000 & 0.27122 & 0.94436 & 0.33308 & Biso & 1.000 & $\mathrm{H}$ \\
\hline $\mathrm{N} 1$ & 1.0000 & 0.19019 & 0.87094 & 0.35060 & Biso & 1.000 & $\mathrm{~N}$ \\
\hline $\mathrm{H} 2$ & 1.0000 & 0.15887 & 0.81204 & 0.30033 & Biso & 1.000 & $\mathrm{H}$ \\
\hline H3 & 1.0000 & 0.13271 & 0.89707 & 0.36281 & Biso & 1.000 & $\mathrm{H}$ \\
\hline $\mathrm{H} 4$ & 1.0000 & 0.19987 & 0.83545 & 0.40877 & Biso & 1.000 & $\mathrm{H}$ \\
\hline \multicolumn{8}{|c|}{ Ti 27} \\
\hline lata_ & & & & & & & \\
\hline \multicolumn{8}{|c|}{ celil length a } \\
\hline \multicolumn{2}{|c|}{ cell length b } & \multicolumn{2}{|l|}{$\begin{array}{l}13.81 \\
13.87\end{array}$} & & & & \\
\hline cell & $\operatorname{th} \mathrm{c}$ & 15.0 & & & & & \\
\hline
\end{tabular}




\begin{tabular}{|c|c|c|c|c|c|c|c|}
\hline cell & alpha & 90 & & & & & \\
\hline _cell_- & beta & 90 & & & & & \\
\hline cell_ & gamma & 120 & & & & & \\
\hline symme & space_g & coup_name & $\mathrm{H}-\mathrm{M}$ & P $1 "$ & & & \\
\hline _symme & int_tab & es_numbe & & & & & \\
\hline loop_ & & & & & & & \\
\hline$T^{\text {sym }}$ & _equiv & pos_as_x & & & & & \\
\hline loop & & & & & & & \\
\hline $\begin{array}{l}\text {-ato } \\
\text {-ato } \\
\text {-ato } \\
\text {-ato } \\
\text {-ato } \\
\text {-ato } \\
\text {-ato } \\
\text { ato }\end{array}$ & $\begin{array}{l}\text { te_labe } \\
\text { te_occu } \\
\text { te_frac } \\
\text { te_frac } \\
\text { te_frac } \\
\text { te_ther } \\
\text { te_B_is } \\
\text { te type }\end{array}$ & $\begin{array}{l}\text { bancy } \\
=\text {-x } \\
\text {-y } \\
\text { nal_displ } \\
\text { al_or_equi } \\
\text { symbol }\end{array}$ & ce_type & & & & \\
\hline$\overline{\mathrm{P}} 1$ & 1.0000 & 0.00918 & 0.23248 & 0.10719 & Biso & 1.000 & $\mathrm{P}$ \\
\hline $\mathrm{P} 2$ & 1.0000 & 0.77877 & 0.78225 & 0.11220 & Biso & 1.000 & $\mathrm{P}$ \\
\hline P3 & 1.0000 & 0.22920 & 0.00159 & 0.09936 & Biso & 1.000 & $\mathrm{P}$ \\
\hline Al1 & 1.0000 & 0.21820 & 0.99266 & 0.88443 & Biso & 1.000 & Al \\
\hline Al2 & 1.0000 & 0.77180 & 0.77520 & 0.89890 & Biso & 1.000 & Al \\
\hline Al3 & 1.0000 & 0.00165 & 0.22865 & 0.89518 & Biso & 1.000 & Al \\
\hline P4 & 1.0000 & 0.66814 & 0.56384 & 0.43954 & Biso & 1.000 & $\mathrm{P}$ \\
\hline Ti1 & 1.0000 & 0.42265 & 0.10576 & 0.43880 & Biso & 1.000 & $\mathrm{Ti}$ \\
\hline P5 & 1.0000 & 0.90107 & 0.33083 & 0.43881 & Biso & 1.000 & $\mathrm{P}$ \\
\hline Al4 & 1.0000 & 0.89992 & 0.33651 & 0.22804 & Biso & 1.000 & Al \\
\hline Al5 & 1.0000 & 0.43545 & 0.10501 & 0.22465 & Biso & 1.000 & Al \\
\hline Al 6 & 1.0000 & 0.67575 & 0.56558 & 0.22926 & Biso & 1.000 & Al \\
\hline P6 & 1.0000 & 0.33228 & 0.88229 & 0.78245 & Biso & 1.000 & $\mathrm{P}$ \\
\hline P7 & 1.0000 & 0.10271 & 0.43541 & 0.77090 & Biso & 1.000 & $\mathrm{P}$ \\
\hline P8 & 1.0000 & 0.56276 & 0.66318 & 0.77324 & Biso & 1.000 & $P$ \\
\hline A17 & 1.0000 & 0.57806 & 0.67671 & 0.56794 & Biso & 1.000 & Al \\
\hline A18 & 1.0000 & 0.09867 & 0.43681 & 0.56849 & Biso & 1.000 & Al \\
\hline Al9 & 1.0000 & 0.33380 & 0.87833 & 0.56694 & Biso & 1.000 & Al \\
\hline P9 & 1.0000 & 0.99360 & 0.76642 & 0.89207 & Biso & 1.000 & $\mathrm{P}$ \\
\hline P10 & 1.0000 & 0.22699 & 0.22372 & 0.88321 & Biso & 1.000 & $\mathrm{P}$ \\
\hline P11 & 1.0000 & 0.77784 & 0.00298 & 0.89204 & Biso & 1.000 & $P$ \\
\hline Al10 & 1.0000 & 0.78154 & 0.00869 & 0.10609 & Biso & 1.000 & Al \\
\hline Al11 & 1.0000 & 0.23641 & 0.23155 & 0.09571 & Biso & 1.000 & Al \\
\hline Al 12 & 1.0000 & 0.00537 & 0.78005 & 0.10621 & Biso & 1.000 & Al \\
\hline P 12 & 1.0000 & 0.67049 & 0.11154 & 0.22571 & Biso & 1.000 & $\mathrm{P}$ \\
\hline P 13 & 1.0000 & 0.90755 & 0.56836 & 0.22972 & Biso & 1.000 & $\mathrm{P}$ \\
\hline $\mathrm{P} 14$ & 1.0000 & 0.44730 & 0.34323 & 0.22038 & Biso & 1.000 & $\mathrm{P}$ \\
\hline Al13 & 1.0000 & 0.42890 & 0.34983 & 0.42928 & Biso & 1.000 & Al \\
\hline Al14 & 1.0000 & 0.89592 & 0.55843 & 0.43959 & Biso & 1.000 & Al \\
\hline Al15 & 1.0000 & 0.66795 & 0.11090 & 0.43360 & Biso & 1.000 & Al \\
\hline P15 & 1.0000 & 0.33637 & 0.46287 & 0.55532 & Biso & 1.000 & $P$ \\
\hline P16 & 1.0000 & 0.56726 & 0.89934 & 0.56341 & Biso & 1.000 & $\mathrm{P}$ \\
\hline P17 & 1.0000 & 0.09581 & 0.66998 & 0.56752 & Biso & 1.000 & $P$ \\
\hline Al16 & 1.0000 & 0.10278 & 0.66826 & 0.77362 & Biso & 1.000 & Al \\
\hline Al17 & 1.0000 & 0.56106 & 0.89308 & 0.77240 & Biso & 1.000 & $\mathrm{Al}$ \\
\hline Al18 & 1.0000 & 0.33032 & 0.43902 & 0.76299 & Biso & 1.000 & Al \\
\hline 01 & 1.0000 & 0.91951 & 0.11177 & 0.12955 & Biso & 1.000 & 0 \\
\hline $\mathrm{O} 2$ & 1.0000 & 0.90023 & 0.81113 & 0.12960 & Biso & 1.000 & 0 \\
\hline 03 & 1.0000 & 0.20192 & 0.09397 & 0.12097 & Biso & 1.000 & 0 \\
\hline 04 & 1.0000 & 0.08337 & 0.88324 & 0.86074 & Biso & 1.000 & 0 \\
\hline 05 & 1.0000 & 0.80914 & 0.91279 & 0.87225 & Biso & 1.000 & 0 \\
\hline 06 & 1.0000 & 0.10566 & 0.19636 & 0.87098 & Biso & 1.000 & 0 \\
\hline 07 & 1.0000 & 0.56750 & 0.44879 & 0.45805 & Biso & 1.000 & 0 \\
\hline 08 & 1.0000 & 0.56979 & 0.15194 & 0.44120 & Biso & 1.000 & 0 \\
\hline 09 & 1.0000 & 0.87684 & 0.42602 & 0.45899 & Biso & 1.000 & 0 \\
\hline 010 & 1.0000 & 0.76141 & 0.23400 & 0.20879 & Biso & 1.000 & 0 \\
\hline 011 & 1.0000 & 0.46913 & 0.24495 & 0.21827 & Biso & 1.000 & 0 \\
\hline 012 & 1.0000 & 0.78724 & 0.54096 & 0.21359 & Biso & 1.000 & 0 \\
\hline 013 & 1.0000 & 0.23757 & 0.76551 & 0.80958 & Biso & 1.000 & 0 \\
\hline 014 & 1.0000 & 0.22597 & 0.47194 & 0.78821 & Biso & 1.000 & 0 \\
\hline 015 & 1.0000 & 0.53146 & 0.75493 & 0.77981 & Biso & 1.000 & 0 \\
\hline 016 & 1.0000 & 0.43781 & 0.58079 & 0.54895 & Biso & 1.000 & 0 \\
\hline 017 & 1.0000 & 0.09662 & 0.56074 & 0.56597 & Biso & 1.000 & 0 \\
\hline 018 & 1.0000 & 0.44218 & 0.85080 & 0.54252 & Biso & 1.000 & 0 \\
\hline 019 & 1.0000 & 0.99239 & 0.31507 & 0.16364 & Biso & 1.000 & 0 \\
\hline 020 & 1.0000 & 0.69818 & 0.68109 & 0.16742 & Biso & 1.000 & 0 \\
\hline 021 & 1.0000 & 0.34037 & 0.02673 & 0.14002 & Biso & 1.000 & 0 \\
\hline 022 & 1.0000 & 0.31665 & 0.97264 & 0.82818 & Biso & 1.000 & 0 \\
\hline 023 & 1.0000 & 0.65139 & 0.68148 & 0.84263 & Biso & 1.000 & 0 \\
\hline $\mathrm{O} 24$ & 1.0000 & 0.02665 & 0.34863 & 0.83909 & Biso & 1.000 & 0 \\
\hline
\end{tabular}




\begin{tabular}{|c|c|c|c|c|c|c|c|}
\hline 025 & 1.0000 & 0.66481 & 0.65291 & 0.49816 & Biso & 1.000 & 0 \\
\hline 026 & 1.0000 & 0.34014 & 0.98886 & 0.51129 & Biso & 1.000 & 0 \\
\hline $\mathrm{O} 27$ & 1.0000 & 0.00013 & 0.34452 & 0.49426 & Biso & 1.000 & 0 \\
\hline 028 & 1.0000 & 0.00614 & 0.67609 & 0.84327 & Biso & 1.000 & 0 \\
\hline O29 & 1.0000 & 0.30568 & 0.32152 & 0.82381 & Biso & 1.000 & 0 \\
\hline 030 & 1.0000 & 0.67374 & 0.97990 & 0.83977 & Biso & 1.000 & 0 \\
\hline 031 & 1.0000 & 0.68689 & 0.03462 & 0.16152 & Biso & 1.000 & 0 \\
\hline 032 & 1.0000 & 0.35589 & 0.32477 & 0.15332 & Biso & 1.000 & 0 \\
\hline 033 & 1.0000 & 0.98944 & 0.66969 & 0.17369 & Biso & 1.000 & 0 \\
\hline 034 & 1.0000 & 0.34106 & 0.38727 & 0.48391 & Biso & 1.000 & 0 \\
\hline 035 & 1.0000 & 0.00128 & 0.66030 & 0.50746 & Biso & 1.000 & 0 \\
\hline 036 & 1.0000 & 0.63951 & 0.99769 & 0.50263 & Biso & 1.000 & 0 \\
\hline 037 & 1.0000 & 0.12454 & 0.24833 & 0.12784 & Biso & 1.000 & 0 \\
\hline 038 & 1.0000 & 0.76614 & 0.88143 & 0.14051 & Biso & 1.000 & 0 \\
\hline 039 & 1.0000 & 0.13523 & 0.89145 & 0.13945 & Biso & 1.000 & 0 \\
\hline 040 & 1.0000 & 0.23484 & 0.12153 & 0.85512 & Biso & 1.000 & 0 \\
\hline 041 & 1.0000 & 0.87892 & 0.75041 & 0.86958 & Biso & 1.000 & 0 \\
\hline 042 & 1.0000 & 0.87411 & 0.11639 & 0.86270 & Biso & 1.000 & 0 \\
\hline 043 & 1.0000 & 0.77476 & 0.56108 & 0.46151 & Biso & 1.000 & 0 \\
\hline 044 & 1.0000 & 0.39638 & 0.21839 & 0.45993 & Biso & 1.000 & 0 \\
\hline 045 & 1.0000 & 0.80024 & 0.21962 & 0.46384 & Biso & 1.000 & 0 \\
\hline 046 & 1.0000 & 0.91937 & 0.46847 & 0.20244 & Biso & 1.000 & 0 \\
\hline 047 & 1.0000 & 0.55689 & 0.09970 & 0.20616 & Biso & 1.000 & 0 \\
\hline 048 & 1.0000 & 0.55474 & 0.44914 & 0.19238 & Biso & 1.000 & 0 \\
\hline O49 & 1.0000 & 0.44427 & 0.89637 & 0.81228 & Biso & 1.000 & 0 \\
\hline 050 & 1.0000 & 0.08656 & 0.53626 & 0.77958 & Biso & 1.000 & 0 \\
\hline 051 & 1.0000 & 0.45921 & 0.55073 & 0.79330 & Biso & 1.000 & 0 \\
\hline 052 & 1.0000 & 0.59892 & 0.80936 & 0.54740 & Biso & 1.000 & 0 \\
\hline 053 & 1.0000 & 0.23245 & 0.47194 & 0.53801 & Biso & 1.000 & 0 \\
\hline 054 & 1.0000 & 0.20638 & 0.76338 & 0.52846 & Biso & 1.000 & 0 \\
\hline 055 & 1.0000 & 0.00120 & 0.25656 & 0.00843 & Biso & 1.000 & 0 \\
\hline 056 & 1.0000 & 0.74931 & 0.75498 & 0.01343 & Biso & 1.000 & 0 \\
\hline 057 & 1.0000 & 0.23572 & 0.98872 & 0.99888 & Biso & 1.000 & 0 \\
\hline 058 & 1.0000 & 0.66988 & 0.59650 & 0.34121 & Biso & 1.000 & 0 \\
\hline 059 & 1.0000 & 0.36903 & 0.04473 & 0.32470 & Biso & 1.000 & $\mathrm{O}$ \\
\hline 060 & 1.0000 & 0.93201 & 0.33455 & 0.34007 & Biso & 1.000 & 0 \\
\hline 061 & 1.0000 & 0.33018 & 0.89509 & 0.68147 & Biso & 1.000 & 0 \\
\hline 062 & 1.0000 & 0.06852 & 0.38380 & 0.67712 & Biso & 1.000 & 0 \\
\hline 063 & 1.0000 & 0.60882 & 0.66397 & 0.67960 & Biso & 1.000 & 0 \\
\hline 064 & 1.0000 & 0.00415 & 0.75263 & 0.99289 & Biso & 1.000 & 0 \\
\hline 065 & 1.0000 & 0.26225 & 0.25405 & 0.98114 & Biso & 1.000 & 0 \\
\hline 066 & 1.0000 & 0.75484 & 0.00449 & 0.99198 & Biso & 1.000 & 0 \\
\hline 067 & 1.0000 & 0.67759 & 0.07651 & 0.32152 & Biso & 1.000 & 0 \\
\hline 068 & 1.0000 & 0.94032 & 0.59913 & 0.32857 & Biso & 1.000 & 0 \\
\hline 069 & 1.0000 & 0.41183 & 0.35905 & 0.31355 & Biso & 1.000 & 0 \\
\hline 070 & 1.0000 & 0.33033 & 0.41323 & 0.64865 & Biso & 1.000 & 0 \\
\hline 071 & 1.0000 & 0.58998 & 0.93833 & 0.66151 & Biso & 1.000 & 0 \\
\hline 072 & 1.0000 & 0.08004 & 0.69808 & 0.66363 & Biso & 1.000 & 0 \\
\hline $\mathrm{H} 1$ & 1.0000 & 0.26219 & 0.93837 & 0.33528 & Biso & 1.000 & $\mathrm{H}$ \\
\hline $\mathrm{N} 1$ & 1.0000 & 0.18082 & 0.86124 & 0.34917 & Biso & 1.000 & $\mathrm{~N}$ \\
\hline $\mathrm{H} 2$ & 1.0000 & 0.15375 & 0.80909 & 0.29494 & Biso & 1.000 & $\mathrm{H}$ \\
\hline H3 & 1.0000 & 0.12236 & 0.88370 & 0.36320 & Biso & 1.000 & $\mathrm{H}$ \\
\hline \multirow{3}{*}{\multicolumn{8}{|c|}{$\begin{array}{l}\mathrm{Zn} 28 \\
\text { data image } 0\end{array}$}} \\
\hline & & & & & & & \\
\hline & & & & & & & \\
\hline \multicolumn{8}{|c|}{ celì length a $\quad 13.875$} \\
\hline \multicolumn{2}{|c|}{ cell length b } & \multirow{2}{*}{\multicolumn{2}{|c|}{$\begin{array}{l}13.875 \\
15.017\end{array}$}} & & & & \\
\hline cell & $\mathrm{ch}-\mathrm{c}$ & & & & & & \\
\hline cell & _èlpha & \multicolumn{2}{|c|}{90} & & & & \\
\hline cell & - beta & 90 & & & & & \\
\hline cell & gamma & 120 & & & & & \\
\hline symme & pace_gr & oup_name & $\mathrm{H}-\mathrm{M}$ & $1 "$ & & & \\
\hline symme & nt_tābl & es_numbe & & & & & \\
\hline loop_ & & & & & & & \\
\hline sym & _equiv & pos_as_x & & & & & \\
\hline loop_ & & & & & & & \\
\hline at & e label & & & & & & \\
\hline ato & e_occup & bancy & & & & & \\
\hline ato & e_fract & $=x$ & & & & & \\
\hline -ato & $e_{-}^{-}$fract & $-y$ & & & & & \\
\hline -ato & $e^{-}$fract & & & & & & \\
\hline ato & e_therm & nal_disp] & ce_type & & & & \\
\hline & e_B_isc & or_equi & & & & & \\
\hline ato & e-type & symbol & & & & & \\
\hline$\overline{\mathrm{A}} 11$ & 1.0000 & 0.99837 & 0.22412 & 0.10375 & Biso & 1.000 & $\mathrm{Al}$ \\
\hline Al2 & 1.0000 & 0.77589 & 0.77269 & 0.10621 & Biso & 1.000 & Al \\
\hline
\end{tabular}




\begin{tabular}{|c|c|c|c|c|c|c|c|}
\hline A13 & 1.0000 & 0.23002 & 0.00240 & 0.09781 & Biso & 1.000 & $\mathrm{Al}$ \\
\hline $\mathrm{P} 1$ & 1.0000 & 0.22627 & 0.00003 & 0.88731 & Biso & 1.000 & $\mathrm{P}$ \\
\hline P2 & 1.0000 & 0.77630 & 0.77030 & 0.89332 & Biso & 1.000 & $\mathrm{P}$ \\
\hline P3 & 1.0000 & 0.99650 & 0.22435 & 0.89108 & Biso & 1.000 & $\mathrm{P}$ \\
\hline Al4 & 1.0000 & 0.66147 & 0.55597 & 0.43599 & Biso & 1.000 & $\mathrm{Al}$ \\
\hline $\mathrm{Zn} 1$ & 1.0000 & 0.45774 & 0.12026 & 0.45788 & Biso & 1.000 & $\mathrm{Zn}$ \\
\hline Al5 & 1.0000 & 0.90377 & 0.33392 & 0.43541 & Biso & 1.000 & Al \\
\hline P4 & 1.0000 & 0.89907 & 0.33826 & 0.22469 & Biso & 1.000 & $\mathrm{P}$ \\
\hline P5 & 1.0000 & 0.44194 & 0.10424 & 0.21844 & Biso & 1.000 & $P$ \\
\hline P6 & 1.0000 & 0.66542 & 0.55994 & 0.22666 & Biso & 1.000 & $\mathrm{P}$ \\
\hline Al6 & 1.0000 & 0.33042 & 0.89052 & 0.76677 & Biso & 1.000 & $\mathrm{Al}$ \\
\hline Al7 & 1.0000 & 0.10700 & 0.43357 & 0.76830 & Biso & 1.000 & Al \\
\hline A18 & 1.0000 & 0.56525 & 0.67035 & 0.77025 & Biso & 1.000 & Al \\
\hline P7 & 1.0000 & 0.57385 & 0.67817 & 0.56201 & Biso & 1.000 & $\mathrm{P}$ \\
\hline P8 & 1.0000 & 0.10625 & 0.43622 & 0.56316 & Biso & 1.000 & $\mathrm{P}$ \\
\hline P9 & 1.0000 & 0.32922 & 0.88196 & 0.55700 & Biso & 1.000 & $\mathrm{P}$ \\
\hline Al9 & 1.0000 & 0.00190 & 0.77015 & 0.89872 & Biso & 1.000 & Al \\
\hline Al10 & 1.0000 & 0.22629 & 0.22809 & 0.89189 & Biso & 1.000 & Al \\
\hline Al11 & 1.0000 & 0.77360 & 0.99578 & 0.89432 & Biso & 1.000 & Al \\
\hline P10 & 1.0000 & 0.77302 & 0.99682 & 0.10761 & Biso & 1.000 & $\mathrm{P}$ \\
\hline P11 & 1.0000 & 0.22842 & 0.22947 & 0.10404 & Biso & 1.000 & $\mathrm{P}$ \\
\hline P12 & 1.0000 & 0.00438 & 0.77660 & 0.11163 & Biso & 1.000 & $\mathrm{P}$ \\
\hline Al12 & 1.0000 & 0.67390 & 0.10612 & 0.23247 & Biso & 1.000 & Al \\
\hline Al13 & 1.0000 & 0.89379 & 0.56112 & 0.23073 & Biso & 1.000 & Al \\
\hline Al1 14 & 1.0000 & 0.43780 & 0.32989 & 0.22877 & Biso & 1.000 & $\mathrm{Al}$ \\
\hline $\mathrm{P} 13$ & 1.0000 & 0.42880 & 0.33009 & 0.43958 & Biso & 1.000 & $\mathrm{P}$ \\
\hline P14 & 1.0000 & 0.88956 & 0.55471 & 0.44243 & Biso & 1.000 & $\mathrm{P}$ \\
\hline P15 & 1.0000 & 0.67918 & 0.11310 & 0.43699 & Biso & 1.000 & $\mathrm{P}$ \\
\hline Al15 & 1.0000 & 0.34192 & 0.45352 & 0.56255 & Biso & 1.000 & Al \\
\hline Al16 & 1.0000 & 0.55987 & 0.89586 & 0.56419 & Biso & 1.000 & $\mathrm{Al}$ \\
\hline Al17 & 1.0000 & 0.09432 & 0.66286 & 0.56939 & Biso & 1.000 & Al \\
\hline P16 & 1.0000 & 0.10302 & 0.66304 & 0.77521 & Biso & 1.000 & $\mathrm{P}$ \\
\hline P 17 & 1.0000 & 0.55894 & 0.89482 & 0.77448 & Biso & 1.000 & $\mathrm{P}$ \\
\hline P 18 & 1.0000 & 0.33827 & 0.44002 & 0.77072 & Biso & 1.000 & $\mathrm{P}$ \\
\hline 01 & 1.0000 & 0.89389 & 0.08759 & 0.12804 & Biso & 1.000 & 0 \\
\hline $\mathrm{O} 2$ & 1.0000 & 0.91360 & 0.80703 & 0.13037 & Biso & 1.000 & 0 \\
\hline $\mathrm{O} 3$ & 1.0000 & 0.20151 & 0.10878 & 0.12219 & Biso & 1.000 & 0 \\
\hline O4 & 1.0000 & 0.10503 & 0.90680 & 0.87273 & Biso & 1.000 & 0 \\
\hline 05 & 1.0000 & 0.80740 & 0.89158 & 0.87331 & Biso & 1.000 & 0 \\
\hline 06 & 1.0000 & 0.08967 & 0.19752 & 0.87171 & Biso & 1.000 & 0 \\
\hline 07 & 1.0000 & 0.55278 & 0.42012 & 0.45047 & Biso & 1.000 & 0 \\
\hline 08 & 1.0000 & 0.61026 & 0.17140 & 0.44024 & Biso & 1.000 & 0 \\
\hline 09 & 1.0000 & 0.86892 & 0.43657 & 0.46077 & Biso & 1.000 & 0 \\
\hline 010 & 1.0000 & 0.77717 & 0.24447 & 0.21328 & Biso & 1.000 & 0 \\
\hline 011 & 1.0000 & 0.47150 & 0.22494 & 0.20523 & Biso & 1.000 & 0 \\
\hline 012 & 1.0000 & 0.75719 & 0.53041 & 0.20956 & Biso & 1.000 & 0 \\
\hline 013 & 1.0000 & 0.22547 & 0.75349 & 0.78961 & Biso & 1.000 & 0 \\
\hline 014 & 1.0000 & 0.24531 & 0.46790 & 0.78831 & Biso & 1.000 & 0 \\
\hline 015 & 1.0000 & 0.52899 & 0.77289 & 0.78918 & Biso & 1.000 & 0 \\
\hline 016 & 1.0000 & 0.44969 & 0.59137 & 0.55079 & Biso & 1.000 & 0 \\
\hline 017 & 1.0000 & 0.11670 & 0.55124 & 0.55832 & Biso & 1.000 & 0 \\
\hline 018 & 1.0000 & 0.41699 & 0.84437 & 0.54824 & Biso & 1.000 & 0 \\
\hline 019 & 1.0000 & 0.97670 & 0.31838 & 0.16453 & Biso & 1.000 & 0 \\
\hline 020 & 1.0000 & 0.68180 & 0.65582 & 0.16607 & Biso & 1.000 & o \\
\hline 021 & 1.0000 & 0.34841 & 0.02373 & 0.15708 & Biso & 1.000 & 0 \\
\hline 022 & 1.0000 & 0.30656 & 0.98320 & 0.82858 & Biso & 1.000 & 0 \\
\hline 023 & 1.0000 & 0.67390 & 0.68889 & 0.83961 & Biso & 1.000 & 0 \\
\hline 024 & 1.0000 & 0.01505 & 0.32632 & 0.83784 & Biso & 1.000 & 0 \\
\hline 025 & 1.0000 & 0.64631 & 0.65097 & 0.50189 & Biso & 1.000 & 0 \\
\hline 026 & 1.0000 & 0.34923 & 0.97351 & 0.49149 & Biso & 1.000 & 0 \\
\hline 027 & 1.0000 & 0.01886 & 0.35593 & 0.49735 & Biso & 1.000 & 0 \\
\hline 028 & 1.0000 & 0.02752 & 0.67488 & 0.84370 & Biso & 1.000 & 0 \\
\hline 029 & 1.0000 & 0.32093 & 0.34178 & 0.82909 & Biso & 1.000 & 0 \\
\hline 030 & 1.0000 & 0.65625 & 0.97244 & 0.83493 & Biso & 1.000 & 0 \\
\hline 031 & 1.0000 & 0.69044 & 0.01719 & 0.16049 & Biso & 1.000 & 0 \\
\hline 032 & 1.0000 & 0.32854 & 0.31105 & 0.15995 & Biso & 1.000 & 0 \\
\hline 033 & 1.0000 & 0.98762 & 0.67921 & 0.17055 & Biso & 1.000 & 0 \\
\hline 034 & 1.0000 & 0.35491 & 0.36788 & 0.48611 & Biso & 1.000 & 0 \\
\hline 035 & 1.0000 & 0.98360 & 0.64101 & 0.50126 & Biso & 1.000 & 0 \\
\hline 036 & 1.0000 & 0.63868 & 0.01583 & 0.50256 & Biso & 1.000 & 0 \\
\hline 037 & 1.0000 & 0.12762 & 0.23978 & 0.13140 & Biso & 1.000 & 0 \\
\hline 038 & 1.0000 & 0.75804 & 0.88402 & 0.13596 & Biso & 1.000 & 0 \\
\hline 039 & 1.0000 & 0.11847 & 0.87721 & 0.13535 & Biso & 1.000 & 0 \\
\hline 040 & 1.0000 & 0.23656 & 0.11194 & 0.86323 & Biso & 1.000 & 0 \\
\hline 041 & 1.0000 & 0.87387 & 0.75388 & 0.86667 & Biso & 1.000 & 0 \\
\hline 042 & 1.0000 & 0.88504 & 0.12442 & 0.86298 & Biso & 1.000 & 0 \\
\hline 043 & 1.0000 & 0.78405 & 0.55842 & 0.46481 & Biso & 1.000 & 0 \\
\hline 044 & 1.0000 & 0.40598 & 0.22043 & 0.48000 & Biso & 1.000 & 0 \\
\hline 045 & 1.0000 & 0.80036 & 0.19893 & 0.46098 & Biso & 1.000 & 0 \\
\hline 046 & 1.0000 & 0.90786 & 0.44871 & 0.19658 & Biso & 1.000 & 0 \\
\hline
\end{tabular}




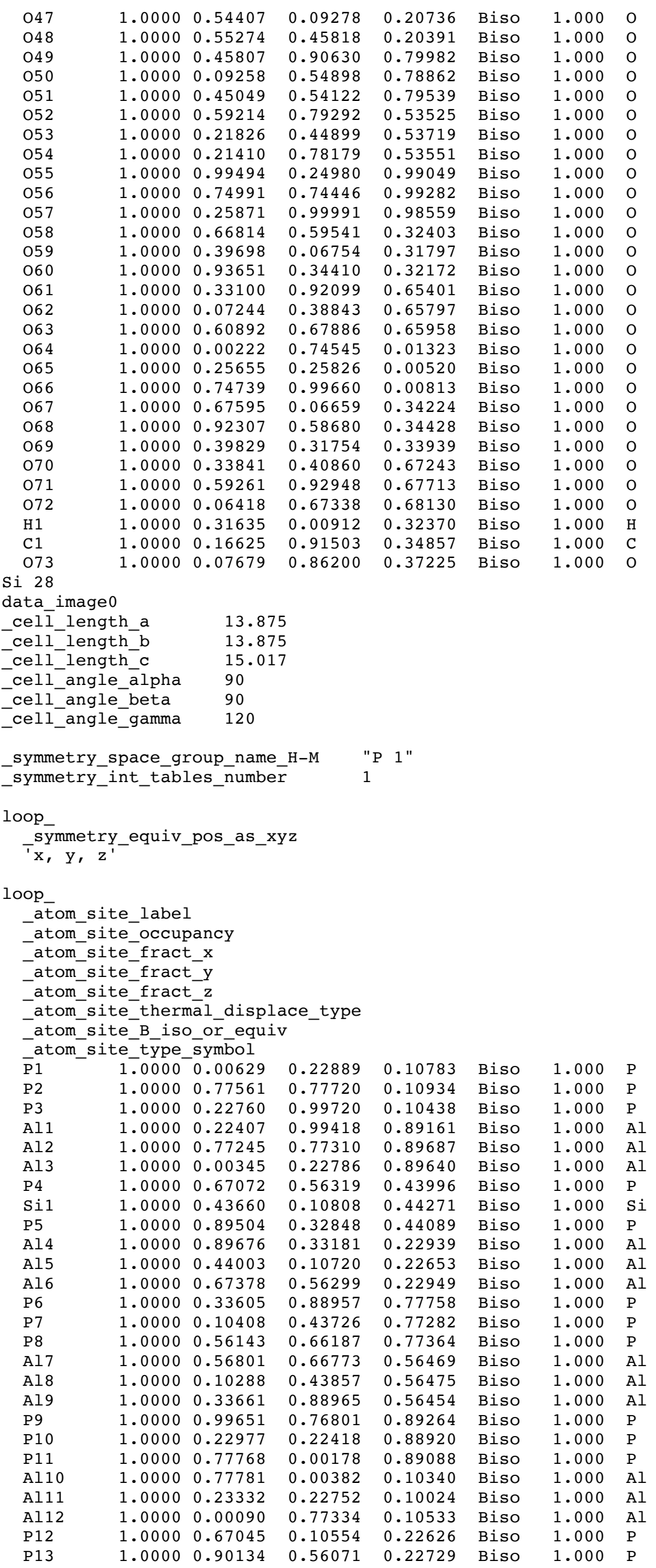




\begin{tabular}{|c|c|c|c|c|c|c|c|}
\hline P14 & 1.0000 & 0.44527 & 0.34005 & 0.22485 & Biso & 1.000 & $\mathrm{P}$ \\
\hline Al13 & 1.0000 & 0.43812 & 0.33986 & 0.43422 & Biso & 1.000 & $\mathrm{Al}$ \\
\hline Al1 14 & 1.0000 & 0.89690 & 0.55791 & 0.43797 & Biso & 1.000 & $\mathrm{Al}$ \\
\hline Al15 & 1.0000 & 0.66615 & 0.10495 & 0.43204 & Biso & 1.000 & Al \\
\hline P15 & 1.0000 & 0.33349 & 0.44540 & 0.55717 & Biso & 1.000 & $\mathrm{P}$ \\
\hline P16 & 1.0000 & 0.56346 & 0.89324 & 0.56095 & Biso & 1.000 & $\mathrm{P}$ \\
\hline P1 7 & 1.0000 & 0.10446 & 0.67125 & 0.56239 & Biso & 1.000 & $\mathrm{P}$ \\
\hline Al16 & 1.0000 & 0.10664 & 0.66843 & 0.77169 & Biso & 1.000 & Al \\
\hline Al17 & 1.0000 & 0.56360 & 0.89250 & 0.77017 & Biso & 1.000 & Al \\
\hline Al18 & 1.0000 & 0.33101 & 0.43737 & 0.76758 & Biso & 1.000 & $\mathrm{Al}$ \\
\hline 01 & 1.0000 & 0.91507 & 0.10776 & 0.12678 & Biso & 1.000 & 0 \\
\hline $\mathrm{O} 2$ & 1.0000 & 0.89726 & 0.80731 & 0.12652 & Biso & 1.000 & $\mathrm{O}$ \\
\hline 03 & 1.0000 & 0.19994 & 0.08986 & 0.12310 & Biso & 1.000 & $\mathrm{O}$ \\
\hline O4 & 1.0000 & 0.08769 & 0.88790 & 0.86982 & Biso & 1.000 & 0 \\
\hline 05 & 1.0000 & 0.80741 & 0.91038 & 0.87236 & Biso & 1.000 & 0 \\
\hline 06 & 1.0000 & 0.10823 & 0.19545 & 0.87570 & Biso & 1.000 & 0 \\
\hline 07 & 1.0000 & 0.57516 & 0.44464 & 0.45816 & Biso & 1.000 & 0 \\
\hline 08 & 1.0000 & 0.56426 & 0.14131 & 0.43218 & Biso & 1.000 & $\mathrm{O}$ \\
\hline 09 & 1.0000 & 0.86856 & 0.42223 & 0.45923 & Biso & 1.000 & 0 \\
\hline 010 & 1.0000 & 0.75882 & 0.22796 & 0.20786 & Biso & 1.000 & 0 \\
\hline 011 & 1.0000 & 0.47254 & 0.24492 & 0.21771 & Biso & 1.000 & 0 \\
\hline 012 & 1.0000 & 0.78005 & 0.53169 & 0.21167 & Biso & 1.000 & 0 \\
\hline 013 & 1.0000 & 0.24326 & 0.76982 & 0.79904 & Biso & 1.000 & 0 \\
\hline 014 & 1.0000 & 0.22616 & 0.46963 & 0.79026 & Biso & 1.000 & 0 \\
\hline 015 & 1.0000 & 0.53231 & 0.75465 & 0.78549 & Biso & 1.000 & 0 \\
\hline 016 & 1.0000 & 0.42981 & 0.56548 & 0.54405 & Biso & 1.000 & $\mathrm{O}$ \\
\hline 017 & 1.0000 & 0.12544 & 0.57321 & 0.55160 & Biso & 1.000 & 0 \\
\hline 018 & 1.0000 & 0.43883 & 0.85183 & 0.54596 & Biso & 1.000 & 0 \\
\hline 019 & 1.0000 & 0.98956 & 0.30986 & 0.16622 & Biso & 1.000 & $\mathrm{O}$ \\
\hline 020 & 1.0000 & 0.69579 & 0.67702 & 0.16586 & Biso & 1.000 & $\mathrm{O}$ \\
\hline 021 & 1.0000 & 0.33151 & 0.01839 & 0.15691 & Biso & 1.000 & 0 \\
\hline 022 & 1.0000 & 0.31992 & 0.97391 & 0.83229 & Biso & 1.000 & 0 \\
\hline 023 & 1.0000 & 0.65566 & 0.67956 & 0.83681 & Biso & 1.000 & 0 \\
\hline 024 & 1.0000 & 0.02567 & 0.34345 & 0.83534 & Biso & 1.000 & 0 \\
\hline 025 & 1.0000 & 0.65953 & 0.64787 & 0.49816 & Biso & 1.000 & $\mathrm{O}$ \\
\hline 026 & 1.0000 & 0.36035 & 0.00441 & 0.50495 & Biso & 1.000 & $\mathrm{O}$ \\
\hline 027 & 1.0000 & 0.99394 & 0.34494 & 0.49774 & Biso & 1.000 & $\mathrm{O}$ \\
\hline 028 & 1.0000 & 0.01258 & 0.68330 & 0.83899 & Biso & 1.000 & 0 \\
\hline 029 & 1.0000 & 0.30850 & 0.32176 & 0.82985 & Biso & 1.000 & 0 \\
\hline 030 & 1.0000 & 0.67696 & 0.98247 & 0.83554 & Biso & 1.000 & 0 \\
\hline 031 & 1.0000 & 0.68262 & 0.02808 & 0.16022 & Biso & 1.000 & 0 \\
\hline 032 & 1.0000 & 0.34981 & 0.31858 & 0.16175 & Biso & 1.000 & 0 \\
\hline 033 & 1.0000 & 0.98098 & 0.66057 & 0.16980 & Biso & 1.000 & $\mathrm{O}$ \\
\hline 034 & 1.0000 & 0.34607 & 0.36489 & 0.49551 & Biso & 1.000 & 0 \\
\hline 035 & 1.0000 & 0.00613 & 0.65390 & 0.50422 & Biso & 1.000 & 0 \\
\hline 036 & 1.0000 & 0.63631 & 0.99131 & 0.49995 & Biso & 1.000 & 0 \\
\hline 037 & 1.0000 & 0.11999 & 0.24188 & 0.13055 & Biso & 1.000 & 0 \\
\hline 038 & 1.0000 & 0.76236 & 0.87642 & 0.13636 & Biso & 1.000 & 0 \\
\hline 039 & 1.0000 & 0.12977 & 0.88620 & 0.13664 & Biso & 1.000 & 0 \\
\hline 040 & 1.0000 & 0.23957 & 0.12268 & 0.86304 & Biso & 1.000 & 0 \\
\hline 041 & 1.0000 & 0.88324 & 0.75406 & 0.86797 & Biso & 1.000 & 0 \\
\hline 042 & 1.0000 & 0.87673 & 0.11461 & 0.86446 & Biso & 1.000 & 0 \\
\hline 043 & 1.0000 & 0.78096 & 0.56913 & 0.46328 & Biso & 1.000 & 0 \\
\hline 044 & 1.0000 & 0.41842 & 0.21120 & 0.45865 & Biso & 1.000 & 0 \\
\hline 045 & 1.0000 & 0.79424 & 0.21670 & 0.46610 & Biso & 1.000 & 0 \\
\hline 046 & 1.0000 & 0.91340 & 0.46091 & 0.19988 & Biso & 1.000 & 0 \\
\hline 047 & 1.0000 & 0.55489 & 0.09242 & 0.21147 & Biso & 1.000 & 0 \\
\hline 048 & 1.0000 & 0.54852 & 0.44841 & 0.19605 & Biso & 1.000 & 0 \\
\hline 049 & 1.0000 & 0.44841 & 0.90197 & 0.80381 & Biso & 1.000 & 0 \\
\hline 050 & 1.0000 & 0.09027 & 0.53794 & 0.79156 & Biso & 1.000 & 0 \\
\hline 051 & 1.0000 & 0.45908 & 0.55019 & 0.79761 & Biso & 1.000 & 0 \\
\hline 052 & 1.0000 & 0.58578 & 0.79810 & 0.53949 & Biso & 1.000 & 0 \\
\hline 053 & 1.0000 & 0.22450 & 0.44159 & 0.53311 & Biso & 1.000 & 0 \\
\hline 054 & 1.0000 & 0.20778 & 0.77803 & 0.53116 & Biso & 1.000 & 0 \\
\hline 055 & 1.0000 & 0.00237 & 0.25766 & 0.00948 & Biso & 1.000 & 0 \\
\hline 056 & 1.0000 & 0.74547 & 0.74803 & 0.01075 & Biso & 1.000 & 0 \\
\hline 057 & 1.0000 & 0.25058 & 0.99224 & 0.00535 & Biso & 1.000 & 0 \\
\hline 058 & 1.0000 & 0.67041 & 0.59450 & 0.34155 & Biso & 1.000 & 0 \\
\hline 059 & 1.0000 & 0.38091 & 0.05636 & 0.33598 & Biso & 1.000 & 0 \\
\hline 060 & 1.0000 & 0.92610 & 0.33014 & 0.34221 & Biso & 1.000 & 0 \\
\hline 061 & 1.0000 & 0.33354 & 0.91454 & 0.67854 & Biso & 1.000 & 0 \\
\hline 062 & 1.0000 & 0.07149 & 0.39732 & 0.67615 & Biso & 1.000 & 0 \\
\hline 063 & 1.0000 & 0.59858 & 0.66096 & 0.67719 & Biso & 1.000 & 0 \\
\hline 064 & 1.0000 & 0.00102 & 0.74461 & 0.99233 & Biso & 1.000 & 0 \\
\hline 065 & 1.0000 & 0.26417 & 0.25596 & 0.98712 & Biso & 1.000 & 0 \\
\hline 066 & 1.0000 & 0.74977 & 0.00163 & 0.98996 & Biso & 1.000 & 0 \\
\hline 067 & 1.0000 & 0.68189 & 0.07154 & 0.32123 & Biso & 1.000 & 0 \\
\hline 068 & 1.0000 & 0.93388 & 0.59082 & 0.32562 & Biso & 1.000 & 0 \\
\hline 069 & 1.0000 & 0.41165 & 0.34906 & 0.32034 & Biso & 1.000 & 0 \\
\hline 070 & 1.0000 & 0.33058 & 0.40824 & 0.65434 & Biso & 1.000 & 0 \\
\hline
\end{tabular}




$\begin{array}{llllllll}071 & 1.0000 & 0.59525 & 0.93113 & 0.65843 & \text { Biso } & 1.000 & 0 \\ \text { O72 } & 1.0000 & 0.07806 & 0.68201 & 0.66025 & \text { Biso } & 1.000 & \text { O } \\ \text { H1 } & 1.0000 & 0.29993 & 0.00044 & 0.33864 & \text { Biso } & 1.000 & \text { H } \\ \text { C1 } & 1.0000 & 0.14189 & 0.90618 & 0.35298 & \text { Biso } & 1.000 & \text { C } \\ \text { 073 } & 1.0000 & 0.04847 & 0.85631 & 0.36528 & \text { Biso } & 1.000 & \text { O }\end{array}$

Mg 28

data_image 0

$\begin{array}{ll}\text {-cel1_length_a } & 13.875 \\ \text { _cell_length_b } & 13.875 \\ \text {-cell_length_c } & 15.017 \\ \text { _cell_angle_alpha } & 90 \\ \text {-cell_angle_beta } & 90 \\ \text {-cell_angle_gamma } & 120\end{array}$

_cell_angle_gamma 120

_symmetry_space_group_name_H-M "P 1 "

symmetry_int_tables_number 1

loop

_symmetry_equiv_pos_as_xyz

' $\mathrm{x}, \mathrm{y}, \mathrm{z}$ '

loop_

_atom_site_label

-atom_site_occupancy

-atom_site_fract_x

-atom_site_fract_y

-atom_site_fract_z

-atom_site_thermäldisplace_type

-atom_site_B_iso_or_equiv

atom site type symbol

\begin{tabular}{|c|c|c|c|c|c|c|c|}
\hline$\overline{\mathrm{A}} 11$ & 1.0000 & 0.99971 & 0.22537 & 0.10364 & Biso & 1.000 & Al \\
\hline Al2 & 1.0000 & 0.77814 & 0.77499 & 0.10720 & Biso & 1.000 & Al \\
\hline Al3 & 1.0000 & 0.23187 & 0.00479 & 0.09686 & Biso & 1.000 & Al \\
\hline P1 & 1.0000 & 0.22567 & 0.99926 & 0.88599 & Biso & 1.000 & $\mathrm{P}$ \\
\hline P2 & 1.0000 & 0.77643 & 0.77095 & 0.89412 & Biso & 1.000 & $P$ \\
\hline P3 & 1.0000 & 0.99533 & 0.22367 & 0.89075 & Biso & 1.000 & $P$ \\
\hline Al4 & 1.0000 & 0.66038 & 0.55652 & 0.43586 & Biso & 1.000 & $\mathrm{Al}$ \\
\hline Mg1 & 1.0000 & 0.44897 & 0.11368 & 0.44813 & Biso & 1.000 & Mg \\
\hline Al5 & 1.0000 & 0.90455 & 0.33370 & 0.43613 & Biso & 1.000 & $\mathrm{Al}$ \\
\hline P 4 & 1.0000 & 0.90189 & 0.33995 & 0.22484 & Biso & 1.000 & $\mathrm{P}$ \\
\hline P5 & 1.0000 & 0.44173 & 0.10432 & 0.22096 & Biso & 1.000 & $P$ \\
\hline P6 & 1.0000 & 0.66752 & 0.55950 & 0.22534 & Biso & 1.000 & $\mathrm{P}$ \\
\hline Al6 & 1.0000 & 0.32799 & 0.88474 & 0.77049 & Biso & 1.000 & Al \\
\hline Al 7 & 1.0000 & 0.10623 & 0.43270 & 0.76797 & Biso & 1.000 & Al \\
\hline Al8 & 1.0000 & 0.56537 & 0.66850 & 0.77007 & Biso & 1.000 & Al \\
\hline P7 & 1.0000 & 0.57632 & 0.67705 & 0.56198 & Biso & 1.000 & $\mathrm{P}$ \\
\hline P8 & 1.0000 & 0.10592 & 0.43617 & 0.56379 & Biso & 1.000 & $P$ \\
\hline P9 & 1.0000 & 0.32763 & 0.87782 & 0.55842 & Biso & 1.000 & $\mathrm{P}$ \\
\hline Al9 & 1.0000 & 0.00117 & 0.76883 & 0.89932 & Biso & 1.000 & Al \\
\hline Al10 & 1.0000 & 0.22419 & 0.22611 & 0.88937 & Biso & 1.000 & Al \\
\hline Al11 & 1.0000 & 0.77321 & 0.99515 & 0.89474 & Biso & 1.000 & Al \\
\hline P10 & 1.0000 & 0.77372 & 0.99787 & 0.10842 & Biso & 1.000 & $P$ \\
\hline P11 & 1.0000 & 0.22950 & 0.23043 & 0.10210 & Biso & 1.000 & $P$ \\
\hline P12 & 1.0000 & 0.00697 & 0.77869 & 0.11211 & Biso & 1.000 & $P$ \\
\hline Al12 & 1.0000 & 0.67680 & 0.10964 & 0.23209 & Biso & 1.000 & Al \\
\hline Al13 & 1.0000 & 0.89891 & 0.56439 & 0.23265 & Biso & 1.000 & Al \\
\hline Al1 14 & 1.0000 & 0.43841 & 0.33607 & 0.22815 & Biso & 1.000 & Al \\
\hline P13 & 1.0000 & 0.42547 & 0.33601 & 0.43580 & Biso & 1.000 & $P$ \\
\hline P14 & 1.0000 & 0.89061 & 0.55556 & 0.44286 & Biso & 1.000 & $P$ \\
\hline P15 & 1.0000 & 0.67936 & 0.11151 & 0.43711 & Biso & 1.000 & $\mathrm{P}$ \\
\hline Al15 & 1.0000 & 0.34113 & 0.45502 & 0.56180 & Biso & 1.000 & Al \\
\hline Al16 & 1.0000 & 0.56087 & 0.89644 & 0.56490 & Biso & 1.000 & Al \\
\hline Al1 17 & 1.0000 & 0.09297 & 0.66358 & 0.57095 & Biso & 1.000 & Al \\
\hline P16 & 1.0000 & 0.10130 & 0.66208 & 0.77701 & Biso & 1.000 & $\mathrm{P}$ \\
\hline P17 & 1.0000 & 0.55847 & 0.89452 & 0.77424 & Biso & 1.000 & $\mathrm{P}$ \\
\hline P18 & 1.0000 & 0.33706 & 0.44178 & 0.77184 & Biso & 1.000 & $\mathrm{P}$ \\
\hline 01 & 1.0000 & 0.89436 & 0.08945 & 0.12868 & Biso & 1.000 & 0 \\
\hline $\mathrm{O} 2$ & 1.0000 & 0.91620 & 0.80927 & 0.13047 & Biso & 1.000 & 0 \\
\hline 03 & 1.0000 & 0.20305 & 0.11042 & 0.12276 & Biso & 1.000 & 0 \\
\hline 04 & 1.0000 & 0.10479 & 0.90488 & 0.87229 & Biso & 1.000 & 0 \\
\hline 05 & 1.0000 & 0.80848 & 0.89219 & 0.87284 & Biso & 1.000 & 0 \\
\hline 06 & 1.0000 & 0.08722 & 0.19524 & 0.87050 & Biso & 1.000 & 0 \\
\hline 07 & 1.0000 & 0.54756 & 0.42496 & 0.45721 & Biso & 1.000 & 0 \\
\hline 08 & 1.0000 & 0.60180 & 0.15915 & 0.44102 & Biso & 1.000 & 0 \\
\hline 09 & 1.0000 & 0.87177 & 0.43804 & 0.46047 & Biso & 1.000 & 0 \\
\hline 010 & 1.0000 & 0.77983 & 0.24757 & 0.21065 & Biso & 1.000 & 0 \\
\hline 011 & 1.0000 & 0.46484 & 0.22359 & 0.21942 & Biso & 1.000 & 0 \\
\hline 012 & 1.0000 & 0.76264 & 0.53409 & 0.21202 & Biso & 1.000 & 0 \\
\hline 013 & 1.0000 & 0.22319 & 0.74920 & 0.79835 & Biso & 1.000 & 0 \\
\hline 014 & 1.0000 & 0.24480 & 0.47022 & 0.79141 & Biso & 1.000 & 0 \\
\hline
\end{tabular}




\begin{tabular}{|c|c|c|c|c|c|c|c|}
\hline 015 & 1.0000 & 0.53041 & 0.77259 & 0.78401 & Biso & 1.000 & 0 \\
\hline 016 & 1.0000 & 0.45367 & 0.58922 & 0.54519 & Biso & 1.000 & O \\
\hline 017 & 1.0000 & 0.10735 & 0.54700 & 0.56307 & Biso & 1.000 & 0 \\
\hline 018 & 1.0000 & 0.41801 & 0.84395 & 0.54727 & Biso & 1.000 & 0 \\
\hline 019 & 1.0000 & 0.98013 & 0.32076 & 0.16481 & Biso & 1.000 & 0 \\
\hline 020 & 1.0000 & 0.68532 & 0.65737 & 0.16667 & Biso & 1.000 & 0 \\
\hline 021 & 1.0000 & 0.35215 & 0.02851 & 0.15503 & Biso & 1.000 & 0 \\
\hline 022 & 1.0000 & 0.30629 & 0.98167 & 0.82836 & Biso & 1.000 & 0 \\
\hline 023 & 1.0000 & 0.67355 & 0.68930 & 0.84100 & Biso & 1.000 & 0 \\
\hline 024 & 1.0000 & 0.01428 & 0.32586 & 0.83771 & Biso & 1.000 & $\mathrm{O}$ \\
\hline 025 & 1.0000 & 0.65347 & 0.65713 & 0.50106 & Biso & 1.000 & O \\
\hline 026 & 1.0000 & 0.34970 & 0.97520 & 0.49975 & Biso & 1.000 & $\mathrm{O}$ \\
\hline 027 & 1.0000 & 0.02026 & 0.35491 & 0.49727 & Biso & 1.000 & 0 \\
\hline 028 & 1.0000 & 0.02280 & 0.67071 & 0.84450 & Biso & 1.000 & 0 \\
\hline 029 & 1.0000 & 0.31819 & 0.34070 & 0.82717 & Biso & 1.000 & 0 \\
\hline 030 & 1.0000 & 0.65516 & 0.97020 & 0.83589 & Biso & 1.000 & 0 \\
\hline 031 & 1.0000 & 0.69055 & 0.01886 & 0.15995 & Biso & 1.000 & 0 \\
\hline 032 & 1.0000 & 0.33167 & 0.31369 & 0.15519 & Biso & 1.000 & 0 \\
\hline 033 & 1.0000 & 0.99146 & 0.68244 & 0.17186 & Biso & 1.000 & 0 \\
\hline 034 & 1.0000 & 0.34623 & 0.35950 & 0.49097 & Biso & 1.000 & O \\
\hline 035 & 1.0000 & 0.98003 & 0.64159 & 0.50516 & Biso & 1.000 & 0 \\
\hline 036 & 1.0000 & 0.64382 & 0.01201 & 0.49995 & Biso & 1.000 & 0 \\
\hline 037 & 1.0000 & 0.12946 & 0.24150 & 0.13043 & Biso & 1.000 & $\mathrm{O}$ \\
\hline 038 & 1.0000 & 0.75966 & 0.88578 & 0.13825 & Biso & 1.000 & 0 \\
\hline 039 & 1.0000 & 0.12127 & 0.87962 & 0.13524 & Biso & 1.000 & 0 \\
\hline 040 & 1.0000 & 0.23489 & 0.11024 & 0.85994 & Biso & 1.000 & 0 \\
\hline 041 & 1.0000 & 0.87323 & 0.75309 & 0.86803 & Biso & 1.000 & 0 \\
\hline 042 & 1.0000 & 0.88303 & 0.12458 & 0.86324 & Biso & 1.000 & 0 \\
\hline 043 & 1.0000 & 0.78206 & 0.55515 & 0.46069 & Biso & 1.000 & O \\
\hline 044 & 1.0000 & 0.40539 & 0.22113 & 0.45635 & Biso & 1.000 & 0 \\
\hline 045 & 1.0000 & 0.79828 & 0.20126 & 0.46375 & Biso & 1.000 & 0 \\
\hline 046 & 1.0000 & 0.91294 & 0.45194 & 0.19862 & Biso & 1.000 & 0 \\
\hline 047 & 1.0000 & 0.54749 & 0.09983 & 0.20864 & Biso & 1.000 & 0 \\
\hline 048 & 1.0000 & 0.55883 & 0.45651 & 0.19618 & Biso & 1.000 & 0 \\
\hline 049 & 1.0000 & 0.45655 & 0.90253 & 0.80286 & Biso & 1.000 & $\mathrm{O}$ \\
\hline 050 & 1.0000 & 0.08696 & 0.54579 & 0.78482 & Biso & 1.000 & 0 \\
\hline 051 & 1.0000 & 0.44965 & 0.54121 & 0.79845 & Biso & 1.000 & $\mathrm{O}$ \\
\hline 052 & 1.0000 & 0.59334 & 0.79258 & 0.54108 & Biso & 1.000 & 0 \\
\hline 053 & 1.0000 & 0.22108 & 0.45833 & 0.53601 & Biso & 1.000 & 0 \\
\hline 054 & 1.0000 & 0.21437 & 0.77725 & 0.53186 & Biso & 1.000 & $\mathrm{O}$ \\
\hline 055 & 1.0000 & 0.99522 & 0.24957 & 0.99024 & Biso & 1.000 & 0 \\
\hline 056 & 1.0000 & 0.75060 & 0.74705 & 0.99390 & Biso & 1.000 & 0 \\
\hline 057 & 1.0000 & 0.25877 & 0.00206 & 0.98451 & Biso & 1.000 & 0 \\
\hline 058 & 1.0000 & 0.66160 & 0.58957 & 0.32285 & Biso & 1.000 & 0 \\
\hline 059 & 1.0000 & 0.39396 & 0.05349 & 0.31816 & Biso & 1.000 & 0 \\
\hline 060 & 1.0000 & 0.93638 & 0.34184 & 0.32225 & Biso & 1.000 & 0 \\
\hline 061 & 1.0000 & 0.32390 & 0.90725 & 0.65727 & Biso & 1.000 & O \\
\hline 062 & 1.0000 & 0.07586 & 0.38484 & 0.65786 & Biso & 1.000 & 0 \\
\hline 063 & 1.0000 & 0.60709 & 0.67032 & 0.65968 & Biso & 1.000 & 0 \\
\hline 064 & 1.0000 & 0.00419 & 0.74635 & 0.01400 & Biso & 1.000 & 0 \\
\hline 065 & 1.0000 & 0.25478 & 0.25568 & 0.00264 & Biso & 1.000 & 0 \\
\hline 066 & 1.0000 & 0.74819 & 0.99564 & 0.00875 & Biso & 1.000 & 0 \\
\hline 067 & 1.0000 & 0.68231 & 0.07064 & 0.34108 & Biso & 1.000 & O \\
\hline 068 & 1.0000 & 0.92970 & 0.59103 & 0.34599 & Biso & 1.000 & 0 \\
\hline 069 & 1.0000 & 0.40157 & 0.34660 & 0.33628 & Biso & 1.000 & 0 \\
\hline 070 & 1.0000 & 0.33737 & 0.41409 & 0.67280 & Biso & 1.000 & O \\
\hline 071 & 1.0000 & 0.59118 & 0.93445 & 0.67770 & Biso & 1.000 & 0 \\
\hline 072 & 1.0000 & 0.06977 & 0.68187 & 0.68305 & Biso & 1.000 & O \\
\hline $\mathrm{H} 1$ & 1.0000 & 0.31242 & 0.99624 & 0.32061 & Biso & 1.000 & $\mathrm{H}$ \\
\hline $\mathrm{C} 1$ & 1.0000 & 0.16243 & 0.90739 & 0.34740 & Biso & 1.000 & C \\
\hline 073 & 1.0000 & 0.07243 & 0.85990 & 0.37082 & Biso & 1.000 & 0 \\
\hline
\end{tabular}

data_image 0

$\begin{array}{ll}\text {-cell_length_a } & 13.625 \\ \text {-cell_length_b } & 13.625 \\ \text {-cell_length_c } & 15.067 \\ \text {-cell_angle_alpha } & 90 \\ \text {-cell_angle_beta } & 90 \\ \text { _cell_angle_gamma } & 120\end{array}$

_symmetry_space_group_name_H-M "P 1 "

_symmetry_int_tables_number

loop

symmetry_equiv_pos_as_xyz

' $\mathrm{x}, \mathrm{y}, \mathrm{z}$ '

loop

_atom_site_label

-atom_site_occupancy 


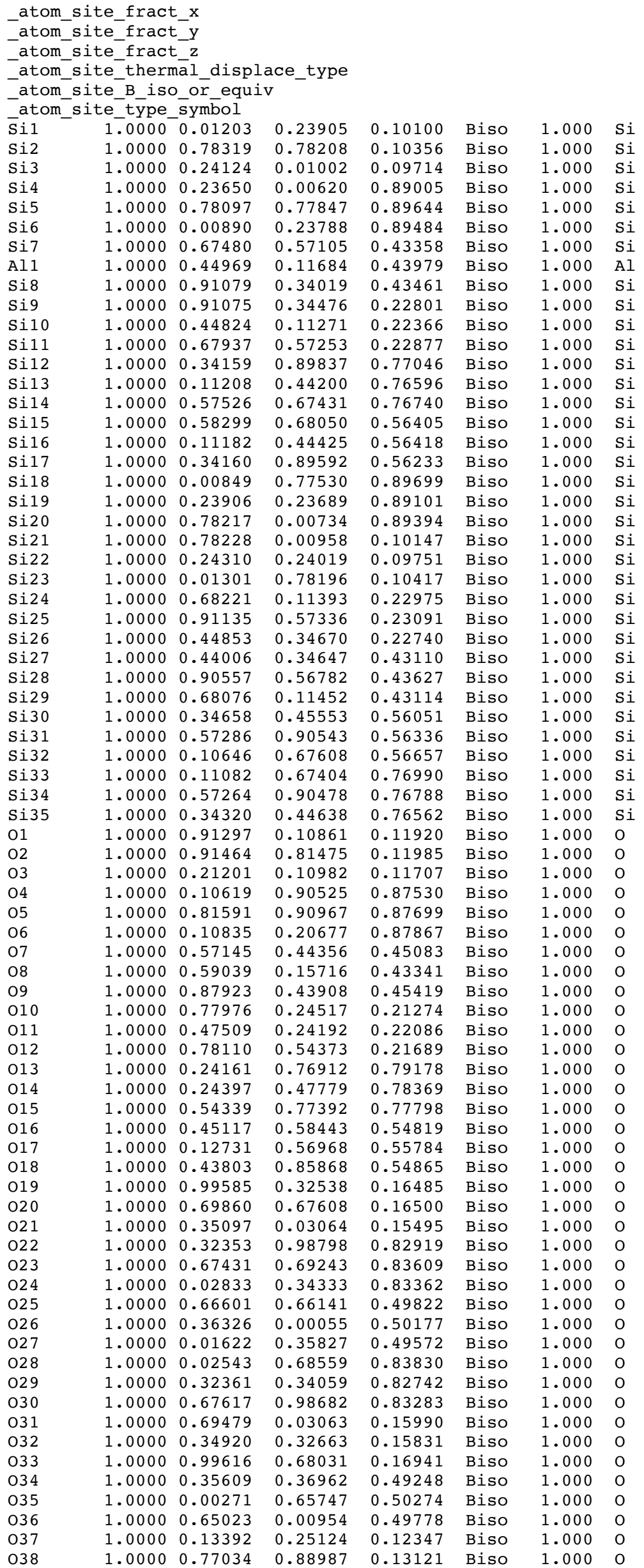




\begin{tabular}{|c|c|c|c|c|c|c|}
\hline 039 & 1.0000 & 0.13474 & 0.89109 & 0.12990 & Biso & 1.000 \\
\hline 040 & 1.0000 & 0.24714 & 0.12619 & 0.86380 & Biso & 1.000 \\
\hline 041 & 1.0000 & 0.88706 & 0.76160 & 0.87169 & Biso & 1.000 \\
\hline 042 & 1.0000 & 0.88913 & 0.12897 & 0.86751 & Biso & 1.000 \\
\hline 043 & 1.0000 & 0.79238 & 0.57399 & 0.45488 & Biso & 1.000 \\
\hline O4 4 & 1.0000 & 0.42095 & 0.22393 & 0.45179 & Biso & 1.000 \\
\hline 045 & 1.0000 & 0.80533 & 0.21738 & 0.45929 & Biso & 1.000 \\
\hline 046 & 1.0000 & 0.92200 & 0.46506 & 0.20067 & Biso & 1.000 \\
\hline 047 & 1.0000 & 0.56040 & 0.10495 & 0.21036 & Biso & 1.000 \\
\hline 048 & 1.0000 & 0.56249 & 0.46139 & 0.19868 & Biso & 1.000 \\
\hline 049 & 1.0000 & 0.46223 & 0.91149 & 0.79861 & Biso & 1.000 \\
\hline 050 & 1.0000 & 0.09678 & 0.55031 & 0.78376 & Biso & 1.000 \\
\hline 051 & 1.0000 & 0.46418 & 0.55452 & 0.79190 & Biso & 1.000 \\
\hline 052 & 1.0000 & 0.59860 & 0.80375 & 0.54246 & Biso & 1.000 \\
\hline 053 & 1.0000 & 0.23095 & 0.45495 & 0.53680 & Biso & 1.000 \\
\hline 054 & 1.0000 & 0.21946 & 0.78879 & 0.53405 & Biso & 1.000 \\
\hline 055 & 1.0000 & 0.00772 & 0.27261 & 0.99808 & Biso & 1.000 \\
\hline 056 & 1.0000 & 0.74743 & 0.74777 & 0.00046 & Biso & 1.000 \\
\hline 057 & 1.0000 & 0.27127 & 0.00715 & 0.99377 & Biso & 1.000 \\
\hline 058 & 1.0000 & 0.67338 & 0.60808 & 0.33075 & Biso & 1.000 \\
\hline 059 & 1.0000 & 0.39407 & 0.05867 & 0.32490 & Biso & 1.000 \\
\hline 060 & 1.0000 & 0.94733 & 0.34619 & 0.33079 & Biso & 1.000 \\
\hline 061 & 1.0000 & 0.33946 & 0.92724 & 0.66664 & Biso & 1.000 \\
\hline 062 & 1.0000 & 0.07572 & 0.39535 & 0.66487 & Biso & 1.000 \\
\hline 063 & 1.0000 & 0.61837 & 0.67393 & 0.66656 & Biso & 1.000 \\
\hline 064 & 1.0000 & 0.01291 & 0.74604 & 0.00139 & Biso & 1.000 \\
\hline 065 & 1.0000 & 0.27793 & 0.27186 & 0.99392 & Biso & 1.000 \\
\hline 066 & 1.0000 & 0.74859 & 0.00663 & 0.99768 & Biso & 1.000 \\
\hline 067 & 1.0000 & 0.68818 & 0.07327 & 0.32976 & Biso & 1.000 \\
\hline 068 & 1.0000 & 0.94926 & 0.60555 & 0.33424 & Biso & 1.000 \\
\hline 069 & 1.0000 & 0.40984 & 0.35649 & 0.32697 & Biso & 1.000 \\
\hline 070 & 1.0000 & 0.34297 & 0.41225 & 0.66210 & Biso & 1.000 \\
\hline 071 & 1.0000 & 0.60740 & 0.94803 & 0.66599 & Biso & 1.000 \\
\hline 072 & 1.0000 & 0.07652 & 0.68900 & 0.66919 & Biso & 1.000 \\
\hline H 1 & 1.0000 & 0.31139 & 0.00100 & 0.32685 & Biso & 1.000 \\
\hline C1 & 1.0000 & 0.15429 & 0.91443 & 0.34923 & Biso & 1.000 \\
\hline 073 & 1.0000 & 0.06124 & 0.87253 & 0.36864 & Biso & 1.000 \\
\hline
\end{tabular}

Ge 28

data image 0

$\begin{array}{ll}\text {-cell_length_a } & 13.875 \\ \text {-cell_length_b } & 13.875 \\ \text {-cell_length_c } & 15.017 \\ \text {-cell_angle_alpha } & 90 \\ \text {-cell_angle_beta } & 90 \\ \text {-cell_angle_gamma } & 120\end{array}$

cell_angle_gamma 120

$\begin{array}{ll}\text { _symmetry_space_group_name_H-M } & \text { "P } 1 \text { " } \\ \text { _symmetry_int_tables_number } & 1\end{array}$

loop

symmetry_equiv_pos_as_xyz

' $\mathrm{x}, \mathrm{y}, \mathrm{z}$ '

loop_

_atom_site_label

-atom_site_occupancy

-atom_site_fract_x

-atom_site_fract_y

-atom_site_fract_z

_atom_site_thermal_displace_type

-atom_site_B_iso_or_equiv

-atom_site_tȳpe_symbol

\begin{tabular}{|c|c|c|c|c|c|c|c|}
\hline P1 & 1.0000 & 0.00735 & 0.22866 & 0.10814 & Biso & 1.000 & $\mathrm{P}$ \\
\hline P2 & 1.0000 & 0.77781 & 0.77895 & 0.11122 & Biso & 1.000 & $P$ \\
\hline P3 & 1.0000 & 0.22861 & 0.99798 & 0.10127 & Biso & 1.000 & P \\
\hline Al1 & 1.0000 & 0.22128 & 0.99221 & 0.88781 & Biso & 1.000 & Al \\
\hline Al2 & 1.0000 & 0.77297 & 0.77328 & 0.89813 & Biso & 1.000 & $\mathrm{Al}$ \\
\hline Al3 & 1.0000 & 0.00243 & 0.22741 & 0.89604 & Biso & 1.000 & Al \\
\hline P4 & 1.0000 & 0.67091 & 0.56183 & 0.44015 & Biso & 1.000 & $P$ \\
\hline Ge1 & 1.0000 & 0.43457 & 0.11144 & 0.44731 & Biso & 1.000 & $\mathrm{Ge}$ \\
\hline P5 & 1.0000 & 0.89915 & 0.32769 & 0.44017 & Biso & 1.000 & $P$ \\
\hline Al4 & 1.0000 & 0.89835 & 0.33263 & 0.22882 & Biso & 1.000 & $\mathrm{Al}$ \\
\hline Al5 & 1.0000 & 0.44162 & 0.10971 & 0.22098 & Biso & 1.000 & Al \\
\hline Al 6 & 1.0000 & 0.67526 & 0.56448 & 0.23065 & Biso & 1.000 & Al \\
\hline P6 & 1.0000 & 0.33461 & 0.88593 & 0.77802 & Biso & 1.000 & $\mathrm{P}$ \\
\hline P7 & 1.0000 & 0.10360 & 0.43453 & 0.77202 & Biso & 1.000 & $P$ \\
\hline P8 & 1.0000 & 0.56230 & 0.66170 & 0.77428 & Biso & 1.000 & $\mathrm{P}$ \\
\hline Al 7 & 1.0000 & 0.57472 & 0.67254 & 0.56741 & Biso & 1.000 & Al \\
\hline Al8 & 1.0000 & 0.09939 & 0.43408 & 0.56834 & Biso & 1.000 & Al \\
\hline Al9 & 1.0000 & 0.33508 & 0.87879 & 0.56455 & Biso & 1.000 & Al \\
\hline
\end{tabular}




\begin{tabular}{|c|c|c|c|c|c|c|c|}
\hline P9 & 1.0000 & 0.99491 & 0.76542 & 0.89312 & Biso & 1.000 & $\mathrm{P}$ \\
\hline P10 & 1.0000 & 0.22836 & 0.22304 & 0.88587 & Biso & 1.000 & $\mathrm{P}$ \\
\hline P11 & 1.0000 & 0.77848 & 0.00153 & 0.89153 & Biso & 1.000 & $\mathrm{P}$ \\
\hline Al10 & 1.0000 & 0.78009 & 0.00474 & 0.10504 & Biso & 1.000 & Al \\
\hline Al11 & 1.0000 & 0.23465 & 0.22834 & 0.09752 & Biso & 1.000 & $\mathrm{Al}$ \\
\hline Al12 & 1.0000 & 0.00239 & 0.77483 & 0.10678 & Biso & 1.000 & $\mathrm{Al}$ \\
\hline P12 & 1.0000 & 0.67071 & 0.10578 & 0.22667 & Biso & 1.000 & $\mathrm{P}$ \\
\hline P13 & 1.0000 & 0.90118 & 0.56049 & 0.22763 & Biso & 1.000 & $\mathrm{P}$ \\
\hline P14 & 1.0000 & 0.44583 & 0.33942 & 0.22206 & Biso & 1.000 & $\mathrm{P}$ \\
\hline Al13 & 1.0000 & 0.43322 & 0.34196 & 0.43355 & Biso & 1.000 & Al \\
\hline Al14 & 1.0000 & 0.89634 & 0.55537 & 0.43908 & Biso & 1.000 & $\mathrm{Al}$ \\
\hline Al15 & 1.0000 & 0.66792 & 0.10759 & 0.43274 & Biso & 1.000 & $\mathrm{Al}$ \\
\hline P15 & 1.0000 & 0.33619 & 0.45588 & 0.55638 & Biso & 1.000 & $\mathrm{P}$ \\
\hline P16 & 1.0000 & 0.56627 & 0.89468 & 0.56309 & Biso & 1.000 & $\mathrm{P}$ \\
\hline P17 & 1.0000 & 0.09783 & 0.66769 & 0.56649 & Biso & 1.000 & $\mathrm{P}$ \\
\hline Al16 & 1.0000 & 0.10402 & 0.66733 & 0.77174 & Biso & 1.000 & $\mathrm{Al}$ \\
\hline Al17 & 1.0000 & 0.56241 & 0.89160 & 0.77188 & Biso & 1.000 & $\mathrm{Al}$ \\
\hline Al18 & 1.0000 & 0.33104 & 0.43689 & 0.76480 & Biso & 1.000 & Al \\
\hline 01 & 1.0000 & 0.91722 & 0.10795 & 0.12980 & Biso & 1.000 & 0 \\
\hline $\mathrm{O} 2$ & 1.0000 & 0.89938 & 0.80937 & 0.12924 & Biso & 1.000 & 0 \\
\hline 03 & 1.0000 & 0.20190 & 0.09104 & 0.12133 & Biso & 1.000 & 0 \\
\hline 04 & 1.0000 & 0.08553 & 0.88410 & 0.86648 & Biso & 1.000 & 0 \\
\hline 05 & 1.0000 & 0.80912 & 0.91081 & 0.87238 & Biso & 1.000 & 0 \\
\hline 06 & 1.0000 & 0.10724 & 0.19587 & 0.87291 & Biso & 1.000 & 0 \\
\hline 07 & 1.0000 & 0.57224 & 0.44382 & 0.45382 & Biso & 1.000 & 0 \\
\hline 08 & 1.0000 & 0.57602 & 0.15798 & 0.43440 & Biso & 1.000 & 0 \\
\hline 09 & 1.0000 & 0.87335 & 0.42145 & 0.46087 & Biso & 1.000 & 0 \\
\hline 010 & 1.0000 & 0.76006 & 0.22815 & 0.20956 & Biso & 1.000 & 0 \\
\hline 011 & 1.0000 & 0.47780 & 0.24834 & 0.20857 & Biso & 1.000 & 0 \\
\hline 012 & 1.0000 & 0.77991 & 0.53123 & 0.21110 & Biso & 1.000 & 0 \\
\hline 013 & 1.0000 & 0.24076 & 0.76718 & 0.80107 & Biso & 1.000 & 0 \\
\hline 014 & 1.0000 & 0.22651 & 0.46944 & 0.78913 & Biso & 1.000 & 0 \\
\hline 015 & 1.0000 & 0.53094 & 0.75322 & 0.78357 & Biso & 1.000 & 0 \\
\hline 016 & 1.0000 & 0.43425 & 0.57587 & 0.54892 & Biso & 1.000 & 0 \\
\hline 017 & 1.0000 & 0.10529 & 0.56153 & 0.56419 & Biso & 1.000 & 0 \\
\hline 018 & 1.0000 & 0.44052 & 0.84531 & 0.54640 & Biso & 1.000 & 0 \\
\hline 019 & 1.0000 & 0.99105 & 0.31090 & 0.16524 & Biso & 1.000 & 0 \\
\hline 020 & 1.0000 & 0.69731 & 0.67797 & 0.16658 & Biso & 1.000 & 0 \\
\hline 021 & 1.0000 & 0.33525 & 0.02031 & 0.14997 & Biso & 1.000 & 0 \\
\hline $\mathrm{O} 22$ & 1.0000 & 0.31786 & 0.97259 & 0.82874 & Biso & 1.000 & 0 \\
\hline $\mathrm{O} 23$ & 1.0000 & 0.65309 & 0.67968 & 0.84129 & Biso & 1.000 & 0 \\
\hline $\mathrm{O} 24$ & 1.0000 & 0.02712 & 0.34708 & 0.83976 & Biso & 1.000 & 0 \\
\hline 025 & 1.0000 & 0.66079 & 0.64580 & 0.50005 & Biso & 1.000 & 0 \\
\hline 026 & 1.0000 & 0.34822 & 0.98848 & 0.50290 & Biso & 1.000 & 0 \\
\hline $\mathrm{O} 27$ & 1.0000 & 0.99814 & 0.34160 & 0.49563 & Biso & 1.000 & 0 \\
\hline $\mathrm{O} 28$ & 1.0000 & 0.01040 & 0.67796 & 0.84294 & Biso & 1.000 & 0 \\
\hline 029 & 1.0000 & 0.30760 & 0.32028 & 0.82634 & Biso & 1.000 & 0 \\
\hline 030 & 1.0000 & 0.67516 & 0.97957 & 0.83865 & Biso & 1.000 & 0 \\
\hline 031 & 1.0000 & 0.68445 & 0.02888 & 0.16111 & Biso & 1.000 & 0 \\
\hline 032 & 1.0000 & 0.35172 & 0.32050 & 0.15825 & Biso & 1.000 & 0 \\
\hline 033 & 1.0000 & 0.98153 & 0.66176 & 0.17159 & Biso & 1.000 & 0 \\
\hline 034 & 1.0000 & 0.34658 & 0.38065 & 0.48755 & Biso & 1.000 & 0 \\
\hline 035 & 1.0000 & 0.00375 & 0.65515 & 0.50511 & Biso & 1.000 & 0 \\
\hline 036 & 1.0000 & 0.63413 & 0.99417 & 0.50192 & Biso & 1.000 & 0 \\
\hline 037 & 1.0000 & 0.12208 & 0.24336 & 0.12931 & Biso & 1.000 & 0 \\
\hline 038 & 1.0000 & 0.76359 & 0.87736 & 0.13888 & Biso & 1.000 & 0 \\
\hline 039 & 1.0000 & 0.13229 & 0.88761 & 0.13643 & Biso & 1.000 & 0 \\
\hline 040 & 1.0000 & 0.23623 & 0.12056 & 0.85919 & Biso & 1.000 & 0 \\
\hline 041 & 1.0000 & 0.88113 & 0.75033 & 0.86817 & Biso & 1.000 & 0 \\
\hline 042 & 1.0000 & 0.87562 & 0.11468 & 0.86283 & Biso & 1.000 & 0 \\
\hline 043 & 1.0000 & 0.77785 & 0.56184 & 0.46499 & Biso & 1.000 & 0 \\
\hline O4 4 & 1.0000 & 0.40267 & 0.21385 & 0.47407 & Biso & 1.000 & 0 \\
\hline 045 & 1.0000 & 0.79892 & 0.21536 & 0.46479 & Biso & 1.000 & 0 \\
\hline 046 & 1.0000 & 0.91402 & 0.46140 & 0.19919 & Biso & 1.000 & 0 \\
\hline 047 & 1.0000 & 0.55581 & 0.09309 & 0.20973 & Biso & 1.000 & 0 \\
\hline 048 & 1.0000 & 0.54754 & 0.45197 & 0.19959 & Biso & 1.000 & 0 \\
\hline 049 & 1.0000 & 0.44642 & 0.89890 & 0.80720 & Biso & 1.000 & 0 \\
\hline 050 & 1.0000 & 0.08911 & 0.53609 & 0.78252 & Biso & 1.000 & 0 \\
\hline 051 & 1.0000 & 0.45954 & 0.54902 & 0.79518 & Biso & 1.000 & 0 \\
\hline 052 & 1.0000 & 0.59792 & 0.80551 & 0.54314 & Biso & 1.000 & 0 \\
\hline 053 & 1.0000 & 0.22912 & 0.45755 & 0.53604 & Biso & 1.000 & 0 \\
\hline 054 & 1.0000 & 0.20769 & 0.76472 & 0.53268 & Biso & 1.000 & 0 \\
\hline 055 & 1.0000 & 0.00040 & 0.25392 & 0.00950 & Biso & 1.000 & 0 \\
\hline 056 & 1.0000 & 0.74901 & 0.75107 & 0.01239 & Biso & 1.000 & 0 \\
\hline 057 & 1.0000 & 0.24658 & 0.99075 & 0.00167 & Biso & 1.000 & 0 \\
\hline 058 & 1.0000 & 0.67583 & 0.59855 & 0.34262 & Biso & 1.000 & 0 \\
\hline 059 & 1.0000 & 0.37887 & 0.06366 & 0.32923 & Biso & 1.000 & 0 \\
\hline 060 & 1.0000 & 0.92949 & 0.33159 & 0.34117 & Biso & 1.000 & 0 \\
\hline 061 & 1.0000 & 0.33448 & 0.90732 & 0.67802 & Biso & 1.000 & 0 \\
\hline 062 & 1.0000 & 0.06900 & 0.38414 & 0.67795 & Biso & 1.000 & 0 \\
\hline
\end{tabular}




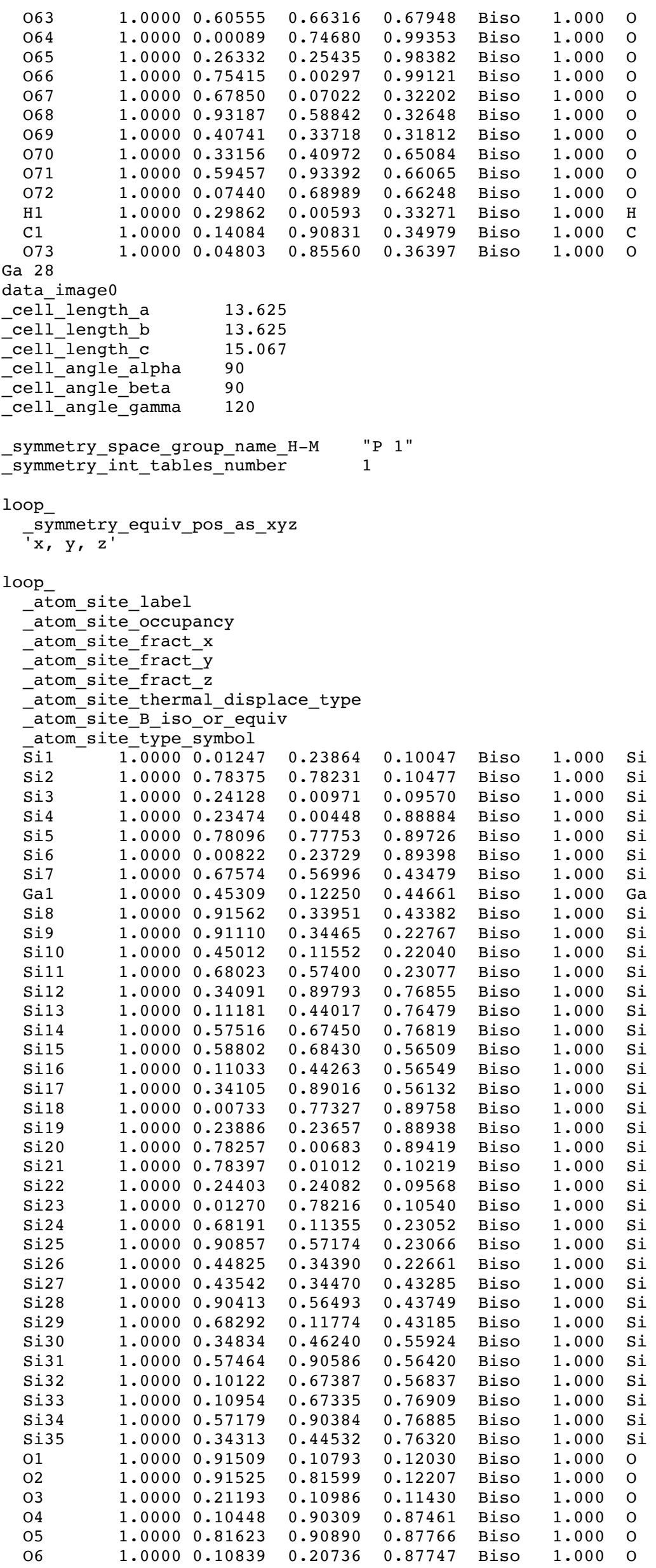




\begin{tabular}{|c|c|c|c|c|c|c|c|}
\hline 07 & 1.0000 & 0.56720 & 0.44414 & 0.44585 & Biso & 1.000 & 0 \\
\hline 08 & 1.0000 & 0.60146 & 0.17208 & 0.43481 & Biso & 1.000 & 0 \\
\hline 09 & 1.0000 & 0.88534 & 0.43883 & 0.45541 & Biso & 1.000 & 0 \\
\hline 010 & 1.0000 & 0.77949 & 0.24517 & 0.21486 & Biso & 1.000 & $\mathrm{O}$ \\
\hline 011 & 1.0000 & 0.48358 & 0.24652 & 0.21017 & Biso & 1.000 & 0 \\
\hline 012 & 1.0000 & 0.77797 & 0.54034 & 0.21396 & Biso & 1.000 & 0 \\
\hline 013 & 1.0000 & 0.24113 & 0.76824 & 0.78904 & Biso & 1.000 & 0 \\
\hline 014 & 1.0000 & 0.24393 & 0.47654 & 0.78268 & Biso & 1.000 & O \\
\hline 015 & 1.0000 & 0.54099 & 0.77248 & 0.77932 & Biso & 1.000 & 0 \\
\hline 016 & 1.0000 & 0.45563 & 0.59009 & 0.54992 & Biso & 1.000 & 0 \\
\hline 017 & 1.0000 & 0.11134 & 0.56124 & 0.56332 & Biso & 1.000 & 0 \\
\hline 018 & 1.0000 & 0.43888 & 0.85443 & 0.55013 & Biso & 1.000 & 0 \\
\hline 019 & 1.0000 & 0.99481 & 0.32494 & 0.16316 & Biso & 1.000 & 0 \\
\hline 020 & 1.0000 & 0.69859 & 0.67646 & 0.16609 & Biso & 1.000 & 0 \\
\hline 021 & 1.0000 & 0.35178 & 0.03172 & 0.15290 & Biso & 1.000 & 0 \\
\hline 022 & 1.0000 & 0.32127 & 0.98688 & 0.82675 & Biso & 1.000 & O \\
\hline 023 & 1.0000 & 0.67229 & 0.69170 & 0.83855 & Biso & 1.000 & 0 \\
\hline 024 & 1.0000 & 0.02814 & 0.34428 & 0.83439 & Biso & 1.000 & 0 \\
\hline 025 & 1.0000 & 0.66899 & 0.66051 & 0.50060 & Biso & 1.000 & 0 \\
\hline 026 & 1.0000 & 0.35709 & 0.98896 & 0.49550 & Biso & 1.000 & 0 \\
\hline 027 & 1.0000 & 0.02141 & 0.35540 & 0.49368 & Biso & 1.000 & 0 \\
\hline 028 & 1.0000 & 0.02636 & 0.68307 & 0.84113 & Biso & 1.000 & O \\
\hline 029 & 1.0000 & 0.32309 & 0.33850 & 0.82407 & Biso & 1.000 & O \\
\hline 030 & 1.0000 & 0.67492 & 0.98490 & 0.83452 & Biso & 1.000 & 0 \\
\hline 031 & 1.0000 & 0.69713 & 0.03169 & 0.16096 & Biso & 1.000 & 0 \\
\hline 032 & 1.0000 & 0.34994 & 0.32638 & 0.15719 & Biso & 1.000 & $\mathrm{O}$ \\
\hline 033 & 1.0000 & 0.99476 & 0.68015 & 0.17081 & Biso & 1.000 & 0 \\
\hline 034 & 1.0000 & 0.35333 & 0.37919 & 0.48566 & Biso & 1.000 & 0 \\
\hline 035 & 1.0000 & 0.00119 & 0.65940 & 0.50179 & Biso & 1.000 & $\mathrm{O}$ \\
\hline 036 & 1.0000 & 0.64688 & 0.01287 & 0.49969 & Biso & 1.000 & 0 \\
\hline 037 & 1.0000 & 0.13551 & 0.25304 & 0.12204 & Biso & 1.000 & 0 \\
\hline 038 & 1.0000 & 0.76988 & 0.88959 & 0.13175 & Biso & 1.000 & O \\
\hline 039 & 1.0000 & 0.13525 & 0.89106 & 0.12985 & Biso & 1.000 & 0 \\
\hline 040 & 1.0000 & 0.24506 & 0.12452 & 0.86334 & Biso & 1.000 & 0 \\
\hline 041 & 1.0000 & 0.88572 & 0.75883 & 0.87103 & Biso & 1.000 & $\mathrm{O}$ \\
\hline 042 & 1.0000 & 0.88891 & 0.12811 & 0.86571 & Biso & 1.000 & 0 \\
\hline 043 & 1.0000 & 0.78748 & 0.56313 & 0.45957 & Biso & 1.000 & 0 \\
\hline 044 & 1.0000 & 0.41407 & 0.22630 & 0.47159 & Biso & 1.000 & 0 \\
\hline 045 & 1.0000 & 0.81041 & 0.21615 & 0.45807 & Biso & 1.000 & $\mathrm{O}$ \\
\hline 046 & 1.0000 & 0.92176 & 0.46481 & 0.20075 & Biso & 1.000 & O \\
\hline 047 & 1.0000 & 0.55965 & 0.10237 & 0.20969 & Biso & 1.000 & 0 \\
\hline 048 & 1.0000 & 0.55850 & 0.46556 & 0.20681 & Biso & 1.000 & 0 \\
\hline 049 & 1.0000 & 0.46156 & 0.91184 & 0.79803 & Biso & 1.000 & 0 \\
\hline 050 & 1.0000 & 0.09656 & 0.54936 & 0.77833 & Biso & 1.000 & 0 \\
\hline 051 & 1.0000 & 0.46440 & 0.55313 & 0.78960 & Biso & 1.000 & 0 \\
\hline 052 & 1.0000 & 0.60627 & 0.80844 & 0.54134 & Biso & 1.000 & 0 \\
\hline 053 & 1.0000 & 0.23584 & 0.46937 & 0.53937 & Biso & 1.000 & 0 \\
\hline 054 & 1.0000 & 0.21957 & 0.78041 & 0.53632 & Biso & 1.000 & 0 \\
\hline 055 & 1.0000 & 0.00582 & 0.27007 & 0.99745 & Biso & 1.000 & 0 \\
\hline 056 & 1.0000 & 0.74935 & 0.74771 & 0.00158 & Biso & 1.000 & 0 \\
\hline 057 & 1.0000 & 0.27015 & 0.00484 & 0.99226 & Biso & 1.000 & 0 \\
\hline 058 & 1.0000 & 0.68402 & 0.61425 & 0.33293 & Biso & 1.000 & 0 \\
\hline 059 & 1.0000 & 0.39474 & 0.07071 & 0.32222 & Biso & 1.000 & 0 \\
\hline 060 & 1.0000 & 0.95079 & 0.34677 & 0.32963 & Biso & 1.000 & 0 \\
\hline 061 & 1.0000 & 0.34088 & 0.92761 & 0.66442 & Biso & 1.000 & 0 \\
\hline 062 & 1.0000 & 0.07536 & 0.38831 & 0.66484 & Biso & 1.000 & 0 \\
\hline 063 & 1.0000 & 0.62260 & 0.67886 & 0.66804 & Biso & 1.000 & 0 \\
\hline 064 & 1.0000 & 0.01091 & 0.74577 & 0.00249 & Biso & 1.000 & 0 \\
\hline 065 & 1.0000 & 0.27895 & 0.27314 & 0.99201 & Biso & 1.000 & 0 \\
\hline 066 & 1.0000 & 0.75124 & 0.00830 & 0.99825 & Biso & 1.000 & 0 \\
\hline 067 & 1.0000 & 0.68504 & 0.07226 & 0.33103 & Biso & 1.000 & 0 \\
\hline 068 & 1.0000 & 0.94267 & 0.60266 & 0.33466 & Biso & 1.000 & 0 \\
\hline 069 & 1.0000 & 0.40269 & 0.33542 & 0.32710 & Biso & 1.000 & 0 \\
\hline 070 & 1.0000 & 0.34342 & 0.41307 & 0.65904 & Biso & 1.000 & $\mathrm{O}$ \\
\hline 071 & 1.0000 & 0.60856 & 0.94716 & 0.66711 & Biso & 1.000 & 0 \\
\hline 072 & 1.0000 & 0.07216 & 0.69177 & 0.67023 & Biso & 1.000 & 0 \\
\hline $\mathrm{H} 1$ & 1.0000 & 0.31259 & 0.01239 & 0.32577 & Biso & 1.000 & $\mathrm{H}$ \\
\hline $\mathrm{C} 1$ & 1.0000 & 0.15457 & 0.92146 & 0.34759 & Biso & 1.000 & C \\
\hline 073 & 1.0000 & 0.06124 & 0.87384 & 0.36667 & Biso & 1.000 & 0 \\
\hline \\
\hline \multicolumn{8}{|c|}{$\begin{array}{l}\text { Ti } 28 \\
\text { data image0 }\end{array}$} \\
\hline \multicolumn{2}{|c|}{ celì length a } & \multicolumn{2}{|c|}{13.875} & & & & \\
\hline \multicolumn{2}{|c|}{ cell length b } & \multicolumn{2}{|c|}{13.875} & & & & \\
\hline cell & $=h-c$ & 15.01 & & & & & \\
\hline cell & alpha & 90 & & & & & \\
\hline $\operatorname{cell}$ & beta & 90 & & & & & \\
\hline cell & gamma & 120 & & & & & \\
\hline & & & & 1 " & & & \\
\hline & $n \tau_{\text {n_t }}$ & & & & & & \\
\hline
\end{tabular}




\begin{tabular}{|c|c|c|c|c|c|c|c|}
\hline \multicolumn{8}{|c|}{ 'symmetry_equiv_pos_as_xyz } \\
\hline \multicolumn{8}{|c|}{ loop_ } \\
\hline \multicolumn{8}{|c|}{ atom site label } \\
\hline \multicolumn{8}{|c|}{ atom site occupancy } \\
\hline \multicolumn{8}{|c|}{ atom_site-fract_x } \\
\hline \multicolumn{8}{|c|}{ atom_site_fract_y } \\
\hline \multicolumn{8}{|c|}{-atom_site_fract_z } \\
\hline -ato & te-therr & nāl_disp. & ace_type & & & & \\
\hline -ato & $\begin{array}{l}\text { te_B_is } \\
\text { te_type }\end{array}$ & $\begin{array}{l}\text { or } \overline{\text { _equ }} \\
\text { symbol }\end{array}$ & & & & & \\
\hline$\overline{\mathrm{P}} 1$ & 1.0000 & 0.00910 & 0.22958 & 0.10741 & Biso & 1.000 & $\mathrm{P}$ \\
\hline $\mathrm{P} 2$ & 1.0000 & 0.77964 & 0.78016 & 0.11264 & Biso & 1.000 & $\mathrm{P}$ \\
\hline P3 & 1.0000 & 0.22897 & 0.99881 & 0.09861 & Biso & 1.000 & $P$ \\
\hline Al1 & 1.0000 & 0.21828 & 0.99041 & 0.88369 & Biso & 1.000 & Al \\
\hline Al2 & 1.0000 & 0.77239 & 0.77287 & 0.89933 & Biso & 1.000 & Al \\
\hline A13 & 1.0000 & 0.00158 & 0.22646 & 0.89555 & Biso & 1.000 & Al \\
\hline $\mathrm{P} 4$ & 1.0000 & 0.67051 & 0.56331 & 0.44019 & Biso & 1.000 & $\mathrm{P}$ \\
\hline Ti1 & 1.0000 & 0.42826 & 0.10789 & 0.44469 & Biso & 1.000 & $\mathrm{Ti}$ \\
\hline P5 & 1.0000 & 0.90276 & 0.32954 & 0.43956 & Biso & 1.000 & $\mathrm{P}$ \\
\hline Al4 & 1.0000 & 0.90044 & 0.33383 & 0.22842 & Biso & 1.000 & Al \\
\hline Al5 & 1.0000 & 0.43941 & 0.10601 & 0.21904 & Biso & 1.000 & Al \\
\hline Al6 & 1.0000 & 0.67654 & 0.56436 & 0.23070 & Biso & 1.000 & Al \\
\hline P 6 & 1.0000 & 0.33281 & 0.88002 & 0.78279 & Biso & 1.000 & $\mathrm{P}$ \\
\hline P7 & 1.0000 & 0.10284 & 0.43324 & 0.77131 & Biso & 1.000 & $\mathrm{P}$ \\
\hline P8 & 1.0000 & 0.56284 & 0.66076 & 0.77462 & Biso & 1.000 & $P$ \\
\hline Al7 & 1.0000 & 0.57971 & 0.67515 & 0.56914 & Biso & 1.000 & Al \\
\hline Al8 & 1.0000 & 0.09976 & 0.43594 & 0.56918 & Biso & 1.000 & Al \\
\hline Al9 & 1.0000 & 0.33395 & 0.87389 & 0.56743 & Biso & 1.000 & Al \\
\hline P9 & 1.0000 & 0.99347 & 0.76382 & 0.89243 & Biso & 1.000 & $\mathrm{P}$ \\
\hline $\mathrm{P} 10$ & 1.0000 & 0.22713 & 0.22111 & 0.88329 & Biso & 1.000 & $\mathrm{P}$ \\
\hline P11 & 1.0000 & 0.77799 & 0.00059 & 0.89224 & Biso & 1.000 & $\mathrm{P}$ \\
\hline Al10 & 1.0000 & 0.78179 & 0.00560 & 0.10606 & Biso & 1.000 & Al \\
\hline Al11 & 1.0000 & 0.23646 & 0.22867 & 0.09561 & Biso & 1.000 & Al \\
\hline Al12 & 1.0000 & 0.00471 & 0.77659 & 0.10699 & Biso & 1.000 & Al \\
\hline $\mathrm{P} 12$ & 1.0000 & 0.67232 & 0.10761 & 0.22716 & Biso & 1.000 & $\mathrm{P}$ \\
\hline P13 & 1.0000 & 0.90478 & 0.56297 & 0.22883 & Biso & 1.000 & $\mathrm{P}$ \\
\hline $\mathrm{P} 14$ & 1.0000 & 0.44670 & 0.34059 & 0.22141 & Biso & 1.000 & $\mathrm{P}$ \\
\hline Al13 & 1.0000 & 0.43011 & 0.34885 & 0.43139 & Biso & 1.000 & Al \\
\hline Al14 & 1.0000 & 0.89764 & 0.55695 & 0.43938 & Biso & 1.000 & $\mathrm{Al}$ \\
\hline Al15 & 1.0000 & 0.67170 & 0.10869 & 0.43433 & Biso & 1.000 & Al \\
\hline P15 & 1.0000 & 0.33742 & 0.46197 & 0.55617 & Biso & 1.000 & $\mathrm{P}$ \\
\hline P16 & 1.0000 & 0.56750 & 0.89662 & 0.56457 & Biso & 1.000 & $\mathrm{P}$ \\
\hline P17 & 1.0000 & 0.09548 & 0.66814 & 0.56872 & Biso & 1.000 & $P$ \\
\hline Al16 & 1.0000 & 0.10207 & 0.66573 & 0.77374 & Biso & 1.000 & $\mathrm{Al}$ \\
\hline Al17 & 1.0000 & 0.56060 & 0.89040 & 0.77372 & Biso & 1.000 & Al \\
\hline Al18 & 1.0000 & 0.33041 & 0.43715 & 0.76388 & Biso & 1.000 & Al \\
\hline 01 & 1.0000 & 0.91949 & 0.10882 & 0.12975 & Biso & 1.000 & 0 \\
\hline $\mathrm{O} 2$ & 1.0000 & 0.90122 & 0.81033 & 0.13037 & Biso & 1.000 & 0 \\
\hline 03 & 1.0000 & 0.20332 & 0.09182 & 0.12215 & Biso & 1.000 & 0 \\
\hline 04 & 1.0000 & 0.08372 & 0.88054 & 0.86105 & Biso & 1.000 & 0 \\
\hline 05 & 1.0000 & 0.80898 & 0.91025 & 0.87249 & Biso & 1.000 & 0 \\
\hline 06 & 1.0000 & 0.10590 & 0.19436 & 0.87220 & Biso & 1.000 & 0 \\
\hline 07 & 1.0000 & 0.56863 & 0.44817 & 0.45695 & Biso & 1.000 & 0 \\
\hline 08 & 1.0000 & 0.57349 & 0.15147 & 0.43746 & Biso & 1.000 & 0 \\
\hline 09 & 1.0000 & 0.87766 & 0.42384 & 0.45992 & Biso & 1.000 & 0 \\
\hline 010 & 1.0000 & 0.76182 & 0.22989 & 0.20951 & Biso & 1.000 & 0 \\
\hline 011 & 1.0000 & 0.47316 & 0.24496 & 0.21574 & Biso & 1.000 & 0 \\
\hline 012 & 1.0000 & 0.78343 & 0.53385 & 0.21366 & Biso & 1.000 & 0 \\
\hline 013 & 1.0000 & 0.23729 & 0.76337 & 0.80895 & Biso & 1.000 & 0 \\
\hline 014 & 1.0000 & 0.22607 & 0.46982 & 0.78926 & Biso & 1.000 & 0 \\
\hline 015 & 1.0000 & 0.53147 & 0.75245 & 0.78117 & Biso & 1.000 & 0 \\
\hline 016 & 1.0000 & 0.43954 & 0.57930 & 0.54920 & Biso & 1.000 & 0 \\
\hline 017 & 1.0000 & 0.09594 & 0.55844 & 0.56821 & Biso & 1.000 & 0 \\
\hline 018 & 1.0000 & 0.44279 & 0.84713 & 0.54241 & Biso & 1.000 & 0 \\
\hline 019 & 1.0000 & 0.99297 & 0.31190 & 0.16462 & Biso & 1.000 & 0 \\
\hline 020 & 1.0000 & 0.69906 & 0.67863 & 0.16745 & Biso & 1.000 & 0 \\
\hline 021 & 1.0000 & 0.34004 & 0.02311 & 0.14036 & Biso & 1.000 & 0 \\
\hline 022 & 1.0000 & 0.31700 & 0.97062 & 0.82791 & Biso & 1.000 & 0 \\
\hline 023 & 1.0000 & 0.65128 & 0.67889 & 0.84405 & Biso & 1.000 & 0 \\
\hline 024 & 1.0000 & 0.02651 & 0.34625 & 0.83935 & Biso & 1.000 & 0 \\
\hline 025 & 1.0000 & 0.66674 & 0.65114 & 0.50004 & Biso & 1.000 & 0 \\
\hline 026 & 1.0000 & 0.34828 & 0.99086 & 0.51487 & Biso & 1.000 & 0 \\
\hline 027 & 1.0000 & 0.00254 & 0.34354 & 0.49406 & Biso & 1.000 & 0 \\
\hline 028 & 1.0000 & 0.00623 & 0.67309 & 0.84470 & Biso & 1.000 & 0 \\
\hline 029 & 1.0000 & 0.30573 & 0.31932 & 0.82426 & Biso & 1.000 & 0 \\
\hline 030 & 1.0000 & 0.67396 & 0.97794 & 0.84012 & Biso & 1.000 & 0 \\
\hline
\end{tabular}




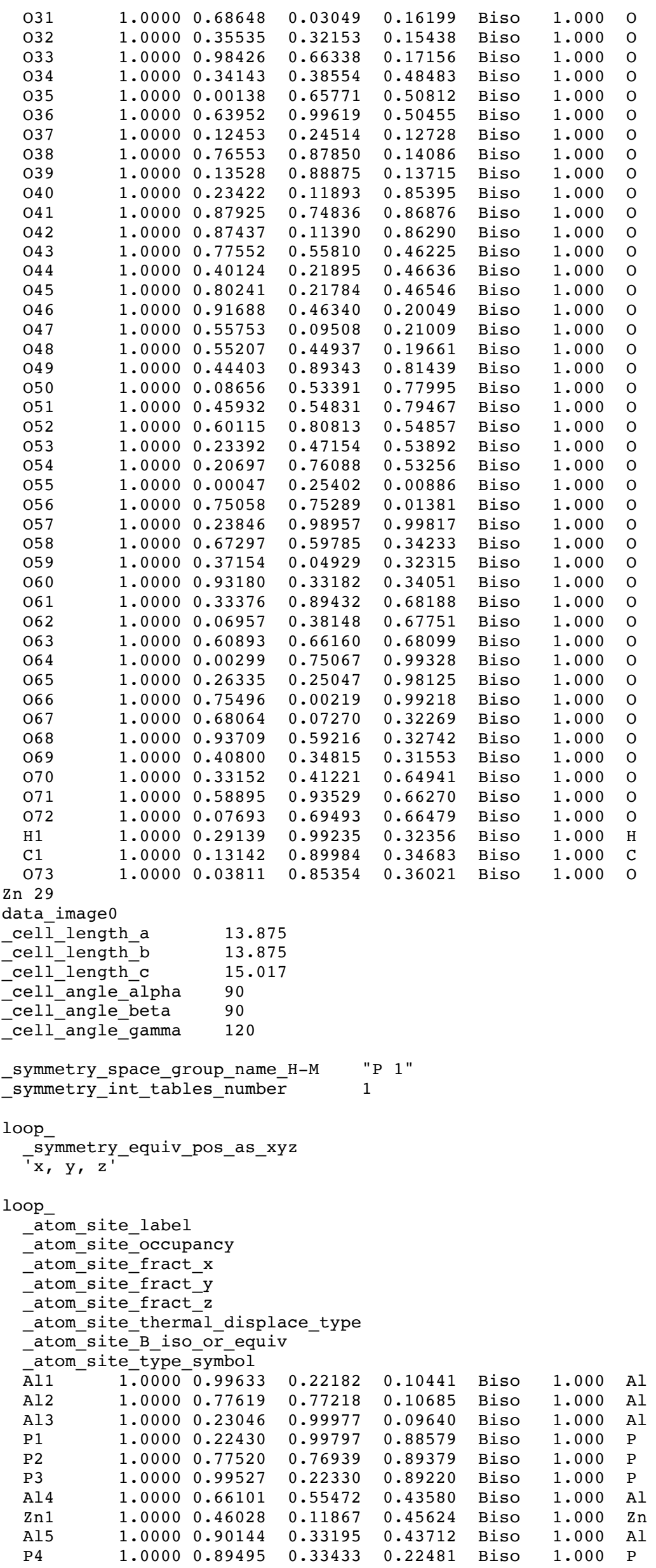




\begin{tabular}{|c|c|c|c|c|c|c|c|}
\hline P5 & 1.0000 & 0.43698 & 0.10004 & 0.22098 & Biso & 1.000 & $\mathrm{P}$ \\
\hline P6 & 1.0000 & 0.66448 & 0.55781 & 0.22682 & Biso & 1.000 & $\mathrm{P}$ \\
\hline Al6 & 1.0000 & 0.32878 & 0.88688 & 0.76899 & Biso & 1.000 & Al \\
\hline Al7 & 1.0000 & 0.10555 & 0.43162 & 0.76761 & Biso & 1.000 & Al \\
\hline A18 & 1.0000 & 0.56385 & 0.66844 & 0.77077 & Biso & 1.000 & Al \\
\hline P7 & 1.0000 & 0.57378 & 0.67645 & 0.56232 & Biso & 1.000 & $\mathrm{P}$ \\
\hline P8 & 1.0000 & 0.10673 & 0.43560 & 0.56230 & Biso & 1.000 & $\mathrm{P}$ \\
\hline P9 & 1.0000 & 0.33002 & 0.87876 & 0.55858 & Biso & 1.000 & $\mathrm{P}$ \\
\hline Al9 & 1.0000 & 0.00001 & 0.76782 & 0.89780 & Biso & 1.000 & Al \\
\hline Al10 & 1.0000 & 0.22444 & 0.22583 & 0.89206 & Biso & 1.000 & Al \\
\hline Al11 & 1.0000 & 0.77205 & 0.99407 & 0.89548 & Biso & 1.000 & Al \\
\hline P10 & 1.0000 & 0.76926 & 0.99401 & 0.10852 & Biso & 1.000 & $P$ \\
\hline P11 & 1.0000 & 0.22663 & 0.22567 & 0.10423 & Biso & 1.000 & $P$ \\
\hline P12 & 1.0000 & 0.00400 & 0.77487 & 0.11080 & Biso & 1.000 & $\mathrm{P}$ \\
\hline Al12 & 1.0000 & 0.67244 & 0.10342 & 0.23493 & Biso & 1.000 & Al \\
\hline Al13 & 1.0000 & 0.89398 & 0.55963 & 0.23137 & Biso & 1.000 & Al \\
\hline Al1 14 & 1.0000 & 0.43723 & 0.32856 & 0.22820 & Biso & 1.000 & Al \\
\hline P13 & 1.0000 & 0.42953 & 0.32881 & 0.43936 & Biso & 1.000 & $\mathrm{P}$ \\
\hline P14 & 1.0000 & 0.89041 & 0.55442 & 0.44236 & Biso & 1.000 & $P$ \\
\hline P15 & 1.0000 & 0.68066 & 0.11158 & 0.43694 & Biso & 1.000 & $\mathrm{P}$ \\
\hline Al15 & 1.0000 & 0.34215 & 0.45211 & 0.56259 & Biso & 1.000 & Al \\
\hline Al16 & 1.0000 & 0.55897 & 0.89359 & 0.56506 & Biso & 1.000 & Al \\
\hline Al17 & 1.0000 & 0.09594 & 0.66294 & 0.56863 & Biso & 1.000 & Al \\
\hline P16 & 1.0000 & 0.10200 & 0.66124 & 0.77571 & Biso & 1.000 & $\mathrm{P}$ \\
\hline P 17 & 1.0000 & 0.55808 & 0.89354 & 0.77492 & Biso & 1.000 & P \\
\hline P18 & 1.0000 & 0.33708 & 0.43875 & 0.77116 & Biso & 1.000 & $\mathrm{P}$ \\
\hline 01 & 1.0000 & 0.88990 & 0.08596 & 0.12809 & Biso & 1.000 & 0 \\
\hline $\mathrm{O} 2$ & 1.0000 & 0.91447 & 0.80712 & 0.12988 & Biso & 1.000 & 0 \\
\hline 03 & 1.0000 & 0.20138 & 0.10555 & 0.12241 & Biso & 1.000 & 0 \\
\hline 04 & 1.0000 & 0.10342 & 0.90413 & 0.87105 & Biso & 1.000 & 0 \\
\hline 05 & 1.0000 & 0.80675 & 0.89073 & 0.87351 & Biso & 1.000 & 0 \\
\hline 06 & 1.0000 & 0.08753 & 0.19507 & 0.87318 & Biso & 1.000 & 0 \\
\hline 07 & 1.0000 & 0.55341 & 0.41835 & 0.45148 & Biso & 1.000 & 0 \\
\hline 08 & 1.0000 & 0.61075 & 0.16896 & 0.43183 & Biso & 1.000 & 0 \\
\hline 09 & 1.0000 & 0.86808 & 0.43583 & 0.46154 & Biso & 1.000 & 0 \\
\hline 010 & 1.0000 & 0.77306 & 0.24150 & 0.21002 & Biso & 1.000 & 0 \\
\hline 011 & 1.0000 & 0.46852 & 0.22138 & 0.20673 & Biso & 1.000 & 0 \\
\hline 012 & 1.0000 & 0.75674 & 0.52837 & 0.21273 & Biso & 1.000 & 0 \\
\hline 013 & 1.0000 & 0.22375 & 0.75074 & 0.79465 & Biso & 1.000 & 0 \\
\hline 014 & 1.0000 & 0.24399 & 0.46665 & 0.78788 & Biso & 1.000 & 0 \\
\hline 015 & 1.0000 & 0.52814 & 0.77147 & 0.78840 & Biso & 1.000 & 0 \\
\hline 016 & 1.0000 & 0.44971 & 0.59000 & 0.54951 & Biso & 1.000 & 0 \\
\hline 017 & 1.0000 & 0.11849 & 0.55122 & 0.55798 & Biso & 1.000 & 0 \\
\hline 018 & 1.0000 & 0.41525 & 0.83773 & 0.55074 & Biso & 1.000 & 0 \\
\hline 019 & 1.0000 & 0.97471 & 0.31524 & 0.16654 & Biso & 1.000 & 0 \\
\hline 020 & 1.0000 & 0.68289 & 0.65404 & 0.16587 & Biso & 1.000 & 0 \\
\hline 021 & 1.0000 & 0.35194 & 0.02307 & 0.15236 & Biso & 1.000 & 0 \\
\hline $\mathrm{O} 22$ & 1.0000 & 0.30539 & 0.98214 & 0.82732 & Biso & 1.000 & 0 \\
\hline 023 & 1.0000 & 0.67220 & 0.68783 & 0.84075 & Biso & 1.000 & 0 \\
\hline $\mathrm{O} 24$ & 1.0000 & 0.01417 & 0.32441 & 0.83754 & Biso & 1.000 & 0 \\
\hline 025 & 1.0000 & 0.64684 & 0.64970 & 0.50251 & Biso & 1.000 & 0 \\
\hline 026 & 1.0000 & 0.35692 & 0.97483 & 0.49649 & Biso & 1.000 & 0 \\
\hline 027 & 1.0000 & 0.01950 & 0.35644 & 0.49585 & Biso & 1.000 & 0 \\
\hline 028 & 1.0000 & 0.02344 & 0.67144 & 0.84210 & Biso & 1.000 & 0 \\
\hline 029 & 1.0000 & 0.31861 & 0.33995 & 0.82934 & Biso & 1.000 & 0 \\
\hline 030 & 1.0000 & 0.65536 & 0.97079 & 0.83540 & Biso & 1.000 & 0 \\
\hline 031 & 1.0000 & 0.68580 & 0.01387 & 0.16092 & Biso & 1.000 & 0 \\
\hline 032 & 1.0000 & 0.32610 & 0.30780 & 0.16066 & Biso & 1.000 & 0 \\
\hline 033 & 1.0000 & 0.98585 & 0.67676 & 0.16940 & Biso & 1.000 & 0 \\
\hline 034 & 1.0000 & 0.35538 & 0.36473 & 0.48793 & Biso & 1.000 & 0 \\
\hline 035 & 1.0000 & 0.98329 & 0.63992 & 0.50237 & Biso & 1.000 & 0 \\
\hline 036 & 1.0000 & 0.63391 & 0.01355 & 0.50215 & Biso & 1.000 & 0 \\
\hline 037 & 1.0000 & 0.12467 & 0.23422 & 0.13130 & Biso & 1.000 & 0 \\
\hline 038 & 1.0000 & 0.75621 & 0.88211 & 0.13771 & Biso & 1.000 & 0 \\
\hline 039 & 1.0000 & 0.11908 & 0.87435 & 0.13398 & Biso & 1.000 & 0 \\
\hline 040 & 1.0000 & 0.23396 & 0.10968 & 0.86193 & Biso & 1.000 & 0 \\
\hline 041 & 1.0000 & 0.87208 & 0.75223 & 0.86651 & Biso & 1.000 & 0 \\
\hline 042 & 1.0000 & 0.88312 & 0.12346 & 0.86536 & Biso & 1.000 & 0 \\
\hline 043 & 1.0000 & 0.78495 & 0.55920 & 0.46252 & Biso & 1.000 & 0 \\
\hline 044 & 1.0000 & 0.40646 & 0.21758 & 0.47665 & Biso & 1.000 & 0 \\
\hline 045 & 1.0000 & 0.79877 & 0.19820 & 0.46792 & Biso & 1.000 & 0 \\
\hline 046 & 1.0000 & 0.90609 & 0.44597 & 0.19739 & Biso & 1.000 & 0 \\
\hline 047 & 1.0000 & 0.53873 & 0.08693 & 0.22183 & Biso & 1.000 & 0 \\
\hline 048 & 1.0000 & 0.55266 & 0.45589 & 0.20187 & Biso & 1.000 & 0 \\
\hline 049 & 1.0000 & 0.45721 & 0.90439 & 0.80148 & Biso & 1.000 & 0 \\
\hline 050 & 1.0000 & 0.09012 & 0.54640 & 0.78796 & Biso & 1.000 & 0 \\
\hline 051 & 1.0000 & 0.44899 & 0.53969 & 0.79689 & Biso & 1.000 & 0 \\
\hline 052 & 1.0000 & 0.59338 & 0.79201 & 0.53661 & Biso & 1.000 & 0 \\
\hline 053 & 1.0000 & 0.21828 & 0.44693 & 0.53666 & Biso & 1.000 & 0 \\
\hline 054 & 1.0000 & 0.21453 & 0.78194 & 0.53286 & Biso & 1.000 & 0 \\
\hline
\end{tabular}




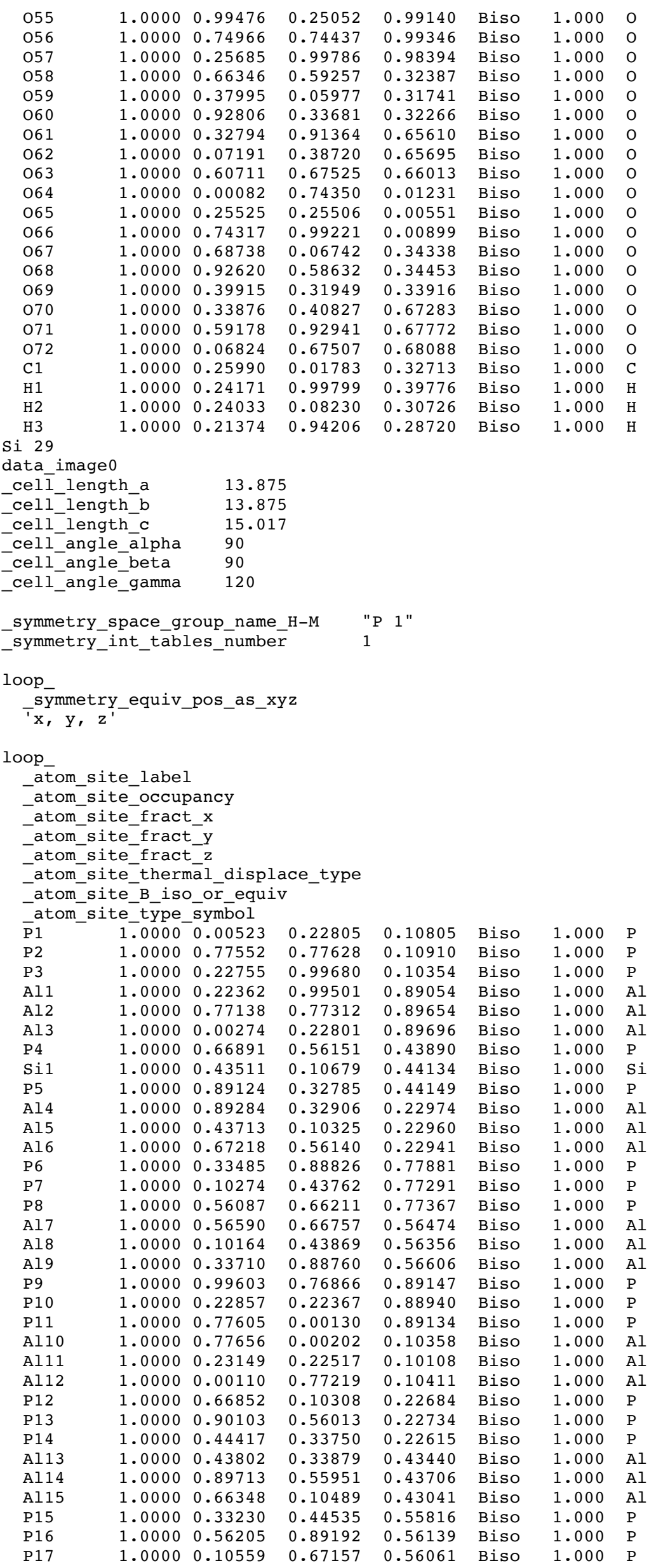




\begin{tabular}{|c|c|c|c|c|c|c|c|}
\hline Al16 & 1.0000 & 0.10660 & 0.66828 & 0.77190 & Biso & 1.000 & Al \\
\hline Al17 & 1.0000 & 0.56361 & 0.89302 & 0.77017 & Biso & 1.000 & Al \\
\hline Al18 & 1.0000 & 0.32980 & 0.43758 & 0.76825 & Biso & 1.000 & Al \\
\hline 01 & 1.0000 & 0.91437 & 0.10621 & 0.12492 & Biso & 1.000 & 0 \\
\hline $\mathrm{O} 2$ & 1.0000 & 0.89723 & 0.80602 & 0.12546 & Biso & 1.000 & 0 \\
\hline 03 & 1.0000 & 0.19738 & 0.08730 & 0.12461 & Biso & 1.000 & $\mathrm{O}$ \\
\hline 04 & 1.0000 & 0.08717 & 0.88874 & 0.86913 & Biso & 1.000 & 0 \\
\hline 05 & 1.0000 & 0.80534 & 0.90993 & 0.87124 & Biso & 1.000 & 0 \\
\hline 06 & 1.0000 & 0.10713 & 0.19517 & 0.87588 & Biso & 1.000 & 0 \\
\hline 07 & 1.0000 & 0.57700 & 0.44084 & 0.45633 & Biso & 1.000 & 0 \\
\hline 08 & 1.0000 & 0.56183 & 0.14183 & 0.42126 & Biso & 1.000 & $\mathrm{O}$ \\
\hline 09 & 1.0000 & 0.86629 & 0.42293 & 0.45829 & Biso & 1.000 & 0 \\
\hline 010 & 1.0000 & 0.75440 & 0.22616 & 0.20721 & Biso & 1.000 & 0 \\
\hline 011 & 1.0000 & 0.47070 & 0.24161 & 0.22216 & Biso & 1.000 & $\mathrm{O}$ \\
\hline 012 & 1.0000 & 0.77953 & 0.53136 & 0.21374 & Biso & 1.000 & 0 \\
\hline 013 & 1.0000 & 0.24239 & 0.76907 & 0.80230 & Biso & 1.000 & 0 \\
\hline 014 & 1.0000 & 0.22476 & 0.46969 & 0.79014 & Biso & 1.000 & 0 \\
\hline 015 & 1.0000 & 0.53290 & 0.75556 & 0.78630 & Biso & 1.000 & 0 \\
\hline 016 & 1.0000 & 0.42613 & 0.56710 & 0.54650 & Biso & 1.000 & 0 \\
\hline 017 & 1.0000 & 0.12725 & 0.57419 & 0.54701 & Biso & 1.000 & $\mathrm{O}$ \\
\hline 018 & 1.0000 & 0.43581 & 0.84467 & 0.54971 & Biso & 1.000 & 0 \\
\hline 019 & 1.0000 & 0.98622 & 0.30678 & 0.16743 & Biso & 1.000 & 0 \\
\hline 020 & 1.0000 & 0.69556 & 0.67527 & 0.16489 & Biso & 1.000 & 0 \\
\hline 021 & 1.0000 & 0.33296 & 0.01945 & 0.15455 & Biso & 1.000 & 0 \\
\hline $\mathrm{O} 22$ & 1.0000 & 0.31991 & 0.97389 & 0.83270 & Biso & 1.000 & 0 \\
\hline 023 & 1.0000 & 0.65486 & 0.67851 & 0.83662 & Biso & 1.000 & $\mathrm{O}$ \\
\hline 024 & 1.0000 & 0.02413 & 0.34197 & 0.83396 & Biso & 1.000 & 0 \\
\hline 025 & 1.0000 & 0.65405 & 0.64278 & 0.49843 & Biso & 1.000 & 0 \\
\hline 026 & 1.0000 & 0.37066 & 0.00724 & 0.50983 & Biso & 1.000 & 0 \\
\hline 027 & 1.0000 & 0.99039 & 0.34463 & 0.49828 & Biso & 1.000 & 0 \\
\hline 028 & 1.0000 & 0.01120 & 0.68448 & 0.83625 & Biso & 1.000 & 0 \\
\hline 029 & 1.0000 & 0.30783 & 0.32319 & 0.83192 & Biso & 1.000 & 0 \\
\hline 030 & 1.0000 & 0.67618 & 0.98390 & 0.83574 & Biso & 1.000 & 0 \\
\hline 031 & 1.0000 & 0.68132 & 0.02672 & 0.16003 & Biso & 1.000 & 0 \\
\hline 032 & 1.0000 & 0.34916 & 0.31498 & 0.16213 & Biso & 1.000 & 0 \\
\hline 033 & 1.0000 & 0.97946 & 0.65805 & 0.16766 & Biso & 1.000 & 0 \\
\hline 034 & 1.0000 & 0.34948 & 0.36772 & 0.49660 & Biso & 1.000 & 0 \\
\hline 035 & 1.0000 & 0.00556 & 0.65410 & 0.50470 & Biso & 1.000 & 0 \\
\hline 036 & 1.0000 & 0.62886 & 0.99101 & 0.49953 & Biso & 1.000 & 0 \\
\hline 037 & 1.0000 & 0.11905 & 0.24140 & 0.13140 & Biso & 1.000 & 0 \\
\hline 038 & 1.0000 & 0.76260 & 0.87539 & 0.13741 & Biso & 1.000 & 0 \\
\hline 039 & 1.0000 & 0.13113 & 0.88412 & 0.13468 & Biso & 1.000 & 0 \\
\hline 040 & 1.0000 & 0.23881 & 0.12313 & 0.86078 & Biso & 1.000 & 0 \\
\hline 041 & 1.0000 & 0.88269 & 0.75509 & 0.86779 & Biso & 1.000 & 0 \\
\hline 042 & 1.0000 & 0.87559 & 0.11449 & 0.86662 & Biso & 1.000 & 0 \\
\hline 043 & 1.0000 & 0.78175 & 0.57255 & 0.46076 & Biso & 1.000 & 0 \\
\hline 044 & 1.0000 & 0.41435 & 0.20826 & 0.45826 & Biso & 1.000 & 0 \\
\hline 045 & 1.0000 & 0.78946 & 0.21712 & 0.46809 & Biso & 1.000 & 0 \\
\hline 046 & 1.0000 & 0.91136 & 0.45903 & 0.20085 & Biso & 1.000 & 0 \\
\hline 047 & 1.0000 & 0.55088 & 0.08611 & 0.21513 & Biso & 1.000 & 0 \\
\hline 048 & 1.0000 & 0.54790 & 0.44493 & 0.19628 & Biso & 1.000 & 0 \\
\hline 049 & 1.0000 & 0.44786 & 0.90143 & 0.80361 & Biso & 1.000 & 0 \\
\hline 050 & 1.0000 & 0.08865 & 0.53761 & 0.79415 & Biso & 1.000 & 0 \\
\hline 051 & 1.0000 & 0.45792 & 0.55081 & 0.79735 & Biso & 1.000 & 0 \\
\hline 052 & 1.0000 & 0.58863 & 0.79988 & 0.53836 & Biso & 1.000 & 0 \\
\hline 053 & 1.0000 & 0.22161 & 0.43734 & 0.53295 & Biso & 1.000 & 0 \\
\hline 054 & 1.0000 & 0.20776 & 0.77960 & 0.52927 & Biso & 1.000 & 0 \\
\hline 055 & 1.0000 & 0.00309 & 0.25924 & 0.01001 & Biso & 1.000 & 0 \\
\hline 056 & 1.0000 & 0.74474 & 0.74845 & 0.01045 & Biso & 1.000 & 0 \\
\hline 057 & 1.0000 & 0.25031 & 0.99458 & 0.00422 & Biso & 1.000 & 0 \\
\hline 058 & 1.0000 & 0.66599 & 0.59339 & 0.34100 & Biso & 1.000 & 0 \\
\hline 059 & 1.0000 & 0.36927 & 0.04925 & 0.33779 & Biso & 1.000 & 0 \\
\hline 060 & 1.0000 & 0.92092 & 0.32649 & 0.34283 & Biso & 1.000 & 0 \\
\hline 061 & 1.0000 & 0.32964 & 0.91056 & 0.67962 & Biso & 1.000 & 0 \\
\hline 062 & 1.0000 & 0.07063 & 0.40071 & 0.67560 & Biso & 1.000 & 0 \\
\hline 063 & 1.0000 & 0.59775 & 0.66162 & 0.67706 & Biso & 1.000 & 0 \\
\hline 064 & 1.0000 & 0.00116 & 0.74416 & 0.99083 & Biso & 1.000 & 0 \\
\hline 065 & 1.0000 & 0.26191 & 0.25237 & 0.98782 & Biso & 1.000 & 0 \\
\hline 066 & 1.0000 & 0.74687 & 0.99858 & 0.99037 & Biso & 1.000 & 0 \\
\hline 067 & 1.0000 & 0.68472 & 0.07089 & 0.32129 & Biso & 1.000 & 0 \\
\hline 068 & 1.0000 & 0.93626 & 0.59271 & 0.32501 & Biso & 1.000 & 0 \\
\hline 069 & 1.0000 & 0.41003 & 0.34891 & 0.32096 & Biso & 1.000 & 0 \\
\hline 070 & 1.0000 & 0.32895 & 0.40742 & 0.65515 & Biso & 1.000 & 0 \\
\hline 071 & 1.0000 & 0.59622 & 0.93116 & 0.65834 & Biso & 1.000 & 0 \\
\hline 072 & 1.0000 & 0.08149 & 0.68060 & 0.65940 & Biso & 1.000 & 0 \\
\hline $\mathrm{C} 1$ & 1.0000 & 0.24654 & 0.98382 & 0.34024 & Biso & 1.000 & C \\
\hline $\mathrm{H} 1$ & 1.0000 & 0.22129 & 0.95421 & 0.40849 & Biso & 1.000 & $\mathrm{H}$ \\
\hline $\mathrm{H} 2$ & 1.0000 & 0.21246 & 0.03683 & 0.31982 & Biso & 1.000 & $\mathrm{H}$ \\
\hline H3 & 1.0000 & 0.21913 & 0.91306 & 0.29495 & Biso & 1.000 & $\mathrm{H}$ \\
\hline
\end{tabular}




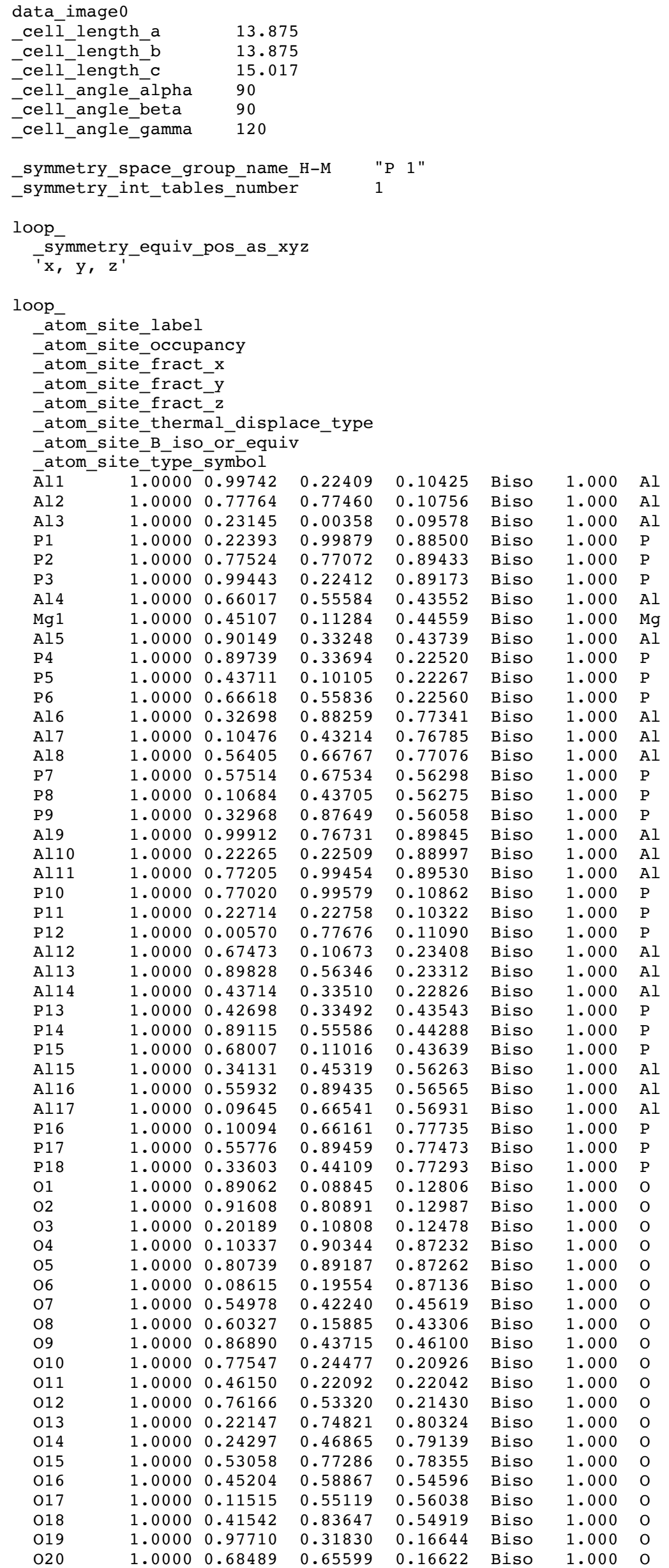




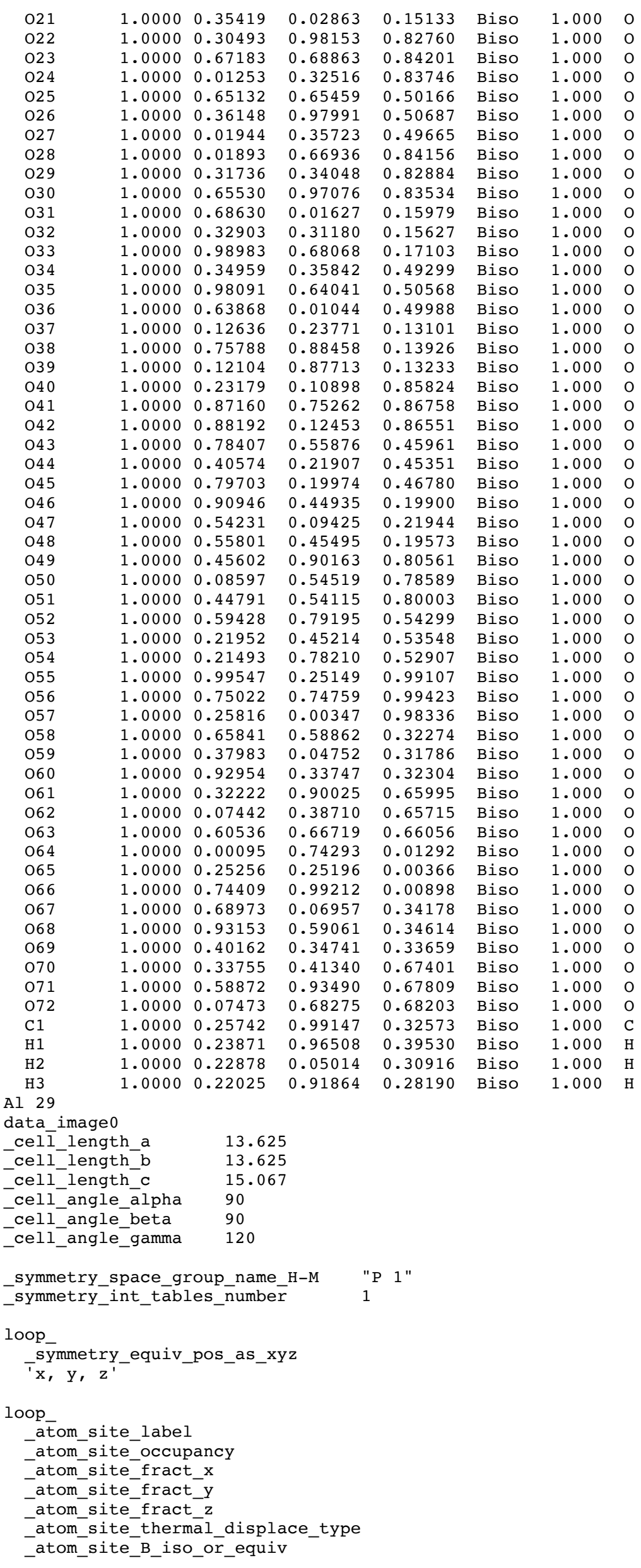




\begin{tabular}{|c|c|c|c|c|c|c|c|}
\hline$\overline{\mathrm{S}} \mathrm{i} 1$ & 1.0000 & 0.01064 & 0.23807 & 0.10165 & Biso & 1.000 & $\mathrm{Si}$ \\
\hline Si2 & 1.0000 & 0.78231 & 0.78125 & 0.10360 & Biso & 1.000 & $\mathrm{Si}$ \\
\hline Si3 & 1.0000 & 0.24012 & 0.00956 & 0.09677 & Biso & 1.000 & Si \\
\hline Si4 & 1.0000 & 0.23586 & 0.00675 & 0.88946 & Biso & 1.000 & $\mathrm{Si}$ \\
\hline Si5 & 1.0000 & 0.77983 & 0.77847 & 0.89608 & Biso & 1.000 & $\mathrm{Si}$ \\
\hline Si6 & 1.0000 & 0.00827 & 0.23777 & 0.89561 & Biso & 1.000 & $\mathrm{Si}$ \\
\hline Si7 & 1.0000 & 0.67393 & 0.57022 & 0.43311 & Biso & 1.000 & $\mathrm{Si}$ \\
\hline Al1 & 1.0000 & 0.44912 & 0.11625 & 0.43858 & Biso & 1.000 & Al \\
\hline Si8 & 1.0000 & 0.90693 & 0.33943 & 0.43541 & Biso & 1.000 & $\mathrm{Si}$ \\
\hline Si9 & 1.0000 & 0.90591 & 0.34195 & 0.22819 & Biso & 1.000 & $\mathrm{Si}$ \\
\hline Silo & 1.0000 & 0.44445 & 0.10903 & 0.22591 & Biso & 1.000 & $\mathrm{Si}$ \\
\hline Si11 & 1.0000 & 0.67804 & 0.57117 & 0.22858 & Biso & 1.000 & $\mathrm{Si}$ \\
\hline Si12 & 1.0000 & 0.34026 & 0.89710 & 0.77226 & Biso & 1.000 & $\mathrm{Si}$ \\
\hline Si13 & 1.0000 & 0.11036 & 0.44166 & 0.76595 & Biso & 1.000 & $\mathrm{Si}$ \\
\hline Si14 & 1.0000 & 0.57442 & 0.67430 & 0.76771 & Biso & 1.000 & $\mathrm{Si}$ \\
\hline Si15 & 1.0000 & 0.58109 & 0.68041 & 0.56414 & Biso & 1.000 & $\mathrm{Si}$ \\
\hline Si16 & 1.0000 & 0.11082 & 0.44435 & 0.56363 & Biso & 1.000 & $\mathrm{Si}$ \\
\hline Si17 & 1.0000 & 0.34244 & 0.89433 & 0.56472 & Biso & 1.000 & $\mathrm{Si}$ \\
\hline Si18 & 1.0000 & 0.00760 & 0.77565 & 0.89585 & Biso & 1.000 & $\mathrm{Si}$ \\
\hline Si19 & 1.0000 & 0.23787 & 0.23648 & 0.89140 & Biso & 1.000 & $\mathrm{Si}$ \\
\hline Si20 & 1.0000 & 0.78062 & 0.00700 & 0.89452 & Biso & 1.000 & $\mathrm{Si}$ \\
\hline Si21 & 1.0000 & 0.78064 & 0.00801 & 0.10188 & Biso & 1.000 & $\mathrm{Si}$ \\
\hline Si22 & 1.0000 & 0.24115 & 0.23848 & 0.09864 & Biso & 1.000 & $\mathrm{Si}$ \\
\hline Si23 & 1.0000 & 0.01213 & 0.78091 & 0.10327 & Biso & 1.000 & $\mathrm{Si}$ \\
\hline Si24 & 1.0000 & 0.68041 & 0.11173 & 0.23107 & Biso & 1.000 & $\mathrm{Si}$ \\
\hline Si25 & 1.0000 & 0.91097 & 0.57312 & 0.23097 & Biso & 1.000 & $\mathrm{Si}$ \\
\hline Si26 & 1.0000 & 0.44829 & 0.34460 & 0.22783 & Biso & 1.000 & $\mathrm{Si}$ \\
\hline Si27 & 1.0000 & 0.44110 & 0.34587 & 0.43167 & Biso & 1.000 & $\mathrm{Si}$ \\
\hline Si28 & 1.0000 & 0.90587 & 0.56933 & 0.43577 & Biso & 1.000 & $\mathrm{Si}$ \\
\hline Si29 & 1.0000 & 0.67921 & 0.11459 & 0.42994 & Biso & 1.000 & $\mathrm{Si}$ \\
\hline Si30 & 1.0000 & 0.34609 & 0.45592 & 0.56112 & Biso & 1.000 & $\mathrm{Si}$ \\
\hline Si31 & 1.0000 & 0.57170 & 0.90455 & 0.56450 & Biso & 1.000 & $\mathrm{Si}$ \\
\hline Si32 & 1.0000 & 0.10838 & 0.67715 & 0.56555 & Biso & 1.000 & $\mathrm{Si}$ \\
\hline Si33 & 1.0000 & 0.11062 & 0.67389 & 0.77039 & Biso & 1.000 & $\mathrm{Si}$ \\
\hline Si34 & 1.0000 & 0.57295 & 0.90571 & 0.76815 & Biso & 1.000 & $\mathrm{Si}$ \\
\hline Si35 & 1.0000 & 0.34219 & 0.44667 & 0.76609 & Biso & 1.000 & $\mathrm{Si}$ \\
\hline 01 & 1.0000 & 0.91176 & 0.10704 & 0.11810 & Biso & 1.000 & 0 \\
\hline $\mathrm{O} 2$ & 1.0000 & 0.91381 & 0.81373 & 0.11966 & Biso & 1.000 & 0 \\
\hline $\mathrm{O3}$ & 1.0000 & 0.20912 & 0.10781 & 0.11872 & Biso & 1.000 & 0 \\
\hline 04 & 1.0000 & 0.10586 & 0.90544 & 0.87421 & Biso & 1.000 & 0 \\
\hline 05 & 1.0000 & 0.81355 & 0.90912 & 0.87573 & Biso & 1.000 & 0 \\
\hline 06 & 1.0000 & 0.10702 & 0.20581 & 0.87894 & Biso & 1.000 & 0 \\
\hline 07 & 1.0000 & 0.57366 & 0.44096 & 0.45029 & Biso & 1.000 & 0 \\
\hline 08 & 1.0000 & 0.58915 & 0.15766 & 0.42334 & Biso & 1.000 & 0 \\
\hline 09 & 1.0000 & 0.87659 & 0.43950 & 0.45325 & Biso & 1.000 & 0 \\
\hline 010 & 1.0000 & 0.77432 & 0.24384 & 0.21123 & Biso & 1.000 & 0 \\
\hline 011 & 1.0000 & 0.47465 & 0.23947 & 0.22244 & Biso & 1.000 & 0 \\
\hline 012 & 1.0000 & 0.78069 & 0.54370 & 0.21799 & Biso & 1.000 & 0 \\
\hline 013 & 1.0000 & 0.24063 & 0.76832 & 0.79550 & Biso & 1.000 & 0 \\
\hline 014 & 1.0000 & 0.24231 & 0.47738 & 0.78285 & Biso & 1.000 & 0 \\
\hline 015 & 1.0000 & 0.54467 & 0.77527 & 0.77863 & Biso & 1.000 & 0 \\
\hline 016 & 1.0000 & 0.44801 & 0.58657 & 0.54937 & Biso & 1.000 & 0 \\
\hline 017 & 1.0000 & 0.13076 & 0.57160 & 0.55606 & Biso & 1.000 & 0 \\
\hline 018 & 1.0000 & 0.43522 & 0.85179 & 0.55431 & Biso & 1.000 & 0 \\
\hline 019 & 1.0000 & 0.99142 & 0.32217 & 0.16579 & Biso & 1.000 & 0 \\
\hline $\mathrm{O} 20$ & 1.0000 & 0.69739 & 0.67437 & 0.16426 & Biso & 1.000 & 0 \\
\hline 021 & 1.0000 & 0.35161 & 0.03116 & 0.15275 & Biso & 1.000 & 0 \\
\hline $\mathrm{O} 22$ & 1.0000 & 0.32393 & 0.98830 & 0.83021 & Biso & 1.000 & 0 \\
\hline 023 & 1.0000 & 0.67332 & 0.69116 & 0.83611 & Biso & 1.000 & 0 \\
\hline $\mathrm{O} 24$ & 1.0000 & 0.02726 & 0.34233 & 0.83343 & Biso & 1.000 & 0 \\
\hline 025 & 1.0000 & 0.66165 & 0.65824 & 0.49798 & Biso & 1.000 & 0 \\
\hline 026 & 1.0000 & 0.37421 & 0.00337 & 0.50655 & Biso & 1.000 & 0 \\
\hline $\mathrm{O} 27$ & 1.0000 & 0.01402 & 0.35952 & 0.49535 & Biso & 1.000 & 0 \\
\hline 028 & 1.0000 & 0.02327 & 0.68566 & 0.83648 & Biso & 1.000 & 0 \\
\hline 029 & 1.0000 & 0.32243 & 0.34157 & 0.82888 & Biso & 1.000 & 0 \\
\hline 030 & 1.0000 & 0.67536 & 0.98874 & 0.83352 & Biso & 1.000 & 0 \\
\hline 031 & 1.0000 & 0.69317 & 0.02964 & 0.15999 & Biso & 1.000 & 0 \\
\hline 032 & 1.0000 & 0.34818 & 0.32378 & 0.15921 & Biso & 1.000 & 0 \\
\hline 033 & 1.0000 & 0.99497 & 0.67844 & 0.16774 & Biso & 1.000 & 0 \\
\hline 034 & 1.0000 & 0.35957 & 0.37246 & 0.49303 & Biso & 1.000 & 0 \\
\hline 035 & 1.0000 & 0.00299 & 0.65701 & 0.50312 & Biso & 1.000 & 0 \\
\hline 036 & 1.0000 & 0.64230 & 0.00917 & 0.49753 & Biso & 1.000 & 0 \\
\hline 037 & 1.0000 & 0.13278 & 0.25095 & 0.12516 & Biso & 1.000 & 0 \\
\hline 038 & 1.0000 & 0.76911 & 0.88861 & 0.13231 & Biso & 1.000 & 0 \\
\hline 039 & 1.0000 & 0.13451 & 0.88946 & 0.12860 & Biso & 1.000 & 0 \\
\hline 040 & 1.0000 & 0.24677 & 0.12670 & 0.86248 & Biso & 1.000 & 0 \\
\hline 041 & 1.0000 & 0.88643 & 0.76273 & 0.87104 & Biso & 1.000 & 0 \\
\hline 042 & 1.0000 & 0.88799 & 0.12889 & 0.86963 & Biso & 1.000 & 0 \\
\hline 043 & 1.0000 & 0.79401 & 0.57826 & 0.45388 & Biso & 1.000 & 0 \\
\hline
\end{tabular}




\begin{tabular}{|c|c|c|c|c|c|c|c|}
\hline 044 & 1.0000 & 0.41887 & 0.22218 & 0.45314 & Biso & 1.000 & 0 \\
\hline 045 & 1.0000 & 0.80123 & 0.21773 & 0.46322 & Biso & 1.000 & 0 \\
\hline 046 & 1.0000 & 0.91994 & 0.46357 & 0.20163 & Biso & 1.000 & 0 \\
\hline 047 & 1.0000 & 0.55484 & 0.09692 & 0.21782 & Biso & 1.000 & 0 \\
\hline 048 & 1.0000 & 0.56197 & 0.45907 & 0.19815 & Biso & 1.000 & 0 \\
\hline 049 & 1.0000 & 0.46168 & 0.91101 & 0.79834 & Biso & 1.000 & 0 \\
\hline 050 & 1.0000 & 0.09511 & 0.54972 & 0.78515 & Biso & 1.000 & 0 \\
\hline 051 & 1.0000 & 0.46253 & 0.55542 & 0.79270 & Biso & 1.000 & 0 \\
\hline 052 & 1.0000 & 0.60101 & 0.80547 & 0.54218 & Biso & 1.000 & 0 \\
\hline 053 & 1.0000 & 0.22808 & 0.45025 & 0.53699 & Biso & 1.000 & 0 \\
\hline 054 & 1.0000 & 0.21980 & 0.79125 & 0.53205 & Biso & 1.000 & 0 \\
\hline 055 & 1.0000 & 0.00876 & 0.27364 & 0.99883 & Biso & 1.000 & 0 \\
\hline 056 & 1.0000 & 0.74693 & 0.74848 & 0.00025 & Biso & 1.000 & 0 \\
\hline 057 & 1.0000 & 0.26990 & 0.00871 & 0.99330 & Biso & 1.000 & 0 \\
\hline 058 & 1.0000 & 0.67034 & 0.60649 & 0.33035 & Biso & 1.000 & 0 \\
\hline 059 & 1.0000 & 0.38146 & 0.05421 & 0.32591 & Biso & 1.000 & 0 \\
\hline 060 & 1.0000 & 0.94027 & 0.34090 & 0.33126 & Biso & 1.000 & 0 \\
\hline 061 & 1.0000 & 0.33472 & 0.92342 & 0.66849 & Biso & 1.000 & 0 \\
\hline 062 & 1.0000 & 0.07345 & 0.39671 & 0.66454 & Biso & 1.000 & 0 \\
\hline 063 & 1.0000 & 0.61638 & 0.67312 & 0.66657 & Biso & 1.000 & 0 \\
\hline 064 & 1.0000 & 0.01181 & 0.74591 & 0.00016 & Biso & 1.000 & 0 \\
\hline 065 & 1.0000 & 0.27547 & 0.26933 & 0.99485 & Biso & 1.000 & 0 \\
\hline 066 & 1.0000 & 0.74600 & 0.00384 & 0.99823 & Biso & 1.000 & 0 \\
\hline 067 & 1.0000 & 0.69472 & 0.07415 & 0.33033 & Biso & 1.000 & 0 \\
\hline 068 & 1.0000 & 0.95052 & 0.60702 & 0.33387 & Biso & 1.000 & 0 \\
\hline 069 & 1.0000 & 0.41044 & 0.35542 & 0.32752 & Biso & 1.000 & 0 \\
\hline 070 & 1.0000 & 0.34343 & 0.41273 & 0.66267 & Biso & 1.000 & 0 \\
\hline 071 & 1.0000 & 0.60927 & 0.94921 & 0.66640 & Biso & 1.000 & 0 \\
\hline 072 & 1.0000 & 0.08012 & 0.68975 & 0.66871 & Biso & 1.000 & $\mathrm{O}$ \\
\hline $\mathrm{C} 1$ & 1.0000 & 0.25628 & 0.98606 & 0.32983 & Biso & 1.000 & C \\
\hline $\mathrm{H} 1$ & 1.0000 & 0.23399 & 0.95805 & 0.39867 & Biso & 1.000 & $\mathrm{H}$ \\
\hline H2 & 1.0000 & 0.22011 & 0.03891 & 0.30992 & Biso & 1.000 & $\mathrm{H}$ \\
\hline H3 & 1.0000 & 0.22766 & 0.91287 & 0.28581 & Biso & 1.000 & $\mathrm{H}$ \\
\hline \\
\hline \multicolumn{8}{|c|}{ data_image 0} \\
\hline \multicolumn{8}{|c|}{13.875} \\
\hline \multicolumn{8}{|c|}{13.875} \\
\hline \multicolumn{8}{|c|}{15.017} \\
\hline \multicolumn{8}{|c|}{90} \\
\hline \multicolumn{8}{|c|}{90} \\
\hline sel1 & _gamma & 120 & & & & & \\
\hline (2) & (2) & מרומ nam & & $1 "$ & & & \\
\hline symme & $n t$ t $\bar{a} b$ & Les_ñumb & & & & & \\
\hline op_ & & & & & & & \\
\hline syn & 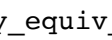 & מחת & & & & & \\
\hline ' $\mathrm{x}$, & & & & & & & \\
\hline op & & & & & & & \\
\hline ato & e labe & & & & & & \\
\hline ato & ee_occul & pancy & & & & & \\
\hline ato & ce frac & $x$ & & & & & \\
\hline ato & ce frac & $=y$ & & & & & \\
\hline ato & ce frac & $=-2$ & & & & & \\
\hline ato & e ther & nal displ & ace type & & & & \\
\hline -ato & ee_B_is & onor_equi & & & & & \\
\hline -ato & ce-type & symb̄ol & & & & & \\
\hline$\overline{\mathrm{P}} 1$ & 1.0000 & 0.00610 & 0.22711 & 0.10823 & Biso & 1.000 & $P$ \\
\hline P2 & 1.0000 & 0.77647 & 0.77691 & 0.11037 & Biso & 1.000 & $\mathrm{P}$ \\
\hline P3 & 1.0000 & 0.22859 & 0.99707 & 0.10027 & Biso & 1.000 & $\mathrm{P}$ \\
\hline Al1 & 1.0000 & 0.22210 & 0.99280 & 0.88718 & Biso & 1.000 & Al \\
\hline Al2 & 1.0000 & 0.77194 & 0.77368 & 0.89707 & Biso & 1.000 & Al \\
\hline Al3 & 1.0000 & 0.00172 & 0.22697 & 0.89645 & Biso & 1.000 & Al \\
\hline P4 & 1.0000 & 0.66853 & 0.56162 & 0.43783 & Biso & 1.000 & $P$ \\
\hline Ge1 & 1.0000 & 0.43395 & 0.11107 & 0.44674 & Biso & 1.000 & $\mathrm{Ge}$ \\
\hline P5 & 1.0000 & 0.89558 & 0.32922 & 0.44077 & Biso & 1.000 & $\mathrm{P}$ \\
\hline Al4 & 1.0000 & 0.89455 & 0.33015 & 0.22888 & Biso & 1.000 & Al \\
\hline Al5 & 1.0000 & 0.43650 & 0.10220 & 0.22730 & Biso & 1.000 & Al \\
\hline Al6 & 1.0000 & 0.67327 & 0.56144 & 0.22877 & Biso & 1.000 & Al \\
\hline P6 & 1.0000 & 0.33311 & 0.88171 & 0.78262 & Biso & 1.000 & $P$ \\
\hline P7 & 1.0000 & 0.10195 & 0.43487 & 0.77154 & Biso & 1.000 & $P$ \\
\hline P8 & 1.0000 & 0.56187 & 0.66112 & 0.77343 & Biso & 1.000 & $\mathrm{P}$ \\
\hline Al7 & 1.0000 & 0.57265 & 0.67296 & 0.56704 & Biso & 1.000 & Al \\
\hline Al8 & 1.0000 & 0.09953 & 0.43759 & 0.56659 & Biso & 1.000 & Al \\
\hline Al9 & 1.0000 & 0.33632 & 0.87957 & 0.56702 & Biso & 1.000 & Al \\
\hline P9 & 1.0000 & 0.99379 & 0.76601 & 0.89164 & Biso & 1.000 & $P$ \\
\hline P 10 & 1.0000 & 0.22659 & 0.22214 & 0.88595 & Biso & 1.000 & $P$ \\
\hline $\mathrm{P} 11$ & 1.0000 & 0.77586 & 0.00099 & 0.89186 & Biso & 1.000 & $\mathrm{P}$ \\
\hline Al10 & 1.0000 & 0.77739 & 0.00222 & 0.10475 & Biso & 1.000 & $\mathrm{Al}$ \\
\hline
\end{tabular}




\begin{tabular}{|c|c|c|c|c|c|c|c|}
\hline Al11 & 1.0000 & 0.23276 & 0.22596 & 0.09789 & Biso & 1.000 & $\mathrm{Al}$ \\
\hline Al12 & 1.0000 & 0.00145 & 0.77333 & 0.10525 & Biso & 1.000 & Al \\
\hline P12 & 1.0000 & 0.66918 & 0.10368 & 0.22782 & Biso & 1.000 & $\mathrm{P}$ \\
\hline P13 & 1.0000 & 0.90333 & 0.56134 & 0.22794 & Biso & 1.000 & $\mathrm{P}$ \\
\hline P14 & 1.0000 & 0.44533 & 0.33768 & 0.22304 & Biso & 1.000 & $\mathrm{P}$ \\
\hline Al13 & 1.0000 & 0.43469 & 0.34504 & 0.43157 & Biso & 1.000 & Al \\
\hline Al14 & 1.0000 & 0.89755 & 0.55931 & 0.43784 & Biso & 1.000 & Al \\
\hline Al15 & 1.0000 & 0.66715 & 0.10822 & 0.43209 & Biso & 1.000 & Al \\
\hline P 15 & 1.0000 & 0.33544 & 0.45670 & 0.55695 & Biso & 1.000 & $P$ \\
\hline P16 & 1.0000 & 0.56373 & 0.89468 & 0.56281 & Biso & 1.000 & $P$ \\
\hline P 17 & 1.0000 & 0.10064 & 0.67197 & 0.56488 & Biso & 1.000 & $P$ \\
\hline Al16 & 1.0000 & 0.10354 & 0.66722 & 0.77311 & Biso & 1.000 & Al \\
\hline Al17 & 1.0000 & 0.56038 & 0.89098 & 0.77248 & Biso & 1.000 & Al \\
\hline Al18 & 1.0000 & 0.32963 & 0.43713 & 0.76508 & Biso & 1.000 & Al \\
\hline 01 & 1.0000 & 0.91548 & 0.10558 & 0.12673 & Biso & 1.000 & 0 \\
\hline $\mathrm{O} 2$ & 1.0000 & 0.89775 & 0.80667 & 0.12908 & Biso & 1.000 & 0 \\
\hline 03 & 1.0000 & 0.19947 & 0.08834 & 0.12099 & Biso & 1.000 & 0 \\
\hline 04 & 1.0000 & 0.08641 & 0.88437 & 0.86646 & Biso & 1.000 & 0 \\
\hline 05 & 1.0000 & 0.80682 & 0.91079 & 0.87175 & Biso & 1.000 & 0 \\
\hline 06 & 1.0000 & 0.10494 & 0.19324 & 0.87270 & Biso & 1.000 & 0 \\
\hline 07 & 1.0000 & 0.57508 & 0.44147 & 0.45490 & Biso & 1.000 & 0 \\
\hline 08 & 1.0000 & 0.57363 & 0.15680 & 0.42450 & Biso & 1.000 & 0 \\
\hline 09 & 1.0000 & 0.87064 & 0.42396 & 0.45964 & Biso & 1.000 & 0 \\
\hline 010 & 1.0000 & 0.75580 & 0.22653 & 0.20829 & Biso & 1.000 & 0 \\
\hline 011 & 1.0000 & 0.47021 & 0.24071 & 0.22136 & Biso & 1.000 & 0 \\
\hline 012 & 1.0000 & 0.78210 & 0.53341 & 0.21453 & Biso & 1.000 & 0 \\
\hline 013 & 1.0000 & 0.23780 & 0.76540 & 0.80971 & Biso & 1.000 & 0 \\
\hline 014 & 1.0000 & 0.22498 & 0.46990 & 0.78819 & Biso & 1.000 & 0 \\
\hline 015 & 1.0000 & 0.53179 & 0.75350 & 0.78247 & Biso & 1.000 & 0 \\
\hline 016 & 1.0000 & 0.43082 & 0.57840 & 0.55101 & Biso & 1.000 & 0 \\
\hline 017 & 1.0000 & 0.11334 & 0.56874 & 0.55882 & Biso & 1.000 & 0 \\
\hline 018 & 1.0000 & 0.43821 & 0.84270 & 0.54297 & Biso & 1.000 & 0 \\
\hline 019 & 1.0000 & 0.98735 & 0.30690 & 0.16656 & Biso & 1.000 & 0 \\
\hline 020 & 1.0000 & 0.69507 & 0.67474 & 0.16435 & Biso & 1.000 & 0 \\
\hline 021 & 1.0000 & 0.33487 & 0.01998 & 0.15001 & Biso & 1.000 & 0 \\
\hline 022 & 1.0000 & 0.31837 & 0.97289 & 0.82781 & Biso & 1.000 & 0 \\
\hline 023 & 1.0000 & 0.65262 & 0.67870 & 0.84033 & Biso & 1.000 & 0 \\
\hline 024 & 1.0000 & 0.02570 & 0.34469 & 0.83756 & Biso & 1.000 & 0 \\
\hline 025 & 1.0000 & 0.65546 & 0.64398 & 0.49757 & Biso & 1.000 & 0 \\
\hline 026 & 1.0000 & 0.36162 & 0.00227 & 0.52009 & Biso & 1.000 & 0 \\
\hline 027 & 1.0000 & 0.99560 & 0.34502 & 0.49570 & Biso & 1.000 & 0 \\
\hline 028 & 1.0000 & 0.00681 & 0.67779 & 0.84031 & Biso & 1.000 & 0 \\
\hline 029 & 1.0000 & 0.30529 & 0.32062 & 0.82719 & Biso & 1.000 & 0 \\
\hline 030 & 1.0000 & 0.67437 & 0.98086 & 0.83723 & Biso & 1.000 & 0 \\
\hline 031 & 1.0000 & 0.68244 & 0.02710 & 0.16149 & Biso & 1.000 & 0 \\
\hline 032 & 1.0000 & 0.35208 & 0.31595 & 0.15733 & Biso & 1.000 & 0 \\
\hline 033 & 1.0000 & 0.98219 & 0.66010 & 0.16908 & Biso & 1.000 & 0 \\
\hline 034 & 1.0000 & 0.35079 & 0.38427 & 0.48864 & Biso & 1.000 & 0 \\
\hline 035 & 1.0000 & 0.00241 & 0.65630 & 0.50729 & Biso & 1.000 & 0 \\
\hline 036 & 1.0000 & 0.63161 & 0.99558 & 0.50281 & Biso & 1.000 & 0 \\
\hline 037 & 1.0000 & 0.12051 & 0.24141 & 0.13093 & Biso & 1.000 & 0 \\
\hline 038 & 1.0000 & 0.76217 & 0.87516 & 0.13874 & Biso & 1.000 & 0 \\
\hline 039 & 1.0000 & 0.13237 & 0.88537 & 0.13329 & Biso & 1.000 & 0 \\
\hline 040 & 1.0000 & 0.23652 & 0.12101 & 0.85858 & Biso & 1.000 & o \\
\hline 041 & 1.0000 & 0.88146 & 0.75383 & 0.86613 & Biso & 1.000 & 0 \\
\hline 042 & 1.0000 & 0.87359 & 0.11483 & 0.86564 & Biso & 1.000 & 0 \\
\hline 043 & 1.0000 & 0.78011 & 0.56965 & 0.45928 & Biso & 1.000 & 0 \\
\hline 044 & 1.0000 & 0.39837 & 0.21271 & 0.46445 & Biso & 1.000 & 0 \\
\hline 045 & 1.0000 & 0.79527 & 0.21792 & 0.46790 & Biso & 1.000 & 0 \\
\hline 046 & 1.0000 & 0.91293 & 0.46018 & 0.19996 & Biso & 1.000 & 0 \\
\hline 047 & 1.0000 & 0.55194 & 0.08729 & 0.21519 & Biso & 1.000 & 0 \\
\hline 048 & 1.0000 & 0.55068 & 0.44412 & 0.19403 & Biso & 1.000 & 0 \\
\hline 049 & 1.0000 & 0.44453 & 0.89493 & 0.81327 & Biso & 1.000 & 0 \\
\hline 050 & 1.0000 & 0.08648 & 0.53538 & 0.78528 & Biso & 1.000 & 0 \\
\hline 051 & 1.0000 & 0.45851 & 0.54911 & 0.79492 & Biso & 1.000 & 0 \\
\hline 052 & 1.0000 & 0.59879 & 0.80760 & 0.54445 & Biso & 1.000 & 0 \\
\hline 053 & 1.0000 & 0.22658 & 0.45374 & 0.53471 & Biso & 1.000 & 0 \\
\hline 054 & 1.0000 & 0.20685 & 0.77295 & 0.52936 & Biso & 1.000 & 0 \\
\hline 055 & 1.0000 & 0.00262 & 0.25607 & 0.00987 & Biso & 1.000 & 0 \\
\hline 056 & 1.0000 & 0.74869 & 0.75068 & 0.01126 & Biso & 1.000 & 0 \\
\hline 057 & 1.0000 & 0.24925 & 0.99264 & 0.00082 & Biso & 1.000 & 0 \\
\hline 058 & 1.0000 & 0.66580 & 0.59398 & 0.34005 & Biso & 1.000 & 0 \\
\hline 059 & 1.0000 & 0.36688 & 0.04591 & 0.33374 & Biso & 1.000 & 0 \\
\hline 060 & 1.0000 & 0.92367 & 0.32895 & 0.34170 & Biso & 1.000 & 0 \\
\hline 061 & 1.0000 & 0.33221 & 0.89486 & 0.68179 & Biso & 1.000 & 0 \\
\hline 062 & 1.0000 & 0.06771 & 0.38867 & 0.67635 & Biso & 1.000 & 0 \\
\hline 063 & 1.0000 & 0.60460 & 0.66170 & 0.67855 & Biso & 1.000 & 0 \\
\hline 064 & 1.0000 & 0.99811 & 0.74527 & 0.99182 & Biso & 1.000 & 0 \\
\hline 065 & 1.0000 & 0.26050 & 0.25272 & 0.98416 & Biso & 1.000 & 0 \\
\hline 066 & 1.0000 & 0.74861 & 0.99925 & 0.99128 & Biso & 1.000 & 0 \\
\hline
\end{tabular}




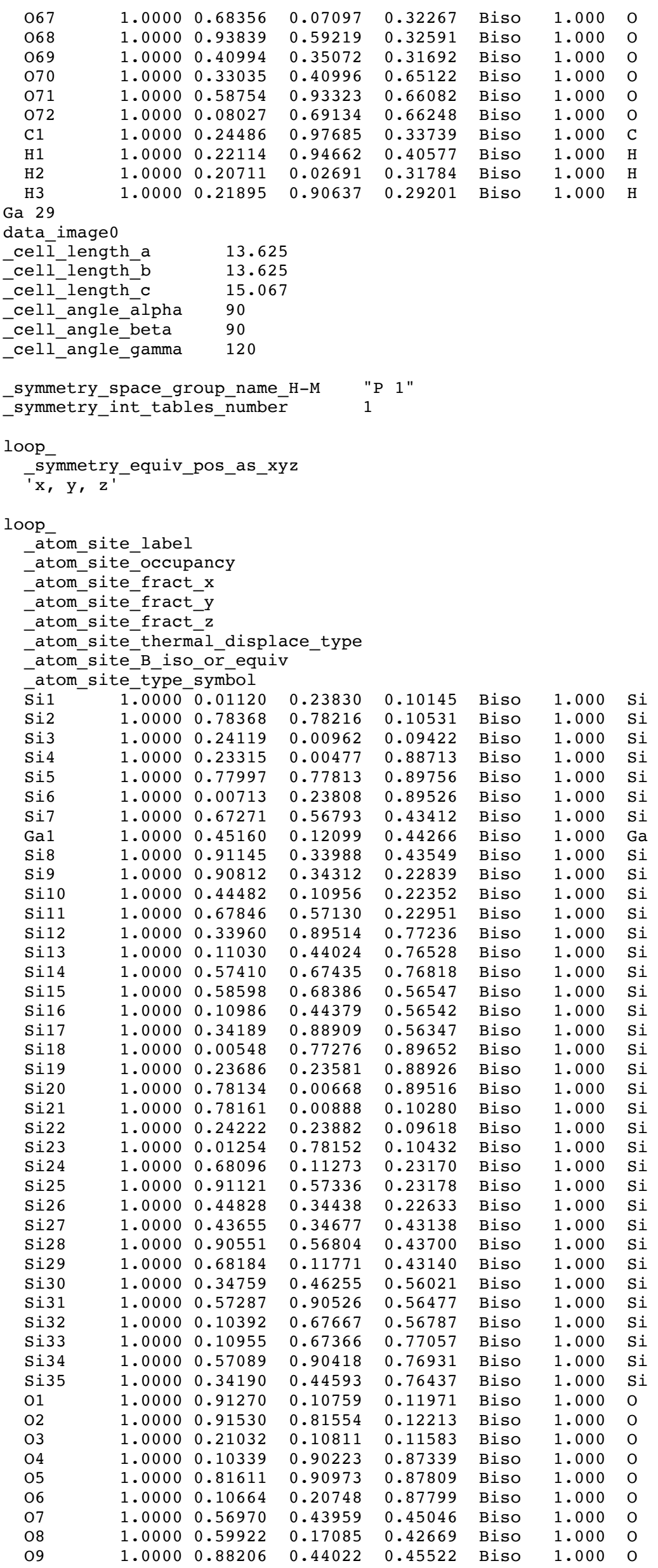




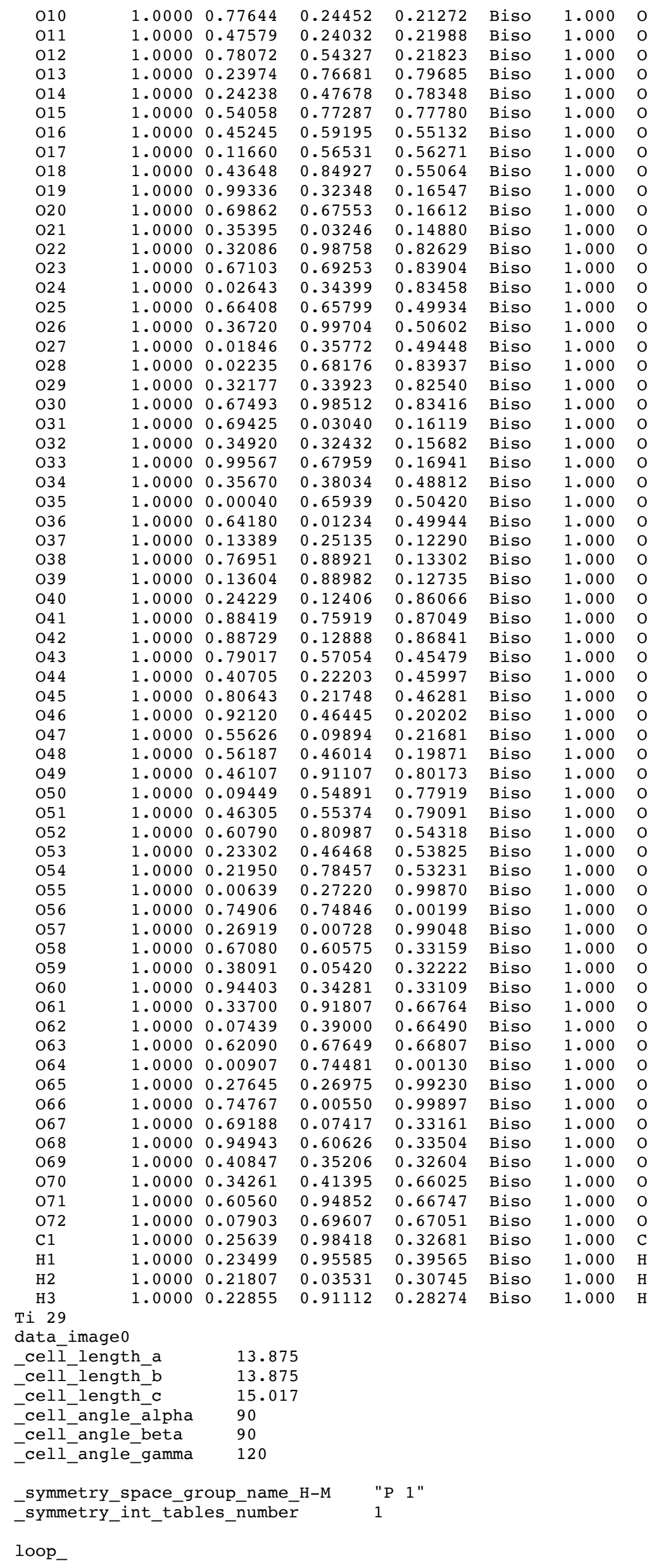




\begin{tabular}{|c|c|c|c|c|c|c|c|}
\hline \multicolumn{8}{|c|}{$\begin{array}{l}\text { 'symmetry_equiv_pos_as_xyz } \\
\text { op_y, } \\
\text {-atom_site_label } \\
\text {-atom_site_occupancy } \\
\text {-atom_site_fract_x } \\
\text {-atom_site_fract_y } \\
\text {-atom_site_fract_z } \\
\text {-atom_site_thermal_displace_type } \\
\text {-atom_site_B_iso_or_equiv } \\
\text {-atom_site_type_symbol }\end{array}$} \\
\hline$\overline{\mathrm{P}} 1$ & 1.0000 & 0.00679 & 0.22742 & 0.10821 & Biso & 1.000 & $\mathrm{P}$ \\
\hline P2 & 1.0000 & 0.77739 & 0.77812 & 0.11209 & Biso & 1.000 & $P$ \\
\hline P3 & 1.0000 & 0.22978 & 0.99766 & 0.09663 & Biso & 1.000 & $\mathrm{P}$ \\
\hline Al1 & 1.0000 & 0.21918 & 0.99126 & 0.88324 & Biso & 1.000 & A. \\
\hline Al2 & 1.0000 & 0.77139 & 0.77379 & 0.89858 & Biso & 1.000 & A. \\
\hline Al3 & 1.0000 & 0.00042 & 0.22701 & 0.89635 & Biso & 1.000 & A. \\
\hline P4 & 1.0000 & 0.66894 & 0.56329 & 0.43937 & Biso & 1.000 & $\mathrm{P}$ \\
\hline Til & 1.0000 & 0.42879 & 0.10830 & 0.44512 & Biso & 1.000 & \\
\hline P5 & 1.0000 & 0.90041 & 0.33033 & 0.44059 & Biso & 1.000 & $P$ \\
\hline Al4 & 1.0000 & 0.89720 & 0.33205 & 0.22879 & Biso & 1.000 & \\
\hline Al5 & 1.0000 & 0.43554 & 0.10177 & 0.22350 & Biso & 1.000 & \\
\hline Al 6 & 1.0000 & 0.67434 & 0.56193 & 0.22996 & Biso & 1.000 & \\
\hline P6 & 1.0000 & 0.33154 & 0.87823 & 0.78414 & Biso & 1.000 & \\
\hline P7 & 1.0000 & 0.10145 & 0.43385 & 0.77144 & Biso & 1.000 & $\mathrm{P}$ \\
\hline P8 & 1.0000 & 0.56151 & 0.66083 & 0.77421 & Biso & 1.000 & $P$ \\
\hline Al 7 & 1.0000 & 0.57873 & 0.67567 & 0.56886 & Biso & 1.000 & \\
\hline Al8 & 1.0000 & 0.09921 & 0.43770 & 0.56889 & Biso & 1.000 & \\
\hline Al9 & 1.0000 & 0.33516 & 0.87306 & 0.56802 & Biso & 1.000 & \\
\hline P9 & 1.0000 & 0.99144 & 0.76401 & 0.89158 & Biso & 1.000 & $\mathrm{P}$ \\
\hline $\mathrm{P} 10$ & 1.0000 & 0.22540 & 0.22149 & 0.88359 & Biso & 1.000 & $\mathrm{P}$ \\
\hline P11 & 1.0000 & 0.77577 & 0.00089 & 0.89290 & Biso & 1.000 & $P$ \\
\hline Al10 & 1.0000 & 0.77809 & 0.00321 & 0.10625 & Biso & 1.000 & \\
\hline Al11 & 1.0000 & 0.23433 & 0.22687 & 0.09576 & Biso & 1.000 & \\
\hline Al12 & 1.0000 & 0.00216 & 0.77487 & 0.10569 & Biso & 1.000 & \\
\hline $\mathrm{P} 12$ & 1.0000 & 0.67073 & 0.10622 & 0.22860 & Biso & 1.000 & \\
\hline P13 & 1.0000 & 0.90458 & 0.56292 & 0.22900 & Biso & 1.000 & $\mathrm{P}$ \\
\hline P14 & 1.0000 & 0.44474 & 0.33828 & 0.22264 & Biso & 1.000 & $P$ \\
\hline Al13 & 1.0000 & 0.42996 & 0.34940 & 0.43169 & Biso & 1.000 & \\
\hline Al14 & 1.0000 & 0.89775 & 0.55903 & 0.43906 & Biso & 1.000 & \\
\hline Al15 & 1.0000 & 0.67160 & 0.10954 & 0.43434 & Biso & 1.000 & \\
\hline P15 & 1.0000 & 0.33697 & 0.46286 & 0.55637 & Biso & 1.000 & $\mathrm{P}$ \\
\hline P16 & 1.0000 & 0.56659 & 0.89649 & 0.56471 & Biso & 1.000 & $\mathrm{P}$ \\
\hline P17 & 1.0000 & 0.09651 & 0.67084 & 0.56788 & Biso & 1.000 & $\mathrm{P}$ \\
\hline Al16 & 1.0000 & 0.10167 & 0.66662 & 0.77404 & Biso & 1.000 & \\
\hline Al17 & 1.0000 & 0.55883 & 0.89052 & 0.77394 & Biso & 1.000 & \\
\hline Al18 & 1.0000 & 0.32926 & 0.43766 & 0.76419 & Biso & 1.000 & \\
\hline 01 & 1.0000 & 0.91627 & 0.10639 & 0.12860 & Biso & 1.000 & 0 \\
\hline $\mathrm{O} 2$ & 1.0000 & 0.89895 & 0.80862 & 0.13080 & Biso & 1.000 & 0 \\
\hline 03 & 1.0000 & 0.20226 & 0.08966 & 0.11927 & Biso & 1.000 & 0 \\
\hline 04 & 1.0000 & 0.08380 & 0.88139 & 0.86368 & Biso & 1.000 & O \\
\hline 05 & 1.0000 & 0.80777 & 0.91135 & 0.87300 & Biso & 1.000 & 0 \\
\hline 06 & 1.0000 & 0.10405 & 0.19418 & 0.87190 & Biso & 1.000 & 0 \\
\hline 07 & 1.0000 & 0.56885 & 0.44739 & 0.45791 & Biso & 1.000 & 0 \\
\hline 08 & 1.0000 & 0.57366 & 0.15297 & 0.43163 & Biso & 1.000 & 0 \\
\hline 09 & 1.0000 & 0.87631 & 0.42545 & 0.46021 & Biso & 1.000 & 0 \\
\hline 010 & 1.0000 & 0.75820 & 0.22872 & 0.20866 & Biso & 1.000 & 0 \\
\hline 011 & 1.0000 & 0.46812 & 0.24037 & 0.22097 & Biso & 1.000 & $\mathrm{O}$ \\
\hline 012 & 1.0000 & 0.78302 & 0.53370 & 0.21491 & Biso & 1.000 & 0 \\
\hline 013 & 1.0000 & 0.23534 & 0.76340 & 0.81341 & Biso & 1.000 & 0 \\
\hline 014 & 1.0000 & 0.22466 & 0.47014 & 0.78900 & Biso & 1.000 & O \\
\hline 015 & 1.0000 & 0.53042 & 0.75277 & 0.77999 & Biso & 1.000 & 0 \\
\hline 016 & 1.0000 & 0.43812 & 0.58090 & 0.54902 & Biso & 1.000 & O \\
\hline 017 & 1.0000 & 0.09921 & 0.56223 & 0.56642 & Biso & 1.000 & 0 \\
\hline 018 & 1.0000 & 0.44175 & 0.84353 & 0.54142 & Biso & 1.000 & 0 \\
\hline 019 & 1.0000 & 0.98984 & 0.30862 & 0.16629 & Biso & 1.000 & 0 \\
\hline 020 & 1.0000 & 0.69632 & 0.67558 & 0.16585 & Biso & 1.000 & $\mathrm{O}$ \\
\hline 021 & 1.0000 & 0.33833 & 0.02102 & 0.14279 & Biso & 1.000 & O \\
\hline 022 & 1.0000 & 0.31600 & 0.97164 & 0.82409 & Biso & 1.000 & $\mathrm{O}$ \\
\hline 023 & 1.0000 & 0.65031 & 0.67972 & 0.84346 & Biso & 1.000 & $\mathrm{O}$ \\
\hline $\mathrm{O} 24$ & 1.0000 & 0.02527 & 0.34625 & 0.83921 & Biso & 1.000 & O \\
\hline 025 & 1.0000 & 0.66457 & 0.65114 & 0.49877 & Biso & 1.000 & 0 \\
\hline 026 & 1.0000 & 0.35728 & 0.99581 & 0.52127 & Biso & 1.000 & O \\
\hline 027 & 1.0000 & 0.00135 & 0.34547 & 0.49402 & Biso & 1.000 & 0 \\
\hline 028 & 1.0000 & 0.00384 & 0.67402 & 0.84234 & Biso & 1.000 & \\
\hline 029 & 1.0000 & 0.30402 & 0.31949 & 0.82436 & Biso & 1.000 & \\
\hline 030 & 1.0000 & 0.67282 & 0.97866 & 0.83942 & Biso & 1.000 & O \\
\hline 031 & 1.0000 & 0.68332 & 0.02882 & 0.16263 & Biso & 1.000 & 0 \\
\hline 032 & 1.0000 & 0.35336 & 0.31820 & 0.15529 & Biso & 1.000 & \\
\hline
\end{tabular}




\begin{tabular}{|c|c|c|c|c|c|c|c|}
\hline 033 & 1.0000 & 0.98326 & 0.66228 & 0.17047 & Biso & 1.000 & 0 \\
\hline 034 & 1.0000 & 0.34208 & 0.38661 & 0.48550 & Biso & 1.000 & 0 \\
\hline 035 & 1.0000 & 0.00049 & 0.65885 & 0.50897 & Biso & 1.000 & 0 \\
\hline 036 & 1.0000 & 0.63717 & 0.99687 & 0.50495 & Biso & 1.000 & 0 \\
\hline 037 & 1.0000 & 0.12161 & 0.24159 & 0.12897 & Biso & 1.000 & 0 \\
\hline 038 & 1.0000 & 0.76231 & 0.87592 & 0.14048 & Biso & 1.000 & 0 \\
\hline 039 & 1.0000 & 0.13428 & 0.88657 & 0.13145 & Biso & 1.000 & 0 \\
\hline 040 & 1.0000 & 0.23308 & 0.11940 & 0.85504 & Biso & 1.000 & 0 \\
\hline 041 & 1.0000 & 0.87877 & 0.75118 & 0.86614 & Biso & 1.000 & 0 \\
\hline 042 & 1.0000 & 0.87229 & 0.11487 & 0.86519 & Biso & 1.000 & 0 \\
\hline 043 & 1.0000 & 0.77578 & 0.56113 & 0.46027 & Biso & 1.000 & 0 \\
\hline 044 & 1.0000 & 0.39976 & 0.21849 & 0.46493 & Biso & 1.000 & 0 \\
\hline 045 & 1.0000 & 0.80040 & 0.21934 & 0.46868 & Biso & 1.000 & 0 \\
\hline 046 & 1.0000 & 0.91581 & 0.46261 & 0.20120 & Biso & 1.000 & 0 \\
\hline 047 & 1.0000 & 0.55406 & 0.09116 & 0.21578 & Biso & 1.000 & 0 \\
\hline 048 & 1.0000 & 0.55150 & 0.44461 & 0.19552 & Biso & 1.000 & 0 \\
\hline 049 & 1.0000 & 0.44280 & 0.89291 & 0.81721 & Biso & 1.000 & 0 \\
\hline 050 & 1.0000 & 0.08531 & 0.53452 & 0.78096 & Biso & 1.000 & 0 \\
\hline 051 & 1.0000 & 0.45798 & 0.54881 & 0.79536 & Biso & 1.000 & 0 \\
\hline 052 & 1.0000 & 0.60349 & 0.81025 & 0.54960 & Biso & 1.000 & 0 \\
\hline 053 & 1.0000 & 0.23257 & 0.47055 & 0.53877 & Biso & 1.000 & 0 \\
\hline 054 & 1.0000 & 0.20645 & 0.76503 & 0.53031 & Biso & 1.000 & 0 \\
\hline 055 & 1.0000 & 0.00076 & 0.25467 & 0.00987 & Biso & 1.000 & 0 \\
\hline 056 & 1.0000 & 0.74990 & 0.75201 & 0.01295 & Biso & 1.000 & 0 \\
\hline 057 & 1.0000 & 0.24620 & 0.99191 & 0.99674 & Biso & 1.000 & 0 \\
\hline 058 & 1.0000 & 0.66824 & 0.59553 & 0.34123 & Biso & 1.000 & 0 \\
\hline 059 & 1.0000 & 0.36312 & 0.04220 & 0.32712 & Biso & 1.000 & 0 \\
\hline 060 & 1.0000 & 0.92682 & 0.32968 & 0.34126 & Biso & 1.000 & 0 \\
\hline 061 & 1.0000 & 0.33230 & 0.88586 & 0.68285 & Biso & 1.000 & 0 \\
\hline 062 & 1.0000 & 0.06790 & 0.38333 & 0.67728 & Biso & 1.000 & 0 \\
\hline 063 & 1.0000 & 0.60698 & 0.66033 & 0.68059 & Biso & 1.000 & 0 \\
\hline 064 & 1.0000 & 0.99692 & 0.74651 & 0.99218 & Biso & 1.000 & 0 \\
\hline 065 & 1.0000 & 0.26106 & 0.25175 & 0.98159 & Biso & 1.000 & 0 \\
\hline 066 & 1.0000 & 0.75023 & 0.00038 & 0.99258 & Biso & 1.000 & 0 \\
\hline 067 & 1.0000 & 0.68470 & 0.07360 & 0.32358 & Biso & 1.000 & 0 \\
\hline 068 & 1.0000 & 0.93853 & 0.59375 & 0.32720 & Biso & 1.000 & 0 \\
\hline 069 & 1.0000 & 0.40768 & 0.35108 & 0.31600 & Biso & 1.000 & 0 \\
\hline 070 & 1.0000 & 0.33167 & 0.41373 & 0.64974 & Biso & 1.000 & 0 \\
\hline 071 & 1.0000 & 0.58585 & 0.93547 & 0.66280 & Biso & 1.000 & 0 \\
\hline 072 & 1.0000 & 0.07964 & 0.69709 & 0.66457 & Biso & 1.000 & 0 \\
\hline $\mathrm{C} 1$ & 1.0000 & 0.24235 & 0.96875 & 0.32942 & Biso & 1.000 & $\mathrm{C}$ \\
\hline $\mathrm{H} 1$ & 1.0000 & 0.21711 & 0.94065 & 0.39817 & Biso & 1.000 & $\mathrm{H}$ \\
\hline $\mathrm{H} 2$ & 1.0000 & 0.20085 & 0.01396 & 0.30615 & Biso & 1.000 & $\mathrm{H}$ \\
\hline H3 & 1.0000 & 0.21986 & 0.89655 & 0.28660 & Biso & 1.000 & $\mathrm{H}$ \\
\hline \multicolumn{8}{|c|}{$\mathrm{Zn} \mathrm{ZOH}$} \\
\hline \multicolumn{8}{|c|}{ data image 0} \\
\hline \multicolumn{8}{|c|}{ celìlength_a $\quad 13.875$} \\
\hline \multicolumn{8}{|c|}{ cell_length_b $\quad 13.875$} \\
\hline \multicolumn{8}{|c|}{ cell length $\quad 15.017$} \\
\hline \multicolumn{8}{|c|}{ cell angle alpha 90} \\
\hline \multicolumn{8}{|c|}{ cell_angle_beta 90} \\
\hline \multicolumn{8}{|c|}{ _cell_angle_gamma } \\
\hline symme & pace_gr & oup name & 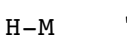 & $1 "$ & & & \\
\hline symme & nt_tabl & es_numbe & & & & & \\
\hline 1oop_ & & & & & & & \\
\hline$T_{\mathrm{x}}^{\mathrm{sym}}$ & _equiv & pos_as_x & & & & & \\
\hline loop & & & & & & & \\
\hline ato & e label & & & & & & \\
\hline ato & e- occup & ancy & & & & & \\
\hline ato & e-fract & $x$ & & & & & \\
\hline ato & eefract & & & & & & \\
\hline ato & e fract & & & & & & \\
\hline _ato & $\begin{array}{l}\text { e-therm } \\
\text { e_B_isc }\end{array}$ & al_or_equi & ce_type & & & & \\
\hline ato & $=e^{-}$type & symb̄ol & & & & & \\
\hline$\overline{\mathrm{A}} 11$ & 1.0000 & 0.99724 & 0.22329 & 0.10507 & Biso & 1.000 & Al \\
\hline Al2 & 1.0000 & 0.77375 & 0.77036 & 0.10638 & Biso & 1.000 & Al \\
\hline A 13 & 1.0000 & 0.22742 & 0.00035 & 0.09721 & Biso & 1.000 & Al \\
\hline $\mathrm{P} 1$ & 1.0000 & 0.22562 & 0.00193 & 0.88752 & Biso & 1.000 & $\mathrm{P}$ \\
\hline $\mathrm{P} 2$ & 1.0000 & 0.77545 & 0.77191 & 0.89341 & Biso & 1.000 & $\mathrm{P}$ \\
\hline P3 & 1.0000 & 0.99599 & 0.22637 & 0.89278 & Biso & 1.000 & $\mathrm{P}$ \\
\hline Al4 & 1.0000 & 0.66055 & 0.55679 & 0.43622 & Biso & 1.000 & Al \\
\hline $\mathrm{Zn} 1$ & 1.0000 & 0.45544 & 0.12448 & 0.46367 & Biso & 1.000 & $\mathrm{Zn}$ \\
\hline Al5 & 1.0000 & 0.90078 & 0.33461 & 0.43695 & Biso & 1.000 & Al \\
\hline P4 & 1.0000 & 0.89465 & 0.33596 & 0.22546 & Biso & 1.000 & $\mathrm{P}$ \\
\hline P5 & 1.0000 & 0.43888 & 0.10022 & 0.21986 & Biso & 1.000 & $\mathrm{P}$ \\
\hline
\end{tabular}




\begin{tabular}{|c|c|c|c|c|c|c|c|}
\hline P6 & 1.0000 & 0.66276 & 0.55813 & 0.22667 & Biso & 1.000 & $\mathrm{P}$ \\
\hline Al6 & 1.0000 & 0.33061 & 0.89514 & 0.76343 & Biso & 1.000 & Al \\
\hline Al7 & 1.0000 & 0.10572 & 0.43576 & 0.76903 & Biso & 1.000 & Al \\
\hline Al8 & 1.0000 & 0.56357 & 0.67248 & 0.77072 & Biso & 1.000 & Al \\
\hline P7 & 1.0000 & 0.57273 & 0.68014 & 0.56231 & Biso & 1.000 & $P$ \\
\hline P8 & 1.0000 & 0.10443 & 0.43762 & 0.56295 & Biso & 1.000 & $P$ \\
\hline P9 & 1.0000 & 0.33113 & 0.88254 & 0.55630 & Biso & 1.000 & $\mathrm{P}$ \\
\hline Al9 & 1.0000 & 0.00122 & 0.77332 & 0.89743 & Biso & 1.000 & Al \\
\hline Al10 & 1.0000 & 0.22577 & 0.23076 & 0.89354 & Biso & 1.000 & Al \\
\hline Al11 & 1.0000 & 0.77194 & 0.99727 & 0.89651 & Biso & 1.000 & Al \\
\hline P 10 & 1.0000 & 0.77182 & 0.99541 & 0.10892 & Biso & 1.000 & $\mathrm{P}$ \\
\hline P11 & 1.0000 & 0.22660 & 0.22847 & 0.10477 & Biso & 1.000 & $P$ \\
\hline P12 & 1.0000 & 0.00216 & 0.77493 & 0.11065 & Biso & 1.000 & $\mathrm{P}$ \\
\hline Al12 & 1.0000 & 0.67152 & 0.10463 & 0.23410 & Biso & 1.000 & $\mathrm{Al}$ \\
\hline Al13 & 1.0000 & 0.89213 & 0.56029 & 0.22967 & Biso & 1.000 & Al \\
\hline Al 14 & 1.0000 & 0.43640 & 0.32694 & 0.23152 & Biso & 1.000 & $\mathrm{Al}$ \\
\hline P13 & 1.0000 & 0.42877 & 0.33206 & 0.44247 & Biso & 1.000 & $\mathrm{P}$ \\
\hline P14 & 1.0000 & 0.88951 & 0.55722 & 0.44145 & Biso & 1.000 & $P$ \\
\hline P15 & 1.0000 & 0.67569 & 0.11548 & 0.43908 & Biso & 1.000 & $\mathrm{P}$ \\
\hline Al15 & 1.0000 & 0.34115 & 0.45703 & 0.56336 & Biso & 1.000 & Al \\
\hline Al16 & 1.0000 & 0.55976 & 0.89675 & 0.56590 & Biso & 1.000 & Al \\
\hline Al17 & 1.0000 & 0.09355 & 0.66444 & 0.56803 & Biso & 1.000 & Al \\
\hline P16 & 1.0000 & 0.10283 & 0.66566 & 0.77314 & Biso & 1.000 & $\mathrm{P}$ \\
\hline P17 & 1.0000 & 0.55846 & 0.89705 & 0.77505 & Biso & 1.000 & $P$ \\
\hline P18 & 1.0000 & 0.33718 & 0.44216 & 0.77141 & Biso & 1.000 & $P$ \\
\hline 01 & 1.0000 & 0.89353 & 0.08568 & 0.12713 & Biso & 1.000 & 0 \\
\hline $\mathrm{O} 2$ & 1.0000 & 0.91084 & 0.80393 & 0.13158 & Biso & 1.000 & 0 \\
\hline 03 & 1.0000 & 0.19774 & 0.10654 & 0.11827 & Biso & 1.000 & 0 \\
\hline 04 & 1.0000 & 0.10358 & 0.91074 & 0.87261 & Biso & 1.000 & 0 \\
\hline 05 & 1.0000 & 0.80644 & 0.89359 & 0.87550 & Biso & 1.000 & 0 \\
\hline 06 & 1.0000 & 0.08858 & 0.19872 & 0.87293 & Biso & 1.000 & 0 \\
\hline 07 & 1.0000 & 0.55348 & 0.42022 & 0.45228 & Biso & 1.000 & 0 \\
\hline 08 & 1.0000 & 0.60688 & 0.17396 & 0.44022 & Biso & 1.000 & 0 \\
\hline 09 & 1.0000 & 0.86842 & 0.43921 & 0.46139 & Biso & 1.000 & 0 \\
\hline 010 & 1.0000 & 0.77226 & 0.24333 & 0.21287 & Biso & 1.000 & 0 \\
\hline 011 & 1.0000 & 0.47126 & 0.22184 & 0.21098 & Biso & 1.000 & 0 \\
\hline 012 & 1.0000 & 0.75531 & 0.52974 & 0.20972 & Biso & 1.000 & 0 \\
\hline 013 & 1.0000 & 0.22579 & 0.75709 & 0.78310 & Biso & 1.000 & 0 \\
\hline 014 & 1.0000 & 0.24393 & 0.46963 & 0.78870 & Biso & 1.000 & 0 \\
\hline 015 & 1.0000 & 0.52671 & 0.77461 & 0.78994 & Biso & 1.000 & 0 \\
\hline 016 & 1.0000 & 0.44774 & 0.59558 & 0.55152 & Biso & 1.000 & 0 \\
\hline 017 & 1.0000 & 0.11608 & 0.55300 & 0.55569 & Biso & 1.000 & 0 \\
\hline 018 & 1.0000 & 0.41532 & 0.83985 & 0.55344 & Biso & 1.000 & 0 \\
\hline 019 & 1.0000 & 0.97243 & 0.31480 & 0.16667 & Biso & 1.000 & 0 \\
\hline 020 & 1.0000 & 0.67796 & 0.65305 & 0.16532 & Biso & 1.000 & 0 \\
\hline 021 & 1.0000 & 0.34621 & 0.02267 & 0.15686 & Biso & 1.000 & 0 \\
\hline 022 & 1.0000 & 0.30432 & 0.98512 & 0.82664 & Biso & 1.000 & 0 \\
\hline 023 & 1.0000 & 0.67278 & 0.69162 & 0.83949 & Biso & 1.000 & 0 \\
\hline $\mathrm{O} 24$ & 1.0000 & 0.01444 & 0.32794 & 0.83879 & Biso & 1.000 & 0 \\
\hline 025 & 1.0000 & 0.64332 & 0.65032 & 0.50235 & Biso & 1.000 & 0 \\
\hline 026 & 1.0000 & 0.35676 & 0.97011 & 0.48476 & Biso & 1.000 & 0 \\
\hline 027 & 1.0000 & 0.01647 & 0.35629 & 0.49793 & Biso & 1.000 & 0 \\
\hline 028 & 1.0000 & 0.02981 & 0.68031 & 0.84223 & Biso & 1.000 & 0 \\
\hline 029 & 1.0000 & 0.31960 & 0.34361 & 0.82948 & Biso & 1.000 & 0 \\
\hline 030 & 1.0000 & 0.65436 & 0.97366 & 0.83707 & Biso & 1.000 & 0 \\
\hline 031 & 1.0000 & 0.69120 & 0.01583 & 0.16459 & Biso & 1.000 & 0 \\
\hline 032 & 1.0000 & 0.32663 & 0.30584 & 0.16264 & Biso & 1.000 & 0 \\
\hline 033 & 1.0000 & 0.98578 & 0.67587 & 0.16717 & Biso & 1.000 & 0 \\
\hline 034 & 1.0000 & 0.35665 & 0.37352 & 0.48642 & Biso & 1.000 & 0 \\
\hline 035 & 1.0000 & 0.98440 & 0.64452 & 0.49897 & Biso & 1.000 & 0 \\
\hline 036 & 1.0000 & 0.63277 & 0.01778 & 0.50443 & Biso & 1.000 & 0 \\
\hline 037 & 1.0000 & 0.12657 & 0.23942 & 0.13363 & Biso & 1.000 & 0 \\
\hline 038 & 1.0000 & 0.75663 & 0.88218 & 0.13596 & Biso & 1.000 & 0 \\
\hline 039 & 1.0000 & 0.11623 & 0.87517 & 0.13450 & Biso & 1.000 & 0 \\
\hline 040 & 1.0000 & 0.23800 & 0.11539 & 0.86627 & Biso & 1.000 & 0 \\
\hline 041 & 1.0000 & 0.87292 & 0.75616 & 0.86495 & Biso & 1.000 & 0 \\
\hline 042 & 1.0000 & 0.88368 & 0.12642 & 0.86610 & Biso & 1.000 & O \\
\hline 043 & 1.0000 & 0.78455 & 0.56195 & 0.46409 & Biso & 1.000 & 0 \\
\hline 044 & 1.0000 & 0.40361 & 0.22322 & 0.48662 & Biso & 1.000 & 0 \\
\hline 045 & 1.0000 & 0.79627 & 0.20087 & 0.46501 & Biso & 1.000 & 0 \\
\hline 046 & 1.0000 & 0.90523 & 0.44689 & 0.19676 & Biso & 1.000 & 0 \\
\hline 047 & 1.0000 & 0.53861 & 0.08436 & 0.20852 & Biso & 1.000 & 0 \\
\hline 048 & 1.0000 & 0.55051 & 0.45510 & 0.20469 & Biso & 1.000 & 0 \\
\hline 049 & 1.0000 & 0.45762 & 0.90988 & 0.79759 & Biso & 1.000 & 0 \\
\hline 050 & 1.0000 & 0.09336 & 0.55244 & 0.78968 & Biso & 1.000 & 0 \\
\hline 051 & 1.0000 & 0.44918 & 0.54336 & 0.79656 & Biso & 1.000 & 0 \\
\hline 052 & 1.0000 & 0.59414 & 0.79592 & 0.53502 & Biso & 1.000 & 0 \\
\hline 053 & 1.0000 & 0.21590 & 0.44870 & 0.53762 & Biso & 1.000 & 0 \\
\hline 054 & 1.0000 & 0.21443 & 0.78426 & 0.53728 & Biso & 1.000 & 0 \\
\hline 055 & 1.0000 & 0.99605 & 0.25293 & 0.99220 & Biso & 1.000 & 0 \\
\hline
\end{tabular}




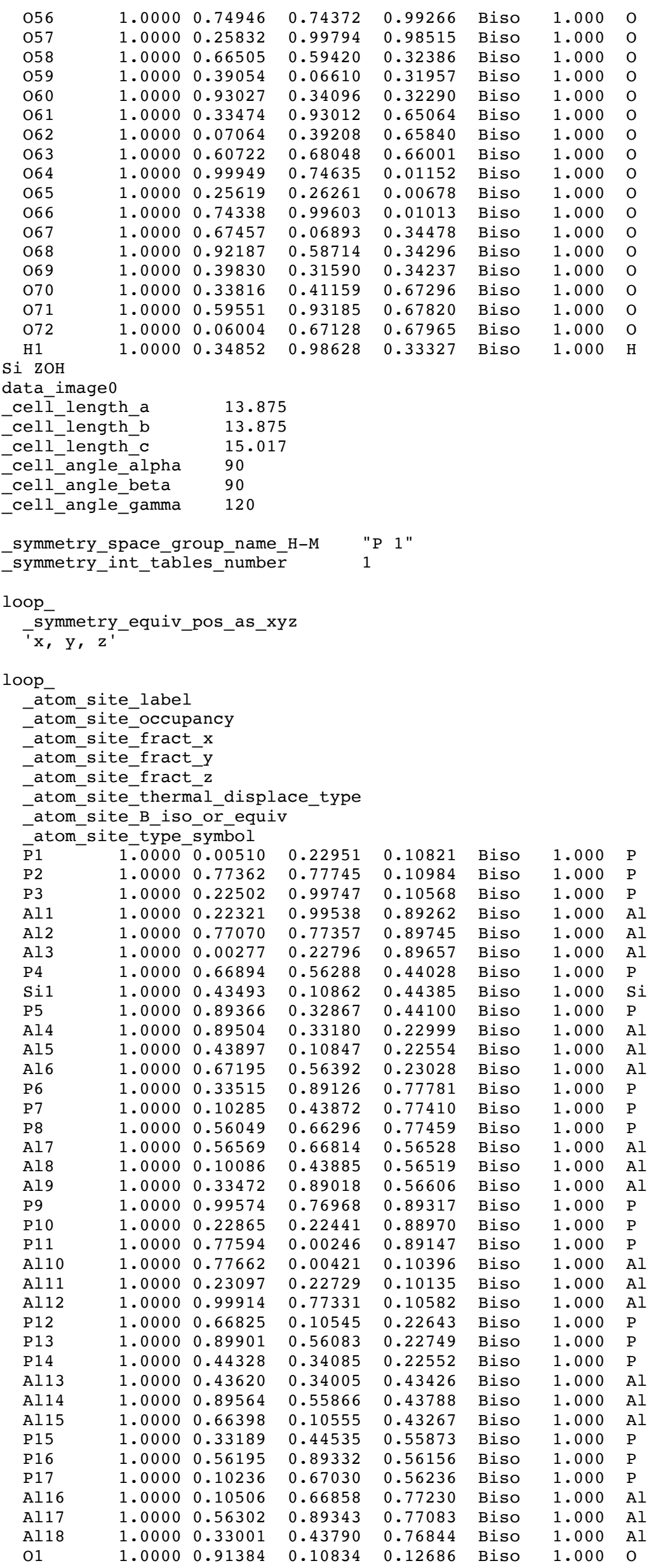




\begin{tabular}{|c|c|c|c|c|c|c|c|}
\hline $\mathrm{O} 2$ & 1.0000 & 0.89500 & 0.80660 & 0.12659 & Biso & 1.000 & 0 \\
\hline 03 & 1.0000 & 0.19743 & 0.08991 & 0.12531 & Biso & 1.000 & $\mathrm{O}$ \\
\hline 04 & 1.0000 & 0.08672 & 0.88973 & 0.87050 & Biso & 1.000 & 0 \\
\hline 05 & 1.0000 & 0.80438 & 0.91031 & 0.87231 & Biso & 1.000 & $\mathrm{O}$ \\
\hline 06 & 1.0000 & 0.10713 & 0.19515 & 0.87500 & Biso & 1.000 & 0 \\
\hline 07 & 1.0000 & 0.57415 & 0.44339 & 0.45684 & Biso & 1.000 & 0 \\
\hline 08 & 1.0000 & 0.56295 & 0.14329 & 0.43397 & Biso & 1.000 & 0 \\
\hline 09 & 1.0000 & 0.86741 & 0.42273 & 0.45856 & Biso & 1.000 & 0 \\
\hline 010 & 1.0000 & 0.75714 & 0.22774 & 0.20881 & Biso & 1.000 & 0 \\
\hline 011 & 1.0000 & 0.47128 & 0.24597 & 0.21928 & Biso & 1.000 & $\mathrm{O}$ \\
\hline 012 & 1.0000 & 0.77783 & 0.53229 & 0.21207 & Biso & 1.000 & $\mathrm{O}$ \\
\hline 013 & 1.0000 & 0.24201 & 0.77113 & 0.79730 & Biso & 1.000 & 0 \\
\hline 014 & 1.0000 & 0.22487 & 0.46992 & 0.78985 & Biso & 1.000 & O \\
\hline 015 & 1.0000 & 0.53238 & 0.75616 & 0.78828 & Biso & 1.000 & 0 \\
\hline 016 & 1.0000 & 0.42689 & 0.56622 & 0.54612 & Biso & 1.000 & 0 \\
\hline 017 & 1.0000 & 0.12436 & 0.57328 & 0.54848 & Biso & 1.000 & 0 \\
\hline 018 & 1.0000 & 0.43704 & 0.85222 & 0.54856 & Biso & 1.000 & 0 \\
\hline 019 & 1.0000 & 0.98733 & 0.31042 & 0.16575 & Biso & 1.000 & 0 \\
\hline 020 & 1.0000 & 0.69339 & 0.67738 & 0.16627 & Biso & 1.000 & 0 \\
\hline 021 & 1.0000 & 0.32910 & 0.01834 & 0.15809 & Biso & 1.000 & $\mathrm{O}$ \\
\hline 022 & 1.0000 & 0.31939 & 0.97419 & 0.83474 & Biso & 1.000 & 0 \\
\hline 023 & 1.0000 & 0.65479 & 0.67898 & 0.83701 & Biso & 1.000 & 0 \\
\hline 024 & 1.0000 & 0.02471 & 0.34354 & 0.83569 & Biso & 1.000 & $\mathrm{O}$ \\
\hline 025 & 1.0000 & 0.65593 & 0.64562 & 0.49951 & Biso & 1.000 & 0 \\
\hline 026 & 1.0000 & 0.35787 & 0.00285 & 0.50354 & Biso & 1.000 & 0 \\
\hline 027 & 1.0000 & 0.99170 & 0.34450 & 0.49866 & Biso & 1.000 & 0 \\
\hline 028 & 1.0000 & 0.01166 & 0.68542 & 0.83877 & Biso & 1.000 & 0 \\
\hline 029 & 1.0000 & 0.30811 & 0.32346 & 0.83196 & Biso & 1.000 & 0 \\
\hline 030 & 1.0000 & 0.67562 & 0.98471 & 0.83631 & Biso & 1.000 & $\mathrm{O}$ \\
\hline 031 & 1.0000 & 0.68123 & 0.02806 & 0.16096 & Biso & 1.000 & 0 \\
\hline 032 & 1.0000 & 0.34858 & 0.31887 & 0.16154 & Biso & 1.000 & O \\
\hline 033 & 1.0000 & 0.97857 & 0.65935 & 0.16888 & Biso & 1.000 & 0 \\
\hline 034 & 1.0000 & 0.34592 & 0.36644 & 0.49632 & Biso & 1.000 & 0 \\
\hline 035 & 1.0000 & 0.00464 & 0.65455 & 0.50425 & Biso & 1.000 & 0 \\
\hline 036 & 1.0000 & 0.63365 & 0.99185 & 0.50059 & Biso & 1.000 & 0 \\
\hline 037 & 1.0000 & 0.11863 & 0.24292 & 0.13223 & Biso & 1.000 & 0 \\
\hline 038 & 1.0000 & 0.76133 & 0.87709 & 0.13738 & Biso & 1.000 & 0 \\
\hline 039 & 1.0000 & 0.12787 & 0.88603 & 0.13736 & Biso & 1.000 & 0 \\
\hline 040 & 1.0000 & 0.23987 & 0.12397 & 0.86271 & Biso & 1.000 & 0 \\
\hline 041 & 1.0000 & 0.88231 & 0.75571 & 0.86917 & Biso & 1.000 & 0 \\
\hline 042 & 1.0000 & 0.87568 & 0.11490 & 0.86535 & Biso & 1.000 & $\mathrm{O}$ \\
\hline 043 & 1.0000 & 0.77951 & 0.56963 & 0.46361 & Biso & 1.000 & 0 \\
\hline 044 & 1.0000 & 0.41494 & 0.21059 & 0.45836 & Biso & 1.000 & 0 \\
\hline 045 & 1.0000 & 0.79244 & 0.21699 & 0.46586 & Biso & 1.000 & 0 \\
\hline 046 & 1.0000 & 0.91017 & 0.46024 & 0.20102 & Biso & 1.000 & 0 \\
\hline 047 & 1.0000 & 0.55316 & 0.09296 & 0.20985 & Biso & 1.000 & 0 \\
\hline 048 & 1.0000 & 0.54654 & 0.44928 & 0.19711 & Biso & 1.000 & $\mathrm{O}$ \\
\hline 049 & 1.0000 & 0.44725 & 0.90250 & 0.80303 & Biso & 1.000 & 0 \\
\hline 050 & 1.0000 & 0.09019 & 0.53941 & 0.79606 & Biso & 1.000 & 0 \\
\hline 051 & 1.0000 & 0.45777 & 0.55137 & 0.79795 & Biso & 1.000 & $\mathrm{O}$ \\
\hline 052 & 1.0000 & 0.58368 & 0.79823 & 0.53816 & Biso & 1.000 & 0 \\
\hline 053 & 1.0000 & 0.22183 & 0.43950 & 0.53531 & Biso & 1.000 & 0 \\
\hline 054 & 1.0000 & 0.20603 & 0.77830 & 0.53400 & Biso & 1.000 & 0 \\
\hline 055 & 1.0000 & 0.00259 & 0.25810 & 0.00964 & Biso & 1.000 & 0 \\
\hline 056 & 1.0000 & 0.74297 & 0.74876 & 0.01126 & Biso & 1.000 & 0 \\
\hline 057 & 1.0000 & 0.24875 & 0.99409 & 0.00660 & Biso & 1.000 & $\mathrm{O}$ \\
\hline 058 & 1.0000 & 0.66903 & 0.59596 & 0.34228 & Biso & 1.000 & 0 \\
\hline 059 & 1.0000 & 0.38067 & 0.05646 & 0.33575 & Biso & 1.000 & 0 \\
\hline 060 & 1.0000 & 0.92536 & 0.32986 & 0.34253 & Biso & 1.000 & 0 \\
\hline 061 & 1.0000 & 0.33300 & 0.91936 & 0.67935 & Biso & 1.000 & 0 \\
\hline 062 & 1.0000 & 0.06881 & 0.40124 & 0.67714 & Biso & 1.000 & 0 \\
\hline 063 & 1.0000 & 0.59724 & 0.66342 & 0.67779 & Biso & 1.000 & $\mathrm{O}$ \\
\hline 064 & 1.0000 & 0.00071 & 0.74577 & 0.99264 & Biso & 1.000 & 0 \\
\hline 065 & 1.0000 & 0.26105 & 0.25431 & 0.98811 & Biso & 1.000 & 0 \\
\hline 066 & 1.0000 & 0.74821 & 0.00197 & 0.99062 & Biso & 1.000 & O \\
\hline 067 & 1.0000 & 0.67727 & 0.07071 & 0.32172 & Biso & 1.000 & 0 \\
\hline 068 & 1.0000 & 0.93208 & 0.59217 & 0.32555 & Biso & 1.000 & O \\
\hline 069 & 1.0000 & 0.40854 & 0.34941 & 0.32069 & Biso & 1.000 & 0 \\
\hline 070 & 1.0000 & 0.32991 & 0.40746 & 0.65553 & Biso & 1.000 & 0 \\
\hline 071 & 1.0000 & 0.59570 & 0.93032 & 0.65893 & Biso & 1.000 & $\mathrm{O}$ \\
\hline 072 & 1.0000 & 0.07418 & 0.67669 & 0.66057 & Biso & 1.000 & $\mathrm{O}$ \\
\hline H 1 & 1.0000 & 0.30708 & 0.99021 & 0.33843 & Biso & 1.000 & $\mathrm{H}$ \\
\hline
\end{tabular}

$\mathrm{Mg} \mathrm{ZOH}$

data image 0

$\begin{array}{ll}\text {-cel1_length_a } & 13.875 \\ \text {-cell_length_b } & 13.875 \\ \text {-cell_length_c } & 15.017 \\ \text {-cell_angle_alpha } & 90 \\ \text {-cell_angle_beta } & 90 \\ \text {-cell_angle_gamma } & 120\end{array}$




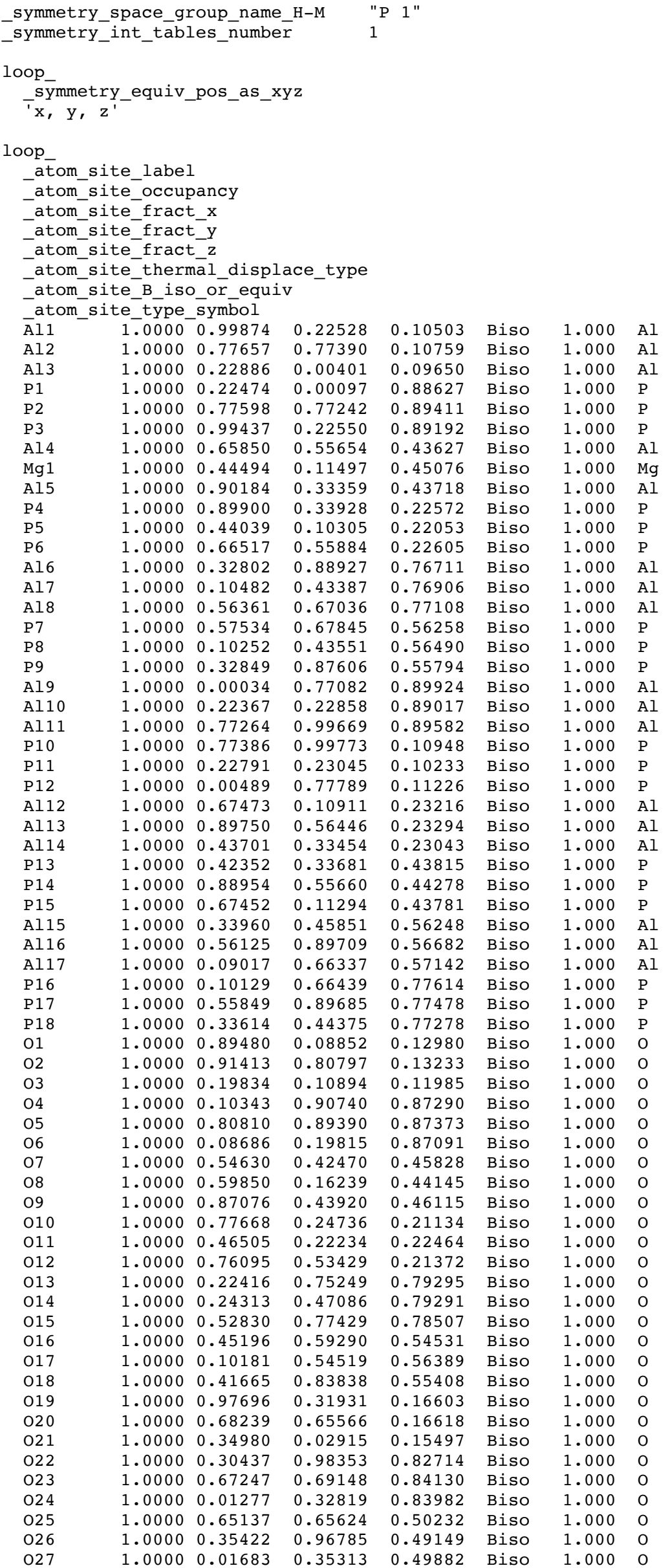




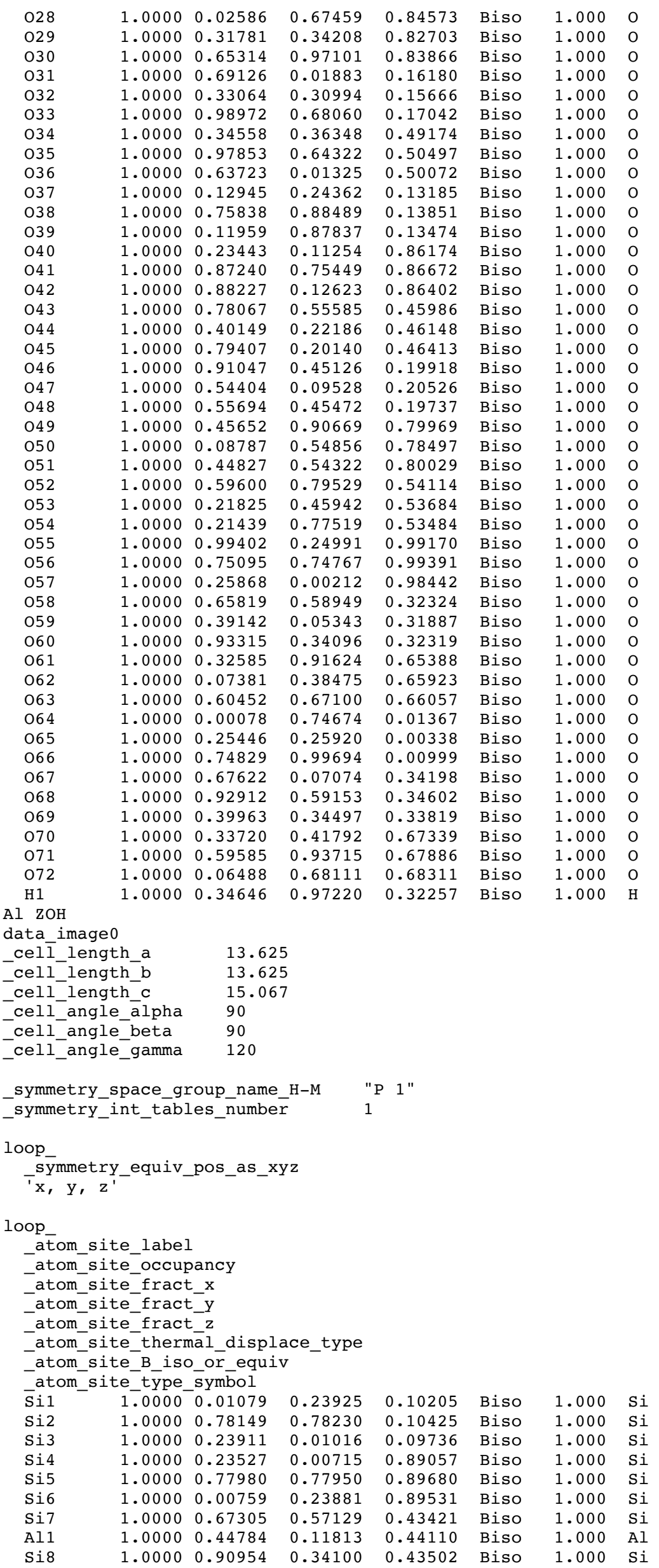




\begin{tabular}{|c|c|c|c|c|c|c|c|}
\hline Si9 & 1.0000 & 0.90920 & 0.34542 & 0.22852 & Biso & 1.000 & $\mathrm{Si}$ \\
\hline Si10 & 1.0000 & 0.44705 & 0.11345 & 0.22301 & Biso & 1.000 & $\mathrm{Si}$ \\
\hline Si11 & 1.0000 & 0.67758 & 0.57287 & 0.22956 & Biso & 1.000 & $\mathrm{Si}$ \\
\hline Si12 & 1.0000 & 0.34061 & 0.90076 & 0.76977 & Biso & 1.000 & \\
\hline Si13 & 1.0000 & 0.11022 & 0.44261 & 0.76684 & Biso & 1.000 & \\
\hline Si14 & 1.0000 & 0.57339 & 0.67536 & 0.76841 & Biso & 1.000 & \\
\hline Si15 & 1.0000 & 0.58143 & 0.68146 & 0.56461 & Biso & 1.000 & \\
\hline Si16 & 1.0000 & 0.10919 & 0.44392 & 0.56541 & Biso & 1.000 & \\
\hline Si17 & 1.0000 & 0.34044 & 0.89547 & 0.56280 & Biso & 1.000 & \\
\hline Si18 & 1.0000 & 0.00717 & 0.77664 & 0.89731 & Biso & 1.000 & \\
\hline Si19 & 1.0000 & 0.23763 & 0.23810 & 0.89148 & Biso & 1.000 & \\
\hline Si20 & 1.0000 & 0.78091 & 0.00846 & 0.89463 & Biso & 1.000 & \\
\hline Si21 & 1.0000 & 0.78128 & 0.01006 & 0.10229 & Biso & 1.000 & \\
\hline Si22 & 1.0000 & 0.24139 & 0.24079 & 0.09813 & Biso & 1.000 & \\
\hline Si23 & 1.0000 & 0.01116 & 0.78270 & 0.10495 & Biso & 1.000 & \\
\hline Si24 & 1.0000 & 0.68061 & 0.11469 & 0.22989 & Biso & 1.000 & \\
\hline Si25 & 1.0000 & 0.90978 & 0.57408 & 0.23133 & Biso & 1.000 & \\
\hline Si26 & 1.0000 & 0.44673 & 0.34715 & 0.22869 & Biso & 1.000 & \\
\hline Si27 & 1.0000 & 0.43803 & 0.34728 & 0.43204 & Biso & 1.000 & \\
\hline Si28 & 1.0000 & 0.90454 & 0.56906 & 0.43645 & Biso & 1.000 & \\
\hline Si29 & 1.0000 & 0.67845 & 0.11617 & 0.43171 & Biso & 1.000 & \\
\hline Si30 & 1.0000 & 0.34528 & 0.45730 & 0.56146 & Biso & 1.000 & \\
\hline Si31 & 1.0000 & 0.57227 & 0.90645 & 0.56436 & Biso & 1.000 & \\
\hline Si32 & 1.0000 & 0.10398 & 0.67611 & 0.56744 & Biso & 1.000 & \\
\hline Si33 & 1.0000 & 0.10960 & 0.67534 & 0.77008 & Biso & 1.000 & \\
\hline Si34 & 1.0000 & 0.57181 & 0.90638 & 0.76838 & Biso & 1.000 & \\
\hline Si35 & 1.0000 & 0.34202 & 0.44751 & 0.76661 & Biso & 1.000 & \\
\hline 01 & 1.0000 & 0.91200 & 0.10871 & 0.12038 & Biso & 1.000 & \\
\hline $\mathrm{O} 2$ & 1.0000 & 0.91283 & 0.81535 & 0.12137 & Biso & 1.000 & \\
\hline $\mathrm{O} 3$ & 1.0000 & 0.21031 & 0.11028 & 0.11657 & Biso & 1.000 & \\
\hline 04 & 1.0000 & 0.10502 & 0.90647 & 0.87535 & Biso & 1.000 & \\
\hline 05 & 1.0000 & 0.81428 & 0.91060 & 0.87742 & Biso & 1.000 & \\
\hline 06 & 1.0000 & 0.10712 & 0.20812 & 0.87782 & Biso & 1.000 & \\
\hline 07 & 1.0000 & 0.56979 & 0.44360 & 0.45141 & Biso & 1.000 & \\
\hline 08 & 1.0000 & 0.58898 & 0.16005 & 0.43436 & Biso & 1.000 & \\
\hline 09 & 1.0000 & 0.87865 & 0.44037 & 0.45439 & Biso & 1.000 & \\
\hline 010 & 1.0000 & 0.77804 & 0.24593 & 0.21334 & Biso & 1.000 & \\
\hline 011 & 1.0000 & 0.47346 & 0.24212 & 0.22382 & Biso & 1.000 & \\
\hline 012 & 1.0000 & 0.77930 & 0.54415 & 0.21784 & Biso & 1.000 & \\
\hline 013 & 1.0000 & 0.24070 & 0.77119 & 0.79027 & Biso & 1.000 & \\
\hline 014 & 1.0000 & 0.24187 & 0.47757 & 0.78436 & Biso & 1.000 & \\
\hline 015 & 1.0000 & 0.54209 & 0.77541 & 0.77877 & Biso & 1.000 & \\
\hline 016 & 1.0000 & 0.44925 & 0.58645 & 0.54818 & Biso & 1.000 & \\
\hline 017 & 1.0000 & 0.12313 & 0.56862 & 0.55915 & Biso & 1.000 & \\
\hline 018 & 1.0000 & 0.43678 & 0.85766 & 0.55158 & Biso & 1.000 & \\
\hline 019 & 1.0000 & 0.99380 & 0.32574 & 0.16506 & Biso & 1.000 & \\
\hline $\mathrm{O} 20$ & 1.0000 & 0.69646 & 0.67593 & 0.16528 & Biso & 1.000 & \\
\hline 021 & 1.0000 & 0.34918 & 0.03089 & 0.15521 & Biso & 1.000 & O \\
\hline 022 & 1.0000 & 0.32252 & 0.98973 & 0.82932 & Biso & 1.000 & 0 \\
\hline 023 & 1.0000 & 0.67280 & 0.69351 & 0.83673 & Biso & 1.000 & 0 \\
\hline $\mathrm{O} 24$ & 1.0000 & 0.02640 & 0.34497 & 0.83522 & Biso & 1.000 & 0 \\
\hline 025 & 1.0000 & 0.66413 & 0.66124 & 0.49925 & Biso & 1.000 & O \\
\hline 026 & 1.0000 & 0.36265 & 0.99750 & 0.49874 & Biso & 1.000 & 0 \\
\hline 027 & 1.0000 & 0.01446 & 0.35795 & 0.49634 & Biso & 1.000 & 0 \\
\hline 028 & 1.0000 & 0.02514 & 0.68691 & 0.83951 & Biso & 1.000 & \\
\hline 029 & 1.0000 & 0.32287 & 0.34152 & 0.82794 & Biso & 1.000 & 0 \\
\hline 030 & 1.0000 & 0.67454 & 0.98814 & 0.83408 & Biso & 1.000 & 0 \\
\hline 031 & 1.0000 & 0.69393 & 0.03115 & 0.16091 & Biso & 1.000 & 0 \\
\hline 032 & 1.0000 & 0.34813 & 0.32628 & 0.15877 & Biso & 1.000 & O \\
\hline 033 & 1.0000 & 0.99413 & 0.68006 & 0.16897 & Biso & 1.000 & 0 \\
\hline 034 & 1.0000 & 0.35479 & 0.37125 & 0.49353 & Biso & 1.000 & 0 \\
\hline 035 & 1.0000 & 0.00126 & 0.65883 & 0.50304 & Biso & 1.000 & o \\
\hline 036 & 1.0000 & 0.64700 & 0.01073 & 0.49811 & Biso & 1.000 & 0 \\
\hline 037 & 1.0000 & 0.13279 & 0.25216 & 0.12546 & Biso & 1.000 & 0 \\
\hline 038 & 1.0000 & 0.76805 & 0.88978 & 0.13171 & Biso & 1.000 & o \\
\hline 039 & 1.0000 & 0.13325 & 0.89137 & 0.13046 & Biso & 1.000 & 0 \\
\hline 040 & 1.0000 & 0.24610 & 0.12742 & 0.86523 & Biso & 1.000 & 0 \\
\hline 041 & 1.0000 & 0.88583 & 0.76281 & 0.87127 & Biso & 1.000 & 0 \\
\hline 042 & 1.0000 & 0.88781 & 0.12999 & 0.86788 & Biso & 1.000 & 0 \\
\hline 043 & 1.0000 & 0.79076 & 0.57430 & 0.45492 & Biso & 1.000 & 0 \\
\hline O4 4 & 1.0000 & 0.41805 & 0.22428 & 0.45267 & Biso & 1.000 & 0 \\
\hline 045 & 1.0000 & 0.80345 & 0.21835 & 0.45940 & Biso & 1.000 & 0 \\
\hline 046 & 1.0000 & 0.92022 & 0.46556 & 0.20128 & Biso & 1.000 & O \\
\hline 047 & 1.0000 & 0.55880 & 0.10528 & 0.20858 & Biso & 1.000 & 0 \\
\hline 048 & 1.0000 & 0.56084 & 0.46132 & 0.19967 & Biso & 1.000 & 0 \\
\hline 049 & 1.0000 & 0.46121 & 0.91357 & 0.79772 & Biso & 1.000 & 0 \\
\hline 050 & 1.0000 & 0.09640 & 0.55193 & 0.78389 & Biso & 1.000 & 0 \\
\hline 051 & 1.0000 & 0.46226 & 0.55605 & 0.79379 & Biso & 1.000 & 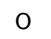 \\
\hline 052 & 1.0000 & 0.59913 & 0.80560 & 0.54280 & Biso & 1.000 & 0 \\
\hline 053 & 1.0000 & 0.22906 & 0.45591 & 0.53864 & Biso & 1.000 & 0 \\
\hline
\end{tabular}




\begin{tabular}{|c|c|c|c|c|c|c|c|}
\hline 054 & 1.0000 & 0.21862 & 0.78759 & 0.53591 & Biso & 1.000 & 0 \\
\hline 055 & 1.0000 & 0.00709 & 0.27234 & 0.99893 & Biso & 1.000 & 0 \\
\hline 056 & 1.0000 & 0.74690 & 0.74869 & 0.00089 & Biso & 1.000 & 0 \\
\hline 057 & 1.0000 & 0.26988 & 0.00702 & 0.99419 & Biso & 1.000 & 0 \\
\hline 058 & 1.0000 & 0.67116 & 0.60854 & 0.33145 & Biso & 1.000 & 0 \\
\hline 059 & 1.0000 & 0.39288 & 0.05909 & 0.32507 & Biso & 1.000 & 0 \\
\hline 060 & 1.0000 & 0.94603 & 0.34660 & 0.33120 & Biso & 1.000 & 0 \\
\hline 061 & 1.0000 & 0.33901 & 0.93122 & 0.66610 & Biso & 1.000 & $\mathrm{O}$ \\
\hline 062 & 1.0000 & 0.07300 & 0.39484 & 0.66606 & Biso & 1.000 & 0 \\
\hline 063 & 1.0000 & 0.61553 & 0.67412 & 0.66737 & Biso & 1.000 & 0 \\
\hline 064 & 1.0000 & 0.01076 & 0.74780 & 0.00183 & Biso & 1.000 & 0 \\
\hline 065 & 1.0000 & 0.27539 & 0.27350 & 0.99455 & Biso & 1.000 & 0 \\
\hline 066 & 1.0000 & 0.74798 & 0.00804 & 0.99851 & Biso & 1.000 & 0 \\
\hline 067 & 1.0000 & 0.68440 & 0.07404 & 0.33031 & Biso & 1.000 & 0 \\
\hline 068 & 1.0000 & 0.94812 & 0.60672 & 0.33446 & Biso & 1.000 & $\mathrm{O}$ \\
\hline 069 & 1.0000 & 0.40776 & 0.35742 & 0.32795 & Biso & 1.000 & 0 \\
\hline 070 & 1.0000 & 0.34337 & 0.41474 & 0.66299 & Biso & 1.000 & 0 \\
\hline 071 & 1.0000 & 0.60841 & 0.94979 & 0.66667 & Biso & 1.000 & 0 \\
\hline 072 & 1.0000 & 0.07331 & 0.68933 & 0.66981 & Biso & 1.000 & 0 \\
\hline $\mathrm{H} 1$ & 1.0000 & 0.32800 & 0.98228 & 0.32630 & Biso & 1.000 & $\mathrm{H}$ \\
\hline $\mathrm{ZOH}$ & & & & & & & \\
\hline . & & & & & & & \\
\hline celì & h_a & 13.87 & & & & & \\
\hline cell__ & $=h_{-}^{-} b$ & 13.87 & & & & & \\
\hline cell- & $\mathrm{h}-\mathrm{C}$ & 15.01 & & & & & \\
\hline cell_ & alpha & 90 & & & & & \\
\hline cell- & beta & 90 & & & & & \\
\hline _cell_- & _gamma & 120 & & & & & \\
\hline symme & pace gr & coup name & & $1 "$ & & & \\
\hline symme & $n t \_t \overline{a b}$ & Les_numbe & & & & & \\
\hline loop & & & & & & & \\
\hline $\bar{s}_{\mathrm{x}}^{\mathrm{sym}}$ & _equiv & pos_as_x & & & & & \\
\hline oop_ & & & & & & & \\
\hline ator & e_label & & & & & & \\
\hline -ator & e-occup & pancy & & & & & \\
\hline -ator & ce-fract & $=x^{2}$ & & & & & \\
\hline -ator & ce_fract & $=-y$ & & & & & \\
\hline ator & e fract & & & & & & \\
\hline -ator & $=e^{-}$therm & nāl_displ & ce_type & & & & \\
\hline -ator & $e^{-} \mathrm{B}$ _isc & oror_equi & & & & & \\
\hline ator & ce_type & symb̄ol & & & & & \\
\hline$\overline{\mathrm{P}} 1$ & 1.0000 & 0.00595 & 0.22909 & 0.10868 & Biso & 1.000 & $\mathrm{P}$ \\
\hline $\mathrm{P} 2$ & 1.0000 & 0.77548 & 0.77857 & 0.11179 & Biso & 1.000 & $\mathrm{P}$ \\
\hline P3 & 1.0000 & 0.22612 & 0.99790 & 0.10178 & Biso & 1.000 & $\mathrm{P}$ \\
\hline Al1 & 1.0000 & 0.21909 & 0.99283 & 0.88810 & Biso & 1.000 & $\mathrm{Al}$ \\
\hline Al2 & 1.0000 & 0.77150 & 0.77362 & 0.89881 & Biso & 1.000 & Al \\
\hline A13 & 1.0000 & 0.00077 & 0.22772 & 0.89642 & Biso & 1.000 & $\mathrm{Al}$ \\
\hline P 4 & 1.0000 & 0.66863 & 0.56075 & 0.44093 & Biso & 1.000 & $\mathrm{P}$ \\
\hline $\mathrm{Ge} 1$ & 1.0000 & 0.43223 & 0.11160 & 0.44817 & Biso & 1.000 & $\mathrm{Ge}$ \\
\hline P5 & 1.0000 & 0.89806 & 0.32847 & 0.44043 & Biso & 1.000 & $P$ \\
\hline Al4 & 1.0000 & 0.89726 & 0.33300 & 0.22956 & Biso & 1.000 & $\mathrm{Al}$ \\
\hline Al5 & 1.0000 & 0.44010 & 0.10997 & 0.21965 & Biso & 1.000 & Al \\
\hline Al 6 & 1.0000 & 0.67342 & 0.56462 & 0.23126 & Biso & 1.000 & Al \\
\hline P6 & 1.0000 & 0.33348 & 0.88803 & 0.77720 & Biso & 1.000 & $P$ \\
\hline P7 & 1.0000 & 0.10220 & 0.43516 & 0.77293 & Biso & 1.000 & $P$ \\
\hline P8 & 1.0000 & 0.56069 & 0.66293 & 0.77479 & Biso & 1.000 & $\mathrm{P}$ \\
\hline Al7 & 1.0000 & 0.57306 & 0.67336 & 0.56789 & Biso & 1.000 & $\mathrm{Al}$ \\
\hline A18 & 1.0000 & 0.09724 & 0.43391 & 0.56926 & Biso & 1.000 & $\mathrm{Al}$ \\
\hline Al9 & 1.0000 & 0.33332 & 0.87905 & 0.56502 & Biso & 1.000 & Al \\
\hline P9 & 1.0000 & 0.99360 & 0.76654 & 0.89360 & Biso & 1.000 & $\mathrm{P}$ \\
\hline P10 & 1.0000 & 0.22687 & 0.22369 & 0.88643 & Biso & 1.000 & $P$ \\
\hline P11 & 1.0000 & 0.77713 & 0.00206 & 0.89241 & Biso & 1.000 & $\mathrm{P}$ \\
\hline Al10 & 1.0000 & 0.77911 & 0.00515 & 0.10591 & Biso & 1.000 & Al \\
\hline Al 11 & 1.0000 & 0.23296 & 0.22857 & 0.09821 & Biso & 1.000 & Al \\
\hline Al 12 & 1.0000 & 0.00066 & 0.77536 & 0.10769 & Biso & 1.000 & $\mathrm{Al}$ \\
\hline P12 & 1.0000 & 0.66874 & 0.10629 & 0.22670 & Biso & 1.000 & $P$ \\
\hline P13 & 1.0000 & 0.89972 & 0.56116 & 0.22806 & Biso & 1.000 & $P$ \\
\hline P14 & 1.0000 & 0.44399 & 0.34042 & 0.22313 & Biso & 1.000 & $\mathrm{P}$ \\
\hline Al13 & 1.0000 & 0.43102 & 0.34260 & 0.43409 & Biso & 1.000 & Al \\
\hline Al 14 & 1.0000 & 0.89564 & 0.55694 & 0.43911 & Biso & 1.000 & Al \\
\hline Al 15 & 1.0000 & 0.66560 & 0.10893 & 0.43374 & Biso & 1.000 & $\mathrm{Al}$ \\
\hline P15 & 1.0000 & 0.33441 & 0.45698 & 0.55763 & Biso & 1.000 & $P$ \\
\hline P16 & 1.0000 & 0.56561 & 0.89565 & 0.56371 & Biso & 1.000 & $P$ \\
\hline P17 & 1.0000 & 0.09541 & 0.66745 & 0.56745 & Biso & 1.000 & $\mathrm{P}$ \\
\hline Al16 & 1.0000 & 0.10255 & 0.66801 & 0.77197 & Biso & 1.000 & Al \\
\hline Al17 & 1.0000 & 0.56134 & 0.89256 & 0.77220 & Biso & 1.000 & Al \\
\hline
\end{tabular}




\begin{tabular}{|c|c|c|c|c|c|c|c|}
\hline Al18 & 1.0000 & 0.32956 & 0.43781 & 0.76584 & Biso & 1.000 & Al \\
\hline 01 & 1.0000 & 0.91609 & 0.10845 & 0.13089 & Biso & 1.000 & 0 \\
\hline $\mathrm{O} 2$ & 1.0000 & 0.89684 & 0.80867 & 0.13005 & Biso & 1.000 & 0 \\
\hline $\mathrm{O} 3$ & 1.0000 & 0.20039 & 0.09147 & 0.12212 & Biso & 1.000 & 0 \\
\hline 04 & 1.0000 & 0.08339 & 0.88521 & 0.86606 & Biso & 1.000 & 0 \\
\hline 05 & 1.0000 & 0.80799 & 0.91143 & 0.87365 & Biso & 1.000 & 0 \\
\hline 06 & 1.0000 & 0.10580 & 0.19650 & 0.87321 & Biso & 1.000 & 0 \\
\hline 07 & 1.0000 & 0.57077 & 0.44221 & 0.45493 & Biso & 1.000 & 0 \\
\hline 08 & 1.0000 & 0.57431 & 0.16018 & 0.43813 & Biso & 1.000 & 0 \\
\hline 09 & 1.0000 & 0.87317 & 0.42298 & 0.46029 & Biso & 1.000 & 0 \\
\hline 010 & 1.0000 & 0.75906 & 0.22835 & 0.21035 & Biso & 1.000 & 0 \\
\hline 011 & 1.0000 & 0.47506 & 0.24826 & 0.21218 & Biso & 1.000 & 0 \\
\hline 012 & 1.0000 & 0.77840 & 0.53194 & 0.21176 & Biso & 1.000 & 0 \\
\hline 013 & 1.0000 & 0.24022 & 0.76839 & 0.79843 & Biso & 1.000 & 0 \\
\hline 014 & 1.0000 & 0.22510 & 0.47033 & 0.79040 & Biso & 1.000 & 0 \\
\hline 015 & 1.0000 & 0.52859 & 0.75388 & 0.78436 & Biso & 1.000 & 0 \\
\hline 016 & 1.0000 & 0.43213 & 0.57719 & 0.55063 & Biso & 1.000 & 0 \\
\hline 017 & 1.0000 & 0.10082 & 0.56017 & 0.56537 & Biso & 1.000 & $\mathrm{O}$ \\
\hline 018 & 1.0000 & 0.43959 & 0.84634 & 0.54858 & Biso & 1.000 & 0 \\
\hline 019 & 1.0000 & 0.98966 & 0.31167 & 0.16532 & Biso & 1.000 & 0 \\
\hline $\mathrm{O} 20$ & 1.0000 & 0.69465 & 0.67791 & 0.16733 & Biso & 1.000 & $\mathrm{O}$ \\
\hline 021 & 1.0000 & 0.33357 & 0.02014 & 0.14942 & Biso & 1.000 & 0 \\
\hline 022 & 1.0000 & 0.31595 & 0.97289 & 0.82985 & Biso & 1.000 & 0 \\
\hline $\mathrm{O} 23$ & 1.0000 & 0.65150 & 0.68095 & 0.84175 & Biso & 1.000 & 0 \\
\hline $\mathrm{O} 24$ & 1.0000 & 0.02563 & 0.34780 & 0.84071 & Biso & 1.000 & 0 \\
\hline 025 & 1.0000 & 0.65771 & 0.64419 & 0.50092 & Biso & 1.000 & $\mathrm{O}$ \\
\hline 026 & 1.0000 & 0.34476 & 0.98495 & 0.49861 & Biso & 1.000 & $\mathrm{O}$ \\
\hline $\mathrm{O} 27$ & 1.0000 & 0.99602 & 0.34119 & 0.49666 & Biso & 1.000 & 0 \\
\hline 028 & 1.0000 & 0.01020 & 0.67926 & 0.84422 & Biso & 1.000 & 0 \\
\hline 029 & 1.0000 & 0.30639 & 0.32131 & 0.82734 & Biso & 1.000 & 0 \\
\hline 030 & 1.0000 & 0.67343 & 0.97960 & 0.83986 & Biso & 1.000 & 0 \\
\hline 031 & 1.0000 & 0.68355 & 0.02875 & 0.16271 & Biso & 1.000 & $\mathrm{O}$ \\
\hline 032 & 1.0000 & 0.35037 & 0.32069 & 0.15861 & Biso & 1.000 & 0 \\
\hline 033 & 1.0000 & 0.97970 & 0.66105 & 0.17072 & Biso & 1.000 & $\mathrm{O}$ \\
\hline 034 & 1.0000 & 0.34578 & 0.38223 & 0.48892 & Biso & 1.000 & 0 \\
\hline 035 & 1.0000 & 0.00284 & 0.65670 & 0.50518 & Biso & 1.000 & 0 \\
\hline 036 & 1.0000 & 0.63232 & 0.99514 & 0.50227 & Biso & 1.000 & 0 \\
\hline 037 & 1.0000 & 0.12086 & 0.24430 & 0.12987 & Biso & 1.000 & 0 \\
\hline 038 & 1.0000 & 0.76161 & 0.87727 & 0.13914 & Biso & 1.000 & 0 \\
\hline 039 & 1.0000 & 0.13050 & 0.88785 & 0.13761 & Biso & 1.000 & 0 \\
\hline 040 & 1.0000 & 0.23504 & 0.12150 & 0.85936 & Biso & 1.000 & 0 \\
\hline 041 & 1.0000 & 0.87931 & 0.75017 & 0.86857 & Biso & 1.000 & 0 \\
\hline 042 & 1.0000 & 0.87397 & 0.11508 & 0.86303 & Biso & 1.000 & 0 \\
\hline 043 & 1.0000 & 0.77632 & 0.56200 & 0.46523 & Biso & 1.000 & 0 \\
\hline 044 & 1.0000 & 0.39775 & 0.21256 & 0.47237 & Biso & 1.000 & 0 \\
\hline 045 & 1.0000 & 0.79692 & 0.21657 & 0.46466 & Biso & 1.000 & 0 \\
\hline 046 & 1.0000 & 0.91197 & 0.46141 & 0.20067 & Biso & 1.000 & 0 \\
\hline 047 & 1.0000 & 0.55476 & 0.09453 & 0.20672 & Biso & 1.000 & 0 \\
\hline 048 & 1.0000 & 0.54636 & 0.45175 & 0.19929 & Biso & 1.000 & 0 \\
\hline 049 & 1.0000 & 0.44546 & 0.90101 & 0.80575 & Biso & 1.000 & 0 \\
\hline 050 & 1.0000 & 0.08760 & 0.53672 & 0.78305 & Biso & 1.000 & 0 \\
\hline 051 & 1.0000 & 0.45832 & 0.54991 & 0.79547 & Biso & 1.000 & 0 \\
\hline 052 & 1.0000 & 0.59680 & 0.80636 & 0.54256 & Biso & 1.000 & 0 \\
\hline 053 & 1.0000 & 0.22728 & 0.45831 & 0.53678 & Biso & 1.000 & 0 \\
\hline 054 & 1.0000 & 0.20687 & 0.76317 & 0.53505 & Biso & 1.000 & 0 \\
\hline 055 & 1.0000 & 0.99857 & 0.25356 & 0.00995 & Biso & 1.000 & 0 \\
\hline 056 & 1.0000 & 0.74679 & 0.75052 & 0.01296 & Biso & 1.000 & 0 \\
\hline 057 & 1.0000 & 0.24321 & 0.99059 & 0.00202 & Biso & 1.000 & 0 \\
\hline 058 & 1.0000 & 0.67241 & 0.59713 & 0.34342 & Biso & 1.000 & 0 \\
\hline 059 & 1.0000 & 0.37854 & 0.06160 & 0.32865 & Biso & 1.000 & 0 \\
\hline 060 & 1.0000 & 0.92914 & 0.33168 & 0.34167 & Biso & 1.000 & 0 \\
\hline 061 & 1.0000 & 0.33378 & 0.91247 & 0.67758 & Biso & 1.000 & 0 \\
\hline 062 & 1.0000 & 0.06787 & 0.38429 & 0.67899 & Biso & 1.000 & 0 \\
\hline 063 & 1.0000 & 0.60439 & 0.66518 & 0.68003 & Biso & 1.000 & 0 \\
\hline 064 & 1.0000 & 0.00008 & 0.74922 & 0.99410 & Biso & 1.000 & $\mathrm{O}$ \\
\hline 065 & 1.0000 & 0.26146 & 0.25439 & 0.98449 & Biso & 1.000 & 0 \\
\hline 066 & 1.0000 & 0.75332 & 0.00430 & 0.99212 & Biso & 1.000 & 0 \\
\hline 067 & 1.0000 & 0.67288 & 0.07057 & 0.32274 & Biso & 1.000 & 0 \\
\hline 068 & 1.0000 & 0.93104 & 0.59071 & 0.32662 & Biso & 1.000 & 0 \\
\hline 069 & 1.0000 & 0.40595 & 0.34098 & 0.31880 & Biso & 1.000 & $\mathrm{O}$ \\
\hline 070 & 1.0000 & 0.32939 & 0.41030 & 0.65191 & Biso & 1.000 & $\mathrm{O}$ \\
\hline 071 & 1.0000 & 0.59563 & 0.93485 & 0.66113 & Biso & 1.000 & 0 \\
\hline 072 & 1.0000 & 0.07092 & 0.68959 & 0.66313 & Biso & 1.000 & 0 \\
\hline $\mathrm{H} 1$ & 1.0000 & 0.31145 & 0.98875 & 0.33370 & Biso & 1.000 & $\mathrm{H}$ \\
\hline \\
\hline \multicolumn{8}{|c|}{$\begin{array}{l}\mathrm{Ga} \mathrm{ZOH} \\
\text { data image } 0\end{array}$} \\
\hline \multicolumn{2}{|c|}{ celil length a } & \multicolumn{2}{|c|}{13.625} & & & & \\
\hline \multicolumn{2}{|c|}{ cell length b } & 13.62 & & & & & \\
\hline cell & $=\mathrm{h}-\mathrm{C}$ & 15.06 & & & & & \\
\hline cell- & $\bar{a} l p h a$ & 90 & & & & & \\
\hline
\end{tabular}




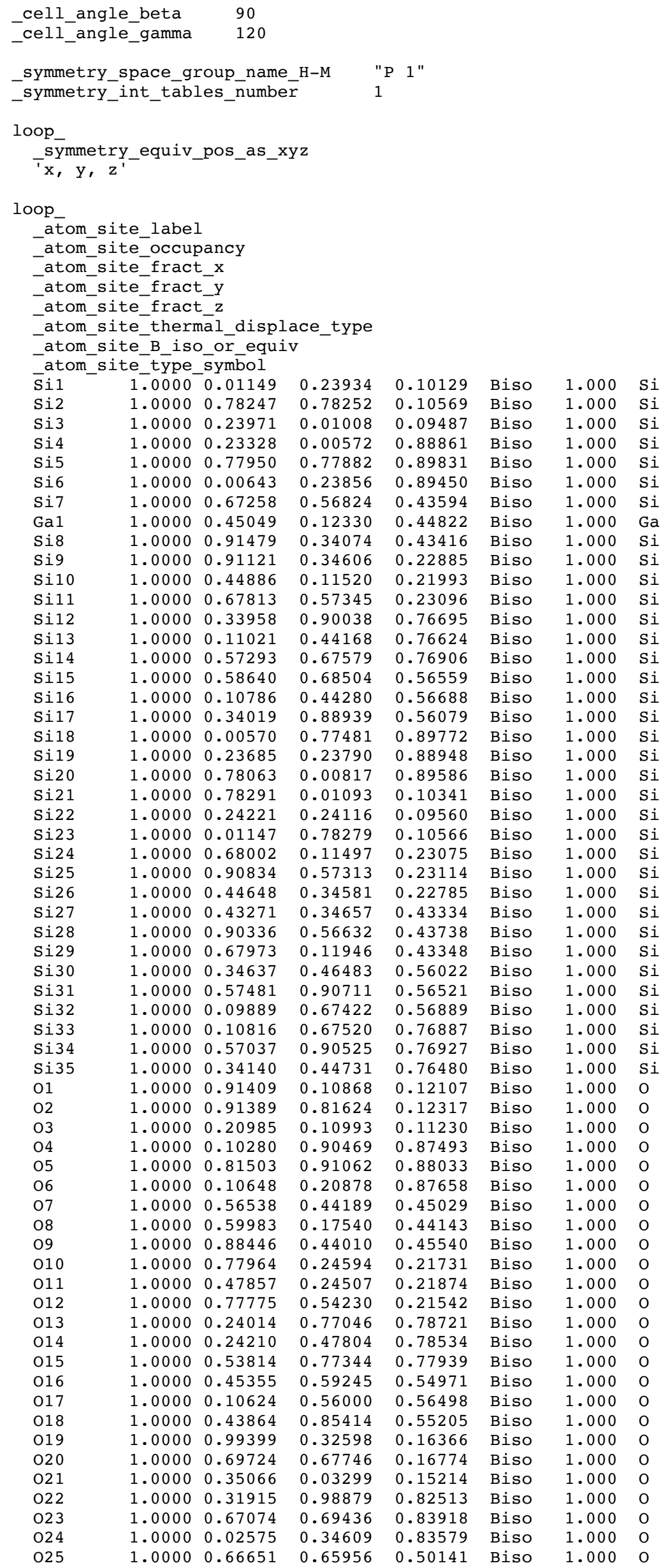




\begin{tabular}{|c|c|c|c|c|c|c|c|}
\hline 026 & 1.0000 & 0.35643 & 0.98512 & 0.49118 & Biso & 1.000 & 0 \\
\hline 027 & 1.0000 & 0.01852 & 0.35462 & 0.49572 & Biso & 1.000 & 0 \\
\hline 028 & 1.0000 & 0.02567 & 0.68514 & 0.84140 & Biso & 1.000 & 0 \\
\hline 029 & 1.0000 & 0.32161 & 0.33953 & 0.82422 & Biso & 1.000 & 0 \\
\hline 030 & 1.0000 & 0.67257 & 0.98500 & 0.83615 & Biso & 1.000 & 0 \\
\hline 031 & 1.0000 & 0.69698 & 0.03187 & 0.16390 & Biso & 1.000 & 0 \\
\hline 032 & 1.0000 & 0.34870 & 0.32536 & 0.15713 & Biso & 1.000 & 0 \\
\hline 033 & 1.0000 & 0.99407 & 0.68024 & 0.17014 & Biso & 1.000 & 0 \\
\hline 034 & 1.0000 & 0.35146 & 0.38017 & 0.48816 & Biso & 1.000 & 0 \\
\hline 035 & 1.0000 & 0.99971 & 0.66090 & 0.50201 & Biso & 1.000 & 0 \\
\hline 036 & 1.0000 & 0.64574 & 0.01418 & 0.50048 & Biso & 1.000 & 0 \\
\hline 037 & 1.0000 & 0.13435 & 0.25368 & 0.12343 & Biso & 1.000 & 0 \\
\hline 038 & 1.0000 & 0.76869 & 0.89007 & 0.13177 & Biso & 1.000 & 0 \\
\hline 039 & 1.0000 & 0.13448 & 0.89136 & 0.12915 & Biso & 1.000 & 0 \\
\hline 040 & 1.0000 & 0.24342 & 0.12592 & 0.86424 & Biso & 1.000 & 0 \\
\hline 041 & 1.0000 & 0.88409 & 0.76033 & 0.87089 & Biso & 1.000 & 0 \\
\hline 042 & 1.0000 & 0.88664 & 0.12948 & 0.86681 & Biso & 1.000 & 0 \\
\hline 043 & 1.0000 & 0.78616 & 0.56391 & 0.45851 & Biso & 1.000 & 0 \\
\hline 044 & 1.0000 & 0.40624 & 0.22403 & 0.46640 & Biso & 1.000 & 0 \\
\hline 045 & 1.0000 & 0.80871 & 0.21700 & 0.45607 & Biso & 1.000 & 0 \\
\hline 046 & 1.0000 & 0.92038 & 0.46539 & 0.20151 & Biso & 1.000 & 0 \\
\hline 047 & 1.0000 & 0.56009 & 0.10614 & 0.20385 & Biso & 1.000 & 0 \\
\hline 048 & 1.0000 & 0.55853 & 0.46413 & 0.20325 & Biso & 1.000 & 0 \\
\hline 049 & 1.0000 & 0.46030 & 0.91452 & 0.79671 & Biso & 1.000 & 0 \\
\hline 050 & 1.0000 & 0.09527 & 0.55124 & 0.77839 & Biso & 1.000 & 0 \\
\hline 051 & 1.0000 & 0.46265 & 0.55464 & 0.79182 & Biso & 1.000 & 0 \\
\hline 052 & 1.0000 & 0.60716 & 0.81022 & 0.54202 & Biso & 1.000 & 0 \\
\hline 053 & 1.0000 & 0.23373 & 0.47141 & 0.53972 & Biso & 1.000 & 0 \\
\hline 054 & 1.0000 & 0.21917 & 0.77850 & 0.53744 & Biso & 1.000 & 0 \\
\hline 055 & 1.0000 & 0.00531 & 0.27082 & 0.99826 & Biso & 1.000 & 0 \\
\hline 056 & 1.0000 & 0.74805 & 0.74721 & 0.00251 & Biso & 1.000 & 0 \\
\hline 057 & 1.0000 & 0.26978 & 0.00513 & 0.99162 & Biso & 1.000 & 0 \\
\hline 058 & 1.0000 & 0.67627 & 0.60935 & 0.33361 & Biso & 1.000 & 0 \\
\hline 059 & 1.0000 & 0.39596 & 0.06534 & 0.32218 & Biso & 1.000 & 0 \\
\hline 060 & 1.0000 & 0.95259 & 0.34953 & 0.33047 & Biso & 1.000 & 0 \\
\hline 061 & 1.0000 & 0.34030 & 0.93095 & 0.66273 & Biso & 1.000 & 0 \\
\hline 062 & 1.0000 & 0.07485 & 0.38890 & 0.66644 & Biso & 1.000 & 0 \\
\hline 063 & 1.0000 & 0.61949 & 0.67860 & 0.66882 & Biso & 1.000 & 0 \\
\hline 064 & 1.0000 & 0.00862 & 0.74673 & 0.00248 & Biso & 1.000 & 0 \\
\hline 065 & 1.0000 & 0.27643 & 0.27524 & 0.99208 & Biso & 1.000 & 0 \\
\hline 066 & 1.0000 & 0.74916 & 0.01041 & 0.99984 & Biso & 1.000 & 0 \\
\hline 067 & 1.0000 & 0.67535 & 0.07256 & 0.33208 & Biso & 1.000 & 0 \\
\hline 068 & 1.0000 & 0.94321 & 0.60454 & 0.33490 & Biso & 1.000 & 0 \\
\hline 069 & 1.0000 & 0.40335 & 0.34668 & 0.32768 & Biso & 1.000 & 0 \\
\hline 070 & 1.0000 & 0.34179 & 0.41675 & 0.66033 & Biso & 1.000 & 0 \\
\hline 071 & 1.0000 & 0.60949 & 0.94907 & 0.66791 & Biso & 1.000 & 0 \\
\hline 072 & 1.0000 & 0.06970 & 0.69332 & 0.67036 & Biso & 1.000 & 0 \\
\hline $\mathrm{H} 1$ & 1.0000 & 0.33730 & 0.98585 & 0.32786 & Biso & 1.000 & $\mathrm{H}$ \\
\hline \multirow{2}{*}{\multicolumn{8}{|c|}{$\begin{array}{l}\text { i zoH } \\
\text { lata image } 0\end{array}$}} \\
\hline & & & & & & & \\
\hline \multicolumn{8}{|c|}{13.875} \\
\hline & \\
\hline \multicolumn{8}{|c|}{15.017} \\
\hline \multicolumn{8}{|c|}{ e_talpha } \\
\hline \multicolumn{8}{|c|}{ e_beta } \\
\hline sell & e_gamma & 120 & & & & & \\
\hline & (מתח & & & $1 "$ & & & \\
\hline ymme & $n t \_t \bar{a} b$ & les_numb & & & & & \\
\hline op_ & & & & & & & \\
\hline sym & 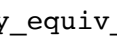 & pos_as_ & & & & & \\
\hline ' $\mathrm{x}$, & & & & & & & \\
\hline op_ & & & & & & & \\
\hline at & Ee_labe & & & & & & \\
\hline ato & te _occur & pancy & & & & & \\
\hline ato & te_fract & E $x$ & & & & & \\
\hline -ato & te_fract & & & & & & \\
\hline -ato & te_fract & & & & & & \\
\hline ato & te thern & nàl_disp. & ace_type & & & & \\
\hline $\begin{array}{l}\text {-ato } \\
\text { ato }\end{array}$ & $\begin{array}{l}\text { te_B_isc } \\
\text { te type }\end{array}$ & $\begin{array}{l}\text { or_equ } \\
\text { symbol }\end{array}$ & & & & & \\
\hline$\overline{\mathrm{P}} 1$ & 1.0000 & 0.00772 & 0.22994 & 0.10824 & Biso & 1.000 & $\mathrm{P}$ \\
\hline P2 & 1.0000 & 0.77794 & 0.78003 & 0.11333 & Biso & 1.000 & $\mathrm{P}$ \\
\hline P3 & 1.0000 & 0.22743 & 0.99943 & 0.09866 & Biso & 1.000 & $\mathrm{P}$ \\
\hline Al1 & 1.0000 & 0.21622 & 0.99098 & 0.88367 & Biso & 1.000 & Al \\
\hline Al2 & 1.0000 & 0.77073 & 0.77281 & 0.90016 & Biso & 1.000 & Al \\
\hline Al3 & 1.0000 & 0.00005 & 0.22709 & 0.89632 & Biso & 1.000 & Al \\
\hline P4 & 1.0000 & 0.66750 & 0.56139 & 0.44102 & Biso & 1.000 & $\mathrm{P}$ \\
\hline
\end{tabular}




\begin{tabular}{|c|c|c|c|c|c|c|}
\hline Ti1 & 1.0000 & 0.42253 & 0.10549 & 0.44335 & Biso & 1.000 \\
\hline P5 & 1.0000 & 0.90021 & 0.33013 & 0.44050 & Biso & 1.000 \\
\hline Al4 & 1.0000 & 0.90047 & 0.33487 & 0.22977 & Biso & 1.000 \\
\hline Al5 & 1.0000 & 0.43828 & 0.10666 & 0.21774 & Biso & 1.000 \\
\hline Al6 & 1.0000 & 0.67527 & 0.56331 & 0.23056 & Biso & 1.000 \\
\hline P6 & 1.0000 & 0.33174 & 0.88131 & 0.78313 & Biso & 1.000 \\
\hline P7 & 1.0000 & 0.10150 & 0.43402 & 0.77278 & Biso & 1.000 \\
\hline P8 & 1.0000 & 0.56152 & 0.66159 & 0.77456 & Biso & 1.000 \\
\hline Al 7 & 1.0000 & 0.57695 & 0.67534 & 0.56886 & Biso & 1.000 \\
\hline A18 & 1.0000 & 0.09670 & 0.43544 & 0.57063 & Biso & 1.000 \\
\hline Al9 & 1.0000 & 0.33174 & 0.87370 & 0.56820 & Biso & 1.000 \\
\hline P9 & 1.0000 & 0.99232 & 0.76478 & 0.89335 & Biso & 1.000 \\
\hline P10 & 1.0000 & 0.22576 & 0.22196 & 0.88350 & Biso & 1.000 \\
\hline P11 & 1.0000 & 0.77662 & 0.00104 & 0.89317 & Biso & 1.000 \\
\hline Al10 & 1.0000 & 0.78042 & 0.00598 & 0.10682 & Biso & 1.000 \\
\hline Al11 & 1.0000 & 0.23498 & 0.22911 & 0.09586 & Biso & 1.000 \\
\hline Al12 & 1.0000 & 0.00404 & 0.77810 & 0.10827 & Biso & 1.000 \\
\hline P12 & 1.0000 & 0.67140 & 0.10945 & 0.22697 & Biso & 1.000 \\
\hline P13 & 1.0000 & 0.90400 & 0.56424 & 0.22947 & Biso & 1.000 \\
\hline P 14 & 1.0000 & 0.44473 & 0.34190 & 0.22237 & Biso & 1.000 \\
\hline Al13 & 1.0000 & 0.42705 & 0.34935 & 0.43117 & Biso & 1.000 \\
\hline Al1 14 & 1.0000 & 0.89624 & 0.55899 & 0.44008 & Biso & 1.000 \\
\hline Al15 & 1.0000 & 0.66807 & 0.10961 & 0.43494 & Biso & 1.000 \\
\hline P15 & 1.0000 & 0.33454 & 0.46249 & 0.55692 & Biso & 1.000 \\
\hline P 16 & 1.0000 & 0.56612 & 0.89744 & 0.56467 & Biso & 1.000 \\
\hline P 17 & 1.0000 & 0.09315 & 0.66794 & 0.57011 & Biso & 1.000 \\
\hline Al16 & 1.0000 & 0.10069 & 0.66657 & 0.77469 & Biso & 1.000 \\
\hline Al1 17 & 1.0000 & 0.55958 & 0.89123 & 0.77393 & Biso & 1.000 \\
\hline Al18 & 1.0000 & 0.32883 & 0.43812 & 0.76478 & Biso & 1.000 \\
\hline 01 & 1.0000 & 0.91795 & 0.10934 & 0.13088 & Biso & 1.000 \\
\hline $\mathrm{O} 2$ & 1.0000 & 0.89978 & 0.81101 & 0.13081 & Biso & 1.000 \\
\hline 03 & 1.0000 & 0.20230 & 0.09259 & 0.12250 & Biso & 1.000 \\
\hline 04 & 1.0000 & 0.08184 & 0.88116 & 0.86060 & Biso & 1.000 \\
\hline 05 & 1.0000 & 0.80759 & 0.91053 & 0.87418 & Biso & 1.000 \\
\hline 06 & 1.0000 & 0.10474 & 0.19573 & 0.87231 & Biso & 1.000 \\
\hline 07 & 1.0000 & 0.56602 & 0.44603 & 0.45861 & Biso & 1.000 \\
\hline 08 & 1.0000 & 0.56808 & 0.15019 & 0.43883 & Biso & 1.000 \\
\hline 09 & 1.0000 & 0.87695 & 0.42591 & 0.45921 & Biso & 1.000 \\
\hline 010 & 1.0000 & 0.76205 & 0.23126 & 0.20966 & Biso & 1.000 \\
\hline 011 & 1.0000 & 0.46822 & 0.24398 & 0.22136 & Biso & 1.000 \\
\hline 012 & 1.0000 & 0.78237 & 0.53336 & 0.21265 & Biso & 1.000 \\
\hline 013 & 1.0000 & 0.23642 & 0.76437 & 0.80883 & Biso & 1.000 \\
\hline 014 & 1.0000 & 0.22465 & 0.47064 & 0.79114 & Biso & 1.000 \\
\hline 015 & 1.0000 & 0.53013 & 0.75322 & 0.78155 & Biso & 1.000 \\
\hline 016 & 1.0000 & 0.43630 & 0.58010 & 0.54990 & Biso & 1.000 \\
\hline 017 & 1.0000 & 0.09111 & 0.55697 & 0.57031 & Biso & 1.000 \\
\hline 018 & 1.0000 & 0.44134 & 0.84828 & 0.54302 & Biso & 1.000 \\
\hline 019 & 1.0000 & 0.99247 & 0.31281 & 0.16544 & Biso & 1.000 \\
\hline 020 & 1.0000 & 0.69803 & 0.67888 & 0.16890 & Biso & 1.000 \\
\hline 021 & 1.0000 & 0.33976 & 0.02443 & 0.13866 & Biso & 1.000 \\
\hline 022 & 1.0000 & 0.31573 & 0.97143 & 0.82890 & Biso & 1.000 \\
\hline 023 & 1.0000 & 0.65037 & 0.67968 & 0.84358 & Biso & 1.000 \\
\hline 024 & 1.0000 & 0.02483 & 0.34727 & 0.84086 & Biso & 1.000 \\
\hline 025 & 1.0000 & 0.66254 & 0.64985 & 0.49926 & Biso & 1.000 \\
\hline 026 & 1.0000 & 0.34353 & 0.98879 & 0.51380 & Biso & 1.000 \\
\hline 027 & 1.0000 & 0.99827 & 0.34241 & 0.49648 & Biso & 1.000 \\
\hline 028 & 1.0000 & 0.00538 & 0.67377 & 0.84638 & Biso & 1.000 \\
\hline 029 & 1.0000 & 0.30481 & 0.32021 & 0.82471 & Biso & 1.000 \\
\hline 030 & 1.0000 & 0.67280 & 0.97826 & 0.84064 & Biso & 1.000 \\
\hline 031 & 1.0000 & 0.68550 & 0.03112 & 0.16320 & Biso & 1.000 \\
\hline 032 & 1.0000 & 0.35419 & 0.32187 & 0.15434 & Biso & 1.000 \\
\hline 033 & 1.0000 & 0.98329 & 0.66387 & 0.17150 & Biso & 1.000 \\
\hline 034 & 1.0000 & 0.33930 & 0.38598 & 0.48608 & Biso & 1.000 \\
\hline 035 & 1.0000 & 0.00012 & 0.65907 & 0.50905 & Biso & 1.000 \\
\hline 036 & 1.0000 & 0.63779 & 0.99704 & 0.50453 & Biso & 1.000 \\
\hline 037 & 1.0000 & 0.12314 & 0.24534 & 0.12780 & Biso & 1.000 \\
\hline 038 & 1.0000 & 0.76343 & 0.87835 & 0.14096 & Biso & 1.000 \\
\hline 039 & 1.0000 & 0.13505 & 0.88971 & 0.13857 & Biso & 1.000 \\
\hline 040 & 1.0000 & 0.23253 & 0.11965 & 0.85399 & Biso & 1.000 \\
\hline 041 & 1.0000 & 0.87766 & 0.74832 & 0.86989 & Biso & 1.000 \\
\hline 042 & 1.0000 & 0.87313 & 0.11418 & 0.86363 & Biso & 1.000 \\
\hline 043 & 1.0000 & 0.77309 & 0.55783 & 0.46433 & Biso & 1.000 \\
\hline 044 & 1.0000 & 0.39499 & 0.21681 & 0.46147 & Biso & 1.000 \\
\hline 045 & 1.0000 & 0.79806 & 0.21961 & 0.46603 & Biso & 1.000 \\
\hline 046 & 1.0000 & 0.91784 & 0.46507 & 0.20323 & Biso & 1.000 \\
\hline 047 & 1.0000 & 0.55775 & 0.09870 & 0.20744 & Biso & 1.000 \\
\hline 048 & 1.0000 & 0.55156 & 0.44799 & 0.19525 & Biso & 1.000 \\
\hline 049 & 1.0000 & 0.44309 & 0.89466 & 0.81432 & Biso & 1.000 \\
\hline 050 & 1.0000 & 0.08532 & 0.53479 & 0.78082 & Biso & 1.000 \\
\hline 051 & 1.0000 & 0.45811 & 0.54915 & 0.79488 & Biso & 1.000 \\
\hline
\end{tabular}




\begin{tabular}{|c|c|c|c|c|c|c|}
\hline 052 & 1.0000 & 0.59929 & 0.80870 & 0.54803 & Biso & 1.000 \\
\hline 053 & 1.0000 & 0.23069 & 0.47135 & 0.53917 & Biso & 1.000 \\
\hline 054 & 1.0000 & 0.20593 & 0.75871 & 0.53438 & Biso & 1.000 \\
\hline 055 & 1.0000 & 0.99871 & 0.25403 & 0.00970 & Biso & 1.000 \\
\hline 056 & 1.0000 & 0.74824 & 0.75173 & 0.01463 & Biso & 1.000 \\
\hline 057 & 1.0000 & 0.23517 & 0.98945 & 0.99817 & Biso & 1.000 \\
\hline 058 & 1.0000 & 0.67009 & 0.59401 & 0.34261 & Biso & 1.000 \\
\hline 059 & 1.0000 & 0.36936 & 0.04327 & 0.32091 & Biso & 1.000 \\
\hline 060 & 1.0000 & 0.93060 & 0.33100 & 0.34191 & Biso & 1.000 \\
\hline 061 & 1.0000 & 0.33276 & 0.89672 & 0.68229 & Biso & 1.000 \\
\hline 062 & 1.0000 & 0.06852 & 0.38167 & 0.67916 & Biso & 1.000 \\
\hline 063 & 1.0000 & 0.60698 & 0.66245 & 0.68066 & Biso & 1.000 \\
\hline 064 & 1.0000 & 0.00294 & 0.75336 & 0.99426 & Biso & 1.000 \\
\hline 065 & 1.0000 & 0.26181 & 0.25097 & 0.98153 & Biso & 1.000 \\
\hline 066 & 1.0000 & 0.75330 & 0.00327 & 0.99301 & Biso & 1.000 \\
\hline 067 & 1.0000 & 0.67671 & 0.07444 & 0.32305 & Biso & 1.000 \\
\hline 068 & 1.0000 & 0.93460 & 0.59532 & 0.32807 & Biso & 1.000 \\
\hline 069 & 1.0000 & 0.40723 & 0.35488 & 0.31545 & Biso & 1.000 \\
\hline 070 & 1.0000 & 0.32864 & 0.41312 & 0.65027 & Biso & 1.000 \\
\hline 071 & 1.0000 & 0.58819 & 0.93594 & 0.66283 & Biso & 1.000 \\
\hline 072 & 1.0000 & 0.07486 & 0.69576 & 0.66595 & Biso & 1.000 \\
\hline H 1 & 1.0000 & 0.29987 & 0.97269 & 0.31762 & Biso & 1.000 \\
\hline
\end{tabular}

1. Goncalves, T. J.; Plessow, P. N.; Studt, F., On the Accuracy of Density Functional Theory in Zeolite Catalysis. Chemcatchem 2019, 11 (17), 4368-4376.

2. $\quad$ Perdew, J. P.; Burke, K.; Ernzerhof, M., Generalized Gradient Approximation Made Simple. Phys. Rev. Lett. 1996, 77 (18), 3865-3868.

3. Grimme, S.; Antony, J.; Ehrlich, S.; Krieg, H., A consistent and accurate ab initio parametrization of density functional dispersion correction (DFT-D) for the 94 elements HPu. J. Chem. Phys. 2010, 132 (15), 154104.

4. Kresse, G.; Furthmüller, J., Efficient iterative schemes for ab initio total-energy calculations using a plane-wave basis set. Phys. Rev. B 1996, 54 (16), 11169-11186.

5. Kresse, G.; Joubert, D., From ultrasoft pseudopotentials to the projector augmentedwave method. Phys. Rev. B 1999, 59 (3), 1758-1775.

6. Plessow, P. N., Efficient Transition State Optimization of Periodic Structures through Automated Relaxed Potential Energy Surface Scans. J. Chem. Theory Comput. 2018, 14 (2), 981-990.

7. Neese, F., The ORCA program system. Wiley Interdiscip. Rev. Comput. Mol. Sci. 2012, 2 (1), 73-78.

8. Saitow, M.; Becker, U.; Riplinger, C.; Valeev, E. F.; Neese, F., A new near-linear scaling, efficient and accurate, open-shell domain-based local pair natural orbital coupled cluster singles and doubles theory. J. Chem. Phys. 2017, 146 (16), 164105.

9. Neese, F.; Wennmohs, F.; Hansen, A.; Becker, U., Efficient, approximate and parallel Hartree-Fock and hybrid DFT calculations. A 'chain-of-spheres' algorithm for the HartreeFock exchange. Chem. Phys. 2009, 356 (1-3), 98-109. 